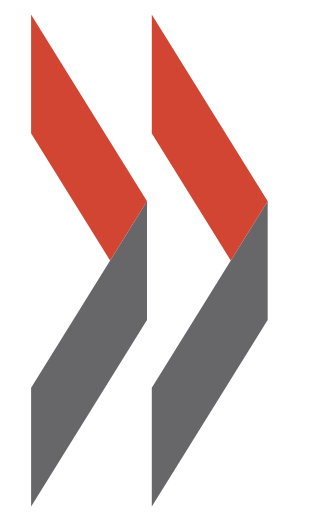

\title{
PISA 2015 Results
}

\section{STUDENTS' WELL-BEING}

\section{VOLUME III}

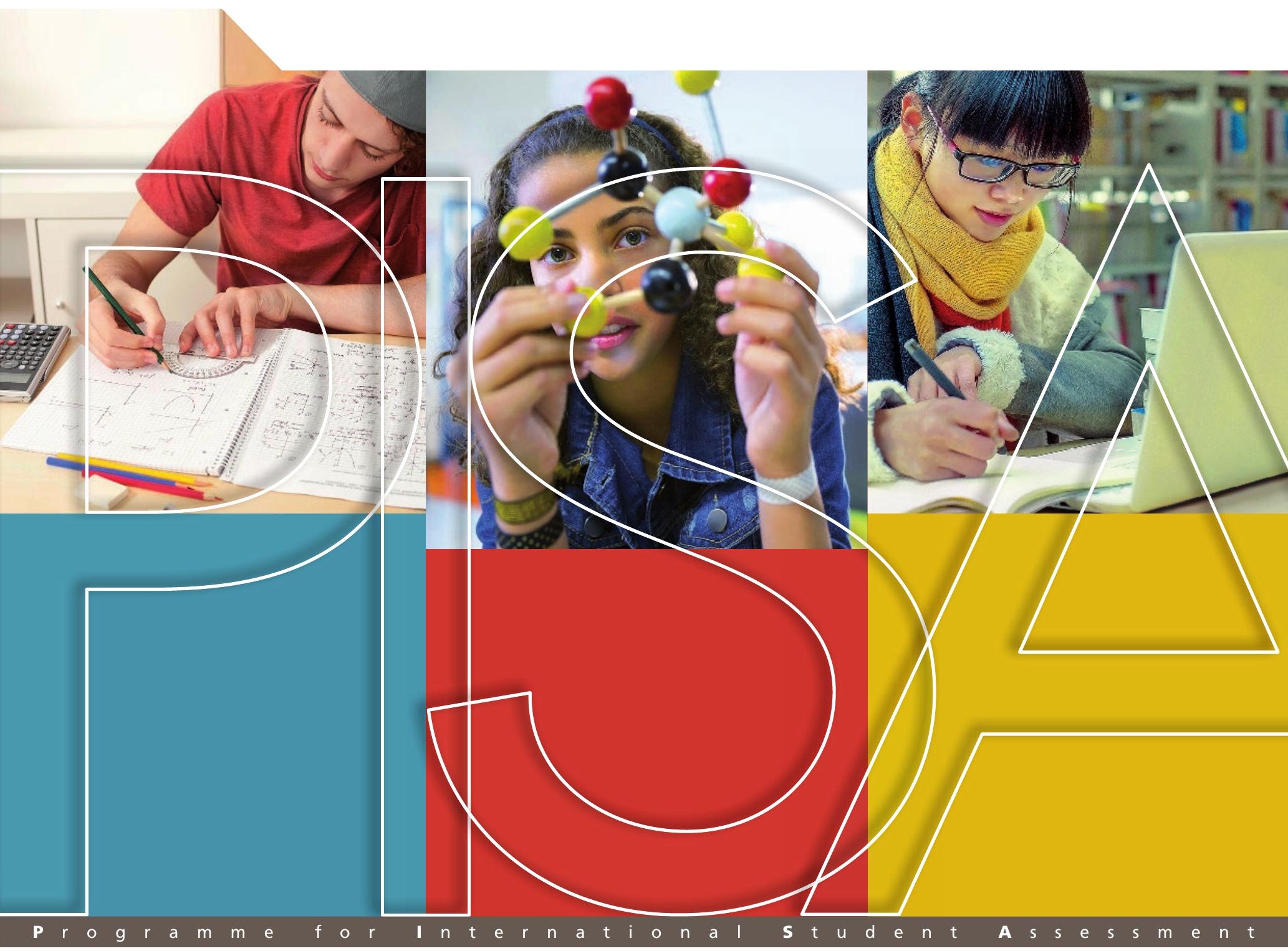

\section{2) OECD}



PISA

\section{PISA 2015 Results (Volume III)}

STUDENTS' WELL-BEING

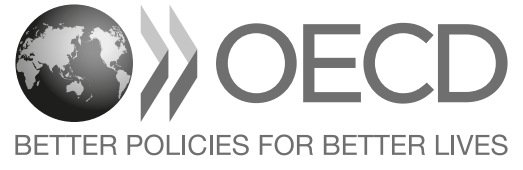


This work is published under the responsibility of the Secretary-General of the OECD. The opinions expressed and the arguments employed herein do not necessarily reflect the official views of the OECD member countries.

This document and any map included herein are without prejudice to the status of or sovereignty over any territory, to the delimitation of international frontiers and boundaries and to the name of any territory, city or area.

The statistical data for Israel are supplied by and under the responsibility of the relevant Israeli authorities. The use of such data by the OECD is without prejudice to the status of the Golan Heights, East Jerusalem and Israeli settlements in the West Bank under the terms of international law.

Please cite this publication as:

OECD (2017), PISA 2015 Results (Volume III): Students' Well-Being, PISA, OECD Publishing, Paris.

http://dx.doi.org/10.1787/9789264273856-en

ISBN (print) 978-92-64-27381-8

ISBN (PDF) 978-92-64-27385-6

Series: PISA

ISSN (print): 1990-8539

ISSN (on line): 1996-3777

Photo credits:

(c) Geostock/ Getty Images

(๑) Hero Images Inc./Hero Images Inc./ Corbis

(c) LIUSHENGFILM/Shutterstock

(c) RelaXimages/Corbis

(c) Shutterstock/Kzenon

(c) Simon Jarratt/Corbis

Corrigenda to OECD publications may be found on line at: www.oecd.org/publishing/corrigenda.

(c) OECD 2017

This work is available under the Creative Commons Attribution-NonCommercial-ShareAlike 3.0 IGO (CC BY-NC-SA 3.0 IGO). For specific information regarding the scope and terms of the licence as well as possible commercial use of this work or the use of PISA data please consult Terms and Conditions on www.oecd.org. 


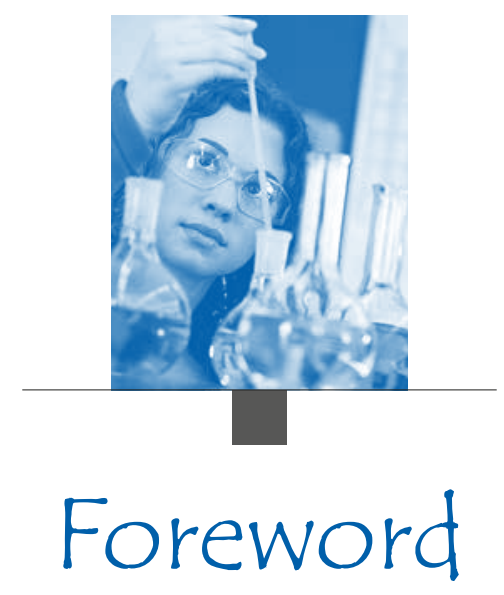

Over the past decade, the OECD Programme for International Student Assessment, PISA, has become the world's premier yardstick for evaluating the quality, equity and efficiency of school systems. But the evidence base that PISA has produced goes well beyond statistical benchmarking. By identifying the characteristics of high-performing education systems, PISA allows governments and educators to identify effective policies that they can then adapt to their local contexts.

While the latest PISA assessment in 2015 focused on science, it also looked beyond students' academic proficiency to offer a more detailed examination of their enjoyment of life. Are students basically happy? Do they feel that they belong to a community at school? Do they enjoy supportive relations with their peers, their teachers and their parents? Is there any association between the quality of students' relationships in and outside of school and their academic performance?

By and large, PISA finds that most 15-year-old students are relatively satisfied with their life, and those who are motivated to achieve reported even greater satisfaction. But PISA results also indicate that schoolwork-related anxiety and the prevalence of bullying at school (on average, there's a bully in every class...) erode students' well-being.

As with improving student performance, there is no single combination of policies and practices that will nurture the well-being of all students, everywhere; and every country has room for improvement, even the top performers. But it is fair to say that unless they are given the support they need to blossom in their life as students, adolescents are unlikely to enjoy well-being as adults.

This report is the product of a collaborative effort between the countries participating in PISA, the national and international experts and institutions working within the framework of the PISA Consortium, and the OECD Secretariat.

The development of this volume was guided by Andreas Schleicher and Yuri Belfali, and managed by Francesco Avvisati and Miyako Ikeda. This volume was drafted by Mario Piacentini with Esther Carvalhaes, Anna Choi, Hélène Guillou, Bonaventura Francesco Pacileo and Judit Pál. The volume was edited by Marilyn Achiron. Statistical and analytical support was provided by Guillaume Bousquet and Nadine Chami. Rose Bolognini co-ordinated production and Fung Kwan Tam designed the publication. Administrative support was provided by Claire Chetcuti, Juliet Evans, Thomas Marwood and Lesley O'Sullivan. Additional members of the OECD PISA and communications teams who provided analytical and communications support include Cassandra Davis, Alfonso Echazarra, Carlos Gonzalez-Sancho, Jeffrey Mo, Giannina Rech, Michael Stevenson and Sophie Vayssettes. Leslie Rutkowski provided external support on the analysis of data on bullying, and Jonas Bertling and René Veenstra acted as external peer reviewers. Communication support was provided by Simone Bloem.

To support the technical implementation of PISA, the OECD contracted an international consortium of institutions and experts, led by Irwin Kirsch of the Educational Testing Service (ETS). Overall co-ordination of the PISA 2015 assessment, the development of instruments, and scaling and analysis were managed by Claudia Tamassia of ETS; development of the electronic platform was managed by Michael Wagner of ETS. Development of the science and collaborative problemsolving frameworks, and adaptation of the frameworks for reading and mathematics, were led by John de Jong and 
managed by Catherine Hayes of Pearson. Survey operations were led by Merl Robinson and managed by Michael Lemay of Westat. Sampling and weighting operations were led by Keith Rust and managed by Sheila Krawchuk of Westat. Design and development of the questionnaires were led by Eckhard Klieme and managed by Nina Jude of the Deutsches Institut für Pädagogische Forschung (DIPF).

Jonathan Osborne chaired the expert group that guided the preparation of the science assessment framework and instruments. This group included Marcus Hammann, Sarah Howie, Jody Clarke-Midura, Robin Millar, Andrée Tiberghien, Russell Tytler and Darren Wong. Charles Alderson and Jean-Francois Rouet assisted in adapting the reading framework, and Zbigniew Marciniak, Berinderjeet Kaur and Oh Nam Kwon assisted in adapting the mathematics framework. David Kaplan chaired the expert group that guided the preparation of the questionnaire framework and instruments. This group included Eckhard Klieme, Gregory Elacqua, Marit Kjærnsli, Leonidas Kyriakides, Henry M. Levin, Naomi Miyake, Jonathan Osborne, Kathleen Scalise, Fons van de Vijver and Ludger Woessmann. Keith Rust chaired the Technical Advisory Group, whose members include Theo Eggen, John de Jong, Jean Dumais, Cees Glas, David Kaplan, Irwin Kirsch, Christian Monseur, Sophia Rabe-Hesketh, Thierry Rocher, Leslie A. Rutkowski, Margaret Wu and Kentaro Yamamoto.

The development of the report was steered by the PISA Governing Board, chaired by Lorna Bertrand (United Kingdom) and Michelle Bruniges (Australia), with Maria Helena Guimarães de Castro (Brazil), Sungsook Kim (Korea) and Dana Kelly (United States) as vice chairs. Annex C of the volume lists the members of the various PISA bodies, including Governing Board members and National Project Managers in participating countries and economies, the PISA Consortium, and the individual experts and consultants who have contributed to PISA in general. 


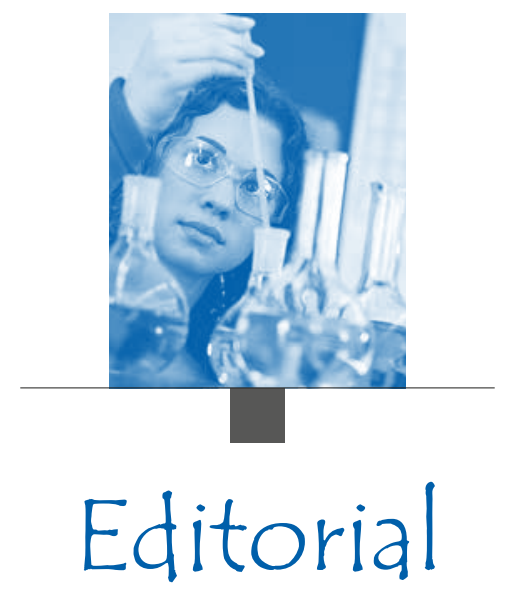

Schools are not just places where students acquire academic skills; they also help students become more resilient in the face of adversity, feel more connected with the people around them, and aim higher in their aspirations for their future. Not least, schools are the first place where children experience society in all its facets, and those experiences can have a profound influence on students' attitudes and behaviour in life.

PISA is best known for its data on learning outcomes, but it also studies students' satisfaction with life, their relationships with peers, teachers and parents, and how they spend their time outside of school. PISA results show that students differ greatly, both between and within countries, in how satisfied they are with their life, their motivation to achieve, how anxious they feel about their schoolwork, their expectations for the future, and their perceptions of being bullied at school or treated unfairly by their teachers. Students in some of the countries that top the PISA league tables in science and mathematics reported comparatively low satisfaction with life; but Finland, the Netherlands and Switzerland seem able to combine good learning outcomes with highly satisfied students.

It is tempting to equate low levels of life satisfaction among students in East Asia or elsewhere to long study hours, but the data show no relationship between the time students spend studying, whether in or outside of school, and their satisfaction with life. And while educators often argue that anxiety is the natural consequence of testing overload, the frequency of tests is also unrelated to students' level of schoolwork-related anxiety.

There are other factors that make a difference to student well-being, and much comes down to teachers, parents and schools.

For a start, PISA finds that one major threat to students' sense of belonging at school is their perception of negative relationships with their teachers. Happier students tended to report positive relations with their teachers. Students in "happy" schools (schools where students' life satisfaction is above the average in the country) reported much greater support from their teachers than did students in "unhappy" schools.

This is important. Teenagers look for strong social ties and value acceptance, care and support from others. Adolescents who feel that they are part of a school community are more likely to perform better academically and be more motivated in school.

Of course, most teachers care about having positive relationships with their students; but some teachers may be insufficiently prepared to deal with difficult students and classroom environments. A stronger focus on classroom and relationship management in professional development may give teachers better means to connect with their students. Teachers should also be better supported to collaborate and exchange information about students' difficulties, character and strengths with their colleagues.

On average across OECD countries, 59\% of students reported that they often worry that taking a test will be difficult, and $66 \%$ reported that they worry about poor grades. Some $55 \%$ of students say they are very anxious for a test even if they are well prepared. In all countries, girls reported greater schoolwork-related anxiety than boys; and anxiety about schoolwork, homework and tests is negatively related to performance. 
PISA suggests that there is much teachers can do about this too. Students were less likely to report anxiety if the science teacher provides individual help when they are struggling. Teachers need to know how to help students develop a good understanding of their strengths and weaknesses, and an awareness of what they can do to mitigate those weaknesses. The design of assessments matters too. More frequent assessments that start with easier goals and gradually increase in difficulty can also help build students' sense of control, as can opportunities for students to demonstrate their skills in low-stakes tests before taking an assessment that counts.

Parents can make a big difference too. Students whose parents reported "spending time just talking to my child", "eating the main meal with my child around a table" or "discussing how well my child is doing at school" regularly were between $22 \%$ and $39 \%$ more likely to report high levels of life satisfaction. "Spending time just talking" is the parental activity most frequently and most strongly associated with students' life satisfaction. And it seems to matter for performance too: students whose parents reported "spending time just talking" were two-thirds of a school year ahead in science learning; and even after accounting for socio-economic status, the advantage remains at one-third of a school year.

Students' perceptions of how interested their parents are in them and in their school life is also related to their own attitudes towards education and their motivation to study. Those relationships are particularly strong among low-performing students - and stronger than the impact of most school resources and other factors measured by PISA.

Parents can help children manage test anxiety by encouraging them to trust in their ability to accomplish various academic tasks. PISA results show that girls who perceive that their parents encourage them to be confident in their abilities were less likely to report that they feel tense when they study.

Most parents also want their children to be motivated at school, and motivated students tend to do better at school. On average, students who are among the most motivated score the equivalent of more than one school year higher in PISA than the least-motivated students. Achievement motivation is also related to life satisfaction in a mutually reinforcing way.

But there can also be downsides to achievement motivation, particularly when it is a response to external pressure. PISA results show that countries where students are highly motivated to achieve also tend to be the countries where many students feel anxious about a test, even if they are well prepared for it. Both teachers and parents need to find ways to encourage students' motivation to learn and achieve without generating an excessive fear of failure.

All in all, a clear way to promote students' well-being is for schools to encourage all parents to be more involved with their child's school life. If parents and teachers establish relationships based on trust, schools can rely on parents as valuable partners in the cognitive and socio-emotional education of their students. Schools can also do a lot to help parents overcome barriers to participation in school activities related to inflexible work schedules, lack of childcare services or language. They can open flexible channels of communication, such as scheduled phone or video calls. Governments can also take action by promoting work-life balance policies.

PISA 2015 asked students how much time they spend on line and how they feel when they are engaged in online activities. Across OECD countries, most students agreed that "the Internet is a great resource for obtaining information" $(88 \%)$ and that "it is very useful to have social networks on the Internet" (84\%). The data also show that most students enjoy using various digital devices and the Internet, but some students are at risk of excessive Internet use. On average, $26 \%$ of students reported that they spend more than six hours per day on line during weekends, and $16 \%$ spend a similar amount of time on line during weekdays. In most participating countries, extreme Internet use - more than six hours per day - has a negative relationship with students' life satisfaction and engagement at school. And with cyberbullying on the rise, the Internet can be as much a source of harassment as a tool for learning.

There are no quick fixes for the risks of the digital era, but schools can create opportunities for students to use the Internet more responsibly, and develop clear prevention and response plans to counter cyberbullying.

Perhaps the most distressing threat to students' well-being is bullying, and it can have serious consequences for the victim, the bully and bystanders. PISA highlights a significant prevalence of all forms of bullying. On average across OECD countries, around $11 \%$ of students reported that they are frequently (at least a few times per month) made fun of, $7 \%$ reported that they are frequently left out of things, and $8 \%$ reported that they are frequently the object of nasty rumours in school. Around $4 \%$ of students - roughly one per class - reported that they are hit or pushed at least a few times per month, a percentage that varies from $1 \%$ to $9.5 \%$ across countries. Another $8 \%$ of students reported they are physically bullied a few times per year. 
There is no one-size-fits-all approach to preventing bullying. What emerges clearly from the PISA data, however, is that schools must do more to foster an environment of safety, tolerance and respect for children. A co-ordinated, international analysis of existing strategies and support mechanisms can shed light on what schools can do in the difficult struggle to assure students' safety at school, and what national and local authorities and services can do to support schools in this effort. Anti-bullying programmes must include training for teachers on how to handle bullying and strategies to engage with parents. Teachers need to communicate to students that they will not tolerate any form of bullying; and parents need to be involved in responses to bullying. In fact, being a victim of bullying is less frequently reported among students who said that their parents support them when they face difficulties at school. And yet, only $44 \%$ of the parents of frequently bullied students reported that they had exchanged ideas about the child's development with teachers over the previous academic year.

The challenges to students' well-being are many, and there are no simple solutions. But the findings from PISA show how teachers, schools and parents can make a real difference. Together they can attend to students' psychological and social needs and help them develop a sense of control over their future and the resilience they need to be successful in life.

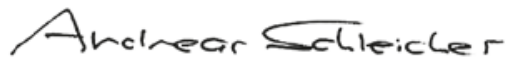

\section{Andreas Schleicher}

Director for Education and Skills and Special Advisor on Education Policy to the Secretary-General 



\section{Table of contents}

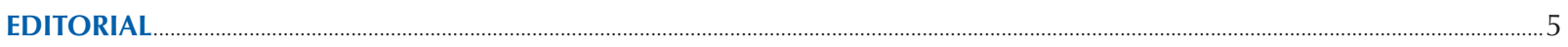

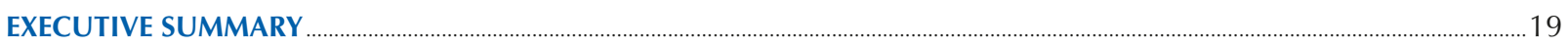

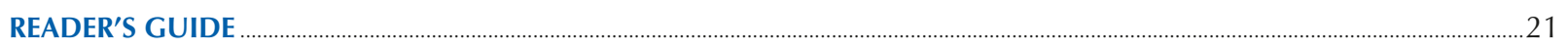

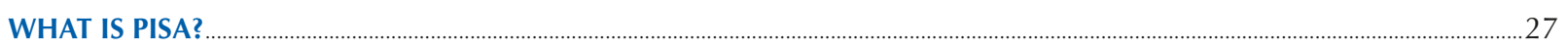

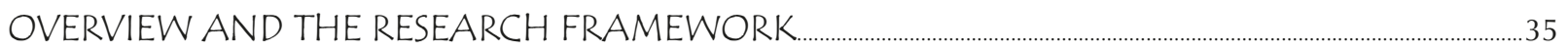

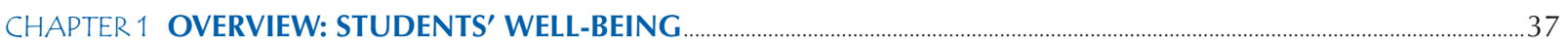

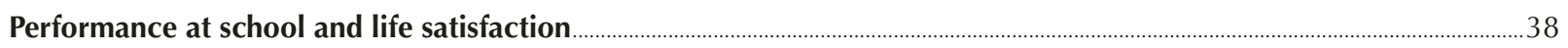

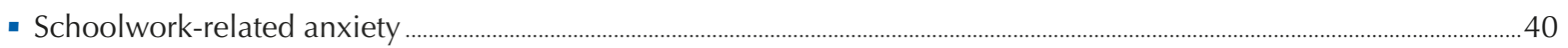

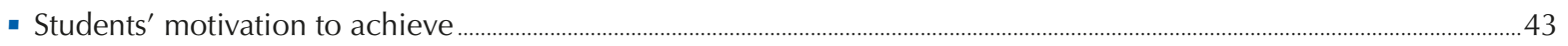

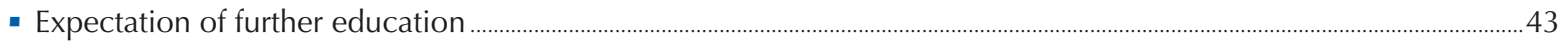

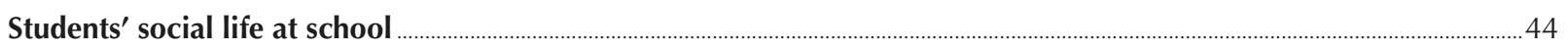

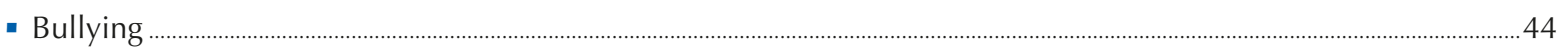

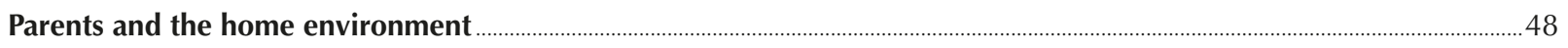

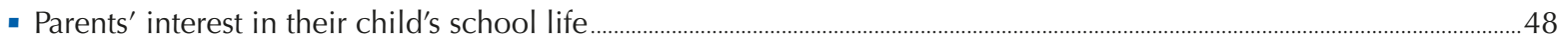

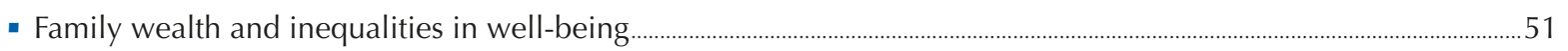

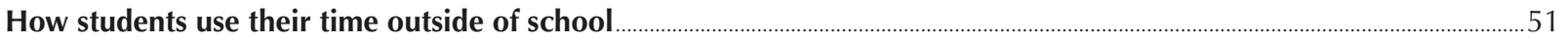

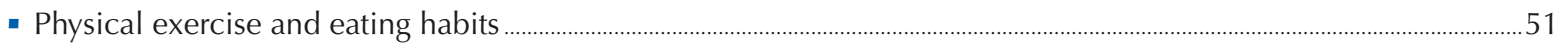

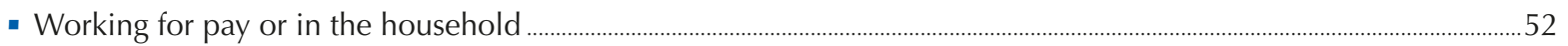

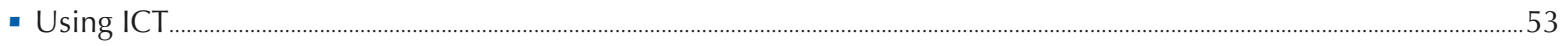

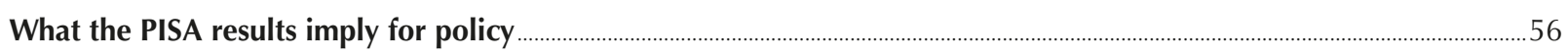

CHAPTER 2 STUDENTS' WELL-BEING: WHAT IT IS AND HOW IT CAN BE MEASURED _................................................59

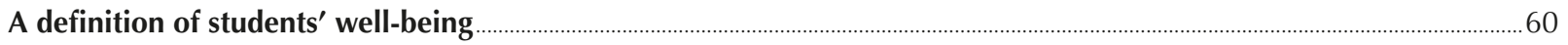

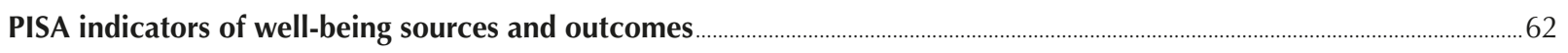

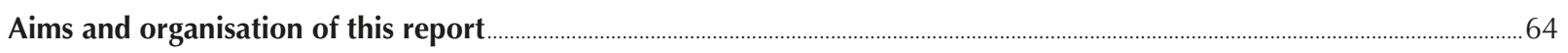

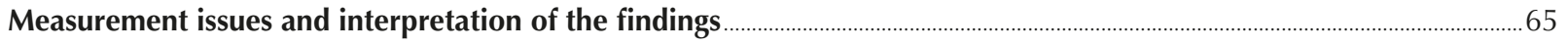

PERFORMANCE AT SCHOOL AND LIFE SATISFACTION

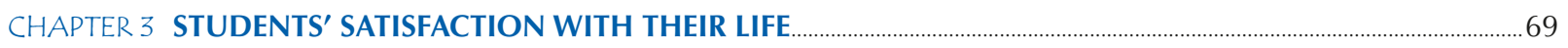

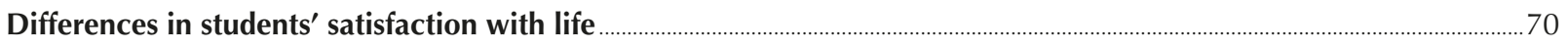

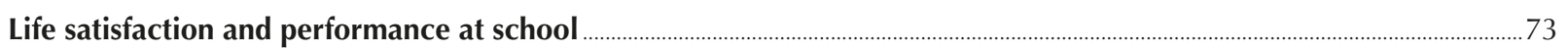

School climate, teaching practices and variations in life satisfaction across schools …….......................................................... 78

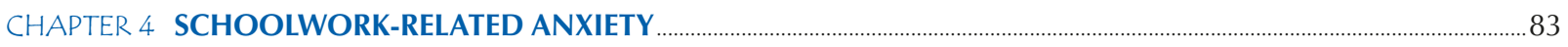

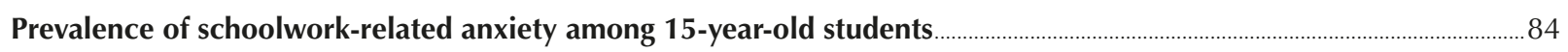

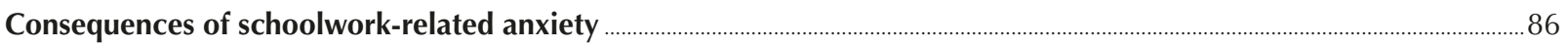

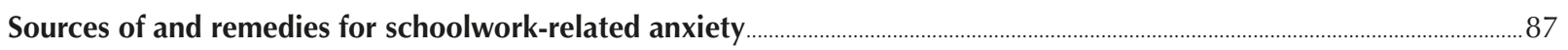


CHAPTER 5 STUDENTS' MOTIVATION TO ACHIEVE.

Differences in achievement motivation between and within education systems …….......................................................... 94

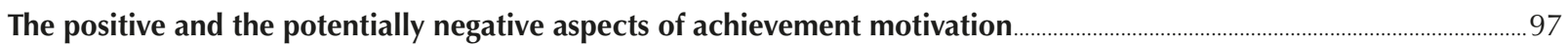

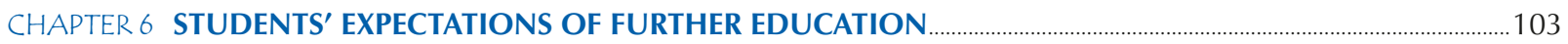

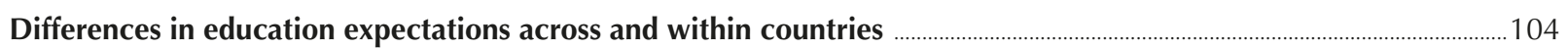

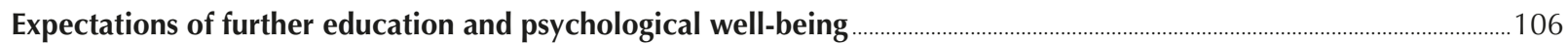

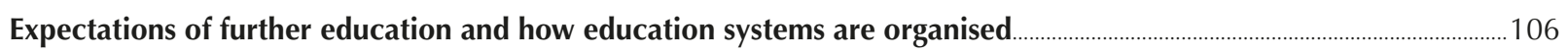

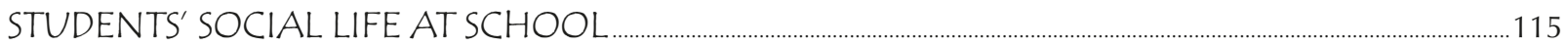

CHAPTER 7 STUDENTS' SENSE OF BELONGING AT SCHOOL AND THEIR RELATIONS WITH TEACHERS ...............117

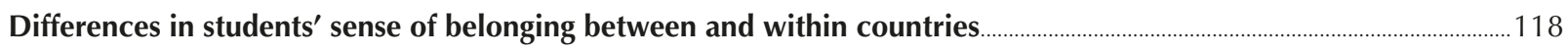

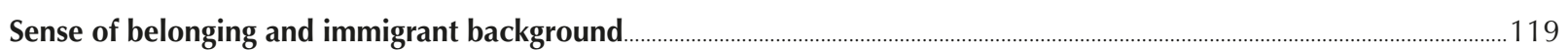

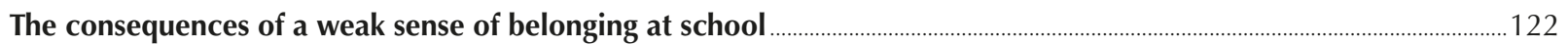

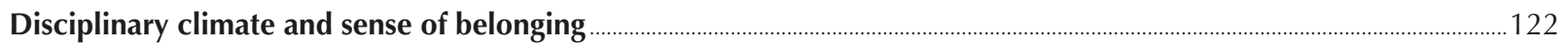

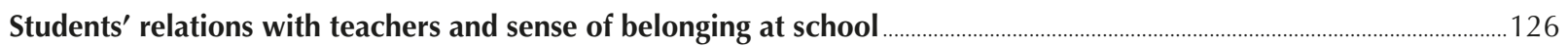

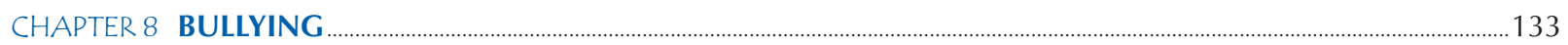

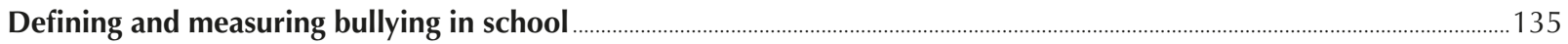

Reported frequency of bullying, victimisation and student characteristics .................................................................... 135

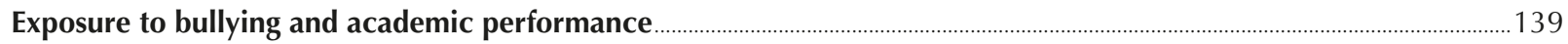

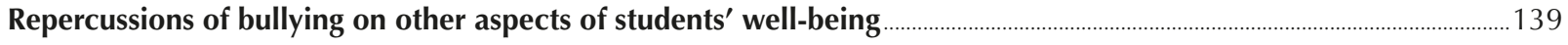

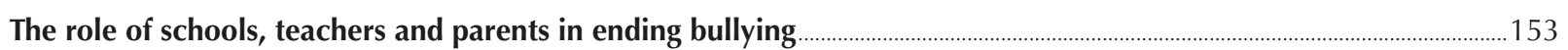

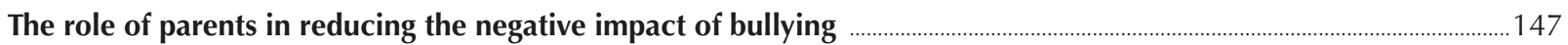

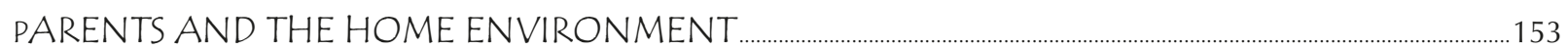

CHAPTER 9 PARENTAL INVOLVEMENT, STUDENT PERFORMANCE AND SATISFACTION WITH LIFE .......................155

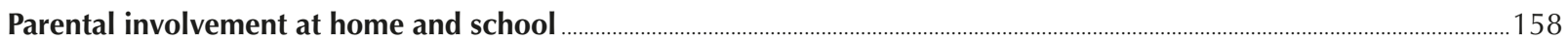

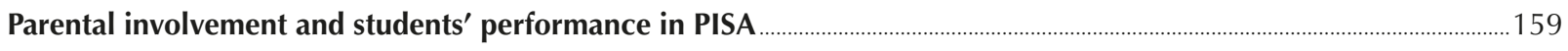

Parental involvement and students' satisfaction with life ............................................................................................................. 162

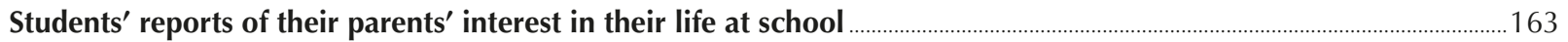

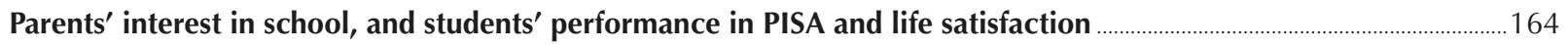

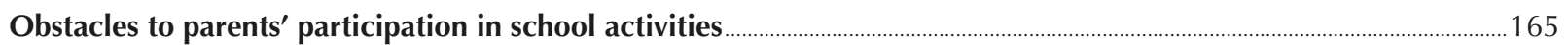

- Language barriers and parents' participation in school activities ……………….................................................................... 167

CHAPTER 10 WEALTH, SOCIAL STATUS AND INEQUALITIES IN WELL-BEING .............................................................. 173

Socio-economic inequalities, social segregation at school and performance ……................................................................... 174

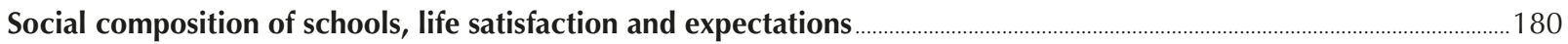

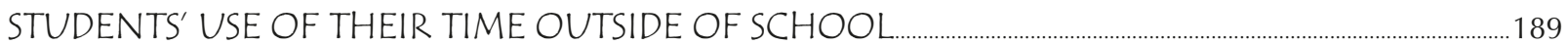

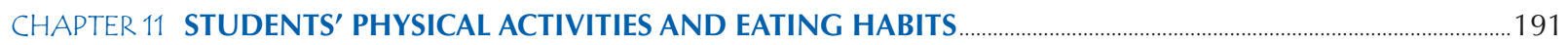

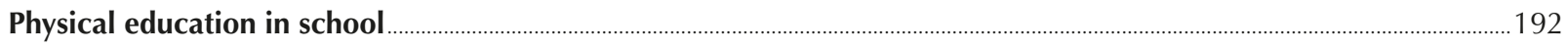

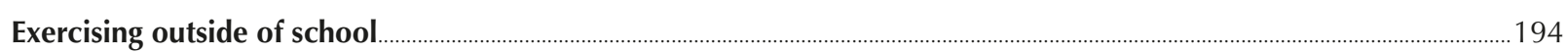


Physical activities and academic performance.

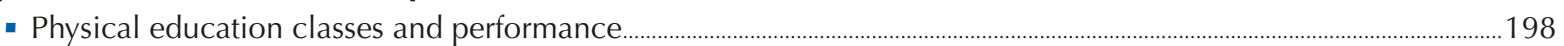

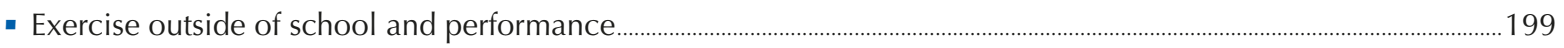

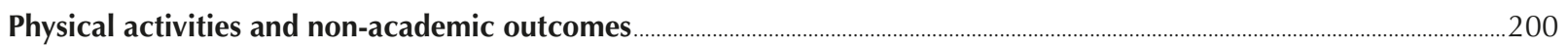

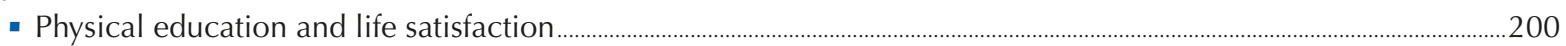

- Physical activities outside of school, life satisfaction and psychological well-being ..................................................200

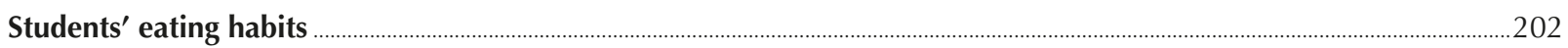

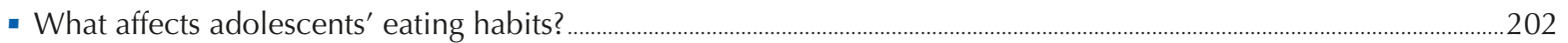

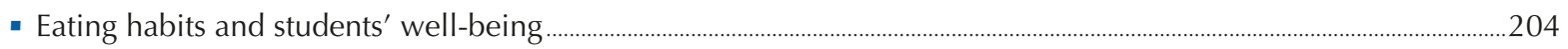

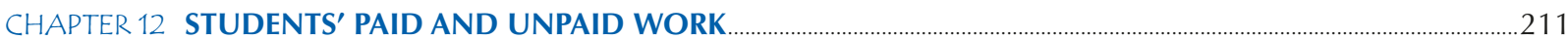

CHAPTER 13 STUDENTS' USE OF ICT OUTSIDE OF SCHOOL

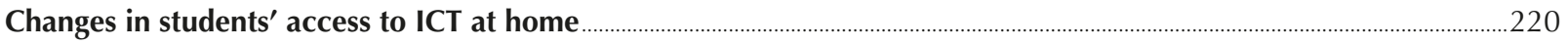

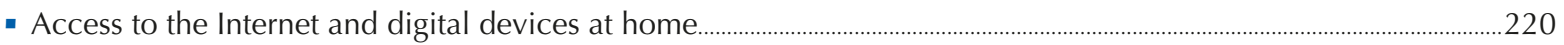

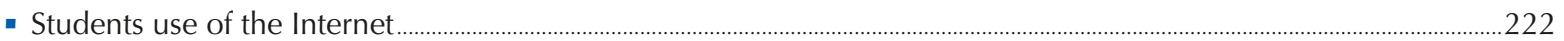

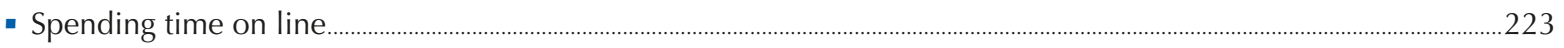

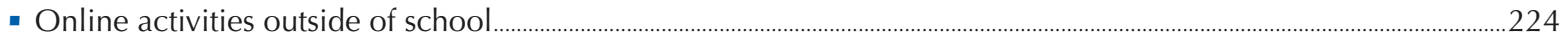

Attitudes towards the Internet

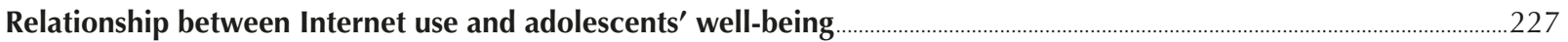

- Consequences of extreme Internet use on students' social and psychological well-being ..........................................227

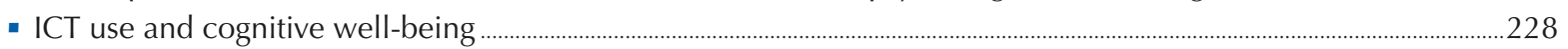

CHAPTER 14 WHAT PISA 2015 RESULTS ON STUDENTS' WELL-BEING IMPLY FOR POLICY …...................................231

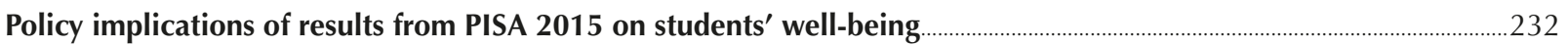

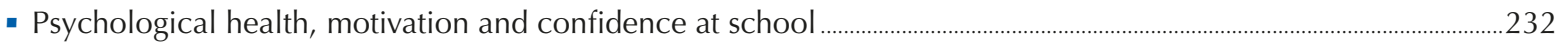

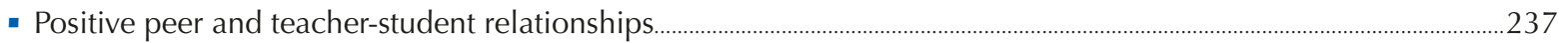

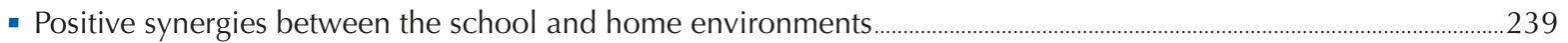

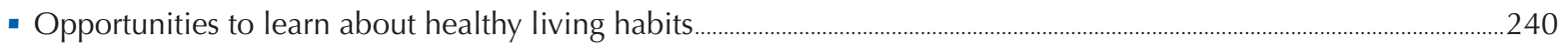

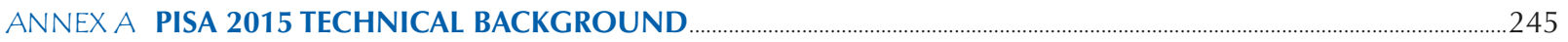

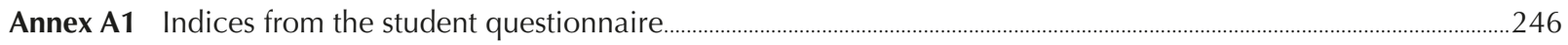

Annex A2 The PISA target population, the PISA samples and the definition of schools ......................................................2256

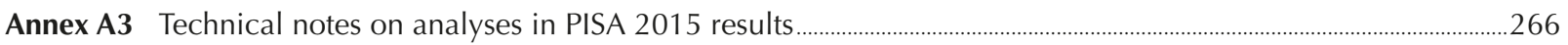

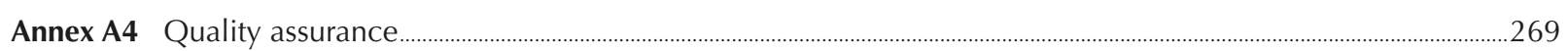

Annex A5 Changes in the administration and scaling of PISA 2015 and implications for trends analyses ......................271

Annex A6 Guidelines and caveats about interpreting the results ................................................................................................2 272

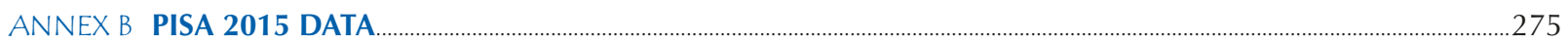

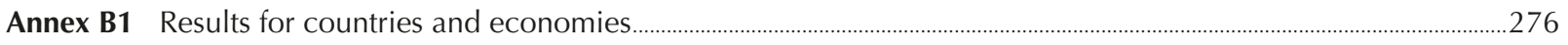

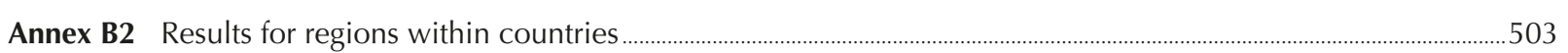

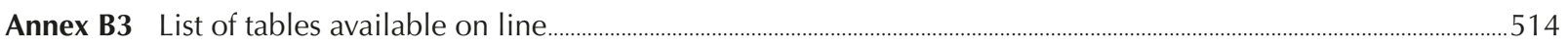

ANNEXC THE DEVELOPMENT AND IMPLEMENTATION OF PISA: A COLLABORATIVE EFFORT .................................519 


\section{BOXES}

Box A.

PISA's contributions to the Sustainable Development Goals

Box B

Key features of PISA 2015 .

Box III.2.1 The OECD How's Life framework for measuring well-being

Box III.2.2 The measurement of cognitive skills in PISA

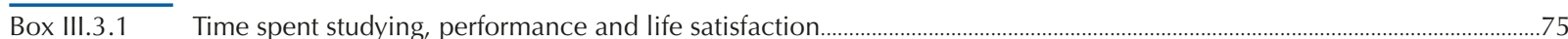

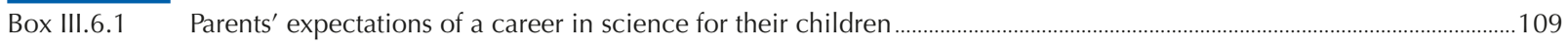

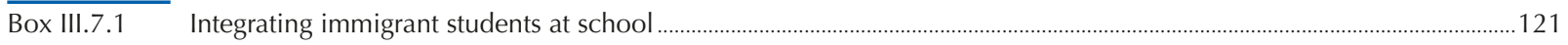

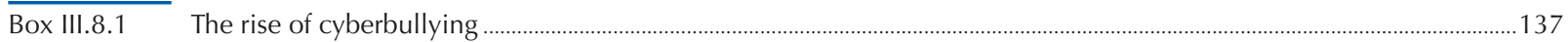

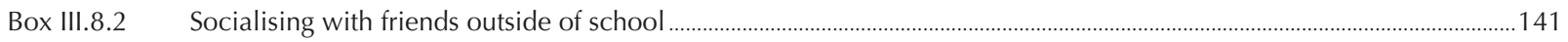

Box III.8.3 Anti-bullying programmes: How they work and evidence of their effectiveness ...........................................................143

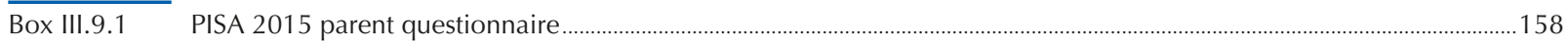

Box III.9.2 Nurturing young scientists

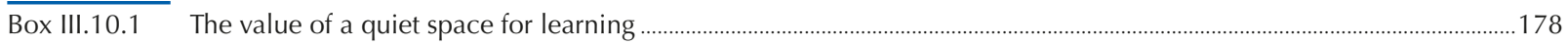

Box III.10.2 Do students expect the same career as their parents?

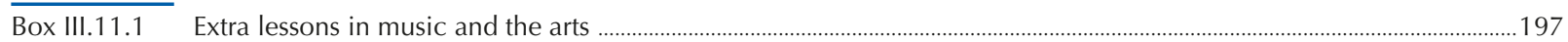

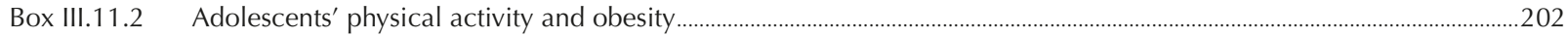

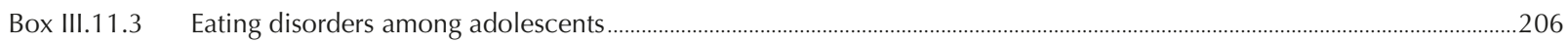

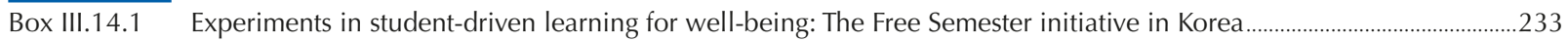

Box III.14.2 Online resources for teachers' professional development on well-being: The Australian Student Wellbeing Hub.......234

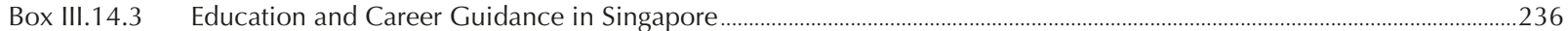

Box III.14.4 Improving the learning environment to fight bullying: The case of Castile and Leon ...............................................................238

\section{FIGURES}

Map of PISA countries and economies

Figure III.1.1 Snapshot of students' life satisfaction

Figure III.2.1 The OECD framework for measuring well-being...

Figure III.2.2 Dimensions and sources of students' well-being

Figure III.3.7 Teacher support in "happy" and "unhappy" schools 


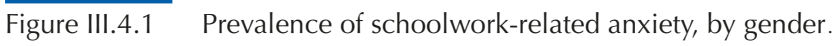

Figure III.4.2 Schoolwork-related anxiety among students in the top and bottom quarters of science performance..............................86

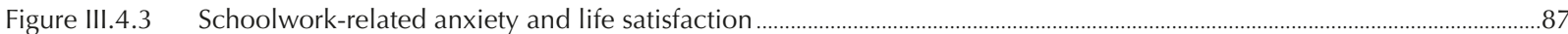

Figure III.4.4 Schoolwork-related anxiety in top-performing schools ..................................................................................................................

Figure III.4.5 Teachers' practices and students' schoolwork-related anxiety …....................................................................................

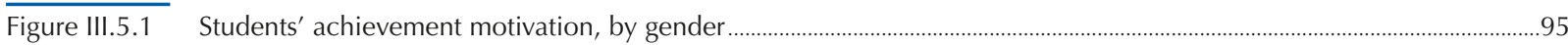

Figure III.5.2 Gender differences in achievement motivation and science performance .................................................................................97

Figure III.5.3 Achievement motivation and students' performance in science _...................................................................................................98

Figure III.5.4 Students' achievement motivation and resilience........................................................................................................................

Figure III.5.5 Achievement motivation and anxiety, between countries .................................................................................................99

Figure III.5.6 Achievement motivation and anxiety, within countries .............................................................................................................. 100

$\overline{\text { Figure III.6.1 }}$ Percentage of students expecting to complete each education level .......................................................................................... 105

Figure III.6.2 Life satisfaction and expectations of completing a university degree ………………........................................................ 107

Figure III.6.3 Expectations of completing a university degree and performance ……………........................................................................ 107

Figure III.6.4 Age at sorting into education tracks and expectations of completing a university degree............................................. 109

Figure III.6.5 Parents who expect a career in science for their child, by student's gender .........................................................................110

Figure III.7.1 Change through 2003, 2012 and 2015 in students' sense of belonging at school............................................................119

Figure III.7.2 Index of sense of belonging, by student characteristics................................................................................................. 120

Figure III.7.3 Immigrant students' sense of belonging at school, by countries of origin and destination.................................................121

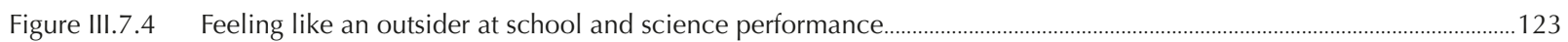

Figure III.7.5 Feeling like an outsider at school and low life satisfaction .................................................................................................... 124

Figure III.7.6 Sense of belonging and disciplinary climate in school ....................................................................................................

Figure III.7.7 Students' perception of teachers' unfairness, by gender ………………………………………………………………………….... 126

Figure III.7.8 Students' sense of belonging at school, by perception of teacher support.................................................................... 127

Figure III.7.9 Students' sense of belonging and perceptions of teachers' unfairness ..........................................................................128

$\overline{\text { Figure III.8.1 }}$ Measures of bullying from the victim's perspective ……......................................................................................................

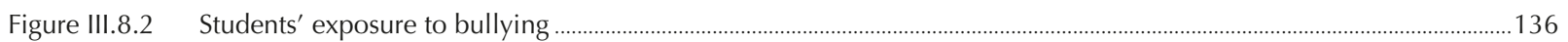

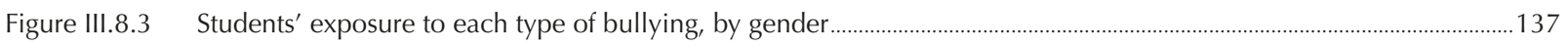

Figure III.8.4 Immigrant students' age at arrival in the host country and exposure to bullying ........................................................ 138

Figure III.8.5 Percentage of frequently bullied students, by science performance ...................................................................................... 139

Figure III.8.6 Prevalence of bullying and school performance in science ……….................................................................................. 140

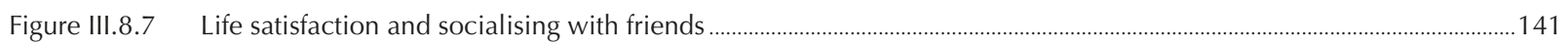

Figure III.8.8 Relationship between being frequently bullied and other student outcomes _............................................................ 142

Figure III.8.9 Exposure to bullying and school's disclipinary climate ........................................................................................ 145

Figure III.8.10 Students' exposure to bullying and perceptions of teachers' unfairness ……............................................................... 146

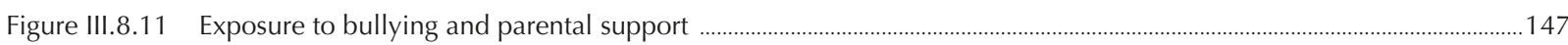

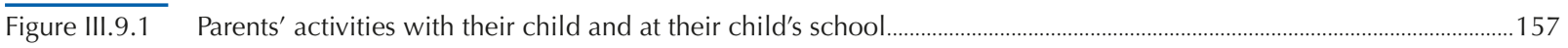

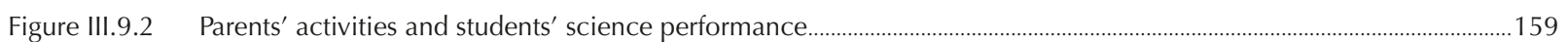

Figure III.9.3 Science-related activities at age 10, and students' enjoyment of and self-efficacy in science ......................................161

Figure III.9.4 Parents' activities and students' life satisfaction ........................................................................................................... 162 
Figure III.9.5 Parents' interest in their child's activities at school, by socio-economic status ......................................................... 163

Figure III.9.6 Parents' interest in their child's activities at school and science performance..................................................................... 164

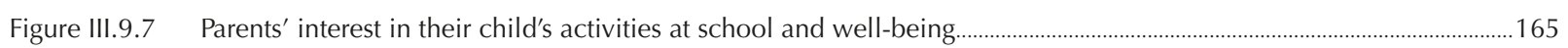

Figure III.9.8 Obstacles to parents' participation in their child's school activities ................................................................................. 166

Figure III.9.9 Parents who initiate talks with their child's teacher, by parents' socio-economic status, gender

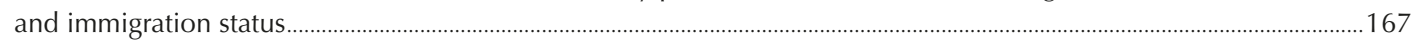

Figure III.9.10 Immigrant background and language skills hindering parents' participation in school activities.................................168

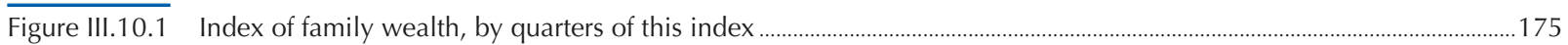

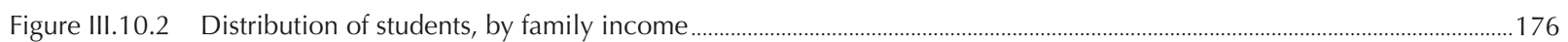

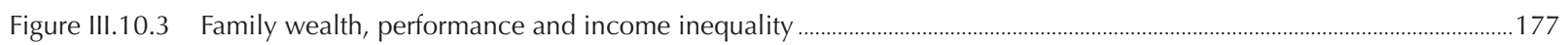

Figure III.10.4 Social segregation at school, by parents' occupation ......................................................................................................... 179

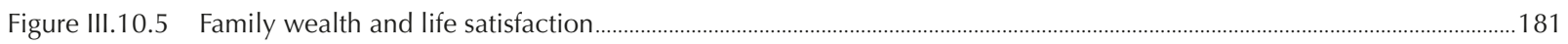

Figure III.10.6 Relative wealth at school and life satisfaction .................................................................................................................... 182

Figure III.10.7 Percentage of students who expect the same career as their parents, by gender ................................................................ 183

Figure III.10.8 Students' expectations and social composition of their school...................................................................................... 185

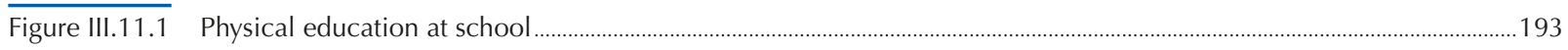

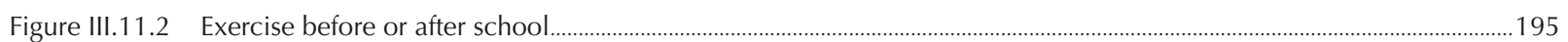

Figure III.11.3 Physical activities outside of school ............................................................................................................................ 196

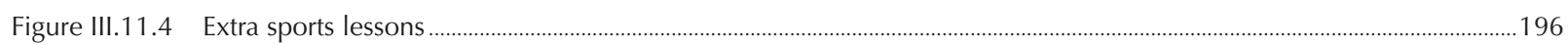

Figure III.11.5 Gender differences in additional music and art lessons................................................................................................................... 197

Figure III.11.6 Physical activities, in and outside of school ......................................................................................................... 198

Figure III.11.7 Physical activity outside of school and science performance, between countries ............................................................. 199

Figure III.11.8 Physical activity outside of school and science performance (OECD average) ...........................................................200

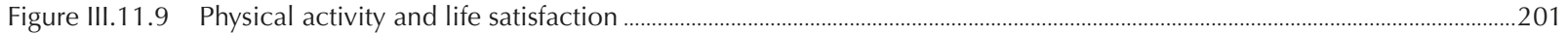

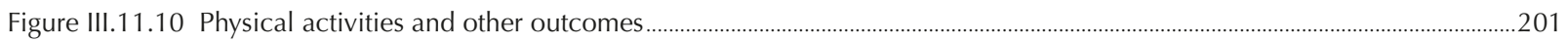

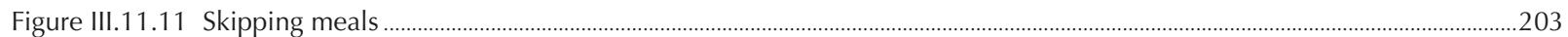

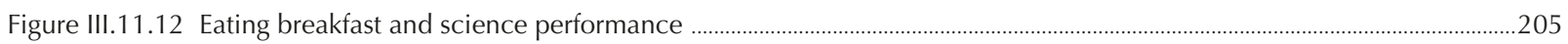

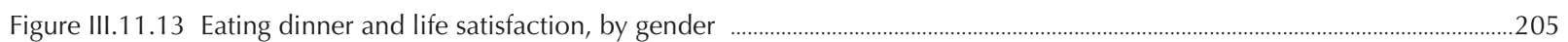

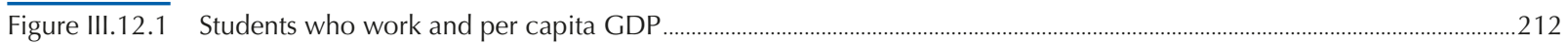

Figure III.12.2 Students who work for pay, by socio-economic status ...................................................................................................2 213

Figure III.12.3 Students who work at home, by gender and socio-economic status........................................................................................2214

Figure III.12.4 Working for pay and science performance ...........................................................................................................................2 216

Figure III.12.5 Working at home and science performance ..............................................................................................................................2 216

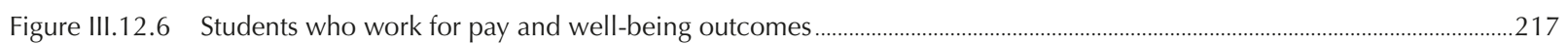

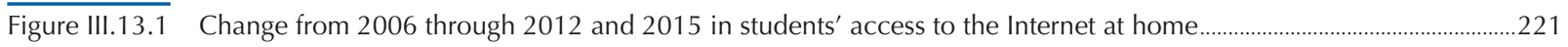

Figure III.13.2 Change between 2012 and 2015 in the share of children who used the Internet when they were

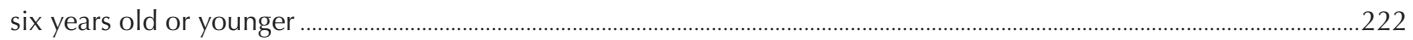

Figure III.13.3 Change between 2012 and 2015 in time spent on line outside of school..........................................................................2223

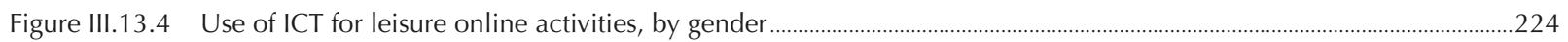

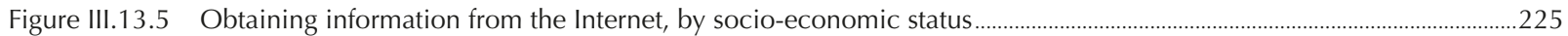

Figure III.13.6 Feeling bad if not connected to the Internet, by gender.............................................................................................................226

Figure III.13.7 Average life satisfaction, by time spent on the Internet outside of school during weekend days ...................................227 
Figure III.13.8 Well-being outcomes, by time spent on the Internet

Figure III.13.9 Science performance, by amount of time spent on the Internet outside of school during weekdays .

$\overline{\text { Figure III.14.1 }}$ The Singapore Education and Career Guidance framework from primary school to working life

\section{TABLES}

Table A1.1

Differences in the definition of science-related career expectations. 
Table III.7.3

Table III.7.4

Table III.7.5

Table III.7.6

Table III.7.8a

Table III.7.10

Table III.7.11

Table III.7.13

Table III.7.14

Table III.7.15

Table III.7.16

Table III.7.17

Table III.7.18

Table III.8.1

Table III.8.2

Table III.8.4

Table III.8.5

Table III.8.6

Table III.8.7a

Table III.8.9

Table III.8.10

Table III.8.15

Table III.8.16

Table III.8.23

Table III.9.1

Table III.9.3

Table III.9.4

Table III.9.6

Table III.9.9

Table III.9.11

Table III.9.13

Table III.9.15

Table III.9.16

Table III.9.18

Table III.9.20

Table III.9.22

Table III.9.23

Table III.9.24

Table III.9.25

Table III.9.26

Table III.10.1

Table III.10.2

Table III.10.6
Students' sense of belonging, by immigrant background . 343

Change between 2003 and 2015 in students' sense of belonging ……............................................................................. 345

Change between 2012 and 2015 in students' sense of belonging ............................................................................34

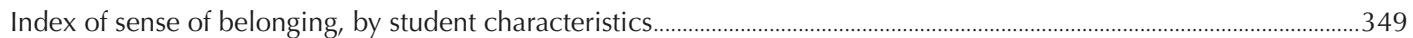

Index of sense of belonging, by student performance in science ……………............................................................................ 352

Science performance and feeling like an outsider ........................................................................................................ 353

Index of sense of belonging and life satisfaction ……………………………………………………………………………. 354

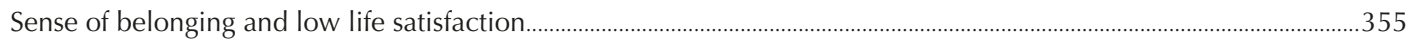

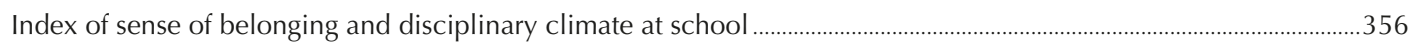

Students' perception of teacher unfairness

Students' perception of teacher unfairness, by gender and socio-economic status ...............................................................360

Students' perception of teacher unfairness, by immigrant background ................................................................................ 366

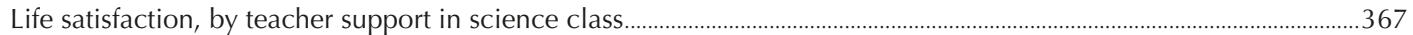

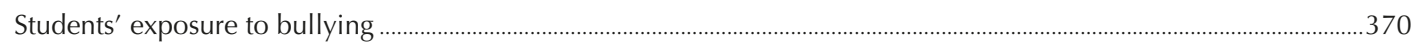

Students' exposure to different types of bullying, by gender and socio-economic status .....................................................374

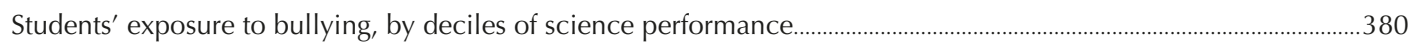

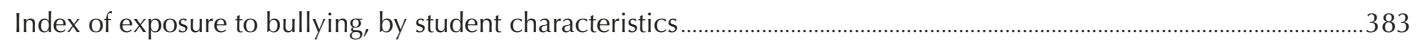

Index of exposure to bullying, by school characteristics .............................................................................................................. 385

Index of exposure to bullying, by student performance in science .................................................................................. 387

Index of exposure to bullying and life satisfaction ………………………………………………………………………….... 388

Difference in science performance between schools with high and low prevalence of bullying......................................389

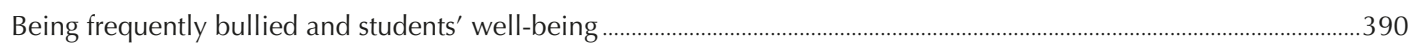

Relationship between being frequently bullied and schools' disciplinary climate ...................................................................393

Relationship between talking with friends and life satisfaction .............................................................................................. 394

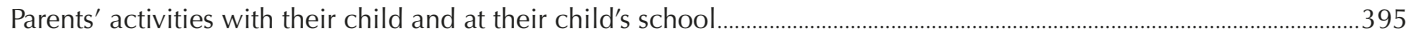

Change between 2012 and 2015 in parents' activities with their child and at their child's school...............................396

Parents' activities and student science performance .......................................................................................................... 398

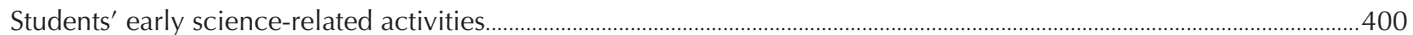

Students' early science-related activities and expectations of a science-related career...................................................401

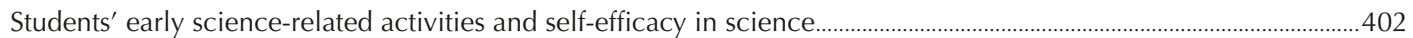

Students' early science-related activities and enjoyment of science ……................................................................................. 403

Students' early science-related activities and performance in science ............................................................................404

Students who talk to their parents before or after school ............................................................................................................... 405

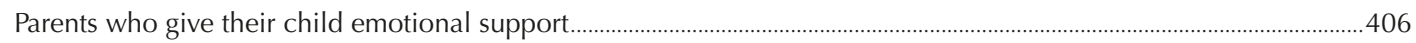

Students' perception of their parents' interest in their school activities ...................................................................... 407

Parents' interest in their child's activities at school and student science performance ……................................................409

Parents who initiate talks with their child's teacher, by parents' socio-economic status, gender

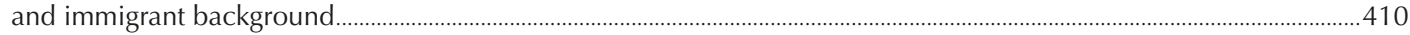

Parents' interest in their child's activities at school and student well-being outcomes ....................................................411

Parents' participation in school activities and language skills, by immigrant background ...................................................412

Obstacles to parents' participation in their child's school activities .................................................................................... 412

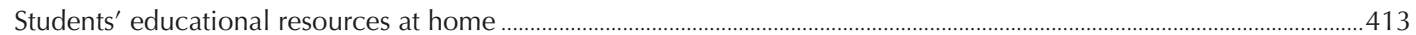

Availability of a quiet place to study and science performance ..................................................................................... 414

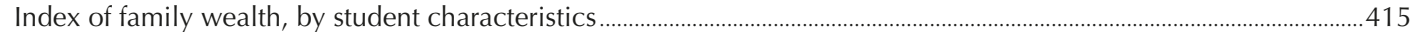


Table III.10.7 Index of family wealth, by student performance in science 417

Table III.10.8 Students' life satisfaction, by the index of family wealth .............................................................................................................. 418

Table III.10.9 Index of family wealth and life satisfaction ..................................................................................................................

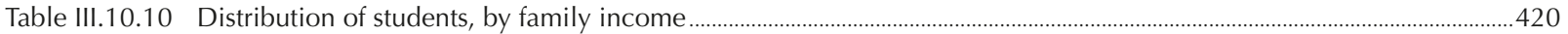

Table III.10.13 Parental occupation, private schools and segregation at school........................................................................................... 421

Table III.10.14 Parental occupation, vocational programmes and segregation at school ............................................................................423

Table III.10.15 Students' expectations and parental occupation .............................................................................................................................. 424

Table III.10.16 Students expecting the same career as their parents.......................................................................................................

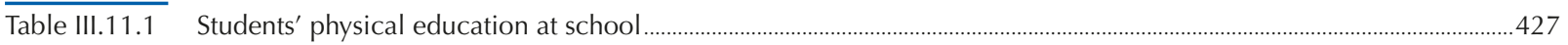

Table III.11.4a Physical activity at school, by student performance in science ……............................................................................428

Table III.11.5 Physical activity at school and life satisfaction.............................................................................................................................. 429

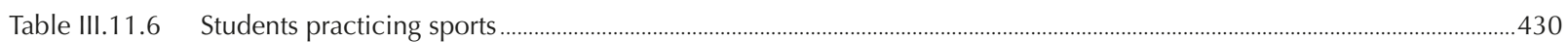

Table III.11.7b Students practicing sports after school, by student characteristics ........................................................................................... 431

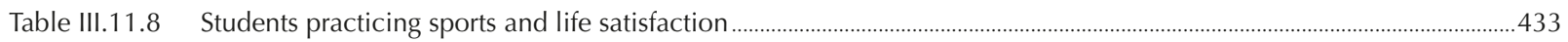

Table III.11.9 Frequency of students' physical activity outside of school ................................................................................................. 434

Table III.11.10 Students who do not engage in physical activity outside of school, by student characteristics.........................................436

Table III.11.11a Engaging in moderate physical activity outside of school and student science performance ........................................438

Table III.11.12a Engaging in vigorous physical activity outside of school and student performance in science.........................................439

Table III.11.13 Frequency of students' physical activity outside of school, by student characteristics _.........................................................440

Table III.11.15 Frequency of students' physical activity outside of school and science performance …................................................444

Table III.11.16 Physical activity outside of school and students' satisfaction with life ..................................................................................446

Table III.11.17 Relationship between students' physical activity in school and outside of school.....................................................448

Table III.11.18 Physical activity outside of school and well-being outcomes …..........................................................................................449

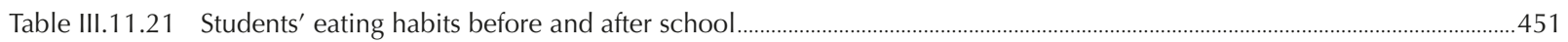

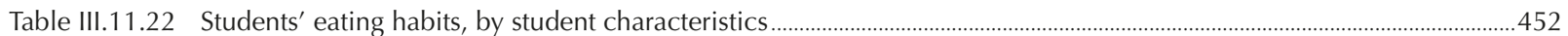

Table III.11.24a Eating breakfast and student performance in science ..................................................................................................................456

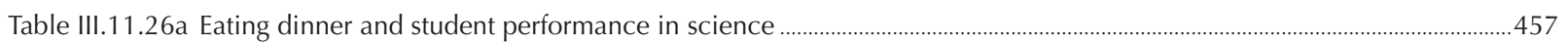

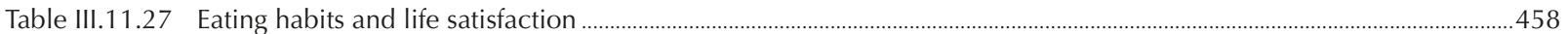

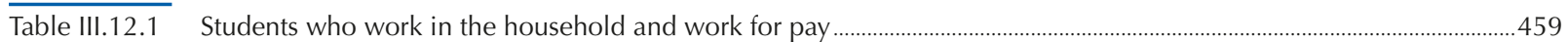

Table III.12.2 Students who work in the household, by student characteristics .................................................................................................. 460

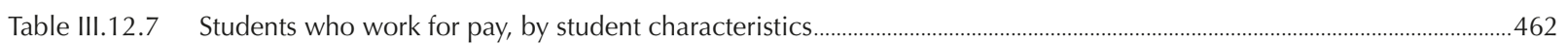

Table III.12.8 Students who work for pay and science performance, by student characteristics ........................................................464

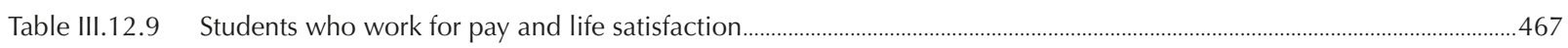

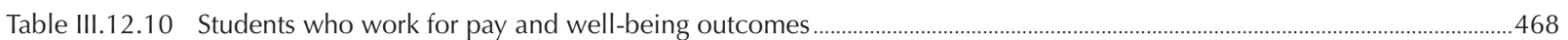

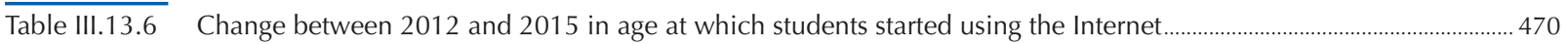

Table III.13.7 Internet use outside of school on a typical weekday, by gender ......................................................................................................472

Table III.13.8 Internet use outside of school on a typical weekend day, by gender ...............................................................................474

Table III.13.9 Change between 2012 and 2015 in time spent using the Internet outside of school ....................................................476

Table III.13.10 Use of Internet/chat/social networks before and after school .....................................................................................................477

Table III.13.11 Use of Internet/chat/social networks before and after school, by student characteristics.............................................478

Table III.13.13 Use of online games/chat/social networks outside of school, by gender and socio-economic status .............................482

Table III.13.16 Students' attitudes towards using the Internet, by gender and socio-economic status ..................................................485

Table III.13.19a Sense of belonging at school, by time spent on the Internet outside of school on weekdays …….................................488 
Table III.13.20a Being bullied at school, by time spent on the Internet outside of school on weekdays ..............................................491

Table III.13.21 Engagement with school, by time spent on the Internet outside of school on weekdays ................................................494

Table III.13.21 Engagement with school, by time spent on the Internet outside of school on weekdays ...............................................495

Table III.13.21 Engagement with school, by time spent on the Internet outside of school on weekdays .............................................496

Table III.13.22 Educational expectations, by time spent on the Internet outside of school on weekdays...................................................497

Table III.13.23 Use of the Internet outside of school and life satisfaction ........................................................................................... 499

Table III.13.24a Time spent on the Internet outside of school on weekdays and performance in science........................................................501

Table III.13.25a Time spent on the Internet outside of school on weekend days and performance in science.......................................502

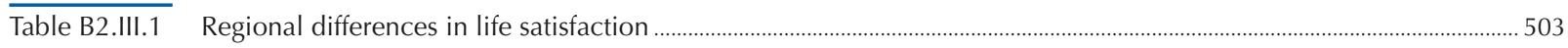

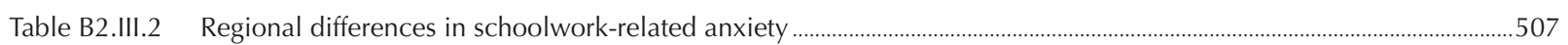

Table B2.III.3 Regional differences in achievement motivation and education expectations .................................................................508

Table B2.III.4 Regional differences in sense of belonging ................................................................................................................................. 510

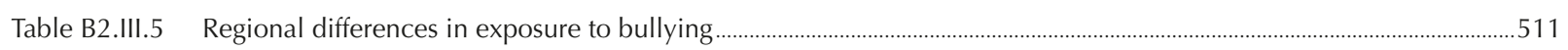

Table B2.III.6 Regional differences in parental support and wealth .............................................................................................................. 512

Table B2.III.7 Regional differences in activities outside of school................................................................................................................. 513

\title{
Follow OECD Publications on:
}

\author{
http://twitter.com/OECD_Pubs \\ f http://www.facebook.com/OECDPublications \\ in. http://www.linkedin.com/groups/OECD-Publications-4645871 \\ Yulbe http://www.youtube.com/oecdilibrary \\ OECD \\ Aleris $\quad h t t p: / / w w w . o e c d . o r g / o e c d d i r e c t /$
}

\section{This book has...}

Look for the StatLinks inis at the bottom of the tables or graphs in this book. To download the matching Excel® spreadsheet, just type the link into your Internet browser, starting with the $h t t p: / / d x . d o i . o r g$ prefix, or click on the link from the e-book edition. 


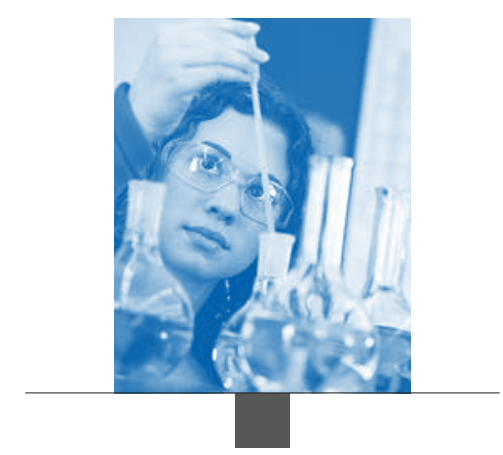

\section{Executive summary}

Schools are not only places where students acquire academic skills; they are also where children develop many of the social and emotional skills that they need to thrive. Schools that nurture children's development in these ways help students attain a sense of control over - and satisfaction with - their life. They can help students become more resilient in the face of adversity, feel more connected with the people around them, and aim higher in their aspirations for their future. In other words, what happens in school is crucial for well-being. Students' well-being, as defined in this report, refers to the psychological, cognitive, social and physical qualities that students need to live a happy and fulfilling life.

PISA 2015 examined students' well-being in four main areas of their life: their performance in school, their relationships with peers and teachers, their home life, and how they spend their time outside of school. On average across OECD countries, students reported a level of 7.3 on a life-satisfaction scale ranging from 0 to 10 . Roughly speaking, this suggests that the "average" adolescent in an OECD country is satisfied with life. However, about $12 \%$ of students, on average across OECD countries - and more than $20 \%$ of students in some countries - reported that they are not satisfied with their life (they rated their satisfaction with life 4 or less on the scale). Satisfaction with life varies considerably between boys and girls (on average across OECD countries, 29\% of girls but 39\% of boys reported that they are very satisfied with their life), while there is little difference in reported life satisfaction between top-achieving and low-achieving students.

Anxiety about schoolwork is one of the sources of stress most often cited by school-age children and adolescents. On average across OECD countries, students who reported the highest levels of anxiety also reported a level of life satisfaction that is 1.2 points lower (on a scale of from 0 to 10) than students who reported the lowest levels of anxiety.

A greater motivation to achieve can give students a sense of purpose in life. It is thus not surprising that, across all countries and economies that participated in PISA 2015, students with greater overall motivation to achieve reported higher satisfaction with life.

\section{SOCIAL RELATIONS AND STUDENTS' WELL-BEING}

In many countries, verbal and psychological bullying occur frequently at school. More than one in ten students - which means at least a couple of students in a typical class - in 34 out of 53 countries and economies reported that their peers make fun of them at least a few times per month. Physical bullying is less frequent, but still a major problem in many schools. Around $4 \%$ of students - that is, roughly one per class - reported that they are hit or pushed at least a few times per month, and another $7.7 \%$ of students reported they are physically bullied a few times per year. On average across OECD countries, $42 \%$ of students who reported that they are frequently bullied also reported feeling like an outsider at school. Students in OECD countries who feel like they are outsiders at school were three times more likely to report that they are not satisfied with their life than those who do not feel like they are outsiders. In many countries and economies, students' sense of belonging at school has declined since PISA 2003.

PISA data show that certain types of parental activities are positively related not only to students' performance, but also to students' satisfaction with their life. Students whose parents reported "spending time just talking to my child", "eating 
the main meal with my child around a table" or "discussing how well my child is doing at school" every week were between $22 \%$ and $62 \%$ more likely to report high levels of life satisfaction than students whose parents reported engaging in these activities less frequently.

In most countries, students reported less satisfaction with life if they perceive that they are not as wealthy as most of the other students in the school. But attending school with more advantaged schoolmates can also have a positive impact on students. On average across 28 countries and economies with available data, the children of blue-collar workers who attend schools where students have parents with white-collar occupations were around twice as likely to expect to earn a university degree than children of blue-collar workers who perform similarly but who attend other schools.

\section{WHAT STUDENTS DO OUTSIDE OF SCHOOL AND THEIR WELL-BEING}

On average across OECD countries, students who reported taking part in some moderate or vigorous physical activity were less likely to report that they feel very anxious about schoolwork and that they feel like an outsider at school. But around $6 \%$ of boys and $7 \%$ of girls reported that they do not participate in any form of physical activity outside of school. Many students spend a lot of their time on the Internet: $26 \%$ of students reported that they spend more than six hours per day on line during weekends, and 16\% spend a similar amount of time on line during weekdays. These "extreme Internet users" are more likely to feel lonely at school, have low expectations of further education, and tend to arrive late for school.

Students who work for pay outside of school reported a level of satisfaction with life that is similar to that of students who do not work. But students who work for pay were more likely to report disengagement from school.

\section{WHAT THE PISA RESULTS IMPLY FOR POLICY}

The data from PISA 2015 show that many of the differences, both between and within countries, in students' well-being are related to students' perceptions about the disciplinary climate in the classroom or about the support their teachers give them. In particular, schools can help eradicate bullying in partnerships with parents, community organisations and health or social services. The data also show that parental involvement and adolescents' perceptions about the support their parents give them are associated with students' feelings about schoolwork, their performance in PISA and their well-being, in general. These results suggest that forging stronger relationships between schools and parents to give adolescents the support they need - academically and psychologically - could go a long way towards improving the well-being of all students. 


\section{Reader's guide}

\section{Data underlying the figures}

The data referred to in this volume are presented in Annex B and, in greater detail, including some additional tables, on the PISA website (www.pisa.oecd.org).

Five symbols are used to denote missing data:

a The category does not apply in the country concerned. Data are therefore missing.

c There are too few observations or no observation to provide reliable estimates (i.e. there are fewer than 30 students or fewer than 5 schools with valid data).

$\mathrm{m}$ Data are not available. These data were not submitted by the country or were collected but subsequently removed from the publication for technical reasons.

w Data have been withdrawn or have not been collected at the request of the country concerned.

\section{Country coverage}

This publication features data on 72 countries and economies, including all 35 OECD countries and 37 partner countries and economies (see Map of PISA countries and economies in "What is PISA").

The statistical data for Israel are supplied by and under the responsibility of the relevant Israeli authorities. The use of such data by the OECD is without prejudice to the status of the Golan Heights, East Jerusalem and Israeli settlements in the West Bank under the terms of international law.

Two notes were added to the statistical data related to Cyprus:

Note by Turkey: The information in this document with reference to "Cyprus" relates to the southern part of the Island. There is no single authority representing both Turkish and Greek Cypriot people on the Island. Turkey recognises the Turkish Republic of Northern Cyprus (TRNC). Until a lasting and equitable solution is found within the context of the United Nations, Turkey shall preserve its position concerning the "Cyprus issue".

Note by all the European Union Member States of the OECD and the European Union: The Republic of Cyprus is recognised by all members of the United Nations with the exception of Turkey. The information in this document relates to the area under the effective control of the Government of the Republic of Cyprus.

B-S-J-G (China) refers to the four PISA-participating China provinces: Beijing, Shanghai, Jiangsu and Guangdong. FYROM refers to the Former Yugoslav Republic of Macedonia.

For the countries below, when results are based on students' or school principals' responses:

Argentina: Only data for the adjudicated region of Ciudad Autónoma de Buenos Aires (CABA) are reported in figures and in the text (see Annex A4).

Kazakhstan: Results for Kazakhstan are reported in a selection of figures (see Annex A4).

Malaysia: Results for Malaysia are reported in a selection of figures (see Annex A4).

\section{International averages}

The OECD average corresponds to the arithmetic mean of the respective country estimates. It was calculated for most indicators presented in this report.

In this publication, the OECD average is generally used when the focus is on comparing characteristics of education systems. In the case of some countries, data may not be available for specific indicators, or specific categories may not apply. Readers should, therefore, keep in mind that the term "OECD average" refers to the OECD countries included in the respective comparisons. In cases where data are not available or do not apply for all sub-categories of a given population or indicator, the "OECD average" may be consistent within each column of a table but not necessarily across all columns of a table. 
In analyses involving data from multiple years, the OECD average is reported on consistent sets of OECD countries, and several averages may be reported in the same table. The "OECD average-35" refers to the average across all the 35 OECD countries, and is reported as missing if fewer than 35 OECD countries have comparable data; for instance, the "OECD average-34" includes only 34 OECD countries that have non-missing values. This restriction allows for valid comparisons of the OECD average over time. A number in the label used in figures and tables indicates the number of countries included in the average.

In analyses involving data from optional questionnaires, in addition to the OECD average, an average across all countries and economies with available data is also reported:

Average-18: Arithmetic mean across all countries which participated in the parent questionnaire.

Average-19: Arithmetic mean across all countries which participated in the teacher questionnaire.

Average-22: Arithmetic mean across all countries which participated in the educational career questionnaire.

In cases where data are not available for all countries that participated in the optional questionnaire, the number of countries included in the average is indicated in a footnote.

\section{Rounding figures}

Because of rounding, some figures in tables may not add up exactly to the totals. Totals, differences and averages are always calculated on the basis of exact numbers and are rounded only after calculation.

All standard errors in this publication have been rounded to one or two decimal places. Where the value 0.0 or 0.00 is shown, this does not imply that the standard error is zero, but that it is smaller than 0.05 or 0.005 , respectively.

\section{Reporting student data}

The report uses "15-year-olds" as shorthand for the PISA target population. PISA covers students who are aged between 15 years 3 months and 16 years 2 months at the time of assessment and who are enrolled in school and have completed at least 6 years of formal schooling, regardless of the type of institution in which they are enrolled, and whether they are in full-time or part-time education, whether they attend academic or vocational programmes, and whether they attend public or private schools or foreign schools within the country.

\section{Reporting school data}

The principals of the schools in which students were assessed provided information on their schools' characteristics by completing a school questionnaire. Where responses from school principals are presented in this publication, they are weighted so that they are proportionate to the number of 15 -year-olds enrolled in the school.

\section{Focusing on statistically significant differences}

This volume discusses only statistically significant differences or changes. These are denoted in darker colours in figures and in bold font in tables. See Annex A3 for further information.

\section{Changes in the PISA methodology}

Several changes were made to the PISA methodology in 2015:

- Change in assessment mode from paper-based to computer. Over the past 20 years, digital technologies have fundamentally transformed the ways in which we read and manage information. To better reflect how students and societies access, use and communicate information, starting with the 2015 round, the assessment was delivered mainly on computers, although countries had the option to use a paper-based version. In order to ensure comparability of results between paper-based tasks that were used in previous PISA assessments and the computer-delivered tasks used in 2015, the 2015 assessment was anchored to previous assessments through a set of items that showed, across countries, the same characteristics in paper- and computer-delivered form. The statistical models used to facilitate the mode change are based on an approach that examines measurement invariance for each item in both modes. In effect, this both accounts for and corrects the potential effect of 
mode differences by assigning the same parameters only for item-response variables that are comparable on paper and computer. It is conceivable, however, that country differences in familiarity with computers, or in student motivation to take the test on computer or on paper could influence differences in country performance. Box I.5.1 in Volume I examines the country-level correlation between students' exposure to computers and changes in mean mathematics performance between 2012 and 2015. The results show that countries where students have greater familiarity with ICT tools are roughly as likely to show positive and negative performance trends, as are countries where students have less familiarity with ICT. For more information, see Annex A5.

- Change in the framework and set of PISA science items. New science items were developed for PISA 2015 to reflect advances in science and other changes that countries had prioritised for the PISA 2015 assessment. Among other goals, the revision of the science framework included the aim to more fully use the capabilities of the new technology-based delivery mode. To verify that the new science assessment allowed for the establishment of reliable trends with previous PISA assessments, an evaluation of dimensionality was conducted. When new and existing science items were treated as related to distinct latent dimensions, the median correlation (across countries/language groups) between these dimensions was 0.92, a very high value (similar to the correlation observed among subscales from the same domain). Model-fit statistics confirmed that a unidimensional model fits the new science assessment, supporting the conclusion that new and existing science items form a coherent unidimensional scale with good reliability. For more information, see Annex A5.

- Changes in scaling procedures include:

- Change from a one-parameter model to a hybrid model that applies both a one- and two-parameter model, as appropriate. The one-parameter (Rasch) model is retained for all items where the model is statistically appropriate; a more general 2-parameter model is used instead if the fit of the one-parameter model could not be established. This approach improves the fit of the model to the observed student responses and reduces model and measurement errors.

- Change in treatment of non-reached items to ensure that the treatment is consistent between the estimation of item parameters and the estimation of the population model to generate proficiency estimates in the form of plausible values. This avoids introducing systematic errors when generating performance estimates.

- Change from cycle-specific scaling to multiple-cycle scaling in order to combine data, and retain and aggregate information about trend items used in previous cycles. This change results in consistent item parameters across cycles, which strengthen and support the inferences made about proficiencies on each scale.

- Change from including only a subsample for item calibration to including the total sample with weights, in order to fully use the available data and reduce the error in item-parameter estimates by increasing the sample size. This reduces the variability of item-parameter estimation due to the random selection of small calibration samples.

- Change from assigning internationally fixed item parameters and dropping a few dodgy items per country, to assigning a few nationally unique item parameters for those items that show significant deviation from the international parameters. This retains a maximum set of internationally equivalent items without dropping data and, as a result, reduces overall measurement errors.

The overall impact of these changes on trend comparisons is quantified by the link errors. As in previous cycles, a major part of the linking error is due to re-estimated item parameters. While the magnitude of link errors is comparable to those estimated in previous rounds, the changes in scaling procedures will result in reduced link errors in future assessment rounds. For more information on the calculation of this quantity and how to use it in analyses, see Annex A5 and the PISA 2015 Technical Report (OECD, forthcoming).

- Changes in population coverage and response rates. Even though PISA has consistently used the same standardised methods to collect comparable and representative samples, and population coverage and response rates were carefully reviewed during the adjudication process, slight changes in population coverage and response rates can affect point estimates of proficiency. The uncertainty around the point estimates due to sampling is quantified in sampling errors, which are the major part of standard errors reported for country mean estimates. For more information, see Annexes A2 and A4. 
- Change in test design from 13 booklets in the paper-based design to 396 booklet instances. Despite the significant increase in the number of booklet types and instances from previous cycles, it is important to bear in mind that all items belonging to the same domain were delivered in consecutive clusters. No student had more than one hour of test questions related to one domain only. This is an improvement over the existing design, which was made possible by computer delivery. It strengthens the overall measurement of each domain and each respondent's proficiency.

- Changes in test administration. As in PISA 2000 (but different from other cycles up to 2012), students in 2015 had to take their break before starting to work on test clusters 3 and 4, and could not work for more than one hour on clusters 1 and 2. This reduces cluster position effects. Another change in test administration is that students who took the test on computers had to solve test questions in a fixed, sequential order, and could not go back to previous questions and revise their answers after reaching the end of the test booklets. This change prepares the ground for introducing adaptive testing in future rounds of PISA.

In sum, changes to the assessment design, the mode of delivery, the framework and the set of science items were carefully examined in order to ensure that the 2015 results can be presented as trend measures at the international level. The data show no consistent association between students' familiarity with ICT and with performance shifts between 2012 and 2015 across countries. Changes in scaling procedures are part of the link error, as they were in the past, where the link error quantified the changes introduced by re-estimating item parameters on a subset of countries and students who participated in each cycle. Changes due to sampling variability are quantified in the sampling error. The remaining changes (changes in test design and administration) are not fully reflected in estimates of the uncertainty of trend comparisons. These changes are a common feature of past PISA rounds as well, and are most likely of secondary importance when analysing trends.

The factors below are examples of potential effects that are relevant for the changes seen from one PISA round to the next. While these can be quantified and related to, for example, census data if available, these are outside of the control of the assessment programme:

- Change in coverage of PISA target population. PISA's target population is 15-year-old students enrolled in grade 7 or above. Some education systems saw a rapid expansion of 15-year-olds' access to school because of a reduction in dropout rates or in grade repetition. This is explained in detail, and countries' performance adjusted for this change is presented in Chapters 2, 4 and 5 in Volume I.

- Change in demographic characteristics. In some countries, there might be changes in the composition of the population of 15-year-old students. For example, there might be more students with an immigrant background.

- Change in student competency. The average proficiency of 15-year-old students in 2015 might be higher or lower than that in 2012 or earlier rounds.

\section{Abbreviations used in this report}

\begin{tabular}{ll|ll}
\hline$\%$ dif. & Percentage-point difference & ISCO & International Standard Classification of Occupations \\
\hline Dif. & Difference & PPP & Purchasing power parity \\
\hline ESCS & PISA index of economic, social and cultural status & S.D. & Standard deviation \\
\hline GDP $\quad$ Gross domestic product & S.E. & Standard error \\
\hline ICT Information and Communications Technology & Score dif. & Score-point difference \\
\hline ISCED International Standard Classification of Education & & \\
\hline
\end{tabular}

\section{Definition of immigrant students in PISA}

PISA classifies students into several categories according to their immigrant background and that of their parents:

- Non-immigrant students are students whose mother or father (or both) was/were born in the country or economy where they sat the PISA test, regardless of whether the student was born in that country or economy. In this chapter, these students are also referred to as "students without an immigrant background". 
- Immigrant students are students whose mother and father were both born in a country/economy other than that where the student sat the PISA test. In this chapter, they are also referred to as "students with an immigrant background". Among immigrant students, a distinction is made between those born in the country/economy of assessment and those born abroad:

- First-generation immigrant students are foreign-born students whose parents are also both foreign-born.

- Second-generation immigrant students are students born in the country/economy where they sat the PISA test and whose parents were both foreign-born.

In some analyses, these two groups of immigrant students are, for the purpose of comparison, considered along with non-immigrant students. In other cases, the outcomes of first- and second-generation immigrant students are examined separately. PISA also provides information on other factors related to students' immigrant background, including the main language spoken at home (i.e. whether students usually speak, at home, the language in which they were assessed in PISA or another language, which could also be an official language of the host country/ economy) or, for first-generation immigrant students, the number of years since the student arrived in the country where he or she sat the PISA test.

\section{Further documentation}

For further information on the PISA assessment instruments and the methods used in PISA, see the PISA 2015 Technical Report (OECD, forthcoming).

This report uses the OECD StatLinks service. Below each table and chart is a URL leading to a corresponding Exce $^{\mathrm{TM}}$ workbook containing the underlying data. These URLs are stable and will remain unchanged over time. In addition, readers of the e-books will be able to click directly on these links and the workbook will open in a separate window, if their Internet browser is open and running. 



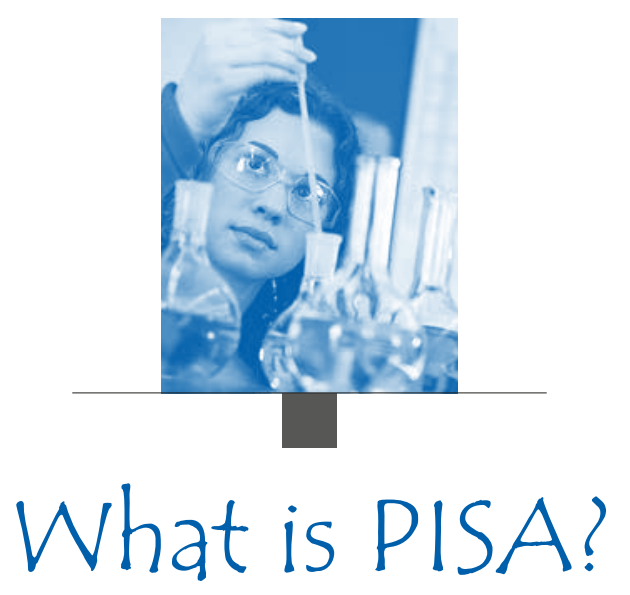

"What is important for citizens to know and be able to do?" In response to that question and to the need for internationally comparable evidence on student performance, the Organisation for Economic Co-operation and Development (OECD) launched the triennial survey of 15-year-old students around the world known as the Programme for International Students Assessment, or PISA. PISA assesses the extent to which 15-year-old students, near the end of their compulsory education, have acquired key knowledge and skills that are essential for full participation in modern societies. The assessment focuses on the core school subjects of science, reading and mathematics. Students' proficiency in an innovative domain is also assessed (in 2015, this domain is collaborative problem solving). The assessment does not just ascertain whether students can reproduce knowledge; it also examines how well students can extrapolate from what they have learned and can apply that knowledge in unfamiliar settings, both in and outside of school. This approach reflects the fact that modern economies reward individuals not for what they know, but for what they can do with what they know.

PISA is an ongoing programme that offers insights for education policy and practice, and that helps monitor trends in students' acquisition of knowledge and skills across countries and in different demographic subgroups within each country. PISA results reveal what is possible in education by showing what students in the highest-performing and most rapidly improving education systems can do. The findings allow policy makers around the world to gauge the knowledge and skills of students in their own countries in comparison with those in other countries, set policy targets against measurable goals achieved by other education systems, and learn from policies and practices applied elsewhere. While PISA cannot identify cause-and-effect relationships between policies/practices and student outcomes, it can show educators, policy makers and the interested public how education systems are similar and different - and what that means for students.

\section{WHAT IS UNIQUE ABOUT PISA?}

PISA is different from other international assessments in its:

- policy orientation, which links data on student learning outcomes with data on students' backgrounds and attitudes towards learning, and on key factors that shape their learning, in and outside of school, in order to highlight differences in performance and identify the characteristics of students, schools and education systems that perform well

- innovative concept of "literacy", which refers to students' capacity to apply knowledge and skills in key subjects, and to analyse, reason and communicate effectively as they identify, interpret and solve problems in a variety of situations

- relevance to lifelong learning, as PISA asks students to report on their motivation to learn, their beliefs about themselves, and their learning strategies

- regularity, which enables countries to monitor their progress in meeting key learning objectives

- breadth of coverage, which, in PISA 2015, encompasses the 35 OECD countries and 37 partner countries and economies. 


\section{Box A. PISA's contributions to the Sustainable Development Goals}

The Sustainable Development Goals (SDGs) were adopted by the United Nations in September 2015. Goal 4 of the SDGs seeks to ensure "inclusive and equitable quality education and promote lifelong learning opportunities for all". More specific targets and indicators spell out what countries need to deliver by 2030. Goal 4 differs from the Millennium Development Goals (MDGs) on education, which were in place between 2000 and 2015, in the following two ways:

- Goal 4 is truly global. The SDGs establish a universal agenda; they do not differentiate between rich and poor countries. Every single country is challenged to achieve the SDGs.

- Goal 4 puts the quality of education and learning outcomes front and centre. Access, participation and enrolment, which were the main focus of the MDG agenda, are still important, and the world is still far from providing equitable access to high-quality education for all. But participation in education is not an end in itself; what matters for people and economies are the skills acquired through education. It is the competence and character qualities that are developed through schooling, rather than the qualifications and credentials gained, that make people successful and resilient in their professional and personal lives. They are also key in determining individual well-being and the prosperity of societies.

In sum, Goal 4 requires education systems to monitor the actual learning outcomes of their young people. PISA, which already provides measurement tools to this end, is committed to improving, expanding and enriching its assessment tools. For example, PISA 2015 assesses the performance in science, reading and mathematics of 15-yearold students in more than 70 high- and middle-income countries. PISA offers a comparable and robust measure of progress so that all countries, regardless of their starting point, can clearly see where they are on the path towards the internationally agreed targets of quality and equity in education.

Through participation in PISA, countries can also build their capacity to develop relevant data. While most countries that have participated in PISA already have adequate systems in place, that isn't true for many low-income countries. To this end, the OECD PISA for Development initiative not only aims to expand the coverage of the international assessment to include more middle- and low-income countries, but it also offers these countries assistance in building their national assessment and data-collection systems. PISA is also expanding its assessment domains to include other skills relevant to Goal 4. In 2015, for example, PISA assesses 15-year-old students' ability to solve problem collaboratively.

Other OECD data, such as those derived from the Survey of Adult Skills (a product of the OECD Programme for the International Assessment of Adult Competencies [PIAAC]) and the OECD Teaching and Learning International Survey (TALIS), provide a solid evidence base for monitoring education systems. OECD analyses promote peer learning as countries can compare their experiences in implementing policies. Together, OECD indicators, statistics and analyses can be seen as a model of how progress towards the SDG education goal can be measured and reported.

Source: OECD (2016), Education at a Glance 2016: OECD Indicators, OECD Publishing, Paris, http://dx.doi.org/10.1787/eag2016-en.

\section{WHICH COUNTRIES AND ECONOMIES PARTICIPATE IN PISA?}

PISA is now used as an assessment tool in many regions around the world. It was implemented in 43 countries and economies in the first assessment (32 in 2000 and 11 in 2002), 41 in the second assessment (2003), 57 in the third assessment (2006), 75 in the fourth assessment (65 in 2009 and 10 in 2010), and 65 in the fifth assessment. So far, 72 countries and economies have participated in PISA 2015.

In addition to all OECD countries, the survey has been or is being conducted in:

- East, South and Southeast Asia: Beijing, Shanghai, Jiangsu and Guangdong (China), Hong Kong (China), Indonesia, Macao (China), Malaysia, Singapore, Chinese Taipei, Thailand and Viet Nam.

- Central, Mediterranean and Eastern Europe, and Central Asia: Albania, Bulgaria, Croatia, Georgia, Kazakhstan, Kosovo, Lebanon, Lithuania, the Former Yugoslav Republic of Macedonia, Malta, Moldova, Montenegro, Romania and the Russian Federation. 
- The Middle East: Jordan, Qatar and the United Arab Emirates.

- Central and South America: Argentina, Brazil, Colombia, Costa Rica, Dominican Republic, Peru, Trinidad and Tobago, Uruguay.

- Africa: Algeria and Tunisia.

\section{Map of PISA countries and economies}

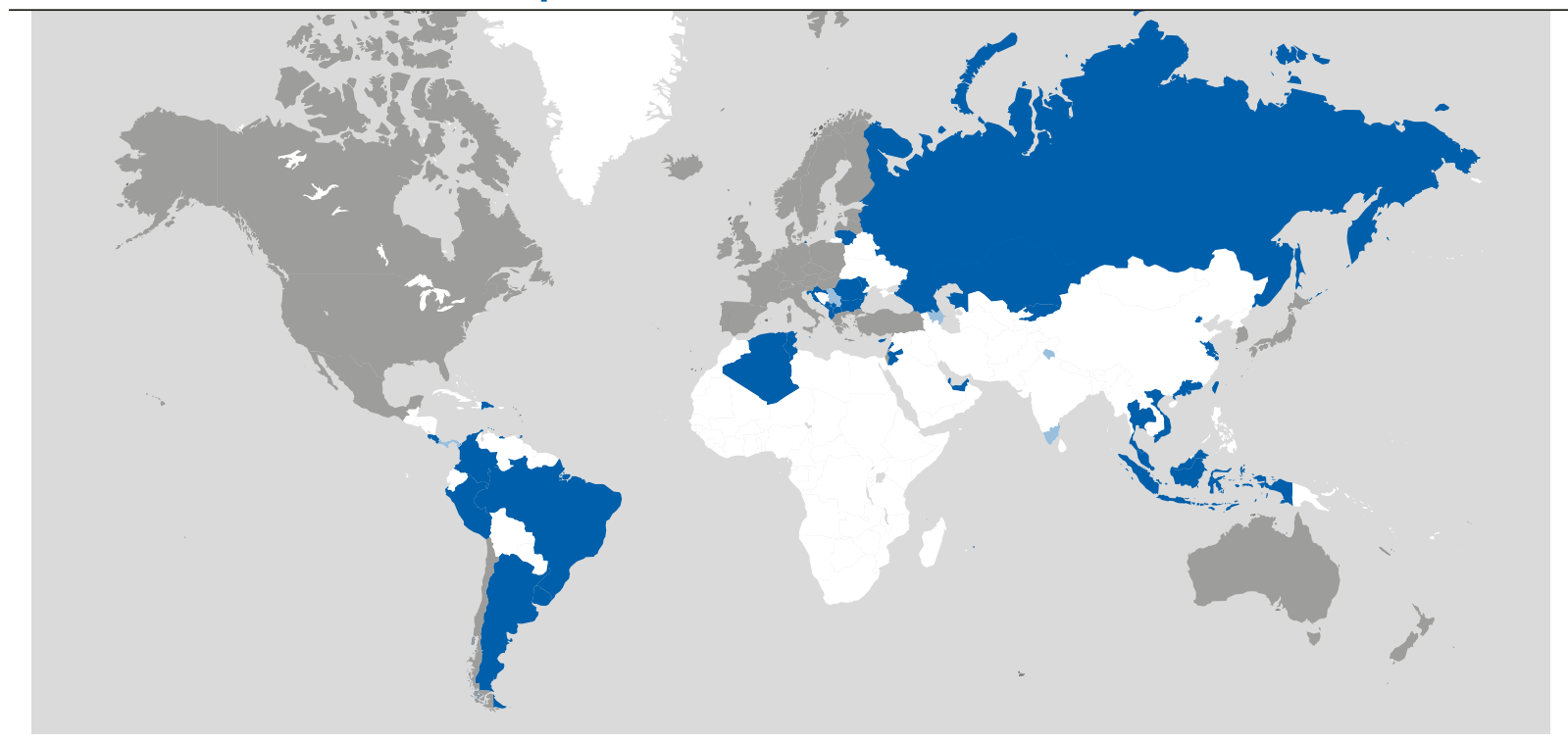

\section{OECD countries}

Australia Korea

Austria Latvia

Belgium Luxembourg

Canada Mexico

Chile The Netherlands

Czech Republic New Zealand

Denmark Norway

Estonia Poland

Finland Portugal

France

Germany

Greece

Hungary

Iceland

Ireland

Israel

Italy

Japan
Partner countries and economies in PISA 2015

Albania

Algeria

Argentina

Brazil

B-S-J-G (China)*

Bulgaria

Colombia

Costa Rica

Croatia

Cyprus $^{1}$

Dominican Republic

Former Yugoslav Republic of Macedonia

Georgia

Hong Kong (China)

Indonesia

Jordan

Kazakhstan

Kosovo

Lebanon
Partner countries and economies in previous cycles Azerbaijan

Himachal Pradesh-India

Kyrgyzstan

Liechtenstein

Mauritius

Miranda-Venezuela

Panama

Serbia

Tamil Nadu-India

* B-S-J-G (China) refers to the four PISA participating China provinces: Beijing, Shanghai, Jiangsu, Guangdong.

1. Note by Turkey: The information in this document with reference to « Cyprus » relates to the southern part of the Island. There is no single authority representing both Turkish and Greek Cypriot people on the Island. Turkey recognises the Turkish Republic of Northern Cyprus (TRNC). Until a lasting and equitable solution is found within the context of the United Nations, Turkey shall preserve its position concerning the "Cyprus issue".

Note by all the European Union Member States of the OECD and the European Union: The Republic of Cyprus is recognised by all members of the United Nations with the exception of Turkey. The information in this document relates to the area under the effective control of the Government of the Republic of Cyprus.

\section{WHAT DOES THE TEST MEASURE?}

In each round of PISA, one of the core domains is tested in detail, taking up nearly half of the total testing time. The major domain in 2015 was science, as it was in 2006. Reading was the major domain in 2000 and 2009, and mathematics was the major domain in 2003 and 2012. With this alternating schedule of major domains, a thorough analysis of achievement in each of the three core areas is presented every nine years; an analysis of trends is offered every three years. 
The PISA 2015 Assessment and Analytical Framework (OECD, 2016a) presents definitions and more detailed descriptions of the domains assessed in PISA 2015:

- Science literacy is defined as the ability to engage with science-related issues, and with the ideas of science, as a reflective citizen. A scientifically literate person is willing to engage in reasoned discourse about science and technology, which requires the competencies to explain phenomena scientifically, evaluate and design scientific enquiry, and interpret data and evidence scientifically.

- Reading literacy is defined as students' ability to understand, use, reflect on and engage with written texts in order to achieve one's goals, develop one's knowledge and potential, and participate in society.

- Mathematical literacy is defined as students' capacity to formulate, employ and interpret mathematics in a variety of contexts. It includes reasoning mathematically and using mathematical concepts, procedures, facts and tools to describe, explain and predict phenomena. It assists individuals in recognising the role that mathematics plays in the world and to make the well-founded judgements and decisions needed by constructive, engaged and reflective citizens.

\section{Box B. Key features of PISA 2015}

\section{The content}

- The PISA 2015 survey focused on science, with reading, mathematics and collaborative problem solving as minor areas of assessment. PISA 2015 also included an assessment of young people's financial literacy, which was optional for countries and economies.

\section{The students}

- Approximately 540000 students completed the assessment in 2015, representing about 29 million 15-year-olds in the schools of the 72 participating countries and economies.

\section{The assessment}

- Computer-based tests were used, with assessments lasting a total of two hours for each student.

- Test items were a mixture of multiple-choice questions and questions requiring students to construct their own responses. The items were organised in groups based on a passage setting out a real-life situation. About 810 minutes of test items for science, reading, mathematics and collaborative problem solving were covered, with different students taking different combinations of test items.

- Students also answered a background questionnaire, which took 35 minutes to complete. The questionnaire sought information about the students themselves, their homes, and their school and learning experiences. School principals completed a questionnaire that covered the school system and the learning environment. For additional information, some countries/economies decided to distribute a questionnaire to teachers. It was the first time that this optional teacher questionnaire was offered to PISA-participating countries/economies. In some countries/economies, optional questionnaires were distributed to parents, who were asked to provide information on their perceptions of and involvement in their child's school, their support for learning in the home, and their child's career expectations, particularly in science. Countries could choose two other optional questionnaires for students: one asked students about their familiarity with and use of information and communication technologies (ICT); and the second sought information about students' education to date, including any interruptions in their schooling, and whether and how they are preparing for a future career.

\section{HOW IS THE ASSESSMENT CONDUCTED?}

For the first time, PISA 2015 delivered the assessment of all subjects via computer. Paper-based assessments were provided for countries that chose not to test their students by computer, but the paper-based assessment was limited to questions that could measure trends in science, reading and mathematics performance. ${ }^{1}$ New questions were developed for the computer-based assessment only. A field trial was used to study the effect of the change in how the assessment was delivered. Data were collected and analysed to establish equivalence between the computer- and paper-based assessments. 
The 2015 computer-based assessment was designed as a two-hour test. Each test form allocated to students comprised four 30-minute clusters of test material. This test design included six clusters from each of the domains of science, reading and mathematics to measure trends. For the major subject of science, an additional six clusters of items were developed to reflect the new features of the 2015 framework. In addition, three clusters of collaborative problem-solving items were developed for the countries that decided to participate in that assessment. ${ }^{2}$ There were 66 different test forms. Students spent one hour on the science assessment (one cluster each of trends and new science items) plus one hour on one or two other subjects - reading, mathematics or collaborative problem solving. For the countries/economies that chose not to participate in the collaborative problem-solving assessment, 36 test forms were prepared.

Countries that chose paper-based delivery for the main survey measured student performance with 30 pencil-and-paper forms containing trend items from two of the three core PISA domains.

Each test form was completed by a sufficient number of students, allowing for estimations of proficiency on all items by students in each country/economy and in relevant subgroups within a country/economy (such as boys and girls, and students from different social and economic backgrounds).

The assessment of financial literacy was offered as an option in PISA 2015 based on the same framework as the one developed for PISA 2012. The financial literacy assessment lasted one hour and comprised two clusters distributed to a subsample of students in combination with the science, mathematics and reading assessments.

To gather contextual information, PISA 2015 asked students and the principal of their school to respond to questionnaires. The student questionnaire took about 35 minutes to complete; the questionnaire for principals took about 45 minutes to complete. The responses to the questionnaires were analysed with the assessment results to provide both a broader and more nuanced picture of student, school and system performance. The PISA 2015 Assessment and Analytical Framework (OECD, 2016a) presents the questionnaire framework in detail. The questionnaires from all assessments since PISA's inception are available on the PISA website: www.pisa.oecd.org.

The questionnaires seek information about:

- students and their family backgrounds, including their economic, social and cultural capital

- aspects of students' lives, such as their attitudes towards learning, their habits and life in and outside of school, and their family environment

- aspects of schools, such as the quality of the schools' human and material resources, public and private management and funding, decision-making processes, staffing practices, and the school's curricular emphasis and extracurricular activities offered

- context of instruction, including institutional structures and types, class size, classroom and school climate, and science activities in class

- aspects of learning, including students' interest, motivation and engagement.

Four additional questionnaires were offered as options:

- a computer familiarity questionnaire, focusing on the availability and use of information and communications technology (ICT) and on students' ability to carry out computer tasks and their attitudes towards computer use

- an educational career questionnaire, which collects additional information on interruptions in schooling, on preparation for students' future career, and on support with science learning

- a parent questionnaire, focusing on parents' perceptions of and involvement in their child's school, their support for learning at home, school choice, their child's career expectations, and their background (immigrant/non-immigrant)

- a teacher questionnaire, which is new to PISA, will help establish the context for students' test results. In PISA 2015, science teachers were asked to describe their teaching practices through a parallel questionnaire that also focuses on teacher-directed teaching and learning activities in science lessons, and a selected set of enquiry-based activities. The teacher questionnaire asked about the content of the school's science curriculum and how it is communicated to parents too. 
The contextual information collected through the student, school and optional questionnaires are complimented by system-level data. Indicators describing the general structure of the education systems, such as expenditure on education, stratification, assessments and examinations, appraisals of teachers and school leaders, instruction time, teachers' salaries, actual teaching time and teacher training are routinely developed and applied by the OECD (e.g. in the annual OECD publication, Education at a Glance). These data are extracted from Education at a Glance 2016 (OECD, $2016 \mathrm{~b})$, Education at a Glance 2015 (OECD, 2015) and Education at a Glance 2014 (OECD, 2014) for the countries that participate in the annual OECD data collection that is administered through the OECD Indicators of Education Systems (INES) Network. For other countries and economies, a special system-level data collection was conducted in collaboration with PISA Governing Board members and National Project Managers.

\section{WHO ARE THE PISA STUDENTS?}

Differences between countries in the nature and extent of pre-primary education and care, in the age at entry into formal schooling, in the structure of the education system, and in the prevalence of grade repetition mean that school grade levels are often not good indicators of where students are in their cognitive development. To better compare student performance internationally, PISA targets students of a specific age. PISA students are aged between 15 years 3 months and 16 years 2 months at the time of the assessment, and have completed at least 6 years of formal schooling. They can be enrolled in any type of institution, participate in full-time or part-time education, in academic or vocational programmes, and attend public or private schools or foreign schools within the country. (For an operational definition of this target population, see Annex A2.) Using this age across countries and over time allows PISA to compare consistently the knowledge and skills of individuals born in the same year who are still in school at age 15, despite the diversity of their education histories in and outside of school.

The population of PISA-participating students is defined by strict technical standards, as are the students who are excluded from participating (see Annex A2). The overall exclusion rate within a country was required to be below $5 \%$ to ensure that, under reasonable assumptions, any distortions in national mean scores would remain within plus or minus 5 score points, i.e. typically within the order of magnitude of 2 standard errors of sampling. Exclusion could take place either through the schools that participated or the students who participated within schools (see Annex A2, Tables A2.1 and A2.2).

There are several reasons why a school or a student could be excluded from PISA. Schools might be excluded because they are situated in remote regions and are inaccessible, because they are very small, or because of organisational or operational factors that precluded participation. Students might be excluded because of intellectual disability or limited proficiency in the language of the assessment.

In 30 out of the 72 countries and economies that participated in PISA 2015, the percentage of school-level exclusions amounted to less than $1 \%$; it was $4.1 \%$ or less in all countries and economies. When the exclusion of students who met the internationally established exclusion criteria is also taken into account, the exclusion rates increase slightly. However, the overall exclusion rate remains below $2 \%$ in 29 participating countries and economies, below $5 \%$ in 60 participating countries, and below 7\% in all countries except the United Kingdom, Luxembourg (both 8.2\%) and Canada (7.5\%). In 13 out of the 35 OECD countries, the percentage of school-level exclusions amounted to less than $1 \%$ and was less than $3 \%$ in 30 OECD countries. When student exclusions within schools are also taken into account, there were 7 OECD countries below $2 \%$ and 25 OECD countries below 5\%. For more detailed information about school and student exclusion from PISA 2015, see Annex A2.

\section{WHAT KINDS OF RESULTS DOES PISA PROVIDE?}

Combined with the information gathered through the tests and the various questionnaires, the PISA assessment provides three main types of outcomes:

- basic indicators that provide a baseline profile of the knowledge and skills of students

- indicators derived from the questionnaires that show how such skills relate to various demographic, social, economic and education variables

- indicators on trends that show changes in outcomes and distributions, and in relationships between student-level, school-level, and system-level background variables and outcomes. 


\section{WHERE CAN YOU FIND THE RESULTS?}

This is the third of five volumes that present the results from PISA 2015. It begins by examining the well-being of students, what it is and how it can be measured. Chapters 3 through 6 discuss students' overall life satisfaction and performance at school and how they vary across countries. Chapter 4 examines the prevalence of schoolwork-related anxiety among students and how that anxiety can affect not only performance but students' overall well-being. Chapter 5 looks at how students' achievement motivation is related to students' gender, socio-economic status and immigrant background. It also discusses how the motivation to achieve can influence student performance and have an impact on students' satisfaction with their life. Chapter 6 examines some of the factors that shape the decision to continue on to higher education, and how this expectation can influence students' performance in school and have an impact on their well-being. Chapter 7 looks at students' sense of belonging at school and their relations with teachers. Chapter 8 examines the relationship between bullying and student performance and well-being. Chapters 9 and 10 discuss how parental involvement and parents' occupation, income and wealth are related to students' performance, satisfaction with life and their expectations for their future. Chapters 11 through 13 examine how students' use of time outside of school hours - physical activities and eating habits; work inside and outside of the home; and time spent using the computer - influences their overall well-being.

As promoting well-being at school has become an important priority for education policy, Chapter 14 discusses several policy initiatives, and frontline interventions by teachers and parents, that could help narrow disparities in well-being among students.

The other four volumes cover the following issues:

- Volume I: Excellence and Equity in Education provides a detailed examination of student performance in science and describes how performance has changed over previous PISA assessments. It also explores students' engagement with and attitudes towards science, including their expectations of working in a science-related career later on. An overview of student performance in reading and mathematics in 2015 is also provided, along with a description of how performance in those subjects has evolved over previous PISA assessments. The volume defines and discusses equity in education, focusing particularly on how socio-economic status and an immigrant background are related to students' performance in PISA and to their attitudes towards science.

- Volume II: Policies and Practices for Successful Schools examines how student performance is associated with various characteristics of individual schools and concerned school systems. The volume first focuses on science, describing the school resources devoted to science and how science is taught in schools. It discusses how both of these are related to student performance in science, students' epistemic beliefs, and students' expectations of pursuing a career in science. Then, the volume analyses schools and school systems and their relationship with education outcomes more generally, covering the learning environment in school, school governance, selecting and grouping students, and the human, financial, educational and time resources allocated to education. Trends in these indicators between 2006 and 2015 are examined when comparable data are available.

- Volume IV: Students' Financial Literacy examines 15-year-old students' understanding about money matters in the 15 countries and economies that participated in this optional assessment. The volume explores how the financial literacy of 15-year-old students is associated with their competencies in science, reading and mathematics, with their socio-economic status, and with their previous experiences with money. The volume also offers an overview of financial education in schools in the participating countries and economies, and provides case studies.

- Volume V: Collaborative Problem Solving examines students' ability to work with two or more people to try to solve a problem. The volume provides the rationale for assessing this particular skill and describes performance within and across countries. In addition, the volume highlights the relative strengths and weaknesses of each school system and examines how they are related to individual student characteristics, such as gender, immigrant background and socio-economic status. The volume also explores the role of education in building young people's skills in solving problems collaboratively.

Volumes I and II were published in December 2016. Volumes IV and V will also be published in 2017.

The frameworks for assessing mathematics, reading and science in 2015 are described in the PISA 2015 Assessment and Analytical Framework: Science, Reading, Mathematic and Financial Literacy (OECD, 2016a). They are also summarised in this volume. 
Technical annexes at the end of this volume describe how questionnaire indices were constructed, and discuss sampling issues, quality-assurance procedures, the reliability of coding, and the process followed for developing the assessment instruments. Many of the issues covered in the technical annexes are elaborated in greater detail in the PISA 2015 Technical Report (OECD, forthcoming).

All data tables referred to in the analyses are included at the end of the respective volume in Annex B1, and a set of additional data tables is available on line (www.pisa.oecd.org). A Reader's Guide is also provided in each volume to aid in interpreting the tables and figures that accompany the report. Data from regions within the participating countries are included in Annex B2.

\section{Notes}

1. The paper-based form was used in 15 countries/economies including Albania, Algeria, Argentina, Georgia, Indonesia, Jordan, Kazakhstan, Kosovo, Lebanon, Macedonia, Malta, Moldova, Romania, Trinidad and Tobago, and Viet Nam, as well as in Puerto Rico, an unincorporated territory of the United States.

2. The collaborative problem solving assessment was not conducted in the countries/economies that delivered the PISA 2015 assessment on paper, nor was it conducted in the Dominican Republic, Ireland, Poland, Qatar or Switzerland.

3. The financial literacy assessment was conducted in Australia, Belgium (Flemish Community only), B-S-J-G (China), Brazil, Canada, Chile, Italy, Lithuania, the Netherlands, Peru, Poland, the Russian Federation, the Slovak Republic, Spain and the United States.

\section{References}

OECD (forthcoming), PISA 2015 Technical Report, OECD Publishing, Paris.

OECD (2016a), PISA 2015 Assessment and Analytical Framework: Science, Reading, Mathematics and Financial Literacy, OECD Publishing, Paris, http://dx.doi.org/10.1787/9789264255425-en.

OECD (2016b), Education at a Glance 2016: OECD Indicators, OECD Publishing, Paris, http://dx.doi.org/10.1787/eag-2016-en.

OECD (2015), Education at a Glance 2015: OECD Indicators, OECD Publishing, Paris, http://dx.doi.org/10.1787/eag-2015-en.

OECD (2014), Education at a Glance 2014: OECD Indicators, OECD Publishing, http://dx.doi.org/10.1787/eag-2014-en. 


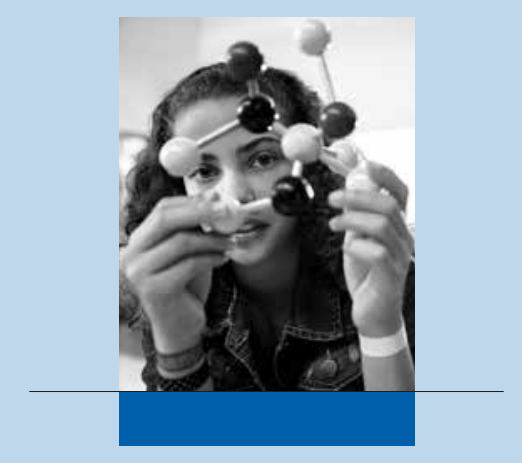

\section{Overview and}

\section{the research framework}

Students' well-being refers to the psychological, cognitive, social and physical functioning and capabilities that students need to live a happy and fulfilling life. PISA 2015 includes data on well-being that cover both positive attitudes and behaviours that promote healthy development (e.g. interest and motivation) as well as some negative outcomes (e.g. anxiety) that undermine students' quality of life. This section describes the PISA data on students' well-being and summarises the main findings of this report. 



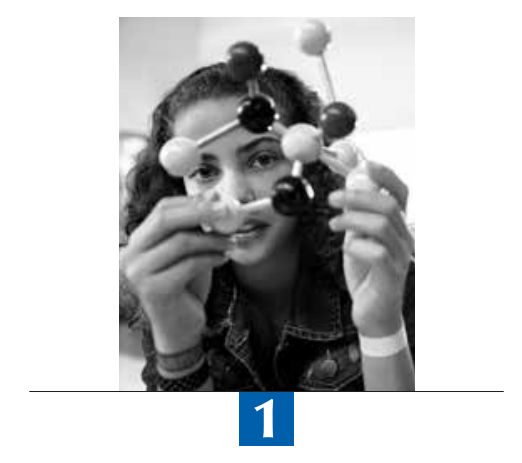

Overview:

Students' well-being 
Children spend a considerable amount of time in the classroom: following lessons, socialising with classmates, and interacting with teachers and other staff members. What happens in school is therefore key to understanding whether students enjoy good physical and mental health, how happy and satisfied they are with different aspects of their life, how connected to others they feel, and the aspirations they have for their future.

PISA 2015 offers a first-of-its-kind set of well-being indicators for adolescents that covers both negative outcomes (e.g. anxiety) and the positive impulses that promote healthy development (e.g. interest, motivation to achieve). Most of the PISA data on well-being are based on students' self-reports, and thus give adolescents the opportunity to express how they feel, what they think of their lives, and what aspirations they have for their future.

PISA also allows for those well-being indicators to be related to students' academic achievement across a large number of economies.

Students' well-being, as defined in this report, refers to the psychological, cognitive, social and physical functioning and capabilities that students need to live a happy and fulfilling life. Well-being is thus first and foremost defined by the quality of life of students as 15-years-old individuals. While investing in future outcomes of children and adolescents is extremely important, policy makers and educators need to pay attention to students' well-being now, while they are students. Well-being is also conceptualised in this report as a dynamic state: without sufficient investment to develop their capacities in the present, students are unlikely to enjoy well-being as adults.

\section{PERFORMANCE AT SCHOOL AND LIFE SATISFACTION}

PISA 2015 asked students to rate their life on a scale from 0 to 10, where 0 means the worst possible life, and 10 means the best possible life. On average across OECD countries, students reported a level of 7.3 on a life-satisfaction scale ranging from 0 to 10 (Figure III.3.1). Roughly speaking, this suggests that the "average" adolescent in an OECD country is satisfied with life.

But there are large variations in life satisfaction across countries. For example, while less than $4 \%$ of students in the Netherlands reported that they are not satisfied with their life (they reported a level of 4 or below on the scale), more than $20 \%$ of students in Korea and Turkey reported so. In Montenegro, and in the Latin American countries of Colombia, Costa Rica, the Dominican Republic and Mexico, more than one in two students reported that they are very satisfied with their life (they reported a life-satisfaction level of 9 or 10 out of 10). Fewer than one in five students in the Asian countries/economies of Hong Kong (China), Korea, Macao (China) and Chinese Taipei reported similar levels of life satisfaction.

Comparing average levels of subjective well-being across countries is challenging. Variations in students' reports of life satisfaction or happiness across countries might be influenced by cultural or local interpretations of what defines a happy life, and by differences in how life experiences are integrated into judgements of life satisfaction. Regardless of the dominant culture in their country/economy or of the language they speak, however, a large number of students in every education system reported that they are very satisfied with their life, and a smaller, but not negligible, number of students reported that they feel dissatisfied with their life. What lies behind these differences?

Gender, for one thing, is related to adolescents' life satisfaction. On average across OECD countries, 29\% of girls but $39 \%$ of boys reported that they are very satisfied with their life - a difference of almost 10 percentage points. Girls were also more likely than boys to report low satisfaction with life. On average across OECD countries, 9\% of boys but 14\% of girls reported a level of life satisfaction equal to 4 or lower on a scale of 0 to 10 (Table III.3.8).

The relationship between performance at school and life satisfaction is weak. In most countries, top-achieving students (those in the top $10 \%$ of the performance distribution) and low-achieving students (those in the bottom $10 \%$ of the performance distribution) reported similar levels of life satisfaction (Figure III.3.3). And, on average, there is no significant relationship between the time students spend studying, whether in or outside of school, and their satisfaction with life (Figure III.3.5).

The environment in which students learn can shape students' development and life satisfaction. Every school has its own distinct climate and there is no universal recipe for creating a "happy" school. But schools, together with other social institutions, can attend to children's fundamental psychological and social needs, and help students develop a sense of control over their life and resilience in the face of unfavourable situations. 
Figure III.1.1 - Snapshot of students' life satisfaction

\begin{tabular}{|c|c|c|c|c|c|c|}
\hline & \multicolumn{6}{|c|}{$\begin{array}{l}\text { Countries/economies with values above the OECD average } \\
\text { Countries/economies with values not significantly different from the OECD average } \\
\text { Countries/economies with values below the OECD average }\end{array}$} \\
\hline & \multicolumn{3}{|c|}{ Students' life satisfaction' } & \multirow[b]{2}{*}{$\begin{array}{c}\text { Gender difference } \\
\text { in life satisfaction } \\
(B-G)\end{array}$} & \multirow{2}{*}{$\begin{array}{l}\text { Socio-economic } \\
\text { disparity in life } \\
\text { satisfaction } \\
\text { (top - bottom quarter } \\
\text { of } \text { ESCS }^{2} \text { ) }\end{array}$} & \multirow{2}{*}{$\begin{array}{l}\text { Difference in life satisfaction } \\
\text { between high-achieving } \\
\text { and low achieving students } \\
\text { in science (top - bottom quarter } \\
\text { of science performance) }\end{array}$} \\
\hline & Average & $\begin{array}{l}\text { Students who } \\
\text { are very satisfied } \\
\text { with life }(9-10)\end{array}$ & $\begin{array}{c}\text { Students who are } \\
\text { not satisfied with } \\
\text { life }(0-4)\end{array}$ & & & \\
\hline & Mean & $\%$ & $\%$ & Dif. & Dif. & Dif. \\
\hline OECD average & 7.31 & 34.1 & 11.8 & 0.58 & 0.44 & 0.12 \\
\hline Australia & $\mathrm{m}$ & $\mathrm{m}$ & $\mathrm{m}$ & $\mathrm{m}$ & $\mathrm{m}$ & $\mathrm{m}$ \\
\hline Austria & 7.52 & 39.7 & 11.1 & 0.86 & 0.49 & 0.16 \\
\hline Belgium (excl. Flemish) & 7.49 & 32.8 & 8.3 & 0.57 & 0.46 & 0.23 \\
\hline Canada & $\mathrm{m}$ & $\mathrm{m}$ & $\mathrm{m}$ & $\mathrm{m}$ & $\mathrm{m}$ & $\mathrm{m}$ \\
\hline Chile & 7.37 & 38.1 & 12.1 & 0.47 & 0.49 & 0.04 \\
\hline Czech Republic & 7.05 & 30.7 & 13.8 & 0.65 & 0.63 & 0.19 \\
\hline Denmark & $\mathrm{m}$ & $\mathrm{m}$ & $\mathrm{m}$ & $\mathrm{m}$ & $\mathrm{m}$ & $\mathrm{m}$ \\
\hline Estonia & 7.50 & 37.0 & 9.3 & 0.46 & 0.70 & 0.15 \\
\hline Finland & 7.89 & 44.4 & 6.7 & 0.74 & 0.47 & 0.18 \\
\hline France & 7.63 & 36.6 & 7.4 & 0.45 & 0.49 & 0.35 \\
\hline Germany & 7.35 & 34.0 & 11.1 & 0.80 & 0.50 & 0.26 \\
\hline Greece & 6.91 & 26.2 & 14.7 & 0.64 & 0.48 & 0.20 \\
\hline Hungary & 7.17 & 31.7 & 13.1 & 0.74 & 0.68 & 0.33 \\
\hline Iceland & 7.80 & 46.7 & 9.5 & 0.93 & 0.73 & 0.55 \\
\hline Ireland & 7.30 & 32.4 & 11.9 & 0.56 & 0.19 & 0.04 \\
\hline Israel & $\mathrm{m}$ & $\mathrm{m}$ & $\mathrm{m}$ & $\mathrm{m}$ & $\mathrm{m}$ & $\mathrm{m}$ \\
\hline Italy & 6.89 & 24.2 & 14.7 & 0.79 & 0.39 & 0.09 \\
\hline Japan & 6.80 & 23.8 & 16.1 & -0.12 & 0.38 & 0.31 \\
\hline Korea & 6.36 & 18.6 & 21.6 & 0.47 & 0.48 & 0.13 \\
\hline Latvia & 7.37 & 31.5 & 8.9 & 0.16 & 0.64 & 0.20 \\
\hline Luxembourg & 7.38 & 36.1 & 11.1 & 0.78 & 0.49 & 0.24 \\
\hline Mexico & 8.27 & 58.5 & 6.4 & 0.12 & 0.12 & 0.06 \\
\hline Netherlands & 7.83 & 32.5 & 3.7 & 0.55 & -0.03 & -0.38 \\
\hline New Zealand & $\mathrm{m}$ & $\mathrm{m}$ & $\mathrm{m}$ & $\mathrm{m}$ & $\mathrm{m}$ & $\mathrm{m}$ \\
\hline Norway & $\mathrm{m}$ & $\mathrm{m}$ & $\mathrm{m}$ & $\mathrm{m}$ & $\mathrm{m}$ & $\mathrm{m}$ \\
\hline Poland & 7.18 & 32.4 & 12.6 & 0.69 & 0.47 & -0.02 \\
\hline Portugal & 7.36 & 31.0 & 8.9 & 0.51 & 0.22 & -0.17 \\
\hline Slovak Republic & 7.47 & 39.4 & 11.3 & 0.59 & 0.43 & 0.06 \\
\hline Slovenia & 7.17 & 32.5 & 13.5 & 0.91 & 0.07 & -0.05 \\
\hline Spain & 7.42 & 33.0 & 9.5 & 0.37 & 0.49 & 0.23 \\
\hline Sweden & $\mathrm{m}$ & $\mathrm{m}$ & $\mathrm{m}$ & $\mathrm{m}$ & $\mathrm{m}$ & $\mathrm{m}$ \\
\hline Switzerland & 7.72 & 39.6 & 7.4 & 0.65 & 0.22 & 0.23 \\
\hline Turkey & 6.12 & 26.3 & 28.6 & 0.59 & 0.29 & -0.18 \\
\hline United Kingdom & 6.98 & 28.3 & 15.6 & 0.68 & 0.58 & 0.10 \\
\hline United States & 7.36 & 35.9 & 11.8 & 0.60 & 0.67 & -0.10 \\
\hline Albania & $\mathrm{m}$ & $\mathrm{m}$ & $\mathrm{m}$ & $\mathrm{m}$ & $\mathrm{m}$ & $\mathrm{m}$ \\
\hline Algeria & $\mathrm{m}$ & $\mathrm{m}$ & $\mathrm{m}$ & $\mathrm{m}$ & $\mathrm{m}$ & $\mathrm{m}$ \\
\hline Brazil & 7.59 & 44.6 & 11.8 & 0.29 & -0.16 & -0.34 \\
\hline$\approx$ B-S-J-G (China) & 6.83 & 26.9 & 15.6 & 0.10 & 0.49 & 0.06 \\
\hline Bulgaria & 7.42 & 42.8 & 13.9 & 0.42 & 0.56 & 0.16 \\
\hline CABA (Argentina) & $\mathrm{m}$ & $\mathrm{m}$ & $\mathrm{m}$ & $\mathrm{m}$ & $\mathrm{m}$ & $\mathrm{m}$ \\
\hline Colombia & 7.88 & 50.9 & 10.1 & 0.37 & -0.29 & -0.49 \\
\hline Costa Rica & 8.21 & 58.4 & 7.1 & 0.35 & 0.04 & -0.33 \\
\hline Croatia & 7.90 & 47.8 & 7.3 & 0.60 & 0.15 & -0.23 \\
\hline Cyprus $^{3}$ & 7.06 & 30.1 & 13.7 & 0.41 & 0.61 & 0.38 \\
\hline Dominican Republic & 8.50 & 67.8 & 8.3 & 0.10 & -0.04 & -0.12 \\
\hline FYROM & $\mathrm{m}$ & $\mathrm{m}$ & $\mathrm{m}$ & $\mathrm{m}$ & $\mathrm{m}$ & $\mathrm{m}$ \\
\hline Georgia & $\mathrm{m}$ & $\mathrm{m}$ & $\mathrm{m}$ & $\mathrm{m}$ & $\mathrm{m}$ & $\mathrm{m}$ \\
\hline Hong Kong (China) & 6.48 & 13.9 & 15.6 & 0.07 & 0.56 & 0.16 \\
\hline Indonesia & $\mathrm{m}$ & $\mathrm{m}$ & $\mathrm{m}$ & $\mathrm{m}$ & $\mathrm{m}$ & $\mathrm{m}$ \\
\hline Jordan & $\mathrm{m}$ & $\mathrm{m}$ & $\mathrm{m}$ & $\mathrm{m}$ & $\mathrm{m}$ & $\mathrm{m}$ \\
\hline Kosovo & $\mathrm{m}$ & $\mathrm{m}$ & $\mathrm{m}$ & $\mathrm{m}$ & $\mathrm{m}$ & $\mathrm{m}$ \\
\hline Lebanon & $\mathrm{m}$ & $\mathrm{m}$ & $\mathrm{m}$ & $\mathrm{m}$ & $\mathrm{m}$ & $\mathrm{m}$ \\
\hline Lithuania & 7.86 & 47.6 & 8.1 & 0.52 & 0.59 & 0.24 \\
\hline Macao (China) & 6.59 & 16.5 & 15.4 & 0.01 & 0.47 & 0.43 \\
\hline Malta & $\mathrm{m}$ & $\mathrm{m}$ & $\mathrm{m}$ & $\mathrm{m}$ & $\mathrm{m}$ & $\mathrm{m}$ \\
\hline Moldova & $\mathrm{m}$ & $\mathrm{m}$ & $\mathrm{m}$ & $\mathrm{m}$ & $\mathrm{m}$ & $\mathrm{m}$ \\
\hline Montenegro & 7.75 & 50.1 & 11.1 & 0.49 & 0.17 & -0.37 \\
\hline Peru & 7.50 & 42.8 & 12.9 & 0.15 & -0.11 & 0.00 \\
\hline Qatar & 7.41 & 42.6 & 13.8 & 0.21 & 0.56 & -0.24 \\
\hline Romania & $\mathrm{m}$ & $\mathrm{m}$ & $\mathrm{m}$ & $\mathrm{m}$ & $\mathrm{m}$ & $\mathrm{m}$ \\
\hline Russia & 7.76 & 46.8 & 10.3 & 0.32 & 0.22 & -0.27 \\
\hline Singapore & $\mathrm{m}$ & $\mathrm{m}$ & $\mathrm{m}$ & $\mathrm{m}$ & $\mathrm{m}$ & $\mathrm{m}$ \\
\hline Chinese Taipei & 6.59 & 18.5 & 16.0 & 0.29 & 0.51 & 0.11 \\
\hline Thailand & 7.71 & 42.7 & 7.8 & 0.04 & -0.16 & -0.22 \\
\hline Trinidad and Tobago & $\mathrm{m}$ & $\mathrm{m}$ & $\mathrm{m}$ & $\mathrm{m}$ & $\mathrm{m}$ & $\mathrm{m}$ \\
\hline Tunisia & 6.90 & 38.5 & 19.3 & 0.17 & 0.80 & 0.03 \\
\hline United Arab Emirates & 7.30 & 39.8 & 14.5 & 0.27 & 0.67 & -0.15 \\
\hline Uruguay & 7.70 & 44.2 & 9.8 & 0.47 & 0.44 & 0.05 \\
\hline Viet Nam & $\mathrm{m}$ & $\mathrm{m}$ & $\mathrm{m}$ & $\mathrm{m}$ & $\mathrm{m}$ & $\mathrm{m}$ \\
\hline
\end{tabular}

1. PISA 2015 asked students to rate their overall satisfaction with life on a scale that ranges from 0 to 10.

2. ESCS refers to the PISA index of economic, social and cultural status. 3. Note by Turkey: The information in this document with reference to " Cyprus " relates to the southern part of the Island. There is no single authority representing both Turkish
and Greek Cypriot people on the Island. Turkey recognises the Turkish Republic of Northern Cyprus (TRNC). Until a lasting and equitable solution is found within the context and Greek Cypriot people on the Island. Turkey recognises the Turkish Republic of Northe

Note by all the European Union Member States of the OECD and the European Union: The Republic of Cyprus is recognised by all members of the United Nations with the exception of Turkey. The information in this document relates to the area under the effective control of the Government of the Republic of Cyprus.

Note: Values that are statistically significant are indicated in bold (see Annex A3).

Source: OECD, PISA 2015 Database, Tables III.3.2, III.3.4 and III.3.8.

StatLink नiाs $\mathrm{http}$ ://dx.doi.org/10.1787/888933470414 
Teachers can play a particularly important role in creating the conditions for students' well-being at school. Happier students tend to report positive relations with their teachers (Table III.3.11). PISA results show that students in "happy" schools (schools where students' life satisfaction is above the average in the country) reported a higher level of support from their science teacher than students in "unhappy" schools (schools where students' life satisfaction is below the average in the country). In other words, students' perceptions of support from teachers seem to be a characteristic feature of schools where students reported greater well-being.

\section{Schoolwork-related anxiety}

In all education systems, as adolescents progress through schooling, they are required to manage increasing academic demands in relatively more formal classroom settings. The pressure to get higher marks and the concern about receiving poor grades are some of the sources of stress most often cited by school-age children and adolescents.

PISA 2015 asked students to report whether they agree, strongly agree, disagree or strongly disagree with the following statements: "I often worry that it will be difficult for me to take a test"; "I worry I will get poor grades at school"; "I feel very anxious even if I am well prepared for a test"; "I get very tense when I study for a test"; and "I get nervous when I do not know how to solve a task at school". On average across OECD countries, 59\% of students reported that they often worry that taking a test will be difficult, and $66 \%$ reported that they worry about poor grades. Some $55 \%$ of students reported feeling very anxious for a test even if they are well prepared; $37 \%$ reported they get very tense when studying; and 52\% reported that they get nervous when they don't know how to solve a task at school (Table III.4.1).

In all countries and economies that participated in PISA 2015, girls reported greater schoolwork-related anxiety than boys (Table III.4.5). On average across OECD countries, boys were about 13 percentage points less likely than girls to report they get very tense when they study (Figure III.4.1). About $64 \%$ of girls but $47 \%$ of boys reported feeling very anxious even when they are well prepared for a test (Table III.4.2). One possible explanation may be that girls are less self-confident than boys and, as a result, experience more worry and discomfort before and during evaluations.

PISA 2015 shows that anxiety about schoolwork, homework and tests is negatively related to performance in science, mathematics and reading. On average across OECD countries, 63\% of low-achieving students in science (students in the bottom quarter of science performance in a country) and $46 \%$ of high-achieving students (students in the top quarter) reported that they feel anxious for a test no matter how well prepared they are (Figure III.4.2). The fear of making mistakes on a test often disrupts the performance of top-performing girls who "choke under pressure". On average across OECD countries, $55 \%$ of girls but $38 \%$ of boys who are among the top $25 \%$ of students in their country in science performance reported that they feel very anxious for a test even if they are well prepared (Table III.4.4). But gender differences in anxiety are also observed among low-achieving students.

On average across OECD countries, students who reported the highest levels of anxiety also reported a level of life satisfaction that is 1.2 points lower (on a scale from 0 to 10) than students who reported the lowest levels of anxiety (Figure III.4.3).

Both parents and educators often argue that anxiety is the natural consequence of testing overload. In about five out of six school systems, students are assessed at least once a year with mandatory standardised tests; in about three out of four countries/economies, students are assessed at least once a year with non-mandatory standardised tests. However, the frequency of tests as reported by school principals seems unrelated to students' level of schoolworkrelated anxiety. Rather, it is students' perception of the assessment as more or less threatening that determines how anxious students feel about tests.

PISA results show that teachers' practices, behaviours and communication in the classroom are associated with students' level of anxiety. After accounting for students' performance and socio-economic status, students who reported that their science teachers adapt the lesson to the class's needs and knowledge were less likely to report feeling anxious even if they are well prepared for a test, or to report that they get very tense when they study (Table III.4.11). Students were also less likely to report anxiety if the science teacher provides individual help when they are struggling. By contrast, negative teacher-student relations can undermine students' confidence and lead to greater anxiety. On average across OECD countries, students are about $60 \%$ more likely to get very tense when they study, and about $29 \%$ more likely to feel anxious before a test if they perceive that their teacher thinks they are less smart than they really are (Table III.4.11). 
Figure III.1.2 [Part 1/2] - Snapshot of students' achievement motivation and schoolwork-related anxiety

\begin{tabular}{|c|c|c|c|c|c|c|}
\hline & $\begin{array}{l}\text { Countries/ec } \\
\text { Countries/ec } \\
\text { Countries/ec }\end{array}$ & $\begin{array}{l}\text { with values above } \\
\text { with values not si } \\
\text { with values belon }\end{array}$ & $\begin{array}{l}\text { e OECD average } \\
\text { ficantly different from } \\
\text { e OECD average }\end{array}$ & OECD average & & \\
\hline & & & Percentage of studen & who agreed/strongl & reed with the following statements & \\
\hline & & $\begin{array}{c}\text { Index } \\
\text { of schoolwork- } \\
\text { related anxiety }\end{array}$ & $\begin{array}{l}\text { Even if I am well } \\
\text { prepared for a test } \\
\text { I feel very anxious }\end{array}$ & $\begin{array}{l}\text { I get very tense } \\
\text { when I study }\end{array}$ & $\begin{array}{c}\text { Gender difference } \\
\text { for "Even if I am well prepared } \\
\text { for a test I feel very anxious" } \\
(B-G)\end{array}$ & $\begin{array}{l}\text { between students in the top } \\
\text { and bottom quarter of the index } \\
\text { of schoolwork-related anxiety } \\
\text { (top - bottom) }\end{array}$ \\
\hline & & Mean index & $\%$ & $\%$ & $\%$ dif. & Dif. \\
\hline & OECD average & 0.01 & 55.5 & 36.6 & -16.7 & -1.18 \\
\hline$O A$ & Australia & 0.19 & 67.5 & 46.9 & -17.1 & $\mathrm{~m}$ \\
\hline A & Austria & -0.10 & 50.8 & 19.3 & -15.3 & -1.52 \\
\hline $\mathrm{B}$ & Belgium $^{2}$ & -0.16 & 42.5 & 28.5 & -18.9 & -0.75 \\
\hline & Canada & 0.17 & 63.9 & 45.5 & -19.9 & $\mathrm{~m}$ \\
\hline & Chile & 0.10 & 56.0 & 40.2 & -11.2 & -1.08 \\
\hline & Czech Republic & -0.21 & 40.3 & 32.4 & -17.0 & -1.20 \\
\hline & Denmark & 0.09 & 64.5 & 45.5 & -23.0 & $\mathrm{~m}$ \\
\hline & Estonia & -0.22 & 52.8 & 27.5 & -15.7 & -1.12 \\
\hline & Finland & -0.41 & 48.6 & 17.8 & -15.6 & -1.37 \\
\hline & France & -0.10 & 47.2 & 29.2 & -16.6 & -0.91 \\
\hline & Germany & -0.33 & 41.6 & 22.4 & -20.8 & -1.63 \\
\hline & Greece & -0.09 & 59.0 & 38.0 & -17.6 & -1.23 \\
\hline & Hungary & -0.10 & 54.5 & 27.1 & -17.3 & -1.16 \\
\hline & Iceland & -0.12 & 51.1 & 36.5 & -24.1 & -2.25 \\
\hline & Ireland & 0.15 & 63.2 & 46.0 & -13.8 & -1.54 \\
\hline & Israel & -0.27 & 44.5 & 33.2 & -15.7 & $\mathrm{~m}$ \\
\hline & Italy & 0.45 & 70.2 & 56.4 & -17.0 & -1.04 \\
\hline & Japan & 0.26 & 62.1 & 32.7 & -9.9 & -0.32 \\
\hline & Korea & 0.10 & 55.3 & 41.9 & -6.8 & -1.56 \\
\hline & Latvia & -0.14 & 43.2 & 27.1 & -10.8 & -0.68 \\
\hline & Luxembourg & -0.16 & 47.9 & 28.1 & -20.9 & -1.34 \\
\hline & Mexico & 0.26 & 60.1 & 49.7 & -10.6 & -0.56 \\
\hline & Netherlands & -0.54 & 39.1 & 14.5 & -13.1 & -0.96 \\
\hline & New Zealand & 0.27 & 72.0 & 50.7 & -13.5 & $\mathrm{~m}$ \\
\hline & Norway & 0.07 & 60.9 & 45.7 & -26.1 & $\mathrm{~m}$ \\
\hline & Poland & -0.11 & 45.1 & 26.0 & -16.7 & -1.25 \\
\hline & Portugal & 0.48 & 69.0 & 46.2 & -20.7 & -0.56 \\
\hline & Slovak Republic & -0.17 & 47.1 & 29.1 & -15.4 & -0.92 \\
\hline & Slovenia & 0.06 & 61.9 & 35.8 & -20.6 & -1.44 \\
\hline & Spain & 0.40 & 67.1 & 48.1 & -14.5 & -0.46 \\
\hline & Sweden & 0.05 & 61.1 & 41.0 & -23.3 & $\mathrm{~m}$ \\
\hline & Switzerland & -0.44 & 33.5 & 20.6 & -14.9 & -1.32 \\
\hline & Turkey & 0.31 & 58.8 & 56.0 & -11.8 & -1.36 \\
\hline & United Kingdom & 0.25 & 71.9 & 52.5 & -19.0 & -2.09 \\
\hline & United States & 0.19 & 67.7 & 43.3 & -20.7 & -1.47 \\
\hline$\therefore \mathrm{A}$ & Albania & $\mathrm{m}$ & $\mathrm{m}$ & $\mathrm{m}$ & $\mathrm{m}$ & $\mathrm{m}$ \\
\hline$\cong \mathrm{A}$ & Algeria & $\mathrm{m}$ & $\mathrm{m}$ & $\mathrm{m}$ & $\mathrm{m}$ & $\mathrm{m}$ \\
\hline $\mathrm{B}$ & Brazil & 0.60 & 80.8 & 56.0 & -12.7 & -0.08 \\
\hline$=\mathrm{B}$ & B-S-J-G (China) & 0.23 & 61.8 & 54.9 & -1.6 & -0.79 \\
\hline & Bulgaria & -0.09 & 55.0 & 46.2 & -14.5 & -0.90 \\
\hline & CABA (Argentina) & $\mathrm{m}$ & $\mathrm{m}$ & $\mathrm{m}$ & $\mathrm{m}$ & $\mathrm{m}$ \\
\hline & Colombia & 0.52 & 78.8 & 57.7 & -7.9 & -0.10 \\
\hline & Costa Rica & 0.60 & 81.2 & 55.2 & -6.6 & -0.19 \\
\hline & Croatia & 0.00 & 47.0 & 36.1 & -22.2 & -0.93 \\
\hline & Cyprus* & -0.08 & 57.7 & 40.0 & -12.8 & -1.48 \\
\hline & Dominican Republic & 0.41 & 80.0 & 53.5 & -2.7 & -0.22 \\
\hline & FYROM & $\mathrm{m}$ & $\mathrm{m}$ & $\mathrm{m}$ & $\mathrm{m}$ & $\mathrm{m}$ \\
\hline & Georgia & $\mathrm{m}$ & $\mathrm{m}$ & $\mathrm{m}$ & $\mathrm{m}$ & $\mathrm{m}$ \\
\hline & Hong Kong (China) & 0.33 & 67.1 & 52.7 & -7.4 & -0.76 \\
\hline & Indonesia & $\mathrm{m}$ & $\mathrm{m}$ & $\mathrm{m}$ & $\mathrm{m}$ & $\mathrm{m}$ \\
\hline & Jordan & $\mathrm{m}$ & $\mathrm{m}$ & $\mathrm{m}$ & $\mathrm{m}$ & $\mathrm{m}$ \\
\hline & Kosovo & $\mathrm{m}$ & $\mathrm{m}$ & $\mathrm{m}$ & $\mathrm{m}$ & $\mathrm{m}$ \\
\hline & Lebanon & $\mathrm{m}$ & $\mathrm{m}$ & $\mathrm{m}$ & $\mathrm{m}$ & $\mathrm{m}$ \\
\hline & Lithuania & -0.07 & 55.7 & 42.6 & -19.5 & -0.94 \\
\hline & Macao (China) & 0.37 & 65.6 & 58.5 & -7.2 & -0.82 \\
\hline & Malta & $\mathrm{m}$ & $\mathrm{m}$ & $\mathrm{m}$ & $\mathrm{m}$ & $\mathrm{m}$ \\
\hline & Moldova & $\mathrm{m}$ & $\mathrm{m}$ & $\mathrm{m}$ & $\mathrm{m}$ & $\mathrm{m}$ \\
\hline & Montenegro & 0.09 & 65.2 & 46.7 & -19.3 & -0.69 \\
\hline & Peru & 0.14 & 71.5 & 43.2 & -2.6 & -0.32 \\
\hline & Qatar & 0.22 & 65.2 & 49.4 & -7.4 & -1.21 \\
\hline & Romania & $\mathrm{m}$ & $\mathrm{m}$ & $\mathrm{m}$ & $\mathrm{m}$ & $\mathrm{m}$ \\
\hline & Russia & -0.05 & 51.1 & 38.9 & -17.3 & -0.65 \\
\hline & Singapore & 0.57 & 76.3 & 59.9 & -6.4 & $\mathrm{~m}$ \\
\hline & Chinese Taipei & 0.39 & 66.6 & 61.5 & -8.7 & -0.75 \\
\hline & Thailand & 0.11 & 63.3 & 46.6 & -7.3 & -0.84 \\
\hline & Trinidad and Tobago & $\mathrm{m}$ & $\mathrm{m}$ & $\mathrm{m}$ & $\mathrm{m}$ & $\mathrm{m}$ \\
\hline & Tunisia & 0.10 & 59.7 & 57.2 & -15.6 & -1.05 \\
\hline & United Arab Emirates & 0.20 & 61.8 & 44.5 & -4.3 & -1.05 \\
\hline & Uruguay & 0.46 & 72.8 & 53.2 & -6.6 & -0.13 \\
\hline & Viet Nam & $\mathrm{m}$ & $\mathrm{m}$ & $\mathrm{m}$ & $\mathrm{m}$ & $\mathrm{m}$ \\
\hline
\end{tabular}

*See note 3 under Figure III.1.1

1. ESCS refers to the PISA index of economic, social and cultural status.

2. Data for life satisfaction do not include the Flemish community of Belgium.

Note: Values that are statistically significant are indicated in bold (see Annex A3).

Source: OECD, PISA 2015 Database, Tables III.4.1, III.4.2, III.4.9, III.5.1, III.5.2 and III.5.3.

StatLink 部实 $\mathrm{http}: / / \mathrm{dx}$.doi.org/10.1787/888933470425 
Figure III.1.2 [Part 2/2] - Snapshot of students' achievement motivation and schoolwork-related anxiety

\begin{tabular}{|c|c|c|c|c|c|}
\hline & \multicolumn{5}{|c|}{$\begin{array}{l}\text { Countries/economies with values above the OECD average } \\
\text { Countries/economies with values not significantly different from the OECD average } \\
\text { Countries/economies with values below the OECD average }\end{array}$} \\
\hline & \multirow[b]{2}{*}{$\begin{array}{c}\text { Index of achievement } \\
\text { motivation }\end{array}$} & \multicolumn{4}{|c|}{ Percentage of students who agreed/strongly agreed with the following statements } \\
\hline & & $\begin{array}{l}\text { I want to be able } \\
\text { to select from among } \\
\text { the best opportunities } \\
\text { available } \\
\text { when I graduate }\end{array}$ & $\begin{array}{l}\text { I want to be one } \\
\text { of the best students } \\
\text { in my class }\end{array}$ & $\begin{array}{l}\text { Gender difference } \\
\text { for "I want to be able } \\
\text { to select from among } \\
\text { the best opportunities" } \\
(B-G)\end{array}$ & $\begin{array}{l}\text { Socio-economic disparity } \\
\text { for "I want to be able } \\
\text { to select from among } \\
\text { the best opportunities" } \\
\text { (top - bottom quarters } \\
\left.\text { of ESCS }{ }^{1}\right)\end{array}$ \\
\hline & Mean index & $\%$ & $\%$ & $\%$ dif. & $\%$ dif. \\
\hline OECD average & -0.01 & 92.7 & 59.2 & -1.9 & 5.6 \\
\hline Australia & 0.33 & 95.8 & 74.2 & -1.8 & 4.4 \\
\hline Austria & -0.26 & 92.3 & 46.8 & 0.3 & 5.1 \\
\hline Belgium ${ }^{2}$ & -0.45 & 91.9 & 41.5 & 0.5 & 3.7 \\
\hline Canada & 0.33 & 95.5 & 73.1 & -2.8 & 4.6 \\
\hline Chile & 0.29 & 95.9 & 72.0 & -0.2 & 2.5 \\
\hline Czech Republic & -0.28 & 93.4 & 41.7 & -1.8 & 5.9 \\
\hline Denmark & -0.15 & 83.2 & 69.2 & -2.0 & 14.6 \\
\hline Estonia & -0.04 & 95.0 & 51.1 & -2.7 & 3.8 \\
\hline Finland & -0.63 & 80.0 & 40.8 & -1.8 & 14.9 \\
\hline France & -0.25 & 94.3 & 44.8 & -2.0 & 5.5 \\
\hline Germany & -0.38 & 90.9 & 42.7 & 0.8 & 5.5 \\
\hline Greece & -0.10 & 95.5 & 63.4 & -3.3 & 3.2 \\
\hline Hungary & -0.30 & 93.1 & 40.4 & -0.8 & 5.5 \\
\hline Iceland & 0.39 & 86.6 & 75.5 & -6.4 & 11.1 \\
\hline Ireland & 0.39 & 97.0 & 72.4 & -0.6 & 3.0 \\
\hline Israel & 0.83 & 96.8 & 86.4 & -3.2 & 1.1 \\
\hline Italy & -0.17 & 95.0 & 52.0 & -1.0 & 2.5 \\
\hline Japan & -0.51 & 87.3 & 32.9 & 1.6 & 8.5 \\
\hline Korea & 0.34 & 96.1 & 81.9 & -2.9 & 5.7 \\
\hline Latvia & -0.03 & 93.3 & 58.6 & -3.2 & 2.0 \\
\hline Luxembourg & -0.17 & 92.5 & 53.8 & -2.8 & 4.5 \\
\hline Mexico & 0.25 & 96.1 & 81.2 & -1.4 & 3.9 \\
\hline Netherlands & -0.44 & 93.9 & 29.7 & 0.1 & 3.2 \\
\hline New Zealand & 0.24 & 94.5 & 70.0 & -0.6 & 6.3 \\
\hline Norway & 0.10 & 95.5 & 64.3 & -3.4 & 3.2 \\
\hline Poland & -0.42 & 86.1 & 46.4 & -1.4 & 11.2 \\
\hline Portugal & 0.20 & 93.1 & 65.5 & -3.0 & 8.2 \\
\hline Slovak Republic & -0.28 & 92.2 & 44.5 & -2.8 & 8.5 \\
\hline Slovenia & -0.43 & 86.1 & 44.3 & -5.8 & 12.0 \\
\hline Spain & -0.16 & 93.8 & 57.4 & -1.0 & 6.0 \\
\hline Sweden & 0.15 & 92.2 & 63.7 & -4.1 & 4.9 \\
\hline Switzerland & -0.43 & 90.6 & 40.0 & -0.8 & 4.5 \\
\hline Turkey & 0.62 & 94.2 & 89.3 & -3.0 & 3.1 \\
\hline United Kingdom & 0.51 & 97.8 & 75.6 & -1.2 & 1.7 \\
\hline United States & 0.65 & 97.3 & 85.4 & -1.7 & 1.4 \\
\hline Albania & $\mathrm{m}$ & $\mathrm{m}$ & $\mathrm{m}$ & $\mathrm{m}$ & $\mathrm{m}$ \\
\hline$\Xi$ Algeria & $\mathrm{m}$ & $\mathrm{m}$ & $\mathrm{m}$ & $\mathrm{m}$ & $\mathrm{m}$ \\
\hline Brazil & 0.12 & 96.7 & 63.9 & -2.2 & 1.1 \\
\hline$=$ B-S-J-G (China) & 0.11 & 96.6 & 81.1 & -0.6 & -1.3 \\
\hline Bulgaria & -0.06 & 93.9 & 67.2 & -5.3 & 6.2 \\
\hline CABA (Argentina) & $\mathrm{m}$ & $\mathrm{m}$ & $\mathrm{m}$ & $\mathrm{m}$ & $\mathrm{m}$ \\
\hline Colombia & 0.50 & 98.3 & 91.6 & -0.3 & 0.9 \\
\hline Costa Rica & 0.51 & 97.9 & 85.5 & -1.3 & 1.3 \\
\hline Croatia & -0.24 & 93.6 & 61.5 & -3.6 & 5.2 \\
\hline Cyprus* & 0.16 & 95.4 & 72.8 & -3.9 & 2.0 \\
\hline Dominican Republic & 0.34 & 93.2 & 90.4 & -0.8 & 4.3 \\
\hline FYROM & $\mathrm{m}$ & $\mathrm{m}$ & $\mathrm{m}$ & $\mathrm{m}$ & $\mathrm{m}$ \\
\hline Georgia & $\mathrm{m}$ & $\mathrm{m}$ & $\mathrm{m}$ & $\mathrm{m}$ & $\mathrm{m}$ \\
\hline Hong Kong (China) & 0.20 & 93.5 & 75.4 & -4.0 & 5.5 \\
\hline Indonesia & $\mathrm{m}$ & $\mathrm{m}$ & $\mathrm{m}$ & $\mathrm{m}$ & $\mathrm{m}$ \\
\hline Jordan & $\mathrm{m}$ & $\mathrm{m}$ & $\mathrm{m}$ & $\mathrm{m}$ & $\mathrm{m}$ \\
\hline Kosovo & $\mathrm{m}$ & $\mathrm{m}$ & $\mathrm{m}$ & $\mathrm{m}$ & $\mathrm{m}$ \\
\hline Lebanon & $\mathrm{m}$ & $\mathrm{m}$ & $\mathrm{m}$ & $\mathrm{m}$ & $\mathrm{m}$ \\
\hline Lithuania & 0.00 & 90.8 & 63.5 & -5.6 & 5.7 \\
\hline Macao (China) & -0.50 & 91.1 & 48.6 & -4.9 & 3.7 \\
\hline Malta & $\mathrm{m}$ & $\mathrm{m}$ & $\mathrm{m}$ & $\mathrm{m}$ & $\mathrm{m}$ \\
\hline Moldova & $\mathrm{m}$ & $\mathrm{m}$ & $\mathrm{m}$ & $\mathrm{m}$ & $\mathrm{m}$ \\
\hline Montenegro & -0.16 & 92.0 & 54.4 & -4.8 & 2.5 \\
\hline Peru & 0.34 & 96.7 & 88.4 & -0.2 & 1.5 \\
\hline Qatar & 0.77 & 94.7 & 89.4 & -5.3 & 3.9 \\
\hline Romania & $\mathrm{m}$ & $\mathrm{m}$ & $\mathrm{m}$ & $\mathrm{m}$ & $\mathrm{m}$ \\
\hline Russia & -0.09 & 94.6 & 55.8 & -1.1 & 4.3 \\
\hline Singapore & 0.41 & 96.5 & 82.3 & -1.5 & 1.5 \\
\hline Chinese Taipei & -0.01 & 97.2 & 68.1 & -1.8 & 4.2 \\
\hline Thailand & 0.24 & 97.4 & 79.7 & -2.7 & 1.1 \\
\hline Trinidad and Tobago & $\mathrm{m}$ & $\mathrm{m}$ & $\mathrm{m}$ & $\mathrm{m}$ & $\mathrm{m}$ \\
\hline Tunisia & 0.67 & 96.5 & 93.1 & -3.2 & 2.1 \\
\hline United Arab Emirates & 0.78 & 95.6 & 91.5 & -3.5 & 2.8 \\
\hline Uruguay & -0.05 & 95.0 & 49.9 & -1.8 & 4.5 \\
\hline Viet Nam & $\mathrm{m}$ & $\mathrm{m}$ & $\mathrm{m}$ & $\mathrm{m}$ & $\mathrm{m}$ \\
\hline
\end{tabular}

*See note 3 under Figure III.1.1

1. ESCS refers to the PISA index of economic, social and cultural status.

2. Data for life satisfaction do not include the Flemish community of Belgium.

Source: OECD, PISA 2015 Database, Tables III.4.1, III.4.2, III.4.9, III.5.1, III.5.2 and III.5.3.

StatLink ailst http://dx.doi.org/10.1787/888933470425 
Parents can help children manage anxiety by encouraging them to trust in their ability to accomplish various academic tasks. PISA results show that, after accounting for differences in performance and socio-economic status, girls who perceive that their parents encourage them to be confident in their abilities were $21 \%$ less likely to report that they feel tense when they study, on average across OECD countries (Table III.4.13). This relationship is stronger among girls than among boys, possibly suggesting that parents have more difficulty communicating with and addressing the insecurities of their sons.

\section{Students' motivation to achieve}

PISA 2015 provides indicators of how motivated students are to achieve - both in school and beyond. Girls were more likely than boys to report that they want top grades at school, and that they care about being able to select among the best opportunities when they graduate. Girls thus seem to care more than boys that their efforts at school are properly recognised, but they were less likely than boys to report that they are ambitious or competitive. On average across OECD countries, $68 \%$ of boys and $62 \%$ of girls reported that they want to be the best, whatever they do (Figure III.5.1 and Table III.5.2).

Socio-economic status is also related to students' motivation to achieve and personal ambition. In almost all countries and economies, disadvantaged students have less motivation to achieve than advantaged students do (Table III.5.3). But even though they may come from a relatively disadvantaged background, many immigrant students hold an ambition to succeed that, in most cases, matches, and in some cases surpasses, the aspirations of students who are native to their host country. PISA 2015 shows that, on average across OECD countries, both first- and second-generation immigrant students have a greater motivation to achieve than students without an immigrant background (Table III.5.3).

Motivated students tend to do better at school. On average across OECD countries, students who are among the most motivated score 38 points higher in science (the equivalent of more than one year of schooling) than students who are among the least motivated (Figure III.5.3).

Achievement motivation is related to life satisfaction in a mutually reinforcing way. Students who are highly satisfied with their life tend to have greater resiliency and are more tenacious in the face of academic challenges. A positive view of the world and life circumstances builds their self-efficacy and their motivation to achieve. In turn, a greater motivation to achieve, paired with realised achievements, gives students a sense of purpose in life. It is thus not surprising that, across all countries and economies that participated in PISA 2015, students with greater overall motivation to achieve reported higher satisfaction with life (Table III.5.6).

But there can also be downsides to achievement motivation, particularly when this motivation is a response to external pressure. PISA results show that countries where students are highly motivated to achieve also tend to be the countries where many students feel anxious about a test, even if they are well prepared for it. Students who want to be able to select among the best opportunities when they graduate, who want to be the best in their class, or who want top grades in all courses are more likely to suffer from anxiety (Figure III.5.6 and Table III.5.8). If a certain amount of tension or concern is essential to motivation and high performance, too much pressure can be counterproductive for a child's cognitive development and psychological well-being. Both teachers and parents have to find ways to encourage students' motivation to learn and achieve without generating an excessive fear of failure.

\section{Expectation of further education}

Students' expectations for their future influence what they choose to study and the activities they pursue. The factors that shape students' expectations include the influence of people close to the student, past academic achievement, the relative flexibility of school systems, and the degree of selectivity of tertiary institutions.

PISA 2015 asked students to report what level of education they expect to complete. Across OECD countries, 44\% of students reported that they expect to complete university (ISCED 5a and 6). In Colombia, Korea, Qatar and the United States, more than three out four students reported that they expect to earn a university degree (Figure III.6.1).

In most countries and economies, girls were more likely than boys to report that they expect to complete university; and in all countries and economies, disadvantaged students were much less likely than advantaged students to report so (Table III.6.2). In addition, PISA results show that students' satisfaction with their life is strongly related to their expectation to complete university education (Figure III.6.2). On average across OECD countries, students who expect to complete university education were $30 \%$ more likely than students without such expectations to report high satisfaction with their life (9 or 10 on a scale from 0 to 10 ). 
In most countries, top performers were more likely than low performers to report that they expect to earn a university degree. On average across OECD countries, almost $70 \%$ of top-performing students and $20 \%$ of low-performing students reported that they expect to complete tertiary education. But large proportions of students hold expectations of further education that do not seem aligned with their performance in school. For example, in Colombia, Costa Rica, the Dominican Republic, Peru, Qatar, Thailand, Turkey, the United Arab Emirates and the United States, more than one in two all-round low performers (students who score below proficiency Level 2 in the PISA reading, mathematics and science tests) expect to complete a university degree (Figure III.6.3 and Table III.6.7). In these countries, the returns in earnings from tertiary education tend to be relatively high. For example, in Colombia in 2014, tertiary-educated workers earned 2.3 times the salary of adult workers with only upper secondary or post-secondary non-tertiary education, on average.

\section{STUDENTS' SOCIAL LIFE AT SCHOOL}

Human beings in general, and teenagers in particular, desire strong social ties and value acceptance, care and support from others. Adolescents who feel that they are part of a school community are more likely to perform better academically and be more motivated in school; they are also less likely to engage in risky and antisocial behaviour. PISA 2015 asked students to report whether they feel like an outsider or left out of things at school, whether they make friends easily, they feel that they belong at school, they feel awkward and out of place at school, they feel that other students like them, or they feel lonely. As school is the primary environment for social interactions among 15-year-olds, these subjective evaluations indicate whether education systems are able to foster students' well-being.

On average across OECD countries in 2015, 73\% of students reported that they feel that they belong at school; but that also means that a quarter of students do not share that feeling. Some $78 \%$ of students agreed or strongly agreed that they can make friends easily at school; $85 \%$ of students disagreed or strongly disagreed that they feel lonely at school; and $83 \%$ of students disagreed or strongly disagreed that they feel like an outsider or feel left out of things. Some $82 \%$ of students reported that they feel that other students like them, and $81 \%$ disagreed or strongly disagreed that they feel awkward and out of place at school. The percentage who report feeling like an outsider at school increased on average and in many countries between 2003 and 2015 (Table III.7.4).

Growing populations of immigrant students pose new challenges to maintaining cohesion at school, as students need to learn how to interact with peers from different cultural backgrounds. In 2015, 12.5\% of students in PISA-participating countries and economies had an immigrant background. On average, and in 24 countries and economies, students without an immigrant background reported a stronger sense of belonging than immigrant students, even after accounting for socio-economic status. The opposite pattern is observed in Australia, Qatar and the United Arab Emirates, where both first- and second-generation immigrant students reported a greater sense of belonging at school than non-immigrant students (Figure III.7.2 and Table III.7.6).

Students across OECD countries who reported that they feel like an outsider at school score 22 points lower in science, on average, than those who did not report so. Even after accounting for students' socio-economic status, this gap remains significant in the large majority of countries (Figure III.7.4).

PISA results also show a strong relationship between the likelihood of reporting low satisfaction with life (a level of 4 or lower on a life-satisfaction scale that ranges from 0 to 10) and feeling like an outsider at school. Students in OECD countries who feel like they are outsiders at school were three times more likely to report that they are not satisfied with their life than those who do not feel like they are outsiders (Figure III.7.5). In Finland, Ireland, Korea, the Netherlands, the United Kingdom and the United States, the likelihood of reporting low satisfaction with life is more than four times higher if the student reported feeling like an outsider. The relationship between belonging at school and life satisfaction remains significant after accounting for students' socio-economic status.

PISA 2015 results show that, on average across OECD countries, students who reported that their science teacher is willing to provide help and is interested in their learning are about 1.8 times more likely to feel that they belong at school than those students who did not report so (Figure III.7.8). Conversely, students who reported that they are treated unfairly by their teacher are much more likely to feel like an outsider at school (Figure III.7.9). Students who reported some unfair treatment by their teachers were 1.7 times more likely to report feeling isolated at school than those who did not report so, on average across OECD countries.

\section{Bullying}

For some students, school is a place of torment. Bullying - a systematic abuse of power - can be inflicted directly, through physical (hitting, punching or kicking) and verbal (name-calling or mocking) abuse. Relational bullying refers to the 
phenomenon of social exclusion, where some children are ignored, excluded from games or parties, rejected by peers, or are the victims of gossip and other forms of public humiliation and shaming. As teenagers use electronic communications more and more, cyberbullying has become a new form of aggression expressed via online tools, particularly mobile phones. Bullying tends to occur frequently during times of transition in children's and adolescents' lives, when they are figuring out where they fit in among new peer groups.

PISA 2015 measured the incidence of bullying using reports from the victim's perspective. Results show that, in many countries, verbal and psychological bullying occur frequently. On average across OECD countries, around $11 \%$ of students reported that they are frequently (at least a few times per month) made fun of, $7 \%$ reported that they are frequently left out of things, and $8 \%$ reported that they are frequently the object of nasty rumours in school. More than $10 \%$ of students in 34 out of 53 countries and economies reported that their peers make fun of them at least a few times per month. A similar proportion of students in 13 of 53 countries and economies reported that others frequently leave them out of things, while in 16 out of 53 countries and economies, more than $10 \%$ of students reported that they are frequently the object of nasty rumours (Figure III.8.2 and Table III.8.1).

Physical bullying is probably the most obvious kind of violence in schools, and educators tend to perceive physical bullying as more serious than verbal and relational bullying. On average across OECD countries, around 4\% of students reported that they are hit or pushed at least a few times per month, although this percentage varies from $1 \%$ to $9.5 \%$ across countries. Another $7.7 \%$ of students reported they are physically bullied a few times per year, similar proportions of students reported that they are threatened by others. Around $4 \%$ of students reported that their belongings have been destroyed or taken away by other students, and another $11 \%$ of students experienced this type of bullying a few times per year (Table III.8.1).

On average across OECD countries, boys were more likely than girls to report being victims of all forms of bullying except being left out of things on purpose and being the object of nasty rumours (Figure III.8.3). Across OECD countries, 9.2\% of girls, on average, reported that they have been victims of nasty rumours at least a few times per month, while $7.6 \%$ of boys reported so. Results also show that the risk of being bullied increases substantially for immigrant students who arrived in the host country at an older age (13-16 years old).

Across OECD countries, low performers were more likely to report exposure to physical, verbal and relational bullying (Figure III.8.5). Frequent exposure to bullying among low performers might be related to the concentration of these students in schools that lack the resources to address disciplinary problems. Results show that, across OECD countries, schools where the incidence of bullying is high by international standards (more than $10 \%$ of students are frequently bullied) score 47 points lower in science, on average, than schools where bullying is less frequent (schools where less than $5 \%$ of students are frequently bullied). This difference in performance between the two types of schools remains substantial (around 25 score points) even after accounting for differences in schools' socio-economic profile (Figure III.8.6).

Students who are frequently bullied may feel constantly insecure and on guard, and have clear difficulties finding their place at school. They tend to feel unaccepted and isolated and, as a result, are often withdrawn. On average across OECD countries, $42 \%$ of students who reported that they are frequently bullied - but only $15 \%$ of students who reported that they are not frequently bullied - reported feeling like an outsider at school (Figure III.8.8).

PISA result shows that $26 \%$ of frequently bullied students reported relatively low satisfaction with life (a value of 4 or lower on a life-satisfaction scale ranging from 0 to 10). Only $10 \%$ of students who are not frequently bullied reported such low satisfaction with their lives. And victims of bullying often decide to stay out of school. On average across OECD countries, $9 \%$ of frequently bullied students (compared with less than half of that percentage among students who are not frequently bullied) reported that they had skipped school more than three or four times in the two weeks prior to the PISA test (Figure III.8.8).

According to PISA results, the proportion of students who reported being victims of bullying is larger in schools with high percentages of students who had repeated a grade, where students reported a poor disciplinary climate in class, and where students reported that their teachers treat them unfairly (Figure III.8.9). Victimisation is less frequently reported by students who said that their parents support them when they face difficulties at school (Figure III.8.11). But parents of bullies are not always aware that their child is bullying others, and some victims of humiliating treatment are often reluctant to talk about the problem with their parents. On average across 15 countries and economies with available data, only $44 \%$ of the parents of frequently bullied students reported that they had exchanged ideas on parenting, family support, or the child's development with teachers over the previous academic year (the parents of around 39\% of students who are not frequently bullied had engaged in such discussions; Table III.8.19). 
Figure III.1.3 [Part 1/2] - Snapshot of sense of belonging at school and bullying

\begin{tabular}{|c|c|c|c|c|c|c|c|}
\hline & & $\begin{array}{l}\text { Countri } \\
\text { Countri } \\
\text { Countri }\end{array}$ & $\begin{array}{l}\text { es/economies with values } \\
\text { es/economies with values } \\
\text { es/economies with values }\end{array}$ & $\begin{array}{l}\text { above the OECD average } \\
\text { not significantly different fro } \\
\text { below the OECD average }\end{array}$ & $\mathrm{m}$ the OECD averag & & \\
\hline & & & $\begin{array}{c}\text { Percentage } \\
\text { of students who agreed/ } \\
\text { strongly agreed with } \\
\text { the following statement }\end{array}$ & $\begin{array}{c}\text { Percentage } \\
\text { of students who disagreed/ } \\
\text { strongly disagreed with } \\
\text { the following statement }\end{array}$ & $\begin{array}{l}\text { Socio-economic } \\
\text { disparity for the }\end{array}$ & $\begin{array}{l}\text { Difference between } \\
\text { non-immigrant and first- } \\
\text { generation immigrant } \\
\text { students in the percentage }\end{array}$ & $\begin{array}{l}\text { Change between } \\
\text { PISA } 2015 \text { and } 2003 \\
\text { in the percentage of }\end{array}$ \\
\hline & & $\begin{array}{l}\text { Index of sense } \\
\text { of belonging }\end{array}$ & $\begin{array}{c}\text { I feel like I belong } \\
\text { at school }\end{array}$ & $\begin{array}{c}\text { I feel like an outsider } \\
\text { (or left out of things) } \\
\text { at school }\end{array}$ & $\begin{array}{c}\text { of belonging } \\
\text { (top - bottom } \\
\text { quarters of ESCS') }\end{array}$ & $\begin{array}{l}\text { strongly agreed with the } \\
\text { following statement: “I feel } \\
\text { like I belong at school" }\end{array}$ & $\begin{array}{l}\text { strongly disagreed with } \\
\text { the following statement: } \\
\text { "I feel like an outsider" }\end{array}$ \\
\hline & & Mean index & $\%$ & $\%$ & Dif. & $\%$ dif. & $\%$ dif. \\
\hline & OECD average & 0.02 & 73.0 & 82.8 & 0.21 & 4.6 & -9.9 \\
\hline 0 & Australia & -0.12 & 71.9 & 76.5 & 0.29 & -8.3 & -15.9 \\
\hline Uي & Austria & 0.44 & 76.0 & 86.1 & 0.22 & 9.7 & -7.9 \\
\hline $\overrightarrow{0}$ & Belgium & 0.01 & 62.0 & 87.1 & 0.15 & 10.1 & -5.2 \\
\hline & Canada & -0.11 & 71.6 & 77.5 & 0.25 & -5.4 & -13.9 \\
\hline & Chile & -0.04 & 77.3 & 79.9 & 0.28 & 3.5 & $\mathrm{~m}$ \\
\hline & Czech Republic & -0.25 & 70.9 & 79.8 & 0.23 & 6.2 & -10.0 \\
\hline & Denmark & 0.14 & 70.3 & 87.6 & 0.24 & 10.5 & -7.2 \\
\hline & Estonia & -0.06 & 78.0 & 87.2 & 0.22 & $\mathrm{C}$ & $\mathrm{m}$ \\
\hline & Finland & 0.09 & 80.3 & 87.7 & 0.23 & 1.7 & -6.9 \\
\hline & France & -0.06 & 40.9 & 76.8 & 0.27 & 2.7 & -15.2 \\
\hline & Germany & 0.29 & 74.9 & 85.5 & 0.18 & 8.1 & -8.4 \\
\hline & Greece & 0.10 & 83.0 & 84.4 & 0.16 & 6.5 & -9.2 \\
\hline & Hungary & 0.06 & 74.5 & 82.1 & 0.30 & -4.6 & -8.6 \\
\hline & Iceland & 0.19 & 78.5 & 82.9 & 0.19 & 12.7 & -7.2 \\
\hline & Ireland & -0.02 & 73.3 & 83.3 & 0.15 & 5.3 & -11.0 \\
\hline & Israel & $\mathrm{m}$ & $\mathrm{m}$ & $\mathrm{m}$ & $\mathrm{m}$ & $\mathrm{m}$ & $\mathrm{m}$ \\
\hline & Italy & 0.05 & 67.3 & 88.9 & 0.09 & 4.6 & -6.4 \\
\hline & Japan & -0.03 & 81.9 & 88.1 & 0.18 & C & -6.2 \\
\hline & Korea & 0.16 & 79.5 & 91.3 & 0.33 & c & -0.2 \\
\hline & Latvia & -0.20 & 78.6 & 84.2 & 0.16 & C & -10.7 \\
\hline & Luxembourg & 0.14 & 66.0 & 83.2 & 0.42 & 16.4 & -9.0 \\
\hline & Mexico & -0.14 & 76.1 & 75.2 & 0.21 & 10.0 & -15.4 \\
\hline & Netherlands & 0.17 & 80.9 & 91.0 & 0.06 & 1.1 & -5.0 \\
\hline & New Zealand & -0.17 & 73.7 & 77.7 & 0.25 & -4.1 & -14.5 \\
\hline & Norway & 0.21 & 75.7 & 87.9 & 0.29 & 2.4 & -6.6 \\
\hline & Poland & -0.25 & 62.4 & 78.5 & 0.07 & $\mathrm{C}$ & -13.3 \\
\hline & Portugal & 0.10 & 82.3 & 87.1 & 0.27 & 10.4 & -7.0 \\
\hline & Slovak Republic & -0.28 & 69.7 & 77.3 & 0.26 & C & -14.6 \\
\hline & Slovenia & -0.10 & 74.5 & 82.4 & 0.09 & 0.7 & $\mathrm{~m}$ \\
\hline & Spain & 0.47 & 87.2 & 89.9 & 0.17 & 8.0 & -6.4 \\
\hline & Sweden & 0.04 & 69.3 & 79.4 & 0.23 & 6.6 & -15.3 \\
\hline & Switzerland & 0.36 & 70.8 & 88.3 & 0.10 & 11.5 & -4.4 \\
\hline & Turkey & -0.44 & 61.4 & 64.3 & 0.17 & C & -21.9 \\
\hline & United Kingdom & -0.09 & 67.8 & 79.9 & 0.22 & -1.0 & -13.1 \\
\hline & United States & -0.09 & 74.2 & 76.2 & 0.30 & -0.4 & $\mathrm{~m}$ \\
\hline$n$ & Albania & 0.40 & 93.1 & 94.5 & 0.17 & C & $\mathrm{m}$ \\
\hline & Algeria & -0.21 & 87.4 & 72.3 & 0.12 & $\mathrm{~m}$ & $\mathrm{~m}$ \\
\hline ปั & Brazil & -0.15 & 76.1 & 79.2 & 0.26 & C & -14.2 \\
\hline 2 & B-S-J-G (China) & -0.33 & 64.6 & 78.0 & 0.31 & c & $\mathrm{m}$ \\
\hline & Bulgaria & -0.34 & 68.0 & 70.3 & 0.24 & c & $\mathrm{m}$ \\
\hline & CABA (Argentina) & 0.38 & 88.7 & 87.5 & 0.41 & 0.0 & $\mathrm{~m}$ \\
\hline & Colombia & -0.31 & 74.3 & 71.1 & 0.14 & C & $\mathrm{m}$ \\
\hline & Costa Rica & -0.16 & 74.7 & 73.2 & 0.18 & 0.7 & $\mathrm{~m}$ \\
\hline & Croatia & 0.05 & 81.2 & 86.0 & 0.14 & 2.6 & $\mathrm{~m}$ \\
\hline & Cyprus* & 0.10 & 80.2 & 82.9 & 0.08 & 10.0 & $\mathrm{~m}$ \\
\hline & Dominican Republic & -0.40 & 66.9 & 60.4 & 0.32 & C & $\mathrm{m}$ \\
\hline & FYROM & 0.35 & 92.1 & 87.9 & 0.36 & c & $\mathrm{m}$ \\
\hline & Georgia & 0.20 & 64.8 & 95.1 & 0.28 & c & $\mathrm{m}$ \\
\hline & Hong Kong (China) & -0.35 & 71.1 & 75.3 & 0.21 & -0.2 & -7.0 \\
\hline & Indonesia & 0.10 & 92.3 & 96.3 & 0.06 & $\mathrm{C}$ & 0.2 \\
\hline & Jordan & 0.19 & 85.9 & 76.8 & 0.30 & 10.2 & $\mathrm{~m}$ \\
\hline & Kosovo & 0.29 & 92.5 & 86.8 & 0.18 & -2.5 & $\mathrm{~m}$ \\
\hline & Lebanon & 0.02 & 74.9 & 74.9 & 0.26 & -15.6 & $\mathrm{~m}$ \\
\hline & Lithuania & -0.27 & 54.5 & 69.3 & 0.29 & $\mathrm{C}$ & $\mathrm{m}$ \\
\hline & Macao (China) & -0.40 & 59.9 & 79.3 & 0.02 & 2.6 & -5.1 \\
\hline & Malta & -0.02 & 69.8 & 79.6 & 0.12 & 19.1 & $\mathrm{~m}$ \\
\hline & Moldova & 0.04 & 67.7 & 91.1 & 0.17 & $\mathrm{c}$ & $\mathrm{m}$ \\
\hline & Montenegro & -0.10 & 53.8 & 82.8 & 0.04 & 3.6 & $\mathrm{~m}$ \\
\hline & Peru & -0.22 & 71.4 & 79.4 & 0.34 & C & $\mathrm{m}$ \\
\hline & Qatar & -0.10 & 70.7 & 75.6 & 0.19 & -7.5 & $\mathrm{~m}$ \\
\hline & Romania & 0.00 & 52.5 & 87.8 & 0.13 & c & $\mathrm{m}$ \\
\hline & Russia & -0.37 & 74.6 & 80.4 & 0.17 & 4.8 & -13.3 \\
\hline & Singapore & -0.21 & 76.0 & 76.5 & 0.20 & -1.2 & $\mathrm{~m}$ \\
\hline & Chinese Taipei & 0.02 & 89.9 & 88.7 & 0.22 & c & $\mathrm{m}$ \\
\hline & Thailand & -0.35 & 78.4 & 79.7 & 0.14 & C & -13.9 \\
\hline & Trinidad and Tobago & 0.05 & 79.7 & 81.9 & 0.28 & 3.8 & $\mathrm{~m}$ \\
\hline & Tunisia & -0.20 & 57.6 & 80.1 & 0.10 & C & -10.3 \\
\hline & United Arab Emirates & -0.10 & 73.9 & 78.7 & 0.21 & -1.9 & $\mathrm{~m}$ \\
\hline & Uruguay & -0.09 & 77.9 & 76.2 & 0.37 & c & -16.5 \\
\hline & Viet Nam & -0.06 & 80.8 & 95.3 & 0.12 & C & $\mathrm{m}$ \\
\hline
\end{tabular}

* See note 3 under Figure III.1.1

1. ESCS refers to the PISA index of economic, social and cultural status.

2. Schools with a high prevalence of bullying are those where more than $10 \%$ of students are frequently bullied. Schools with a low prevalence of bullying are those where $5 \%$ of students or less are frequently bullied. A student is frequently bullied if he or she is in the top $10 \%$ of the index of exposure to bullying among all countries/economies. Note: Values that are statistically significant are indicated in bold (see Annex A3)

Source: OECD, PISA 2015 Database, Tables III.7.1, III.7.3, III.7.4, III.7.6, III.8.1, III.8.6 and III.8.10.

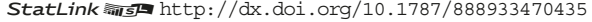


Figure III.1.3 [Part 2/2] - Snapshot of sense of belonging at school and bullying

\begin{tabular}{|c|c|c|c|c|c|c|c|}
\hline & & $\begin{array}{l}\text { Countries/€ } \\
\text { Countries/€ } \\
\text { Countries/ }\end{array}$ & $\begin{array}{l}\text { omies with valu } \\
\text { omies with valu } \\
\text { omies with valu }\end{array}$ & $\begin{array}{l}\text { ove the OECD av } \\
\text { t significantly diff } \\
\text { low the OECD av }\end{array}$ & ge from the OECD a & rage & \\
\hline & & & Percentage & $\begin{array}{l}\text { udents who repor } \\
\text { ast a few times a n }\end{array}$ & $\begin{array}{l}\text { being bullied } \\
\text { th }\end{array}$ & $\begin{array}{l}\text { Socio-economic disparity } \\
\text { in the index of exposure }\end{array}$ & Difference in science \\
\hline & & $\begin{array}{l}\text { Index of exposure } \\
\text { to bullying }\end{array}$ & $\begin{array}{c}\text { Any type } \\
\text { of bullying act }\end{array}$ & $\begin{array}{l}\text { Other students } \\
\text { made fun of me }\end{array}$ & $\begin{array}{l}\text { I got hit } \\
\text { or pushed around } \\
\text { by other students }\end{array}$ & $\begin{array}{l}\text { socio-economic profile } \\
\text { (top-bottom quarter } \\
\text { of school ESCS') }\end{array}$ & $\begin{array}{l}\text { schools with high } \\
\text { incidence and low } \\
\text { incidence of bullying }\end{array}$ \\
\hline & & Mean & $\%$ & $\%$ & $\%$ & Dif. & Score dif. \\
\hline & OECD average & 0.00 & 18.7 & 10.9 & 4.3 & -0.10 & -47 \\
\hline 0 & Australia & 0.45 & 24.2 & 15.1 & 5.7 & -0.35 & -46 \\
\hline 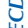 & Austria & 0.10 & 19.1 & 11.9 & 4.2 & 0.02 & -51 \\
\hline & Belgium & 0.18 & 18.5 & 11.1 & 3.1 & -0.16 & -82 \\
\hline & Canada & 0.39 & 20.3 & 13.4 & 5.0 & -0.16 & -33 \\
\hline & Chile & 0.15 & 18.0 & 9.6 & 3.2 & -0.06 & -48 \\
\hline & Czech Republic & 0.15 & 25.4 & 11.1 & 7.5 & -0.11 & -48 \\
\hline & Denmark & 0.22 & 20.1 & 11.2 & 3.5 & -0.05 & -28 \\
\hline & Estonia & 0.24 & 20.2 & 13.7 & 4.7 & -0.07 & -29 \\
\hline & Finland & 0.23 & 16.9 & 10.5 & 4.6 & -0.09 & -22 \\
\hline & France & -0.08 & 17.9 & 11.7 & 3.1 & -0.27 & -113 \\
\hline & Germany & 0.17 & 15.7 & 9.2 & 2.3 & -0.09 & -61 \\
\hline & Greece & -0.55 & 16.7 & 10.0 & 4.3 & -0.15 & -83 \\
\hline & Hungary & -0.06 & 20.3 & 9.6 & 3.9 & -0.17 & -75 \\
\hline & Iceland & -0.43 & 11.9 & 6.7 & 2.4 & -0.21 & -17 \\
\hline & Ireland & 0.1 & 14.7 & 8.5 & 3.1 & 0.03 & -4 \\
\hline & Israel & $\mathrm{m}$ & $\mathrm{m}$ & $\mathrm{m}$ & $\mathrm{m}$ & $\mathrm{m}$ & $\mathrm{m}$ \\
\hline & Italy & $\mathrm{m}$ & $\mathrm{m}$ & $\mathrm{m}$ & $\mathrm{m}$ & $\mathrm{m}$ & $\mathrm{m}$ \\
\hline & Japan & -0.21 & 21.9 & 17.0 & 8.9 & 0.17 & -47 \\
\hline & Korea & -1.44 & 11.9 & 10.2 & 0.9 & 0.12 & $\mathrm{~m}$ \\
\hline & Latvia & 0.65 & 30.6 & 15.0 & 8.4 & -0.14 & -20 \\
\hline & Luxembourg & -0.15 & 15.7 & 8.6 & 3.5 & -0.10 & -91 \\
\hline & Mexico & 0.13 & 20.2 & 13.0 & 5.3 & -0.14 & -34 \\
\hline & Netherlands & -0.33 & 9.3 & 4.3 & 1.8 & -0.08 & -88 \\
\hline & New Zealand & 0.61 & 26.1 & 17.4 & 6.7 & -0.25 & -32 \\
\hline & Norway & -0.01 & 17.7 & 9.4 & 4.6 & -0.06 & -15 \\
\hline & Poland & 0.27 & 21.1 & 11.7 & 4.1 & -0.03 & -17 \\
\hline & Portugal & -0.52 & 11.8 & 6.7 & 2.3 & -0.11 & -64 \\
\hline & Slovak Republic & 0.1 & 22.5 & 10.4 & 4.9 & -0.28 & -65 \\
\hline & Slovenia & 0.01 & 16.4 & 8.8 & 4.1 & -0.14 & -63 \\
\hline & Spain & -0.09 & 14.0 & 8.0 & 2.9 & -0.01 & -21 \\
\hline & Sweden & -0.11 & 17.9 & 9.4 & 5.4 & -0.18 & -36 \\
\hline & Switzerland & 0.24 & 16.8 & 10.7 & 2.8 & -0.11 & -44 \\
\hline & Turkey & -0.97 & 18.6 & 9.2 & 4.5 & -0.09 & -67 \\
\hline & United Kingdom & 0.4 & 23.9 & 15.1 & 5.4 & -0.04 & -38 \\
\hline & United States & 0.16 & 18.9 & 11.4 & 3.8 & 0.05 & -10 \\
\hline$n$ & Albania & $\mathrm{m}$ & $\mathrm{m}$ & $\mathrm{m}$ & $\mathrm{m}$ & $\mathrm{m}$ & $\mathrm{m}$ \\
\hline & Algeria & $\mathrm{m}$ & $\mathrm{m}$ & $\mathrm{m}$ & $\mathrm{m}$ & $\mathrm{m}$ & $\mathrm{m}$ \\
\hline$\approx$ & Brazil & -0.23 & 17.5 & 9.3 & 3.2 & 0.00 & -26 \\
\hline & B-S-J-G (China) & 0.1 & 22.5 & 12.3 & 4.2 & -0.30 & -92 \\
\hline & Bulgaria & 0.14 & 24.7 & 12.4 & 9.1 & -0.17 & -81 \\
\hline & CABA (Argentina) & $\mathrm{m}$ & $\mathrm{m}$ & $\mathrm{m}$ & $\mathrm{m}$ & $\mathrm{m}$ & $\mathrm{m}$ \\
\hline & Colombia & 0.16 & 22.1 & 11.5 & 4.0 & -0.06 & -29 \\
\hline & Costa Rica & 0.1 & 20.8 & 11.8 & 2.7 & 0.03 & -2 \\
\hline & Croatia & -0.12 & 17.1 & 8.0 & 3.9 & -0.19 & -53 \\
\hline & Cyprus* & $\mathrm{m}$ & 18.1 & 11.2 & 6.5 & $\mathrm{~m}$ & $\mathrm{~m}$ \\
\hline & Dominican Republic & -0.29 & 30.1 & 15.3 & 4.8 & -0.02 & -13 \\
\hline & FYROM & $\mathrm{m}$ & $\mathrm{m}$ & $\mathrm{m}$ & $\mathrm{m}$ & $\mathrm{m}$ & $\mathrm{m}$ \\
\hline & Georgia & $\mathrm{m}$ & $\mathrm{m}$ & $\mathrm{m}$ & $\mathrm{m}$ & $\mathrm{m}$ & $\mathrm{m}$ \\
\hline & Hong Kong (China) & 0.21 & 32.3 & 26.1 & 9.5 & -0.06 & -42 \\
\hline & Indonesia & $\mathrm{m}$ & $\mathrm{m}$ & $\mathrm{m}$ & $\mathrm{m}$ & $\mathrm{m}$ & $\mathrm{m}$ \\
\hline & Jordan & $\mathrm{m}$ & $\mathrm{m}$ & $\mathrm{m}$ & $\mathrm{m}$ & $\mathrm{m}$ & $\mathrm{m}$ \\
\hline & Kosovo & $\mathrm{m}$ & $\mathrm{m}$ & $\mathrm{m}$ & $\mathrm{m}$ & $\mathrm{m}$ & $\mathrm{m}$ \\
\hline & Lebanon & $\mathrm{m}$ & $\mathrm{m}$ & $\mathrm{m}$ & $\mathrm{m}$ & $\mathrm{m}$ & $\mathrm{m}$ \\
\hline & Lithuania & -0.10 & 16.4 & 9.2 & 4.4 & -0.28 & -55 \\
\hline & Macao (China) & 0.49 & 27.3 & 19.9 & 4.2 & 0.24 & $\mathrm{~m}$ \\
\hline & Malta & $\mathrm{m}$ & $\mathrm{m}$ & $\mathrm{m}$ & $\mathrm{m}$ & $\mathrm{m}$ & $\mathrm{m}$ \\
\hline & Moldova & $\mathrm{m}$ & $\mathrm{m}$ & $\mathrm{m}$ & $\mathrm{m}$ & $\mathrm{m}$ & $\mathrm{m}$ \\
\hline & Montenegro & -0.91 & 16.4 & 6.8 & 3.5 & 0.00 & -58 \\
\hline & Peru & -0.23 & 18.4 & 7.7 & 3.6 & $\begin{array}{c}-0.18 \\
\end{array}$ & -37 \\
\hline & Qatar & 0.36 & 25.0 & 14.6 & 8.8 & -0.33 & -61 \\
\hline & Romania & $\mathrm{m}$ & $\mathrm{m}$ & $\mathrm{m}$ & $\mathrm{m}$ & $\mathrm{m}$ & $\mathrm{m}$ \\
\hline & Russia & -0.01 & 27.5 & 11.8 & 3.1 & 0.17 & -18 \\
\hline & Singapore & 0.51 & 25.1 & 18.3 & 5.1 & -0.35 & -96 \\
\hline & Chinese Taipei & -0.57 & 10.7 & 6.8 & 0.8 & 0.06 & -42 \\
\hline & Thailand & 0.11 & 27.2 & 19.9 & 7.1 & -0.36 & -56 \\
\hline & Trinidad and Tobago & $\mathrm{m}$ & $\mathrm{m}$ & $\mathrm{m}$ & $\mathrm{m}$ & $\mathrm{m}$ & $\mathrm{m}$ \\
\hline & Tunisia & 0.32 & 28.2 & 13.1 & 8.6 & -0.14 & -39 \\
\hline & United Arab Emirates & 0.30 & 27.0 & 15.9 & 8.0 & -0.20 & -59 \\
\hline & Uruguay & -0.05 & 16.9 & 10.3 & 4.0 & 0.03 & -28 \\
\hline & Viet Nam & $\mathrm{m}$ & $\mathrm{m}$ & $\mathrm{m}$ & $\mathrm{m}$ & $\mathrm{m}$ & $\mathrm{m}$ \\
\hline
\end{tabular}

*See note 3 under Figure III.1.1

1. ESCS refers to the PISA index of economic, social and cultural status. $2 \%$ of students are frequently bullied. Schools with a low prevalence of bullying are those where $5 \%$ of students or less are frequently bullied. A student is frequently bullied if he or she is in the top $10 \%$ of the index of exposure to bullying among all countries/economies.

Note: Values that are statistically significant are indicated in bold (see Annex A3)

Source: OECD, PISA 2015 Database, Tables III.7.1, III.7.3, III.7.4, III.7.6, III.8.1, III.8.6 and III.8.10.

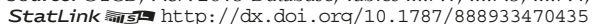




\section{PARENTS AND THE HOME ENVIRONMENT}

Families are the first social unit in which children learn and develop. It is not surprising, then, that interactions with parents have consistently been shown to influence students' achievement, expectations, attitudes and psychological health. In spite of the difficulties parents encounter in balancing their professional and private lives and their struggle to find "quality time" to spend with their child and to get involved in their child's education, PISA data paint a positive picture of how parents and children spend time together. Across the 18 countries and economies that distributed the parent questionnaire, an average of $82 \%$ of parents reported that they eat the main meal with their child around a table, $70 \%$ reported that they spend time just talking to their child, and 52\% reported that they discuss how well their child is doing at school every day or almost every day. In Belgium (Flemish community), France, Italy, Portugal and Spain, more than $90 \%$ of parents eat a meal with their child daily or nearly every day (Figure III.9.1).

Among school-based activities, the activity most frequently reported by parents is attending a scheduled meeting or conferences for parents in their child's school. Some $77 \%$ of parents, on average, reported having done so during the previous academic year. Slightly more than half of the parents reported that they had "discussed my child's behaviour with a teacher on my own initiative", "discussed my child's progress with a teacher on my own initiative" or "talked about how to support learning at home and homework with my child's teachers" (Figure III.9.1).

Parents' activities that typically take place at home or in the context of the family, namely "asking how my child is performing in science class", "discussing how well my child is doing at school", "eating the main meal with my child around a table" and "spending time just talking to my child" are all positively related to their child's science performance in PISA 2015. An activity as simple as eating a meal together at least once a week is associated with an increase of at least 12 score points in science, on average, after accounting for students' socio-economic status (Figure III.9.2).

Conversely, most activities that reflect parents' direct involvement in their child's education have a negative relationship with the student's performance. Students whose parents reported that they "help my child with his/her science homework" or "obtain science-related materials (e.g. applications, software, study guides, etc.) for my child" at least once a week, score at least 23 points lower in science, on average, than students whose parents engage in these activities less frequently. In these cases, parents might be more directly involved in their child's school work because their child is performing poorly in science (Figure III.9.2).

PISA data show that certain types of parental activities are positively related not only to students' performance, but also to students' satisfaction with their life. Students whose parents reported "spending time just talking to my child", "eating the main meal with my child around a table" or "discussing how well my child is doing at school" every week were between $22 \%$ and $62 \%$ more likely to report high levels of life satisfaction (i.e. their responses put them at the equivalent of 9 or 10 on a scale of 0 to 10) than students whose parents reported engaging in these activities less frequently (Figure III.9.4). While countries vary in which parental activities are most strongly related to students' life satisfaction, "spending time just talking" is the parental activity most frequently and most strongly associated with students' life satisfaction. In most countries, students were more likely to report being very satisfied with their lives when their parents reported engaging in at least one of these home-based activities on a regular basis.

\section{Parents' interest in their child's school life}

In addition, students' perceptions of how interested their parents are in them and in their school life can affect their own attitudes towards education. Students who reported that their parents are interested in their school activities perform better in PISA than students who reported a lack of interest from their parents. This is true at all levels of performance in science, although this association is stronger among low-performing students (Figure III.9.6). In fact, students who "agree" or "strongly agree" that their parents are interested in their school activities are also more motivated to do well in school. Across OECD countries, these students were 2.5 times more likely to report that they "want top grades in school", on average (Figure III.9.7). Likewise, students who hold these perceptions of their parents' interest were almost twice as likely to report being highly satisfied with their life (reporting 9 or 10 on a scale of 0-10 of life satisfaction) than students who do not hold those perceptions.

A growing understanding that parents and teachers can be effective partners in helping children succeed in school has led policy makers and school leaders in many countries to take deliberate actions to increase parents' participation in school life. Parents' involvement not only provides additional support to their child's learning, but it also brings greater accountability to education systems. But even interested parents are sometimes prevented from being as engaged as they might wish to be. 
Figure III.1.4 [Part 1/2] - Snapshot of parental support and education expectations

\begin{tabular}{|c|c|c|c|c|}
\hline & $\begin{array}{l}\text { Countries/economies w } \\
\text { Countries/economies w } \\
\text { Countries/economies w }\end{array}$ & $\begin{array}{l}\text { alues above the OECD average } \\
\text { alues not significantly different } f \\
\text { alues below the OECD average }\end{array}$ & the OECD average & \\
\hline & $\begin{array}{l}\text { Percentage of students } \\
\text { who reported talking } \\
\text { to their parents after school }\end{array}$ & $\begin{array}{l}\text { Gender difference } \\
\text { in the percentage of students } \\
\text { who reported talking } \\
\text { to their parents after school } \\
(B-G):\end{array}$ & $\begin{array}{l}\text { Percentage of students } \\
\text { who agreed/strongly agreed } \\
\text { with the following statement: } \\
\text { "My parents are interested } \\
\text { in my school activities" }\end{array}$ & $\begin{array}{c}\text { Socio-economic disparity } \\
\text { for "My parents are interested } \\
\text { in my school activities" } \\
\text { (top - bottom quarter of ESCS }{ }^{1} \text { ) }\end{array}$ \\
\hline & $\%$ & $\%$ dif. & $\%$ & $\%$ dif. \\
\hline OECD average & 86.1 & -2.1 & 93.5 & 5.3 \\
\hline Australia & 90.1 & -0.5 & 94.1 & 6.9 \\
\hline Austria & 84.1 & -3.4 & 95.8 & 2.8 \\
\hline Belgium ${ }^{3}$ & 85.4 & -1.3 & 93.9 & 4.8 \\
\hline Canada & 88.2 & -1.1 & 92.5 & 7.9 \\
\hline Chile & 81.2 & -1.9 & 91.1 & 4.2 \\
\hline Czech Republic & 85.6 & -1.6 & 91.0 & 7.0 \\
\hline Denmark & 87.2 & -0.1 & 94.5 & 4.6 \\
\hline Estonia & 87.9 & -2.7 & 91.7 & 5.2 \\
\hline Finland & 82.8 & -2.1 & 96.4 & 3.7 \\
\hline France & 80.8 & -1.6 & 95.3 & 6.0 \\
\hline Germany & 86.9 & -2.8 & 95.6 & 4.3 \\
\hline Greece & 88.5 & -1.2 & 94.6 & 4.6 \\
\hline Hungary & 89.4 & -1.1 & 96.0 & 3.4 \\
\hline Iceland & 90.2 & -1.5 & 93.5 & 7.2 \\
\hline Ireland & 92.1 & -1.0 & 96.5 & 2.4 \\
\hline Israel & 88.0 & -6.6 & $\mathrm{~m}$ & $\mathrm{~m}$ \\
\hline Italy & 89.3 & -2.0 & 96.1 & 2.1 \\
\hline Japan & 90.2 & -4.7 & 85.9 & 10.0 \\
\hline Korea & 79.4 & -3.8 & 96.5 & 4.0 \\
\hline Latvia & 89.4 & -1.7 & 92.5 & 1.6 \\
\hline Luxembourg & 82.4 & -4.3 & 95.3 & 4.4 \\
\hline Mexico & 79.7 & -1.8 & 91.1 & 4.7 \\
\hline Netherlands & 89.0 & -1.2 & 97.2 & 2.7 \\
\hline New Zealand & 88.8 & 0.1 & 92.3 & 9.1 \\
\hline Norway & 87.6 & -0.6 & 93.3 & 7.3 \\
\hline Poland & 83.4 & -2.4 & 94.5 & 3.6 \\
\hline Portugal & 92.0 & -0.7 & 97.6 & 2.6 \\
\hline Slovak Republic & 81.8 & -4.4 & 91.8 & 7.6 \\
\hline Slovenia & 79.8 & -4.9 & 95.3 & 3.1 \\
\hline Spain & 84.0 & -3.0 & 95.2 & 4.4 \\
\hline Sweden & 87.4 & -1.8 & 92.6 & 7.7 \\
\hline Switzerland & 82.7 & -2.7 & 96.5 & 1.7 \\
\hline Turkey & 80.0 & -3.4 & 77.8 & 13.9 \\
\hline United Kingdom & 88.7 & 1.0 & 93.7 & 6.8 \\
\hline United States & 88.2 & -1.6 & 91.7 & 9.6 \\
\hline Albania & $\mathrm{m}$ & $\mathrm{m}$ & $\mathrm{m}$ & $\mathrm{m}$ \\
\hline Algeria & $\mathrm{m}$ & $\mathrm{m}$ & $\mathrm{m}$ & $\mathrm{m}$ \\
\hline Brazil & 85.2 & -1.1 & 93.4 & 4.0 \\
\hline$\approx$ B-S-J-G (China) & 72.1 & -2.7 & 93.1 & 5.2 \\
\hline Bulgaria & 84.1 & -4.1 & 83.8 & 4.0 \\
\hline CABA (Argentina) & $\mathrm{m}$ & $\mathrm{m}$ & $\mathrm{m}$ & $\mathrm{m}$ \\
\hline Colombia & 82.5 & -0.5 & 93.0 & 2.9 \\
\hline Costa Rica & 83.5 & -1.0 & 95.4 & 2.5 \\
\hline Croatia & 85.8 & -3.5 & 95.6 & 1.6 \\
\hline Cyprus* & 86.1 & -6.6 & 94.7 & 1.5 \\
\hline Dominican Republic & 86.6 & 1.5 & 88.3 & 7.1 \\
\hline FYROM & $\mathrm{m}$ & $\mathrm{m}$ & $\mathrm{m}$ & $\mathrm{m}$ \\
\hline Georgia & $\mathrm{m}$ & $\mathrm{m}$ & $\mathrm{m}$ & $\mathrm{m}$ \\
\hline Hong Kong (China) & 76.8 & -2.6 & 70.2 & 21.7 \\
\hline Indonesia & $\mathrm{m}$ & $\mathrm{m}$ & $\mathrm{m}$ & $\mathrm{m}$ \\
\hline Jordan & $\mathrm{m}$ & $\mathrm{m}$ & $\mathrm{m}$ & $\mathrm{m}$ \\
\hline Kosovo & $\mathrm{m}$ & $\mathrm{m}$ & $\mathrm{m}$ & $\mathrm{m}$ \\
\hline Lebanon & $\mathrm{m}$ & $\mathrm{m}$ & $\mathrm{m}$ & $\mathrm{m}$ \\
\hline Lithuania & 89.7 & -3.4 & 93.8 & 3.6 \\
\hline Macao (China) & 72.5 & -2.1 & 72.0 & 17.6 \\
\hline Malta & $\mathrm{m}$ & $\mathrm{m}$ & $\mathrm{m}$ & $\mathrm{m}$ \\
\hline Moldova & $\mathrm{m}$ & $\mathrm{m}$ & $\mathrm{m}$ & $\mathrm{m}$ \\
\hline Montenegro & 79.8 & -3.4 & 91.8 & 4.8 \\
\hline Peru & 81.7 & -0.7 & 92.9 & 0.9 \\
\hline Qatar & 88.6 & -2.8 & 86.5 & 8.6 \\
\hline Romania & $\mathrm{m}$ & $\mathrm{m}$ & 0.0 & $\mathrm{~m}$ \\
\hline Russia & 92.6 & -0.8 & 94.6 & 4.2 \\
\hline Singapore & 77.2 & -1.1 & 85.9 & 18.6 \\
\hline Chinese Taipei & 56.3 & -5.5 & 84.2 & 13.9 \\
\hline Thailand & 92.6 & -3.6 & 94.5 & 0.3 \\
\hline Trinidad and Tobago & $\mathrm{m}$ & $\mathrm{m}$ & $\mathrm{m}$ & $\mathrm{m}$ \\
\hline Tunisia & 90.6 & -1.4 & 86.5 & 7.5 \\
\hline United Arab Emirates & 90.5 & -2.3 & 85.6 & 8.1 \\
\hline Uruguay & 81.2 & -0.7 & 94.9 & 4.8 \\
\hline Viet Nam & $\mathrm{m}$ & $\mathrm{m}$ & $\mathrm{m}$ & $\mathrm{m}$ \\
\hline
\end{tabular}

* See note 3 under Figure III.1.1

2. Blue-collar occupations include skilled agricultural, forestry and fishery workers (ISCO-08 category 6), craft and related trades workers (ISCO-08 category 7), plant and machine operators and assemblers (ISCO-08 category 8) and elementary occupations (ISCO-08 category 9).

White-collar occupations include managers (ISCO-08 category 1), professionals (ISCO-08 category 2) and technicians and associate professionals (ISCO-08 category 3 )

3. Data for life satisfaction do not include the Flemish community of Belgium.

Source: OECD, PISA 2015 Database, III.9.16, III.9.17, III.9.18, III.9.19, III.10.9 and III.10.15

StatLink 到s http: //dx.doi.org/10.1787/888933470449 
Figure III.1.4 [Part 2/2] - Snapshot of parental support and education expectations

\begin{tabular}{|c|c|c|c|c|c|c|}
\hline & & $\begin{array}{l}\text { Countries/economi } \\
\text { Countries/economi } \\
\text { Countries/economi }\end{array}$ & $\begin{array}{l}\text { es with values above the OEC } \\
\text { sith values not significant } \\
\text { with values below the OEC }\end{array}$ & $\begin{array}{l}C D \text { average } \\
\text { tly different from the OECD ave } \\
C D \text { average }\end{array}$ & rage & \\
\hline & & $\begin{array}{c}\text { Percentage of students } \\
\text { who agreed/strongly agreed } \\
\text { with the following } \\
\text { statement: "My parents } \\
\text { support me when I am } \\
\text { facing difficulties at school" }\end{array}$ & $\begin{array}{l}\text { Socio-economic disparity } \\
\text { for "My parents support } \\
\text { me when I am facing } \\
\text { difficulties at school" } \\
\text { (top - bottom quarter } \\
\text { of ESCS') }\end{array}$ & $\begin{array}{c}\text { Difference in life } \\
\text { satisfaction between } \\
\text { students in the top and } \\
\text { bottom quarter of the index } \\
\text { of wealth (top - bottom) }\end{array}$ & $\begin{array}{l}\text { Percentage of students } \\
\text { who expect to complete } \\
\text { a university degree }\end{array}$ & $\begin{array}{c}\text { Difference in the } \\
\text { percentage of children } \\
\text { of white-collar workers } \\
\text { and children of blue-collar } \\
\text { workers }{ }^{2} \text { who expect } \\
\text { to complete } \\
\text { a university degree } \\
\text { (white - blue) }\end{array}$ \\
\hline & & $\%$ & \% dif. & Dif. & $\%$ & $\%$ dif. \\
\hline & OECD average & 90.6 & 5.8 & 0.66 & 44.2 & 25.5 \\
\hline 0 & Australia & 91.2 & 6.3 & $\mathrm{~m}$ & 54.2 & 25.7 \\
\hline క్త & Austria & 91.6 & 8.1 & 0.75 & 27.1 & 25.8 \\
\hline 0 & Belgium $^{3}$ & 91.6 & 5.0 & 0.71 & 32.9 & 22.8 \\
\hline & Canada & 90.1 & 7.5 & $\mathrm{~m}$ & 63.5 & 27.4 \\
\hline & Chile & 88.8 & 5.5 & 0.72 & 66.6 & 27.2 \\
\hline & Czech Republic & 88.6 & 4.3 & 0.71 & 55.6 & 36.3 \\
\hline & Denmark & 94.3 & 4.3 & $\mathrm{~m}$ & 37.2 & 20.4 \\
\hline & Estonia & 86.9 & 6.2 & 1.08 & 42.8 & 32.8 \\
\hline & Finland & 90.9 & 8.8 & 0.39 & 27.1 & 24.1 \\
\hline & France & 89.9 & 5.9 & 0.76 & 32.0 & 27.8 \\
\hline & Germany & 91.3 & 9.9 & 0.51 & 17.8 & 17.2 \\
\hline & Greece & 90.2 & 5.2 & 0.79 & 66.3 & 32.0 \\
\hline & Hungary & 93.1 & 2.7 & 0.92 & 35.5 & 39.5 \\
\hline & Iceland & 93.0 & 7.0 & 0.84 & 38.9 & 18.8 \\
\hline & Ireland & 94.1 & 2.4 & 0.60 & 46.3 & 24.2 \\
\hline & Israel & $\mathrm{m}$ & $\mathrm{m}$ & $\mathrm{m}$ & 57.0 & 27.7 \\
\hline & Italy & 89.3 & 5.7 & 0.74 & 38.3 & 27.0 \\
\hline & Japan & 87.1 & 3.1 & 0.31 & 58.7 & 28.5 \\
\hline & Korea & 92.9 & 4.4 & 0.70 & 75.3 & 19.8 \\
\hline & Latvia & 86.2 & 6.3 & 0.78 & 24.7 & 22.5 \\
\hline & Luxembourg & 88.5 & 11.9 & 0.54 & 41.4 & 34.6 \\
\hline & Mexico & 87.6 & 4.4 & 0.22 & 58.4 & 21.2 \\
\hline & Netherlands & 96.6 & 2.1 & 0.40 & 17.4 & 16.4 \\
\hline & New Zealand & 88.8 & 9.6 & $\mathrm{~m}$ & 45.2 & 21.5 \\
\hline & Norway & 93.0 & 5.7 & $\mathrm{~m}$ & 24.1 & 11.3 \\
\hline & Poland & 88.4 & 6.1 & 0.83 & 48.0 & 35.0 \\
\hline & Portugal & 94.6 & 5.5 & 0.65 & 39.9 & 32.8 \\
\hline & Slovak Republic & 88.1 & 6.9 & 0.67 & $\mathrm{~m}$ & $\mathrm{~m}$ \\
\hline & Slovenia & 90.1 & 1.6 & 0.41 & 25.8 & 23.8 \\
\hline & Spain & 90.5 & 5.2 & 0.72 & 51.0 & 33.7 \\
\hline & Sweden & 92.2 & 6.0 & $\mathrm{~m}$ & 38.7 & 25.5 \\
\hline & Switzerland & 91.8 & 5.3 & 0.24 & 27.0 & 23.6 \\
\hline & Turkey & 86.6 & 5.4 & 0.73 & 70.6 & 15.4 \\
\hline & United Kingdom & 91.5 & 5.8 & 0.83 & 41.8 & 22.5 \\
\hline & United States & 91.1 & 5.3 & 0.89 & 76.0 & 20.7 \\
\hline$n$ & Albania & $\mathrm{m}$ & $\mathrm{m}$ & $\mathrm{m}$ & $\mathrm{m}$ & $\mathrm{m}$ \\
\hline ఏ & Algeria & $\mathrm{m}$ & $\mathrm{m}$ & $\mathrm{m}$ & $\mathrm{m}$ & $\mathrm{m}$ \\
\hline 竧 & Brazil & 88.0 & 2.3 & 0.16 & 46.2 & 22.3 \\
\hline 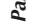 & B-S-J-G (China) & 91.7 & 3.3 & 0.66 & 37.7 & 32.6 \\
\hline & Bulgaria & 93.7 & 5.3 & 0.99 & 39.4 & 28.4 \\
\hline & CABA (Argentina) & $\mathrm{m}$ & $\mathrm{m}$ & $\mathrm{m}$ & $\mathrm{m}$ & $\mathrm{m}$ \\
\hline & Colombia & 87.6 & 1.0 & -0.20 & 76.3 & 16.7 \\
\hline & Costa Rica & 94.7 & 2.0 & 0.24 & 54.4 & 7.4 \\
\hline & Croatia & 95.0 & 0.8 & 0.71 & 36.1 & 31.0 \\
\hline & Cyprus* & 90.4 & 4.1 & 0.72 & 77.8 & 27.0 \\
\hline & Dominican Republic & 75.3 & 9.8 & 0.16 & 63.5 & 6.9 \\
\hline & FYROM & $\mathrm{m}$ & $\mathrm{m}$ & $\mathrm{m}$ & $\mathrm{m}$ & $\mathrm{m}$ \\
\hline & Georgia & $\mathrm{m}$ & $\mathrm{m}$ & $\mathrm{m}$ & $\mathrm{m}$ & $\mathrm{m}$ \\
\hline & Hong Kong (China) & 88.5 & 8.3 & 0.65 & 54.9 & 21.6 \\
\hline & Indonesia & $\mathrm{m}$ & $\mathrm{m}$ & $\mathrm{m}$ & $\mathrm{m}$ & $\mathrm{m}$ \\
\hline & Jordan & $\mathrm{m}$ & $\mathrm{m}$ & $\mathrm{m}$ & $\mathrm{m}$ & $\mathrm{m}$ \\
\hline & Kosovo & $\mathrm{m}$ & $\mathrm{m}$ & $\mathrm{m}$ & $\mathrm{m}$ & $\mathrm{m}$ \\
\hline & Lebanon & $\mathrm{m}$ & $\mathrm{m}$ & $\mathrm{m}$ & $\mathrm{m}$ & $\mathrm{m}$ \\
\hline & Lithuania & 88.0 & 8.0 & 1.03 & 53.6 & 39.4 \\
\hline & Macao (China) & 83.2 & 10.6 & 0.84 & 46.7 & 12.0 \\
\hline & Malta & $\mathrm{m}$ & $\mathrm{m}$ & $\mathrm{m}$ & $\mathrm{m}$ & $\mathrm{m}$ \\
\hline & Moldova & $\mathrm{m}$ & $\mathrm{m}$ & $\mathrm{m}$ & $\mathrm{m}$ & $\mathrm{m}$ \\
\hline & Montenegro & 91.8 & 3.6 & 0.74 & 65.4 & 25.9 \\
\hline & Peru & 85.1 & 3.1 & -0.06 & 64.3 & 23.3 \\
\hline & Qatar & 89.4 & 8.0 & 1.07 & 76.5 & 10.1 \\
\hline & Romania & 0.0 & $\mathrm{~m}$ & $\mathrm{~m}$ & $\mathrm{~m}$ & $\mathrm{~m}$ \\
\hline & Russia & 90.5 & 1.8 & 0.69 & 16.9 & 13.1 \\
\hline & Singapore & 86.6 & 9.8 & $\mathrm{~m}$ & 62.8 & 36.3 \\
\hline & Chinese Taipei & 92.1 & 4.8 & 0.68 & 47.1 & 28.9 \\
\hline & Thailand & 95.7 & 2.1 & 0.06 & 68.9 & 20.9 \\
\hline & Trinidad and Tobago & $\mathrm{m}$ & $\mathrm{m}$ & $\mathrm{m}$ & $\mathrm{m}$ & $\mathrm{m}$ \\
\hline & Tunisia & 85.5 & 9.2 & 1.29 & 51.5 & 20.3 \\
\hline & United Arab Emirates & 91.4 & 7.3 & 1.10 & 72.0 & 12.4 \\
\hline & Uruguay & 89.8 & 6.6 & 0.82 & 42.6 & 29.5 \\
\hline & Viet Nam & $\mathrm{m}$ & $\mathrm{m}$ & $\mathrm{m}$ & $\mathrm{m}$ & $\mathrm{m}$ \\
\hline & 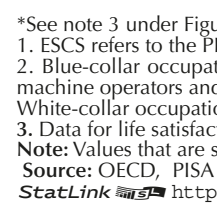 & $\begin{array}{l}\text { I.1.1 } \\
\text { ndex of economic, social and } \\
\text { include skilled agricultural, f } \\
\text { emblers (ISCO-08 category } 8 \text { ) } \\
\text { nclude managers (ISCO-08 ca } \\
\text { do not include the Flemish co } \\
\text { tically significant are indicatec } \\
5 \text { Database, III.9.16, III.9.17, I } \\
\text { dx. doi. org/10.1787/88893 }\end{array}$ & $\begin{array}{l}\text { cultural status. } \\
\text { orestry and fishery workers } \\
\text { and elementary occupations } \\
\text { egory } 1) \text {, professionals (ISCC } \\
\text { nmunity of Belgium. } \\
\text { in bold (see Annex A3). } \\
1.9 .18 \text {, III.9.19, III.10.9 and I } \\
470449\end{array}$ & $\begin{array}{l}\text { (ISCO-08 category 6), craft an } \\
\text { (ISCO-08 category 9). } \\
\text { O-08 category 2) and technicia } \\
\text { III. } 10.15 \text {. }\end{array}$ & $\begin{array}{l}\text { d related trades workers (IS } \\
\text { ns and associate profession }\end{array}$ & $\begin{array}{l}\text { CO-08 category 7), plant and } \\
\text { Is (ISCO-08 category } 3 \text { ) }\end{array}$ \\
\hline
\end{tabular}


Parents who completed the parent questionnaire in PISA 2015 cited the inability to get time off from work (cited by $36 \%$ of parents), the inconvenience of school meeting times (cited by 33\% of parents) and the lack of knowledge about how to participate in school activities (cited by $17 \%$ of parents) as among the most common barriers to their participation in school activities (Figure III.9.8).

\section{Family wealth and inequalities in well-being}

Wealth and social status can influence well-being at school, because the family background is often related to the type of school children attend and to how students evaluate themselves in comparison with their peers. PISA data show that there are large differences across countries in the strength of the relationship between socio-economic advantage and students' outcomes, suggesting that effective policies and school practices can help level the playing field and increase social mobility. Schools can promote social mobility if they help all students develop a positive view of themselves and their future.

The most visible and well-documented impact of wealth and income inequalities on students' well-being is the relatively low performance of students at the bottom of the socio-economic ladder. PISA consistently finds that disadvantaged students perform worse than advantaged students, even if the strength of the relationship varies greatly across countries. PISA results show a strong relationship between the variation in science performance related to family wealth and the overall income inequality of countries (Figure III.10.3). This association suggests that the inequalities observed more broadly in a country are reflected in student performance. In other words, in all systems, rich parents may use their wealth to provide better education for their children, but in more unequal societies, wealthy parents pass on more of that advantage to their children.

Family affluence and social status are not only related to academic performance but can also affect adolescents' satisfaction with life, perceptions about themselves and their aspirations for the future. In most countries, a greater proportion of wealthy students (among the 25\% most wealthy in their country/economy) reported being "very satisfied" with their lives compared to the share of students who were among the $25 \%$ least wealthy who reported the same (Figure III.10.5). And in most countries, students reported less satisfaction with life if they are not as wealthy as the other students in the school (their relative wealth is lower) (Figure III.10.6).

Adolescents form opinions about themselves based on comparisons with their schoolmates. Disadvantaged students who attend advantaged schools may suffer from social isolation or even feel discriminated against if they are not prepared to be a member of a disadvantaged minority in the school. Does this mean that disadvantaged students are better off when they attend disadvantaged schools? When it comes to developing high personal ambitions, PISA results show that the answer to that question is a resounding "no". On average across 28 countries and economies with available data, the children of blue-collar workers who attend schools where students have parents with white-collar occupations were around twice as likely to expect to earn a tertiary degree and work in a management or professional occupation than children of blue-collar workers who perform similarly but who attend other schools (Figure III.10.8). In other words, the education and career expectations of disadvantaged students are related to the socio-economic profile and composition of their school. This result suggests that in schools with a high concentration of students with pro-school attitudes and high expectations for themselves, students of all social status tend to develop higher ambitions for their future.

\section{HOW STUDENTS USE THEIR TIME OUTSIDE OF SCHOOL Physical exercise and eating habits}

Students' overall physical fitness and health are important pre-requisites for social and emotional well-being. People who exercise regularly are less likely to suffer from certain diseases and are in better overall health than people who do not. There is also strong evidence that participating in physical activity reduces depression and anxiety, and boosts self-esteem. Regular physical activity also appears to improve memory, perseverance and self-regulation.

In PISA 2015, students were asked four questions related to physical activities in and outside of school. Students reported the number of days per week they attended physical education classes at school, the number of days per week they engage in moderate physical activity outside of school for at least 60 minutes per day, or in vigorous activity outside of school for at least 20 minutes per day, and whether or not they exercise or practice sports before or after school.

In the majority of the countries and economies that participated in PISA 2015, most students take at least one physical education class per week, on average (Figure III.11.1). Students tend to participate less in physical education at school as they get older. On average across OECD countries, students in upper secondary school (ISCED 3) reported spending almost half a day less per week in physical education than students in lower secondary school (ISCED 2) (Table III.11.3). 
On average across OECD countries, 43\% of students reported that they exercise or practice sports before school, and $66 \%$ reported that they exercise or practice sports after school. Overall, boys were more likely than girls to report that they exercise both before and after school (Figure III.11.2). But, on average across OECD countries, about 5.7\% of boys and $7.5 \%$ of girls reported that they do not participate in any form of physical activity outside of school. And socio-economic status is also related to adolescents' level of physical activity. Advantaged students were more likely than disadvantaged students to report that they engage in moderate or vigorous physical activity outside of school (Table III.11.10).

PISA results show that there is a positive relationship between the number of days students engage in moderate physical activity outside of school and a school system's average science performance (Figure III.11.7). Physical activities, such as walking and cycling can be considered moderate if they raise a person's heart rate and the person breaks into a sweat. Activities such as hiking, jogging, or playing tennis or football are considered vigorous if breathing becomes difficult and fast, and the heart rate increases rapidly. Within countries, an additional day of moderate physical activity is positively albeit modestly - associated with students' science performance, after accounting for gender and socio-economic status; the opposite holds true for vigorous physical activity (Tables III.11.11a and III.11.12a).

A stronger association is found between physical exercise and non-cognitive outcomes. On average across OECD countries, students who reported taking part in some moderate or vigorous physical activity are 2.9 percentage points less likely to feel very anxious about tests, 6.7 percentage points less likely to feel like an outsider at school, 3 percentage points less likely to skip school frequently, and 2.2 percentage points less likely to be frequently bullied than students who do not engage in any form of physical activity outside of school (Table III.11.18). These differences suggest that students who are completely inactive outside of school may potentially enhance their well-being through engaging in some exercise at school.

Like physical exercise, eating well - and regularly - can have an impact on students' well-being. To learn more about adolescents' eating habits, PISA 2015 asked students to report whether they ate breakfast before school or ate dinner after school on the most recent day they attended school. On average across OECD countries, $26 \%$ of girls and $18 \%$ of boys reported that they had skipped breakfast. A considerably smaller proportion of students reported that they had skipped dinner. Still, girls were more likely to have skipped dinner than boys, although the difference between girls and boys was less pronounced than that concerning skipping breakfast (Figure III.11.11 and Table III.11.22).

Eating breakfast is positively related to students' science performance, on average across OECD countries, but the relationship differs considerably across countries. On average across OECD countries, boys who reported that they had eaten breakfast before school score 10 points higher in science than boys who had skipped breakfast. Girls who reported that they had eaten breakfast score six points higher than girls who reported that they had skipped breakfast (Figure III.11.12).

The family environment can also play a role in shaping adolescents' eating habits. Research suggests that in households where families eat dinner together, teenagers tend to enjoy better physical and emotional well-being, possibly because dinner provides time for informal discussions, and during that time, parents can promote healthy eating habits. Among students in OECD countries, those who reported that they had eaten dinner reported greater satisfaction with life than those who had skipped dinner. On average, boys who had eaten dinner reported a life satisfaction of 7.6 on a scale from 0 to $10-0.7$ point higher than boys who had skipped dinner. The relationship is even stronger among girls, with a difference of one point on the scale of life satisfaction (Figure III.11.13).

\section{Working for pay or in the household}

For the first time, PISA 2015 asked students to report whether they worked for pay and/or worked in the home (or cared for family members) before or after school during the most recent day that they attended school. On average across OECD countries, $23 \%$ of students reported that they work for pay and $73 \%$ reported that they work in the house before or after school (Table III.12.1). Gender and socio-economic status are related to students' paid work status. In the majority of the countries, more boys than girls reported that they work for pay. The difference between the shares of boys and girls who reported that they work for pay is 11 percentage points in favour of boys, on average across OECD countries. And the share of disadvantaged students across OECD countries who reported that they work for pay is 6.3 percentage points larger than the share of advantaged students who so reported (Figure III.12.2 and Table III.12.7).

In the majority of countries and economies, more than one in two students reported that they help with housework or take care of family members outside of school hours (Table III.12.1). In 39 countries and economies, girls were significantly 
more likely than boys to report that they help with housework (Table III.12.5). In Beijing-Shanghai-Jiangsu-Guangdong (China) (hereafter "B-S-J-G [China]") and Colombia disadvantaged girls were over 20 percentage points more likely than advantaged girls to report working in the house.

Students who work for pay or work in the home tend to score lower in science than those who do not work at all (Figures III.12.4 and III.12.5). The performance difference is greater among students who work for pay. On average across OECD countries, the score-point difference in science performance between students who work in the household and those who do not is 13 points, while the difference is 55 points between students who work for pay and those who do not, after accounting for gender and socio-economic status (Tables III.12.3 and III.12.8). The negative relationship between students' work status and science performance is stronger among advantaged students than among disadvantaged students. On average across OECD countries, advantaged students who reported working for pay score 68 points lower in science than advantaged students who do not work for pay; among disadvantaged students, this difference is 49 points.

Students who work for pay reported a level of satisfaction with life that is similar to that of students who do not work. By contrast, students who work for pay were almost 5 percentage points more likely than students who do not work for pay to report that they feel like an outsider at school, on average across OECD countries, with one in five students who work for pay reporting that he or she feels like an outsider. Students who work for pay are also 11 percentage points more likely to expect to leave formal education at the end of secondary school, 9 percentage points more likely to arrive late for school, and 4 percentage points more likely to skip school frequently, on average across OECD countries (Figure III.12.6 and Table III.12.10). These findings suggest that disengagement from school is correlated with students' employment status.

\section{Using ICT}

Over the past two decades, information and communication technologies (ICT) have transformed the ways 15-year-old students learn, socialise and play. Internet tools, including online networks, social media and interactive technologies, are giving rise to new learning styles where young people see themselves as agents of their own learning, where they can produce multimedia content, update and redefine their interests, and learn more about the world, others and themselves. But adolescents' use of ICT is also a source of concern among parents, teachers and policy makers, as it may lead to dangerous online relationships with strangers, being the victim or perpetrator of cyberbullying, and possibly problematic behaviour, including extreme videogaming, compulsive texting and overuse of smartphones.

According to PISA 2015 data, on average across OECD countries 91\% of students have access to a cell phone at home that is connected to the Internet (smartphone), $74 \%$ have access to a portable laptop, close to $60 \%$ have access to a desktop computer and nearly 55\% have access to a tablet that is connected to the Internet (Table III.13.4). Around the world, increasing numbers of children start playing with connected devices even before they can read well. On average across OECD countries, $61 \%$ of students reported that they accessed the Internet for the first time when they were younger than 10 , and $18 \%$ reported they did so at the age of 6 or younger (Table III.13.6).

PISA 2015 asked students how much time they spend using the Internet at home within a typical school week. On average across OECD countries, students spend more than two hours on line during a typical weekday after school, and more than three hours on line during a typical weekend day (Tables III.13.7 and III.13.8). Between 2012 and 2015, the time spent on line outside of school increased by 40 minutes per day on both weekdays and weekends.

Students were also asked how they feel about the time they spend on line and how they feel when they are engaged in online activities. Across OECD countries, most students agreed that "the Internet is a great resource for obtaining information" (88\%) and that "it is very useful to have social networks on the Internet" (84\%). Some $67 \%$ of students reported that they are excited to discover new digital devices and applications. The data also show that most students enjoy using various digital devices and the Internet, but many of them are at risk of excessive Internet use. Across OECD countries, $90 \%$ of students enjoy using digital devices and $61 \%$ reported that they forget time when using them. More than one in two students (54\%) reported that they feel bad if no Internet connection is available (Table III.13.15).

Given the amount of time 15-year-old students spend on the Internet every day, it is crucial to understand whether and how Internet use influences students' well-being. On the one hand, using the Internet may increase life satisfaction as it provides entertainment and removes logistical obstacles to socialising. On the other hand, online activities pose several risks to well-being. For example, sitting for long hours in front of a screen might be associated with doing less physical activity, sleeping disorders, obesity and weight gain. Extensive use of digital media and videogaming can also undermine students' motivation and concentration, and could also lead to social isolation. 
Figure III.1.5 [Part 1/2] - Snapshot of students' activities outside of school

\begin{tabular}{|c|c|c|c|c|c|}
\hline & & $\begin{array}{l}\text { Countries/economies witl } \\
\text { Countries/economies with } \\
\text { Countries/economies witl }\end{array}$ & $\begin{array}{l}\text { alues above the OECD average } \\
\text { alues not significantly different fro } \\
\text { alues below the OECD average }\end{array}$ & the OECD average & \\
\hline & & $\begin{array}{c}\text { Percentage of students } \\
\text { who reported that they exercise } \\
\text { or practice sports before } \\
\text { or after school }\end{array}$ & $\begin{array}{l}\text { Gender difference in students } \\
\text { reporting they exercise } \\
\text { or practice sports after school } \\
(B-G)\end{array}$ & $\begin{array}{c}\text { Percentage of students } \\
\text { who reported eating breakfast } \\
\text { before school }\end{array}$ & $\begin{array}{l}\text { Gender difference in students } \\
\text { reporting they eat breakfast } \\
\text { before school }(B-G)\end{array}$ \\
\hline & & $\%$ & $\%$ dif. & $\%$ & $\%$ dif. \\
\hline & OECD average & 69.8 & 12.2 & 78.0 & 7.5 \\
\hline 0 & Australia & 71.7 & 8.9 & 78.6 & 11.2 \\
\hline U & Austria & 61.4 & 18.0 & 64.2 & 11.3 \\
\hline & Belgium $^{2}$ & 73.1 & 11.9 & 79.1 & 7.2 \\
\hline & Canada & 74.2 & 8.3 & 75.8 & 8.7 \\
\hline & Chile & 65.6 & 20.8 & 70.1 & 11.9 \\
\hline & Czech Republic & 68.1 & 7.2 & 70.7 & 4.3 \\
\hline & Denmark & 65.5 & 5.9 & 84.6 & 6.4 \\
\hline & Estonia & 72.1 & 5.0 & 83.0 & 3.9 \\
\hline & Finland & 69.6 & 2.6 & 83.5 & 3.3 \\
\hline & France & 62.9 & 15.3 & 77.9 & 12.0 \\
\hline & Germany & 70.0 & 10.5 & 71.4 & 6.7 \\
\hline & Greece & 63.0 & 19.8 & 79.3 & 6.7 \\
\hline & Hungary & 80.2 & 9.1 & 69.3 & 12.6 \\
\hline & Iceland & 71.6 & 7.9 & 81.2 & 9.9 \\
\hline & Ireland & 78.6 & 13.4 & 82.9 & 8.9 \\
\hline & Israel & 67.4 & 17.0 & 72.1 & 9.6 \\
\hline & Italy & 68.2 & 14.8 & 75.3 & 11.0 \\
\hline & Japan & 57.7 & 19.5 & 92.5 & -1.5 \\
\hline & Korea & 46.3 & 26.3 & 78.8 & 5.0 \\
\hline & Latvia & 76.3 & 8.5 & 80.9 & 4.1 \\
\hline & Luxembourg & 75.4 & 9.2 & 74.9 & 5.4 \\
\hline & Mexico & 76.1 & 18.6 & 81.7 & 5.5 \\
\hline & Netherlands & 78.0 & 5.3 & 88.8 & 4.9 \\
\hline & New Zealand & 73.0 & 5.9 & 79.8 & 10.8 \\
\hline & Norway & 71.5 & 4.0 & 82.1 & 5.4 \\
\hline & Poland & 79.0 & 10.3 & 80.4 & 8.3 \\
\hline & Portugal & 70.9 & 16.9 & 92.6 & 5.7 \\
\hline & Slovak Republic & 79.3 & 10.3 & 70.4 & 6.6 \\
\hline & Slovenia & 55.9 & 10.3 & 65.5 & 7.9 \\
\hline & Spain & 73.8 & 15.1 & 85.1 & 7.4 \\
\hline & Sweden & 66.6 & 5.9 & 83.4 & 5.0 \\
\hline & Switzerland & 73.1 & 8.8 & 73.6 & 4.4 \\
\hline & Turkey & 70.7 & 25.6 & 79.1 & 9.8 \\
\hline & United Kingdom & 63.4 & 18.8 & 71.1 & 14.0 \\
\hline & United States & 73.4 & 12.7 & 71.7 & 7.5 \\
\hline$n$ & Albania & $\mathrm{m}$ & $\mathrm{m}$ & $\mathrm{m}$ & $\mathrm{m}$ \\
\hline ఏ & Algeria & $\mathrm{m}$ & $\mathrm{m}$ & $\mathrm{m}$ & $\mathrm{m}$ \\
\hline ปั & Brazil & 66.0 & 24.1 & 76.9 & 4.3 \\
\hline & B-S-J-G (China) & 75.6 & 17.5 & 94.0 & -1.0 \\
\hline & Bulgaria & 78.3 & 12.9 & 74.7 & 11.7 \\
\hline & CABA (Argentina) & $\mathrm{m}$ & $\mathrm{m}$ & $\mathrm{m}$ & $\mathrm{m}$ \\
\hline & Colombia & 73.9 & 22.6 & 86.8 & 3.9 \\
\hline & Costa Rica & 67.4 & 26.2 & 86.8 & 6.1 \\
\hline & Croatia & 65.4 & 21.5 & 80.6 & 8.5 \\
\hline & Cyprus* & 72.8 & 16.7 & 74.1 & 9.8 \\
\hline & Dominican Republic & 76.0 & 20.2 & 76.5 & 6.0 \\
\hline & FYROM & $\mathrm{m}$ & $\mathrm{m}$ & 84.6 & 8.4 \\
\hline & Georgia & $\mathrm{m}$ & $\mathrm{m}$ & $\mathrm{m}$ & $\mathrm{m}$ \\
\hline & Hong Kong (China) & 64.7 & 17.4 & $\mathrm{~m}$ & $\mathrm{~m}$ \\
\hline & Indonesia & $\mathrm{m}$ & $\mathrm{m}$ & 82.7 & -0.8 \\
\hline & Jordan & $\mathrm{m}$ & $\mathrm{m}$ & $\mathrm{m}$ & $\mathrm{m}$ \\
\hline & Kosovo & $\mathrm{m}$ & $\mathrm{m}$ & $\mathrm{m}$ & $\mathrm{m}$ \\
\hline & Lebanon & $\mathrm{m}$ & $\mathrm{m}$ & $\mathrm{m}$ & $\mathrm{m}$ \\
\hline & Lithuania & 80.2 & 13.7 & $\mathrm{~m}$ & $\mathrm{~m}$ \\
\hline & Macao (China) & 67.8 & 20.8 & 80.0 & 8.0 \\
\hline & Malta & $\mathrm{m}$ & $\mathrm{m}$ & 88.4 & 0.6 \\
\hline & Moldova & $\mathrm{m}$ & $\mathrm{m}$ & $\mathrm{m}$ & $\mathrm{m}$ \\
\hline & Montenegro & 85.2 & 12.7 & $\mathrm{~m}$ & $\mathrm{~m}$ \\
\hline & Peru & 75.1 & 21.9 & 89.7 & 1.8 \\
\hline & Qatar & 78.6 & 12.5 & 90.2 & 4.1 \\
\hline & Romania & $\mathrm{m}$ & $\mathrm{m}$ & 78.5 & 9.0 \\
\hline & Russia & 79.8 & 12.3 & $\mathrm{~m}$ & $\mathrm{~m}$ \\
\hline & Singapore & 58.7 & 19.4 & 88.4 & 3.8 \\
\hline & Chinese Taipei & 63.6 & 19.1 & 65.7 & 6.9 \\
\hline & Thailand & 76.5 & 16.3 & 87.3 & 1.0 \\
\hline & Trinidad and Tobago & $\mathrm{m}$ & $\mathrm{m}$ & $\mathrm{m}$ & $\mathrm{m}$ \\
\hline & Tunisia & 74.4 & 23.3 & 82.4 & 10.9 \\
\hline & United Arab Emirates & 79.1 & 14.1 & 76.3 & 12.2 \\
\hline & Uruguay & 70.3 & 23.9 & 81.0 & 6.9 \\
\hline & Viet Nam & $\mathrm{m}$ & $\mathrm{m}$ & $\mathrm{m}$ & $\mathrm{m}$ \\
\hline
\end{tabular}

*See note 3 under Figure III.1.1

1. Categories of Internet users are based on students' responses to questions about how much time they spend on line, outside of school, during a typical weekday. Low Internet users: one hour or less; woderate Internet users: 1 to 2 hours; high Internet users: 2 to 6 hours; extreme Internet users: more than 6 hours.

2. Data for life satisfaction do not include the Flemish community of Belgium.

Note: Values that are statistically significant are indicated in bold (see Annex A3).

Source: OECD, PISA 2015 Database, Tables III.11.6, III.11.7b, III.11.21, III.11.22, III.12.1, III.12.7, III.13.9 and III.13.23.

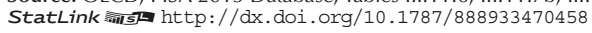


Figure III.1.5 [Part 2/2] - Snapshot of students' activities outside of school

\begin{tabular}{|c|c|c|c|c|c|c|}
\hline & & $\left\{\begin{array}{l}\text { Countries/econ } \\
\text { Countries/econ } \\
\text { Countries/econ }\end{array}\right.$ & $\begin{array}{l}\text { es with values above the } \\
\text { es with values not significa } \\
\text { es with values below the }\end{array}$ & $\begin{array}{l}\text { ECD average } \\
\text { tlly different from the OECD } \\
\text { ECD average }\end{array}$ & verage & \\
\hline & & $\begin{array}{l}\text { Percentage of students } \\
\text { who reported working } \\
\text { for pay before } \\
\text { or after school }\end{array}$ & $\begin{array}{l}\text { Gender difference in } \\
\text { students reporting they } \\
\text { work for pay before } \\
\text { or after school (B - G) }\end{array}$ & $\begin{array}{l}\text { Average time, in minutes } \\
\text { per day, students spend } \\
\text { on the Internet outside } \\
\text { of school, during weekdays }\end{array}$ & $\begin{array}{l}\text { Average time, in minutes } \\
\text { per day, students spend } \\
\text { on the Internet outside } \\
\text { of school, during } \\
\text { weekend days }\end{array}$ & $\begin{array}{c}\text { Difference in life } \\
\text { satisfaction during } \\
\text { weekdays between extreme } \\
\text { and other Internet users } \\
\text { (low, moderate and high) }\end{array}$ \\
\hline & & $\%$ & $\%$ dif. & Minutes & Minutes & Dif. \\
\hline & OECD average & 23.3 & 10.5 & 146 & 184 & -0.38 \\
\hline 5 & Australia & 34.4 & 0.2 & 164 & 197 & $\mathrm{~m}$ \\
\hline 5 & Austria & 18.3 & 12.2 & 149 & 179 & -0.45 \\
\hline & Belgium $^{2}$ & 21.9 & 8.8 & 146 & 199 & -0.49 \\
\hline & Canada & 34.7 & 5.4 & $\mathrm{~m}$ & $\mathrm{~m}$ & $\mathrm{~m}$ \\
\hline & Chile & 23.5 & 12.5 & 195 & 230 & -0.08 \\
\hline & Czech Republic & 18.6 & 11.0 & 149 & 183 & -0.33 \\
\hline & Denmark & 33.1 & 3.2 & 159 & 210 & $\mathrm{~m}$ \\
\hline & Estonia & 16.4 & 13.7 & 163 & 192 & -0.66 \\
\hline & Finland & 12.5 & 8.1 & 138 & 174 & -0.64 \\
\hline & France & 14.3 & 9.1 & 127 & 191 & -0.25 \\
\hline & Germany & 17.9 & 7.5 & $\mathrm{~m}$ & $\mathrm{~m}$ & $\mathrm{~m}$ \\
\hline & Greece & 22.5 & 17.2 & 126 & 171 & -0.35 \\
\hline & Hungary & 24.0 & 16.2 & 161 & 197 & -0.35 \\
\hline & Iceland & 30.3 & 5.4 & 145 & 188 & -0.95 \\
\hline & Ireland & 20.0 & 11.3 & 144 & 185 & -0.49 \\
\hline & Israel & 32.3 & 8.5 & 135 & 158 & $\mathrm{~m}$ \\
\hline & Italy & 26.5 & 15.2 & 165 & 169 & -0.11 \\
\hline & Japan & 8.1 & 0.6 & 90 & 144 & -0.46 \\
\hline & Korea & 5.9 & 5.0 & 55 & 107 & -0.64 \\
\hline & $\begin{array}{l}\text { Latvia } \\
\end{array}$ & 18.4 & 17.3 & 147 & 180 & -0.38 \\
\hline & Luxembourg & 20.4 & 10.5 & 155 & 192 & -0.29 \\
\hline & Mexico & 26.9 & 18.6 & 121 & 136 & -0.02 \\
\hline & Netherlands & 38.0 & 6.9 & 159 & 211 & -0.21 \\
\hline & New Zealand & 36.1 & 8.9 & 163 & 196 & $\mathrm{~m}$ \\
\hline & Norway & 32.7 & 9.6 & $\mathrm{~m}$ & $\mathrm{~m}$ & $\mathrm{~m}$ \\
\hline & Poland & 18.4 & 17.1 & 146 & 183 & -0.33 \\
\hline & Portugal & 15.4 & 10.1 & 140 & 191 & -0.17 \\
\hline & Slovak Republic & 27.3 & 20.3 & 152 & 177 & -0.42 \\
\hline & Slovenia & 11.6 & 10.9 & 120 & 159 & -0.34 \\
\hline & Spain & 30.4 & 8.5 & 167 & 215 & -0.22 \\
\hline & Sweden & 16.6 & 8.5 & 187 & 228 & $\mathrm{~m}$ \\
\hline & Switzerland & 20.2 & 9.3 & 126 & 168 & -0.39 \\
\hline & Turkey & 34.6 & 21.7 & $\mathrm{~m}$ & $\mathrm{~m}$ & $\mathrm{~m}$ \\
\hline & United Kingdom & 23.2 & 7.9 & 188 & 224 & -0.51 \\
\hline & United States & 30.4 & 11.4 & $\mathrm{~m}$ & $\mathrm{~m}$ & $\mathrm{~m}$ \\
\hline 2 & Albania & $\mathrm{m}$ & $\mathrm{m}$ & $\mathrm{m}$ & $\mathrm{m}$ & $\mathrm{m}$ \\
\hline ま & Algeria & $\mathrm{m}$ & $\mathrm{m}$ & $\mathrm{m}$ & $\mathrm{m}$ & $\mathrm{m}$ \\
\hline ปั & Brazil & 43.7 & 10.6 & 190 & 209 & -0.17 \\
\hline & B-S-J-G (China) & 13.4 & 4.1 & 42 & 99 & 0.05 \\
\hline & Bulgaria & 28.9 & 20.6 & 187 & 211 & 0.01 \\
\hline & CABA (Argentina) & $\mathrm{m}$ & $\mathrm{m}$ & $\mathrm{m}$ & $\mathrm{m}$ & $\mathrm{m}$ \\
\hline & Colombia & 12.3 & 15.7 & 143 & 159 & -0.36 \\
\hline & Costa Rica & 45.3 & 11.9 & 182 & 205 & -0.18 \\
\hline & Croatia & 15.2 & 20.6 & 141 & 188 & -0.23 \\
\hline & Cyprus* & 20.4 & 17.4 & $\mathrm{~m}$ & $\mathrm{~m}$ & $\mathrm{~m}$ \\
\hline & Dominican Republic & 34.9 & 20.3 & 130 & 153 & 0.11 \\
\hline & FYROM & 36.5 & $\mathrm{~m}$ & $\mathrm{~m}$ & $\mathrm{~m}$ & $\mathrm{~m}$ \\
\hline & Georgia & $\mathrm{m}$ & $\mathrm{m}$ & $\mathrm{m}$ & $\mathrm{m}$ & $\mathrm{m}$ \\
\hline & Hong Kong (China) & $\mathrm{m}$ & 8.3 & 123 & 167 & -0.46 \\
\hline & Indonesia & 14.4 & $\mathrm{~m}$ & $\mathrm{~m}$ & $\mathrm{~m}$ & $\mathrm{~m}$ \\
\hline & Jordan & $\mathrm{m}$ & $\mathrm{m}$ & $\mathrm{m}$ & $\mathrm{m}$ & $\mathrm{m}$ \\
\hline & Kosovo & $\mathrm{m}$ & $\mathrm{m}$ & $\mathrm{m}$ & $\mathrm{m}$ & $\mathrm{m}$ \\
\hline & Lebanon & $\mathrm{m}$ & $\mathrm{m}$ & $\mathrm{m}$ & $\mathrm{m}$ & $\mathrm{m}$ \\
\hline & Lithuania & $\mathrm{m}$ & 19.1 & 137 & 162 & -0.19 \\
\hline & Macao (China) & 25.1 & -2.6 & 130 & 200 & -0.20 \\
\hline & Malta & 14.2 & $\mathrm{~m}$ & $\mathrm{~m}$ & $\mathrm{~m}$ & $\mathrm{~m}$ \\
\hline & Moldova & $\mathrm{m}$ & $\mathrm{m}$ & $\mathrm{m}$ & $\mathrm{m}$ & $\mathrm{m}$ \\
\hline & Montenegro & $\mathrm{m}$ & 16.9 & $\mathrm{~m}$ & $\mathrm{~m}$ & $\mathrm{~m}$ \\
\hline & Peru & 43.8 & 18.3 & 92 & 117 & -0.32 \\
\hline & Qatar & 28.1 & 6.9 & $\mathrm{~m}$ & $\mathrm{~m}$ & $\mathrm{~m}$ \\
\hline & Romania & 45.3 & $\mathrm{~m}$ & $\mathrm{~m}$ & $\mathrm{~m}$ & $\mathrm{~m}$ \\
\hline & Russia & $\mathrm{m}$ & 19.2 & 161 & 193 & -0.25 \\
\hline & Singapore & 32.7 & 4.9 & 147 & 198 & $\mathrm{~m}$ \\
\hline & Chinese Taipei & 11.6 & 6.2 & 120 & 195 & -0.04 \\
\hline & $\begin{array}{l}\text { Thailand } \\
\end{array}$ & 43.9 & 16.8 & 122 & 193 & -0.30 \\
\hline & Trinidad and Tobago & $\mathrm{m}$ & $\mathrm{m}$ & $\mathrm{m}$ & $\mathrm{m}$ & $\mathrm{m}$ \\
\hline & Tunisia & 47.2 & 17.0 & $\mathrm{~m}$ & $\mathrm{~m}$ & $\mathrm{~m}$ \\
\hline & United Arab Emirates & 41.7 & 10.0 & $\mathrm{~m}$ & $\mathrm{~m}$ & $\mathrm{~m}$ \\
\hline & Uruguay & 24.7 & 18.2 & 185 & 199 & -0.23 \\
\hline & Viet Nam & $\mathrm{m}$ & $\mathrm{m}$ & $\mathrm{m}$ & $\mathrm{m}$ & $\mathrm{m}$ \\
\hline
\end{tabular}

*See note 3 under Figure III.1.1

1. Categories of Internet users are based on students' responses to questions about how much time they spend on line, outside of school, during a typical weekday. Low Internet users: one hour or less; woderate Internet users: 1 to 2 hours; high Internet users: 2 to 6 hours; extreme Internet users: more than 6 hours.

2. Data for life satisfaction do not include the Flemish community of Belgium.

Note: Values that are statistically significant are indicated in bold (see Annex A3).

StatLink ants http://dx.doi.org/10.1787/888933470458 
PISA 2015 results show that, in most participating countries and economies, extreme Internet use - more than six hours per day - has a negative relationship with students' life satisfaction. Across OECD countries, "extreme Internet users" reported themselves as 0.4 point lower on the life-satisfaction scale than those who use the Internet less (Figure III.13.7). Some $17 \%$ of "extreme Internet users" across OECD countries also reported that they feel lonely at school, compared with $14 \%$ of "low Internet users" (students who use the Internet less than one hour a day), 12\% of "moderate Internet users" (those who spend between one and two hours per day on Internet) and 13\% of "high Internet users" (those who spend between two and six hours per day on Internet). "Low" and "extreme Internet users" were also more likely than "moderate" and "high Internet users" to report that they are bullied at school (Figure III.13.8).

PISA data also reveal that both "extreme" and "high Internet users" are at greater risk of disengagement from school. One in four "extreme Internet users" reported that they had arrived late for school in the two weeks prior to the PISA test a share 10 percentage points larger than the share of "moderate Internet users" who so reported (Figure III.13.8). "Extreme Internet users" were also more likely to report low expectations of further education than moderate Internet users. And after accounting for students' socio-economic status, "extreme Internet users" score around 30 points lower in all subjects PISA assesses than students who use the Internet less (Figure III.13.9).

\section{WHAT THE PISA RESULTS IMPLY FOR POLICY}

The data from PISA 2015 show that students differ greatly, both between and within countries, in how satisfied they are with their lives, their motivation to achieve, how anxious they feel about their schoolwork, their participation in physical activities, their expectations for the future, and their perceptions of being bullied at school or treated unfairly by their teachers. Many of these differences are related to students' perceptions about the disciplinary climate in the classroom or about the support their teachers give them. The data also show that parents can make a big difference to students' feelings about schoolwork and their performance in PISA.

To try to reduce schoolwork-related anxiety among students, specific professional development can be offered to teachers so that they can identify those students who suffer from anxiety and teach these students how to learn from mistakes. For example, one way to encourage a positive attitude towards mistakes is to take the most common mistakes that the class made on a test or quiz and let the students analyse them together. In addition, teachers can help students set realistic but challenging - goals for themselves, since students are more likely to value what they are learning, and to enjoy the process of learning, when they can attain the goals they set. Strategies for encouraging goal-setting and enhancing intrinsic motivation to learn include providing meaningful rationales for learning activities, acknowledging students' feelings about the tasks, and avoiding excessive pressure and control. Providing constructive feedback on the results of assessments can also nurture students' confidence and intrinsic motivation.

PISA finds that one major threat to students' feelings of belonging at school are their perceptions of negative relationships with their teachers. To build better teacher-student relations, teachers should be trained in basic methods of observation, listening and intercultural communication so that they can better take into account individual learners' needs. Teachers should also be encouraged to collaborate and exchange information about students' difficulties, character and strengths with their colleagues, so that they can collectively find the best approach to make students feel part of the school community.

The data also show that a large proportion of students report being victims of bullying at school. Effective anti-bullying programmes follow a whole-of-school approach that includes training for teachers on bullying behaviour and how to handle it, anonymous surveys of students to monitor the prevalence of bullying, and strategies to provide information to and engage with parents. Teachers and parents have a particularly important role to play in preventing bullying at school: teachers need to communicate to students that they will not tolerate any form of bullying; and parents need to be involved in school planning and responses to bullying.

PISA results from 18 culturally and economically diverse countries show that students whose parents routinely engage in day-to-day home-based activities, such as eating a meal together or spending time "just talking" not only score higher in PISA, but are also more satisfied with their lives. Schools can help parents become more involved in their child's education by removing any barriers to their participation in school events, such as offering flexible channels of communication for busy working parents, and suggesting ways in which parents can get involved both at home and in school.

To improve students' well-being, schools should also teach students the benefits of an active and healthy lifestyle through physical and health education. Engaging physical education at school can reduce the number of students who are physically inactive out of school. 
Too many students spend too much time on the Internet: $26 \%$ of students reported that they spend more than six hours per day on line during weekends, and $16 \%$ spend a similar amount of time on line during weekdays. And with cyberbullying on the rise, the Internet can be as much a source of harassment as a tool for learning. Schools can consider investing in a comprehensive education and supervision plan to assist students in gaining the knowledge, skills and motivation they need to use the Internet safely and responsibly. 


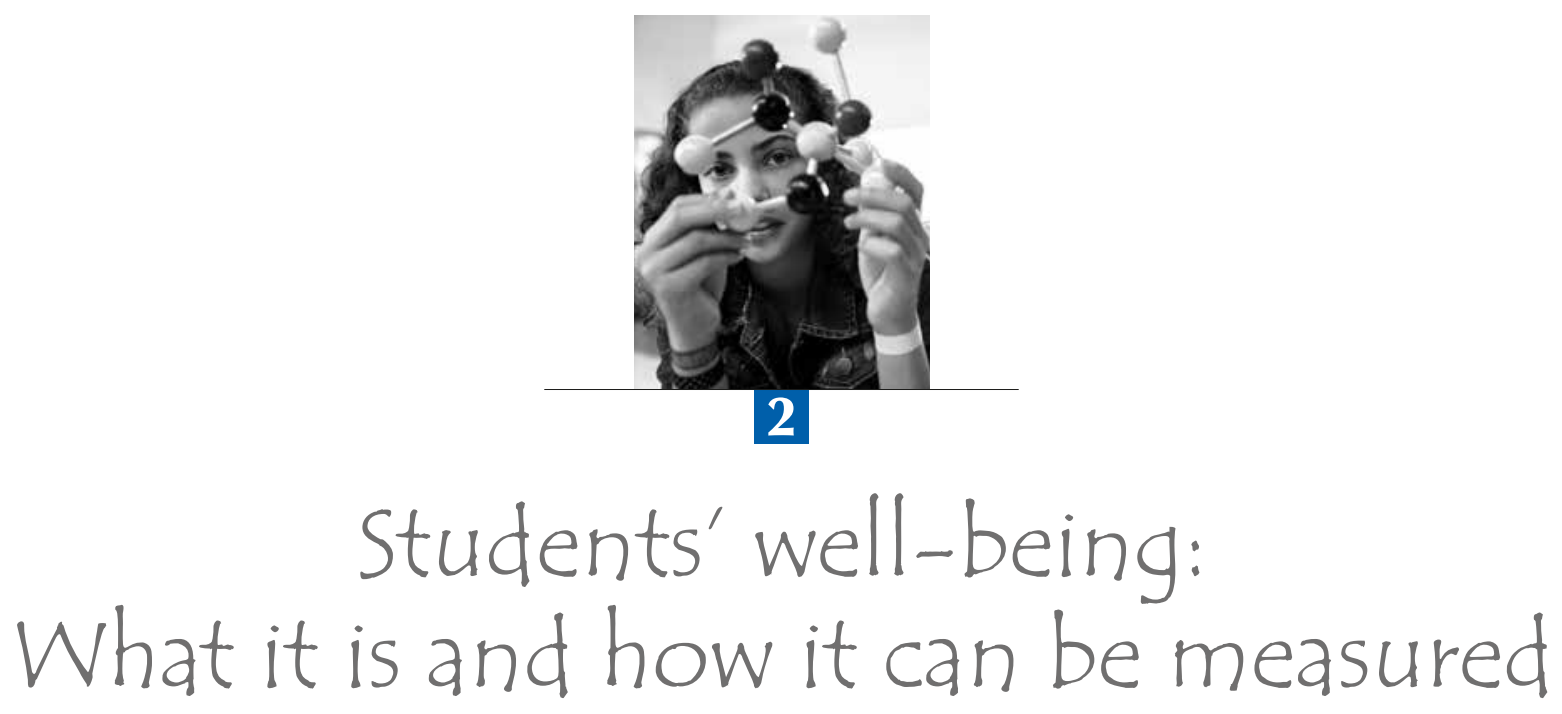

With student well-being increasingly incorporated into education policy, interest is growing in comparing how well different education systems promote students' development and quality of life. This chapter defines students' well-being and examines how it is measured by PISA. The chapter also discusses the aims of this volume as part of the PISA 2015 Results. 
If parents around the world are asked what they want for their children, some might mention "achievement" or "success", but most would reply "happiness", "confidence", "kindness", "health", "satisfaction", and the like (Seligman et al., 2009). In short, people value well-being. Student well-being, defined as students' overall development and quality of life, is increasingly integrated into education policy. Not surprisingly, interest is growing in comparing countries not only in terms of how well students fare academically, but also in how well education systems promote students' skills and attitudes for well-being.

Children spend a considerable amount of time in the classroom - following lessons, socialising with classmates, and interacting with teachers and other staff members. By the time they enter school, children differ in how easily and intensely they become anxious, frustrated or positively excited. They also differ in capacities for attention and selfregulation. Some of these differences are linked to children's genetic endowment (Rothbart et al., 2011). But children's temperament, self-regulation and capacity for attention continue to develop throughout the school years (Rothbart and Jones, 1998). Experiences of success and failure during a child's adjustment to the challenges of school influence the child's representations and evaluations of self, peers and adults. What happens in school is key to understanding whether students enjoy good physical and mental health, how happy and satisfied they are with different aspects of their life, how connected to others they feel, and the aspirations they have for their future (Adamson, 2013; Bradshaw et al., 2007; Currie et al., 2012; Huebner et al., 2004; Rees and Main, 2015).

Teachers are powerful figures in the lives of most children (UNESCO, 2016). A positive class atmosphere where efforts are encouraged and rewarded and in which children are accepted and supported by their teachers, regardless of their intellect and temperament, is often associated with more positive reactions to the demands of schooling (Huebner et al., 2004), and to lower school-related stress (Torsheim et al., 2001). Even the most vulnerable child has capacities for positive experiences at school. "Accentuating the positive" in the child's experience of school can serve to increase autonomy, motivation and resilience, essential qualities for success both in and outside of school.

While there is a growing body of research on the topic, only a few large-scale studies of adolescents have taken a comprehensive view of well-being. One important exception is the Health Behaviour in School-Aged Children (HSBC), a large cross-national study conducted every four years across Europe and North America to gain insights into young people's well-being, health behaviours and their social context (http://www.hbsc.org/). National indicators on children have traditionally focused on threats to children's mental and physical health. It is now important to develop international data that extend beyond the study of adolescents' disorders, deficits and disabilities, and that put more emphasis on the positive attributes that define the success of students (Huebner et al., 2004). By examining students' strengths, assets and abilities, it will be possible to identify the core elements that enable them to flourish and thrive (Pollard and Lee, 2003). Understanding how education policy shapes students' well-being requires more data, both subjective and objective, on how students feel, what they do in and outside of school, and what they value most in life. Measuring the well-being of 15-year-old students, the target PISA population, is particularly important, as students at this age are in a key transition phase of physical and emotional development. Feeling well, and developing decision-making skills and psychological coping mechanisms at this age are the foundations for self-awareness and relationship-building - key competencies needed for self-fulfilment.

PISA offers the opportunity to produce a comprehensive set of well-being indicators for adolescents that covers both negative outcomes (e.g. anxiety, low performance) and the positive impulses that promote healthy development (e.g. interest, engagement, motivation to achieve). Most of the PISA data on well-being are based on students' answers to a questionnaire. Self-reported data give adolescents the opportunity to express how they feel, what they think of their lives and what aspirations they have for their future. PISA holds a unique advantage over other studies in that well-being indicators can be related directly to the academic achievement of students across a large number of economies. Even if PISA 2015 was not designed to provide complete coverage of all the dimensions of students' well-being, the studentlevel data in PISA can shed light on different manifestations of students' well-being both across and within countries.

\section{A DEFINITION OF STUDENTS' WELL-BEING}

Well-being is a complex, multi-dimensional construct that cannot be properly measured by a sole indicator in a single domain (Borgonovi and Pál, 2016). In order to accurately monitor well-being, it is critical that measurement tools take into consideration its multi-dimensional nature.

Most of the theoretical and measurement work on well-being, such as the OECD How's Life framework for measuring well-being and progress (Box III.2.1), is conceptually rooted in adult life. As such, it needs to be adapted to the PISA population of 15-year-old students and to the PISA focus on education policy. Adolescents might have priorities for their well-being that do not necessarily coincide with those of adults. A recent survey illustrates this well: when a large sample 
of 14- and 15-year-olds were asked what having a good life means to them, the five most commonly used terms were "friends", "family", "bullying", "parents", and "school" (The Children's Society, 2015). Many adolescents also have limited financial autonomy and they are dependent on adults for their material well-being.

\section{Box III.2.1 The OECD How's Life framework for measuring well-being}

Although different individuals will place different weight on what aspects of life are most important to them, there is a high degree of convergence in identifying the main dimensions of well-being across different authors and using different methodologies (OECD, 2015). The OECD How's Life framework for measuring well-being identifies 11 dimensions of well-being under two broad headings (Figure III.2.1). Under the heading "material conditions", the framework groups those aspects of well-being that are grounded in market transactions: income and wealth, jobs and earnings, and housing. Higher GDP does not necessarily lead to improved material conditions, because some of the activities included in GDP actually correspond to a reduction in people's well-being (as in the case of higher transport costs due to increased congestion and longer commuting). These activities are called "regrettables" in the figure. "Quality of life" encompasses those things that are important to people's welfare but that lie primarily outside the market: health status, work-life balance, education and skills, social connections, civic engagement and governance, environmental quality, personal security, and subjective well-being.

Figure III.2.1 - The OECD framework for measuring well-being

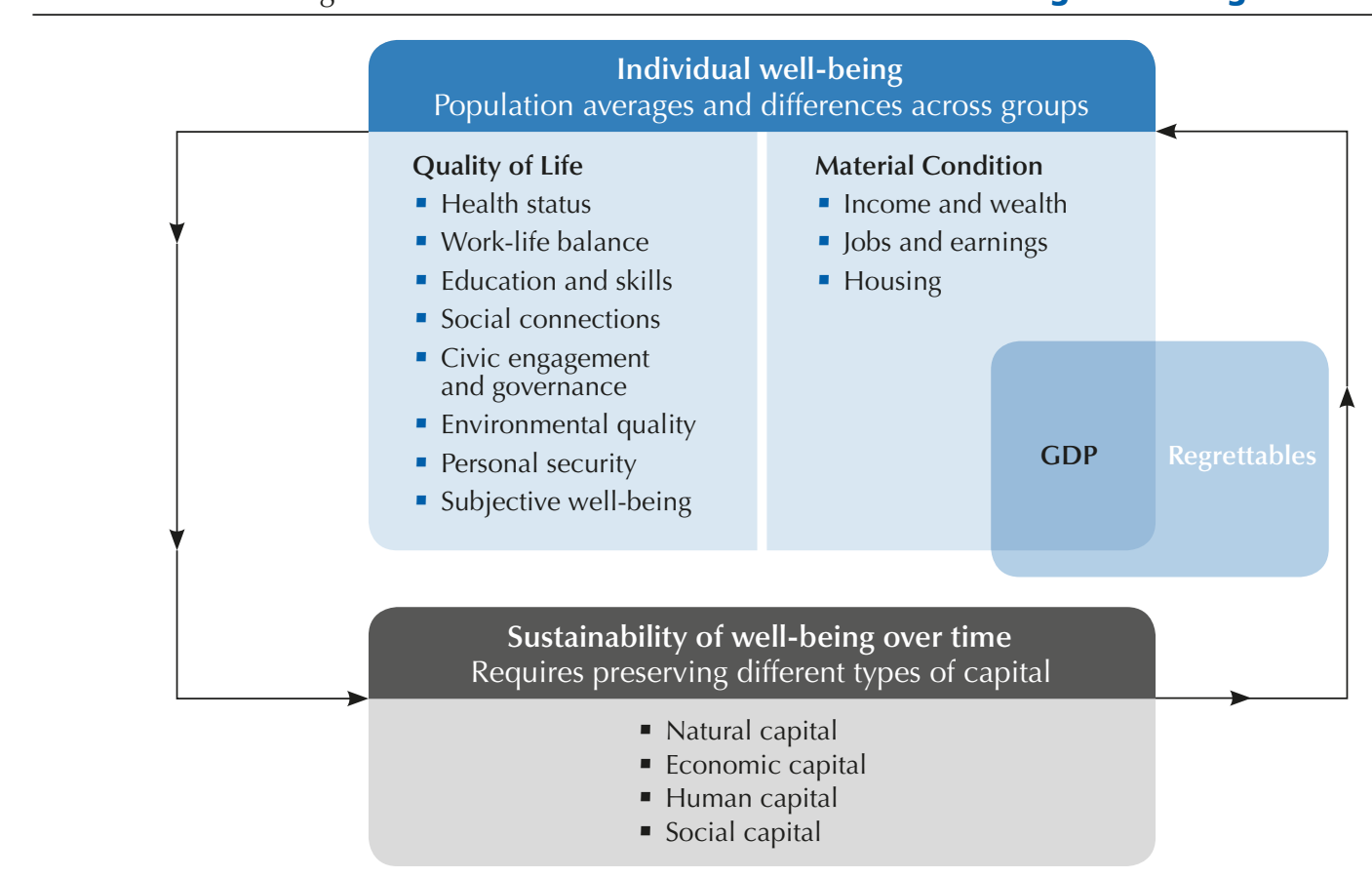

Source: OECD (2015), How's Life? 2015: Measuring Well-being, OECD Publishing, Paris, http://dx.doi.org/10.1787/how life-2015-en.

The OECD approach to assessing the resources for future well-being focuses on the broader natural, economic, human and social systems that embed and sustain individual well-being over time. The approach thus goes beyond simply measuring "stocks" to consider how these resources are managed, maintained or threatened.

Well-being as measured in the How's Life framework is concerned with individuals rather than with aggregate conditions. The indicators focus on outcomes rather than inputs or outputs. This is because the achieved wellbeing outcomes of a person (e.g. their health status) may be only imperfectly correlated with the relevant inputs (health expenditure) or outputs (e.g. surgical interventions). Distribution matters, since the implications for the well-being of individuals depend on what people actually experience, not just the average level achieved across society. Finally, well-being is measured through both objective and subjective indicators.

Students' well-being, as defined in this report, refers to the psychological, cognitive, social and physical functioning and capabilities that students need to live a happy and fulfilling life. This definition of well-being combines a "children's rights 
approach", that emphasises the right of all children to have a happy life "here and now", with a "development approach", that underscores the importance of students developing the skills to improve their well-being in the present and in the future (Ben-Arieh et al., 2013). The evaluation of students' well-being must be sensitive to both their actual states and achievements ("functioning") and the freedom they have ("capabilities") to pursue what they value in life (Sen, 1999).

While investing in future outcomes of children and adolescents is extremely important, policy makers and educators need to pay attention to students' well-being now, while they are students. Children and adolescents should not be reduced to "human becomings" (Ben-Arieh et al., 2013). Too much focus on developing skills for the future might, for example, mean that students spend all their waking hours studying, with no time left for socialisation and leisure. Childhood and adolescence are, in themselves, important stages of life to be lived and enjoyed.

The sustainability of students' well-being demands investments in acquiring academic, non-cognitive and work-related skills that are necessary to function well in the present and in the future. Well-being is in fact a dynamic state: without sufficient investments to develop capabilities in the present, students are unlikely to enjoy well-being as adults. No trade-off between "being well" now and "becoming ready" for the future is necessary if the development of skills is well balanced with other essential social and leisure activities, and if such development happens in a supportive and caring environment.

\section{PISA INDICATORS OF WELL-BEING SOURCES AND OUTCOMES}

In this report, students' well-being is not quantified by a single measure, but is composed of various dimensions, and aspects within each dimension, that are more readily measurable. As Figure III.2.2 illustrates, students' well-being is the result of interactions among four distinct but closely related domains: psychological, social, cognitive and physical. Each dimension can be considered both as an outcome and as an enabling condition with respect to the other dimensions, and ultimately with students' overall quality of life.

\section{Figure III.2.2 - Dimensions and sources of students' well-being}

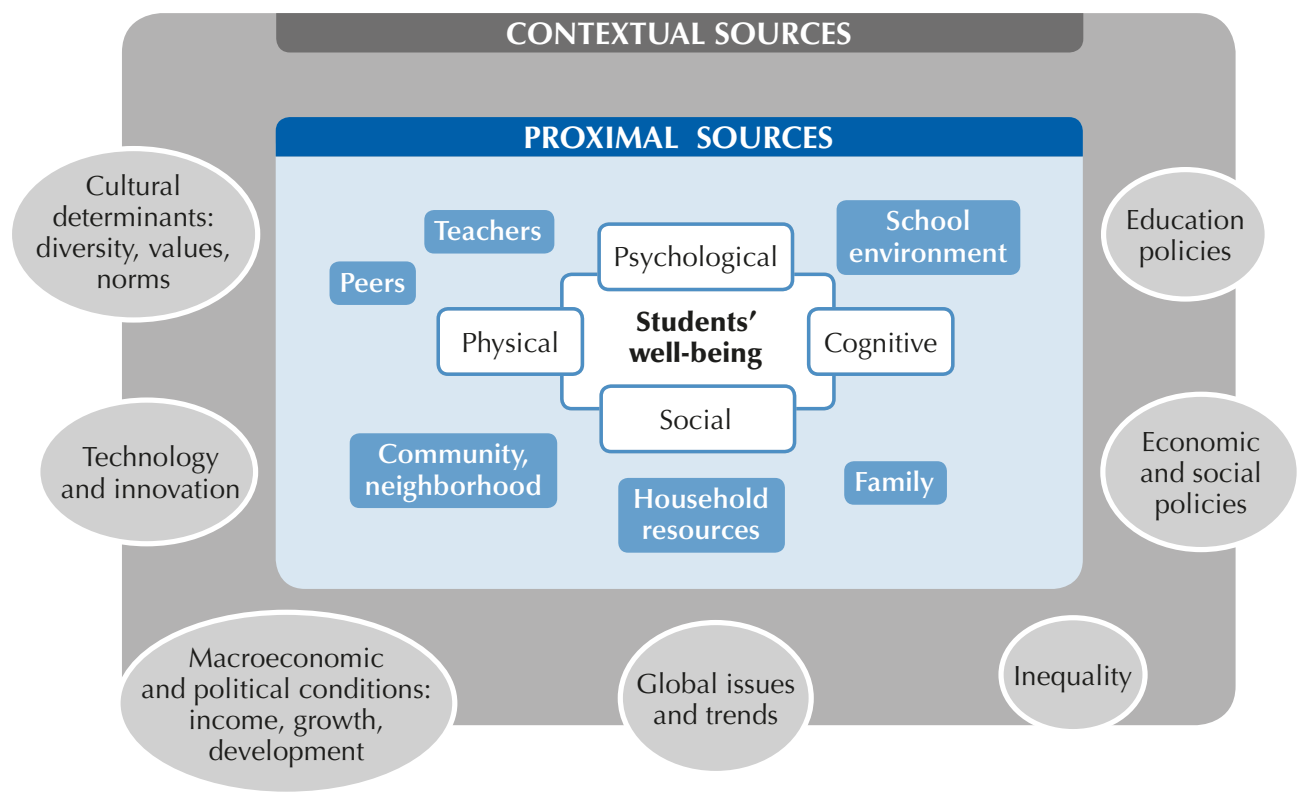

The psychological dimension of students' well-being includes students' sense of purpose in life, self-awareness, affective states and emotional strength. Psychological well-being is supported by self-esteem, motivation, resilience, self-efficacy, hope and optimism; it is hindered by anxiety, stress, depression and distorted views of the self and others. PISA 2015 measures some aspects of psychological well-being through students' reports of their motivation for achievement and schoolwork-related anxiety. 
The social dimension of students' well-being refers to the quality of their social lives. It includes students' relationships with their family, their peers and their teachers, and students' feelings about their social life in and outside of school (Pollard and Lee, 2003). In PISA 2015, the main measure of students' social well-being is their self-reported sense of belonging at school. The quality of students' social relationships at school is also measured through students' self-reported exposure to bullying and perceptions of teachers' fairness.

The cognitive dimension of students' well-being refers to the cognitive foundations students need to participate fully in today's society, as lifelong learners, effective workers and engaged citizens. It comprises students' proficiency in using academic knowledge to solve problems alone or in collaboration with others, and high-order reasoning skills, such as critical thinking and being able to confront ideas from various perspectives. In PISA 2015, cognitive well-being is primarily measured through performance across the PISA domains (Box III.2.2).

The physical dimension of students' well-being refers to students' health and the adoption of a healthy lifestyle (Statham and Chase, 2010). PISA 2015 does not measure students' health status as such. However, it provides self-reported information on how much physical activity students engage in and on whether they eat regularly.

\section{Box III.2.2 The measurement of cognitive skills in PISA}

PISA is based on a dynamic and forward-looking model of lifelong learning, exploring the knowledge and skills students need to adapt successfully in a rapidly changing world and to apply their knowledge to real-world issues. This model reflects the fact that educators focus increasingly on what students can do with what they learn at school.

PISA also recognises that 15-year-olds cannot be expected to have learned everything they will need to know as adults, but they need to understand core processes and principles. Thus, PISA assesses students' ability to complete tasks relating to real life and not solely how well they have absorbed the content knowledge of the core subjects taught in school. The skills students have acquired up to age 15 are the product of a complex inter-relationship among their experience as students in different schools and classes, their life within their close and extended families, and their interactions with peers and acquaintances. Competency at age 15 is the sum of the infinite number of experiences that children have accumulated over the years.

International experts defined each of the competency domains that were examined in PISA 2015: science (the main domain for 2015), reading, mathematics, collaborative problem solving, and financial literacy, and drafted the assessment frameworks for each. Competency is not something that an individual either does or does not have; rather, it is measured on a continuum. There is no exact threshold that determines who is fully competent and who is not. However, it is necessary for measurement purposes to define at which level of competencies students are able to participate productively in society. In PISA, international experts set the baseline at Level 2 on the PISA proficiency scales.

In addition to assessing competencies in the three core domains of reading, mathematics and science, PISA has progressively examined competencies across disciplines and modes of delivery. For example, PISA delivered in 2012 an assessment of individual problem solving and, in 2015, an assessment of collaborative problem-solving. In 2018, PISA will include an assessment of global competence which will test students' ability to understand global issues and diverse cultural perspectives.

When analysing the relationship between the cognitive dimension of well-being and other well-being outcomes, the analysis in this volume focuses on students' performance in science, the major domain for 2015. All students were assessed in science, but only a proportion also responded to questions in the remaining domains. PISA 2015 defines scientific literacy as "the ability to engage with science-related issues, and with the ideas of science, as a reflective citizen" (OECD, 2016c). A scientifically competent person is willing to engage in reasoned discourse about science and technology. This requires the competencies to: explain phenomena scientifically (recognising, offering and evaluating explanations for a range of natural and technological phenomena); evaluate and design scientific enquiry (describing and appraising scientific investigations, and proposing ways to address questions scientifically); and interpret data and evidence scientifically (analysing and evaluating data, claims and arguments in a variety of representations, and drawing appropriate scientific conclusions). 
PISA 2015 also asked students to report, on a scale from 0 to 10, how satisfied they are with their life. This scale shows the students' subjective evaluation of their own lives across all four dimensions. Even if this life satisfaction scale is a useful summary indicator, and it is used as such in this report, it is no substitute for a multi-dimensional measurement of well-being based on different indicators.

PISA data on the four dimensions of well-being can provide a description of the life of students across the world. However, a policy-relevant analysis of students' well-being also needs to examine the context of students' psychological, social, cognitive and physical functioning. While well-being is defined in this report at the "individual level" - looking at students' outcomes in the four dimensions - the development of well-being is analysed at the "environmental level" by looking at the relationship between the contexts in which the adolescent lives and his or her well-being outcomes.

Students' individual well-being is a result of their interaction with their environment, the material resources they have access to, and students' responses to external opportunities and stress factors. The student, with all of his or her personal characteristics and character strengths, interacts first and foremost with his or her family, teachers and peers, but also with a range of other actors in his or her proximal community. The material and social resources that the student obtains from the family and closer community are, in turn, influenced by the macro-economic social and cultural environment (at the local, national and global levels), and by economic, social and education policies (the external circle in Figure III.2.2). In a well-functioning system, these three levels - the student's self, his or her close networks and resources, and the macro/ policy level - are interdependent and influence each other as they evolve over time. For example, students' perceptions of their quality of life at school (at the micro level) should not just be influenced by education policies (at the macro/ policy level) but should also inform the design of policy reforms.

\section{AIMS AND ORGANISATION OF THIS REPORT}

The purpose of this volume is to describe the relationships between 15-year-old students' life satisfaction, social life, learning attitudes and school performance in a large number of school systems around the world. Drawing on data from PISA 2015, this volume analyses a broad set of indicators that, collectively, paint a comparative picture of how well adolescent students in different countries and economies are learning and faring in various aspects of life. The report illustrates both the strengths and the weaknesses of the available PISA data on well-being. Although PISA 2015 contains instruments to measure several aspects of well-being, it remains first and foremost a study of adolescents' cognitive skills.

This volume does not provide a ranking that shows which countries are most successful in promoting students' wellbeing. For such a ranking to be useful for policy, it should be based on a complete accounting of students' functioning and capabilities across all four dimensions of well-being. PISA 2015 measures some dimensions of well-being better than others. The dataset offers an unprecedented opportunity to describe students' school environments, the way students interact with their parents, how students use the Internet, students' level of physical activity, their aspirations for further education, and their overall life satisfaction. These states, activities and capabilities can be related with each other and with cognitive skills. However, PISA 2015 provides only limited information on the physical and mental health or emotional states of students, on how students spend their time, and how satisfied they are with different aspects of their lives.

This report uses PISA data to address specific policy questions, such as: "Are highly competitive school environments compatible with students' life satisfaction?"; "How much of a problem is bullying at school?"; "What can teachers do to foster a greater sense of belonging at school with an increasingly diverse student population?"; "What type of parental engagement and support helps students derive greater satisfaction from life and perform better in school?". The report describes the interactions between outcome indicators in different dimensions of students' well-being, and analyses a selected set of relationships between sources and outcomes of well-being.

The volume is organised in four sections. The first section (Chapters 3 through 6 ) analyses the relationships between how students learn (at what level they perform, how much time they invest in learning, how confident they feel when they study, what shapes their learning environment, what are their motivations to learn), their own perceptions about the quality of their life, and their expectations of further education. The second section (Chapters 7 and 8) focuses on students' relationships with their peers and teachers at school, and looks at the factors that affect students' sense of belonging at school. The third section (Chapters 9 and 10) analyses the social and material resources available in students' homes, with a focus on the importance of parental support for both cognitive achievement and life satisfaction. The fourth section (Chapters 11 through 13) describes the PISA data on physical activity and eating habits, and analyses how students' well-being is related to their use of the Internet and to the work they do in or outside the home. The concluding chapter discusses the policy implications of this first analysis of PISA data on students' well-being. 
This report should be read together with the first two volumes of PISA 2015 Results (OECD, 2016a; OECD, 2016c). For example, this volume includes references to analyses of student performance (a core element of students' cognitive well-being) already published in PISA 2015 Results (Volume I): Excellence and Equity in Education, and to indicators of school environment and education policies presented in PISA 2015 Results (Volume II): Policies and Practices for Successful Schools.

\section{MEASUREMENT ISSUES AND INTERPRETATION OF THE FINDINGS}

Some caution is needed in interpreting the PISA data on well-being. While PISA aims to provide robust measures of complex constructs, it must do so while keeping the questionnaires relatively short, minimising perceived intrusiveness of the questions, and maximising cross-national and cross-cultural comparability of responses. Despite the extensive investments PISA makes in selecting questions and analysing the quality of the data, full comparability across countries and subpopulations cannot be guaranteed.

The PISA questionnaires use student self-reports to derive indices or to measure different dimensions of student well-being. Self-reported responses are informative and useful, but they are susceptible to three possible biases: social desirability (the tendency to respond in a manner that is more acceptable in one's own social and cultural context; Edwards, 1953); reference-group bias (what the comparison group is); and response-style bias (extreme responses, heaping, modesty). These biases can operate differently in different cultural contexts, thus limiting the cross-country comparability of responses (Hemert, Poortinga and Vijver, 2007). If students in different countries use different response styles or understand questions differently, empirical findings may reflect differences in reporting rather than in the underlying associations.

A number of questions based on self-reports in previous editions of PISA are used in this report to monitor trends over time. Students' and school principals' reports were designed to measure latent constructs (theoretical variables, such as life quality, that cannot be directly measured). However, the relationship between these measures and the latent constructs can vary through time, introducing a possible bias in comparisons across time.

Measurement difficulties are often more evident in well-being than in other domains. Many key indicators of well-being, such as life satisfaction, involve a strong subjective component, which, by definition, can be influenced by cultural norms and by the personality of the respondent. "Culture", in particular, plays a key role in influencing how one's perception of well-being is constructed, so that self-evaluations of well-being are grounded in a specific "time" but can differ across "place". In order to minimise the risk of misleading interpretations, possible cultural explanations of country differences in scales or in responses to individual questions are explicitly mentioned in the text. 


\section{References}

Adamson, P. (2013), "Child well-being in rich countries: A comparative overview", Innocenti Report Card, No. 11, https://ideas.repec. org/p/ucf/inreca/inreca683.html.

Ben-Arieh, A. et al. (eds.) (2013), Measuring and Monitoring Children's Well-Being, Springer, the Netherlands.

Borgonovi, F. and J. Pál (2016), "A framework for the analysis of student well-being in the PISA 2015 study", OECD Education Working Papers, No. 140, OECD Publishing, Paris, http://dx.doi.org/10.1787/5jlpszwghvvb-en.

Bradshaw, J., P. Hoelscher and D. Richardson (2007), "An index of child well-being in the European Union", Social Indicators Research, Vol. 80/1, pp. 133-177, http://dx.doi.org/10.1007/s11205-006-9024-z.

Currie, C. et al. (eds.) (2012), Social Determinants of Health and Well-Being among Young People, World Health Organization Regional Office for Europe, Copenhagen, Denmark, www.hbsc.unito.it/it/images/pdf/hbsc/prelims-part1.pdf.

Edwards, A.L. (1953), "The relationship between the judged desirability of a trait and the probability that the trait will be endorsed", Journal of Applied Psychology Vol. 37/2, pp. 90-93, http://dx.doi.org/10.1037/h0058073.

Exton, C., C. Smith and D. Vandendriessche (2015), "Comparing happiness across the world", OECD Statistics Working Papers, No. 2015/04, OECD Publishing, Paris, http://dx.doi.org/10.1787/5jrappzd9bs2-en.

Huebner, E.S. et al. (2004), "Life satisfaction in children and youth: Empirical foundations and implications for school psychologists", Psychology in the Schools Vol. 41/1, pp. 81-93, http://dx.doi.org/10.1002/pits.10140.

OECD (2016a), PISA 2015 Results (Volume II): Policies and Practices for Successful Schools, OECD Publishing, Paris, http://dx.doi. org/10.1787/9789267510-en.

OECD (2016b), PISA 2015 Assessment and Analytical Framework: Science, Reading, Mathematic and Financial Literacy, OECD Publishing, Paris, http://dx.doi.org/10.1787/9789264255425-en.

OECD (2016c), PISA 2015 Results (Volume I): Excellence and Equity in Education, OECD Publishing, Paris, http://dx.doi. org/10.1787/9789264266490-en.

OECD (2015), How's Life? 2015: Measuring Well-being, OECD Publishing, Paris, http://dx.doi.org/10.1787/how_life-2015-en.

Pollard, E.L., and P.D. Lee (2003), "Child well-being: A systematic review of the literature", Social Indicators Research, Vol. 61/1 pp. 59-78, http://dx.doi.org/10.1023/A:1021284215801.

Rees, G., and G. Main (eds.) (2015), "Children's views on their lives and well-being in 15 countries: An initial report on the children's worlds Survey, 2013-14." Children's Worlds Project, (ISCWeb), York, UK, www.isciweb.org/ Uploads/dbsAttachedFiles/ ChildrensWorlds2015-FullReport-Final.pdf.

Rothbart, M.K. and L. Jones (1998), "Temperament, self-regulation, and education", School Psychology Review Vol. 27/4, pp. 479-491.

Rothbart, M.K et al. (2011), "Developing mechanisms of self-regulation in early life", Emotion Review, Vol. 3/2, pp. 207-13, http://dx.doi. org/10.1177/1754073910387943.

Seligman, M.E.P. et al. (2009), "Positive education: Positive psychology and classroom interventions", Oxford Review of Education, Vol. 35/3, pp. 293-311, http://dx.doi.org/10.1080/03054980902934563.

Sen, A. (1999), Development as Freedom, Oxford University Press, UK.

Statham, J. and E. Chase (2010), "Childhood wellbeing: A brief overview", Loughborough: Childhood Wellbeing Research Centre, www.researchgate.net/profile//une Statham/publication/242676811 Childhood Wellbeing A brief overview/links/549bd87c0 cf2b80371372fc7.pdf.

The Children's Society (2015), The Good Childhood Report 2015, The Children's Society, www.childrenssociety.org.uk/what-we-do/ resources-and-publications/the-good-childhood-report-2015.

Torsheim, T., L.E. Aaroe and B. Wold (2001), "Sense of coherence and school-related stress as predictors of subjective health complaints in early adolescence: Interactive, indirect or direct relationships?", Social Science \& Medicine (1982), Vol. 53/5, pp. 603-614.

UNESCO (2016), "Happy schools! A framework for learner well-being in the Asia-pacific", UNESCO, Paris, http://unesdoc.unesco.org/ images/0024/002441/244140E.pdf.

van Hemert, D.A., Y.H. Poortinga and F.J.R. van de Vijver (2007), "Emotion and culture: A meta-analysis", Cognition and Emotion Vol. 21/5, pp. 913-943, http://dx.doi.org/10.1080/02699930701339293. 


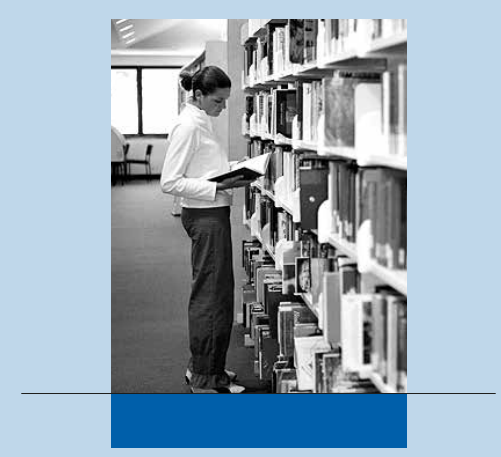

\section{Performance at school and life satisfaction}

A successful student not only performs well academically but is also happy at school. This section analyses the relationship between how students learn (at what level they perform, how much time they invest in learning, what are their self-beliefs and drivers to learning, what shapes their learning environment) and their own perceptions about their quality of life. PISA data on students' overall level of life satisfaction, schoolwork-related anxiety, achievement motivation and expectations of further education shed light on how schools and education systems can promote both high academic achievement and psychological well-being. 



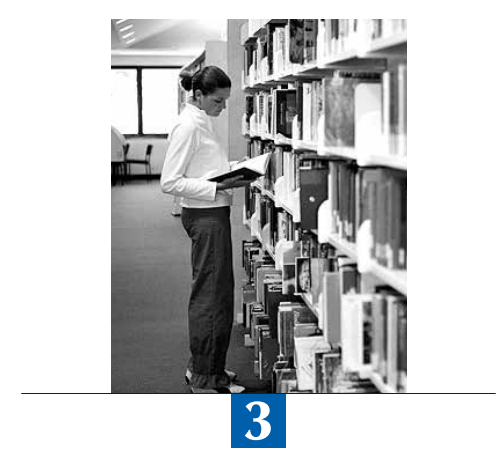

\section{Students' satisfaction with their life}

This chapter discusses how students' overall satisfaction with their life varies across countries, among subgroups of students within a country, and by school characteristics. The chapter also examines the associations between students' satisfaction with life, performance at school and the time students invest in studying. 
Good educators strive to improve children's life prospects but also care about the quality of their students' current life. Much of the thinking around the link between education and the quality of students' lives has focused on mental health problems that children might manifest at school. Teenagers are particularly at risk of psychological disorders, because adolescence is a period of intense emotional upheaval (Gilman and Huebner, 2003). Satisfaction with life is known to decrease during adolescence (Goldbeck et al., 2007), and low life satisfaction has been linked to school dropout, substance abuse, aggression and misbehaviour among students (Huebner and Alderman, 1993; Valois et al., 2001; Zullig et al., 2001). Approaches that aim only to address mental health and behavioural problems might not devote enough attention to creating the conditions in which children and adolescents can flourish. Helping students find greater satisfaction with their lives, rather than just responding when students exhibit behaviours associated with dissatisfaction with life, can sustain the psychological, social and cognitive development of all students (Huebner and Hills, 2013; Suldo and Huebner, 2006).

\section{What the data tell us}

- On average across OECD countries, 15-year-old students are satisfied with the life they are living: they report a level of 7.3 on a scale of life satisfaction that ranges from 0 to 10.

- Girls and disadvantaged students are less likely than boys and advantaged students to report high levels of life satisfaction (a level of 9 or 10 on the scale).

- The relationship between performance at school and overall life satisfaction is weak. In most countries, topachieving students report similar levels of life satisfaction as low-achieving students.

- On average, there is no significant relationship between the time students spend studying, whether in or outside of school, and their satisfaction with life.

- Students in schools where their peers collectively reported higher-than-average life satisfaction reported that they receive more support from teachers than students in schools where their peers reported lower-than-average life satisfaction.

Life satisfaction can be defined as a subjective appraisal of the quality of one's life (Diener et al., 1999). Satisfaction with life is one measure of students' "subjective" well-being (defined as people's self-reported experience and evaluation of life), together with the frequency of positive emotions, such as joy and pride, the frequency of negative emotions, such as anger or sadness, and the sense of having a purpose in life (OECD, 2015a). This chapter presents the measure of students' overall life satisfaction in PISA 2015, discusses variations in life satisfaction between countries and across groups or schools within countries, and analyses the relationship between life satisfaction, performance at school and time spent studying. The relationships between life satisfaction and other aspects of well-being (e.g. quality of social life at school, living habits outside of school) will be explored in the next chapters.

\section{DIFFERENCES IN STUDENTS' SATISFACTION WITH LIFE}

PISA 2015 asked students to rate their life on a scale from 0 to 10, where 0 means the worst possible life and 10 means the best possible life. Self-reported measures of life satisfaction are more stable indicators of subjective well-being than reports of positive or negative affective states (Gilman et al., 2008).

Figure III.3.1 shows that, on average across OECD countries, students reported a level of 7.3 on a life satisfaction scale ranging from 0 to 10 . Roughly speaking, this figure suggests that the "average" adolescent in an OECD country is satisfied with life. Still, there are large variations in life satisfaction across countries. For example, while less than $4 \%$ of students in the Netherlands reported that they are not satisfied with their lives (they reported a level of 4 or below on the scale), more than 20\% of students in Korea and Turkey reported so. In Montenegro, and in the Latin American countries of Colombia, Costa Rica, the Dominican Republic and Mexico, more than one in two students reported that they are very satisfied with their life (they reported a life satisfaction level of 9 or 10 out of 10). Fewer than one in five students in the Asian countries/economies of Hong Kong (China), Korea, Macao (China) and Chinese Taipei reported similarly high levels of life satisfaction.

There is no evident relationship between adolescents' life satisfaction and a country's/economy's per capita GDP or similar measures of economic development. This finding is markedly different from what is observed among adults, who tend to report greater satisfaction with life if they live in higher-income countries (Deaton, 2008; Helliwell, Layard and 
Sachs, 2016). In fact, countries where students reported the highest levels of life satisfaction in PISA are not necessarily those where adults were most satisfied with their life (among the countries with available data, the correlation between students' life satisfaction, as measured by PISA, and the life satisfaction reported by adults in the Gallup survey is only 0.2; see Table III.3.12). The lack of a correlation between per capita GDP and students' satisfaction with life might be partly explained by the fact that PISA includes only those 15-year-olds who are enrolled in school, thereby excluding large numbers of adolescents in low-income countries who are not enrolled and tend to live in poverty. The PISA for Development initiative is now piloting a programme that specifically targets the out-of-school population of adolescents in low-income countries. The relationship between income and life satisfaction within countries is explored in Chapter 10.

Comparing average levels of subjective well-being across countries is challenging. Variations in students' reports of life satisfaction or happiness across countries might be influenced by cultural interpretations of what defines a happy life, and by differences in how life experiences are integrated into judgements of life satisfaction (Diener, Oishi and Lucas, 2003; Park, Peterson and Ruch, 2009; Proctor, Linley and Maltby, 2009).

Figure III.3.1 - Life satisfaction among 15-year-old students Percentage of students, by level of life satisfaction

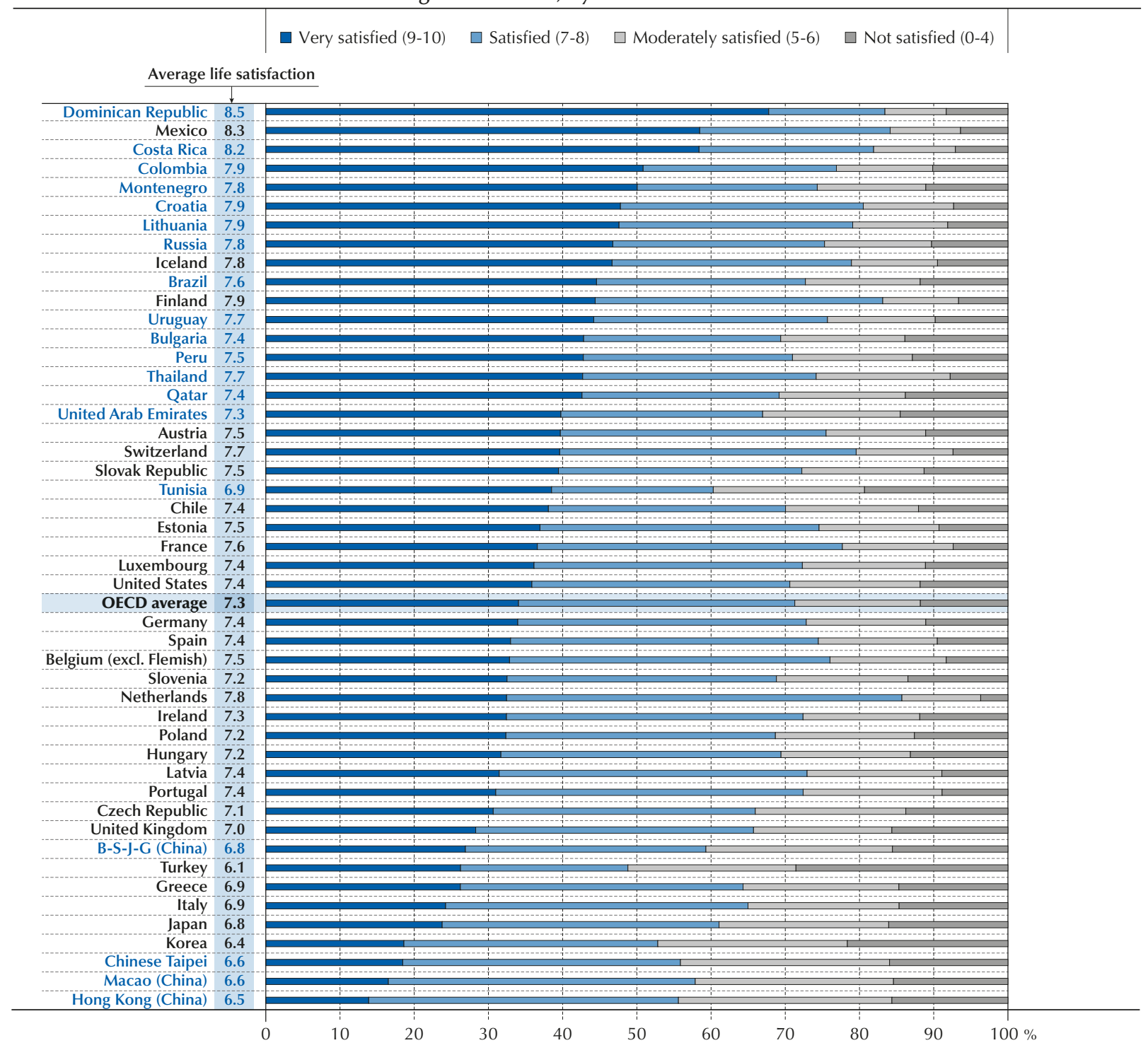

Countries and economies are ranked in descending order of the percentage of students who reported being very satisfied with their life. Source: OECD, PISA 2015 Database, Tables III.3.2 and III.3.8.

StatLink 세엔 http://dx.doi.org/10.1787/888933470599 
Research has documented cultural differences in how people think about "happiness", a construct that is closely related to life satisfaction. In some languages, including Chinese, Estonian, French, German, Japanese, Korean, Norwegian and Russian, happiness is closely associated with luck, while in others, notably Italian, Portuguese and Spanish, definitions of happiness focus on the realisation of one's desires, wishes and goals (Oishi, 2010). Tsai et al. (2007) found that American children's picture-book characters had wider smiles than those in Taiwanese books, and concluded that Americans value high-activation emotions, such as excitement, more than East Asians do. Differences in self-presentation can also play an important role. In some cultures, for example, it might not be desirable to say that you are happy, while in others it might be highly desirable to say so.

Overall life satisfaction summarises students' satisfaction with different aspects of their life, such as their autonomy, feelings and use of time (the "self"), peer relationships, and quality of family and community life. The relative importance of all these aspects in students' overall life satisfaction can differ across cultures. Research has found that for adolescents from Western cultures, such as that in the United States, where independence, personal feelings and interests are highly valued, self-related aspects are more important for overall judgements of life satisfaction. On the other hand, in Asian cultures, such as that in Korea, where social obligations and education are highly valued, meeting these social norms and expectations are the primary sources of life satisfaction for students (Park and Huebner, 2005).

In all countries, however, large variations in students' reports of life satisfaction are observed. Regardless of the dominant culture in their country/economy or of their language, a large number of students in every education system reported that they are very satisfied with their life, and a smaller, but not negligible, number of students reported that they feel dissatisfied with their life. This suggests that, notwithstanding the possible effect of cultural differences on the country averages, the measure of life satisfaction in PISA can be useful for identifying personal, school and other factors that might influence students' self-reported well-being within each country.

Gender, for example, is related to adolescents' life satisfaction. On average across OECD countries, around $29 \%$ of girls but $39 \%$ of boys reported that they are very satisfied with their life - a difference of almost 10 percentage points (Figure III.3.2 and Table III.3.8). Girls were also more likely than boys to report low satisfaction with life. On average across OECD countries, about $9 \%$ of boys but $14 \%$ of girls reported a level of life satisfaction equal to 4 or lower on a scale of 0 to 10 . Gender differences in favour of boys are thus more marked at the top of the life satisfaction scale.

Figure III.3.2 - Gender differences in life satisfaction

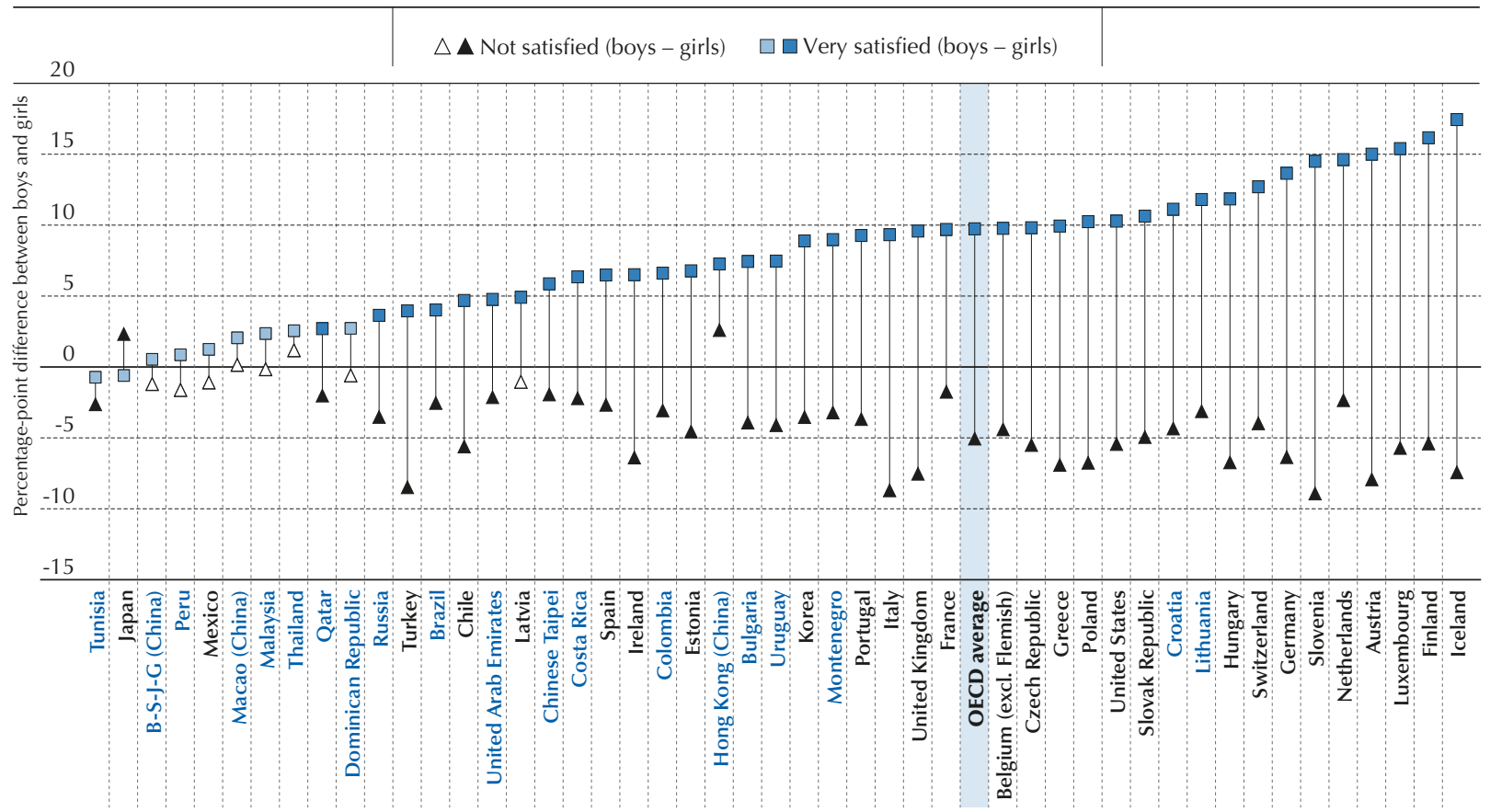

Note: Statistically significant values are marked in a darker tone (see Annex A3).

Countries and economies are ranked in ascending order of the percentage-point difference between boys and girls who reported being very satisfied with their life. Source: OECD, PISA 2015 Database, Table III.3.8.

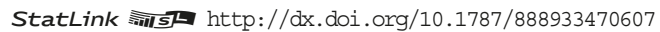


In no country did larger shares of girls than boys report to be very satisfied with their life (Figure III.3.2). In Austria, Finland, Iceland, Luxembourg, the Netherlands, and Slovenia - all countries where students' satisfaction with life is higher than the OECD average - the difference in the share of boys and girls who reported high life satisfaction is greater than 14 percentage points in favour of boys. In Austria, Iceland, Italy, Slovenia Turkey and the United Kingdom, girls were at least 7 percentage points more likely than boys to report that they are not satisfied with their life. Research has found that the relationship between life satisfaction and behaviour tends to be stronger for boys than for girls. In particular, boys are at greater risk of ill health and disruptive behaviour than girls when they are dissatisfied with their life (Heffner and Antaramian, 2016).

Among adults, gender does not seem to play a major role in shaping people's evaluation of their own lives (OECD, 2013). The lower life satisfaction reported by 15-year-old girls in PISA seems linked to the transition from childhood to adulthood, and is possibly a reflection of girls' harsh self-criticism, particularly related to their image of their own bodies, as they undergo dramatic physical changes (Goldbeck et al., 2007). PISA 2015 does not collect data on students' body image, but other research suggests that exposure to images of overly thin girls and young women in traditional media and to photo sharing in new social media has a significant negative impact on adolescent girls' satisfaction with themselves (Voelker, Reel and Greenleaf 2015; see also Box III.8.3). Weight-based teasing from peers is also associated with body dissatisfaction among girls (Schaefer and Blodgett Salafia, 2014).

Differences in life satisfaction related to socio-economic status are also marked in the majority of PISA-participating countries and economies. On average across OECD countries, disadvantaged students report themselves around 0.4 points lower than advantaged students on the 10-point life satisfaction scale (Table III.3.2). Differences greater than 0.6 point between advantaged and disadvantaged students are observed in the Czech Republic, Estonia, Hungary, Iceland, Latvia, Tunisia, the United Arab Emirates and the United States. Only in Brazil and Colombia did disadvantaged students report higher life satisfaction than advantaged students.

Students from advantaged families might have easier access to resources that enable them to fulfil basic needs and achieve their material, education, health and leisure goals. The association between socio-economic status and satisfaction with life might strengthen in times of economic crisis, as the most disadvantaged groups often shoulder the heaviest burden when living conditions become more difficult. Markers of wealth or social status can also influence how adolescents evaluate themselves in comparison with their peers (see Chapter 10). Research has shown that wealth can affect a person's perceptions about his or her life, but greater wealth does not buy happiness (Kahneman and Deaton, 2010).

Immigrants often experience culture shock and stress while adjusting to their new life in their host country; and changes in living conditions and peer influences may affect adolescents more than adults. Data from PISA 2015 show that students with an immigrant background reported lower life satisfaction than students without an immigrant background, on average across OECD countries (Table III.3.2). First-generation immigrant students (foreign-born students whose parents are also foreign-born) reported, on average, a life satisfaction of 0.2 point lower than non-immigrant students. This is particularly evident in Qatar and Spain (a difference of more than 0.6 point), which saw large increases in the shares of first-generation immigrant students between 2006 and 2015 (Table I.7.1). Important mediators of life satisfaction among immigrants include how students perceive their country of origin and culture, the proximity of young people from the same cultural background, and exposure to open and welcoming peers and teachers in the host country (Liebkind and Jasinskaja-Lahti, 2000; OECD, 2015b).

\section{LIFE SATISFACTION AND PERFORMANCE AT SCHOOL}

Are students who do better at school more satisfied with their life? As schoolwork represents one of the main life activities for 15-year-old students, high-performing students can be expected to have a sense of achievement and a more positive outlook on life. But empirical evidence of "the virtuous circle" - high achievement increases students' life satisfaction, which, in turn, motivates students to work harder - is limited. Perceived academic competence has been shown to predict life satisfaction (Huebner, Gilman and Laughlin, 1999; Suldo and Huebner, 2004), but the relationship between objective indicators of academic achievement and life satisfaction is much less clear (Chang et al., 2003).

Data from PISA 2015 show that, across countries, there is a modest, negative relationship between average performance in science and the average life satisfaction of 15-year-old students (Figure III.3.3). In other words, students in low-achieving countries tend to report higher levels of life satisfaction than students in high-achieving countries. Some countries stand out from this general pattern. In Finland, the Netherlands and Switzerland, for example, students perform above average in science and were more likely to report that they are satisfied with their life. Students in Turkey score below average in science and were more likely to report low life satisfaction. 
Students in the countries in the upper left quadrant of Figure III.3.3, notably those in Colombia, Costa Rica, the Dominican Republic, Mexico and Montenegro, reported relatively high life satisfaction, but the countries score lower than average in science. Countries and economies in East Asia, including Hong Kong (China), Korea, Macao (China) and Chinese Taipei, perform much better than the OECD average, but students in these countries and economies reported relatively low satisfaction with life.

This correlation should not be interpreted as evidence of a trade-off between high achievement and student well-being. The results might, in fact, partly reflect cultural differences in response styles and self-presentation. The data cannot distinguish cultural factors that might affect adolescents' reports of life satisfaction from school influences on students' quality of life.

Figure III.3.3 - Life satisfaction and performance across education systems

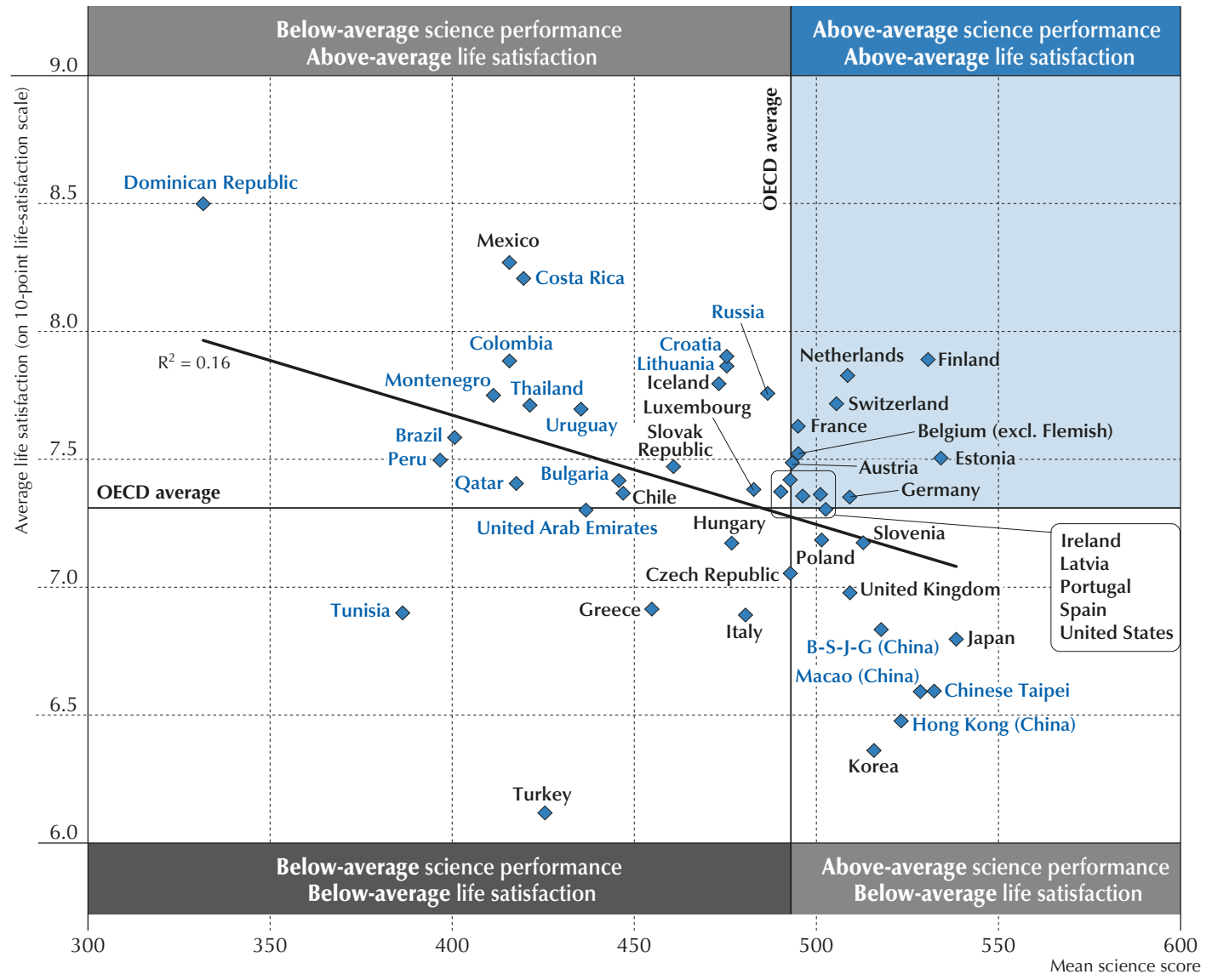

Source: OECD, PISA 2015 Database, Tables I.2.3 and III.3.2.

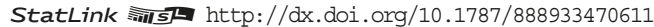

Analyses of the within-country variation in students' satisfaction with their life can provide a more nuanced picture of the relationship between performance and self-reported well-being. In most countries, top-achieving students (those in the top $10 \%$ of the performance distribution) and low-achieving students (those in the bottom $10 \%$ of the performance distribution) reported similar levels of life satisfaction (Tables III.3.3a and III.3.3b). Higher scores in reading are not associated with higher life satisfaction, on average, while stronger performance in mathematics and science is related to modest increases in self-reported quality of life (Figure III.3.4). Only in France, Japan and Macao (China) are top achievers in reading more satisfied with their life than low achievers.

The relationship between performance and life satisfaction tends to be stronger among girls than among boys (Table III.3.5). On average across OECD countries, top-achieving girls in science reported an average life satisfaction of 7.3, while lowachieving girls reported 6.9 (a difference of 0.4 point). Top-achieving and low-achieving boys in science reported the 
same level of life satisfaction (both 7.6). In Costa Rica, Croatia, the Netherlands and the Russian Federation (hereafter "Russia"), top-achieving boys in science reported a life satisfaction that is at least 0.5 point below low-achieving boys, while in France, Macao (China) and Peru, high-achieving boys reported higher life satisfaction than low-achieving boys by around 0.5 point.

Figure III.3.4 - Life satisfaction and performance in core PISA subjects

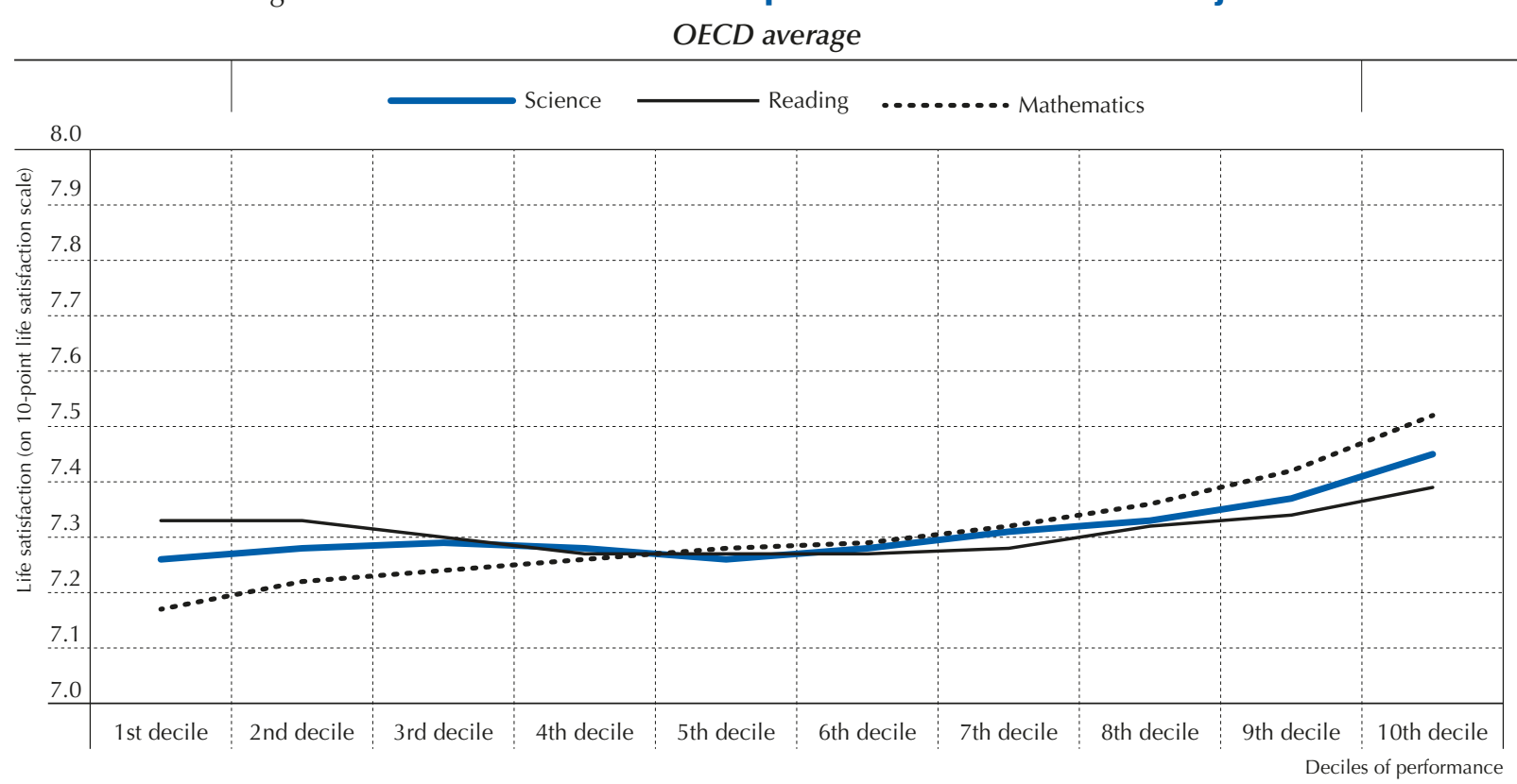

Source: OECD, PISA 2015 Database, Tables III.3.3a and III.3.3b.

StatLink त्ताजा http://dx.doi.org/10.1787/888933470626

\section{Box III.3.1 Time spent studying, performance and life satisfaction}

It has become conventional wisdom that the highest-achieving education systems build their success on making students work around the clock. Educators and parents are increasingly concerned about the culture of overwork in education, where high achievement equals hours of homework, catch-up classes, after-school lessons, long school terms and frequent testing (The Guardian, 2014; Deb et al., 2015; Leonard et al., 2015; Shanghai Daily, 2015). Adolescents, just like adults, need time every day to unwind and interact with their peers. Too much pressure in schools might mean that students feel compelled to spend more time studying, leaving less time for these non-academic activities, at the expense of students' quality of life.

Data from PISA can help establish whether these concerns about overwork are well placed or exaggerated. In 2015, students from Beijing-Shanghai-Jiangsu-Guangdong (China) (hereafter "B-S-J-G [China]"), Chile, Costa Rica, Korea, Chinese Taipei, Thailand and Tunisia spent at least 30 hours per week in regular lessons (all subjects combined; Table II.6.32). Long hours of study at school are observed among both the high-performing and low-achieving students of these school systems.

A significant number of 15-year-old students spend a large fraction of their waking hours in school lessons or studying school subjects. On average across OECD countries, 13\% of students spend at least 60 hours per week studying at school (taking science, language-of-instruction and mathematics lessons) and outside of school (on homework, additional instruction, and in private study; Figure III.3.5). More than 40\% of students in B-S-J-G (China) and the United Arab Emirates reported spending that many hours studying, while less than $5 \%$ of students in Finland and Germany reported so. 
Figure III.3.5 - Long study hours, performance and life satisfaction

Differences between students who study at least 60 hours per week and students who study up to 40 hours per week in and out of school

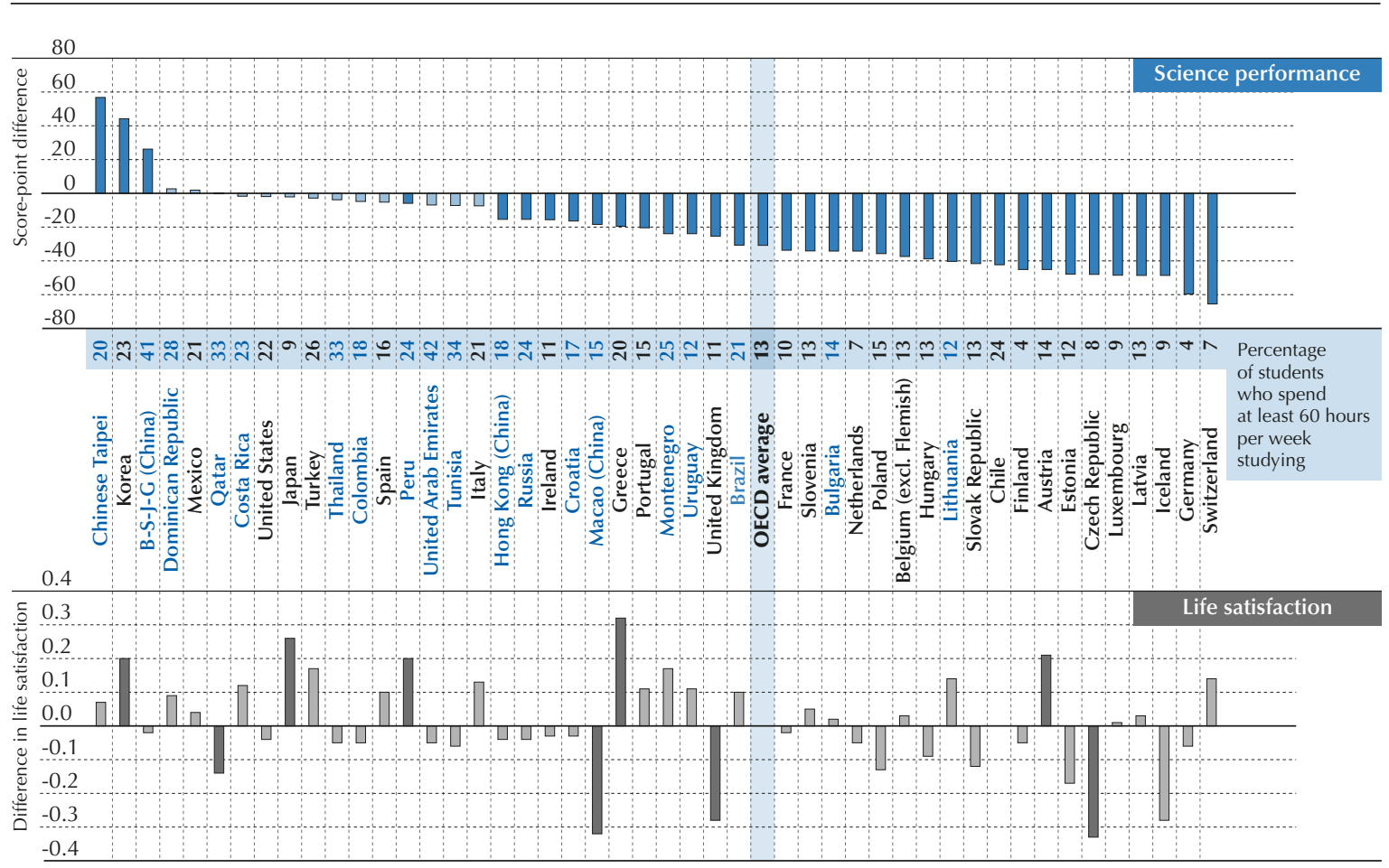

Note: Statistically significant values are marked in a darker tone (see Annex A3).

Countries and economies are ranked in descending order of the score-point difference in science between students who study at least 60 hours a week and students who study up to 40 hours a week.

Source: OECD, PISA 2015 Database, Tables III.3.6 and III.3.7.

StatLink त्ताजा http://dx.doi.org/10.1787/888933470632

Do long hours of study result in better performance on the PISA test? Previous analysis of PISA 2015 data shows that more time spent in science lessons is positively related to performance, while additional hours of study after school are related to poorer performance (OECD, 2016). On average across OECD countries, students who spend at least 60 hours per week on schoolwork (either at school or outside of school) score 28 points lower in mathematics, 33 points lower in reading, and 31 points lower in science than students who study 40 hours per week at most, after accounting for students' socio-economic status (Table III.3.6). This result is clearly related to the fact that, in most countries, low-achieving students are more likely than high-achievers to attend additional lessons for remedial purposes (OECD, 2016).

Differences across countries in the association between long study time and performance are striking, and reflect institutional and cultural variations in how after-school learning activities are organised, what they are intended to achieve, and how students are selected for them. In Germany and Switzerland, students who study for long hours score 60 points or more lower in science than students who spend fewer hours studying; while in B-S-J-G (China), Korea and Chinese Taipei, studying 60 hours or more per week is associated with large improvements in performance (Figure III.3.5). In these Asian countries/economies, spending many hours on homework and in additional instruction seems to be central to the life of top-performing students.

Studying very long hours is not necessarily associated with a lower quality of life, as perceived by students. On average, students who spend 60 hours or more per week on their studies report the same level of life satisfaction as students who study 40 hours per week or less. After accounting for students' socio-economic status, in Austria, Greece, Japan, Korea and Peru, students who study longer hours reported life satisfaction at least 0.2 point higher on the life satisfaction scale than students who reported studying fewer hours. The opposite relationship is found in the Czech Republic, Macao (China), and the United Kingdom. Korea is the only countries where students who 
spend many hours studying reported higher life satisfaction and score higher than students who spend fewer hours studying. Korean adolescents who work hard and are successful in their studies may be more likely to receive positive feedback, attention, and respect from parents and teachers, which can, in turn, contribute to a greater satisfaction with life (Park and Huebner, 2005).

The relationship between study time and life satisfaction is likely to depend on how much students enjoy learning, and on the motivations that lead them to study outside of regular school hours. In particular, a student who spends more than 60 hours per week studying, but believes that this is what is expected from any 15-year-old student, and is what must be done to succeed (i.e. the student has internalised the cultural norms and value of long hours of study) is less likely to perceive an imbalance in the use of his or her time than a student who studies 40 hours per week only because his or her parents insist, or because all of his or her peers do.

\section{The prevalence of additional instruction after school hours}

The PISA educational career questionnaire includes detailed information on additional instruction in 22 countries and economies. Figure III.3.6 shows that, on average across these 22 countries and economies, about $60 \%$ of students take additional lessons in science and $72 \%$ take additional lessons in mathematics. Students in Thailand are most likely to attend additional lessons in both subjects (more than $89 \%$ of students do) and spend more hours on extra courses (over five hours per week, on average, in both subjects). In Korea, students start to take additional lessons when they are still very young. On average, 15-year-old Korean students who sit the PISA test have already taken 6.4 years of extra courses. At least one in two students across the 22 countries and economies reported taking extra courses with their regular teacher.

Figure III.3.6 - Prevalence of and motivations for additional instruction

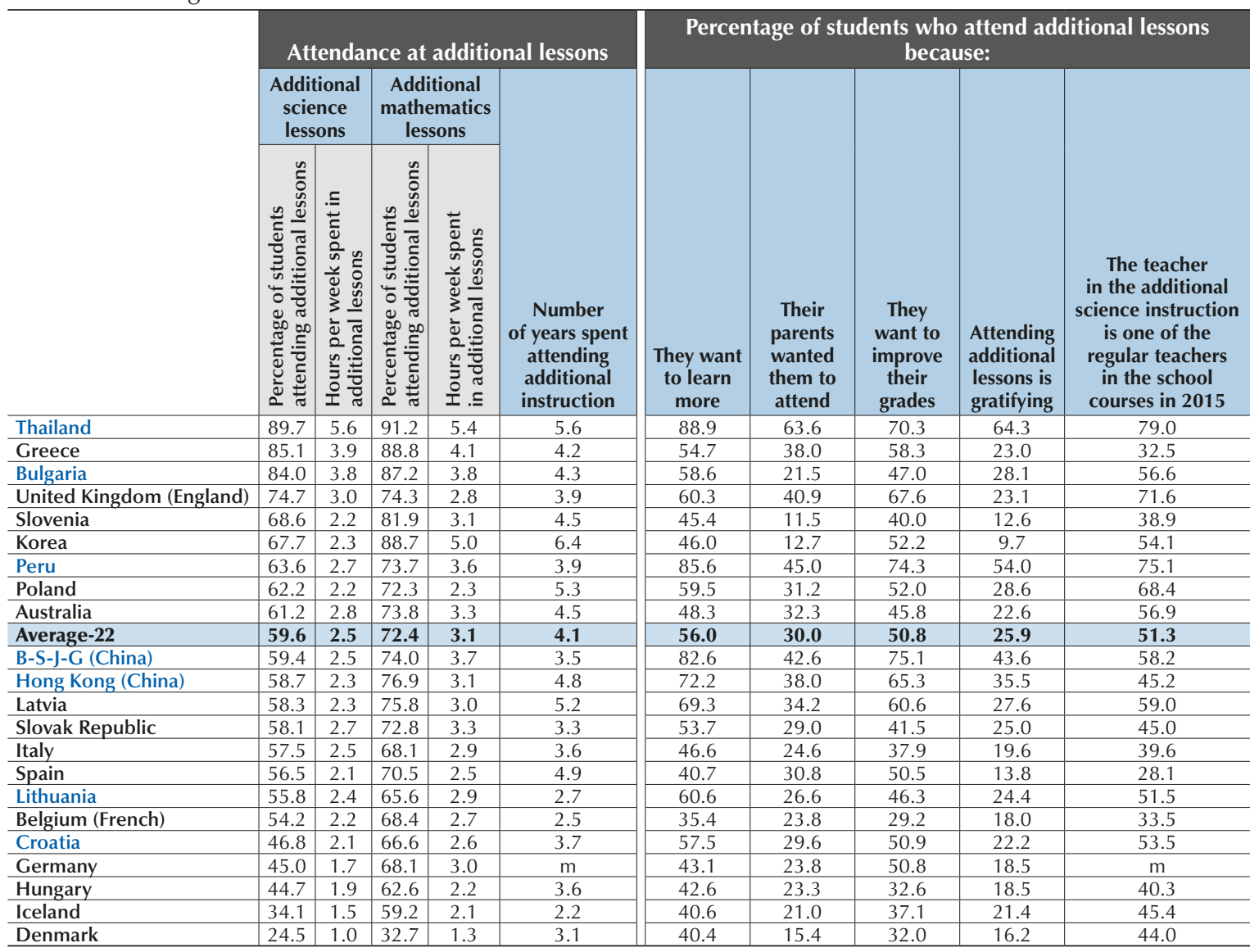

Note: The figure only includes countries and economies that participated in the optional Education Career questionnaire.

Countries and economies are ranked in descending order of the percentage of students attending additional science lessons.

Source: OECD, PISA 2015 Database, Table III.3.9.

StatLink 게 SL http://dx.doi.org/10.1787/888933470644 
According to students' self-reports, the desire to learn more and improve their school marks motivates students to take additional lessons, particularly so in B-S-J-G (China), Hong Kong (China), Peru and Thailand. It was much less common for students to report that they take additional lessons because their parents want them to. For example, in Korea and Slovenia only one in eight students so reported. The pleasure of learning is not often cited as a reason for taking additional lessons. Some $64 \%$ of students in Thailand and $54 \%$ of students in Peru reported that they take additional lessons because they find it gratifying to study; only $10 \%$ of Korean students cited the pleasure of studying as a motive for taking additional classes.

The weak relationship between performance in PISA and students' satisfaction with their life does not necessarily mean that efforts invested in schoolwork and success at school cannot improve students' quality of life. The relationship between students' perceived quality of life and the effort they put into their schoolwork is complex. If some aspects of high academic performance, such as a sense of achievement, can boost students' satisfaction with life, other aspects, such as intense competition, psychological pressure and a work-leisure imbalance, might sap the energy and positive attitudes that adolescents need to flourish in life (Suldo et al., 2013).

\section{SCHOOL CLIMATE, TEACHING PRACTICES AND VARIATIONS IN LIFE SATISFACTION ACROSS SCHOOLS}

Adolescence is a turning point in life: depending on the kinds of care and opportunities that adults and institutions provide to adolescents, young people emerge from this phase of life full of promise, or full of problems (Roeser, Eccles and Sameroff, 2000). Schools are one of the most important social institutions for most adolescents, and the environment in which students learn can shape students' development and life satisfaction (Aldridge et al., 2016). Every school has its own distinct climate, which is composed of both psychological and institutional attributes (Modin and Östberg, 2009). There is no universal recipe to make a "happy school", and schools cannot be expected to make every student feel very satisfied with their life. But a growing body of research shows that schools, together with other social institutions, can attend to children's fundamental psychological and social needs, and help students develop a sense of control over their life and resilience in the face of unfavourable situations (Natvig et al., 2003; Suldo, 2016).

Specific instructional, interpersonal and organisational processes at school can be associated with students' socioemotional functioning, depending on whether or not they meet adolescents' needs for competence, autonomy and quality relationships (Roeser, Eccles and Sameroff, 2000). Empirical studies, school interventions and interviews with school-aged children have identified the following characteristics common to schools where students feel the most satisfied (Aldridge et al., 2016; Comer and Ben-Avie, 1996; Gilman and Huebner, 2003; Suldo et al., 2013): engaging academic activities; order and discipline; parental involvement; care, respect and trust among students; positive student-teacher relations (i.e. competence and relational ability of teachers); and fairness (i.e. boys and girls of all ethnicities and socio-economic status are treated equally by adults in the school and have access to the same materials, activities and opportunities).

Teachers can play a particularly important role in creating the conditions for students' psychological well-being at school. Happier students tend to report positive relations with their teachers (Hoge, Smit and Hanson, 1990; Reddy, Rhodes and Mulhall, 2003; Roeser, Eccles and Sameroff, 1998). When students perceive that their teachers support them, they can cope better with stress at school (Malecki and Demaray, 2006).

PISA 2015 includes several questions on students' perceptions about their learning environment, with a focus on science classes. PISA asked students how often ("every lesson", "most lessons", "some lessons" or "never or hardly ever") their science teachers show an interest in every student's learning; give extra help when students need it; help students with their learning; continue teaching until students understand the material; and give students an opportunity to express their opinions. Students' responses were combined to create the index of teacher support in science classes (OECD, 2016). Figure III.3.7 shows that relatively "happy" schools (schools where students' life satisfaction is above the average in the country) have a higher index of teacher support than relatively "unhappy" schools (schools where students' life satisfaction is below the average in the country). In other words, students' perceptions of support from teachers seem to be a characteristic feature of schools where students report greater subjective well-being. 
Figure III.3.7 - Teacher support in "happy" and "unhappy" schools

Index of teacher support in schools where students' life satisfaction is statistically significantly above/below the average in the country/economy

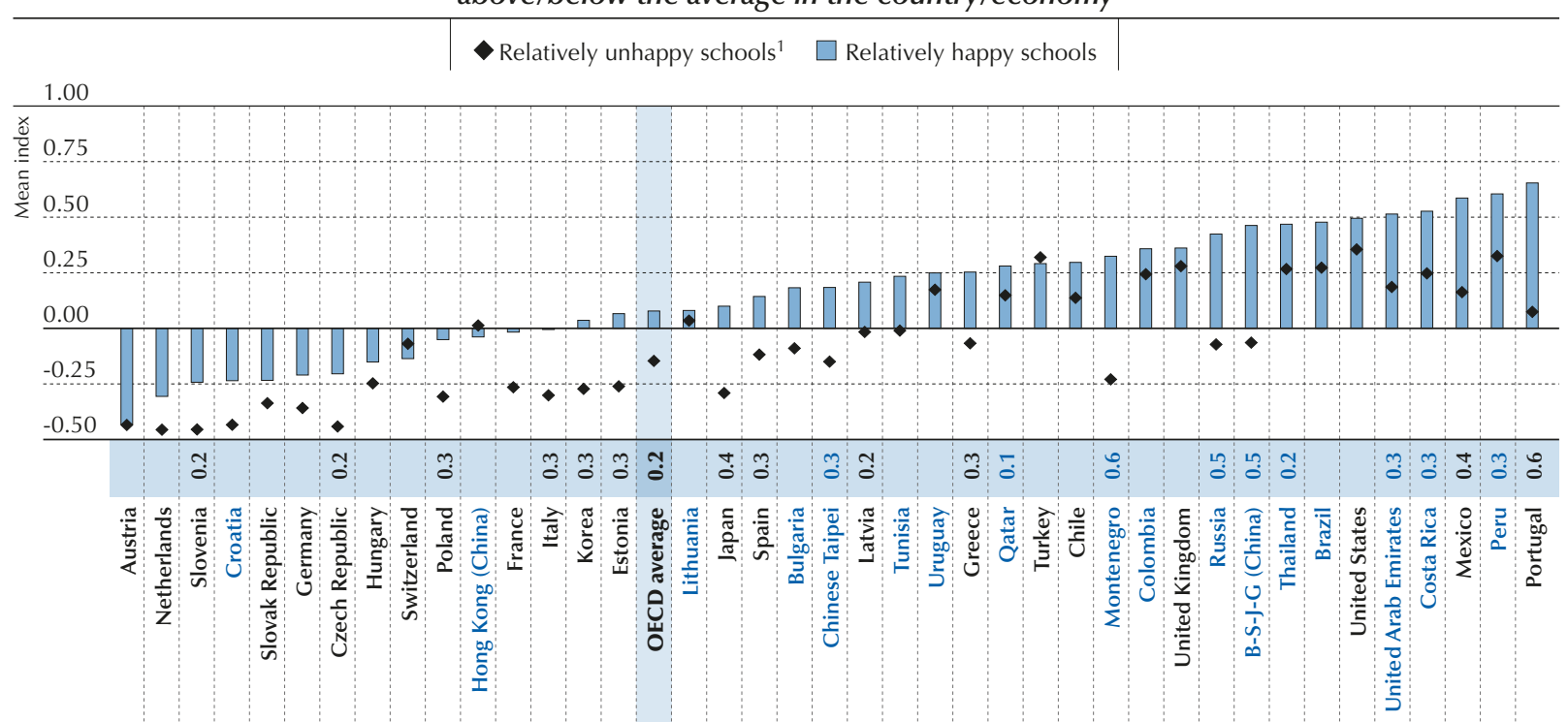

1. Relatively happy (unhappy) schools are schools where students' life satisfaction is statistically significantly above (below) the average in the country/ economy.

Note: Statistically significant differences in the index of teacher support between schools that are relatively happy and those that are relatively unhappy are shown next to the country/economy name (see Annex A3).

Countries and economies are ranked in ascending order of the index of teacher support in relatively happy schools.

Source: OECD, PISA 2015 Database, Table III.3.10.

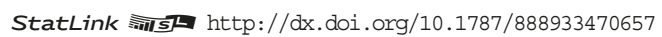

Table III.3.11 shows that other students' perceptions about their science teachers are also more marked in happy schools than in unhappy schools. On average across OECD countries, the PISA index of adaptive instruction (how much science teachers in the school tailor lessons to the students in their classes, including to individual students who are struggling with a task), the index of perceived feedback (how much students perceive that their science teachers provide them with regular feedback), the index of enquiry-based instruction (the extent to which students engage in experimentation, debate and hands-on activities in their science classes) are all higher in happy schools than in unhappy schools.

More analysis is needed to identify the methods of teaching, assigning tasks, grading and communicating with students that can make the process of learning more enjoyable and rewarding for students, so that more students see their time learning at school and studying outside of school as time well spent. More research is also needed to determine the direction of the relationships between the school climate, teaching practices, and students' life satisfaction.

\section{What do these results imply for policy?}

- The weak link between life satisfaction and performance at school suggests that academic excellence does not always result in a better quality of life for students. Education systems should explore solutions that make learning more enjoyable and fulfilling for all students, so that high performance and personal happiness become self-reinforcing goals.

- More analysis of characteristics of schools where most students report high levels of life satisfaction could shed light on teaching practices that support psychological well-being (particularly among girls and disadvantaged students). This analysis can have implications for teacher education and training. 


\section{References}

Aldridge, J.M. et al. (2016), "Students' perceptions of school climate as determinants of wellbeing, resilience and identity", Improving Schools, Vol. 19/1, pp. 5-26, http://dx.doi.org/10.1177/1365480215612616.

Chang, L. et al. (2003), "Life satisfaction, self-concept, and family relations in Chinese adolescents and children", International Journal of Behavioral Development, Vol. 27/2, pp. 182-189, http://dx.doi.org/10.1080/01650250244000182.

Comer, J.P. et al. (eds.) (1996), Rallying the Whole Village: The Comer Process for Reforming Education, Teachers College Press, New York, NY.

Deaton, A. (2008), "Income, health, and well-being around the world: Evidence from the Gallup World Poll", Journal of Economic Perspectives, Vol. 22/2, pp. 53-72, http://dx.doi.org/10.1257/jep.22.2.53.

Deb, S. et al. (2015), "Academic stress, parental pressure, anxiety and mental health among Indian high school students", International Journal of Psychology and Behavioral Sciences, Vol. 5/1, pp. 26-34, http://dx.doi.org/10.5923/j.ijpbs.20150501.04.

Diener, E., S. Oshi and R.E. Lucas (2003), "Personality, culture, and subjective well-being", Annual Review of Psychology, Vol. 54, pp. 403-425, http://dx.doi.org/10.1146/annurev.psych.54.101601.145056.

Diener, E. et al. (1999), "Subjective well-being: Three decades of progress", Psychological Bulletin, Vol. 125/2, pp. $276-302$.

Gilman, R. et al. (2008), "Cross-national adolescent multidimensional life satisfaction reports: Analyses of mean scores and response style differences", Journal of Youth and Adolescence, Vol. 37/2, pp. 142-154, http://dx.doi.org/10.1007/s10964-007-9172-8.

Gilman, R. and S. Huebner (2003), "A review of life satisfaction research with children and adolescents", School Psychology Quarterly, Vol. 18/2, pp. 192-205, http://dx.doi.org/10.1521/scpq.18.2.192.21858.

Goldbeck, L. et al. (2007), "Life satisfaction decreases during adolescence", Quality of Life Research: An International Journal of Quality of Life Aspects of Treatment, Care and Rehabilitation, Vol. 16/6, pp. 969-979, http://dx.doi.org/10.1007/s11136-007-9205-5.

Heffner, A.L. and S.P. Antaramian (2016), "The role of life satisfaction in predicting student engagement and achievement", Journal of Happiness Studies, Vol. 17/4, pp. 1681-1701, http://dx.doi.org/10.1007/s10902-015-9665-1.

Helliwell, J., R. Layard and J. Sachs (2016), World Happiness Report, web page, http://worldhappiness.report/ (accessed 3 April 2017).

Hoge, D.R., E.K. Smit and S.L. Hanson (1990), "School experiences predicting changes in self-esteem of sixth- and seventh-grade students", Journal of Educational Psychology, Vol. 82/1, pp. 117-127, http://dx.doi.org/10.1037/0022-0663.82.1.117.

Huebner, E.S. and K.J. Hills (2013), "Assessment of subjective well-being in children and adolescents", in D.H. Saklofske, C.R. Reynolds and V. Schwean (eds.), The Oxford Handbook of Child Psychological Assessment, Oxford University Press, New York, NY.

Huebner, E.S., Gilman, R. and J.E. Laughlin (1999), "A multimethod investigation of the multidimensionality of children's well-being reports: Discriminant validity of life satisfaction and self-esteem", Social Indicators Research, Vol. 46/1, pp. 1-22, http://dx.doi. org/10.1023/A:1006821510832.

Huebner, E.S. and G.L. Alderman (1993), "Convergent and discriminant validation of a children's life satisfaction scale: Its relationship to self- and teacher-reported psychological problems and school functioning", Social Indicators Research, Vol. 30/1, pp. 71-82, http://dx.doi.org/10.1007/BF01080333.

Kahneman, and A. Deaton (2010), "High income improves evaluation of life but not emotional well-being", Proceedings of the National Academy of Sciences, Vol. 107/38, pp. 16489-16493.

Leonard, N.R. et al. (2015), "A multi-method exploratory study of stress, coping, and substance use among high school youth in private schools", Frontiers in Psychology, Vol. 6, https:// dx.doi.org/10.3389/fpsyg.2015.01028.

Liebkind, K. and I. Jasinskaja-Lahti (2000), "The influence of experiences of discrimination on psychological stress: A comparison of seven immigrant groups", Journal of Community and Applied Social Psychology, Vol. 10/1, pp. 1-16, https://dx.doi.org/10.1002/ (SICI)1099-1298(200001/02)10:1<1::AID-CASP521>3.0.CO;2-5.

Malecki, C.K. and M.K. Demaray (2006), "Social support as a buffer in the relationship between socioeconomic status and academic performance", School Psychology Quarterly, Vol. 21/4, pp. 375-395, https://dx.doi.org/10.1037/h0084129.

Modin, B. and V. Östberg (2009), "School climate and psychosomatic health: A multilevel analysis", School Effectiveness and School Improvement, Vol. 20/4, pp. 433-455, https://dx.doi.org/10.1080/09243450903251507.

Natvig, G.K., G. Albrektsen and U. Qvarnstrøm (2003), "Associations between psychosocial factors and happiness among school adolescents", International Journal of Nursing Practice, Vol. 9/3, pp. 166-175.

OECD (2016), PISA 2015 Results (Volume II): Policies and Practices for Successful Schools, OECD Publishing, Paris, http://dx.doi. org/10.1787/9789264267510-en. 
OECD (2015a), How's Life? 2015: Measuring Well-being, OECD Publishing, Paris, http://dx.doi.org/10.1787/how life-2015-en.

OECD (2015b), Immigrant Students at School: Easing the Journey towards Integration, OECD Publishing, Paris, http://dx.doi.org/ 10.1787/9789264249509-en.

OECD (2013), OECD Guidelines on Measuring Subjective Well-being, OECD Publishing, Paris, http://dx.doi.org/10.1787/ 9789264191655-en.

Oishi, S. (2010), "Culture and well-being: conceptual and methodological issues", in E. Diener, D. Kahneman and J. Helliwell (eds.), International Differences in Well-Being, Oxford Positive Psychology, Oxford University Press, New York, NY.

Park, N., C. Peterson and W. Ruch (2009), "Orientations to happiness and life satisfaction in twenty-seven nations", Journal of Positive Psychology, Vol. 4/4, pp. 273-279.

Park, N. and E.S. Huebner (2005), "A cross-cultural study of the levels and correlates of life satisfaction among adolescents", Journal of Cross-Cultural Psychology, Vol. 36/4, pp. 444-456, http://dx.doi.org/10.1177/0022022105275961.

Proctor, C.P., A. Linley and J. Maltby (2009), "Youth life satisfaction measures: A review", The Journal of Positive Psychology, Vol. 4/2, pp. 128-144, http://dx.doi.org/10.1080/17439760802650816.

Reddy, R., J.E. Rhodes and P. Mulhall (2003), "The influence of teacher support on student adjustment in the middle school years: A latent growth curve study", Development and Psychopathology, Vol. 15/1, pp. 119-138, http://dx.doi.org/10.1017.S0954579403000075.

Roeser, R.W., J.S. Eccles and A.J. Sameroff (2000), "School as a context of early adolescents' academic and social-emotional development: A summary of research findings", The Elementary School Journal, Vol. 100/5, pp. 443-471, http://dx.doi.org/10.1086/499650.

Roeser, R.W., J.S. Eccles and A.J. Sameroff (1998), "Academic and emotional functioning in early adolescence: Longitudinal relations, patterns, and prediction by experience in middle school", Development and Psychopathology, Vol. 10/2, pp. 321-352, http://dx.doi. org/10.1017/S0954579498001631.

Schaefer, M.K. and E.H. Blodgett Salafia (2014), "The connection of teasing by parents, siblings, and peers with girls' body dissatisfaction and boys' drive for muscularity: The role of social comparison as a mediator", Eating Behaviors, Vol. 15/4, pp. 599-608, http://dx.doi. org/10.1016/j.eatbeh.2014.08.018.

Shanghai Daily (2015), "For overworked students, no relief in sight," web article, www.shanghaidaily.com/feature/news-feature/Foroverworked-students-no-relief-in-sight/shdaily.shtml (accessed 3 April 2017).

Suldo, S.M. (2016), Promoting Student Happiness: Positive Psychology Interventions in Schools, Guilford Press, New York, NY.

Suldo, S.M. et al. (2013), "Understanding middle school students life satisfaction: Does school climate matter?", Applied Research in Quality of Life, Vol. 8/2, pp. 169-182, http://dx.doi.org/10.1007/s11482-012-9185-7.

Suldo, S.M. and E.S. Huebner (2006), "Is extremely high life satisfaction during adolescence advantageous?", Social Indicators Research, Vol. 78/2, pp. 179-203, http://dx.doi.org/10.1007/s11205-005-8208-2.

Suldo, S.M. and E.S. Huebner (2004), "Does life satisfaction moderate the effects of stressful life events on psychopathological behavior during adolescence?", School Psychology Quarterly, Vol. 19/2, pp. 93-105, http://dx.doi.org/10.1521/scpq.19.2.93.33313.

The Guardian (2014), "Education's culture of overwork is turning children and teachers into ghosts," web page, https://www.theguardian. com/commentisfree/2014/apr/16/culture-overwork-teachers-children-ghosts-schools (accessed 3 April 2017).

Tsai, J.L. et al. (2007), "Influence and adjustment goals: Sources of cultural differences in ideal affect", Journal of Personality and Social Psychology, Vol. 92/6, pp. 1102-1117, http://dx.doi.org/10.1037/0022-3514.92.6.1102.

Valois, R. F. et al. (2001), "Relationship between life satisfaction and violent behaviors among adolescents", American Journal of Health Behavior, Vol. 25/4, pp. 353-366.

Voelker, D.K, J.J. Reel and C. Greenleaf (2015), "Weight status and body image perceptions in adolescents: Current perspectives", Adolescent Health, Medicine and Therapeutics, Vol. 6 (August), pp. 149-158, http://dx.doi.org/10.2147/AHMT.S68344.

Zullig, K.J. et al. (2001), "Relationship between perceived life satisfaction and adolescents' substance abuse", The Journal of Adolescent Health: Official Publication of the Society for Adolescent Medicine, Vol. 29/4, pp. 279-288, http://dx.doi.org/10.1016/S1054-139X(01) 00269-5. 



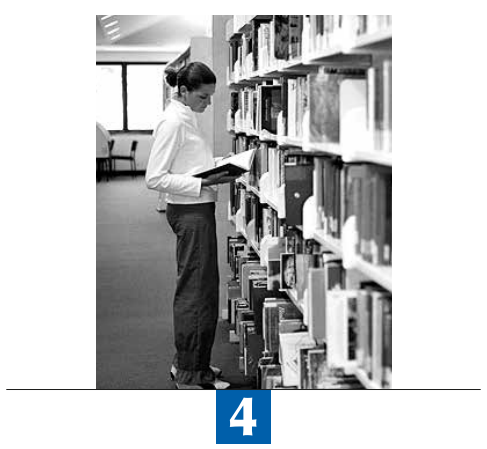

\section{Schoolwork-related anxiety}

For many students, assignments and tests present less a motivation to learn useful skills than a source of deep anxiety. This chapter examines the prevalence of schoolwork-related anxiety among students and how that anxiety can affect not only performance but students' overall well-being. The chapter concludes with a discussion of how teachers and parents can help reduce students' anxiety at school. 
Although some students regard academic challenges and assessments as a way to improve themselves, many others develop serious anxiety when they cannot solve tasks at school, when they have problems with homework or when they know they are to be tested. This is especially true for students who have low confidence in their skills and for those who believe that their worth depends on doing better than others (Zeidner, 2007).

\section{What the data tell us}

- Feelings of anxiety related to schoolwork are common among 15-year-old students. On average across OECD countries, more than one in two students often worry about the difficulty of exams and feel very anxious, even if they are well prepared for a test.

- Anxiety is more frequent among girls than among boys. Around $64 \%$ of girls but $47 \%$ of boys reported that they agree or strongly agree that they feel very anxious even if they are well prepared for a test. In all countries and economies with the exception of Japan, girls were also more likely than boys to report that they get very tense when they study and that they get nervous when they don't know how to solve a task at school.

- Schoolwork-related anxiety is negatively related to performance at school and to life satisfaction.

- Students who reported that their science teachers adapt the lesson to the class's needs or provide individual help are less likely to feel anxious about their schoolwork.

- Girls whose parents encourage them to be confident were less likely to report feeling tense when they study.

The anxiety related to school tasks and tests, along with the pressure to get higher marks and the concern about receiving poor grades, is one of the sources of stress most often cited by school-age children and adolescents. Students who suffer from anxiety are more likely to perform poorly, be frequently absent from school, and drop out of school altogether (Cortina, 2008; Ramirez and Beilock, 2011). Excessive levels of anxiety can also negatively affect student's social and emotional development and sense of self-worth, prompt students to use chemical substances to reduce stress, and lead to exhaustion (Salend, 2012; Zeidner, 1998).

\section{PREVALENCE OF SCHOOLWORK-RELATED ANXIETY AMONG 15-YEAR-OLD STUDENTS}

Anxiety has different dimensions, and PISA 2015 chose to focus on the students' cognitive and emotional reactions to schoolwork. PISA 2015 asked students to report whether they strongly agree, agree, disagree or strongly disagree with the following statements: "I often worry that it will be difficult for me to take a test"; "I worry I will get poor grades at school"; "I feel very anxious even if I am well prepared for a test"; "I get very tense when I study for a test"; and "I get nervous when I do not know how to solve a task at school". The PISA questions thus cover both study-and test-related anxiety. Students' responses were used to construct the index of schoolwork-related anxiety, standardised to have a mean of 0 and a standard deviation of 1 across OECD countries. Positive values on the index indicate that students reported higher levels of schoolwork-related anxiety than the average student across OECD countries; negative values indicate that students reported lower levels of anxiety than the average student.

On average across OECD countries, about 59\% of students reported that they often worry that taking a test will be difficult, and $66 \%$ reported that they worry about poor grades. Some $55 \%$ of students reported feeling very anxious for a test even if they are well prepared; $37 \%$ reported they get very tense when studying; and 52\% reported that they get nervous when they don't know how to solve a task at school (Table III.4.1). There is a weak, negative correlation between an education system's performance in PISA and students' reported anxiety. Among the three countries where students reported the highest degree of schoolwork-related anxiety, Brazil and Costa Rica perform significantly below average, while Singapore is the top-performing country in PISA 2015 (Table III.4.5 and Figure I.2.13).

In all countries and economies that participated in PISA 2015, girls reported greater anxiety than boys (Table III.4.5). On average across OECD countries, boys were about 13 percentage points less likely than girls to report they get very tense when they study (Figure III.4.1). About $64 \%$ of girls but $47 \%$ of boys reported feeling very anxious even when they are well prepared for a test. This gender difference is particularly striking in the Nordic countries of Denmark, Iceland, Norway and Sweden (Table III.4.2). One possible explanation may be that girls are less self-confident than boys and, as a result, experience more worry and discomfort before and during evaluations (Zeidner, 1998). For girls, the prospect 
of an assessment, particularly in subjects like mathematics and science, may pose what psychologists call a "stereotype threat" (Stoet and Geary, 2012) - the possibility that poor performance will confirm negative assumptions about the group to which they belong (for example, the stereotype that girls cannot excel in mathematics and science) (Stoet and Geary, 2012). Another possibility is that boys choose not to report being anxious in PISA because of social norms that expect boys to be strong and confident.

Figure III.4.1 - Prevalence of schoolwork-related anxiety, by gender Percentage of students who reported that they "agree" or "strongly agree" with the following statements

\begin{tabular}{|l|c|}
\multicolumn{2}{|c|}{} \\
\multicolumn{1}{|c|}{$\begin{array}{c}\text { Index of } \\
\text { schoolwork- } \\
\text { related anxiety }\end{array}$} \\
\hline Uustralia & 0.2 \\
\hline Austria & -0.1 \\
\hline Belgium & -0.2 \\
\hline Canada & 0.2 \\
\hline Chile & 0.1 \\
\hline Czech Republic & -0.2 \\
\hline Denmark & 0.1 \\
\hline Estonia & -0.2 \\
\hline Finland & -0.4 \\
\hline France & -0.1 \\
\hline Germany & -0.3 \\
\hline Greece & -0.1 \\
\hline Hungary & -0.1 \\
\hline Iceland & -0.1 \\
\hline Ireland & 0.1 \\
\hline Israel & -0.3 \\
Italy & 0.5 \\
\hline Japan & 0.3 \\
\hline Korea & 0.1 \\
\hline Latvia & -0.1 \\
\hline Luxembourg & -0.2 \\
\hline Mexico & 0.3 \\
\hline Netherlands & -0.5 \\
\hline New Zealand & 0.3 \\
\hline Norway & 0.1 \\
\hline Poland & -0.1 \\
\hline Portugal & 0.5 \\
\hline Slovak Republic & -0.2 \\
\hline Slovenia & 0.1 \\
\hline Spain & 0.4 \\
\hline Sweden & 0.0 \\
\hline Switzerland & -0.4 \\
\hline Turkey & 0.3 \\
\hline United Kingdom & 0.3 \\
\hline United States & 0.2 \\
\hline
\end{tabular}

\begin{tabular}{|c|c|c|c|c|}
\hline A & B & C & D & E \\
\hline 62 & 65 & 68 & 47 & 60 \\
64 & 63 & 51 & 19 & 43 \\
\hline 56 & 65 & 42 & 28 & 54 \\
59 & 64 & 64 & 46 & 63 \\
59 & 81 & 56 & 40 & 54 \\
55 & 58 & 40 & 32 & 49 \\
55 & 65 & 64 & 46 & 54 \\
51 & 55 & 53 & 28 & 41 \\
38 & 44 & 49 & 18 & 37 \\
62 & 65 & 47 & 29 & 55 \\
52 & 53 & 42 & 22 & 35 \\
46 & 48 & 59 & 38 & 65 \\
62 & 66 & 54 & 27 & 46 \\
48 & 59 & 51 & 37 & 44 \\
62 & 69 & 63 & 46 & 55 \\
58 & 50 & 44 & 33 & 43 \\
66 & 85 & 70 & 56 & 77 \\
78 & 82 & 62 & 33 & 50 \\
69 & 75 & 55 & 42 & 52 \\
53 & 68 & 43 & 27 & 47 \\
58 & 64 & 48 & 28 & 44 \\
72 & 79 & 60 & 50 & 65 \\
34 & 45 & 39 & 14 & 26 \\
65 & 67 & 72 & 51 & 61 \\
51 & 66 & 61 & 46 & 49 \\
62 & 70 & 45 & 26 & 41 \\
84 & 88 & 69 & 46 & 65 \\
61 & 62 & 47 & 29 & 45 \\
61 & 72 & 62 & 36 & 51 \\
75 & 88 & 67 & 48 & 56 \\
56 & 56 & 61 & 41 & 59 \\
48 & 56 & 34 & 21 & 35 \\
70 & 74 & 59 & 56 & 69 \\
62 & 67 & 72 & 52 & 55 \\
63 & 61 & 68 & 43 & 65 \\
& & & & \\
\hline 53
\end{tabular}

\section{OECD average}

$\square$ Boys $\square$ Girls $\diamond$ All students
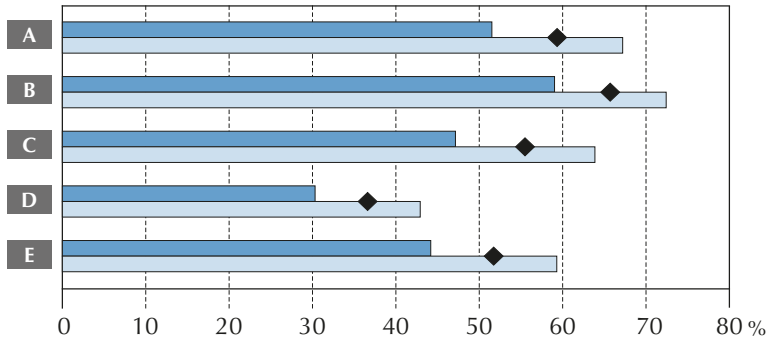

\begin{tabular}{|l|c|}
\hline Brazil & 0.6 \\
B-S-J-G (China) & 0.2 \\
Bulgaria & -0.1 \\
\hline Colombia & 0.5 \\
Costa Rica & 0.6 \\
Croatia & 0.0 \\
\hline Dominican Republic & 0.4 \\
Hong Kong (China) & 0.3 \\
Lithuania & -0.1 \\
Macao (China) & 0.4 \\
Montenegro & 0.1 \\
Peru & 0.1 \\
Qatar & 0.2 \\
Russia & -0.1 \\
Singapore & 0.6 \\
Chinese Taipei & 0.4 \\
Thailand & 0.1 \\
Tunisia & 0.1 \\
United Arab Emirates & 0.2 \\
Uruguay & 0.5 \\
\hline
\end{tabular}

\begin{tabular}{|l|l|l|l|l|}
\hline 79 & 93 & 81 & 56 & 74 \\
66 & 79 & 62 & 55 & 60 \\
52 & 61 & 55 & 46 & 62 \\
74 & 87 & 79 & 58 & 72 \\
78 & 92 & 81 & 55 & 61 \\
72 & 74 & 47 & 36 & 43 \\
65 & 82 & 80 & 53 & 64 \\
71 & 82 & 67 & 53 & 58 \\
61 & 65 & 56 & 43 & 48 \\
74 & 78 & 66 & 58 & 58 \\
65 & 68 & 65 & 47 & 58 \\
60 & 79 & 72 & 43 & 49 \\
71 & 69 & 65 & 49 & 55 \\
52 & 71 & 51 & 39 & 60 \\
74 & 86 & 76 & 60 & 71 \\
74 & 82 & 67 & 62 & 68 \\
66 & 77 & 63 & 47 & 57 \\
58 & 73 & 60 & 57 & 52 \\
68 & 72 & 62 & 44 & 63 \\
72 & 90 & 73 & 53 & 67 \\
\hline
\end{tabular}

Note: All gender differences are statistically significant (see Annex A3).

Source: OECD, PISA 2015 Database, Tables III.4.1, III.4.2 and III.4.5.

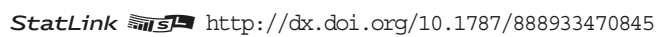

Socio-economic status is related to schoolwork-related anxiety in the majority of countries and economies that participated in PISA 2015. Differences in anxiety related to socio-economic status are particularly wide in Denmark, Luxembourg and Sweden (Table III.4.2). In Sweden, for example, 65\% of disadvantaged students but only 48\% of advantaged students reported they often worry about the difficulty of a test. In Luxembourg and Tunisia, disadvantaged students were at 
least 18 percentage points more likely than advantaged students to feel anxious about a test, regardless of how well prepared they are. By contrast, advantaged students in Colombia, the Dominican Republic, Korea, Peru and Spain were at least 5 percentage points more likely than disadvantaged students to report that they worry about getting poor results. Advantaged students in Korea, in particular, were more likely than disadvantaged students to also report feeling tense when studying and feeling anxious even if they felt well prepared for the test. Sources of academic anxiety vary across cultures (Zeidner et al., 2005), and in some cultures parental expectations increase as socio-economic status rises (Ang and Huan, 2006; Chen, 2012; Xiao, 2013).

\section{CONSEQUENCES OF SCHOOLWORK-RELATED ANXIETY}

Anxiety can be highly disabling (Herzer, Wendt and Hamm, 2014). People with high levels of anxiety are more likely than people with low levels of anxiety to think and behave in ways that are irrelevant to the task at hand, thus undermining their performance (Sarason, Sarason and Pierce, 1990; Spielberger, 2013). Highly anxious students often feel that they have no influence over the outcome of the evaluation (Schunk, 1991).

PISA 2015 shows that anxiety is negatively related to performance in science, mathematics and reading. On average across OECD countries, $63 \%$ of low-achieving students in science (students in the bottom quarter of science performance in a country) and $46 \%$ of high-achieving students (students in the top quarter) reported that they feel anxious for a test no matter how well prepared they are (Figure III.4.2). The difference in schoolwork-related anxiety between low-achieving and high-achieving students in science is particularly large (over 25 percentage points) in Austria, Chile, Germany, Iceland and Tunisia (Table III.4.3a). By contrast, in Brazil, Colombia, Costa Rica, the Dominican Republic, Korea, Peru, Spain, Thailand and Tunisia, high-achieving students in science are more concerned than low-achievers about getting poor grades. At the cross-national level, there is a weak, negative relationship between the index of schoolwork-related anxiety and the system's science performance.

Figure III.4.2 - Schoolwork-related anxiety among students in the top and bottom quarters of science performance

Percentage of students who reported that they "agree" or "strongly agree" with the statement "Even if I am well prepared for a test, I feel very anxious"

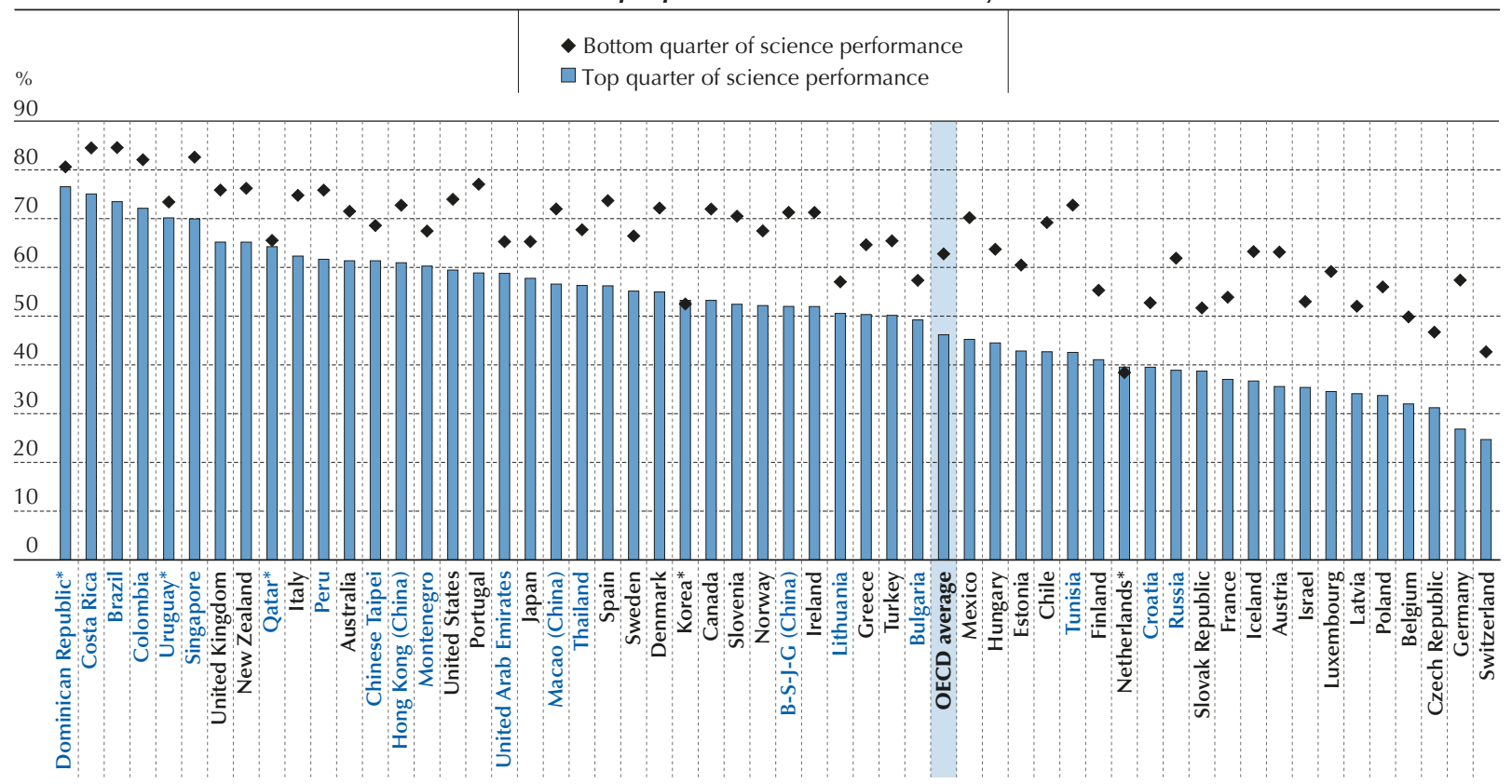

Note: Differences in the percentage of students who feel anxious that are not statistically significant are marked with an asterisk next to the country/ economy name (see Annex A3).

Countries and economies are ranked in descending order of the percentage of high-performing students in science who reported that they feel very anxious even if they are well prepared for a test.

Source: OECD, PISA 2015 Database, Table III.4.3a.

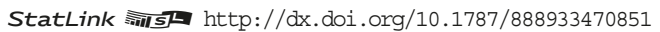


The fear of making mistakes on a test often disrupts the performance of top-performing students who "choke under pressure" (OECD, 2015). On average across OECD countries, 55\% of girls but 38\% of boys who are among the top $25 \%$ of students in their country in science performance reported that they feel very anxious for a test even if they are well prepared (Table III.4.4). But gender differences in anxiety are also observed among low-achieving students. Some $71 \%$ of low-achieving girls but $54 \%$ of low-achieving boys in science reported that they feel very anxious even if they are well prepared.

On average across OECD countries, students in the top quarter of the index of schoolwork-related anxiety reported a level of life satisfaction that is 1.2 points lower (over half of a standard deviation on the life satisfaction scale, which ranges from 0 to 10) than students in the bottom quarter of the index (Figure III.4.3 and Table III.4.9). The relationship between life satisfaction and schoolwork-related anxiety is particularly strong in Iceland and the United Kingdom (over two points of a difference on the scale between students in the top quarter and those in the bottom quarter of the index of schoolwork-related anxiety). Only in Brazil, Colombia, Costa Rica, the Dominican Republic and Uruguay is this relationship not statistically significant.

Figure III.4.3 - Schoolwork-related anxiety and life satisfaction Average life satisfaction, by quarter of the index of schoolwork-related anxiety

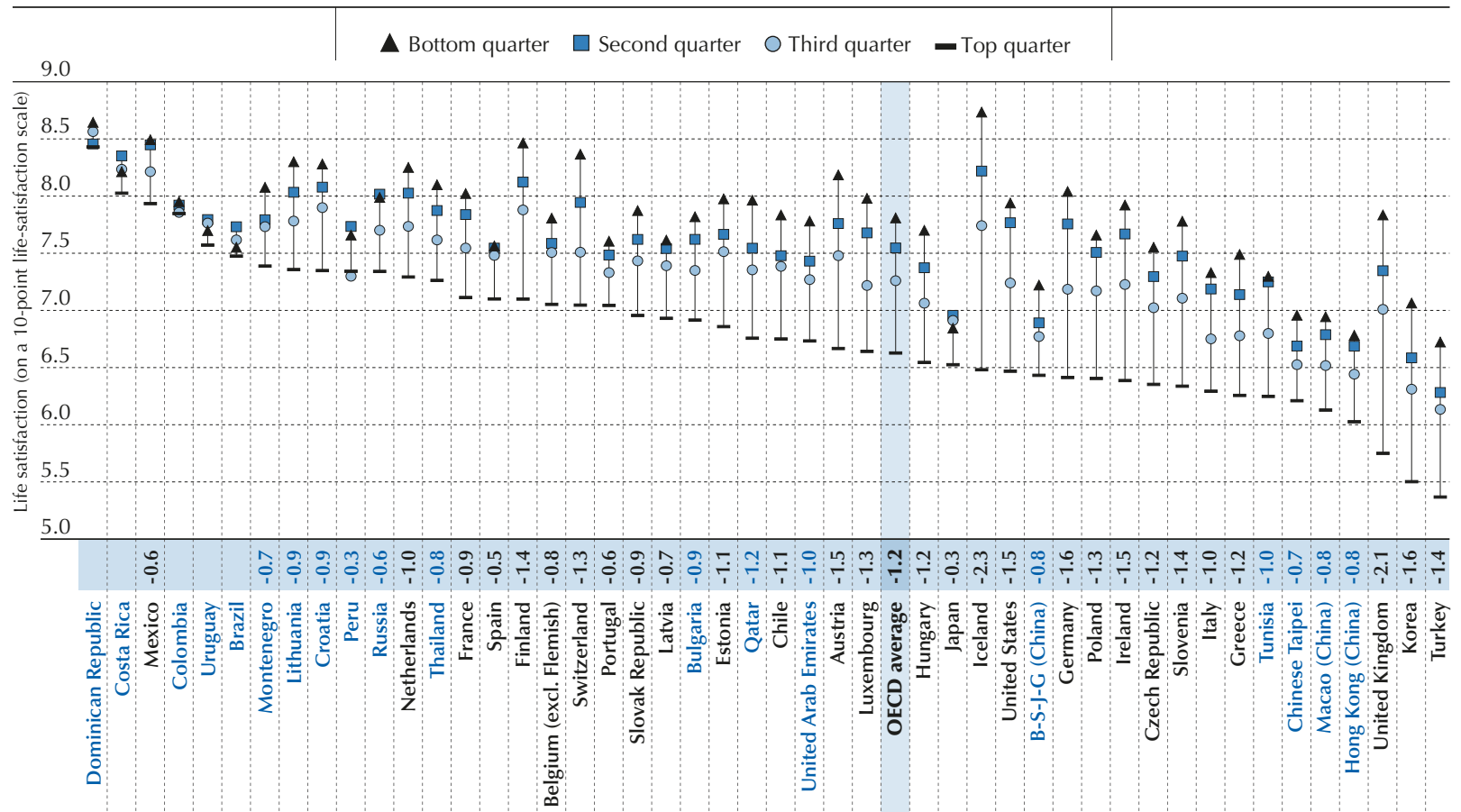

Note: Statistically significant differences between the top and bottom quarters on the distribution of schoolwork-related anxiety are shown next to the country/economy name (see Annex A3).

Countries and economies are ranked in descending order of the average life satisfaction among students in the top quarter of the index of schoolworkrelated anxiety.

Source: OECD, PISA 2015 Database, Table III.4.9.

StatLink त्नाजम http://dx.doi.org/10.1787/888933470868

\section{SOURCES OF AND REMEDIES FOR SCHOOLWORK-RELATED ANXIETY}

Students who attend schools with high performance standards may face a greater risk of developing anxiety about schoolwork, particularly if they feel that they cannot keep up with the achievements of their peers, and if teachers and school leaders assign a high value to rankings and competition within the classroom. Parents of students in elite schools often pay substantial tuition fees and expect their children to gain admission to top-tier universities. These elite tertiary institutions are becoming more and more selective, and some schools are responding to this competitive climate by providing more difficult classes, not always appropriate to the students' developmental levels. Students in these schools may feel caught in a cycle of escalating demands that is largely out of their control (Leonard et al., 2015). Figure III.4.4 shows that, after accounting for the performance of individual students, schoolwork-related anxiety is greater in top-performing schools (those whose students' average science performance is in the top decile of the country). 
In other words, for given level of performance, students report greater anxiety if they attend more competitive schools. This result suggests that comparisons with peers can be a source of anxiety, and that a highly competitive learning environment can be a double-edged sword: some students thrive on competition, while others cannot cope with the stress.

Long study hours represent another possible factor of schoolwork-related anxiety. Students in selective, high-pressure schools might feel obliged to invest extra hours of work to comply with external expectations and with their own motivation for academic achievement. Table III.4.10 shows that, on average across OECD countries, students in schools where the average student studies more than 50 hours per week were more likely to report anxiety than students in schools where the average study time is between 35 and 40 hours per week. The relationship between study time in school and anxiety is more evident in some countries than in others. For example, in Belgium and Israel, students in schools with long study time are at least 11 percentage points more likely to report that they feel anxious for a test even if well prepared than students in schools with short study time.

Figure III.4.4 - Schoolwork-related anxiety in top-performing schools

Difference in prevalence of schoolwork-related anxiety between schools in the top decile of science performance and all other schools, after accounting for students' performance

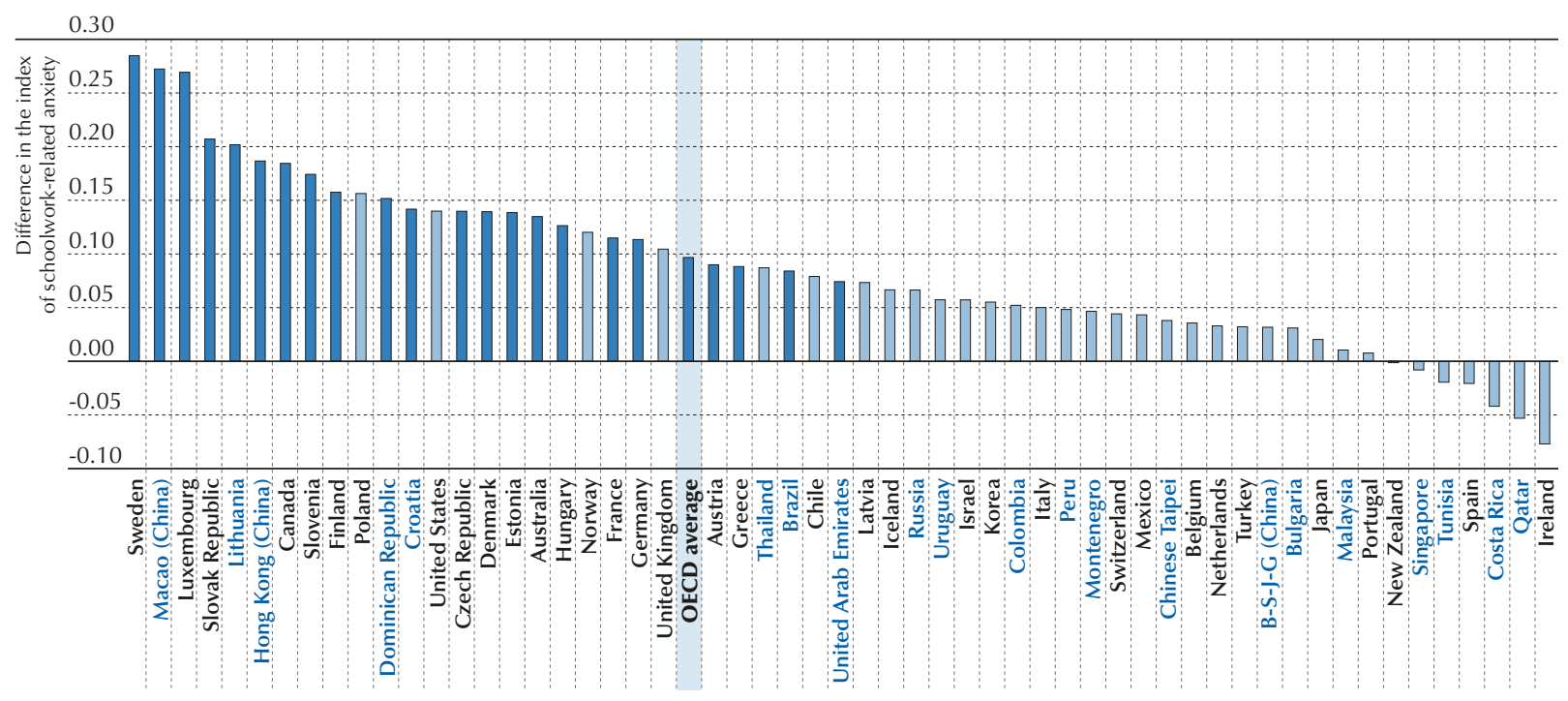

Note: Statistically significant differences are marked in a darker tone (see Annex A3).

Countries and economies are ranked in descending order of the difference in schoolwork-related anxiety between schools in the top decile of science performance and all other schools.

Source: OECD, PISA 2015 Database, Table III.4.8a.

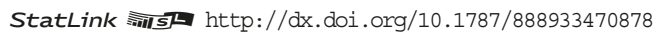

Both parents and educators often argue that anxiety is the natural consequence of testing overload. In about five out of six school systems, students are assessed at least once a year with mandatory standardised tests; in about three out of four countries/economies, students are assessed at least once a year with non-mandatory standardised tests (OECD, 2016). However, the frequency of tests as reported by school principals seems unrelated to students' level of anxiety. In fact, on average across OECD countries, students who are assessed through standardised or teacher-developed tests at least once a month reported the same level of anxiety, on average, as students who are assessed less frequently (Table III.4.15).

One interpretation of this result is that it is not the frequency of tests, but rather students' perception of the assessment as more or less threatening that determines how anxious students feel about tests. This perception is influenced by characteristics of the evaluation itself and by personal factors. According to Zeidner (1998), the nature of the task, difficulty, atmosphere, time constraints, examiner characteristics, mode of administration and physical setting determine whether an assessment is more or less likely to generate anxiety. These features of the testing environment interact with personal characteristics, such as study skills, test-taking skills, the desire for achievement, self-efficacy and academic ability. An important caveat in the interpretation of this result is that PISA data do not make a distinction between high-stake tests and low-stake tests. 
Teachers can reduce anxiety and stress by regularly teaching students effective study methods. They can also help students feel prepared for the test by going over the content likely to be used in high-stakes exams, and by designing and conducting mock tests so that students are not confronted with completely unfamiliar material during the real test.

The way teachers communicate to students about homework and tests is important too. Under pressure to improve their students' test performance, teachers may emphasise the need to do well on a test to gain access to better jobs or university later on (Putwain, 2008). But these appeals to students' fears can make students feel threatened - and make them much more anxious (Putwain and Symes, 2014; Putwain and Best, 2012).

The quality of student-teacher relations and the classroom environment can greatly enhance students' resilience, motivation and confidence about schoolwork (den Brok, Brekelmans and Wubbels, 2004; von der Embse et al., 2016). For teachers, this means working to build students' self-efficacy and self-confidence by communicating clear, concrete and realistic expectations for performance. When teachers help students to set realistic learning goals, students are more likely to define and experience success on their own terms, regardless of their overall grade or the performance of their classmates (Ormrod, 2014).

Figure III.4.5 shows that teachers' practices, behaviours and communication in the classroom are associated with students' feelings about assessments. On average across OECD countries (and in 12 countries and economies with available data [Table III.4.11]), after accounting for students' performance and socio-economic status, students who reported that their science teachers adapt the lesson to the class's needs and knowledge were less likely to report feeling anxious even if they are well prepared for a test, or to report that they get very tense when they study. Students were also, on average, less likely to report anxiety if the science teacher provides individual help when they experience difficulties.

Figure III.4.5 - Teachers' practices and students' schoolwork-related anxiety

Likelihood that students feel anxious for a test even if they are well prepared or get very tense when they study for a test associated with teachers' practices

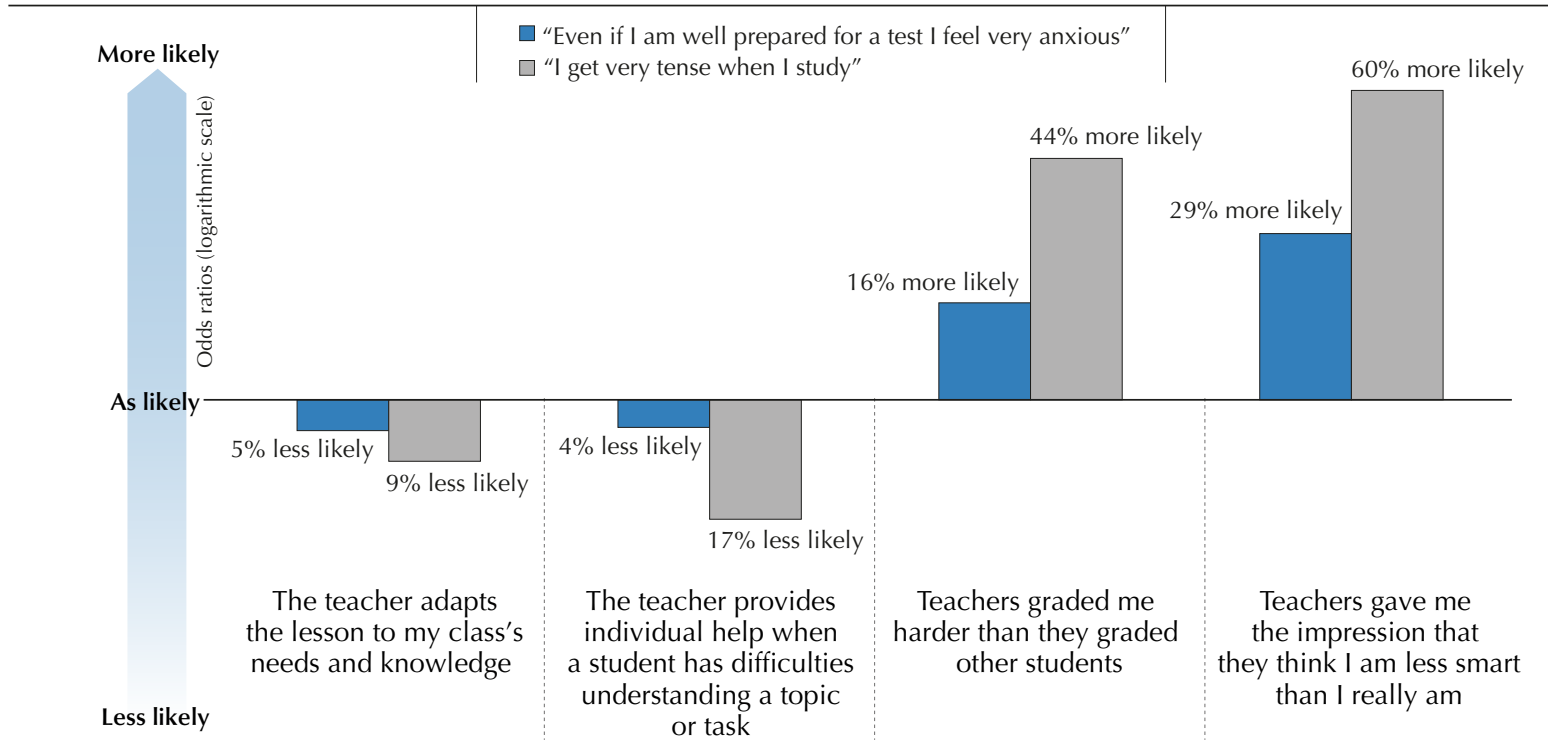

Notes: A logarithmic transformation of the odd ratios is plotted to make the values below one and above one comparable in the graph. The interpretation of the odd ratios (in terms of percentage change in the likelihood of the outcome) is indicated above or below each bar.

The values account for students' differences in the PISA index of economic, social and cultural status (ESCS) and performance in science.

All values are statistically significant (see Annex A3).

Source: OECD, PISA 2015 Database, Table III.4.11.

StatLink 게느 http://dx.doi.org/10.1787/888933470882

By contrast, negative teacher-student relations can threaten students' confidence and lead to greater anxiety. Figure III.4.5 also shows that, on average across OECD countries (and in the majority of countries and economies with available data [Table III.4.11]), students are $60 \%$ more likely to report feeling very tense when they study, and about $29 \%$ more likely to report feeling anxious before a test, if they perceive that their teacher thinks they are less smart than they 
really are. Neuroscience research has shown that even short-term negative emotions at school (for example, the fear that arises in response to a teacher's facial expression showing anger) can exacerbate students' test and study anxiety (Raufelder et al., 2016).

Positive relationships with parents are another form of social support that enables adolescents to cope with stressful events (Baumrind, 1991; Cohen and Wills, 1985). Parents can help children manage anxiety by encouraging them to trust in their ability to accomplish various academic tasks. Parents who put excessive pressure on their children, by attributing too much importance to test scores and grades or setting unrealistically high expectations, can make students worry more and undermine their confidence (Gherasim and Butnaru, 2012; Putwain, Woods and Symes, 2010).

On average across OECD countries, almost $90 \%$ of students reported that their parents encourage them to be confident (Table III.9.18). Table III.4.13 shows that, after accounting for differences in performance and socio-economic status, girls who perceive that they get this form of emotional support from their parents were $21 \%$ less likely to report that they feel tense when they study, on average across OECD countries. This relationship is stronger among girls than among boys, possibly suggesting that parents have more difficulty communicating with and addressing the insecurities of their sons. This finding is consistent with previous research showing that boys have a tendency to perceive any intervention from their parents as a form of pressure, whereas girls are better at distinguishing between parental support and parental pressure (Leff and Hoyle, 1995; Raufelder et al., 2016).

\section{What these results mean for policy}

- Teachers, school leaders and school psychologists should be aware of the impact on well-being of severe schoolwork-related anxiety, and act together to create a more supportive and positive learning environment.

- Schools can educate parents about the deleterious effects of chronic anxiety among students, and engage families and students in a dialogue about expectations for achievement and the definition of success. 


\section{References}

Ang, R. P. and V.S. Huan (2006), "Academic expectations stress inventory: Development, factor analysis, reliability, and validity", Educational and Psychological Measurement, Vol. 66/3, pp. 522-539, http://dx.doi.org/10.1177/0013164405282461.

Baumrind, D. (1991), "The influence of parenting style on adolescent competence and substance use", The Journal of Early Adolescence, Vol.11/1, pp. 56-95, http://dx.doi.org/10.1177/0272431691111004.

Chen, H. (2012), "Impact of parent's socioeconomic status on perceived parental pressure and test anxiety among Chinese high school students", International Journal of Psychological Studies, Vol. 4/2, pp. 235-245, http://dx.doi.org/10.5539/ijps.v4n2p235.

Cohen, S. and T.A. Wills (1985), "Stress, social support, and the buffering hypothesis", Psychological Bulletin, Vol. 98/2, pp. 310-357.

Cortina, K.S. (2008), "Leistungsängstlichkeit [Performance anxiety]", in W. Schneider and M. Hasselhorn (eds.), Handbuch Der Pädagogischen Psychologie, Hogrefe, Göttingen, Germany, pp. 50-61.

den Brok, P., M. Brekelmans and T. Wubbels (2004), "Interpersonal teacher behaviour and student outcomes", School Effectiveness and School Improvement, Vol. 15/3-4, pp. 407-442, http://dx.doi.org/10.1080/09243450512331383262.

Gherasim, L.R. and S. Butnaru (2012), "The effort attribution, test anxiety and achievement in sciences: The moderating effect of parental behaviour", International Journal of Learning, Vol. 18/10, pp. 283-291.

Herzer, F., J. Wendt and A.O. Hamm (2014), "Discriminating clinical from nonclinical manifestations of test anxiety: A validation study", Behavior Therapy, Vol. 45/2, pp. 222-231, http://dx.doi.org/10.1016/j.beth.2013.11.001.

Leff, S.S. and R.H. Hoyle (1995), "Young athletes' perceptions of parental support and pressure", Journal of Youth and Adolescence, Vol. 24/2, pp. 187-203, http://dx.doi.org/10.1007/BF01537149.

Leonard, N.R. et al. (2015), "A multi-method exploratory study of stress, coping, and substance use among high school youth in private schools", Frontiers in Psychology, Vol. 6/1028, http://dx.doi.org/10.3389/fpsyg.2015.01028.

OECD (2016), PISA 2015 Results (Volume II): Policies and Practices for Successful Schools, OECD Publishing, Paris, http://dx.doi. org/10.1787/9789264267510-en.

OECD (2015), The ABC of Gender Equality in Education: Aptitude, Behaviour, Confidence, OECD Publishing, Paris, http://dx.doi. org/10.1787/9789264229945-en.

Ormrod, J.E. (2014), Educational Psychology: Developing Learners, $8^{\text {th }}$ edition, Pearson Education, Upper Saddle River, NJ.

Putwain, D. (2008), "Examination stress and test anxiety", The Psychologist, Vol. 21/12, pp. 1026-1029.

Putwain, D. and N. Best (2012), "Do highly test anxious students respond differentially to fear appeals made prior to a test?", Research in Education, Vol. 88/1, pp. 1-10.

Putwain, D.W., K.A. Woods and W. Symes (2010), "Personal and situational predictors of test anxiety of students in post-compulsory education", British Journal of Educational Psychology, Vol. 80/1, pp. 137-160, http://dx.doi.org/10.1348/000709909X466082.

Ramirez, G. and S.L. Beilock (2011), "Writing about testing worries boosts exam performance in the classroom", Science, Vol. 331/6014, pp. 211-213, http://dx.doi.org/10.1126/science.1199427.

Raufelder, D. et al. (2016), "Adolescents' socio-motivational relationships with teachers, amygdala response to teacher's negative facial expressions, and test anxiety", Journal of Research on Adolescence, Vol. 26/4, pp. 706-722, http://dx.doi.org/10.1111/jora.12220.

Salend, S.J. (2012), "Teaching students not to sweat the test", Phi Delta Kappan, Vol. 93/6, pp. 20-25, http://dx.doi.org/10.1177/ $\underline{003172171209300605 .}$

Sarason, B., I. Sarason and G. Pierce (1990), "Traditional views of social support and their impact on assessment", online article, https://www.researchgate.net/publication/232474109 Traditional views of social support and their impact on assessment (accessed 3 April 2017).

Schunk, D.H. (1991), "Self-efficacy and academic motivation", Educational Psychologist, Vol. 26/3-4, pp. 207-231, http://dx.doi.org/1 $\underline{0.1080 / 00461520.1991 .9653133 .}$.

Spielberger, C.D. (ed.) (2013), Anxiety: Current Trends in Theory and Research, Academic Press, London, UK.

Stoet, G. and D.C. Geary (2012), "Can stereotype threat explain the gender gap in mathematics performance and achievement?", Review of General Psychology, Vol. 16/1, pp. 93-102, http://dx.doi.org/10.1037/a0026617.

Vogl, E. and R. Pekrun (2016), "Emotions that matter to achievement" in Brown, G.T.L. and L. Harris (eds.), Handbook of Human and Social Conditions in Assessment, Routledge: Taylor and Francis Group, New York, NY, pp. 111-128.

von der Embse, N.P. et al. (2016), "Teacher stress, teaching-efficacy, and job satisfaction in response to test-based educational accountability policies", Learning and Individual Differences, Vol. 50, pp. 308-317, http://dx.doi.org/10.1016/j.lindif.2016.08.001. 
Xiao, J. (2003), Academic Stress, Test Anxiety, and Performance in a Chinese High School Sample: The Moderating Effects of Coping Strategies and Perceived Social Support, Doctoral dissertation, Georgia State University, Atlanta, GA, http://scholarworks.gsu.edu/ cps diss/88 (accessed: 3 April 2017).

Zeidner, M. (2007), "Test anxiety in educational contexts: Concepts, findings, and future directions", in P.A. Schutz and R. Pekrun (eds.), Emotion in Education, Educational Psychology Series: Elsevier Academic Press, San Diego, CA, pp. 165-184.

Zeidner, M. (1998), Test Anxiety - The State of the Art, Kluwer Academic/Plenum Publishers, New York, NY.

Zeidner, M. et al. (2005), "Evaluation anxiety: Current theory and research", in A.J. Elliot and C.S. Dweck (eds.), Handbook of Competence and Motivation, Guilford Publications, New York, NY, pp. 141-166. 


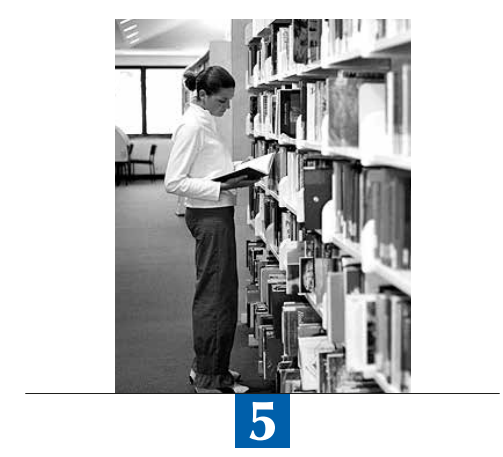

\section{Students' motivation to achieve}

Motivation is frequently what makes the difference between success and failure, in school as in life. This chapter examines how students' achievement motivation differs among countries and how it is related to students' gender, socio-economic status and immigrant background. It also discusses how the motivation to achieve can influence student performance and have an impact on students' satisfaction with their life. 
One of the most important ingredients of achievement, both in school and in life, is motivation to achieve (OECD, 2013). In many cases, individuals with less talent, but greater motivation to reach their goals, are more likely to succeed than those who have talent but are not capable of setting goals for themselves and to stay focused on achieving them (Duckworth et al., 2011; Eccles and Wigfield, 2002). The motivation to achieve goals not only leads individuals to pursue work they perceive to be valuable, it also prompts them to compete with others (Covington, 2000). This drive may come from an internal or external source. Achievement motivation is intrinsic when it is sparked by an interest or enjoyment in the task itself. It is organic to the person, not a product of external pressure. Achievement motivation can be instead extrinsic when it comes from outside the person. Common sources of extrinsic motivation among students are rewards like good marks, or praise from parents and teachers.

Motivating students is one of the major challenges teachers face on a daily basis. Adolescents have new capabilities and interests that should motivate them to do well at school. As they become older, children become more able to exercise complex thought, have greater capacities for self-regulation, and hold a stronger desire for meaningful work (Damon, Menon, and Cotton Bronk, 2003). Despite these blossoming abilities and attitudes, steep declines in motivation to do schoolwork are often documented during adolescence (Lepper, Corpus, and Iyengar, 2005). At a period in life when school should be seen as more relevant, students rate school as less useful and important for their well-being (Wigfield and Cambria, 2010). The capacity to set goals and regulate efforts to achieve these goals is not just a characteristic of the individual but also a result of the home and school environments children encounter (Eccles and Wigfield, 2002). Because people tend to form beliefs about what they can achieve in life at a young age, the development of positive motivation to achieve at school is a prerequisite for success in life.

\section{What the data tell us}

- Girls were more likely than boys to report that they want top grades at school and that they care more than boys about being able to select among the best opportunities when they graduate. But boys were more likely than girls to describe themselves as ambitious and to aspire to be the best, whatever they do.

- In all PISA countries and economies except Belgium and Switzerland, disadvantaged students have lower levels of achievement motivation than advantaged students. On average across OECD countries, immigrant students reported higher achievement motivation than non-immigrant students.

- Achievement motivation is positively related to performance at school and to life satisfaction. On average across OECD countries, students in the top quarter of the index of achievement motivation score 37 points higher in science and reported 0.7 point higher life satisfaction (on a scale from 0 to 10) than students in the bottom quarter of the index.

- Students who want to be the best in their class or want top grades were more likely to report that they are very anxious about tests even if they are well prepared.

\section{DIFFERENCES IN ACHIEVEMENT MOTIVATION BETWEEN AND WITHIN EDUCATION SYSTEMS}

For the first time, PISA 2015 asked students to report whether they "strongly agree", "agree", "disagree" or "strongly disagree" with the following statements: "I want top grades in most or all of my courses"; "I want to be able to select from among the best opportunities available when I graduate"; "I want to be the best, whatever I do"; "I see myself as an ambitious person"; and "I want to be one of the best students in my class". Student responses to these five questions were used to construct the index of achievement motivation, which has a mean of 0 and a standard deviation of 1 across OECD countries.

This new measure of achievement motivation provides useful information on the goals students set for themselves. However, the data do not allow for distinguishing between students who have these achievement goals because they are intrinsically motivated (students who internalise and accept as their own the values and activities associated with excellence in and out of school) and students who strive to attain goals that are externally imposed on them. Extrinsically motivated actions can lead to passive compliance, or become seemingly intrinsic as individuals identify with and fully assimilate the external regulation (Ryan and Deci, 2000a). In other words, students can be extrinsically motivated by their parents or community to achieve good results at school, and still be committed and authentic in what they do (Ryan and Deci, 2000b). Striving for good grades and valuing what one learns are not necessarily incompatible goals (Covington, 2000; Hidi and Harackiewicz, 2000). 
The degree of internalisation of achievement norms makes a difference for students' outcomes. Students who make efforts because they consciously value a goal or regulation enjoy positive learning outcomes, greater well-being, and value what school has to offer (Fredricks, Blumenfeld, and Paris, 2004). Students whose achievement motivation is instead mostly driven by external incentives and controlling conditions often fail to experience the feelings of joy, enthusiasm and interest that are crucial for autonomous learning. Instead, they suffer from anxiety, boredom or alienation. They are no longer interested in what is taught, but only in learning what content will be tested. Given the difficulty of distinguishing between intrinsically and extrinsically motivated goals in the PISA questions on achievement motivation, the results in this chapter should be considered together with the analysis on students' interest in and enjoyment of science - two clear manifestations of intrinsic motivation - that appears in the first volume of the PISA 2015 report (OECD, 2016a)

Figure III.5.1 - Students' achievement motivation, by gender Percentage of students who reported that they "agree" or "strongly agree" with the following statements

want top grades in most or all of my courses

I want to be able to select from among the best opportunities available when I graduate I want to be the best, whatever I do

I see myself as an ambitious person

I want to be one of the best students in my class*

\section{OECD average}

$\square$ Boys $\square$ Girls $\bullet$ All students

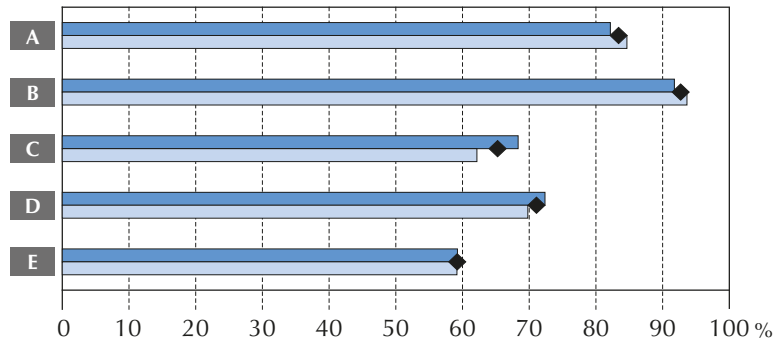

\begin{tabular}{|c|c|c|}
\hline & & $\begin{array}{l}\text { Index of } \\
\text { achievement } \\
\text { motivation } \\
\text { (mean index) }\end{array}$ \\
\hline 0 & Australia & 0.3 \\
\hline$\underline{\Delta}$ & Austria & -0.3 \\
\hline & Belgium & -0.5 \\
\hline & Canada & 0.3 \\
\hline & Czech Republic & 0.3 \\
\hline & Denmark & -0.3 \\
\hline & Estonia & -0.1 \\
\hline & Finland & 0.0 \\
\hline & France & -0.6 \\
\hline & Germany & -0.3 \\
\hline & Greece & -0.4 \\
\hline & Hungary & -0.1 \\
\hline & Iceland & -0.3 \\
\hline & Ireland & 0.4 \\
\hline & Israel & 0.4 \\
\hline & Italy & 0.8 \\
\hline & Japan & -0.2 \\
\hline & Korea & -0.5 \\
\hline & Latvia & 0.3 \\
\hline & Lithuania & 0.0 \\
\hline & Luxembourg & -0.2 \\
\hline & Mexico & 0.2 \\
\hline & Netherlands & -0.4 \\
\hline & New Zealand & 0.2 \\
\hline & Norway & 0.1 \\
\hline & Poland & -0.4 \\
\hline & Portugal & 0.2 \\
\hline & Slovak Republic & -0.3 \\
\hline & Slovenia & -0.4 \\
\hline & Spain & -0.2 \\
\hline & Sweden & 0.1 \\
\hline & Switzerland & -0.4 \\
\hline & Turkey & 0.6 \\
\hline & United Kingdom & 0.5 \\
\hline & United States & 0.6 \\
\hline
\end{tabular}

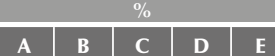

\begin{tabular}{|c|c|c|c|c|c|c|}
\hline Brazil & 0.1 & 95 & 97 & 80 & 40 & 64 \\
\hline B-S-J-G (China) & 0.1 & 72 & 97 & 89 & 73 & 81 \\
\hline Bulgaria & -0.1 & 79 & 94 & 57 & 82 & 67 \\
\hline Chile & 0.5 & 97 & 98 & 92 & 40 & 92 \\
\hline Colombia & -0.2 & 68 & 94 & 59 & 73 & 61 \\
\hline Costa Rica & 0.3 & 91 & 93 & 85 & 26 & 90 \\
\hline Croatia & 0.2 & 88 & 94 & 82 & 64 & 75 \\
\hline Dominican Republic & 0.0 & 83 & 91 & 66 & 71 & 64 \\
\hline Hong Kong (China) & -0.5 & 50 & 91 & 57 & 56 & 49 \\
\hline Macao (China) & -0.2 & 77 & 92 & 66 & 81 & 54 \\
\hline Montenegro & 0.3 & 96 & 97 & 90 & 39 & 88 \\
\hline Peru & 0.8 & 93 & 95 & 90 & 87 & 89 \\
\hline Qatar & -0.1 & 81 & 95 & 73 & 89 & 56 \\
\hline Russia & 0.4 & 88 & 96 & 89 & 75 & 82 \\
\hline Singapore & 0.0 & 79 & 97 & 68 & 73 & 68 \\
\hline Chinese Taipei & 0.5 & 98 & 98 & 84 & 51 & 86 \\
\hline Thailand & 0.2 & 92 & 97 & 97 & 67 & 80 \\
\hline Tunisia & 0.7 & 97 & 96 & 89 & 91 & 93 \\
\hline United Arab Emirates & 0.8 & 94 & 96 & 92 & 89 & 92 \\
\hline Uruguay & 0.0 & 88 & 95 & 75 & 47 & 50 \\
\hline
\end{tabular}

Note: Gender differences that are not statistically significant are shown with an asterisk next to the statement (see Annex A3). Source: OECD, PISA 2015 Database, Tables III.5.1, III.5.2 and III.5.3.

StatLink 제대 http://dx.doi.org/10.1787/888933470981 
The responses to the five statements show that boys and girls differ in their motivation to achieve. Girls were more likely than boys to report that they want top grades at school, and that they care more than boys about being able to select among the best opportunities when they graduate. Girls thus seem to care more than boys that their efforts at school are properly recognised, but they were less likely than boys to report that they are ambitious or competitive in contexts that are not necessarily related to school. On average across OECD countries, about $68 \%$ of boys and $62 \%$ of girls reported that they want to be the best, whatever they do (Figure III.5.1). In particular, boys in Austria, Italy, the Netherlands and Switzerland were at least 14 percentage points more likely than girls to report that they want to be the best, whatever they do. Some $72 \%$ of boys, and $70 \%$ of girls, described themselves as an ambitious person. In the Spanish-speaking countries of Chile, Colombia, Costa Rica, Mexico, Spain and Uruguay, boys were at least 13 percentage points more likely than girls to describe themselves as ambitious (Table III.5.2).

Several studies suggest that many boys do not want to be seen by their peers as interested in schoolwork (OECD 2015a; Skelton, Francis, and Valkanova, 2012). Boys can adopt a notion of masculinity that includes a disregard for authority, academic work and formal achievement. For these boys, academic achievement is not "cool" (Salisbury, Rees, and Gorard, 1999) and being studious is regarded as a feminine attribute (Skelton, Francis, and Valkanova, 2012). By contrast, studies show that girls seem to "allow" their female peers to work hard at school, as long as they are also perceived as "cool" outside of school (Van Houtte, 2004). Although a boy may understand the importance of achievement at school, he will choose not to show too much effort for fear of being excluded by his male classmates. Indeed, some have suggested that boys' motivation to achieve at school dissipates from the age of eight onwards, mostly due to the scarcity of male role models in the classroom (Salisbury, Rees, and Gorard, 1999). Low motivation related to peer pressure can be a relevant source of underachievement among boys, particularly among socio-economically disadvantaged boys (OECD, 2015a; Fryer and Austen-Smith, 2005).

Some argue that girls' and women's relative lack of competitiveness and ambition explains gender differences in pay and career advancement (Dreber, Essen, and Ranehill, 2011; Gneezy, Niederle, and Rustichini, 2003; Niederle and Vesterlund, 2007). Society might equate upper-level management roles and men (Heilman, Block, and Martell, 1995; Ridgeway and Correll, 2004), but in many countries, teenage girls are at least as likely (if not more so) as teenage boys to aspire to a professional or managerial job requiring high academic qualifications (Francis, 2002; Mello, 2008; Schoon, 2006; Schoon, Martin, and Ross, 2007). Still, large gender differences persist in students' ambitions to pursue sciencerelated careers (OECD, 2016a).

Gender differences in either intrinsic or extrinsic motivation to achieve can be related to gender disparities in performance. Figure III.5.2 shows gender gaps in science performance (in favour of girls) are larger in countries, such as Bulgaria and Qatar, where girls care more than boys about being able to select from among the best opportunities available when they graduate. Similar relationships are observed when using the other PISA questions on achievement motivation. This finding suggests that an inability to set clear achievement goals in their school work could be a factor behind the underperformance of many boys.

Socio-economic status is also related to the development of ambition. Young people from privileged homes benefit from more home-based and external opportunities for education, access to resources for their plans, role models, knowledge about career possibilities, and informal networks (Schoon, Martin, and Ross, 2007). Their parents also tend to have high educational aspirations for them. These resources encourage advantaged students to develop ambitious aspirations and the motivation to turn these aspirations into reality. Students who do less well in school may internalise their teachers' low expectations for them as they develop their own beliefs about their abilities and set the goals they wish to achieve.

In almost all countries and economies, disadvantaged students have less achievement motivation than advantaged students (Table III.5.3). In Canada, Iceland, Korea, Lithuania and Portugal, disadvantaged students are more than half a standard deviation below their advantaged peers on the index of achievement motivation. On average across OECD countries, disadvantaged students were 11 percentage points less likely than advantaged students to report that they want to be among the best students in the class, and 13 percentage points less likely to see themselves as an ambitious person (Table III.5.2). In Colombia, the percentage of advantaged students who reported that they are ambitious is twice as large as the percentage of disadvantaged students who so reported.

Even though they may come from a relatively disadvantaged background, many immigrant students hold an ambition to succeed that in most cases matches, and in some cases surpasses, the aspirations of students who are native to their host country (OECD, 2015b). PISA 2015 shows that, on average across OECD countries, both first- and second-generation 
immigrant students have a greater motivation to achieve (as measured by the PISA index of achievement motivation) than students without an immigrant background (Table III.5.3). Only in Brazil and Israel are first-generation immigrant students lower on the index of achievement motivation than non-immigrant students.

Figure III.5.2 - Gender differences in achievement motivation and science performance

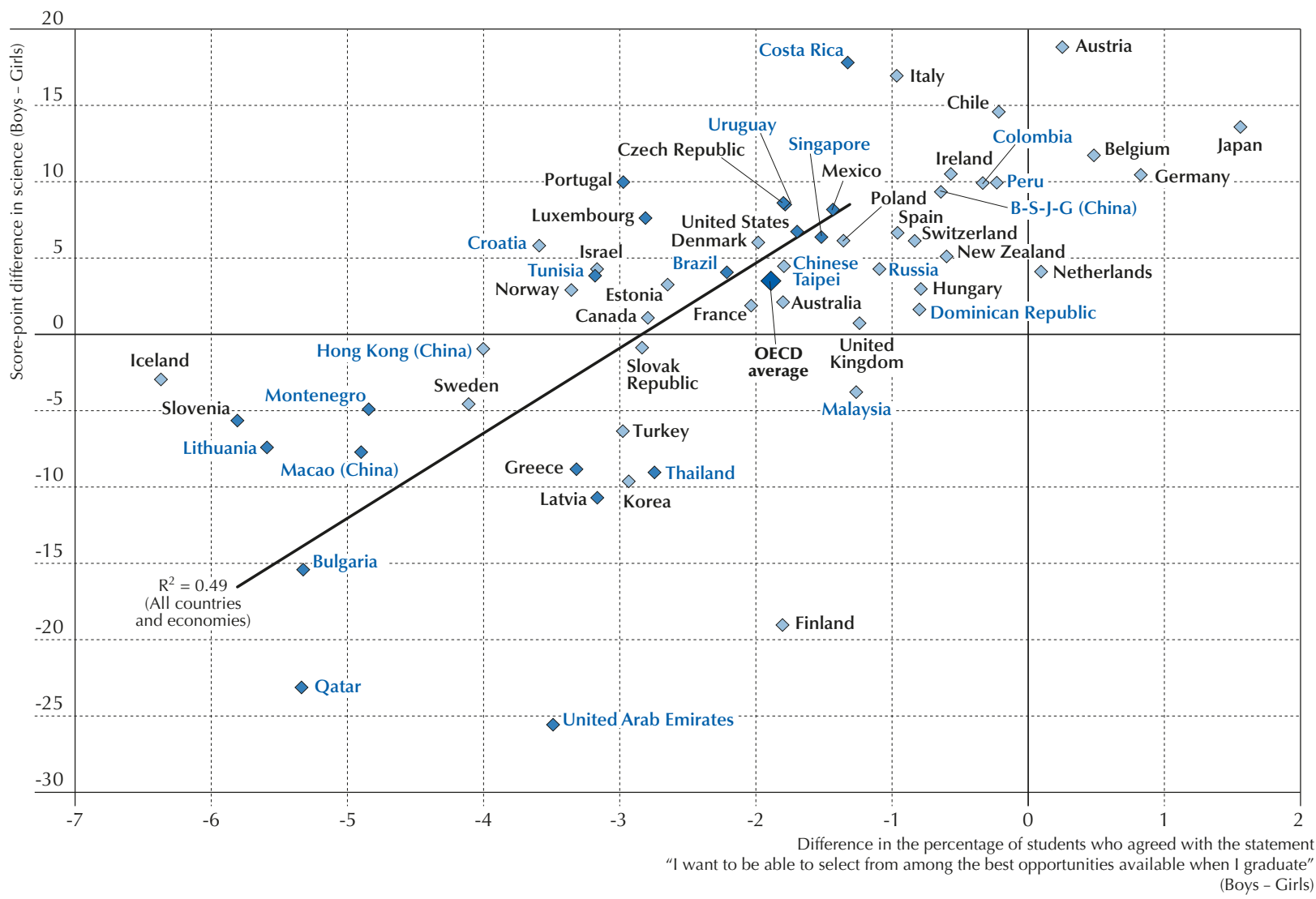

Note: Gender gaps in both performance and achievement motivation that are statistically significant are shown in a darker tone (see Annex A3). Source: OECD, PISA 2015 Database, Tables I.2.8a and III.5.2.

StatLink 제교 http://dx.doi.org/10.1787/888933470990

\section{THE POSITIVE AND THE POTENTIALLY NEGATIVE ASPECTS OF ACHIEVEMENT MOTIVATION}

Students with high achievement goals tend to do better at school. With higher autonomous and internalised achievement motivation often come higher self-esteem, stronger cognitive flexibility (McGraw and McCullers, 1979) and greater effort invested at school (Burton et al., 2006; Sheldon et al., 2004). Students who are highly motivated to achieve goals they consciously value are often autonomous individuals who believe that they can affect their environment in positive ways and solve problems, keep their living and work spaces organised, have a sense of duty and obligation in their personal and work lives, devote great effort toward achieving success, and regulate their behaviour to achieve their goals (Carter et al., 2012).

On average across OECD countries, students in the top quarter of the index of achievement motivation score 38 points higher in science (the equivalent of more than one year of schooling) than students in the bottom quarter of the index (Figure III.5.3). The difference in performance between the students in the top quarter and those in the bottom quarter of the index of achievement motivation is over 50 points in Denmark, Finland, Iceland, Korea, Lithuania, Norway, Portugal, the Slovak Republic, Spain and Chinese Taipei. 
Figure III.5.3 - Achievement motivation and students' performance in science Science performance, by quartiles of achievement motivation

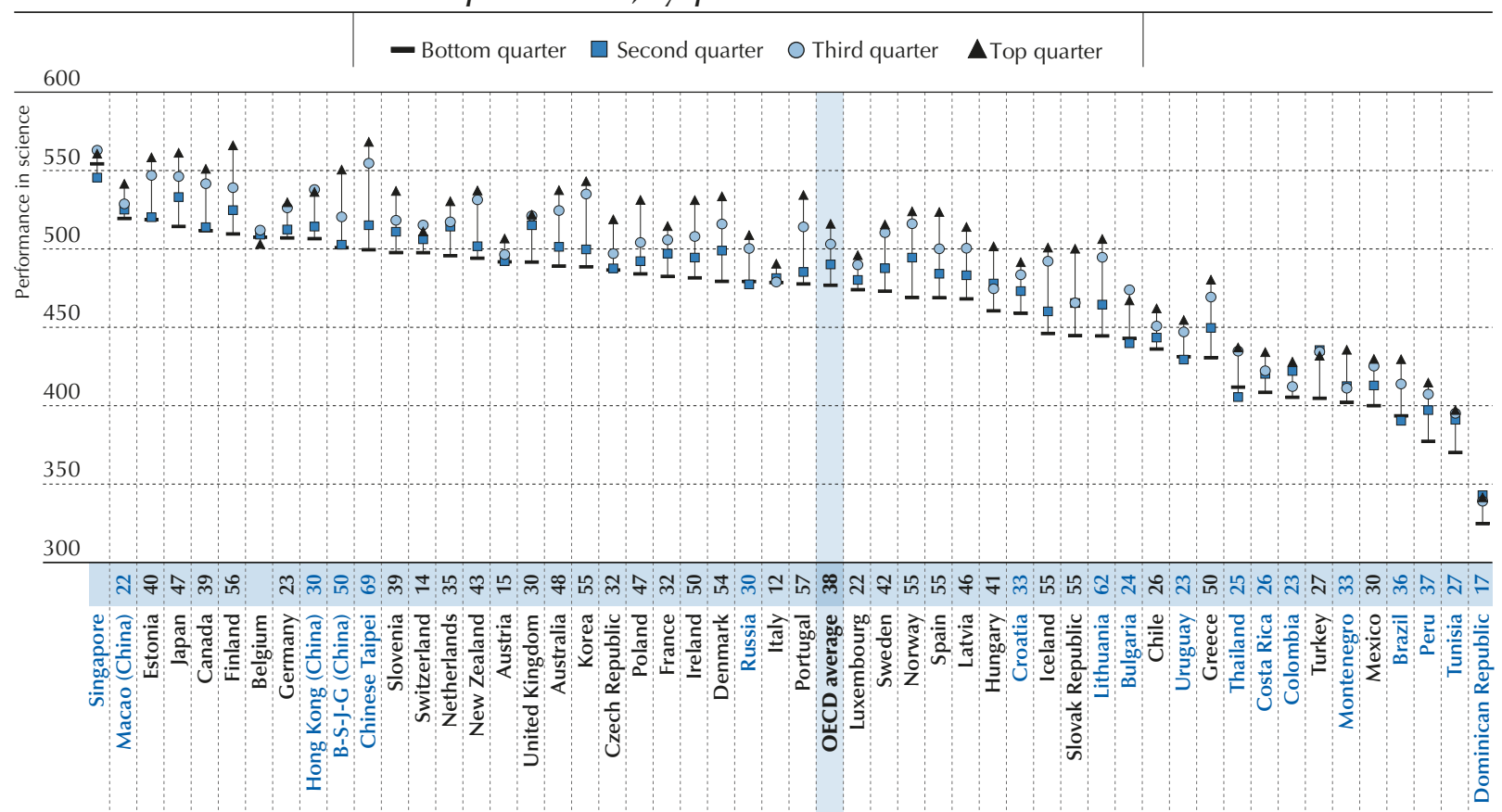

Note: Statistically significant differences in science performance between the top and bottom quarters on the distribution of achievement motivation are shown next to the country/economy name (see Annex A3).

Countries and economies are ranked in descending order of the average science performance in the bottom quarter on the distribution of achievement motivation.

Source: OECD, PISA 2015 Database, Table III.5.5.

StatLink त्ञाI $\mathrm{http}: / / \mathrm{dx} . \mathrm{doi} . \mathrm{org} / 10.1787 / 888933471004$

Figure III.5.4 - Students' achievement motivation and resilience

Difference between resilient students and non-resilient students ${ }^{1}$

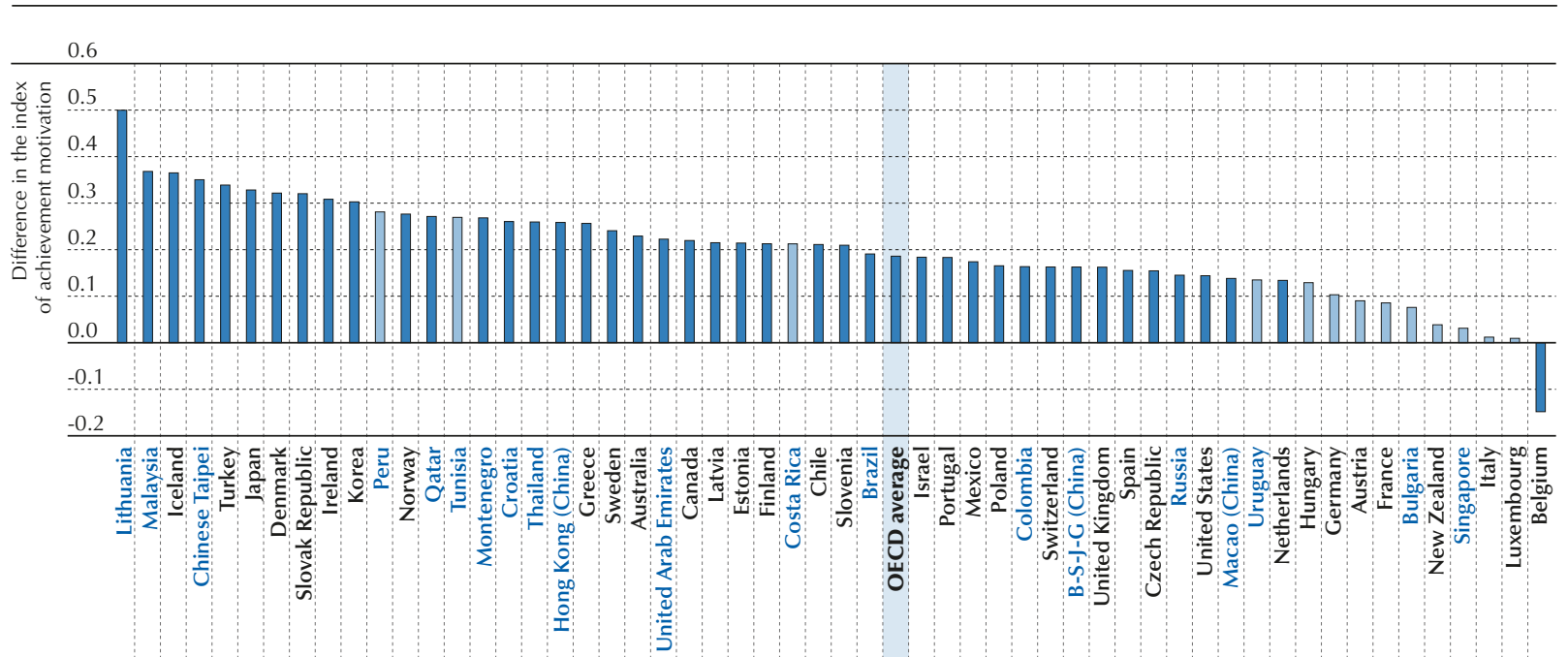

1. Resilient students are students who are in the bottom quarter of the PISA index of economic, social and cultural status (ESCS) in their country, and perform in the top quarter of students across all countries and economies, after accounting for socio-economic status. Non-resilient students are students in the bottom quarter of ESCS who do not perform in the top quarter of all students.

Note: Statistically significant differences in the index of achievement motivation are marked in a darker tone (see Annex A3).

Countries and economies are ranked in descending order of the difference in the index of achievement motivation between resilient and non-resilient students.

Source: OECD, PISA 2015 Database, Table III.5.7.

StatLink 제프 http://dx.doi.org/10.1787/888933471016 
Lack of achievement motivation can explain at least some of the low performance among disadvantaged students. These students, many of whom also live in disadvantaged neighbourhoods, need extraordinary motivation to overcome the many obstacles to succeeding at school. But some disadvantaged students manage to find in themselves the motivation to reach high levels of achievement; and for many of them, high performance at school is required if they are to qualify for financial support to continue their education beyond compulsory schooling. Figure III.5.4 shows that resilient students - those disadvantaged students who beat the odds against them and perform in the top quarter among all students tested in PISA, after taking their socio-economic status into account - have a significantly higher level of achievement motivation than disadvantaged students who are not resilient. Educators in disadvantaged communities need to be aware of the need to nurture autonomous goal-setting by supporting their students' expectations of success (students' beliefs that they can perform particular tasks, and that they are responsible for their own performance) and showing them why learning is valuable (Bandura, 2010; Schultz, 1993; OECD, 2016a, 2016b).

Achievement motivation is related to life satisfaction in a mutually reinforcing way. Students with high life satisfaction tend to have greater resiliency and are more tenacious in the face of academic challenges. A positive view of the world and life circumstances builds their self-efficacy and their motivation to achieve. In turn, a higher motivation to achieve, paired with realised achievements, energises behaviour and gives students a sense of purpose in life. It is thus not surprising that, across all countries and economies that participated in PISA 2015, except Macao (China), students with higher overall achievement motivation reported greater satisfaction with life (Table III.5.6). On average across OECD countries, students in the top quarter of the index of achievement motivation reported a level of life satisfaction of 7.6 on a scale from 0 to 10, while students in the bottom quarter of the index reported a level of 6.9.

But there can be downsides to achievement motivation, when the goals originate from outside the student and are not internalised by the student. Very high external motivation can easily turn into a disabling form of perfectionism, especially when the goals are overambitious and the impetus to devote effort to a task stems from externally regulated feelings of obligation, guilt or shame. "Maladaptive perfectionists" fear that failure will invoke criticism or ridicule from teachers, parents and peers. They are also their own harshest critics, frequently berating themselves over any small thing that goes wrong (Dacanay, 2016). Because perfectionists fear being unable to complete a task perfectly, they often procrastinate. The dysfunctional thinking of perfectionism often leads to discouragement, self-doubt and mental exhaustion.

Figure III.5.5 - Achievement motivation and anxiety, between countries

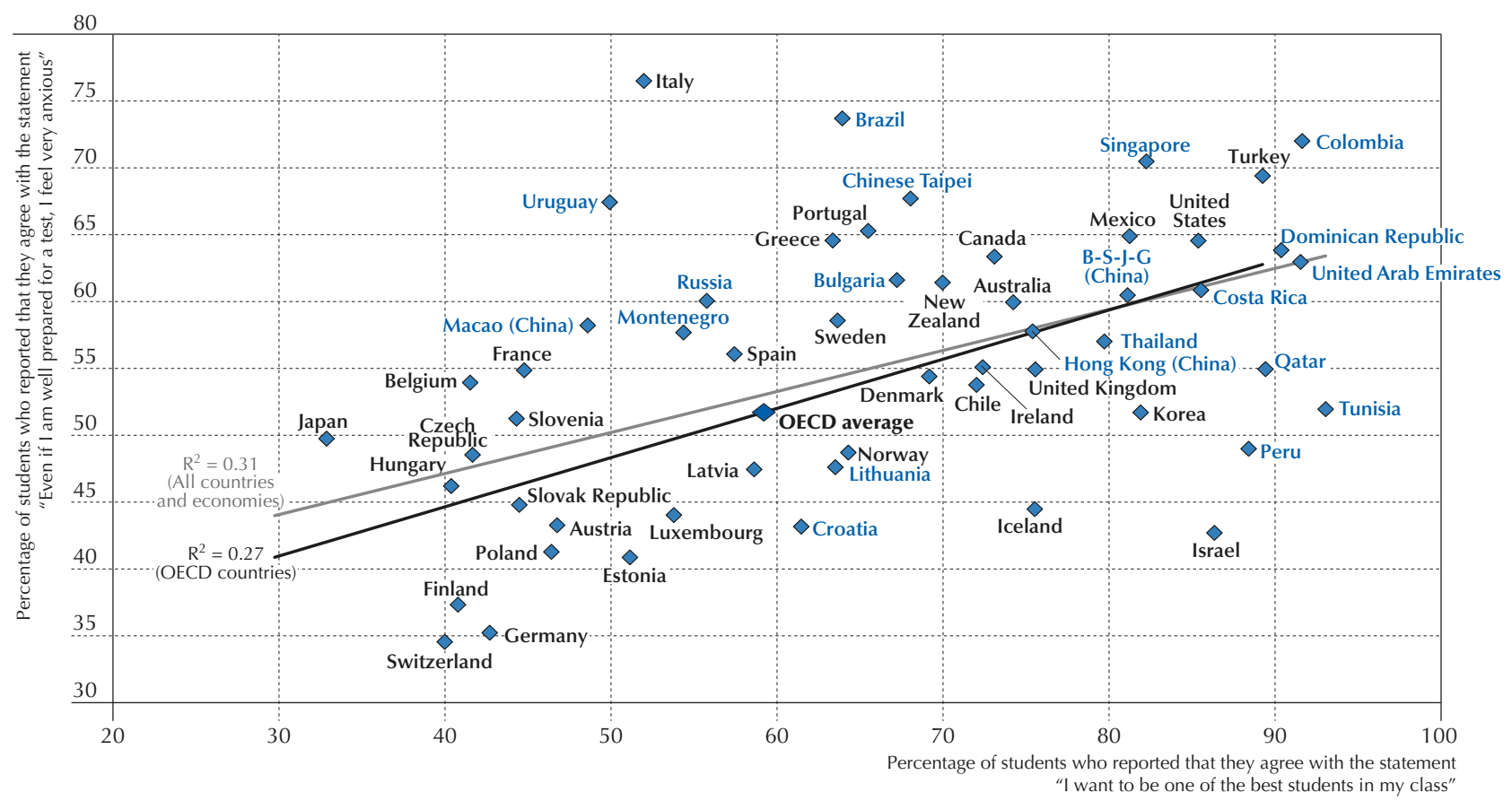

Source: OECD, PISA 2015 Database, Tables III.2.1 and III.5.1.

StatLink 젶ㄴ http://dx.doi.org/10.1787/888933471022 
Figure III.5.5 shows that countries where students have high achievement motivation also tend to be those where many students feel anxious about a test, even if they are well prepared for the test. Students who want to be able to select among the best opportunities when they graduate, who want to be the best in their class, or who want top grades in all courses are more likely to suffer from anxiety (Figure III.5.6; Table III.5.8). On average across OECD countries, a student who sees himself or herself as an ambitious person is less likely to feel anxious about a test than a student who does not report being ambitious, possibly because ambition is the most intrinsic facet of achievement motivation among those measured in PISA. This relationship suggests that there are different manifestations of achievement motivation, and not all of them are positively related to students' well-being. If a certain amount of tension or concern is essential to motivation and high performance, too much pressure can be counterproductive for a child's cognitive development and psychological well-being.

Figure III.5.6 - Achievement motivation and anxiety, within countries

Percentage of students who reported that they "agree" or "disagree" with the statement "Even when I am well prepared for a test, I feel very anxious", by motivation to be the one of the best students in the class

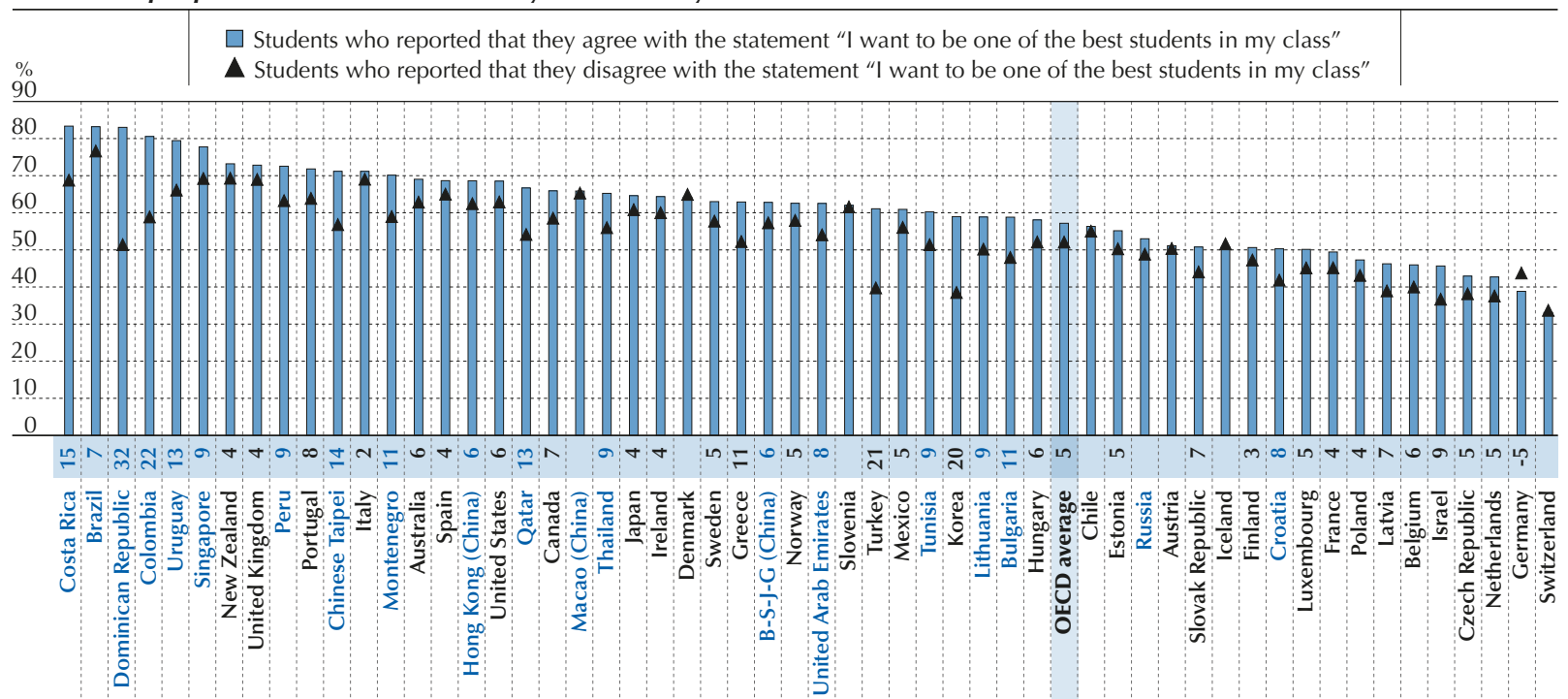

Note: Statistically significant differences in the percentage of students who feel anxious between those who agreed that they want to be one of the best and those who disagreed are shown next to the country/economy name (see Annex A3).

Countries and economies are ranked in descending order of the percentage of students who reported feeling anxious even when they are well prepared for a test, among students who agreed that they want to be one of the best students.

Source: OECD, PISA 2015 Database, Table III.5.9.

StatLink 部西 http://dx.doi.org/10.1787/888933471030

Both teachers and parents have to find ways to encourage motivation to learn and achieve without generating an excessive fear of failure. Teachers can, for example, provide students with tangible rewards that are related to the act of learning, such as the opportunity to share the results of their work with others, or to explain why what they learned was important to them (Covington and Müeller, 2001). Motivating students, particularly academically unmotivated students, requires preparation, sensitivity and attention to the needs, feelings and attitudes of each individual child.

\section{What these results mean for policy}

- Education systems that cultivate, foster and communicate the belief that all students can achieve at high levels can increase students' intrinsic drive to succeed and reduce gender or socio-economic disparities in achievement motivation.

- Disadvantaged students, in particular, would benefit from programmes that specifically target students most at risk of losing motivation, and also from teachers' efforts to strengthen intrinsic motivations to learn.

- Students who make efforts at school to please others or meet goals set by others may experience greater schoolwork-related anxiety. It is important that parents and educators help students develop intrinsic motivation to achieve, rather than expose them to exaggerated expectations and pressures. Schools and families can also educate students about the potential dangers of perfectionism. 


\section{References}

Bandura, A. (2010), "Self-Efficacy" in I.B. Weiner and W.E. Craighead (eds.), The Corsini Encyclopedia of Psychology, John Wiley \& Sons, Inc., New Jersey, NY, pp. 1534-1536, http://dx.doi.org/10.1037/0033-295X.84.2.191.

Burton, K.D. et al. (2006), "The differential effects of intrinsic and identified motivation on well-being and performance: Prospective, experimental, and implicit approaches to self-determination theory", Journal of Personality and Social Psychology, Vol. 91/4, pp. 750-762, http://dx.doi.org/10.1037/0022-3514.91.4.750.

Carter, C.P. et al. (2012), "Measuring student engagement among elementary students: Pilot of the student engagement instrument elementary version", School Psychology Quarterly, Vol. 27/2, pp. 61-73, http://dx.doi.org/10.1037/a0029229.

Covington, M.V. (2000), "Goal theory, motivation, and school achievement: An integrative review", Annual Review of Psychology, Vol. 51/1, pp. 171-200, http://dx.doi.org/ 10.1146/annurev.psych.51.1.171.

Covington, M.V. and K. J. Müeller (2001), "Intrinsic versus extrinsic motivation: An approach/avoidance reformulation", Educational Psychology Review, Vol. 13/2, pp.157-176, http://dx.doi.org/10.1023/A:1009009219144.

Dacanay, A. (2016), "A model exploring cognitive test anxiety: Personality and goal orientation", dissertation, Ball State University, http://cardinalscholar.bsu.edu/handle/123456789/200157 (accessed 7 April 2017).

Damon, W., J. Menon and K.C. Bronk (2003), "The development of purpose during adolescence", Journal of Applied Developmental Science, Vol. 7/3, pp. 119-128, http://dx.doi.org/10.1207/S1532480XADS0703 2.

Dreber, A., E. von Essen and E. Ranehill (2011), "Outrunning the gender gap - Boys and girls compete equally", Experimental Economics, Vol. 14/4, pp. 567-582, http://dx.doi.org/10.1007/s10683-011-9282-8.

Duckworth, A.L. et al. (2011), "Self-regulation strategies improve self-discipline in adolescents: Benefits of mental contrasting and implementation intentions", Educational Psychology, Vol. 31/1, pp. 17-26, http://dx.doi.org/10.1080/01443410.2010.506003.

Eccles, J.S. and A. Wigfield (2002), "Motivational beliefs, values, and goals", Annual Review of Psychology, Vol.53, pp. 109-132, http://dx.doi.org/10.1146/annurev.psych.53.100901.135153.

Francis, B. (2002), "Is the future really female? The impact and implications of gender for 14-16 year olds' career choices", Journal of Education and Work, Vol. 15/1, pp. 75-88, http://dx.doi.org/10.1080/13639080120106730.

Fredricks, J.A., P.C. Blumenfeld and A.H. Paris (2004), "School engagement: potential of the concept, state of the evidence", Review of Educational Research, Vol. 74/1, pp. 59-109, http://dx.doi.org/10.3102/00346543074001059.

Fryer, R.G. and D. Austen-Smith (2005), "An economic analysis of 'Acting White'”, Quarterly Journal of Economics, Vol. 120/2, pp. 551-583, http://dx.doi.org/10.1093/qje/120.2.551.

Gneezy, U., M. Niederle and A. Rustichini (2003), "Performance in competitive environments: Gender differences", The Quarterly Journal of Economics Vol. 118/3, pp. 1049-1074, http://dx.doi.org/10.1162/00335530360698496.

Heilman, M.E., C.J. Block and R.F. Martell (1995), "Sex stereotypes: Do they influence perceptions of managers?", Journal of Social Behavior \& Personality, Vol. 10/6, pp. 237-252.

Hidi, S. and J.M. Harackiewicz (2000), "Motivating the academically unmotivated: A critical issue for the 21st century", Review of Educational Research, Vol. 70/2, pp. 151-179, http://dx.doi.org/10.3102/00346543070002151.

Lepper, M.R., J.H. Corpus and S.S. Iyengar (2005), "Intrinsic and extrinsic motivational orientations in the classroom: Age differences and academic correlates", Journal of Educational Psychology, Vol. 97/2, pp. 184-196, http://dx.doi.org/10.1037/0022-0663.97.2.184.

McGraw, K.O. and J.C. McCullers (1979), "Evidence of a detrimental effect of extrinsic incentives on breaking a mental set", Journal of Experimental Social Psychology, Vol. 15/3, pp. 285-294, http://dx.doi.org/10.1016/0022-1031(79)90039-8.

Mello, Z.R. (2008), "Gender variation in developmental trajectories of educational and occupational expectations and attainment from adolescence to adulthood", Developmental Psychology, Vol. 44/4, pp. 1069-1080, http://dx.doi.org/10.1037/0012-1649.44.4.1069.

Niederle, M. and L. Vesterlund (2007), "Do women shy away from competition? Do men compete too much?", The Quarterly Journal of Economics, Vol. 122/3, pp. 1067-1101, http://dx.doi.org/10.1162/qjec.122.3.1067.

OECD (2016a), PISA 2015 Results (Volume I): Excellence and Equity in Education, OECD Publishing, Paris, http://dx.doi.org/10.1787/ 9789264266490-en.

OECD (2016b), PISA 2015 Results (Volume II): Policies and Practices for Successful Schools, OECD Publishing, Paris. http://dx.doi. org/10.1787/9789264267510-en.

OECD (2015a), The ABC of Gender Equality in Education: Aptitude, Behaviour, Confidence, OECD Publishing, Paris, http://dx.doi. org/10.1787/9789264229945-en. 
OECD (2015b), Immigrant Students at School - Easing the Journey towards Integration, OECD Publishing, Paris, http://dx.doi.org/ 10.1787/9789264249509-en.

OECD (2013), PISA 2012 Results: Ready to Learn (Volume III): Students' Engagement, Drive and Self-Beliefs, OECD Publishing, Paris, http://dx.doi.org/ 10.1787/9789264201170-en.

Ridgeway, C.L. and S.J. Correll (2004), "Unpacking the gender system: A theoretical perspective on gender beliefs and social relations", Gender and Society, Vol. 18/4, pp. 510-531, http://dx.doi.org/10.1177/0891243204265269.

Ryan, R.M. and E. L. Deci (2000a), "Self-determination theory and the facilitation of intrinsic motivation, social development, and wellbeing", The American Psychologist, Vol. 55/1, pp. 68-78, http://dx.doi.org/10.1037/0003-066X.55.1.68.

Ryan, R.M. and E.L. Deci (2000b), "Intrinsic and extrinsic motivations: Classic definitions and new directions", Contemporary Educational Psychology, Vol. 25/1. pp. 54-67, http://dx.doi.org/10.1006/ceps.1999.1020.

Salisbury, J., G. Rees and S. Gorard (1999), "Accounting for the differential attainment of boys and girls at school", School Leadership \& Management, Vol. 19/4, pp. 403-426, http://dx.doi.org/10.1080/13632439968943.

Schoon, I. (2006), Risk and Resilience: Adaptations in Changing Times, Cambridge University Press, New York, NY.

Schoon, I., P. Martin and A. Ross (2007), "Career transitions in times of social change. His and her story", Journal of Vocational Behavior, Vol. 70/1, pp. 78-96, http://dx.doi.org/10.1016/j.jvb.2006.04.009.

Schultz, G.F. (1993), "Socioeconomic advantage and achievement motivation: Important mediators of academicperformance in minority children in urban schools", The Urban Review, Vol. 25/3, pp. 221-232, http://dx.doi.org/10.1007/BF01112109.

Sheldon, K.M. et al. (2004), "The independent effects of goal contents and motives on well-being: it's both what you pursue and why you pursue it", Personality \& Social Psychology Bulletin, Vol. 30/4, pp. 475-86, http://dx.doi.org/10.1177/0146167203261883.

Skelton, C., B. Francis and Y. Valkanova (2012), "Breaking down the stereotypes : Gender and achievement in schools", Working Paper Series (Great Britain. Equal Opportunities Commision) No. 59, Manchester.

Van Houtte, M. (2004) "Why boys achieve less at school than girls: the difference between boys' and girls' academic culture", Educational Studies, Vol. 30/2, pp. 159-173, http://dx.doi.org/10.1080/0305569032000159804.

Wigfield, A. and J. Cambria (2010), "Students' achievement values, goal orientations, and interest: Definitions, development, and relations to achievement outcomes", Developmental Review, Vol. 30/1, pp. 1-35, http://dx.doi.org/10.1016/j.dr.2009.12.001. 


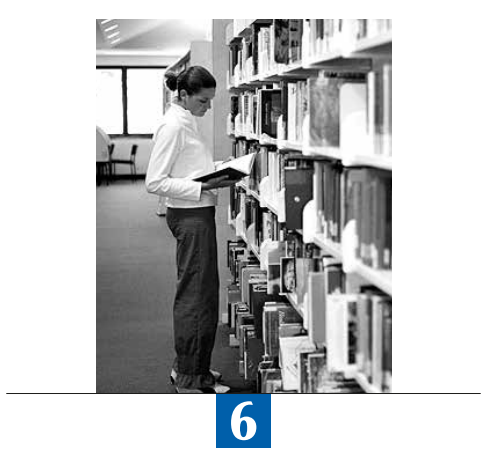

\section{Students' expectations of further education}

Which 15-year-old students are more likely to continue into higher education? This chapter examines some of the factors that shape that decision, and how the expectation of completing university can, in turn, influence students' performance in school and have an impact on their well-being, in general. The chapter also discusses how parents' attitudes can affect students' expectations of further education and how certain education policies can promote - or undermine - those expectations. 
Adolescence is a time when students begin to think seriously about their future, when their aspirations become more closely aligned with their interests, their abilities and the opportunities available to them, and when their vision of themselves can be influenced by the peers and adults around them (Beal and Crockett, 2010). Students' expectations for their future influence what they choose to study and the activities they pursue, which, in turn, determine subsequent accomplishments (Nurmi, 2004).

Students' expectations can be self-fulfilling prophecies, as the effort students invest to meet their expectations often pay off (OECD, 2012). For example, when comparing students of similar socio-economic backgrounds and academic achievement, students who expect to graduate from university are more likely to complete this degree than their peers who do not have such high expectations (Beal and Crockett, 2010). Conversely, students who expect to drop out of school without qualifications are more likely to do so (Morgan, 2005; Perna, 2000). Positive expectations for the future are associated with high self-esteem and effective coping mechanisms. Negative or ambivalent expectations are instead often associated with a sense of hopelessness (Correa, Errico and Poggi, 2011).

\section{What the data tell us}

- On average across OECD countries, 44\% of 15-years-old students in 2015 expected that they will complete university. In Colombia, Korea, Qatar and the United States, more than three out of four students expected so.

- In most countries and economies, girls were more likely than boys to expect to complete university; and in all countries and economies, disadvantaged students were much less likely than advantaged students to expect to earn a university degree.

- Top-performing students in all education systems were more likely than low-performing students to have high expectations for further education; but in several countries, large proportions of low-performing students expect to complete university.

- Students' expectations of further education are influenced by education policy, particularly the degree of sorting students into different education tracks.

A 15-year-old's expectation to participate in higher education is not a guarantee that the student will, in fact, pursue further education. Expectations of further education are based on students' evaluation of the costs and benefits of investments in further education (Morgan, 1998) and on students' self-assessment of their capacities to realise their aspirations. Adolescents frequently question their own opinions about their future, and often change their aspirations and expectations. The factors that shape students' expectations include the influence of people close to the student, such as peers, family members and teachers, past academic achievement, the degree of selectivity of universities, the direct financial and opportunity costs of participating in higher education, the returns associated with different choices, and the rigidity of the education system, which may restrict access to some education opportunities to only those students who have followed a particular path through the system. The variety of these factors explains how and why the expectations of 15-year-old students vary so considerably both within and across countries (Buchmann and Dalton, 2002; Mateju et al., 2007; Sewell et al., 2003; OECD, 2012). This chapter illustrates differences in education expectations between and within countries. In subsequent chapters, students' expectations of further education are examined in relation to students' social relationships at school, family resources and the activities students engage in outside of school.

\section{DIFFERENCES IN EDUCATION EXPECTATIONS ACROSS AND WITHIN COUNTRIES}

PISA 2015 asked students to report what level of education they expect to complete. The same question was asked in 2003, and to students in a group of countries and economies participating in the optional PISA educational career questionnaire in 2009. Across OECD countries, 44\% of students reported that they expect to complete a university degree, defined as advanced research programmes or university programmes qualifying for advanced research (ISCED 5A and 6). In Colombia, Korea, Qatar and the United States, more than three out of four students reported that they expect to earn a university degree (Figure III.6.1).

Should countries and economies be concerned that only a minority of students expects to complete university? It is difficult to accurately predict the number of university graduates a country needs to sustain innovation, growth and sociocultural development. Tertiary graduation rates illustrate a country's capacity to provide the workforce with advanced and specialised knowledge and skills (OECD, 2016c). Earning a university degree is often a pathway to higher salaries 
and better employment prospects. On average across OECD countries, the unemployment rate is $12.4 \%$ for adults who have not attained upper secondary education, while it is $4.9 \%$ for tertiary-educated adults (OECD 2016c). But university education also requires significant investments and means postponing the entry into the labour market. For some students, the opportunity costs of pursuing a university degree and the difficulties they must overcome to earn a degree may outweigh the benefits they will derive from enrolling in university. Not all students need a university degree to contribute productively to the economy and society, and to enjoy a fulfilling professional life.

Figure III.6.1 - Percentage of students expecting to complete each education level OECD average

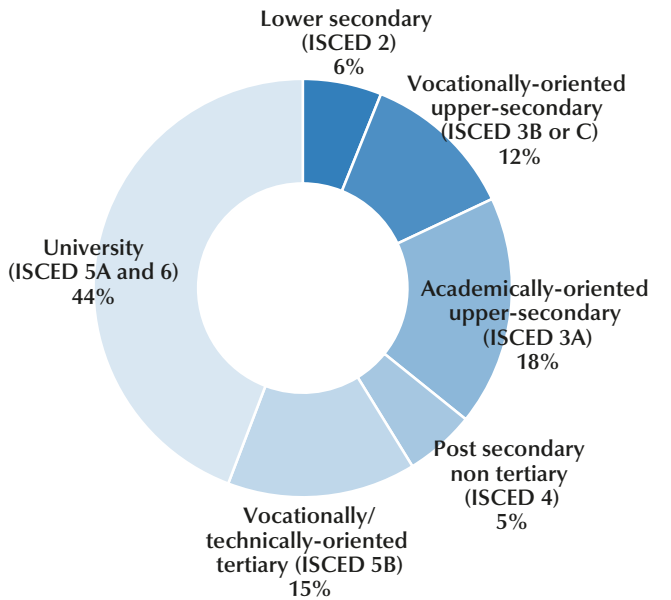

\begin{tabular}{|c|c|c|c|c|c|c|c|c|}
\hline & \multirow[b]{2}{*}{$\begin{array}{l}\text { Percentage } \\
\text { of students } \\
\text { in ISCED } 2\end{array}$} & \multicolumn{6}{|c|}{$\begin{array}{l}\text { Percentage of students expecting } \\
\text { to complete }\end{array}$} \\
\hline & & & $\begin{array}{l}\text { ISCED } \\
2 \\
\end{array}$ & $\begin{array}{l}\text { ISCED } \\
3 \mathrm{~A} / \mathrm{C}\end{array}$ & $\begin{array}{l}\text { ISCED } \\
3 \mathrm{~A}\end{array}$ & $\begin{array}{l}\text { ISCED } \\
4\end{array}$ & $\begin{array}{l}\text { ISCED } \\
5 \mathrm{~B}\end{array}$ & $\begin{array}{l}\text { ISCED } \\
5 \mathrm{~A} \& 6\end{array}$ \\
\hline \multirow{35}{*}{ ర્山ّ } & Australia & 86 & 2.8 & 4.7 & 30.5 & 4.6 & 3.2 & 54.2 \\
\hline & Austria & 2 & 2.0 & 21.9 & 39.7 & 2.0 & 7.3 & 27.1 \\
\hline & Belgium & 9 & 2.9 & 7.9 & 16.0 & 12.8 & 27.5 & 32.9 \\
\hline & Canada & 12 & 1.3 & 0.0 & 11.7 & 7.2 & 16.4 & 63.5 \\
\hline & Chile & 6 & 0.7 & 11.3 & 5.9 & 2.3 & 13.3 & 66.6 \\
\hline & Czech Republic & 54 & 0.5 & 7.9 & 28.4 & 0.0 & 7.5 & 55.6 \\
\hline & Denmark & 99 & 21.6 & 7.9 & 29.9 & 0.0 & 3.4 & 37.2 \\
\hline & Estonia & 99 & 4.0 & 7.6 & 13.3 & 10.3 & 22.1 & 42.8 \\
\hline & Finland & 100 & 15.7 & 0.0 & 38.8 & 4.7 & 13.7 & 27.1 \\
\hline & France & 24 & 9.6 & 19.6 & 27.1 & 0.0 & 11.7 & 32.0 \\
\hline & Germany & 96 & 34.5 & 2.6 & 39.8 & 3.8 & 1.5 & 17.8 \\
\hline & Greece & 5 & 1.5 & 8.4 & 6.2 & 7.1 & 10.6 & 66.3 \\
\hline & Hungary & 10 & 6.4 & 28.6 & 11.7 & 11.6 & 6.3 & 35.5 \\
\hline & Iceland & 100 & 6.1 & 20.4 & 8.3 & 9.8 & 16.5 & 38.9 \\
\hline & Ireland & 62 & 12.4 & 4.6 & 14.1 & 3.8 & 18.8 & 46.3 \\
\hline & Israel & 11 & 1.1 & 2.5 & 28.0 & 2.7 & 8.7 & 57.0 \\
\hline & Italy & 1 & 2.1 & 3.8 & 26.1 & 9.1 & 20.6 & 38.3 \\
\hline & Japan & $\mathrm{m}$ & $\mathrm{m}$ & 12.0 & 10.9 & $\mathrm{~m}$ & 18.5 & 58.7 \\
\hline & Korea & 9 & 0.4 & 6.8 & 3.2 & 0.0 & 14.3 & 75.3 \\
\hline & Latvia & 96 & 3.8 & 14.1 & 9.6 & 11.2 & 36.5 & 24.7 \\
\hline & Luxembourg & 57 & 7.4 & 17.5 & 16.9 & 5.2 & 11.5 & 41.4 \\
\hline & Mexico & 39 & 5.5 & 2.8 & 16.9 & 0.0 & 16.4 & 58.4 \\
\hline & Netherlands & 71 & 13.2 & 0.0 & 13.1 & 28.9 & 27.3 & 17.4 \\
\hline & New Zealand & 6 & 3.0 & 14.0 & 23.8 & 5.1 & 8.8 & 45.2 \\
\hline & Norway & 100 & 3.1 & 17.5 & 7.0 & 11.1 & 37.3 & 24.1 \\
\hline & Poland & 99 & 1.6 & 5.9 & 27.9 & 15.6 & 0.9 & 48.0 \\
\hline & Portugal & 35 & 6.1 & 21.2 & 8.2 & 2.7 & 21.8 & 39.9 \\
\hline & Slovak Republic & 47 & $\mathrm{~m}$ & $\mathrm{~m}$ & $\mathrm{~m}$ & $\mathrm{~m}$ & $\mathrm{~m}$ & $\mathrm{~m}$ \\
\hline & Slovenia & 5 & 1.9 & 34.7 & 7.2 & 4.0 & 26.3 & 25.8 \\
\hline & Spain & 100 & 13.0 & 7.7 & 15.5 & 0.0 & 12.9 & 51.0 \\
\hline & Sweden & 98 & 7.6 & 18.6 & 14.4 & 0.5 & 20.2 & 38.7 \\
\hline & Switzerland & 77 & 11.4 & 29.8 & 17.4 & 3.7 & 10.7 & 27.0 \\
\hline & Turkey & 3 & 2.1 & 15.1 & 7.0 & 0.0 & 5.3 & 70.6 \\
\hline & United Kingdom & 0 & 1.4 & 27.4 & 18.2 & 0.6 & 10.6 & 41.8 \\
\hline & United States & 10 & 0.5 & 0.0 & 12.1 & 4.2 & 7.2 & 76.0 \\
\hline \multirow{21}{*}{ ఏँ } & Brazil & 22 & 3.5 & 5.3 & 26.6 & 9.4 & 9.0 & 46.2 \\
\hline & B-S-J-G (China) & 63 & 11.9 & 14.6 & 13.3 & 7.2 & 15.3 & 37.7 \\
\hline & Bulgaria & 3 & 3.3 & 13.8 & 7.2 & 12.8 & 23.5 & 39.4 \\
\hline & Colombia & 40 & 1.8 & 0.0 & 13.9 & 0.0 & 8.1 & 76.3 \\
\hline & Costa Rica & 53 & 2.3 & 8.8 & 6.5 & 7.2 & 20.7 & 54.4 \\
\hline & Croatia & 0 & 0.2 & 12.9 & 19.2 & 19.2 & 12.4 & 36.1 \\
\hline & Dominican Republic & 21 & 7.4 & 8.6 & 17.2 & 2.3 & 1.1 & 63.5 \\
\hline & Hong Kong (China) & 33 & 2.1 & 2.3 & 13.4 & 11.5 & 15.9 & 54.9 \\
\hline & Lithuania & 100 & 2.5 & 8.5 & 8.2 & 10.2 & 17.0 & 53.6 \\
\hline & Macao (China) & 45 & 2.6 & 2.4 & 9.8 & 20.2 & 18.4 & 46.7 \\
\hline & Montenegro & 3 & 0.5 & 13.6 & 1.0 & 19.6 & 0.0 & 65.4 \\
\hline & Peru & 25 & 1.0 & 0.0 & 15.4 & 7.1 & 12.2 & 64.3 \\
\hline & Qatar & 21 & 2.3 & 5.9 & 6.3 & 1.9 & 7.2 & 76.5 \\
\hline & Romania & 100 & $\mathrm{~m}$ & $\mathrm{~m}$ & $\mathrm{~m}$ & $\mathrm{~m}$ & $\mathrm{~m}$ & $\mathrm{~m}$ \\
\hline & Russia & 87 & 10.9 & 21.1 & 14.2 & 2.7 & 34.2 & 16.9 \\
\hline & Singapore & 2 & 0.4 & 0.0 & 2.6 & 6.5 & 27.7 & 62.8 \\
\hline & Chinese Taipei & 35 & 1.9 & 19.0 & 8.0 & $\mathrm{~m}$ & 24.0 & 47.1 \\
\hline & Thailand & 25 & 2.3 & 5.2 & 8.3 & 15.3 & 0.0 & 68.9 \\
\hline & Tunisia & 34 & 7.6 & 2.6 & 23.3 & 9.4 & 5.6 & 51.5 \\
\hline & United Arab Emirates & 14 & 2.0 & 3.8 & 13.2 & 3.5 & 5.5 & 72.0 \\
\hline & Uruguay & 38 & 18.7 & 12.4 & 17.1 & 4.7 & 4.6 & 42.6 \\
\hline
\end{tabular}

Note: The classification of education programmes follows the ISCED 1997 classification.

Source: OECD, PISA 2015 Database, Table III.6.1.

StatLink 겍ㄴ http://dx.doi.org/10.1787/888933471209 
In 2015, across all countries and economies, disadvantaged students were much less likely than advantaged students to expect to complete a university degree. A lack of financial resources and a paucity of role models can undermine the aspirations of disadvantaged students, with negative consequences on the effort they invest at school. Costa Rica and the Dominican Republic are the only countries where the difference between advantaged and disadvantaged students in expectations to complete a university degree is less than 10 percentage points. In Beijing-Shanghai-Jiangsu-Guangdong (China) (hereafter "B-S-J-G [China]"), the Czech Republic, Hungary, Lithuania, Poland, Portugal and Spain, this gap is over 50 percentage points (Table III.6.2)

Immigrants often leave their countries with the determination to give their children high-quality education (Dustmann and Glitz, 2011). Immigrant students hold an ambition to succeed and progress in school that often matches, and in some cases surpasses, the aspirations of children in their host country (OECD, 2015). In 2015, both first- and second-generation immigrant students were as likely as non-immigrants to expect to complete a university degree, on average across OECD countries (Table III.6.2). Among the countries where more than 10\% of students have an immigrant background, in Australia, Canada, Latvia, New Zealand, Qatar, Singapore, Sweden, the United Arab Emirates and the United Kingdom, first-generation immigrant students were more likely to report that they expect to complete a university degree than students without an immigrant background. In Austria, Brazil, Germany, Greece, Hong Kong (China), Iceland, Israel, Italy, Slovenia, Spain and the United States, first-generation immigrant students had lower expectations for further education than non-immigrant students.

In 2015, girls were more likely than boys to expect to complete university. The largest differences between the shares of girls and boys who reported that they expect to earn a university degree (over 15 percentage points in favour of girls) are observed in Bulgaria, Estonia, Greece, Thailand, Tunisia and Uruguay. Only in France, Germany, the Netherlands and Chinese Taipei were boys as likely as girls to hold expectations of completing university education (Table III.6.2).

Girls' high expectations for their future education are reflected in high enrolment rates in universities. But even though women are over-represented among university graduates (57\% of first-time graduates in 2014 were women in OECD countries, on average), they remain under-represented in certain fields of study, such as science and engineering. On average across OECD countries, there are three times more male graduates in engineering than female graduates (OECD, 2016c).

On average across OECD countries, about $36 \%$ of students expect that they will complete their education with a secondary degree (either lower or upper secondary, Figure III.6.1 and Table III.6.4). The share of students who expect to end their education at the secondary level is smallest in Singapore (3\%) and largest in Germany (77\%). Many students who are enrolled in secondary programmes that prepare students for a university education (ISCED 3A courses) expect to finish their education with their current degree (Table III.6.1).

In many countries and economies, students who attend schools in rural areas are less likely to expect to earn a university degree than students who attend urban schools. On average across OECD countries, $31 \%$ of students whose school is in a rural area or a village with fewer than 3000 people, $42 \%$ of students in schools located in towns with up to 100000 people, and $50 \%$ of students in cities with over 100000 people expect to complete a university education. Differences in these expectations between urban and rural students were particularly large (over 40 percentage points) in Hungary and Turkey (Table III.6.3).

\section{EXPECTATIONS OF FURTHER EDUCATION AND PSYCHOLOGICAL WELL-BEING}

Positive expectations for the future signal high self-esteem and effective coping mechanisms. Figure III.6.2 shows that self-reported satisfaction with life is significantly related to students' expectations to complete university education. On average across OECD countries, students who expect to complete university education were $30 \%$ more likely than students without such expectations to report high satisfaction with their life (9 or 10 on a scale from 0 to 10). This relationship suggests that students' psychological and social well-being at school is strictly connected to how adolescents see their future as students (see also Figure III.8.8 on the relationship between exposure to bullying and education expectations).

\section{EXPECTATIONS OF FURTHER EDUCATION AND HOW EDUCATION SYSTEMS ARE ORGANISED}

Figure III.6.3 shows the percentage of low performers in all subjects (students who score below proficiency Level 2 in the PISA reading, mathematics and science tests) and top performers in at least one subject (those who score at Level 5 or 6) who expect to complete university education. In all countries and economies, top performers were more likely than low performers to report that they expect to earn a university degree. On average across OECD countries, about $70 \%$ of top-performing students and $20 \%$ of low-performing students reported that they expect to complete a university degree. 
Figure III.6.2 - Life satisfaction and expectations of completing a university degree Increased likelihood of feeling highly satisfied with life associated with the expectation of completing a university degree

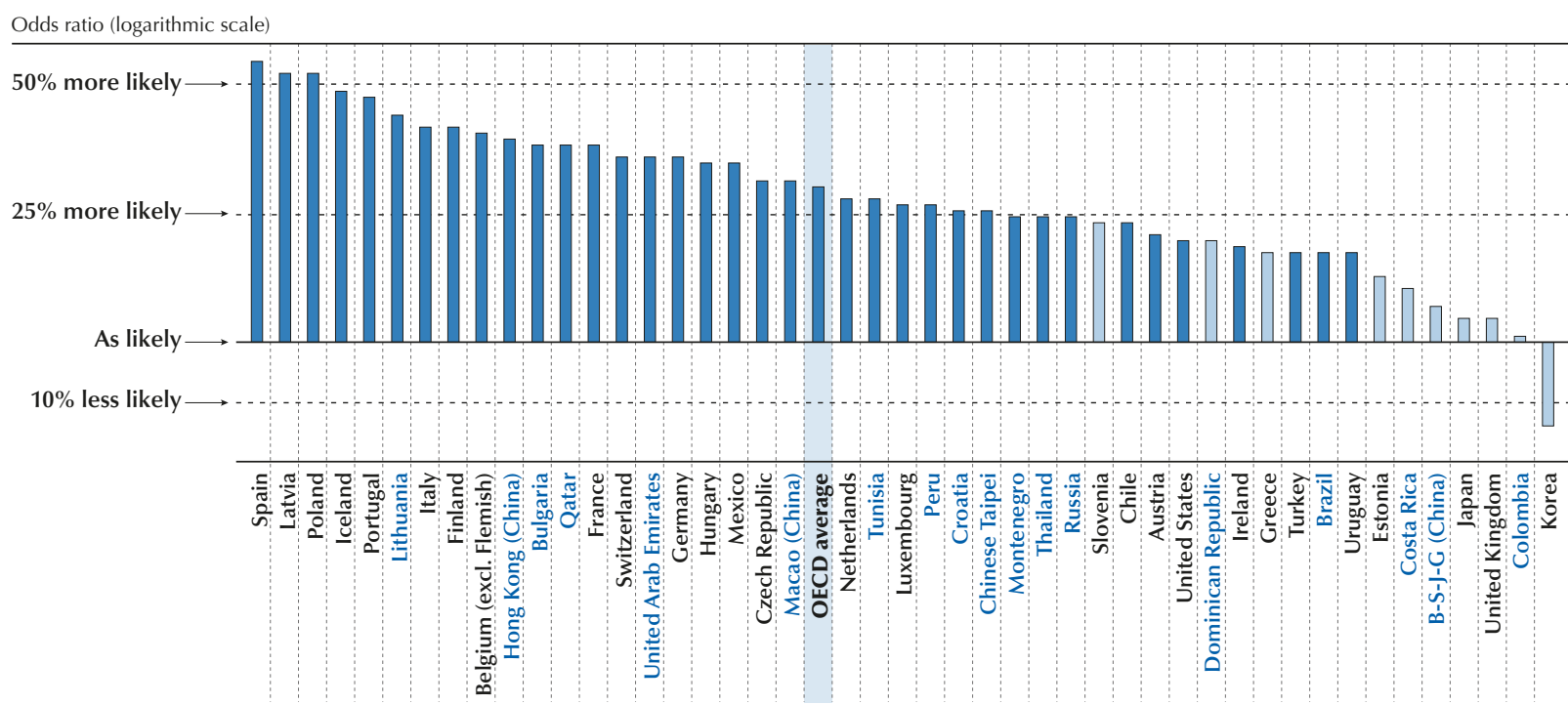

Notes: Statistically significant values are shown in a darker tone (see Annex A3).

Highly satisfied students are students who reported 9 or 10 on the life-satisfaction scale, which ranges from 0 to 10.

Countries and economies are ranked in descending order of the likelihood of feeling highly satisfied with life associated with expectations of completing a university degree.

Source: OECD, PISA 2015 Database, Table III.6.8.

StatLink 제내 http://dx.doi.org/10.1787/888933471215

Figure III.6.3 - Expectations of completing a university degree and performance Percentage of students expecting to complete a university degree, by performance in core PISA subjects

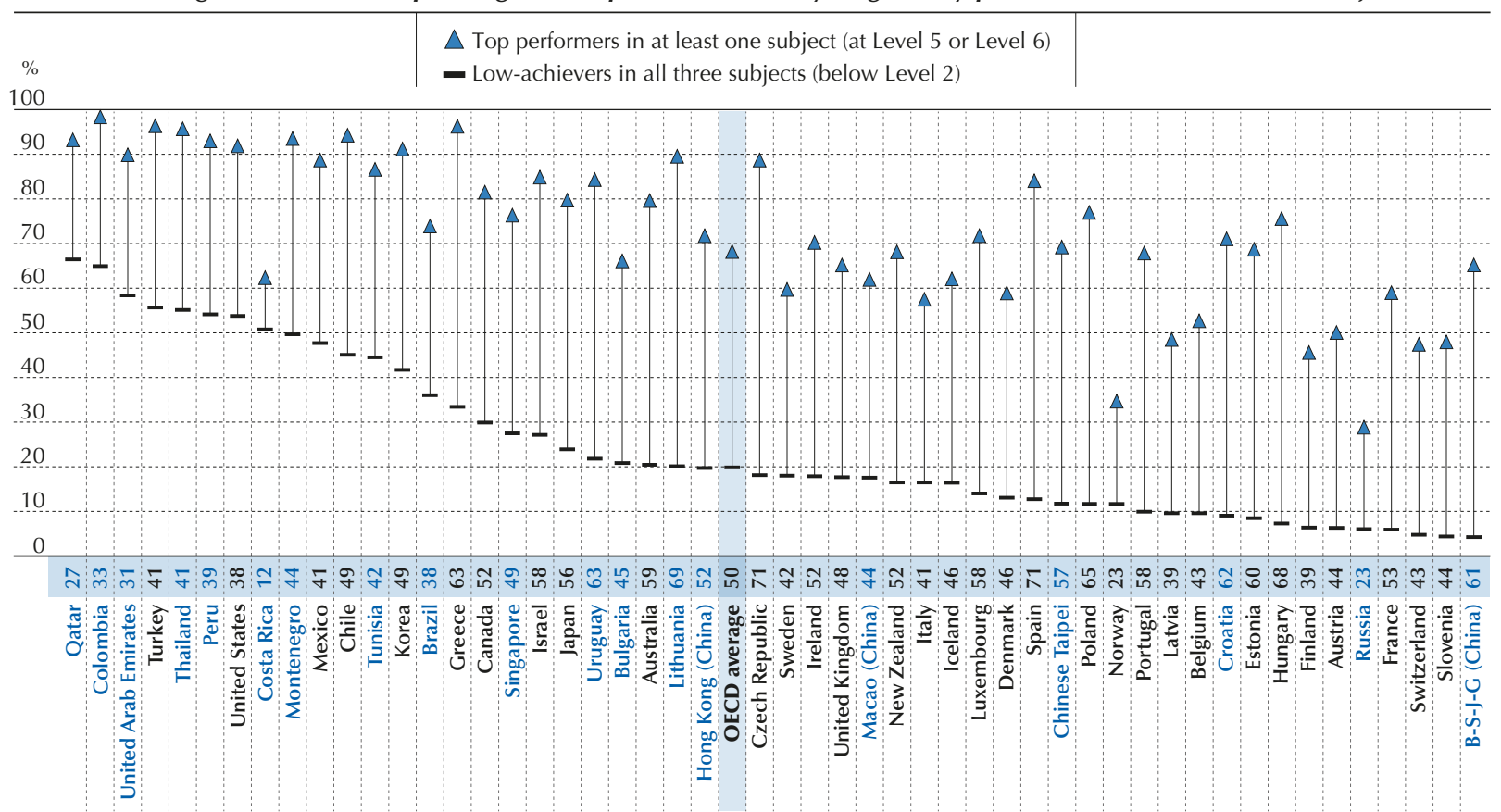

Notes: Only countries with available data for both low-achievers and top performers are shown.

Statistically significant differences between top-performers and low-achievers are shown next to the country/economy name (see Annex A3).

Countries and economies are ranked in descending order of the percentage of low-achievers expecting to complete a university degree.

Source: OECD, PISA 2015 Database, Table III.6.7.

StatLink 젶ㄴ http://dx.doi.org/10.1787/888933471227 
Large proportions of students hold expectations of further education that do not seem aligned with their performance in school. For example, in Colombia, Costa Rica, Peru, Qatar, Thailand, Turkey, the United Arab Emirates and the United States, more than one in two all-round low performers (students who score below proficiency Level 2 in the PISA reading, mathematics and science tests) reported that they expect to complete a university degree (Figure III.6.3). In these countries, the returns in earnings from higher education tend to be relatively high. For example, in Colombia in 2014, workers with higher education degrees earned 2.3 times the salary of adult workers with only upper secondary or post-secondary non-tertiary education, on average (OECD, 2016c, Table A6.1). If a large share of these low-performing students enrols in university, higher education institutions might be either forced to impose highly selective admissions and progression rules, or to lower the standards of their courses. In Finland, Germany, Latvia, the Netherlands, Norway, the Russian Federation (hereafter "Russia"), Slovenia and Switzerland, fewer than one in two students who are top performers in at least one PISA subject expect to earn a university degree (Table III.6.7). In some of these countries (Latvia, the Netherlands, Norway, Russia and Slovenia) more than one in four students expect to complete a tertiary vocational programme (ISCED 5B).

Promoting high expectations for further education among top-performing students is particularly important, considering that these are the students who are most likely to succeed in higher education. But students at all levels of proficiency should receive some counselling so that they develop a realistic understanding of the requirements of higher education and how they can work to fulfil them (see box III.14.3 for a concrete example of how this can be done).

Students' expectations of further education are also influenced by the structure of education systems. In flexible education systems, students who have low expectations at age 15 can change their minds later on and pursue a university education. Longitudinal studies have shown that, in these systems, it is not uncommon for students to revise their expectations based on their performance and on changes in the external environment (Anders and Micklewright, 2015). In more rigid education systems, low expectations reflect the reality that 15-year-old students have already been judged as likely (or not) to qualify for admission to university.

In Austria, Denmark, Finland, France, Germany and Switzerland, more than one in two students reported that they expect to finish their education careers upon acquiring a lower or upper secondary degree (Table III.6.1). Three of these six countries - Austria, Germany and Switzerland - separate students into academically and non-academically oriented programmes before they are 13 years old. In Germany, a large proportion of students, particularly disadvantaged students, expects to leave education at the end of the first cycle of secondary schooling, when they have received around nine or ten years of general training (either academic or work-oriented, depending on the education track into which students are selected at age 10). This dual system in Germany aims to reduce youth unemployment by preparing all students for a smooth transition into the labour market. In France, only $13 \%$ of disadvantaged students expect to complete university (Table III.6.2). In Austria, France and Switzerland, many 15-year-old students expect to finish their education at the end of their vocational training programmes at the upper secondary level (ISCED $3 \mathrm{~B} / \mathrm{C}$ ).

School systems that track students into different education paths give students a strong signal about their likely careers, channelling their expectations and giving low-achieving students the means to access the labour market. Boys and girls in education systems that separate students into different types of schools tend to have lower expectations for further education than those in systems that have a comprehensive approach to schooling at the primary and lower secondary levels (Buchmann and Dalton, 2002; Buchmann and Park, 2009; Kerckhoff, 2000; Mateju et al., 2007; McDaniel, 2010; Rosenbaum, 2001).

The socio-economic status of students strongly influences their placement into upper or lower tracks. Advantaged students are most likely to attend academically oriented programmes that provide a direct pathway to university (OECD, 2016b). Figure III.6.4 shows that in systems where students are tracked between the ages of 10 and 12, only $21 \%$ of disadvantaged students, on average, expect that they will complete university, while in countries where students are separated into different tracks between the ages of 13 and 15,36\% of disadvantaged students, on average, expect to complete a university degree. The difference in expectations between advantaged and disadvantaged students is slightly larger in systems with early tracking. If sorting into different programmes is not based entirely on merit, these systems may waste academic talent, as some academically capable students might end up in the wrong track and cannot pursue a university degree because movement across tracks is rare and difficult.

Besides tracking, another way education systems can guide students' expectations is through high-stakes evaluations. Marks on assessments are an important source of information about students' potential success in future education. They can thus help high-performing students understand their academic potential and the need to cultivate it further. 


\section{Figure III.6.4 - Age at sorting into education tracks and expectations of completing a university degree}

Average across all countries and economies with available data

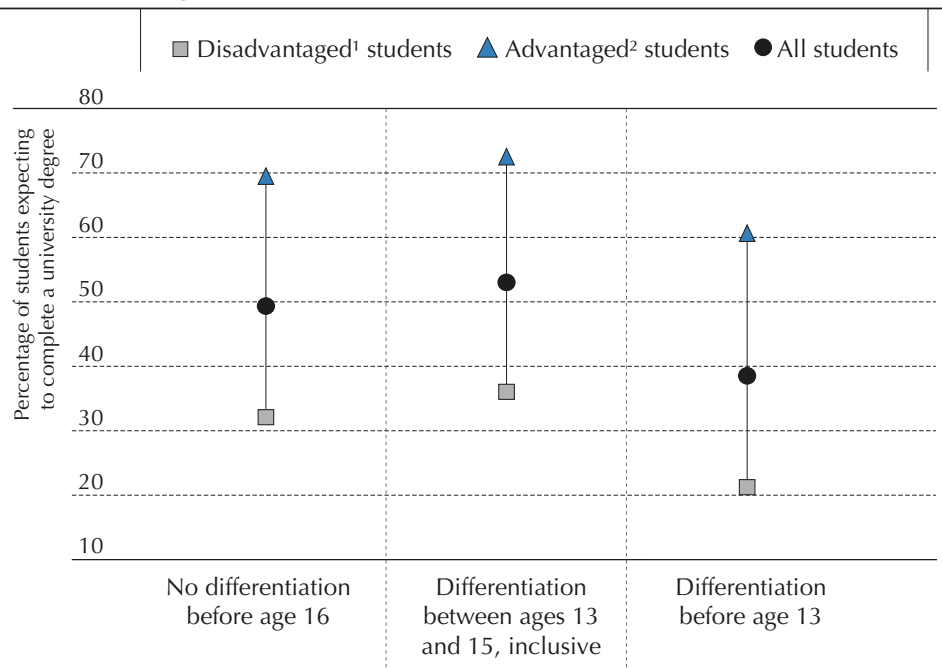

1. A socio-economically disadvantaged student is a student in the bottom quarter of the PISA index of economic, social and cultural status (ESCS) in their country/economy.

2. A socio-economically advantaged student is a student who is in the top quarter of the PISA index of economic, social and cultural status (ESCS) in their country/economy.

Note: All differences between advantaged and disadvantaged students are statistically significant (see Annex A3).

Source: OECD, PISA 2015 Database, Table III.6.10.

StatLink 제피 http://dx.doi.org/10.1787/888933471238

If fully based on merit, this source of "institutional information" might also reduce inequalities in expectations by making students' self-assessments less dependent on the influence of their social group. However, for students who are not adequately supported by teachers and parents, failure in an important test can result in lowered expectations, and might even encourage students to drop out of school altogether. For example, Reardon and Galindo (2002) find that, among students with similar performance, the requirement to pass a promotion test in the United States is strongly associated with an increased probability of students dropping out of school.

The evidence on the relationship between testing policies and early dropout is not conclusive, as it is difficult to identify causal effects without randomised experiments (e.g. by randomly assigning students with the same characteristics to hightesting and low-testing environments). PISA data can only add descriptive evidence on this relationship. Table III.6.12 shows that, on average across OECD countries, students who attend schools that assess students with mandatory standardised tests at least once a year are as likely as students who are not assessed in this way to expect to earn a university degree.

\section{Box III.6.1 Parents' expectations of a career in science for their children}

Students' expectations of further education are oriented by the occupation they expect to be working in later on. Parents can influence both sets of expectations. Most parents are concerned about their children's work prospects and they encourage their children to fulfil their aspirations. But parents follow different approaches when influencing how their children think about their future. Qualitative evidence (Irwin and Elley, 2013) suggests that some parents adopt a laissez-faire approach, only responding to their children's requests for information and support, while others believe that they can shape the future success of their children by choosing what is best for them.

PISA 2015 data provide information on whether parents expect that their children will pursue a career in a science-related occupation, broadly defined as a career that requires studying science at the university level (OECD, 2016a). These data can identify the background characteristics of both children and their parents that are more closely related with expectations, and the degree of alignment between students' expectations and those of their parents (see also box III.10.2 for more data on students' occupation expectations). 
Across countries that distributed the parental questionnaire, parents were more likely to expect a sciencerelated career for their sons than for their daughters, especially in Asian countries. For instance, in Hong Kong (China), Korea and Macao (China), the share of parents who expected a science career for their sons was at least 10 percentage points larger than the share of parents who expected the same for their daughters. But in Chile, the Dominican Republic and Georgia parents of female students were more likely to have expectations of a science career for their child than parents of male students (Figure III.6.5).

Figure III.6.5 - Parents who expect a career in science for their child, by student's gender Results based on parents' reports

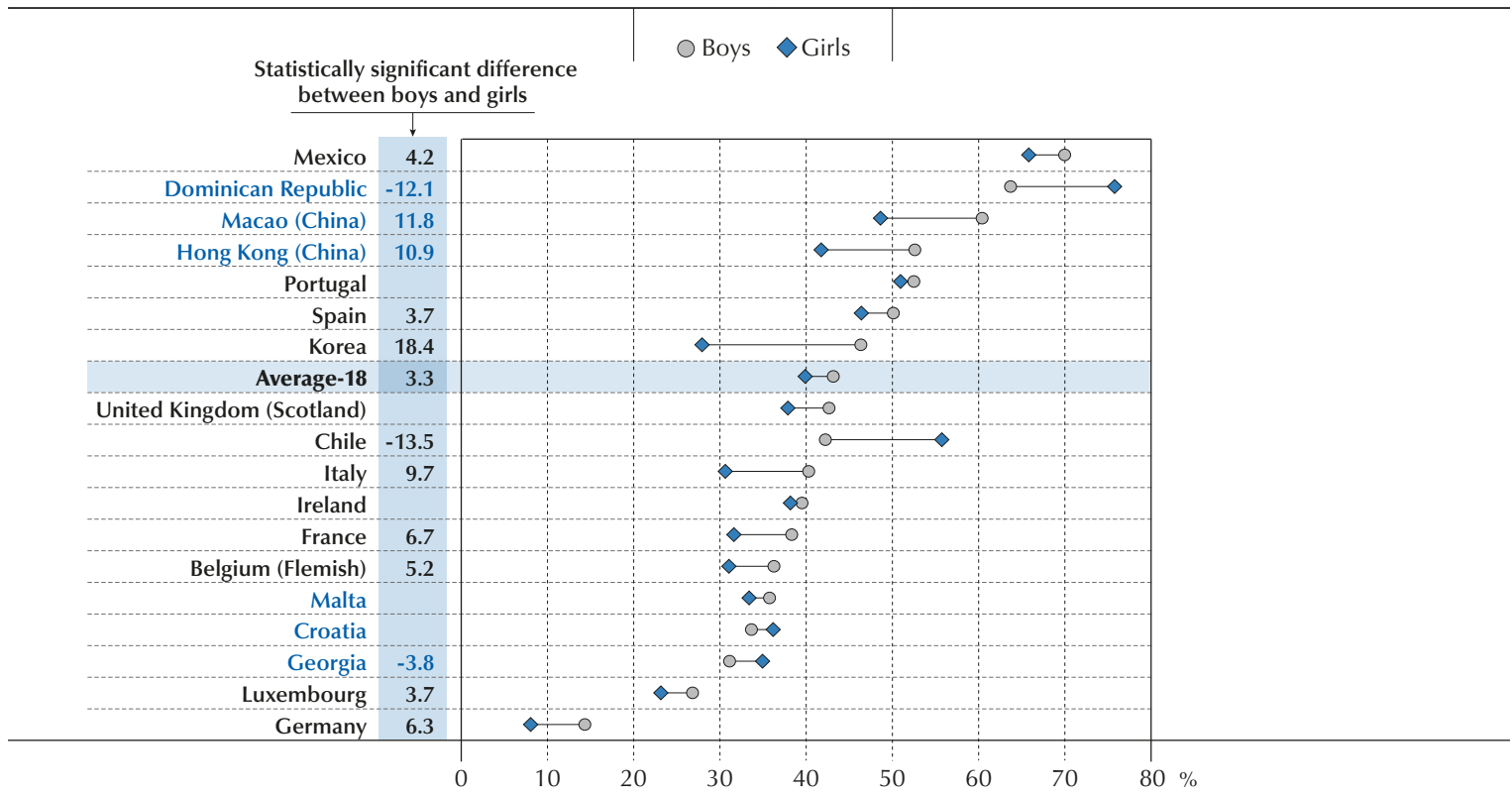

Note: Statistically significant differences between boys and girls are shown next to the country/economy name (see Annex A3).

Countries and economies are ranked in descending order of the percentage of boys whose parents reported that they expect a science-related career for them.

Source: OECD, PISA 2015 Database, Table III.6.13.

StatLink त्नाज http://dx.doi.org/10.1787/888933471248

Gender and gender roles are not the only factors that can explain differences in how parents form their expectations. Parents are also influenced by their own life experiences and social context. Across countries, 57\% of parents who reported that someone in their family (including themselves) works in a science-related career expected the same for their child, while only $36 \%$ of parents in families where no one works in science expected their child to work in a science-related job. Moreover, parents with a university degree were more likely than less-educated parents to expect that their children will seek a career in science. The difference between parents with a university degree and those who have not attained that level of education is particularly large in Belgium (Flemish Community), France, Korea, Malta, Portugal, Scotland (United Kingdom) and Spain (Table III.6.13).

The expectations of children and parents are strongly aligned. After accounting for the child's socio-economic status and performance in science, children whose parents expect that they will work in science were more likely to expect a career in science for themselves (Table III.6.14).

A possible consequence of failing a high-stakes test is the obligation to repeat a year of school. Repeating a grade is arguably the most visible demonstration of academic "failure". As such, it can adversely affect a student's expectations for himself or herself - and the expectations of others for the student - for a long time. Alexander, Entwisle and Dauber (2003) found that students in the city of Baltimore who had repeated a grade early in their schooling were more likely than their peers who had been promoted to drop out of school in adolescence, even if the former group of students performed better at school than their classmates who were promoted. The students who had repeated a grade, they explained, suffered from a weaker attachment to school. Table III.6.11 shows that, in the majority of countries and economies, students who had 
repeated a grade are less likely than students who had not repeated a grade to expect to complete university, even after accounting for differences in gender, socio-economic status and performance in science and reading. This relationship is not causal, as students who had repeated a grade might differ from those who had not in ways that are not measured by PISA.

\section{What these results imply for policy}

- Expectations shape students' careers and can contribute to students' well-being. Schools should provide academic and career counselling to all students so that they develop ambitious - yet realistic - expectations about their education and career prospects.

- Disengagement among boys needs to be tackled so that more boys can develop expectations that are aligned with their academic potential.

- Where inequalities in education and career expectations are prevalent, opportunities for social mobility are limited. In systems that separate students at an early age, disadvantaged students are over-represented in the lower tracks and tend to develop low expectations of further education. Easing transitions between tracks could reduce the effects of differentiation on inequalities in expectations, skills and opportunities. 


\section{References}

Alexander, K.L., D.R. Entwisle and S.L. Dauber (2003), On the Success of Failure: A Reassessment of the Effects of Retention in the Primary School Grades, 2nd edition, Cambridge University Press, Cambridge, UK.

Anders, J. and J. Micklewright (2015), "Teenagers' expectations of applying to university: How do they change?", Education Sciences, Vol. 5/4, pp. 281-305, http://dx.doi.org/10.3390/educsci5040281.

Beal, S.J. and L.J. Crockett (2010), "Adolescents' occupational and educational aspirations and expectations: Links to high school activities and adult educational attainment", Developmental Psychology, Vol. 46/1, pp. 258-265, http://dx.doi.org/10.1037/a0017416.

Buchmann, C. and B. Dalton (2002), "Interpersonal influences and educational aspirations in 12 countries: The importance of institutional context", Sociology of Education, Vol. 75/2, pp. 99-122, http://dx.doi.org/10.2307/3090287.

Buchmann, C. and H. Park (2009), "Stratification and the formation of expectations in highly differentiated educational systems", Research in Social Stratification and Mobility, Vol. 27/4, pp. 245-267, http://dx.doi.org/10.1016/j.rssm.2009.10.003.

Correa, L., F. D'Errico and I. Poggi (2011), "School and life for teenagers. Expectations and hopes in Italy and Brazil", International Journal of Developmental and Educational Psychology: INFAD. Revista de Psicología, Vol. 1/2, pp. 433-442, http://infad.eu/ RevistalNFAD/2011/n1/volumen2/INFAD_010223_433-442.pdf.

Dustmann, C. and A. Glitz (2011), "Migration and education", Norface Discussion Paper Series, No. 2011011, Norface Research Programme on Migration, Department of Economics, University College, London, https://ideas.repec.org/p/nor/wpaper/2011011. html.

Irwin, S. and S. Elley (2013), "Parents' hopes and expectations for their children's future occupations", The Sociological Review, Vol. 61/1, pp. 111-30, http://dx.doi.org/10.1111/j.1467-954X.2012.02139.x.

Kerckhoff, A.C. (2000), "Transition from school to work in comparative perspective", in M.T. Hallinan (ed.), Handbook of the Sociology of Education, Springer, New York, NY, pp. 453-474.

Mateju, P. et al. (2007), "Determination of college expectations in OECD countries: The role of individual and structural factors", Sociologický Časopis / Czech Sociological Review, Vol. 43/6, pp. 1121-1148.

McDaniel, A. (2010), "Cross-national gender gaps in educational expectations: The influence of national-level gender ideology and educational systems", Comparative Education Review, Vol. 54/1, pp. 27-50, http://dx.doi.org/10.1086/648060.

Morgan, S. (2005), On the Edge of Commitment: Educational Attainment and Race in the United States, Studies in Social Inequality, Stanford University Press, Stanford, CA.

Morgan, S. (1998), "Adolescent educational expectations: Rationalized, fantasized, or both?", Rationality and Society, Vol. 10/2, pp. 131-162, http://dx.doi.org/10.1177/104346398010002001.

Nurmi, J.E. (2004), Socialization and self-development: Channeling, selection, adjustment, and reflection, in R.M. Lerner and L. Steinberg (eds.), Handbook of Adolescent Psychology, John Wiley \& Sons, Hoboken, NJ, pp. 85-124.

OECD (2016a), PISA 2015 Results (Volume I): Excellence and Equity in Education, OECD Publishing, Paris, http://dx.doi.org/10.1787/ 9789264266490-en.

OECD (2016b), PISA 2015 Results (Volume II): Policies and Practices for Successful Schools, OECD Publishing, Paris, http://dx.doi. org/10.1787/9789264267510-en.

OECD (2016c), Education at a Glance 2016: OECD Indicators, OECD Publishing, Paris, http://dx.doi.org/10.1787/eag-2016-en.

OECD (2015), Immigrant Students at School: Easing the Journey towards Integration, OECD Publishing, Paris, http://dx.doi.org/ 10.1787/9789264249509-en.

OECD (2012), Grade Expectations: How Marks and Education Policies Shape Students' Ambitions, OECD Publishing, Paris, http:// dx.doi.org/10.1787/9789264187528-en.

Perna, L.W. (2000), "Differences in the decision to attend college among African Americans, Hispanics, and Whites", The Journal of Higher Education, Vol. 71/2, pp. 117-141.

Reardon, S.F. and C. Galindo (2002), "Do high-stakes tests affect students' decisions to drop out of school? Evidence from NELS Working Paper", Institute of Education Sciences, Pennsylvania State University. 
Rosenbaum, J. (2001), Beyond College for All: Career Paths for the Forgotten Half, Russell Sage Foundation, New York.

Sewell, W.H. et al. (2003), "As we age: A review of the Wisconsin Longitudinal Study, 1957-2001", Research in Social Stratification and Mobility, Vol. 20, pp. 3-111, http://dx.doi.org/10.1016/S0276-5624(03)20001-9. 



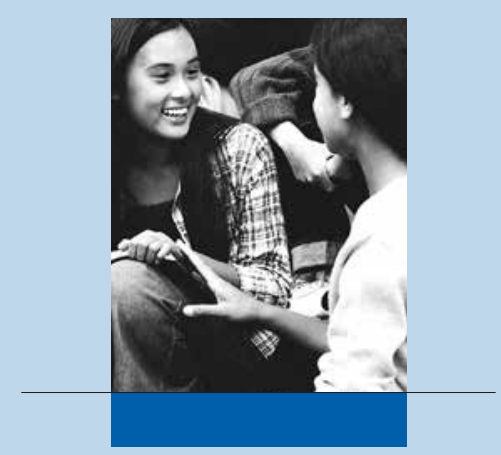

\section{Students' social life at school}

The quality and the type of students' relationships at school are key indicators of their well-being. As fifteen-year-old students spend a substantial amount of time at school, those students who feel that they are part of their school and are accepted by their school community attribute more meaning to their life and have higher selfconfidence. This section presents the PISA data on students' sense of belonging in schools and indicators of exposure to negative social interactions in schools, such as bullying by classmates and perceptions of unfair treatment from teachers. It further discusses the role of school climate in improving students' feelings of belonging at school and how school communities can help reduce the incidence of bullying. 



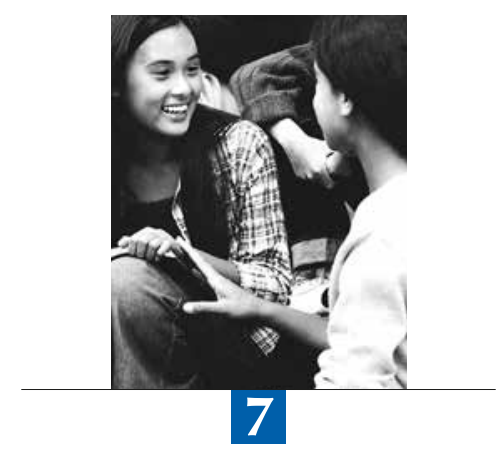

\section{Students' sense of belonging at school and their relations with teachers}

When students feel that they are a part of a school community, they are more likely to perform better academically and are more motivated to learn. This chapter examines differences between countries in the strength of students' sense of belonging at school, and how a sense of belonging is associated with students' gender, socio-economic status and immigrant background. The chapter also explores how the climate at school and students' relations with their teachers can affect students' feelings of being a valued member of the school community. 
A sense of belonging is defined as feeling accepted and liked by the rest of the group, feeling connected to others and feeling like a member of a community (Baumeister and Leary, 1995; Maslow, 1943). Human beings in general, and teenagers in particular, desire strong social ties and value acceptance, care and support from others. In school, a sense of belonging gives students feelings of security, identity and community, which, in turn, support academic, psychological and social development (Jethwani-Keyser, 2008).

\section{What the data tell us}

- The majority of students in 67 countries and economies feel that they belong to the school community. However, in several countries students' sense of belonging at school has weakened since 2003.

- On average across countries, disadvantaged students were 7.7 percentage points less likely than advantaged students to report that they feel that they belong at school. First-generation immigrant students were 4.6 percentage points less likely than students without an immigrant background to feel a sense of belonging at school.

- On average across OECD countries, students who reported that they feel like an outsider at school score 22 points lower in science than students who did not report so. Students in OECD countries who reported that they feel like outsiders at school were three times more likely to report that they are not satisfied with their life than those who do not feel like outsiders at school.

- Some $20 \%$ of students reported that they experienced some form of unfair treatment by their teachers (they were harshly disciplined, or felt offended or ridiculed in front of others) at least a few times in a given month. Students who reported that their teachers treat them fairly and support them in their learning, and can work in disciplined classrooms, have a stronger sense of belonging at school.

Adolescents who feel that they are part of a school community are more likely to perform better academically and be more motivated in school (Battistich et al., 1997; Goodenow, 1993). When children and adolescents feel a connection with school, they are less likely to engage in risky and antisocial behaviour (Catalano et al., 2004; Hawkins and Weis, 1985). Students with strong and rewarding social ties at school are less likely to drop out of school and never return (Lee and Burkam, 2003), or to engage in substance abuse and truancy (Schulenberg et al., 1994). Furthermore, researchers find that an absence of a feeling of connectedness at school is an antecedent of depression among adolescents (Shochet et al., 2006).

\section{DIFFERENCES IN STUDENTS' SENSE OF BELONGING BETWEEN AND WITHIN COUNTRIES}

In PISA 2015 students were asked to report whether they feel like an outsider or left out of things, whether they make friends easily, they feel that they belong at school, they feel awkward and out of place at school, they feel that other students like them, or they feel lonely. Since the same questions were asked in previous PISA cycles, education systems can monitor changes in the quality of students' engagement with their school community. As school is the primary environment for social interactions among 15-year-olds, these subjective evaluations indicate whether education systems are able to foster students' well-being. Students' responses to these questions were used to construct the index of sense of belonging, which was standardised to have a mean of 0 and a standard deviation of 1 across OECD countries. Positive values on this scale mean that the student has a greater sense of belonging than the average student in OECD countries.

Figure III.7.1 shows the percentage of students who reported their agreement or disagreement with statements related to sense of belonging that were included in PISA 2003, 2012 and 2015. The second, third and fifth items were worded such that "agree" or "strongly agree" indicates a greater sense of belonging. The first, fourth and sixth items were worded such that "disagree" or "strongly disagree" indicates a greater sense of belonging. Higher points in the chart indicate a greater sense of belonging.

On average across OECD countries in 2015, 73\% of students felt that they belong at school; $78 \%$ of students agreed or strongly agreed that they can make friends easily at school; $85 \%$ of students disagreed or strongly disagreed that they feel lonely at school; and $83 \%$ of students disagreed or strongly disagreed that they feel like an outsider or feel left out of things. Some $82 \%$ of students felt that other students like them, and $81 \%$ disagreed or strongly disagreed that they feel awkward and out of place at school. Most students thus reported that they feel socially connected at school. However, in some countries sizable minorities of students feel lonely or isolated (Table III.7.6). Students in the Dominican Republic, Macao (China) and Turkey reported the weakest sense of belonging at school. 
Figure III.7.1 - Change through 2003, 2012 and 2015 in students' sense of belonging at school Percentage of students who reported "agree" or "strongly agree" or who reported "disagree" or "strongly disagree" (OECD average-301)

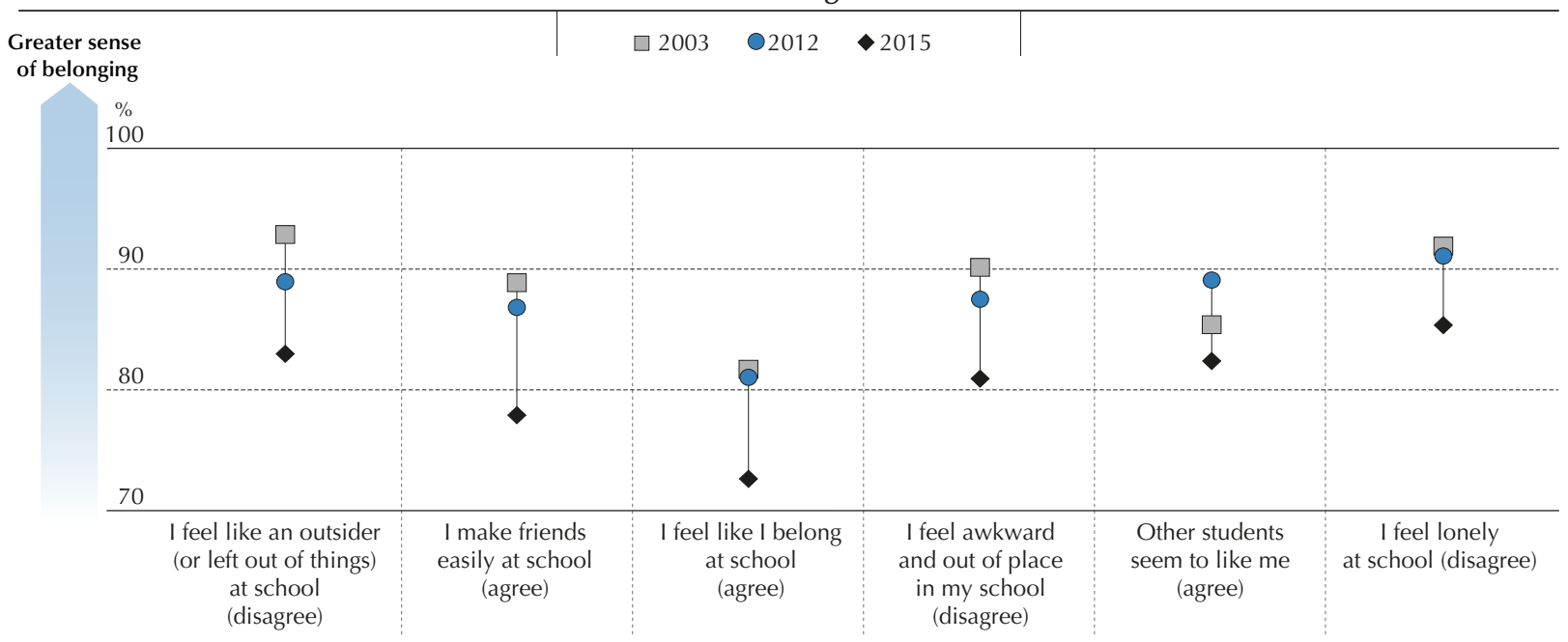

1. OECD average-30 includes all OECD countries, with the exception of Chile, Estonia, Israel, Slovenia and the United States. Note: All changes between 2003 and 2015, and 2012 and 2015 are statistically significant. Source: OECD, PISA 2015 Database, Tables III.7.4 and III.7.5.

StatLink 제으 http://dx.doi.org/10.1787/888933471478

Across OECD countries, students' sense of belonging deteriorated between 2012 and 2015, on average (Figure III.7.1). The proportion of students who disagreed or strongly disagreed that they feel like an outsider decreased, on average across countries, by around 6 percentage points over the period. This trend seems to be part of a gradual decline in students' feelings of connectedness at school over the past 12 years. In 2003, around 7\% of students reported that they feel like an outsider; by 2012, that proportion had grown by 4 percentage points, and by 2015 it had grown by 10 percentage points. In none of the participating countries and economies did the percentage of students who reported that they feel like an outsider at school decrease significantly between 2003 and 2015.

Differences within countries are also very large. A substantial part of the variation within countries is explained by students' socio-economic status. In 65 countries and economies, advantaged students tend to feel more socially connected at school than disadvantaged students. The difference in sense of belonging related to socio-economic status is particularly large in Beijing-Shanghai-Jiangsu-Guangdong (China) (hereafter "B-S-J-G [China]"), Ciudad Autonoma de Buenos Aires (Argentina) (hereafter "CABA [Argentina]"), the Dominican Republic, the Former Yugoslav Republic of Macedonia (hereafter "FYROM"), Hungary, Jordan, Kazakhstan, Korea, Luxembourg, Peru, the United States and Uruguay (Table III.7.6).

In 28 countries, boys were more likely than girls to report a greater sense of belonging at school. Differences in favour of boys are particularly noticeable (around one-fifth of a standard deviation) in Australia, Denmark, Finland, Ireland, Norway, the United Kingdom and the United States, while in Jordan, Qatar and Turkey, girls reported a much stronger sense of belonging than boys (over one-fifth of a standard deviation; Table III.7.6).

\section{SENSE OF BELONGING AND IMMIGRANT BACKGROUND}

Growing populations of immigrant students pose new challenges to maintaining cohesion at school, as students need to learn how to interact with peers from different cultural backgrounds (OECD, 2015b). Results from PISA indicate that, on average across OECD countries, $12.5 \%$ of students in 2015 had an immigrant background compared to $9.4 \%$ of students in 2006 (OECD, 2016, Table I.7.1). Countries vary widely in the extent to which first-generation immigrant students (foreign-born students whose parents are also foreign-born) and second-generation immigrant students (those who were born in the country of assessment but whose parents are foreign-born) are more or less likely than students without an immigrant background to feel that they belong at school. On average, and in 29 countries and economies, students without an immigrant background reported a stronger sense of belonging than immigrant students, even after accounting for socio-economic status (Figure III.7.2 and Table III.7.6). The opposite pattern is observed in Australia, Qatar and the United Arab Emirates, where both first- and second-generation immigrant students reported a greater sense of belonging at school than non-immigrant students. 
Figure III.7.2 - Index of sense of belonging, by student characteristics Results based on students' self-reports

Index of sense of belonging

$-0.5$

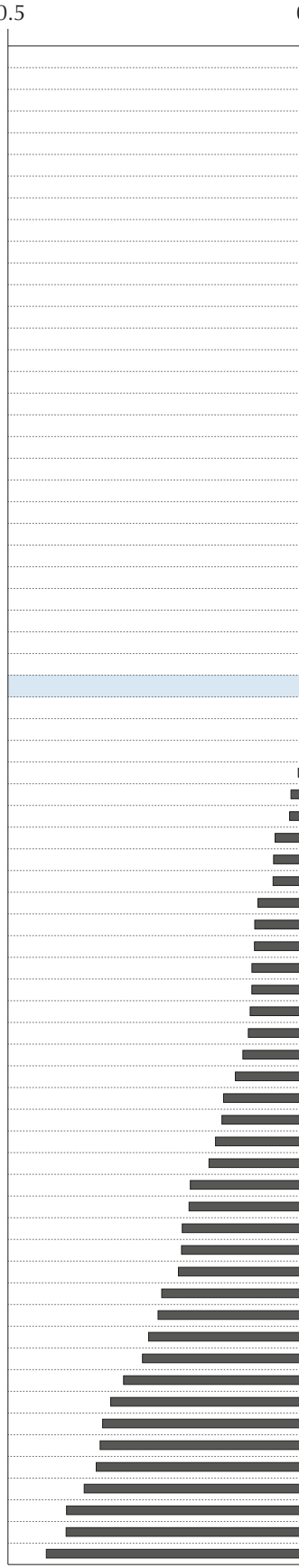

0.0

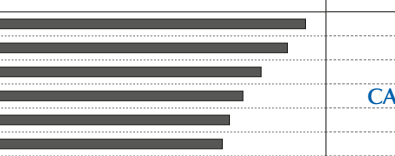
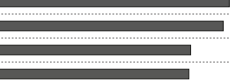

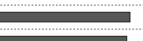

-

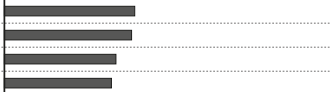

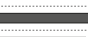

$+\cdots$

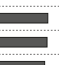

$+\cdots$

$+$

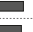

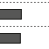

루

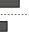

a

(1)

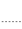
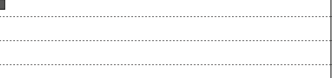

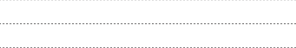

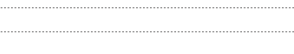
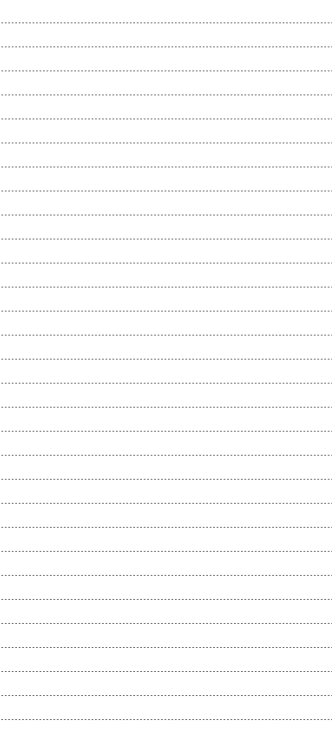

\begin{tabular}{|c|}
\hline Spain \\
\hline Austria \\
\hline Albania \\
\hline CABA (Argentina) \\
\hline Switzerland \\
\hline FYROM \\
\hline Kazakhstan \\
\hline Germany \\
\hline Kosovo \\
\hline Norway \\
\hline Georgia \\
\hline Iceland \\
\hline Jordan \\
\hline Netherlands \\
\hline Korea \\
\hline Denmark \\
\hline Luxembourg \\
\hline Indonesia \\
\hline Portugal \\
\hline Greece \\
\hline Finland \\
\hline Hungary \\
\hline Italy \\
\hline Trinidad and Tobago \\
\hline Croatia \\
\hline Sweden \\
\hline Moldova \\
\hline Chinese Taipei \\
\hline Lebanon \\
\hline OECD average \\
\hline Belgium \\
\hline Romania \\
\hline Ireland \\
\hline Malta \\
\hline Japan \\
\hline Chile \\
\hline France \\
\hline Viet Nam \\
\hline Estonia \\
\hline United States \\
\hline Uruguay \\
\hline United Kingdom \\
\hline Slovenia \\
\hline United Arab Emirates \\
\hline Montenegro \\
\hline Qatar \\
\hline Canada \\
\hline Australia \\
\hline Mexico \\
\hline Brazil \\
\hline Costa Rica \\
\hline New Zealand \\
\hline Tunisia \\
\hline Latvia \\
\hline Singapore \\
\hline Algeria \\
\hline Peru \\
\hline Czech Republic \\
\hline Poland \\
\hline Lithuania \\
\hline Slovak Republic \\
\hline Colombia \\
\hline B-S-J-G (China) \\
\hline Bulgaria \\
\hline Hong Kong (China) \\
\hline Thailand \\
\hline Russia \\
\hline $\begin{array}{c}\text { Dominican Republic } \\
\text { Macao (China) }\end{array}$ \\
\hline $\begin{array}{c}\text { Macao (China) } \\
\text { Turkey }\end{array}$ \\
\hline
\end{tabular}

Education systems with a positive difference/association Education systems with no difference/association Education systems with a negative difference/association

Education systems with a positive difference/association Education systems with a negative difference/association Difference/association not significant Missing values

\section{Differences in the index of sense of belonging,}
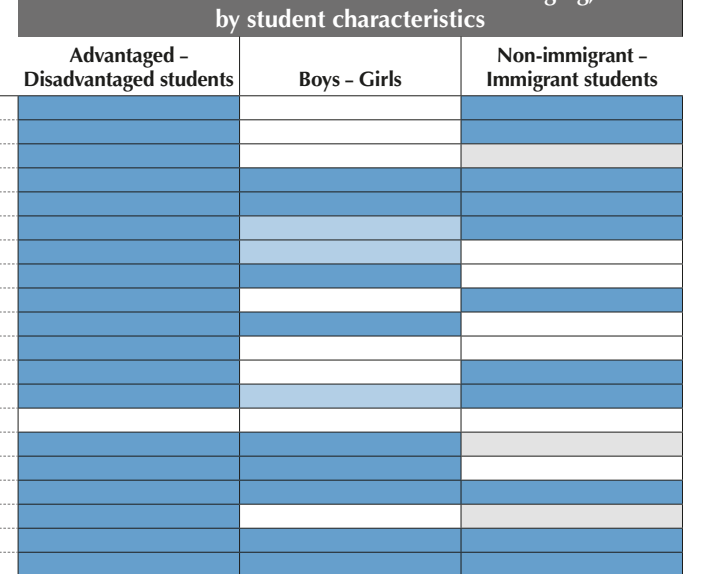$$
\text { - }
$$

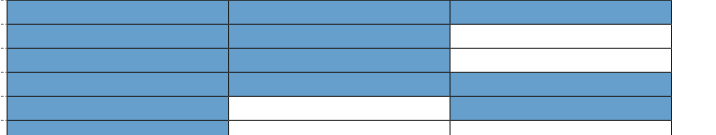

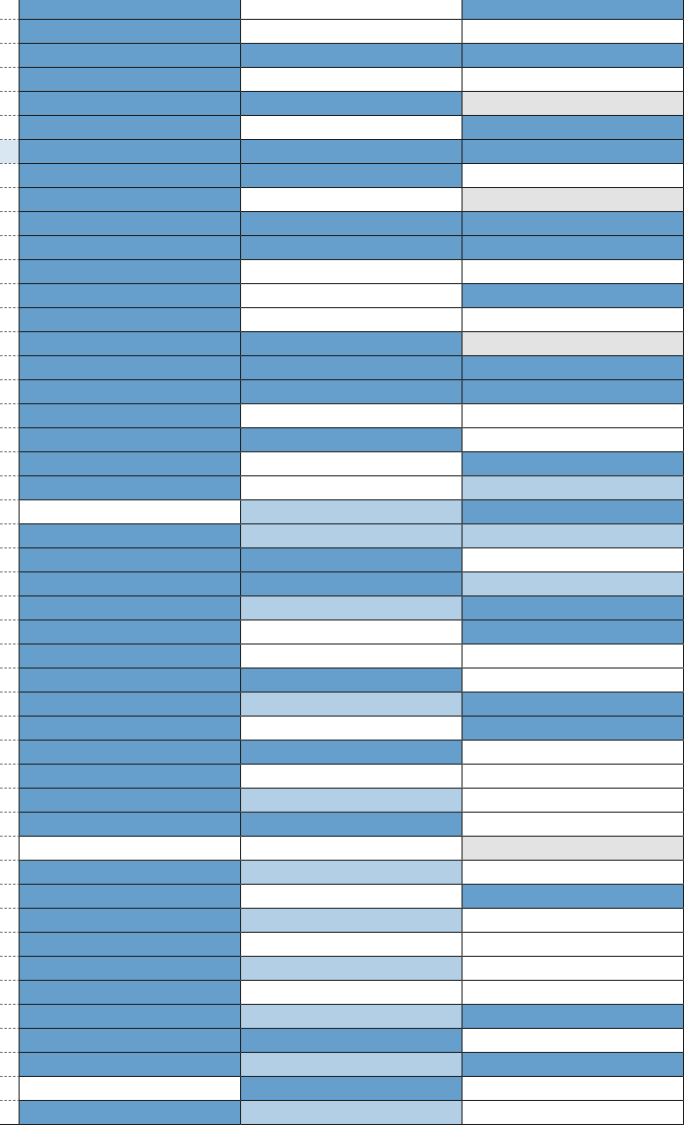

\begin{tabular}{|c|c|c|c|}
\hline 65 & 28 & 29 \\
\hline & 4 & 27 & 30 \\
\hline & 0 & 14 & 3 \\
\hline
\end{tabular}

Countries and economies are ranked in descending order of the index of sense of belonging.

Source: OECD, PISA 2015 Database, Table III.7.6.

StatLink त्ताज http://dx.doi.org/10.1787/888933471487 
In Brazil, FYROM, Iceland, Latvia, Luxembourg, Norway, Spain, Sweden and Switzerland, first-generation immigrant students reported the greatest sense of alienation from schools compared to students without an immigrant background. Second-generation immigrant students expressed a stronger sense of belonging at school than first-generation immigrant students, particularly in Austria, Chile, FYROM, Jordan, Norway, Spain, Sweden and Switzerland (with a difference of over a third of a standard deviation) (Table III.7.6).

\section{Box III.7.1 Integrating immigrant students at school}

Children of immigrants often have to overcome many barriers in order to succeed at school. For some, the lack of familiarity with the language of instruction and precarious living conditions can turn the first years spent in their new country into a particularly stressful experience (OECD, 2015b). School plays a key role in assimilating immigrant adolescents because it is often the first social and cultural institution that children of immigrants have contact with (Chiu et al., 2012). Many students attend schools where there are deep divisions between immigrants and native-born students, or between newcomers and more acculturated immigrants. Teachers in these schools are often not sufficiently trained to address these divisions (OECD, 2010; Suárez-Orozco and Suárez-Orozco, 2013).

In PISA 2015 foreign-born students tended to report a weaker sense of belonging than non-immigrant students, on average, but this difference varies greatly across countries and economies (Table III.7.3). Figure III.7.3 shows the percentage of immigrant students who reported that they feel that they belong at school, by country of origin and country of destination, taking into account differences in the socio-economic status of students from the same country of origin who settled in different countries. Around $83 \%$ of students who were born in, or whose parents were born in, Arabic-speaking countries and who settled in the Netherlands reported feeling that they belong at school, but only $67 \%$ of students from Arabic-speaking countries who settled in Denmark reported the same.

\section{Figure III.7.3 - Immigrant students' sense of belonging at school, by countries of origin and destination}

\section{Percentage of students with an immigrant background who reported that they feel like they belong at school,} adjusted for differences in socio-economic status

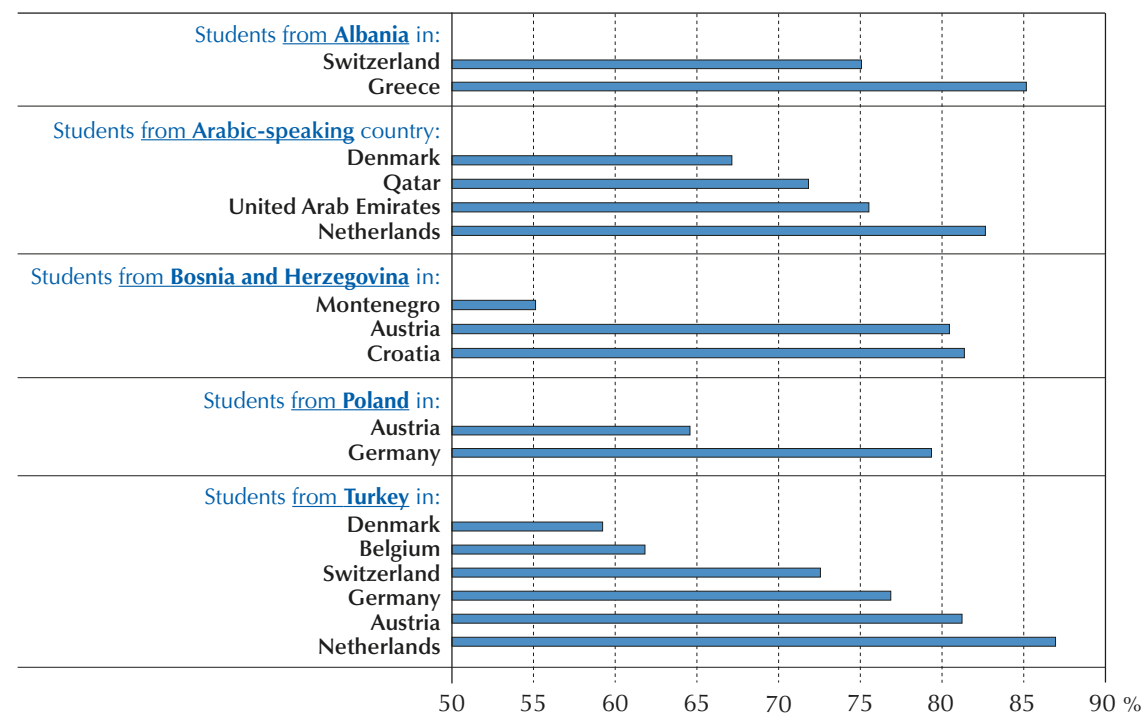

Notes: The estimates are obtained from pooled data from the PISA 2012 and 2015 databases. Only countries where the percentage of immigrant students in PISA 2015 is higher than 5\% are shown.

The estimates are adjusted for differences in socio-economic status by assigning the same value of socio-economic status to all students of one origin group independently of the destination country.

The coverage of destination countries is limited by the fact that only some countries collect detailed information on immigrants' country of birth. Results are only shown for pairs of origin and destination countries/economies with data for 20 or more immigrant students.

Sources: OECD, PISA 2006, 2009, 2012 and 2015 Databases, Table III.7.9.

StatLink त्माज् http://dx.doi.org/10.1787/888933471493 
Similarly, only 55\% of students who migrated to Montenegro from Bosnia reported that they feel that they belong at school, while $81 \%$ of the Bosnians who migrated to Croatia so reported. These results suggest that the psychological well-being of immigrant students is affected not only by cultural differences between the country of origin and the host country, but also by how schools and communities help these students handle the daily problems of living, learning and communicating. Providing dedicated support to immigrant students to help them integrate into their new school community can strengthen the overall performance of education systems, particularly in those countries that recently saw a surge in migrant inflows.

\section{THE CONSEQUENCES OF A WEAK SENSE OF BELONGING AT SCHOOL}

There are many reasons why policy makers, teachers and parents should care about students' sense of belonging at school. First, there is an association between feelings of belonging at school and academic achievement. Research examining this association generally shows a positive circular relationship: a sense of belonging leads to higher academic achievement, and high academic achievement leads to greater social acceptance and sense of belonging (Wentzel, 1998). However, the link between social bonding with peers at school and achievement is likely to differ significantly across countries and across groups of students. In some countries, academic achievement is considered socially desirable among teenagers; in others, academic achievement is not a factor in social acceptance, and sometimes it is even sanctioned (Ogbu, 2003).

The relationship between belonging at school and performance in PISA is strong for those students with the least sense of belonging. Beyond a certain threshold, the relationship between sense of belonging and performance becomes flat. On average across OECD countries, the difference in science performance between students in the second quarter and students in the bottom quarter of the index of sense of belonging is 13 score points, while the difference between students in the top quarter and students in the third quarter is only 5 points (Table III.7.8a). It is thus important to identify and support those students with a very weak sense of belonging, because these students are likely to be adversely affected both in their personal well-being and in their academic performance (Anderman, 2002; Goodenow, 1993).

Looking at the individual components used to create the index of sense of belonging, students across OECD countries who reported that they feel like an outsider at school score 22 points lower in science, on average, than those who did not report so (Figure III.7.4). Even after accounting for students' socio-economic status, this gap remains significant in the large majority of countries. The negative relationship between feeling like an outsider and performance in science holds true in the large majority of countries and economies. In Lebanon, the difference in science performance between these two groups of students is as wide as 67 points, after accounting for students' and schools' socio-economic profile.

A sense of belonging and acceptance at school is important for adolescents' sense of self-worth and overall satisfaction with life (Juvonen, 2006). Figure III.7.5 shows a strong relationship between the likelihood of reporting low satisfaction with life (a level of 4 or lower on a scale from 0 to 10) and feeling like an outsider at school. Students in OECD countries who feel like they are outsiders at school were three times more likely to report that they are not satisfied with their life than those who do not feel like they are outsiders (Figure III.7.5). In Finland, Ireland, Korea, the Netherlands, the United Kingdom and the United States, the likelihood of reporting low satisfaction with life is more than four times higher if the student reported feeling like an outsider. The relationship between feeling like an outsider and life satisfaction remains significant after accounting for students' socio-economic status.

A weak sense of belonging at school might also discourage students from pursuing further education. Table III.7.12 shows that, on average across OECD countries, students in the bottom quarter of the index of sense of belonging were 11 percentage points more likely to expect to end their education at the secondary level than students in the top quarter of the index.

\section{DISCIPLINARY CLIMATE AND SENSE OF BELONGING}

Differences in students' sense of belonging are larger within schools than between schools (Table III.7.7; Ma, 2003). However, the quality of the school environment also matters. In particular, a disciplined and fair learning environment at school can help adolescents build the social skills they need to establish rewarding relationships with their educators and peers. 
Figure III.7.4 - Feeling like an outsider at school and science performance

Score-point difference in science performance between students who feel like outsiders at school and students who do not feel like outsiders

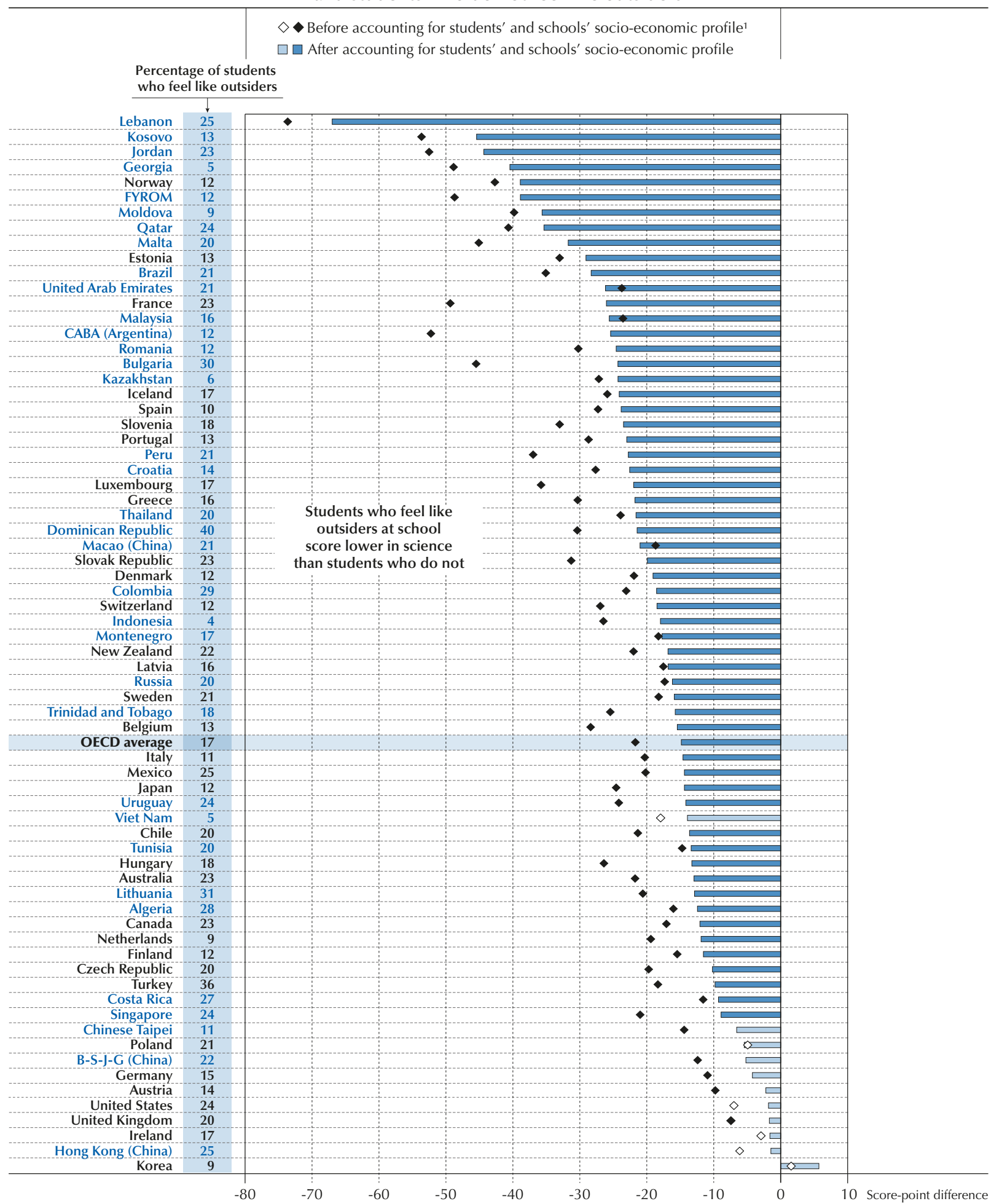

1. The socio-economic profile is measured by the PISA index of economic, social and cultural status (ESCS).

Note: Statistically significant values are marked in a darker tone (see Annex A3).

Countries and economies are ranked in ascending order of the score-point difference between students who feel like outsiders and students who do not, after accounting for students' and schools' socio-economic profile.

Source: OECD, PISA 2015 Database, Table III.7.10.

StatLink 제으 $h$ htp://dx.doi.org/10.1787/888933471504 
Figure III.7.5 - Feeling like an outsider at school and low life satisfaction

Likelihood that students are not satisfied" with their life if they "feel like an outsider at school", after accounting for students' and schools' socio-economic profile ${ }^{2}$

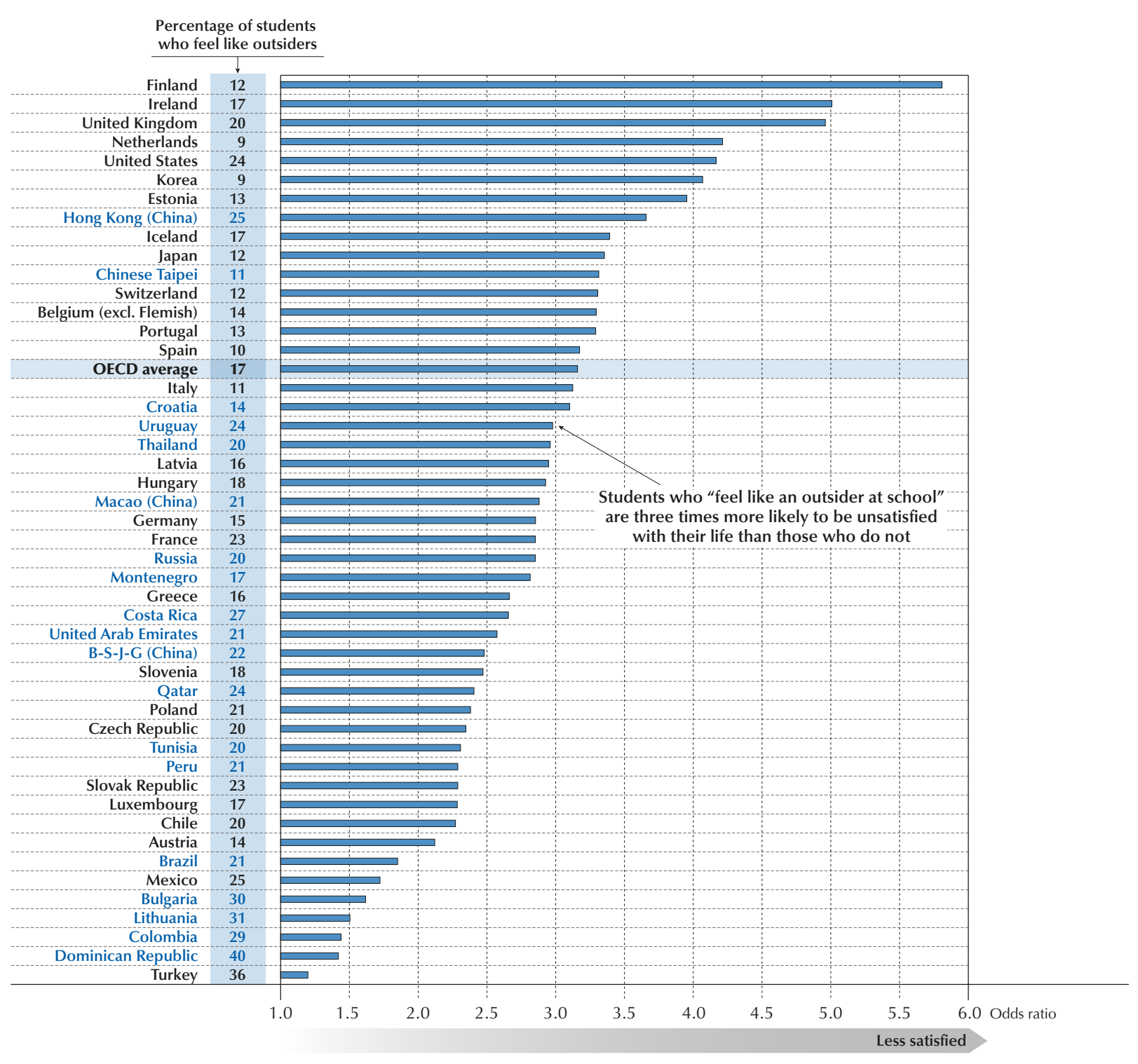

1. A student is classified as "not satisfied" if he or she reported between 0 and 4 on the life-satisfaction scale. The life-satisfaction scale ranges between 0 and 10 .

2. The socio-economic profile is measured by the PISA index of economic, social and cultural status (ESCS).

Note: All values are statistically significant (see Annex A3).

Countries and economies are ranked in descending order of the odds of reporting low life satisfaction, after accounting for students' and schools' socioeconomic profile.

Source: OECD, PISA 2015 Database, Table III.7.13

StatLink त्ताs http: //dx.doi.org/10.1787/888933471518

A school's disciplinary climate is a strong predictor of a student's sense of belonging at school (Arum and Velez, 2012; Chiu et al., 2016; OECD, 2003). Figure III.7.6 shows that working in a disciplined classroom can have a positive influence on students' sense of belonging at school. PISA 2015 measures disciplinary climate by an index based on students' reports of the frequency with which interruptions occur in science classes. Each bar in the figure reflects the difference in the index of sense of belonging between students in schools with a more favourable disciplinary climate in science classes (the average index of disciplinary climate is significantly above the country mean) and students in schools with a less favourable disciplinary climate (the average index of disciplinary climate is significantly below the country mean). 
Figure III.7.6 - Sense of belonging and disciplinary climate in school

Difference on the index of sense of belonging between students who attend schools with a positive disciplinary climate ${ }^{1}$ and those who attend schools with a negative disciplinary climate

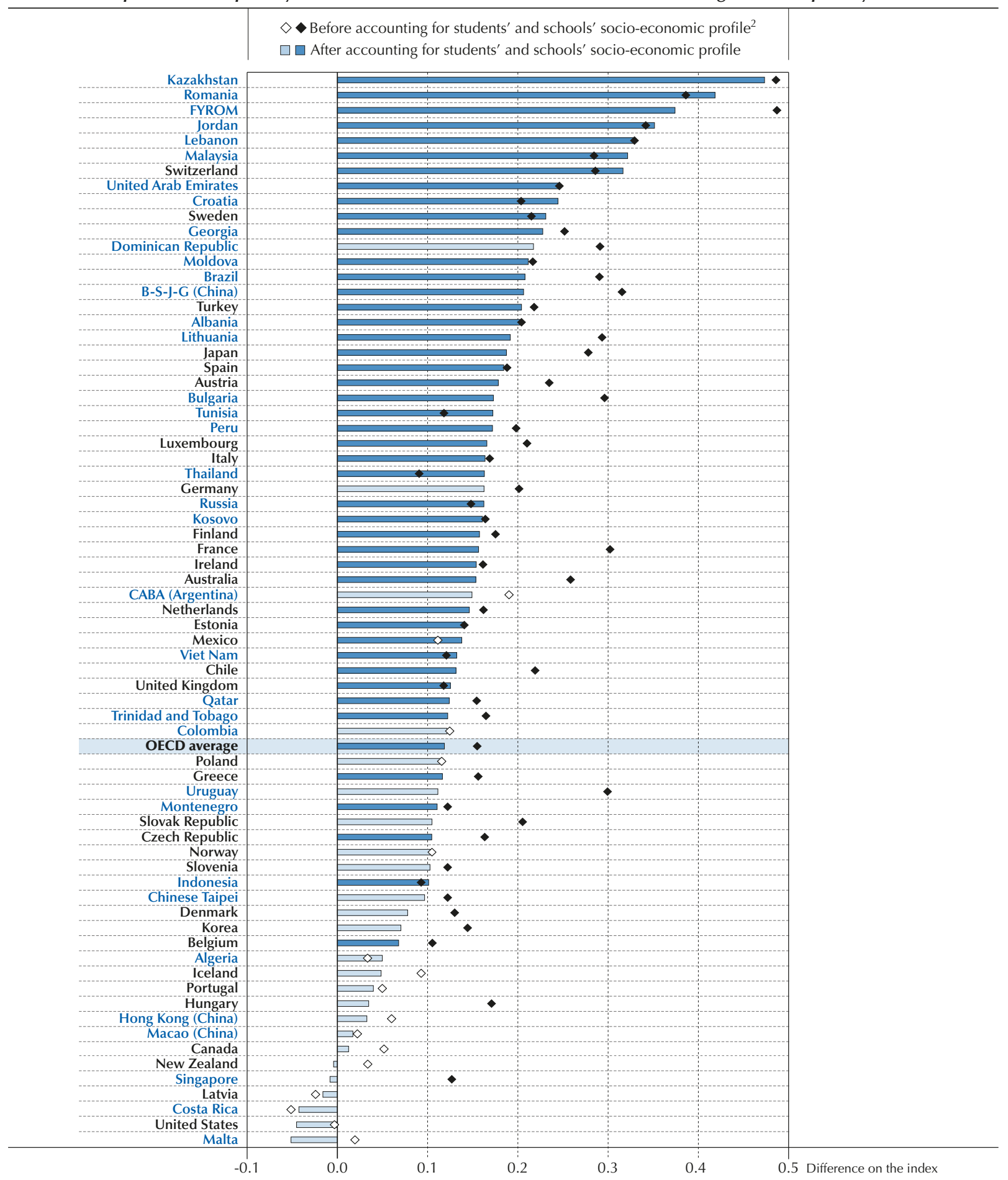

1. Schools with positive (negative) disciplinary climate are those whose average index of disciplinary climate is statistically higher (lower) than the average level in the country/economy.

2. The socio-economic profile is measured by the PISA index of economic, social and cultural status (ESCS).

Note: Statistically significant values are marked in a darker tone (see Annex A3).

Countries and economies are ranked in descending order of the difference in sense of belonging between students in schools with a positive disciplinary climate and those in schools with a negative disciplinary climate, after accounting for students' and schools' socio-economic profile.

Source: OECD, PISA 2015 Database, Table III.7.14.

StatLink 제의 http://dx.doi.org/10.1787/888933471524 
On average, this difference is 0.15 and remains significant after taking into account the socio-economic profile of schools (Figure III.7.6). In FYROM, Kazakhstan, Jordan, Lebanon, Malaysia, Romania and Switzerland, students' sense of belonging is much stronger when they attend classes with a good disciplinary climate. A possible interpretation of this relationship is that reducing disciplinary problems in class might not only lead to better student performance, but might also provide the kind of orderly learning environment that is conducive to supportive social relationships.

\section{STUDENTS' RELATIONS WITH TEACHERS AND SENSE OF BELONGING AT SCHOOL}

The quality of teacher-student relations can influence students' engagement with school and their socio-emotional development (Anderman, 2003; Battistich et al., 1995; Chiu et al., 2016; Ma, 2003; Noble et al., 2008). Teachers and school staff can promote students' healthy social and emotional development by creating a caring and respectful learning environment (Battistich et al., 1997; Noble et al., 2008). Positive relationships between teachers and students are particularly important for the social and emotional well-being of disadvantaged students (Battistich et al., 1997).

Analyses of PISA 2012 data have shown that positive and constructive teacher-student relations are associated with both better performance in mathematics and with a stronger sense of belonging at school (OECD, 2015a). In PISA 2015 students were asked to report whether their teachers call on them less often than they call on other students, grade them harder than they grade other students, give them the impression that they are less smart than they really are, discipline them more harshly than others, or ridicule them or tell them something insulting in front of others. PISA 2015 also asked students whether they perceive that their science teacher is interested in students' learning and is willing to provide support to students who experience difficulties.

A substantial proportion of students in PISA-participating countries and economies perceive that their teachers engage in different types of unfair behaviour. It is important to bear in mind that these data reflect only students' perceptions, and do not allow for assessing the gravity of what happens in the classroom. On average across OECD countries, 35\% of students reported that, at least a few times per month, their teachers calls on them less than they call on others; $21 \%$ reported that their teachers give them the impression that they are less intelligent than they actually are; $18 \%$ of students reported that their teachers grade them more harshly than others; $14 \%$ reported that their teachers discipline them more harshly than others; $10 \%$ reported that their teachers ridicule them in front of others; and $9 \%$ reported that their teachers insult them in front of others (Figure III.7.7). As shown in Figure III.7.7, boys were more likely than girls to report that their teachers do not treat them fairly.

Figure III.7.7 - Students' perception of teachers' unfairness, by gender Percentage of students who reported that their teachers behave unfairly "once a week or more" or "a few times a month" (OECD average)

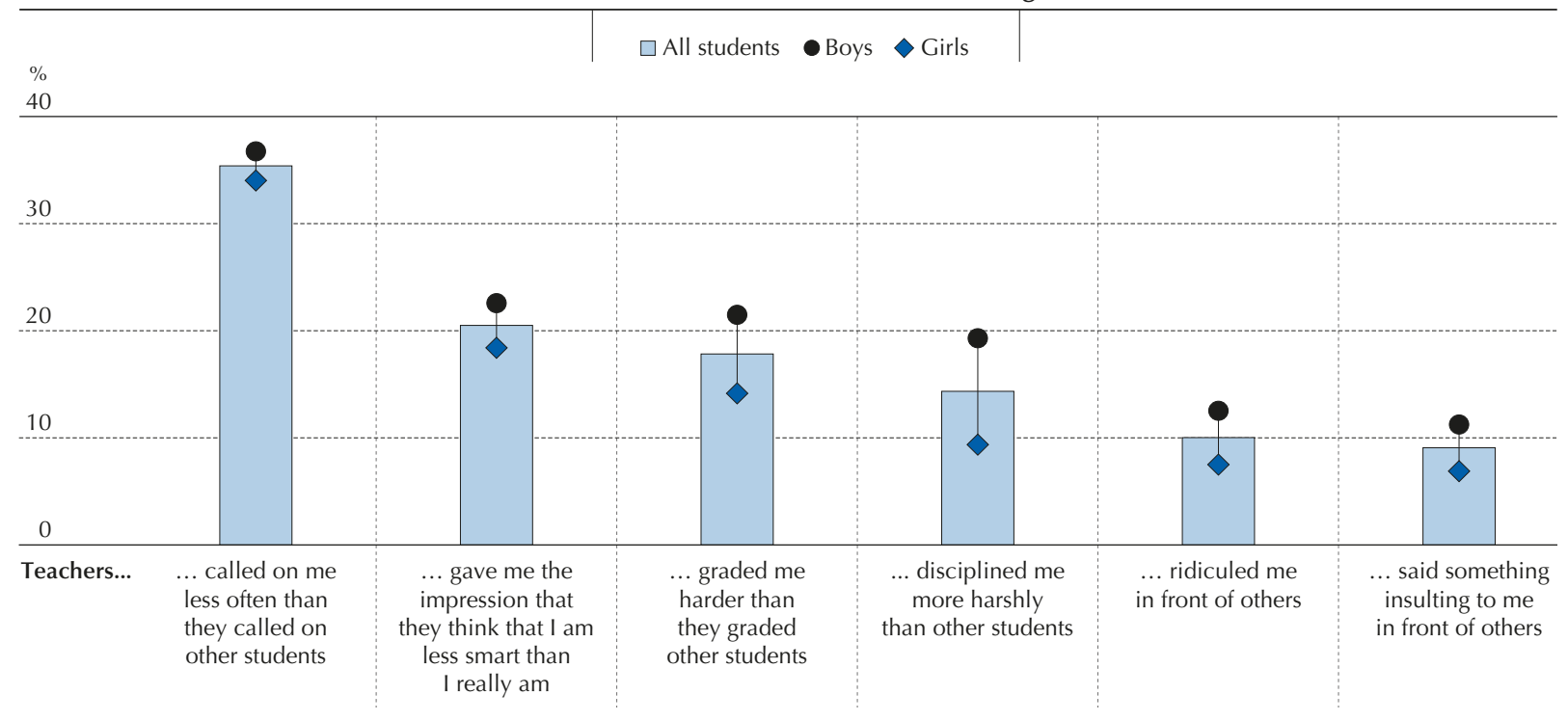

Source: OECD, PISA 2015 Database, Tables III.7.15 and III.7.16.

StatLink 체에 $h$ htp://dx.doi.org/10.1787/888933471534 
Figure III.7.8 - Students' sense of belonging at school, by perception of teacher support Likelihood of reporting "I feel like I belong at school" associated with students' perceptions of teachers' supportive behaviour ${ }^{1}$

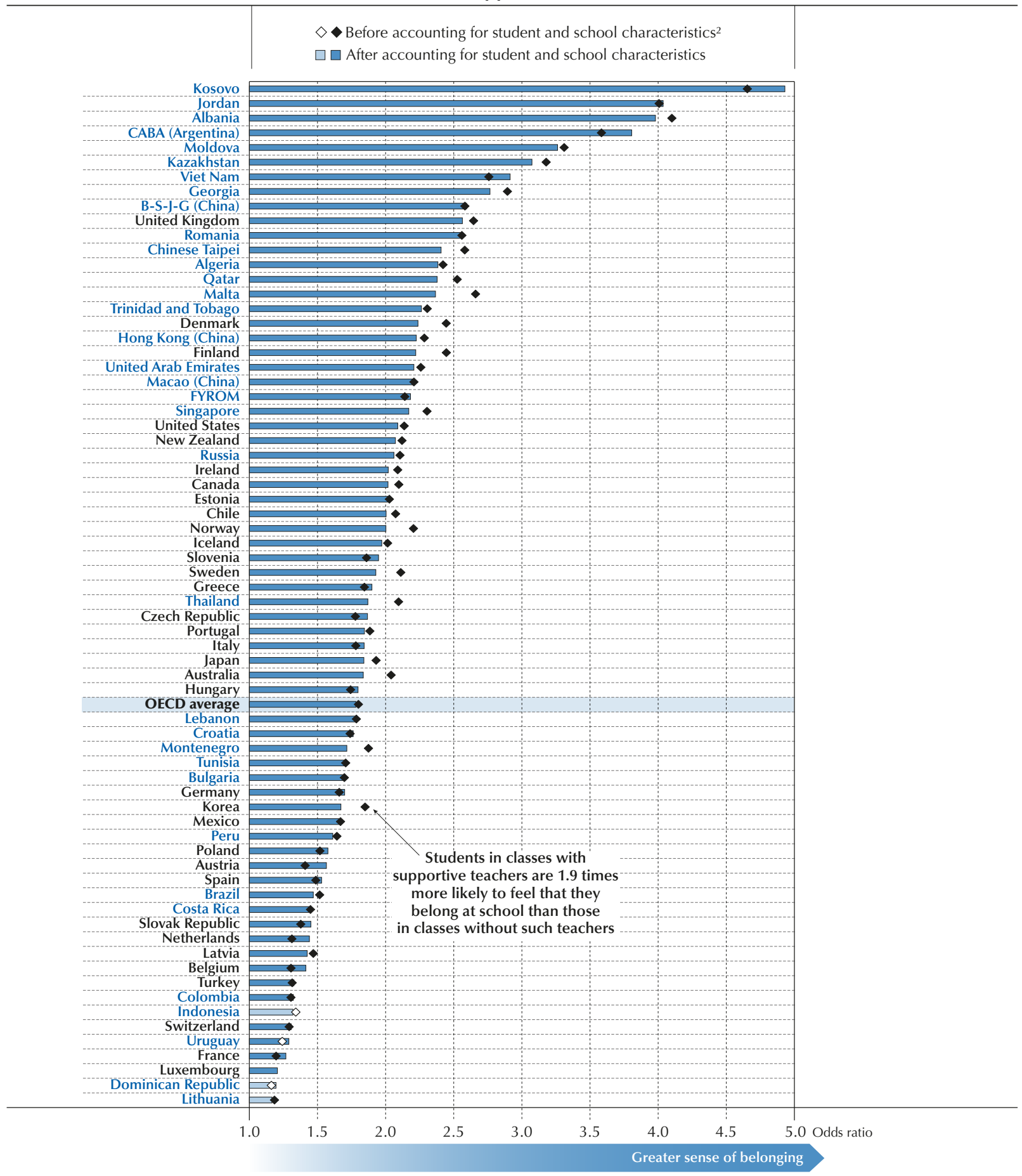

1. Perceived teacher support refers to students reporting "every lesson" or "most lessons" to the statements "The teacher shows an interest in every student's learning", "The teacher gives extra help when students need it" and "The teacher helps students with their learning".

2. Student and school characteristics include gender, performance in reading and science, and the PISA index of economic, social and cultural status (ESCS) at the student and school levels.

Note: Statistically significant values are marked in darker tone (see Annex A3).

Countries and economies are ranked in descending order of the odds ratio of reporting "I feel like I belong at school", after accounting for student and school characteristics.

Source: OECD, PISA 2015 Database, Table III.7.19.

StatLink 젶ㄴ http://dx.doi.org/10.1787/888933471544 
Figure III.7.9 - Students' sense of belonging and perceptions of teachers' unfairness

Likelihood of reporting "I feel like an outsider" associated with students' perceptions of teachers' unfair behaviour ${ }^{1}$

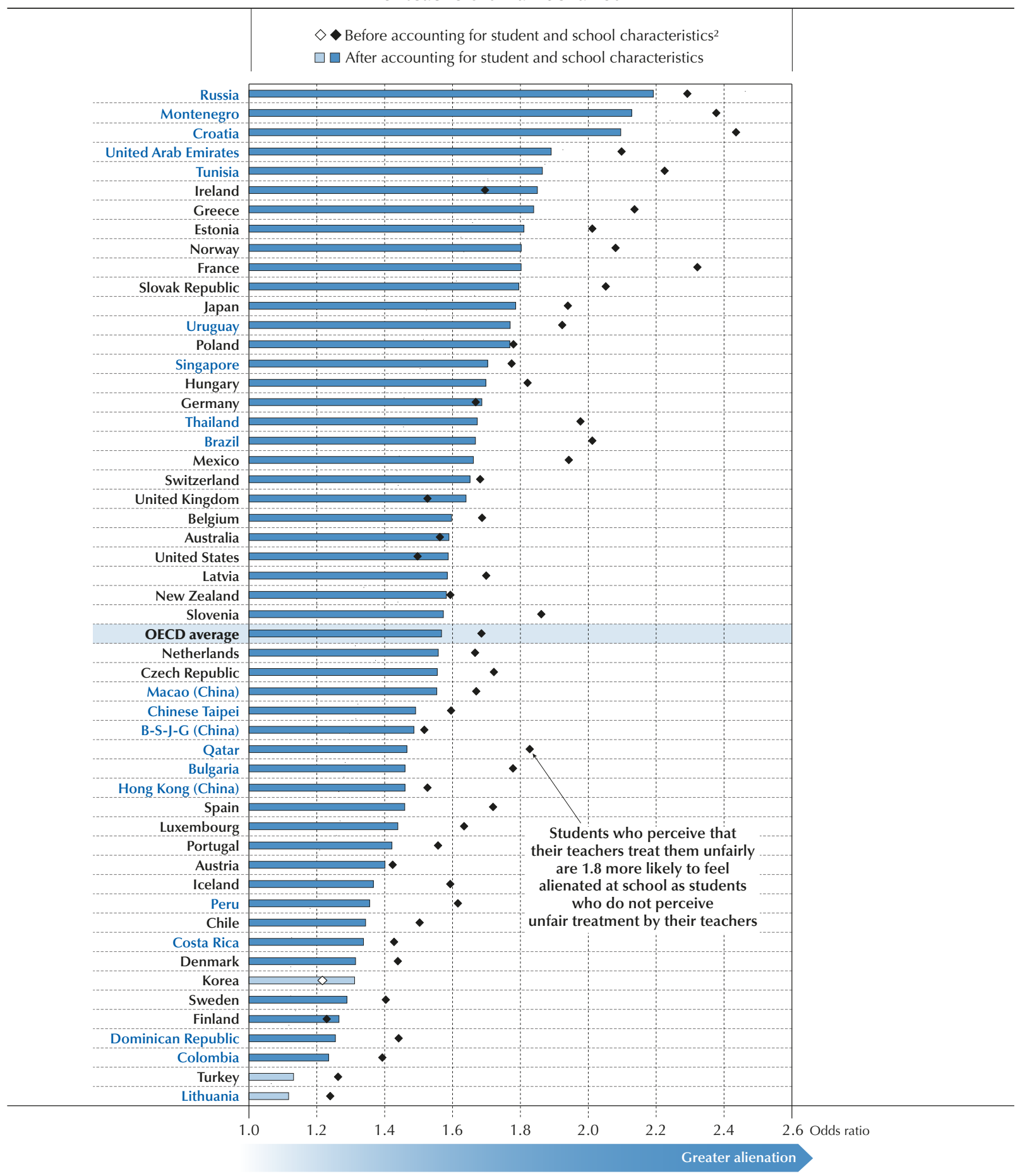

1. Perception of teachers behaving unfairly refers to students reporting "a few times a month" or "once a week or more" to the statements "Teachers disciplined me more harshly than other students", "Teachers ridiculed me in front of others" or "Teachers said something insulting to me in front of others". 2. Student and school characteristics include gender, performance in reading and science, and the PISA index of economic, social and cultural status (ESCS) at the student and school levels.

Notes: Statistically significant values are marked in darker tone (see Annex A3).

Countries and economies are ranked in descending order of the odds of reporting "I feel like an outsider (or left out of things)", after accounting for student and school characteristics.

Source: OECD, PISA 2015 Database, Table III.7.20.

StatLink त्ञाज ht htp://dx.doi.org/10.1787/888933471559 
Disadvantaged students and students with an immigrant background were also more likely to report unfair teacher behaviour (Tables III.7.16 and III.7.17). For example, disadvantaged students were 5 percentage points more likely than advantaged students to report that their teachers say something insulting to them in front of others. On average across OECD countries, students with an immigrant background were 4 percentage points more likely than students without an immigrant background to report that they frequently experience at least one of the six types of unfair treatments measured in PISA 2015 (Table III.7.17).

On the one hand, students who perceive that their teachers are supportive reported a greater sense of belonging at school (Figure III.7.8). On average across OECD countries, students who reported that their science teacher is willing to provide help and is interested in their learning are about 1.8 times more likely to feel that they belong at school than those students who did not report so. These results suggest that teachers may play a role in improving students' sense of belonging by showing attention and care to individual students.

On the other hand, across OECD countries, students who reported that they are treated unfairly by their teachers (they perceived that their teachers discipline them more harshly than other students, ridicule them in front of others or say something insulting to them in front of others) are 1.6 times more likely to feel like an outsider at school, on average across OECD countries, after accounting for student and school characteristics (Figure III.7.9). In Croatia, Montenegro and the Russian Federation (hereafter "Russia") students who reported that they are frequently treated unfairly by teachers were at least twice as likely to report that they feel like an outsider at school as students who reported that their teachers do not treat them unfairly, after accounting for socio-economic status. A similar association is observed when perceptions of unfair treatment are measured at the school level: in schools where perceptions of unfairness are pervasive (e.g. the share of students reporting unfair treatment is above the national average), students were more likely to report feeling like an outsider, after accounting for student and school characteristics (Table III.7.20).

One of the ways in which schools can improve their learning climate is by giving voice to students. Students can contribute perspectives on issues related to school climate and relationships that differ from those of principals or teachers (Levin, 2000; Mitra, 2003). Furthermore, by having a formal instrument to express their views, students themselves can develop a stronger sense of ownership and autonomy in their schools (Mitra, 2003; Rudduck and Flutter, 2000).

In PISA 2015, principals responded to a series of questions about quality assurance in their schools, one of which asks about the practice of seeking student feedback on teaching, resources and lessons. On average across OECD countries, around $10 \%$ of students were in schools that seek feedback from students because it is mandatory, $59 \%$ were in schools that seek feedback based on the school's initiative, and 31\% attend schools that do not have any mechanism in place to collect student feedback (Table III.7.21). Differences across countries are large: in the Dominican Republic, more than 96\% of students were in schools with this feedback mechanism (either mandatory or based on school initiative), while only $23 \%$ of students in France could provide feedback to the school administration. On average across OECD countries, students in advantaged schools were more likely to be asked for their feedback than students in disadvantaged schools. Private schools were also more likely than public schools to use this tool as a way to improve their students' learning experience.

These findings imply that policies and practices that promote communication and respectful interactions between teachers and students might help to enhance students' well-being (Anderman, 2003; O'Brien and Bowles, 2013). Improving students' sense of acceptance and belonging at school might also help students develop stronger interpersonal skills, openness and healthy attitudes towards other groups in society - qualities that are crucial for students' lives beyond school (O'Connor et al., 2010; Osterman, 2000; Shochet et al., 2006).

\section{What these results imply for policy}

- A sense of belonging at school makes a difference for both student performance and adolescents' satisfaction with life. School administrators and teachers need to put in place strategies to identify those students who are most at risk of social exclusion and provide them with the means to establish positive social ties with educators and peers.

- At 15, many students have strong perceptions that their teachers behave unfairly, and these perceptions can affect their sense of belonging and engagement at school. Teacher-training programmes might consider emphasising communication skills, the ability to manage behavioural problems and pedagogical approaches to establish positive and supportive relationships with students. Schools can also consider regularly collecting feedback from students on the quality of the learning climate and the relationships they maintain at school. 


\section{References}

Anderman, E.M. (2002), "School effects on psychological outcomes during adolescence", Journal of Educational Psychology, Vol. 94/4, pp. 795-809, http://dx.doi.org/10.1037/0022-0663.94.4.795.

Anderman, L.H. (2003), "Academic and social perceptions as predictors of change in middle school students' sense of school belonging", The Journal of Experimental Education, Vol. 72/1, pp. 5-22, http://dx.doi.org/10.1080/00220970309600877.

Arum, R. and M. Velez (eds.) (2012), Improving Learning Environments: School Discipline and Student Achievement in Comparative Perspective, Stanford University Press, Stanford, CA.

Battistich, V. et al. (1997), "Caring school communities", Educational Psychologist, Vol. 32/3, pp. 137-151, http://dx.doi.org/10.1207/ s15326985ep3203 1.

Battistich, V. et al. (1995), "Schools as communities, poverty levels of student populations, and students' attitudes, motives, and performance: a multilevel analysis", American Educational Research Journal, Vol. 32/3, pp. 627-658, http://dx.doi.org/10.2307/1163326.

Baumeister, R. F. and M. R. Leary (1995), "The need to belong: desire for interpersonal attachments as a fundamental human motivation", Psychological Bulletin, Vol. 117/3, pp. 497-529, http://dx.doi.org/10.1037/0033-2909.117.3.497.

Catalano, R.F. et al. (2004), "The importance of bonding to school for healthy development: findings from the social development research group", Journal of School Health, Vol. 74/7, pp. 252-261, http://dx.doi.org/10.1111/j.1746-1561.2004.tb08281.x.

Chiu, M.M. et al. (2016), "Students' sense of belonging at school in 41 countries cross-cultural variability", Journal of Cross-Cultural Psychology, Vol. 47/2, pp. 175-196, http://dx.doi.org/10.1177/0022022115617031.

Chiu, M.M. et al. (2012) "Immigrant students' emotional and cognitive engagement at school: a multilevel analysis of students in 41 countries", Journal of Youth and Adolescence, Vol. 41/11, pp. 1409-1425, http://dx.doi.org/10.1007/s10964-012-9763-x.

Goodenow, C. (1993), "Classroom belonging among early adolescent students: relationships to motivation and achievement", The Journal of Early Adolescence, Vol. 13/1, pp. 21-43, http://dx.doi.org/10.1177/0272431693013001002.

Hawkins, J.D. and J.G. Weis (1985), "The social development model: An integrated approach to delinquency prevention", The Journal of Primary Prevention, Vol. 6/2, pp. 73-97, http://dx.doi.org/10.1007/BF01325432.

Jethwani-Keyser, M.M. (2008), "When teachers treat me well, I think I belong": School belonging and the psychological and academic well being of adolescent girls in urban India", Unpublished Dissertation, New York University, New York, NY.

Juvonen, J. (2006) "Sense of belonging, social bonds, and school functioning", in P.A. Alexander and P.H. Winne (eds.), Handbook of Educational Psychology, Vol. 2, pp. 655-674, Lawrence Erlbaum Associates Publishers, New Jersey, http://psycnet.apa.org/psycinfo/ 2006-07986-028.

Lee, V.E. and D.T. Burkam (2003), "Dropping out of high school: The role of school organization and structure", American Educational Research Journal, Vol. 40/2, pp. 353-393, http://journals.sagepub.com/doi/abs/10.3102/00028312040002353.

Levin, B. (2000), "Putting students at the centre in education reform", Journal of Educational Change, Vol. 1/2, pp. 155-172, http://dx.doi. org/10.1023/A:1010024225888.

Maslow, A.H. (1943), "A theory of human motivation", Psychological Review, Vol. 50/4, pp. 370-396, http://dx.doi.org/10.1037/ h0054346.

Ma, X. (2003), "Sense of belonging to school: Can schools make a difference?", The Journal of Educational Research, Vol. 96/6, pp. 340-349, http://dx.doi.org/10.1080/00220670309596617.

Mitra, D. (2003), "Student voice in school reform: Reframing student-teacher relationships", McGill Journal of Education, Vol. 38/002, http://mje.mcgill.ca/article/view/8686 (accesed 4 April 2017).

Noble, T. et al. (eds.) (2008), "Scoping study into approaches to student wellbeing: Final report", Australian Catholic University and Erebus International, Brisbane, Qld, Au., http://researchdirect.westernsydney.edu.au/islandora/object/uws\%3A29490/.

O'Brien, K.A. and T.V. Bowles. (2013), "The importance of belonging foradolescents in secondary school settings", The European Journal of Social \& Behavioural Sciences, Vol. 5/2, pp. 976-984, http://dx.doi.org/10.15405/ejsbs.72.

O'Connor, M. et al. (2010), "Predictors of positive development in emerging adulthood", Journal of Youth and Adolescence, Vol. 40/7, pp. 860-874, http://dx.doi.org/10.1007/s10964-010-9593-7.

OECD (2016), PISA 2015 Results (Volume I): Excellence and Equity in Education, OECD Publishing, Paris, http://dx.doi.org/10.1787/ 9789264266490-en.

OECD (2015a), "Do teacher-student relations affect students' well-being at school?", PISA in Focus, No. 50, OECD Publishing, Paris, http://dx.doi.org/10.1787/5js391zxjjf1-en. 
OECD (2015b), Immigrant Students at School: Easing the Journey towards Integration, OECD Publishing, Paris, http://dx.doi.org/ 10.1787/9789264249509-en.

OECD (2010), Educating Teachers for Diversity: Meeting the Challenge, OECD Publishing, Paris, http://dx.doi.org/10.1787/9789264 079731-en.

OECD (2003), Student Engagement at School: A Sense of Belonging and Participation: Results from PISA 2000, OECD Publishing, Paris, http://dx.doi.org/10.1787/9789264018938-en.

Ogbu, J.U. (2003), Black American Students in An Affluent Suburb: A Study of Academic Disengagement, Routledge, New Jersey, NJ.

Osterman, K.F. (2000), "Students' need for belonging in the school community", Review of Educational Research, Vol. 70/3, pp. 323-367, http://dx.doi.org/10.3102/00346543070003323.

Rudduck, J. and J. Flutter (2000), "Pupil participation and pupil perspective: 'Carving a new order of experience'”, Cambridge Journal of Education, Vol. 30/1, pp. 75-89, http://dx.doi.org/10.1080/03057640050005780.

Schulenberg, J. et al. (1994), "High school educational success and subsequent substance use: A panel analysis following adolescents into young adulthood", Journal of Health and Social Behavior, Vol. 35/1, pp. 45-62, http://dx.doi.org/10.2307/2137334.

Shochet, I.M. et al. (2006) "School connectedness is an underemphasized parameter in adolescent mental health: Results of a community prediction study", Journal of Clinical Child \& Adolescent Psychology, Vol. 35/2, pp. 170-179, http://dx.doi.org/10.1207/ s15374424jсcp3502_1.

Suárez-Orozco, M.M. and C. Suárez-Orozco (2013), "Immigrant kids, adrift", The New York Times, web article, www.nytimes. com/2013/04/23/opinion/immigrant-kids-adrift.html, (accessed 7 April 2017).

Wentzel, K.R. (1998), "Social relationships and motivation in middle school: The role of parents, teachers, and peers", Journal of Educational Psychology, Vol. 90/2, pp. 202-209, http://dx.doi.org/10.1037/0022-0663.90.2.202. 


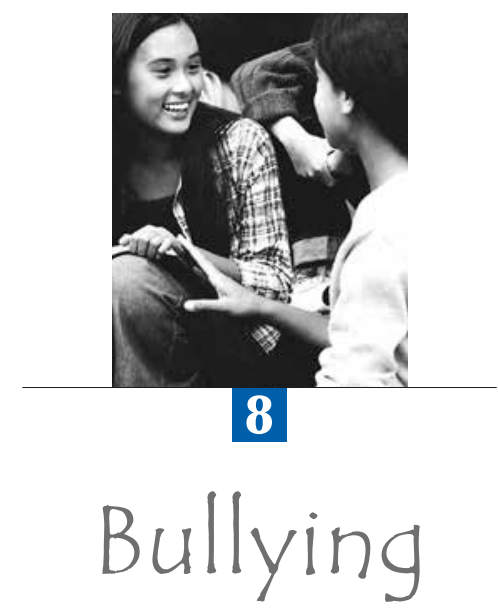

Bullying at school can have long-lasting consequences for students' (both victims and bullies) psychological well-being. This chapter defines bullying according to PISA and explains how PISA measures the incidence of bullying. It discusses the prevalence of bullying around the world and which students might be more likely to be victims of bullying. The chapter examines the relationship between bullying and student performance, and between bullying and other dimensions of students' well-being. The chapter concludes with a discussion on how schools, teachers and parents can help reduce the incidence of bullying. 
Education policy makers around the world are becoming increasingly concerned about bullying (Nansel et al., 2004; Rigby, 2007; Rivara and Le Menestrel, 2016). Bullying is a systematic abuse of power, and can be identified by three key traits: repetition, intention to harm, and an unequal power between the bully and the victim (Woods and Wolke, 2004). The prevalence of bullying has been shown to vary significantly across countries (Craig et al., 2009; Nansel et al., 2004). But in all countries bullying has harmful effects on individual students, their families and the school community.

\section{What the data tell us}

- Some $4 \%$ of students across OECD countries reported they are hit or pushed around by other students at least a few times per month. Around $11 \%$ of students reported that other students make fun of them at least a few times per month. Girls are less likely than boys to be victims of physical aggression, but are more likely to be the objects of nasty rumours. Recently arrived immigrant students were also more likely to report being victims of all types of bullying.

- Low-performing students are more likely to become victims of bullying. Students in schools where bullying is frequent, by international standards, score 47 points lower in science than students in schools where bullying occurs less frequently.

- Students who reported being frequently exposed to bullying also reported a weaker sense of belonging at school and less satisfaction with life. Students who are frequently bullied are also more likely to be truant.

- The proportion of students who reported being victims of bullying is larger in schools with high percentages of students who had repeated a grade, where students reported a poor disciplinary climate in class, and where students reported that their teachers treat them unfairly. Victimisation was less frequently reported by students who said that their parents support them when facing difficulties at school.

Bullying has serious consequences for both the bully and the victim (Rivers, 2000). Adolescents engaged in bullying as perpetrators, victims, or both are more likely to skip classes, drop out of school, and perform worse academically than schoolmates who have no conflictual relationships with their peers (Konishi et al., 2010; Townsend et al., 2008). Adolescents who bully or are bullied are more likely to show symptoms of depression and anxiety, have low selfesteem, feel lonely, change their eating patterns, and lose interest in activities (Haynie et al., 2001; Kochel et al., 2012; Striegel-Moore et al., 2002). Emotional and behavioural problems suffered by both victims and bullies may continue into adulthood, leading to long-term negative outcomes, including less participation in the labour force (Drydakis, 2014).

Bystanders are also negatively affected by bullying. Those who witness bullying often report feelings of guilt or helplessness for not confronting the bully and/or supporting the victim (Huitsing and Veenstra, 2012).

The likelihood of becoming a bully, or the victim of a bully, is often associated in the literature with certain personal characteristics, such as age, physical appearance, gender and ethnicity. For example, students who are obese are more likely to become victims or bullies than their peers who are not obviously overweight (Griffiths et al., 2006; Janssen et al., 2004). Research also shows that adolescents who are physically less developed, unhappy with their appearance, or socially isolated are also more likely to be victims of bullying (Faris and Felmlee, 2014). Adolescents who are victims of violence or aggression at home, or who are exposed to violent or abusive relationships between their parents, are more likely to become bullies themselves (Wolke and Skew, 2011).

But the fact that some types of adolescents are more at risk than others should not lead to the erroneous conclusion that only students with a specific personality or social profile can become bullies or victims of bullying. Bullies do not necessarily come from difficult homes, and they vary considerably in their levels of social skills. Some are leaders within their social groups; others are marginalised in the peer group and may, themselves, be victimised (Ma, 2004). Recent research has also shown the dynamic and fluid nature of children's involvement in bullying across roles and over time. For instance, a student may be victimised by classmates at school but bully his or her siblings at home (Swearer and Hymel, 2015).

Group dynamics are important in explaining and understanding bullying (Huitsing and Veenstra, 2012). Bullying involves more than solely those who bully and those who are bullied in the classroom (Salmivalli et al., 1996; Sutton et al., 1999). The physical or psychological abuse generally occurs in the presence of peers, who play a critical role in strengthening, maintaining or ending the bullying behaviours (Pepler, Craig and O'Connell, 2010). School policies can limit bullying by influencing group norms in the classroom (Card and Hodges, 2006). 


\section{DEFINING AND MEASURING BULLYING IN SCHOOL}

Bullying can take different forms. Physical (hitting, punching or kicking) and verbal (name-calling or mocking) bullying refers to direct forms of abuse (Smith and Sharp, 1994). Relational bullying refers to the phenomenon of social exclusion, where some children are ignored, excluded from games or parties, rejected by peers, or are the victims of gossip and other forms of public humiliation and shaming (Woods and Wolke, 2004).

As teenagers use electronic communications more and more, cyberbullying has become a new form of aggression expressed via online tools, particularly mobile phones (e.g. instant messaging, social networks and e-mails) (Box III.8.1). The different types of bullying - physical, verbal, relational, cyber - tend to occur concurrently. Bullying is particularly frequent during times of transition in children's and adolescents' lives, when they are figuring out where they fit in among new peer groups.

The rates of prevalence of bullying vary greatly across studies, reflecting differences in assessment approaches, as well as differences across contexts and cultures. PISA 2015 measures the incidence of bullying using reports from the victim's perspective. Figure III.8.1 shows the six questions on bullying included in PISA 2015 that are analysed in this report and the type of bullying they aim to measure. The index of exposure to bullying summarises students' reported experiences with these six forms of bullying (see Annex A1 for a detailed explanation of the construction of this index). The index was standardised to have a mean of 0 and a standard deviation of 1 across OECD countries. Positive values on the index indicate students who reported to be more frequently bullied than the average student in OECD countries, while negative values indicate students who reported less frequent exposure to bullying than the average student in OECD countries.

Students are classified as frequently bullied if they are among the $10 \%$ of students with the highest value on the index of exposure across all countries and economies with available data (a value greater than 1.59 on the index of exposure to bullying). This cut-off was selected because most of the students at or above this level are frequently exposed (at least a few times per month) to at least three of the six forms of bullying measured by the index (see Table A1.7 in Annex A1). Across all countries and economies with available data, more than one in two of the students who are classified as frequently bullied in this way reported they are made fun of, are excluded on purpose, or are objects of nasty rumours at least a few times per month; almost four out of ten reported that they are hit or pushed, threatened or have their belongings taken away or destroyed at least a few times per month.

Figure III.8.1 - Measures of bullying from the victim's perspective

\begin{tabular}{|c|c|}
\hline \multicolumn{2}{|c|}{ During the past 12 months, how often have you had the following experiences in school? } \\
\hline Action & Type of bullying \\
\hline Other students left me out of things on purpose. & Relational \\
\hline Other students made fun of me. & Verbal \\
\hline I was threatened by other students. & Verbal/physical \\
\hline Other students took away or destroyed things that belong to me. & Physical \\
\hline I got hit or pushed around by other students. & Physical \\
\hline Other students spread nasty rumours about me. & Relational \\
\hline
\end{tabular}

\section{REPORTED FREQUENCY OF BULLYING, VICTIMISATION AND STUDENT CHARACTERISTICS}

Certain types of bullying occur more frequently than others. Making fun of other students is usually the most common form of bullying (Wang, lannotti and Nansel, 2009). While the incidence of physical bullying and cyberbullying peaks among middle-school students and declines as students age, verbal and relational bullying remain frequent among upper secondary students (Williams and Guerra, 2007). PISA 2015 shows that, in many countries, verbal and psychological bullying occur frequently. On average across OECD countries, around $11 \%$ of students reported that they are frequently (at least a few times per month) made fun of, $8 \%$ reported that they are frequently the object of nasty rumours in school, and $7 \%$ reported that they are frequently left out of things. More than $10 \%$ of students in 34 out of 53 countries and economies reported that their peers make fun of them at least a few times per month. A similar proportion of students in 16 of 53 countries and economies reported that they are frequently the object of rumours, while in 13 out of 53 countries and economies, more than $10 \%$ of students reported that others frequently leave them out of things (Table III.8.1 and Figure III.8.2). 
Figure III.8.2 - Students' exposure to bullying

Results based on students' self-reports and index of exposure to bullying

\begin{tabular}{|c|c|c|c|c|c|c|c|c|c|c|c|}
\hline \multirow{2}{*}{\multicolumn{4}{|c|}{ Index of exposure to bullying }} & \multirow[b]{2}{*}{$\begin{array}{c}\text { Percentage } \\
\text { of } \\
\text { frequently } \\
\text { bullied } \\
\text { students }\end{array}$} & \multicolumn{7}{|c|}{ Percentage of students who reported being bullied at least "a few times a month" } \\
\hline & & & & & $\begin{array}{c}\text { Any type } \\
\text { of bullying } \\
\text { act }\end{array}$ & $\begin{array}{c}\text { Other } \\
\text { students } \\
\text { left me out } \\
\text { of things } \\
\text { on } \\
\text { purpose }\end{array}$ & $\begin{array}{c}\text { Other } \\
\text { students } \\
\text { made fun } \\
\text { of me }\end{array}$ & $\begin{array}{l}\text { I was } \\
\text { threatened } \\
\text { by other } \\
\text { students }\end{array}$ & $\begin{array}{l}\text { Other } \\
\text { students } \\
\text { took } \\
\text { away or } \\
\text { destroyed } \\
\text { things that } \\
\text { belong } \\
\text { to me }\end{array}$ & $\begin{array}{c}\text { I got hit } \\
\text { or pushed } \\
\text { around } \\
\text { by other } \\
\text { students }\end{array}$ & $\begin{array}{l}\text { Other } \\
\text { students } \\
\text { spread } \\
\text { nasty } \\
\text { rumours } \\
\text { about me }\end{array}$ \\
\hline & & $2+$ & Latvia & 17.5 & 30.6 & 12.7 & 15.0 & 6.5 & 7.2 & 8.4 & 13.2 \\
\hline & & 8 & New Zealand & 18.3 & 26.1 & 12.8 & 17.4 & 8.3 & 6.3 & 6.7 & 12.8 \\
\hline & & 要 & Singapore & 14.5 & 25.1 & 11.9 & 18.3 & 4.4 & 5.1 & 5.1 & 8.7 \\
\hline & & 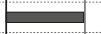 & Macao (China) & 14.4 & 27.3 & 9.5 & 19.9 & 6.2 & 8.5 & 4.2 & 9.3 \\
\hline & & 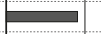 & Australia & 14.8 & 24.2 & 12.8 & 15.1 & 7.2 & 5.7 & 5.7 & 11.2 \\
\hline & & 8 & United Kingdom & 14.2 & 23.9 & 11.4 & 15.1 & 6.5 & 4.7 & 5.4 & 11.1 \\
\hline & & 8 & Canada & 12.9 & 20.3 & 9.5 & 13.4 & 4.7 & 4.0 & 5.0 & 7.8 \\
\hline & & 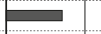 & Qatar & 19.1 & 25.0 & 12.2 & 14.6 & 8.7 & 9.1 & 8.8 & 12.3 \\
\hline & & 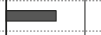 & Tunisia & 16.2 & 28.2 & 11.7 & 13.1 & 9.4 & 7.4 & 8.6 & 12.6 \\
\hline & & 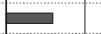 & United Arab Emirates & 17.8 & 27.0 & 12.4 & 15.9 & 8.2 & 9.4 & 8.0 & 12.7 \\
\hline & & 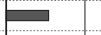 & Poland & 10.7 & 21.1 & 8.3 & 11.7 & 3.9 & 4.2 & 4.1 & 13.0 \\
\hline & & $\equiv$ & Estonia & 9.5 & 20.2 & 6.6 & 13.7 & 3.0 & 3.9 & 4.7 & 6.9 \\
\hline & & - & Switzerland & 7.3 & 16.8 & 5.6 & 10.7 & 2.4 & 4.6 & 2.8 & 7.0 \\
\hline & & Oa & Finland & 9.5 & 16.9 & 7.2 & 10.5 & 3.1 & 2.7 & 4.6 & 6.8 \\
\hline & & 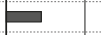 & Denmark & 6.4 & 20.1 & 6.0 & 11.2 & 1.9 & 4.2 & 3.5 & 7.7 \\
\hline & & $B$ & Hong Kong (China) & 15.4 & 32.3 & 8.5 & 26.1 & 7.1 & 10.5 & 9.5 & 9.4 \\
\hline & & $\theta$ & Belgium & 7.2 & 18.5 & 5.9 & 11.1 & 2.7 & 3.0 & 3.1 & 8.8 \\
\hline & & $\theta$ & Germany & 6.1 & 15.7 & 5.4 & 9.2 & 1.7 & 3.8 & 2.3 & 7.3 \\
\hline & & $\theta$ & United States & 10.0 & 18.9 & 10.0 & 11.4 & 4.9 & 3.5 & 3.8 & 7.9 \\
\hline & & $\theta$ & Colombia & 7.6 & 22.1 & 8.3 & 11.5 & 3.3 & 4.5 & 4.0 & 10.9 \\
\hline & & $\theta$ & Czech Republic & 11.7 & 25.4 & 9.8 & 11.1 & 4.5 & 7.3 & 7.5 & 13.3 \\
\hline & & $\theta$ & Chile & 7.9 & 18.0 & 7.4 & 9.6 & 2.9 & 4.6 & 3.2 & 9.6 \\
\hline & & $\beta$ & Bulgaria & 13.8 & 24.7 & 8.1 & 12.4 & 5.9 & 7.4 & 9.1 & 12.4 \\
\hline & & B & Mexico & 10.1 & 20.2 & 9.0 & 13.0 & 4.1 & 4.6 & 5.3 & 9.3 \\
\hline & & E & Thailand & 17.5 & 27.2 & 12.3 & 19.9 & 8.6 & 9.6 & 7.1 & 11.1 \\
\hline & & $\theta$ & Slovak Republic & 11.5 & 22.5 & 10.3 & 10.4 & 4.9 & 6.2 & 4.9 & 12.4 \\
\hline & & $P$ & Costa Rica & 10.9 & 20.8 & 8.1 & 11.8 & 4.6 & 2.0 & 2.7 & 12.2 \\
\hline & & E & Ireland & 6.8 & 14.7 & 5.9 & 8.5 & 2.9 & 3.4 & 3.1 & 6.0 \\
\hline & & E & B-S-J-G (China) & 10.5 & 22.5 & 7.9 & 12.3 & 3.5 & 12.5 & 4.2 & 6.3 \\
\hline & & F & Austria & 7.9 & 19.1 & 5.7 & 11.9 & 2.9 & 5.3 & 4.2 & 7.7 \\
\hline & & & Slovenia & 7.3 & 16.4 & 5.4 & 8.8 & 2.7 & 3.4 & 4.1 & 8.2 \\
\hline & & & OECD average & 8.9 & 18.7 & 7.2 & 10.9 & 3.7 & 4.2 & 4.3 & 8.4 \\
\hline & & & Norway & 9.6 & 17.7 & 7.0 & 9.4 & 3.8 & 5.0 & 4.6 & 8.4 \\
\hline & & & Russia & 9.5 & 27.5 & 18.1 & 11.8 & 5.0 & 5.6 & 3.1 & 9.0 \\
\hline & t. & t & Uruguay & 9.5 & 16.9 & 8.8 & 10.3 & 4.2 & 4.1 & 4.0 & 7.8 \\
\hline & - & . & Hungary & 9.3 & 20.3 & 9.4 & 9.6 & 3.9 & 5.0 & 3.9 & 11.8 \\
\hline & a & & France & 6.7 & 17.9 & 6.7 & 11.7 & 3.0 & 3.0 & 3.1 & 7.7 \\
\hline & G & 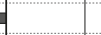 & Spain & 6.0 & 14.0 & 4.5 & 8.0 & 2.6 & 3.8 & 2.9 & 6.0 \\
\hline & G & & Lithuania & 9.6 & 16.4 & 6.8 & 9.2 & 4.8 & 4.2 & 4.4 & 7.9 \\
\hline & 可 & & Sweden & 8.4 & 17.9 & 6.4 & 9.4 & 3.9 & 4.5 & 5.4 & 7.1 \\
\hline & 可 & & Croatia & 6.7 & 17.1 & 5.1 & 8.0 & 3.9 & 3.5 & 3.9 & 9.5 \\
\hline & 日 & & Luxembourg & 7.9 & 15.7 & 5.7 & 8.6 & 3.4 & 4.2 & 3.5 & 7.9 \\
\hline & $\square$ & & Japan & 5.1 & 21.9 & 4.7 & 17.0 & 2.5 & 2.8 & 8.9 & 6.1 \\
\hline & E & & Brazil & 9.0 & 17.5 & 7.8 & 9.3 & 4.1 & 5.3 & 3.2 & 7.9 \\
\hline & $\square$ & & Peru & 6.1 & 18.4 & 6.2 & 7.7 & 2.7 & 5.4 & 3.6 & 9.6 \\
\hline & 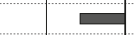 & & Dominican Republic & 12.2 & 30.1 & 16.2 & 15.3 & 8.3 & 11.4 & 4.8 & 13.1 \\
\hline & 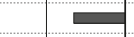 & & Netherlands & 3.3 & 9.3 & 2.5 & 4.3 & 1.3 & 2.2 & 1.8 & 4.9 \\
\hline & $\square$ & & Iceland & 5.1 & 11.9 & 4.6 & 6.7 & 2.9 & 1.8 & 2.4 & 4.9 \\
\hline & & & Portugal & 5.7 & 11.8 & 4.7 & 6.7 & 3.2 & 3.0 & 2.3 & 5.6 \\
\hline & & & Greece & 6.7 & 16.7 & 4.9 & 10.0 & 3.2 & 4.6 & 4.3 & 7.3 \\
\hline & & & Chinese Taipei & 3.1 & 10.7 & 3.3 & 6.8 & 1.0 & 3.5 & 0.8 & 3.5 \\
\hline & & & Montenegro & 7.0 & 16.4 & 4.9 & 6.8 & 6.2 & 4.0 & 3.5 & 9.9 \\
\hline & & & Turkey & 8.8 & 18.6 & 8.6 & 9.2 & 6.0 & 5.5 & 4.5 & 9.0 \\
\hline & & & Korea & 2.1 & 11.9 & 1.4 & 10.2 & 0.9 & 1.6 & 0.9 & 2.8 \\
\hline
\end{tabular}

1. A student is frequently bullied if he or she is in the top $10 \%$ of the index of exposure to bullying among all countries/economies. See Annex A1 for information on the index of exposure to bullying.

Note: The frequency of students' exposure to bullying is measured according to a three-point scale: 1) "Never or almost never"; 2) "A few times a year"; 3) "At least a few times a month". For detailed information on how the index of exposure to bullying was derived, see Annex A1.

Countries and economies are ranked in descending order of the index of frequent exposure to bullying.

Source: OECD, PISA 2015 Database, Table III.8.1.

StatLink : तiा ST http://dx.doi.org/10.1787/888933471563 
Physical bullying is probably the most obvious kind of violence in schools, and educators tend to perceive physical bullying as more serious than verbal and relational bullying (Craig et al., 2009; Rivara and Le Menestrel, 2016). On average across OECD countries, around $4 \%$ of students reported that they are hit or pushed at least a few times per month, although this percentage varies from around $1 \%$ to $9.5 \%$ across countries (Figure III.8.2). Another $7.7 \%$ of students reported they are physically bullied a few times per year (Table III.8.1). Similar proportions of students reported that they are threatened by others, and about $11 \%$ of students reported that their belongings have been destroyed or taken away by other students a few times per year.

\section{Box III.8.1 The rise of cyberbullying}

With the advent of social media and electronic communications, a new type of bullying has emerged: cyberbullying. Cyberbullying can take various forms, including sending nasty text messages, chats or comments, spreading rumours via online posts, or excluding someone from online groups. Online victims tend to be offline victims too (Salmivalli, Sainio and Hodges, 2013). But unlike traditional bullying, where a victim can find refuge at home, cyberbullying affects its victims anytime, anywhere - to the extent that a victim may feel incapable of escaping it (Agatston, Kowalski and Limber, 2007). Cyberbullying can also enable a relatively less "powerful" student to bully someone who is seen as more powerful (Rivara and Le Menestrel, 2016).

While boys are more likely to be bullies in traditional forms of bullying, girls are more likely to be involved in cyberbullying as victims and as perpetrators (Dukes, Stein and Zane, 2010; Mishna et al., 2012; Smith, 2013). The most recent data from the Health Behaviour in School-aged Children (HBSC) survey suggest that cyberbullying occurs less frequently than traditional forms of bullying, with between $1 \%$ and $12 \%$ of students in participating countries reporting to be victims of cyberbullying (Currie et al., 2012). Other studies find that between $7 \%$ and $15 \%$ of youth are affected by cyberbullying (Rivara and Le Menestrel, 2016). Students' ethnicity, sexual orientation, physical appearance, obvious health problems and disabilities are all related to the risk of becoming a victim of online harassment (Rivara and Le Menestrel, 2016).

The rise in the incidence of cyberbullying has been related to behavioural and psychosocial problems among young people (Ybarra and Mitchell, 2007). Victims and bullies are more likely to report feeling angry, anxious, sad or depressed. They often skip school, are harassed in other ways, and are unable to focus on school tasks (Juvonen and Gross, 2008; Li, 2005; Tokunaga, 2010). In extreme cases, victims may contemplate and even attempt suicide (DeSmet et al., 2014).

On average across OECD countries, boys were more likely than girls to report being bullied in all forms of bullying except being left out of things on purpose and being the object of nasty rumours (Figure III.8.3). Across OECD countries, 9.2\% of girls, on average, reported that they are victims of nasty rumours at least a few times per month while $7.6 \%$ of boys reported so.

Figure III.8.3 - Students' exposure to each type of bullying, by gender Percentage of students who reported being bullied at least a few times a month (OECD average)

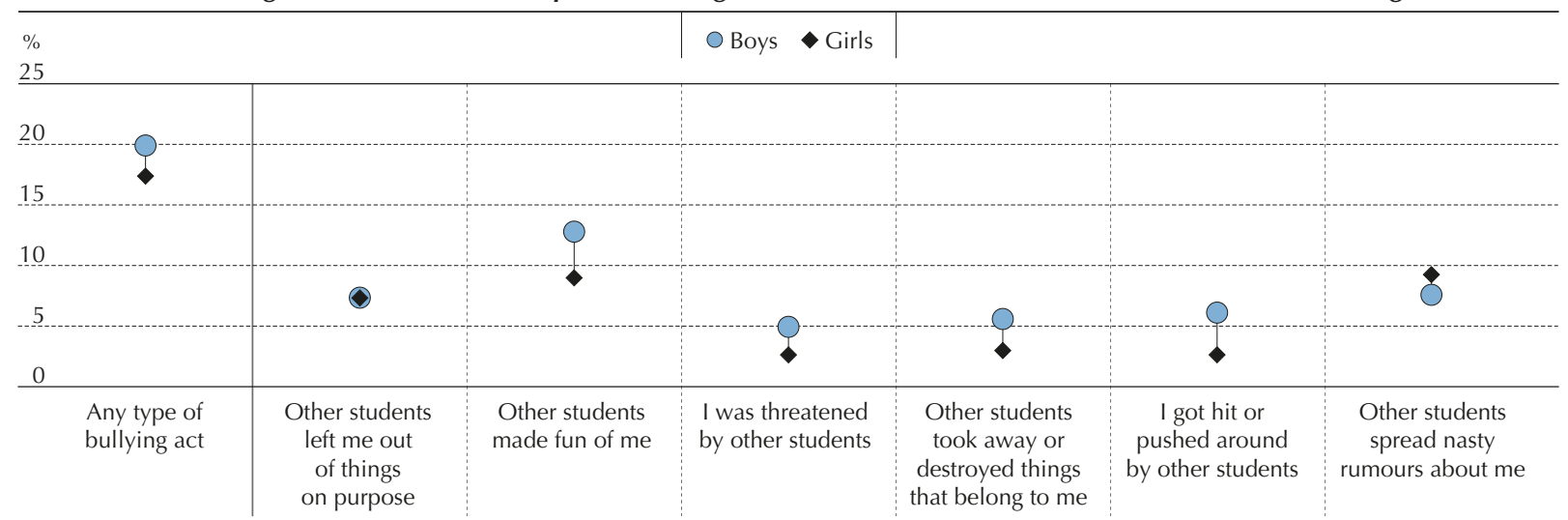

Note: All gender differences are statistically significant except for the statement "Other students left me out of things on purpose" (see Annex A3). Source: OECD, PISA 2015 Database, Table III.8.2.

StatLink 젶ㄴ http://dx.doi.org/10.1787/888933471577 
The difference between girls and boys in the percentage of students who reported that others spread nasty rumours about them is greater than five percentage points, in favour of girls, in Hong Kong (China), Macao (China), Qatar, Thailand, Tunisia and the United Arab Emirates. But the difference between boys and girls in the share of students who reported being frequently hit or pushed is larger than six percentage points, in favour of boys, in the Czech Republic, Hong Kong (China), Japan, Qatar, Singapore, Thailand, Tunisia and the United Arab Emirates (Table III.8.2). These findings are in line with previous research on gender differences in bullying that shows that boys are more often bullies than girls and are more likely to be physically violent towards each other (Camodeca et al., 2002; Veenstra et al., 2005).

Previous studies suggest that low socio-economic status is associated with a higher likelihood that children will be involved in bullying, either as a bully, a victim, or both ( Tippett and Wolke, 2014). Data from PISA 2015 show that, across OECD countries, the difference in the likelihood of being frequently bullied that is related to socio-economic status is not very large: on average between 1 and 2 percentage points, depending on the type of bullying (Table III.8.2). Concentration of disadvantage might, however, be related to a higher incidence of bullying. In 29 countries and economies with available data, students in disadvantaged schools were more likely to report being a victim of bullying than students in advantaged schools. Only in Japan, Korea and Macao (China) were students in advantaged schools more likely than students in disadvantaged schools to report so (Table III.8.6).

Because of differences in language, culture, ethnicity and appearance, children of immigrants might be more likely to be victimised (Qin, Way and Rana, 2008). Figure III.8.4 shows that the risk of being bullied increases substantially for those immigrant students who were 13 to 16 years old when they arrived in the host country. Poor language proficiency can be one reason why recently arrived students become targets of rumours or mocking (Peguero, 2008). In some contexts, long-standing conflicts between ethnic or national groups can lead to ethnic-based victimisation at school, and recent arrivals with weaker social networks can be easy targets for bullies (McKenney et al., 2006). The high rates of victimisation among recent arrivals suggest that there is a need for schools to provide activities that promote a common identity and instil an openness to cultural differences (OECD, 2016; Strohmeier and Spiel, 2003).

Figure III.8.4 - Immigrant students' age at arrival in the host country and exposure to bullying Percentage of immigrant students who reported being bullied at least a few times a month, by their age at arrival (OECD average)

\begin{tabular}{|c|c|}
\hline $\begin{array}{r}\% \\
25 \\
\end{array}$ & $\begin{array}{l}\square \text { I got hit or pushed around by other students } \\
\Delta \text { Other students made fun of me } \\
\diamond \text { Other students spread nasty rumours about me }\end{array}$ \\
\hline
\end{tabular}

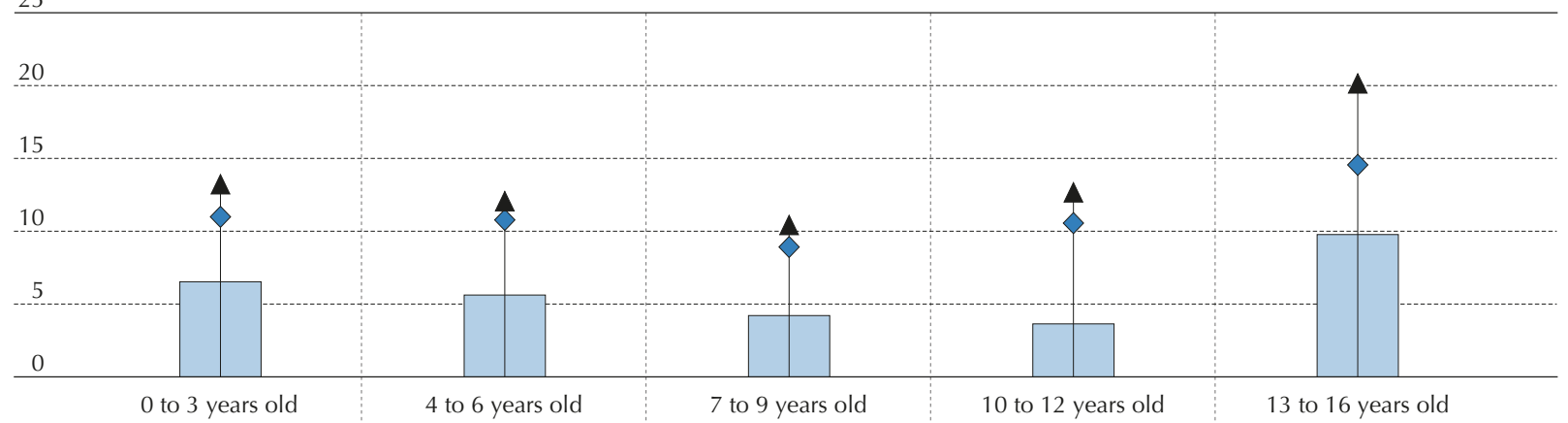

Source: OECD, PISA 2015 Database, Table III.8.11.

StatLink 페대 http://dx.doi.org/10.1787/888933471582

Age differences can be another risk factor for bullying and victimisation at school. Grade repetition is a common practice used to give children and adolescents an extra year to develop academically, socially and/or behaviourally (OECD, 2016). But an unintended consequence of grade repetition can be an increase in bullying, given that students who are older than most of their classmates tend to display more aggression during adolescence than students who may also be low achievers, but who are promoted to the next grade with the rest of their classmates (Crothers et al., 2010). Table III.8.14 shows that, in most countries and economies, the larger the share of students in a school who had repeated a grade, the higher the likelihood of students reporting that they are frequently bullied. This relationship is still observed after accounting for differences in the socio-economic profile of the schools. This finding does not establish a causal relationship between 
grade repetition and bullying behaviours; other school characteristics not accounted for in the analysis might be related to both a greater incidence of grade repetition and more frequent bullying. The finding might be related to the fact that students who have repeated a grade may have difficulty adjusting, socially and emotionally, to their status in class. Indeed, children frequently report that repeating a grade was the single most stressful event in their lives (Jimerson et al., 2002).

\section{EXPOSURE TO BULLYING AND ACADEMIC PERFORMANCE}

Being bullied can negatively affect academic achievement (Nakamoto and Schwartz, 2010) because the emotional, behavioural and psychological consequences of victimisation influence students' capacity to focus on academic tasks. Figure III.8.5 shows the percentage of students reporting that they are victims of certain types of bullying by deciles of science performance in PISA 2015. Across OECD countries, low performers tend to report greater exposure to physical, verbal and relational bullying. In Qatar, Thailand and the United Arab Emirates, students in the bottom decile of science performance were more likely - by at least 15 percentage points - to report being pushed or hit than students in the top decile of performance (Table III.8.4).

Figure III.8.5 - Percentage of frequently bullied students, by science performance Percentage of students who reported being bullied at least a few times a month (OECD average)

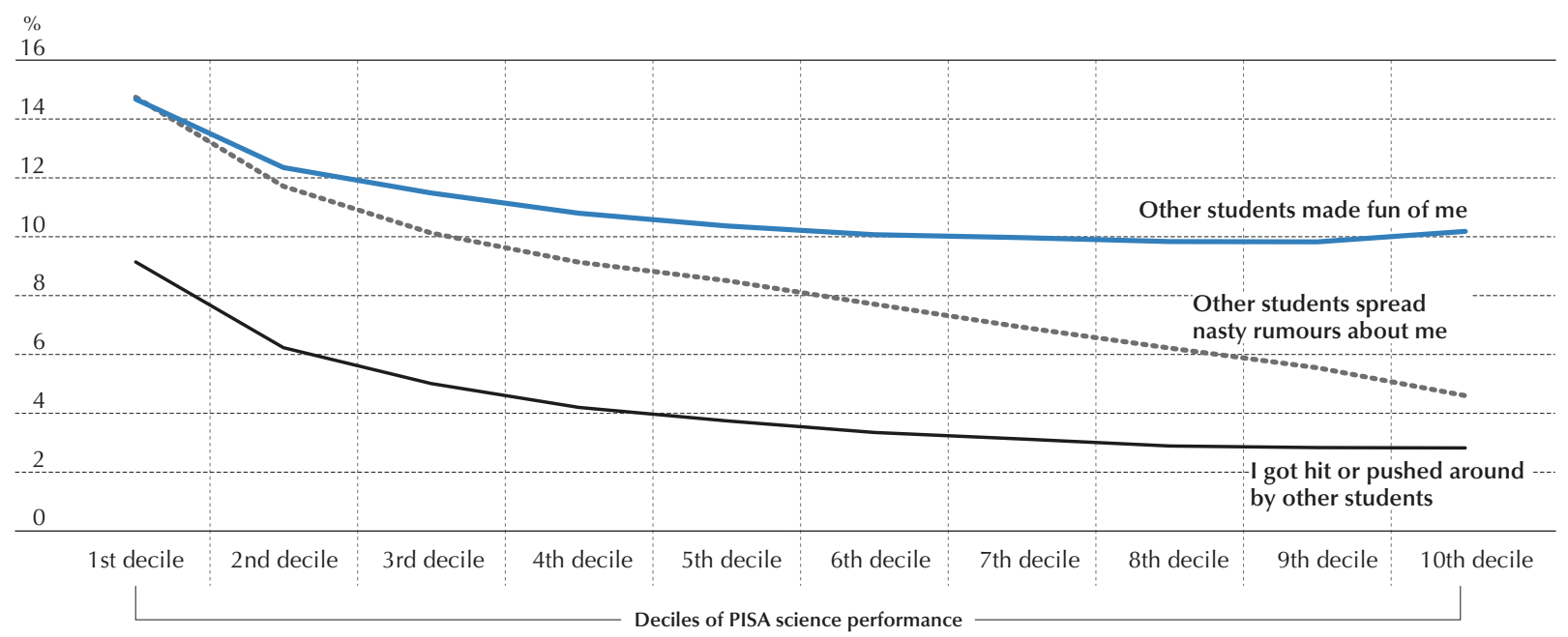

Source: OECD, PISA 2015 Database, Table III.8.4.

StatLink 제그 http://dx.doi.org/10.1787/888933471598

Frequent exposure to bullying among low performers might be related to the concentration of these students in schools that lack the resources to address disciplinary problems. Figure III.8.6 shows that, across OECD countries, schools where the incidence of bullying is high by international standards (more than 10\% of students are frequently bullied) score 47 points lower in science, on average, than schools where bullying is less frequent (schools where less than $5 \%$ of students are frequently bullied). This difference in performance between the two types of schools remains substantial (around 25 score points) even after accounting for differences in schools' socio-economic profile. When comparing schools with similar socio-economic profiles, the association between science performance and reported bullying is particularly strong in Greece. This relationship suggests that bullying can both stem from and may exacerbate students' disengagement with school and underperformance.

\section{REPERCUSSIONS OF BULLYING ON OTHER ASPECTS OF STUDENTS' WELL-BEING}

Being bullied, especially being constantly bullied, is stressful for anyone. While research on both animals and humans shows that moderate stress can have beneficial effects, chronic exposure to high levels of stress can be detrimental to both psychological and physical health (Rivara and Le Menestrel, 2016). Prolonged exposure to the stress hormone cortisol can alter parts of the brain architecture, such as the amygdala and the hippocampus, that are critical for regulating emotions. These negative effects are more problematic for young people because the body's system for handling stress is particularly sensitive during this period of development (McEwen and Morrison, 2013; Rivara and Le Menestrel, 2016). 
Figure III.8.6 - Prevalence of bullying and school performance in science

Score-point difference in science performance between schools with high and low prevalence of bullying ${ }^{1}$

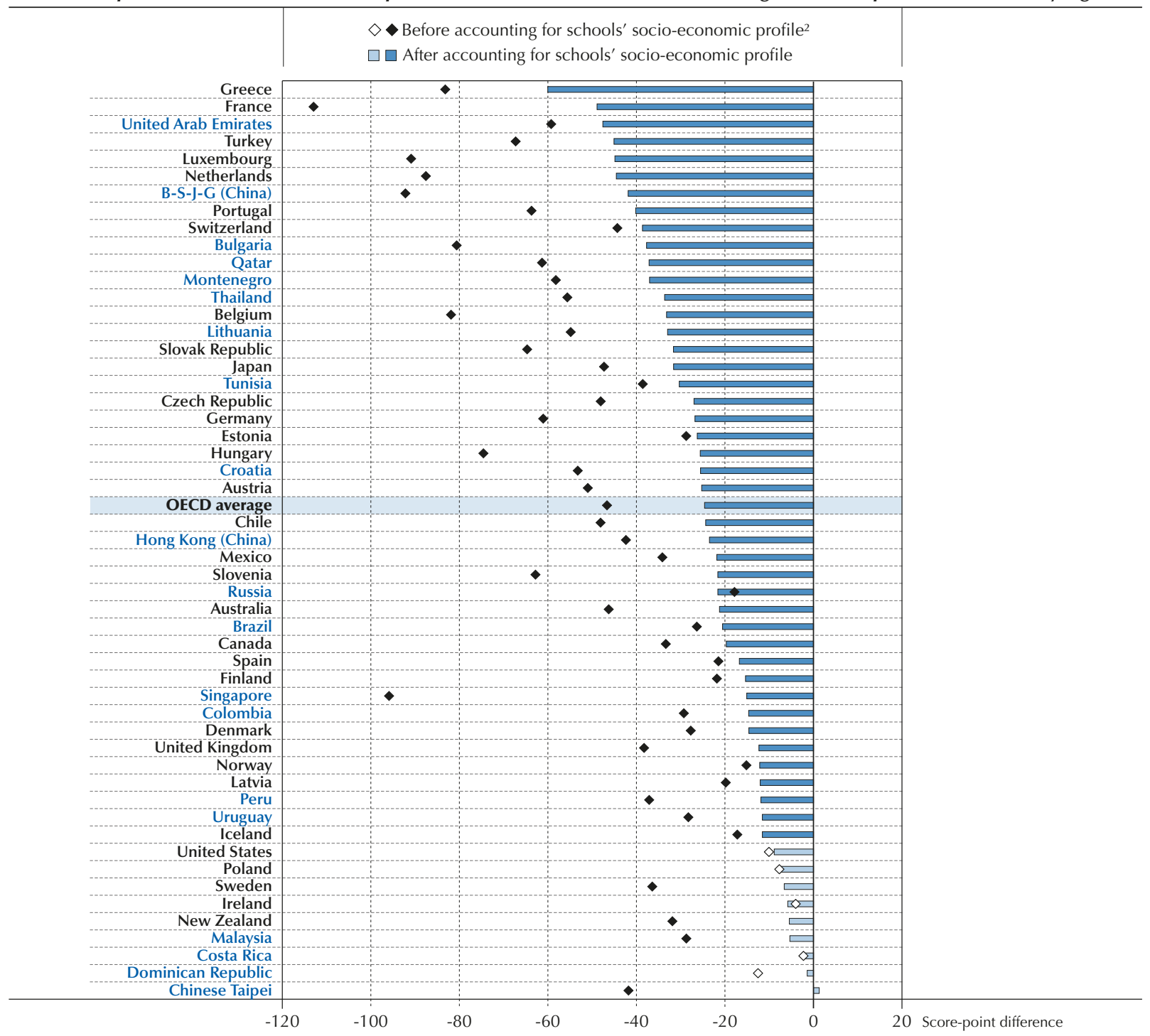

1. Schools with a high prevalence of bullying are those where more than $10 \%$ of students are frequently bullied. Schools with a low prevalence of bullying are those where $5 \%$ of students or less are frequently bullied. A student is frequently bullied if he or she is in the top $10 \%$ of the index of exposure to bullying among all countries/economies. See Annex A1 for information on the index of exposure to bullying.

2. The socio-economic profile is measured by the PISA index of economic, social and cultural status (ESCS).

Note: Statistically significant values are marked in a darker tone (see Annex A3).

Countries and economies are ranked in ascending order of the score-point difference in science performance between schools with a high prevalence of bullying and schools with a low prevalence of bullying, after accounting for schools' socio-economic profile.

Source: OECD, PISA 2015 Database, Table III.8.10.

StatLink तilst http://dx.doi.org/10.1787/888933471604

Figure III.8.7 indicates a negative association between being frequently bullied and several indicators of students' wellbeing, specifically students' sense of belonging at school, life satisfaction, expectations to remain in education, and engagement with school and confidence.

Students who are frequently bullied may feel constantly insecure and on guard, and have clear difficulties finding their place at school (Rivara and Le Menestrel, 2016). They tend to feel unaccepted and isolated and, as a result, are often withdrawn. As a way to reduce their exposure to bullies, they often forego making friends or miss out on taking chances that could help them become better integrated with their schoolmates (Juvonen and Graham, 2014). On average across OECD countries, about $42 \%$ of students who are frequently bullied - but only $15 \%$ of students who are not frequently bullied - reported feeling like an outsider at school (Figure III.8.8). 


\section{Box III.8.2 Socialising with friends outside of school}

Relationships with peers strongly affect teenagers' well-being. Adolescents develop friendships that are more intimate, exclusive and constant than in earlier years. Frequent and positive interactions with friends may give students a greater sense of belonging at school, and be a source of happiness and self-esteem (Goodenow and Grady, 1993). Adolescents who do not have friends are often depressed (Parker and Asher, 1993). Having healthy relationships with peers can also motivate young people to study harder in school, participate in sports, volunteer and engage in other productive activities.

Figure III.8.7 • Life satisfaction and socialising with friends

Change in life satisfaction associated with talking or meeting with friends after school, after accounting for student characteristics ${ }^{1}$

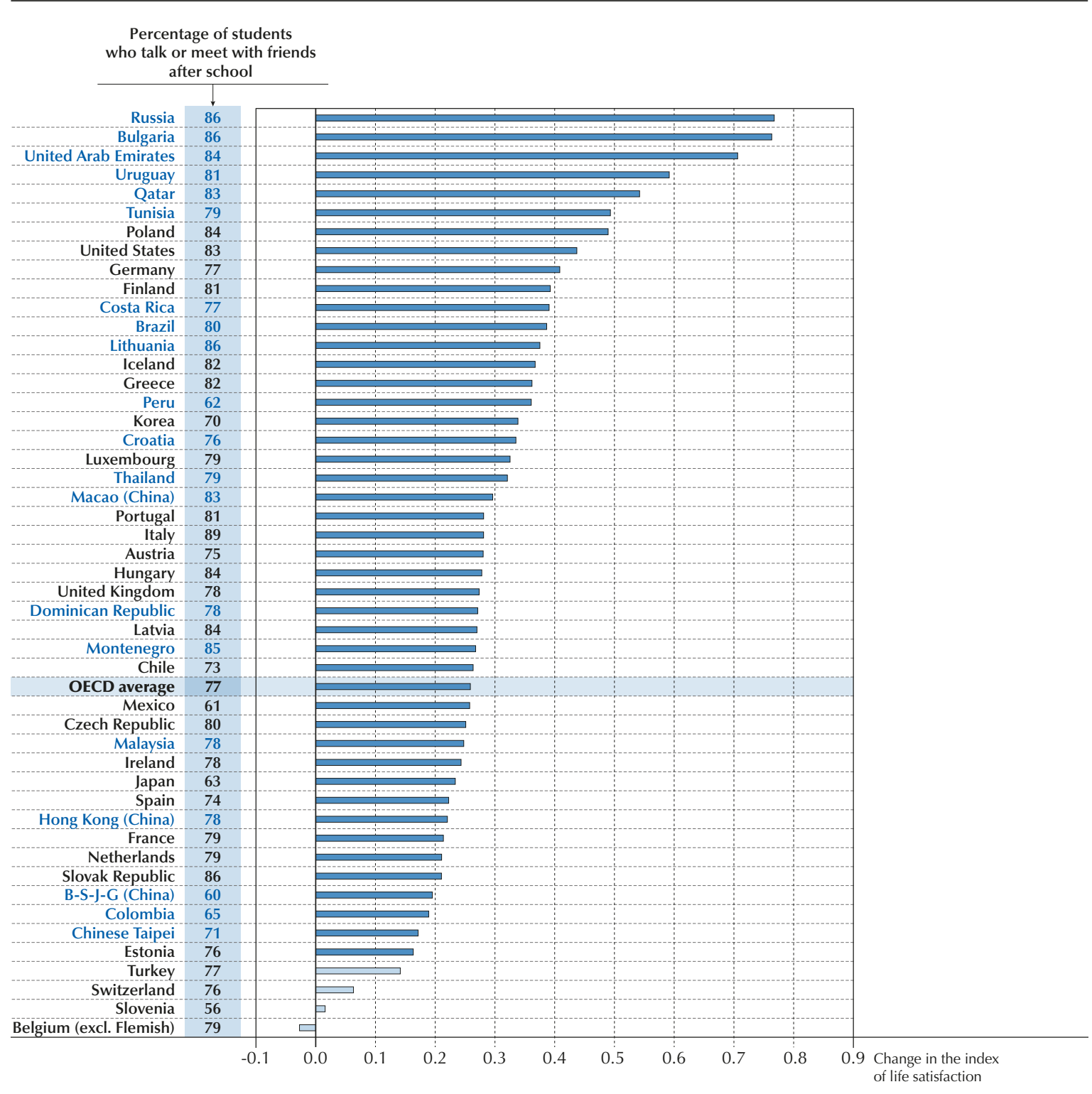

1. Student characteristics include the PISA index of economic, social and cultural status (ESCS) and gender.

Note: Statistically significant values are marked in a darker tone (see Annex A3).

Countries and economies are ranked in descending order of difference in life satisfaction associated with talking with friends after school.

Source: OECD, PISA 2015 Database, Tables III.8.21 and III.8.23.

StatLink 제피 http://dx.doi.org/10.1787/888933471615 
But peers can also have adverse effects on adolescents, such as when the social group does not value school or education, or when it disparages the drive to achieve at school (Berndt, 1999). Peer pressure may also encourage adolescents to drink, smoke, use drugs, vandalise or steal (Bauman and Ennett, 1994).

PISA 2015 asked students whether they meet or talk with friends before or after school. The questionnaires that elicited this information did not ask students to give details about the number or gender of their friends, or about the duration, frequency and types of interactions students have with their friends.

Some $77.5 \%$ of students reported that they meet or talk with friends after school and $57.7 \%$ of students reported that they interact with friends before school, on average across OECD countries (Table III.8.21). In Italy and Israel, close to $90 \%$ of students reported that they meet or talk with friends after school, while in Beijing-ShanghaiJiangsu-Guangdong (China) (hereafter "B-S-J-G [China]") and Slovenia, the share is closer to $60 \%$. In the majority of countries, girls were more likely than boys to report that they socialise with friends, but the gender difference in the share of students who reported so is 10 percentage points or less across all countries and economies. In most countries and economies, students with an immigrant background were less likely than students without an immigrant background to report that they interact with friends before or after school (Table III.8.22).

Students who meet or talk with friends either before or after school tended to report higher levels of life satisfaction. On average across OECD countries, students who talk with or meet friends after school reported a level of life satisfaction around 0.3 point higher on the life satisfaction scale (which ranges from 0 to 10) than students who do not talk with or meet friends after school. In Bulgaria, the Russian Federation and the United Arab Emirates, the difference between the two groups is larger than 0.7 point (Figure III.8.7).

Stressful life events, like bullying, can lead to depression, anxiety and symptoms of other psychological problems, such as sleep disorders (Swearer and Hymel, 2015). Victims of severe bullying think more often about suicide (Ybarra et al., 2006). Figure III.8.8 shows that $26 \%$ of frequently bullied students reported relatively low satisfaction with life (a value less than or equal to 4 on a scale from 0 to 10). Only around $10 \%$ of students who are not frequently bullied reported such low satisfaction with their life. In Korea, Turkey and the United Kingdom, more than one in three frequently bullied students reported low satisfaction with life (Table III.8.15). This relationship does not seem to be affected by the gender of the student, his or her socio-economic status or the socio-economic profile of the school. Victims of bullying are also more likely to experience schoolwork-related anxiety, either because anxious individuals are easy targets of bullies or because negative results at school are more worrying for students who are picked on by their peers (Berry and Hunt, 2009). Table III.8.15 shows that, in the majority of countries and economies, frequently bullied students are more likely than students who are not frequently bullied to report feeling anxious before a test, even if well prepared.

Figure III.8.8 - Relationship between being frequently bullied and other student outcomes Results based on students' self-reports (OECD average)

\begin{tabular}{|c|c|c|c|c|c|}
\hline $\begin{array}{c}\% \\
70 \\
\end{array}$ & & $\begin{array}{l}\boldsymbol{\Delta} \mathrm{Fr} \\
\square \mathrm{N}\end{array}$ & $\begin{array}{l}\text { tly bullied }{ }^{1} \\
\text { uently bullied }\end{array}$ & & \\
\hline 60 & & & & & $\Delta$ \\
\hline 50 & & & & & 口 \\
\hline 40 & $\mathbf{A}$ & $A$ & & & \\
\hline 30 & 口 & & & & \\
\hline 20 & & & $\mathbf{A}$ & & \\
\hline 10 & & $\square$ & & & \\
\hline 0 & & & & 둠 & \\
\hline Students who.... & $\begin{array}{l}\text {... expect to end } \\
\text { their education } \\
\text { at the secondary level }\end{array}$ & $\begin{array}{c}\text {... feel like an outsider } \\
\text { (or left out of things) } \\
\text { at school }\end{array}$ & $\begin{array}{c}\ldots \text { are not satisfied } \\
\text { with life }{ }^{2}\end{array}$ & $\begin{array}{l}\text {... skipped school } \\
\text { at least 3-4 days } \\
\text { in previous two weeks }\end{array}$ & $\begin{array}{l}\ldots \text { feel anxious } \\
\text { for a test even } \\
\text { if well prepared }\end{array}$ \\
\hline
\end{tabular}

1. A student is frequently bullied if he or she is in the top $10 \%$ of the index of exposure to bullying among all countries/economies. See Annex A1 for information on the index of exposure to bullying.

2. A student is classified as "not satisfied" with life if he or she reported between 0 and 4 on the life-satisfaction scale. The life-satisfaction scale ranges from 0 to 10 .

Note: All differences between frequently bullied and not frequently bullied students are statistically significant (see Annex A3).

Source: OECD, PISA 2015 Database, Table III.8.15.

StatLink त्ञात्र http://dx.doi.org/10.1787/888933471624 
Exposure to severe bullying can affect not just how young people feel but also how they behave. The behavioural consequences of bullying others and being bullied include aggression, misbehaviour, irresponsible risk-taking, and the use of illegal substances (Kretschmer et al., 2016). Victims of bullying often decide to stay out of school. On average across OECD countries, about $9 \%$ of frequently bullied students (compared with less than half of that percentage among students who are not frequently bullied) reported that they had skipped school more than three or four times in the two weeks prior to the PISA test (Figure III.8.8)'

Bullied students are also more likely to develop negative expectations about the future. If children feel anxious about their social life at school, they might consider leaving formal education altogether. Figure III.8.8 shows that around $45 \%$ of frequently bullied students (compared with 35\% of students who are not frequently bullied) expect to leave school at the end of their secondary education. This relationship is more strongly mediated by the socio-economic profile and performance of students and schools than the other relationships shown in Figure III.8.8 (Table III.8.15).

\section{THE ROLE OF SCHOOLS, TEACHERS AND PARENTS IN ENDING BULLYING}

Teachers and school staff are in a unique position to promote healthy relationships among students, intervene in instances of bullying and, with parents, help bullies and their victims learn how to build, or re-build, strong and healthy relationships with their peers (Pepler et al., 2006). Protecting children from abuse is the responsibility of all the adults in their lives, primarily parents and teachers. Close communication among these adults is essential for conveying consistent messages and supporting children in all the contexts in which they live, work and play. Young people who are more connected with their teachers and parents are less likely to be bullied; and even if they are bullied, they are less likely to develop crippling psychological problems as a result (Morin et al., 2012).

Educators can reduce aggression and victimisation by creating a climate of support and empathy both in and outside of the classroom (Espelage et al., 2013; Goldweber, Waasdorp and Bradshaw, 2013; Johnson, 2009). A school's disciplinary structure and adult support of students are the two key components of a positive school climate to counter bullying (Gregory and Cornell, 2009). Disciplinary structure refers to the idea that school rules are perceived as strict but fairly enforced. Adult support refers to students' perceptions that their teachers and other school staff members treat them with respect and want them to be successful (Konold, 2014). Schools with a low incidence of physical and relational violence tend to have more students who are aware of school rules, believe that these rules are fair, and have positive relations with their teachers (Gregory and Cornell, 2009).

\section{Box III.8.3 Anti-bullying programmes: How they work and evidence of their effectiveness}

School-based bullying-prevention programmes run the gamut from putting in place preventive measures to emphasising monitoring and surveillance in schools. Many anti-bullying programmes involve a whole-of-school approach, with co-ordinated engagement among teachers, students and parents. Several of these holistic programmes include training for teachers on bullying behaviour and how to handle it, anonymous surveys of students to monitor the prevalence of bullying, and a strategy to provide information to and engage with parents (Smith, Pepler and Rigby, 2004).

The Olweus Bullying Prevention Programme, first developed and implemented in Norway, has greatly influenced the design of anti-bullying strategies around the world. This programme includes meetings among teachers, improved supervision, surveys of students, parent-teacher meetings, role-playing among students to learn how to handle bullies, gathering and disseminating information about bullying for students and parents, developing class rules against bullying, and talking with bullies and their parents without imposing punitive measures (Ttofi and Farrington, 2009). Other prevention programmes include KiVa, which was developed in Finland and is now implemented in Belgium, Estonia, Hungary, Italy, the Netherlands and Sweden (Salmivalli, Kärnä and Poskiparta, 2011; Salmivalli, Kaukiainen and Voeten, 2005), the Kia Kaha programme, developed in New Zealand (Raskauskas, 2007), and the Respect programme in Norway (Ertesvåg and Vaaland, 2007). Castile and Leon (Spain) recently launched an anti-bullying strategy that co-ordinates the plans and actions of all public and private institutions involved in the fight against bullying (see box III.14.4).

The majority of studies evaluating bullying-prevention programmes find a positive impact (Evans, Fraser and Cotter, 2014; Ferguson et al., 2007; Smith, Pepler and Rigby, 2004; Ttofi and Farrington, 2010, 2009). But in most cases, 
the impact is modest. Randomised control trials found that the KiVa programme had a significant impact on reducing the incidence of bullying, and also made a difference in students' attitudes toward bullies and victims (Nocentini and Menesini, 2016; Salmivalli, Kärnä and Poskiparta, 2011).

After comparing the impact of the individual components of anti-bullying programmes, Ttoffi and Farrington (2009) found that training and information for parents, better supervision in the playground, improved disciplinary measures, working with peers, and classroom management are the most effective measures against bullying (Ttofi and Farrington, 2009). Programmes also need to be long-term, and frequently monitored and evaluated to be effective (Ttofi and Farrington, 2010). And programmes that combine systematic monitoring and targeting of high-risk youth tend to be more effective than programmes that do not include these actions (Ferguson et al., 2007; Smith, Pepler and Rigby, 2004).

Although these programmes may not eliminate bullying entirely, appropriate interventions can change the norms, attitudes towards and perceptions of bullying among students, teachers and parents. Over the medium and long term, these changes in attitude can help to mitigate the harmful effects of bullying and being bullied.

One of the common factors related to a lower incidence of bullying and victimisation is class and school discipline (Cornell and Huang, 2016; Gregory et al., 2010). When they work in a structured and orderly environment, students feel more secure, become more engaged with school work, and are less inclined to engage in high-risk behaviours (Kuperminc, 2001). Figure III.8.9 shows that, on average across OECD countries, the proportion of frequently bullied students is about 7 percentage points larger in schools with a poor disciplinary climate (worse than the country average) than the proportion in schools with a good disciplinary climate (better than the country average), before accounting for students' and schools' socio-economic profile (the difference is equal to 6 percentage points after accounting for socioeconomic background). The relationship between bullying and disciplinary climate at school is particularly strong in Macao (China), the Slovak Republic and the United Arab Emirates, before accounting for schools' socio-economic profile.

Perceptions of teacher unfairness might lead some children to believe they have the right to offend others as a way of exercising power. Students who have been humiliated or have had their self-confidence undermined often try to regain it by asserting their superiority over more vulnerable groups. Figure III.8.10 shows that, on average across OECD countries, students who attend schools with pervasive perceptions of teachers' unfair behaviour (perceptions of unfairness in the school are above the national average) are 12 percentage points more likely to be frequently bullied than students in schools where these perceptions are not as pervasive (perceptions of unfairness are below the national average). This could indicate that bullying is more frequent in schools where students do not perceive their teachers as effective in transmitting norms of respectful and non-violent behaviour. This relationship is only partly related to other characteristics of the schools, such as average performance or socio-economic profile. The association between perceptions of teacher unfairness in the school and student victimisation by bullies is particularly strong (over 10 percentage points, after accounting for student and school characteristics) in Brazil, Chile, the Czech Republic, the Dominican Republic, Greece, New Zealand, the Slovak Republic, Slovenia, Thailand and Tunisia. Teachers might help to limit bullying by being models of fair behaviour and respect (Veenstra et al., 2014).

While teachers are at the frontlines of implementing anti-bullying strategies, many are not aware of the frequency and severity of bullying in their school, and are not sufficiently prepared to intervene to prevent bullying (Veenstra et al., 2014). On average across the countries and economies that participated in the 2013 OECD Teaching and Learning International Survey (TALIS), $13 \%$ of lower secondary teachers (40\% in Japan and 30\% in Korea) reported a high need for professional development activities in the area of classroom management (OECD, 2014). Targeted training for school personnel can improve their bullying-intervention skills and their self-efficacy in working with students to prevent bullying (Duy, 2013; Gorsek and Cunningham, 2014).

PISA does not include data on teachers' participation in bullying-prevention programmes. But in the 19 countries and economies that distributed the teacher questionnaire, teachers reported whether their initial education or their professional development activities included training on student behaviour and classroom management. On average across these 19 countries and economies, 70\% of students have teachers who reported that they attended courses during initial teacher training on how to manage students' behaviour. On average, only $42 \%$ of students have teachers who participated in professional development activities (i.e. additional training) focused on addressing behavioural issues. In Australia, Germany and Chinese Taipei, teachers in disadvantaged schools are more likely than teachers in advantaged schools to participate in these types of professional development activities (Table III.8.20). 
Figure III.8.9 - Exposure to bullying and school's disclipinary climate

Estimated difference in the percentage of frequently bullied students ${ }^{1}$ between schools with positive and negative disciplinary climate ${ }^{2}$

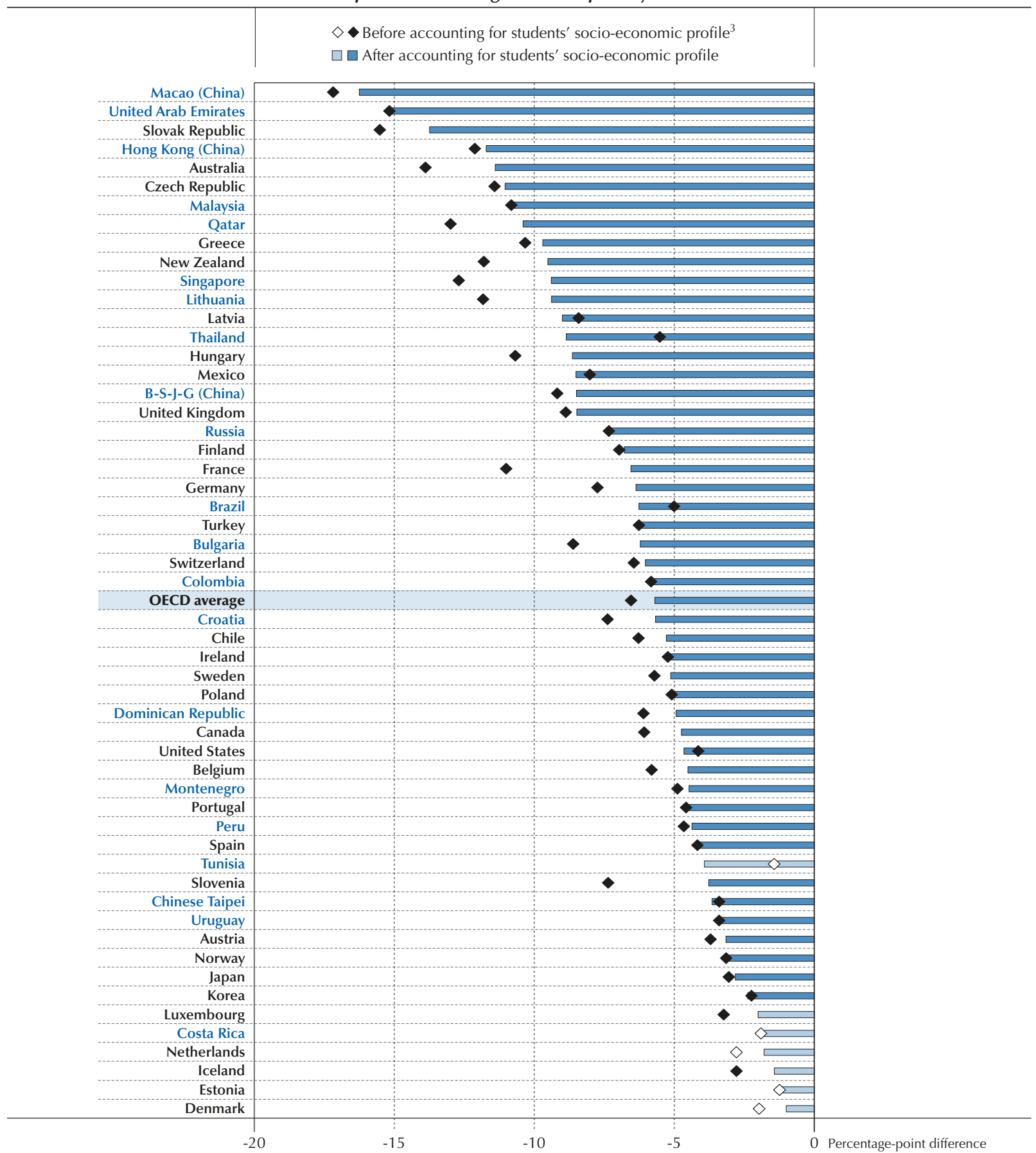

1. A student is frequently bullied if he or she is in the top $10 \%$ of the index of exposure to bullying among all countries/economies. See Annex A1 for information on the index of exposure to bullying.

2. Schools with positive (negative) disciplinary climate are those whose average index of disciplinary climate is statistically higher (lower) than the country/ economy average.

3. The socio-economic profile is measured by the PISA index of economic, social and cultural status (ESCS).

Note: Values that are statistically significant are indicated in a darker tone (see Annex A3).

Countries and economies are ranked in ascending order of the difference in the percentage of bullied students between schools with a positive disciplinary climate and schools with a negative disciplinary climate, after accounting for students' and schools' socio-economic profile.

Source: OECD, PISA 2015 Database, Table III.8.16.

StatLink 세개 http://dx.doi.org/10.1787/888933471630 
Figure III.8.10 - Students' exposure to bullying and perceptions of teachers' unfairness Difference in the percentage of frequently bullied students ${ }^{1}$ between schools with pervasive/not pervasive student perceptions of teachers' unfair behaviour ${ }^{2}$

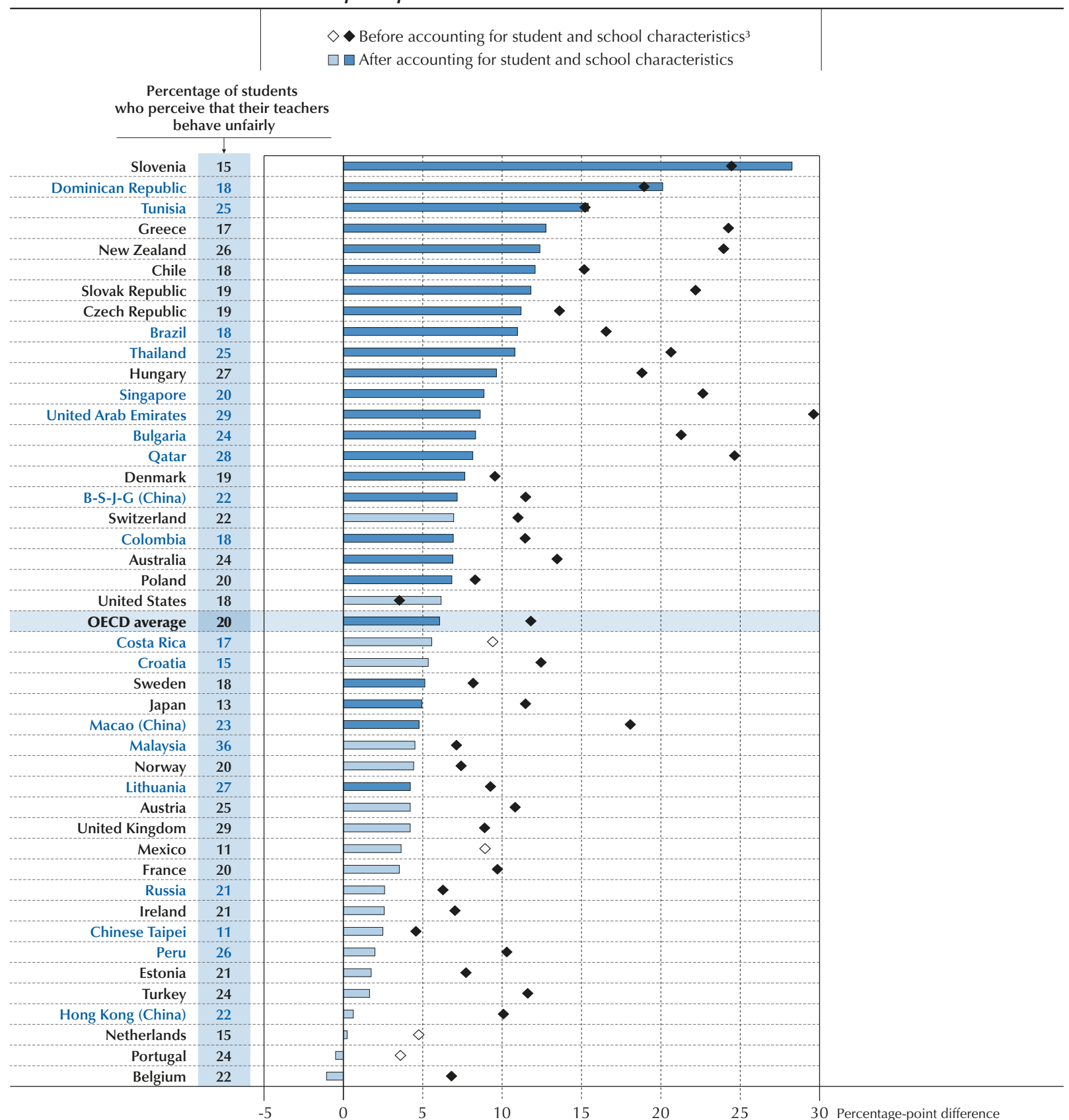

1. A student is frequently bullied if he or she is in the top $10 \%$ of the index of exposure to bullying among all countries/economies. See Annex A1 for information on the index of exposure to bullying.

2. Perception of teachers' unfair behaviour is defined by a student reporting that "Teachers discipline [him/her] more harshly than other students", that "Teachers ridicule [him/her] in front of others" or that "Teachers say something insulting to [him/her] in front of others" at least a few times a month. Schools with high (low) percentages of frequently bullied students are those where the percentage of students who perceive that teachers treat them unfairly are higher (lower) than the national average.

3. Student and school characteristics include gender, the PISA index of economic, social and cultural status (ESCS) at the student and at the school levels, and science performance at the school level.

Note: Statistically significant differences are shows in a darker tone (see Annex A3).

Countries and economies are ranked in descending order of the difference in the percentage of frequently bullied students between schools with pervasive perceptions of teachers' unfair behaviour and those where perceptions of teachers' unfair behaviour are not pervasive, after accounting for student and school characteristics.

Source: OECD, PISA 2015 Database, Table III.8.17.

StatLink 제프 http://dx.doi.org/10.1787/888933471640 


\section{THE ROLE OF PARENTS IN REDUCING THE NEGATIVE IMPACT OF BULLYING}

Stable emotional support from parents - including listening, offering praise, affection, trust and respect - is particularly important for adolescent victims of bullying (Amato, 1994; Gorman-Smith, Henry and Tolan, 2004; Leadbeater, Hoglund and Woods, 2003). Research has shown that caring parents can reduce the stress and pain of students who have been bullied (Rivara and Le Menestrel, 2016). Conversely, a home environment where parents unduly criticise their children, impose few rules, mistreat their children or are violent towards each other has been linked to greater incidence of bullying and victimisation (Holt, Kantor and Finkelhor, 2008 ).

In PISA 2015, students were asked to report the degree of emotional support they receive from their parents. On average across OECD countries, around $91 \%$ of students reported that their parents support them when facing difficulties at school (Table III.9.18). Disadvantaged students were less likely to report so), possibly because parents who are financially stressed are less likely to have the time, and the emotional and psychological presence to be fully supportive. As Figure III.8.11 illustrates, across OECD countries, the average share of students who reported being frequently bullied is substantially larger among students who also reported that their parents are not emotionally supportive.

Figure III.8.11 - Exposure to bullying and parental support

Percentage of students who are bullied a few times a month or more among students with and without supportive parents ${ }^{1}$

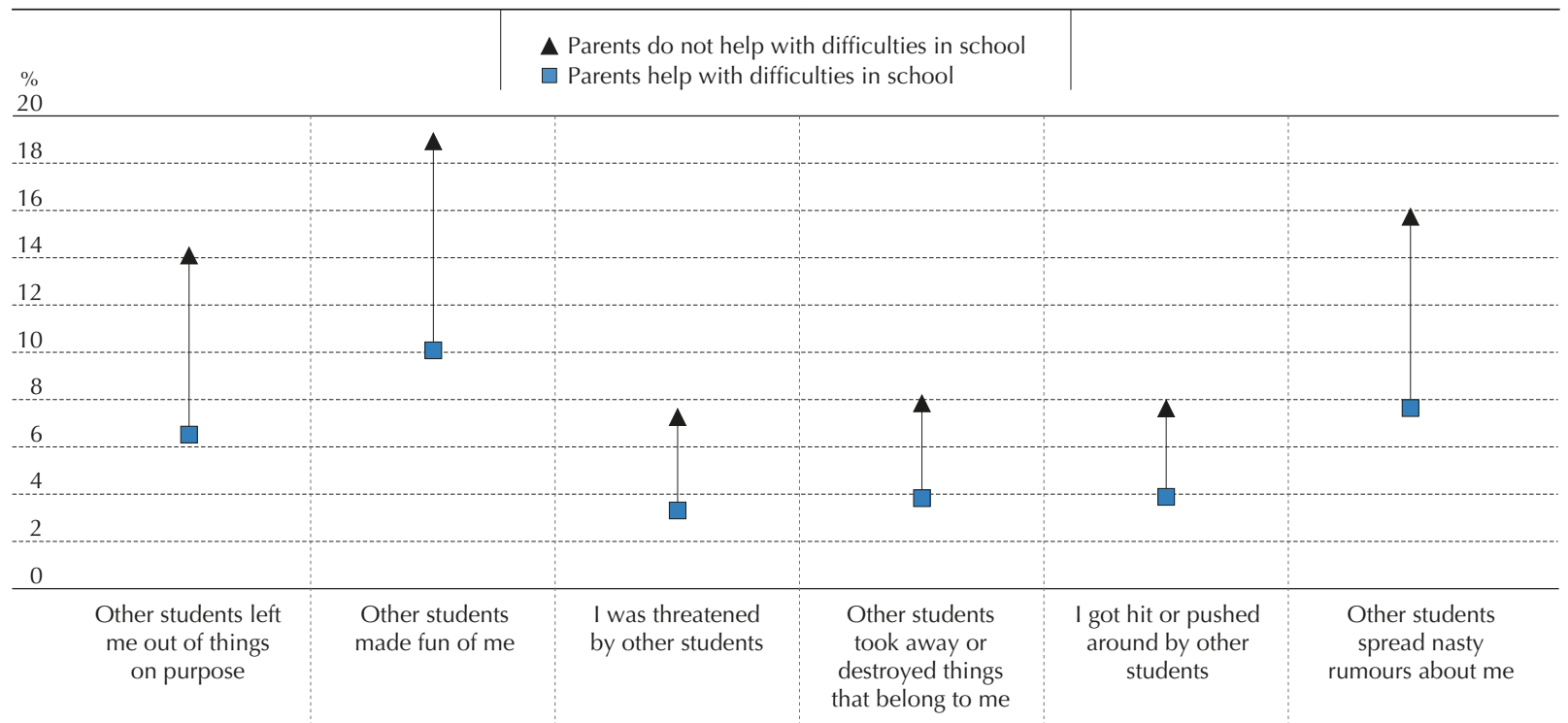

1. Students with (without) supportive parents reported that they "agree" or "strongly agree" ("disagree" or "strongly disagree") that their parents help them when they have difficulties in school.

Note: All differences between students with and without supportive parents are statistically significant (see Annex A3).

Source: OECD, PISA 2015 Database, Table III.8.18.

StatLink 제피 http://dx.doi.org/10.1787/888933471653

Schools can help parents in these efforts by including them in prevention strategies. An open line of communication with teachers and school staff can help parents acquire a greater awareness of the problem and take action. Parents of bullies are not always aware that their child is bullying others (Holt, Kantor and Finkelhor, 2008), and some victims of humiliating treatment are often reluctant to talk about the problem with their parents. On average across 15 countries and economies with available data, only $46 \%$ of the parents of frequently bullied students reported that they had exchanged ideas on parenting, family support, or the child's development with teachers over the previous academic year (around $41 \%$ of students who are not frequently bullied have parents who had engaged in such discussions). In France and Ireland, less than $30 \%$ of parents whose children are frequently bullied had exchanged such ideas and information with teachers (Table III.8.19). 


\section{What these results imply for policy}

- Bullying occurs frequently in all countries and economies, and has long-lasting consequences on students' well-being. Policy makers need to invest more resources in sharing and implementing effective anti-bullying strategies.

- Teachers can do much to reduce bullying, but they need to become more aware of the gravity of non-physical forms of bullying. They also need to communicate to students that they will not tolerate any form of bullying, and act as role models in the classroom. Incorporating bullying-prevention modules in teacher training is essential.

- School leaders, teachers and students need to work together in the classroom to reduce the incidence of bullying. Whole-of-school prevention and intervention strategies can make everyone responsible for students' well-being by teaching students and teachers strategies to support victims and communicate with bullies, and by changing classroom norms.

- Bullying-prevention programmes need to make parents aware of their critical role in helping their children become agents to prevent, rather than bystanders to, all forms of bullying. 


\section{Note}

1. The fact that victims of bullying are more likely to skip school might imply that PISA, as other surveys undertaken in schools, underestimate the actual percentage of students that are victims of bullying.

\section{References}

Agatston, P.W., R. Kowalski and S. Limber (2007), "Students' perspectives on cyber bullying", Journal of Adolescent Health,Vol. 41/6, pp. S59-S60, http://dx.doi.org/10.1016/j.jadohealth.2007.09.003.

Amato, P.R. (1994), "Father-child relations, mother-child relations, and offspring psychological well-being in early adulthood", Journal of Marriage and Family, Vol. 56/4, pp. 1031-1042, http://dx.doi.org/10.2307/353611.

Bauman, K.E. and S.T. Ennett (1994), "Peer influence on adolescent drug use", American Psychologist, Vol. 49/9, pp. 820-822, http:// dx.doi.org/10.1037/0003-066X.49.9.820.

Berndt, T.J. (1999), "Friends' influence on students' adjustment to school", Educational Psychologist, Vol. 34/1, pp. 15-28.

Berry, K. and C.J. Hunt (2009), "Evaluation of an intervention program for anxious adolescent boys who are bullied at school", Journal of Adolescent Health, Vol. 45/4, pp. 376-382, http://dx.doi.org/10.1016/j.jadohealth.2009.04.023.

Camodeca, M. et al. (2002), "Bullying and victimization among school-age children: Stability and links to proactive and reactive aggression", Social Development, Vol. 11/3, pp. 332-345, http://dx.doi.org/10.1111/1467-9507.00203.

Card, N.A. and E.V.E. Hodges (2006), "Shared targets for aggression by early adolescent friends", Developmental Psychology, Vol. 42/6, pp. 1327-1338, http://dx.doi.org/10.1037/0012-1649.42.6.1327.

Cornell, D. and F. Huang (2016), "Authoritative school climate and high school student risk behavior: A cross-sectional multi-level analysis of student self-reports", Journal of Youth and Adolescence, Vol. 45/11, pp. 2246-2259, http://dx.doi.org/10.1007/s10964-016-0424-3.

Craig, W. et al. (2009), "A cross-national profile of bullying and victimization among adolescents in 40 Countries", International Journal of Public Health, Vol. 54/2, pp. 216-224, http://dx.doi.org/10.1007/s00038-009-5413-9.

Crothers, L.M. et al. (2010), "A preliminary study of bully and victim behavior in old-for-grade students: Another potential hidden cost of grade retention or delayed school entry", Journal of Applied School Psychology, Vol. 26/4, pp. 327-338, http://dx.doi.org/10.1080/ 15377903.2010.518843.

Currie, C. et al. (eds.) (2012), Social Determinants of Health and Well-Being among Young People - Health Behaviour in School-Aged Children (HBSC) Study: International Report from the 2009/2010 Survey, World Health Organization Regional Office for Europe, Copenhagen, Denmark.

DeSmet, A. et al. (2014), "Traditional and cyberbullying victimization as correlates of psychosocial distress and barriers to a healthy lifestyle among severely obese adolescents - a matched case - control study on prevalence and results from a cross-sectional study", BMC Public Health, Vol. 14, pp. 224, http://dx.doi.org/10.1186/1471-2458-14-224.

Drydakis, N. (2014), "Bullying at school and labour market outcomes", International Journal of Manpower, Vol. 35/8, pp. 1185-1211, http://dx.doi.org/10.1108/IJM-08-2012-0122.

Dukes, R.L., J.A. Stein and J.I. Zane (2010), "Gender differences in the relative impact of physical and relational bullying on adolescent injury and weapon carrying", Journal of School Psychology, Vol. 48/6, pp. 511-532, http://dx.doi.org/10.1016/j.jsp.2010.08.001.

Duy, B. (2013), "Teachers' attitudes toward different types of bullying and victimization in Turkey", Psychology in the Schools, Vol. 50/10, pp. 987-1002, http://dx.doi.org/10.1002/pits.21729.

Ertesvåg, S.K. and G.S. Vaaland (2007), "Prevention and reduction of behavioural problems in school: An evaluation of the respect program", Educational Psychology, Vol. 27/6, pp. 713-736, http://dx.doi.org/10.1080/01443410701309258.

Espelage, D.L. et al. (2013), "The impact of a middle school program to reduce aggression, victimization, and sexual violence", The Journal of Adolescent Health: Official Publication of the Society for Adolescent Medicine, Vol. 53/2, pp. 180-186, http://dx.doi. org/10.1016/j.jadohealth.2013.02.021.

Evans, C.B.R., M.W. Fraser and K.L. Cotter (2014), "The effectiveness of school-based bullying prevention programs: A systematic review", Aggression and Violent Behavior, Vol. 19/5, pp. 532-544, http://dx.doi.org/10.1016/j.avb.2014.07.004.

Faris, R. and D. Felmlee (2014), "Casualties of social combat school networks of peer victimization and their consequences", American Sociological Review, Vol. 79/2, pp. 228-257, http://dx.doi.org/10.1177/0003122414524573.

Ferguson, C.J. et al. (2007), "The effectiveness of school-based anti-bullying programs: A meta-analytic review", Criminal Justice Review, Vol. 32/4, pp. 401-414, http://dx.doi.org/10.1177/0734016807311712. 
Goldweber, A., T.E. Waasdorp and C.P. Bradshaw (2013), "Examining associations between race, urbanicity, and patterns of bullying involvement", Journal of Youth and Adolescence, Vol. 42/2, pp. 206-219, http://dx.doi.org/10.1007/s10964-012-9843-y.

Goodenow, C. and K.E. Grady (1993), "The relationship of school belonging and friends' values to academic motivation among urban adolescent students", The Journal of Experimental Education, Vol 62/1, pp. 60-71, http://dx.doi.org/10.1080/00220973.1993.9943831.

Gorman-Smith, D., D.B. Henry and P.H. Tolan (2004), "Exposure to community violence and violence perpetration: The protective effects of family functioning", Journal of Clinical Child and Adolescent Psychology: The Official Journal for the Society of Clinical Child and Adolescent Psychology, American Psychological Association, Division 53, Vol. 33/3, pp. 439-449, http://dx.doi.org/10.1207/ s15374424jсcp3303_2.

Gorsek, A. and M. Cunningham (2014), "A review of teachers' perceptions and training regarding school bullying", PURE Insights, Vol. 3/1, http://digitalcommons.wou.edu/pure/vol3/iss1/6.

Gregory, A. and D. Cornell (2009), "Tolerating' adolescent needs: Moving beyond zero tolerance policies in high school", Theory Into Practice, Vol. 48/2, pp. 106-113, http://dx.doi.org/10.1080/00405840902776327.

Gregory, A. et al. (2010), "Authoritative school discipline: High school practices associated with lower bullying and victimization", Journal of Educational Psychology, Vol. 102/2, pp. 483-496, http://dx.doi.org/10.1037/a0018562.

Griffiths, L.J. et al. (2006), "Obesity and bullying: Different effects for boys and girls", Archives of Disease in Childhood, Vol. 91/2, pp. 121-125, http://dx.doi.org/10.1136/adc.2005.072314.

Haynie, D.L. et al. (2001), "Bullies, victims, and bully/victims: Distinct groups of at-risk youth", The Journal of Early Adolescence, Vol. 21/1, pp. 29-49, http://dx.doi.org/10.1177/0272431601021001002.

Holt, M.K., G. Kaufman Kantor and D. Finkelhor (2008), "Parent/child concordance about bullying involvement and family characteristics related to bullying and peer victimization", Journal of School Violence, Vol. 8/1, pp. 42-63, http://dx.doi.org/10.1080/ 15388220802067813.

Huitsing, G. and R. Veenstra (2012), "Bullying in classrooms: participant roles from a social network perspective", Aggressive Behavior, Vol. 38 (6), pp. 494-509, http://dx.doi.org/10.1002/ab.21438.

Janssen, I. et al. (2004), "Associations between overweight and obesity with bullying behaviors in school-aged children", Pediatrics, Vol. 113/5, pp. 1187-1194.

Jimerson, S.R. et al. (2002), "Exploring the association between grade retention and dropout: A Longitudinal study examining socioemotional, behavioral, and achievement characteristics of retained students", The California School Psychologist, Vol. 7/1, pp. 51-62, http://dx.doi.org/10.1007/BF03340889.

Johnson, S.L. (2009), "Improving the school environment to reduce school violence: A review of the literature", The Journal of School Health, Vol. 79/10, pp. 451-465, http://dx.doi.org/10.1111/j.1746-1561.2009.00435.x.

Juvonen, J. and S. Graham (2014), "Bullying in schools: The power of bullies and the plight of victims", Annual Review of Psychology, Vol. 65/1, pp. 159-185, http://dx.doi.org/10.1146/annurev-psych-010213-115030.

Juvonen, J. and E.F. Gross (2008), "Extending the school grounds? Bullying experiences in cyberspace", Journal of School Health, Vol. 78/9, pp. 496-505, http://dx.doi.org/10.1111/j.1746-1561.2008.00335.x.

Kochel, K.P., G.W. Ladd and K.D. Rudolph (2012), "Longitudinal associations among youths' depressive symptoms, peer victimization, and low peer acceptance: An interpersonal process perspective", Child Development, Vol. 83/2, pp. 637-650, http://dx.doi.org/10.1111/ j.1467-8624.2011.01722.x.

Konishi, C. et al. (2010), "Do school bullying and student-teacher relationships matter for academic achievement? A multilevel analysis", Canadian Journal of School Psychology, Vol. 25/1, pp. 19-39, http://dx.doi.org/10.1177/0829573509357550.

Konold, T.C. (2014), "Multilevel multi-informant structure of the authoritative school climate survey", School Psychology Quarterly, Vol. 29/3, pp. 238-255, http://dx.doi.org/10.1037/spq0000062.

Kretschmer, T. et al. (2016), "Bullying development across adolescence, its antecedents, outcomes, and gender-specific patterns", Development and Psychopathology, July, 1-15, http://dx.doi.org/10.1017/S0954579416000596.

Kuperminc, G.P., B.J. Leadbeater and S.J. Blatt (2001), "School social climate and individual differences in vulnerability to psychopathology among middle school students", Journal of School Psychology, Vol. 39/2, pp. 141-159, http://dx.doi.org/10.1016/ S0022-4405(01)00059-0.

Leadbeater, B., W. Hoglund and T. Woods (2003), "Changing contexts? The effects of a primary prevention program on classroom levels of peer relational and physical victimization", Journal of Community Psychology, Vol. 31/4, pp. 397-418, http://dx.doi.org/10.1002/jcop.10057.

Li, T.B.Q. (2005), "Cyber-harassment: A study of a new method for an old behavior", Journal of Educational Computing Research, Vol. 32/3, pp. 265-277, http://dx.doi.org/10.2190/8YQM-B04H-PG4D-BLLH. 
Ma, X. (2004), "Who are the victims", in C.E. Sanders and G.D. (eds.), Bullying Implications for the Classroom, Elsevier Academic Press, London, UK, pp. 20-31.

McEwen, B.S. and J.H. Morrison (2013), "The brain on stress: Vulnerability and plasticity of the prefrontal cortex over the life course", Neuron, Vol. 79/1, pp. 16-29, http://dx.doi.org/10.1016/j.neuron.2013.06.028.

McKenney, K.S. et al. (2006), "Peer victimization and psychosocial adjustment: The experiences of canadian immigrant youth", Electronic Journal of Research in Educational Psychology, Vol. 4/2, pp. 239-264.

Mishna, F. et al. (2012), "Risk factors for involvement in cyber bullying: victims, bullies and bully-victims", Children and Youth Services Review, Vol. 34/1, pp. 63-70, http://dx.doi.org/10.1016/j.childyouth.2011.08.032.

Morin, A.J.S. et al. (2012), "Academic achievement and smoking initiation in adolescence: A general growth mixture analysis", Addiction, Vol. 107/4, pp. 819-828, http://dx.doi.org/10.1111/j.1360-0443.2011.03725.x.

Nakamoto, J. and D. Schwartz (2010), "Is peer victimization associated with academic achievement? A meta-analytic review", Social Development, Vol. 19/2, pp. 221-242, http://dx.doi.org/10.1111/j.1467-9507.2009.00539.x.

Nansel, T.R. et al. (2004), "Cross-national consistency in the relationship between bullying behaviors and psychosocial adjustment", Archives of Pediatrics and Adolescent Medicine, Vol. 158/8, pp. 730-736, http://dx.doi.org/10.1001/archpedi.158.8.730.

Nocentini, A. and E. Menesini (2016), "KiVa Anti-Bullying Program in Italy: Evidence of effectiveness in a randomized control trial", Prevention Science, Vol. 17/8, pp. 1012-1023, http://dx.doi.org/10.1007/s11121-016-0690-z.

OECD (2016), PISA 2015 Results (Volume II): Policies and Practices for Successful Schools, OECD Publishing, Paris, http://dx.doi. org/10.1787/9789264267510-en.

OECD (2014), TALIS 2013 Results: An International Perspective on Teaching and Learning, OECD Publishing, Paris, http://dx.doi.org/ 10.1787/9789264196261-en.

Olweus, D. (1994), "Bullying at school: Basic facts and effects of a school based intervention program", The Journal of Child Psychology and Psychiatry, Vol. 35/7, pp. 1171-1190, http://dx.doi.org/10.1111/j.1469-7610.1994.tb01229.x.

Parker, J.G. and S.R. Asher (1993), "Friendship and friendship quality in middle childhood: Links with peer group acceptance and feelings of loneliness and social dissatisfaction", Developmental Psychology, Vol. 29/4, pp. 611-621, http://dx.doi.org/10.1037/00121649.29.4.611.

Peguero, A.A. (2008), "Is immigrant status relevant in school violence research? An analysis with Latino students", Journal of School Health, Vol. 78/7, pp. 397-404, http://dx.doi.org/10.1111/j.1746-1561.2008.00320.x.

Pepler, D., W. Craig and P. O'Connell (2010), "Peer processes in bullying: Informing prevention and intervention strategies", in S.R. Jimerson, S.M. Swearer and D.L. Espelage (eds), Handbook of Bullying in Schools: An International Perspective, New York, Routledge, New York, NY, Routledge, pp. 469-479.

Pepler, D.J. et al. (2006), "A developmental perspective on bullying", Aggressive Behavior, Vol. 32/4, pp. 376-384, http://dx.doi. org/10.1002/ab.20136.

Qin, D.B., N. Way and M. Rana (2008), "The 'model minority' and their discontent: Examining peer discrimination and harassment of Chinese American immigrant youth", New Directions for Child and Adolescent Development, Vol. 2008/121, pp. 27-42, http://dx.doi. org/10.1002/cd.221.

Raskauskas, J. (2007), Evaluation of The Kia Kaha Anti-Bullying Programme for Students in Years 5-8, web document, http://thehub. superu.govt.nz/project/evaluation-kia-kaha-anti-bullying-programme-students-years-5-8, (accessed 5 April 2017).

Rigby, K. (2007), Bullying in Schools: And What to Do about It, Australian Council for Education Research, Melbourne, AU.

Rivara, F. and Le Menestrel, S. (eds.) (2016), Preventing Bullying Through Science, Policy, and Practice, National Academies Press, Washington, D.C.

Rivers, I. (2000), "Long-term consequences of bullying", in C. Neal and D. Davies (eds.), Issues in Therapy with Lesbian, Gay, Bisexual and Transgender Clients, Open University Press, Maidenhead, BRK, England, pp. 146-159.

Salmivalli, C, A. Kärnä and E. Poskiparta (2011), "Counteracting bullying in Finland: The KiVa Program and its effects on different forms of being bullied", International Journal of Behavioral Development, Vol. 35/5, pp. 405-411, http://dx.doi.org/10.1177/0165025411407457.

Salmivalli, C., A. Kaukiainen and M. Voeten (2005), "Anti-bullying intervention: Implementation and outcome", The British Journal of Educational Psychology, Vol. 75/3, pp. 465-487, http://dx.doi.org/10.1348/000709905X26011.

Salmivalli, C. et al. (1996), "Bullying as a group process: Participant roles and their relations to social status within the group", Aggressive Behavior, Vol. 22/1, pp. 1-15, http://dx.doi.org/10.1002/(SICI)1098-2337(1996)22:1<1::AID-AB1>3.0.CO;2-T.

Salmivalli, C, M. Sainio and E.V.E. Hodges (2013), "Electronic victimization: Correlates, antecedents, and consequences among elementary and middle school students", Journal of Clinical Child and Adolescent Psychology, Vol. 42/4, pp. 442-453, http://dx.doi.org/ 


\subsection{0/15374416.2012.759228.}

Smith, P.K. (2013), "School bullying", Sociologia, Problemas E Práticas, Vol. 2013/71, pp. 81-98.

Smith, P.K., D. Pepler and K. Rigby (eds.) (2004), Bullying in Schools: How Successful Can Interventions Be?, Cambridge University Press, Cambridge, UK.

Smith, P.K. and S. Sharp (eds.) (1994), Tackling Bullying in Your School: A Practical Handbook for Teachers, Routledge, London, UK.

Striegel-Moore, R.H. et al. (2002), "Abuse, bullying, and discrimination as risk factors for binge eating disorder", The American Journal of Psychiatry, Vol. 159/11, pp. 1902-1907, http://dx.doi.org/10.1176/appi.ajp.159.11.1902.

Strohmeier, D. and C. Spiel (2003), "Immigrant children in Austria”, Journal of Applied School Psychology, Vol. 19/2, pp. 99-116, http:// dx.doi.org/10.1300/J008v19n02 07.

Sutton, J., P.K. Smith, and J. Swettenham (1999), "Social cognition and bullying: Social inadequacy or skilled manipulation?", British Journal of Developmental Psychology, Vol. 17/3, pp. 435-450, http://dx.doi.org/10.1348/026151099165384.

Swearer, S.M., and S. Hymel (2015), "Understanding the psychology of bullying: Moving toward a social-ecological diathesis-stress model", The American Psychologist, Vol. 70/4, pp. 344-353, http://dx.doi.org/10.1037/a0038929.

Tippett, N. and D. Wolke (2014), "Socioeconomic status and bullying: A meta-analysis", American Journal of Public Health, Vol. 104/6, pp. e48-e59, http://dx.doi.org/10.2105/AJPH.2014.301960.

Tokunaga, R.S. (2010), "Following you home from school: A critical review and synthesis of research on cyberbullying victimization", Computers in Human Behavior, Vol. 26/3, pp. 277-287, http://dx.doi.org/10.1016/j.chb.2009.11.014.

Townsend, L. et al. (2008), "The relationship between bullying behaviours and high school dropout in Cape Town, South Africa", South African Journal of Psychology, Vol. 38/1, pp. 21-32, http://dx.doi.org/10.1177/008124630803800102.

Ttofi, M.M. and D.P. Farrington (2010), "Effectiveness of school-based programs to reduce bullying: A systematic and meta-analytic review", Journal of Experimental Criminology, Vol. 7/1, pp. 27-56, http://dx.doi.org/10.1007/s11292-010-9109-1.

Ttofi, M.M. and D.P. Farrington (2009), "What works in preventing bullying: Effective elements of anti-bullying programmes", Journal of Aggression, Conflict and Peace Research, Vol. 1/1, pp. 13-24, http://dx.doi.org/10.1108/17596599200900003.

Ybarra, M.L. and K.J. Mitchell (2007), "Prevalence and frequency of Internet harassment instigation: Implications for adolescent health", The Journal of Adolescent Health: Official Publication of the Society for Adolescent Medicine, Vol. 41/2, pp. 189-195, http://dx.doi. org/10.1016/j.jadohealth.2007.03.005.

Ybarra, M.L. et al. (2006), "Examining characteristics and associated distress related to Internet harassment: Findings from the second youth internet safety survey", Pediatrics, Vol. 118/4, pp. e1169-e1177, http://dx.doi.org/10.1542/peds.2006-0815.

Veenstra, R. et al. (2014), "The role of teachers in bullying: The relation between antibullying attitudes, efficacy, and efforts to reduce bullying", Journal of Educational Psychology, Vol. 106/4, pp. 1135-1143, http://dx.doi.org/10.1037/a0036110.

Veenstra, R. et al. (2005), "Bullying and victimization in elementary schools: A comparison of bullies, victims, bully/victims, and uninvolved preadolescents", Developmental Psychology, Vol. 41/4, pp. 672-682, http://dx.doi.org/10.1037/0012-1649.41.4.672.

Wang, J., R.J. lannotti and T.R. Nansel (2009), "School bullying among adolescents in the United States: Physical, verbal, relational, and cyber", Journal of Adolescent Health, Vol. 45/4, pp. 368-375, http://dx.doi.org/10.1016/j.jadohealth.2009.03.021.

Williams, K.R. and N.G. Guerra (2007), "Prevalence and predictors of internet bullying", Journal of Adolescent Health Vol. 41/6, Supplement, pp. S14-S21, http://dx.doi.org/10.1016/j.jadohealth.2007.08.018.

Wolke, D. and A.J. Skew (2011), "Bullied at home and at school: Relationship to behaviour problems and unhappiness", in S.L. McFall and C. Garrington (eds.), Understanding Society: Early Findings from the First Wave of The UK's Household Longitudinal Study, Institute for Social and Economic Research, University of Essex, Wivenhoe Park, Colchester, UK, pp. 23-32.

Woods, S. and D. Wolke (2004), "Direct and relational bullying among primary school children and academic achievement", Journal of School Psychology, Vol. 42/2, pp. 135-155, http://dx.doi.org/10.1016/j.jsp.2003.12.002. 


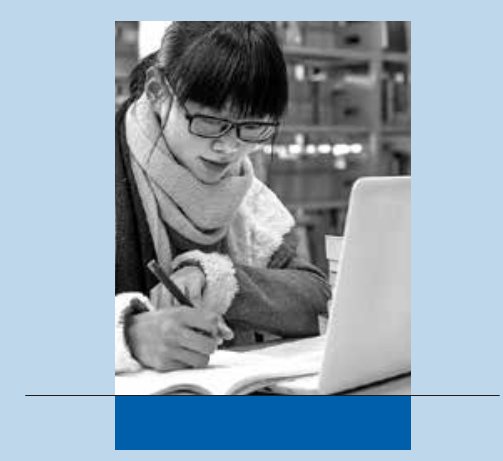

\section{Parents and}

\section{the home environment}

Students differ greatly in their material, social and cultural resources at home. These differences can be a significant source of inequality in students' well-being. Parents from disadvantaged backgrounds might have fewer resources to invest in their child's education, and less time to spend with their child. A way to promote students' well-being is to encourage all parents to be more involved with their child's interests and concerns, show interest in their school activities, and participate in school life. This section presents PISA data on activities that parents do with their children and in their children's schools and identifies some typical barriers to parental participation in school activities. It also analyses how inequalities in material resources as well as the socioeconomic composition of schools relates to inequalities in students' views of their life and their future. 



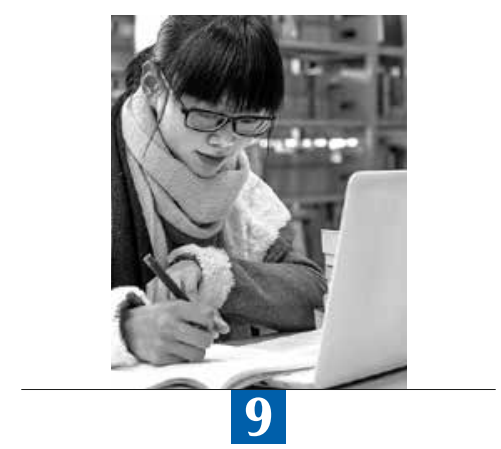

\section{Parental involvement, student performance and satisfaction with life}

This chapter examines how parents' interest in their child's life, certain parent-child activities, and parents' participation in school-related activities are associated with students' performance and students' satisfaction with their own life. The chapter also discusses the factors that parents cite as obstacles to participation in their child's school activities. 
Few relationships in life are as significant and enduring as the relationship between children and their parents or the adults who raised them. Families are the first social unit in which children learn and develop. Good parenting can take different forms and be shaped by various social and cultural forces, but it invariably involves providing children with the support, care, love, guidance and protection that set the conditions for healthy physical, mental and social development. It is not surprising, then, that interactions with parents have consistently been shown to influence students' achievement, expectations, attitudes and psychological health (Fan and Williams, 2010; Hill and Tyson, 2009; Juang and Silbereisen, 2002; Kaplan, 2013). The activities parents and children do together, parents' expectations for their children's future, and the behaviours and attitudes parents model for their children are all associated with children's psychological well-being (Marchant, Paulson and Rothlisberg, 2001; OECD, 2012; Parker et al., 1999; Shumow and Lomax, 2002). Parents are also key players in helping their children succeed at school; after all, they are their children's first and longest-serving teachers.

As children grow, the connection with their parents also evolves. The relationship between parents and their 15-year-old children often reflects the greater autonomy and desire for independence that come with adolescence (Catsambis, 2002; Hartras, 2015; Seginer, 2006). Activities that parents and their young children once shared, such as reading together or helping with homework, often give way to adolescent children exploring their own interests by themselves, and to more mature interactions with their parents, involving discussion and negotiation (Seginer, 2006; Smetana, 2011).

This chapter explores how some forms of parental involvement, such as interest in their child's life, the activities they engage in together, and parents' participation in school-related activities, are associated with how well students do in school and how satisfied they are with their own life. It concludes with a discussion of factors that parents regard as obstacles hindering their participation in their child's school activities.

\section{What the data tell us}

- On average across 18 countries and economies, $82 \%$ of parents reported that they eat the main meal with their child around a table, $70 \%$ reported that they spend time just talking to their child, and 52\% reported that they discuss how well their child is doing at school every day or almost every day. Students whose parents engage in these activities at least once a week score higher in the PISA science test and are more likely to report high levels of life satisfaction.

- "Spending time just talking" is the parent-child activity most strongly associated with students' life satisfaction.

- Most students in PISA-participating countries and economies reported that their parents are interested in their life at school. Students' positive perceptions about their parents' interest in their life at school are associated with higher scores in the PISA science test, and in particular, with a lower risk of low performance.

- Parents cited the inability to get time off from work (cited by $36 \%$ of parents), the inconvenience of school meeting times (cited by 33\% of parents) and the lack of knowledge about how to participate in school activities (cited by $17 \%$ of parents) as among the most common barriers to their participation in school activities.

\section{PARENTAL INVOLVEMENT AT HOME AND SCHOOL}

Over the past 30 years, the number of single-income families has dropped significantly in many OECD countries, giving rise to increasing numbers of two-income households (OECD, 2012). More than ever, parents struggle to find a balance between their professional and private lives; very often, their interactions with their children are squeezed into the few "free" hours of busy days. At the same time, their adolescent children are beginning to have their own social lives; and the realities of various family configurations - such as parents who live apart or single parents who work long hours - may add to the difficulties that parents face in finding "quality time" to spend with their children and in getting involved in their education. In spite of all this, PISA data paint a positive picture of how parents and children spend time together.

PISA asked parents how often they engage in certain activities at home with their child, and whether in the previous academic year they had interacted with their child's teacher in school (Figure III.9.1). Across the 18 countries and economies that distributed the parent questionnaire, eating the main meal together is by far the most common activity reported by parents. On average, $82 \%$ of parents reported that they eat the main meal with their child around a table, followed by $70 \%$ who reported that they spend time just talking to their child, and $52 \%$ who reported that they discuss how well their child is doing at school every day or almost every day. In Belgium (Flemish community), France, Italy, Portugal and Spain, more than $90 \%$ of parents eat a meal with their child daily or nearly every day. 
Figure III.9.1 - Parents' activities with their child and at their child's school

Percentage of parents who reported engaging in home-based activities routinely and who had participated in school-related activities during the previous academic year (average for 18 countries/economies)

Percentage of parents who reported that they engage in the following activities "every day or almost every day"

Discuss how well my child is doing at schoo

Spend time just talking to my child

Eat $<$ the main meal $>$ with my child around a table

B Percentage of parents who reported that they had participated in the following school-related activities in the previous academic year

4 Exchanged ideas on parenting, family support, or the child's development with my child's teacher

5 Discussed my child's progress with a teacher on my own initiative

6 Talked about how to support learning at home and homework with my child's teachers

7 Discussed my child's behaviour with a teacher on my own initiative

8 Attended a scheduled meeting or conferences for parents

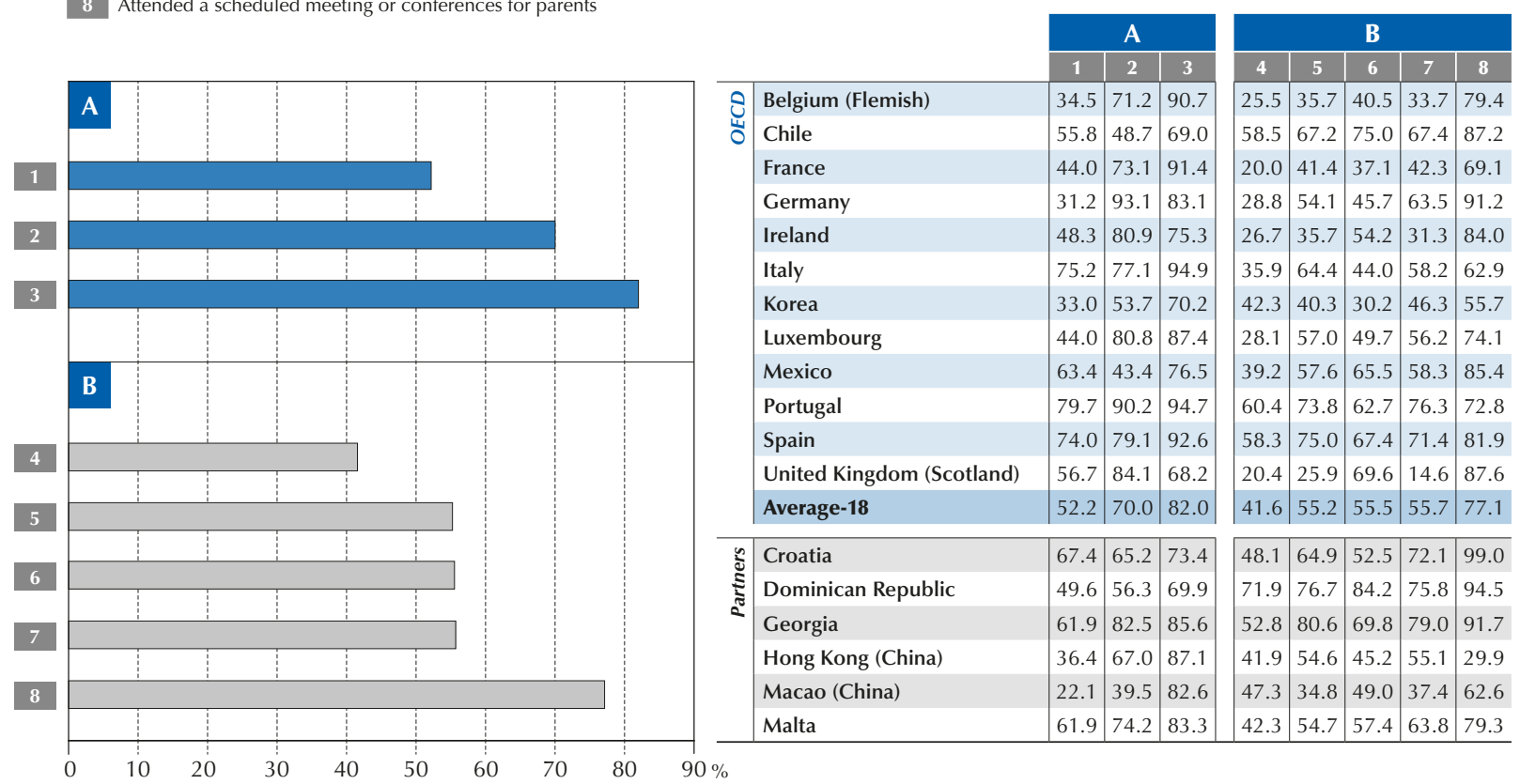

Source: OECD, PISA 2015 Database, Table III.9.1.

StatLink 겐 http://dx.doi.org/10.1787/888933472181

Spending time just talking, while relatively less frequent, is also practiced routinely by most parents in 18 countries with available data. Overall, the share of parents who reported that they talk with their child about how he or she is doing at school is both smaller and more variable than that of parents who eat a meal with their child or spend time just talking to their child on a daily or nearly daily basis (Table III.9.1). Nonetheless, in Italy, Portugal and Spain, about $75 \%$ of parents reported that they discuss how well their child is doing at school at least almost every day. Such discussions are much less frequent in some high-performing Asian countries and economies. In Hong-Kong (China) and Korea, for example, slightly more than one in three parents reported that they talk with their child about school daily or nearly every day; in Macao (China), only around one in five parents so reported. These differences between Asian countries and other countries might partly reflect the higher response rates to the parent questionnaire in Asian countries (Box III.9.1).

The responses provided by parents in 2015 closely follow the pattern observed in 2012 with a slight upward trend in some activities. The most frequent home-based activity in 2012 was eating the main meal together (which increased by 2.6 percentage points in 2015), followed by spending time just talking to the child (which increased by 0.8 percentage point in 2015) and discussing with the child how well he or she is doing at school daily or almost every day (no significant changes observed compared to 2012). Trend data are available for 10 countries and show no dramatic change at the country level for most of them. The largest increase in the level of parental engagement in these activities (between 4.7 and 10.4 percentage points) was observed in Korea (Table III.9.3). 


\section{Box III.9.1 PISA 2015 parent questionnaire}

PISA has assessed parental involvement in education since 2006 when the parent questionnaire was distributed for the first time, directly addressing the parents of the PISA students. For PISA 2015, specific aspects of parental involvement were added to the school questionnaire (on parent-school communication and collaboration), and to the student questionnaire (on parental support in learning). In particular, four items focusing on parental support appear in both the student and parent questionnaires so that students' and their parents' perceptions can be compared.

Analysis of the 2009 round of the PISA parent questionnaire has shown that some forms of parental involvement are more strongly related to cognitive and non-cognitive student outcomes than others (Borgonovi and Montt, 2012). These include reading to children when they are young, engaging in discussions that promote critical thinking and setting a good example.

In 2015, 18 countries and economies distributed the parent questionnaire to students who sat the PISA test. Parents were asked to complete the questionnaire at home. The parent questionnaire seeks information about the activities parents engage in with their child and the science-related activities the child used to participate in when they were 10 years old; parents' perceptions of their child's school, the criteria they value in choosing a school for their child, and their participation in school activities; the education their child might have benefitted from during early childhood, including attendance at pre-primary school and other types of care arrangements; parents' views on science and the environment; and parents' country of birth, income and expenditure on education.

Since students are asked to take the questionnaire home to their parents and return it to school the next day, response rates may decrease if students forget to bring the questionnaire home, forget to show it to their parents and/or forget to bring it to school once the questionnaire has been completed. Lower response rates may introduce bias in the estimates if certain kinds of students (those with more involved parents, higher achievers, etc.) are more likely to return the answered questionnaire than others (Borgonovi and Montt, 2012).

In every country and economy, the response rate for the parent questionnaire tends to be lower than that of the PISA student questionnaire. Some countries have significantly higher rates of non-response than others. For example, the parents of less than $5 \%$ of the students in the Dominican Republic, Georgia, Hong Kong (China) and Macao (China), and the parents of more than $40 \%$ of students in Germany and Scotland (United Kingdom) did not provide a response to the question: "How often do you or someone else in your home discuss how well [my] child is doing at school?" (see Table A1.8c in Annex A1). Some questions are more sensitive than others, and thus have higher rates of non-response. The most sensitive question concerns parents' income. Only in the Dominican Republic, Hong Kong (China) and Korea was the non-response rate lower than $10 \%$, while it was higher than $50 \%$ in Germany and Scotland (United Kingdom). A comparison of the characteristics of students with complete responses and those with missing responses in the parent questionnaire shows that, in most countries/economies, the former group of students is more socio-economically advantaged and performs better in science than the latter group of students, even if there are variations in these differences across countries.

Among the school-based activities shown in Figure III.9.1, the activity most frequently reported by parents is attending a scheduled meeting or conferences for parents in their child's school. Some $77 \%$ of parents, on average, reported having done so during the previous academic year. Slightly more than half of the parents reported that they had "discussed my child's behaviour with a teacher on my own initiative", "discussed my child's progress with a teacher on my own initiative" or "talked about how to support learning at home and homework with my child's teachers". Compared to most other countries, smaller shares of parents (between 15\% and 37\%) in Belgium (Flemish community), Ireland, Macao (China) and Scotland (United Kingdom) reported that they had conversed with their child's teacher at their own initiative. In Chile, Hong Kong (China), Korea, Macao (China) and Mexico, there was an increase of between 2.3 and 13.5 percentage points since 2012 in the proportion of parents who reported that they discussed their child's progress with the teacher. These countries and economies, in addition to Croatia and Italy, also show a significant increase (ranging from 2.4 to 11 percentage points) since 2012 in the proportion of parents who discussed their child's behaviour with the teacher (Table III.9.3). 
On average, parents reported that they had "exchanged ideas on parenting, family support, or the child's development with my child's teacher" less often than the activities mentioned above. Around $42 \%$ of parents reported that they had done so during the previous academic year. This could reflect a perception among some parents that these topics are more private than school-related in nature. Smaller proportions of parents reported that they had engaged in other school-related activities, such as participating in local school government (e.g. parent council or school-management committee; 19\%), volunteering in physical or extracurricular activities (15\%), and volunteering to support school activities (12\%) (Table III.9.1).

In Asian countries and economies, parents reported fewer interactions with their children at home and less participation in school-based activities compared to the other countries with available data. The findings on home-based activities may reflect social and cultural differences in parents' style of communication; how parents balance the fine line between encouraging their children and pressuring them to do well in school; or larger societal expectations related to high academic achievement. In cultures where every student is expected to excel in school, parents may rely more strongly on school and peer influences to help keep their children on track academically. The differences in school-based activities may suggest cultural differences in forms and frequencies of parental involvement, in the relationship between families and schools, or both. Some degree of social desirability bias may also be at play here. Social desirability is the tendency of survey respondents to answer certain questions in ways that they believe are more socially acceptable or desirable (Edwards, 1953). Parents in different cultures may vary in how sensitive they are to this type of survey bias.

Overall, these results are an encouraging indication that most parents in participating countries and economies have been able to find some time to be with their children and that they have cultivated the habit of routinely talking with their children, eating with them, and participating in their school life. Such simple daily or weekly family interactions can provide students with the structure, regularity and support they need to thrive on their own.

\section{PARENTAL INVOLVEMENT AND STUDENTS' PERFORMANCE IN PISA}

The literature consistently documents positive associations between a range of home- and school-based parental activities and children's educational achievement, measured either as school marks or standardised test scores. This positive relationship holds in various disciplines, across ethnic groups, gender and over time (Bogenschneider, 1997; Catsambis, 2002; Fan and Williams, 2010; Kaplan and Seginer, 2015; Keith et al., 1998; Marjoribanks, 1996; Rodriguez, 2002; Shumow and Lomax, 2002). However, not every type of shared activity between parents and their child has been demonstrated to have a positive link to learning. Figure III.9.2 shows how parental engagement in a set of selected activities is associated with differences in students' performance in science.

Figure III.9.2 - Parents' activities and students' science performance

Difference in science performance between students whose parents engage in selected activities at least once a week and those whose parents engage in such activities less frequently (average for 18 countries/economies)

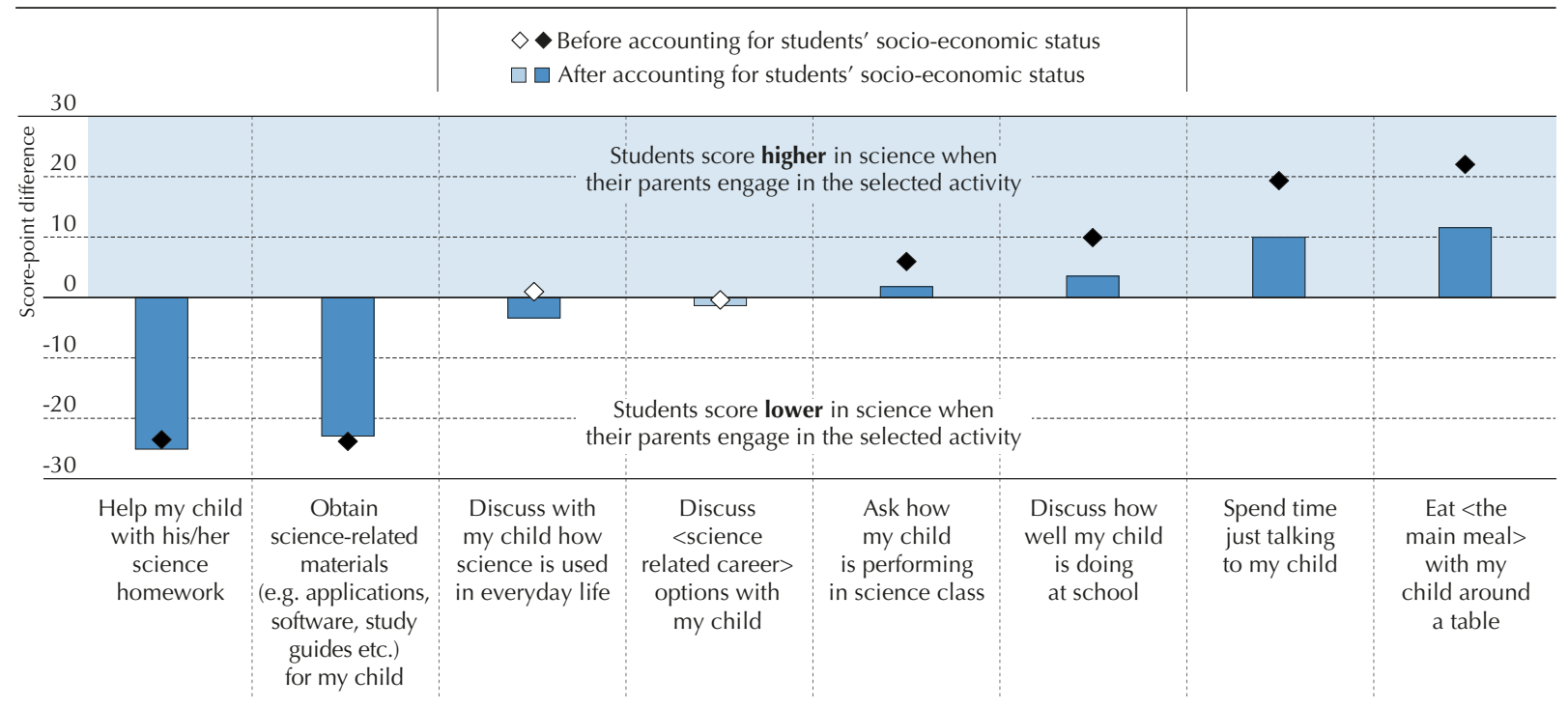

Note: Statistically significant values are marked in a darker tone (see Annex A3).

Source: OECD, PISA 2015 Database, Table III.9.4.

StatLink 젶ㄴ http://dx.doi.org/10.1787/888933472199 
Parents' activities that typically take place at home or in the context of the family, namely "discussing how well my child is doing at school", "eating the main meal with my child around a table" and "spending time just talking to my child" are all positively related to the child's science performance in PISA 2015. An activity as simple as eating a meal together at least once a week is associated with an increase of at least 12 score points in science, on average, after accounting for students' socio-economic status. While there is no theoretical reason to expect a direct connection between students' performance in school and routinely eating a meal with their parents, the observed relationship may be capturing underlying traits of families that nurture this habit, traits that are more closely related to children's performance at school. For example, parents may use meal time as an occasion to encourage their children, monitor their progress in school and show support. These families may also be able to maintain an orderly, structured environment for their children at home with less stress and greater stability. This relationship is positive and significant in 7 out of 18 countries and economies, including Hong Kong (China), where the score difference is 18 points, and Macao (China), where the score difference is 30 points - two economies where relatively small shares of parents reported that they routinely eat a meal together with their child. The relationship is negative in only one country, Croatia, with a score difference of 16 points after accounting for socio-economic status (Table III.9.4).

Similarly, students whose parents "spend time just talking" to them at least once a week score 10 points higher, on average, than students of similar socio-economic status whose parents do so less frequently. This relationship is positive and significant in Georgia, Hong Kong (China), Korea and Portugal. Another possible explanation for the positive relationship between parent-child discussions and performance is that parents might find it easier to talk about school with children who perform relatively well and are engaged at school.

Conversely, most activities that reflect parents' direct involvement in their child's science education have a negative relationship with the student's science score. Students whose parents reported that they "help my child with his/her science homework" or "obtain science-related materials (e.g. applications, software, study guides, etc.) for my child" at least once a week, score over 20 points lower in science, on average, than students whose parents engage in these activities less frequently (Figure III.9.2). Poor performance in science may be the reason why parents are more directly involved in their child's school work.

PISA results are also consistent with research findings showing a negative relationship between parental help with homework and student performance in early adolescence and beyond (Fan, 2001; Hill and Tyson, 2009; HooverDempsey et al., 2001). While help with homework might have been effective in the early years of school, during adolescence, students may respond better to other forms of parental support that respect their growing need for autonomy. This is illustrated by the positive associations found between students' performance in science and parents reporting that they "discuss how well my child is doing at school" or "spend time just talking to my child".

As Figure III.9.2 shows, parents' involvement in science homework or in monitoring their child's progress in science education is not strongly related to socio-economic status. This suggests that while advantaged and disadvantaged parents may differ widely in how they interact with their children at home, parents from all socio-economic groups try to help their children when they are struggling in school.

\section{Box III.9.2 Nurturing young scientists}

Science is not only the domain of scientists. Everyone needs to be able to "think like a scientist" to some extent. From reading food labels about nutrition facts, to understanding doctors' treatment options for a disease, to deciding to act in ways that are less harmful to the environment, contemporary society is full of opportunities for making use of scientific thinking. This means weighing evidence, coming to evidence-based conclusions, and understanding that scientific "truth" may change over time as new discoveries are made (OECD, 2016). Learning and reasoning scientifically are the result of a cumulative process that unfolds both at school and at home, and most children show an interest in science from an early age. Parents who value their children's education could stimulate their interests further by engaging in activities that increase their capacity to learn or by encouraging them to do so.

PISA asked parents whether their children, when they were 10 years old, used to spend time in various activities that signalled an interest in science. According to parents, the most popular activity was playing with construction games (e.g. plastic building bricks) (47\% of parents reported that their children used to do this regularly or very often), followed by watching TV programmes about science (22\% of parents reported this). Around $11 \%$ of parents reported that their children used to experiment with a science kit or visit websites about science topics; only $3 \%$ of parents reported that their child had attended a science club when he or she was 10 years old (Table III.9.6). 
Some of these activities are associated with higher performance in science and with students' expectation to pursue a career in science later on (Tables III.9.9 and III.9.15; OECD, 2008). But not all parents value these activities to the same degree or can afford to offer them. Providing a telescope or a science kit for kids to play with may be far down the list of priorities for many parents. On average across 18 countries and economies, $14 \%$ of children with tertiaryeducated parents did experiments with a science kit or used a telescope when they were 10 years old, compared to $9 \%$ of children whose parents are not tertiary-educated. Differences related to parents' education vary from country to country and are largest (in favour of parents with a tertiary education) in Korea, Malta and Portugal (Table III.9.7).

Watching the sky with a telescope or playing with a chemistry kit could nurture children's interest in science and strengthen their confidence about their own abilities in science. Students' engagement in science is shaped by two forces: how students think about themselves - what they think they are good at and what they think is good for them - and students' attitudes towards science and towards science-related activities - that is, whether they perceive these activities as important, enjoyable and useful (OECD, 2016).

Figure III.9.3 shows that among students who perform similarly in science and who are of similar socio-economic status, those who used to visit websites about science topics when they were 10 were more likely to be among the top quarter of students in their country in the level of enjoyment of science (by $78 \%$ ) and in science self-efficacy (by $70 \%$ ), as measured by PISA. Reading books on scientific discoveries, watching TV programmes about science and experimenting with a science kit were also associated with high levels of enjoyment of and self-efficacy in science. These associations do not show any causal link, but they reveal a close relationship between an early engagement in science activities and attitudes towards science at age 15. These students might have engaged in such activities more often than others because they were more interested in science to begin with. But it is also possible that engaging in these activities led to a deeper enjoyment of science and made these students more confident about learning science. As is the case with so much of what happens in learning, activities and interests may have a mutually reinforcing role, one that attentive parents can observe and foster to the benefit of their child.

Figure III.9.3 - Science-related activities at age 10, and students' enjoyment of and self-efficacy in science

Students' likelihood of being in the top quarter of the indices of enjoyment of science and science selfefficacy in their own country/economy if they engaged in science-related activities at age 10 (average for 18 countries/economies)

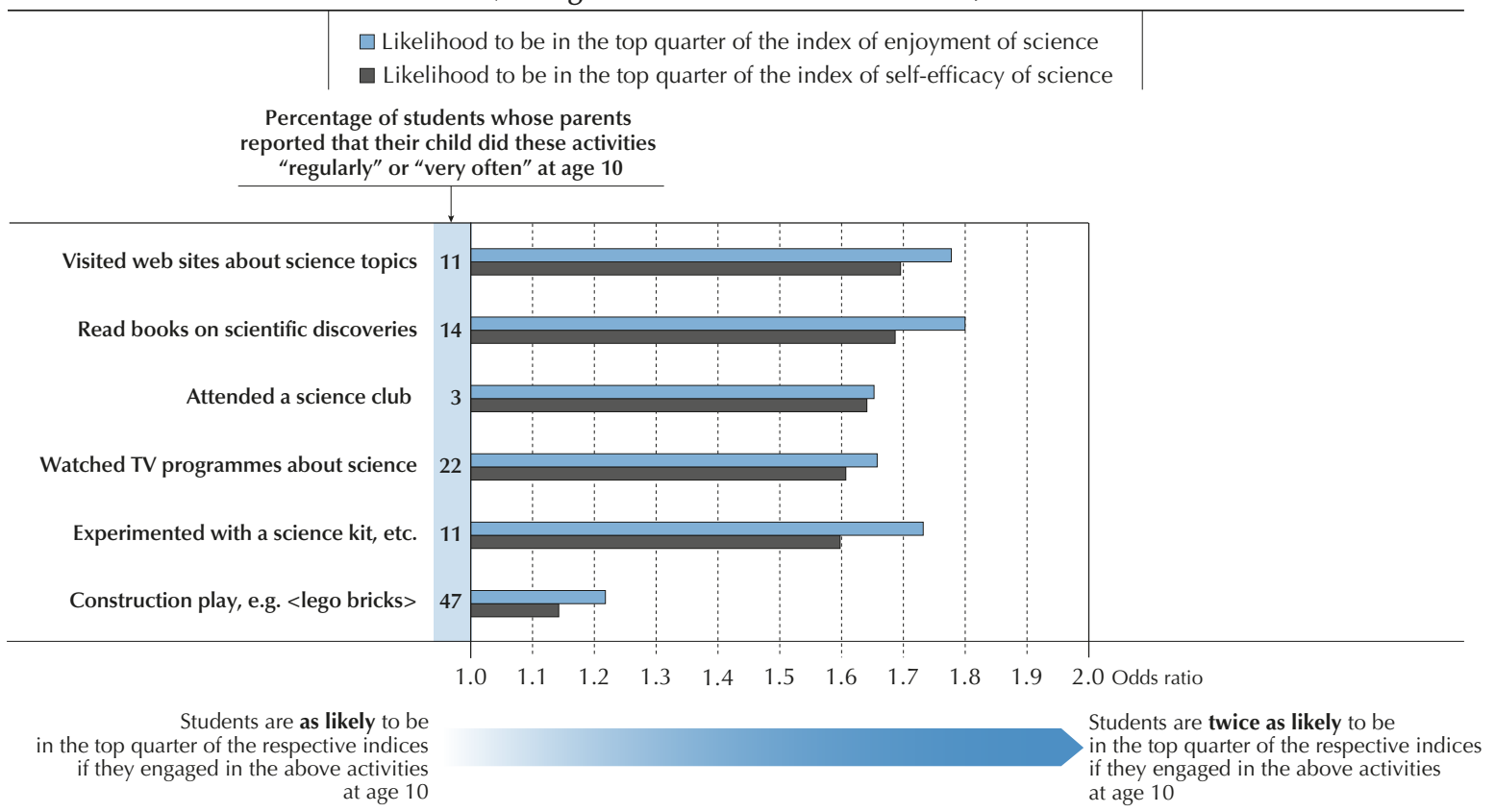

Note: Statistically significant values are marked in a darker tone (see Annex A3).

Source: OECD, PISA 2015 Database, Tables III.9.6, III.9.11 and III.9.13.

StatLink 제 


\section{PARENTAL INVOLVEMENT AND STUDENTS' SATISFACTION WITH LIFE}

PISA data show that certain types of parental activities are positively related not only to students' performance, but also to other areas of their life, such as how satisfied students are with their own life. Students whose parents reported "spending time just talking to my child", "eating the main meal with my child around a table" or "discussing how well my child is doing at school" at least once a week were between $22 \%$ and $62 \%$ more likely to report high levels of life satisfaction (i.e. their responses put them at the equivalent of 9 or 10 on a scale of 0 to 10) than students whose parents reported engaging in these activities less frequently (Figure III.9.4). Some school-related forms of parental involvement, such as having attended a school meeting or conferences for parents in the previous academic year or having interacted with their child's teacher, are also positively related to students' satisfaction with life, but the strength of these associations is considerably weaker. Parents of students who are struggling in school, and perhaps less satisfied with their life, may be more likely to interact with their child's teachers and school more often, which could partially explain these weaker associations.

Countries vary in which parental activities are most strongly related to students' life satisfaction. In Croatia, France, Hong Kong (China) and Portugal, for example, students were approximately twice as likely to report being very satisfied with their life if their parents reported eating the main meal with them; but they were less than $60 \%$ as likely to report being very satisfied with their life when their parents reported spending time just talking to them. In Mexico, by contrast, students were almost $80 \%$ more likely to report being very satisfied with their life when their parents reported spending time just talking to them, but less than $60 \%$ as likely to report being very satisfied with life if their parents reported eating with them frequently (Table III.9.5).

Figure III.9.4 - Parents' activities and students' life satisfaction

Students' likelihood of reporting being highly satisfied ${ }^{1}$ with their life when their parents reported having engaged in the selected activities, after accounting for students'socio-economic status (average of all countries and economies with available data)

\begin{tabular}{|c|c|}
\hline & $\begin{array}{l}\square \square \text { Students' likelihood of being very satisfied with their life when their parents reported } \\
\text { having participated in these school-related activities in the previous academic year } \\
\square \text { Students' likelihood of being very satisfied with their life when parents reported } \\
\text { engaging in these activities "at least once a week" }\end{array}$ \\
\hline
\end{tabular}

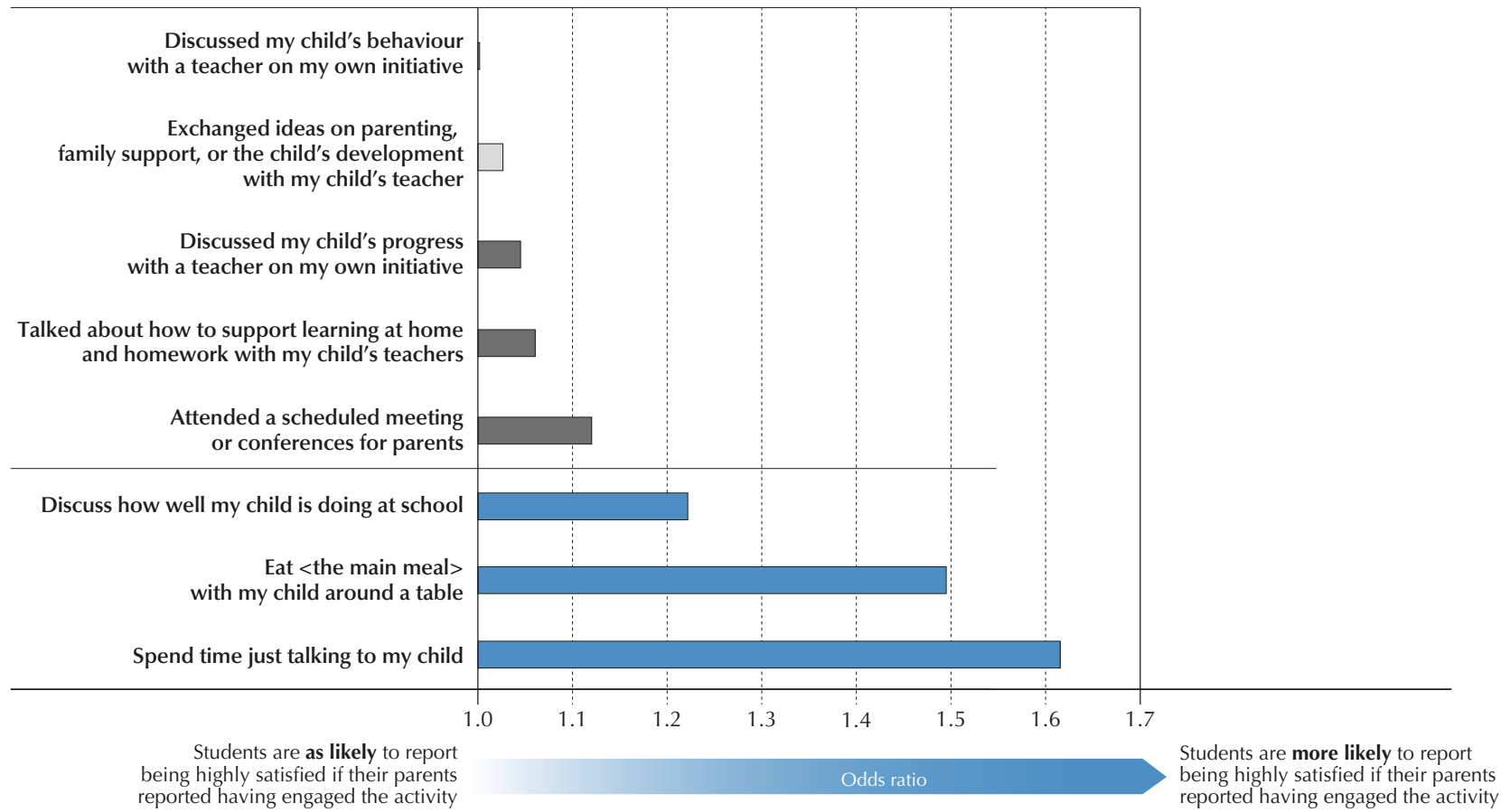

1. A student is classified as "very satisfied" with life if he or she reported 9 or 10 on the life-satisfaction scale. The life-satisfaction scale ranges from 0 to 10. Notes: Statistically significant values are marked in a darker tone (see Annex A3). All values regarding activities parents reported engaging in "at least once a week" are statistically significant.

Source: OECD, PISA 2015 Database, Table III.9.5.

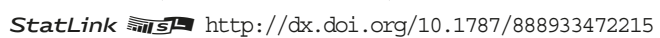


In spite of these differences, "spending time just talking" is the parental activity most frequently and most strongly associated with students' life satisfaction across all countries with available data. Only in Germany, Italy and Korea is this activity not significantly related to students' life satisfaction. In 12 countries, students were more likely to report being very satisfied with their lives when their parents reported engaging in at least one of these home-based activities at least once a week.

It is not possible from these results to determine the direction of the relationship between communication within the family and students' life satisfaction. Parents may be more likely to engage in these activities if their children are, in general, more satisfied with their life, which makes them more open to communicating and sharing a closer interaction with their parents and others. How adolescents perceive their parents' attempts to communicate with them can also play a role. Research shows that parental behaviour perceived as supportive is associated with a lower incidence of depression in their adolescent children; but if that behaviour is perceived as controlling, it is associated with a higher incidence of depression and antisocial behaviour (Barber, Stolz and Olsen, 2005; McNeely and Barber, 2010). It is also possible that by engaging in conversation and keeping a regular meal routine at home, parents are modelling social behaviours that help their children develop their own communication and social skills, which builds their self-confidence and makes them more satisfied with their life (Bandura, 1977).

\section{STUDENTS' REPORTS OF THEIR PARENTS' INTEREST IN THEIR LIFE AT SCHOOL}

Through the activities they engage in at home and at school, parents manifest their values as well as the aspirations and concerns they have for their child's life, in general, and for his or her success in school, in particular. But what parents tell their children, how they show affection and interest in them and how they support their academic achievement are ultimately subject to their children's interpretation. When asked about their perceptions regarding their parents' interest in their school life, 94\% of PISA-participating students across OECD countries reported that they "agree" or "strongly agree" that "my parents are interested in my school activities" (Table III.9.18).

Figure III.9.5 - Parents' interest in their child's activities at school, by socio-economic status Percentage of students who reported "agree" or "strongly agree" with the statement "My parents are interested in my school activities"

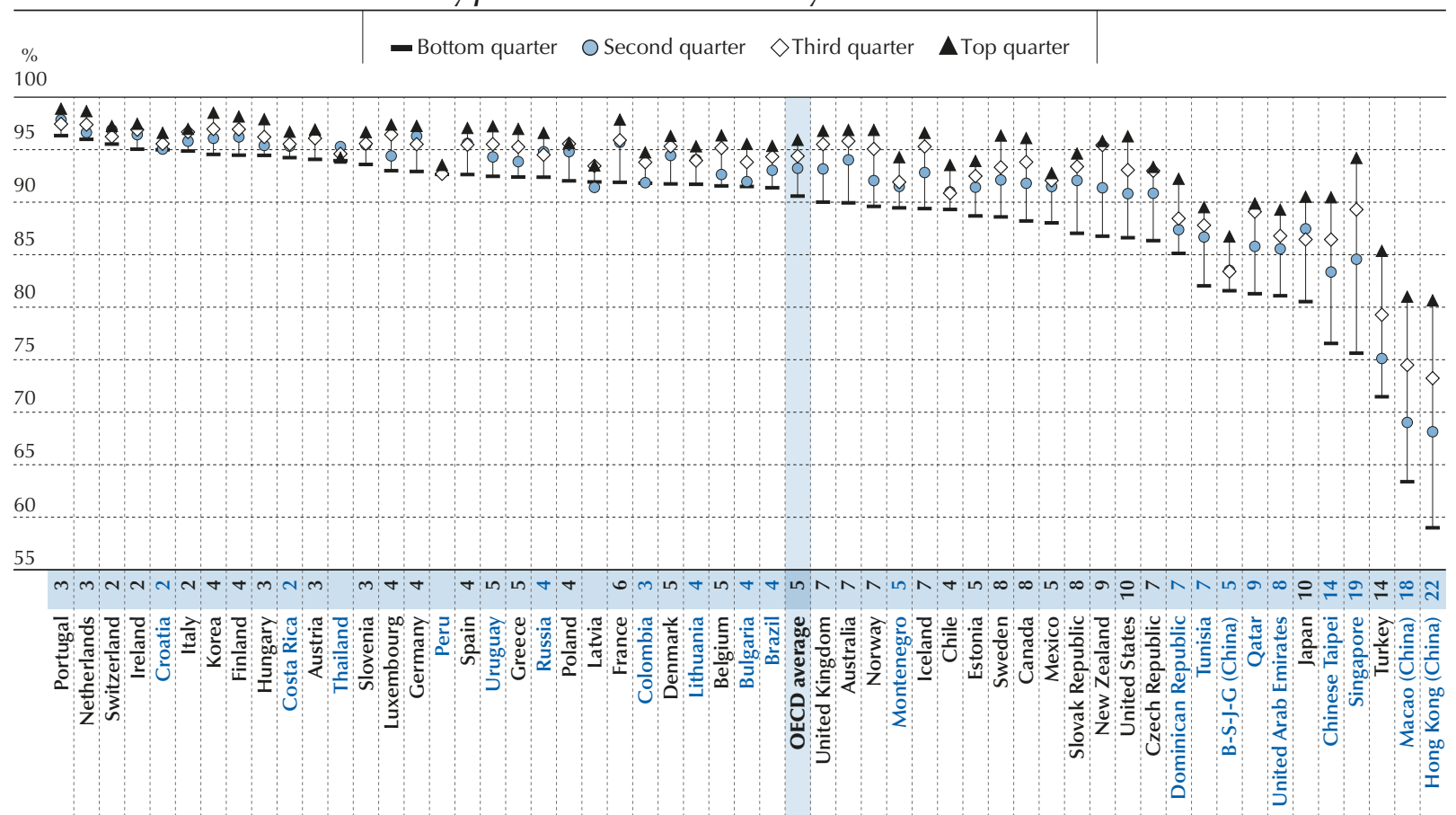

Note: Statistically significant differences in the percentage of students who reported that their parents are interested in their school activities, between students in the top and bottom quarters of the PISA index of economic, social and cultural status, are shown next to the country/economy name (see Annex A3).

Countries and economies are ranked in descending order of the percentage of students in the bottom quarter of the ESCS index who reported that their parents are interested in their school activities.

Source: OECD, PISA 2015 Database, Table III.9.20.

StatLink त्ञाज् http://dx.doi.org/10.1787/888933472221 
In most countries where this proportion is above the OECD average, there is little variation in students' responses related to socio-economic status (Table III.9.19 and Figure III.9.5). However, in countries where this proportion is below the OECD average, the share of students who "agree" or "strongly agree" that their parents are interested in their school activities is significantly smaller among disadvantaged students. The difference in this proportion between students in the bottom quarter of the PISA index of economic, social and cultural status and those in the top quarter of that index is between 10 and 15 percentage points in Japan, Chinese Taipei, Turkey and the United States. The largest gaps are observed in Hong Kong (China) (a gap of 22 percentage points), Macao (China) (a gap of 18 percentage points) and Singapore (a gap of 19 percentage points).

\section{PARENTS' INTEREST IN SCHOOL, AND STUDENTS' PERFORMANCE IN PISA AND LIFE SATISFACTION}

Students' perceptions of how interested their parents are in them and in their school life can influence their own views on the value of education, the goals they set for themselves and how much effort they put into learning - all of which may affect their performance and their motivation to do well in school (d'Ailly, 2003; Grolnick and Slowiaczek, 1994; Grolnick et al., 1991). These perceptions may also be related to students' feelings and beliefs about their parents' appreciation, care and love in general (McNeely and Barber, 2010), which may be linked to how satisfied they are with their own life.

Indeed, students who reported that their parents are interested in their school activities perform better in PISA than students who reported a lack of interest from their parents. This is true at all levels of performance in science, although this association is stronger among low-performing students (Figure III.9.6). This may indicate that parental interest acts as a protective factor against low performance, without necessarily being an equally powerful catalyst for high performance.

Figure III.9.6 - Parents' interest in their child's activities at school and science performance Score-point difference between students who reported that their parents are interested in their school activities ${ }^{1}$ and those who reported otherwise, by student performance in science (OECD average)

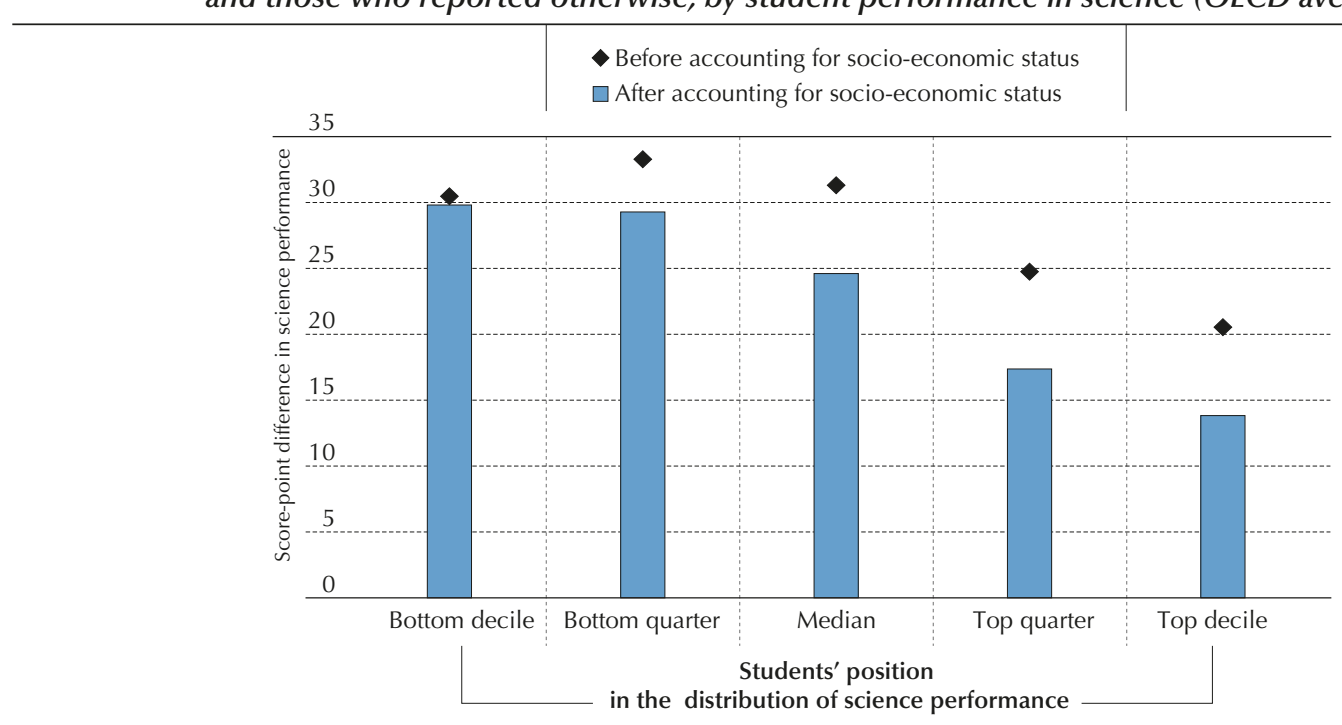

1. Students who reported "agree" or "strongly agree" with the statement "My parents are interested in my school activities".

Note: All values are statistically significant (see Annex A3).

Source: OECD, PISA 2015 Database, Table III.9.22.

StatLink त्ञाज http://dx.doi.org/10.1787/888933472232

In fact, students who "agree" or "strongly agree" that their parents are interested in their school activities are also more motivated to do well in school. Across OECD countries, these students were 2.5 times more likely to report that they "want top grades in school", on average (Figure III.9.7). Likewise, students who hold these perceptions of their parents' interest were almost twice as likely to report being highly satisfied with their life (reporting 9 or 10 on a scale from 0 to 10 of life satisfaction) than students who do not hold those perceptions. Students' positive views of their parents' interest in their school activities may signal some underlying protective effect in supportive parent-child relationships, as these students were also less likely to report feeling lonely at school and to report low satisfaction with life. 
Figure III.9.7 - Parents' interest in their child's activities at school and well-being

Increased likelihood of students to report the following measures of well-being ${ }^{1}$ if they agree or strongly agree that their parents are interested in their school activities, after accounting for students' socio-economic status (OECD average)

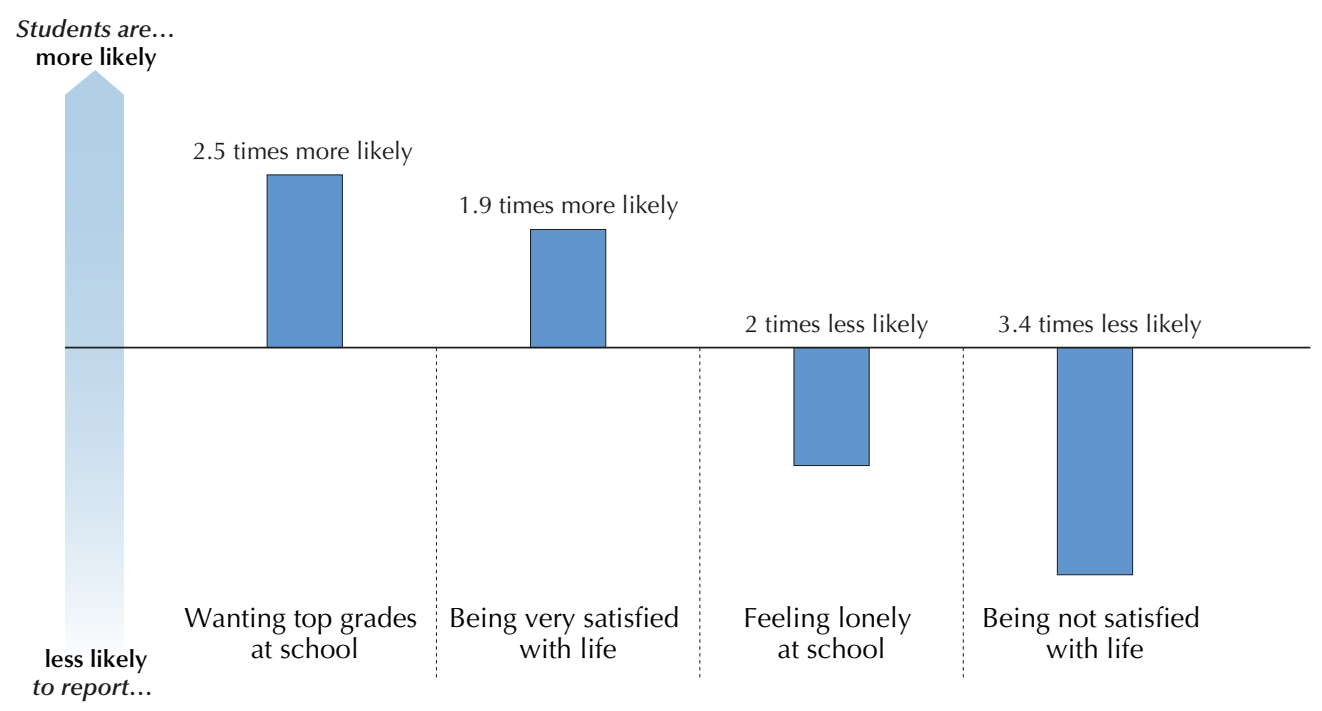

1. Students want top grades at school or feel lonely at school if they agree or strongly agree to related statements in the questionnaire. Students who are very (not) satisfied with life are those with self-reported values of 9 or 10 (between 0 and 4 ) on the life satisfaction scale, which ranges from 0 to 10 points. Notes: The figure reports a logarithmic transformation of the odds ratios of the outcome (e.g. wanting top grades at school) related to parents' interest. The logarithm transformation makes the values of odds ratios below one and above one comparable in the graph. The label at the end of each bar displays the corresponding odds ratios (change in the likelihood of the outcome).

All values are statistically significant (see Annex A3).

Source: OECD, PISA 2015 Database, Table III.9.24.

StatLink 제에 $\mathrm{http}: / / \mathrm{dx}$.doi.org/10.1787/888933472242

\section{OBSTACLES TO PARENTS' PARTICIPATION IN SCHOOL ACTIVITIES}

Schools have not always been interested in encouraging parents to participate in their activities. Parents, especially those from disadvantaged and immigrant groups, were regarded by many teachers, school leaders and policy makers as obstacles to the creation of a society based on dominant values and ideology (Bowles and Gintis, 2000; Johnson, 1976; Ministère de l'Éducation nationale, de l'Enseignment Supérieur et de la Recherche, 2006; Seginer, 2006). Recently, a growing understanding that parents and teachers can be effective partners in helping children succeed in school has led policy makers and school leaders in many countries to take deliberate actions to increase parents' participation in school life (Bronfenbrenner, 1989; D’Agostino et al., 2001; Epstein, 2001; Raikes and Love, 2002). Policies and school-level practices to increase parental participation have been shown to facilitate students' positive behaviours and attitudes at school (Avvisati et al., 2014; Berlinski et al. 2016; Dizon-Ross, 2016). Parents' involvement not only provides additional support to their child's learning, but it also brings greater accountability to education systems. Thus, one meaningful way for school leaders to help parents engage more often and more effectively with their child's school is to help remove the barriers that hinder their regular participation in school activities.

Some of these barriers may be related to factors external to school, for example, when meetings and other school activities conflict with parents' work schedule, when parents are unable to participate due to transportation problems or childcare needs, or when parents and teachers do not speak the same language. Others may be related to a lack of familiarity with the institution, a lack of information about opportunities for parental involvement, or intimidation related to language or cultural distance - all barriers that schools can help remove.

PISA asked parents whether these kinds of factors have hindered their participation in activities at their child's school during the previous academic year. Considering factors external to school, 36\% of parents reported that "I was not able to get off from work", 33\% reported that "the meeting times were inconvenient", and 13\% of parents selected "I had no one to take care of my child/children", on average across 18 countries (Figure III.9.8). Considering barriers 
related to communication, $17 \%$ reported that "I do not know how I could participate in school activities". Some $13 \%$ of parents selected the following reasons as obstacles: "I think participation is not relevant for my child's development" and "My child does not want me to participate". Some $8 \%$ of parents cited language barriers, and $7 \%$ mentioned problems with transportation.

Parents often face several of these obstacles at once. These barriers can be related to the neighbourhoods in which families live, the work arrangements they may have, the infrastructure and other human and social services available in their area, and the demographics of the region. In most countries and economies, relatively more parents reported that meeting times at school were inconvenient or that they were not able to get off from work than reported other reasons for not participating (Table III.9.26 and Figure III.9.8). In Hong Kong (China), 68\% of parents reported that they are unable to get off from work and $66 \%$ reported that meeting times are inconvenient. These two reasons can overlap, as parents may have reported that meeting times are inconvenient because they cannot get time off from work to participate. Meeting times are also a serious impediment for around $66 \%$ of Korean parents. In these countries and economies, work constraints and inflexible schedules seem to be the major barriers to participation.

Figure III.9.8 - Obstacles to parents' participation in their child's school activities

Percentage of parents who agreed or strongly agreed that the following factors hindered their participation in their child's school activities in the previous year (average for 18 countries/economies)

was not able to get off from work

The meeting times were inconvenient

I do not know how I could participate in school activities

I think participation is not relevant for my child's development

I had no one to take care of my child/children

My child does not want me to participate

My language skills were not sufficient

I had problems with transportation

\begin{tabular}{|c|c|c|c|c|c|c|c|c|c|}
\hline & & $A$ & B & C & D & E & $\mathbf{F}$ & G & H \\
\hline 8 & Belgium (Flemish) & 16.6 & 19.6 & 7.0 & 11.7 & 5.2 & 4.9 & 3.9 & 3.6 \\
\hline ठّ & Chile & 30.9 & 24.9 & 19.0 & 21.2 & 18.2 & 22.9 & 4.6 & 15.1 \\
\hline & France & 41.5 & 39.1 & 14.9 & 4.1 & 11.1 & 3.6 & 2.6 & 5.8 \\
\hline & Germany & 35.7 & 35.0 & 6.5 & 14.8 & 7.5 & 6.8 & 2.6 & 2.7 \\
\hline & Ireland & 19.0 & 16.7 & 16.1 & 5.7 & 8.5 & 8.9 & 3.6 & 3.4 \\
\hline & Italy & 31.1 & 31.9 & 17.5 & 11.2 & 8.9 & 7.7 & 6.0 & 9.0 \\
\hline & Korea & 59.2 & 66.3 & 15.4 & 16.4 & 12.4 & 11.8 & 5.3 & 5.1 \\
\hline & Luxembourg & 27.4 & 26.2 & 13.0 & 9.8 & 8.7 & 6.7 & 9.3 & 3.2 \\
\hline & Mexico & 45.5 & 45.9 & 32.3 & 28.8 & 32.7 & 32.3 & 30.5 & 14.8 \\
\hline & Portugal & 37.2 & 29.8 & 13.4 & 7.6 & 10.7 & 5.7 & 6.1 & 7.7 \\
\hline & Spain & 34.5 & 24.7 & 14.8 & 12.1 & 10.8 & 8.8 & 4.8 & 3.4 \\
\hline & United Kingdom (Scotland) & 20.5 & 18.5 & 12.5 & 5.7 & 8.0 & 11.2 & 1.5 & 3.7 \\
\hline & Average-18 & 35.7 & 32.8 & 16.8 & 13.0 & 12.8 & 12.6 & 8.4 & 6.9 \\
\hline$\frac{2}{2}$ & Croatia & 22.9 & 20.2 & 19.7 & 4.8 & 6.0 & 5.6 & 1.9 & 8.7 \\
\hline ปั & Dominican Republic & 44.4 & 29.5 & 40.7 & 36.5 & 33.2 & 45.5 & 26.2 & 9.7 \\
\hline & Georgia & 29.1 & 19.8 & 13.5 & 14.1 & 8.7 & 12.9 & 6.4 & 4.4 \\
\hline & Hong Kong (China) & 68.3 & 66.1 & 10.5 & 10.0 & 15.5 & 11.1 & 13.4 & 4.7 \\
\hline & Macao (China) & 44.2 & 39.3 & 20.0 & 10.5 & 13.0 & 11.3 & 12.0 & 6.8 \\
\hline & Malta & 35.1 & 36.9 & 15.5 & 10.0 & 11.1 & 8.8 & 11.1 & 11.8 \\
\hline
\end{tabular}

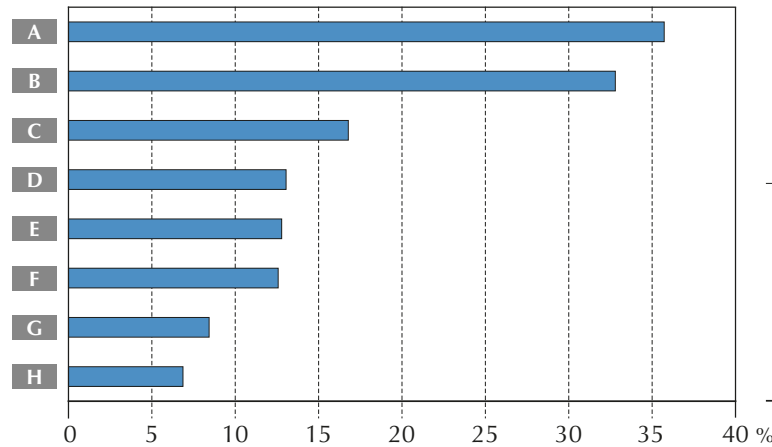

Source: OECD, PISA 2015 Database, Table III.9.26

StatLink 需西 http://dx.doi.org/10.1787/888933472257

In Latin American countries, such as Chile, the Dominican Republic and Mexico, in addition to scheduling times and inflexible work schedules, parents frequently reported a lack of childcare services and problems with transportation (Figure III.9.8). These countries also show some of the largest shares of parents who reported that they do not know how they can participate in school activities, who think that their participation is not relevant for their child's development, or who reported that their child does not want them to participate. Between $29 \%$ and $46 \%$ of parents in the Dominican Republic and Mexico reported at least one of these reasons as obstacles to participation. Schools and teachers can reach out to parents and help educate them about the value of their involvement in their child's education, and about the many ways of getting involved in school activities while respecting their child's need for autonomy.

The PISA question about barriers to parents' participation in their child's school activities reveals the concerns of parents whose interaction with the school is constrained in various ways. But what can one learn about parents who do participate in their child's school life? Do these parents differ in any way from those who do not participate? PISA data show that parents' or guardians' levels of education, their income level, how much they spend on education, and their gender are all significant indicators of whether or not a parent takes the initiative to speak with his or her child's teacher (Figure III.9.9). 
In particular, parents with a tertiary education were $21 \%$ more likely to report that they had "discussed their child's progress with the teacher at their own initiative" during the previous academic year, after accounting for students' performance. High-earning parents were $14 \%$ more likely, and those who spend more on education were 33\% more likely to report that they had done so. Mothers or female guardians were, on average, 13\% more likely than fathers or male guardians to report that they had talked to their child's teacher about his or her progress in school (survey respondents included only one of the two parents for each child); foreign-born parents were as likely as native-born parents to report that they had done so, after accounting for their child's performance in PISA.

Figure III.9.9 - Parents who initiate talks with their child's teacher, by parents' socio-economic status, gender and immigration status

Parents' likelihood of having discussed child's progress with the teacher on their own initiative, by parent/guardian's characteristics (average for 18 countries/economies)

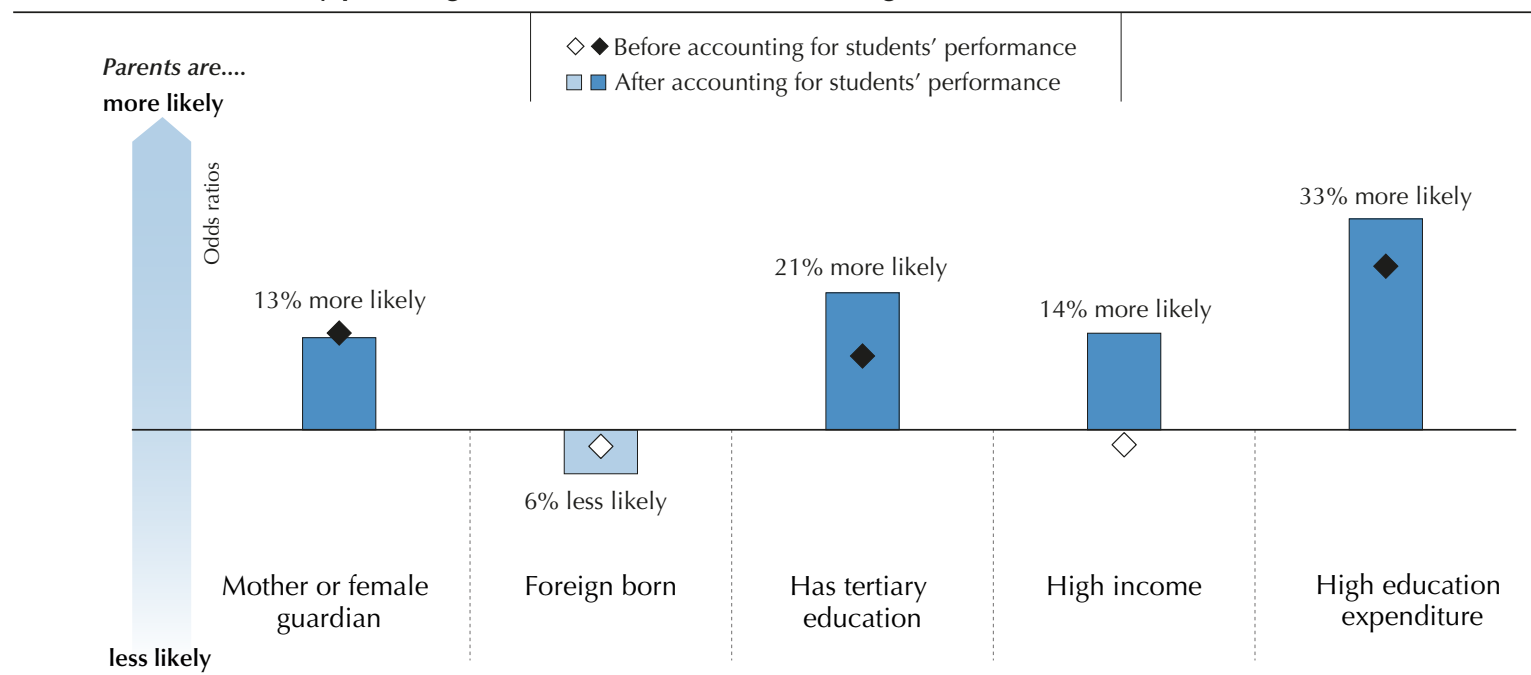

Notes: The figure reports a logarithmic transformation of the odds ratios of initiating talks with the teacher related to parents' characteristics. The logarithm transformation makes the values of odds ratios below one and above one comparable in the graph. The interpretation of the odds ratios (in terms of percentage change in the likelihood of the outcome), after accounting for students' performance, is indicated at the end of each bar. The analysis excludes students whose two parents or guardians responded together to the parent questionnaire.

Students' parents were asked to report their family income before taxes and their total expenditures in education. Their answers were coded in six income (expenditure) classes, defined independently by each country. Low (high)-income (expenditure) students are students in the bottom (top) two categories of family income (expenditures). See Table III.10.10 for the income values corresponding to the categories.

Statistically significant values are marked in a darker tone (see Annex A3).

Source: OECD, PISA 2015 Database, Table III.9.23

StatLink 제근 http://dx.doi.org/10.1787/888933472263

\section{Language barriers and parents' participation in school activities}

It is reasonable to expect that language barriers to parents' participation at school is more of a concern among immigrant parents, which might explain the relatively low percentage of parents who cite language as a reason for not participating in school activities (language barriers might also be related to the response rates to the parent questionnaire). But the reality is that there are large variations across countries in the proportion of parents who reported that their "language skills were not sufficient" (Table III.9.26). In 8 out of 18 countries, less than 5\% of parents so reported; but in the Dominican Republic, $26 \%$ of parents reported that their "language skills were not sufficient" as did 31\% of parents in Mexico. The wording of this question seems to capture not only parents who speak a language other than the official language(s) at school, but also native-born parents with less education who feel inhibited by their language skills when interacting with well-educated teachers and school staff. It is not possible to determine the extent to which these parents may be implying that the school environment is socially intimidating.

Some caution is advised in interpreting cross-country comparisons based on the immigrant background of students and their families, as observed differences are bound to be influenced by differences in immigrant populations in the countries and economies involved. That said, some patterns identified in the PISA data provide insights into how students' immigrant background is linked to their parents' inability to participate in school activities because of their language skills. The differences in parents' responses related to their child's immigrant background can also indicate which countries do a better job at integrating immigrant parents into their child's school life. 
Figure III.9.10 shows that, on average across 18 countries and economies, among non-immigrant students, $7 \%$ of parents reported that they do not participate in school activities due to language barriers; among first-generation immigrant students, $21 \%$ of parents so reported; and among second-generation immigrant students, $17 \%$ of parents so reported. In a number of European countries and economies, namely Belgium (Flemish Community), France, Germany, Ireland, Italy and Scotland (United Kingdom), the share of parents who reported insufficient language skills as a barrier to participation is at least 20 percentage points larger among first-generation immigrant students than among non-immigrant students. In Germany, 36\% of first-generation immigrant students have parents who reported such difficulties compared to less than $1 \%$ of non-immigrant students.

\section{Figure III.9.10 - Immigrant background and language skills hindering parents' participation in school activities}

Percentage of students whose parents reported that participation in their child's school activities in the previous academic year was hindered by insufficient language skills

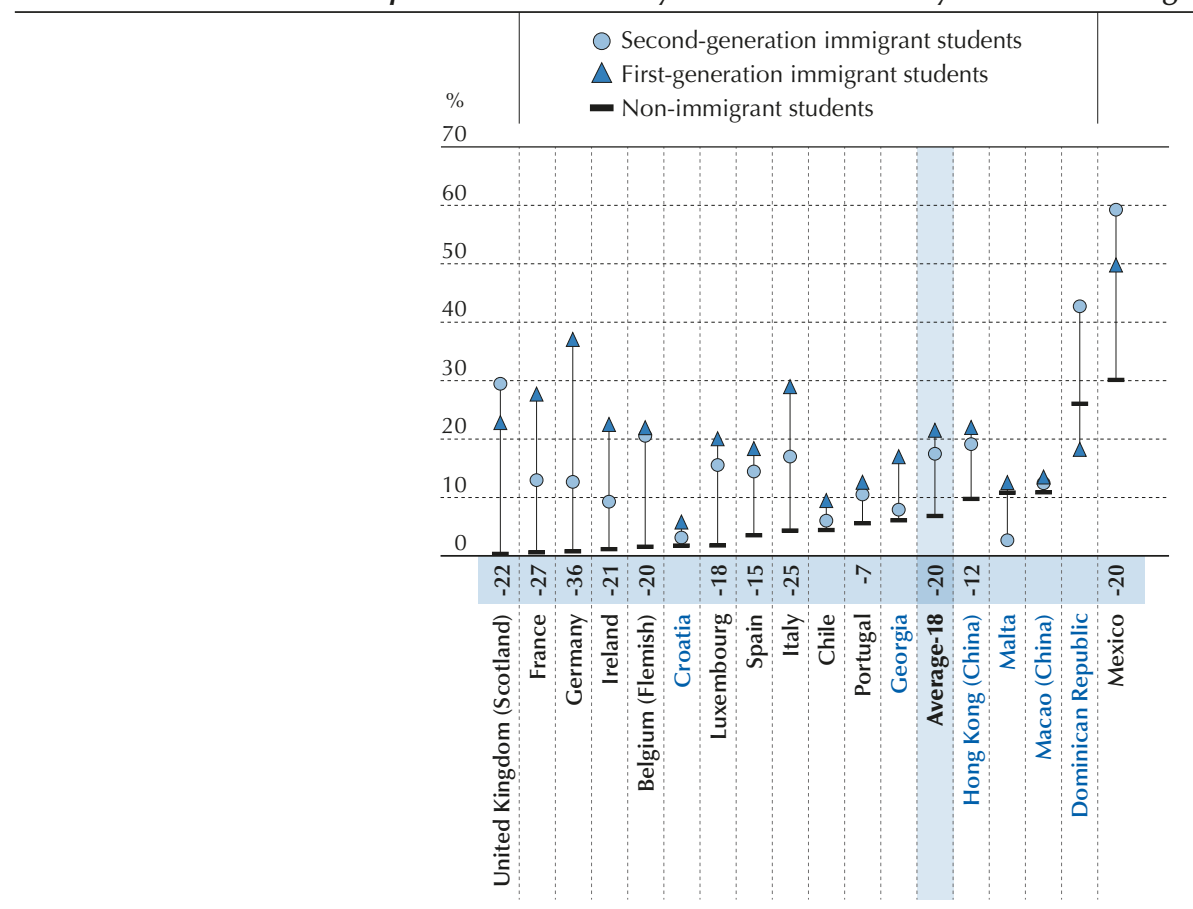

Note: Statistically significant differences between the percentage of non-immigrant students and the percentage of first-generation immigrant students whose parents reported that their language skills hindered participation in their child's school activities is shown next to the country/economy name (see Annex A3).

Countries and economies are ranked in ascending order of the percentage of non-immigrant students whose parents reported that insufficient language skills hindered participation in their child's school activities in the previous academic year.

Source: OECD, PISA 2015 Database, Table III.9.25.

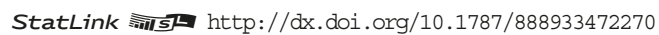

Immigrant families whose children were born in the host country (i.e. second-generation immigrant students) should, in principle, have had more time and opportunities to learn the host language and gradually feel more confident to participate in their child's school activities. But in several countries and economies, parents of second-generation students reported similar language constraints as parents of first-immigrant students (Table III.9.25). This pattern might be related to changes in the skills composition of immigrants over time, or to feelings of social exclusion shared by first- and secondgeneration immigrants. Policy makers should take a careful look at what aspects of their education, social, labour and immigration policies are keeping immigrant groups at the margin of their societies, and work across policy areas to encourage faster social and economic integration of these families.

Non-immigrant families can also face communication barriers. In Hong Kong (China), Macao (China) and Malta, the parents of around $10 \%$ of non-immigrant students reported insufficient language skills as a barrier to school participation (Figure III.9.10). In the Dominican Republic and Mexico, this proportion is remarkably large: nearly one in three nonimmigrant students has a parent who cites insufficient language skills as an obstacle to participation. The problem might 
be even more pervasive among socio-economically disadvantaged families. In Mexico, 44\% of disadvantaged parents reported this problem compared with $15 \%$ of parents in advantaged families. In the Dominican Republic, 32\% of disadvantaged parents so reported - nearly double the proportion observed among advantaged parents (Table III.9.27).

Linguistic diversity among non-immigrants, especially among indigenous populations, is one possible explanation for these findings. But factors other than parents' ability to speak the country's/economy's official language(s) might also be at play and might disproportionally affect less-educated, less-privileged parents. The school environment may seem unfriendly to them, teachers may hold stereotypical views about lack of parental interest in poor families, or the school may be using inefficient communication strategies, such as relying mostly on written instructions that may be difficult to follow by illiterate or less-educated parents. Schools need to consider how they can welcome parents from culturally, linguistically and socio-economically diverse backgrounds.

\section{What these results imply for policy}

- Parents can be encouraged to adopt simple and healthy routines - such as eating a meal together and talking together - that bring them closer to their child. Shared activities, adapted to various cultural contexts, need to respect adolescents' preferred modes of engagement and the growing need for autonomy that comes with adolescence.

- Schools can identify those parents who may be unable to participate in school activities for reasons other than a lack of interest. Building some flexibility in the ways in which parents can communicate with the school may encourage greater parental involvement. Scheduled phone or video calls may be as effective as some face-to-face meetings and may better fit the busy schedule of some parents.

- Teachers can be encouraged to welcome all parents as partners in education, particularly those from disadvantaged backgrounds whose children need their support the most to do well in school and in life. Through their engagement in their child's education, parents can help build a learning environment that encourages both high academic performance and the well-being of all students.

- Removing language barriers to parents' participation in school activities may require partnerships beyond the school. In countries with large immigrant populations, including many European countries, schools may need to seek collaboration with immigration and social services agencies, as these might offer useful services, including interpreters, that can help facilitate communication between the school and immigrant families.

- Governments can provide incentives to employers who adopt work-life balance policies so that parents have adequate time to attend to their children's needs. Healthy young people are more engaged and productive participants in society, so advancing policies that support parents' involvement in their children's lives is one way for governments to build more inclusive societies. 


\section{References}

Avvisati, F. et al. (2014), "Getting parents involved: A field experiment in deprived schools", The Review of Economic Studies, Vol. 81/1, pp. 57-83, http://dx.doi.org/10.1093/restud/rdt027.

Bandura, A. (1977), Social Learning Theory, General Learning Press, New York, NY.

Barber, B., H. Stolz and J.O. Olsen (2005), "Parental support, psychological control, and behavioral control: Assessing relevance across time, culture, and method", Monographs of the Society for Research in Child Development, Vol. 70/4, pp. 1-147, www.jstor.org/ stable/3701442.

Berlinski, S. et al. (2016), "Reducing parent-school information gaps and improving education outcomes: Evidence from high frequency text messaging in Chile", J-PAL Working Paper, https://www.povertyactionlab.org/sites/default/files/publications/726_\%20ReducingParent-School-information-gap BBDM-Dec2016.pdf (accessed 4 April 2017).

Bogenschneider, K. (1997). "Parental involvement in adolescent schooling: A proximal process with transcontextual validity", Journal of Marriage and the Family, Vol. 59, pp. 718-733, http://dx.doi.org/10.2307/353956.

Borgonovi, F. and G. Montt (2012), "Parental involvement in selected PISA countries and economies", OECD Education Working Papers, No. 73, OECD Publishing, Paris, http://dx.doi.org/10.1787/5k990rk0jsjj-en.

Bowles, S. and Gintis, H. (2000), "The origins of mass public education", in R. Lowe (ed.), History of Education: Vol. 2. Major Themes, Routledge Falmer, London, UK, pp. 61-91.

Bronfenbrenner, U. (1989), "Ecological systems theory", in R. Vasta (ed.), Annals of Child Development: Vol. 6. Six Theories of Child Development: Revised Formulations and Current Issues, JAI Press Greenwich, CT, pp. 187-249.

Catsambis, S. (2002), "Expanding knowledge of parental involvement in children's secondary education: Connections with high seniors' academic success", Social Psychology of Education, Vol. 5/2, pp. 149-177. http://dx.doi.org/10.1023/A:1014478001512.

D'Agostino, J.V., Hedges, L. V. and Borman, G.D. (2001), "Title I parent involvement programs: Effects on parenting practices and student achievement", in G.D. Borman, S.C. Stringfield and R. Slavin (eds.), Title I: Contemporary Education at the Crossroads Lawrence Erlbaum Associates Inc., Mahwah, NJ, pp. 117-136.

d'Ailly, H. (2003), "Children's autonomy and perceived control in learning: A model of motivation and achievement in Taiwan", Journal of Educational Psychology, Vol. 95/1, pp. 84-96, http://dx.doi.org/10.1037/0022-0663.95.1.84.

Dizon-Ross, R. (2016), "Parents' beliefs and children's education: Experimental evidence from Malawi", Unpublished Manuscript, Booth School of Business, University of Chicago, Chicago, IL.

Edwards, A.L. (1953), "The relationship between the judged desirability of a trait and the probability that the trait will be endorsed", Journal of Applied Psychology, Vol. 37/2, pp. 90-93, http://dx.doi.org/10.1037/h0058073.

Epstein, J.L. (2001), School, Family, and Community Partnerships: Preparing Educators and Improving Schools, Westview Press, Boulder, CO.

Fan, X. (2001), "Parental involvement and students' academic achievement: A growth modeling analysis", The Journal of Experimental Education, Vol. 70/1, pp. 27-61, http://dx.doi.org/10.1080/00220970109599497.

Fan, W. and C.M. Williams (2010), "The effects of parental involvement on students' academic self-efficacy, engagement and intrinsic motivation", Educational Psychology, Vol. 30/1, pp. 53-74, http://dx.doi.org/10.1080/01443410903353302.

Grolnick, W.S. and Slowiaczek, M.L. (1994), "Parents' involvement in children's schooling: A multidimensional conceptualization and motivational model", Child Development, Vol. 65/1, pp. 237-252, http://dx.doi.org/10.1111/j.1467-8624.1994.tb00747.x.

Grolnick, W.S., R.M. Ryan and Deci, E.L. (1991), "Inner resources for school achievement: Motivational mediators of children perceptions of their parents", Journal of Educational Psychology, 83, pp. 508-517, http://dx.doi.org/10.1037/0022-0663.83.4.508.

Hill, N.E. and Tyson, D.F. (2009), "Parental involvement in middle school: A meta-analytic assessment of the strategies that promote achievement", Developmental Psychology, Vol. 45, pp. 740-763, http://dx.doi.org/10.1037/a0015362.

Hoover-Dempsey, K.V. et al. (2001), "Parental involvement in homework", Educational Psychology, Vol. 36/3, pp. 195-209, http:// dx.doi.org/10.1207/S15326985EP3603 5 .

Johnson, R. (1976). "Notes on the schooling of the English working class 1780-1850", in R. Dale, G. Esland and M. Macdonald (eds.), Schooling and Capitalism, Routledge/Kegan Paul, London, UK, pp. 44-54.

Juang, L.P. and R.K. Silbereisen (2002), "The relationship between adolescent academic capability beliefs, parenting and school grades", Journal of Adolescence, Vol. 25/1, pp. 3-18, http://dx.doi.org/10.1006/jado.2001.0445.

Kaplan T.N. (2013), "The multiple dimensions of parental involvement and its links to young adolescent self-evaluation and academic achievement", Psychology in the Schools, Vol. 50/6, pp. 634-649, http://dx.doi.org/10.1002/pits.21698. 
Kaplan T.N. and R. Seginer (2015), "Classroom climate, parental educational involvement, and student school functioning in early adolescence: A longitudinal study", Social Psychology of Education, Vol. 18/4, pp. 811-827, http://dx.doi.org/10.1007/s11218-0159316-8.

Keith, T. Z. et al. (1998), "Longitudinal effects of parent involvement on high school grades: Similarities and differences across gender and ethnic groups", Journal of School Psychology, Vol. 36/3, pp. 335-363, http://dx.doi.org/10.1016/S0022-4405(98)00008-9.

Marchant, G.J., S.E. Paulson and B.A. Rothlisberg (2001), "Relations of middle students' perceptions of family and school contexts with academic achievement", Psychology in the Schools, Vol. 38/6, pp. 505-519, http://dx.doi.org/10.1002/pits.1039.

Marjoribanks, K. (1996), "Ethnicity, proximal family environment, and young adolescents' cognitive performance", Journal of Early Adolescence, Vol. 16/3, pp. 340-359, http://dx.doi.org/10.1177/0272431696016003005.

McNeely, C. and Barber, B. (2010), "How do parents make adolescents feel loved? Perspectives on supportive parenting from adolescents in 12 cultures", Journal of Adolescent Research, Vol. 25/4, pp. 601-631, https://doi.org/10.1177/0743558409357235.

Ministère de l'Éducation nationale, de l'Enseignment Supérieur et de la Recherche (2006), La Place et le Rôle des Parents dans I'École, Rapport - n 2006-057, web document www.education.gouv.fr/archives/2012/refondonslecole/wp-content/uploads/2012/07/ rapport igen_igaenr_la place_et_le_role_des_parents_dans_I_ecole_octobre_2006.pdf (accessed 4 April 2017).

OECD (2016), PISA 2015 Results (Volume I): Excellence and Equity in Education, OECD Publishing, Paris, http://dx.doi.org/10.1787/ 9789264266490-en.

OECD (2012), The Future of Families to 2030, OECD Publishing, Paris, http://dx.doi.org/10.1787/9789264168367-en.

OECD (2008), Encouraging Student Interest in Science and Technology Studies, OECD Publishing, Paris, http://dx.doi.org/10.1787/ 9789264040892-en.

Parker, F. L. et al. (1999), "Parent-child relationship, home learning environment, and school readiness", Social Psychology Review, Vol. 28/3, pp. 413-425.

Raikes, H.H. and J.M. Love (2002), "Early Head Start: A dynamic new program for infants and toddlers and their families", Infant Mental Health Journal, Vol. 23/1-2, pp. 1-13, https://doi.org/10.1002/imhj.10000.

Rodriguez, J.L. (2002), "Family environment and achievement among three generations of Mexican American high school students", Applied Developmental Science, Vol. 6/2, pp. 88-94, http://dx.doi.org/10.1207/S1532480XADS0602 4.

Seginer, R. (2006), "Parents' educational involvement: A developmental ecology perspective", Parenting: Science and Practice, Vol. 6/1, pp. 1-48, http://dx.doi.org/10.1207/s15327922par0601 1.

Shumow, L. and Lomax, R. (2002), "Parental efficacy: Predictor of parenting behavior and adolescent outcome", Parenting: Science and Practice, Vol. 2/2, pp. 127-150, http://dx.doi.org/10.1207/S15327922PAR020203.

Smetana, J.G. (2011), "Adolescents' social reasoning and relationships with parents: Conflicts and coordinations within and across domains", in E. Amsel and J.G. Smetana (eds.), Adolescent Vulnerabilities and Opportunities: Constructivist and Developmental Perspectives, Cambridge University Press, New York, NY, pp. 139-158. 



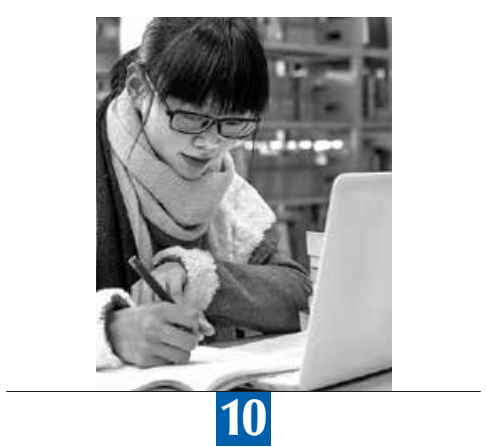

\section{Wealth, social status \\ and inequalities in well-being}

This chapter examines how parents' occupation, income and wealth are related to students' performance, satisfaction with life, and their expectations of further education and a career later on. It also shows how the socio-economic composition of schools is related to disadvantaged students' evaluations of the quality of their life and their expectations for their future. 
Money is an obvious enabler of education opportunities: cash buys books, high-quality pre-schooling and daycare, enrichment activities, and access to private tutoring if needed. Low income adversely affects parents' ability to nurture and provide for their children's needs, so that poverty during childhood and adolescence is often associated with slower cognitive development and poorer health (Case et al., 2001; Currie et al., 2012). Wealth and social status can influence well-being at school, because the family background is often related to the type of school children attend and to how students evaluate themselves in comparison with their peers (Pajares and Urdan, 2006).

\section{What the data tell us}

- Family wealth is more strongly related to student performance in countries with relatively high income inequality than in countries with relatively low income inequality.

- The concentration of students in schools according to their parents' occupation is related to characteristics of education systems, such as differences between private and public schools or between vocational and academic schools.

- Life satisfaction is associated with a student's relative status at school, as measured by the difference between his or her wealth and the wealth of the other students in the school.

- Children of blue-collar workers reported holding higher education and career expectations when they attend schools with a large proportion of children of white-collar workers.

This chapter examines how parents' occupation, income and wealth are related to the socio-economic composition of the schools that students attend and to students' performance, life satisfaction and expectations. PISA 2015 Results, Volume I documented a strong link between academic performance and socio-economic status, as measured by a summary index of parents' education, occupation, assets and cultural resources (the PISA index of economic, social and cultural status; see OECD, 2016a). This relationship varies greatly across countries, and school systems can become more equitable over a relatively short time (OECD, 2017). The chapter extends this analysis by looking at relationships between multiple measures of students' well-being and inequalities in different types of household resources, thus peeking inside the black box of socio-economic status. Disentangling the different sources of the strong relationship between socio-economic status and students' well-being is important, because the policy responses to inequalities depend on the ways through which socio-economic advantage gets transmitted from one generation to the next. Understanding the implications of socio-economic inequalities on different aspects of students' well-being can also inform the design of policies for equal opportunities at the system level and guide school-level practices for creating equitable learning spaces.

\section{SOCIO-ECONOMIC INEQUALITIES, SOCIAL SEGREGATION AT SCHOOL AND PERFORMANCE}

Recent trends in income distribution in OECD countries show signs of "polarisation": more families fall into either extreme end of the distribution, and fewer are in the middle (OECD, 2015). Income inequality is less of a concern if children in low-income families have a good chance of climbing up the income ladder when they grow up. However, income inequality tends to reproduce itself generation after generation (Corak, 2013).

PISA data on household possessions and family income can describe inequalities in the material conditions of students. The PISA index of family wealth is based on the number and type of home possessions, such as cell phones, computers, cars and rooms with a bath or shower. Figure III.10.1 shows that the values of this index vary greatly both between and within countries. Disparities in wealth, as measured by the difference between students in the top quarter and in the bottom quarter of the index, were relatively large (3.5 units or more) in Peru, Qatar and the United Arab Emirates (Table III.10.6). In general, inequalities in household possessions, as reported by students, were high in countries with a relatively low per capita income.

In 16 countries and economies where the parent questionnaire was distributed, parents also provided information on their household income. This information was coded into six categories (e.g. below " $X$ " dollars; above " $X$ " dollars and below "XX" dollars, etc.), defined at the national level by the participating countries. Figure III.10.2 shows that students are not equally distributed across the six income categories in the countries with available data. The Dominican Republic and Mexico are the two countries with the highest percentages of tested students with relatively low income (in the bottom two categories of family income). In the Dominican Republic, for example, 74\% of students live in lowincome families where parents reported an annual family income below USD 1110 (in purchasing power parities), and $12 \%$ live in high-income families where the annual family income, as reported by parents, was above USD 1860. 
Figure III.10.1 - Index of family wealth, by quarters of this index Results based on students' self-reports

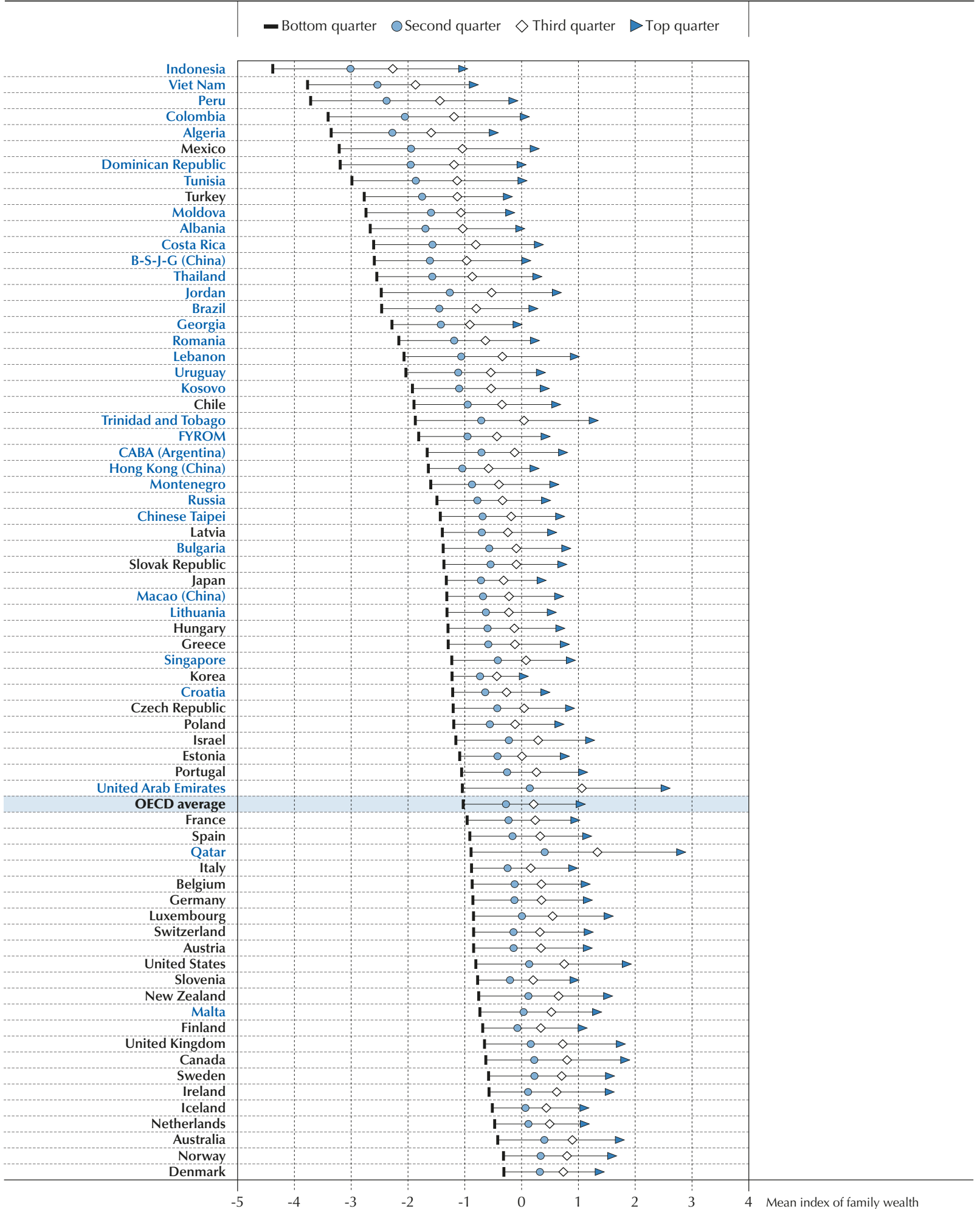

Notes: The index of family wealth is based on the number and type of home possessions, such as cell phones, computers, cars and rooms with a bath or shower reported by the student.

Countries and economies are ranked in ascending order of the mean index of family wealth for students in the bottom quarter of this index.

Source: OECD, PISA 2015 Database, Table III.10.6

StatLink 쳎ㄴ http://dx.doi.org/10.1787/888933472442 
Figure III.10.2 - Distribution of students, by family income

Percentage of students in high- and low-income families and corresponding income (in USD)

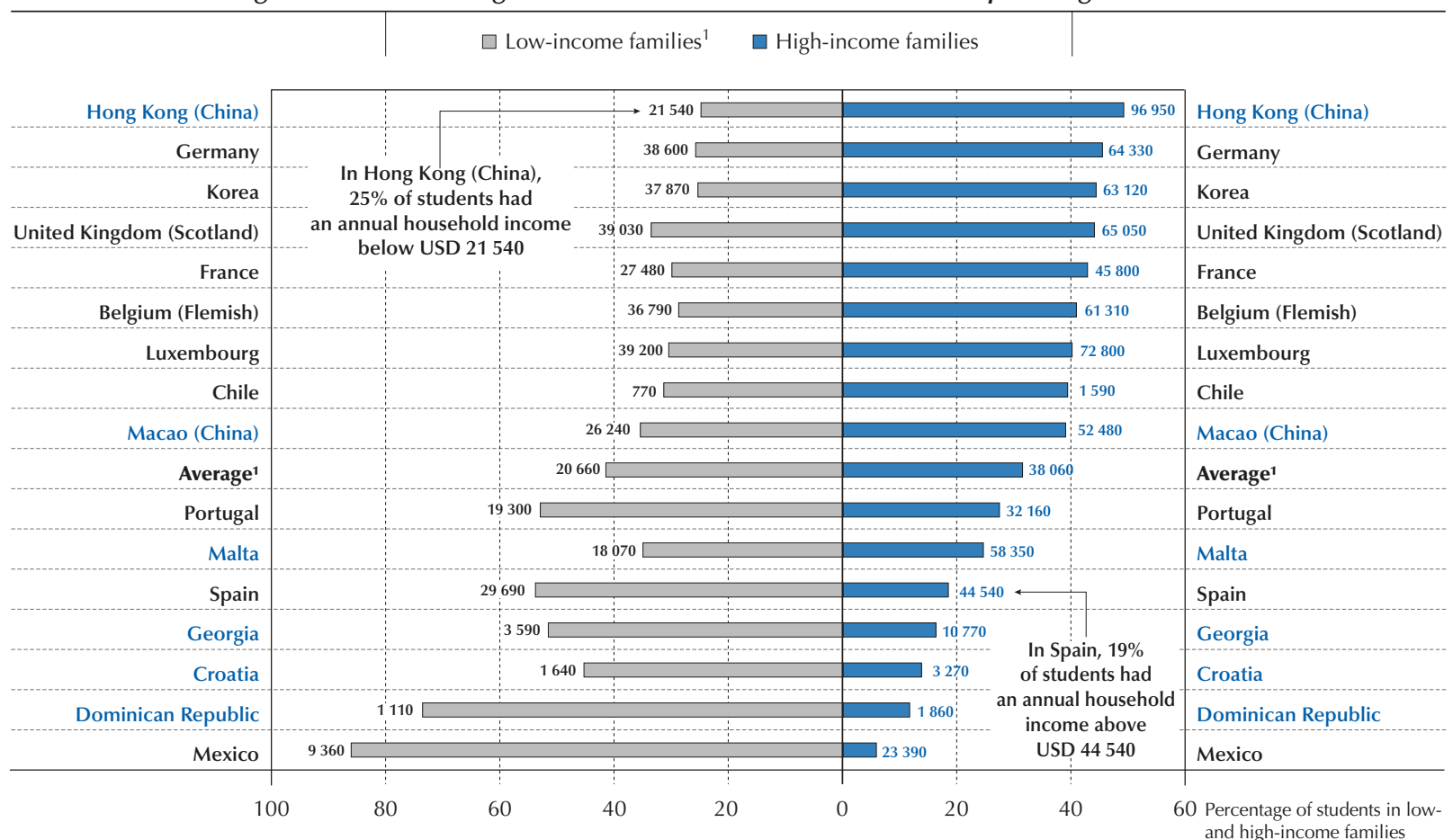

1. "Average" includes all countries and economies with available data.

Notes: Students' parents were asked to report their family income before taxes. Their answers were coded in six income categories, defined independently by each country. Low(high)-income students are students in the bottom(top) two categories of family income.

The income level (USD) corresponding to the top two and bottom two income categories are shown next to the corresponding percentage bar.

Countries and economies are ranked in descending order of the percentage of students in high-income families.

Source: OECD, PISA 2015 Database, Table III.10.10.

StatLink त्ञाज ht htp://dx.doi.org/10.1787/888933472457

By contrast, Belgium, France, Germany, Hong Kong (China), Korea, Luxembourg and Scotland (United Kingdom) show relatively large shares $(40 \%$ or higher) of high-income students, and the threshold defining these students was also high in those countries (from USD 45800 in France to USD 96950 in Hong Kong [China]). Differences in the income available to individual children might be higher than what is shown in the figure if low-income families have more household members than high-income families.

The most visible and well-documented impact of wealth and income inequalities on students' well-being is the relatively low performance of students at the bottom of the socio-economic ladder. PISA consistently finds that disadvantaged students perform worse than advantaged students, even if the strength of the relationship varies greatly across countries (OECD, 2016a). On average across OECD countries, a one-unit change in the index of family wealth corresponds to an increase of 10 points in a student's science score, before accounting for differences in parents' education, and an increase of 4 points after accounting for parents' education (Table III.10.7). Similarly, students in high-income families perform better in science than students in low-income families (Table III.10.11).

Does family wealth matter more for education success in more unequal societies? The fraction of the variation in performance in PISA that is explained by the wealth index is a measure of the relevance of the material resources of one generation for the education success of the next generation (Sandefur, 2015). Figure III.10.3 shows a strong relationship between the variation in science performance related to family wealth and the overall income inequality of countries. Among OECD countries, the level of income inequality (as measured by the Gini Index) is not as high as in several partner countries, on average, and the index of wealth accounts for only $2 \%$ of the variation in performance (Table III.10.7). Countries with high income inequality, such as Brazil, Colombia, the Dominican Republic and Uruguay also show a strong relationship between the wealth index and science performance. For example, in Colombia, income inequalities are high (the Gini index is 54 out of 100) and household possessions account for around 14\% of the variation in performance. 
This association suggests that the inequalities observed more broadly in a country are reflected in student performance. In other words, in all systems, rich parents may use their wealth to provide better education for their children, but in more unequal societies, wealthy parents pass on more of that advantage to their children (Sandefur, 2015). This finding confirms the negative relationship between income inequality and intergenerational mobility that has been called the Great Gatsby Curve (Corak, 2013). It suggests that education is an important mediator of the relationship between social mobility and income inequality (Jerrim and Macmillan, 2015).

Figure III.10.3 - Family wealth, performance and income inequality Association between the Gini index and the percentage of variation in science performance explained by family wealth

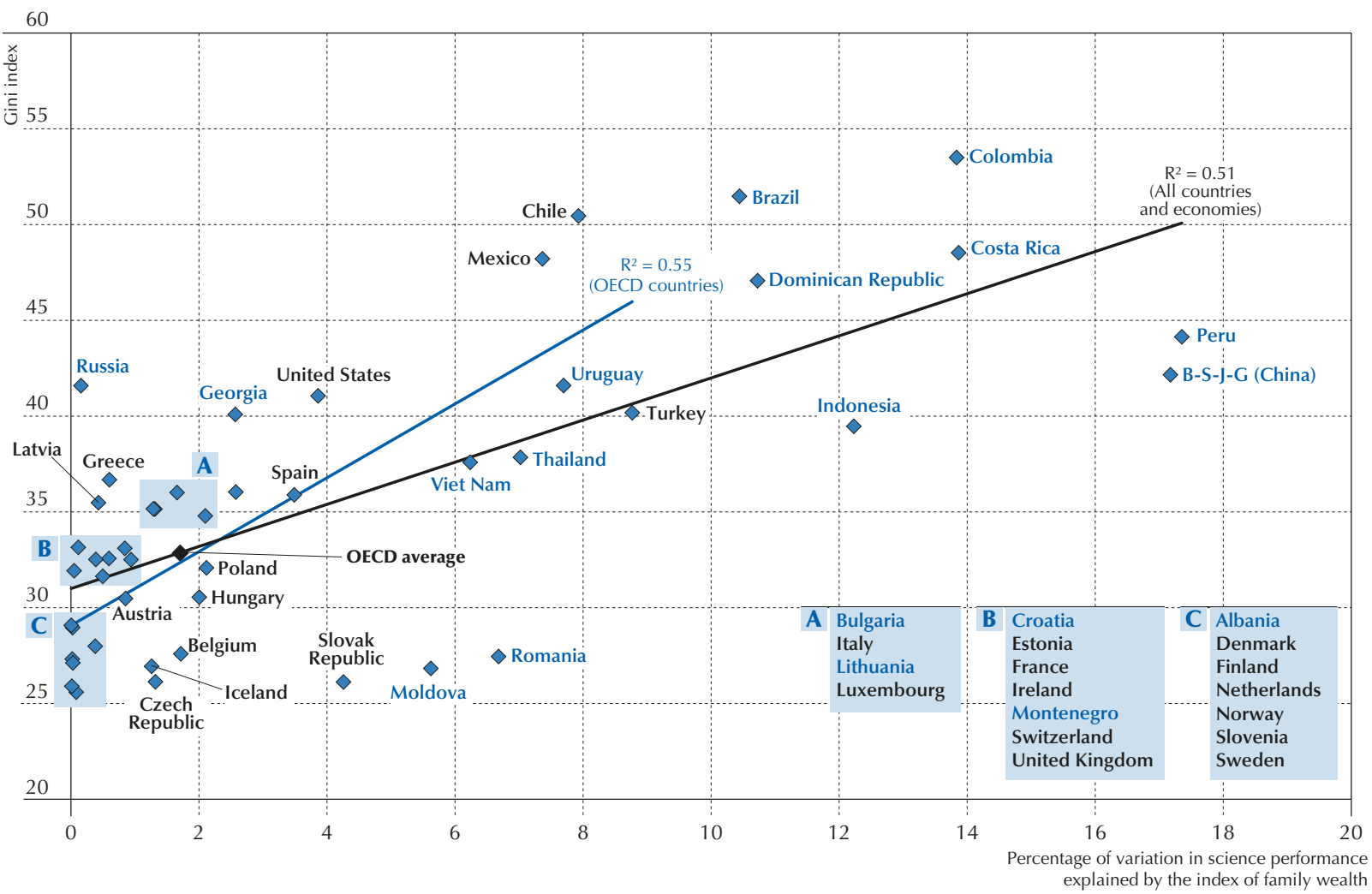

Notes: The index of family wealth is based on the number and type of home possessions, such as cell phones, computers, cars and rooms with a bath or shower reported by the student. The percentage of variation in performance in PISA that is explained by the index of family wealth is a measure of the relevance of material resources of one generation for the education success of the next generation.

The Gini index measures the extent to which the distribution of income among households within an economy deviates from a perfectly equal distribution. A Gini index of zero represents perfect equality and an index of 100 represents perfect inequality.

Source: OECD, PISA 2015 Database, Table III.10.7.

StatLink 제요 http://dx.doi.org/10.1787/888933472460

The strength of the link between inequality in society and inequalities in academic outcomes should not lead to the wrong conclusion that education policies cannot influence opportunities for upward mobility. The design of education systems, in fact, mediates the relationship between parents' resources and learning outcomes by influencing, for example, the level of resources available to public and private schools, or to urban schools and schools in remote rural areas (Greenwald, Hedges and Laine, 1996; OECD, 2016b; Rivkin, Hanushek and Kain, 2005).

Differences in the social composition of schools are often related to structural characteristics of education systems. For example, a large country with a clear rural-urban divide is likely to show, all else being equal, more polarisation in the social composition of schools than a small, homogenous economy. But education policies can play an important role too. The social mix of schools can be analysed by looking at the concentration of students in schools according 
to their parents' occupation, where occupation is classified in the two categories of blue-collar or white-collar jobs ${ }^{1}$ (Figure III.10.4). This concentration is measured by a social segregation index ranging from 0 to 100 , with values close to 0 indicating that children of blue-collar and white-collar workers are distributed evenly across schools, and values closer to 100 indicating that children of blue-collar and white-collar workers are likely to attend different schools ${ }^{2}$ (Hutchens, 2004; Hutchens, 2001; Jenkins et al., 2008). The three countries where children of white-collar workers and children of blue-collar workers are more likely to mix in the same school are Algeria, the Former Yugoslav Republic of Macedonia (hereafter "FYROM") and Montenegro. The countries and economies with more pronounced segregation at school (above 25), based on parents' occupation, are Australia, Bulgaria, Chile, Ciudad Autonoma de Buenos Aires (Argentina) (hereafter "CABA [Argentina]"), Hungary, Indonesia, Israel, Norway, Peru, Qatar and the United Arab Emirates (Figure III.10.4).

\section{Box III.10.1 The value of a quiet space for learning}

The family and the household are the first social system where students begin to acquire the fundamental cognitive and social skills necessary for school and for life (Machida et al., 2002; OECD, 2012). The material resources available in the household where students live can influence their cognitive and psychological development; but some resources matter more than others.

Living in a home where children have a quiet space to study or to engage in other activities is particularly important for students' learning. Across OECD countries, around 92\% of students reported that they have a desk to study at and a quiet place to concentrate. But in Colombia, Indonesia, Mexico, Thailand, and Trinidad and Tobago, at least one in four students reported that they do not have a quiet place to study at home (Table III.10.1).

Students in poorer families are more likely to share a room and to live in more crowded conditions, where it is more difficult to concentrate. A crowded space might also make it harder for parents to maintain a calm, orderly home. It is thus not surprising that, across OECD countries, students who reported that they have a quiet place to study at home score roughly 30 points higher in science (the equivalent of one year of schooling; see Box I.2.1 in OECD, 2016a) than students who do not have such a place (Table III.10.2). The performance advantage of students with a quiet place to study remains significant after accounting for parents' education and is the largest in Beijing-Shanghai-Jiangsu-Guangdong (China) (hereafter "B-S-J-G [China]"), one of the few economies where the study time spent out of school is positively related to PISA scores. In B-S-J-G (China), 61\% of students in advantaged schools have access to a room in their school where they can do their homework, while only $14 \%$ of students in disadvantaged schools have access to such a room (OECD, 2016b, Table II.6.43). In Japan, 96\% of students have access to a quiet place to study at school, and there is no difference in access between advantaged and disadvantaged schools.

In Belgium, France, Germany and Luxembourg, the score-point difference in science performance between children who reported that they have a quiet place to study and other children is between 46 and 61 points (Table III.10.2). In these countries, the shares of students who reported that they do not have a quiet place to study are well below the OECD average of $8 \%$ (Table III.10.1). These disadvantaged students probably suffer from other forms of material deprivation and benefit less from a protective family environment. PISA cannot prove that there is a causal relationship between overcrowding or disorder at home and academic performance. But an analysis based on random variations in overcrowding (based on the fact that same-sex siblings are more likely to share a room) shows that the relationship between disadvantaged living conditions and academic failure is plausibly one of cause and effect (Goux and Maurin, 2005). The negative association between the availability of a quiet space for learning and academic achievement originates in early childhood and may build over time.

While financial and social aid to the poorest families can improve their children's performance in school, interventions at the school level can also help reduce unequal education opportunities. Whole-school strategies involving administrators, teachers, counsellors, parents, and public and civic-society organisations are necessary to identify the resources that low-performing children lack and the type of support that schools can provide. But even small and relatively easy-to-implement interventions, such as giving students access to a quiet place to study in the afternoon, can make a difference to materially deprived children. 
Figure III.10.4 - Social segregation at school, by parents' occupation

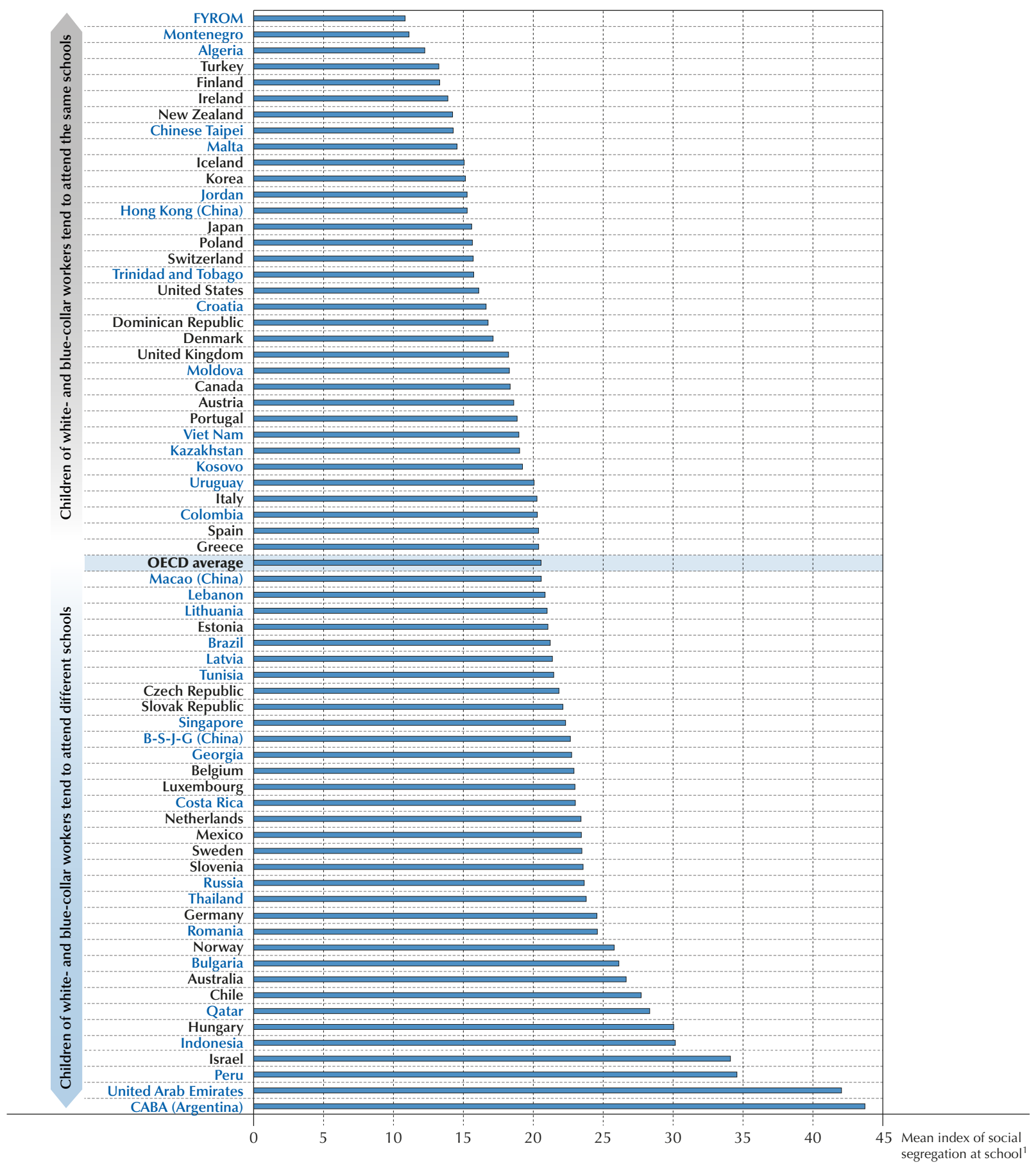

1. The index of social segregation at school measures the concentration of students in different schools according to their parents' occupation (Jenkins et al., 2008; Hutchens, 2001 and 2004). It has values between 0 and 100, with values closer to 100 indicating that children of blue-collar and white-collar workers are distributed unevenly across schools.

White-collar workers are defined as managers (ISCO-08 category 1), professionals (ISCO-08 category 2) and technicians and associate professionals (ISCO-08 category 3).

Blue-collar workers are defined as skilled agricultural, forestry and fishery workers (ISCO-08 category 6), craft and related trades workers (ISCO-08 category 7), plant and machine operators and assemblers (ISCO-08 category 8) and workers in elementary occupations (ISCO-08 category 9).

Countries and economies are ranked in ascending order of the index of social segregation at school.

Source: OECD, PISA 2015 Database, Table III.10.14.

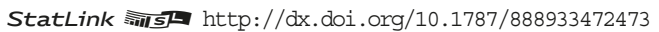


In Brazil, CABA (Argentina), Colombia, the Dominican Republic, Malta, Peru, Spain and Uruguay (all economies with relatively high income inequality), more than $20 \%$ of the index of segregation is explained by differences in the social composition of students attending private and public schools (Table III.10.13). In other words, much of the uneven distribution of children across schools reflects the fact that children of white-collar workers are more likely to study in private schools than the children of blue-collar workers. Highly selective private education is thus a potential source of socio-economic segregation across an education system, and private schools are more exclusive in some countries than in others (Jenkins et al., 2008).

In several European countries, a large fraction of social segregation at school is related to the fact that children of whitecollar workers tend to be enrolled in school programmes that prepare them for university and children of blue-collar workers tend to attend vocational schools. Table III.10.14 shows that, in Croatia, 45\% of the index of segregation is explained by differences in social background between the students enrolled in academic tracks and those enrolled in vocational tracks (in Montenegro, 33\% of the index of segregation is so explained; in Italy, 31\%; in Slovenia, 29\%; and in the Netherlands, $27 \%$ of the index is so explained). Education policies can thus have an impact on the polarisation found in the social composition of schools, together with structural factors, such as rural-urban and residential inequalities.

\section{SOCIAL COMPOSITION OF SCHOOLS, LIFE SATISFACTION AND EXPECTATIONS}

Family affluence and social status are not only related to academic performance but can also affect adolescents' satisfaction with life, their perceptions about themselves and their aspirations for the future. Economic conditions can affect adolescents' well-being by limiting their consumption and leisure opportunities. Adolescents from disadvantaged families may have to go without things perceived as important for them to participate in mainstream society and to conform with their peers (Becchetti and Pisani, 2014). Research has shown that measures of objective socio-economic status - like family or neighbourhood wealth - are related to students' subjective social status at school, where students place themselves on a ladder where the highest rung represents the people in their school with the most respect and the highest standing (Goodman et al., 2001). These perceived placements in the group may contribute to students' evaluation of their satisfaction with their own life (Sweeting and Hunt, 2014).

Figure III.10.5 shows how students' reports of life satisfaction vary according to their family's wealth. The right side of the graph (positive values) shows that, in most countries, a greater proportion of wealthy students (those at the top quarter of the wealth index) reported being "very satisfied" with their life compared to the share of students at the low end of the index (bottom quarter of the wealth index) who reported the same. This difference corresponds to 10 percentage points, on average, across OECD countries, but is at least twice as large in Estonia, Lithuania and Qatar. Wealthy students were also less likely than their less-privileged peers to report "low levels of life satisfaction", as seen on the left side of the graph (negative values). On average across OECD countries, the share of students who reported "low life satisfaction" is about 7 percentage points larger among students in the bottom quarter of the wealth index than among those at the top quarter of the index. This gap ranges between 10 and 16 percentage points in Hungary, Tunisia, Turkey and the United Arab Emirates, and is negligible in Colombia and Switzerland.

In a few countries, however, wealthy students are less likely to be very satisfied with their life than less-privileged students are. In Brazil, Colombia, Peru and Thailand, students at the lower end of the wealth index were between 4 and 10 percentage points more likely to report high life satisfaction than those at the top of the index. One possible explanation for this finding points to the role of social capital in relatively deprived communities (Woolcock and Narayan, 2000). When income and wealth are insufficient to buy comfort, safety, and a number of social and cultural goods, people may be more inclined to rely on each other and build nets of solidarity around practical matters (e.g. childcare, transportation, social life), which can help boost their sense of social integration and life satisfaction (Saegert et al., 2001). Other explanations for these results are plausible, too. For example, the factors students take into account when assessing their own life satisfaction may themselves be dependent on the students' socio-economic status (Diener et al., 2003; Neff, 2007; Tucker et al., 2006). Even in those countries where the difference in favour of the poorest students is largest, a substantial proportion of wealthy students (38\% in Peru, 39\% in Thailand, $43 \%$ in Brazil and $47 \%$ in Colombia) reported high levels of life satisfaction (Table III.10.8)

Figure III.10.6 shows the relationship between a student's life satisfaction and the wealth of his or her schoolmates. In most countries, students reported less life satisfaction if they are not as wealthy as the other students in their school (their relative wealth is lower), after accounting for students' index of family wealth (their absolute level of wealth). This relationship is most prominent in Croatia, Montenegro and the Russian Federation (hereafter "Russia"). Both absolute and relative wealth can thus have an influence on students' life satisfaction (Hudson, 2013). 
Figure III.10.5 - Family wealth and life satisfaction

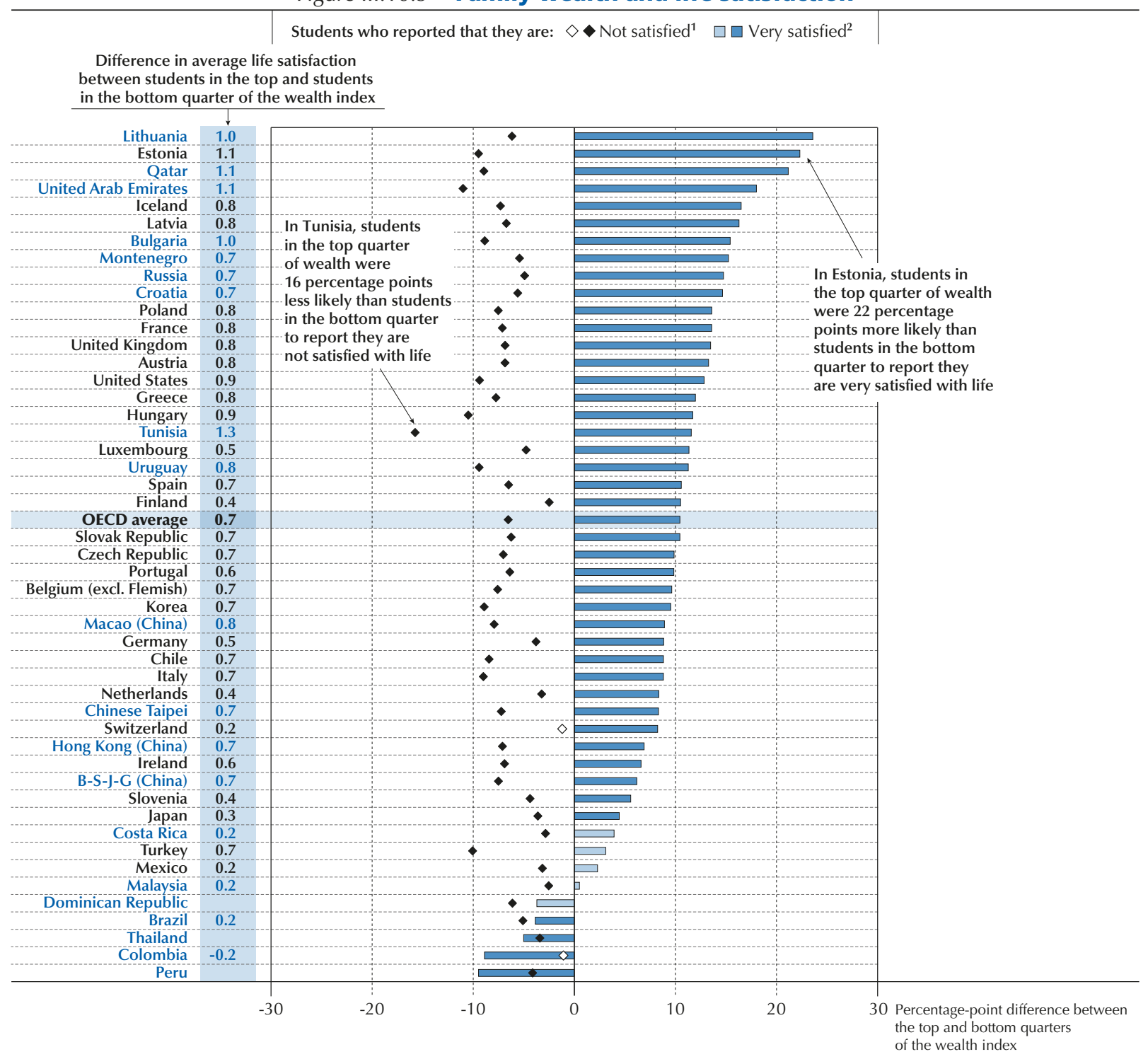

1. A student is classified as "not satisfied" with life if he or she reported between 0 and 4 on the life-satisfaction scale. The life-satisfaction scale ranges from 0 to 10 .

2. A student is classified as "very satisfied" with life if he or she reported between 9 to 10 on the life-satisfaction scale. The life-satisfaction scale ranges from 0 to 10 .

Notes: The index of family wealth is based on the number and type of home possessions, such as cell phones, computers, cars and rooms with a bath or shower, as reported by the student.

Statistically significant values are marked in a darker tone (see Annex A3).

Countries and economies are ranked in descending order of the difference in the percentage of students who reported feeling very satisfied with their life, between students in the top quarter and students in the bottom quarter of the index of wealth.

Source: OECD, PISA 2015 Database, Tables III.10.8 and III.10.9.

StatLink 제에 $h$ htp://dx.doi.org/10.1787/888933472483

Adolescents form opinions about themselves based on comparisons with their schoolmates. Disadvantaged students who attend advantaged schools may suffer from social isolation or even feelings of discrimination if they are not prepared to be a member of a disadvantaged minority in the school. For example, many disadvantaged students in the United States dropped out of integration programmes (Carter, 2007; Davis, 2014). Poor students in Chile have also had problems integrating socially in prestigious schools (Montt, 2012).

Does this mean that disadvantaged students are better off when they attend disadvantaged schools? On the one hand, comparing oneself with advantaged peers can undermine the self-belief and life satisfaction of a disadvantaged student. 
On the other hand, disadvantaged students who attend the same school and learn in the same classroom as their advantaged peers might absorb the attitudes of their schoolmates and develop high aspirations and expectations for themselves.

Students' aspirations for further education and their career later on are shaped by family wealth, social status and neighbourhood characteristics (Stewart et al., 2007). Table III.10.15 shows that, on average across OECD countries, $29 \%$ of the children of blue-collar workers and 55\% of the children of white-collar workers reported that they expect to complete a university education. Children of blue-collar workers were also much less likely to expect to work as managers or professionals than children of white-collar workers (with an average difference of 21 percentage points across OECD countries).

Figure III.10.6 - Relative wealth at school and life satisfaction Change in a student's life satisfaction associated with a one-unit increase in the average wealth of the other students in the school

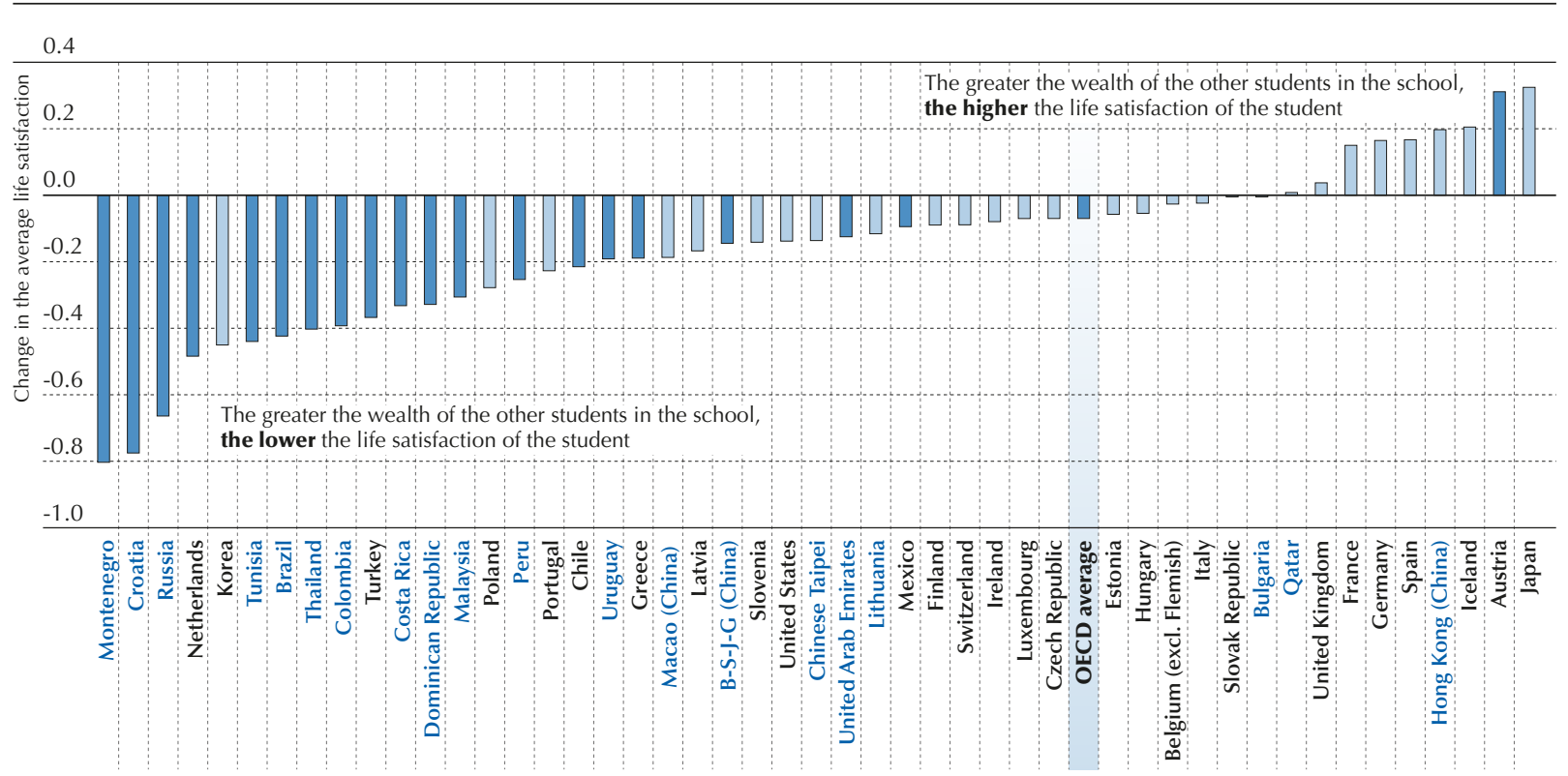

Notes: The index of family wealth is based on the number and type of home possessions, such as cell phones, computers, cars and rooms with a bath or shower, as reported by the student. The life-satisfaction scale ranges from 0 to 10 .

Statistically significant values are marked in a darker tone (see Annex A3).

Countries and economies are ranked in ascending order of the change in life satisfaction associated with a one-unit change in the average index of family wealth of the other students of the school.

Source: OECD, PISA 2015 Database, Table III.10.9.

StatLink 需实 http://dx.doi.org/10.1787/888933472499

\section{Box III.10.2 Do students expect the same career as their parents?}

In his research linking a father's earnings to a son's adult earnings, Miles Corak has shown that more unequal economies tend to have less fluid societies (Corak, 2013). According to Corak's findings, in some places, like the United Kingdom and United States, around 50\% of income differences in one generation are attributable to differences in the previous generation, while in some of the more egalitarian countries in Northern Europe, less than $30 \%$ of income differences in one generation are so attributable. But according to other research that examines the over-representation of aristocratic names in elite positions, much of a family's social status is transmitted from generation to generation across a span of centuries - even in Sweden (Clark, 2012).

Some of the persistence of socio-economic advantage stems from adolescents' expectations to pursue the same career as their parents. Parents are key role models who set an example, provide opportunities, and give advice to either aim for or steer clear of their own lines of work. Some parents want their children to follow their footsteps, while others encourage their children to explore other avenues and realise their own ambitions. 
Figure III.10.7 - Percentage of students who expect the same career as their parents, by gender

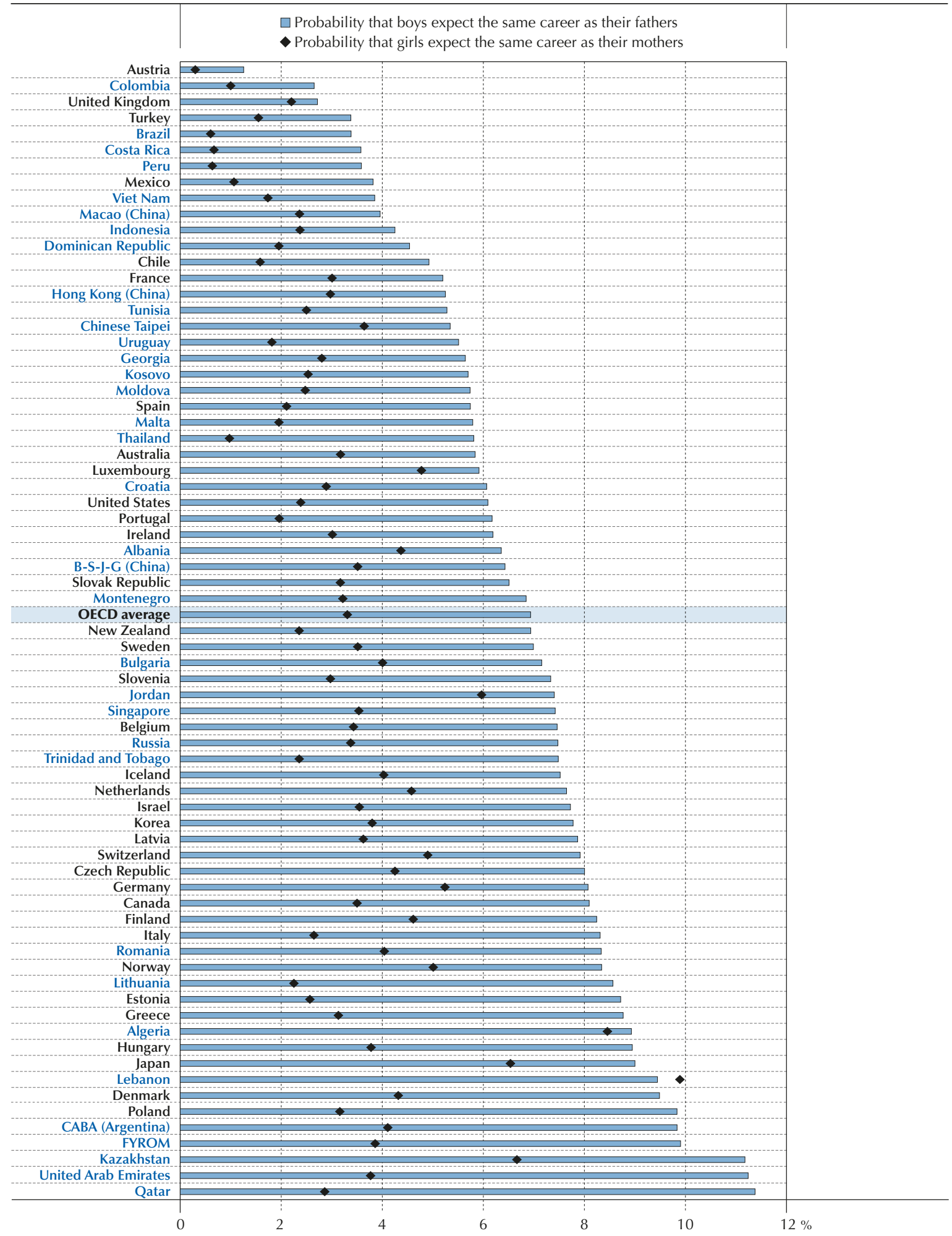

Note: Students reported their expected occupation when they are 30 years old. Students' expected occupation and parents' current occupation are coded according to the International Standard Classification of Occupations, 2008 edition (ISCO-08), at the 3 digit level (e.g., 111 ISCO code: Senior officials and legislators).

Countries and economies are ranked in ascending order of the percentage of boys who expect to have the same career as their father. Source: OECD, PISA 2015 Database, Table III.10.16.

StatLink ज्ञाज http://dx.doi.org/10.1787/888933472502 
PISA 2015 asked students what occupation they expect to be working in when they are 30 years old. Students could enter any job title or description in an open-entry field; their answers were classified according to the International Standard Classification of Occupations, 2008 edition (ISCO-08). Across OECD countries and economies, around 7\% of students expect to do the same job as their parents when they are 30 (Table III.10.16). This percentage ranges from around $1 \%$ in Indonesia, Peru, Turkey and Viet Nam, to more than 10\% in Algeria and Lebanon (this analysis defines a job as a three-digit ISCO group: for example, Nursing and Midwifery Professionals [code 222] form one job).

A comparison of boys and girls adds interesting nuances to these data. In theory, virtually all careers should be available to both men and women, but this availability is not always perceived by adolescents as realistic. This perception arises, in part, from the influence of gender stereotypes in occupational choices. On average across OECD countries, $7 \%$ of boys expect to be working in the same occupation as their fathers, while only $3 \%$ of girls expect the same job as their mothers (Figure III.10.7). On average, around $2 \%$ of boys expect to be working in the same occupation as their mothers, and $2 \%$ of girls in the same occupation as their fathers. In Qatar and the United Arab Emirates, more than $10 \%$ of boys expect to be working in the same occupation as their fathers. In Algeria, Germany, Japan, Jordan and Lebanon, at least 5\% of girls to follow in their mothers' footsteps, whereas less than $1 \%$ of girls in Austria, Brazil, Costa Rica and Peru reported so. In Albania, Denmark, Germany and Lebanon more than $15 \%$ of girls expect to work in the same job as their mothers (Table III.10.16).

Gender differences partly stem from the fact that girls' career expectations are concentrated in a more limited number of jobs that do not generally correspond to those of their fathers or mothers. On average across OECD countries, around $35 \%$ of boys expect to work in one of the five most popular occupations for male students in their countries, while around $38 \%$ of girls have this expectation (Table III.10.16). On average across OECD countries, over $9 \%$ of girls expect to work as medical doctors when they are 30 years old (Table III.10.17). In Algeria, Colombia, Costa Rica, the Dominican Republic, Lebanon, Qatar and Tunisia more than one in five girls aspire to become a doctor. Other popular occupations among girls are social scientists and social sector occupations ( $7 \%$ on average across OECD countries), and legal professionals ( $5 \%$ ). On average across OECD countries, about $7 \%$ of boys aspire to work as engineers, $5 \%$ as sports and fitness workers, $4 \%$ as mechanics and $4 \%$ as medical doctors. Around $6 \%$ of boys and $5 \%$ of girls reported that they do not know what occupations they will work in when they are about 30 years old.

More analyses of adolescents' career expectations might shed more light on socio-economic and gender inequalities in positions of power, leadership and prestige. They could also reveal more about how social mobility and children's well-being are shaped by parents' attitudes and social norms.

Figure III.10.8 shows that, on average across OECD countries with available data, the children of blue-collar workers who attend schools where students have parents with white-collar occupations were around twice as likely to expect to earn a university degree and work in a management or professional occupation than children of blue-collar workers who perform similarly but who attend other schools. In other words, the education and occupation expectations of disadvantaged students are related to the socio-economic profile and composition of their school. This result suggests that in schools with a high concentration of optimistic students with pro-school attitudes and high expectations, students of all social status tend to develop greater ambitions for their future. Social segregation that clusters poor students in poor schools might, instead, tamp down students' expectations for, and beliefs in, themselves. The relationship shown in Figure III.10.8 might also reflect the likelihood that disadvantaged students who attend advantaged schools are a group of select students who not only perform better than other disadvantaged students but also hold higher expectations for their future.

These results show that students are affected not only by the socio-economic background of their parents, but also by that of the other students around them - and in ways that go well beyond academic achievement. In schools with a diverse student body, those at the bottom of the socio-economic hierarchy are more at risk of being less satisfied with their life than those from a more advantaged background. In systems and contexts with more homogeneous but socially segregated schools, disadvantaged students might be less likely to develop higher expectations for their education and career because their peers at school have low motivation and aspirations.

The complex interplay between harmful and benevolent peer influences on the well-being of disadvantaged students can be an opportunity to be seized by teachers and schools in every country. Teachers can be trained to better understand the dynamics of diversity - social, economic and cultural - and work with all students to reduce some of their negative effects on the most vulnerable students. Teacher training that includes a focus on equity, cultural and social diversity can give 
teachers some practical tools on how to counter the negative effects of social comparison that may lower adolescents' self-esteem and life satisfaction (Gorski, 2013). Skilful interventions by teachers can also make peer influences work towards a positive end, especially during adolescence, helping to raise the expectations of disadvantaged students about what they can accomplish, with hard work and dedication, in school and in life.

Figure III.10.8 - Students' expectations and social composition of their school Education and career expectations of children of blue-collar workers in schools where the other students are predominantly children of white-collar workers

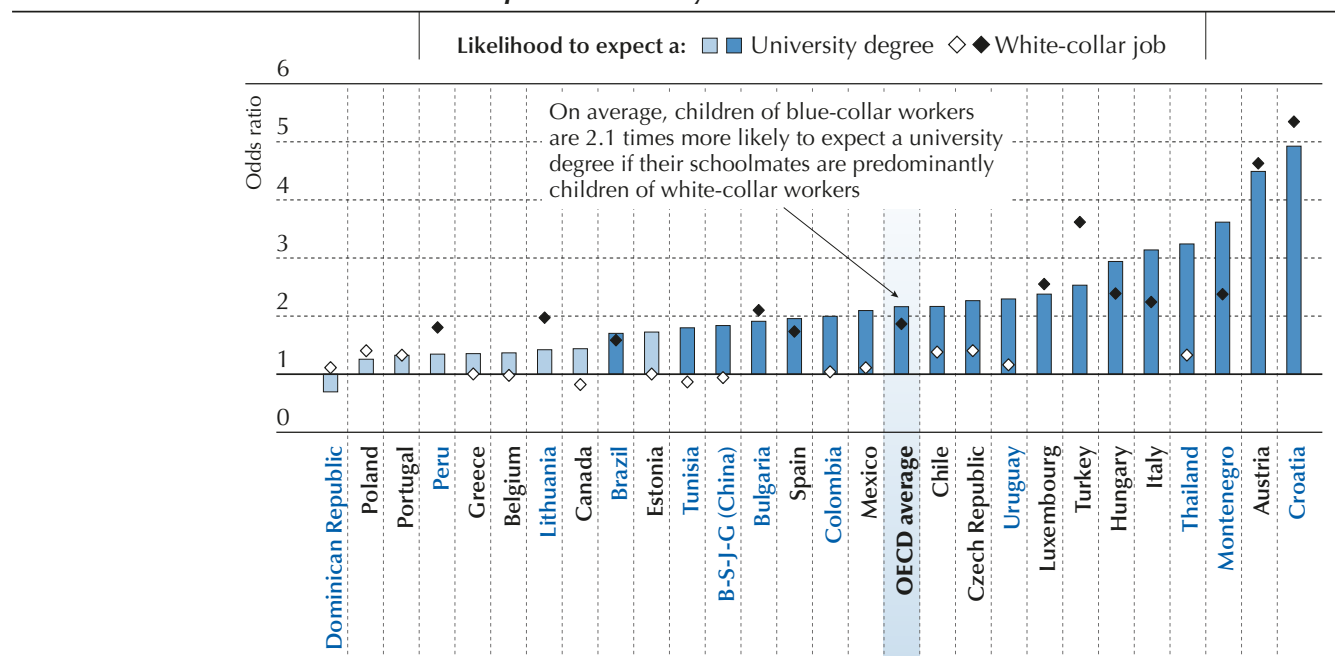

Notes: Workers in white-collar occupations are defined as managers (ISCO-08 category 1), professionals (ISCO-08 category 2) and technicians and associate professionals (ISCO-08 category 3).

Workers in blue-collar occupations are defined as skilled agricultural, forestry and fishery workers (ISCO-08 category 6), craft and related trades workers (ISCO-08 category 7), plant and machine operators and assemblers (ISCO-08 category 8) and workers in elementary occupations (ISCO-08 category 9). Schools with students mostly from a white-collar background are schools where the percentage of children of white-collar workers is statistically significantly above the country/economy average.

Statistically significant values are marked in a darker tone (see Annex A3).

In order to increase international comparability, odds ratios are reported only for countries with at least fifty children of blue-collar workers in white-collar schools.

Countries and economies are ranked in ascending order of the likelihood that children of blue-collar workers expect to complete a university degree if their schoolmates' parents are predominantly white-collar workers.

Source: OECD, PISA 2015 Database, Table III.10.15.

StatLink 제근 http://dx.doi.org/10.1787/888933472516

PISA 2015 data show that there are large differences across countries in the strength of the relationship between socioeconomic advantage and students' well-being outcomes, suggesting that policies and school practices can help level the playing field and increase social mobility (OECD, 2016b). Upward social mobility is possible only if disadvantaged students hold high aspirations for their future (Pajares and Urdan, 2006). Schools can promote social mobility if they help all students develop a positive view of themselves and their future.

\section{What these results mean for policy}

- Providing sufficient funding to public schools so that they can attain the quality standards of selective private schools, delaying early tracking, and improving the quality and image of vocational schools could reduce social segregation at school and boost upward social mobility.

- Schools should work in partnership with the wider community and other institutions to identify the resources that disadvantaged children might lack at home, and the support that they can provide.

- School leaders need to embrace social and economic diversity in their school and work to understand the challenges and opportunities of educating mixed groups of students. Schools may indeed reflect existing inequalities in the broader society, but school leaders can work to reduce the impact of these inequalities on students' lives by creating a school environment that is welcoming, stimulating and inclusive for teachers, staff members and students from all walks of life. 
- Rather than ignoring the role of socio-economic differences between students, teachers should pay close attention to what aspects of these differences may be harming the well-being of the most vulnerable students. They can work with all students to reduce the negative effects of social comparisons and encourage the beneficial effects of peer influences by valuing students' achievements and effort, treating all students with the same level of attention and respect, showing interest in the various cultural traditions represented in the student body, and having high expectations for all students.

- Providing high-quality and personalised career guidance might be particularly valuable in disadvantaged schools, where peer pressure can negatively affect students' aspirations and expectations.

\section{Notes}

1. White-collar occupations include managers (ISCO-08 category 1), professionals (ISCO-08 category 2) and technicians and associate professionals (ISCO-08 category 3). Blue-collar occupations are defined as occupations as skilled agricultural, forestry and fishery workers (ISCO-08 category 6), craft and related trades workers (ISCO-08 category 7), plant and machine operators and assemblers (ISCO-08 category 8), and elementary occupations (ISCO-08 category 9).

2. The index of social segregation, as defined in Jenkins et al. (2008) and originally in Hutchens (2001, 2004), can be expressed as follows: where $i=1, \ldots, S$ is the number of students per school, the share of students with a low (high) social position is denoted by and $P$ and $R$ are the number of students in the country with a low and high social position, respectively. Then $H$ is the sum, over all schools, of each school's shortfall from distributional evenness of the two groups. In order to understand how much of the measured segregation is associated with the type of schools children attend, the index can be split into two components: a part that is related to differences in the social composition between different types of schools (for example between private and public schools, or between vocational and general schools), and a part that is explained by differences across schools within each type: $\mathrm{H}=$ where and . This is with school types (e.g. private and public schools), the weight of the school type $t$, and the number of students in school type t with respectively a low and high social position. 


\section{References}

Becchetti, L. and F. Pisani (2014), "Family economic well-being, and (class) relative wealth: An empirical analysis of life satisfaction of secondary school students in three Italian cities", Journal of Happiness Studies, Vol. 15/3, pp. 503-525, http://dx.doi.org/10.1007/ s10902-013-9433-z.

Carter, P.L. (2007), Keepin'It Real: School Success Beyond Black and White, Oxford University Press, New York, NY.

Case, A., D. Lubotsky and C. Paxson (2002), "Economic status and health in childhood: The origins of the gradient", The American Economic Review, Vol. 92/5, pp. 1308-1334, http://doi.org/10.1257/000282802762024520.

Clark, G. (2012), "What is the true rate of social mobility in sweden? A surname analysis, 1700-2012", Unpublished manuscript, University of California, Davis, http://faculty.econ.ucdavis.edu/faculty/gclark/papers/Sweden\%202012\%20AUG.pdf (accessed 4 April 2017).

Corak, M. (2013), "Income inequality, equality of opportunity, and intergenerational mobility", The Journal of Economic Perspectives, Vol. 27/3, pp. 79-102, http://doi.org/10.1257/jep.27.3.79.

Currie, C. et al. (eds.) (2012), Social Determinants of Health and Well-Being among Young People - Health Behaviour in School-Aged Children (HBSC) Study: International Report from the 2009/2010 Survey, World Health Organization Regional Office for Europe, Copenhagen, Denmark.

Davis, T.M. (2014), "School choice and segregation: 'Tracking' racial equity in magnet schools", Education and Urban Society, Vol. 46/4, pp. 399-433, http://doi.org/10.1177/0013124512448672.

Diener, E., S. Oishi and R.E. Lucas (2003), "Personality, culture, and subjective well-being", Annual Review of Psychology, Vol. 54, pp. 403-425, http://doi.org/10.1146/annurev.psych.54.101601.145056.

Goodman, E. et al. (2001), "Adolescents' perceptions of social status: Development and evaluation of a new indicator", Pediatrics, Vol. 108/2, pp. e31-e38.

Gorski, P.C. (2013), Reaching and Teaching Students in Poverty, Teachers College Press, New York, NY.

Goux, D. and E. Maurin (2005), "The effect of overcrowded housing on children's performance at school", Journal of Public Economics, Vol. 89/5-6, pp. 797-819, http://dx.doi.org/10.1016/j.jpubeco.2004.06.005.

Greenwald, R., L.V. Hedges and R.D. Laine (1996), "The effect of school resources on student achievement", Review of Educational Research, Vol. 66/3, pp. 361-396, http://dx.doi.org/10.3102/00346543066003361.

Hudson, E. (2013), "Does relative material wealth matter for child and adolescent life satisfaction?", The Journal of Socio-Economics, Vol. 46, pp. 38-47, http://dx.doi.org/10.1016/j.socec.2013.06.007.

Hutchens, R. (2004), "One measure of segregation", International Economic Review, Vol. 45/2, pp. 555-578, http://dx.doi.org/10.1111/ j.1468-2354.2004.00136.x.

Hutchens, R. (2001), "Numerical measures of segregation: Desirable properties and their implications", Mathematical Social Science, Vol. 42/1, pp. 13-29, http://dx.doi.org/10.1016/S0165-4896(00)00070-6.

Jenkins, S.P., J. Micklewright and S.V. Schnepf (2008), "Social segregation in secondary schools: How does England compare with other countries?", Oxford Review of Education, Vol. 34/1, pp. 21-37, http://dx.doi.org/10.1080/03054980701542039.

Jerrim, J. and L. Macmillan (2015), "Income inequality, intergenerational mobility, and the Great Gatsby curve: Is education the key?", Social Forces, Vol. 94/2, pp. 505-533, http://dx.doi.org/10.1093/sf/sov075.

Machida, S., A.R. Taylor and J.Kim (2002), "The role of maternal beliefs in predicting home learning activities in head start families", Family Relations, Vol. 51/2, pp. 176-184, http://dx.doi.org/10.1111/j.1741-3729.2002.00176.x.

Montt, G. (2012), Socioeconomic School Composition Effects on Student Outcomes, Doctoral dissertation, University of Notre Dame, Notre Dame, IN, https://curate.nd.edu/show/sn009w05g5g, (accessed 4 April 2017).

Neff, D.F. (2007), "Subjective well-being, poverty and ethnicity in South Africa: Insights from an exploratory analysis", Social Indicators Research, Vol. 80/2, pp. 313-341, http://dx.doi.org/10.1007/s11205-005-5920-x.

OECD (2017), "Where did equity in education improve over the past decade?", PISA in Focus, No. 68, OECD Publishing, Paris, http://dx.doi.org/10.1787/33602e45-en.

OECD (2016a), PISA 2015 Results (Volume I): Excellence and Equity in Education, OECD Publishing, Paris, http://dx.doi. org/10.1787/9789264266490-en.

OECD (2016b), PISA 2015 Results (Volume II): Policies and Practices for Successful Schools, OECD Publishing, Paris, http://dx.doi. org/10.1787/9789264267510-en. 
OECD (2015), In It Together: Why Less Inequality Benefits All, OECD Publishing, Paris, http://dx.doi.org/10.1787/9789264235120-en.

OECD (2012), Equity and Quality in Education: Supporting Disadvantaged Students and Schools, OECD Publishing, Paris, http://dx.doi. org/10.1787/9789264130852-en.

Pajares, F. and T.C. Urdan (eds.) (2006), Self-Efficacy Beliefs of Adolescents, Information Age Publishing, Greenwich, CT.

Rivkin, S.G., E.A. Hanushek and J.F. Kain (2005), "Teachers, schools, and academic achievement", Econometrica, Vol. 73/2, pp. 417-458, http://dx.doi.org/10.1111/j.1468-0262.2005.00584.x.

Saegert, S., J.P. Thompson and M.R. Warren (eds.) (2001), Social Capital and Poor Communities, Russell Sage Foundation, New York, NY.

Sandefur, J. (2015), "Great Gatsby revisited: How inequality explains learning outcomes around the world", blog post, www.cgdev. org/blog/great-gatsby-curve-younger-and-poorer-how-inequality-explains-learning-outcomes-around-world, (accessed 4 April 2017).

Stewart, E.B., E.A. Stewart and R.L. Simons (2007), "The effect of neighborhood context on the college aspirations of African American adolescents", American Educational Research Journal, Vol. 44/4, pp. 896-919, http://dx.doi.org/10.3102/0002831207308637.

Sweeting, H. and K. Hunt (2014), "Adolescent socio-economic and school-based social status, health and well-being", Social Science \& Medicine, Vol. 121, pp. 39-47, http://dx.doi.org/10.1016/j.socscimed.2014.09.037.

Tucker, K.L. et al. (2006), "Testing for measurement invariance in the satisfaction with life scale: A comparison of Russians and North Americans", Social Indicators Research, Vol. 78/2, pp. 341-360, http://dx.doi.org/10.1007/s11205-005-1037-5.

Woolcock, M. and D. Narayan (2000), "Social capital: Implications for development theory, research, and policy", The World Bank Research Observer, Vol. 15/2, pp. 225-249, http://dx.doi.org/10.1093/wbro/15.2.225. 


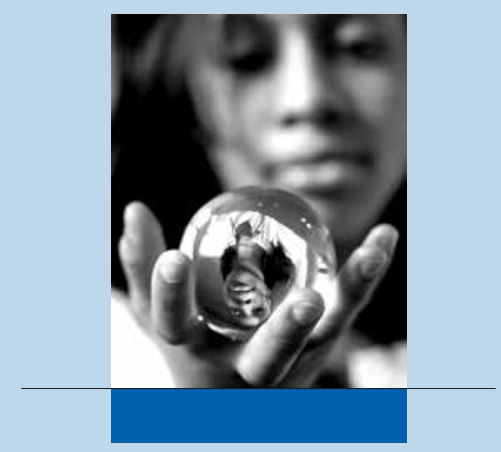

\section{Students' use of their time outside of school}

How adolescents spend their time outside of school also affects their development and well-being. This section focuses on students' activities outside of school and their relationship with well-being, using PISA data on students' physical activities, eating habits, work and Internet use. The data illustrate the importance of efforts at school to encourage students to exercise, eat healthily and use the Internet wisely. 



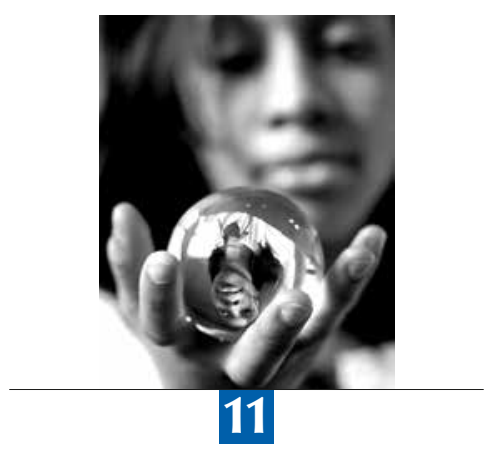

\section{Students' physical activities and eating habits}

Regular exercise and healthy eating are important for people of all ages, but perhaps particularly so for teenagers, as adolescence is the period when many lifelong habits are formed. This chapter examines the extent of students' physical activities in and outside of school, and how regular physical activity (or the lack of it) is related to student performance and well-being. The chapter also describes students' eating habits, including eating disorders among adolescents, and the benefits of eating meals with parents. 
Students' overall physical fitness and health are important pre-requisites for high academic performance, and social and emotional well-being. People who exercise regularly are less likely to suffer from diabetes or cardiovascular diseases (Haskell et al., 2007) and are in better overall health (Penedo and Dahn, 2005) than people who do not. In many highincome countries, and in a growing number of middle- and low-income countries, a sedentary lifestyle is one of the primary contributors to obesity (Bauman et al., 2012). There is strong evidence that participating in physical activity reduces depression and anxiety disorders, and boosts self-esteem (Biddle and Asare, 2011). Regular physical activity also appears to improve memory, perseverance and self-regulation (Biddle and Asare, 2011).

\section{What the data tell us}

- About $6.6 \%$ of students across OECD countries do not engage in any kind of moderate or vigorous physical activity outside of school. The share of physically inactive students is 1.8 percentage points higher among girls than among boys.

- Countries where students do more moderate physical activity tend to perform better in PISA. Within countries, students who do not engage in any moderate physical activities or do it every day score worse in science, on average, than students who exercise between one and six days per week.

- Physically active students are less likely than those who do not participate in any kind of physical activity outside of school to skip school, feel like an outsider at school, feel very anxious about schoolwork, or be frequently bullied.

- On average across OECD countries, $26 \%$ of girls and $18 \%$ of boys reported that they had skipped breakfast before school.

- Having dinner regularly is positively associated with adolescents' satisfaction with life, particularly among girls.

According to specialists, 14-18 year-old students should engage in some physical activity at least three days per week to strengthen their muscles and bones (Janssen and LeBlanc, 2010; Strong et al., 2005). However, analysis of data from the Health Behaviour in School-Aged Children (HBSC) survey finds that the majority of teenagers do not meet the recommended levels of physical activity, even if trends in those levels for 11-, 13- and 15-year-olds increased moderately between 2002 and 2010 (Hallal et al., 2012). Adolescents, and particularly girls, are less physically active as they grow older (Hallal et al., 2012). Since the habits established during adolescence often carry through into adulthood (Bailey, 2006), it is important to understand what influences these behaviours.

In addition to physical activity, eating habits are another important factor to consider for physical well-being. Among students (as, arguably, among all people), what, when and how one eats is closely related to physical and psychological well-being (Cooper, Bandelow and Nevill, 2011). Research shows that eating patterns can affect teenagers' quality of life in three ways. First, eating habits support (or undermine) a healthy lifestyle. Second, good eating habits are related to both physical growth and cognitive development (Birch, Savage and Ventura, 2007). Third, eating habits formed during adolescence are usually maintained through adulthood, influencing health and emotional well-being later on (Kemm, 1987; Videon and Manning, 2003).

In PISA 2015, students were asked four questions related to physical activities in and outside of school. Students reported the number of days per week they attended physical education classes at school, the number of days per week they engage in moderate physical activity outside of school for at least 60 minutes per day, or in vigorous activity outside of school for at least 20 minutes per day, and whether or not they exercise or practice sports before or after school. Physical activities, such as walking and cycling can be considered moderate if they raise a person's heart rate and the person breaks into a sweat. Activities such as hiking, jogging, or playing tennis or football are considered vigorous if breathing becomes difficult and fast, and the heart rate increases rapidly (Centers for Disease Control and Prevention, 2017).

\section{PHYSICAL EDUCATION IN SCHOOL}

Fifteen-year-olds engage in moderate and vigorous physical activity through physical education classes at school and sports activities outside of school. Physical education aims to develop and promote students' physical competencies, a healthy lifestyle, and students' ability to apply those skills and knowledge to a range of activities (Bailey, 2006). Over the years, physical education has evolved from its original focus on teaching hygiene to teaching children the skills needed for a healthy and active lifestyle (Committee on Physical Activity and Physical Education in the School, Food and Nutrition Board, and Institute of Medicine, 2013). 
In the majority of the countries and economies that participated in PISA 2015, most students take at least one physical education class per week, on average (Figure III.11.1). In Hungary, Poland, the Russian Federation (hereafter "Russia"), Canada, Japan and the United States - listed in descending order - more than one in two students reported that they take three or more physical education classes per week. In New Zealand and the United States, physical education is often an elective subject, as around $40 \%$ of students reported that they take no physical education class. Students are sometimes allowed to opt out of physical education for nonmedical reasons, often to give these students more time to learn other subjects.

Figure III.11.1 - Physical education at school Number of days per week students reported that they attend physical education classes

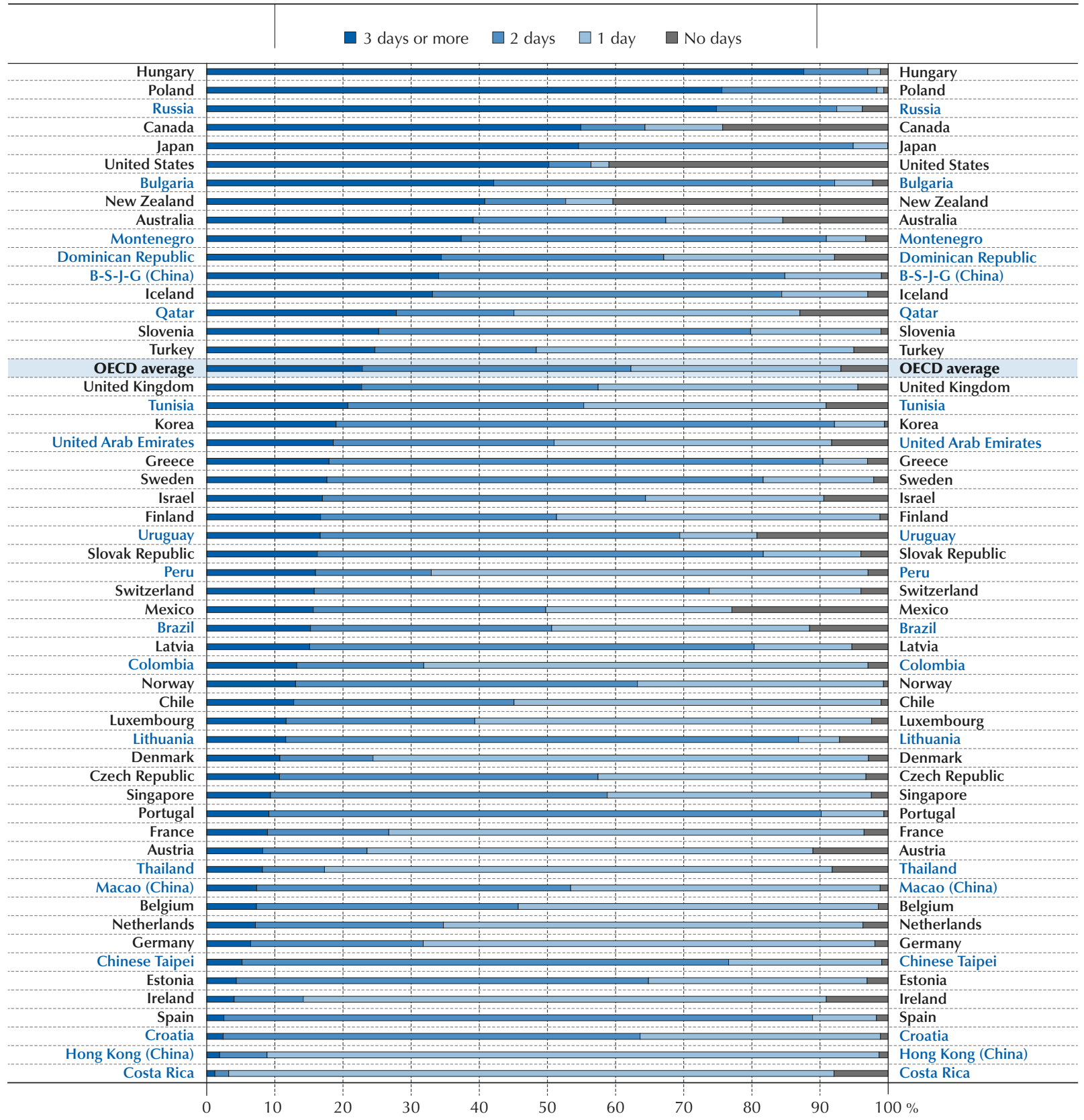

Countries and economies are ranked in descending order of the percentage of students who reported that they attend physical education classes at least 3 days a week.

Source: OECD, PISA 2015 Database, Table III.11.1

StatLink 제에 $\mathrm{http}: / / \mathrm{dx}$.doi.org/10.1787/888933472868 
The emphasis on physical education classes tends to decrease as students get older. On average across OECD countries, students in upper secondary school (ISCED 3) reported spending almost half a day less per week in physical education than students in lower secondary school (ISCED 2) (Table III.11.3). In Austria, Korea and Montenegro, the difference between the two groups of students is greater than one day per week. Only in Hungary, where more time is devoted to physical education than in any other PISA-participating country or economy, did students in upper secondary programmes report attending more physical education classes than students in lower secondary programmes.

Students in rural areas reported spending more hours in physical education classes than students in cities, on average, possibly because rural schools are less likely to face space constraints for physical activities. The difference in favour of rural students was particularly large in Chile, while urban students in Hungary reported taking more physical education classes than students in rural areas (Table III. 11.3).

\section{EXERCISING OUTSIDE OF SCHOOL}

Students may choose to use their time before and after school to exercise or practice sports. Figure III.11.2 shows the share of students who exercised or practiced sports on the most recent day they attended school. On average across OECD countries, $43 \%$ of students reported that they exercise or practice sports before school, and $66 \%$ reported that they exercise or practice sports after school. Overall, boys were more likely than girls to report that they exercise both before and after school. The difference in the shares of boys and girls who reported that they engage in physical activities after school is greater than 20 percentage points (in favour of boys) in Korea, Costa Rica, Turkey, Brazil, Uruguay, Tunisia, Colombia, Peru, Croatia, Chile, Macao (China) and the Dominican Republic (in descending order of that difference) (Table III.11.7b).

On average across OECD countries, $5.7 \%$ of boys and $7.5 \%$ of girls reported that they do not participate in any form of physical activity outside of school (Figure III.11.3). In Japan and the United Arab Emirates, more than 20\% of girls reported doing no moderate or vigorous physical activity. In Brazil, Korea, Tunisia and the United Arab Emirates, the percentage of girls who reported doing no physical activity is at least 10 percentage points larger than the percentage of boys who reported so. Conversely, in the Czech Republic, Denmark, Finland, Norway, the Slovak Republic and Sweden, a slightly larger share of boys than girls reported that they do not do any physical activity outside of school (Figure.III.11.3).

As observed when considering physical education classes at school, students in upper secondary programmes (ISCED 3) were slightly less likely than lower secondary students to report that they participate in vigorous physical activities outside of school (Table III.11.14). In Beijing-Shanghai-Jiangsu-Guangdong (China) (hereafter "B-S-J-G [China]), Chile, Korea and Tunisia, upper secondary students reported participating in less vigorous physical activity in the previous week (by more than half a day) than students in lower secondary education.

Socio-economic status is also related to adolescents' level of physical activity. On average across OECD countries, the share of disadvantaged students who reported that they do not engage in moderate or vigorous physical activity outside of school is 4.5 percentage points larger than the share of advantaged students who reported so (Table III.11.10).

Students in the 22 countries and economies that distributed the educational career questionnaire reported the hours they participate in after-school sports instruction. The decision to take additional sports lessons may depend on students' personal preferences as well as on the availability of such lessons in the location where they live or study. But in most cases, sports lessons involve some costs. Figure III.11.4 shows the difference in the percentage of disadvantaged and advantaged students who take additional sports lessons outside of school. In nine countries and economies, advantaged students were more likely to report that they take extra sports lessons than disadvantaged students; the opposite was true in B-S-J-G (China), Peru and Thailand. On average across the 22 countries, the share of advantaged students who take additional sports lessons is about 3 percentage points larger than the share of disadvantaged students who do; and this difference is larger among girls than among boys, on average.

Under pressure to improve performance, education systems may be tempted to shift instruction time from physical education classes to subjects like reading, science or mathematics. Reductions in the time devoted to physical education may have negative long-term consequences if students do not compensate the little physical training they receive at school with some physical activities outside of school. One of the objectives of physical education is to instil a lifelong habit of physical activity. Students who learn to appreciate sports during education classes might also be more inclined to do sports outside of school (Kohl and Cook, 2013). 
Figure III.11.2 - Exercise before or after school

Percentage of students who reported that they exercise or practice sports before or after school

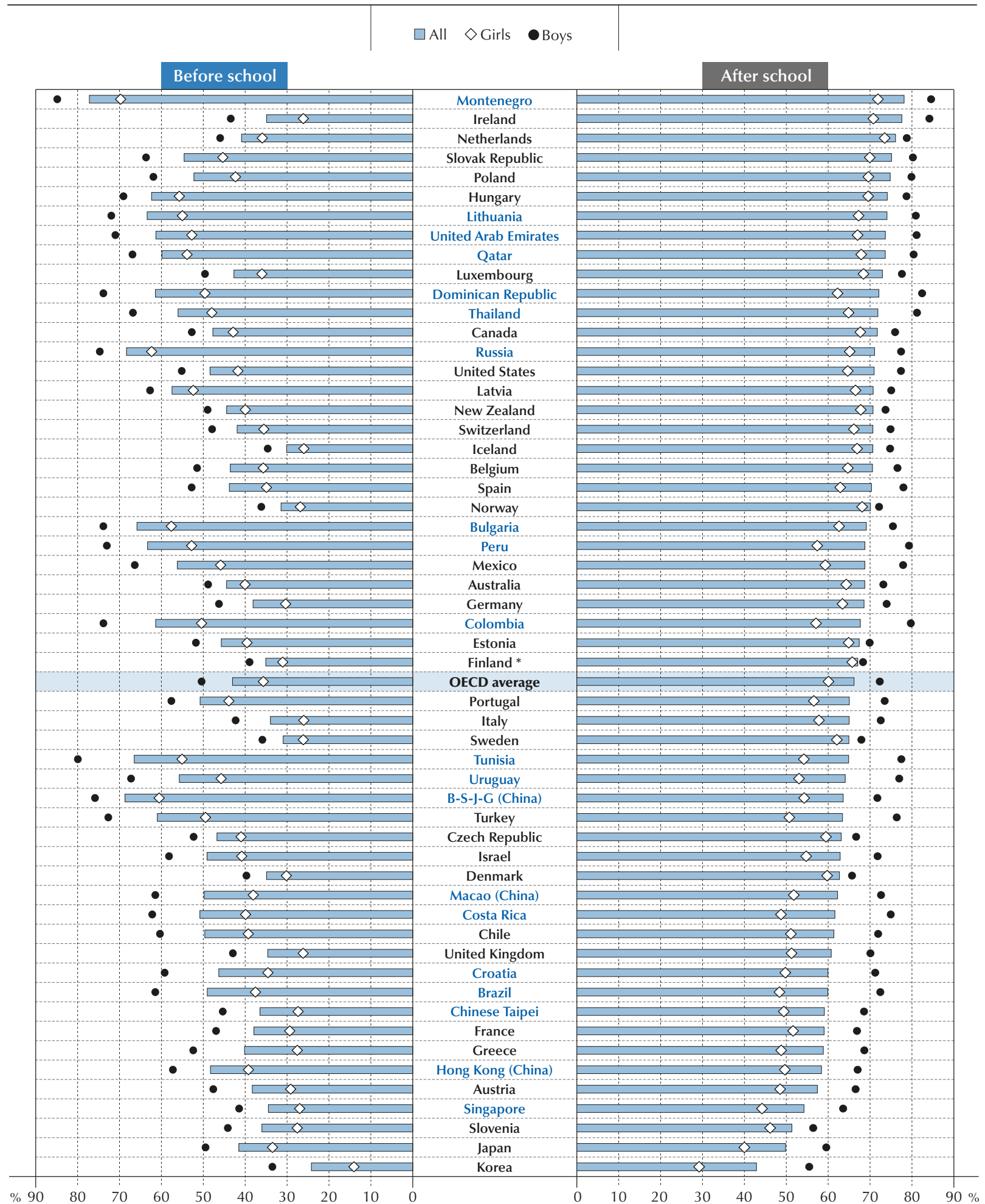

Note: All gender differences for exercise before school are statistically significant. Gender differences for exercise after school that are not statistically significant are shown with an asterisk after the country/economy name (see Annex A3).

Countries and economies are ranked in descending order of the percentage of students who exercise or practice sports after school, among all students. Source: OECD, PISA 2015 Database, Tables III.11.6, III.11.7a and III.11.7b.

StatLink 제느 http://dx.doi.org/10.1787/888933472876 
Figure III.11.3 - Physical activities outside of school

Percentage of students who reported that they do not practice any vigorous or moderate physical activity outside of school

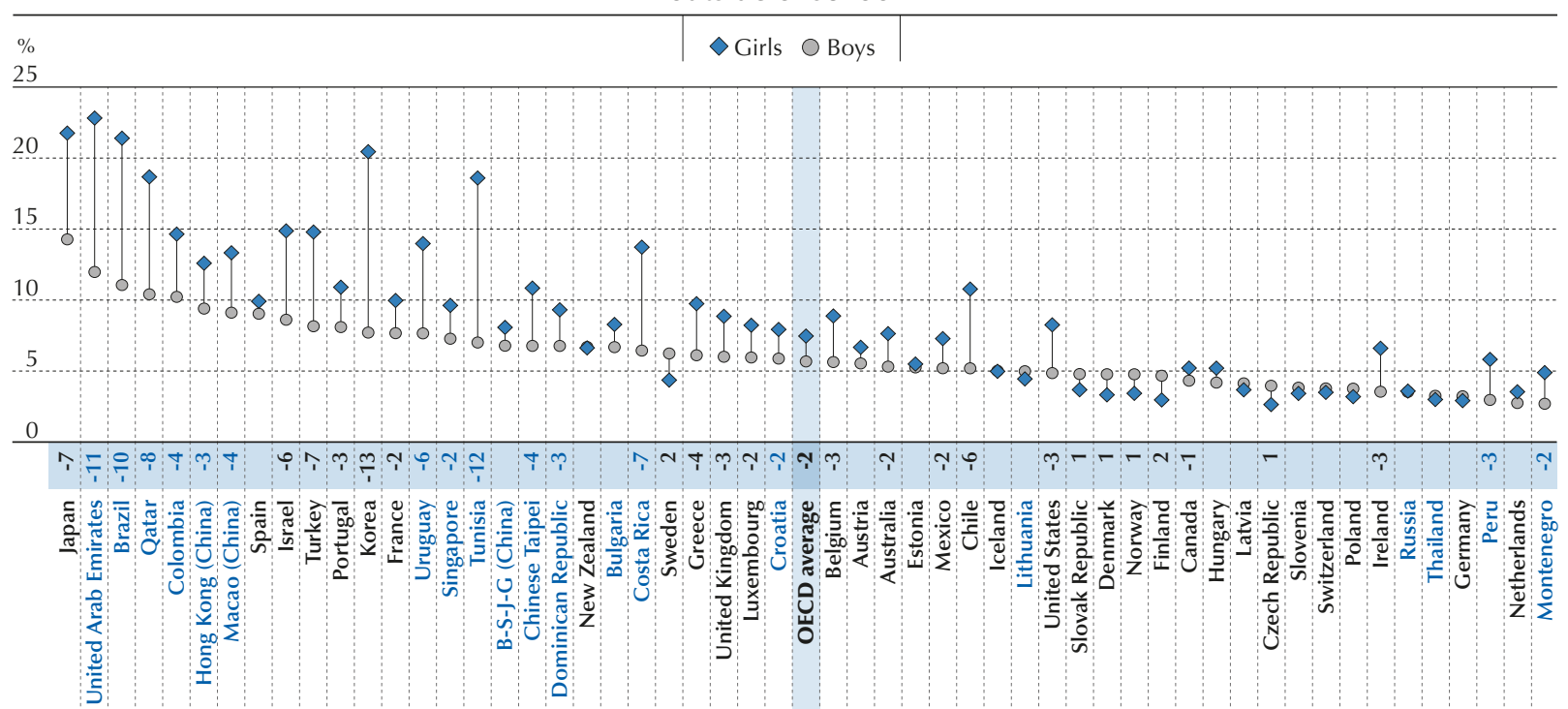

Note: Statistically significant differences between boys and girls are shown next to the country/economy name (see Annex A3).

Countries and economies are ranked in descending order of the percentage of boys who reported that they do not practice any physical activity outside of school.

Source: OECD, PISA 2015 Database, Table III.11.10.

StatLink 제피 http://dx.doi.org/10.1787/888933472889

Figure III.11.4 - Extra sports lessons

Percentage-point difference between advantaged and disadvantaged students in attendance of sports lessons outside of school, by gender

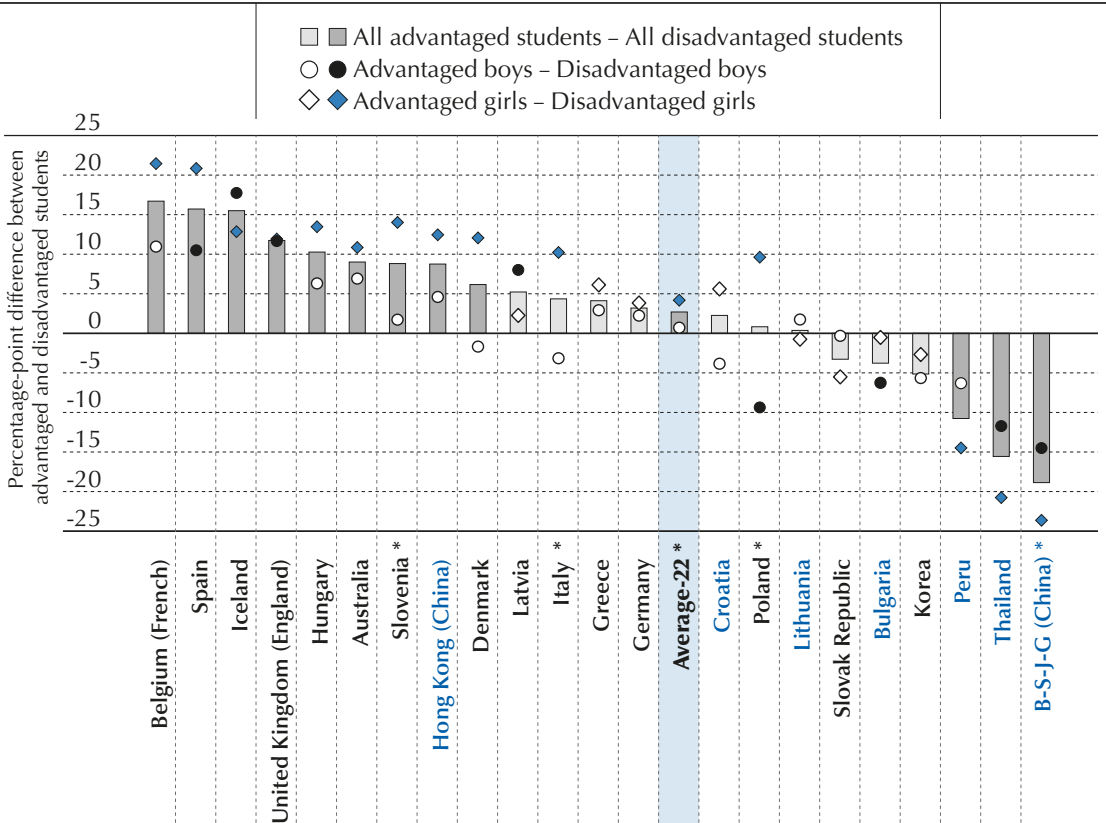

Notes: Statistically significant differences between advantaged and disadvantaged students are marked in a darker tone. Statistically significant differences in the socio-economic disparity between boys and girls are marked with an asterisk next to the country/economy name (see Annex A3).

A socio-economically advantaged (disadvantaged) student is a student in the top (bottom) quarter of the PISA index of economic, social and cultural status (ESCS) within his or her country/economy.

Countries and economies are ranked in descending order of the percentage-point difference between advantaged and disadvantaged students who take additional sports lessons, among all students.

Source: OECD, PISA 2015 Database, Table III.11.19.

StatLink त्ञाज 


\section{Box III.11.1 Extra lessons in music and the arts}

Some students may prefer to engage in leisure activities other than sports, such as practicing music (instruments, choir, composition), performing arts (dancing, acting) or visual arts (drawing, sculpting, photography) during their after-school hours. Engaging in leisure activities can have a positive effect on adolescents' psychological development and their satisfaction with life (Leversen et al., 2012).

Through these lessons and activities, adolescents have an opportunity to connect with peers who have similar interests and preferences. Practicing music or instruments during childhood and adolescence is positively correlated with working memory capacity, processing speed and reasoning (Bergman, Nutley Darki and Klingberg, 2014). Engaging in musical activities can also have an impact on a person's well-being through emotion regulation (Chin and Rickard, 2014). A study in the United States found that 10th-grade students who participated in performing arts activities were less likely to be involved in risky behaviours, such as drinking alcohol, during adolescence and early adulthood (Eccles et al., 2003).

As with sports lessons, participating in these activities depends on an individual's preference, the availability of discretionary time, and financial resources. Demographic characteristics, particularly gender and socio-economic status, may affect the likelihood of taking additional lessons in arts and music outside of school. Students in the 22 countries and economies that distributed the educational career questionnaire reported the number of hours per week that they participate in performing or visual arts and/or music lessons in addition to their mandatory school classes.

On average across these 22 countries, around 38\% of students take extra music lessons, $31 \%$ participate in performing arts lessons, and 33\% take visual arts lessons outside of school (Table III.11.20). On average, the share of boys taking extra music lessons is 2.9 percentage points larger than the share of girls who do, whereas boys are 2.3 percentage points less likely than girls to take extra performing arts lessons (Figure III.11.5).

Figure III.11.5 - Gender differences in additional music and art lessons Difference in the percentage of boys and girls who take additional music and art lessons

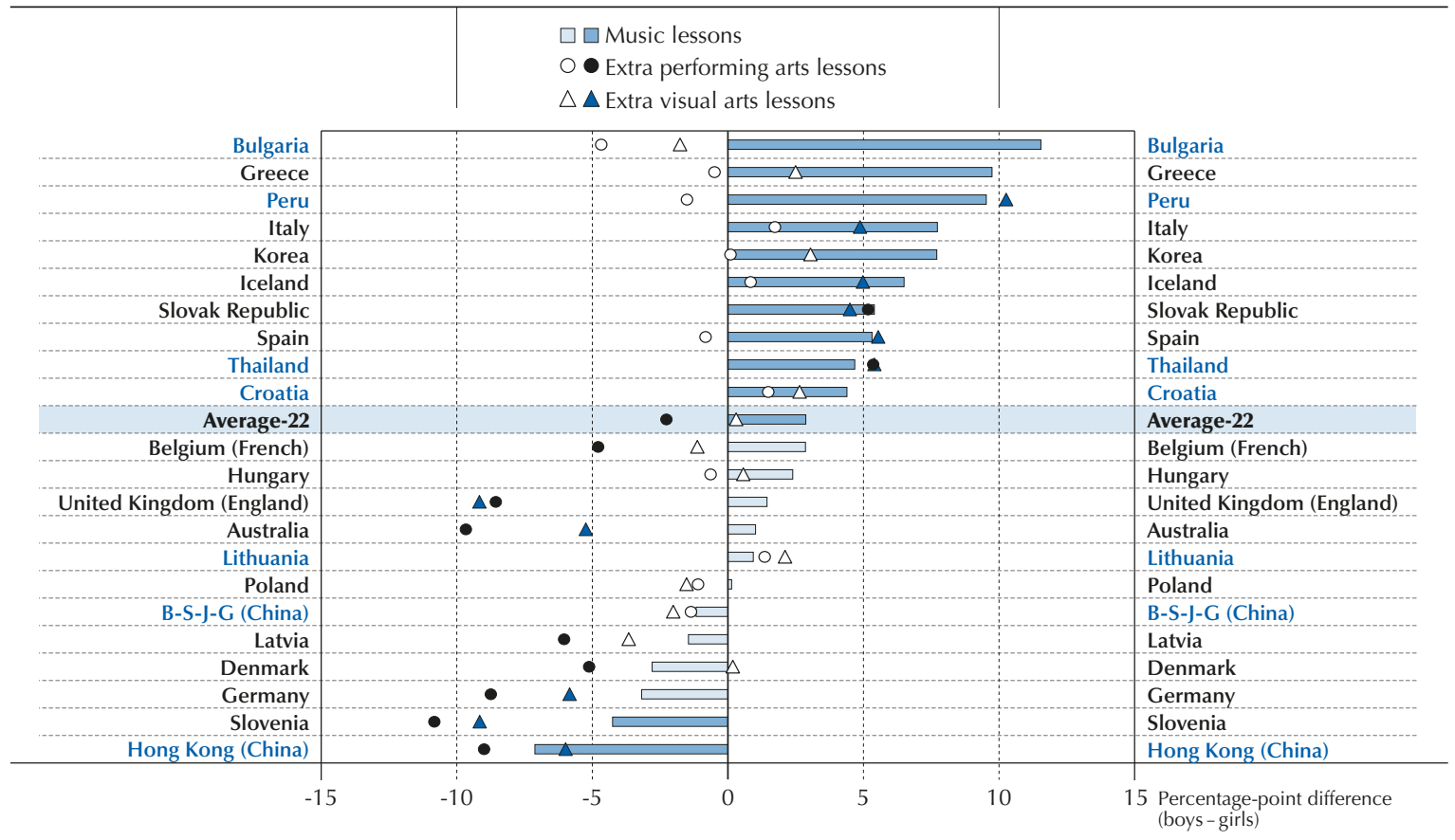

Countries and economies are ranked in descending order of the difference between the percentage of boys and girls who take extra music lessons. Source: OECD, PISA 2015 Database, Table III.11.20.

StatLink 제은 http://dx.doi.org/10.1787/888933472906 
Figure III.11.6 compares how much time per week students who participate in at least two physical education classes in school - and those who take none or only one class per week - engage in moderate or vigorous physical activity outside of school. In all but eight countries, students who take physical education classes at school are significantly more active outside of school. On average across OECD countries, students who participate in at least two physical education classes at school exercise moderately about 0.5 day per week more than students who do not take physical education classes (Table III.11.17). In Canada, Finland, New Zealand and the United States, the difference between the two groups of students in time spent engaged in moderate physical activity outside of school is equal to or greater than one day per week. This finding suggests that participating in physical activities at school might lead students to value sports more, even if it might also reflect the fact that some of the students who do not take any physical education class at school might opt out for medical reasons.

Figure III.11.6 - Physical activities, in and outside of school

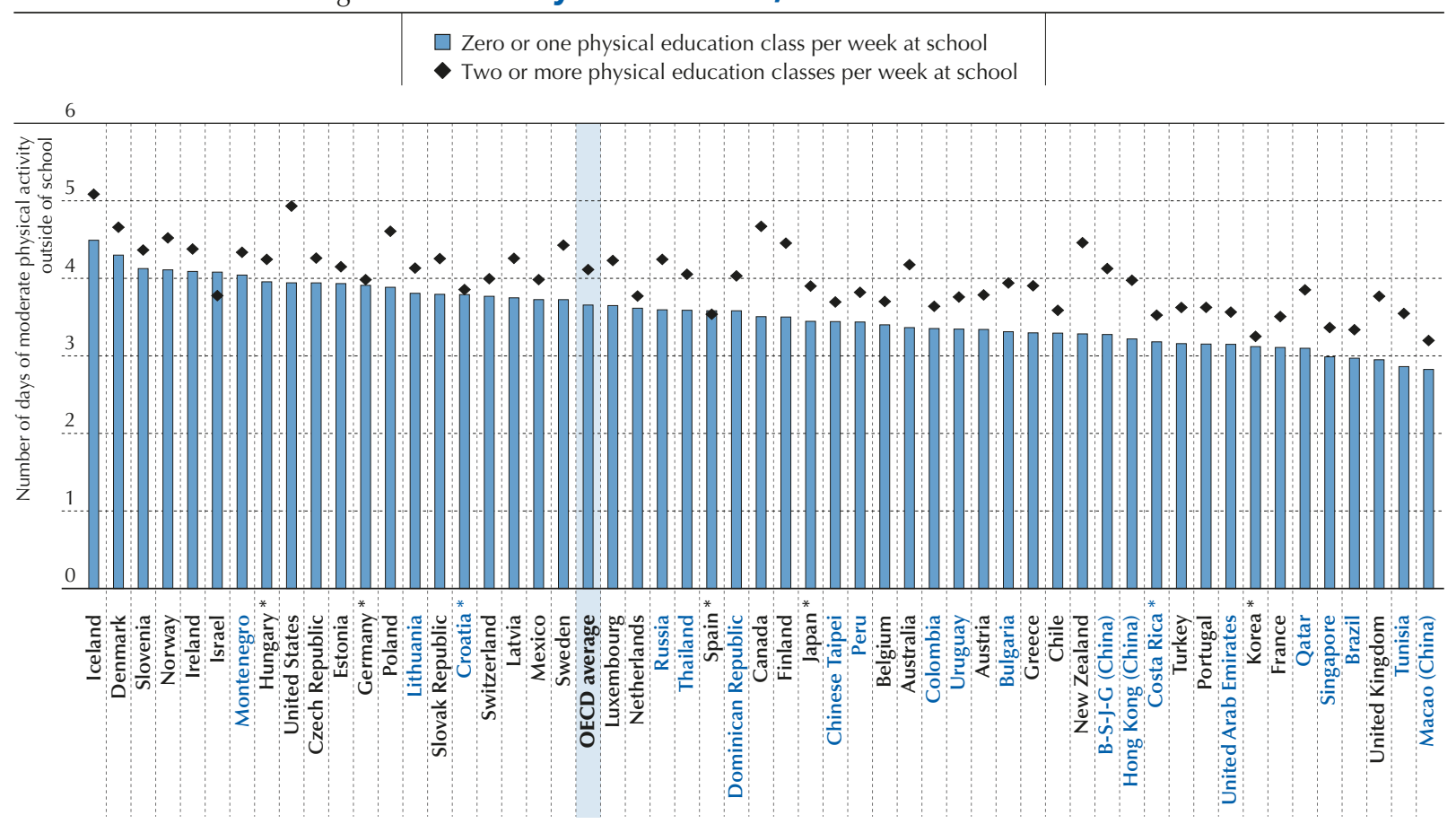

Note: Differences in the number of days of moderate physical activities that are not statistically significant are marked with an asterisk next to the country/ economy name (see Annex A3).

Countries and economies are ranked in descending order of the average number of days of moderate physical activity outside of school with no physical education classes in school.

Source: OECD, PISA 2015 Database, Table III.11.17.

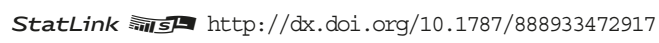

\section{PHYSICAL ACTIVITIES AND ACADEMIC PERFORMANCE}

Many studies have examined the relationship between students' physical activity and academic performance (EstebanCornejo et al., 2015; Busch et al., 2014; Singh et al., 2012). The evidence is mixed, as some researchers find a significant positive relationship between exercise and performance while others find no significant relationship. Research suggests that regular physical activity through sports or physical education classes can have a positive impact on students' academic performance because of its positive effects on cognitive functions (Sofi et al., 2011), executive functions (Allan, McMinn, and Daly, 2016), behaviour, concentration during classes (Singh et al., 2012), and psychological health (Busch et al., 2014).

\section{Physical education classes and performance}

On average across OECD countries, students who frequently attend physical education classes tend to have lower science scores in PISA (Table III.11.4a). This relationship is modest in the majority of countries (only $2.3 \%$ of the variation in science performance across OECD countries is explained by the number of days students attend physical education classes). 
This association is unlikely to be due to any direct negative effect of exercise on academic skills, since good physical health is vital for healthy brain functions and the ability to learn (Strong et al., 2005). Research has also found that children respond faster and with greater accuracy to a variety of cognitive tasks after participating in a session of physical activity at school (Budde et al., 2008; Hillman et al., 2009; Pesce et al., 2009). A more plausible explanation is that students with poorer academic skills attend schools that provide more hours of physical education or attend optional physical education classes (Levine, Etchison, and Oppenheimer, 2014).

\section{Exercise outside of school and performance}

Figure III.11.7 shows that there is a positive relationship between the number of days students engage in moderate physical activity outside of school and the average science performance of education systems. The system-level relationship between the average number of days of vigorous physical activity outside of school and science performance is much weaker.

Figure III.11.7 - Physical activity outside of school and science performance, between countries

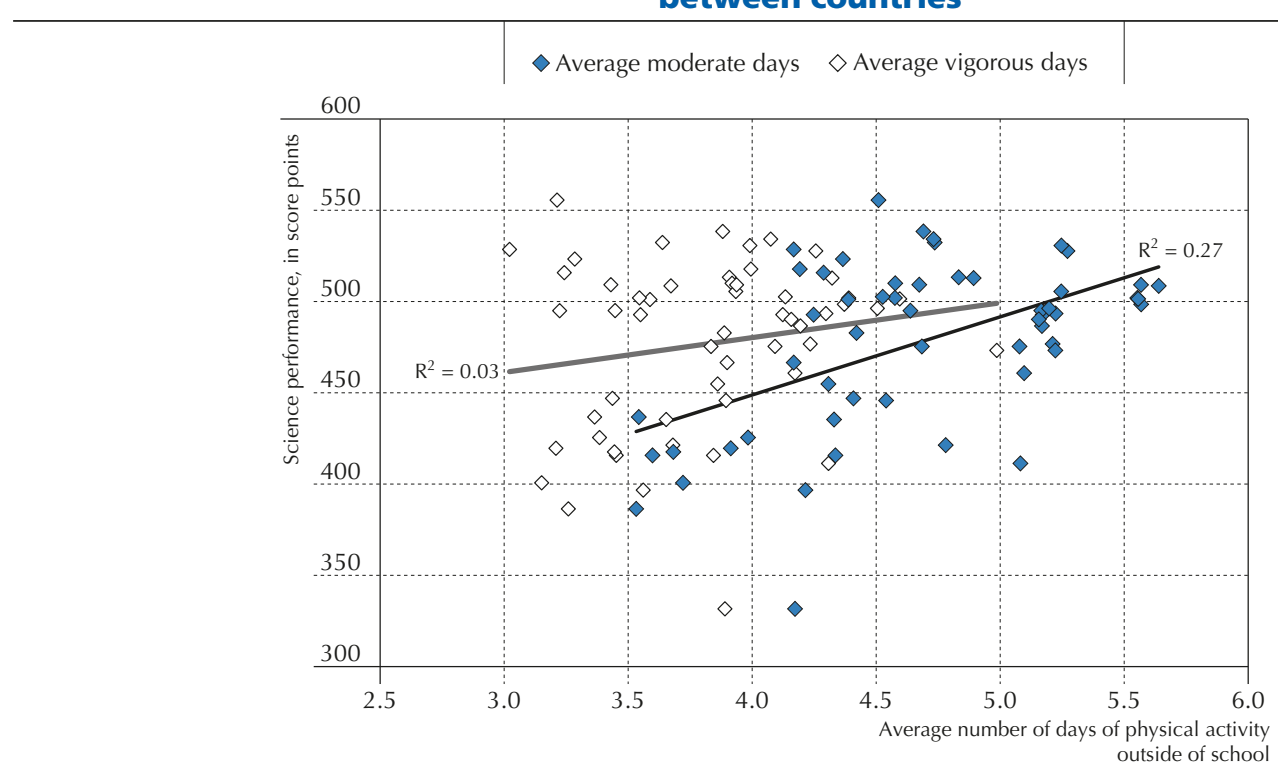

Source: OECD, PISA 2015 Database, Tables I.2.3 and III.11.13.

StatLink 제매 http://dx.doi.org/10.1787/888933472921

Within countries, an additional day of moderate physical activity is positively - albeit modestly - associated with students' science performance, after accounting for gender and socio-economic status; the opposite holds true for vigorous physical activity (Tables III.11.11a and III.11.12a). On average across OECD countries, an additional day of vigorous physical activity is linked to a three-point decrease in science scores, while an additional day of moderate physical activity is associated with a two-point increase, after accounting for students' gender and socio-economic status.

The difference in science scores related to an additional day of moderate physical activity, after accounting for gender and socio-economic status, is five points or greater in Belgium, Bulgaria, Montenegro, the Netherlands, Qatar, the Slovak Republic and Switzerland. In some of the top-performing countries in the PISA science assessment, such as Estonia, Hong Kong (China) and Singapore, the negative association between an additional day of vigorous physical activity and science performance is stronger than in other countries (Figure I.2.13 and Table III.11.12a).

Figure III.11.8 shows that students who engage in physical activity every day - especially vigorous physical activity perform significantly worse than other students. On average across OECD countries, students who engage in vigorous physical activity every day score 25 points lower in science than students who exercise vigorously 4 days per week. Some of the students in the former group are a select group of "student athletes" who assign a higher priority to success in sports than to academic achievement. Student athletes may also face a higher risk of burnout and injuries due to too much training and pressure (Brenner, 2007). 


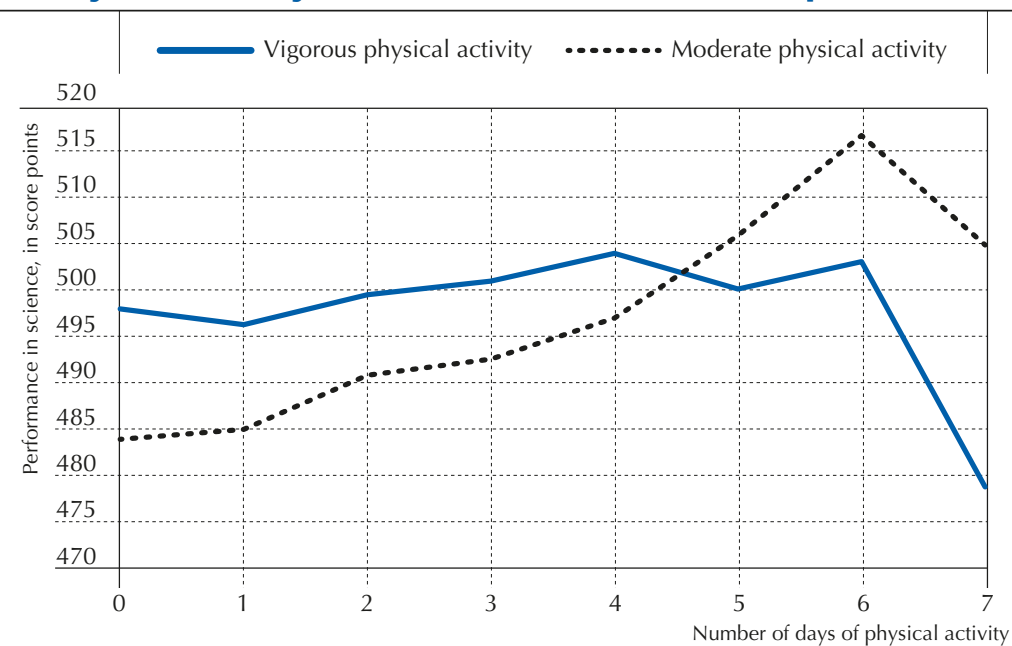

Source: OECD, PISA 2015 Database, Table III.11.15.

StatLink 제내 http://dx.doi.org/10.1787/888933472936

The relationship shown in Figure III.11.8 does not establish a causal relationship between physical activities and students' academic performance, and thus should not be treated as a prescription for or against the amount of physical activity an average 15-year-old student should engage in. The weak and often negative association between sports activities and performance in PISA highlights the need for further research to study the possible trade-offs between physical and cognitive performance. Students in highly competitive schools might be forced to reduce their physical activity, given the time they have to spend on homework and preparing for classes.

Asking students to reduce their physical activity to devote more time to study could backfire. A review of 50 studies finds that spending more time in school-based physical education classes and relatively less time on other school subjects does not adversely affect academic performance (Centers for Disease Control and Prevention, 2010). In addition, evidence from Shanghai suggests that low-performing students might perform worse if they replace the time spent on physical activities with extra homework or study (Zhang et al., 2015).

\section{PHYSICAL ACTIVITIES AND NON-ACADEMIC OUTCOMES}

\section{Physical education and life satisfaction}

The expected psychological and social benefits of physical education include a greater sense of self-efficacy, self-concept and self-worth (Haugen, Säfvenbom and Ommundsen, 2011), positive attitudes towards school, greater motivation and more focused goal orientation (Digelidis et al., 2003), connectedness with other students and teachers, and team building (Byrd and Ross, 1991; de la Haye et al., 2011; Macdonald-Wallis et al., 2011). But there are significant gaps among the intent of the curriculum, the expected psychological or social benefits, and the reality of physical education programmes in many schools (HHS, 2013). These gaps are partly linked to the low status often attributed to physical education in the hierarchy of school subjects. In addition, physical education classes can be a source of anxiety and feelings of failure for unfit, uncoordinated and overweight youth.

PISA 2015 data show a weak, positive relationship between the number of physical education classes a student attends and the student's satisfaction with life (Table III.11.5). France is the only PISA-participating country where physical education and life satisfaction are negatively related.

\section{Physical activities outside of school, life satisfaction and psychological well-being}

Is the amount of time students spend engaged in physical activity linked with their satisfaction with life? Figure III.11.9 shows the difference in the average level of life satisfaction reported by students who engage in three or more days of vigorous or moderate physical activity per week and those who do not engage in any physical activity. In the majority of countries, students who exercise three or more days per week reported greater satisfaction with life than students who do not exercise outside of school. The difference in average life satisfaction is slightly larger when considering vigorous as opposed to moderate physical activity. 
Figure III.11.9 - Physical activity and life satisfaction

Difference in average life satisfaction between students who engage in 3 or more days of moderate and vigorous physical activity per week and those who engage in no physical activity

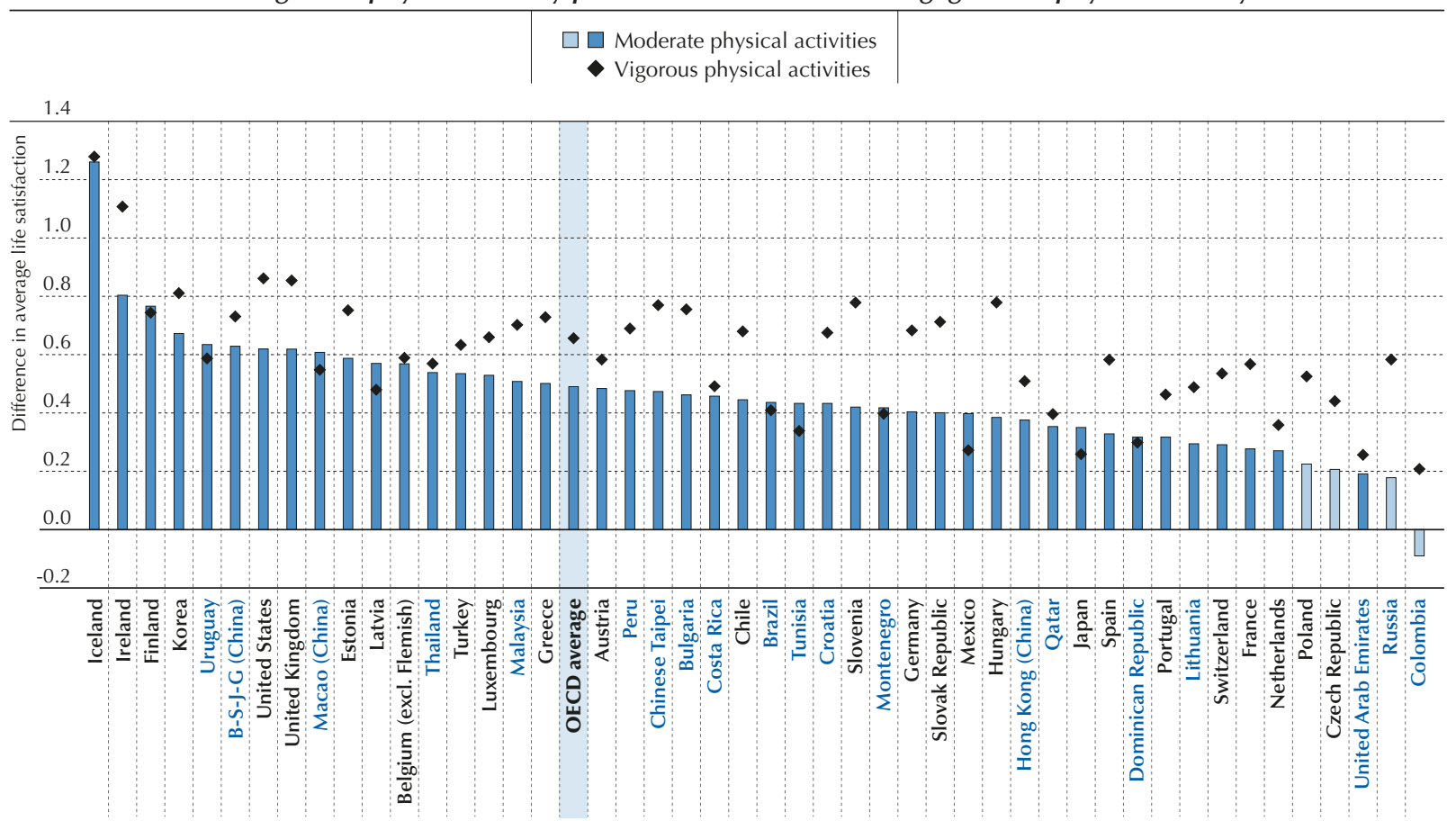

Note: All differences in life satisfaction relative to engaging in vigorous physical activities are statistically significant. Statistically significant values for moderate physical activities are marked in a darker tone (see Annex A3).

Countries and economies are ranked in descending order of the difference in average life satisfaction among all students who engage in moderate physical activities.

Source: OECD, PISA 2015 Database, Table III.11.16.

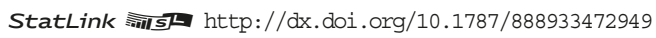

Figure III.11.10 - Physical activities and other outcomes $O E C D$ average

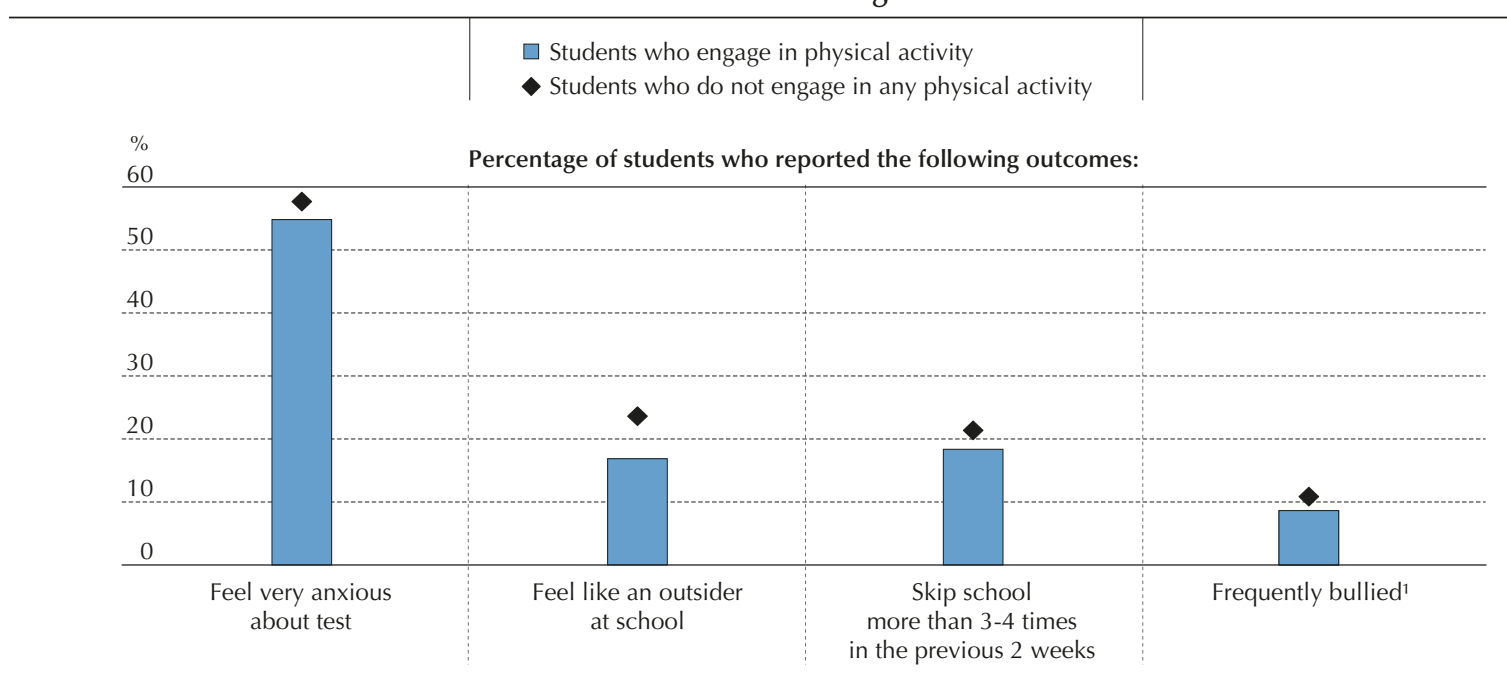

1. A student is frequently bullied if he or she is in the top $10 \%$ of the index of exposure to bullying among all countries/economies. See Annex A 1 for information on the index of exposure to bullying.

Note: All differences are statistically significant (see Annex A3).

Source: OECD, PISA 2015 Database, Table III.11.18

StatLink 제개 http://dx.doi.org/10.1787/888933472953 
On average across OECD countries, students who do not engage in any moderate physical activity reported a life satisfaction level of 6.9 on a scale from 0 to 10; students who exercise moderately at least 3 days per week reported a life satisfaction level of 7.4 on the scale (Table III.11.16). Similarly, students who exercise vigorously three days per week or more reported a satisfaction with life about 0.7 point higher than those who do not engage in any physical activity. This relationship should be interpreted with some caution because some of the students who do not report any physical activity might suffer from a physical disability.

Figure III.11.10 suggests that students who do not engage in any kind of physical activity outside of school tend to fare poorly in several psychosocial outcomes and are more likely to engage in risky behaviours. On average across OECD countries, students who reported taking part in some moderate or vigorous physical activity are 2.9 percentage points less likely to feel very anxious about schoolwork, 6.7 percentage points less likely to feel like an outsider at school, 3 percentage points less likely to skip school frequently, and 2.2 percentage points less likely to be frequently bullied than students who do not engage in any form of physical activity outside of school.

\section{Box III.11.2 Adolescents' physical activity and obesity}

The number of overweight or obese children and adolescents across the world has been increasing over the past few decades, particularly in developed countries (Lobstein et al., 2015). According to 2013-14 data from the Health Behaviour in School-aged Children survey, $22 \%$ of 15 -year-old boys and 13\% of 15 -year-old girls are overweight or obese (based on students' self-reported weight and height measures), on average across 42 participating countries. In all participating countries and economies except Denmark, England, Greenland, Malta and the Netherlands, boys were more likely to be overweight or obese than girls; and in half of the countries, socio-economic status was negatively associated with the incidence of obesity. In countries where children practice more sports (defined as doing at least 60 minutes of moderate to vigorous physical activity per day), students are less likely to be overweight or obese, even if the relationship is relatively weak (a correlation of -0.18 for 15 -year-old students). A stronger association is found among girls, however, with a correlation coefficient of -0.29 across 42 countries.

Source: (Quick et al., 2014).

Previous research on what works to increase physical activity among adolescents does not reach a single, simple conclusion. But potentially effective strategies include high-quality physical education through improved teacher pedagogy and professional development activities (Dudley et al., 2011; Lonsdale et al., 2013). Supportive and well-trained physical education teachers can encourage students to be more active (Bailey, 2006; Borra et al., 2003). In addition, when parents believe that physical training is beneficial, their adolescent children tend to participate in physical activities (Heitzler et al., 2006). Schools could thus provide tips to parents on how to communicate the importance of exercise to their children.

\section{STUDENTS' EATING HABITS}

\section{What affects adolescents' eating habits?}

Different factors, such as health concerns, cultural habits and traditions, all influence what teenagers eat. Eating habits can also be shaped by such factors as family and peers, self-image, preferences and availability of food (Videon and Manning, 2003). Students can experience a drastic change in eating habits as they transition into adolescence. Teenagers become conscious of their own body and how it is perceived by others. Consequently, they may modify their diet in order to meet the expectations of their peers and respond to social pressure. In addition, as adolescents gain more autonomy, they, rather than their parents, decide how much time they want to spend eating, and when and what they eat (NeumarkSztainer et al., 1999). One study using international data from the Health Behaviours in School-aged Children (HBSC) survey shows that, between 2002 and 2010, daily breakfast consumption among 11-15 year-olds increased significantly in only 6 out of the 19 countries and regions examined, while it decreased in 11 countries (Lazzeri et al., 2016).

To learn more about adolescents' eating habits, PISA 2015 asked students to report whether they ate breakfast before school or ate dinner after school on the most recent day they attended school. Figure III.11.11 indicates the share of students, by gender, who skipped breakfast or dinner. On average across OECD countries, 26\% of girls and 18\% of boys reported that they had skipped breakfast. In every country and economy except B-S-J-G (China), Hong Kong (China) and Japan, girls were more likely than boys to skip breakfast. The difference between the share of boys and girls who reported that they had 
skipped breakfast ranges from 14 percentage points in the United Kingdom to 1 percentage point in Thailand. This gender difference may be partly due to the fact that girls are more likely than boys to be influenced by their perception of their own bodies (Paxton et al., 1991; Furnham, Badmin, and Sneade, 2002; McCabe and Ricciardelli, 2001; Jones, 2001). The PISA estimates represent an upper bound of the actual percentage of students skipping breakfast, as some students may choose to have breakfast when they arrive at school.

Compared to the share of students who had skipped breakfast, a considerably smaller proportion of students reported that they had skipped dinner (Table III.11.21). Still, girls were more likely to have skipped dinner than boys, but the difference between girls and boys was less pronounced than that concerning skipping breakfast (Figure III.11.11). On average across OECD countries, $7 \%$ of girls and $6 \%$ of boys reported that they had skipped dinner after school.

Figure III.11.11 - Skipping meals

\section{Percentage of students who reported that they had skipped breakfast or dinner}

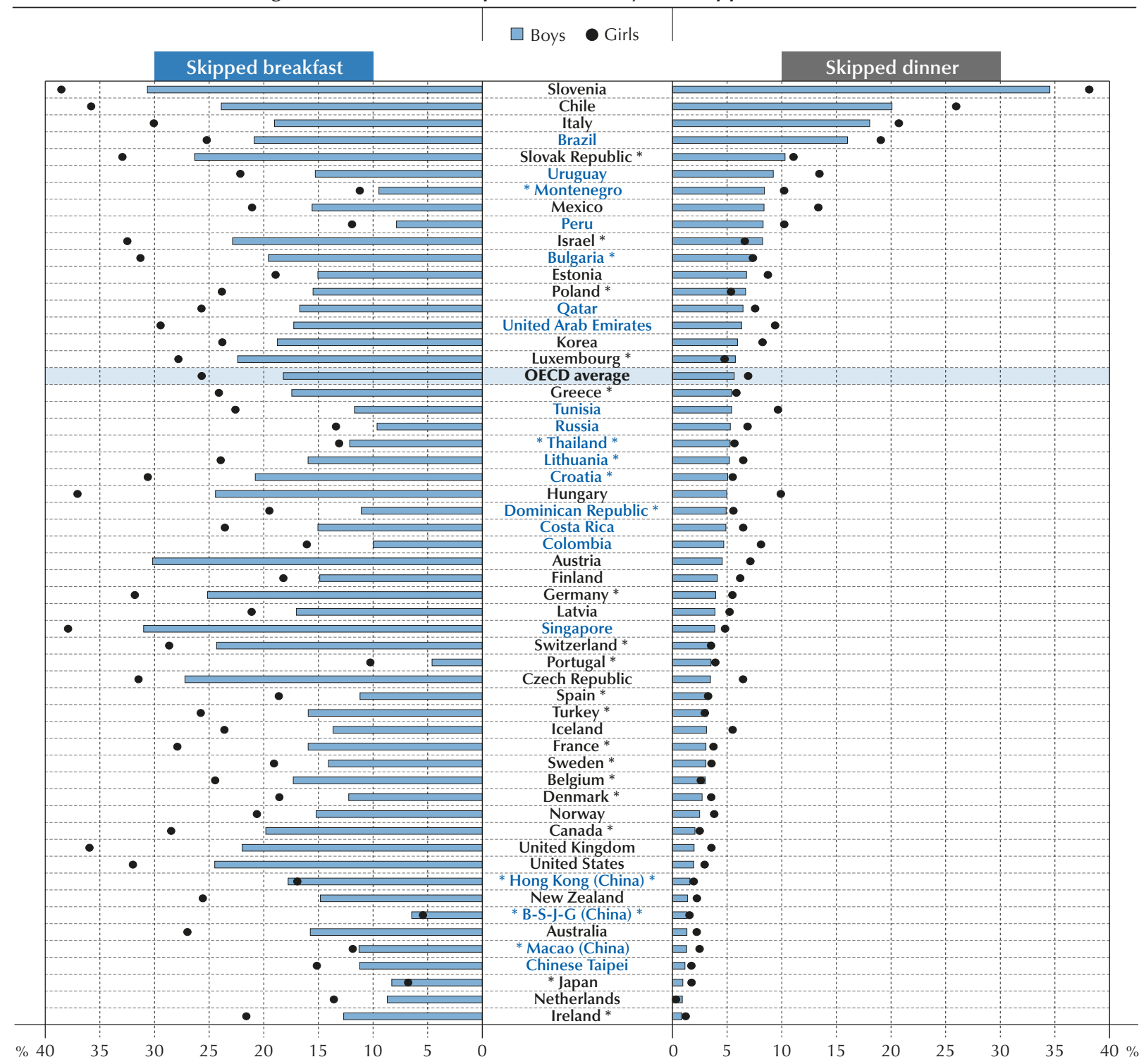

Note: Differences that are not statistically significant are shown with an asterisk before (for skipping breakfast) and after (for skipping dinner) the country/ economy name (see Annex A3).

Countries and economies are ranked in descending order of the percentage of boys who skipped dinner.

Source: OECD, PISA 2015 Database, Table III.11.22.

StatLink 제의 http://dx.doi.org/10.1787/888933472960 
In all countries and economies except Brazil, Chile, Italy and Slovenia, less than $15 \%$ of students reported that they had skipped dinner (Table III.11.21).

Research has shown that adolescents' eating habits are related to the quality of family relationships and to socio-economic status (Keski-Rahkonen et al., 2003). Students living in families that enjoy closeness and good communication are more likely to have eaten breakfast before school (Berge et al., 2013). Fathers' education level and employment status are also significantly associated with eating breakfast before school (Hussein, 2014). Students from socio-economically advantaged backgrounds may be more aware of the importance of eating breakfast than disadvantaged students.

On average across OECD countries, $74 \%$ of disadvantaged students reported that they had eaten breakfast before school while $82 \%$ of advantaged students reported so. In Belgium, Singapore and the United Kingdom, the difference between the share of advantaged and disadvantaged students who ate breakfast before school is greater than or equal to 15 percentage points. Similarly, a larger share of advantaged students than disadvantaged students reported that they had eaten dinner. Across OECD countries, the average difference between the two groups of students is 2.3 percentage points (Table III.11.22).

\section{Eating habits and students' well-being}

Eating breakfast can have an impact on other aspects of adolescents' lives beyond health. Students who eat breakfast might perform better in school because they are better able to concentrate and pay attention than students who skip breakfast (Adolphus, Lawton, and Dye, 2013).

Eating breakfast is positively related to students' science performance, on average across OECD countries. The association is not strong, however, as in a number of countries eating breakfast and performance are negatively related. On average across OECD countries, boys who reported that they had eaten breakfast before school score 10 points higher in science than boys who had skipped breakfast. Girls who reported that they had eaten breakfast score six points higher than those who reported that they had skipped breakfast (Figure III.11.12). After accounting for socio-economic status, eating breakfast is positively associated with science performance among boys in 27 countries and among girls in 19 countries. Girls might be more likely than boys to skip breakfast because they think they are overweight, and a self-image of being overweight is associated with poor performance, particularly among girls (Florin, Shults, and Stettler, 2011).

The family environment can also play a role in shaping adolescents' eating habits. Eating the evening meal together, as a family, can ensure that teenagers consume enough fruits and vegetables, and reduce the likelihood that adolescents will skip breakfast (Videon and Manning, 2003). Research suggests that in households where families eat dinner together, teenagers tend to enjoy better physical and emotional well-being, possibly because dinner provides time for informal discussions, and during that time, parents can promote healthy eating habits (Videon and Manning, 2003). Korean middle-school students who frequently have dinner with their families are more likely to have a balanced and nutritious meal, report higher life satisfaction, and have better emotional control than students who do not have frequent family meals (Kwon et al., 2013).

Among students in OECD countries, those who reported that they had eaten dinner reported greater satisfaction with life than those who had skipped dinner. On average, boys who had eaten dinner reported a life satisfaction of 7.6 on a scale from 0 to 10, 0.7 point higher than boys who had skipped dinner. The relationship is even stronger among girls, with a difference of one point on the scale of life satisfaction. In B-J-S-G (China), Finland, Germany, Hong Kong (China), Ireland and the United States, the average level of life satisfaction among boys who reported that they had eaten dinner with their families was at least one point higher on the scale than that among boys who reported that they had skipped dinner (Figure III.11.13). Similarly, there is a positive relationship between eating breakfast and students' life satisfaction, although the magnitude of the difference in average life satisfaction is smaller than that related to eating dinner (Table III.11.27). Overall, the relationship between eating meals (dinner or breakfast) and life satisfaction varies across countries; but in the majority of countries and economies, the relationship is stronger among girls than among boys (Table III.11.28).

Although these associations do not establish cause and effect between eating meals and adolescents' satisfaction with life (nor the existence of such a direct relationship, as other factors might be related to both life satisfaction and eating habits), they align with evidence showing eating disorders to be strongly related to low satisfaction with life among adolescents (Matthews et al., 2012). Given that girls are more likely to suffer eating disorders and to be sensitive to body image, it may be beneficial to target policies that support a positive body image and that promote regular meals at girls and young women in particular (Box III.11.3). Schools can play an important role in both targeted and universal interventions to prevent eating disorders (chapter 14). 
Figure III.11.12 - Eating breakfast and science performance

Score-point difference in science performance, after accounting for students' socio-economic status

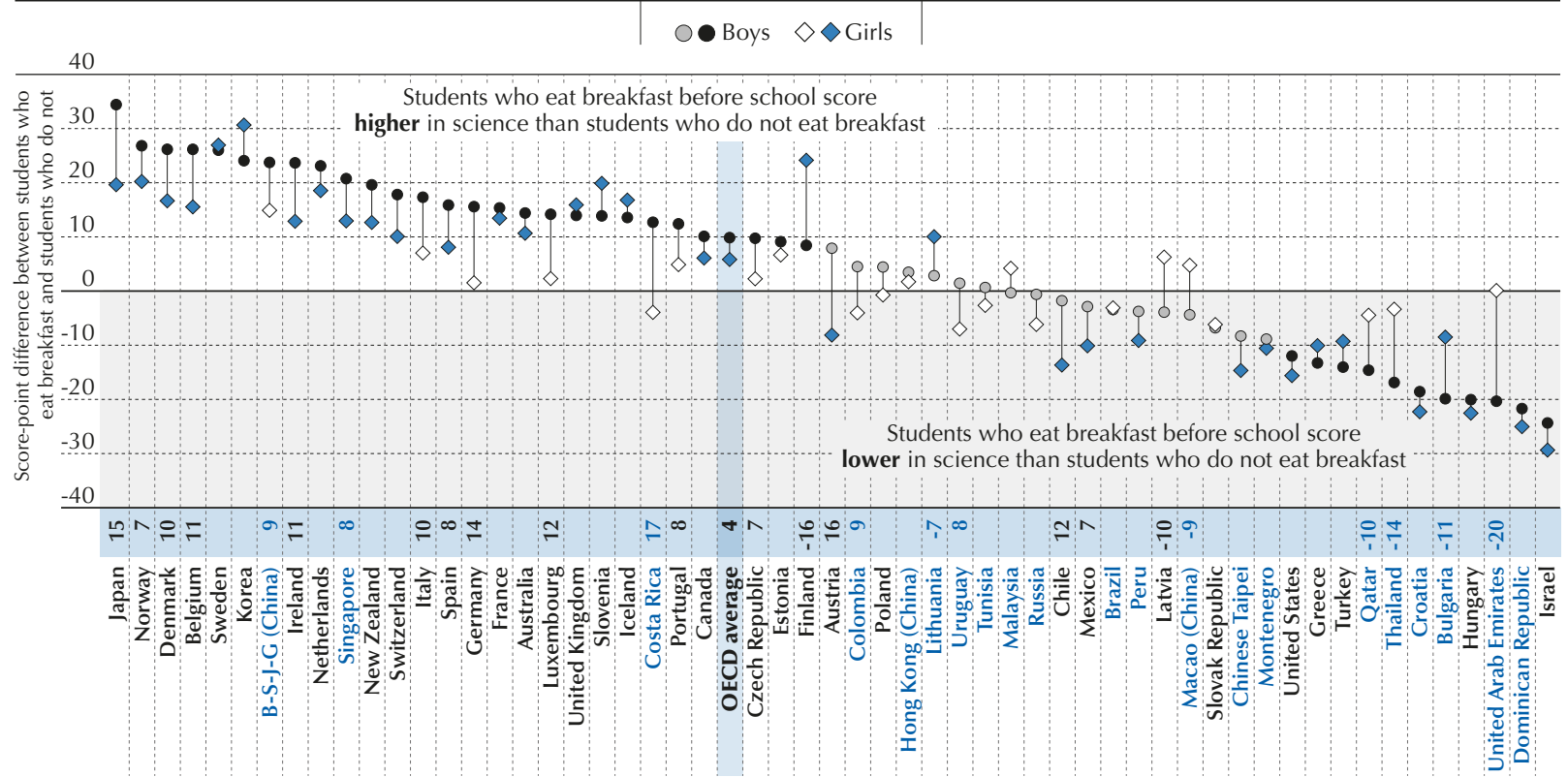

Notes: Only countries and economies with valid values for both genders are shown.

Statistically significant differences between students who eat breakfast and those who do not are marked in a darker tone. Statistically significant differences between boys and girls are shown next to the country/economy name (see Annex A3).

Countries and economies are ranked in descending order of the score-point difference associated with eating breakfast, among boys.

Source: OECD, PISA 2015 Database, Table III.11.25.

StatLink 제으 http://dx.doi.org/10.1787/888933472978

Figure III.11.13 - Eating dinner and life satisfaction, by gender

Difference in life satisfaction associated with eating dinner, after accounting for students' socio-economic status

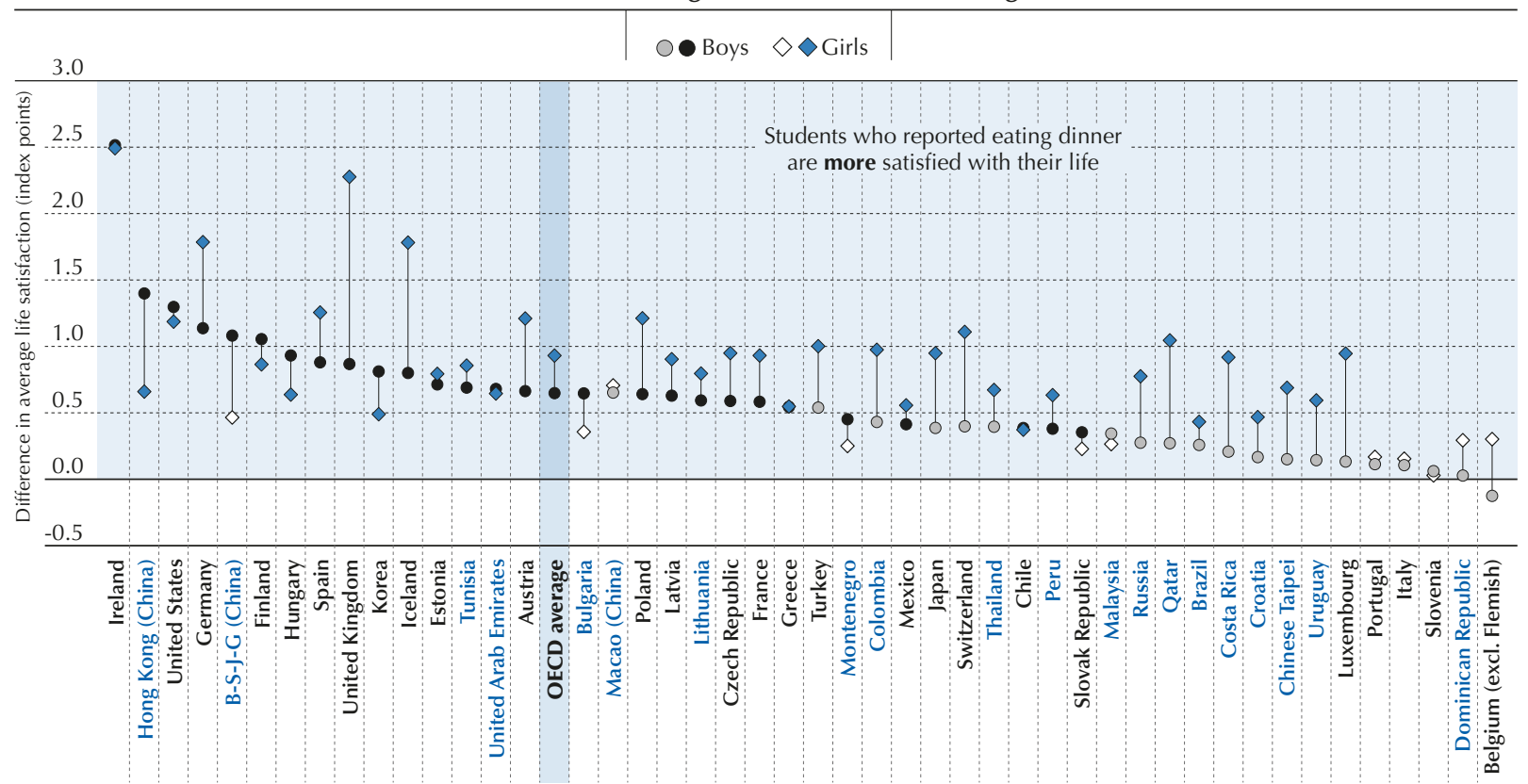

Notes: Only countries and economies with valid values for both genders are shown.

Statistically significant differences are marked in a darker tone (see Annex A3).

Countries and economies are ranked in descending order of the difference in average life satisfaction among boys, by whether or not they eat dinner.

Source: OECD, PISA 2015 Database, Table III.11.28.

StatLink 제에 $\mathrm{http}: / / \mathrm{dx}$.doi.org/10.1787/888933472983 


\section{Box III.11.3 Eating disorders among adolescents}

In most industrialised economies, healthy bodies are regarded as an ideal, but thinness is often equated with beauty. This mixed message may produce an obsession with weight that is particularly distressing for adolescents. Eating disorders among teenagers, such as binge eating, bulimia or anorexia nervosa, can pose serious health risks (Zipfel et al., 2000) and psychosocial problems (Herpertz-Dahlmann et al., 2001). In severe cases, anorexia can lead to death, through suicide or medical complications (Fairburn and Harrison, 2003; Pompili and Tatarelli, 2005). In a recent meta-analysis of 35 published articles, the crude mortality rate for anorexia nervosa was about $0.51 \%$ (Smink, van Hoeken and Hoek, 2012).

Different eating disorders share common symptoms, and individuals can be diagnosed with multiple disorders. For example, those with symptoms of anorexia and bulimia both tend to base their feelings of self-worth on their (usually distorted) view of their own body weight and shape (Fairburn and Harrison, 2003). Some 20-30\% of bulimics previously had anorexia (Kaye, 2008).

Eating disorders can be triggered by a variety of factors, including dissatisfaction with one's own body, a distorted image of one's body, depression, low self-esteem, excessive dieting, compulsive behaviour, stress, social or cultural pressure to be thin, bullying or problems with friends, genetic predisposition, difficulties with family members, and stressful events in the family (Nilsson et al., 2007; Kaye, 2008; Fairburn and Harrison, 2003). Because many of these risk factors are related to psychosocial and mental health, treatments for eating disorders often include psychotherapy and can sometimes involve antidepressants or antipsychotics (Jaite et al., 2013).

Eating disorders are more commonly found among girls and young women, particularly those between the ages of 15 and 19 (Smink, van Hoeken, and Hoek, 2012). Around 90\% of patients diagnosed with eating disorders are teenagers or young women (Kreipe and Birndorf, 2000).

Studies in Australia, Denmark, the Netherlands, Norway and the United Kingdom have found slightly increasing prevalence rates for all types of eating disorders, except bulimia, particularly among adolescent girls ( Currin et al., 2005; Mitchison et al., 2012; Steinhausen and Jensen, 2015; von Soest and Wichstrøm, 2014; Smink, et al. 2016).

The prevalence of eating disorders tends to be higher in Western countries (Makino, Tsuboi and Dennerstein, 2004). Frequent exposure to mass-media images that convey the notion that thin bodies are the ideal is related to dissatisfaction with one's own body, particularly among women (Grabe, 2008). According to HBSC data, 43\% of 15 -year-old girls and $22 \%$ of boys that age reported that they are too fat, and in all of the participating countries, girls were at least twice as likely as boys to report so.

Adolescents who are identified and treated early in the course of an eating disorder have a significantly better chance of recovery when compared with those who have been living with an eating disorder longer. However, the median duration of treatment delay is extraordinarily long for eating disorders, partly because people with eating disorders experience significant barriers to seeking help. A person who has an eating disorder may need guidance and support from those around him or her to take the first steps towards preventing or treating an eating disorder. It is therefore important that educators deepen their understanding about eating disorders. School strategies to prevent, intervene early and manage students' eating disorders can reduce the stigma and misconceptions that surround eating disorders.

\section{What these results imply for policy}

- Schools can encourage and organise regular physical activity to reduce the negative effects on well-being of not engaging in any kind of moderate or vigorous physical activity outside of school.

- Providing counseling to those students who are at risk of developing eating disorders may be beneficial, particularly for girls. Schools can work with parents, communities and social services to address issues related to eating habits. 


\section{Notes}

1. The PISA estimates on skipping breakfast represent an upper bound of the actual percentage of students skipping breakfast. Some students may choose to have breakfast when they arrive at school if their schools offer breakfast. Because the PISA questionnaire only asks if students had breakfast before going to school, some of these students may appear as if they skipped breakfast when in fact they did not.

\section{References}

Adolphus, K., C.L. Lawton and L. Dye (2013), "The effects of breakfast on behavior and academic performance in children and adolescents", Frontiers in Human Neuroscience, Vol. 7, http://dx.doi.org/10.3389/fnhum.2013.00425.

Allan, J.L., D. McMinn and M. Daly (2016), "A bidirectional relationship between executive function and health behavior: evidence, implications, and future directions", Frontiers in Neuroscience, Vol. 10, http://dx.doi.org/10.3389/fnins.2016.00386.

Bailey, R. (2006), "Physical education and sport in schools: a review of benefits and outcomes", Journal of School Health, Vol. 76/8, pp. 397-401, http://dx.doi.org/10.1111/j.1746-1561.2006.00132.x.

Bauman, A.E. et al. (2012), "Correlates of physical activity: why are some people physically active and others not?", The Lancet, Vol. 380/9838, pp. 258-71, http://dx.doi.org/10.1016/S0140-6736(12)60735-1.

Berge, J.M. et al. (2013), "Family functioning: associations with weight status, eating behaviors, and physical activity in adolescents", Journal of Adolescent Health, Vol. 52/3, pp. 351-57, http://dx.doi.org/10.1016/j.jadohealth.2012.07.006.

Bergman Nutley, S., F. Darki and T. Klingberg (2014), "Music practice is associated with development of working memory during childhood and adolescence", Frontiers in Human Neuroscience, Vol. 7, http://dx.doi.org/10.3389/fnhum.2013.00926.

Biddle, S.J.H. and M. Asare (2011), "Physical activity and mental health in children and adolescents: a review of reviews", British Journal of Sports Medicine, Vol. 45, pp. 886-895, http://dx.doi.org/10.1136/bjsports-2011-090185.

Birch, L., J.S. Savage and A. Ventura (2007), "Influences on the development of children's eating behaviours: from infancy to adolescence", Canadian Journal of Dietetic Practice and Research, Vol. 68 /1, pp. s1-s56.

Borra, S.T. et al. (2003), "Developing health messages: qualitative studies with children, parents, and teachers help identify communications opportunities for healthful lifestyles and the prevention of obesity", Journal of the American Dietetic Association, Vol. 103/6, pp. 721-28, http://dx.doi.org/10.1053/jada.2003.50140.

Brenner, J.S. (2007), "Overuse injuries, overtraining, and burnout in child and adolescent athletes", Pediatrics, Vol. 119/6, pp. 1242-45, http://dx.doi.org/10.1542/peds.2007-0887.

Budde, H. et al. (2008), "Acute coordinative exercise improves attentional performance in adolescents", Neuroscience Letters, Vol. 441/2, pp. 219-23, http://dx.doi.org/10.1016/j.neulet.2008.06.024.

Busch, V. et al. (2014), "The effects of adolescent health-related behavior on academic performance: a systematic review of the longitudinal evidence", Review of Educational Research, Vol. 84/2, pp. 245-74, http://dx.doi.org/10.3102/0034654313518441.

Byrd, C.E. and S.M. Ross (1991), "The influence of participation in junior high athletics on students' attitudes and grades", Vol. 48/4, pp. 170.

Centers for Disease Control and Prevention (2017), "How much physical activity do adults need?", https://www.cdc.gov/ physicalactivity/basics/adults/index.htm.

Centres for Disease Control and Prevention (2010), "The association between school based physical activity, including physical education, and academic performance", U.S. Department of Health and Human Services, https://www.cdc.gov/healthyschools/pecat/ pa-pe paper.pdf.

Chin, T. and N.S. Rickard (2014), "Emotion regulation strategy mediates both positive and negative relationships between music uses and well-being", Psychology of Music, Vol. 42/5, pp. 692-713, http://dx.doi.org/10.1177/0305735613489916.

Cooper, S.B., S. Bandelow and M.E. Nevill (2011) "Breakfast consumption and cognitive function in adolescent schoolchildren", Physiology \& Behavior, Vol. 103/5, pp. 431-439.

Currin, L. et al. (2005), "Time trends in eating disorder incidence", The British Journal of Psychiatry, Vol. 186/2, pp. 132-5, http://dx.doi. org/10.1192/bjp.186.2.132.

Digelidis, N. et al. (2003), "A one-year intervention in 7th grade physical education classes aiming to change motivational climate and attitudes towards exercise", Psychology of Sport and Exercise, Vol. 4/3, pp. 195-210, http://dx.doi.org/10.1016/S1469-0292(02)00002-X.

Dudley, D. et al. (2011), "A systematic review of the effectiveness of physical education and school sport interventions targeting physical activity, movement skills and enjoyment of physical activity", European Physical Education Review, Vol. 17/3, pp. 353-78, http://dx.doi. org/10.1177/1356336X11416734. 
Eccles, J.S. et al. (2003), "Extracurricular activities and adolescent development", Journal of Social Issues, Vol. 59/4, pp. 865-89, http://dx.doi.org/10.1046/j.0022-4537.2003.00095.x.

Esteban-Cornejo, I. et al. (2015), "Physical activity and cognition in adolescents: a systematic review", Journal of Science and Medicine in Sport, Vol. 18/5, pp. 534-39, http://dx.doi.org/10.1016/j.jsams.2014.07.007.

Fairburn, C.G, and P.J. Harrison (2003), "Eating disorders", The Lancet, Vol. 361/9355, pp. 407-16, http://dx.doi.org/10.1016/S01406736(03)12378-1.

Florin, T.A., J. Shults and N. Stettler (2011), "Perception of overweight is associated with poor academic performance in US adolescents", Journal of School Health, Vol. 81/11, pp. 663-70, http://dx.doi.org/10.1111/j.1746-1561.2011.00642.x.

Furnham, A., N. Badmin and I. Sneade (2002), "Body image dissatisfaction: gender differences in eating attitudes, self-esteem, and reasons for exercise", The Journal of Psychology, Vol. 136/6, pp. 581-96, http://dx.doi.org/10.1080/00223980209604820.

Grabe, S.W. (2008), "The role of the media in body image concerns among women: a meta-analysis of experimental and correlational studies", Psychological Bulletin, Vol. 134/3, pp. 460-76, http://dx.doi.org/10.1037/0033-2909.134.3.460.

Hallal, P.C. et al. (2012), "Global physical activity levels: surveillance progress, pitfalls, and prospects", The Lancet, Vol. 380/9838, pp. 247-57, http://dx.doi.org/10.1016/S0140-6736(12)60646-1.

Haskell, W. et al. (2007), "Physical activity and public health: updated recommendation for adults from the american college of sports medicine and the american heart association", Circulation, Vol. 116, pp. 1081-93.

Haugen, T., R. Säfvenbom and Y. Ommundsen (2011), "Physical activity and global self-worth: the role of physical self-esteem indices and gender", Mental Health and Physical Activity, Vol. 4/2, pp. 49-56, http://dx.doi.org/10.1016/j.mhpa.2011.07.001.

de la Haye, K. et al. (2011), "How physical activity shapes, and is shaped by, adolescent friendships", Social Science \& Medicine, Vol. 73/5, pp. 719-28, http://dx.doi.org/10.1016/j.socscimed.2011.06.023.

Heitzler, C.D. et al. (2006), "Correlates of physical activity in a national sample of children aged 9-13 years", Preventive Medicine, Vol. 42/4, pp. 254-60, http://dx.doi.org/10.1016/j.ypmed.2006.01.010.

Herpertz-Dahlmann, B. et al. (2001), "Prospective 10-year follow-up in adolescent anorexia nervosa--course, outcome, psychiatric comorbidity, and psychosocial adaptation", Journal of Child Psychology and Psychiatry, and Allied Disciplines, Vol. 42/5, pp. 603-12, http://dx.doi.org/10.1111/1469-7610.00756.

HHS. (2013), "Physical activity guidelines for Americans midcourse report: strategies to increase physical activity among youth", https://health.gov/paguidelines/midcourse/.

Hillman, C. H. et al. (2009), "The effect of acute treadmill walking on cognitive control and academic achievement in preadolescent children", Neuroscience, Vol. 159/3, pp. 1044-54, http://dx.doi.org/10.1016/j.neuroscience.2009.01.057.

Hussein, R. (2014), "Socioeconomic status and dietary habits as predictors of home breakfast skipping in young women", The Journal of the Egyptian Public Health Association, Vol. 89/2, pp. 100-104, http://dx.doi.org/10.1097/01.EPX.0000452288.49308.40.

Jaite, C. et al. (2013), "Prevalence, comorbidities and outpatient treatment of anorexia and bulimia nervosa in german children and adolescents", Eating and Weight Disorders - Studies on Anorexia, Bulimia and Obesity, Vol. 18/2, pp.157-65, http://dx.doi.org/10.1007/ s40519-013-0020-4.

Janssen, I. and A. G. LeBlanc (2010) "Systematic review of the health benefits of physical activity and fitness in school-aged children and youth", International Journal of Behavioral Nutrition and Physical Activity, Vol. 7/40, http://dx.doi.org/10.1186/1479-5868-7-40.

Jones, D.C. (2001), "Social comparison and body image: attractiveness comparisons to models and peers among adolescent girls and boys", Sex Roles, Vol. 45/9-10, pp. 645-64. http://dx.doi.org/10.1023/A:1014815725852.

Kaye, W. (2008), "Neurobiology of Anorexia and Bulimia Nervosa", Physiology \& Behavior, Vol. 94/1, pp. 121-35, http://dx.doi. org/10.1016/j.physbeh.2007.11.037.

Kemm, J.R. (1987), "Eating patterns in childhood and adult health", Nutrition and Health, Vol. 4/4, pp. 205-215.

Kohl, H.W. and H.D. Cook (2013), "Physical activity, fitness, and physical education: effects on academic performance" in Educating the Student Body: Taking Physical Activity and Physical Education to School, National Academies Press (US).

Kreipe, R.E. and S.A. Birndorf (2000), "Eating disorders in adolescents and young adults", Medical Clinics of North America, Vol. 84/4, pp. 1027-49, http://dx.doi.org/10.1016/S0025-7125(05)70272-8.

Kwon, J. E. et al. (2013), "The relationships of dietary behavior, food intake, and life satisfaction with family meal frequency in middle school students", Journal of the Korean Society of Food Culture, Vol. 28/3, pp. 272-81, http://dx.doi.org/10.7318/KJFC/2013.28.3.272.

Lazzeri, G. et al. (2016) "Trends from 2002 to 2010 in daily breakfast consumption and its socio-demographic correlates in adolescents across 31 countries participating in the HBSCstudy", PLOS ONE, Vol. 11/3, http://dx.doi.org/10.1371/journal.pone.0151052. 
Leversen, I. et al. (2012), "Basic psychological need satisfaction in leisure activities and adolescents' life satisfaction", Journal of Youth and Adolescence, Vol. 41/12, pp. 1588-1599, http://dx.doi.org/10.1007/s10964-012-9776-5.

Levine, J., S. Etchison and D.M. Oppenheimer (2014), "Pluralistic ignorance among student-athlete populations: a factor in academic underperformance", Higher Education, Vol. 68/4, pp. 525-540, http://dx.doi.org/10.1007/s10734-014-9726-0.

Lobstein, T. et al. (2015) "Child and adolescent obesity: part of a bigger picture", The Lancet, Vol. 385/9986, pp. 2510-2520, http:// dx.doi.org/10.1016/S0140-6736(14)61746-3.

Lonsdale, C. et al. (2013), "A systematic review and meta-analysis of interventions designed to increase moderate-to-vigorous physical activity in school physical education lessons", Preventive Medicine, Vol. 56/2, pp. 152-161, http://dx.doi.org/10.1016/j.ypmed. 2012.12.004.

Macdonald-Wallis, K. et al. (2011), "School-based friendship networks and children's physical activity: a spatial analytical approach", Social Science \& Medicine, Vol. 73/1, pp. 6-12, http://dx.doi.org/10.1016/j.socscimed.2011.04.018.

Makino, M., K. Tsuboi and L. Dennerstein (2004), "Prevalence of eating disorders: a comparison of western and non-western countries", Medscape General Medicine, Vol. 6/3.

Matthews, M. et al. (2012), "An analysis of specific life satisfaction domains and disordered eating among college students", Social Indicators Research, Vol. 107/1, pp. 55-56, http://dx.doi.org/10.1007/s11205-011-9826-5.

McCabe, M.P, and L.A Ricciardelli (2001), "Parent, peer, and media influences on body image and strategies to both increase and decrease body size among adolescent boys and girls", Adolescence, Vol. 36/142, pp. 225-240.

Mitchison, D. et al. (2012), "Time trends in population prevalence of eating disorder behaviors and their relationship to quality of life", PLOS ONE, Vol.7/11, http://dx.doi.org/10.1371/journal.pone.0048450.

Neumark-Sztainer, D. et al. (1999) "Factors influencing food choices of adolescents: findings from focus-group discussions with adolescents", Journal of the American Dietetic Association, Vol. 99/8, pp. 929-937. http://dx.doi.org/10.1016/S0002-8223(99)00222-9.

Nilsson, K. et al. (2007), "Causes of adolescent onset anorexia nervosa: patient perspectives", Eating Disorders, Vol. 15/2, pp. 125-133, http://dx.doi.org/10.1080/10640260701190642.

Paxton, S.J. et al. (1991), "Body image satisfaction, dieting beliefs, and weight loss behaviors in adolescent girls and boys", Journal of Youth and Adolescence, Vol. 20/3, pp. 361-379, http://dx.doi.org/10.1007/BF01537402.

Penedo, F.J. and J.R. Dahn (2005), "Exercise and well-being: a review of mental and physical health benefits associated with physical activity", Current Opinion in Psychiatry, Vol. 18/2, pp. 189-193.

Pesce, C. et al. (2009), "Physical activity and mental performance in preadolescents: effects of acute exercise on free-recall memory", Mental Health and Physical Activity, Vol. 2/1, pp. 16-22, http://dx.doi.org/10.1016/j.mhpa.2009.02.001.

Pompili, M. and R. Tatarelli (2005), "Eating disorders, especially anorexia nervosa, are associated with an increased risk of attempted suicide in young women", Evidence Based Mental Health, Vol. 8/1, p. 20, http://dx.doi.org/10.1136/ebmh.8.1.20.

Quick, V. et al. (2014), "Body size perception and weight control in youth: 9-year international trends from 24 countries", International Journal of Obesity, Vol. 38/7, pp. 988-994, http://dx.doi.org/10.1038/ijo.2014.62.

Singh, A. etal. (2012), "Physical activity and performance at school: a systematic review of the literature including a methodological quality assessment", Archives of Pediatrics \& Adolescent Medicine, Vol. 166/1, pp. 49-55, http://dx.doi.org/10.1001/archpediatrics.2011.716.

Smink, F.R.E. et al. (2016), "Three decades of eating disorders in Dutch primary care: decreasing incidence of bulimia nervosa but not of anorexia nervosa", Psychological Medicine, Vol. 46/6, pp. 1189-1196, http://dx.doi.org/10.1017/S003329171500272X.

Smink, F.R.E., D. van Hoeken and H.W. Hoek (2012), "Epidemiology of eating disorders: incidence, prevalence and mortality rates", Current Psychiatry Reports, Vol. 14/4, pp. 406-414, http://dx.doi.org/10.1007/s11920-012-0282-y.

von Soest, T. and L. Wichstrøm (2014), "Secular trends in eating problems among Norwegian adolescents from 1992 to 2010 ", International Journal of Eating Disorders, Vol. 47/5, pp. 448-457, http://dx.doi.org/10.1002/eat.22271.

Sofi, F. et al. (2011), "Physical activity and risk of cognitive decline: a meta-analysis of prospective studies", Journal of Internal Medicine, Vol. 269/1, pp. 107-117, http://dx.doi.org/10.1111/j.1365-2796.2010.02281.x.

Steinhausen, H. and C.M. Jensen (2015), "Time trends in lifetime incidence rates of first-time diagnosed anorexia nervosa and bulimia nervosa across 16 years in a Danish nationwide psychiatric registry study", International Journal of Eating Disorders, Vol. 48/7, pp. 845-850, http://dx.doi.org/10.1002/eat.22402.

Strong, W.B. et al. (2005), "Evidence based physical activity for school-age youth", The Journal of Pediatrics, Vol. 146 /6, pp. 732-737, http://dx.doi.org/10.1016/j.jpeds.2005.01.055. 
Videon, T.M and C.K. Manning (2003), "Influences on adolescent eating patterns: the importance of family meals", Journal of Adolescent Health, Vol. 32/5, pp. 365-373, http://dx.doi.org/10.1016/S1054-139X(02)00711-5.

Zhang, Y. et al. (2015), "Association between physical activity and teacher-reported academic performance among fifth-graders in Shanghai: A quantile regression", PLOS ONE, Vol. 10/3, http://dx.doi.org/10.1371/journal.pone.0115483.

Zipfel, S. et al. (2000) "Long-term prognosis in anorexia nervosa: lessons from a 21-year follow-up study", The Lancet, Vol. 355/9205, pp. 721-722, http://dx.doi.org/10.1016/S0140-6736(99)05363-5. 

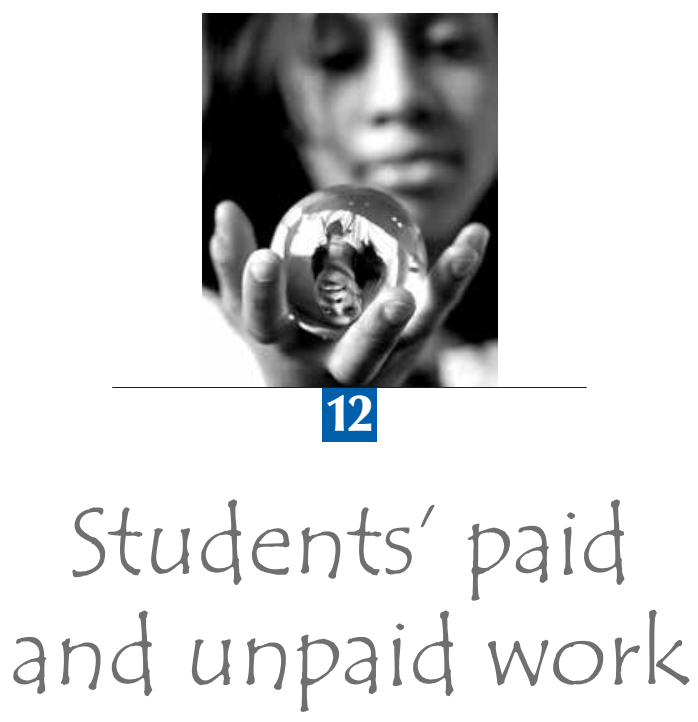

For the first time, PISA 2015 asked students to report whether they worked for pay and/or worked in the home (or cared for family members) before or after school during the most recent day that they attended school. This chapter reveals the extent to which 15-year-old students around the world work for pay, or work unpaid in the household, before or after school. The chapter examines which students are more likely to work for pay and which are more likely to do household work without pay. It also discusses the relationship between paid and unpaid work, and students' performance in and attitudes towards school. 
One crucial factor for an individual's capability to flourish is the amount of leisure time available to him or her. Students' engagement with paid or unpaid work in addition to time spent at school and on homework is an important determinant for the available time for leisure or non-academic activities. By choosing to spend their leisure time working for pay students can gain new experience and knowledge, explore career options, and earn money, but they may also spend less time on studying and on leisure activities.

\section{What the data tell us}

- Working for pay or working in the home is common among adolescents. On average across OECD countries, around $23 \%$ of students reported that they worked for pay and $73 \%$ reported that they work in the house before or after school.

- More boys than girls work for pay, and fewer boys than girls do unpaid household chores.

- Disadvantaged students are about 6 percentage points more likely to work for pay than advantaged students, on average across OECD countries.

- Students who work for pay tend to score lower in science than those who do not work for pay.

- Students who work for pay were more likely than those who do not work for pay to report feeling like an outsider at school, having low expectations for further education, arriving late for school, and skipping school.

For the first time, PISA 2015 asked students to report whether they worked for pay and/or worked in the home (or cared for family members) before or after school during the most recent day that they attended school. Although the PISA questionnaires did not capture details on the duration, frequency and the types of work students are engaged in, the data can provide a glimpse of the work activities among 15-year-olds, and the relationship between working and well-being outcomes.

Family characteristics and socio-economic status can affect the probability of working in the household or working for pay (Gager, Cooney and Call, 1999). Having many siblings, or living with a single parent or in a multi-generational household tends to increase the demand for adolescents to work (Gager, Cooney and Call, 1999). Figure III.12.1 shows that there is no strong correlation between a country's/economy's per capita GDP and the average share of students working in the home or working for pay. In several countries, being financially independent earlier on in life is accepted as a cultural norm, and it is not unusual for teenagers to look for part-time jobs, irrespective of their family's income.

Figure III.12.1 - Students who work and per capita GDP
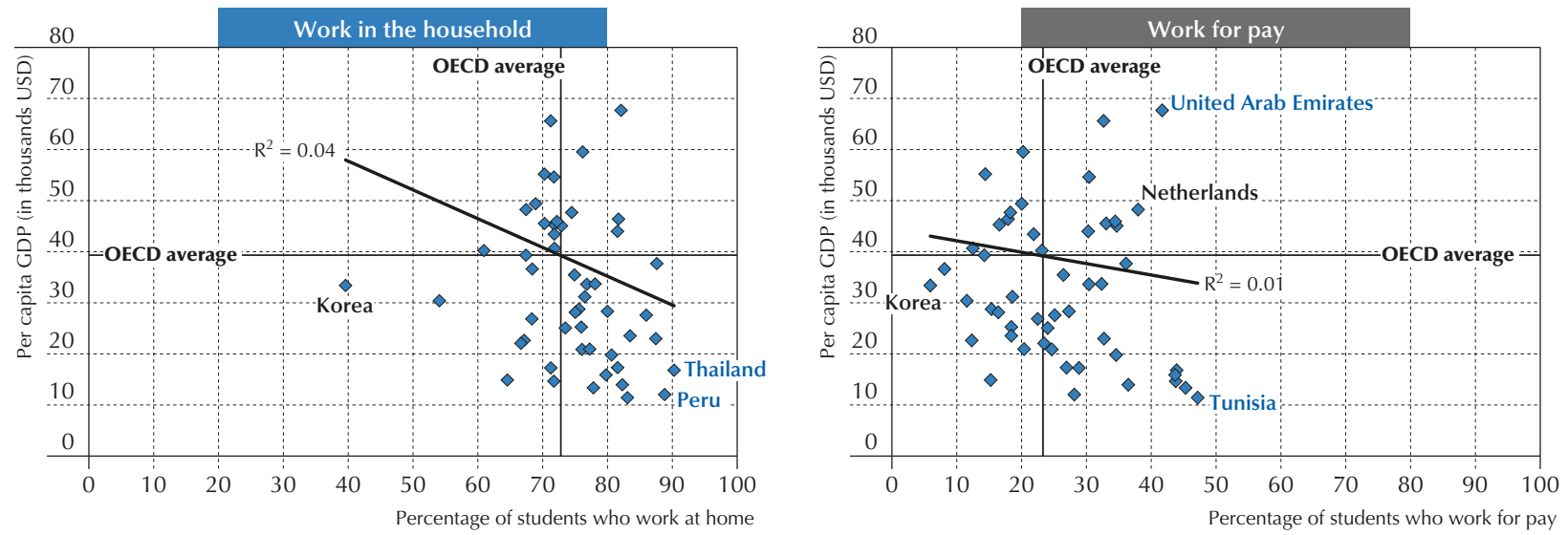

Source: OECD, PISA 2015 Database, Tables II.6.59 and III.12.1.

StatLink त्ञात 
In Australia, Canada, Denmark, Iceland, the Netherlands, Norway, Qatar, the United Arab Emirates and the United States, for example, per capita GDP exceeds the OECD average, and yet more than $30 \%$ of students reported that they work for pay - higher than the OECD average (Tables II.6.59 and III.12.1). In these countries, at least 26\% of advantaged students reported that they work for pay (Table III.12.7).

On average across OECD countries, 23\% of students reported that they work for pay and $73 \%$ reported that they work in the house before or after school (Table III.12.1). In the majority of the countries, more boys than girls reported that they work for pay. The difference between the shares of boys and girls who reported that they work for pay is 11 percentage points in favour of boys, on average across OECD countries (Table III.12.7). In countries that separate students in different tracks, part of this difference is likely to be the result of the more limited opportunities of vocational education for female adolescents than for male adolescent (Karaca et al., 2016).

Disadvantaged students were also more likely than advantaged students to report that they work for pay. The difference between the shares of advantaged and disadvantaged students who reported working for pay is 6 percentage points, on average across OECD countries (Figure III.12.2). Figure III.12.2 shows the shares of students who work for pay by quarters of the PISA index of socio-economic and cultural status. In 40 countries and economies, students in the top quarter of the index are less likely to work for pay than students in the bottom quarter of the index (Table III.12.7). On average across OECD countries, $26 \%$ of disadvantaged students, but $20 \%$ of advantaged students, reported that they work for pay. The relationship between students' socio-economic status and paid employment is strongest in Peru, where advantaged students were 29 percentage points less likely to work for pay than disadvantaged students. Earnings from part-time jobs can help families economically, in that adolescents who work for pay can then purchase items for themselves that their parents would otherwise have to provide.

Figure III.12.2 - Students who work for pay, by socio-economic status Quarters of the PISA index of economic, social and cultural status

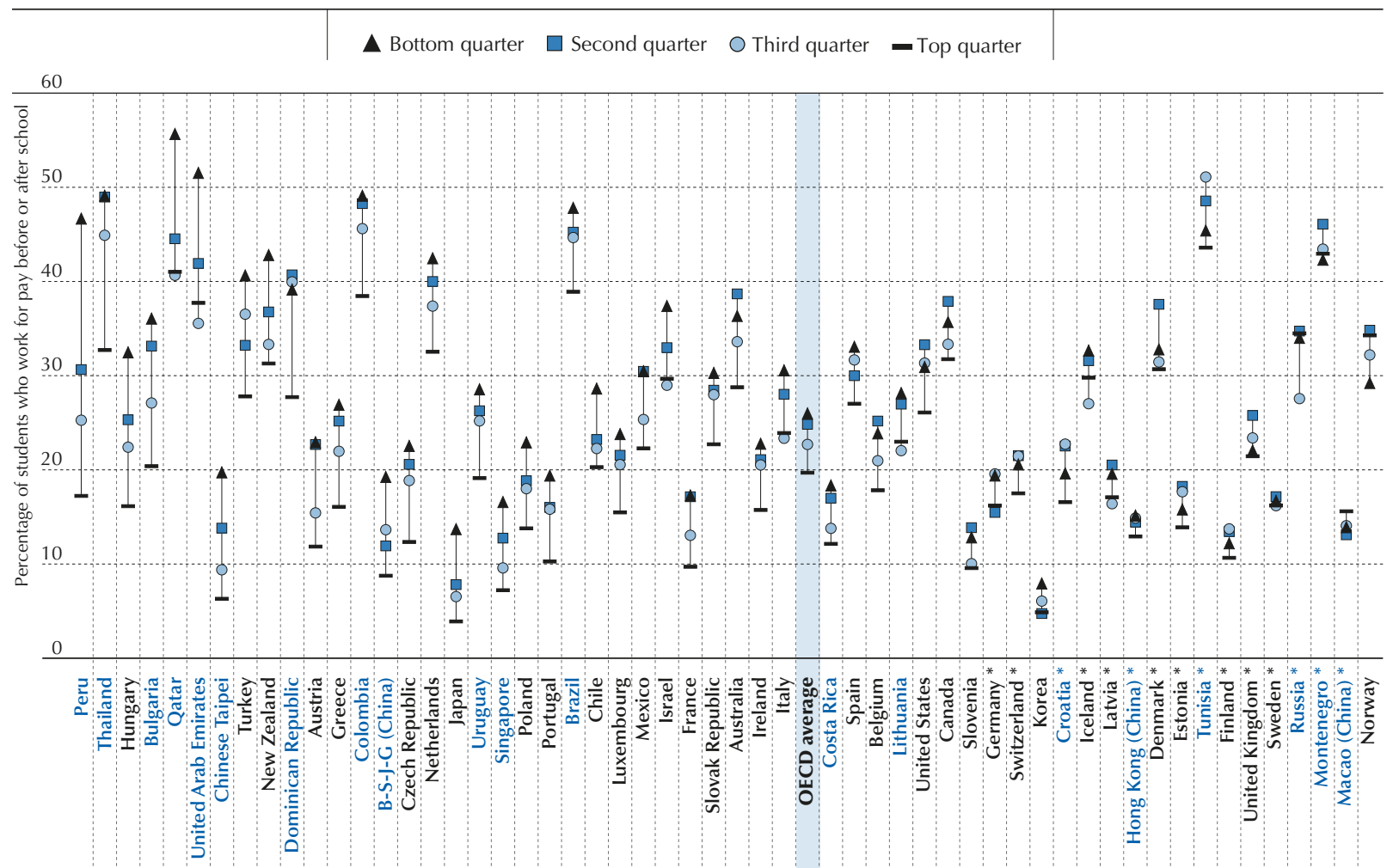

Note: Differences between the top and bottom quarters of the PISA index of economic, social and cultural status that are not statistically significant are shown with an asterisk next to the country/economy name (see Annex A3).

Countries and economies are ranked in ascending order of the difference in the percentage of students who work for pay between the top and bottom quarters of the PISA index of economic, social and cultural status.

Source: OECD, PISA 2015 Database, Table III.12.7.

StatLink 제요 http://dx.doi.org/10.1787/888933473000 
Figure III.12.3 - Students who work at home, by gender and socio-economic status

$\diamond$ Disadvantaged students $\quad \square \square$ Advantaged students

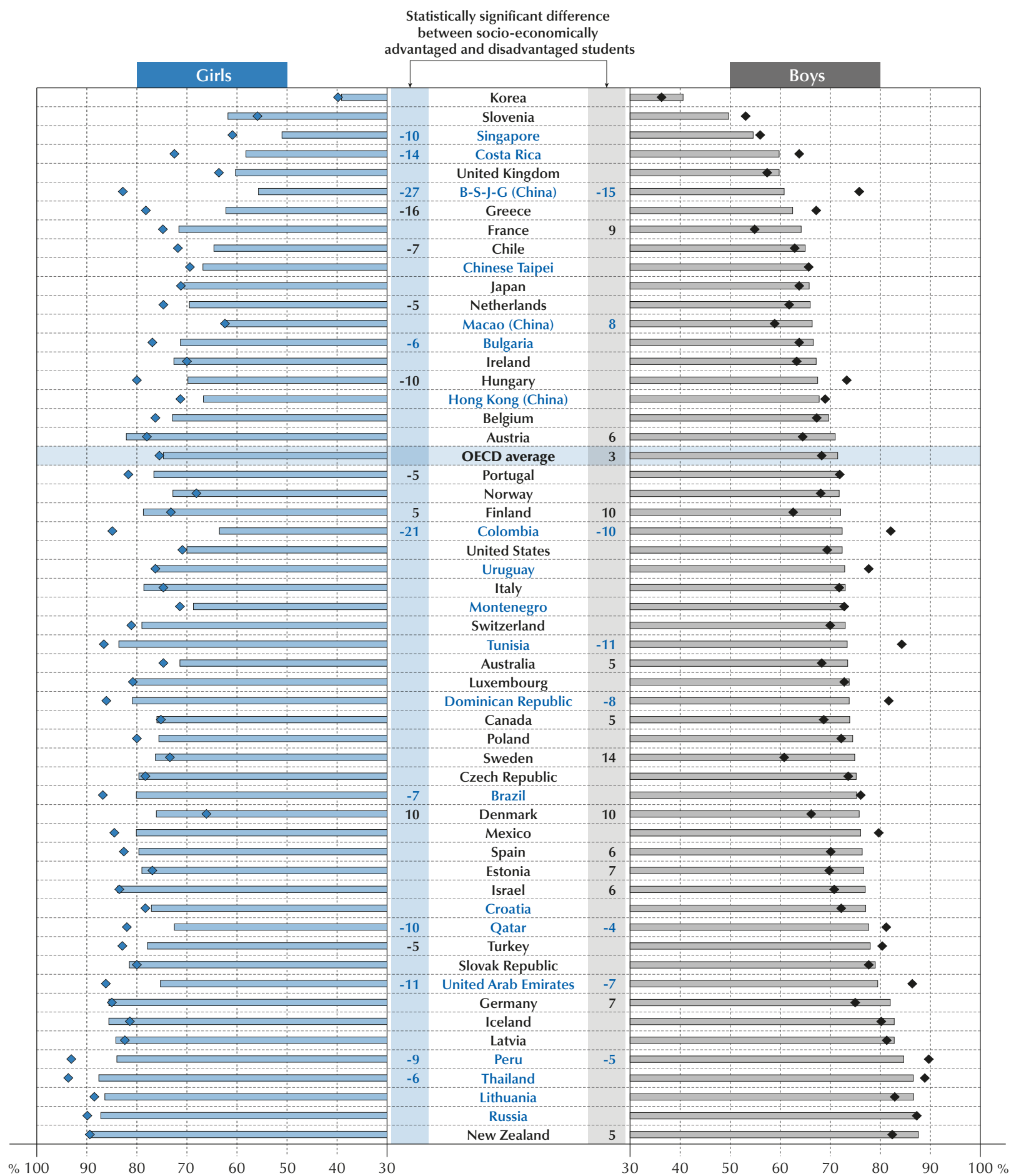

Notes: Statistically significant differences between advantaged and disadvantaged students are shown before (for girls) and after (for boys) the country/economy name (see Annex A3).

A socio-economically advantaged (disadvantaged) student is a student in the top (bottom) quarter of the distribution of the PISA index of economic, social and cultural status (ESCS) within his or her country/economy.

Countries and economies are ranked in ascending order of the percentage of advantaged boys who work at home.

Source: OECD, PISA 2015 Database, Table III.12.5

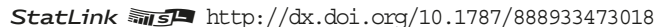


More students reported that they help out with household chores than work for pay. In the majority of countries and economies, more than one in two students reported that they help with housework or take care of family members outside of school hours (Table III.12.1). In 39 countries and economies, girls were significantly more likely than boys to report helping with housework (Table III.12.2); in Austria and France, girls were 11 percentage points more likely than boys to report doing so.

In 16 countries and economies (Greece, Hungary, Mexico, Turkey and most partner countries/economies with available data), disadvantaged students were more likely to report working in the home than advantaged students (Table III.12.5). In Beijing-Shanghai-Jiangsu-Guangdong (China) (hereafter "B-S-J-G [China]"), Colombia, Peru, Qatar and the United Arab Emirates, both disadvantaged boys and disadvantaged girls were significantly more likely to report working in the house than advantaged boys and girls (Figure III.12.3 and Table III.12.5). In B-J-S-G (China), Colombia, Costa Rica, Greece, Hungary, Peru, Qatar, Singapore and the United Arab Emirates, disadvantaged girls were at least 10 percentage points more likely than advantaged girls to report doing housework. However, on average across OECD countries, and in all the Nordic countries except Iceland, advantaged students were more likely than disadvantaged students to help with household chores (Table III.12.5).

Social and cultural norms often influence the likelihood that boys or girls help out with household chores. Research on 16 developing countries in Africa and Asia finds that girls, particularly girls with brothers, are more likely to do housework than boys (Webbink, Smits and de Jong, 2012). This difference is particularly pronounced in Asian countries.

There is no consensus on the desirability of paid work for adolescents. Many parents, and young people themselves, think that employment can help students develop a wide range of competencies, such as the capacity to assume responsibility, manage time, overcome shyness with adults and authority figures, and handle money. Work experience can instil positive traits that are also useful for learning at school, including independence, responsibility and a solid work ethic. But some educators complain that working teenagers who put in too many hours on their jobs may come to school tired, and have less time to focus on their studies and to engage in extracurricular activities (Mortimer, 2010).

Working outside of school hours may affect students' academic performance. The association between work activities and academic performance mostly depends on whether working takes time away from learning activities. For example, a study based on time-use data found that American students who have a job tend to spend less time on homework (Kalenkoski and Pabilonia, 2012).

As shown in Figures III.12.4 and III.12.5, students who work for pay or work in the home tend to score lower in science than those who do not work at all. The performance difference is greater among students who work for pay. On average across OECD countries, the score-point difference in science performance between students who work in the household and those who do not is 13 points, while the difference is 55 points among students who work for pay and those who do not.

Some fraction of these academic "costs" of employment can be attributed to self-selection. Students who enter adolescence with strong academic interests and achievement goals may choose to work very little during high school, and even if they have jobs, they may limit their hours of employment so as not to jeopardise their marks. By contrast, those who choose to work long hours tend to have less of a sense of belonging at school, engage in some disruptive behaviour, and are given lower marks, even at the start of high school (Staff, Messersmith and Schulenberg, 2009). For many students who are disengaged with school, getting a job can be a precursor to dropping out of school entirely (Warren and Lee, 2003). From this perspective, employment does not directly interfere with success at school; it is an activity pursued by students who are already not inclined to strive for academic success or to complete high levels of education.

The negative relationship between students' work status and science performance is stronger among advantaged students than among disadvantaged students. On average across OECD countries, advantaged students who reported working for pay score 68 points lower in science than advantaged students who do not work for pay (Figure III.12.4). Among disadvantaged students, this difference is 49 points. Differences across countries are also large. In Denmark, the score-point difference in science performance among advantaged students who work for pay and those who do not is 26 points, while in Korea - where relatively few students have a paid job - this difference is 122 points - the largest difference among all countries. Although more data are needed to fully understand students' motivation to work and to measure the intensity of work, it is unlikely that advantaged students choose to work for pay because they are obliged to. The strong correlation between science performance and work for pay probably indicates that the advantaged students who work for pay may be disengaged from school.

Helping with housework is less strongly related to science performance than working for pay. On average across OECD countries, boys who reported that they work in the house score 14 points lower in science than those who do not, and girls who reported that they work in the house score 10 points lower in science than those who do not (Figure III.12.5). Paid work may require longer working hours and a more regular commitment than helping out at home. 
Figure III.12.4 - Working for pay and science performance Score-point difference in science performance associated with working for pay before or after school

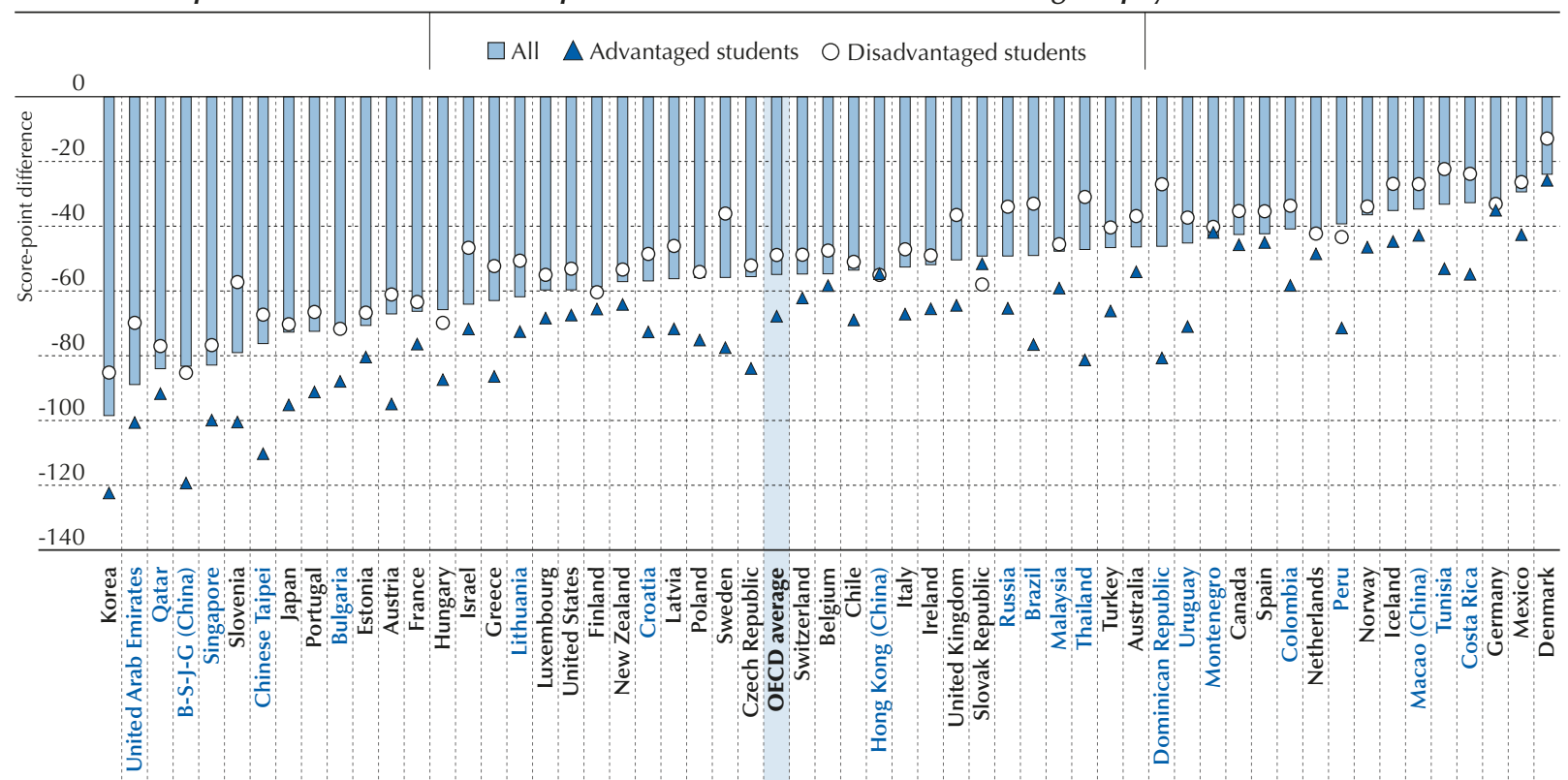

Notes: All score-point differences are statistically significant (see Annex A3).

A socio-economically advantaged (disadvantaged) student is a student in the top (bottom) quarter of the distribution of the PISA index of economic, social and cultural status (ESCS) within his or her country/economy.

Countries and economies are ranked in ascending order of the score-point difference in science performance among all students who work for pay, after accounting for gender and socio-economic status.

Source: OECD, PISA 2015 Database, Table III.12.8.

StatLink 部占 http://dx.doi.org/10.1787/888933473029

Figure III.12.5 - Working at home and science performance

Score-point difference in science performance associated with working at home before or after school, after accounting for students' socio-economic status

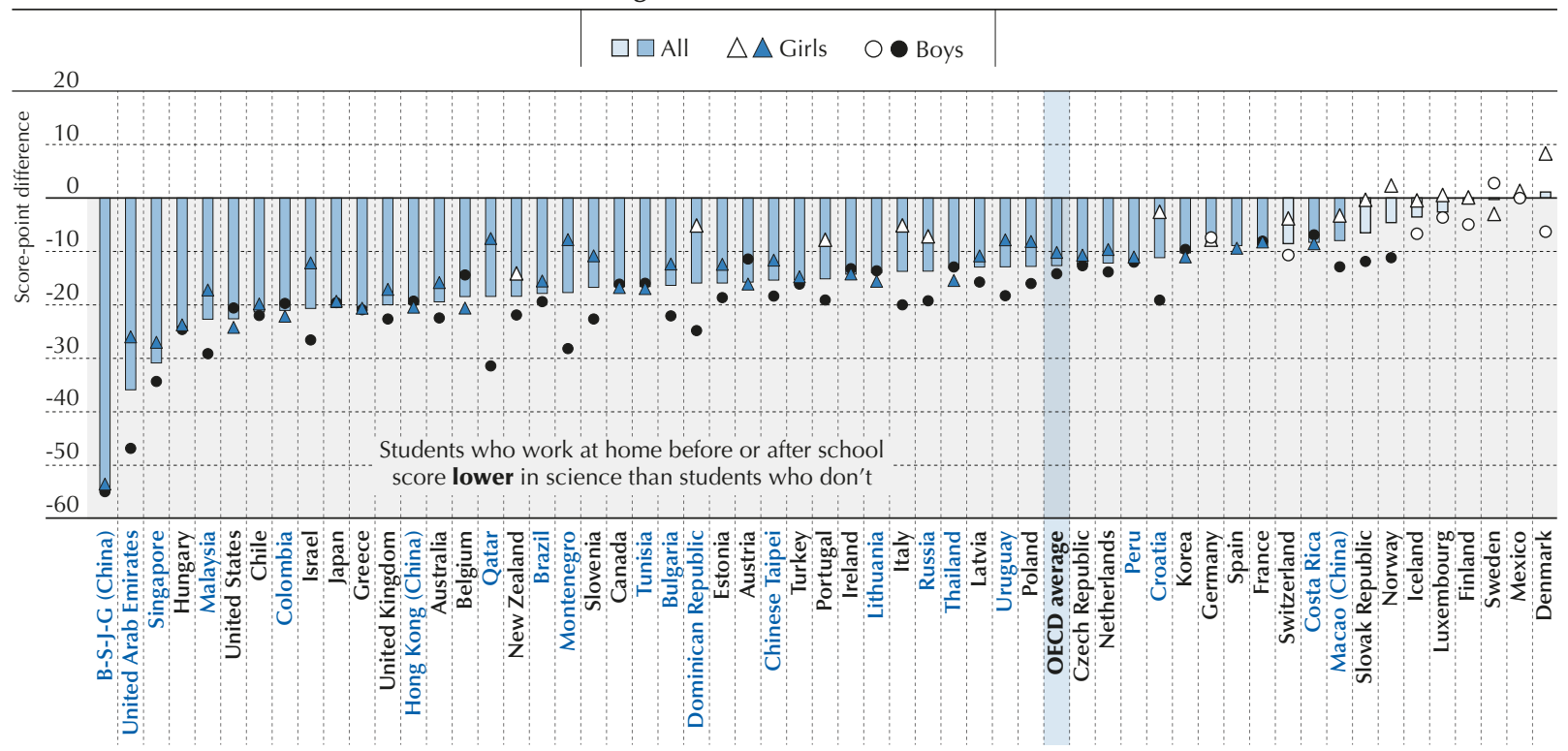

Note: Statistically significant differences are marked in a darker tone (see Annex A3).

Countries and economies are ranked in ascending order of the score-point difference in science performance among all students who work at home, after accounting for gender and socio-economic status.

Source: OECD, PISA 2015 Database, Table III.12.3.

StatLink 部 SL http://dx.doi.org/10.1787/888933473035 
Students' participation in the labour market or help around the house can influence other aspects of students' well-being. Some teenagers decide to work because they want to learn, explore or earn money; others may be obliged to work for financial or other extrinsic reasons. Students in the former group are more likely to derive greater satisfaction from work than those in the latter group. Other students may choose to work because they want to leave formal education and enter the job market sooner.

Students who work for pay reported a level of satisfaction with life that is similar to that of students who do not work. The difference is just 0.2 point on a scale from 0 to 10, on average across OECD countries (Table III.12.9). By contrast, students who work for pay were 5 percentage points more likely than students who do not work for pay to report that they feel like an outsider at school, on average across OECD countries, with one out of five students who works for pay reporting feeling like an outsider (Figure III.12.6). They are also 11 percentage points more likely to expect to leave formal education at the end of secondary school, 9 percentage points more likely to arrive late for school, and 4 percentage points more likely to skip school frequently, on average across OECD countries (Table III.12.10). By contrast, housework is less likely than paid work to be related to students' negative feelings about school. These findings suggest that disengagement from school is strongly correlated with students' employment status.

Figure III.12.6 - Students who work for pay and well-being outcomes Percentage of students who reported "agree" " "strongly agree", by work status (OECD average)

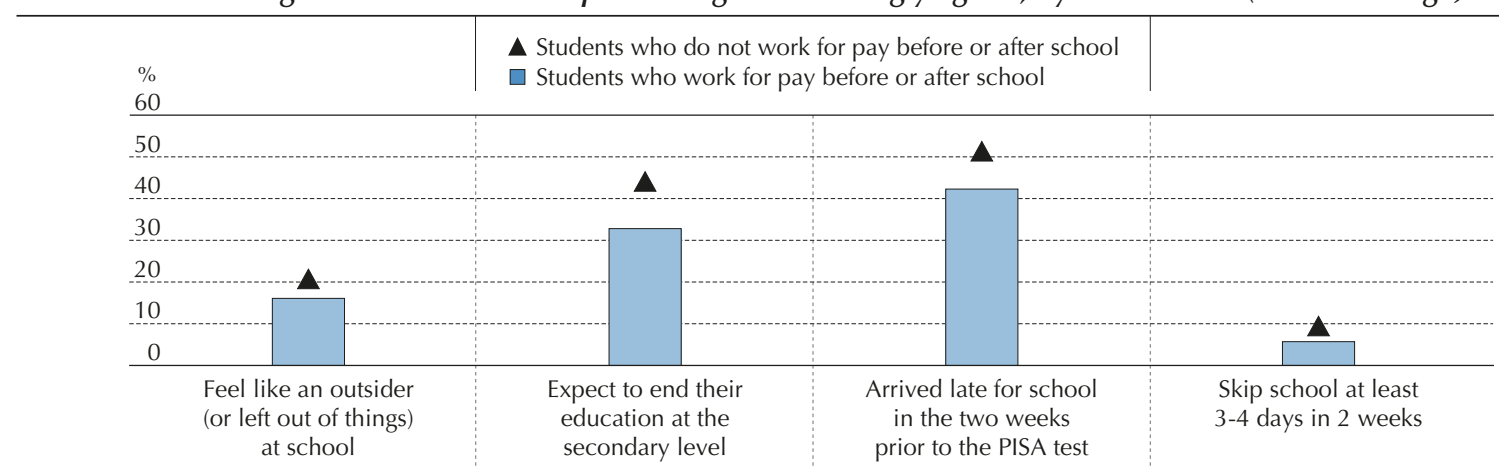

Note: All percentage-point differences between students who work for pay before or after school and those who do not are statistically significant (see Annex A3).

Source: OECD, PISA 2015 Database, Table III.12.10.

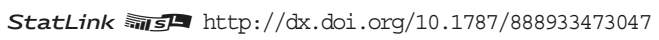

Working for pay might also have stronger implications on students' satisfaction with specific aspects of their life than on students' overall evaluation of the quality of their life. For example, a study in Turkey found that adolescents who do not work were more satisfied than working adolescents with their family relations. To fully understand the consequences of working on students' well-being, more data and research are needed on the quantity and quality of adolescents' work, and on their motivations to work (Mortimer, 2010).

\section{What these results imply for policy}

- Many of the students who choose to work might do so because they feel disengaged from school. Working long hours can exacerbate disengagement and even result in students' dropping out of school entirely. Tackling the root causes of students' disengagement from school can help ensure that students still devote sufficient time to their learning, even if they also work after school.

- In several countries, disadvantaged students were more likely than advantaged students to report that they work in the house. Having to do intensive work in the home can sap students' energy and reduce time available for study, which could, in turn, widen inequalities in performance. Education and social policies that target disadvantaged families can help these students maintain a better balance between schoolwork and housework.

- More data on the intensity and type of jobs students do are needed to understand how working before or after school affects students' well-being. 


\section{References}

Gager, C.T., T.M. Cooney and K.T. Call (1999), "The effects of family characteristics and time use on teenagers' household labor", Journal of Marriage and Family, Vol. 61/2, pp. 982-994, http://dx.doi.org/10.2307/354018.

Kalenkoski, C.M. and S.W. Pabilonia (2012), "Time to work or time to play: The effect of student employment on homework, sleep, and screen time", Labour Economics, Vol. 19/2, pp. 211-221, http://dx.doi.org/10.1016/j.labeco.2011.10.002.

Karaca, S. et al. (2016), "Comparison of subjective wellbeing and positive future expectations in between working and nonworking adolescents in Turkey", Iranian Red Crescent Medical Journal, Vol. 18/2, pp. 1-6, http://dx.doi.org/10.5812/ircmj.21055.

Mortimer, J.T. (2010), "The benefits and risks of adolescent employment", The Prevention Researcher, Vol. 17/2, pp. 8-11.

Staff, J, E.E. Messersmith and J.E. Schulenberg (2009). "Adolescents and the world of work", in R. Lerner and L. Steinberg (eds.) Handbook of Adolescent Psychology, John Wiley and Sons, New York, pp. 270-313.

Warren, J.R. and J.C. Lee (2003), "The impact of adolescent employment on high school dropout: Differences by individual and labor-market characteristics", Social Science Research, Vol. 32/1, pp. 98-128, http://dx.doi.org/10.1016/S0049-089X(02)00021-2.

Webbink, E., J. Smits and E. de Jong (2012), "Hidden child labor: Determinants of housework and family business work of children in 16 developing countries", World Development, Vol. 40/3, pp. 631-642, http://dx.doi.org/10.1016/j.worlddev.2011.07.005. 

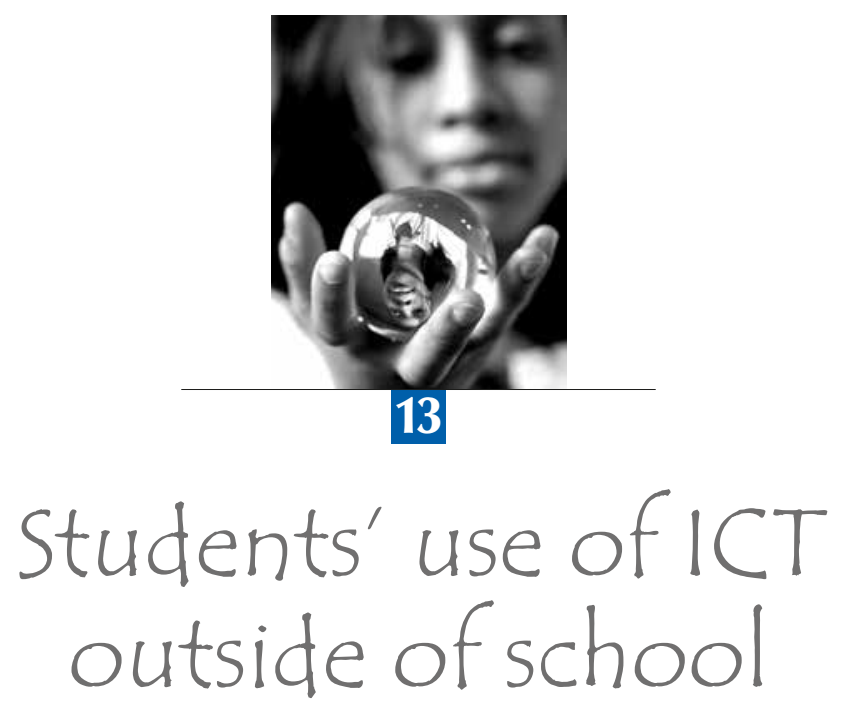

This chapter describes how students spend their time on line outside of school. It examines students' access to the Internet, how they use the web, and the relationship between online activities - and the number of hours spent on line - and students' well-being. The chapter also discusses the digital divides related to socio-economic status that persist both between and within countries. 
Over the past two decades, information and communication technologies (ICT) have transformed the ways 15-year-old students learn, socialise and play (OECD, 2015). Internet tools, including online networks, social media and interactive technologies, are giving rise to new learning styles where young people see themselves as agents of their own learning, and where they can produce multimedia content, update and redefine their interests, and learn more about the world, others and themselves. Using ICT at school allows students to access learning material tailored to their age and interests, promotes positive social behaviour, such as teamwork (American Academy of Pediatrics, Commitee on Public Education, 2001), and enables discussions with other young people around the globe.

\section{What the data tell us}

- Between 2006 and 2015, home access to the Internet became almost universal for students in most PISA-participating countries and economies. By 2015, 95\% of students, on average across OECD countries, reported they had a link to the Internet at home. But in some participating countries and economies, such as Mexico and Peru, only one in two students could access the Internet from their home.

- On average across OECD countries, students spend more than two hours on line during a typical weekday after school, and more than three hours on line during a typical weekend day. Between 2012 and 2015, the time spent on line outside of school increased by at least 40 minutes per day on both weekdays and weekends.

- The majority of students reported that the Internet is a great resource for obtaining information, and more than one in two students in OECD countries reported that they feel bad if no Internet connection is available.

- Students who spend more than six hours on line per weekday outside of school were more likely to report that they are not satisfied with their life or that they feel lonely at school, and were less proficient in science than students who spend fewer hours on line.

But adolescents' use of ICT is also a source of concern among parents, teachers and policy makers. Students might develop dangerous relationships with strangers on line or may become victims of cyberbullying (Smith et al., 2008). Extreme videogaming, compulsive texting and overuse of smartphones are also increasingly documented. These behaviours can have serious physical, social, psychological and cognitive consequences. For example, spending long hours staring at screens is associated with less physical activity, sleeping disorders and obesity (Currie et al., 2012; Punamäki et al., 2007). Excessive use of ICT also undermines motivation and academic achievement (Borgonovi, 2016; Johnson et al., 2007), and can lead to social isolation and depression (Finn and Gorr, 1988; Kim et al., 2006; Wood et al., 2004).

This chapter uses PISA 2015 data to describe how students spend their time on line outside of school. In particular, it investigates students' access to the Internet, how they use the web, and the relationship between online activities and students' cognitive, social and psychological well-being. The results also illustrate the digital divides related to socioeconomic status that persist both between and within countries.

\section{CHANGES IN STUDENTS' ACCESS TO ICT AT HOME Access to the Internet and digital devices at home}

By 2015, the Internet had become an everyday tool for most 15-year-old students. Most digital devices are connected to the Internet to access web-based services, such as social networking sites, cloud computing services, online wikis or videogames. Many of these services support formal and informal learning, provide information on almost anything, offer entertainment, and help maintain connections with friends, family and teachers. Without an Internet connection at home, students might have only limited access to information that is important for their cognitive development.

Data collected from students participating in the PISA assessment show that, by 2015, almost every student (95\%) in most OECD countries reported that they had a link to the Internet at home. However, this average masks large differences between countries and economies. In Denmark, Estonia, Finland, Iceland, Norway, Slovenia and Switzerland, almost all students had Internet access at home. In the lower-income countries of Algeria, Indonesia, Peru and Viet Nam, fewer than one in two students reported that they had Internet access at home (Table III.10.4).

Between 2006 and 2015, hundreds of thousands of students gained access to the Internet from their homes for the first time (Figure III.13.1). The expansion in Internet access was the greatest in Chile, Romania, the Russian Federation (hereafter "Russia") and the Slovak Republic, with an increase of more than 50 percentage points in the population of "wired" 15-year-olds (Table III.10.4). In almost all countries and economies, Internet access increased between the shorter period of 2012 to 2015. The largest increases during this period - those greater than 15 percentage points - were observed in Albania, Thailand, Tunisia and Viet Nam (Table III.10.5). 
Figure III.13.1 - Change from 2006 through 2012 and 2015 in students' access to the Internet at home

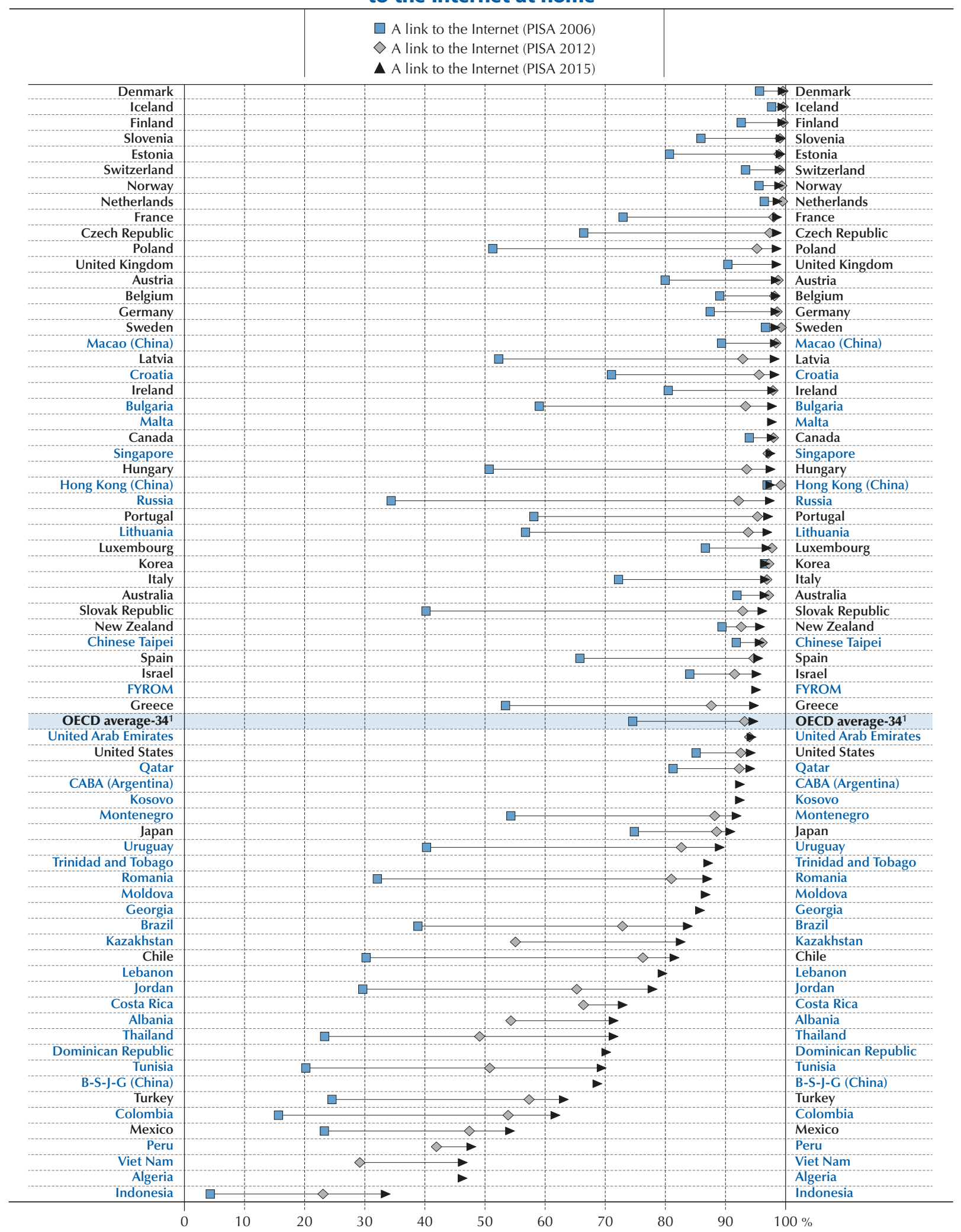

1. "OECD average-34" includes all OECD countries with available data for PISA 2006, PISA 2012 and PISA 2015.

Countries and economies are ranked in descending order of the percentage of students who accessed the Internet at home in 2015.

Source: OECD, PISA 2006 and 2015 Databases, Tables III.10.4 and III.10.5.

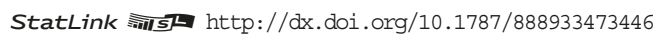


In $2015,91 \%$ of students had access to a cell phone at home that was connected to the Internet (smartphone), $74 \%$ had access to a portable laptop, $60 \%$ had access to a desktop computer and $53 \%$ had access to a tablet that was connected to the Internet. But large differences in ownership of digital devices are observed between countries and economies. In Australia, Austria, Belgium, Denmark, Iceland, Luxembourg, the Netherlands and Portugal, more than $80 \%$ of students had access to a portable laptop or a notebook at home. In Beijing-Shanghai-Jiangsu-Guangdong (China) (hereafter "B-S-J-G [China]"), the Dominican Republic and Peru, less than $40 \%$ of students had access to such devices. In Colombia, the Dominican Republic, Mexico and Peru, only two in three students had access to a smartphone at home (Table III.13.4).

Between 2012 and 2015, the share of 15-year-old students across OECD countries who had access to a smartphone increased by 19 percentage points. Access to connected tablets at home increased by an even larger margin: 30 percentage points. These data not only show the fast-growing popularity of these tools, but also signal the enormous changes in teenagers' behaviour and activities outside of school (Table III.13.4).

\section{Students use of the Internet}

Around the world, increasing numbers of children start playing with connected devices even before they can read well. On average across OECD countries, $61 \%$ of students reported that they accessed the Internet for the first time when they were younger than 10, and 18\% reported that they did so at the age of 6 or younger. In Denmark, Estonia and Finland, more than $80 \%$ of students were younger than 10 when they first browsed the Internet. By contrast, in B-S-J-G (China), the Dominican Republic, Mexico and Peru, at least one in five students was older than 13 when they first used the Internet; and in B-S-J-G (China), more than 5\% of 15-year-old students reported that they have never used the Internet (Table III.13.6).

The share of students across OECD countries who reported that they were six years old or younger when they first used the Internet increased by three percentage points between 2012 and 2015 (Figure III.13.2); in Hungary, Iceland, Poland and Uruguay, this proportion increased by more than seven percentage points during the period. Across OECD countries, the share of students who reported that they have never used the Internet remained constant during the period at $0.3 \%$ (Table III.13.6). These results indicate that there is still a large disparity in Internet use between students in OECD countries and those in developing partner countries.

Figure III.13.2 - Change between 2012 and 2015 in the share of children who used the Internet when they were six years old or younger

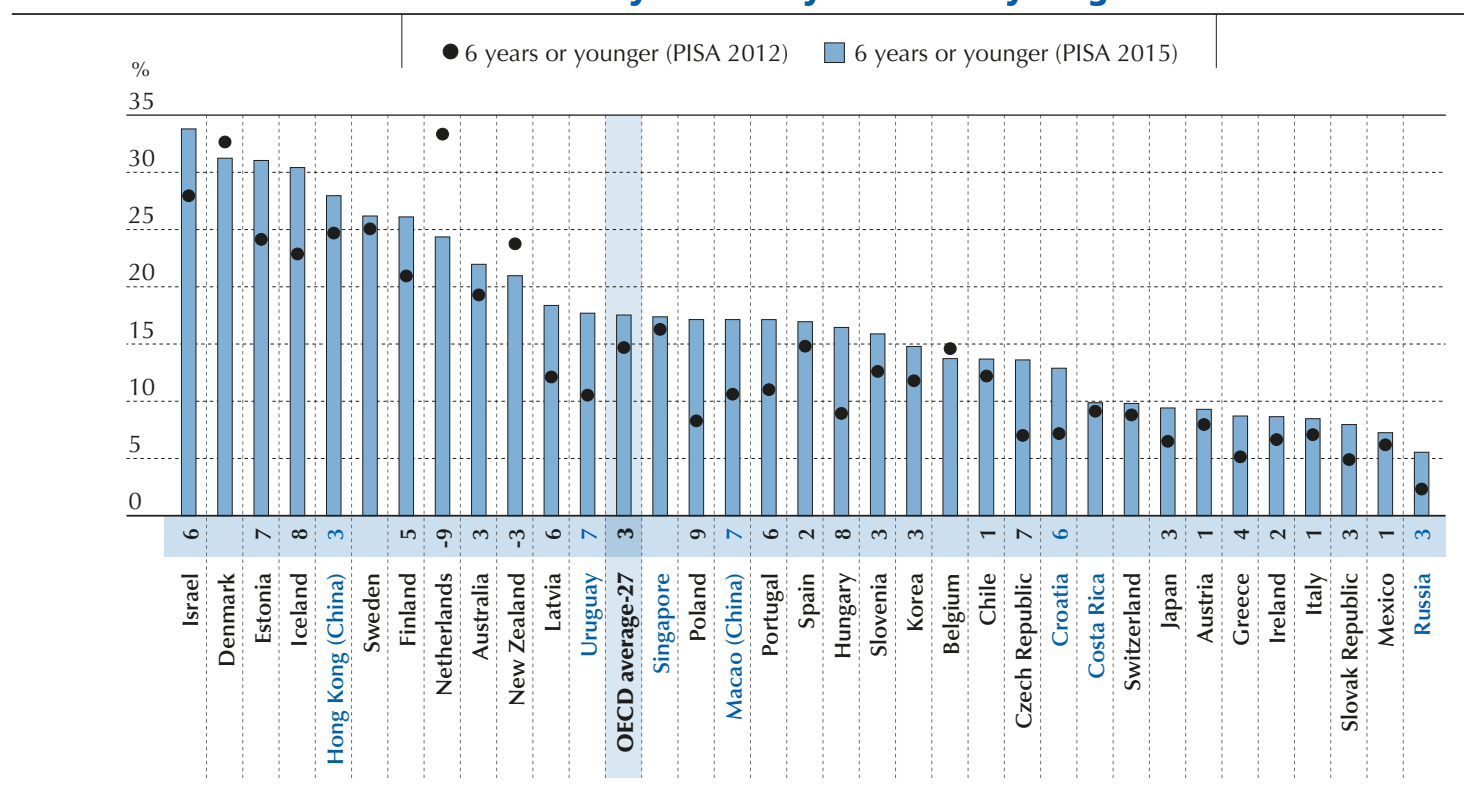

1. "OECD average-27" includes OECD countries with available data for both PISA 2012 and PISA 2015.

Notes: Only countries and economies with available data for both PISA cycles are shown.

Statistically significant differences between 2012 and 2015 are shown next to country/economy name (see Annex A3).

Countries and economies are ranked in descending order of the percentage of students who started using computers at age 6 or younger in 2015.

Source: OECD, PISA 2012 and PISA 2015 Databases, Table III.13.6.

StatLink त्ञात http://dx.doi.org/10.1787/888933473450 


\section{Spending time on line}

Acquiring proficiency in digital reading and online navigation requires time and practice. The more time students spend practicing these skills, the quicker they become confident and independent players in the digital space. For most teenagers, time spent on line is relatively well balanced with other leisure activities and obligations; for others, the desire to be on line can become problematic.

PISA 2015 asked students how much time they spend using the Internet at home within a typical school week. ${ }^{1}$ On average across OECD countries, students reported spending about two hours and 26 minutes per day on line after school on a typical weekday, and more than three hours on line on a typical weekend day (Tables III.3.7 and III.3.8). But there are large differences between countries and economies. In Brazil, Bulgaria, Chile, Costa Rica, Sweden, the United Kingdom and Uruguay, students spend more than three hours on line per typical weekday, while in B-S-J-G (China) and Korea they spend less than one hour on line after school. Students in Bulgaria, Chile, the Netherlands, Spain, Sweden and the United Kingdom reported that they spend at least three and a half hours on line on a typical weekend day, while those in B-S-J-G (China), Korea and Peru reported spending less than two hours on line during a typical weekend day. On average across OECD countries, 26\% of students could be considered "extreme Internet users" during weekend days, as they spend more than six hours on line during those days. Some $16 \%$ of students can be classified as "extreme Internet users" during weekdays.

In almost all countries and economies, the time spent on line outside of school increased between 2012 and 2015 . The OECD average increase was around 40 minutes, on both weekdays and weekends. This increase was largest - by more than one hour and 20 minutes - in Chile and Costa Rica (Figure III.13.3 and Table III.13.9).

Figure III.13.3 - Change between 2012 and 2015 in time spent on line outside of school Minutes per day spent using the Internet

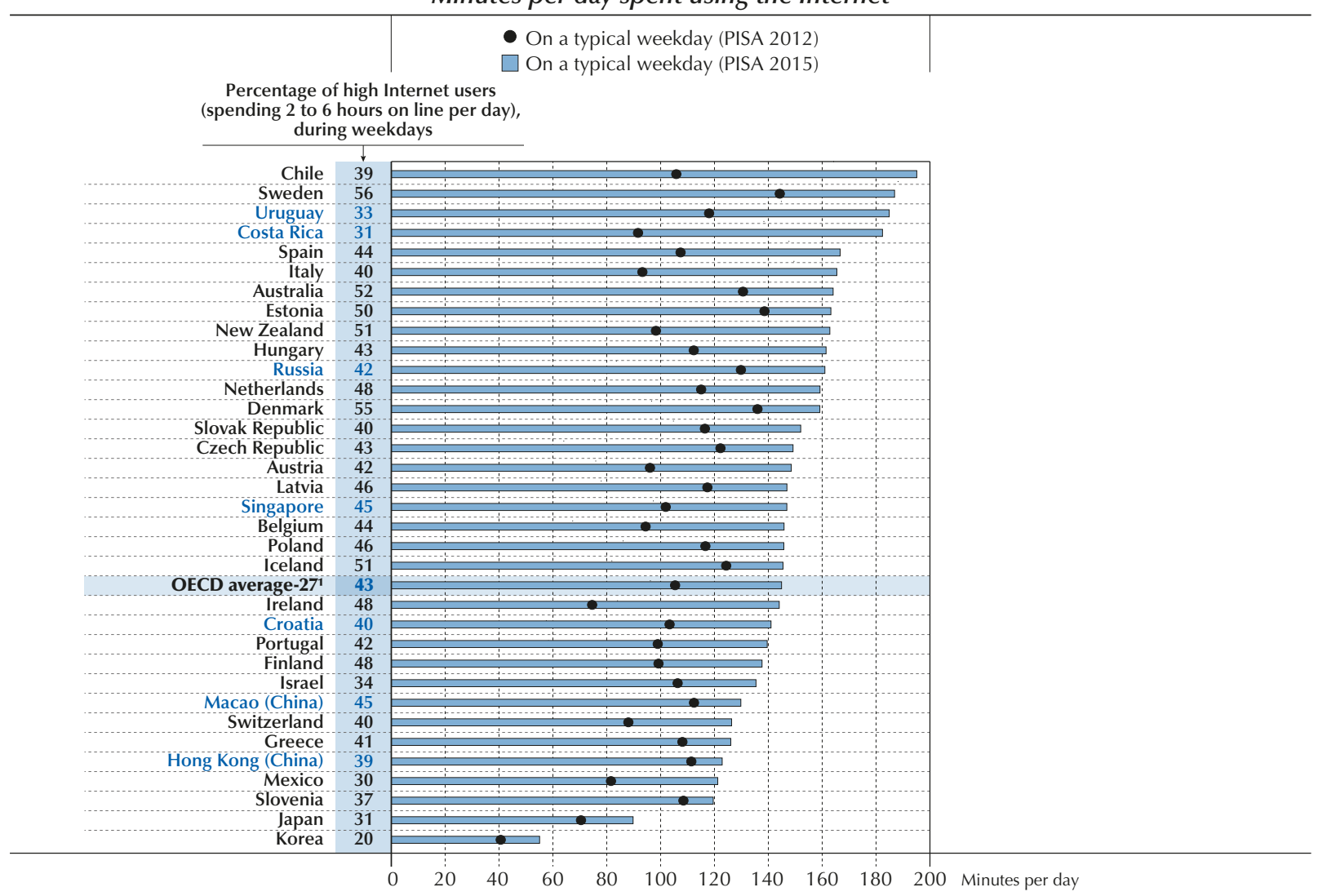

1. "OECD average-27" includes OECD countries with available data for both PISA 2012 and PISA 2015.

Notes: As the answers were given on a categorical scale, it is not possible to compute exactly the average time students spend on line. The numbers in this figure thus report a lower bound for the number of minutes students spend on online activities, whereby the answer "between one and two hours", for instance, is converted into "61 minutes at least".

Only countries and economies with avalailable data for both PISA cycles are shown.

Countries and economies are ranked in descending order of the time per day spent using the Internet in 2015.

Source: OECD, PISA 2012 and 2015 Databases, Tables III.13.7 and III.13.9.

StatLink त्ञाज http://dx.doi.org/10.1787/888933473465 
Only in some countries is there a noticeable gender gap in Internet use. In Denmark and Korea, boys spend half an hour more on line than girls outside of school on a typical weekend day, while in Israel, girls spend half an hour more on line than boys during those days. In Denmark and Sweden, the share of boys who could be considered "extreme Internet users" (they use the Internet more than six hours per day) is at least 10 percentage points larger than the share of girls who could be so considered. In B-S-J-G (China) and Korea, girls are 10 to 20 percentage points more likely than boys to be "low Internet users", meaning that they use the Internet for less than one hour during weekend days (Table III.3.8).

\section{Online activities outside of school} Use of ICT for leisure online activities

What are students doing on line? PISA 2015 asked students whether they use the Internet/chat/social networks before and after school, and how often they engage in online activities, such as playing one-player or collaborative online games, chatting on line or participating in social networks.

Figure III.13.4 - Use of ICT for leisure online activities, by gender

Difference in the percentages of boys and girls who play online games, chat on line or participate in social networks every day outside of school

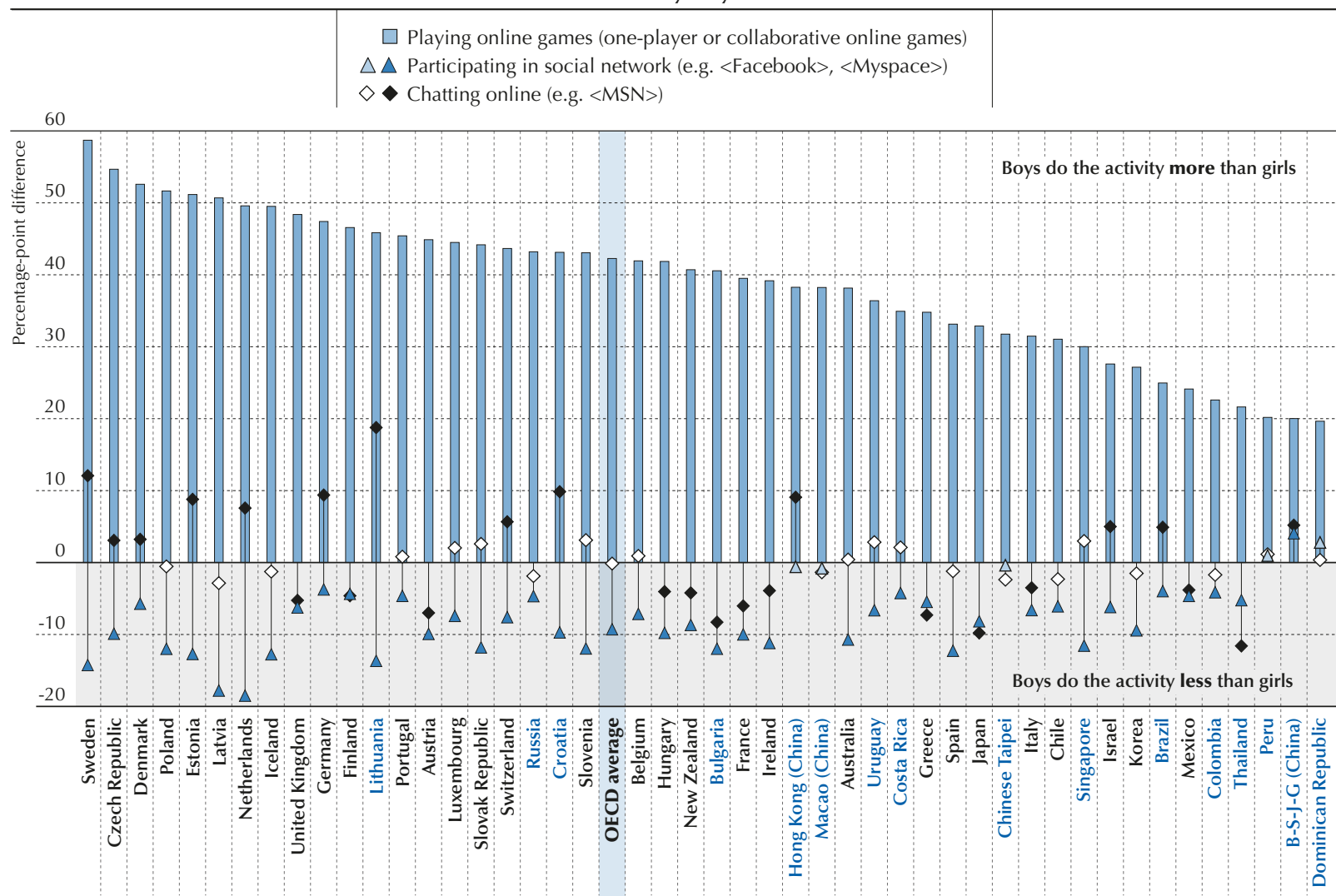

Note: Statistically significant differences are marked in a darker tone. All differences for "playing online games" are statistically significant (see Annex A3). Countries and economies are ranked in descending order of the difference in the percentages of boys and girls who play online games.

Source: OECD, PISA 2015 Database, Table III.13.13.

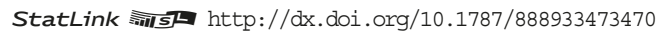

Participating in social networks was the most popular online leisure activity across OECD countries, followed by chatting on line. Almost three out of four students reported that they participate in social networks every day or almost every day, and at least three out of five students reported that they chat on line. On average across OECD countries, 34\% of students reported that they play online games every day or almost every day, and the same share of students said that they never play online videogames (Table III.13.12).

Between 2012 and 2015, the share of students who reported that they engage in online activity every day or almost every day grew by four percentage points, on average. In 15 out of 35 countries and economies with comparable data 
for 2012 and 2015, the share of students who play online videogames, chat on line or participate in social networks outside of school increased over the period. Japan and Korea show an increase of more than 30 percentage points in the share of students engaged in online activities, while in Germany and Israel the share of these students shrank by more than 12 percentage points. On average across OECD countries, the share of students who spend time on online chats and the share of students who play online games increased by around five percentage points (Table III.13.14).

Figure III.13.4 reveals large differences in what boys and girls do on line. Some $85 \%$ of boys and $86 \%$ of girls reported that they participate in at least one of the three online activities considered (chatting, participating in social networks, playing videogames) almost every day, on average across OECD countries (Table III.13.13). But boys are more likely than girls to play online videogames. In the Czech Republic, Denmark, Estonia, Latvia, Poland and Sweden, at least twice as many boys as girls play online videogames almost every day. Girls are nine percentage points more likely than boys to visit social networking sites, on average across OECD countries; and in Latvia and the Netherlands, this gender gap is almost twice as large as the average. Chatting on line is popular among both boys and girls.

Socio-economic status exerts an additional influence on the choice of online activities. In OECD countries, the share of socio-economically advantaged students who participate daily in any of the three online activities is five percentage points larger than the share of disadvantaged students who do. Disparities in online activities related to socio-economic status are particularly large in Colombia, Mexico and Peru (over 40 percentage points in favour of advantaged students [Table III.13.13]).

\section{ATTITUDES TOWARDS THE INTERNET}

For the first time, PISA 2015 asked students how they feel about the time they spend on line. Across OECD countries, most students agreed that "the Internet is a great resource for obtaining information" (88\%) and that "it is very useful to have social networks on the Internet" (84\%). Some $67 \%$ of students reported that they are excited to discover new digital devices and applications. In Ireland and Denmark, around 95\% of students agreed that the Internet is a great resource for obtaining information, while in Japan and Korea, less than $80 \%$ of students agreed with this statement (Table III.13.15).

Socio-economically advantaged students are more likely than their disadvantaged peers to think that the Internet is a great resource for obtaining information. In Mexico, the difference between these two groups of students is 20 percentage points, while in B-S-J-G (China), Bulgaria, Colombia, the Dominican Republic, Japan and Peru, more than 15 percentage points separate the two groups. By contrast, in Denmark, Iceland, Macao (China) and Portugal, this gap is narrower than five percentage points (Figure III.13.5).

Figure III.13.5 - Obtaining information from the Internet, by socio-economic status Percentage of students who reported they "agree" or "strongly agree" that the Internet is a great resource for obtaining information

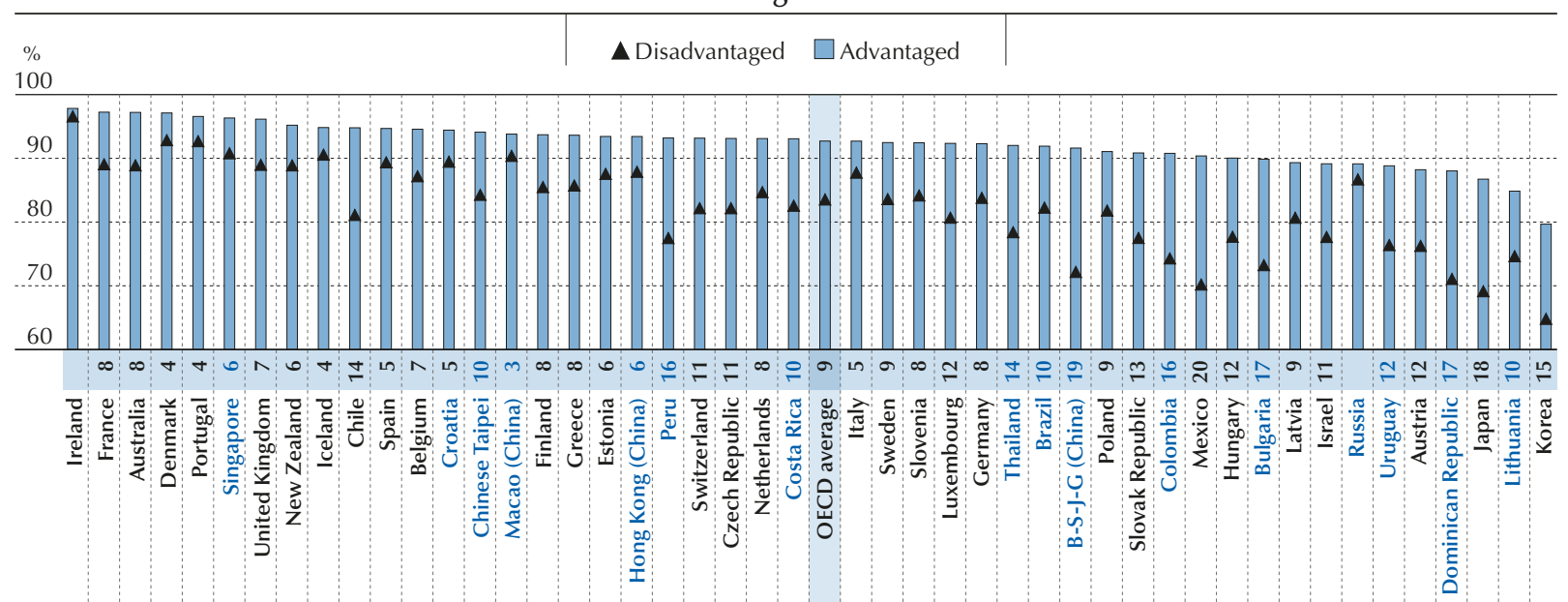

Notes: Statistically significant differences between advantaged and disadvantaged students are shown next to country/economy name (see Annex A3). Advantaged (disadvantaged) students are those in the top (bottom) quarter of the PISA index of economic, social and cultural status (ESCS).

Countries and economies are ranked in descending order of the percentage of advantaged students who think that the Internet is a great resource for obtaining information.

Source: OECD, PISA 2015 Database, Table III.13.16.

StatLink 제의 http://dx.doi.org/10.1787/888933473481 
Boys and girls have different attitudes towards the Internet. While boys seem more enthusiastic about new digital devices and applications than girls ( 11 percentage points more, on average across OECD countries, and 20 percentage points more in the Czech Republic and Denmark), girls are more likely than boys to see the Internet as a useful tool for obtaining information. Girls are also more likely than boys to think that it is useful to participate in social networks on the Internet (Table III.13.16).

PISA 2015 also asked students how they feel when they are engaged in online activities. The data show that most students enjoy using various digital devices and the Internet, but many of them are at risk of problematic Internet use. Across OECD countries, $90 \%$ of students enjoy using digital devices and $61 \%$ reported that they forget time when using them. More than one in two students (54\%) reported that they feel bad if no Internet connection is available. In some countries and economies, the share of students who showed some signs of problematic Internet use is even larger. In France, Greece, Portugal, Sweden and Chinese Taipei, more than $77 \%$ of students reported that they feel bad when no Internet connection is available. In Estonia and Slovenia, fewer than two in five students feel badly when they have no access to the Internet (Table III.13.15).

Figure III.13.6 shows that girls are slightly more likely than boys to feel bad when no Internet connection is available, on average across OECD countries. In B-S-J-G (China), boys were 11 percentage points more likely than girls to report that they feel bad when no Internet connection is available, while the opposite gender pattern is observed in Israel, Russia and Sweden. These data suggest that policies promoting the responsible use of the Internet should target both boys and girls.

Figure III.13.6 - Feeling bad if not connected to the Internet, by gender Percentage of students who reported "agree" or "strongly agree"

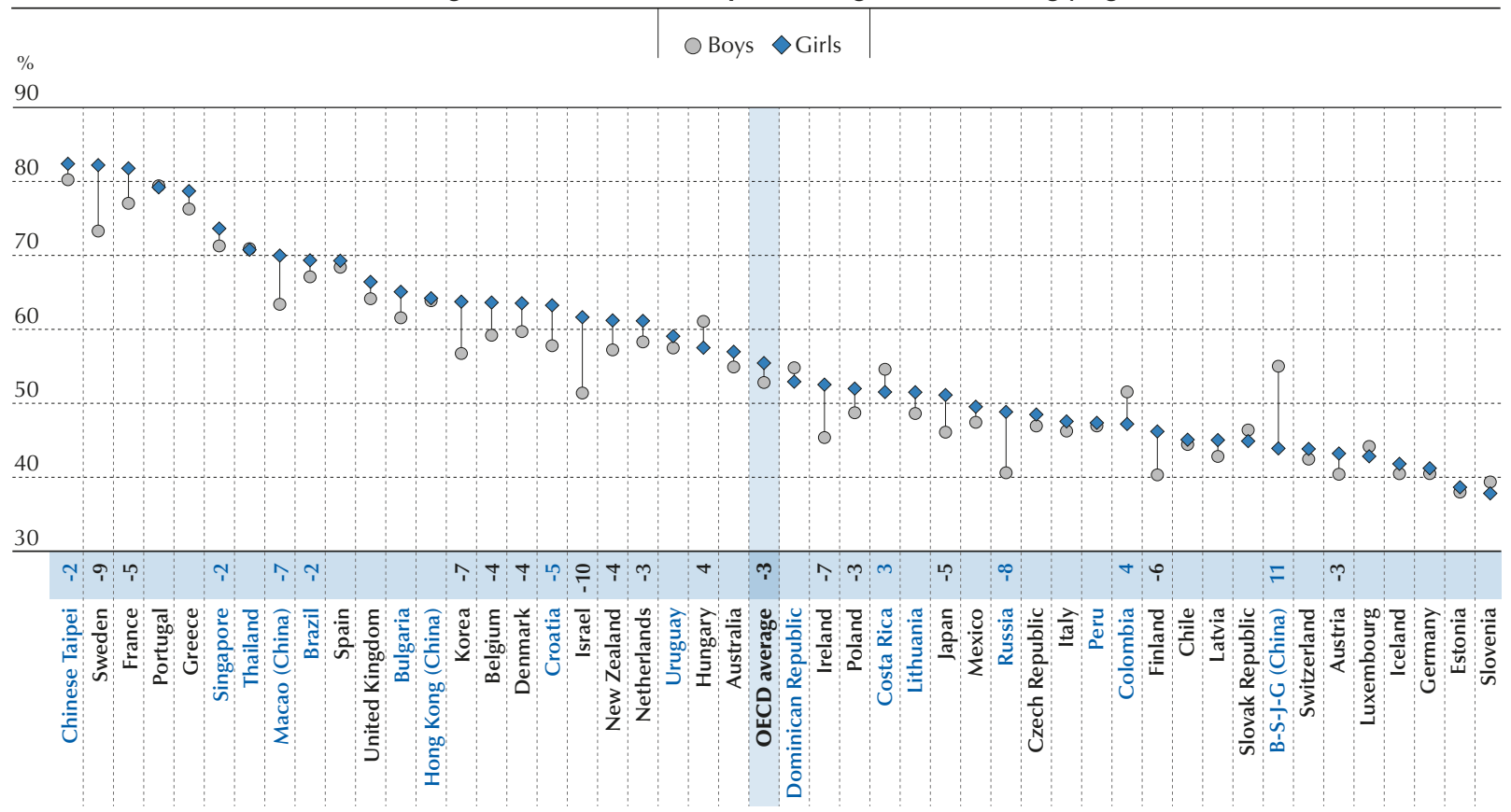

Note: Statistically significant differences between boys and girls are shown next to country/economy name (see Annex A3).

Countries and economies are ranked in descending order of the percentage of girls who feel bad if there is no Internet connection available. Source: OECD, PISA 2015 Database, Table III.13.16.

StatLink 部

Across OECD countries, 52\% of advantaged students and 56\% of disadvantaged students reported that they feel bad when no Internet connection is available. In European countries, including Belgium, the Czech Republic, Germany and Slovenia, socio-economically advantaged students were much less likely than disadvantaged students to report that they feel bad without an Internet connection (a difference greater than 12 percentage points). The opposite pattern is observed in those countries where the digital divide in access to the Internet is still wide, such as Colombia, Mexico and Thailand. In high-income countries, advantaged students may have more options for offline activities, or might have more supervision and education about Internet use (Table III.13.16; see Chapter 12). 


\section{RELATIONSHIP BETWEEN INTERNET USE AND ADOLESCENTS' WELL-BEING}

Given the amount of time 15-year-old students spend on the Internet every day, it is crucial to understand whether and how Internet use influences students' well-being. On the one hand, Internet use may increase life satisfaction by providing entertainment and removing logistical obstacles to socialising. On the other hand, online activities pose several risks to well-being. Extensive use of digital media can also undermine students' motivation and concentration, compromising academic achievement (Johnson et al., 2007). Excessive use of the Internet and videogaming could also lead to social isolation (Wood et al., 2004).

\section{Consequences of extreme Internet use on students' social and psychological well-being}

In most participating countries and economies, "extreme Internet use" - more than six hours per day - has a negative relationship with students' life satisfaction. PISA 2015 asked students to rate their life satisfaction on a scale from 0 to 10 , where 0 means the worst possible life and 10 means the best possible life. Figure III.13.7 shows that across OECD countries, "extreme Internet users" reported themselves as 0.4 point lower on the life satisfaction scale than other Internet users. In Iceland, the difference between these groups is even larger: around 1 point.

Figure III.13.7 - Average life satisfaction, by time spent on the Internet outside of school during weekend days

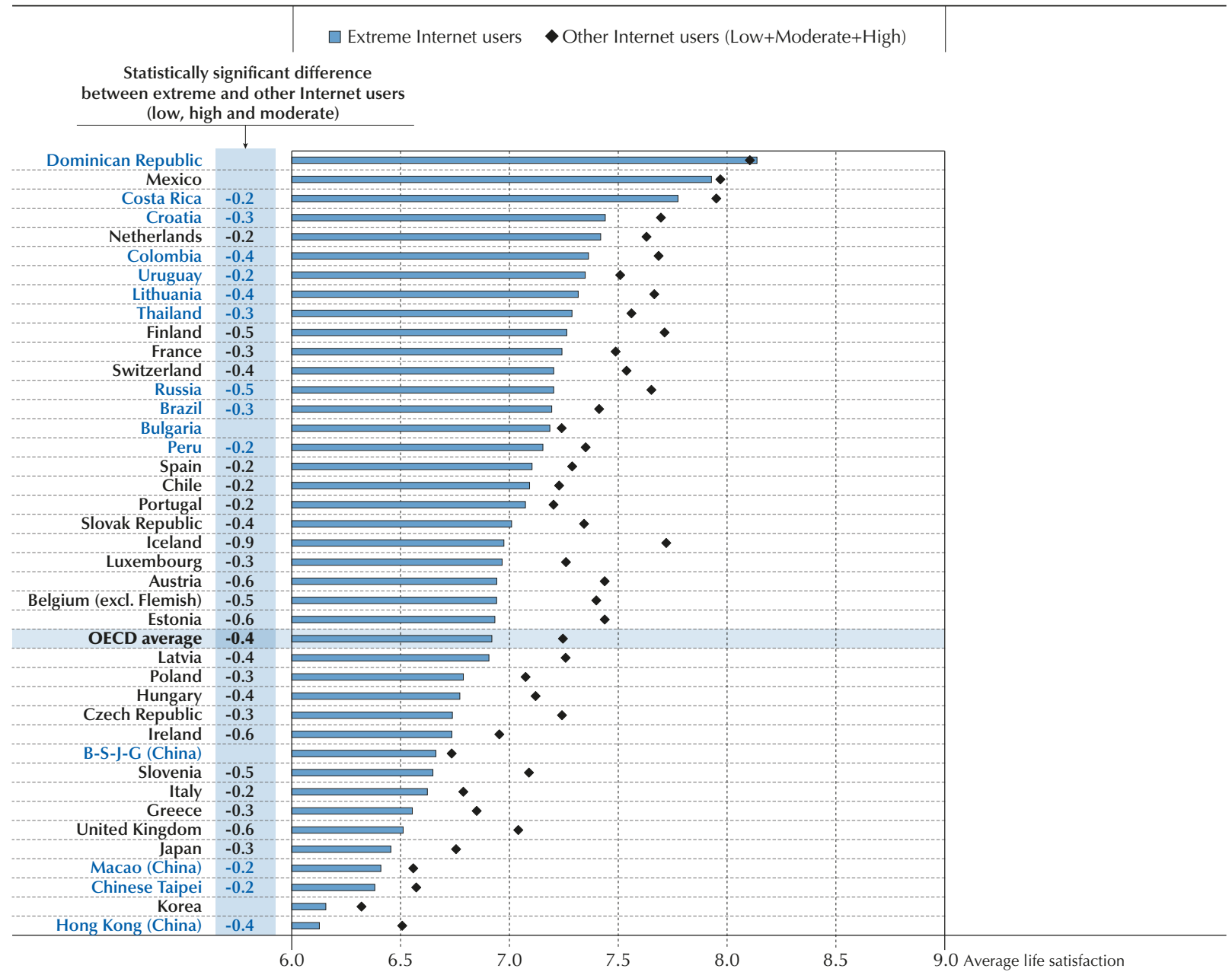

Notes: Categories of Internet users are based on students' responses to questions about how much time they spend on line, outside of school, during a typical weekend day. Low Internet users: one hour or less; moderate Internet users: 1 to 2 hours; high Internet users: 2 to 6 hours; extreme Internet users: more than 6 hours.

Statistically significant differences in life satisfaction between extreme Internet users and other Internet users are shown next to the country/economy name (see Annex A3).

Countries and economies are ranked in descending order of the average life satisfaction of extreme Internet users.

Source: OECD, PISA 2015 Database, Table III.13.23.

StatLink 젶ㄴ http://dx.doi.org/10.1787/888933473509 
Extreme Internet use is also related to other dimensions of social and psychological well-being (OECD, 2015). Figure III.13.8 shows that, across OECD countries, 17\% of "extreme Internet users" feel lonely at school, compared with $14 \%$ of "low Internet users" (students who use the Internet less than one hour per day), 12\% of "moderate Internet users" (those who spend between one and two hours per day on the Internet) and 13\% of "high Internet users" (those who spend between two and six hours per day on the Internet). "Low" and "extreme Internet users" were also more likely than "moderate" or "high Internet users" to report that they are bullied at school.

PISA data also reveal that both "extreme" and "high Internet users" are at greater risk of disengagement from school. One in four "extreme Internet users" reported that they had arrived late for school in the two weeks prior to the PISA test a share of 11 percentage points larger than the share of "moderate Internet users" who so reported. "Extreme Internet users" were also more likely to report lower expectations of further education than moderate Internet users (Figure III.13.8).

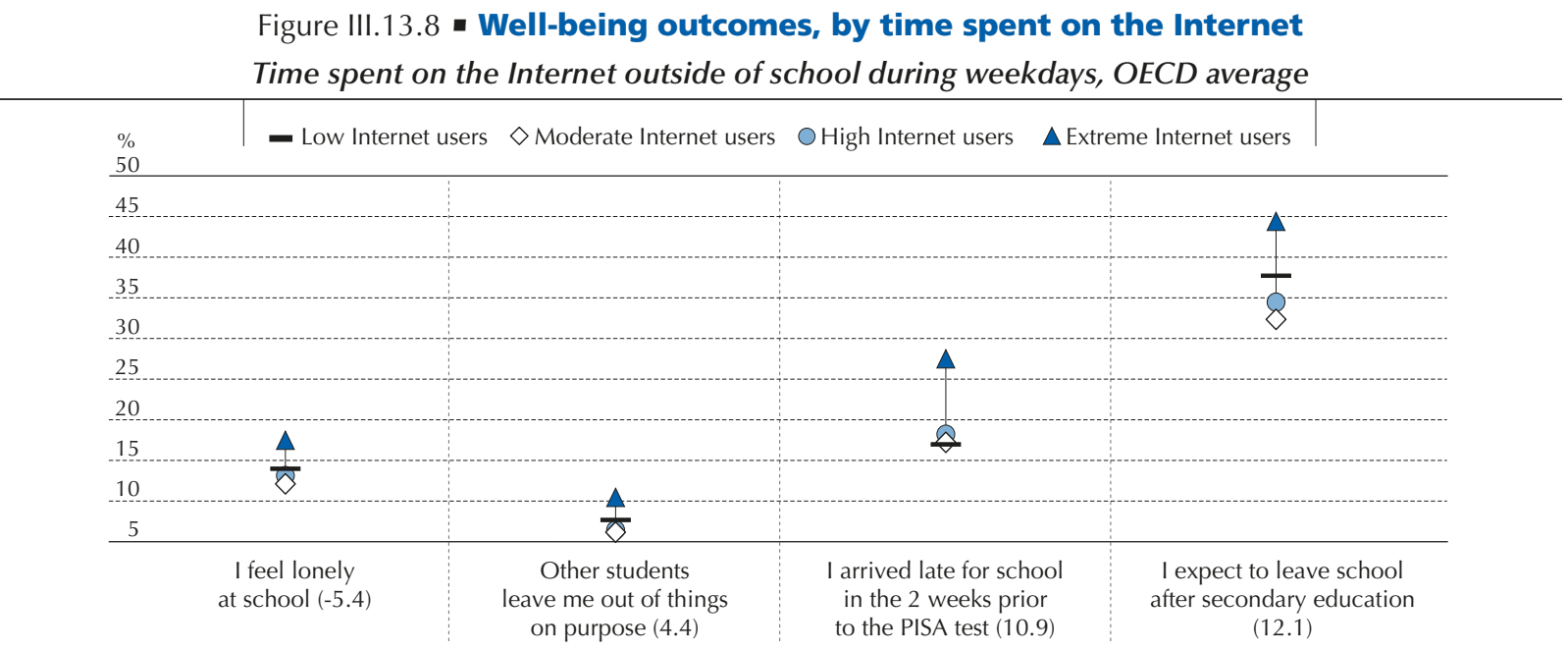

Notes: Categories of Internet users are based on students' responses to questions about how much time they spend on line, outside of school, during a typical weekday. Low Internet users: one hour or less; moderate Internet users: 1 to 2 hours; high Internet users: 2 to 6 hours; extreme Internet users: more than 6 hours.

Statistically significant differences between extreme and moderate Internet users are shown next to the category name (see Annex A3).

Source: OECD, PISA 2015 Database, Tables III.13.19a, III.13.20a, III.13.21 and III.13.22.

StatLink 젶ㄴ http://dx.doi.org/10.1787/888933473519

\section{ICT use and cognitive well-being}

Extreme Internet use is negatively related to academic performance. After accounting for students' socio-economic status, "extreme Internet users" score around 30 points lower than all the other groups of students across all subjects. In some countries, the score-point difference is extremely large. For instance, in B-S-J-G (China), Belgium, France, Switzerland and Chinese Taipei, "extreme Internet users" score 50 points lower in science than other students (Figure III.13.9 and Table III.13.24a).

One possible explanation of the negative relationship between "extreme Internet use" and performance might be that students who spend many hours on line take time away from homework, or get distracted in class because they feel the need to stay connected with their on line friends during school time. But it is also possible that students who spend many hours on line would perform worse even if the Internet did not exist, because they are not interested in their schoolwork, have short attention spans or other reasons.

Table III.13.12 shows that in all countries and economies with available data, except Korea, students who spend more than six hours on line outside of school during weekdays are also more likely to use online chats or e-mail during school hours. On average across OECD countries, $14 \%$ of students reported that they chat on line at school every day, and $5 \%$ use their e-mail at school every day.

But the use of smartphones and other online communication devices does not necessarily reduce attention spans or discipline. Some studies suggest that smartphones at school could increase students' academic engagement, if they are used for educational purposes (Brooks-Young, 2010; OECD, 2015). Using technologies at school for high-quality educational activities might reduce problems associated with the misuse of the Internet, both in and outside of school. 
Figure III.13.9 - Science performance, by amount of time spent on the Internet outside of school during weekdays

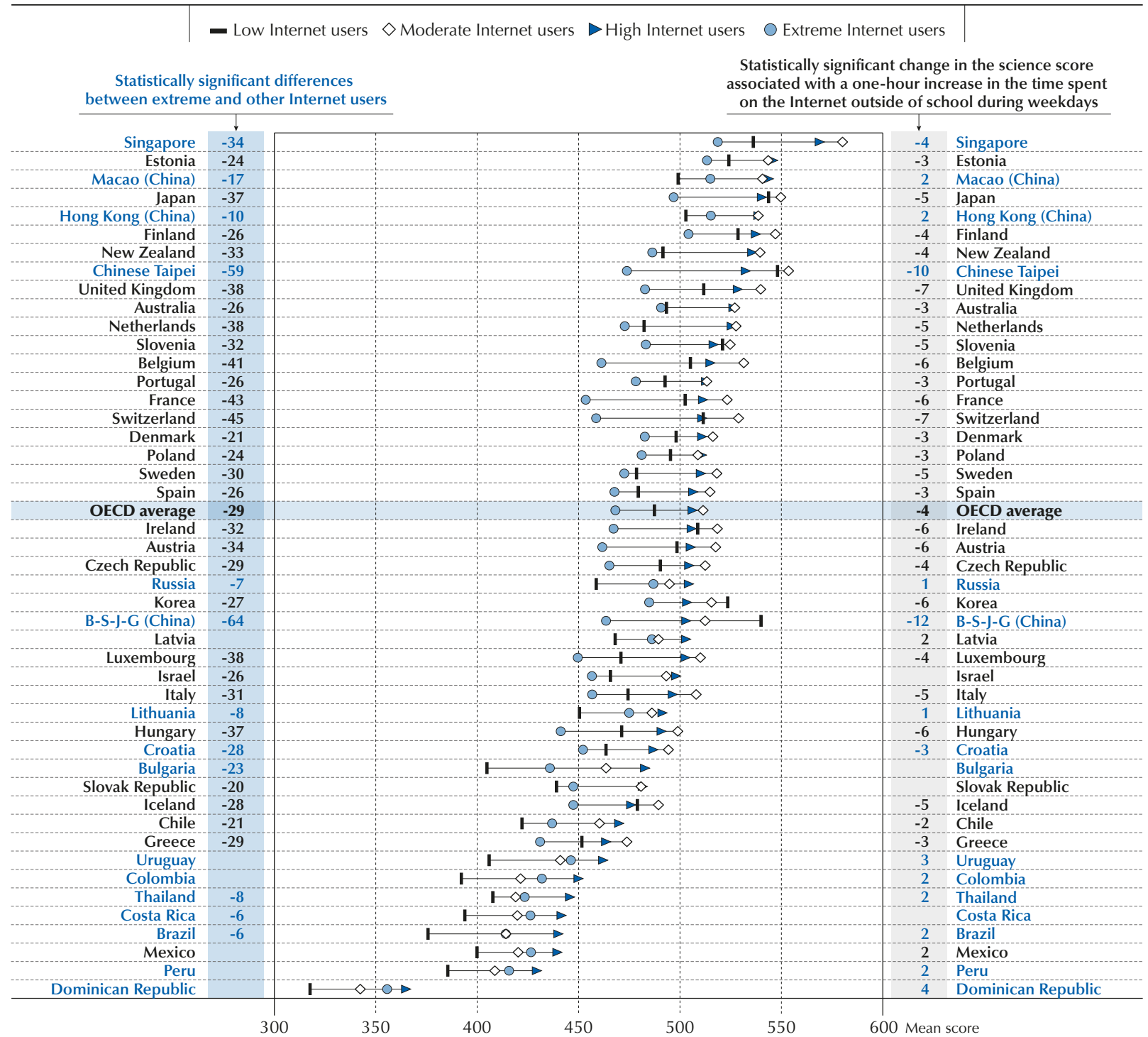

Notes: Categories of Internet users are based on students' responses to questions about how much time they spend on line, outside of school, during a typical weekday. Low Internet users: one hour or less; moderate Internet users: 1 to 2 hours; high Internet users: 2 to 6 hours; extreme Internet users: more than 6 hours.

Statistically significant differences between extreme and other Internet users (low, high and moderate), before accounting for students' socio-economis status, are shown next to country/economy name (see Annex A3).

Countries and economies are ranked in descending order of science score among high Internet users.

Source: OECD, PISA 2015 Database, Table III.13.24a.

StatLink 제매 http://dx.doi.org/10.1787/888933473521

\section{What these results imply for policy}

- Providing access to the Internet and digital devices in schools, and teaching students how to use these tools responsibly and critically, can reduce the impact of the digital divide between advantaged and disadvantaged students.

- School-based prevention and intervention strategies can make everyone aware of the negative consequences of Internet overuse. Parents, teachers and students can work together to establish clear boundaries for responsible Internet use. 


\section{Notes}

1. As the answers were given on a categorical scale, the average time spent on line is approximated with reference to its lower bound. For example, the answer "between one and two hours" is converted into "at least 61 minutes" (OECD, 2015, pp. 39).

\section{References}

American Academy of Pediatrics, Commitee on Public Education (2001), "Children, adolescents, and television", Pediatrics, Vol. 107/2, pp. 423-426, http://dx.doi.org/10.1542/peds.107.2.423.

Borgonovi, F. (2016), "Video Gaming and gender differences in digital and printed reading performance among 15-year-olds students in 26 countries", Journal of Adolescence, Vol. 48 (April), pp. 45-61, http://dx.doi.org/10.1016/j.adolescence.2016.01.004.

Brooks-Young, S. (2010), Teaching with The Tools Kids Really Use: Learning with Web and Mobile Technologies, Corwin Press, Thousand Oaks, CA.

Currie, C. et al. (eds.) (2012), Social Determinants of Health and Well-Being among Young People - Health Behaviour in School-Aged Children (HBSC) Study: International Report from the 2009/2010 Survey, World Health Organization Regional Office for Europe, Copenhagen, Denmark.

Finn, S. and M. Gorr (1988), "Social isolation and social support as correlates of television viewing motivations", Communication Research, Vol. 15/2, pp. 135-158, http://dx.doi.org/10.1177/009365088015002002.

Johnson J.G. et al. (2007), "Extensive television viewing and the development of attention and learning difficulties during adolescence", Archives of Pediatrics \& Adolescent Medicine, Vol. 161/5, pp. 480-486, http://dx.doi.org/10.1001/archpedi.161.5.480.

Kim, K. et al. (2006), "Internet addiction in Korean adolescents and its relation to depression and suicidal ideation: A questionnaire survey", International Journal of Nursing Studies, Vol. 43/2, pp. 185-192, http://dx.doi.org/10.1016/j.ijnurstu.2005.02.005.

OECD (2015), Students, Computers and Learning: Making the Connection, OECD Publishing, Paris, http://dx.doi.org/10.1787/ 9789264239555-en.

Punamäki, R.-L. et al. (2007), "Use of information and communication technology (ICT) and perceived health in adolescence: The role of sleeping habits and waking-time tiredness", Journal of Adolescence, Vol. 30/4, pp. 569-585, http://dx.doi.org/10.1016/j. adolescence.2006.07.004.

Smith, P.K. et al. (2008), "Cyberbullying: Its nature and impact in secondary school pupils", Journal of Child Psychology and Psychiatry, Vol. 49/4, pp. 376-385, http://dx.doi.org/10.1111/j.1469-7610.2007.01846.x.

Wood, R.T.A. et al (2004), "Video game playing and gambling in adolescents: common risk factors", Journal of Child \& Adolescent Substance Abuse, Vol. 14/1, pp. 77-100, http://dx.doi.org/10.1300//029v14n01 05. 


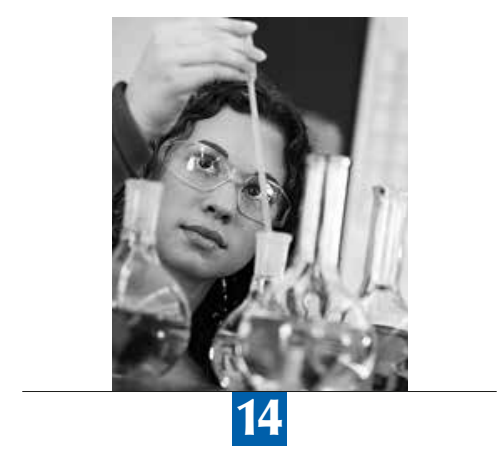

\section{What PISA 2015 results on students' well-being imply for policy}

Promoting well-being at school has become an important priority for education policy. Yet researchers, educators and parents still do not agree about the policies and practices that are more effective in fostering the healthy psychological, social, cognitive and physical development of students. This chapter discusses several policy initiatives, and frontline interventions by teachers and parents, that could help narrow disparities in well-being among students. 
What is a successful student? Even if definitions of success vary, most educators and parents would agree that a successful student not only performs well academically but is also happy at school. Indeed, schools are not only places where students acquire academic skills; they are also social environments where children can develop the social and emotional competencies that they need to thrive.

All actors involved in education can promote students' well-being with four main objectives: to improve children's sense of purpose and positive feelings about their life; to prevent psychological and physical ill health; to nurture social interactions at school and create school environments that favour the development of caring, responsible and respectful adolescents; and to increase students' confidence and engagement at school, so as to promote autonomous learning and thinking.

However, there is no consensus on which well-being programmes at school or curriculum changes are most needed. Some argue that other institutions should assume responsibility for children's well-being - the family, above all. Others are concerned that directly teaching skills and behaviour at school to improve well-being (through prevention programmes for mental health, or activities that are explicitly designed to develop social or character skills, for example) might promote values that are espoused by educators or politicians but not by some parents (Arthur, 2005). Parents, educators and policy makers are also concerned that well-being programmes could affect student achievement by diverting time and money away from the teaching of academic subjects (Benninga et al., 2006).

Better data and more rigorous programme evaluations can provide essential information about the costs and benefits of integrating well-being activities in school curricula (Spence and Shortt, 2007). The data from PISA 2015 show that students differ greatly, both between and within countries, in how satisfied they are with their lives, in their motivation to achieve, in how anxious they feel about their schoolwork, in their participation in physical activities, in their expectations for the future, in their experiences of being bullied by their peers and in their perception of being treated unfairly by their teachers. Many of these differences are related to students' impressions about the disciplinary climate in the classroom and the support their teachers give them. The data also show that parental involvement and adolescents' sense of their parents' support are associated with students' feelings about schoolwork and their performance in PISA.

\section{POLICY IMPLICATIONS OF RESULTS FROM PISA 2015 ON STUDENTS' WELL-BEING Psychological health, motivation and confidence at school}

PISA data show that in the majority of countries and economies, 15-year-old students rate their satisfaction with life at 7.3 on a scale from 0 to 10, on average (Chapter 3). However, a significant number of students in all countries reported worryingly low levels of life satisfaction. This international evidence is consistent with country studies showing that, at any one point in time, 3-5\% of adolescents report suffering some degree of depression (Costello et al., 2003; Maughan, Collishaw and Stringaris, 2013).

Different types of interventions at school can help reduce the prevalence of serious psychological distress among adolescents. Universal prevention programmes can be applied to the entire student body, irrespective of individual students' risk status; targeted programmes focus on adolescents who have a high risk of developing mental health problems (Sawyer et al., 2010). Universal programmes avoid stigmatising target groups and can benefit large numbers of students. However, these programmes are often difficult to implement as part of routine practice in schools (Sawyer et al., 2010).

Preventing mental ill health and promoting psychological well-being at school have focused on helping students develop optimistic thinking, self-regulation, problem-solving and coping skills, and techniques to relax (Merry et al., 2011). Experts in positive psychology argue that universal interventions at school can produce measurable improvements in students' well-being and behaviour, with minimal demands on students' time (Seligman et al., 2009).

While many schools are now investing considerable resources in universal mental health or positive psychology programmes, the evidence on the effectiveness of these initiatives is still limited (Sawyer et al., 2010). Most interventions have been relatively brief, and thus perhaps insufficient to produce lasting changes in attitudes and behaviours. Implementing school-based, universal interventions requires substantial planning and funding over several years. The effectiveness of these programmes also requires teachers to be fully engaged with the interventions and trained to implement them.

A complementary strategy to specific well-being programmes focuses on changing school environments (Sawyer et al., 2010). PISA data suggest in fact that students' perceptions about their learning environment and their teachers are strongly related to their psychological well-being at school (Chapters 3 and 7). 


\section{Box III.14.1 Experiments in student-driven learning for well-being: The Free Semester initiative in Korea}

Korean students are well known for their top marks in international assessments and their work ethic. But those high marks might be earned at a considerable cost: $22 \%$ of Korean students reported a level of life satisfaction that is less than or equal to 4 on a scale from 0 to 10 - nearly double the proportion of students across OECD countries who reported so (Table III.3.1). The Korean Ministry of Education's Plan for 2014 seeks to improve students' well-being through: a Free Semester initiative; curriculum changes, including the new Integrated Curriculum of Liberal Arts and Science; a stronger focus on humanities, arts, sports and character-building through activities and clubs; and the "Violence-Free Safe Schools" policy, which seeks to strengthen students' mental health by introducing anonymous counselling systems, education to prevent cyberbullying, and early-detection systems to identify students at risk of depression (UNESCO, 2016).

The Free Semester initiative has attracted considerable attention. Since 2013, students in participating schools have an opportunity to take a semester "free" from exams and other formal methods of assessments in their first or second year of secondary school. In 2016, more than 3000 lower secondary schools participated in this initiative. During the free semester, students spend half of their day on academic subjects, following student-driven learning methods that encourage engagement through experiments, student-led discussions, moot courts and other collaborative projects. Students spend the rest of the day in extracurricular activities (visual arts, music, sports) and exploring careers (externship/internship, job shadowing, external lectures) that give them a stronger sense of their aspirations and greater awareness of the skills they need to realise them.

During the free semester, teachers assess students using a qualitative and informative approach. Teachers provide more extensive performance feedback and give students more opportunities to reflect on their own performance. Although no nationwide evaluation of the initiative is available yet, survey results from 42 participating schools indicate that students and teachers who completed the free semester report higher satisfaction with their life at school, on average (Korea Education Development Institute, 2015). Critics of the initiative claim that not enough activities have been developed and that the loss of traditional teaching time may increase the workload for teachers, create more academic burdens for the remaining semesters, and have a negative impact on learners' achievement in core subjects (UNESCO, 2016). Parents also expressed worries that the programme could impose more financial burdens if students need to make up for lost class hours with private education. If future evaluations show positive outcomes for learners' development and well-being, the initiative could be expanded to other levels of education.

\section{Train teachers to recognise and address schoolwork-related anxiety}

PISA 2015 data show that schoolwork-related anxiety is common among adolescents (Chapter 4). Often, this anxiety is students' reaction to, and interpretation of, the mistakes they make - or are afraid to make. Students internalise mistakes as evidence that they are not smart enough. Educators need to know how to help students develop a good understanding of their strengths and weaknesses, and an awareness of what they can do to overcome or mitigate their weaknesses.

Specific professional development can be offered to teachers so that they can identify those students who suffer from anxiety and teach these students how to learn from mistakes. Such training should provide teachers with practical tools they can use in their daily teaching. For example, one way to encourage a positive attitude towards mistakes is to take the most common mistakes that the class made on a test or quiz and let the students analyse them together.

Effective teacher training for students' well-being combines theoretical knowledge with learning in practice under the guidance of accomplished practitioners. It also lets teachers reflect on their own practice, their roles, and students' outcomes (Vescio, Ross and Adams, 2008). One example of such training combining theory, classroom practice and reflection about one own's practice is the Preservice Health Education Programme developed at the University of Southampton (United Kingdom). The programme centres on an annual Health Day at the university, early in the training programme, consisting of an introductory lecture, a range of interactive workshops (e.g. gaining confidence in teaching sensitive issues, healthy eating, emotional health and well-being), and an exhibition in which various health and education agencies participate (Byrne et al., 2016). Later in the course, the trainee teachers consolidate their learning by completing follow-up, school-based tasks, such as finding out about the school's education programmes, or observing, co-planning 
and teaching lessons on health and well-being. Teachers reported that, after the training, they felt more confident teaching and dealing with students' health and personal issues, and held more positive attitudes about promoting the well-being of their students (Byrne et al., 2016).

PISA 2015 data suggest that it is not the frequency of tests, but rather students' perception of tests and other schoolwork as threatening that determines how anxious students feel (Chapter 4). More frequent assessments that start with easier goals and gradually increase in difficulty can build students' competence and sense of control, as can opportunities for students to demonstrate their skills in other tasks or low-stakes tests before taking an assessment that counts.

Greater collaboration with specialised health services can help schools identify and treat students with the most serious anxiety disorders. Primary healthcare providers and family members can provide information about what the school might do, and the school can inform parents and healthcare providers about the student's responses to school interventions. Developing a referral system of trusted health professionals is a simple practice that can yield long-term benefits for students and their families.

\section{Box III.14.2 Online resources for teachers' professional development on well-being: The Australian Student Wellbeing Hub}

Teachers play a crucial role in students' well-being. In their daily work, teachers need to address a variety of issues concerning the well-being of their students - issues that may have traditionally been considered the domain of families - and are generally willing to learn how to do so (Byrne et al., 2016). However, limited time and resources for professional learning may lead educators to feel they lack the knowledge and skills to address some life challenges their students are facing. Complex problems, like cyberbullying, require specific solutions for detecting risks and deciding on appropriate responses. Explicit training on social and emotional well-being can improve the level and type of support educators can offer their students, increase their confidence when they discuss emotional problems with students, and also help them make better sense of their daily experiences as teachers. Not all of this training needs to happen in a classroom. Carefully developed online learning resources can, in fact, offer dynamic and flexible opportunities for teachers' professional development. The online environment has garnered increasing interest from educators as a place where they can meet their learning needs, know what other teachers are doing, and collaborate (Ola and Olofsson, 2010; Shute and Slee, 2016).

The Australian Government developed the Student Wellbeing Hub (studentwellbeinghub.edu.au/) as a one-stopshop for information and resources on student well-being for the whole school community, including students and their parents. A wide pool of experts, academics, employers, and professional and civil society associations have contributed to the development of the online platform. The Educator section of the Hub is designed to advance teachers' awareness of curricular and pedagogical approaches for well-being, and help schools build respectful and supportive learning communities. By navigating the hub, teachers can autonomously build their capacity to make a positive difference to their students' well-being.

Through the site, educators can access targeted support to improve their practices for students' well-being, including:

- self-paced professional learning modules, with videos, support materials, podcasts and practical strategies

- a school-audit survey tool through which school leaders and teachers can assess the effectiveness of their policies and procedures in relation to student safety and well-being

- classroom resources for teaching key topics, including the prevention of bullying, online safety, gender and cultural identity, and healthy habits

- helpful advice about effective methods for working with parents to ensure that students have safe interactions with peers and adults, both on line and off line.

These online resources complement, but are not a substitute for, more formal professional development activities and structured collaboration among teachers. Governments that want to invest in similar online platforms should consider including online opportunities for networking and coaching-style discussions, to allow for online contact with instructors and peers.

To find out more about the Australian Student Wellbeing Hub, go to: www.studentwellbeinghub.edu.au/. 


\section{Identify and share good practices to raise intrinsic motivation to achieve}

Most students who participate in PISA reported that they set concrete, short-term goals for their school life, such as achieving a certain grade, or long-term goals, such as having the best opportunities when they graduate, for example (Chapter 5). These forms of motivation to learn are positively related to performance in PISA and to greater resilience among disadvantaged students. High levels of achievement motivation are also more common among students who reported that they are satisfied with their life.

Students who are encouraged to set realistic goals for their schoolwork may thus be able to boost their achievement and self-control, and find a sense of purpose in their time at school. Goal-setting might be particularly beneficial for boys, as PISA data suggest that underachievement among boys is related to boys' lower motivation to achieve at school. Offering tangible rewards, like grades, or some moderate competition in the classroom might prompt greater efforts towards learning, especially if students see a particular assignment as boring or as a chore.

The issue is whether offering rewards focuses undue attention on tangible payoffs, instead of on the material that students are learning. In most classrooms, students compete for a limited number of rewards (e.g. good grades). Although this may increase motivation to achieve good results, students might be more motivated to "beat" others or avoid losing - both of which can instil a fear of failure and a sense of frustration (Covington and Müeller, 2001). PISA data show that students who want to be one of the best students in the class are often those who suffer the most anxiety (Chapter 5).

Strategies for enhancing intrinsic motivation to learn include providing choice and meaningful rationales for learning activities, acknowledging students' feelings about the tasks, and avoiding excessive pressure and control. The first step for educators and education policy makers is to design education programmes and environments in which students can use and develop their abilities in productive and satisfying ways, while learning that, by investing greater effort, they can master more difficult skills.

Students are more likely to value what they are learning, and to enjoy the process of learning, when they set realistic goals for themselves and reach these goals; when the primary reason for investing effort are task-oriented and not related to seeking approval or avoiding failure; when students' personal interests are stimulated by what they are studying; and when tasks are related to real-world experiences. It is important to set students' goals at an appropriate level of difficulty. If the goal is set too high, it can reduce motivation and raise anxiety by undermining students' sense of competence and control; but if the goal is too easily attainable, it will not be meaningful.

The need to promote productive forms of achievement motivation also has implications for the design of assessments. Challenging assessments can spur students to work harder, without necessarily provoking anxiety, frustration or fear of failure. For an assessment to be motivating, educators need to make clear to students what they need to learn to do well on the assessment and reward the achievement of mastery-based goals, such as demonstrating growth in their understanding, skills and content knowledge. Assessments that reward creativity, effort and strategising can also have a positive effect on motivation to learn (Usher, 2012). Providing constructive feedback on the results of assessments can nurture autonomy and intrinsic motivation.

\section{Give students the means to take well-informed decisions for their future studies and careers}

Psychological well-being is rooted in a sense of purpose in life. During their adolescence, students take many decisions that will have critical implications for their future. Adolescents thus need to be given the opportunity to reflect on the options they have for their careers, and to think about what they would like to do as adults with a fully informed perspective on the costs and benefits of different choices.

Chapter 6 shows that disadvantaged students are much less likely to expect that they will complete university than advantaged students. For many, it is a problem of access to information. If these students are the first in their family to think about attending university, the process of choosing courses and searching for scholarships might seem daunting and beyond their control. Some disadvantaged students might think that only "rich kids" go to university, and thus feel that it is worthless to try (Usher and Kobler, 2012). Some other disadvantaged students may have limited information about the lifelong gains (in salary and job security, to name just two) associated with higher education, or may not realise that a university degree might now be a requirement for the job they would like to do.

Social influences and lack of accurate information might also distort students' choices in the opposite direction. Students from relatively advantaged families might think that a university degree is the only option for their education career, and not consider opportunities in vocational or technical education that might be a better fit for their work preferences and talents. 


\section{Box III.14.3 Education and Career Guidance in Singapore}

Singapore has done well in PISA 2015, but is continuing to make important changes in its education system to prepare students even better for the future. Taking a lifelong perspective, multiple education-career pathways are being created that will enable students to discover and pursue their interests, and continuously develop socialemotional and cognitive skills. Education and career guidance is one important element to help students make informed decisions along their education and career journey (Ministry of Education, Singapore, 2017).

The Education and Career Guidance programme allows Singaporean students to receive support in different aspects of education and career planning through counselling, mentoring and online courses (Cheng and Tan, 2016). The programme's counsellors provide individualised support to students all the way from secondary to tertiary education, and work with various stakeholders to implement an education and career guidance plan customised for the individual student. Activities such as talks, fairs and learning journeys are also organised in collaboration with community and industry partners to help students explore their strengths and interests, in relation to their aspirations. These activities foster students' social and emotional competencies (including self-identity, awareness, motivation and self-directedness), and improve workplace readiness.

Figure III.14.1 - The Singapore Education and Career Guidance framework from primary school to working life

Upper primary $>$ Secondary (13-16/17 years old) $>$ Post-secondary (17/18-20 years old) $>$ New entrants (20s)

\begin{tabular}{l|l|l|l|l}
\hline \multicolumn{1}{|c|}{ Awareness } & \multicolumn{1}{|c|}{ Exploring and planning } & Crystallisation and planning & Developing and transitting \\
\hline $\begin{array}{l}\text { Building self-awareness } \\
\text { and personal management }\end{array}$ & $\begin{array}{l}\text { Explore personal } \\
\text { strengths, hobbies, } \\
\text { interests }\end{array}$ & $\begin{array}{l}\text { Develop self-awareness } \\
\text { in areas of interest, abilities, } \\
\text { values } \\
\text { and career aspiration }\end{array}$ & Develop career self-concept & $\begin{array}{l}\text { Take ownership of } \\
\text { own career development }\end{array}$ \\
$\begin{array}{l}\text { Exploring education, } \\
\text { training and careers }\end{array}$ & $\begin{array}{l}\text { Build awareness } \\
\text { about the wide array } \\
\text { of occupations } \\
\text { in the world of work }\end{array}$ & $\begin{array}{l}\text { Explore relevant courses } \\
\text { of study and pathways } \\
\text { linking to the world } \\
\text { of work }\end{array}$ & $\begin{array}{l}\text { Develop skills in acquiring } \\
\text { and using sectorial career } \\
\text { information }\end{array}$ & $\begin{array}{l}\text { Develop skills and networks } \\
\text { to facilitate entry into } \\
\text { the chosen career }\end{array}$ \\
\hline $\begin{array}{l}\text { Develop plans and } \\
\text { decision-making }\end{array}$ & $\begin{array}{l}\text { Explore secondary } \\
\text { schools and set goals } \\
\text { in learning }\end{array}$ & $\begin{array}{l}\text { Develop skills to plan, } \\
\text { discuss with relevant others } \\
\text { and make decisions on } \\
\text { post-secondary education } \\
\text { choices and careers }\end{array}$ & $\begin{array}{l}\text { Develop school-to-work } \\
\text { transition skills. Develop } \\
\text { skills in planning and making } \\
\text { informed decisions for further } \\
\text { education and jobs }\end{array}$ & $\begin{array}{l}\text { Navigate the world of work } \\
\text { confidently and manage } \\
\text { career transitions }\end{array}$ \\
\hline
\end{tabular}

Source: Adapted from Cheng, V. and E. Tan (2016), "Overview of education and career guidance (ECG) implementation in Singapore schools", www.asiapacificcda.org/resources/Documents/2016Conference/261_Overview_ECG\%20in\%20Sg\%20Schs.pdf.

As part of the strategy to encourage young people to take greater ownership of their own learning throughout life, Singapore is launching a one-stop education, training and career guidance online portal for students and people in the workforce (SkillsFuture Singapore, 2017). By navigating a user-friendly platform, students can discover their interests and strengths, and explore various education and career pathways to realise their aspirations. This will be extended beyond schools so that when they join the workforce, they can use the portal to search for suitable jobs, manage their careers, and learn about new skills.

To find out more, go to: "SkillsFuture Programmes \& Initiatives for you", www.skillsfuture.sg/skillsfuture-for-you.

Schools, and local and national governments need to establish programmes that help students navigate education pathways and working opportunities. Education and career counselling at school can empower students to create their own paths to success by supporting their motivation to achieve and their resilience at school. This help should acknowledge that different students may have different goals, based on their mindsets, talents and career preferences. Partnerships with civil society, employers and professional organisations can help schools increase the effectiveness of these counselling programmes (OECD, 2004). 


\section{Positive peer and teacher-student relationships}

Supportive social relationships are the foundation of resilience and well-being. Diener and Seligman (2002) compared extremely happy students with a control group of students who were not happy. When the researchers examined the characteristics of the happy students, they found that they differ significantly from the others in their rich and satisfying social life. These students had close relationships and intimate friendships. In an international survey led by UNESCO, friendships and positive relationships in the school community were ranked by both students and educators as the most important ingredient of a "happy" school (UNESCO, 2016).

Students' level of engagement or disengagement with school is largely dependent on the degree to which their needs for competence, autonomy and belonging are fulfilled. Students' psychological and social needs are met when they participate in a cohesive, caring group with a shared purpose - that is, when schools function as communities that value and promote understanding of and respect for others, and are inclusive and open (Battistich et al., 1997). The benefits of participating in a caring school community may be particularly great for disadvantaged students and, in particular, for disadvantaged students with an immigrant background or from minority groups.

\section{Provide effective teacher training on classroom and relationship management}

PISA 2015 data show that students differ significantly in their sense of belonging at school (Chapter 7). Disadvantaged students and students with an immigrant background tend to report less of a sense of belonging at school than other students. In PISA, a greater sense of belonging is significantly related to a large number of desirable outcomes, including better performance. PISA data also reveal that students' sense of belonging at school has declined over the past decade, and that one major threat to students' feelings of belonging at school are their perceptions of negative relationships with their teachers.

Schools can function as caring communities only if they have engaged teachers. Teachers who work hard to get to know their students, treat students as individuals with qualities and strengths, and communicate interest in the students' personal lives outside of school often become inspiring figures in students' lives. Most teachers care about having positive relationships with their students; but some teachers might be less prepared to deal with difficult students and classroom environments.

A stronger focus on classroom and relationship management in teacher training and professional development can give teachers the means to connect with their students and support their engagement at school. Classroom management is a complex issue and consists of far more than establishing and imposing rules, rewards and incentives to manage behaviour. Effective classroom management involves practices and instructional techniques to create a learning environment that facilitates and supports active engagement in learning, encourages co-operation and promotes behaviour that benefits other people or society as a whole (McDonald, 2013). Teachers' mastery of classroom management facilitates both teaching and learning (OECD, 2016a), supports students' sense of belonging (Chapter 7), and reduces the incidence and negative effects of offensive behaviour (Chapter 8). Through effective training in relationship management, teachers can more effectively support their students. In most contexts, such training should teach educators how to take into account diverse learners' needs - especially those of minority groups - and give teachers a command of basic methods of observation, listening and intercultural communication.

Schools can also identify further professional development needs by regularly collecting feedback from students on the quality of the learning environment. By having a formal instrument to express their views and needs, students can develop a stronger sense of ownership and autonomy in their schools.

\section{Prevent bullying and provide support to victims, bullies and bystanders}

PISA 2015 data show that a significant proportion of students reported being victims of bullying at school (Chapter 8). Bullying has serious consequences for the victim, the bully and the bystanders. There is no one-size-fits-all approach to preventing bullying. What emerges clearly from the PISA data, however, is that schools must do more to foster an environment of safety, tolerance and respect for children. A co-ordinated, international analysis of existing strategies and support mechanisms can shed light on what schools can do in the difficult struggle to assure students' safety at school, and what national and local authorities can do to support schools in this effort.

Effective anti-bullying programmes involve a whole- school approach, with co-ordinated engagement among teachers, students and parents. Several of the anti-bullying programmes that have proved to be successful include training for teachers on how to handle bullying behaviour and its associated group processes, anonymous surveys of students to monitor the prevalence of bullying, and strategies to provide information to and engage with parents. 


\section{Box III.14.4 Improving the learning environment to fight bullying: The case of Castile and Leon}

Castile and Leon is a sparsely populated region in northwest Spain with a per capita GDP slightly below the Spanish average and about 15\% lower than the European Union average (OECD, 2016b). Yet students in Castile and Leon have consistently shown outstanding performance since they first participated in PISA in 2003, particularly in science, leading some commentators to dub the region the "Spanish Finland". In PISA 2015, students in Castile and Leon scored 519 points in science, 522 points in reading and 506 points in mathematics. Only $5 \%$ of students were low achievers in all three subjects, compared to $13 \%$ of students across OECD countries (OECD, 2016a).

Castile and Leon has also been exemplary in students' well-being since 2004, when it implemented the School Learning Environment Plan (Plan de Convivencia Escolar), which made students' well-being a policy priority. The central goal of the plan was to create a positive learning environment where the rights and duties of all education stakeholders are guaranteed, and students can learn to become engaged citizens by developing their cognitive, emotional, social and physical skills. The plan includes multiple actions, including anti-bullying procedures, public recognition for schools with good well-being practices, and the appointment of a school environment co-ordinator. Two of the main instruments of the plan are CONV and Sociescuela.

CONV is an information system that monitors schools' learning environment and identifies schools that are struggling with student behaviour problems. Twice a year, virtually all publicly funded schools report on their learning environment plan; the frequency, seriousness and types of behavioural problems in their schools and the corrective measures taken, if any; and the meetings and activities organised to create a better learning environment. Schools then use this information to draft a report describing their learning environment, which is then incorporated into the provincial and regional reports.

Sociescuela is an online survey that any student can take to assess their well-being. Head teachers can use the survey to assess students' relationships in a particular class or in the entire school. The survey includes questions about students' well-being, their self-confidence, and their friendships and conflicts, and about the school's disciplinary climate. Based on students' self-reports and witnesses' testimonies, the survey identifies the (potential) victims of bullying, the type of bullying, the bullies, and the students who are considered respectful and supportive. The group report also contains detailed information on the behaviour, attitudes and personality of the victims, as perceived by their classmates. In short, the report includes the type of information that principals and teachers need to deal effectively with a case of bullying.

Data from Spain (Díaz-Aguado Jalón et al, 2010) show that in the year 2007-08, bullying rates were lower in Castile and Leon, affecting 1 in 40 students, than in Spain as whole, where 1 in 26 students reported being bullied. PISA 2015 data confirm that students in Castile and Leon reported one of the lowest bullying rates among Spanish Autonomous Communities. For instance, only $1.7 \%$ of students in Castile and Leon agreed or strongly agreed that they were threatened by other students, compared to $2.6 \%$ of students in Spain and $3.7 \%$ of students, on average, across OECD countries.

Recently, Castile and Leon is adopting more systemic, participative and integrated approach for well-being at school. An example of this new strategy is the new anti-bullying plan (Plan antiacoso y por el buen trato), that incorporates new measures to reduce the prevalence of bullying even further. These measures include:

- a stronger focus on supporting victims and re-educating offenders, in addition to the traditional goal of eradicating bullying

- updating the intervention protocol in bullying incidents, particularly those related to cyberbullying, following the goals and principles of awareness, prevention, protection, confidentiality, co-ordinated action, collective solutions, systematisation, efficacy and urgency

- co-ordinating the plans and actions of all public and private institutions involved in the fight against bullying.

Links to further information:

Sociescuela [online student well-being survey] (website available in Spanish only), https://sociescuela.es/es/index.php. Convivencia escolar [the school learning environment in Castile and Leon] (website available in Spanish only), http://www.educa.jcyl.es/convivencia/es. 
Teachers have a particularly important role to play in preventing bullying. They need to communicate to students that they will not tolerate any form of bullying, and act as role models in the classroom. Teachers who clearly stand for antibullying norms strengthen their students' goal to act appropriately (Veenstra et al., 2014). Students and teachers can work together at reducing bullying. For this cooperation to happen, teachers need to play a central role in antibullying interventions. Furthermore, incorporating bullying-prevention modules in initial teacher training can ensure that all teachers have basic preparation in detecting and reacting to different acts of bullying.

Another important strategy against bullying is building partnerships between schools and parents. Parents need to be involved in school planning and responses to bullying.

Effectively organising antibullying interventions is crucial. With a combination of universal, whole-group interventions and targeted interventions to tackle acute cases of bullying, schools can effectively cooperate with other services to prevent and solve many cases of bullying.

\section{Positive synergies between the school and home environments}

Even within the same school, students differ greatly in their material, social and cultural resources at home. These differences can be a significant source of inequality in students' well-being. Parents from disadvantaged backgrounds might have less resources to invest in their child's education, and less time to spend with their child. A way to promote students' well-being is to encourage all parents to be more involved with their child's interests and concerns, show interest in their school life, and be more aware of the challenges children face at school.

Schools can create an environment of co-operation with parents and communities. Teachers can be given better tools to enlist parents' support, and schools can address some critical deficiencies of disadvantaged children, such as the lack of a quiet space for studying. If parents and teachers establish relationships based on trust, schools can rely on parents as valuable partners in the cognitive and socio-emotional education of their students. Parents can also more confidently rely on teachers for exchanging information and views on the social and psychological development of their children. Accounting for students' differences in their family resources also means creating equitable learning spaces at school, where children from all socio-economic backgrounds are treated equally and can develop high expectations for themselves.

\section{Encourage parental involvement and remove barriers to participation in school activities}

During adolescence, some changes in how children communicate with their parents and in which activities they enjoy together are inevitable. Children may show an increased interest (even preference) for the company of their peers. Add to this the long hours many parents spend at work and it is easy to see that "quality time" for parents and their adolescent children may need to be scheduled in advance. But such efforts are worthwhile: PISA data from 18 countries confirm that across wide cultural, socio-economic and individual differences, the value of supportive parents cannot be overestimated (Chapter 9). Students whose parents routinely engage in day-to-day home-based activities, such as eating a meal together or spending time "just talking" not only score higher in PISA, but are also more satisfied with their lives.

PISA 2015 findings underline the importance of students' perception of their parents' interest in their school activities. Students who regard their parents as being interested in their school life perform better, reported higher achievement motivation, and are more likely to be highly satisfied with their lives than students who reported a lack of parental interest. Low-performing students might benefit even more than high-performers from supportive parenting.

For some parents, spending time just talking to their child is a rare occurrence; others find it difficult to participate in their children's school life. These difficulties may be related to inflexible work schedules, lack of childcare services, or language barriers. But schools can do a lot to help parents overcome these barriers. They can first try to identify those parents who may be unable to participate in school activities. They can open flexible channels of communication, such as scheduled phone or video calls, which are simple, but effective, solutions to accommodate busy parents who cannot easily leave work to attend school meetings. Governments can also take action by providing incentives to employers who adopt policies to improve the work-life balance.

In those countries and communities where large shares of parents reported not knowing how they can participate in their child's school life or who believe that their participation is not relevant for their child's development, schools and teachers can help raise awareness among parents about the importance and benefits of their participation and suggest ways in which they can get involved both at home and in school. Parents' lack of familiarity with school rules, 
lack of information about opportunities for involvement, or their perception of an intimidating social divide are all obstacles that schools can help dismantle. Teachers can plan welcoming "open houses" and encourage all parents to participate, particularly those from disadvantaged backgrounds whose children need their support the most. Through their engagement, parents can be a powerful force in building a learning environment that encourages both high achievement and the well-being of students.

Removing language barriers can also increase the level of parents' participation in school activities. In countries with large immigrant populations, including many European countries, schools may need to partner with immigration and social service agencies to provide interpreters, for example. In some other countries, non-immigrant parents reported confronting language barriers, a problem that disproportionally affects less-educated, less-privileged parents. This may be an indication that some parents feel intimidated when interacting with well-educated teachers and school staff. Schools may need to improve the way they welcome parents from culturally, linguistically and socio-economically diverse backgrounds.

\section{Address the impact of socio-economic inequalities on students' perceptions about themselves and their aspirations for the future}

PISA data show that the education and occupation expectations of disadvantaged students are related to the socioeconomic profile and composition of their school (Chapter 10). Social segregation that groups poor students in poor schools might inadvertently set limits on students' expectations for, and beliefs in, themselves, reducing social mobility. Governments should strive to have excellent schools in every neighbourhood that are accessible and welcoming to all children and families (OECD, 2016a). However, school segregation is difficult to eliminate, as it is usually related to structural features of labour markets, institutions and residential markets.

Students could also be given the means to think critically about inequality - about the obstacles disadvantaged students face, and the internal or external resources they can use to overcome these obstacles. Teachers can follow specific professional development modules to better understand the dynamics of social, economic and cultural diversity, and work with all students to reduce some of their negative effects on the self-esteem and expectations of the most vulnerable students. Rather than ignoring the effects of socio-economic differences among students, teachers could try to identify the aspects of these differences that may be harming the well-being of the most vulnerable students. Skilful interventions by teachers can also make peer influences a force for good, helping to raise the expectations of disadvantaged students about what they can accomplish, with hard work and dedication, in school and in life.

Teachers who have good relationships with their students are better equipped to address some learning difficulties that are related to disadvantaged students' life outside of school. For example, PISA data show that many disadvantaged students work for pay before or after school (Chapter 12). These students might have a harder time meeting their school obligations and might need extra support from their teachers and school.

School leaders also need to understand the challenges and opportunities of educating mixed groups of students. Schools may indeed reflect existing inequalities in the broader society, but school leaders can work to reduce the impact of these inequalities on students' lives by creating a school environment that is welcoming, stimulating and inclusive for all teachers, staff members and students.

\section{Opportunities to learn about healthy living habits}

\section{Teach the benefits of an active and healthy lifestyle through physical and health education}

PISA data in Chapter 11 show that students' participation in physical education differs across countries. Students' participation in physical activities in school is positively associated with their physical activity outside of school. The quality of physical and health education might also differ within countries (Bailey, 2006).

Over the years, several education systems have promoted new curricula and approaches to physical education that help students to build physical literacy (the ability to move with competence in a variety of physical activities) and health literacy (the skills needed to find, understand and use information to make good decisions for health). For example, the 2015 Health and Curriculum of Ontario (Canada) defines a comprehensive set of knowledge and skills that students should acquire through health and physical education (Ministry of Education [Ontario], 2015). The practical approach adopted in all courses in this curriculum is related to the everyday experiences of students. The curriculum also promotes important education values and goals that help develop character and create supportive school communities. These include striving to achieve one's personal best, equity and fair play, sensitivity and respect for individual differences. 
Sharing similar good practices in health and physical education internationally can increase the positive effects on well-being of the hours that students dedicate to these pursuits. An effective physical and health education curriculum is balanced if it addresses the physical, cognitive, psychological and social needs of students, thus focusing on group activities that are specifically designed to foster interaction skills. The curriculum content and learning activities in physical education should be constantly updated so that they reflect the real-life contexts and opportunities for sports and an active life that are available to students in their own community. The format and content of the courses should also be adaptable and recognise individual differences, allowing for differentiation of instruction according to a student's readiness, physical ability and interests.

PISA does not collect data on students' body image; but the data suggest that some students, particularly girls, do not eat their meals regularly (Chapter 11), possibly because they have an unrealistic idea of what they look like - or think they "should" look like (Box III.11.4). Education about body image and the risks of eating disorders is an important aspect of physical and health education. Having the correct information and education can help prevent children from developing an eating disorder, ease the suffering of young people in the early stages of an eating disorder, and reduce the stigma and misconceptions that surround such disorders. Efforts to promote positive body image and healthy lifestyle choices can be integrated into every school's teaching programme as way to prevent eating disorders from developing, rather than as a response to existing problems.

\section{Promote healthy and productive use of the Internet}

The objective of schools is to prepare students for active, effective and responsible participation in society. Online resources have become an essential component of this preparation. PISA data in Chapter 13 show that young people have fully embraced the Internet as a tool for socialising, and many think that the Internet is a great resource to search for the most up-to-date information.

Teenagers often spend a significant amount of time on the Internet, disengaging from other forms of recreation and face-to-face interactions. In PISA 2015, 26\% of students reported that they spend more than six hours per day on line during weekends, and $16 \%$ spend a similar amount of time on line during weekdays. More than one in two students reported that they feel bad if they do not have access to the Internet. In most participating countries and economies, extreme Internet use - more than six hours per day - has a negative relationship with students' life satisfaction, sense of belonging and engagement at school.

Cyberbullying represents another risk associated with online activities. While PISA does not distinguish between online and face-to-face bullying, other evidence shows that the incidence of cyberbullying is on the rise (Box III.8.1).

There are no quick fixes for these two risks of the digital era. Schools need to create opportunities for students to share their understanding of digital technology and challenges with adults and peers. They can also develop a clear incident-response plan for staff in the event of violations of safety norms and cyberbullying, provide access to in-school counselling to students involved in cyber-related incidents, and introduce a "digital safety" theme across school policies and practices. Parents should also be involved in discussions and decisions about online safety. Digital safety plans should be integrated into a wider education strategy to strengthen psychological and social skills, such as resilience, empathy, ethical decision-making and conflict resolution.

Preventing the misuse of the Internet at school also requires making sure that technologies are used at school for high-quality educational activities - which, in turn, calls for investments in professional and curriculum development. 


\section{References}

Arthur, J. (2005), "The re-emergence of character education in British education policy", British Journal of Educational Studies, Vol. 53/3, pp. 239-254, http://dx.doi.org/10.1111/j.1467-8527.2005.00293.x.

Bailey, R. (2006), "Physical education and sport in schools: A review of benefits and outcomes", Journal of School Health, Vol. 76/8, pp. 397-401, http://dx.doi.org/10.1111/j.1746-1561.2006.00132.x.

Battistich, V. et al. (1997), "Caring school communities", Educational Psychologist, Vol. 32/3, pp. 137-151, http://dx.doi.org/10.1207/ s15326985ep3203_1.

Benninga, J.S. et al. (2006), "Character and academics: What good schools do", Phi Delta Kappan, Vol. 87/6, pp. 448-452, http://dx.doi. org/10.1177/003172170608700610.

Byrne, J. et al. (2016), "A longitudinal study to explore the impact of preservice teacher health training on early career teachers' roles as health promoters", Pedagogy in Health Promotion, Vol. 2/3, pp. 170-183, http://dx.doi.org/10.1177/2373379916644449.

Cheng, V. and E. Tan (2016), "Overview of education and career guidance (ECG) implementation in Singapore schools", web document, www.asiapacificcda.org/resources/Documents/2016Conference/261_Overview_ECG\%20in\%20Sg\%20Schs.pdf (accessed 20 March 2017).

Costello, E.J. et al. (2003), "Prevalence and development of psychiatric disorders in childhood and adolescence", Archives of General Psychiatry, Vol. 60/8, pp. 837-844, http://dx.doi.org/10.1001/archpsyc.60.8.837.

Covington, M.V. and K.J. Müeller (2001), "Intrinsic versus extrinsic motivation: An approach/avoidance reformulation", Educational Psychology Review, Vol. 13/2, pp. 157-176, http://dx.doi.org/10.1023/A:1009009219144.

Díaz-Aguado Jalón, M.J., R. Martínez Arias and J. Martín Babarro (2010), "Estudio estatal sobre la convivencia escolar en la Educación Secundaria Obligatoria", Observatorio de Convivencia Escolar, Ministerio de Educación, https://sede.educacion.gob.es/publiventa/ descarga.action?f codigo agc=13567 19 (accessed 20 March 2017).

Diener, E. and M.E.P. Seligman (2002), "Very happy people", Psychological Science, Vol. 13/1, pp. 81-84, http://dx.doi.org/10.1111/1467$\underline{9280.00415 .}$.

Junta de Castilla y León (n.d.), Convivencia escolar [the school learning environment in Castile and Leon] www.educa.jcyl.es/ convivencia/es (accessed 6 April 2017).

Korea Education Development Institute (2015), Report on 2015 free semester system satisfaction survey, Korea Education Development Institute.

Maughan, B., S. Collishaw and A. Stringaris (2013), "Depression in childhood and adolescence", Journal of the Canadian Academy of Child and Adolescent Psychiatry, Vol. 22/1, pp. 35-40.

McDonald, T. (2013), Classroom Management, 2nd edition, Oxford University Press, South Melbourne, AU.

Merry, S.N. et al. (2011), "Psychological and educational interventions for preventing depression in children and adolescents", The Cochrane Database of Systematic Reviews, Vol. 7/5, pp. 1409-1685, http://dx.doi.org/10.1002/14651858.CD003380.pub3.

Ministry of Education, Singapore (2017), "Education and Career Guidance", Ministry of Education, Singapore, web page, https://www. moe.gov.sg/education/programmes/social-and-emotional-learning/education-and-career-guidance (accessed 11 April 2017).

OECD (2016a), PISA 2015 Results (Volume II): Policies and Practices for Successful Schools, OECD Publishing, Paris, http://dx.doi. org/10.1787/9789264267510-en.

OECD (2016b), OECD Regions at a Glance 2016, OECD Publishing, Paris, http://dx.doi.org/10.1787/reg glance-2016-en.

OECD (2004), Career Guidance and Public Policy: Bridging the Gap, OECD Publishing, Paris, http://dx.doi.org/10.1787/9789264105669en.

Ola Lindberg, J. and A. D. Olofsson (2010), Online Learning Communities and Teacher Professional Development: Methods for Improved Education Delivery, IGI Global.

Ontario, Ministry of Education (2015), The Ontario Curriculum, Grades 9-12: Health and Physical Education, web document, www.edu. gov.on.ca/eng/curriculum/secondary/health9to12.pdf (accessed 6 April 2017).

Sawyer, M.G. et al. (2010), "School-based prevention of depression: A randomised controlled study of the beyondblue schools research initiative", Journal of Child Psychology and Psychiatry, and Allied Disciplines, Vol. 51/2, pp. 199-209, http://dx.doi.org/10.1111/j.14697610.2009.02136.x.

Seligman, M.E.P. et al. (2009), "Positive education: Positive psychology and classroom interventions", Oxford Review of Education, Vol. 35/3, pp. 293-311, http://dx.doi.org/10.1080/03054980902934563.

Shute, R.H. and P.T. Slee (eds.) (2016), Mental Health and Wellbeing through Schools: The Way Forward, Routledge. 
SkillsFuture Singapore (2017), "SkillsFuture Programmes \& Initiatives for You", SkillsFuture Singapore, web page, www.skillsfuture.sg/ skillsfuture-for-you (accessed 11 April 2017).

Spence, S.H. and A.L. Shortt (2007), "Research review: Can we justify the widespread dissemination of universal, school-based interventions for the prevention of depression among children and adolescents?", Journal of Child Psychology and Psychiatry, and Allied Disciplines, Vol. 48/6, pp. 526-542, http://dx.doi.org/10.1111/j.1469-7610.2007.01738.x.

Sociescuela (n.d.), [online student well-being survey], https://sociescuela.es/es/index.php (accessed 6 April 2017).

UNESCO (2016), Happy Schools! A Framework for Learner Well-Being in the Asia-Pacific", UNESCO Asia and Pacific Regional Bureau for Education, Bankok, Thailand, web document http://unesdoc.unesco.org/images/0024/002441/244140E.pdf (accessed 6 April 2017).

Usher, A. and N. Kober (2012), "Can goals motivate students?", Center on Education Policy, Washington, D.C., web document , http:// files.eric.ed.gov/fulltext/ED532668.pdf (accessed 6 April 2017).

Vescio, V., D. Ross and A. Adams (2008), "A review of research on the impact of professional learning communities on teaching practice and student learning", Teaching and Teacher Education, Vol. 24/1, pp. 80-91, http://dx.doi.org/10.1016/j.tate.2007.01.004.

Veenstra, R. et al. (2014), "The role of teachers in bullying: The relation between antibullying attitudes, efficacy, and efforts to reduce bullying", Journal of Educational Psychology, Vol. 106/4, pp. 1135-1143, http://dx.doi.org/10.1037/a0036110. 



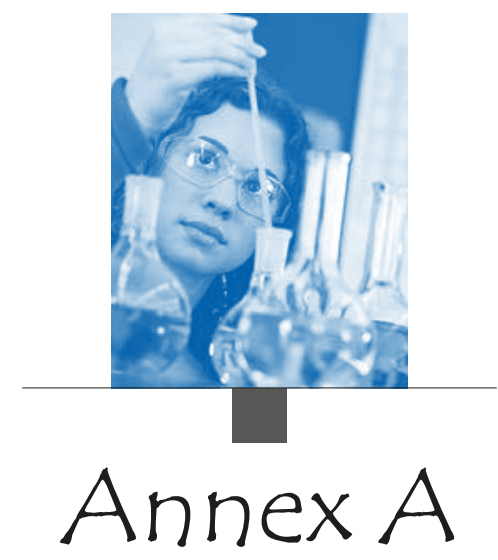

\section{PISA 2015 TECHNICAL BACKGROUND}

All tables in Annex A are available on line

Annex A1: Indices from the student questionnaire

Annex A2: The PISA target population, the PISA samples and the definition of schools http://dx.doi.org/10.1787/888933433129

Annex A3: Technical notes on analyses in this volume

Annex A4: Quality assurance

Annex A5: Changes in the administration and scaling of PISA 2015 and implications for trends analyses

Annex A6: Guidelines and caveats about interpreting the results

Note regarding B-S-J-G (China)

B-S-J-G (China) refers to the four PISA participating China provinces : Beijing, Shanghai, Jiangsu, Guangdong.

Note regarding CABA (Argentina)

CABA (Argentina) refers to the Ciudad Autónoma de Buenos Aires, Argentina.

Note regarding FYROM

FYROM refers to the Former Yugoslav Republic of Macedonia.

\section{Notes regarding Cyprus}

Note by Turkey: The information in this document with reference to "Cyprus" relates to the southern part of the Island. There is no single authority representing both Turkish and Greek Cypriot people on the Island. Turkey recognises the Turkish Republic of Northern Cyprus (TRNC). Until a lasting and equitable solution is found within the context of the United Nations, Turkey shall preserve its position concerning the "Cyprus issue".

Note by all the European Union Member States of the OECD and the European Union: The Republic of Cyprus is recognised by all members of the United Nations with the exception of Turkey. The information in this document relates to the area under the effective control of the Government of the Republic of Cyprus.

\section{A note regarding Israel}

The statistical data for Israel are supplied by and under the responsibility of the relevant Israeli authorities. The use of such data by the OECD is without prejudice to the status of the Golan Heights, East Jerusalem and Israeli settlements in the West Bank under the terms of international law. 


\section{ANNEX A1 INDICES FROM THE STUDENT QUESTIONNAIRE}

\section{Explanation of the indices}

This section explains the indices derived from the PISA 2015 student and school context questionnaires used in this volume.

Several PISA measures reflect indices that summarise responses from students, their parents, teachers or school representatives (typically principals) to a series of related questions. The questions were selected from a larger pool of questions on the basis of theoretical considerations and previous research. The PISA 2015 Assessment and Analytical Framework (OECD, 2016) provides an in-depth description of this conceptual framework. Structural equation modelling was used to confirm the theoretically expected behaviour of the indices and to validate their comparability across countries. For this purpose, a model was estimated separately for each country and collectively for all OECD countries. For a detailed description of other PISA indices and details on the methods, see the PISA 2015 Technical Report (OECD, forthcoming).

There are three types of indices: simple indices, new scale indices, and trend scale indices.

Simple indices are the variables that are constructed through the arithmetic transformation or recoding of one or more items in exactly the same way across assessments. Here, item responses are used to calculate meaningful variables, such as the recoding of the four-digit ISCO-08 codes into "Highest parents' socio-economic index (HISEI)" or teacher-student ratio based on information from the school questionnaire.

New and trend scale indices are the variables constructed through the scaling of multiple items. Unless otherwise indicated, the index was scaled using a two-parameter item response model (a generalised partial credit model was used in the case of items with more than two categories) and values of the index correspond to Warm likelihood estimates (WLE) (Warm, 1989). For details on how each scale index was constructed, see the PISA 2015 Technical Report (OECD, forthcoming). In general, the scaling was done in three stages:

1. The item parameters were estimated from equally-weighted samples of students from all countries and economies; only cases with a minimum number of three valid responses to items that are part of the index were included. In the case of trend indices, a common calibration linking procedure was used: countries/economies that participated in both PISA 2006 and PISA 2015 contributed both samples to the calibration of item parameters; each cycle, and, within each cycle, each country/ economy contributed equally to the estimation.

2. The estimates were computed for all students and all schools by anchoring the item parameters obtained in the preceding step.

3. For new scale indices, the Warm likelihood estimates were then standardised so that the mean of the index value for the OECD student population was zero and the standard deviation was one (countries being given equal weight in the standardisation process). Trend indices were equated so that the mean and standard deviation across OECD countries of rescaled PISA 2006 estimates and of the original estimates included in the PISA 2006 database matched. Trend indices are therefore reported on the same scale as used originally in PISA 2006, so that values can be directly compared to those included in the PISA 2006 database.

Sequential codes were assigned to the different response categories of the questions in the sequence in which the latter appeared in the student, school or parent questionnaires. Where indicated in this section, these codes were inverted for the purpose of constructing indices or scales. Negative values for an index do not necessarily imply that students responded negatively to the underlying questions. A negative value merely indicates that the respondents answered less positively than all respondents did on average across OECD countries. Likewise, a positive value on an index indicates that the respondents answered more favourably, or more positively, on average, than respondents in OECD countries did. Terms enclosed in brackets $<>$ in the following descriptions were replaced in the national versions of the student, school and parent questionnaires by the appropriate national equivalent. For example, the term <qualification at ISCED level 5 A $>$ was translated in the United States into "Bachelor's degree, post-graduate certificate program, Master's degree program or first professional degree program". Similarly the term <classes in the language of assessment> in Luxembourg was translated into "German classes" or "French classes", depending on whether students received the German or French version of the assessment instruments.

In addition to simple and scaled indices described in this annex, there are a number of variables from the questionnaires that were used in this volume and correspond to single items not used to construct indices. These non-recoded variables have prefix of "ST" for the questionnaire items in the student questionnaire and "SC" for the items in the school questionnaire. All the context questionnaires, and the PISA international database, including all variables, are available through www.oecd.org/pisa. 


\section{Student-level simple indices}

\section{Student age}

The age of a student (AGE) was calculated as the difference between the year and month of the testing and the year and month of a student's birth. Data on student's age were obtained from both the questionnaire (ST003) and the student tracking forms. If the month of testing was not known for a particular student, the median month for that country was used in the calculation.

\section{Parents' level of education}

Students' responses on questions ST005, ST006, ST007 and ST008 regarding parental education were classified using ISCED 1997 (OECD, 1999). Indices on parental education were constructed by recoding educational qualifications into the following categories: (0) None, (1) <ISCED level 1> (primary education), (2) <ISCED level 2> (lower secondary), (3) <ISCED level 3B or 3C $>$ (vocational/prevocational upper secondary), (4) $<$ ISCED level 3A $>$ (general upper secondary) and/or $<$ ISCED level $4>$ (non-tertiary post-secondary), (5) $<$ ISCED level 5B $>$ (vocational tertiary) and (6) $<$ ISCED level 5A $>$ and/or $<$ ISCED level $6>$ (theoretically oriented tertiary and postgraduate). Indices with these categories were provided for a student's mother (MISCED) and father (FISCED). In addition, the index of highest education level of parents (HISCED) corresponds to the higher ISCED level of either parent. The index of highest education level of parents was also recoded into estimated number of years of schooling (PARED). The correspondence between education levels and years of schooling is available in the PISA 2015 Technical Report (OECD, forthcoming).

\section{Parents' highest occupational status}

Occupational data for both the student's father and the student's mother were obtained from responses to open-ended questions. The responses were coded to four-digit ISCO codes (ILO, 2007) and then mapped to the international socio-economic index of occupational status (ISEI) (Ganzeboom and Treiman, 2003). In PISA 2015, as in PISA 2012, the new ISCO and ISEI in their 2008 version were used rather than the 1988 versions that had been applied in the previous four cycles (Ganzeboom, 2010). Three indices were calculated based on this information: father's occupational status (BFMJ2); mother's occupational status (BMMJ1); and the highest occupational status of parents (HISEI) which corresponds to the higher ISEI score of either parent or to the only available parent's ISEI score. For all three indices, higher ISEI scores indicate higher levels of occupational status.

\section{Immigrant background}

The PISA database contains three country-specific variables relating to the students' country of birth, their mother and father (COBN_S, COBN_M and COBN_F). The items ST019Q01TA, ST019Q01TB and ST019Q01TC were recoded into the following categories: (1) country of birth is the same as country of assessment and (2) other. The index of immigrant background (IMMIG) was calculated from these variables with the following categories: (1) non-immigrant students (those students who had at least one parent born in the country), (2) second-generation immigrant students (those born in the country of assessment but whose parent(s) were born in another country) and (3) first-generation immigrant students (those students born outside the country of assessment and whose parents were also born in another country). Students with missing responses for either the student or for both parents were assigned missing values for this variable.

\section{Grade repetition}

The grade repetition variable (REPEAT) was computed by recoding variables ST127Q01TA, ST127Q02TA and ST127Q03TA. REPEAT took the value of " 1 " if the student had repeated a grade in at least one ISCED level and the value of "0" if "no, never" was chosen at least once, given that none of the repeated grade categories were chosen. The index is assigned a missing value if none of the three categories were ticked in any levels.

\section{Study programme}

PISA collects data on study programmes available to 15-year old students in each country. This information is obtained through the student tracking form and the student questionnaire. In the final database, all national programmes are included in a separate derived variable (PROGN) where the first six digits represent the National Centre code, and the last two digits are the nationally specific programme code. All study programmes were classified using the International Standard Classification of Education (ISCED) (OECD, 1999). The following indices were derived from the data on study programmes:

- Programme level (ISCEDL) indicates whether students were at the lower or upper secondary level (ISCED 2 or ISCED 3 ).

- Programme designation (ISCEDD) indicates the designation of the study programme (A = general programmes designed to give access to the next programme level, $\mathrm{B}=$ programmes designed to give access to vocational studies at the next programme level, $\mathrm{C}=$ programmes designed to give direct access to the labour market, $\mathrm{M}=$ modular programmes that combine any or all of these characteristics).

- Programme orientation (ISCEDO) indicates whether the programme's curricular content was general, pre-vocational or vocational.

\section{Learning time}

Learning time in test language regular lessons (LMINS) was computed by multiplying the number of minutes on average in the test language class by number of test language class periods per week (ST061 and ST059). Comparable indices were computed for mathematics (MMINS) and science (SMINS). Learning time in total (TMINS) was computed using information about the average minutes in a <class period $>$ (ST061) in relation to information about the number of class periods per week attended in total (ST060). For convenience purposes, the information on learning time has been transformed into hours. 


\section{Out-of-school study time}

Students were asked in a slider-format question how much time they spent studying in addition to their required school schedule (ST071). The index OUTHOURS was computed by summing the time spent studying for different school subjects.

\section{Skipping classes or days of school}

Students' responses over whether, in the two weeks before the PISA test, they skipped classes (ST09) or days of school (ST115) at least once were used to derive an indicator of student truancy which takes value 0 if students reported not skipping any class and not skipping any day of school in the two weeks before the PISA test and value 1 if students reported skipping classes or days of school at least once in the same period.

\section{Arriving late for school}

Students responded to a question whether and how frequently they arrived late for school during the last two weeks before the PISA test (ST062). This variable is used to derive an indicator of student truancy which takes a value of 0 if students reported not arriving late to school or arrived to school less than 3 days in the last two weeks and takes a value of 1 if students reported arriving to school late at least three days in the same period.

\section{Perceived teacher support}

Perceived teacher support refers to students reporting "every lesson" or "most lessons" to the statements "The teacher shows an interest in every student's learning", "The teacher gives extra help when students need it" and "The teacher helps students with their learning" in their responses to a question on things that happen during their science lessons (ST100).

\section{Perceptions of teachers behaving unfairly}

Perception of teachers behaving unfairly refers to students reporting "a few times a month" or "once a week or more" to the statements "Teachers disciplined me more harshly than other students", "Teachers ridiculed me in front of others" or "Teachers said something insulting to me in front of others" in their responses to a question on their school experiences with teachers (ST039).

\section{Science-related career expectations}

In PISA 2015, students were asked to answer a question (ST114) about "what kind of job [they] expect to have when [they] are about 30 years old". Answers to this open-ended question were coded to four-digit ISCO codes (ILO, 2007), in variable OCOD3. This variable was used to derive the index of science-related career expectations.

Science-related career expectations are defined as those career expectations whose realisation requires further engagement with the study of science beyond compulsory education, typically in formal tertiary education settings. The classification of careers into science-related and non-science-related is based on the four-digit ISCO-08 classification of occupations.

Only professionals (major ISCO group 2) and technicians/associate professionals (major ISCO group 3) were considered to fit the definition of science-related career expectations. In a broad sense, several managerial occupations (major ISCO group 1) are clearly science-related: these include research and development managers, hospital managers, construction managers, and other occupations classified under production and specialised services managers (submajor group 13). However, it was considered that when science-related experience and training is an important requirement of a managerial occupation, these are not entry-level jobs and 15-year-old students with science-related career expectations would not expect to be in such a position by age 30 .

Several skilled agriculture, forestry and fishery workers (major ISCO group 6) could also be considered to work in science-related occupations. The United States O*NET OnLine (2016) classification of science, technology, engineering and mathematics (STEM) occupations indeed include these occupations. These, however, do not typically require formal science-related training or study after compulsory education. On these grounds, only major occupation groups that require ISCO skill levels 3 and 4 were included among science-related occupational expectations.

Among professionals and technicians/associate professionals, the boundary between science-related and non-science related occupations is sometimes blurred, and different classifications draw different lines.

The classification used in this report includes four groups of jobs: ${ }^{1}$

1. Science and engineering professionals: All science and engineering professionals (submajor group 21), except product and garment designers (2163), graphic and multimedia designers (2166).

2. Health professionals: All health professionals in submajor group 22 (e.g. doctors, nurses, veterinarians), with the exception of traditional and complementary medicine professionals (minor group 223).

3. ICT professionals: All information and communications technology professionals (submajor group 25).

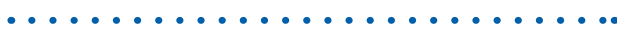

1. In the United Kingdom (excluding Scotland), career expectations were coded to the three-digit level only. As a result, the occupations of product and garment designers (ISCO08: 2163) and graphic and multimedia designers (2166) are included among science and engineering professionals, medical and dental prosthetic technicians (3214) are included among science technicians and associate professionals, while telecommunications engineering technicians (3522) are excluded. These careers represent a small percentage of the students classified as having science-related career expectations, such that results are not greatly affected. 
4. Science technicians and associate professionals, including:

- physical and engineering science technicians (minor group 311)

- life science technicians and related associate professionals (minor group 314)

- air traffic safety electronic technicians (3155)

- medical and pharmaceutical technicians (minor group 321), except medical and dental prosthetic technicians (3214)

- telecommunications engineering technicians (3522).

\section{How this classification compares to existing classifications}

When three existing classifications of 15-year-olds' science career expectations, all based on the International Standard Classification of Occupations (ISCO), 1988 edition (ISCO-88), are compared to the present classification, based on ISCO-08, a few differences emerge. Some are due to the updated version of occupational codings (as discussed in the next section); the remaining differences are summarised in Table A1.1.

Table A1.1 - Differences in the definition of science-related career expectations

\begin{tabular}{|c|c|c|c|c|}
\hline & $\begin{array}{l}\text { This } \\
\text { classification }\end{array}$ & $\begin{array}{l}\text { OECD } \\
(2007)\end{array}$ & $\begin{array}{c}\text { Sikora and } \\
\text { Pokropek (2012) }\end{array}$ & $\begin{array}{c}\text { Kjærnsli } \\
\text { and Lie (2011) }\end{array}$ \\
\hline Science-related managerial jobs & out & in & in & out \\
\hline Psychologists & out & in & in & out \\
\hline Sociologists and social work professionals & out & in & out & out \\
\hline $\begin{array}{l}\text { Photographers and image and sound recording equipment } \\
\text { operators, broadcasting and telecommunications equipment } \\
\text { operators }\end{array}$ & out & in & in & out \\
\hline Statistical, mathematical and related associate professionals & out & out & in & out \\
\hline Aircraft controllers (e.g. pilots, air traffic controllers) & out & in & in & out \\
\hline Ship controllers (Ships' desk officers, etc.) & out & out & in & out \\
\hline $\begin{array}{l}\text { Medical assistants, dental assistants, veterinary assistants, } \\
\text { nursing and midwifery associate professionals }\end{array}$ & out & in & in & out \\
\hline $\begin{array}{l}\text { Computer assistants, computer equipment operators } \\
\text { and industrial robot controllers }\end{array}$ & out & out & out & in \\
\hline Air traffic safety electronic technicians & in & in & in & out \\
\hline Pharmaceutical technicians and assistants & in & in & in & out \\
\hline Dieticians and nutritionists & in & in & in & out \\
\hline
\end{tabular}

\section{Developing a comparable classification for ISCO-88}

The same open-ended question was also included in the PISA 2006 questionnaire (ID in 2006: ST30), but students' answers were coded in the PISA 2006 database according to ISCO-88. It is not possible to ensure a strictly comparable classification. To report changes over time, the correspondence described in Table A1.2 was used to derive a similar classification based on PISA 2006 data:

Table A1.2 - ISC0-08 to ISC0-88 correspondence table for science-related career expectations

\begin{tabular}{l|l|l}
\hline Group & ISCO-08 & ISCO-88 \\
\hline Science and engineering professionals & $21 \mathrm{xx}($ except 2163 and 2166) & 21xx (except 213x), 221x \\
\hline Health professionals & $22 \mathrm{xx}($ except 223x) & $22 \mathrm{xx}(\mathrm{except} 221 \mathrm{x}), 3223,3226$ \\
\hline ICT professionals & $25 \mathrm{xx}$ & $213 \mathrm{x}$ \\
\hline $\begin{array}{l}\text { Science technicians and associate } \\
\text { professionals }\end{array}$ & $311 \mathrm{x}, 314 \mathrm{x}, 3155,321 \mathrm{x}(\mathrm{except} 3214)$, & $311 \mathrm{x}, 3133,3145,3151,321 \mathrm{x}, 3228$ \\
\hline
\end{tabular}

The main differences between ISCO-88 and ISCO-08, for the purpose of deriving the index of science-related career expectations, are the following:

- Medical equipment operators (ISCO-88: 3133) correspond to medical imaging and therapeutic equipment technicians in ISCO-08; air traffic safety technicians (ISCO-88: 3145) correspond to air traffic safety electronics technicians in ISCO-08; building and fire inspectors (ISCO-88: 3151) mostly correspond to civil engineering technicians in ISCO-08.

- Dieticians and nutritionists (ISC0-88: 3223) are classified among professionals in ISCO-08. For consistency, this ISCO-88 occupation was classified among health professionals. 
- Physiotherapists and related associate professionals (ISCO-88: 3226) form two distinct categories in ISCO-08, with physiotherapists classified among professionals. Given that students who expect to work as physiotherapists far outnumber those who expect to work as related associate professionals, this ISCO-88 occupation was classified among health professionals.

- Several health-related occupations classified as "modern health associate professionals" in ISCO-88 are included among health professionals in ISCO-08 (e.g. speech therapist, ophthalmic opticians). While health professionals are, in general, included among science-related careers, health associate professionals are not included among science-related careers. In applying the classification to ISCO-88, the entire code was excluded from science-related careers.

- Telecommunications engineering technicians (ISCO-08: 3522) do not form a separate occupation in ISCO-88, where they can be found among electronics and telecommunications engineering technicians (ISCO-88: 3114).

- Information and communications technology professionals form a distinct submajor group (25) in ISCO-08 but are classified among physical, mathematical and engineering science professionals in ISCO-88.

\title{
Student-level scale indices \\ New scale indices
}

\section{Schoolwork-related anxiety}

The index of schoolwork-related anxiety (ANXTEST) was constructed using student responses to question (ST118) over the extent they strongly agreed, agreed, disagreed or strongly disagreed with the following statements when asked to think about him or herself: I often worry that it will be difficult for me taking a test; I worry that I will get poor <grades> at school; Even if I am well prepared for a test I feel very anxious; I get very tense when I study; I get nervous when I don't know how to solve a task at school.

\begin{abstract}
Achievement motivation
The index of achievement motivation (MOTIVAT) was constructed using students' responses to a new question developed for PISA 2015 (ST119). Students reported, on a four-point Likert scale with the answering categories "strongly disagree", "disagree", "agree", and "strongly agree", their agreement with the following statements: I want top grades in most or all of my courses; I want to be able to select from among the best opportunities available when I graduate; I want to be the best, whatever I do; I see myself as an ambitious person; I want to be one of the best students in my class. Higher values indicate that students have greater achievement motivation.
\end{abstract}

\section{Trend scale indices}

Enjoyment of science

The index of enjoyment of science (JOYSCIE) was constructed based on a trend question (ST094) from PISA 2006 (ID in 2006 : ST16), asking students on a four-point Likert scale with the categories "strongly agree", "agree", "disagree", and "strongly disagree" about their agreement with the following statements: I generally have fun when I am learning <broad science> topics; I like reading about <broad science>; I am happy working on <broad science > topics; I enjoy acquiring new knowledge in $<$ broad science $>$; and I am interested in learning about <broad science $>$. The derived variable JOYSCIE was equated to the corresponding scale in the PISA 2006 database, thus allowing for a trend comparison between PISA 2006 and PISA 2015. Higher values on the index reflect greater levels of agreement with these statements.

\section{Sense of belonging}

The index of sense of belonging (BELONG) was constructed using students' responses to a trend question about their sense of belonging to school. Students reported, on a four-point Likert scale with the answering categories "strongly agree", "agree", "disagree", and "strongly disagree", their agreement with the following statements (ST034): I feel like an outsider (or left out of things) at school; I make friends easily at school; I feel like I belong at school; I feel awkward and out of place in my school; Other students seem to like me; I feel lonely at school. The answers to three items were reversed-coded so that higher values in the index indicate a greater sense of belonging.

\section{Science learning in school}

PISA 2015 focused on science learning in school by including several questions about the learning environment in science lessons. They asked how often specific activities happened in the school science course. The questions were used to create the following indices: teacher-directed instruction, perceived feedback, adaptive instruction, enquiry-based instruction, teacher support to students and disciplinary climate. Higher values in these indices indicate that the activities happened more frequently in science lessons.

\section{Teacher-directed instruction}

The index of teacher-directed instruction (TDTEACH) was constructed from students' reports on how often ("never or almost never"; "some lessons"; "many lessons"; "every lesson or almost every lesson") the following happened in their science lessons (ST103): The teacher explains scientific ideas; A whole class discussion takes place with the teacher; The teacher discusses our questions; The teacher demonstrates an idea. 


\section{Perceived feedback}

The index of perceived feedback (PERFEED) was constructed from students' reports on how often ("never or almost never"; "some lessons"; "many lessons"; "every lesson or almost every lesson") the following happened in their science lessons (ST104): The teacher tells me how I am performing in this course; The teacher gives me feedback on my strengths in this <school science> subject; The teacher tells me in which areas I can still improve; The teacher tells me how I can improve my performance; The teacher advises me on how to reach my learning goals.

\section{Adaptive instruction}

The index of adaptive instruction (ADINST) was constructed from students' reports on how often ("never or almost never"; "some lessons"; "many lessons"; "every lesson or almost every lesson") the following happened in their science lessons (ST107): The teacher adapts the lesson to my class's needs and knowledge; The teacher provides individual help when a student has difficulties understanding a topic or task; The teacher changes the structure of the lesson on a topic that most students find difficult to understand.

\section{Enquiry-based instruction}

The index of enquiry-based instruction (IBTEACH) was constructed from students' reports on how often ("in all lessons"; "in most lessons"; "in some lessons"; "never or hardly ever") the following happened in their science lessons (ST098): Students are given opportunities to explain their ideas; Students spend time in the laboratory doing practical experiments; Students are required to argue about science questions; Students are asked to draw conclusions from an experiment they have conducted; The teacher explains how a science idea can be applied to a number of different phenomena; Students are allowed to design their own experiments; There is a class debate about investigations; The teacher clearly explains the relevance of science concepts to our lives; Students are asked to do an investigation to test ideas.

\section{Disciplinary climate}

The index of disciplinary climate (DISCLISCI) was constructed from students' reports on how often ("every lesson", "most lessons", "some lessons", "never or hardly ever") the following happened in their science lessons (ST097): The teacher shows an interest in every student's learning; The teacher gives extra help when students need it; The teacher helps students with their learning; The teacher continues teaching until students understand the material; The teacher gives students an opportunity to express their opinions. Schools were classified with having a positive disciplinary climate if the index of disciplinary climate for the school is above the national average and classified as having a negative disciplinary climate if below the national average.

\section{Science self-efficacy}

The index of science self-efficacy (SCIEEFF) was constructed based on a trend question (ST129) that was taken from PISA 2006 (ID in 2006: ST17). Students were asked, using a four-point answering scale with the categories "I could do this easily", "I could do this with a bit of effort", "I would struggle to do this on my own", and "I couldn't do this", to rate how they would perform in the following science tasks: recognise the science question that underlies a newspaper report on a health issue; explain why earthquakes occur more frequently in some areas than in others; describe the role of antibiotics in the treatment of disease; identify the science question associated with the disposal of garbage; predict how changes to an environment will affect the survival of certain species; interpret the scientific information provided on the labelling of food items; discuss how new evidence can lead you to change your understanding about the possibility of life on Mars; and identify the better of two explanations for the formation of acid rain. Responses were reverse-coded so that higher values of the index correspond to higher levels of science self-efficacy. The derived variable SCIEEFF was equated to the corresponding scale in the PISA 2006 database, thus allowing for a trend comparison between PISA 2006 and PISA 2015.

\section{Scaling of indices related to the PISA index of economic social and cultural status}

The PISA index of economic, social and cultural status (ESCS) was derived, as in previous cycles, from three variables related to family background: parents' highest level of education (PARED), parents' highest occupation status (HISEI), and home possessions (HOMEPOS), including books in the home. PARED and HISEI are simple indices, described above. HOMEPOS is a proxy measure for family wealth.

\section{Household possessions}

In PISA 2015, students reported the availability of 16 household items at home (ST011) including three country-specific household items that were seen as appropriate measures of family wealth within the country's context. In addition, students reported the amount of possessions and books at home (ST012 and ST013).

HOMEPOS is a summary index of all household and possession items (ST011, ST012 and ST013). The home possessions scale for PISA 2015 was computed differently than in the previous cycles, to align the IRT model to the one used for all cognitive and non-cognitive scales. Categories for the number of books in the home are unchanged in PISA 2015. The ST011 items (1 = "yes", $2="$ no") were reverse-coded so that a higher level indicates the presence of the indicator.

\section{Family wealth}

In PISA 2015, students reported the availability at home of a link to the Internet and a room of their own. They also reported the number of number of televisions, cars, rooms with a bath or shower, smartphones, computers (desktop computer, portable 
laptop, or notebook), tablet computers, e-book readers, they have at home. In addition, countries added three specific household items that were seen as appropriate measures of family wealth within the country's context. The index of family wealth was derived from this information.

\section{Computation of ESCS}

For the purpose of computing the PISA index of economic, social and cultural status (ESCS), values for students with missing PARED, HISEI or HOMEPOS were imputed with predicted values plus a random component based on a regression on the other two variables. If there were missing data on more than one of the three variables, ESCS was not computed and a missing value was assigned for ESCS.

The PISA index of economic, social and cultural status was derived from a principal component analysis of standardised variables (each variable has an OECD mean of zero and a standard deviation of one), taking the factor scores for the first principal component as measures of the PISA index of economic, social and cultural status. All countries and economies (both OECD and partner countries/economies) contributed equally to the principal component analysis, while in previous cycles, the principal component analysis was based on OECD countries only. However, for the purpose of reporting the ESCS scale has been transformed with zero being the score of an average OECD student and one being the standard deviation across equally weighted OECD countries.

Principal component analysis was also performed for each participating country or economy separately, to determine to what extent the components of the index operate in similar ways across countries or economy.

\section{School-level simple indices School type}

Schools are classified as either public or private according to whether a private entity or a public agency has the ultimate power for decision making concerning its affairs (SC013). As in previous PISA surveys, the index on school type (SCHLTYPE) has three categories, based on two questions: SC013 which asks if the school is a public or a private school, and SC016 which asks about the sources of funding. This index was calculated in 2015 and in all previous cycles.

\section{Year of reference for the trends in resources, policies and practices}

Resources, policies and practices are compared between PISA 2015 and previous PISA cycles throughout the report. Whenever possible, the report compares PISA 2015 to PISA 2006 since science was the core subject in both cycles. However, PISA 2015 is compared to more recent cycles when the questions were not included in the PISA 2006 questionnaires, the wording of the questions changed (even slightly), or the number/order of the items within each question changed substantively between cycles.

\section{Proportion of missing observations for variables used in this volume}

Unless otherwise indicated, no adjustment is made for non-response to questionnaires in analyses included in this volume. The reported percentages and estimates based on indices refer to the proportion of the sample with valid responses to the corresponding questionnaire items. Tables A1.8a, A1.8b and A1.8c, available online, report the proportion of the sample covered by analyses based on student or school questionnaire variables. Where this proportion shows large variation across countries/economies or across time, caution is required when comparing results on these dimensions. Table A1.8d reports the differences in student characteristics between students with available data and students with missing data.

\section{Derivation of the index of exposure to bullying}

The development of comparable measures of student and school characteristics from the student and school questionnaires is a major goal of PISA. Cross-country validity of the measured items requires more than a thorough process of translation into different languages. It also makes assumptions about having measured similar characteristics in different national and cultural contexts. Many questionnaire items in PISA are designed to be combined in some way in order to measure latent constructs that cannot be observed directly (e.g. a student's achievement motivation). Transformations or scaling procedures are applied to these items in order to construct meaningful indices (OECD, forthcoming).

PISA 2015 includes eight items on students' exposure to bullying or bullying victimisation. A scale for exposure to bullying is not included in the international database, but was derived for this report using confirmatory factor analysis (CFA). This annex describes how the scale was constructed and reports the results of tests of the measurement reliability and cross-country invariance of the scale. These tests are important because international comparisons and analysis based on the scale are possible as long as the latent construct ("exposure to bullying" in this case) is the same and measured in the same way across different countries and economies. The scaling analysis used the software Mplus, Version 7.1 (Muthén and Muthén, 1998-2012).

Exploratory analysis of the data showed that the first two of the eight items on bullying did not load well onto a unidimensional construct and were also not strongly correlated with the other six items. The averages of these two items also vary across countries much more than the other six items, potentially indicating measurement issues (e.g. students in some countries might have interpreted the questions differently from students in other countries). In order to produce a scale of bullying with a sufficiently good model fit in all countries and comparability across countries, the scaling was limited to the six other items. Students reported how frequently they were exposed to the types of bullying described by the six items, according to 
a four-point scale: 1) "Never or almost never"; 2) "A few times a year"; 3) "A few times a month"; 4) "Once a week or more". In alignment with how previous literature has defined "frequent bullying" [Salmivalli et al., 2011], categories 3) and 4) were aggregated into a single category. Such aggregation only marginally affected the overall fit of the scale but improved the international invariance of the scale. Students might find it relatively difficult to distinguish between "a few times a month" and "once a week or more", so that the variation between the two categories might reflect different interpretations of the question or different response styles across countries, rather than real differences in exposure to bullying. Figure A1.1 summarises how the original data in PISA 2015 were selected and recoded for scaling purposes.

Figure A1.1 - Questionnaire items used for the scale of exposure to bullying

\begin{tabular}{l|c|c|c}
\hline & $\begin{array}{c}\text { "Never or } \\
\text { almost never" }\end{array}$ & $\begin{array}{c}\text { "A few times } \\
\text { a year" }\end{array}$ & $\begin{array}{c}\text { "A few times a month" } \\
\text { or "Once a week or more" } \\
\text { (the two categories are merged) }\end{array}$ \\
\hline Q01: Iot (Not used for the scale) & $\square_{7}$ & $\square_{z}$ & $\square_{3}$ \\
\hline Q02: I got picked on by other students. (Not used for the scale) & $\square_{7}$ & $\square_{z}$ & $\square_{3}$ \\
\hline Q03: Other students left me out of things on purpose. & $\square_{1}$ & $\square_{2}$ & $\square_{3}$ \\
\hline Q04: Other students made fun of me. & $\square_{1}$ & $\square_{2}$ & $\square_{3}$ \\
\hline Q05: I was threatened by other students. & $\square_{1}$ & $\square_{2}$ & $\square_{3}$ \\
\hline Q06: Other students took away or destroyed things that belonged to me. & $\square_{1}$ & $\square_{2}$ & $\square_{3}$ \\
\hline Q07: I got hit or pushed around by other students. & $\square_{1}$ & $\square_{2}$ & $\square_{3}$ \\
\hline Q08: Other students spread nasty rumours about me. & $\square_{1}$ & $\square_{2}$ & $\square_{3}$ \\
\hline
\end{tabular}

The data on bullying are not continuous but take one of the three frequency categories, and thus require a model that explicitly accounts for this categorical distribution (Muthén, 1997, 1993). The model assumes that an observed variable, $x$ (one of the six types of bullying), comes from a latent response variable, $x^{*}$ (the student's actual exposure to that type of bullying). The observed categories of $x$ for each student $i$ correspond to particular thresholds along the continuum of the latent variable $x^{*}$ :

And

$$
\begin{aligned}
& x_{i}=\text { "Never or almost never"(category } 1 \text { ) if } x_{i}^{*} \leq \tau_{i, 1} ; \\
& x_{i}=\text { "A few times a year" (category 2) if } \tau_{i, 1}<x_{i}^{*} \leq \tau_{i, 2} ;
\end{aligned}
$$

$$
\mathrm{x}_{i}=\text { "A few times a month" or "once a week or more" (category } 3 \text { ); if } \mathrm{x}_{i}^{*}>\tau_{i, 2}
$$

The thresholds are parameters to be estimated in the model. Figure A1.2 provides a graphical representation of the model used to scale the six items on bullying. The model uses a theta parameterisation and fixes for identification the first factor loading to 1 , the latent variable means to 0 and the residual variance to 1 across all groups.

\section{Figure A1.2 - Representation of the categorical model for the scale of exposure to bullying}

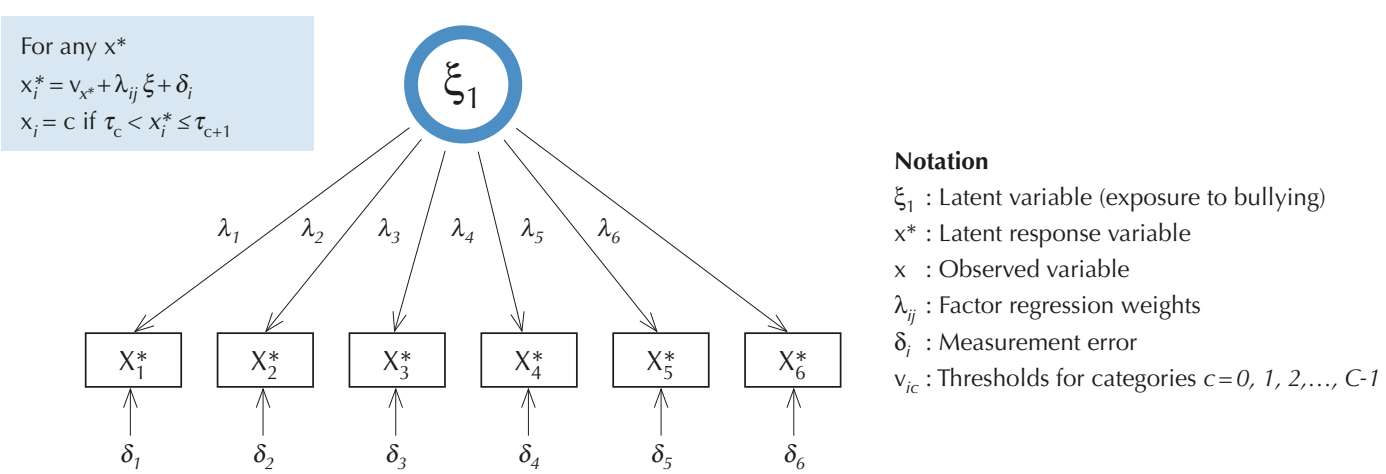

A first method to check the reliability of the scale is to estimate the correlation between the different items included in the scale across all countries. Cronbach's alpha measures the average covariance between item pairs, and can be used to check the internal consistency of a scaled index within the countries and to compare it between the countries (OECD, forthcoming). Table A1.4 shows that, on average (assigning equal weight to all countries with available data) the scale of exposure to bullying has a Cronbach alpha of 0.83. The Cronbach alpha ranges between 0.71 (lowest) for Korea to 0.9 (highest) for Qatar, suggesting that the correlation between the six items included in the scale is acceptable in most countries. 
Measurement invariance of the scale is usually established through a set of hierarchical tests, ranging from least strict to most strict. Chi-square tests, chi-square difference tests, fit indices, and changes in fit indices across specifications are typical measures of measurement invariance. Three levels of invariance are analysed in this annex: 1) configural (or baseline) invariance; 2) metric (or equal slopes) invariance; 3) scalar (or equal slopes and thresholds) invariance. Configural invariance is verified if, for two or more populations, the same construct is measured with the same indicators in the same way. Metric invariance requires that, in addition to configural invariance, all factor loadings are statistically equivalent. For scalar invariance, in addition to metric invariance, all thresholds should be statistically equivalent.

When the slope and thresholds for all items in the measurement model are not significantly different across groups, full scalar equivalence is achieved. However, Byrne et al. (1989) have argued that full scalar equivalence is not a necessary condition for comparisons to be valid. If at least two items per latent variable (namely, the item that is fixed at unity to identify the model and one other item) are equivalent, comparisons can be validly made across countries (Steenkamp and Baumgartner, 1998). Thus, partial equivalence does not require the invariance of all loadings and intercepts in all countries. The final model used for the bullying scale was based on a partial-invariance specification in which at least three items are fixed across all countries, and up to three items are allowed to vary across 11 countries and economies (see Table A1.5 for details on which constraints were relaxed in which countries). The selection of the country-items pairs that were freely estimated was determined empirically, on the basis on the deterioration of fit associated with constraining these items to baseline values.

Table A1.5 reports the contribution of the different countries/economies to the Chi-square fit statistic under three different model specifications (configural, scalar and scalar with partial invariance). A high value of the Chi-square test statistic indicates a worse fit of the model. The Chi-square is sensitive to sample size (Bentler and Bonett, 1980).

Table A1.3 shows the change in model fit associated with assuming metric and scalar invariance, under the full and partial invariance specifications. The model fit is measured by the comparative fit index (CFI) and by the Root Mean Square Error of Approximation (RMSEA). A value of CFI equal to 1 indicates perfect fit; a value around 0.9 is generally considered acceptable. A value of the RMSEA equal to 0.00 indicates perfect fit; values between 0.05 and 0.08 are considered acceptable. As can be seen from the table, allowing up to three items to be estimated freely in a limited number of countries significantly reduces the deterioration in the model fit associated with assuming equal slopes in all countries. When allowing factor loadings to vary for up to 3 items in 11 countries and economies, the change in the model fit is within defensible criteria for measurement invariance in categorical models (Rutkowski and Svetina, 2017; Rutkowski and Svetina, 2013). These findings support, to some extent, the international comparisons described in Chapter 8. However, given that only partial and not full invariance could be verified, some caution needs to be exercised in interpreting cross-country analysis based on this scale.

Table A1.3 - Change in fit indexes with restrictions for full and partial invariance

\begin{tabular}{l|c|c|c|c|c}
\hline & Configural & Metric & Scalar & Change in model fit (Metric - Configural) & Change in model fit (Scalar-Configural) \\
\cline { 2 - 6 } & 0.989 & 0.978 & 0.979 & -0.011 & -0.010 \\
\hline CFI $^{1}$ & 0.069 & 0.066 & 0.076 & -0.003 & 0.007 \\
\hline RMSEA $^{2}$ & \multicolumn{7}{|c}{ Pull invariance } \\
\hline & 0.989 & 0.984 & 0.982 & -0.005 & -0.007 \\
\hline CFI & 0.069 & 0.068 & 0.061 & -0.001 & -0.008 \\
\hline RMSEA & &
\end{tabular}

1. Comparative Fit Index.

2. Root Mean Square Error Of Approximation.

Tables A1.6a, A1.6b and A1.6c report the factor loadings and thresholds for the baseline model (configural) and for the specification with partially fixed slopes and thresholds (scalar) that accounts for PISA's complex sampling scheme. Table A1.7 shows the rate of victimisation by item of students in the top $10 \%$ of the international index of exposure to bullying.

\section{Table available online}

Table A1.4 Cronbach Alpha reliability coefficients for the scale of exposure to bullying (http://dx.doi.org/10.1787/888933473532)

Table A1.5 Chi-Square tests of model fit (http://dx.doi.org/10.1787/888933473544)

Table A1.6a Factor loadings for the configural (baseline) model (http://dx.doi.org/10.1787/888933473558)

Table A1.6b Factor loadings for the scalar model with partial invariance and replicate weights (http://dx.doi.org/10.1787/888933473565) 
Table A1.6c Estimated thresholds for the configural (baseline) model (http://dx.doi.org/10.1787/888933473578)

Table A1.6d Estimated thresholds for the scalar model with partial invariance and replicate weights (http://dx.doi.org/10.1787/888933473585)

Table A1.7 Rate of victimisation of "frequently bullied students" (http://dx.doi.org/10.1787/888933473597)

Table A1.8a Weighted share of responding students covered by analyses based on student and educational career questionnaire (http://dx.doi.org/10.1787/888933473606)

Table A1.8b Weighted share of responding students covered by analyses based on school questionnaire (http://dx.doi.org/10.1787/888933473611)

Table A1.8c Weighted share of responding students covered by analyses based on parent questionnaire (http://dx.doi.org/10.1787/888933473622)

Table A1.8d Differences between students with complete and students with missing observations on the parental questionnaire (http://dx.doi.org/10.1787/888933473637)

\section{References}

Bentler, P. M. and D.G. Bonett (1980), "Significance tests and goodness of fit in the analysis of covariance structures", Psychological Bulletin, Vol. 88/3, pp. 588-606, http://dx.doi.org/10.1037/0033-2909.88.3.588.

Byrne, B. M., R.J. Shavelson and B. Muthén (1989), "Testing for the equivalence of factor covariance and mean structures: The issue of partial measurement invariance", Psychological Bulletin, Vol. 105/3, pp. 456-466, http://dx.doi.org/10.1037/0033-2909.105.3.456.

Ganzeboom, H.B.G. (2010), "A new international socio-economic index [ISEI] of occupational status for the International Standard Classification of Occupation 2008 [ISCO-08] constructed with data from the ISSP 2002-2007; with an analysis of quality of occupational measurement in ISSP", Conference paper presented at the Annual Conference of International Social Survey Programme, Lisbon, Portugal.

Ganzeboom, H. B.G. and D.J. Treiman (2003), "Three internationally standardised measures for comparative research on occupational status", in J.H.P. Hoffmeyer-Zlotnik and C. Wolf (eds.), Advances in Cross-National Comparison: A European Working Book for Demographic and SocioEconomic Variables, Kluwer Academic Press, New York, NY, pp. 159-193.

Kjærnsli, M. and S. Lie (2011), "Students' preference for science careers: International comparisons based on PISA 2006", International Journal of Science Education, Vol. 33/1, pp. 121-44, http://dx.doi.org/10.1080/09500693.2010.518642.

OECD (forthcoming), PISA 2015 Technical Report, PISA, OECD Publishing, Paris.

OECD (2016), PISA 2015 Assessment and Analytical Framework: Science, Reading, Mathematic and Financial Literacy, PISA, OECD Publishing, Paris, http://dx.doi.org/10.1787/9789264255425-en.

OECD (2007), PISA 2006: Science Competencies for Tomorrow's World, OECD Publishing, Paris, http://dx.doi.org/10.1787/9789264040014-en.

OECD (1999), Classifying Educational Programmes: Manual for ISCED-97 Implementation in OECD Countries, OECD Publishing, Paris.

O*NET OnLine (n.d), "All STEM disciplines", web page, www.onetonline.org/find/stem?t=0, (accessed 4 October 2016).

Rutkowski, L. and D. Svetina (2017), "Measurement invariance in international surveys: Categorical indicators and fit measure performance", Applied Measurement in Education, Vol. 30/1, pp. 39-51,

Rutkowski, L. and D. Svetina (2013), "Assessing the hypothesis of measurement invariance in the context of large-scale international surveys", Educational and Psychological Measurement, Vol. 74/1, pp. 31-57, http://dx.doi.org/110.1177/0013164413498257.

Sikora, J. and A. Pokropek (2012), "Gender segregation of adolescent science career plans in 50 countries", Science Education, Vol. 96/2, pp. 234-264, http://dx.doi.org/10.1002/sce.20479.

Salmivalli C., A. Kärnä and E. Poskiparta (2011), "Counteracting bullying in Finland: The KiVa Program and its effects on different forms of being bullied", International Journal of Behavioral Development, Vol. 35, pp. 405-411, http://doi.org/10.1177/0165025411407457.

Steenkamp, J. and H. Baumgartner (1998), "Assessing measurement invariance in cross-national consumer research", Journal of Consumer Research, Vol. 25/1, pp. 78-107, http://doi.org/10.1086/209528.

Warm, T.A. (1989), "Weighted likelihood estimation of ability in item response theory", Psychometrika, Vol. 54/3, pp. 427-450, http://doi. org/10.1007/BF02294627. 
ANNEX A2

THE PISA TARGET POPULATION, THE PISA SAMPLES AND THE DEFINITION OF SCHOOLS

\section{Definition of the PISA target population}

PISA 2015 provides an assessment of the cumulative outcomes of education and learning at a point at which most young adults are still enrolled in initial education.

A major challenge for an international survey is to ensure that international comparability of national target populations is guaranteed.

Differences between countries in the nature and extent of pre-primary education and care, the age at entry into formal schooling and the institutional structure of education systems do not allow for a definition of internationally comparable grade levels. Consequently, international comparisons of performance in education typically define their populations with reference to a target age group. Some previous international assessments have defined their target population on the basis of the grade level that provides maximum coverage of a particular age cohort. A disadvantage of this approach is that slight variations in the age distribution of students across grade levels often lead to the selection of different target grades in different countries, or between education systems within countries, raising serious questions about the comparability of results across, and at times within, countries. In addition, because not all students of the desired age are usually represented in grade-based samples, there may be a more serious potential bias in the results if the unrepresented students are typically enrolled in the next higher grade in some countries and the next lower grade in others. This would exclude students with potentially higher levels of performance in the former countries and students with potentially lower levels of performance in the latter.

In order to address this problem, PISA uses an age-based definition for its target population, i.e. a definition that is not tied to the institutional structures of national education systems. PISA assesses students who were aged between 15 years and 3 (complete) months and 16 years and 2 (complete) months at the beginning of the assessment period, plus or minus a 1-month allowable variation, and who were enrolled in an educational institution with grade 7 or higher, regardless of the grade level or type of institution in which they were enrolled, and regardless of whether they were in full-time or part-time education. Educational institutions are generally referred to as schools in this publication, although some educational institutions (in particular, some types of vocational education establishments) may not be termed schools in certain countries. As expected from this definition, the average age of students across OECD countries was 15 years and 9 months. The range in country means was 2 months and 18 days ( 0.20 years), from the minimum country mean of 15 years and 8 months to the maximum country mean of 15 years and 10 months.

Given this definition of population, PISA makes statements about the knowledge and skills of a group of individuals who were born within a comparable reference period, but who may have undergone different educational experiences both in and outside school. In PISA, these knowledge and skills are referred to as the outcomes of education at an age that is common across countries. Depending on countries' policies on school entry, selection and promotion, these students may be distributed over a narrower or a wider range of grades across different education systems, tracks or streams. It is important to consider these differences when comparing PISA results across countries, as observed differences between students at age 15 may no longer appear later on as/if students' educational experiences converge over time.

If a country's scores in science, reading or mathematics are significantly higher than those in another country, it cannot automatically be inferred that the schools or particular parts of the education system in the first country are more effective than those in the second. However, one can legitimately conclude that the cumulative impact of learning experiences in the first country, starting in early childhood and up to the age of 15, and embracing experiences in school, home and beyond, have resulted in higher outcomes in the literacy domains that PISA measures.

The PISA target population does not include residents attending schools in a foreign country. It does, however, include foreign nationals attending schools in the country of assessment.

To accommodate countries that requested grade-based results for the purpose of national analyses, PISA 2015 provided a sampling option to supplement age-based sampling with grade-based sampling.

\section{Population coverage}

All countries and economies attempted to maximise the coverage of 15-year-olds enrolled in education in their national samples, including students enrolled in special-education institutions. As a result, PISA 2015 reached standards of population coverage that are unprecedented in international surveys of this kind.

The sampling standards used in PISA permitted countries to exclude up to a total of $5 \%$ of the relevant population either by excluding schools or by excluding students within schools. All but 12 countries - the United Kingdom (8.22\%), Luxembourg $(8.16 \%)$, Canada (7.49\%), Norway $(6.75 \%)$, New Zealand (6.54\%), Sweden $(5.71 \%)$, Estonia $(5.52 \%)$, Australia $(5.31 \%)$, 
Montenegro (5.17\%), Lithuania (5.12\%), Latvia (5.07\%), and Denmark (5.04\%) - achieved this standard, and in 29 countries and economies, the overall exclusion rate was less than $2 \%$. When language exclusions were accounted for (i.e. removed from the overall exclusion rate), Denmark, Latvia, New Zealand and Sweden no longer had an exclusion rate greater than $5 \%$. For details, see www.pisa.oecd.org.

Exclusions within the above limits include:

- At the school level: schools that were geographically inaccessible or where the administration of the PISA assessment was not considered feasible; and schools that provided teaching only for students in the categories defined under "within-school exclusions", such as schools for the blind. The percentage of 15-year-olds enrolled in such schools had to be less than $2.5 \%$ of the nationally desired target population ( $0.5 \%$ maximum for the former group and $2 \%$ maximum for the latter group). The magnitude, nature and justification of school-level exclusions are documented in the PISA 2015 Technical Report (OECD, forthcoming).

- At the student level: students with an intellectual disability; students with a functional disability; students with limited assessment language proficiency; other (a category defined by the national centres and approved by the international centre); and students taught in a language of instruction for the main domain for which no materials were available. Students could not be excluded solely because of low proficiency or common disciplinary problems. The percentage of 15-year-olds excluded within schools had to be less than $2.5 \%$ of the nationally desired target population.

Table A2.1 describes the target population of the countries participating in PISA 2015. Further information on the target population and the implementation of PISA sampling standards can be found in the PISA 2015 Technical Report (OECD, forthcoming).

- Column 1 shows the total number of 15 -year-olds according to the most recent available information, which in most countries means the year 2014 as the year before the assessment.

- Column 2 shows the number of 15-year-olds enrolled in schools in grade 7 or above (as defined above), which is referred to as the "eligible population".

- Column 3 shows the national desired target population. Countries were allowed to exclude up to $0.5 \%$ of students a priori from the eligible population, essentially for practical reasons. The following a priori exclusions exceed this limit but were agreed with the PISA Consortium: Belgium excluded $0.21 \%$ of its population for a particular type of student educated while working; Canada excluded $1.22 \%$ of its population from Territories and Aboriginal reserves; Chile excluded $0.04 \%$ of its students who live in Easter Island, Juan Fernandez Archipelago and Antarctica; and the United Arab Emirates excluded 0.04\% of its students who had no information available. The adjudicated region of Massachusetts in the United States excluded $13.11 \%$ of its students, and North Carolina excluded $5.64 \%$ of its students. For these two regions, the desired target populations cover 15 -year-old students in grade 7 or above in public schools only. The students excluded from the desired population are private school students.

- Column 4 shows the number of students enrolled in schools that were excluded from the national desired target population, either from the sampling frame or later in the field during data collection.

- Column 5 shows the size of the national desired target population after subtracting the students enrolled in excluded schools. This is obtained by subtracting Column 4 from Column 3.

- Column 6 shows the percentage of students enrolled in excluded schools. This is obtained by dividing Column 4 by Column 3 and multiplying by 100 .

- Column 7 shows the number of students participating in PISA 2015. Note that in some cases this number does not account for 15-year-olds assessed as part of additional national options.

- Column 8 shows the weighted number of participating students, i.e. the number of students in the nationally defined target population that the PISA sample represents.

- Each country attempted to maximise the coverage of PISA's target population within the sampled schools. In the case of each sampled school, all eligible students, namely those 15 years of age, regardless of grade, were first listed. Sampled students who were to be excluded had still to be included in the sampling documentation, and a list drawn up stating the reason for their exclusion. Column 9 indicates the total number of excluded students, which is further described and classified into specific categories in Table A2.2.

- Column 10 indicates the weighted number of excluded students, i.e. the overall number of students in the nationally defined target population represented by the number of students excluded from the sample, which is also described and classified by exclusion categories in Table A2.2. Excluded students were excluded based on five categories: students with an intellectual disability (the student has a mental or emotional disability and is cognitively delayed such that he/she cannot perform in the PISA testing situation); students with a functional disability (the student has a moderate to severe permanent physical disability such that he/she cannot perform in the PISA testing situation); students with limited proficiency in the assessment language (the student is unable to read or speak any of the languages of the assessment in the country and would be unable to overcome the language barrier in the testing situation - typically a student who has received less than one year of instruction in the languages of assessment may be excluded); other (a category defined by the national centres and approved by the international centre); and students taught in a language of instruction for the main domain for which no materials were available. 


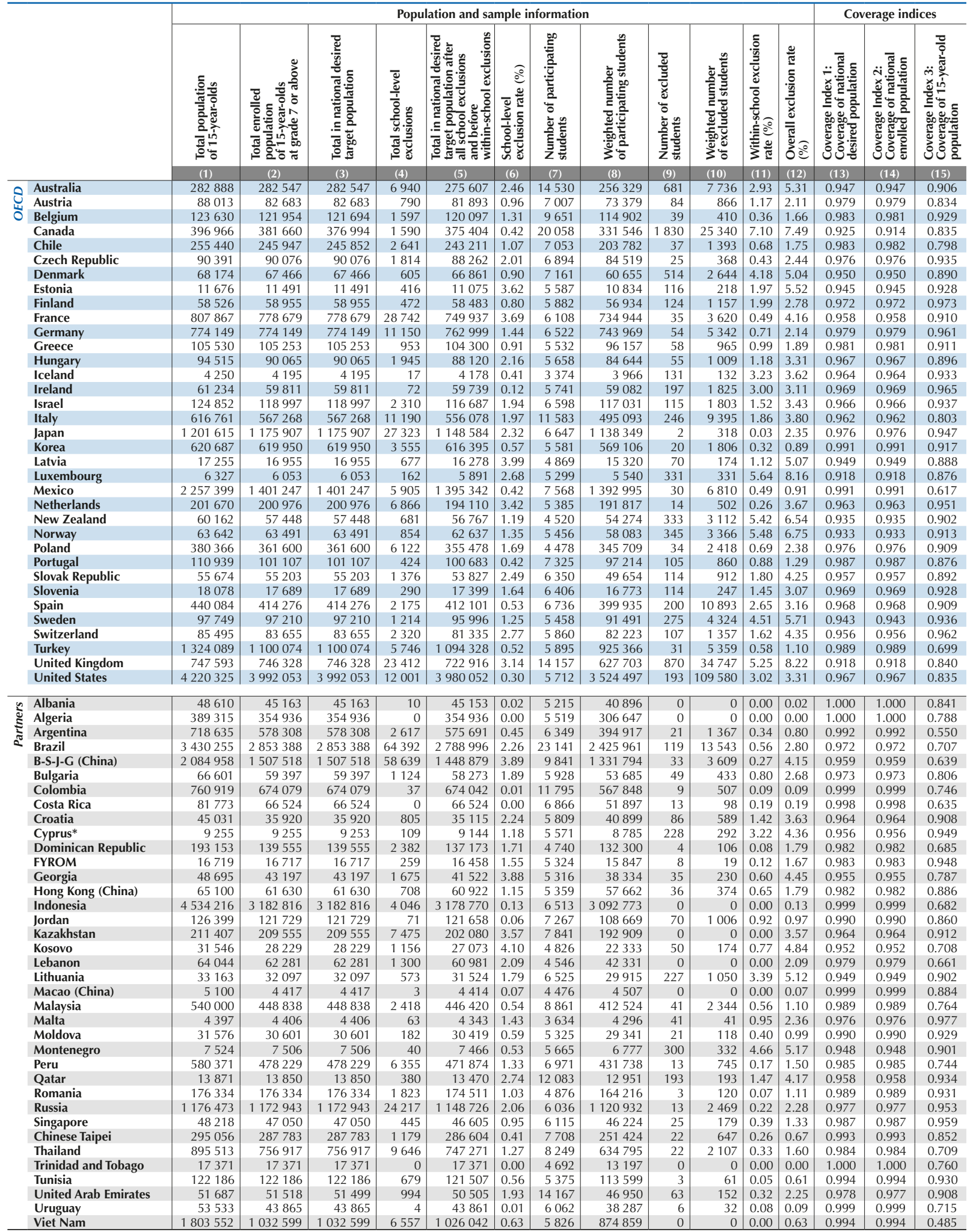

Notes: For a full explanation of the details in this table please refer to the PISA 2015 Technical Report (OECD, forthcoming).

The figure for total national population of 15 -year-olds enrolled in Column 2 may occasionally be larger than the total number of 15 -year-olds in Column 1 due to differing data sources.

For Mexico, in 2015, the Total population of 15-year-olds enrolled in grade 7 or above is an estimate of the target population size of the sample frame from which the 15-year-olds students were selected for the PISA test. At the time Mexico provided the information to PISA, the official figure for this population was 1573952.

* See note at the beginning of this Annex.

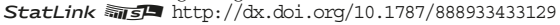




\begin{tabular}{|c|c|c|c|c|c|c|c|}
\hline & \multicolumn{6}{|c|}{ Student exclusions (unweighted) } \\
\hline & & $\begin{array}{c}\text { Number } \\
\text { of excluded students } \\
\text { with functional } \\
\text { disability } \\
\text { (Code 1) }\end{array}$ & $\begin{array}{c}\text { Number } \\
\text { of excluded students } \\
\text { with intellectual } \\
\text { disability } \\
\text { (Code 2) }\end{array}$ & $\begin{array}{c}\text { Number } \\
\text { of excluded students } \\
\text { because of language } \\
\text { (Code 3) }\end{array}$ & $\begin{array}{c}\text { Number } \\
\text { of excluded students } \\
\text { for other reasons } \\
\text { (Code 4) }\end{array}$ & $\begin{array}{c}\text { Number } \\
\text { of excluded students } \\
\text { because of } \\
\text { no materials available } \\
\text { in the language } \\
\text { of instruction } \\
\text { (Code 5) }\end{array}$ & $\begin{array}{c}\text { School-level } \\
\text { exclusion rate } \\
\text { (\%) }\end{array}$ \\
\hline & & (1) & (2) & (3) & (4) & (5) & (6) \\
\hline \multirow{35}{*}{ త్ } & Australia & 85 & 528 & 68 & 0 & 0 & 681 \\
\hline & Austria & 8 & 15 & 61 & 0 & 0 & 84 \\
\hline & Belgium & 4 & 18 & 17 & 0 & 0 & 39 \\
\hline & Canada & 156 & 1308 & 366 & 0 & 0 & 1830 \\
\hline & Chile & 6 & 30 & 1 & 0 & 0 & 37 \\
\hline & Czech Republic & 2 & 9 & 14 & 0 & 0 & 25 \\
\hline & Denmark & 18 & 269 & 156 & 70 & 1 & 514 \\
\hline & Estonia & 17 & 93 & 6 & 0 & 0 & 116 \\
\hline & Finland & 2 & 90 & 17 & 8 & 7 & 124 \\
\hline & France & 5 & 21 & 9 & 0 & 0 & 35 \\
\hline & Germany & 4 & 25 & 25 & 0 & 0 & 54 \\
\hline & Greece & 3 & 44 & 11 & 0 & 0 & 58 \\
\hline & Hungary & 3 & 13 & 9 & 30 & 0 & 55 \\
\hline & Iceland & 9 & 66 & 47 & 9 & 0 & 131 \\
\hline & Ireland & 25 & 57 & 55 & 60 & 0 & 197 \\
\hline & Israel & 22 & 68 & 25 & 0 & 0 & 115 \\
\hline & Italy & 78 & 147 & 21 & 0 & 0 & 246 \\
\hline & Japan & 0 & 2 & 0 & 0 & 0 & 2 \\
\hline & Korea & 3 & 17 & 0 & 0 & 0 & 20 \\
\hline & Latvia & 7 & 47 & 16 & 0 & 0 & 70 \\
\hline & Luxembourg & 4 & 254 & 73 & 0 & 0 & 331 \\
\hline & Mexico & 4 & 23 & 3 & 0 & 0 & 30 \\
\hline & Netherlands & 1 & 13 & 0 & 0 & 0 & 14 \\
\hline & New Zealand & 23 & 140 & 167 & 0 & 3 & 333 \\
\hline & Norway & 11 & 253 & 81 & 0 & 0 & 345 \\
\hline & Poland & 11 & 20 & 0 & 3 & 0 & 34 \\
\hline & Portugal & 4 & 99 & 2 & 0 & 0 & 105 \\
\hline & Slovak Republic & 7 & 71 & 2 & 34 & 0 & 114 \\
\hline & Slovenia & 33 & 36 & 45 & 0 & 0 & 114 \\
\hline & Spain & 9 & 144 & 47 & 0 & 0 & 200 \\
\hline & Sweden & 154 & 0 & 121 & 0 & 0 & 275 \\
\hline & Switzerland & 8 & 42 & 57 & 0 & 0 & 107 \\
\hline & Turkey & 1 & 23 & 7 & 0 & 0 & 31 \\
\hline & United Kingdom & 77 & 690 & 102 & 0 & 1 & 870 \\
\hline & United States & 16 & 120 & 44 & 13 & 0 & 193 \\
\hline \multirow{37}{*}{ ฏ } & Albania & 0 & 0 & 0 & 0 & 0 & 0 \\
\hline & Algeria & 0 & 0 & 0 & 0 & 0 & 0 \\
\hline & Argentina & 10 & 10 & 1 & 0 & 0 & 21 \\
\hline & Brazil & 20 & 99 & 0 & 0 & 0 & 119 \\
\hline & B-S-J-G (China) & 6 & 25 & 2 & 0 & 0 & 33 \\
\hline & Bulgaria & 39 & 6 & 4 & 0 & 0 & 49 \\
\hline & Colombia & 3 & 4 & 2 & 0 & 0 & 9 \\
\hline & Costa Rica & 3 & 1 & 0 & 9 & 0 & 13 \\
\hline & Croatia & 2 & 75 & 9 & 0 & 0 & 86 \\
\hline & Cyprus* & 12 & 164 & 52 & 0 & 0 & 228 \\
\hline & Dominican Republic & 1 & 3 & 0 & 0 & 0 & 4 \\
\hline & FYROM & 7 & 1 & 0 & 0 & 0 & 8 \\
\hline & Georgia & 3 & 25 & 7 & 0 & 0 & 35 \\
\hline & Hong Kong (China) & 0 & 35 & 1 & 0 & 0 & 36 \\
\hline & Indonesia & 0 & 0 & 0 & 0 & 0 & 0 \\
\hline & Jordan & 43 & 17 & 10 & 0 & 0 & 70 \\
\hline & Kazakhstan & 0 & 0 & 0 & 0 & 0 & 0 \\
\hline & Kosovo & 9 & 13 & 27 & 0 & 0 & 50 \\
\hline & Lebanon & 0 & 0 & 0 & 0 & 0 & 0 \\
\hline & Lithuania & 12 & 213 & 2 & 0 & 0 & 227 \\
\hline & Macao (China) & 0 & 0 & 0 & 0 & 0 & 0 \\
\hline & Malaysia & 10 & 22 & 9 & 0 & 0 & 41 \\
\hline & Malta & 8 & 27 & 6 & 0 & 0 & 41 \\
\hline & Moldova & 12 & 8 & 1 & 0 & 0 & 21 \\
\hline & Montenegro & 14 & 23 & 5 & 0 & 258 & 300 \\
\hline & Peru & 4 & 9 & 0 & 0 & 0 & 13 \\
\hline & Qatar & 76 & 110 & 7 & 0 & 0 & 193 \\
\hline & Romania & 1 & 1 & 1 & 0 & 0 & 3 \\
\hline & Russia & 3 & 10 & 0 & 0 & 0 & 13 \\
\hline & Singapore & 3 & 15 & 7 & 0 & 0 & 25 \\
\hline & Chinese Taipei & 3 & 19 & 0 & 0 & 0 & 22 \\
\hline & Thailand & 1 & 19 & 2 & 0 & 0 & 22 \\
\hline & Trinidad and Tobago & 0 & 0 & 0 & 0 & 0 & 0 \\
\hline & Tunisia & 0 & 0 & 3 & 0 & 0 & 3 \\
\hline & United Arab Emirates & 16 & 24 & 23 & 0 & 0 & 63 \\
\hline & Uruguay & 2 & 4 & 0 & 0 & 0 & 6 \\
\hline & Viet Nam & 0 & 0 & 0 & 0 & 0 & 0 \\
\hline
\end{tabular}

Exclusion codes:

Code 2: Intellectual disity - student has a moderate to severe permanent physical disability. Code 2: Intified staff to be cognitively delayed.

Code 3: Limited assessment language proficiency - student is not a native speaker of any of the languages of the assessment in the country and has been resident in the country for less than one year.

Code 4: Other reasons defined by the national centres and approved by the international centre.

Code 5: No materials available in the language of instruction.

Note: For a full explanation of the details in this table please refer to the PISA 2015 Technical Report (OECD, forthcoming).

* See note at the beginning of this Annex.

StatLink 部 S1 http://dx.doi.org/10.1787/888933433129 


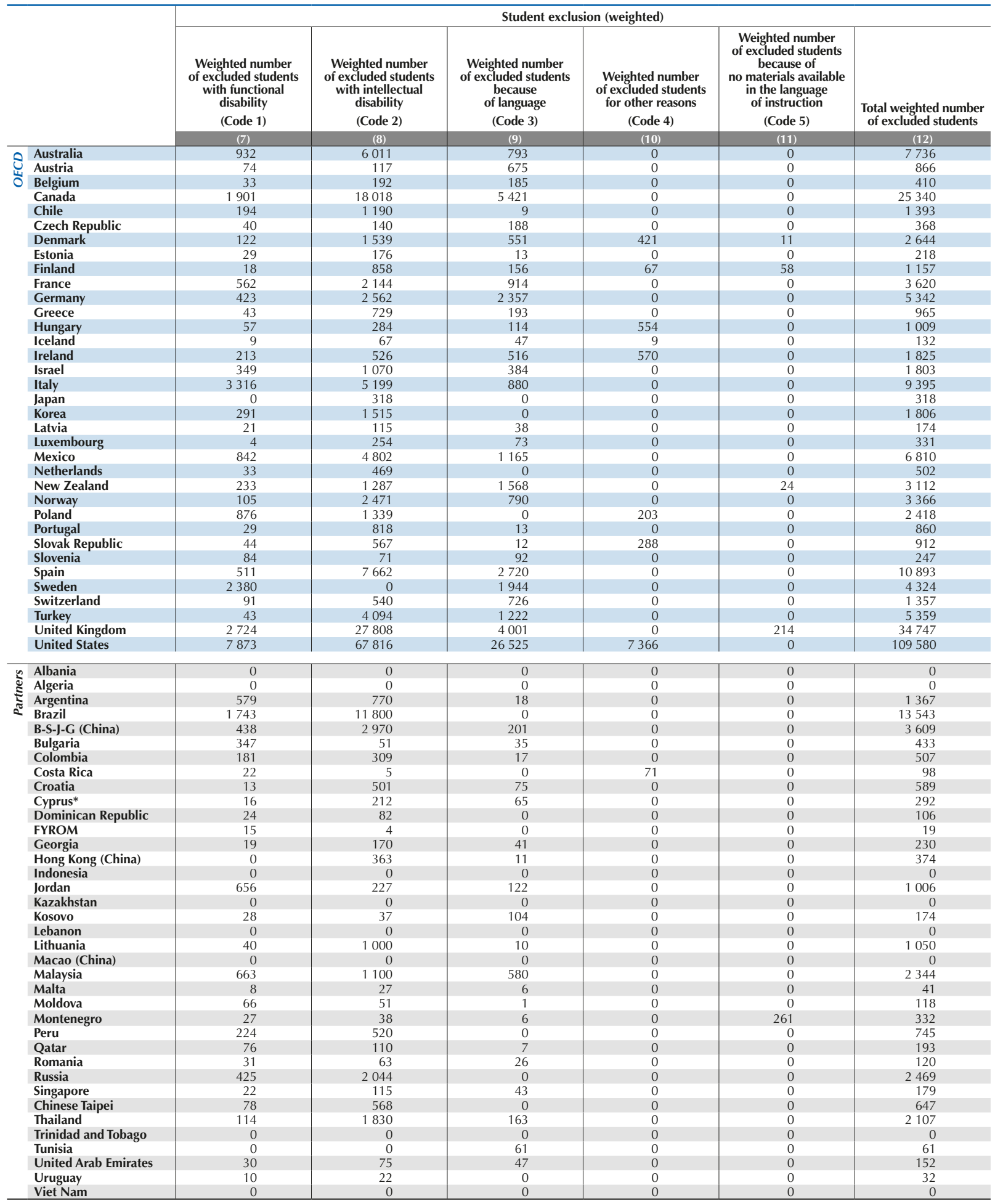

Exclusion codes:

disability - student has a moderate to severe permanent physical disability.

Code 2: Intellectual disability - student has a mental or emotional disability and has either been tested as cognitively delayed or is considered in the professional opinion of qualified staff to be cognitively delayed.

Code 3: Limited assessment language proficiency - student is not a native speaker of any of the languages of the assessment in the country and has been resident in the country for less than one year.

Code 4: Other reasons defined by the national centres and approved by the international centre.

Code 5: No materials available in the language of instruction.

Note: For a full explanation of the details in this table please refer to the PISA 2015 Technical Report (OECD, forthcoming).

* See note at the beginning of this Annex.

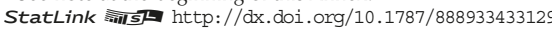


- Column 11 shows the percentage of students excluded within schools. This is calculated as the weighted number of excluded students (Column 10), divided by the weighted number of excluded and participating students (Column 8 plus Column 10), then multiplied by 100 .

- Column 12 shows the overall exclusion rate, which represents the weighted percentage of the national desired target population excluded from PISA either through school-level exclusions or through the exclusion of students within schools. It is calculated as the school-level exclusion rate (Column 6 divided by 100) plus within-school exclusion rate (Column 11 divided by 100) multiplied by 1 minus the school-level exclusion rate (Column 6 divided by 100). This result is then multiplied by 100 .

- Column 13 presents an index of the extent to which the national desired target population is covered by the PISA sample. Australia, Canada, Denmark, Estonia, Latvia, Lithuania, Luxembourg, Montenegro, New Zealand, Norway, Sweden and the United Kingdom were the only countries where the coverage is below 95\%.

- Column 14 presents an index of the extent to which 15-year-olds enrolled in schools are covered by the PISA sample. The index measures the overall proportion of the national enrolled population that is covered by the non-excluded portion of the student sample. The index takes into account both school-level and student-level exclusions. Values close to 100 indicate that the PISA sample represents the entire education system as defined for PISA 2015. The index is the weighted number of participating students (Column 8) divided by the weighted number of participating and excluded students (Column 8 plus Column 10), times the nationally defined target population (Column 5) divided by the eligible population (Column 2) (times 100).

- Column 15 presents an index of the coverage of the 15-year-old population. This index is the weighted number of participating students (Column 8) divided by the total population of 15-year-old students (Column 1).

This high level of coverage contributes to the comparability of the assessment results. For example, even assuming that the excluded students would have systematically scored worse than those who participated, and that this relationship is moderately strong, an exclusion rate on the order of $5 \%$ would likely lead to an overestimation of national mean scores of less than 5 score points (on a scale with an international mean of 500 score points and a standard deviation of 100 score points). This assessment is based on the following calculations: if the correlation between the propensity of exclusions and student performance is 0.3 , resulting mean scores would likely be overestimated by 1 score point if the exclusion rate is $1 \%$, by 3 score points if the exclusion rate is $5 \%$, and by 6 score points if the exclusion rate is $10 \%$. If the correlation between the propensity of exclusions and student performance is 0.5 , resulting mean scores would be overestimated by 1 score point if the exclusion rate is $1 \%$, by 5 score points if the exclusion rate is $5 \%$, and by 10 score points if the exclusion rate is $10 \%$. For this calculation, a model was used that assumes a bivariate normal distribution for performance and the propensity to participate. For details, see the PISA 2015 Technical Report (OECD, forthcoming).

\section{Sampling procedures and response rates}

The accuracy of any survey results depends on the quality of the information on which national samples are based as well as on the sampling procedures. Quality standards, procedures, instruments and verification mechanisms were developed for PISA that ensured that national samples yielded comparable data and that the results could be compared with confidence.

Most PISA samples were designed as two-stage stratified samples (where countries applied different sampling designs, these are documented in the PISA 2015 Technical Report [OECD, forthcoming]). The first stage consisted of sampling individual schools in which 15-year-old students could be enrolled. Schools were sampled systematically with probabilities proportional to size, the measure of size being a function of the estimated number of eligible (15-year-old) students enrolled. At least 150 schools were selected in each country (where this number existed), although the requirements for national analyses often required a somewhat larger sample. As the schools were sampled, replacement schools were simultaneously identified, in case a sampled school chose not to participate in PISA 2015.

In the case of Iceland, Luxembourg, Macao (China), Malta and Qatar, all schools and all eligible students within schools were included in the sample.

Experts from the PISA Consortium performed the sample selection process for most participating countries and monitored it closely in those countries that selected their own samples. The second stage of the selection process sampled students within sampled schools. Once schools were selected, a list of each sampled school's 15-year-old students was prepared. From this list, 42 students were then selected with equal probability (all 15-year-old students were selected if fewer than 42 were enrolled). The number of students to be sampled per school could deviate from 42, but could not be less than 20.

Data-quality standards in PISA required minimum participation rates for schools as well as for students. These standards were established to minimise the potential for response biases. In the case of countries meeting these standards, it was likely that any bias resulting from non-response would be negligible, i.e. typically smaller than the sampling error.

A minimum response rate of $85 \%$ was required for the schools initially selected. Where the initial response rate of schools was between $65 \%$ and $85 \%$, however, an acceptable school-response rate could still be achieved through the use of replacement schools. 
This procedure brought with it a risk of increased response bias. Participating countries were, therefore, encouraged to persuade as many of the schools in the original sample as possible to participate. Schools with a student participation rate between $25 \%$ and $50 \%$ were not regarded as participating schools, but data from these schools were included in the database and contributed to the various estimations. Data from schools with a student participation rate of less than $25 \%$ were excluded from the database.

PISA 2015 also required a minimum participation rate of $80 \%$ of students within participating schools. This minimum participation rate had to be met at the national level, not necessarily by each participating school. Follow-up sessions were required in schools in which too few students had participated in the original assessment sessions. Student participation rates were calculated over all original schools, and also over all schools, whether original sample or replacement schools, and from the participation of students in both the original assessment and any follow-up sessions. A student who participated in the original or follow-up cognitive sessions was regarded as a participant. Those who attended only the questionnaire session were included in the international database and contributed to the statistics presented in this publication if they provided at least a description of their father's or mother's occupation.

Table A2.3 shows the response rates for students and schools, before and after replacement.

- Column 1 shows the weighted participation rate of schools before replacement. This is obtained by dividing Column 2 by Column 3.

- Column 2 shows the weighted number of responding schools before school replacement (weighted by student enrolment).

- Column 3 shows the weighted number of sampled schools before school replacement (including both responding and non-responding schools, weighted by student enrolment).

- Column 4 shows the unweighted number of responding schools before school replacement.

- Column 5 shows the unweighted number of responding and non-responding schools before school replacement.

- Column 6 shows the weighted participation rate of schools after replacement. This is obtained by dividing Column 7 by Column 8 .

- Column 7 shows the weighted number of responding schools after school replacement (weighted by student enrolment).

- Column 8 shows the weighted number of schools sampled after school replacement (including both responding and non-responding schools, weighted by student enrolment).

- Column 9 shows the unweighted number of responding schools after school replacement.

- Column 10 shows the unweighted number of responding and non-responding schools after school replacement.

- Column 11 shows the weighted student participation rate after replacement. This is obtained by dividing Column 12 by Column 13.

- Column 12 shows the weighted number of students assessed.

- Column 13 shows the weighted number of students sampled (including both students who were assessed and students who were absent on the day of the assessment).

- Column 14 shows the unweighted number of students assessed. Note that any students in schools with student-response rates of less than $50 \%$ were not included in these rates (both weighted and unweighted).

- Column 15 shows the unweighted number of students sampled (including both students that were assessed and students who were absent on the day of the assessment). Note that any students in schools where fewer than half of the eligible students were assessed were not included in these rates (neither weighted nor unweighted).

\section{Definition of schools}

In some countries, subunits within schools were sampled instead of schools, and this may affect the estimation of the betweenschool variance components. In Austria, the Czech Republic, Germany, Hungary, Japan, Romania and Slovenia, schools with more than one study programme were split into the units delivering these programmes. In the Netherlands, for schools with both lower and upper secondary programmes, schools were split into units delivering each programme level. In the Flemish community of Belgium, in the case of multi-campus schools, implantations (campuses) were sampled, whereas in the French community, in the case of multi-campus schools, the larger administrative units were sampled. In Australia, for schools with more than one campus, the individual campuses were listed for sampling. In Argentina and Croatia, schools that had more than one campus had the locations listed for sampling. In Spain, the schools in the Basque region with multi-linguistic models were split into linguistic models for sampling. In Luxembourg, a school on the border with Germany was split according to the country in which the students resided. In addition, the International schools in Luxembourg were split into the students who were instructed in any of the three official languages, and those in the part of the schools that was excluded because no materials were available in the languages of instruction. The United Arab Emirates had schools split by curricula, and sometimes by gender, with other schools remaining whole. Because of reorganisation, some of Sweden's schools were split into parts, with each part having one principal. In Portugal, schools were reorganised into clusters, with teachers and the principal shared by all units in the school cluster. 


\begin{tabular}{|c|c|c|c|c|c|c|c|c|c|c|c|c|c|c|c|c|}
\hline & \multicolumn{5}{|c|}{$\begin{array}{c}\text { Initial sample - } \\
\text { before school replacement }\end{array}$} & \multicolumn{5}{|c|}{$\begin{array}{l}\text { Final sample - } \\
\text { after school replacement }\end{array}$} & \multicolumn{5}{|c|}{$\begin{array}{l}\text { Final sample - students within schools } \\
\text { after school replacement }\end{array}$} \\
\hline & & 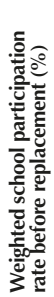 & 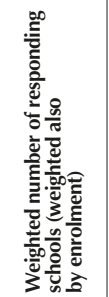 & 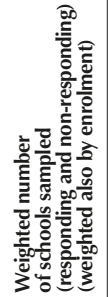 & 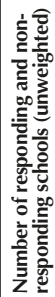 & 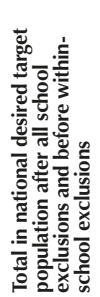 & 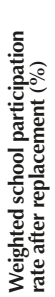 & 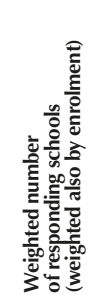 & 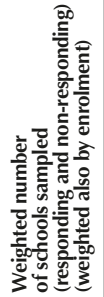 & 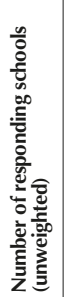 & 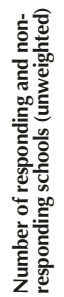 & 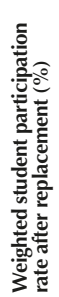 & 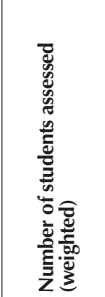 & 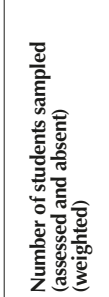 & 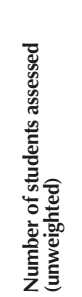 & 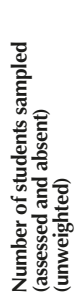 \\
\hline & & (1) & (2) & (3) & (4) & (5) & (6) & (7) & (8) & (9) & (10) & (11) & (12) & (13) & (14) & (15) \\
\hline & Australia & 94 & 260657 & 276072 & 720 & 788 & 95 & 262130 & 276072 & 723 & 788 & 84 & 204763 & 243789 & 14089 & 17477 \\
\hline & Austria & 100 & 81690 & 81730 & 269 & 273 & 100 & 81690 & 81730 & 269 & 273 & 87 & 63660 & 73521 & 7007 & 9868 \\
\hline & Belgium & 83 & 98786 & 118915 & 244 & 301 & 95 & 113435 & 118936 & 286 & 301 & 91 & 99760 & 110075 & 9635 & 10602 \\
\hline & Canada & 74 & 283853 & 381133 & 703 & 1008 & 79 & 299512 & 381189 & 726 & 1008 & 81 & 210476 & 260487 & 19604 & 24129 \\
\hline & Chile & 92 & 215139 & 232756 & 207 & 232 & 99 & 230749 & 232757 & 226 & 232 & 93 & 189206 & 202774 & 7039 & 7515 \\
\hline & Czech Republic & 98 & 86354 & 87999 & 339 & 344 & 98 & 86354 & 87999 & 339 & 344 & 89 & 73386 & 82672 & 6835 & 7693 \\
\hline & Denmark & 90 & 57803 & 63897 & 327 & 371 & 92 & 58837 & 63931 & 331 & 371 & 89 & 49732 & 55830 & 7149 & 8184 \\
\hline & Estonia & 100 & 11142 & 11154 & 206 & 207 & 100 & 11142 & 11154 & 206 & 207 & 93 & 10088 & 10822 & 5587 & 5994 \\
\hline & Finland & 100 & 58653 & 58782 & 167 & 168 & 100 & 58800 & 58800 & 168 & 168 & 93 & 53198 & 56934 & 5882 & 6294 \\
\hline & France & 91 & 679984 & 749284 & 232 & 255 & 94 & 706838 & 749284 & 241 & 255 & 88 & 611563 & 693336 & 5980 & 6783 \\
\hline & Germany & 96 & 764423 & 794206 & 245 & 256 & 99 & 785813 & 794206 & 253 & 256 & 93 & 685972 & 735487 & 6476 & 6944 \\
\hline & Greece & 92 & 95030 & 103031 & 190 & 212 & 98 & 101653 & 103218 & 209 & 212 & 94 & 89588 & 94986 & 5511 & 5838 \\
\hline & Hungary & 93 & 83897 & 89808 & 231 & 251 & 99 & 88751 & 89825 & 244 & 251 & 92 & 77212 & 83657 & 5643 & 6101 \\
\hline & Iceland & 99 & 4114 & 4163 & 122 & 129 & 99 & 4114 & 4163 & 122 & 129 & 86 & 3365 & 3908 & 3365 & 3908 \\
\hline & Ireland & 99 & 61023 & 61461 & 167 & 169 & 99 & 61023 & 61461 & 167 & 169 & 89 & 51947 & 58630 & 5741 & 6478 \\
\hline & Israel & 91 & 105192 & 115717 & 169 & 190 & 93 & 107570 & 115717 & 173 & 190 & 90 & 98572 & 108940 & 6598 & 7294 \\
\hline & Italy & 74 & 383933 & 516113 & 414 & 532 & 88 & 451098 & 515515 & 464 & 532 & 88 & 377011 & 430041 & 11477 & 12841 \\
\hline & Japan & 94 & 1087414 & 1151305 & 189 & 200 & 99 & 1139734 & 1151305 & 198 & 200 & 97 & 1096193 & 1127265 & 6647 & 6838 \\
\hline & Korea & 100 & 612937 & 615107 & 168 & 169 & 100 & 612937 & 615107 & 168 & 169 & 99 & 559121 & 567284 & 5581 & 5664 \\
\hline & Latvia & 86 & 14122 & 16334 & 231 & 269 & 93 & 15103 & 16324 & 248 & 269 & 90 & 12799 & 14155 & 4845 & 5368 \\
\hline & Luxembourg & 100 & 5891 & 5891 & 44 & 44 & 100 & 5891 & 5891 & 44 & 44 & 96 & 5299 & 5540 & 5299 & 5540 \\
\hline & Mexico & 95 & 1311608 & 1373919 & 269 & 284 & 98 & 1339901 & 1373919 & 275 & 284 & 95 & 1290435 & 1352237 & 7568 & 7938 \\
\hline & Netherlands & 63 & 121527 & 191966 & 125 & 201 & 93 & 178929 & 191966 & 184 & 201 & 85 & 152346 & 178985 & 5345 & 6269 \\
\hline & New Zealand & 71 & 40623 & 56875 & 145 & 210 & 85 & 48094 & 56913 & 176 & 210 & 80 & 36860 & 45897 & 4453 & 5547 \\
\hline & Norway & 95 & 58824 & 61809 & 229 & 241 & 95 & 58824 & 61809 & 229 & 241 & 91 & 50163 & 55277 & 5456 & 6016 \\
\hline & Poland & 88 & 314288 & 355158 & 151 & 170 & 99 & 352754 & 355158 & 168 & 170 & 88 & 300617 & 343405 & 4466 & 5108 \\
\hline & Portugal & 86 & 87756 & 102193 & 213 & 254 & 95 & 97516 & 102537 & 238 & 254 & 82 & 75391 & 91916 & 7180 & 8732 \\
\hline & Slovak Republic & 93 & 50513 & 54499 & 272 & 295 & 99 & 53908 & 54562 & 288 & 295 & 92 & 45357 & 49103 & 6342 & 6900 \\
\hline & Slovenia & 98 & 16886 & 17286 & 332 & 349 & 98 & 16896 & 17286 & 333 & 349 & 92 & 15072 & 16424 & 6406 & 7009 \\
\hline & Spain & 99 & 404640 & 409246 & 199 & 201 & 100 & 409246 & 409246 & 201 & 201 & 89 & 356509 & 399935 & 6736 & 7540 \\
\hline & Sweden & 100 & 93819 & 94097 & 202 & 205 & 100 & 93819 & 94097 & 202 & 205 & 91 & 82582 & 91081 & 5458 & 6013 \\
\hline & Switzerland & 93 & 75482 & 81026 & 212 & 232 & 98 & 79481 & 81375 & 225 & 232 & 92 & 74465 & 80544 & 5838 & 6305 \\
\hline & Turkey & 97 & 1057318 & 1091317 & 175 & 195 & 99 & 1081935 & 1091528 & 187 & 195 & 95 & 874609 & 918816 & 5895 & 6211 \\
\hline & United Kingdom & 84 & 591757 & 707415 & 506 & 598 & 93 & 654992 & 707415 & 547 & 598 & 89 & 517426 & 581252 & 14120 & 16123 \\
\hline & United States & 67 & 2601386 & 3902089 & 142 & 213 & 83 & 3244399 & 3893828 & 177 & 213 & 90 & 2629707 & 2929771 & 5712 & 6376 \\
\hline & Albania & 100 & 43809 & 43919 & 229 & 230 & 100 & 43809 & 43919 & 229 & 230 & 94 & 38174 & 40814 & 5213 & 5555 \\
\hline & Algeria & 96 & 341463 & 355216 & 159 & 166 & 96 & 341463 & 355216 & 159 & 166 & 92 & 274121 & 296434 & 5494 & 5934 \\
\hline & Argentina & 89 & 508448 & 572941 & 212 & 238 & 97 & 556478 & 572941 & 231 & 238 & 90 & 345508 & 382352 & 6311 & 7016 \\
\hline & Brazil & 93 & 2509198 & 2692686 & 806 & 889 & 94 & 2533711 & 2693137 & 815 & 889 & 87 & 1996574 & 2286505 & 22791 & 26586 \\
\hline & B-S-J-G (China) & 88 & 1259845 & 1437201 & 248 & 268 & 100 & 1437652 & 1437652 & 268 & 268 & 97 & 1287710 & 1331794 & 9841 & 10097 \\
\hline & Bulgaria & 100 & 56265 & 56483 & 179 & 180 & 100 & 56600 & 56600 & 180 & 180 & 95 & 50931 & 53685 & 5928 & 6240 \\
\hline & Colombia & 99 & 664664 & 673817 & 364 & 375 & 100 & 672526 & 673835 & 371 & 375 & 95 & 535682 & 566734 & 11777 & 12611 \\
\hline & Costa Rica & 99 & 66485 & 67073 & 204 & 206 & 99 & 66485 & 67073 & 204 & 206 & 92 & 47494 & 51369 & 6846 & 7411 \\
\hline & Croatia & 100 & 34575 & 34652 & 160 & 162 & 100 & 34575 & 34652 & 160 & 162 & 91 & 37275 & 40803 & 5809 & 6354 \\
\hline & Cyprus* & 97 & 8830 & 9126 & 122 & 132 & 97 & 8830 & 9126 & 122 & 132 & 94 & 8016 & 8526 & 5561 & 5957 \\
\hline & Dominican Republic & 99 & 136669 & 138187 & 193 & 195 & 99 & 136669 & 138187 & 193 & 195 & 94 & 122620 & 130700 & 4731 & 5026 \\
\hline & FYROM & 100 & 16426 & 16472 & 106 & 107 & 100 & 16426 & 16472 & 106 & 107 & 95 & 14999 & 15802 & 5324 & 5617 \\
\hline & Georgia & 97 & 40552 & 41595 & 256 & 267 & 99 & 41081 & 41566 & 262 & 267 & 94 & 35567 & 37873 & 5316 & 5689 \\
\hline & Hong Kong (China) & 75 & 45603 & 60716 & 115 & 153 & 90 & 54795 & 60715 & 138 & 153 & 93 & 48222 & 51806 & 5359 & 5747 \\
\hline & Indonesia & 98 & 3126468 & 3176076 & 232 & 236 & 100 & 3176076 & 3176076 & 236 & 236 & 98 & 3015844 & 3092773 & 6513 & 6694 \\
\hline & Jordan & 100 & 119024 & 119024 & 250 & 250 & 100 & 119024 & 119024 & 250 & 250 & 97 & 105868 & 108669 & 7267 & 7462 \\
\hline & Kazakhstan & 100 & 202701 & 202701 & 232 & 232 & 100 & 202701 & 202701 & 232 & 232 & 97 & 187683 & 192921 & 7841 & 8059 \\
\hline & Kosovo & 100 & 26924 & 26924 & 224 & 224 & 100 & 26924 & 26924 & 224 & 224 & 99 & 22016 & 22333 & 4826 & 4896 \\
\hline & Lebanon & 67 & 40542 & 60882 & 208 & 308 & 87 & 53091 & 60797 & 270 & 308 & 95 & 36052 & 38143 & 4546 & 4788 \\
\hline & Lithuania & 99 & 31386 & 31588 & 309 & 311 & 100 & 31543 & 31588 & 310 & 311 & 91 & 27070 & 29889 & 6523 & 7202 \\
\hline & Macao (China) & 100 & 4414 & 4414 & 45 & 45 & 100 & 4414 & 4414 & 45 & 45 & 99 & 4476 & 4507 & 4476 & 4507 \\
\hline & Malaysia & 51 & 229340 & 446237 & 147 & 230 & 98 & 437424 & 446100 & 224 & 230 & 97 & 393785 & 407396 & 8843 & 9097 \\
\hline & Malta & 100 & 4341 & 4343 & 59 & 61 & 100 & 4341 & 4343 & 59 & 61 & 85 & 3634 & 4294 & 3634 & 4294 \\
\hline & Moldova & 100 & 30145 & 30145 & 229 & 229 & 100 & 30145 & 30145 & 229 & 229 & 98 & 28754 & 29341 & 5325 & 5436 \\
\hline & Montenegro & 100 & 7301 & 7312 & 64 & 65 & 100 & 7301 & 7312 & 64 & 65 & 94 & 6346 & 6766 & 5665 & 6043 \\
\hline & Peru & 100 & 468406 & 470651 & 280 & 282 & 100 & 469662 & 470651 & 281 & 282 & 99 & 426205 & 430959 & 6971 & 7054 \\
\hline & Qatar & 99 & 13333 & 13470 & 166 & 168 & 99 & 13333 & 13470 & 166 & 168 & 94 & 12061 & 12819 & 12061 & 12819 \\
\hline & Romania & 99 & 171553 & 172652 & 181 & 182 & 100 & 172495 & 172495 & 182 & 182 & 99 & 162918 & 164216 & 4876 & 4910 \\
\hline & Russia & 99 & 1181937 & 1189441 & 209 & 210 & 99 & 1181937 & 1189441 & 209 & 210 & 97 & 1072914 & 1108068 & 6021 & 6215 \\
\hline & Singapo & 97 & 45299 & 46620 & 175 & 179 & 98 & 45553 & 46620 & 176 & 179 & 93 & 42241 & 45259 & 6105 & 6555 \\
\hline & Chinese Taipei & 100 & 286778 & 286778 & 214 & 214 & 100 & 286778 & 286778 & 214 & 214 & 98 & 246408 & 251424 & 7708 & 7871 \\
\hline & Thailand & 99 & 739772 & 751010 & 269 & 273 & 100 & 751010 & 751010 & 273 & 273 & 97 & 614996 & 634795 & 8249 & 8491 \\
\hline & Trinidad and Tobago & 92 & 15904 & 17371 & 141 & 163 & 92 & 15904 & 17371 & 141 & 163 & 79 & 9674 & 12188 & 4587 & 5745 \\
\hline & Tunisia & 99 & 121751 & 122767 & 162 & 165 & 99 & 121838 & 122792 & 163 & 165 & 86 & 97337 & 112665 & 5340 & 6175 \\
\hline & United Arab Emirates & 99 & 49310 & 50060 & 473 & 477 & 99 & 49310 & 50060 & 473 & 477 & 95 & 43774 & 46263 & 14167 & 15014 \\
\hline & Uruguay & 98 & 42986 & 43737 & 217 & 221 & 99 & 43442 & 43737 & 219 & 221 & 86 & 32762 & 38023 & 6059 & 7026 \\
\hline & Viet Nam & 100 & 996757 & 996757 & 188 & 188 & 100 & 996757 & 996757 & 188 & 188 & 100 & 871353 & 874859 & 5826 & 5849 \\
\hline
\end{tabular}

* See note at the beginning of this Annex.

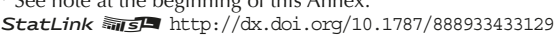




\section{Grade levels}

Students assessed in PISA 2015 are at various grade levels. The percentage of students at each grade level is presented by country in Table A2.4a and by gender within each country in Table A2.4b.

Table A2.4a Percentage of students at each grade level

\begin{tabular}{|c|c|c|c|c|c|c|c|c|c|c|c|c|c|}
\hline & \multicolumn{12}{|c|}{ All students } \\
\hline & & \multicolumn{2}{|c|}{ 7th grade } & \multicolumn{2}{|c|}{ 8th grade } & \multicolumn{2}{|c|}{ 9th grade } & & & & & 12th gra & id above \\
\hline & & $\%$ & S.E. & $\%$ & S.E. & $\%$ & S.E. & $\%$ & S.E. & $\%$ & S.E. & $\%$ & S.E. \\
\hline 0 & Australia & 0.0 & $(0.0)$ & 0.1 & $(0.0)$ & 11.2 & $(0.3)$ & 74.6 & (0.4) & 14.0 & $(0.4)$ & 0.1 & $(0.0)$ \\
\hline U & Austria & 0.0 & $(0.0)$ & 2.0 & $(0.6)$ & 20.8 & $(0.9)$ & 71.2 & $(1.0)$ & 5.9 & $(0.3)$ & 0.0 & $(0.0)$ \\
\hline$\overline{0}$ & Belgium & 0.6 & $(0.1)$ & 6.4 & $(0.5)$ & 30.7 & $(0.7)$ & 61.0 & $(0.9)$ & 1.3 & $(0.1)$ & 0.0 & $(0.0)$ \\
\hline & Canada & 0.1 & $(0.0)$ & 0.7 & $(0.1)$ & 10.8 & $(0.5)$ & 87.6 & $(0.6)$ & 0.8 & $(0.1)$ & 0.0 & $(0.0)$ \\
\hline & Chile & 1.7 & $(0.3)$ & 4.1 & $(0.6)$ & 24.0 & $(0.7)$ & 68.1 & (1.0) & 2.1 & $(0.2)$ & 0.0 & $(0.0)$ \\
\hline & Czech Republic & 0.5 & $(0.1)$ & 3.9 & $(0.3)$ & 49.4 & $(1.2)$ & 46.2 & $(1.2)$ & 0.0 & $(0.0)$ & 0.0 & C \\
\hline & Denmark & 0.2 & $(0.1)$ & 16.4 & $(0.6)$ & 81.9 & $(0.7)$ & 1.4 & $(0.5)$ & 0.0 & C & 0.0 & c \\
\hline & Estonia & 0.8 & $(0.2)$ & 21.3 & $(0.6)$ & 76.6 & $(0.6)$ & 1.3 & $(0.3)$ & 0.0 & c & 0.0 & $(0.0)$ \\
\hline & Finland & 0.5 & $(0.1)$ & 13.6 & $(0.4)$ & 85.7 & $(0.4)$ & 0.0 & $(0.0)$ & 0.2 & $(0.1)$ & 0.0 & c \\
\hline & France & 0.0 & $(0.0)$ & 1.0 & $(0.2)$ & 23.1 & $(0.6)$ & 72.5 & $(0.7)$ & 3.2 & $(0.2)$ & 0.1 & $(0.1)$ \\
\hline & Germany & 0.5 & $(0.1)$ & 7.7 & $(0.4)$ & 47.3 & $(0.8)$ & 43.1 & $(0.8)$ & 1.5 & $(0.5)$ & 0.0 & $(0.0)$ \\
\hline & Greece & 0.2 & $(0.1)$ & 0.7 & $(0.2)$ & 3.8 & $(0.8)$ & 95.3 & $(0.9)$ & 0.0 & $\mathrm{C}$ & 0.0 & $\mathrm{C}$ \\
\hline & Hungary & 1.7 & $(0.3)$ & 8.5 & $(0.5)$ & 75.8 & $(0.7)$ & 14.0 & $(0.5)$ & 0.0 & c & 0.0 & c \\
\hline & Iceland & 0.0 & C & 0.0 & c & 0.0 & c & 100.0 & C & 0.0 & c & 0.0 & c \\
\hline & Ireland & 0.0 & $(0.0)$ & 1.8 & $(0.2)$ & 60.6 & $(0.7)$ & 26.5 & (1.1) & 11.1 & $(0.9)$ & 0.0 & c \\
\hline & Israel & 0.0 & $\mathrm{C}$ & 0.1 & $(0.0)$ & 16.4 & $(0.9)$ & 82.7 & $(0.9)$ & 0.9 & $(0.3)$ & 0.0 & c \\
\hline & Italy & 0.1 & $(0.0)$ & 1.0 & $(0.2)$ & 15.2 & $(0.6)$ & 77.2 & $(0.7)$ & 6.6 & $(0.3)$ & 0.0 & c \\
\hline & Japan & 0.0 & C & 0.0 & C & 0.0 & $\mathrm{C}$ & 100.0 & $(0.0)$ & 0.0 & $\mathrm{C}$ & 0.0 & c \\
\hline & Korea & 0.0 & c & 0.0 & c & 9.1 & $(0.8)$ & 90.4 & $(0.8)$ & 0.5 & $(0.1)$ & 0.0 & c \\
\hline & Latvia & 0.9 & $(0.2)$ & 11.7 & $(0.5)$ & 84.4 & $(0.6)$ & 2.9 & $(0.3)$ & 0.0 & $(0.0)$ & 0.0 & c \\
\hline & Luxembourg & 0.3 & $(0.1)$ & 7.9 & $(0.1)$ & 50.9 & $(0.1)$ & 40.3 & $(0.1)$ & 0.6 & $(0.0)$ & 0.0 & c \\
\hline & Mexico & 2.3 & $(0.3)$ & 4.8 & $(0.4)$ & 31.9 & (1.4) & 60.3 & (1.6) & 0.5 & $(0.1)$ & 0.2 & $(0.0)$ \\
\hline & Netherlands & 0.1 & $(0.0)$ & 2.8 & $(0.3)$ & 41.6 & $(0.6)$ & 54.8 & (0.6) & 0.8 & $(0.2)$ & 0.0 & $(0.0)$ \\
\hline & New Zealand & 0.0 & C & 0.0 & c & 0.0 & $(0.0)$ & 6.2 & $(0.3)$ & 88.8 & $(0.5)$ & 5.0 & $(0.5)$ \\
\hline & Norway & 0.0 & c & 0.0 & c & 0.6 & $(0.1)$ & 99.3 & $(0.2)$ & 0.1 & $(0.1)$ & 0.0 & c \\
\hline & Poland & 0.6 & $(0.1)$ & 4.9 & $(0.3)$ & 93.8 & $(0.4)$ & 0.6 & $(0.2)$ & 0.0 & c & 0.0 & c \\
\hline & Portugal & 3.2 & $(0.3)$ & 8.4 & $(0.5)$ & 22.9 & $(0.9)$ & 65.1 & $(1.2)$ & 0.4 & $(0.1)$ & 0.0 & c \\
\hline & Slovak Republic & 2.2 & $(0.4)$ & 4.6 & $(0.4)$ & 42.6 & (1.3) & 50.6 & $(1.2)$ & 0.1 & $(0.0)$ & 0.0 & c \\
\hline & Slovenia & 0.0 & c & 0.3 & $(0.1)$ & 4.8 & $(0.3)$ & 94.6 & $(0.4)$ & 0.3 & $(0.1)$ & 0.0 & c \\
\hline & Spain & 0.1 & $(0.0)$ & 8.6 & $(0.5)$ & 23.4 & $(0.6)$ & 67.9 & $(0.9)$ & 0.1 & $(0.1)$ & 0.0 & c \\
\hline & Sweden & 0.1 & $(0.1)$ & 3.1 & $(0.4)$ & 94.9 & $(0.8)$ & 1.8 & $(0.7)$ & 0.1 & $(0.1)$ & 0.0 & c \\
\hline & Switzerland & 0.5 & $(0.1)$ & 11.8 & $(0.7)$ & 61.3 & $(1.2)$ & 25.9 & $(1.3)$ & 0.5 & $(0.1)$ & 0.0 & $(0.0)$ \\
\hline & Turkey & 0.6 & $(0.1)$ & 2.6 & $(0.4)$ & 20.7 & $(1.0)$ & 72.9 & $(1.2)$ & 3.0 & $(0.3)$ & 0.1 & $(0.0)$ \\
\hline & United Kingdom & 0.0 & C & 0.0 & C & 0.0 & $\mathrm{c}$ & 1.6 & $(0.3)$ & 97.4 & $(0.4)$ & 1.0 & $(0.3)$ \\
\hline & United States & 0.0 & $(0.0)$ & 0.5 & $(0.3)$ & 9.6 & $(0.7)$ & 72.4 & $(0.9)$ & 17.3 & (0.6) & 0.1 & $(0.0)$ \\
\hline$\approx$ & Albania & 0.2 & $(0.1)$ & 1.0 & $(0.2)$ & 35.8 & $(2.3)$ & 61.7 & (2.3) & 1.2 & $(0.7)$ & 0.0 & $(0.0)$ \\
\hline ఏ & Algeria & 18.8 & $(1.0)$ & 23.5 & $(1.1)$ & 35.1 & (1.5) & 19.4 & $(2.1)$ & 3.2 & $(0.7)$ & 0.0 & c \\
\hline ป & Brazil & 3.5 & $(0.2)$ & 6.4 & $(0.4)$ & 12.5 & $(0.5)$ & 35.9 & $(0.9)$ & 39.2 & $(0.8)$ & 2.5 & $(0.2)$ \\
\hline & B-S-J-G (China) & 1.1 & $(0.2)$ & 9.2 & $(0.7)$ & 52.7 & $(1.7)$ & 34.6 & $(2.0)$ & 2.2 & $(0.5)$ & 0.1 & $(0.0)$ \\
\hline & Bulgaria & 0.5 & $(0.2)$ & 3.0 & $(0.6)$ & 92.2 & $(0.8)$ & 4.3 & $(0.4)$ & 0.0 & c & 0.0 & c \\
\hline & Colombia & 5.3 & $(0.4)$ & 12.3 & $(0.6)$ & 22.7 & $(0.6)$ & 40.2 & $(0.7)$ & 19.5 & $(0.6)$ & 0.0 & c \\
\hline & Costa Rica & 6.2 & $(0.7)$ & 14.0 & $(0.7)$ & 33.0 & $(1.2)$ & 46.5 & (1.6) & 0.2 & $(0.1)$ & 0.1 & $(0.1)$ \\
\hline & Croatia & 0.0 & c & 0.2 & $(0.2)$ & 79.2 & $(0.5)$ & 20.6 & $(0.4)$ & 0.0 & c & 0.0 & c \\
\hline & Cyprus* & 0.0 & c & 0.3 & $(0.0)$ & 5.8 & $(0.1)$ & 93.1 & $(0.1)$ & 0.7 & $(0.1)$ & 0.0 & c \\
\hline & Dominican Republic & 7.1 & $(0.8)$ & 13.8 & $(1.2)$ & 20.6 & $(0.8)$ & 41.9 & (1.1) & 14.2 & $(0.7)$ & 2.4 & $(0.3)$ \\
\hline & FYROM & 0.1 & $(0.1)$ & 0.1 & $(0.1)$ & 70.2 & $(0.2)$ & 29.7 & $(0.2)$ & 0.0 & c & 0.0 & c \\
\hline & Georgia & 0.1 & $(0.0)$ & 0.8 & $(0.2)$ & 22.0 & $(0.8)$ & 76.0 & (0.9) & 1.1 & $(0.3)$ & 0.0 & $\mathrm{c}$ \\
\hline & Hong Kong (China) & 1.1 & $(0.1)$ & 5.6 & $(0.4)$ & 26.0 & $(0.7)$ & 66.7 & $(0.7)$ & 0.6 & $(0.5)$ & 0.0 & c \\
\hline & Indonesia & 2.1 & $(0.3)$ & 8.1 & $(0.7)$ & 42.1 & $(1.5)$ & 45.5 & (1.6) & 2.3 & $(0.4)$ & 0.0 & $(0.0)$ \\
\hline & Jordan & 0.2 & $(0.1)$ & 0.6 & $(0.1)$ & 6.6 & $(0.4)$ & 92.6 & $(0.4)$ & 0.0 & c & 0.0 & c \\
\hline & Kosovo & 0.0 & $(0.1)$ & 0.6 & $(0.1)$ & 24.9 & $(0.8)$ & 72.4 & $(0.9)$ & 2.1 & $(0.2)$ & 0.0 & c \\
\hline & Lebanon & 3.7 & $(0.5)$ & 8.3 & $(0.8)$ & 16.6 & (1.1) & 62.3 & (1.4) & 9.0 & $(0.8)$ & 0.1 & $(0.1)$ \\
\hline & Lithuania & 0.1 & $(0.0)$ & 2.6 & $(0.2)$ & 86.3 & $(0.4)$ & 11.0 & $(0.4)$ & 0.0 & $(0.0)$ & 0.0 & $\mathrm{c}$ \\
\hline & Macao (China) & 2.9 & $(0.1)$ & 12.2 & $(0.2)$ & 29.7 & $(0.2)$ & 54.5 & $(0.1)$ & 0.6 & $(0.1)$ & 0.0 & c \\
\hline & Malta & 0.0 & $\mathrm{C}$ & 0.0 & c & 0.3 & $(0.1)$ & 6.1 & $(0.2)$ & 93.6 & $(0.1)$ & 0.1 & $(0.0)$ \\
\hline & Moldova & 0.2 & $(0.1)$ & 7.6 & $(0.5)$ & 84.5 & $(0.8)$ & 7.5 & $(0.8)$ & 0.0 & $(0.0)$ & 0.0 & c \\
\hline & Montenegro & 0.0 & C & 0.0 & c & 83.7 & $(0.1)$ & 16.3 & $(0.1)$ & 0.0 & c & 0.0 & c \\
\hline & Peru & 2.5 & $(0.3)$ & 6.6 & $(0.4)$ & 15.9 & $(0.5)$ & 50.2 & $(0.8)$ & 24.8 & $(0.8)$ & 0.0 & c \\
\hline & Qatar & 0.9 & $(0.1)$ & 3.5 & $(0.1)$ & 16.3 & $(0.1)$ & 60.7 & $(0.1)$ & 18.0 & $(0.1)$ & 0.6 & $(0.0)$ \\
\hline & Romania & 1.4 & $(0.3)$ & 8.9 & $(0.5)$ & 74.8 & $(0.9)$ & 14.9 & $(0.7)$ & 0.0 & c & 0.0 & c \\
\hline & Russia & 0.2 & $(0.1)$ & 6.6 & $(0.3)$ & 79.7 & (1.5) & 13.4 & (1.5) & 0.1 & $(0.0)$ & 0.0 & c \\
\hline & Singapore & 0.0 & $(0.0)$ & 1.9 & $(0.3)$ & 7.9 & $(0.8)$ & 90.0 & $(1.0)$ & 0.1 & $(0.0)$ & 0.1 & $(0.0)$ \\
\hline & Chinese Taipei & 0.0 & c & 0.0 & c & 35.4 & $(0.7)$ & 64.6 & $(0.7)$ & 0.0 & c & 0.0 & c \\
\hline & Thailand & 0.2 & $(0.1)$ & 0.6 & $(0.2)$ & 23.8 & $(1.0)$ & 72.9 & (1.0) & 2.4 & $(0.4)$ & 0.0 & c \\
\hline & Trinidad and Tobago & 3.3 & $(0.2)$ & 10.8 & $(0.3)$ & 27.3 & $(0.3)$ & 56.5 & $(0.3)$ & 2.2 & $(0.2)$ & 0.0 & c \\
\hline & Tunisia & 4.3 & $(0.3)$ & 10.6 & $(0.8)$ & 19.6 & (1.3) & 60.9 & (1.7) & 4.6 & $(0.4)$ & 0.0 & c \\
\hline & United Arab Emirates & 0.6 & $(0.1)$ & 2.5 & $(0.3)$ & 10.6 & $(0.7)$ & 53.4 & $(0.8)$ & 31.4 & $(0.8)$ & 1.5 & $(0.1)$ \\
\hline & Uruguay & 7.5 & $(0.6)$ & 9.7 & $(0.5)$ & 20.7 & $(0.7)$ & 61.3 & $(1.2)$ & 0.8 & $(0.1)$ & 0.0 & c \\
\hline & Viet Nam & 0.3 & $(0.1)$ & 1.7 & $(0.4)$ & 7.7 & (1.8) & 90.4 & $(2.2)$ & 0.0 & $(0.0)$ & 0.0 & c \\
\hline & Argentina** & 1.6 & $(0.4)$ & 9.7 & $(0.8)$ & 27.4 & $(1.2)$ & 58.5 & (1.6) & 2.8 & $(0.3)$ & 0.0 & c \\
\hline & Kazakhstan** & 0.1 & $(0.1)$ & 2.7 & $(0.3)$ & 60.4 & $(1.7)$ & 36.2 & (1.8) & 0.6 & $(0.1)$ & 0.0 & c \\
\hline & Malaysia** & 0.0 & $\mathrm{C}$ & 0.0 & $\mathrm{C}$ & 3.2 & $(0.6)$ & 96.4 & $(0.7)$ & 0.4 & $(0.3)$ & 0.0 & $\mathrm{C}$ \\
\hline
\end{tabular}

* See note at the beginning of this Annex.

** Coverage is too small to ensure comparability (see Annex A4).

StatLink त्नाls $\mathrm{http}: / / \mathrm{dx}$.doi.org/10.1787/888933433129 


\begin{tabular}{|c|c|c|c|c|c|c|c|c|c|c|c|c|c|c|c|c|c|c|c|c|c|c|c|}
\hline & & & & & & & & oys & & & & & & & & & & & & irls & & & \\
\hline & & 7th & grade & 8th & grade & 9th $\mathrm{g}$ & grade & 10th & grade & 11th & grade & $\begin{array}{l}\text { 12th } \\
\text { and }\end{array}$ & $\begin{array}{l}\text { grade } \\
\text { above }\end{array}$ & 7th & grade & 8th g & grade & 9th $\mathrm{g}$ & grade & 10th & grade & 11th & grade \\
\hline & & $\%$ & S.E. & $\%$ & S.E. & $\%$ & S.E. & $\%$ & S.E. & $\%$ & S.E. & $\%$ & S.E. & $\%$ & S.E. & $\%$ & S.E. & $\%$ & S.E. & $\%$ & S.E. & $\%$ & S.E. \\
\hline s & Australia & 0.0 & $(0.0)$ & 0.2 & $(0.1)$ & 13.2 & $(0.4)$ & 73.5 & $(0.5)$ & 13.1 & $(0.5)$ & 0.0 & $(0.0)$ & 0.0 & $(0.0)$ & 0.1 & $(0.0)$ & 9.2 & $(0.3)$ & 75.7 & $(0.5)$ & 14.9 & $(0.6)$ \\
\hline 过 & Austria & 0.1 & $(0.1)$ & 2.0 & $(0.4)$ & 21.6 & (1.2) & 71.1 & $(1.2)$ & 5.2 & $(0.4)$ & 0.0 & $(0.0)$ & 0.0 & c & 2.0 & $(0.9)$ & 20.0 & (1.0) & 71.4 & (1.3) & 6.6 & $(0.4)$ \\
\hline & Belgium & 0.7 & $(0.1)$ & 6.7 & $(0.5)$ & 33.6 & (1.0) & 57.9 & $(1.1)$ & 1.2 & $(0.2)$ & 0.0 & c & 0.6 & $(0.1)$ & 6.2 & $(0.5)$ & 27.7 & $(0.8)$ & 64.2 & (1.1) & 1.3 & $(0.1)$ \\
\hline & Canada & 0.1 & $(0.1)$ & 1.0 & $(0.2)$ & 11.7 & $(0.6)$ & 86.5 & $(0.6)$ & 0.7 & $(0.1)$ & 0.0 & $(0.0)$ & 0.1 & $(0.0)$ & 0.4 & $(0.1)$ & 9.9 & $(0.6)$ & 88.8 & $(0.6)$ & 0.8 & $(0.1)$ \\
\hline & Chile & 2.2 & $(0.5)$ & 4.8 & $(0.8)$ & 26.4 & $(0.9)$ & 64.8 & $(1.3)$ & 1.8 & $(0.2)$ & 0.1 & $(0.1)$ & 1.2 & $(0.4)$ & 3.5 & $(0.7)$ & 21.5 & $(0.8)$ & 71.4 & (1.1) & 2.4 & $(0.3)$ \\
\hline & Czech Republic & 0.6 & $(0.2)$ & 5.5 & $(0.5)$ & 52.3 & (1.5) & 41.5 & $(1.6)$ & 0.0 & $(0.0)$ & 0.0 & c & 0.4 & $(0.2)$ & 2.2 & $(0.3)$ & 46.2 & (1.5) & 51.2 & (1.6) & 0.0 & c \\
\hline & Denmark & 0.3 & $(0.1)$ & 21.9 & $(0.9)$ & 76.6 & (1.0) & 1.2 & $(0.5)$ & 0.0 & c & 0.0 & c & 0.1 & $(0.1)$ & 10.8 & $(0.5)$ & 87.3 & $(0.7)$ & 1.7 & $(0.6)$ & 0.0 & c \\
\hline & Estonia & 1.3 & $(0.3)$ & 23.7 & $(0.9)$ & 74.2 & $(0.8)$ & 0.8 & $(0.3)$ & 0.0 & c & 0.0 & $(0.0)$ & 0.2 & $(0.1)$ & 18.8 & $(0.8)$ & 79.1 & $(0.8)$ & 1.9 & $(0.4)$ & 0.0 & c \\
\hline & Finland & 0.4 & $(0.1)$ & 15.5 & $(0.6)$ & 83.9 & (0.6) & 0.0 & $(0.0)$ & 0.2 & $(0.1)$ & 0.0 & c & 0.5 & $(0.1)$ & 11.5 & $(0.5)$ & 87.7 & $(0.5)$ & 0.0 & c & 0.3 & $(0.2)$ \\
\hline & France & 0.0 & c & 1.0 & $(0.2)$ & 26.1 & $(0.9)$ & 69.6 & $(1.0)$ & 3.1 & $(0.3)$ & 0.2 & $(0.1)$ & 0.1 & $(0.1)$ & 1.0 & $(0.2)$ & 20.1 & $(0.6)$ & 75.4 & $(0.8)$ & 3.3 & $(0.3)$ \\
\hline & Germany & 0.7 & $(0.2)$ & 9.0 & $(0.5)$ & 50.1 & (1.0) & 38.8 & $(1.0)$ & 1.4 & $(0.4)$ & 0.0 & $(0.0)$ & 0.3 & $(0.1)$ & 6.3 & (0.6) & 44.3 & $(0.9)$ & 47.5 & (1.0) & 1.6 & $(0.6)$ \\
\hline & Greece & 0.4 & $(0.2)$ & 1.1 & $(0.3)$ & 4.7 & (1.0) & 93.8 & $(1.2)$ & 0.0 & c & 0.0 & C & 0.1 & $(0.1)$ & 0.2 & $(0.1)$ & 2.8 & $(0.8)$ & 96.9 & $(0.8)$ & 0.0 & C \\
\hline & Hungary & 1.8 & $(0.4)$ & 10.1 & $(0.6)$ & 75.6 & (0.9) & 12.5 & $(0.6)$ & 0.0 & c & 0.0 & c & 1.6 & $(0.4)$ & 6.9 & $(0.8)$ & 76.0 & $(0.9)$ & 15.5 & $(0.7)$ & 0.0 & c \\
\hline & Iceland & 0.0 & c & 0.0 & c & 0.0 & C & 100.0 & C & 0.0 & c & 0.0 & c & 0.0 & c & 0.0 & c & 0.0 & c & 100.0 & c & 0.0 & c \\
\hline & Ireland & 0.0 & c & 2.2 & $(0.3)$ & 62.8 & $(0.9)$ & 24.1 & (1.2) & 10.9 & (1.0) & 0.0 & c & 0.0 & $(0.0)$ & 1.4 & $(0.2)$ & 58.2 & $(0.9)$ & 29.0 & (1.4) & 11.3 & (1.1) \\
\hline & Israel & 0.0 & C & 0.1 & $(0.1)$ & 18.0 & (1.2) & 80.9 & $(1.3)$ & 1.1 & $(0.6)$ & 0.0 & c & 0.0 & 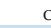 & 0.1 & $(0.0)$ & 14.9 & $(0.8)$ & 84.4 & $(0.8)$ & 0.7 & $(0.1)$ \\
\hline & Italy & 0.2 & $(0.1)$ & 1.3 & $(0.3)$ & 18.1 & $(0.8)$ & 75.0 & $(0.9)$ & 5.4 & $(0.4)$ & 0.0 & c & 0.1 & $(0.0)$ & 0.7 & $(0.2)$ & 12.2 & $(0.8)$ & 79.3 & (1.0) & 7.7 & $(0.5)$ \\
\hline & Japan & 0.0 & C & 0.0 & c & 0.0 & c & 100.0 & C & 0.0 & c & 0.0 & c & 0.0 & c & 0.0 & c & 0.0 & c & 100.0 & c & 0.0 & c \\
\hline & Korea & 0.0 & c & 0.0 & c & 10.1 & (1.4) & 89.4 & $(1.4)$ & 0.5 & $(0.1)$ & 0.0 & c & 0.0 & c & 0.0 & c & 8.0 & $(0.8)$ & 91.5 & $(0.8)$ & 0.5 & $(0.1)$ \\
\hline & Latvia & 1.5 & $(0.4)$ & 14.7 & $(0.8)$ & 81.8 & $(0.9)$ & 1.9 & $(0.3)$ & 0.0 & $(0.0)$ & 0.0 & c & 0.4 & $(0.2)$ & 8.7 & $(0.7)$ & 87.0 & $(0.7)$ & 3.9 & $(0.4)$ & 0.0 & c \\
\hline & Luxembc & 0.2 & $(0.1)$ & 9.4 & $(0.2)$ & 52.4 & $(0.3)$ & 37.3 & $(0.2)$ & 0.7 & $(0.1)$ & 0.0 & C & 0.3 & $(0.1)$ & 6.4 & $(0.2)$ & 49.4 & $(0.2)$ & 43.3 & $(0.2)$ & 0.6 & $(0.1)$ \\
\hline & Mexico & 3.1 & $(0.5)$ & 5.9 & $(0.6)$ & 32.2 & (1.5) & 58.0 & $(1.6)$ & 0.6 & $(0.2)$ & 0.2 & $(0.0)$ & 1.5 & $(0.3)$ & 3.7 & $(0.4)$ & 31.6 & (1.7) & 62.5 & (1.7) & 0.4 & $(0.1)$ \\
\hline & Netherlands & 0.0 & $(0.0)$ & 3.8 & $(0.4)$ & 45.3 & $(0.8)$ & 50.2 & $(0.8)$ & 0.8 & $(0.3)$ & 0.0 & c & 0.1 & $(0.0)$ & 1.9 & $(0.3)$ & 38.0 & $(0.7)$ & 59.3 & $(0.7)$ & 0.7 & $(0.2)$ \\
\hline & New Zealand & 0.0 & c & 0.0 & C & 0.0 & c & 6.9 & $(0.5)$ & 88.6 & $(0.8)$ & 4.5 & $(0.5)$ & 0.0 & $\mathrm{c}$ & 0.0 & C & 0.0 & $(0.0)$ & 5.4 & $(0.4)$ & 89.1 & $(0.6)$ \\
\hline & Norway & 0.0 & c & 0.0 & c & 0.8 & $(0.2)$ & 99.1 & $(0.2)$ & 0.1 & $(0.1)$ & 0.0 & c & 0.0 & c & 0.0 & c & 0.3 & $(0.1)$ & 99.6 & $(0.1)$ & 0.1 & $(0.1)$ \\
\hline & Poland & 0.9 & $(0.2)$ & 6.8 & $(0.5)$ & 92.1 & (0.6) & 0.2 & $(0.2)$ & 0.0 & $\mathrm{c}$ & 0.0 & C & 0.4 & $(0.1)$ & 3.0 & $(0.3)$ & 95.6 & $(0.5)$ & 1.1 & $(0.3)$ & 0.0 & C \\
\hline & Portugal & 4.2 & $(0.4)$ & 10.5 & $(0.7)$ & 25.4 & (1.0) & 59.6 & $(1.4)$ & 0.3 & $(0.1)$ & 0.0 & c & 2.1 & $(0.4)$ & 6.4 & $(0.5)$ & 20.5 & $(0.9)$ & 70.5 & $(1.2)$ & 0.5 & $(0.1)$ \\
\hline & Slovak Republic & 2.4 & $(0.4)$ & 4.8 & $(0.5)$ & 43.5 & (1.6) & 49.4 & $(1.8)$ & 0.0 & c & 0.0 & c & 1.9 & $(0.5)$ & 4.3 & $(0.6)$ & 41.7 & (1.8) & 51.9 & (1.8) & 0.1 & $(0.1)$ \\
\hline & Slovenia & 0.0 & & 0.5 & $(0.2)$ & 5.4 & $(0.7)$ & 93.9 & $(0.7)$ & 0.2 & $(0.1)$ & 0.0 & c & 0.0 & c & 0.2 & $(0.1)$ & 4.1 & $(0.6)$ & 95.3 & $(0.6)$ & 0.4 & $(0.2)$ \\
\hline & Spain & 0.1 & $(0.1)$ & 10.7 & $(0.7)$ & 25.4 & $(0.8)$ & 63.7 & $(1.1)$ & 0.1 & $(0.1)$ & 0.0 & c & 0.0 & c & 6.5 & $(0.5)$ & 21.3 & $(0.8)$ & 72.1 & (1.0) & 0.1 & $(0.1)$ \\
\hline & Sweden & 0.1 & $(0.1)$ & 3.5 & $(0.5)$ & 95.0 & $(0.9)$ & 1.4 & $(0.7)$ & 0.1 & $(0.1)$ & 0.0 & c & 0.2 & $(0.1)$ & 2.6 & $(0.4)$ & 94.9 & (1.0) & 2.3 & $(0.9)$ & 0.1 & $(0.1)$ \\
\hline & Switzerland & 0.7 & $(0.2)$ & 13.4 & $(0.8)$ & 60.7 & (1.1) & 24.7 & $(1.2)$ & 0.5 & $(0.1)$ & 0.0 & c & 0.3 & $(0.1)$ & 10.1 & $(0.8)$ & 62.0 & (1.7) & 27.2 & (1.9) & 0.5 & $(0.2)$ \\
\hline & Turkey & 0.8 & $(0.3)$ & 3.1 & $(0.6)$ & 25.4 & (1.2) & 68.4 & - (1.6) & 2.2 & $(0.4)$ & 0.1 & $(0.1)$ & 0.4 & $(0.2)$ & 2.1 & $(0.4)$ & 16.1 & (1.1) & 77.5 & (1.3) & 3.8 & $(0.4)$ \\
\hline & United Kingdom & 0.0 & c & 0.0 & c & 0.0 & c & 1.9 & $(0.5)$ & 97.3 & $(0.6)$ & 0.9 & $(0.3)$ & 0.0 & c & 0.0 & C & 0.0 & c & 1.4 & $(0.2)$ & 97.5 & $(0.3)$ \\
\hline & United States & 0.0 & C & 0.5 & $(0.4)$ & 11.6 & $(0.8)$ & 72.4 & (1.0) & 15.3 & $(0.7)$ & 0.2 & $(0.1)$ & 0.1 & $(0.1)$ & 0.5 & $(0.2)$ & 7.6 & $(0.6)$ & 72.4 & $(0.9)$ & 19.4 & $(0.7)$ \\
\hline$\approx$ & Albania & 0.2 & $(0.2)$ & 0.9 & $(0.2)$ & 41.2 & (2.7) & 56.3 & (2.6) & 1.3 & (0.9) & 0.0 & $(0.0)$ & 0.1 & $(0.1)$ & 1.1 & $(0.3)$ & 30.4 & (2.1) & 67.1 & $(2.2)$ & 1.2 & $\begin{array}{ll}(0.5) \\
\end{array}$ \\
\hline$\theta$ & Algeria & 24.4 & (1.3) & 25.7 & $(1.2)$ & 32.6 & (1.5) & 14.7 & (1.9) & 2.6 & $(0.7)$ & 0.0 & C & 12.6 & (1.1) & 21.0 & $(1.2)$ & 37.9 & (2.0) & 24.6 & (2.5) & 3.9 & (0.8) \\
\hline & Brazil & 4.6 & $(0.3)$ & 7.8 & $(0.6)$ & 13.9 & $(0.6)$ & 36.5 & (1.0) & 35.3 & $(0.9)$ & 1.8 & $(0.2)$ & 2.4 & $(0.2)$ & 5.0 & $(0.4)$ & 11.1 & (0.6) & 35.3 & $(0.9)$ & 43.0 & (0.9) \\
\hline & B-S-J-G (C & 1.2 & $(0.2)$ & 9.9 & $(0.7)$ & 55.4 & (1.7) & 31.6 & (1.9) & 1.9 & $(0.5)$ & 0.1 & $(0.0)$ & 1.1 & $(0.2)$ & 8.4 & $(0.8)$ & 49.6 & (1.8) & 38.1 & $(2.2)$ & 2.6 & $(0.5)$ \\
\hline & Bulgaria & 0.6 & $(0.2)$ & 4.1 & $(0.8)$ & 91.8 & (1.0) & 3.5 & $(0.4)$ & 0.0 & 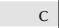 & 0.0 & c & 0.4 & $(0.2)$ & 1.8 & $(0.4)$ & 92.7 & $(0.7)$ & 5.2 & $(0.4)$ & 0.0 & c \\
\hline & Colombia & 7.2 & $(0.6)$ & 14.3 & $(0.8)$ & 25.2 & $(0.8)$ & 37.1 & $(0.9)$ & 16.2 & $(0.8)$ & 0.0 & c & 3.6 & $(0.4)$ & 10.5 & $(0.7)$ & 20.5 & (0.9) & 42.9 & (1.0) & 22.5 & $(0.8)$ \\
\hline & Costa Rica & 7.8 & $(0.8)$ & 16.7 & $(0.8)$ & 34.3 & $(1.2)$ & 41.2 & (1.5) & 0.1 & $(0.0)$ & 0.0 & c & 4.7 & $(0.7)$ & 11.4 & $(0.7)$ & 31.8 & (1.4) & 51.6 & (1.8) & 0.3 & $(0.1)$ \\
\hline & Croatia & 0.0 & c & 0.2 & $(0.1)$ & 80.5 & $(0.5)$ & 19.4 & $(0.5)$ & 0.0 & c & 0.0 & c & 0.0 & c & 0.3 & $(0.2)$ & 78.0 & $(0.7)$ & 21.7 & $(0.7)$ & 0.0 & c \\
\hline & Cyprus* & 0.0 & c & 0.3 & $(0.1)$ & 6.6 & $(0.2)$ & 92.4 & $(0.2)$ & 0.6 & $(0.1)$ & 0.0 & c & 0.0 & c & 0.3 & $(0.1)$ & 5.1 & $(0.2)$ & 93.8 & $(0.2)$ & 0.8 & (0.1) \\
\hline & Dominica & 10.3 & (1.1) & 16.4 & (1.5) & 23.3 & (1.2) & 37.2 & (1.4) & 11.1 & $(0.8)$ & 1.7 & $(0.3)$ & 4.0 & (0.6) & 11.2 & (1.1) & 18.1 & $(0.8)$ & 46.5 & (1.1) & 17.2 & (0.8) \\
\hline & FYROM & 0.2 & $(0.2)$ & 0.2 & $(0.2)$ & 70.9 & $(0.3)$ & 28.8 & $(0.2)$ & 0.0 & c & 0.0 & c & 0.0 & c & 0.0 & c & 69.4 & $(0.3)$ & 30.6 & $(0.3)$ & 0.0 & c \\
\hline & Georgia & 0.1 & $(0.0)$ & 0.9 & $(0.2)$ & 23.0 & (1.0) & 75.2 & (1.0) & 0.8 & $(0.2)$ & 0.0 & c & 0.1 & (0.1) & 0.7 & $(0.2)$ & 20.9 & (0.9) & 76.8 & (1.0) & 1.5 & (0.4) \\
\hline & Hong Ko & 1.3 & $(0.2)$ & 6.4 & $(0.5)$ & 28.5 & $(0.8)$ & 63.3 & (0.9) & 0.5 & $(0.4)$ & 0.0 & c & 1.0 & $(0.2)$ & 4.7 & $(0.4)$ & 23.5 & $(0.8)$ & 70.2 & $(0.9)$ & 0.6 & (0.6) \\
\hline & Indonesia & 2.5 & $(0.4)$ & 8.9 & $(0.9)$ & 44.3 & (1.9) & 42.1 & (2.0) & 2.1 & (0.4) & 0.0 & $(0.0)$ & 1.7 & $(0.3)$ & 7.2 & (1.0) & 39.8 & (1.9) & 48.9 & (2.1) & 2.4 & (0.4) \\
\hline & Jordan & 0.1 & $(0.1)$ & 0.5 & $(0.1)$ & 6.6 & $(0.7)$ & 92.9 & $(0.7)$ & 0.0 & c & 0.0 & c & 0.2 & $(0.1)$ & 0.7 & $(0.1)$ & 6.6 & (0.6) & 92.4 & $(0.6)$ & 0.0 & c \\
\hline & Kosovo & 0.1 & $(0.1)$ & 0.5 & $(0.1)$ & 26.4 & (0.9) & 71.5 & (1.0) & 1.6 & $(0.3)$ & 0.0 & c & 0.0 & c & 0.7 & $(0.2)$ & 23.5 & (1.0) & 73.3 & (1.0) & 2.5 & (0.3) \\
\hline & Lebanon & 4.0 & $(0.6)$ & 8.2 & $(0.9)$ & 17.2 & (1.4) & 63.5 & (1.7) & 6.9 & $(0.7)$ & 0.2 & $(0.1)$ & 3.4 & (0.6) & 8.3 & (1.0) & 16.1 & (1.2) & 61.2 & (1.8) & 10.8 & (1.2) \\
\hline & Lithuania & 0.2 & $(0.1)$ & 3.5 & $(0.3)$ & 87.4 & $(0.6)$ & 8.8 & $(0.5)$ & 0.0 & $(0.0)$ & 0.0 & c & 0.0 & $(0.0)$ & 1.7 & $(0.2)$ & 85.1 & $(0.7)$ & 13.1 & $(0.6)$ & 0.0 & $(0.0)$ \\
\hline & Macao (China) & 4.3 & $(0.2)$ & 16.4 & $(0.3)$ & 30.8 & $(0.2)$ & 48.2 & $(0.2)$ & 0.4 & $(0.1)$ & 0.0 & c & 1.6 & $(0.2)$ & 8.0 & $(0.2)$ & 28.7 & (0.3) & 60.8 & $(0.3)$ & 0.9 & $(0.2)$ \\
\hline & Malta & 0.0 & & 0.0 & & 0.5 & $(0.1)$ & 6.8 & $(0.3)$ & 92.7 & $(0.2)$ & 0.0 & c & 0.0 & c & 0.0 & c & 0.1 & $(0.0)$ & 5.4 & $(0.2)$ & 94.4 & $(0.2)$ \\
\hline & Moldova & 0.3 & $(0.1)$ & 8.2 & $(0.7)$ & 86.3 & $(0.9)$ & 5.0 & $(0.9)$ & 0.1 & $(0.1)$ & 0.0 & c & 0.2 & $(0.1)$ & 7.0 & $(0.6)$ & 82.8 & (1.2) & 10.1 & (1.2) & 0.0 & c \\
\hline & Montenegro & 0.0 & c & 0.0 & c & 85.2 & $(0.2)$ & 14.8 & $(0.2)$ & 0.0 & c & 0.0 & c & 0.0 & c & 0.0 & c & 82.2 & $(0.2)$ & 17.8 & $(0.2)$ & 0.0 & c \\
\hline & Peru & 3.0 & $(0.5)$ & 7.5 & $(0.5)$ & 17.9 & $(0.7)$ & 48.7 & (0.9) & 22.9 & (1.0) & 0.0 & c & 1.9 & $(0.3)$ & 5.6 & $(0.5)$ & 14.0 & (0.6) & 51.7 & (1.0) & 26.8 & (0.9) \\
\hline & Qatar & 0.8 & $(0.1)$ & 3.6 & $(0.1)$ & 18.0 & $(0.2)$ & 59.3 & $(0.2)$ & 17.6 & $(0.2)$ & 0.6 & $(0.1)$ & 1.0 & $(0.1)$ & 3.4 & $(0.1)$ & 14.5 & $(0.1)$ & 62.1 & $(0.2)$ & 18.4 & $(0.2)$ \\
\hline & Romania & 1.7 & $(0.4)$ & 10.7 & $(0.8)$ & 74.3 & (1.0) & 13.3 & $(0.7)$ & 0.0 & c & 0.0 & c & 1.1 & $(0.4)$ & 7.2 & $(0.8)$ & 75.3 & (1.1) & 16.4 & $(0.8)$ & 0.0 & c \\
\hline & Russia & 0.2 & $(0.1)$ & 7.2 & $(0.5)$ & 80.1 & (1.7) & 12.4 & (1.7) & 0.0 & $(0.0)$ & 0.0 & c & 0.1 & $(0.1)$ & 6.0 & $(0.4)$ & 79.3 & (1.5) & 14.4 & (1.6) & 0.1 & $(0.1)$ \\
\hline & Singapore & 0.1 & $(0.0)$ & 1.8 & $(0.3)$ & 8.9 & $(0.9)$ & 89.1 & (1.1) & 0.1 & $(0.1)$ & 0.0 & $(0.0)$ & 0.0 & $(0.0)$ & 2.0 & $(0.4)$ & 6.9 & $(0.8)$ & 90.8 & (1.1) & 0.2 & $(0.1)$ \\
\hline & Chinese Taipei & 0.0 & c & 0.0 & c & 36.5 & (1.3) & 63.5 & (1.3) & 0.0 & c & 0.0 & C & 0.0 & c & 0.0 & c & 34.3 & (1.3) & 65.7 & (1.3) & 0.0 & c \\
\hline & Thailand & 0.2 & $(0.1)$ & 0.8 & $(0.3)$ & 25.4 & (1.2) & 71.4 & (1.2) & 2.3 & $(0.4)$ & 0.0 & c & 0.3 & $(0.1)$ & 0.5 & $(0.2)$ & 22.5 & (1.3) & 74.1 & (1.3) & 2.6 & (0.4) \\
\hline & Trinidad a & 3.7 & $(0.3)$ & 14.2 & $(0.5)$ & 30.8 & $(0.5)$ & 48.9 & $(0.5)$ & 2.4 & $(0.2)$ & 0.0 & c & 2.8 & $(0.2)$ & 7.5 & $(0.4)$ & 23.8 & $(0.4)$ & 63.9 & $(0.5)$ & 2.0 & $(0.3)$ \\
\hline & Tunisia & 5.9 & $(0.5)$ & 13.8 & (1.0) & 22.0 & (1.4) & 54.0 & (1.9) & 4.3 & $(0.5)$ & 0.0 & c & 3.0 & $(0.3)$ & 7.8 & $(0.7)$ & 17.5 & (1.4) & 67.0 & (1.8) & 4.8 & $(0.5)$ \\
\hline & United Arab Emirate & 0.7 & $(0.1)$ & 2.9 & $(0.4)$ & 11.4 & (1.1) & 54.0 & (1.3) & 29.6 & (1.0) & 1.4 & $(0.2)$ & 0.4 & $(0.1)$ & 2.2 & $(0.5)$ & 9.9 & $(0.9)$ & 52.8 & $(0.9)$ & 33.1 & (1.1) \\
\hline & Uruguay & 9.2 & $(0.8)$ & 11.2 & $(0.7)$ & 22.5 & $(0.9)$ & 56.5 & (1.5) & 0.5 & $(0.1)$ & 0.0 & c & 6.0 & $(0.7)$ & 8.3 & $(0.6)$ & 19.0 & $(0.8)$ & 65.6 & (1.1) & 1.1 & $(0.2)$ \\
\hline & Viet Nam & 0.5 & $(0.2)$ & 2.3 & (0.6) & $\mid 11.1$ & (2.6) & 86.1 & (3.2) & 0.0 & c & 0.0 & C & 0.1 & $(0.0)$ & 1.1 & $(0.4)$ & 4.6 & (1.2) & 94.2 & (1.4) & 0.0 & $(0.0)$ \\
\hline & & 2.3 & $(0.6)$ & 11.5 & $(0.9)$ & 27.8 & (1.3) & 56.0 & (1.8) & 2.4 & (0.3) & 0.0 & C & 1. & $(0$. & 8.1 & (0.9) & 26.9 & (1.4) & 60.8 & (1.7) & 3.2 & $(0.3)$ \\
\hline & $\tan * *$ & 0.1 & $(0.1)$ & 3.1 & $(0.4)$ & 62.8 & $(2.3)$ & 33.5 & (2.4) & 0.5 & $(0.1)$ & 0.0 & & 0.1 & $(0.1)$ & 2.3 & $(0.3)$ & 57.8 & (1.7) & 39.0 & (1.8) & 0.7 & $(0.1)$ \\
\hline & Malaysia** & 0.0 & & 0.0 & & 4.2 & $(0.8)$ & 95.4 & $(0.9)$ & 0.4 & $(0.3)$ & 0.0 & & 0.0 & & 0.0 & & 2.3 & $(0.5)$ & 97.2 & $(0.6)$ & 0.4 & $(0.4)$ \\
\hline
\end{tabular}

* See note at the beginning of this Annex.

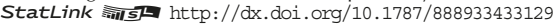

\section{Reference}

OECD (forthcoming), PISA 2015 Technical Report, PISA, OECD Publishing, Paris. 
ANNEX A3

TECHNICAL NOTES ON ANALYSES IN PISA 2015 RESULTS

\section{Methods and definitions}

\section{Odds ratio}

The odds ratio is a measure of the relative likelihood of a particular outcome across two groups. The odds ratio for observing the outcome when an antecedent is present is simply

$O R=\frac{\left(p_{11} / p_{12}\right)}{\left(p_{21} / p_{22}\right)}$

where $p_{11} / p_{12}$ represents the "odds" of observing the outcome when the antecedent is present, and $p_{21} / p_{22}$ represents the "odds" of observing the outcome when the antecedent is not present.

Logistic regression can be used to estimate the log ratio: the exponentiated logit coefficient for a binary variable is equivalent to the odds ratio. A "generalised" odds ratio, after accounting for other differences across groups, can be estimated by introducing control variables in the logistic regression.

\section{Statistics based on multilevel models}

Statistics based on multilevel models include variance components (between- and within-school variance), the index of inclusion derived from these components, and regression coefficients where this has been indicated. Multilevel models are generally specified as two-level regression models (the student and school levels), with normally distributed residuals, and estimated with maximum likelihood estimation. Where the dependent variable is science, reading or mathematics performance, the estimation uses ten plausible values for each student's performance on the mathematics scale. Models were estimated using the Stata ${ }^{\circledR}$ (version 14.1) "mixed" module. The three-level regression models are estimated with HLM® (version 6.06) using only five plausible values of science performance.

In multilevel models, weights are used at both the student and school levels. The purpose of these weights is to account for differences in the probabilities of students being selected in the sample. Since PISA applies a two-stage sampling procedure, these differences are due to factors at both the school and the student levels. For the multilevel models, student final weights (W_FSTUWT) were used. Within-school weights correspond to student final weights, rescaled to amount to the sample size within each school. Between-school weights correspond to the sum of final student weights (W_FSTUWT) within each school. The definition of between-school weights is the same as in PISA 2012 initial reports. For the three-level regression models, the sum of the weights is the same across education systems so that each education system contributes equally to the results.

The index of inclusion is based on the intraclass correlation and is estimated as:

$100 * \frac{\sigma_{w}^{2}}{\sigma_{w}^{2}+\sigma_{b}^{2}}$

where $\sigma_{w}^{2}$ and $\sigma_{b}^{2}$ represent the within- and between-variance estimates, respectively.

The results in multilevel models, and the between-school variance estimate in particular, depend on how schools are defined and organised within countries and by the units that were chosen for sampling purposes. For example, in some countries, some of the schools in the PISA sample were defined as administrative units (even if they spanned several geographically separate institutions, as in Italy); in others they were defined as those parts of larger educational institutions that serve 15-year-olds; in still others they were defined as physical school buildings; and in others they were defined from a management perspective (e.g. entities having a principal). The PISA 2015 Technical Report (OECD, forthcoming) and Annex A2 provide an overview of how schools are defined. In Slovenia, the primary sampling unit is defined as a group of students who follow the same study programme within a school (an education track within a school). So in this case, the between-school variation is actually the between-track variation. The use of stratification variables in the selection of schools may also affect the estimate of the between-school variation, particularly if stratification variables are associated with between-school differences.

Because of the manner in which students were sampled, the within-school variation includes variation between classes as well as between students. 


\section{Multiple imputation}

Multiple imputation replaces each missing value with a set of plausible values that represent the uncertainty about the right value to impute. The multiple imputed data sets are then analysed by using standard procedures for complete data and by combining results from these analyses. For the three-level regression models, five imputed values were computed for each missing value using the predictive mean matching method in SAS® PROC MI. Five plausible values of science performance were then analysed by the HLM® software using one of the five imputed data sets.

\section{Diversity index of grade levels}

The diversity index of grade levels is based on the Herfindahl index and can be interpreted as the probability (in \%) that two students selected at random are enrolled in different grades. It is defined as:

$$
\left.D=100-\left(\left(\sum_{g=1}^{C} p_{g}^{2}\right) * 100\right)\right)
$$

where $p_{g}$ is the proportion of students enrolled in grade level $g$.

\section{Standard errors and significance tests}

The statistics in this report represent estimates of national performance based on samples of students, rather than values that could be calculated if every student in every country had answered every question. Consequently, it is important to measure the degree of uncertainty of the estimates. In PISA, each estimate has an associated degree of uncertainty, which is expressed through a standard error. The use of confidence intervals provides a way to make inferences about the population means and proportions in a manner that reflects the uncertainty associated with the sample estimates. From an observed sample statistic and assuming a normal distribution, it can be inferred that the corresponding population result would lie within the confidence interval in 95 out of 100 replications of the measurement on different samples drawn from the same population.

In many cases, readers are primarily interested in whether a given value in a particular country is different from a second value in the same or another country, e.g. whether girls in a country perform better than boys in the same country. In the tables and charts used in this report, differences are labelled as statistically significant if the probability of reporting a difference when there is actually no such difference in corresponding population values is lower than $5 \%$. Similarly, the risk of reporting a correlation as significant if there is, in fact, no correlation between two measures, is contained at $5 \%$.

Throughout the report, significance tests were undertaken to assess the statistical significance of the comparisons made.

\section{Differences between subgroup means}

Differences between groups of students (e.g. students who have skipped a day of school and students who have not skipped a day of school) or categories of schools (e.g. advantaged and disadvantaged schools) were tested for statistical significance. The definitions of the subgroups can, in general, be found in the tables and the text accompanying the analysis. Socio-economically (dis)advantaged schools, for instance, are defined as schools in the (bottom) top quarter of the distribution of the average PISA index of economic, social and cultural status (ESCS) across schools within each country/economy. All differences marked in bold in the tables presented in Annex B of this report are statistically significant at the $95 \%$ level.

\section{Change in the performance per unit of an index}

For many tables, the difference in student performance per unit of an index was calculated. Figures in bold indicate that the differences are statistically significantly different from zero at the 95\% confidence level.

\section{Odds ratio}

Figures in bold in the data tables presented in Annex B of this report indicate that the relative risk/odds ratio is statistically significantly different from 1 at the 95\% confidence level. To compute statistical significance around the value of 1 (the null hypothesis), the relative-risk/odds-ratio statistic is assumed to follow a log-normal distribution, rather than a normal distribution, under the null hypothesis.

\section{Multilevel models}

The standard errors of multilevel models are not estimated with the usual replication method, which accounts for stratification and sampling rates from finite populations. Instead, standard errors are "model-based": their computation assumes that schools, and students within schools, are sampled at random (with sampling probabilities reflected in school and student weights) from a theoretical, infinite population of schools and students which complies with the model's parametric assumptions.

The standard error for the estimated index of inclusion is calculated by deriving an approximate distribution for it from the (model-based) standard errors for the variance components, using the delta-method. 


\section{Multiple imputation}

The standard errors take into account the between-imputation variance. The standard errors of the results therefore consist of sampling variance, cognitive test measurement variance and error due to the imputation of missing values.

\section{Reference}

Gorard, S. and C. Taylor (2002), "What is segregation ? A comparison of measures in terms of 'strong' and 'weak' compositional invariance", Sociology, Vol.36/4, pp. 875-895, http://dx.doi.org/ 10.1177/003803850203600405. 


\section{ANNEX A4 \\ QUALITY ASSURANCE}

Quality assurance procedures were implemented in all parts of PISA 2015, as was done for all previous PISA surveys. The PISA 2015 Technical Standards (www.oecd.org/pisa/) specify the way in which PISA must be implemented in each country, economy and adjudicated region. International contractors monitor the implementation in each of these and adjudicate on their adherence to the standards.

The consistent quality and linguistic equivalence of the PISA 2015 assessment instruments were facilitated by assessing the ease with which the original English version could be translated. Two source versions of the assessment instruments, in English and French were prepared (except for the financial literacy assessment and the operational manuals, which were provided only in English) in order for countries to conduct a double translation design, i.e. two independent translations from the source language(s), and reconciliation by a third person. Detailed instructions for the localisation (adaptation, translation and validation) of the instruments for the field trial and for their review for the main survey, and translation/adaptation guidelines were supplied. An independent team of expert verifiers, appointed and trained by the PISA Consortium, verified each national version against the English and/or French source versions. These translators' mother tongue was the language of instruction in the country concerned, and the translators were knowledgeable about education systems. For further information on PISA translation procedures, see the PISA 2015 Technical Report (OECD, forthcoming).

The survey was implemented through standardised procedures. The PISA Consortium provided comprehensive manuals that explained the implementation of the survey, including precise instructions for the work of school co-ordinators and scripts for test administrators to use during the assessment sessions. Proposed adaptations to survey procedures, or proposed modifications to the assessment session script, were submitted to the PISA Consortium for approval prior to verification. The PISA Consortium then verified the national translation and adaptation of these manuals.

To establish the credibility of PISA as valid and unbiased and to encourage uniformity in administering the assessment sessions, test administrators in participating countries were selected using the following criteria: it was required that the test administrator not be the science, reading or mathematics instructor of any students in the sessions he or she would conduct for PISA; and it was considered preferable that the test administrator not be a member of the staff of any school in the PISA sample. Participating countries organised an in-person training session for test administrators.

Participating countries and economies were required to ensure that test administrators worked with the school co-ordinator to prepare the assessment session, including reviewing and updating the Student Tracking Form; completing the Session Attendance Form, which is designed to record students' attendance and instruments allocation; completing the Session Report Form, which is designed to summarise session times, any disturbance to the session, etc.; ensuring that the number of test booklets and questionnaires collected from students tallied with the number sent to the school (paper-based assessment countries) or ensuring that the number of USB sticks used for the assessment were accounted for (computer-based assessment countries); and sending the school questionnaire, student questionnaires, parent and teacher questionnaires (if applicable), and all test materials (both completed and not completed) to the national centre after the testing.

The PISA Consortium responsible for overseeing survey operations implemented all phases of the PISA Quality Monitor (PQM) process: interviewing and hiring PQM candidates in each of the countries, organising their training, selecting the schools to visit, and collecting information from the PQM visits. PQMs are independent contractors located in participating countries who are hired by the international survey operations contractor. They visit a sample of schools to observe test administration and to record the implementation of the documented field-operations procedures in the main survey.

Typically, two or three PQMs were hired for each country, and they visited an average of 15 schools in each country. If there were adjudicated regions in a country, it was usually necessary to hire additional PQMs, as a minimum of five schools were observed in adjudicated regions.

All quality-assurance data collected throughout the PISA 2015 assessment were entered and collated in a central dataadjudication database on the quality of field operations, printing, translation, school and student sampling, and coding. 
Comprehensive reports were then generated for the PISA Adjudication Group. This group was formed by the Technical Advisory Group and the Sampling Referee. Its role is to review the adjudication database and reports to recommend adequate treatment to preserve the quality of PISA data. For further information, see the PISA 2015 Technical Report (OECD, forthcoming).

The results of adjudication and subsequent further examinations showed that the PISA Technical Standards were met in all countries and economies that participated in PISA 2015 except for those countries listed below:

- In Albania, the PISA assessment was conducted in accordance with the operational standards and guidelines of the OECD. However, because of the ways in which the data were captured, it was not possible to match the data in the test with the data from the student questionnaire. As a result, Albania cannot be included in analyses that relate students' responses from the questionnaires to the test results.

- In Argentina, the PISA assessment was conducted in accordance with the operational standards and guidelines of the OECD. However, there was a significant decline in the proportion of 15-year-olds who were covered by the test, both in absolute and relative numbers. There had been a re-structuring of Argentina's secondary schools, except for those in the adjudicated region of Ciudad Autónoma de Buenos Aires, which is likely to have affected the coverage of eligible schools listed in the sampling frame. As a result, Argentina's results may not be comparable to those of other countries or to results for Argentina from previous years.

- In Kazakhstan, the national coders were found to be lenient in marking. Consequently, the human-coded items did not meet PISA standards and were excluded from the international data. Since human-coded items form an important part of the constructs that are tested by PISA, the exclusion of these items resulted in a significantly smaller coverage of the PISA test. As a result, Kazakhstan's results may not be comparable to those of other countries or to results for Kazakhstan from previous years.

- In Malaysia, the PISA assessment was conducted in accordance with the operational standards and guidelines of the OECD. However, the weighted response rate among the initially sampled Malaysian schools (51\%) falls well short of the standard PISA response rate of $85 \%$. Therefore, the results may not be comparable to those of other countries or to results for Malaysia from previous years.

\section{Reference}

OECD (forthcoming), PISA 2015 Technical Report, OECD Publishing, Paris. 


\section{ANNEX A5}

CHANGES IN THE ADMINISTRATION AND SCALING OF PISA 2015 AND IMPLICATIONS FOR TRENDS ANALYSES

Available on line only.

It can be found at: www.oecd.org/pisa 
ANNEX A6

\section{GUIDELINES AND CAVEATS ABOUT INTERPRETING THE RESULTS}

\section{Interpreting the data from students, parents and schools}

PISA 2015 asked students and school principals to answer questions about the learning environment and organisation of schools, and the social and economic contexts in which learning takes place. Information based on their responses has been weighted so that it reflects the number of 15 -year-old students enrolled in grade 7 or above. These are self-reports rather than external observations and may be influenced by cultural differences in how individuals respond. For example, individual students in the same classroom may perceive and report classroom situations in different ways, or respondents may provide responses that are considered to be more socially desirable or acceptable than others.

In addition to the general limitation of self-reported data, there are other limitations, particularly those concerning the information collected from principals, that should be taken into account when interpreting the data:

- On average across OECD countries, 268 principals were surveyed, but in 10 countries and economies, fewer than 150 principals were surveyed, and in Ciudad Autónoma de Buenos Aires (Argentina), Luxembourg, Macao (China), Malta and Montenegro, fewer than 100 principals were surveyed (see Table A7.1 from Annex A7 of Volume II). Although principals can provide information about their schools, generalising from a single source of information for each school is not straightforward. Also, principals' perceptions may not be the most appropriate sources of some information related to teachers, such as teachers' morale and commitment.

- Students' attitudes towards learning and their performance in each subject depend on many factors, including all the education that they have acquired in previous years and their experiences outside the school setting. In most cases, 15-year-old students have been in their current school for only two or three years. The learning environment examined by PISA may therefore only partially reflect the learning environment that shaped students' experiences in education earlier in their school careers. To the extent that students' current learning environment differs from that of their earlier school years, the contextual data collected by PISA are an imperfect proxy for students' cumulative learning environments.

- In some countries and economies, the definition of the school in which students are taught is not straightforward because schools vary in the level and purpose of education. For example, in some countries and economies, subunits within schools (e.g. study programmes, shifts and campuses) were sampled instead of schools as administrative units. See Annex A2 for further information.

- The age-based sampling followed in PISA means that, in some education systems, students are not always representative of their schools. Interpreting differences between schools correctly therefore requires specific knowledge about how school systems are structured.

Despite these caveats, information from the school questionnaire provides unique insights into the ways in which national and subnational authorities seek to realise their education objectives.

\section{Schooling and school effects}

In using results from non-experimental data on school performance, such as the PISA Database, it is important to bear in mind the distinction between school effects and the effects of schooling, particularly when interpreting the modest association between factors such as school resources, policies and institutional characteristics and student performance. School effects are education researchers' shorthand for the effect on academic performance of attending one school or another, usually schools that differ in resources or policies and institutional characteristics. Where schools and school systems do not vary in fundamental ways, the school effect can be modest. Nevertheless, modest school effects should not be confused with a lack of an effect of schooling (the influence on performance of not being schooled compared with being schooled).

\section{Interpreting correlations}

A correlation is a simple statistic that measures the degree to which two variables are associated with each other, but does not prove causality between the two.

\section{Interpreting results before and after accounting for socio-economic status}

When examining the relationship between education outcomes and resources, policies and practices within school systems, this volume takes into account the socio-economic differences among students and schools. The advantage of doing this lies in comparing similar entities, namely students and schools with similar socio-economic profiles. At the same time, there is a risk that such adjusted comparisons underestimate the strength of the relationship between student performance and resources, policies and practices, since most of the differences in performance are often attributable to both policies and socio-economic status. 
Conversely, analyses that do not take socio-economic status into account can overstate the relationship between student performance and resources, policies and practices, as the level of resources and the kinds of policies adopted may also relate to the socio-economic profile of students, schools and countries and economies. At the same time, analyses without adjustments may paint a more realistic picture of the schools that parents choose for their children. They may also provide more information for other stakeholders who are interested in the overall performance of students, schools and systems, including any effects that may be related to the socio-economic profile of schools and systems. For example, parents may be primarily interested in a school's absolute performance standards, even if a school's higher achievement record stems partially from the fact that the school has a larger proportion of advantaged students.

\section{Interpreting the results by school characteristics}

When presenting the results by the socio-economic profile of schools, the location of schools, the type of school or the education level, the number of students and schools in each subsample has to meet the PISA reporting requirements of at least 30 students and 5 schools. Even when these reporting requirements are met, the reader should interpret the results cautiously when the number of students or schools is just above the threshold. Table A7.1 (OECD, 2016) shows the unweighted number of students and schools by school characteristics in the PISA sample so that the reader can interpret the results appropriately.

\section{Interpreting odds ratios}

An odds ratio indicates the degree to which an explanatory variable is associated with a categorical outcome variable with two categories (e.g. yes/no) or more than two categories. An odds ratio below one denotes a negative association; an odds ratio above one indicates a positive association; and an odds ratio of one means that there is no association.

Imagine that the association between being a boy and having repeated a grade is being analysed, the following odds ratios would be interpreted as:

- $0.2>$ Boys are five times less likely to have repeated a grade than girls.

- $0.5>$ Boys are half as likely to have repeated a grade as girls.

- $0.9>$ Boys are $10 \%$ less likely to have repeated a grade than girls.

- $1.0>$ Boys and girls are equally likely to have repeated a grade.

- $1.1>$ Boys are 10\% more likely to have repeated a grade than girls.

- $2.0>$ Boys are twice more likely to have repeated a grade than girls.

- $5.0>$ Boys are five times more likely to have repeated a grade than girls.

\section{Reference}

OECD (2016), PISA 2015 Results (Volume II): Policies and Practices for Successful Schools, OECD Publishing, Paris, http://dx.doi. org/10.1787/9789264267510-en. 



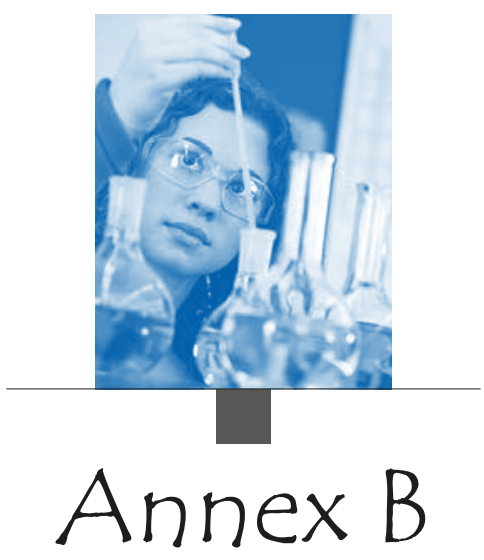

\section{PISA 2015 DATA}

All tables in Annex B are available on line

Annex B1: Results for countries and economies

Annex B2: Results for regions within countries

Annex B3: List of tables available on line

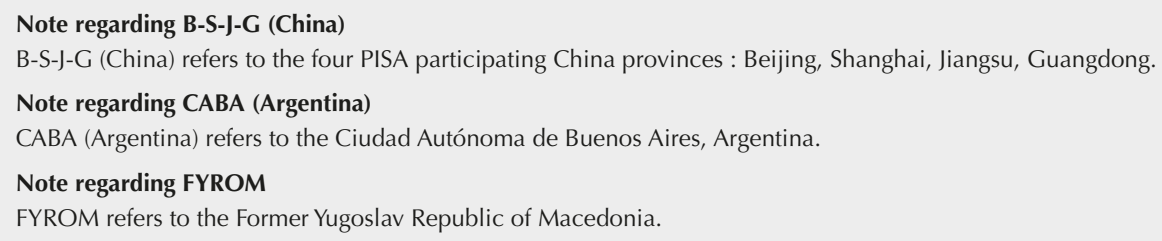

\section{Notes regarding Cyprus}

Note by Turkey: The information in this document with reference to "Cyprus" relates to the southern part of the Island. There is no single authority representing both Turkish and Greek Cypriot people on the Island. Turkey recognises the Turkish Republic of Northern Cyprus (TRNC). Until a lasting and equitable solution is found within the context of the United Nations, Turkey shall preserve its position concerning the "Cyprus issue".

Note by all the European Union Member States of the OECD and the European Union: The Republic of Cyprus is recognised by all members of the United Nations with the exception of Turkey. The information in this document relates to the area under the effective control of the Government of the Republic of Cyprus.

\section{A note regarding Israel}

The statistical data for Israel are supplied by and under the responsibility of the relevant Israeli authorities. The use of such data by the OECD is without prejudice to the status of the Golan Heights, East Jerusalem and Israeli settlements in the West Bank under the terms of international law. 


\section{ANNEX B1}

\section{RESULTS FOR COUNTRIES AND ECONOMIES}

[Part 1/3]

\section{Table III.3.2 Life satisfaction, by student characteristics}

Results based on students' self-reports

\begin{tabular}{|c|c|c|c|c|c|c|c|c|c|c|c|c|}
\hline & \multicolumn{12}{|c|}{ Average life satisfaction, by: } \\
\hline & \multicolumn{4}{|c|}{ All students } & \multicolumn{8}{|c|}{ National quarters of life satisfaction indicators } \\
\hline & \multicolumn{2}{|c|}{ All students } & \multicolumn{2}{|c|}{ Variability } & \multicolumn{2}{|c|}{ Bottom quarter } & \multicolumn{2}{|c|}{ Second quarter } & \multicolumn{2}{|c|}{ Third quarter } & \multicolumn{2}{|c|}{ Top quarter } \\
\hline & Mean & S.E. & S.D. & S.E. & Mean & S.E. & Mean & S.E. & Mean & S.E. & Mean & S.E. \\
\hline Australia & $\mathrm{m}$ & $\mathrm{m}$ & $\mathrm{m}$ & $\mathrm{m}$ & $\mathrm{m}$ & $\mathrm{m}$ & $\mathrm{m}$ & $\mathrm{m}$ & $\mathrm{m}$ & $\mathrm{m}$ & $\mathrm{m}$ & $\mathrm{m}$ \\
\hline Austria & 7.52 & $(0.04)$ & 2.20 & $(0.03)$ & 4.35 & $(0.09)$ & 7.46 & $(0.03)$ & 8.59 & $(0.03)$ & 9.69 & $(0.02)$ \\
\hline Belgium (excl. Flemish) & 7.49 & $(0.04)$ & 1.99 & $(0.03)$ & 4.73 & $(0.11)$ & 7.31 & $(0.04)$ & 8.32 & $(0.04)$ & 9.60 & $(0.03)$ \\
\hline Canada & $\mathrm{m}$ & $\mathrm{m}$ & $\mathrm{m}$ & $\mathrm{m}$ & $\mathrm{m}$ & $\mathrm{m}$ & $\mathrm{m}$ & $\mathrm{m}$ & $\mathrm{m}$ & $\mathrm{m}$ & $\mathrm{m}$ & $\mathrm{m}$ \\
\hline Chile & 7.37 & $(0.04)$ & 2.31 & $(0.03)$ & 4.08 & $(0.08)$ & 7.07 & $(0.06)$ & 8.53 & $(0.03)$ & 9.81 & $(0.03)$ \\
\hline Czech Republic & 7.05 & $(0.04)$ & 2.30 & $(0.02)$ & 3.80 & $(0.06)$ & 6.66 & $(0.07)$ & 8.23 & $(0.03)$ & 9.55 & $(0.02)$ \\
\hline Denmark & $\mathrm{m}$ & $\mathrm{m}$ & $\mathrm{m}$ & $\mathrm{m}$ & $\mathrm{m}$ & $\mathrm{m}$ & $\mathrm{m}$ & $\mathrm{m}$ & $\mathrm{m}$ & $\mathrm{m}$ & $\mathrm{m}$ & $\mathrm{m}$ \\
\hline Estonia & 7.50 & $(0.03)$ & 2.10 & $(0.02)$ & 4.51 & $(0.06)$ & 7.36 & $(0.05)$ & 8.48 & $(0.04)$ & 9.69 & $(0.03)$ \\
\hline Finland & 7.89 & $(0.03)$ & 1.85 & $(0.02)$ & 5.34 & $(0.06)$ & 7.81 & $(0.03)$ & 8.78 & $(0.03)$ & 9.64 & $(0.03)$ \\
\hline France & 7.63 & $(0.03)$ & 1.94 & $(0.03)$ & 4.96 & $(0.07)$ & 7.43 & $(0.03)$ & 8.47 & $(0.03)$ & 9.68 & $(0.02)$ \\
\hline Germany & 7.35 & $(0.04)$ & 2.17 & $(0.03)$ & 4.28 & $(0.07)$ & 7.19 & $(0.05)$ & 8.36 & $(0.03)$ & 9.59 & $(0.02)$ \\
\hline Greece & 6.91 & $(0.03)$ & 2.30 & $(0.02)$ & 3.70 & $(0.06)$ & 6.57 & $(0.03)$ & 7.90 & $(0.05)$ & 9.50 & $(0.02)$ \\
\hline Hungary & 7.17 & $(0.04)$ & 2.31 & $(0.03)$ & 3.91 & $(0.08)$ & 6.92 & $(0.06)$ & 8.27 & $(0.03)$ & 9.61 & $(0.02)$ \\
\hline Iceland & 7.80 & $(0.04)$ & 2.21 & $(0.04)$ & 4.66 & $(0.10)$ & 7.70 & $(0.03)$ & 8.87 & $(0.04)$ & 9.96 & $(0.03)$ \\
\hline Ireland & 7.30 & $(0.03)$ & 2.15 & $(0.02)$ & 4.26 & $(0.06)$ & 7.12 & $(0.05)$ & 8.30 & $(0.03)$ & 9.56 & $(0.02)$ \\
\hline Israel & $\mathrm{m}$ & $\mathrm{m}$ & $\mathrm{m}$ & $\mathrm{m}$ & $\mathrm{m}$ & $\mathrm{m}$ & $\mathrm{m}$ & $\mathrm{m}$ & $\mathrm{m}$ & $\mathrm{m}$ & $\mathrm{m}$ & $\mathrm{m}$ \\
\hline Italy & 6.89 & $(0.04)$ & 2.25 & $(0.03)$ & 3.70 & $(0.07)$ & 6.60 & $(0.05)$ & 7.89 & $(0.04)$ & 9.38 & $(0.04)$ \\
\hline Japan & 6.80 & $(0.03)$ & 2.29 & $(0.02)$ & 3.65 & $(0.05)$ & 6.35 & $(0.05)$ & 7.76 & $(0.03)$ & 9.46 & $(0.04)$ \\
\hline Korea & 6.36 & $(0.04)$ & 2.35 & $(0.02)$ & 3.22 & $(0.06)$ & 5.73 & $(0.06)$ & 7.40 & $(0.03)$ & 9.12 & $(0.04)$ \\
\hline Latvia & 7.37 & $(0.04)$ & 2.02 & $(0.03)$ & 4.58 & $(0.07)$ & 7.11 & $(0.06)$ & 8.27 & $(0.03)$ & 9.56 & $(0.02)$ \\
\hline Luxembourg & 7.38 & $(0.03)$ & 2.21 & $(0.03)$ & 4.25 & $(0.07)$ & 7.20 & $(0.05)$ & 8.45 & $(0.03)$ & 9.64 & $(0.02)$ \\
\hline Mexico & 8.27 & $(0.03)$ & 2.02 & $(0.03)$ & 5.40 & $(0.08)$ & 8.34 & $(0.03)$ & 9.36 & $(0.03)$ & 10.00 & $(0.00)$ \\
\hline Netherlands & 7.83 & $(0.02)$ & 1.54 & $(0.02)$ & 5.90 & $(0.05)$ & 7.56 & $(0.03)$ & 8.30 & $(0.03)$ & 9.55 & $(0.03)$ \\
\hline New Zealand & $\mathrm{m}$ & $\mathrm{m}$ & $\mathrm{m}$ & $\mathrm{m}$ & $\mathrm{m}$ & $\mathrm{m}$ & $\mathrm{m}$ & $\mathrm{m}$ & $\mathrm{m}$ & $\mathrm{m}$ & $\mathrm{m}$ & $\mathrm{m}$ \\
\hline Norway & $\mathrm{m}$ & $\mathrm{m}$ & $\mathrm{m}$ & $\mathrm{m}$ & $\mathrm{m}$ & $\mathrm{m}$ & $\mathrm{m}$ & $\mathrm{m}$ & $\mathrm{m}$ & $\mathrm{m}$ & $\mathrm{m}$ & $\mathrm{m}$ \\
\hline Poland & 7.18 & $(0.04)$ & 2.30 & $(0.03)$ & 3.96 & $(0.08)$ & 6.84 & $(0.06)$ & 8.30 & $(0.03)$ & 9.65 & $(0.02)$ \\
\hline Portugal & 7.36 & $(0.03)$ & 1.99 & $(0.02)$ & 4.60 & $(0.06)$ & 7.06 & $(0.05)$ & 8.24 & $(0.03)$ & 9.55 & $(0.02)$ \\
\hline Slovak Republic & 7.47 & $(0.03)$ & 2.29 & $(0.02)$ & 4.20 & $(0.06)$ & 7.26 & $(0.05)$ & 8.58 & $(0.03)$ & 9.86 & (0.03) \\
\hline Slovenia & 7.17 & $(0.04)$ & 2.29 & $(0.03)$ & 3.93 & $(0.08)$ & 6.89 & $(0.06)$ & 8.31 & $(0.03)$ & 9.60 & $(0.02)$ \\
\hline Spain & 7.42 & $(0.03)$ & 2.07 & $(0.03)$ & 4.51 & $(0.06)$ & 7.30 & $(0.05)$ & 8.32 & $(0.03)$ & 9.56 & $(0.02)$ \\
\hline Sweden & $\mathrm{m}$ & $\mathrm{m}$ & $\mathrm{m}$ & $\mathrm{m}$ & $\mathrm{m}$ & $\mathrm{m}$ & $\mathrm{m}$ & $\mathrm{m}$ & $\mathrm{m}$ & $\mathrm{m}$ & $\mathrm{m}$ & $\mathrm{m}$ \\
\hline Switzerland & 7.72 & $(0.03)$ & 1.97 & $(0.03)$ & 5.04 & $(0.07)$ & 7.54 & $(0.03)$ & 8.59 & $(0.03)$ & 9.71 & $(0.03)$ \\
\hline Turkey & 6.12 & $(0.06)$ & 2.93 & $(0.02)$ & 2.13 & $(0.07)$ & 5.17 & $(0.06)$ & 7.50 & $(0.11)$ & 9.68 & $(0.03)$ \\
\hline United Kingdom & 6.98 & $(0.04)$ & 2.31 & $(0.02)$ & 3.69 & $(0.07)$ & 6.63 & $(0.03)$ & 8.10 & $(0.06)$ & 9.50 & $(0.02)$ \\
\hline United States & 7.36 & $(0.03)$ & 2.21 & $(0.02)$ & 4.24 & $(0.06)$ & 7.04 & $(0.06)$ & 8.44 & $(0.03)$ & 9.72 & $(0.02)$ \\
\hline OECD average & 7.31 & $(0.01)$ & 2.17 & $(0.01)$ & 4.27 & $(0.01)$ & 7.04 & $(0.01)$ & 8.32 & $(0.01)$ & 9.62 & $(0.00)$ \\
\hline
\end{tabular}

\begin{tabular}{|c|c|c|c|c|c|c|c|c|c|c|c|c|}
\hline Albania & $\mathrm{m}$ & $\mathrm{m}$ & $\mathrm{m}$ & $\mathrm{m}$ & $\mathrm{m}$ & $\mathrm{m}$ & $\mathrm{m}$ & $\mathrm{m}$ & $\mathrm{m}$ & $\mathrm{m}$ & $\mathrm{m}$ & $\mathrm{m}$ \\
\hline Algeria & $\mathrm{m}$ & $\mathrm{m}$ & $\mathrm{m}$ & $\mathrm{m}$ & $\mathrm{m}$ & $\mathrm{m}$ & $\mathrm{m}$ & $\mathrm{m}$ & $\mathrm{m}$ & $\mathrm{m}$ & $\mathrm{m}$ & $\mathrm{m}$ \\
\hline Brazil & 7.59 & $(0.03)$ & 2.42 & $(0.02)$ & 4.09 & $(0.05)$ & 7.37 & $(0.04)$ & 8.90 & $(0.05)$ & 10.00 & $(0.00)$ \\
\hline B-S-J-G (China) & 6.83 & $(0.04)$ & 2.34 & $(0.02)$ & 3.71 & $(0.05)$ & 6.18 & $(0.06)$ & 7.89 & $(0.06)$ & 9.57 & $(0.03)$ \\
\hline Bulgaria & 7.42 & $(0.04)$ & 2.53 & $(0.02)$ & 3.78 & $(0.07)$ & 7.09 & $(0.05)$ & 8.82 & $(0.05)$ & 10.00 & $(0.00)$ \\
\hline CABA (Argentina) & $\mathrm{m}$ & $\mathrm{m}$ & $\mathrm{m}$ & $\mathrm{m}$ & $\mathrm{m}$ & $\mathrm{m}$ & $\mathrm{m}$ & $\mathrm{m}$ & $\mathrm{m}$ & $\mathrm{m}$ & $\mathrm{m}$ & $\mathrm{m}$ \\
\hline Colombia & 7.88 & $(0.04)$ & 2.36 & $(0.03)$ & 4.44 & $(0.08)$ & 7.73 & $(0.06)$ & 9.38 & $(0.04)$ & 10.00 & $(0.00)$ \\
\hline Costa Rica & 8.21 & $(0.03)$ & 2.12 & $(0.03)$ & 5.13 & $(0.06)$ & 8.27 & $(0.06)$ & 9.46 & $(0.05)$ & 10.00 & $(0.00)$ \\
\hline Croatia & 7.90 & $(0.04)$ & 2.05 & $(0.03)$ & 5.05 & $(0.09)$ & 7.70 & $(0.03)$ & 8.91 & $(0.03)$ & 9.95 & $(0.03)$ \\
\hline Cyprus* & 7.06 & $(0.03)$ & 2.31 & $(0.02)$ & 3.83 & $(0.06)$ & 6.67 & $(0.04)$ & 8.21 & $(0.04)$ & 9.57 & $(0.02)$ \\
\hline Dominican Republic & 8.50 & $(0.04)$ & 2.32 & $(0.04)$ & 5.12 & $(0.11)$ & 8.90 & $(0.07)$ & 10.00 & $(0.00)$ & 10.00 & $(0.00)$ \\
\hline FYROM & $\mathrm{m}$ & $\mathrm{m}$ & $\mathrm{m}$ & $\mathrm{m}$ & $\mathrm{m}$ & $\mathrm{m}$ & $\mathrm{m}$ & $\mathrm{m}$ & $\mathrm{m}$ & $\mathrm{m}$ & $\mathrm{m}$ & $\mathrm{m}$ \\
\hline Georgia & $\mathrm{m}$ & $\mathrm{m}$ & $\mathrm{m}$ & $\mathrm{m}$ & $\mathrm{m}$ & $\mathrm{m}$ & $\mathrm{m}$ & $\mathrm{m}$ & $\mathrm{m}$ & $\mathrm{m}$ & $\mathrm{m}$ & $\mathrm{m}$ \\
\hline Hong Kong (China) & 6.48 & $(0.04)$ & 2.06 & $(0.03)$ & 3.74 & $(0.07)$ & 6.06 & $(0.07)$ & 7.33 & $(0.03)$ & 8.80 & $(0.03)$ \\
\hline Indonesia & $\mathrm{m}$ & $\mathrm{m}$ & $\mathrm{m}$ & $\mathrm{m}$ & $\mathrm{m}$ & $\mathrm{m}$ & $\mathrm{m}$ & $\mathrm{m}$ & $\mathrm{m}$ & $\mathrm{m}$ & $\mathrm{m}$ & $\mathrm{m}$ \\
\hline Jordan & $\mathrm{m}$ & $\mathrm{m}$ & $\mathrm{m}$ & $\mathrm{m}$ & $\mathrm{m}$ & $\mathrm{m}$ & $\mathrm{m}$ & $\mathrm{m}$ & $\mathrm{m}$ & $\mathrm{m}$ & $\mathrm{m}$ & $\mathrm{m}$ \\
\hline Kosovo & $\mathrm{m}$ & $\mathrm{m}$ & $\mathrm{m}$ & $\mathrm{m}$ & $\mathrm{m}$ & $\mathrm{m}$ & $\mathrm{m}$ & $\mathrm{m}$ & $\mathrm{m}$ & $\mathrm{m}$ & $\mathrm{m}$ & $\mathrm{m}$ \\
\hline Lebanon & $\mathrm{m}$ & $\mathrm{m}$ & $\mathrm{m}$ & $\mathrm{m}$ & $\mathrm{m}$ & $\mathrm{m}$ & $\mathrm{m}$ & $\mathrm{m}$ & $\mathrm{m}$ & $\mathrm{m}$ & $\mathrm{m}$ & $\mathrm{m}$ \\
\hline Lithuania & 7.86 & $(0.03)$ & 2.15 & $(0.03)$ & 4.82 & $(0.07)$ & 7.69 & $(0.03)$ & 8.96 & $(0.06)$ & 10.00 & $(0.00)$ \\
\hline Macao (China) & 6.59 & $(0.03)$ & 2.12 & $(0.03)$ & 3.75 & $(0.06)$ & 6.14 & $(0.06)$ & 7.54 & $(0.03)$ & 8.95 & $(0.03)$ \\
\hline Malta & $\mathrm{m}$ & $\mathrm{m}$ & $\mathrm{m}$ & $\mathrm{m}$ & $\mathrm{m}$ & $\mathrm{m}$ & $\mathrm{m}$ & $\mathrm{m}$ & $\mathrm{m}$ & $\mathrm{m}$ & $\mathrm{m}$ & $\mathrm{m}$ \\
\hline Moldova & $\mathrm{m}$ & $\mathrm{m}$ & $\mathrm{m}$ & $\mathrm{m}$ & $\mathrm{m}$ & $\mathrm{m}$ & $\mathrm{m}$ & $\mathrm{m}$ & $\mathrm{m}$ & $\mathrm{m}$ & $\mathrm{m}$ & $\mathrm{m}$ \\
\hline Montenegro & 7.75 & $(0.03)$ & 2.49 & $(0.03)$ & 4.11 & $(0.07)$ & 7.54 & $(0.07)$ & 9.36 & $(0.03)$ & 10.00 & $(0.00)$ \\
\hline Peru & 7.50 & $(0.04)$ & 2.43 & $(0.03)$ & 3.99 & $(0.07)$ & 7.22 & $(0.05)$ & 8.80 & $(0.06)$ & 10.00 & $(0.00)$ \\
\hline Qatar & 7.41 & $(0.02)$ & 2.55 & $(0.02)$ & 3.73 & $(0.05)$ & 7.08 & $(0.03)$ & 8.81 & $(0.05)$ & 10.00 & $(0.00)$ \\
\hline Romania & $\mathrm{m}$ & $\mathrm{m}$ & $\mathrm{m}$ & $\mathrm{m}$ & 2.00 & $(0.00)$ & $\mathrm{m}$ & $\mathrm{m}$ & $\mathrm{m}$ & $\mathrm{m}$ & $\mathrm{m}$ & $\mathrm{m}$ \\
\hline Russia & 7.76 & $(0.04)$ & 2.28 & $(0.04)$ & 4.46 & $(0.09)$ & 7.54 & $(0.04)$ & 9.05 & $(0.06)$ & 10.00 & $(0.00)$ \\
\hline Singapore & $\mathrm{m}$ & $\mathrm{m}$ & $\mathrm{m}$ & $\mathrm{m}$ & $\mathrm{m}$ & $\mathrm{m}$ & $\mathrm{m}$ & $\mathrm{m}$ & $\mathrm{m}$ & $\mathrm{m}$ & $\mathrm{m}$ & $\mathrm{m}$ \\
\hline Chinese Taipei & 6.59 & $(0.03)$ & 2.11 & $(0.02)$ & 3.84 & $(0.04)$ & 5.97 & $(0.05)$ & 7.51 & $(0.03)$ & 9.07 & $(0.04)$ \\
\hline Thailand & 7.71 & $(0.03)$ & 2.11 & $(0.03)$ & 4.67 & $(0.06)$ & 7.43 & $(0.05)$ & 8.76 & $(0.06)$ & 10.00 & $(0.00)$ \\
\hline Trinidad and Tobago & $\mathrm{m}$ & $\mathrm{m}$ & $\mathrm{m}$ & $\mathrm{m}$ & $\mathrm{m}$ & $\mathrm{m}$ & $\mathrm{m}$ & $\mathrm{m}$ & $\mathrm{m}$ & $\mathrm{m}$ & $\mathrm{m}$ & $\mathrm{m}$ \\
\hline Tunisia & 6.90 & $(0.04)$ & 2.89 & $(0.03)$ & 2.86 & $(0.07)$ & 6.15 & $(0.07)$ & 8.58 & $(0.08)$ & 10.00 & $(0.00)$ \\
\hline United Arab Emirates & 7.30 & $(0.03)$ & 2.50 & $(0.03)$ & 3.73 & $(0.05)$ & 6.85 & $(0.07)$ & 8.64 & $(0.05)$ & 10.00 & $(0.00)$ \\
\hline Uruguay & 7.70 & $(0.03)$ & 2.27 & $(0.03)$ & 4.43 & $(0.07)$ & 7.53 & $(0.03)$ & 8.83 & $(0.05)$ & 10.00 & $(0.00)$ \\
\hline Viet Nam & $\mathrm{m}$ & $\mathrm{m}$ & $\mathrm{m}$ & $\mathrm{m}$ & $\mathrm{m}$ & $\mathrm{m}$ & $\mathrm{m}$ & m & $\mathrm{m}$ & $\mathrm{m}$ & $\mathrm{m}$ & $\mathrm{m}$ \\
\hline Argentina** & $\mathrm{m}$ & $\mathrm{m}$ & $\mathrm{m}$ & $\mathrm{m}$ & $\mathrm{m}$ & $\mathrm{m}$ & $\mathrm{m}$ & $\mathrm{m}$ & $\mathrm{m}$ & $\mathrm{m}$ & $\mathrm{m}$ & $\mathrm{m}$ \\
\hline Kazakhstan** & $\mathrm{m}$ & $\mathrm{m}$ & $\mathrm{m}$ & $\mathrm{m}$ & $\mathrm{m}$ & $\mathrm{m}$ & $\mathrm{m}$ & $\mathrm{m}$ & $\mathrm{m}$ & $\mathrm{m}$ & $\mathrm{m}$ & $\mathrm{m}$ \\
\hline Malaysia** & 7.07 & $(0.04)$ & 2.13 & $(0.02)$ & 4.23 & $(0.04)$ & 6.36 & $(0.06)$ & 8.10 & $(0.06)$ & 9.59 & $(0.03)$ \\
\hline
\end{tabular}

1. ESCS refers to the PISA index of economic, social and cultural status.

Note: Values that are statistically significant are indicated in bold (see Annex A3).

* See note at the beginning of this Annex.

is too small to ensure comparability (see Annex A4).

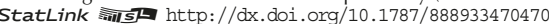




\begin{tabular}{|c|c|c|c|c|c|c|c|c|c|c|}
\hline & \multicolumn{10}{|c|}{ Average life satisfaction, by: } \\
\hline & \multicolumn{10}{|c|}{ National quarters of the ESCS ${ }^{1}$ index } \\
\hline & \multicolumn{2}{|c|}{ Bottom quarter } & \multicolumn{2}{|c|}{ Second quarter } & \multicolumn{2}{|c|}{ Third quarter } & \multicolumn{2}{|c|}{ Top quarter } & \multicolumn{2}{|c|}{ Top - bottom quarter } \\
\hline & Mean & S.E. & Mean & S.E. & Mean & S.E. & Mean & S.E. & Mean & S.E. \\
\hline Australia & $\mathrm{m}$ & $\mathrm{m}$ & $\mathrm{m}$ & $\mathrm{m}$ & $\mathrm{m}$ & $\mathrm{m}$ & $\mathrm{m}$ & $\mathrm{m}$ & $\mathrm{m}$ & $\mathrm{m}$ \\
\hline Austria & 7.26 & $(0.07)$ & 7.48 & $(0.07)$ & 7.62 & $(0.06)$ & 7.75 & $(0.04)$ & 0.49 & $(0.08)$ \\
\hline Belgium (excl. Flemish) & 7.22 & $(0.10)$ & 7.39 & $(0.08)$ & 7.64 & $(0.06)$ & 7.69 & $(0.07)$ & 0.46 & $(0.12)$ \\
\hline Canada & $\mathrm{m}$ & $\mathrm{m}$ & $\mathrm{m}$ & $\mathrm{m}$ & $\mathrm{m}$ & $\mathrm{m}$ & $\mathrm{m}$ & $\mathrm{m}$ & $\mathrm{m}$ & $\mathrm{m}$ \\
\hline Chile & 7.09 & $(0.07)$ & 7.40 & $(0.08)$ & 7.38 & $(0.07)$ & 7.58 & $(0.06)$ & 0.49 & $(0.08)$ \\
\hline Czech Republic & 6.72 & $(0.08)$ & 6.98 & $(0.07)$ & 7.16 & $(0.08)$ & 7.35 & $(0.05)$ & 0.63 & $(0.10)$ \\
\hline Denmark & m & $\mathrm{m}$ & m & $\mathrm{m}$ & m & $\mathrm{m}$ & $\mathrm{m}$ & $\mathrm{m}$ & $\mathrm{m}$ & $\mathrm{m}$ \\
\hline Estonia & 7.16 & $(0.07)$ & 7.44 & $(0.06)$ & 7.55 & $(0.07)$ & 7.86 & $(0.06)$ & 0.70 & $(0.09)$ \\
\hline Finland & 7.68 & $(0.06)$ & 7.79 & $(0.05)$ & 7.95 & $(0.06)$ & 8.15 & $(0.04)$ & 0.47 & $(0.07)$ \\
\hline France & 7.41 & $(0.07)$ & 7.57 & $(0.05)$ & 7.65 & $(0.06)$ & 7.89 & $(0.04)$ & 0.49 & $(0.08)$ \\
\hline Germany & 7.06 & $(0.08)$ & 7.41 & $(0.07)$ & 7.35 & $(0.05)$ & 7.56 & $(0.06)$ & 0.50 & $(0.09)$ \\
\hline Greece & 6.64 & $(0.08)$ & 6.89 & $(0.07)$ & 7.01 & $(0.07)$ & 7.11 & $(0.07)$ & 0.48 & $(0.10)$ \\
\hline Hungary & 6.85 & $(0.08)$ & 7.20 & $(0.08)$ & 7.10 & $(0.07)$ & 7.53 & $(0.07)$ & 0.68 & $(0.11)$ \\
\hline Iceland & 7.47 & $(0.09)$ & 7.65 & $(0.09)$ & 7.84 & $(0.08)$ & 8.21 & $(0.07)$ & 0.73 & $(0.12)$ \\
\hline Ireland & 7.25 & $(0.07)$ & 7.15 & $(0.09)$ & 7.36 & $(0.07)$ & 7.44 & $(0.05)$ & 0.19 & $(0.08)$ \\
\hline Israel & $\mathrm{m}$ & $\mathrm{m}$ & $\mathrm{m}$ & $\mathrm{m}$ & $\mathrm{m}$ & $\mathrm{m}$ & $\mathrm{m}$ & $\mathrm{m}$ & $\mathrm{m}$ & $\mathrm{m}$ \\
\hline Italy & 6.68 & $(0.07)$ & 6.84 & $(0.06)$ & 6.97 & $(0.08)$ & 7.07 & $(0.05)$ & 0.39 & $(0.09)$ \\
\hline Japan & 6.58 & $(0.06)$ & 6.85 & $(0.06)$ & 6.85 & $(0.07)$ & 6.96 & $(0.07)$ & 0.38 & $(0.10)$ \\
\hline Korea & 6.19 & $(0.07)$ & 6.22 & $(0.07)$ & 6.38 & $(0.07)$ & 6.67 & $(0.06)$ & 0.48 & $(0.09)$ \\
\hline Latvia & 7.08 & $(0.07)$ & 7.27 & $(0.07)$ & 7.38 & $(0.06)$ & 7.73 & $(0.07)$ & 0.64 & $(0.10)$ \\
\hline Luxembourg & 7.20 & $(0.07)$ & 7.16 & $(0.07)$ & 7.47 & $(0.05)$ & 7.69 & $(0.05)$ & 0.49 & $(0.09)$ \\
\hline Mexico & 8.21 & $(0.08)$ & 8.32 & $(0.05)$ & 8.21 & $(0.07)$ & 8.33 & $(0.05)$ & 0.12 & $(0.09)$ \\
\hline Netherlands & 7.85 & $(0.06)$ & 7.81 & $(0.05)$ & 7.82 & $(0.05)$ & 7.82 & $(0.03)$ & -0.03 & $(0.07)$ \\
\hline New Zealand & $\mathrm{m}$ & $\mathrm{m}$ & $\mathrm{m}$ & $\mathrm{m}$ & $\mathrm{m}$ & $\mathrm{m}$ & $\mathrm{m}$ & $\mathrm{m}$ & $\mathrm{m}$ & $\mathrm{m}$ \\
\hline Norway & $\mathrm{m}$ & $\mathrm{m}$ & $\mathrm{m}$ & $\mathrm{m}$ & $\mathrm{m}$ & $\mathrm{m}$ & $\mathrm{m}$ & $\mathrm{m}$ & $\mathrm{m}$ & $\mathrm{m}$ \\
\hline Poland & 6.88 & $(0.09)$ & 7.24 & $(0.08)$ & 7.27 & $(0.08)$ & 7.35 & $(0.07)$ & 0.47 & $(0.12)$ \\
\hline Portugal & 7.24 & $(0.06)$ & 7.42 & $(0.07)$ & 7.35 & $(0.06)$ & 7.46 & $(0.06)$ & 0.22 & $(0.09)$ \\
\hline Slovak Republic & 7.18 & $(0.07)$ & 7.49 & $(0.07)$ & 7.58 & $(0.06)$ & 7.61 & $(0.05)$ & 0.43 & $(0.08)$ \\
\hline Slovenia & 7.18 & $(0.07)$ & 7.22 & $(0.08)$ & 7.05 & $(0.08)$ & 7.25 & $(0.08)$ & 0.07 & $(0.11)$ \\
\hline Spain & 7.24 & $(0.06)$ & 7.24 & $(0.07)$ & 7.47 & $(0.06)$ & 7.73 & $(0.05)$ & 0.49 & $(0.07)$ \\
\hline Sweden & $\mathrm{m}$ & $\mathrm{m}$ & $\mathrm{m}$ & $\mathrm{m}$ & $\mathrm{m}$ & $\mathrm{m}$ & $\mathrm{m}$ & $\mathrm{m}$ & $\mathrm{m}$ & $\mathrm{m}$ \\
\hline Switzerland & 7.65 & $(0.06)$ & 7.67 & $(0.07)$ & 7.68 & $(0.07)$ & 7.88 & $(0.05)$ & 0.22 & $(0.07)$ \\
\hline Turkey & 5.97 & $(0.13)$ & 6.07 & $(0.11)$ & 6.16 & $(0.09)$ & 6.26 & $(0.09)$ & 0.29 & $(0.16)$ \\
\hline United Kingdom & 6.69 & $(0.07)$ & 6.98 & $(0.08)$ & 7.01 & $(0.06)$ & 7.27 & $(0.06)$ & 0.58 & $(0.08)$ \\
\hline United States & 7.00 & $(0.08)$ & 7.29 & $(0.07)$ & 7.47 & $(0.06)$ & 7.67 & $(0.07)$ & 0.67 & $(0.11)$ \\
\hline OECD average & 7.09 & $(0.01)$ & 7.27 & $(0.01)$ & 7.35 & $(0.01)$ & 7.53 & $(0.01)$ & 0.44 & $(0.02)$ \\
\hline
\end{tabular}

\begin{tabular}{|c|c|c|c|c|c|c|c|c|c|c|}
\hline Albania & $\mathrm{m}$ & $\mathrm{m}$ & $\mathrm{m}$ & $\mathrm{m}$ & $\mathrm{m}$ & $\mathrm{m}$ & $\mathrm{m}$ & $\mathrm{m}$ & $\mathrm{m}$ & $\mathrm{m}$ \\
\hline Algeria & $\mathrm{m}$ & $\mathrm{m}$ & $\mathrm{m}$ & $\mathrm{m}$ & $\mathrm{m}$ & $\mathrm{m}$ & $\mathrm{m}$ & $\mathrm{m}$ & $\mathrm{m}$ & $\mathrm{m}$ \\
\hline Brazil & 7.72 & $(0.05)$ & 7.50 & $(0.05)$ & 7.56 & $(0.05)$ & 7.56 & $(0.05)$ & -0.16 & $(0.07)$ \\
\hline B-S-J-G (China) & 6.56 & $(0.07)$ & 6.80 & $(0.06)$ & 6.93 & $(0.09)$ & 7.05 & $(0.09)$ & 0.49 & $(0.12)$ \\
\hline Bulgaria & 7.09 & $(0.08)$ & 7.46 & $(0.09)$ & 7.45 & $(0.07)$ & 7.66 & $(0.06)$ & 0.56 & $(0.10)$ \\
\hline CABA (Argentina) & $\mathrm{m}$ & $\mathrm{m}$ & $\mathrm{m}$ & $\mathrm{m}$ & $\mathrm{m}$ & $\mathrm{m}$ & $\mathrm{m}$ & $\mathrm{m}$ & $\mathrm{m}$ & $\mathrm{m}$ \\
\hline Colombia & 8.05 & $(0.07)$ & 7.93 & $(0.05)$ & 7.80 & $(0.08)$ & 7.76 & $(0.06)$ & -0.29 & $(0.08)$ \\
\hline Costa Rica & 8.21 & $(0.07)$ & 8.25 & $(0.07)$ & 8.13 & $(0.07)$ & 8.25 & $(0.07)$ & 0.04 & $(0.09)$ \\
\hline Croatia & 7.79 & $(0.07)$ & 7.93 & $(0.06)$ & 7.94 & $(0.06)$ & 7.94 & $(0.05)$ & 0.15 & $(0.08)$ \\
\hline Cyprus* & 6.74 & $(0.07)$ & 7.09 & $(0.07)$ & 7.07 & $(0.07)$ & 7.35 & $(0.07)$ & 0.61 & $(0.11)$ \\
\hline Dominican Republic & 8.54 & $(0.09)$ & 8.47 & $(0.08)$ & 8.49 & $(0.08)$ & 8.50 & $(0.08)$ & -0.04 & $(0.12)$ \\
\hline FYROM & $\mathrm{m}$ & $\mathrm{m}$ & $\mathrm{m}$ & $\mathrm{m}$ & $\mathrm{m}$ & $\mathrm{m}$ & $\mathrm{m}$ & $\mathrm{m}$ & $\mathrm{m}$ & $\mathrm{m}$ \\
\hline Georgia & $\mathrm{m}$ & $\mathrm{m}$ & $\mathrm{m}$ & $\mathrm{m}$ & $\mathrm{m}$ & $\mathrm{m}$ & $\mathrm{m}$ & $\mathrm{m}$ & $\mathrm{m}$ & $\mathrm{m}$ \\
\hline Hong Kong (China) & 6.23 & $(0.08)$ & 6.36 & $(0.06)$ & 6.56 & $(0.08)$ & 6.79 & $(0.06)$ & 0.56 & $(0.09)$ \\
\hline Indonesia & $\mathrm{m}$ & $\mathrm{m}$ & $\mathrm{m}$ & $\mathrm{m}$ & $\mathrm{m}$ & $\mathrm{m}$ & $\mathrm{m}$ & $\mathrm{m}$ & $\mathrm{m}$ & $\mathrm{m}$ \\
\hline Jordan & $\mathrm{m}$ & $\mathrm{m}$ & $\mathrm{m}$ & $\mathrm{m}$ & $\mathrm{m}$ & $\mathrm{m}$ & $\mathrm{m}$ & $\mathrm{m}$ & $\mathrm{m}$ & $\mathrm{m}$ \\
\hline Kosovo & $\mathrm{m}$ & $\mathrm{m}$ & $\mathrm{m}$ & $\mathrm{m}$ & $\mathrm{m}$ & $\mathrm{m}$ & $\mathrm{m}$ & $\mathrm{m}$ & $\mathrm{m}$ & $\mathrm{m}$ \\
\hline Lebanon & $\mathrm{m}$ & $\mathrm{m}$ & $\mathrm{m}$ & $\mathrm{m}$ & $\mathrm{m}$ & $\mathrm{m}$ & $\mathrm{m}$ & $\mathrm{m}$ & $\mathrm{m}$ & $\mathrm{m}$ \\
\hline Lithuania & 7.60 & $(0.07)$ & 7.84 & $(0.06)$ & 7.83 & $(0.06)$ & 8.20 & $(0.06)$ & 0.59 & $(0.09)$ \\
\hline Macao (China) & 6.33 & $(0.07)$ & 6.60 & $(0.07)$ & 6.64 & $(0.08)$ & 6.80 & $(0.06)$ & 0.47 & $(0.09)$ \\
\hline Malta & $\mathrm{m}$ & $\mathrm{m}$ & $\mathrm{m}$ & $\mathrm{m}$ & $\mathrm{m}$ & $\mathrm{m}$ & $\mathrm{m}$ & $\mathrm{m}$ & $\mathrm{m}$ & $\mathrm{m}$ \\
\hline Moldova & $\mathrm{m}$ & $\mathrm{m}$ & $\mathrm{m}$ & $\mathrm{m}$ & $\mathrm{m}$ & $\mathrm{m}$ & $\mathrm{m}$ & $\mathrm{m}$ & $\mathrm{m}$ & $\mathrm{m}$ \\
\hline Montenegro & 7.59 & $(0.07)$ & 7.82 & $(0.06)$ & 7.83 & $(0.07)$ & 7.76 & $(0.07)$ & 0.17 & $(0.11)$ \\
\hline Peru & 7.57 & $(0.09)$ & 7.56 & $(0.07)$ & 7.40 & $(0.06)$ & 7.46 & $(0.06)$ & -0.11 & $(0.11)$ \\
\hline Qatar & 7.16 & $(0.05)$ & 7.29 & $(0.05)$ & 7.44 & $(0.04)$ & 7.72 & $(0.04)$ & 0.56 & $(0.06)$ \\
\hline Romania & $\mathrm{m}$ & $\mathrm{m}$ & 2.00 & $\mathrm{~m}$ & $\mathrm{~m}$ & $\mathrm{~m}$ & $\mathrm{~m}$ & $\mathrm{~m}$ & $\mathrm{~m}$ & $\mathrm{~m}$ \\
\hline Russia & 7.70 & $(0.07)$ & 7.69 & $(0.06)$ & 7.71 & $(0.07)$ & 7.92 & $(0.06)$ & 0.22 & $(0.08)$ \\
\hline Singapore & $\mathrm{m}$ & $\mathrm{m}$ & $\mathrm{m}$ & $\mathrm{m}$ & $\mathrm{m}$ & $\mathrm{m}$ & $\mathrm{m}$ & $\mathrm{m}$ & $\mathrm{m}$ & $\mathrm{m}$ \\
\hline Chinese Taipei & 6.31 & $(0.05)$ & 6.64 & $(0.06)$ & 6.61 & $(0.05)$ & 6.82 & $(0.05)$ & 0.51 & $(0.07)$ \\
\hline Thailand & 7.75 & $(0.07)$ & 7.87 & $(0.06)$ & 7.63 & $(0.07)$ & 7.59 & $(0.06)$ & -0.16 & (0.09) \\
\hline Trinidad and Tobago & $\mathrm{m}$ & $\mathrm{m}$ & $\mathrm{m}$ & $\mathrm{m}$ & $\mathrm{m}$ & $\mathrm{m}$ & $\mathrm{m}$ & $\mathrm{m}$ & $\mathrm{m}$ & $\mathrm{m}$ \\
\hline Tunisia & 6.43 & $(0.09)$ & 6.79 & $(0.09)$ & 7.13 & $(0.09)$ & 7.23 & $(0.08)$ & 0.80 & $(0.12)$ \\
\hline United Arab Emirates & 7.03 & $(0.06)$ & 7.17 & $(0.06)$ & 7.30 & $(0.06)$ & 7.70 & $(0.06)$ & 0.67 & $(0.08)$ \\
\hline Uruguay & 7.48 & $(0.07)$ & 7.61 & $(0.07)$ & 7.78 & $(0.07)$ & 7.92 & $(0.06)$ & 0.44 & $(0.09)$ \\
\hline Viet Nam & $\mathrm{m}$ & $\mathrm{m}$ & $\mathrm{m}$ & $\mathrm{m}$ & $\mathrm{m}$ & $\mathrm{m}$ & $\mathrm{m}$ & $\mathrm{m}$ & $\mathrm{m}$ & $\mathrm{m}$ \\
\hline Argentina** & $\mathrm{m}$ & $\mathrm{m}$ & $\mathrm{m}$ & $\mathrm{m}$ & $\mathrm{m}$ & $\mathrm{m}$ & $\mathrm{m}$ & $\mathrm{m}$ & $\mathrm{m}$ & $\mathrm{m}$ \\
\hline Kazakhstan** & $\mathrm{m}$ & $\mathrm{m}$ & $\mathrm{m}$ & $\mathrm{m}$ & $\mathrm{m}$ & $\mathrm{m}$ & $\mathrm{m}$ & $\mathrm{m}$ & $\mathrm{m}$ & $\mathrm{m}$ \\
\hline Malaysia** & 6.94 & $(0.07)$ & 7.07 & $(0.07)$ & 7.12 & $(0.06)$ & 7.14 & $(0.05)$ & 0.20 & $(0.09)$ \\
\hline
\end{tabular}

1. ESCS refers to the PISA index of economic, social and cultural status.

Note: Values that are statistically significant are indicated in bold (see Annex A3).

* See note at the beginning of this Annex.

* Coverage is too small to ensure comparability (see Annex A4).

StatLink त्नाजम http://dx.doi.org/10.1787/888933470470 
[Part 3/3]

Table III.3.2 Life satisfaction, by student characteristics

Results based on students' self-reports

\begin{tabular}{|c|c|c|c|c|c|c|c|c|c|c|c|c|c|c|}
\hline & \multicolumn{14}{|c|}{ Average life satisfaction, by: } \\
\hline & \multicolumn{6}{|c|}{ Gender } & \multicolumn{8}{|c|}{ Immigrant background } \\
\hline & \multicolumn{2}{|c|}{ Boys } & \multicolumn{2}{|c|}{ Girls } & \multicolumn{2}{|c|}{$\begin{array}{c}\text { Gender difference } \\
(B-G)\end{array}$} & \multicolumn{2}{|c|}{ Non-immigrant } & \multicolumn{2}{|c|}{ First-generation } & \multicolumn{2}{|c|}{ Second-generation } & \multicolumn{2}{|c|}{$\begin{array}{c}\text { Difference } \\
\text { by migrant status } \\
\text { (non-immigrant - } \\
\text { first-generation) }\end{array}$} \\
\hline & Mean & S.E. & Mean & S.E. & Dif. & S.E. & Mean & S.E. & Mean & S.E. & Mean & S.E. & Dif. & S.E. \\
\hline Australia & $\mathrm{m}$ & $\mathrm{m}$ & $\mathrm{m}$ & $\mathrm{m}$ & $\mathrm{m}$ & $\mathrm{m}$ & $\mathrm{m}$ & $\mathrm{m}$ & $\mathrm{m}$ & $\mathrm{m}$ & $\mathrm{m}$ & $\mathrm{m}$ & $\mathrm{m}$ & $\mathrm{m}$ \\
\hline Austria & 7.95 & $(0.04)$ & 7.09 & $(0.05)$ & 0.86 & $(0.06)$ & 7.59 & $(0.04)$ & 7.15 & $(0.16)$ & 7.33 & $(0.08)$ & 0.45 & $(0.16)$ \\
\hline Belgium (excl. Flemish) & 7.77 & $(0.05)$ & 7.20 & $(0.06)$ & 0.57 & $(0.07)$ & 7.50 & $(0.05)$ & 7.40 & $(0.13)$ & 7.59 & $(0.13)$ & 0.11 & $(0.14)$ \\
\hline Canada & $\mathrm{m}$ & $\mathrm{m}$ & $\mathrm{m}$ & $\mathrm{m}$ & $\mathrm{m}$ & m & $\mathrm{m}$ & $\mathrm{m}$ & $\mathrm{m}$ & $\mathrm{m}$ & $\mathrm{m}$ & $\mathrm{m}$ & $\mathrm{m}$ & $\mathrm{m}$ \\
\hline Chile & 7.60 & $(0.05)$ & 7.13 & $(0.06)$ & 0.47 & $(0.08)$ & 7.38 & $(0.04)$ & 6.93 & $(0.28)$ & 7.52 & $(0.45)$ & 0.44 & $(0.29)$ \\
\hline Czech Republic & 7.37 & $(0.04)$ & 6.72 & $(0.05)$ & 0.65 & $(0.07)$ & 7.06 & $(0.04)$ & 6.83 & $(0.27)$ & 6.83 & $(0.33)$ & 0.23 & $(0.28)$ \\
\hline Denmark & $\mathrm{m}$ & $\mathrm{m}$ & $\mathrm{m}$ & $\mathrm{m}$ & $\mathrm{m}$ & $\mathrm{m}$ & $\mathrm{m}$ & $\mathrm{m}$ & $\mathrm{m}$ & $\mathrm{m}$ & $\mathrm{m}$ & $\mathrm{m}$ & $\mathrm{m}$ & $\mathrm{m}$ \\
\hline Estonia & 7.73 & $(0.04)$ & 7.27 & $(0.05)$ & 0.46 & $(0.06)$ & 7.51 & $(0.04)$ & 7.69 & $(0.43)$ & 7.40 & $(0.10)$ & -0.17 & $(0.44)$ \\
\hline Finland & 8.25 & $(0.04)$ & 7.51 & $(0.04)$ & 0.74 & $(0.05)$ & 7.90 & $(0.03)$ & 7.72 & $(0.22)$ & 7.99 & $(0.19)$ & 0.17 & $(0.22)$ \\
\hline France & 7.86 & $(0.04)$ & 7.41 & $(0.04)$ & 0.45 & $(0.05)$ & 7.66 & $(0.03)$ & 7.34 & $(0.13)$ & 7.50 & $(0.12)$ & 0.32 & $(0.13)$ \\
\hline Germany & 7.76 & $(0.04)$ & 6.96 & $(0.04)$ & 0.80 & $(0.05)$ & 7.36 & $(0.04)$ & 7.29 & $(0.16)$ & 7.31 & $(0.10)$ & 0.07 & $(0.17)$ \\
\hline Greece & 7.22 & $(0.05)$ & 6.59 & $(0.04)$ & 0.64 & $(0.06)$ & 6.94 & $(0.03)$ & 6.81 & $(0.24)$ & 6.55 & $(0.15)$ & 0.13 & $(0.24)$ \\
\hline Hungary & 7.54 & $(0.05)$ & 6.80 & $(0.06)$ & 0.74 & $(0.09)$ & 7.17 & $(0.04)$ & 7.17 & $(0.32)$ & 7.53 & $(0.20)$ & 0.00 & $(0.32)$ \\
\hline Iceland & 8.28 & $(0.05)$ & 7.35 & $(0.05)$ & 0.93 & $(0.07)$ & 7.82 & $(0.04)$ & 7.39 & $(0.24)$ & 7.43 & $(0.44)$ & 0.43 & $(0.24)$ \\
\hline Ireland & 7.58 & $(0.04)$ & 7.02 & $(0.04)$ & 0.56 & $(0.05)$ & 7.36 & $(0.03)$ & 7.15 & $(0.10)$ & 6.55 & $(0.20)$ & 0.21 & $(0.11)$ \\
\hline Israel & $\mathrm{m}$ & $\mathrm{m}$ & $\mathrm{m}$ & $\mathrm{m}$ & $\mathrm{m}$ & $\mathrm{m}$ & $\mathrm{m}$ & $\mathrm{m}$ & $\mathrm{m}$ & $\mathrm{m}$ & $\mathrm{m}$ & $\mathrm{m}$ & $\mathrm{m}$ & $\mathrm{m}$ \\
\hline Italy & 7.29 & $(0.04)$ & 6.50 & $(0.06)$ & 0.79 & $(0.07)$ & 6.92 & $(0.04)$ & 6.76 & $(0.15)$ & 6.45 & $(0.20)$ & 0.16 & $(0.16)$ \\
\hline Japan & 6.74 & $(0.05)$ & 6.86 & $(0.05)$ & -0.12 & $(0.07)$ & 6.80 & $(0.03)$ & $\mathrm{m}$ & $\mathrm{m}$ & $\mathrm{m}$ & $\mathrm{m}$ & $\mathrm{m}$ & $\mathrm{m}$ \\
\hline Korea & 6.59 & $(0.05)$ & 6.12 & $(0.05)$ & 0.47 & $(0.07)$ & 6.36 & $(0.04)$ & $\mathrm{m}$ & $\mathrm{m}$ & $\mathrm{m}$ & $\mathrm{m}$ & $\mathrm{m}$ & $\mathrm{m}$ \\
\hline Latvia & 7.46 & $(0.05)$ & 7.29 & $(0.05)$ & 0.16 & $(0.06)$ & 7.38 & $(0.03)$ & 7.04 & $(0.50)$ & 7.17 & $(0.15)$ & 0.34 & $(0.49)$ \\
\hline Luxembourg & 7.78 & $(0.04)$ & 6.99 & $(0.05)$ & 0.78 & $(0.06)$ & 7.43 & $(0.04)$ & 7.32 & $(0.07)$ & 7.33 & $(0.05)$ & 0.11 & $(0.08)$ \\
\hline Mexico & 8.33 & $(0.04)$ & 8.21 & $(0.04)$ & 0.12 & $(0.05)$ & 8.28 & $(0.03)$ & 8.02 & $(0.39)$ & $\mathrm{m}$ & $\mathrm{m}$ & 0.26 & $(0.40)$ \\
\hline Netherlands & 8.11 & $(0.03)$ & 7.56 & $(0.04)$ & 0.55 & $(0.05)$ & 7.80 & $(0.03)$ & 7.74 & $(0.20)$ & 8.10 & $(0.08)$ & 0.06 & $(0.20)$ \\
\hline New Zealand & $\mathrm{m}$ & $\mathrm{m}$ & $\mathrm{m}$ & $\mathrm{m}$ & $\mathrm{m}$ & $\mathrm{m}$ & $\mathrm{m}$ & $\mathrm{m}$ & $\mathrm{m}$ & $\mathrm{m}$ & $\mathrm{m}$ & $\mathrm{m}$ & $\mathrm{m}$ & $\mathrm{m}$ \\
\hline Norway & $\mathrm{m}$ & $\mathrm{m}$ & $\mathrm{m}$ & $\mathrm{m}$ & $\mathrm{m}$ & $\mathrm{m}$ & $\mathrm{m}$ & $\mathrm{m}$ & $\mathrm{m}$ & $\mathrm{m}$ & $\mathrm{m}$ & $\mathrm{m}$ & $\mathrm{m}$ & $\mathrm{m}$ \\
\hline Poland & 7.53 & $(0.05)$ & 6.83 & $(0.06)$ & 0.69 & $(0.07)$ & 7.18 & $(0.04)$ & $\mathrm{m}$ & $\mathrm{m}$ & $\mathrm{m}$ & $\mathrm{m}$ & $\mathrm{m}$ & $\mathrm{m}$ \\
\hline Portugal & 7.61 & $(0.04)$ & 7.11 & $(0.04)$ & 0.51 & $(0.05)$ & 7.38 & $(0.03)$ & 7.18 & $(0.16)$ & 7.21 & $(0.17)$ & 0.19 & $(0.17)$ \\
\hline Slovak Republic & 7.76 & $(0.04)$ & 7.17 & $(0.05)$ & 0.59 & $(0.07)$ & 7.47 & $(0.03)$ & $\mathrm{m}$ & $\mathrm{m}$ & 6.94 & $(0.63)$ & $\mathrm{m}$ & $\mathrm{m}$ \\
\hline Slovenia & 7.62 & $(0.04)$ & 6.71 & $(0.06)$ & 0.91 & $(0.08)$ & 7.19 & $(0.04)$ & 7.01 & $(0.21)$ & 6.99 & $(0.19)$ & 0.18 & $(0.22)$ \\
\hline Spain & 7.60 & $(0.04)$ & 7.24 & $(0.05)$ & 0.37 & $(0.06)$ & 7.48 & $(0.04)$ & 6.82 & $(0.11)$ & 7.40 & $(0.19)$ & 0.66 & $(0.11)$ \\
\hline Sweden & $\mathrm{m}$ & $\mathrm{m}$ & $\mathrm{m}$ & $\mathrm{m}$ & $\mathrm{m}$ & $\mathrm{m}$ & $\mathrm{m}$ & $\mathrm{m}$ & $\mathrm{m}$ & $\mathrm{m}$ & $\mathrm{m}$ & $\mathrm{m}$ & $\mathrm{m}$ & $\mathrm{m}$ \\
\hline Switzerland & 8.03 & $(0.04)$ & 7.38 & $(0.04)$ & 0.65 & $(0.06)$ & 7.79 & $(0.04)$ & 7.45 & $(0.11)$ & 7.65 & $(0.06)$ & 0.34 & $(0.12)$ \\
\hline Turkey & 6.41 & $(0.07)$ & 5.83 & $(0.08)$ & 0.59 & $(0.10)$ & 6.13 & $(0.06)$ & $\mathrm{m}$ & $\mathrm{m}$ & 5.59 & $(0.54)$ & $\mathrm{m}$ & $\mathrm{m}$ \\
\hline United Kingdom & 7.31 & $(0.04)$ & 6.64 & $(0.05)$ & 0.68 & $(0.06)$ & 7.03 & $(0.04)$ & 6.75 & $(0.09)$ & 6.74 & $(0.16)$ & 0.29 & $(0.10)$ \\
\hline United States & 7.66 & $(0.05)$ & 7.06 & $(0.04)$ & 0.60 & $(0.06)$ & 7.42 & $(0.04)$ & 7.07 & $(0.15)$ & 7.20 & $(0.09)$ & 0.34 & $(0.16)$ \\
\hline OECD average & 7.60 & $(0.01)$ & 7.02 & $(0.01)$ & 0.58 & $(0.01)$ & 7.33 & $(0.01)$ & 7.22 & $(0.05)$ & 7.18 & $(0.05)$ & 0.23 & $(0.05)$ \\
\hline
\end{tabular}

\begin{tabular}{|c|c|c|c|c|c|c|c|c|c|c|c|c|c|c|}
\hline Albania & $\mathrm{m}$ & $\mathrm{m}$ & $\mathrm{m}$ & $\mathrm{m}$ & $\mathrm{m}$ & $\mathrm{m}$ & $\mathrm{m}$ & $\mathrm{m}$ & $\mathrm{m}$ & $\mathrm{m}$ & $\mathrm{m}$ & $\mathrm{m}$ & $\mathrm{m}$ & $\mathrm{m}$ \\
\hline Algeria & $\mathrm{m}$ & $\mathrm{m}$ & $\mathrm{m}$ & $\mathrm{m}$ & $\mathrm{m}$ & $\mathrm{m}$ & $\mathrm{m}$ & $\mathrm{m}$ & $\mathrm{m}$ & $\mathrm{m}$ & $\mathrm{m}$ & $\mathrm{m}$ & $\mathrm{m}$ & $\mathrm{m}$ \\
\hline Brazil & 7.74 & $(0.03)$ & 7.45 & $(0.03)$ & 0.29 & $(0.04)$ & 7.59 & $(0.03)$ & 7.53 & $(0.62)$ & 7.70 & $(0.47)$ & 0.06 & $(0.62)$ \\
\hline B-S-J-G (China) & 6.88 & $(0.04)$ & 6.78 & $(0.06)$ & 0.10 & $(0.06)$ & 6.84 & $(0.04)$ & $\mathrm{m}$ & $\mathrm{m}$ & $\mathrm{m}$ & $\mathrm{m}$ & $\mathrm{m}$ & $\mathrm{m}$ \\
\hline Bulgaria & 7.62 & $(0.05)$ & 7.20 & $(0.05)$ & 0.42 & $(0.07)$ & 7.42 & $(0.04)$ & $\mathrm{m}$ & $\mathrm{m}$ & $\mathrm{m}$ & $\mathrm{m}$ & $\mathrm{m}$ & $\mathrm{m}$ \\
\hline CABA (Argentina) & $\mathrm{m}$ & $\mathrm{m}$ & $\mathrm{m}$ & $\mathrm{m}$ & $\mathrm{m}$ & $\mathrm{m}$ & $\mathrm{m}$ & $\mathrm{m}$ & $\mathrm{m}$ & $\mathrm{m}$ & $\mathrm{m}$ & $\mathrm{m}$ & $\mathrm{m}$ & $\mathrm{m}$ \\
\hline Colombia & 8.08 & $(0.04)$ & 7.71 & $(0.05)$ & 0.37 & $(0.05)$ & 7.88 & $(0.04)$ & $\mathrm{m}$ & $\mathrm{m}$ & 8.07 & $(0.48)$ & $\mathrm{m}$ & $\mathrm{m}$ \\
\hline Costa Rica & 8.39 & $(0.04)$ & 8.04 & $(0.05)$ & 0.35 & $(0.06)$ & 8.22 & $(0.03)$ & 8.04 & $(0.20)$ & 8.15 & $(0.13)$ & 0.17 & $(0.20)$ \\
\hline Croatia & 8.21 & $(0.05)$ & 7.62 & $(0.05)$ & 0.60 & $(0.06)$ & 7.89 & $(0.04)$ & 7.38 & $(0.35)$ & 8.08 & $(0.10)$ & 0.51 & $(0.35)$ \\
\hline Cyprus* & 7.27 & $(0.05)$ & 6.86 & $(0.05)$ & 0.41 & $(0.07)$ & 7.10 & $(0.03)$ & 6.79 & $(0.13)$ & 6.85 & $(0.16)$ & 0.31 & $(0.13)$ \\
\hline Dominican Republic & 8.55 & $(0.06)$ & 8.45 & $(0.06)$ & 0.10 & $(0.09)$ & 8.49 & $(0.04)$ & 7.76 & $(0.46)$ & 9.20 & $(0.21)$ & 0.74 & $(0.46)$ \\
\hline FYROM & $\mathrm{m}$ & $\mathrm{m}$ & $\mathrm{m}$ & $\mathrm{m}$ & $\mathrm{m}$ & $\mathrm{m}$ & $\mathrm{m}$ & $\mathrm{m}$ & $\mathrm{m}$ & $\mathrm{m}$ & $\mathrm{m}$ & $\mathrm{m}$ & $\mathrm{m}$ & $\mathrm{m}$ \\
\hline Georgia & $\mathrm{m}$ & $\mathrm{m}$ & $\mathrm{m}$ & $\mathrm{m}$ & $\mathrm{m}$ & $\mathrm{m}$ & $\mathrm{m}$ & $\mathrm{m}$ & $\mathrm{m}$ & $\mathrm{m}$ & $\mathrm{m}$ & $\mathrm{m}$ & $\mathrm{m}$ & $\mathrm{m}$ \\
\hline Hong Kong (China) & 6.51 & $(0.06)$ & 6.44 & $(0.05)$ & 0.07 & $(0.07)$ & 6.53 & $(0.04)$ & 6.48 & $(0.10)$ & 6.31 & $(0.08)$ & 0.05 & $(0.10)$ \\
\hline Indonesia & $\mathrm{m}$ & $\mathrm{m}$ & $\mathrm{m}$ & $\mathrm{m}$ & $\mathrm{m}$ & $\mathrm{m}$ & $\mathrm{m}$ & $\mathrm{m}$ & $\mathrm{m}$ & $\mathrm{m}$ & $\mathrm{m}$ & $\mathrm{m}$ & $\mathrm{m}$ & $\mathrm{m}$ \\
\hline Jordan & $\mathrm{m}$ & $\mathrm{m}$ & $\mathrm{m}$ & $\mathrm{m}$ & $\mathrm{m}$ & $\mathrm{m}$ & $\mathrm{m}$ & $\mathrm{m}$ & $\mathrm{m}$ & $\mathrm{m}$ & $\mathrm{m}$ & $\mathrm{m}$ & $\mathrm{m}$ & $\mathrm{m}$ \\
\hline Kosovo & $\mathrm{m}$ & $\mathrm{m}$ & $\mathrm{m}$ & $\mathrm{m}$ & $\mathrm{m}$ & $\mathrm{m}$ & $\mathrm{m}$ & $\mathrm{m}$ & $\mathrm{m}$ & $\mathrm{m}$ & $\mathrm{m}$ & $\mathrm{m}$ & $\mathrm{m}$ & $\mathrm{m}$ \\
\hline Lebanon & $\mathrm{m}$ & $\mathrm{m}$ & $\mathrm{m}$ & $\mathrm{m}$ & $\mathrm{m}$ & $\mathrm{m}$ & $\mathrm{m}$ & $\mathrm{m}$ & $\mathrm{m}$ & $\mathrm{m}$ & $\mathrm{m}$ & $\mathrm{m}$ & $\mathrm{m}$ & $\mathrm{m}$ \\
\hline Lithuania & 8.12 & $(0.04)$ & 7.60 & $(0.04)$ & 0.52 & $(0.06)$ & 7.88 & $(0.03)$ & 6.45 & $(0.78)$ & 7.66 & $(0.23)$ & 1.42 & $(0.78)$ \\
\hline Macao (China) & 6.60 & $(0.05)$ & 6.59 & $(0.04)$ & 0.01 & $(0.06)$ & 6.64 & $(0.04)$ & 6.72 & $(0.07)$ & 6.50 & $(0.05)$ & -0.07 & $(0.08)$ \\
\hline Malta & $\mathrm{m}$ & $\mathrm{m}$ & $\mathrm{m}$ & $\mathrm{m}$ & $\mathrm{m}$ & $\mathrm{m}$ & $\mathrm{m}$ & $\mathrm{m}$ & $\mathrm{m}$ & $\mathrm{m}$ & $\mathrm{m}$ & $\mathrm{m}$ & $\mathrm{m}$ & $\mathrm{m}$ \\
\hline Moldova & $\mathrm{m}$ & $\mathrm{m}$ & $\mathrm{m}$ & $\mathrm{m}$ & $\mathrm{m}$ & $\mathrm{m}$ & $\mathrm{m}$ & $\mathrm{m}$ & $\mathrm{m}$ & $\mathrm{m}$ & $\mathrm{m}$ & $\mathrm{m}$ & $\mathrm{m}$ & $\mathrm{m}$ \\
\hline Montenegro & 7.99 & $(0.04)$ & 7.50 & $(0.05)$ & 0.49 & $(0.06)$ & 7.77 & $(0.04)$ & 7.35 & $(0.20)$ & 7.45 & $(0.21)$ & 0.43 & $(0.20)$ \\
\hline Peru & 7.57 & $(0.04)$ & 7.42 & $(0.06)$ & 0.15 & $(0.07)$ & 7.51 & $(0.04)$ & $\mathrm{m}$ & $\mathrm{m}$ & $\mathrm{m}$ & $\mathrm{m}$ & $\mathrm{m}$ & $\mathrm{m}$ \\
\hline Qatar & 7.51 & $(0.03)$ & 7.30 & $(0.03)$ & 0.21 & $(0.05)$ & 7.75 & $(0.03)$ & 7.12 & $(0.03)$ & 7.25 & $(0.07)$ & 0.63 & $(0.05)$ \\
\hline Romania & $\mathrm{m}$ & $\mathrm{m}$ & $\mathrm{m}$ & $\mathrm{m}$ & $\mathrm{m}$ & $\mathrm{m}$ & $\mathrm{m}$ & $\mathrm{m}$ & $\mathrm{m}$ & $\mathrm{m}$ & $\mathrm{m}$ & $\mathrm{m}$ & $\mathrm{m}$ & $\mathrm{m}$ \\
\hline Russia & 7.92 & $(0.05)$ & 7.60 & $(0.05)$ & 0.32 & $(0.07)$ & 7.75 & $(0.04)$ & 7.86 & $(0.24)$ & 7.79 & $(0.19)$ & -0.11 & $(0.26)$ \\
\hline Singapore & $\mathrm{m}$ & $\mathrm{m}$ & $\mathrm{m}$ & $\mathrm{m}$ & $\mathrm{m}$ & $\mathrm{m}$ & $\mathrm{m}$ & $\mathrm{m}$ & $\mathrm{m}$ & $\mathrm{m}$ & $\mathrm{m}$ & $\mathrm{m}$ & $\mathrm{m}$ & $\mathrm{m}$ \\
\hline Chinese Taipei & 6.74 & $(0.04)$ & 6.45 & $(0.03)$ & 0.29 & $(0.05)$ & 6.60 & $(0.03)$ & $\mathrm{m}$ & $\mathrm{m}$ & $\mathrm{m}$ & $\mathrm{m}$ & $\mathrm{m}$ & $\mathrm{m}$ \\
\hline Thailand & 7.73 & $(0.05)$ & 7.70 & $(0.04)$ & 0.04 & $(0.06)$ & 7.72 & $(0.03)$ & $\mathrm{m}$ & $\mathrm{m}$ & 7.14 & $(0.38)$ & $\mathrm{m}$ & $\mathrm{m}$ \\
\hline Trinidad and Tobago & $\mathrm{m}$ & $\mathrm{m}$ & $\mathrm{m}$ & $\mathrm{m}$ & $\mathrm{m}$ & $\mathrm{m}$ & $\mathrm{m}$ & $\mathrm{m}$ & $\mathrm{m}$ & $\mathrm{m}$ & $\mathrm{m}$ & $\mathrm{m}$ & $\mathrm{m}$ & $\mathrm{m}$ \\
\hline Tunisia & 6.99 & $(0.07)$ & 6.82 & $(0.06)$ & 0.17 & $(0.10)$ & 6.91 & $(0.04)$ & $\mathrm{m}$ & $\mathrm{m}$ & 6.99 & $(0.41)$ & $\mathrm{m}$ & $\mathrm{m}$ \\
\hline United Arab Emirates & 7.44 & $(0.05)$ & 7.17 & $(0.04)$ & 0.27 & $(0.06)$ & 7.60 & $(0.05)$ & 7.13 & $(0.05)$ & 7.11 & $(0.06)$ & 0.47 & $(0.06)$ \\
\hline Uruguay & 7.95 & $(0.04)$ & 7.47 & $(0.04)$ & 0.47 & $(0.06)$ & 7.69 & $(0.03)$ & $\mathrm{m}$ & $\mathrm{m}$ & $\mathrm{m}$ & $\mathrm{m}$ & $\mathrm{m}$ & $\mathrm{m}$ \\
\hline Viet Nam & $\mathrm{m}$ & $\mathrm{m}$ & $\mathrm{m}$ & $\mathrm{m}$ & $\mathrm{m}$ & $\mathrm{m}$ & $\mathrm{m}$ & $\mathrm{m}$ & $\mathrm{m}$ & $\mathrm{m}$ & $\mathrm{m}$ & $\mathrm{m}$ & $\mathrm{m}$ & $\mathrm{m}$ \\
\hline Argentina** & $\mathrm{m}$ & $\mathrm{m}$ & $\mathrm{m}$ & $\mathrm{m}$ & $\mathrm{m}$ & $\mathrm{m}$ & $\mathrm{m}$ & $\mathrm{m}$ & $\mathrm{m}$ & $\mathrm{m}$ & $\mathrm{m}$ & $\mathrm{m}$ & $\mathrm{m}$ & $\mathrm{m}$ \\
\hline Kazakhstan** & $\mathrm{m}$ & $\mathrm{m}$ & $\mathrm{m}$ & $\mathrm{m}$ & $\mathrm{m}$ & $\mathrm{m}$ & $\mathrm{m}$ & $\mathrm{m}$ & $\mathrm{m}$ & $\mathrm{m}$ & $\mathrm{m}$ & $\mathrm{m}$ & $\mathrm{m}$ & $\mathrm{m}$ \\
\hline Malaysia** & 7.12 & $(0.05)$ & 7.02 & $(0.05)$ & 0.11 & $(0.07)$ & 7.08 & $(0.04)$ & $\mathrm{m}$ & $\mathrm{m}$ & 6.79 & $(0.33)$ & $\mathrm{m}$ & $\mathrm{m}$ \\
\hline
\end{tabular}

1. ESCS refers to the PISA index of economic, social and cultural status.

Note: Values that are statistically significant are indicated in bold (see Annex A3).

* See note at the beginning of this Annex.

is too small to ensure comparability (see A 


\begin{tabular}{|c|c|c|c|c|c|c|c|c|c|c|c|c|c|}
\hline & \multicolumn{12}{|c|}{ Average life satisfaction, by: } \\
\hline & & \multicolumn{12}{|c|}{ Science performance } \\
\hline & & 1st decile & 2nd decile & 3rd decile & 4th decile & 5th decile & 6th decile & 7th decile & 8th decile & 9th decile & 10th decile & $\begin{array}{l}\text { Diff } \\
\text { betweer } \\
\text { and the }\end{array}$ & $\begin{array}{l}\text { ence } \\
\text { the } 10 \text { th } \\
\text { st decile }\end{array}$ \\
\hline & & Mean S.E. & Mean S.E. & Mean S.E. & Mean S.E. & Mean S.E. & Mean S.E. & Mean S.E. & Mean S.E. & Mean S.E. & Mean S.E. & Dif. & S.E. \\
\hline$\theta$ & Australia & $\mathrm{m}$ & $\mathrm{m}$ & & & $\mathrm{m}$ & $\mathrm{m}$ & $\mathrm{m}$ & $\mathrm{m}$ & $\mathrm{m}$ & $\mathrm{m}$ & $\mathrm{m}$ & $\mathrm{m}$ \\
\hline Uي山ّ & Austria & $7.54(0.18)$ & $7.42(0.16)$ & $7.41(0.13)$ & $7.43(0.14)$ & $7.46(0.12)$ & $7.50(0.11)$ & $\mid 7.58(0.13)$ & $7.55(0.11)$ & $7.58(0.10)$ & $7.75(0.08)$ & 0.21 & $(0.20)$ \\
\hline & Belgium (excl. Flemish) & $7.26(0.17)$ & $7.42(0.18)$ & $7.50(0.18)$ & $7.46(0.17)$ & $7.45(0.14)$ & $7.50(0.15)$ & $7.52(0.13)$ & $7.56(0.15)$ & $7.59(0.14)$ & $7.62(0.10)$ & 0.36 & $(0.20)$ \\
\hline & Canada & $\mathrm{m}$ & $\mathrm{m}$ & $\mathrm{m}$ & $\mathrm{m}$ & $\mathrm{m}$ & $\mathrm{m}$ & $\mathrm{m}$ & $\mathrm{m}$ & $\mathrm{m}$ & $\mathrm{m}$ & $\mathrm{m}$ & $\mathrm{m}$ \\
\hline & Chile & $7.35(0.16)$ & $7.33(0.17)$ & $7.35(0.19)$ & \begin{tabular}{|l}
7.37 \\
$(0.18)$
\end{tabular} & $7.35(0.18)$ & \begin{tabular}{|ll}
7.37 & $(0.16)$ \\
\end{tabular} & $7.43(0.14)$ & $7.35(0.17)$ & $7.40(0.13)$ & $7.37(0.10)$ & 0.02 & $(0.19)$ \\
\hline & Czech Republic & $6.99(0.16)$ & $6.96(0.15)$ & $7.05(0.16)$ & $7.00(0.20)$ & $6.92(0.14)$ & $6.99(0.14)$ & $7.08(0.13)$ & $7.14(0.11)$ & $7.17(0.10)$ & $7.21(0.09)$ & 0.22 & $(0.16)$ \\
\hline & Denmark & & $m \quad m$ & $m \quad m$ & $\mathrm{~m} \quad \mathrm{~m}$ & $\mathrm{~m} \quad \mathrm{~m}$ & m $\quad \mathrm{m}$ & m $\quad \mathrm{m}$ & m $\quad \mathrm{m}$ & $\mathrm{m}$ & $\mathrm{m}$ & $\mathrm{m}$ & $\mathrm{m}$ \\
\hline & Estonia & $7.55(0.14)$ & $7.49(0.14)$ & $7.42(0.18)$ & $7.45(0.15)$ & $7.37(0.13)$ & $7.39(0.14)$ & $\mid 7.44(0.14)$ & $7.58(0.15)$ & $7.59(0.13)$ & $7.77(0.11)$ & 0.22 & $(0.18)$ \\
\hline & Finland & $7.81(0.12)$ & $7.83(0.11)$ & $7.83(0.13)$ & $7.82(0.12)$ & $7.86(0.11)$ & $7.88(0.10)$ & $7.92(0.10)$ & $7.94(0.09)$ & $8.00(0.09)$ & $8.01(0.08)$ & 0.19 & $(0.14)$ \\
\hline & France & $7.43(0.15)$ & $7.51(0.13)$ & $7.48(0.12)$ & $7.53(0.11)$ & $7.58(0.11)$ & $\mid 7.63(0.12)$ & $7.68(0.10)$ & $7.71(0.10)$ & $7.78(0.09)$ & $7.90(0.07)$ & 0.47 & $(0.17)$ \\
\hline & Germany & $7.27(0.16)$ & $7.29(0.17)$ & $7.33(0.15)$ & $7.25(0.14)$ & $7.25(0.13)$ & $7.22(0.12)$ & $7.28(0.16)$ & $7.33(0.12)$ & $7.50(0.11)$ & $7.73(0.09)$ & 0.46 & $(0.17)$ \\
\hline & Greece & $6.91(0.18)$ & $6.80(0.19)$ & \begin{tabular}{|lll} 
& 6.81 & $(0.19)$
\end{tabular} & $6.84(0.15)$ & $6.81(0.15)$ & $\mid 6.91(0.15)$ & $6.93(0.15)$ & $6.98(0.13)$ & $7.03(0.12)$ & $7.11(0.09)$ & 0.21 & $(0.21)$ \\
\hline & Hungary & $6.96(0.17)$ & $7.10(0.20)$ & $7.12(0.19)$ & $7.13(0.16)$ & $7.09(0.16)$ & $7.16(0.15)$ & $7.10(0.13)$ & $7.24(0.12)$ & $7.33(0.11)$ & $7.49(0.11)$ & 0.53 & $(0.20)$ \\
\hline & Iceland & $7.31(0.19)$ & $7.58(0.22)$ & $7.68(0.20)$ & $7.78(0.20)$ & \begin{tabular}{|l}
$7.77(0.17)$ \\
\end{tabular} & $7.83(0.19)$ & \begin{tabular}{|l|}
$7.92(0.13)$ \\
\end{tabular} & $7.92(0.13)$ & $8.06(0.15)$ & $8.07(0.14)$ & 0.75 & $(0.23)$ \\
\hline & Ireland & $7.19(0.14)$ & $7.28(0.14)$ & $7.37(0.14)$ & $7.30(0.13)$ & $7.30(0.13)$ & $7.28(0.15)$ & $7.38(0.11)$ & $7.36(0.11)$ & $7.33(0.11)$ & $7.26(0.09)$ & 0.07 & $(0.17)$ \\
\hline & Israel & $\mathrm{m}$ & $\mathrm{m}$ & $\mathrm{m}$ & $\mathrm{m}$ & $\mathrm{m}$ & $\mathrm{m}$ & $\mathrm{m}$ & $\mathrm{m}$ & $\mathrm{m}$ & $\mathrm{m}$ & $\mathrm{m}$ & $\mathrm{m}$ \\
\hline & Italy & $7.05(0.17)$ & $6.84(0.16)$ & $6.80(0.16)$ & $6.77(0.12)$ & $6.75(0.15)$ & $6.77(0.15)$ & $6.92(0.14)$ & $6.93(0.13)$ & $6.93(0.11)$ & $7.16(0.10)$ & 0.11 & $(0.21)$ \\
\hline & Japan & $6.53(0.13)$ & $6.62(0.12)$ & $6.73(0.12)$ & $6.84(0.12)$ & $6.88(0.14)$ & $6.88(0.14)$ & $\begin{array}{|ll|}6.82 & (0.15)\end{array}$ & $6.84(0.13)$ & $6.89(0.12)$ & $6.93(0.10)$ & 0.41 & $(0.17)$ \\
\hline & Korea & $6.39(0.14)$ & $6.32(0.14)$ & $6.31(0.14)$ & $6.29(0.16)$ & $6.28(0.16)$ & $6.27(0.14)$ & $6.34(0.15)$ & $6.40(0.13)$ & $6.55(0.13)$ & $6.46(0.12)$ & 0.06 & $(0.18)$ \\
\hline & Latvia & $7.25(0.15)$ & $7.34(0.16)$ & $7.30(0.16)$ & $7.34(0.14)$ & \begin{tabular}{|ll} 
& \\
\end{tabular} & $7.32(0.13)$ & $\mid 7.35(0.13)$ & $\mid 7.39(0.12)$ & $7.46(0.12)$ & $7.63(0.10)$ & 0.38 & $(0.18)$ \\
\hline & Luxembourg & $7.31(0.16)$ & $7.27(0.16)$ & $7.30(0.14)$ & $7.29(0.15)$ & $7.39(0.13)$ & $7.37(0.11)$ & $7.39(0.13)$ & $7.35(0.12)$ & $7.45(0.13)$ & $7.69(0.11)$ & 0.38 & $(0.19)$ \\
\hline & Mexico & $7.96(0.16)$ & $8.30(0.15)$ & $8.37(0.13)$ & $8.35(0.14)$ & $8.33(0.12)$ & $8.29(0.11)$ & $8.33(0.11)$ & $8.31(0.11)$ & $8.28(0.09)$ & $8.16(0.09)$ & 0.21 & $(0.17)$ \\
\hline & Netherlands & $8.17(0.13)$ & $8.03(0.12)$ & $7.97(0.10)$ & $7.85(0.10)$ & $7.80(0.10)$ & $7.80(0.10)$ & $7.70(0.09)$ & $7.66(0.11)$ & $7.68(0.08)$ & $7.70(0.09)$ & -0.47 & $(0.15)$ \\
\hline & New Zealand & $\mathrm{m}$ & $\mathrm{m} \quad \mathrm{m}$ & $\mathrm{m} \quad \mathrm{m}$ & $\mathrm{m} \quad \mathrm{m}$ & $\mathrm{m}$ & $\mathrm{m}$ & $\mathrm{m}$ & $\mathrm{m}$ & $\mathrm{m} \quad \mathrm{m}$ & $\mathrm{m}$ & $\mathrm{m}$ & $\mathrm{m}$ \\
\hline & Norway & $\mathrm{m}$ & $\mathrm{m}$ & $\mathrm{m}$ & $\mathrm{m}$ & $\mathrm{m}$ & $\mathrm{m}$ & $\mathrm{m}$ & $\mathrm{m}$ & $\mathrm{m}$ & $\mathrm{m}$ & $\mathrm{m}$ & $\mathrm{m}$ \\
\hline & Poland & $7.15(0.14)$ & $7.29(0.17)$ & $7.24(0.16)$ & $7.18(0.17)$ & $7.08(0.15)$ & $\mid 7.09(0.16)$ & \begin{tabular}{|l|}
$7.16(0.14)$ \\
\end{tabular} & $7.27(0.15)$ & $\mid 7.23(0.14)$ & $7.15(0.14)$ & 0.00 & $(0.19)$ \\
\hline & Portugal & $7.48(0.13)$ & $7.48(0.14)$ & $7.46(0.13)$ & $7.36(0.12)$ & $7.30(0.15)$ & $7.33(0.13)$ & $7.30(0.14)$ & $7.28(0.12)$ & $7.25(0.11)$ & $7.39(0.09)$ & -0.09 & $(0.17)$ \\
\hline & Slovak Republic & $7.43(0.17)$ & $7.50(0.16)$ & $7.43(0.17)$ & $7.36(0.14)$ & $7.37(0.13)$ & $7.46(0.12)$ & $7.57(0.12)$ & $7.52(0.14)$ & $7.49(0.14)$ & $7.58(0.10)$ & 0.15 & $(0.19)$ \\
\hline & Slovenia & $7.32(0.14)$ & $7.21(0.15)$ & $7.19(0.17)$ & $7.19(0.14)$ & $7.09(0.16)$ & $7.16(0.15)$ & $7.08(0.17)$ & $7.04(0.14)$ & $7.06(0.17)$ & $7.41(0.13)$ & 0.09 & $(0.19)$ \\
\hline & Spain & $7.36(0.13)$ & $7.35(0.12)$ & $7.34(0.12)$ & $7.31(0.12)$ & $7.36(0.14)$ & $\mid 7.40(0.14)$ & $7.41(0.12)$ & $7.45(0.11)$ & $7.56(0.11)$ & $7.66(0.09)$ & 0.31 & $(0.15)$ \\
\hline & Sweden & $\mathrm{m}$ & $\mathrm{m}$ & $\mathrm{m}$ & $\mathrm{m}$ & $\mathrm{m}$ & $\mathrm{m}$ & $\mathrm{m}$ & $\mathrm{m}$ & $\mathrm{m}$ & $\mathrm{m}$ & $\mathrm{m}$ & $\mathrm{m}$ \\
\hline & Switzerland & $7.70(0.14)$ & $7.61(0.18)$ & $7.60(0.17)$ & $7.66(0.13)$ & $7.68(0.12)$ & $\mid 7.69(0.13)$ & $\mid 7.71(0.16)$ & $7.73(0.17)$ & $7.88(0.11)$ & $7.90(0.09)$ & 0.20 & $(0.18)$ \\
\hline & Turkey & $6.34(0.19)$ & $6.29(0.18)$ & $6.16(0.19)$ & $6.10(0.21)$ & $5.99(0.23)$ & $5.94(0.19)$ & $6.07(0.19)$ & $6.09(0.21)$ & $6.03(0.17)$ & $6.19(0.17)$ & -0.16 & $(0.26)$ \\
\hline & United Kingdom & $6.85(0.15)$ & $6.95(0.15)$ & \begin{tabular}{|ll}
7.01 & $(0.14)$ \\
\end{tabular} & $7.01(0.14)$ & $6.99(0.14)$ & $6.96(0.13)$ & $7.00(0.15)$ & $6.98(0.14)$ & $6.97(0.11)$ & $7.06(0.09)$ & 0.21 & $(0.18)$ \\
\hline & United States & $7.33(0.13)$ & $7.42(0.15)$ & $7.46(0.15)$ & $7.46(0.14)$ & $7.38(0.14)$ & $7.36(0.13)$ & \begin{tabular}{|ll}
7.31 & $(0.12)$ \\
\end{tabular} & $7.34(0.14)$ & $7.33(0.14)$ & $7.20(0.13)$ & -0.13 & $(0.20)$ \\
\hline & OECD average & $7.26(0.03)$ & $7.28(0.03)$ & $|7.29(0.03)|$ & $|7.28(0.03)|$ & $|7.26(0.03)|$ & $|7.28(0.03)|$ & $|7.31(0.03)|$ & $7.33(0.03)$ & $7.37(0.02)$ & $7.45(0.02)$ & 0.19 & $(0.04)$ \\
\hline & Albania & $\mathrm{m}$ & $\mathrm{m}$ & $\mathrm{m}$ & $\mathrm{m}$ & $\mathrm{m}$ & $\mathrm{m}$ & $\mathrm{m}$ & $\mathrm{m}$ & $\mathrm{m}$ & $\mathrm{m}$ & $\mathrm{m}$ & $m$ \\
\hline & Algeria & $\mathrm{m}$ & $\mathrm{m}$ & $\mathrm{m}$ & $\mathrm{m}$ & $\mathrm{m}$ & $\mathrm{m}$ & $\mathrm{m}$ & $\mathrm{m}$ & $\mathrm{m}$ & $\mathrm{m}$ & $\mathrm{m}$ & $\mathrm{m}$ \\
\hline & Brazil & $7.67(0.12)$ & $7.79(0.12)$ & $7.75(0.11)$ & $7.70(0.14)$ & $7.63(0.10)$ & $7.58(0.10)$ & $7.56(0.11)$ & 7.47 (0.08) & $7.44(0.09)$ & $7.36(0.08)$ & -0.30 & $(0.14)$ \\
\hline & B-S-J-G (C & $6.88(0.14)$ & $6.87(0.14)$ & $6.74(0.15)$ & $6.73(0.16)$ & $6.70(0.16)$ & $6.81(0.16)$ & $6.90(0.15)$ & $6.91(0.17)$ & $6.93(0.15)$ & $6.87(0.16)$ & -0.01 & $(0.21)$ \\
\hline & Bulgaria & $7.09(0.20)$ & $7.38(0.16)$ & $7.49(0.19)$ & $7.41(0.18)$ & $7.49(0.16)$ & $7.45(0.15)$ & $7.41(0.15)$ & $7.42(0.13)$ & $7.50(0.13)$ & $7.46(0.11)$ & 0.37 & $(0.23)$ \\
\hline & CABA (Argentina) & $\mathrm{m}$ & $\mathrm{m}$ & $\mathrm{m}$ & $\mathrm{m}$ & $\mathrm{m}$ & $\mathrm{m}$ & $\mathrm{m}$ & $\mathrm{m}$ & $\mathrm{m}$ & $\mathrm{m}$ & $\mathrm{m}$ & $\mathrm{m}$ \\
\hline & Colombia & $8.03(0.13)$ & $8.19(0.16)$ & $8.17(0.13)$ & $8.10(0.13)$ & $7.98(0.14)$ & $7.82(0.16)$ & $7.73(0.15)$ & $7.58(0.12)$ & $7.62(0.12)$ & $7.67(0.08)$ & -0.35 & $(0.15)$ \\
\hline & Costa Rica & $8.39(0.13)$ & $8.36(0.14)$ & $8.32(0.17)$ & $8.26(0.14)$ & $8.25(0.15)$ & $8.21(0.14)$ & $8.17(0.16)$ & $8.14(0.13)$ & $8.07(0.13)$ & $7.95(0.12)$ & -0.44 & $(0.16)$ \\
\hline & Croatia & $8.17(0.12)$ & $7.96(0.14)$ & $7.92(0.13)$ & $7.92(0.12)$ & $\begin{array}{|ll|}7.88 & (0.15) \\
\end{array}$ & $7.89(0.14)$ & $7.84(0.12)$ & $7.88(0.12)$ & $7.82(0.10)$ & $7.75(0.10)$ & -0.42 & $(0.16)$ \\
\hline & Cyprus* & $7.05(0.14)$ & $6.83(0.16)$ & $6.89(0.17)$ & $6.92(0.17)$ & $6.96(0.13)$ & $\mid 7.02(0.14)$ & $\mid 7.12(0.14)$ & $7.15(0.11)$ & $7.25(0.11)$ & $7.43(0.10)$ & 0.37 & $(0.17)$ \\
\hline & Dominican Republic & $8.32(0.20)$ & $8.49(0.20)$ & $8.60(0.20)$ & $8.64(0.18)$ & $8.67(0.16)$ & $8.70(0.15)$ & $8.57(0.15)$ & $8.42(0.16)$ & $8.23(0.15)$ & $8.36(0.10)$ & 0.04 & $(0.22)$ \\
\hline & FYROM & $\mathrm{m}$ & $\mathrm{m}$ & $\mathrm{m}$ & $\mathrm{m}$ & $\mathrm{m}$ & $\mathrm{m}$ & $\mathrm{m}$ & $\mathrm{m}$ & $\mathrm{m}$ & $\mathrm{m}$ & $\mathrm{m}$ & $\mathrm{m}$ \\
\hline & Georgia & $\mathrm{m}$ & $\mathrm{m}$ & $\mathrm{m}$ & $\mathrm{m}$ & $\mathrm{m}$ & $\mathrm{m}$ & $\mathrm{m}$ & $\mathrm{m}$ & $\mathrm{m}$ & $\mathrm{m}$ & $\mathrm{m}$ & $\mathrm{m}$ \\
\hline & Hong Kong (China) & $6.37(0.17)$ & $6.46(0.15)$ & $6.39(0.14)$ & $6.41(0.15)$ & $6.50(0.15)$ & $6.46(0.13)$ & $6.50(0.13)$ & $6.57(0.12)$ & $6.56(0.12)$ & $6.55(0.12)$ & 0.18 & $(0.21)$ \\
\hline & Indonesia & $m \quad m$ & $\mathrm{~m} \quad \mathrm{~m}$ & $\mathrm{~m} \quad \mathrm{~m}$ & $\mathrm{~m} \quad \mathrm{~m}$ & $\mathrm{~m} \quad \mathrm{~m}$ & $\begin{array}{ll}m & m\end{array}$ & $\begin{array}{ll}m & m\end{array}$ & $\begin{array}{ll}m & m\end{array}$ & $m \quad m$ & $\mathrm{~m} \quad \mathrm{~m}$ & $\mathrm{~m}$ & $\mathrm{~m}$ \\
\hline & Jordan & $\mathrm{m}$ & $\mathrm{m}$ & $\mathrm{m}$ & $\mathrm{m}$ & $\mathrm{m}$ & $\mathrm{m}$ & $\mathrm{m}$ & $\mathrm{m}$ & $\mathrm{m}$ & $\mathrm{m}$ & $\mathrm{m}$ & $\mathrm{m}$ \\
\hline & Kosovo & $\mathrm{m}$ & $\mathrm{m}$ & $\mathrm{m}$ & $\mathrm{m}$ & $\mathrm{m}$ & $\mathrm{m}$ & $\mathrm{m}$ & $\mathrm{m}$ & $\mathrm{m}$ & $\mathrm{m}$ & $\mathrm{m}$ & $\mathrm{m}$ \\
\hline & Lebanon & $\mathrm{m}$ & $\mathrm{m}$ & $\mathrm{m}$ & $\mathrm{m}$ & $\mathrm{m}$ & $\mathrm{m}$ & $\mathrm{m}$ & $\mathrm{m}$ & $\mathrm{m}$ & $\mathrm{m}$ & $\mathrm{m}$ & $\mathrm{m}$ \\
\hline & Lithuania & $7.52(0.14)$ & $7.75(0.15)$ & $7.97(0.13)$ & $7.93(0.12)$ & $7.97(0.15)$ & $7.86(0.14)$ & $7.86(0.12)$ & $7.90(0.15)$ & $7.91(0.12)$ & $7.96(0.09)$ & 0.43 & $(0.16)$ \\
\hline & Macao (China) & $6.21(0.14)$ & $6.41(0.14)$ & $6.52(0.16)$ & $6.57(0.16)$ & $6.57(0.15)$ & $6.68(0.13)$ & $6.68(0.13)$ & $6.71(0.12)$ & $6.76(0.12)$ & $6.80(0.12)$ & 0.59 & $(0.18)$ \\
\hline & Malta & $\mathrm{m}$ & $\mathrm{m}$ & $\mathrm{m}$ & $\mathrm{m}$ & $\mathrm{m}$ & $\mathrm{m}$ & $\mathrm{m}$ & $\mathrm{m}$ & $\mathrm{m}$ & $\mathrm{m}$ & $\mathrm{m}$ & $\mathrm{m}$ \\
\hline & Moldova & $\mathrm{m}$ & $\mathrm{m}$ & $\mathrm{m}$ & $\mathrm{m}$ & $\mathrm{m}$ & $\mathrm{m}$ & $\mathrm{m}$ & $\mathrm{m}$ & $\mathrm{m}$ & $\mathrm{m}$ & $\mathrm{m}$ & $\mathrm{m}$ \\
\hline & Montenegro & $8.12(0.16)$ & $7.90(0.15)$ & $7.85(0.18)$ & $7.81(0.14)$ & $7.82(0.18)$ & $7.68(0.17)$ & $7.58(0.15)$ & $7.56(0.14)$ & $7.67(0.16)$ & $7.57(0.14)$ & -0.55 & $(0.20)$ \\
\hline & Peru & $7.09(0.17)$ & $7.49(0.16)$ & $7.63(0.14)$ & $7.65(0.15)$ & $7.69(0.14)$ & $7.62(0.13)$ & $7.60(0.12)$ & $7.48(0.11)$ & $7.37(0.11)$ & $7.31(0.11)$ & 0.22 & $(0.20)$ \\
\hline & Qatar & $7.44(0.14)$ & $7.54(0.11)$ & $7.58(0.11)$ & $7.47(0.14)$ & $7.47(0.13)$ & $7.42(0.11)$ & $7.34(0.09)$ & $7.31(0.09)$ & $7.27(0.08)$ & $7.27(0.07)$ & -0.17 & $(0.15)$ \\
\hline & Romania & & $\mathrm{m}$ & $\mathrm{m}$ & $\mathrm{m}$ & $\mathrm{m}$ & $\mathrm{m}$ & $\mathrm{m}$ & $\mathrm{m}$ & $\mathrm{m}$ & $\mathrm{m}$ & $\mathrm{m}$ & $\mathrm{m}$ \\
\hline & Russia & $7.90(0.14)$ & $7.88(0.15)$ & $7.82(0.18)$ & $7.78(0.16)$ & $7.77(0.16)$ & $7.77(0.16)$ & $7.79(0.15)$ & $7.72(0.16)$ & $7.64(0.14)$ & $7.52(0.11)$ & -0.38 & $(0.18)$ \\
\hline & Singa & & $\mathrm{m}$ & & $\mathrm{m}$ & $\mathrm{m}$ & $\mathrm{m}$ & $\mathrm{m}$ & $\mathrm{m}$ & $\mathrm{m}$ & $\mathrm{m}$ & $\mathrm{m}$ & $\mathrm{m}$ \\
\hline & Chinese Taipei & $6.60(0.13)$ & $6.56(0.13)$ & $6.57(0.12)$ & $6.55(0.11)$ & $6.53(0.11)$ & $6.56(0.11)$ & $6.57(0.13)$ & $6.59(0.12)$ & $6.65(0.11)$ & $6.76(0.08)$ & 0.16 & $(0.15)$ \\
\hline & Thailand & $7.67(0.14)$ & $7.81(0.14)$ & $7.76(0.12)$ & $7.84(0.13)$ & $7.87(0.16)$ & $7.76(0.14)$ & $7.78(0.12)$ & $7.67(0.14)$ & $7.57(0.11)$ & $7.40(0.10)$ & -0.28 & $(0.17)$ \\
\hline & Trinidad and Tobago & $\mathrm{m}$ & $\mathrm{m}$ & $\mathrm{m}$ & $\mathrm{m}$ & $\mathrm{m}$ & $\mathrm{m}$ & $\mathrm{m}$ & $\mathrm{m}$ & $\mathrm{m}$ & $\mathrm{m}$ & $\mathrm{m}$ & $\mathrm{m}$ \\
\hline & Tunisia & $6.80(0.25)$ & $6.80(0.20)$ & $6.94(0.24)$ & $6.94(0.21)$ & $7.00(0.25)$ & $6.93(0.21)$ & $6.95(0.18)$ & $6.90(0.16)$ & $6.82(0.20)$ & $6.91(0.13)$ & 0.11 & $(0.27)$ \\
\hline & United Ar & $7.19(0.13)$ & $7.43(0.14)$ & $7.42(0.13)$ & $7.39(0.11)$ & $7.35(0.12)$ & $7.33(0.12)$ & 7.32 (0.11) & $7.24(0.11)$ & $7.23(0.10)$ & $7.13(0.09)$ & -0.07 & $(0.14)$ \\
\hline & Uruguay & $7.59(0.16)$ & $7.82(0.14)$ & $7.68(0.14)$ & $7.75(0.14)$ & $7.66(0.15)$ & $7.59(0.14)$ & $7.63(0.13)$ & $7.71(0.13)$ & $7.74(0.10)$ & $7.79(0.09)$ & 0.20 & $(0.19)$ \\
\hline & Viet Nam & $m$ & $\mathrm{~m}$ & $\mathrm{~m}$ & $\mathrm{~m}$ & $\mathrm{~m}$ & $\mathrm{~m}$ & $\mathrm{~m}$ & $\mathrm{~m}$ & $\mathrm{~m}$ & $\mathrm{~m}$ & $\mathrm{~m}$ & $\mathrm{~m}$ \\
\hline & Argentina** $^{* *}$ & $\mathrm{~m}$ & $\mathrm{~m}$ & $\mathrm{~m}$ & $\mathrm{~m}$ & $\mathrm{~m}$ & $\mathrm{~m}$ & $\mathrm{~m}$ & $\mathrm{~m}$ & $\mathrm{~m}$ & $\mathrm{~m}$ & $\mathrm{~m}$ & $\mathrm{~m}$ \\
\hline & Kazakhstan** & $\mathrm{m}$ & $\mathrm{m}$ & $\mathrm{m}$ & $\mathrm{m}$ & $\mathrm{m}$ & $\mathrm{m}$ & $\mathrm{m}$ & $\mathrm{m}$ & $\mathrm{m}$ & $\mathrm{m}$ & $\mathrm{m}$ & $\mathrm{m}$ \\
\hline & Malaysia** & $6.88(0.14)$ & $7.08(0.14)$ & $7.10(0.16)$ & $7.09(0.16)$ & $7.09(0.15)$ & $\mid 7.09(0.15)$ & $7.04(0.13)$ & $7.13(0.11)$ & $7.11(0.09)$ & $7.07(0.10)$ & 0.19 & $(0.17)$ \\
\hline
\end{tabular}

Note: Values that are statistically significant are indicated in bold (see Annex A3).

* See note at the beginning of this Annex.

** Coverage is too small to ensure comparability (see Annex A4).

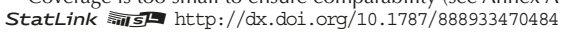




\begin{tabular}{|c|c|c|c|c|c|c|c|c|c|c|c|c|}
\hline & \multicolumn{12}{|c|}{ Boys } \\
\hline & 1st decile & 2nd decile & 3rd decile & 4th decile & 5th decile & 6th decile & 7th decile & 8th decile & 9th decile & 10th decile & \multicolumn{2}{|c|}{$\begin{array}{l}\text { Difference } \\
\text { between the 10th } \\
\text { and the } 1 \text { st decile }\end{array}$} \\
\hline & Mean S.E. & Mean S.E. & Mean S.E. & Mean S.E. & Mean S.E. & Mean S.E. & Mean S.E. & Mean S.E. & Mean S.E. & Mean S.E. & Dif. & S.E. \\
\hline Australia & & & $\mathrm{m}$ & & & $\mathrm{m}$ & $\mathrm{m}$ & $\mathrm{m}$ & $\mathrm{m}$ & $\mathrm{m}$ & $\mathrm{m}$ & $\mathrm{m}$ \\
\hline Austria & $8.12(0.18)$ & $8.04(0.20)$ & $7.99(0.18)$ & $8.01(0.17)$ & $7.89(0.18)$ & $7.97(0.17)$ & $7.95(0.17)$ & $7.85(0.15)$ & $7.80(0.14)$ & $7.92(0.12)$ & -0.20 & $(0.23)$ \\
\hline Belgium (excl. Flemish) & $7.73(0.21)$ & $7.87(0.24)$ & $7.86(0.27)$ & $7.83(0.28)$ & $7.77(0.27)$ & $7.81(0.20)$ & $7.73(0.23)$ & $7.76(0.21)$ & $7.64(0.19)$ & $7.74(0.15)$ & 0.01 & $(0.26)$ \\
\hline Canada & $\mathrm{m}$ & $\mathrm{m}$ & $\mathrm{m}$ & $\mathrm{m}$ & $\mathrm{m}$ & $\mathrm{m}$ & $\mathrm{m}$ & $\mathrm{m}$ & $\mathrm{m}$ & $\mathrm{m}$ & $\mathrm{m}$ & $\mathrm{m}$ \\
\hline Chile & $7.79(0.19)$ & $7.69(0.24)$ & $7.58(0.24)$ & $7.65(0.26)$ & $7.58(0.22)$ & $7.55(0.21)$ & $7.54(0.24)$ & $7.55(0.19)$ & $7.58(0.17)$ & $7.55(0.13)$ & -0.24 & $(0.23)$ \\
\hline Czech Rep & $7.44(0.22)$ & $7.36(0.22)$ & $7.51(0.20)$ & $7.46(0.24)$ & $7.34(0.20)$ & $7.37(0.19)$ & $7.40(0.18)$ & $7.31(0.17)$ & $7.33(0.15)$ & $7.21(0.14)$ & -0.23 & $(0.25)$ \\
\hline Denmark & $\mathrm{m}$ & $\mathrm{m}$ & $\mathrm{m}$ & $\mathrm{m}$ & $\mathrm{m}$ & $\mathrm{m}$ & $\mathrm{m}$ & $\mathrm{m}$ & $\mathrm{m}$ & $\mathrm{m}$ & $\mathrm{m}$ & $\mathrm{m}$ \\
\hline Estonia & $7.71(0.17)$ & $7.79(0.18)$ & $7.76(0.22)$ & $7.73(0.22)$ & $7.59(0.18)$ & $7.62(0.20)$ & $\mid 7.67(0.19)$ & $7.75(0.18)$ & $7.78(0.16)$ & $7.91(0.13)$ & 0.20 & $(0.20)$ \\
\hline Finland & $7.99(0.15)$ & $8.22(0.14)$ & $8.20(0.17)$ & $8.34(0.15)$ & $8.35(0.15)$ & $8.29(0.11)$ & $8.29(0.11)$ & $8.25(0.11)$ & $8.26(0.12)$ & $8.29(0.10)$ & 0.29 & $(0.18)$ \\
\hline France & $7.54(0.22)$ & $7.85(0.18)$ & $7.82(0.16)$ & $7.87(0.18)$ & $7.91(0.14)$ & $7.86(0.15)$ & $7.86(0.13)$ & $7.86(0.14)$ & $7.91(0.11)$ & $8.02(0.10)$ & 0.48 & $(0.23)$ \\
\hline Germany & $7.78(0.19)$ & $7.81(0.21)$ & $7.75(0.23)$ & $7.75(0.19)$ & $7.61(0.21)$ & $7.64(0.21)$ & $7.73(0.20)$ & $7.72(0.16)$ & $7.83(0.15)$ & $7.90(0.11)$ & 0.12 & $(0.22)$ \\
\hline Greece & $7.35(0.25)$ & $7.37(0.27)$ & $7.22(0.28)$ & $7.20(0.23)$ & $7.07(0.21)$ & $7.07(0.19)$ & $7.16(0.20)$ & $7.24(0.18)$ & $7.28(0.15)$ & $7.28(0.13)$ & -0.07 & $(0.26)$ \\
\hline Hungary & $7.48(0.25)$ & $7.62(0.21)$ & $7.61(0.26)$ & $7.63(0.23)$ & $7.60(0.21)$ & $7.51(0.22)$ & $7.40(0.20)$ & $7.53(0.18)$ & $7.50(0.15)$ & $7.53(0.15)$ & 0.04 & $(0.30)$ \\
\hline Iceland & $7.91(0.24)$ & $8.14(0.28)$ & $8.36(0.25)$ & $8.37(0.25)$ & $8.44(0.19)$ & $8.43(0.20)$ & $8.33(0.19)$ & $8.20(0.18)$ & $8.25(0.20)$ & $8.33(0.14)$ & 0.42 & $(0.28)$ \\
\hline Ireland & $7.41(0.21)$ & $7.57(0.17)$ & $7.75(0.18)$ & $7.60(0.16)$ & $7.57(0.18)$ & $7.78(0.14)$ & $7.75(0.13)$ & $7.62(0.15)$ & $7.42(0.14)$ & $7.29(0.12)$ & -0.12 & $(0.25)$ \\
\hline Israel & $\mathrm{m}$ & $\mathrm{m}$ & $\mathrm{m}$ & $\mathrm{m}$ & $\mathrm{m}$ & $\mathrm{m}$ & $\mathrm{m}$ & $\mathrm{m}$ & $\mathrm{m}$ & $\mathrm{m}$ & $\mathrm{m}$ & $\mathrm{m}$ \\
\hline Italy & $7.53(0.20)$ & $7.28(0.23)$ & $7.36(0.19)$ & $7.25(0.18)$ & $7.13(0.22)$ & $7.26(0.24)$ & $7.35(0.19)$ & $7.27(0.20)$ & $7.19(0.15)$ & $7.32(0.15)$ & -0.21 & $(0.26)$ \\
\hline Japan & $6.50(0.19)$ & $6.50(0.21)$ & $6.74(0.22)$ & $6.85(0.21)$ & $6.82(0.19)$ & $6.77(0.18)$ & $6.67(0.20)$ & $6.80(0.17)$ & $6.83(0.17)$ & $6.87(0.16)$ & 0.37 & $(0.26)$ \\
\hline Korea & $6.75(0.19)$ & $6.65(0.21)$ & $6.68(0.24)$ & $6.69(0.24)$ & $6.49(0.25)$ & $6.49(0.25)$ & $6.44(0.25)$ & $6.50(0.22)$ & $6.62(0.22)$ & $6.59(0.16)$ & -0.16 & $(0.24)$ \\
\hline Latvia & $7.28(0.22)$ & $7.43(0.24)$ & $7.50(0.26)$ & $7.46(0.21)$ & $7.54(0.18)$ & $7.36(0.18)$ & $7.36(0.20)$ & $7.41(0.19)$ & $7.53(0.16)$ & $7.69(0.14)$ & 0.42 & $(0.27)$ \\
\hline Luxembo & $7.80(0.22)$ & $7.76(0.21)$ & $7.71(0.19)$ & $7.73(0.20)$ & $7.82(0.19)$ & $7.75(0.16)$ & $7.71(0.15)$ & $7.75(0.16)$ & $7.82(0.14)$ & $7.91(0.12)$ & 0.11 & $(0.26)$ \\
\hline Mexico & $7.83(0.21)$ & $8.35(0.19)$ & $8.41(0.16)$ & $8.49(0.19)$ & $8.45(0.19)$ & $8.44(0.16)$ & $8.42(0.14)$ & $8.34(0.14)$ & $8.34(0.13)$ & $8.19(0.13)$ & 0.36 & $(0.23)$ \\
\hline Netherlands & $8.47(0.18)$ & $8.40(0.18)$ & $8.32(0.15)$ & $8.19(0.15)$ & $8.06(0.14)$ & $8.09(0.14)$ & $8.03(0.12)$ & $7.94(0.14)$ & $7.92(0.12)$ & $7.80(0.11)$ & -0.67 & $(0.21)$ \\
\hline New Zealand & & $\mathrm{m}$ & $\mathrm{m}$ & $\mathrm{m}$ & $\mathrm{m}$ & $\mathrm{m}$ & $\mathrm{m}$ & $\mathrm{m}$ & $\mathrm{m}$ & $\mathrm{m}$ & $\mathrm{m}$ & $\mathrm{m}$ \\
\hline Norway & $\mathrm{m}$ & $\mathrm{m}$ & $\mathrm{m}$ & $\mathrm{m}$ & $\mathrm{m}$ & $\mathrm{m}$ & $\mathrm{m}$ & $\mathrm{m}$ & $\mathrm{m}$ & $\mathrm{m}$ & $\mathrm{m}$ & $\mathrm{m}$ \\
\hline Poland & $7.37(0.21)$ & $7.63(0.23)$ & $7.73(0.20)$ & $7.67(0.20)$ & $7.54(0.21)$ & $7.52(0.20)$ & $7.46(0.21)$ & $7.47(0.22)$ & $7.49(0.22)$ & $7.37(0.16)$ & 0.00 & $(0.26)$ \\
\hline Portugal & $7.72(0.19)$ & $7.83(0.20)$ & $7.75(0.19)$ & $7.62(0.20)$ & $7.55(0.21)$ & $7.60(0.19)$ & $7.53(0.17)$ & $7.43(0.16)$ & $7.48(0.15)$ & $7.63(0.14)$ & -0.10 & $(0.24)$ \\
\hline Slovak Republic & $7.69(0.25)$ & $7.82(0.21)$ & $7.86(0.19)$ & $7.71(0.19)$ & $7.67(0.20)$ & $7.71(0.17)$ & $7.89(0.18)$ & $7.85(0.19)$ & $7.71(0.17)$ & $7.68(0.13)$ & 0.00 & $(0.29)$ \\
\hline Slovenia & $7.98(0.15)$ & $7.75(0.22)$ & $7.74(0.23)$ & $7.71(0.22)$ & $7.59(0.20)$ & $7.63(0.18)$ & $7.49(0.25)$ & $7.34(0.18)$ & $7.31(0.19)$ & $7.68(0.17)$ & -0.30 & $(0.24)$ \\
\hline Spain & $7.82(0.18)$ & $7.63(0.20)$ & $7.48(0.18)$ & $7.49(0.17)$ & $7.51(0.16)$ & $7.53(0.20)$ & $\mid 7.59(0.18)$ & $7.63(0.15)$ & $7.62(0.18)$ & $7.75(0.11)$ & -0.08 & $(0.22)$ \\
\hline Swede & $\mathrm{m}$ & & $\mathrm{m}$ & $\mathrm{m}$ & $\mathrm{m}$ & $\mathrm{m}$ & $\mathrm{m}$ & $\mathrm{m}$ & $\mathrm{m}$ & $\mathrm{m}$ & $\mathrm{m}$ & $\mathrm{m}$ \\
\hline Switzerland & $8.08(0.15)$ & $7.97(0.26)$ & $7.96(0.21)$ & $8.10(0.19)$ & $8.08(0.15)$ & $8.08(0.16)$ & $7.95(0.19)$ & $7.96(0.20)$ & $8.06(0.14)$ & $8.05(0.14)$ & -0.04 & $(0.20)$ \\
\hline Turkey & $6.59(0.25)$ & $6.65(0.28)$ & $6.50(0.31)$ & $6.53(0.27)$ & $6.38(0.25)$ & $6.33(0.27)$ & $6.32(0.24)$ & $6.27(0.28)$ & $6.16(0.22)$ & $6.43(0.21)$ & -0.16 & $(0.33)$ \\
\hline United Kingdom & $7.35(0.19)$ & $7.38(0.21)$ & $7.39(0.18)$ & $7.46(0.20)$ & $7.33(0.17)$ & $7.29(0.18)$ & $7.26(0.18)$ & $7.22(0.16)$ & $7.25(0.15)$ & $7.20(0.15)$ & -0.15 & $(0.25)$ \\
\hline United States & $7.73(0.18)$ & $7.75(0.22)$ & $7.79(0.19)$ & $7.80(0.22)$ & $7.68(0.20)$ & $7.61(0.17)$ & $7.63(0.17)$ & $7.62(0.17)$ & $7.62(0.17)$ & $7.36(0.14)$ & -0.37 & $(0.22)$ \\
\hline OECD average & $7.60(0.04)$ & $7.65(0.04)$ & $7.65(0.04)$ & $\mid 7.65(0.04)$ & $\mid 7.58(0.04)$ & $\mid 7.58(0.04)$ & $7.57(0.04)$ & $7.55(0.03)$ & $7.55(0.03)$ & $7.59(0.03)$ & -0.01 & $(0.05)$ \\
\hline
\end{tabular}

\begin{tabular}{|c|c|c|c|c|c|c|c|c|c|c|c|c|c|}
\hline \multirow{4}{*}{ 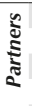 } & Albania & $\mathrm{m}$ & $\mathrm{m}$ & $\mathrm{m}$ & $\mathrm{m}$ & $\mathrm{m}$ & $\mathrm{m}$ & $\mathrm{m}$ & $\mathrm{m}$ & $\mathrm{m}$ & $\mathrm{m}$ & $\mathrm{m}$ & $\mathrm{m}$ \\
\hline & Algeria & $\mathrm{m}$ & $\mathrm{m}$ & $\mathrm{m}$ & $\mathrm{m}$ & $\mathrm{m}$ & $\mathrm{m}$ & $\mathrm{m}$ & $\mathrm{m}$ & $\mathrm{m}$ & $\mathrm{m}$ & $\mathrm{m}$ & $\mathrm{m}$ \\
\hline & Brazil & $7.78(0.17)$ & $7.90(0.16)$ & $7.94(0.18)$ & $7.89(0.17)$ & $7.80(0.13)$ & $7.81(0.12)$ & $7.76(0.14)$ & $7.62(0.13)$ & $7.54(0.13)$ & $7.43(0.12)$ & -0.35 & $(0.20)$ \\
\hline & B-S-J-G (China) & $6.98(0.17)$ & $6.97(0.19)$ & $6.88(0.20)$ & $6.83(0.19)$ & $6.77(0.18)$ & $6.87(0.20)$ & $6.87(0.21)$ & $6.88(0.23)$ & $6.86(0.20)$ & $6.89(0.17)$ & -0.10 & $(0.24)$ \\
\hline & Bulgaria & $7.02(0.29)$ & $7.54(0.28)$ & $7.68(0.29)$ & $7.74(0.22)$ & $7.68(0.21)$ & $7.66(0.19)$ & $7.65(0.19)$ & $7.74(0.17)$ & $7.75(0.18)$ & $7.57(0.16)$ & 0.55 & $(0.34)$ \\
\hline & CABA (Argentina) & $\mathrm{m}$ & $\mathrm{m}$ & $\mathrm{m}$ & $\mathrm{m}$ & $\mathrm{m}$ & $\mathrm{m}$ & $\mathrm{m}$ & $\mathrm{m}$ & $\mathrm{m}$ & $\mathrm{m}$ & $\mathrm{m}$ & $\mathrm{m}$ \\
\hline & Colombia & $8.09(0.20)$ & $8.46(0.22)$ & $8.38(0.19)$ & $8.39(0.19)$ & $8.12(0.20)$ & $8.02(0.18)$ & $7.96(0.19)$ & $7.83(0.18)$ & $7.86(0.16)$ & $7.76(0.14)$ & -0.32 & $(0.25)$ \\
\hline & Costa Rica & $8.57(0.17)$ & $8.61(0.17)$ & $8.52(0.24)$ & $8.43(0.21)$ & $8.48(0.21)$ & $8.46(0.17)$ & $8.42(0.17)$ & $8.31(0.16)$ & $8.09(0.15)$ & $8.06(0.15)$ & -0.51 & $(0.22)$ \\
\hline & Croatia & $8.51(0.15)$ & $8.48(0.18)$ & $8.32(0.20)$ & $8.28(0.18)$ & $8.16(0.16)$ & $8.16(0.19)$ & $8.10(0.17)$ & $8.13(0.15)$ & $8.07(0.13)$ & $7.96(0.15)$ & -0.55 & $(0.21)$ \\
\hline & Cyprus* & $7.37(0.19)$ & $7.16(0.23)$ & $7.09(0.21)$ & $7.22(0.21)$ & $7.23(0.22)$ & $7.24(0.19)$ & $7.25(0.19)$ & $7.26(0.16)$ & $7.44(0.16)$ & $7.48(0.14)$ & 0.11 & $(0.24)$ \\
\hline & Dominican Republic & $8.21(0.36)$ & $8.35(0.30)$ & $8.52(0.30)$ & $8.59(0.29)$ & $8.64(0.29)$ & $8.82(0.25)$ & $8.77(0.20)$ & $8.59(0.26)$ & $8.44(0.19)$ & $8.50(0.15)$ & 0.28 & $(0.37)$ \\
\hline & FYROM & $\mathrm{m}$ & $\mathrm{m}$ & $\mathrm{m}$ & $\mathrm{m}$ & $\mathrm{m}$ & $\mathrm{m}$ & $\mathrm{m}$ & $\mathrm{m}$ & $\mathrm{m}$ & $\mathrm{m}$ & $\mathrm{m}$ & $\mathrm{m}$ \\
\hline & Georgia & & $\mathrm{m}$ & $\mathrm{m}$ & $\mathrm{m}$ & $\mathrm{m}$ & $\mathrm{m}$ & $\mathrm{m}$ & $\mathrm{m}$ & $\mathrm{m}$ & $\mathrm{m}$ & $\mathrm{m}$ & $\mathrm{m}$ \\
\hline & Hong Kong (China) & $6.41(0.25)$ & $6.58(0.22)$ & $6.48(0.25)$ & $6.55(0.23)$ & $6.59(0.23)$ & $6.52(0.23)$ & $6.52(0.18)$ & $6.57(0.19)$ & $6.47(0.21)$ & $6.44(0.17)$ & 0.04 & $(0.31)$ \\
\hline & Indonesia & $\mathrm{m}$ & $\mathrm{m}$ & $\mathrm{m}$ & $\mathrm{m}$ & $\mathrm{m}$ & $\mathrm{m}$ & $\mathrm{m}$ & $\mathrm{m}$ & $\mathrm{m}$ & $\mathrm{m}$ & $\mathrm{m}$ & m \\
\hline & Jordan & $\mathrm{m}$ & $\mathrm{m}$ & $\mathrm{m}$ & $\mathrm{m}$ & $\mathrm{m}$ & $\mathrm{m}$ & $\mathrm{m}$ & $\mathrm{m}$ & $\mathrm{m}$ & $\mathrm{m}$ & $\mathrm{m}$ & $\mathrm{m}$ \\
\hline & Kosovo & $\mathrm{m}$ & $\mathrm{m}$ & $\mathrm{m}$ & $\mathrm{m}$ & $\mathrm{m}$ & $\mathrm{m}$ & $\mathrm{m}$ & $\mathrm{m}$ & $\mathrm{m}$ & $\mathrm{m}$ & $\mathrm{m}$ & $\mathrm{m}$ \\
\hline & Lebanon & $\mathrm{m}$ & $\mathrm{m}$ & $\mathrm{m}$ & $\mathrm{m}$ & $\mathrm{m}$ & $\mathrm{m}$ & $\mathrm{m}$ & $\mathrm{m}$ & $\mathrm{m}$ & $\mathrm{m}$ & $\mathrm{m}$ & $\mathrm{m}$ \\
\hline & Lithuania & $7.92(0.19)$ & $8.11(0.20)$ & $8.28(0.18)$ & $8.22(0.19)$ & $8.23(0.19)$ & $8.15(0.17)$ & $8.14(0.18)$ & $8.04(0.21)$ & $8.07(0.15)$ & $8.07(0.13)$ & 0.15 & $(0.22)$ \\
\hline & Macao (China) & $6.19(0.17)$ & $6.44(0.18)$ & $6.48(0.19)$ & $6.62(0.20)$ & $6.63(0.21)$ & $6.71(0.20)$ & $6.72(0.20)$ & $6.73(0.18)$ & $6.74(0.18)$ & $6.70(0.18)$ & 0.51 & $(0.24)$ \\
\hline & Malta & & $\mathrm{m}$ & $\mathrm{m}$ & $\mathrm{m}$ & $\mathrm{m}$ & $\mathrm{m}$ & $\mathrm{m}$ & $\mathrm{m}$ & $\mathrm{m}$ & $\mathrm{m}$ & $\mathrm{m}$ & $\mathrm{m}$ \\
\hline & Moldova & $\mathrm{m}$ & $\mathrm{m}$ & $\mathrm{m}$ & $\mathrm{m}$ & $\mathrm{m}$ & $\mathrm{m}$ & $\mathrm{m}$ & $\mathrm{m}$ & $\mathrm{m}$ & $\mathrm{m}$ & $\mathrm{m}$ & $\mathrm{m}$ \\
\hline & Montenegro & $8.25(0.25)$ & $8.10(0.22)$ & $8.12(0.29)$ & $8.07(0.21)$ & $8.12(0.22)$ & $8.00(0.21)$ & $7.86(0.18)$ & $7.77(0.19)$ & $7.90(0.19)$ & $7.82(0.18)$ & -0.43 & $(0.29)$ \\
\hline & Peru & $6.91(0.20)$ & $7.44(0.21)$ & $7.61(0.18)$ & $7.77(0.19)$ & $7.82(0.16)$ & $7.74(0.18)$ & $7.78(0.15)$ & $7.68(0.15)$ & $7.52(0.18)$ & $7.39(0.14)$ & 0.48 & $(0.24)$ \\
\hline & Qatar & $7.46(0.20)$ & $7.63(0.21)$ & $7.68(0.19)$ & $7.61(0.15)$ & $7.57(0.17)$ & $7.57(0.15)$ & $7.44(0.12)$ & $7.37(0.12)$ & $7.37(0.13)$ & $7.51(0.11)$ & 0.06 & $(0.22)$ \\
\hline & Romania & $\mathrm{m}$ & $\mathrm{m}$ & $\mathrm{m}$ & $\mathrm{m}$ & $\mathrm{m}$ & $\mathrm{m}$ & $\mathrm{m}$ & $\mathrm{m}$ & $\mathrm{m}$ & $\mathrm{m}$ & $\mathrm{m}$ & $\mathrm{m}$ \\
\hline & Russia & $8.10(0.21)$ & $8.04(0.22)$ & $8.04(0.25)$ & $7.99(0.25)$ & $8.01(0.21)$ & $8.02(0.21)$ & $7.88(0.21)$ & $7.88(0.21)$ & $7.72(0.24)$ & $7.55(0.14)$ & -0.55 & $(0.26)$ \\
\hline & Singa & $\mathrm{m}$ & $\mathrm{m}$ & $\mathrm{m}$ & $\mathrm{m}$ & $\mathrm{m}$ & $\mathrm{m}$ & $\mathrm{m}$ & $\mathrm{m}$ & $\mathrm{m}$ & $\mathrm{m}$ & $\mathrm{m}$ & $\mathrm{m}$ \\
\hline & Chinese Taipei & $6.85(0.19)$ & $6.74(0.20)$ & $6.74(0.15)$ & $6.69(0.15)$ & $6.66(0.18)$ & $6.70(0.17)$ & $6.74(0.20)$ & $6.68(0.17)$ & $6.73(0.18)$ & $6.83(0.12)$ & -0.02 & $(0.24)$ \\
\hline & Thailand & $7.65(0.22)$ & $7.77(0.21)$ & $7.83(0.21)$ & $7.99(0.22)$ & $8.03(0.22)$ & $7.87(0.23)$ & $7.81(0.19)$ & $7.66(0.26)$ & $7.50(0.22)$ & $7.23(0.18)$ & -0.41 & $(0.30)$ \\
\hline & Trinidad and Tobago & $\mathrm{m}$ & $\mathrm{m}$ & $\mathrm{m}$ & $\mathrm{m}$ & $\mathrm{m}$ & $\mathrm{m}$ & $\mathrm{m}$ & $\mathrm{m}$ & $\mathrm{m}$ & $\mathrm{m}$ & $\mathrm{m}$ & $\mathrm{m}$ \\
\hline & Tunisia & $6.76(0.31)$ & $6.87(0.32)$ & $6.99(0.30)$ & $7.11(0.29)$ & $7.09(0.34)$ & $7.07(0.26)$ & $7.09(0.30)$ & $6.95(0.27)$ & $6.92(0.27)$ & $7.05(0.18)$ & 0.29 & $(0.33)$ \\
\hline & United Arab Emirates & $7.12(0.21)$ & $7.41(0.20)$ & $7.47(0.19)$ & $7.54(0.18)$ & $7.51(0.21)$ & $7.48(0.17)$ & $7.54(0.16)$ & $7.49(0.19)$ & $7.39(0.16)$ & $7.42(0.12)$ & 0.30 & $(0.24)$ \\
\hline & Uruguay & $8.02(0.21)$ & $8.11(0.20)$ & $7.95(0.18)$ & $8.01(0.20)$ & $7.91(0.20)$ & $7.92(0.23)$ & $7.82(0.19)$ & $7.91(0.13)$ & $7.89(0.17)$ & $7.93(0.13)$ & -0.09 & $(0.26)$ \\
\hline & Viet Nam & $\mathrm{m}$ & $\mathrm{m}$ & $\mathrm{m}$ & $\mathrm{m}$ & $\mathrm{m}$ & $\mathrm{m}$ & $\mathrm{m}$ & $\mathrm{m}$ & $\mathrm{m}$ & $\mathrm{m}$ & $\mathrm{m}$ & $\mathrm{m}$ \\
\hline & $\mathrm{Ar}$ & $\mathrm{m}$ & $\mathrm{m}$ & $\mathrm{m}$ & $\mathrm{m}$ & $\mathrm{m}$ & $\mathrm{m}$ & $\mathrm{m}$ & $\mathrm{m}$ & $\mathrm{m}$ & $\mathrm{m}$ & $\mathrm{m}$ & $\mathrm{m}$ \\
\hline & $\mathrm{Kaz}$ & $\mathrm{m}$ & $\mathrm{m}$ & $\mathrm{m}$ & $\mathrm{m}$ & $\mathrm{m}$ & $\mathrm{m}$ & $\mathrm{m}$ & $\mathrm{m}$ & $\mathrm{m}$ & $\mathrm{m}$ & $\mathrm{m}$ & $\mathrm{m}$ \\
\hline & Malaysia** & $6.95(0.21)$ & $7.14(0.22)$ & $7.14(0.21)$ & $7.24(0.22)$ & $7.19(0.18)$ & $7.15(0.17)$ & $7.05(0.18)$ & $7.14(0.18)$ & $7.14(0.17)$ & $7.09(0.14)$ & 0.15 & $(0.24)$ \\
\hline
\end{tabular}

Note: Values that are statistically significant are indicated in bold (see Annex A3)

* See note at the beginning of this Annex.

** Coverage is too small to ensure comparability (see Annex A4).

StatLink न्ताs $\mathrm{http}$ ://dx.doi.org/10.1787/888933470512 


\begin{tabular}{|c|c|c|c|c|c|c|c|c|c|c|c|c|c|}
\hline & \multicolumn{12}{|c|}{ Average life satisfaction, by deciles of science performance } \\
\hline & & \multicolumn{12}{|c|}{ Girls } \\
\hline & & 1st decile & 2nd decile & 3rd decile & 4th decile & 5th decile & 6th decile & 7th decile & 8th decile & 9th decile & 10th decile & $\begin{array}{l}\text { Dif } \\
\text { betwe } \\
\text { and th }\end{array}$ & $\begin{array}{l}\text { nce } \\
\text { e 10th } \\
\text { decile }\end{array}$ \\
\hline & & Mean S.E. & Mean S.E. & Mean S.E. & Mean S.E. & Mean S.E. & Mean S.E. & Mean S.E. $\wedge$ & Mean S.E. & Mean S.E. & Mean S.E. & Dif. & S.E. \\
\hline 0 & Australia & $\mathrm{m}$ & $\mathrm{m}$ & $\mathrm{m}$ & & & $\mathrm{m}$ & $\mathrm{m}$ & $\mathrm{m}$ & $\mathrm{m}$ & $\mathrm{m}$ & $\mathrm{m}$ & $\mathrm{m}$ \\
\hline & Austria & $7.05(0.24)$ & $6.97(0.24)$ & $6.92(0.19)$ & $6.87(0.22)$ & $7.01(0.18)$ & \begin{tabular}{|l|}
$7.04(0.18)$ \\
\end{tabular} & \begin{tabular}{|l|l}
$7.23(0.19)$ \\
\end{tabular} & $7.15(0.19)$ & $7.22(0.18)$ & $7.44(0.15)$ & 0.40 & $(0.28)$ \\
\hline & Belgium (excl. Flemish) & $6.88(0.26)$ & $6.97(0.28)$ & $7.16(0.23)$ & $7.13(0.24)$ & $7.15(0.22)$ & $7.18(0.24)$ & $7.29(0.21)$ & $7.31(0.22)$ & $7.44(0.18)$ & $7.50(0.15)$ & 0.62 & $(0.31)$ \\
\hline & Canada & $\mathrm{m} \quad \mathrm{m}$ & $\mathrm{m} \quad \mathrm{m}$ & $\mathrm{m} \quad \mathrm{m}$ & $\mathrm{m} \quad \mathrm{m}$ & $\mathrm{m} \quad \mathrm{m}$ & $\mathrm{m} \quad \mathrm{m}$ & $\mathrm{m} \quad \mathrm{m}$ & $\mathrm{m} \quad \mathrm{m}$ & $\mathrm{m} \quad \mathrm{m}$ & $\mathrm{m} \quad \mathrm{m}$ & $\mathrm{m}$ & $\mathrm{m}$ \\
\hline & Chile & $7.01(0.25)$ & $7.06(0.26)$ & $7.03(0.26)$ & $7.17(0.22)$ & $7.15(0.25)$ & $7.16(0.22)$ & $7.26(0.21)$ & $7.19(0.22)$ & $7.21(0.18)$ & $7.07(0.17)$ & 0.05 & $(0.31)$ \\
\hline & Czech Republic & $6.52(0.24)$ & $6.51(0.26)$ & $6.63(0.26)$ & $6.65(0.25)$ & $6.53(0.20)$ & $6.64(0.20)$ & $6.74(0.25)$ & $6.89(0.21)$ & $6.93(0.16)$ & $7.16(0.15)$ & 0.65 & $(0.29)$ \\
\hline & Denmark & $\mathrm{m} \quad \mathrm{m}$ & $\mathrm{m} \quad \mathrm{m}$ & $\mathrm{m} \quad \mathrm{m}$ & $\mathrm{m} \quad \mathrm{m}$ & $\mathrm{m} \quad \mathrm{m}$ & $\mathrm{m} \quad \mathrm{m}$ & $\mathrm{m} \quad \mathrm{m}$ & $\mathrm{m} \quad \mathrm{m}$ & $\mathrm{m} \quad \mathrm{m}$ & $\mathrm{m} \quad \mathrm{m}$ & $\mathrm{m}$ & $\mathrm{m}$ \\
\hline & Estonia & $7.30(0.19)$ & $7.26(0.21)$ & $7.13(0.22)$ & $7.20(0.23)$ & $7.12(0.20)$ & $7.14(0.20)$ & $7.22(0.19)$ & $7.37(0.21)$ & $7.38(0.20)$ & $7.58(0.15)$ & 0.29 & $(0.25)$ \\
\hline & Finland & $7.35(0.16)$ & $7.32(0.16)$ & $7.28(0.16)$ & $7.33(0.17)$ & $7.43(0.17)$ & $7.56(0.16)$ & $7.56(0.17)$ & $7.70(0.15)$ & $7.77(0.13)$ & $7.74(0.12)$ & 0.39 & $(0.20)$ \\
\hline & France & $7.29(0.22)$ & $7.16(0.18)$ & $7.13(0.20)$ & $7.26(0.17)$ & $7.31(0.16)$ & $7.42(0.15)$ & \begin{tabular}{|l|l}
$7.51(0.17)$ \\
\end{tabular} & $7.54(0.14)$ & $7.65(0.14)$ & $7.75(0.12)$ & 0.46 & $(0.25)$ \\
\hline & Germany & $6.86(0.23)$ & $6.91(0.23)$ & $6.89(0.20)$ & $6.75(0.22)$ & $6.90(0.21)$ & $6.88(0.18)$ & $6.86(0.19)$ & $6.93(0.18)$ & $7.09(0.17)$ & $7.45(0.13)$ & 0.59 & $(0.26)$ \\
\hline & Greece & $6.21(0.26)$ & $6.20(0.23)$ & $6.40(0.24)$ & $6.43(0.22)$ & $6.64(0.21)$ & $6.77(0.21)$ & $6.74(0.19)$ & $6.74(0.20)$ & $6.77(0.20)$ & $6.91(0.15)$ & 0.70 & $(0.32)$ \\
\hline & Hungary & $6.46(0.25)$ & $6.50(0.26)$ & $6.63(0.25)$ & $6.64(0.23)$ & $6.61(0.21)$ & $6.84(0.20)$ & $6.85(0.18)$ & $6.95(0.21)$ & $7.15(0.16)$ & $7.38(0.16)$ & 0.92 & $(0.28)$ \\
\hline & Iceland & $6.68(0.29)$ & $7.02(0.30)$ & $7.13(0.28)$ & $7.21(0.29)$ & $7.21(0.28)$ & $7.26(0.29)$ & $\begin{array}{|ll|}7.58(0.23) \\
\end{array}$ & $7.67(0.22)$ & $7.86(0.21)$ & $7.82(0.19)$ & 1.14 & $(0.33)$ \\
\hline & Ireland & $6.96(0.18)$ & $6.99(0.19)$ & $6.98(0.21)$ & $7.07(0.17)$ & $7.03(0.20)$ & $6.90(0.19)$ & $7.00(0.23)$ & $7.01(0.20)$ & $7.08(0.17)$ & $7.17(0.15)$ & 0.22 & $(0.24)$ \\
\hline & Israel & $\mathrm{m} \quad \mathrm{m}$ & $\mathrm{m} \quad \mathrm{m}$ & $\mathrm{m} \quad \mathrm{m}$ & $\mathrm{m} \quad \mathrm{m}$ & $\mathrm{m} \quad \mathrm{m}$ & $\mathrm{m} \quad \mathrm{m}$ & $\mathrm{m}$ & $\mathrm{m} \quad \mathrm{m}$ & $\mathrm{m} \quad \mathrm{m}$ & $\mathrm{m} \quad \mathrm{m}$ & $\mathrm{m}$ & $\mathrm{m}$ \\
\hline & Italy & $6.69(0.27)$ & $6.47(0.28)$ & $6.32(0.24)$ & $6.35(0.19)$ & $6.36(0.23)$ & $6.42(0.21)$ & $6.45(0.23)$ & $6.56(0.19)$ & $6.55(0.17)$ & $6.84(0.15)$ & 0.15 & $0.32)$ \\
\hline & Japan & $6.53(0.17)$ & $6.74(0.20)$ & $6.72(0.20)$ & $6.83(0.20)$ & $6.93(0.20)$ & $6.95(0.18)$ & $6.97(0.18)$ & $6.89(0.18)$ & $7.01(0.17)$ & $7.01(0.16)$ & 0.48 & .24) \\
\hline & Korea & $5.83(0.22)$ & $5.95(0.24)$ & $5.87(0.18)$ & $5.96(0.23)$ & $6.14(0.19)$ & $6.11(0.21)$ & $6.22(0.18)$ & $6.32(0.18)$ & $6.44(0.23)$ & $6.31(0.17)$ & 0.47 & $.27)$ \\
\hline & Latvia & $7.21(0.20)$ & $7.16(0.19)$ & $7.11(0.19)$ & $7.16(0.17)$ & $7.27(0.17)$ & $7.31(0.20)$ & \begin{tabular}{|l|l|}
$7.37(0.17)$ \\
\end{tabular} & $7.35(0.18)$ & $7.42(0.19)$ & $7.55(0.15)$ & 0.34 & $(0.27)$ \\
\hline & Luxembourg & $6.82(0.19)$ & $6.84(0.23)$ & $6.91(0.23)$ & $6.87(0.21)$ & $6.99(0.18)$ & $7.01(0.16)$ & $7.10(0.18)$ & $7.07(0.19)$ & $6.99(0.20)$ & $7.35(0.16)$ & 0.54 & $(0.24)$ \\
\hline & Mexico & $8.06(0.22)$ & $8.30(0.22)$ & $8.31(0.18)$ & $8.27(0.17)$ & $8.22(0.17)$ & $8.17(0.17)$ & $8.24(0.16)$ & $8.19(0.17)$ & $8.26(0.14)$ & $8.08(0.11)$ & 0.02 & $(0.25)$ \\
\hline & Netherlands & $7.89(0.16)$ & $7.66(0.16)$ & $7.63(0.15)$ & $7.57(0.14)$ & $7.55(0.14)$ & $7.56(0.15)$ & $7.41(0.13)$ & $7.40(0.14)$ & $7.41(0.12)$ & $7.56(0.10)$ & -0.33 & $(0.20)$ \\
\hline & New Zealand & $\mathrm{m} \quad \mathrm{m}$ & $\mathrm{m} \quad \mathrm{m}$ & $\begin{array}{ll}m & m\end{array}$ & $\mathrm{~m} \quad \mathrm{~m}$ & $\mathrm{~m} \quad \mathrm{~m}$ & $\begin{array}{ll}\mathrm{m} & \mathrm{m}\end{array}$ & $\mathrm{m} \quad \mathrm{m}$ & $\mathrm{m} \quad \mathrm{m}$ & $\mathrm{m} \quad \mathrm{m}$ & $\begin{array}{ll}\mathrm{m} & \mathrm{m}\end{array}$ & $\mathrm{m}$ & $\mathrm{m}$ \\
\hline & Norway & $\mathrm{m}$ & $\mathrm{m}$ & $\mathrm{m}$ & $\mathrm{m}$ & $\mathrm{m}$ & $\mathrm{m}$ & $\mathrm{m}$ & $\mathrm{m}$ & $\mathrm{m}$ & $\mathrm{m}$ & $\mathrm{m}$ & $\mathrm{m}$ \\
\hline & Poland & $6.91(0.21)$ & $6.93(0.22)$ & $6.77(0.26)$ & $6.71(0.27)$ & $6.61(0.23)$ & $6.73(0.26)$ & $\mid 6.87(0.22)$ & $7.00(0.20)$ & $6.96(0.23)$ & $6.84(0.20)$ & -0.08 & $(0.30)$ \\
\hline & Portugal & $7.20(0.18)$ & $\mid 7.17(0.18)$ & $7.18(0.19)$ & $7.15(0.16)$ & 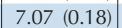 & $7.08(0.18)$ & \begin{tabular}{|l|}
$7.06(0.18)$ \\
\end{tabular} & $7.13(0.17)$ & $7.02(0.19)$ & $7.02(0.13)$ & -0.18 & $(0.23)$ \\
\hline & Slovak Republic & $7.14(0.22)$ & $7.09(0.24)$ & $6.96(0.24)$ & $7.05(0.20)$ & $7.07(0.18)$ & $7.19(0.21)$ & $7.27(0.16)$ & $7.19(0.18)$ & $7.25(0.17)$ & $7.44(0.15)$ & 0.30 & $(0.27)$ \\
\hline & Slovenia & $6.52(0.22)$ & $6.56(0.24)$ & $6.62(0.25)$ & $6.63(0.24)$ & $6.59(0.23)$ & $6.75(0.23)$ & $6.71(0.23)$ & $6.75(0.23)$ & $6.79(0.24)$ & $7.12(0.21)$ & 0.60 & $(0.30)$ \\
\hline & Spain & $6.90(0.18)$ & $7.08(0.19)$ & $7.23(0.19)$ & $7.13(0.17)$ & $7.23(0.18)$ & $7.27(0.17)$ & $7.28(0.17)$ & $7.28(0.18)$ & $7.40(0.16)$ & $7.58(0.13)$ & 0.69 & $(0.21)$ \\
\hline & Sweden & $\mathrm{m}$ & $\mathrm{m} \quad \mathrm{m}$ & $\mathrm{m} \quad \mathrm{m}$ & $\mathrm{m} \quad \mathrm{m}$ & $\mathrm{m} \quad \mathrm{m}$ & $\mathrm{m}$ & $\mathrm{m}$ & $\mathrm{m}$ & $\mathrm{m}$ & $\mathrm{m}$ & $\mathrm{m}$ & $\mathrm{m}$ \\
\hline & Switzerland & $7.22(0.22)$ & $\mid 7.29(0.21)$ & $\mid 7.22(0.22)$ & $7.28(0.22)$ & $7.32(0.24)$ & $7.28(0.22)$ & $7.35(0.25)$ & $7.46(0.22)$ & $7.62(0.18)$ & $7.72(0.13)$ & 0.50 & $(0.25)$ \\
\hline & Turkey & $6.08(0.33)$ & $5.88(0.26)$ & $5.77(0.35)$ & $5.65(0.35)$ & $5.62(0.31)$ & $5.66(0.25)$ & $5.80(0.29)$ & $5.94(0.31)$ & $5.89(0.28)$ & $5.98(0.24)$ & -0.10 & $(0.43)$ \\
\hline & United Kingdom & $6.34(0.21)$ & $6.53(0.24)$ & $6.61(0.24)$ & $6.55(0.22)$ & $6.63(0.19)$ & $6.67(0.20)$ & $6.74(0.25)$ & $6.74(0.22)$ & $6.67(0.16)$ & $6.87(0.14)$ & 0.53 & $(0.27)$ \\
\hline & United States & $6.92(0.22)$ & $7.11(0.22)$ & $7.15(0.21)$ & $7.18(0.18)$ & $7.14(0.21)$ & $7.09(0.24)$ & $6.99(0.17)$ & $7.04(0.21)$ & $6.99(0.18)$ & $6.98(0.18)$ & 0.06 & $(0.29)$ \\
\hline & OECD average & $6.89(0.04)$ & $6.91(0.04)$ & $6.92(0.04)$ & $6.93(0.04)$ & $6.96(0.04)$ & $7.00(0.04)$ & $7.06(0.04)$ & $7.10(0.04)$ & $7.15(0.04)$ & $7.26(0.03)$ & 0.37 & $(0.05)$ \\
\hline & Albania & $\mathrm{m}$ & $\mathrm{m}$ & $\mathrm{m}$ & $\mathrm{m}$ & $\mathrm{m}$ & $\mathrm{m}$ & $\mathrm{m}$ & $\mathrm{m}$ & $\mathrm{m}$ & $\mathrm{m}$ & $\mathrm{m}$ & $\mathrm{m}$ \\
\hline & Algeria & $\mathrm{m}$ & $\mathrm{m}$ & $\mathrm{m}$ & $\mathrm{m}$ & $\mathrm{m}$ & $\mathrm{m}$ & $\mathrm{m}$ & $\mathrm{m}$ & $\mathrm{m}$ & $\mathrm{m}$ & $\mathrm{m}$ & $\mathrm{m}$ \\
\hline & Brazil & $7.53(0.18)$ & $7.71(0.15)$ & $7.56(0.16)$ & $7.55(0.16)$ & $7.48(0.17)$ & $7.39(0.15)$ & $7.41(0.15)$ & $7.33(0.12)$ & $7.30(0.11)$ & $7.27(0.10)$ & -0.26 & $(0.21)$ \\
\hline & B-S-J-G (China) & $6.76(0.21)$ & $6.74(0.22)$ & $6.64(0.22)$ & $6.60(0.28)$ & $6.64(0.25)$ & $6.69(0.22)$ & $6.92(0.22)$ & $6.95(0.22)$ & $6.96(0.19)$ & $6.92(0.23)$ & 0.16 & $(0.32)$ \\
\hline & Bulgaria & $7.08(0.28)$ & $7.14(0.23)$ & $7.09(0.28)$ & $7.16(0.24)$ & $7.29(0.25)$ & $7.24(0.28)$ & $7.21(0.22)$ & $7.12(0.21)$ & $7.25(0.18)$ & $7.34(0.16)$ & 0.26 & $(0.34)$ \\
\hline & CABA (Argentina) & $\mathrm{m}$ & $\mathrm{m}$ & $\mathrm{m}$ & $\mathrm{m}$ & $\mathrm{m}$ & $\mathrm{m}$ & $\mathrm{m}$ & $\mathrm{m}$ & $\mathrm{m}$ & $\mathrm{m}$ & $\mathrm{m}$ & $\mathrm{m}$ \\
\hline & Colombia & $8.01(0.20)$ & $7.98(0.21)$ & $7.99(0.16)$ & $7.86(0.19)$ & $7.82(0.18)$ & $7.68(0.24)$ & $7.55(0.17)$ & $7.38(0.16)$ & $7.37(0.16)$ & $7.54(0.13)$ & -0.47 & $(0.23)$ \\
\hline & Costa Rica & $8.24(0.19)$ & $8.25(0.18)$ & $8.10(0.22)$ & $8.15(0.20)$ & $8.07(0.18)$ & $8.03(0.24)$ & $7.99(0.21)$ & $7.83(0.18)$ & $7.89(0.17)$ & $7.84(0.14)$ & -0.40 & $(0.24)$ \\
\hline & Croatia & $7.83(0.20)$ & $7.51(0.20)$ & $7.59(0.19)$ & $7.59(0.19)$ & $7.67(0.19)$ & $7.67(0.19)$ & $7.60(0.18)$ & $7.66(0.15)$ & $7.57(0.15)$ & $7.47(0.15)$ & -0.36 & $(0.25)$ \\
\hline & Cyprus* & $6.45(0.21)$ & $6.54(0.20)$ & $6.62(0.20)$ & $6.70(0.21)$ & $6.78(0.24)$ & $6.88(0.17)$ & $7.09(0.24)$ & $7.02(0.20)$ & $7.11(0.17)$ & $7.37(0.14)$ & 0.92 & $(0.26)$ \\
\hline & Dominican Republic & $8.45(0.30)$ & $8.60(0.27)$ & $8.65(0.24)$ & $8.71(0.27)$ & $8.64(0.22)$ & $8.61(0.21)$ & $8.39(0.27)$ & $8.27(0.27)$ & $8.08(0.22)$ & $8.16(0.17)$ & -0.29 & $(0.36)$ \\
\hline & FYROM & $\mathrm{m}$ & & $\mathrm{m}$ & $\mathrm{m}$ & $\mathrm{m}$ & $\mathrm{m}$ & $\mathrm{m}$ & $\mathrm{m}$ & $\mathrm{m}$ & $\mathrm{m}$ & $\mathrm{m}$ & $\mathrm{m}$ \\
\hline & Georgia & & $\mathrm{m}$ & $\mathrm{m}$ & $\mathrm{m}$ & $\mathrm{m}$ & $\mathrm{m}$ & $\mathrm{m}$ & $\mathrm{m}$ & $\mathrm{m}$ & $\mathrm{m}$ & $\mathrm{m}$ & $\mathrm{m}$ \\
\hline & Hong Kong & $6.31(0.22)$ & $6.35(0.20)$ & $6.26(0.19)$ & $6.33(0.20)$ & $6.39(0.19)$ & $6.39(0.19)$ & $6.45(0.17)$ & $6.57(0.19)$ & $6.65(0.15)$ & $6.67(0.12)$ & 0.36 & $(0.26)$ \\
\hline & Indonesia & & $\mathrm{m}$ & $\mathrm{m}$ & $\mathrm{m}$ & $\mathrm{m}$ & $\mathrm{m}$ & $\mathrm{m}$ & $\mathrm{m}$ & $\mathrm{m}$ & $\mathrm{m}$ & $\mathrm{m}$ & $\mathrm{m}$ \\
\hline & Jordan & $\mathrm{m}$ & $\mathrm{m}$ & $\mathrm{m}$ & $\mathrm{m}$ & $\mathrm{m}$ & $\mathrm{m}$ & $\mathrm{m}$ & $\mathrm{m}$ & $\mathrm{m}$ & $\mathrm{m}$ & $\mathrm{m}$ & $\mathrm{m}$ \\
\hline & Kosovo & $\mathrm{m}$ & $\mathrm{m}$ & $\mathrm{m}$ & $\mathrm{m}$ & $\mathrm{m}$ & $\mathrm{m}$ & $\mathrm{m}$ & $\mathrm{m}$ & $\mathrm{m}$ & $\mathrm{m}$ & $\mathrm{m}$ & $\mathrm{m}$ \\
\hline & Lebanon & $\mathrm{m}$ & $\mathrm{m}$ & $\mathrm{m}$ & $\mathrm{m}$ & $\mathrm{m}$ & $\mathrm{m}$ & $\mathrm{m}$ & $\mathrm{m}$ & $\mathrm{m}$ & $\mathrm{m}$ & $\mathrm{m}$ & $\mathrm{m}$ \\
\hline & Lithuania & $7.00(0.22)$ & $7.33(0.20)$ & $7.74(0.19)$ & $7.65(0.19)$ & $7.69(0.21)$ & $7.58(0.24)$ & $7.64(0.17)$ & $7.78(0.20)$ & $7.76(0.16)$ & $7.83(0.15)$ & 0.82 & $0.27)$ \\
\hline & Macao (China) & $6.19(0.18)$ & $6.42(0.21)$ & $6.52(0.22)$ & $6.54(0.20)$ & $6.55(0.22)$ & $6.62(0.19)$ & $6.67(0.20)$ & $6.66(0.21)$ & $6.81(0.19)$ & $6.90(0.15)$ & 0.71 & $(0.23)$ \\
\hline & Malta & & $\mathrm{m}$ & $\mathrm{m}$ & $\mathrm{m}$ & $\mathrm{m}$ & $\mathrm{m}$ & $\mathrm{m}$ & $\mathrm{m}$ & $\mathrm{m}$ & $\mathrm{m}$ & $\mathrm{m}$ & $\mathrm{m}$ \\
\hline & Moldova & $\mathrm{m}$ & $\mathrm{m}$ & $\mathrm{m}$ & $\mathrm{m}$ & $\mathrm{m}$ & $\mathrm{m}$ & $\mathrm{m}$ & $\mathrm{m}$ & $\mathrm{m}$ & $\mathrm{m}$ & $\mathrm{m}$ & $\mathrm{m}$ \\
\hline & Montenegro & $7.93(0.23)$ & $7.69(0.25)$ & $7.58(0.24)$ & $7.53(0.27)$ & $7.50(0.26)$ & $7.42(0.26)$ & $7.30(0.22)$ & $7.41(0.21)$ & $7.46(0.21)$ & $7.27(0.18)$ & -0.66 & $(0.30)$ \\
\hline & Peru & $7.27(0.25)$ & $7.52(0.23)$ & $7.69(0.21)$ & $7.57(0.23)$ & $7.58(0.22)$ & $7.53(0.22)$ & $7.46(0.20)$ & $7.25(0.21)$ & $7.18(0.15)$ & $7.19(0.15)$ & -0.08 & $(0.28)$ \\
\hline & Qatar & $7.33(0.15)$ & $7.46(0.15)$ & $7.41(0.16)$ & $7.40(0.15)$ & $7.38(0.15)$ & $7.30(0.13)$ & $7.30(0.12)$ & $7.26(0.12)$ & $7.17(0.11)$ & $7.02(0.11)$ & -0.31 & $(0.18)$ \\
\hline & Romania & & $\mathrm{m}$ & $\mathrm{m}$ & $\mathrm{m}$ & $\mathrm{m}$ & $\mathrm{m}$ & $\mathrm{m}$ & $\mathrm{m}$ & $\mathrm{m}$ & $\mathrm{m}$ & $\mathrm{m}$ & $\mathrm{m}$ \\
\hline & Russia & $7.73(0.19)$ & $7.69(0.20)$ & $7.65(0.23)$ & $7.60(0.19)$ & $7.56(0.22)$ & $7.52(0.24)$ & $7.66(0.21)$ & $7.58(0.20)$ & $7.57(0.19)$ & $7.48(0.20)$ & -0.25 & $(0.27)$ \\
\hline & Singapore & & $\mathrm{m}$ & $\mathrm{m}$ & $\mathrm{m}$ & $\mathrm{m}$ & $\mathrm{m}$ & $\mathrm{m}$ & $\mathrm{m}$ & $\mathrm{m}$ & $\mathrm{m}$ & $\mathrm{m}$ & $\mathrm{m}$ \\
\hline & Chinese Taipei & $6.31(0.16)$ & $6.39(0.15)$ & $6.42(0.16)$ & $6.41(0.15)$ & $6.41(0.14)$ & $6.41(0.18)$ & $6.44(0.19)$ & $6.43(0.16)$ & $6.58(0.17)$ & $6.68(0.11)$ & 0.37 & $(0.21)$ \\
\hline & Thailand & $7.73(0.18)$ & $7.75(0.18)$ & $7.69(0.21)$ & $7.76(0.17)$ & $7.73(0.18)$ & $7.72(0.17)$ & $7.75(0.14)$ & $7.71(0.13)$ & $7.64(0.15)$ & $7.50(0.12)$ & -0.23 & $(0.22)$ \\
\hline & Trinidad ar & $\mathrm{m}$ & $\mathrm{m}$ & $\mathrm{m}$ & $\mathrm{m}$ & $\mathrm{m}$ & $\mathrm{m}$ & $\mathrm{m}$ & $\mathrm{m}$ & $\mathrm{m}$ & $\mathrm{m}$ & $\mathrm{m}$ & $\mathrm{m}$ \\
\hline & Tunisia & $6.86(0.33)$ & $6.72(0.29)$ & $6.89(0.30)$ & $6.87(0.31)$ & $6.85(0.30)$ & $6.81(0.26)$ & $6.87(0.26)$ & $6.82(0.23)$ & $6.75(0.23)$ & $6.77(0.17)$ & -0.09 & $(0.39)$ \\
\hline & United Arab Emirates & $7.27(0.17)$ & $7.35(0.18)$ & $7.27(0.16)$ & $7.25(0.17)$ & $7.24(0.18)$ & $7.22(0.16)$ & $7.14(0.17)$ & $7.06(0.15)$ & $7.11(0.15)$ & $6.85(0.11)$ & -0.42 & $(0.20)$ \\
\hline & Uruguay & $7.25(0.24)$ & $7.52(0.23)$ & $7.46(0.25)$ & $7.52(0.21)$ & $7.43(0.25)$ & $7.38(0.23)$ & $7.44(0.21)$ & $7.51(0.20)$ & $7.55(0.17)$ & $7.65(0.14)$ & 0.39 & $(0.28)$ \\
\hline & Viet Nam & $\mathrm{m}$ & $\mathrm{m}$ & $\mathrm{m}$ & $\mathrm{m}$ & $\mathrm{m}$ & $\mathrm{m}$ & $\mathrm{m}$ & $\mathrm{m}$ & $\mathrm{m}$ & $\mathrm{m}$ & $\mathrm{m}$ & $\mathrm{m}$ \\
\hline & Argentina** & $\mathrm{m}$ & $\mathrm{m}$ & $\mathrm{m}$ & $\mathrm{m}$ & $\mathrm{m}$ & $\mathrm{m}$ & $\mathrm{m}$ & $\mathrm{m}$ & $\mathrm{m}$ & $\mathrm{m}$ & $\mathrm{m}$ & $\mathrm{m}$ \\
\hline & Kazakhstan** & $\mathrm{m}$ & $\mathrm{m}$ & $\mathrm{m}$ & $\mathrm{m}$ & $\mathrm{m}$ & $\mathrm{m}$ & $\mathrm{m}$ & $\mathrm{m}$ & $\mathrm{m}$ & $\mathrm{m}$ & $\mathrm{m}$ & $\mathrm{m}$ \\
\hline & Malaysia** & $6.79(0.20)$ & $7.02(0.20)$ & $7.02(0.19)$ & $7.02(0.16)$ & $6.98(0.17)$ & $7.03(0.16)$ & $7.06(0.16)$ & $7.12(0.14)$ & $7.09(0.14)$ & $7.05(0.14)$ & 0.25 & $(0.23)$ \\
\hline
\end{tabular}

Note: Values that are statistically significant are indicated in bold (see Annex A3).

* See note at the beginning of this Annex.

** Coverage is too small to ensure comparability (see Annex A4).

StatLink त्ञात ht http://dx.doi.org/10.1787/888933470512 


\begin{tabular}{|c|c|c|c|c|c|c|c|c|c|c|c|c|c|}
\hline & \multicolumn{12}{|c|}{ Gender difference (B-G) } \\
\hline & & 1st decile & 2nd decile & 3rd decile & 4th decile & 5th decile & 6th decile & 7th decile & 8th decile & 9th decile & 10th decile & $\begin{array}{r}\mathrm{Di} \\
\text { betwe } \\
\text { and th }\end{array}$ & $\begin{array}{l}\text { ence } \\
\text { the 10th } \\
\text { st decile }\end{array}$ \\
\hline & & Mean S.E. & Mean S.E. & Mean S.E. & Mean S.E. & Mean S.E. & Mean S.E. & Mean S.E. & Mean S.E. & Mean S.E. & Mean S.E. & Dif. & S.E. \\
\hline & Australia & & & $\mathrm{m}$ & $\mathrm{m}$ & $\mathrm{m}$ & $\mathrm{m}$ & $\mathrm{m}$ & $\mathrm{m}$ & $\mathrm{m}$ & $\mathrm{m}$ & $\mathrm{m}$ & $\mathrm{m}$ \\
\hline & Austria & $\mathbf{1 . 0 8}(0.28)$ & $\mathbf{1 . 0 7}(0.30)$ & $\mathbf{1 . 0 7}(0.27)$ & $1.14(0.26)$ & $\mathbf{0 . 8 8}(0.27)$ & $\mathbf{0 . 9 3}(0.26)$ & $\mathbf{0 . 7 1}(0.27)$ & $\mathbf{0 . 7 0}(0.25)$ & $\mathbf{0 . 5 8}(0.26)$ & $\mathbf{0 . 4 8}(0.20)$ & -0.60 & $(0.36)$ \\
\hline & Belgium (excl. Flemish) & $\mathbf{0 . 8 5}(0.33)$ & $\mathbf{0 . 9 0}(0.38)$ & $0.70(0.40)$ & $0.70(0.40)$ & $0.62(0.35)$ & $\mathbf{0 . 6 3}(0.29)$ & $0.44(0.31)$ & $0.44(0.32)$ & $0.20(0.26)$ & $0.24(0.22)$ & -0.61 & $0.41)$ \\
\hline & Canada & $\mathrm{m}$ & $\mathrm{m}$ & $\mathrm{m}$ & $\mathrm{m}$ & $\mathrm{m}$ & $\mathrm{m}$ & $\mathrm{m}$ & $\mathrm{m}$ & $\mathrm{m}$ & $\mathrm{m}$ & $\mathrm{m}$ & $\mathrm{m}$ \\
\hline & Chile & $\mathbf{0 . 7 8}(0.31)$ & $\mathbf{0 . 6 4}(0.32)$ & $0.55(0.30)$ & $0.47(0.33)$ & $0.42(0.36)$ & $0.40(0.29)$ & $0.29(0.33)$ & $0.36(0.28)$ & $0.38(0.22)$ & $\mathbf{0 . 4 8}(0.20)$ & -0.30 & 0.39) \\
\hline & Czech Republic & $\mathbf{0 . 9 3}(0.33)$ & $\mathbf{0 . 8 5}(0.37)$ & $\mathbf{0 . 8 8}(0.32)$ & $\mathbf{0 . 8 1}(0.30)$ & $\mathbf{0 . 8 1}(0.29)$ & $\mathbf{0 . 7 3}(0.27)$ & $\mathbf{0 . 6 6}(0.31)$ & $0.42(0.27)$ & $0.40(0.21)$ & $0.05(0.19)$ & -0.88 & $(0.38)$ \\
\hline & Denmark & & $\mathrm{m}$ & $\mathrm{m}$ & $\mathrm{m}$ & $\mathrm{m}$ & $\mathrm{m}$ & $\mathrm{m}$ & $\mathrm{m}$ & $\mathrm{m}$ & $\mathrm{m}$ & $\mathrm{m}$ & $\mathrm{m}$ \\
\hline & Estonia & $0.41(0.23)$ & $0.53(0.29)$ & $\mathbf{0 . 6 3}(0.29)$ & $0.54(0.31)$ & $0.47(0.26)$ & $0.48(0.27)$ & $0.45(0.25)$ & $0.38(0.24)$ & $0.40(0.25)$ & $0.33(0.18)$ & -0.08 & $(0.28)$ \\
\hline & Finland & $\mathbf{0 . 6 4}(0.22)$ & $\mathbf{0 . 9 0}(0.22)$ & $\mathbf{0 . 9 2}(0.21)$ & $\mathbf{1 . 0 1}(0.23)$ & $\mathbf{0 . 9 1}(0.23)$ & $\mathbf{0 . 7 4}(0.20)$ & $\mathbf{0 . 7 3}(0.19)$ & $\mathbf{0 . 5 5}(0.18)$ & $\mathbf{0 . 4 9}(0.18)$ & $\mathbf{0 . 5 5}(0.15)$ & -0.09 & $(0.25)$ \\
\hline & France & $0.25(0.31)$ & $\mathbf{0 . 6 9}(0.27)$ & $\mathbf{0 . 6 9}(0.24)$ & $\mathbf{0 . 6 1}(0.26)$ & $\mathbf{0 . 5 9}(0.22)$ & $\mathbf{0 . 4 4}(0.20)$ & $0.35(0.22)$ & $0.32(0.20)$ & $0.25(0.17)$ & $0.27(0.15)$ & 0.02 & $0.34)$ \\
\hline & Germany & $\mathbf{0 . 9 2}(0.29)$ & $\mathbf{0 . 9 0}(0.31)$ & $\mathbf{0 . 8 7}(0.29)$ & $\mathbf{1 . 0 0}(0.28)$ & $\mathbf{0 . 7 0}(0.32)$ & $\mathbf{0 . 7 6}(0.30)$ & $\mathbf{0 . 8 8}(0.25)$ & $\mathbf{0 . 7 9}(0.26)$ & $\mathbf{0 . 7 4}(0.23)$ & $\mathbf{0 . 4 5}(0.16)$ & -0.47 & $(0.32)$ \\
\hline & Greece & $\mathbf{1 . 1 4}(0.39)$ & $\mathbf{1 . 1 8}(0.36)$ & $\mathbf{0 . 8 2}(0.40)$ & $\mathbf{0 . 7 7}(0.33)$ & $0.43(0.31)$ & $0.31(0.28)$ & $0.42(0.24)$ & $0.50(0.28)$ & $\mathbf{0 . 5 0}(0.23)$ & $0.37(0.20)$ & -0.77 & .43) \\
\hline & Hungary & $\mathbf{1 . 0 2}(0.39)$ & $1.12(0.33)$ & $\mathbf{0 . 9 8}(0.35)$ & $\mathbf{0 . 9 9}(0.32)$ & $\mathbf{0 . 9 9}(0.29)$ & $\mathbf{0 . 6 7}(0.29)$ & $\mathbf{0 . 5 5}(0.27)$ & $0.58(0.31)$ & $0.34(0.23)$ & $0.15(0.20)$ & -0.87 & $0.44)$ \\
\hline & Iceland & $\mathbf{1 . 2 3}(0.37)$ & $\mathbf{1 . 1 1}(0.35)$ & $1.24(0.36)$ & $\mathbf{1 . 1 6}(0.31)$ & $1.23(0.33)$ & $1.17(0.36)$ & $\mathbf{0 . 7 5}(0.31)$ & $0.53(0.31)$ & $0.39(0.29)$ & $\mathbf{0 . 5 2}(0.22)$ & -0.72 & $(0.41)$ \\
\hline & Ireland & $0.46(0.28)$ & $\mathbf{0 . 5 9}(0.26)$ & $\mathbf{0 . 7 7}(0.26)$ & $\mathbf{0 . 5 3}(0.24)$ & $0.54(0.28)$ & $\mathbf{0 . 8 7}(0.23)$ & $\mathbf{0 . 7 5}(0.26)$ & $\mathbf{0 . 6 1}(0.24)$ & $0.34(0.21)$ & $0.12(0.19)$ & -0.34 & $(0.34)$ \\
\hline & Israel & & & $\mathrm{m}$ & $\mathrm{m}$ & $\mathrm{m}$ & $\mathrm{m}$ & $\mathrm{m}$ & $\mathrm{m}$ & $\mathrm{m}$ & $\mathrm{m}$ & $\mathrm{m}$ & $\mathrm{m}$ \\
\hline & Italy & $\mathbf{0 . 8 3}(0.32)$ & $\mathbf{0 . 8 1}(0.36)$ & $\mathbf{1 . 0 4}(0.27)$ & $\mathbf{0 . 9 0}(0.25)$ & $0.77(0.30)$ & $\mathbf{0 . 8 5}(0.31)$ & $\mathbf{0 . 9 0}(0.31)$ & $\mathbf{0 . 7 1}(0.26)$ & $\mathbf{0 . 6 4}(0.23)$ & $\mathbf{0 . 4 8}(0.20)$ & -0.36 & $0.38)$ \\
\hline & Japan & $-0.03(0.24)$ & $-0.24(0.31)$ & $0.02(0.30)$ & $0.02(0.30)$ & $-0.11(0.29)$ & $-0.18(0.26)$ & $-0.31(0.27)$ & $-0.10(0.26)$ & $-0.17(0.24)$ & $-0.13(0.24)$ & -0.11 & 9.36) \\
\hline & Korea & $0.92(0.30)$ & $\mathbf{0 . 7 0}(0.31)$ & $\mathbf{0 . 8 1}(0.30)$ & $\mathbf{0 . 7 3}(0.33)$ & $0.35(0.29)$ & $0.38(0.31)$ & $0.21(0.30)$ & $0.18(0.30)$ & $0.18(0.37)$ & $0.28(0.24)$ & -0.64 & $0.37)$ \\
\hline & Latvia & $0.07(0.30)$ & $0.27(0.29)$ & $0.39(0.30)$ & $0.30(0.26)$ & $0.27(0.26)$ & $0.05(0.29)$ & $-0.01(0.26)$ & $0.06(0.26)$ & $0.12(0.27)$ & $0.14(0.21)$ & 0.07 & $0.40)$ \\
\hline & Luxembourg & $0.99(0.28)$ & $\mathbf{0 . 9 2}(0.32)$ & $\mathbf{0 . 8 0}(0.30)$ & $\mathbf{0 . 8 7}(0.26)$ & $\mathbf{0 . 8 3}(0.24)$ & $\mathbf{0 . 7 3}(0.24)$ & $\mathbf{0 . 6 1}(0.23)$ & $\mathbf{0 . 6 8}(0.25)$ & $\mathbf{0 . 8 2}(0.24)$ & $\mathbf{0 . 5 6}(0.18)$ & -0.43 & 0.31) \\
\hline & Mexico & $-0.24(0.28)$ & $0.05(0.29)$ & $0.10(0.22)$ & $0.22(0.24)$ & $0.23(0.26)$ & $0.26(0.22)$ & $0.19(0.23)$ & $0.15(0.23)$ & $0.08(0.19)$ & $0.11(0.17)$ & 0.34 & $(0.34)$ \\
\hline & Netherlands & $\mathbf{0 . 5 7}(0.23)$ & $\mathbf{0 . 7 4}(0.24)$ & $\mathbf{0 . 6 8}(0.23)$ & $\mathbf{0 . 6 2}(0.20)$ & $\mathbf{0 . 5 1}(0.20)$ & $\mathbf{0 . 5 3}(0.18)$ & $\mathbf{0 . 6 2}(0.17)$ & $\mathbf{0 . 5 4}(0.16)$ & $\mathbf{0 . 5 1}(0.14)$ & $0.24(0.13)$ & -0.34 & $(0.27)$ \\
\hline & New Zealand & $\mathrm{m}$ & $\mathrm{m}$ & $\mathrm{m}$ & $\mathrm{m}$ & $\mathrm{m}$ & $\mathrm{m}$ & $\mathrm{m}$ & $\mathrm{m}$ & $\mathrm{m}$ & $\mathrm{m}$ & $\mathrm{m}$ & $\mathrm{m}$ \\
\hline & Norway & $\mathrm{m}$ & $\mathrm{m}$ & $\mathrm{m}$ & $\mathrm{m}$ & $\mathrm{m}$ & $\mathrm{m}$ & $\mathrm{m}$ & $\mathrm{m}$ & $\mathrm{m}$ & $\mathrm{m}$ & $\mathrm{m}$ & $\mathrm{m}$ \\
\hline & Poland & $0.46(0.31)$ & $\mathbf{0 . 7 1}(0.31)$ & $\mathbf{0 . 9 6}(0.35)$ & $\mathbf{0 . 9 5}(0.29)$ & $\mathbf{0 . 9 3}(0.30)$ & $\mathbf{0 . 7 9}(0.33)$ & $0.59(0.32)$ & $0.47(0.30)$ & $0.53(0.32)$ & $\mathbf{0 . 5 4}(0.25)$ & 0.08 & $0.41)$ \\
\hline & Portugal & $0.53(0.26)$ & $\mathbf{0 . 6 6}(0.25)$ & $\mathbf{0 . 5 6}(0.27)$ & $0.47(0.26)$ & $0.48(0.26)$ & $\mathbf{0 . 5 3}(0.23)$ & $\mathbf{0 . 4 7}(0.23)$ & $0.30(0.22)$ & $0.46(0.24)$ & $\mathbf{0 . 6 1}(0.20)$ & 0.08 & $(0.32)$ \\
\hline & Slovak Re & $0.54(0.32)$ & $\mathbf{0 . 7 3}(0.31)$ & $\mathbf{0 . 9 0}(0.29)$ & $\mathbf{0 . 6 6}(0.27)$ & $\mathbf{0 . 6 1}(0.26)$ & $0.53(0.28)$ & $\mathbf{0 . 6 2}(0.24)$ & $\mathbf{0 . 6 6}(0.24)$ & $\mathbf{0 . 4 5}(0.20)$ & $0.24(0.20)$ & -0.30 & 0.40) \\
\hline & Slovenia & $1.46(0.26)$ & $\mathbf{1 . 1 9}(0.32)$ & $1.13(0.34)$ & $\mathbf{1 . 0 9}(0.34)$ & $\mathbf{1 . 0 0}(0.31)$ & $\mathbf{0 . 8 8}(0.27)$ & $\mathbf{0 . 7 7}(0.32)$ & $0.59(0.31)$ & $0.53(0.30)$ & $\mathbf{0 . 5 6}(0.28)$ & -0.91 & 0.41) \\
\hline & Spain & $\mathbf{0 . 9 3}(0.24)$ & $0.56(0.31)$ & $0.25(0.27)$ & $0.36(0.24)$ & $0.28(0.22)$ & $0.26(0.25)$ & $0.30(0.24)$ & $0.35(0.22)$ & $0.22(0.20)$ & $0.16(0.15)$ & -0.76 & $(0.29)$ \\
\hline & Sweden & & $\mathrm{m}$ & $\mathrm{m}$ & $\mathrm{m}$ & $\mathrm{m}$ & $\mathrm{m}$ & $\mathrm{m}$ & $\mathrm{m}$ & $\mathrm{m}$ & $\mathrm{m}$ & $\mathrm{m}$ & $\mathrm{m}$ \\
\hline & Switzerland & $\mathbf{0 . 8 6}(0.26)$ & $\mathbf{0 . 6 8}(0.33)$ & $\mathbf{0 . 7 3}(0.30)$ & $\mathbf{0 . 8 2}(0.32)$ & $\mathbf{0 . 7 6}(0.30)$ & $\mathbf{0 . 8 0}(0.26)$ & $\mathbf{0 . 6 0}(0.30)$ & $\mathbf{0 . 5 1}(0.26)$ & $\mathbf{0 . 4 4}(0.22)$ & $0.32(0.19)$ & -0.54 & $0.29)$ \\
\hline & Turkey & $0.51(0.44)$ & $\mathbf{0 . 7 7}(0.37)$ & $0.73(0.56)$ & $0.87(0.49)$ & $0.75(0.39)$ & $0.67(0.37)$ & $0.51(0.38)$ & $0.33(0.40)$ & $0.27(0.38)$ & $0.45(0.31)$ & -0.06 & $0.56)$ \\
\hline & United Kingdom & $\mathbf{1 . 0 1}(0.28)$ & $\mathbf{0 . 8 6}(0.35)$ & $\mathbf{0 . 7 9}(0.30)$ & $\mathbf{0 . 9 1}(0.30)$ & $\mathbf{0 . 6 9}(0.24)$ & $\mathbf{0 . 6 2}(0.27)$ & $0.52(0.31)$ & $0.49(0.29)$ & $\mathbf{0 . 5 8}(0.24)$ & $0.33(0.21)$ & -0.68 & (0.37) \\
\hline & United States & $\mathbf{0 . 8 1}(0.31)$ & $\mathbf{0 . 6 3}(0.31)$ & $0.64(0.28)$ & $\mathbf{0 . 6 2}(0.26)$ & $\mathbf{0 . 5 5}(0.27)$ & $0.52(0.28)$ & $\mathbf{0 . 6 3}(0.24)$ & $\mathbf{0 . 5 8}(0.26)$ & $\mathbf{0 . 6 4}(0.24)$ & $0.38(0.21)$ & -0.43 & $(0.37)$ \\
\hline & OECD average & $0.71(0.06)$ & $0.73(0.06)$ & $0.74(0.06)$ & $0.72(0.06)$ & $\mathbf{0 . 6 2}(0.05)$ & $\mathbf{0 . 5 8}(0.05)$ & $\mathbf{0 . 5 1}(0.05)$ & $|\mathbf{0 . 4 5}(0.05)|$ & $\mathbf{0 . 4 0}(0.05)$ & $\mathbf{0 . 3 3}(0.04)$ & -0.38 & $0.07)$ \\
\hline & Albania & & $\mathrm{m}$ & & & & $\mathrm{m}$ & $\mathrm{m}$ & $\mathrm{m}$ & $\mathrm{m}$ & $\mathrm{m}$ & $\mathrm{m}$ & m \\
\hline & Algeria & $\mathrm{m}$ & $\mathrm{m}$ & $\mathrm{m}$ & $\mathrm{m}$ & $\mathrm{m}$ & $\mathrm{m}$ & $\mathrm{m}$ & $\mathrm{m}$ & $\mathrm{m}$ & $\mathrm{m}$ & $\mathrm{m}$ & $\mathrm{m}$ \\
\hline & Brazil & $0.25(0.27)$ & $0.18(0.21)$ & $0.39(0.24)$ & $0.34(0.19)$ & $0.32(0.21)$ & $\mathbf{0 . 4 1}(0.20)$ & $0.35(0.21)$ & $0.29(0.18)$ & $0.24(0.18)$ & $0.16(0.13)$ & -0.09 & 0.30) \\
\hline & B-S-J-G (C & $0.22(0.28)$ & $0.23(0.31)$ & $0.24(0.31)$ & $0.23(0.34)$ & $0.13(0.32)$ & $0.17(0.30)$ & $-0.05(0.29)$ & $-0.07(0.30)$ & $-0.10(0.22)$ & $-0.03(0.23)$ & -0.26 & $0.36)$ \\
\hline & Bulgaria & $-0.06(0.40)$ & $0.40(0.40)$ & $0.58(0.40)$ & $0.58(0.34)$ & $0.39(0.31)$ & $0.42(0.34)$ & $0.44(0.29)$ & $\mathbf{0 . 6 2}(0.27)$ & $\mathbf{0 . 5 0}(0.23)$ & $0.23(0.23)$ & 0.29 & $(0.48)$ \\
\hline & CABA $(\mathrm{Ar}$ & & $\mathrm{m}$ & $\mathrm{m}$ & $\mathrm{m}$ & $\mathrm{m}$ & $\mathrm{m}$ & $\mathrm{m}$ & $\mathrm{m}$ & $\mathrm{m}$ & $\mathrm{m}$ & $\mathrm{m}$ & $\mathrm{m}$ \\
\hline & Colombia & $0.08(0.28)$ & $0.48(0.26)$ & $0.39(0.24)$ & $\mathbf{0 . 5 3}(0.26)$ & $0.30(0.25)$ & $0.34(0.25)$ & $0.41(0.27)$ & $0.45(0.24)$ & $\mathbf{0 . 4 9}(0.24)$ & $0.22(0.22)$ & 0.14 & $(0.36)$ \\
\hline & Costa Rica & $0.33(0.26)$ & $0.36(0.25)$ & $0.42(0.27)$ & $0.29(0.29)$ & $0.41(0.30)$ & $0.42(0.32)$ & $0.43(0.26)$ & $\mathbf{0 . 4 7}(0.24)$ & $0.20(0.22)$ & $0.22(0.18)$ & -0.11 & $0.32)$ \\
\hline & Croatia & $\mathbf{0 . 6 8}(0.25)$ & $\mathbf{0 . 9 7}(0.27)$ & $\mathbf{0 . 7 4}(0.28)$ & $\mathbf{0 . 6 8}(0.29)$ & $0.49(0.25)$ & 0.49 & $0.50(0.26)$ & $\mathbf{0 . 4 6}(0.21)$ & $\mathbf{0 . 4 9}(0.22)$ & $\mathbf{0 . 4 9}(0.20)$ & 19 & 0) \\
\hline & Cyprus* & $\mathbf{0 . 9 1}(0.29)$ & $\mathbf{0 . 6 2}(0.29)$ & $0.47(0.29)$ & $0.52(0.32)$ & $0.45(0.30)$ & $0.35(0.26)$ & $0.16(0.33)$ & $0.24(0.27)$ & $0.33(0.22)$ & $0.11(0.20)$ & -0.81 & $(0.36)$ \\
\hline & Dominican R & $-0.24(0.53)$ & $-0.26(0.38)$ & $-0.14(0.39)$ & $-0.12(0.40)$ & $0.00(0.33)$ & $0.20(0.35)$ & $0.37(0.36)$ & $0.32(0.39)$ & $0.36(0.31)$ & $0.34(0.23)$ & 0.57 & $(0.57)$ \\
\hline & FYROM & $\mathrm{m}$ & $\mathrm{m}$ & $\mathrm{m}$ & $\mathrm{m}$ & $\mathrm{m}$ & $\mathrm{m}$ & $\mathrm{m}$ & $\mathrm{m}$ & $\mathrm{m}$ & $\mathrm{m}$ & $\mathrm{m}$ & $\mathrm{m}$ \\
\hline & Georgia & $\mathrm{m}$ & $\mathrm{m}$ & $\mathrm{m}$ & $\mathrm{m}$ & $\mathrm{m}$ & $\mathrm{m}$ & $\mathrm{m}$ & $\mathrm{m}$ & $\mathrm{m}$ & $\mathrm{m}$ & $\mathrm{m}$ & $\mathrm{m}$ \\
\hline & Hong Kong (China) & $0.10(0.33)$ & $0.23(0.30)$ & $0.21(0.30)$ & $0.22(0.28)$ & $0.21(0.30)$ & $0.13(0.31)$ & $0.07(0.24)$ & $0.00(0.29)$ & $-0.19(0.28)$ & $-0.23(0.21)$ & -0.33 & 0.37) \\
\hline & Indonesia & $\mathrm{m}$ & $\mathrm{m}$ & $\mathrm{m}$ & $\mathrm{m}$ & $\mathrm{m}$ & $\mathrm{m}$ & $\mathrm{m}$ & $\mathrm{m}$ & $\mathrm{m}$ & $\mathrm{m}$ & $\mathrm{m}$ & $\mathrm{m}$ \\
\hline & Jordan & $\mathrm{m}$ & $\mathrm{m}$ & $\mathrm{m}$ & $\mathrm{m}$ & $\mathrm{m}$ & $\mathrm{m}$ & $\mathrm{m}$ & $\mathrm{m}$ & $\mathrm{m}$ & $\mathrm{m}$ & $\mathrm{m}$ & $\mathrm{m}$ \\
\hline & Kosovo & $\mathrm{m}$ & $\mathrm{m}$ & $\mathrm{m}$ & $\mathrm{m}$ & $\mathrm{m}$ & $\mathrm{m}$ & $\mathrm{m}$ & $\mathrm{m}$ & $\mathrm{m}$ & $\mathrm{m}$ & $\mathrm{m}$ & $\mathrm{m}$ \\
\hline & Lebanon & $\mathrm{m}$ & $\mathrm{m}$ & $\mathrm{m}$ & $\mathrm{m}$ & $\mathrm{m}$ & $\mathrm{m}$ & $\mathrm{m}$ & $\mathrm{m}$ & $\mathrm{m}$ & $\mathrm{m}$ & $\mathrm{m}$ & $\mathrm{m}$ \\
\hline & Lithuania & $0.92(0.30)$ & $\mathbf{0 . 7 8}(0.26)$ & $\mathbf{0 . 5 5}(0.28)$ & $\mathbf{0 . 5 6}(0.25)$ & $\mathbf{0 . 5 4}(0.24)$ & $\mathbf{0 . 5 8}(0.26)$ & $\mathbf{0 . 5 0}(0.24)$ & $0.26(0.29)$ & $0.31(0.22)$ & $0.24(0.21)$ & -0.67 & $(0.37)$ \\
\hline & Macao (China) & $0.00(0.24)$ & $0.02(0.27)$ & $-0.04(0.31)$ & $0.08(0.28)$ & $0.08(0.33)$ & $0.09(0.29)$ & $0.04(0.30)$ & $0.07(0.30)$ & $-0.06(0.27)$ & $-0.20(0.22)$ & -0.20 & $(0.30)$ \\
\hline & Malta & $\mathrm{m}$ & $\mathrm{m}$ & $\mathrm{m}$ & $\mathrm{m}$ & $\mathrm{m}$ & $\mathrm{m}$ & $\mathrm{m}$ & $\mathrm{m}$ & $\mathrm{m}$ & $\mathrm{m}$ & $\mathrm{m}$ & $\mathrm{m}$ \\
\hline & Moldo & $\mathrm{m}$ & $\mathrm{m}$ & $\mathrm{m}$ & $\mathrm{m}$ & $\mathrm{m}$ & $\mathrm{m}$ & $\mathrm{m}$ & $\mathrm{m}$ & $\mathrm{m}$ & $\mathrm{m}$ & $\mathrm{m}$ & m \\
\hline & Monte & $32(0.33)$ & $0.41(0.35)$ & $0.54(0.37)$ & $0.54(0.37)$ & $\mathbf{0 . 6 3}(0.27)$ & $0.58(0.33)$ & $\mathbf{0 . 5 6}(0.28)$ & $0.37(0.29)$ & $0.44(0.24)$ & $\mathbf{0 . 5 5}(0.25)$ & 0.23 & 0.43) \\
\hline & Peru & $-0.36(0.32)$ & $-0.09(0.33)$ & $-0.08(0.26)$ & $0.20(0.33)$ & $0.24(0.26)$ & $0.21(0.29)$ & $0.32(0.25)$ & $0.43(0.27)$ & $0.34(0.21)$ & $0.20(0.20)$ & 0.56 & $(0.37)$ \\
\hline & Qatar & $0.13(0.25)$ & $0.17(0.29)$ & $0.27(0.27)$ & $0.21(0.22)$ & $0.19(0.24)$ & $0.27(0.20)$ & $0.14(0.17)$ & $0.11(0.16)$ & $0.19(0.17)$ & $\mathbf{0 . 4 9}(0.16)$ & 0.36 & $(0.29)$ \\
\hline & Romania & $\mathrm{m}$ & $\mathrm{m}$ & $\mathrm{m}$ & $\mathrm{m}$ & $\mathrm{m}$ & $\mathrm{m}$ & $\mathrm{m}$ & $\mathrm{m}$ & $\mathrm{m}$ & $\mathrm{m}$ & $\mathrm{m}$ & $\mathrm{m}$ \\
\hline & Russia & $0.37(0.29)$ & $0.36(0.30)$ & $0.39(0.31)$ & $0.39(0.33)$ & $0.45(0.31)$ & $0.49(0.33)$ & $0.22(0.28)$ & $0.30(0.29)$ & $0.15(0.30)$ & $0.07(0.25)$ & -0.31 & 0.38) \\
\hline & & & & $\mathrm{m}$ & $\mathrm{m}$ & $\mathrm{m}$ & $\mathrm{m}$ & $\mathrm{m}$ & $\mathrm{m}$ & $\mathrm{m}$ & $\mathrm{m}$ & $\mathrm{m}$ & $\mathrm{m}$ \\
\hline & Chir & $54(0.24)$ & $0.36(0.25)$ & $0.32(0.21)$ & $0.28(0.20)$ & $0.25(0.20)$ & $0.29(0.27)$ & $0.30(0.27)$ & $0.25(0.24)$ & $0.14(0.25)$ & $0.15(0.17)$ & -0.39 & $(0.32)$ \\
\hline & Thailand & $-0.08(0.27)$ & $0.03(0.28)$ & $0.14(0.31)$ & $0.23(0.31)$ & $0.31(0.29)$ & $0.15(0.26)$ & $0.07(0.23)$ & $-0.05(0.30)$ & $-0.14(0.27)$ & $-0.27(0.20)$ & -0.19 & $(0.37)$ \\
\hline & Trinidad and Tobago & $\mathrm{m}$ & $\mathrm{m}$ & $\mathrm{m}$ & $\mathrm{m}$ & $\mathrm{m}$ & $\mathrm{m}$ & $\mathrm{m}$ & $\mathrm{m}$ & $\mathrm{m}$ & $\mathrm{m}$ & $\mathrm{m}$ & $\mathrm{m}$ \\
\hline & Tunisia & $-0.10(0.39)$ & $0.15(0.46)$ & $0.11(0.40)$ & $0.24(0.44)$ & $0.24(0.42)$ & $0.26(0.36)$ & $0.23(0.45)$ & $0.13(0.36)$ & $0.17(0.33)$ & $0.28(0.26)$ & 0.38 & $(0.48)$ \\
\hline & United Arab Er & $-0.15(0.27)$ & $0.06(0.26)$ & $0.21(0.23)$ & $0.29(0.27)$ & $0.27(0.26)$ & $0.26(0.22)$ & $0.40(0.25)$ & $0.43(0.27)$ & $0.28(0.22)$ & $\mathbf{0 . 5 7}(0.15)$ & 0.73 & $(0.32)$ \\
\hline & Uruguay & $\mathbf{0 . 7 6}(0.32)$ & $0.60(0.33)$ & $0.49(0.33)$ & $0.50(0.27)$ & $0.48(0.36)$ & $0.54(0.35)$ & $0.39(0.26)$ & $0.39(0.25)$ & $0.34(0.26)$ & $0.28(0.20)$ & -0.48 & $(0.40)$ \\
\hline & Viet Nam & $\mathrm{m}$ & $\mathrm{m}$ & $\mathrm{m}$ & $\mathrm{m}$ & $\mathrm{m}$ & $\mathrm{m}$ & $\mathrm{m}$ & $m$ & $\mathrm{~m}$ & $\mathrm{~m}$ & $\mathrm{~m}$ & $\mathrm{~m}$ \\
\hline & A & $\mathrm{m}$ & $\mathrm{m}$ & $\mathrm{m}$ & $\mathrm{m}$ & $\mathrm{m}$ & $\mathrm{m}$ & $\mathrm{m}$ & $\mathrm{m}$ & $\mathrm{m}$ & $\mathrm{m}$ & $\mathrm{m}$ & $\mathrm{m}$ \\
\hline & & 111 & m & $\mathrm{m}$ & $\mathrm{m}$ & m & $\mathrm{m}$ & $\mathrm{m}$ & $\mathrm{m}$ & III & $\mathrm{m}$ & $\mathrm{m}$ & $\mathrm{m}$ \\
\hline & Malaysia** & $0.15(0.29)$ & $0.13(0.31)$ & $0.12(0.27)$ & $0.22(0.26)$ & $0.21(0.25)$ & $0.12(0.21)$ & $-0.01(0.24)$ & $0.02(0.22)$ & $0.05(0.24)$ & $0.04(0.19)$ & -0.11 & $(0.32)$ \\
\hline
\end{tabular}

Note: Values that are statistically significant are indicated in bold (see Annex A3)

* See note at the beginning of this Annex.

** Coverage is too small to ensure comparability (see Annex A4).

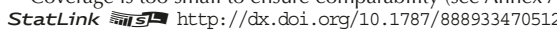




\begin{tabular}{|c|c|c|c|c|c|c|c|c|c|c|c|c|c|c|}
\hline & \multicolumn{6}{|c|}{ Percentage of students who study: } & \multicolumn{8}{|c|}{ Science performance } \\
\hline & \multirow{2}{*}{\multicolumn{2}{|c|}{$\begin{array}{c}\text { Less than } \\
40 \text { hours per week }\end{array}$}} & \multirow{2}{*}{\multicolumn{2}{|c|}{$\begin{array}{c}\text { Between } \\
40 \text { and } 60 \text { hours }\end{array}$}} & \multirow{2}{*}{\multicolumn{2}{|c|}{$\begin{array}{l}60 \text { hours or more } \\
\text { per week }\end{array}$}} & \multirow{2}{*}{\multicolumn{2}{|c|}{$\begin{array}{c}\text { Students who } \\
\text { study less than } \\
40 \text { hours per week }\end{array}$}} & \multirow{2}{*}{\multicolumn{2}{|c|}{$\begin{array}{c}\text { Students who } \\
\text { study } 60 \text { hours } \\
\text { or more per week }\end{array}$}} & \multicolumn{4}{|c|}{$\begin{array}{l}\text { Difference in science score between } \\
\text { students who study at least } 60 \text { hours } \\
\text { per week and students who study } \\
\text { less than } 40 \text { hours per week }\end{array}$} \\
\hline & & & & & & & & & & & \multicolumn{2}{|c|}{$\begin{array}{l}\text { Before accounting } \\
\text { for students' socio- } \\
\text { economic status }\end{array}$} & \multicolumn{2}{|c|}{$\begin{array}{l}\text { After accounting } \\
\text { for students' socio- } \\
\text { economic status }\end{array}$} \\
\hline & $\%$ & S.E. & $\%$ & S.E. & $\%$ & S.E. & $\begin{array}{l}\text { Mean } \\
\text { score }\end{array}$ & S.E. & $\begin{array}{l}\text { Mean } \\
\text { score }\end{array}$ & S.E. & $\begin{array}{l}\text { Score } \\
\text { dif. }\end{array}$ & S.E. & $\begin{array}{c}\text { Score } \\
\text { dif. }\end{array}$ & S.E. \\
\hline Australia & 50.3 & $(0.6)$ & 40.4 & $(0.6)$ & 9.3 & $(0.4)$ & 537 & $(2.0)$ & 498 & $(4.8)$ & -38 & $(5.0)$ & -39 & $(5.0)$ \\
\hline Austria & 44.1 & $(1.1)$ & 42.4 & $(0.8)$ & 13.5 & $(0.6)$ & 522 & (3.3) & 469 & (4.5) & -53 & $(4.6)$ & -45 & (4.4) \\
\hline Belgium (excl. Flemish) & 46.2 & $(1.0)$ & 41.0 & $(1.0)$ & 12.8 & $(0.9)$ & 521 & $(4.7)$ & 484 & (5.9) & -37 & (6.4) & -47 & (3.8) \\
\hline Canada & 46.5 & $(0.8)$ & 38.1 & $(0.6)$ & 15.4 & $(0.6)$ & 552 & $(2.3)$ & 528 & (3.6) & -25 & (3.6) & -27 & (3.4) \\
\hline Chile & 35.2 & $(1.1)$ & 40.8 & $(1.1)$ & 24.1 & $(1.0)$ & 484 & $(4.7)$ & 435 & $(4.4)$ & -49 & (5.4) & -42 & (5.3) \\
\hline Czech Republic & 57.0 & $(0.8)$ & 34.8 & $(0.8)$ & 8.2 & $(0.5)$ & 524 & $(2.2)$ & 468 & (5.8) & -55 & $(6.1)$ & -48 & (5.7) \\
\hline Denmark & 44.3 & $(1.0)$ & 39.0 & $(0.9)$ & 16.6 & $(0.6)$ & 534 & $(2.5)$ & 493 & $(3.7)$ & -41 & $(4.2)$ & -36 & $(4.0)$ \\
\hline Estonia & 53.8 & $(0.8)$ & 34.3 & $(0.8)$ & 11.9 & (0.5) & 557 & (2.6) & 505 & (4.4) & -52 & (4.5) & -48 & (4.4) \\
\hline Finland & 73.3 & $(0.9)$ & 22.5 & $(0.8)$ & 4.1 & $(0.3)$ & 548 & $(2.2)$ & 500 & (8.6) & -48 & (8.3) & -45 & (8.0) \\
\hline France & 49.5 & $(0.9)$ & 40.9 & $(0.8)$ & 9.6 & $(0.4)$ & 522 & $(2.5)$ & 486 & $(4.9)$ & -36 & (5.5) & -34 & (4.9) \\
\hline Germany & 75.6 & $(0.8)$ & 20.4 & $(0.7)$ & 4.0 & $(0.3)$ & 538 & (2.5) & 470 & (7.6) & -64 & (7.4) & -60 & $(7.2)$ \\
\hline Greece & 34.0 & $(0.9)$ & 45.6 & $(0.9)$ & 20.4 & $(0.7)$ & 469 & $(4.0)$ & 454 & (5.3) & -15 & $(4.2)$ & -19 & $(4.1)$ \\
\hline Hungary & 48.3 & $(0.9)$ & 38.7 & $(0.7)$ & 13.0 & $(0.7)$ & 495 & (2.7) & 457 & (5.6) & -38 & (5.9) & -39 & $(5.2)$ \\
\hline Iceland & 56.0 & (1.0) & 34.6 & (0.9) & 9.4 & $(0.5)$ & 495 & (2.3) & 447 & (6.4) & -48 & (6.7) & -49 & (6.6) \\
\hline Ireland & 44.9 & $(0.8)$ & 43.7 & $(0.8)$ & 11.4 & $(0.5)$ & 511 & (2.5) & 498 & (4.5) & -13 & $(4.0)$ & -16 & (3.7) \\
\hline Israel & 45.0 & (1.2) & 39.2 & (1.0) & 15.8 & $(0.7)$ & 493 & (3.7) & 453 & (4.8) & -40 & (4.9) & -37 & (4.9) \\
\hline Italy & 28.3 & (1.0) & 50.8 & $(0.8)$ & 20.9 & (0.5) & 490 & (3.8) & 486 & $(4.0)$ & -4 & (5.0) & -7 & $(4.4)$ \\
\hline Japan & 56.3 & (1.1) & 34.4 & $(0.9)$ & 9.3 & (0.5) & 542 & (3.2) & 550 & (5.9) & 9 & (5.6) & -2 & (4.8) \\
\hline Korea & 27.8 & (1.1) & 49.0 & $(0.8)$ & 23.2 & (1.1) & 491 & (3.9) & 551 & $(4.0)$ & 61 & (5.2) & 44 & $(4.6)$ \\
\hline Latvia & 52.5 & $(0.8)$ & 34.5 & $(0.7)$ & 13.0 & $(0.6)$ & 510 & $(2.4)$ & 462 & $(4.0)$ & -49 & (4.9) & -49 & (4.7) \\
\hline Luxembourg & 55.3 & $(0.7)$ & 35.3 & $(0.7)$ & 9.4 & $(0.4)$ & 514 & (1.9) & 461 & $(4.7)$ & -52 & (5.5) & -48 & $(5.2)$ \\
\hline Mexico & 36.6 & (1.1) & 42.2 & $(0.9)$ & 21.2 & $(0.8)$ & 421 & (2.9) & 427 & (3.0) & 6 & (3.3) & 2 & (3.1) \\
\hline Netherlands & 57.7 & (1.0) & 35.5 & $(0.9)$ & 6.7 & $(0.5)$ & 527 & $(2.5)$ & 486 & (7.3) & -42 & $(7.1)$ & -34 & $(6.2)$ \\
\hline New Zealand & 53.2 & (1.1) & 38.2 & $(1.0)$ & 8.6 & $(0.5)$ & 552 & (3.0) & 504 & $(7.0)$ & -45 & (7.3) & -42 & (6.6) \\
\hline Norway & 50.2 & $(1.0)$ & 38.5 & $(0.8)$ & 11.3 & $(0.5)$ & 525 & $(2.6)$ & 488 & (4.7) & -36 & (4.8) & -35 & $(4.8)$ \\
\hline Poland & 38.6 & $(1.0)$ & 46.9 & $(0.9)$ & 14.5 & $(0.6)$ & 520 & $(2.8)$ & 483 & (4.6) & -36 & (4.6) & -36 & (4.2) \\
\hline Portugal & 44.2 & $(0.9)$ & 40.6 & $(0.9)$ & 15.1 & $(0.8)$ & 515 & $(3.2)$ & 500 & (5.4) & -15 & $(5.2)$ & -20 & (4.6) \\
\hline Slovak Republic & 52.7 & $(1.0)$ & 34.5 & $(0.9)$ & 12.9 & $(0.6)$ & 491 & $(2.7)$ & 444 & $(4.3)$ & -46 & $(4.7)$ & -42 & (4.6) \\
\hline Slovenia & 49.6 & $(0.9)$ & 37.1 & $(0.9)$ & 13.3 & $(0.7)$ & 543 & $(2.5)$ & 510 & $(4.7)$ & -33 & (5.3) & -34 & (4.8) \\
\hline Spain & 36.0 & $(0.9)$ & 48.0 & $(0.7)$ & 16.0 & $(0.7)$ & 501 & $(2.7)$ & 498 & (3.7) & -3 & $(4.1)$ & -5 & $(4.0)$ \\
\hline Sweden & 62.8 & $(1.0)$ & 29.9 & $(0.8)$ & 7.3 & $(0.5)$ & 522 & (3.4) & 468 & (6.5) & -53 & (6.4) & -54 & (6.1) \\
\hline Switzerland & 64.3 & (1.0) & 29.2 & $(0.9)$ & 6.5 & $(0.5)$ & 538 & $(2.7)$ & 465 & $(7.4)$ & -73 & $(7.7)$ & -65 & $(7.8)$ \\
\hline Turkey & 29.3 & $(0.9)$ & 44.8 & $(0.9)$ & 25.9 & $(0.8)$ & 430 & $(4.6)$ & 429 & (4.8) & -1 & (4.9) & -3 & (4.5) \\
\hline United Kingdom & 50.2 & $(0.8)$ & 39.0 & $(0.7)$ & 10.8 & $(0.5)$ & 534 & $(2.5)$ & 511 & (5.5) & -23 & (5.5) & -25 & (5.2) \\
\hline United States & 33.5 & $(0.9)$ & 44.7 & $(0.8)$ & 21.8 & $(0.8)$ & 509 & $(4.4)$ & 511 & $(4.5)$ & 3 & $(5.5)$ & -2 & $(5.0)$ \\
\hline OECD average & 48.1 & $(0.2)$ & 38.6 & $(0.1)$ & 13.3 & $(0.1)$ & 514 & $(0.5)$ & 483 & $(0.9)$ & -31 & $(0.9)$ & -31 & $(0.9)$ \\
\hline
\end{tabular}

\begin{tabular}{|c|c|c|c|c|c|c|c|c|c|c|c|c|c|c|}
\hline Albania & $\mathrm{m}$ & $\mathrm{m}$ & $\mathrm{m}$ & $\mathrm{m}$ & $\mathrm{m}$ & $\mathrm{m}$ & $\mathrm{m}$ & $\mathrm{m}$ & $\mathrm{m}$ & $\mathrm{m}$ & $\mathrm{m}$ & $\mathrm{m}$ & $\mathrm{m}$ & $\mathrm{m}$ \\
\hline Algeria & $\mathrm{m}$ & $\mathrm{m}$ & $\mathrm{m}$ & $\mathrm{m}$ & $\mathrm{m}$ & $\mathrm{m}$ & $\mathrm{m}$ & $\mathrm{m}$ & $\mathrm{m}$ & $\mathrm{m}$ & $\mathrm{m}$ & $\mathrm{m}$ & $\mathrm{m}$ & $\mathrm{m}$ \\
\hline ถู่ Brazil & 47.9 & $(0.9)$ & 30.9 & $(0.7)$ & 21.2 & $(0.7)$ & 431 & $(2.9)$ & 405 & (3.9) & -26 & $(4.0)$ & -31 & (3.6) \\
\hline B-S-J-G (China) & 21.3 & $(0.9)$ & 38.0 & $(0.8)$ & 40.7 & $(1.0)$ & 494 & $(4.6)$ & 535 & (6.3) & 41 & $(6.7)$ & 26 & $(5.0)$ \\
\hline Bulgaria & 52.0 & $(1.0)$ & 34.5 & $(0.8)$ & 13.5 & $(0.6)$ & 470 & $(4.5)$ & 442 & (5.4) & -28 & (5.8) & -34 & (4.6) \\
\hline CABA (Argentina) & $\mathrm{m}$ & $\mathrm{m}$ & $\mathrm{m}$ & $\mathrm{m}$ & $\mathrm{m}$ & $\mathrm{m}$ & $\mathrm{m}$ & $\mathrm{m}$ & $\mathrm{m}$ & $\mathrm{m}$ & $\mathrm{m}$ & $\mathrm{m}$ & $\mathrm{m}$ & $\mathrm{m}$ \\
\hline Colombia & 41.5 & $(0.9)$ & 40.1 & $(0.8)$ & 18.4 & $(0.6)$ & 424 & $(2.9)$ & 425 & (3.8) & 1 & $(4.0)$ & -5 & (3.5) \\
\hline Costa Rica & 31.2 & $(1.2)$ & 45.8 & $(0.9)$ & 23.0 & $(0.8)$ & 419 & (2.6) & 423 & (3.5) & 4 & $(4.2)$ & -2 & (3.6) \\
\hline Croatia & 45.2 & $(0.8)$ & 37.6 & $(0.8)$ & 17.2 & $(0.6)$ & 484 & (3.1) & 474 & (3.7) & -10 & $(4.0)$ & -16 & (3.8) \\
\hline Cyprus* & 44.4 & $(0.7)$ & 39.0 & $(0.6)$ & 16.6 & $(0.6)$ & 458 & $(2.4)$ & 421 & (3.8) & -37 & $(4.6)$ & -40 & (4.5) \\
\hline Dominican Republic & 39.3 & (1.5) & 32.8 & (1.3) & 27.9 & $(1.3)$ & 349 & $(4.9)$ & 352 & (5.0) & 3 & $(5.2)$ & 3 & (4.8) \\
\hline FYROM & $\mathrm{m}$ & $\mathrm{m}$ & $\mathrm{m}$ & $\mathrm{m}$ & $\mathrm{m}$ & $\mathrm{m}$ & $\mathrm{m}$ & $\mathrm{m}$ & $\mathrm{m}$ & $\mathrm{m}$ & $\mathrm{m}$ & $\mathrm{m}$ & $\mathrm{m}$ & $\mathrm{m}$ \\
\hline Georgia & $\mathrm{m}$ & $\mathrm{m}$ & $\mathrm{m}$ & $\mathrm{m}$ & $\mathrm{m}$ & $\mathrm{m}$ & $\mathrm{m}$ & $\mathrm{m}$ & $\mathrm{m}$ & $\mathrm{m}$ & $\mathrm{m}$ & $\mathrm{m}$ & $\mathrm{m}$ & $\mathrm{m}$ \\
\hline Hong Kong (China) & 44.5 & (1.1) & 37.7 & $(0.9)$ & 17.8 & $(0.7)$ & 530 & $(2.8)$ & 518 & (3.7) & -12 & (3.6) & -15 & (3.5) \\
\hline Indonesia & $\mathrm{m}$ & $\mathrm{m}$ & $\mathrm{m}$ & $\mathrm{m}$ & $\mathrm{m}$ & $\mathrm{m}$ & $\mathrm{m}$ & $\mathrm{m}$ & $\mathrm{m}$ & $\mathrm{m}$ & $\mathrm{m}$ & $\mathrm{m}$ & $\mathrm{m}$ & $\mathrm{m}$ \\
\hline Jordan & $\mathrm{m}$ & $\mathrm{m}$ & $\mathrm{m}$ & $\mathrm{m}$ & $\mathrm{m}$ & $\mathrm{m}$ & $\mathrm{m}$ & $\mathrm{m}$ & $\mathrm{m}$ & $\mathrm{m}$ & $\mathrm{m}$ & $\mathrm{m}$ & $\mathrm{m}$ & $\mathrm{m}$ \\
\hline Kosovo & $\mathrm{m}$ & $\mathrm{m}$ & $\mathrm{m}$ & $\mathrm{m}$ & $\mathrm{m}$ & $\mathrm{m}$ & $\mathrm{m}$ & $\mathrm{m}$ & $\mathrm{m}$ & $\mathrm{m}$ & $\mathrm{m}$ & $\mathrm{m}$ & $\mathrm{m}$ & $\mathrm{m}$ \\
\hline Lebanon & $\mathrm{m}$ & $\mathrm{m}$ & $\mathrm{m}$ & $\mathrm{m}$ & $\mathrm{m}$ & $\mathrm{m}$ & $\mathrm{m}$ & $\mathrm{m}$ & $\mathrm{m}$ & $\mathrm{m}$ & $\mathrm{m}$ & $\mathrm{m}$ & $\mathrm{m}$ & $\mathrm{m}$ \\
\hline Lithuania & 51.4 & $(0.8)$ & 37.0 & $(0.8)$ & 11.5 & $(0.5)$ & 492 & $(3.2)$ & 452 & $(4.0)$ & -40 & (4.6) & -40 & (4.5) \\
\hline Macao (China) & 47.8 & $(0.7)$ & 37.3 & $(0.7)$ & 14.8 & $(0.5)$ & 533 & (1.8) & 518 & (3.7) & -15 & $(4.3)$ & -18 & (4.1) \\
\hline Malta & $\mathrm{m}$ & $\mathrm{m}$ & $\mathrm{m}$ & $\mathrm{m}$ & $\mathrm{m}$ & $\mathrm{m}$ & $\mathrm{m}$ & $\mathrm{m}$ & $\mathrm{m}$ & $\mathrm{m}$ & $\mathrm{m}$ & $\mathrm{m}$ & $\mathrm{m}$ & $\mathrm{m}$ \\
\hline Moldova & $\mathrm{m}$ & $\mathrm{m}$ & $\mathrm{m}$ & $\mathrm{m}$ & $\mathrm{m}$ & $\mathrm{m}$ & $\mathrm{m}$ & $\mathrm{m}$ & $\mathrm{m}$ & $\mathrm{m}$ & $\mathrm{m}$ & $\mathrm{m}$ & $\mathrm{m}$ & $\mathrm{m}$ \\
\hline Montenegro & 39.8 & $(0.7)$ & 35.4 & $(0.8)$ & 24.8 & $(0.7)$ & 436 & $(2.1)$ & 413 & (3.3) & -23 & (3.8) & -24 & (3.8) \\
\hline Peru & 29.5 & $(0.9)$ & 46.1 & $(0.8)$ & 24.4 & $(0.8)$ & 410 & $(3.0)$ & 408 & (3.2) & -2 & (3.4) & -6 & (2.9) \\
\hline Qatar & 26.1 & $(0.5)$ & 41.3 & $(0.5)$ & 32.6 & $(0.5)$ & 450 & $(2.3)$ & 450 & (2.5) & 0 & $(3.2)$ & 0 & (3.1) \\
\hline Romania & $\mathrm{m}$ & $\mathrm{m}$ & $\mathrm{m}$ & $\mathrm{m}$ & $\mathrm{m}$ & $\mathrm{m}$ & $\mathrm{m}$ & $\mathrm{m}$ & $\mathrm{m}$ & $\mathrm{m}$ & $\mathrm{m}$ & $\mathrm{m}$ & $\mathrm{m}$ & $\mathrm{m}$ \\
\hline Russia & 36.3 & (1.1) & 39.7 & (1.1) & 24.0 & $(0.9)$ & 502 & (3.6) & 488 & $(4.2)$ & -14 & $(4.8)$ & -15 & (4.7) \\
\hline Singapore & 27.5 & $(0.7)$ & 47.7 & $(0.7)$ & 24.8 & $(0.7)$ & 552 & $(3.0)$ & 570 & (3.2) & 17 & $(4.6)$ & 10 & (4.4) \\
\hline Chinese Taipei & 33.8 & $(0.9)$ & 45.8 & $(0.7)$ & 20.3 & $(0.6)$ & 495 & $(2.8)$ & 571 & (3.1) & 76 & (3.7) & 57 & (3.4) \\
\hline Thailand & 21.0 & $(1.0)$ & 45.7 & $(1.0)$ & 33.3 & $(1.2)$ & 432 & $(4.1)$ & 435 & $(4.2)$ & 3 & (4.3) & -4 & (3.9) \\
\hline Trinidad and Tobago & $\mathrm{m}$ & $\mathrm{m}$ & $\mathrm{m}$ & $\mathrm{m}$ & $\mathrm{m}$ & $\mathrm{m}$ & $\mathrm{m}$ & $\mathrm{m}$ & $\mathrm{m}$ & $\mathrm{m}$ & $\mathrm{m}$ & $\mathrm{m}$ & $\mathrm{m}$ & $\mathrm{m}$ \\
\hline Tunisia & 22.6 & $(0.9)$ & 42.9 & $(1.0)$ & 34.5 & (1.1) & 397 & $(4.1)$ & 390 & $(2.8)$ & -6 & $(4.2)$ & -7 & (4.1) \\
\hline United Arab Emirates & 17.6 & $(0.5)$ & 40.0 & $(0.7)$ & 42.4 & $(0.8)$ & 461 & $(4.1)$ & 454 & $(2.8)$ & -7 & (3.7) & -7 & (3.8) \\
\hline Uruguay & 58.2 & $(1.0)$ & 29.8 & $(0.9)$ & 12.1 & $(0.7)$ & 459 & $(2.9)$ & 436 & (5.7) & -23 & (5.6) & -24 & $(5.1)$ \\
\hline Viet Nam & $\mathrm{m}$ & $\mathrm{m}$ & $\mathrm{m}$ & $\mathrm{m}$ & $\mathrm{m}$ & $\mathrm{m}$ & $\mathrm{m}$ & $\mathrm{m}$ & $\mathrm{m}$ & $\mathrm{m}$ & $\mathrm{m}$ & $\mathrm{m}$ & $\mathrm{m}$ & $\mathrm{m}$ \\
\hline Argentina** & $\mathrm{m}$ & $\mathrm{m}$ & $\mathrm{m}$ & $\mathrm{m}$ & $\mathrm{m}$ & $\mathrm{m}$ & $\mathrm{m}$ & $\mathrm{m}$ & $\mathrm{m}$ & $\mathrm{m}$ & $\mathrm{m}$ & $\mathrm{m}$ & $\mathrm{m}$ & $\mathrm{m}$ \\
\hline Kazakhstan** & $\mathrm{m}$ & $\mathrm{m}$ & $\mathrm{m}$ & $\mathrm{m}$ & $\mathrm{m}$ & $\mathrm{m}$ & $\mathrm{m}$ & $\mathrm{m}$ & $\mathrm{m}$ & $\mathrm{m}$ & $\mathrm{m}$ & $\mathrm{m}$ & $\mathrm{m}$ & $\mathrm{m}$ \\
\hline Malaysia** & 29.3 & $(1.1)$ & 45.5 & (1.1) & 25.2 & (1.0) & 440 & (3.4) & 456 & $(4.5)$ & 16 & (3.7) & 10 & (3.3) \\
\hline
\end{tabular}

Note: Values that are statistically significant are indicated in bold (see Annex A3).

* See note at the beginning of this Annex.

** Coverage is too small to ensure comparability (see Annex A4).

StatLink त्गाडs http://dx.doi.org/10.1787/888933470524 
[Part 2/2]

Table III.3.6 Time spent studying in and out of school and performance in core PISA subjects

Results based on students' self-reports

\begin{tabular}{|c|c|c|c|c|c|c|c|c|c|c|c|c|c|c|c|c|}
\hline & \multicolumn{8}{|c|}{ Mathematics performance } & \multicolumn{8}{|c|}{ Reading performance } \\
\hline & \multirow{2}{*}{\multicolumn{2}{|c|}{$\begin{array}{c}\text { Students who } \\
\text { study less than } \\
40 \text { hours } \\
\text { per week } \\
\end{array}$}} & \multirow{2}{*}{\multicolumn{2}{|c|}{$\begin{array}{l}\text { Students who } \\
\text { study } 60 \text { hours } \\
\text { or more } \\
\text { per week }\end{array}$}} & \multicolumn{4}{|c|}{$\begin{array}{l}\text { Difference in mathematics score between } \\
\text { students who study at least } 60 \text { hours } \\
\text { per week and students who study } \\
\text { less than } 40 \text { hours per week }\end{array}$} & \multirow{2}{*}{\multicolumn{2}{|c|}{$\begin{array}{l}\text { Students who } \\
\text { study less than } \\
40 \text { hours } \\
\text { per week }\end{array}$}} & \multirow{2}{*}{\multicolumn{2}{|c|}{$\begin{array}{l}\text { Students who } \\
\text { study } 60 \text { hours } \\
\text { or more } \\
\text { per week }\end{array}$}} & \multicolumn{4}{|c|}{$\begin{array}{l}\text { Difference in reading score between } \\
\text { students who study at least } 60 \text { hours } \\
\text { per week and students who study } \\
\text { less than } 40 \text { hours per week }\end{array}$} \\
\hline & & & & & \multicolumn{2}{|c|}{\begin{tabular}{|c|} 
Before accounting \\
for students' socio- \\
economic status
\end{tabular}} & \multicolumn{2}{|c|}{$\begin{array}{l}\text { After accounting } \\
\text { for students' socio- } \\
\text { economic status }\end{array}$} & & & & & $\begin{array}{l}\text { Before } \\
\text { for stud } \\
\text { econo }\end{array}$ & $\begin{array}{l}\text { ounting } \\
\text { s' socio- }^{\text {status }}\end{array}$ & $\begin{array}{l}\text { After ac } \\
\text { for stude } \\
\text { econon }\end{array}$ & $\begin{array}{l}\text { unting } \\
s^{\prime} \text { socio- } \\
\text { status }\end{array}$ \\
\hline & $\begin{array}{l}\text { Mean } \\
\text { score }\end{array}$ & S.E. & $\begin{array}{l}\text { Mean } \\
\text { score }\end{array}$ & S.E. & $\begin{array}{c}\text { Score } \\
\text { dif. }\end{array}$ & S.E. & $\begin{array}{c}\text { Score } \\
\text { dif. }\end{array}$ & S.E. & $\begin{array}{l}\text { Mean } \\
\text { score }\end{array}$ & S.E. & $\begin{array}{l}\text { Mean } \\
\text { score }\end{array}$ & S.E. & $\begin{array}{c}\text { Score } \\
\text { dif. }\end{array}$ & S.E. & $\begin{array}{c}\text { Score } \\
\text { dif. }\end{array}$ & S.E. \\
\hline Australia & 517 & $(2.1)$ & 485 & $(4.4)$ & -32 & $(4.4)$ & -32 & $(4.5)$ & 531 & $(2.1)$ & 491 & $(5.0)$ & -39 & $(5.2)$ & -39 & $(5.2)$ \\
\hline Austria & 521 & (3.6) & 475 & $(4.4)$ & -46 & $(4.5)$ & -39 & $(4.2)$ & 516 & (3.4) & 452 & $(5.1)$ & -64 & $(5.2)$ & -57 & $(5.0)$ \\
\hline Belgium (excl. Flemish) & 522 & $(4.7)$ & 489 & $(5.2)$ & -33 & $(6.4)$ & -44 & $(4.0)$ & 520 & $(4.6)$ & 482 & (6.0) & -38 & $(6.2)$ & -47 & (3.7) \\
\hline Canada & 539 & $(2.7)$ & 514 & (3.8) & -26 & $(4.0)$ & -28 & $(3.8)$ & 551 & $(2.2)$ & 527 & (3.8) & -24 & (3.7) & -26 & (3.6) \\
\hline Chile & 457 & $(4.7)$ & 415 & $(4.7)$ & -42 & $(6.0)$ & -35 & $(5.6)$ & 496 & $(4.7)$ & 448 & $(4.4)$ & -48 & (5.6) & -41 & (5.4) \\
\hline Czech Republic & 521 & (2.4) & 471 & (5.6) & -49 & $(5.8)$ & -42 & $(5.5)$ & 522 & $(2.5)$ & 461 & (6.9) & -60 & $(6.8)$ & -53 & (6.5) \\
\hline Denmark & 540 & $(2.3)$ & 503 & (3.4) & -37 & (3.8) & -33 & (3.6) & 533 & (2.5) & 494 & $(4.1)$ & -39 & $(4.3)$ & -35 & $(4.2)$ \\
\hline Estonia & 539 & (2.5) & 494 & (4.5) & -45 & (4.6) & -41 & (4.4) & 540 & (2.7) & 494 & (4.8) & -46 & (4.9) & -42 & $(4.7)$ \\
\hline Finland & 525 & $(2.2)$ & 486 & (7.5) & -39 & (7.3) & -36 & (6.9) & 544 & $(2.2)$ & 491 & (8.0) & -54 & $(7.7)$ & -51 & (7.3) \\
\hline France & 517 & (2.5) & 482 & (5.0) & -34 & (5.3) & -32 & $(4.7)$ & 530 & $(2.7)$ & 488 & (5.7) & -41 & (6.2) & -39 & (5.6) \\
\hline Germany & 529 & $(2.8)$ & 469 & $(8.3)$ & -59 & (7.9) & -55 & (7.8) & 540 & $(2.7)$ & 469 & (8.9) & -69 & (8.6) & -65 & (8.7) \\
\hline Greece & 466 & (3.9) & 453 & (5.4) & -13 & (4.5) & -18 & (4.5) & 481 & $(4.5)$ & 467 & (5.6) & -13 & (4.5) & -19 & $(4.3)$ \\
\hline Hungary & 494 & (2.9) & 459 & (5.6) & -35 & $(6.2)$ & -36 & (5.5) & 486 & $(2.9)$ & 451 & (5.7) & -35 & (5.8) & -36 & (5.1) \\
\hline Iceland & 509 & $(2.5)$ & 464 & (6.4) & -46 & (6.4) & -46 & (6.3) & 507 & $(2.7)$ & 449 & (6.9) & -58 & (7.0) & -58 & $(6.8)$ \\
\hline Ireland & 511 & $(2.3)$ & 498 & $(3.8)$ & -13 & $(3.6)$ & -15 & $(3.4)$ & 530 & $(2.6)$ & 514 & $(4.7)$ & -16 & $(4.4)$ & -18 & $(4.1)$ \\
\hline Israel & 495 & (4.0) & 454 & (5.3) & -41 & (5.3) & -38 & $(5.2)$ & 511 & (3.8) & 460 & (5.9) & -51 & (5.7) & -49 & (5.7) \\
\hline Italy & 500 & $(4.1)$ & 494 & $(4.3)$ & -5 & $(5.4)$ & -8 & $(4.9)$ & 493 & $(4.0)$ & 488 & $(4.4)$ & -5 & (5.5) & -9 & $(4.7)$ \\
\hline Japan & 534 & (3.5) & 544 & $(6.0)$ & 10 & $(5.9)$ & -1 & $(5.3)$ & 519 & (3.5) & 528 & $(6.3)$ & 9 & $(6.1)$ & -1 & (5.4) \\
\hline Korea & 497 & (4.4) & 562 & $(5.0)$ & 66 & $(6.0)$ & 44 & (5.1) & 493 & $(4.0)$ & 550 & $(4.2)$ & 57 & (5.1) & 41 & $(4.6)$ \\
\hline Latvia & 501 & $(2.4)$ & 458 & $(4.5)$ & -43 & $(5.0)$ & -42 & $(4.6)$ & 509 & $(2.4)$ & 457 & $(4.3)$ & -52 & $(5.3)$ & -52 & (5.0) \\
\hline Luxembourg & 515 & (1.8) & 467 & (4.5) & -47 & (5.1) & -44 & $(4.7)$ & 515 & $(2.2)$ & 459 & (5.3) & -56 & $(6.0)$ & -52 & (5.6) \\
\hline Mexico & 413 & (3.2) & 418 & (3.3) & 5 & (4.1) & 2 & $(4.0)$ & 431 & (3.5) & 433 & (3.5) & 3 & (3.8) & -1 & (3.5) \\
\hline Netherlands & 530 & (2.5) & 491 & (6.5) & -39 & (6.1) & -33 & (5.5) & 523 & (2.6) & 479 & $(7.2)$ & -44 & $(7.0)$ & -37 & $(6.2)$ \\
\hline New Zealand & 525 & (3.0) & 487 & (6.5) & -36 & (6.9) & -33 & $(6.3)$ & 548 & (2.9) & 497 & $(8.1)$ & -46 & (8.4) & -44 & (7.9) \\
\hline Norway & 525 & $(2.4)$ & 494 & $(4.3)$ & -31 & $(4.3)$ & -30 & $(4.2)$ & 539 & $(2.8)$ & 508 & $(5.0)$ & -31 & $(5.0)$ & -30 & $(5.1)$ \\
\hline Poland & 524 & $(2.9)$ & 486 & $(4.5)$ & -37 & $(4.5)$ & -37 & $(4.1)$ & 524 & $(2.8)$ & 487 & (4.6) & -35 & (4.9) & -35 & $(4.6)$ \\
\hline Portugal & 505 & (3.4) & 493 & (5.8) & -11 & $(6.0)$ & -17 & (5.3) & 512 & (3.5) & 499 & (5.8) & -13 & (5.4) & -19 & (4.9) \\
\hline Slovak Republic & 504 & $(2.8)$ & 460 & (4.4) & -43 & $(4.5)$ & -39 & (4.3) & 488 & (3.1) & 433 & $(4.7)$ & -54 & (5.4) & -49 & (5.4) \\
\hline Slovenia & 536 & $(2.5)$ & 506 & $(4.3)$ & -30 & (4.9) & -31 & $(4.4)$ & 532 & (2.4) & 505 & (4.8) & -27 & (5.1) & -28 & $(4.6)$ \\
\hline Spain & 493 & $(2.9)$ & 490 & (3.5) & -3 & $(4.1)$ & -5 & $(3.9)$ & 504 & $(3.0)$ & 499 & (3.9) & -5 & $(4.1)$ & -7 & $(4.2)$ \\
\hline Sweden & 518 & (3.1) & 477 & (5.4) & -41 & $(5.5)$ & -42 & (5.3) & 529 & $(3.2)$ & 475 & (6.4) & -53 & (6.4) & -54 & $(6.2)$ \\
\hline Switzerland & 552 & (3.0) & 481 & $(8.2)$ & -71 & $(8.1)$ & -64 & $(8.1)$ & 524 & $(2.8)$ & 451 & $(8.1)$ & -73 & $(8.2)$ & -65 & $(8.0)$ \\
\hline Turkey & 425 & (4.9) & 424 & (5.3) & -1 & (5.1) & -3 & $(4.7)$ & 433 & $(4.5)$ & 432 & (5.0) & -1 & $(5.0)$ & -3 & $(4.6)$ \\
\hline United Kingdom & 512 & (2.4) & 496 & (5.4) & -16 & $(5.4)$ & -18 & $(5.3)$ & 521 & (3.0) & 498 & (5.4) & -23 & $(5.0)$ & -24 & $(4.7)$ \\
\hline United States & 479 & $(4.2)$ & 484 & (4.6) & 6 & (5.5) & 1 & (4.9) & 510 & (4.4) & 513 & (5.1) & 3 & (5.8) & -2 & (5.3) \\
\hline OECD average & 508 & $(0.5)$ & 481 & $(0.9)$ & -27 & $(0.9)$ & -28 & $(0.9)$ & 514 & $(0.5)$ & 481 & $(1.0)$ & -33 & $(1.0)$ & -33 & $(1.0)$ \\
\hline
\end{tabular}

\begin{tabular}{|c|c|c|c|c|c|c|c|c|c|c|c|c|c|c|c|c|}
\hline Albania & $\mathrm{m}$ & $\mathrm{m}$ & $\mathrm{m}$ & $\mathrm{m}$ & $\mathrm{m}$ & $\mathrm{m}$ & $\mathrm{m}$ & $\mathrm{m}$ & $\mathrm{m}$ & $\mathrm{m}$ & $\mathrm{m}$ & $\mathrm{m}$ & $\mathrm{m}$ & $\mathrm{m}$ & $\mathrm{m}$ & $\mathrm{m}$ \\
\hline Algeria & $\mathrm{m}$ & $\mathrm{m}$ & $\mathrm{m}$ & $\mathrm{m}$ & $\mathrm{m}$ & $\mathrm{m}$ & $\mathrm{m}$ & $\mathrm{m}$ & $\mathrm{m}$ & $\mathrm{m}$ & $\mathrm{m}$ & $\mathrm{m}$ & $\mathrm{m}$ & $\mathrm{m}$ & $\mathrm{m}$ & $\mathrm{m}$ \\
\hline Brazil & 404 & (3.6) & 383 & $(4.8)$ & -21 & $(4.5)$ & -26 & (4.1) & 443 & (3.5) & 411 & $(4.2)$ & -32 & $(4.0)$ & -37 & (3.7) \\
\hline B-S-J-G (China) & 507 & (4.9) & 549 & (6.3) & 42 & (6.6) & 27 & (5.3) & 473 & $(4.9)$ & 512 & (6.9) & 39 & $(7.2)$ & 22 & (5.3) \\
\hline Bulgaria & 462 & $(4.1)$ & 439 & (5.5) & -22 & $(5.6)$ & -28 & (4.6) & 461 & $(5.1)$ & 428 & (6.2) & -33 & (6.4) & -40 & $(5.2)$ \\
\hline CABA (Argentina) & $\mathrm{m}$ & $\mathrm{m}$ & $\mathrm{m}$ & $\mathrm{m}$ & $\mathrm{m}$ & $\mathrm{m}$ & $\mathrm{m}$ & $\mathrm{m}$ & $\mathrm{m}$ & $\mathrm{m}$ & $\mathrm{m}$ & $\mathrm{m}$ & $\mathrm{m}$ & $\mathrm{m}$ & $\mathrm{m}$ & $\mathrm{m}$ \\
\hline Colombia & 397 & (2.8) & 399 & (3.8) & 2 & (3.8) & -3 & (3.5) & 436 & (3.4) & 436 & $(4.4)$ & -1 & $(4.6)$ & -7 & $(4.0)$ \\
\hline Costa Rica & 400 & (3.5) & 404 & $(3.7)$ & 4 & $(4.5)$ & -1 & (4.1) & 429 & (3.0) & 430 & $(4.3)$ & 1 & $(4.8)$ & -5 & $(4.2)$ \\
\hline Croatia & 474 & (3.3) & 460 & (4.4) & -13 & $(4.2)$ & -20 & (4.0) & 493 & (3.2) & 489 & $(4.0)$ & -5 & $(4.1)$ & -11 & (3.7) \\
\hline Cyprus* & 462 & (2.5) & 427 & (3.8) & -35 & $(4.6)$ & -39 & (4.5) & 471 & $(2.7)$ & 429 & $(4.0)$ & -42 & (4.9) & -45 & $(4.9)$ \\
\hline Dominican Republic & 342 & (4.5) & 345 & $(5.0)$ & 3 & $(5.4)$ & 2 & (5.0) & 378 & (5.6) & 381 & (5.3) & 3 & (6.3) & 2 & (5.6) \\
\hline FYROM & $\mathrm{m}$ & $\mathrm{m}$ & $\mathrm{m}$ & $\mathrm{m}$ & $\mathrm{m}$ & $\mathrm{m}$ & $\mathrm{m}$ & $\mathrm{m}$ & $\mathrm{m}$ & $\mathrm{m}$ & $\mathrm{m}$ & $\mathrm{m}$ & $\mathrm{m}$ & $\mathrm{m}$ & $\mathrm{m}$ & $\mathrm{m}$ \\
\hline Georgia & $\mathrm{m}$ & $\mathrm{m}$ & $\mathrm{m}$ & $\mathrm{m}$ & $\mathrm{m}$ & $\mathrm{m}$ & $\mathrm{m}$ & $\mathrm{m}$ & $\mathrm{m}$ & $\mathrm{m}$ & $\mathrm{m}$ & $\mathrm{m}$ & $\mathrm{m}$ & $\mathrm{m}$ & $\mathrm{m}$ & $\mathrm{m}$ \\
\hline Hong Kong (China) & 554 & (3.4) & 542 & $(4.4)$ & -12 & $(4.4)$ & -16 & (4.3) & 535 & (3.2) & 521 & (4.4) & -15 & $(4.7)$ & -18 & $(4.6)$ \\
\hline Indonesia & $\mathrm{m}$ & $\mathrm{m}$ & $\mathrm{m}$ & $\mathrm{m}$ & $\mathrm{m}$ & $\mathrm{m}$ & $\mathrm{m}$ & $\mathrm{m}$ & $\mathrm{m}$ & $\mathrm{m}$ & $\mathrm{m}$ & $\mathrm{m}$ & $\mathrm{m}$ & $\mathrm{m}$ & $\mathrm{m}$ & $\mathrm{m}$ \\
\hline Jordan & $\mathrm{m}$ & $\mathrm{m}$ & $\mathrm{m}$ & $\mathrm{m}$ & $\mathrm{m}$ & $\mathrm{m}$ & $\mathrm{m}$ & $\mathrm{m}$ & $\mathrm{m}$ & $\mathrm{m}$ & $\mathrm{m}$ & $\mathrm{m}$ & $\mathrm{m}$ & $\mathrm{m}$ & $\mathrm{m}$ & $\mathrm{m}$ \\
\hline Kosovo & $\mathrm{m}$ & $\mathrm{m}$ & $\mathrm{m}$ & $\mathrm{m}$ & $\mathrm{m}$ & $\mathrm{m}$ & $\mathrm{m}$ & $\mathrm{m}$ & $\mathrm{m}$ & $\mathrm{m}$ & $\mathrm{m}$ & $\mathrm{m}$ & $\mathrm{m}$ & $\mathrm{m}$ & $\mathrm{m}$ & $\mathrm{m}$ \\
\hline Lebanon & $\mathrm{m}$ & $\mathrm{m}$ & $\mathrm{m}$ & $\mathrm{m}$ & $\mathrm{m}$ & $\mathrm{m}$ & $\mathrm{m}$ & $\mathrm{m}$ & $\mathrm{m}$ & $\mathrm{m}$ & $\mathrm{m}$ & $\mathrm{m}$ & $\mathrm{m}$ & $\mathrm{m}$ & $\mathrm{m}$ & $\mathrm{m}$ \\
\hline Lithuania & 494 & (2.8) & 455 & (3.9) & -38 & $(4.3)$ & -39 & $(4.2)$ & 491 & (3.4) & 444 & $(4.0)$ & -46 & (4.6) & -47 & $(4.5)$ \\
\hline Macao (China) & 546 & (1.7) & 540 & (3.8) & -6 & $(4.3)$ & -10 & (4.3) & 513 & (1.9) & 498 & (3.9) & -15 & (4.4) & -19 & $(4.3)$ \\
\hline Malta & $\mathrm{m}$ & $\mathrm{m}$ & $\mathrm{m}$ & $\mathrm{m}$ & $\mathrm{m}$ & $\mathrm{m}$ & $\mathrm{m}$ & $\mathrm{m}$ & $\mathrm{m}$ & $\mathrm{m}$ & $\mathrm{m}$ & $\mathrm{m}$ & $\mathrm{m}$ & $\mathrm{m}$ & $\mathrm{m}$ & $\mathrm{m}$ \\
\hline Moldova & $\mathrm{m}$ & $\mathrm{m}$ & $\mathrm{m}$ & $\mathrm{m}$ & $\mathrm{m}$ & $\mathrm{m}$ & $\mathrm{m}$ & $\mathrm{m}$ & $\mathrm{m}$ & $\mathrm{m}$ & $\mathrm{m}$ & $\mathrm{m}$ & $\mathrm{m}$ & $\mathrm{m}$ & $\mathrm{m}$ & $\mathrm{m}$ \\
\hline Montenegro & 443 & (2.5) & 420 & (3.6) & -23 & $(4.4)$ & -24 & $(4.4)$ & 454 & $(2.7)$ & 433 & (3.4) & -21 & $(4.2)$ & -22 & $(4.2)$ \\
\hline Peru & 398 & $(3.7)$ & 399 & $(4.0)$ & 1 & $(4.2)$ & -3 & (3.8) & 414 & (3.7) & 407 & (3.8) & -8 & (4.1) & -13 & (3.4) \\
\hline Qatar & 429 & (2.9) & 436 & (2.3) & 7 & (3.4) & 7 & (3.3) & 441 & (2.4) & 438 & $(2.7)$ & -4 & (3.3) & -4 & (3.3) \\
\hline Romania & $\mathrm{m}$ & $\mathrm{m}$ & $\mathrm{m}$ & $\mathrm{m}$ & $\mathrm{m}$ & $\mathrm{m}$ & $\mathrm{m}$ & $\mathrm{m}$ & $\mathrm{m}$ & $\mathrm{m}$ & $\mathrm{m}$ & $\mathrm{m}$ & $\mathrm{m}$ & $\mathrm{m}$ & $\mathrm{m}$ & $\mathrm{m}$ \\
\hline Russia & 505 & (4.6) & 497 & $(4.0)$ & -8 & $(5.0)$ & -9 & $(4.7)$ & 511 & $(4.1)$ & 495 & $(4.2)$ & -17 & (5.1) & -18 & (5.1) \\
\hline Singapore & 560 & (3.1) & 579 & $(2.7)$ & 19 & $(4.1)$ & 13 & (4.2) & 534 & (3.1) & 545 & (3.8) & 11 & $(4.8)$ & 4 & $(4.4)$ \\
\hline Chinese Taipei & 505 & (3.3) & 580 & (3.8) & 74 & (4.1) & 56 & (3.8) & 464 & $(2.8)$ & 530 & (3.1) & 66 & (3.7) & 50 & (3.5) \\
\hline Thailand & 426 & (4.4) & 427 & $(4.8)$ & 1 & $(4.4)$ & -5 & (4.1) & 421 & $(5.0)$ & 421 & $(4.8)$ & 0 & $(4.8)$ & -7 & $(4.4)$ \\
\hline Trinidad and Tobago & $\mathrm{m}$ & $\mathrm{m}$ & $\mathrm{m}$ & $\mathrm{m}$ & $\mathrm{m}$ & $\mathrm{m}$ & $\mathrm{m}$ & $\mathrm{m}$ & $\mathrm{m}$ & $\mathrm{m}$ & $\mathrm{m}$ & $\mathrm{m}$ & $\mathrm{m}$ & $\mathrm{m}$ & $\mathrm{m}$ & $\mathrm{m}$ \\
\hline Tunisia & 380 & (4.9) & 370 & (3.9) & -10 & (5.1) & -12 & (5.1) & 373 & $(5.2)$ & 367 & $(4.0)$ & -6 & (5.3) & -8 & $(5.0)$ \\
\hline United Arab Emirates & 448 & (3.9) & 442 & (3.0) & -6 & (3.9) & -6 & (3.9) & 462 & $(4.3)$ & 451 & (3.3) & -10 & $(4.0)$ & -10 & $(4.0)$ \\
\hline Uruguay & 439 & $(3.2)$ & 418 & $(5.8)$ & -21 & (6.0) & -21 & (5.6) & 465 & (3.3) & 434 & (6.6) & -31 & (6.4) & -32 & (5.9) \\
\hline Viet Nam & $\mathrm{m}$ & $\mathrm{m}$ & $\mathrm{m}$ & $\mathrm{m}$ & $\mathrm{m}$ & $\mathrm{m}$ & $\mathrm{m}$ & $\mathrm{m}$ & $\mathrm{m}$ & $\mathrm{m}$ & $\mathrm{m}$ & $\mathrm{m}$ & $\mathrm{m}$ & $\mathrm{m}$ & $\mathrm{m}$ & $\mathrm{m}$ \\
\hline Argentina** & $\mathrm{m}$ & $\mathrm{m}$ & $\mathrm{m}$ & $\mathrm{m}$ & $\mathrm{m}$ & $\mathrm{m}$ & $\mathrm{m}$ & $\mathrm{m}$ & $\mathrm{m}$ & $\mathrm{m}$ & $\mathrm{m}$ & $\mathrm{m}$ & $\mathrm{m}$ & $\mathrm{m}$ & $\mathrm{m}$ & $\mathrm{m}$ \\
\hline Kazakhstan** & $\mathrm{m}$ & $\mathrm{m}$ & $\mathrm{m}$ & $\mathrm{m}$ & $\mathrm{m}$ & $\mathrm{m}$ & $\mathrm{m}$ & $\mathrm{m}$ & $\mathrm{m}$ & $\mathrm{m}$ & $\mathrm{m}$ & $\mathrm{m}$ & $\mathrm{m}$ & $\mathrm{m}$ & $\mathrm{m}$ & $\mathrm{m}$ \\
\hline Malaysia** & 441 & (3.9) & 461 & (4.6) & 20 & $(4.3)$ & 13 & (3.7) & 428 & $(4.1)$ & 444 & (4.9) & 15 & $(4.3)$ & 9 & $(4.1)$ \\
\hline
\end{tabular}

Note: Values that are statistically significant are indicated in bold (see Annex A3).

* See note at the beginning of this Annex.

** Coverage is too small to ensure comparability (see Annex A4).

StatLink 完isL http://dx.doi.org/10.1787/888933470524 


\begin{tabular}{|c|c|c|c|c|c|c|c|c|c|c|c|c|c|c|c|}
\hline & \multicolumn{6}{|c|}{ Percentage of students who study: } & \multicolumn{8}{|c|}{ Average life satisfaction } \\
\hline & & \multirow{2}{*}{\multicolumn{2}{|c|}{$\begin{array}{c}\text { Less than } \\
40 \text { hours per week }\end{array}$}} & \multirow{2}{*}{\multicolumn{2}{|c|}{$\begin{array}{c}\text { Between } \\
40 \text { and } 60 \text { hours }\end{array}$}} & \multirow{2}{*}{\multicolumn{2}{|c|}{$\begin{array}{l}60 \text { hours or more } \\
\text { per week }\end{array}$}} & \multirow{2}{*}{\multicolumn{2}{|c|}{$\begin{array}{c}\text { Students who } \\
\text { study less than } \\
40 \text { hours per week }\end{array}$}} & \multirow{2}{*}{\multicolumn{2}{|c|}{$\begin{array}{c}\text { Students who } \\
\text { study } 60 \text { hours } \\
\text { or more per week }\end{array}$}} & \multicolumn{4}{|c|}{$\begin{array}{l}\text { Difference in life satisfaction between } \\
\text { students who study at least } 60 \text { hours } \\
\text { per week and students who study } \\
\text { less than } 40 \text { hours per week }\end{array}$} \\
\hline & & & & & & & & & & & & \multicolumn{2}{|c|}{$\begin{array}{l}\text { Before accounting } \\
\text { for students' socio- } \\
\text { economic status }\end{array}$} & \multicolumn{2}{|c|}{$\begin{array}{l}\text { After accounting } \\
\text { for students' socio- } \\
\text { economic status }\end{array}$} \\
\hline & & $\%$ & S.E. & $\%$ & S.E. & $\%$ & S.E. & $\begin{array}{l}\text { Mean } \\
\text { score }\end{array}$ & S.E. & $\begin{array}{l}\text { Mean } \\
\text { score }\end{array}$ & S.E. & $\begin{array}{l}\text { Score } \\
\text { dif. }\end{array}$ & S.E. & $\begin{array}{l}\text { Score } \\
\text { dif. }\end{array}$ & S.E. \\
\hline 0 & Australia & 50.3 & $(0.6)$ & 40.4 & $(0.6)$ & 9.3 & $(0.4)$ & $\mathrm{m}$ & $\mathrm{m}$ & $\mathrm{m}$ & $\mathrm{m}$ & $\mathrm{m}$ & $\mathrm{m}$ & $\mathrm{m}$ & $\mathrm{m}$ \\
\hline ப & Austria & 44.1 & $(1.1)$ & 42.4 & $(0.8)$ & 13.5 & $(0.6)$ & 7.49 & $(0.04)$ & 7.66 & $(0.09)$ & 0.18 & $(0.09)$ & 0.21 & $(0.10)$ \\
\hline & Belgium (excl. Flemish) & 46.2 & $(1.0)$ & 41.0 & $(1.0)$ & 12.8 & $(0.9)$ & 7.56 & $(0.05)$ & 7.59 & $(0.11)$ & 0.03 & $(0.11)$ & 0.03 & $(0.11)$ \\
\hline & Canada & 46.5 & $(0.8)$ & 38.1 & $(0.6)$ & 15.4 & $(0.6)$ & $\mathrm{m}$ & $\mathrm{m}$ & $\mathrm{m}$ & $\mathrm{m}$ & $\mathrm{m}$ & $\mathrm{m}$ & $\mathrm{m}$ & $\mathrm{m}$ \\
\hline & Chile & 35.2 & (1.1) & 40.8 & $(1.1)$ & 24.1 & $(1.0)$ & 7.42 & $(0.06)$ & 7.36 & $(0.08)$ & -0.04 & $(0.10)$ & 0.00 & $(0.10)$ \\
\hline & Czech Republic & 57.0 & $(0.8)$ & 34.8 & $(0.8)$ & 8.2 & $(0.5)$ & 7.10 & $(0.03)$ & 6.74 & $(0.14)$ & -0.36 & $(0.13)$ & -0.33 & $(0.13)$ \\
\hline & Denmark & 44.3 & $(1.0)$ & 39.0 & $(0.9)$ & 16.6 & $(0.6)$ & $\mathrm{m}$ & $\mathrm{m}$ & $\mathrm{m}$ & $\mathrm{m}$ & $\mathrm{m}$ & $\mathrm{m}$ & $\mathrm{m}$ & $\mathrm{m}$ \\
\hline & Estonia & 53.8 & $(0.8)$ & 34.3 & $(0.8)$ & 11.9 & (0.5) & 7.53 & $(0.04)$ & 7.32 & $(0.09)$ & -0.21 & (0.09) & -0.17 & $(0.09)$ \\
\hline & Finland & 73.3 & $(0.9)$ & 22.5 & $(0.8)$ & 4.1 & $(0.3)$ & 7.90 & $(0.03)$ & 7.84 & $(0.13)$ & -0.07 & $(0.13)$ & -0.05 & $(0.13)$ \\
\hline & France & 49.5 & $(0.9)$ & 40.9 & $(0.8)$ & 9.6 & $(0.4)$ & 7.64 & $(0.03)$ & 7.59 & $(0.09)$ & -0.03 & $(0.10)$ & -0.02 & (0.09) \\
\hline & Germany & 75.6 & $(0.8)$ & 20.4 & $(0.7)$ & 4.0 & $(0.3)$ & 7.37 & $(0.04)$ & 7.25 & $(0.19)$ & -0.08 & $(0.20)$ & -0.06 & $(0.20)$ \\
\hline & Greece & 34.0 & $(0.9)$ & 45.6 & $(0.9)$ & 20.4 & $(0.7)$ & 6.84 & $(0.04)$ & 7.17 & $(0.08)$ & 0.33 & $(0.08)$ & 0.32 & $(0.08)$ \\
\hline & Hungary & 48.3 & $(0.9)$ & 38.7 & $(0.7)$ & 13.0 & $(0.7)$ & 7.19 & $(0.04)$ & 7.10 & $(0.09)$ & -0.10 & $(0.09)$ & -0.09 & $(0.09)$ \\
\hline & Iceland & 56.0 & (1.0) & 34.6 & (0.9) & 9.4 & $(0.5)$ & 7.86 & $(0.04)$ & 7.57 & $(0.14)$ & -0.28 & (0.15) & -0.28 & $(0.15)$ \\
\hline & Ireland & 44.9 & $(0.8)$ & 43.7 & $(0.8)$ & 11.4 & $(0.5)$ & 7.31 & $(0.03)$ & 7.29 & $(0.10)$ & -0.02 & $(0.10)$ & -0.03 & $(0.10)$ \\
\hline & Israel & 45.0 & (1.2) & 39.2 & (1.0) & 15.8 & $(0.7)$ & $\mathrm{m}$ & $\mathrm{m}$ & $\mathrm{m}$ & $\mathrm{m}$ & $\mathrm{m}$ & $\mathrm{m}$ & $\mathrm{m}$ & $\mathrm{m}$ \\
\hline & Italy & 28.3 & (1.0) & 50.8 & $(0.8)$ & 20.9 & (0.5) & 6.85 & $(0.05)$ & 6.99 & $(0.07)$ & 0.14 & $(0.07)$ & 0.13 & $(0.07)$ \\
\hline & Japan & 56.3 & (1.1) & 34.4 & $(0.9)$ & 9.3 & (0.5) & 6.82 & $(0.04)$ & 7.12 & $(0.10)$ & 0.29 & $(0.10)$ & 0.26 & $(0.10)$ \\
\hline & Korea & 27.8 & (1.1) & 49.0 & $(0.8)$ & 23.2 & (1.1) & 6.28 & $(0.04)$ & 6.56 & $(0.08)$ & 0.28 & $(0.08)$ & 0.20 & $(0.08)$ \\
\hline & Latvia & 52.5 & $(0.8)$ & 34.5 & $(0.7)$ & 13.0 & $(0.6)$ & 7.37 & $(0.04)$ & 7.40 & $(0.09)$ & 0.03 & $(0.10)$ & 0.03 & $(0.10)$ \\
\hline & Luxembourg & 55.3 & $(0.7)$ & 35.3 & $(0.7)$ & 9.4 & $(0.4)$ & 7.41 & $(0.03)$ & 7.41 & $(0.11)$ & 0.00 & $(0.12)$ & 0.01 & $(0.12)$ \\
\hline & Mexico & 36.6 & (1.1) & 42.2 & $(0.9)$ & 21.2 & $(0.8)$ & 8.26 & $(0.03)$ & 8.32 & $(0.06)$ & 0.05 & $(0.07)$ & 0.04 & $(0.07)$ \\
\hline & Netherlands & 57.7 & $(1.0)$ & 35.5 & $(0.9)$ & 6.7 & $(0.5)$ & 7.82 & $(0.03)$ & 7.77 & $(0.10)$ & -0.05 & $(0.11)$ & -0.05 & $(0.11)$ \\
\hline & New Zealand & 53.2 & (1.1) & 38.2 & $(1.0)$ & 8.6 & $(0.5)$ & $\mathrm{m}$ & $\mathrm{m}$ & $\mathrm{m}$ & $\mathrm{m}$ & $\mathrm{m}$ & $\mathrm{m}$ & $\mathrm{m}$ & $\mathrm{m}$ \\
\hline & Norway & 50.2 & $(1.0)$ & 38.5 & $(0.8)$ & 11.3 & $(0.5)$ & $\mathrm{m}$ & $\mathrm{m}$ & $\mathrm{m}$ & $\mathrm{m}$ & $\mathrm{m}$ & $\mathrm{m}$ & $\mathrm{m}$ & $\mathrm{m}$ \\
\hline & Poland & 38.6 & $(1.0)$ & 46.9 & $(0.9)$ & 14.5 & $(0.6)$ & 7.19 & $(0.04)$ & 7.05 & $(0.10)$ & -0.13 & $(0.11)$ & -0.13 & $(0.11)$ \\
\hline & Portugal & 44.2 & $(0.9)$ & 40.6 & $(0.9)$ & 15.1 & $(0.8)$ & 7.36 & $(0.04)$ & 7.47 & $(0.08)$ & 0.11 & $(0.08)$ & 0.11 & $(0.08)$ \\
\hline & Slovak Republic & 52.7 & $(1.0)$ & 34.5 & $(0.9)$ & 12.9 & $(0.6)$ & 7.50 & $(0.04)$ & 7.36 & $(0.11)$ & -0.14 & $(0.12)$ & -0.12 & $(0.12)$ \\
\hline & Slovenia & 49.6 & $(0.9)$ & 37.1 & $(0.9)$ & 13.3 & $(0.7)$ & 7.14 & $(0.04)$ & 7.19 & $(0.12)$ & 0.05 & $(0.12)$ & 0.05 & $(0.12)$ \\
\hline & Spain & 36.0 & $(0.9)$ & 48.0 & $(0.7)$ & 16.0 & $(0.7)$ & 7.43 & $(0.04)$ & 7.53 & $(0.06)$ & 0.09 & $(0.08)$ & 0.10 & $(0.08)$ \\
\hline & Sweden & 62.8 & $(1.0)$ & 29.9 & $(0.8)$ & 7.3 & $(0.5)$ & $\mathrm{m}$ & $\mathrm{m}$ & $\mathrm{m}$ & $\mathrm{m}$ & $\mathrm{m}$ & $\mathrm{m}$ & $\mathrm{m}$ & $\mathrm{m}$ \\
\hline & Switzerland & 64.3 & $(1.0)$ & 29.2 & $(0.9)$ & 6.5 & $(0.5)$ & 7.75 & $(0.03)$ & 7.88 & $(0.12)$ & 0.12 & $(0.13)$ & 0.14 & $(0.13)$ \\
\hline & Turkey & 29.3 & $(0.9)$ & 44.8 & $(0.9)$ & 25.9 & $(0.8)$ & 6.07 & $(0.06)$ & 6.25 & $(0.09)$ & 0.17 & $(0.09)$ & 0.17 & $(0.09)$ \\
\hline & United Kingdom & 50.2 & $(0.8)$ & 39.0 & $(0.7)$ & 10.8 & $(0.5)$ & 6.99 & $(0.04)$ & 6.73 & $(0.11)$ & -0.27 & $(0.12)$ & -0.28 & $(0.12)$ \\
\hline & United States & 33.5 & $(0.9)$ & 44.7 & $(0.8)$ & 21.8 & $(0.8)$ & 7.37 & $(0.05)$ & 7.35 & $(0.09)$ & -0.02 & $(0.10)$ & -0.04 & $(0.10)$ \\
\hline & OECD average & 48.1 & $(0.2)$ & 38.6 & $(0.1)$ & 13.3 & $(0.1)$ & 7.31 & $(0.01)$ & 7.32 & $(0.02)$ & 0.00 & $(0.02)$ & 0.00 & $(0.02)$ \\
\hline
\end{tabular}

\begin{tabular}{|c|c|c|c|c|c|c|c|c|c|c|c|c|c|c|}
\hline Albania & $\mathrm{m}$ & $\mathrm{m}$ & $\mathrm{m}$ & $\mathrm{m}$ & $\mathrm{m}$ & $\mathrm{m}$ & $\mathrm{m}$ & $\mathrm{m}$ & $\mathrm{m}$ & $\mathrm{m}$ & $\mathrm{m}$ & $\mathrm{m}$ & $\mathrm{m}$ & $\mathrm{m}$ \\
\hline Algeria & $\mathrm{m}$ & $\mathrm{m}$ & $\mathrm{m}$ & $\mathrm{m}$ & $\mathrm{m}$ & $\mathrm{m}$ & $\mathrm{m}$ & $\mathrm{m}$ & $\mathrm{m}$ & $\mathrm{m}$ & $\mathrm{m}$ & $\mathrm{m}$ & $\mathrm{m}$ & $\mathrm{m}$ \\
\hline Brazil & 47.9 & $(0.9)$ & 30.9 & $(0.7)$ & 21.2 & $(0.7)$ & 7.50 & $(0.04)$ & 7.61 & $(0.07)$ & 0.10 & $(0.08)$ & 0.10 & $(0.08)$ \\
\hline B-S-J-G (China) & 21.3 & $(0.9)$ & 38.0 & $(0.8)$ & 40.7 & $(1.0)$ & 6.82 & $(0.04)$ & 6.83 & $(0.06)$ & 0.01 & $(0.06)$ & -0.02 & $(0.06)$ \\
\hline Bulgaria & 52.0 & $(1.0)$ & 34.5 & $(0.8)$ & 13.5 & $(0.6)$ & 7.38 & $(0.05)$ & 7.43 & $(0.10)$ & 0.04 & $(0.12)$ & 0.02 & $(0.12)$ \\
\hline CABA (Argentina) & $\mathrm{m}$ & $\mathrm{m}$ & $\mathrm{m}$ & $\mathrm{m}$ & $\mathrm{m}$ & $\mathrm{m}$ & $\mathrm{m}$ & $\mathrm{m}$ & $\mathrm{m}$ & $\mathrm{m}$ & $\mathrm{m}$ & $\mathrm{m}$ & $\mathrm{m}$ & $\mathrm{m}$ \\
\hline Colombia & 41.5 & $(0.9)$ & 40.1 & $(0.8)$ & 18.4 & $(0.6)$ & 7.85 & $(0.05)$ & 7.79 & $(0.08)$ & -0.05 & $(0.08)$ & -0.05 & $(0.08)$ \\
\hline Costa Rica & 31.2 & $(1.2)$ & 45.8 & $(0.9)$ & 23.0 & $(0.8)$ & 8.16 & $(0.04)$ & 8.28 & $(0.07)$ & 0.13 & $(0.08)$ & 0.12 & $(0.08)$ \\
\hline Croatia & 45.2 & $(0.8)$ & 37.6 & $(0.8)$ & 17.2 & $(0.6)$ & 7.90 & $(0.04)$ & 7.88 & $(0.08)$ & -0.02 & $(0.08)$ & -0.03 & $(0.08)$ \\
\hline Cyprus* & 44.4 & $(0.7)$ & 39.0 & $(0.6)$ & 16.6 & $(0.6)$ & 7.10 & $(0.04)$ & 7.03 & $(0.10)$ & -0.07 & $(0.10)$ & -0.08 & $(0.10)$ \\
\hline Dominican Republic & 39.3 & (1.5) & 32.8 & (1.3) & 27.9 & (1.3) & 8.39 & $(0.06)$ & 8.49 & $(0.09)$ & 0.10 & $(0.10)$ & 0.09 & $(0.10)$ \\
\hline FYROM & $\mathrm{m}$ & $\mathrm{m}$ & $\mathrm{m}$ & $\mathrm{m}$ & $\mathrm{m}$ & $\mathrm{m}$ & $\mathrm{m}$ & $\mathrm{m}$ & $\mathrm{m}$ & $\mathrm{m}$ & $\mathrm{m}$ & $\mathrm{m}$ & $\mathrm{m}$ & $\mathrm{m}$ \\
\hline Georgia & $\mathrm{m}$ & $\mathrm{m}$ & $\mathrm{m}$ & $\mathrm{m}$ & $\mathrm{m}$ & $\mathrm{m}$ & $\mathrm{m}$ & $\mathrm{m}$ & $\mathrm{m}$ & $\mathrm{m}$ & $\mathrm{m}$ & $\mathrm{m}$ & $\mathrm{m}$ & $\mathrm{m}$ \\
\hline Hong Kong (China) & 44.5 & (1.1) & 37.7 & $(0.9)$ & 17.8 & $(0.7)$ & 6.52 & $(0.04)$ & 6.50 & $(0.08)$ & -0.01 & $(0.08)$ & -0.04 & $(0.08)$ \\
\hline Indonesia & $\mathrm{m}$ & $\mathrm{m}$ & $\mathrm{m}$ & $\mathrm{m}$ & $\mathrm{m}$ & $\mathrm{m}$ & $\mathrm{m}$ & $\mathrm{m}$ & $\mathrm{m}$ & $\mathrm{m}$ & $\mathrm{m}$ & $\mathrm{m}$ & $\mathrm{m}$ & $\mathrm{m}$ \\
\hline Jordan & $\mathrm{m}$ & $\mathrm{m}$ & $\mathrm{m}$ & $\mathrm{m}$ & $\mathrm{m}$ & $\mathrm{m}$ & $\mathrm{m}$ & $\mathrm{m}$ & $\mathrm{m}$ & $\mathrm{m}$ & $\mathrm{m}$ & $\mathrm{m}$ & $\mathrm{m}$ & $\mathrm{m}$ \\
\hline Kosovo & $\mathrm{m}$ & $\mathrm{m}$ & $\mathrm{m}$ & $\mathrm{m}$ & $\mathrm{m}$ & $\mathrm{m}$ & $\mathrm{m}$ & $\mathrm{m}$ & $\mathrm{m}$ & $\mathrm{m}$ & $\mathrm{m}$ & $\mathrm{m}$ & $\mathrm{m}$ & $\mathrm{m}$ \\
\hline Lebanon & $\mathrm{m}$ & $\mathrm{m}$ & $\mathrm{m}$ & $\mathrm{m}$ & $\mathrm{m}$ & $\mathrm{m}$ & $\mathrm{m}$ & $\mathrm{m}$ & $\mathrm{m}$ & $\mathrm{m}$ & $\mathrm{m}$ & $\mathrm{m}$ & $\mathrm{m}$ & $\mathrm{m}$ \\
\hline Lithuania & 51.4 & $(0.8)$ & 37.0 & $(0.8)$ & 11.5 & $(0.5)$ & 7.84 & $(0.04)$ & 7.99 & $(0.09)$ & 0.13 & $(0.10)$ & 0.14 & $(0.10)$ \\
\hline Macao (China) & 47.8 & $(0.7)$ & 37.3 & $(0.7)$ & 14.8 & $(0.5)$ & 6.64 & $(0.03)$ & 6.37 & $(0.10)$ & -0.28 & $(0.10)$ & -0.32 & $(0.10)$ \\
\hline Malta & $\mathrm{m}$ & $\mathrm{m}$ & $\mathrm{m}$ & $\mathrm{m}$ & $\mathrm{m}$ & $\mathrm{m}$ & $\mathrm{m}$ & $\mathrm{m}$ & $\mathrm{m}$ & $\mathrm{m}$ & $\mathrm{m}$ & $\mathrm{m}$ & $\mathrm{m}$ & $\mathrm{m}$ \\
\hline Moldova & $\mathrm{m}$ & $\mathrm{m}$ & $\mathrm{m}$ & $\mathrm{m}$ & $\mathrm{m}$ & $\mathrm{m}$ & $\mathrm{m}$ & $\mathrm{m}$ & $\mathrm{m}$ & $\mathrm{m}$ & $\mathrm{m}$ & $\mathrm{m}$ & $\mathrm{m}$ & $\mathrm{m}$ \\
\hline Montenegro & 39.8 & $(0.7)$ & 35.4 & $(0.8)$ & 24.8 & $(0.7)$ & 7.64 & $(0.05)$ & 7.81 & $(0.07)$ & 0.17 & $(0.09)$ & 0.17 & $(0.09)$ \\
\hline Peru & 29.5 & $(0.9)$ & 46.1 & $(0.8)$ & 24.4 & $(0.8)$ & 7.51 & $(0.05)$ & 7.71 & $(0.07)$ & 0.19 & $(0.08)$ & 0.20 & $(0.08)$ \\
\hline Qatar & 26.1 & $(0.5)$ & 41.3 & $(0.5)$ & 32.6 & $(0.5)$ & 7.37 & $(0.04)$ & 7.22 & $(0.05)$ & -0.14 & $(0.07)$ & -0.14 & $(0.07)$ \\
\hline Romania & $\mathrm{m}$ & $\mathrm{m}$ & $\mathrm{m}$ & $\mathrm{m}$ & $\mathrm{m}$ & $\mathrm{m}$ & $\mathrm{m}$ & $\mathrm{m}$ & $\mathrm{m}$ & $\mathrm{m}$ & $\mathrm{m}$ & $\mathrm{m}$ & $\mathrm{m}$ & $\mathrm{m}$ \\
\hline Russia & 36.3 & (1.1) & 39.7 & (1.1) & 24.0 & $(0.9)$ & 7.78 & $(0.04)$ & 7.74 & $(0.06)$ & -0.03 & $(0.07)$ & -0.04 & $(0.07)$ \\
\hline Singapore & 27.5 & $(0.7)$ & 47.7 & $(0.7)$ & 24.8 & $(0.7)$ & $\mathrm{m}$ & $\mathrm{m}$ & $\mathrm{m}$ & $\mathrm{m}$ & $\mathrm{m}$ & $\mathrm{m}$ & $\mathrm{m}$ & $\mathrm{m}$ \\
\hline Chinese Taipei & 33.8 & $(0.9)$ & 45.8 & $(0.7)$ & 20.3 & $(0.6)$ & 6.57 & $(0.03)$ & 6.73 & $(0.06)$ & 0.16 & $(0.07)$ & 0.07 & $(0.07)$ \\
\hline Thailand & 21.0 & $(1.0)$ & 45.7 & $(1.0)$ & 33.3 & $(1.2)$ & 7.63 & $(0.06)$ & 7.57 & $(0.07)$ & -0.05 & $(0.09)$ & -0.05 & $(0.08)$ \\
\hline Trinidad and Tobago & $\mathrm{m}$ & $\mathrm{m}$ & $\mathrm{m}$ & $\mathrm{m}$ & $\mathrm{m}$ & $\mathrm{m}$ & $\mathrm{m}$ & $\mathrm{m}$ & $\mathrm{m}$ & $\mathrm{m}$ & $\mathrm{m}$ & $\mathrm{m}$ & $\mathrm{m}$ & $\mathrm{m}$ \\
\hline Tunisia & 22.6 & $(0.9)$ & 42.9 & $(1.0)$ & 34.5 & $(1.1)$ & 6.93 & $(0.07)$ & 6.87 & $(0.09)$ & -0.06 & $(0.11)$ & -0.06 & $(0.11)$ \\
\hline United Arab Emirates & 17.6 & $(0.5)$ & 40.0 & $(0.7)$ & 42.4 & $(0.8)$ & 7.34 & $(0.04)$ & 7.28 & $(0.05)$ & -0.06 & $(0.06)$ & -0.05 & $(0.06)$ \\
\hline Uruguay & 58.2 & $(1.0)$ & 29.8 & $(0.9)$ & 12.1 & $(0.7)$ & 7.70 & $(0.05)$ & 7.81 & $(0.13)$ & 0.10 & $(0.14)$ & 0.11 & $(0.14)$ \\
\hline Viet Nam & $\mathrm{m}$ & $\mathrm{m}$ & $\mathrm{m}$ & $\mathrm{m}$ & $\mathrm{m}$ & $\mathrm{m}$ & $\mathrm{m}$ & $\mathrm{m}$ & $\mathrm{m}$ & $\mathrm{m}$ & $\mathrm{m}$ & $\mathrm{m}$ & $\mathrm{m}$ & $\mathrm{m}$ \\
\hline Argentina** & $\mathrm{m}$ & $\mathrm{m}$ & $\mathrm{m}$ & $\mathrm{m}$ & $\mathrm{m}$ & $\mathrm{m}$ & $\mathrm{m}$ & $\mathrm{m}$ & $\mathrm{m}$ & $\mathrm{m}$ & $\mathrm{m}$ & $\mathrm{m}$ & $\mathrm{m}$ & $\mathrm{m}$ \\
\hline Kazakhstan** & $\mathrm{m}$ & $\mathrm{m}$ & $\mathrm{m}$ & $\mathrm{m}$ & $\mathrm{m}$ & $\mathrm{m}$ & $\mathrm{m}$ & $\mathrm{m}$ & $\mathrm{m}$ & $\mathrm{m}$ & $\mathrm{m}$ & $\mathrm{m}$ & $\mathrm{m}$ & $\mathrm{m}$ \\
\hline Malaysia** & 29.3 & $(1.1)$ & 45.5 & (1.1) & 25.2 & $(1.0)$ & 6.98 & $(0.04)$ & 7.15 & $(0.07)$ & 0.17 & $(0.07)$ & 0.16 & $(0.07)$ \\
\hline
\end{tabular}

Note: Values that are statistically significant are indicated in bold (see Annex A3)

* See note at the beginning of this Annex.

** Coverage is too small to ensure comparability (see Annex A4).

StatLink त्नाडs http://dx.doi.org/10.1787/888933470535 
[Part 1/2]

Table III.3.8 Students' satisfaction with life, by gender

Results based on students' self-reports

\begin{tabular}{|c|c|c|c|c|c|c|c|c|c|c|c|c|c|c|c|c|}
\hline & \multicolumn{8}{|c|}{ Percentage of students who reported the following feelings about their life: } & \multicolumn{8}{|c|}{ Percentage of boys who reported the following feelings about their life: } \\
\hline & \multicolumn{2}{|c|}{$\begin{array}{c}\text { Not satisfied } \\
\text { (Students who } \\
\text { reported } \\
\text { 0 to } 4 \text { on the life } \\
\text { satisfaction scale) }\end{array}$} & \multicolumn{2}{|c|}{$\begin{array}{c}\text { Moderately } \\
\text { satisfied } \\
\text { (Students who } \\
\text { reported } \\
5 \text { or } 6 \text { on the life } \\
\text { satisfaction scale) }\end{array}$} & \multicolumn{2}{|c|}{$\begin{array}{c}\text { Satisfied } \\
\text { (Students who } \\
\text { reported } \\
7 \text { or } 8 \text { on the life } \\
\text { satisfaction scale) }\end{array}$} & \multicolumn{2}{|c|}{$\begin{array}{c}\text { Very satisfied } \\
\text { (Students who } \\
\text { reported } \\
9 \text { or } 10 \text { on the life } \\
\text { satisfaction scale) }\end{array}$} & \multicolumn{2}{|c|}{$\begin{array}{c}\text { Not satisfied } \\
\text { (Students who } \\
\text { reported } \\
0 \text { to } 4 \text { on the life } \\
\text { satisfaction scale) }\end{array}$} & \multicolumn{2}{|c|}{$\begin{array}{c}\text { Moderately } \\
\text { satisfied } \\
\text { (Students who } \\
\text { reported } \\
5 \text { or } 6 \text { on the life } \\
\text { satisfaction scale) }\end{array}$} & \multicolumn{2}{|c|}{$\begin{array}{c}\text { Satisfied } \\
\text { (Students who } \\
\text { reported } \\
7 \text { or } 8 \text { on the life } \\
\text { satisfaction scale) }\end{array}$} & \multicolumn{2}{|c|}{$\begin{array}{c}\text { Very satisfied } \\
\text { (Students who } \\
\text { reported } \\
9 \text { or } 10 \text { on the life } \\
\text { satisfaction scale) }\end{array}$} \\
\hline & $\%$ & S.E. & $\%$ & S.E. & $\%$ & S.E. & $\%$ & S.E. & $\%$ & S.E. & $\%$ & S.E. & $\%$ & S.E. & $\%$ & S.E. \\
\hline Australia & $\mathrm{m}$ & $\mathrm{m}$ & $\mathrm{m}$ & $\mathrm{m}$ & $\mathrm{m}$ & $\mathrm{m}$ & $\mathrm{m}$ & $\mathrm{m}$ & $\mathrm{m}$ & $\mathrm{m}$ & $\mathrm{m}$ & $\mathrm{m}$ & $\mathrm{m}$ & $\mathrm{m}$ & $\mathrm{m}$ & $\mathrm{m}$ \\
\hline ¿ Austria & 11.1 & $(0.5)$ & 13.4 & $(0.5)$ & 35.8 & (0.6) & 39.7 & $(0.8)$ & 7.1 & $(0.5)$ & 9.6 & $(0.6)$ & 36.1 & $(0.9)$ & 47.2 & (1.1) \\
\hline$\overline{0}$ Belgium (excl. Flemish) & 8.3 & (0.6) & 15.7 & $(0.6)$ & 43.2 & (1.1) & 32.8 & (1.1) & 6.1 & $(0.6)$ & 12.9 & $(0.9)$ & 43.3 & (1.6) & 37.7 & (1.6) \\
\hline Canada & $\mathrm{m}$ & $\mathrm{m}$ & $\mathrm{m}$ & $\mathrm{m}$ & $\mathrm{m}$ & $\mathrm{m}$ & $\mathrm{m}$ & $\mathrm{m}$ & $\mathrm{m}$ & $\mathrm{m}$ & $\mathrm{m}$ & $\mathrm{m}$ & $\mathrm{m}$ & $\mathrm{m}$ & $\mathrm{m}$ & $\mathrm{m}$ \\
\hline Chile & 12.0 & $(0.5)$ & 17.9 & $(0.6)$ & 32.0 & $(0.7)$ & 38.1 & $(0.8)$ & 9.2 & $(0.6)$ & 16.0 & $(0.9)$ & 34.4 & (1.0) & 40.4 & $(1.0)$ \\
\hline Czech Republic & 13.8 & $(0.6)$ & 20.3 & $(0.5)$ & 35.3 & $(0.7)$ & 30.6 & $(0.7)$ & 11.1 & $(0.6)$ & 17.2 & $(0.8)$ & 36.3 & (1.1) & 35.4 & (1.1) \\
\hline Denmark & $\mathrm{m}$ & $\mathrm{m}$ & $\mathrm{m}$ & $\mathrm{m}$ & $\mathrm{m}$ & $\mathrm{m}$ & $\mathrm{m}$ & $\mathrm{m}$ & $\mathrm{m}$ & $\mathrm{m}$ & $\mathrm{m}$ & $\mathrm{m}$ & $\mathrm{m}$ & $\mathrm{m}$ & $\mathrm{m}$ & $\mathrm{m}$ \\
\hline Estonia & 9.3 & $(0.5)$ & 16.2 & $(0.6)$ & 37.6 & $(0.8)$ & 36.9 & $(0.9)$ & 7.0 & $(0.5)$ & 14.6 & $(0.7)$ & 38.1 & (1.0) & 40.3 & $(1.2)$ \\
\hline Finland & 6.6 & $(0.3)$ & 10.2 & $(0.4)$ & 38.7 & $(0.7)$ & 44.4 & $(0.8)$ & 4.0 & $(0.4)$ & 7.4 & $(0.4)$ & 36.4 & $(0.9)$ & 52.2 & $(1.1)$ \\
\hline France & 7.4 & $(0.4)$ & 14.9 & $(0.5)$ & 41.1 & $(0.7)$ & 36.6 & $(0.7)$ & 6.5 & $(0.5)$ & 11.4 & $(0.6)$ & 40.7 & (0.9) & 41.5 & $(0.9)$ \\
\hline Germany & 11.1 & $(0.4)$ & 16.1 & $(0.4)$ & 38.9 & $(0.7)$ & 34.0 & $(0.7)$ & 7.9 & $(0.5)$ & 12.1 & $(0.6)$ & 39.2 & (0.9) & 40.9 & $(0.9)$ \\
\hline Greece & 14.7 & $(0.5)$ & 21.0 & $(0.6)$ & 38.1 & $(0.7)$ & 26.2 & $(0.7)$ & 11.3 & $(0.7)$ & 18.5 & $(0.7)$ & 39.1 & (0.9) & 31.0 & $(0.9)$ \\
\hline Hungary & 13.1 & $(0.5)$ & 17.4 & $(0.5)$ & 37.7 & $(0.8)$ & 31.7 & $(0.7)$ & 9.8 & $(0.7)$ & 14.7 & $(0.8)$ & 37.9 & (1.0) & 37.6 & (1.0) \\
\hline Iceland & 9.5 & $(0.5)$ & 11.6 & $(0.5)$ & 32.3 & $(0.8)$ & 46.7 & $(0.9)$ & 5.6 & $(0.6)$ & 7.8 & $(0.7)$ & 30.8 & (1.1) & 55.7 & $(1.2)$ \\
\hline Ireland & 11.9 & (0.4) & 15.7 & $(0.5)$ & 40.0 & $(0.7)$ & 32.4 & $(0.7)$ & 8.8 & $(0.5)$ & 13.3 & $(0.8)$ & 42.4 & (0.9) & 35.6 & $(0.9)$ \\
\hline Israel & $\mathrm{m}$ & $\mathrm{m}$ & $\mathrm{m}$ & $\mathrm{m}$ & $\mathrm{m}$ & $\mathrm{m}$ & $\mathrm{m}$ & $\mathrm{m}$ & $\mathrm{m}$ & $\mathrm{m}$ & $\mathrm{m}$ & $\mathrm{m}$ & $\mathrm{m}$ & $\mathrm{m}$ & $\mathrm{m}$ & $\mathrm{m}$ \\
\hline Italy & 14.7 & (0.6) & 20.4 & $(0.6)$ & 40.7 & $(0.7)$ & 24.2 & $(0.7)$ & 10.3 & $(0.6)$ & 16.6 & $(0.7)$ & 44.2 & (1.1) & 29.0 & $(1.0)$ \\
\hline Japan & 16.1 & (0.5) & 22.9 & $(0.4)$ & 37.3 & $(0.6)$ & 23.8 & (0.6) & 17.2 & $(0.8)$ & 22.5 & (0.6) & 36.9 & (0.9) & 23.5 & $(0.7)$ \\
\hline Korea & 21.6 & $(0.6)$ & 25.5 & $(0.6)$ & 34.2 & $(0.7)$ & 18.6 & $(0.5)$ & 19.9 & $(0.8)$ & 22.5 & $(0.8)$ & 34.7 & (0.9) & 22.9 & $(0.8)$ \\
\hline Latvia & 8.9 & $(0.5)$ & 18.2 & $(0.7)$ & 41.5 & $(0.7)$ & 31.5 & $(0.8)$ & 8.4 & $(0.7)$ & 17.3 & $(0.9)$ & 40.4 & $(1.0)$ & 33.9 & $(1.0)$ \\
\hline Luxembourg & 11.1 & $(0.5)$ & 16.6 & $(0.5)$ & 36.2 & $(0.6)$ & 36.1 & $(0.6)$ & 8.2 & $(0.5)$ & 12.3 & $(0.7)$ & 35.5 & $(1.0)$ & 43.9 & (1.0) \\
\hline Mexico & 6.4 & $(0.3)$ & 9.5 & $(0.4)$ & 25.7 & $(0.6)$ & 58.5 & $(0.7)$ & 5.8 & $(0.4)$ & 8.4 & $(0.5)$ & 26.6 & $(0.8)$ & 59.1 & $(0.8)$ \\
\hline Netherlands & 3.7 & $(0.3)$ & 10.6 & $(0.5)$ & 53.3 & $(0.7)$ & 32.5 & $(0.7)$ & 2.5 & $(0.3)$ & 7.9 & $(0.6)$ & 49.7 & $(1.0)$ & 39.9 & (1.1) \\
\hline New Zealand & $\mathrm{m}$ & $\mathrm{m}$ & $\mathrm{m}$ & $\mathrm{m}$ & $\mathrm{m}$ & $\mathrm{m}$ & $\mathrm{m}$ & $\mathrm{m}$ & $\mathrm{m}$ & $\mathrm{m}$ & $\mathrm{m}$ & $\mathrm{m}$ & $\mathrm{m}$ & $\mathrm{m}$ & $\mathrm{m}$ & $\mathrm{m}$ \\
\hline Norway & $\mathrm{m}$ & $\mathrm{m}$ & $\mathrm{m}$ & $\mathrm{m}$ & $\mathrm{m}$ & $\mathrm{m}$ & $\mathrm{m}$ & $\mathrm{m}$ & $\mathrm{m}$ & $\mathrm{m}$ & $\mathrm{m}$ & $\mathrm{m}$ & $\mathrm{m}$ & $\mathrm{m}$ & $\mathrm{m}$ & $\mathrm{m}$ \\
\hline Poland & 12.6 & $(0.5)$ & 18.7 & $(0.6)$ & 36.3 & $(0.8)$ & 32.4 & $(0.8)$ & 9.3 & $(0.6)$ & 15.8 & $(0.8)$ & 37.5 & (1.1) & 37.4 & (1.1) \\
\hline Portugal & 8.9 & $(0.4)$ & 18.7 & $(0.5)$ & 41.4 & $(0.6)$ & 31.0 & $(0.7)$ & 7.1 & $(0.6)$ & 15.2 & $(0.6)$ & 42.1 & $(0.8)$ & 35.6 & $(0.9)$ \\
\hline Slovak Republic & 11.3 & $(0.4)$ & 16.5 & $(0.5)$ & 32.8 & $(0.6)$ & 39.4 & (0.6) & 8.9 & $(0.6)$ & 14.1 & $(0.6)$ & 32.4 & (0.9) & 44.6 & $(1.0)$ \\
\hline Slovenia & 13.5 & $(0.6)$ & 17.7 & $(0.6)$ & 36.3 & $(0.9)$ & 32.5 & $(0.7)$ & 9.1 & $(0.7)$ & 13.8 & $(0.7)$ & 37.5 & $(1.2)$ & 39.6 & $(1.1)$ \\
\hline Spain & 9.5 & $(0.4)$ & 16.0 & $(0.5)$ & 41.5 & $(0.6)$ & 33.0 & $(0.7)$ & 8.2 & $(0.5)$ & 13.9 & $(0.6)$ & 41.7 & (0.9) & 36.2 & $(0.9)$ \\
\hline Sweden & $\mathrm{m}$ & $\mathrm{m}$ & $\mathrm{m}$ & $\mathrm{m}$ & $\mathrm{m}$ & $\mathrm{m}$ & $\mathrm{m}$ & $\mathrm{m}$ & $\mathrm{m}$ & $\mathrm{m}$ & $\mathrm{m}$ & $\mathrm{m}$ & $\mathrm{m}$ & $\mathrm{m}$ & $\mathrm{m}$ & $\mathrm{m}$ \\
\hline Switzerland & 7.4 & $(0.4)$ & 13.1 & $(0.5)$ & 39.9 & $(0.9)$ & 39.6 & $(0.8)$ & 5.5 & $(0.5)$ & 9.1 & $(0.6)$ & 39.7 & (1.1) & 45.7 & $(1.1)$ \\
\hline Turkey & 28.6 & $(0.7)$ & 22.6 & $(0.6)$ & 22.5 & $(0.6)$ & 26.2 & $(0.9)$ & 24.3 & $(0.8)$ & 22.6 & $(0.9)$ & 24.8 & $(0.9)$ & 28.2 & $(1.3)$ \\
\hline United Kingdom & 15.6 & (0.5) & 18.6 & $(0.6)$ & 37.4 & $(0.7)$ & 28.3 & $(0.7)$ & 11.9 & $(0.5)$ & 16.4 & $(0.7)$ & 38.6 & (0.9) & 33.0 & $(0.9)$ \\
\hline United States & 11.8 & $(0.4)$ & 17.6 & $(0.5)$ & 34.8 & $(0.6)$ & 35.9 & $(0.8)$ & 9.1 & $(0.6)$ & 14.3 & $(0.7)$ & 35.6 & (1.0) & 41.0 & (1.1) \\
\hline OECD average & 11.8 & $(0.1)$ & 16.9 & $(0.1)$ & 37.2 & $(0.1)$ & 34.1 & $(0.1)$ & 9.3 & $(0.1)$ & 14.2 & $(0.1)$ & 37.6 & $(0.2)$ & 38.9 & $(0.2)$ \\
\hline
\end{tabular}

\begin{tabular}{|c|c|c|c|c|c|c|c|c|c|c|c|c|c|c|c|c|c|}
\hline \multirow{4}{*}{ 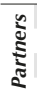 } & Albania & $\mathrm{m}$ & $\mathrm{m}$ & $\mathrm{m}$ & $\mathrm{m}$ & $\mathrm{m}$ & $\mathrm{m}$ & $\mathrm{m}$ & $\mathrm{m}$ & $\mathrm{m}$ & $\mathrm{m}$ & $\mathrm{m}$ & $\mathrm{m}$ & $\mathrm{m}$ & $\mathrm{m}$ & $\mathrm{m}$ & $\mathrm{m}$ \\
\hline & Algeria & $\mathrm{m}$ & $\mathrm{m}$ & $\mathrm{m}$ & $\mathrm{m}$ & $\mathrm{m}$ & $\mathrm{m}$ & $\mathrm{m}$ & $\mathrm{m}$ & $\mathrm{m}$ & $\mathrm{m}$ & $\mathrm{m}$ & $\mathrm{m}$ & $\mathrm{m}$ & $\mathrm{m}$ & $\mathrm{m}$ & $\mathrm{m}$ \\
\hline & Brazil & 11.8 & $(0.3)$ & 15.5 & $(0.4)$ & 28.1 & $(0.4)$ & 44.6 & $(0.5)$ & 10.5 & (0.4) & 14.1 & $(0.4)$ & 28.7 & $(0.6)$ & 46.7 & $(0.6)$ \\
\hline & B-S-J-G (China) & 15.6 & (0.5) & 25.1 & $(0.6)$ & 32.4 & $(0.7)$ & 26.9 & $(0.8)$ & 15.0 & $(0.6)$ & 24.7 & $(0.8)$ & 33.2 & (1.0) & 27.2 & (1.0) \\
\hline & Bulgaria & 13.9 & (0.6) & 16.7 & $(0.5)$ & 26.6 & $(0.7)$ & 42.8 & $(0.7)$ & 12.0 & $(0.7)$ & 15.6 & $(0.8)$ & 26.0 & (1.0) & 46.4 & (1.0) \\
\hline & CABA (Argentina) & $\mathrm{m}$ & $\mathrm{m}$ & $\mathrm{m}$ & $\mathrm{m}$ & $\mathrm{m}$ & $\mathrm{m}$ & $\mathrm{m}$ & $\mathrm{m}$ & $\mathrm{m}$ & $\mathrm{m}$ & $\mathrm{m}$ & $\mathrm{m}$ & $\mathrm{m}$ & $\mathrm{m}$ & $\mathrm{m}$ & $\mathrm{m}$ \\
\hline & Colombia & 10.1 & $(0.4)$ & 13.0 & $(0.4)$ & 26.0 & $(0.7)$ & 50.8 & $(0.9)$ & 8.5 & $(0.5)$ & 11.3 & (0.6) & 25.9 & $(0.9)$ & 54.3 & $(0.9)$ \\
\hline & Costa Rica & 7.1 & $(0.4)$ & 11.0 & $(0.4)$ & 23.5 & $(0.7)$ & 58.4 & $(0.9)$ & 6.0 & $(0.5)$ & 9.8 & $(0.6)$ & 22.7 & $(0.9)$ & 61.6 & (1.1) \\
\hline & Croatia & 7.3 & $(0.4)$ & 12.2 & $(0.4)$ & 32.7 & (0.6) & 47.8 & $(0.8)$ & 5.1 & $(0.5)$ & 9.3 & $(0.7)$ & 32.1 & $(1.0)$ & 53.6 & (1.2) \\
\hline & Cyprus* & 13.7 & $(0.5)$ & 19.7 & $(0.5)$ & 36.5 & $(0.6)$ & 30.1 & $(0.6)$ & 12.2 & $(0.6)$ & 18.0 & $(0.7)$ & 34.6 & $(0.8)$ & 35.1 & (0.9) \\
\hline & Dominican Republic & 8.3 & $(0.5)$ & 8.3 & $(0.5)$ & 15.7 & (0.6) & 67.8 & $(0.8)$ & 8.0 & $(0.7)$ & 8.1 & $(0.7)$ & 14.7 & (1.0) & 69.2 & (1.1) \\
\hline & FYROM & $\mathrm{m}$ & $\mathrm{m}$ & $\mathrm{m}$ & $\mathrm{m}$ & $\mathrm{m}$ & $\mathrm{m}$ & $\mathrm{m}$ & $\mathrm{m}$ & $\mathrm{m}$ & $\mathrm{m}$ & $\mathrm{m}$ & $\mathrm{m}$ & $\mathrm{m}$ & $\mathrm{m}$ & $\mathrm{m}$ & $\mathrm{m}$ \\
\hline & Georgia & $\mathrm{m}$ & $\mathrm{m}$ & $\mathrm{m}$ & $\mathrm{m}$ & $\mathrm{m}$ & $\mathrm{m}$ & $\mathrm{m}$ & $\mathrm{m}$ & $\mathrm{m}$ & $\mathrm{m}$ & $\mathrm{m}$ & $\mathrm{m}$ & $\mathrm{m}$ & $\mathrm{m}$ & $\mathrm{m}$ & $\mathrm{m}$ \\
\hline & Hong Kong (China) & 15.6 & $(0.7)$ & 28.8 & $(0.7)$ & 41.7 & $(0.9)$ & 13.9 & $(0.5)$ & 16.9 & $(0.9)$ & 27.2 & (1.0) & 38.4 & (1.1) & 17.5 & $(0.7)$ \\
\hline & Indonesia & $\mathrm{m}$ & $\mathrm{m}$ & $\mathrm{m}$ & $\mathrm{m}$ & $\mathrm{m}$ & $\mathrm{m}$ & $\mathrm{m}$ & $\mathrm{m}$ & $\mathrm{m}$ & $\mathrm{m}$ & $\mathrm{m}$ & $\mathrm{m}$ & $\mathrm{m}$ & $\mathrm{m}$ & $\mathrm{m}$ & $\mathrm{m}$ \\
\hline & Jordan & $\mathrm{m}$ & $\mathrm{m}$ & $\mathrm{m}$ & $\mathrm{m}$ & $\mathrm{m}$ & $\mathrm{m}$ & $\mathrm{m}$ & $\mathrm{m}$ & $\mathrm{m}$ & $\mathrm{m}$ & $\mathrm{m}$ & $\mathrm{m}$ & $\mathrm{m}$ & $\mathrm{m}$ & $\mathrm{m}$ & $\mathrm{m}$ \\
\hline & Kosovo & $\mathrm{m}$ & $\mathrm{m}$ & $\mathrm{m}$ & $\mathrm{m}$ & $\mathrm{m}$ & $\mathrm{m}$ & $\mathrm{m}$ & $\mathrm{m}$ & $\mathrm{m}$ & $\mathrm{m}$ & $\mathrm{m}$ & $\mathrm{m}$ & $\mathrm{m}$ & $\mathrm{m}$ & $\mathrm{m}$ & $\mathrm{m}$ \\
\hline & Lebanon & $\mathrm{m}$ & $\mathrm{m}$ & $\mathrm{m}$ & $\mathrm{m}$ & $\mathrm{m}$ & $\mathrm{m}$ & $\mathrm{m}$ & $\mathrm{m}$ & $\mathrm{m}$ & $\mathrm{m}$ & $\mathrm{m}$ & $\mathrm{m}$ & $\mathrm{m}$ & $\mathrm{m}$ & $\mathrm{m}$ & $\mathrm{m}$ \\
\hline & Lithuania & 8.1 & $(0.4)$ & 12.8 & $(0.5)$ & 31.5 & $(0.7)$ & 47.6 & $(0.8)$ & 6.6 & $(0.5)$ & 10.4 & $(0.6)$ & 29.5 & $(1.0)$ & 53.4 & (1.1) \\
\hline & Macao (China) & 15.4 & (0.6) & 26.7 & $(0.8)$ & 41.3 & (0.9) & 16.5 & $(0.5)$ & 15.5 & $(0.9)$ & 27.2 & (1.1) & 39.8 & (1.0) & 17.5 & $(0.8)$ \\
\hline & Malta & $\mathrm{m}$ & $\mathrm{m}$ & $\mathrm{m}$ & $\mathrm{m}$ & $\mathrm{m}$ & $\mathrm{m}$ & $\mathrm{m}$ & $\mathrm{m}$ & $\mathrm{m}$ & $\mathrm{m}$ & $\mathrm{m}$ & $\mathrm{m}$ & $\mathrm{m}$ & $\mathrm{m}$ & $\mathrm{m}$ & $\mathrm{m}$ \\
\hline & Moldova & $\mathrm{m}$ & $\mathrm{m}$ & $\mathrm{m}$ & $\mathrm{m}$ & $\mathrm{m}$ & $\mathrm{m}$ & $\mathrm{m}$ & $\mathrm{m}$ & $\mathrm{m}$ & $\mathrm{m}$ & $\mathrm{m}$ & $\mathrm{m}$ & $\mathrm{m}$ & $\mathrm{m}$ & $\mathrm{m}$ & $\mathrm{m}$ \\
\hline & Montenegro & 11.1 & $(0.4)$ & 14.6 & $(0.5)$ & 24.3 & (0.6) & 50.1 & $(0.7)$ & 9.5 & $(0.6)$ & 12.2 & (0.6) & 23.8 & $(0.8)$ & 54.5 & $(0.8)$ \\
\hline & Peru & 12.9 & $(0.5)$ & 16.2 & $(0.4)$ & 28.2 & $(0.6)$ & 42.8 & $(0.8)$ & 12.1 & $(0.6)$ & 15.5 & $(0.7)$ & 29.3 & $(0.8)$ & 43.2 & $(0.9)$ \\
\hline & Qatar & 13.8 & $(0.3)$ & 17.0 & $(0.3)$ & 26.6 & $(0.4)$ & 42.6 & $(0.4)$ & 12.8 & $(0.4)$ & 15.7 & $(0.5)$ & 27.5 & $(0.6)$ & 44.0 & $(0.6)$ \\
\hline & Romania & $\mathrm{m}$ & $\mathrm{m}$ & $\mathrm{m}$ & $\mathrm{m}$ & $\mathrm{m}$ & $\mathrm{m}$ & $\mathrm{m}$ & $\mathrm{m}$ & $\mathrm{m}$ & $\mathrm{m}$ & $\mathrm{m}$ & $\mathrm{m}$ & $\mathrm{m}$ & $\mathrm{m}$ & $\mathrm{m}$ & $\mathrm{m}$ \\
\hline & Russia & 10.3 & $(0.5)$ & 14.4 & $(0.5)$ & 28.5 & $(0.7)$ & 46.8 & $(0.8)$ & 8.5 & $(0.6)$ & 13.1 & $(0.7)$ & 29.8 & $(1.2)$ & 48.6 & (1.1) \\
\hline & Singapore & $\mathrm{m}$ & $\mathrm{m}$ & $\mathrm{m}$ & $\mathrm{m}$ & $\mathrm{m}$ & $\mathrm{m}$ & $\mathrm{m}$ & $\mathrm{m}$ & $\mathrm{m}$ & $\mathrm{m}$ & $\mathrm{m}$ & $\mathrm{m}$ & $\mathrm{m}$ & $\mathrm{m}$ & $\mathrm{m}$ & $\mathrm{m}$ \\
\hline & Chinese Taipei & 16.0 & $(0.5)$ & 28.2 & $(0.6)$ & 37.4 & $(0.6)$ & 18.5 & $(0.5)$ & 15.0 & $(0.7)$ & 26.1 & $(0.7)$ & 37.5 & $(0.9)$ & 21.4 & $(0.8)$ \\
\hline & Thailand & 7.8 & $(0.5)$ & 18.1 & (0.6) & 31.5 & (0.8) & 42.7 & $(0.8)$ & 8.5 & $(0.7)$ & 18.0 & (0.8) & 29.4 & $(1.2)$ & 44.2 & (1.3) \\
\hline & Trinidad and Tobago & $\mathrm{m}$ & $\mathrm{m}$ & $\mathrm{m}$ & $\mathrm{m}$ & $\mathrm{m}$ & $\mathrm{m}$ & $\mathrm{m}$ & $\mathrm{m}$ & $\mathrm{m}$ & $\mathrm{m}$ & $\mathrm{m}$ & $\mathrm{m}$ & $\mathrm{m}$ & $\mathrm{m}$ & $\mathrm{m}$ & $\mathrm{m}$ \\
\hline & Tunisia & 19.3 & $(0.6)$ & 20.4 & $(0.7)$ & 21.8 & $(0.6)$ & 38.5 & $(0.8)$ & 17.9 & $(0.9)$ & 20.0 & (1.0) & 24.0 & $(1.0)$ & 38.1 & (1.1) \\
\hline & United Arab Emirates & 14.5 & $(0.4)$ & 18.5 & $(0.4)$ & 27.2 & (0.6) & 39.8 & $(0.6)$ & 13.4 & $(0.7)$ & 16.7 & $(0.7)$ & 27.6 & $(0.9)$ & 42.3 & $(0.8)$ \\
\hline & Uruguay & 9.8 & $(0.4)$ & 14.5 & $(0.5)$ & 31.5 & $(0.5)$ & 44.2 & $(0.7)$ & 7.6 & $(0.5)$ & 13.2 & (0.6) & 31.0 & $(0.9)$ & 48.1 & (0.9) \\
\hline & Viet Nam & $\mathrm{m}$ & $\mathrm{m}$ & $\mathrm{m}$ & $\mathrm{m}$ & $\mathrm{m}$ & $\mathrm{m}$ & $\mathrm{m}$ & $\mathrm{m}$ & $\mathrm{m}$ & $\mathrm{m}$ & $\mathrm{m}$ & $\mathrm{m}$ & $\mathrm{m}$ & $\mathrm{m}$ & $\mathrm{m}$ & $\mathrm{m}$ \\
\hline & Argentina** & $\mathrm{m}$ & $\mathrm{m}$ & $\mathrm{m}$ & $\mathrm{m}$ & $\mathrm{m}$ & $\mathrm{m}$ & $\mathrm{m}$ & $\mathrm{m}$ & $\mathrm{m}$ & $\mathrm{m}$ & $\mathrm{m}$ & $\mathrm{m}$ & $\mathrm{m}$ & $\mathrm{m}$ & $\mathrm{m}$ & $\mathrm{m}$ \\
\hline & Kazakhstan** & $\mathrm{m}$ & $\mathrm{m}$ & $\mathrm{m}$ & $\mathrm{m}$ & $\mathrm{m}$ & $\mathrm{m}$ & $\mathrm{m}$ & $\mathrm{m}$ & $\mathrm{m}$ & $\mathrm{m}$ & $\mathrm{m}$ & $\mathrm{m}$ & $\mathrm{m}$ & $\mathrm{m}$ & $\mathrm{m}$ & $\mathrm{m}$ \\
\hline & Malaysia** & 11.0 & (0.5) & 27.5 & (0.6) & 31.6 & $(0.7)$ & 29.9 & (0.8) & 10.9 & $(0.7)$ & 26.2 & (0.8) & 31.7 & (1.0) & 31.1 & (1.1) \\
\hline
\end{tabular}

Note: Values that are statistically significant are indicated in bold (see Annex A3).

* See note at the beginning of this Annex.

** Coverage is too small to ensure comparability (see Annex A4).

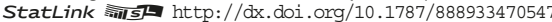


Results based on students' self-reports

\begin{tabular}{|c|c|c|c|c|c|c|c|c|c|c|c|c|c|c|c|c|c|}
\hline & \multicolumn{8}{|c|}{ Percentage of girls who reported the following feelings about their life: } & \multicolumn{8}{|c|}{ Difference between boys and girls (B - G): } \\
\hline & & \multicolumn{2}{|c|}{$\begin{array}{c}\text { Not satisfied } \\
\text { (Students who } \\
\text { reported } \\
0 \text { to } 4 \text { on the life } \\
\text { satisfaction scale) }\end{array}$} & \multicolumn{2}{|c|}{\begin{tabular}{|c|}
$\begin{array}{c}\text { Moderately } \\
\text { satisfied } \\
\text { (Students who } \\
\text { reported } \\
5 \text { or } 6 \text { on the life } \\
\text { satisfaction scale) }\end{array}$ \\
\end{tabular}} & \multicolumn{2}{|c|}{$\begin{array}{c}\text { Satisfied } \\
\text { (Students who } \\
\text { reported } \\
7 \text { or } 8 \text { on the life } \\
\text { satisfaction scale) }\end{array}$} & \multicolumn{2}{|c|}{$\begin{array}{c}\text { Very satisfied } \\
\text { (Students who } \\
\text { reported } \\
9 \text { or } 10 \text { on the life } \\
\text { satisfaction scale) }\end{array}$} & \multicolumn{2}{|c|}{$\begin{array}{c}\text { Not satisfied } \\
\text { (Students who } \\
\text { reported } \\
0 \text { to } 4 \text { on the life } \\
\text { satisfaction scale) }\end{array}$} & \multicolumn{2}{|c|}{\begin{tabular}{|c|}
$\begin{array}{c}\text { Moderately } \\
\text { satisfied } \\
\text { (Students who } \\
\text { reported } \\
5 \text { or } 6 \text { on the life } \\
\text { satisfaction scale) }\end{array}$ \\
\end{tabular}} & \multicolumn{2}{|c|}{$\begin{array}{c}\text { Satisfied } \\
\text { (Students who } \\
\text { reported } \\
7 \text { or } 8 \text { on the life } \\
\text { satisfaction scale) }\end{array}$} & \multicolumn{2}{|c|}{$\begin{array}{c}\text { Very satisfied } \\
\text { (Students who } \\
\text { reported } \\
9 \text { or } 10 \text { on the life } \\
\text { satisfaction scale) }\end{array}$} \\
\hline & & $\%$ & S.E. & $\%$ & S.E. & $\%$ & S.E. & $\%$ & S.E. & $\%$ dif. & S.E. & $\%$ dif. & S.E. & $\%$ dif. & S.E. & $\%$ dif. & S.E. \\
\hline \multirow{36}{*}{ ర్ } & Australia & $\mathrm{m}$ & $\mathrm{m}$ & $\mathrm{m}$ & $\mathrm{m}$ & $\mathrm{m}$ & $\mathrm{m}$ & $\mathrm{m}$ & $\mathrm{m}$ & $\mathrm{m}$ & $\mathrm{m}$ & $\mathrm{m}$ & $\mathrm{m}$ & $\mathrm{m}$ & $\mathrm{m}$ & $\mathrm{m}$ & $\mathrm{m}$ \\
\hline & Austria & 15.1 & $(0.7)$ & 17.2 & $(0.7)$ & 35.5 & $(0.9)$ & 32.2 & (1.1) & -7.9 & $(0.9)$ & -7.6 & $(0.8)$ & 0.5 & (1.4) & 15.0 & (1.5) \\
\hline & Belgium (excl. Flemish) & 10.5 & $(0.9)$ & 18.5 & $(0.8)$ & 43.1 & (1.4) & 27.9 & (1.3) & -4.4 & (1.0) & -5.6 & $(1.2)$ & 0.3 & $(2.1)$ & 9.8 & (1.9) \\
\hline & Canada & $\mathrm{m}$ & $\mathrm{m}$ & $\mathrm{m}$ & $\mathrm{m}$ & $\mathrm{m}$ & $\mathrm{m}$ & $\mathrm{m}$ & $\mathrm{m}$ & $\mathrm{m}$ & $\mathrm{m}$ & $\mathrm{m}$ & $\mathrm{m}$ & $\mathrm{m}$ & $\mathrm{m}$ & $\mathrm{m}$ & $\mathrm{m}$ \\
\hline & Chile & 14.8 & $(0.8)$ & 19.9 & $(0.8)$ & 29.5 & $(1.0)$ & 35.7 & $(1.2)$ & -5.6 & $(1.1)$ & -3.9 & $(1.2)$ & 4.8 & $(1.4)$ & 4.7 & $(1.6)$ \\
\hline & Czech Republic & 16.6 & $(0.9)$ & 23.6 & $(0.6)$ & 34.2 & $(1.0)$ & 25.6 & $(0.9)$ & -5.5 & $(1.1)$ & -6.4 & (1.1) & 2.1 & (1.5) & 9.8 & (1.5) \\
\hline & Denmark & $\mathrm{m}$ & $\mathrm{m}$ & $\mathrm{m}$ & $\mathrm{m}$ & $\mathrm{m}$ & $\mathrm{m}$ & $\mathrm{m}$ & $\mathrm{m}$ & $\mathrm{m}$ & $\mathrm{m}$ & $\mathrm{m}$ & $\mathrm{m}$ & $\mathrm{m}$ & $\mathrm{m}$ & $\mathrm{m}$ & $\mathrm{m}$ \\
\hline & Estonia & 11.6 & $(0.7)$ & 17.8 & $(0.9)$ & 37.1 & $(1.2)$ & 33.5 & $(1.3)$ & -4.6 & $(0.9)$ & -3.2 & (1.1) & 1.0 & (1.5) & 6.8 & (1.6) \\
\hline & Finland & 9.4 & $(0.5)$ & 13.2 & $(0.7)$ & 41.3 & $(0.9)$ & 36.1 & $(0.9)$ & -5.4 & $(0.6)$ & -5.8 & $(0.8)$ & -4.9 & $(1.2)$ & 16.2 & (1.3) \\
\hline & France & 8.2 & $(0.6)$ & 18.4 & $(0.8)$ & 41.5 & (1.0) & 31.8 & $(0.8)$ & -1.7 & $(0.7)$ & -7.1 & $(1.0)$ & -0.9 & $(1.2)$ & 9.7 & $(1.2)$ \\
\hline & Germany & 14.2 & $(0.7)$ & 20.0 & $(0.7)$ & 38.6 & $(0.9)$ & 27.2 & $(0.9)$ & -6.4 & $(0.8)$ & -7.9 & (1.0) & 0.6 & $(1.2)$ & 13.7 & $(1.2)$ \\
\hline & Greece & 18.2 & $(0.7)$ & 23.6 & $(0.8)$ & 37.0 & (1.1) & 21.1 & $(0.9)$ & -6.9 & (1.0) & -5.1 & (1.1) & 2.1 & (1.4) & 9.9 & $(1.2)$ \\
\hline & Hungary & 16.5 & $(0.8)$ & 20.2 & $(0.8)$ & 37.5 & $(1.0)$ & 25.8 & (1.0) & -6.7 & (1.1) & -5.5 & $(1.2)$ & 0.4 & $(1.2)$ & 11.8 & (1.6) \\
\hline & Iceland & 13.1 & $(0.7)$ & 15.1 & $(0.8)$ & 33.6 & (1.1) & 38.2 & (1.0) & -7.4 & $(0.9)$ & -7.3 & (1.1) & -2.7 & (1.4) & 17.4 & (1.5) \\
\hline & Ireland & 15.1 & $(0.7)$ & 18.3 & $(0.8)$ & 37.5 & $(1.0)$ & 29.1 & $(1.0)$ & -6.4 & $(0.7)$ & -5.0 & $(1.2)$ & 4.9 & (1.4) & 6.5 & (1.4) \\
\hline & Israel & $\mathrm{m}$ & $\mathrm{m}$ & $\mathrm{m}$ & $\mathrm{m}$ & $\mathrm{m}$ & $\mathrm{m}$ & $\mathrm{m}$ & $\mathrm{m}$ & $\mathrm{m}$ & $\mathrm{m}$ & $\mathrm{m}$ & $\mathrm{m}$ & $\mathrm{m}$ & $\mathrm{m}$ & $\mathrm{m}$ & $\mathrm{m}$ \\
\hline & Italy & 19.0 & $(0.8)$ & 24.0 & (1.0) & 37.4 & $(0.9)$ & 19.6 & (1.0) & -8.7 & (1.0) & -7.4 & $(1.2)$ & 6.8 & (1.5) & 9.3 & (1.4) \\
\hline & Japan & 14.9 & $(0.7)$ & 23.3 & $(0.7)$ & 37.8 & $(0.9)$ & 24.1 & $(0.8)$ & 2.3 & (1.1) & -0.8 & (1.0) & -0.9 & (1.3) & -0.6 & (1.0) \\
\hline & Korea & 23.5 & $(0.9)$ & 28.9 & $(0.9)$ & 33.7 & (1.0) & 14.0 & $(0.7)$ & -3.5 & $(1.2)$ & -6.4 & $(1.1)$ & 1.0 & (1.3) & 8.9 & (1.0) \\
\hline & Latvia & 9.4 & $(0.6)$ & 19.0 & $(0.9)$ & 42.5 & (1.1) & 29.0 & $(1.1)$ & -1.1 & $(0.9)$ & -1.7 & (1.3) & -2.1 & (1.6) & 4.9 & (1.4) \\
\hline & Luxembourg & 13.9 & $(0.8)$ & 20.8 & $(0.7)$ & 36.8 & $(0.8)$ & 28.5 & $(0.8)$ & -5.7 & $(0.9)$ & -8.5 & $(0.9)$ & -1.2 & (1.3) & 15.4 & $(1.2)$ \\
\hline & Mexico & 6.9 & $(0.5)$ & 10.6 & $(0.6)$ & 24.7 & $(0.8)$ & 57.8 & $(1.0)$ & -1.1 & $(0.7)$ & -2.1 & $(0.7)$ & 2.0 & $(1.2)$ & 1.2 & $(1.2)$ \\
\hline & Netherlands & 4.8 & $(0.4)$ & 13.2 & $(0.8)$ & 56.7 & $(1.1)$ & 25.3 & (1.0) & -2.3 & $(0.5)$ & -5.3 & $(1.0)$ & -7.0 & (1.5) & 14.6 & (1.5) \\
\hline & New Zealand & $\mathrm{m}$ & $\mathrm{m}$ & $\mathrm{m}$ & $\mathrm{m}$ & $\mathrm{m}$ & $\mathrm{m}$ & $\mathrm{m}$ & $\mathrm{m}$ & $\mathrm{m}$ & $\mathrm{m}$ & $\mathrm{m}$ & $\mathrm{m}$ & $\mathrm{m}$ & $\mathrm{m}$ & $\mathrm{m}$ & $\mathrm{m}$ \\
\hline & Norway & $\mathrm{m}$ & $\mathrm{m}$ & $\mathrm{m}$ & $\mathrm{m}$ & $\mathrm{m}$ & $\mathrm{m}$ & $\mathrm{m}$ & $\mathrm{m}$ & $\mathrm{m}$ & $\mathrm{m}$ & $\mathrm{m}$ & $\mathrm{m}$ & $\mathrm{m}$ & $\mathrm{m}$ & $\mathrm{m}$ & $\mathrm{m}$ \\
\hline & Poland & 16.0 & $(0.8)$ & 21.7 & $(0.9)$ & 35.1 & $(1.1)$ & 27.1 & $(1.2)$ & -6.8 & $(1.0)$ & -5.9 & $(1.1)$ & 2.4 & (1.5) & 10.2 & (1.6) \\
\hline & Portugal & 10.7 & $(0.6)$ & 22.3 & $(0.9)$ & 40.7 & (1.0) & 26.3 & $(1.0)$ & -3.7 & $(0.9)$ & -7.0 & $(1.1)$ & 1.4 & (1.3) & 9.3 & $(1.3)$ \\
\hline & Slovak Republic & 13.8 & $(0.7)$ & 18.9 & $(0.7)$ & 33.2 & $(0.9)$ & 34.0 & $(1.0)$ & -4.9 & $(0.9)$ & -4.8 & $(0.9)$ & -0.9 & (1.3) & 10.6 & (1.4) \\
\hline & Slovenia & 18.0 & (1.0) & 21.8 & (1.0) & 35.1 & $(1.2)$ & 25.1 & $(1.0)$ & -8.9 & $(1.2)$ & -8.0 & $(1.3)$ & 2.4 & (1.6) & 14.5 & (1.5) \\
\hline & Spain & 10.8 & $(0.6)$ & 18.2 & $(0.7)$ & 41.2 & $(1.0)$ & 29.8 & $(0.9)$ & -2.7 & $(0.9)$ & -4.3 & $(0.9)$ & 0.4 & (1.4) & 6.5 & $(1.0)$ \\
\hline & Sweden & $\mathrm{m}$ & $\mathrm{m}$ & $\mathrm{m}$ & $\mathrm{m}$ & $\mathrm{m}$ & $\mathrm{m}$ & $\mathrm{m}$ & $\mathrm{m}$ & $\mathrm{m}$ & $\mathrm{m}$ & $\mathrm{m}$ & $\mathrm{m}$ & $\mathrm{m}$ & $\mathrm{m}$ & $\mathrm{m}$ & $\mathrm{m}$ \\
\hline & Switzerland & 9.5 & $(0.6)$ & 17.4 & $(0.9)$ & 40.2 & $(1.1)$ & 33.0 & (1.1) & -4.0 & $(0.6)$ & -8.3 & $(1.0)$ & -0.4 & (1.3) & 12.7 & (1.5) \\
\hline & Turkey & 32.8 & (1.0) & 22.6 & $(0.8)$ & 20.3 & $(0.8)$ & 24.3 & $(1.2)$ & -8.5 & $(1.3)$ & 0.0 & $(1.2)$ & 4.5 & $(1.2)$ & 4.0 & (1.8) \\
\hline & United Kingdom & 19.4 & $(0.9)$ & 20.9 & $(0.8)$ & 36.2 & $(1.0)$ & 23.4 & $(0.9)$ & -7.5 & (1.0) & -4.5 & (1.0) & 2.4 & $(1.3)$ & 9.6 & (1.1) \\
\hline & United States & 14.5 & $(0.7)$ & 20.8 & $(0.8)$ & 33.9 & $(0.9)$ & 30.7 & $(0.9)$ & -5.4 & (1.0) & -6.5 & (1.0) & 1.7 & (1.3) & 10.3 & $(1.2)$ \\
\hline & OECD average & 14.3 & $(0.1)$ & 19.7 & $(0.2)$ & 36.9 & $(0.2)$ & 29.2 & $(0.2)$ & -5.0 & $(0.2)$ & -5.4 & $(0.2)$ & 0.7 & $(0.3)$ & 9.7 & $(0.3)$ \\
\hline
\end{tabular}

\begin{tabular}{|c|c|c|c|c|c|c|c|c|c|c|c|c|c|c|c|c|c|}
\hline 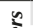 & Albania & $\mathrm{m}$ & $\mathrm{m}$ & $\mathrm{m}$ & $\mathrm{m}$ & $\mathrm{m}$ & $\mathrm{m}$ & $\mathrm{m}$ & $\mathrm{m}$ & $\mathrm{m}$ & $\mathrm{m}$ & $\mathrm{m}$ & $\mathrm{m}$ & $\mathrm{m}$ & $\mathrm{m}$ & $\mathrm{m}$ & $\mathrm{m}$ \\
\hline ฏ & Algeria & $\mathrm{m}$ & $\mathrm{m}$ & $\mathrm{m}$ & $\mathrm{m}$ & $\mathrm{m}$ & $\mathrm{m}$ & $\mathrm{m}$ & $\mathrm{m}$ & $\mathrm{m}$ & $\mathrm{m}$ & $\mathrm{m}$ & $\mathrm{m}$ & $\mathrm{m}$ & $\mathrm{m}$ & $\mathrm{m}$ & $\mathrm{m}$ \\
\hline ฮ & Brazil & 13.0 & $(0.4)$ & 16.7 & 0.5 & 27.6 & $(0.6)$ & 42.6 & $(0.7)$ & -2.5 & $(0.5)$ & -2.5 & (0.6) & 1.1 & $(0.8)$ & 4.0 & (0.9) \\
\hline & B-S-J-G (China) & 16.2 & $(0.8)$ & 25.7 & $(0.8)$ & 31.5 & $(0.9)$ & 26.6 & $(1.2)$ & -1.2 & $(0.9)$ & -1.0 & $(1.2)$ & 1.7 & $(1.2)$ & 0.5 & (1.5) \\
\hline & Bulgaria & 15.9 & $(0.9)$ & 18.0 & $(0.8)$ & 27.1 & $(1.0)$ & 38.9 & $(0.9)$ & -3.9 & (1.1) & -2.4 & (1.1) & -1.1 & (1.5) & 7.4 & (1.4) \\
\hline & CABA (Argentina) & $\mathrm{m}$ & $\mathrm{m}$ & $\mathrm{m}$ & $\mathrm{m}$ & $\mathrm{m}$ & $\mathrm{m}$ & $\mathrm{m}$ & $\mathrm{m}$ & $\mathrm{m}$ & $\mathrm{m}$ & $\mathrm{m}$ & $\mathrm{m}$ & $\mathrm{m}$ & $\mathrm{m}$ & $\mathrm{m}$ & $\mathrm{m}$ \\
\hline & Colombia & 11.6 & $(0.6)$ & 14.5 & $(0.7)$ & 26.2 & $(0.8)$ & 47.7 & (1.1) & -3.1 & $(0.8)$ & -3.2 & $(0.9)$ & -0.3 & (1.0) & 6.6 & (1.1) \\
\hline & Costa Rica & 8.2 & $(0.6)$ & 12.2 & $(0.6)$ & 24.4 & $(0.9)$ & 55.3 & (1.1) & -2.2 & $(0.7)$ & -2.5 & $(0.7)$ & -1.7 & (1.1) & 6.4 & (1.3) \\
\hline & Croatia & 9.4 & $(0.6)$ & 14.8 & $(0.7)$ & 33.3 & $(0.8)$ & 42.5 & $(1.0)$ & -4.3 & $(0.7)$ & -5.5 & (1.1) & -1.3 & (1.3) & 11.1 & (1.4) \\
\hline & Cyprus* & 15.0 & $(0.8)$ & 21.4 & $(0.9)$ & 38.4 & (1.0) & 25.2 & (1.0) & -2.8 & (1.1) & -3.4 & (1.1) & -3.7 & (1.3) & 9.9 & (1.5) \\
\hline & Dominican Republic & 8.6 & $(0.7)$ & 8.4 & $(0.8)$ & 16.5 & $(1.0)$ & 66.4 & (1.3) & -0.6 & (1.0) & -0.3 & (1.1) & -1.8 & (1.5) & 2.7 & (1.8) \\
\hline & FYROM & $\mathrm{m}$ & $\mathrm{m}$ & $\mathrm{m}$ & $\mathrm{m}$ & $\mathrm{m}$ & $\mathrm{m}$ & $\mathrm{m}$ & $\mathrm{m}$ & $\mathrm{m}$ & $\mathrm{m}$ & $\mathrm{m}$ & $\mathrm{m}$ & $\mathrm{m}$ & $\mathrm{m}$ & $\mathrm{m}$ & $\mathrm{m}$ \\
\hline & Georgia & $\mathrm{m}$ & $\mathrm{m}$ & $\mathrm{m}$ & $\mathrm{m}$ & $\mathrm{m}$ & $\mathrm{m}$ & $\mathrm{m}$ & $\mathrm{m}$ & $\mathrm{m}$ & $\mathrm{m}$ & $\mathrm{m}$ & $\mathrm{m}$ & $\mathrm{m}$ & $\mathrm{m}$ & $\mathrm{m}$ & $\mathrm{m}$ \\
\hline & Hong Kong (China) & 14.3 & (0.9) & 30.4 & $(0.8)$ & 45.1 & $(1.2)$ & 10.2 & $(0.7)$ & 2.6 & $(1.2)$ & -3.2 & $(1.2)$ & -6.7 & (1.5) & 7.3 & $(0.9)$ \\
\hline & Indonesia & $\mathrm{m}$ & $\mathrm{m}$ & $\mathrm{m}$ & $\mathrm{m}$ & $\mathrm{m}$ & $\mathrm{m}$ & $\mathrm{m}$ & $\mathrm{m}$ & $\mathrm{m}$ & $\mathrm{m}$ & $\mathrm{m}$ & $\mathrm{m}$ & $\mathrm{m}$ & $\mathrm{m}$ & $\mathrm{m}$ & $\mathrm{m}$ \\
\hline & Jordan & $\mathrm{m}$ & $\mathrm{m}$ & $\mathrm{m}$ & $\mathrm{m}$ & $\mathrm{m}$ & $\mathrm{m}$ & $\mathrm{m}$ & $\mathrm{m}$ & $\mathrm{m}$ & $\mathrm{m}$ & $\mathrm{m}$ & $\mathrm{m}$ & $\mathrm{m}$ & $\mathrm{m}$ & $\mathrm{m}$ & $\mathrm{m}$ \\
\hline & Kosovo & $\mathrm{m}$ & $\mathrm{m}$ & $\mathrm{m}$ & $\mathrm{m}$ & $\mathrm{m}$ & $\mathrm{m}$ & $\mathrm{m}$ & $\mathrm{m}$ & $\mathrm{m}$ & $\mathrm{m}$ & $\mathrm{m}$ & $\mathrm{m}$ & $\mathrm{m}$ & $\mathrm{m}$ & $\mathrm{m}$ & $\mathrm{m}$ \\
\hline & Lebanon & $\mathrm{m}$ & $\mathrm{m}$ & $\mathrm{m}$ & $\mathrm{m}$ & $\mathrm{m}$ & $\mathrm{m}$ & $\mathrm{m}$ & $\mathrm{m}$ & $\mathrm{m}$ & $\mathrm{m}$ & $\mathrm{m}$ & $\mathrm{m}$ & $\mathrm{m}$ & $\mathrm{m}$ & $\mathrm{m}$ & $\mathrm{m}$ \\
\hline & Lithuania & 9.7 & $(0.6)$ & 15.2 & $(0.7)$ & 33.5 & $(0.9)$ & 41.6 & $(1.0)$ & -3.1 & $(0.7)$ & -4.8 & $(0.9)$ & -3.9 & $(1.3)$ & 11.8 & (1.4) \\
\hline & Macao (China) & 15.3 & $(0.8)$ & 26.3 & (1.1) & 42.9 & $(1.3)$ & 15.5 & $(0.8)$ & 0.1 & $(1.2)$ & 0.9 & (1.5) & -3.1 & (1.5) & 2.1 & (1.1) \\
\hline & Malta & $\mathrm{m}$ & $\mathrm{m}$ & $\mathrm{m}$ & $\mathrm{m}$ & $\mathrm{m}$ & $\mathrm{m}$ & $\mathrm{m}$ & $\mathrm{m}$ & $\mathrm{m}$ & $\mathrm{m}$ & $\mathrm{m}$ & $\mathrm{m}$ & $\mathrm{m}$ & $\mathrm{m}$ & $\mathrm{m}$ & $\mathrm{m}$ \\
\hline & Moldova & $\mathrm{m}$ & $\mathrm{m}$ & $\mathrm{m}$ & $\mathrm{m}$ & $\mathrm{m}$ & $\mathrm{m}$ & $\mathrm{m}$ & $\mathrm{m}$ & $\mathrm{m}$ & $\mathrm{m}$ & $\mathrm{m}$ & $\mathrm{m}$ & $\mathrm{m}$ & $\mathrm{m}$ & $\mathrm{m}$ & $\mathrm{m}$ \\
\hline & Montenegro & 12.7 & $(0.7)$ & 17.1 & $(0.8)$ & 24.7 & $(0.8)$ & 45.5 & (1.0) & -3.2 & $(0.9)$ & -4.9 & (1.0) & -0.9 & (1.1) & 9.0 & $(1.2)$ \\
\hline & Peru & 13.7 & $(0.7)$ & 16.9 & $(0.7)$ & 27.1 & $(0.9)$ & 42.4 & $(1.2)$ & -1.6 & $(0.9)$ & -1.4 & (1.0) & 2.2 & (1.1) & 0.9 & (1.4) \\
\hline & Qatar & 14.8 & $(0.4)$ & 18.2 & $(0.4)$ & 25.7 & $(0.5)$ & 41.3 & $(0.5)$ & -2.0 & $(0.6)$ & -2.5 & (0.6) & 1.8 & $(0.9)$ & 2.7 & $(0.9)$ \\
\hline & Romania & $\mathrm{m}$ & $\mathrm{m}$ & $\mathrm{m}$ & $\mathrm{m}$ & $\mathrm{m}$ & $\mathrm{m}$ & $\mathrm{m}$ & $\mathrm{m}$ & $\mathrm{m}$ & $\mathrm{m}$ & $\mathrm{m}$ & $\mathrm{m}$ & $\mathrm{m}$ & $\mathrm{m}$ & $\mathrm{m}$ & $\mathrm{m}$ \\
\hline & Russia & 12.0 & $(0.7)$ & 15.7 & $(0.9)$ & 27.3 & $(0.8)$ & 45.0 & $(0.9)$ & -3.5 & $(0.9)$ & -2.6 & (1.1) & 2.5 & (1.5) & 3.6 & (1.4) \\
\hline & Singapore & $\mathrm{m}$ & $\mathrm{m}$ & $\mathrm{m}$ & $\mathrm{m}$ & $\mathrm{m}$ & $\mathrm{m}$ & $\mathrm{m}$ & $\mathrm{m}$ & $\mathrm{m}$ & $\mathrm{m}$ & $\mathrm{m}$ & $\mathrm{m}$ & $\mathrm{m}$ & $\mathrm{m}$ & $\mathrm{m}$ & $\mathrm{m}$ \\
\hline & Chinese Taipei & 16.9 & $(0.7)$ & 30.2 & $(0.8)$ & 37.3 & $(0.7)$ & 15.5 & (0.6) & -1.9 & $(0.9)$ & -4.1 & (1.0) & 0.2 & $(1.2)$ & 5.9 & (1.0) \\
\hline & Thailand & 7.3 & $(0.6)$ & 18.1 & $(0.7)$ & 33.0 & $(0.9)$ & 41.6 & (1.0) & 1.2 & $(0.9)$ & -0.1 & $(1.0)$ & -3.6 & (1.4) & 2.6 & (1.6) \\
\hline & Trinidad and Tobago & $\mathrm{m}$ & $\mathrm{m}$ & $\mathrm{m}$ & $\mathrm{m}$ & $\mathrm{m}$ & $\mathrm{m}$ & $\mathrm{m}$ & $\mathrm{m}$ & $\mathrm{m}$ & $\mathrm{m}$ & $\mathrm{m}$ & $\mathrm{m}$ & $\mathrm{m}$ & $\mathrm{m}$ & $\mathrm{m}$ & $\mathrm{m}$ \\
\hline & Tunisia & 20.5 & $(0.8)$ & 20.7 & $(0.9)$ & 19.9 & $(0.8)$ & 38.8 & $(1.0)$ & -2.6 & $(1.2)$ & -0.7 & (1.3) & 4.0 & $(1.3)$ & -0.7 & (1.4) \\
\hline & United Arab Emirates & 15.5 & $(0.5)$ & 20.2 & $(0.6)$ & 26.8 & $(0.7)$ & 37.5 & $(0.8)$ & -2.1 & $(0.9)$ & -3.5 & (1.0) & 0.9 & (1.2) & 4.8 & (1.1) \\
\hline & Uruguay & 11.7 & $(0.5)$ & 15.7 & $(0.7)$ & 31.9 & $(0.8)$ & 40.7 & $(0.9)$ & -4.1 & $(0.7)$ & -2.5 & (0.9) & -0.8 & (1.4) & 7.5 & $(1.3)$ \\
\hline & Viet Nam & $\mathrm{m}$ & $\mathrm{m}$ & m & $\mathrm{m}$ & $\mathrm{m}$ & $\mathrm{m}$ & $\mathrm{m}$ & $\mathrm{m}$ & $\mathrm{m}$ & $\mathrm{m}$ & $\mathrm{m}$ & $\mathrm{m}$ & $\mathrm{m}$ & $\mathrm{m}$ & $\mathrm{m}$ & $\mathrm{m}$ \\
\hline & Argentina** & $\mathrm{m}$ & $\mathrm{m}$ & $\mathrm{m}$ & $\mathrm{m}$ & $\mathrm{m}$ & $\mathrm{m}$ & $\mathrm{m}$ & $\mathrm{m}$ & $\mathrm{m}$ & $\mathrm{m}$ & $\mathrm{m}$ & $\mathrm{m}$ & $\mathrm{m}$ & $\mathrm{m}$ & $\mathrm{m}$ & $\mathrm{m}$ \\
\hline & Kazakhstan** & $\mathrm{m}$ & $\mathrm{m}$ & $\mathrm{m}$ & $\mathrm{m}$ & $\mathrm{m}$ & $\mathrm{m}$ & $\mathrm{m}$ & $\mathrm{m}$ & $\mathrm{m}$ & $\mathrm{m}$ & $\mathrm{m}$ & $\mathrm{m}$ & $\mathrm{m}$ & $\mathrm{m}$ & $\mathrm{m}$ & $\mathrm{m}$ \\
\hline & Malaysia** & 11.1 & $(0.7)$ & 28.6 & $(0.8)$ & 31.5 & $(0.9)$ & 28.8 & (1.1) & -0.2 & (1.0) & -2.3 & (1.1) & 0.1 & (1.2) & 2.4 & (1.4) \\
\hline
\end{tabular}

Note: Values that are statistically significant are indicated in bold (see Annex A3).

* See note at the beginning of this Annex.

** Coverage is too small to ensure comparability (see Annex A4).

StatLink 刑四 http://dx.doi.org/10.1787/888933470547 
[Part 1/1]

Table III.3.9 Students attending additional instruction

Results based on students' self-reports

\begin{tabular}{|c|c|c|c|c|c|c|c|c|c|c|c|c|c|c|c|c|c|c|c|c|c|}
\hline & \multicolumn{14}{|c|}{ Percentage of students who reported the following } & \multicolumn{4}{|c|}{$\begin{array}{l}\text { Total time per week spent } \\
\text { in additional instruction in: }\end{array}$} & \multirow{2}{*}{\multicolumn{2}{|c|}{$\begin{array}{l}\text { Years spent } \\
\text { attending } \\
\text { additional } \\
\text { instruction }\end{array}$}} \\
\hline & & \multicolumn{2}{|c|}{$\begin{array}{c}\text { They attend } \\
\text { additional } \\
\text { instruction } \\
\text { in school } \\
\text { science } \\
\text { or broad } \\
\text { science }\end{array}$} & \multicolumn{2}{|c|}{$\begin{array}{c}\text { They attend } \\
\text { additional } \\
\text { mandatory } \\
\text { lessons in } \\
\text { mathematics }\end{array}$} & \multicolumn{2}{|c|}{$\begin{array}{c}\text { They attend } \\
\text { additional } \\
\text { instruction } \\
\text { because } \\
\text { they want } \\
\text { to learn } \\
\text { more }\end{array}$} & \multicolumn{2}{|c|}{$\begin{array}{l}\text { They want } \\
\text { to improve } \\
\text { their grades }\end{array}$} & \multicolumn{2}{|c|}{$\begin{array}{l}\text { Inspired by } \\
\text { additional } \\
\text { lessons }\end{array}$} & \multicolumn{2}{|c|}{$\begin{array}{l}\text { Their } \\
\text { parents } \\
\text { wanted } \\
\text { them } \\
\text { to attend }\end{array}$} & \multicolumn{2}{|c|}{$\begin{array}{l}\text { The teacher } \\
\text { in the } \\
\text { additional } \\
\text { science } \\
\text { instruction } \\
\text { is one } \\
\text { of the } \\
\text { regular } \\
\text { teachers in } \\
\text { the school } \\
\text { courses in } \\
\text { PISA } 2015\end{array}$} & \multicolumn{2}{|c|}{$\begin{array}{c}\text { Science or } \\
\text { broad science }\end{array}$} & \multicolumn{2}{|c|}{ Mathematics } & & \\
\hline & & $\%$ & S.E. & $\%$ & S.E. & $\%$ & S.E. & $\%$ & S.E. & $\%$ & S.E. & $\%$ & S.E. & $\%$ & S.E. & Hours & S.E. & Hours & S.E. & Years & S.E. \\
\hline \multirow{17}{*}{$\begin{array}{l}\text { తి } \\
\text { ல }\end{array}$} & Australia & 61.2 & $(0.8)$ & 73.8 & $(0.7)$ & 48.3 & $(1.0)$ & 45.8 & (1.2) & 22.6 & $(0.9)$ & 32.3 & $(0.8)$ & 56.9 & $(1.0)$ & 3 & $(0.1)$ & 3 & $(0.1)$ & 5 & $(0.1)$ \\
\hline & Belgium (French) & 54.2 & (1.5) & 68.4 & $(1.2)$ & 35.4 & (1.5) & 29.2 & (1.3) & 18.0 & (1.4) & 23.8 & (1.8) & 33.5 & (1.6) & 2 & $(0.1)$ & 3 & $(0.1)$ & 3 & $(0.1)$ \\
\hline & Denmark & 24.5 & $(1.3)$ & 32.7 & (1.3) & 40.4 & $(2.2)$ & 32.0 & (2.1) & 16.2 & (1.5) & 15.4 & (1.4) & 44.0 & (1.9) & 1 & $(0.1)$ & 1 & $(0.1)$ & 3 & $(0.1)$ \\
\hline & Germany & 45.0 & (1.3) & 68.1 & (1.0) & 43.1 & (1.7) & 50.8 & (1.6) & 18.5 & (1.1) & 23.8 & (1.4) & $\mathrm{m}$ & $\mathrm{m}$ & 2 & $(0.1)$ & 3 & $(0.1)$ & $\mathrm{m}$ & $\mathrm{m}$ \\
\hline & Greece & 85.1 & $(0.8)$ & 88.8 & $(0.7)$ & 54.7 & (1.1) & 58.3 & (1.1) & 23.0 & $(0.7)$ & 38.0 & $(0.8)$ & 32.5 & $(1.2)$ & 4 & $(0.1)$ & 4 & $(0.1)$ & 4 & $(0.1)$ \\
\hline & Hungary & 44.7 & (1.4) & 62.6 & (1.1) & 42.6 & (1.7) & 32.6 & (1.4) & 18.5 & $(1.2)$ & 23.3 & (1.4) & 40.3 & (1.7) & 2 & $(0.1)$ & 2 & $(0.1)$ & 4 & $(0.1)$ \\
\hline & Iceland & 34.1 & (1.0) & 59.2 & (1.1) & 40.6 & $(2.1)$ & 37.1 & (1.9) & 21.4 & (1.7) & 21.0 & (1.9) & 45.4 & (2.2) & 1 & $(0.1)$ & 2 & $(0.1)$ & 2 & $(0.1)$ \\
\hline & Italy & 57.5 & (1.4) & 68.1 & (1.1) & 46.6 & $(1.3)$ & 37.9 & $(1.2)$ & 19.6 & (0.9) & 24.6 & (1.0) & 39.6 & (1.0) & 3 & $(0.1)$ & 3 & $(0.1)$ & 4 & $(0.1)$ \\
\hline & Korea & 67.7 & (1.4) & 88.7 & $(0.8)$ & 46.0 & $(0.9)$ & 52.2 & $(1.2)$ & 9.7 & (0.6) & 12.7 & $(0.7)$ & 54.1 & (1.8) & 2 & $(0.1)$ & 5 & $(0.1)$ & 6 & $(0.1)$ \\
\hline & Latvia & 58.3 & (1.1) & 75.8 & $(0.8)$ & 69.3 & $(1.2)$ & 60.6 & (1.5) & 27.6 & (0.9) & 34.2 & (1.1) & 59.0 & $(1.2)$ & 2 & $(0.1)$ & 3 & $(0.1)$ & 5 & $(0.1)$ \\
\hline & Poland & 62.2 & (1.1) & 72.3 & (1.0) & 59.5 & $(1.3)$ & 52.0 & (1.1) & 28.6 & (1.1) & 31.2 & (1.0) & 68.4 & (1.2) & 2 & $(0.1)$ & 2 & $(0.1)$ & 5 & $(0.1)$ \\
\hline & Slovak Republic & 58.1 & $(1.2)$ & 72.8 & (1.1) & 53.7 & $(1.2)$ & 41.5 & (1.2) & 25.0 & (0.9) & 29.0 & (1.0) & 45.0 & $(1.2)$ & 3 & $(0.1)$ & 3 & $(0.1)$ & 3 & $(0.1)$ \\
\hline & Slovenia & 68.6 & (1.0) & 81.9 & $(0.8)$ & 45.4 & (1.2) & 40.0 & (1.1) & 12.6 & $(0.8)$ & 11.5 & (0.6) & 38.9 & (0.9) & 2 & $(0.1)$ & 3 & $(0.1)$ & 5 & $(0.1)$ \\
\hline & Spain & 56.5 & (1.1) & 70.5 & $(0.9)$ & 40.7 & (1.3) & 50.5 & (1.1) & 13.8 & (0.9) & 30.8 & (1.3) & 28.1 & (1.2) & 2 & $(0.1)$ & 3 & $(0.1)$ & 5 & $(0.1)$ \\
\hline & United Kingdom (England) & 74.7 & $(1.1)$ & 74.3 & (1.0) & 60.3 & (1.1) & 67.6 & (1.3) & 23.1 & (0.8) & 40.9 & (1.0) & 71.6 & (1.3) & 3 & $(0.1)$ & 3 & $(0.1)$ & 4 & $(0.1)$ \\
\hline & OECD average & 56.8 & $(0.3)$ & 70.5 & $(0.3)$ & 48.4 & $(0.4)$ & 45.9 & $(0.4)$ & 19.9 & $(0.3)$ & 26.2 & $(0.3)$ & 46.9 & $(0.4)$ & 2 & $(0.0)$ & 3 & $(0.0)$ & 4 & $(0.0)$ \\
\hline & Average-22 & 59.6 & $(0.2)$ & 72.4 & $(0.2)$ & 56.0 & $(0.3)$ & 50.8 & $(0.3)$ & 25.9 & $(0.2)$ & 30.0 & $(0.2)$ & 51.3 & $(0.3)$ & 3 & (0.0) & 3 & $(0.0)$ & 4 & $(0.0)$ \\
\hline \multirow{7}{*}{ ఏँ় } & B-S-J-G (China) & 59.4 & $(1.2)$ & 74.0 & (1.2) & 82.6 & $(0.8)$ & 75.1 & (0.9) & 43.6 & (1.3) & 42.6 & (1.3) & 58.2 & (1.3) & 2 & $(0.1)$ & 4 & $(0.1)$ & 4 & $(0.1)$ \\
\hline & Bulgaria & 84.0 & (1.0) & 87.2 & $(0.8)$ & 58.6 & (1.1) & 47.0 & (0.9) & 28.1 & (1.0) & 21.5 & (0.9) & 56.6 & (1.0) & 4 & $(0.1)$ & 4 & $(0.1)$ & 4 & $(0.1)$ \\
\hline & Croatia & 46.8 & (1.1) & 66.6 & (1.1) & 57.5 & (1.2) & 50.9 & (1.6) & 22.2 & (1.3) & 29.6 & (1.3) & 53.5 & (1.4) & 2 & $(0.1)$ & 3 & $(0.1)$ & 4 & $(0.1)$ \\
\hline & Hong Kong (China) & 58.7 & $(1.2)$ & 76.9 & $(0.9)$ & 72.2 & $(0.9)$ & 65.3 & (1.2) & 35.5 & (1.1) & 38.0 & $(1.2)$ & 45.2 & (1.5) & 2 & $(0.1)$ & 3 & $(0.1)$ & 5 & $(0.1)$ \\
\hline & Lithuania & 55.8 & (1.0) & 65.6 & (1.0) & 60.6 & $(1.2)$ & 46.3 & (1.3) & 24.4 & (1.0) & 26.6 & (0.9) & 51.5 & (1.1) & 2 & $(0.1)$ & 3 & $(0.1)$ & 3 & $(0.0)$ \\
\hline & Peru & 63.6 & $(0.9)$ & 73.7 & $(0.9)$ & 85.6 & $(0.5)$ & 74.3 & $(0.8)$ & 54.0 & (1.1) & 45.0 & (0.9) & 75.1 & (0.9) & 3 & $(0.1)$ & 4 & $(0.1)$ & 4 & $(0.1)$ \\
\hline & Thailand & 89.7 & $(0.7)$ & 91.2 & $(0.7)$ & 88.9 & $(0.5)$ & 70.3 & (1.0) & 64.3 & (0.9) & 63.6 & (1.0) & 79.0 & (0.9) & 6 & $(0.1)$ & 5 & $(0.1)$ & 6 & $(0.1)$ \\
\hline
\end{tabular}

StatLink त्ना15t http://dx.doi.org/10.1787/888933470552 


\begin{tabular}{|c|c|c|c|c|c|c|c|c|c|c|c|c|c|c|c|c|c|c|c|}
\hline & \multicolumn{6}{|c|}{ Index of disciplinary climate } & \multicolumn{6}{|c|}{ Index of teacher support } & \multicolumn{6}{|c|}{ Index of adaptive instruction } \\
\hline & & \multicolumn{2}{|c|}{$\begin{array}{l}\text { Relatively } \\
\text { unhappy } \\
\text { schools }\end{array}$} & \multicolumn{2}{|c|}{$\begin{array}{c}\text { Relatively } \\
\text { happy schools }\end{array}$} & \multicolumn{2}{|c|}{$\begin{array}{c}\text { Difference } \\
\text { between happy } \\
\text { and unhappy } \\
\text { schools (happy - } \\
\text { unhappy) }\end{array}$} & \multicolumn{2}{|c|}{$\begin{array}{c}\text { Relatively } \\
\text { unhappy schools }\end{array}$} & \multicolumn{2}{|c|}{$\begin{array}{c}\text { Relatively } \\
\text { happy schools }\end{array}$} & \multicolumn{2}{|c|}{$\begin{array}{c}\text { Difference } \\
\text { between happy } \\
\text { and unhappy } \\
\text { schools (happy - } \\
\text { unhappy) }\end{array}$} & \multicolumn{2}{|c|}{$\begin{array}{c}\text { Relatively } \\
\text { unhappy schools }\end{array}$} & \multicolumn{2}{|c|}{$\begin{array}{c}\text { Relatively } \\
\text { happy schools }\end{array}$} & \multicolumn{2}{|c|}{$\begin{array}{c}\text { Difference } \\
\text { between happy } \\
\text { and unhappy } \\
\text { schools (happy } \\
\text { unhappy) }\end{array}$} \\
\hline & & Mean & S.E. & Mean & S.E. & Dif. & S.E. & Mean & S.E. & Mean & S.E. & Dif. & S.E. & Mean & S.E. & Mean & S.E. & Dif. & S.E. \\
\hline & Australia & $\mathrm{m}$ & $\mathrm{m}$ & $\mathrm{m}$ & $\mathrm{m}$ & $\mathrm{m}$ & $\mathrm{m}$ & $\mathrm{m}$ & $\mathrm{m}$ & $\mathrm{m}$ & $\mathrm{m}$ & $\mathrm{m}$ & $\mathrm{m}$ & $\mathrm{m}$ & $\mathrm{m}$ & $\mathrm{m}$ & $\mathrm{m}$ & $\mathrm{m}$ & $\mathrm{m}$ \\
\hline & Austria & 0.04 & $(0.12)$ & 0.38 & $(0.08)$ & 0.33 & $(0.16)$ & -0.43 & $(0.11)$ & -0.43 & $(0.07)$ & 0.00 & $(0.12)$ & -0.30 & $(0.08)$ & -0.16 & $(0.06)$ & 0.14 & $(0.10)$ \\
\hline & Belgium (excl. Flemish) & c & C & -0.19 & $(0.07)$ & c & C & c & $\mathrm{C}$ & -0.07 & $(0.12)$ & C & c & c & C & -0.18 & $(0.07)$ & C & c \\
\hline & Canada & $\mathrm{m}$ & $\mathrm{m}$ & $\mathrm{m}$ & $\mathrm{m}$ & $\mathrm{m}$ & $\mathrm{m}$ & $\mathrm{m}$ & $\mathrm{m}$ & $\mathrm{m}$ & $\mathrm{m}$ & $\mathrm{m}$ & $\mathrm{m}$ & $\mathrm{m}$ & $\mathrm{m}$ & $\mathrm{m}$ & $\mathrm{m}$ & $\mathrm{m}$ & $\mathrm{m}$ \\
\hline & Chile & 0.01 & $(0.12)$ & 0.02 & $(0.07)$ & 0.00 & $(0.15)$ & 0.14 & $(0.06)$ & 0.30 & $(0.06)$ & 0.16 & $(0.09)$ & 0.11 & $(0.08)$ & 0.17 & $(0.05)$ & 0.06 & $(0.11)$ \\
\hline & Czech Republic & -0.35 & $(0.09)$ & -0.19 & $(0.11)$ & 0.16 & $(0.14)$ & -0.44 & $(0.06)$ & -0.20 & $(0.08)$ & 0.24 & $(0.11)$ & -0.27 & $(0.07)$ & -0.06 & $(0.07)$ & 0.21 & $(0.11)$ \\
\hline & Denmark & $\mathrm{m}$ & $\mathrm{m}$ & $\mathrm{m}$ & $\mathrm{m}$ & $\mathrm{m}$ & $\mathrm{m}$ & $\mathrm{m}$ & $\mathrm{m}$ & m & $\mathrm{m}$ & $\mathrm{m}$ & $\mathrm{m}$ & $\mathrm{m}$ & $\mathrm{m}$ & $\mathrm{m}$ & $\mathrm{m}$ & $\mathrm{m}$ & $\mathrm{m}$ \\
\hline & Estonia & -0.01 & $(0.14)$ & 0.04 & $(0.07)$ & 0.04 & $(0.16)$ & -0.26 & $(0.12)$ & 0.07 & $(0.06)$ & 0.33 & $(0.14)$ & -0.24 & $(0.12)$ & -0.06 & $(0.04)$ & 0.17 & $(0.12)$ \\
\hline & Finland & C & c & 0.12 & $(0.06)$ & c & c & C & C & 0.38 & $(0.07)$ & c & $\mathrm{C}$ & c & C & 0.09 & $(0.09)$ & c & c \\
\hline & France & -0.65 & $(0.17)$ & -0.23 & $(0.08)$ & 0.41 & $(0.19)$ & -0.27 & $(0.13)$ & -0.02 & $(0.08)$ & 0.25 & $(0.15)$ & -0.60 & $(0.10)$ & -0.18 & $(0.06)$ & 0.42 & $(0.11)$ \\
\hline & Germany & -0.06 & $(0.16)$ & 0.07 & $(0.07)$ & 0.14 & $(0.18)$ & -0.36 & $(0.08)$ & -0.21 & $(0.09)$ & 0.15 & $(0.11)$ & -0.45 & $(0.10)$ & -0.12 & $(0.09)$ & 0.34 & $(0.15)$ \\
\hline & Greece & -0.33 & $(0.05)$ & -0.22 & $(0.10)$ & 0.11 & $(0.11)$ & -0.07 & $(0.08)$ & 0.25 & (0.09) & 0.32 & $(0.12)$ & -0.02 & $(0.11)$ & 0.22 & $(0.06)$ & 0.24 & $(0.12)$ \\
\hline & Hungary & -0.15 & $(0.16)$ & 0.04 & $(0.08)$ & 0.19 & $(0.17)$ & -0.25 & $(0.16)$ & -0.15 & $(0.07)$ & 0.10 & $(0.17)$ & -0.35 & $(0.08)$ & -0.02 & $(0.06)$ & 0.33 & $(0.11)$ \\
\hline & Iceland & C & c & 0.09 & $(0.01)$ & C & c & C & c & 0.51 & $(0.00)$ & C & C & C & c & 0.24 & $(0.00)$ & C & C \\
\hline & Ireland & $\mathrm{C}$ & c & 0.29 & $(0.12)$ & c & c & c & c & 0.25 & (0.07) & c & c & c & c & 0.12 & $(0.04)$ & c & c \\
\hline & Israel & $\mathrm{m}$ & $\mathrm{m}$ & $\mathrm{m}$ & $\mathrm{m}$ & $\mathrm{m}$ & $\mathrm{m}$ & $\mathrm{m}$ & $\mathrm{m}$ & $\mathrm{m}$ & $\mathrm{m}$ & $\mathrm{m}$ & $\mathrm{m}$ & $\mathrm{m}$ & $\mathrm{m}$ & $\mathrm{m}$ & $\mathrm{m}$ & $\mathrm{m}$ & $\mathrm{m}$ \\
\hline & Italy & -0.30 & $(0.11)$ & 0.03 & $(0.10)$ & 0.33 & $(0.14)$ & -0.30 & $(0.08)$ & -0.01 & $(0.05)$ & 0.30 & $(0.09)$ & -0.22 & $(0.05)$ & 0.01 & $(0.05)$ & 0.23 & $(0.08)$ \\
\hline & Japan & 0.52 & $(0.21)$ & 0.98 & $(0.10)$ & 0.46 & $(0.23)$ & -0.29 & $(0.06)$ & 0.10 & $(0.06)$ & 0.39 & $(0.09)$ & -0.26 & $(0.06)$ & -0.03 & $(0.05)$ & 0.23 & $(0.08)$ \\
\hline & Korea & 0.76 & $(0.07)$ & 0.71 & $(0.11)$ & -0.05 & $(0.14)$ & -0.27 & $(0.06)$ & 0.04 & $(0.11)$ & 0.31 & $(0.13)$ & -0.11 & $(0.07)$ & 0.13 & $(0.12)$ & 0.24 & $(0.13)$ \\
\hline & Latvia & -0.28 & $(0.05)$ & -0.06 & $(0.09)$ & 0.22 & $(0.10)$ & -0.02 & $(0.05)$ & 0.21 & $(0.06)$ & 0.22 & $(0.08)$ & 0.20 & $(0.03)$ & 0.42 & $(0.06)$ & 0.22 & $(0.07)$ \\
\hline & Luxembourg & c & c & 0.09 & $(0.00)$ & c & c & c & c & -0.38 & $(0.00)$ & c & c & c & c & -0.33 & $(0.00)$ & c & c \\
\hline & Mexico & -0.13 & $(0.08)$ & 0.08 & $(0.06)$ & 0.21 & $(0.10)$ & 0.16 & $(0.08)$ & 0.59 & $(0.06)$ & 0.42 & $(0.10)$ & 0.07 & $(0.09)$ & 0.40 & $(0.05)$ & 0.33 & $(0.11)$ \\
\hline & Netherlands & -0.10 & $(0.11)$ & -0.14 & $(0.07)$ & -0.04 & $(0.13)$ & -0.46 & $(0.11)$ & -0.31 & $(0.07)$ & 0.15 & $(0.12)$ & 0.02 & $(0.09)$ & -0.24 & $(0.05)$ & -0.26 & $(0.11)$ \\
\hline & New Zealand & $\mathrm{m}$ & $\mathrm{m}$ & $\mathrm{m}$ & $\mathrm{m}$ & $\mathrm{m}$ & $\mathrm{m}$ & $\mathrm{m}$ & $\mathrm{m}$ & $\mathrm{m}$ & $\mathrm{m}$ & $\mathrm{m}$ & $\mathrm{m}$ & $\mathrm{m}$ & $\mathrm{m}$ & $\mathrm{m}$ & $\mathrm{m}$ & $\mathrm{m}$ & $\mathrm{m}$ \\
\hline & Norway & $\mathrm{m}$ & $\mathrm{m}$ & $\mathrm{m}$ & $\mathrm{m}$ & $\mathrm{m}$ & $\mathrm{m}$ & $\mathrm{m}$ & $\mathrm{m}$ & $\mathrm{m}$ & $\mathrm{m}$ & $\mathrm{m}$ & $\mathrm{m}$ & $\mathrm{m}$ & $\mathrm{m}$ & $\mathrm{m}$ & $\mathrm{m}$ & $\mathrm{m}$ & $\mathrm{m}$ \\
\hline & Poland & -0.20 & $(0.09)$ & 0.06 & $(0.08)$ & 0.25 & $(0.12)$ & -0.31 & $(0.11)$ & -0.05 & $(0.06)$ & 0.26 & $(0.13)$ & -0.10 & $(0.08)$ & -0.04 & $(0.05)$ & 0.06 & $(0.10)$ \\
\hline & Portugal & -0.23 & $(0.22)$ & 0.32 & $(0.09)$ & 0.55 & $(0.24)$ & 0.07 & $(0.12)$ & 0.65 & $(0.04)$ & 0.58 & $(0.13)$ & 0.30 & $(0.12)$ & 0.78 & $(0.06)$ & 0.47 & $(0.13)$ \\
\hline & Slovak Republic & -0.05 & $(0.08)$ & -0.14 & $(0.07)$ & -0.09 & $(0.10)$ & -0.34 & $(0.11)$ & -0.23 & $(0.05)$ & 0.10 & $(0.11)$ & -0.24 & $(0.09)$ & -0.22 & $(0.05)$ & 0.01 & $(0.11)$ \\
\hline & Slovenia & -0.27 & $(0.01)$ & -0.12 & $(0.02)$ & 0.15 & $(0.03)$ & -0.45 & $(0.00)$ & -0.24 & $(0.02)$ & 0.21 & $(0.02)$ & -0.25 & $(0.00)$ & -0.10 & $(0.02)$ & 0.15 & $(0.02)$ \\
\hline & Spain & -0.33 & $(0.12)$ & 0.08 & $(0.10)$ & 0.40 & (0.15) & -0.12 & $(0.05)$ & 0.14 & $(0.11)$ & 0.26 & $(0.12)$ & 0.06 & $(0.06)$ & 0.19 & $(0.08)$ & 0.13 & $(0.10)$ \\
\hline & Sweden & $\mathrm{m}$ & $\mathrm{m}$ & $\mathrm{m}$ & $\mathrm{m}$ & $\mathrm{m}$ & $\mathrm{m}$ & $\mathrm{m}$ & $\mathrm{m}$ & $\mathrm{m}$ & $\mathrm{m}$ & $\mathrm{m}$ & $\mathrm{m}$ & $\mathrm{m}$ & $\mathrm{m}$ & $\mathrm{m}$ & $\mathrm{m}$ & $\mathrm{m}$ & $\mathrm{m}$ \\
\hline & Switzerland & 0.08 & $(0.10)$ & 0.26 & $(0.12)$ & 0.17 & $(0.13)$ & -0.07 & $(0.06)$ & -0.14 & $(0.07)$ & -0.07 & $(0.09)$ & -0.10 & $(0.03)$ & 0.02 & $(0.07)$ & 0.12 & $(0.08)$ \\
\hline & Turkey & 0.07 & $(0.11)$ & -0.07 & $(0.07)$ & -0.14 & $(0.13)$ & 0.32 & $(0.06)$ & 0.29 & $(0.05)$ & -0.03 & $(0.08)$ & 0.14 & $(0.07)$ & 0.14 & $(0.06)$ & 0.00 & $(0.10)$ \\
\hline & United Kingdom & -0.14 & $(0.15)$ & 0.12 & $(0.08)$ & 0.26 & $(0.15)$ & 0.28 & (0.08) & 0.36 & $(0.03)$ & 0.08 & $(0.07)$ & 0.11 & $(0.13)$ & 0.36 & $(0.04)$ & 0.24 & $(0.13)$ \\
\hline & United States & 0.35 & $(0.12)$ & 0.44 & (0.09) & 0.09 & (0.16) & 0.35 & $(0.13)$ & 0.49 & (0.07) & 0.14 & $(0.15)$ & 0.27 & $(0.14)$ & 0.37 & $(0.09)$ & 0.10 & $(0.17)$ \\
\hline & OECD average & -0.08 & $(0.03)$ & 0.10 & $(0.02)$ & 0.18 & $(0.03)$ & -0.15 & $(0.02)$ & 0.08 & $(0.01)$ & 0.21 & $(0.02)$ & -0.10 & $(0.02)$ & 0.07 & $(0.01)$ & 0.18 & $(0.02)$ \\
\hline
\end{tabular}

\begin{tabular}{|c|c|c|c|c|c|c|c|c|c|c|c|c|c|c|c|c|c|c|c|}
\hline 2 & Albania & $\mathrm{m}$ & $\mathrm{m}$ & $\mathrm{m}$ & $\mathrm{m}$ & $\mathrm{m}$ & $\mathrm{m}$ & $\mathrm{m}$ & $\mathrm{m}$ & $\mathrm{m}$ & $\mathrm{m}$ & $\mathrm{m}$ & $\mathrm{m}$ & $\mathrm{m}$ & $\mathrm{m}$ & $\mathrm{m}$ & $\mathrm{m}$ & $\mathrm{m}$ & $\mathrm{m}$ \\
\hline 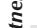 & Algeria & $\mathrm{m}$ & $\mathrm{m}$ & $\mathrm{m}$ & $\mathrm{m}$ & $\mathrm{m}$ & $\mathrm{m}$ & $\mathrm{m}$ & $\mathrm{m}$ & $\mathrm{m}$ & $\mathrm{m}$ & $\mathrm{m}$ & $\mathrm{m}$ & $\mathrm{m}$ & $\mathrm{m}$ & $\mathrm{m}$ & $\mathrm{m}$ & $\mathrm{m}$ & $\mathrm{m}$ \\
\hline & Brazil & -0.24 & $(0.07)$ & -0.18 & $(0.06)$ & 0.06 & $(0.09)$ & 0.27 & $(0.10)$ & 0.48 & $(0.04)$ & 0.20 & $(0.11)$ & -0.01 & $(0.10)$ & 0.13 & $(0.04)$ & 0.14 & $(0.12)$ \\
\hline & B-S-J-G (China) & 0.11 & $(0.05)$ & 0.65 & $(0.09)$ & 0.54 & $(0.10)$ & -0.06 & $(0.16)$ & 0.46 & $(0.07)$ & 0.53 & $(0.18)$ & -0.13 & $(0.07)$ & 0.34 & $(0.07)$ & 0.48 & $(0.09)$ \\
\hline & Bulgaria & -0.22 & $(0.15)$ & -0.18 & $(0.09)$ & 0.03 & $(0.17)$ & -0.09 & $(0.13)$ & 0.18 & $(0.07)$ & 0.27 & $(0.14)$ & 0.14 & $(0.06)$ & 0.29 & $(0.06)$ & 0.15 & $(0.09)$ \\
\hline & CABA (Argentina) & $\mathrm{m}$ & $\mathrm{m}$ & $\mathrm{m}$ & $\mathrm{m}$ & $\mathrm{m}$ & $\mathrm{m}$ & $\mathrm{m}$ & $\mathrm{m}$ & $\mathrm{m}$ & $\mathrm{m}$ & $\mathrm{m}$ & $\mathrm{m}$ & $\mathrm{m}$ & $\mathrm{m}$ & $\mathrm{m}$ & $\mathrm{m}$ & $\mathrm{m}$ & $\mathrm{m}$ \\
\hline & Colombia & -0.01 & $(0.06)$ & 0.11 & $(0.08)$ & 0.11 & $(0.10)$ & 0.24 & $(0.05)$ & 0.36 & $(0.06)$ & 0.11 & $(0.08)$ & 0.06 & $(0.03)$ & 0.01 & $(0.07)$ & -0.05 & $(0.08)$ \\
\hline & Costa Rica & 0.08 & $(0.13)$ & 0.16 & $(0.06)$ & 0.08 & $(0.11)$ & 0.25 & $(0.08)$ & 0.53 & $(0.08)$ & 0.28 & $(0.12)$ & -0.06 & $(0.06)$ & 0.29 & $(0.08)$ & 0.35 & $(0.11)$ \\
\hline & Croatia & -0.17 & $(0.09)$ & -0.15 & $(0.07)$ & 0.02 & $(0.11)$ & -0.43 & $(0.08)$ & -0.24 & $(0.07)$ & 0.20 & $(0.10)$ & -0.35 & $(0.07)$ & -0.13 & $(0.06)$ & 0.22 & $(0.09)$ \\
\hline & Cyprus* & -0.40 & $(0.01)$ & -0.22 & $(0.01)$ & 0.19 & $(0.01)$ & -0.21 & $(0.01)$ & 0.37 & $(0.01)$ & 0.58 & $(0.01)$ & -0.18 & $(0.01)$ & 0.20 & $(0.00)$ & 0.39 & $(0.01)$ \\
\hline & Dominican Republic & c & c & 0.04 & $(0.08)$ & c & c & c & c & 0.77 & $(0.07)$ & c & c & c & c & 0.20 & $(0.09)$ & c & c \\
\hline & FYROM & $\mathrm{m}$ & $\mathrm{m}$ & $\mathrm{m}$ & $\mathrm{m}$ & $\mathrm{m}$ & $\mathrm{m}$ & $\mathrm{m}$ & $\mathrm{m}$ & $\mathrm{m}$ & $\mathrm{m}$ & $\mathrm{m}$ & $\mathrm{m}$ & $\mathrm{m}$ & $\mathrm{m}$ & $\mathrm{m}$ & $\mathrm{m}$ & $\mathrm{m}$ & $\mathrm{m}$ \\
\hline & Georgia & $\mathrm{m}$ & $\mathrm{m}$ & $\mathrm{m}$ & $\mathrm{m}$ & $\mathrm{m}$ & $\mathrm{m}$ & $\mathrm{m}$ & $\mathrm{m}$ & $\mathrm{m}$ & $\mathrm{m}$ & $\mathrm{m}$ & $\mathrm{m}$ & $\mathrm{m}$ & $\mathrm{m}$ & $\mathrm{m}$ & $\mathrm{m}$ & $\mathrm{m}$ & $\mathrm{m}$ \\
\hline & Hong Kong (China) & 0.13 & $(0.11)$ & 0.38 & $(0.15)$ & 0.25 & $(0.18)$ & 0.01 & $(0.06)$ & -0.04 & $(0.05)$ & -0.05 & $(0.08)$ & 0.04 & $(0.06)$ & 0.08 & $(0.04)$ & 0.04 & $(0.07)$ \\
\hline & Indonesia & $\mathrm{m}$ & $\mathrm{m}$ & $\mathrm{m}$ & $\mathrm{m}$ & $\mathrm{m}$ & $\mathrm{m}$ & $\mathrm{m}$ & $\mathrm{m}$ & $\mathrm{m}$ & $\mathrm{m}$ & $\mathrm{m}$ & $\mathrm{m}$ & $\mathrm{m}$ & $\mathrm{m}$ & $\mathrm{m}$ & $\mathrm{m}$ & $\mathrm{m}$ & $\mathrm{m}$ \\
\hline & Jordan & $\mathrm{m}$ & $\mathrm{m}$ & $\mathrm{m}$ & $\mathrm{m}$ & $\mathrm{m}$ & $\mathrm{m}$ & $\mathrm{m}$ & $\mathrm{m}$ & $\mathrm{m}$ & $\mathrm{m}$ & $\mathrm{m}$ & $\mathrm{m}$ & $\mathrm{m}$ & $\mathrm{m}$ & $\mathrm{m}$ & $\mathrm{m}$ & $\mathrm{m}$ & $\mathrm{m}$ \\
\hline & Kosovo & $\mathrm{m}$ & $\mathrm{m}$ & $\mathrm{m}$ & $\mathrm{m}$ & $\mathrm{m}$ & $\mathrm{m}$ & $\mathrm{m}$ & $\mathrm{m}$ & $\mathrm{m}$ & $\mathrm{m}$ & $\mathrm{m}$ & $\mathrm{m}$ & $\mathrm{m}$ & $\mathrm{m}$ & $\mathrm{m}$ & $\mathrm{m}$ & $\mathrm{m}$ & $\mathrm{m}$ \\
\hline & Lebanon & $\mathrm{m}$ & $\mathrm{m}$ & $\mathrm{m}$ & $\mathrm{m}$ & $\mathrm{m}$ & $\mathrm{m}$ & $\mathrm{m}$ & $\mathrm{m}$ & $\mathrm{m}$ & $\mathrm{m}$ & $\mathrm{m}$ & $\mathrm{m}$ & $\mathrm{m}$ & $\mathrm{m}$ & $\mathrm{m}$ & $\mathrm{m}$ & $\mathrm{m}$ & $\mathrm{m}$ \\
\hline & Lithuania & -0.18 & $(0.13)$ & 0.04 & $(0.07)$ & 0.22 & $(0.15)$ & 0.03 & $(0.07)$ & 0.08 & $(0.07)$ & 0.05 & $(0.10)$ & -0.26 & $(0.07)$ & -0.11 & $(0.06)$ & 0.15 & $(0.09)$ \\
\hline & Macao (China) & c & c & 0.01 & $(0.00)$ & c & C & c & c & -0.09 & $(0.00)$ & C & c & c & c & -0.04 & $(0.00)$ & C & C \\
\hline & Malta & $\mathrm{m}$ & $\mathrm{m}$ & $\mathrm{m}$ & $\mathrm{m}$ & $\mathrm{m}$ & $\mathrm{m}$ & $\mathrm{m}$ & $\mathrm{m}$ & $\mathrm{m}$ & $\mathrm{m}$ & $\mathrm{m}$ & $\mathrm{m}$ & $\mathrm{m}$ & $\mathrm{m}$ & $\mathrm{m}$ & $\mathrm{m}$ & $\mathrm{m}$ & $\mathrm{m}$ \\
\hline & Moldova & $\mathrm{m}$ & $\mathrm{m}$ & $\mathrm{m}$ & $\mathrm{m}$ & $\mathrm{m}$ & $\mathrm{m}$ & $\mathrm{m}$ & $\mathrm{m}$ & $\mathrm{m}$ & $\mathrm{m}$ & $\mathrm{m}$ & $\mathrm{m}$ & $\mathrm{m}$ & $\mathrm{m}$ & $\mathrm{m}$ & $\mathrm{m}$ & $\mathrm{m}$ & $\mathrm{m}$ \\
\hline & Montenegro & 0.07 & $(0.00)$ & 0.01 & $(0.01)$ & -0.06 & $(0.01)$ & -0.23 & $(0.00)$ & 0.32 & $(0.02)$ & 0.55 & $(0.02)$ & -0.20 & $(0.00)$ & 0.18 & $(0.02)$ & 0.39 & $(0.02)$ \\
\hline & Peru & 0.07 & $(0.07)$ & 0.32 & $(0.05)$ & 0.26 & $(0.08)$ & 0.32 & $(0.13)$ & 0.60 & $(0.06)$ & 0.28 & $(0.14)$ & 0.07 & $(0.12)$ & 0.15 & $(0.05)$ & 0.08 & $(0.13)$ \\
\hline & Qatar & 0.07 & $(0.00)$ & -0.24 & $(0.00)$ & -0.31 & $(0.00)$ & 0.15 & $(0.00)$ & 0.28 & $(0.00)$ & 0.13 & $(0.00)$ & 0.19 & $(0.00)$ & 0.06 & $(0.00)$ & -0.13 & $(0.00)$ \\
\hline & Romania & $\mathrm{m}$ & $\mathrm{m}$ & $\mathrm{m}$ & $\mathrm{m}$ & $\mathrm{m}$ & $\mathrm{m}$ & $\mathrm{m}$ & $\mathrm{m}$ & $\mathrm{m}$ & $\mathrm{m}$ & $\mathrm{m}$ & $\mathrm{m}$ & $\mathrm{m}$ & $\mathrm{m}$ & $\mathrm{m}$ & $\mathrm{m}$ & $\mathrm{m}$ & $\mathrm{m}$ \\
\hline & Russia & 0.11 & $(0.08)$ & 0.70 & $(0.07)$ & 0.59 & $(0.11)$ & -0.07 & $(0.06)$ & 0.42 & $(0.06)$ & 0.50 & $(0.08)$ & 0.05 & $(0.06)$ & 0.36 & $(0.06)$ & 0.30 & $(0.07)$ \\
\hline & Singapore & $\mathrm{m}$ & $\mathrm{m}$ & $\mathrm{m}$ & $\mathrm{m}$ & $\mathrm{m}$ & $\mathrm{m}$ & $\mathrm{m}$ & $\mathrm{m}$ & $\mathrm{m}$ & $\mathrm{m}$ & $\mathrm{m}$ & $\mathrm{m}$ & $\mathrm{m}$ & $\mathrm{m}$ & $\mathrm{m}$ & $\mathrm{m}$ & $\mathrm{m}$ & $\mathrm{m}$ \\
\hline & Chinese Taipei & 0.10 & $(0.06)$ & 0.19 & $(0.06)$ & 0.09 & $(0.09)$ & -0.15 & $(0.07)$ & 0.18 & $(0.06)$ & 0.33 & $(0.09)$ & -0.18 & $(0.05)$ & 0.13 & $(0.07)$ & 0.31 & $(0.09)$ \\
\hline & Thailand & 0.27 & $(0.06)$ & 0.52 & $(0.04)$ & 0.25 & $(0.07)$ & 0.27 & $(0.08)$ & 0.47 & $(0.03)$ & 0.20 & $(0.08)$ & 0.15 & $(0.07)$ & 0.20 & $(0.04)$ & 0.05 & $(0.08)$ \\
\hline & Trinidad and Tobago & $\mathrm{m}$ & $\mathrm{m}$ & $\mathrm{m}$ & $\mathrm{m}$ & $\mathrm{m}$ & $\mathrm{m}$ & $\mathrm{m}$ & $\mathrm{m}$ & $\mathrm{m}$ & $\mathrm{m}$ & $\mathrm{m}$ & $\mathrm{m}$ & $\mathrm{m}$ & $\mathrm{m}$ & $\mathrm{m}$ & $\mathrm{m}$ & $\mathrm{m}$ & $\mathrm{m}$ \\
\hline & Tunisia & -0.49 & $(0.09)$ & -0.26 & $(0.11)$ & 0.23 & $(0.13)$ & -0.01 & $(0.09)$ & 0.23 & $(0.12)$ & 0.24 & $(0.15)$ & 0.11 & $(0.10)$ & 0.21 & $(0.09)$ & 0.10 & $(0.14)$ \\
\hline & United Arab Emirates & 0.19 & $(0.05)$ & 0.11 & $(0.05)$ & -0.08 & $(0.07)$ & 0.19 & $(0.05)$ & 0.51 & $(0.06)$ & 0.33 & $(0.07)$ & 0.25 & $(0.06)$ & 0.26 & $(0.05)$ & 0.01 & $(0.08)$ \\
\hline & Uruguay & -0.19 & $(0.11)$ & 0.09 & $(0.05)$ & 0.28 & $(0.12)$ & 0.17 & $(0.09)$ & 0.25 & $(0.07)$ & 0.08 & $(0.12)$ & 0.00 & $(0.04)$ & 0.05 & $(0.07)$ & 0.05 & $(0.08)$ \\
\hline & Viet Nam & $\mathrm{m}$ & $\mathrm{m}$ & $\mathrm{m}$ & $\mathrm{m}$ & $\mathrm{m}$ & $\mathrm{m}$ & $\mathrm{m}$ & $\mathrm{m}$ & $\mathrm{m}$ & $\mathrm{m}$ & $\mathrm{m}$ & $\mathrm{m}$ & $\mathrm{m}$ & $\mathrm{m}$ & $\mathrm{m}$ & $\mathrm{m}$ & $\mathrm{m}$ & $\mathrm{m}$ \\
\hline & Argentina** & $\mathrm{m}$ & $\mathrm{m}$ & $\mathrm{m}$ & $\mathrm{m}$ & $\mathrm{m}$ & $\mathrm{m}$ & $\mathrm{m}$ & $\mathrm{m}$ & $\mathrm{m}$ & $\mathrm{m}$ & $\mathrm{m}$ & $\mathrm{m}$ & $\mathrm{m}$ & $\mathrm{m}$ & $\mathrm{m}$ & $\mathrm{m}$ & $\mathrm{m}$ & $\mathrm{m}$ \\
\hline & Kazakhstan** & $\mathrm{m}$ & $\mathrm{m}$ & $\mathrm{m}$ & $\mathrm{m}$ & $\mathrm{m}$ & $\mathrm{m}$ & $\mathrm{m}$ & $\mathrm{m}$ & $\mathrm{m}$ & $\mathrm{m}$ & $\mathrm{m}$ & $\mathrm{m}$ & $\mathrm{m}$ & $\mathrm{m}$ & $\mathrm{m}$ & $\mathrm{m}$ & $\mathrm{m}$ & $\mathrm{m}$ \\
\hline & Malaysia** & 0.00 & $(0.05)$ & 0.28 & $(0.07)$ & 0.28 & $(0.09)$ & 0.27 & $(0.06)$ & 0.61 & $(0.06)$ & 0.35 & $(0.09)$ & 0.29 & $(0.06)$ & 0.56 & $(0.05)$ & 0.27 & $(0.08)$ \\
\hline
\end{tabular}

1. Relatively happy (unhappy) schools are schools where students' life satisfaction is statistically significantly above (below) the average in the country/economy. Note: Values that are statistically significant are indicated in bold (see Annex A3).

* See note at the beginning of this Annex.

Coverage is too small to ensure comparability (see Annex A4)

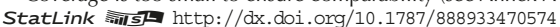




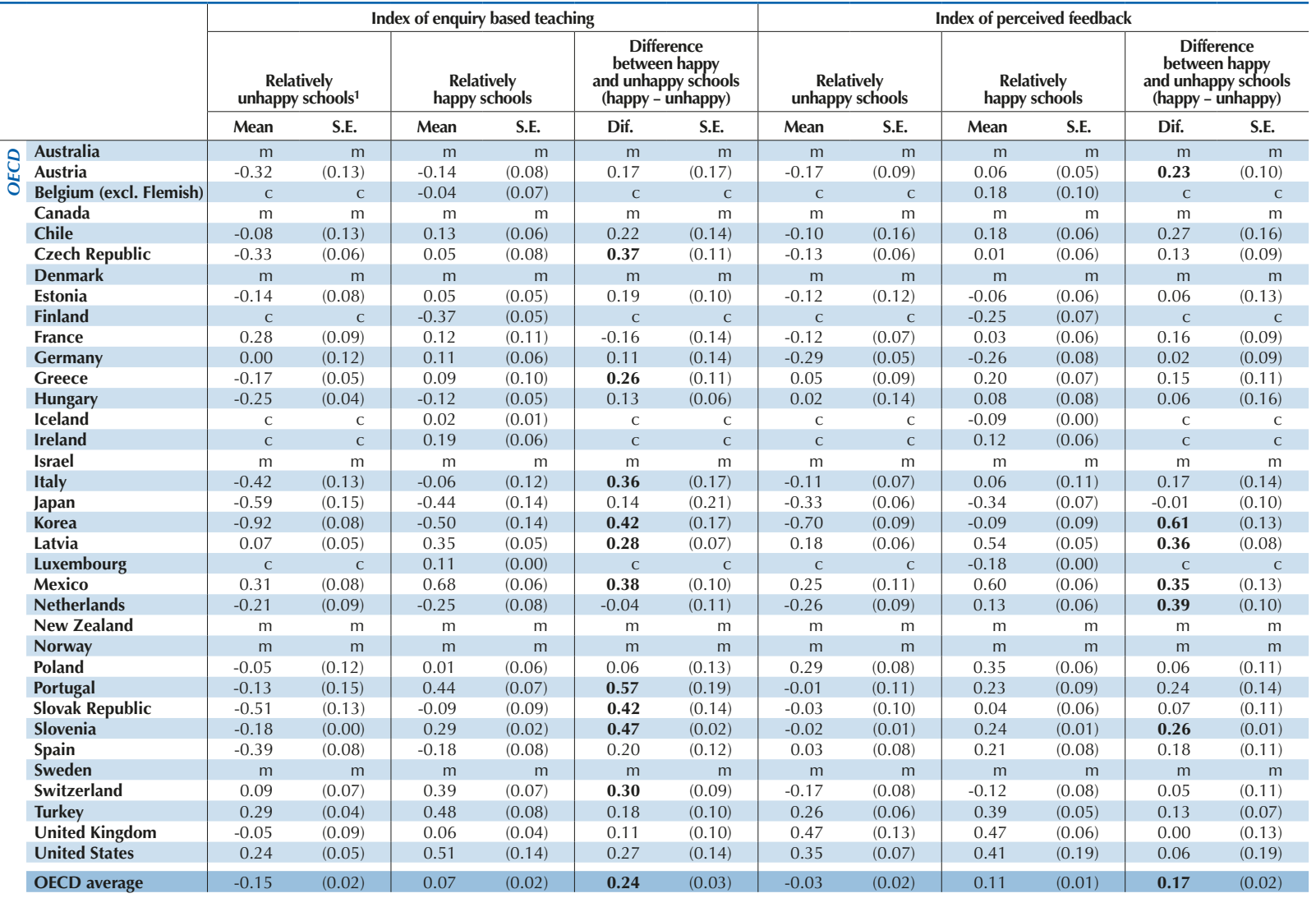

\begin{tabular}{|c|c|c|c|c|c|c|c|c|c|c|c|c|}
\hline Albania & $\mathrm{m}$ & $\mathrm{m}$ & $\mathrm{m}$ & $\mathrm{m}$ & $\mathrm{m}$ & $\mathrm{m}$ & $\mathrm{m}$ & $\mathrm{m}$ & $\mathrm{m}$ & $\mathrm{m}$ & $\mathrm{m}$ & $\mathrm{m}$ \\
\hline Algeria & $\mathrm{m}$ & $\mathrm{m}$ & $\mathrm{m}$ & $\mathrm{m}$ & $\mathrm{m}$ & $\mathrm{m}$ & $\mathrm{m}$ & $\mathrm{m}$ & $\mathrm{m}$ & $\mathrm{m}$ & $\mathrm{m}$ & $\mathrm{m}$ \\
\hline Brazil & -0.11 & $(0.08)$ & 0.09 & $(0.05)$ & 0.19 & $(0.10)$ & 0.08 & $(0.06)$ & 0.26 & $(0.04)$ & 0.18 & $(0.07)$ \\
\hline B-S-J-G (China) & -0.66 & $(0.12)$ & 0.16 & $(0.11)$ & 0.82 & $(0.17)$ & 0.00 & $(0.08)$ & 0.54 & $(0.08)$ & 0.54 & $(0.12)$ \\
\hline Bulgaria & 0.04 & $(0.07)$ & 0.28 & $(0.12)$ & 0.24 & $(0.13)$ & 0.40 & $(0.09)$ & 0.47 & $(0.09)$ & 0.07 & $(0.12)$ \\
\hline CABA (Argentina) & $\mathrm{m}$ & $\mathrm{m}$ & $\mathrm{m}$ & $\mathrm{m}$ & $\mathrm{m}$ & $\mathrm{m}$ & $\mathrm{m}$ & $\mathrm{m}$ & $\mathrm{m}$ & $\mathrm{m}$ & $\mathrm{m}$ & $\mathrm{m}$ \\
\hline Colombia & 0.24 & $(0.06)$ & 0.29 & $(0.06)$ & 0.05 & $(0.09)$ & 0.26 & $(0.05)$ & 0.50 & $(0.06)$ & 0.25 & $(0.09)$ \\
\hline Costa Rica & -0.17 & $(0.03)$ & -0.07 & $(0.06)$ & 0.10 & $(0.07)$ & -0.03 & $(0.07)$ & 0.29 & $(0.08)$ & 0.32 & $(0.11)$ \\
\hline Croatia & -0.36 & $(0.12)$ & -0.11 & $(0.04)$ & 0.26 & $(0.12)$ & -0.06 & $(0.07)$ & 0.15 & $(0.04)$ & 0.21 & $(0.09)$ \\
\hline Cyprus* & 0.13 & $(0.01)$ & 0.51 & $(0.00)$ & 0.38 & $(0.01)$ & 0.27 & $(0.01)$ & 0.45 & $(0.01)$ & 0.17 & $(0.02)$ \\
\hline Dominican Republic & c & c & 0.93 & $(0.09)$ & c & c & c & c & 0.84 & $(0.08)$ & c & c \\
\hline FYROM & $\mathrm{m}$ & $\mathrm{m}$ & $\mathrm{m}$ & $\mathrm{m}$ & $\mathrm{m}$ & $\mathrm{m}$ & $\mathrm{m}$ & $\mathrm{m}$ & $\mathrm{m}$ & $\mathrm{m}$ & $\mathrm{m}$ & $\mathrm{m}$ \\
\hline Georgia & $\mathrm{m}$ & $\mathrm{m}$ & $\mathrm{m}$ & $\mathrm{m}$ & $\mathrm{m}$ & $\mathrm{m}$ & $\mathrm{m}$ & $\mathrm{m}$ & $\mathrm{m}$ & $\mathrm{m}$ & $\mathrm{m}$ & $\mathrm{m}$ \\
\hline Hong Kong (China) & 0.11 & $(0.07)$ & 0.04 & $(0.10)$ & -0.07 & $(0.11)$ & 0.22 & $(0.08)$ & 0.20 & $(0.06)$ & -0.02 & $(0.11)$ \\
\hline Indonesia & $\mathrm{m}$ & $\mathrm{m}$ & $\mathrm{m}$ & $\mathrm{m}$ & $\mathrm{m}$ & $\mathrm{m}$ & $\mathrm{m}$ & $\mathrm{m}$ & $\mathrm{m}$ & $\mathrm{m}$ & $\mathrm{m}$ & $\mathrm{m}$ \\
\hline Jordan & $\mathrm{m}$ & $\mathrm{m}$ & $\mathrm{m}$ & $\mathrm{m}$ & $\mathrm{m}$ & $\mathrm{m}$ & $\mathrm{m}$ & $\mathrm{m}$ & $\mathrm{m}$ & $\mathrm{m}$ & $\mathrm{m}$ & $\mathrm{m}$ \\
\hline Kosovo & $\mathrm{m}$ & $\mathrm{m}$ & $\mathrm{m}$ & $\mathrm{m}$ & $\mathrm{m}$ & $\mathrm{m}$ & $\mathrm{m}$ & $\mathrm{m}$ & $\mathrm{m}$ & $\mathrm{m}$ & $\mathrm{m}$ & $\mathrm{m}$ \\
\hline Lebanon & $\mathrm{m}$ & $\mathrm{m}$ & $\mathrm{m}$ & $\mathrm{m}$ & $\mathrm{m}$ & $\mathrm{m}$ & $\mathrm{m}$ & $\mathrm{m}$ & $\mathrm{m}$ & $\mathrm{m}$ & $\mathrm{m}$ & $\mathrm{m}$ \\
\hline Lithuania & 0.21 & $(0.08)$ & 0.24 & $(0.07)$ & 0.03 & $(0.11)$ & 0.14 & $(0.07)$ & 0.30 & $(0.08)$ & 0.16 & $(0.10)$ \\
\hline Macao (China) & c & c & -0.05 & $(0.00)$ & c & c & c & c & -0.03 & $(0.00)$ & c & c \\
\hline Malta & $\mathrm{m}$ & $\mathrm{m}$ & $\mathrm{m}$ & $\mathrm{m}$ & $\mathrm{m}$ & $\mathrm{m}$ & $\mathrm{m}$ & $\mathrm{m}$ & $\mathrm{m}$ & $\mathrm{m}$ & $\mathrm{m}$ & $\mathrm{m}$ \\
\hline Moldova & $\mathrm{m}$ & $\mathrm{m}$ & $\mathrm{m}$ & $\mathrm{m}$ & $\mathrm{m}$ & $\mathrm{m}$ & $\mathrm{m}$ & $\mathrm{m}$ & $\mathrm{m}$ & $\mathrm{m}$ & $\mathrm{m}$ & $\mathrm{m}$ \\
\hline Montenegro & -0.38 & $(0.00)$ & 0.16 & $(0.02)$ & 0.54 & $(0.02)$ & 0.18 & $(0.00)$ & 0.48 & $(0.02)$ & 0.30 & $(0.02)$ \\
\hline Peru & 0.65 & $(0.11)$ & 0.83 & $(0.07)$ & 0.17 & $(0.13)$ & 0.27 & $(0.10)$ & 0.50 & $(0.05)$ & 0.23 & $(0.12)$ \\
\hline Qatar & 0.24 & $(0.00)$ & 0.61 & $(0.00)$ & 0.37 & $(0.00)$ & 0.58 & $(0.00)$ & 0.45 & $(0.00)$ & -0.13 & $(0.00)$ \\
\hline Romania & $\mathrm{m}$ & $\mathrm{m}$ & $\mathrm{m}$ & $\mathrm{m}$ & $\mathrm{m}$ & $\mathrm{m}$ & $\mathrm{m}$ & $\mathrm{m}$ & $\mathrm{m}$ & $\mathrm{m}$ & $\mathrm{m}$ & $\mathrm{m}$ \\
\hline Russia & 0.28 & $(0.06)$ & 0.69 & $(0.04)$ & 0.41 & $(0.07)$ & 0.38 & $(0.08)$ & 0.52 & $(0.05)$ & 0.14 & $(0.09)$ \\
\hline Singapore & $\mathrm{m}$ & $\mathrm{m}$ & $\mathrm{m}$ & $\mathrm{m}$ & $\mathrm{m}$ & $\mathrm{m}$ & $\mathrm{m}$ & $\mathrm{m}$ & $\mathrm{m}$ & $\mathrm{m}$ & $\mathrm{m}$ & $\mathrm{m}$ \\
\hline Chinese Taipei & -0.61 & $(0.12)$ & -0.34 & $(0.06)$ & 0.28 & $(0.13)$ & 0.04 & $(0.06)$ & 0.37 & $(0.07)$ & 0.33 & $(0.09)$ \\
\hline Thailand & 0.15 & $(0.06)$ & 0.20 & $(0.05)$ & 0.05 & $(0.08)$ & 0.19 & $(0.09)$ & 0.35 & $(0.04)$ & 0.15 & $(0.10)$ \\
\hline Trinidad and Tobago & $\mathrm{m}$ & $\mathrm{m}$ & $\mathrm{m}$ & $\mathrm{m}$ & $\mathrm{m}$ & $\mathrm{m}$ & $\mathrm{m}$ & $\mathrm{m}$ & $\mathrm{m}$ & $\mathrm{m}$ & $\mathrm{m}$ & $\mathrm{m}$ \\
\hline Tunisia & 0.43 & $(0.14)$ & 0.60 & $(0.13)$ & 0.17 & $(0.17)$ & 0.57 & $(0.08)$ & 0.66 & $(0.12)$ & 0.09 & $(0.14)$ \\
\hline United Arab Emirates & 0.24 & $(0.07)$ & 0.68 & $(0.07)$ & 0.44 & $(0.10)$ & 0.32 & $(0.07)$ & 0.64 & $(0.04)$ & 0.32 & $(0.08)$ \\
\hline Uruguay & -0.13 & $(0.06)$ & 0.06 & $(0.05)$ & 0.19 & $(0.08)$ & 0.07 & $(0.07)$ & 0.04 & $(0.05)$ & -0.03 & $(0.09)$ \\
\hline Viet Nam & $\mathrm{m}$ & $\mathrm{m}$ & $\mathrm{m}$ & $\mathrm{m}$ & $\mathrm{m}$ & $\mathrm{m}$ & $\mathrm{m}$ & $\mathrm{m}$ & $\mathrm{m}$ & $\mathrm{m}$ & $\mathrm{m}$ & $\mathrm{m}$ \\
\hline Argentina** $^{* *}$ & $\mathrm{~m}$ & $\mathrm{~m}$ & $\mathrm{~m}$ & $\mathrm{~m}$ & $\mathrm{~m}$ & $\mathrm{~m}$ & $\mathrm{~m}$ & $\mathrm{~m}$ & $\mathrm{~m}$ & $\mathrm{~m}$ & $\mathrm{~m}$ & $\mathrm{~m}$ \\
\hline Kazakhstan** & $\mathrm{m}$ & $\mathrm{m}$ & $\mathrm{m}$ & $\mathrm{m}$ & $\mathrm{m}$ & $\mathrm{m}$ & $\mathrm{m}$ & $\mathrm{m}$ & $\mathrm{m}$ & $\mathrm{m}$ & $\mathrm{m}$ & $\mathrm{m}$ \\
\hline Malaysia** & 0.30 & $(0.05)$ & 0.46 & $(0.05)$ & 0.16 & $(0.07)$ & 0.41 & $(0.08)$ & 0.88 & $(0.06)$ & 0.47 & $(0.11)$ \\
\hline
\end{tabular}

1. Relatively happy (unhappy) schools are schools where students' life satisfaction is statistically significantly above (below) the average in the country/economy. Note: Values that are statistically significant are indicated in bold (see Annex A3).

* See note at the beginning of this Annex.

to small to ensure comparability (see Annex A4).

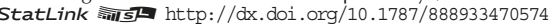




\begin{tabular}{|c|c|c|c|c|c|c|c|c|c|c|c|c|c|}
\hline & \multicolumn{6}{|c|}{ Time per week spent learning in regular lessons } & \multicolumn{6}{|c|}{ After school study time } \\
\hline & & \multicolumn{2}{|c|}{$\begin{array}{c}\text { Relatively } \\
\text { unhappy schools }{ }^{1}\end{array}$} & $\begin{array}{r}\mathrm{Re} \\
\text { hap! }\end{array}$ & ely & $\begin{array}{r}\text { D } \\
\text { betv } \\
\text { and un } \\
\text { (happ }\end{array}$ & $\begin{array}{l}\text { cce } \\
\text { lappy } \\
\text { schools } \\
\text { happy) }\end{array}$ & $\begin{array}{r}\operatorname{Re} \\
\text { unhap }\end{array}$ & $\begin{array}{l}\text { ely } \\
\text { chools }\end{array}$ & $\begin{array}{r}\mathrm{Re} \\
\text { happ }\end{array}$ & ly & $\begin{array}{r}\text { Di } \\
\text { betw } \\
\text { and unh } \\
\text { (happy }\end{array}$ & $\begin{array}{l}\text { lce } \\
\text { lappy } \\
\text { schools } \\
\text { happy) }\end{array}$ \\
\hline & & Hours & S.E. & Hours & S.E. & Dif. & S.E. & Hours & S.E. & Hours & S.E. & Hours & S.E. \\
\hline$\theta$ & Australia & $\mathrm{m}$ & $\mathrm{m}$ & $\mathrm{m}$ & $\mathrm{m}$ & $\mathrm{m}$ & $\mathrm{m}$ & $\mathrm{m}$ & $\mathrm{m}$ & $\mathrm{m}$ & $\mathrm{m}$ & $\mathrm{m}$ & $\mathrm{m}$ \\
\hline 出 & Austria & 31 & $(1.2)$ & 31 & $(0.9)$ & 0.46 & (1.6) & 16 & $(0.9)$ & 18.4 & $(0.7)$ & 1.96 & $(1.2)$ \\
\hline 0 & Belgium (excl. Flemish) & c & C & 28 & $(0.4)$ & c & c & C & c & 16.5 & $(0.7)$ & $\mathrm{C}$ & c \\
\hline & Canada & $\mathrm{m}$ & $\mathrm{m}$ & $\mathrm{m}$ & $\mathrm{m}$ & $\mathrm{m}$ & $\mathrm{m}$ & $\mathrm{m}$ & $\mathrm{m}$ & $\mathrm{m}$ & $\mathrm{m}$ & $\mathrm{m}$ & $\mathrm{m}$ \\
\hline & Chile & 31 & $(1.0)$ & 32 & $(0.8)$ & 0.87 & (1.5) & 17 & (1.0) & 17.6 & $(0.6)$ & 0.69 & (1.1) \\
\hline & Czech Republic & 25 & $(0.3)$ & 25 & $(0.3)$ & 0.06 & $(0.5)$ & 16 & $(0.8)$ & 16.6 & $(0.7)$ & 0.14 & $(1.0)$ \\
\hline & Denmark & $\mathrm{m}$ & $\mathrm{m}$ & $\mathrm{m}$ & $\mathrm{m}$ & $\mathrm{m}$ & $\mathrm{m}$ & $\mathrm{m}$ & $\mathrm{m}$ & $\mathrm{m}$ & $\mathrm{m}$ & $\mathrm{m}$ & $\mathrm{m}$ \\
\hline & Estonia & 26 & $(0.3)$ & 26 & $(0.1)$ & 0.33 & $(0.3)$ & 20 & (1.0) & 18.6 & (1.1) & -1.24 & (1.5) \\
\hline & Finland & c & c & 23 & $(0.2)$ & c & c & $\mathrm{c}$ & c & 12.4 & $(0.6)$ & c & c \\
\hline & France & 27 & $(1.0)$ & 27 & $(0.5)$ & -0.59 & $(1.0)$ & 17 & (2.3) & 15.5 & $(0.8)$ & -1.86 & (2.3) \\
\hline & Germany & 26 & $(0.6)$ & 25 & $(0.4)$ & -0.31 & $(0.8)$ & 12 & $(1.3)$ & 11.5 & $(0.6)$ & -0.41 & (1.5) \\
\hline & Greece & 27 & $(0.6)$ & 27 & $(1.0)$ & -0.20 & $(1.2)$ & 21 & (1.6) & 20.4 & $(1.0)$ & -0.80 & (1.9) \\
\hline & Hungary & 26 & $(0.8)$ & 26 & $(0.4)$ & -0.05 & $(0.9)$ & 16 & $(1.0)$ & 17.6 & $(0.7)$ & 1.25 & $(1.2)$ \\
\hline & Iceland & c & c & 26 & $(0.0)$ & c & C & c & c & 15.0 & $(0.1)$ & $\mathrm{C}$ & c \\
\hline & Ireland & c & c & 29 & $(0.3)$ & c & c & C & C & 16.0 & $(0.6)$ & C & c \\
\hline & Israel & $\mathrm{m}$ & $\mathrm{m}$ & $\mathrm{m}$ & $\mathrm{m}$ & $\mathrm{m}$ & $\mathrm{m}$ & $\mathrm{m}$ & $\mathrm{m}$ & $\mathrm{m}$ & $\mathrm{m}$ & $\mathrm{m}$ & $\mathrm{m}$ \\
\hline & Italy & 28 & $(0.7)$ & 28 & $(0.8)$ & -0.14 & (1.1) & 23 & (1.3) & 19.6 & $(0.9)$ & -3.04 & (1.7) \\
\hline & Japan & 27 & $(1.0)$ & 28 & $(0.4)$ & 0.89 & $(1.0)$ & 11 & (1.1) & 14.2 & $(0.9)$ & 3.44 & (1.3) \\
\hline & Korea & 31 & $(0.6)$ & 30 & $(1.0)$ & -1.19 & $(1.2)$ & 19 & $(1.0)$ & 18.5 & (1.4) & -0.24 & $(1.7)$ \\
\hline & Latvia & 26 & $(0.6)$ & 25 & $(0.3)$ & -1.33 & $(0.7)$ & 17 & $(0.5)$ & 18.0 & $(1.0)$ & 0.70 & (1.1) \\
\hline & Luxembourg & c & C & 26 & $(0.0)$ & C & c & c & c & 14.5 & $(0.0)$ & C & c \\
\hline & Mexico & 25 & $(1.8)$ & 28 & $(0.7)$ & 2.70 & (1.9) & 20 & (1.3) & 21.9 & $(0.6)$ & 1.54 & (1.4) \\
\hline & Netherlands & 28 & $(0.4)$ & 27 & $(0.4)$ & -1.38 & $(0.6)$ & 14 & $(0.8)$ & 16.2 & $(0.7)$ & 2.62 & (1.1) \\
\hline & New Zealand & $\mathrm{m}$ & $\mathrm{m}$ & $\mathrm{m}$ & $\mathrm{m}$ & $\mathrm{m}$ & $\mathrm{m}$ & $\mathrm{m}$ & $\mathrm{m}$ & $\mathrm{m}$ & $\mathrm{m}$ & m & $\mathrm{m}$ \\
\hline & Norway & $\mathrm{m}$ & $\mathrm{m}$ & $\mathrm{m}$ & $\mathrm{m}$ & $\mathrm{m}$ & $\mathrm{m}$ & $\mathrm{m}$ & $\mathrm{m}$ & $\mathrm{m}$ & $\mathrm{m}$ & $\mathrm{m}$ & $\mathrm{m}$ \\
\hline & Poland & 28 & $(0.3)$ & 28 & $(0.4)$ & -0.06 & $(0.5)$ & 20 & (1.0) & 19.6 & $(0.5)$ & 0.02 & $(1.1)$ \\
\hline & Portugal & 31 & $(2.8)$ & 29 & $(0.5)$ & -1.75 & $(2.8)$ & 17 & $(0.5)$ & 18.0 & (1.5) & 1.14 & (1.6) \\
\hline & Slovak Republic & 24 & $(0.6)$ & 25 & $(0.4)$ & 0.75 & $(0.7)$ & 18 & (1.6) & 20.1 & $(0.9)$ & 1.96 & (2.0) \\
\hline & Slovenia & 27 & $(0.1)$ & 27 & $(0.2)$ & 0.86 & $(0.2)$ & 16 & $(0.1)$ & 16.6 & $(0.5)$ & 0.27 & $(0.5)$ \\
\hline & Spain & 28 & $(0.6)$ & 28 & $(0.5)$ & 0.75 & $(0.8)$ & 17 & $(0.8)$ & 17.7 & $(0.9)$ & 0.85 & $(1.2)$ \\
\hline & Sweden & $\mathrm{m}$ & $\mathrm{m}$ & $\mathrm{m}$ & $\mathrm{m}$ & $\mathrm{m}$ & $\mathrm{m}$ & $\mathrm{m}$ & $\mathrm{m}$ & $\mathrm{m}$ & $\mathrm{m}$ & $\mathrm{m}$ & $\mathrm{m}$ \\
\hline & Switzerland & 25 & $(1.7)$ & 26 & $(0.5)$ & 0.86 & (1.7) & 13 & (1.0) & 14.3 & $(1.0)$ & 0.86 & (1.3) \\
\hline & Turkey & 27 & $(0.7)$ & 26 & $(0.4)$ & -0.69 & $(0.8)$ & 22 & $(2.3)$ & 24.7 & $(0.8)$ & 2.71 & $(2.5)$ \\
\hline & United Kingdom & 26 & $(0.6)$ & 27 & $(0.4)$ & 0.44 & $(0.7)$ & 18 & (1.5) & 16.9 & $(0.6)$ & -1.54 & (1.7) \\
\hline & United States & 28 & $(1.1)$ & 28 & $(0.9)$ & -0.37 & (1.4) & 21 & (1.4) & 20.5 & (1.2) & -0.59 & (1.8) \\
\hline & OECD average & 27 & $(0.2)$ & 27 & $(0.1)$ & 0.04 & $(0.2)$ & 18 & $(0.3)$ & 17.4 & $(0.2)$ & 0.45 & $(0.3)$ \\
\hline$\tilde{c}$ & Albania & $\mathrm{m}$ & $\mathrm{m}$ & $\mathrm{m}$ & $\mathrm{m}$ & $\mathrm{m}$ & $\mathrm{m}$ & $\mathrm{m}$ & $\mathrm{m}$ & $\mathrm{m}$ & $\mathrm{m}$ & $\mathrm{m}$ & $\mathrm{m}$ \\
\hline క & Algeria & $\mathrm{m}$ & $\mathrm{m}$ & $\mathrm{m}$ & $\mathrm{m}$ & $\mathrm{m}$ & $\mathrm{m}$ & 21 & $(0.8)$ & 23.3 & $(0.7)$ & 2.60 & $(1.2)$ \\
\hline ปั & Brazil & 26 & $(0.7)$ & 25 & $(0.5)$ & -0.72 & $(1.0)$ & 26 & $(1.2)$ & 26.4 & $(1.3)$ & 0.52 & $(1.8)$ \\
\hline & B-S-J-G (China) & 32 & $(2.5)$ & 31 & $(0.6)$ & -1.63 & (2.6) & 18 & $(0.8)$ & 19.5 & $(0.9)$ & 1.48 & $(1.2)$ \\
\hline & Bulgaria & 24 & $(0.5)$ & 25 & $(0.6)$ & 0.98 & $(0.8)$ & $\mathrm{m}$ & $\mathrm{m}$ & $\mathrm{m}$ & $\mathrm{m}$ & $\mathrm{m}$ & $\mathrm{m}$ \\
\hline & CABA (Argentina) & $\mathrm{m}$ & $\mathrm{m}$ & $\mathrm{m}$ & $\mathrm{m}$ & $\mathrm{m}$ & $\mathrm{m}$ & 21 & (1.0) & 19.7 & $(0.8)$ & -1.18 & $(1.2)$ \\
\hline & Colombia & 27 & $(0.5)$ & 27 & $(0.8)$ & -0.15 & $(1.0)$ & 18 & $(0.8)$ & 18.3 & $(0.6)$ & 0.14 & $(1.0)$ \\
\hline & Costa Rica & 29 & $(1.0)$ & 32 & $(0.8)$ & 3.08 & $(1.2)$ & 20 & $(0.8)$ & 18.8 & $(0.5)$ & -1.32 & $(0.9)$ \\
\hline & Croatia & 27 & $(0.6)$ & 25 & $(0.3)$ & -1.62 & $(0.7)$ & 21 & $(0.1)$ & 19.6 & $(0.2)$ & -1.41 & $(0.2)$ \\
\hline & Cyprus* & 28 & $(0.1)$ & 27 & $(0.1)$ & -1.20 & $(0.1)$ & c & C & 25.2 & $(1.3)$ & C & C \\
\hline & Dominican Republic & c & C & 25 & (1.3) & c & c & $\mathrm{m}$ & $\mathrm{m}$ & $\mathrm{m}$ & $\mathrm{m}$ & $\mathrm{m}$ & $\mathrm{m}$ \\
\hline & FYROM & $\mathrm{m}$ & $\mathrm{m}$ & $\mathrm{m}$ & $\mathrm{m}$ & $\mathrm{m}$ & $\mathrm{m}$ & $\mathrm{m}$ & $\mathrm{m}$ & $\mathrm{m}$ & $\mathrm{m}$ & $\mathrm{m}$ & $\mathrm{m}$ \\
\hline & Georgia & $\mathrm{m}$ & $\mathrm{m}$ & $\mathrm{m}$ & $\mathrm{m}$ & $\mathrm{m}$ & $\mathrm{m}$ & 19 & $(0.8)$ & 18.5 & $(1.2)$ & -0.81 & (1.4) \\
\hline & Hong Kong (China) & 29 & $(0.5)$ & 28 & $(0.7)$ & -1.51 & $(0.9)$ & $\mathrm{m}$ & $\mathrm{m}$ & $\mathrm{m}$ & $\mathrm{m}$ & $\mathrm{m}$ & $\mathrm{m}$ \\
\hline & Indonesia & $\mathrm{m}$ & $\mathrm{m}$ & $\mathrm{m}$ & $\mathrm{m}$ & $\mathrm{m}$ & $\mathrm{m}$ & $\mathrm{m}$ & $\mathrm{m}$ & $\mathrm{m}$ & $\mathrm{m}$ & $\mathrm{m}$ & $\mathrm{m}$ \\
\hline & Jordan & $\mathrm{m}$ & $\mathrm{m}$ & $\mathrm{m}$ & $\mathrm{m}$ & $\mathrm{m}$ & $\mathrm{m}$ & $\mathrm{m}$ & $\mathrm{m}$ & $\mathrm{m}$ & $\mathrm{m}$ & $\mathrm{m}$ & $\mathrm{m}$ \\
\hline & Kosovo & $\mathrm{m}$ & $\mathrm{m}$ & $\mathrm{m}$ & $\mathrm{m}$ & $\mathrm{m}$ & $\mathrm{m}$ & $\mathrm{m}$ & $\mathrm{m}$ & $\mathrm{m}$ & $\mathrm{m}$ & $\mathrm{m}$ & $\mathrm{m}$ \\
\hline & Lebanon & $\mathrm{m}$ & $\mathrm{m}$ & $\mathrm{m}$ & $\mathrm{m}$ & $\mathrm{m}$ & $\mathrm{m}$ & 19 & (0.6) & 18.7 & $(0.7)$ & -0.23 & $(0.9)$ \\
\hline & Lithuania & 25 & $(0.2)$ & 25 & $(0.2)$ & -0.20 & $(0.2)$ & c & c & 16.2 & $(0.0)$ & C & c \\
\hline & Macao (China) & c & C & 28 & $(0.0)$ & c & c & $\mathrm{m}$ & $\mathrm{m}$ & $\mathrm{m}$ & $\mathrm{m}$ & $\mathrm{m}$ & $\mathrm{m}$ \\
\hline & Malta & $\mathrm{m}$ & $\mathrm{m}$ & $\mathrm{m}$ & m & $\mathrm{m}$ & $\mathrm{m}$ & $\mathrm{m}$ & $\mathrm{m}$ & $\mathrm{m}$ & $\mathrm{m}$ & $\mathrm{m}$ & $\mathrm{m}$ \\
\hline & Moldova & $\mathrm{m}$ & $\mathrm{m}$ & $\mathrm{m}$ & $\mathrm{m}$ & $\mathrm{m}$ & $\mathrm{m}$ & 24 & $(0.0)$ & 24.3 & $(0.3)$ & -0.20 & $(0.3)$ \\
\hline & Montenegro & 26 & $(0.0)$ & 26 & $(0.1)$ & 0.03 & $(0.1)$ & 22 & $(1.2)$ & 20.4 & $(0.9)$ & -1.29 & (1.5) \\
\hline & Peru & 28 & $(1.5)$ & 28 & $(0.6)$ & -0.28 & (1.6) & 29 & $(0.0)$ & 25.8 & $(0.0)$ & -2.76 & $(0.0)$ \\
\hline & Qatar & 30 & $(0.0)$ & 27 & $(0.0)$ & -3.04 & $(0.0)$ & $\mathrm{m}$ & $\mathrm{m}$ & $\mathrm{m}$ & $\mathrm{m}$ & $\mathrm{m}$ & $\mathrm{m}$ \\
\hline & Romania & $\mathrm{m}$ & $\mathrm{m}$ & $\mathrm{m}$ & $\mathrm{m}$ & $\mathrm{m}$ & $\mathrm{m}$ & 24 & $(1.8)$ & 21.6 & (1.5) & -1.95 & (2.5) \\
\hline & Russia & 26 & $(0.4)$ & 26 & $(0.4)$ & -0.04 & $(0.5)$ & $\mathrm{m}$ & $\mathrm{m}$ & $\mathrm{m}$ & $\mathrm{m}$ & $\mathrm{m}$ & $\mathrm{m}$ \\
\hline & Singapore & $\mathrm{m}$ & $\mathrm{m}$ & $\mathrm{m}$ & $\mathrm{m}$ & $\mathrm{m}$ & $\mathrm{m}$ & 15 & (1.0) & 18.1 & (1.5) & 2.66 & (1.8) \\
\hline & Chinese Taipei & 32 & $(0.8)$ & 32 & $(0.7)$ & -0.26 & $(1.1)$ & 25 & $(1.2)$ & 23.0 & (1.4) & -2.35 & (1.9) \\
\hline & Thailand & 32 & $(0.7)$ & 32 & $(0.6)$ & -0.27 & $(0.9)$ & $\mathrm{m}$ & $\mathrm{m}$ & $\mathrm{m}$ & $\mathrm{m}$ & $\mathrm{m}$ & $\mathrm{m}$ \\
\hline & Trinidad and Tobago & $\mathrm{m}$ & $\mathrm{m}$ & $\mathrm{m}$ & $\mathrm{m}$ & $\mathrm{m}$ & $\mathrm{m}$ & 25 & $(0.9)$ & 24.6 & (1.4) & -0.48 & (1.6) \\
\hline & Tunisia & 30 & $(1.3)$ & 29 & $(1.2)$ & -1.03 & (1.8) & 30 & $(0.8)$ & 31.2 & $(0.8)$ & 1.09 & (1.1) \\
\hline & United Arab Emirates & 29 & $(0.5)$ & 29 & $(0.4)$ & 0.63 & $(0.6)$ & 16 & (1.3) & 15.5 & $(0.6)$ & -0.75 & (1.6) \\
\hline & Uruguay & 23 & $(0.9)$ & 26 & $(0.7)$ & 2.50 & (1.1) & $\mathrm{m}$ & $\mathrm{m}$ & $\mathrm{m}$ & $\mathrm{m}$ & $\mathrm{m}$ & $\mathrm{m}$ \\
\hline & Viet Nam & $\mathrm{m}$ & m & $\mathrm{m}$ & m & $\mathrm{m}$ & $\mathrm{m}$ & $\mathrm{m}$ & $\mathrm{m}$ & $\mathrm{m}$ & $\mathrm{m}$ & $\mathrm{m}$ & $\mathrm{m}$ \\
\hline & Argentina** $^{* *}$ & $\mathrm{~m}$ & $\mathrm{~m}$ & $\mathrm{~m}$ & $\mathrm{~m}$ & $\mathrm{~m}$ & $\mathrm{~m}$ & 22 & (0.9) & 24.4 & $(0.9)$ & 2.28 & (1.3) \\
\hline & Kazakhstan** & $\mathrm{m}$ & $\mathrm{m}$ & $\mathrm{m}$ & $\mathrm{m}$ & $\mathrm{m}$ & $\mathrm{m}$ & $\mathrm{m}$ & $\mathrm{m}$ & $\mathrm{m}$ & $\mathrm{m}$ & $\mathrm{m}$ & $\mathrm{m}$ \\
\hline & Malaysia** & 27 & $(0.9)$ & 31 & $(0.7)$ & 3.89 & $(1.1)$ & $\mathrm{m}$ & $\mathrm{m}$ & $\mathrm{m}$ & $\mathrm{m}$ & $\mathrm{m}$ & $\mathrm{m}$ \\
\hline
\end{tabular}

1. Relatively happy (unhappy) schools are schools where students' life satisfaction is statistically significantly above (below) the average in the country/economy. Note: Values that are statistically significant are indicated in bold (see Annex A3).

* See note at the beginning of this Annex.

Coverage is too small to ensure comparability (see Annex A4).

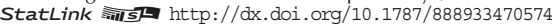


[Part 1/2]

Table III.4.1 Students' schoolwork-related anxiety

Based on students' self reports

\begin{tabular}{|c|c|c|c|c|c|c|c|c|c|c|c|c|c|c|c|c|c|c|c|c|}
\hline & & & & & & & & & Per & & 013 & $\pi$ & hor & port & the & w & & $\mathbf{s}$ & & \\
\hline & & & & en & $\begin{aligned} & r y \text { the } \\
& \text { r me }\end{aligned}$ & & & & & & & & at & & & & & & 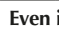 & I ar \\
\hline & & & & Dis & agree & & ree & $\begin{array}{r}\text { Stro } \\
\text { ag }\end{array}$ & $\begin{array}{l}\text { ongly } \\
\text { ree }\end{array}$ & & & Disa & gree & Ag & ree & & & & & Disa \\
\hline & & $\%$ & S.E. & $\%$ & S.E. & $\%$ & S.E. & $\%$ & S.E. & $\%$ & S.E. & $\%$ & S.E. & $\%$ & S.E. & $\%$ & S.E. & $\%$ & S.E. & $\%$ \\
\hline & Australia & 7.5 & $(0.3)$ & 30.8 & $(0.5)$ & 47.0 & $(0.5)$ & 14.7 & $(0.4)$ & 6.8 & $(0.2)$ & 28.0 & $(0.4)$ & 45.2 & $(0.5)$ & 20.0 & $(0.4)$ & 7.4 & $(0.3)$ & 25.1 \\
\hline & Austria & 9.1 & $(0.4)$ & 26.4 & (0.6) & 40.3 & $(0.6)$ & 24.2 & $(0.7)$ & 9.5 & $(0.4)$ & 27.3 & $(0.7)$ & 37.8 & $(0.7)$ & 25.5 & (0.6) & 19.9 & (0.6) & 29.3 \\
\hline & Belgium & 13.3 & $(0.5)$ & 31.1 & (0.5) & 42.2 & $(0.6)$ & 13.3 & $(0.4)$ & 10.1 & $(0.4)$ & 25.0 & $(0.4)$ & 47.6 & (0.5) & 17.3 & $(0.4)$ & 21.2 & (0.5) & 36.3 \\
\hline & Canada & 10.2 & $(0.3)$ & 30.6 & $(0.5)$ & 42.3 & $(0.5)$ & 6.9 & $(0.3)$ & 9.3 & $(0.3)$ & 26.5 & $(0.4)$ & 42.2 & (0.6) & 22.0 & $(0.5)$ & 10.6 & $(0.3)$ & 25.4 \\
\hline & Chile & 9.5 & $(0.4)$ & 31.2 & $(0.7)$ & 47.2 & $(0.8)$ & 12.1 & $(0.4)$ & 5.8 & $(0.3)$ & 12.8 & $(0.5)$ & 44.9 & $(0.7)$ & 36.5 & $(0.7)$ & 16.0 & $(0.5)$ & 28.0 \\
\hline & Czech Republic & 11.1 & $(0.5)$ & 34.1 & (0.6) & 43.0 & (0.6) & 11.7 & $(0.5)$ & 10.6 & $(0.5)$ & 31.7 & $(0.7)$ & 46.9 & $(0.8)$ & 10.7 & $(0.4)$ & 16.9 & (0.6) & 42.7 \\
\hline & Denmark & 0.4 & $(0.5)$ & 34.9 & $(0.7)$ & 42.6 & $(0.7)$ & 12.1 & $(0.5)$ & 7.8 & $(0.4)$ & 27.6 & $(0.7)$ & 46.2 & $(0.7)$ & 18.3 & $(0.6)$ & 7.6 & $(0.4)$ & 27.9 \\
\hline & Estonia & 1.6 & $(0.5)$ & 37.4 & $(0.8)$ & 40.6 & $(0.8)$ & 10.4 & $(0.4)$ & 11.7 & (0.5) & 32.9 & $(0.7)$ & 44.9 & (0.8) & 10.5 & (0.3) & 15.2 & (0.6) & 32.0 \\
\hline & Finland & 17.7 & $(0.5)$ & 44.7 & $(0.7)$ & 30.7 & $(0.7)$ & 6.9 & $(0.3)$ & 17.3 & $(0.6)$ & 38.3 & $(0.8)$ & 35.9 & $(0.8)$ & 8.6 & $(0.4)$ & 14.4 & $(0.5)$ & 37.0 \\
\hline & France & 2.7 & $(0.4)$ & 24.8 & $(0.5)$ & 45.6 & (0.6) & 16.9 & $(0.5)$ & 11.3 & $(0.4)$ & 23.3 & (0.6) & 46.1 & $(0.8)$ & 19.3 & $(0.7)$ & 20.8 & (0.6) & 32.0 \\
\hline & Germany & .6 & (0.5) & 36.5 & (0.6) & 38.5 & $(0.7)$ & 13.3 & $(0.4)$ & 12.7 & $(0.4)$ & 34.0 & $(0.7)$ & 37.1 & (0.6) & 16.2 & (0.5) & 24.5 & $(0.7)$ & 33.9 \\
\hline & Greece & 9 & $(0.6)$ & 39.9 & (0.6) & 37.4 & (0.7) & 8.9 & $(0.4)$ & 14.2 & (0.6) & 37.7 & (0.6) & 36.7 & (0.8) & 11.3 & (0.5) & 14.6 & $(0.5)$ & 26.5 \\
\hline & Hungary & 0.7 & $(0.5)$ & 27.5 & $(0.7)$ & 47.5 & $(0.7)$ & 14.2 & $(0.5)$ & 9.2 & $(0.5)$ & 24.6 & $(0.6)$ & 50.0 & $(0.8)$ & 16.2 & $(0.6)$ & 16.8 & (0.6) & 28.7 \\
\hline & Iceland & 16.8 & (0.6) & 34.7 & $(0.9)$ & 34.5 & (0.8) & 13.9 & $(0.7)$ & 13.1 & $(0.6)$ & 27.6 & $(0.8)$ & 38.4 & $(0.8)$ & 20.9 & $(0.8)$ & 16.8 & (0.6) & 32.1 \\
\hline & Ireland & 6.9 & $(0.4)$ & 31.6 & $(0.8)$ & 50.1 & $(0.8)$ & 1.5 & $(0.5)$ & 5.0 & $(0.3)$ & 26.0 & (0.6) & 49.8 & $(0.7)$ & 19.1 & (0.6) & 7.9 & (0.4) & 28.9 \\
\hline & Israel & 14.7 & $(0.6)$ & 27.5 & (0.6) & 47.5 & $(0.8)$ & 10.3 & $(0.4)$ & 17.1 & $(0.7)$ & 32.5 & (0.8) & 38.6 & $(0.7)$ & 11.8 & $(0.4)$ & 22.3 & (0.6) & 33.3 \\
\hline & Italy & 8.3 & $(0.4)$ & 26.1 & $(0.7)$ & 47.4 & (0.6) & 18.2 & $(0.6)$ & 4.0 & $(0.3)$ & 10.5 & $(0.5)$ & 47.3 & (0.6) & 8.1 & (0.6) & 8.8 & (0.4) & 21.0 \\
\hline & Japan & 4 & $(0.3)$ & 15.5 & (0.5) & 45.1 & (0.6) & 3.0 & $(0.6)$ & 5.3 & $(0.3)$ & 12.8 & $(0.4)$ & 41.7 & $(0.7)$ & 40.2 & $(0.7)$ & 10.7 & (0.5) & 27.2 \\
\hline & Korea & 6.1 & $(0.3)$ & 24.8 & (0.6) & 54.5 & $(0.7)$ & 4.6 & $(0.5)$ & 6.1 & $(0.3)$ & 19.3 & $(0.5)$ & 52.9 & $(0.7)$ & 21.7 & $(0.6)$ & 9.3 & $(0.4)$ & 35.4 \\
\hline & Latviz & 0.5 & $(0.4)$ & 36.2 & $(0.7)$ & 41.0 & $(0.7)$ & 2.3 & $(0.6)$ & 7.9 & & & $(0.7)$ & & $(0.8)$ & 18.3 & (0.6) & 15.1 & (0.5) & 41.7 \\
\hline & Luxe & 12.4 & $(0.4$ & 29.1 & (0.6) & 40.8 & (0.7) & 17.7 & $(0.5)$ & 10.6 & $(0.4)$ & 25 & (0.5) & 40.6 & (0.7) & 23.2 & (0.6) & 21.9 & (0.6) & 30.2 \\
\hline & Mexico & 7.9 & $(0.4)$ & 19.9 & (0.5) & 54.9 & (0.6) & 17.3 & $(0.6)$ & 6.7 & $(0.4)$ & 14 & $(0.5)$ & 47.2 & (0.6) & 31.8 & $(0.7)$ & 2.7 & (0.5) & 27.2 \\
\hline & Netherla & 17.0 & $(0.7)$ & 49.1 & (0.7) & 29.1 & (0.6) & 4.8 & $(0.3)$ & 12.9 & $(0.5)$ & 42.2 & $(0.7)$ & 37.9 & (0.8) & 7.0 & (0.4) & 21.0 & $(0.7)$ & 40.0 \\
\hline & New Zealand & 6.7 & $(0.4)$ & 28.1 & $(0.7)$ & 49.6 & $(0.8)$ & 15.6 & $(0.5)$ & 6.8 & $(0.3)$ & 26.6 & $(0.8)$ & 44.9 & $(0.9)$ & 21.6 & $(0.6)$ & 6.2 & $(0.4)$ & 21.8 \\
\hline & Norway & 13.6 & (0.6) & 35.2 & (0.9) & 36.2 & (0.8) & 15.0 & $(0.5)$ & 10.1 & $(0.5)$ & 23.6 & $(0.7)$ & 42.5 & $(0.7)$ & 23.8 & (0.6) & 10.9 & (0.5) & 28.1 \\
\hline & Polan & 9.8 & $(0.5$ & 28.6 & $(0.7)$ & 47.2 & $(0.8)$ & 14.3 & $(0.5)$ & 7.0 & & 22.5 & (0.6) & & $(0.7)$ & 16.4 & $(0.5)$ & 17.3 & $(0.6)$ & 37.5 \\
\hline & Portu & 3.2 & $(0.3$ & 12.4 & $(0.5)$ & 55.4 & $(0.7)$ & 29.0 & $(0$. & 3.0 & $(0.2)$ & 8. & $(0.3)$ & 47.4 & $(0.7)$ & 40.8 & $(0.7)$ & 8.5 & $(0.4)$ & 22.5 \\
\hline & Slovak Re & 1.4 & $(0.5)$ & 28.0 & $(0.6)$ & 49.1 & $(0.8)$ & 11.5 & $(0.4)$ & 9.6 & $(0.4)$ & 28.3 & (0.7) & 50.8 & $(0.7)$ & 11.4 & (0.5) & 6.7 & $(0.7)$ & 36.3 \\
\hline & Slovenia & 8.2 & $(0.5)$ & 30.9 & $(0.7)$ & 47.6 & $(0.7)$ & 13.3 & $(0.5)$ & 6.3 & $(0.4)$ & 21.6 & $(0.7)$ & 52.3 & $(0.9)$ & 19.9 & $(0.7)$ & 10.9 & (0.5) & 27.3 \\
\hline & Spain & 6.7 & $(0.3)$ & 18.5 & $(0.5)$ & 50.4 & $(0.7)$ & 24.4 & $(0.7)$ & 3.4 & $(0.2)$ & 8.2 & $(0.4)$ & 43.9 & $(0.7)$ & 44.5 & $(0.7)$ & 10.6 & $(0.4)$ & 22.3 \\
\hline & Swe & 1.8 & $(0.5$ & 32.4 & $(0.8)$ & 40.3 & $(0.8)$ & 15.5 & $(0.6)$ & 13.1 & $(0$. & 31. & $(0.7)$ & 36.4 & $(0.7)$ & 19.5 & $(0.6)$ & 9 & $(0.5)$ & 28.0 \\
\hline & Swit & .3 & $(0.5)$ & 36.8 & $(0.8)$ & 37.2 & (1.0) & 10.6 & $(0.5)$ & 12.4 & $(0.5)$ & 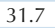 & $(0.8)$ & 40.6 & $(0.9)$ & 15.3 & $(0.6)$ & .2 & $(0.7)$ & 35.2 \\
\hline & Turkey & 9.7 & $(0.6)$ & 20.5 & $(0.7)$ & 47.0 & $(0.8)$ & 2.8 & $(0.7)$ & 8.3 & $(0.4)$ & 7.3 & $(0.7)$ & 49.2 & (0.8) & 5.2 & $(0.8)$ & 4.1 & (0.6) & 27.1 \\
\hline & United & 7.6 & $(0.4)$ & 30.1 & $(0.7)$ & 46.9 & $(0.7)$ & 15.4 & $(0.6)$ & 6.3 & $(0.3)$ & 26.4 & $(0.6)$ & 44.5 & $(0.7)$ & 22.8 & (0.6) & 6.5 & $(0.3)$ & 21.6 \\
\hline & United States & 8.6 & $(0.3)$ & 28.1 & $(0.7)$ & 45.4 & $(0.7)$ & 17.9 & $(0.7)$ & 10.6 & $(0.5)$ & 28.2 & (0.8) & 39.7 & $(0.7)$ & 21.5 & $(0.7)$ & 8.9 & (0.4) & 23.3 \\
\hline & OECD average & 10.5 & $(0.1)$ & 30.1 & $(0.1)$ & 44.1 & $(0.1)$ & 15.3 & $(0.1)$ & 9.2 & $(0.1)$ & 25.1 & $(0.1)$ & 44.4 & $(0.1)$ & 21.4 & $(0.1)$ & 14.4 & $(0.1)$ & 30.1 \\
\hline & Albania & $\mathrm{m}$ & & $\mathrm{m}$ & 111 & 111 & & $\mathrm{~m}$ & 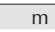 & $\mathrm{m}$ & 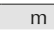 & & & $\mathrm{m}$ & $m$ & II & & $\mathrm{m}$ & $\mathrm{m}$ & $\mathrm{m}$ \\
\hline & Algeria & $\mathrm{m}$ & & $\mathrm{m}$ & $\mathrm{m}$ & $\mathrm{m}$ & $\mathrm{m}$ & $\mathrm{m}$ & $\mathrm{m}$ & $\mathrm{m}$ & $\mathrm{m}$ & $\mathrm{m}$ & $\mathrm{m}$ & $\mathrm{m}$ & $\mathrm{m}$ & $\mathrm{m}$ & $\mathrm{m}$ & $\mathrm{m}$ & $\mathrm{m}$ & $\mathrm{m}$ \\
\hline & Brazil & 5.7 & $(0.2)$ & 14.9 & $(0.3)$ & 57.4 & $(0.5)$ & 21.9 & $(0.4)$ & 2.3 & $(0.1)$ & 4.3 & $(0.2)$ & 46.9 & $(0.5)$ & 46.5 & (0.5) & 5.0 & $(0.2)$ & 14.2 \\
\hline & B-S-J-G (China) & 6.0 & $(0.4)$ & 28.3 & $(0.7)$ & 51.7 & $(0.8)$ & 14.1 & $(0.6)$ & 4.6 & $(0.3)$ & 16.0 & (0.5) & 54.7 & $(0.7)$ & 24.7 & (0.6) & 7.2 & $(0.4)$ & 31.1 \\
\hline & Bul & 0.2 & $(0.7)$ & 27.5 & (0.6) & 41.6 & $(0.8)$ & 10.7 & $(0.5)$ & 14.2 & $(0.5)$ & 24.6 & (0.6) & 47.0 & $(0.7)$ & 14.1 & (0.6) & 18.6 & (0.6) & 26.4 \\
\hline & CA & $\mathrm{m}$ & & $\mathrm{m}$ & $\mathrm{m}$ & $\mathrm{m}$ & $\mathrm{m}$ & $\mathrm{m}$ & $\mathrm{m}$ & $\mathrm{m}$ & 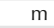 & $\mathrm{m}$ & $\mathrm{m}$ & $\mathrm{m}$ & $\mathrm{m}$ & $\mathrm{m}$ & & $\mathrm{m}$ & $\mathrm{m}$ & $\mathrm{m}$ \\
\hline & Col & 6.5 & $(0.4)$ & 9.5 & (0.6) & 55.7 & (0.8) & 8.3 & $(0.6)$ & 6.2 & $(0.3)$ & 6.5 & $(0.4)$ & 36.5 & $(0.7)$ & 50.8 & (0.8) & 4.4 & $(0.2)$ & 16.8 \\
\hline & Costa Ric & & $(0.4)$ & 15.9 & (0.6) & 51.1 & $(0.8)$ & 26.7 & $(0.7)$ & 3.7 & $(0.3)$ & 4.7 & $(0.3)$ & 33.7 & $(0.7)$ & 7.8 & $(0.7)$ & 5.1 & $(0.3)$ & 13.7 \\
\hline & Croatia & 6.5 & $(0.5)$ & 21.6 & (0.6) & 54.4 & $(0.8)$ & 17.5 & $(0.6)$ & 5.9 & $(0.4)$ & 19.8 & $(0.6)$ & 54.7 & $(0.5)$ & 19.5 & $(0.5)$ & 16.4 & (0.6) & 36.6 \\
\hline & & .1 & $(0.5$ & 5 & $(0.7)$ & 37.5 & (0.6) & 12.8 & $(0.5)$ & 13.7 & $(0.5)$ & 36.9 & $(0.7)$ & 36.1 & $(0.7)$ & 13.3 & $(0.5)$ & 14.8 & $(0.5)$ & 27.5 \\
\hline & Dot & 4.6 & $(0.7)$ & 20.0 & (0.6) & 45.9 & $(0.9)$ & 19.5 & $(0.7)$ & 10.6 & $(0.6)$ & 7.1 & $(0.5)$ & 35.1 & $(0.9)$ & 47.3 & (1.0) & 8.0 & (0.5) & 12.0 \\
\hline & FYRC & $\mathrm{m}$ & & $\mathrm{m}$ & $\mathrm{m}$ & $\mathrm{m}$ & $m$ & $\mathrm{~m}$ & $\mathrm{~m}$ & $\mathrm{~m}$ & $\mathrm{~m}$ & $\mathrm{~m}$ & $\mathrm{~m}$ & $\mathrm{~m}$ & $\mathrm{~m}$ & $\mathrm{~m}$ & $\mathrm{~m}$ & $\mathrm{~m}$ & $\mathrm{~m}$ & $\mathrm{~m}$ \\
\hline & Geo & $\mathrm{n}$ & & $\mathrm{m}$ & $\mathrm{m}$ & $\mathrm{m}$ & $\mathrm{m}$ & $\mathrm{m}$ & $\mathrm{m}$ & $\mathrm{m}$ & 1 & $\mathrm{~m}$ & $\mathrm{~m}$ & $\mathrm{~m}$ & $\mathrm{~m}$ & $\mathrm{~m}$ & I & $\mathrm{m}$ & $\mathrm{m}$ & $\mathrm{m}$ \\
\hline & Hong $\mathrm{K}$ & 5.5 & $(0.3)$ & 23.1 & (0.5) & 50.7 & $(0.8)$ & 20.6 & $(0.7)$ & 4.3 & $(0.3)$ & 13.3 & $(0.5)$ & 53.1 & $(0.8)$ & 29.3 & $(0.7)$ & 6.4 & $(0.4)$ & 26.5 \\
\hline & Indonesi & $\mathrm{m}$ & $\mathrm{m}$ & $\mathrm{m}$ & $\mathrm{m}$ & $\mathrm{m}$ & $\mathrm{m}$ & $\mathrm{m}$ & $\mathrm{m}$ & $\mathrm{m}$ & $\mathrm{m}$ & $\mathrm{m}$ & $\mathrm{m}$ & $\mathrm{m}$ & $\mathrm{m}$ & $\mathrm{m}$ & $\mathrm{m}$ & $\mathrm{m}$ & $\mathrm{m}$ & $\mathrm{m}$ \\
\hline & Jordan & $\mathrm{m}$ & $\mathrm{m}$ & $\mathrm{m}$ & $\mathrm{m}$ & $\mathrm{m}$ & $\mathrm{m}$ & $\mathrm{m}$ & $\mathrm{m}$ & $\mathrm{m}$ & $\mathrm{m}$ & $\mathrm{m}$ & $\mathrm{m}$ & $\mathrm{m}$ & $\mathrm{m}$ & $\mathrm{m}$ & $\mathrm{m}$ & $\mathrm{m}$ & $\mathrm{m}$ & $\mathrm{m}$ \\
\hline & & , & & $\mathrm{m}$ & $\mathrm{m}$ & $\mathrm{m}$ & $\mathrm{m}$ & $\mathrm{m}$ & m & $\mathrm{m}$ & $\mathrm{m}$ & $\mathrm{m}$ & & $\mathrm{m}$ & $\mathrm{m}$ & $\mathrm{m}$ & & $\mathrm{m}$ & II & $\mathrm{m}$ \\
\hline & & 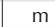 & & $\mathrm{m}$ & $\mathrm{m}$ & $\mathrm{m}$ & & $\mathrm{m}$ & n & $\mathrm{m}$ & ר & $\mathrm{m}$ & $\mathrm{m}$ & $\mathrm{m}$ & n & $\mathrm{m}$ & ר & $\mathrm{m}$ & $m$ & $\mathrm{~m}$ \\
\hline & Lithuania & 7.7 & $(0.5)$ & 21.0 & (0.6) & 44.2 & $(0.7)$ & 17.2 & $(0.5)$ & 14.8 & $(0.5)$ & 20.5 & $(0.6)$ & 43.6 & $(0.7)$ & 21.1 & (0.6) & 24.0 & (0.6) & 20.3 \\
\hline & Macao & 5.7 & $(0.3)$ & 20.8 & (0.6) & 49.2 & $(0.7)$ & 24.4 & $(0.7)$ & 5.2 & $(0.3)$ & 17.0 & $(0.6)$ & 48.7 & $(0.7)$ & 29.1 & $(0.6)$ & 7.0 & $(0.4)$ & 27.4 \\
\hline & Malta & $\mathrm{m}$ & & $\mathrm{m}$ & & $\mathrm{m}$ & $\mathrm{m}$ & $\mathrm{m}$ & $\mathrm{m}$ & $\mathrm{m}$ & $\mathrm{m}$ & $\mathrm{m}$ & $\mathrm{m}$ & $\mathrm{m}$ & $\mathrm{m}$ & $\mathrm{m}$ & $\mathrm{m}$ & $\mathrm{m}$ & $\mathrm{m}$ & $\mathrm{m}$ \\
\hline & & $\mathrm{m}$ & & $\mathrm{m}$ & $\mathrm{m}$ & $\mathrm{m}$ & $\mathrm{m}$ & $\mathrm{m}$ & & $\mathrm{m}$ & n & $\mathrm{m}$ & $\mathrm{m}$ & $\mathrm{m}$ & $\mathrm{m}$ & $\mathrm{m}$ & & $\mathrm{m}$ & $m$ & $\mathrm{~m}$ \\
\hline & Mo & 3.4 & $.5)$ & 2.1 & (0.6) & 49.3 & (0.6) & 15.2 & $(0.5)$ & 10.3 & $(0.4)$ & .4 & (0.6) & 49.4 & $(0.6)$ & 18.8 & $(0.5)$ & 12.8 & (0.5) & 22.1 \\
\hline & Peru & 1 & $(0.4)$ & 32.0 & $(0.6)$ & 50.6 & $(0.7)$ & 9.4 & $(0.4)$ & 6.6 & $(0.4)$ & 14.7 & (0.5) & 48.8 & $(0.7)$ & 30.0 & $(0.7)$ & 6.8 & $(0.3)$ & 21.7 \\
\hline & Qatar & 8.4 & $(0.2)$ & 20.9 & $(0.4)$ & 49.0 & $(0.5)$ & 21.6 & $(0.4)$ & 9.3 & $(0.3)$ & 21.5 & $(0.3)$ & 41.2 & $(0.5)$ & 28.0 & $(0.4)$ & 11.4 & $(0.3)$ & 23.4 \\
\hline & Roman & $\mathrm{m}$ & & $\mathrm{m}$ & & $\mathrm{m}$ & & $\mathrm{m}$ & $\mathrm{m}$ & $\mathrm{m}$ & $\mathrm{m}$ & $\mathrm{m}$ & $\mathrm{m}$ & $\mathrm{m}$ & $\mathrm{m}$ & $\mathrm{m}$ & $\mathrm{m}$ & $\mathrm{m}$ & $\mathrm{m}$ & $\mathrm{m}$ \\
\hline & Russia & .4 & (0.6) & 36.4 & $(0.7)$ & 43.1 & (0.9) & 9.1 & (0.6) & 6.9 & (0.4) & 22.4 & (0.6) & 57.7 & (0.8) & 12.9 & (0.6) & 13.6 & $(0.7)$ & 35.3 \\
\hline & & & $(0$. & 20.7 & (0.6) & 50 & (0.6) & 24.4 & $(0$. & 3.4 & & 10.8 & $(0$. & & $(0.6)$ & 4 & $(0$. & 4.8 & $(0.3)$ & 18.9 \\
\hline & & & $(0$. & 21.5 & $(0.5)$ & 53 & $(0$. & 19.9 & $(0.5)$ & 4.1 & $(0.3)$ & 3 & $(0.4)$ & 53.4 & (0.5) & 28.2 & & 6.0 & $(0.3)$ & 27.4 \\
\hline & & 5.5 & $(0.4)$ & 28.8 & $(0.7)$ & 56.9 & $(0.6)$ & 8.8 & $(0.5)$ & 4.0 & $(0.3)$ & 19.2 & $(0.6)$ & 60.8 & $(0.7)$ & 16.0 & $(0.7)$ & 5.9 & $(0.3)$ & 30.8 \\
\hline & Trinidad & $\mathrm{m}$ & & $\mathrm{m}$ & $\mathrm{m}$ & $\mathrm{m}$ & $\mathrm{m}$ & $\mathrm{m}$ & $\mathrm{m}$ & $\mathrm{m}$ & $\mathrm{m}$ & $\mathrm{m}$ & $\mathrm{m}$ & $\mathrm{m}$ & $\mathrm{m}$ & $\mathrm{m}$ & $\mathrm{m}$ & $\mathrm{m}$ & $\mathrm{m}$ & $\mathrm{m}$ \\
\hline & & 6.0 & (0.6) & 26.4 & (0.9) & 46.4 & (0.8) & 11.3 & $(0.4)$ & 13.5 & $(0.6)$ & 13.9 & (0.6) & 42.7 & $(0.8)$ & 29.9 & $(0.8)$ & 15.9 & (0.6) & 24.3 \\
\hline & & 9 & $(0.4)$ & 23.1 & (0.5) & 48.4 & (0.6) & 19.5 & $(0.5$ & 9.2 & $(0.3)$ & 18.4 & (0.6) & 40.2 & $(0.7)$ & 32.2 & $(0.7)$ & 12.2 & $(0.4)$ & 26.0 \\
\hline & & 8.0 & (0.4) & 19.6 & (0.5) & 54.6 & $(0.7)$ & 17.7 & $(0.5)$ & 4.2 & $(0.3)$ & 5.5 & (0.3) & 41.0 & $(0.7)$ & 49.4 & $(0.7)$ & 6.9 & (0.4) & 20.3 \\
\hline & Viet Nam & $\mathrm{m}$ & $\mathrm{m}$ & $\mathrm{m}$ & $\mathrm{m}$ & $\mathrm{m}$ & $\mathrm{m}$ & $\mathrm{m}$ & $\mathrm{m}$ & $\mathrm{m}$ & $\mathrm{m}$ & $\mathrm{m}$ & $\mathrm{m}$ & $\mathrm{m}$ & $\mathrm{m}$ & $\mathrm{m}$ & $\mathrm{m}$ & $\mathrm{m}$ & $\mathrm{m}$ & $\mathrm{m}$ \\
\hline & & $\mathrm{m}$ & & $\mathrm{m}$ & $\mathrm{m}$ & $\mathrm{m}$ & $\mathrm{m}$ & $\mathrm{m}$ & $\mathrm{n}$ & $\mathrm{m}$ & $\mathrm{m}$ & $\mathrm{m}$ & $\mathrm{m}$ & $\mathrm{m}$ & $\mathrm{m}$ & $\mathrm{m}$ & $\mathrm{m}$ & $\mathrm{m}$ & $\mathrm{m}$ & $\mathrm{m}$ \\
\hline & & & & $\mathrm{m}$ & & $\mathrm{m}$ & & $\mathrm{m}$ & & ר & & 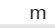 & & $m$ & & $\mathrm{~m}$ & & $\mathrm{~m}$ & $\mathrm{~m}$ & $\mathrm{~m}$ \\
\hline & Malaysia** & 4.4 & $(0.3)$ & 28.7 & $(0.7)$ & 56.8 & $(0.7)$ & 10.1 & $(0.5)$ & 4.1 & $(0.3)$ & 15.7 & $(0.7)$ & 52.7 & $(0.7)$ & 27.4 & $(0.7)$ & 2.7 & $(0.2)$ & 15.7 \\
\hline
\end{tabular}

* See note at the beginning of this Annex.

** Coverage is too small to ensure comparability (see Annex A4).

StatLink 年1 St http://dx.doi.org/10.1787/888933470665 


\section{\begin{tabular}{l|l} 
Percentage of students who reported the following statements \\
\cline { 2 - 3 }
\end{tabular}}

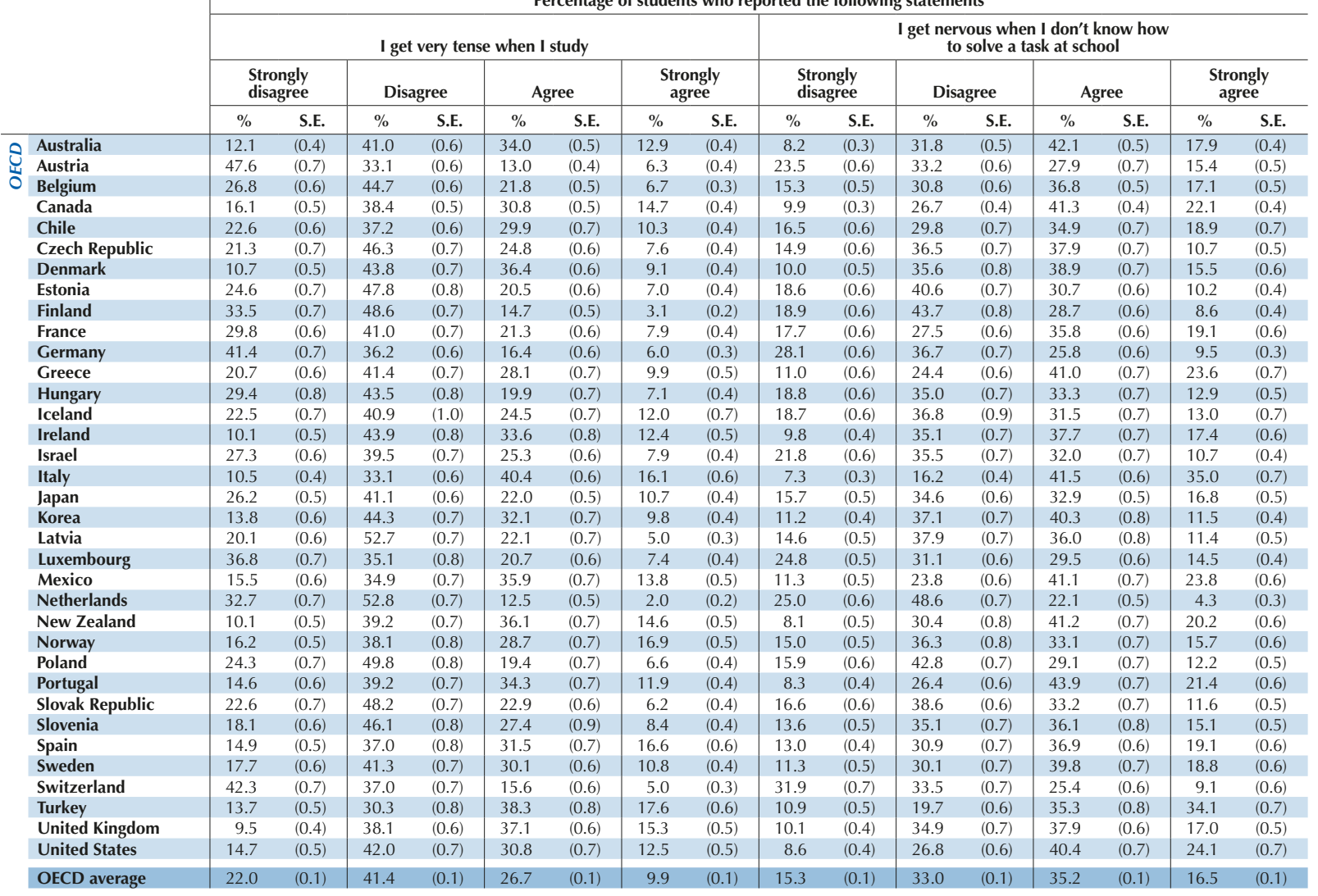

\begin{tabular}{|c|c|c|c|c|c|c|c|c|c|c|c|c|c|c|c|c|c|}
\hline \multirow{4}{*}{ 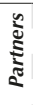 } & Albania & $\mathrm{m}$ & $\mathrm{m}$ & $\mathrm{m}$ & $\mathrm{m}$ & $\mathrm{m}$ & $\mathrm{m}$ & $\mathrm{m}$ & $\mathrm{m}$ & $\mathrm{m}$ & $\mathrm{m}$ & $\mathrm{m}$ & $\mathrm{m}$ & $\mathrm{m}$ & $\mathrm{m}$ & $\mathrm{m}$ & $\mathrm{m}$ \\
\hline & Algeria & $\mathrm{m}$ & $\mathrm{m}$ & $\mathrm{m}$ & $\mathrm{m}$ & $\mathrm{m}$ & $\mathrm{m}$ & $\mathrm{m}$ & $\mathrm{m}$ & $\mathrm{m}$ & $\mathrm{m}$ & $\mathrm{m}$ & $\mathrm{m}$ & $\mathrm{m}$ & $\mathrm{m}$ & $\mathrm{m}$ & $\mathrm{m}$ \\
\hline & Brazil & 9.7 & $(0.3)$ & 34.3 & (0.6) & 39.7 & (0.5) & 16.3 & $(0.3)$ & 6.5 & $(0.2)$ & 19.7 & $(0.4)$ & 43.2 & (0.4) & 30.5 & $(0.5)$ \\
\hline & B-S-J-G (China) & 8.0 & $(0.3)$ & 37.0 & $(0.7)$ & 43.9 & $(0.7)$ & 11.0 & $(0.4)$ & 7.9 & $(0.4)$ & 31.6 & $(0.8)$ & 47.4 & $(0.7)$ & 13.1 & $(0.5)$ \\
\hline & Bulgaria & 20.2 & $(0.7)$ & 33.5 & $(0.8)$ & 35.9 & $(0.8)$ & 10.4 & $(0.4)$ & 15.4 & $(0.6)$ & 23.0 & (0.6) & 40.3 & $(0.7)$ & 21.3 & (0.6) \\
\hline & CABA (Argentina) & $\mathrm{m}$ & $\mathrm{m}$ & $\mathrm{m}$ & $\mathrm{m}$ & $\mathrm{m}$ & $\mathrm{m}$ & $\mathrm{m}$ & $\mathrm{m}$ & $\mathrm{m}$ & $\mathrm{m}$ & $\mathrm{m}$ & $\mathrm{m}$ & $\mathrm{m}$ & $\mathrm{m}$ & $\mathrm{m}$ & $\mathrm{m}$ \\
\hline & Colombia & 11.0 & $(0.5)$ & 31.2 & (0.6) & 39.5 & $(0.7)$ & 18.3 & $(0.5)$ & 8.3 & $(0.3)$ & 19.7 & $(0.5)$ & 42.2 & $(0.7)$ & 29.8 & $(0.6)$ \\
\hline & Costa Rica & 15.0 & $(0.5)$ & 29.9 & $(0.8)$ & 32.2 & $(0.7)$ & 23.0 & $(0.6)$ & 14.1 & $(0.5)$ & 25.1 & $(0.7)$ & 35.4 & $(0.6)$ & 25.5 & $(0.6)$ \\
\hline & Croatia & 20.1 & $(0.6)$ & 43.8 & $(0.7)$ & 27.1 & $(0.6)$ & 9.0 & $(0.4)$ & 19.0 & (0.6) & 37.9 & $(0.8)$ & 31.3 & $(0.7)$ & 11.9 & $(0.6)$ \\
\hline & Cyprus* & 20.8 & $(0.6)$ & 39.3 & $(0.7)$ & 29.8 & $(0.6)$ & 10.2 & $(0.4)$ & 13.7 & $(0.4)$ & 29.8 & $(0.6)$ & 37.8 & $(0.7)$ & 18.8 & $(0.6)$ \\
\hline & Dominican Republic & 16.7 & $(0.7)$ & 29.9 & (0.7) & 35.2 & $(0.8)$ & 18.2 & $(0.7)$ & 15.1 & $(0.7)$ & 21.0 & (0.6) & 36.9 & $(0.9)$ & 27.0 & $(0.7)$ \\
\hline & FYROM & $\mathrm{m}$ & $\mathrm{m}$ & $\mathrm{m}$ & $\mathrm{m}$ & $\mathrm{m}$ & $\mathrm{m}$ & $\mathrm{m}$ & $\mathrm{m}$ & $\mathrm{m}$ & $\mathrm{m}$ & $\mathrm{m}$ & $\mathrm{m}$ & $\mathrm{m}$ & $\mathrm{m}$ & $\mathrm{m}$ & $\mathrm{m}$ \\
\hline & Georgia & $\mathrm{m}$ & $\mathrm{m}$ & $\mathrm{m}$ & $\mathrm{m}$ & $\mathrm{m}$ & $\mathrm{m}$ & $\mathrm{m}$ & $\mathrm{m}$ & $\mathrm{m}$ & $\mathrm{m}$ & $\mathrm{m}$ & $\mathrm{m}$ & $\mathrm{m}$ & $\mathrm{m}$ & $\mathrm{m}$ & $\mathrm{m}$ \\
\hline & Hong Kong (China) & 9.9 & $(0.5)$ & 37.4 & $(0.7)$ & 38.4 & $(0.7)$ & 14.2 & $(0.6)$ & 8.9 & $(0.5)$ & 33.3 & $(0.7)$ & 43.3 & $(0.7)$ & 14.5 & $(0.6)$ \\
\hline & Indonesia & $\mathrm{m}$ & $\mathrm{m}$ & $\mathrm{m}$ & $\mathrm{m}$ & $\mathrm{m}$ & $\mathrm{m}$ & $\mathrm{m}$ & $\mathrm{m}$ & $\mathrm{m}$ & $\mathrm{m}$ & $\mathrm{m}$ & $\mathrm{m}$ & $\mathrm{m}$ & $\mathrm{m}$ & $\mathrm{m}$ & $\mathrm{m}$ \\
\hline & Jordan & $\mathrm{m}$ & $\mathrm{m}$ & $\mathrm{m}$ & $\mathrm{m}$ & $\mathrm{m}$ & $\mathrm{m}$ & $\mathrm{m}$ & $\mathrm{m}$ & $\mathrm{m}$ & $\mathrm{m}$ & $\mathrm{m}$ & $\mathrm{m}$ & $\mathrm{m}$ & $\mathrm{m}$ & $\mathrm{m}$ & $\mathrm{m}$ \\
\hline & Kosovo & $\mathrm{m}$ & $\mathrm{m}$ & $\mathrm{m}$ & $\mathrm{m}$ & $\mathrm{m}$ & $\mathrm{m}$ & $\mathrm{m}$ & $\mathrm{m}$ & $\mathrm{m}$ & $\mathrm{m}$ & $\mathrm{m}$ & $\mathrm{m}$ & $\mathrm{m}$ & $\mathrm{m}$ & $\mathrm{m}$ & $\mathrm{m}$ \\
\hline & Lebanon & $\mathrm{m}$ & $\mathrm{m}$ & $\mathrm{m}$ & $\mathrm{m}$ & $\mathrm{m}$ & $\mathrm{m}$ & $\mathrm{m}$ & $\mathrm{m}$ & $\mathrm{m}$ & $\mathrm{m}$ & $\mathrm{m}$ & $\mathrm{m}$ & $\mathrm{m}$ & $\mathrm{m}$ & $\mathrm{m}$ & $\mathrm{m}$ \\
\hline & Lithuania & 27.5 & $(0.7)$ & 29.9 & $(0.6)$ & 28.3 & (0.6) & 14.3 & $(0.5)$ & 27.5 & $(0.7)$ & 24.9 & (0.6) & 29.4 & (0.6) & 18.2 & $(0.5)$ \\
\hline & Macao (China) & 7.9 & $(0.4)$ & 33.6 & $(0.8)$ & 41.6 & $(0.8)$ & 16.9 & $(0.5)$ & 9.1 & $(0.4)$ & 32.7 & $(0.7)$ & 42.7 & $(0.9)$ & 15.5 & $(0.5)$ \\
\hline & Malta & $\mathrm{m}$ & $\mathrm{m}$ & $\mathrm{m}$ & $\mathrm{m}$ & $\mathrm{m}$ & $\mathrm{m}$ & $\mathrm{m}$ & $\mathrm{m}$ & $\mathrm{m}$ & $\mathrm{m}$ & $\mathrm{m}$ & $\mathrm{m}$ & $\mathrm{m}$ & $\mathrm{m}$ & $\mathrm{m}$ & $\mathrm{m}$ \\
\hline & Moldova & $\mathrm{m}$ & $\mathrm{m}$ & $\mathrm{m}$ & $\mathrm{m}$ & $\mathrm{m}$ & $\mathrm{m}$ & $\mathrm{m}$ & $\mathrm{m}$ & $\mathrm{m}$ & $\mathrm{m}$ & $\mathrm{m}$ & $\mathrm{m}$ & $\mathrm{m}$ & $\mathrm{m}$ & $\mathrm{m}$ & $\mathrm{m}$ \\
\hline & Montenegro & 17.6 & $(0.5)$ & 35.7 & $(0.7)$ & 33.4 & $(0.6)$ & 13.3 & $(0.5)$ & 16.4 & $(0.4)$ & 25.9 & $(0.7)$ & 37.5 & (0.6) & 20.2 & $(0.5)$ \\
\hline & Peru & 14.2 & $(0.5)$ & 42.6 & (0.6) & 35.0 & $(0.7)$ & 8.2 & $(0.4)$ & 14.4 & $(0.5)$ & 36.6 & $(0.7)$ & 37.2 & (0.7) & 11.8 & $(0.4)$ \\
\hline & Qatar & 15.8 & $(0.3)$ & 34.8 & (0.4) & 33.9 & $(0.4)$ & 15.6 & $(0.4)$ & 15.5 & $(0.3)$ & 29.5 & $(0.4)$ & 34.9 & $(0.5)$ & 20.1 & $(0.4)$ \\
\hline & Romania & $\mathrm{m}$ & $\mathrm{m}$ & $\mathrm{m}$ & $\mathrm{m}$ & $\mathrm{m}$ & $\mathrm{m}$ & $\mathrm{m}$ & $\mathrm{m}$ & $\mathrm{m}$ & $\mathrm{m}$ & $\mathrm{m}$ & $\mathrm{m}$ & $\mathrm{m}$ & $\mathrm{m}$ & $\mathrm{m}$ & $\mathrm{m}$ \\
\hline & Russia & 14.8 & $(0.8)$ & 46.3 & $(0.7)$ & 32.1 & $(0.7)$ & 6.8 & $(0.4)$ & 10.0 & $(0.5)$ & 29.9 & $(0.8)$ & 44.1 & $(0.9)$ & 15.9 & $(0.6)$ \\
\hline & Singapore & 7.8 & $(0.4)$ & 32.4 & $(0.7)$ & 40.8 & (0.6) & 19.0 & $(0.6)$ & 6.0 & $(0.4)$ & 23.5 & (0.6) & 45.3 & $(0.7)$ & 25.2 & $(0.6)$ \\
\hline & Chinese Taipei & 7.3 & $(0.3)$ & 31.2 & $(0.6)$ & 44.8 & (0.6) & 16.7 & $(0.5)$ & 7.0 & $(0.3)$ & 25.2 & (0.6) & 50.3 & (0.6) & 17.4 & $(0.5)$ \\
\hline & Thailand & 9.2 & $(0.5)$ & 44.3 & $(0.7)$ & 39.0 & $(0.8)$ & 7.6 & $(0.4)$ & 8.2 & $(0.4)$ & 34.8 & $(0.7)$ & 47.9 & $(0.8)$ & 9.1 & $(0.4)$ \\
\hline & Trinidad and Tobago & $\mathrm{m}$ & $\mathrm{m}$ & $\mathrm{m}$ & $\mathrm{m}$ & $\mathrm{m}$ & $\mathrm{m}$ & $\mathrm{m}$ & $\mathrm{m}$ & $\mathrm{m}$ & $\mathrm{m}$ & $\mathrm{m}$ & $\mathrm{m}$ & $\mathrm{m}$ & $\mathrm{m}$ & $\mathrm{m}$ & $\mathrm{m}$ \\
\hline & Tunisia & 16.1 & $(0.6)$ & 26.7 & $(0.7)$ & 40.1 & $(0.9)$ & 17.1 & $(0.6)$ & 21.6 & $(0.6)$ & 26.4 & $(0.7)$ & 30.1 & $(0.7)$ & 21.8 & $(0.7)$ \\
\hline & United Arab Emirates & 17.9 & $(0.4)$ & 37.6 & $(0.7)$ & 32.3 & $(0.5)$ & 12.2 & $(0.4)$ & 11.3 & $(0.4)$ & 25.7 & (0.6) & 41.0 & $(0.6)$ & 22.0 & (0.5) \\
\hline & Uruguay & 15.2 & $(0.6)$ & 31.6 & $(0.7)$ & 32.5 & $(0.7)$ & 20.7 & $(0.6)$ & 9.0 & $(0.5)$ & 23.5 & $(0.6)$ & 40.0 & $(0.8)$ & 27.4 & $(0.7)$ \\
\hline & Viet Nam & $\mathrm{m}$ & $\mathrm{m}$ & $\mathrm{m}$ & $\mathrm{m}$ & $\mathrm{m}$ & $\mathrm{m}$ & $\mathrm{m}$ & $\mathrm{m}$ & $\mathrm{m}$ & $\mathrm{m}$ & $\mathrm{m}$ & $\mathrm{m}$ & $\mathrm{m}$ & $\mathrm{m}$ & $\mathrm{m}$ & $\mathrm{m}$ \\
\hline & Argentina** & $\mathrm{m}$ & $\mathrm{m}$ & $\mathrm{m}$ & $\mathrm{m}$ & $\mathrm{m}$ & $\mathrm{m}$ & $\mathrm{m}$ & $\mathrm{m}$ & $\mathrm{m}$ & $\mathrm{m}$ & $\mathrm{m}$ & $\mathrm{m}$ & $\mathrm{m}$ & $\mathrm{m}$ & $\mathrm{m}$ & $\mathrm{m}$ \\
\hline & Kazakhstan** & $\mathrm{m}$ & $\mathrm{m}$ & $\mathrm{m}$ & $\mathrm{m}$ & $\mathrm{m}$ & $\mathrm{m}$ & $\mathrm{m}$ & $\mathrm{m}$ & $\mathrm{m}$ & $\mathrm{m}$ & $\mathrm{m}$ & $\mathrm{m}$ & $\mathrm{m}$ & $\mathrm{m}$ & $\mathrm{m}$ & $\mathrm{m}$ \\
\hline & Malaysia** & 6.8 & $(0.4)$ & 38.9 & $(0.8)$ & 42.5 & (0.9) & 11.8 & $(0.5)$ & 4.8 & $(0.3)$ & 22.8 & (0.6) & 52.2 & $(0.7)$ & 20.2 & $(0.7)$ \\
\hline
\end{tabular}

* See note at the beginning of this Annex.

** Coverage is too small to ensure comparability (see Annex A4).

StatLink न्ता st http://dx.doi.org/10.1787/888933470665 
[Part 1/3]

Table III.4.2 Students' schoolwork-related anxiety, by gender and socio-economic status

Percentage of students who reported "agree" or "strongly agree"

\begin{tabular}{|c|c|c|c|c|c|c|c|c|c|c|c|c|c|c|c|c|c|c|c|c|c|}
\hline & & & ercer & e o & s n & o agre & Nith & e fol & ng & tements & & & erce & e o & 10 & agr & VItI & TO & ng & teme & \\
\hline & & \begin{tabular}{|} 
I often \\
that \\
be di \\
for me \\
a t \\
\end{tabular} & $\begin{array}{l}\text { orry } \\
\text { vill } \\
\text { cult } \\
\text { king } \\
\text { t }\end{array}$ & $\begin{array}{r}\text { I worr } \\
\text { will ge } \\
<\text { gra } \\
\text { at sc }\end{array}$ & $\begin{array}{l}\text { hat I } \\
\text { ooor } \\
\text { s> } \\
\text { ol } \\
\end{array}$ & $\begin{array}{r}\text { Even } \\
\text { well p } \\
\text { for } \\
\text { I fee } \\
\text { anx }\end{array}$ & $\begin{array}{l}\text { am } \\
\text { ared } \\
\text { est } \\
\text { ery } \\
\text { us } \\
\end{array}$ & $\begin{array}{r}\text { I get } \\
\text { tense } \\
\text { I st }\end{array}$ & & $\begin{array}{l}\text { I get ne } \\
\text { when I } \\
\text { know } \\
\text { to sol } \\
\text { task at }\end{array}$ & $\begin{array}{l}\text { vous } \\
\text { lon't } \\
\text { ow } \\
\text { e a } \\
\text { hool } \\
\end{array}$ & $\begin{array}{r}\text { I often } \\
\text { that it } \\
\text { be dif } \\
\text { for me } \\
\text { a te }\end{array}$ & $\begin{array}{l}\text { vorry } \\
\text { will } \\
\text { icult } \\
\text { aking } \\
\text { st }\end{array}$ & $\begin{array}{r}\text { I worry } \\
\text { will ge } \\
<\text { grac } \\
\text { at sch }\end{array}$ & $\begin{array}{l}\text { nat I } \\
\text { oor } \\
\text { s> } \\
\text { ol }\end{array}$ & $\begin{array}{l}\text { Even } \\
\text { well pr } \\
\text { for } \\
\text { I fee } \\
\text { anx }\end{array}$ & $\begin{array}{l}\text { am } \\
\text { ared } \\
\text { est } \\
\text { ery } \\
\text { us } \\
\end{array}$ & $\begin{array}{c}\text { tens } \\
\text { Is }\end{array}$ & $\begin{array}{l}\text { hen } \\
y\end{array}$ & $\begin{array}{c}\text { I get } \\
\text { wher } \\
\text { kno } \\
\text { to } \\
\text { task }\end{array}$ & $\begin{array}{l}\text { don't } \\
\text { low } \\
\text { e a } \\
\text { chool }\end{array}$ \\
\hline & & $\%$ & S.E. & $\%$ & S.E. & $\%$ & S.E. & $\%$ & S.E. & $\%$ & S.E. & $\%$ & S.E. & $\%$ & S.E. & $\%$ & S.E. & $\%$ & S.E. & $\%$ & S.E. \\
\hline & Australia & 53.4 & (0.7) & 57.0 & $(0.7)$ & 59.0 & \begin{tabular}{l|l}
$(0.8)$ \\
\end{tabular} & 37.4 & $(0.8)$ & 50.2 & $(0.8)$ & 70.0 & $(0.7)$ & 73.5 & (0.6) & 76.0 & $(0.8)$ & 56.4 & $(0.8)$ & 69.7 & $(0.7)$ \\
\hline & Austria & 59.0 & $(0.9)$ & 57.2 & (1.1) & 43.2 & (1.1) & 17.5 & $(0.7)$ & 39.2 & (1.0) & 70.0 & (1.0) & 69.3 & (1.1) & 58.5 & (1.1) & 21.2 & $(0.8)$ & 47.4 & $(0.8)$ \\
\hline & Belgium & 45.4 & (0.9) & 56.7 & $(0.7)$ & 33.0 & (0.9) & 23.5 & $(0.7)$ & 47.1 & $(0.8)$ & 65.6 & (0.7) & 73.1 & $(0.7)$ & 1.9 & $(0.8)$ & 33.4 & $(0.9)$ & 0.8 & $(0.7)$ \\
\hline & Canada & 50.3 & (0.9) & 56.2 & $(0.7)$ & 53.9 & $(0.7)$ & 36.8 & (0.6) & 53.3 & $(0.6)$ & 68.0 & (0.7) & 72.0 & $(0.7)$ & 73.8 & $(0.7)$ & 54.1 & $(0.8)$ & 3.3 & $(0.6)$ \\
\hline & Chile & 55.0 & (1.0) & 78.1 & (0.9) & 50.4 & (1.1) & 36.1 & (1.0) & 48.5 & (1.2) & 63.6 & (1.0) & 84.7 & $(0.7)$ & 1.6 & $(0.9)$ & 4.3 & $(0.9)$ & 9.1 & (1.0) \\
\hline & Czech Republic & 48.1 & (1.0) & 49.8 & $(1.0)$ & 32.0 & (0.9) & 28.0 & (0.8) & 43.1 & $(1.0)$ & 61.7 & (0.9) & 65.9 & (0.9) & 49.0 & (0.9) & 37.0 & $(0.9)$ & t.3 & (1.0) \\
\hline & Denmark & 41.9 & (1.1) & 53.8 & (1.0) & 53.0 & (1.0) & 37.0 & (0.8) & 43.7 & (1.0) & 67.4 & (1.0) & 75.1 & (1.0) & 5.9 & (1.0) & 3.9 & (1.0) & 5.1 & (1.0) \\
\hline & Estonia & 41.2 & (1.1) & 47.3 & (1.0) & .1 & (1.1) & 21.6 & (0.9) & 32.9 & $(1.0)$ & 61.1 & (1.1) & 3.8 & (1.2) & 0.8 & (1.0) & 3.7 & $(0.9)$ & 9.1 & (1.1) \\
\hline & Finland & 31.9 & $(0.9)$ & 40.2 & (1.2) & 41.1 & (1.0) & 13.2 & (0.6) & 30.0 & $(0.8)$ & 43.7 & (1.0) & 9.0 & (1.1) & 6.7 & (1.0) & 2.7 & $(0.8)$ & 5.0 & (1.0) \\
\hline & France & 51.3 & $(0.9)$ & 56.9 & (1.1) & 38.7 & (1.0) & 24.9 & (1.0) & 48.5 & $(1.0)$ & 73.3 & (0.9) & 3.7 & $(0.9)$ & 5.3 & $(0.9)$ & 3.3 & $(0.9)$ & 1.0 & $(0.9)$ \\
\hline & Germany & 43.5 & (1.0) & 5 & (1.0) & 1 & $(0$. & 2 & $(0.7)$ & 4 & $(0.9)$ & 9.8 & & 8 & (0.9) & 3 & $(1.0)$ & 8 & & & $(0.9)$ \\
\hline & Greece & 43.1 & (1.1) & 46.0 & (1.0) & 50.4 & (1.1) & 32.8 & (0.9) & 59.6 & (1.1) & 49.6 & (0.8) & 0.2 & (1.1) & 8.0 & $(0.9)$ & 3.5 & $(0.9)$ & 9.9 & $(0.8)$ \\
\hline & Hungary & 54.4 & (1.2) & 60.5 & (1.2) & 45.8 & (1.1) & 22.0 & (0.9) & 39.3 & (1.0) & 69.1 & (0.9) & 1.9 & (0.9) & & (1.1) & 2.2 & (1.0) & 3.1 & (1.1) \\
\hline & Icelan & 3.5 & $(1.2)$ & 4 & (1.1) & .6 & (1. & 2 & (1.0) & 303 & (1.0) & 57.7 & (1.3) & 2 & (1.1) & 7 & (1.1) & 8 & & 6 & (1.1) \\
\hline & Ireland & 55.1 & (1.3) & 3 & (0.9) & 56.5 & (1.0) & 38.3 & (1.3) & 0 & (1.0) & 68.4 & (1.2) & 7.0 & (1.0) & 3 & $(0.9)$ & 54.0 & (1.2) & 4.7 & (1.0) \\
\hline & Israel & 50.2 & (1.1) & 44.1 & (1.0) & 36.4 & $(0.8)$ & 26.3 & (0.9) & 35.2 & (1.0) & 65.0 & (0.9) & 6.3 & (1.0) & 52.1 & (11) & 39.7 & & 9.8 & (1.0) \\
\hline & Italy & 58.5 & (0.9) & & (0.8) & & $(0$. & 4 & (1.0) & 6 & (0.8) & 72.5 & $(0$. & & $(0$ & & $(0$ & & & & $(0.7)$ \\
\hline & Japan & 75.0 & (0.9) & 77.7 & $(0.8)$ & 57.2 & (1.0) & 31.9 & $(0.8)$ & 49.9 & $(0.9)$ & 81.2 & $(0.8)$ & 86.1 & $(0.8)$ & 7.1 & (1.0) & 3.6 & & .6 & (0.9) \\
\hline & Korea & 65.1 & (0.9) & 68.9 & (0.8) & 52.0 & (1.1) & 39.4 & (1.0) & 47.8 & (1.0) & 73.6 & (1.1) & 80.9 & (1.0) & 3.8 & (1.0) & 4.7 & (1.2) & 5.0 & (1.2) \\
\hline & Latvia & 45.9 & (1.2) & 62.7 & (1.1) & 3 & (1. & 23.1 & (1.0) & 4 & (1.3) & 0.7 & & 7 & $(1$ & & (1 & 1 & & & (1.2) \\
\hline & Luxembo & 48.5 & (0.9) & 56.3 & (0.9) & 3 & (1. & 23.7 & (0.9) & .4 & (0.9) & 68.1 & (1.0) & 1.3 & (0.9) & 2 & (1.0) & 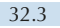 & & 1.5 & $(0.9)$ \\
\hline & Mexico & 66.6 & (1.0) & 74.2 & (0.9) & 54.9 & (1.0) & 44.9 & (0.9) & 57.9 & (1.1) & 78.0 & (0.8) & 4.0 & $(0.7)$ & & $(0$. & 6 & (1.1) & 2.1 & $(0.9)$ \\
\hline & Netherla & 26.4 & (0.9) & 38. & (1.1) & 3 & (1. & 10.5 & (0.7) & 2 & (0.8) & 3 & (1. & 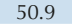 & (1.1) & & $(1$ & 3 & $(0$ & 2 & $(0.9)$ \\
\hline & New Zeal & 59.0 & $(1.2)$ & 59.7 & (1.2) & 65.3 & (1. & 42.6 & (1.2) & 53.3 & (1.2) & 1.5 & (0.9) & 4 & (0.9) & 7 & (0.9) & 7 & $(0.8)$ & 5 & (1.0) \\
\hline & Norway & 39.4 & $(1.2)$ & 56.5 & (1.2) & 48.0 & (1.1) & 30.7 & (0.9) & 35.8 & (1.0) & 63.0 & (1.2) & 1 & $(0.8)$ & & (1. & & & & (1.1) \\
\hline & Poland & 53.4 & (1.2) & & (1.1) & & & & (0.9) & 33. & (1.1) & 9 & & & (1.0) & & $(1$ & 30 & & & (1.1) \\
\hline & Portugal & 77.4 & (1.0) & 8 & $(0.7)$ & 5 & (1. & 36.7 & (1.0) & 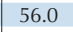 & (1.0) & 5 & (0.5) & 4 & $(0.4)$ & $t$ & $(0.8)$ & 7 & (1.0) & 8 & $(0.8)$ \\
\hline & Slovak Republic & 53.7 & (1.1) & 56.2 & (1.0) & 35 & $(1.0)$ & 25.7 & $(0.8)$ & 40.2 & $(1.0)$ & 67.8 & (1.0) & & $(0$ & & (1 & & $\begin{array}{llll}(1 & & \end{array}$ & & (1.1) \\
\hline & Sloveni & 50.8 & $(1.0)$ & & (1.1) & & (1. & 2 & (0.9) & & (1.2) & 71.6 & (1.0) & 81 & (0.9) & & $(1$. & $T$ & $(1$ & & (1.2) \\
\hline & Spain & 68.1 & $(0.9)$ & 85.3 & $(0.7)$ & 9 & (1. & 40.3 & (0.9) & 8 & (0.9) & 1.6 & (0.7) & - & $(0.5)$ & 3 & $(0.8)$ & 8 & (1.0) & 3 & $(0.9)$ \\
\hline & Sweden & 45.4 & (1.1) & 45.3 & $(0.9)$ & 4 & (1.1) & 29.9 & (0.9) & 5.5 & (1.1) & 6.1 & (1.2) & 5 & (1.0) & 3 & $(1$ & 0 & $(1.2)$ & & $(1.0)$ \\
\hline & Swit & D & (1.1) & & (1.3) & & $(0$. & 18 & (0.9) & & (1.0) & 4 & (1.3) & 2 & (1.2) & & & & & & (1.2) \\
\hline & Turkey & 61.8 & (1.1) & & (1.3) & & (1.2) & 49.1 & (1.1) & 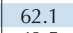 & (1.3) & 7.8 & (0.9) & 1 & $(0.8)$ & & (1.0) & 2.8 & (1.1) & 6.7 & (1.0) \\
\hline & United I & 53.3 & $(1.0)$ & 58.6 & $(0.9)$ & 62.5 & (1.0) & 43.1 & $(0.9)$ & 3.5 & $(0.7)$ & 1.5 & (1.0) & 3 & (0.9) & 4 & $(0.8)$ & 2.0 & $(0.9)$ & 6.6 & (1.0) \\
\hline & United States & 53.5 & $(1.0)$ & 54.1 & $(1.0)$ & 57.4 & (1.0) & 34.1 & (0.9) & 53.2 & $(0.9)$ & 73.1 & (1.0) & 68.2 & (1.1) & 78.0 & $(0.7)$ & 52.4 & (1.0) & 75.8 & $(0.9)$ \\
\hline & OECD average & 51.5 & $(0.2)$ & 59.0 & $(0.2)$ & 47.1 & $(0.2)$ & 30.3 & $(0.2)$ & 44.2 & $(0.2)$ & 67.2 & $(0.2)$ & 72.4 & $(0.2)$ & 63.9 & $(0.2)$ & 42.9 & 0.2 & 9.3 & $0.2)$ \\
\hline & Alba & $\mathrm{m}$ & " & III & $\mathrm{m}$ & 1 & $\mathrm{~m}$ & 1 & $\mathrm{~m}$ & $\mathrm{~m}$ & $\mathrm{~m}$ & $\mathrm{~m}$ & $\mathrm{~m}$ & $\mathrm{~m}$ & 11 & 111 & $\mathrm{~m}$ & in & & $\mathrm{m}$ & $\mathrm{m}$ \\
\hline & Algeria & $\mathrm{m}$ & $\mathrm{m}$ & $\mathrm{m}$ & $\mathrm{m}$ & $\mathrm{m}$ & $\mathrm{m}$ & $\mathrm{m}$ & $\mathrm{m}$ & $\mathrm{m}$ & $\mathrm{m}$ & $\mathrm{m}$ & $\mathrm{m}$ & $\mathrm{m}$ & $\mathrm{m}$ & $\mathrm{m}$ & iII & $\mathrm{m}$ & $\mathrm{m}$ & $\mathrm{m}$ & $\mathrm{m}$ \\
\hline & Brazil & 74.8 & $(0.7)$ & 91.0 & $(0.3)$ & 74.1 & (0.6) & 48.5 & $(0.7)$ & 65.8 & $(0.7)$ & 83.6 & (0.5) & 95.6 & $(0.3)$ & 86.8 & $(0.4)$ & 53.0 & $(0.7)$ & 1.0 & $(0.5)$ \\
\hline & B-S-J-C & .4 & $(1.2)$ & & $(0.7)$ & & (0 & 53.0 & (1.0) & & (1.1) & 9.6 & (1. & & $(0$. & & & & & & $(1.2)$ \\
\hline & Bulg & 45.3 & $(1.0)$ & 55.7 & (1.0) & 48.1 & (0.9) & 40.6 & (1.1) & 54.8 & (1.1) & 60.0 & (1.1) & 7.1 & $(1.2)$ & 2.5 & $(0.9)$ & 2.4 & $(1.0)$ & 9.0 & $(1.0)$ \\
\hline & CABA (Argentina) & $\mathrm{m}$ & $\mathrm{m}$ & $\mathrm{m}$ & $\mathrm{m}$ & $\mathrm{m}$ & $\mathrm{m}$ & $\mathrm{m}$ & $\mathrm{m}$ & $\mathrm{m}$ & $\mathrm{m}$ & $\mathrm{m}$ & $\mathrm{m}$ & $\mathrm{m}$ & $\mathrm{m}$ & $\mathrm{m}$ & $\mathrm{m}$ & $\mathrm{m}$ & $\mathrm{m}$ & $\mathrm{m}$ & $\mathrm{m}$ \\
\hline & Colo & 0.9 & (1.0) & 84.7 & (0.7) & 74.7 & $(0.9)$ & 53.9 & (1.0) & 65.7 & (1.0) & 6.7 & (0.8) & 9.6 & $(0.6)$ & 2.5 & (0.6) & 1.1 & $(0.8)$ & 7.6 & $(0.7)$ \\
\hline & Costa & 73.5 & $(0.8$ & 8 & $(0-7$ & 77.8 & $(0$. & 45.8 & (11) & 52.8 & (1.1) & 2.0 & $(0.8)$ & 93.7 & (0.6) & 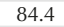 & $(0.8)$ & 4.1 & (1. & 3.6 & $(0.8)$ \\
\hline & Croatia & 63.1 & (1.1) & 66.7 & (1.0) & 35.5 & (1.1) & 29.1 & (0.9) & 39.9 & (0.9) & 80.0 & (0.8) & 81.2 & $(0.7)$ & 7.6 & (1.0) & 2.6 & (1.0) & 6.2 & (1.0) \\
\hline & & & $(1.0)$ & & & & & & $(0.8)$ & & & 4 & & 5 & (1.0) & & $(1$ & & & 8 & (1.1) \\
\hline & Domi & 62.2 & $(1.2)$ & 78.6 & .0) & 78.6 & $\Rightarrow 1$ & 49.8 & (1.2) & 58.4 & $(1.2)$ & 68.5 & (1.1) & 5.9 & $(0.8)$ & 1.3 & $(0.9)$ & 6.9 & (1.1) & 9.0 & (1.1) \\
\hline & FYROM & $\mathrm{m}$ & $\mathrm{m}$ & $\mathrm{m}$ & $\mathrm{m}$ & $\mathrm{m}$ & $\mathrm{m}$ & $\mathrm{m}$ & $\mathrm{m}$ & $\mathrm{m}$ & $\mathrm{m}$ & $\mathrm{m}$ & $\mathrm{m}$ & $\mathrm{m}$ & $\mathrm{m}$ & $\mathrm{m}$ & $\mathrm{m}$ & $\mathrm{m}$ & $\mathrm{m}$ & $\mathrm{m}$ & $\mathrm{m}$ \\
\hline & Geor & $\mathrm{m}$ & $\mathrm{m}$ & $\mathrm{m}$ & $\mathrm{m}$ & $\mathrm{m}$ & . & $\mathrm{m}$ & $\mathrm{m}$ & $\mathrm{m}$ & $\mathrm{m}$ & $\mathrm{m}$ & $\mathrm{m}$ & $\mathrm{m}$ & $\mathrm{m}$ & $\mathrm{m}$ & t & $\mathrm{m}$ & $\mathrm{m}$ & $\mathrm{m}$ & $\mathrm{m}$ \\
\hline & Hong & 65.1 & (0.9) & 77.0 & (0.9) & 63.5 & (1.0) & 48.2 & (1.1) & 54.5 & (1.1) & 77.7 & (0.9) & 87.9 & (0.6) & 70.8 & (1.0) & 57.1 & (1.0) & 61.2 & (1.0) \\
\hline & Indonesi & $\mathrm{m}$ & $\mathrm{m}$ & $\mathrm{m}$ & $\mathrm{m}$ & $\mathrm{m}$ & $\mathrm{m}$ & $\mathrm{m}$ & $\mathrm{m}$ & $\mathrm{m}$ & $\mathrm{m}$ & $\mathrm{m}$ & $\mathrm{m}$ & $\mathrm{m}$ & $\mathrm{m}$ & $\mathrm{m}$ & $\mathrm{m}$ & $\mathrm{m}$ & $\mathrm{m}$ & $\mathrm{m}$ & $\mathrm{m}$ \\
\hline & Jordan & $\mathrm{m}$ & $\mathrm{m}$ & $\mathrm{m}$ & $\mathrm{m}$ & $\mathrm{m}$ & $\mathrm{m}$ & $\mathrm{m}$ & $\mathrm{m}$ & $\mathrm{m}$ & $\mathrm{m}$ & $\mathrm{m}$ & $\mathrm{m}$ & $\mathrm{m}$ & $\mathrm{m}$ & $\mathrm{m}$ & $\mathrm{m}$ & $\mathrm{m}$ & $\mathrm{m}$ & $m$ & $\mathrm{~m}$ \\
\hline & Kosov & 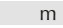 & & & & $\mathrm{m}$ & & $\mathrm{m}$ & & $m$ & . & $\mathrm{m}$ & & $\mathrm{m}$ & & n & & III & & $\mathrm{m}$ & $\mathrm{m}$ \\
\hline & Lebar & $\mathrm{m}$ & $\mathrm{m}$ & $\mathrm{m}$ & $\mathrm{m}$ & $\mathrm{m}$ & $\mathrm{m}$ & $\mathrm{m}$ & $\mathrm{m}$ & $\mathrm{m}$ & $\mathrm{m}$ & $\mathrm{m}$ & $\mathrm{m}$ & $\mathrm{m}$ & $\mathrm{m}$ & $\mathrm{m}$ & $\mathrm{m}$ & $\mathrm{m}$ & $\mathrm{m}$ & $\mathrm{m}$ & $\mathrm{m}$ \\
\hline & & .7 & 1) & 56.0 & (4) & 0 & 1) & 35.9 & )) & 7.5 & (0.9) & 2.1 & (0.9) & 3.6 & (0.8) & 5.5 & )) & 9.3 & 1) & .9 & (1.0) \\
\hline & Mac & .0 & $.0)$ & 73.6 & 6) & 62.0 & 1) & 55.0 & ) & 51.8 & (1.1) & 78.1 & (0.9) & 81.9 & $(0.7)$ & 9.2 & (1.1) & 2.0 & (1.1) & 4.7 & (1.0) \\
\hline & Malta & $\mathrm{m}$ & $\mathrm{m}$ & $\mathrm{m}$ & $\mathrm{m}$ & $\mathrm{m}$ & $\mathrm{m}$ & $\mathrm{m}$ & $\mathrm{m}$ & $\mathrm{m}$ & $\mathrm{m}$ & $\mathrm{m}$ & $\mathrm{m}$ & $\mathrm{m}$ & $\mathrm{m}$ & $\mathrm{m}$ & $\mathrm{m}$ & $\mathrm{m}$ & $\mathrm{m}$ & $\mathrm{m}$ & $\mathrm{m}$ \\
\hline & Mol & $\mathrm{m}$ & $\mathrm{m}$ & $\mathrm{m}$ & $\mathrm{m}$ & $\mathrm{m}$ & 1 & $\mathrm{~m}$ & $\mathrm{~m}$ & $\mathrm{~m}$ & $\mathrm{~m}$ & $\mathrm{~m}$ & $\mathrm{~m}$ & $n$ & $\mathrm{~m}$ & $\mathrm{~m}$ & $m$ & m & $\mathrm{m}$ & $\mathrm{m}$ & $\mathrm{m}$ \\
\hline & Mon & 5.8 & 10) & & 20) & & 2) & 9.1 & $.0)$ & 0.0 & .9) & 3.4 & $(0.9)$ & 4.1 & 9) & 4.9 & 8) & 4.4 & b) & 5.5 & $(1.0)$ \\
\hline & Peru & 7.0 & $(0.9)$ & 75.9 & $(0.7)$ & 70.2 & (0.8) & 41.8 & (0.9) & 44.5 & $(0.9)$ & 63.0 & (1.0) & 81.6 & $(0.8)$ & 2.8 & $(0.8)$ & 4.7 & $(0.8)$ & 3.5 & $(0.9)$ \\
\hline & Qat & 64.7 & $(0.7)$ & 63.7 & 0.6) & 61.4 & $(0.7)$ & 46.6 & $(0.7)$ & 51.7 & $(0.7)$ & 76.4 & (0.6) & 74.5 & $(0.5)$ & 68.8 & (0.6) & 52.1 & $(0.7)$ & 58.1 & $(0.6)$ \\
\hline & & $\mathrm{m}$ & & & & & & & & $\mathrm{m}$ & & $\mathrm{m}$ & & $\mathrm{m}$ & & $\mathrm{m}$ & & $\mathrm{m}$ & & $\mathrm{m}$ & $\mathrm{m}$ \\
\hline & Russi & 44.9 & (1.1) & 64.0 & (1.0) & 42.3 & (1.3) & 34.2 & (1.0) & 50.9 & (1.8) & 59.2 & (1.3) & 77.0 & (1.0) & 59.6 & (1.0) & 43.4 & (1.1) & 68.9 & (1.2) \\
\hline & & 9 & $(0.9)$ & 82 & 0.8 & & $(0.8$ & 55.8 & (2) & 66.4 & (1) & 79.3 & (0.7) & 89.8 & (0.6) & 79.6 & $(0.9)$ & 64.2 & $(0.9)$ & 4.9 & $(0.9)$ \\
\hline & & & $(0$. & & & & & 57 & & 80 & & 78.0 & (0.7) & 85.5 & (0.6) & 71 & $(0.8)$ & 5.5 & $(0.8)$ & 2.5 & $(0.7)$ \\
\hline & Thai & 59.0 & (1.1) & 71.2 & 1.0) & 59.2 & (1.0) & 44.5 & 1.1) & 54.9 & 1.2) & 70.7 & (1.0) & 81.0 & (0.9) & 66.5 & (1.0) & 48.2 & (1.1) & 58.6 & (1.1) \\
\hline & Trin & $\mathrm{m}$ & $\mathrm{m}$ & $\mathrm{m}$ & $\mathrm{m}$ & $\mathrm{m}$ & $\mathrm{m}$ & $\mathrm{m}$ & $\mathrm{m}$ & $\mathrm{m}$ & $\mathrm{m}$ & $\mathrm{m}$ & $\mathrm{m}$ & $\mathrm{m}$ & $\mathrm{m}$ & $\mathrm{m}$ & $\mathrm{m}$ & $\mathrm{m}$ & $\mathrm{m}$ & $\mathrm{m}$ & $\mathrm{m}$ \\
\hline & & 54.1 & $(1.3)$ & 70.1 & t) & 51.2 & $(1.3$ & 48.8 & 2) & 47.2 & 3) & 0.6 & 0) & 74.7 & (0.9) & 6.8 & (1.0) & 4.3 & (1.1) & 6.0 & (1.0) \\
\hline & Uni & 61.9 & $(0.9)$ & 66.0 & $(0.8$ & 59.6 & (0.9) & 42.4 & (0.9) & 58.6 & (0.8) & 73.4 & (0.8) & 78.3 & (0.8) & 63.8 & (1.0) & 46.5 & $(0.9)$ & 67.1 & (1.0) \\
\hline & Urugua & 67.3 & $(0.9)$ & 87.6 & $(0.7)$ & 69.3 & $(0.9)$ & 44.8 & (1.1) & 60.3 & (1.2) & 76.8 & (0.8) & 92.8 & (0.5) & 75.9 & (1.0) & 60.5 & (1.0) & 73.7 & $(0.9)$ \\
\hline & Viet Nam & $\mathrm{m}$ & $\mathrm{m}$ & $\mathrm{m}$ & $\mathrm{m}$ & $\mathrm{m}$ & $\mathrm{m}$ & $\mathrm{m}$ & $\mathrm{m}$ & $\mathrm{m}$ & $\mathrm{m}$ & $\mathrm{m}$ & $\mathrm{m}$ & $\mathrm{m}$ & $\mathrm{m}$ & $\mathrm{m}$ & $\mathrm{m}$ & $\mathrm{m}$ & $\mathrm{m}$ & $\mathrm{m}$ & $\mathrm{m}$ \\
\hline & Arg & $\mathrm{m}$ & m & $\mathrm{m}$ & $\mathrm{m}$ & $\mathrm{m}$ & $\mathrm{m}$ & $\mathrm{m}$ & $\mathrm{m}$ & $\mathrm{m}$ & $\mathrm{m}$ & $\mathrm{m}$ & $\mathrm{m}$ & $\mathrm{m}$ & $\mathrm{m}$ & $\mathrm{m}$ & $\mathrm{m}$ & $\mathrm{m}$ & & $\mathrm{m}$ & $m$ \\
\hline & Kaz & $\mathrm{m}$ & $\mathrm{m}$ & $\mathrm{m}$ & $\mathrm{m}$ & $\mathrm{m}$ & $\mathrm{m}$ & $\mathrm{m}$ & $m$ & m & $\mathrm{m}$ & m & $\mathrm{m}$ & m & $m$ & $\mathrm{~m}$ & I & m & & $\mathrm{m}$ & 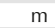 \\
\hline & Malaysia** & 63.3 & (1.0) & 75.1 & (1.1) & 77.3 & (0.9) & 53.4 & (1.2) & 66.4 & (1.0) & 70.1 & (1.0) & 84.7 & $(0.8)$ & 85.5 & $(0.7)$ & 55.0 & $(1.2)$ & 77.7 & (0.9) \\
\hline
\end{tabular}

1. A socio-economically disadvantaged student is a student in the bottom quarter of the PISA index of economic, social and cultural status (ESCS) within his or her own country/economy. 2. A socio-economically advantaged student is a student in the top quarter of the PISA index of economic, social and cultural status (ESCS) within his or her own country/economy.

Note: Values that are statistically significant are indicated in bold (see Annex A3).

** See note at the beginning of this Annex.

Coverage is too small to ensure comparability (see Annex A4). 


\begin{tabular}{|c|c|c|c|c|c|c|c|c|c|c|c|c|c|c|c|c|c|c|c|c|}
\hline & & & $r g$ & the & $\begin{array}{l}\text { perce } \\
\text { ollowi }\end{array}$ & stateme & $s($ & who agr & & & & & & with the & ie foll & ig stat & ment & tider & & \\
\hline & $\begin{array}{r}\text { I often } \\
\text { that } \\
\text { be dif } \\
\text { for me } \\
\text { a te }\end{array}$ & $\begin{array}{l}\text { worry } \\
\text { twill } \\
\text { ficult } \\
\text { taking } \\
\text { est }\end{array}$ & $\begin{array}{l}\text { I worr } \\
\text { will ge } \\
<\text { gra } \\
\text { at sc }\end{array}$ & $\begin{array}{l}\text { that I } \\
\text { poor } \\
\text { s> } \\
\text { ool }\end{array}$ & $\begin{array}{c}\text { Even if if } \\
\text { well pre } \\
\text { for a } \\
\text { I feel } \\
\text { anxi }\end{array}$ & $\begin{array}{l}f \text { I am } \\
\text { epared } \\
\text { test } \\
\text { very } \\
\text { ous }\end{array}$ & $\begin{array}{c}\text { I get } \\
\text { tense } \\
\text { I stu }\end{array}$ & $\begin{array}{l}\text { when } \\
\text { why } \\
\text { uny }\end{array}$ & $\begin{array}{c}\text { I get n } \\
\text { when } \\
\text { know } \\
\text { to so } \\
\text { task at }\end{array}$ & $\begin{array}{l}\text { ervous } \\
\text { don't } \\
\text { dow } \\
\text { lie a } \\
\text { school }\end{array}$ & $\begin{array}{r}\text { I often } \\
\text { that } \\
\text { be di } \\
\text { for me } \\
\text { a }\end{array}$ & $\begin{array}{l}\text { worry } \\
\text { twill } \\
\text { ficult } \\
\text { taking } \\
\text { est }\end{array}$ & $\begin{array}{l}\text { I worr } \\
\text { will ge } \\
<\text { gra } \\
\text { at sc }\end{array}$ & $\begin{array}{l}\text { that I } \\
\text { t poor } \\
\text { des> } \\
\text { hool }\end{array}$ & $\begin{array}{r}\text { Even } \\
\text { well pr } \\
\text { for } \\
\text { I feel } \\
\text { anx }\end{array}$ & $\begin{array}{l}\mathrm{f} I \mathrm{am} \\
\text { epared } \\
\text { test } \\
\text { very } \\
\text { vous }\end{array}$ & $\begin{array}{l}\text { I get } \\
\text { tense } \\
\text { I stu }\end{array}$ & & $\begin{array}{c}\text { I get n } \\
\text { when } \\
\text { knou } \\
\text { to so } \\
\text { task at }\end{array}$ & $\begin{array}{l}\text { ervous } \\
\text { Idon't } \\
\text { how } \\
\text { love a } \\
\text { school }\end{array}$ \\
\hline & \% dif. & S.E. & $\%$ dif. & S.E. & $\%$ dif. & S.E. & $\%$ dif. & S.E. & $\%$ dif. & S.E. & $\%$ & S.E. & $\%$ & S.E. & $\%$ & S.E. & $\%$ & S.E. & $\%$ & S.E. \\
\hline Australia & -16.6 & (1.0) & -16.6 & (1.0) & \begin{tabular}{|l|}
-17.1 \\
\end{tabular} & (1.1) & $\mid-19.0$ & (1.2) & \begin{tabular}{|l|}
-19.5 \\
\end{tabular} & (1.0) & 65.7 & $\begin{array}{l}(0.9) \\
\end{array}$ & 68.7 & $\begin{array}{l}(0.9) \\
\end{array}$ & 69.0 & $(1.0)$ & 49.9 & (1.1) & 62.1 & (1.2) \\
\hline Austria & $\mid-11.1$ & (1.4) & $\mid-12.1$ & (1.5) & -15.3 & (1.4) & -3.8 & (1.1) & -8.2 & (1.3) & 69.8 & (1.2) & 70.4 & (1.3) & 57.6 & (1.6) & 22.7 & (1.1) & 47.2 & (1.4) \\
\hline Belgium & -20.2 & (1.0) & $\mid-16.4$ & (1.0) & 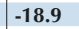 & (1.3) & -9.9 & (1.1) & $|-13.7|$ & (1.1) & 56.4 & (1.4) & 64.7 & (1.3) & 45.5 & (1.3) & 34.8 & (1.3) & 54.5 & (1.1) \\
\hline Canada & $|-17.7|$ & $(1.2)$ & $\mid-15.9$ & (1.0) & \begin{tabular}{|l|} 
\\
\end{tabular} & (1.1) & $\mid-17.3$ & (0.9) & \begin{tabular}{|l|}
-20.0 \\
\end{tabular} & (0.9) & 62.4 & (1.0) & 67.0 & (1.0) & 66.1 & (0.9) & 46.8 & (0.9) & 63.7 & $(1.0)$ \\
\hline Chile & -8.7 & (1.4) & -6.7 & (1.1) & $\mid-11.2$ & (1.4) & -8.2 & (1.5) & $\mid-10.7$ & (1.4) & & & & & 0.0 & & & (1.4) & & \\
\hline Czech Rep & -13.6 & (1.3) & $|-16.1|$ & (1.3) & \begin{tabular}{|l|} 
\\
\end{tabular} & $(1.2)$ & -8.9 & (1.1) & \begin{tabular}{|l|}
-11.2 \\
\end{tabular} & & & & & & - & & & .4) & 6.8 & \\
\hline Denm & $\mid-25.4$ & (1.5) & 3 & (1.4) & -2 & (1.3) & $\mid-16.9$ & (1.4) & -21 & (1. & 1 & (1.7) & .3 & (1.3) & 71.2 & (1.4) & 50.0 & 1.5) & 7.6 & (1. \\
\hline Eston & -19.9 & (1.6) & \begin{tabular}{|l|} 
\\
\end{tabular} & (1.5) & 7 & (1.5) & $|-12.1|$ & (1.3) & -1 & (1.4) & .0 & (1.6) & .9 & 5) & .1 & 6) & 29.3 & 1.4) & 2 & (1.8) \\
\hline Finland & $\mid-11.8$ & (1.1) & -8.8 & (1.3) & -15.6 & (1.2) & -9.6 & (0.9) & \begin{tabular}{|l|} 
\\
\end{tabular} & (1.2) & .7 & (1.4) & 9.5 & (2.0) & 3.4 & (1.7) & 3.6 & (1.2) & .5 & (1.3) \\
\hline France & $\mid-22.0$ & (1.3) & \begin{tabular}{|l|}
-16.8 \\
\end{tabular} & (1.3) & \begin{tabular}{|l|} 
\\
\end{tabular} & (1.3) & -8.3 & (1.2) & \begin{tabular}{|l|}
-12.5 \\
\end{tabular} & (1.4) & 3.1 & (1.3) & 3.0 & (1.4) & 9.8 & (1.3) & 32.9 & (1.2) & 2.3 & (1.4) \\
\hline Germany & \begin{tabular}{|l|}
-16.3 \\
\end{tabular} & (1.3) & $\mid-11.3$ & (1.3) & \begin{tabular}{|l|}
-20.8 \\
\end{tabular} & (1.4) & -2.9 & (1.3) & \begin{tabular}{|l|}
-9.6 \\
\end{tabular} & $(1.2)$ & 4.1 & (1.8) & 4.7 & (1.7) & 6.1 & (1.4) & 23.9 & (1.4) & 6.0 & (1.4) \\
\hline Greece & \begin{tabular}{|l|}
-6.4 \\
\end{tabular} & (1.4) & -4.2 & (1.5) & -17.6 & (1.5) & -10.7 & (1.1) & 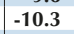 & $(1.3)$ & 7.1 & (1.9) & 54.0 & (1.3) & 62.2 & (1.4) & 40.2 & (1.6) & 64.3 & (1.4) \\
\hline Hung & -14.7 & (1.4) & 11 & (1.5) & & (1) & & & & & & & & & & & & & & \\
\hline & & (1.5) & & (1. & & (1. & & (1. & & & & & & & & & & & & \\
\hline Irel & -1 & (1.6) & -1 & (1.3) & $\mid-1$ & (1.1) &. & (1.4) & -1 & (1. & & (1.3) & 2.2 & (1.3) & 0.0 & & 50 & & 5.4 & t) \\
\hline Israel & -1 & (1.3) & \begin{tabular}{|l|}
$\mid-12.2$ \\
\end{tabular} & (1.1) & -1 & (1.2) & $\mid-13.4$ & (1.3) & $\mid-14.6$ & (1.4) & .8 & 5) & .9 & 7 & .9 & 6) & 38.1 & .4) & .8 & (1.4) \\
\hline Italy & -14.0 & (1.1) & \begin{tabular}{|l|} 
\\
\end{tabular} & (1.0) & $\mid-1$ & (1.1) & $\mid-19.6$ & (1.4) & $|-13.1|$ & (1.0) & 6.9 & (1.4) & 1.9 & & 2.1 & & 1.1 & .7) & 6 & (1.2) \\
\hline Japan & \begin{tabular}{|l|}
-6.2 \\
\end{tabular} & (1.1) & -8.4 & (1.1) & -9.9 & (1.3) & -1.7 & (1.1) & 0.3 & (1.2) & .8 & (1.1) & .8 & .1) & 3.3 & .5) & 0.7 & 1.2) & 44.0 & (1.5) \\
\hline Korea & -8.5 & (1.3) & $\mid-12.0$ & (1.3) & -6.8 & (1.4) & -5.4 & (1.5) & -8.3 & (1.5) & 8.0 & (1.3) & 3.1 & (1.4) & 51.8 & (1.5) & 38.1 & (1.5) & 2.5 & (1.5) \\
\hline Latvia & -14.7 & (1.7) & -11.1 & (1.4) & \begin{tabular}{|l|}
-10.8 \\
\end{tabular} & (1.5) & -8.1 & (1.5) & $\mid-14.7$ & $(1.7)$ & 0 & (1.6) & .5 & 5 & 4.9 & 1.6) & 7.9 & (1.6) & 8.1 & $(1.6)$ \\
\hline & & (1.3) & & (1.3) & & & -8 & & -15 & & & & & & & & & & & \\
\hline & & (1.1 & \begin{tabular}{|l|} 
\\
\end{tabular} & & & & -9 & & & & & & & & & & & & & \\
\hline $\mathrm{Ne}$ & -14.9 & (1.1 & \begin{tabular}{|lll}
-1 &
\end{tabular} & (1.2) & -13. & (1. & -7 & (1.1) & -7 & (1.2) & & (1.3) & & & & & & .1) & & (1.2) \\
\hline $\mathrm{N}$ & & (1.4) & .7 & (1.2) & $\mid-13.5$ & (1.3) & $|-16.1|$ & 5) & -16 & (1.4) & .1 & 4) & .7 & 3) & 4 & (1.3) & 54.4 & .3) & 9 & (1) \\
\hline Norwa & & (1.4) & & (1.2) & $|-26.1|$ & (1.5) & 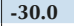 & (1.2) & -25 & (1.3) & 5.9 & (1.9) & & (1.7) & & (1.5) & & (1.4) & 1.2 & (1.6) \\
\hline Poland & $\mid-16.5$ & (1.5) & \begin{tabular}{|l|}
-14.3 \\
\end{tabular} & (1.4) & \begin{tabular}{|l|}
-16.7 \\
\end{tabular} & (1.5) & -9.1 & (1.3) & \begin{tabular}{|l|}
-16.3 \\
\end{tabular} & (1.6) & 5.6 & (1.4) & 3.5 & (1.3) & 0.6 & (1.4) & 31.2 & (1.4) & 45.6 & (1.6) \\
\hline Portugal & & (1.1) & -10.2 & $(0.8)$ & -20.6 & (1.3) & -19.0 & (1.5) & \begin{tabular}{|c|} 
\\
\end{tabular} & $(1.2)$ & 9 & (1.0) & 3.5 & $(0.9)$ & 3.7 & (1.3) & 50.8 & (1.5) & 67.1 & (1.5) \\
\hline Sloval & & (1.4) & -12.3 & (1.1) & -15. & (1.4) & -7.0 & (1.3) & -9 & $(1.4)$ & 6 & (1. & 61 & (1. & & & 31. & $(1.4)$ & J & $(1.4)$ \\
\hline Slove & & (1.5) & -17 & (1.3) & & & -16 & & $\mid-15$ & & & & & & & & & & & \\
\hline & & (1. & & & & & & & & & & & & & & & & & & \\
\hline & & (1. & -21. & $(1$ & & (1 & -2 & & & & & & & & & & & & & \\
\hline Sw & -1 & (1.5) & -1 & (1.5) & & (1.3) & -4 & (1.2) & & (1 & .1 & (1 & & (1 & & & 4 & 3) & 3 & \\
\hline Turke & & (1.4) & -1 & (1.5) & & (1.6) & -13 & (1.5) & $\mid-1$ & (1 & & & & & & & 0 & (1.5) & .8 & \\
\hline United $\mathrm{K}$ & 1.1 & (1.5) & \begin{tabular}{|l|}
-17.7 \\
\end{tabular} & (1.1) & \begin{tabular}{|l|} 
\\
\end{tabular} & (1.2) & $\mid-1$ & (1.3) & \begin{tabular}{|l}
-23 \\
\end{tabular} & (1.0) & 6 & (1.4) & 7 & (1.4) & 7 & (1.0) & 5.2 & (1.3) & 57.8 & (1. \\
\hline United States & -19.5 & (1.3) & -14.1 & (1.4) & $\mid-20.7$ & (1.0) & -18.3 & (1.3) & -22.6 & (1.2) & 67.6 & (1.3) & 69.0 & (1.6) & 69.6 & $(1.3)$ & 46.6 & (1.4) & 68.7 & (1.4) \\
\hline OECD average & $\mid-15.7$ & $(0.2)$ & $\mid-13.4$ & $(0.2)$ & -16.7 & $(0.2)$ & -12.6 & $(0.2)$ & $\mid-15.1$ & $(0.2)$ & 62.5 & $(0.2)$ & 67.9 & $(0.2)$ & 58.7 & $(0.2)$ & 39.7 & $(0.2)$ & 53.2 & $(0.3)$ \\
\hline & $\mathrm{m}$ & $\mathrm{m}$ & $\mathrm{m}$ & $\mathrm{m}$ & $\mathrm{m}$ & $\mathrm{m}$ & $\mathrm{m}$ & $\mathrm{m}$ & $\mathrm{m}$ & $\mathrm{m}$ & & $\mathrm{m}$ & & & & & & & & \\
\hline ger & $\mathrm{m}$ & $\mathrm{m}$ & $\mathrm{m}$ & $\mathrm{m}$ & $\mathrm{m}$ & $\mathrm{m}$ & $\mathrm{m}$ & $\mathrm{m}$ & $\mathrm{m}$ & $\mathrm{m}$ & $\mathrm{m}$ & $\mathrm{m}$ & $\mathrm{m}$ & $\mathrm{m}$ & $\mathrm{m}$ & $\mathrm{m}$ & m & $\mathrm{m}$ & $\mathrm{m}$ & \\
\hline Braz & -8.8 & $(0.8)$ & -4.6 & $(0.5)$ & $\mid-12.7$ & $(0.7)$ & $\mid-14.5$ & (0.9) & -15 & (0.8) & 812 & $(0.7)$ & & (0.5) & & 9) & & 1.0) & & \\
\hline B-S-J-G (C & -7.1 & (1.5) & -7.9 & (1.0) & -1.6 & (1.4) & -4.2 & (1.5) & -6.7 & (1.5) & 0.1 & (1.3) & .6 & (1.4) & 1 & (1.6) & 6.3 & (1.7) & 66.2 & $(1.5$ \\
\hline Bulga & -14.7 & (1.4) & -11.4 & (1.5) & -14.5 & (1.2) & $\mid-11.8$ & (1.4) & $\mid-14.2$ & (1.5) & 56.5 & (1.6) & 5.5 & (1.6) & 8.9 & (1.6) & 51.3 & (1.5) & 0.7 & (1.) \\
\hline CAI & $\mathrm{m}$ & $\mathrm{m}$ & $\mathrm{m}$ & $\mathrm{m}$ & $\mathrm{m}$ & $\mathrm{m}$ & $\mathrm{m}$ & $\mathrm{m}$ & $\mathrm{m}$ & $\mathrm{m}$ & m & m & $\mathrm{m}$ & (1.0) & $\mathrm{m}$ & . & $\mathrm{m}$ & $\mathrm{m}$ & $\mathrm{m}$ & (1.) \\
\hline & -5.8 & (1. & -4.9 & & 0 & & 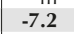 & 3) & -1 & & & & & & & & & & .8 & \\
\hline & 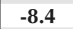 & (1. & -4 & $(0$ & & & & & & & & & & & & & & & & \\
\hline & & $(1$. & & & & & & & 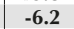 & & & & & & & & & & & \\
\hline & -4 & $(1.4$ & -0 & $(1.5)$ & & (1). & -7 & (1.2) & -0 & & & & & & & & & & & \\
\hline Dom & -6.3 & (1.6) & -7.3 & (1.0) & -2.6 & (1.4) & -7.1 & (1.5) & -10.6 & (1.6) & 64. & (1.6) & 9.1 & (1.5) & 8.9 & (1.5) & 6.2 & (1.8) & 9.3 & (1. \\
\hline & $\mathrm{m}$ & $\mathrm{m}$ & $\mathrm{m}$ & $\mathrm{m}$ & $\mathrm{m}$ & $\mathrm{m}$ & $\mathrm{m}$ & $\mathrm{m}$ & $\mathrm{m}$ & $\mathrm{m}$ & $\mathrm{m}$ & $\mathrm{m}$ & $\mathrm{m}$ & $\mathrm{m}$ & $\mathrm{m}$ & $\mathrm{m}$ & $\mathrm{m}$ & $\mathrm{m}$ & $\mathrm{m}$ & \\
\hline & & & & $\mathrm{m}$ & $\mathrm{m}$ & $\mathrm{m}$ & $\mathrm{m}$ & $\mathrm{m}$ & & & & 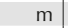 & & & & & & & & \\
\hline Ho & 12.7 & (1.3) & \begin{tabular}{|l|}
-10.9 \\
\end{tabular} & (1.1) & -7.3 & (1.4) & -8.9 & (1.5) & -6.7 & (1.6) & 71.0 & (1.3) & 81.9 & $(0.9)$ & 67.0 & $(1.2)$ & 52.2 & (1.3) & 58.4 & (1.3) \\
\hline Ind & $\mathrm{m}$ & & $\mathrm{m}$ & m & $\mathrm{m}$ & (1.7) & $\mathrm{m}$ & $\mathrm{m}$ & $\mathrm{m}$ & (1.0) & 1.0 & (3) & $\mathrm{m}$ & $\mathrm{m}$ & $\mathrm{m}$ & $\mathrm{m}$ & $\mathrm{m}$ & $\mathrm{m}$ & $\mathrm{m}$ & \\
\hline & $m$ & & $\mathrm{~m}$ & & $m$ & & 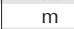 & $\mathrm{m}$ & $\mathrm{m}$ & & & & & & & & & & 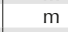 & \\
\hline & $\mathrm{m}$ & $\mathrm{m}$ & $\mathrm{m}$ & & $\mathrm{m}$ & & $\mathrm{m}$ & $\mathrm{m}$ & $\mathrm{m}$ & & & & & & & & & & & \\
\hline & 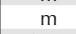 & $\mathrm{m}$ & $\mathrm{m}$ & $\mathrm{m}$ & III & $\mathrm{m}$ & $\mathrm{m}$ & $\mathrm{m}$ & $\mathrm{m}$ & & im & & & & & & & & & \\
\hline & .4 & (1.4) & -17.6 & 1.4) & -19.5 & $.5)$ & 3.4 & .4) & -20.4 & (1.4) & 61.2 & (1. & 8 & (1.4) & & & & 5 & 2 & (1. \\
\hline & 0 & (1.4) & \begin{tabular}{|l|}
-8 \\
\end{tabular} & (1.1) & & (1.4 & \begin{tabular}{|l|l|}
-7.0 \\
\end{tabular} & (1.4) &. & (1. & & (1.) & .1 & $(1.3)$ & 8.7 & 1.5) & 0.3 & $1.4)$ & 6.8 & (1.) \\
\hline & & & & & $\mathrm{m}$ & & $\mathrm{m}$ & & $\mathrm{m}$ & & $\mathrm{m}$ & & $\mathrm{m}$ & & 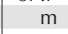 & & & & & \\
\hline & $\mathrm{m}$ & & III & ? & $\mathrm{m}$ & $\mathrm{m}$ & $\mathrm{m}$ & $\mathrm{m}$ & $\mathrm{m}$ & $\mathrm{m}$ & $m$ & $\mathrm{~m}$ & $\mathrm{~m}$ & $\mathrm{~m}$ & n & n & $\mathrm{m}$ & $\mathrm{m}$ & $\mathrm{m}$ & \\
\hline & & (1.3) & -11.6 & $(1.2)$ & -19.3 & $(1.3)$ & -15.4 & $(1.5)$ & -15.4 & (1.3) & & (1 & 3.4 & $(1.3)$ & 3.1 & (1 & 1.5 & (1.4) & 0.8 & \\
\hline & & (1.3) & & (1 & & & -2 & & & & & & & & & & & & & \\
\hline & 7 & $(0.9)$ & 0.8 & (0. & & 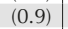 & $=$ & (1.0 & 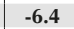 & & & & & & & & & & & \\
\hline & $\mathrm{m}$ & & $\mathrm{m}$ & n & $\mathrm{m}$ & & $\mathrm{m}$ & $\mathrm{m}$ & $\mathrm{n}$ & & & & & & & & & & & \\
\hline & & (1. & & 11 & & (1. & & 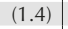 & & & & & & & & & & & & \\
\hline & & & & & & & & & & & & & & & & & & & & \\
\hline & & & & & & & & & & & & & & & & & 61.4 & & 69.4 & (1. \\
\hline & 1.6 & (1.5) & -9.8 & (1.2) & -7.3 & $(1.3)$ & -3.6 & (1.4) & -3.7 & $(1.6)$ & 63.3 & $(1.3)$ & 75.0 & (1.4) & 63.9 & $(1.4)$ & 46.7 & $\begin{array}{l}(1.5) \\
\end{array}$ & 57.7 & (1.3) \\
\hline & $\mathrm{m}$ & & $\mathrm{m}$ & & $\mathrm{m}$ & & & & $\mathrm{m}$ & & $\mathrm{m}$ & & $\mathrm{m}$ & & $\mathrm{m}$ & & $\mathrm{m}$ & $\mathrm{m}$ & $\mathrm{m}$ & \\
\hline & -6.4 & (1.6) & -4.5 & (1.3) & -15.6 & (1.5) & $\mid-15.5$ & (1.5) & -8.9 & (1.5) & 0.8 & $(1.7)$ & 70.5 & (1.7) & 68.1 & (1.6) & 65.5 & (1.4) & 57.8 & .2) \\
\hline & & & & & & & & & & & & & & & & & & & & \\
\hline & -9.5 & $(1.2$ & -5.1 & (0. & -6. & & 5. & 4 & 3 & & & & & & 7 & & 2.9 & & & \\
\hline Viet Nam & $\mathrm{m}$ & $\mathrm{m}$ & $\mathrm{m}$ & $n$ & $\mathrm{~m}$ & $\mathrm{~m}$ & $\mathrm{~m}$ & $\mathrm{~m} \mid$ & $\mathrm{m}$ & $\mathrm{m} \mid$ & $\mathrm{m}$ & III & $\mathrm{m}$ & $\mathrm{m}$ & $\mathrm{m}$ & $\mathrm{m}$ & $\mathrm{m}$ & $\mathrm{m}$ & $\mathrm{m}$ & \\
\hline & $\mathrm{m}$ & & $\mathrm{m}$ & & $\mathrm{m}$ & & $\mathrm{m}$ & & & & & & & & & & & & & \\
\hline & & & & & & & III & & & & & & & & & $\mathrm{m}$ & III & III & $\mathrm{m}$ & \\
\hline Malaysia* & -6.8 & $(1.2)$ & -9.6 & (1.1) & -8.2 & (1.1) & -1.6 & (1.5) & -11.4 & (1.2) & 64.0 & (1.6) & 75.5 & (1.5) & 81.9 & $(0.8)$ & 51.2 & (1.5) & 75.1 & (1.3) \\
\hline
\end{tabular}

1. A socio-economically disadvantaged student is a student in the bottom quarter of the PISA index of economic, social and cultural status (ESCS) within his or her own country/economy. 2. A socio-economically advantaged student is a student in the top quarter of the PISA index of economic, social and cultural status (ESCS) within his or her own country/economy. Note: Values that are statistically significant are indicated in bold (see Annex A3).

* See note at the beginning of this Annex.

** Coverage is too small to ensure comparability (see Annex A4).

StatLink त्नात्र http://dx.doi.org/10.1787/888933470677 
[Part 3/3]

Table III.4.2 Students' schoolwork-related anxiety, by gender and socio-economic status

Percentage of students who reported "agree" or "strongly agree"

\begin{tabular}{|c|c|c|c|c|c|c|c|c|c|c|c|c|c|c|c|c|c|c|c|c|c|}
\hline & & & tag & sc & con & mical & var & $\mathrm{ed}^{2}$ & & & & s & & $\begin{array}{l}\text { nic } \\
\text { oll }\end{array}$ & $\begin{array}{l}\text { ar } \\
\text { ig }\end{array}$ & net & d & $\begin{array}{l}\text { ge or } \\
\text { taged }\end{array}$ & & age & \\
\hline & & $\begin{array}{r}\text { I often } \\
\text { that i } \\
\text { be dif } \\
\text { for me } \\
\text { a t }\end{array}$ & $\begin{array}{l}\text { worry } \\
\text { t will } \\
\text { ficult } \\
\text { taking } \\
\text { est }\end{array}$ & $\begin{array}{c}\text { I worr } \\
\text { will g } \\
\text { <gra } \\
\text { at ss } \\
\end{array}$ & $\begin{array}{l}\text { nat I } \\
\text { oor } \\
\text { s> } \\
\text { ol } \\
\end{array}$ & $\begin{array}{r}\text { Even } \\
\text { well pr } \\
\text { for a } \\
\text { I feel } \\
\text { anxi }\end{array}$ & $\begin{array}{l}\text { am } \\
\text { ared } \\
\text { est } \\
\text { ery } \\
\text { us }\end{array}$ & $\begin{array}{r}\text { I get } \\
\text { tense } \\
\text { I st }\end{array}$ & & $\begin{array}{l}\text { I get ne } \\
\text { when I } \\
\text { know } \\
\text { to sol } \\
\text { task at }\end{array}$ & $\begin{array}{l}\text { vous } \\
\text { lon't } \\
\text { ow } \\
\text { ew a } \\
\text { hool } \\
\end{array}$ & $\begin{array}{r}\text { I often } \\
\text { that it } \\
\text { be dif } \\
\text { for me } \\
\text { a te }\end{array}$ & $\begin{array}{l}\text { worry } \\
\text { twill } \\
\text { ficult } \\
\text { taking } \\
\text { est }\end{array}$ & $\begin{array}{r}\text { will ge } \\
<\text { grad } \\
\text { at sch }\end{array}$ & $\begin{array}{l}\text { that I } \\
\text { poor } \\
\text { s> } \\
\text { ool } \\
\end{array}$ & $\begin{array}{r}\text { Even if } \\
\text { well pre } \\
\text { for a } \\
\text { I feel } \\
\text { anxi }\end{array}$ & $\begin{array}{l}f \text { I am } \\
\text { epared } \\
\text { test } \\
\text { very } \\
\text { ous }\end{array}$ & $\begin{array}{c}\text { I get } \\
\text { tense } \\
\text { I stu }\end{array}$ & $\begin{array}{l}\text { ery } \\
\text { hen } \\
\text { y }\end{array}$ & $\begin{array}{l}\text { I get ne } \\
\text { when I } \\
\text { know } \\
\text { to sol } \\
\text { task at }\end{array}$ & $\begin{array}{l}\text { vous } \\
\text { lon't } \\
\text { low } \\
\text { e a } \\
\text { chool } \\
\end{array}$ \\
\hline & & $\%$ & S.E. & $\%$ & S.E. & $\%$ & S.E. & $\%$ & S.E. & $\%$ & S.E. & $\%$ dif. & S.E. & $\%$ dif. & S.E. & $\%$ dif. & S.E. & $\%$ dif. & S.E. & $\%$ dif. & S.E. \\
\hline & Australia & 57.5 & (0.9) & 61.3 & (1.1) & 66.4 & (1.0) & 44.2 & (1.0) & 58.1 & (1.0) & -8.2 & (1.3) & -7.4 & (1.5) & -2.6 & (1.4) & -5.7 & (1.3) & -4.0 & (1.6) \\
\hline & Austria & 58.2 & (1.4) & 55.6 & (1.7) & 43.7 & (1.3) & 17.1 & (1.1) & 40.1 & (1.3) & -11.6 & (2.0) & $\mid-14.8$ & (2.1) & -13.9 & $(2.2)$ & -5.6 & (1.7) & -7.1 & (2.0) \\
\hline & Belgium & 51.9 & $(1.4)$ & 62.7 & (1.3) & 37.1 & (1.2) & 22.8 & $(1.2)$ & 52.3 & (1.1) & -4.5 & (2.1) & -1.9 & (1.9) & -8.3 & $(2.0)$ & -12.0 & (1.8) & -2.1 & (1.6) \\
\hline & Canada & 53.2 & (1.1) & 58.4 & (1.0) & 61.4 & (0.9) & 43.5 & (1.0) & 61.5 & (1.1) & -9.2 & (1.5) & -8.6 & (1.4) & -4.7 & (1.5) & -3.2 & (1.4) & -2.2 & (1.5) \\
\hline & Chile & 56.3 & (1.6) & 79.0 & (1.1) & 49.3 & (1.5) & 36.1 & (1.4) & 47.4 & (1.5) & -6.7 & (2.4) & -2.9 & (1.8) & $\mid-10.7$ & (2.1) & -8.6 & (2.0) & $\mid-13.2$ & 2.0) \\
\hline & Czech Repu & 53.0 & (1.2) & 59.1 & (1.5) & 39.6 & (1.5) & 27.3 & (1.1) & 48.7 & (1.3) & -3.2 & (2.0) & 3.6 & (1.9) & -0.9 & (2.1) & -9.0 & (1.9) & 1.9 & $(2.1)$ \\
\hline & Denmark & 46.6 & (1.6) & 58.5 & (1.5) & 58.8 & (1.3) & 38.6 & (1.5) & 51.1 & (1.3) & -16.5 & (2.3) & $\mid-11.8$ & (2.0) & $\mid-12.4$ & (2.0) & -11.5 & (2.2) & -6.5 & (2.0) \\
\hline & Estonia & 45.0 & (1.3) & 51.0 & (1.5) & 50.6 & (1.2) & 24.0 & (1.2) & 37.1 & (1.3) & -11.0 & (2.2) & -6.9 & (2.0) & -3.5 & (1.9) & -5.3 & (1.8) & -5.1 & 2.1) \\
\hline & Finland & 29.1 & (1.5) & 36.4 & (1.4) & 46.0 & (1.2) & 16.8 & (1.1) & 36.5 & (1.4) & -13.6 & (2.0) & $\mid-13.0$ & (2.1) & -2.4 & (2.0) & -1.8 & (1.6) & 0.0 & 1.9) \\
\hline & France & 59.8 & (1.2) & 66.2 & (1.4) & 42.3 & (1.4) & 23.9 & (1.0) & 58.0 & (1.3) & -3.3 & (1.7) & 3.2 & (1.6) & -7.4 & (1.9) & -9.0 & 1.6) & 5.7 & 1.8) \\
\hline & Germany & 44.5 & (1.4) & 47.3 & (1.5) & 33.0 & (1.3) & 1 & (1.3) & 3 & (1.2) & -9.7 & (2.3) & -7.5 & (2.4) & $\mid-13.2$ & (2.0) & -4.3 & 3) & -3.3 & \\
\hline & Greece & 41.9 & (1.5) & 41.2 & (1.6) & 54.4 & (1.5) & 34.4 & (1.5) & 63.2 & (1.4) & -5.3 & (2.7) & -12.8 & $(2.2)$ & -7.8 & (2.1) & -5.8 & (2.5) & -1.1 & $(2.0)$ \\
\hline & Hungary & 58.1 & (1.4) & 62.5 & (1.3) & 47.3 & (1.5) & 22.6 & (1.2) & 42.8 & (1.2) & -5.3 & (2.1) & -5.8 & $(2.2)$ & -12.0 & (2.3) & -8.3 & & -6.8 & (1.7) \\
\hline & Icelan & 39.9 & $(1.8)$ & 52.1 & $(2.1)$ & 44.7 & (1.9) & 33.3 & (1.4) & 38. & (1.8) & -15.9 & (2.4) & -11.7 & $(2.8)$ & -10.9 & (2.6) & -6.1 & (2.5) & -8.3 & (3.0) \\
\hline & Ireland & 55.7 & (1.5) & 63.1 & $(1.2)$ & 57.2 & (1.2) & 39.0 & (1.7) & 52.0 & (1.6) & -8.8 & (2.0) & -9.1 & (1.7) & -8.4 & (2.1) & $\mid-11.2$ & (2.0) & -3.4 & 2.3) \\
\hline & Israel & 53.7 & (1.4) & 47.7 & (1.6) & 40.1 & (13) & 29.1 & (1.3) & 39 & (1.4) & -8.1 & (2.0) & -6.2 & (2.1) & $\mid-11.8$ & $(2.2)$ & -9.1 & (1.8) & -10.6 & (1.9) \\
\hline & Italy & 61.6 & (1.4) & 84.6 & $(0.9)$ & 1 & (1. & 50.2 & (1. & 7 & (1.0) & -5.2 & (2.0) & -0.3 & (1.6) & -7.0 & (1.7) & -10.8 & (1.8) & -0.2 & $.6)$ \\
\hline & Japan & .7 & (1.1) & 81.6 & (1.0) & 61.1 & (1.4) & 34.1 & $(1.2)$ & 54.0 & (1.3) & 2.9 & (1.4) & 0.7 & (1.5) & -2.2 & $(2.2)$ & 3.4 & (1.6) & 9.9 & (2.0) \\
\hline & Korea & 69.5 & (1.5) & 78.0 & (1.3) & 57.2 & (1.4) & 45.9 & (1.6) & 4 & (1.5) & 1.5 & (2.1) & 9.9 & (2.2) & 5.4 & (2.0) & 7.8 & & -3.6 & .1) \\
\hline & Latvia & 46.3 & (1.5) & 62.9 & $(1.3)$ & 40.6 & $(1.7)$ & 24.7 & (1.3) & 43.8 & (1.7) & -11.7 & (2.5) & -7.6 & (1.8) & -4.3 & (2.3) & -3.2 & (2.2) & 4.3 & $(2.2)$ \\
\hline & Luxembou & 52.0 & (1.4) & 54.4 & (1.3) & 38.3 & (1.4) & 21.7 & (1.1) & 40.1 & (1.4) & $\mid-13.1$ & (2.0) & -18.3 & (1.8) & -18.9 & (2.1) & $\mid-14.3$ & & .7 & б) \\
\hline & Mexi & 0.6 & (1.3) & 79.1 & (1.1) & 2 & (1. & 4 & 1. & 6 & (1.3) & -3 & (1.8) & 1. & (1.9) & -9 & ) & -10 & & & \\
\hline & Neth & 1 & (1.3) & 44.8 & (1.5) & 39.9 & (1. & 1. & (1.1) & 1 & (1.3) & 0. & (1.8) & 0 . & $(2.0)$ & 2.4 & (1.9) & -3.3 & & 4 & (1.9) \\
\hline & New $Z$ & 2.6 & (1.5) & 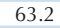 & (1.5) & 7 & (1. & 4 & $(1$ & & (1.7) & -5 . & (2.1) & -7 & (1.9) & -4.2 & & 5.5 & & .1 & \\
\hline & Norwa & 44.9 & (1.6) & 62.7 & (1.5) & 55.2 & (1. & 4 & (1. & 4 & (1.7) & -12.0 & $(2.2)$ & -5 . & $(2.2)$ & 10.3 & (2. & -7.2 & )) & .6 & 3) \\
\hline & Poland & 57.6 & (1.7) & 66.3 & (1.4) & 39.2 & (1.5) & 23.3 & $(1.2)$ & 36.6 & (1.7) & -8.0 & $(2.1)$ & -7.3 & (1.8) & $\mid-11.4$ & (2.0) & -7.8 & (1.7) & -8.9 & (2.3) \\
\hline & Portugal & 79.5 & (1.3) & 86.1 & $(0.9)$ & 629 & (1.6) & 39 & (1. & 6 & (1.5) & -7.4 & (1.6) & -2.4 & (1.3) & $\mid-10.8$ & (2.1) & $\mid-11.3$ & ) & 4.0 & (2.3) \\
\hline & Slova & 60.0 & (1.5) & 61.1 & (1.4) & .9 & $(1.5$ & 26.3 & $(1.3$ & 4 & (1.4) & -1.5 & (1.9) & -0.5 & (1.9) & -5.7 & (2.0) & -5.2 & (18) & 6.0 & 2.1) \\
\hline & Slovenia & 55.0 & (1.5) & 67.3 & (1.5) & 57.6 & (1.6) & 34.4 & (1.8) & 50.6 & (1.4) & -11.9 & (2.0) & -8.3 & (1.9) & -8.1 & (2.0) & -3.6 & (2.2) & 0.1 & (1.9) \\
\hline & Spain & 72.9 & (1.1) & 91.6 & $(0.7)$ & 6 & (1.3) & 39.8 & (1. & 5 & (1.4) & -1.8 & (1.7) & 67 & (1.1) & -6.5 & (1.8) & -12.9 & & 7.0 & 7) \\
\hline & Swed & 47.0 & (1.6) & 48.4 & (1.7) & 54.8 & (1. & 35.7 & (1. & 5 & (1.3) & -18.4 & (2.0) & 17.1 & (2.0) & -12.0 & (2.0) & $\mid-11.2$ & )) & 4.8 & 3) \\
\hline & Switzerla & 42.4 & $(2.2)$ & 50.4 & $(2.1)$ & 266 & (1.5) & 17. & (1. & & (16) & -9 & (2.9) & $\mid-1$ & (2.5) & & & -6.4 & & 2.5 & \\
\hline & Turkey & 0.0 & (1.5) & 72.5 & (1.4) & 4.7 & (1.3) & 53. & $(1$. & . & (1.5) & 1. & (2.4) & -1. & (2.2) & -6.0 & (2. & -3.4 & $(2.1)$ & 7.0 & 4) \\
\hline & United I & 58.0 & (1.6) & 63.2 & (1.5) & 68.5 & (1.7) & 49.5 & (1.7) & 53.6 & (1.3) & -7.0 & $(2.0)$ & -7.4 & (1.9) & -7.1 & (1.8) & -5.8 & (2.1) & -4.2 & (1.9) \\
\hline & United States & 58.4 & (1.5) & 55.6 & (1.9) & 63.6 & (1.6) & 39.7 & (1.6) & 60.7 & (1.4) & -9.2 & (1.8) & -13.4 & $(2.3)$ & -5.9 & $(2.1)$ & -7.0 & (2.2) & -8.0 & (2.0) \\
\hline & OECD average & 55.0 & $(0.2)$ & 62.2 & $(0.2)$ & 51.2 & $(0.2)$ & 33.1 & $(0.2)$ & 49.5 & $(0.2)$ & -7.4 & $(0.3)$ & -5.8 & $(0.3)$ & -7.6 & $(0.3)$ & -6.7 & $(0.3)$ & -3.7 & $(0.3)$ \\
\hline & Albania & $\mathrm{m}$ & $\mathrm{m}$ & 7 & $\mathrm{~m}$ & $\mathrm{~m}$ & $\mathrm{~m}$ & $\mathrm{~m}$ & $\mathrm{~m}$ & 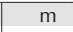 & $\mathrm{m}$ & $\mathrm{m}$ & $\mathrm{m}$ & $n$ & $\mathrm{~m}$ & $\mathrm{~m}$ & & $\mathrm{~m}$ & 1 & $n$ & $n$ \\
\hline & Algeria & $\mathrm{m}$ & $\mathrm{m}$ & $\mathrm{m}$ & $\mathrm{m}$ & $\mathrm{m}$ & $\mathrm{m}$ & $\mathrm{m}$ & 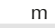 & $\mathrm{m}$ & $\mathrm{m}$ & $\mathrm{m}$ & 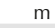 & $\mathrm{m}$ & $m$ & $\mathrm{~m}$ & $\mathrm{~m}$ & $\mathrm{~m}$ & $\mathrm{~m}$ & $\mathrm{~m}$ & $\mathrm{~m}$ \\
\hline & Brazil & 7.2 & $(0.8)$ & 92.5 & $(0.5)$ & 76.0 & $(0.8)$ & 49.9 & (1.1) & 68.7 & (0.9) & -4.0 & (1.0) & -0.9 & $(0.7)$ & -7.8 & (1.1) & -12.0 & (1.3) & -10.0 & (1.2) \\
\hline & B-S-J-C & 0.3 & (1.4) & 77.3 & (1.1) & 59.3 & (1.3) & & $(1.2)$ & & (14) & -9. & (1.8) & -2.4 & (1.7) & -38 & & -4.6 & & -9.8 & (2.0) \\
\hline & Bulg & 9.4 & (1.3) & 56.8 & (1.4) & 53.2 & (1.3) & 44.0 & (1.3) & 63.4 & (1.6) & -7.2 & (2.2) & -8.6 & (2.1) & -5.7 & (2.2) & -7.4 & (1.8) & 2.7 & 2.3) \\
\hline & $\mathrm{CAB}$ & $\mathrm{m}$ & $\mathrm{m}$ & $\mathrm{m}$ & $\mathrm{m}$ & $\mathrm{m}$ & $\mathrm{m}$ & $\mathrm{m}$ & $\mathrm{m}$ & $\mathrm{m}$ & $\mathrm{m}$ & $\mathrm{m}$ & $\mathrm{m}$ & $\mathrm{m}$ & $\mathrm{m}$ & $\mathrm{m}$ & $\mathrm{m}$ & $\mathrm{m}$ & $\mathrm{m}$ & $\mathrm{m}$ & $\mathrm{m}$ \\
\hline & Colo & 2.9 & $(1.2)$ & 89.6 & $(0.7)$ & 76.0 & (1.3) & 56.2 & (1.3) & 66.2 & (1.4) & -1.4 & (1.9) & 0 & (1.3) & -7.2 & (1.5) & -2.6 & .7) & 0.5 & .7) \\
\hline & Cost & .0 & $(1.5$ & 92.7 & (0) & 79.5 & & 4 & (1. & 5 & 1 & -3.4 & (2. & 3. & (1.4) & -3.1 & (1.8) & -11.2 & 2) & -15.3 & 2.2) \\
\hline & Croa & 4 & (1.4) & 73.6 & ) & 4 & (1) & & & & & -2.4 & $(1$ & -4.0 & (1.6) & -3.6 & $(2$ & -3.9 & & 1.6 & \\
\hline & Cyp & & & & & & & & & & & 14 & 2 & -15.5 & $(2$ & -8 & & -8 & & -6.9 & \\
\hline & Dominica & 64.5 & (1.7) & 88.2 & (1.3) & 77.7 & (1.4) & 50.3 & (1.5) & 61.1 & (1.7) & 0.2 & (2.3) & 9.1 & (2.0) & -1.2 & 1.9) & -5.9 & 2.5) & -8.2 & 2.5) \\
\hline & FYROM & $\mathrm{m}$ & $\mathrm{m}$ & $\mathrm{m}$ & $\mathrm{m}$ & $\mathrm{m}$ & $\mathrm{m}$ & $\mathrm{m}$ & $\mathrm{m}$ & $\mathrm{m}$ & $\mathrm{m}$ & $\mathrm{m}$ & $\mathrm{m}$ & $\mathrm{m}$ & $\mathrm{m}$ & $\mathrm{m}$ & $\mathrm{m}$ & $\mathrm{m}$ & $\mathrm{m}$ & $\mathrm{m}$ & $\mathrm{m}$ \\
\hline & Geor & & & & & $\mathrm{m}$ & & $\mathrm{m}$ & & $\mathrm{m}$ & & $\mathrm{m}$ & & $\mathrm{m}$ & & $\mathrm{m}$ & & $m$ & & 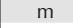 & \\
\hline & Hong & 69.5 & (1.5) & 82.1 & (1.3) & 66.0 & (1.5) & 51.4 & (1.7) & 56.5 & (2.0) & -1.4 & $(2.0)$ & 0.2 & (1.6) & -1.0 & (2.0) & -0.9 & (2.4) & -2.0 & (2.4) \\
\hline & Indone & $\mathrm{m}$ & $\mathrm{m}$ & $\mathrm{m}$ & $\mathrm{m}$ & $\mathrm{m}$ & $\mathrm{m}$ & $\mathrm{m}$ & $\mathrm{m}$ & $\mathrm{m}$ & $\mathrm{m}$ & $\mathrm{m}$ & 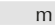 & $\mathrm{m}$ & $\mathrm{m}$ & $\mathrm{m}$ & $\mathrm{m}$ & $\mathrm{m}$ & $\mathrm{m}$ & $\mathrm{m}$ & $\mathrm{m}$ \\
\hline & Jordan & $\mathrm{m}$ & & $m$ & & $m$ & & $m$ & & $m$ & & $m$ & & $\mathrm{~m}$ & & $\mathrm{~m}$ & & $\mathrm{~m}$ & & $\mathrm{~m}$ & $\mathrm{~m}$ \\
\hline & Kosovo & $\mathrm{m}$ & $\mathrm{m}$ & $\mathrm{m}$ & $\mathrm{m}$ & $\mathrm{m}$ & 1 & $\mathrm{m}$ & $\mathrm{m}$ & $\mathrm{m}$ & $\mathrm{m}$ & $\mathrm{m}$ & $\mathrm{m}$ & $\mathrm{m}$ & $\mathrm{m}$ & m & $\mathrm{m}$ & $\mathrm{m}$ & $\mathrm{m}$ & $\mathrm{m}$ & $\mathrm{m}$ \\
\hline & & $m$ & & $\mathrm{~m}$ & & $m$ & & $\mathrm{~m}$ & & $m$ & & $m$ & & 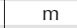 & & $m$ & & $m$ & & $\mathrm{~m}$ & $\mathrm{n}$ \\
\hline & Lith & 9.4 & (1.3) & 63.8 & (1.4) & 4.1 & (1.3) & 38.9 & (1.5) & 48.1 & (1.5) & 1.9 & (2.0) & 0.1 & (2.1) & -1.9 & (2.0) & -6.1 & 2.0) & 1.9 & 2.3) \\
\hline & Macao & 68.1 & (1.4) & 73.4 & (1.4) & 62.9 & (1.6) & 54.7 & (1.6) & 59.3 & (1.5) & 7.5 & (1.8) & 5.7 & (2.1) & -4.9 & (2.0) & -5.6 & (2.0) & 2.5 & (2.2) \\
\hline & Mal & $\mathrm{m}$ & $\mathrm{m}$ & $\mathrm{m}$ & $\mathrm{m}$ & $\mathrm{m}$ & $\mathrm{m}$ & $\mathrm{m}$ & $\mathrm{m}$ & $\mathrm{m}$ & $\mathrm{m}$ & $\mathrm{m}$ & m & $\mathrm{m}$ & $\mathrm{m}$ & $\mathrm{m}$ & $\mathrm{m}$ & $\mathrm{m}$ & $\mathrm{m}$ & $\mathrm{m}$ & $\mathrm{m}$ \\
\hline & & III & $\mathrm{m}$ & $\mathrm{m}$ & $\mathrm{n}$ & $\mathrm{m}$ & & $\mathrm{m}$ & $\mathrm{m}$ & $\mathrm{m}$ & $\mathrm{m}$ & $\mathrm{m}$ & $\mathrm{m}$ & $\mathrm{m}$ & 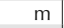 & $\mathrm{m}$ & & $\mathrm{m}$ & & $\mathrm{m}$ & $\mathrm{m}$ \\
\hline & Mont & .4 & (1.2) & & 1 & 3.0 & (1. & 4 & (1.5) & 4.3 & (1.5) & -8.4 & (1.8) & -12.1 & (2.0) & -5.1 & (1.8) & -8.0 & ..1) & .5 & ..0) \\
\hline & Per & & & & & & & & & & & 2 & (17) & 126 & $(1.7)$ & & & -10.8 & & -10.7 & \\
\hline & Qata & 68.7 & (1.0) & 68.6 & (0.9) & 63.4 & (0.9) & 48.5 & (1.1) & 53.4 & (1.0) & -3.9 & (1.3) & -2.4 & (1.4) & -1.7 & (1.4) & -3.8 & (1.5) & -1.8 & (1.6) \\
\hline & Ron & $\mathrm{m}$ & $\mathrm{m}$ & $\mathrm{m}$ & $\mathrm{m}$ & $\mathrm{m}$ & $\mathrm{m}$ & $\mathrm{m}$ & $\mathrm{m}$ & $\mathrm{m}$ & $\mathrm{m}$ & $\mathrm{m}$ & $\mathrm{m}$ & $\mathrm{m}$ & $\mathrm{m}$ & $\mathrm{m}$ & $\mathrm{m}$ & $\mathrm{m}$ & $\mathrm{m}$ & $\mathrm{m}$ & $\mathrm{m}$ \\
\hline & & & t & 6.2 & (1.4) & 54 & $(1.7$ & 25 & 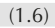 & 557 & 2) & 4. & 0 & -6. & (2.0) & -11.5 & (2.3) & -15.9 & ) & -7.9 & 5) \\
\hline & Sing & 1.8 & $(1.2)$ & 81.3 & (1.2) & 71.4 & (1.5) & 55.2 & (1.4) & 66.7 & (1.5) & -4.7 & (1.7) & -6.6 & (1.3) & -8.4 & (1.7) & -9.0 & (2.0) & -5.8 & (1.8) \\
\hline & Chir & .2 & $(1.4$ & 81.5 & (1. & 65.1 & (1. & 59.2 & (1. & 64.5 & (1. & -6.2 & (1.8) & 0.9 & (1.5) & -0.5 & (1.8) & -2.2 & (1.9) & -4.9 & (1.7) \\
\hline & & 9.8 & (1.4) & 79.6 & (1) & 63.8 & 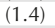 & 49.2 & 1 & 55.4 & (1.7) & 6.5 & (1.8) & 4.5 & (1.9) & -0.1 & $(2.0)$ & 2.5 & (2.0) & -2.3 & (2.0) \\
\hline & Trin & $\mathrm{m}$ & $\mathrm{m}$ & $\mathrm{m}$ & $\mathrm{m}$ & $\mathrm{m}$ & $\mathrm{m}$ & $\mathrm{m}$ & $\mathrm{m}$ & $\mathrm{m}$ & $\mathrm{m}$ & $\mathrm{m}$ & $\mathrm{m}$ & $\mathrm{m}$ & $\mathrm{m}$ & $\mathrm{m}$ & $\mathrm{m}$ & $\mathrm{m}$ & $\mathrm{m}$ & $\mathrm{m}$ & $\mathrm{m}$ \\
\hline & & .5 & .5) & & .4) & 9.5 & & 45.2 & & 5.8 & .7) & 1.3 & 2) & 3.1 & 2.1) & $\mid-18.6$ & 2.5) & 20.3 & 4) & -12.0 & \\
\hline & Un & 64.4 & (1.1) & 69.7 & (1. & 61.2 & (1. & 46.4 & & 62.3 & (0.9) & -6.3 & (1.5) & -4.7 & (1.6) & -0.4 & (1.6) & 1.3 & (1.7) & -1.8 & (1.5) \\
\hline & Urugua & 66.5 & (1.3) & 90.9 & $(0.8)$ & 72.5 & (1.4) & 42.0 & (1.6) & 61.8 & (1.3) & \begin{tabular}{|l|}
-10.8 \\
\end{tabular} & (1.5) & 1.2 & (1.3) & -0.9 & $(1.8)$ & -20.9 & (2.0) & -12.1 & (2.0) \\
\hline & Viet Nam & $\mathrm{m}$ & $\mathrm{m}$ & $\mathrm{m}$ & $\mathrm{m}$ & $\mathrm{m}$ & $\mathrm{m}$ & $\mathrm{m}$ & $\mathrm{m}$ & $\mathrm{m}$ & $\mathrm{m}$ & $\mathrm{m}$ & $\mathrm{m}$ & $\mathrm{m}$ & $\mathrm{m}$ & $\mathrm{m}$ & $\mathrm{m}$ & $\mathrm{m}$ & $\mathrm{m}$ & $\mathrm{m}$ & $\mathrm{m}$ \\
\hline & Ar & $\mathrm{m}$ & $\mathrm{m}$ & $\mathrm{m}$ & $\mathrm{m}$ & $\mathrm{m}$ & $\mathrm{m}$ & $\mathrm{m}$ & & $\mathrm{m}$ & $\mathrm{m}$ & $\mathrm{m}$ & $\mathrm{m}$ & $\mathrm{m}$ & $\mathrm{m}$ & $\mathrm{m}$ & $\mathrm{m}$ & $\mathrm{m}$ & $\mathrm{m}$ & $\mathrm{m}$ & $\mathrm{m}$ \\
\hline & & $\mathrm{m}$ & & $\mathrm{m}$ & $\mathrm{m}$ & $\mathrm{m}$ & 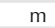 & $\mathrm{m}$ & $\mathrm{m}$ & $\mathrm{m}$ & $\mathrm{m}$ & $\mathrm{m}$ & $\mathrm{m}$ & $\mathrm{m}$ & $\mathrm{m}$ & $\mathrm{m}$ & $\mathrm{m}$ & $\mathrm{m}$ & $\mathrm{m}$ & $\mathrm{m}$ & $\mathrm{n}$ \\
\hline & Mal & 66.8 & (1.5) & 82.3 & $(1.2)$ & 79.6 & $(1.2)$ & 57.2 & (1.4) & 69.2 & $(1.2)$ & 2.7 & (2.1) & 6.8 & (1.7) & -2.3 & (1.3) & 6.0 & (1.8) & -6.0 & (1.7) \\
\hline
\end{tabular}

1. A socio-economically disadvantaged student is a student in the bottom quarter of the PISA index of economic, social and cultural status (ESCS) within his or her own country/economy. 2. A socio-economically advantaged student is a student in the top quarter of the PISA index of economic, social and cultural status (ESCS) within his or her own country/economy.

Note: Values that are statistically significant are indicated in bold (see Annex A3).

* See note at the beginning of this Annex.

** Coverage is too small to ensure comparability (see Annex A4).

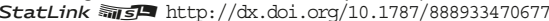


Percentage of students who reported "agree" or "strongly agree"

\begin{tabular}{|c|c|c|c|c|c|c|c|c|c|c|c|c|c|c|c|c|c|c|c|c|c|}
\hline & & & tag & of st & $\begin{array}{l}s \text { in } t \\
\text { eed } n\end{array}$ & bo & $\begin{array}{l}\text { iqu } \\
\text { bllou }\end{array}$ & & & & & & & & & $\begin{array}{l}n \text { the } \\
\text { with }\end{array}$ & & & & & \\
\hline & & $\begin{array}{r}\text { I ofter } \\
\text { that } \\
\text { be di } \\
\text { for me } \\
\text { a }\end{array}$ & $\begin{array}{l}\text { worry } \\
\text { t will } \\
\text { ficult } \\
\text { taking } \\
\text { est }\end{array}$ & $\begin{array}{c}\text { I worr } \\
\text { will ge } \\
<\text { gra } \\
\text { at } s 0\end{array}$ & $\begin{array}{l}\text { that I } \\
\text { poor } \\
\text { es> } \\
\text { ool } \\
\end{array}$ & $\begin{array}{r}\text { Even } \\
\text { well pr } \\
\text { for } \\
\text { I fee } \\
\text { anx }\end{array}$ & $\begin{array}{l}\text { I am } \\
\text { pared } \\
\text { test } \\
\text { very } \\
\text { us } \\
\end{array}$ & $\begin{array}{r}\text { I ge } \\
\text { tense } \\
\text { Is }\end{array}$ & $\begin{array}{l}\text { ery } \\
\text { hen } \\
\text { dy }\end{array}$ & $\begin{array}{l}\text { I get ne } \\
\text { when I } \\
\text { know } \\
\text { to so } \\
\text { task at }\end{array}$ & $\begin{array}{l}\text { ervous } \\
\text { don't } \\
\text { how } \\
\text { lve a } \\
\text { school }\end{array}$ & $\begin{array}{r}\text { I often } \\
\text { that } \\
\text { be dif } \\
\text { for me } \\
\text { a t }\end{array}$ & $\begin{array}{l}\text { worry } \\
\text { twill } \\
\text { ficult } \\
\text { taking } \\
\text { est }\end{array}$ & $\begin{array}{c}\text { I wor } \\
\text { will g } \\
<\text { gr } \\
\text { at s } \\
\end{array}$ & $\begin{array}{l}\text { that I } \\
\text { thoor } \\
\text { les> } \\
\text { nool }\end{array}$ & $\begin{array}{r}\text { Even } \\
\text { well } p \\
\text { for } \\
\text { I fe } \\
\text { an }\end{array}$ & $\begin{array}{l}\text { I am } \\
\text { epared } \\
\text { test } \\
\text { very } \\
\text { ous }\end{array}$ & tens & & $\begin{array}{l}\text { I get } n \\
\text { when } \\
\text { know } \\
\text { to so } \\
\text { task at }\end{array}$ & $\begin{array}{l}\text { rvous } \\
\text { don't } \\
\text { how } \\
\text { ve a } \\
\text { chool }\end{array}$ \\
\hline & & $\%$ & S.E. & $\%$ & S.E. & $\%$ & S.E. & $\%$ & S.E. & $\%$ & S.E. & $\%$ & S.E. & $\%$ & S.E. & $\%$ & S.E. & $\%$ & S.E. & $\%$ & S.E. \\
\hline 0 & Australia & 69.8 & $(1.1)$ & 72.0 & (1.0) & 71.2 & (1.1) & 53.8 & $(1.3)$ & 62.3 & (1.3) & 50.8 & $(1.2)$ & 55.0 & (1.1) & 61.1 & (1.2) & 40.1 & (1.2) & 57.0 & (1.3) \\
\hline & Austria & 74.2 & (1.4) & 73.3 & (1.5) & 62.9 & (1.9) & 29.1 & (1.4) & 49.1 & (1.5) & 50.2 & (1.4) & 47.4 & (1.7) & 35.4 & (1.4) & 12.2 & (1.0) & 37.8 & (1.3) \\
\hline & Belgium & 61.3 & (1.4) & 67.4 & (1.3) & 49.7 & (1.3) & 40.1 & (1.5) & 57.4 & (1.5) & 45.8 & (1.2) & 57.6 & $(1.2)$ & 31.9 & (1.1) & 17.9 & $(0.9)$ & 49.2 & (1.1) \\
\hline & Canada & 69.1 & (1.1) & 71.6 & (1.0) & 71.7 & (1.0) & 55.7 & (1.1) & 64.1 & $(1.2)$ & 45.5 & (1.4) & 53.5 & (1.3) & 53.0 & (1.1) & 33.8 & 1.2) & 61.9 & (1.0) \\
\hline & Chile & 69.8 & (1.6) & 84.7 & (1.4) & 68.9 & (1.7) & 54.5 & (1.8) & 65.4 & (1.8) & 46.5 & (1.6) & 75.7 & (1.3) & 42.5 & (1.6) & 28.3 & (1.3) & 43.2 & (1.7) \\
\hline & Czech F & 61.4 & (1.9) & 59.8 & (1.9) & 46.6 & (1.7) & 45.5 & (1.8) & 48.5 & (1.9) & 44.6 & (1.5) & 52.0 & (12) & 1.1 & (12) & 19.5 & 1.0) & 48.9 & 1.5) \\
\hline & Denmark & 67.1 & (1.5) & 72.4 & (1.5) & 71.9 & (1.4) & 55.8 & (1.5) & 59.3 & (2.0) & 38.7 & (1.7) & 3.9 & (1.6) & 4.8 & (1.7) & 38.6 & (1.5) & .5 & 7) \\
\hline & Estonia & 62.7 & (1.7) & 66.3 & (1.6) & 60.3 & (1.6) & 39.3 & (1.8) & 46.0 & (1.9) & 34.4 & (1.6) & 40.1 & (1.7) & 42.7 & (1.5) & 16.2 & (1.3) & 35.3 & (1.5) \\
\hline & Finland & 54.9 & (1.5) & 62.6 & (1.9) & 55.1 & (1.6) & 24.4 & (1.3) & 41.7 & (1.4) & 20.2 & (1.5) & 25.7 & (1.6) & 40.9 & (1.4) & 13.8 & (1.1) & 35.6 & (1.5) \\
\hline & France & 64.9 & (1.3) & 63.6 & (1.5) & 53.7 & $(1$. & 40.4 & (1.7) & 53.6 & (1.5) & .9 & (1. & & (1.5) & .9 & 1) & 9.3 & & 3 & $.3)$ \\
\hline & Germany & .4 & (1.8) & 60.3 & (1.8) & 57 & $(1$. & 28.8 & (1.7) & 38.9 & (1.8) & 39.1 & (1.5) & 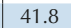 & (1. & 5.7 & (1. & 16.9 & (1.3) & 3 & 5) \\
\hline & Greece & 52.2 & $(2.0)$ & 57.5 & (1.7) & 64.4 & (1.8) & 44.3 & (2.1) & 63.9 & (2.0) & 38.0 & (1.6) & 35.4 & (1.6) & 50.1 & (1.5) & 29.8 & (1.5) & 65.4 & (1.5) \\
\hline & Hungary & 64.9 & $(2.1)$ & 68.7 & (1.9) & 63.5 & (1.9) & 39.1 & (2.0) & 54.8 & (1.8) & 53.2 & (1.4) & 59.8 & (1.6) & 44.4 & (1.6) & 17.7 & (1.1) & 0.6 & (1.6) \\
\hline & Iceland & 65.3 & $(2.2)$ & 73.1 & (1.6) & & (2.1) & & $(2.2)$ & 52.5 & (2.1) & & (1.9) & & (2. & .6 & (1.7) & 8 & 8) & .1 & 2.0) \\
\hline & Ireland & 70.6 & (1.4) & 75.4 & $(1.4)$ & 71.0 & $(1.6$ & 5 & (1.9) & 58.6 & (1.7) & 7.8 & (1.6) & U & (1.6) & 1.8 & (1.5) & 5.1 & (1.6) & 0.4 & 4) \\
\hline & Israel & 57.3 & (1.8) & 48.0 & $(2.0)$ & 52.8 & (1.8) & 41.8 & (1.8) & 48.3 & (1.7) & 52.1 & (1.5) & 47.8 & (1.5) & 35.3 & (1.5) & 26.2 & (1.5) & 36.4 & (1.5) \\
\hline & Italy & 68.5 & (1.6) & 83.1 & (1.4) & 74.5 & (1.5) & 64.5 & (1.6) & 74.9 & (1.5) & & (1. & & (1. & & (1) & & & & 1.3) \\
\hline & Japan & 78.3 & (1.3) & 80.8 & (1.4) & 65.1 & $(1.6$ & 32.2 & $(1$. & 41.9 & (1.5) & 77.1 & (1. & 8 & (1. & & (1) & 33.1 & (1 & .8 & 1.6) \\
\hline & Korea & 65.7 & (1.5) & 65.0 & (1.6) & 52 & (1. & 42 & (1. & 5 & (1. & 67.1 & (1.5) & 7 & (1. & 53.0 & (1.5) & 40.8 & 5) & 5 & \\
\hline & Latvia & 62.8 & (1.8) & 72.7 & (1.6) & 51.8 & (1.8) & 36.7 & (1.8) & 0 & (1.8) & 39.9 & (1.6) & 61.2 & (1. & 34.0 & (1.8) & 18.7 & ) & 44.9 & 1.9) \\
\hline & Luxembo & 65.0 & (1.7) & 73.2 & (1.4) & & $(1.5$ & 42.9 & (1.9) & & (1. & & $(1$. & & (1. & & (1. & 2 & (1 & & 5) \\
\hline & Mexico & 75.6 & (1.4) & 76.2 & $(1.4$ & 6 & (1. & & (1. & & (1. & & (1. & & (1. & & (1 & & (1) & & 5) \\
\hline & Netherla & 7.1 & $(1.7)$ & 45.0 & $(2.1$ & 3 & $(1$. & 1 & (1.5) & 2 & (1.5) & 3 & (1.5) & 4 & (1.7) & .4 & (1. & 1.8 & ) & 9 & 2) \\
\hline & New Zealand & 75.4 & (1.4) & 74.5 & (1.4) & 9 & $(1.4)$ & 63 & (1.7) & 7 & (1.9) & 4 & (1.7) & & (2. & 9 & (1. & 3 & (1.7) & 9 & 8) \\
\hline & Norway & 1 & (1.6) & 70.6 & $(1.6$ & 6 & $(1$. & 5 & (1. & & (1. & & $(1$ & & $(1$. & & (1. & 9 & $(1$ & 9 & 5) \\
\hline & Poland & .6 & (1.5) & 76.8 & $(1.4$ & 5 & $(1$. & 36 & (1. & 5 & $(1$. & & (1. & & (1. & 3.6 & 1 & 16.3 & 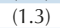 & .4 & 6) \\
\hline & Portugal & .9 & $(1.0)$ & 89.4 & $(0.9)$ & 76.8 & $(1.2)$ & 56.0 & (1.7) & 68.7 & (1.3) & 77.5 & (1. & 8 & (1. & 58.7 & (1.6) & 35.1 & (1.6) & .7 & (1.7) \\
\hline & Slovak Republic & 60.5 & $(1.7)$ & 63.9 & $(1.8)$ & 51.5 & $(1.8)$ & 39.9 & $(1.8)$ & 4 & (1.8) & 4 & (1.5) & 5 & $(1$. & 6 & (1.5) & 21.2 & $(1.2)$ & 0 & (1.6) \\
\hline & Slovenia & 72.2 & $(1.6)$ & 78.0 & $(1.2)$ & $7 c$ & $(1$. & 44 & $(1$. & & $(1$. & & $(1$. & & $(1$. & & $(1$. & 28.5 & $(1$ & .2 & 1.7) \\
\hline & Spain & 77.6 & $(1.3)$ & 82.4 & $(1.2)$ & 73.4 & $(1$. & 60.2 & (1.4) & 62.7 & (1.5) & 66.9 & (1.4) & 89.7 & $(0.8)$ & 6.0 & (1.6) & 33.8 & (1.5) & 47.9 & (1.4) \\
\hline & Sweden & 69.7 & $(1.7)$ & 68.0 & $(1.6)$ & 66.2 & (1.9) & 50.1 & (1.7) & 60.4 & (1.5) & 40.7 & $(1.8)$ & 42.8 & (1.6) & 54.9 & (1.6) & 31.6 & $(1.7)$ & 56.6 & (1.6) \\
\hline & Switzerland & 56.7 & $(1.5)$ & 62.4 & $(1.7)$ & 4 & (1.5) & 2 & (1.6) & 3 & $(1$. & 9 & (1 & 4 & $(1$ & 2 & (1. & 1 & $(1.2)$ & 8 & (1.9) \\
\hline & Turkey & 70.6 & (2.0) & 73.3 & $(2.2)$ & 65.2 & $(2.0$ & & (1.8) & 63.7 & (1. & & (1. & & (1. & 0.0 & (1.9) & 52.3 & (1.7) & 72.8 & (1.7) \\
\hline & United K & 69.8 & (1.4) & 74.4 & (1.3) & 75.6 & $(1.2)$ & 60.0 & (1.4) & & (1.4) & 52.7 & (1.3) & 57.1 & (1.4) & 65.0 & (1.4) & 44.7 & (1.7) & 49.3 & (1.8) \\
\hline & United States & 73.3 & (1.4) & 69.3 & (1.5) & 73.7 & (1.5) & 54.9 & (1.6) & 68.1 & (1.4) & 50.7 & (1.7) & 51.2 & (1.8) & 59.2 & (1.9) & 34.8 & (1.6) & 62.4 & (1.7) \\
\hline & OECD average & 66.4 & $(0.3)$ & 70.2 & $(0.3)$ & 62.5 & $(0.3)$ & 45.8 & $(0.3)$ & 55.2 & $(0.3)$ & 48.5 & $(0.3)$ & 57.6 & $(0.3)$ & 46.0 & $(0.3)$ & 28.0 & $(0.2)$ & 48.1 & $(0.3)$ \\
\hline & $\mathbf{A}$ & $\mathrm{m}$ & $\mathrm{m}$ & III & $\mathrm{m}$ & $\mathrm{m}$ & .1. & & 11 & $\mathrm{~m}$ & 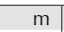 & .1. & $\mathrm{m}$ & $\mathrm{m}$ & & $\mathrm{m}$ & $\mathrm{m}$ & $\mathrm{m}$ & & $\mathrm{m}$ & $\mathrm{m}$ \\
\hline & Algeria & $\mathrm{m}$ & $\mathrm{m}$ & $\mathrm{m}$ & $\mathrm{m}$ & $\mathrm{m}$ & $\mathrm{m}$ & $\mathrm{m}$ & $\mathrm{m}$ & $\mathrm{m}$ & $\mathrm{m}$ & $\mathrm{m}$ & $\mathrm{m}$ & $\mathrm{m}$ & $\mathrm{m}$ & $\mathrm{m}$ & $\mathrm{m}$ & $\mathrm{m}$ & $\mathrm{m}$ & $\mathrm{m}$ & $\mathrm{m}$ \\
\hline & Brazil & 79.8 & $(1.0)$ & 89.9 & $(0.7)$ & 84.3 & $(0.9)$ & 67.0 & (1.3) & 79.0 & (1.0) & 76.4 & $(0.9)$ & 94.6 & $(0.5)$ & 73.2 & (1.0) & 43.0 & .2) & 6.8 & $.0)$ \\
\hline & B-S-J-G & 77.2 & $(1.2)$ & 82.1 & (1.3) & 71.0 & (1.6) & 65.0 & (1.5) & 67.6 & (1.5) & & (1.4) & 75.0 & (1. & 518 & (1. & .0 & (1.5) & 53.1 & 1.6) \\
\hline & Bulgaria & 53.7 & $(2.0)$ & 62.1 & (2.0) & 57.1 & (1.9) & 54.8 & (1.9) & 59.0 & (1.7) & 46.1 & (1.7) & 53.3 & (1.5) & 49.1 & (1.5) & 37.8 & (1.9) & 61.4 & 1.5) \\
\hline & CABA (Argentina) & $\mathrm{m}$ & $\mathrm{m}$ & $\mathrm{m}$ & $\mathrm{m}$ & $\mathrm{m}$ & $\mathrm{m}$ & $\mathrm{m}$ & $\mathrm{m}$ & $\mathrm{m}$ & $\mathrm{m}$ & $\mathrm{m}$ & $\mathrm{m}$ & $\mathrm{m}$ & $\mathrm{m}$ & $\mathrm{m}$ & $\mathrm{m}$ & $\mathrm{m}$ & $\mathrm{m}$ & $\mathrm{m}$ & $\mathrm{m}$ \\
\hline & Colo & 4.4 & (1.7) & 78.3 & (1.5) & 81.8 & $(1.2)$ & 0.5 & $(1.8)$ & 74.7 & (1.3) & 69.5 & $(1.5)$ & 92.3 & $(0.8)$ & 71.9 & (1. & 1.4 & 4) & 3.4 & $.5)$ \\
\hline & Cost & 30.9 & $(1.2)$ & 87.7 & $(1.2$ & 84 & $(1.2$ & 66 & $(1$. & 67.1 & (1.8) & 7 & (1. & 0 & $(0$. & 74.8 & (1.5) & 3 & 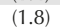 & 51.8 & 8) \\
\hline & Croatia & 3.9 & $(1.8)$ & 75.9 & (1.5) & 52.5 & (1.7) & 45.2 & (1.6) & 49.0 & (1.8) & 67.4 & (1.7) & 69.9 & (1.4) & 39.4 & (1.7) & 28.3 & (1.5) & 39.5 & (1.4) \\
\hline & Cyprus* & 60.8 & $(1.5)$ & 62.6 & (1.4) & 64.1 & (1.5) & 49.0 & (1.7) & 60.5 & (1.5) & 35.6 & $(1.7)$ & 33.2 & (1.5) & 46.9 & (1.6) & 28.0 & (1.4) & 51.8 & (1.8) \\
\hline & Dominica & 63.0 & (2.4) & 69.3 & $(2.0)$ & 80.3 & $(2.0)$ & 58.9 & $(2.1)$ & 66.6 & $(2.2)$ & 65.3 & (1.7) & 92.4 & $(0.9)$ & 76.3 & (1.8) & 46.1 & (1.9) & 58.9 & 2.1) \\
\hline & FYROM & $\mathrm{m}$ & $\mathrm{m}$ & $\mathrm{m}$ & $\mathrm{m}$ & $\mathrm{m}$ & $m$ & $\mathrm{~m}$ & $x$ & $\mathrm{~m}$ & $\mathrm{~m}$ & $\mathrm{~m}$ & $\mathrm{~m}$ & $\mathrm{~m}$ & $m$ & $\mathrm{~m}$ & $\mathrm{~m}$ & $\mathrm{n}$ & $m$ & $\mathrm{~m}$ & $\mathrm{~m}$ \\
\hline & Georgia & $\mathrm{m}$ & $\mathrm{m}$ & $\mathrm{m}$ & $\mathrm{m}$ & $\mathrm{m}$ & $\mathrm{m}$ & $\mathrm{m}$ & $\mathrm{m}$ & $\mathrm{m}$ & $\mathrm{m}$ & $\mathrm{m}$ & $\mathrm{m}$ & $\mathrm{m}$ & $\mathrm{m}$ & $\mathrm{m}$ & $\mathrm{m}$ & $\mathrm{m}$ & $\mathrm{m}$ & $\mathrm{m}$ & $\mathrm{m}$ \\
\hline & Hong Kor & 76.1 & (1.4) & 84.7 & $(1.1)$ & 72.5 & (1.5) & 62.2 & (1.6) & 62.1 & 1.7) & 65.7 & 1.8) & 78.6 & 1.6) & 60.7 & 1.9) & 42.8 & 1.7) & 53.5 & 1.8) \\
\hline & Indonesia & $\mathrm{m}$ & $\mathrm{m}$ & $\mathrm{m}$ & $\mathrm{m}$ & $\mathrm{m}$ & $\mathrm{m}$ & $\mathrm{m}$ & $\mathrm{m}$ & $\mathrm{m}$ & $\mathrm{m}$ & $\mathrm{m}$ & $\mathrm{m}$ & $\mathrm{m}$ & $\mathrm{m}$ & $\mathrm{m}$ & $\mathrm{m}$ & $\mathrm{m}$ & $\mathrm{m}$ & $\mathrm{m}$ & $\mathrm{m}$ \\
\hline & Jordan & $\mathrm{m}$ & $\mathrm{m}$ & $\mathrm{m}$ & $\mathrm{m}$ & $\mathrm{m}$ & & $\mathrm{m}$ & 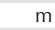 & $\mathrm{m}$ & $m$ & $\mathrm{~m}$ & 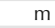 & $\mathrm{m}$ & $\mathrm{m}$ & $\mathrm{n}$ & 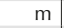 & 11 & $\mathrm{~m}$ & $\mathrm{~m}$ & $\mathrm{~m}$ \\
\hline & Kosovo & $\mathrm{m}$ & $\mathrm{m}$ & $\mathrm{m}$ & $\mathrm{m}$ & $\mathrm{m}$ & $\mathrm{m}$ & $\mathrm{m}$ & $\mathrm{m}$ & $\mathrm{m}$ & $\mathrm{m}$ & $\mathrm{m}$ & $\mathrm{m}$ & $\mathrm{m}$ & $\mathrm{m}$ & $\mathrm{m}$ & $\mathrm{m}$ & $\mathrm{m}$ & $\mathrm{m}$ & $\mathrm{m}$ & $\mathrm{m}$ \\
\hline & Lebanon & $\mathrm{m}$ & $\mathrm{m}$ & $\mathrm{m}$ & $\mathrm{m}$ & $\mathrm{m}$ & $\mathrm{m}$ & $\mathrm{m}$ & $\mathrm{m}$ & $\mathrm{m}$ & $\mathrm{m}$ & $\mathrm{m}$ & $\mathrm{m}$ & $\mathrm{m}$ & $\mathrm{m}$ & $\mathrm{m}$ & $\mathrm{m}$ & $\mathrm{m}$ & $\mathrm{m}$ & $\mathrm{m}$ & $\mathrm{m}$ \\
\hline & Lithuani & 3.2 & (1.6) & 63.4 & (1.9) & 6.8 & (1.5) & 0.9 & (1.9) & 8.9 & (1.7) & 3.5 & $(1$. & 60.7 & (1.5) & 0.4 & (1.5) & 2.6 & (1.6) & 45.4 & 1.6) \\
\hline & Macao (China & 80.3 & (1.2) & 81.7 & (1.2) & 71.7 & (1.5) & 68.9 & (1.6) & 61.2 & (1.7) & 63.0 & (1.6) & 70.0 & (1.7) & 56.4 & (1.8) & 46.4 & (1.8) & 55.1 & (1.8) \\
\hline & Malta & $\mathrm{m}$ & $\mathrm{m}$ & $\mathrm{m}$ & $\mathrm{m}$ & $\mathrm{m}$ & $\mathrm{m}$ & $\mathrm{m}$ & $\mathrm{m}$ & $\mathrm{m}$ & $\mathrm{m}$ & $\mathrm{m}$ & $\mathrm{m}$ & $\mathrm{m}$ & $\mathrm{m}$ & $\mathrm{m}$ & $\mathrm{m}$ & $\mathrm{m}$ & $\mathrm{m}$ & $\mathrm{m}$ & $\mathrm{m}$ \\
\hline & Moldo & $\mathrm{m}$ & $\mathrm{m}$ & $\mathrm{m}$ & $\mathrm{m}$ & $\mathrm{m}$ & $\mathrm{m}$ & $\mathrm{m}$ & $\mathrm{m}$ & $\mathrm{m}$ & III & $\mathrm{m}$ & $\mathrm{m}$ & $\mathrm{m}$ & $\mathrm{m}$ & $\mathrm{m}$ & $\mathrm{m}$ & $\mathrm{m}$ & $\mathrm{m}$ & $\mathrm{m}$ & $\mathrm{m}$ \\
\hline & Mont & 8.1 & (1.7) & 73.7 & (1.5) & 67.2 & (1.8) & 69 & (1.8 & 4.5 & 1 & 8.3 & (1. & 9.7 & (1. & 0.1 & (15) & 6.1 & 1.5) & 1.7 & 1.5) \\
\hline & Peru & 9.9 & (1.6) & 67.2 & (1.5) & 75.6 & (1.5) & 53.1 & (1.5) & 53.9 & (1.6) & 55.3 & (1.4) & 83.9 & $(0.9)$ & 61.4 & (1.3) & 30.1 & (1.6) & 40.9 & (1.5) \\
\hline & Qatar & 71.3 & $(0.9)$ & 67.2 & $(1.0)$ & 65.3 & (1.1) & 60.1 & (1.2) & 57.7 & $(1.2)$ & 60.2 & (1.1) & 60.7 & $(0.9)$ & 64.0 & $(0.9)$ & 38.9 & (1.0) & 52.9 & (1.0) \\
\hline & Romani & $\mathrm{m}$ & $\mathrm{m}$ & $\mathrm{m}$ & $\mathrm{m}$ & $\mathrm{m}$ & $\mathrm{m}$ & $\mathrm{m}$ & $\mathrm{m}$ & $\mathrm{m}$ & $\mathrm{m}$ & $\mathrm{m}$ & $\mathrm{m}$ & $\mathrm{m}$ & $\mathrm{m}$ & $\mathrm{m}$ & $\mathrm{m}$ & $\mathrm{m}$ & $\mathrm{m}$ & $\mathrm{m}$ & $\mathrm{m}$ \\
\hline & Russia & 3 & $(2.3$ & 2.3 & (1.8) & 17 & (2 & 10 & 0 & 3.3 & (1) & 1.0 & 1 & 5.9 & (1.2) & 8.8 & 1) & 8.0 & 1.8) & 56.2 & 2.6) \\
\hline & Singa & 1.0 & $(1.2)$ & 89.3 & $(0.8)$ & 82.3 & $(1.2)$ & 72.0 & (1.3) & 76.9 & (1.4) & 68.1 & (1.5) & 80.3 & (1.5) & 69.7 & (1.4) & 46.8 & (1.6) & 63.5 & (1.7) \\
\hline & Chine & 77.9 & (1.0) & 80.2 & (1.C & 68.3 & (1.3) & 64.7 & (1. & 66.9 & (1.2) & 64.4 & (1.3) & 79.8 & (1.1) & 61.1 & (1.5) & 54.5 & (1.3) & 66.6 & (1.6) \\
\hline & Thai & 62.5 & (1.6) & 73.2 & (1.5) & 67.5 & (1.6) & 52.0 & (2.0) & 62.2 & (1.7) & 66.0 & (1.6) & 78.7 & (1.4) & 56.1 & (1.7) & 41.1 & (1.5) & 50.3 & (1.7) \\
\hline & & - & & 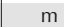 & & 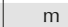 & & 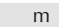 & & $\mathrm{m}$ & & $\mathrm{m}$ & & $\mathrm{m}$ & & $\mathrm{m}$ & & $\mathrm{m}$ & $\mathrm{m}$ & $\mathrm{m}$ & $\mathrm{m}$ \\
\hline & Tunisia & 58.3 & $(2.1)$ & 62.2 & (2.4) & 72.5 & (1.9) & 72.2 & (1.8) & 58.9 & (1.8) & 50.6 & (1.7) & 79.0 & $(1.2)$ & 42.4 & (2.0) & 39.1 & (2.1) & 42.5 & (1.9) \\
\hline & United $A$ & 69.1 & (1.2) & 70.5 & (1.2) & 65.0 & (1.1) & 54.2 & (1.4) & 63.9 & (1.3) & 57.1 & (1.3) & 65.4 & (1.1) & 58.6 & $(1.2)$ & 36.4 & $(1.2)$ & 59.6 & (1.1) \\
\hline & Uruguay & 79.0 & (1.5) & 87.8 & (1.3) & 73.1 & (1.4) & 69.7 & (1.7) & 77.3 & (1.7) & 59.9 & (1.4) & 90.0 & $(0.9)$ & 69.9 & (1.6) & 34.6 & (1.8) & 55.1 & (1.8) \\
\hline & Viet Nam & $\mathrm{m}$ & $\mathrm{m}$ & $\mathrm{m}$ & $\mathrm{m}$ & $\mathrm{m}$ & $\mathrm{m}$ & $\mathrm{m}$ & $\mathrm{m}$ & $\mathrm{m}$ & $\mathrm{m}$ & $\mathrm{m}$ & $\mathrm{m}$ & $\mathrm{m}$ & $\mathrm{m}$ & $\mathrm{m}$ & $\mathrm{m}$ & $\mathrm{m}$ & $\mathrm{m}$ & $\mathrm{m}$ & $\mathrm{m}$ \\
\hline & $A_{t}$ & $\mathrm{~m}$ & $\mathrm{~m}$ & $\mathrm{~m}$ & $\mathrm{~m}$ & $\mathrm{~m}$ & $\mathrm{~m}$ & $\mathrm{~m}$ & $\mathrm{~m}$ & $\mathrm{~m}$ & $\mathrm{~m}$ & $\mathrm{~m}$ & $\mathrm{n}$ & $\mathrm{m}$ & $\mathrm{m}$ & $\mathrm{m}$ & $\mathrm{m}$ & $\mathrm{m}$ & $\mathrm{m}$ & $\mathrm{m}$ & $\mathrm{m}$ \\
\hline & Kazakhstan** & $\mathrm{m}$ & $\mathrm{m}$ & $\mathrm{m}$ & $\mathrm{m}$ & $\mathrm{m}$ & $\mathrm{m}$ & $\mathrm{m}$ & $m$ & $\mathrm{~m}$ & $\mathrm{~m}$ & $\mathrm{~m}$ & $\mathrm{~m}$ & $\mathrm{~m}$ & $\mathrm{~m}$ & $\mathrm{~m}$ & $\mathrm{~m}$ & $\mathrm{~m}$ & $\mathrm{~m}$ & $\mathrm{~m}$ & $\mathrm{~m}$ \\
\hline & Malaysia** & 68.4 & (1.5) & 71.0 & (1.7) & 82.4 & (1.3) & 57.8 & $(1.8)$ & 71.8 & (1.5) & 63.9 & (1.4) & 84.3 & (1.1) & 76.4 & (1.2) & 52.0 & (1.3) & 70.1 & (1.4) \\
\hline
\end{tabular}

Note: Values that are statistically significant are indicated in bold (see Annex A3).

* See note at the beginning of this Annex.

** Coverage is too small to ensure comparability (see Annex A4).

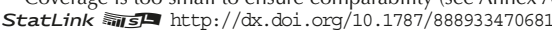


[Part 2/2]

Table III.4.3a Students' schoolwork-related anxiety, by student performance in science

Percentage of students who reported "agree" or "strongly agree"

\begin{tabular}{|c|c|c|c|c|c|c|c|c|c|c|c|}
\hline & \multicolumn{10}{|c|}{$\begin{array}{c}\text { Difference between the percentage of students in the top quarter and students in the bottom quarter of science performance who agreed } \\
\text { with the following statements (top - bottom) }\end{array}$} \\
\hline & & \multicolumn{2}{|c|}{$\begin{array}{l}\text { I often worry that it will be } \\
\text { difficult for me taking a test }\end{array}$} & \multicolumn{2}{|c|}{$\begin{array}{l}\text { I worry that I will get poor } \\
<\text { grades }>\text { at school }\end{array}$} & \multicolumn{2}{|c|}{$\begin{array}{l}\text { Even if I am well prepared } \\
\text { for a test I feel very anxious }\end{array}$} & I ge & $\begin{array}{l}\text { ense } \\
\text { Idy }\end{array}$ & $\begin{array}{r}\text { I get n } \\
\text { I don't kn } \\
\text { a tas }\end{array}$ & $\begin{array}{l}\text { when } \\
\text { v to solve } \\
\text { nool }\end{array}$ \\
\hline & & $\%$ dif. & S.E. & $\%$ dif. & S.E. & $\%$ dif. & S.E. & $\%$ dif. & S.E. & $\%$ dif. & S.E. \\
\hline 0 & Australia & -19.0 & (1.6) & -17.0 & (1.5) & -10.1 & (1.7) & -13.6 & (1.7) & -5.3 & (1.9) \\
\hline u & Austria & -24.0 & $(1.8)$ & -25.9 & $(2.1)$ & -27.5 & $(2.3)$ & -17.0 & (1.6) & -11.3 & $(2.0)$ \\
\hline ठృ & Belgium & -15.5 & (1.8) & -9.8 & (1.7) & -17.8 & (1.7) & -22.2 & (1.9) & -8.2 & (1.9) \\
\hline & Canada & -23.6 & $(1.7)$ & -18.1 & $(1.7)$ & -18.7 & (1.5) & -21.9 & $(1.8)$ & -2.2 & (1.6) \\
\hline & Chile & -23.4 & $(2.3)$ & -9.0 & (1.9) & -26.4 & $(2.2)$ & -26.2 & (2.3) & -22.2 & (2.4) \\
\hline & Czech Republic & -16.8 & (2.5) & -7.8 & $(2.3)$ & -15.4 & $(2.0)$ & -26.0 & (1.9) & 0.3 & $(2.3)$ \\
\hline & Denmark & -28.4 & (2.3) & -18.5 & $(2.0)$ & -17.1 & $(2.3)$ & -17.1 & $(2.2)$ & -9.8 & (2.6) \\
\hline & Estonia & -28.3 & $(2.2)$ & -26.1 & $(2.3)$ & -17.6 & $(2.2)$ & -23.1 & $(2.2)$ & -10.6 & (2.4) \\
\hline & Finland & -34.7 & $(2.1)$ & -36.8 & $(2.2)$ & -14.2 & $(2.1)$ & -10.6 & (1.7) & -6.0 & $(2.1)$ \\
\hline & France & -12.9 & $(1.8)$ & -2.5 & (1.9) & -16.8 & $(2.1)$ & -21.1 & $(2.1)$ & 1.7 & $(2.0)$ \\
\hline & Germany & -22.2 & $(2.5)$ & -18.6 & (2.6) & -30.4 & (2.5) & -11.9 & $(2.1)$ & -6.6 & (2.4) \\
\hline & Greece & -14.2 & (2.6) & -22.1 & $(2.2)$ & -14.3 & (2.4) & -14.5 & $(2.7)$ & 1.5 & $(2.7)$ \\
\hline & Hungary & -11.7 & $(2.5)$ & -8.9 & $(2.2)$ & -19.1 & (2.3) & -21.4 & $(2.2)$ & -14.1 & $(2.5)$ \\
\hline & Iceland & -39.1 & $(3.0)$ & -30.4 & (2.6) & -26.5 & $(2.7)$ & -22.3 & $(2.7)$ & -15.4 & $(2.7)$ \\
\hline & Ireland & -22.8 & (1.9) & -18.8 & $(2.1)$ & -19.2 & $(2.2)$ & -20.1 & $(2.2)$ & -8.2 & (2.1) \\
\hline & Israel & -5.1 & $(2.3)$ & -0.2 & (2.5) & -17.5 & (2.5) & -15.7 & $(2.3)$ & -11.8 & $(2.2)$ \\
\hline & Italy & -11.4 & $(2.1)$ & 1.0 & $(1.7)$ & -12.4 & $(2.1)$ & -18.9 & $(2.2)$ & 0.8 & $(2.0)$ \\
\hline & Japan & -1.2 & (1.8) & -0.6 & $(2.0)$ & -7.5 & (2.3) & 0.9 & $(2.1)$ & 13.9 & $(2.1)$ \\
\hline & Korea & 1.5 & $(2.1)$ & 13.5 & $(2.2)$ & 0.7 & $(2.2)$ & -1.7 & $(2.2)$ & 0.0 & (2.4) \\
\hline & Latvia & -23.0 & $(2.4)$ & -11.5 & $(2.3)$ & -17.9 & (2.6) & -18.0 & $(2.2)$ & -6.0 & (2.6) \\
\hline & Luxembourg & -18.5 & $(2.3)$ & -24.2 & $(2.1)$ & -24.5 & $(2.1)$ & -25.7 & $(2.1)$ & -12.5 & $(2.0)$ \\
\hline & Mexico & -11.1 & $(2.1)$ & 1.8 & (1.9) & -24.9 & (2.3) & -26.8 & (2.5) & -13.6 & (2.4) \\
\hline & Netherlands & -6.5 & $(2.1)$ & -1.6 & $(2.6)$ & 1.1 & $(2.4)$ & -7.6 & (1.9) & -2.3 & $(2.0)$ \\
\hline & New Zealand & -23.0 & $(2.2)$ & -21.4 & (2.4) & -11.0 & $(2.1)$ & -24.1 & $(2.2)$ & -16.7 & (2.4) \\
\hline & Norway & -27.8 & $(2.1)$ & -13.9 & (2.4) & -15.3 & (2.3) & -19.7 & $(2.2)$ & -10.8 & (2.2) \\
\hline & Poland & -17.8 & $(2.1)$ & -17.2 & $(2.1)$ & -22.2 & $(2.5)$ & -19.8 & $(2.2)$ & -19.2 & (2.5) \\
\hline & Portugal & -11.4 & (1.8) & -6.0 & (1.5) & -18.1 & (1.9) & -20.9 & (2.3) & -7.0 & $(2.2)$ \\
\hline & Slovak Republic & -5.2 & $(2.2)$ & -6.1 & $(2.4)$ & -12.9 & (2.4) & -18.8 & $(2.2)$ & -7.0 & $(2.3)$ \\
\hline & Slovenia & -25.9 & $(2.6)$ & -12.0 & (2.4) & -18.0 & (2.6) & -16.0 & $(2.4)$ & -6.9 & (2.5) \\
\hline & Spain & -10.7 & (1.9) & 7.3 & (1.5) & -17.4 & (2.0) & -26.4 & (2.0) & -14.8 & (2.0) \\
\hline & Sweden & -29.0 & $(2.4)$ & -25.2 & $(2.2)$ & -11.3 & $(2.4)$ & -18.5 & (2.5) & -3.8 & $(2.0)$ \\
\hline & Switzerland & -20.7 & $(2.1)$ & -16.1 & (2.4) & -17.9 & $(2.3)$ & -14.2 & $(1.7)$ & -5.1 & (2.6) \\
\hline & Turkey & -4.0 & $(2.7)$ & -1.1 & $(2.7)$ & -15.2 & (2.9) & -5.4 & (2.4) & 9.1 & (2.6) \\
\hline & United Kingdom & -17.1 & $(2.1)$ & -17.2 & (1.9) & -10.6 & (1.7) & -15.3 & $(2.3)$ & -11.8 & $(2.5)$ \\
\hline & United States & -22.6 & $(2.2)$ & -18.0 & (2.5) & -14.5 & (2.4) & -20.1 & (2.3) & -5.7 & $(2.2)$ \\
\hline & OECD average & -17.9 & $(0.4)$ & -12.5 & $(0.4)$ & -16.5 & $(0.4)$ & -17.8 & $(0.4)$ & -7.1 & $(0.4)$ \\
\hline 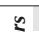 & Albania & $\mathrm{m}$ & $\mathrm{m}$ & $\mathrm{m}$ & $\mathrm{m}$ & $\mathrm{m}$ & $\mathrm{m}$ & $\mathrm{m}$ & $\mathrm{m}$ & $\mathrm{m}$ & $\mathrm{m}$ \\
\hline ఏ & Algeria & $\mathrm{m}$ & $\mathrm{m}$ & $\mathrm{m}$ & $\mathrm{m}$ & $\mathrm{m}$ & $\mathrm{m}$ & $\mathrm{m}$ & $\mathrm{m}$ & $\mathrm{m}$ & $\mathrm{m}$ \\
\hline ปั้ & Brazil & -3.4 & $(1.3)$ & 4.7 & $(0.9)$ & -11.1 & (1.5) & -23.9 & (1.8) & -12.2 & (1.5) \\
\hline & B-S-J-G (China) & -23.1 & (1.8) & -7.2 & (1.9) & -19.2 & $(2.3)$ & -20.0 & $(2.1)$ & -14.5 & $(2.1)$ \\
\hline & Bulgaria & -7.5 & $(2.8)$ & -8.9 & $(2.7)$ & -8.1 & (2.5) & -17.0 & $(2.8)$ & 2.4 & $(2.3)$ \\
\hline & CABA (Argentina) & $\mathrm{m}$ & $\mathrm{m}$ & $\mathrm{m}$ & $\mathrm{m}$ & $\mathrm{m}$ & $\mathrm{m}$ & $\mathrm{m}$ & $\mathrm{m}$ & $\mathrm{m}$ & $\mathrm{m}$ \\
\hline & Colombia & -5.0 & $(2.2)$ & 14.1 & (1.6) & -9.9 & $(1.8)$ & -9.0 & $(2.2)$ & -11.3 & $(2.0)$ \\
\hline & Costa Rica & -12.2 & $(1.9)$ & 5.5 & (1.5) & -9.4 & $(2.0)$ & -25.3 & $(2.4)$ & -15.3 & $(2.8)$ \\
\hline & Croatia & -6.5 & $(2.4)$ & -6.0 & $(2.0)$ & -13.2 & $(2.3)$ & -16.9 & $(2.2)$ & -9.4 & (2.4) \\
\hline & Cyprus* & -25.2 & $(2.4)$ & -29.3 & $(2.3)$ & -17.2 & (2.4) & -21.0 & $(2.1)$ & -8.7 & (2.3) \\
\hline & Dominican Republic & 2.2 & (3.1) & 23.1 & $(2.2)$ & -4.1 & $(2.8)$ & -12.7 & $(2.9)$ & -7.7 & (3.1) \\
\hline & FYROM & $\mathrm{m}$ & $\mathrm{m}$ & $\mathrm{m}$ & $\mathrm{m}$ & $\mathrm{m}$ & $\mathrm{m}$ & $\mathrm{m}$ & $\mathrm{m}$ & $\mathrm{m}$ & $\mathrm{m}$ \\
\hline & Georgia & $\mathrm{m}$ & $\mathrm{m}$ & $\mathrm{m}$ & $\mathrm{m}$ & $\mathrm{m}$ & $\mathrm{m}$ & $\mathrm{m}$ & $\mathrm{m}$ & $\mathrm{m}$ & $\mathrm{m}$ \\
\hline & Hong Kong (China) & -10.4 & $(2.4)$ & -6.1 & $(2.0)$ & -11.7 & $(2.7)$ & -19.5 & $(2.5)$ & -8.6 & $(2.7)$ \\
\hline & Indonesia & $\mathrm{m}$ & $\mathrm{m}$ & $\mathrm{m}$ & $\mathrm{m}$ & $\mathrm{m}$ & $\mathrm{m}$ & $\mathrm{m}$ & $\mathrm{m}$ & $\mathrm{m}$ & $\mathrm{m}$ \\
\hline & Jordan & $\mathrm{m}$ & $\mathrm{m}$ & $\mathrm{m}$ & $\mathrm{m}$ & $\mathrm{m}$ & $\mathrm{m}$ & $\mathrm{m}$ & $\mathrm{m}$ & $\mathrm{m}$ & $\mathrm{m}$ \\
\hline & Kosovo & $\mathrm{m}$ & $\mathrm{m}$ & $\mathrm{m}$ & $\mathrm{m}$ & $\mathrm{m}$ & $\mathrm{m}$ & $\mathrm{m}$ & $\mathrm{m}$ & $\mathrm{m}$ & $\mathrm{m}$ \\
\hline & Lebanon & $\mathrm{m}$ & $\mathrm{m}$ & $\mathrm{m}$ & $\mathrm{m}$ & $\mathrm{m}$ & $\mathrm{m}$ & $\mathrm{m}$ & $\mathrm{m}$ & $\mathrm{m}$ & $\mathrm{m}$ \\
\hline & Lithuania & -9.7 & $(2.2)$ & -2.7 & (2.4) & -6.5 & $(2.1)$ & -18.3 & (2.4) & -3.5 & (2.5) \\
\hline & Macao (China) & -17.3 & $(2.1)$ & -11.6 & $(2.1)$ & -15.4 & (2.4) & -22.5 & $(2.4)$ & -6.0 & (2.3) \\
\hline & Malta & $\mathrm{m}$ & $\mathrm{m}$ & $\mathrm{m}$ & $\mathrm{m}$ & $\mathrm{m}$ & $\mathrm{m}$ & $\mathrm{m}$ & $\mathrm{m}$ & $\mathrm{m}$ & $\mathrm{m}$ \\
\hline & Moldova & $\mathrm{m}$ & $\mathrm{m}$ & $\mathrm{m}$ & $\mathrm{m}$ & $\mathrm{m}$ & $\mathrm{m}$ & $\mathrm{m}$ & $\mathrm{m}$ & $\mathrm{m}$ & $\mathrm{m}$ \\
\hline & Montenegro & -9.8 & $(2.1)$ & -14.0 & $(2.4)$ & -7.2 & $(2.4)$ & -20.7 & $(2.4)$ & -12.8 & $(2.1)$ \\
\hline & Peru & -4.6 & $(2.3)$ & 16.7 & (1.8) & -14.1 & $(2.1)$ & -23.1 & $(2.3)$ & -12.9 & $(2.3)$ \\
\hline & Qatar & -11.0 & (1.5) & -6.6 & (1.4) & -1.3 & (1.6) & -21.1 & (1.8) & -4.9 & (1.5) \\
\hline & Romania & $\mathrm{m}$ & $\mathrm{m}$ & $\mathrm{m}$ & $\mathrm{m}$ & $\mathrm{m}$ & $\mathrm{m}$ & $\mathrm{m}$ & $\mathrm{m}$ & $\mathrm{m}$ & $\mathrm{m}$ \\
\hline & Russia & -20.3 & $(2.7)$ & -6.4 & $(2.2)$ & -22.9 & $(3.1)$ & -23.0 & $(2.9)$ & -7.0 & (3.1) \\
\hline & Singapore & -12.9 & (1.8) & -9.0 & (1.6) & -12.6 & (1.7) & -25.2 & $(2.1)$ & -13.5 & $(2.0)$ \\
\hline & Chinese Taipei & -13.4 & $(1.5)$ & -0.4 & (1.5) & -7.2 & $(2.1)$ & -10.2 & $(1.8)$ & -0.3 & (1.9) \\
\hline & Thailand & 3.4 & $(2.1)$ & 5.5 & $(2.1)$ & -11.4 & $(2.3)$ & -10.9 & $(2.7)$ & -11.8 & (2.5) \\
\hline & Trinidad and Tobago & $\mathrm{m}$ & $\mathrm{m}$ & $\mathrm{m}$ & $\mathrm{m}$ & $\mathrm{m}$ & $\mathrm{m}$ & $\mathrm{m}$ & $\mathrm{m}$ & $\mathrm{m}$ & $\mathrm{m}$ \\
\hline & Tunisia & -7.7 & $(2.8)$ & 16.8 & (2.5) & -30.1 & $(2.8)$ & -33.1 & $(2.8)$ & -16.4 & (2.6) \\
\hline & United Arab Emirates & -12.0 & (1.8) & -5.1 & (1.6) & -6.5 & (1.6) & -17.8 & (1.9) & -4.3 & $(1.8)$ \\
\hline & Uruguay & -19.0 & $(2.0)$ & 2.2 & (1.6) & -3.2 & $(2.2)$ & -35.1 & $(2.2)$ & -22.3 & (2.4) \\
\hline & Viet Nam & $\mathrm{m}$ & $\mathrm{m}$ & $\mathrm{m}$ & $\mathrm{m}$ & $\mathrm{m}$ & $\mathrm{m}$ & $\mathrm{m}$ & $\mathrm{m}$ & $\mathrm{m}$ & $\mathrm{m}$ \\
\hline & Argentina** & $\mathrm{m}$ & $\mathrm{m}$ & $\mathrm{m}$ & $\mathrm{m}$ & $\mathrm{m}$ & $\mathrm{m}$ & $\mathrm{m}$ & $\mathrm{m}$ & $\mathrm{m}$ & $\mathrm{m}$ \\
\hline & Kazakhstan** & $\mathrm{m}$ & $\mathrm{m}$ & $\mathrm{m}$ & $\mathrm{m}$ & $\mathrm{m}$ & $\mathrm{m}$ & $\mathrm{m}$ & $\mathrm{m}$ & $\mathrm{m}$ & $\mathrm{m}$ \\
\hline & Malaysia** & -4.4 & $(2.0)$ & 13.3 & $(2.0)$ & -6.0 & (1.9) & -5.8 & $(2.2)$ & -1.6 & $(2.0)$ \\
\hline
\end{tabular}

Note: Values that are statistically significant are indicated in bold (see Annex A3).

* See note at the beginning of this Annex.

** Coverage is too small to ensure comparability (see Annex A4).

StatLink *iगाडL http://dx.doi.org/10.1787/888933470681 
Results based on students' self-reports

\begin{tabular}{|c|c|c|c|c|c|c|c|c|c|c|c|c|c|}
\hline & & \multicolumn{12}{|c|}{ Index of schoolwork-related anxiety, by: } \\
\hline & & \multicolumn{4}{|c|}{ All students } & \multicolumn{8}{|c|}{ National quarters of the index of schoolwork-related anxiety } \\
\hline & & \multicolumn{2}{|c|}{ Average } & \multicolumn{2}{|c|}{ Variability of this index } & \multicolumn{2}{|c|}{ Bottom quarter } & \multicolumn{2}{|c|}{ Second quarter } & \multicolumn{2}{|c|}{ Third quarter } & \multicolumn{2}{|c|}{ Top quarter } \\
\hline & & Mean index & S.E. & S.D. & S.E. & Mean index & S.E. & Mean index & S.E. & Mean index & S.E. & Mean index & S.E. \\
\hline 0 & Australia & 0.19 & $(0.01)$ & 0.97 & $(0.01)$ & -0.95 & $(0.01)$ & -0.12 & $(0.00)$ & 0.41 & $(0.00)$ & 1.43 & $(0.01)$ \\
\hline 5 & Austria & -0.10 & $(0.02)$ & 1.03 & $(0.01)$ & -1.34 & $(0.01)$ & -0.47 & $(0.01)$ & 0.15 & $(0.01)$ & 1.24 & $(0.02)$ \\
\hline & Belgium & -0.16 & $(0.01)$ & 0.99 & $(0.01)$ & -1.38 & $(0.02)$ & -0.43 & $(0.00)$ & 0.11 & $(0.00)$ & 1.05 & $(0.01)$ \\
\hline & Canada & 0.17 & $(0.01)$ & 1.06 & $(0.01)$ & -1.10 & $(0.01)$ & -0.17 & $(0.00)$ & 0.43 & $(0.00)$ & 1.51 & $(0.01)$ \\
\hline & Chile & 0.10 & $(0.02)$ & 0.92 & $(0.01)$ & -1.04 & $(0.01)$ & -0.20 & $(0.00)$ & 0.36 & $(0.00)$ & 1.26 & $(0.01)$ \\
\hline & Czech Republic & -0.21 & $(0.02)$ & 0.91 & $(0.01)$ & -1.31 & $(0.02)$ & -0.43 & $(0.00)$ & 0.03 & $(0.00)$ & 0.89 & $(0.01)$ \\
\hline & Denmark & 0.09 & $(0.01)$ & 0.91 & $(0.01)$ & -1.00 & $(0.02)$ & -0.20 & $(0.00)$ & 0.32 & $(0.00)$ & 1.22 & $(0.01)$ \\
\hline & Estonia & -0.22 & $(0.01)$ & 0.93 & $(0.01)$ & -1.33 & $(0.02)$ & -0.46 & $(0.00)$ & 0.01 & $(0.00)$ & 0.92 & $(0.02)$ \\
\hline & Finland & -0.41 & $(0.01)$ & 0.87 & $(0.01)$ & -1.49 & $(0.02)$ & -0.63 & $(0.00)$ & -0.19 & $(0.00)$ & 0.66 & $(0.01)$ \\
\hline & France & -0.10 & $(0.02)$ & 1.04 & $(0.01)$ & -1.38 & $(0.02)$ & -0.37 & $(0.00)$ & 0.19 & $(0.00)$ & 1.17 & $(0.02)$ \\
\hline & Germany & -0.33 & $(0.01)$ & 0.94 & $(0.01)$ & -1.47 & $(0.01)$ & -0.64 & $(0.00)$ & -0.09 & $(0.00)$ & 0.88 & $(0.01)$ \\
\hline & Greece & -0.09 & $(0.01)$ & 0.88 & $(0.01)$ & -1.16 & $(0.02)$ & -0.35 & $(0.00)$ & 0.15 & $(0.00)$ & 1.00 & $(0.02)$ \\
\hline & Hungary & -0.10 & $(0.02)$ & 0.96 & $(0.01)$ & -1.27 & $(0.02)$ & -0.36 & $(0.00)$ & 0.17 & $(0.00)$ & 1.07 & $(0.02)$ \\
\hline & Iceland & -0.12 & $(0.02)$ & 1.17 & $(0.02)$ & -1.52 & $(0.02)$ & -0.48 & $(0.01)$ & 0.17 & $(0.01)$ & 1.37 & $(0.03)$ \\
\hline & Ireland & 0.15 & $(0.02)$ & 0.89 & $(0.01)$ & -0.90 & $(0.02)$ & -0.14 & $(0.00)$ & 0.35 & $(0.00)$ & 1.26 & $(0.02)$ \\
\hline & Israel & -0.27 & $(0.02)$ & 0.96 & $(0.01)$ & -1.45 & $(0.02)$ & -0.51 & $(0.01)$ & 0.00 & $(0.00)$ & 0.90 & $(0.02)$ \\
\hline & Italy & 0.45 & $(0.01)$ & 0.95 & $(0.01)$ & -0.73 & $(0.01)$ & 0.18 & $(0.00)$ & 0.72 & $(0.01)$ & 1.64 & $(0.01)$ \\
\hline & Japan & 0.26 & $(0.01)$ & 0.99 & $(0.01)$ & -0.94 & $(0.02)$ & -0.02 & $(0.00)$ & 0.50 & $(0.00)$ & 1.50 & $(0.01)$ \\
\hline & Korea & 0.10 & $(0.01)$ & 0.94 & $(0.01)$ & -1.01 & $(0.02)$ & -0.16 & $(0.00)$ & 0.35 & $(0.00)$ & 1.23 & $(0.02)$ \\
\hline & Latvia & -0.14 & $(0.01)$ & 0.88 & $(0.01)$ & -1.17 & $(0.01)$ & -0.40 & $(0.00)$ & 0.05 & $(0.01)$ & 0.96 & $(0.02)$ \\
\hline & Luxembourg & -0.16 & $(0.01)$ & 1.05 & $(0.01)$ & -1.46 & $(0.02)$ & -0.47 & $(0.00)$ & 0.14 & $(0.00)$ & 1.16 & $(0.02)$ \\
\hline & Mexico & 0.26 & $(0.02)$ & 0.93 & $(0.01)$ & -0.89 & $(0.01)$ & -0.01 & $(0.01)$ & 0.52 & $(0.00)$ & 1.42 & $(0.01)$ \\
\hline & Netherlands & -0.54 & $(0.02)$ & 0.86 & $(0.01)$ & -1.64 & $(0.02)$ & -0.69 & $(0.00)$ & -0.31 & $(0.00)$ & 0.48 & $(0.01)$ \\
\hline & New Zealand & 0.27 & $(0.01)$ & 0.96 & $(0.01)$ & -0.87 & $(0.02)$ & -0.03 & $(0.01)$ & 0.48 & $(0.00)$ & 1.50 & $(0.02)$ \\
\hline & Norway & 0.07 & $(0.02)$ & 1.09 & $(0.01)$ & -1.24 & $(0.02)$ & -0.28 & $(0.00)$ & 0.34 & $(0.00)$ & 1.46 & $(0.02)$ \\
\hline & Poland & -0.11 & $(0.02)$ & 0.95 & $(0.01)$ & -1.23 & $(0.02)$ & -0.39 & $(0.00)$ & 0.09 & $(0.01)$ & 1.08 & $(0.02)$ \\
\hline & Portugal & 0.48 & $(0.01)$ & 0.93 & $(0.01)$ & -0.65 & $(0.01)$ & 0.20 & $(0.00)$ & 0.70 & $(0.01)$ & 1.66 & $(0.02)$ \\
\hline & Slovak Republic & -0.17 & $(0.02)$ & 0.92 & $(0.01)$ & -1.30 & $(0.02)$ & -0.39 & $(0.00)$ & 0.09 & $(0.00)$ & 0.92 & $(0.01)$ \\
\hline & Slovenia & 0.06 & $(0.01)$ & 0.91 & $(0.01)$ & -1.03 & $(0.02)$ & -0.22 & $(0.00)$ & 0.30 & $(0.00)$ & 1.18 & $(0.02)$ \\
\hline & Spain & 0.40 & $(0.01)$ & 0.88 & $(0.01)$ & -0.69 & $(0.01)$ & 0.13 & $(0.00)$ & 0.67 & $(0.00)$ & 1.48 & $(0.01)$ \\
\hline & Sweden & 0.05 & $(0.02)$ & 1.05 & $(0.02)$ & -1.20 & $(0.02)$ & -0.29 & $(0.00)$ & 0.30 & $(0.00)$ & 1.37 & $(0.02)$ \\
\hline & Switzerland & -0.44 & $(0.01)$ & 0.97 & $(0.01)$ & -1.64 & $(0.02)$ & -0.72 & $(0.01)$ & -0.18 & $(0.01)$ & 0.78 & $(0.02)$ \\
\hline & Turkey & 0.31 & $(0.02)$ & 1.06 & $(0.01)$ & -0.97 & $(0.02)$ & 0.00 & $(0.00)$ & 0.55 & $(0.00)$ & 1.66 & $(0.02)$ \\
\hline & United Kingdom & 0.25 & $(0.01)$ & 0.97 & $(0.01)$ & -0.89 & $(0.02)$ & -0.07 & $(0.00)$ & 0.46 & $(0.00)$ & 1.51 & $(0.02)$ \\
\hline & United States & 0.19 & $(0.02)$ & 1.00 & $(0.01)$ & -1.01 & $(0.02)$ & -0.13 & $(0.00)$ & 0.44 & $(0.00)$ & 1.46 & $(0.02)$ \\
\hline & OECD average & 0.01 & $(0.00)$ & 0.96 & $(0.00)$ & -1.16 & $(0.00)$ & -0.28 & $(0.00)$ & 0.25 & $(0.00)$ & 1.21 & $(0.00)$ \\
\hline
\end{tabular}

\begin{tabular}{|c|c|c|c|c|c|c|c|c|c|c|c|c|c|}
\hline 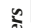 & Albania & $\mathrm{m}$ & $\mathrm{m}$ & $\mathrm{m}$ & $\mathrm{m}$ & $\mathrm{m}$ & $\mathrm{m}$ & $\mathrm{m}$ & $\mathrm{m}$ & $\mathrm{m}$ & $\mathrm{m}$ & $\mathrm{m}$ & $\mathrm{m}$ \\
\hline 9 & Algeria & $\mathrm{m}$ & $\mathrm{m}$ & $\mathrm{m}$ & $\mathrm{m}$ & $\mathrm{m}$ & $\mathrm{m}$ & $\mathrm{m}$ & $\mathrm{m}$ & $\mathrm{m}$ & $\mathrm{m}$ & $\mathrm{m}$ & $\mathrm{m}$ \\
\hline ฐ & Brazil & 0.60 & $(0.01)$ & 0.82 & $(0.01)$ & -0.36 & $(0.01)$ & 0.36 & $(0.00)$ & 0.74 & $(0.00)$ & 1.66 & $(0.01)$ \\
\hline & B-S-J-G (China) & 0.23 & $(0.01)$ & 0.88 & $(0.01)$ & -0.79 & $(0.01)$ & -0.03 & $(0.00)$ & 0.44 & $(0.00)$ & 1.30 & $(0.02)$ \\
\hline & Bulgaria & -0.09 & $(0.02)$ & 1.05 & $(0.01)$ & -1.43 & $(0.02)$ & -0.31 & $(0.00)$ & 0.26 & $(0.00)$ & 1.12 & $(0.02)$ \\
\hline & CABA (Argentina) & $\mathrm{m}$ & $\mathrm{m}$ & $\mathrm{m}$ & $\mathrm{m}$ & $\mathrm{m}$ & $\mathrm{m}$ & $\mathrm{m}$ & $\mathrm{m}$ & $\mathrm{m}$ & $\mathrm{m}$ & $\mathrm{m}$ & $\mathrm{m}$ \\
\hline & Colombia & 0.52 & $(0.01)$ & 0.76 & $(0.01)$ & -0.39 & $(0.01)$ & 0.29 & $(0.00)$ & 0.70 & $(0.00)$ & 1.47 & $(0.01)$ \\
\hline & Costa Rica & 0.60 & $(0.01)$ & 0.89 & $(0.01)$ & -0.46 & $(0.02)$ & 0.31 & $(0.01)$ & 0.80 & $(0.00)$ & 1.75 & $(0.02)$ \\
\hline & Croatia & 0.00 & $(0.02)$ & 0.91 & $(0.02)$ & -1.08 & $(0.02)$ & -0.27 & $(0.00)$ & 0.23 & $(0.00)$ & 1.13 & $(0.02)$ \\
\hline & Cyprus* & -0.08 & $(0.01)$ & 0.96 & $(0.01)$ & -1.24 & $(0.02)$ & -0.37 & $(0.00)$ & 0.19 & $(0.00)$ & 1.12 & $(0.01)$ \\
\hline & Dominican Republic & 0.41 & $(0.02)$ & 0.94 & $(0.01)$ & -0.72 & $(0.02)$ & 0.16 & $(0.01)$ & 0.62 & $(0.00)$ & 1.59 & $(0.02)$ \\
\hline & FYROM & $\mathrm{m}$ & $\mathrm{m}$ & $\mathrm{m}$ & $\mathrm{m}$ & $\mathrm{m}$ & $\mathrm{m}$ & $\mathrm{m}$ & $\mathrm{m}$ & $\mathrm{m}$ & $\mathrm{m}$ & $\mathrm{m}$ & $\mathrm{m}$ \\
\hline & Georgia & $\mathrm{m}$ & $\mathrm{m}$ & $\mathrm{m}$ & $\mathrm{m}$ & $\mathrm{m}$ & $\mathrm{m}$ & $\mathrm{m}$ & $\mathrm{m}$ & $\mathrm{m}$ & $\mathrm{m}$ & $\mathrm{m}$ & $\mathrm{m}$ \\
\hline & Hong Kong (China) & 0.33 & $(0.01)$ & 0.99 & $(0.02)$ & -0.85 & $(0.02)$ & 0.06 & $(0.00)$ & 0.53 & $(0.00)$ & 1.57 & $(0.02)$ \\
\hline & Indonesia & $\mathrm{m}$ & $\mathrm{m}$ & $\mathrm{m}$ & $\mathrm{m}$ & $\mathrm{m}$ & $\mathrm{m}$ & $\mathrm{m}$ & $\mathrm{m}$ & $\mathrm{m}$ & $\mathrm{m}$ & $\mathrm{m}$ & $\mathrm{m}$ \\
\hline & Jordan & $\mathrm{m}$ & $\mathrm{m}$ & $\mathrm{m}$ & $\mathrm{m}$ & $\mathrm{m}$ & $\mathrm{m}$ & $\mathrm{m}$ & $\mathrm{m}$ & $\mathrm{m}$ & $\mathrm{m}$ & $\mathrm{m}$ & $\mathrm{m}$ \\
\hline & Kosovo & $\mathrm{m}$ & $\mathrm{m}$ & $\mathrm{m}$ & $\mathrm{m}$ & $\mathrm{m}$ & $\mathrm{m}$ & $\mathrm{m}$ & $\mathrm{m}$ & $\mathrm{m}$ & $\mathrm{m}$ & $\mathrm{m}$ & $\mathrm{m}$ \\
\hline & Lebanon & $\mathrm{m}$ & $\mathrm{m}$ & $\mathrm{m}$ & $\mathrm{m}$ & $\mathrm{m}$ & $\mathrm{m}$ & $\mathrm{m}$ & $\mathrm{m}$ & $\mathrm{m}$ & $\mathrm{m}$ & $\mathrm{m}$ & $\mathrm{m}$ \\
\hline & Lithuania & -0.07 & $(0.02)$ & 1.12 & $(0.01)$ & -1.50 & $(0.02)$ & -0.37 & $(0.01)$ & 0.28 & $(0.01)$ & 1.32 & $(0.02)$ \\
\hline & Macao (China) & 0.37 & $(0.01)$ & 0.98 & $(0.01)$ & -0.80 & $(0.02)$ & 0.07 & $(0.01)$ & 0.58 & $(0.00)$ & 1.62 & $(0.02)$ \\
\hline & Malta & $\mathrm{m}$ & $\mathrm{m}$ & $\mathrm{m}$ & $\mathrm{m}$ & $\mathrm{m}$ & $\mathrm{m}$ & $\mathrm{m}$ & $\mathrm{m}$ & $\mathrm{m}$ & $\mathrm{m}$ & $\mathrm{m}$ & $\mathrm{m}$ \\
\hline & Moldova & $\mathrm{m}$ & $\mathrm{m}$ & $\mathrm{m}$ & $\mathrm{m}$ & $\mathrm{m}$ & $\mathrm{m}$ & $\mathrm{m}$ & $\mathrm{m}$ & $\mathrm{m}$ & $\mathrm{m}$ & $\mathrm{m}$ & $\mathrm{m}$ \\
\hline & Montenegro & 0.09 & $(0.01)$ & 1.04 & $(0.01)$ & -1.21 & $(0.02)$ & -0.15 & $(0.01)$ & 0.40 & $(0.00)$ & 1.33 & $(0.02)$ \\
\hline & Peru & 0.14 & $(0.01)$ & 0.71 & $(0.01)$ & -0.72 & $(0.01)$ & -0.08 & $(0.00)$ & 0.34 & $(0.00)$ & 1.01 & $(0.01)$ \\
\hline & Qatar & 0.22 & $(0.01)$ & 0.97 & $(0.01)$ & -0.94 & $(0.01)$ & -0.07 & $(0.00)$ & 0.45 & $(0.00)$ & 1.45 & $(0.01)$ \\
\hline & Romania & $\mathrm{m}$ & $\mathrm{m}$ & $\mathrm{m}$ & $\mathrm{m}$ & $\mathrm{m}$ & $\mathrm{m}$ & $\mathrm{m}$ & $\mathrm{m}$ & $\mathrm{m}$ & $\mathrm{m}$ & $\mathrm{m}$ & $\mathrm{m}$ \\
\hline & Russia & -0.05 & $(0.02)$ & 0.87 & $(0.01)$ & -1.10 & $(0.02)$ & -0.27 & $(0.00)$ & 0.19 & $(0.00)$ & 0.98 & $(0.02)$ \\
\hline & Singapore & 0.57 & $(0.01)$ & 0.95 & $(0.01)$ & -0.58 & $(0.02)$ & 0.28 & $(0.00)$ & 0.78 & $(0.01)$ & 1.80 & $(0.01)$ \\
\hline & Chinese Taipei & 0.39 & $(0.01)$ & 0.92 & $(0.01)$ & -0.72 & $(0.01)$ & 0.14 & $(0.00)$ & 0.57 & $(0.00)$ & 1.55 & $(0.01)$ \\
\hline & Thailand & 0.11 & $(0.02)$ & 0.80 & $(0.01)$ & -0.85 & $(0.02)$ & -0.09 & $(0.00)$ & 0.39 & $(0.00)$ & 1.01 & $(0.01)$ \\
\hline & Trinidad and Tobago & $\mathrm{m}$ & $\mathrm{m}$ & $\mathrm{m}$ & $\mathrm{m}$ & $\mathrm{m}$ & $\mathrm{m}$ & $\mathrm{m}$ & $\mathrm{m}$ & $\mathrm{m}$ & $\mathrm{m}$ & $\mathrm{m}$ & $\mathrm{m}$ \\
\hline & Tunisia & 0.10 & $(0.02)$ & 0.92 & $(0.01)$ & -1.03 & $(0.02)$ & -0.18 & $(0.00)$ & 0.36 & $(0.00)$ & 1.24 & $(0.02)$ \\
\hline & United Arab Emirates & 0.20 & $(0.01)$ & 0.93 & $(0.01)$ & -0.92 & $(0.01)$ & -0.08 & $(0.00)$ & 0.44 & $(0.00)$ & 1.36 & $(0.01)$ \\
\hline & Uruguay & 0.46 & $(0.01)$ & 0.87 & $(0.01)$ & -0.60 & $(0.02)$ & 0.22 & $(0.01)$ & 0.70 & $(0.00)$ & 1.53 & $(0.01)$ \\
\hline & Viet Nam & $\mathrm{m}$ & $\mathrm{m}$ & $\mathrm{m}$ & $\mathrm{m}$ & $\mathrm{m}$ & $\mathrm{m}$ & $\mathrm{m}$ & $\mathrm{m}$ & $\mathrm{m}$ & $\mathrm{m}$ & $\mathrm{m}$ & $\mathrm{m}$ \\
\hline & Argentina** & $\mathrm{m}$ & $\mathrm{m}$ & $\mathrm{m}$ & $\mathrm{m}$ & $\mathrm{m}$ & $\mathrm{m}$ & $\mathrm{m}$ & $\mathrm{m}$ & $\mathrm{m}$ & $\mathrm{m}$ & $\mathrm{m}$ & $\mathrm{m}$ \\
\hline & Kazakhstan** & $\mathrm{m}$ & $\mathrm{m}$ & $\mathrm{m}$ & $\mathrm{m}$ & $\mathrm{m}$ & $\mathrm{m}$ & $\mathrm{m}$ & $\mathrm{m}$ & $\mathrm{m}$ & $\mathrm{m}$ & $\mathrm{m}$ & $\mathrm{m}$ \\
\hline & Malaysia** & 0.36 & $(0.01)$ & 0.72 & $(0.01)$ & -0.50 & $(0.01)$ & 0.14 & $(0.00)$ & 0.52 & $(0.00)$ & 1.26 & $(0.01)$ \\
\hline
\end{tabular}

1. ESCS refers to the PISA index of economic, social and cultural status.

Note: Values that are statistically significant are indicated in bold (see Annex A3).

* See note at the beginning of this Annex.

Corage is too small to ensure comparability (see Annex A4).

StatLink 츄 S녀 http://dx.doi.org/10.1787/888933470715 
[Part 2/3]

Table III.4.5 Index of schoolwork-related anxiety, by student characteristics

Results based on students' self-reports

\begin{tabular}{|c|c|c|c|c|c|c|c|c|c|c|}
\hline & \multicolumn{10}{|c|}{ Index of schoolwork-related anxiety, by: } \\
\hline & \multicolumn{10}{|c|}{ National quarters of the ESCS ${ }^{1}$ index } \\
\hline & \multicolumn{2}{|c|}{ Bottom quarter } & \multicolumn{2}{|c|}{ Second quarter } & \multicolumn{2}{|c|}{ Third quarter } & \multicolumn{2}{|c|}{ Top quarter } & \multicolumn{2}{|c|}{ Top - bottom quarter } \\
\hline & Mean index & S.E. & Mean index & S.E. & Mean index & S.E. & Mean index & S.E. & Dif. & S.E. \\
\hline Australia & 0.26 & $(0.02)$ & 0.19 & $(0.02)$ & 0.19 & $(0.02)$ & 0.14 & $(0.02)$ & -0.12 & $(0.03)$ \\
\hline Austria & 0.04 & $(0.03)$ & -0.08 & $(0.03)$ & -0.13 & $(0.03)$ & -0.25 & $(0.03)$ & -0.29 & $(0.05)$ \\
\hline$\widehat{\widehat{O}}$ Belgium & -0.12 & $(0.03)$ & -0.12 & $(0.02)$ & -0.17 & $(0.02)$ & -0.24 & $(0.03)$ & -0.13 & $(0.04)$ \\
\hline Canada & 0.20 & $(0.02)$ & 0.22 & $(0.02)$ & 0.18 & $(0.02)$ & 0.07 & $(0.03)$ & -0.13 & $(0.04)$ \\
\hline Chile & 0.19 & $(0.02)$ & 0.12 & $(0.03)$ & 0.09 & $(0.03)$ & -0.02 & $(0.03)$ & -0.21 & $(0.04)$ \\
\hline Czech Republic & -0.20 & $(0.02)$ & -0.19 & $(0.03)$ & -0.19 & $(0.03)$ & -0.23 & $(0.03)$ & -0.03 & $(0.03)$ \\
\hline Denmark & 0.23 & $(0.03)$ & 0.15 & $(0.03)$ & 0.05 & $(0.03)$ & -0.07 & $(0.03)$ & -0.29 & $(0.05)$ \\
\hline Estonia & -0.18 & $(0.03)$ & -0.14 & $(0.03)$ & -0.23 & $(0.03)$ & -0.32 & $(0.03)$ & -0.14 & $(0.04)$ \\
\hline Finland & -0.35 & $(0.03)$ & -0.34 & $(0.03)$ & -0.42 & $(0.02)$ & -0.53 & $(0.02)$ & -0.18 & $(0.04)$ \\
\hline France & -0.10 & $(0.03)$ & -0.02 & $(0.03)$ & -0.15 & $(0.03)$ & -0.11 & $(0.03)$ & -0.01 & $(0.04)$ \\
\hline Germany & -0.26 & $(0.03)$ & -0.23 & $(0.03)$ & -0.31 & $(0.02)$ & -0.49 & $(0.03)$ & -0.23 & $(0.04)$ \\
\hline Greece & -0.03 & $(0.03)$ & -0.07 & $(0.02)$ & -0.06 & $(0.03)$ & -0.21 & $(0.03)$ & -0.18 & $(0.04)$ \\
\hline Hungary & -0.04 & $(0.03)$ & -0.10 & $(0.04)$ & -0.08 & $(0.03)$ & -0.19 & $(0.03)$ & -0.15 & $(0.04)$ \\
\hline Iceland & -0.01 & $(0.04)$ & -0.01 & $(0.04)$ & -0.13 & $(0.05)$ & -0.31 & $(0.05)$ & -0.30 & $(0.07)$ \\
\hline Ireland & 0.20 & $(0.03)$ & 0.24 & $(0.03)$ & 0.14 & $(0.03)$ & 0.00 & $(0.03)$ & -0.20 & $(0.04)$ \\
\hline Israel & -0.15 & $(0.03)$ & -0.26 & $(0.03)$ & -0.28 & $(0.03)$ & -0.37 & $(0.03)$ & -0.22 & $(0.04)$ \\
\hline Italy & 0.49 & $(0.03)$ & 0.47 & $(0.02)$ & 0.48 & $(0.03)$ & 0.38 & $(0.03)$ & -0.11 & $(0.04)$ \\
\hline Japan & 0.19 & $(0.03)$ & 0.26 & $(0.03)$ & 0.30 & $(0.03)$ & 0.30 & $(0.02)$ & 0.11 & $(0.04)$ \\
\hline Korea & 0.03 & $(0.03)$ & 0.11 & $(0.02)$ & 0.14 & $(0.02)$ & 0.14 & $(0.03)$ & 0.11 & $(0.04)$ \\
\hline Latvia & -0.09 & $(0.03)$ & -0.11 & $(0.03)$ & -0.12 & $(0.02)$ & -0.22 & $(0.03)$ & -0.14 & $(0.04)$ \\
\hline Luxembourg & 0.03 & $(0.03)$ & -0.10 & $(0.03)$ & -0.21 & $(0.03)$ & -0.33 & $(0.03)$ & -0.36 & $(0.04)$ \\
\hline Mexico & 0.30 & $(0.03)$ & 0.30 & $(0.03)$ & 0.22 & $(0.03)$ & 0.22 & $(0.03)$ & -0.08 & $(0.04)$ \\
\hline Netherlands & -0.53 & $(0.03)$ & -0.54 & $(0.03)$ & -0.55 & $(0.03)$ & -0.54 & $(0.02)$ & -0.01 & $(0.04)$ \\
\hline New Zealand & 0.35 & $(0.03)$ & 0.31 & $(0.03)$ & 0.22 & $(0.03)$ & 0.20 & $(0.03)$ & -0.16 & $(0.04)$ \\
\hline Norway & 0.15 & $(0.04)$ & 0.12 & $(0.03)$ & 0.07 & $(0.04)$ & -0.06 & $(0.03)$ & -0.21 & $(0.05)$ \\
\hline Poland & 0.00 & $(0.03)$ & -0.12 & $(0.03)$ & -0.12 & $(0.03)$ & -0.20 & $(0.03)$ & -0.20 & $(0.04)$ \\
\hline Portugal & 0.53 & $(0.03)$ & 0.51 & $(0.02)$ & 0.52 & $(0.03)$ & 0.36 & $(0.03)$ & -0.17 & $(0.04)$ \\
\hline Slovak Republic & -0.14 & $(0.03)$ & -0.14 & $(0.02)$ & -0.18 & $(0.03)$ & -0.20 & $(0.03)$ & -0.06 & $(0.04)$ \\
\hline Slovenia & 0.14 & $(0.03)$ & 0.05 & $(0.03)$ & 0.05 & $(0.03)$ & -0.01 & $(0.03)$ & -0.15 & $(0.04)$ \\
\hline Spain & 0.41 & $(0.03)$ & 0.43 & $(0.03)$ & 0.42 & $(0.02)$ & 0.34 & $(0.02)$ & -0.07 & $(0.03)$ \\
\hline Sweden & 0.23 & $(0.03)$ & 0.08 & $(0.03)$ & 0.01 & $(0.03)$ & -0.12 & $(0.03)$ & -0.35 & $(0.04)$ \\
\hline Switzerland & -0.34 & $(0.03)$ & -0.44 & $(0.03)$ & -0.41 & $(0.03)$ & -0.55 & $(0.04)$ & -0.21 & $(0.05)$ \\
\hline Turkey & 0.30 & $(0.04)$ & 0.34 & $(0.03)$ & 0.32 & $(0.03)$ & 0.27 & $(0.03)$ & -0.03 & $(0.05)$ \\
\hline United Kingdom & 0.32 & $(0.03)$ & 0.28 & $(0.03)$ & 0.26 & $(0.03)$ & 0.16 & $(0.03)$ & -0.15 & $(0.04)$ \\
\hline United States & 0.30 & $(0.03)$ & 0.26 & $(0.03)$ & 0.15 & $(0.03)$ & 0.06 & $(0.04)$ & -0.24 & $(0.05)$ \\
\hline OECD average & 0.07 & $(0.01)$ & 0.04 & $(0.00)$ & 0.00 & $(0.00)$ & -0.08 & $(0.00)$ & -0.15 & $(0.01)$ \\
\hline
\end{tabular}

\begin{tabular}{|c|c|c|c|c|c|c|c|c|c|c|}
\hline Albania & $\mathrm{m}$ & $\mathrm{m}$ & $\mathrm{m}$ & $\mathrm{m}$ & $\mathrm{m}$ & $\mathrm{m}$ & $\mathrm{m}$ & $\mathrm{m}$ & $\mathrm{m}$ & $\mathrm{m}$ \\
\hline Algeria & $\mathrm{m}$ & $\mathrm{m}$ & $\mathrm{m}$ & $\mathrm{m}$ & $\mathrm{m}$ & $\mathrm{m}$ & $\mathrm{m}$ & $\mathrm{m}$ & $\mathrm{m}$ & $\mathrm{m}$ \\
\hline Brazil & 0.65 & $(0.02)$ & 0.58 & $(0.01)$ & 0.60 & $(0.02)$ & 0.57 & $(0.02)$ & -0.08 & $(0.02)$ \\
\hline B-S-J-G (China) & 0.24 & $(0.03)$ & 0.26 & $(0.03)$ & 0.27 & $(0.02)$ & 0.15 & $(0.02)$ & -0.08 & $(0.04)$ \\
\hline Bulgaria & -0.04 & $(0.03)$ & -0.10 & $(0.03)$ & -0.09 & $(0.04)$ & -0.13 & $(0.03)$ & -0.09 & $(0.05)$ \\
\hline CABA (Argentina) & $\mathrm{m}$ & $\mathrm{m}$ & $\mathrm{m}$ & $\mathrm{m}$ & $\mathrm{m}$ & $\mathrm{m}$ & $\mathrm{m}$ & $\mathrm{m}$ & $\mathrm{m}$ & $\mathrm{m}$ \\
\hline Colombia & 0.56 & $(0.03)$ & 0.50 & $(0.02)$ & 0.52 & $(0.02)$ & 0.50 & $(0.02)$ & -0.06 & $(0.03)$ \\
\hline Costa Rica & 0.67 & $(0.02)$ & 0.63 & $(0.03)$ & 0.55 & $(0.03)$ & 0.55 & $(0.03)$ & -0.12 & $(0.04)$ \\
\hline Croatia & 0.03 & $(0.02)$ & 0.00 & $(0.03)$ & -0.03 & $(0.03)$ & 0.01 & $(0.03)$ & -0.02 & $(0.04)$ \\
\hline Cyprus* & 0.08 & $(0.03)$ & -0.09 & $(0.03)$ & -0.10 & $(0.03)$ & -0.20 & $(0.02)$ & -0.28 & $(0.04)$ \\
\hline Dominican Republic & 0.42 & $(0.03)$ & 0.43 & $(0.03)$ & 0.40 & $(0.04)$ & 0.41 & $(0.02)$ & -0.01 & $(0.04)$ \\
\hline FYROM & $\mathrm{m}$ & $\mathrm{m}$ & $\mathrm{m}$ & $\mathrm{m}$ & $\mathrm{m}$ & $\mathrm{m}$ & $\mathrm{m}$ & $\mathrm{m}$ & $\mathrm{m}$ & $\mathrm{m}$ \\
\hline Georgia & $\mathrm{m}$ & $\mathrm{m}$ & $\mathrm{m}$ & $\mathrm{m}$ & $\mathrm{m}$ & $\mathrm{m}$ & $\mathrm{m}$ & $\mathrm{m}$ & $\mathrm{m}$ & $\mathrm{m}$ \\
\hline Hong Kong (China) & 0.30 & $(0.03)$ & 0.34 & $(0.03)$ & 0.37 & $(0.04)$ & 0.30 & $(0.04)$ & 0.00 & $(0.04)$ \\
\hline Indonesia & $\mathrm{m}$ & $\mathrm{m}$ & $\mathrm{m}$ & $\mathrm{m}$ & $\mathrm{m}$ & $\mathrm{m}$ & $\mathrm{m}$ & $\mathrm{m}$ & $\mathrm{m}$ & $\mathrm{m}$ \\
\hline Jordan & $\mathrm{m}$ & $\mathrm{m}$ & $\mathrm{m}$ & $\mathrm{m}$ & $\mathrm{m}$ & $\mathrm{m}$ & $\mathrm{m}$ & $\mathrm{m}$ & $\mathrm{m}$ & $\mathrm{m}$ \\
\hline Kosovo & $\mathrm{m}$ & $\mathrm{m}$ & $\mathrm{m}$ & $\mathrm{m}$ & $\mathrm{m}$ & $\mathrm{m}$ & $\mathrm{m}$ & $\mathrm{m}$ & $\mathrm{m}$ & $\mathrm{m}$ \\
\hline Lebanon & $\mathrm{m}$ & $\mathrm{m}$ & $\mathrm{m}$ & $\mathrm{m}$ & $\mathrm{m}$ & $\mathrm{m}$ & $\mathrm{m}$ & $\mathrm{m}$ & $\mathrm{m}$ & $\mathrm{m}$ \\
\hline Lithuania & -0.10 & $(0.03)$ & -0.02 & $(0.03)$ & -0.07 & $(0.03)$ & -0.09 & $(0.03)$ & 0.01 & $(0.05)$ \\
\hline Macao (China) & 0.43 & $(0.03)$ & 0.39 & $(0.03)$ & 0.39 & $(0.03)$ & 0.26 & $(0.03)$ & -0.17 & $(0.04)$ \\
\hline Malta & $\mathrm{m}$ & $\mathrm{m}$ & $\mathrm{m}$ & $\mathrm{m}$ & $\mathrm{m}$ & $\mathrm{m}$ & $\mathrm{m}$ & $\mathrm{m}$ & $\mathrm{m}$ & $\mathrm{m}$ \\
\hline Moldova & $\mathrm{m}$ & $\mathrm{m}$ & $\mathrm{m}$ & $\mathrm{m}$ & $\mathrm{m}$ & $\mathrm{m}$ & $\mathrm{m}$ & $\mathrm{m}$ & $\mathrm{m}$ & $\mathrm{m}$ \\
\hline Montenegro & 0.17 & $(0.03)$ & 0.15 & $(0.03)$ & 0.05 & $(0.03)$ & 0.00 & $(0.03)$ & -0.17 & $(0.04)$ \\
\hline Peru & 0.12 & $(0.02)$ & 0.17 & $(0.02)$ & 0.17 & $(0.02)$ & 0.09 & $(0.02)$ & -0.03 & $(0.03)$ \\
\hline Qatar & 0.27 & $(0.02)$ & 0.23 & $(0.02)$ & 0.20 & $(0.02)$ & 0.18 & $(0.02)$ & -0.09 & $(0.03)$ \\
\hline Romania & $\mathrm{m}$ & $\mathrm{m}$ & $\mathrm{m}$ & $\mathrm{m}$ & $\mathrm{m}$ & $\mathrm{m}$ & $\mathrm{m}$ & $\mathrm{m}$ & $\mathrm{m}$ & $\mathrm{m}$ \\
\hline Russia & 0.06 & $(0.03)$ & -0.03 & $(0.03)$ & -0.06 & $(0.03)$ & -0.17 & $(0.04)$ & -0.23 & $(0.04)$ \\
\hline Singapore & 0.65 & $(0.03)$ & 0.62 & $(0.03)$ & 0.57 & $(0.03)$ & 0.44 & $(0.03)$ & -0.21 & $(0.03)$ \\
\hline Chinese Taipei & 0.36 & $(0.02)$ & 0.41 & $(0.02)$ & 0.41 & $(0.02)$ & 0.36 & $(0.03)$ & 0.00 & $(0.04)$ \\
\hline Thailand & 0.08 & $(0.03)$ & 0.07 & $(0.03)$ & 0.13 & $(0.03)$ & 0.19 & $(0.03)$ & 0.11 & $(0.03)$ \\
\hline Trinidad and Tobago & $\mathrm{m}$ & $\mathrm{m}$ & $\mathrm{m}$ & $\mathrm{m}$ & $\mathrm{m}$ & $\mathrm{m}$ & $\mathrm{m}$ & $\mathrm{m}$ & $\mathrm{m}$ & $\mathrm{m}$ \\
\hline Tunisia & 0.21 & $(0.03)$ & 0.17 & $(0.03)$ & 0.08 & $(0.03)$ & -0.08 & $(0.04)$ & -0.29 & $(0.05)$ \\
\hline United Arab Emirates & 0.23 & $(0.02)$ & 0.18 & $(0.02)$ & 0.21 & $(0.02)$ & 0.18 & $(0.02)$ & -0.06 & $(0.03)$ \\
\hline Uruguay & 0.57 & $(0.03)$ & 0.49 & $(0.03)$ & 0.42 & $(0.03)$ & 0.38 & $(0.03)$ & -0.20 & $(0.04)$ \\
\hline Viet Nam & $\mathrm{m}$ & $\mathrm{m}$ & $\mathrm{m}$ & $\mathrm{m}$ & $\mathrm{m}$ & $\mathrm{m}$ & $\mathrm{m}$ & $\mathrm{m}$ & $\mathrm{m}$ & $\mathrm{m}$ \\
\hline Argentina** & $\mathrm{m}$ & $\mathrm{m}$ & $\mathrm{m}$ & $\mathrm{m}$ & $\mathrm{m}$ & $\mathrm{m}$ & $\mathrm{m}$ & $\mathrm{m}$ & $\mathrm{m}$ & $\mathrm{m}$ \\
\hline Kazakhstan** & $\mathrm{m}$ & $\mathrm{m}$ & $\mathrm{m}$ & $\mathrm{m}$ & $\mathrm{m}$ & $\mathrm{m}$ & $\mathrm{m}$ & $\mathrm{m}$ & $\mathrm{m}$ & $\mathrm{m}$ \\
\hline Malaysia** & 0.29 & $(0.02)$ & 0.35 & $(0.02)$ & 0.38 & $(0.02)$ & 0.40 & $(0.02)$ & 0.11 & $(0.03)$ \\
\hline
\end{tabular}

1. ESCS refers to the PISA index of economic, social and cultural status.

Note: Values that are statistically significant are indicated in bold (see Annex A3).

* See note at the beginning of this Annex.

* Coverage is too small to ensure comparability (see Annex A4).

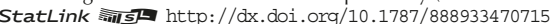


[Part 3/3]

Table III.4.5 Index of schoolwork-related anxiety, by student characteristics

Results based on students' self-reports

\begin{tabular}{|c|c|c|c|c|c|c|c|c|c|c|c|c|c|c|}
\hline & \multicolumn{14}{|c|}{ Index of schoolwork-related anxiety, by: } \\
\hline & \multicolumn{6}{|c|}{ Gender } & \multicolumn{8}{|c|}{ Immigrant background } \\
\hline & \multicolumn{2}{|c|}{ Boys } & \multicolumn{2}{|c|}{ Girls } & \multicolumn{2}{|c|}{$\begin{array}{c}\text { Gender difference } \\
\qquad(B-G)\end{array}$} & \multicolumn{2}{|c|}{ Non-immigrant } & \multicolumn{2}{|c|}{ First-generation } & \multicolumn{2}{|c|}{ Second-generation } & \multicolumn{2}{|c|}{$\begin{array}{c}\text { Difference } \\
\text { by immigrant } \\
\text { background } \\
\text { (non-immigrant - } \\
\text { first-generation) }\end{array}$} \\
\hline & $\begin{array}{l}\text { Mean } \\
\text { index }\end{array}$ & S.E. & $\begin{array}{l}\text { Mean } \\
\text { index }\end{array}$ & S.E. & Dif. & S.E. & $\begin{array}{l}\text { Mean } \\
\text { index }\end{array}$ & S.E. & $\begin{array}{l}\text { Mean } \\
\text { index }\end{array}$ & S.E. & $\begin{array}{l}\text { Mean } \\
\text { index }\end{array}$ & S.E. & Dif. & S.E. \\
\hline Australia & -0.07 & $(0.02)$ & 0.45 & $(0.02)$ & -0.52 & $(0.02)$ & 0.16 & $(0.01)$ & 0.25 & $(0.03)$ & 0.32 & $(0.03)$ & -0.09 & $(0.03)$ \\
\hline Austria & -0.27 & $(0.02)$ & 0.06 & $(0.02)$ & -0.33 & $(0.03)$ & -0.17 & $(0.02)$ & 0.12 & $(0.06)$ & 0.14 & $(0.03)$ & -0.28 & $(0.06)$ \\
\hline Belgium & -0.40 & $(0.02)$ & 0.08 & $(0.02)$ & -0.48 & $(0.02)$ & -0.17 & $(0.01)$ & -0.10 & $(0.05)$ & -0.16 & $(0.04)$ & -0.06 & $(0.05)$ \\
\hline Canada & -0.12 & $(0.02)$ & 0.45 & $(0.02)$ & -0.57 & $(0.03)$ & 0.13 & $(0.01)$ & 0.20 & $(0.03)$ & 0.28 & $(0.03)$ & -0.06 & $(0.03)$ \\
\hline Chile & -0.04 & $(0.02)$ & 0.24 & $(0.02)$ & -0.28 & $(0.03)$ & 0.10 & $(0.02)$ & -0.03 & $(0.08)$ & -0.26 & $(0.11)$ & 0.12 & $(0.08)$ \\
\hline Czech Republic & -0.38 & $(0.02)$ & -0.02 & $(0.02)$ & -0.36 & $(0.02)$ & -0.20 & $(0.02)$ & -0.35 & $(0.16)$ & -0.15 & $(0.10)$ & 0.15 & $(0.15)$ \\
\hline Denmark & -0.22 & $(0.02)$ & 0.39 & $(0.02)$ & -0.60 & $(0.03)$ & 0.08 & $(0.01)$ & 0.15 & $(0.10)$ & 0.20 & $(0.03)$ & -0.08 & $(0.10)$ \\
\hline Estonia & -0.44 & $(0.02)$ & 0.01 & $(0.02)$ & -0.46 & $(0.03)$ & -0.22 & $(0.01)$ & -0.03 & $(0.25)$ & -0.17 & $(0.05)$ & -0.19 & $(0.25)$ \\
\hline Finland & -0.58 & $(0.02)$ & -0.23 & $(0.02)$ & -0.35 & $(0.02)$ & -0.42 & $(0.01)$ & -0.07 & $(0.09)$ & -0.12 & $(0.08)$ & -0.36 & $(0.09)$ \\
\hline France & -0.34 & $(0.02)$ & 0.14 & $(0.02)$ & -0.48 & $(0.03)$ & -0.12 & $(0.02)$ & 0.06 & $(0.06)$ & -0.01 & $(0.06)$ & -0.17 & $(0.06)$ \\
\hline Germany & -0.53 & $(0.02)$ & -0.14 & (0.02) & -0.39 & $(0.02)$ & -0.35 & $(0.01)$ & -0.14 & $(0.08)$ & -0.23 & $(0.03)$ & -0.21 & (0.08) \\
\hline Greece & -0.24 & $(0.02)$ & 0.07 & $(0.02)$ & -0.30 & $(0.02)$ & -0.11 & $(0.01)$ & -0.11 & $(0.10)$ & 0.09 & $(0.07)$ & 0.01 & $(0.10)$ \\
\hline Hungary & -0.28 & $(0.02)$ & 0.08 & $(0.02)$ & -0.36 & $(0.03)$ & -0.10 & $(0.02)$ & -0.15 & $(0.21)$ & -0.09 & $(0.09)$ & 0.05 & $(0.22)$ \\
\hline Iceland & -0.49 & $(0.03)$ & 0.23 & (0.03) & -0.71 & $(0.04)$ & -0.13 & $(0.02)$ & 0.01 & $(0.11)$ & 0.25 & $(0.21)$ & -0.14 & $(0.10)$ \\
\hline Ireland & -0.05 & $(0.02)$ & 0.35 & (0.02) & -0.41 & $(0.03)$ & 0.13 & $(0.02)$ & 0.19 & $(0.04)$ & 0.25 & $(0.07)$ & -0.06 & $(0.04)$ \\
\hline Israel & -0.47 & $(0.02)$ & -0.07 & $(0.02)$ & -0.40 & $(0.02)$ & -0.28 & $(0.02)$ & -0.34 & $(0.09)$ & -0.17 & $(0.05)$ & 0.06 & $(0.09)$ \\
\hline Italy & 0.22 & $(0.02)$ & 0.69 & $(0.02)$ & -0.47 & $(0.02)$ & 0.45 & $(0.01)$ & 0.44 & $(0.09)$ & 0.60 & $(0.07)$ & 0.01 & $(0.09)$ \\
\hline Japan & 0.16 & $(0.02)$ & 0.37 & $(0.02)$ & -0.21 & $(0.03)$ & 0.26 & $(0.01)$ & C & $\mathrm{C}$ & C & $\mathrm{C}$ & C & $\mathrm{C}$ \\
\hline Korea & 0.00 & $(0.02)$ & 0.22 & $(0.02)$ & -0.22 & $(0.03)$ & 0.10 & $(0.01)$ & c & c & $\mathrm{m}$ & $\mathrm{m}$ & C & c \\
\hline Latvia & -0.30 & $(0.02)$ & 0.03 & $(0.02)$ & -0.33 & $(0.03)$ & -0.14 & $(0.01)$ & -0.17 & $(0.17)$ & -0.11 & (0.08) & 0.03 & $(0.17)$ \\
\hline Luxembourg & -0.41 & $(0.02)$ & 0.10 & $(0.02)$ & -0.51 & $(0.03)$ & -0.26 & $(0.02)$ & -0.09 & $(0.03)$ & -0.03 & $(0.02)$ & -0.18 & $(0.04)$ \\
\hline Mexico & 0.10 & $(0.02)$ & 0.42 & $(0.02)$ & -0.32 & $(0.02)$ & 0.25 & $(0.02)$ & 0.35 & $(0.08)$ & C & c & -0.10 & $(0.08)$ \\
\hline Netherlands & -0.72 & $(0.02)$ & -0.36 & $(0.02)$ & -0.36 & $(0.02)$ & -0.56 & $(0.02)$ & -0.29 & $(0.10)$ & -0.37 & $(0.04)$ & -0.28 & $(0.10)$ \\
\hline New Zealand & 0.05 & $(0.02)$ & 0.49 & $(0.02)$ & -0.44 & $(0.03)$ & 0.26 & $(0.02)$ & 0.26 & $(0.04)$ & 0.35 & $(0.04)$ & 0.00 & $(0.05)$ \\
\hline Norway & -0.30 & $(0.02)$ & 0.44 & $(0.02)$ & -0.74 & $(0.03)$ & 0.04 & $(0.02)$ & 0.25 & $(0.07)$ & 0.30 & $(0.05)$ & -0.21 & $(0.07)$ \\
\hline Poland & -0.31 & $(0.02)$ & 0.09 & $(0.02)$ & -0.40 & $(0.03)$ & -0.11 & $(0.02)$ & C & C & C & C & c & c \\
\hline Portugal & 0.20 & $(0.02)$ & 0.76 & $(0.02)$ & -0.56 & $(0.03)$ & 0.48 & $(0.01)$ & 0.45 & $(0.07)$ & 0.32 & $(0.07)$ & 0.03 & $(0.07)$ \\
\hline Slovak Republic & -0.34 & $(0.02)$ & 0.01 & $(0.02)$ & -0.35 & $(0.03)$ & -0.16 & $(0.02)$ & -0.64 & $(0.28)$ & -0.41 & $(0.23)$ & 0.48 & $(0.28)$ \\
\hline Slovenia & -0.18 & $(0.02)$ & 0.32 & $(0.02)$ & -0.50 & $(0.02)$ & 0.05 & $(0.01)$ & 0.25 & $(0.07)$ & 0.16 & $(0.07)$ & -0.20 & $(0.07)$ \\
\hline Spain & 0.19 & $(0.02)$ & 0.60 & $(0.02)$ & -0.41 & $(0.02)$ & 0.38 & $(0.01)$ & 0.51 & $(0.04)$ & 0.56 & $(0.08)$ & -0.12 & $(0.04)$ \\
\hline Sweden & -0.27 & $(0.02)$ & 0.36 & $(0.03)$ & -0.63 & $(0.04)$ & 0.00 & $(0.02)$ & 0.23 & $(0.05)$ & 0.27 & $(0.04)$ & -0.23 & $(0.06)$ \\
\hline Switzerland & -0.64 & $(0.02)$ & -0.22 & $(0.02)$ & -0.42 & $(0.03)$ & -0.52 & $(0.02)$ & -0.26 & $(0.04)$ & -0.25 & $(0.03)$ & -0.26 & $(0.05)$ \\
\hline Turkey & 0.09 & $(0.03)$ & 0.52 & $(0.02)$ & -0.43 & $(0.03)$ & 0.32 & $(0.02)$ & c & c & 0.15 & $(0.30)$ & c & \\
\hline United Kingdom & -0.03 & $(0.02)$ & 0.53 & $(0.02)$ & -0.56 & $(0.02)$ & 0.26 & $(0.02)$ & 0.27 & $(0.05)$ & 0.27 & $(0.04)$ & -0.01 & $(0.05)$ \\
\hline United States & -0.08 & $(0.02)$ & 0.46 & $(0.02)$ & -0.53 & $(0.03)$ & 0.15 & $(0.02)$ & 0.35 & $(0.05)$ & 0.35 & $(0.03)$ & -0.21 & $(0.06)$ \\
\hline OECD average & -0.21 & $(0.00)$ & 0.23 & $(0.00)$ & -0.44 & $(0.00)$ & -0.01 & $(0.00)$ & 0.05 & $(0.02)$ & 0.07 & $(0.02)$ & -0.08 & $(0.02)$ \\
\hline
\end{tabular}

\begin{tabular}{|c|c|c|c|c|c|c|c|c|c|c|c|c|c|c|}
\hline Albania & $\mathrm{m}$ & $\mathrm{m}$ & $\mathrm{m}$ & $\mathrm{m}$ & $\mathrm{m}$ & $\mathrm{m}$ & $\mathrm{m}$ & $\mathrm{m}$ & $\mathrm{m}$ & $\mathrm{m}$ & $\mathrm{m}$ & $\mathrm{m}$ & $\mathrm{m}$ & $\mathrm{m}$ \\
\hline Algeria & $\mathrm{m}$ & $\mathrm{m}$ & $\mathrm{m}$ & $\mathrm{m}$ & $\mathrm{m}$ & $\mathrm{m}$ & $\mathrm{m}$ & $\mathrm{m}$ & $\mathrm{m}$ & $\mathrm{m}$ & $\mathrm{m}$ & $\mathrm{m}$ & $\mathrm{m}$ & $\mathrm{m}$ \\
\hline Brazil & 0.42 & $(0.01)$ & 0.76 & $(0.01)$ & -0.34 & $(0.02)$ & 0.60 & $(0.01)$ & -0.08 & $(0.19)$ & 0.47 & $(0.14)$ & 0.69 & $(0.19)$ \\
\hline B-S-J-G (China) & 0.17 & $(0.02)$ & 0.30 & $(0.02)$ & -0.13 & $(0.03)$ & 0.23 & $(0.01)$ & $\mathrm{m}$ & $\mathrm{m}$ & $\mathrm{m}$ & $\mathrm{m}$ & $\mathrm{m}$ & $\mathrm{m}$ \\
\hline Bulgaria & -0.27 & $(0.02)$ & 0.11 & $(0.02)$ & -0.39 & $(0.03)$ & -0.09 & $(0.02)$ & $\mathrm{m}$ & $\mathrm{m}$ & $\mathrm{m}$ & $\mathrm{m}$ & $\mathrm{m}$ & $\mathrm{m}$ \\
\hline CABA (Argentina) & $\mathrm{m}$ & $\mathrm{m}$ & $\mathrm{m}$ & $\mathrm{m}$ & $\mathrm{m}$ & $\mathrm{m}$ & $\mathrm{m}$ & $\mathrm{m}$ & $\mathrm{m}$ & $\mathrm{m}$ & $\mathrm{m}$ & $\mathrm{m}$ & $\mathrm{m}$ & $\mathrm{m}$ \\
\hline Colombia & 0.39 & $(0.02)$ & 0.64 & $(0.02)$ & -0.25 & $(0.02)$ & 0.52 & $(0.01)$ & c & c & 0.69 & $(0.20)$ & c & c \\
\hline Costa Rica & 0.42 & $(0.02)$ & 0.77 & $(0.02)$ & -0.34 & $(0.03)$ & 0.60 & $(0.01)$ & 0.47 & $(0.07)$ & 0.62 & $(0.05)$ & 0.14 & $(0.08)$ \\
\hline Croatia & -0.22 & $(0.02)$ & 0.21 & $(0.02)$ & -0.43 & $(0.03)$ & 0.00 & $(0.02)$ & 0.11 & $(0.11)$ & 0.01 & $(0.05)$ & -0.11 & $(0.11)$ \\
\hline Cyprus* & -0.19 & $(0.02)$ & 0.03 & $(0.02)$ & -0.22 & $(0.03)$ & -0.09 & $(0.01)$ & 0.05 & $(0.05)$ & 0.02 & $(0.07)$ & -0.14 & $(0.05)$ \\
\hline Dominican Republic & 0.32 & $(0.02)$ & 0.50 & $(0.02)$ & -0.18 & $(0.03)$ & 0.42 & $(0.02)$ & 0.14 & $(0.21)$ & 0.31 & $(0.10)$ & 0.28 & $(0.21)$ \\
\hline FYROM & $\mathrm{m}$ & $\mathrm{m}$ & $\mathrm{m}$ & $\mathrm{m}$ & $\mathrm{m}$ & $\mathrm{m}$ & $\mathrm{m}$ & $\mathrm{m}$ & $\mathrm{m}$ & $\mathrm{m}$ & $\mathrm{m}$ & $\mathrm{m}$ & $\mathrm{m}$ & $\mathrm{m}$ \\
\hline Georgia & $\mathrm{m}$ & $\mathrm{m}$ & $\mathrm{m}$ & $\mathrm{m}$ & $\mathrm{m}$ & $\mathrm{m}$ & $\mathrm{m}$ & $\mathrm{m}$ & $\mathrm{m}$ & $\mathrm{m}$ & $\mathrm{m}$ & $\mathrm{m}$ & $\mathrm{m}$ & $\mathrm{m}$ \\
\hline Hong Kong (China) & 0.18 & $(0.02)$ & 0.48 & $(0.02)$ & -0.30 & $(0.03)$ & 0.33 & $(0.02)$ & 0.18 & $(0.04)$ & 0.42 & $(0.03)$ & 0.15 & $(0.04)$ \\
\hline Indonesia & $\mathrm{m}$ & $\mathrm{m}$ & $\mathrm{m}$ & $\mathrm{m}$ & $\mathrm{m}$ & $\mathrm{m}$ & $\mathrm{m}$ & $\mathrm{m}$ & $\mathrm{m}$ & $\mathrm{m}$ & $\mathrm{m}$ & $\mathrm{m}$ & $\mathrm{m}$ & $\mathrm{m}$ \\
\hline Jordan & $\mathrm{m}$ & $\mathrm{m}$ & $\mathrm{m}$ & $\mathrm{m}$ & $\mathrm{m}$ & $\mathrm{m}$ & $\mathrm{m}$ & $\mathrm{m}$ & $\mathrm{m}$ & $\mathrm{m}$ & $\mathrm{m}$ & $\mathrm{m}$ & $\mathrm{m}$ & $\mathrm{m}$ \\
\hline Kosovo & $\mathrm{m}$ & $\mathrm{m}$ & $\mathrm{m}$ & $\mathrm{m}$ & $\mathrm{m}$ & $\mathrm{m}$ & $\mathrm{m}$ & $\mathrm{m}$ & $\mathrm{m}$ & $\mathrm{m}$ & $\mathrm{m}$ & $\mathrm{m}$ & $\mathrm{m}$ & $\mathrm{m}$ \\
\hline Lebanon & $\mathrm{m}$ & $\mathrm{m}$ & $\mathrm{m}$ & $\mathrm{m}$ & $\mathrm{m}$ & $\mathrm{m}$ & $\mathrm{m}$ & $\mathrm{m}$ & $\mathrm{m}$ & $\mathrm{m}$ & $\mathrm{m}$ & $\mathrm{m}$ & $\mathrm{m}$ & $\mathrm{m}$ \\
\hline Lithuania & -0.36 & $(0.02)$ & 0.23 & $(0.02)$ & -0.59 & $(0.03)$ & -0.06 & $(0.01)$ & -0.29 & $(0.40)$ & -0.08 & $(0.09)$ & 0.22 & $(0.40)$ \\
\hline Macao (China) & 0.24 & $(0.02)$ & 0.49 & $(0.02)$ & -0.25 & $(0.03)$ & 0.39 & $(0.02)$ & 0.28 & $(0.03)$ & 0.39 & $(0.02)$ & 0.11 & $(0.05)$ \\
\hline Malta & $\mathrm{m}$ & $\mathrm{m}$ & $\mathrm{m}$ & $\mathrm{m}$ & $\mathrm{m}$ & $\mathrm{m}$ & $\mathrm{m}$ & $\mathrm{m}$ & $\mathrm{m}$ & $\mathrm{m}$ & $\mathrm{m}$ & $\mathrm{m}$ & $\mathrm{m}$ & $\mathrm{m}$ \\
\hline Moldova & $\mathrm{m}$ & $\mathrm{m}$ & $\mathrm{m}$ & $\mathrm{m}$ & $\mathrm{m}$ & $\mathrm{m}$ & $\mathrm{m}$ & $\mathrm{m}$ & $\mathrm{m}$ & $\mathrm{m}$ & $\mathrm{m}$ & $\mathrm{m}$ & $\mathrm{m}$ & $\mathrm{m}$ \\
\hline Montenegro & -0.15 & $(0.02)$ & 0.34 & $(0.02)$ & -0.48 & $(0.03)$ & 0.10 & $(0.01)$ & -0.19 & $(0.13)$ & 0.17 & $(0.07)$ & 0.29 & $(0.13)$ \\
\hline Peru & 0.07 & $(0.01)$ & 0.20 & $(0.01)$ & -0.14 & $(0.02)$ & 0.14 & $(0.01)$ & c & c & C & c & C & c \\
\hline Qatar & 0.08 & $(0.01)$ & 0.35 & $(0.01)$ & -0.27 & $(0.02)$ & 0.30 & $(0.02)$ & 0.15 & $(0.01)$ & 0.19 & $(0.02)$ & 0.14 & $(0.02)$ \\
\hline Romania & $\mathrm{m}$ & $\mathrm{m}$ & $\mathrm{m}$ & $\mathrm{m}$ & $\mathrm{m}$ & $\mathrm{m}$ & $\mathrm{m}$ & $\mathrm{m}$ & $\mathrm{m}$ & $\mathrm{m}$ & $\mathrm{m}$ & $\mathrm{m}$ & $\mathrm{m}$ & $\mathrm{m}$ \\
\hline Russia & -0.25 & $(0.02)$ & 0.14 & $(0.02)$ & -0.38 & $(0.03)$ & -0.06 & $(0.02)$ & 0.06 & $(0.09)$ & 0.06 & $(0.07)$ & -0.12 & $(0.09)$ \\
\hline Singapore & 0.44 & $(0.02)$ & 0.71 & $(0.02)$ & -0.27 & $(0.03)$ & 0.63 & $(0.01)$ & 0.31 & $(0.05)$ & 0.39 & $(0.04)$ & 0.32 & $(0.05)$ \\
\hline Chinese Taipei & 0.28 & $(0.02)$ & 0.49 & $(0.01)$ & -0.21 & $(0.03)$ & 0.39 & $(0.01)$ & c & c & C & C & c & C \\
\hline Thailand & 0.02 & $(0.02)$ & 0.19 & $(0.02)$ & -0.17 & $(0.03)$ & 0.12 & $(0.02)$ & C & c & 0.09 & $(0.06)$ & c & c \\
\hline Trinidad and Tobago & $\mathrm{m}$ & $\mathrm{m}$ & $\mathrm{m}$ & $\mathrm{m}$ & $\mathrm{m}$ & $\mathrm{m}$ & $\mathrm{m}$ & $\mathrm{m}$ & $\mathrm{m}$ & $\mathrm{m}$ & $\mathrm{m}$ & $\mathrm{m}$ & $\mathrm{m}$ & $\mathrm{m}$ \\
\hline Tunisia & -0.07 & $(0.03)$ & 0.23 & $(0.02)$ & -0.30 & $(0.03)$ & 0.10 & $(0.02)$ & c & c & -0.11 & $(0.11)$ & c & C \\
\hline United Arab Emirates & 0.08 & $(0.02)$ & 0.32 & $(0.02)$ & -0.24 & $(0.02)$ & 0.25 & $(0.02)$ & 0.15 & $(0.02)$ & 0.20 & $(0.02)$ & 0.11 & $(0.02)$ \\
\hline Uruguay & 0.30 & $(0.02)$ & 0.61 & $(0.02)$ & -0.31 & $(0.02)$ & 0.46 & $(0.01)$ & $\mathrm{C}$ & $\mathrm{C}$ & C & $\mathrm{C}$ & $\mathrm{C}$ & C \\
\hline Viet Nam & $\mathrm{m}$ & $\mathrm{m}$ & $\mathrm{m}$ & $\mathrm{m}$ & $\mathrm{m}$ & $\mathrm{m}$ & $\mathrm{m}$ & $\mathrm{m}$ & $\mathrm{m}$ & $\mathrm{m}$ & $\mathrm{m}$ & $\mathrm{m}$ & $\mathrm{m}$ & $\mathrm{m}$ \\
\hline Argentina** $^{* *}$ & $\mathrm{~m}$ & $\mathrm{~m}$ & $\mathrm{~m}$ & $\mathrm{~m}$ & $\mathrm{~m}$ & $\mathrm{~m}$ & $\mathrm{~m}$ & $\mathrm{~m}$ & $\mathrm{~m}$ & $\mathrm{~m}$ & $\mathrm{~m}$ & $\mathrm{~m}$ & $\mathrm{~m}$ & $\mathrm{~m}$ \\
\hline Kazakhstan** & $\mathrm{m}$ & $\mathrm{m}$ & $\mathrm{m}$ & $\mathrm{m}$ & $\mathrm{m}$ & $\mathrm{m}$ & $\mathrm{m}$ & $\mathrm{m}$ & $\mathrm{m}$ & $\mathrm{m}$ & $\mathrm{m}$ & $\mathrm{m}$ & $\mathrm{m}$ & $\mathrm{m}$ \\
\hline Malaysia** & 0.25 & $(0.01)$ & 0.45 & $(0.02)$ & -0.21 & $(0.02)$ & 0.36 & $(0.01)$ & c & c & 0.32 & $(0.09)$ & c & c \\
\hline
\end{tabular}

1. ESCS refers to the PISA index of economic, social and cultural status.

Note: Values that are statistically significant are indicated in bold (see Annex A3).

* See note at the beginning of this Annex.

* Coverage is too small to ensure comparability (see Annex A4).

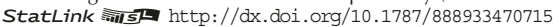


[Part 1/1]

Table III.4.8a Index of schoolwork-related anxiety, by schools' performance in science

Results based on students' self-reports

\begin{tabular}{|c|c|c|c|c|c|c|c|c|c|c|c|c|c|}
\hline & \multicolumn{8}{|c|}{$\begin{array}{l}\text { Average index of schoolwork-related anxiety, } \\
\text { by schools's science performance }\end{array}$} & \multicolumn{4}{|c|}{$\begin{array}{l}\text { Difference between schools } \\
\text { in the top 10th percentile } \\
\text { of science performance and all other schools }\end{array}$} \\
\hline & & \multicolumn{2}{|c|}{$\begin{array}{l}\text { Schools in the bottom } \\
10 \text { th percentile } \\
\text { of science } \\
\text { performance }\end{array}$} & $\begin{array}{r}\text { Schools } \\
25 \text { th } \\
\text { of } \\
\text { perf }\end{array}$ & $\begin{array}{l}\text { e bottom } \\
\text { entile } \\
\text { nce } \\
\text { ance }\end{array}$ & $\begin{array}{r}\text { School } \\
25 \text { th } \\
\text { of } \\
\text { perf }\end{array}$ & $\begin{array}{l}\text { the top } \\
\text { entile } \\
\text { nce } \\
\text { ance }\end{array}$ & $\begin{array}{r}\text { School } \\
10 \text { th } \\
\text { of } \\
\text { perf }\end{array}$ & $\begin{array}{l}\text { the top } \\
\text { entile } \\
\text { ice } \\
\text { ance }\end{array}$ & $\begin{array}{c}\text { Before } \\
\text { for } \\
\text { perf } \\
\text { in }\end{array}$ & $\begin{array}{l}\text { unting } \\
\text { ents' } \\
\text { ance } \\
\text { ice }\end{array}$ & $\begin{array}{l}\text { After } \\
\text { for } \\
\text { perf } \\
\text { in }\end{array}$ & $\begin{array}{l}\text { unting } \\
\text { ents' } \\
\text { ance } \\
\text { ice }\end{array}$ \\
\hline & & Mean & S.E. & Mean & S.E. & Mean & S.E. & Mean & S.E. & Dif. & S.E. & Dif. & S.E. \\
\hline 0 & Australia & 0.23 & $(0.04)$ & 0.23 & $(0.02)$ & 0.17 & $(0.02)$ & 0.20 & $(0.04)$ & 0.01 & $(0.05)$ & 0.14 & $(0.05)$ \\
\hline 议 & Austria & 0.14 & $(0.12)$ & 0.07 & $(0.06)$ & -0.21 & $(0.02)$ & -0.28 & $(0.03)$ & -0.20 & $(0.04)$ & 0.09 & $(0.04)$ \\
\hline 0 & Belgium & -0.12 & $(0.14)$ & -0.03 & $(0.04)$ & -0.21 & $(0.02)$ & -0.26 & $(0.04)$ & -0.11 & $(0.04)$ & 0.04 & $(0.05)$ \\
\hline & Canada & 0.15 & $(0.05)$ & 0.18 & $(0.03)$ & 0.16 & $(0.03)$ & 0.19 & $(0.05)$ & 0.03 & $(0.05)$ & 0.18 & $(0.06)$ \\
\hline & Chile & c & c & 0.17 & $(0.07)$ & 0.02 & $(0.03)$ & -0.06 & $(0.04)$ & -0.18 & $(0.04)$ & 0.08 & $(0.04)$ \\
\hline & Czech Republic & -0.31 & $(0.08)$ & -0.25 & $(0.04)$ & -0.22 & $(0.02)$ & -0.26 & $(0.03)$ & -0.06 & $(0.03)$ & 0.14 & $(0.04)$ \\
\hline & Denmark & 0.12 & $(0.05)$ & 0.13 & $(0.03)$ & 0.05 & $(0.03)$ & 0.07 & $(0.05)$ & -0.02 & $(0.05)$ & 0.14 & $(0.05)$ \\
\hline & Estonia & -0.28 & $(0.07)$ & -0.21 & $(0.04)$ & -0.25 & $(0.03)$ & -0.26 & $(0.05)$ & -0.04 & $(0.05)$ & 0.14 & $(0.05)$ \\
\hline & Finland & -0.38 & $(0.06)$ & -0.39 & $(0.03)$ & -0.45 & $(0.03)$ & -0.41 & $(0.06)$ & 0.00 & $(0.06)$ & 0.16 & $(0.07)$ \\
\hline & France & -0.07 & $(0.09)$ & -0.12 & $(0.04)$ & -0.08 & $(0.03)$ & -0.09 & $(0.05)$ & 0.01 & $(0.05)$ & 0.12 & $(0.05)$ \\
\hline & Germany & -0.22 & $(0.11)$ & -0.26 & $(0.04)$ & -0.39 & $(0.02)$ & -0.43 & $(0.04)$ & -0.11 & $(0.05)$ & 0.11 & $(0.05)$ \\
\hline & Greece & 0.07 & $(0.13)$ & -0.12 & $(0.06)$ & -0.10 & $(0.02)$ & -0.12 & $(0.03)$ & -0.03 & $(0.04)$ & 0.09 & $(0.04)$ \\
\hline & Hungary & 0.00 & $(0.19)$ & 0.01 & $(0.07)$ & -0.13 & $(0.02)$ & -0.15 & $(0.04)$ & -0.06 & $(0.04)$ & 0.13 & $(0.05)$ \\
\hline & Iceland & 0.03 & $(0.10)$ & -0.08 & $(0.05)$ & -0.16 & $(0.06)$ & -0.26 & $(0.10)$ & -0.15 & $(0.10)$ & 0.07 & $(0.10)$ \\
\hline & Ireland & 0.20 & $(0.07)$ & 0.21 & $(0.04)$ & 0.04 & $(0.03)$ & -0.03 & $(0.05)$ & -0.19 & $(0.05)$ & -0.08 & $(0.05)$ \\
\hline & Israel & -0.47 & $(0.09)$ & -0.31 & $(0.05)$ & -0.28 & $(0.03)$ & -0.30 & $(0.06)$ & -0.03 & $(0.06)$ & 0.06 & $(0.06)$ \\
\hline & Italy & 0.43 & $(0.09)$ & 0.41 & $(0.04)$ & 0.48 & $(0.02)$ & 0.42 & $(0.02)$ & -0.04 & $(0.03)$ & 0.05 & $(0.04)$ \\
\hline & Japan & 0.08 & $(0.06)$ & 0.12 & $(0.03)$ & 0.36 & $(0.03)$ & 0.30 & $(0.05)$ & 0.04 & $(0.05)$ & 0.02 & $(0.06)$ \\
\hline & Korea & -0.20 & $(0.06)$ & -0.09 & $(0.04)$ & 0.19 & $(0.04)$ & 0.18 & $(0.06)$ & 0.08 & $(0.06)$ & 0.06 & $(0.06)$ \\
\hline & Latvia & -0.13 & $(0.10)$ & -0.15 & $(0.05)$ & -0.17 & $(0.03)$ & -0.19 & $(0.04)$ & -0.06 & $(0.05)$ & 0.07 & $(0.05)$ \\
\hline & Luxembourg & 0.01 & $(0.06)$ & -0.05 & $(0.03)$ & -0.27 & $(0.03)$ & -0.17 & $(0.05)$ & -0.01 & $(0.05)$ & 0.27 & $(0.05)$ \\
\hline & Mexico & 0.22 & $(0.10)$ & 0.24 & $(0.05)$ & 0.19 & $(0.03)$ & 0.15 & $(0.04)$ & -0.12 & $(0.04)$ & 0.04 & $(0.05)$ \\
\hline & Netherlands & -0.61 & $(0.05)$ & -0.58 & $(0.03)$ & -0.49 & $(0.03)$ & -0.53 & $(0.06)$ & 0.01 & $(0.06)$ & 0.03 & $(0.07)$ \\
\hline & New Zealand & 0.37 & $(0.07)$ & 0.37 & $(0.04)$ & 0.19 & $(0.03)$ & 0.14 & $(0.05)$ & -0.15 & $(0.05)$ & 0.00 & $(0.06)$ \\
\hline & Norway & 0.06 & $(0.06)$ & 0.08 & $(0.04)$ & 0.03 & $(0.04)$ & 0.06 & $(0.06)$ & -0.01 & $(0.07)$ & 0.12 & $(0.06)$ \\
\hline & Poland & -0.07 & $(0.06)$ & -0.08 & $(0.03)$ & -0.17 & $(0.05)$ & -0.16 & $(0.08)$ & -0.06 & $(0.09)$ & 0.16 & (0.09) \\
\hline & Portugal & 0.55 & $(0.06)$ & 0.50 & $(0.03)$ & 0.42 & $(0.03)$ & 0.40 & $(0.05)$ & -0.09 & $(0.05)$ & 0.01 & $(0.05)$ \\
\hline & Slovak Republic & -0.24 & $(0.09)$ & -0.23 & $(0.04)$ & -0.11 & $(0.02)$ & -0.10 & $(0.03)$ & 0.08 & $(0.03)$ & 0.21 & $(0.04)$ \\
\hline & Slovenia & 0.14 & $(0.10)$ & 0.03 & $(0.04)$ & 0.07 & $(0.02)$ & 0.05 & $(0.04)$ & -0.01 & $(0.04)$ & 0.17 & $(0.05)$ \\
\hline & Spain & 0.44 & $(0.05)$ & 0.46 & $(0.03)$ & 0.31 & $(0.02)$ & 0.30 & $(0.04)$ & -0.11 & $(0.04)$ & -0.02 & $(0.04)$ \\
\hline & Sweden & 0.17 & $(0.08)$ & 0.07 & $(0.04)$ & 0.04 & $(0.03)$ & 0.10 & $(0.09)$ & 0.06 & $(0.09)$ & 0.29 & $(0.10)$ \\
\hline & Switzerland & -0.54 & $(0.05)$ & -0.51 & $(0.04)$ & -0.46 & $(0.04)$ & -0.57 & $(0.07)$ & -0.15 & $(0.07)$ & 0.04 & $(0.09)$ \\
\hline & Turkey & -0.02 & $(0.24)$ & 0.17 & $(0.08)$ & 0.31 & $(0.02)$ & 0.26 & $(0.04)$ & -0.06 & $(0.05)$ & 0.03 & $(0.06)$ \\
\hline & United Kingdom & 0.25 & $(0.06)$ & 0.29 & $(0.04)$ & 0.22 & $(0.03)$ & 0.22 & $(0.06)$ & -0.03 & $(0.06)$ & 0.10 & $(0.06)$ \\
\hline & United States & 0.18 & $(0.08)$ & 0.23 & $(0.03)$ & 0.15 & $(0.05)$ & 0.19 & $(0.07)$ & -0.01 & $(0.08)$ & 0.14 & $(0.08)$ \\
\hline & OECD average & 0.00 & $(0.02)$ & 0.02 & $(0.01)$ & -0.02 & $(0.01)$ & -0.04 & $(0.01)$ & -0.05 & $(0.01)$ & 0.10 & $(0.01)$ \\
\hline$n$ & Albania & $\mathrm{m}$ & $\mathrm{m}$ & $\mathrm{m}$ & $\mathrm{m}$ & $\mathrm{m}$ & $\mathrm{m}$ & $\mathrm{m}$ & $\mathrm{m}$ & $\mathrm{m}$ & $\mathrm{m}$ & $\mathrm{m}$ & $\mathrm{m}$ \\
\hline 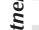 & Algeria & $\mathrm{m}$ & $\mathrm{m}$ & $\mathrm{m}$ & $\mathrm{m}$ & $\mathrm{m}$ & $\mathrm{m}$ & $\mathrm{m}$ & $\mathrm{m}$ & $\mathrm{m}$ & $\mathrm{m}$ & $\mathrm{m}$ & $\mathrm{m}$ \\
\hline एँ & Brazil & 0.46 & $(0.05)$ & 0.54 & $(0.02)$ & 0.62 & $(0.02)$ & 0.61 & $(0.03)$ & 0.01 & $(0.03)$ & 0.08 & $(0.04)$ \\
\hline 2 & B-S-J-G (China) & 0.28 & $(0.06)$ & 0.28 & $(0.03)$ & 0.18 & $(0.03)$ & 0.13 & $(0.04)$ & -0.12 & $(0.05)$ & 0.03 & $(0.05)$ \\
\hline & Bulgaria & -0.20 & $(0.14)$ & -0.15 & $(0.07)$ & -0.07 & $(0.03)$ & -0.11 & $(0.04)$ & -0.03 & $(0.05)$ & 0.03 & $(0.05)$ \\
\hline & CABA (Argentina) & $\mathrm{m}$ & $\mathrm{m}$ & $\mathrm{m}$ & $\mathrm{m}$ & $\mathrm{m}$ & $\mathrm{m}$ & $\mathrm{m}$ & $\mathrm{m}$ & $\mathrm{m}$ & $\mathrm{m}$ & $\mathrm{m}$ & $\mathrm{m}$ \\
\hline & Colombia & 0.40 & $(0.10)$ & 0.44 & $(0.04)$ & 0.54 & $(0.02)$ & 0.54 & $(0.04)$ & 0.02 & $(0.04)$ & 0.05 & $(0.05)$ \\
\hline & Costa Rica & 0.61 & $(0.06)$ & 0.59 & $(0.03)$ & 0.55 & $(0.03)$ & 0.45 & $(0.05)$ & -0.17 & $(0.06)$ & -0.04 & $(0.06)$ \\
\hline & Croatia & -0.04 & $(0.08)$ & -0.08 & $(0.04)$ & 0.08 & $(0.03)$ & 0.03 & $(0.06)$ & 0.03 & $(0.07)$ & 0.14 & $(0.07)$ \\
\hline & Cyprus* & -0.06 & $(0.07)$ & -0.01 & $(0.04)$ & -0.12 & $(0.02)$ & -0.10 & $(0.04)$ & -0.03 & $(0.05)$ & 0.17 & $(0.05)$ \\
\hline & Dominican Republic & 0.27 & $(0.15)$ & 0.35 & $(0.07)$ & 0.46 & $(0.02)$ & 0.52 & $(0.03)$ & 0.12 & $(0.04)$ & 0.15 & $(0.05)$ \\
\hline & FYROM & $\mathrm{m}$ & $\mathrm{m}$ & $\mathrm{m}$ & $\mathrm{m}$ & $\mathrm{m}$ & $\mathrm{m}$ & $\mathrm{m}$ & $\mathrm{m}$ & $\mathrm{m}$ & $\mathrm{m}$ & $\mathrm{m}$ & $\mathrm{m}$ \\
\hline & Georgia & $\mathrm{m}$ & $\mathrm{m}$ & $\mathrm{m}$ & $\mathrm{m}$ & $\mathrm{m}$ & $\mathrm{m}$ & $\mathrm{m}$ & $\mathrm{m}$ & $\mathrm{m}$ & $\mathrm{m}$ & $\mathrm{m}$ & $\mathrm{m}$ \\
\hline & Hong Kong (China) & 0.31 & $(0.05)$ & 0.26 & $(0.03)$ & 0.38 & $(0.03)$ & 0.41 & $(0.05)$ & 0.10 & $(0.05)$ & 0.19 & $(0.05)$ \\
\hline & Indonesia & $\mathrm{m}$ & $\mathrm{m}$ & $\mathrm{m}$ & $\mathrm{m}$ & $\mathrm{m}$ & $\mathrm{m}$ & $\mathrm{m}$ & $\mathrm{m}$ & $\mathrm{m}$ & $\mathrm{m}$ & $\mathrm{m}$ & $\mathrm{m}$ \\
\hline & Jordan & $\mathrm{m}$ & $\mathrm{m}$ & $\mathrm{m}$ & $\mathrm{m}$ & $\mathrm{m}$ & $\mathrm{m}$ & $\mathrm{m}$ & $\mathrm{m}$ & $\mathrm{m}$ & $\mathrm{m}$ & $\mathrm{m}$ & $\mathrm{m}$ \\
\hline & Kosovo & $\mathrm{m}$ & $\mathrm{m}$ & $\mathrm{m}$ & $\mathrm{m}$ & $\mathrm{m}$ & $\mathrm{m}$ & $\mathrm{m}$ & $\mathrm{m}$ & $\mathrm{m}$ & $\mathrm{m}$ & $\mathrm{m}$ & $\mathrm{m}$ \\
\hline & Lebanon & $\mathrm{m}$ & $\mathrm{m}$ & $\mathrm{m}$ & $\mathrm{m}$ & $\mathrm{m}$ & $\mathrm{m}$ & $\mathrm{m}$ & $\mathrm{m}$ & $\mathrm{m}$ & $\mathrm{m}$ & $\mathrm{m}$ & $\mathrm{m}$ \\
\hline & Lithuania & -0.41 & $(0.10)$ & -0.23 & $(0.06)$ & 0.00 & $(0.03)$ & -0.01 & $(0.04)$ & 0.07 & $(0.05)$ & 0.20 & $(0.05)$ \\
\hline & Macao (China) & 0.08 & $(0.08)$ & 0.16 & $(0.05)$ & 0.43 & $(0.02)$ & 0.49 & $(0.04)$ & 0.14 & $(0.04)$ & 0.27 & $(0.05)$ \\
\hline & Malta & $\mathrm{m}$ & $\mathrm{m}$ & $\mathrm{m}$ & $\mathrm{m}$ & $\mathrm{m}$ & $\mathrm{m}$ & $\mathrm{m}$ & $\mathrm{m}$ & $\mathrm{m}$ & $\mathrm{m}$ & $\mathrm{m}$ & $\mathrm{m}$ \\
\hline & Moldova & $\mathrm{m}$ & $\mathrm{m}$ & $\mathrm{m}$ & $\mathrm{m}$ & $\mathrm{m}$ & $\mathrm{m}$ & $\mathrm{m}$ & $\mathrm{m}$ & $\mathrm{m}$ & $\mathrm{m}$ & $\mathrm{m}$ & $\mathrm{m}$ \\
\hline & Montenegro & -0.05 & $(0.06)$ & 0.05 & $(0.04)$ & 0.04 & $(0.02)$ & 0.05 & $(0.05)$ & -0.05 & $(0.06)$ & 0.05 & $(0.06)$ \\
\hline & Peru & -0.01 & $(0.05)$ & 0.02 & $(0.03)$ & 0.13 & $(0.02)$ & 0.11 & $(0.02)$ & -0.03 & $(0.03)$ & 0.05 & $(0.03)$ \\
\hline & Qatar & 0.10 & $(0.06)$ & 0.18 & $(0.03)$ & 0.20 & $(0.01)$ & 0.08 & $(0.02)$ & -0.16 & $(0.03)$ & -0.05 & $(0.03)$ \\
\hline & Romania & $\mathrm{m}$ & $\mathrm{m}$ & $\mathrm{m}$ & $\mathrm{m}$ & $\mathrm{m}$ & $\mathrm{m}$ & $\mathrm{m}$ & $\mathrm{m}$ & $\mathrm{m}$ & $\mathrm{m}$ & $\mathrm{m}$ & $\mathrm{m}$ \\
\hline & Russia & 0.15 & $(0.12)$ & 0.03 & $(0.06)$ & -0.11 & $(0.03)$ & -0.11 & $(0.04)$ & -0.07 & $(0.05)$ & 0.07 & $(0.05)$ \\
\hline & Singapore & 0.72 & $(0.04)$ & 0.68 & $(0.02)$ & 0.41 & $(0.03)$ & 0.39 & $(0.05)$ & -0.20 & $(0.05)$ & -0.01 & $(0.05)$ \\
\hline & Chinese Taipei & 0.26 & $(0.04)$ & 0.34 & $(0.03)$ & 0.39 & $(0.03)$ & 0.38 & $(0.05)$ & 0.00 & $(0.06)$ & 0.04 & $(0.06)$ \\
\hline & Thailand & 0.03 & $(0.05)$ & 0.05 & $(0.04)$ & 0.17 & $(0.03)$ & 0.16 & $(0.04)$ & 0.05 & $(0.04)$ & 0.09 & $(0.05)$ \\
\hline & Trinidad and Tobago & $\mathrm{m}$ & $\mathrm{m}$ & $\mathrm{m}$ & $\mathrm{m}$ & $\mathrm{m}$ & $\mathrm{m}$ & $\mathrm{m}$ & $\mathrm{m}$ & $\mathrm{m}$ & $\mathrm{m}$ & $\mathrm{m}$ & $\mathrm{m}$ \\
\hline & Tunisia & 0.12 & $(0.09)$ & 0.18 & $(0.04)$ & -0.01 & $(0.03)$ & -0.04 & $(0.05)$ & -0.16 & $(0.05)$ & -0.02 & $(0.05)$ \\
\hline & United Arab Emirates & 0.10 & $(0.04)$ & 0.15 & $(0.02)$ & 0.18 & $(0.02)$ & 0.16 & $(0.03)$ & -0.05 & $(0.03)$ & 0.07 & $(0.04)$ \\
\hline & Uruguay & 0.49 & $(0.07)$ & 0.50 & $(0.04)$ & 0.38 & $(0.02)$ & 0.34 & $(0.04)$ & -0.14 & $(0.04)$ & 0.06 & $(0.04)$ \\
\hline & Viet Nam & $\mathrm{m}$ & $\mathrm{m}$ & $\mathrm{m}$ & $\mathrm{m}$ & $\mathrm{m}$ & $\mathrm{m}$ & $\mathrm{m}$ & $\mathrm{m}$ & $\mathrm{m}$ & m & $\mathrm{m}$ & $\mathrm{m}$ \\
\hline & Argentina** & $\mathrm{m}$ & $\mathrm{m}$ & $\mathrm{m}$ & $\mathrm{m}$ & $\mathrm{m}$ & $\mathrm{m}$ & $\mathrm{m}$ & $\mathrm{m}$ & $\mathrm{m}$ & $\mathrm{m}$ & $\mathrm{m}$ & $\mathrm{m}$ \\
\hline & Kazakhstan** & $\mathrm{m}$ & $\mathrm{m}$ & $\mathrm{m}$ & $\mathrm{m}$ & $\mathrm{m}$ & $\mathrm{m}$ & $\mathrm{m}$ & $\mathrm{m}$ & $\mathrm{m}$ & $\mathrm{m}$ & $\mathrm{m}$ & $\mathrm{m}$ \\
\hline & Malaysia** & 0.27 & $(0.04)$ & 0.29 & $(0.02)$ & 0.43 & $(0.02)$ & 0.39 & $(0.03)$ & 0.04 & $(0.03)$ & 0.01 & $(0.03)$ \\
\hline
\end{tabular}

Note: Values that are statistically significant are indicated in bold (see Annex A3).

* See note at the beginning of this Annex.

Coverage is too small to ensure comparability (see Annex A4).

StatLink 霜s $\mathrm{http}: / / \mathrm{dx} . \mathrm{doi}$. org/10.1787/888933470744 
[Part 1/1]

Table III.4.9 Index of schoolwork-related anxiety and life satisfaction

Results based on students' self-reports

\begin{tabular}{|c|c|c|c|c|c|c|c|c|c|c|c|c|c|c|c|}
\hline & \multicolumn{10}{|c|}{$\begin{array}{l}\text { Average life satisfaction, } \\
\text { by national quarters of the index of schoolwork-related anxiety }\end{array}$} & \multicolumn{4}{|c|}{$\begin{array}{l}\text { Change in life satisfaction associated } \\
\text { with a one-unit change in the index } \\
\text { of schoolwork-related anxiety }\end{array}$} \\
\hline & & \multicolumn{2}{|c|}{ Bottom quarter } & \multicolumn{2}{|c|}{ Second quarter } & \multicolumn{2}{|c|}{ Third quarter } & \multicolumn{2}{|c|}{ Top quarter } & \multicolumn{2}{|c|}{ Top - bottom quarter } & \multicolumn{2}{|c|}{$\begin{array}{c}\text { Before accounting } \\
\text { for students' } \\
\text { socio-economic } \\
\text { status }\end{array}$} & \multicolumn{2}{|c|}{$\begin{array}{c}\text { After accounting } \\
\text { for students' } \\
\text { socio-economic } \\
\text { status }\end{array}$} \\
\hline & & Mean & S.E. & Mean & S.E. & Mean & S.E. & Mean & S.E. & Dif. & S.E. & $\begin{array}{c}\text { Mean } \\
\text { change }\end{array}$ & S.E. & $\begin{array}{c}\text { Mean } \\
\text { change }\end{array}$ & S.E. \\
\hline 0 & Australia & $\mathrm{m}$ & $\mathrm{m}$ & $\mathrm{m}$ & $\mathrm{m}$ & $\mathrm{m}$ & $\mathrm{m}$ & $\mathrm{m}$ & $\mathrm{m}$ & $\mathrm{m}$ & $\mathrm{m}$ & $\mathrm{m}$ & $\mathrm{m}$ & $\mathrm{m}$ & $\mathrm{m}$ \\
\hline$\pi$ & Austria & 8.19 & $(0.06)$ & 7.76 & $(0.05)$ & 7.48 & $(0.08)$ & 6.67 & $(0.06)$ & -1.52 & $(0.08)$ & -0.56 & $(0.03)$ & -0.54 & $(0.03)$ \\
\hline & Belgium (excl. Flemish) & 7.81 & $(0.07)$ & 7.59 & $(0.06)$ & 7.51 & $(0.07)$ & 7.05 & $(0.09)$ & -0.75 & $(0.11)$ & -0.26 & $(0.04)$ & -0.24 & $(0.04)$ \\
\hline & Canada & $\mathrm{m}$ & $\mathrm{m}$ & $\mathrm{m}$ & $\mathrm{m}$ & $\mathrm{m}$ & $\mathrm{m}$ & $\mathrm{m}$ & $\mathrm{m}$ & $\mathrm{m}$ & $\mathrm{m}$ & $\mathrm{m}$ & $\mathrm{m}$ & $\mathrm{m}$ & $\mathrm{m}$ \\
\hline & Chile & 7.84 & $(0.06)$ & 7.48 & $(0.07)$ & 7.39 & $(0.06)$ & 6.75 & $(0.09)$ & -1.08 & $(0.10)$ & -0.44 & $(0.04)$ & -0.43 & $(0.04)$ \\
\hline & Czech Republic & 7.55 & $(0.06)$ & 7.30 & $(0.06)$ & 7.02 & $(0.06)$ & 6.35 & $(0.08)$ & -1.20 & $(0.09)$ & -0.49 & $(0.04)$ & -0.49 & $(0.04)$ \\
\hline & Denmark & $\mathrm{m}$ & $\mathrm{m}$ & $\mathrm{m}$ & $\mathrm{m}$ & $\mathrm{m}$ & $\mathrm{m}$ & $\mathrm{m}$ & $\mathrm{m}$ & $\mathrm{m}$ & $\mathrm{m}$ & $\mathrm{m}$ & $\mathrm{m}$ & $\mathrm{m}$ & $\mathrm{m}$ \\
\hline & Estonia & 7.98 & $(0.06)$ & 7.67 & $(0.06)$ & 7.51 & $(0.06)$ & 6.86 & $(0.08)$ & -1.12 & $(0.10)$ & -0.48 & $(0.04)$ & -0.46 & $(0.04)$ \\
\hline & Finland & 8.46 & $(0.05)$ & 8.12 & $(0.05)$ & 7.88 & $(0.05)$ & 7.10 & $(0.06)$ & -1.37 & $(0.07)$ & -0.61 & $(0.03)$ & -0.59 & $(0.03)$ \\
\hline & France & 8.02 & $(0.05)$ & 7.84 & $(0.05)$ & 7.55 & $(0.05)$ & 7.11 & $(0.06)$ & -0.91 & $(0.08)$ & -0.33 & $(0.03)$ & -0.32 & $(0.03)$ \\
\hline & Germany & 8.04 & $(0.05)$ & 7.76 & $(0.05)$ & 7.19 & $(0.06)$ & 6.41 & $(0.08)$ & -1.63 & $(0.08)$ & -0.70 & $(0.04)$ & -0.69 & $(0.04)$ \\
\hline & Greece & 7.49 & $(0.07)$ & 7.14 & $(0.07)$ & 6.78 & $(0.06)$ & 6.26 & $(0.08)$ & -1.23 & $(0.12)$ & -0.57 & $(0.05)$ & -0.56 & $(0.05)$ \\
\hline & Hungary & 7.70 & $(0.07)$ & 7.37 & $(0.07)$ & 7.06 & $(0.07)$ & 6.55 & $(0.08)$ & -1.16 & $(0.11)$ & -0.44 & $(0.04)$ & -0.43 & $(0.04)$ \\
\hline & Iceland & 8.74 & $(0.07)$ & 8.22 & $(0.06)$ & 7.74 & $(0.10)$ & 6.48 & $(0.09)$ & -2.25 & $(0.11)$ & -0.75 & $(0.03)$ & -0.73 & $(0.03)$ \\
\hline & Ireland & 7.92 & $(0.05)$ & 7.67 & $(0.05)$ & 7.23 & $(0.06)$ & 6.39 & $(0.07)$ & -1.54 & (0.09) & -0.65 & $(0.04)$ & -0.64 & $(0.04)$ \\
\hline & Israel & $\mathrm{m}$ & $\mathrm{m}$ & $\mathrm{m}$ & $\mathrm{m}$ & $\mathrm{m}$ & $\mathrm{m}$ & $\mathrm{m}$ & $\mathrm{m}$ & $\mathrm{m}$ & $\mathrm{m}$ & $\mathrm{m}$ & $\mathrm{m}$ & $\mathrm{m}$ & $\mathrm{m}$ \\
\hline & Italy & 7.33 & $(0.06)$ & 7.19 & $(0.07)$ & 6.75 & $(0.07)$ & 6.29 & $(0.07)$ & -1.04 & (0.09) & -0.44 & $(0.04)$ & -0.43 & $(0.04)$ \\
\hline & Japan & 6.84 & $(0.07)$ & 6.96 & (0.05) & 6.91 & $(0.05)$ & 6.53 & $(0.06)$ & -0.32 & (0.09) & -0.11 & $(0.04)$ & -0.11 & $(0.03)$ \\
\hline & Korea & 7.06 & $(0.06)$ & 6.59 & $(0.07)$ & 6.31 & $(0.07)$ & 5.50 & $(0.08)$ & -1.56 & $(0.09)$ & -0.57 & $(0.03)$ & -0.58 & $(0.03)$ \\
\hline & Latvia & 7.62 & $(0.07)$ & 7.54 & $(0.06)$ & 7.39 & $(0.06)$ & 6.93 & $(0.07)$ & -0.68 & $(0.10)$ & -0.34 & $(0.05)$ & -0.32 & $(0.04)$ \\
\hline & Luxembourg & 7.98 & $(0.07)$ & 7.68 & $(0.05)$ & 7.22 & $(0.07)$ & 6.64 & $(0.07)$ & -1.34 & $(0.09)$ & -0.49 & $(0.03)$ & -0.47 & $(0.03)$ \\
\hline & Mexico & 8.49 & $(0.05)$ & 8.45 & (0.05) & 8.21 & $(0.05)$ & 7.93 & $(0.07)$ & -0.56 & $(0.08)$ & -0.24 & $(0.03)$ & -0.24 & $(0.03)$ \\
\hline & Netherlands & 8.25 & $(0.04)$ & 8.03 & $(0.04)$ & 7.74 & $(0.04)$ & 7.29 & $(0.05)$ & -0.96 & $(0.07)$ & -0.46 & $(0.03)$ & -0.46 & $(0.03)$ \\
\hline & New Zealand & $\mathrm{m}$ & $\mathrm{m}$ & $\mathrm{m}$ & $\mathrm{m}$ & $\mathrm{m}$ & $\mathrm{m}$ & $\mathrm{m}$ & $\mathrm{m}$ & $\mathrm{m}$ & $\mathrm{m}$ & $\mathrm{m}$ & $\mathrm{m}$ & $\mathrm{m}$ & $\mathrm{m}$ \\
\hline & Norway & $\mathrm{m}$ & $\mathrm{m}$ & $\mathrm{m}$ & $\mathrm{m}$ & $\mathrm{m}$ & $\mathrm{m}$ & $\mathrm{m}$ & $\mathrm{m}$ & $\mathrm{m}$ & $\mathrm{m}$ & $\mathrm{m}$ & $\mathrm{m}$ & $\mathrm{m}$ & $\mathrm{m}$ \\
\hline & Poland & 7.66 & $(0.08)$ & 7.51 & $(0.07)$ & 7.17 & $(0.07)$ & 6.41 & $(0.09)$ & -1.25 & $(0.12)$ & -0.51 & $(0.04)$ & -0.50 & $(0.04)$ \\
\hline & Portugal & 7.61 & $(0.05)$ & 7.48 & $(0.05)$ & 7.33 & $(0.06)$ & 7.04 & $(0.06)$ & -0.56 & $(0.08)$ & -0.23 & $(0.03)$ & -0.23 & $(0.03)$ \\
\hline & Slovak Republic & 7.87 & $(0.06)$ & 7.62 & $(0.06)$ & 7.43 & $(0.06)$ & 6.96 & $(0.07)$ & -0.92 & $(0.09)$ & -0.41 & $(0.04)$ & -0.41 & $(0.04)$ \\
\hline & Slovenia & 7.78 & $(0.07)$ & 7.48 & $(0.06)$ & 7.11 & $(0.07)$ & 6.34 & $(0.08)$ & -1.44 & $(0.11)$ & -0.65 & $(0.04)$ & -0.65 & $(0.04)$ \\
\hline & Spain & 7.56 & $(0.06)$ & 7.55 & $(0.06)$ & 7.48 & $(0.05)$ & 7.10 & $(0.07)$ & -0.46 & $(0.09)$ & -0.21 & $(0.03)$ & -0.20 & $(0.03)$ \\
\hline & Sweden & $\mathrm{m}$ & $\mathrm{m}$ & $\mathrm{m}$ & $\mathrm{m}$ & $\mathrm{m}$ & $\mathrm{m}$ & $\mathrm{m}$ & $\mathrm{m}$ & $\mathrm{m}$ & $\mathrm{m}$ & $\mathrm{m}$ & $\mathrm{m}$ & $\mathrm{m}$ & $\mathrm{m}$ \\
\hline & Switzerland & 8.37 & $(0.05)$ & 7.95 & $(0.05)$ & 7.51 & $(0.06)$ & 7.05 & $(0.08)$ & -1.32 & $(0.09)$ & -0.53 & $(0.04)$ & -0.52 & $(0.04)$ \\
\hline & Turkey & 6.72 & $(0.09)$ & 6.28 & $(0.10)$ & 6.13 & $(0.09)$ & 5.37 & $(0.09)$ & -1.36 & $(0.13)$ & -0.48 & $(0.05)$ & -0.48 & $(0.05)$ \\
\hline & United Kingdom & 7.84 & $(0.06)$ & 7.35 & $(0.06)$ & 7.01 & $(0.06)$ & 5.75 & $(0.08)$ & -2.09 & $(0.10)$ & -0.81 & $(0.03)$ & -0.80 & $(0.03)$ \\
\hline & United States & 7.94 & $(0.06)$ & 7.77 & $(0.06)$ & 7.24 & $(0.07)$ & 6.47 & $(0.07)$ & -1.47 & $(0.09)$ & -0.56 & $(0.04)$ & -0.54 & $(0.04)$ \\
\hline & OECD average & 7.81 & $(0.01)$ & 7.55 & $(0.01)$ & 7.26 & $(0.01)$ & 6.63 & $(0.01)$ & -1.18 & $(0.02)$ & -0.48 & $(0.01)$ & -0.47 & $(0.01)$ \\
\hline
\end{tabular}

\begin{tabular}{|c|c|c|c|c|c|c|c|c|c|c|c|c|c|c|}
\hline Albania & $\mathrm{m}$ & $\mathrm{m}$ & $\mathrm{m}$ & $\mathrm{m}$ & $\mathrm{m}$ & $\mathrm{m}$ & $\mathrm{m}$ & $\mathrm{m}$ & $\mathrm{m}$ & $\mathrm{m}$ & $\mathrm{m}$ & $\mathrm{m}$ & $\mathrm{m}$ & $\mathrm{m}$ \\
\hline Algeria & $\mathrm{m}$ & $\mathrm{m}$ & $\mathrm{m}$ & $\mathrm{m}$ & $\mathrm{m}$ & $\mathrm{m}$ & $\mathrm{m}$ & $\mathrm{m}$ & $\mathrm{m}$ & $\mathrm{m}$ & $\mathrm{m}$ & $\mathrm{m}$ & $\mathrm{m}$ & $\mathrm{m}$ \\
\hline Brazil & 7.55 & $(0.04)$ & 7.73 & $(0.04)$ & 7.62 & $(0.04)$ & 7.48 & $(0.06)$ & -0.08 & $(0.07)$ & -0.01 & $(0.03)$ & -0.01 & $(0.03)$ \\
\hline B-S-J-G (China) & 7.22 & $(0.07)$ & 6.89 & $(0.07)$ & 6.77 & $(0.07)$ & 6.43 & $(0.09)$ & -0.79 & $(0.11)$ & -0.34 & $(0.04)$ & -0.33 & $(0.04)$ \\
\hline Bulgaria & 7.82 & $(0.08)$ & 7.62 & $(0.07)$ & 7.35 & $(0.07)$ & 6.92 & $(0.08)$ & -0.90 & $(0.11)$ & -0.32 & $(0.04)$ & -0.31 & $(0.04)$ \\
\hline CABA (Argentina) & $\mathrm{m}$ & $\mathrm{m}$ & $\mathrm{m}$ & $\mathrm{m}$ & $\mathrm{m}$ & $\mathrm{m}$ & $\mathrm{m}$ & $\mathrm{m}$ & $\mathrm{m}$ & $\mathrm{m}$ & $\mathrm{m}$ & $\mathrm{m}$ & $\mathrm{m}$ & $\mathrm{m}$ \\
\hline Colombia & 7.95 & $(0.07)$ & 7.92 & $(0.06)$ & 7.86 & $(0.07)$ & 7.85 & $(0.07)$ & -0.10 & $(0.09)$ & -0.05 & $(0.05)$ & -0.05 & $(0.05)$ \\
\hline Costa Rica & 8.21 & $(0.07)$ & 8.35 & $(0.07)$ & 8.24 & $(0.06)$ & 8.03 & $(0.07)$ & -0.19 & $(0.10)$ & -0.10 & $(0.04)$ & -0.10 & $(0.04)$ \\
\hline Croatia & 8.28 & $(0.06)$ & 8.08 & $(0.06)$ & 7.90 & $(0.07)$ & 7.35 & $(0.07)$ & -0.93 & $(0.09)$ & -0.36 & $(0.04)$ & -0.36 & $(0.04)$ \\
\hline Cyprus* & 7.76 & $(0.06)$ & 7.24 & $(0.06)$ & 6.97 & $(0.06)$ & 6.28 & $(0.07)$ & -1.48 & $(0.09)$ & -0.54 & $(0.04)$ & -0.52 & $(0.04)$ \\
\hline Dominican Republic & 8.65 & $(0.08)$ & 8.46 & $(0.07)$ & 8.56 & $(0.08)$ & 8.43 & $(0.09)$ & -0.22 & $(0.11)$ & -0.05 & $(0.04)$ & -0.05 & $(0.04)$ \\
\hline FYROM & $\mathrm{m}$ & $\mathrm{m}$ & $\mathrm{m}$ & $\mathrm{m}$ & $\mathrm{m}$ & $\mathrm{m}$ & $\mathrm{m}$ & $\mathrm{m}$ & $\mathrm{m}$ & $\mathrm{m}$ & $\mathrm{m}$ & $\mathrm{m}$ & $\mathrm{m}$ & $\mathrm{m}$ \\
\hline Georgia & $\mathrm{m}$ & $\mathrm{m}$ & $\mathrm{m}$ & $\mathrm{m}$ & $\mathrm{m}$ & $\mathrm{m}$ & $\mathrm{m}$ & $\mathrm{m}$ & $\mathrm{m}$ & $\mathrm{m}$ & $\mathrm{m}$ & $\mathrm{m}$ & $\mathrm{m}$ & $\mathrm{m}$ \\
\hline Hong Kong (China) & 6.78 & $(0.08)$ & 6.69 & $(0.07)$ & 6.44 & $(0.07)$ & 6.03 & $(0.06)$ & -0.76 & $(0.10)$ & -0.29 & $(0.04)$ & -0.29 & $(0.04)$ \\
\hline Indonesia & $\mathrm{m}$ & $\mathrm{m}$ & $\mathrm{m}$ & $\mathrm{m}$ & $\mathrm{m}$ & $\mathrm{m}$ & $\mathrm{m}$ & $\mathrm{m}$ & $\mathrm{m}$ & $\mathrm{m}$ & $\mathrm{m}$ & $\mathrm{m}$ & $\mathrm{m}$ & $\mathrm{m}$ \\
\hline Jordan & $\mathrm{m}$ & $\mathrm{m}$ & $\mathrm{m}$ & $\mathrm{m}$ & $\mathrm{m}$ & $\mathrm{m}$ & $\mathrm{m}$ & $\mathrm{m}$ & $\mathrm{m}$ & $\mathrm{m}$ & $\mathrm{m}$ & $\mathrm{m}$ & $\mathrm{m}$ & $\mathrm{m}$ \\
\hline Kosovo & $\mathrm{m}$ & $\mathrm{m}$ & $\mathrm{m}$ & $\mathrm{m}$ & $\mathrm{m}$ & $\mathrm{m}$ & $\mathrm{m}$ & $\mathrm{m}$ & $\mathrm{m}$ & $\mathrm{m}$ & $\mathrm{m}$ & $\mathrm{m}$ & $\mathrm{m}$ & $\mathrm{m}$ \\
\hline Lebanon & $\mathrm{m}$ & $\mathrm{m}$ & $\mathrm{m}$ & $\mathrm{m}$ & $\mathrm{m}$ & $\mathrm{m}$ & $\mathrm{m}$ & $\mathrm{m}$ & $\mathrm{m}$ & $\mathrm{m}$ & $\mathrm{m}$ & $\mathrm{m}$ & $\mathrm{m}$ & $\mathrm{m}$ \\
\hline Lithuania & 8.30 & $(0.06)$ & 8.03 & $(0.05)$ & 7.78 & $(0.06)$ & 7.36 & $(0.06)$ & -0.94 & $(0.08)$ & -0.32 & $(0.03)$ & -0.32 & $(0.03)$ \\
\hline Macao (China) & 6.94 & $(0.06)$ & 6.79 & $(0.05)$ & 6.52 & $(0.07)$ & 6.13 & $(0.07)$ & -0.82 & $(0.09)$ & -0.34 & $(0.04)$ & -0.32 & $(0.04)$ \\
\hline Malta & $\mathrm{m}$ & $\mathrm{m}$ & $\mathrm{m}$ & $\mathrm{m}$ & $\mathrm{m}$ & $\mathrm{m}$ & $\mathrm{m}$ & $\mathrm{m}$ & $\mathrm{m}$ & $\mathrm{m}$ & $\mathrm{m}$ & $\mathrm{m}$ & $\mathrm{m}$ & $\mathrm{m}$ \\
\hline Moldova & $\mathrm{m}$ & $\mathrm{m}$ & $\mathrm{m}$ & $\mathrm{m}$ & $\mathrm{m}$ & $\mathrm{m}$ & $\mathrm{m}$ & $\mathrm{m}$ & $\mathrm{m}$ & $\mathrm{m}$ & $\mathrm{m}$ & $\mathrm{m}$ & $\mathrm{m}$ & $\mathrm{m}$ \\
\hline Montenegro & 8.08 & $(0.07)$ & 7.79 & $(0.07)$ & 7.73 & $(0.07)$ & 7.39 & $(0.06)$ & -0.69 & $(0.09)$ & -0.21 & $(0.03)$ & -0.21 & $(0.03)$ \\
\hline Peru & 7.66 & $(0.07)$ & 7.73 & $(0.06)$ & 7.30 & $(0.06)$ & 7.34 & $(0.07)$ & -0.32 & $(0.10)$ & -0.23 & $(0.05)$ & -0.23 & $(0.05)$ \\
\hline Qatar & 7.96 & $(0.04)$ & 7.54 & $(0.05)$ & 7.35 & $(0.04)$ & 6.76 & $(0.05)$ & -1.21 & $(0.06)$ & -0.46 & $(0.03)$ & -0.45 & $(0.03)$ \\
\hline Romania & $\mathrm{m}$ & $\mathrm{m}$ & $\mathrm{m}$ & $\mathrm{m}$ & $\mathrm{m}$ & $\mathrm{m}$ & $\mathrm{m}$ & $\mathrm{m}$ & $\mathrm{m}$ & $\mathrm{m}$ & $\mathrm{m}$ & $\mathrm{m}$ & $\mathrm{m}$ & $\mathrm{m}$ \\
\hline Russia & 7.99 & $(0.07)$ & 8.02 & $(0.06)$ & 7.70 & $(0.07)$ & 7.34 & $(0.08)$ & -0.65 & $(0.10)$ & -0.31 & $(0.05)$ & -0.30 & $(0.05)$ \\
\hline Singapore & $\mathrm{m}$ & $\mathrm{m}$ & $\mathrm{m}$ & $\mathrm{m}$ & $\mathrm{m}$ & $\mathrm{m}$ & $\mathrm{m}$ & $\mathrm{m}$ & $\mathrm{m}$ & $\mathrm{m}$ & $\mathrm{m}$ & $\mathrm{m}$ & $\mathrm{m}$ & $\mathrm{m}$ \\
\hline Chinese Taipei & 6.96 & $(0.06)$ & 6.69 & $(0.05)$ & 6.53 & $(0.05)$ & 6.21 & $(0.05)$ & -0.75 & $(0.08)$ & -0.33 & $(0.03)$ & -0.33 & $(0.03)$ \\
\hline Thailand & 8.10 & $(0.06)$ & 7.87 & $(0.06)$ & 7.62 & $(0.06)$ & 7.26 & $(0.06)$ & -0.84 & $(0.08)$ & -0.41 & $(0.04)$ & -0.41 & $(0.04)$ \\
\hline Trinidad and Tobago & $\mathrm{m}$ & $\mathrm{m}$ & $\mathrm{m}$ & $\mathrm{m}$ & $\mathrm{m}$ & $\mathrm{m}$ & $\mathrm{m}$ & $\mathrm{m}$ & $\mathrm{m}$ & $\mathrm{m}$ & $\mathrm{m}$ & $\mathrm{m}$ & $\mathrm{m}$ & $\mathrm{m}$ \\
\hline Tunisia & 7.30 & $(0.08)$ & 7.25 & $(0.09)$ & 6.80 & $(0.09)$ & 6.25 & $(0.09)$ & -1.05 & $(0.13)$ & -0.46 & $(0.05)$ & -0.43 & $(0.05)$ \\
\hline United Arab Emirates & 7.78 & $(0.07)$ & 7.43 & $(0.05)$ & 7.27 & $(0.05)$ & 6.73 & $(0.07)$ & -1.05 & $(0.10)$ & -0.43 & $(0.04)$ & -0.43 & $(0.04)$ \\
\hline Uruguay & 7.70 & $(0.06)$ & 7.80 & $(0.06)$ & 7.76 & $(0.06)$ & 7.57 & $(0.06)$ & -0.13 & $(0.08)$ & -0.05 & $(0.04)$ & -0.03 & $(0.04)$ \\
\hline Viet Nam & $\mathrm{m}$ & $\mathrm{m}$ & $\mathrm{m}$ & $\mathrm{m}$ & $\mathrm{m}$ & $\mathrm{m}$ & $\mathrm{m}$ & $\mathrm{m}$ & $\mathrm{m}$ & $\mathrm{m}$ & $\mathrm{m}$ & $\mathrm{m}$ & $\mathrm{m}$ & $\mathrm{m}$ \\
\hline Argentina** & $\mathrm{m}$ & $\mathrm{m}$ & $\mathrm{m}$ & $\mathrm{m}$ & $\mathrm{m}$ & $\mathrm{m}$ & $\mathrm{m}$ & $\mathrm{m}$ & $\mathrm{m}$ & $\mathrm{m}$ & $\mathrm{m}$ & $\mathrm{m}$ & $\mathrm{m}$ & $\mathrm{m}$ \\
\hline Kazakhstan** & $\mathrm{m}$ & $\mathrm{m}$ & $\mathrm{m}$ & $\mathrm{m}$ & $\mathrm{m}$ & $\mathrm{m}$ & $\mathrm{m}$ & $\mathrm{m}$ & $\mathrm{m}$ & $\mathrm{m}$ & $\mathrm{m}$ & $\mathrm{m}$ & $\mathrm{m}$ & $\mathrm{m}$ \\
\hline Malaysia** & 7.40 & $(0.06)$ & 7.25 & $(0.07)$ & 6.92 & $(0.07)$ & 6.70 & $(0.06)$ & -0.70 & $(0.08)$ & -0.42 & $(0.04)$ & -0.43 & $(0.05)$ \\
\hline
\end{tabular}

Note: Values that are statistically significant are indicated in bold (see Annex A3).

* See note at the beginning of this Annex.

** Coverage is too small to ensure comparability (see Annex A4).

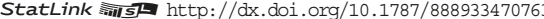


[Part 1/3]

Table III.4.10 Students' anxiety and study time in and outside of school

Percentage of students, by average study time of students in their school

\begin{tabular}{|c|c|c|c|c|c|c|c|c|}
\hline & & & Percentage $\mathrm{c}$ & by average st & udy time ${ }^{1}$ of & their school & & \\
\hline & Between 35 & rs per week & Between 40 & Irs per week & Between 45 & Irs per week & More tha & er week \\
\hline & $\%$ & S.E. & $\%$ & S.E. & $\%$ & S.E. & $\%$ & S.E. \\
\hline Australia & 27.9 & (1.8) & 42.6 & (2.0) & 21.9 & (1.4) & 7.6 & $(1.2)$ \\
\hline Austria & 12.6 & $(2.7)$ & 37.7 & (3.0) & 31.5 & (3.3) & 18.1 & (1.9) \\
\hline Belgium & 13.5 & (2.1) & 64.3 & (3.3) & 17.9 & $(2.7)$ & 4.3 & (1.4) \\
\hline Canada & 16.1 & (1.5) & 32.5 & $(2.7)$ & 33.5 & (2.3) & 18.0 & (2.3) \\
\hline Chile & 3.2 & (1.4) & 18.1 & (3.0) & 37.2 & (3.9) & 41.5 & (3.8) \\
\hline Czech Republic & 39.7 & (2.8) & 42.6 & (2.9) & 12.1 & $(1.8)$ & 5.6 & $(1.2)$ \\
\hline Denmark & 9.6 & (1.9) & 33.7 & (3.3) & 37.7 & (3.3) & 19.0 & (2.7) \\
\hline Estonia & 25.0 & (2.1) & 47.9 & (2.6) & 23.1 & (2.5) & 4.0 & (1.0) \\
\hline Finland & 79.4 & $(4.1)$ & 14.4 & (3.7) & 5.1 & $(2.0)$ & 1.1 & (1.0) \\
\hline France & 25.0 & (2.8) & 51.8 & (3.2) & 17.8 & (2.5) & 5.4 & (1.4) \\
\hline Germany & 72.8 & (3.8) & 21.8 & (3.6) & 5.0 & (1.6) & 0.4 & $(0.4)$ \\
\hline Greece & 1.2 & $(0.4)$ & 20.9 & (3.2) & 45.8 & $(3.7)$ & 32.2 & (3.9) \\
\hline Hungary & 14.9 & (2.6) & 46.6 & (3.5) & 28.5 & (3.1) & 10.1 & (2.1) \\
\hline Iceland & 36.1 & $(0.2)$ & 48.2 & $(0.3)$ & 14.6 & $(0.2)$ & 1.1 & $(0.1)$ \\
\hline Ireland & 6.9 & (2.0) & 57.0 & $(4.3)$ & 33.5 & $(4.2)$ & 2.6 & $(1.3)$ \\
\hline Israel & 17.3 & (2.8) & 31.6 & (3.6) & 23.4 & (3.1) & 27.7 & (2.5) \\
\hline Italy & 2.5 & (1.1) & 12.0 & (2.3) & 39.6 & (3.0) & 45.8 & (2.7) \\
\hline Japan & 40.0 & (3.1) & 34.8 & (3.4) & 17.5 & (2.4) & 7.6 & (1.9) \\
\hline Korea & 5.4 & (1.6) & 20.4 & (2.9) & 20.3 & (3.4) & 53.9 & (3.4) \\
\hline Latvia & 26.3 & (2.6) & 39.5 & $(2.7)$ & 25.6 & (2.5) & 8.6 & (1.6) \\
\hline Luxembourg & 22.6 & $(0.1)$ & 70.7 & $(0.1)$ & 6.7 & $(0.1)$ & 0.0 & C \\
\hline Mexico & 5.2 & (1.6) & 24.9 & (3.3) & 37.1 & (3.3) & 32.8 & (3.1) \\
\hline Netherlands & 41.5 & (3.9) & 49.7 & (3.7) & 8.4 & $(2.1)$ & 0.4 & $(0.4)$ \\
\hline New Zealand & 29.5 & (3.7) & 54.8 & (3.8) & 11.7 & $(2.3)$ & 4.0 & $(1.2)$ \\
\hline Norway & 23.6 & (3.2) & 48.9 & (3.6) & 22.4 & $(2.9)$ & 5.1 & (1.3) \\
\hline Poland & 3.9 & (1.6) & 34.7 & (3.9) & 48.2 & $(4.0)$ & 13.2 & (2.8) \\
\hline Portugal & 9.3 & $(2.1)$ & 41.1 & $(4.1)$ & 39.4 & $(4.0)$ & 10.1 & $(2.1)$ \\
\hline Slovak Republic & 27.7 & (2.8) & 40.9 & (3.2) & 17.8 & (2.6) & 13.7 & (1.8) \\
\hline Slovenia & 18.1 & $(0.5)$ & 40.7 & $(0.4)$ & 31.1 & $(0.3)$ & 10.1 & $(0.4)$ \\
\hline Spain & 3.3 & (1.3) & 33.2 & (3.5) & 47.5 & (3.8) & 16.1 & (3.0) \\
\hline Sweden & 49.5 & (3.5) & 42.1 & (3.4) & 7.3 & $(2.1)$ & 1.1 & $(0.8)$ \\
\hline Switzerland & 48.7 & (4.3) & 39.8 & (4.3) & 9.9 & $(2.2)$ & 1.6 & $(0.5)$ \\
\hline Turkey & 2.0 & (1.3) & 5.2 & (1.6) & 34.6 & $(4.1)$ & 58.2 & $(4.0)$ \\
\hline United Kingdom & 23.6 & $(2.7)$ & 48.8 & (3.4) & 24.1 & (2.6) & 3.6 & (1.0) \\
\hline United States & 4.7 & (1.6) & 17.5 & (2.9) & 42.5 & (3.9) & 35.3 & (3.5) \\
\hline OECD average & 22.5 & $(0.4)$ & 37.5 & $(0.5)$ & 25.2 & $(0.5)$ & 14.9 & $(0.4)$ \\
\hline
\end{tabular}

\begin{tabular}{|c|c|c|c|c|c|c|c|c|}
\hline Albania & $\mathrm{m}$ & $\mathrm{m}$ & $\mathrm{m}$ & $\mathrm{m}$ & $\mathrm{m}$ & $\mathrm{m}$ & $\mathrm{m}$ & $\mathrm{m}$ \\
\hline$\cong$ Algeria & $\mathrm{m}$ & $\mathrm{m}$ & $\mathrm{m}$ & $\mathrm{m}$ & $\mathrm{m}$ & $\mathrm{m}$ & $\mathrm{m}$ & $\mathrm{m}$ \\
\hline ¿ Brazil & 14.6 & (1.9) & 27.5 & $(2.1)$ & 26.2 & $(2.5)$ & 31.7 & (2.1) \\
\hline B-S-J-G (China) & 1.2 & $(0.5)$ & 2.1 & (1.0) & 9.4 & $(2.1)$ & 87.3 & $(2.0)$ \\
\hline Bulgaria & 19.3 & (3.0) & 46.4 & (3.5) & 28.7 & (3.4) & 5.6 & (1.6) \\
\hline CABA (Argentina) & $\mathrm{m}$ & $\mathrm{m}$ & $\mathrm{m}$ & $\mathrm{m}$ & $\mathrm{m}$ & $\mathrm{m}$ & $\mathrm{m}$ & $\mathrm{m}$ \\
\hline Colombia & 9.9 & (1.9) & 32.4 & (3.3) & 38.9 & (3.3) & 18.8 & (2.8) \\
\hline Costa Rica & 4.8 & (1.3) & 17.3 & $(2.7)$ & 31.5 & (3.4) & 46.4 & (3.6) \\
\hline Croatia & 9.2 & (2.3) & 36.5 & (3.5) & 43.8 & (3.8) & 10.5 & (2.2) \\
\hline Cyprus* & 0.8 & $(0.1)$ & 51.7 & $(0.2)$ & 37.6 & $(0.1)$ & 9.9 & $(0.1)$ \\
\hline Dominican Republic & 5.3 & (1.6) & 18.9 & (3.2) & 25.4 & (3.5) & 50.3 & (4.1) \\
\hline FYROM & $\mathrm{m}$ & $\mathrm{m}$ & $\mathrm{m}$ & $\mathrm{m}$ & $\mathrm{m}$ & $\mathrm{m}$ & $\mathrm{m}$ & $\mathrm{m}$ \\
\hline Georgia & $\mathrm{m}$ & $\mathrm{m}$ & $\mathrm{m}$ & $\mathrm{m}$ & $\mathrm{m}$ & $\mathrm{m}$ & $\mathrm{m}$ & $\mathrm{m}$ \\
\hline Hong Kong (China) & 3.6 & (1.7) & 34.4 & (3.9) & 45.2 & $(4.3)$ & 16.9 & (3.5) \\
\hline Indonesia & $\mathrm{m}$ & $\mathrm{m}$ & $\mathrm{m}$ & $\mathrm{m}$ & $\mathrm{m}$ & $\mathrm{m}$ & $\mathrm{m}$ & $\mathrm{m}$ \\
\hline Jordan & $\mathrm{m}$ & $\mathrm{m}$ & $\mathrm{m}$ & $\mathrm{m}$ & $\mathrm{m}$ & $\mathrm{m}$ & $\mathrm{m}$ & $\mathrm{m}$ \\
\hline Kosovo & $\mathrm{m}$ & $\mathrm{m}$ & $\mathrm{m}$ & $\mathrm{m}$ & $\mathrm{m}$ & $\mathrm{m}$ & $\mathrm{m}$ & $\mathrm{m}$ \\
\hline Lebanon & $\mathrm{m}$ & $\mathrm{m}$ & $\mathrm{m}$ & $\mathrm{m}$ & $\mathrm{m}$ & $\mathrm{m}$ & $\mathrm{m}$ & $\mathrm{m}$ \\
\hline Lithuania & 21.2 & (2.0) & 47.1 & (3.1) & 25.5 & $(2.7)$ & 6.2 & (1.4) \\
\hline Macao (China) & 14.9 & $(0.1)$ & 37.4 & $(0.1)$ & 39.4 & $(0.1)$ & 8.3 & $(0.0)$ \\
\hline Malta & $\mathrm{m}$ & $\mathrm{m}$ & $\mathrm{m}$ & $\mathrm{m}$ & $\mathrm{m}$ & $\mathrm{m}$ & $\mathrm{m}$ & $\mathrm{m}$ \\
\hline Moldova & $\mathrm{m}$ & $\mathrm{m}$ & $\mathrm{m}$ & $\mathrm{m}$ & $\mathrm{m}$ & $\mathrm{m}$ & $\mathrm{m}$ & $\mathrm{m}$ \\
\hline Montenegro & 0.3 & $(0.1)$ & 14.2 & $(0.2)$ & 49.3 & $(0.5)$ & 36.2 & $(0.5)$ \\
\hline Peru & 3.5 & $(1.2)$ & 18.7 & (2.5) & 31.4 & $(3.0)$ & 46.4 & (2.8) \\
\hline Qatar & 0.1 & $(0.0)$ & 4.1 & $(0.0)$ & 18.4 & $(0.1)$ & 77.4 & $(0.1)$ \\
\hline Romania & $\mathrm{m}$ & $\mathrm{m}$ & $\mathrm{m}$ & $\mathrm{m}$ & $\mathrm{m}$ & $\mathrm{m}$ & $\mathrm{m}$ & $\mathrm{m}$ \\
\hline Russia & 4.0 & (1.1) & 18.2 & (3.4) & 39.8 & $(4.3)$ & 38.0 & (3.2) \\
\hline Singapore & 0.6 & $(0.0)$ & 4.7 & $(0.5)$ & 41.8 & $(1.0)$ & 52.9 & (1.2) \\
\hline Chinese Taipei & 12.3 & (1.8) & 14.0 & (2.3) & 30.5 & (3.0) & 43.2 & (2.6) \\
\hline Thailand & 0.5 & $(0.2)$ & 5.7 & (1.9) & 16.3 & $(2.8)$ & 77.5 & (3.5) \\
\hline Trinidad and Tobago & $\mathrm{m}$ & $\mathrm{m}$ & $\mathrm{m}$ & $\mathrm{m}$ & $\mathrm{m}$ & $\mathrm{m}$ & $\mathrm{m}$ & $\mathrm{m}$ \\
\hline Tunisia & 0.0 & c & 3.1 & (1.3) & 10.9 & (2.6) & 86.0 & (2.9) \\
\hline United Arab Emirates & 0.3 & $(0.0)$ & 0.6 & $(0.1)$ & 5.3 & $(0.4)$ & 93.8 & (0.4) \\
\hline Uruguay & 42.8 & (3.5) & 35.7 & (3.8) & 14.1 & $(2.5)$ & 7.4 & (1.5) \\
\hline Viet Nam & $\mathrm{m}$ & $\mathrm{m}$ & $\mathrm{m}$ & $\mathrm{m}$ & $\mathrm{m}$ & $\mathrm{m}$ & $\mathrm{m}$ & $\mathrm{m}$ \\
\hline Argentina** & $\mathrm{m}$ & $\mathrm{m}$ & $\mathrm{m}$ & $\mathrm{m}$ & $\mathrm{m}$ & $\mathrm{m}$ & $\mathrm{m}$ & $\mathrm{m}$ \\
\hline Kazakhstan** & $\mathrm{m}$ & $\mathrm{m}$ & $\mathrm{m}$ & $\mathrm{m}$ & $\mathrm{m}$ & $\mathrm{m}$ & $\mathrm{m}$ & $\mathrm{m}$ \\
\hline Malaysia** & 0.7 & $(0.7)$ & 11.2 & $(2.7)$ & 33.4 & (3.9) & 54.8 & $(4.0)$ \\
\hline
\end{tabular}

1. Average study time is the average number of hours per week students in a particular school spend studying, both in and outside of school.

2. Student and school characteristics include gender, the PISA index of economic, cultural and social status (ESCS) at student and at school level, and science performance.

Note: Values that are statistically significant are indicated in bold (see Annex A3).

* See note at the beginning of this Annex.

ensure comparability (see Annex A4).

StatLink त्ता St http://dx.doi.org/10.1787/888933470777 


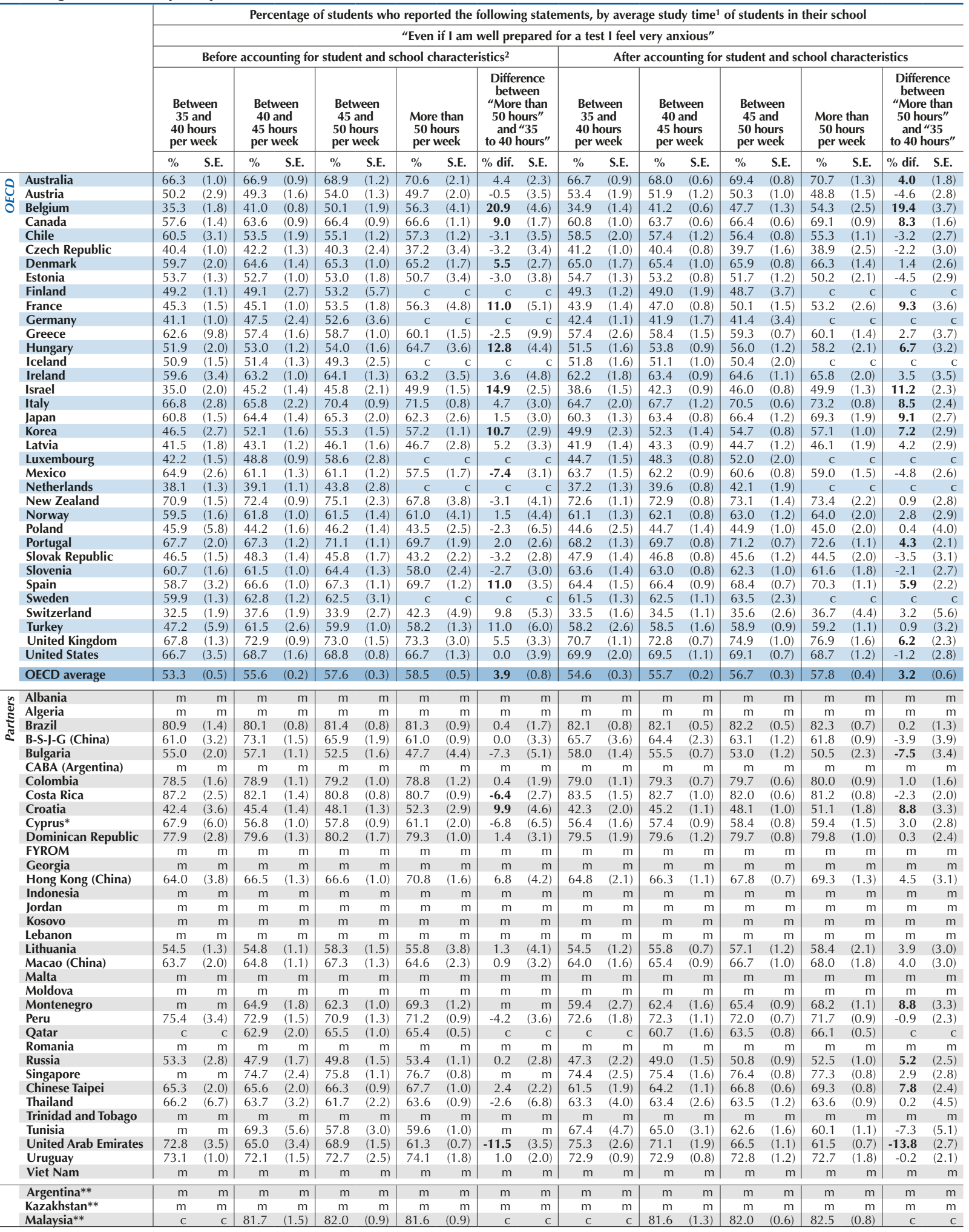

1. Average study time is the average number of hours per week students in a particular school spend studying, both in and outside of school. 
[Part 3/3]

Table III.4.10 Students' anxiety and study time in and outside of school

Percentage of students by study time in their school

\begin{tabular}{|c|c|c|c|c|c|c|c|c|c|c|c|c|c|c|c|c|c|c|c|}
\hline & & & & & & & & & & $110 y$ & sta & & & . & & 015 & tis & Tent & ool \\
\hline & & & & & & & & & "I ge & t very te & nse & n I & ly fo & test" & & & & & \\
\hline & & & Befor & acco & ting & stud & t and & hool & aracte & ristics $^{2}$ & & & Afte & accot & ting $\mathrm{f}$ & studen & $t$ and & hool ch & aracter \\
\hline & & $\begin{array}{c}\text { Bet } \\
35 \\
40 \\
\text { per }\end{array}$ & $\begin{array}{l}\text { ween } \\
\text { and } \\
\text { lours } \\
\text { week }\end{array}$ & $\begin{array}{c}\text { Bet } \\
40 \\
45 \mathrm{~h} \\
\text { per }\end{array}$ & $\begin{array}{l}\text { veen } \\
\text { and } \\
\text { ours } \\
\text { veek }\end{array}$ & $\begin{array}{c}\text { Bet } \\
45 \\
50 \mathrm{~h} \\
\text { per }\end{array}$ & $\begin{array}{l}\text { veen } \\
\text { and } \\
\text { ours } \\
\text { veek }\end{array}$ & $\begin{array}{l}\text { More } \\
50 \mathrm{~h} \\
\text { per }\end{array}$ & $\begin{array}{l}\text { than } \\
\text { ours } \\
\text { veek }\end{array}$ & $\begin{array}{c}\text { Differ } \\
\text { betw } \\
\text { "More } \\
50 \text { ho } \\
\text { and } \\
\text { to } 40 \mathrm{~h}\end{array}$ & $\begin{array}{l}\text { rence } \\
\text { veen } \\
\text { e than } \\
\text { ours" } \\
\text { "35 } \\
\text { hours" }\end{array}$ & $\begin{array}{c}\text { Betv } \\
35 \\
40 \mathrm{~h} \\
\text { per }\end{array}$ & $\begin{array}{l}\text { veen } \\
\text { Ind } \\
\text { ours } \\
\text { veek }\end{array}$ & $\begin{array}{c}\text { Bet } \\
40 \\
45 \mathrm{~h} \\
\text { per }\end{array}$ & $\begin{array}{l}\text { een } \\
\text { ad } \\
\text { urs } \\
\text { eek }\end{array}$ & $\begin{array}{c}\text { Betv } \\
45 \\
50 \mathrm{~h} \\
\text { per }\end{array}$ & $\begin{array}{l}\text { een } \\
\text { id } \\
\text { urs } \\
\text { eek }\end{array}$ & & \\
\hline & & $\%$ & S.E. & $\%$ & S.E. & $\%$ & S.E. & $\%$ & S.E. & $\%$ dif. & S.E. & $\%$ & S.E. & $\%$ & S.E. & $\%$ & S.E. & $\%$ & S.E. \\
\hline & Australia & 45.4 & (1.0) & 46.6 & $(0.9)$ & 48.6 & $(1.3)$ & 48.2 & (2.6) & 2.8 & $(2.7)$ & 45.4 & $(0.9)$ & 46.6 & (0.6) & 47.8 & $(0.9)$ & 48.9 & (1.5) \\
\hline & Austria & 16.7 & (1.5) & 18.3 & $(0.9)$ & 20.3 & (1.0) & 20.2 & (1.6) & 3.5 & (2.2) & 18.6 & (1.1) & 18.3 & $(0.6)$ & 18.0 & $(0.7)$ & 17.6 & (1.1) \\
\hline & Belgium & 23.7 & (1.6) & 27.7 & $(0.8)$ & 32.5 & (1.9) & 37.6 & (3.2) & 13.9 & (3.5) & 25.2 & (1.1) & 27.1 & $(0.6)$ & 29.1 & (1.0) & 31.2 & 8) \\
\hline & Canada & 38.5 & (1.4) & 45.3 & $(0.9)$ & 47.5 & $(0.9)$ & 49.0 & (1.3) & 10.4 & $(2.0)$ & 40.8 & (1.1) & 43.7 & $(0.7)$ & 46.7 & (0.6) & 49.7 & (1.1) \\
\hline & Chile & 41.3 & (2.7) & 39.0 & (1.8) & 39.0 & (1.3) & 41.2 & (1.1) & -0.1 & (2.9) & 42.3 & (1.9) & 41.0 & (1.1) & 39.7 & $(0.7)$ & 38.4 & (0.9) \\
\hline & Czech Rep & 29.1 & (1.1) & 35.8 & (1.0) & 35.7 & $(2.3)$ & 33.5 & (3.0) & 4.4 & (3.1) & 31.8 & (1.2) & 32.1 & 7) & 32.3 & (1.4) & 32.6 & $(2.3)$ \\
\hline & Denmark & 41.6 & (3.3) & 45.8 & (1.2) & 46.6 & (1.1) & 44.3 & (1.8) & 2.6 & (3.9) & 46.1 & (1.7) & 45.6 & $(0.8)$ & 45.0 & $(0.7)$ & 44.5 & (1.5) \\
\hline & Estonia & 23.9 & (1.3) & 27.9 & (1.0) & 30.8 & (1.7) & 27.8 & (3.9) & 3.9 & (4.1) & 24.5 & $(1.2)$ & 26.0 & $(0.7)$ & 27.7 & (1.3) & 29.4 & (2.3) \\
\hline & Finland & 17.7 & (0.7) & 16.7 & $(2.2)$ & 22.2 & (2.0) & c & c & c & c & 16.5 & $(0.8)$ & 16.2 & (1.1) & 15.9 & $(2.1)$ & $\mathrm{C}$ & C \\
\hline & France & 26.2 & (1.3) & 27.8 & $(1.0)$ & 34.4 & $(1.9)$ & 36.6 & (3.1) & 10.4 & (3.2) & 25.9 & (1.1) & 28.1 & $(0$. & 30.4 & (1.0) & 32.8 & 1.7) \\
\hline & Germany & 20.8 & (1.0) & 25.4 & (1.9) & 27.8 & (3.5) & C & c & $\mathrm{C}$ & $\mathrm{C}$ & 21.4 & (1.0) & 22.1 & (1.2) & 22.8 & (2.6) & C & $\mathrm{c}$ \\
\hline & Greece & 55.0 & (12.6) & 39.9 & (1.7) & 36.2 & $(0.9)$ & 38.4 & (1.5) & -16.6 & (12.6) & 40.5 & (2.6) & 39.1 & (1.4) & 37.7 & $(0.7)$ & 36.3 & (1.3) \\
\hline & Hungary & 29.7 & (2.2) & 23.9 & (0.9) & 27.4 & (1.5) & 34.3 & $(2.9)$ & 4.5 & (3.8) & 25.2 & (1.2) & 25.6 & $(0.8)$ & 26.0 & $(0.9)$ & 26.3 & (1.5) \\
\hline & Iceland' & 36.9 & (1.6) & 36.9 & (1.3) & 33.5 & $(2.3)$ & c & c & C & c & 36.7 & (1.6) & 34.8 & (1.0) & 32.9 & (1.7) & c & c \\
\hline & Ireland & 44.8 & (2.8) & 45.4 & $(1.2)$ & 47.8 & $(2.2)$ & 37.9 & (7.4) & -7.0 & (7.8) & 45.5 & $(2.0)$ & 45.7 & (1.0) & 45.9 & (1.7) & 5.1 & 1) \\
\hline & Israel & 28.6 & (2.0) & 35.1 & (1.5) & 34.6 & (1.9) & 33.5 & (1.5) & 4.9 & (2.5) & 32.0 & (1.4) & 32.5 & (0.9) & 33.0 & $(0.9)$ & 33.4 & .4) \\
\hline & Italy & 51.7 & (3.0) & 50.7 & (1.8) & 56.2 & $(1.2)$ & 58.5 & (1.1) & 6.8 & (3.0) & 47.7 & (1.8) & 51.7 & (1. & 55.7 & $(0$ & 59.7 & 5) \\
\hline & Japan & 31.0 & (1.1) & 35.2 & $(1.2)$ & 34.8 & $(1.2)$ & 35.5 & $(2.7)$ & 4.5 & (3.0) & 32.3 & (1.0) & 33.5 & $(0$. & 34.8 & (1.3) & 36.1 & ). \\
\hline & Korea & 36.3 & (2.9) & 39.7 & (1.7) & 41.2 & (1.4) & 43.6 & (1.0) & 7.3 & (3.1) & 36.7 & (2.3) & 39.0 & (1. & 41.3 & $(0$. & 7 & 1) \\
\hline & Latvia & 23.6 & (1.6) & 28.2 & $(1.2)$ & 29.2 & (1.5) & 32.3 & (3.0) & 8.6 & (3.4) & 24.4 & (1.2) & 26.4 & $(0$. & 28.4 & (1. & 0.5 & $2.0)$ \\
\hline & Luxembourg & 21.5 & (1.3) & 29.0 & $(0.8)$ & 41.0 & (3.1) & c & c & C & c & 22.3 & (1.3) & 27.5 & $(0.7)$ & 33.4 & $(2.2)$ & c & c \\
\hline & Mexico & 49.0 & (2.9) & 49.3 & (1.6) & 51.3 & (1.3) & 47.2 & (1.6) & -1.8 & (3.4) & 49.8 & (2.1) & 49.6 & (1. & 45 & $(0.9)$ & 49.0 & (1.4) \\
\hline & Netherla & 12.7 & $(0.8)$ & 14.6 & $(0.8)$ & 20.7 & (2.6) & c & c & $\mathrm{C}$ & c & 12 & $(0.8)$ & 14.2 & (0. & 16 & 1 & c & 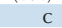 \\
\hline & New Zeal & 48.4 & (2.0) & 51.0 & (1.0) & 52.1 & $(2.0)$ & 51.7 & (3.6) & 3.3 & (4.1) & 4 & $(1$. & 50 & $(0$. & & $(1$ & 51.7 & (1.9) \\
\hline & Norway & 47.0 & (1.6) & 46.3 & $(1.0)$ & 43.5 & $(1.9)$ & 45.5 & (5.6) & -1.4 & (5.6) & 46.5 & (1.4) & 45.3 & $(0$. & 44 & (1. & 42.9 & (2.5) \\
\hline & Poland & 27.1 & (6.6) & 25.9 & $(1.0)$ & 25.7 & (1.1) & 26.7 & $(2.0)$ & -0.3 & (7.0) & 24.6 & $(2.3)$ & 24.8 & $(1.2)$ & 24.9 & $(0.8)$ & 5.0 & (1.6) \\
\hline & Portugal & 40.6 & (2.3) & 45.9 & $(1.2)$ & 47.7 & $(1.0)$ & 46.9 & $(2.4)$ & 6.2 & (3.4) & 43.5 & (1.5) & 45.1 & (0.9) & 46.8 & $(0.7)$ & 8.4 & $(1.3)$ \\
\hline & Slovak Re & 27.6 & (1.2) & 29.0 & $(1.0)$ & 29.3 & (1.4) & 32.3 & $(2.4)$ & 4.7 & (2.6) & 27.8 & (1.0) & 28.3 & $(0.7)$ & 28.8 & (1.0) & 9.4 & (1.7) \\
\hline & Slovenia & 34.9 & (2.1) & 35.7 & $(1.1)$ & 37.0 & $(1.5)$ & 34.3 & $(2.2)$ & -0.6 & (3.2) & 35.8 & (1.6) & 35.3 & $(0$. & 3 & (1. & 2 & (1.8) \\
\hline & Spain & 50.8 & (7.7) & 48.4 & (1.4) & 47.8 & $(1.2)$ & 47.9 & $(2.0)$ & -2.9 & (8.0) & 49.0 & $(2.3)$ & 48.4 & (1.2) & 47 & $(0$. & 47.3 & $(1.7)$ \\
\hline & Sweden & 37.8 & (1.1) & 43.8 & $(1.2)$ & 46.8 & (3.3) & c & c & $\mathrm{C}$ & C & 38 & (1.2) & 41 & $(0$. & 1 & (2. & C & C \\
\hline & Switzerla & 18.3 & (1.2) & 23.3 & $(0.9)$ & 23.3 & (1.9) & 31.0 & (8.3) & 12.7 & (8.4) & 19.2 & $(1.2)$ & 20.9 & $(0$. & 8 & (1.7) & 4.8 & (3.1) \\
\hline & Turkey & 35.5 & (6.9) & 58.3 & (3.9) & 57.7 & $(1.2)$ & 55.5 & $(1.1)$ & 20.0 & (6.9) & 53 & $(4.6)$ & 54.6 & $(2$. & 5 & (1. & 6.7 & (1.1) \\
\hline & United Kingdo & 47.3 & (1.3) & 54.3 & $(0.9)$ & 53.6 & (1.4) & 50.0 & (3.6) & 2.7 & (3.9) & 50.3 & (1.1) & 52.3 & $(0.7)$ & 54.4 & $(0.9)$ & 56.4 & (1.4) \\
\hline & United States & 37.6 & (3.0) & 42.8 & (1.9) & 43.8 & (1.1) & 43.8 & (1.3) & 6.2 & (3.3) & 39.6 & (1.9) & 41.2 & (1.1) & 42.7 & $(0.8)$ & 44.3 & (1.3) \\
\hline & OECD average & 34.2 & (0.6) & 36.8 & $(0.2)$ & 38.5 & $(0.3)$ & 40.2 & $(0.6)$ & 3.9 & (0.9) & 34.9 & $(0.3)$ & 35.8 & $(0.2)$ & 36.8 & $(0.2)$ & 37.8 & $(0.4)$ \\
\hline & Albania & $\mathrm{m}$ & $\mathrm{m}$ & $\mathrm{m}$ & $\mathrm{m}$ & $\mathrm{m}$ & $\mathrm{m}$ & $\mathrm{m}$ & $\mathrm{m}$ & $\mathrm{m}$ & $\mathrm{m}$ & $\mathrm{m}$ & $\mathrm{m}$ & $\mathrm{m}$ & $\mathrm{m}$ & $\mathrm{m}$ & $\mathrm{m}$ & $\mathrm{m}$ & $\mathrm{m}$ \\
\hline & Algeria & $\mathrm{m}$ & $\mathrm{m}$ & $\mathrm{m}$ & $\mathrm{m}$ & $\mathrm{m}$ & $\mathrm{m}$ & $m$ & $\mathrm{~m}$ & $\mathrm{~m}$ & $\mathrm{~m}$ & $m$ & 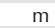 & $m$ & & 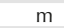 & & $\mathrm{m}$ & 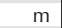 \\
\hline & Brazil & 56.5 & (1.6) & 54.6 & $(1.1)$ & 56.4 & (1.1) & 57.2 & $(1.1)$ & 0.8 & (1.9) & 56.4 & $(1.0)$ & 56.5 & $(0.7)$ & 56.5 & $(0.7)$ & 56.5 & $(1.0)$ \\
\hline & B-S-J-C & 5.4 & (3.2) & 59.2 & (2.7) & 61.0 & $(2.3)$ & 54.2 & $(0.8)$ & -1.3 & (3.4) & & (3.3) & & $(2$. & & & & $(0.8)$ \\
\hline & Bulgaria & 43.7 & (2.4) & 47.0 & (1.1) & 45.7 & (1.5) & 47.8 & (3.5) & 4.1 & (4.0) & 45.8 & (1.5) & 45.9 & $(0.8)$ & 46.0 & (1.4) & 46.1 & (2.4) \\
\hline & CABA & $\mathrm{m}$ & $\mathrm{m}$ & $\mathrm{m}$ & $\mathrm{m}$ & $\mathrm{m}$ & $\mathrm{m}$ & $\mathrm{m}$ & $\mathrm{m}$ & $\mathrm{m}$ & $\mathrm{m}$ & $\mathrm{m}$ & $\mathrm{m}$ & $\mathrm{m}$ & $\mathrm{m}$ & $\mathrm{m}$ & $\mathrm{m}$ & $\mathrm{m}$ & $\mathrm{m}$ \\
\hline & Colo & 7.3 & (1.8) & 59.1 & (1.3) & 56.6 & (1.2) & 58.2 & (1.6) & 0.8 & (2.2) & 58.5 & (1.5) & 58.1 & (0.9) & 57.7 & $(0.7)$ & 57.3 & (1.3) \\
\hline & Costa & 58.8 & (4.9) & 56.3 & (1.5) & 56.6 & (1.6) & 53.1 & (1.3) & -5.7 & (4.9) & 57.6 & (2.5) & 56.6 & (1.6) & 55.5 & $(0.9)$ & 54.5 & (1.2) \\
\hline & Croat & 9 & (3.4) & 36.1 & (1.3) & 36.0 & (1.1) & 37.6 & $(20)$ & 2. & (4.0) & & & & (1. & & & 378 & 4) \\
\hline & Cypr & 50.3 & (6.5) & 37.4 & $(0.9)$ & 41.9 & (1.0) & 45.3 & $(2.0)$ & -5.0 & (6.8) & 35.0 & (1.5) & 37.8 & $(0.8)$ & 40.8 & $(0.8)$ & 43.8 & (1.5) \\
\hline & Dom & 55.2 & (4.4) & 52.4 & (1.6) & 52.4 & $(2.0)$ & 52.8 & $(1.2)$ & -2.4 & (4.7) & 52.9 & $(2.4)$ & 52.9 & (1.5) & 52.8 & $(0.9)$ & 52.8 & (1.1) \\
\hline & FYROM & $\mathrm{m}$ & $\mathrm{m}$ & $\mathrm{m}$ & $\mathrm{m}$ & $\mathrm{m}$ & $\mathrm{m}$ & $\mathrm{m}$ & $\mathrm{m}$ & $\mathrm{m}$ & $\mathrm{m}$ & $\mathrm{m}$ & $\mathrm{m}$ & $\mathrm{m}$ & 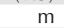 & $\mathrm{m}$ & $m$ & $\mathrm{~m}$ & $\mathrm{~m}$ \\
\hline & Georg & $\mathrm{m}$ & $\mathrm{m}$ & $\mathrm{m}$ & $\mathrm{m}$ & $\mathrm{m}$ & $\mathrm{m}$ & $\mathrm{m}$ & $\mathrm{m}$ & $\mathrm{m}$ & $\mathrm{m}$ & $\mathrm{m}$ & $\mathrm{m}$ & $\mathrm{m}$ & $\mathrm{m}$ & $\mathrm{m}$ & $\mathrm{m}$ & $\mathrm{m}$ & $\mathrm{m}$ \\
\hline & Hong & 52.2 & (6.3) & 51.6 & (1.3) & 52.3 & $(1.0)$ & 56.1 & (1.8) & 4.0 & (6.6) & 50.4 & (2.4) & 51.7 & (1.3) & 53.1 & (0.8) & 54.5 & (1.7) \\
\hline & Indonesi & $\mathrm{m}$ & $\mathrm{m}$ & $\mathrm{m}$ & $\mathrm{m}$ & $\mathrm{m}$ & $\mathrm{m}$ & $\mathrm{m}$ & $\mathrm{m}$ & $\mathrm{m}$ & $\mathrm{m}$ & $\mathrm{m}$ & $\mathrm{m}$ & $\mathrm{m}$ & $\mathrm{m}$ & $\mathrm{m}$ & $\mathrm{m}$ & $\mathrm{m}$ & $\mathrm{m}$ \\
\hline & Jordan & $\mathrm{m}$ & $\mathrm{m}$ & $\mathrm{m}$ & $\mathrm{m}$ & $\mathrm{m}$ & $\mathrm{m}$ & $\mathrm{m}$ & $\mathrm{m}$ & $\mathrm{m}$ & $\mathrm{m}$ & $\mathrm{m}$ & $\mathrm{m}$ & $\mathrm{m}$ & $\mathrm{m}$ & $\mathrm{m}$ & $\mathrm{m}$ & $\mathrm{m}$ & $\mathrm{m}$ \\
\hline & Kosovo & $\mathrm{m}$ & $\mathrm{m}$ & $\mathrm{m}$ & $\mathrm{m}$ & $\mathrm{m}$ & $\mathrm{m}$ & $\mathrm{m}$ & $\mathrm{m}$ & II & $\mathrm{m}$ & $\mathrm{m}$ & $\mathrm{m}$ & $\mathrm{m}$ & $\mathrm{m}$ & $\mathrm{m}$ & $\mathrm{m}$ & $\mathrm{m}$ & $\mathrm{m}$ \\
\hline & Leba & $\mathrm{m}$ & $\mathrm{m}$ & $\mathrm{m}$ & 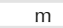 & $\mathrm{m}$ & n & $\mathrm{m}$ & $n$ & n & $\mathrm{m}$ & $\mathrm{m}$ & $\mathrm{m}$ & $\mathrm{m}$ & $\mathrm{m}$ & $\mathrm{m}$ & $\mathrm{m}$ & $\mathrm{m}$ & $\mathrm{m}$ \\
\hline & Lithuar & 9.8 & (1.5) & 42.3 & $(1.2)$ & 44.6 & (1.5) & 6.0 & (3.0) & 6.2 & (3.6) & 0.8 & (1.3) & 42.1 & (0.8) & 43.3 & (1.2) & 4.5 & (2.0) \\
\hline & Macao & 55.1 & (1.7) & 57.8 & (1.1) & 61.1 & (1.3) & 55.6 & $(2.1)$ & 0.5 & (2.5) & 55.1 & (1.6) & 57.7 & $(0.9)$ & 60.4 & (1.1) & 63.0 & (1.8) \\
\hline & Malta & $\mathrm{m}$ & $\mathrm{m}$ & $\mathrm{m}$ & $\mathrm{m}$ & $\mathrm{m}$ & 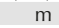 & $\mathrm{m}$ & $\mathrm{m}$ & $\mathrm{m}$ & $\mathrm{m}$ & $\mathrm{m}$ & $\mathrm{m}$ & $\mathrm{m}$ & II & $\mathrm{m}$ & $\mathrm{m}$ & $\mathrm{m}$ & $\mathrm{m}$ \\
\hline & Moldo & $\mathrm{m}$ & $\mathrm{m}$ & $\mathrm{m}$ & $\mathrm{m}$ & $\mathrm{m}$ & $\mathrm{m}$ & $\mathrm{m}$ & $\mathrm{m}$ & 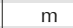 & $\mathrm{m}$ & $\mathrm{m}$ & $\mathrm{m}$ & $\mathrm{m}$ & $\mathrm{m}$ & $\mathrm{m}$ & $\mathrm{m}$ & $\mathrm{m}$ & $\mathrm{m}$ \\
\hline & Mon & III & & 4 & ) & & 10 & 2.4 & ) & m & $\mathrm{m}$ & .7 & 2) & 42.8 & $(1.4$ & 5.9 & $(0.8)$ & 9.0 & (1.0) \\
\hline & Peru & 8.3 & (4.3) & 43.2 & (1.7) & 42.5 & (1.3) & 44.0 & $(0.8)$ & 5.8 & (4.2) & 39.6 & (1.6) & 41.1 & (1.1) & 42.6 & $(0.7)$ & 44.1 & $(0.8)$ \\
\hline & Qat & C & c & 48.4 & $(2.2)$ & 50.3 & (1.0) & 49.3 & $(0.5)$ & c & c & 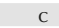 & c & 45.8 & (1.5) & 47.9 & $(0.8)$ & 49.9 & (0.5) \\
\hline & & $\mathrm{m}$ & $\mathrm{m}$ & $\mathrm{m}$ & & $\mathrm{m}$ & & $m$ & & 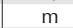 & $\mathrm{m}$ & $m$ & & $\mathrm{~m}$ & & $\mathrm{~m}$ & & $\mathrm{~m}$ & $m$ \\
\hline & Rus & 2.3 & (4.9) & 37.9 & $(2.2)$ & 37.6 & (1.2) & 39.8 & (1.4) & -2.5 & (5.9) & 37.9 & (2.6) & 38.0 & (1.5) & 38.1 & (0.8) & 38.3 & (1.4) \\
\hline & & $\mathrm{m}$ & & 62.9 & 3 & & $(10$ & 60 & (1.1) & $\mathrm{m}$ & $\mathrm{m}$ & 575 & & 58.7 & (2. & & (1. & 60.9 & (1.0) \\
\hline & Chin & 3.0 & (2.0) & 62.9 & (1.4) & 61.4 & (1.2) & 60.7 & (1.0) & -2.3 & (2.2) & 59.5 & (1.9) & 60.6 & (1.1) & 61.6 & (0.6) & 62.6 & (1.0) \\
\hline & & 9.7 & (9.8) & 43.2 & $(4.3)$ & 44.7 & (1.9) & 47.1 & (1.0) & -2.6 & (9.8) & 43.7 & (4.3) & 44.7 & (2.8) & 45.7 & (1.4) & 46.8 & (1.0) \\
\hline & Trin & $\mathrm{m}$ & $\mathrm{m}$ & $\mathrm{m}$ & & $\mathrm{m}$ & $\mathrm{m}$ & $\mathrm{m}$ & $\mathrm{m}$ & $\mathrm{m}$ & $\mathrm{m}$ & $\mathrm{m}$ & $\mathrm{m}$ & $\mathrm{m}$ & & $\mathrm{m}$ & & $\mathrm{m}$ & $\mathrm{m}$ \\
\hline & Tun & $\mathrm{m}$ & $\mathrm{m}$ & 69.8 & (4.8) & 54.3 & (3.3) & 57.3 & $(1.0)$ & $\mathrm{m}$ & $\mathrm{m}$ & 65.7 & (3.6) & 63.1 & (2.4) & 60.3 & (1.3) & 57.5 & (1.1) \\
\hline & Uni & 60.3 & (4.5) & 46.9 & (3.3) & 49.3 & (1.6) & 44.1 & $(0.7)$ & -16.2 & (4.6) & 57.6 & (3.3) & 53.1 & (2.3) & 48.5 & (1.3) & 43.9 & $(0.7)$ \\
\hline & Uruguay & 51.3 & (1.4) & 51.6 & (1.8) & 52.7 & (1.9) & 55.4 & (4.0) & 4.1 & (4.2) & 51.8 & (1.3) & 52.0 & (1.0) & 52.1 & $(1.5)$ & 52.3 & $(2.4)$ \\
\hline & Viet Nam & $\mathrm{m}$ & $\mathrm{m}$ & $\mathrm{m}$ & $\mathrm{m}$ & $\mathrm{m}$ & $\mathrm{m}$ & $\mathrm{m}$ & $\mathrm{m}$ & $\mathrm{m}$ & $\mathrm{m}$ & $\mathrm{m}$ & $\mathrm{m}$ & $\mathrm{m}$ & $\mathrm{m}$ & $\mathrm{m}$ & $\mathrm{m}$ & $\mathrm{m}$ & $\mathrm{m}$ \\
\hline & Argentina* & $\mathrm{m}$ & $\mathrm{m}$ & $\mathrm{m}$ & $\mathrm{m}$ & $\mathrm{m}$ & $\mathrm{m}$ & $\mathrm{m}$ & $\mathrm{m}$ & $\mathrm{m}$ & $\mathrm{m}$ & $\mathrm{m}$ & $\mathrm{m}$ & $\mathrm{m}$ & $\mathrm{m}$ & $\mathrm{m}$ & $\mathrm{m}$ & $\mathrm{m}$ & $\mathrm{m}$ \\
\hline & Kaz & $\mathrm{m}$ & $\mathrm{m}$ & $\mathrm{m}$ & $\mathrm{m}$ & $\mathrm{m}$ & $\mathrm{m}$ & $\mathrm{m}$ & $\mathrm{m}$ & $\mathrm{m}$ & $\mathrm{m}$ & $\mathrm{m}$ & $\mathrm{m}$ & $\mathrm{m}$ & $\mathrm{m}$ & $\mathrm{m}$ & $\mathrm{m}$ & $\mathrm{m}$ & $\mathrm{m}$ \\
\hline & Mal & C & C & 53.0 & (3.2) & 53.5 & $(1.7)$ & 55.0 & (1.3) & C & C & C & C & 54.3 & (2.2) & 54.4 & (1.1) & C & C \\
\hline
\end{tabular}

Average study time is the average number of hours per week students in a particular school spend studying, both in and outside of school.

2. Student and school characteristics include gender, the PISA index of economic, cultural and social status (ESCS) at student and at school level, and science performance.

Note: Values that are statistically significant are indicated in bold (see Annex A3).

* See note at the beginning of this Annex.

* Coverage is too small to ensure comparability (see Annex A4).

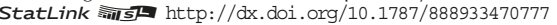


Increased likelihood that students get very tense when they study

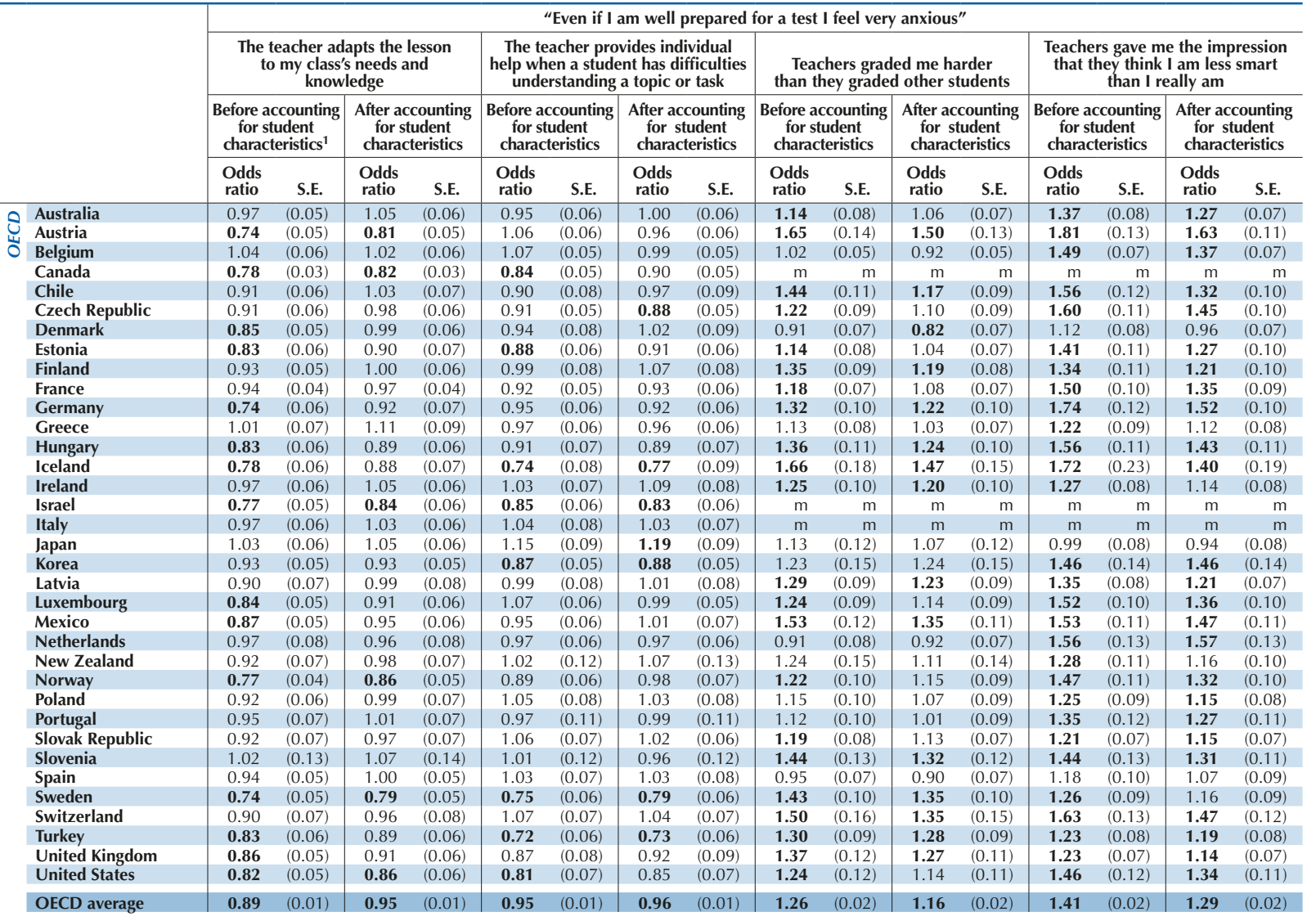

\begin{tabular}{|c|c|c|c|c|c|c|c|c|c|c|c|c|c|c|c|c|c|}
\hline in & Albania & $\mathrm{m}$ & $\mathrm{m}$ & $\mathrm{m}$ & $m$ & $\mathrm{~m}$ & $\mathrm{~m}$ & $\mathrm{~m}$ & $\mathrm{~m}$ & $\mathrm{~m}$ & $\mathrm{~m}$ & $\mathrm{~m}$ & $\mathrm{~m}$ & $\mathrm{~m}$ & $\mathrm{~m}$ & $\mathrm{~m}$ & $\mathrm{~m}$ \\
\hline § & Algeria & $\mathrm{m}$ & $\mathrm{m}$ & $\mathrm{m}$ & $\mathrm{m}$ & $\mathrm{m}$ & $\mathrm{m}$ & $\mathrm{m}$ & $\mathrm{m}$ & $\mathrm{m}$ & $\mathrm{m}$ & $\mathrm{m}$ & $\mathrm{m}$ & $\mathrm{m}$ & $\mathrm{m}$ & $\mathrm{m}$ & $\mathrm{m}$ \\
\hline I & Brazil & 0.99 & $(0.06)$ & 1.16 & $(0.07)$ & 1.26 & $(0.09)$ & 1.36 & $(0.11)$ & 1.00 & $(0.07)$ & 0.87 & $(0.07)$ & 1.03 & $(0.07)$ & 0.94 & $(0.07)$ \\
\hline & B-S-J-G (China) & 0.88 & $(0.05)$ & 0.96 & $(0.06)$ & 0.92 & $(0.08)$ & 1.00 & $(0.08)$ & 1.29 & $(0.08)$ & 1.22 & $(0.07)$ & 1.43 & $(0.08)$ & 1.41 & $(0.08)$ \\
\hline & Bulgaria & 0.94 & $(0.06)$ & 0.97 & $(0.06)$ & 0.87 & $(0.06)$ & 0.85 & $(0.06)$ & 1.05 & $(0.07)$ & 1.06 & $(0.07)$ & 1.30 & $(0.09)$ & 1.28 & $(0.09)$ \\
\hline & CABA (Argentina) & $\mathrm{m}$ & $\mathrm{m}$ & $\mathrm{m}$ & $\mathrm{m}$ & $\mathrm{m}$ & $\mathrm{m}$ & $\mathrm{m}$ & $\mathrm{m}$ & $\mathrm{m}$ & $\mathrm{m}$ & $\mathrm{m}$ & $\mathrm{m}$ & $\mathrm{m}$ & $\mathrm{m}$ & $\mathrm{m}$ & $\mathrm{m}$ \\
\hline & Colombia & 1.08 & $(0.06)$ & 1.19 & $(0.07)$ & 1.22 & $(0.09)$ & 1.25 & $(0.09)$ & 0.82 & $(0.06)$ & 0.83 & $(0.06)$ & 0.93 & $(0.10)$ & 0.86 & $(0.10)$ \\
\hline & Costa Rica & 1.15 & $(0.09)$ & 1.23 & $(0.10)$ & 0.99 & $(0.12)$ & 1.04 & $(0.13)$ & 0.99 & $(0.09)$ & 0.96 & $(0.09)$ & 0.89 & $(0.11)$ & 0.80 & $(0.10)$ \\
\hline & Croatia & 0.84 & $(0.05)$ & 0.87 & $(0.06)$ & 0.81 & $(0.05)$ & 0.79 & $(0.05)$ & 1.32 & $(0.09)$ & 1.26 & $(0.09)$ & 1.60 & $(0.10)$ & 1.54 & $(0.10)$ \\
\hline & Cyprus* & 0.97 & $(0.06)$ & 1.06 & $(0.07)$ & 0.83 & $(0.06)$ & 0.90 & $(0.07)$ & 1.37 & $(0.08)$ & 1.26 & $(0.08)$ & 1.42 & $(0.09)$ & 1.29 & $(0.09)$ \\
\hline & Dominican Republic & 1.24 & $(0.12)$ & 1.32 & $(0.12)$ & 0.99 & $(0.12)$ & 0.99 & $(0.12)$ & 1.32 & $(0.14)$ & 1.26 & $(0.14)$ & 1.13 & $(0.14)$ & 1.08 & $(0.14)$ \\
\hline & FYROM & $\mathrm{m}$ & $\mathrm{m}$ & $\mathrm{m}$ & $\mathrm{m}$ & $\mathrm{m}$ & $\mathrm{m}$ & $\mathrm{m}$ & $\mathrm{m}$ & $\mathrm{m}$ & $\mathrm{m}$ & $\mathrm{m}$ & $\mathrm{m}$ & $\mathrm{m}$ & $\mathrm{m}$ & $\mathrm{m}$ & $\mathrm{m}$ \\
\hline & Georgia & $\mathrm{m}$ & $\mathrm{m}$ & $\mathrm{m}$ & $\mathrm{m}$ & $\mathrm{m}$ & $\mathrm{m}$ & $\mathrm{m}$ & $\mathrm{m}$ & $\mathrm{m}$ & $\mathrm{m}$ & $\mathrm{m}$ & $\mathrm{m}$ & $\mathrm{m}$ & $\mathrm{m}$ & $\mathrm{m}$ & $\mathrm{m}$ \\
\hline & Hong Kong (China) & 0.87 & $(0.06)$ & 0.92 & $(0.06)$ & 0.99 & $(0.09)$ & 1.05 & $(0.10)$ & 1.15 & $(0.08)$ & 1.08 & $(0.07)$ & 1.09 & $(0.09)$ & 1.03 & $(0.08)$ \\
\hline & Indonesia & $\mathrm{m}$ & $\mathrm{m}$ & $\mathrm{m}$ & $\mathrm{m}$ & $\mathrm{m}$ & $\mathrm{m}$ & $\mathrm{m}$ & $\mathrm{m}$ & $\mathrm{m}$ & $\mathrm{m}$ & $\mathrm{m}$ & $\mathrm{m}$ & $\mathrm{m}$ & $\mathrm{m}$ & $\mathrm{m}$ & $\mathrm{m}$ \\
\hline & Jordan & $\mathrm{m}$ & $\mathrm{m}$ & $\mathrm{m}$ & $\mathrm{m}$ & $\mathrm{m}$ & $\mathrm{m}$ & $\mathrm{m}$ & $\mathrm{m}$ & $\mathrm{m}$ & $\mathrm{m}$ & $\mathrm{m}$ & $\mathrm{m}$ & $\mathrm{m}$ & $\mathrm{m}$ & $\mathrm{m}$ & $\mathrm{m}$ \\
\hline & Kosovo & $\mathrm{m}$ & $\mathrm{m}$ & $\mathrm{m}$ & $\mathrm{m}$ & $\mathrm{m}$ & $\mathrm{m}$ & $\mathrm{m}$ & $\mathrm{m}$ & $\mathrm{m}$ & $\mathrm{m}$ & $\mathrm{m}$ & $\mathrm{m}$ & $\mathrm{m}$ & $\mathrm{m}$ & $\mathrm{m}$ & $\mathrm{m}$ \\
\hline & Lebanon & $\mathrm{m}$ & $\mathrm{m}$ & $\mathrm{m}$ & $\mathrm{m}$ & $\mathrm{m}$ & $\mathrm{m}$ & $\mathrm{m}$ & $\mathrm{m}$ & $\mathrm{m}$ & $\mathrm{m}$ & $\mathrm{m}$ & $\mathrm{m}$ & $\mathrm{m}$ & $\mathrm{m}$ & $\mathrm{m}$ & $\mathrm{m}$ \\
\hline & Lithuania & 0.89 & $(0.05)$ & 0.91 & $(0.05)$ & 0.94 & $(0.06)$ & 0.96 & $(0.06)$ & 1.25 & $(0.08)$ & 1.21 & $(0.08)$ & 1.26 & $(0.08)$ & 1.20 & $(0.07)$ \\
\hline & Macao (China) & 0.96 & $(0.07)$ & 1.03 & $(0.08)$ & 0.78 & $(0.06)$ & 0.82 & $(0.06)$ & 1.31 & $(0.12)$ & 1.22 & $(0.12)$ & 1.61 & $(0.13)$ & 1.52 & $(0.12)$ \\
\hline & Malta & $\mathrm{m}$ & $\mathrm{m}$ & $\mathrm{m}$ & $\mathrm{m}$ & $\mathrm{m}$ & $\mathrm{m}$ & $\mathrm{m}$ & $\mathrm{m}$ & $\mathrm{m}$ & $\mathrm{m}$ & $\mathrm{m}$ & $\mathrm{m}$ & $\mathrm{m}$ & $\mathrm{m}$ & $\mathrm{m}$ & $\mathrm{m}$ \\
\hline & Moldova & $\mathrm{m}$ & $\mathrm{m}$ & $\mathrm{m}$ & $\mathrm{m}$ & $\mathrm{m}$ & $\mathrm{m}$ & $\mathrm{m}$ & $\mathrm{m}$ & $\mathrm{m}$ & $\mathrm{m}$ & $\mathrm{m}$ & $\mathrm{m}$ & $\mathrm{m}$ & $\mathrm{m}$ & $\mathrm{m}$ & $\mathrm{m}$ \\
\hline & Montenegro & 1.06 & $(0.07)$ & 1.08 & $(0.07)$ & 1.04 & $(0.08)$ & 0.99 & $(0.08)$ & 1.25 & $(0.09)$ & 1.25 & $(0.09)$ & 1.22 & $(0.09)$ & 1.21 & $(0.09)$ \\
\hline & Peru & 1.01 & $(0.06)$ & 1.02 & $(0.06)$ & 1.10 & $(0.10)$ & 1.11 & $(0.10)$ & 1.11 & $(0.07)$ & 1.07 & $(0.08)$ & 1.20 & $(0.09)$ & 1.16 & $(0.08)$ \\
\hline & Qatar & 1.07 & $(0.04)$ & 1.09 & $(0.05)$ & 0.82 & $(0.05)$ & 0.83 & $(0.05)$ & 1.28 & $(0.06)$ & 1.27 & $(0.06)$ & 1.37 & $(0.07)$ & 1.35 & $(0.07)$ \\
\hline & Romania & $\mathrm{m}$ & $\mathrm{m}$ & $\mathrm{m}$ & $\mathrm{m}$ & $\mathrm{m}$ & $\mathrm{m}$ & $\mathrm{m}$ & $\mathrm{m}$ & $\mathrm{m}$ & $\mathrm{m}$ & $\mathrm{m}$ & $\mathrm{m}$ & $\mathrm{m}$ & $\mathrm{m}$ & $\mathrm{m}$ & $\mathrm{m}$ \\
\hline & Russia & 0.97 & $(0.06)$ & 1.09 & $(0.07)$ & 1.02 & $(0.08)$ & 1.04 & $(0.08)$ & 1.21 & $(0.07)$ & 1.14 & $(0.07)$ & 1.32 & $(0.10)$ & 1.22 & $(0.10)$ \\
\hline & Singapore & 0.72 & $(0.05)$ & 0.80 & $(0.06)$ & 0.80 & $(0.08)$ & 0.88 & $(0.09)$ & 1.18 & $(0.12)$ & 0.99 & $(0.10)$ & 1.51 & $(0.13)$ & 1.39 & $(0.13)$ \\
\hline & Chinese Taipei & 0.98 & $(0.06)$ & 0.98 & $(0.06)$ & 0.96 & $(0.06)$ & 0.99 & $(0.06)$ & 1.09 & $(0.12)$ & 1.06 & $(0.12)$ & 1.27 & $(0.09)$ & 1.23 & $(0.09)$ \\
\hline & Thailand & 0.87 & $(0.06)$ & 0.90 & $(0.06)$ & 0.80 & $(0.06)$ & 0.84 & $(0.07)$ & 1.52 & $(0.11)$ & 1.41 & $(0.10)$ & 1.63 & $(0.11)$ & 1.52 & $(0.11)$ \\
\hline & Trinidad and Tobago & $\mathrm{m}$ & $\mathrm{m}$ & $\mathrm{m}$ & $\mathrm{m}$ & $\mathrm{m}$ & $\mathrm{m}$ & $\mathrm{m}$ & $\mathrm{m}$ & $\mathrm{m}$ & $\mathrm{m}$ & $\mathrm{m}$ & $\mathrm{m}$ & $\mathrm{m}$ & $\mathrm{m}$ & $\mathrm{m}$ & $\mathrm{m}$ \\
\hline & Tunisia & 0.98 & $(0.07)$ & 1.04 & $(0.07)$ & 0.98 & $(0.08)$ & 0.95 & $(0.08)$ & 1.30 & $(0.12)$ & 1.16 & $(0.10)$ & 1.52 & $(0.11)$ & 1.40 & $(0.10)$ \\
\hline & United Arab Emirates & 0.86 & $(0.04)$ & 0.89 & $(0.04)$ & 0.78 & $(0.05)$ & 0.81 & $(0.05)$ & 1.32 & $(0.08)$ & 1.27 & $(0.08)$ & 1.57 & $(0.10)$ & 1.51 & $(0.10)$ \\
\hline & Uruguay & 1.05 & $(0.08)$ & 1.09 & $(0.08)$ & 1.16 & $(0.10)$ & 1.15 & $(0.10)$ & 1.08 & $(0.07)$ & 1.07 & $(0.07)$ & 0.85 & $(0.08)$ & 0.82 & $(0.08)$ \\
\hline & Viet Nam & $\mathrm{m}$ & $\mathrm{m}$ & $\mathrm{m}$ & $\mathrm{m}$ & $\mathrm{m}$ & $\mathrm{m}$ & $\mathrm{m}$ & $\mathrm{m}$ & $\mathrm{m}$ & $\mathrm{m}$ & $\mathrm{m}$ & $\mathrm{m}$ & $\mathrm{m}$ & $\mathrm{m}$ & $\mathrm{m}$ & $\mathrm{m}$ \\
\hline & Argentina** & $\mathrm{m}$ & $\mathrm{m}$ & $\mathrm{m}$ & $\mathrm{m}$ & $\mathrm{m}$ & $\mathrm{m}$ & $\mathrm{m}$ & $\mathrm{m}$ & $\mathrm{m}$ & $\mathrm{m}$ & $\mathrm{m}$ & $\mathrm{m}$ & $\mathrm{m}$ & $\mathrm{m}$ & $\mathrm{m}$ & $\mathrm{m}$ \\
\hline & Kazakhstan** & $\mathrm{m}$ & $\mathrm{m}$ & $\mathrm{m}$ & $\mathrm{m}$ & $\mathrm{m}$ & $\mathrm{m}$ & $\mathrm{m}$ & $\mathrm{m}$ & $\mathrm{m}$ & $\mathrm{m}$ & $\mathrm{m}$ & $\mathrm{m}$ & $\mathrm{m}$ & $\mathrm{m}$ & $\mathrm{m}$ & $\mathrm{m}$ \\
\hline & Malaysia** & 1.02 & $(0.07)$ & 1.10 & $(0.07)$ & 1.09 & $(0.11)$ & 1.17 & $(0.11)$ & 1.07 & $(0.08)$ & 1.00 & $(0.07)$ & 1.10 & $(0.08)$ & 1.03 & $(0.08)$ \\
\hline
\end{tabular}

1. Student characteristics include the PISA index of economic, social and cultural status (ESCS) and performance in science.

Note: Values that are statistically significant are indicated in bold (see Annex A3).

* See note at the beginning of this Annex.

** Coverage is too small to ensure comparability (see Annex A4).

StatLink न्ना15 http://dx.doi.org/10.1787/888933470788 
[Part 2/2]

Table III.4.11 Schoolwork-related anxiety and teachers' behaviour

Increased likelihood that students get very tense when they study

\begin{tabular}{|c|c|c|c|c|c|c|c|c|c|c|c|c|c|c|c|c|c|}
\hline & \multicolumn{16}{|c|}{ "I get very tense when I study" } \\
\hline & & The $t$ & $\begin{array}{l}\text { eacher ad } \\
\text { to my clas } \\
\text { and kno }\end{array}$ & $\begin{array}{l}\text { apts the } \\
\text { ss's needs } \\
\text { owledge }\end{array}$ & & $\begin{array}{r}\text { The te } \\
\text { help wh } \\
\text { unde }\end{array}$ & $\begin{array}{l}\text { acher prov } \\
\text { en a studen } \\
\text { standing a }\end{array}$ & $\begin{array}{l}\text { vides inc } \\
\text { nt has d } \\
\text { a topic }\end{array}$ & $\begin{array}{l}\text { idual } \\
\text { iculties } \\
\text { task }\end{array}$ & $\begin{array}{r}\text { Teac } \\
\text { than tl }\end{array}$ & $\begin{array}{l}\text { hers grade } \\
\text { ley graded }\end{array}$ & $\begin{array}{l}\text { ed me } \\
\text { d other }\end{array}$ & $\begin{array}{l}\text { der } \\
\text { dents }\end{array}$ & $\begin{array}{r}\text { Teach } \\
\text { that }\end{array}$ & $\begin{array}{l}\text { s gave m } \\
\text { ey think } \\
\text { than I re }\end{array}$ & $\begin{array}{l}\text { e the im } \\
\text { I am les. } \\
\text { eally am }\end{array}$ & $\begin{array}{l}\text { ession } \\
\text { mart }\end{array}$ \\
\hline & & $\begin{array}{r}\text { Before ac } \\
\text { for st } \\
\text { charact }\end{array}$ & $\begin{array}{l}\text { counting } \\
\text { udent } \\
\text { eristics } 1\end{array}$ & $\begin{array}{r}\text { After ac } \\
\text { for st } \\
\text { charac }\end{array}$ & $\begin{array}{l}\text { counting } \\
\text { udent } \\
\text { teristics }\end{array}$ & $\begin{array}{r}\text { Before a } \\
\text { for st } \\
\text { charac }\end{array}$ & $\begin{array}{l}\text { counting } \\
\text { Ident } \\
\text { eristics }\end{array}$ & $\begin{array}{l}\text { After a } \\
\text { for } \\
\text { chara }\end{array}$ & $\begin{array}{l}\text { counting } \\
\text { udent } \\
\text { eristics }\end{array}$ & $\begin{array}{r}\text { Before ac } \\
\text { for st } \\
\text { charac }\end{array}$ & $\begin{array}{l}\text { counting } \\
\text { udent } \\
\text { eristics }\end{array}$ & $\begin{array}{r}\text { After ac } \\
\text { for } s \\
\text { charac }\end{array}$ & $\begin{array}{l}\text { counting } \\
\text { udent } \\
\text { eristics }\end{array}$ & $\begin{array}{r}\text { Before a } \\
\text { for s } \\
\text { charac }\end{array}$ & $\begin{array}{l}\text { counting } \\
\text { udent } \\
\text { eristics }\end{array}$ & $\begin{array}{l}\text { After ac } \\
\text { for } s \\
\text { charac }\end{array}$ & $\begin{array}{l}\text { counting } \\
\text { udent } \\
\text { eristics }\end{array}$ \\
\hline & & $\begin{array}{l}\text { Odds } \\
\text { ratio }\end{array}$ & S.E. & $\begin{array}{l}\text { Odds } \\
\text { ratio }\end{array}$ & S.E. & $\begin{array}{l}\text { Odds } \\
\text { ratio }\end{array}$ & S.E. & $\begin{array}{l}\text { Odds } \\
\text { ratio }\end{array}$ & S.E. & $\begin{array}{l}\text { Odds } \\
\text { ratio }\end{array}$ & S.E. & $\begin{array}{l}\text { Odds } \\
\text { ratio }\end{array}$ & S.E. & $\begin{array}{l}\text { Odds } \\
\text { ratio }\end{array}$ & S.E. & $\begin{array}{l}\text { Odds } \\
\text { ratio }\end{array}$ & S.E. \\
\hline & Australia & 0.85 & $(0.04)$ & 0.92 & $(0.05)$ & 0.76 & $(0.05)$ & 0.81 & $(0.05)$ & 1.48 & $(0.09)$ & 1.37 & $(0.08)$ & 1.60 & $(0.08)$ & 1.48 & $(0.08)$ \\
\hline & Austria & 0.85 & $(0.06)$ & 0.92 & $(0.07)$ & 1.05 & $(0.08)$ & 0.95 & $(0.07)$ & 2.27 & $(0.19)$ & 2.08 & $(0.17)$ & 2.46 & $(0.18)$ & 2.24 & $(0.16)$ \\
\hline & Belgium & 1.03 & $(0.07)$ & 1.00 & $(0.07)$ & 1.04 & $(0.06)$ & 0.93 & $(0.06)$ & 1.36 & $(0.09)$ & 1.20 & $(0.09)$ & 1.74 & $(0.11)$ & 1.56 & $(0.11)$ \\
\hline & Canada & 0.76 & $(0.04)$ & 0.81 & $(0.04)$ & 0.71 & $(0.05)$ & 0.75 & $(0.05)$ & $\mathrm{m}$ & $\mathrm{m}$ & m & $\mathrm{m}$ & $\mathrm{m}$ & $\mathrm{m}$ & $\mathrm{m}$ & $\mathrm{m}$ \\
\hline & Chile & 0.78 & $(0.05)$ & 0.87 & $(0.06)$ & 0.73 & $(0.07)$ & 0.77 & $(0.07)$ & 1.57 & $(0.12)$ & 1.29 & $(0.10)$ & 1.94 & $(0.18)$ & 1.66 & $(0.15)$ \\
\hline & Czech Republic & 0.77 & $(0.05)$ & 0.87 & $(0.06)$ & 0.97 & $(0.06)$ & 0.91 & $(0.06)$ & 1.41 & $(0.13)$ & 1.20 & $(0.12)$ & 1.84 & $(0.13)$ & 1.53 & $(0.11)$ \\
\hline & Denmark & 0.77 & $(0.05)$ & 0.87 & $(0.05)$ & 0.83 & $(0.06)$ & 0.89 & $(0.07)$ & 1.23 & $(0.08)$ & 1.14 & $(0.08)$ & 1.51 & $(0.11)$ & 1.35 & $(0.10)$ \\
\hline & Estonia & 0.80 & $(0.06)$ & 0.90 & $(0.07)$ & 0.66 & $(0.05)$ & 0.68 & $(0.06)$ & 1.84 & $(0.12)$ & 1.64 & $(0.11)$ & 2.17 & $(0.17)$ & 1.87 & $(0.15)$ \\
\hline & Finland & 0.80 & $(0.07)$ & 0.86 & $(0.07)$ & 0.69 & $(0.07)$ & 0.76 & $(0.08)$ & 1.73 & $(0.18)$ & 1.49 & $(0.15)$ & 1.78 & $(0.19)$ & 1.58 & $(0.17)$ \\
\hline & France & 0.98 & $(0.06)$ & 1.02 & $(0.06)$ & 0.78 & (0.05) & 0.78 & $(0.05)$ & 1.50 & $(0.12)$ & 1.32 & $(0.10)$ & 1.58 & $(0.11)$ & 1.36 & $(0.10)$ \\
\hline & Germany & 0.66 & $(0.06)$ & 0.73 & $(0.07)$ & 0.75 & $(0.05)$ & 0.73 & $(0.05)$ & 2.01 & $(0.16)$ & 1.93 & $(0.15)$ & 2.26 & $(0.18)$ & 2.10 & $(0.17)$ \\
\hline & Greece & 0.85 & $(0.06)$ & 0.91 & $(0.06)$ & 0.79 & $(0.05)$ & 0.78 & $(0.06)$ & 1.51 & $(0.12)$ & 1.40 & $(0.11)$ & 1.74 & $(0.13)$ & 1.60 & $(0.12)$ \\
\hline & Hungary & 0.78 & $(0.06)$ & 0.86 & $(0.07)$ & 0.90 & $(0.06)$ & 0.87 & $(0.07)$ & 1.88 & $(0.13)$ & 1.68 & $(0.12)$ & 1.99 & $(0.13)$ & 1.78 & $(0.12)$ \\
\hline & Iceland & 0.76 & $(0.05)$ & 0.84 & $(0.06)$ & 0.62 & $(0.07)$ & 0.64 & $(0.07)$ & 1.93 & $(0.21)$ & 1.72 & $(0.18)$ & 2.26 & $(0.32)$ & 1.90 & $(0.27)$ \\
\hline & Ireland & 0.86 & $(0.05)$ & 0.93 & $(0.05)$ & 0.80 & $(0.05)$ & 0.84 & $(0.05)$ & 1.52 & $(0.12)$ & 1.46 & $(0.12)$ & 1.66 & $(0.11)$ & 1.51 & $(0.10)$ \\
\hline & Israel & 0.72 & $(0.04)$ & 0.78 & $(0.05)$ & 0.76 & $(0.05)$ & 0.75 & $(0.05)$ & $\mathrm{m}$ & $\mathrm{m}$ & $\mathrm{m}$ & $\mathrm{m}$ & $\mathrm{m}$ & $\mathrm{m}$ & $\mathrm{m}$ & $\mathrm{m}$ \\
\hline & Italy & 1.00 & $(0.05)$ & 1.07 & $(0.06)$ & 0.95 & $(0.06)$ & 0.94 & $(0.06)$ & $\mathrm{m}$ & $\mathrm{m}$ & $\mathrm{m}$ & $\mathrm{m}$ & $\mathrm{m}$ & $\mathrm{m}$ & $\mathrm{m}$ & $\mathrm{m}$ \\
\hline & Japan & 1.18 & $(0.07)$ & 1.17 & $(0.07)$ & 1.05 & $(0.08)$ & 1.05 & $(0.08)$ & 1.34 & $(0.15)$ & 1.36 & $(0.15)$ & 1.17 & $(0.12)$ & 1.18 & $(0.12)$ \\
\hline & Korea & 0.95 & $(0.05)$ & 0.97 & $(0.05)$ & 0.93 & $(0.06)$ & 0.94 & $(0.06)$ & 1.35 & $(0.15)$ & 1.32 & $(0.14)$ & 1.23 & $(0.09)$ & 1.21 & $(0.09)$ \\
\hline & Latvia & 0.79 & (0.05) & 0.89 & $(0.06)$ & 0.87 & $(0.06)$ & 0.89 & $(0.07)$ & 1.15 & $(0.10)$ & 1.09 & $(0.09)$ & 1.35 & $(0.10)$ & 1.18 & $(0.09)$ \\
\hline & Luxembourg & 0.90 & $(0.06)$ & 1.00 & $(0.07)$ & 1.24 & $(0.10)$ & 1.13 & $(0.09)$ & 1.59 & $(0.14)$ & 1.43 & $(0.12)$ & 1.97 & $(0.14)$ & 1.71 & $(0.13)$ \\
\hline & Mexico & 0.82 & $(0.05)$ & 0.90 & $(0.05)$ & 0.80 & $(0.07)$ & 0.84 & $(0.07)$ & 1.63 & $(0.10)$ & 1.44 & $(0.09)$ & 1.58 & $(0.11)$ & 1.52 & $(0.11)$ \\
\hline & Netherlands & 0.81 & $(0.09)$ & 0.88 & $(0.10)$ & 0.85 & $(0.08)$ & 0.81 & $(0.08)$ & 1.32 & $(0.15)$ & 1.21 & $(0.13)$ & 2.27 & $(0.24)$ & 2.18 & $(0.23)$ \\
\hline & New Zealand & 0.89 & $(0.06)$ & 0.96 & $(0.06)$ & 0.88 & $(0.09)$ & 0.93 & $(0.10)$ & 1.57 & $(0.14)$ & 1.33 & $(0.12)$ & 1.77 & $(0.13)$ & 1.53 & $(0.12)$ \\
\hline & Norway & 0.67 & $(0.04)$ & 0.76 & $(0.05)$ & 0.69 & $(0.05)$ & 0.77 & $(0.06)$ & 1.64 & $(0.10)$ & 1.52 & $(0.10)$ & 1.83 & $(0.12)$ & 1.59 & $(0.11)$ \\
\hline & Poland & 0.77 & $(0.06)$ & 0.84 & $(0.07)$ & 0.74 & $(0.07)$ & 0.72 & $(0.07)$ & 1.46 & $(0.13)$ & 1.35 & $(0.12)$ & 1.81 & $(0.14)$ & 1.66 & $(0.13)$ \\
\hline & Portugal & 0.91 & $(0.05)$ & 0.97 & $(0.06)$ & 0.88 & $(0.11)$ & 0.88 & $(0.11)$ & 1.49 & $(0.11)$ & 1.36 & $(0.11)$ & 1.67 & $(0.12)$ & 1.58 & $(0.12)$ \\
\hline & Slovak Republic & 0.99 & $(0.06)$ & 1.08 & $(0.07)$ & 1.02 & $(0.07)$ & 0.95 & $(0.06)$ & 1.36 & $(0.10)$ & 1.25 & $(0.09)$ & 1.48 & $(0.11)$ & 1.38 & $(0.10)$ \\
\hline & Slovenia & 1.06 & $(0.15)$ & 1.13 & $(0.16)$ & 0.73 & $(0.07)$ & 0.68 & $(0.07)$ & 1.70 & $(0.14)$ & 1.57 & $(0.12)$ & 1.73 & $(0.13)$ & 1.58 & $(0.12)$ \\
\hline & Spain & 0.83 & $(0.04)$ & 0.88 & $(0.05)$ & 0.86 & $(0.05)$ & 0.85 & $(0.05)$ & 1.10 & $(0.08)$ & 1.03 & $(0.07)$ & 1.52 & $(0.09)$ & 1.35 & $(0.08)$ \\
\hline & Sweden & 0.71 & $(0.04)$ & 0.78 & $(0.05)$ & 0.60 & $(0.04)$ & 0.65 & $(0.04)$ & 1.83 & $(0.12)$ & 1.67 & $(0.11)$ & 2.01 & $(0.14)$ & 1.80 & $(0.13)$ \\
\hline & Switzerland & 0.88 & $(0.08)$ & 0.93 & $(0.08)$ & 0.90 & $(0.05)$ & 0.88 & $(0.05)$ & 1.94 & $(0.20)$ & 1.74 & $(0.19)$ & 1.79 & $(0.16)$ & 1.61 & $(0.14)$ \\
\hline & Turkey & 0.82 & $(0.05)$ & 0.84 & $(0.06)$ & 0.78 & $(0.06)$ & 0.79 & $(0.06)$ & 1.66 & $(0.12)$ & 1.66 & $(0.11)$ & 1.42 & $(0.10)$ & 1.40 & $(0.10)$ \\
\hline & United Kingdom & 0.87 & $(0.05)$ & 0.92 & $(0.06)$ & 0.77 & $(0.07)$ & 0.81 & $(0.08)$ & 1.65 & $(0.14)$ & 1.54 & $(0.13)$ & 1.54 & $(0.10)$ & 1.44 & $(0.10)$ \\
\hline & United States & 0.78 & $(0.04)$ & 0.82 & $(0.04)$ & 0.83 & $(0.07)$ & 0.88 & $(0.08)$ & 1.48 & $(0.12)$ & 1.35 & $(0.11)$ & 1.92 & $(0.15)$ & 1.75 & $(0.14)$ \\
\hline & OECD average & 0.85 & $(0.01)$ & 0.91 & $(0.01)$ & 0.83 & $(0.01)$ & 0.83 & $(0.01)$ & 1.58 & $(0.02)$ & 1.44 & $(0.02)$ & 1.77 & $(0.03)$ & 1.60 & $(0.02)$ \\
\hline an & Albania & $\mathrm{m}$ & $\mathrm{m}$ & $\mathrm{m}$ & $\mathrm{m}$ & $\mathrm{m}$ & $\mathrm{m}$ & $\mathrm{m}$ & $\mathrm{m}$ & $\mathrm{m}$ & $\mathrm{m}$ & $\mathrm{m}$ & $\mathrm{m}$ & $\mathrm{m}$ & $\mathrm{m}$ & $\mathrm{m}$ & $\mathrm{m}$ \\
\hline ¿ & Algeria & $\mathrm{m}$ & $\mathrm{m}$ & $\mathrm{m}$ & $\mathrm{m}$ & $\mathrm{m}$ & $\mathrm{m}$ & $\mathrm{m}$ & $\mathrm{m}$ & $\mathrm{m}$ & $\mathrm{m}$ & $\mathrm{m}$ & $\mathrm{m}$ & $\mathrm{m}$ & $\mathrm{m}$ & m & $\mathrm{m}$ \\
\hline & Brazil & 0.87 & $(0.04)$ & 1.02 & $(0.05)$ & 1.04 & $(0.06)$ & 1.12 & $(0.07)$ & 1.31 & $(0.07)$ & 1.15 & $(0.07)$ & 1.40 & $(0.07)$ & 1.27 & $(0.06)$ \\
\hline & B-S-J-G (China) & 0.93 & $(0.05)$ & 1.03 & $(0.06)$ & 0.96 & $(0.09)$ & 1.05 & $(0.09)$ & 1.31 & $(0.08)$ & 1.24 & $(0.07)$ & 1.29 & $(0.08)$ & 1.27 & $(0.08)$ \\
\hline & Bulgaria & 0.87 & $(0.05)$ & 0.92 & $(0.06)$ & 0.96 & $(0.06)$ & 0.93 & $(0.06)$ & 1.12 & $(0.05)$ & 1.14 & $(0.05)$ & 1.39 & $(0.08)$ & 1.36 & $(0.08)$ \\
\hline & CABA (Argentina) & $\mathrm{m}$ & $\mathrm{m}$ & $\mathrm{m}$ & $\mathrm{m}$ & $\mathrm{m}$ & $\mathrm{m}$ & $\mathrm{m}$ & $\mathrm{m}$ & $\mathrm{m}$ & $\mathrm{m}$ & $\mathrm{m}$ & $\mathrm{m}$ & $\mathrm{m}$ & $\mathrm{m}$ & m & $\mathrm{m}$ \\
\hline & Colombia & 0.84 & $(0.04)$ & 0.89 & $(0.05)$ & 0.81 & $(0.05)$ & 0.82 & $(0.06)$ & 1.27 & $(0.08)$ & 1.27 & $(0.08)$ & 1.48 & $(0.13)$ & 1.41 & $(0.13)$ \\
\hline & Costa Rica & 0.78 & $(0.05)$ & 0.85 & $(0.05)$ & 0.71 & $(0.07)$ & 0.75 & $(0.07)$ & 1.41 & $(0.12)$ & 1.38 & $(0.12)$ & 1.68 & $(0.17)$ & 1.49 & $(0.15)$ \\
\hline & Croatia & 0.79 & $(0.04)$ & 0.82 & $(0.04)$ & 0.84 & $(0.05)$ & 0.81 & $(0.04)$ & 1.65 & $(0.10)$ & 1.55 & $(0.10)$ & 1.92 & $(0.13)$ & 1.85 & $(0.13)$ \\
\hline & Cyprus* & 0.78 & $(0.05)$ & 0.86 & $(0.05)$ & 0.59 & $(0.04)$ & 0.64 & $(0.05)$ & 1.67 & $(0.11)$ & 1.53 & $(0.10)$ & 1.77 & $(0.11)$ & 1.59 & $(0.10)$ \\
\hline & Dominican Republic & 0.96 & $(0.06)$ & 1.03 & $(0.07)$ & 0.82 & $(0.08)$ & 0.82 & $(0.09)$ & 1.15 & $(0.09)$ & 1.09 & $(0.09)$ & 1.63 & $(0.16)$ & 1.56 & $(0.15)$ \\
\hline & FYROM & $\mathrm{m}$ & $\mathrm{m}$ & $\mathrm{m}$ & $\mathrm{m}$ & $\mathrm{m}$ & $\mathrm{m}$ & $\mathrm{m}$ & $\mathrm{m}$ & $\mathrm{m}$ & $\mathrm{m}$ & $\mathrm{m}$ & $\mathrm{m}$ & $\mathrm{m}$ & $\mathrm{m}$ & $\mathrm{m}$ & $\mathrm{m}$ \\
\hline & Georgia & $\mathrm{m}$ & $\mathrm{m}$ & $\mathrm{m}$ & $\mathrm{m}$ & $\mathrm{m}$ & $\mathrm{m}$ & $\mathrm{m}$ & $\mathrm{m}$ & $\mathrm{m}$ & $\mathrm{m}$ & $\mathrm{m}$ & $\mathrm{m}$ & $\mathrm{m}$ & $\mathrm{m}$ & m & $\mathrm{m}$ \\
\hline & Hong Kong (China) & 0.80 & $(0.06)$ & 0.86 & $(0.07)$ & 0.81 & $(0.08)$ & 0.88 & $(0.09)$ & 1.30 & $(0.08)$ & 1.20 & $(0.08)$ & 1.13 & $(0.07)$ & 1.05 & $(0.06)$ \\
\hline & Indonesia & $\mathrm{m}$ & $\mathrm{m}$ & $\mathrm{m}$ & $\mathrm{m}$ & $\mathrm{m}$ & $\mathrm{m}$ & $\mathrm{m}$ & $\mathrm{m}$ & $\mathrm{m}$ & $\mathrm{m}$ & $\mathrm{m}$ & $\mathrm{m}$ & $\mathrm{m}$ & $\mathrm{m}$ & $\mathrm{m}$ & $\mathrm{m}$ \\
\hline & Jordan & $\mathrm{m}$ & $\mathrm{m}$ & $\mathrm{m}$ & $\mathrm{m}$ & $\mathrm{m}$ & $\mathrm{m}$ & $\mathrm{m}$ & $\mathrm{m}$ & $\mathrm{m}$ & $\mathrm{m}$ & $\mathrm{m}$ & $\mathrm{m}$ & $\mathrm{m}$ & $\mathrm{m}$ & $\mathrm{m}$ & $\mathrm{m}$ \\
\hline & Kosovo & $\mathrm{m}$ & $\mathrm{m}$ & $\mathrm{m}$ & $\mathrm{m}$ & $\mathrm{m}$ & $\mathrm{m}$ & $\mathrm{m}$ & $\mathrm{m}$ & $\mathrm{m}$ & $\mathrm{m}$ & $\mathrm{m}$ & $\mathrm{m}$ & $\mathrm{m}$ & $\mathrm{m}$ & $\mathrm{m}$ & $\mathrm{m}$ \\
\hline & Lebanon & $\mathrm{m}$ & $\mathrm{m}$ & $\mathrm{m}$ & $\mathrm{m}$ & $\mathrm{m}$ & $\mathrm{m}$ & $\mathrm{m}$ & $\mathrm{m}$ & $\mathrm{m}$ & $\mathrm{m}$ & $\mathrm{m}$ & $\mathrm{m}$ & $\mathrm{m}$ & $\mathrm{m}$ & m & $\mathrm{m}$ \\
\hline & Lithuania & 0.85 & $(0.06)$ & 0.89 & $(0.07)$ & 0.79 & $(0.06)$ & 0.83 & $(0.07)$ & 1.47 & $(0.10)$ & 1.39 & $(0.10)$ & 1.59 & $(0.11)$ & 1.43 & $(0.10)$ \\
\hline & Macao (China) & 0.85 & $(0.06)$ & 0.93 & $(0.07)$ & 0.71 & $(0.05)$ & 0.76 & $(0.06)$ & 1.34 & $(0.10)$ & 1.21 & $(0.09)$ & 1.70 & $(0.12)$ & 1.57 & $(0.11)$ \\
\hline & Malta & $\mathrm{m}$ & $\mathrm{m}$ & $\mathrm{m}$ & $\mathrm{m}$ & $\mathrm{m}$ & $\mathrm{m}$ & $\mathrm{m}$ & $\mathrm{m}$ & $\mathrm{m}$ & $\mathrm{m}$ & $\mathrm{m}$ & $\mathrm{m}$ & $\mathrm{m}$ & $\mathrm{m}$ & $\mathrm{m}$ & $\mathrm{m}$ \\
\hline & Moldova & $\mathrm{m}$ & $\mathrm{m}$ & $\mathrm{m}$ & $\mathrm{m}$ & $\mathrm{m}$ & $\mathrm{m}$ & $\mathrm{m}$ & $\mathrm{m}$ & $\mathrm{m}$ & $\mathrm{m}$ & $\mathrm{m}$ & $\mathrm{m}$ & $\mathrm{m}$ & $\mathrm{m}$ & m & $\mathrm{m}$ \\
\hline & Montenegro & 0.97 & $(0.07)$ & 0.99 & $(0.07)$ & 1.00 & $(0.06)$ & 0.93 & $(0.06)$ & 1.32 & $(0.10)$ & 1.31 & $(0.10)$ & 1.41 & $(0.10)$ & 1.38 & $(0.10)$ \\
\hline & Peru & 0.87 & $(0.05)$ & 0.88 & $(0.05)$ & 0.98 & $(0.10)$ & 0.99 & $(0.10)$ & 1.27 & $(0.07)$ & 1.22 & $(0.07)$ & 1.64 & $(0.09)$ & 1.55 & $(0.09)$ \\
\hline & Qatar & 0.86 & $(0.03)$ & 0.96 & $(0.04)$ & 0.67 & $(0.04)$ & 0.74 & $(0.04)$ & 1.49 & $(0.07)$ & 1.32 & $(0.06)$ & 1.74 & $(0.09)$ & 1.55 & $(0.08)$ \\
\hline & Romania & $\mathrm{m}$ & $\mathrm{m}$ & $\mathrm{m}$ & $\mathrm{m}$ & $\mathrm{m}$ & $\mathrm{m}$ & $\mathrm{m}$ & $\mathrm{m}$ & $\mathrm{m}$ & $\mathrm{m}$ & $\mathrm{m}$ & $\mathrm{m}$ & $\mathrm{m}$ & $\mathrm{m}$ & $\mathbf{m}$ & $\mathrm{m}$ \\
\hline & Russia & 1.05 & $(0.07)$ & 1.18 & $(0.08)$ & 1.04 & $(0.07)$ & 1.05 & $(0.07)$ & 1.28 & $(0.07)$ & 1.22 & $(0.07)$ & 1.42 & $(0.10)$ & 1.32 & $(0.10)$ \\
\hline & Singapore & 0.69 & $(0.03)$ & 0.80 & $(0.04)$ & 0.73 & $(0.06)$ & 0.83 & $(0.07)$ & 1.37 & $(0.12)$ & 1.07 & $(0.09)$ & 1.74 & $(0.15)$ & 1.54 & $(0.14)$ \\
\hline & Chinese Taipei & 1.06 & $(0.06)$ & 1.07 & $(0.06)$ & 0.98 & $(0.07)$ & 1.03 & $(0.08)$ & 1.16 & $(0.11)$ & 1.12 & $(0.11)$ & 1.12 & $(0.08)$ & 1.06 & $(0.07)$ \\
\hline & Thailand & 0.88 & $(0.05)$ & 0.90 & $(0.06)$ & 0.75 & $(0.05)$ & 0.78 & $(0.05)$ & 1.57 & $(0.10)$ & 1.48 & $(0.10)$ & 1.79 & $(0.12)$ & 1.69 & $(0.11)$ \\
\hline & Trinidad and Tobago & $\mathrm{m}$ & $\mathrm{m}$ & $\mathrm{m}$ & $\mathrm{m}$ & $\mathrm{m}$ & $\mathrm{m}$ & $\mathrm{m}$ & $\mathrm{m}$ & $\mathrm{m}$ & $\mathrm{m}$ & $\mathrm{m}$ & $\mathrm{m}$ & $\mathrm{m}$ & $\mathrm{m}$ & $\mathbf{m}$ & $\mathrm{m}$ \\
\hline & Tunisia & 0.91 & $(0.06)$ & 0.97 & $(0.07)$ & 0.92 & $(0.07)$ & 0.89 & $(0.07)$ & 1.28 & $(0.11)$ & 1.14 & $(0.10)$ & 1.49 & $(0.11)$ & 1.36 & $(0.11)$ \\
\hline & Unite & 0.78 & $(0.03)$ & 0.85 & $(0.04)$ & 0.67 & $(0.04)$ & 0.72 & $(0.04)$ & 1.56 & $(0.08)$ & 1.42 & $(0.08)$ & 1.74 & $(0.10)$ & 1.60 & $(0.09)$ \\
\hline & Uruguay & 0.93 & $(0.06)$ & 1.12 & $(0.07)$ & 1.10 & $(0.09)$ & 1.07 & $(0.09)$ & 1.14 & $(0.08)$ & 1.14 & $(0.08)$ & 1.34 & $(0.13)$ & 1.12 & $(0.11)$ \\
\hline & Viet Nam & $\mathrm{m}$ & $\mathrm{m}$ & $\mathrm{m}$ & $\mathrm{m}$ & $\mathrm{m}$ & $\mathrm{m}$ & $\mathrm{m}$ & $\mathrm{m}$ & $\mathrm{m}$ & $\mathrm{m}$ & $\mathrm{m}$ & $\mathrm{m}$ & $\mathrm{m}$ & $\mathrm{m}$ & $\mathrm{m}$ & $\mathrm{m}$ \\
\hline & Argentina** & $\mathrm{m}$ & $\mathrm{m}$ & $\mathrm{m}$ & $\mathrm{m}$ & $\mathrm{m}$ & $\mathrm{m}$ & $\mathrm{m}$ & $\mathrm{m}$ & $\mathrm{m}$ & $\mathrm{m}$ & $\mathrm{m}$ & $\mathrm{m}$ & $\mathrm{m}$ & $\mathrm{m}$ & m & $\mathrm{m}$ \\
\hline & Kazakhstan** & $\mathrm{m}$ & $\mathrm{m}$ & $\mathrm{m}$ & $\mathrm{m}$ & $\mathrm{m}$ & $\mathrm{m}$ & $\mathrm{m}$ & $\mathrm{m}$ & $\mathrm{m}$ & $\mathrm{m}$ & $\mathrm{m}$ & $\mathrm{m}$ & $\mathrm{m}$ & $\mathrm{m}$ & $\mathrm{m}$ & $\mathrm{m}$ \\
\hline & Malaysia** & 0.90 & $(0.06)$ & 0.93 & $(0.06)$ & 0.57 & $(0.05)$ & 0.59 & $(0.05)$ & 1.11 & $(0.06)$ & 1.06 & $(0.06)$ & 1.46 & $(0.08)$ & 1.40 & $(0.08)$ \\
\hline
\end{tabular}

1. Student characteristics include the PISA index of economic, social and cultural status (ESCS) and performance in science.

Note: Values that are statistically significant are indicated in bold (see Annex A3).

* See note at the beginning of this Annex.

** Coverage is too small to ensure comparability (see Annex A4).

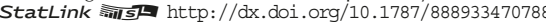




\begin{tabular}{|c|c|c|c|c|c|c|c|c|c|c|c|c|c|c|c|c|c|c|c|c|}
\hline & & & & & & & & & Percer & tage & of stud & ents w & ho rep & ported & the fol & Ilowing & g stater & ments & & \\
\hline & & & I wa & ant top & frade $\mathrm{my}$ & es in & nost & & & & $\begin{array}{l}\text { want to } \\
\text { st oppo }\end{array}$ & be ab & le to & eles & om & & & & I wan & nt to be \\
\hline & & $\begin{array}{l}\text { Stro } \\
\text { disa }\end{array}$ & $\begin{array}{l}\text { ongly } \\
\text { agreee }\end{array}$ & Disa & igree & & zree & $\begin{array}{c}\text { Stro } \\
\text { agr }\end{array}$ & $\begin{array}{l}\text { ingly } \\
\text { ree }\end{array}$ & $\begin{array}{l}\text { Stro } \\
\text { disa }\end{array}$ & $\begin{array}{l}\text { ongly } \\
\text { gree }\end{array}$ & Disa & gree & $\mathrm{Ag}$ & ree & $\begin{array}{c}\text { Stro } \\
\text { agr }\end{array}$ & & $\begin{array}{l}\text { Stro } \\
\text { disa }\end{array}$ & $\begin{array}{l}\text { ingly } \\
\text { gree }\end{array}$ & Disa \\
\hline & & $\%$ & S.E. & $\%$ & S.E. & $\%$ & S.E. & $\%$ & S.E. & $\%$ & S.E. & $\%$ & S.E. & $\%$ & S.E. & $\%$ & S.E. & $\%$ & S.E. & $\%$ \\
\hline 6 & Australia & 1.5 & $(0.1)$ & 9.3 & $(0.3)$ & \begin{tabular}{|l|}
44.8 \\
\end{tabular} & $(0.5)$ & 44.4 & $(0.6)$ & 0.9 & $(0.1)$ & 3.3 & $(0.2)$ & 39.8 & $(0.5)$ & 56.0 & $\begin{array}{l}(0.6) \\
\end{array}$ & 1.3 & $(0.1)$ & \begin{tabular}{|l|}
12.1 \\
\end{tabular} \\
\hline & Austria & 4.8 & $(0.3)$ & 17.3 & $(0.5)$ & 38.6 & $(0.6)$ & 39.4 & $(0.7)$ & 1.6 & $(0.2)$ & 6.1 & $(0.3)$ & 33.3 & $(0.8)$ & 58.9 & $(0.8)$ & 17.2 & $(0.6)$ & 36.6 \\
\hline & Belgium & 4.2 & $(0.2)$ & 23.7 & $(0.4)$ & 46.3 & (0.6) & 25.8 & $(0.6)$ & 1.3 & $(0.1)$ & 6.8 & $(0.2)$ & 49.4 & (0.6) & 42.5 & (0.6) & 13.3 & $(0.3)$ & 47.3 \\
\hline & Canada & 1.5 & $(0.1)$ & 9.8 & $(0.3)$ & 41.9 & (0.5) & 46.8 & $(0.7)$ & 0.9 & $(0.1)$ & 3.7 & $(0.2)$ & 38.8 & $(0.6)$ & 56.7 & (0.6) & 2.7 & $(0.2)$ & 15.5 \\
\hline & Chile & 2.2 & $(0.2)$ & 5.6 & $(0.3)$ & 41.5 & $(0.7)$ & 50.7 & $(0.8)$ & 1.8 & $(0.2)$ & 2.4 & $(0.2)$ & 30.8 & $(0.7)$ & 65.0 & $(0.8)$ & 2.9 & $(0.2)$ & 13.6 \\
\hline & Czech Republic & 2.6 & $(0.2)$ & 16.3 & (0.6) & 55.3 & $(0.7)$ & 25.8 & $(0.7)$ & 1.3 & $(0.2)$ & 5.3 & $(0.3)$ & 53.0 & $(0.7)$ & 40.4 & $(0.7)$ & 3.1 & $(0.2)$ & 30.0 \\
\hline & Denmark & 2.9 & $(0.2)$ & 20.1 & (0.6) & 44.0 & (0.6) & 33.0 & (0.6) & 2.0 & $(0.2)$ & 14.8 & (0.6) & 45.9 & $(0.7)$ & 37.3 & $(0.8)$ & 7.7 & $(0.4)$ & 42.5 \\
\hline & Estonia & 1.4 & $(0.2)$ & 6.5 & $(0.4)$ & 46.7 & $(0.8)$ & 45.3 & $(0.7)$ & 1.3 & $(0.2)$ & 3.8 & $(0.3)$ & 44.1 & $(0.8)$ & 50.9 & $(0.7)$ & 3.6 & $(0.3)$ & 30.8 \\
\hline & Finland & 4.8 & $(0.3)$ & 34.6 & $(0.7)$ & 43.5 & (0.7) & 17.1 & $(0.6)$ & 2.6 & $(0.2)$ & 17.4 & (0.7) & 54.5 & $(0.7)$ & 25.5 & (0.9) & 13.3 & (0.5) & 50.5 \\
\hline & France & 2.4 & $(0.2)$ & 12.3 & (0.5) & 50.1 & (0.7) & 35.1 & $(0.8)$ & 1.5 & $(0.2)$ & 4.2 & (0.3) & 42.3 & $(0.7)$ & 52.0 & $(0.7)$ & 11.3 & $(0.4)$ & 41.1 \\
\hline & Germany & 3.3 & $(0.2)$ & 20.1 & (0.6) & 46.7 & (0.7) & 29.8 & $(0.7)$ & 1.2 & $(0.2)$ & 7.9 & (0.4) & 40.4 & $(0.9)$ & 50.5 & $(0.9)$ & 16.1 & (0.6) & 42.4 \\
\hline & Greece & 4.2 & (0.3) & 22.9 & $(0.6)$ & 48.0 & (0.8) & 24.9 & $(0.7)$ & 1.2 & $(0.2)$ & 3.3 & (0.4) & 38.1 & (1.0) & 57.4 & (1.1) & 4.6 & $(0.3)$ & 29.2 \\
\hline & Hungary & 3.1 & (0.3) & 20.6 & $(0.6)$ & 51.3 & (0.7) & 25.0 & $(0.6)$ & 1.4 & $(0.2)$ & 5.6 & $(0.3)$ & 50.0 & $(0.7)$ & 43.1 & $(0.8)$ & 4.9 & $(0.3)$ & 30.9 \\
\hline & Iceland & 1.4 & $(0.2)$ & 2.4 & (0.3) & 25.8 & $(0.8)$ & 70.4 & $(0.8)$ & 2.5 & $(0.3)$ & 10.9 & (0.5) & 31.5 & $(0.7)$ & 55.1 & $(0.8)$ & 2.9 & $(0.3)$ & 22.1 \\
\hline & Ireland & 0.9 & $(0.1)$ & 6.4 & $(0.4)$ & 43.5 & (0.7) & 49.2 & $(0.7)$ & 0.6 & $(0.1)$ & 2.3 & $(0.2)$ & $\mid 33.1$ & (0.6) & 64.0 & $(0.7)$ & 1.3 & $(0.2)$ & 12.0 \\
\hline & Israel & 2.1 & $(0.2)$ & 1.8 & $(0.2)$ & 18.9 & $(0.7)$ & 77.1 & $(0.8)$ & 1.5 & $(0.2)$ & 1.8 & $(0.2)$ & 19.6 & $(0.6)$ & 77.1 & $(0.7)$ & 1.7 & $(0.2)$ & 8.0 \\
\hline & Italy & 1.8 & $(0.2)$ & 10.2 & (0.5) & 51.6 & (0.6) & 36.5 & $(0.7)$ & 1.0 & $(0.1)$ & 4.0 & $(0.3)$ & 44.6 & $(0.7)$ & 50.4 & $(0.7)$ & 8.3 & $(0.3)$ & 36.4 \\
\hline & Japan & 7.2 & (0.3) & 28.0 & $(0.7)$ & 37.9 & (0.6) & 26.9 & (0.7) & 3.1 & $(0.2)$ & 9.6 & (0.4) & 41.1 & $(0.7)$ & 46.2 & (0.9) & 15.3 & (0.5) & 46.0 \\
\hline & Korea & 2.2 & $(0.2)$ & 11.2 & (0.5) & 37.5 & (0.7) & 49.1 & (0.9) & 0.8 & $(0.1)$ & 3.1 & $(0.3)$ & 41.5 & (0.9) & 54.6 & (1.0) & 1.2 & $(0.1)$ & 18.7 \\
\hline & Latvia & 4.3 & $(0.3)$ & 7.2 & (0.4) & 46.0 & (0.7) & 42.5 & $(0.7)$ & 3.8 & $(0.3)$ & 2.9 & (0.3) & 42.0 & $(0.8)$ & 51.3 & $(0.8)$ & 4.8 & $(0.3)$ & 30.4 \\
\hline & Luxembourg & 3.7 & $(0.2)$ & 13.7 & (0.4) & 44.5 & (0.6) & 38.1 & (0.6) & 1.9 & $(0.2)$ & 5.6 & (0.3) & 38.2 & $(0.7)$ & 54.3 & $(0.7)$ & 11.9 & (0.4) & 37.8 \\
\hline & Mexico & 2.1 & $(0.2)$ & 1.6 & $(0.2)$ & 35.1 & (0.7) & 61.3 & $(0.8)$ & 1.8 & $(0.2)$ & 2.1 & $(0.2)$ & 36.5 & $(0.7)$ & 59.6 & (0.8) & 2.7 & $(0.3)$ & 14.2 \\
\hline & Netherlands & 0.9 & (0.1) & 7.1 & $(0.4)$ & 60.3 & $(0.9)$ & 31.7 & $(0.9)$ & 0.6 & $(0.1)$ & 5.6 & $(0.3)$ & 62.6 & $(0.8)$ & 31.2 & $(0.8)$ & 9.6 & $(0.5)$ & 53.5 \\
\hline & New Zealand & 1.8 & $(0.2)$ & 9.5 & $(0.4)$ & 47.4 & $(0.8)$ & 41.3 & $(0.8)$ & 1.3 & $(0.2)$ & 4.2 & $(0.3)$ & 43.2 & $(0.7)$ & 51.3 & (0.6) & 1.8 & $(0.2)$ & 12.6 \\
\hline & Norway & 3.3 & $(0.3)$ & 13.3 & (0.5) & 38.9 & (0.8) & 44.6 & $(0.8)$ & 1.4 & $(0.1)$ & 3.1 & $(0.2)$ & 39.0 & $(0.8)$ & 56.5 & $(0.8)$ & 4.2 & $(0.3)$ & 31.0 \\
\hline & Poland & 5.8 & $(0.4)$ & 29.3 & (0.6) & 47.5 & (0.8) & 17.4 & (0.6) & 2.2 & $(0.2)$ & 11.8 & (0.5) & 57.7 & $(0.7)$ & 28.4 & $(0.7)$ & 4.8 & $(0.3)$ & 37.1 \\
\hline & Portugal & 0.4 & (0.1) & 3.9 & $(0.2)$ & 38.9 & (0.7) & 56.8 & $(0.8)$ & 1.1 & $(0.1)$ & 5.8 & $(0.4)$ & 38.9 & $(0.8)$ & 54.2 & $(0.8)$ & 3.1 & $(0.2)$ & 20.2 \\
\hline & Slovak Republic & 5.6 & (0.3) & 20.9 & (0.6) & 51.5 & (0.6) & 22.1 & $(0.5)$ & 3.0 & $(0.2)$ & 4.8 & $(0.3)$ & 51.3 & $(0.7)$ & 40.9 & $(0.7)$ & 3.9 & $(0.3)$ & 25.5 \\
\hline & Slovenia & 4.4 & $(0.3)$ & 26.1 & $(0.7)$ & 46.4 & $(0.8)$ & 23.1 & $(0.7)$ & 3.5 & $(0.3)$ & 10.4 & (0.5) & 51.2 & $(0.8)$ & 35.0 & $(0.8)$ & 7.0 & $(0.4)$ & 43.6 \\
\hline & Spain & 3.9 & $(0.3)$ & 18.9 & $(0.6)$ & 44.0 & $(0.7)$ & 33.1 & $(0.8)$ & 1.4 & $(0.2)$ & 4.8 & $(0.3)$ & 39.2 & $(0.7)$ & 54.7 & $(0.8)$ & 7.9 & $(0.3)$ & 30.8 \\
\hline & Sweden & 3.4 & $(0.2)$ & 16.6 & $(0.5)$ & 36.8 & $(0.8)$ & 43.2 & $(0.7)$ & 1.7 & $(0.2)$ & 6.1 & $(0.3)$ & 37.3 & $(0.7)$ & 54.9 & $(0.8)$ & 3.2 & $(0.3)$ & 23.8 \\
\hline & Switzerland & 4.5 & $(0.4)$ & 18.2 & $(0.7)$ & 47.6 & $(0.8)$ & 29.7 & $(0.7)$ & 1.7 & $(0.2)$ & 7.7 & (0.5) & 43.0 & (0.6) & 47.6 & $(0.7)$ & 18.9 & $(0.6)$ & 41.8 \\
\hline & Turkey & 3.8 & (0.3) & 2.7 & $(0.2)$ & 23.7 & $(0.8)$ & 69.7 & (1.0) & 3.5 & $(0.3)$ & 2.3 & $(0.3)$ & 26.5 & (0.9) & 67.7 & (1.1) & 3.8 & $(0.3)$ & 10.7 \\
\hline & United Kingdor & 0.9 & (0.1) & 3.7 & $(0.3)$ & 35.7 & (0.6) & 59.7 & $(0.7)$ & 0.7 & $(0.1)$ & 1.5 & $(0.2)$ & 33.6 & $(0.7)$ & 64.2 & $(0.7)$ & 1.2 & $(0.1)$ & 9.2 \\
\hline & United States & 0.8 & (0.1) & 4.9 & $(0.3)$ & 39.0 & $(0.7)$ & 55.3 & $(0.7)$ & 0.7 & $(0.1)$ & 2.0 & $(0.2)$ & 32.3 & $(0.7)$ & 65.0 & $(0.7)$ & 0.8 & $(0.1)$ & 6.0 \\
\hline & OECD average & 3.0 & $(0.0)$ & 13.6 & $(0.1)$ & 42.8 & (0.1) & 10.6 & $(0.1)$ & 1.7 & $(0.0)$ & 5.6 & $(0.1)$ & 41.3 & $(0.1)$ & 51.4 & $(0.1)$ & 6.4 & $(0.1)$ & 28.4 \\
\hline a & Albania & $\mathrm{m}$ & $\mathrm{m}$ & $\mathrm{m}$ & $\mathrm{m}$ & $\mathrm{m}$ & $\mathrm{m}$ & $\mathrm{m}$ & $\mathrm{m}$ & $\mathrm{m}$ & $\mathrm{m}$ & $\mathrm{m}$ & & $\mathrm{m}$ & $\mathrm{m}$ & $\mathrm{m}$ & $\mathrm{m}$ & $\mathrm{m}$ & $\mathrm{m}$ & $\mathrm{m}$ \\
\hline & Algeria & $\mathrm{m}$ & & $\mathrm{m}$ & $\mathrm{m}$ & $\mathrm{m}$ & $\mathrm{m}$ & $\mathrm{m}$ & $\mathrm{m}$ & $\mathrm{m}$ & $\mathrm{m}$ & $\mathrm{m}$ & $\mathrm{m}$ & $\mathrm{m}$ & $\mathrm{m}$ & $\mathrm{m}$ & $\mathrm{m}$ & $\mathrm{m}$ & $\mathrm{m}$ & $\mathrm{m}$ \\
\hline & Brazil & 1.1 & $(0.1)$ & 3.9 & $(0.2)$ & 42.6 & (0.5) & 52.5 & $(0.6)$ & 1.0 & $(0.1)$ & 2.3 & $(0.1)$ & 38.1 & $(0.5)$ & 58.6 & $(0.5)$ & 3.0 & $(0.2)$ & 16.8 \\
\hline & B-S-J-G (China & 2.5 & $(0.2)$ & 25.1 & $(0.5)$ & 47.4 & $(0.7)$ & 25.0 & (0.6) & 0.7 & $(0.1)$ & 2.7 & $(0.2)$ & 49.7 & $(0.8)$ & 46.9 & (0.9) & 0.9 & $(0.1)$ & 10.3 \\
\hline & Bulgaria & 5.2 & $(0.3)$ & 16.3 & $(0.6)$ & 46.4 & $(0.7)$ & 32.2 & $(0.8)$ & 2.4 & $(0.2)$ & 3.7 & $(0.3)$ & 44.5 & $(0.8)$ & 49.4 & (1.0) & 7.8 & $(0.4)$ & 34.8 \\
\hline & CABA (Argentina) & $\mathrm{m}$ & & $\mathrm{m}$ & $\mathrm{m}$ & $\mathrm{m}$ & $\mathrm{m}$ & $\mathrm{m}$ & $\mathrm{m}$ & $\mathrm{m}$ & $\mathrm{m}$ & $\mathrm{m}$ & $\mathrm{m}$ & $\mathrm{m}$ & $\mathrm{m}$ & $\mathrm{m}$ & $\mathrm{m}$ & $\mathrm{m}$ & $\mathrm{m}$ & $\mathrm{m}$ \\
\hline & Colombia & 1.0 & (0.1) & 2.4 & $(0.2)$ & 35.5 & $(0.7)$ & 61.1 & $(0.7)$ & 0.8 & $(0.1)$ & 0.9 & $(0.1)$ & 23.4 & $(0.6)$ & 74.9 & (0.6) & 1.3 & $(0.1)$ & 6.8 \\
\hline & Costa Rica & 0.8 & $(0.1)$ & 1.5 & $(0.2)$ & 25.0 & (0.6) & 72.7 & $(0.7)$ & 0.8 & $(0.1)$ & 1.4 & $(0.2)$ & 24.8 & $(0.6)$ & 73.1 & $(0.7)$ & 2.6 & $(0.2)$ & 13.2 \\
\hline & Croatia & 5.4 & (0.3) & 26.2 & $(0.6)$ & 46.7 & (0.6) & 21.7 & $(0.6)$ & 1.3 & $(0.2)$ & 5.1 & $(0.3)$ & 48.9 & $(0.7)$ & 44.7 & $(0.7)$ & 5.5 & $(0.3)$ & 35.3 \\
\hline & Cyprus* & 3.7 & $(0.3)$ & 13.8 & $(0.5)$ & 41.4 & $(0.8)$ & 41.1 & $(0.8)$ & 1.6 & $(0.1)$ & 3.0 & $(0.2)$ & 35.2 & $(0.7)$ & 60.2 & $(0.7)$ & 3.9 & $(0.3)$ & 21.5 \\
\hline & Dominican Republic & 5.0 & $(0.4)$ & 3.9 & $(0.3)$ & 32.4 & (0.9) & 58.7 & $(0.9)$ & 4.3 & $(0.4)$ & 2.5 & $(0.3)$ & 30.2 & $(0.8)$ & 63.1 & $(0.9)$ & 4.9 & $(0.4)$ & 10.3 \\
\hline & FYROM & $\mathrm{m}$ & & $\mathrm{m}$ & $\mathrm{m}$ & $\mathrm{m}$ & $\mathrm{m}$ & $\mathrm{m}$ & $\mathrm{m}$ & $\mathrm{m}$ & $\mathrm{m}$ & $\mathrm{m}$ & $\mathrm{m}$ & $\mathrm{m}$ & $\mathrm{m}$ & $\mathrm{m}$ & $\mathrm{m}$ & $\mathrm{m}$ & $\mathrm{m}$ & $\mathrm{m}$ \\
\hline & Georgia & $\mathrm{m}$ & & $\mathrm{m}$ & $\mathrm{m}$ & $\mathrm{m}$ & $\mathrm{m}$ & $\mathrm{m}$ & $\mathrm{m}$ & $\mathrm{m}$ & $\mathrm{m}$ & $\mathrm{m}$ & $\mathrm{m}$ & $\mathrm{m}$ & $\mathrm{m}$ & $\mathrm{m}$ & $\mathrm{m}$ & $\mathrm{m}$ & $\mathrm{m}$ & $\mathrm{m}$ \\
\hline & Hong Kon & 2.1 & $(0.2)$ & 9.8 & $(0.5)$ & 41.2 & $(0.8)$ & 47.0 & $(0.9)$ & 1.3 & $(0.2)$ & 5.2 & $(0.4)$ & 45.7 & $(0.8)$ & 47.8 & $(0.7)$ & 1.8 & $(0.2)$ & 15.7 \\
\hline & Indonesia & $\mathrm{m}$ & $\mathrm{m}$ & $\mathrm{m}$ & $\mathrm{m}$ & $\mathrm{m}$ & $\mathrm{m}$ & $\mathrm{m}$ & $\mathrm{m}$ & $\mathrm{m}$ & $\mathrm{m}$ & $\mathrm{m}$ & $\mathrm{m}$ & $\mathrm{m}$ & $\mathrm{m}$ & $\mathrm{m}$ & $\mathrm{m}$ & $\mathrm{m}$ & $\mathrm{m}$ & $\mathrm{m}$ \\
\hline & Jordan & $\mathrm{m}$ & $\mathrm{m}$ & $\mathrm{m}$ & $\mathrm{m}$ & $\mathrm{m}$ & $\mathrm{m}$ & $\mathrm{m}$ & $\mathrm{m}$ & $\mathrm{m}$ & $\mathrm{m}$ & $\mathrm{m}$ & $\mathrm{m}$ & $\mathrm{m}$ & $\mathrm{m}$ & $\mathrm{m}$ & $\mathrm{m}$ & $\mathrm{m}$ & $\mathrm{m}$ & $\mathrm{m}$ \\
\hline & Kosovo & $\mathrm{m}$ & $\mathrm{m}$ & $\mathrm{m}$ & $\mathrm{m}$ & $\mathrm{m}$ & $\mathrm{m}$ & $\mathrm{m}$ & $\mathrm{m}$ & $\mathrm{m}$ & $\mathrm{m}$ & $\mathrm{m}$ & $\mathrm{m}$ & $\mathrm{m}$ & $\mathrm{m}$ & $\mathrm{m}$ & $\mathrm{m}$ & $\mathrm{m}$ & $\mathrm{m}$ & $\mathrm{m}$ \\
\hline & Lebanon & $\mathrm{m}$ & & $\mathrm{m}$ & $\mathrm{m}$ & $\mathrm{m}$ & $\mathrm{m}$ & $\mathrm{m}$ & $\mathrm{m}$ & $\mathrm{m}$ & $\mathrm{m}$ & $\mathrm{m}$ & $\mathrm{m}$ & $\mathrm{m}$ & $\mathrm{m}$ & $\mathrm{m}$ & $\mathrm{m}$ & $\mathrm{m}$ & $\mathrm{m}$ & $\mathrm{m}$ \\
\hline & Lithuania & 5.8 & (0.4) & 11.1 & $(0.5)$ & 41.9 & $(0.7)$ & 41.2 & $(0.8)$ & 3.3 & $(0.2)$ & 5.9 & $(0.4)$ & 29.2 & $(0.8)$ & 61.5 & (0.9) & 9.3 & $(0.4)$ & 24.2 \\
\hline & Macao (China) & 6.5 & (0.3) & 43.8 & $(0.7)$ & 36.9 & (0.6) & 12.9 & $(0.5)$ & 1.3 & $(0.2)$ & 7.6 & (0.4) & 59.3 & $(0.8)$ & 31.8 & $(0.7)$ & 4.6 & $(0.3)$ & 38.4 \\
\hline & Malta & $\mathrm{m}$ & $\mathrm{m}$ & $\mathrm{m}$ & $\mathrm{m}$ & $\mathrm{m}$ & & $\mathrm{m}$ & $\mathrm{m}$ & $\mathrm{m}$ & $\mathrm{m}$ & $\mathrm{m}$ & $\mathrm{m}$ & $\mathrm{m}$ & $\mathrm{m}$ & $\mathrm{m}$ & $\mathrm{m}$ & $\mathrm{m}$ & $\mathrm{m}$ & $\mathrm{m}$ \\
\hline & Moldova & $\mathrm{m}$ & $\mathrm{m}$ & $\mathrm{m}$ & $\mathrm{m}$ & $\mathrm{m}$ & $\mathrm{m}$ & $\mathrm{m}$ & $\mathrm{m}$ & $\mathrm{m}$ & $\mathrm{m}$ & $\mathrm{m}$ & $\mathrm{m}$ & $\mathrm{m}$ & $\mathrm{m}$ & $\mathrm{m}$ & $\mathrm{m}$ & $\mathrm{m}$ & $\mathrm{m}$ & $\mathrm{m}$ \\
\hline & Montenegro & 5.4 & (0.3) & 17.8 & $(0.4)$ & 47.3 & (0.7) & 29.5 & (0.6) & 2.3 & $(0.2)$ & 5.6 & (0.3) & 50.6 & (0.6) & 41.4 & $(0.7)$ & 5.9 & $(0.3)$ & 28.0 \\
\hline & Peru & 1.3 & (0.1) & 2.2 & $(0.2)$ & 40.5 & (0.7) & 56.0 & $(0.7)$ & 1.3 & $(0.1)$ & 2.0 & $(0.2)$ & 36.3 & $(0.7)$ & 60.4 & $(0.7)$ & 1.3 & $(0.1)$ & 9.0 \\
\hline & Qatar & 3.5 & $(0.2)$ & 3.1 & $(0.1)$ & 26.2 & $(0.4)$ & 67.2 & $(0.5)$ & 2.3 & $(0.2)$ & 3.1 & $(0.1)$ & 25.1 & $(0.4)$ & 69.5 & $(0.4)$ & 2.9 & $(0.2)$ & 7.1 \\
\hline & Romaniz & $\mathrm{m}$ & & $\mathrm{m}$ & $\mathrm{m}$ & $\mathrm{m}$ & $\mathrm{m}$ & $\mathrm{m}$ & $\mathrm{m}$ & $\mathrm{m}$ & $\mathrm{m}$ & $\mathrm{m}$ & $\mathrm{m}$ & $\mathrm{m}$ & $\mathrm{m}$ & $\mathrm{m}$ & $\mathrm{m}$ & $\mathrm{m}$ & $\mathrm{m}$ & $\mathrm{m}$ \\
\hline & Russia & 1.8 & $(0.3)$ & 17.3 & $(0.5)$ & 55.0 & $(0.8)$ & 25.9 & $(0.7)$ & 1.1 & $(0.2)$ & 4.3 & $(0.4)$ & 58.2 & (1.0) & 36.4 & (1.0) & 2.5 & $(0.3)$ & 24.4 \\
\hline & Singapore & 1.5 & $(0.2)$ & 10.4 & $(0.4)$ & 43.2 & (0.7) & 44.9 & $(0.7)$ & 0.8 & $(0.1)$ & 2.7 & $(0.2)$ & 35.6 & $(0.7)$ & 60.9 & $(0.7)$ & 1.2 & $(0.1)$ & 10.3 \\
\hline & Chinese Taipei & 2.4 & $(0.2)$ & 18.2 & $(0.4)$ & 48.5 & (0.6) & 30.9 & $(0.6)$ & 0.6 & $(0.1)$ & 2.2 & $(0.2)$ & 43.7 & $(0.7)$ & 53.5 & $(0.7)$ & 2.1 & $(0.2)$ & 29.5 \\
\hline & Thailand & 1.0 & (0.1) & 7.5 & $(0.3)$ & 52.9 & $(0.8)$ & 38.7 & $(0.9)$ & 0.5 & $(0.1)$ & 2.1 & $(0.2)$ & 48.3 & (1.0) & 49.1 & (1.2) & 0.6 & $(0.1)$ & 2.2 \\
\hline & Trinidad a & $\mathrm{m}$ & & $\mathrm{m}$ & $\mathrm{m}$ & $\mathrm{m}$ & & $\mathrm{m}$ & $\mathrm{m}$ & $\mathrm{m}$ & $\mathrm{m}$ & $\mathrm{m}$ & $\mathrm{m}$ & $\mathrm{m}$ & $\mathrm{m}$ & $\mathrm{m}$ & $\mathrm{m}$ & $\mathrm{m}$ & $\mathrm{m}$ & $\mathrm{m}$ \\
\hline & Tunisia & 1.5 & $(0.2)$ & 2.0 & $(0.2)$ & 31.3 & $(0.8)$ & 65.2 & $(0.9)$ & 0.9 & $(0.2)$ & 2.6 & $(0.3)$ & 41.0 & $(0.9)$ & 55.5 & (1.0) & 1.5 & $(0.2)$ & 9.1 \\
\hline & United Arab Emirates & 2.6 & $(0.2)$ & 3.8 & $(0.2)$ & 30.5 & (0.6) & 63.1 & $(0.6)$ & 1.7 & $(0.2)$ & 2.8 & $(0.2)$ & 28.2 & $(0.6)$ & 67.4 & (0.6) & 1.7 & $(0.1)$ & 6.1 \\
\hline & Uruguay & 2.5 & $(0.2)$ & 9.0 & $(0.4)$ & 45.6 & (0.6) & 42.9 & $(0.7)$ & 1.4 & $(0.2)$ & 3.6 & $(0.3)$ & 39.6 & $(0.8)$ & 55.4 & $(0.7)$ & 3.9 & $(0.3)$ & 20.6 \\
\hline & Viet Nam & $\mathrm{m}$ & $\mathrm{m}$ & $\mathrm{m}$ & $\mathrm{m}$ & $\mathrm{m}$ & $\mathrm{m}$ & $\mathrm{m}$ & $\mathrm{m}$ & $\mathrm{m}$ & $\mathrm{m}$ & $\mathrm{m}$ & $\mathrm{m}$ & $\mathrm{m}$ & $\mathrm{m}$ & $\mathrm{m}$ & $\mathrm{m}$ & $\mathrm{m}$ & $\mathrm{m}$ & $\mathrm{m}$ \\
\hline & Arger & $\mathrm{m}$ & $\mathrm{m}$ & $\mathrm{m}$ & $\mathrm{m}$ & $\mathrm{m}$ & & $\mathrm{m}$ & $\mathrm{m}$ & $\mathrm{m}$ & $\mathrm{m}$ & $\mathrm{m}$ & III & $\mathrm{m}$ & $\mathrm{m}$ & $\mathrm{m}$ & 111 & $\mathrm{~m}$ & $\mathrm{~m}$ & $\mathrm{~m}$ \\
\hline & Kazakhstan** & & & $\mathrm{m}$ & $\mathrm{m}$ & $\mathrm{m}$ & & $\mathrm{m}$ & $\mathrm{m}$ & $\mathrm{m}$ & $\mathrm{m}$ & $\mathrm{m}$ & $\mathrm{m}$ & $\mathrm{m}$ & $\mathrm{m}$ & $\mathrm{m}$ & $\mathrm{m}$ & $\mathrm{m}$ & $\mathrm{m}$ & $\mathrm{m}$ \\
\hline & Malaysia** & 0.7 & $(0.1)$ & 4.6 & $(0.4)$ & 31.0 & (1.0) & 63.7 & (1.3) & 0.3 & $(0.1)$ & 2.2 & (0.3) & 32.1 & (0.9) & 65.4 & (1.1) & 0.4 & $(0.1)$ & 4.0 \\
\hline
\end{tabular}

* See note at the beginning of this Annex.

** Coverage is too small to ensure comparability (see Annex A4).

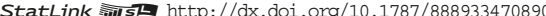


[Part 2/2]

Table III.5.1 Students' achievement motivation

Results based on students' self-reports

\begin{tabular}{|c|c|c|c|c|c|c|c|c|c|c|c|c|c|c|c|c|}
\hline & \multicolumn{16}{|c|}{ Percentage of students who reported the following statements } \\
\hline & \multicolumn{8}{|c|}{ I see myself as an ambitious person } & \multicolumn{8}{|c|}{ I want to be one of the best students in my class } \\
\hline & \multicolumn{2}{|c|}{$\begin{array}{l}\text { Strongly } \\
\text { disagree }\end{array}$} & \multicolumn{2}{|c|}{ Disagree } & \multicolumn{2}{|c|}{ Agree } & \multicolumn{2}{|c|}{$\begin{array}{c}\text { Strongly } \\
\text { agree }\end{array}$} & \multicolumn{2}{|c|}{$\begin{array}{l}\text { Strongly } \\
\text { disagree }\end{array}$} & \multicolumn{2}{|c|}{ Disagree } & \multicolumn{2}{|c|}{ Agree } & \multicolumn{2}{|c|}{$\begin{array}{c}\text { Strongly } \\
\text { agree }\end{array}$} \\
\hline & $\%$ & S.E. & $\%$ & S.E. & $\%$ & S.E. & $\%$ & S.E. & $\%$ & S.E. & $\%$ & S.E. & $\%$ & S.E. & $\%$ & S.E. \\
\hline Australia & 1.9 & $(0.1)$ & 17.1 & $(0.3)$ & 53.2 & $(0.5)$ & 27.8 & $(0.5)$ & 3.3 & $(0.2)$ & 22.5 & $(0.4)$ & 44.2 & $(0.4)$ & 30.0 & $(0.4)$ \\
\hline Austria & 8.8 & $(0.4)$ & 24.7 & $(0.7)$ & 41.3 & $(0.7)$ & 25.2 & $(0.8)$ & 19.9 & $(0.6)$ & 33.3 & $(0.6)$ & 28.1 & (0.6) & 18.7 & $(0.6)$ \\
\hline Belgium & 6.3 & $(0.3)$ & 31.3 & $(0.6)$ & 49.1 & $(0.6)$ & 13.3 & $(0.4)$ & 16.3 & $(0.4)$ & 42.2 & $(0.6)$ & 30.5 & $(0.5)$ & 11.0 & $(0.4)$ \\
\hline Canada & 2.1 & $(0.1)$ & 15.8 & $(0.4)$ & 50.6 & $(0.5)$ & 31.5 & $(0.6)$ & 4.6 & $(0.2)$ & 22.3 & $(0.5)$ & 40.7 & $(0.4)$ & 32.4 & $(0.6)$ \\
\hline Chile & 7.6 & (0.4) & 23.1 & $(0.6)$ & 41.1 & $(0.7)$ & 28.2 & $(0.7)$ & 5.1 & $(0.3)$ & 22.9 & $(0.6)$ & 45.4 & $(0.8)$ & 26.6 & $(0.6)$ \\
\hline Czech Republic & 4.6 & $(0.2)$ & 34.8 & $(0.7)$ & 47.1 & (0.6) & 13.5 & $(0.5)$ & 11.5 & $(0.4)$ & 46.8 & $(0.8)$ & 31.1 & $(0.7)$ & 10.5 & $(0.5)$ \\
\hline Denmark & 2.7 & $(0.3)$ & 17.2 & $(0.6)$ & 57.5 & $(0.7)$ & 22.6 & $(0.7)$ & 4.5 & $(0.3)$ & 26.3 & $(0.7)$ & 43.9 & (0.8) & 25.2 & $(0.7)$ \\
\hline Estonia & 2.7 & $(0.3)$ & 22.6 & $(0.6)$ & 57.5 & $(0.7)$ & 17.2 & (0.6) & 8.4 & $(0.4)$ & 40.5 & $(0.7)$ & 35.5 & $(0.6)$ & 15.6 & $(0.6)$ \\
\hline Finland & 9.4 & $(0.5)$ & 34.5 & $(0.8)$ & 43.5 & $(0.8)$ & 12.6 & $(0.5)$ & 16.2 & $(0.6)$ & 43.0 & $(0.7)$ & 28.9 & $(0.7)$ & 11.9 & $(0.5)$ \\
\hline France & 5.5 & $(0.3)$ & 24.0 & $(0.6)$ & 53.5 & $(0.7)$ & 17.1 & $(0.6)$ & 17.4 & $(0.5)$ & 37.9 & $(0.7)$ & 29.9 & $(0.6)$ & 14.9 & $(0.6)$ \\
\hline Germany & 6.7 & $(0.3)$ & 28.1 & $(0.6)$ & 45.2 & (0.6) & 19.9 & $(0.5)$ & 17.8 & $(0.5)$ & 39.5 & $(0.8)$ & 28.0 & (0.6) & 14.7 & $(0.5)$ \\
\hline Greece & 3.5 & $(0.3)$ & 18.9 & $(0.5)$ & 56.3 & $(0.7)$ & 21.4 & $(0.6)$ & 7.0 & $(0.4)$ & 29.6 & $(0.7)$ & 44.1 & $(0.7)$ & 19.2 & $(0.6)$ \\
\hline Hungary & 5.6 & $(0.4)$ & 33.2 & $(0.8)$ & 46.4 & $(0.8)$ & 14.8 & $(0.5)$ & 14.9 & $(0.5)$ & 44.7 & $(0.7)$ & 29.0 & $(0.7)$ & 11.4 & $(0.5)$ \\
\hline Iceland & 3.8 & (0.3) & 17.2 & (0.6) & 45.4 & (0.9) & 33.6 & (0.8) & 4.2 & $(0.3)$ & 20.3 & $(0.7)$ & 38.9 & (1.0) & 36.7 & $(0.9)$ \\
\hline Ireland & 1.3 & $(0.2)$ & 13.8 & $(0.5)$ & 51.2 & $(0.7)$ & 33.8 & $(0.6)$ & 2.8 & $(0.2)$ & 24.8 & $(0.7)$ & 45.3 & $(0.7)$ & 27.1 & $(0.6)$ \\
\hline Israel & 2.5 & $(0.2)$ & 10.7 & $(0.5)$ & 41.6 & $(0.6)$ & 45.1 & $(0.8)$ & 2.9 & $(0.2)$ & 10.7 & $(0.6)$ & 33.6 & $(0.6)$ & 52.8 & $(0.8)$ \\
\hline Italy & 4.4 & $(0.3)$ & 22.8 & $(0.7)$ & 53.7 & $(0.7)$ & 19.1 & $(0.6)$ & 11.5 & $(0.5)$ & 36.5 & $(0.7)$ & 38.4 & $(0.7)$ & 13.6 & $(0.5)$ \\
\hline Japan & 7.8 & $(0.4)$ & 34.2 & $(0.7)$ & 43.8 & $(0.7)$ & 14.2 & $(0.5)$ & 20.9 & $(0.6)$ & 46.2 & $(0.6)$ & 19.3 & $(0.5)$ & 13.6 & $(0.5)$ \\
\hline Korea & 2.3 & $(0.2)$ & 30.5 & $(0.8)$ & 47.6 & $(0.7)$ & 19.6 & $(0.7)$ & 2.1 & $(0.2)$ & 16.0 & $(0.6)$ & 42.0 & $(0.7)$ & 39.9 & $(0.9)$ \\
\hline Latvia & 4.0 & $(0.3)$ & 20.8 & $(0.7)$ & 55.4 & $(0.8)$ & 19.8 & $(0.8)$ & 7.7 & $(0.4)$ & 33.6 & $(0.7)$ & 38.6 & $(0.8)$ & 20.1 & $(0.7)$ \\
\hline Luxembourg & 8.6 & $(0.4)$ & 28.3 & $(0.7)$ & 42.8 & $(0.7)$ & 20.3 & $(0.5)$ & 13.5 & $(0.5)$ & 32.7 & $(0.6)$ & 32.7 & $(0.7)$ & 21.1 & $(0.5)$ \\
\hline Mexico & 23.2 & $(0.7)$ & 37.6 & $(0.6)$ & 27.4 & $(0.6)$ & 11.8 & $(0.6)$ & 3.3 & $(0.2)$ & 15.4 & $(0.6)$ & 51.3 & $(0.7)$ & 29.9 & $(0.7)$ \\
\hline Netherlands & 2.4 & $(0.2)$ & 24.9 & $(0.7)$ & 62.2 & $(0.7)$ & 10.5 & $(0.5)$ & 15.1 & $(0.6)$ & 55.2 & $(0.8)$ & 23.1 & $(0.7)$ & 6.7 & $(0.4)$ \\
\hline New Zealand & 2.6 & $(0.2)$ & 19.9 & $(0.6)$ & 50.9 & $(0.7)$ & 26.6 & (0.6) & 4.1 & $(0.3)$ & 25.9 & $(0.7)$ & 43.4 & $(0.8)$ & 26.5 & $(0.7)$ \\
\hline Norway & 3.7 & $(0.3)$ & 19.5 & $(0.6)$ & 52.9 & $(0.7)$ & 24.0 & $(0.7)$ & 7.0 & $(0.4)$ & 28.7 & $(0.7)$ & 36.3 & $(0.7)$ & 28.0 & $(0.6)$ \\
\hline Poland & 3.6 & $(0.3)$ & 22.0 & $(0.7)$ & 57.3 & $(0.7)$ & 17.1 & $(0.7)$ & 9.4 & $(0.5)$ & 44.2 & $(0.7)$ & 35.4 & $(0.7)$ & 11.0 & $(0.5)$ \\
\hline Portugal & 5.2 & $(0.3)$ & 23.0 & $(0.6)$ & 48.2 & $(0.6)$ & 23.6 & $(0.6)$ & 6.5 & $(0.3)$ & 28.0 & $(0.6)$ & 41.6 & (0.8) & 23.9 & $(0.6)$ \\
\hline Slovak Republic & 4.6 & (0.3) & 25.1 & (0.6) & 52.9 & $(0.8)$ & 17.5 & (0.6) & 11.5 & $(0.5)$ & 44.0 & $(0.7)$ & 33.3 & $(0.6)$ & 11.1 & $(0.5)$ \\
\hline Slovenia & 5.0 & $(0.3)$ & 30.2 & $(0.7)$ & 51.0 & $(0.8)$ & 13.8 & $(0.6)$ & 12.5 & $(0.5)$ & 43.2 & $(0.7)$ & 31.9 & $(0.8)$ & 12.4 & $(0.5)$ \\
\hline Spain & 14.1 & $(0.5)$ & 32.4 & (0.6) & 36.0 & $(0.7)$ & 17.5 & (0.4) & 9.5 & (0.4) & 33.0 & (0.8) & 39.0 & (0.8) & 18.5 & $(0.6)$ \\
\hline Sweden & 3.1 & $(0.3)$ & 14.8 & $(0.6)$ & 52.4 & $(0.8)$ & 29.7 & $(0.8)$ & 7.6 & $(0.4)$ & 28.7 & $(0.7)$ & 33.1 & $(0.8)$ & 30.5 & $(0.7)$ \\
\hline Switzerland & 6.8 & $(0.4)$ & 25.8 & $(0.7)$ & 48.7 & $(0.8)$ & 18.8 & $(0.5)$ & 21.9 & $(0.6)$ & 38.2 & $(0.7)$ & 27.6 & $(0.7)$ & 12.4 & $(0.6)$ \\
\hline Turkey & 7.0 & $(0.3)$ & 20.2 & $(0.7)$ & 40.9 & $(0.8)$ & 32.0 & (0.9) & 4.2 & $(0.3)$ & 6.5 & $(0.4)$ & 35.5 & (0.8) & 53.8 & $(0.9)$ \\
\hline United Kingdom & 2.0 & $(0.2)$ & 14.5 & $(0.5)$ & 47.9 & $(0.7)$ & 35.6 & $(0.7)$ & 3.5 & $(0.3)$ & 20.9 & $(0.5)$ & 44.2 & (0.6) & 31.4 & $(0.7)$ \\
\hline United States & 1.5 & $(0.2)$ & 11.5 & $(0.5)$ & 48.1 & $(0.7)$ & 38.9 & $(0.8)$ & 1.8 & $(0.2)$ & 12.8 & $(0.5)$ & 42.2 & $(0.8)$ & 43.2 & $(0.9)$ \\
\hline OECD average & 5.3 & $(0.1)$ & 23.6 & $(0.1)$ & 48.6 & $(0.1)$ & 22.5 & $(0.1)$ & 9.4 & $(0.1)$ & 31.3 & $(0.1)$ & 36.2 & $(0.1)$ & 23.0 & $(0.1)$ \\
\hline
\end{tabular}

\begin{tabular}{|c|c|c|c|c|c|c|c|c|c|c|c|c|c|c|c|c|}
\hline Albania & $\mathrm{m}$ & $\mathrm{m}$ & $\mathrm{m}$ & $\mathrm{m}$ & $\mathrm{m}$ & $\mathrm{m}$ & $\mathrm{m}$ & $\mathrm{m}$ & $\mathrm{m}$ & $\mathrm{m}$ & $\mathrm{m}$ & $\mathrm{m}$ & $\mathrm{m}$ & $\mathrm{m}$ & $\mathrm{m}$ & $\mathrm{m}$ \\
\hline Algeria & $\mathrm{m}$ & $\mathrm{m}$ & $\mathrm{m}$ & $\mathrm{m}$ & $\mathrm{m}$ & $\mathrm{m}$ & $\mathrm{m}$ & $\mathrm{m}$ & $\mathrm{m}$ & $\mathrm{m}$ & $\mathrm{m}$ & $\mathrm{m}$ & $\mathrm{m}$ & $\mathrm{m}$ & $\mathrm{m}$ & $\mathrm{m}$ \\
\hline Brazil & 19.2 & $(0.4)$ & 40.6 & $(0.4)$ & 26.9 & $(0.5)$ & 13.2 & $(0.4)$ & 6.5 & $(0.2)$ & 29.6 & $(0.5)$ & 42.2 & $(0.5)$ & 21.7 & $(0.4)$ \\
\hline B-S-J-G (China) & 2.1 & $(0.2)$ & 24.9 & $(0.7)$ & 52.1 & $(0.6)$ & 21.0 & $(0.6)$ & 2.4 & $(0.2)$ & 16.4 & $(0.6)$ & 52.2 & $(0.7)$ & 28.9 & $(0.7)$ \\
\hline Bulgaria & 4.0 & $(0.3)$ & 14.5 & $(0.5)$ & 54.6 & $(0.7)$ & 26.9 & $(0.8)$ & 7.0 & $(0.4)$ & 25.8 & $(0.7)$ & 43.4 & $(0.7)$ & 23.8 & $(0.7)$ \\
\hline CABA (Argentina) & $\mathrm{m}$ & $\mathrm{m}$ & $\mathrm{m}$ & $\mathrm{m}$ & $\mathrm{m}$ & $\mathrm{m}$ & $\mathrm{m}$ & $\mathrm{m}$ & $\mathrm{m}$ & $\mathrm{m}$ & $\mathrm{m}$ & $\mathrm{m}$ & $\mathrm{m}$ & $\mathrm{m}$ & $\mathrm{m}$ & $\mathrm{m}$ \\
\hline Colombia & 22.9 & (0.8) & 36.9 & $(0.7)$ & 26.3 & $(0.6)$ & 13.9 & $(0.5)$ & 1.3 & $(0.1)$ & 7.0 & $(0.3)$ & 46.4 & $(0.7)$ & 45.2 & $(0.8)$ \\
\hline Costa Rica & 16.6 & $(0.6)$ & 32.2 & $(0.6)$ & 30.2 & $(0.6)$ & 21.0 & $(0.6)$ & 2.5 & $(0.2)$ & 12.0 & $(0.6)$ & 43.5 & $(0.7)$ & 42.0 & $(0.8)$ \\
\hline Croatia & 3.8 & $(0.3)$ & 22.9 & $(0.6)$ & 56.5 & $(0.7)$ & 16.8 & $(0.6)$ & 7.7 & $(0.4)$ & 30.8 & $(0.6)$ & 45.2 & (0.6) & 16.3 & (0.5) \\
\hline Cyprus* & 3.7 & $(0.3)$ & 16.6 & $(0.5)$ & 54.4 & $(0.7)$ & 25.4 & $(0.6)$ & 5.5 & $(0.3)$ & 21.7 & $(0.6)$ & 44.8 & $(0.7)$ & 28.0 & (0.6) \\
\hline Dominican Republic & 36.9 & $(0.8)$ & 37.3 & $(0.8)$ & 15.1 & $(0.7)$ & 10.7 & $(0.6)$ & 4.4 & $(0.4)$ & 5.2 & $(0.3)$ & 36.7 & $(0.9)$ & 53.7 & (0.9) \\
\hline FYROM & $\mathrm{m}$ & $\mathrm{m}$ & $\mathrm{m}$ & $\mathrm{m}$ & $\mathrm{m}$ & $\mathrm{m}$ & $\mathrm{m}$ & $\mathrm{m}$ & $\mathrm{m}$ & $\mathrm{m}$ & $\mathrm{m}$ & $\mathrm{m}$ & $\mathrm{m}$ & $\mathrm{m}$ & $\mathrm{m}$ & $\mathrm{m}$ \\
\hline Georgia & $\mathrm{m}$ & $\mathrm{m}$ & $\mathrm{m}$ & $\mathrm{m}$ & $\mathrm{m}$ & $\mathrm{m}$ & $\mathrm{m}$ & $\mathrm{m}$ & $\mathrm{m}$ & $\mathrm{m}$ & $\mathrm{m}$ & $\mathrm{m}$ & $\mathrm{m}$ & $\mathrm{m}$ & $\mathrm{m}$ & $\mathrm{m}$ \\
\hline Hong Kong (China) & 4.0 & $(0.3)$ & 31.9 & $(0.8)$ & 44.2 & $(0.8)$ & 19.9 & $(0.6)$ & 4.7 & $(0.4)$ & 19.9 & $(0.7)$ & 45.6 & $(0.7)$ & 29.8 & $(0.7)$ \\
\hline Indonesia & $\mathrm{m}$ & $\mathrm{m}$ & $\mathrm{m}$ & $\mathrm{m}$ & $\mathrm{m}$ & $\mathrm{m}$ & $\mathrm{m}$ & $\mathrm{m}$ & $\mathrm{m}$ & $\mathrm{m}$ & $\mathrm{m}$ & $\mathrm{m}$ & $\mathrm{m}$ & $\mathrm{m}$ & $\mathrm{m}$ & $\mathrm{m}$ \\
\hline Jordan & $\mathrm{m}$ & $\mathrm{m}$ & $\mathrm{m}$ & $\mathrm{m}$ & $\mathrm{m}$ & $\mathrm{m}$ & $\mathrm{m}$ & $\mathrm{m}$ & $\mathrm{m}$ & $\mathrm{m}$ & $\mathrm{m}$ & $\mathrm{m}$ & $\mathrm{m}$ & $\mathrm{m}$ & $\mathrm{m}$ & $\mathrm{m}$ \\
\hline Kosovo & $\mathrm{m}$ & $\mathrm{m}$ & $\mathrm{m}$ & $\mathrm{m}$ & $\mathrm{m}$ & $\mathrm{m}$ & $\mathrm{m}$ & $\mathrm{m}$ & $\mathrm{m}$ & $\mathrm{m}$ & $\mathrm{m}$ & $\mathrm{m}$ & $\mathrm{m}$ & $\mathrm{m}$ & $\mathrm{m}$ & $\mathrm{m}$ \\
\hline Lebanon & $\mathrm{m}$ & $\mathrm{m}$ & $\mathrm{m}$ & $\mathrm{m}$ & $\mathrm{m}$ & $\mathrm{m}$ & $\mathrm{m}$ & $\mathrm{m}$ & $\mathrm{m}$ & $\mathrm{m}$ & $\mathrm{m}$ & $\mathrm{m}$ & $\mathrm{m}$ & $\mathrm{m}$ & $\mathrm{m}$ & $\mathrm{m}$ \\
\hline Lithuania & 7.7 & $(0.4)$ & 21.3 & $(0.7)$ & 46.3 & $(0.9)$ & 24.7 & $(0.7)$ & 13.7 & $(0.6)$ & 22.8 & $(0.5)$ & 36.8 & $(0.7)$ & 26.8 & $(0.7)$ \\
\hline Macao (China) & 7.1 & $(0.4)$ & 37.4 & $(0.8)$ & 41.3 & $(0.8)$ & 14.2 & $(0.5)$ & 9.7 & $(0.4)$ & 41.7 & $(0.9)$ & 36.4 & $(0.8)$ & 12.2 & $(0.5)$ \\
\hline Malta & $\mathrm{m}$ & $\mathrm{m}$ & $\mathrm{m}$ & $\mathrm{m}$ & $\mathrm{m}$ & $\mathrm{m}$ & $\mathrm{m}$ & $\mathrm{m}$ & $\mathrm{m}$ & $\mathrm{m}$ & $\mathrm{m}$ & $\mathrm{m}$ & $\mathrm{m}$ & $\mathrm{m}$ & $\mathrm{m}$ & $\mathrm{m}$ \\
\hline Moldova & $\mathrm{m}$ & $\mathrm{m}$ & $\mathrm{m}$ & $\mathrm{m}$ & $\mathrm{m}$ & $\mathrm{m}$ & $\mathrm{m}$ & $\mathrm{m}$ & $\mathrm{m}$ & $\mathrm{m}$ & $\mathrm{m}$ & $\mathrm{m}$ & $\mathrm{m}$ & $\mathrm{m}$ & $\mathrm{m}$ & $\mathrm{m}$ \\
\hline Montenegro & 4.0 & $(0.3)$ & 15.1 & $(0.5)$ & 55.1 & $(0.7)$ & 25.8 & $(0.6)$ & 11.1 & $(0.5)$ & 34.5 & $(0.8)$ & 36.7 & $(0.6)$ & 17.7 & $(0.5)$ \\
\hline Peru & 20.6 & $(0.6)$ & 40.6 & $(0.6)$ & 27.2 & $(0.6)$ & 11.6 & $(0.5)$ & 1.7 & $(0.1)$ & 9.9 & $(0.4)$ & 53.1 & $(0.7)$ & 35.4 & $(0.7)$ \\
\hline Qatar & 3.3 & $(0.2)$ & 9.7 & $(0.3)$ & 39.4 & $(0.4)$ & 47.6 & $(0.4)$ & 3.0 & $(0.1)$ & 7.6 & $(0.2)$ & 34.5 & (0.4) & 54.9 & $(0.4)$ \\
\hline Romania & $\mathrm{m}$ & $\mathrm{m}$ & $\mathrm{m}$ & $\mathrm{m}$ & $\mathrm{m}$ & $\mathrm{m}$ & $\mathrm{m}$ & $\mathrm{m}$ & $\mathrm{m}$ & $\mathrm{m}$ & $\mathrm{m}$ & $\mathrm{m}$ & $\mathrm{m}$ & $\mathrm{m}$ & $\mathrm{m}$ & $\mathrm{m}$ \\
\hline Russia & 1.3 & $(0.2)$ & 9.9 & $(0.5)$ & 58.6 & $(0.7)$ & 30.1 & $(0.8)$ & 5.3 & $(0.3)$ & 39.0 & $(0.8)$ & 40.2 & $(0.7)$ & 15.6 & (0.6) \\
\hline Singapore & 3.2 & $(0.2)$ & 22.0 & $(0.5)$ & 46.8 & $(0.7)$ & 28.0 & $(0.6)$ & 2.7 & $(0.2)$ & 15.1 & $(0.4)$ & 44.2 & (0.6) & 38.0 & $(0.6)$ \\
\hline Chinese Taipei & 3.0 & $(0.2)$ & 23.9 & $(0.6)$ & 51.1 & $(0.6)$ & 22.0 & $(0.6)$ & 4.6 & $(0.2)$ & 27.3 & $(0.5)$ & 47.2 & (0.6) & 20.9 & $(0.5)$ \\
\hline Thailand & 2.9 & $(0.2)$ & 30.1 & $(0.7)$ & 55.5 & $(0.7)$ & 11.5 & $(0.4)$ & 2.3 & $(0.3)$ & 18.0 & $(0.7)$ & 57.3 & $(0.9)$ & 22.4 & $(0.7)$ \\
\hline Trinidad and Tobago & $\mathrm{m}$ & $\mathrm{m}$ & $\mathrm{m}$ & $\mathrm{m}$ & $\mathrm{m}$ & $\mathrm{m}$ & $\mathrm{m}$ & $\mathrm{m}$ & $\mathrm{m}$ & $\mathrm{m}$ & $\mathrm{m}$ & $\mathrm{m}$ & $\mathrm{m}$ & $\mathrm{m}$ & $\mathrm{m}$ & $\mathrm{m}$ \\
\hline Tunisia & 2.2 & $(0.2)$ & 7.2 & $(0.4)$ & 46.9 & $(0.9)$ & 43.7 & $(0.9)$ & 1.7 & $(0.2)$ & 5.2 & $(0.3)$ & 39.6 & $(0.8)$ & 53.4 & $(0.9)$ \\
\hline United Arab Emirates & 2.2 & $(0.1)$ & 8.4 & $(0.3)$ & 40.0 & $(0.5)$ & 49.3 & $(0.6)$ & 2.3 & $(0.2)$ & 6.2 & $(0.3)$ & 35.4 & (0.6) & 56.2 & $(0.7)$ \\
\hline Uruguay & 16.3 & $(0.5)$ & 36.2 & $(0.6)$ & 31.0 & $(0.6)$ & 16.5 & $(0.6)$ & 11.4 & $(0.4)$ & 38.7 & $(0.7)$ & 34.8 & $(0.7)$ & 15.1 & (0.6) \\
\hline Viet Nam & $\mathrm{m}$ & $\mathrm{m}$ & $\mathrm{m}$ & $\mathrm{m}$ & $\mathrm{m}$ & $\mathrm{m}$ & $\mathrm{m}$ & $\mathrm{m}$ & $\mathrm{m}$ & $\mathrm{m}$ & $\mathrm{m}$ & $\mathrm{m}$ & $\mathrm{m}$ & $\mathrm{m}$ & $\mathrm{m}$ & $\mathrm{m}$ \\
\hline Argentina** & $\mathrm{m}$ & $\mathrm{m}$ & $\mathrm{m}$ & $\mathrm{m}$ & $\mathrm{m}$ & $\mathrm{m}$ & $\mathrm{m}$ & $\mathrm{m}$ & $\mathrm{m}$ & $\mathrm{m}$ & $\mathrm{m}$ & $\mathrm{m}$ & $\mathrm{m}$ & $\mathrm{m}$ & $\mathrm{m}$ & $\mathrm{m}$ \\
\hline Kazakhstan** & $\mathrm{m}$ & $\mathrm{m}$ & $\mathrm{m}$ & $\mathrm{m}$ & $\mathrm{m}$ & $\mathrm{m}$ & $\mathrm{m}$ & $\mathrm{m}$ & $\mathrm{m}$ & $\mathrm{m}$ & $\mathrm{m}$ & $\mathrm{m}$ & $\mathrm{m}$ & $\mathrm{m}$ & $\mathrm{m}$ & $\mathrm{m}$ \\
\hline Malaysia** & 0.8 & $(0.1)$ & 10.5 & $(0.6)$ & 49.5 & $(0.8)$ & 39.3 & (1.0) & 1.1 & $(0.2)$ & 7.2 & $(0.5)$ & 38.7 & (0.9) & 53.0 & (1.2) \\
\hline
\end{tabular}

* See note at the beginning of this Annex.

** Coverage is too small to ensure comparability (see Annex A4).

StatLink त्नाls $\mathrm{ht}$ htp://dx.doi.org/10.1787/888933470890 


\begin{tabular}{|c|c|c|c|c|c|c|c|c|c|c|c|c|c|c|c|c|c|c|c|c|}
\hline & & ercent & age of bo & jys why & agreed & with $\mathrm{t}$ & ce follon & ing sta & atement & & & cents & age of $g$ & rls whe & agre & with $t$ & he foll & ving st. & atements & \\
\hline & $\begin{array}{c}\text { I wan } \\
\text { grad } \\
\text { most o } \\
\text { my co }\end{array}$ & $\begin{array}{l}\text { top } \\
\text { s in } \\
\text { all of } \\
\text { urses }\end{array}$ & $\begin{array}{c}\text { I want } \\
\text { able to } \\
\text { from } \\
\text { the } \\
\text { opportt } \\
\text { avail } \\
\text { wh } \\
\text { I grad }\end{array}$ & $\begin{array}{l}\text { to be } \\
\text { select } \\
\text { mong } \\
\text { est } \\
\text { unities } \\
\text { able } \\
\text { en } \\
\text { uate }\end{array}$ & $\begin{array}{l}\text { I wan } \\
\text { be the } \\
\text { what } \\
\text { Id }\end{array}$ & & $\begin{array}{c}\text { I see } n \\
\text { as } \\
\text { ambit } \\
\text { pers }\end{array}$ & & $\begin{array}{c}\text { I wan } \\
\text { one } \\
\text { best st } \\
\text { in } \mathrm{my}\end{array}$ & & $\begin{array}{c}\text { I wa } \\
\text { grad } \\
\text { most } 0 \\
\text { my ce }\end{array}$ & $\begin{array}{l}\text { top } \\
\text { in } \\
\text { all of } \\
\text { rses }\end{array}$ & $\begin{array}{l}\text { I wan } \\
\text { able te } \\
\text { from } \\
\text { the } \\
\text { oppor } \\
\text { avai } \\
\text { wh } \\
\text { I gra }\end{array}$ & $\begin{array}{l}\text { o be } \\
\text { elect } \\
\text { ong } \\
\text { st } \\
\text { ities } \\
\text { be } \\
\text { late } \\
\text { ate }\end{array}$ & $\begin{array}{l}\text { I war } \\
\text { be the } \\
\text { what }\end{array}$ & & $\begin{array}{r}\text { I see } \\
\text { as } \\
\text { amb } \\
\text { per }\end{array}$ & & $\begin{array}{c}\text { one } \\
\text { best stu } \\
\text { in my }\end{array}$ & $\begin{array}{l}\text { to be } \\
\text { f the } \\
\text { udents } \\
\text { class }\end{array}$ \\
\hline & $\%$ & S.E. & $\%$ & S.E. & $\%$ & S.E. & $\%$ & S.E. & $\%$ & S.E. & $\%$ & S.E. & $\%$ & S.E. & $\%$ & S.E. & $\%$ & S.E. & $\%$ & S.E. \\
\hline Australia & 87.5 & $(0.5)$ & 94.9 & $(0.4)$ & 87.5 & (0.5) & 80.8 & $(0.5)$ & 73.5 & $(0.7)$ & 91.0 & $(0.4)$ & 96.7 & $(0.3)$ & \begin{tabular}{|l|}
85.8 \\
\end{tabular} & $(0.6)$ & 81.3 & $(0.6)$ & 74.9 & $(0.7)$ \\
\hline Austria & 76.8 & (0.6) & 92.4 & $(0.5)$ & 53.5 & $(0.9)$ & 67.5 & $(0.9)$ & 51.4 & $(0.9)$ & 79.1 & $(0.8)$ & 92.1 & $(0.5)$ & $\begin{array}{l}85.0 \\
38.9\end{array}$ & (1.2) & 65.5 & $\begin{array}{l}(1.1) \\
(1.1)\end{array}$ & 42.1 & $(1.2)$ \\
\hline Belgium & 72.7 & $(0.7)$ & 92.2 & $(0.4)$ & 44.8 & (0.9) & 65.2 & (0.8) & 43.5 & (0.8) & 71.5 & (0.6) & 91.7 & $(0.4)$ & 33.9 & (0.8) & 59.5 & (0.9) & 39.5 & $(0.8)$ \\
\hline Canada & 86.3 & (0.6) & 94.0 & (0.4) & 82.5 & (0.6) & 81.1 & (0.6) & 71.4 & (0.9) & 91.1 & (0.4) & 96.8 & $(0.3)$ & \begin{tabular}{|l|}
81.1 \\
\end{tabular} & $(0.7)$ & 83.1 & $(0.6)$ & 74.8 & $(0.7)$ \\
\hline Chile & 91.7 & (0.5) & 95.8 & (0.5) & 85.9 & $(0.8)$ & 76.3 & $(0.8)$ & 71.5 & (1.0) & 92.8 & $(0.6)$ & 96.0 & $(0.5)$ & \begin{tabular}{|l|}
81.1 \\
\end{tabular} & $(0.8)$ & 62.3 & (1.0) & 72.5 & (1.0) \\
\hline Czech Republic & 79.9 & $(0.8)$ & 92.5 & $(0.5)$ & 70.2 & $(0.9)$ & 62.9 & $(0.9)$ & 42.9 & (1.0) & 82.3 & $(0.8)$ & 94.3 & $(0.5)$ & 63.5 & (1.2) & 58.3 & (1.1) & 40.3 & (1.1) \\
\hline Denmark & 73.2 & (0.9) & 82.2 & $(0.8)$ & 51.7 & (1.2) & 78.6 & (1.0) & 68.1 & $(0.9)$ & 80.7 & $(0.8)$ & 84.2 & $(0.7)$ & 48.0 & (1.0) & 81.7 & $(0.8)$ & 70.3 & (1.1) \\
\hline Estonia & 90.4 & $(0.8)$ & 93.7 & $(0.5)$ & 65.6 & $(1.0)$ & 73.9 & $(0.9)$ & 48.9 & $(1.1)$ & 93.7 & $(0.5)$ & 96.3 & $(0.4)$ & 65 & $(1.0)$ & 75 & $(1.0)$ & 53.5 & $(1.0)$ \\
\hline Finlan & 62.1 & (1.0) & 79.1 & (1.0) & 41.3 & (1.1) & 54.9 & (1.3) & 40.5 & (1. & 59 & (1.1) & 80 & $(0.8)$ & 30 & (1 & 57.4 & (1.1) & 41.1 & (1.0) \\
\hline France & 85.2 & $(0.6)$ & 93.3 & $(0.5)$ & 52.9 & (1.1) & 71.4 & $(0.8)$ & 46.0 & (1.0) & 85.3 & $(0.6)$ & 95.3 & $(0.4)$ & \begin{tabular}{|l|} 
\\
\end{tabular} & (1.0) & 69.6 & $(0.9)$ & 43.6 & (1.2) \\
\hline Germany & 76.7 & (0.9) & 91.3 & (0.6) & 47.4 & (0.9) & 66.8 & $(0.8)$ & 5.5 & (1.0) & 76.4 & $(0.8)$ & 90.5 & $(0.6)$ & \begin{tabular}{|l|}
35.8 \\
\end{tabular} & $(0.9)$ & 63.5 & (1.0) & 0.0 & $(0.9)$ \\
\hline Greece & 69.8 & (0.9) & 93.9 & (0.6) & 67.4 & (1.0) & 80.5 & $(0.8)$ & 60.3 & (1.0) & 76.1 & $(0.8)$ & 97.2 & $(0.3)$ & \begin{tabular}{|l|}
65.0 \\
\end{tabular} & $(0.9)$ & 74.7 & $(0.9)$ & 66.6 & (1.1) \\
\hline Hungary & 76.7 & $(0.9)$ & 92.7 & $(0.6)$ & 69.0 & $(0.9)$ & 65.1 & (1.1) & 39.7 & (1.0) & 75.9 & $(0.9)$ & 93.5 & $(0.5)$ & \begin{tabular}{|l|}
59.5 \\
\end{tabular} & (1.0) & 57.4 & (1.0) & 41.1 & (1.1) \\
\hline Iceland & 94.8 & $(0.5)$ & 83.3 & $(0.9)$ & 77.1 & (1.1) & 80.1 & (1.0) & 74.1 & (1.2) & 97.5 & $(0.4)$ & 89.7 & $(0.7)$ & \begin{tabular}{|l|}
73.1 \\
\end{tabular} & (1.1) & 77.9 & (1.0) & 76.8 & (1.0) \\
\hline Ireland & 93.0 & $(0.5)$ & 96.8 & $(0.3)$ & 89.6 & $(0.6)$ & 86.5 & $(0.6)$ & 75.4 & $(0.9)$ & 92.4 & $(0.5)$ & 97.3 & $(0.2)$ & \begin{tabular}{|l|}
83.7 \\
\end{tabular} & $(0.7)$ & 83.4 & $(0.7)$ & 69.2 & (1.0) \\
\hline Israel & 94.3 & $(0.6)$ & 95.1 & $(0.6)$ & 89.4 & $(0.7)$ & 85.4 & $(0.8)$ & 85.0 & $(1.0)$ & 97.7 & (0.3) & 98.3 & $(0.2)$ & \begin{tabular}{|l|}
91.2 \\
\end{tabular} & $(0.6)$ & 88.0 & $(0.6)$ & 87.6 & $(0.8)$ \\
\hline Italy & 86.1 & $(0.8)$ & 94.5 & $(0$. & 62.9 & (1.0) & 74.8 & $(0.9)$ & 52.3 & (1.0) & 89.9 & $(0.6)$ & 95.5 & $(0.4)$ & 47 & (1.1) & & $(1.3)$ & & \\
\hline Japan & 66.0 & $(0.9)$ & 88.1 & $(0.6)$ & 44.3 & (1.1) & 59.9 & (1.0) & 37.8 & $(1.0)$ & 63.6 & $(1.1)$ & 86.5 & $(0.7)$ & 33 & $(1.0)$ & & (1.1) & 7.9 & 9) \\
\hline Korea & 84.7 & $(0.8)$ & 94.7 & 0. & 78.8 & $(0.8)$ & 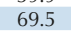 & (1) & 7 & 0.9 & 88.8 & (106) & 97 & & 81 & & & 1) & 3.2 & 9) \\
\hline Latvia & 86.9 & (0.7) & 91.7 & $(0.7)$ & 66.7 & (1.1) & 3.2 & (1.0) & 4.9 & (1.3) & 90.2 & $(0.6)$ & 94.9 & $(0.6)$ & 33.0 & $(1.0)$ & 77.1 & (1.0) & 62.3 & .2) \\
\hline Luxembot & 82.3 & (0.7) & 91.1 & (0.5) & 55.4 & (0.9) & 4.7 & (0.9) & 45 & (0.9) & 83.0 & $(0.6)$ & 93.9 & $(0.5)$ & \begin{tabular}{|l|}
45.3 \\
\end{tabular} & $(0.8)$ & 615 & $(0.9)$ & 53.1 & $(0.9)$ \\
\hline Mexico & 95.7 & (0.4) & 95.4 & (0.5) & 85.3 & (0.8) & 45.7 & (1.1) & 82.0 & (0.9) & 97.0 & $(0.4)$ & 96.8 & $(0.3)$ & \begin{tabular}{|l|}
80.8 \\
\end{tabular} & $(0.9)$ & 32.5 & (1.0) & 80.4 & $(0.8)$ \\
\hline Netherlands & 91.9 & (0.5) & 93.9 & (0.5) & 44.6 & (1.3) & 73.3 & (1.0) & 33.9 & $(1.2)$ & 92.1 & $(0.5)$ & 93.8 & $(0.4)$ & 29.6 & $(0.9)$ & 72.2 & (1.1) & 25.7 & (1.0) \\
\hline New Zealand & 87.8 & $(0.8)$ & 94.2 & $(0.6)$ & 86.0 & $(0.9)$ & 76.6 & (1.0) & 69.7 & (1.1) & 89.7 & $(0.6)$ & 94.8 & $(0.5)$ & \begin{tabular}{|l|} 
\\
5.1
\end{tabular} & $(0.7)$ & 78.3 & $(0.8)$ & 70.2 & (1.0) \\
\hline Norway & 80.1 & $(0.9)$ & 93.8 & $(0.5)$ & 67.1 & $(0.9)$ & 77.2 & $(0.8)$ & 62.5 & $(0.9)$ & 86.9 & $(0.7)$ & 97.2 & $(0.3)$ & 62.4 & (1.1) & 76.4 & (1.1) & 66.1 & (1.1) \\
\hline Poland & 61.0 & (1.1) & 85.4 & $(0.8)$ & 63.2 & $(1.1)$ & 76.3 & $(0.9)$ & 44.3 & $(1.0)$ & 68.8 & (1.1) & 86.8 & $(0.8)$ & 52.7 & $(1$ & 72 & (1.1) & 48.6 & $(1.2)$ \\
\hline Portu & 94.2 & 0. & 91.6 & $(0.5)$ & 80.8 & $(0.7)$ & 75 & & 65.0 & $(0$ & 97.2 & & 9 & & 72 & & & (1.1) & & \\
\hline Slo & 69.7 & $(0.9)$ & 90.8 & $(0.6)$ & 73.2 & $(0.9)$ & 71.3 & $(0.9)$ & 44.6 & $(1.0)$ & 77.6 & & 93.7 & & 6 & & & (1.1) & & \\
\hline Slove & 68.7 & (1.0) & 83.3 & $(0.8)$ & 53.8 & $(0.9)$ & 63.5 & (1.1) & 45.2 & (1.0) & 70.2 & (1.0) & 89.1 & $(0.7)$ & 449 & (1. & 61 & (1.1) & 3.3 & (1.1) \\
\hline Spain & 75.6 & $(0.8)$ & 93.4 & $(0.5)$ & 66.1 & $(0.9)$ & 60.5 & (1.0) & 58.2 & (1.1) & 78.7 & $(0.9)$ & 94.3 & $(0.5)$ & \begin{tabular}{|l|}
56.6 \\
\end{tabular} & (1.1) & 46.5 & (1.2) & 56.7 & (1.1) \\
\hline Sweden & 77.0 & $(0.9)$ & 90.1 & $(0.6)$ & 75.6 & $(0.9)$ & 80.5 & $(0.9)$ & 60.6 & (1.1) & 82.9 & $(0.8)$ & 94.3 & $(0.4)$ & 70.4 & $(0.8)$ & 83.7 & $(0.8)$ & 66.6 & (1.1) \\
\hline Switzerland & 77.7 & $(0.9)$ & 90.2 & $(0.7)$ & 46.2 & (1.2) & 68.7 & (1.0) & 43.8 & (1.1) & 76.9 & (1.0) & 91.0 & $(0.6)$ & \begin{tabular}{|l|}
31.9 \\
\end{tabular} & (1.1) & 66.1 & (1.0) & 35.9 & (1.2) \\
\hline Turkey & 91.9 & $(0.7)$ & 92.7 & $(0.6)$ & 83.9 & $(0.7)$ & 74.0 & (1.1) & 87.0 & $(0.7)$ & 95.0 & $(0.4)$ & 95.7 & $(0.4)$ & 87.0 & $(0.8)$ & 71.7 & (1.0) & 91.5 & $(0.5)$ \\
\hline United Kingdom & 94.8 & $(0.4)$ & 97.2 & $(0.4)$ & 89.3 & $(0.5)$ & 83.5 & $(0.7)$ & 75.4 & $(0.8)$ & 96.0 & $(0.4)$ & 98.4 & $(0.2)$ & 90.1 & $(0.5)$ & 83.4 & $(0.7)$ & 75.7 & $(0.7)$ \\
\hline United States & 92.9 & $(0.6)$ & 96.4 & $(0.4)$ & 93.0 & $(0.6)$ & 86.7 & $(0.7)$ & 83.4 & $(0.9)$ & 95.7 & $(0.4)$ & 98.1 & $(0.3)$ & 93.5 & (0.5) & 87.3 & $(0.7)$ & 87.4 & $(0.5)$ \\
\hline OECD average & 82.2 & $(0.1)$ & 91.8 & $(0.1)$ & 68.3 & $(0.2)$ & 72.4 & $(0.2)$ & 59.2 & $(0.2)$ & 84.6 & $(0.1)$ & 93.6 & $(0.1)$ & 62.2 & $(0.2)$ & 69.8 & $(0.2)$ & 59.2 & $(0.2)$ \\
\hline Albania & $\mathrm{m}$ & $\mathrm{m}$ & $\mathrm{m}$ & $\mathrm{m}$ & $\mathrm{m}$ & $\mathrm{m}$ & $\mathrm{m}$ & $\mathrm{m}$ & $\mathrm{m}$ & $\mathrm{m}$ & $\mathrm{m}$ & $\mathrm{m}$ & $\mathrm{m}$ & $\mathrm{m}$ & $\mathrm{m}$ & $\mathrm{m}$ & $\mathrm{m}$ & $\mathrm{m}$ & $\mathrm{m}$ & $\mathrm{m}$ \\
\hline Algeria & $\mathrm{m}$ & $\mathrm{m}$ & $\mathrm{m}$ & $\mathrm{m}$ & $\mathrm{m}$ & $\mathrm{m}$ & $\mathrm{m}$ & $\mathrm{m}$ & $\mathrm{m}$ & $\mathrm{m}$ & $\mathrm{m}$ & $\mathrm{m}$ & $\mathrm{m}$ & $\mathrm{m}$ & $\mathrm{m}$ & $\mathrm{m}$ & $\mathrm{m}$ & $\mathrm{m}$ & $\mathrm{m}$ & $\mathrm{m}$ \\
\hline Brazil & 94.4 & $(0.3)$ & 95.6 & $(0.3)$ & 81.2 & (0.6) & 44.4 & $(0.8)$ & 63.6 & $(0.7)$ & 95.7 & $(0.3)$ & 97.8 & $(0.2)$ & \begin{tabular}{|l|}
79.2 \\
\end{tabular} & $(0.6)$ & 36.2 & $(0.6)$ & 64.3 & $(0.7)$ \\
\hline B-S-J-G (China) & 75.2 & $(0.8)$ & 96.3 & $(0.3)$ & 88.3 & $(0.7)$ & 79.0 & (1.1) & 78.6 & $(0.9)$ & 69.2 & (1.1) & 97.0 & $(0.3)$ & 89.4 & $(0.7)$ & 66.3 & $(0.9)$ & 84.0 & $(0.8)$ \\
\hline Bulga & 75.7 & (0.9) & 91.4 & (0.6) & 58.6 & (1.0) & 78.6 & (0.9) & 63.8 & (1.0) & 81.6 & (1.0) & 96.7 & $(0.4)$ & \begin{tabular}{|l|}
56.2 \\
\end{tabular} & $(1.2)$ & 84.7 & $(0.8)$ & 70.9 & (1.1) \\
\hline CABA & $\mathrm{m}$ & & $\mathrm{m}$ & $\mathrm{m}$ & $\mathrm{m}$ & $\mathrm{m}$ & $\mathrm{m}$ & $\mathrm{m}$ & $\mathrm{m}$ & $\mathrm{m}$ & $\mathrm{m}$ & $\mathrm{m}$ & $\mathrm{m}$ & $\mathrm{m}$ & $\mathrm{m}$ & $\mathrm{m}$ & $\mathrm{m}$ & $\mathrm{m}$ & $\mathrm{m}$ & $\mathrm{m}$ \\
\hline Colc & 96.0 & $(0.3)$ & & $(0.2)$ & .6 & & 0 & 1) & 4 & $(0.5)$ & 97.2 & $(0.3)$ & 98.5 & $(0.2)$ & 91.3 & $(0.5)$ & 34.1 & $(0.9)$ & 92.7 & $(0.4)$ \\
\hline Costa Ric & 97.2 & $(0.3)$ & 97.2 & $(0.3)$ & 86.7 & $(0.6)$ & 58.7 & $(0.9)$ & 83.7 & $(0.8)$ & 98.2 & $(0.3)$ & 98.5 & $(0.2)$ & 81 & $(0.9)$ & 0 & $(1.1)$ & 7.3 & $(0.7)$ \\
\hline Croat & 67.9 & (1.1) & 91.7 & $(0.6)$ & & (1.0) & & $(1$ & & $(1$ & & & & & & (1.0) & & & & 9) \\
\hline Cypru & 78.6 & $(0.8)$ & 93.4 & $(0.5)$ & 74.8 & $(0.9)$ & 80.9 & $(0.8)$ & 70. & $(1.0)$ & 86.3 & $(0.7)$ & 97.3 & $(0.3)$ & 74 & $(0$ & 78.6 & $(0.8)$ & 75.0 & $(0.9)$ \\
\hline Dominican Republic & 90.9 & $(0.8)$ & 92.8 & $(0.6)$ & 85.7 & $(0.7)$ & 29.3 & $\begin{array}{l}(1.0) \\
(1.1)\end{array}$ & 90.3 & $(0.7)$ & 91.4 & $(0.6)$ & 93.6 & $(0.6)$ & 83.8 & $(0.9)$ & 22.4 & $\begin{array}{l}(1.0) \\
(1.1)\end{array}$ & 90.4 & $(0.6)$ \\
\hline FYROM & $\mathrm{m}$ & $\mathrm{m}$ & $\mathrm{m}$ & $\mathrm{m}$ & $\mathrm{m}$ & $\mathrm{m}$ & $\mathrm{m}$ & $\mathrm{m}$ & $\mathrm{m}$ & $\mathrm{m}$ & $\mathrm{m}$ & $\mathrm{m}$ & $\mathrm{m}$ & $\mathrm{m}$ & $\mathrm{m}$ & $\mathrm{m}$ & $\mathrm{m}$ & $\mathrm{m}$ & $\mathrm{m}$ & $\mathrm{m}$ \\
\hline Geor & & $\mathrm{m}$ & $\mathrm{m}$ & $\mathrm{m}$ & $\mathrm{m}$ & $\mathrm{m}$ & $\mathrm{m}$ & $\mathrm{m}$ & $\mathrm{m}$ & $\mathrm{m}$ & $\mathrm{m}$ & $\mathrm{m}$ & $\mathrm{m}$ & $\mathrm{m}$ & $\mathrm{m}$ & $\mathrm{m}$ & $\mathrm{m}$ & & $\mathrm{m}$ & $\mathrm{m}$ \\
\hline gg (China) & 85.5 & $(0.9)$ & 91.5 & $(0.7)$ & 80.6 & $(1.0)$ & 67.3 & (1.0) & 72.3 & (1.1) & 90.8 & $(0.6)$ & 95.5 & $(0.4)$ & 84.4 & $(0.6)$ & 60.8 & $(1.1)$ & 78.6 & $(1.0)$ \\
\hline Indones & $\mathrm{m}$ & & $\mathrm{m}$ & $\mathrm{m}$ & $\mathrm{m}$ & & $\mathrm{m}$ & & $\mathrm{m}$ & & $\mathrm{m}$ & & $\mathrm{m}$ & 7 & $\mathrm{~m}$ & & 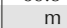 & & $\mathrm{m}$ & $\mathrm{m}$ \\
\hline Jordan & $\mathrm{m}$ & $\mathrm{m}$ & $\mathrm{m}$ & $\mathrm{m}$ & $\mathrm{m}$ & $\mathrm{m}$ & $\mathrm{m}$ & $\mathrm{m}$ & $\mathrm{m}$ & $\mathrm{m}$ & $\mathrm{m}$ & $\mathrm{m}$ & $\mathrm{m}$ & $\mathrm{m}$ & $\mathrm{m}$ & $n$ & $\mathrm{n}$ & $\mathrm{n}$ & $\mathrm{m}$ & $\mathrm{m}$ \\
\hline Koso & $\mathrm{m}$ & & ... & & & & $\mathrm{m}$ & . & ... & $\mathrm{m}$ & $\mathrm{m}$ & ... & ... & & $\ldots$ & & & & & $\mathrm{m}$ \\
\hline & $\mathrm{m}$ & in & . & $\mathrm{m}$ & ... & ... & & ... & & & III & & & & & & & 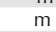 & m & $\mathrm{m}$ \\
\hline & 9.6 & $(0.9)$ & iII & $(0.7)$ & 67.3 & $(1$ & & (1 & & II & & 1 & & & & & & III & II & \\
\hline$M$ & 46.7 & $(1.0)$ & 88.7 & $(0.7)$ & 57.4 & (1.0) & 59.5 & (1.2) & 46.2 & (1.1) & 52.8 & $(1.1)$ & 93.6 & $(0.6)$ & 56.8 & $(1.1)$ & 51.5 & (1.1) & 51.0 & $(1.2)$ \\
\hline & $\mathrm{m}$ & & $\mathrm{m}$ & & $\mathrm{m}$ & & $\mathrm{m}$ & & $\mathrm{m}$ & & $\mathrm{m}$ & & $\mathrm{m}$ & $\mathrm{m}$ & $\mathrm{m}$ & $\mathrm{m}$ & $\mathrm{m}$ & & $\mathrm{m}$ & $\mathrm{m}$ \\
\hline & $\mathrm{m}$ & $\mathrm{m}$ & $\mathrm{m}$ & $\mathrm{m}$ & $\mathrm{m}$ & $\mathrm{m}$ & $\mathrm{m}$ & & 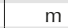 & n & & & & & . & & $\mathrm{m}$ & $\mathrm{m}$ & $\mathrm{m}$ & $\mathrm{m}$ \\
\hline M & 73.0 & $(0.9)$ & 89.6 & (0.6) & $67 ?$ & $(0.9)$ & 787 & $(0.7)$ & 515 & $(0.9)$ & 7 & & 94.5 & & 64.9 & & 83.1 & $(0.6)$ & 57.3 & $(0.8)$ \\
\hline Peru & 96.4 & (0.3) & 96.6 & $(0.3)$ & 90.3 & (0.5) & 45.0 & $(0.9)$ & 88.0 & $(0.5)$ & 96.6 & $(0.3)$ & 96.8 & $(0.3)$ & \begin{tabular}{|l|}
89.0 \\
\end{tabular} & $(0.6)$ & 32.7 & $(0.9)$ & 88.9 & $(0.5)$ \\
\hline Qa & 90.4 & $(0.4)$ & 91.9 & $(0.3)$ & 88.6 & $(0.4)$ & 85.7 & $(0.4)$ & 87.9 & $(0.4)$ & 96.4 & $(0.2)$ & 97.3 & $(0.2)$ & 91.3 & $(0.4)$ & 88.4 & $(0.4)$ & 90.9 & $(0.4)$ \\
\hline Rom & $\begin{array}{c}90.4 \\
\mathrm{~m}\end{array}$ & 10.4) & 91.9 & & m & (0.4) & $\begin{array}{l}03.7 \\
\mathrm{~m}\end{array}$ & & $\mathrm{~m}$ & $\begin{array}{r}\text { (1).4) } \\
\mathrm{m}\end{array}$ & $\begin{array}{l}0.4 \\
\mathrm{~m}\end{array}$ & $\begin{array}{r}\mathrm{m} \\
\mathrm{T}\end{array}$ & $\mathrm{m}$ & m & 91.3 & $\begin{array}{r}0.4) \\
\mathrm{m}\end{array}$ & 兽o.4 $\mathrm{m}$ & m & m & $\begin{array}{r}(0.4) \\
\mathrm{m}\end{array}$ \\
\hline & 80.4 & (1.1) & 94.1 & (0. & 751 & $(0$. & 90.0 & $(0.9)$ & & (1.1) & 31.3 & $(0.6)$ & ... & $(0.5)$ & 70.9 & (1.1) & 87.5 & $(0.5)$ & 57.0 & (1.0) \\
\hline & 8 & $(0$ & & (0 & & & & & & & & & & & 897 & & - & & 4 & \\
\hline & & $(0$ & (1) & $(0$ & & (1 & & & & & & & & & & & & & & \\
\hline & 90.6 & $(0.6$ & 95.9 & $(0$. & 95.7 & $(0$. & 68.5 & (1.1) & $\begin{array}{l}73.0 \\
76.7\end{array}$ & $\begin{array}{l}(1.1) \\
(1.1)\end{array}$ & 92.2 & $(0.5)$ & $\begin{array}{l}70.1 \\
98.6\end{array}$ & $\begin{array}{l}(0.2) \\
(0.2)\end{array}$ & 98.4 & $(0.2)$ & 65.9 & $(0.9)$ & 82.0 & $(0.7)$ \\
\hline Tr & & & & & & & & & & & & & & & & & & & & \\
\hline Tun & 94.9 & $(0.5)$ & 94.8 & $(0.5)$ & 86.4 & $(0$. & 90.4 & $(0$. & 91.0 & $(0.7)$ & 97.8 & $(0.3)$ & 97.9 & $(0.2)$ & 92.0 & $(0.6)$ & 90.7 & $(0.6)$ & 94.8 & $(0.4)$ \\
\hline Unite & 91.2 & $(0.5)$ & 93.8 & $(0.5)$ & 90.9 & $(0.4)$ & 88.9 & $(0.5)$ & 90.0 & $(0.4)$ & 95.9 & $(0.4)$ & 97.3 & $(0.3)$ & 93.5 & $(0.4)$ & 89.8 & $(0.5)$ & 93.0 & $(0.5)$ \\
\hline Urugu & 87.6 & $(0.7)$ & 94.1 & $(0.5)$ & 80.5 & (0.9) & 55.8 & $(1.0)$ & 52.3 & (1.1) & 89.3 & $\begin{array}{l}(0.6) \\
(0.6)\end{array}$ & 95.8 & $(0.4)$ & 70.9 & $(0.9)$ & 40.1 & $(1.0)$ & 47.8 & $(1.0)$ \\
\hline Viet Nam & $\mathrm{m}$ & & $\mathrm{m}$ & & & & & & & & & & 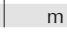 & & 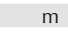 & & & & 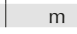 & \\
\hline Arge & $\mathrm{m}$ & & $\mathrm{m}$ & $\mathrm{m}$ & $\mathrm{m}$ & & $\mathrm{m}$ & & & & $\mathrm{m}$ & & $\mathrm{m}$ & & $\mathrm{m}$ & & $\mathrm{m}$ & & $\mathrm{m}$ & \\
\hline & III & III & in & . & $\mathrm{m}$ & & & & & & & & & & & & & & & \\
\hline & 3.9 & in & 5.8 & 14) & 5.2 & 14) & 8.2 & 1.7) & 0.2 & ).7. & 0.5 & 0.4 & 8.1 & 8.3 & 66.0 & (0.5) & 39.2 & $0.7)$ & 93.0 & $(0.5)$ \\
\hline
\end{tabular}

1. A socio-economically disadvantaged student is a student in the bottom quarter of the PISA index of economic, social and cultural status (ESCS) within his or her own country/economy. 2. A socio-economically advantaged student is a student in the top quarter of the PISA index of economic, social and cultural status (ESCS) within his or her own country/economy. Note: Values that are statistically significant are indicated in bold (see Annex A3).

* See note at the beginning of this Annex.

Coverage is too small to ensure comparability (see Annex A4).

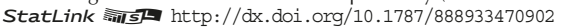


[Part 2/3]

Table III.5.2 Students' achievement motivation, by gender and socio-economic status

Percentage of students who reported that they "agree" or "strongly agree"

\begin{tabular}{|c|c|c|c|c|c|c|c|c|c|c|c|c|c|c|c|c|c|c|c|c|c|}
\hline & & & Gender & $\begin{array}{l}\text { differen } \\
\text { with }\end{array}$ & in $t$ & $\begin{array}{l}\text { he perce } \\
\text { llowing }\end{array}$ & & $\begin{array}{l}\text { studen } \\
\text { ts (B - }\end{array}$ & its $w$ & & & & Perc & $\begin{array}{l}\text { age c } \\
\text { who }\end{array}$ & cic & & & $d v$ & ged & & \\
\hline & & $\begin{array}{r}\text { I wan } \\
\text { grade } \\
\text { most o } \\
\text { my co }\end{array}$ & $\begin{array}{l}\text { t top } \\
\text { es in } \\
r \text { all of } \\
\text { urses }\end{array}$ & $\begin{array}{l}\text { I want } \\
\text { able to } \\
\text { from a } \\
\text { the } \\
\text { opport } \\
\text { avail } \\
\text { wh } \\
\text { I grad }\end{array}$ & $\begin{array}{l}\text { to be } \\
\text { select } \\
\text { mong } \\
\text { est } \\
\text { unities } \\
\text { able } \\
\text { en } \\
\text { uate }\end{array}$ & $\begin{array}{l}\text { I wat } \\
\text { be the } \\
\text { what }\end{array}$ & $\begin{array}{l}\text { to } \\
\text { est, } \\
\text { er }\end{array}$ & $\begin{array}{r}\text { I see } \mathrm{m} \\
\text { as } \\
\text { ambit } \\
\text { pers }\end{array}$ & $\begin{array}{l}\text { nyself } \\
\text { an } \\
\text { tious } \\
\text { son }\end{array}$ & $\begin{array}{c}\text { I want } \\
\text { one o } \\
\text { best st } \\
\text { in my }\end{array}$ & $\begin{array}{l}\text { to be } \\
\text { f the } \\
\text { udents } \\
\text { class }\end{array}$ & $\begin{array}{r}\text { grad } \\
\text { most o } \\
\text { my co }\end{array}$ & $\begin{array}{l}\text { top } \\
\text { in } \\
\text { all of } \\
\text { irses }\end{array}$ & $\begin{array}{l}\text { I wan } \\
\text { able to } \\
\text { from } \\
\text { the } \\
\text { oppor } \\
\text { avai } \\
\text { wh } \\
\text { I gra }\end{array}$ & $\begin{array}{l}\text { to be } \\
\text { select } \\
\text { mong } \\
\text { est } \\
\text { unities } \\
\text { able } \\
\text { en } \\
\text { uate }\end{array}$ & $\begin{array}{r}\text { be th } \\
\text { why } \\
\text { I }\end{array}$ & $\begin{array}{l}\text { to } \\
\text { est, } \\
\text { ver }\end{array}$ & $\begin{array}{r}\text { as } \\
\text { ambi } \\
\text { per }\end{array}$ & $\begin{array}{l}\text { self } \\
\text { ous } \\
\text { n }\end{array}$ & $\begin{array}{c}\text { I wa } \\
\text { one } \\
\text { best } \\
\text { in } n\end{array}$ & $\begin{array}{l}\text { to be } \\
\text { the } \\
\text { dents } \\
\text { dlass }\end{array}$ \\
\hline & & $\%$ dif. & S.E. & $\%$ dif. & S.E. & $\%$ dif. & S.E. & $\%$ dif. & S.E. & $\%$ dif. & S.E. & $\%$ & S.E. & $\%$ & S.E. & $\%$ & S.E. & $\%$ & S.E. & $\%$ & S.E. \\
\hline & Australia & -3.5 & $(0.6)$ & -1.8 & (0.5) & 1.7 & $(0.8)$ & -0.5 & $(0.9)$ & -1.4 & $(1.0)$ & 86.2 & $(0.7)$ & 93.2 & $(0.6)$ & 85.9 & $(0.7)$ & 76.0 & $(0.9)$ & 68.0 & $(1.0)$ \\
\hline & Austria & -2.4 & (1.1) & 0.3 & $(0.8)$ & 14.6 & (1.5) & 2.0 & (1.4) & 9.4 & (1.4) & 81.4 & (0.8) & 89.4 & $(0.8)$ & 46.2 & (1.7) & 61.7 & (1.2) & 46.1 & (1.5) \\
\hline & Belgium & 1.2 & (1.0) & 0.5 & $(0.6)$ & 10.9 & $(1.2)$ & 5.7 & (1.1) & 4.0 & (1.0) & 73.3 & (1.1) & 89.4 & $(0.7)$ & 40.9 & (1.3) & 55.4 & (1.4) & 42.6 & (1.5) \\
\hline & Canada & -4.8 & $(0.7)$ & -2.8 & (0.5) & 1.4 & $(0.7)$ & -2.0 & $(0.8)$ & -3.4 & (1.0) & 84.0 & $(0.8)$ & 92.7 & $(0.5)$ & 77.5 & $(0.9)$ & 77.4 & (0.9) & 64.9 & (1.1) \\
\hline & Chile & -1.1 & $(0.8)$ & -0.2 & $(0.7)$ & 4.8 & (0.9) & 14.0 & (1.3) & -1.0 & (1.4) & 91.3 & (0.9) & 94.7 & $(0.7)$ & 80.6 & (1.3) & 59.4 & (1.7) & 69.9 & (1.5) \\
\hline & Czech Republic & -2.4 & $(1.0)$ & -1.8 & $(0.6)$ & 6.8 & (1.6) & 4.5 & (1.4) & 2.6 & (1.5) & 76.9 & (1.2) & 90.1 & $(0.9)$ & 64.3 & $(1.2)$ & 52.2 & (1.6) & 33.0 & 1.4) \\
\hline & Denmark & -7.5 & $(1.2)$ & -2.0 & (1.0) & 3.7 & (1.5) & -3.1 & (1.2) & -2.2 & (1.3) & 70.7 & (1.4) & 75.7 & $(1.2)$ & 46.0 & (1.5) & 72.8 & 8) & .2 & 1.3) \\
\hline & Estonia & -3.3 & $(0.8)$ & -2.6 & (0.6) & -0.1 & (1.4) & -1.5 & (1.4) & -4.6 & (1.5) & 89.5 & (1.2) & 93.1 & (1.0) & 63.5 & (1.6) & 67.7 & (1.3) & 44.5 & (1.9) \\
\hline & Finland & 3.1 & (1.1) & -1.8 & (1.1) & 10.6 & (1.4) & -2.4 & (1.5) & -0.6 & (1.2) & 52.7 & (1.5) & 72.8 & (1.5) & 31.8 & (1.7) & 45.4 & (1.5) & 28.8 & $1.6)$ \\
\hline & France & -0.1 & $(0.8)$ & -2.0 & (0.6) & 10.4 & (1.2) & 1.8 & (1.2) & 2.4 & (1.3) & 83.5 & (1.1) & 91.5 & $(0.8)$ & 43.6 & (1.6) & 64.4 & & 41.4 & 1.7) \\
\hline & Germany & 0.2 & (1.1) & 0.8 & (0.9) & 11.6 & (1.2) & 3.3 & (1.4) & 5.6 & (1.3) & 75.4 & (1.6) & 87.7 & (1.0) & 37.6 & (1.6) & 59.6 & (1.7) & 37.9 & 1.2) \\
\hline & Greece & -6.3 & (1.0) & -3.3 & (0.6) & 2.4 & (1.2) & 5.8 & (1.3) & -6.4 & (1.3) & 68.7 & (1. & 93.9 & $(0$. & & (1.7) & 76.5 & (1.2) & 3 & 1.8) \\
\hline & Hungary & 0.8 & (1.2) & -0.8 & $(0.8)$ & 9.5 & $(1.2)$ & 7.8 & (1. & -1.4 & (1.4) & 73.8 & (1. & & (1. & 6 & (1. & & (1.7) & .6 & 1.7) \\
\hline & Iceland & -2.7 & $(0.7)$ & -6.4 & (1.1) & 4.0 & (1.5) & 2.1 & (1. & -2.7 & (1. & 4 & (0. & 8 & (1. & 6 & (1. & 3 & (1.6) & 8.5 & 1.5) \\
\hline & Ireland & 0.5 & $(0.7)$ & -0.6 & (0.5) & 6.0 & $(0 . c$ & 3.1 & $(0$. & 6.2 & (1. & .6 & (0. & & $(0$. & 8 & $(1.0)$ & 80.4 & (1.0) & 66.6 & 1.1) \\
\hline & Israel & -3.4 & $(0.6)$ & -3.2 & $(0.6)$ & -1.8 & $(0.9)$ & -2.6 & (1.0) & -2.6 & (1.3) & 95.3 & $(0.6)$ & 96.1 & (0.6) & 91.4 & (0.8) & 85.0 & (1.1) & 89.1 & (1.0) \\
\hline & Italy & -3.8 & (1.0) & -1.0 & (0.6) & 14.9 & (1.5) & 3.9 & (1.6) & 0.7 & (1.4) & 88.0 & (0. & & $(0.7)$ & 55.5 & (1. & 69.3 & 3) & 49.9 & 1.6) \\
\hline & Japan & 2.4 & (1.3) & 1.6 & (0.9) & 11.2 & (1.3) & 3.8 & (1.3) & 9.9 & (1.3) & 58.3 & (1. & 82.9 & (1.1) & 32.6 & (1 & 51.0 & t) & 26.0 & 1.3) \\
\hline & Korea & -4.1 & (1.1) & -2.9 & $(0.6$ & -2.6 & (1. & 5.0 & (1. & -2.5 & (1. & & (1. & & (0. & & (1. & 59.0 & & 3 & $.1)$ \\
\hline & Latvia & -3.3 & $(0.9)$ & -3.2 & (0.9) & 3.6 & (1.6 & -3.8 & (1.4) & -7 & (1. & 88.3 & $(1$. & 9 & $(0$. & 60.0 & 1 & 71.8 & ) & .5 & .7) \\
\hline & Luxembourg & -0.7 & $(1.0)$ & -2.8 & $(0.8)$ & 10.1 & (1.2) & 3.2 & (1.2) & 1.3 & (1.3) & 84.1 & (1. & 90.6 & $(0.9)$ & 49.1 & (1) & 56.7 & ) & 0 & 1.2) \\
\hline & Mexi & -1.4 & $(0.5)$ & -1.4 & $(0.5$ & 4.5 & (1.1) & 13.2 & (1.1) & & (1. & & $(0$. & & $(0$. & & & & & & .2) \\
\hline & Netherland & 2 & $(0.7)$ & 0.1 & $(0.8)$ & 15.1 & (1.6) & 1.2 & (1.4) & 8. & (1. & .1 & (0. & 9 & $(0$ & 2 & 1 & 3.4 & ) & 1 & .5) \\
\hline & New Zeal & -1.9 & (1.1) & -0.6 & $(0.8)$ & 0.9 & (1.1) & -1.7 & (1.4) & -0.5 & (1. & 9 & (1. & & $(1$ & & (1) & 4 & ) & .1 & 1.9) \\
\hline & Norway & -6.8 & (1.0) & -3.4 & (0.6) & 4.6 & (1.4) & 0.8 & (1. & 3.7 & (1. & & (1. & & $(0$ & & (1 & 68 & ) & .2 & 1.7) \\
\hline & Poland & -7.8 & (1.6) & -1.4 & $(1.1)$ & 10.5 & $(1$. & 3 & (1. & -4.2 & (1. & 6 & $(1$ & & & & (1 & & & 5 & ) \\
\hline & Portugal & -3.1 & $(0.5)$ & -3.0 & (0.6) & 8.1 & (1.1) & 8.4 & (1.3) & -1.1 & (1.4) & 93.9 & $(0$. & 88 & $(0$. & 74 & (1.1) & 61.5 & ) & 58.5 & 1.4) \\
\hline & Slovak Republic & -7.9 & (1.1) & -2.8 & $(0.8)$ & 5.4 & (1.4) & 1.8 & (1.4) & 0.2 & (1.4) & 66.1 & (1.7) & 86.5 & (1.4) & 64.1 & (1.5) & 60.7 & (1.7) & 39.4 & (1.4) \\
\hline & Slovenia & -1.5 & (1.3) & -5.8 & $(1.0)$ & 8.9 & (1.4) & -2.6 & (1. 6 & 1. & (1.4) & 6 & (1.2) & & (1. & & (1. & 1 & (1.5) & 39.3 & 1.3) \\
\hline & Spain & -3.1 & $(1.2)$ & -1.0 & $(0.7)$ & 9.5 & (1.2) & 14.0 & (1.5) & 1.5 & (1.4) & 73.7 & (1.4) & 9 & $(0.7)$ & 53.2 & (1.5) & 40.6 & (1.4) & 49.8 & 1.6) \\
\hline & Sweden & -5.9 & $(1.2)$ & -4.1 & $(0.7)$ & 5.2 & $(1$. & -3.2 & $(1$. & -6.0 & (1.4) & 7 & $(1$ & & $(0$. & 7 & $(1$ & & $(1.2)$ & 57.6 & (1.6) \\
\hline & Switzerla & 0.8 & (1.4) & -0.8 & $(0.9)$ & 14.2 & (1.5) & 2. & (1.3) & 7.9 & (1.6) & 79.4 & (1. & & (1. & 7 & (1.6) & 6.0 & (1.3) & 38.6 & (1.6) \\
\hline & Turkey & -3.1 & $(0.7)$ & -3.0 & $(0.7)$ & -3.0 & (1.1) & 23 & (1.4) & -4.5 & $(0.8)$ & 93.4 & $(0.7)$ & 92.7 & $(0.9)$ & 84.2 & (1 0 & 68.0 & $(2.2)$ & 90.7 & $(1.2)$ \\
\hline & United K & -1.2 & $(0.5)$ & -1.2 & $(0.4)$ & -0.8 & $(0.7)$ & 0.0 & $(0$. & 3 & $(1.0)$ & 2 & $(0.7)$ & & $(0.6)$ & & (1.0) & 78.5 & (1.2) & 69.5 & $(1.3)$ \\
\hline & United States & -2.9 & $(0.7)$ & -1.7 & $(0.5)$ & -0.4 & $(0.7)$ & -0.6 & $(0.9)$ & -4.0 & (1.0) & 93.2 & $(0.7)$ & 96.8 & $(0.4)$ & 92.7 & $(0.7)$ & 81.4 & (1.3) & 82.6 & (1.1) \\
\hline & OECD average & -2.5 & $(0.2)$ & -1.9 & $(0.1)$ & 6.2 & $(0.2)$ & 2.6 & $(0.2)$ & 0.1 & $(0.2)$ & 81.1 & $(0.2)$ & 89.7 & $(0.2)$ & 62.6 & $(0.2)$ & 64.6 & $(0.2)$ & 54.3 & $(0.2)$ \\
\hline 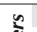 & Albania & $\mathrm{m}$ & $\mathrm{m}$ & $\mathrm{m}$ & $\mathrm{m}$ & $\mathrm{m}$ & $\mathrm{m}$ & $n$ & $\mathrm{~m}$ & $\mathrm{~m}$ & $\mathrm{~m}$ & $\mathrm{~m}$ & $\mathrm{~m}$ & $\mathrm{~m}$ & $\mathrm{~m}$ & $\mathrm{~m}$ & $\mathrm{n}$ & $\mathrm{m}$ & .1. & $\mathrm{m}$ & $\mathrm{m}$ \\
\hline & Algeria & $\mathrm{m}$ & $\mathrm{m}$ & $\mathrm{m}$ & $\mathrm{m}$ & $\mathrm{m}$ & $\mathrm{m}$ & $\mathrm{m}$ & 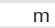 & $m$ & $m$ & $\mathrm{~m}$ & & $m$ & & 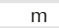 & & $\mathrm{m}$ & $\mathrm{m}$ & m & $\mathrm{m}$ \\
\hline & Brazil & -1.2 & $(0.4)$ & -2.2 & $(0.4)$ & 2.0 & $(0.8)$ & 8.2 & $(0.9)$ & -0.7 & $(0.8)$ & 3.2 & $(0$. & 96.1 & $(0.4)$ & 9.4 & $(0.8)$ & 30.2 & 1.1) & 55.3 & 1.0) \\
\hline & B-S-J-C & 6.0 & (1.6) & -0.6 & $(0.4)$ & -1.1 & (1.0) & 12.7 & (1.5) & -5.4 & (1. & & & & $(0$. & & (0. & & & & 3) \\
\hline & Bulga & -5.9 & (1.4) & -5.3 & $(0.7)$ & 2.4 & (1.5) & -6.2 & (1.1) & -7.1 & (1.5) & 76.1 & (1.6) & 0.9 & $(0.9)$ & 8.5 & (1.9) & 75.6 & 1.8) & 65.2 & 1.5) \\
\hline & $\mathrm{CAB}$ & $\mathrm{m}$ & $\mathrm{m}$ & $\mathrm{m}$ & $\mathrm{m}$ & $\mathrm{m}$ & $\mathrm{m}$ & $\mathrm{m}$ & $\mathrm{m}$ & $\mathrm{m}$ & $\mathrm{m}$ & $\mathrm{m}$ & $\mathrm{m}$ & $\mathrm{m}$ & $\mathrm{m}$ & $\mathrm{m}$ & $\mathrm{m}$ & $\mathrm{m}$ & $\mathrm{m}$ & $\mathrm{m}$ & $\mathrm{m}$ \\
\hline & Colombi & 1.2 & $(0.5)$ & -0.3 & $(0.3)$ & 1.3 & $(0.7)$ & 13.0 & (1.2) & -2.3 & $(0.7)$ & 7.6 & (0.5) & 98.1 & $(0.4)$ & 39.9 & $(0.8)$ & 27.9 & .3) & 93.0 & $0.7)$ \\
\hline & Cost & -0.9 & $(0.4)$ & -1 & $(0.3)$ & 4.9 & (1.1) & 14.7 & (1.4) & -3 & (1.0) & 9 & $(0$ & & $(0$ & 8 & $(1$ & 38.9 & (1.3) & 2 & (1.0) \\
\hline & Cro & & (1.5) & -3 & $(0.7$ & 7.9 & & -4.5 & & & & & & & & & & & & & (1.5) \\
\hline & Сур & -7.7 & $(1.0$ & -3.9 & $(0.6$ & 0.2 & $(1.2)$ & 2.2 & (1.1) & -4.5 & (1. & 76 & (1. & & $(0$. & 0 & (1. & 77.8 & (1.2) & 66.8 & (1.4) \\
\hline & Dominica & -0.5 & $(1.0)$ & -0.8 & (0.9) & 1.9 & (1.1) & 6.9 & (1.3) & -0.1 & (1.0) & 89.7 & (1.3) & 91.4 & (1.0) & 85.1 & (1.4) & 19.0 & (1.6) & 89.4 & (1.0) \\
\hline & FYROM & $\mathrm{m}$ & $\mathrm{m}$ & $\mathrm{m}$ & $\mathrm{m}$ & $\mathrm{m}$ & $m$ & $\mathrm{~m}$ & $m$ & $\mathrm{~m}$ & $\mathrm{~m}$ & $\mathrm{~m}$ & $\mathrm{~m}$ & $\mathrm{~m}$ & $\mathrm{~m}$ & $\mathrm{~m}$ & 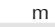 & $\mathrm{m}$ & $\mathrm{m}$ & $\mathrm{m}$ & $\mathrm{m}$ \\
\hline & Georgia & $\mathrm{m}$ & $\mathrm{m}$ & $\mathrm{m}$ & $\mathrm{m}$ & $\mathrm{m}$ & $\mathrm{m}$ & $\mathrm{m}$ & $\mathrm{m}$ & $\mathrm{m}$ & $\mathrm{m}$ & $\mathrm{m}$ & 11 & $\mathrm{~m}$ & $\mathrm{~m}$ & $\mathrm{~m}$ & 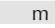 & $\mathrm{m}$ & $\mathrm{m}$ & $\mathrm{m}$ & $\mathrm{m}$ \\
\hline & Hong & -5.4 & (1.1) & -4.0 & $(0.8)$ & -3.7 & (1.2) & 6.5 & (1.3) & -6.3 & (1.5) & 85.4 & (1.0) & 90.3 & $(0.9)$ & 31.2 & 1.2) & 62.4 & 1.6) & 71.2 & 1.4) \\
\hline & Indonesi & $\mathrm{m}$ & $\mathrm{m}$ & $\mathrm{m}$ & $\mathrm{m}$ & $\mathrm{m}$ & $m$ & $\mathrm{~m}$ & $m$ & $\mathrm{~m}$ & 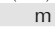 & $\mathrm{m}$ & 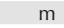 & $\mathrm{m}$ & 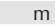 & $\mathrm{m}$ & , & $\mathrm{m}$ & . & $\mathrm{m}$ & $\mathrm{m}$ \\
\hline & Jordan & $\mathrm{m}$ & $\mathrm{m}$ & $\mathrm{m}$ & $\mathrm{m}$ & $\mathrm{m}$ & $\mathrm{m}$ & $\mathrm{m}$ & $\mathrm{m}$ & $\mathrm{m}$ & $\mathrm{m}$ & $\mathrm{m}$ & $\mathrm{m}$ & $\mathrm{m}$ & $\mathrm{m}$ & $\mathrm{m}$ & $\mathrm{m}$ & $\mathrm{m}$ & $\mathrm{m}$ & $\mathrm{m}$ & $\mathrm{m}$ \\
\hline & Kosovo & $\mathrm{m}$ & $n$ & $\mathrm{~m}$ & $\mathrm{~m}$ & $m$ & 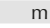 & 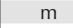 & & $\mathrm{m}$ & $\mathrm{m}$ & $\mathrm{m}$ & $\mathrm{m}$ & $\mathrm{m}$ & $\mathrm{m}$ & $\mathrm{m}$ & & $\mathrm{m}$ & $\mathrm{m}$ & III & $\mathrm{m}$ \\
\hline & Lebano & $\mathrm{m}$ & $\mathrm{m}$ & $\mathrm{m}$ & $\mathrm{m}$ & $\mathrm{m}$ & $\mathrm{m}$ & $\mathrm{m}$ & $\mathrm{m}$ & $\mathrm{m}$ & $\mathrm{m}$ & $\mathrm{m}$ & $\mathrm{m}$ & $\mathrm{m}$ & $\mathrm{m}$ & $\mathrm{m}$ & $\mathrm{m}$ & $\mathrm{m}$ & $\mathrm{m}$ & $\mathrm{m}$ & $\mathrm{m}$ \\
\hline & Lithua & & (1.1) & 56 & $(0.8)$ & 16 & $(1$ & -8.1 & $(1.2$ & 8.8 & & & & 3 & & 4 & ) & 7 & 1) & .1 & $.5)$ \\
\hline & Macao & -6.1 & (1.6) & -4.9 & (0.9) & 0.6 & (1.5) & 8.0 & (1.7) & -4.7 & (1.4) & 41.7 & (1.4) & 88.9 & $(0.9)$ & 0.1 & (1.4) & 49.8 & (1.5) & 42.2 & (1.4) \\
\hline & Malta & $\mathrm{m}$ & $\mathrm{m}$ & $\mathrm{m}$ & $\mathrm{m}$ & $\mathrm{m}$ & $\mathrm{m}$ & $\mathrm{m}$ & $\mathrm{m}$ & $\mathrm{m}$ & $\mathrm{m}$ & $\mathrm{m}$ & $\mathrm{m}$ & $\mathrm{m}$ & $\mathrm{m}$ & $\mathrm{m}$ & $\mathrm{m}$ & $\mathrm{m}$ & $\mathrm{m}$ & $\mathrm{m}$ & $\mathrm{m}$ \\
\hline & & & & 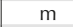 & & $m$ & & $\mathrm{~m}$ & & & & $\mathrm{~m}$ & & $\mathrm{~m}$ & & $\mathrm{~m}$ & & m & & $\mathrm{m}$ & $\mathrm{m}$ \\
\hline & Mont & -7.7 & (1.1) & -4.8 & $(0.7)$ & 2.3 & (1.2) & -4.5 & (1.0) & -5.8 & (1.2) & 77.2 & (1.0) & 91.0 & $(0.7)$ & 5.8 & (1.3) & 76.7 & 1) & 54.1 & 1.3) \\
\hline & Peru & & $(0$. & & $(0$. & 1. & (0. & & (1. & -0.9 & $(0$ & & & & & 8.0 & 0 & 29.0 & ) & 89.7 & $0.8)$ \\
\hline & Qatar & -6.0 & $(0.5)$ & -5.3 & (0.4) & -2.6 & (0.6) & -2.7 & $(0.6)$ & -3.0 & $(0.5)$ & 91.1 & $(0.5)$ & 92.1 & $(0.5)$ & 88.2 & $(0.6)$ & 84.3 & $(0.8)$ & 87.9 & $(0.6)$ \\
\hline & Rom & $\mathrm{m}$ & & & & $\mathrm{m}$ & & $m$ & & & & $\mathrm{~m}$ & & $\mathrm{~m}$ & & $\mathrm{~m}$ & & $\mathrm{~m}$ & $\mathrm{~m}$ & $\mathrm{~m}$ & $\mathrm{~m}$ \\
\hline & Russ & -1.0 & (1.3) & -1.1 & (0.6) & 4.5 & $(1$. & 2.4 & (1.0) & -2 & $(1$. & 76.3 & (1.4) & 91.5 & (1.1) & 70.9 & (1.7) & 85.0 & (1.4) & 50.2 & (1.7) \\
\hline & & -0.4 & $(0.8)$ & -1 & (0.5) & 1. & $(0.8$ & 2 & (1.1) & -2 & (1.0) & 87.0 & $(0$. & 95.4 & $(0.5)$ & 88.6 & $(0.8)$ & 72.1 & (1.0) & 79.6 & (1.1) \\
\hline & & & $(1$. & -1 & $(0.4$ & -3.4 & (1. & -0.1 & & & & & (1. & 94.6 & $(0.6)$ & 64.7 & $(1.2)$ & 63.6 & 1) & 60.1 & 1.1) \\
\hline & Thail & -1.7 & $(0.8)$ & -2.7 & $(0.4)$ & -2.7 & (0.4) & 2.5 & (1.4) & -5.3 & (1.1) & 91.7 & $(0.8)$ & 96.7 & $(0.5)$ & 96.7 & $(0.5)$ & 63.0 & (1.4) & 81.7 & (1.3) \\
\hline & & $\mathrm{m}$ & & $\mathrm{m}$ & & $\mathrm{m}$ & & $\mathrm{m}$ & & $\mathrm{m}$ & & $\mathrm{m}$ & & $\mathrm{m}$ & & $\mathrm{m}$ & & $\mathrm{m}$ & $\mathrm{m}$ & $\mathrm{m}$ & $\mathrm{m}$ \\
\hline & Tun & -2.9 & $(0.6)$ & -3.2 & (0.6) & -5.6 & (1.0) & -0.3 & $(0.8)$ & -3.8 & $(0.8)$ & 96.5 & (0.6) & 94.9 & $(0.7)$ & 89.0 & $(0.9)$ & 89.7 & $(0.9)$ & 94.1 & $(0.7)$ \\
\hline & Unit & -4.7 & $(0.7)$ & -3.5 & $(0.6)$ & -2.6 & $(0.5$ & -0.9 & $(0.7)$ & -3. & $(0.7)$ & 91.6 & $(0.7)$ & 93.8 & $(0.6)$ & 91.3 & $(0.7)$ & 88.6 & $(0.9)$ & 90.5 & $(0.7)$ \\
\hline & & -1.7 & $(0.9)$ & -1.8 & $(0.6)$ & 9.6 & (1.2) & 15.7 & (1.4) & 4.6 & (1.4) & 89.8 & $(0.7)$ & 92.7 & $(0.7)$ & 72.9 & (1.4) & 37.3 & (1.4) & 50.7 & (1.3) \\
\hline & Viet Nam & $\mathrm{m}$ & $\mathrm{m}$ & $\mathrm{m}$ & $\mathrm{m}$ & $\mathrm{m}$ & $\mathrm{m}$ & $\mathrm{m}$ & $\mathrm{m}$ & $\mathrm{m}$ & $\mathrm{m}$ & $\mathrm{m}$ & $\mathrm{m}$ & $\mathrm{m}$ & $\mathrm{m}$ & $\mathrm{m}$ & $\mathrm{m}$ & $\mathrm{m}$ & $\mathrm{m}$ & $\mathrm{m}$ & $\mathrm{m}$ \\
\hline & & $\mathrm{m}$ & $\mathrm{m}$ & $\mathrm{m}$ & $\mathrm{m}$ & $\mathrm{m}$ & $\mathrm{m}$ & $\mathrm{m}$ & 11 & $\mathrm{~m}$ & 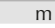 & $\mathrm{m}$ & $\mathrm{m}$ & $\mathrm{m}$ & $\mathrm{m}$ & $\mathrm{m}$ & $\mathrm{m}$ & $\mathrm{m}$ & $\mathrm{m}$ & $\mathrm{m}$ & $\mathrm{m}$ \\
\hline & & & & $\mathrm{m}$ & & mi & & III & & $\mathrm{m}$ & & III & & m & & 1 & & $\mathrm{~m}$ & & m & $\mathrm{m}$ \\
\hline & Malaysia** & -1.6 & (0.6) & -1.3 & $(0.4)$ & -0.8 & (0.5) & -1.0 & $(0.8)$ & -2.8 & $(0.7)$ & 95.1 & $(0.8)$ & 96.9 & (0.6) & 96.2 & (0.6) & 88.7 & (1.0) & 91.4 & (1.0) \\
\hline
\end{tabular}

1. A socio-economically disadvantaged student is a student in the bottom quarter of the PISA index of economic, social and cultural status (ESCS) within his or her own country/economy. 2. A socio-economically advantaged student is a student in the top quarter of the PISA index of economic, social and cultural status (ESCS) within his or her own country/economy. Note: Values that are statistically significant are indicated in bold (see Annex A3).

* See note at the beginning of this Annex.

Coverage is too small to ensure comparability (see Annex A4).

StatLink त्ताज् http://dx.doi.org/10.1787/888933470902 
Percentage of students who reported that they "agree" or "strongly agree"

\begin{tabular}{|c|c|c|c|c|c|c|c|c|c|c|c|c|c|c|c|c|c|c|c|c|c|}
\hline & & & centage & of soci & $\begin{array}{l}\text { o-econo } \\
\text { with th }\end{array}$ & $\begin{array}{l}\text { mica } \\
\text { e fol }\end{array}$ & $\begin{array}{l}\text { advan } \\
\text { ing sta }\end{array}$ & $\begin{array}{l}\operatorname{sed}^{2} s \\
\text { ment }\end{array}$ & dents & ho a & & $\begin{array}{r}\text { Differe } \\
\text { stat }\end{array}$ & $\begin{array}{l}\text { ence in } \\
\text { tements }\end{array}$ & $\begin{array}{l}\text { the per } \\
\text {, by soc }\end{array}$ & intage & $\begin{array}{l}\text { of stud } \\
\text { mic st }\end{array}$ & $\begin{array}{l}\text { nts w } \\
\text { tus (a }\end{array}$ & $\begin{array}{l}0 \text { agree } \\
\text { vantag }\end{array}$ & $\begin{array}{l}\text { with } \\
\text { d-disa }\end{array}$ & $\begin{array}{l}\text { he foll } \\
\text { vantag }\end{array}$ & $\begin{array}{l}\text { wing } \\
\text { d) }\end{array}$ \\
\hline & & $\begin{array}{r}\text { I wa } \\
\text { grad } \\
\text { most c } \\
\text { my c } \\
\end{array}$ & $\begin{array}{l}\text { t top } \\
\text { es in } \\
r \text { all of } \\
\text { urses }\end{array}$ & $\begin{array}{c}\text { I war } \\
\text { able } t \\
\text { from } \\
\text { the } \\
\text { oppor } \\
\text { ava } \\
\text { w } \\
\text { I gra } \\
\end{array}$ & $\begin{array}{l}\text { to be } \\
\text { select } \\
\text { among } \\
\text { best } \\
\text { tunities } \\
\text { lable } \\
\text { en } \\
\text { duate }\end{array}$ & $\begin{array}{r}\text { I we } \\
\text { be th } \\
\text { why } \\
\text { I }\end{array}$ & $\begin{array}{l}\text { nt to } \\
\text { e best, } \\
\text { tever } \\
\text { do }\end{array}$ & $\begin{array}{r}\text { I see } \\
\text { as } \\
\text { amb } \\
\text { pe }\end{array}$ & $\begin{array}{l}\text { nyself } \\
\text { an } \\
\text { tious } \\
\text { son } \\
\end{array}$ & $\begin{array}{l}\text { I wan } \\
\text { one } \\
\text { best st } \\
\text { in } \mathrm{my}\end{array}$ & $\begin{array}{l}\text { to be } \\
\text { of the } \\
\text { udents } \\
\text { class }\end{array}$ & $\begin{array}{c}\text { I wan } \\
\text { grad } \\
\text { most o } \\
\text { my co }\end{array}$ & $\begin{array}{l}\text { t top } \\
\text { es in } \\
\text { r all of } \\
\text { ourses }\end{array}$ & $\begin{array}{l}\text { I want } \\
\text { able to } \\
\text { from a } \\
\text { the } \\
\text { opport } \\
\text { avail } \\
\text { wh } \\
\text { I grad }\end{array}$ & $\begin{array}{l}\text { to be } \\
\text { select } \\
\text { among } \\
\text { best } \\
\text { unities } \\
\text { lable } \\
\text { len } \\
\text { duate }\end{array}$ & $\begin{array}{l}\text { I war } \\
\text { be the } \\
\text { what } \\
\text { Id }\end{array}$ & $\begin{array}{l}\text { nt to } \\
\text { best, } \\
\text { tever } \\
\text { do }\end{array}$ & $\begin{array}{c}\text { I see } n \\
\text { as } \\
\text { ambi } \\
\text { per }\end{array}$ & $\begin{array}{l}\text { myself } \\
\text { an } \\
\text { itious } \\
\text { son }\end{array}$ & $\begin{array}{c}\text { I want } \\
\text { one o } \\
\text { best st } \\
\text { in my }\end{array}$ & $\begin{array}{l}t \text { to be } \\
\text { of the } \\
\text { udents } \\
\text { class }\end{array}$ \\
\hline & & $\%$ & S.E. & $\%$ & S.E. & $\%$ & S.E. & $\%$ & S.E. & $\%$ & S.E. & $\%$ dif. & S.E. & $\%$ dif. & S.E. & $\%$ dif. & S.E. & $\%$ dif. & S.E. & $\%$ dif. & S.E. \\
\hline & Australia & \begin{tabular}{|l|}
91.8 \\
\end{tabular} & (0.6) & 97.6 & $(0.4)$ & 87.1 & $(0.7)$ & 86.1 & $(0.7)$ & 81.5 & $(0.7)$ & 5.5 & $(0.9)$ & 4.4 & $(0.7)$ & 1.2 & $(0.9)$ & \begin{tabular}{|l|}
10.1 \\
\end{tabular} & $(1.1)$ & \begin{tabular}{|l|l|}
13.5 \\
\end{tabular} & $(1.2)$ \\
\hline 5 & Austria & \begin{tabular}{|l|}
75.0 \\
\end{tabular} & (1.3) & \begin{tabular}{|l|l}
94.4 \\
\end{tabular} & $(0.7)$ & 50.5 & (1.7) & 71.4 & (1.3) & 50.2 & (1.6) & -6.4 & (1.5) & 5.1 & (1.1) & 4.3 & $(2.3)$ & \begin{tabular}{|l}
9.7 \\
\end{tabular} & (1.6) & 4.0 & $(2.2)$ \\
\hline & Belgium & 69.4 & $(1.2)$ & 93.1 & $(0.6)$ & 38.2 & (1.1) & 69.5 & (1.1) & 43.3 & (1.3) & -3.9 & (1.8) & 3.7 & $(0.9)$ & -2.7 & $(1.8)$ & $\mid 14.1$ & (1.7) & 0.7 & (1.9) \\
\hline & Canada & 92.4 & $(0.5)$ & 97.3 & $(0.3)$ & 85.8 & $(0.8)$ & 87.6 & $(0.8)$ & 81.7 & (0.7) & 8.4 & (1.0) & 4.6 & $(0.6)$ & 8.2 & (1.3) & \begin{tabular}{|l|}
10.2 \\
\end{tabular} & $(1.2)$ & \begin{tabular}{|l|}
16.8 \\
\end{tabular} & (1.3) \\
\hline & Chile & 92.2 & $(0.6)$ & 97.2 & $(0.4)$ & 84.6 & (1.0) & 78.7 & (1.1) & 72.9 & (1.3) & 0.9 & (1.1) & 2.5 & $(0.8)$ & 4.0 & (1.5) & 19.3 & $(2.0)$ & 3.0 & (1.9) \\
\hline & Czech Repu & 81.5 & (1.0) & 96.0 & $(0.6)$ & 67.8 & $(1.2)$ & 66.6 & (1.3) & 50.4 & (1.3) & 4.6 & (1.4) & 5.8 & (1.1) & 3.5 & (1.6) & 14.4 & $(2.1)$ & 17.4 & (2.1) \\
\hline & Denmark & 82.9 & (1.1) & 90.3 & $(1.0)$ & 52.1 & (1.5) & 84.5 & (1.1) & 75.4 & (1.5) & 12.2 & (1.9) & 14.6 & (1.7) & 6.2 & $(2.1)$ & 11.7 & $(2.2)$ & 14.2 & $(2.3)$ \\
\hline & Estonia & \begin{tabular}{|l|l|}
94.7 \\
\end{tabular} & (0.6) & 96.9 & $(0.5)$ & 68.8 & (1.4) & 82.1 & (1.4) & 59.2 & (1.4) & 5.1 & (1.4) & 3.8 & $(1.1)$ & 5.3 & $(2.2)$ & \begin{tabular}{|l|}
14.4 \\
\end{tabular} & $(2.0)$ & 14.7 & $(2.5)$ \\
\hline & Finland & 70.0 & (1.4) & 87.7 & $(0.8)$ & 41.6 & (1.4) & 67.5 & (1.5) & 54.1 & (1.6) & 17.3 & $(2.2)$ & 14.9 & (1.7) & 9.8 & $(2.0)$ & 22.1 & $(2.2)$ & 25.3 & $(2.2)$ \\
\hline & France & \begin{tabular}{|l|}
89.4 \\
\end{tabular} & $(0.8)$ & 97.0 & $(0.5)$ & 53.2 & (1.6) & 75.0 & (1.1) & 53.9 & (1.5) & 5.9 & (1.3) & 5.5 & (1.0) & 9.6 & $(2.1)$ & 10.6 & (1.8) & 12.5 & $(2.1)$ \\
\hline & Germany & 77.6 & (1.1) & 93.3 & $(0.7)$ & 44.7 & (1.4) & 68.7 & (1.4) & 48.5 & (1.8) & 2.2 & (1.8) & 5.5 & $(1.2)$ & 7.1 & $(2.2)$ & 9.0 & $(2.2)$ & 10.6 & $(2.1)$ \\
\hline & Greece & 80.0 & (1.1) & 97.0 & $(0.5)$ & 72.2 & (1.1) & 77.7 & (1.3) & 72.0 & (1.5) & 11.3 & $(1.7)$ & 3.2 & $(0.8)$ & 12.3 & (1.9) & 1.3 & $(2.0)$ & 16.7 & $(2.2)$ \\
\hline & Hungary & 79.5 & $(1.2)$ & 96.2 & $(0.6)$ & 66.3 & (1.5) & 69.6 & (1.4) & 44.4 & (1.6) & 5.7 & (2.0) & 5.5 & $(1.2)$ & 6.1 & (2.4) & 19.6 & $(2.1)$ & 7.8 & (2.5) \\
\hline & Iceland & 97.6 & $(0.6)$ & 92.6 & $(0.9)$ & 82.3 & $(1.2)$ & 86.3 & (1.2) & 82.1 & (1.4) & 2.2 & $(1.0)$ & \begin{tabular}{|l|}
11.1 \\
\end{tabular} & (1.6) & 12.7 & $(2.2)$ & 15.0 & (1.9) & 13.7 & (2.1) \\
\hline & Ireland & 94.0 & $(0.6)$ & 98.1 & $(0.4)$ & 85.7 & $(1.2)$ & 88.4 & $(0.9)$ & 78.6 & (1.1) & 2.5 & $(0.9)$ & 3.0 & $(0.6)$ & -2.5 & $(1.5)$ & 8.0 & $(1.2)$ & 12.0 & (1.5) \\
\hline & Israel & \begin{tabular}{|l|}
97.1 \\
7
\end{tabular} & $(0.5)$ & 97.2 & $(0.5)$ & 90.3 & $(0.8)$ & 89.5 & (1.0) & 85.9 & (1.0) & 1.8 & $(0.8)$ & 1.1 & (0.6) & -1.1 & (1.1) & 4.4 & (1.5) & -3.2 & (1.3) \\
\hline & Italy & 87.9 & (0.9) & 95.9 & $(0.5)$ & 55.3 & (1.3) & 77.8 & (1.3) & 53.7 & (1.6) & -0.1 & (1.3) & 2.5 & $(0.9)$ & -0.3 & (1.9) & 8.5 & $(1.7)$ & 3.8 & (2.3) \\
\hline & Japan & \begin{tabular}{|l|}
72.1 \\
\end{tabular} & (1.3) & 91.4 & $(0.8)$ & 46.8 & (1.3) & 66.5 & (1.3) & 41.9 & (1.3) & 13.8 & (1.7) & 8.5 & $(1.3)$ & 14.2 & (1.7) & 15.5 & $(1.8)$ & 15.9 & (1.8) \\
\hline & Korea & 93.1 & $(0.8)$ & 98.4 & $(0.4)$ & 86.6 & (1.0) & 76.6 & (1.4) & 91.1 & $(1.0)$ & 12.1 & (1.5) & 5.7 & $(0.7)$ & 13.5 & (1.5) & 17.6 & $(2.0)$ & $\mid 17.8$ & (1.5) \\
\hline & Latvia & 89.6 & (1.0) & 94.5 & $(0.7)$ & 70.2 & (1.5) & 80.3 & (1.2) & 67.5 & (1.4) & 1.4 & (1.6) & 2.0 & $(1.0)$ & 10.2 & (1.9) & 8.6 & (1.9) & 17.0 & (1.9) \\
\hline & Luxembourg & 83.1 & (1.0) & 95.0 & $(0.6)$ & 54.4 & (1.4) & 72.7 & (1.2) & 58.3 & (1.3) & -0.9 & (1.4) & 4.5 & $(1.0)$ & 5.2 & $(2.1)$ & 16.1 & (1.8) & 5.2 & $(2.0)$ \\
\hline & Mexico & \begin{tabular}{|l|}
96.8 \\
\end{tabular} & $(0.4)$ & 97.5 & $(0.5)$ & 86.6 & $(0.9)$ & 50.3 & (1.6) & 82.1 & $(1.1)$ & 1.5 & $(0.8)$ & 3.9 & $(0.9)$ & 5.2 & (1.3) & 20.7 & $(2.1)$ & -0.7 & (1.4) \\
\hline & Netherland & 92.4 & $(0.7)$ & 94.8 & $(0.7)$ & 39.5 & (1.6) & 76.5 & (1.4) & 33.5 & $(1.2)$ & 1.3 & (1.3) & 3.2 & $(1.1)$ & 4.3 & $(2.2)$ & 8.2 & $(2.1)$ & 4.3 & (1.9) \\
\hline & New Zealand & 92.6 & $(0.8)$ & 97.7 & $(0.5)$ & 88.2 & $(1.0)$ & 84.1 & $(1.2)$ & 78.8 & $(1.3)$ & 7.6 & $(1.5)$ & 6.3 & $(1.2)$ & 5.0 & $(1.7)$ & 11.7 & $(2.1)$ & 16.6 & $(2.4)$ \\
\hline & Norway & 89.4 & $(0.9)$ & 97.0 & $(0.5)$ & 69.3 & (1.4) & 84.7 & $(1.0)$ & 73.9 & $(1.2)$ & 11.7 & (1.9) & 3.2 & $(0.9)$ & 8.7 & $(2.0)$ & 16.5 & (1.8) & 18.7 & $(2.0)$ \\
\hline & Poland & \begin{tabular}{|l|}
68.7 \\
\end{tabular} & (1.5) & 92.2 & $(0.9)$ & 64.1 & (1.5) & 80.0 & (1.3) & 56.9 & (1.4) & 6.1 & $(2.1)$ & $\mid 11.2$ & $(1.4)$ & 7.9 & $(2.1)$ & 12.6 & $(2.2)$ & 19.3 & $(2.2)$ \\
\hline & Portugal & 97.2 & $(0.4)$ & 96.4 & $(0.8)$ & 79.7 & $(1.2)$ & 81.2 & $(1.2)$ & 73.7 & $(1.2)$ & 3.3 & $(0.9)$ & 8.2 & $(1.0)$ & 5.5 & (1.6) & 19.7 & $(2.0)$ & 15.2 & $(1.6)$ \\
\hline & Slovak Republic & \begin{tabular}{|l|}
79.2 \\
\end{tabular} & $(1.0)$ & 94.9 & $(0.6)$ & 73.9 & $(1.3)$ & 75.8 & $(1.0)$ & 51.1 & (1.4) & 13.1 & (1.9) & 8.4 & $(1.5)$ & 9.9 & (1.9) & 15.1 & $(1.8)$ & 11.8 & (1.9) \\
\hline & Slovenia & 71.5 & (1.6) & 91.2 & $(1.0)$ & 51.7 & $(1.8)$ & 74.6 & (1.5) & 50.1 & (1.6) & 3.1 & $(2.0)$ & 12.0 & $(1.7)$ & 5.4 & $(2.5)$ & 17.5 & $(2.1)$ & 10.8 & $(2.1)$ \\
\hline & Spain & 82.5 & $(1.2)$ & 97.0 & $(0.4)$ & 68.4 & (1.1) & 64.3 & (1.2) & 66.6 & (1.4) & 8.7 & (1.9) & 6.0 & $(0.8)$ & 15.1 & (1.8) & 23.6 & (1.8) & 16.8 & (2.1) \\
\hline & Sweden & 85.1 & (1.1) & 94.3 & $(0.7)$ & 75.0 & (1.3) & 87.1 & (1.1) & 71.3 & (1.5) & 10.4 & (1.9) & 4.9 & $(1.1)$ & 3.8 & (1.9) & 10.6 & (1.6) & 13.7 & $(2.2)$ \\
\hline & Switzerland & \begin{tabular}{|l|l} 
& 74.9 \\
\end{tabular} & $(1.3)$ & 93.0 & $(0.6)$ & 36.6 & (1.4) & 71.1 & (1.3) & 39.5 & $(1.5)$ & -4.5 & $(2.1)$ & 4.5 & $(1.3)$ & -6.1 & $(2.1)$ & 5.1 & $(2.0)$ & 0.8 & $(2.2)$ \\
\hline & Turkey & 93.7 & $(0.8)$ & 95.8 & $(0.6)$ & 87.3 & $(0.9)$ & 72.2 & (1.7) & 87.8 & $(0.9)$ & 0.3 & $(0.9)$ & 3.1 & $(1.0)$ & 3.2 & (1.3) & 4.2 & $(2.8)$ & -2.9 & (1.4) \\
\hline & United Kingdom & 96.8 & $(0.5)$ & 98.6 & $(0.3)$ & 89.9 & $(0.6)$ & 87.8 & $(0.8)$ & 82.5 & (1.1) & 2.7 & $(0.7)$ & 1.7 & $(0.7)$ & 0.7 & $(1.2)$ & 9.3 & (1.4) & 13.0 & (1.7) \\
\hline & United States & 95.7 & $(0.7)$ & 98.2 & $(0.4)$ & 93.8 & $(0.7)$ & 92.5 & $(0.8)$ & 89.1 & $(1.0)$ & 2.5 & $(1.0)$ & 1.4 & $(0.5)$ & 1.1 & $(0.9)$ & 11.1 & $(1.4)$ & 6.5 & (1.5) \\
\hline & OECD average & 85.9 & $(0.2)$ & 95.3 & $(0.1)$ & 68.2 & $(0.2)$ & 77.3 & $(0.2)$ & 65.2 & $(0.2)$ & 4.8 & $(0.3)$ & 5.6 & $(0.2)$ & 5.6 & $(0.3)$ & 12.7 & $(0.3)$ & 11.0 & $(0.3)$ \\
\hline & Albania & $\mathrm{m}$ & $\mathrm{m}$ & $\mathrm{m}$ & $\mathrm{m}$ & $m$ & $\mathrm{~m}$ & $\mathrm{~m}$ & $\mathrm{~m}$ & 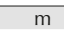 & III & III & II & $\mathrm{m}$ & IIt & $\mathrm{m}$ & II & $\mathrm{m}$ & mi & $\mathrm{m}$ & $\mathrm{m}$ \\
\hline ळ & Algeria & $\mathrm{m}$ & $\mathrm{m}$ & $\mathrm{m}$ & $\mathrm{m}$ & $\mathrm{m}$ & $\mathrm{m}$ & $\mathrm{m}$ & $\mathrm{m}$ & $\mathrm{m}$ & $\mathrm{m}$ & $\mathrm{m}$ & $\mathrm{m}$ & $\mathrm{m}$ & $\mathrm{m}$ & $\mathrm{m}$ & $\mathrm{m}$ & $\mathrm{m}$ & $\mathrm{m}$ & $\mathrm{m}$ & $\mathrm{m}$ \\
\hline & Brazil & 95.2 & $(0.4)$ & 97.2 & $(0.3)$ & 81.4 & $(0.7)$ & 52.6 & (1.0) & 63.4 & $(1.2)$ & 2.1 & $(0.6)$ & 1.1 & $(0.5)$ & 2.0 & $(1.2)$ & 22.4 & (1.5) & -2.0 & (1.6) \\
\hline & B-S-J-G (China) & $\mid 73.7$ & (1.7) & 95.9 & $(0.5)$ & 88.1 & (1.1) & 76.9 & (1.1) & 84.5 & $(1.1)$ & 6.1 & (2.5) & -1.3 & $(0.6)$ & -0.7 & $(1.2)$ & 8.6 & (1.4) & 7.3 & (1.6) \\
\hline & Bulgaria & 81.0 & (1.1) & 97.1 & $(0.5)$ & 56.9 & $(1.5)$ & 85.7 & $(0.9)$ & 71.4 & (1.3) & 4.9 & (1.9) & 6.2 & (1.0) & -1.6 & (2.5) & 10.1 & (1.9) & 6.2 & (1.9) \\
\hline & CABA (Argentina) & $\mathrm{m}$ & $\mathrm{m}$ & $\mathrm{m}$ & $\mathrm{m}$ & $\mathrm{m}$ & $\mathrm{m}$ & $\mathrm{m}$ & $\mathrm{m}$ & $\mathrm{m}$ & $\mathrm{m}$ & $\mathrm{m}$ & $\mathrm{m}$ & $\mathrm{m}$ & $\mathrm{m}$ & $\mathrm{m}$ & $\mathrm{m}$ & $\mathrm{m}$ & $\mathrm{m}$ & $\mathrm{m}$ & $\mathrm{m}$ \\
\hline & Colombia & 96.2 & $(0.5)$ & 99.0 & $(0.2)$ & 94.0 & $(0.7)$ & 56.3 & (1.7) & 90.4 & $(0.6)$ & -1.4 & $(0.7)$ & 0.9 & $(0.4)$ & 4.1 & $(1.1)$ & 28.4 & $(2.1)$ & -2.6 & $(1.0)$ \\
\hline & Costa Rica & 96.9 & $(0.6)$ & 98.5 & $(0.3)$ & 87.4 & $(0.9)$ & 66.9 & (1.1) & 83.6 & $(1.2)$ & -1.0 & $(0.7)$ & 1.3 & $(0.6)$ & 6.7 & (1.6) & 28.0 & $(1.8)$ & -5.7 & (1.5) \\
\hline & Croatia & 72.4 & $(1.3)$ & 96.2 & $(0.6)$ & 61.6 & (1.5) & 79.4 & (1.3) & 65.5 & (1.3) & 6.6 & (1.9) & 5.2 & $(1.0)$ & 3.6 & $(2.0)$ & 10.9 & $(2.1)$ & 5.7 & $(2.0)$ \\
\hline & Cyprus* & 88.4 & $(0.9)$ & 96.2 & $(0.5)$ & 78.3 & (1.1) & 81.9 & $(1.0)$ & 80.7 & $(1.3)$ & 11.6 & (1.6) & 2.0 & $(0.7)$ & 7.5 & (1.7) & 4.1 & $(1.5)$ & 13.8 & (1.8) \\
\hline & Dominican Republic & 92.5 & $(0.9)$ & 95.6 & $(0.8)$ & 86.0 & (1.1) & 32.8 & (1.4) & 90.9 & $(0.9)$ & 2.8 & (1.6) & 4.3 & (1.3) & 0.8 & (1.9) & 13.8 & $(2.1)$ & 1.5 & (1.4) \\
\hline & FYROM & $\mathrm{m}$ & $\mathrm{m}$ & $\mathrm{m}$ & $\mathrm{m}$ & $\mathrm{m}$ & $\mathrm{m}$ & $\mathrm{m}$ & $\mathrm{m}$ & $\mathrm{m}$ & $\mathrm{m}$ & $\mathrm{m}$ & $\mathrm{m}$ & $\mathrm{m}$ & $\mathrm{m}$ & $\mathrm{m}$ & $\mathrm{m}$ & $\mathrm{m}$ & $\mathrm{m}$ & $\mathrm{m}$ & $\mathrm{m}$ \\
\hline & Georgia & $\mathrm{m}$ & $\mathrm{m}$ & $\mathrm{m}$ & $\mathrm{m}$ & $\mathrm{m}$ & $\mathrm{m}$ & $\mathrm{m}$ & $\mathrm{m}$ & $\mathrm{m}$ & $\mathrm{m}$ & $\mathrm{m}$ & $\mathrm{m}$ & $\mathrm{m}$ & $\mathrm{m}$ & $\mathrm{m}$ & $\mathrm{m}$ & $\mathrm{m}$ & $\mathrm{m}$ & $\mathrm{m}$ & $\mathrm{m}$ \\
\hline & Hong Kong (China) & 91.4 & $(1.0)$ & 95.8 & $(0.9)$ & 84.0 & $(1.0)$ & 67.0 & $(1.4)$ & 81.3 & $(1.1)$ & 6.1 & (1.4) & 5.4 & $(1.2)$ & 2.8 & (1.6) & 4.5 & $(1.9)$ & 10.0 & (1.6) \\
\hline & Indonesia & $\mathrm{m}$ & $\mathrm{m}$ & $\mathrm{m}$ & $\mathrm{m}$ & $\mathrm{m}$ & $\mathrm{m}$ & $\mathrm{m}$ & $\mathrm{m}$ & $\mathrm{m}$ & $\mathrm{m}$ & $\mathrm{m}$ & $\mathrm{m}$ & $\mathrm{m}$ & $\mathrm{m}$ & $\mathrm{m}$ & $\mathrm{m}$ & $\mathrm{m}$ & $\mathrm{m}$ & $\mathrm{m}$ & $\mathrm{m}$ \\
\hline & Jordan & $\mathrm{m}$ & $\mathrm{m}$ & $\mathrm{m}$ & $\mathrm{m}$ & $\mathrm{m}$ & $\mathrm{m}$ & $\mathrm{m}$ & $\mathrm{m}$ & $\mathrm{m}$ & $\mathrm{m}$ & $\mathrm{m}$ & $\mathrm{m}$ & $\mathrm{m}$ & $\mathrm{m}$ & $\mathrm{m}$ & $\mathrm{m}$ & $\mathrm{m}$ & $\mathrm{m}$ & $\mathrm{m}$ & $\mathrm{m}$ \\
\hline & Kosovo & $\mathrm{m}$ & $\mathrm{m}$ & $\mathrm{m}$ & $\mathrm{m}$ & $\mathrm{m}$ & $\mathrm{m}$ & $\mathrm{m}$ & $\mathrm{m}$ & $\mathrm{m}$ & $\mathrm{m}$ & $\mathrm{m}$ & $\mathrm{m}$ & $\mathrm{m}$ & $\mathrm{m}$ & $\mathrm{m}$ & $\mathrm{m}$ & $\mathrm{m}$ & $\mathrm{m}$ & $\mathrm{m}$ & $\mathrm{m}$ \\
\hline & Lebanon & $\mathrm{m}$ & $\mathrm{m}$ & $\mathrm{m}$ & $\mathrm{m}$ & $\mathrm{m}$ & $\mathrm{m}$ & $\mathrm{m}$ & $\mathrm{m}$ & $\mathrm{m}$ & $\mathrm{m}$ & $\mathrm{m}$ & $\mathrm{m}$ & $\mathrm{m}$ & $\mathrm{m}$ & $\mathrm{m}$ & $\mathrm{m}$ & $\mathrm{m}$ & $\mathrm{m}$ & $\mathrm{m}$ & $\mathrm{m}$ \\
\hline & Lithuania & 87.7 & $(1.0)$ & 93.9 & $(0.8)$ & 74.9 & $(1.2)$ & 82.1 & (1.1) & 74.3 & $(1.2)$ & 10.8 & (1.7) & 5.6 & (1.3) & 18.6 & $(2.2)$ & 19.4 & $(1.8)$ & 22.2 & $(2.0)$ \\
\hline & Macao (China) & 60.0 & (1.4) & 92.6 & $(0.8)$ & 65.3 & $(1.4)$ & 62.9 & (1.5) & 57.5 & (1.6) & 18.3 & $(2.0)$ & 3.7 & $(1.3)$ & 15.2 & (1.9) & 13.2 & $(2.1)$ & 15.3 & $(2.0)$ \\
\hline & Malta & $\mathrm{m}$ & $\mathrm{m}$ & $\mathrm{m}$ & $\mathrm{m}$ & $\mathrm{m}$ & $\mathrm{m}$ & $\mathrm{m}$ & $\mathrm{m}$ & $\mathrm{m}$ & $\mathrm{m}$ & $\mathrm{m}$ & $\mathrm{m}$ & $\mathrm{m}$ & $\mathrm{m}$ & $\mathrm{m}$ & $\mathrm{m}$ & $\mathrm{m}$ & $\mathrm{m}$ & $\mathrm{m}$ & $\mathrm{m}$ \\
\hline & Moldov & $\mathrm{m}$ & & $\mathrm{m}$ & $\mathrm{m}$ & $\mathrm{m}$ & $\mathrm{m}$ & $\mathrm{m}$ & $\mathrm{m}$ & $\mathrm{m}$ & $\mathrm{m}$ & $\mathrm{m}$ & $\mathrm{m}$ & $\mathrm{m}$ & $\mathrm{m}$ & $\mathrm{m}$ & $\mathrm{m}$ & $\mathrm{m}$ & $\mathrm{m}$ & $\mathrm{m}$ & $\mathrm{m}$ \\
\hline & Montenegro & 79.6 & (1.1) & 93.5 & $(0.7)$ & 68.0 & $(1.5)$ & 82.6 & (1.1) & 57.2 & $(1.4)$ & 2.4 & (1.5) & 2.5 & (1.1) & 2.2 & $(2.0)$ & 5.9 & $(1.6)$ & 3.0 & $(2.0)$ \\
\hline & Peru & 96.0 & $(0.5)$ & 97.5 & $(0.4)$ & 91.4 & $(0.7)$ & 51.0 & (1.7) & 87.0 & $(1.1)$ & -1.0 & $(0.7)$ & 1.5 & $(0.7)$ & 3.4 & (1.1) & 21.9 & $(2.2)$ & -2.7 & (1.3) \\
\hline & Qatar & 95.1 & $(0.4)$ & 96.0 & $(0.4)$ & 92.3 & $(0.5)$ & 90.7 & $(0.6)$ & 91.0 & $(0.6)$ & 4.0 & $(0.6)$ & 3.9 & $(0.7)$ & 4.1 & $(0.8)$ & 6.4 & $(0.9)$ & 3.1 & $(0.9)$ \\
\hline & Romani & $\mathrm{m}$ & $\mathrm{m}$ & $\mathrm{m}$ & $\mathrm{m}$ & $\mathrm{m}$ & $\mathrm{m}$ & $\mathrm{m}$ & $\mathrm{m}$ & $\mathrm{m}$ & $\mathrm{m}$ & $\mathrm{m}$ & $\mathrm{m}$ & $\mathrm{m}$ & $\mathrm{m}$ & $\mathrm{m}$ & $\mathrm{m}$ & $\mathrm{m}$ & $\mathrm{m}$ & $\mathrm{m}$ & $\mathrm{m}$ \\
\hline & Russia & 4.2 & $(0.9)$ & 95.8 & $(0.6)$ & 76.0 & $(1.4)$ & 91.5 & $(0.9)$ & 63.4 & $(1.2)$ & 7.9 & $(1.7)$ & 4.3 & $(1.1)$ & 5.1 & $(2.4)$ & 6.5 & $(1.4)$ & 13.2 & $(2.1)$ \\
\hline & Singapore & 89.8 & $(1.0)$ & 96.9 & $(0.5)$ & 88.7 & $(1.0)$ & 79.1 & (1.3) & 84.7 & $(1.0)$ & 2.8 & (1.4) & 1.5 & $(0.7)$ & 0.1 & (1.4) & 7.0 & (1.7) & 5.1 & (1.6) \\
\hline & Chinese Tai & 87.2 & $(0.9)$ & 98.7 & $(0.2)$ & 71.0 & $(1.2)$ & 79.8 & $(1.3)$ & 75.5 & $(1.2)$ & 17.1 & (1.3) & 4.2 & $(0.6)$ & 6.3 & (1.5) & 16.2 & (1.6) & 15.4 & (1.6) \\
\hline & Thailand & 90.6 & $(0.7)$ & 97.8 & $(0.4)$ & 97.4 & $(0.5)$ & 69.4 & (1.5) & 75.7 & $(1.2)$ & -1.1 & (1.0) & 1.1 & $(0.6)$ & 0.7 & $(0.6)$ & 6.4 & (1.9) & -6.0 & (1.8) \\
\hline & Trinidad and Tobago & $\mathrm{m}$ & $\mathrm{m}$ & $\mathrm{m}$ & $\mathrm{m}$ & $\mathrm{m}$ & $\mathrm{m}$ & $\mathrm{m}$ & $\mathrm{m}$ & $\mathrm{m}$ & $\mathrm{m}$ & $\mathrm{m}$ & $\mathrm{m}$ & $\mathrm{m}$ & $\mathrm{m}$ & $\mathrm{m}$ & $\mathrm{m}$ & $\mathrm{m}$ & $\mathrm{m}$ & $\mathrm{m}$ & $\mathrm{m}$ \\
\hline & Tunisia & 96.3 & $(0.6)$ & 97.1 & $(0.5)$ & 90.0 & $(1.0)$ & 91.6 & $(0.8)$ & 92.6 & $(0.8)$ & -0.2 & $(0.8)$ & 2.1 & $(0.9)$ & 1.0 & (1.3) & 1.8 & $(1.2)$ & -1.5 & $(1.0)$ \\
\hline & United Arab Emirates & 95.4 & $(0.4)$ & 96.6 & $(0.4)$ & 93.8 & $(0.5)$ & 91.4 & $(0.6)$ & 92.6 & $(0.6)$ & 3.9 & $(0.8)$ & 2.8 & $(0.6)$ & 2.5 & $(0.9)$ & 2.7 & $(1.1)$ & 2.1 & $(1.0)$ \\
\hline & Uruguay & 88.5 & $(0.9)$ & 97.2 & $(0.5)$ & 77.1 & $(1.2)$ & 60.9 & (1.5) & 51.7 & $(1.6)$ & -1.3 & $(1.1)$ & 4.5 & $(0.9)$ & 4.2 & (1.9) & 23.7 & $(2.0)$ & 1.0 & (1.9) \\
\hline & Viet Nam & $\mathrm{m}$ & $\mathrm{m}$ & $\mathrm{m}$ & $\mathrm{m}$ & $\mathrm{m}$ & $\mathrm{m}$ & $\mathrm{m}$ & $\mathrm{m}$ & $\mathrm{m}$ & $\mathrm{m}$ & $\mathrm{m}$ & $\mathrm{m}$ & $\mathrm{m}$ & $\mathrm{m}$ & $\mathrm{m}$ & $\mathrm{m}$ & $\mathrm{m}$ & $\mathrm{m}$ & $\mathrm{m}$ & $\mathrm{m}$ \\
\hline & Argen & $\mathrm{m}$ & $\mathrm{m}$ & $\mathrm{m}$ & $\mathrm{m}$ & $\mathrm{m}$ & $\mathrm{m}$ & $\mathrm{m}$ & $\mathrm{m}$ & $\mathrm{m}$ & $\mathrm{m}$ & $\mathrm{m}$ & $\mathrm{m}$ & $\mathrm{m}$ & $\mathrm{m}$ & $\mathrm{m}$ & $\mathrm{m}$ & $\mathrm{m}$ & $\mathrm{m}$ & $\mathrm{m}$ & $\mathrm{m}$ \\
\hline & Kazo & $\mathrm{m}$ & $\mathrm{m}$ & $\mathrm{m}$ & $\mathrm{m}$ & $\mathrm{m}$ & $\mathrm{m}$ & $\mathrm{m}$ & & $\mathrm{m}$ & & $\mathrm{m}$ & $\mathrm{m}$ & $\mathrm{m}$ & $\mathrm{m}$ & $\mathrm{m}$ & $\mathrm{m}$ & $\mathrm{m}$ & $\mathrm{m}$ & $\mathrm{m}$ & $\mathrm{m}$ \\
\hline & Malaysia** & 0.8 & $(0.8)$ & 0.5 & $(0.5)$ & 0.8 & $(0.8)$ & 0.9 & $(0.9)$ & 0.9 & $(0.9)$ & -1.7 & (1.1) & 1.0 & $(0.6)$ & -2.3 & (1.0) & -1.1 & (1.4) & 0.3 & (1.4) \\
\hline
\end{tabular}

1. A socio-economically disadvantaged student is a student in the bottom quarter of the PISA index of economic, social and cultural status (ESCS) within his or her own country/economy. 2. A socio-economically advantaged student is a student in the top quarter of the PISA index of economic, social and cultural status (ESCS) within his or her own country/economy. Note: Values that are statistically significant are indicated in bold (see Annex A3).

* See note at the beginning of this Annex.

** Coverage is too small to ensure comparability (see Annex A4).

StatLink 部西 http://dx.doi.org/10.1787/888933470902 
[Part 1/3]

Table III.5.3 Index of achievement motivation, by student characteristics

Results based on students' self-reports

\begin{tabular}{|c|c|c|c|c|c|c|c|c|c|c|c|c|}
\hline & & & & & Index & achieve & ent motivatio & by: & & & & \\
\hline & & All & Idents & & & & tional quarter & of the in & ex of achiever & ent moti & tion & \\
\hline & Aver & & Variabili & this index & Bottom & Iarter & Second & uarter & Third $q$ & arter & Top qu & rter \\
\hline & Mean index & S.E. & S.D. & S.E. & Mean index & S.E. & Mean index & S.E. & Mean index & S.E. & Mean index & S.E. \\
\hline Australia & 0.33 & $(0.01)$ & 0.96 & $(0.01)$ & -0.82 & $(0.01)$ & -0.08 & $(0.00)$ & 0.58 & $(0.00)$ & 1.65 & $(0.01)$ \\
\hline Austria & -0.26 & $(0.02)$ & 0.99 & $(0.01)$ & -1.44 & $(0.01)$ & -0.65 & $(0.00)$ & -0.01 & $(0.01)$ & 1.07 & $(0.02)$ \\
\hline 0 Belgium & -0.45 & $(0.01)$ & 0.87 & $(0.01)$ & -1.43 & $(0.01)$ & -0.80 & $(0.00)$ & -0.30 & $(0.00)$ & 0.72 & $(0.01)$ \\
\hline Canada & 0.33 & $(0.01)$ & 1.00 & $(0.01)$ & -0.88 & $(0.01)$ & -0.10 & $(0.00)$ & 0.59 & $(0.01)$ & 1.70 & $(0.01)$ \\
\hline Chile & 0.29 & $(0.01)$ & 0.94 & $(0.01)$ & -0.86 & $(0.02)$ & -0.04 & $(0.00)$ & 0.56 & $(0.01)$ & 1.52 & $(0.01)$ \\
\hline Czech Republic & -0.28 & $(0.01)$ & 0.81 & $(0.01)$ & -1.18 & $(0.01)$ & -0.60 & $(0.00)$ & -0.14 & $(0.00)$ & 0.81 & $(0.02)$ \\
\hline Denmark & -0.15 & $(0.02)$ & 0.98 & $(0.01)$ & -1.29 & $(0.01)$ & -0.54 & $(0.00)$ & 0.04 & $(0.01)$ & 1.19 & $(0.02)$ \\
\hline Estonia & -0.04 & $(0.01)$ & 0.86 & $(0.01)$ & -1.03 & $(0.01)$ & -0.38 & $(0.00)$ & 0.16 & $(0.01)$ & 1.10 & $(0.02)$ \\
\hline Finland & -0.63 & $(0.02)$ & 0.92 & $(0.01)$ & -1.65 & $(0.01)$ & -0.99 & $(0.00)$ & -0.46 & $(0.00)$ & 0.59 & $(0.02)$ \\
\hline France & -0.25 & $(0.02)$ & 0.90 & $(0.01)$ & -1.28 & $(0.01)$ & -0.63 & $(0.00)$ & -0.08 & $(0.00)$ & 0.97 & $(0.02)$ \\
\hline Germany & -0.38 & $(0.01)$ & 0.91 & $(0.01)$ & -1.45 & $(0.01)$ & -0.73 & $(0.00)$ & -0.17 & $(0.01)$ & 0.83 & $(0.01)$ \\
\hline Greece & -0.10 & $(0.02)$ & 0.86 & $(0.01)$ & -1.11 & $(0.01)$ & -0.40 & $(0.00)$ & 0.07 & $(0.00)$ & 1.04 & $(0.02)$ \\
\hline Hungary & -0.30 & $(0.01)$ & 0.87 & $(0.01)$ & -1.29 & $(0.01)$ & -0.63 & $(0.00)$ & -0.13 & $(0.00)$ & 0.85 & $(0.02)$ \\
\hline Iceland & 0.39 & $(0.02)$ & 1.01 & $(0.01)$ & -0.89 & $(0.02)$ & 0.03 & $(0.01)$ & 0.70 & $(0.01)$ & 1.70 & $(0.01)$ \\
\hline Ireland & 0.39 & $(0.01)$ & 0.91 & $(0.01)$ & -0.69 & $(0.01)$ & -0.01 & $(0.00)$ & 0.65 & $(0.01)$ & 1.63 & $(0.01)$ \\
\hline Israel & 0.83 & $(0.02)$ & 0.95 & $(0.01)$ & -0.43 & $(0.02)$ & 0.55 & $(0.01)$ & 1.36 & $(0.01)$ & 1.85 & $\mathrm{~m}$ \\
\hline Italy & -0.17 & $(0.01)$ & 0.83 & $(0.01)$ & -1.14 & $(0.01)$ & -0.48 & $(0.00)$ & 0.01 & $(0.00)$ & 0.92 & $(0.01)$ \\
\hline Japan & -0.51 & $(0.02)$ & 1.02 & $(0.01)$ & -1.66 & $(0.01)$ & -0.92 & $(0.00)$ & -0.34 & $(0.01)$ & 0.87 & $(0.02)$ \\
\hline Korea & 0.34 & $(0.02)$ & 0.98 & $(0.01)$ & -0.86 & $(0.01)$ & -0.11 & $(0.00)$ & 0.65 & $(0.01)$ & 1.66 & $(0.01)$ \\
\hline Latvia & -0.03 & $(0.01)$ & 0.93 & $(0.01)$ & -1.13 & $(0.02)$ & -0.35 & $(0.00)$ & 0.19 & $(0.01)$ & 1.17 & $(0.02)$ \\
\hline Luxembourg & -0.17 & $(0.01)$ & 1.01 & $(0.01)$ & -1.36 & $(0.01)$ & -0.56 & $(0.01)$ & 0.06 & $(0.01)$ & 1.17 & $(0.01)$ \\
\hline Mexico & 0.25 & $(0.02)$ & 0.82 & $(0.01)$ & -0.75 & $(0.01)$ & -0.03 & $(0.00)$ & 0.47 & $(0.00)$ & 1.29 & $(0.01)$ \\
\hline Netherlands & -0.44 & $(0.01)$ & 0.72 & $(0.01)$ & -1.18 & $(0.01)$ & -0.75 & $(0.00)$ & -0.34 & $(0.00)$ & 0.53 & $(0.02)$ \\
\hline New Zealand & 0.24 & $(0.01)$ & 0.98 & $(0.01)$ & -0.93 & $(0.02)$ & -0.16 & $(0.00)$ & 0.48 & $(0.01)$ & 1.57 & $(0.01)$ \\
\hline Norway & 0.10 & $(0.02)$ & 1.03 & $(0.01)$ & -1.14 & $(0.01)$ & -0.31 & $(0.00)$ & 0.36 & $(0.01)$ & 1.50 & $(0.01)$ \\
\hline Poland & -0.42 & $(0.01)$ & 0.84 & $(0.01)$ & -1.35 & $(0.01)$ & -0.74 & $(0.00)$ & -0.29 & $(0.00)$ & 0.69 & $(0.02)$ \\
\hline Portugal & 0.20 & $(0.01)$ & 0.89 & $(0.01)$ & -0.87 & $(0.01)$ & -0.15 & $(0.00)$ & 0.41 & $(0.01)$ & 1.42 & $(0.01)$ \\
\hline Slovak Republic & -0.28 & $(0.01)$ & 0.88 & $(0.01)$ & -1.30 & $(0.02)$ & -0.59 & $(0.00)$ & -0.12 & $(0.00)$ & 0.86 & $(0.02)$ \\
\hline Slovenia & -0.43 & $(0.01)$ & 0.88 & $(0.01)$ & -1.44 & $(0.01)$ & -0.76 & $(0.00)$ & -0.26 & $(0.00)$ & 0.73 & $(0.02)$ \\
\hline Spain & -0.16 & $(0.02)$ & 0.92 & $(0.01)$ & -1.25 & $(0.01)$ & -0.50 & $(0.00)$ & 0.06 & $(0.00)$ & 1.06 & $(0.01)$ \\
\hline Sweden & 0.15 & $(0.02)$ & 1.04 & $(0.01)$ & -1.12 & $(0.01)$ & -0.28 & $(0.01)$ & 0.43 & $(0.01)$ & 1.56 & $(0.01)$ \\
\hline Switzerland & -0.43 & $(0.01)$ & 0.91 & $(0.01)$ & -1.49 & $(0.01)$ & -0.79 & $(0.01)$ & -0.23 & $(0.00)$ & 0.77 & $(0.02)$ \\
\hline Turkey & 0.62 & $(0.02)$ & 1.03 & $(0.02)$ & -0.73 & $(0.02)$ & 0.35 & $(0.01)$ & 1.07 & $(0.01)$ & 1.78 & $(0.01)$ \\
\hline United Kingdom & 0.51 & $(0.02)$ & 0.93 & $(0.01)$ & -0.63 & $(0.01)$ & 0.13 & $(0.01)$ & 0.80 & $(0.01)$ & 1.77 & $(0.00)$ \\
\hline United States & 0.65 & $(0.02)$ & 0.94 & $(0.01)$ & -0.53 & $(0.01)$ & 0.21 & $(0.01)$ & 1.05 & $(0.01)$ & 1.85 & m \\
\hline OECD average & -0.01 & $(0.00)$ & 0.92 & $(0.00)$ & -1.10 & $(0.00)$ & -0.37 & $(0.00)$ & 0.22 & $(0.00)$ & 1.21 & $(0.00)$ \\
\hline
\end{tabular}

\begin{tabular}{|c|c|c|c|c|c|c|c|c|c|c|c|c|c|}
\hline \multirow{4}{*}{ 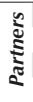 } & Albania & $\mathrm{m}$ & $\mathrm{m}$ & $\mathrm{m}$ & $\mathrm{m}$ & $\mathrm{m}$ & $\mathrm{m}$ & $\mathrm{m}$ & $\mathrm{m}$ & $\mathrm{m}$ & $\mathrm{m}$ & $\mathrm{m}$ & $\mathrm{m}$ \\
\hline & Algeria & $\mathrm{m}$ & $\mathrm{m}$ & $\mathrm{m}$ & $\mathrm{m}$ & $\mathrm{m}$ & $\mathrm{m}$ & $\mathrm{m}$ & $\mathrm{m}$ & $\mathrm{m}$ & $\mathrm{m}$ & $\mathrm{m}$ & $\mathrm{m}$ \\
\hline & Brazil & 0.12 & $(0.01)$ & 0.79 & $(0.01)$ & -0.81 & $(0.01)$ & -0.20 & $(0.00)$ & 0.31 & $(0.00)$ & 1.19 & $(0.01)$ \\
\hline & B-S-J-G (China) & 0.11 & $(0.01)$ & 0.85 & $(0.01)$ & -0.83 & $(0.01)$ & -0.23 & $(0.00)$ & 0.20 & $(0.01)$ & 1.31 & $(0.02)$ \\
\hline & Bulgaria & -0.06 & $(0.02)$ & 0.99 & $(0.01)$ & -1.22 & $(0.02)$ & -0.38 & $(0.00)$ & 0.09 & $(0.01)$ & 1.28 & $(0.01)$ \\
\hline & CABA (Argentina) & $\mathrm{m}$ & $\mathrm{m}$ & $\mathrm{m}$ & $\mathrm{m}$ & $\mathrm{m}$ & $\mathrm{m}$ & $\mathrm{m}$ & $\mathrm{m}$ & $\mathrm{m}$ & $\mathrm{m}$ & $\mathrm{m}$ & $\mathrm{m}$ \\
\hline & Colombia & 0.50 & $(0.01)$ & 0.76 & $(0.01)$ & -0.45 & $(0.01)$ & 0.23 & $(0.00)$ & 0.78 & $(0.00)$ & 1.45 & $(0.01)$ \\
\hline & Costa Rica & 0.51 & $(0.01)$ & 0.82 & $(0.01)$ & -0.52 & $(0.01)$ & 0.22 & $(0.00)$ & 0.75 & $(0.00)$ & 1.58 & $(0.01)$ \\
\hline & Croatia & -0.24 & $(0.01)$ & 0.87 & $(0.01)$ & -1.24 & $(0.01)$ & -0.56 & $(0.00)$ & -0.07 & $(0.00)$ & 0.91 & $(0.02)$ \\
\hline & Cyprus* & 0.16 & $(0.01)$ & 0.96 & $(0.01)$ & -0.99 & $(0.01)$ & -0.19 & $(0.00)$ & 0.39 & $(0.01)$ & 1.45 & $(0.01)$ \\
\hline & Dominican Republic & 0.34 & $(0.02)$ & 0.92 & $(0.01)$ & -0.83 & $(0.03)$ & 0.09 & $(0.01)$ & 0.74 & $(0.01)$ & 1.35 & $(0.01)$ \\
\hline & FYROM & $\mathrm{m}$ & $\mathrm{m}$ & $\mathrm{m}$ & $\mathrm{m}$ & $\mathrm{m}$ & $\mathrm{m}$ & $\mathrm{m}$ & $\mathrm{m}$ & $\mathrm{m}$ & $\mathrm{m}$ & $\mathrm{m}$ & $\mathrm{m}$ \\
\hline & Georgia & $\mathrm{m}$ & $\mathrm{m}$ & $\mathrm{m}$ & $\mathrm{m}$ & $\mathrm{m}$ & $\mathrm{m}$ & $\mathrm{m}$ & $\mathrm{m}$ & $\mathrm{m}$ & $\mathrm{m}$ & $\mathrm{m}$ & $\mathrm{m}$ \\
\hline & Hong Kong (China) & 0.20 & $(0.02)$ & 0.95 & $(0.01)$ & -0.92 & $(0.01)$ & -0.19 & $(0.00)$ & 0.39 & $(0.01)$ & 1.51 & $(0.01)$ \\
\hline & Indonesia & $\mathrm{m}$ & $\mathrm{m}$ & $\mathrm{m}$ & $\mathrm{m}$ & $\mathrm{m}$ & $\mathrm{m}$ & $\mathrm{m}$ & $\mathrm{m}$ & $\mathrm{m}$ & $\mathrm{m}$ & $\mathrm{m}$ & $\mathrm{m}$ \\
\hline & Jordan & $\mathrm{m}$ & $\mathrm{m}$ & $\mathrm{m}$ & $\mathrm{m}$ & $\mathrm{m}$ & $\mathrm{m}$ & $\mathrm{m}$ & $\mathrm{m}$ & $\mathrm{m}$ & $\mathrm{m}$ & $\mathrm{m}$ & $\mathrm{m}$ \\
\hline & Kosovo & $\mathrm{m}$ & $\mathrm{m}$ & $\mathrm{m}$ & $\mathrm{m}$ & $\mathrm{m}$ & $\mathrm{m}$ & $\mathrm{m}$ & $\mathrm{m}$ & $\mathrm{m}$ & $\mathrm{m}$ & $\mathrm{m}$ & $\mathrm{m}$ \\
\hline & Lebanon & $\mathrm{m}$ & $\mathrm{m}$ & $\mathrm{m}$ & $\mathrm{m}$ & $\mathrm{m}$ & $\mathrm{m}$ & $\mathrm{m}$ & $\mathrm{m}$ & $\mathrm{m}$ & $\mathrm{m}$ & $\mathrm{m}$ & $\mathrm{m}$ \\
\hline & Lithuania & 0.00 & $(0.02)$ & 1.05 & $(0.01)$ & -1.33 & $(0.02)$ & -0.32 & $(0.01)$ & 0.31 & $(0.01)$ & 1.34 & $(0.01)$ \\
\hline & Macao (China) & -0.50 & $(0.01)$ & 0.81 & $(0.01)$ & -1.40 & $(0.01)$ & -0.84 & $(0.01)$ & -0.33 & $(0.00)$ & 0.58 & $(0.02)$ \\
\hline & Malta & $\mathrm{m}$ & $\mathrm{m}$ & $\mathrm{m}$ & $\mathrm{m}$ & $\mathrm{m}$ & $\mathrm{m}$ & $\mathrm{m}$ & $\mathrm{m}$ & $\mathrm{m}$ & $\mathrm{m}$ & $\mathrm{m}$ & $\mathrm{m}$ \\
\hline & Moldova & $\mathrm{m}$ & $\mathrm{m}$ & $\mathrm{m}$ & $\mathrm{m}$ & $\mathrm{m}$ & $\mathrm{m}$ & $\mathrm{m}$ & $\mathrm{m}$ & $\mathrm{m}$ & $\mathrm{m}$ & $\mathrm{m}$ & $\mathrm{m}$ \\
\hline & Montenegro & -0.16 & $(0.01)$ & 0.96 & $(0.01)$ & -1.27 & $(0.02)$ & -0.49 & $(0.01)$ & -0.02 & $(0.00)$ & 1.14 & $(0.01)$ \\
\hline & Peru & 0.34 & $(0.01)$ & 0.78 & $(0.01)$ & -0.59 & $(0.01)$ & 0.02 & $(0.00)$ & 0.56 & $(0.00)$ & 1.35 & $(0.01)$ \\
\hline & Qatar & 0.77 & $(0.01)$ & 1.04 & $(0.01)$ & -0.62 & $(0.02)$ & 0.47 & $(0.01)$ & 1.38 & $(0.01)$ & 1.85 & $\mathrm{~m}$ \\
\hline & Romania & $\mathrm{m}$ & $\mathrm{m}$ & $\mathrm{m}$ & $\mathrm{m}$ & $\mathrm{m}$ & $\mathrm{m}$ & $\mathrm{m}$ & $\mathrm{m}$ & $\mathrm{m}$ & $\mathrm{m}$ & $\mathrm{m}$ & $\mathrm{m}$ \\
\hline & Russia & -0.09 & $(0.02)$ & 0.87 & $(0.01)$ & -1.05 & $(0.01)$ & -0.39 & $(0.00)$ & -0.03 & $(0.00)$ & 1.11 & $(0.02)$ \\
\hline & Singapore & 0.41 & $(0.01)$ & 0.94 & $(0.01)$ & -0.72 & $(0.01)$ & -0.02 & $(0.00)$ & 0.70 & $(0.01)$ & 1.69 & $(0.01)$ \\
\hline & Chinese Taipei & -0.01 & $(0.01)$ & 0.88 & $(0.01)$ & -1.03 & $(0.01)$ & -0.34 & $(0.00)$ & 0.13 & $(0.01)$ & 1.20 & $(0.01)$ \\
\hline & Thailand & 0.24 & $(0.01)$ & 0.76 & $(0.01)$ & -0.58 & $(0.01)$ & -0.13 & $(0.00)$ & 0.37 & $(0.01)$ & 1.29 & $(0.01)$ \\
\hline & Trinidad and Tobago & $\mathrm{m}$ & $\mathrm{m}$ & $\mathrm{m}$ & $\mathrm{m}$ & $\mathrm{m}$ & $\mathrm{m}$ & $\mathrm{m}$ & $\mathrm{m}$ & $\mathrm{m}$ & $\mathrm{m}$ & $\mathrm{m}$ & $\mathrm{m}$ \\
\hline & Tunisia & 0.67 & $(0.02)$ & 0.87 & $(0.01)$ & -0.43 & $(0.01)$ & 0.30 & $(0.01)$ & 0.97 & $(0.01)$ & 1.82 & $(0.00)$ \\
\hline & United Arab Emirates & 0.78 & $(0.01)$ & 0.98 & $(0.01)$ & -0.51 & $(0.01)$ & 0.44 & $(0.00)$ & 1.32 & $(0.01)$ & 1.85 & $\mathrm{~m}$ \\
\hline & Uruguay & -0.05 & $(0.01)$ & 0.86 & $(0.01)$ & -1.06 & $(0.01)$ & -0.37 & $(0.00)$ & 0.14 & $(0.01)$ & 1.09 & $(0.02)$ \\
\hline & Viet Nam & $\mathrm{m}$ & $\mathrm{m}$ & $\mathrm{m}$ & $\mathrm{m}$ & $\mathrm{m}$ & $\mathrm{m}$ & $\mathrm{m}$ & $\mathrm{m}$ & $\mathrm{m}$ & $\mathrm{m}$ & $\mathrm{m}$ & $\mathrm{m}$ \\
\hline & Argentina** & $\mathrm{m}$ & $\mathrm{m}$ & $\mathrm{m}$ & $\mathrm{m}$ & $\mathrm{m}$ & $\mathrm{m}$ & $\mathrm{m}$ & $\mathrm{m}$ & $\mathrm{m}$ & $\mathrm{m}$ & $\mathrm{m}$ & $\mathrm{m}$ \\
\hline & Kazakhstan** & $\mathrm{m}$ & $\mathrm{m}$ & $\mathrm{m}$ & $\mathrm{m}$ & $\mathrm{m}$ & $\mathrm{m}$ & $\mathrm{m}$ & $\mathrm{m}$ & $\mathrm{m}$ & $\mathrm{m}$ & $\mathrm{m}$ & $\mathrm{m}$ \\
\hline & Malaysia** & 0.77 & $(0.02)$ & 0.90 & $(0.01)$ & -0.41 & $(0.01)$ & 0.42 & $(0.01)$ & 1.21 & $(0.01)$ & 1.85 & $\mathrm{~m}$ \\
\hline
\end{tabular}

1. ESCS refers to the PISA index of economic, social and cultural status.

Note: Values that are statistically significant are indicated in bold (see Annex A3).

* See note at the beginning of this Annex.

** Coverage is too small to ensure comparability (see Annex A4).

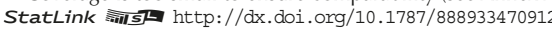




\begin{tabular}{|c|c|c|c|c|c|c|c|c|c|c|}
\hline & \multicolumn{10}{|c|}{ Index of achievement motivation, by: } \\
\hline & \multicolumn{10}{|c|}{ National quarters of the ESCS ${ }^{1}$ index } \\
\hline & \multicolumn{2}{|c|}{ Bottom quarter } & \multicolumn{2}{|c|}{ Second quarter } & \multicolumn{2}{|c|}{ Third quarter } & \multicolumn{2}{|c|}{ Top quarter } & \multicolumn{2}{|c|}{ Top - bottom quarter } \\
\hline & Mean index & S.E. & Mean index & S.E. & Mean index & S.E. & Mean index & S.E. & Dif. & S.E. \\
\hline Australia & 0.13 & $(0.02)$ & 0.26 & $(0.02)$ & 0.38 & $(0.02)$ & 0.55 & $(0.02)$ & 0.42 & $(0.02)$ \\
\hline Austria & -0.29 & $(0.03)$ & -0.31 & $(0.03)$ & -0.28 & $(0.03)$ & -0.15 & $(0.04)$ & 0.14 & $(0.05)$ \\
\hline$\widehat{\partial}$ Belgium & -0.45 & $(0.03)$ & -0.50 & $(0.02)$ & -0.44 & $(0.02)$ & -0.43 & $(0.02)$ & 0.02 & $(0.04)$ \\
\hline Canada & 0.08 & $(0.02)$ & 0.24 & $(0.02)$ & 0.40 & $(0.02)$ & 0.59 & $(0.02)$ & 0.51 & $(0.03)$ \\
\hline Chile & 0.15 & $(0.03)$ & 0.30 & $(0.03)$ & 0.33 & $(0.03)$ & 0.40 & $(0.02)$ & 0.25 & $(0.03)$ \\
\hline Czech Republic & -0.46 & $(0.02)$ & -0.31 & $(0.02)$ & -0.24 & $(0.02)$ & -0.13 & $(0.02)$ & 0.33 & $(0.03)$ \\
\hline Denmark & -0.36 & $(0.03)$ & -0.21 & $(0.03)$ & -0.09 & $(0.03)$ & 0.06 & $(0.03)$ & 0.41 & $(0.04)$ \\
\hline Estonia & -0.24 & $(0.03)$ & -0.08 & $(0.02)$ & -0.01 & $(0.03)$ & 0.18 & $(0.03)$ & 0.41 & $(0.04)$ \\
\hline Finland & -0.86 & $(0.03)$ & -0.70 & $(0.03)$ & -0.59 & $(0.03)$ & -0.37 & $(0.03)$ & 0.49 & $(0.04)$ \\
\hline France & -0.38 & $(0.03)$ & -0.32 & $(0.02)$ & -0.27 & $(0.03)$ & -0.04 & $(0.03)$ & 0.34 & $(0.04)$ \\
\hline Germany & -0.51 & $(0.03)$ & -0.42 & $(0.03)$ & -0.35 & $(0.02)$ & -0.26 & $(0.03)$ & 0.25 & $(0.04)$ \\
\hline Greece & -0.28 & $(0.03)$ & -0.17 & $(0.03)$ & -0.06 & $(0.03)$ & 0.10 & $(0.02)$ & 0.38 & $(0.04)$ \\
\hline Hungary & -0.46 & $(0.03)$ & -0.33 & $(0.03)$ & -0.28 & $(0.02)$ & -0.13 & $(0.03)$ & 0.33 & $(0.04)$ \\
\hline Iceland & 0.15 & $(0.03)$ & 0.28 & $(0.03)$ & 0.46 & $(0.04)$ & 0.66 & $(0.03)$ & 0.51 & $(0.05)$ \\
\hline Ireland & 0.25 & $(0.03)$ & 0.33 & $(0.03)$ & 0.41 & $(0.02)$ & 0.58 & $(0.02)$ & 0.33 & $(0.03)$ \\
\hline Israel & 0.80 & $(0.03)$ & 0.80 & $(0.03)$ & 0.82 & $(0.03)$ & 0.91 & $(0.03)$ & 0.11 & $(0.04)$ \\
\hline Italy & -0.21 & $(0.03)$ & -0.19 & $(0.03)$ & -0.16 & $(0.03)$ & -0.12 & $(0.03)$ & 0.09 & $(0.04)$ \\
\hline Japan & -0.70 & $(0.03)$ & -0.60 & $(0.03)$ & -0.46 & $(0.03)$ & -0.27 & $(0.03)$ & 0.44 & $(0.04)$ \\
\hline Korea & 0.06 & $(0.03)$ & 0.24 & $(0.04)$ & 0.41 & $(0.03)$ & 0.65 & $(0.03)$ & 0.60 & $(0.04)$ \\
\hline Latvia & -0.19 & $(0.03)$ & -0.11 & $(0.03)$ & 0.00 & $(0.03)$ & 0.19 & $(0.03)$ & 0.38 & $(0.04)$ \\
\hline Luxembourg & -0.26 & $(0.03)$ & -0.24 & $(0.03)$ & -0.17 & $(0.03)$ & -0.02 & $(0.03)$ & 0.24 & $(0.04)$ \\
\hline Mexico & 0.14 & $(0.03)$ & 0.20 & $(0.02)$ & 0.26 & $(0.03)$ & 0.38 & $(0.03)$ & 0.24 & $(0.04)$ \\
\hline Netherlands & -0.49 & $(0.03)$ & -0.49 & $(0.02)$ & -0.41 & $(0.02)$ & -0.36 & $(0.03)$ & 0.13 & $(0.04)$ \\
\hline New Zealand & 0.03 & $(0.03)$ & 0.13 & $(0.03)$ & 0.32 & $(0.03)$ & 0.50 & $(0.03)$ & 0.47 & $(0.05)$ \\
\hline Norway & -0.13 & $(0.03)$ & 0.03 & $(0.03)$ & 0.17 & $(0.03)$ & 0.35 & $(0.03)$ & 0.48 & $(0.05)$ \\
\hline Poland & -0.59 & $(0.02)$ & -0.49 & $(0.03)$ & -0.40 & $(0.03)$ & -0.20 & $(0.03)$ & 0.39 & $(0.03)$ \\
\hline Portugal & -0.06 & $(0.02)$ & 0.15 & $(0.02)$ & 0.23 & $(0.02)$ & 0.50 & $(0.03)$ & 0.57 & $(0.03)$ \\
\hline Slovak Republic & -0.53 & $(0.04)$ & -0.28 & $(0.02)$ & -0.25 & $(0.02)$ & -0.08 & $(0.03)$ & 0.45 & $(0.04)$ \\
\hline Slovenia & -0.57 & $(0.02)$ & -0.50 & $(0.03)$ & -0.39 & $(0.03)$ & -0.27 & $(0.03)$ & 0.30 & $(0.04)$ \\
\hline Spain & -0.39 & $(0.03)$ & -0.26 & $(0.03)$ & -0.09 & $(0.02)$ & 0.10 & $(0.03)$ & 0.49 & $(0.04)$ \\
\hline Sweden & -0.04 & $(0.04)$ & 0.05 & $(0.03)$ & 0.20 & $(0.03)$ & 0.39 & $(0.04)$ & 0.43 & $(0.05)$ \\
\hline Switzerland & -0.43 & $(0.03)$ & -0.47 & $(0.03)$ & -0.40 & $(0.03)$ & -0.43 & $(0.03)$ & 0.01 & $(0.04)$ \\
\hline Turkey & 0.56 & $(0.04)$ & 0.57 & $(0.03)$ & 0.66 & $(0.03)$ & 0.69 & $(0.03)$ & 0.13 & $(0.05)$ \\
\hline United Kingdom & 0.32 & $(0.03)$ & 0.51 & $(0.03)$ & 0.53 & $(0.03)$ & 0.70 & $(0.03)$ & 0.37 & $(0.04)$ \\
\hline United States & 0.51 & $(0.03)$ & 0.60 & $(0.03)$ & 0.66 & $(0.03)$ & 0.82 & $(0.03)$ & 0.31 & $(0.04)$ \\
\hline OECD average & -0.16 & $(0.00)$ & -0.07 & $(0.00)$ & 0.03 & $(0.00)$ & 0.17 & $(0.00)$ & 0.33 & $(0.01)$ \\
\hline
\end{tabular}

\begin{tabular}{|c|c|c|c|c|c|c|c|c|c|c|}
\hline Albania & $\mathrm{m}$ & $\mathrm{m}$ & $\mathrm{m}$ & $\mathrm{m}$ & $\mathrm{m}$ & $\mathrm{m}$ & $\mathrm{m}$ & $\mathrm{m}$ & $\mathrm{m}$ & $\mathrm{m}$ \\
\hline Algeria & $\mathrm{m}$ & $\mathrm{m}$ & $\mathrm{m}$ & $\mathrm{m}$ & $\mathrm{m}$ & $\mathrm{m}$ & $\mathrm{m}$ & $\mathrm{m}$ & $\mathrm{m}$ & $\mathrm{m}$ \\
\hline Brazil & 0.01 & $(0.01)$ & 0.08 & $(0.02)$ & 0.14 & $(0.02)$ & 0.26 & $(0.02)$ & 0.25 & $(0.03)$ \\
\hline B-S-J-G (China) & -0.07 & $(0.02)$ & 0.09 & $(0.03)$ & 0.17 & $(0.02)$ & 0.25 & $(0.03)$ & 0.32 & $(0.04)$ \\
\hline Bulgaria & -0.22 & $(0.03)$ & -0.11 & $(0.03)$ & -0.02 & $(0.03)$ & 0.12 & $(0.03)$ & 0.35 & $(0.05)$ \\
\hline CABA (Argentina) & $\mathrm{m}$ & $\mathrm{m}$ & $\mathrm{m}$ & $\mathrm{m}$ & $\mathrm{m}$ & $\mathrm{m}$ & $\mathrm{m}$ & $\mathrm{m}$ & $\mathrm{m}$ & $\mathrm{m}$ \\
\hline Colombia & 0.42 & $(0.02)$ & 0.46 & $(0.02)$ & 0.50 & $(0.02)$ & 0.62 & $(0.02)$ & 0.20 & $(0.03)$ \\
\hline Costa Rica & 0.43 & $(0.03)$ & 0.45 & $(0.03)$ & 0.51 & $(0.02)$ & 0.65 & $(0.02)$ & 0.23 & $(0.04)$ \\
\hline Croatia & -0.33 & $(0.02)$ & -0.31 & $(0.02)$ & -0.25 & $(0.02)$ & -0.07 & $(0.03)$ & 0.26 & $(0.04)$ \\
\hline Cyprus* & -0.03 & $(0.03)$ & 0.12 & $(0.03)$ & 0.19 & $(0.03)$ & 0.37 & $(0.03)$ & 0.40 & $(0.04)$ \\
\hline Dominican Republic & 0.28 & $(0.04)$ & 0.28 & $(0.03)$ & 0.37 & $(0.03)$ & 0.42 & $(0.03)$ & 0.15 & $(0.05)$ \\
\hline FYROM & $\mathrm{m}$ & $\mathrm{m}$ & $\mathrm{m}$ & $\mathrm{m}$ & $\mathrm{m}$ & $\mathrm{m}$ & $\mathrm{m}$ & $\mathrm{m}$ & $\mathrm{m}$ & $\mathrm{m}$ \\
\hline Georgia & $\mathrm{m}$ & $\mathrm{m}$ & $\mathrm{m}$ & $\mathrm{m}$ & $\mathrm{m}$ & $\mathrm{m}$ & $\mathrm{m}$ & $\mathrm{m}$ & $\mathrm{m}$ & $\mathrm{m}$ \\
\hline Hong Kong (China) & 0.09 & $(0.03)$ & 0.16 & $(0.03)$ & 0.18 & $(0.04)$ & 0.36 & $(0.03)$ & 0.27 & $(0.04)$ \\
\hline Indonesia & $\mathrm{m}$ & $\mathrm{m}$ & $\mathrm{m}$ & $\mathrm{m}$ & $\mathrm{m}$ & $\mathrm{m}$ & $\mathrm{m}$ & $\mathrm{m}$ & $\mathrm{m}$ & $\mathrm{m}$ \\
\hline Jordan & $\mathrm{m}$ & $\mathrm{m}$ & $\mathrm{m}$ & $\mathrm{m}$ & $\mathrm{m}$ & $\mathrm{m}$ & $\mathrm{m}$ & $\mathrm{m}$ & $\mathrm{m}$ & $\mathrm{m}$ \\
\hline Kosovo & $\mathrm{m}$ & $\mathrm{m}$ & $\mathrm{m}$ & $\mathrm{m}$ & $\mathrm{m}$ & $\mathrm{m}$ & $\mathrm{m}$ & $\mathrm{m}$ & $\mathrm{m}$ & $\mathrm{m}$ \\
\hline Lebanon & $\mathrm{m}$ & $\mathrm{m}$ & $\mathrm{m}$ & $\mathrm{m}$ & $\mathrm{m}$ & $\mathrm{m}$ & $\mathrm{m}$ & $\mathrm{m}$ & $\mathrm{m}$ & $\mathrm{m}$ \\
\hline Lithuania & -0.30 & $(0.03)$ & -0.04 & $(0.03)$ & 0.03 & $(0.04)$ & 0.32 & $(0.03)$ & 0.61 & $(0.05)$ \\
\hline Macao (China) & -0.65 & $(0.02)$ & -0.53 & $(0.03)$ & -0.50 & $(0.02)$ & -0.31 & $(0.03)$ & 0.35 & $(0.03)$ \\
\hline Malta & $\mathrm{m}$ & $\mathrm{m}$ & $\mathrm{m}$ & $\mathrm{m}$ & $\mathrm{m}$ & $\mathrm{m}$ & $\mathrm{m}$ & $\mathrm{m}$ & $\mathrm{m}$ & $\mathrm{m}$ \\
\hline Moldova & $\mathrm{m}$ & $\mathrm{m}$ & $\mathrm{m}$ & $\mathrm{m}$ & $\mathrm{m}$ & $\mathrm{m}$ & $\mathrm{m}$ & $\mathrm{m}$ & $\mathrm{m}$ & $\mathrm{m}$ \\
\hline Montenegro & -0.23 & $(0.02)$ & -0.20 & $(0.03)$ & -0.19 & $(0.03)$ & -0.02 & $(0.03)$ & 0.21 & $(0.04)$ \\
\hline Peru & 0.23 & $(0.02)$ & 0.31 & $(0.02)$ & 0.36 & $(0.02)$ & 0.45 & $(0.02)$ & 0.22 & $(0.03)$ \\
\hline Qatar & 0.63 & $(0.02)$ & 0.69 & $(0.02)$ & 0.81 & $(0.02)$ & 0.95 & $(0.02)$ & 0.32 & $(0.02)$ \\
\hline Romania & $\mathrm{m}$ & $\mathrm{m}$ & $\mathrm{m}$ & $\mathrm{m}$ & $\mathrm{m}$ & $\mathrm{m}$ & $\mathrm{m}$ & $\mathrm{m}$ & $\mathrm{m}$ & $\mathrm{m}$ \\
\hline Russia & -0.29 & $(0.03)$ & -0.14 & $(0.04)$ & -0.05 & $(0.02)$ & 0.12 & $(0.03)$ & 0.41 & $(0.04)$ \\
\hline Singapore & 0.32 & $(0.02)$ & 0.38 & $(0.03)$ & 0.45 & $(0.03)$ & 0.52 & $(0.03)$ & 0.20 & $(0.04)$ \\
\hline Chinese Taipei & -0.25 & $(0.02)$ & -0.03 & $(0.02)$ & 0.03 & $(0.02)$ & 0.22 & $(0.02)$ & 0.48 & $(0.03)$ \\
\hline Thailand & 0.21 & $(0.03)$ & 0.21 & $(0.02)$ & 0.23 & $(0.02)$ & 0.30 & $(0.02)$ & 0.08 & $(0.03)$ \\
\hline Trinidad and Tobago & $\mathrm{m}$ & $\mathrm{m}$ & $\mathrm{m}$ & $\mathrm{m}$ & $\mathrm{m}$ & $\mathrm{m}$ & $\mathrm{m}$ & $\mathrm{m}$ & $\mathrm{m}$ & $\mathrm{m}$ \\
\hline Tunisia & 0.61 & $(0.03)$ & 0.64 & $(0.02)$ & 0.67 & $(0.03)$ & 0.74 & $(0.03)$ & 0.13 & $(0.04)$ \\
\hline United Arab Emirates & 0.67 & $(0.03)$ & 0.70 & $(0.03)$ & 0.81 & $(0.02)$ & 0.93 & $(0.02)$ & 0.26 & $(0.03)$ \\
\hline Uruguay & -0.15 & $(0.02)$ & -0.14 & $(0.02)$ & -0.03 & $(0.03)$ & 0.12 & $(0.03)$ & 0.27 & $(0.04)$ \\
\hline Viet Nam & $\mathrm{m}$ & $\mathrm{m}$ & $\mathrm{m}$ & $\mathrm{m}$ & $\mathrm{m}$ & $\mathrm{m}$ & $\mathrm{m}$ & $\mathrm{m}$ & $\mathrm{m}$ & $\mathrm{m}$ \\
\hline Argentina** & $\mathrm{m}$ & $\mathrm{m}$ & $\mathrm{m}$ & $\mathrm{m}$ & $\mathrm{m}$ & $\mathrm{m}$ & $\mathrm{m}$ & $\mathrm{m}$ & $\mathrm{m}$ & $\mathrm{m}$ \\
\hline Kazakhstan** & $\mathrm{m}$ & $\mathrm{m}$ & $\mathrm{m}$ & $\mathrm{m}$ & $\mathrm{m}$ & $\mathrm{m}$ & $\mathrm{m}$ & $\mathrm{m}$ & $\mathrm{m}$ & $\mathrm{m}$ \\
\hline Malaysia** & 0.69 & $(0.04)$ & 0.79 & $(0.03)$ & 0.77 & $(0.03)$ & 0.82 & $(0.03)$ & 0.13 & $(0.05)$ \\
\hline
\end{tabular}

1. ESCS refers to the PISA index of economic, social and cultural status.

Note: Values that are statistically significant are indicated in bold (see Annex A3).

* See note at the beginning of this Annex.

** Coverage is too small to ensure comparability (see Annex A4).

StatLink त्नाइ $\mathrm{ht}$ htp://dx.doi.org/10.1787/888933470912 
[Part 3/3]

Table III.5.3 Index of achievement motivation, by student characteristics

Results based on students' self-reports

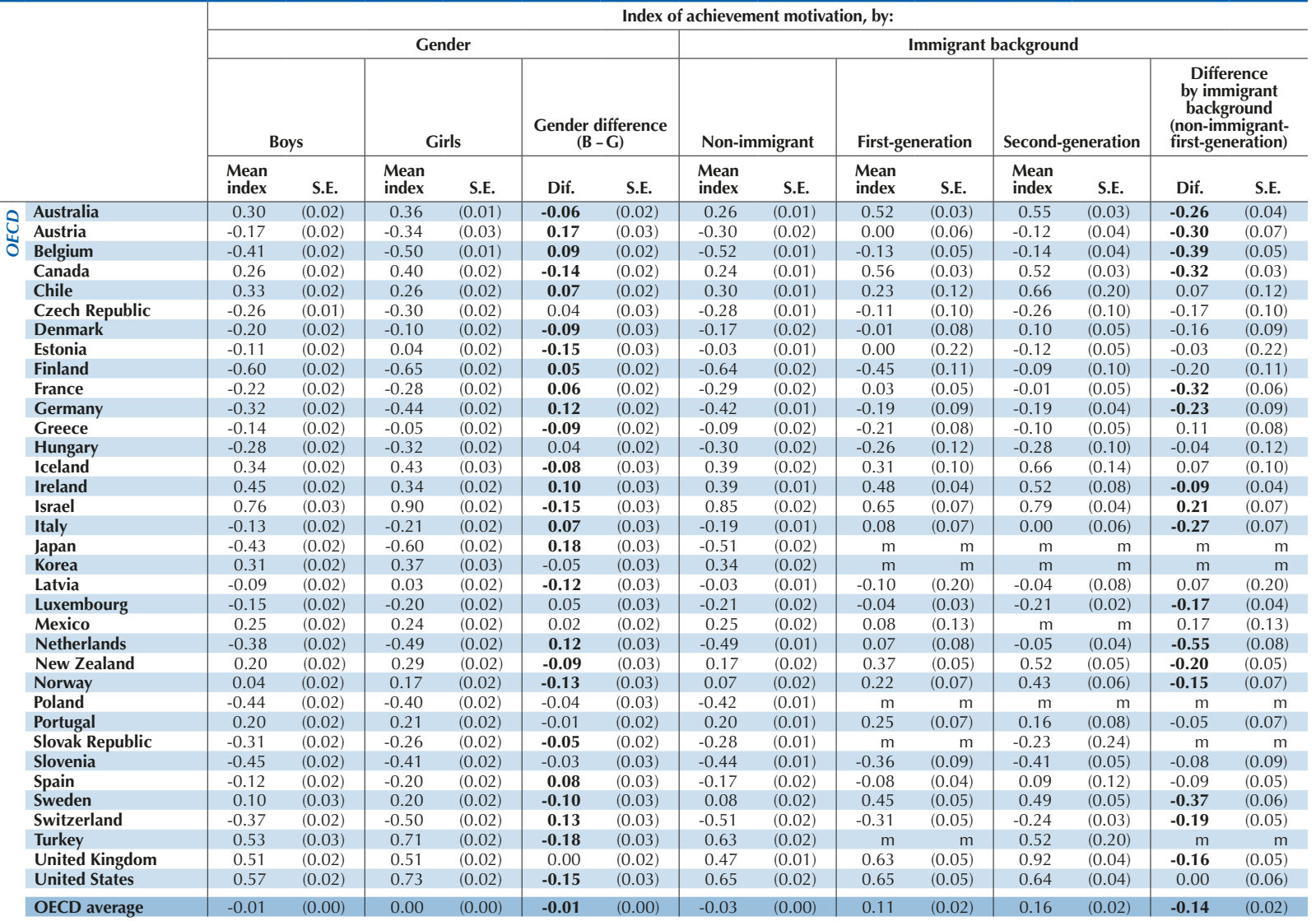

\begin{tabular}{|c|c|c|c|c|c|c|c|c|c|c|c|c|c|c|}
\hline Albania & $\mathrm{m}$ & $\mathrm{m}$ & $\mathrm{m}$ & $\mathrm{m}$ & $\mathrm{m}$ & $\mathrm{m}$ & $\mathrm{m}$ & $\mathrm{m}$ & $\mathrm{m}$ & $\mathrm{m}$ & $\mathrm{m}$ & $\mathrm{m}$ & $\mathrm{m}$ & $\mathrm{m}$ \\
\hline Algeria & $\mathrm{m}$ & $\mathrm{m}$ & $\mathrm{m}$ & $\mathrm{m}$ & $\mathrm{m}$ & $\mathrm{m}$ & $\mathrm{m}$ & $\mathrm{m}$ & $\mathrm{m}$ & $\mathrm{m}$ & $\mathrm{m}$ & $\mathrm{m}$ & $\mathrm{m}$ & $\mathrm{m}$ \\
\hline Brazil & 0.11 & $(0.01)$ & 0.13 & $(0.01)$ & -0.02 & $(0.01)$ & 0.13 & $(0.01)$ & -0.43 & $(0.23)$ & -0.01 & $(0.15)$ & 0.55 & $(0.23)$ \\
\hline B-S-J-G (China) & 0.15 & $(0.02)$ & 0.07 & $(0.02)$ & 0.08 & $(0.02)$ & 0.12 & $(0.01)$ & $\mathrm{m}$ & $\mathrm{m}$ & $\mathrm{m}$ & $\mathrm{m}$ & $\mathrm{m}$ & $\mathrm{m}$ \\
\hline Bulgaria & -0.14 & $(0.02)$ & 0.03 & $(0.02)$ & -0.18 & $(0.03)$ & -0.05 & $(0.02)$ & $\mathrm{m}$ & $\mathrm{m}$ & $\mathrm{m}$ & $\mathrm{m}$ & $\mathrm{m}$ & $\mathrm{m}$ \\
\hline CABA (Argentina) & $\mathrm{m}$ & $\mathrm{m}$ & $\mathrm{m}$ & $\mathrm{m}$ & $\mathrm{m}$ & $\mathrm{m}$ & $\mathrm{m}$ & $\mathrm{m}$ & $\mathrm{m}$ & $\mathrm{m}$ & $\mathrm{m}$ & $\mathrm{m}$ & $\mathrm{m}$ & $\mathrm{m}$ \\
\hline Colombia & 0.48 & $(0.01)$ & 0.52 & $(0.01)$ & -0.03 & $(0.02)$ & 0.50 & $(0.01)$ & $\mathrm{m}$ & $\mathrm{m}$ & 0.46 & $(0.16)$ & $\mathrm{m}$ & $\mathrm{m}$ \\
\hline Costa Rica & 0.54 & $(0.02)$ & 0.48 & $(0.02)$ & 0.06 & $(0.02)$ & 0.51 & $(0.01)$ & 0.43 & $(0.06)$ & 0.49 & $(0.06)$ & 0.08 & $(0.06)$ \\
\hline Croatia & -0.23 & $(0.02)$ & -0.25 & $(0.02)$ & 0.03 & $(0.03)$ & -0.24 & $(0.01)$ & -0.22 & $(0.10)$ & -0.20 & $(0.04)$ & -0.02 & $(0.10)$ \\
\hline Cyprus* & 0.10 & $(0.02)$ & 0.23 & $(0.02)$ & -0.13 & $(0.03)$ & 0.17 & $(0.01)$ & 0.12 & $(0.04)$ & 0.34 & $(0.08)$ & 0.05 & $(0.04)$ \\
\hline Dominican Republic & 0.34 & $(0.02)$ & 0.33 & $(0.02)$ & 0.01 & $(0.03)$ & 0.35 & $(0.01)$ & 0.49 & $(0.21)$ & 0.40 & $(0.16)$ & -0.14 & $(0.21)$ \\
\hline FYROM & $\mathrm{m}$ & $\mathrm{m}$ & $\mathrm{m}$ & $\mathrm{m}$ & $\mathrm{m}$ & $\mathrm{m}$ & $\mathrm{m}$ & $\mathrm{m}$ & $\mathrm{m}$ & $\mathrm{m}$ & $\mathrm{m}$ & $\mathrm{m}$ & $\mathrm{m}$ & $\mathrm{m}$ \\
\hline Georgia & $\mathrm{m}$ & $\mathrm{m}$ & $\mathrm{m}$ & $\mathrm{m}$ & $\mathrm{m}$ & $\mathrm{m}$ & $\mathrm{m}$ & $\mathrm{m}$ & $\mathrm{m}$ & $\mathrm{m}$ & $\mathrm{m}$ & $\mathrm{m}$ & $\mathrm{m}$ & $\mathrm{m}$ \\
\hline Hong Kong (China) & 0.13 & $(0.02)$ & 0.26 & $(0.02)$ & -0.13 & $(0.03)$ & 0.19 & $(0.02)$ & 0.20 & $(0.04)$ & 0.22 & $(0.03)$ & 0.00 & $(0.04)$ \\
\hline Indonesia & $\mathrm{m}$ & $\mathrm{m}$ & $\mathrm{m}$ & $\mathrm{m}$ & $\mathrm{m}$ & $\mathrm{m}$ & $\mathrm{m}$ & $\mathrm{m}$ & $\mathrm{m}$ & $\mathrm{m}$ & $\mathrm{m}$ & $\mathrm{m}$ & $\mathrm{m}$ & $\mathrm{m}$ \\
\hline Jordan & $\mathrm{m}$ & $\mathrm{m}$ & $\mathrm{m}$ & $\mathrm{m}$ & $\mathrm{m}$ & $\mathrm{m}$ & $\mathrm{m}$ & $\mathrm{m}$ & $\mathrm{m}$ & $\mathrm{m}$ & $\mathrm{m}$ & $\mathrm{m}$ & $\mathrm{m}$ & $\mathrm{m}$ \\
\hline Kosovo & $\mathrm{m}$ & $\mathrm{m}$ & $\mathrm{m}$ & $\mathrm{m}$ & $\mathrm{m}$ & $\mathrm{m}$ & $\mathrm{m}$ & $\mathrm{m}$ & $\mathrm{m}$ & $\mathrm{m}$ & $\mathrm{m}$ & $\mathrm{m}$ & $\mathrm{m}$ & $\mathrm{m}$ \\
\hline Lebanon & $\mathrm{m}$ & $\mathrm{m}$ & $\mathrm{m}$ & $\mathrm{m}$ & $\mathrm{m}$ & $\mathrm{m}$ & $\mathrm{m}$ & $\mathrm{m}$ & $\mathrm{m}$ & $\mathrm{m}$ & $\mathrm{m}$ & $\mathrm{m}$ & $\mathrm{m}$ & $\mathrm{m}$ \\
\hline Lithuania & -0.10 & $(0.03)$ & 0.11 & $(0.02)$ & -0.21 & $(0.03)$ & 0.01 & $(0.02)$ & -0.32 & $(0.42)$ & -0.22 & $(0.09)$ & 0.34 & $(0.42)$ \\
\hline Macao (China) & -0.54 & $(0.02)$ & -0.45 & $(0.02)$ & -0.09 & $(0.03)$ & -0.56 & $(0.02)$ & -0.37 & $(0.03)$ & -0.50 & $(0.02)$ & -0.19 & $(0.04)$ \\
\hline Malta & $\mathrm{m}$ & $\mathrm{m}$ & $\mathrm{m}$ & $\mathrm{m}$ & $\mathrm{m}$ & $\mathrm{m}$ & $\mathrm{m}$ & $\mathrm{m}$ & $\mathrm{m}$ & $\mathrm{m}$ & $\mathrm{m}$ & $\mathrm{m}$ & $\mathrm{m}$ & $\mathrm{m}$ \\
\hline Moldova & $\mathrm{m}$ & $\mathrm{m}$ & $\mathrm{m}$ & $\mathrm{m}$ & $\mathrm{m}$ & $\mathrm{m}$ & $\mathrm{m}$ & $\mathrm{m}$ & $\mathrm{m}$ & $\mathrm{m}$ & $\mathrm{m}$ & $\mathrm{m}$ & $\mathrm{m}$ & $\mathrm{m}$ \\
\hline Montenegro & -0.23 & $(0.02)$ & -0.09 & $(0.02)$ & -0.14 & $(0.03)$ & -0.15 & $(0.01)$ & -0.20 & $(0.11)$ & -0.23 & $(0.07)$ & 0.05 & $(0.11)$ \\
\hline Peru & 0.33 & $(0.01)$ & 0.34 & $(0.01)$ & -0.02 & $(0.02)$ & 0.34 & $(0.01)$ & $\mathrm{m}$ & $\mathrm{m}$ & $\mathrm{m}$ & $\mathrm{m}$ & $\mathrm{m}$ & $\mathrm{m}$ \\
\hline Qatar & 0.68 & $(0.01)$ & 0.86 & $(0.01)$ & -0.18 & $(0.02)$ & 0.78 & $(0.01)$ & 0.76 & $(0.01)$ & 0.84 & $(0.03)$ & 0.02 & $(0.02)$ \\
\hline Romania & $\mathrm{m}$ & $\mathrm{m}$ & $\mathrm{m}$ & $\mathrm{m}$ & $\mathrm{m}$ & $\mathrm{m}$ & $\mathrm{m}$ & $\mathrm{m}$ & $\mathrm{m}$ & $\mathrm{m}$ & $\mathrm{m}$ & $\mathrm{m}$ & $\mathrm{m}$ & $\mathrm{m}$ \\
\hline Russia & -0.10 & $(0.02)$ & -0.08 & $(0.02)$ & -0.01 & $(0.02)$ & -0.09 & $(0.02)$ & 0.00 & $(0.10)$ & 0.00 & $(0.08)$ & -0.09 & $(0.10)$ \\
\hline Singapore & 0.42 & $(0.02)$ & 0.41 & $(0.02)$ & 0.01 & $(0.03)$ & 0.41 & $(0.01)$ & 0.50 & $(0.05)$ & 0.29 & $(0.05)$ & -0.09 & $(0.05)$ \\
\hline Chinese Taipei & -0.06 & $(0.02)$ & 0.04 & $(0.02)$ & -0.10 & $(0.02)$ & -0.01 & $(0.01)$ & $\mathrm{m}$ & $\mathrm{m}$ & $\mathrm{m}$ & $\mathrm{m}$ & $\mathrm{m}$ & $\mathrm{m}$ \\
\hline Thailand & 0.15 & $(0.02)$ & 0.30 & $(0.02)$ & -0.15 & $(0.02)$ & 0.24 & $(0.01)$ & $\mathrm{m}$ & $\mathrm{m}$ & 0.18 & $(0.15)$ & $\mathrm{m}$ & $\mathrm{m}$ \\
\hline Trinidad and Tobago & $\mathrm{m}$ & $\mathrm{m}$ & $\mathrm{m}$ & $\mathrm{m}$ & $\mathrm{m}$ & $\mathrm{m}$ & $\mathrm{m}$ & $\mathrm{m}$ & $\mathrm{m}$ & $\mathrm{m}$ & $\mathrm{m}$ & $\mathrm{m}$ & $\mathrm{m}$ & $\mathrm{m}$ \\
\hline Tunisia & 0.54 & $(0.02)$ & 0.77 & $(0.02)$ & -0.23 & $(0.03)$ & 0.68 & $(0.02)$ & $\mathrm{m}$ & $\mathrm{m}$ & 0.25 & $(0.15)$ & $\mathrm{m}$ & $\mathrm{m}$ \\
\hline United Arab Emirates & 0.71 & $(0.02)$ & 0.84 & $(0.02)$ & -0.13 & $(0.03)$ & 0.82 & $(0.02)$ & 0.77 & $(0.02)$ & 0.79 & $(0.02)$ & 0.05 & $(0.03)$ \\
\hline Uruguay & 0.01 & $(0.02)$ & -0.10 & $(0.01)$ & 0.11 & $(0.02)$ & -0.05 & $(0.01)$ & $\mathrm{m}$ & $\mathrm{m}$ & $\mathrm{m}$ & $\mathrm{m}$ & $\mathrm{m}$ & $\mathrm{m}$ \\
\hline Viet Nam & $\mathrm{m}$ & $\mathrm{m}$ & $\mathrm{m}$ & $\mathrm{m}$ & $\mathrm{m}$ & $\mathrm{m}$ & $\mathrm{m}$ & $\mathrm{m}$ & $\mathrm{m}$ & $\mathrm{m}$ & $\mathrm{m}$ & $\mathrm{m}$ & $\mathrm{m}$ & $\mathrm{m}$ \\
\hline Argentina** & $\mathrm{m}$ & $\mathrm{m}$ & $\mathrm{m}$ & $\mathrm{m}$ & $\mathrm{m}$ & $\mathrm{m}$ & $\mathrm{m}$ & $\mathrm{m}$ & $\mathrm{m}$ & $\mathrm{m}$ & $\mathrm{m}$ & $\mathrm{m}$ & $\mathrm{m}$ & $\mathrm{m}$ \\
\hline Kazakhstan** & $\mathrm{m}$ & $\mathrm{m}$ & $\mathrm{m}$ & $\mathrm{m}$ & $\mathrm{m}$ & $\mathrm{m}$ & $\mathrm{m}$ & $\mathrm{m}$ & $\mathrm{m}$ & $\mathrm{m}$ & $\mathrm{m}$ & $\mathrm{m}$ & $\mathrm{m}$ & $\mathrm{m}$ \\
\hline Malaysia** & 0.66 & $(0.03)$ & 0.86 & $(0.03)$ & -0.21 & $(0.03)$ & 0.78 & $(0.02)$ & $\mathrm{m}$ & $\mathrm{m}$ & 0.71 & $(0.12)$ & $\mathrm{m}$ & $\mathrm{m}$ \\
\hline
\end{tabular}

1. ESCS refers to the PISA index of economic, social and cultural status.

Note: Values that are statistically significant are indicated in bold (see Annex A3).

* See note at the beginning of this Annex.

is too small to ensure comparability (see Ar

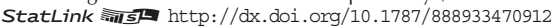


A corrigendum has been issued for this page. See: http://www.oecd.org/about/publishing/Corrigenda_PISA2015IR_VolumellI.pdf

[Part 1/1]

Table III.5.5a Index of achievement motivation, by student performance in science

Results based on students' self-reports

\begin{tabular}{|c|c|c|c|c|c|c|c|c|c|c|c|c|c|c|c|c|}
\hline & \multicolumn{10}{|c|}{$\begin{array}{l}\text { Science performance, by national quarters } \\
\text { of the index of achievement motivation }\end{array}$} & \multicolumn{4}{|c|}{$\begin{array}{l}\text { Before accounting } \\
\text { for students' and schools' } \\
\text { socio-economic profile }{ }^{\prime}\end{array}$} & \begin{tabular}{|r} 
A \\
acco \\
for st \\
and s \\
socio- \\
pr
\end{tabular} & $\begin{array}{l}\text { ter } \\
\text { nting } \\
\text { dents' } \\
\text { hools } \\
\text { honomic } \\
\text { ofile }\end{array}$ \\
\hline & Bottor & quarter & Secon & quarter & Third & uarter & Top & uarter & Top- & $\begin{array}{l}\text { ottom } \\
\text { rter }\end{array}$ & $\begin{array}{c}\text { Cha } \\
\text { science } \\
\text { one-ur } \\
\text { on the } \\
\text { achi } \\
\text { mot }\end{array}$ & $\begin{array}{l}\text { ge in } \\
\text { core per } \\
\text { change } \\
\text { ndex of } \\
\text { ement } \\
\text { ation }\end{array}$ & 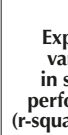 & $\begin{array}{l}\text { ined } \\
\text { nce } \\
\text { dent } \\
\text { nance } \\
\text { d x 100) }\end{array}$ & \begin{tabular}{|c} 
Cha \\
science \\
one-un \\
on the \\
achie \\
mot
\end{tabular} & $\begin{array}{l}\text { ge in } \\
\text { core per } \\
\text { change } \\
\text { icdex of } \\
\text { ement } \\
\text { ation }\end{array}$ \\
\hline & $\begin{array}{l}\text { Mean } \\
\text { score }\end{array}$ & S.E. & $\begin{array}{l}\text { Mean } \\
\text { score }\end{array}$ & S.E. & $\begin{array}{l}\text { Mean } \\
\text { score }\end{array}$ & S.E. & $\begin{array}{l}\text { Mean } \\
\text { score }\end{array}$ & S.E. & $\begin{array}{c}\text { Score } \\
\text { dif. }\end{array}$ & S.E. & $\begin{array}{c}\text { Score } \\
\text { dif. }\end{array}$ & S.E. & $\%$ & S.E. & $\begin{array}{c}\text { Score } \\
\text { dif. }\end{array}$ & S.E. \\
\hline Australia & 489 & $(2.5)$ & 501 & $(2.6)$ & 525 & $(2.2)$ & 537 & $(2.6)$ & 48 & $(3.1)$ & 20 & $(1.1)$ & 3.5 & $(0.4)$ & 14 & $(1.0)$ \\
\hline Austria & 492 & (3.0) & 492 & (3.0) & 496 & $(3.6)$ & 507 & (3.5) & 15 & (3.8) & 6 & (1.3) & 0.4 & $(0.2)$ & 7 & (1.1) \\
\hline Belgium (excl. Flemish) & 507 & $(2.3)$ & 509 & $(2.6)$ & 512 & (3.4) & 503 & $(4.2)$ & -4 & $(4.1)$ & -2 & $(1.8)$ & 0.1 & $(0.1)$ & 1 & $(1.4)$ \\
\hline Canada & 512 & $(2.8)$ & 514 & $(3.3)$ & 542 & $\begin{array}{l}(2.9) \\
(2.9)\end{array}$ & 551 & (3.0) & 39 & (3.6) & 16 & $(1.2)$ & 3.2 & $(0.4)$ & 11 & $(1.1)$ \\
\hline Chile & 436 & (3.0) & 443 & $(3.7)$ & 451 & (3.4) & 462 & (3.5) & 26 & $\begin{array}{l}(3.0) \\
(3.9)\end{array}$ & 11 & (1.5) & 1.5 & $\begin{array}{l}0.4) \\
(0.4)\end{array}$ & 7 & (1.3) \\
\hline Czech Republic & 487 & $(3.1)$ & 488 & $(2.8)$ & 497 & (3.1) & 519 & (3.4) & 32 & $(4.4)$ & 17 & $(2.0)$ & 2.2 & $(0.5)$ & 11 & $(1.7)$ \\
\hline Denmark & 479 & $(4.2)$ & $\begin{array}{l}400 \\
499\end{array}$ & (3.6) & 516 & $\begin{array}{l}(3.2) \\
(3.2)\end{array}$ & 533 & $\begin{array}{l}(0.4) \\
(3.5)\end{array}$ & 54 & $\begin{array}{l}\text { (4.4) } \\
(4.1)\end{array}$ & 21 & $(1.4)$ & 5.4 & $(0.7)$ & 17 & (1.4) \\
\hline Estonia & 519 & $(4.4)$ & 520 & $(4.4)$ & 547 & $(2.7)$ & 558 & $(3.3)$ & 40 & $(5.2)$ & 18 & $(1.8)$ & 3.0 & $(0.6)$ & 12 & (1.6) \\
\hline Finland & 510 & (2.8) & 525 & (3.7) & 539 & (3.1) & 566 & (3.9) & 56 & $(4.0)$ & 23 & $(1.6)$ & 4.9 & $(0.7)$ & 17 & (1.6) \\
\hline France & 482 & $\begin{array}{l}(2.0) \\
(2.9)\end{array}$ & $\begin{array}{l}323 \\
497\end{array}$ & (2.8) & 506 & $\begin{array}{l}(3.1) \\
(2.7)\end{array}$ & $\begin{array}{l}360 \\
514\end{array}$ & $\begin{array}{l}(3.9) \\
\text { (3.9) }\end{array}$ & $\begin{array}{l}30 \\
32\end{array}$ & $\begin{array}{l}\text { (4.0) } \\
(5.0)\end{array}$ & 13 & $\begin{array}{l}(1.6) \\
(2.0)\end{array}$ & $\begin{array}{l}4.9 \\
1.5\end{array}$ & $(0.4)$ & 6 & $\begin{array}{l}(1.0) \\
(1.4)\end{array}$ \\
\hline Germany & $\begin{array}{l}462 \\
507\end{array}$ & $\begin{array}{l}(2.9) \\
(3.6)\end{array}$ & 512 & $\begin{array}{l}(2.0) \\
(3.9)\end{array}$ & 526 & $(4.7)$ & 530 & $\begin{array}{l}(3.9) \\
(4.2)\end{array}$ & 23 & $\begin{array}{l}(3.0) \\
(4.8)\end{array}$ & 10 & $(2.0)$ & $\begin{array}{l}.5 \\
0.9\end{array}$ & $\begin{array}{l}(0.4) \\
(0.4)\end{array}$ & $\begin{array}{l}6 \\
8\end{array}$ & (1.3) \\
\hline $\begin{array}{l}\text { Germany } \\
\text { Greece }\end{array}$ & 431 & $\begin{array}{l}\text { (3.6) } \\
(4.5)\end{array}$ & 450 & $\begin{array}{l}\text { (3.9) } \\
(4.5)\end{array}$ & $\begin{array}{l}526 \\
469\end{array}$ & (4.5) & 480 & $\begin{array}{l}(4.2) \\
(4.4)\end{array}$ & 50 & $\begin{array}{l}(4.8) \\
(4.2)\end{array}$ & 22 & $\begin{array}{l}(2.0) \\
(1.7)\end{array}$ & $\begin{array}{l}.9 \\
4.2\end{array}$ & $\begin{array}{l}(0.4) \\
(0.6)\end{array}$ & 14 & $\begin{array}{l}(1.3) \\
(1.5)\end{array}$ \\
\hline Hungary & 461 & (3.6) & 478 & (3.9) & 475 & (3.9) & 502 & (3.7) & 41 & (5.1) & 17 & $(2.3)$ & 2.2 & $(0.6)$ & 6 & (1.6) \\
\hline $\begin{array}{l}\text { Iceland } \\
\text { Indy }\end{array}$ & 401 & $\begin{array}{l}(3.0) \\
(3.0)\end{array}$ & 460 & (4.9) & 492 & (1.3) & 501 & (3.4) & $\begin{array}{l}41 \\
55\end{array}$ & $(4.4)$ & 23 & (1.5) & $\begin{array}{l}2.2 \\
6.5\end{array}$ & $\begin{array}{l}(0.0) \\
(0.8)\end{array}$ & 20 & $\begin{array}{l}(1.0) \\
(1.5)\end{array}$ \\
\hline Ireland & 482 & (3.3) & 494 & (2.9) & 508 & (3.1) & 531 & (3.2) & 50 & (3.7) & 19 & (1.4) & 3.8 & $(0.5)$ & 15 & (1.3) \\
\hline Israel & $\begin{array}{l}402 \\
448\end{array}$ & (5.4) & $\begin{array}{l}494 \\
485\end{array}$ & $\begin{array}{l}(2.9) \\
(4.7)\end{array}$ & 475 & (2.9) & $\mathrm{m}$ & $\begin{array}{l}\text { (3.2) } \\
\mathrm{m}\end{array}$ & $\mathrm{m}$ & $\mathrm{m}$ & 13 & (1.0) & $\begin{array}{l}3.0 \\
1.5\end{array}$ & $(0.4)$ & 13 & (1.6) \\
\hline Italy & 479 & (3.2) & 481 & (4.1) & 479 & (3.8) & 491 & (3.8) & 12 & $(4.3)$ & 5 & $(2.0)$ & 0.2 & $(0.2)$ & 5 & (1.6) \\
\hline Japan & 514 & (3.8) & 533 & (3.9) & 546 & (3.7) & 561 & $(4.0)$ & 47 & $(4.1)$ & 17 & (1.4) & 3.4 & $(0.6)$ & 7 & $(1.4)$ \\
\hline Korea & 489 & (3.6) & 500 & (4.3) & 535 & (8.3) & 543 & (10.1) & 55 & (10.4) & 25 & (1.7) & 6.5 & $(0.8)$ & 16 & (1.3) \\
\hline Latvia & 468 & $(2.5)$ & 483 & (3.3) & 500 & $(2.7)$ & 514 & $(2.7)$ & 46 & $(3.4)$ & 18 & $(1.4)$ & 4.2 & $(0.6)$ & 14 & $\begin{array}{l}(1.3) \\
(1.3)\end{array}$ \\
\hline Luxembourg & 474 & $(2.9)$ & 480 & (2.4) & 490 & (2.8) & 496 & (3.1) & 22 & $(4.7)$ & 9 & (1.6) & 0.9 & $(0.3)$ & $\begin{array}{r}14 \\
6\end{array}$ & (1.3) \\
\hline Mexico & 400 & $(2.5)$ & 413 & $(2.6)$ & 425 & (2.6) & 430 & (3.1) & 30 & (3.2) & 15 & (1.4) & 2.9 & $(0.5)$ & 10 & (1.3) \\
\hline Netherlands & 496 & (3.2) & 514 & (3.9) & 517 & (4.0) & 530 & (4.6) & 35 & (5.2) & 14 & $(2.6)$ & 1.1 & $(0.4)$ & 11 & (2.3) \\
\hline New Zealand & 494 & (3.4) & 502 & $(4.2)$ & 531 & (3.8) & 537 & $(4.8)$ & 43 & $(6.0)$ & 18 & $(2.1)$ & 3.1 & $(0.7)$ & 11 & $\begin{array}{l}(2.3) \\
(1.9)\end{array}$ \\
\hline Norway & 469 & (3.6) & 494 & (3.9) & 516 & (5.3) & 524 & $(4.9)$ & 55 & $(5.7)$ & 20 & $(1.7)$ & 4.5 & $(0.7)$ & 16 & \\
\hline Poland & 484 & (3.6) & 492 & (5.2) & 504 & (6.9) & 531 & (3.8) & 47 & $(4.3)$ & 20 & $(1.7)$ & 3.3 & $(0.6)$ & 13 & (1.5) \\
\hline Portugal & 478 & (3.7) & 485 & (3.7) & 514 & (3.5) & 534 & (3.6) & 57 & $(4.5)$ & 24 & $(1.7)$ & 5.6 & $(0.7)$ & 15 & $\begin{array}{l}(1.6) \\
(1.7)\end{array}$ \\
\hline Slovak Republic & 445 & (3.5) & 465 & (3.9) & 466 & (3.5) & 500 & $(3.0)$ & 55 & $(4.0)$ & 22 & $(1.6)$ & 4.3 & $(0.6)$ & 13 & $(1.3)$ \\
\hline Slovenia & 498 & (3.0) & 511 & (3.7) & 518 & (3.8) & 537 & (3.1) & 39 & $(4.5)$ & 18 & $(1.8)$ & 2.9 & (0.6) & 12 & (1.5) \\
\hline Spain & 469 & (3.3) & 484 & $(2.6)$ & 500 & (3.0) & 523 & $(3.0)$ & 55 & (3.8) & 23 & (1.4) & 6.0 & $(0.7)$ & 16 & (1.4) \\
\hline Sweden & 473 & $(4.8)$ & 488 & $(4.3)$ & 510 & (4.6) & 516 & $(5.1)$ & 42 & $(4.8)$ & 17 & (1.6) & 3.3 & $(0.6)$ & 14 & (1.5) \\
\hline Switzerland & 498 & $(4.1)$ & 506 & $(4.6)$ & 515 & (4.0) & 511 & $(4.0)$ & 14 & $(4.3)$ & 6 & $(1.8)$ & 0.3 & $(0.2)$ & 6 & $(1.6)$ \\
\hline Turkey & 405 & (5.1) & 435 & $(4.7)$ & 434 & (4.1) & 432 & (4.5) & 27 & (4.9) & 10 & (1.5) & 1.8 & $(0.5)$ & 7 & (1.3) \\
\hline United Kingdom & 492 & $(3.1)$ & 515 & (3.5) & 521 & (3.5) & 522 & $(4.7)$ & 30 & $(4.4)$ & 14 & $(1.5)$ & 1.6 & $(0.4)$ & 12 & (1.4) \\
\hline United States & 479 & (3.5) & 502 & (4.3) & 509 & (4.0) & $\mathrm{m}$ & $\mathrm{m}$ & $\mathrm{m}$ & $\mathrm{m}$ & 10 & $(1.6)$ & 0.9 & $(0.3)$ & 7 & $(1.5)$ \\
\hline OECD average & 477 & $(0.6)$ & 490 & $(0.6)$ & 503 & $(0.7)$ & 516 & $(0.7)$ & 38 & $(0.8)$ & 16 & $(0.3)$ & 2.9 & $(0.1)$ & 11 & $(0.3)$ \\
\hline Albania & $\mathrm{m}$ & $\mathrm{m}$ & $\mathrm{m}$ & $\mathrm{m}$ & $\mathrm{m}$ & $\mathrm{m}$ & $\mathrm{m}$ & $\mathrm{m}$ & $\mathrm{m}$ & $\mathrm{m}$ & $\mathrm{m}$ & $\mathrm{m}$ & $\mathrm{m}$ & $\mathrm{m}$ & $\mathrm{m}$ & $\mathrm{m}$ \\
\hline Algeria & & & $\mathrm{m}$ & & $\mathrm{m}$ & $\mathrm{m}$ & $\mathrm{m}$ & $\mathrm{m}$ & $\mathrm{m}$ & m & $\mathrm{m}$ & III & $\mathrm{m}$ & & $\mathrm{m}$ & $\mathrm{m}$ \\
\hline$\$$ Brazil & 394 & $(2.4)$ & 390 & $(2.3)$ & 414 & (3.3) & 430 & $(4.5)$ & 36 & $(4.2)$ & 18 & $(1.5)$ & 2.6 & $(0.4)$ & 11 & $(1.1)$ \\
\hline ¿ B-S-J-G (China) & 501 & $(4.9)$ & 503 & (5.9) & 520 & (5.5) & 551 & (5.2) & 50 & $(4.5)$ & 21 & $(1.8)$ & 3.0 & $(0.5)$ & 11 & (1.6) \\
\hline $\begin{array}{l}\text { B-S-j-G (Cnina) } \\
\text { Bulgaria }\end{array}$ & 443 & $\begin{array}{l}(4.9) \\
(5.0)\end{array}$ & 440 & $\begin{array}{l}(3.9) \\
(4.6)\end{array}$ & $\begin{array}{l}520 \\
474\end{array}$ & $\begin{array}{l}(5.3) \\
(4.3)\end{array}$ & 467 & $\begin{array}{l}(3.2) \\
(4.8)\end{array}$ & $\begin{array}{l}50 \\
24\end{array}$ & $\begin{array}{l}(4.5) \\
(4.3)\end{array}$ & 11 & (1.5) & $\begin{array}{l}3.0 \\
1.3\end{array}$ & $(0.4)$ & 5 & $\begin{array}{l}(1.6) \\
(1.2)\end{array}$ \\
\hline CABA (Argentina) & $\mathrm{m}$ & $\mathrm{m}$ & $\mathrm{m}$ & $\mathrm{m}$ & $\mathrm{m}$ & & $\mathrm{m}$ & & $\mathrm{m}$ & & $\mathrm{m}$ & $\mathrm{m}$ & $\mathrm{m}$ & $\mathrm{m}$ & $\mathrm{m}$ & $\mathrm{m}$ \\
\hline Colombia & 405 & $(3.8)$ & 422 & (3.5) & 412 & (3.3) & 428 & (3.1) & 23 & $(3$. & 10 & (1.6) & 0.9 & $(0.3)$ & 6 & $(1.3)$ \\
\hline Costa Rica & 409 & $(3.1)$ & 420 & $(2.9)$ & 422 & (2.6) & $\begin{array}{l}420 \\
434\end{array}$ & $(4.5)$ & 26 & $\begin{array}{l}(3.0) \\
(4.8)\end{array}$ & 12 & (1.5) & 1.8 & $(0.5)$ & 7 & (1.4) \\
\hline Croatia & 459 & (3.0) & 473 & (3.4) & 484 & (3.8) & 491 & (3.4) & 33 & (3. & 14 & (1.6) & 1.8 & $(0.4)$ & 8 & (1.4) \\
\hline Cyprus* & 400 & $(2.7)$ & 425 & (3.4) & 447 & $(2.9)$ & 471 & $\begin{array}{l}1.44 \\
(2.7\end{array}$ & 70 & $(3.9$ & 27 & $(1.4)$ & $\begin{array}{l}1.0 \\
8.0\end{array}$ & $\begin{array}{l}(0.4) \\
(0.7)\end{array}$ & 23 & (1.3) \\
\hline Dominican Republic & 325 & $(4.0)$ & 343 & $(3.7)$ & 339 & (3.0) & 342 & (3.7) & 17 & $(4.1)$ & 7 & $(1.4)$ & 0.7 & $(0.3)$ & 5 & $(1.3)$ \\
\hline FYROM & $\mathrm{m}$ & $\mathrm{m}$ & $\mathrm{m}$ & $\mathrm{m}$ & $\mathrm{m}$ & $\mathrm{m}$ & $\mathrm{m}$ & $\mathrm{m}$ & $\mathrm{m}$ & $\mathrm{m}$ & $\mathrm{m}$ & $\mathrm{m}$ & $\mathrm{m}$ & $\mathrm{m}$ & $\mathrm{m}$ & $\mathrm{m}$ \\
\hline & $\mathrm{m}$ & $\mathrm{m}$ & $\mathrm{m}$ & $\mathrm{m}$ & $\mathrm{m}$ & $\mathrm{m}$ & $\mathrm{m}$ & $\mathrm{m}$ & III & III & $\mathrm{m}$ & $\mathrm{m}$ & $\mathrm{m}$ & $\mathrm{m}$ & $\mathrm{m}$ & $\mathrm{m}$ \\
\hline Hong Kong (China) & 507 & (3.5) & 514 & $(4.0)$ & 538 & (3.1) & 536 & (3.1) & 30 & (3.7) & 12 & $(1.3)$ & 1.9 & $(0.4)$ & 9 & $(1.3)$ \\
\hline Indonesia & $\mathrm{m}$ & $\mathrm{m}$ & $\mathrm{m}$ & $\mathrm{m}$ & $\mathrm{m}$ & $\mathrm{m}$ & $\mathrm{m}$ & $\mathrm{m}$ & $\mathrm{m}$ & $\mathrm{m}$ & $\mathrm{m}$ & $\mathrm{m}$ & $\mathrm{m}$ & $\mathrm{m}$ & $\mathrm{m}$ & $\mathrm{m}$ \\
\hline Jordan & $\mathrm{m}$ & & $\mathrm{m}$ & $\mathrm{m}$ & $\mathrm{m}$ & $\mathrm{m}$ & $\mathrm{m}$ & $\mathrm{m}$ & $\mathrm{m}$ & $\mathrm{m}$ & $\mathrm{m}$ & $\mathrm{m}$ & $\mathrm{m}$ & $\mathrm{m}$ & $\mathrm{m}$ & $\mathrm{m}$ \\
\hline Kosovo & $\mathrm{m}$ & $\mathrm{m}$ & $\mathrm{m}$ & $\mathrm{m}$ & $\mathrm{m}$ & $\mathrm{m}$ & $\mathrm{m}$ & $\mathrm{m}$ & $\mathrm{m}$ & $\mathrm{m}$ & $\mathrm{m}$ & $\mathrm{m}$ & $\mathrm{m}$ & $\mathrm{m}$ & $\mathrm{m}$ & $\mathrm{m}$ \\
\hline Lebanon & $\mathrm{m}$ & $\mathrm{m}$ & $\mathrm{m}$ & $\mathrm{m}$ & $\mathrm{m}$ & $\mathrm{m}$ & $\mathrm{m}$ & $\mathrm{m}$ & $\mathrm{m}$ & $\mathrm{m}$ & $\mathrm{m}$ & $\mathrm{m}$ & $\mathrm{m}$ & $\mathrm{m}$ & $\mathrm{m}$ & $\mathrm{m}$ \\
\hline Lithuania & 445 & (3.4) & 465 & $(3.8)$ & 495 & (3.6) & 506 & $(3.2)$ & 62 & $(3.7)$ & 22 & $(1.2)$ & 6.8 & $(0.7)$ & 15 & $(1.3)$ \\
\hline Macao (China) & 519 & (2.4) & 525 & (2.6) & 529 & (2.8) & 541 & $(2.7)$ & 22 & (3.7) & 11 & (1.7) & 1.2 & $(0.4)$ & 9 & $(1.7)$ \\
\hline Malta & $\mathrm{m}$ & $\mathrm{m}$ & $\mathrm{m}$ & $\mathrm{m}$ & $\mathrm{m}$ & $\mathrm{m}$ & $\mathrm{m}$ & $\mathrm{m}$ & $\mathrm{m}$ & $m$ & $\mathrm{~m}$ & $\mathrm{~m}$ & $\mathrm{~m}$ & $\mathrm{~m}$ & $\mathrm{~m}$ & $\mathrm{~m}$ \\
\hline Moldova & $\mathrm{m}$ & $\mathrm{m}$ & $\mathrm{m}$ & $\mathrm{m}$ & $\mathrm{m}$ & $\mathrm{m}$ & $\mathrm{m}$ & $\mathrm{m}$ & $\mathrm{m}$ & $\mathrm{n}$ & $\mathrm{m}$ & $\mathrm{m}$ & $\mathrm{m}$ & $\mathrm{m}$ & $\mathrm{m}$ & $\mathrm{m}$ \\
\hline Montenegro & 402 & $(2.9)$ & 413 & (10.1) & 411 & (18.9) & 436 & $(2.8)$ & 33 & $(4.8)$ & 14 & $(1.5)$ & 2.4 & $(0.5)$ & 13 & $(1.3)$ \\
\hline Peru & 377 & (2.9) & 397 & $(2.8)$ & 407 & (3.6) & 415 & (5.3) & 37 & $(5.2)$ & 19 & (1.7) & 4.0 & $(0.7)$ & 13 & (1.4) \\
\hline Qa & 391 & (1.9) & 439 & $(1.9)$ & 432 & (1.4) & $\mathrm{m}$ & $m$ & $\mathrm{~m}$ & $m$ & 15 & $(0.8)$ & 2.5 & $(0.3)$ & 12 & $(0.8)$ \\
\hline Romania & $\mathrm{m}$ & & $\mathrm{m}$ & & $\mathrm{m}$ & & $\mathrm{m}$ & $\mathrm{m}$ & $\mathrm{m}$ & . & $\mathrm{m}$ & $\mathrm{m}$ & $\mathrm{m}$ & $\mathrm{m}$ & $\mathrm{m}$ & $\mathrm{m}$ \\
\hline Russia & 479 & $(3.7)$ & 477 & (3.5) & 500 & $(4.3)$ & 509 & (3.5) & 30 & $(3.3$ & 14 & $(1.3)$ & 2.3 & $(0.4)$ & 10 & (1.3) \\
\hline Singapo & 554 & $(2.6)$ & 546 & (3.1) & 563 & $(2.7)$ & 561 & $(2.8)$ & 6 & (3. & 6 & $(1.5)$ & 0.3 & $(0.1)$ & 3 & (1.4) \\
\hline Chinese Taipei & 499 & (3.1) & 515 & (3.4) & 555 & (3.7) & 568 & (3.4) & 69 & $(3$. & 31 & (1.5) & 7.5 & $(0.6)$ & 20 & (1.3) \\
\hline Thailand & 412 & $(4.8)$ & 406 & $(9.4)$ & 435 & $(4.7)$ & 437 & $(5.0)$ & 25 & (6.0) & 15 & (1.5) & 2.0 & $(0.4)$ & 13 & (1.6) \\
\hline Trinidad and Tobago & 1.2 & & $\mathrm{~m}$ & & $\mathrm{~m}$ & & $\mathrm{~m}$ & (1). & $\mathrm{m}$ & (10.0) & $\mathrm{m}$ & (1..) & $\mathrm{m}$ & (10.1) & $\mathrm{m}$ & (1...) \\
\hline Tunisia & 370 & $(3.1)$ & 391 & $(3.5)$ & 395 & $(2.5)$ & 397 & $(2.8)$ & 27 & $(3.7)$ & 11 & $(1.5)$ & 2.3 & $(0.6)$ & 10 & $(1.4)$ \\
\hline United Arab Emirates & 415 & (7.0) & 444 & $(5.4)$ & 451 & $(2.9)$ & $\mathrm{m}$ & $\mathrm{m}$ & $\mathrm{m}$ & $\mathrm{m}$ & 16 & $(1.2)$ & 2.6 & $(0.4)$ & 15 & $(1.2)$ \\
\hline Uruguay & 431 & $(2.8)$ & 429 & $\begin{array}{l}(3.4) \\
(3.0)\end{array}$ & 447 & $(2.8)$ & 455 & (3.5) & 23 & $(3.7)$ & 13 & $(1.7)$ & $\begin{array}{l}1.0 \\
1.8\end{array}$ & $(0.4)$ & 8 & (1.3) \\
\hline Viet Nam & $\mathrm{m}$ & $\mathrm{m}$ & $\mathrm{m}$ & $\mathrm{m}$ & $\mathrm{m}$ & $\mathrm{m}$ & $\mathrm{m}$ & $\mathrm{m}$ & $\mathrm{m}$ & $\mathrm{m}$ & $\mathrm{m}$ & $\mathrm{m}$ & $\mathrm{m}$ & $\mathrm{m}$ & $\mathrm{m}$ & $\mathrm{m}$ \\
\hline Argent & $\mathrm{m}$ & $\mathrm{m}$ & $\mathrm{m}$ & $\mathrm{m}$ & $\mathrm{m}$ & $\mathrm{m}$ & $\mathrm{m}$ & $\mathrm{m}$ & $\mathrm{m}$ & $\mathrm{m}$ & $\mathrm{m}$ & $\mathrm{m}$ & $\mathrm{m}$ & $\mathrm{m}$ & $\mathrm{m}$ & $\mathrm{m}$ \\
\hline Kazakhstan** & $\mathrm{m}$ & $\mathrm{m}$ & $\mathrm{m}$ & m & $\mathrm{m}$ & & $\mathrm{m}$ & $\mathrm{m}$ & $\mathrm{m}$ & $\mathrm{m}$ & $\mathrm{m}$ & $\mathrm{m}$ & $\mathrm{m}$ & $\mathrm{m}$ & $\mathrm{m}$ & $\mathrm{m}$ \\
\hline Malaysia** & 419 & (5.5) & 441 & (3.5) & 457 & $(2.9)$ & $\mathrm{m}$ & $\mathrm{m}$ & $\mathrm{m}$ & $\mathrm{m}$ & 16 & $(2.1)$ & 3.7 & $(1.0)$ & 15 & $(1.8)$ \\
\hline
\end{tabular}

1. The socio-economic profile is measured by the PISA index of economic, social and cultural status (ESCS).

Note: Values that are statistically significant are indicated in bold (see Annex A3).

* See note at the beginning of this Annex.

** Coverage is too small to ensure comparability (see Annex A4).

StatLink त्नाता http://dx.doi.org/10.1787/888933470937 
[Part 1/2]

Table III.5.6 Students' motivation to achieve and life satisfaction

Results based on students' self-reports

\begin{tabular}{|c|c|c|c|c|c|c|c|c|c|c|c|}
\hline & \multicolumn{6}{|c|}{ Average life satisfaction, by: } & \multicolumn{4}{|c|}{$\begin{array}{l}\text { Life satisfaction, by national quarters } \\
\text { of the index of achievement motivation }\end{array}$} \\
\hline & & \multicolumn{2}{|c|}{$\begin{array}{l}\text { Students who do not want top } \\
\text { grades in most or all courses }\end{array}$} & \multicolumn{2}{|c|}{$\begin{array}{l}\text { Students who want top grades } \\
\text { in most or all courses }\end{array}$} & $\begin{array}{r}\text { Difference } \\
\text { who do an } \\
\text { want to } \\
\text { or }\end{array}$ & $\begin{array}{l}\text { en students } \\
\text { who do not } \\
\text { s in most } \\
\text { sses }\end{array}$ & Bot & uarter & Seco & uarter \\
\hline & & Mean & S.E. & Mean & S.E. & Dif. & S.E. & Mean & S.E. & Mean & S.E. \\
\hline 0 & Australia & $\mathrm{m}$ & $\mathrm{m}$ & $\mathrm{m}$ & $\mathrm{m}$ & $\mathrm{m}$ & $\mathrm{m}$ & $\mathrm{m}$ & $\mathrm{m}$ & $\mathrm{m}$ & $\mathrm{m}$ \\
\hline U & Austria & 7.17 & $(0.07)$ & 7.62 & $(0.04)$ & 0.45 & $(0.08)$ & 7.10 & $(0.07)$ & 7.53 & $(0.06)$ \\
\hline ठ & Belgium (excl. Flemish) & 6.93 & $(0.13)$ & 7.57 & $(0.05)$ & 0.64 & $(0.14)$ & 7.08 & $(0.08)$ & 7.55 & $(0.07)$ \\
\hline & Canada & $\mathrm{m}$ & $\mathrm{m}$ & $\mathrm{m}$ & $\mathrm{m}$ & $\mathrm{m}$ & $\mathrm{m}$ & $\mathrm{m}$ & $\mathrm{m}$ & $\mathrm{m}$ & $\mathrm{m}$ \\
\hline & Chile & 6.84 & $(0.12)$ & 7.41 & $(0.04)$ & 0.57 & $(0.12)$ & 6.97 & $(0.08)$ & 7.34 & $(0.07)$ \\
\hline & Czech Republic & 6.52 & $(0.10)$ & 7.18 & $(0.03)$ & 0.66 & $(0.09)$ & 6.58 & $(0.08)$ & 7.05 & $(0.07)$ \\
\hline & Denmark & $\mathrm{m}$ & $\mathrm{m}$ & $\mathrm{m}$ & $\mathrm{m}$ & $\mathrm{m}$ & $\mathrm{m}$ & $\mathrm{m}$ & $\mathrm{m}$ & $\mathrm{m}$ & $\mathrm{m}$ \\
\hline & Estonia & 7.10 & $(0.12)$ & 7.54 & $(0.04)$ & 0.44 & $(0.13)$ & 7.18 & $(0.07)$ & 7.43 & $(0.06)$ \\
\hline & Finland & 7.59 & $(0.04)$ & 8.08 & $(0.03)$ & 0.49 & $(0.05)$ & 7.56 & $(0.05)$ & 7.81 & $(0.05)$ \\
\hline & France & 7.20 & $(0.06)$ & 7.71 & $(0.03)$ & 0.51 & $(0.07)$ & 7.32 & $(0.04)$ & 7.63 & $(0.06)$ \\
\hline & Germany & 6.92 & $(0.06)$ & 7.49 & $(0.04)$ & 0.57 & $(0.07)$ & 6.92 & $(0.06)$ & 7.22 & $(0.06)$ \\
\hline & Greece & 6.53 & $(0.07)$ & 7.06 & $(0.04)$ & 0.53 & $(0.08)$ & 6.51 & $(0.08)$ & 6.75 & $(0.08)$ \\
\hline & Hungary & 6.54 & $(0.08)$ & 7.37 & $(0.04)$ & 0.83 & $(0.09)$ & 6.58 & $(0.08)$ & 7.09 & $(0.07)$ \\
\hline & Iceland & 7.45 & $(0.25)$ & 7.81 & $(0.04)$ & 0.36 & $(0.25)$ & 7.20 & $(0.09)$ & 7.73 & $(0.08)$ \\
\hline & Ireland & 6.72 & $(0.11)$ & 7.35 & $(0.03)$ & 0.62 & $(0.12)$ & 6.88 & $(0.06)$ & 7.37 & $(0.06)$ \\
\hline & Israel & $\mathrm{m}$ & m & $\mathrm{m}$ & $\mathrm{m}$ & $\mathrm{m}$ & $\mathrm{m}$ & $\mathrm{m}$ & $\mathrm{m}$ & $\mathrm{m}$ & $\mathrm{m}$ \\
\hline & Italy & 6.54 & $(0.08)$ & 6.94 & $(0.04)$ & 0.40 & $(0.08)$ & 6.43 & $(0.08)$ & 6.86 & $(0.06)$ \\
\hline & Japan & 6.60 & $(0.06)$ & 6.90 & $(0.04)$ & 0.30 & $(0.06)$ & 6.34 & $(0.07)$ & 6.85 & $(0.06)$ \\
\hline & Korea & 6.27 & $(0.09)$ & 6.38 & $(0.04)$ & 0.11 & $(0.09)$ & 6.18 & $(0.06)$ & 6.37 & $(0.07)$ \\
\hline & Latvia & 7.06 & $(0.10)$ & 7.41 & $(0.04)$ & 0.35 & $(0.11)$ & 7.01 & $(0.07)$ & 7.35 & $(0.07)$ \\
\hline & Luxembourg & 6.90 & $(0.08)$ & 7.48 & $(0.04)$ & 0.59 & $(0.08)$ & 6.98 & $(0.07)$ & 7.41 & $(0.06)$ \\
\hline & Mexico & 7.43 & $(0.22)$ & 8.30 & $(0.03)$ & 0.88 & $(0.22)$ & 7.98 & $(0.06)$ & 8.18 & $(0.06)$ \\
\hline & Netherlands & 7.57 & $(0.08)$ & 7.85 & $(0.03)$ & 0.28 & $(0.09)$ & 7.63 & $(0.05)$ & 7.81 & $(0.04)$ \\
\hline & New Zealand & $\mathrm{m}$ & $\mathrm{m}$ & $\mathrm{m}$ & $\mathrm{m}$ & $\mathrm{m}$ & $\mathrm{m}$ & $\mathrm{m}$ & $\mathrm{m}$ & $\mathrm{m}$ & $\mathrm{m}$ \\
\hline & Norway & $\mathrm{m}$ & $\mathrm{m}$ & $\mathrm{m}$ & $\mathrm{m}$ & $\mathrm{m}$ & $\mathrm{m}$ & $\mathrm{m}$ & $\mathrm{m}$ & $\mathrm{m}$ & $\mathrm{m}$ \\
\hline & Poland & 7.01 & $(0.06)$ & 7.28 & $(0.05)$ & 0.27 & $(0.07)$ & 6.69 & $(0.07)$ & 7.13 & $(0.08)$ \\
\hline & Portugal & 6.72 & $(0.15)$ & 7.39 & $(0.03)$ & 0.67 & $(0.16)$ & 6.99 & $(0.06)$ & 7.35 & $(0.06)$ \\
\hline & Slovak Republic & 7.22 & $(0.07)$ & 7.56 & $(0.04)$ & 0.34 & $(0.07)$ & 7.14 & $(0.07)$ & 7.46 & $(0.08)$ \\
\hline & Slovenia & 6.90 & $(0.06)$ & 7.29 & $(0.04)$ & 0.39 & $(0.07)$ & 6.86 & $(0.07)$ & 7.08 & $(0.08)$ \\
\hline & Spain & 6.88 & $(0.07)$ & 7.58 & $(0.03)$ & 0.70 & $(0.07)$ & 6.88 & $(0.06)$ & 7.32 & $(0.07)$ \\
\hline & Sweden & $\mathrm{m}$ & m & $\mathrm{m}$ & $\mathrm{m}$ & $\mathrm{m}$ & $\mathrm{m}$ & m & $\mathrm{m}$ & $\mathrm{m}$ & $\mathrm{m}$ \\
\hline & Switzerland & 7.49 & $(0.06)$ & 7.78 & $(0.04)$ & 0.29 & $(0.07)$ & 7.52 & $(0.06)$ & 7.56 & $(0.06)$ \\
\hline & Turkey & 5.91 & $(0.16)$ & 6.14 & $(0.06)$ & 0.23 & $(0.17)$ & 5.89 & $(0.10)$ & 6.01 & $(0.09)$ \\
\hline & United Kingdom & 6.37 & $(0.15)$ & 7.01 & $(0.04)$ & 0.63 & $(0.15)$ & 6.52 & $(0.07)$ & 6.92 & $(0.06)$ \\
\hline & United States & 6.62 & $(0.14)$ & 7.40 & $(0.03)$ & 0.78 & $(0.14)$ & 6.96 & $(0.07)$ & 7.24 & $(0.07)$ \\
\hline & OECD average & 6.89 & $(0.02)$ & 7.39 & $(0.01)$ & 0.49 & $(0.02)$ & 6.92 & $(0.01)$ & 7.26 & $(0.01)$ \\
\hline 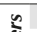 & Albania & $\mathrm{m}$ & $\mathrm{m}$ & $\mathrm{m}$ & $\mathrm{m}$ & $\mathrm{m}$ & $\mathrm{m}$ & $\mathrm{m}$ & $\mathrm{m}$ & $\mathrm{m}$ & $\mathrm{m}$ \\
\hline$\Xi$ & Algeria & $\mathrm{m}$ & $\mathrm{m}$ & $\mathrm{m}$ & $\mathrm{m}$ & $\mathrm{m}$ & $\mathrm{m}$ & $\mathrm{m}$ & $\mathrm{m}$ & $\mathrm{m}$ & $\mathrm{m}$ \\
\hline ฐั้ & Brazil & 7.02 & $(0.14)$ & 7.62 & $(0.03)$ & 0.60 & $(0.14)$ & 7.42 & $(0.05)$ & 7.63 & $(0.04)$ \\
\hline 0 & B-S-J-G (China) & 6.67 & $(0.07)$ & 6.90 & $(0.04)$ & 0.23 & $(0.07)$ & 6.61 & $(0.07)$ & 6.81 & $(0.07)$ \\
\hline & Bulgaria & 7.15 & $(0.08)$ & 7.50 & $(0.04)$ & 0.35 & $(0.09)$ & 7.03 & $(0.08)$ & 7.40 & $(0.08)$ \\
\hline & CABA (Argentina) & $\mathrm{m}$ & $\mathrm{m}$ & $\mathrm{m}$ & $\mathrm{m}$ & $\mathrm{m}$ & $\mathrm{m}$ & $\mathrm{m}$ & $\mathrm{m}$ & $\mathrm{m}$ & $\mathrm{m}$ \\
\hline & Colombia & 7.21 & $(0.20)$ & 7.91 & $(0.04)$ & 0.70 & $(0.20)$ & 7.64 & $(0.07)$ & 7.72 & $(0.06)$ \\
\hline & Costa Rica & 7.48 & $(0.24)$ & 8.22 & $(0.03)$ & 0.74 & $(0.24)$ & 7.84 & $(0.07)$ & 8.19 & $(0.06)$ \\
\hline & Croatia & 7.74 & $(0.06)$ & 7.98 & $(0.04)$ & 0.24 & $(0.06)$ & 7.68 & $(0.07)$ & 7.94 & $(0.06)$ \\
\hline & Cyprus* & 6.62 & $(0.08)$ & 7.16 & $(0.03)$ & 0.54 & $(0.09)$ & 6.54 & $(0.07)$ & 7.00 & $(0.06)$ \\
\hline & Dominican Republic & 8.38 & $(0.12)$ & 8.53 & $(0.04)$ & 0.15 & $(0.13)$ & 8.32 & $(0.09)$ & 8.33 & $(0.09)$ \\
\hline & FYROM & $\mathrm{m}$ & $\mathrm{m}$ & $\mathrm{m}$ & $\mathrm{m}$ & $\mathrm{m}$ & $\mathrm{m}$ & $\mathrm{m}$ & $\mathrm{m}$ & $\mathrm{m}$ & $\mathrm{m}$ \\
\hline & Georgia & $\mathrm{m}$ & $\mathrm{m}$ & $\mathrm{m}$ & $\mathrm{m}$ & $\mathrm{m}$ & $\mathrm{m}$ & $\mathrm{m}$ & $\mathrm{m}$ & $\mathrm{m}$ & $\mathrm{m}$ \\
\hline & Hong Kong (China) & 6.08 & $(0.11)$ & 6.53 & $(0.04)$ & 0.44 & $(0.10)$ & 6.18 & $(0.07)$ & 6.63 & $(0.07)$ \\
\hline & Indonesia & $\mathrm{m}$ & $\mathrm{m}$ & $\mathrm{m}$ & $\mathrm{m}$ & $\mathrm{m}$ & $\mathrm{m}$ & $\mathrm{m}$ & $\mathrm{m}$ & $\mathrm{m}$ & $\mathrm{m}$ \\
\hline & Jordan & $\mathrm{m}$ & $\mathrm{m}$ & $\mathrm{m}$ & $\mathrm{m}$ & $\mathrm{m}$ & $\mathrm{m}$ & $\mathrm{m}$ & $\mathrm{m}$ & $\mathrm{m}$ & $\mathrm{m}$ \\
\hline & Kosovo & $\mathrm{m}$ & $\mathrm{m}$ & $\mathrm{m}$ & $\mathrm{m}$ & $\mathrm{m}$ & $\mathrm{m}$ & $\mathrm{m}$ & $\mathrm{m}$ & $\mathrm{m}$ & $\mathrm{m}$ \\
\hline & Lebanon & $\mathrm{m}$ & $\mathrm{m}$ & $\mathrm{m}$ & $\mathrm{m}$ & $\mathrm{m}$ & $\mathrm{m}$ & $\mathrm{m}$ & $\mathrm{m}$ & $\mathrm{m}$ & $\mathrm{m}$ \\
\hline & Lithuania & 7.62 & $(0.08)$ & 7.91 & $(0.03)$ & 0.29 & $(0.08)$ & 7.62 & $(0.07)$ & 7.83 & $(0.06)$ \\
\hline & Macao (China) & 6.53 & $(0.04)$ & 6.66 & $(0.04)$ & 0.13 & $(0.06)$ & 6.49 & $(0.07)$ & 6.60 & $(0.07)$ \\
\hline & Malta & $\mathrm{m}$ & $\mathrm{m}$ & $\mathrm{m}$ & $\mathrm{m}$ & $\mathrm{m}$ & $\mathrm{m}$ & $\mathrm{m}$ & $\mathrm{m}$ & $\mathrm{m}$ & $\mathrm{m}$ \\
\hline & Moldova & $\mathrm{m}$ & $\mathrm{m}$ & $\mathrm{m}$ & $\mathrm{m}$ & $\mathrm{m}$ & $\mathrm{m}$ & $\mathrm{m}$ & $\mathrm{m}$ & $\mathrm{m}$ & $\mathrm{m}$ \\
\hline & Montenegro & 7.47 & $(0.07)$ & 7.85 & $(0.04)$ & 0.38 & $(0.08)$ & 7.50 & $(0.06)$ & 7.62 & $(0.06)$ \\
\hline & Peru & 6.80 & $(0.20)$ & 7.53 & $(0.04)$ & 0.74 & $(0.19)$ & 7.28 & $(0.07)$ & 7.33 & $(0.07)$ \\
\hline & Qatar & 6.95 & $(0.12)$ & 7.43 & $(0.02)$ & 0.48 & $(0.12)$ & 7.01 & $(0.05)$ & 7.19 & $(0.05)$ \\
\hline & Romania & $\mathrm{m}$ & $\mathrm{m}$ & $\mathrm{m}$ & $\mathrm{m}$ & $\mathrm{m}$ & $\mathrm{m}$ & $\mathrm{m}$ & $\mathrm{m}$ & $\mathrm{m}$ & $\mathrm{m}$ \\
\hline & Russia & 7.48 & $(0.08)$ & 7.83 & $(0.05)$ & 0.35 & $(0.10)$ & 7.54 & $(0.07)$ & 7.67 & $(0.08)$ \\
\hline & Singapore & $\mathrm{m}$ & $\mathrm{m}$ & $\mathrm{m}$ & $\mathrm{m}$ & $\mathrm{m}$ & $\mathrm{m}$ & $\mathrm{m}$ & $\mathrm{m}$ & $\mathrm{m}$ & $\mathrm{m}$ \\
\hline & Chinese Taipei & 6.28 & $(0.07)$ & 6.67 & $(0.03)$ & 0.39 & $(0.07)$ & 6.29 & $(0.06)$ & 6.60 & $(0.05)$ \\
\hline & Thailand & 7.40 & $(0.10)$ & 7.74 & $(0.03)$ & 0.34 & $(0.10)$ & 7.50 & $(0.06)$ & 7.74 & $(0.06)$ \\
\hline & Trinidad and Tobago & $\mathrm{m}$ & $\mathrm{m}$ & $\mathrm{m}$ & $\mathrm{m}$ & $\mathrm{m}$ & $\mathrm{m}$ & $\mathrm{m}$ & $\mathrm{m}$ & $\mathrm{m}$ & $\mathrm{m}$ \\
\hline & Tunisia & 5.99 & $(0.24)$ & 6.94 & $(0.05)$ & 0.95 & $(0.24)$ & 6.63 & $(0.09)$ & 6.92 & $(0.08)$ \\
\hline & United Arab Emirates & 6.35 & $(0.14)$ & 7.36 & $(0.03)$ & 1.01 & $(0.14)$ & 6.77 & $(0.06)$ & 7.18 & $(0.06)$ \\
\hline & Uruguay & 7.07 & $(0.09)$ & 7.78 & $(0.03)$ & 0.71 & $(0.10)$ & 7.25 & $(0.07)$ & 7.69 & $(0.05)$ \\
\hline & Viet Nam & $\mathrm{m}$ & $\mathrm{m}$ & $\mathrm{m}$ & $\mathrm{m}$ & $\mathrm{m}$ & $\mathrm{m}$ & $\mathrm{m}$ & $\mathrm{m}$ & $\mathrm{m}$ & $\mathrm{m}$ \\
\hline & Argentina** $^{* *}$ & $\mathrm{~m}$ & $\mathrm{~m}$ & $\mathrm{~m}$ & $\mathrm{~m}$ & $\mathrm{~m}$ & $\mathrm{~m}$ & $\mathrm{~m}$ & $\mathrm{~m}$ & $\mathrm{~m}$ & $\mathrm{~m}$ \\
\hline & Kazakhstan** & $\mathrm{m}$ & $\mathrm{m}$ & $\mathrm{m}$ & $\mathrm{m}$ & $\mathrm{m}$ & $\mathrm{m}$ & $\mathrm{m}$ & $\mathrm{m}$ & $\mathrm{m}$ & $\mathrm{m}$ \\
\hline & Malaysia** & 6.33 & $(0.15)$ & 7.11 & $(0.04)$ & 0.78 & $(0.15)$ & 6.74 & $(0.07)$ & 6.99 & $(0.06)$ \\
\hline
\end{tabular}

Note: Values that are statistically significant are indicated in bold (see Annex A3).

* See note at the beginning of this Annex.

** Coverage is too small to ensure comparability (see Annex A4).

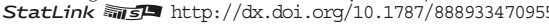


[Part 2/2]

Table III.5.6 Students' motivation to achieve and life satisfaction

Results based on students' self-reports

\begin{tabular}{|c|c|c|c|c|c|c|c|c|c|c|c|}
\hline & \multicolumn{6}{|c|}{$\begin{array}{l}\text { Life satisfaction, by national quarters } \\
\text { of the index of achievement motivation }\end{array}$} & \multicolumn{4}{|c|}{$\begin{array}{l}\text { Change in the index of achievement motivation } \\
\text { associated with a one-unit change in life satisfaction }\end{array}$} \\
\hline & & \multicolumn{2}{|c|}{ Third quarter } & \multicolumn{2}{|c|}{ Top quarter } & Top - $\mathrm{t}$ & quarter & $\begin{array}{r}\text { Before ac } \\
\text { for students' s } \\
\text { sta }\end{array}$ & $\begin{array}{l}\text { Inting } \\
\text {-economic }\end{array}$ & $\begin{array}{r}\text { After ac } \\
\text { for students' s } \\
\text { sta }\end{array}$ & nting \\
\hline & & Mean & S.E. & Mean & S.E. & Dif. & S.E. & Mean change & S.E. & Mean change & S.E. \\
\hline 0 & Australia & $\mathrm{m}$ & $\mathrm{m}$ & $\mathrm{m}$ & $\mathrm{m}$ & $\mathrm{m}$ & $\mathrm{m}$ & $\mathrm{m}$ & $\mathrm{m}$ & $\mathrm{m}$ & $\mathrm{m}$ \\
\hline 4 & Austria & 7.62 & $(0.07)$ & 7.84 & $(0.07)$ & 0.73 & $(0.09)$ & 0.25 & $(0.04)$ & 0.24 & $(0.04)$ \\
\hline ప & Belgium (excl. Flemish) & 7.55 & $(0.09)$ & 7.76 & (0.09) & 0.68 & $(0.11)$ & 0.28 & $(0.05)$ & 0.28 & $(0.05)$ \\
\hline & Canada & $\mathrm{m}$ & m & $\mathrm{m}$ & m & $\mathrm{m}$ & $\mathrm{m}$ & $\mathrm{m}$ & $\mathrm{m}$ & $\mathrm{m}$ & $\mathrm{m}$ \\
\hline & Chile & 7.51 & $(0.06)$ & 7.63 & $(0.07)$ & 0.66 & $(0.09)$ & 0.25 & $(0.03)$ & 0.23 & $(0.03)$ \\
\hline & Czech Republic & 7.25 & $(0.05)$ & 7.35 & $(0.07)$ & 0.77 & (0.09) & 0.38 & $(0.04)$ & 0.34 & $(0.04)$ \\
\hline & Denmark & m & $\mathrm{m}$ & $\mathrm{m}$ & m & $\mathrm{m}$ & $\mathrm{m}$ & $\mathrm{m}$ & $\mathrm{m}$ & $\mathrm{m}$ & $\mathrm{m}$ \\
\hline & Estonia & 7.62 & $(0.07)$ & 7.78 & $(0.06)$ & 0.60 & $(0.10)$ & 0.28 & $(0.04)$ & 0.22 & $(0.04)$ \\
\hline & Finland & 8.08 & $(0.04)$ & 8.11 & $(0.05)$ & 0.56 & $(0.07)$ & 0.23 & $(0.03)$ & 0.20 & $(0.03)$ \\
\hline & France & 7.67 & $(0.05)$ & 7.93 & $(0.06)$ & 0.61 & $(0.08)$ & 0.26 & $(0.03)$ & 0.23 & $(0.03)$ \\
\hline & Germany & 7.60 & $(0.06)$ & 7.67 & $(0.07)$ & 0.74 & $(0.09)$ & 0.36 & $(0.04)$ & 0.34 & $(0.04)$ \\
\hline & Greece & 7.07 & $(0.07)$ & 7.33 & $(0.07)$ & 0.82 & $(0.10)$ & 0.42 & $(0.04)$ & 0.39 & $(0.04)$ \\
\hline & Hungary & 7.36 & $(0.07)$ & 7.65 & $(0.06)$ & 1.07 & $(0.09)$ & 0.45 & $(0.04)$ & 0.42 & $(0.04)$ \\
\hline & Iceland & 7.97 & $(0.09)$ & 8.26 & $(0.07)$ & 1.05 & $(0.11)$ & 0.39 & $(0.04)$ & 0.34 & $(0.04)$ \\
\hline & Ireland & 7.39 & $(0.08)$ & 7.58 & $(0.06)$ & 0.69 & $(0.09)$ & 0.28 & $(0.03)$ & 0.27 & $(0.03)$ \\
\hline & Israel & $\mathrm{m}$ & $\mathrm{m}$ & $\mathrm{m}$ & $\mathrm{m}$ & $\mathrm{m}$ & $\mathrm{m}$ & $\mathrm{m}$ & $\mathrm{m}$ & $\mathrm{m}$ & $\mathrm{m}$ \\
\hline & Italy & 6.97 & $(0.06)$ & 7.32 & $(0.08)$ & 0.89 & $(0.09)$ & 0.37 & $(0.04)$ & 0.36 & $(0.04)$ \\
\hline & Japan & 6.95 & $(0.06)$ & 7.08 & $(0.07)$ & 0.74 & $(0.09)$ & 0.26 & $(0.03)$ & 0.24 & $(0.03)$ \\
\hline & Korea & 6.21 & $(0.09)$ & 6.70 & $(0.09)$ & 0.52 & $(0.11)$ & 0.16 & $(0.03)$ & 0.12 & $(0.03)$ \\
\hline & Latvia & 7.55 & $(0.07)$ & 7.58 & (0.05) & 0.58 & (0.09) & 0.23 & $(0.04)$ & 0.20 & $(0.04)$ \\
\hline & Luxembourg & 7.47 & $(0.06)$ & 7.65 & $(0.06)$ & 0.67 & $(0.09)$ & 0.24 & $(0.03)$ & 0.22 & $(0.03)$ \\
\hline & Mexico & 8.43 & $(0.06)$ & 8.49 & $(0.05)$ & 0.51 & $(0.08)$ & 0.24 & $(0.04)$ & 0.24 & $(0.04)$ \\
\hline & Netherlands & 7.91 & $(0.05)$ & 7.95 & $(0.05)$ & 0.32 & $(0.06)$ & 0.18 & $(0.03)$ & 0.18 & $(0.03)$ \\
\hline & New Zealand & $\mathrm{m}$ & $\mathrm{m}$ & $\mathrm{m}$ & $\mathrm{m}$ & $\mathrm{m}$ & $\mathrm{m}$ & $\mathrm{m}$ & $\mathrm{m}$ & $\mathrm{m}$ & $\mathrm{m}$ \\
\hline & Norway & $\mathrm{m}$ & $\mathrm{m}$ & $\mathrm{m}$ & $\mathrm{m}$ & $\mathrm{m}$ & $\mathrm{m}$ & $\mathrm{m}$ & $\mathrm{m}$ & $\mathrm{m}$ & $\mathrm{m}$ \\
\hline & Poland & 7.48 & $(0.07)$ & 7.43 & $(0.07)$ & 0.74 & $(0.10)$ & 0.30 & $(0.04)$ & 0.27 & $(0.04)$ \\
\hline & Portugal & 7.48 & $(0.06)$ & 7.65 & $(0.06)$ & 0.65 & $(0.08)$ & 0.27 & $(0.03)$ & 0.26 & $(0.03)$ \\
\hline & Slovak Republic & 7.57 & $(0.07)$ & 7.73 & $(0.06)$ & 0.59 & $(0.08)$ & 0.25 & $(0.04)$ & 0.21 & $(0.04)$ \\
\hline & Slovenia & 7.27 & $(0.07)$ & 7.49 & $(0.07)$ & 0.63 & (0.09) & 0.29 & $(0.04)$ & 0.30 & $(0.04)$ \\
\hline & Spain & 7.61 & $(0.05)$ & 7.89 & $(0.05)$ & 1.00 & $(0.09)$ & 0.40 & $(0.03)$ & 0.36 & $(0.03)$ \\
\hline & Sweden & $\mathrm{m}$ & $\mathrm{m}$ & $\mathrm{m}$ & m & $\mathrm{m}$ & $\mathrm{m}$ & $\mathrm{m}$ & $\mathrm{m}$ & $\mathrm{m}$ & $\mathrm{m}$ \\
\hline & Switzerland & 7.81 & $(0.05)$ & 7.99 & $(0.06)$ & 0.48 & $(0.08)$ & 0.21 & $(0.04)$ & 0.21 & $(0.04)$ \\
\hline & Turkey & 6.14 & $(0.10)$ & 6.46 & $(0.10)$ & 0.56 & $(0.13)$ & 0.17 & $(0.05)$ & 0.16 & $(0.05)$ \\
\hline & United Kingdom & 7.15 & $(0.06)$ & 7.37 & $(0.07)$ & 0.85 & $(0.10)$ & 0.34 & $(0.04)$ & 0.31 & $(0.04)$ \\
\hline & United States & 7.40 & $(0.07)$ & 7.82 & $(0.05)$ & 0.86 & $(0.09)$ & 0.36 & $(0.03)$ & 0.33 & $(0.03)$ \\
\hline & OECD average & 7.43 & $(0.01)$ & 7.62 & $(0.01)$ & 0.70 & $(0.02)$ & 0.29 & $(0.01)$ & 0.27 & $(0.01)$ \\
\hline$n$ & Albania & $\mathrm{m}$ & $\mathrm{m}$ & $\mathrm{m}$ & $\mathrm{m}$ & $\mathrm{m}$ & $\mathrm{m}$ & $\mathrm{m}$ & $\mathrm{m}$ & $\mathrm{m}$ & $\mathrm{m}$ \\
\hline ఏ & Algeria & $\mathrm{m}$ & $\mathrm{m}$ & $\mathrm{m}$ & $\mathrm{m}$ & $\mathrm{m}$ & $\mathrm{m}$ & $\mathrm{m}$ & $\mathrm{m}$ & $\mathrm{m}$ & $\mathrm{m}$ \\
\hline ฐั & Brazil & 7.65 & $(0.05)$ & 7.68 & $(0.04)$ & 0.26 & $(0.07)$ & 0.13 & $(0.03)$ & 0.14 & $(0.03)$ \\
\hline$a$ & B-S-J-G (China) & 6.91 & $(0.06)$ & 7.01 & $(0.07)$ & 0.40 & $(0.09)$ & 0.22 & $(0.04)$ & 0.19 & $(0.04)$ \\
\hline & Bulgaria & 7.58 & $(0.07)$ & 7.70 & $(0.09)$ & 0.66 & $(0.12)$ & 0.25 & $(0.05)$ & 0.22 & $(0.05)$ \\
\hline & CABA (Argentina) & $\mathrm{m}$ & $\mathrm{m}$ & $\mathrm{m}$ & $\mathrm{m}$ & $\mathrm{m}$ & $\mathrm{m}$ & $\mathrm{m}$ & $\mathrm{m}$ & $\mathrm{m}$ & $\mathrm{m}$ \\
\hline & Colombia & 8.11 & $(0.06)$ & 8.08 & $(0.06)$ & 0.44 & $(0.08)$ & 0.27 & $(0.04)$ & 0.28 & $(0.04)$ \\
\hline & Costa Rica & 8.27 & $(0.06)$ & 8.52 & $(0.05)$ & 0.68 & $(0.08)$ & 0.31 & $(0.03)$ & 0.32 & $(0.03)$ \\
\hline & Croatia & 7.98 & $(0.07)$ & 8.01 & $(0.08)$ & 0.34 & $(0.10)$ & 0.16 & $(0.04)$ & 0.15 & $(0.04)$ \\
\hline & Cyprus* & 7.23 & $(0.05)$ & 7.50 & $(0.06)$ & 0.97 & $(0.08)$ & 0.37 & $(0.03)$ & 0.34 & $(0.04)$ \\
\hline & Dominican Republic & 8.76 & $(0.10)$ & 8.68 & $(0.07)$ & 0.36 & $(0.11)$ & 0.17 & $(0.04)$ & 0.17 & $(0.04)$ \\
\hline & FYROM & $\mathrm{m}$ & $\mathrm{m}$ & $\mathrm{m}$ & $\mathrm{m}$ & $\mathrm{m}$ & $\mathrm{m}$ & $\mathrm{m}$ & $\mathrm{m}$ & $\mathrm{m}$ & $\mathrm{m}$ \\
\hline & Georgia & $\mathrm{m}$ & $\mathrm{m}$ & $\mathrm{m}$ & $\mathrm{m}$ & $\mathrm{m}$ & $\mathrm{m}$ & $\mathrm{m}$ & $\mathrm{m}$ & $\mathrm{m}$ & $\mathrm{m}$ \\
\hline & Hong Kong (China) & 6.69 & $(0.06)$ & 6.43 & $(0.07)$ & 0.26 & $(0.09)$ & 0.09 & $(0.03)$ & 0.06 & $(0.03)$ \\
\hline & Indonesia & $\mathrm{m}$ & $\mathrm{m}$ & $\mathrm{m}$ & $\mathrm{m}$ & $\mathrm{m}$ & $\mathrm{m}$ & $\mathrm{m}$ & $\mathrm{m}$ & $\mathrm{m}$ & $\mathrm{m}$ \\
\hline & Jordan & $\mathrm{m}$ & $\mathrm{m}$ & $\mathrm{m}$ & $\mathrm{m}$ & $\mathrm{m}$ & $\mathrm{m}$ & $\mathrm{m}$ & $\mathrm{m}$ & $\mathrm{m}$ & $\mathrm{m}$ \\
\hline & Kosovo & $\mathrm{m}$ & $\mathrm{m}$ & $\mathrm{m}$ & $\mathrm{m}$ & $\mathrm{m}$ & $\mathrm{m}$ & $\mathrm{m}$ & $\mathrm{m}$ & $\mathrm{m}$ & $\mathrm{m}$ \\
\hline & Lebanon & $\mathrm{m}$ & $\mathrm{m}$ & $\mathrm{m}$ & $\mathrm{m}$ & $\mathrm{m}$ & $\mathrm{m}$ & $\mathrm{m}$ & $\mathrm{m}$ & $\mathrm{m}$ & $\mathrm{m}$ \\
\hline & Lithuania & 7.95 & $(0.05)$ & 8.06 & $(0.06)$ & 0.44 & $(0.09)$ & 0.18 & $(0.03)$ & 0.14 & $(0.03)$ \\
\hline & Macao (China) & 6.68 & $(0.07)$ & 6.61 & $(0.07)$ & 0.12 & $(0.10)$ & 0.05 & $(0.04)$ & 0.01 & $(0.04)$ \\
\hline & Malta & $\mathrm{m}$ & $\mathrm{m}$ & $\mathrm{m}$ & $\mathrm{m}$ & $\mathrm{m}$ & $\mathrm{m}$ & $\mathrm{m}$ & $\mathrm{m}$ & $\mathrm{m}$ & $\mathrm{m}$ \\
\hline & Moldova & $\mathrm{m}$ & $\mathrm{m}$ & $\mathrm{m}$ & $\mathrm{m}$ & $\mathrm{m}$ & $\mathrm{m}$ & $\mathrm{m}$ & $\mathrm{m}$ & $\mathrm{m}$ & $\mathrm{m}$ \\
\hline & Montenegro & 7.88 & $(0.08)$ & 8.01 & $(0.06)$ & 0.52 & $(0.08)$ & 0.22 & $(0.03)$ & 0.21 & $(0.03)$ \\
\hline & Peru & 7.66 & $(0.07)$ & 7.76 & $(0.07)$ & 0.48 & (0.09) & 0.24 & $(0.04)$ & 0.25 & $(0.04)$ \\
\hline & Qatar & 7.43 & $(0.05)$ & 7.95 & $(0.04)$ & 0.94 & $(0.06)$ & 0.31 & $(0.02)$ & 0.29 & $(0.02)$ \\
\hline & Romania & $\mathrm{m}$ & $\mathrm{m}$ & $\mathrm{m}$ & $\mathrm{m}$ & $\mathrm{m}$ & $\mathrm{m}$ & $\mathrm{m}$ & $\mathrm{m}$ & $\mathrm{m}$ & $\mathrm{m}$ \\
\hline & Russia & 7.80 & $(0.08)$ & 8.03 & $(0.06)$ & 0.49 & $(0.08)$ & 0.23 & $(0.03)$ & 0.22 & $(0.04)$ \\
\hline & Singapore & $\mathrm{m}$ & $\mathrm{m}$ & $\mathrm{m}$ & $\mathrm{m}$ & $\mathrm{m}$ & $\mathrm{m}$ & $\mathrm{m}$ & $\mathrm{m}$ & $\mathrm{m}$ & $\mathrm{m}$ \\
\hline & Chinese Taipei & 6.71 & $(0.05)$ & 6.78 & $(0.06)$ & 0.49 & $(0.08)$ & 0.20 & $(0.03)$ & 0.16 & $(0.03)$ \\
\hline & Thailand & 7.72 & $(0.06)$ & 7.89 & $(0.06)$ & 0.39 & $(0.07)$ & 0.20 & $(0.04)$ & 0.20 & $(0.04)$ \\
\hline & Trinidad and Tobago & $\mathrm{m}$ & $\mathrm{m}$ & $\mathrm{m}$ & $\mathrm{m}$ & $\mathrm{m}$ & $\mathrm{m}$ & $\mathrm{m}$ & $\mathrm{m}$ & $\mathrm{m}$ & $\mathrm{m}$ \\
\hline & Tunisia & 6.87 & $(0.09)$ & 7.23 & $(0.08)$ & 0.60 & $(0.12)$ & 0.25 & $(0.05)$ & 0.24 & $(0.05)$ \\
\hline & United Arab Emirates & 7.39 & $(0.07)$ & 7.86 & $(0.06)$ & 1.09 & $(0.09)$ & 0.42 & $(0.04)$ & 0.40 & $(0.03)$ \\
\hline & Uruguay & 7.80 & $(0.05)$ & 8.08 & $(0.06)$ & 0.82 & $(0.09)$ & 0.37 & $(0.03)$ & 0.34 & $(0.03)$ \\
\hline & Viet Nam & $\mathrm{m}$ & $\mathrm{m}$ & $\mathrm{m}$ & $\mathrm{m}$ & $\mathrm{m}$ & $\mathrm{m}$ & $\mathrm{m}$ & $\mathrm{m}$ & $\mathrm{m}$ & $\mathrm{m}$ \\
\hline & Argentina** & $\mathrm{m}$ & $\mathrm{m}$ & $\mathrm{m}$ & $\mathrm{m}$ & $\mathrm{m}$ & $\mathrm{m}$ & $\mathrm{m}$ & $\mathrm{m}$ & $\mathrm{m}$ & $\mathrm{m}$ \\
\hline & Kazakhstan** & $\mathrm{m}$ & $\mathrm{m}$ & $\mathrm{m}$ & $\mathrm{m}$ & $\mathrm{m}$ & $\mathrm{m}$ & $\mathrm{m}$ & $\mathrm{m}$ & $\mathrm{m}$ & $\mathrm{m}$ \\
\hline & Malaysia** & 7.04 & $(0.06)$ & 7.49 & $(0.06)$ & 0.74 & $(0.09)$ & 0.30 & $(0.04)$ & 0.30 & $(0.04$ \\
\hline
\end{tabular}

Note: Values that are statistically significant are indicated in bold (see Annex A3).

* See note at the beginning of this Annex.

** Coverage is too small to ensure comparability (see Annex A4).

StatLink न्ना St http://dx.doi.org/10.1787/888933470955 
[Part 1/2]

Table III.5.7 Students' achievement motivation, by resilience and performance in core PISA subjects

Results based on students' self-reports

\begin{tabular}{|c|c|c|c|c|c|c|c|c|c|c|c|c|c|}
\hline & \multirow{2}{*}{\multicolumn{2}{|c|}{$\begin{array}{l}\text { Percentage of resilient } \\
\text { students }^{1} \text { in science }\end{array}$}} & \multirow{2}{*}{\multicolumn{2}{|c|}{$\begin{array}{l}\text { Percentage of resilient } \\
\text { students in mathematics }\end{array}$}} & \multirow{2}{*}{\multicolumn{2}{|c|}{$\begin{array}{l}\text { Percentage of resilient } \\
\text { students in reading }\end{array}$}} & & Average i & ex of ach & ment mc & tivation, b & \\
\hline & & & & & & & & $\begin{array}{c}\text { Non-res } \\
\text { in }\end{array}$ & $\begin{array}{l}\text { t students } \\
\text { nce }\end{array}$ & $\begin{array}{c}\text { Resilie } \\
\text { in }\end{array}$ & $\begin{array}{l}\text { udents } \\
\text { ice }\end{array}$ & $\begin{array}{r}\text { Differe } \\
\text { resilient a } \\
\text { studer }\end{array}$ & $\begin{array}{l}\text { etween } \\
\text { n-resilient } \\
\text { science }\end{array}$ \\
\hline & & $\%$ & S.E. & $\%$ & S.E. & $\%$ & S.E. & Mean & S.E. & Mean & S.E. & Dif. & S.E. \\
\hline 0 & Australia & 31.2 & $(1.1)$ & 27.1 & (1.0) & 30.2 & (1.3) & 0.06 & $(0.02)$ & 0.29 & $(0.04)$ & 0.23 & $(0.05)$ \\
\hline$\pi$ & Austria & 24.2 & (1.6) & 28.8 & (1.8) & 22.6 & (1.8) & -0.31 & $(0.03)$ & -0.22 & $(0.06)$ & 0.09 & $(0.07)$ \\
\hline ప & Belgium & 25.4 & (1.4) & 31.7 & (1.4) & 26.9 & (1.6) & -0.41 & $(0.03)$ & -0.56 & $(0.04)$ & -0.15 & $(0.04)$ \\
\hline & Canada & 36.5 & (1.4) & 34.4 & (1.3) & 36.5 & (1.4) & 0.00 & $(0.03)$ & 0.22 & $(0.04)$ & 0.22 & $(0.04)$ \\
\hline & Chile & 13.3 & $(1.2)$ & 10.4 & $(1.2)$ & 20.1 & (1.8) & 0.12 & $(0.03)$ & 0.33 & $(0.08)$ & 0.21 & $(0.09)$ \\
\hline & Czech Republic & 23.0 & $(1.6)$ & 25.2 & (1.6) & 22.3 & $(1.7)$ & -0.50 & $(0.03)$ & -0.34 & $(0.05)$ & 0.15 & $(0.07)$ \\
\hline & Denmark & 25.4 & (1.6) & 32.0 & (1.8) & 25.5 & (1.6) & -0.44 & $(0.03)$ & -0.12 & $(0.06)$ & 0.32 & $(0.08)$ \\
\hline & Estonia & 46.0 & $(1.8)$ & 42.4 & (1.9) & 40.6 & $(1.7)$ & -0.33 & $(0.04)$ & -0.12 & $(0.04)$ & 0.21 & $(0.06)$ \\
\hline & Finland & 40.4 & $(1.9)$ & 33.6 & $(1.8)$ & 40.4 & $(2.0)$ & -0.95 & $(0.04)$ & -0.73 & $(0.05)$ & 0.21 & $(0.06)$ \\
\hline & France & 25.0 & $(1.3)$ & 27.0 & $(1.7)$ & 28.7 & (1.5) & -0.40 & $(0.04)$ & -0.31 & $(0.05)$ & 0.09 & $(0.06)$ \\
\hline & Germany & 31.3 & $(1.7)$ & 35.5 & (1.9) & 36.2 & $(2.1)$ & -0.54 & $(0.04)$ & -0.44 & $(0.05)$ & 0.10 & $(0.06)$ \\
\hline & Greece & 16.6 & (1.4) & 19.7 & (1.8) & 21.6 & (1.9) & -0.32 & $(0.03)$ & -0.06 & $(0.07)$ & 0.26 & $(0.09)$ \\
\hline & Hungary & 17.6 & (1.4) & 20.5 & $(1.8)$ & 16.0 & (1.6) & -0.48 & $(0.03)$ & -0.35 & $(0.06)$ & 0.13 & $(0.07)$ \\
\hline & Iceland & 15.6 & (1.4) & 21.3 & (1.7) & 19.8 & (1.5) & 0.09 & $(0.04)$ & 0.46 & $(0.10)$ & 0.36 & $(0.11)$ \\
\hline & Ireland & 27.5 & (1.8) & 31.5 & (1.8) & 37.5 & (1.8) & 0.17 & $(0.03)$ & 0.48 & $(0.05)$ & 0.31 & $(0.06)$ \\
\hline & Israel & 14.3 & $(1.2)$ & 18.1 & (1.6) & 20.6 & (1.6) & 0.78 & $(0.03)$ & 0.96 & $(0.08)$ & 0.18 & $(0.09)$ \\
\hline & Italy & 24.7 & $(1.6)$ & 32.0 & $(2.1)$ & 26.8 & $(1.6)$ & -0.21 & $(0.03)$ & -0.20 & $(0.05)$ & 0.01 & $(0.05)$ \\
\hline & Japan & 46.6 & (1.9) & 48.0 & $(1.8)$ & 38.4 & $(2.0)$ & -0.86 & $(0.04)$ & -0.53 & $(0.04)$ & 0.33 & $(0.06)$ \\
\hline & Korea & 38.0 & (1.9) & 42.4 & $(2.3)$ & 40.0 & $(2.0)$ & -0.06 & $(0.03)$ & 0.24 & $(0.05)$ & 0.30 & $(0.06)$ \\
\hline & Latvia & 32.6 & $(1.7)$ & 31.5 & $(2.0)$ & 33.3 & (1.9) & -0.26 & $(0.03)$ & -0.05 & $(0.05)$ & 0.21 & $(0.06)$ \\
\hline & Luxembourg & 19.0 & (1.4) & 25.7 & (1.4) & 22.7 & (1.3) & -0.26 & $(0.03)$ & -0.25 & $(0.07)$ & 0.01 & $(0.08)$ \\
\hline & Mexico & 11.2 & $(1.2)$ & 16.3 & (1.6) & 17.0 & (1.5) & 0.12 & $(0.03)$ & 0.30 & $(0.08)$ & 0.17 & $(0.08)$ \\
\hline & Netherlands & 29.0 & (1.7) & 37.1 & (1.9) & 29.6 & $(2.0)$ & -0.53 & $(0.03)$ & -0.39 & $(0.06)$ & 0.13 & $(0.06)$ \\
\hline & New Zealand & 28.4 & $(2.0)$ & 25.1 & (1.9) & 29.6 & $(2.2)$ & 0.02 & $(0.04)$ & 0.05 & $(0.06)$ & 0.04 & $(0.07)$ \\
\hline & Norway & 24.5 & (1.4) & 27.4 & (1.5) & 33.0 & (1.6) & -0.20 & $(0.04)$ & 0.07 & $(0.05)$ & 0.28 & $(0.06)$ \\
\hline & Poland & 32.4 & $(1.8)$ & 39.2 & $(2.1)$ & 36.3 & $(1.8)$ & -0.64 & $(0.03)$ & -0.48 & $(0.04)$ & 0.17 & $(0.05)$ \\
\hline & Portugal & 35.7 & (1.8) & 38.8 & (2.0) & 38.0 & (1.9) & -0.13 & $(0.02)$ & 0.05 & $(0.04)$ & 0.18 & $(0.05)$ \\
\hline & Slovak Republic & 16.3 & (1.4) & 23.3 & $(1.7)$ & 15.3 & (1.4) & -0.59 & $(0.04)$ & -0.27 & $(0.06)$ & 0.32 & $(0.07)$ \\
\hline & Slovenia & 32.5 & $(1.5)$ & 37.5 & (1.9) & 33.0 & $(2.0)$ & -0.64 & $(0.03)$ & -0.43 & $(0.05)$ & 0.21 & $(0.06)$ \\
\hline & Spain & 36.6 & (1.4) & 39.2 & (1.6) & 42.6 & (1.7) & -0.44 & $(0.03)$ & -0.29 & $(0.04)$ & 0.16 & $(0.05)$ \\
\hline & Sweden & 22.9 & $(1.4)$ & 24.1 & (1.5) & 28.1 & (1.5) & -0.10 & $(0.04)$ & 0.14 & $(0.07)$ & 0.24 & $(0.08)$ \\
\hline & Switzerland & 27.0 & $(1.6)$ & 39.6 & $(2.0)$ & 24.9 & (1.7) & -0.48 & $(0.04)$ & -0.32 & $(0.06)$ & 0.16 & $(0.07)$ \\
\hline & Turkey & 19.7 & $(2.3)$ & 26.0 & (2.6) & 25.8 & (2.6) & 0.50 & $(0.04)$ & 0.83 & $(0.07)$ & 0.34 & $(0.08)$ \\
\hline & United Kingdom & 33.5 & (1.6) & 29.4 & (1.5) & 30.1 & $(1.3)$ & 0.27 & $(0.04)$ & 0.43 & $(0.05)$ & 0.16 & $(0.06)$ \\
\hline & United States & 29.6 & $(1.7)$ & 22.7 & $(1.7)$ & 34.4 & (1.9) & 0.47 & $(0.03)$ & 0.61 & $(0.05)$ & 0.14 & $(0.06)$ \\
\hline & OECD average & 27.2 & $(0.3)$ & 29.8 & $(0.3)$ & 29.3 & $(0.3)$ & -0.21 & $(0.01)$ & -0.03 & $(0.01)$ & 0.19 & $(0.01)$ \\
\hline 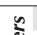 & Albania & 23.0 & $(2.7)$ & 23.8 & (2.4) & 21.5 & $(2.2)$ & $\mathrm{C}$ & C & C & c & c & C \\
\hline ฐ & Algeria & 6.4 & $(1.1)$ & 6.5 & $(1.0)$ & 4.7 & $(0.8)$ & C & C & $\mathrm{c}$ & $\mathrm{C}$ & c & c \\
\hline ฐ & Brazil & 8.4 & $(0.7)$ & 6.4 & $(0.7)$ & 15.2 & (0.9) & -0.01 & $(0.02)$ & 0.18 & $(0.05)$ & 0.19 & $(0.06)$ \\
\hline$a$ & B-S-J-G (China) & 42.9 & $(2.5)$ & 54.5 & $(2.3)$ & 34.4 & (2.6) & -0.14 & $(0.03)$ & 0.03 & $(0.03)$ & 0.16 & $(0.04)$ \\
\hline & Bulgaria & 12.2 & $(1.4)$ & 13.6 & (1.4) & 11.4 & (1.4) & -0.23 & $(0.03)$ & -0.16 & $(0.08)$ & 0.08 & $(0.08)$ \\
\hline & CABA (Argentina) & 13.0 & $(1.8)$ & 12.1 & (2.4) & 18.4 & $(3.2)$ & c & c & c & c & c & c \\
\hline & Colombia & 9.8 & $(1.0)$ & 8.1 & $(1.1)$ & 16.9 & (1.6) & 0.41 & $(0.02)$ & 0.57 & $(0.07)$ & 0.16 & $(0.07)$ \\
\hline & Costa Rica & 8.2 & $(0.9)$ & 7.7 & $(0.9)$ & 13.1 & $(1.3)$ & 0.41 & $(0.03)$ & 0.62 & $(0.11)$ & 0.21 & $(0.12)$ \\
\hline & Croatia & 22.4 & $(1.7)$ & 21.6 & (1.8) & 28.8 & (1.9) & -0.39 & $(0.03)$ & -0.13 & $(0.05)$ & 0.26 & $(0.05)$ \\
\hline & Cyprus* & 9.1 & $(1.0)$ & 10.8 & $(1.2)$ & 15.2 & $(1.3)$ & -0.08 & $(0.03)$ & 0.46 & $(0.10)$ & 0.54 & $(0.10)$ \\
\hline & Dominican Republic & 0.4 & $(0.2)$ & 0.3 & $(0.2)$ & 2.2 & $(0.6)$ & 0.28 & $(0.04)$ & c & c & c & c \\
\hline & FYROM & 3.5 & $(0.6)$ & 4.3 & $(0.7)$ & 2.6 & $(0.7)$ & c & c & c & c & c & c \\
\hline & Georgia & 6.7 & $(1.0)$ & 6.2 & $(0.9)$ & 6.5 & $(0.9)$ & c & c & $\mathrm{c}$ & c & c & c \\
\hline & Hong Kong (China) & 59.2 & (1.9) & 70.9 & $(1.8)$ & 61.4 & (1.9) & -0.06 & $(0.05)$ & 0.20 & $(0.03)$ & 0.26 & $(0.06)$ \\
\hline & Indonesia & 9.3 & $(1.3)$ & 10.9 & (1.5) & 12.9 & (1.3) & C & c & c & c & c & c \\
\hline & Jordan & 6.7 & $(0.9)$ & 4.5 & $(1.0)$ & 9.9 & $(1.0)$ & c & c & c & c & c & c \\
\hline & Kosovo & 2.2 & $(0.7)$ & 1.4 & $(0.7)$ & 0.5 & $(0.4)$ & c & c & c & c & c & c \\
\hline & Lebanon & 5.4 & (1.1) & 10.7 & (1.6) & 3.2 & $(0.8)$ & c & c & c & c & c & c \\
\hline & Lithuania & 21.0 & $(1.5)$ & 26.5 & (1.9) & 21.3 & (1.5) & -0.40 & $(0.04)$ & 0.10 & $(0.06)$ & 0.50 & $(0.07)$ \\
\hline & Macao (China) & 62.2 & $(1.5)$ & 71.9 & $(1.8)$ & 52.9 & $(2.0)$ & -0.74 & $(0.04)$ & -0.60 & $(0.03)$ & 0.14 & $(0.05)$ \\
\hline & Malta & 20.4 & (1.5) & 29.0 & (1.5) & 19.4 & (1.4) & c & c & c & c & c & c \\
\hline & Moldova & 12.0 & (1.4) & 13.0 & (1.5) & 10.8 & (1.1) & c & c & $\mathrm{C}$ & c & c & c \\
\hline & Montenegro & 8.5 & $(0.8)$ & 11.5 & $(1.0)$ & 13.0 & $(1.0)$ & -0.25 & $(0.03)$ & 0.02 & $(0.09)$ & 0.27 & $(0.10)$ \\
\hline & Peru & 2.6 & $(0.5)$ & 4.8 & $(0.9)$ & 3.5 & $(0.6)$ & 0.22 & $(0.02)$ & 0.50 & $(0.17)$ & 0.28 & $(0.18)$ \\
\hline & Qatar & 5.1 & $(0.4)$ & 4.1 & $(0.5)$ & 4.7 & $(0.5)$ & 0.61 & $(0.02)$ & 0.89 & $(0.07)$ & 0.27 & $(0.08)$ \\
\hline & Romania & 9.9 & $(1.3)$ & 14.9 & (1.9) & 11.5 & (1.4) & C & c & C & c & C & c \\
\hline & Russia & 23.2 & (1.8) & 33.8 & $(2.4)$ & 28.0 & $(2.0)$ & -0.33 & $(0.03)$ & -0.18 & $(0.07)$ & 0.15 & $(0.07)$ \\
\hline & Singapore & 46.5 & $(1.6)$ & 57.1 & $(1.8)$ & 41.1 & (1.5) & 0.30 & $(0.03)$ & 0.33 & $(0.04)$ & 0.03 & $(0.05)$ \\
\hline & Chinese Taipei & 44.3 & $(1.8)$ & 51.9 & (1.8) & 33.5 & (1.8) & -0.41 & $(0.02)$ & -0.06 & $(0.04)$ & 0.35 & $(0.05)$ \\
\hline & Thailand & 16.3 & $(1.5)$ & 22.0 & (1.9) & 14.3 & (1.5) & 0.17 & $(0.03)$ & 0.43 & $(0.06)$ & 0.26 & $(0.06)$ \\
\hline & Trinidad and Tobago & 11.5 & $(1.2)$ & 13.0 & $(1.2)$ & 14.9 & (1.4) & c & c & c & c & c & c \\
\hline & Tunisia & 3.9 & $(0.7)$ & 6.0 & $(0.8)$ & 3.8 & $(0.7)$ & 0.60 & $(0.03)$ & 0.87 & $(0.16)$ & 0.27 & $(0.16)$ \\
\hline & United Arab Emirates & 7.0 & $(0.6)$ & 7.0 & $(0.7)$ & 7.8 & $(0.9)$ & 0.66 & $(0.03)$ & 0.88 & $(0.09)$ & 0.22 & $(0.09)$ \\
\hline & Uruguay & 12.4 & $(1.2)$ & 11.5 & $(1.2)$ & 16.7 & (1.4) & -0.17 & $(0.02)$ & -0.03 & $(0.07)$ & 0.13 & $(0.07)$ \\
\hline & Viet Nam & 72.7 & $(3.0)$ & 63.1 & (3.6) & 60.1 & $(3.1)$ & $\mathrm{C}$ & C & C & $\mathrm{C}$ & c & $\mathrm{C}$ \\
\hline & Argentina** & 14.4 & (1.4) & 14.4 & (1.9) & 15.2 & (1.5) & c & c & c & c & c & c \\
\hline & Kazakhstan** & 15.0 & $(1.7)$ & 21.7 & $(2.4)$ & 8.9 & (1.3) & c & c & c & c & c & c \\
\hline & Malaysia** & 13.7 & (1.6) & 17.7 & (1.5) & 13.0 & (1.4) & 0.64 & $(0.04)$ & 1.01 & $(0.07)$ & 0.37 & $(0.08)$ \\
\hline
\end{tabular}

1. A student is classified as resilient if he or she is in the bottom quarter of the PISA index of economic, social and cultural status (ESCS) in the country/economy of assessment and performs in the top quarter of students among all countries and economies, after accounting for socio-economic status.

Note: Values that are statistically significant are indicated in bold (see Annex A3).

*ee note at the beginning of this Annex.

** Coverage is too small to ensure comparability (see Annex A4).

StatLink न्ता sग $\mathrm{http}: / / \mathrm{dx}$.doi.org/10.1787/888933470961 


\begin{tabular}{|c|c|c|c|c|c|c|c|c|c|c|c|c|}
\hline & & & & & Average & $x$ of achiev & ement $m$ & ation, by: & & & & \\
\hline & $\begin{array}{r}\text { Non-resil } \\
\text { in } \mathrm{ma}\end{array}$ & $\begin{array}{l}t^{1} \text { students } \\
\text { matics }\end{array}$ & $\begin{array}{c}\text { Resilie } \\
\text { in ma }\end{array}$ & $\begin{array}{l}\text { udents } \\
\text { natics }\end{array}$ & $\begin{array}{l}\text { Differe } \\
\text { resilient a } \\
\text { students }\end{array}$ & $\begin{array}{l}\text { etween } \\
\text { on-resilient } \\
\text { thematics }\end{array}$ & $\begin{array}{c}\text { Non-res } \\
\text { in }\end{array}$ & $\begin{array}{l}\text { t students } \\
\text { ling }\end{array}$ & $\begin{array}{c}\text { Resilie } \\
\text { in }\end{array}$ & $\begin{array}{l}\text { udents } \\
\text { ing }\end{array}$ & $\begin{array}{r}\text { Differ } \\
\text { resilient a } \\
\text { studer }\end{array}$ & $\begin{array}{l}\text { between } \\
\text { on-resilient } \\
\text { reading }\end{array}$ \\
\hline & Mean & S.E. & Mean & S.E. & Dif. & S.E. & Mean & S.E. & Mean & S.E. & Dif. & S.E. \\
\hline Australia & 0.05 & $(0.02)$ & 0.34 & $(0.04)$ & 0.29 & $(0.05)$ & 0.04 & $(0.03)$ & 0.35 & $(0.04)$ & 0.31 & $(0.06)$ \\
\hline Austria & -0.32 & $(0.04)$ & -0.19 & $(0.05)$ & 0.13 & $(0.07)$ & -0.31 & $(0.04)$ & -0.21 & $(0.06)$ & 0.10 & $(0.08)$ \\
\hline ठ̄ Belgium & -0.40 & $(0.03)$ & -0.54 & $(0.04)$ & -0.13 & $(0.05)$ & -0.41 & $(0.03)$ & -0.55 & $(0.04)$ & -0.14 & $(0.05)$ \\
\hline Canada & 0.00 & $(0.03)$ & 0.23 & $(0.04)$ & 0.22 & $(0.05)$ & -0.01 & $(0.03)$ & 0.24 & $(0.04)$ & 0.26 & $(0.05)$ \\
\hline Chile & 0.14 & $(0.03)$ & 0.26 & $(0.09)$ & 0.13 & $(0.10)$ & 0.10 & $(0.04)$ & 0.35 & $(0.07)$ & 0.25 & $(0.08)$ \\
\hline Czech Republic & -0.51 & $(0.03)$ & -0.32 & $(0.05)$ & 0.19 & $(0.07)$ & -0.50 & $(0.02)$ & -0.33 & $(0.06)$ & 0.16 & $(0.07)$ \\
\hline Denmark & -0.45 & $(0.03)$ & -0.18 & $(0.05)$ & 0.27 & $(0.07)$ & -0.45 & $(0.04)$ & -0.12 & $(0.07)$ & 0.32 & $(0.09)$ \\
\hline Estonia & -0.34 & $(0.04)$ & -0.09 & $(0.05)$ & 0.25 & $(0.06)$ & -0.35 & $(0.04)$ & -0.08 & $(0.04)$ & 0.27 & $(0.06)$ \\
\hline Finland & -0.94 & $(0.03)$ & -0.70 & $(0.05)$ & 0.24 & $(0.06)$ & -0.93 & $(0.04)$ & -0.76 & $(0.04)$ & 0.17 & $(0.05)$ \\
\hline France & -0.40 & $(0.04)$ & -0.31 & $(0.06)$ & 0.09 & $(0.06)$ & -0.39 & $(0.04)$ & -0.35 & $(0.05)$ & 0.03 & $(0.06)$ \\
\hline Germany & -0.55 & $(0.04)$ & -0.43 & $(0.05)$ & 0.13 & $(0.07)$ & -0.55 & $(0.04)$ & -0.44 & $(0.05)$ & 0.10 & $(0.07)$ \\
\hline Greece & -0.34 & $(0.03)$ & -0.03 & $(0.06)$ & 0.30 & $(0.07)$ & -0.34 & $(0.04)$ & -0.07 & $(0.05)$ & 0.27 & $(0.07)$ \\
\hline Hungary & -0.49 & $(0.03)$ & -0.35 & $(0.06)$ & 0.13 & $(0.07)$ & -0.48 & $(0.03)$ & -0.36 & $(0.07)$ & 0.12 & $(0.08)$ \\
\hline Iceland & 0.08 & $(0.04)$ & 0.41 & $(0.09)$ & 0.33 & $(0.10)$ & 0.08 & $(0.04)$ & 0.45 & $(0.10)$ & 0.37 & $(0.12)$ \\
\hline Ireland & 0.15 & $(0.03)$ & 0.47 & $(0.05)$ & 0.32 & $(0.06)$ & 0.16 & $(0.03)$ & 0.41 & $(0.05)$ & 0.25 & $(0.07)$ \\
\hline Israel & 0.78 & $(0.03)$ & 0.92 & $(0.07)$ & 0.14 & $(0.07)$ & 0.76 & $(0.03)$ & 0.95 & $(0.07)$ & 0.19 & $(0.07)$ \\
\hline Italy & -0.23 & $(0.03)$ & -0.17 & $(0.05)$ & 0.06 & $(0.05)$ & -0.23 & $(0.03)$ & -0.17 & $(0.05)$ & 0.06 & $(0.05)$ \\
\hline Japan & -0.88 & $(0.04)$ & -0.51 & $(0.04)$ & 0.37 & $(0.06)$ & -0.81 & $(0.03)$ & -0.53 & $(0.05)$ & 0.29 & $(0.06)$ \\
\hline Korea & -0.11 & $(0.03)$ & 0.29 & $(0.05)$ & 0.40 & $(0.06)$ & -0.08 & $(0.03)$ & 0.26 & $(0.05)$ & 0.34 & $(0.07)$ \\
\hline Latvia & -0.27 & $(0.03)$ & -0.03 & $(0.06)$ & 0.24 & $(0.07)$ & -0.26 & $(0.04)$ & -0.06 & $(0.06)$ & 0.20 & $(0.07)$ \\
\hline Luxembourg & -0.28 & $(0.03)$ & -0.21 & $(0.06)$ & 0.07 & $(0.07)$ & -0.26 & $(0.03)$ & -0.27 & $(0.06)$ & -0.01 & $(0.07)$ \\
\hline Mexico & 0.12 & $(0.03)$ & 0.26 & $(0.07)$ & 0.14 & $(0.08)$ & 0.11 & $(0.03)$ & 0.30 & $(0.06)$ & 0.19 & $(0.07)$ \\
\hline Netherlands & -0.55 & $(0.03)$ & -0.39 & $(0.05)$ & 0.15 & $(0.05)$ & -0.53 & $(0.03)$ & -0.40 & $(0.05)$ & 0.12 & $(0.05)$ \\
\hline New Zealand & 0.00 & $(0.04)$ & 0.12 & $(0.07)$ & 0.12 & $(0.08)$ & -0.02 & $(0.04)$ & 0.13 & $(0.06)$ & 0.14 & $(0.07)$ \\
\hline Norway & -0.22 & $(0.04)$ & 0.09 & $(0.05)$ & 0.31 & $(0.07)$ & -0.25 & $(0.04)$ & 0.09 & $(0.05)$ & 0.34 & $(0.07)$ \\
\hline Poland & -0.65 & $(0.03)$ & -0.49 & $(0.04)$ & 0.16 & $(0.05)$ & -0.63 & $(0.03)$ & -0.51 & $(0.04)$ & 0.12 & $(0.05)$ \\
\hline Portugal & -0.13 & $(0.02)$ & 0.03 & $(0.04)$ & 0.16 & $(0.05)$ & -0.12 & $(0.03)$ & 0.03 & $(0.04)$ & 0.15 & $(0.06)$ \\
\hline Slovak Republic & -0.61 & $(0.04)$ & -0.31 & $(0.07)$ & 0.30 & $(0.08)$ & -0.59 & $(0.04)$ & -0.25 & $(0.07)$ & 0.34 & $(0.07)$ \\
\hline Slovenia & -0.64 & $(0.03)$ & -0.45 & $(0.04)$ & 0.19 & $(0.06)$ & -0.64 & $(0.03)$ & -0.44 & $(0.05)$ & 0.19 & $(0.07)$ \\
\hline Spain & -0.46 & $(0.04)$ & -0.28 & $(0.04)$ & 0.17 & $(0.05)$ & -0.45 & $(0.04)$ & -0.30 & $(0.05)$ & 0.14 & $(0.06)$ \\
\hline Sweden & -0.10 & $(0.04)$ & 0.14 & $(0.07)$ & 0.25 & $(0.09)$ & -0.15 & $(0.04)$ & 0.21 & $(0.06)$ & 0.35 & $(0.08)$ \\
\hline Switzerland & -0.51 & $(0.04)$ & -0.32 & $(0.05)$ & 0.19 & $(0.06)$ & -0.48 & $(0.03)$ & -0.32 & $(0.06)$ & 0.16 & $(0.07)$ \\
\hline Turkey & 0.47 & $(0.05)$ & 0.83 & $(0.06)$ & 0.36 & $(0.07)$ & 0.48 & $(0.05)$ & 0.81 & $(0.06)$ & 0.33 & $(0.07)$ \\
\hline United Kingdom & 0.26 & $(0.03)$ & 0.47 & $(0.05)$ & 0.21 & $(0.06)$ & 0.24 & $(0.04)$ & 0.51 & $(0.05)$ & 0.27 & $(0.07)$ \\
\hline United States & 0.47 & $(0.03)$ & 0.65 & $(0.07)$ & 0.18 & $(0.08)$ & 0.44 & $(0.03)$ & 0.65 & $(0.05)$ & 0.21 & $(0.06)$ \\
\hline OECD average & -0.22 & $(0.01)$ & -0.02 & $(0.01)$ & 0.20 & $(0.01)$ & -0.22 & $(0.01)$ & -0.02 & $(0.01)$ & 0.20 & $(0.01)$ \\
\hline
\end{tabular}

\begin{tabular}{|c|c|c|c|c|c|c|c|c|c|c|c|c|}
\hline Albania & c & c & c & C & C & c & c & $\mathrm{C}$ & C & c & c & $\mathrm{c}$ \\
\hline$\cong$ Algeria & C & C & $\mathrm{C}$ & C & C & C & c & $\mathrm{C}$ & C & c & c & $\mathrm{c}$ \\
\hline ถู Brazil & 0.00 & $(0.02)$ & 0.17 & $(0.07)$ & 0.17 & $(0.07)$ & -0.02 & $(0.02)$ & 0.14 & $(0.04)$ & 0.16 & $(0.05)$ \\
\hline B-S-J-G (China) & -0.15 & $(0.03)$ & 0.00 & $(0.03)$ & 0.15 & $(0.05)$ & -0.11 & $(0.02)$ & 0.02 & $(0.04)$ & 0.13 & $(0.04)$ \\
\hline Bulgaria & -0.23 & $(0.03)$ & -0.19 & $(0.08)$ & 0.04 & $(0.09)$ & -0.23 & $(0.03)$ & -0.14 & $(0.08)$ & 0.10 & $(0.09)$ \\
\hline CABA (Argentina) & c & c & C & c & C & c & c & $\mathrm{C}$ & C & c & c & $\mathrm{c}$ \\
\hline Colombia & 0.40 & $(0.02)$ & 0.64 & $(0.09)$ & 0.24 & $(0.09)$ & 0.39 & $(0.02)$ & 0.56 & $(0.05)$ & 0.16 & $(0.06)$ \\
\hline Costa Rica & 0.41 & $(0.03)$ & 0.57 & $(0.11)$ & 0.16 & $(0.11)$ & 0.40 & $(0.03)$ & 0.57 & $(0.07)$ & 0.17 & $(0.07)$ \\
\hline Croatia & -0.38 & $(0.02)$ & -0.16 & $(0.05)$ & 0.22 & $(0.06)$ & -0.40 & $(0.03)$ & -0.17 & $(0.05)$ & 0.23 & $(0.05)$ \\
\hline Cyprus* & -0.07 & $(0.03)$ & 0.36 & $(0.09)$ & 0.43 & $(0.09)$ & -0.09 & $(0.03)$ & 0.35 & $(0.08)$ & 0.45 & $(0.09)$ \\
\hline Dominican Republic & 0.28 & $(0.04)$ & c & c & c & c & 0.27 & $(0.04)$ & c & c & c & c \\
\hline FYROM & c & c & $\mathrm{C}$ & c & c & c & C & C & c & c & c & c \\
\hline Georgia & c & c & c & c & c & c & c & c & c & c & c & c \\
\hline Hong Kong (China) & -0.10 & $(0.06)$ & 0.17 & $(0.03)$ & 0.27 & $(0.07)$ & -0.07 & $(0.05)$ & 0.19 & $(0.03)$ & 0.27 & $(0.07)$ \\
\hline Indonesia & c & c & c & c & c & c & c & c & c & c & c & c \\
\hline Jordan & c & C & c & c & c & c & c & C & c & c & c & c \\
\hline Kosovo & c & c & c & c & c & c & c & c & c & c & c & c \\
\hline Lebanon & c & c & $\mathrm{c}$ & c & c & c & c & c & c & c & c & $\mathrm{c}$ \\
\hline Lithuania & -0.41 & $(0.04)$ & 0.02 & $(0.06)$ & 0.44 & $(0.07)$ & -0.40 & $(0.04)$ & 0.10 & $(0.06)$ & 0.50 & $(0.07)$ \\
\hline Macao (China) & -0.76 & $(0.05)$ & -0.61 & $(0.03)$ & 0.15 & $(0.06)$ & -0.72 & $(0.04)$ & -0.59 & $(0.03)$ & 0.13 & $(0.06)$ \\
\hline Malta & c & c & c & c & c & c & c & c & c & c & c & c \\
\hline Moldova & c & c & c & c & c & c & c & $\mathrm{C}$ & c & c & c & $\mathrm{c}$ \\
\hline Montenegro & -0.25 & $(0.03)$ & -0.03 & $(0.08)$ & 0.22 & $(0.09)$ & -0.26 & $(0.03)$ & -0.02 & $(0.08)$ & 0.23 & $(0.09)$ \\
\hline Peru & 0.21 & $(0.02)$ & 0.49 & $(0.12)$ & 0.27 & $(0.12)$ & 0.22 & $(0.02)$ & 0.43 & $(0.13)$ & 0.21 & $(0.14)$ \\
\hline Qatar & 0.62 & $(0.02)$ & 0.84 & $(0.08)$ & 0.22 & $(0.09)$ & 0.62 & $(0.02)$ & 0.80 & $(0.08)$ & 0.18 & $(0.08)$ \\
\hline Romania & c & c & c & c & c & c & c & c & c & c & c & c \\
\hline Russia & -0.33 & $(0.03)$ & -0.21 & $(0.05)$ & 0.12 & $(0.06)$ & -0.34 & $(0.03)$ & -0.18 & $(0.05)$ & 0.16 & $(0.06)$ \\
\hline Singapore & 0.31 & $(0.04)$ & 0.32 & $(0.03)$ & 0.01 & $(0.06)$ & 0.30 & $(0.03)$ & 0.35 & $(0.04)$ & 0.05 & $(0.06)$ \\
\hline Chinese Taipei & -0.44 & $(0.03)$ & -0.08 & $(0.03)$ & 0.36 & $(0.04)$ & -0.38 & $(0.03)$ & -0.01 & $(0.04)$ & 0.36 & $(0.05)$ \\
\hline Thailand & 0.18 & $(0.03)$ & 0.31 & $(0.05)$ & 0.13 & $(0.06)$ & 0.18 & $(0.03)$ & 0.41 & $(0.07)$ & 0.23 & $(0.08)$ \\
\hline Trinidad and Tobago & c & c & c & c & c & c & c & c & c & c & c & c \\
\hline Tunisia & 0.60 & $(0.03)$ & 0.80 & $(0.12)$ & 0.19 & $(0.13)$ & 0.60 & $(0.03)$ & 0.98 & $(0.17)$ & 0.38 & $(0.17)$ \\
\hline United Arab Emirates & 0.67 & $(0.03)$ & 0.78 & $(0.10)$ & 0.11 & $(0.10)$ & 0.66 & $(0.03)$ & 0.85 & $(0.09)$ & 0.19 & $(0.09)$ \\
\hline Uruguay & -0.17 & $(0.03)$ & 0.03 & $(0.09)$ & 0.20 & $(0.10)$ & -0.16 & $(0.03)$ & -0.12 & $(0.07)$ & 0.04 & $(0.08)$ \\
\hline Viet Nam & c & c & c & c & c & c & c & c & c & c & c & c \\
\hline Argentina** & c & c & c & c & c & c & C & c & c & c & c & c \\
\hline Kazakhstan** & c & c & c & c & c & c & c & C & c & c & C & c \\
\hline Malaysia** & 0.65 & $(0.04)$ & 0.89 & $(0.08)$ & 0.24 & $(0.08)$ & 0.64 & $(0.04)$ & 1.07 & $(0.06)$ & 0.43 & $(0.07)$ \\
\hline
\end{tabular}

1. A student is classified as resilient if he or she is in the bottom quarter of the PISA index of economic, social and cultural status (ESCS) in the country/economy of assessment and performs in the top quarter of students among all countries and economies, after accounting for socio-economic status.

Note: Values that are statistically significant are indicated in bold (see Annex A3).

* See note at the beginning of this Annex.

** Coverage is too small to ensure comparability (see Annex A4).

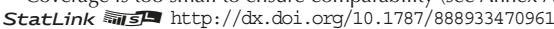


[Part 1/4]

Table III.5.8 Students' achievement motivation and schoolwork-related anxiety

Percentage of students who reported that they "agree"|"strongly agree" or "disagree"I"strongly disagree" "Even if I am well prepared for a test I feel very anxious"

\begin{tabular}{|c|c|c|c|c|c|c|c|c|c|c|c|c|c|c|c|c|c|c|c|c|}
\hline & & & age & f & te & disa & d v & the & wi & staten & & & ent & e of & ents wl & o a & d wi & he f & $\operatorname{vin}$ & ter \\
\hline & & $\begin{array}{r}\text { I wan } \\
\text { grades } \\
\text { or all } \\
\text { cour }\end{array}$ & $\begin{array}{l}\text { op } \\
\text { most } \\
\text { my } \\
\text { s }\end{array}$ & $\begin{array}{l}\text { I want } \\
\text { able to } \\
\text { from a } \\
\text { the } \\
\text { opport } \\
\text { avail } \\
\text { wh } \\
\text { I grad }\end{array}$ & \begin{tabular}{l|} 
to be \\
select \\
mong \\
est \\
unities \\
able \\
en \\
uate \\
\end{tabular} & $\begin{array}{l}\text { I wa } \\
\text { be th } \\
\text { whate }\end{array}$ & $\begin{array}{l}\text { o } \\
\text { est, } \\
\text { I do }\end{array}$ & $\begin{array}{r}\text { I see n } \\
\text { an am } \\
\text { pe }\end{array}$ & $\begin{array}{l}\text { If as } \\
\text { ous }\end{array}$ & $\begin{array}{c}\text { I wan } \\
\text { be one } \\
\text { best stu } \\
\text { in my }\end{array}$ & $\begin{array}{l}\text { o } \\
\text { the } \\
\text { ents } \\
\text { iss }\end{array}$ & $\begin{array}{c}\text { I wan } \\
\text { grades } \\
\text { or all } \\
\text { cou }\end{array}$ & $\begin{array}{l}\text { op } \\
\text { nost } \\
\text { my } \\
\text { s } \\
\end{array}$ & $\begin{array}{l}\text { I wan } \\
\text { able to } \\
\text { from } \\
\text { the } \\
\text { opport } \\
\text { avai } \\
\text { wh } \\
\text { I gra }\end{array}$ & $\begin{array}{l}\text { be } \\
\text { lect } \\
\text { ong } \\
\text { st } \\
\text { ities } \\
\text { le } \\
\text { te } \\
\end{array}$ & $\begin{array}{r}\text { I w } \\
\text { be tt } \\
\text { what }\end{array}$ & $\begin{array}{l}\text { to } \\
\text { est, } \\
\text { I do }\end{array}$ & $\begin{array}{c}\text { I see } \\
\text { an an } \\
\text { pe }\end{array}$ & $\begin{array}{l}\text { elf as } \\
\text { ious } \\
\mathrm{n}\end{array}$ & $\begin{array}{c}\text { I } \mathrm{u} \\
\text { be or } \\
\text { best } \\
\text { in } n \\
\end{array}$ \\
\hline & & $\%$ & S.E. & $\%$ & S.E. & $\%$ & S.E. & $\%$ & S.E. & $\%$ & S.E. & $\%$ & S.E. & $\%$ & S.E. & $\%$ & S.E. & $\%$ & S.E. & $\%$ \\
\hline & Australia & 56.2 & (1.7) & 51.5 & $(2.8)$ & 60.3 & $(1.4)$ & 65.9 & (1.1) & 62.9 & $(0.9)$ & 68.8 & $(0.6)$ & 68.2 & $(0.6)$ & 68.5 & $(0.6)$ & 67.8 & (0.6) & 69.1 \\
\hline & Austria & 44.2 & (1.7) & 45.1 & (2.6) & 50.2 & (1.0) & 53.8 & (1.1) & 50.4 & (1.1) & 52.6 & $(0.8)$ & 51.3 & (0.9) & 51.5 & (1.0) & 49.2 & (0.9) & 51.1 \\
\hline & Belgium & 32.5 & (1.0) & 33.7 & (1.8) & 40.7 & $(0.7)$ & 42.5 & (0.9) & 40.0 & $(0.7)$ & 46.3 & $(0.7)$ & 43.2 & $(0.6)$ & 5.1 & $(0.9)$ & 2.2 & (0.7) & 6.0 \\
\hline & Canada & 53.2 & (1.2) & 42.7 & (2.1) & 57.6 & (1.1) & 62.0 & (1.1) & 58.6 & $(0.9)$ & 65.3 & (0.5) & 65.0 & $(0.4)$ & 5.4 & $(0.5)$ & 4.4 & (0.5) & 5.9 \\
\hline & Chile & 44.4 & $(2.2)$ & 44.6 & (3.3) & 53.7 & (1.8) & 57.8 & (1.3) & 55.1 & (1.2) & 56.9 & $(0.7)$ & 56.6 & $(0.7)$ & 6.3 & $(0.7)$ & 5.3 & $(0.7)$ & 56.4 \\
\hline & Czech Republic & 30.1 & (1.6) & 30.4 & (2.3) & 36.4 & (1.1) & 41.5 & (1.2) & 38.2 & $(0.9)$ & 42.7 & $(0.8)$ & 1.0 & $(0.8)$ & 2.1 & (1.0) & & (0.9) & 3.0 \\
\hline & Denmark & 61.0 & (1.6) & 65.6 & (2.0) & 63.5 & (1.0) & 64.4 & (1.4) & 65.0 & (1.2) & 65.5 & $(0$. & 3 & $(0.8)$ & & (1.1) & & (0.8) & 2 \\
\hline & Estonia & 35.4 & (2.2) & 38.7 & (3.6) & 50.0 & (1.4) & 53.7 & (1.5) & 50.3 & $(1.0)$ & 54.3 & $(0.8)$ & 53.5 & $(0.8)$ & 4.4 & (0.9) & 2.5 & (0.9) & 5.2 \\
\hline & Finland & 44.5 & $(1.0)$ & 45.0 & (1.5) & 48.2 & $(0.9)$ & 49.1 & (1.1) & 3 & $(0.9)$ & 51.5 & $(0.9)$ & 6 & $(0.8)$ & 5 & $(1.2)$ & 3.4 & (1.0) & 0.6 \\
\hline & France & 36.5 & (1.7) & 35.6 & (2.6) & 46.1 & $(0.9)$ & 46.8 & (1.3) & 45.2 & $(0.8)$ & 48.9 & $(0.7)$ & 47.7 & $(0.7)$ & 1 & (1.0) & 9 & $(0.8)$ & 9.5 \\
\hline & Germany & 39.5 & (1.5) & 42.3 & (2.4) & 42.6 & (1.0) & 43.6 & (1.2) & 43.8 & (1.0) & 42.2 & (0.8) & 4 & $(0.7)$ & & (1.1) & & (0.8) & \\
\hline & Greece & 48.6 & $(1.4)$ & 45.6 & (3.7) & 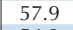 & (1.4) & 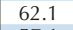 & (1.4) & 52.3 & (1.1) & 9 & $(0.9)$ & & $(0.7)$ & & $(0.9)$ & & $(0.8)$ & \\
\hline & Hungary & 51.6 & (1.6) & 53.9 & (2.8) & 54.3 & (1.3) & 7.1 & (1.2) & 52.2 & (1.0) & 5.5 & $(0.9)$ & 1.6 & $(0.8)$ & 4.8 & $(0.9)$ & 5 & (1.0) & 3.1 \\
\hline & Iceland & 43.5 & (4.4) & 47.7 & $(2.7)$ & 51.9 & (1.9) & 5 & (1.9) & 5 & $(2.0)$ & 1.4 & $(0.9)$ & & $(0.9)$ & & (1.0) & & (0.9) & 7 \\
\hline & Ireland & 49.9 & (2.5) & 50.1 & (4.4) & 5 & (1.8) & 0 & (1.9) & 60.0 & (1.5) & 4.2 & $(0.8)$ & 5 & $(0.7)$ & 1 & $(0.8)$ & & (0.8) & 4 \\
\hline & Israel & 37.0 & (3.9) & 32.1 & (3.6) & 4 & (2.0) & 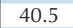 & (1.7) & 36.7 & (1.6) & 44.8 & $(0$. & & $(0$. & & $(0$. & & (0.8) & \\
\hline & Italy & 57.1 & $(1.6)$ & 58.6 & (3.2) & 7 & (0.9) & 7 & (1.1) & 69.1 & $(0.7)$ & 7 & (0. & & $(0.6)$ & & $(0.7)$ & & (0.6) & \\
\hline & Japan & 54.6 & (1.2) & 47.4 & (1.7) & 60.5 & $(0.8)$ & 59.7 & (1.1) & 60.9 & $(0.9)$ & 66.2 & $(0.8)$ & 6 & $(0.8)$ & 6 & (1.1) & 8 & (0.8) & 6 \\
\hline & Korea & 37.7 & (1.8) & 21.3 & (3.0) & 46.5 & (1.4) & 53.9 & (1.3) & 38.5 & (1.5) & 57.9 & $(0.8)$ & & $(0.8)$ & & $(0.8)$ & & (0.9) & 0 \\
\hline & Latvia & 33.0 & (2.1) & 3 & (2.7) & 3 & (1. & 4 & (16) & 39.0 & $(1.1)$ & 16 & $(0$. & & $(0$. & & (10) & & (1.0) & \\
\hline & Luxembourg & 38.3 & (1.8) & 39.2 & (2.4) & 4 & (1.0) & 48.9 & (1.1) & 45.2 & (1.0) & 49.8 & $(0$. & 5 & $(0.7)$ & 3 & (0.9) & 7 & (0.9) & 2 \\
\hline & Mexico & 42.7 & (3.9) & 42.6 & $(3.8$ & 5 & (1.6) & 6 & (0.9) & 5 & (1.6) & 7 & $(0$. & & $(0.8)$ & & (0.9) & & ). & \\
\hline & Netherla & 28.2 & (2.4) & 31.5 & (2.5) & 35 & (1. & 37.8 & (1.5) & 6 & $(0.9)$ & 0.0 & $(0$. & 5 & $(0$. & & (1.2) & & $(0.8)$ & 7 \\
\hline & New Zealand & 62.1 & (1.9) & 51.4 & (3.1) & 63.7 & (1.9) & 5 & (1.5) & 6 & (1.1) & 3 & $(0$. & & $(0$ & & $(0.8)$ & & $(0.9)$ & 2 \\
\hline & Norway & 52.3 & (1.9) & 37.8 & (2.8) & 57. & (1.3) & 6 & (1.6) & 58 & (1.2) & 6 & $(0$. & & $(0$. & & $(0.7)$ & & (0.8) & \\
\hline & Poland & 37.1 & (1.4) & 39.3 & (2.1) & 43.7 & (1.4) & 50.6 & (1.8) & 43.1 & (1.3) & 49.4 & (1.1) & 1 & $(0.9)$ & 1 & (1.0) & 1 & (1.0) & 3 \\
\hline & Portugal & 48.3 & (3.6) & 56.1 & (2.9) & 67.0 & (1.4) & 6 & (1.5) & 9 & (1.1) & 0 & $(0.7)$ & 1 & $(0.7)$ & & $(0.7)$ & & $(0.7)$ & 8 \\
\hline & Slovak Re & 37.0 & (1.4) & 31.4 & (2.6) & 44.9 & (1.3) & 49.5 & (1.4) & 44.1 & $(0.9)$ & 50.7 & $(0.9)$ & 3 & $(0.8)$ & 3 & $(0.9)$ & 7 & (0.9) & 50.8 \\
\hline & Slovenia & 563 & (1.4) & 58.9 & $(2.2)$ & 605 & (1.2) & 640 & $(1.2)$ & 616 & $(0.9)$ & 64.3 & $(0.9)$ & & $(0.8)$ & & $(1.0)$ & & & \\
\hline & Spain & 59.8 & (1.4) & 51.8 & (2.6) & 66.1 & (1.0) & .9 & (1.0) & 0.1 & $(1.2)$ & J.J & $(0.7)$ & 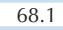 & $(0.7)$ & & $(0.9)$ & & (1.0) & 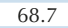 \\
\hline & Swede & 53.1 & (1.4) & 47.2 & (2.5) & 60.5 & (1.5) & 582 & (1.6) & 7.8 & (1.1) & 3.1 & $(1.0)$ & 3 & $(0.8)$ & 5 & $(0.9)$ & 6 & $(0.9)$ & 0 \\
\hline & Switzerland & 26.7 & $(1.2)$ & 29.2 & $(2.4)$ & 32.3 & $(0.8)$ & 1 & $(1.2)$ & 7 & $(0$. & 5 & $(0$ & & $(0$ & & $(1$ & & (1.1) & \\
\hline & Turkey & 32.6 & (2.9) & 32.8 & $(3.2)$ & 44.8 & (1.9) & 54.8 & (1.4) & 9.8 & $(2.4)$ & 0.6 & $(0.8)$ & 3 & $(0.8)$ & & $(0.8)$ & 2 & (0.9) & 1.1 \\
\hline & United Kingdom & 61.2 & (3.4) & 49.8 & (5.1) & 63.2 & (2.0) & 73.4 & (1.5) & 69.0 & (1.4) & 72.3 & $(0.7)$ & 72.3 & $(0.7)$ & 8 & $(0.7)$ & 1.5 & $(0.7)$ & 2.9 \\
\hline & United States & 52.3 & $(2.9)$ & 50.3 & (4.3) & 59.6 & (2.6) & 66.7 & (1.5) & 62.9 & (1.7) & 68.7 & $(0.7)$ & 68.3 & $(0.7)$ & 68.3 & $(0.7)$ & 68.0 & (0.8) & 68.6 \\
\hline & OECD average & 45.1 & $(0.4)$ & 43.3 & (0.5) & 52.2 & $(0.2)$ & 56.1 & $(0.2)$ & 52.1 & $(0.2)$ & 57.3 & $(0.1)$ & 56.2 & $(0.1)$ & 56.5 & $(0.2)$ & 55.1 & $(0.1)$ & 7.2 \\
\hline & Albania & $\mathrm{m}$ & $\mathrm{m}$ & $\mathrm{m}$ & $\mathrm{m}$ & $\mathrm{m}$ & $\mathrm{m}$ & $\mathrm{m}$ & $\mathrm{m}$ & $\mathrm{m}$ & $\mathrm{m}$ & $\mathrm{m}$ & $\mathrm{m}$ & $\mathrm{m}$ & $\mathrm{m}$ & $\mathrm{m}$ & $\mathrm{m}$ & $\mathrm{m}$ & IIII & $\mathrm{m}$ \\
\hline & Algeria & $\mathrm{m}$ & $\mathrm{m}$ & $\mathrm{m}$ & $\mathrm{m}$ & $\mathrm{m}$ & $\mathrm{m}$ & $\mathrm{m}$ & $\mathrm{m}$ & $\mathrm{m}$ & $\mathrm{m}$ & $\mathrm{m}$ & $\mathrm{m}$ & $\mathrm{m}$ & $\mathrm{m}$ & $\mathrm{m}$ & $\mathrm{m}$ & $\mathrm{m}$ & $\mathrm{m}$ & $\mathrm{m}$ \\
\hline & Brazil & 4.5 & (2.0) & 57.7 & (2.6) & 77.2 & $(0.9)$ & 81.8 & (0.5) & 76.7 & $(0.7)$ & 1.7 & $(0.4)$ & 1.7 & $(0.4)$ & 1.7 & $(0.5)$ & 9.5 & (0.6) & 3.2 \\
\hline & B-S-J-G (C & 1.6 & (1.5) & 41.2 & (4.0) & 52.4 & (1.9) & 60.6 & (1.4) & 57.3 & (1.4) & 5.6 & $(0$. & 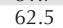 & $(0.8)$ & & (0.8) & 2 & $(0.8)$ & 8 \\
\hline & Bulgaria & 43.7 & (1.4) & 35.6 & (3.0) & 51.6 & (1.0) & 50.2 & (1.9) & 48.0 & (1.0) & 58.2 & $(0.7)$ & 56.4 & (0.6) & 57.8 & (0.9) & 56.1 & (0.8) & 58.8 \\
\hline & CABA & $m$ & $\mathrm{~m}$ & $m$ & $m$ & $m$ & $m$ & $\mathrm{~m}$ & $\mathrm{~m}$ & $m$ & 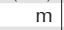 & $m$ & & $\mathrm{~m}$ & & $\mathrm{~m}$ & t & $m$ & $m$ & $m$ \\
\hline & Colo & 0.1 & (3.2) & 41.6 & (4.4) & 67.2 & (1.9) & 9.1 & (0.6) & 8.9 & $(2$. & 9.8 & $(0$. & 79.4 & $(0$. & 9 & $(0.6)$ & 8.3 & 1.0) & 0.6 \\
\hline & Costa Rica & 22 & (3.9) & 52.5 & $(4$. & 731 & (1) 7 & & $(0.7)$ & 6 & (1.7) & & $(0$. & & $(0$ & & $(0.5)$ & & & \\
\hline & Croa & 3.5 & (1.5) & 32 & $(2$. & & 1 & 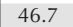 & (1 & & (1. & 0 & $(0$ & +2 & (0. & & (1.0) & & (0.9) & 3 \\
\hline & Cypru & 49.5 & (1.6) & 42.8 & (3.2) & 56.5 & (1.3) & 59.0 & (1.5) & 53.3 & (1.4) & 59.5 & $(0.8)$ & 58.4 & $(0.7)$ & 58.2 & $(0.7)$ & 7.5 & $(0.8)$ & 9.4 \\
\hline & Dom & 49.3 & (2.6) & 41.2 & (3.6) & 65.4 & (2.1) & 79.7 & (1.0) & 51.4 & (2.5) & 82.9 & $(0.8)$ & 82.7 & $(0.8)$ & 82.8 & $(0.8)$ & 1.7 & (1.3) & 3.0 \\
\hline & FYROM & $m$ & $\mathrm{~m}$ & $\mathrm{~m}$ & $m$ & $\mathrm{~m}$ & $m$ & $\mathrm{~m}$ & $\mathrm{~m}$ & $\mathrm{~m}$ & $m$ & $\mathrm{~m}$ & $\mathrm{~m}$ & $\mathrm{~m}$ & $\mathrm{~m}$ & $\mathrm{~m}$ & $\mathrm{~m}$ & $\mathrm{~m}$ & $\mathrm{~m}$ & $\mathrm{~m}$ \\
\hline & Georg & $\mathrm{m}$ & $\mathrm{m}$ & $\mathrm{m}$ & $\mathrm{m}$ & $\mathrm{m}$ & $\mathrm{m}$ & m & $\mathrm{m}$ & m & $\mathrm{m}$ & $\mathrm{m}$ & $\mathrm{m}$ & $\mathrm{m}$ & $\mathrm{m}$ & $\mathrm{m}$ & $\mathrm{m}$ & $\mathrm{m}$ & $\mathrm{m}$ & $\mathrm{m}$ \\
\hline & Hong & 64.7 & (2.0) & 59.5 & (2.7) & 58.1 & (1.8) & 64.9 & 1.2) & 62.5 & 1.3) & 67.4 & (0.7) & 67.6 & (0.7) & 9.1 & $(0.7)$ & 8.2 & $(0.7)$ & 8.6 \\
\hline & Indonesi & $\mathrm{m}$ & $\mathrm{m}$ & $\mathrm{m}$ & $\mathrm{m}$ & $\mathrm{m}$ & $\mathrm{m}$ & $\mathrm{m}$ & $\mathrm{m}$ & $\mathrm{m}$ & $m$ & $\mathrm{~m}$ & $\mathrm{~m}$ & $\mathrm{~m}$ & $\mathrm{~m}$ & $\mathrm{~m}$ & $\mathrm{~m}$ & $\mathrm{n}$ & $\mathrm{m}$ & $\mathrm{m}$ \\
\hline & Jordan & $\mathrm{m}$ & $\mathrm{m}$ & $\mathrm{m}$ & $\mathrm{m}$ & $\mathrm{m}$ & $\mathrm{m}$ & $\mathrm{m}$ & $\mathrm{m}$ & $\mathrm{m}$ & $\mathrm{m}$ & $\mathrm{m}$ & $\mathrm{m}$ & $\mathrm{m}$ & $\mathrm{m}$ & $\mathrm{m}$ & $\mathrm{m}$ & $\mathrm{m}$ & $\mathrm{m}$ & $\mathrm{m}$ \\
\hline & Kosovo & 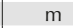 & & m & & $\mathrm{m}$ & & $\mathrm{m}$ & & $\mathrm{m}$ & & $\mathrm{m}$ & 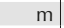 & $\mathrm{m}$ & $\mathrm{m}$ & $\mathrm{m}$ & $\mathrm{m}$ & $\mathrm{m}$ & $\mathrm{m}$ & $\mathrm{m}$ \\
\hline & Lebanon & $\mathrm{m}$ & $\mathrm{m}$ & $\mathrm{m}$ & $\mathrm{m}$ & $\mathrm{m}$ & $\mathrm{m}$ & $\mathrm{m}$ & $\mathrm{m}$ & $\mathrm{m}$ & $\mathrm{m}$ & $\mathrm{m}$ & $\mathrm{m}$ & $\mathrm{m}$ & $\mathrm{m}$ & $\mathrm{m}$ & $\mathrm{m}$ & $\mathrm{m}$ & $\mathrm{m}$ & $\mathrm{m}$ \\
\hline & Lithe & .5 & (1.9) & 40.0 & 5) & 2.6 & ) & .4 & 3) & 0.2 & 2) & 3.4 & 7) & & $(0.7)$ & .4 & 8) & 0 & 8) & .9 \\
\hline & Mac & 3.8 & (1.0) & 54.5 & (2.4) & 4.0 & (1.2) & 66.7 & 1) & 65.3 & 5) & 7.5 & .0) & 6.7 & (0.8) & 6.8 & (1.1) & 4.8 & 1.0) & 5.9 \\
\hline & Malta & $\mathrm{m}$ & $\mathrm{m}$ & m & $\mathrm{m}$ & $\mathrm{m}$ & $\mathrm{m}$ & $\mathrm{m}$ & $\mathrm{m}$ & $\mathrm{m}$ & $\mathrm{m}$ & $\mathrm{m}$ & $\mathrm{m}$ & $\mathrm{m}$ & $\mathrm{m}$ & $\mathrm{m}$ & $\mathrm{m}$ & $\mathrm{m}$ & $\mathrm{m}$ & $\mathrm{m}$ \\
\hline & Moldo & $\mathrm{m}$ & & $\mathrm{m}$ & & & & $\mathrm{m}$ & & $\mathrm{m}$ & & $\mathrm{m}$ & & $\mathrm{m}$ & & $\mathrm{m}$ & & $\mathrm{m}$ & & $\mathrm{m}$ \\
\hline & Monte & 3.4 & (1.7) & 44.8 & (2.6) & 61.6 & (1.2) & 59.5 & (1.3) & 59.0 & (1.1) & 68.7 & $(0.8)$ & 66.9 & $(0.8)$ & 7.0 & (1.0) & 66.4 & (0.9) & 70.2 \\
\hline & Peru & & & & (3. & & & & & & (1. & & $(0$. & 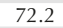 & $(0$. & & (0.6) & & (1.0) & .6 \\
\hline & Qat & 3.2 & 10 & 42.7 & . & 52.2 & (2) & 61.6 & (1.3) & 54.2 & (1) & 6.9 & $(04)$ & 66.6 & (1) & 6.9 & $(0.4)$ & 5.9 & $0.4)$ & 6.7 \\
\hline & Romani & $\mathrm{m}$ & $\mathrm{m}$ & $\mathrm{m}$ & $\mathrm{m}$ & m & $\mathrm{m}$ & m & $\mathrm{m}$ & $\mathrm{m}$ & $\mathrm{m}$ & $\mathrm{m}$ & $\mathrm{m}$ & $\mathrm{m}$ & $\mathrm{m}$ & $\mathrm{m}$ & $\mathrm{m}$ & $\mathrm{m}$ & $\mathrm{m}$ & $\mathrm{m}$ \\
\hline & Rus: & & 11 & 48.2 & & & & 53.5 & & 48.9 & & 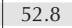 & & & (0.8) & 1.2 & 9) & 9 & 8) & 3.0 \\
\hline & Sing & 3 & (1.8) & 59.6 & (3. & 66.9 & (1.9) & 73.8 & (1.1) & 69.3 & (1.5) & 77.5 & $(0.7)$ & 76.9 & $(0.6)$ & 77.5 & (0.6) & 7.2 & $(0.8)$ & 77.8 \\
\hline & & & (1.4) & 35 & (3. & & (1. & 63.2 & (1.2) & 56.8 & (1.2) & 70.8 & $(0.6)$ & 67.5 & $(0.6)$ & 70.4 & $(0.7)$ & 7.8 & (0.6) & 1.2 \\
\hline & & 45.9 & $(2.0)$ & 39.3 & (3.7) & 37.1 & (4.3) & 58.8 & (1.1) & 56.0 & (1.6) & 64.9 & $(0.8)$ & 64.1 & $(0.8)$ & 64.0 & $(0.8)$ & 5.6 & $(1.0)$ & 5.3 \\
\hline & Trin & $\mathrm{m}$ & $\mathrm{m}$ & $\mathrm{m}$ & $-t$ & $\mathrm{~m}$ & $\mathrm{~m}$ & $\mathrm{~m}$ & & $\mathrm{~m}$ & 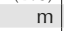 & $\mathrm{m}$ & $\mathrm{m}$ & $\mathrm{m}$ & 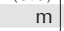 & $\mathrm{m}$ & $m$ & $\mathrm{~m}$ & $\mathrm{~m}$ & $\mathrm{~m}$ \\
\hline & & & (3.7) & 44.9 & (5.2) & 53.4 & & 61.5 & & 1.4 & & 0.3 & (0.9) & 0.3 & (0.9) & 0.4 & (0.9) & 9.4 & (0.9) & 0.3 \\
\hline & Unit & 50.1 & (2.4) & 48.4 & (2.7) & 55.0 & (2.3) & 58.4 & (1.5) & 54.1 & $(2.3)$ & 62.5 & $(0.7)$ & 62.4 & $(0.7)$ & 62.4 & $(0.7)$ & 62.0 & $(0.7)$ & 62.5 \\
\hline & Uru & 56.2 & $(2.2)$ & 46.8 & (3.3) & 66.0 & (1.4) & 70.2 & (0.9) & 66.1 & (1.0) & 75.0 & $(0.7)$ & 74.2 & $(0.7)$ & 75.0 & $(0.7)$ & 76.0 & (1.0) & 79.5 \\
\hline & Viet Nam & $\mathrm{m}$ & $\mathrm{m}$ & $\mathrm{m}$ & $\mathrm{m}$ & $\mathrm{m}$ & $\mathrm{m}$ & $\mathrm{m}$ & $\mathrm{m}$ & $\mathrm{m}$ & $\mathrm{m}$ & $\mathrm{m}$ & $\mathrm{m}$ & $\mathrm{m}$ & $\mathrm{m}$ & $\mathrm{m}$ & $\mathrm{m}$ & $\mathrm{m}$ & $\mathrm{m}$ & $\mathrm{m}$ \\
\hline & Argentina** & $\mathrm{m}$ & & $\mathrm{m}$ & $\mathrm{m}$ & $\mathrm{m}$ & $\mathrm{m}$ & $\mathrm{m}$ & $\mathrm{m}$ & $\mathrm{m}$ & $\mathrm{m}$ & $\mathrm{m}$ & $\mathrm{m}$ & $\mathrm{m}$ & $\mathrm{m}$ & $\mathrm{m}$ & $\mathrm{m}$ & $\mathrm{m}$ & $\mathrm{m}$ & $\mathrm{m}$ \\
\hline & & $\mathrm{m}$ & $\mathrm{m}$ & $\mathrm{m}$ & III & m & $\mathrm{m}$ & m & $\mathrm{m}$ & III & & $\mathrm{m}$ & $\mathrm{m}$ & III & i1) & 111 & $\mathrm{~m}$ & m & $\mathrm{m}$ & III \\
\hline & Malaysia** & 63.8 & (3.0) & 57.1 & (4.0) & 64.9 & (3.4) & 76.5 & (1.8) & 67.4 & (2.2) & 82.6 & (0.5) & 82.3 & (0.5) & 82.4 & (0.5) & 82.3 & (0.6) & 82.9 \\
\hline
\end{tabular}

Note: Values that are statistically significant are indicated in bold (see Annex A3).

* See note at the beginning of this Annex.

** Coverage is too small to ensure comparability (see Annex A4).

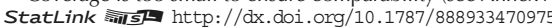


Percentage of students who reported that they "agree"|"strongly agree" or "disagree"I"strongly disagree" "Even if I am well prepared for a test I feel very anxious"

\begin{tabular}{|c|c|c|c|c|c|c|c|c|c|c|}
\hline & & ifference & tween the & tages of $s t$ & ts who a & ind thos & disagree & he foll & statemen & \\
\hline & $\begin{array}{l}\text { I want to to } \\
\text { or all }\end{array}$ & $\begin{array}{l}s \text { in most } \\
\text { ourses }\end{array}$ & $\begin{array}{l}\text { I want to } \\
\text { from a } \\
\text { opportu } \\
\text { wher }\end{array}$ & $\begin{array}{l}\text { to select } \\
\text { e best } \\
\text { vailable } \\
\text { uate }\end{array}$ & $\begin{array}{l}\text { I want } \\
\text { wh }\end{array}$ & $\begin{array}{l}\text { le best, } \\
\text { do }\end{array}$ & $\begin{array}{r}\text { I se } \\
\text { an am }\end{array}$ & $\begin{array}{l}\text { f as } \\
\text { eerson }\end{array}$ & be one of & $\begin{array}{l}\text { t t students } \\
\text { ss }\end{array}$ \\
\hline & $\%$ dif. & S.E. & $\%$ dif. & S.E. & $\%$ dif. & S.E. & $\%$ dif. & S.E. & $\%$ dif. & S.E. \\
\hline Australia & 12.6 & $(1.8)$ & 16.7 & $(2.8)$ & 8.2 & $(1.5)$ & 1.9 & $(1.2)$ & 6.2 & $(1.0)$ \\
\hline Austria & 8.4 & (1.6) & 6.3 & (2.5) & 1.3 & $(1.1)$ & -4.6 & (1.1) & 0.7 & (1.3) \\
\hline 0 Belgium & 13.8 & (1.3) & 9.5 & (2.0) & 4.4 & $(1.2)$ & -0.3 & (1.1) & 5.9 & (1.1) \\
\hline Canada & 12.1 & (1.3) & 22.3 & $(2.2)$ & 7.8 & (1.4) & 2.4 & (1.4) & 7.4 & $(1.2)$ \\
\hline Chile & 12.5 & $(2.3)$ & 11.9 & (3.3) & 2.6 & (1.9) & -2.5 & (1.3) & 1.3 & (1.4) \\
\hline Czech Republic & 12.6 & $(1.8)$ & 10.6 & (2.5) & 5.7 & (1.5) & -2.1 & (1.6) & 4.8 & (1.4) \\
\hline Denmark & 4.5 & (1.6) & -1.4 & $(2.1)$ & 2.0 & $(1.5)$ & 0.0 & (1.5) & -0.8 & (1.4) \\
\hline Estonia & 19.0 & (2.4) & 14.8 & (3.6) & 4.4 & (1.6) & -1.2 & $(1.7)$ & 4.9 & (1.3) \\
\hline Finland & 7.1 & $(1.2)$ & 4.6 & (1.6) & 1.3 & $(1.5)$ & -0.7 & (1.5) & 3.3 & (1.4) \\
\hline France & 12.4 & $(1.8)$ & 12.0 & $(2.7)$ & 2.1 & $(1.2)$ & 0.1 & (1.4) & 4.2 & (1.1) \\
\hline Germany & 2.8 & (1.7) & -0.9 & $(2.7)$ & -2.3 & $(1.6)$ & -2.9 & (1.5) & -4.9 & (1.6) \\
\hline Greece & 14.2 & $(1.7)$ & 14.0 & (3.7) & 1.7 & $(1.8)$ & -3.8 & $(1.7)$ & 10.7 & (1.5) \\
\hline Hungary & 4.0 & (1.7) & 0.7 & $(2.7)$ & 0.5 & $(1.3)$ & -4.5 & (1.3) & 5.9 & $(1.6)$ \\
\hline Iceland & 7.9 & (4.4) & 3.9 & $(2.8)$ & -1.1 & $(2.1)$ & -10.8 & (2.1) & -0.9 & (2.4) \\
\hline Ireland & 14.3 & $(2.5)$ & 13.5 & (4.3) & 6.6 & (1.8) & 0.2 & (1.8) & 4.3 & (1.5) \\
\hline Israel & 7.8 & $(4.0)$ & 12.8 & (3.6) & 12.2 & $(2.1)$ & 4.7 & (1.8) & 9.0 & (1.7) \\
\hline Italy & 14.8 & (1.7) & 12.2 & (3.3) & -2.3 & $(1.1)$ & -2.0 & (1.3) & 2.1 & $(1.0)$ \\
\hline Japan & 11.6 & (1.3) & 16.7 & (1.8) & 4.1 & $(1.1)$ & 4.1 & (1.2) & 3.8 & (1.0) \\
\hline Korea & 20.2 & (1.9) & 35.3 & $(3.2)$ & 10.9 & (1.5) & 2.0 & (1.6) & 20.5 & (1.6) \\
\hline Latvia & 11.6 & $(2.3)$ & 10.5 & $(2.8)$ & 5.8 & (1.6) & -1.0 & (1.8) & 7.3 & (1.6) \\
\hline Luxembourg & 11.5 & $(2.0)$ & 9.3 & (2.4) & 2.9 & $(1.3)$ & -2.2 & (1.4) & 5.0 & (1.4) \\
\hline Mexico & 18.0 & (3.9) & 18.1 & (3.7) & 5.5 & (1.9) & -2.4 & (1.4) & 4.9 & (1.7) \\
\hline Netherlands & 11.8 & (2.4) & 8.1 & (2.5) & 0.2 & (1.6) & 1.8 & (1.6) & 5.1 & (1.4) \\
\hline New Zealand & 11.2 & $(2.0)$ & 21.9 & (3.2) & 9.7 & $(2.2)$ & 3.1 & (1.9) & 3.9 & (1.5) \\
\hline Norway & 10.3 & $(2.1)$ & 24.3 & (3.0) & 4.7 & (1.5) & -0.5 & $(1.7)$ & 4.6 & (1.4) \\
\hline Poland & 12.3 & (1.6) & 6.8 & (2.1) & 2.4 & $(1.7)$ & -7.6 & (2.0) & 4.2 & (1.9) \\
\hline Portugal & 21.7 & (3.7) & 14.0 & (3.0) & 2.7 & (1.5) & 0.6 & (1.6) & 7.9 & $(1.2)$ \\
\hline Slovak Republic & 13.6 & (1.5) & 16.9 & (2.6) & 2.8 & $(1.5)$ & -3.8 & (1.5) & 6.7 & (1.3) \\
\hline Slovenia & 8.0 & $(1.7)$ & 3.4 & (2.3) & 2.5 & (1.6) & -3.3 & (1.6) & 0.4 & (1.5) \\
\hline Spain & 9.6 & (1.5) & 16.3 & (2.6) & 1.7 & $(1.3)$ & -4.8 & (1.4) & 3.6 & (1.4) \\
\hline Sweden & 10.0 & $(1.7)$ & 15.2 & (2.6) & 0.9 & (1.6) & 3.4 & (1.8) & 5.3 & (1.4) \\
\hline Switzerland & 8.8 & (1.6) & 4.7 & (2.6) & 2.8 & $(1.7)$ & -2.6 & (1.7) & -0.6 & (1.6) \\
\hline Turkey & 28.0 & $(2.9)$ & 27.5 & (3.2) & 16.4 & (1.8) & 5.4 & (1.6) & 21.3 & (2.6) \\
\hline United Kingdom & 11.1 & (3.6) & 22.5 & $(5.2)$ & 9.5 & $(2.2)$ & -2.0 & (1.6) & 3.8 & (1.5) \\
\hline United States & 16.5 & (2.9) & 18.0 & (4.4) & 8.7 & $(2.7)$ & 1.3 & (1.7) & 5.6 & (1.9) \\
\hline OECD average & 12.2 & $(0.4)$ & 12.9 & $(0.5)$ & 4.3 & $(0.3)$ & -1.0 & $(0.3)$ & 5.1 & $(0.3)$ \\
\hline
\end{tabular}

\begin{tabular}{|c|c|c|c|c|c|c|c|c|c|c|}
\hline Albania & $\mathrm{m}$ & $\mathrm{m}$ & $\mathrm{m}$ & $\mathrm{m}$ & $\mathrm{m}$ & $\mathrm{m}$ & $\mathrm{m}$ & $\mathrm{m}$ & $\mathrm{m}$ & $\mathrm{m}$ \\
\hline$§$ Algeria & $\mathrm{m}$ & $\mathrm{m}$ & $\mathrm{m}$ & $\mathrm{m}$ & $\mathrm{m}$ & $\mathrm{m}$ & $\mathrm{m}$ & $\mathrm{m}$ & $\mathrm{m}$ & $\mathrm{m}$ \\
\hline Brazil & 17.2 & $(2.0)$ & 24.0 & (2.6) & 4.5 & (1.0) & -2.3 & $(0.8)$ & 6.5 & $(0.9)$ \\
\hline B-S-J-G (China) & 14.0 & (1.7) & 21.2 & (3.9) & 10.5 & (2.0) & 1.6 & (1.5) & 5.5 & (1.4) \\
\hline Bulgaria & 14.5 & (1.6) & 20.8 & (3.0) & 6.2 & (1.3) & 5.9 & (2.2) & 10.9 & (1.3) \\
\hline CABA (Argentina) & $\mathrm{m}$ & $\mathrm{m}$ & $\mathrm{m}$ & $\mathrm{m}$ & $\mathrm{m}$ & $\mathrm{m}$ & $\mathrm{m}$ & $\mathrm{m}$ & $\mathrm{m}$ & $\mathrm{m}$ \\
\hline Colombia & 29.7 & (3.2) & 37.8 & $(4.5)$ & 12.7 & (2.1) & -0.8 & $(1.2)$ & 21.7 & $(2.2)$ \\
\hline Costa Rica & 33.8 & $(4.1)$ & 29.3 & $(4.8)$ & 9.7 & (1.8) & 2.8 & $(1.0)$ & 14.6 & (1.8) \\
\hline Croatia & 12.4 & (1.5) & 15.5 & $(2.8)$ & 4.4 & (1.4) & 0.5 & (1.4) & 8.4 & (1.3) \\
\hline Cyprus* & 10.0 & (1.9) & 15.6 & (3.4) & 1.7 & (1.5) & -1.6 & (1.7) & 6.1 & (1.6) \\
\hline Dominican Republic & 33.6 & $(2.6)$ & 41.5 & (3.5) & 17.4 & (2.0) & 1.9 & (1.5) & 31.6 & (2.5) \\
\hline FYROM & $\mathrm{m}$ & $\mathrm{m}$ & $\mathrm{m}$ & $\mathrm{m}$ & $\mathrm{m}$ & $\mathrm{m}$ & $\mathrm{m}$ & $\mathrm{m}$ & $\mathrm{m}$ & $\mathrm{m}$ \\
\hline Georgia & $\mathrm{m}$ & $\mathrm{m}$ & $\mathrm{m}$ & $\mathrm{m}$ & $\mathrm{m}$ & $\mathrm{m}$ & $\mathrm{m}$ & $\mathrm{m}$ & $\mathrm{m}$ & $\mathrm{m}$ \\
\hline Hong Kong (China) & 2.6 & $(2.2)$ & 8.1 & $(2.8)$ & 11.0 & (1.8) & 3.3 & (1.3) & 6.1 & (1.5) \\
\hline Indonesia & $\mathrm{m}$ & $\mathrm{m}$ & $\mathrm{m}$ & $\mathrm{m}$ & $\mathrm{m}$ & $\mathrm{m}$ & $\mathrm{m}$ & $\mathrm{m}$ & $\mathrm{m}$ & $\mathrm{m}$ \\
\hline Jordan & $\mathrm{m}$ & $\mathrm{m}$ & $\mathrm{m}$ & $\mathrm{m}$ & $\mathrm{m}$ & $\mathrm{m}$ & $\mathrm{m}$ & $\mathrm{m}$ & $\mathrm{m}$ & $\mathrm{m}$ \\
\hline Kosovo & $\mathrm{m}$ & $\mathrm{m}$ & $\mathrm{m}$ & $\mathrm{m}$ & $\mathrm{m}$ & $\mathrm{m}$ & $\mathrm{m}$ & $\mathrm{m}$ & $\mathrm{m}$ & $\mathrm{m}$ \\
\hline Lebanon & $\mathrm{m}$ & $\mathrm{m}$ & $\mathrm{m}$ & $\mathrm{m}$ & $\mathrm{m}$ & $\mathrm{m}$ & $\mathrm{m}$ & $\mathrm{m}$ & $\mathrm{m}$ & $\mathrm{m}$ \\
\hline Lithuania & 15.9 & $(2.1)$ & 17.3 & $(2.7)$ & 4.8 & (1.6) & 7.6 & (1.5) & 8.6 & (1.4) \\
\hline Macao (China) & 3.7 & (1.3) & 12.1 & (2.6) & 2.8 & (1.6) & -1.9 & (1.4) & 0.5 & (1.3) \\
\hline Malta & $\mathrm{m}$ & $\mathrm{m}$ & $\mathrm{m}$ & $\mathrm{m}$ & $\mathrm{m}$ & $\mathrm{m}$ & $\mathrm{m}$ & $\mathrm{m}$ & $\mathrm{m}$ & $\mathrm{m}$ \\
\hline Moldova & $\mathrm{m}$ & $\mathrm{m}$ & $\mathrm{m}$ & $\mathrm{m}$ & $\mathrm{m}$ & $\mathrm{m}$ & $\mathrm{m}$ & $\mathrm{m}$ & $\mathrm{m}$ & $\mathrm{m}$ \\
\hline Montenegro & 15.2 & (1.8) & 22.1 & $(2.7)$ & 5.4 & (1.5) & 6.9 & (1.3) & 11.2 & (1.3) \\
\hline Peru & 17.2 & (3.1) & 21.0 & (3.7) & 13.2 & (2.0) & -0.9 & $(1.2)$ & 9.3 & (1.7) \\
\hline Qatar & 23.7 & $(2.0)$ & 23.9 & $(2.1)$ & 14.7 & (1.4) & 4.3 & (1.3) & 12.5 & (1.3) \\
\hline Romania & $\mathrm{m}$ & $\mathrm{m}$ & $\mathrm{m}$ & $\mathrm{m}$ & $\mathrm{m}$ & $\mathrm{m}$ & $\mathrm{m}$ & $\mathrm{m}$ & $\mathrm{m}$ & $\mathrm{m}$ \\
\hline Russia & 8.8 & (1.9) & 3.2 & (3.3) & 0.0 & (2.1) & -2.7 & (2.9) & 4.1 & (2.2) \\
\hline Singapore & 10.2 & (1.9) & 17.3 & (3.6) & 10.6 & (1.8) & 3.4 & (1.3) & 8.5 & (1.6) \\
\hline Chinese Taipei & 20.7 & (1.5) & 32.0 & (3.7) & 11.8 & (1.5) & 4.6 & (1.3) & 14.4 & (1.3) \\
\hline Thailand & 19.1 & (2.1) & 24.7 & (3.8) & 26.8 & (4.5) & 6.7 & (1.5) & 9.2 & (1.9) \\
\hline Trinidad and Tobago & $\mathrm{m}$ & $\mathrm{m}$ & $\mathrm{m}$ & $\mathrm{m}$ & $\mathrm{m}$ & $\mathrm{m}$ & $\mathrm{m}$ & $\mathrm{m}$ & $\mathrm{m}$ & $\mathrm{m}$ \\
\hline Tunisia & 16.1 & (3.7) & 15.5 & (3.3) & 7.0 & (2.5) & -2.1 & $(2.8)$ & 8.9 & (3.1) \\
\hline United Arab Emirates & 12.4 & (2.4) & 14.0 & (2.8) & 7.4 & (2.5) & 3.7 & (1.6) & 8.5 & (2.3) \\
\hline Uruguay & 18.8 & $(2.2)$ & 27.5 & (3.4) & 9.0 & (1.5) & 5.9 & (1.3) & 13.3 & (1.3) \\
\hline Viet Nam & $\mathrm{m}$ & $\mathrm{m}$ & $\mathrm{m}$ & $\mathrm{m}$ & $\mathrm{m}$ & $\mathrm{m}$ & $\mathrm{m}$ & $\mathrm{m}$ & $\mathrm{m}$ & $\mathrm{m}$ \\
\hline Argentina** & $\mathrm{m}$ & $\mathrm{m}$ & $\mathrm{m}$ & $\mathrm{m}$ & $\mathrm{m}$ & $\mathrm{m}$ & $\mathrm{m}$ & $\mathrm{m}$ & $\mathrm{m}$ & $\mathrm{m}$ \\
\hline Kazakhstan** & $\mathrm{m}$ & $\mathrm{m}$ & $\mathrm{m}$ & $\mathrm{m}$ & $\mathrm{m}$ & $\mathrm{m}$ & $\mathrm{m}$ & $\mathrm{m}$ & $\mathrm{m}$ & $\mathrm{m}$ \\
\hline Malaysia** & 18.8 & (3.0) & 25.2 & $(4.0)$ & 17.6 & (3.4) & 5.7 & (1.9) & 15.5 & (2.3) \\
\hline
\end{tabular}

Note: Values that are statistically significant are indicated in bold (see Annex A3).

* See note at the beginning of this Annex.

** Coverage is too small to ensure comparability (see Annex A4)

StatLink त्ना5 http://dx.doi.org/10.1787/888933470975 
[Part 3/4]

Table III.5.8 Students' achievement motivation and schoolwork-related anxiety

Percentage of students who reported that they "agree"|"strongly agree" or "disagree"I"strongly disagree"

"I get very tense when I study"

\begin{tabular}{|c|c|c|c|c|c|c|c|c|c|c|c|c|c|c|c|c|c|c|c|c|}
\hline & & Perc & entage & of stuc & its wh & o disagre & ed wit & h the fol & lowing & statem & & & centage & e of stuc & lents $\mathrm{u}$ & ho agre & d with & the foll & wing st & tatemen \\
\hline & & $\begin{array}{r}\text { I wan } \\
\text { grades } \\
\text { or all } \\
\text { cour }\end{array}$ & $\begin{array}{l}\text { op } \\
\text { most } \\
\text { my } \\
\text { es }\end{array}$ & $\begin{array}{l}\text { I want } \\
\text { able to } \\
\text { from a } \\
\text { the } \\
\text { opport } \\
\text { avail } \\
\text { wh } \\
\text { I grac }\end{array}$ & $\begin{array}{l}\text { to be } \\
\text { select } \\
\text { nong } \\
\text { est } \\
\text { nities } \\
\text { ble } \\
\text { n } \\
\text { uate } \\
\end{array}$ & $\begin{array}{l}\text { I wa } \\
\text { be th } \\
\text { whate }\end{array}$ & $\begin{array}{l}\text { o } \\
\text { est, } \\
\text { I do }\end{array}$ & $\begin{array}{r}\text { I see } r \\
\text { an an } \\
\text { pe }\end{array}$ & $\begin{array}{l}\text { If as } \\
\text { ous } \\
\end{array}$ & $\begin{array}{c}\text { I wa } \\
\text { be one } \\
\text { best st } \\
\text { in } \mathrm{my}\end{array}$ & $\begin{array}{l}\text { the } \\
\text { ents } \\
\text { ass }\end{array}$ & $\begin{array}{c}\text { grades } \\
\text { or all } \\
\text { cou }\end{array}$ & $\begin{array}{l}\text { op } \\
\text { nost } \\
\text { my } \\
\text { s }\end{array}$ & $\begin{array}{c}\text { I want } \\
\text { able to } \\
\text { from a } \\
\text { the } \\
\text { opport } \\
\text { avail } \\
\text { wh } \\
\text { I grac }\end{array}$ & $\begin{array}{l}\text { to be } \\
\text { select } \\
\text { mong } \\
\text { est } \\
\text { unities } \\
\text { able } \\
\text { en } \\
\text { uate }\end{array}$ & $\begin{array}{r}\text { In } \\
\text { be t } \\
\text { what }\end{array}$ & $\begin{array}{l}\text { t to } \\
\text { best, } \\
\text { er I do }\end{array}$ & $\begin{array}{c}\text { I see } \\
\text { an ar } \\
\text { p }\end{array}$ & $\begin{array}{l}\text { elf as } \\
\text { ious } \\
\mathrm{n}\end{array}$ & $\begin{array}{l}\text { be o } \\
\text { best } \\
\text { in } n\end{array}$ \\
\hline & & $\%$ & S.E. & $\%$ & S.E. & $\%$ & S.E. & $\%$ & S.E. & $\%$ & S.E. & $\%$ & S.E. & $\%$ & S.E. & $\%$ & S.E. & $\%$ & S.E. & $\%$ \\
\hline & Australia & 38.8 & (1.8) & 34.2 & (2.7) & 40.5 & (1.2) & 45.2 & (1.3) & 41.9 & $(0.8)$ & 47.9 & $(0.6)$ & 47.4 & $(0.6)$ & 47.8 & $(0.6)$ & 47.3 & (0.6) & 48.6 \\
\hline & Austria & 20.9 & $(1.2)$ & 20.8 & (1.9) & 17.9 & (0.6) & 23.0 & (0.9) & 19.6 & $(0.7)$ & 18.8 & (0.6) & 19.1 & $(0.5)$ & 20.6 & $(0.9)$ & 17.3 & $(0.7)$ & 18.9 \\
\hline & Belgium & 22.0 & (0.9) & 24.0 & (1.5) & 25.7 & $(0.7)$ & 28.2 & (0.9) & 26.8 & (0.7) & 31.0 & $(0.7)$ & 28.8 & $(0.6)$ & 32.7 & $(0.9)$ & 8.2 & (0.7) & 30.8 \\
\hline & Canada & 39.2 & (1.4) & 35.0 & (2.1) & 41.1 & (1.1) & 44.8 & (1.1) & 42.4 & (1.1) & 46.3 & (0.6) & 46.0 & $(0.6)$ & 46.4 & $(0.6)$ & 45.6 & (0.6) & 46.6 \\
\hline & Chile & 34.7 & (2.0) & 36.5 & (3.2) & 34.6 & (1.7) & 40.2 & (1.2) & 39.0 & (1.1) & 40.6 & $(0.7)$ & 40.3 & $(0.7)$ & 1.2 & $(0.8)$ & 0.0 & (0.8) & 40.6 \\
\hline & Czech Republic & 27.0 & (1.3) & 30.4 & (2.5) & 30.8 & $(1.2)$ & 35.2 & (1.0) & 31.2 & $(0.9)$ & 33.5 & $(0.8)$ & 32.3 & $(0.7)$ & 33.0 & $(0.9)$ & 0.2 & (0.9) & 33.5 \\
\hline & Denmark & 41.2 & (1.3) & 44.1 & (1.6) & 43.1 & $(0.8)$ & 45.9 & (1.8) & 44.3 & $(1.2)$ & 46.7 & $(0.7)$ & 45.6 & $(0.7)$ & 8 & $(0.9)$ & 5.3 & (0.6) & 5.9 \\
\hline & Estonia & 23.3 & (2.4) & 24.9 & (3.0) & 24.0 & (1.1) & 31.6 & (1.3) & 27.4 & $(0.8)$ & 27.9 & $(0.7)$ & 27.7 & $(0.7)$ & 4 & $(0.8)$ & 1 & $(0.7)$ & 7.6 \\
\hline & Finland & 15.7 & $(0.6)$ & 16.0 & (0.9) & 16.0 & $(0.5)$ & 17.9 & (0.6) & 16.8 & (0.5) & 19.2 & $(0.7)$ & 18.1 & $(0.7)$ & 1.0 & (1.1) & 17.6 & (0.8) & 9.4 \\
\hline & France & 21.8 & (1.3) & 26.9 & (2.5) & 27.0 & (0.9) & 29.3 & (1.2) & 27.3 & (1.0) & 30.3 & $(0.8)$ & & $(0.7)$ & & (0.9) & 8.9 & $(0.8)$ & 1.5 \\
\hline & Germany & 27.6 & (1.2) & 25.9 & (2.2) & 21.5 & $(0.8)$ & 26.0 & (1.1) & 24.1 & (0.8) & 20.6 & $(0.7)$ & 21.9 & (0.6) & 4 & $(0.8)$ & 3 & (0.7) & 9.9 \\
\hline & Greece & 34.7 & (1.3) & 34.6 & (4.0) & 34.4 & (1.2) & 38.9 & (1.4) & 35.6 & $(1.2)$ & 39.2 & (0.9) & 38.1 & $(0.7)$ & 7 & (0.9) & 7 & $(0.8)$ & 2 \\
\hline & Hungary & 25.2 & (1.5) & 28.6 & (2.5) & 24.5 & (1.2) & 2 & $(1.2)$ & 25 & (0.9) & 27.5 & (0.9) & 26.8 & $(0.7)$ & 4 & $(0.9)$ & 8 & (0.9) & \\
\hline & Iceland & 35.0 & (4.7) & 32.5 & (2.5) & 36.7 & (2.0) & 47.5 & (2.0) & 37.3 & (2.1) & 36.6 & (0.9) & 37.1 & $(0.9)$ & 6.4 & (0.9) & 3.6 & (0.9) & 6.1 \\
\hline & Ireland & 39.0 & (2.6) & 42.0 & (4.1) & 42.1 & (1.9) & 50.1 & (1.9) & 45.0 & (1.5) & 46.5 & (1.0) & 46.1 & (1.0) & & (1.0) & 1 & (1.1) & 6.2 \\
\hline & Israel & 28.0 & (3.0) & 26.3 & (4.2) & 26.7 & (2.0) & 31.8 & (1.6) & 28.4 & (1.8) & 33.3 & $(0.8)$ & 33. & $(0.8)$ & 33.8 & $(0.8)$ & 3.4 & $(0.8)$ & 3.8 \\
\hline & Italy & 46.6 & (1.5) & 45.9 & (2.8) & 55.6 & (1.0) & 55.8 & (1.4) & 53.1 & (0.9) & 57.8 & $(0.7)$ & 5 & $(0.7)$ & 57.0 & (0.8) & 6 & (0.7) & 9.4 \\
\hline & Japan & 26.4 & (1.0) & 21.6 & (1.6) & 29.3 & (0.8) & 30.0 & (0.9) & 30.0 & $(0.8)$ & 1 & $(0.7)$ & & $(0.6)$ & & (1.0) & & (0.8) & .2 \\
\hline & Korea & 25.1 & (1.6) & 14.7 & (2.4) & 32.9 & (1.5) & 38. & (1.3) & 28.3 & (1.8) & 44.5 & (0. & 43 & $(0.8)$ & 44. & (0.9) & 5 & (0.9) & 9 \\
\hline & Latvia & 23.0 & (1.8) & 25.9 & (2.8) & 23.2 & (1.1) & 28. & (1.4) & 25 & (1. & 7 & (0. & & $(0$. & & (0.9) & & (0.8) & 5 \\
\hline & Luxembo & 22.8 & (1.5) & 24.5 & (2.2) & 24.8 & (0.9) & 26.8 & (1.1) & 25.8 & (1. & 29.0 & (0. & 28 & $(0.7)$ & 1 & (0.9) & & (0.8) & .9 \\
\hline & Mexico & 41.5 & (4.2) & 40.3 & (3.1) & 45.8 & (1.7) & 48.4 & (1.0) & 45.3 & (1.6) & 49.9 & (0.9) & 50.0 & $(0.9)$ & 2 & (0.9) & 1.3 & (1.2) & 0.6 \\
\hline & Netherlands & 12.1 & (2.1) & 18.2 & (2.9) & 12.8 & $(0.7)$ & 14.4 & (1.0) & 13.2 & $(0.7)$ & 6 & (0.6) & & $(0.6)$ & & (1.0) & & $(0.7)$ & \\
\hline & New Zealand & 43.8 & (2.2) & 38.2 & (3.2) & 42.6 & (1.9) & 48.2 & (1.5) & 46.5 & $(1.2)$ & 1.5 & $(0.8)$ & 5 & $(0.7)$ & 51. & $(0.8)$ & 1 & (0.9) & 5 \\
\hline & Norway & 41.8 & (1.8) & 36.2 & (3.4) & 43.2 & (1.3) & 47.2 & (1.6) & 4 & (1.2) & 4 & (0.9) & 4 & $(0.8)$ & & (0.9) & 3 & (0.9) & 3 \\
\hline & Poland & 23.5 & (1.1) & 26.4 & (1.7) & 24.4 & (1.2) & 33.4 & (1.6) & 2 & (1.0) & 7.2 & (0.9) & 25. & $(0.7)$ & 27. & (0.9) & 2 & $(0.8)$ & 0.7 \\
\hline & Portugal & 34.3 & (3.0) & 36.8 & (2.3) & 40.7 & (1.4) & 3 & (1.3) & 41.1 & (1.1) & 46.7 & $(0.7)$ & 46.9 & $(0.7)$ & 8 & $(0.7)$ & 3 & $(0.8)$ & 8.7 \\
\hline & Slovak Rep & 24.5 & (1.0) & 26 & (2.3) & 27.6 & (1.0) & 4 & (1.1) & 2 & $(0$. & 30.7 & (0. & & $(0$ & & $(0.8)$ & 2 & $(0.8)$ & 3 \\
\hline & Sloven & 33.3 & (1.4) & 29. & (2.2) & 33.6 & (1.2) & 36 & (1.3) & & (1. & 36 & (0.9) & & $(0$. & & (1.0) & & (1.0) & 5 \\
\hline & Spain & 44.1 & (1.6) & 44.4 & (3.0) & 48.3 & (1.3) & 51.1 & (1.1) & 48.3 & (1.2) & 49.2 & (0.9) & 48.3 & $(0.8)$ & 7.8 & (0.9) & 5.2 & (0.9) & 7.9 \\
\hline & Sweden & 33.0 & (1.5) & 31.9 & (2.3) & 38.5 & (1.5) & 2 & (1.6) & 37.3 & (1.2) & 43.0 & (0.8) & 41.7 & $(0.8)$ & 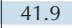 & $(0.8)$ & 8 & (0.8) & 0 \\
\hline & Switzerla & 18.2 & (1.1) & 18.2 & (1.7) & 18.9 & $(0.7)$ & 21.4 & (1.1) & 19.8 & $(0.7)$ & 21.3 & $(0.8)$ & 20.8 & $(0.7)$ & 2 & (1.1) & 0 & $(0.8)$ & 9 \\
\hline & Turkey & 33.9 & (3.2) & 34. & (3.2) & 44.6 & (2.0) & 0 & (1.4) & 3 & (2.0) & 5 & $(0$. & 5 & $(0$ & & $(0.9)$ & & (0.9) & 0 \\
\hline & United K & 46.6 & (3.6) & 42.9 & (6.4) & 42.7 & (2.0) & 55.0 & (1.7) & 48.1 & (1.4) & 52.7 & $(0.7)$ & 52.6 & $(0.7)$ & 53.6 & $(0.7)$ & 9 & $(0.7)$ & 54.0 \\
\hline & United States & 37.7 & (2.7) & 38.9 & (4.4) & 35.2 & (2.4) & 41.9 & (1.9) & 41.8 & (1.6) & 43.7 & $(0.7)$ & 43.4 & $(0.7)$ & 43.8 & $(0.8)$ & 43.5 & (0.8) & 43.5 \\
\hline & OECD average & 31.0 & (0.4) & 30.8 & (0.5) & 32.9 & $(0.2)$ & 37.3 & $(0.2)$ & 33.8 & $(0.2)$ & 37.5 & (0.1) & 36.9 & $(0.1)$ & 38.2 & $(0.1)$ & 36.2 & $(0.1)$ & 38.0 \\
\hline 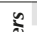 & Albania & $\mathrm{m}$ & $\mathrm{m}$ & $\mathrm{m}$ & $\mathrm{m}$ & $\mathrm{m}$ & $\mathrm{m}$ & $\mathrm{m}$ & $\mathrm{m}$ & $\mathrm{m}$ & $\mathrm{m}$ & $\mathrm{m}$ & $\mathrm{m}$ & $\mathrm{m}$ & $\pi$ & $\mathrm{m}$ & $\mathrm{m}$ & $\mathrm{m}$ & $\cdots$ & $\mathrm{m}$ \\
\hline & Algeria & $\mathrm{m}$ & $\mathrm{m}$ & $\mathrm{m}$ & $\mathrm{m}$ & $\mathrm{m}$ & $\mathrm{m}$ & $\mathrm{m}$ & $\mathrm{m}$ & $\mathrm{m}$ & $\mathrm{m}$ & $\mathrm{m}$ & $\mathrm{m}$ & $\mathrm{m}$ & 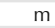 & $\mathrm{m}$ & $\mathrm{m}$ & $\mathrm{m}$ & $\mathrm{m}$ & $\mathrm{m}$ \\
\hline & Brazil & 48.5 & (2.3) & 42.6 & (2.5) & 49.7 & (1.1) & 53.9 & $(0.7)$ & 49.3 & $(0.8)$ & 6.3 & $(0.6)$ & 6.4 & $(0.6)$ & 7.4 & $(0.6)$ & 8.6 & (0.8) & 59.5 \\
\hline & B-S-J-G (China) & 44.8 & $(1.2)$ & 40.7 & (3.4) & 44.8 & (1.9) & 50.8 & (1.4) & 48.0 & (1.7) & 58.8 & (0.9) & 55.4 & $(0.8)$ & 56.1 & $(0.8)$ & 56.4 & (0.8) & 56.5 \\
\hline & Bulgaria & 36.7 & (1.3) & 29.6 & (2.7) & 41.1 & (1.0) & 43.1 & (1.7) & 38.9 & (1.1) & 48.8 & (0.9) & 47.2 & $(0.8)$ & 50.1 & (0.9) & 46.9 & (0.9) & 49.8 \\
\hline & $\mathrm{CAB}$ & $\mathrm{m}$ & $\mathrm{m}$ & $\mathrm{m}$ & $\mathrm{m}$ & $\mathrm{m}$ & $\mathrm{m}$ & $\mathrm{m}$ & $\mathrm{m}$ & $\mathrm{m}$ & $\mathrm{m}$ & $\mathrm{m}$ & $\mathrm{m}$ & $\mathrm{m}$ & $\mathrm{m}$ & $\mathrm{m}$ & $\mathrm{m}$ & $\mathrm{m}$ & $\mathrm{m}$ & $\mathrm{m}$ \\
\hline & Colo & 7.7 & (2.7) & 46.5 & (5.0) & 48.8 & (2.4) & 56.3 & (0.8) & 52.3 & (2.0) & 8.1 & $(0$. & 7.9 & $(0.7)$ & 8.4 & $(0.7)$ & 9.6 & (1.1) & 58.2 \\
\hline & Costa Ric & 40.5 & (3.8) & 34.3 & (4.8) & 49.8 & (2.0) & 53.7 & (1.1) & 46.6 & $(2.1)$ & 55.5 & (0.9) & 55.6 & $(0$. & 6.1 & (0.9) & 6.4 & (1.2) & 6.5 \\
\hline & Croatia & 31.0 & (1.1) & 28.7 & (2.3) & 32.6 & (1.1) & 34.9 & (1.3) & 31.7 & (1.1) & 38.4 & (0.9) & 36.5 & $(0.7)$ & 38.4 & $(0.8)$ & 6.6 & $(0.8)$ & 3.9 \\
\hline & Cyprus* & .5 & (1.3) & 33.3 & (3.2) & 37.5 & (1.4) & 42.0 & (1.5) & 1 & $(1$. & 40.5 & $(0.7)$ & 3 & $(0.7)$ & 8 & $(0.8)$ & 5 & (0.8) & 2 \\
\hline & Dominican Republic & 35.3 & (2.6) & 30.6 & (3.1) & 43.1 & (2.2) & 50.3 & $(0.9)$ & 36.9 & (2.3) & 55.1 & $(0.8)$ & 55.0 & $(0.9)$ & 55.4 & (1.0) & 61.2 & (1.6) & 55.2 \\
\hline & FYROM & $\mathrm{m}$ & $\mathrm{m}$ & $\mathrm{m}$ & $\mathrm{m}$ & $\mathrm{m}$ & $\mathrm{m}$ & $\mathrm{m}$ & $\mathrm{m}$ & $\mathrm{m}$ & $\mathrm{m}$ & $\mathrm{m}$ & $\mathrm{m}$ & $\mathrm{m}$ & $\mathrm{m}$ & $\mathrm{m}$ & $\mathrm{m}$ & $\mathrm{m}$ & $\mathrm{m}$ & $\mathrm{m}$ \\
\hline & Georgia & $\mathrm{m}$ & & $\mathrm{m}$ & & $\mathrm{m}$ & & $\mathrm{m}$ & & $\mathrm{m}$ & & $\mathrm{m}$ & & $\mathrm{m}$ & & $\mathrm{m}$ & & $\mathrm{m}$ & $\mathrm{n}$ & $\mathrm{m}$ \\
\hline & Hong Kong (China) & 49.5 & (2.0) & 44.5 & (3.2) & 42.6 & (1.9) & 48.4 & (1.3) & 47.4 & (1.3) & 53.1 & $(0.7)$ & 53.3 & $(0.7)$ & 54.9 & $(0.8)$ & 54.9 & (0.9) & 54.3 \\
\hline & Indonesia & $\mathrm{m}$ & $\mathrm{m}$ & $\mathrm{m}$ & $\mathrm{m}$ & $\mathrm{m}$ & $\mathrm{m}$ & $\mathrm{m}$ & $\mathrm{m}$ & $\mathrm{m}$ & $\mathrm{m}$ & $\mathrm{m}$ & $\mathrm{m}$ & $\mathrm{m}$ & $\mathrm{m}$ & $\mathrm{m}$ & $\mathrm{m}$ & $\mathrm{m}$ & $\mathrm{m}$ & $\mathrm{m}$ \\
\hline & Jordan & $\mathrm{m}$ & & $\mathrm{m}$ & & $\mathrm{m}$ & & $\mathrm{m}$ & $\mathrm{m}$ & $\mathrm{m}$ & & $\mathrm{m}$ & 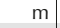 & D & $\mathrm{m}$ & $\mathrm{n}$ & $\mathrm{m}$ & $\mathrm{m}$ & $\mathrm{m}$ & $\mathrm{m}$ \\
\hline & Kosovo & $\mathrm{m}$ & $\mathrm{m}$ & $\mathrm{m}$ & $\mathrm{m}$ & $\mathrm{m}$ & $\mathrm{m}$ & $\mathrm{m}$ & $\mathrm{m}$ & $\mathrm{m}$ & $\mathrm{m}$ & $\mathrm{m}$ & $\mathrm{m}$ & $\mathrm{m}$ & $\mathrm{m}$ & $\mathrm{m}$ & $\mathrm{m}$ & $\mathrm{m}$ & $\mathrm{m}$ & $\mathrm{m}$ \\
\hline & Lebanon & $\mathrm{m}$ & & $\mathrm{m}$ & & $\mathrm{m}$ & & $\mathrm{m}$ & $\mathrm{m}$ & $\mathrm{m}$ & & $\mathrm{m}$ & $m$ & $\mathrm{~m}$ & & $\mathrm{~m}$ & $m$ & $\mathrm{~m}$ & -1 & $\mathrm{~m}$ \\
\hline & Lithuania & 3.2 & (1.9) & 34.1 & (2.4) & 41.4 & (1.3) & 38.6 & (1.3) & 39.6 & (1.3) & 44.4 & (0.8) & 43.4 & $(0.8)$ & 43.2 & (0.9) & 44.1 & (0.9) & 44.3 \\
\hline & Maca & 56.1 & (1.1) & 46.9 & (2.6) & 56.3 & $(1.2)$ & 58.2 & (1.2) & 57.8 & (1.0) & 61.0 & (1.1) & 59.8 & $(0.9)$ & 60.0 & (1.0) & 58.7 & (1.0) & 59.2 \\
\hline & Malta & $\mathrm{m}$ & $m$ & $\mathrm{~m}$ & 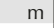 & $m$ & $\mathrm{~m}$ & 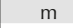 & $\mathrm{m}$ & $\mathrm{m}$ & $\mathrm{m}$ & $\mathrm{m}$ & $\mathrm{m}$ & $\mathrm{m}$ & $\mathrm{m}$ & $\mathrm{m}$ & $\mathrm{m}$ & $\mathrm{m}$ & $\mathrm{m}$ & $\mathrm{m}$ \\
\hline & Moldov & $\mathrm{m}$ & $\mathrm{m}$ & $\mathrm{m}$ & $\mathrm{m}$ & $\mathrm{m}$ & $\mathrm{m}$ & $\mathrm{m}$ & $\mathrm{m}$ & $\mathrm{m}$ & $\mathrm{m}$ & $\mathrm{m}$ & $\mathrm{m}$ & $\mathrm{m}$ & $\mathrm{m}$ & $\mathrm{m}$ & $\mathrm{m}$ & $\mathrm{m}$ & $\mathrm{m}$ & $\mathrm{m}$ \\
\hline & Mon & .7 & ) & 3 & )) & 43.3 & (1.2) & 3.2 & (1.6) & 1 & 18 & 9.4 & $(0.7)$ & 7.8 & $(0.7)$ & 3.2 & $(0.8)$ & 7.1 & 8) & 1.2 \\
\hline & Peru & .0 & (3.2) & 35 & (3.6) & 39 & (1.9) & & $(0.8)$ & 41 & (1.7) & 43.3 & (0.6) & 4 & $(0.7)$ & .5 & $(0.7)$ & 2 & (1.2) & 3.4 \\
\hline & Qata & 40.2 & (1.8) & 38.9 & (2.1) & 40.4 & (1.5) & 47.8 & (1.5) & 41.8 & (1.5) & 50.0 & $(0.5)$ & 49.9 & $(0.5)$ & 50.4 & $(0.5)$ & 49.5 & (0.5) & 50.3 \\
\hline & Rom & 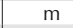 & & & & 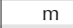 & & $m$ & & $n$ & & $\mathrm{~m}$ & & $\mathrm{~m}$ & & $\mathrm{~m}$ & & $\mathrm{~m}$ & 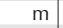 & $\mathrm{m}$ \\
\hline & Russi & 5.6 & (1.8) & 44.2 & (2.8) & 37.4 & (1.1) & 39.7 & (2.3) & 36.8 & $(1.2)$ & 39.7 & $(0.8)$ & 38.7 & $(0.8)$ & 39.4 & (0.9) & 38.7 & $(0.7)$ & 40.4 \\
\hline & & & $(2.3$ & 45.2 & (3.2) & 47.0 & (2.0) & 1 & (1.5) & 5 & (1.7) & 1.1 & (0.8) & 60.4 & $(0.7)$ & 1.5 & $(0.7)$ & 1.5 & (0.8) & 1.6 \\
\hline & & 0 & $(1.3$ & 35. & (3.6) & 52.2 & (1.1) & & & 5 & & 65.8 & $(0.7)$ & 62.3 & (0.6) & 9 & $(0.8)$ & 3.3 & $(0.7)$ & 6.9 \\
\hline & Thailand & 30.6 & (1.8) & 33.6 & (4.0) & 27.0 & (3.8) & 39.6 & (1.3) & 40.7 & (1.5) & 48.1 & (0.9) & 47.0 & $(0.9)$ & 47.2 & $(0.9)$ & 50.1 & (1.0) & 48.1 \\
\hline & Trini & $\mathrm{m}$ & & $\mathrm{m}$ & $\mathrm{m}$ & $\mathrm{m}$ & & $\mathrm{m}$ & & $\mathrm{m}$ & $\cdots$ & $\mathrm{m}$ & $\mathrm{m}$ & $\mathrm{m}$ & $\mathrm{m}$ & $\mathrm{m}$ & $\mathrm{m}$ & $\mathrm{m}$ & $\mathrm{m}$ & $\mathrm{m}$ \\
\hline & Tun & 44.3 & (4.3) & 47.2 & (4.1) & 48.9 & (2.5) & 58.2 & (2.7) & 46.7 & (3.1) & 57.7 & (0.9) & 57.5 & $(0.9)$ & 58.2 & (0.9) & 57.1 & (1.0) & 58.0 \\
\hline & Unite & 41.0 & (2.2) & 38.7 & (2.6) & 37.3 & (2.0) & 44.2 & (1.3) & 40.0 & (2.0) & 44.7 & $(0.7)$ & 44.6 & $(0.7)$ & 45.1 & $(0.7)$ & 44.4 & $(0.7)$ & 44.8 \\
\hline & Urug & 42.5 & (2.4) & 38.9 & (3.3) & 48.8 & (1.6) & 53.0 & (1.1) & 48.0 & (1.0) & 54.2 & (0.8) & 53.7 & $(0.9)$ & 54.1 & $(0.9)$ & 52.3 & (1.2) & 57.4 \\
\hline & Viet Nam & $\mathrm{m}$ & $\mathrm{m}$ & $\mathrm{m}$ & $\mathrm{m}$ & $\mathrm{m}$ & $\mathrm{m}$ & $\mathrm{m}$ & $\mathrm{m}$ & $\mathrm{m}$ & $\mathrm{m}$ & $\mathrm{m}$ & $\mathrm{m}$ & $\mathrm{m}$ & $\mathrm{m}$ & $\mathrm{m}$ & $\mathrm{m}$ & $\mathrm{m}$ & $\mathrm{m}$ & $\mathrm{m}$ \\
\hline & Argentina** & $\mathrm{m}$ & & $\mathrm{m}$ & $\mathrm{m}$ & $\mathrm{m}$ & $\mathrm{m}$ & $\mathrm{m}$ & $\mathrm{m}$ & $\mathrm{m}$ & $\mathrm{m}$ & $\mathrm{m}$ & $\mathrm{m}$ & $\mathrm{m}$ & $\mathrm{m}$ & $\mathrm{m}$ & $\mathrm{m}$ & $\mathrm{m}$ & $\mathrm{m}$ & $\mathrm{m}$ \\
\hline & & $\mathrm{m}$ & & $\mathrm{m}$ & $\mathrm{m}$ & $\mathrm{m}$ & & $\mathrm{m}$ & & $\mathrm{m}$ & & $\mathrm{m}$ & $\mathrm{n}$ & $\mathrm{m}$ & $\mathrm{m}$ & $\mathrm{m}$ & $\mathrm{m}$ & $\mathrm{m}$ & $\mathrm{m}$ & $\mathrm{m}$ \\
\hline & Mala & 55.8 & (2.8) & 48.2 & (4.3) & 52.8 & (2.7) & 59.4 & (1.9) & 57.4 & $(2.2)$ & 54.1 & (1.0) & 54.4 & $(0.9)$ & 54.3 & (1.0) & 53.6 & (1.0) & 53.9 \\
\hline
\end{tabular}

Note: Values that are statistically significant are indicated in bold (see Annex A3).

* See note at the beginning of this Annex.

** Coverage is too small to ensure comparability (see Annex A4).

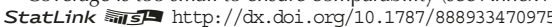


Percentage of students who reported that they "agree"|"strongly agree" or "disagree"I"strongly disagree"

"I get very tense when I study"

\begin{tabular}{|c|c|c|c|c|c|c|c|c|c|c|}
\hline & & ifference & tween the & tages of st & ts who a & nd thos & disagree & he follo & statemen & \\
\hline & $\begin{array}{l}\text { I want to to } \\
\text { or all }\end{array}$ & $\begin{array}{l}s \text { in most } \\
\text { ourses }\end{array}$ & $\begin{array}{l}\text { I want to } \\
\text { from a } \\
\text { opportu } \\
\text { wher }\end{array}$ & $\begin{array}{l}\text { to select } \\
\text { he best } \\
\text { vailable } \\
\text { uate }\end{array}$ & $\begin{array}{l}\text { I want } \\
\text { wh }\end{array}$ & $\begin{array}{l}\text { e best, } \\
\text { do }\end{array}$ & $\begin{array}{r}\text { I se } \\
\text { a am }\end{array}$ & $\begin{array}{l}\text { f as } \\
\text { eerson }\end{array}$ & be one of & students \\
\hline & $\%$ dif. & S.E. & $\%$ dif. & S.E. & $\%$ dif. & S.E. & $\%$ dif. & S.E. & $\%$ dif. & S.E. \\
\hline Australia & 9.1 & $(1.8)$ & 13.2 & $(2.8)$ & 7.3 & $(1.3)$ & 2.1 & $(1.3)$ & 6.7 & $(0.9)$ \\
\hline Austria & -2.1 & (1.4) & -1.7 & $(2.0)$ & 2.7 & (1.1) & -5.7 & $(1.2)$ & -0.7 & (1.1) \\
\hline 0 Belgium & 9.0 & (1.0) & 4.8 & (1.6) & 7.0 & $(1.1)$ & 0.1 & $(1.0)$ & 4.0 & (1.0) \\
\hline Canada & 7.0 & (1.6) & 11.0 & $(2.3)$ & 5.3 & (1.2) & 0.8 & $(1.2)$ & 4.2 & (1.3) \\
\hline Chile & 5.8 & $(2.3)$ & 3.9 & (3.3) & 6.5 & (1.9) & -0.2 & (1.4) & 1.6 & (1.4) \\
\hline Czech Republic & 6.5 & (1.6) & 1.9 & (2.5) & 2.2 & (1.6) & -4.9 & (1.4) & 2.3 & (1.3) \\
\hline Denmark & 5.5 & (1.5) & 1.5 & (1.8) & 4.7 & (1.3) & -0.6 & (2.0) & 1.6 & (1.5) \\
\hline Estonia & 4.6 & (2.6) & 2.8 & (3.1) & 5.4 & (1.4) & -5.4 & (1.5) & 0.3 & (1.3) \\
\hline Finland & 3.6 & $(0.9)$ & 2.1 & $(1.2)$ & 5.0 & $(1.2)$ & -0.2 & $(1.0)$ & 2.6 & (1.0) \\
\hline France & 8.6 & (1.5) & 2.3 & (2.6) & 4.4 & $(1.2)$ & -0.3 & $(1.3)$ & 4.2 & (1.2) \\
\hline Germany & -6.9 & $(1.3)$ & -4.1 & $(2.3)$ & 1.9 & (1.1) & -5.8 & $(1.2)$ & -4.2 & (1.2) \\
\hline Greece & 4.5 & (1.6) & 3.4 & $(4.2)$ & 5.3 & (1.5) & -1.2 & (1.7) & 3.7 & (1.5) \\
\hline Hungary & 2.3 & (1.8) & -1.8 & (2.5) & 3.9 & (1.4) & -0.1 & (1.4) & 4.7 & (1.5) \\
\hline Iceland & 1.6 & (4.9) & 4.6 & (2.6) & -0.3 & (2.1) & -13.9 & $(2.2)$ & -1.2 & (2.4) \\
\hline Ireland & 7.4 & $(2.7)$ & 4.1 & $(4.1)$ & 4.4 & (1.9) & -5.0 & (2.0) & 1.2 & (1.5) \\
\hline Israel & 5.4 & (3.1) & 7.1 & $(4.3)$ & 7.1 & (2.1) & 1.6 & (1.7) & 5.4 & (1.9) \\
\hline Italy & 11.1 & (1.6) & 11.0 & (3.1) & 1.4 & (1.1) & 0.8 & (1.6) & 6.3 & (1.2) \\
\hline Japan & 9.7 & $(1.2)$ & 12.7 & (1.7) & 8.9 & (1.4) & 4.7 & $(1.2)$ & 8.2 & (1.4) \\
\hline Korea & 19.4 & (1.8) & 28.3 & $(2.7)$ & 11.3 & (1.8) & 5.0 & (1.5) & 16.7 & (2.1) \\
\hline Latvia & 4.7 & (2.0) & 1.2 & (2.9) & 5.9 & (1.4) & -2.3 & (1.6) & 3.2 & (1.3) \\
\hline Luxembourg & 6.3 & (1.6) & 3.7 & $(2.2)$ & 6.3 & (1.2) & 1.2 & (1.3) & 4.1 & (1.3) \\
\hline Mexico & 8.4 & $(4.2)$ & 9.7 & (3.1) & 4.5 & (1.8) & 2.9 & (1.4) & 5.3 & (1.5) \\
\hline Netherlands & 2.6 & (2.1) & -4.0 & (3.0) & 4.5 & (1.3) & 0.0 & $(1.2)$ & 4.4 & (1.3) \\
\hline New Zealand & 7.7 & (2.4) & 13.1 & (3.3) & 9.3 & (2.1) & 2.9 & (2.0) & 5.9 & (1.5) \\
\hline Norway & 4.6 & $(2.0)$ & 9.9 & (3.5) & 3.7 & (1.3) & -2.4 & (1.7) & 4.8 & (1.3) \\
\hline Poland & 3.7 & $(1.3)$ & -0.5 & $(1.7)$ & 2.5 & (1.4) & -10.3 & (1.9) & -0.3 & (1.5) \\
\hline Portugal & 12.4 & (3.0) & 10.1 & (2.3) & 7.1 & (1.6) & 3.9 & (1.6) & 7.7 & (1.5) \\
\hline Slovak Republic & 6.2 & (1.3) & 3.2 & (2.3) & 2.0 & (1.3) & -2.2 & (1.3) & 7.8 & (1.1) \\
\hline Slovenia & 3.5 & (1.7) & 7.8 & (2.2) & 4.2 & (1.5) & -1.2 & (1.6) & 1.4 & (1.4) \\
\hline Spain & 5.0 & (1.8) & 3.9 & (3.1) & -0.4 & (1.5) & -6.0 & (1.3) & -0.4 & (1.6) \\
\hline Sweden & 10.0 & (1.7) & 9.8 & (2.5) & 3.5 & (1.7) & -0.4 & (1.9) & 5.7 & (1.6) \\
\hline Switzerland & 3.1 & (1.3) & 2.5 & (1.8) & 4.0 & $(1.2)$ & -1.4 & $(1.3)$ & 2.1 & (1.1) \\
\hline Turkey & 23.6 & (3.5) & 22.5 & (3.4) & 13.3 & (2.1) & 5.4 & (1.6) & 18.4 & (2.3) \\
\hline United Kingdom & 6.1 & (3.7) & 9.7 & (6.5) & 10.9 & $(2.3)$ & -3.2 & (1.8) & 5.9 & (1.7) \\
\hline United States & 6.0 & $(2.7)$ & 4.6 & (4.4) & 8.6 & (2.5) & 1.6 & (2.1) & 1.7 & (1.7) \\
\hline OECD average & 6.5 & $(0.4)$ & 6.1 & $(0.5)$ & 5.3 & $(0.3)$ & -1.1 & $(0.3)$ & 4.2 & $(0.2)$ \\
\hline
\end{tabular}

\begin{tabular}{|c|c|c|c|c|c|c|c|c|c|c|}
\hline Albania & $\mathrm{m}$ & $\mathrm{m}$ & $\mathrm{m}$ & $\mathrm{m}$ & $\mathrm{m}$ & $\mathrm{m}$ & $\mathrm{m}$ & $\mathrm{m}$ & $\mathrm{m}$ & $\mathrm{m}$ \\
\hline$§$ Algeria & $\mathrm{m}$ & $\mathrm{m}$ & $\mathrm{m}$ & $\mathrm{m}$ & $\mathrm{m}$ & $\mathrm{m}$ & $\mathrm{m}$ & $\mathrm{m}$ & $\mathrm{m}$ & $\mathrm{m}$ \\
\hline Brazil & 7.7 & $(2.3)$ & 13.7 & (2.5) & 7.8 & (1.1) & 4.7 & $(1.0)$ & 10.2 & (1.0) \\
\hline B-S-J-G (China) & 14.0 & (1.4) & 14.8 & (3.5) & 11.3 & (1.9) & 5.7 & (1.5) & 8.5 & (1.7) \\
\hline Bulgaria & 12.1 & (1.6) & 17.6 & (2.9) & 9.0 & (1.3) & 3.7 & (1.9) & 10.9 & $(1.3)$ \\
\hline CABA (Argentina) & $\mathrm{m}$ & $\mathrm{m}$ & $\mathrm{m}$ & $\mathrm{m}$ & $\mathrm{m}$ & $\mathrm{m}$ & $\mathrm{m}$ & $\mathrm{m}$ & $\mathrm{m}$ & $\mathrm{m}$ \\
\hline Colombia & 10.4 & $(2.7)$ & 11.4 & $(5.0)$ & 9.7 & (2.6) & 3.3 & (1.3) & 6.0 & $(2.1)$ \\
\hline Costa Rica & 15.1 & $(4.1)$ & 21.3 & (5.2) & 6.3 & (2.0) & 2.7 & (1.5) & 9.9 & (2.3) \\
\hline Croatia & 7.5 & (1.4) & 7.8 & (2.4) & 5.8 & (1.3) & 1.7 & (1.4) & 7.2 & (1.3) \\
\hline Cyprus* & 3.0 & (1.6) & 7.0 & (3.4) & 3.3 & (1.7) & -2.4 & (1.8) & 1.1 & (1.7) \\
\hline Dominican Republic & 19.8 & $(2.6)$ & 24.4 & (3.2) & 12.3 & (2.5) & 10.8 & (1.8) & 18.2 & (2.5) \\
\hline FYROM & $\mathrm{m}$ & $\mathrm{m}$ & $\mathrm{m}$ & $\mathrm{m}$ & $\mathrm{m}$ & $\mathrm{m}$ & $\mathrm{m}$ & $\mathrm{m}$ & $\mathrm{m}$ & $\mathrm{m}$ \\
\hline Georgia & $\mathrm{m}$ & $\mathrm{m}$ & $\mathrm{m}$ & $\mathrm{m}$ & $\mathrm{m}$ & $\mathrm{m}$ & $\mathrm{m}$ & $\mathrm{m}$ & $\mathrm{m}$ & $\mathrm{m}$ \\
\hline Hong Kong (China) & 3.6 & $(2.1)$ & 8.8 & (3.3) & 12.2 & (2.1) & 6.4 & (1.6) & 6.9 & (1.6) \\
\hline Indonesia & $\mathrm{m}$ & $\mathrm{m}$ & $\mathrm{m}$ & $\mathrm{m}$ & $\mathrm{m}$ & $\mathrm{m}$ & $\mathrm{m}$ & $\mathrm{m}$ & $\mathrm{m}$ & $\mathrm{m}$ \\
\hline Jordan & $\mathrm{m}$ & $\mathrm{m}$ & $\mathrm{m}$ & $\mathrm{m}$ & $\mathrm{m}$ & $\mathrm{m}$ & $\mathrm{m}$ & $\mathrm{m}$ & $\mathrm{m}$ & $\mathrm{m}$ \\
\hline Kosovo & $\mathrm{m}$ & $\mathrm{m}$ & $\mathrm{m}$ & $\mathrm{m}$ & $\mathrm{m}$ & $\mathrm{m}$ & $\mathrm{m}$ & $\mathrm{m}$ & $\mathrm{m}$ & $\mathrm{m}$ \\
\hline Lebanon & $\mathrm{m}$ & $\mathrm{m}$ & $\mathrm{m}$ & $\mathrm{m}$ & $\mathrm{m}$ & $\mathrm{m}$ & $\mathrm{m}$ & $\mathrm{m}$ & $\mathrm{m}$ & $\mathrm{m}$ \\
\hline Lithuania & 11.2 & (2.0) & 9.4 & (2.4) & 1.8 & (1.4) & 5.5 & (1.5) & 4.8 & (1.5) \\
\hline Macao (China) & 4.9 & (1.5) & 12.9 & $(2.7)$ & 3.7 & (1.4) & 0.5 & (1.5) & 1.4 & (1.3) \\
\hline Malta & $\mathrm{m}$ & $\mathrm{m}$ & $\mathrm{m}$ & $\mathrm{m}$ & $\mathrm{m}$ & $\mathrm{m}$ & $\mathrm{m}$ & $\mathrm{m}$ & $\mathrm{m}$ & $\mathrm{m}$ \\
\hline Moldova & $\mathrm{m}$ & $\mathrm{m}$ & $\mathrm{m}$ & $\mathrm{m}$ & $\mathrm{m}$ & $\mathrm{m}$ & $\mathrm{m}$ & $\mathrm{m}$ & $\mathrm{m}$ & $\mathrm{m}$ \\
\hline Montenegro & 11.7 & (1.5) & 16.4 & (2.4) & 4.9 & (1.5) & 3.9 & (1.9) & 10.1 & (1.6) \\
\hline Peru & 6.3 & (3.3) & 8.3 & (3.7) & 3.9 & (2.0) & 1.9 & (1.5) & 2.4 & (1.8) \\
\hline Qatar & 9.7 & (1.8) & 11.0 & $(2.1)$ & 10.0 & (1.5) & 1.7 & (1.5) & 8.5 & (1.5) \\
\hline Romania & $\mathrm{m}$ & $\mathrm{m}$ & $\mathrm{m}$ & $\mathrm{m}$ & $\mathrm{m}$ & $\mathrm{m}$ & $\mathrm{m}$ & $\mathrm{m}$ & $\mathrm{m}$ & $\mathrm{m}$ \\
\hline Russia & 4.0 & (2.0) & -5.5 & (2.9) & 2.0 & (1.3) & -1.0 & (2.4) & 3.6 & (1.4) \\
\hline Singapore & 10.6 & (2.4) & 15.2 & (3.2) & 14.5 & (2.1) & 6.4 & (1.6) & 10.1 & (1.7) \\
\hline Chinese Taipei & 20.8 & (1.6) & 27.3 & (3.7) & 13.7 & (1.5) & 6.9 & (1.1) & 16.8 & (1.2) \\
\hline Thailand & 17.5 & (2.1) & 13.5 & (4.1) & 20.2 & (3.9) & 10.6 & (1.6) & 7.4 & (1.7) \\
\hline Trinidad and Tobago & $\mathrm{m}$ & $\mathrm{m}$ & $\mathrm{m}$ & $\mathrm{m}$ & $\mathrm{m}$ & $\mathrm{m}$ & $\mathrm{m}$ & $\mathrm{m}$ & $\mathrm{m}$ & $\mathrm{m}$ \\
\hline Tunisia & 13.4 & (4.3) & 10.4 & (4.1) & 9.3 & (2.4) & -1.1 & (2.9) & 11.3 & (3.1) \\
\hline United Arab Emirates & 3.6 & (2.3) & 5.9 & (2.7) & 7.7 & (2.0) & 0.2 & (1.4) & 4.8 & (2.1) \\
\hline Uruguay & 11.8 & (2.5) & 14.8 & (3.4) & 5.3 & (1.8) & -0.7 & (1.6) & 9.4 & (1.3) \\
\hline Viet Nam & $\mathrm{m}$ & $\mathrm{m}$ & $\mathrm{m}$ & $\mathrm{m}$ & $\mathrm{m}$ & $\mathrm{m}$ & $\mathrm{m}$ & $\mathrm{m}$ & $\mathrm{m}$ & $\mathrm{m}$ \\
\hline Argentina** & $\mathrm{m}$ & $\mathrm{m}$ & $\mathrm{m}$ & $\mathrm{m}$ & $\mathrm{m}$ & $\mathrm{m}$ & $\mathrm{m}$ & $\mathrm{m}$ & $\mathrm{m}$ & $\mathrm{m}$ \\
\hline Kazakhstan** & $\mathrm{m}$ & $\mathrm{m}$ & $\mathrm{m}$ & $\mathrm{m}$ & $\mathrm{m}$ & $\mathrm{m}$ & $\mathrm{m}$ & $\mathrm{m}$ & $\mathrm{m}$ & $\mathrm{m}$ \\
\hline Malaysia** & -1.7 & (2.9) & 6.1 & (4.3) & 1.5 & (2.8) & -5.8 & $(2.1)$ & -3.5 & (2.3) \\
\hline
\end{tabular}

Note: Values that are statistically significant are indicated in bold (see Annex A3).

* See note at the beginning of this Annex.

** Coverage is too small to ensure comparability (see Annex A4)

StatLink त्ना5 http://dx.doi.org/10.1787/888933470975 
[Part 1/1]

Table III.6.1 Students' expectations of further education

Percentage of students who expect to complete different levels of education

\begin{tabular}{|c|c|c|c|c|c|c|c|c|c|c|c|c|c|c|c|c|c|}
\hline & \multicolumn{12}{|c|}{ Students' expectations of further education } & & ents' e & Ication & \\
\hline & & $\begin{array}{l}\text { ISCE } \\
\text { (lower } \\
\text { edu }\end{array}$ & $\begin{array}{l}\text { evel } 2 \\
\text { ondary } \\
\text { ion) }\end{array}$ & \begin{tabular}{|} 
ISCED \\
(upper \\
voca \\
ori \\
edu \\
provid \\
acces \\
labou \\
or to I \\
progr
\end{tabular} & $\begin{array}{l}\text { vel 3B } \\
\text { ondary, } \\
\text { ondally } \\
\text { nalled } \\
\text { ed } \\
\text { ion } \\
\text { direct } \\
\text { o the } \\
\text { arket } \\
\text { ED 5B } \\
\text { imes) }\end{array}$ & $\begin{array}{l}\text { ISCED } \\
\text { (upper } \\
\text { acade } \\
\text { ori } \\
\text { edu } \\
\text { providi } \\
\text { to IS } \\
\text { progr }\end{array}$ & $\begin{array}{l}\text { vel 3A } \\
\text { condary, } \\
\text { ically } \\
\text { ted } \\
\text { tion } \\
\text { access } \\
\text { D 5A } \\
\text { imes) }\end{array}$ & $\begin{array}{c}\text { ISCEE } \\
\text { (non- } \\
\text { post-s } \\
\text { progr }\end{array}$ & $\begin{array}{l}\text { evel } 4 \\
\text { tiary } \\
\text { ondary } \\
\text { imes) }\end{array}$ & $\begin{array}{r}\text { ISCED } \\
\text { (vocat } \\
\text { tech } \\
\text { oriente } \\
\text { educ }\end{array}$ & $\begin{array}{l}\text { vel 5B } \\
\text { nally/ } \\
\text { cally } \\
\text { ertiary } \\
\text { ion) }\end{array}$ & $\begin{array}{c}\text { ISCED } \\
\text { (unive } \\
\text { tertiary } \\
\text { or ac } \\
\text { res } \\
\text { prog }\end{array}$ & $\begin{array}{l}\text { el } 5 \mathrm{~A} \\
\text { y level } \\
\text { ucation } \\
\text { nced } \\
\text { ch } \\
\text { mes) }\end{array}$ & ISCE & evel 2 & ISCED & vel $3 \mathrm{~A}$ \\
\hline & & $\%$ & S.E. & $\%$ & S.E. & $\%$ & S.E. & $\%$ & S.E. & $\%$ & S.E. & $\%$ & S.E. & $\%$ & S.E. & $\%$ & S.E. \\
\hline & Australia & 2.8 & $(0.1)$ & 4.7 & $(0.2)$ & 30.5 & $(0.5)$ & 4.6 & $(0.2)$ & 3.2 & $(0.2)$ & 54.2 & $(0.6)$ & 86.0 & $(0.4)$ & 14.0 & $(0.4)$ \\
\hline & Austria & 2.0 & $(0.3)$ & 21.9 & $(0.8)$ & 39.7 & $(0.8)$ & 2.0 & $(0.4)$ & 7.3 & $(0.4)$ & 27.1 & $(0.8)$ & 2.0 & $(0.6)$ & 98.0 & $(0.6)$ \\
\hline 0 & Belgium & 2.9 & $(0.2)$ & 7.9 & $(0.4)$ & 16.0 & $(0.5)$ & 12.8 & $(0.6)$ & 27.5 & (0.6) & 32.9 & $(0.9)$ & 9.3 & $(0.6)$ & 90.7 & $(0.6)$ \\
\hline & Canada & 1.3 & $(0.1)$ & 0.0 & c & 11.7 & $(0.4)$ & 7.2 & $(0.3)$ & 16.4 & $(0.5)$ & 63.5 & $(0.8)$ & 11.6 & $(0.6)$ & 88.4 & $(0.6)$ \\
\hline & Chile & 0.7 & $(0.2)$ & 11.3 & $(0.6)$ & 5.9 & $(0.4)$ & 2.3 & $(0.2)$ & 13.3 & (0.6) & 66.6 & (1.0) & 5.8 & $(0.8)$ & 94.2 & $(0.8)$ \\
\hline & Czech Republic & 0.5 & $(0.1)$ & 7.9 & $(0.5)$ & 28.4 & $(0.8)$ & 0.0 & $\mathrm{C}$ & 7.5 & $(0.4)$ & 55.6 & $(0.8)$ & 54.4 & (1.2) & 45.6 & $(1.2)$ \\
\hline & Denmark & 21.6 & $(0.7)$ & 7.9 & $(0.5)$ & 29.9 & $(0.9)$ & 0.0 & c & 3.4 & $(0.3)$ & 37.2 & (1.0) & 99.3 & $(0.4)$ & 0.7 & $(0.4)$ \\
\hline & Estonia & 4.0 & $(0.3)$ & 7.6 & $(0.4)$ & 13.3 & $(0.6)$ & 10.3 & $(0.5)$ & 22.1 & $(0.6)$ & 42.8 & (1.0) & 98.7 & $(0.3)$ & 1.3 & $(0.3)$ \\
\hline & Finland & 15.7 & $(0.6)$ & 0.0 & c & 38.8 & $(0.7)$ & 4.7 & $(0.3)$ & 13.7 & $(0.5)$ & 27.1 & (1.1) & 99.8 & $(0.1)$ & 0.2 & $(0.1)$ \\
\hline & France & 9.6 & $(0.4)$ & 19.6 & $(0.7)$ & 27.1 & $(0.8)$ & 0.0 & $\mathrm{C}$ & 11.7 & (0.5) & 32.0 & (0.9) & 24.1 & (0.6) & 75.9 & $(0.6)$ \\
\hline & Germany & 34.5 & $(1.2)$ & 2.6 & $(0.2)$ & 39.8 & $(0.9)$ & 3.8 & $(0.3)$ & 1.5 & $(0.2)$ & 17.8 & $(0.9)$ & 96.2 & $(0.8)$ & 3.8 & $(0.8)$ \\
\hline & Greece & 1.5 & $(0.2)$ & 8.4 & (1.1) & 6.2 & $(0.3)$ & 7.1 & $(0.5)$ & 10.6 & $(0.9)$ & 66.3 & $(1.9)$ & 4.7 & $(0.9)$ & 95.3 & $(0.9)$ \\
\hline & Hungary & 6.4 & $(0.6)$ & 28.6 & (0.9) & 11.7 & $(0.5)$ & 11.6 & $(0.6)$ & 6.3 & $(0.4)$ & 35.5 & (1.1) & 10.2 & $(0.5)$ & 89.8 & $(0.5)$ \\
\hline & Iceland & 6.1 & $(0.4)$ & 20.4 & $(0.6)$ & 8.3 & $(0.4)$ & 9.8 & $(0.5)$ & 16.5 & $(0.7)$ & 38.9 & $(0.8)$ & 100.0 & C & 0.0 & c \\
\hline & Ireland & 12.4 & $(0.5)$ & 4.6 & $(0.4)$ & 14.1 & $(0.6)$ & 3.8 & $(0.3)$ & 18.8 & $(0.5)$ & 46.3 & (0.8) & 62.4 & $(0.8)$ & 37.6 & $(0.8)$ \\
\hline & Israel & 1.1 & $(0.2)$ & 2.5 & $(0.3)$ & 28.0 & $(0.9)$ & 2.7 & $(0.2)$ & 8.7 & $(0.5)$ & 57.0 & (1.2) & 10.9 & (1.0) & 89.1 & $(1.0)$ \\
\hline & Italy & 2.1 & $(0.2)$ & 3.8 & $(0.3)$ & 26.1 & $(1.0)$ & 9.1 & $(0.5)$ & 20.6 & $(0.7)$ & 38.3 & $(1.2)$ & 1.1 & $(0.3)$ & 98.9 & $(0.3)$ \\
\hline & Japan & $\mathrm{m}$ & $\mathrm{m}$ & 12.0 & $(0.9)$ & 10.9 & $(0.6)$ & $\mathrm{m}$ & $\mathrm{m}$ & 18.5 & $(0.7)$ & 58.7 & $(1.1)$ & $\mathrm{m}$ & $\mathrm{m}$ & 100.0 & $(0.0)$ \\
\hline & Korea & 0.4 & $(0.1)$ & 6.8 & $(0.5)$ & 3.2 & $(0.3)$ & 0.0 & C & 14.3 & $(0.6)$ & 75.3 & (0.9) & 9.1 & $(0.8)$ & 90.9 & $(0.8)$ \\
\hline & Latvia & 3.8 & $(0.3)$ & 14.1 & $(0.6)$ & 9.6 & $(0.5)$ & 11.2 & (0.5) & 36.5 & $(0.8)$ & 24.7 & $(0.8)$ & 96.3 & $(0.5)$ & 3.7 & $(0.5)$ \\
\hline & Luxembourg & 7.4 & $(0.4)$ & 17.5 & (0.5) & 16.9 & $(0.5)$ & 5.2 & $(0.3)$ & 11.5 & (0.4) & 41.4 & (0.6) & 56.5 & $(0.1)$ & 43.5 & $(0.1)$ \\
\hline & Mexico & 5.5 & $(0.5)$ & 2.8 & $(0.2)$ & 16.9 & $(0.6)$ & 0.0 & C & 16.4 & (0.5) & 58.4 & (1.0) & 39.0 & (1.6) & 61.0 & (1.6) \\
\hline & Netherlands & 13.2 & $(0.6)$ & 0.0 & C & 13.1 & $(0.5)$ & 28.9 & $(0.6)$ & 27.3 & $(0.8)$ & 17.4 & $(0.7)$ & 70.5 & $(0.6)$ & 29.5 & $(0.6)$ \\
\hline & New Zealand & 3.0 & $(0.3)$ & 14.0 & $(0.6)$ & 23.8 & $(0.9)$ & 5.1 & $(0.4)$ & 8.8 & $(0.5)$ & 45.2 & (1.0) & 6.2 & $(0.3)$ & 93.8 & $(0.3)$ \\
\hline & Norway & 3.1 & $(0.3)$ & 17.5 & $(0.6)$ & 7.0 & $(0.4)$ & 11.1 & $(0.5)$ & 37.3 & $(0.8)$ & 24.1 & $(0.7)$ & 99.9 & $(0.1)$ & 0.1 & $(0.1)$ \\
\hline & Poland & 1.6 & $(0.2)$ & 5.9 & $(0.4)$ & 27.9 & $(0.9)$ & 15.6 & $(0.6)$ & 0.9 & $(0.1)$ & 48.0 & (1.1) & 99.4 & $(0.2)$ & 0.6 & $(0.2)$ \\
\hline & Portugal & 6.1 & $(0.3)$ & 21.2 & $(0.9)$ & 8.2 & $(0.5)$ & 2.7 & $(0.2)$ & 21.8 & $(0.6)$ & 39.9 & $(1.2)$ & 34.7 & (1.3) & 65.3 & (1.3) \\
\hline & Slovak Republic & $\mathrm{m}$ & $\mathrm{m}$ & $\mathrm{m}$ & $\mathrm{m}$ & $\mathrm{m}$ & $\mathrm{m}$ & $\mathrm{m}$ & $\mathrm{m}$ & $\mathrm{m}$ & $\mathrm{m}$ & $\mathrm{m}$ & $\mathrm{m}$ & 47.4 & (1.1) & 52.6 & (1.1) \\
\hline & Slovenia & 1.9 & $(0.3)$ & 34.7 & $(0.7)$ & 7.2 & $(0.4)$ & 4.0 & $(0.3)$ & 26.3 & $(0.7)$ & 25.8 & $(0.6)$ & 5.1 & $(0.4)$ & 94.9 & $(0.4)$ \\
\hline & Spain & 13.0 & $(0.6)$ & 7.7 & $(0.4)$ & 15.5 & $(0.5)$ & 0.0 & C & 12.9 & $(0.4)$ & 51.0 & (1.0) & 99.9 & $(0.1)$ & 0.1 & $(0.1)$ \\
\hline & Sweden & 7.6 & $(0.4)$ & 18.6 & $(0.8)$ & 14.4 & $(0.5)$ & 0.5 & $(0.1)$ & 20.2 & $(0.5)$ & 38.7 & $(1.0)$ & 98.1 & $(0.7)$ & 1.9 & $(0.7)$ \\
\hline & Switzerland & 11.4 & $(0.6)$ & 29.8 & (1.0) & 17.4 & $(0.7)$ & 3.7 & $(0.3)$ & 10.7 & $(0.4)$ & 27.0 & (1.0) & 77.0 & $(1.2)$ & 23.0 & $(1.2)$ \\
\hline & Turkey & 2.1 & $(0.3)$ & 15.1 & $(0.8)$ & 7.0 & $(0.4)$ & 0.0 & c & 5.3 & $(0.3)$ & 70.6 & (1.1) & 3.2 & $(0.5)$ & 96.8 & $(0.5)$ \\
\hline & United Kingdom & 1.4 & $(0.2)$ & 27.4 & $(0.8)$ & 18.2 & $(0.5)$ & 0.6 & $(0.1)$ & 10.6 & $(0.4)$ & 41.8 & $(0.9)$ & 0.2 & $(0.1)$ & 99.8 & $(0.1)$ \\
\hline & United States & 0.5 & $(0.1)$ & 0.0 & c & 12.1 & $(0.6)$ & 4.2 & $(0.3)$ & 7.2 & $(0.4)$ & 76.0 & $(0.8)$ & 10.2 & $(0.7)$ & 89.8 & $(0.7)$ \\
\hline & OECD average & 6.1 & $(0.1)$ & 11.9 & $(0.1)$ & 17.8 & $(0.1)$ & 5.4 & $(0.1)$ & 14.6 & $(0.1)$ & 44.2 & $(0.2)$ & 46.5 & $(0.1)$ & 53.5 & $(0.1)$ \\
\hline$\approx$ & Albania & $\mathrm{m}$ & $\mathrm{m}$ & $\mathrm{m}$ & $\mathrm{m}$ & $\mathrm{m}$ & $\mathrm{m}$ & $\mathrm{m}$ & $\mathrm{m}$ & $\mathrm{m}$ & $\mathrm{m}$ & $\mathrm{m}$ & $\mathrm{m}$ & 37.0 & (2.3) & 63.0 & (2.3) \\
\hline$\div$ & Algeria & $\mathrm{m}$ & $\mathrm{m}$ & $\mathrm{m}$ & $\mathrm{m}$ & $\mathrm{m}$ & $\mathrm{m}$ & $\mathrm{m}$ & $\mathrm{m}$ & $\mathrm{m}$ & $\mathrm{m}$ & $\mathrm{m}$ & $\mathrm{m}$ & 76.9 & (2.5) & 23.1 & (2.5) \\
\hline సั้ & Brazil & 3.5 & $(0.2)$ & 5.3 & $(0.2)$ & 26.6 & $(0.6)$ & 9.4 & $(0.3)$ & 9.0 & $(0.3)$ & 46.2 & $(0.6)$ & 22.3 & $(0.8)$ & 77.7 & $(0.8)$ \\
\hline 0 & B-S-J-G (China) & 11.9 & $(1.0)$ & 14.6 & $(0.9)$ & 13.3 & $(0.6)$ & 7.2 & $(0.4)$ & 15.3 & $(0.8)$ & 37.7 & (1.8) & 63.0 & $(2.0)$ & 37.0 & $(2.0)$ \\
\hline & Bulgaria & 3.3 & $(0.4)$ & 13.8 & $(0.8)$ & 7.2 & $(0.5)$ & 12.8 & $(0.5)$ & 23.5 & $(0.6)$ & 39.4 & (1.1) & 3.1 & $(0.7)$ & 96.9 & $(0.7)$ \\
\hline & CABA (Argentina) & $\mathrm{m}$ & $\mathrm{m}$ & $\mathrm{m}$ & $\mathrm{m}$ & $\mathrm{m}$ & $\mathrm{m}$ & $\mathrm{m}$ & $\mathrm{m}$ & $\mathrm{m}$ & $\mathrm{m}$ & $\mathrm{m}$ & $\mathrm{m}$ & 92.5 & (2.3) & 7.5 & $(2.3)$ \\
\hline & Colombia & 1.8 & $(0.2)$ & 0.0 & $\mathrm{C}$ & 13.9 & $(0.6)$ & 0.0 & c & 8.1 & $(0.4)$ & 76.3 & $(0.9)$ & 40.3 & $(1.0)$ & 59.7 & $(1.0)$ \\
\hline & Costa Rica & 2.3 & $(0.3)$ & 8.8 & $(0.5)$ & 6.5 & $(0.3)$ & 7.2 & $(0.4)$ & 20.7 & $(0.7)$ & 54.4 & $(0.8)$ & 53.2 & (1.6) & 46.8 & (1.6) \\
\hline & Croatia & 0.2 & $(0.1)$ & 12.9 & $(0.8)$ & 19.2 & $(0.7)$ & 19.2 & $(0.6)$ & 12.4 & $(0.5)$ & 36.1 & $(1.0)$ & 0.2 & $(0.2)$ & 99.8 & $(0.2)$ \\
\hline & Cyprus* & 1.6 & $(0.2)$ & 6.3 & $(0.2)$ & 5.3 & $(0.3)$ & 5.8 & $(0.3)$ & 3.2 & $(0.2)$ & 77.8 & $(0.5)$ & 6.1 & $(0.1)$ & 93.9 & $(0.1)$ \\
\hline & Dominican Republic & 7.4 & $(0.6)$ & 8.6 & $(0.5)$ & 17.2 & $(0.8)$ & 2.3 & $(0.3)$ & 1.1 & $(0.2)$ & 63.5 & $(1.0)$ & 20.9 & (1.4) & 79.1 & (1.4) \\
\hline & FYROM & $\mathrm{m}$ & $\mathrm{m}$ & $\mathrm{m}$ & $\mathrm{m}$ & $\mathrm{m}$ & $\mathrm{m}$ & $\mathrm{m}$ & $\mathrm{m}$ & $\mathrm{m}$ & $\mathrm{m}$ & $\mathrm{m}$ & $\mathrm{m}$ & 0.2 & $(0.2)$ & 99.8 & $(0.2)$ \\
\hline & Georgia & $\mathrm{m}$ & $\mathrm{m}$ & $\mathrm{m}$ & $\mathrm{m}$ & $\mathrm{m}$ & $\mathrm{m}$ & $\mathrm{m}$ & $\mathrm{m}$ & $\mathrm{m}$ & $\mathrm{m}$ & $\mathrm{m}$ & $\mathrm{m}$ & 22.5 & $(0.9)$ & 77.5 & $(0.9)$ \\
\hline & Hong Kong (China) & 2.1 & $(0.3)$ & 2.3 & $(0.2)$ & 13.4 & $(0.6)$ & 11.5 & $(0.6)$ & 15.9 & $(0.6)$ & 54.9 & (1.1) & 32.7 & $(0.9)$ & 67.3 & $(0.9)$ \\
\hline & Indonesia & $\mathrm{m}$ & $\mathrm{m}$ & $\mathrm{m}$ & m & $\mathrm{m}$ & m & $\mathrm{m}$ & $\mathrm{m}$ & $\mathrm{m}$ & $\mathrm{m}$ & $\mathrm{m}$ & $\mathrm{m}$ & 52.2 & $(1.7)$ & 47.8 & $(1.7)$ \\
\hline & Jordan & $\mathrm{m}$ & $\mathrm{m}$ & $\mathrm{m}$ & $\mathrm{m}$ & $\mathrm{m}$ & $\mathrm{m}$ & $\mathrm{m}$ & $\mathrm{m}$ & $\mathrm{m}$ & $\mathrm{m}$ & $\mathrm{m}$ & $\mathrm{m}$ & 100.0 & c & 0.0 & C \\
\hline & Kosovo & $\mathrm{m}$ & $\mathrm{m}$ & $\mathrm{m}$ & $\mathrm{m}$ & $\mathrm{m}$ & $\mathrm{m}$ & $\mathrm{m}$ & $\mathrm{m}$ & $\mathrm{m}$ & $\mathrm{m}$ & $\mathrm{m}$ & $\mathrm{m}$ & 25.6 & $(0.8)$ & 74.4 & $(0.8)$ \\
\hline & Lebanon & $\mathrm{m}$ & $\mathrm{m}$ & $\mathrm{m}$ & $\mathrm{m}$ & $\mathrm{m}$ & $\mathrm{m}$ & $\mathrm{m}$ & $\mathrm{m}$ & $\mathrm{m}$ & $\mathrm{m}$ & $\mathrm{m}$ & $\mathrm{m}$ & 28.6 & (1.3) & 71.4 & (1.3) \\
\hline & Lithuania & 2.5 & $(0.2)$ & 8.5 & $(0.5)$ & 8.2 & $(0.5)$ & 10.2 & $(0.5)$ & 17.0 & $(0.6)$ & 53.6 & $(1.3)$ & 100.0 & $(0.0)$ & 0.0 & $(0.0)$ \\
\hline & Macao (China) & 2.6 & $(0.2)$ & 2.4 & $(0.3)$ & 9.8 & $(0.4)$ & 20.2 & $(0.6)$ & 18.4 & $(0.6)$ & 46.7 & $(0.8)$ & 44.9 & $(0.1)$ & 55.1 & $(0.1)$ \\
\hline & Malta & $\mathrm{m}$ & $\mathrm{m}$ & $\mathrm{m}$ & $\mathrm{m}$ & $\mathrm{m}$ & $\mathrm{m}$ & $\mathrm{m}$ & $\mathrm{m}$ & $\mathrm{m}$ & $\mathrm{m}$ & $\mathrm{m}$ & $\mathrm{m}$ & 0.3 & $(0.1)$ & 99.7 & $(0.1)$ \\
\hline & Moldova & $\mathrm{m}$ & $\mathrm{m}$ & $\mathrm{m}$ & $\mathrm{m}$ & $\mathrm{m}$ & $\mathrm{m}$ & $\mathrm{m}$ & $\mathrm{m}$ & $\mathrm{m}$ & $\mathrm{m}$ & $\mathrm{m}$ & $\mathrm{m}$ & 92.4 & $(0.8)$ & 7.6 & $(0.8)$ \\
\hline & Montenegro & 0.5 & $(0.1)$ & 13.6 & $(0.4)$ & 1.0 & $(0.1)$ & 19.6 & $(0.6)$ & 0.0 & $\mathrm{c}$ & 65.4 & $(0.7)$ & 2.6 & $(0.4)$ & 97.4 & $(0.4)$ \\
\hline & Peru & 1.0 & $(0.1)$ & 0.0 & c & 15.4 & $(0.5)$ & 7.1 & $(0.4)$ & 12.2 & $(0.4)$ & 64.3 & $(0.8)$ & 25.3 & $(0.9)$ & 74.7 & $(0.9)$ \\
\hline & Qatar & 2.3 & $(0.1)$ & 5.9 & $(0.2)$ & 6.3 & $(0.2)$ & 1.9 & $(0.1)$ & 7.2 & $(0.2)$ & 76.5 & $(0.4)$ & 20.7 & $(0.1)$ & 79.3 & $(0.1)$ \\
\hline & Romania & $\mathrm{m}$ & $\mathrm{m}$ & $\mathrm{m}$ & $\mathrm{m}$ & $\mathrm{m}$ & $\mathrm{m}$ & $\mathrm{m}$ & $\mathrm{m}$ & $\mathrm{m}$ & $\mathrm{m}$ & $\mathrm{m}$ & $\mathrm{m}$ & 100.0 & c & 0.0 & c \\
\hline & Russia & 10.9 & $(0.5)$ & 21.1 & $(1.2)$ & 14.2 & $(0.6)$ & 2.7 & $(0.3)$ & 34.2 & $(1.0)$ & 16.9 & $(0.7)$ & 86.5 & (1.5) & 13.5 & (1.5) \\
\hline & Singapore & 0.4 & $(0.1)$ & 0.0 & c & 2.6 & $(0.2)$ & 6.5 & $(0.4)$ & 27.7 & $(0.6)$ & 62.8 & $(0.6)$ & 2.0 & $(0.3)$ & 98.0 & $(0.3)$ \\
\hline & Chinese Taipei & 1.9 & $(0.2)$ & 19.0 & $(0.6)$ & 8.0 & $(0.5)$ & $\mathrm{m}$ & $\mathrm{m}$ & 24.0 & $(0.6)$ & 47.1 & $(0.9)$ & 35.4 & $(0.7)$ & 64.6 & $(0.7)$ \\
\hline & Thailand & 2.3 & $(0.2)$ & 5.2 & $(0.5)$ & 8.3 & $(0.6)$ & 15.3 & $(0.6)$ & 0.0 & $\mathrm{C}$ & 68.9 & $(1.2)$ & 24.6 & (1.0) & 75.4 & $(1.0)$ \\
\hline & Trinidad and Tobago & $\mathrm{m}$ & $\mathrm{m}$ & $\mathrm{m}$ & $\mathrm{m}$ & $\mathrm{m}$ & $\mathrm{m}$ & $\mathrm{m}$ & $\mathrm{m}$ & $\mathrm{m}$ & $\mathrm{m}$ & $\mathrm{m}$ & $\mathrm{m}$ & 41.3 & $(0.2)$ & 58.7 & $(0.2)$ \\
\hline & Tunisia & 7.6 & $(0.4)$ & 2.6 & $(0.3)$ & 23.3 & $(0.7)$ & 9.4 & $(0.5)$ & 5.6 & $(0.5)$ & 51.5 & $(1.0)$ & 34.5 & (1.9) & 65.5 & (1.9) \\
\hline & United Arab Emirates & 2.0 & $(0.2)$ & 3.8 & $(0.2)$ & 13.2 & $(0.4)$ & 3.5 & $(0.2)$ & 5.5 & $(0.2)$ & 72.0 & $(0.6)$ & 13.5 & $(0.9)$ & 86.5 & $(0.9)$ \\
\hline & Uruguay & 18.7 & $(0.6)$ & 12.4 & $(0.5)$ & 17.1 & $(0.6)$ & 4.7 & $(0.3)$ & 4.6 & $(0.3)$ & 42.6 & $(0.9)$ & 37.9 & (1.1) & 62.1 & (1.1) \\
\hline & Viet Nam & $\mathrm{m}$ & $\mathrm{m}$ & $\mathrm{m}$ & $\mathrm{m}$ & $\mathrm{m}$ & $\mathrm{m}$ & $\mathrm{m}$ & $\mathrm{m}$ & $\mathrm{m}$ & $\mathrm{m}$ & $\mathrm{m}$ & $\mathrm{m}$ & 9.1 & (2.1) & 90.9 & (2.1) \\
\hline & Argentina** $^{* *}$ & $\mathrm{~m}$ & $\mathrm{~m}$ & $\mathrm{~m}$ & $\mathrm{~m}$ & $\mathrm{~m}$ & $\mathrm{~m}$ & $\mathrm{~m}$ & $\mathrm{~m}$ & $\mathrm{~m}$ & $\mathrm{~m}$ & $\mathrm{~m}$ & $\mathrm{~m}$ & 38.7 & (1.6) & 61.3 & (1.6) \\
\hline & Kazakhstan** & $\mathrm{m}$ & $\mathrm{m}$ & $\mathrm{m}$ & $\mathrm{m}$ & $\mathrm{m}$ & $\mathrm{m}$ & $\mathrm{m}$ & $\mathrm{m}$ & $\mathrm{m}$ & $\mathrm{m}$ & $\mathrm{m}$ & $\mathrm{m}$ & 73.5 & (1.1) & 26.5 & (1.1) \\
\hline & Malaysia** & 2.0 & $(0.3)$ & 1.6 & $(0.2)$ & 12.1 & $(0.7)$ & 1.6 & $(0.2)$ & 15.1 & $(0.8)$ & 67.6 & $(1.2)$ & 3.2 & $(0.6)$ & 96.8 & (0.6) \\
\hline
\end{tabular}

* See note at the beginning of this Annex.

** Coverage is too small to ensure comparability (see Annex A4).

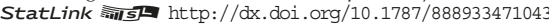




\begin{tabular}{|c|c|c|c|c|c|c|c|c|c|c|c|c|c|}
\hline & \multicolumn{12}{|c|}{ Percentage of students who expect to complete a university degree, by: } \\
\hline & & \multirow{2}{*}{\multicolumn{2}{|c|}{ All students }} & \multicolumn{10}{|c|}{ National quarters of the ESCS ${ }^{1}$ index } \\
\hline & & & & \multicolumn{2}{|c|}{ Bottom quarter } & \multicolumn{2}{|c|}{ Second quarter } & \multicolumn{2}{|c|}{ Third quarter } & \multicolumn{2}{|c|}{ Top quarter } & \multicolumn{2}{|c|}{ Top - bottom quarter } \\
\hline & & $\%$ & S.E. & $\%$ & S.E. & $\%$ & S.E. & $\%$ & S.E. & $\%$ & S.E. & $\%$ dif. & S.E. \\
\hline 0 & Australia & 54.2 & $(0.6)$ & 33.9 & $(1.0)$ & 46.2 & $(1.1)$ & 60.6 & $(1.3)$ & 76.4 & $(0.9)$ & 42.5 & $(1.3)$ \\
\hline 过 & Austria & 27.1 & $(0.8)$ & 10.3 & $(1.0)$ & 16.6 & $(1.0)$ & 29.1 & (1.7) & 52.6 & $(2.1)$ & 42.3 & (2.4) \\
\hline & Belgium & 32.9 & $(0.9)$ & 15.8 & $(1.1)$ & 25.3 & $(1.3)$ & 36.7 & $(1.3)$ & 52.6 & (1.6) & 36.8 & $(2.0)$ \\
\hline & Canada & 63.5 & $(0.8)$ & 41.7 & $(1.2)$ & 56.6 & (1.4) & 71.5 & $(1.0)$ & 83.9 & (1.1) & 42.2 & (1.3) \\
\hline & Chile & 66.6 & $(1.0)$ & 46.1 & $(1.8)$ & 65.1 & (1.9) & 71.5 & (1.4) & 84.2 & (1.1) & 38.1 & $(2.0)$ \\
\hline & Czech Republic & 55.6 & $(0.8)$ & 30.1 & $(1.6)$ & 47.9 & (1.4) & 62.1 & (1.9) & 81.8 & (1.1) & 51.7 & (2.0) \\
\hline & Denmark & 37.2 & $(1.0)$ & 22.0 & $(1.0)$ & 29.5 & $(1.4)$ & 39.8 & $(2.2)$ & 57.1 & (1.8) & 35.2 & $(2.1)$ \\
\hline & Estonia & 42.8 & $(1.0)$ & 23.3 & (1.6) & 31.3 & (1.6) & 47.2 & (1.6) & 69.6 & (1.4) & 46.3 & $(2.2)$ \\
\hline & Finland & 27.1 & (1.1) & 10.0 & $(0.9)$ & 18.8 & (1.3) & 29.8 & (1.8) & 49.3 & (1.9) & 39.4 & (1.8) \\
\hline & France & 32.0 & $(0.9)$ & 12.9 & $(1.0)$ & 22.0 & (1.5) & 35.3 & (1.4) & 58.1 & (1.9) & 45.2 & (2.1) \\
\hline & Germany & 17.8 & $(0.9)$ & 6.2 & $(0.9)$ & 11.0 & $(1.0)$ & 16.5 & (1.3) & 37.7 & (1.8) & 31.5 & (1.8) \\
\hline & Greece & 66.3 & (1.9) & 44.1 & $(3.0)$ & 61.6 & $(2.7)$ & 72.1 & $(2.3)$ & 87.5 & (1.4) & 43.4 & (2.8) \\
\hline & Hungary & 35.5 & $(1.1)$ & 11.2 & $(1.3)$ & 26.1 & $(1.8)$ & 37.6 & $(1.8)$ & 66.5 & (1.6) & 55.4 & (1.9) \\
\hline & Iceland & 38.9 & $(0.8)$ & 23.2 & (1.5) & 34.1 & (1.9) & 42.8 & $(1.7)$ & 55.4 & (1.6) & 32.1 & $(2.1)$ \\
\hline & Ireland & 46.3 & $(0.8)$ & 28.1 & $(1.4)$ & 39.7 & $(1.7)$ & 50.0 & (1.5) & 67.7 & $(2.0)$ & 39.7 & $(2.8)$ \\
\hline & Israel & 57.0 & $(1.2)$ & 38.5 & $(1.7)$ & 52.1 & (1.9) & 62.7 & (1.6) & 75.6 & (1.4) & 37.1 & $(2.0)$ \\
\hline & Italy & 38.3 & $(1.2)$ & 20.5 & $(1.6)$ & 31.0 & (1.5) & 43.1 & $(2.1)$ & 58.4 & (1.8) & 38.0 & $(2.3)$ \\
\hline & Japan & 58.7 & $(1.1)$ & 34.4 & $(1.8)$ & 54.8 & (1.6) & 67.0 & (1.9) & 79.5 & (1.1) & 45.1 & (2.0) \\
\hline & Korea & 75.3 & $(0.9)$ & 57.5 & (1.8) & 72.4 & (1.9) & 82.1 & (1.3) & 89.2 & (1.4) & 31.7 & $(2.5)$ \\
\hline & Latvia & 24.7 & $(0.8)$ & 10.5 & $(1.0)$ & 16.9 & (1.1) & 25.7 & $(2.0)$ & 45.7 & (1.6) & 35.2 & (2.0) \\
\hline & Luxembourg & 41.4 & $(0.6)$ & 23.0 & (1.1) & 29.7 & (1.1) & 45.3 & (1.5) & 67.7 & (1.2) & 44.8 & $(1.5)$ \\
\hline & Mexico & 58.4 & $(1.0)$ & 43.4 & $(1.9)$ & 53.8 & $(1.6)$ & 62.2 & $(2.2)$ & 74.3 & (1.3) & 30.9 & $(2.2)$ \\
\hline & Netherlands & 17.4 & $(0.7)$ & 7.3 & $(0.8)$ & 11.0 & (1.1) & 17.0 & $(1.3)$ & 33.6 & $(1.7)$ & 26.3 & $(2.0)$ \\
\hline & New Zealand & 45.2 & $(1.0)$ & 26.3 & (1.3) & 37.2 & $(2.1)$ & 51.7 & (1.8) & 67.0 & (1.8) & 40.7 & $(2.1)$ \\
\hline & Norway & 24.1 & $(0.7)$ & 13.1 & $(1.1)$ & 17.3 & $(1.3)$ & 25.0 & $(1.4)$ & 41.4 & (1.4) & 28.3 & (1.6) \\
\hline & Poland & 48.0 & (1.1) & 22.8 & $(1.5)$ & 38.3 & $(1.8)$ & 51.2 & $(2.3)$ & 80.2 & (1.5) & 57.3 & (1.9) \\
\hline & Portugal & 39.9 & $(1.2)$ & 18.1 & (1.4) & 30.5 & (1.5) & 41.6 & (2.0) & 69.7 & (1.9) & 51.7 & $(2.1)$ \\
\hline & Slovak Republic & $\mathrm{m}$ & $\mathrm{m}$ & $\mathrm{m}$ & $\mathrm{m}$ & $\mathrm{m}$ & $\mathrm{m}$ & $\mathrm{m}$ & $\mathrm{m}$ & $\mathrm{m}$ & $\mathrm{m}$ & $\mathrm{m}$ & $\mathrm{m}$ \\
\hline & Slovenia & 25.8 & $(0.6)$ & 9.5 & $(1.0)$ & 14.6 & (1.1) & 29.1 & (1.6) & 49.6 & (1.7) & 40.1 & $(2.0)$ \\
\hline & Spain & 51.0 & $(1.0)$ & 27.2 & $(1.3)$ & 42.9 & (1.5) & 56.1 & $(2.0)$ & 78.2 & $(1.2)$ & 51.0 & (1.5) \\
\hline & Sweden & 38.7 & (1.0) & 21.7 & (1.1) & 30.3 & (1.6) & 41.3 & (1.8) & 61.1 & $(2.0)$ & 39.4 & $(2.3)$ \\
\hline & Switzerland & 27.0 & $(1.0)$ & 10.4 & $(0.8)$ & 17.5 & (1.4) & 29.3 & $(2.0)$ & 51.2 & $(2.1)$ & 40.7 & $(2.3)$ \\
\hline & Turkey & 70.6 & (1.1) & 61.7 & (1.6) & 66.1 & (1.8) & 71.0 & (1.7) & 83.7 & $(2.2)$ & 22.0 & (2.9) \\
\hline & United Kingdom & 41.8 & $(0.9)$ & 24.3 & (1.3) & 32.7 & (1.5) & 46.2 & (1.7) & 64.4 & (1.6) & 40.2 & $(2.0)$ \\
\hline & United States & 76.0 & $(0.8)$ & 60.3 & (1.4) & 69.2 & (1.4) & 82.8 & (1.5) & 91.6 & $(0.8)$ & 31.4 & (1.6) \\
\hline & OECD average & 44.2 & $(0.2)$ & 26.2 & $(0.2)$ & 36.8 & $(0.3)$ & 48.0 & $(0.3)$ & 66.0 & $(0.3)$ & 39.8 & $(0.4)$ \\
\hline
\end{tabular}

\begin{tabular}{|c|c|c|c|c|c|c|c|c|c|c|c|c|c|}
\hline \multirow{37}{*}{ 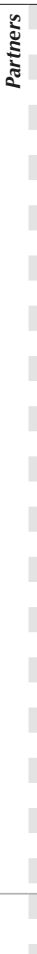 } & Albania & $\mathrm{m}$ & $\mathrm{m}$ & $\mathrm{m}$ & $\mathrm{m}$ & $\mathrm{m}$ & $\mathrm{m}$ & $\mathrm{m}$ & $\mathrm{m}$ & $\mathrm{m}$ & $\mathrm{m}$ & $\mathrm{m}$ & $\mathrm{m}$ \\
\hline & Algeria & $\mathrm{m}$ & $\mathrm{m}$ & $\mathrm{m}$ & $\mathrm{m}$ & $\mathrm{m}$ & $\mathrm{m}$ & $\mathrm{m}$ & $\mathrm{m}$ & $\mathrm{m}$ & $\mathrm{m}$ & $\mathrm{m}$ & $\mathrm{m}$ \\
\hline & Brazil & 46.2 & $(0.6)$ & 32.9 & $(0.8)$ & 41.1 & $(1.0)$ & 47.6 & $(1.2)$ & 63.5 & $(1.2)$ & 30.6 & (1.4) \\
\hline & B-S-J-G (China) & 37.7 & (1.8) & 15.8 & (1.6) & 28.0 & (2.3) & 40.2 & (2.3) & 66.7 & (3.4) & 50.8 & (3.4) \\
\hline & Bulgaria & 39.4 & (1.1) & 19.5 & (1.7) & 32.3 & (1.5) & 46.1 & (2.1) & 59.7 & (1.4) & 40.2 & (2.1) \\
\hline & CABA (Argentina) & $\mathrm{m}$ & $\mathrm{m}$ & $\mathrm{m}$ & $\mathrm{m}$ & $\mathrm{m}$ & $\mathrm{m}$ & $\mathrm{m}$ & $\mathrm{m}$ & $\mathrm{m}$ & $\mathrm{m}$ & $\mathrm{m}$ & $\mathrm{m}$ \\
\hline & Colombia & 76.3 & $(0.9)$ & 67.7 & (1.7) & 69.9 & (1.6) & 77.9 & (1.6) & 89.7 & $(1.2)$ & 21.9 & $(2.2)$ \\
\hline & Costa Rica & 54.4 & $(0.8)$ & 50.7 & (1.5) & 52.3 & (1.5) & 56.4 & (1.4) & 58.4 & $(2.1)$ & 7.8 & $(2.5)$ \\
\hline & Croatia & 36.1 & (1.0) & 19.0 & (1.4) & 27.2 & (1.9) & 37.5 & (1.5) & 60.6 & (1.6) & 41.6 & $(2.0)$ \\
\hline & Cyprus* & 77.8 & (0.5) & 59.6 & (1.4) & 76.1 & (1.3) & 84.3 & (1.0) & 91.2 & $(0.8)$ & 31.6 & (1.5) \\
\hline & Dominican Republic & 63.5 & (1.0) & 62.1 & $(2.0)$ & 63.2 & (1.9) & 60.9 & (1.6) & 67.9 & (1.5) & 5.7 & $(2.4)$ \\
\hline & FYROM & $\mathrm{m}$ & $\mathrm{m}$ & $\mathrm{m}$ & $\mathrm{m}$ & $\mathrm{m}$ & $\mathrm{m}$ & $\mathrm{m}$ & $\mathrm{m}$ & $\mathrm{m}$ & $\mathrm{m}$ & $\mathrm{m}$ & $\mathrm{m}$ \\
\hline & Georgia & $\mathrm{m}$ & $\mathrm{m}$ & $\mathrm{m}$ & $\mathrm{m}$ & $\mathrm{m}$ & $\mathrm{m}$ & $\mathrm{m}$ & $\mathrm{m}$ & $\mathrm{m}$ & $\mathrm{m}$ & $\mathrm{m}$ & $\mathrm{m}$ \\
\hline & Hong Kong (China) & 54.9 & (1.1) & 38.8 & (1.7) & 48.3 & (1.9) & 58.4 & (1.7) & 74.0 & (1.6) & 35.2 & $(2.3)$ \\
\hline & Indonesia & $\mathrm{m}$ & $\mathrm{m}$ & $\mathrm{m}$ & $\mathrm{m}$ & $\mathrm{m}$ & $\mathrm{m}$ & $\mathrm{m}$ & $\mathrm{m}$ & $\mathrm{m}$ & $\mathrm{m}$ & $\mathrm{m}$ & $\mathrm{m}$ \\
\hline & Jordan & $\mathrm{m}$ & $\mathrm{m}$ & $\mathrm{m}$ & $\mathrm{m}$ & $\mathrm{m}$ & $\mathrm{m}$ & $\mathrm{m}$ & $\mathrm{m}$ & $\mathrm{m}$ & $\mathrm{m}$ & $\mathrm{m}$ & $\mathrm{m}$ \\
\hline & Kosovo & $\mathrm{m}$ & $\mathrm{m}$ & $\mathrm{m}$ & $\mathrm{m}$ & $\mathrm{m}$ & $\mathrm{m}$ & $\mathrm{m}$ & $\mathrm{m}$ & $\mathrm{m}$ & $\mathrm{m}$ & $\mathrm{m}$ & $\mathrm{m}$ \\
\hline & Lebanon & $\mathrm{m}$ & $\mathrm{m}$ & $\mathrm{m}$ & $\mathrm{m}$ & $\mathrm{m}$ & $\mathrm{m}$ & $\mathrm{m}$ & $\mathrm{m}$ & $\mathrm{m}$ & $\mathrm{m}$ & $\mathrm{m}$ & $\mathrm{m}$ \\
\hline & Lithuania & 53.6 & (1.3) & 25.5 & $(1.2)$ & 43.0 & $(2.0)$ & 63.8 & (2.1) & 82.5 & (1.8) & 56.9 & (2.3) \\
\hline & Macao (China) & 46.7 & $(0.8)$ & 35.2 & (1.5) & 42.2 & (1.3) & 47.0 & (1.7) & 62.5 & (1.5) & 27.3 & $(2.2)$ \\
\hline & Malta & $\mathrm{m}$ & $\mathrm{m}$ & $\mathrm{m}$ & $\mathrm{m}$ & $\mathrm{m}$ & $\mathrm{m}$ & $\mathrm{m}$ & $\mathrm{m}$ & $\mathrm{m}$ & $\mathrm{m}$ & $\mathrm{m}$ & $\mathrm{m}$ \\
\hline & Moldova & $\mathrm{m}$ & $\mathrm{m}$ & $\mathrm{m}$ & $\mathrm{m}$ & $\mathrm{m}$ & $\mathrm{m}$ & $\mathrm{m}$ & $\mathrm{m}$ & $\mathrm{m}$ & $\mathrm{m}$ & $\mathrm{m}$ & $\mathrm{m}$ \\
\hline & Montenegro & 65.4 & $(0.7)$ & 49.4 & (1.5) & 59.9 & $(1.4)$ & 68.9 & (1.5) & 83.2 & $(1.0)$ & 33.8 & (1.9) \\
\hline & Peru & 64.3 & $(0.8)$ & 50.9 & (1.6) & 61.0 & (1.5) & 65.7 & (1.5) & 79.6 & $(1.2)$ & 28.8 & (1.9) \\
\hline & Qatar & 76.5 & $(0.4)$ & 65.2 & $(0.9)$ & 74.5 & $(0.9)$ & 81.3 & $(0.7)$ & 85.2 & $(0.7)$ & 20.0 & (1.1) \\
\hline & Romania & $\mathrm{m}$ & $\mathrm{m}$ & $\mathrm{m}$ & $\mathrm{m}$ & $\mathrm{m}$ & $\mathrm{m}$ & $\mathrm{m}$ & $\mathrm{m}$ & $\mathrm{m}$ & $\mathrm{m}$ & $\mathrm{m}$ & $\mathrm{m}$ \\
\hline & Russia & 16.9 & $(0.7)$ & 7.2 & (1.1) & 11.9 & (1.3) & 19.1 & (1.4) & 29.4 & (1.4) & 22.3 & (1.7) \\
\hline & Singapore & 62.8 & $(0.6)$ & 38.1 & (1.2) & 55.4 & $(1.2)$ & 71.5 & $(1.2)$ & 86.4 & $(0.9)$ & 48.2 & (1.4) \\
\hline & Chinese Taipei & 47.1 & $(0.9)$ & 23.6 & (1.5) & 38.8 & (1.3) & 53.5 & (1.6) & 72.5 & (1.6) & 48.9 & (2.2) \\
\hline & Thailand & 68.9 & (1.2) & 56.0 & (1.7) & 63.1 & (1.6) & 69.6 & (1.6) & 87.2 & $(2.0)$ & 31.2 & $(2.4)$ \\
\hline & Trinidad and Tobago & $\mathrm{m}$ & $\mathrm{m}$ & $\mathrm{m}$ & $\mathrm{m}$ & $\mathrm{m}$ & $\mathrm{m}$ & $\mathrm{m}$ & $\mathrm{m}$ & $\mathrm{m}$ & $\mathrm{m}$ & $\mathrm{m}$ & $\mathrm{m}$ \\
\hline & Tunisia & 51.5 & (1.0) & 40.9 & (1.8) & 48.8 & (1.7) & 49.7 & (1.6) & 66.0 & (1.8) & 25.2 & $(2.7)$ \\
\hline & United Arab Emirates & 72.0 & $(0.6)$ & 58.7 & (1.1) & 71.0 & (1.1) & 77.9 & (1.0) & 80.4 & $(0.9)$ & 21.7 & $(1.2)$ \\
\hline & Uruguay & 42.6 & $(0.9)$ & 23.2 & (1.6) & 32.6 & (1.4) & 45.5 & (1.8) & 68.6 & (1.6) & 45.4 & $(2.2)$ \\
\hline & Viet Nam & $\mathrm{m}$ & $\mathrm{m}$ & $\mathrm{m}$ & $\mathrm{m}$ & $\mathrm{m}$ & $\mathrm{m}$ & $\mathrm{m}$ & $\mathrm{m}$ & $\mathrm{m}$ & $\mathrm{m}$ & $\mathrm{m}$ & $\mathrm{m}$ \\
\hline & Argentina** $^{* *}$ & $\mathrm{~m}$ & $\mathrm{~m}$ & $\mathrm{~m}$ & $\mathrm{~m}$ & $\mathrm{~m}$ & $\mathrm{~m}$ & $\mathrm{~m}$ & $\mathrm{~m}$ & $\mathrm{~m}$ & $\mathrm{~m}$ & $\mathrm{~m}$ & $\mathrm{~m}$ \\
\hline & Kazakhstan** & $\mathrm{m}$ & $\mathrm{m}$ & $\mathrm{m}$ & $\mathrm{m}$ & $\mathrm{m}$ & $\mathrm{m}$ & $\mathrm{m}$ & $\mathrm{m}$ & $\mathrm{m}$ & $\mathrm{m}$ & $\mathrm{m}$ & $\mathrm{m}$ \\
\hline & Malaysia** & 67.6 & $(1.2)$ & 56.3 & $(1.8)$ & 63.1 & $(1.8)$ & 71.0 & (1.9) & 80.1 & (1.6) & 23.8 & $(2.2)$ \\
\hline
\end{tabular}

1. ESCS refers to the the PISA index of economic, social and cultural status.

Note: Values that are statistically significant are indicated in bold (see Annex A3).

* See note at the beginning of this Annex.

** Coverage is too small to ensure comparability (see Annex A4).

StatLink न्ता St http://dx.doi.org/10.1787//888933471051 
[Part 2/2]

Table III.6.2 Students' expectations to complete a university degree, by student characteristics

Results based on students' self-reports

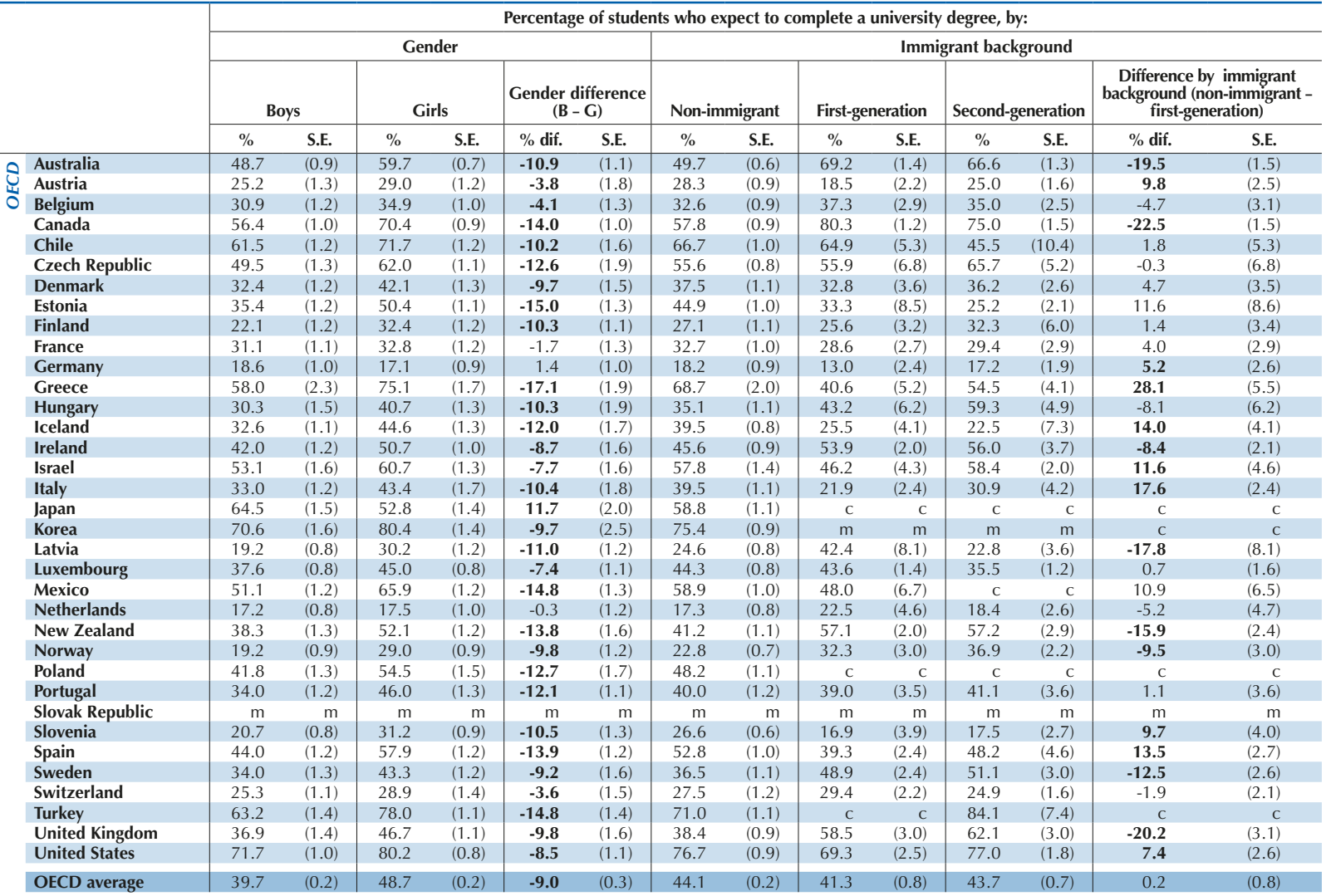

\begin{tabular}{|c|c|c|c|c|c|c|c|c|c|c|c|c|c|c|}
\hline Albania & $\mathrm{m}$ & $\mathrm{m}$ & $\mathrm{m}$ & $\mathrm{m}$ & $\mathrm{m}$ & $\mathrm{m}$ & $\mathrm{m}$ & $\mathrm{m}$ & $\mathrm{m}$ & $\mathrm{m}$ & $\mathrm{m}$ & $\mathrm{m}$ & $\mathrm{m}$ & $\mathrm{m}$ \\
\hline Algeria & $\mathrm{m}$ & $\mathrm{m}$ & $\mathrm{m}$ & $\mathrm{m}$ & $\mathrm{m}$ & $\mathrm{m}$ & $\mathrm{m}$ & $\mathrm{m}$ & $\mathrm{m}$ & $\mathrm{m}$ & $\mathrm{m}$ & $\mathrm{m}$ & $\mathrm{m}$ & $\mathrm{m}$ \\
\hline Brazil & 39.3 & $(0.8)$ & 52.7 & $(0.7)$ & -13.4 & $(0.9)$ & 46.7 & $(0.6)$ & 23.3 & (8.1) & 29.9 & (6.2) & 23.5 & (8.0) \\
\hline B-S-J-G (China) & 34.6 & (1.7) & 41.2 & (2.0) & -6.7 & (1.4) & 38.1 & $(1.8)$ & c & c & c & c & c & c \\
\hline Bulgaria & 31.2 & $(1.2)$ & 48.4 & (1.3) & -17.2 & (1.4) & 39.7 & (1.1) & c & c & c & c & c & c \\
\hline CABA (Argentina) & $\mathrm{m}$ & $\mathrm{m}$ & $\mathrm{m}$ & $\mathrm{m}$ & $\mathrm{m}$ & $\mathrm{m}$ & $\mathrm{m}$ & $\mathrm{m}$ & $\mathrm{m}$ & $\mathrm{m}$ & $\mathrm{m}$ & $\mathrm{m}$ & $\mathrm{m}$ & $\mathrm{m}$ \\
\hline Colombia & 70.1 & (1.4) & 81.7 & $(0.8)$ & -11.6 & (1.3) & 76.9 & $(0.9)$ & c & c & 69.6 & (10.4) & c & c \\
\hline Costa Rica & 50.7 & $(1.0)$ & 58.0 & (1.1) & -7.4 & (1.4) & 54.7 & $(0.8)$ & 49.1 & (4.6) & 51.5 & (3.3) & 5.6 & (4.6) \\
\hline Croatia & 30.5 & $(1.2)$ & 41.2 & (1.3) & -10.7 & (1.6) & 36.9 & $(1.0)$ & 35.5 & (5.1) & 29.8 & (2.1) & 1.4 & (5.1) \\
\hline Cyprus* & 69.4 & $(0.7)$ & 86.0 & $(0.6)$ & -16.6 & $(0.9)$ & 79.1 & $(0.5)$ & 64.1 & (1.9) & 82.9 & (2.7) & 15.0 & (2.0) \\
\hline Dominican Republic & 57.0 & (1.5) & 69.7 & (1.1) & -12.6 & (1.8) & 64.5 & (1.0) & 69.5 & (7.8) & 53.7 & (10.6) & -4.9 & (7.8) \\
\hline FYROM & $\mathrm{m}$ & $\mathrm{m}$ & $\mathrm{m}$ & $\mathrm{m}$ & $\mathrm{m}$ & $\mathrm{m}$ & $\mathrm{m}$ & $\mathrm{m}$ & $\mathrm{m}$ & $\mathrm{m}$ & $\mathrm{m}$ & $\mathrm{m}$ & $\mathrm{m}$ & $\mathrm{m}$ \\
\hline Georgia & $\mathrm{m}$ & $\mathrm{m}$ & $\mathrm{m}$ & $\mathrm{m}$ & $\mathrm{m}$ & $\mathrm{m}$ & $\mathrm{m}$ & $\mathrm{m}$ & $\mathrm{m}$ & $\mathrm{m}$ & $\mathrm{m}$ & c & $\mathrm{m}$ & $\mathrm{m}$ \\
\hline Hong Kong (China) & 52.3 & (1.4) & 57.5 & (1.7) & -5.2 & $(2.2)$ & 56.7 & (1.4) & 50.8 & (2.0) & 52.5 & (1.8) & 6.0 & (2.3) \\
\hline Indonesia & $\mathrm{m}$ & $\mathrm{m}$ & $\mathrm{m}$ & $\mathrm{m}$ & $\mathrm{m}$ & $\mathrm{m}$ & $\mathrm{m}$ & $\mathrm{m}$ & $\mathrm{m}$ & $\mathrm{m}$ & $\mathrm{m}$ & $\mathrm{m}$ & $\mathrm{m}$ & $\mathrm{m}$ \\
\hline Jordan & $\mathrm{m}$ & $\mathrm{m}$ & $\mathrm{m}$ & $\mathrm{m}$ & $\mathrm{m}$ & $\mathrm{m}$ & $\mathrm{m}$ & $\mathrm{m}$ & $\mathrm{m}$ & $\mathrm{m}$ & $\mathrm{m}$ & $\mathrm{m}$ & $\mathrm{m}$ & $\mathrm{m}$ \\
\hline Kosovo & $\mathrm{m}$ & $\mathrm{m}$ & $\mathrm{m}$ & $\mathrm{m}$ & $\mathrm{m}$ & $\mathrm{m}$ & $\mathrm{m}$ & $\mathrm{m}$ & $\mathrm{m}$ & $\mathrm{m}$ & $\mathrm{m}$ & $\mathrm{m}$ & $\mathrm{m}$ & $\mathrm{m}$ \\
\hline Lebanon & $\mathrm{m}$ & $\mathrm{m}$ & $\mathrm{m}$ & $\mathrm{m}$ & $\mathrm{m}$ & $\mathrm{m}$ & $\mathrm{m}$ & $\mathrm{m}$ & $\mathrm{m}$ & $\mathrm{m}$ & $\mathrm{m}$ & $\mathrm{m}$ & $\mathrm{m}$ & $\mathrm{m}$ \\
\hline Lithuania & 46.9 & (1.5) & 60.4 & (1.4) & -13.5 & (1.4) & 53.7 & (1.3) & 68.5 & (11.6) & 52.6 & $(4.4)$ & -14.8 & (11.7) \\
\hline Macao (China) & 42.1 & (1.0) & 51.3 & (1.0) & -9.2 & (1.4) & 45.9 & (1.1) & 48.8 & (1.8) & 46.9 & (1.1) & -2.9 & (2.2) \\
\hline Malta & $\mathrm{m}$ & $\mathrm{m}$ & $\mathrm{m}$ & $\mathrm{m}$ & $\mathrm{m}$ & $\mathrm{m}$ & $\mathrm{m}$ & $\mathrm{m}$ & $\mathrm{m}$ & $\mathrm{m}$ & $\mathrm{m}$ & $\mathrm{m}$ & $\mathrm{m}$ & $\mathrm{m}$ \\
\hline Moldova & $\mathrm{m}$ & $\mathrm{m}$ & $\mathrm{m}$ & $\mathrm{m}$ & $\mathrm{m}$ & $\mathrm{m}$ & $\mathrm{m}$ & $\mathrm{m}$ & $\mathrm{m}$ & $\mathrm{m}$ & $\mathrm{m}$ & $\mathrm{m}$ & $\mathrm{m}$ & $\mathrm{m}$ \\
\hline Montenegro & 58.4 & $(0.9)$ & 72.5 & $(0.8)$ & -14.1 & (1.1) & 65.4 & $(0.7)$ & 72.8 & (3.8) & 64.5 & (3.1) & -7.4 & (3.8) \\
\hline Peru & 60.3 & (1.1) & 68.4 & $(1.0)$ & -8.0 & (1.3) & 64.7 & $(0.8)$ & c & c & c & c & c & c \\
\hline Qatar & 72.7 & $(0.6)$ & 80.2 & $(0.5)$ & -7.6 & $(0.7)$ & 71.6 & $(0.6)$ & 81.9 & $(0.6)$ & 79.9 & (1.0) & -10.3 & $(0.8)$ \\
\hline Romania & $\mathrm{m}$ & $\mathrm{m}$ & $\mathrm{m}$ & $\mathrm{m}$ & $\mathrm{m}$ & $\mathrm{m}$ & $\mathrm{m}$ & $\mathrm{m}$ & $\mathrm{m}$ & $\mathrm{m}$ & $\mathrm{m}$ & $\mathrm{m}$ & $\mathrm{m}$ & $\mathrm{m}$ \\
\hline Russia & 13.5 & (1.1) & 20.1 & $(0.9)$ & -6.6 & (1.4) & 16.5 & $(0.7)$ & 15.5 & (2.8) & 28.2 & (3.9) & 1.0 & (2.9) \\
\hline Singapore & 58.2 & $(0.9)$ & 67.7 & $(0.8)$ & -9.5 & $(1.2)$ & 59.0 & $(0.7)$ & 80.0 & (2.1) & 70.7 & (2.3) & -21.0 & (2.3) \\
\hline Chinese Taipei & 45.8 & (1.5) & 48.4 & (1.4) & -2.6 & (2.3) & 47.1 & $(0.9)$ & c & c & c & c & c & c \\
\hline Thailand & 55.3 & (1.9) & 79.3 & (1.0) & -24.0 & $(2.1)$ & 69.6 & $(1.2)$ & c & c & 38.8 & (11.5) & c & c \\
\hline Trinidad and Tobago & $\mathrm{m}$ & $\mathrm{m}$ & $\mathrm{m}$ & $\mathrm{m}$ & $\mathrm{m}$ & $\mathrm{m}$ & $\mathrm{m}$ & $\mathrm{m}$ & $\mathrm{m}$ & $\mathrm{m}$ & $\mathrm{m}$ & $\mathrm{m}$ & $\mathrm{m}$ & $\mathrm{m}$ \\
\hline Tunisia & 40.9 & (1.3) & 60.5 & (1.1) & -19.6 & (1.5) & 52.5 & $(1.0)$ & c & c & 36.5 & (8.2) & c & c \\
\hline United Arab Emirates & 67.7 & (1.0) & 76.0 & $(0.8)$ & -8.3 & $(1.3)$ & 65.6 & $(0.9)$ & 78.3 & (1.1) & 76.5 & (1.0) & -12.7 & (1.5) \\
\hline Uruguay & 31.8 & (1.1) & 52.2 & (1.0) & -20.3 & $(1.2)$ & 42.8 & $(0.9)$ & c & c & c & c & c & c \\
\hline Viet Nam & $\mathrm{m}$ & $\mathrm{m}$ & $\mathrm{m}$ & $\mathrm{m}$ & $\mathrm{m}$ & $\mathrm{m}$ & $\mathrm{m}$ & $\mathrm{m}$ & $\mathrm{m}$ & $\mathrm{m}$ & $\mathrm{m}$ & $\mathrm{m}$ & $\mathrm{m}$ & $\mathrm{m}$ \\
\hline Argentina** & $\mathrm{m}$ & $\mathrm{m}$ & $\mathrm{m}$ & $\mathrm{m}$ & $\mathrm{m}$ & $\mathrm{m}$ & $\mathrm{m}$ & $\mathrm{m}$ & $\mathrm{m}$ & $\mathrm{m}$ & $\mathrm{m}$ & $\mathrm{m}$ & $\mathrm{m}$ & $\mathrm{m}$ \\
\hline Kazakhstan** & $\mathrm{m}$ & $\mathrm{m}$ & $\mathrm{m}$ & $\mathrm{m}$ & $\mathrm{m}$ & $\mathrm{m}$ & $\mathrm{m}$ & $\mathrm{m}$ & $\mathrm{m}$ & $\mathrm{m}$ & $\mathrm{m}$ & $\mathrm{m}$ & $\mathrm{m}$ & $\mathrm{m}$ \\
\hline Malaysia** & 58.5 & (1.5) & 75.7 & $(1.2)$ & -17.1 & $(1.4)$ & 68.3 & $(1.2)$ & C & C & 59.8 & (8.1) & C & C \\
\hline
\end{tabular}

1. ESCS refers to the the PISA index of economic, social and cultural status.

Note: Values that are statistically significant are indicated in bold (see Annex A3).

* See note at the beginning of this Annex.

** Coverage is too small to ensure comparability (see Annex A4).

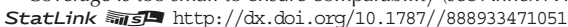




\begin{tabular}{|c|c|c|c|c|c|c|c|c|c|c|c|c|c|c|c|c|c|c|c|}
\hline & & & & & & centage & of stud & ts wh & expect & comp & ete a ur & iversity & egree, & & & & & \\
\hline & & & & & chools & socio-e & onomic & orofile ${ }^{1}$ & & & & & & & School & ocation & & & \\
\hline & & & & & & & & & & $\begin{array}{r}\text { Top - } \\
\text { qua }\end{array}$ & & $\begin{array}{r}\text { Rura } \\
\text { or v } \\
\text { (few } \\
3000\end{array}$ & $\begin{array}{l}\text { area } \\
\text { llage } \\
r \text { than } \\
\text { eeople) }\end{array}$ & $\begin{array}{r}\text { To } \\
(3 \\
\text { to } 10 \\
\text { peo }\end{array}$ & $\begin{array}{l}\text { ln } \\
00 \\
000 \\
\text { le) }\end{array}$ & $\underset{\text { pever }}{C}$ & $\begin{array}{l}y \\
0000 \\
0 \text { le) }\end{array}$ & City - ru & Iral area \\
\hline & & $\%$ & S.E. & $\%$ & S.E. & $\%$ & S.E. & $\%$ & S.E. & $\%$ dif. & S.E. & $\%$ & S.E. & $\%$ & S.E. & $\%$ & S.E. & $\%$ dif. & S.E. \\
\hline & Australia & 37.1 & (1.1) & 46.4 & (1.3) & 56.2 & (1.5) & 76.5 & (1.4) & 39.4 & (1.8) & 33.7 & (2.4) & 43.5 & (1.3) & 60.1 & $(0.8)$ & 26.4 & (2.6) \\
\hline & Austria & 7.0 & (1.5) & 15.2 & (2.3) & 28.0 & $(2.2)$ & 58.4 & (2.4) & 51.4 & (3.0) & 14.2 & (4.4) & 26.3 & (1.5) & 31.8 & $(2.7)$ & 17.6 & (5.3) \\
\hline & Belgium & 16.8 & (1.8) & 20.7 & (2.3) & 38.7 & $(2.2)$ & 53.2 & (2.2) & 36.4 & (3.0) & 40.0 & (5.3) & 31.0 & (1.3) & 37.1 & (3.1) & -2.9 & (6.7) \\
\hline & Canada & 47.4 & (1.6) & 60.5 & $(2.0)$ & 67.2 & (1.3) & 78.6 & (1.7) & 31.2 & (2.4) & 43.9 & (4.5) & 57.4 & (1.3) & 71.1 & (1.1) & 27.2 & (4.6) \\
\hline & Chile & 47.1 & $(2.2)$ & 56.7 & (2.1) & 76.4 & (2.8) & 86.0 & (1.4) & 38.9 & (2.5) & 44.2 & (12.3) & 60.6 & (2.4) & 70.2 & (1.4) & 26.1 & (12.5) \\
\hline & Czech Republic & 29.5 & (2.4) & 48.4 & $(2.0)$ & 57.3 & $(2.3)$ & 85.2 & (1.7) & 55.7 & (2.8) & 39.4 & $(2.7)$ & 54.6 & (1.3) & 66.1 & $(2.1)$ & 26.7 & (3.5) \\
\hline & Denmark & 26.5 & $(2.0)$ & 33.3 & (1.7) & 39.0 & $(2.2)$ & 49.8 & (2.1) & 23.3 & (2.6) & 35.4 & (3.1) & 35.9 & (1.3) & 46.5 & (1.8) & 11.2 & (3.7) \\
\hline & Estonia & 26.5 & (1.6) & 37.6 & (2.3) & 41.3 & $(2.1)$ & 65.7 & (1.8) & 39.3 & (2.5) & 36.1 & (2.5) & 43.6 & (1.3) & 46.9 & $(2.0)$ & 10.8 & (3.2) \\
\hline & Finland & 17.2 & (1.9) & 21.5 & (1.1) & 28.2 & (1.5) & 40.8 & (3.1) & 23.6 & (3.7) & 19.1 & (2.0) & 24.3 & (1.0) & 36.3 & (2.5) & 17.2 & (3.1) \\
\hline & France & 8.4 & (1.4) & 22.1 & (2.0) & 39.7 & (2.4) & 56.0 & (2.1) & 47.5 & (2.6) & 25.2 & (4.7) & 28.6 & (1.1) & 39.9 & (3.0) & 14.7 & (5.5) \\
\hline & Germany & 2.9 & $(0.6)$ & 7.8 & $(0.8)$ & 20.4 & $(2.4)$ & 38.0 & (1.6) & 35.1 & (1.7) & 10.3 & (3.3) & 17.5 & (1.4) & 23.6 & (2.8) & 13.3 & (4.5) \\
\hline & Greece & 33.9 & (5.9) & 64.0 & (3.9) & 79.4 & (1.4) & 87.9 & (1.4) & 54.0 & (6.2) & 57.8 & (6.6) & 62.3 & (3.2) & 75.4 & $(2.3)$ & 17.6 & (6.8) \\
\hline & Hungary & 6.4 & (1.3) & 18.9 & $(2.1)$ & 43.2 & (3.3) & 73.2 & (1.9) & 66.8 & $(2.2)$ & 2.8 & (2.7) & 29.8 & $(2.2)$ & 43.8 & $(2.3)$ & 41.0 & (3.6) \\
\hline & Iceland & 30.0 & (1.6) & 38.2 & (1.6) & 40.2 & (1.6) & 47.3 & (1.6) & 17.2 & (2.5) & 26.6 & (1.8) & 42.2 & (1.1) & 40.9 & (1.7) & 14.3 & (2.4) \\
\hline & Ireland & 34.2 & (1.8) & 44.1 & (1.4) & 49.2 & (1.7) & 57.7 & $(2.2)$ & 23.5 & (2.8) & 44.9 & (2.0) & 45.1 & (1.1) & 49.5 & (2.1) & 4.6 & (2.9) \\
\hline & Israel & 39.6 & (3.5) & 52.9 & $(2.5)$ & 63.1 & (2.6) & 72.9 & $(2.6)$ & 33.3 & (4.6) & 54.7 & (3.8) & 57.0 & $(2.2)$ & 57.5 & (2.4) & 2.9 & $(4.8)$ \\
\hline & Italy & 15.5 & $(2.0)$ & 23.1 & $(2.0)$ & 47.8 & (3.2) & 66.2 & (2.4) & 50.7 & (3.2) & 12.9 & (4.4) & 38.8 & (2.1) & 44.2 & (3.2) & 31.3 & (5.8) \\
\hline & Japan & 21.4 & (2.6) & 42.2 & (3.1) & 78.6 & (3.5) & 92.7 & (1.1) & 71.3 & (2.8) & c & c & 47.3 & (3.6) & 63.1 & $(1.7)$ & C & C \\
\hline & Korea & 51.2 & (3.5) & 76.4 & (2.5) & 84.3 & (2.4) & 89.4 & (2.9) & 38.3 & (4.6) & c & C & 68.1 & $(4.7)$ & 76.6 & (1.1) & c & C \\
\hline & Latvia & 15.0 & (1.6) & 19.1 & $(1.7)$ & 26.2 & $(1.3)$ & 38.4 & (2.1) & 23.3 & (2.9) & 18.1 & (1.7) & 24.7 & (1.3) & 29.7 & (1.8) & 11.6 & (2.8) \\
\hline & Luxembourg & 22.4 & (1.1) & 29.6 & (1.1) & 47.0 & (1.2) & 69.2 & $(1.2)$ & 46.8 & (1.5) & $\mathrm{m}$ & $\mathrm{m}$ & 33.9 & $(0.7)$ & 51.5 & $(0.9)$ & $\mathrm{m}$ & $\mathrm{m}$ \\
\hline & Mexico & 43.2 & (2.3) & 54.7 & $(2.2)$ & 59.4 & (2.9) & 76.6 & (1.9) & 33.4 & (2.9) & 38.3 & (2.9) & 60.1 & (1.6) & 64.5 & (1.8) & 26.2 & (3.3) \\
\hline & Netherlands & 1.8 & $(0.7)$ & 5.4 & $(2.2)$ & 18.6 & (2.9) & 41.4 & (2.4) & 39.6 & (2.6) & c & c & 14.6 & $(1.7)$ & 26.2 & $(4.2)$ & C & c \\
\hline & New Zealand & 29.7 & $(2.0)$ & 39.8 & $(2.1)$ & 48.6 & (2.6) & 62.5 & (2.6) & 32.7 & (3.7) & 32.7 & (10.9) & 39.1 & (1.6) & 52.8 & (1.6) & 20.1 & $(11.2)$ \\
\hline & Norway & 19.5 & (1.5) & 20.2 & (1.4) & 23.9 & (1.1) & 33.0 & (1.7) & 13.5 & (2.1) & 15.7 & (1.5) & 24.5 & $(0.9)$ & 31.5 & (1.6) & 15.8 & (2.0) \\
\hline & Poland & 33.2 & (1.9) & 40.1 & $(2.0)$ & 52.5 & (2.4) & 66.4 & (2.3) & 33.2 & (3.1) & 36.7 & (1.7) & 49.3 & $(2.0)$ & 61.7 & $(2.7)$ & 25.0 & (3.2) \\
\hline & Portugal & 22.3 & (1.9) & 33.8 & $(1.8)$ & 42.6 & $(2.8)$ & 61.2 & $(2.3)$ & 38.8 & (3.2) & 22.7 & (6.1) & 36.8 & (1.4) & 52.9 & (2.6) & 30.2 & (6.5) \\
\hline & Slovak Republic & $\mathrm{m}$ & $\mathrm{m}$ & $\mathrm{m}$ & $\mathrm{m}$ & $\mathrm{m}$ & $\mathrm{m}$ & $\mathrm{m}$ & $\mathrm{m}$ & $\mathrm{m}$ & $\mathrm{m}$ & $\mathrm{m}$ & $\mathrm{m}$ & $\mathrm{m}$ & $\mathrm{m}$ & $\mathrm{m}$ & $\mathrm{m}$ & $\mathrm{m}$ & $\mathrm{m}$ \\
\hline & Slovenia & 6.6 & $(0.8)$ & 10.4 & $(1.0)$ & 31.0 & (1.4) & 55.0 & (1.9) & 48.4 & (2.0) & 18.6 & (3.3) & 25.1 & $(0.6)$ & 28.5 & (1.6) & 9.9 & (3.9) \\
\hline & Spain & 34.8 & (1.8) & 43.2 & (1.5) & 53.2 & $(2.0)$ & 72.4 & $(2.0)$ & 37.7 & (2.5) & 49.5 & (2.9) & 48.3 & (1.4) & 56.1 & (2.0) & 6.6 & (3.4) \\
\hline & Sweden & 29.8 & (1.8) & 34.5 & (1.5) & 37.3 & (1.9) & 52.9 & (2.9) & 23.1 & (3.5) & 24.8 & (2.7) & 36.1 & $(1.0)$ & 47.9 & (2.0) & 23.1 & (3.6) \\
\hline & Switzerland & 11.5 & (1.6) & 16.0 & (1.7) & 24.2 & (3.6) & 56.4 & $(2.1)$ & 44.9 & (2.4) & 16.9 & (2.6) & 25.1 & (1.5) & 35.4 & (3.1) & 18.5 & (4.1) \\
\hline & Turkey & 56.4 & $(2.7)$ & 62.8 & $(2.9)$ & 75.0 & $(3.2)$ & 87.7 & (2.5) & 31.2 & (4.0) & 17.6 & (2.9) & 71.2 & $(2.4)$ & 71.6 & (1.5) & 53.9 & (3.2) \\
\hline & United Kingdom & 33.4 & $(2.1)$ & 32.9 & $(2.1)$ & 39.7 & $(2.2)$ & 60.7 & (1.9) & 27.3 & (2.9) & 39.3 & (3.7) & 40.1 & (1.3) & 46.5 & $(3.2)$ & 7.2 & (5.0) \\
\hline & United States & 65.8 & (1.8) & 73.1 & (1.6) & 77.8 & (1.8) & 86.9 & (1.7) & 21.1 & (2.7) & 70.5 & (3.0) & 78.9 & (1.1) & 73.7 & (1.4) & 3.2 & (3.2) \\
\hline & OECD average & 27.2 & $(0.4)$ & 36.6 & $(0.3)$ & 48.1 & $(0.4)$ & 64.6 & $(0.4)$ & 37.4 & $(0.5)$ & 31.4 & $(0.8)$ & 41.8 & $(0.3)$ & 50.3 & $(0.4)$ & 18.4 & (0.9) \\
\hline$n$ & Albania & $\mathrm{m}$ & $\mathrm{m}$ & $\mathrm{m}$ & $\mathrm{m}$ & $\mathrm{m}$ & $\mathrm{m}$ & $\mathrm{m}$ & $\mathrm{m}$ & $\mathrm{m}$ & $\mathrm{m}$ & $\mathrm{m}$ & $\mathrm{m}$ & $\mathrm{m}$ & $\mathrm{m}$ & $\mathrm{m}$ & $\mathrm{m}$ & $\mathrm{m}$ & $\mathrm{m}$ \\
\hline ב & Algeria & $\mathrm{m}$ & $\mathrm{m}$ & $\mathrm{m}$ & $\mathrm{m}$ & $\mathrm{m}$ & $\mathrm{m}$ & $\mathrm{m}$ & $\mathrm{m}$ & $\mathrm{m}$ & $\mathrm{m}$ & $\mathrm{m}$ & $\mathrm{m}$ & $\mathrm{m}$ & $\mathrm{m}$ & $\mathrm{m}$ & $\mathrm{m}$ & $\mathrm{m}$ & $\mathrm{m}$ \\
\hline ฮั & Brazil & 34.8 & $(1.2)$ & 40.2 & (1.5) & 45.1 & (1.3) & 64.1 & (1.3) & 29.3 & (1.9) & 30.2 & (3.1) & 43.9 & (1.1) & 50.5 & $(1.2)$ & 20.3 & (3.5) \\
\hline & B-S-J-G (China) & 11.5 & $(1.8)$ & 23.2 & $(4.0)$ & 50.1 & (4.6) & 66.1 & (3.8) & 54.7 & (4.4) & 16.5 & (6.2) & 30.2 & $(2.7)$ & 54.7 & (3.2) & 38.2 & (7.1) \\
\hline & Bulgaria & 19.7 & (2.3) & 28.4 & (1.7) & 44.6 & $(3.0)$ & 64.5 & (2.0) & 44.7 & (2.9) & 12.3 & (4.9) & 37.2 & (1.7) & 45.0 & (1.9) & 32.7 & (5.4) \\
\hline & CABA (Argentina) & $\mathrm{m}$ & $\mathrm{m}$ & $\mathrm{m}$ & $\mathrm{m}$ & $\mathrm{m}$ & $\mathrm{m}$ & $\mathrm{m}$ & $\mathrm{m}$ & $\mathrm{m}$ & $\mathrm{m}$ & $\mathrm{m}$ & $\mathrm{m}$ & $\mathrm{m}$ & $\mathrm{m}$ & $\mathrm{m}$ & $\mathrm{m}$ & $\mathrm{m}$ & $\mathrm{m}$ \\
\hline & Colombia & 64.1 & $(2.2)$ & 73.0 & (2.0) & 78.2 & $(1.0)$ & 90.1 & (1.8) & 26.0 & (2.8) & 64.5 & (3.2) & 74.5 & (1.9) & 82.2 & (1.3) & 17.6 & (3.5) \\
\hline & Costa Rica & 51.6 & (1.5) & 54.3 & (2.5) & 54.5 & $(2.2)$ & 57.5 & (1.7) & 5.9 & (2.3) & 52.2 & (1.7) & 55.3 & $(1.0)$ & 54.2 & (2.1) & 2.0 & (2.9) \\
\hline & Croatia & 13.2 & $(2.1)$ & 23.5 & (2.5) & 39.3 & (3.9) & 67.9 & (2.1) & 54.8 & (3.0) & C & C & 32.3 & (1.5) & 42.3 & (1.8) & c & c \\
\hline & Cyprus* & 50.9 & (3.1) & 82.0 & (1.9) & 87.2 & $(0.9)$ & 90.6 & $(0.8)$ & 39.6 & (3.2) & 66.5 & (2.0) & 77.1 & $(0.7)$ & 80.8 & $(0.7)$ & 14.3 & (2.2) \\
\hline & Dominican Republic & 56.7 & $(2.6)$ & 63.5 & (2.6) & 63.5 & $(2.1)$ & 70.2 & (1.6) & 13.5 & (3.2) & 61.3 & (3.8) & 63.1 & (1.5) & 66.0 & (1.9) & 4.7 & $(4.3)$ \\
\hline & FYROM & $\mathrm{m}$ & $\mathrm{m}$ & $\mathrm{m}$ & $\mathrm{m}$ & $\mathrm{m}$ & $\mathrm{m}$ & $\mathrm{m}$ & $\mathrm{m}$ & $\mathrm{m}$ & $\mathrm{m}$ & $\mathrm{m}$ & $\mathrm{m}$ & $\mathrm{m}$ & $\mathrm{m}$ & $\mathrm{m}$ & $\mathrm{m}$ & $\mathrm{m}$ & $\mathrm{m}$ \\
\hline & Georgia & $\mathrm{m}$ & $\mathrm{m}$ & $\mathrm{m}$ & $\mathrm{m}$ & $\mathrm{m}$ & $\mathrm{m}$ & $\mathrm{m}$ & $\mathrm{m}$ & $\mathrm{m}$ & $\mathrm{m}$ & $\mathrm{m}$ & $\mathrm{m}$ & $\mathrm{m}$ & $\mathrm{m}$ & $\mathrm{m}$ & $\mathrm{m}$ & $\mathrm{m}$ & $\mathrm{m}$ \\
\hline & Hong Kong (China) & 35.0 & $(2.3)$ & 45.1 & (3.6) & 62.2 & (3.5) & 77.5 & (2.4) & 42.5 & (3.5) & $\mathrm{m}$ & $\mathrm{m}$ & $\mathrm{m}$ & $\mathrm{m}$ & 54.9 & (1.1) & $\mathrm{m}$ & $\mathrm{m}$ \\
\hline & Indonesia & $\mathrm{m}$ & $\mathrm{m}$ & $\mathrm{m}$ & $\mathrm{m}$ & $\mathrm{m}$ & $\mathrm{m}$ & $\mathrm{m}$ & $\mathrm{m}$ & $\mathrm{m}$ & $\mathrm{m}$ & $\mathrm{m}$ & $\mathrm{m}$ & $\mathrm{m}$ & $\mathrm{m}$ & $\mathrm{m}$ & $\mathrm{m}$ & $\mathrm{m}$ & $\mathrm{m}$ \\
\hline & Jordan & $\mathrm{m}$ & $\mathrm{m}$ & $\mathrm{m}$ & $\mathrm{m}$ & $\mathrm{m}$ & $\mathrm{m}$ & $\mathrm{m}$ & $\mathrm{m}$ & $\mathrm{m}$ & $\mathrm{m}$ & $\mathrm{m}$ & $\mathrm{m}$ & $\mathrm{m}$ & $\mathrm{m}$ & $\mathrm{m}$ & $\mathrm{m}$ & $\mathrm{m}$ & $\mathrm{m}$ \\
\hline & Kosovo & $\mathrm{m}$ & $\mathrm{m}$ & $\mathrm{m}$ & $\mathrm{m}$ & $\mathrm{m}$ & $\mathrm{m}$ & $\mathrm{m}$ & $\mathrm{m}$ & $\mathrm{m}$ & $\mathrm{m}$ & $\mathrm{m}$ & $\mathrm{m}$ & $\mathrm{m}$ & $\mathrm{m}$ & $\mathrm{m}$ & $\mathrm{m}$ & $\mathrm{m}$ & $\mathrm{m}$ \\
\hline & Lebanon & $\mathrm{m}$ & $\mathrm{m}$ & $\mathrm{m}$ & $\mathrm{m}$ & $\mathrm{m}$ & $\mathrm{m}$ & $\mathrm{m}$ & $\mathrm{m}$ & $\mathrm{m}$ & $\mathrm{m}$ & $\mathrm{m}$ & $\mathrm{m}$ & $\mathrm{m}$ & $\mathrm{m}$ & $\mathrm{m}$ & $\mathrm{m}$ & $\mathrm{m}$ & $\mathrm{m}$ \\
\hline & Lithuania & 25.7 & (1.8) & 44.9 & $(2.7)$ & 62.5 & (3.0) & 81.6 & (1.8) & 55.9 & (2.5) & 30.7 & (1.9) & 53.4 & (1.8) & 66.5 & (2.6) & 35.9 & (3.3) \\
\hline & Macao (China) & 37.7 & $(1.2)$ & 48.3 & (1.6) & 45.8 & (1.3) & 56.6 & (1.5) & 18.9 & (2.1) & c & c & c & C & 46.7 & $(0.8)$ & c & c \\
\hline & Malta & $\mathrm{m}$ & $\mathrm{m}$ & $\mathrm{m}$ & $\mathrm{m}$ & $\mathrm{m}$ & $\mathrm{m}$ & $\mathrm{m}$ & $\mathrm{m}$ & $\mathrm{m}$ & $\mathrm{m}$ & $\mathrm{m}$ & $\mathrm{m}$ & $\mathrm{m}$ & $\mathrm{m}$ & $\mathrm{m}$ & $\mathrm{m}$ & $\mathrm{m}$ & $\mathrm{m}$ \\
\hline & Moldova & $\mathrm{m}$ & $\mathrm{m}$ & $\mathrm{m}$ & $\mathrm{m}$ & $\mathrm{m}$ & $\mathrm{m}$ & $\mathrm{m}$ & $\mathrm{m}$ & $\mathrm{m}$ & $\mathrm{m}$ & $\mathrm{m}$ & $\mathrm{m}$ & $\mathrm{m}$ & $\mathrm{m}$ & $\mathrm{m}$ & $\mathrm{m}$ & $\mathrm{m}$ & $\mathrm{m}$ \\
\hline & Montenegro & 45.3 & $(1.4)$ & 60.6 & $(1.5)$ & 72.8 & (3.1) & 85.5 & (1.1) & 40.1 & (1.8) & c & $\mathrm{c}$ & 66.4 & $(0.8)$ & 63.1 & (1.3) & c & c \\
\hline & Peru & 52.0 & (1.9) & 59.8 & (1.7) & 66.5 & (1.6) & 78.9 & (1.6) & 26.9 & (2.2) & 56.2 & (2.2) & 66.6 & (1.1) & 69.8 & (2.0) & 13.5 & (3.0) \\
\hline & Qatar & 68.2 & $(0.8)$ & 75.5 & $(0.8)$ & 82.1 & $(0.7)$ & 81.8 & $(0.7)$ & 13.5 & (1.0) & 76.5 & (1.8) & 73.5 & $(0.7)$ & 79.2 & $(0.5)$ & 2.6 & (1.8) \\
\hline & Romania & $\mathrm{m}$ & $\mathrm{m}$ & $\mathrm{m}$ & $\mathrm{m}$ & $\mathrm{m}$ & $\mathrm{m}$ & $\mathrm{m}$ & $\mathrm{m}$ & $\mathrm{m}$ & $\mathrm{m}$ & $\mathrm{m}$ & $\mathrm{m}$ & $\mathrm{m}$ & $\mathrm{m}$ & $\mathrm{m}$ & $\mathrm{m}$ & $\mathrm{m}$ & $\mathrm{m}$ \\
\hline & Russia & 9.6 & (1.4) & 12.7 & (1.6) & 18.0 & (1.6) & 27.3 & (1.8) & 17.7 & (2.3) & 9.7 & (1.7) & 13.8 & (1.1) & 21.0 & (1.0) & 11.3 & (2.0) \\
\hline & Singapore & 43.6 & $(1.2)$ & 53.4 & $(1.2)$ & 66.9 & $(2.2)$ & 87.9 & (1.4) & 44.2 & (1.7) & $\mathrm{m}$ & $\mathrm{m}$ & $\mathrm{m}$ & $\mathrm{m}$ & 62.7 & $(0.6)$ & $\mathrm{m}$ & $\mathrm{m}$ \\
\hline & Chinese Taipei & 21.2 & (2.5) & 39.0 & $(2.1)$ & 52.5 & (2.4) & 75.4 & (3.4) & 54.2 & (4.8) & $\mathrm{m}$ & $\mathrm{m}$ & 34.1 & (1.8) & 55.8 & (1.5) & $\mathrm{m}$ & $\mathrm{m}$ \\
\hline & Thailand & 52.2 & $(2.7)$ & 62.8 & (3.4) & 69.9 & (3.0) & 91.3 & (1.4) & 39.1 & (3.2) & 50.1 & (3.5) & 70.7 & (1.4) & 82.8 & (2.7) & 32.6 & $(4.7)$ \\
\hline & Trinidad a & $\mathrm{m}$ & II & $\mathrm{m}$ & $\mathrm{m}$ & $\mathrm{m}$ & III & $\mathrm{m}$ & 1 & $\mathrm{~m}$ & $\mathrm{~m}$ & $\mathrm{~m}$ & $\mathrm{~m}$ & $\mathrm{~m}$ & $\mathrm{~m}$ & $\mathrm{~m}$ & $\mathrm{~m}$ & $\mathrm{~m}$ & $\mathrm{~m}$ \\
\hline & Tunisia & 41.2 & (2.5) & 45.7 & $(3.2)$ & 52.9 & $(2.3)$ & 66.0 & $(2.1)$ & 24.7 & (3.2) & 42.0 & (5.4) & 48.3 & (1.6) & 57.5 & (3.3) & 15.5 & (6.2) \\
\hline & United Arab Emirates & 63.1 & (1.8) & 69.7 & (1.4) & 75.7 & (1.4) & 79.2 & $(1.2)$ & 16.1 & (2.3) & 63.0 & (3.6) & 67.9 & (1.5) & 74.6 & (0.9) & 11.6 & (3.9) \\
\hline & Uruguay & 22.3 & (2.1) & 29.0 & (2.4) & 51.1 & (2.9) & 67.6 & (1.6) & 45.2 & (2.5) & 35.4 & (3.6) & 40.1 & (1.5) & 47.0 & (1.8) & 11.5 & (4.0) \\
\hline & Viet Nam & $\mathrm{m}$ & $\mathrm{m}$ & $\mathrm{m}$ & $\mathrm{m}$ & $\mathrm{m}$ & $\mathrm{m}$ & $\mathrm{m}$ & $\mathrm{m}$ & m & $\mathrm{m}$ & $\mathrm{m}$ & $\mathrm{m}$ & m & $\mathrm{m}$ & $\mathrm{m}$ & $\mathrm{m}$ & $\mathrm{m}$ & $\mathrm{m}$ \\
\hline & Argen & $\mathrm{m}$ & $\mathrm{m}$ & $\mathrm{m}$ & $\mathrm{m}$ & $\mathrm{m}$ & $\mathrm{m}$ & $\mathrm{m}$ & $\mathrm{m}$ & $\mathrm{m}$ & $\mathrm{m}$ & $\mathrm{m}$ & $\mathrm{m}$ & $\mathrm{m}$ & $\mathrm{m}$ & $\mathrm{m}$ & $\mathrm{m}$ & $\mathrm{m}$ & $\mathrm{m}$ \\
\hline & Kazakhstan** & $\mathrm{m}$ & $\mathrm{m}$ & $\mathrm{m}$ & $\mathrm{m}$ & $\mathrm{m}$ & $\mathrm{m}$ & $\mathrm{m}$ & $\mathrm{m}$ & $\mathrm{m}$ & $\mathrm{m}$ & $\mathrm{m}$ & $\mathrm{m}$ & $\mathrm{m}$ & $\mathrm{m}$ & $\mathrm{m}$ & $\mathrm{m}$ & $\mathrm{m}$ & $\mathrm{m}$ \\
\hline & Malaysia** & 57.5 & $(2.1)$ & 59.6 & $(2.8)$ & 74.3 & (2.9) & 79.1 & (2.8) & 21.5 & (3.6) & 63.9 & $(4.2)$ & 67.5 & (1.8) & 69.3 & (2.2) & 5.4 & (4.8) \\
\hline
\end{tabular}

1. The socio-economic profile is measured by the PISA index of economic, social and cultural status (ESCS)

Note: Values that are statistically significant are indicated in bold (see Annex A3).

* See note at the beginning of this Annex.

Coverage is too small to ensure comparability (see Annex A4). 
[Part 2/2]

Table III.6.3 Students' expectations to complete a university degree, by school characteristics

Results based on students' self-reports

\begin{tabular}{|c|c|c|c|c|c|c|c|c|c|c|c|c|}
\hline & \multicolumn{12}{|c|}{ Percentage of students who expect to complete a university degree, by: } \\
\hline & \multicolumn{6}{|c|}{ Type of school } & \multicolumn{6}{|c|}{ Education level } \\
\hline & \multicolumn{2}{|c|}{ Public } & \multicolumn{2}{|c|}{ Private } & \multicolumn{2}{|c|}{ Private - public } & \multicolumn{2}{|c|}{$\begin{array}{l}\text { Lower secondary } \\
\text { (ISCED 2) }\end{array}$} & \multicolumn{2}{|c|}{$\begin{array}{l}\text { Upper secondary } \\
\text { (ISCED 3) }\end{array}$} & \multicolumn{2}{|c|}{ ISCED 3 - ISCED 2} \\
\hline & $\%$ & S.E. & $\%$ & S.E. & $\%$ dif. & S.E. & $\%$ & S.E. & $\%$ & S.E. & $\%$ dif. & S.E. \\
\hline Australia & 46.8 & $(0.9)$ & 64.6 & $(0.9)$ & 17.8 & $(1.2)$ & 54.9 & $(0.6)$ & 49.8 & $(1.2)$ & -5.0 & (1.3) \\
\hline Austria & 24.8 & $(0.8)$ & 44.6 & (5.5) & 19.8 & (5.9) & 2.9 & (1.9) & 27.5 & $(0.8)$ & 24.6 & $(2.2)$ \\
\hline 0 Belgium & w & w & w & w & w & w & 14.3 & (2.2) & 34.2 & (1.0) & 20.0 & $(2.5)$ \\
\hline Canada & 62.2 & $(1.0)$ & 77.9 & $(2.0)$ & 15.7 & (2.3) & 56.7 & (2.0) & 64.4 & $(0.9)$ & 7.8 & $(2.1)$ \\
\hline Chile & 58.1 & (1.7) & 71.9 & (1.1) & 13.8 & (2.0) & 35.0 & (3.7) & 68.5 & $(0.9)$ & 33.5 & $(3.8)$ \\
\hline Czech Republic & 55.0 & $(1.0)$ & 65.0 & (4.9) & 10.0 & $(5.2)$ & 51.6 & $(1.2)$ & 60.2 & $(1.3)$ & 8.6 & $(1.9)$ \\
\hline Denmark & 36.5 & (1.3) & 41.4 & (2.6) & 4.9 & (3.0) & 37.2 & (1.0) & 43.5 & $(30.0)$ & 6.3 & (30.0) \\
\hline Estonia & 42.0 & $(1.0)$ & 51.3 & (8.4) & 9.4 & (8.5) & 42.7 & $(0.9)$ & 52.3 & $(10.2)$ & 9.7 & (10.1) \\
\hline Finland & 26.2 & (1.1) & 46.8 & (6.8) & 20.6 & (7.1) & 27.0 & (1.1) & C & C & c & c \\
\hline France & 30.5 & (1.1) & 39.9 & $(3.2)$ & 9.4 & (3.5) & 8.0 & $(0.8)$ & 39.1 & $(1.2)$ & 31.2 & $(1.4)$ \\
\hline Germany & 17.4 & (1.1) & 25.5 & (3.6) & 8.1 & (3.8) & 17.6 & $(0.8)$ & 24.9 & (5.0) & 7.3 & $(4.8)$ \\
\hline Greece & 64.7 & $(2.0)$ & 93.9 & (1.0) & 29.1 & $(2.2)$ & 19.9 & (4.3) & 68.5 & (2.0) & 48.6 & $(4.9)$ \\
\hline Hungary & 32.2 & (1.5) & 49.6 & (3.7) & 17.4 & (4.3) & 12.3 & (2.9) & 38.1 & (1.1) & 25.8 & $(3.2)$ \\
\hline Iceland & 38.9 & $(0.9)$ & C & c & c & c & 38.9 & $(0.8)$ & $\mathrm{m}$ & $\mathrm{m}$ & $\mathrm{m}$ & $\mathrm{m}$ \\
\hline Ireland & 41.0 & (1.0) & 50.1 & $(1.2)$ & 9.1 & (1.5) & 42.9 & $(0.9)$ & 51.9 & (1.3) & 9.1 & $(1.4)$ \\
\hline Israel & $\mathrm{m}$ & $\mathrm{m}$ & $\mathrm{m}$ & $\mathrm{m}$ & $\mathrm{m}$ & $\mathrm{m}$ & 50.3 & (2.6) & 57.8 & $(1.3)$ & 7.4 & $(2.8)$ \\
\hline Italy & 40.1 & (1.6) & 37.8 & (9.6) & -2.3 & (9.8) & 7.7 & (2.4) & 38.6 & $(1.2)$ & 30.9 & $(2.6)$ \\
\hline Japan & 54.4 & $(1.3)$ & 67.8 & $(2.1)$ & 13.4 & $(2.6)$ & $\mathrm{m}$ & $\mathrm{m}$ & 58.7 & $(1.1)$ & $\mathrm{m}$ & $\mathrm{m}$ \\
\hline Korea & 72.5 & (1.8) & 80.5 & (2.0) & 8.0 & (3.5) & 71.5 & (2.6) & 75.7 & (1.0) & 4.2 & $(2.7)$ \\
\hline Latvia & 24.6 & (0.8) & 28.2 & (6.6) & 3.6 & (6.6) & 24.0 & $(0.8)$ & 41.7 & (5.1) & 17.6 & $(5.0)$ \\
\hline Luxembourg & 41.5 & (0.6) & 40.5 & (1.5) & -1.1 & (1.6) & 27.4 & $(0.7)$ & 59.0 & (1.0) & 31.6 & $(1.2)$ \\
\hline Mexico & 56.2 & (1.1) & 74.1 & (2.8) & 17.9 & (3.1) & 47.4 & (1.7) & 65.4 & (1.3) & 18.0 & $(2.1)$ \\
\hline Netherlands & 21.8 & (3.4) & 14.6 & (1.5) & -7.2 & (3.9) & 8.0 & $(0.5)$ & 38.7 & (1.7) & 30.7 & $(1.7)$ \\
\hline New Zealand & 43.8 & $(1.2)$ & 81.9 & (3.8) & 38.1 & $(4.0)$ & 37.8 & (3.1) & 45.7 & (1.0) & 7.9 & $(3.0)$ \\
\hline Norway & 24.2 & $(0.7)$ & 17.1 & (7.9) & -7.0 & (8.1) & 24.0 & $(0.7)$ & c & C & c & c \\
\hline Poland & 46.9 & (1.1) & 75.1 & (6.4) & 28.2 & (6.4) & 47.8 & (1.2) & C & C & C & c \\
\hline Portugal & 38.2 & (1.1) & 61.9 & $(5.7)$ & 23.7 & (5.8) & 14.9 & (1.1) & 52.9 & (1.3) & 38.0 & $(1.5)$ \\
\hline Slovak Republic & $\mathrm{m}$ & $\mathrm{m}$ & $\mathrm{m}$ & $\mathrm{m}$ & $\mathrm{m}$ & $\mathrm{m}$ & $\mathrm{m}$ & $\mathrm{m}$ & $\mathrm{m}$ & $\mathrm{m}$ & $\mathrm{m}$ & $\mathrm{m}$ \\
\hline Slovenia & 25.2 & $(0.7)$ & 55.3 & (5.6) & 30.1 & (5.6) & 9.1 & (2.9) & 26.7 & $(0.6)$ & 17.6 & $(2.9)$ \\
\hline Spain & 44.2 & (1.1) & 65.8 & $(2.0)$ & 21.6 & (2.3) & 51.0 & (1.0) & c & C & c & c \\
\hline Sweden & 37.1 & $(1.0)$ & 45.9 & (2.6) & 8.8 & (2.6) & 37.9 & $(0.9)$ & 78.6 & (7.6) & 40.8 & $(7.5)$ \\
\hline Switzerland & 26.1 & $(1.0)$ & 36.5 & (5.6) & 10.4 & (5.6) & 22.2 & (1.1) & 43.7 & (2.1) & 21.6 & $(2.3)$ \\
\hline Turkey & 70.4 & $(1.2)$ & 76.2 & (7.9) & 5.8 & $(8.2)$ & 30.8 & (5.5) & 71.9 & (1.1) & 41.1 & (5.6) \\
\hline United Kingdom & 39.8 & (1.1) & 68.9 & $(4.8)$ & 29.1 & (5.0) & 40.5 & (5.1) & 41.8 & (0.9) & 1.3 & $(5.1)$ \\
\hline United States & 75.2 & $(0.8)$ & 85.7 & (1.8) & 10.6 & (2.0) & 56.4 & (2.7) & 78.1 & $(0.7)$ & 21.7 & $(2.7)$ \\
\hline OECD average & 42.1 & $(0.2)$ & 55.7 & $(0.8)$ & 13.5 & (0.9) & 32.4 & $(0.4)$ & 51.7 & (1.2) & 19.9 & (1.3) \\
\hline
\end{tabular}

\begin{tabular}{|c|c|c|c|c|c|c|c|c|c|c|c|c|}
\hline Albania & $\mathrm{m}$ & $\mathrm{m}$ & $\mathrm{m}$ & $\mathrm{m}$ & $\mathrm{m}$ & $\mathrm{m}$ & $\mathrm{m}$ & $\mathrm{m}$ & $\mathrm{m}$ & $\mathrm{m}$ & $\mathrm{m}$ & $\mathrm{m}$ \\
\hline Algeria & $\mathrm{m}$ & $\mathrm{m}$ & $\mathrm{m}$ & $\mathrm{m}$ & $\mathrm{m}$ & $\mathrm{m}$ & $\mathrm{m}$ & $\mathrm{m}$ & $\mathrm{m}$ & $\mathrm{m}$ & $\mathrm{m}$ & $\mathrm{m}$ \\
\hline Brazil & 43.4 & $(0.7)$ & 68.8 & (1.9) & 25.3 & (2.1) & 27.9 & (1.0) & 51.2 & $(0.7)$ & 23.3 & $(1.2)$ \\
\hline B-S-J-G (China) & 38.1 & $(2.0)$ & 36.1 & (7.0) & -1.9 & (7.7) & 24.2 & (1.3) & 61.0 & (3.1) & 36.8 & (3.4) \\
\hline Bulgaria & 39.1 & $(1.2)$ & c & c & c & c & 16.5 & $(4.1)$ & 40.1 & (1.1) & 23.6 & $(4.2)$ \\
\hline CABA (Argentina) & $\mathrm{m}$ & $\mathrm{m}$ & $\mathrm{m}$ & $\mathrm{m}$ & $\mathrm{m}$ & $\mathrm{m}$ & $\mathrm{m}$ & $\mathrm{m}$ & $\mathrm{m}$ & $\mathrm{m}$ & $\mathrm{m}$ & $\mathrm{m}$ \\
\hline Colombia & 73.7 & (1.1) & 86.6 & (2.2) & 13.0 & (2.4) & 64.6 & (1.4) & 84.1 & $(0.8)$ & 19.5 & (1.2) \\
\hline Costa Rica & 54.8 & $(0.8)$ & 51.6 & (1.9) & -3.2 & (1.9) & 50.7 & (1.1) & 58.5 & (1.1) & 7.8 & (1.6) \\
\hline Croatia & 35.6 & (1.1) & 57.0 & (10.1) & 21.4 & $(10.5)$ & c & c & 36.1 & $(1.0)$ & $\mathrm{m}$ & $\mathrm{m}$ \\
\hline Cyprus* & 76.5 & $(0.5)$ & 84.9 & $(1.2)$ & 8.4 & (1.3) & 42.3 & (2.2) & 80.0 & $(0.5)$ & 37.7 & (2.3) \\
\hline Dominican Republic & 62.2 & $(1.2)$ & 67.6 & (1.8) & 5.4 & (2.2) & 48.2 & (2.7) & 67.5 & (1.0) & 19.3 & (2.9) \\
\hline FYROM & $\mathrm{m}$ & $\mathrm{m}$ & $\mathrm{m}$ & $\mathrm{m}$ & $\mathrm{m}$ & $\mathrm{m}$ & $\mathrm{m}$ & $\mathrm{m}$ & $\mathrm{m}$ & $\mathrm{m}$ & $\mathrm{m}$ & $\mathrm{m}$ \\
\hline Georgia & $\mathrm{m}$ & $\mathrm{m}$ & $\mathrm{m}$ & $\mathrm{m}$ & $\mathrm{m}$ & $\mathrm{m}$ & $\mathrm{m}$ & $\mathrm{m}$ & $\mathrm{m}$ & $\mathrm{m}$ & $\mathrm{m}$ & $\mathrm{m}$ \\
\hline Hong Kong (China) & 60.9 & (5.4) & 54.6 & $(1.2)$ & -6.3 & (5.5) & 44.1 & (1.4) & 60.1 & (1.3) & 16.1 & (1.7) \\
\hline Indonesia & $\mathrm{m}$ & $\mathrm{m}$ & $\mathrm{m}$ & $\mathrm{m}$ & $\mathrm{m}$ & $\mathrm{m}$ & $\mathrm{m}$ & $\mathrm{m}$ & $\mathrm{m}$ & $\mathrm{m}$ & $\mathrm{m}$ & $\mathrm{m}$ \\
\hline Jordan & $\mathrm{m}$ & $\mathrm{m}$ & $\mathrm{m}$ & $\mathrm{m}$ & $\mathrm{m}$ & $\mathrm{m}$ & $\mathrm{m}$ & $\mathrm{m}$ & $\mathrm{m}$ & $\mathrm{m}$ & $\mathrm{m}$ & $\mathrm{m}$ \\
\hline Kosovo & $\mathrm{m}$ & $\mathrm{m}$ & $\mathrm{m}$ & $\mathrm{m}$ & $\mathrm{m}$ & $\mathrm{m}$ & $\mathrm{m}$ & $\mathrm{m}$ & $\mathrm{m}$ & $\mathrm{m}$ & $\mathrm{m}$ & $\mathrm{m}$ \\
\hline Lebanon & $\mathrm{m}$ & $\mathrm{m}$ & $\mathrm{m}$ & $\mathrm{m}$ & $\mathrm{m}$ & $\mathrm{m}$ & $\mathrm{m}$ & $\mathrm{m}$ & $\mathrm{m}$ & $\mathrm{m}$ & $\mathrm{m}$ & $\mathrm{m}$ \\
\hline Lithuania & 52.9 & (1.1) & 82.1 & (8.3) & 29.1 & (8.1) & 53.6 & (1.3) & c & c & c & c \\
\hline Macao (China) & c & c & 47.1 & $(0.8)$ & c & C & 35.2 & (1.0) & 56.0 & (1.0) & 20.8 & (1.4) \\
\hline Malta & $\mathrm{m}$ & $\mathrm{m}$ & $\mathrm{m}$ & $\mathrm{m}$ & $\mathrm{m}$ & $\mathrm{m}$ & $\mathrm{m}$ & $\mathrm{m}$ & $\mathrm{m}$ & $\mathrm{m}$ & $\mathrm{m}$ & $\mathrm{m}$ \\
\hline Moldova & $\mathrm{m}$ & $\mathrm{m}$ & $\mathrm{m}$ & $\mathrm{m}$ & $\mathrm{m}$ & $\mathrm{m}$ & $\mathrm{m}$ & $\mathrm{m}$ & $\mathrm{m}$ & $\mathrm{m}$ & $\mathrm{m}$ & $\mathrm{m}$ \\
\hline Montenegro & 65.3 & $(0.7)$ & c & c & c & c & 49.3 & (11.5) & 65.8 & $(0.6)$ & 16.4 & (11.5) \\
\hline Peru & 60.1 & $(1.0)$ & 73.7 & (1.3) & 13.6 & (1.7) & 48.0 & (1.4) & 69.8 & $(0.9)$ & 21.8 & (1.7) \\
\hline Qatar & 74.7 & $(0.5)$ & 79.1 & (0.6) & 4.4 & $(0.7)$ & 60.9 & (1.1) & 80.5 & $(0.4)$ & 19.6 & (1.1) \\
\hline Romania & $\mathrm{m}$ & $\mathrm{m}$ & $\mathrm{m}$ & $\mathrm{m}$ & $\mathrm{m}$ & $\mathrm{m}$ & $\mathrm{m}$ & $\mathrm{m}$ & $\mathrm{m}$ & $\mathrm{m}$ & $\mathrm{m}$ & $\mathrm{m}$ \\
\hline Russia & 16.9 & $(0.8)$ & c & c & c & c & 15.8 & $(0.7)$ & 24.0 & (2.5) & 8.3 & (2.5) \\
\hline Singapore & 61.4 & $(0.6)$ & 78.5 & $(2.2)$ & 17.0 & $(2.2)$ & 67.4 & (5.1) & 62.7 & $(0.6)$ & -4.7 & (5.2) \\
\hline Chinese Taipei & 52.0 & $(1.2)$ & 38.2 & (1.4) & -13.8 & (1.8) & 42.4 & (1.1) & 49.7 & (1.3) & 7.3 & (1.7) \\
\hline Thailand & 69.5 & $(1.3)$ & 65.3 & (2.9) & -4.3 & (3.2) & 60.3 & (1.8) & 71.8 & $(1.3)$ & 11.5 & $(2.2)$ \\
\hline Trinidad and Tobago & $\mathrm{m}$ & $\mathrm{m}$ & $\mathrm{m}$ & $\mathrm{m}$ & $\mathrm{m}$ & $\mathrm{m}$ & $\mathrm{m}$ & $\mathrm{m}$ & $\mathrm{m}$ & $\mathrm{m}$ & $\mathrm{m}$ & $\mathrm{m}$ \\
\hline Tunisia & 51.5 & $(1.2)$ & 30.3 & (13.0) & -21.3 & $(13.2)$ & 30.3 & (1.6) & 62.0 & (1.0) & 31.8 & (1.9) \\
\hline United Arab Emirates & 64.8 & (1.1) & 77.1 & (1.0) & 12.4 & (1.6) & 54.7 & (1.9) & 74.6 & $(0.6)$ & 19.9 & (1.9) \\
\hline Uruguay & 37.0 & $(1.0)$ & 72.8 & (1.8) & 35.8 & (2.1) & 17.9 & (1.1) & 57.2 & (1.1) & 39.3 & (1.6) \\
\hline Viet Nam & $\mathrm{m}$ & $\mathrm{m}$ & $\mathrm{m}$ & $\mathrm{m}$ & $\mathrm{m}$ & $\mathrm{m}$ & $\mathrm{m}$ & $\mathrm{m}$ & $\mathrm{m}$ & $\mathrm{m}$ & $\mathrm{m}$ & $\mathrm{m}$ \\
\hline Argentina** & $\mathrm{m}$ & $\mathrm{m}$ & $\mathrm{m}$ & $\mathrm{m}$ & $\mathrm{m}$ & $\mathrm{m}$ & $\mathrm{m}$ & $\mathrm{m}$ & $\mathrm{m}$ & $\mathrm{m}$ & $\mathrm{m}$ & $\mathrm{m}$ \\
\hline Kazakhstan** & $\mathrm{m}$ & $\mathrm{m}$ & $\mathrm{m}$ & $\mathrm{m}$ & $\mathrm{m}$ & $\mathrm{m}$ & $\mathrm{m}$ & $\mathrm{m}$ & $\mathrm{m}$ & $\mathrm{m}$ & $\mathrm{m}$ & $\mathrm{m}$ \\
\hline Malaysia** & 67.3 & $(1.2)$ & 71.7 & $(8.7)$ & 4.3 & (8.9) & 19.7 & (3.6) & 69.2 & $(1.1)$ & 49.5 & (3.9) \\
\hline
\end{tabular}

1. The socio-economic profile is measured by the PISA index of economic, social and cultural status (ESCS).

Note: Values that are statistically significant are indicated in bold (see Annex A3).

* See note at the beginning of this Annex.

** Coverage is too small to ensure comparability (see Annex A4).

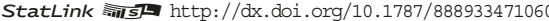


[Part 1/3]

Table III.6.7 Expectations of further education, by student performance in core PISA subjects

Results based on students' self-reports

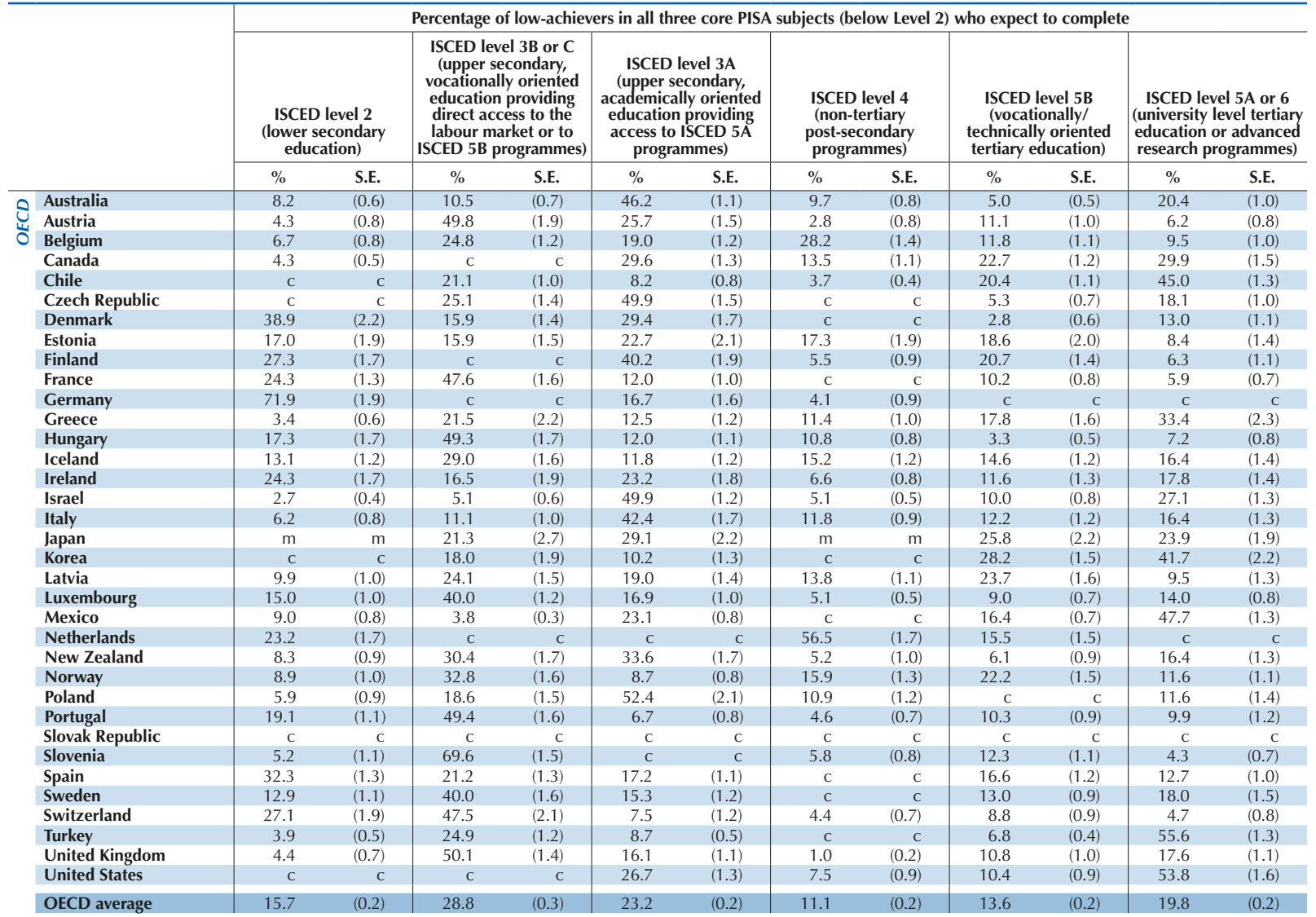

\begin{tabular}{|c|c|c|c|c|c|c|c|c|c|c|c|c|c|}
\hline \multirow{4}{*}{ ఏँ } & Albania & $\mathrm{m}$ & $\mathrm{m}$ & $\mathrm{m}$ & $\mathrm{m}$ & $\mathrm{m}$ & $\mathrm{m}$ & $\mathrm{m}$ & $\mathrm{m}$ & $\mathrm{m}$ & $\mathrm{m}$ & $\mathrm{m}$ & $\mathrm{m}$ \\
\hline & Algeria & $\mathrm{m}$ & $\mathrm{m}$ & $\mathrm{m}$ & $\mathrm{m}$ & $\mathrm{m}$ & $\mathrm{m}$ & $\mathrm{m}$ & $\mathrm{m}$ & $\mathrm{m}$ & $\mathrm{m}$ & $\mathrm{m}$ & $\mathrm{m}$ \\
\hline & Brazil & 5.4 & $(0.3)$ & 6.5 & $(0.3)$ & 36.7 & $(0.7)$ & 9.6 & $(0.3)$ & 5.8 & $(0.3)$ & 36.0 & $(0.6)$ \\
\hline & B-S-J-G (China) & 37.0 & (2.5) & 27.9 & (1.9) & 17.5 & (1.6) & 8.6 & $(0.9)$ & 4.9 & $(0.7)$ & 4.2 & $(0.7)$ \\
\hline & Bulgaria & 6.7 & $(0.7)$ & 26.2 & (1.3) & 11.8 & (0.9) & 15.3 & $(0.7)$ & 19.2 & $(0.9)$ & 20.8 & (1.1) \\
\hline & CABA (Argentina) & $\mathrm{m}$ & $\mathrm{m}$ & $\mathrm{m}$ & $\mathrm{m}$ & $\mathrm{m}$ & $\mathrm{m}$ & $\mathrm{m}$ & $\mathrm{m}$ & $\mathrm{m}$ & $\mathrm{m}$ & $\mathrm{m}$ & $\mathrm{m}$ \\
\hline & Colombia & 3.2 & $(0.4)$ & c & c & 21.5 & $(0.9)$ & c & c & 10.4 & (0.6) & 64.9 & (1.1) \\
\hline & Costa Rica & 3.5 & $(0.4)$ & 12.1 & $(0.9)$ & 8.7 & (0.5) & 9.4 & (0.6) & 15.6 & (0.7) & 50.7 & (1.1) \\
\hline & Croatia & $\mathrm{C}$ & c & 36.6 & (1.6) & 27.0 & (1.4) & 22.2 & (1.0) & 4.7 & $(0.5)$ & 9.0 & $(0.9)$ \\
\hline & Cyprus* & 3.5 & $(0.4)$ & 14.0 & (0.6) & 8.6 & (0.6) & 9.2 & $(0.5)$ & 5.2 & (0.5) & 59.6 & $(0.9)$ \\
\hline & Dominican Republic & 8.6 & $(0.7)$ & 9.5 & $(0.6)$ & 17.2 & $(0.8)$ & 2.5 & $(0.3)$ & 1.3 & $(0.2)$ & 60.8 & (1.1) \\
\hline & FYROM & $\mathrm{m}$ & $\mathrm{m}$ & $\mathrm{m}$ & $\mathrm{m}$ & $\mathrm{m}$ & $\mathrm{m}$ & $\mathrm{m}$ & $\mathrm{m}$ & $\mathrm{m}$ & $\mathrm{m}$ & $\mathrm{m}$ & $\mathrm{m}$ \\
\hline & Georgia & $\mathrm{m}$ & $\mathrm{m}$ & $\mathrm{m}$ & $\mathrm{m}$ & $\mathrm{m}$ & $\mathrm{m}$ & $\mathrm{m}$ & $\mathrm{m}$ & $\mathrm{m}$ & $\mathrm{m}$ & $\mathrm{m}$ & $\mathrm{m}$ \\
\hline & Hong Kong (China) & 8.9 & (1.5) & 7.6 & (1.0) & 33.0 & (2.7) & 16.8 & (2.0) & 14.1 & (1.4) & 19.7 & (2.1) \\
\hline & Indonesia & $\mathrm{m}$ & $\mathrm{m}$ & $\mathrm{m}$ & $\mathrm{m}$ & $\mathrm{m}$ & $\mathrm{m}$ & $\mathrm{m}$ & $\mathrm{m}$ & $\mathrm{m}$ & $\mathrm{m}$ & $\mathrm{m}$ & $\mathrm{m}$ \\
\hline & Jordan & $\mathrm{m}$ & $\mathrm{m}$ & $\mathrm{m}$ & $\mathrm{m}$ & $\mathrm{m}$ & $\mathrm{m}$ & $\mathrm{m}$ & $\mathrm{m}$ & $\mathrm{m}$ & $\mathrm{m}$ & $\mathrm{m}$ & $\mathrm{m}$ \\
\hline & Kosovo & $\mathrm{m}$ & $\mathrm{m}$ & $\mathrm{m}$ & $\mathrm{m}$ & $\mathrm{m}$ & $\mathrm{m}$ & $\mathrm{m}$ & $\mathrm{m}$ & $\mathrm{m}$ & $\mathrm{m}$ & $\mathrm{m}$ & $\mathrm{m}$ \\
\hline & Lebanon & $\mathrm{m}$ & $\mathrm{m}$ & $\mathrm{m}$ & $\mathrm{m}$ & $\mathrm{m}$ & $\mathrm{m}$ & $\mathrm{m}$ & $\mathrm{m}$ & $\mathrm{m}$ & $\mathrm{m}$ & $\mathrm{m}$ & $\mathrm{m}$ \\
\hline & Lithuania & 6.9 & $(0.7)$ & 21.2 & $(1.0)$ & 16.2 & (1.1) & 16.6 & (1.0) & 19.1 & (1.0) & 20.1 & $(1.0)$ \\
\hline & Macao (China) & 12.6 & (1.7) & 8.6 & (1.4) & 26.1 & (2.3) & 21.3 & (1.9) & 13.8 & (1.5) & 17.5 & (1.9) \\
\hline & Malta & $\mathrm{m}$ & $\mathrm{m}$ & $\mathrm{m}$ & $\mathrm{m}$ & $\mathrm{m}$ & $\mathrm{m}$ & $\mathrm{m}$ & $\mathrm{m}$ & $\mathrm{m}$ & $\mathrm{m}$ & $\mathrm{m}$ & $\mathrm{m}$ \\
\hline & Moldova & $\mathrm{m}$ & $\mathrm{m}$ & $\mathrm{m}$ & $\mathrm{m}$ & $\mathrm{m}$ & $\mathrm{m}$ & $\mathrm{m}$ & $\mathrm{m}$ & $\mathrm{m}$ & $\mathrm{m}$ & $\mathrm{m}$ & $\mathrm{m}$ \\
\hline & Montenegro & c & c & 22.5 & $(0.7)$ & 1.2 & $(0.2)$ & 25.9 & $(0.9)$ & c & c & 49.6 & (1.0) \\
\hline & Peru & 1.5 & $(0.2)$ & c & C & 18.5 & $(0.7)$ & 9.7 & $(0.5)$ & 16.2 & $(0.5)$ & 54.1 & $(0.9)$ \\
\hline & Qatar & 3.8 & $(0.2)$ & 8.2 & $(0.3)$ & 9.6 & (0.4) & 2.6 & $(0.2)$ & 9.3 & $(0.3)$ & 66.4 & $(0.7)$ \\
\hline & Romania & $\mathrm{m}$ & $\mathrm{m}$ & $\mathrm{m}$ & $\mathrm{m}$ & $\mathrm{m}$ & $\mathrm{m}$ & $\mathrm{m}$ & $\mathrm{m}$ & $\mathrm{m}$ & $\mathrm{m}$ & $\mathrm{m}$ & $\mathrm{m}$ \\
\hline & Russia & 28.3 & (1.6) & 30.6 & (2.1) & 16.4 & (1.0) & 5.3 & $(0.6)$ & 13.4 & (1.1) & 6.0 & $(0.9)$ \\
\hline & Singapore & c & c & c & c & 7.4 & (1.1) & 16.2 & (1.4) & 46.8 & (2.3) & 27.4 & (1.6) \\
\hline & Chinese Taipei & 5.7 & $(0.8)$ & 43.3 & (1.6) & 15.6 & (1.7) & $\mathrm{m}$ & $\mathrm{m}$ & 23.7 & (1.3) & 11.7 & (1.1) \\
\hline & Thailand & 3.3 & $(0.3)$ & 7.8 & $(0.7)$ & 12.4 & (0.9) & 21.3 & $(0.9)$ & C & $\mathrm{C}$ & 55.1 & (1.4) \\
\hline & Trinidad and Tobago & $\mathrm{m}$ & $\mathrm{m}$ & $\mathrm{m}$ & $\mathrm{m}$ & $\mathrm{m}$ & $\mathrm{m}$ & $\mathrm{m}$ & $\mathrm{m}$ & $\mathrm{m}$ & $\mathrm{m}$ & $\mathrm{m}$ & $\mathrm{m}$ \\
\hline & Tunisia & 9.3 & $(0.5)$ & 3.2 & $(0.4)$ & 27.0 & $(0.9)$ & 10.5 & (0.6) & 5.4 & $(0.5)$ & 44.5 & (1.1) \\
\hline & United Arab Emirates & 4.0 & $(0.4)$ & 7.0 & $(0.5)$ & 18.6 & $(0.6)$ & 5.4 & $(0.3)$ & 6.6 & $(0.3)$ & 58.4 & $(0.8)$ \\
\hline & Uruguay & 34.2 & (1.1) & 14.0 & $(0.6)$ & 17.7 & (0.8) & 7.3 & (0.6) & 4.9 & (0.5) & 21.8 & (1.0) \\
\hline & Viet Nam & $\mathrm{m}$ & $\mathrm{m}$ & $\mathrm{m}$ & m & $\mathrm{m}$ & $\mathrm{m}$ & $\mathrm{m}$ & $\mathrm{m}$ & $\mathrm{m}$ & $\mathrm{m}$ & $\mathrm{m}$ & $\mathrm{m}$ \\
\hline & Argentina** & $\mathrm{m}$ & $\mathrm{m}$ & $\mathrm{m}$ & $\mathrm{m}$ & $\mathrm{m}$ & $\mathrm{m}$ & $\mathrm{m}$ & $\mathrm{m}$ & $\mathrm{m}$ & $\mathrm{m}$ & $\mathrm{m}$ & $\mathrm{m}$ \\
\hline & Kazakhstan** & $\mathrm{m}$ & $\mathrm{m}$ & $\mathrm{m}$ & $\mathrm{m}$ & $\mathrm{m}$ & $\mathrm{m}$ & $\mathrm{m}$ & $\mathrm{m}$ & $\mathrm{m}$ & $\mathrm{m}$ & $\mathrm{m}$ & $\mathrm{m}$ \\
\hline & Malaysia** & 4.1 & (0.6) & 3.5 & $(0.4)$ & 21.9 & (1.1) & 2.8 & $(0.4)$ & 22.4 & (1.0) & 45.3 & (1.5) \\
\hline
\end{tabular}

Note: Values that are statistically significant are indicated in bold (see Annex A3).

* See note at the beginning of this Annex.

** Coverage is too small to ensure comparability (see Annex A4).

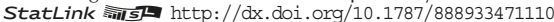


[Part 2/3]

Table III.6.7 Expectations of further education, by student performance in core PISA subjects

Results based on students' self-reports

\begin{tabular}{|c|c|c|c|c|c|c|c|c|c|c|c|c|}
\hline & & Perce & tage of to & formers in & at least $o$ & re PISA st & ect $(a b$ & evel 50 & vel 6) w & pect to & omplete & \\
\hline & $\begin{array}{r}\text { ISCE } \\
\text { (lower } \\
\text { ed }\end{array}$ & $\begin{array}{l}\text { el } 2 \\
\text { ndary } \\
\text { n) }\end{array}$ & \begin{tabular}{|} 
ISCED \\
(uppe \\
vocatio \\
educati \\
direct \\
labour \\
ISCED 5
\end{tabular} & $\begin{array}{l}\text { 3B or C } \\
\text { ondary, } \\
\text { oriented } \\
\text { roviding } \\
\text { s to the } \\
\text { et or to } \\
\text { grammes) }\end{array}$ & $\begin{array}{r}\text { ISCE } \\
\text { (uppe } \\
\text { academ } \\
\text { educat } \\
\text { access } \\
\text { pro } \\
\end{array}$ & $\begin{array}{l}\text { el } 3 A \\
\text { ndary, } \\
\text { oriented } \\
\text { oviding } \\
\text { EDD 5A } \\
\text { nes) }\end{array}$ & $\begin{array}{r}\text { ISC } \\
\text { (no } \\
\text { post- } \\
\text { pro }\end{array}$ & $\begin{array}{l}\text { vel } 4 \\
\text { iary } \\
\text { idary } \\
\text { nes) }\end{array}$ & $\begin{array}{r}\text { ISCE } \\
\text { (voc } \\
\text { technic } \\
\text { tertiar) }\end{array}$ & $\begin{array}{l}\text { el 5B } \\
\text { ally/ } \\
\text { riented } \\
\text { cation) }\end{array}$ & $\begin{array}{l}\text { ISCED } \\
\text { (universit } \\
\text { educatio } \\
\text { research }\end{array}$ & $\begin{array}{l}5 \text { A or } 6 \\
\text { el tertiary } \\
\text { advanced } \\
\text { rammes) }\end{array}$ \\
\hline & $\%$ & S.E. & $\%$ & S.E. & $\%$ & S.E. & $\%$ & S.E. & $\%$ & S.E. & $\%$ & S.E. \\
\hline Australia & 0.6 & $(0.1)$ & 1.2 & $(0.2)$ & 15.6 & $(0.7)$ & 1.1 & $(0.1)$ & 2.0 & $(0.2)$ & 79.6 & $(0.8)$ \\
\hline Austria & $\mathrm{C}$ & $\mathrm{C}$ & 4.3 & $(0.6)$ & 40.0 & (1.6) & c & $\mathrm{C}$ & 4.2 & $(0.6)$ & 50.0 & (1.5) \\
\hline Belgium & c & C & c & C & 8.4 & $(0.5)$ & 2.5 & $(0.3)$ & 35.0 & (1.0) & 52.6 & $(1.2)$ \\
\hline Canada & 0.4 & $(0.1)$ & c & c & 4.8 & $(0.4)$ & 3.8 & $(0.3)$ & 9.5 & $(0.5)$ & 81.5 & $(0.7)$ \\
\hline Chile & c & c & c & c & c & c & c & c & c & c & 94.2 & $(1.0)$ \\
\hline Czech Republic & c & C & c & c & 5.4 & $(0.7)$ & c & c & 5.8 & $(0.6)$ & 88.7 & $(0.9)$ \\
\hline Denmark & 9.2 & $(0.7)$ & 2.3 & $(0.4)$ & 25.8 & (1.4) & c & c & 3.8 & $(0.4)$ & 58.9 & (1.5) \\
\hline Estonia & c & C & 2.4 & $(0.4)$ & 5.2 & $(0.5)$ & 4.4 & $(0.5)$ & 18.8 & (1.1) & 68.7 & (1.4) \\
\hline Finland & 8.8 & $(0.6)$ & c & $\mathrm{c}$ & 30.9 & (1.1) & 4.1 & $(0.4)$ & 10.6 & $(0.7)$ & 45.5 & (1.5) \\
\hline France & 1.6 & $(0.3)$ & 1.8 & $(0.3)$ & 27.9 & (1.1) & c & C & 9.8 & $(0.7)$ & 58.9 & (1.4) \\
\hline Germany & 10.5 & $(1.0)$ & c & c & 50.1 & (1.3) & 3.0 & $(0.4)$ & 1.6 & $(0.2)$ & 33.4 & (1.3) \\
\hline Greece & c & $\mathrm{c}$ & c & C & C & $\mathrm{C}$ & C & C & c & c & 96.2 & $(0.6)$ \\
\hline Hungary & c & c & 5.4 & $(0.9)$ & 6.6 & $(0.8)$ & 5.8 & $(0.6)$ & 6.2 & $(0.7)$ & 75.6 & (1.4) \\
\hline Iceland & c & $\mathrm{c}$ & 11.8 & (1.0) & 4.6 & $(0.7)$ & 5.7 & $(0.7)$ & 14.4 & $(1.2)$ & 62.0 & (1.5) \\
\hline Ireland & 5.5 & $(0.5)$ & c & c & 6.2 & $(0.6)$ & 1.7 & $(0.3)$ & 15.3 & $(0.8)$ & 70.2 & $(1.1)$ \\
\hline Israel & c & c & c & c & 7.5 & $(0.8)$ & c & $\mathrm{C}$ & 5.6 & $(0.7)$ & 84.8 & (1.3) \\
\hline Italy & c & $\mathrm{c}$ & 0.4 & $(0.1)$ & 11.6 & $(1.2)$ & 4.7 & $(0.5)$ & 25.5 & (1.1) & 57.5 & (1.6) \\
\hline Japan & c & $\mathrm{C}$ & 6.3 & $(0.8)$ & 4.3 & $(0.4)$ & c & $\mathrm{C}$ & 9.8 & $(0.8)$ & 79.7 & $(1.2)$ \\
\hline Korea & c & c & 1.5 & (0.5) & c & c & c & c & 6.4 & $(0.6)$ & 91.1 & $(0.8)$ \\
\hline Latvia & C & $\mathrm{C}$ & 3.3 & $(0.6)$ & C & c & 5.5 & $(0.7)$ & 39.5 & (1.9) & 48.5 & (1.8) \\
\hline Luxembourg & c & c & c & $\mathrm{c}$ & 11.9 & $(0.8)$ & 4.6 & $(0.5)$ & 9.0 & $(0.7)$ & 71.7 & $(1.0)$ \\
\hline Mexico & c & c & c & c & C & C & c & c & c & c & 88.7 & $(2.5)$ \\
\hline Netherlands & 3.2 & $(0.5)$ & c & c & 19.2 & $(0.7)$ & 5.4 & $(0.5)$ & 32.7 & (1.5) & 39.6 & (1.4) \\
\hline New Zealand & c & C & 3.9 & $(0.5)$ & 13.8 & $(0.9)$ & 4.4 & $(0.6)$ & 9.1 & $(0.7)$ & 68.1 & (1.4) \\
\hline Norway & c & c & 7.4 & $(0.7)$ & 4.6 & $(0.5)$ & 7.2 & $(0.7)$ & 45.4 & (1.1) & 34.6 & $(1.0)$ \\
\hline Poland & c & $\mathrm{C}$ & C & c & 9.6 & $(0.8)$ & 12.1 & $(0.8)$ & c & c & 76.9 & $(1.2)$ \\
\hline Portugal & c & c & 2.3 & $(0.4)$ & 5.2 & $(0.7)$ & c & c & 22.9 & $(1.0)$ & 67.8 & (1.3) \\
\hline Slovak Republic & c & C & c & c & C & c & c & c & C & c & c & c \\
\hline Slovenia & c & C & 9.1 & $(0.8)$ & 10.5 & $(0.9)$ & 2.1 & $(0.4)$ & 29.8 & (1.4) & 47.9 & (1.4) \\
\hline Spain & c & C & C & $\mathrm{C}$ & 7.8 & $(0.7)$ & C & $\mathrm{C}$ & 6.0 & $(0.6)$ & 84.0 & (1.0) \\
\hline Sweden & 2.5 & $(0.4)$ & 5.8 & $(0.6)$ & 10.1 & $(0.8)$ & c & c & 21.6 & $(1.0)$ & 59.7 & (1.5) \\
\hline Switzerland & 2.5 & $(0.4)$ & 12.8 & $(0.9)$ & 23.2 & $(1.0)$ & 2.8 & $(0.4)$ & 11.2 & $(0.7)$ & 47.4 & (1.4) \\
\hline Turkey & c & c & C & c & C & c & c & $\mathrm{C}$ & $\mathrm{C}$ & c & 96.4 & (1.3) \\
\hline United Kingdom & C & C & 10.5 & $(0.9)$ & 15.3 & $(0.9)$ & c & $\mathrm{C}$ & 8.6 & $(0.7)$ & 65.1 & (1.5) \\
\hline United States & c & C & c & c & 3.0 & $(0.5)$ & C & c & 3.9 & $(0.6)$ & 91.9 & $(0.7)$ \\
\hline OECD average & 4.5 & $(0.2)$ & 5.1 & $(0.1)$ & 13.9 & $(0.2)$ & 4.5 & $(0.1)$ & 14.6 & $(0.2)$ & 68.2 & $(0.2)$ \\
\hline
\end{tabular}

\begin{tabular}{|c|c|c|c|c|c|c|c|c|c|c|c|c|}
\hline Albania & $\mathrm{m}$ & $\mathrm{m}$ & $\mathrm{m}$ & $\mathrm{m}$ & $\mathrm{m}$ & $\mathrm{m}$ & $\mathrm{m}$ & $\mathrm{m}$ & $\mathrm{m}$ & $\mathrm{m}$ & $\mathrm{m}$ & $\mathrm{m}$ \\
\hline$\cong$ Algeria & $\mathrm{m}$ & $\mathrm{m}$ & $\mathrm{m}$ & $\mathrm{m}$ & $\mathrm{m}$ & $\mathrm{m}$ & $\mathrm{m}$ & $\mathrm{m}$ & $\mathrm{m}$ & $\mathrm{m}$ & $\mathrm{m}$ & $\mathrm{m}$ \\
\hline ก Brazil & c & c & c & C & 5.2 & $(0.8)$ & 3.8 & (0.6) & 15.7 & (1.4) & 73.9 & (1.6) \\
\hline B-S-J-G (China) & 1.5 & $(0.3)$ & 4.0 & $(0.5)$ & 7.7 & $(0.7)$ & 4.0 & (0.4) & 17.6 & $(1.2)$ & 65.2 & (1.7) \\
\hline Bulgaria & c & c & c & c & c & c & 6.5 & $(1.0)$ & 23.0 & (1.3) & 66.1 & (1.7) \\
\hline CABA (Argentina) & $\mathrm{m}$ & $\mathrm{m}$ & $\mathrm{m}$ & $\mathrm{m}$ & $\mathrm{m}$ & $\mathrm{m}$ & $\mathrm{m}$ & $\mathrm{m}$ & $\mathrm{m}$ & $\mathrm{m}$ & $\mathrm{m}$ & $\mathrm{m}$ \\
\hline Colombia & c & c & c & c & c & c & c & c & c & c & 98.3 & (0.6) \\
\hline Costa Rica & c & c & c & c & c & c & c & c & 31.8 & (5.1) & 62.3 & (5.8) \\
\hline Croatia & c & c & c & c & 6.2 & $(0.7)$ & 7.2 & $(0.8)$ & 15.0 & (1.1) & 71.0 & (1.5) \\
\hline Cyprus* & c & c & c & c & c & c & c & c & c & C & 96.9 & $(0.6)$ \\
\hline Dominican Republic & $\mathrm{m}$ & $\mathrm{m}$ & $\mathrm{m}$ & $\mathrm{m}$ & $\mathrm{m}$ & $\mathrm{m}$ & $\mathrm{m}$ & $\mathrm{m}$ & $\mathrm{m}$ & $\mathrm{m}$ & $\mathrm{m}$ & $\mathrm{m}$ \\
\hline FYROM & $\mathrm{m}$ & $\mathrm{m}$ & $\mathrm{m}$ & $\mathrm{m}$ & $\mathrm{m}$ & $\mathrm{m}$ & $\mathrm{m}$ & $\mathrm{m}$ & $\mathrm{m}$ & $\mathrm{m}$ & $\mathrm{m}$ & $\mathrm{m}$ \\
\hline Georgia & $\mathrm{m}$ & $\mathrm{m}$ & $\mathrm{m}$ & $\mathrm{m}$ & $\mathrm{m}$ & $\mathrm{m}$ & $\mathrm{m}$ & $\mathrm{m}$ & $\mathrm{m}$ & $\mathrm{m}$ & $\mathrm{m}$ & $\mathrm{m}$ \\
\hline Hong Kong (China) & c & c & c & c & 5.8 & $(0.5)$ & 7.2 & $(0.7)$ & 14.1 & $(0.8)$ & 71.7 & (1.3) \\
\hline Indonesia & $\mathrm{m}$ & $\mathrm{m}$ & $\mathrm{m}$ & $\mathrm{m}$ & $\mathrm{m}$ & $\mathrm{m}$ & $\mathrm{m}$ & $\mathrm{m}$ & $\mathrm{m}$ & $\mathrm{m}$ & $\mathrm{m}$ & $\mathrm{m}$ \\
\hline Jordan & $\mathrm{m}$ & $\mathrm{m}$ & $\mathrm{m}$ & $\mathrm{m}$ & $\mathrm{m}$ & $\mathrm{m}$ & $\mathrm{m}$ & $\mathrm{m}$ & $\mathrm{m}$ & $\mathrm{m}$ & $\mathrm{m}$ & $\mathrm{m}$ \\
\hline Kosovo & $\mathrm{m}$ & $\mathrm{m}$ & $\mathrm{m}$ & $\mathrm{m}$ & $\mathrm{m}$ & $\mathrm{m}$ & $\mathrm{m}$ & $\mathrm{m}$ & $\mathrm{m}$ & $\mathrm{m}$ & $\mathrm{m}$ & $\mathrm{m}$ \\
\hline Lebanon & $\mathrm{m}$ & $\mathrm{m}$ & $\mathrm{m}$ & $\mathrm{m}$ & $\mathrm{m}$ & $\mathrm{m}$ & $\mathrm{m}$ & $\mathrm{m}$ & $\mathrm{m}$ & $\mathrm{m}$ & $\mathrm{m}$ & $\mathrm{m}$ \\
\hline Lithuania & c & c & c & c & c & c & 2.6 & $(0.4)$ & 5.9 & $(0.7)$ & 89.5 & (0.9) \\
\hline Macao (China) & c & c & c & c & 3.8 & $(0.4)$ & 15.9 & $(0.8)$ & 17.4 & $(0.8)$ & 61.9 & (1.0) \\
\hline Malta & $\mathrm{m}$ & $\mathrm{m}$ & $\mathrm{m}$ & $\mathrm{m}$ & $\mathrm{m}$ & $\mathrm{m}$ & $\mathrm{m}$ & $\mathrm{m}$ & $\mathrm{m}$ & $\mathrm{m}$ & $\mathrm{m}$ & $\mathrm{m}$ \\
\hline Moldova & $\mathrm{m}$ & $\mathrm{m}$ & $\mathrm{m}$ & $\mathrm{m}$ & $\mathrm{m}$ & $\mathrm{m}$ & $\mathrm{m}$ & $\mathrm{m}$ & $\mathrm{m}$ & $\mathrm{m}$ & $\mathrm{m}$ & $\mathrm{m}$ \\
\hline Montenegro & c & $\mathrm{c}$ & c & c & $\mathrm{c}$ & c & c & c & c & c & 93.5 & $(0.9)$ \\
\hline Peru & c & c & $\mathrm{c}$ & $\mathrm{c}$ & c & c & c & C & c & c & 93.0 & (2.0) \\
\hline Qatar & c & c & c & c & c & c & c & c & 3.1 & $(0.5)$ & 93.2 & $(0.7)$ \\
\hline Romania & $\mathrm{m}$ & $\mathrm{m}$ & $\mathrm{m}$ & $\mathrm{m}$ & $\mathrm{m}$ & $\mathrm{m}$ & $\mathrm{m}$ & $\mathrm{m}$ & $\mathrm{m}$ & $\mathrm{m}$ & $\mathrm{m}$ & $\mathrm{m}$ \\
\hline Russia & 2.5 & $(0.3)$ & 9.9 & $(0.9)$ & 10.5 & $(0.8)$ & c & c & 47.6 & (1.1) & 28.8 & (1.1) \\
\hline Singapore & c & c & c & c & 1.5 & $(0.2)$ & 5.1 & (0.4) & 17.0 & $(0.5)$ & 76.3 & $(0.6)$ \\
\hline Chinese Taipei & c & c & 6.1 & $(0.5)$ & 5.9 & $(0.4)$ & c & c & 18.2 & $(0.8)$ & 69.2 & (1.0) \\
\hline Thailand & C & c & C & C & C & c & c & c & c & c & 95.7 & (1.4) \\
\hline Trinidad and Tobago & $\mathrm{m}$ & $\mathrm{m}$ & $\mathrm{m}$ & $\mathrm{m}$ & $\mathrm{m}$ & $\mathrm{m}$ & $\mathrm{m}$ & $\mathrm{m}$ & $\mathrm{m}$ & $\mathrm{m}$ & $\mathrm{m}$ & $\mathrm{m}$ \\
\hline Tunisia & c & c & c & c & c & c & c & $\mathrm{c}$ & C & C & 86.6 & (2.4) \\
\hline United Arab Emirates & c & c & c & c & 6.7 & $(0.7)$ & c & $\mathrm{c}$ & 2.3 & $(0.4)$ & 89.9 & (0.8) \\
\hline Uruguay & c & c & c & c & 7.2 & (1.3) & c & C & C & C & 84.3 & (2.1) \\
\hline Viet Nam & $\mathrm{m}$ & $\mathrm{m}$ & $\mathrm{m}$ & $\mathrm{m}$ & $\mathrm{m}$ & $\mathrm{m}$ & $\mathrm{m}$ & $\mathrm{m}$ & $\mathrm{m}$ & $\mathrm{m}$ & $\mathrm{m}$ & $\mathrm{m}$ \\
\hline Argentina** & $\mathrm{m}$ & $\mathrm{m}$ & $\mathrm{m}$ & $\mathrm{m}$ & $\mathrm{m}$ & $\mathrm{m}$ & $\mathrm{m}$ & $\mathrm{m}$ & $\mathrm{m}$ & $\mathrm{m}$ & $\mathrm{m}$ & $\mathrm{m}$ \\
\hline Kazakhstan** & $\mathrm{m}$ & $\mathrm{m}$ & $\mathrm{m}$ & $\mathrm{m}$ & $\mathrm{m}$ & $\mathrm{m}$ & $\mathrm{m}$ & $\mathrm{m}$ & $\mathrm{m}$ & $\mathrm{m}$ & $\mathrm{m}$ & $\mathrm{m}$ \\
\hline Malaysia** & c & c & c & c & c & C & c & c & 10.7 & $(1.8)$ & 86.0 & (1.9) \\
\hline
\end{tabular}

Note: Values that are statistically significant are indicated in bold (see Annex A3).

* See note at the beginning of this Annex.

** Coverage is too small to ensure comparability (see Annex A4).

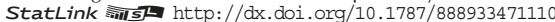


[Part 3/3]

Table III.6.7 Expectations of further education, by student performance in core PISA subjects

Results based on students' self-reports

\begin{tabular}{|c|c|c|c|c|c|c|c|c|c|c|c|c|c|}
\hline & \multicolumn{12}{|c|}{$\begin{array}{l}\text { Difference in the percentage of top performers in at least one core PISA subject (above Level } 5 \text { or Level 6) } \\
\text { and low-achievers in all core PISA subjects (below Level 2) who reported that they expect to complete }\end{array}$} \\
\hline & & \multicolumn{2}{|c|}{$\begin{array}{c}\begin{array}{c}\text { ISCED level } 2 \\
\text { (lower secondary } \\
\text { education) }\end{array} \\
\end{array}$} & \multicolumn{2}{|c|}{\begin{tabular}{|c|} 
ISCED level 3B or C \\
(upper secondary, \\
vocationally oriented \\
education providing \\
direct access to the \\
labour market or to \\
ISCED 5B programmes)
\end{tabular}} & $\begin{array}{r}\text { ISCED } \\
\text { (upper } \\
\text { academi } \\
\text { educatic } \\
\text { access t } \\
\text { prog }\end{array}$ & $\begin{array}{l}\text { el } 3 \mathrm{~A} \\
\text { ondary, } \\
\text { oriented } \\
\text { roviding } \\
\text { CED 5A } \\
\text { mes) }\end{array}$ & $\begin{array}{r}\text { ISCE } \\
\text { (non } \\
\text { post-s } \\
\text { prog } \\
\end{array}$ & $\begin{array}{l}\text { vel } 4 \\
\text { tiary } \\
\text { ndary } \\
\text { mes) }\end{array}$ & $\begin{array}{r}\text { ISCEL } \\
\text { (voca } \\
\text { technica } \\
\text { tertiary } \\
\end{array}$ & $\begin{array}{l}\text { el 5B } \\
\text { ally/ } \\
\text { oriented } \\
\text { cation) } \\
\end{array}$ & $\begin{array}{l}\text { ISCED } \\
\text { (universit } \\
\text { educatio } \\
\text { research }\end{array}$ & $\begin{array}{l}5 \text { A or } 6 \\
\text { el tertiary } \\
\text { idvanced } \\
\text { rammes) }\end{array}$ \\
\hline & & $\%$ dif. & S.E. & $\%$ dif. & S.E. & $\%$ dif. & S.E. & $\%$ dif. & S.E. & $\%$ dif. & S.E. & $\%$ dif. & S.E. \\
\hline 0 & Australia & -7.6 & (0.6) & -9.3 & $(0.7)$ & -30.7 & $(1.3)$ & -8.6 & $(0.8)$ & -3.0 & $(0.5)$ & 59.2 & (1.3) \\
\hline & Austria & C & C & -45.5 & (1.8) & 14.3 & $(2.3)$ & C & C & -6.9 & $(1.1)$ & 43.8 & (1.6) \\
\hline 0 & Belgium & $\mathrm{c}$ & $\mathrm{C}$ & c & $\mathrm{C}$ & -10.5 & $(1.2)$ & -25.7 & $(1.4)$ & 23.1 & $(1.5)$ & 43.1 & $(1.7)$ \\
\hline & Canada & -3.9 & $(0.5)$ & c & c & -24.8 & $(1.2)$ & -9.7 & $(1.2)$ & -13.2 & $(1.3)$ & 51.6 & (1.4) \\
\hline & Chile & $\mathrm{C}$ & C & c & c & C & C & $\mathrm{C}$ & C & C & C & 49.2 & (1.6) \\
\hline & Czech Republic & C & C & c & c & -44.5 & (1.6) & C & c & 0.4 & $(1.0)$ & 70.6 & (1.3) \\
\hline & Denmark & -29.7 & $(2.4)$ & -13.5 & (1.5) & -3.6 & $(2.0)$ & c & c & 1.0 & $(0.8)$ & 45.9 & $(1.8)$ \\
\hline & Estonia & C & c & -13.6 & (1.5) & -17.5 & $(2.2)$ & -12.9 & $(2.0)$ & 0.3 & $(2.1)$ & 60.3 & $(1.8)$ \\
\hline & Finland & -18.5 & $(1.7)$ & C & c & -9.3 & $(2.1)$ & -1.3 & $(1.0)$ & -10.1 & $(1.5)$ & 39.2 & (1.5) \\
\hline & France & -22.7 & (1.4) & -45.8 & (1.6) & 15.8 & $(1.4)$ & C & C & -0.4 & $(1.0)$ & 53.1 & (1.4) \\
\hline & Germany & -61.3 & $(2.1)$ & c & c & 33.4 & $(2.0)$ & -1.0 & $(1.0)$ & c & c & C & c \\
\hline & Greece & C & c & C & C & C & C & C & C & C & c & 62.9 & $(2.3)$ \\
\hline & Hungary & C & c & -43.9 & $(1.8)$ & -5.4 & $(1.3)$ & -5.0 & $(1.1)$ & 2.9 & $(0.8)$ & 68.3 & $(1.7)$ \\
\hline & Iceland & C & c & -17.2 & (2.1) & -7.2 & $(1.4)$ & -9.5 & $(1.4)$ & -0.3 & $(1.5)$ & 45.7 & $(2.1)$ \\
\hline & Ireland & -18.8 & $(1.7)$ & C & c & -17.0 & (1.8) & -4.8 & $(0.9)$ & 3.7 & $(1.5)$ & 52.4 & (1.8) \\
\hline & Israel & C & c & c & C & -42.4 & (1.4) & C & c & -4.5 & (1.1) & 57.7 & (1.9) \\
\hline & Italy & C & c & -10.6 & $(1.0)$ & -30.8 & $(2.0)$ & -7.1 & $(1.1)$ & 13.4 & $(1.5)$ & 41.0 & $(2.0)$ \\
\hline & Japan & C & C & -15.0 & (2.9) & -24.8 & $(2.2)$ & $\mathrm{C}$ & C & -16.0 & $(2.4)$ & 55.8 & $(2.4)$ \\
\hline & Korea & C & c & -16.4 & (2.0) & c & c & C & c & -21.7 & $(1.5)$ & 49.5 & (2.4) \\
\hline & Latvia & C & C & -20.8 & (1.6) & C & c & -8.3 & $(1.3)$ & 15.8 & $(2.5)$ & 38.9 & $(2.3)$ \\
\hline & Luxembourg & $\mathrm{C}$ & $\mathrm{C}$ & C & C & -5.0 & $(1.2)$ & -0.5 & $(0.7)$ & 0.0 & $(0.9)$ & 57.8 & (1.3) \\
\hline & Mexico & C & C & c & C & C & c & c & C & C & C & 41.0 & $(2.9)$ \\
\hline & Netherlands & -20.1 & $(1.7)$ & c & C & $\mathrm{C}$ & C & -51.2 & $(1.6)$ & 17.2 & $(2.1)$ & c & c \\
\hline & New Zealand & C & c & -26.5 & $(1.8)$ & -19.8 & (1.9) & -0.8 & $(1.2)$ & 3.0 & $(1.2)$ & 51.7 & $(1.7)$ \\
\hline & Norway & C & c & -25.4 & (1.6) & -4.1 & $(0.9)$ & -8.7 & (1.4) & 23.2 & $(1.8)$ & 23.0 & (1.5) \\
\hline & Poland & C & c & C & C & -42.8 & $(2.3)$ & 1.2 & $(1.3)$ & C & C & 65.3 & (1.8) \\
\hline & Portugal & c & c & -47.2 & (1.7) & -1.4 & $(1.0)$ & c & c & 12.6 & $(1.5)$ & 58.0 & $(1.7)$ \\
\hline & Slovak Republic & C & C & C & c & C & C & C & C & C & C & C & c \\
\hline & Slovenia & $\mathrm{C}$ & $\mathrm{c}$ & -60.5 & (1.6) & C & c & -3.7 & $(0.9)$ & 17.5 & $(1.8)$ & 43.6 & (1.5) \\
\hline & Spain & $\mathrm{C}$ & C & C & C & -9.4 & (1.4) & C & c & -10.6 & $(1.3)$ & 71.3 & (1.4) \\
\hline & Sweden & -10.5 & $(1.1)$ & -34.2 & $(1.7)$ & -5.1 & $(1.5)$ & c & c & 8.6 & $(1.4)$ & 41.7 & (2.0) \\
\hline & Switzerland & -24.6 & (2.0) & -34.7 & $(2.2)$ & 15.8 & (1.6) & -1.6 & $(0.7)$ & 2.4 & $(1.2)$ & 42.7 & (1.6) \\
\hline & Turkey & $\mathrm{C}$ & C & C & $\mathrm{c}$ & c & C & $\mathrm{c}$ & c & c & c & 40.7 & (1.9) \\
\hline & United Kingdom & $\mathrm{C}$ & $\mathrm{C}$ & -39.6 & (1.6) & -0.8 & $(1.5)$ & C & C & -2.2 & $(1.2)$ & 47.5 & (1.8) \\
\hline & United States & C & C & C & C & -23.7 & $(1.4)$ & C & c & -6.5 & (1.1) & 38.1 & (1.8) \\
\hline & OECD average & -21.8 & $(0.5)$ & -28.9 & $(0.4)$ & -11.6 & $(0.3)$ & -8.8 & $(0.3)$ & 1.8 & $(0.3)$ & 50.3 & $(0.3)$ \\
\hline$\approx$ & Albania & $\mathrm{m}$ & $\mathrm{m}$ & $\mathrm{m}$ & $\mathrm{m}$ & $\mathrm{m}$ & $\mathrm{m}$ & $\mathrm{m}$ & $\mathrm{m}$ & $\mathrm{m}$ & $\mathrm{m}$ & $\mathrm{m}$ & $\mathrm{m}$ \\
\hline ఏ & Algeria & $\mathrm{m}$ & $\mathrm{m}$ & $\mathrm{m}$ & $\mathrm{m}$ & $\mathrm{m}$ & $\mathrm{m}$ & $\mathrm{m}$ & $\mathrm{m}$ & $\mathrm{m}$ & $\mathrm{m}$ & $\mathrm{m}$ & $\mathrm{m}$ \\
\hline ฐัต & Brazil & c & c & c & c & -31.5 & (1.1) & -5.8 & $(0.7)$ & 9.9 & (1.4) & 37.9 & $(1.7)$ \\
\hline & B-S-J-G (China) & -35.6 & (2.5) & -23.8 & $(2.0)$ & -9.8 & $(1.7)$ & -4.6 & $(1.0)$ & 12.8 & (1.3) & 61.0 & (1.8) \\
\hline & Bulgaria & C & C & C & $\mathrm{C}$ & C & C & -8.7 & (1.3) & 3.8 & (1.7) & 45.3 & $(2.1)$ \\
\hline & CABA (Argentina) & $\mathrm{m}$ & $\mathrm{m}$ & $\mathrm{m}$ & $\mathrm{m}$ & $\mathrm{m}$ & $\mathrm{m}$ & $\mathrm{m}$ & $\mathrm{m}$ & $\mathrm{m}$ & $\mathrm{m}$ & $\mathrm{m}$ & $\mathrm{m}$ \\
\hline & Colombia & $\mathrm{c}$ & c & $\mathrm{c}$ & c & $\mathrm{c}$ & $\mathrm{c}$ & $\mathrm{c}$ & c & $\mathrm{c}$ & c & 33.4 & $(1.2)$ \\
\hline & Costa Rica & $\mathrm{C}$ & $\mathrm{c}$ & c & c & c & c & C & c & 16.1 & $(5.0)$ & 11.6 & (5.9) \\
\hline & Croatia & c & c & c & c & -20.8 & $(1.7)$ & -15.0 & $(1.2)$ & 10.4 & $(1.2)$ & 62.0 & (1.9) \\
\hline & Cyprus* & C & c & c & c & c & c & C & c & $\mathrm{C}$ & c & 37.3 & $(1.1)$ \\
\hline & Dominican Republic & $\mathrm{m}$ & $\mathrm{m}$ & $\mathrm{m}$ & $\mathrm{m}$ & $\mathrm{m}$ & $\mathrm{m}$ & $\mathrm{m}$ & $\mathrm{m}$ & $\mathrm{m}$ & $\mathrm{m}$ & $\mathrm{m}$ & $\mathrm{m}$ \\
\hline & FYROM & $\mathrm{m}$ & $\mathrm{m}$ & $\mathrm{m}$ & $\mathrm{m}$ & $\mathrm{m}$ & $\mathrm{m}$ & $\mathrm{m}$ & $\mathrm{m}$ & $\mathrm{m}$ & $\mathrm{m}$ & $\mathrm{m}$ & $\mathrm{m}$ \\
\hline & Georgia & $\mathrm{m}$ & $\mathrm{m}$ & $\mathrm{m}$ & $\mathrm{m}$ & $\mathrm{m}$ & $\mathrm{m}$ & $\mathrm{m}$ & $\mathrm{m}$ & $\mathrm{m}$ & $\mathrm{m}$ & $\mathrm{m}$ & $\mathrm{m}$ \\
\hline & Hong Kong (China) & C & c & c & c & -27.2 & $(2.7)$ & -9.6 & $(2.0)$ & 0.0 & (1.6) & 52.0 & (2.5) \\
\hline & Indonesia & $\mathrm{m}$ & $\mathrm{m}$ & $\mathrm{m}$ & $\mathrm{m}$ & $\mathrm{m}$ & $\mathrm{m}$ & $\mathrm{m}$ & $\mathrm{m}$ & $\mathrm{m}$ & $\mathrm{m}$ & $\mathrm{m}$ & $\mathrm{m}$ \\
\hline & Jordan & $\mathrm{m}$ & $\mathrm{m}$ & $\mathrm{m}$ & $\mathrm{m}$ & $\mathrm{m}$ & $\mathrm{m}$ & $\mathrm{m}$ & $\mathrm{m}$ & $\mathrm{m}$ & $\mathrm{m}$ & $\mathrm{m}$ & $\mathrm{m}$ \\
\hline & Kosovo & $\mathrm{m}$ & $\mathrm{m}$ & $\mathrm{m}$ & $\mathrm{m}$ & $\mathrm{m}$ & $\mathrm{m}$ & $\mathrm{m}$ & $\mathrm{m}$ & $\mathrm{m}$ & $\mathrm{m}$ & $\mathrm{m}$ & $\mathrm{m}$ \\
\hline & Lebanon & $\mathrm{m}$ & $\mathrm{m}$ & $\mathrm{m}$ & $\mathrm{m}$ & $\mathrm{m}$ & $\mathrm{m}$ & $\mathrm{m}$ & $\mathrm{m}$ & $\mathrm{m}$ & $\mathrm{m}$ & $\mathrm{m}$ & $\mathrm{m}$ \\
\hline & Lithuania & $\mathrm{C}$ & c & c & c & $\mathrm{C}$ & c & -14.0 & $(1.1)$ & -13.2 & $(1.2)$ & 69.4 & $(1.4)$ \\
\hline & Macao (China) & C & c & c & c & -22.3 & $(2.3)$ & -5.4 & $(2.0)$ & 3.6 & (1.7) & 44.4 & $(2.1)$ \\
\hline & Malta & $\mathrm{m}$ & $\mathrm{m}$ & $\mathrm{m}$ & $\mathrm{m}$ & $\mathrm{m}$ & $\mathrm{m}$ & $\mathrm{m}$ & $\mathrm{m}$ & $\mathrm{m}$ & $\mathrm{m}$ & $\mathrm{m}$ & $\mathrm{m}$ \\
\hline & Moldova & $\mathrm{m}$ & $\mathrm{m}$ & $\mathrm{m}$ & $\mathrm{m}$ & $\mathrm{m}$ & $\mathrm{m}$ & $\mathrm{m}$ & $\mathrm{m}$ & $\mathrm{m}$ & $\mathrm{m}$ & $\mathrm{m}$ & $\mathrm{m}$ \\
\hline & Montenegro & $\mathrm{C}$ & $\mathrm{c}$ & $\mathrm{c}$ & $\mathrm{c}$ & $\mathrm{C}$ & c & $\mathrm{C}$ & c & $\mathrm{C}$ & c & 43.8 & (1.4) \\
\hline & Peru & C & c & c & c & C & c & C & C & C & c & 38.9 & $(2.2)$ \\
\hline & Qatar & $\mathrm{C}$ & c & c & c & c & c & c & c & -6.2 & $(0.7)$ & 26.8 & $(0.9)$ \\
\hline & Romania & $\mathrm{m}$ & $\mathrm{m}$ & $\mathrm{m}$ & $\mathrm{m}$ & $\mathrm{m}$ & $\mathrm{m}$ & $\mathrm{m}$ & $\mathrm{m}$ & $\mathrm{m}$ & $\mathrm{m}$ & $\mathrm{m}$ & $\mathrm{m}$ \\
\hline & Russia & -25.8 & (1.5) & -20.7 & $(2.2)$ & -5.9 & (1.1) & c & c & 34.2 & (1.4) & 22.8 & $(1.3)$ \\
\hline & Singapore & $\mathrm{C}$ & $\mathrm{C}$ & C & $\mathrm{C}$ & -6.0 & $(1.1)$ & -11.1 & $(1.4)$ & -29.7 & (2.4) & 48.9 & (1.7) \\
\hline & Chinese Taipei & C & C & -37.2 & (1.7) & -9.7 & (1.7) & C & $\mathrm{C}$ & -5.5 & (1.5) & 57.5 & (1.6) \\
\hline & Thailand & C & c & c & c & c & c & C & c & C & c & 40.6 & $(2.0)$ \\
\hline & Trinidad and Tobago & $\mathrm{m}$ & $\mathrm{m}$ & $\mathrm{m}$ & $\mathrm{m}$ & $\mathrm{m}$ & $\mathrm{m}$ & $\mathrm{m}$ & $\mathrm{m}$ & $\mathrm{m}$ & $\mathrm{m}$ & $\mathrm{m}$ & $\mathrm{m}$ \\
\hline & Tunisia & C & c & c & c & $\mathrm{c}$ & c & C & c & $\mathrm{c}$ & c & 42.1 & (2.6) \\
\hline & United Arab Emirates & c & c & c & c & -11.8 & $(1.0)$ & c & c & -4.3 & $(0.5)$ & 31.5 & $(1.2)$ \\
\hline & Uruguay & $\mathrm{C}$ & $\mathrm{c}$ & C & $\mathrm{C}$ & -10.5 & (1.4) & C & C & C & C & 62.5 & (2.4) \\
\hline & Viet Nam & $\mathrm{m}$ & $\mathrm{m}$ & $\mathrm{m}$ & $\mathrm{m}$ & $\mathrm{m}$ & $\mathrm{m}$ & $\mathrm{m}$ & $\mathrm{m}$ & $\mathrm{m}$ & $\mathrm{m}$ & $\mathrm{m}$ & $\mathrm{m}$ \\
\hline & Argentina** $^{* *}$ & $\mathrm{~m}$ & $\mathrm{~m}$ & $\mathrm{~m}$ & $\mathrm{~m}$ & $\mathrm{~m}$ & $\mathrm{~m}$ & $\mathrm{~m}$ & $\mathrm{~m}$ & $\mathrm{~m}$ & $\mathrm{~m}$ & $\mathrm{~m}$ & $\mathrm{~m}$ \\
\hline & Kazakhstan** & $\mathrm{m}$ & $\mathrm{m}$ & $\mathrm{m}$ & $\mathrm{m}$ & $\mathrm{m}$ & $\mathrm{m}$ & $\mathrm{m}$ & $\mathrm{m}$ & $\mathrm{m}$ & $\mathrm{m}$ & $\mathrm{m}$ & $\mathrm{m}$ \\
\hline & Malaysia** & C & c & c & c & C & c & c & c & -11.7 & $(2.1)$ & 40.7 & $(2.3)$ \\
\hline
\end{tabular}

Note: Values that are statistically significant are indicated in bold (see Annex A3).

* See note at the beginning of this Annex.

** Coverage is too small to ensure comparability (see Annex A4).

StatLink 需吉 http://dx.doi.org/10.1787/888933471110 
[Part 1/1]

Table III.6.8 Students' expectations to complete a university degree and life satisfaction

\begin{tabular}{|c|c|c|c|c|c|c|c|c|c|c|c|}
\hline & \multicolumn{6}{|c|}{ Average life satisfaction, by: } & \multicolumn{4}{|c|}{$\begin{array}{l}\text { Increased likelihood of students who expect to complete } \\
\text { university to report being highly satisfied with life } \\
\text { (to report } 9 \text { or } 10 \text { on the life satisfaction scale) }\end{array}$} \\
\hline & & \multicolumn{2}{|c|}{$\begin{array}{l}\text { Students who reported they } \\
\text { do not expect to complete } \\
\text { a university degree }\end{array}$} & \multicolumn{2}{|c|}{$\begin{array}{l}\text { Students who reported that } \\
\text { they expect to complete } \\
\text { a university degree }\end{array}$} & $\begin{array}{l}\text { Differ } \\
\text { students } \\
\text { they exp } \\
\text { a uni } \\
\text { and the }\end{array}$ & $\begin{array}{l}\text { tween } \\
\text { orted that } \\
\text { omplete } \\
\text { egree } \\
\text { did not }\end{array}$ & $\begin{array}{r}\text { Before } \\
\text { for student }\end{array}$ & $\begin{array}{l}\text { Inting } \\
\text { cteristics }{ }^{1}\end{array}$ & $\begin{array}{r}\text { After a } \\
\text { for student }\end{array}$ & $\begin{array}{l}\text { nting } \\
\text { acteristics }\end{array}$ \\
\hline & & Mean & S.E. & Mean & S.E. & Dif. & S.E. & Odds ratio & S.E. & Odds ratio & S.E. \\
\hline$a$ & Australia & $\mathrm{m}$ & $\mathrm{m}$ & $\mathrm{m}$ & $\mathrm{m}$ & $\mathrm{m}$ & $\mathrm{m}$ & $\mathrm{m}$ & $\mathrm{m}$ & $\mathrm{m}$ & $\mathrm{m}$ \\
\hline 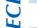 & Austria & 7.47 & $(0.04)$ & 7.70 & $(0.05)$ & 0.24 & $(0.07)$ & 1.13 & $(0.06)$ & 1.16 & $(0.08)$ \\
\hline పే & Belgium (excl. Flemish) & 7.37 & $(0.07)$ & 7.69 & $(0.05)$ & 0.32 & $(0.08)$ & 1.13 & $(0.08)$ & 1.41 & $(0.11)$ \\
\hline & Canada & $\mathrm{m}$ & $\mathrm{m}$ & $\mathrm{m}$ & $\mathrm{m}$ & $\mathrm{m}$ & $\mathrm{m}$ & $\mathrm{m}$ & $\mathrm{m}$ & $\mathrm{m}$ & $\mathrm{m}$ \\
\hline & Chile & 7.22 & $(0.07)$ & 7.44 & $(0.05)$ & 0.22 & $(0.08)$ & 1.07 & $(0.07)$ & 1.22 & $(0.09)$ \\
\hline & Czech Republic & 6.87 & $(0.06)$ & 7.21 & $(0.04)$ & 0.34 & $(0.06)$ & 1.08 & $(0.07)$ & 1.34 & $(0.10)$ \\
\hline & Denmark & $\mathrm{m}$ & $\mathrm{m}$ & $\mathrm{m}$ & $\mathrm{m}$ & $\mathrm{m}$ & $\mathrm{m}$ & $\mathrm{m}$ & $\mathrm{m}$ & $\mathrm{m}$ & $\mathrm{m}$ \\
\hline & Estonia & 7.41 & $(0.05)$ & 7.63 & $(0.04)$ & 0.22 & $(0.06)$ & 1.18 & $(0.08)$ & 1.12 & $(0.09)$ \\
\hline & Finland & 7.82 & $(0.03)$ & 8.08 & $(0.04)$ & 0.25 & $(0.05)$ & 1.33 & $(0.09)$ & 1.40 & $(0.12)$ \\
\hline & France & 7.53 & $(0.03)$ & 7.85 & $(0.04)$ & 0.32 & $(0.05)$ & 1.27 & $(0.07)$ & 1.35 & $(0.08)$ \\
\hline & Germany & 7.28 & $(0.04)$ & 7.72 & $(0.05)$ & 0.44 & $(0.07)$ & 1.27 & $(0.11)$ & 1.29 & $(0.12)$ \\
\hline & Greece & 6.74 & $(0.07)$ & 7.00 & $(0.04)$ & 0.26 & $(0.08)$ & 0.90 & $(0.08)$ & 1.20 & $(0.13)$ \\
\hline & Hungary & 7.02 & $(0.05)$ & 7.45 & $(0.05)$ & 0.42 & $(0.07)$ & 1.17 & $(0.06)$ & 1.34 & $(0.09)$ \\
\hline & Iceland & 7.59 & $(0.05)$ & 8.12 & $(0.05)$ & 0.53 & $(0.08)$ & 1.38 & $(0.11)$ & 1.51 & $(0.12)$ \\
\hline & Ireland & 7.26 & $(0.04)$ & 7.36 & $(0.05)$ & 0.10 & $(0.06)$ & 1.01 & $(0.06)$ & 1.18 & $(0.08)$ \\
\hline & Israel & $\mathrm{m}$ & $\mathrm{m}$ & $\mathrm{m}$ & $\mathrm{m}$ & $\mathrm{m}$ & $\mathrm{m}$ & $\mathrm{m}$ & $\mathrm{m}$ & $\mathrm{m}$ & $\mathrm{m}$ \\
\hline & Italy & 6.80 & $(0.04)$ & 7.04 & $(0.06)$ & 0.24 & $(0.06)$ & 1.17 & $(0.09)$ & 1.43 & $(0.10)$ \\
\hline & Japan & 6.69 & $(0.05)$ & 6.88 & $(0.05)$ & 0.19 & $(0.06)$ & 1.02 & $(0.07)$ & 1.05 & $(0.07)$ \\
\hline & Korea & 6.34 & $(0.07)$ & 6.37 & $(0.04)$ & 0.03 & $(0.09)$ & 0.78 & $(0.06)$ & 0.90 & $(0.08)$ \\
\hline & Latvia & 7.27 & $(0.04)$ & 7.70 & $(0.07)$ & 0.44 & $(0.09)$ & 1.58 & $(0.14)$ & 1.55 & $(0.16)$ \\
\hline & Luxembourg & 7.29 & $(0.04)$ & 7.56 & $(0.04)$ & 0.27 & $(0.06)$ & 1.14 & $(0.07)$ & 1.26 & $(0.09)$ \\
\hline & Mexico & 8.14 & $(0.05)$ & 8.37 & $(0.03)$ & 0.23 & $(0.06)$ & 1.22 & $(0.06)$ & 1.35 & $(0.07)$ \\
\hline & Netherlands & 7.84 & $(0.03)$ & 7.77 & $(0.06)$ & -0.08 & $(0.06)$ & 0.80 & $(0.07)$ & 1.27 & $(0.14)$ \\
\hline & New Zealand & $\mathrm{m}$ & $\mathrm{m}$ & $\mathrm{m}$ & $\mathrm{m}$ & $\mathrm{m}$ & $\mathrm{m}$ & $\mathrm{m}$ & $\mathrm{m}$ & $\mathrm{m}$ & $\mathrm{m}$ \\
\hline & Norway & $\mathrm{m}$ & $\mathrm{m}$ & $\mathrm{m}$ & $\mathrm{m}$ & $\mathrm{m}$ & $\mathrm{m}$ & $\mathrm{m}$ & $\mathrm{m}$ & $\mathrm{m}$ & $\mathrm{m}$ \\
\hline & Poland & 7.00 & $(0.05)$ & 7.38 & $(0.06)$ & 0.37 & $(0.07)$ & 1.25 & $(0.08)$ & 1.58 & $(0.12)$ \\
\hline & Portugal & 7.28 & $(0.04)$ & 7.50 & $(0.05)$ & 0.21 & $(0.06)$ & 1.07 & $(0.07)$ & 1.51 & $(0.11)$ \\
\hline & Slovak Republic & $\mathrm{m}$ & $\mathrm{m}$ & $\mathrm{m}$ & $\mathrm{m}$ & $\mathrm{m}$ & $\mathrm{m}$ & $\mathrm{m}$ & $\mathrm{m}$ & $\mathrm{m}$ & $\mathrm{m}$ \\
\hline & Slovenia & 7.18 & $(0.04)$ & 7.16 & $(0.08)$ & -0.02 & $(0.09)$ & 0.96 & $(0.08)$ & 1.18 & $(0.11)$ \\
\hline & Spain & 7.17 & $(0.05)$ & 7.65 & $(0.03)$ & 0.48 & $(0.05)$ & 1.29 & $(0.07)$ & 1.62 & $(0.11)$ \\
\hline & Sweden & $\mathrm{m}$ & $\mathrm{m}$ & $\mathrm{m}$ & $\mathrm{m}$ & $\mathrm{m}$ & $\mathrm{m}$ & $\mathrm{m}$ & $\mathrm{m}$ & $\mathrm{m}$ & $\mathrm{m}$ \\
\hline & Switzerland & 7.63 & $(0.04)$ & 7.94 & $(0.06)$ & 0.31 & $(0.07)$ & 1.21 & $(0.09)$ & 1.34 & $(0.10)$ \\
\hline & Turkey & 6.02 & $(0.08)$ & 6.15 & $(0.07)$ & 0.13 & $(0.09)$ & 0.95 & $(0.06)$ & 1.18 & $(0.09)$ \\
\hline & United Kingdom & 6.94 & $(0.05)$ & 7.02 & $(0.06)$ & 0.08 & $(0.08)$ & 0.98 & $(0.06)$ & 1.05 & $(0.07)$ \\
\hline & United States & 7.04 & $(0.07)$ & 7.46 & $(0.04)$ & 0.42 & $(0.08)$ & 1.05 & $(0.07)$ & 1.21 & $(0.09)$ \\
\hline & OECD average & 7.19 & $(0.01)$ & 7.45 & $(0.01)$ & 0.26 & $(0.01)$ & 1.13 & $(0.02)$ & 1.30 & $(0.02)$ \\
\hline$n$ & Albania & $\mathrm{m}$ & $\mathrm{m}$ & $\mathrm{m}$ & $\mathrm{m}$ & $\mathrm{m}$ & $\mathrm{m}$ & $\mathrm{m}$ & $\mathrm{m}$ & $\mathrm{m}$ & $\mathrm{m}$ \\
\hline ఏ & Algeria & $\mathrm{m}$ & $\mathrm{m}$ & $\mathrm{m}$ & $\mathrm{m}$ & $\mathrm{m}$ & $\mathrm{m}$ & $\mathrm{m}$ & $\mathrm{m}$ & $\mathrm{m}$ & $\mathrm{m}$ \\
\hline ขั & Brazil & 7.58 & $(0.04)$ & 7.60 & $(0.03)$ & 0.03 & $(0.05)$ & 0.94 & $(0.04)$ & 1.16 & $(0.05)$ \\
\hline 2 & B-S-J-G (China) & 6.75 & $(0.04)$ & 6.97 & $(0.07)$ & 0.22 & $(0.08)$ & 0.89 & $(0.06)$ & 1.06 & $(0.08)$ \\
\hline & Bulgaria & 7.29 & $(0.05)$ & 7.61 & $(0.06)$ & 0.32 & $(0.07)$ & 1.23 & $(0.07)$ & 1.40 & $(0.07)$ \\
\hline & CABA (Argentina) & $\mathrm{m}$ & $\mathrm{m}$ & $\mathrm{m}$ & $\mathrm{m}$ & $\mathrm{m}$ & $\mathrm{m}$ & $\mathrm{m}$ & $\mathrm{m}$ & $\mathrm{m}$ & $\mathrm{m}$ \\
\hline & Colombia & 8.00 & $(0.07)$ & 7.85 & $(0.04)$ & -0.15 & $(0.08)$ & 0.75 & $(0.05)$ & 1.02 & $(0.07)$ \\
\hline & Costa Rica & 8.24 & $(0.05)$ & 8.19 & $(0.04)$ & -0.05 & $(0.06)$ & 1.03 & $(0.06)$ & 1.10 & $(0.07)$ \\
\hline & Croatia & 7.86 & $(0.05)$ & 7.98 & $(0.04)$ & 0.11 & $(0.06)$ & 0.98 & $(0.06)$ & 1.25 & $(0.09)$ \\
\hline & Cyprus* & 6.75 & $(0.07)$ & 7.15 & $(0.04)$ & 0.41 & $(0.08)$ & 1.04 & $(0.07)$ & 1.22 & $(0.10)$ \\
\hline & Dominican Republic & 8.37 & $(0.08)$ & 8.57 & $(0.04)$ & 0.20 & $(0.09)$ & 1.05 & $(0.09)$ & 1.18 & $(0.11)$ \\
\hline & FYROM & $\mathrm{m}$ & $\mathrm{m}$ & $\mathrm{m}$ & $\mathrm{m}$ & $\mathrm{m}$ & $\mathrm{m}$ & $\mathrm{m}$ & $\mathrm{m}$ & $\mathrm{m}$ & $\mathrm{m}$ \\
\hline & Georgia & $\mathrm{m}$ & $\mathrm{m}$ & $\mathrm{m}$ & $\mathrm{m}$ & $\mathrm{m}$ & $\mathrm{m}$ & $\mathrm{m}$ & $\mathrm{m}$ & $\mathrm{m}$ & $\mathrm{m}$ \\
\hline & Hong Kong (China) & 6.32 & $(0.05)$ & 6.61 & $(0.06)$ & 0.30 & $(0.07)$ & 1.15 & $(0.10)$ & 1.43 & $(0.13)$ \\
\hline & Indonesia & $\mathrm{m}$ & $\mathrm{m}$ & $\mathrm{m}$ & $\mathrm{m}$ & $\mathrm{m}$ & $\mathrm{m}$ & $\mathrm{m}$ & $\mathrm{m}$ & $\mathrm{m}$ & $\mathrm{m}$ \\
\hline & Jordan & $\mathrm{m}$ & $\mathrm{m}$ & $\mathrm{m}$ & $\mathrm{m}$ & $\mathrm{m}$ & $\mathrm{m}$ & $\mathrm{m}$ & $\mathrm{m}$ & $\mathrm{m}$ & $\mathrm{m}$ \\
\hline & Kosovo & $\mathrm{m}$ & $\mathrm{m}$ & $\mathrm{m}$ & $\mathrm{m}$ & $\mathrm{m}$ & $\mathrm{m}$ & $\mathrm{m}$ & $\mathrm{m}$ & $\mathrm{m}$ & $\mathrm{m}$ \\
\hline & Lebanon & $\mathrm{m}$ & $\mathrm{m}$ & $\mathrm{m}$ & $\mathrm{m}$ & $\mathrm{m}$ & $\mathrm{m}$ & $\mathrm{m}$ & $\mathrm{m}$ & $\mathrm{m}$ & $\mathrm{m}$ \\
\hline & Lithuania & 7.67 & $(0.05)$ & 8.03 & $(0.04)$ & 0.36 & $(0.07)$ & 1.31 & $(0.08)$ & 1.51 & $(0.12)$ \\
\hline & Macao (China) & 6.45 & $(0.05)$ & 6.75 & $(0.05)$ & 0.30 & $(0.07)$ & 1.26 & $(0.10)$ & 1.32 & $(0.12)$ \\
\hline & Malta & $\mathrm{m}$ & $\mathrm{m}$ & $\mathrm{m}$ & $\mathrm{m}$ & $\mathrm{m}$ & $\mathrm{m}$ & $\mathrm{m}$ & $\mathrm{m}$ & $\mathrm{m}$ & $\mathrm{m}$ \\
\hline & Moldova & $\mathrm{m}$ & $\mathrm{m}$ & $\mathrm{m}$ & $\mathrm{m}$ & $\mathrm{m}$ & $\mathrm{m}$ & $\mathrm{m}$ & $\mathrm{m}$ & $\mathrm{m}$ & $\mathrm{m}$ \\
\hline & Montenegro & 7.71 & $(0.06)$ & 7.78 & $(0.04)$ & 0.06 & $(0.06)$ & 1.00 & $(0.05)$ & 1.26 & $(0.07)$ \\
\hline & Peru & 7.30 & $(0.06)$ & 7.61 & $(0.04)$ & 0.31 & $(0.06)$ & 1.02 & $(0.05)$ & 1.25 & $(0.07)$ \\
\hline & Qatar & 7.10 & $(0.05)$ & 7.49 & $(0.02)$ & 0.39 & $(0.06)$ & 1.14 & $(0.05)$ & 1.39 & $(0.06)$ \\
\hline & Romania & $\mathrm{m}$ & $\mathrm{m}$ & $\mathrm{m}$ & $\mathrm{m}$ & $\mathrm{m}$ & $\mathrm{m}$ & $\mathrm{m}$ & $\mathrm{m}$ & $\mathrm{m}$ & $\mathrm{m}$ \\
\hline & Russia & 7.75 & $(0.04)$ & 7.81 & $(0.12)$ & 0.06 & $(0.12)$ & 1.15 & $(0.10)$ & 1.21 & $(0.11)$ \\
\hline & Singapore & $\mathrm{m}$ & $\mathrm{m}$ & $\mathrm{m}$ & $\mathrm{m}$ & $\mathrm{m}$ & $\mathrm{m}$ & $\mathrm{m}$ & $\mathrm{m}$ & $\mathrm{m}$ & $\mathrm{m}$ \\
\hline & Chinese Taipei & 6.48 & $(0.04)$ & 6.73 & $(0.04)$ & 0.25 & $(0.06)$ & 1.07 & $(0.07)$ & 1.24 & $(0.09)$ \\
\hline & Thailand & 7.66 & $(0.06)$ & 7.73 & $(0.04)$ & 0.07 & $(0.07)$ & 0.89 & $(0.06)$ & 1.24 & $(0.10)$ \\
\hline & Trinidad and Tobago & $\mathrm{m}$ & $\mathrm{m}$ & $\mathrm{m}$ & $\mathrm{m}$ & $\mathrm{m}$ & $\mathrm{m}$ & $\mathrm{m}$ & $\mathrm{m}$ & $\mathrm{m}$ & $\mathrm{m}$ \\
\hline & Tunisia & 6.72 & $(0.07)$ & 7.10 & $(0.06)$ & 0.38 & $(0.09)$ & 1.15 & $(0.07)$ & 1.27 & $(0.09)$ \\
\hline & United Arab Emirates & 6.99 & $(0.06)$ & 7.41 & $(0.04)$ & 0.43 & $(0.07)$ & 1.17 & $(0.06)$ & 1.36 & $(0.08)$ \\
\hline & Uruguay & 7.61 & $(0.04)$ & 7.82 & $(0.04)$ & 0.21 & $(0.06)$ & 0.95 & $(0.06)$ & 1.17 & $(0.09)$ \\
\hline & Viet Nam & $\mathrm{m}$ & $\mathrm{m}$ & $\mathrm{m}$ & $\mathrm{m}$ & $\mathrm{m}$ & $\mathrm{m}$ & $\mathrm{m}$ & $\mathrm{m}$ & $\mathrm{m}$ & $\mathrm{m}$ \\
\hline & Argentina** & $\mathrm{m}$ & $\mathrm{m}$ & $\mathrm{m}$ & $\mathrm{m}$ & $\mathrm{m}$ & $\mathrm{m}$ & $\mathrm{m}$ & $\mathrm{m}$ & $\mathrm{m}$ & $\mathrm{m}$ \\
\hline & Kazakhstan** & $\mathrm{m}$ & $\mathrm{m}$ & $\mathrm{m}$ & $\mathrm{m}$ & $\mathrm{m}$ & $\mathrm{m}$ & $\mathrm{m}$ & $\mathrm{m}$ & $\mathrm{m}$ & $\mathrm{m}$ \\
\hline & Malaysia** & 6.87 & $(0.06)$ & 7.16 & $(0.04)$ & 0.30 & $(0.07)$ & 1.14 & $(0.07)$ & 1.39 & $(0.09)$ \\
\hline
\end{tabular}

1. Student characteristics include the PISA index of economic, social and cultural status (ESCS), gender and science performance.

Note: Values that are statistically significant are indicated in bold (see Annex A3).

* See note at the beginning of this Annex.

** Coverage is too small to ensure comparability (see Annex A4).

StatLink intsl $\mathrm{http}: / / \mathrm{dx}$.doi.org/10.1787/888933471123 
Table III.6.10 Tracking policies and students' expectations to complete a university degree

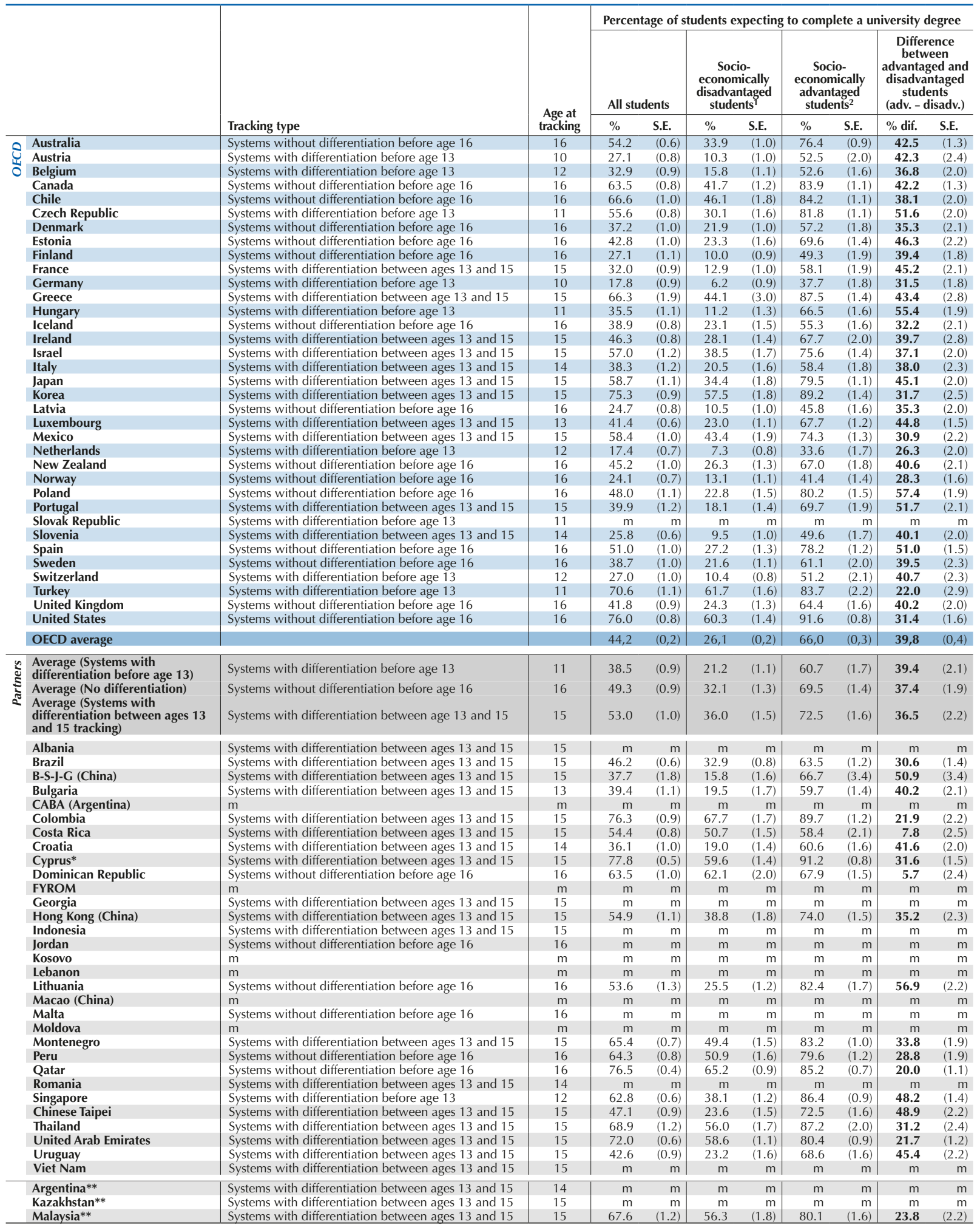

1. A socio-economically disadvantaged student is a student in the bottom quarter of the distribution of the PISA index of economic, social and cultural status (ESCS) within his or her country/economy.

2. A socio-economically advantaged student is a student in the top quarter of the distribution of the PISA index of economic, social and cultural status (ESCS) within his or her country/economy.

Note: Values that are statistically significant are indicated in bold (see Annex A3).

* See note at the beginning of this Annex.

** Coverage is too small to ensure comparability (see Annex A4).

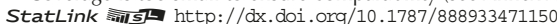


[Part 1/3]

Table III.7.1 Students' sense of belonging

Results based on students' self-reports

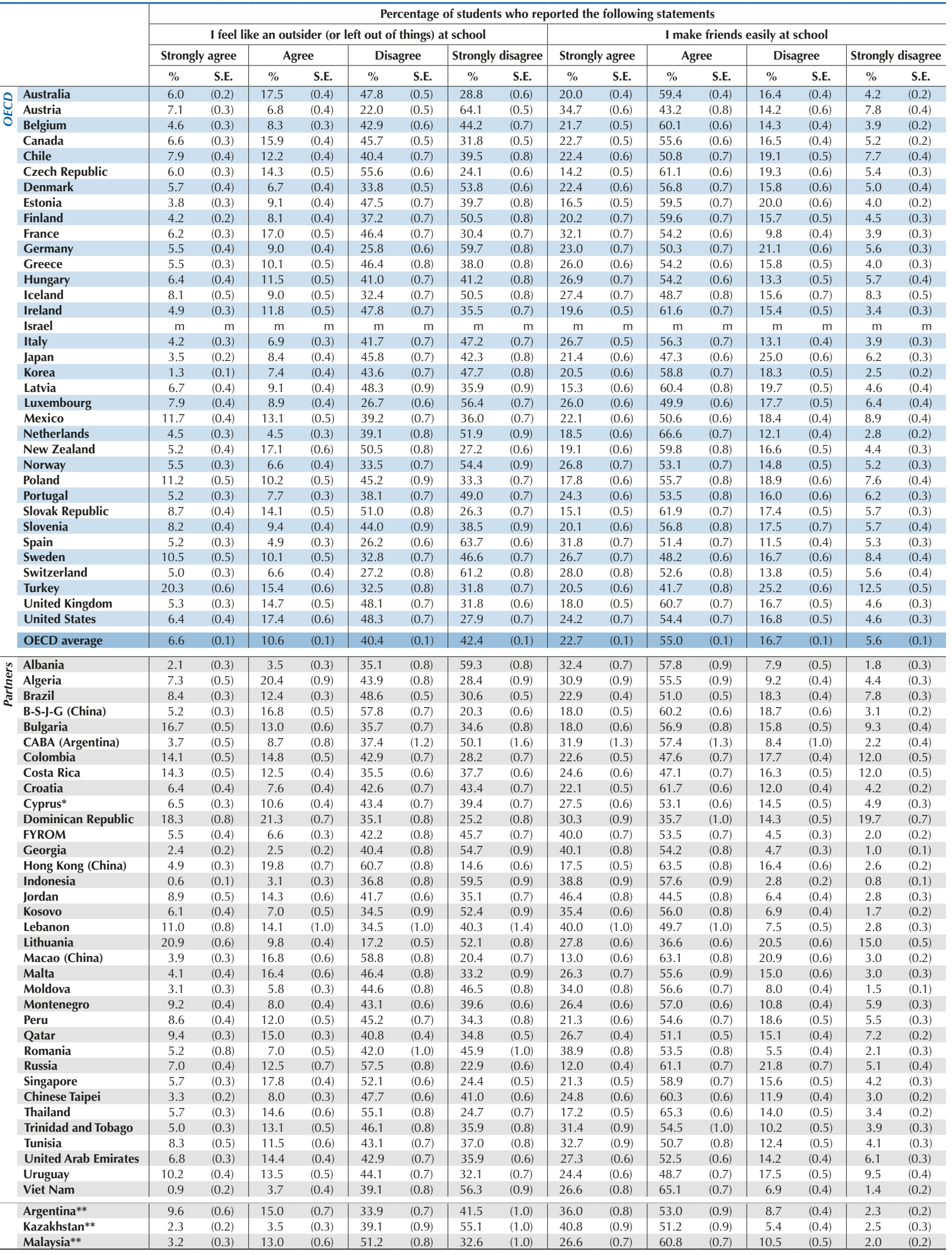

* See note at the beginning of this Annex.

** Coverage is too small to ensure comparability (see Annex A4).

StatLink न्ता St http://dx.doi.org/10.1787/888933471259 


\begin{tabular}{|c|c|c|c|c|c|c|c|c|c|c|c|c|c|c|c|c|c|}
\hline & \multicolumn{16}{|c|}{ Percentage of students who reported the following statements } \\
\hline & & & & & like I b & ng at s & & & & & & awkw: & and 0 & of plac & n my sc & hool & \\
\hline & & Stron & agree & & & & & Strongl & lisagree & Stron & agree & & & & & Strongl & disagree \\
\hline & & $\%$ & S.E. & $\%$ & S.E. & $\%$ & S.E. & $\%$ & S.E. & $\%$ & S.E. & $\%$ & S.E. & $\%$ & S.E. & $\%$ & S.E. \\
\hline 0 & Australia & 15.6 & (0.4) & 56.3 & (0.5) & 21.1 & $(0.5)$ & 7.0 & $(0.2)$ & 5.2 & $(0.2)$ & 16.6 & $(0.4)$ & 49.8 & (0.6) & 28.3 & $(0.6)$ \\
\hline$\pi$ & Austria & 34.1 & (0.7) & 41.9 & $(0.7)$ & 15.8 & $(0.5)$ & 8.2 & $(0.3)$ & 9.5 & (0.4) & 7.7 & $(0.4)$ & 21.8 & (0.6) & 61.0 & $(0.7)$ \\
\hline 0 & Belgium & 11.8 & (0.4) & 50.3 & (0.5) & 27.1 & (0.5) & 10.9 & $(0.4)$ & 4.9 & $(0.3)$ & 10.8 & (0.4) & 48.4 & (0.6) & 35.9 & $(0.6)$ \\
\hline & Canada & 16.3 & (0.5) & 55.3 & $(0.5)$ & 20.1 & $(0.4)$ & 8.3 & $(0.3)$ & 6.6 & $(0.2)$ & 17.1 & (0.4) & 48.1 & (0.5) & 28.2 & $(0.5)$ \\
\hline & Chile & 25.4 & $(0.7)$ & 51.9 & $(0.7)$ & 15.5 & $(0.6)$ & 7.3 & $(0.4)$ & 7.8 & $(0.4)$ & 12.1 & $(0.5)$ & 44.7 & $(0.8)$ & 35.3 & $(0.8)$ \\
\hline & Czech Republic & 11.8 & (0.5) & 59.1 & $(0.7)$ & 22.0 & $(0.7)$ & 7.1 & $(0.4)$ & 5.1 & $(0.3)$ & 13.6 & (0.6) & 56.0 & $(0.7)$ & 25.3 & $(0.6)$ \\
\hline & Denmark & 18.6 & (0.6) & 51.6 & $(0.7)$ & 22.2 & (0.6) & 7.6 & $(0.5)$ & 5.7 & $(0.3)$ & 9.5 & (0.4) & 40.1 & (0.8) & 44.7 & $(0.7)$ \\
\hline & Estonia & 18.5 & (0.6) & 59.5 & $(0.7)$ & 17.0 & $(0.6)$ & 5.0 & $(0.3)$ & 4.1 & $(0.3)$ & 12.5 & $(0.5)$ & 51.3 & (0.7) & 32.1 & $(0.7)$ \\
\hline & Finland & 20.3 & $(0.7)$ & 60.0 & $(0.8)$ & 14.3 & (0.6) & 5.4 & $(0.3)$ & 5.3 & $(0.3)$ & 12.0 & $(0.5)$ & 45.2 & $(0.7)$ & 37.5 & $(0.8)$ \\
\hline & France & 9.3 & $(0.4)$ & 31.6 & $(0.7)$ & 38.3 & $(0.6)$ & 20.7 & $(0.5)$ & 4.7 & $(0.3)$ & 11.5 & $(0.4)$ & 43.3 & $(0.7)$ & 40.4 & $(0.6)$ \\
\hline & Germany & 26.8 & $(0.7)$ & 48.1 & $(0.7)$ & 17.7 & (0.6) & 7.5 & $(0.4)$ & 7.4 & $(0.4)$ & 10.2 & $(0.4)$ & 27.6 & $(0.7)$ & 54.8 & $(0.9)$ \\
\hline & Greece & 25.9 & (0.7) & 57.1 & (0.8) & 13.0 & $(0.4)$ & 4.0 & $(0.3)$ & 4.6 & $(0.3)$ & 11.0 & $(0.4)$ & 44.5 & (0.8) & 40.0 & $(0.8)$ \\
\hline & Hungary & 19.5 & $(0.7)$ & 55.0 & (0.8) & 18.8 & $(0.7)$ & 6.7 & $(0.4)$ & 6.7 & $(0.4)$ & 10.8 & $(0.4)$ & 39.0 & $(0.7)$ & 43.4 & $(0.9)$ \\
\hline & Iceland & 30.1 & $(0.8)$ & 48.4 & (0.9) & 13.0 & $(0.6)$ & 8.5 & $(0.5)$ & 8.9 & $(0.5)$ & 10.6 & $(0.5)$ & 34.0 & (0.8) & 46.5 & $(0.9)$ \\
\hline & Ireland & 15.7 & $(0.5)$ & 57.6 & $(0.8)$ & 19.8 & $(0.7)$ & 6.8 & $(0.4)$ & 4.1 & $(0.2)$ & 13.2 & $(0.6)$ & 49.1 & $(0.8)$ & 33.6 & $(0.7)$ \\
\hline & Israel & $\mathrm{m}$ & $\mathrm{m}$ & $\mathrm{m}$ & $\mathrm{m}$ & $\mathrm{m}$ & $\mathrm{m}$ & $\mathrm{m}$ & $\mathrm{m}$ & $\mathrm{m}$ & $\mathrm{m}$ & $\mathrm{m}$ & $\mathrm{m}$ & $\mathrm{m}$ & $\mathrm{m}$ & $\mathrm{m}$ & $\mathrm{m}$ \\
\hline & Italy & 13.4 & $(0.5)$ & 53.9 & $(0.7)$ & 24.8 & $(0.5)$ & 7.9 & $(0.4)$ & 4.2 & $(0.3)$ & 9.5 & $(0.4)$ & 49.7 & $(0.7)$ & 36.6 & $(0.8)$ \\
\hline & Japan & 19.9 & $(0.6)$ & 61.9 & $(0.7)$ & 14.2 & $(0.5)$ & 3.9 & $(0.3)$ & 4.9 & $(0.3)$ & 14.6 & (0.5) & 51.1 & $(0.6)$ & 29.5 & $(0.7)$ \\
\hline & Korea & 19.2 & $(0.7)$ & 60.3 & $(0.7)$ & 15.4 & $(0.7)$ & 5.1 & $(0.3)$ & 1.6 & $(0.2)$ & 8.6 & $(0.4)$ & 44.0 & $(0.8)$ & 45.9 & $(0.8)$ \\
\hline & Latvia & 14.1 & $(0.6)$ & 64.5 & $(0.7)$ & 17.3 & $(0.6)$ & 4.1 & $(0.4)$ & 6.9 & $(0.4)$ & 17.5 & $(0.5)$ & 52.1 & $(0.7)$ & 23.5 & $(0.6)$ \\
\hline & Luxembourg & 22.2 & $(0.6)$ & 43.8 & $(0.7)$ & 22.6 & $(0.6)$ & 11.4 & $(0.4)$ & 8.0 & $(0.3)$ & 12.0 & $(0.5)$ & 34.2 & $(0.7)$ & 45.7 & $(0.7)$ \\
\hline & Mexico & 25.9 & $(0.6)$ & 50.2 & $(0.7)$ & 15.5 & $(0.5)$ & 8.4 & $(0.5)$ & 10.2 & (0.5) & 13.6 & (0.5) & 44.2 & $(0.7)$ & 32.0 & $(0.7)$ \\
\hline & Netherlands & 13.5 & $(0.6)$ & 67.4 & $(0.8)$ & 14.9 & $(0.6)$ & 4.1 & $(0.3)$ & 4.2 & $(0.3)$ & 7.0 & $(0.5)$ & 46.0 & $(0.8)$ & 42.8 & $(0.7)$ \\
\hline & New Zealand & 15.3 & $(0.6)$ & 58.5 & (0.6) & 19.1 & (0.6) & 7.2 & $(0.4)$ & 5.0 & $(0.3)$ & 17.1 & (0.6) & 50.3 & $(0.8)$ & 27.6 & $(0.7)$ \\
\hline & Norway & 23.5 & (0.6) & 52.3 & $(0.7)$ & 16.0 & $(0.5)$ & 8.2 & $(0.4)$ & 6.2 & $(0.3)$ & 11.2 & $(0.5)$ & 36.4 & $(0.8)$ & 46.2 & $(0.7)$ \\
\hline & Poland & 10.8 & (0.6) & 51.6 & $(0.9)$ & 28.7 & $(0.6)$ & 8.9 & $(0.5)$ & 10.8 & $(0.5)$ & 12.2 & $(0.4)$ & 46.2 & $(0.8)$ & 30.8 & $(0.7)$ \\
\hline & Portugal & 24.1 & $(0.6)$ & 58.2 & (0.6) & 13.0 & $(0.5)$ & 4.8 & $(0.3)$ & 6.8 & $(0.4)$ & 17.4 & (0.5) & 41.9 & $(0.6)$ & 33.9 & $(0.7)$ \\
\hline & Slovak Republic & 11.6 & (0.5) & 58.2 & $(0.7)$ & 22.5 & $(0.6)$ & 7.8 & $(0.4)$ & 8.6 & $(0.4)$ & 14.0 & $(0.4)$ & 49.4 & $(0.7)$ & 28.1 & $(0.7)$ \\
\hline & Slovenia & 13.0 & (0.6) & 61.5 & $(0.8)$ & 19.7 & $(0.7)$ & 5.8 & $(0.4)$ & 7.1 & $(0.4)$ & 10.4 & $(0.4)$ & 47.0 & $(0.9)$ & 35.6 & $(0.8)$ \\
\hline & Spain & 38.9 & $(0.7)$ & 48.3 & $(0.7)$ & 7.4 & $(0.4)$ & 5.4 & $(0.3)$ & 6.5 & $(0.3)$ & 7.5 & $(0.3)$ & 31.1 & $(0.7)$ & 54.8 & $(0.7)$ \\
\hline & Sweden & 22.0 & $(0.7)$ & 47.3 & $(0.8)$ & 20.6 & $(0.6)$ & 10.1 & $(0.4)$ & 10.4 & $(0.5)$ & 10.0 & $(0.5)$ & 34.5 & $(0.7)$ & 45.1 & $(0.8)$ \\
\hline & Switzerland & 27.4 & $(0.8)$ & 43.5 & $(0.9)$ & 19.1 & $(0.5)$ & 10.0 & $(0.6)$ & 6.4 & $(0.4)$ & 8.5 & $(0.4)$ & 28.7 & $(0.6)$ & 56.5 & $(0.8)$ \\
\hline & Turkey & 20.1 & $(0.7)$ & 41.3 & $(0.6)$ & 25.4 & $(0.6)$ & 13.3 & $(0.4)$ & 18.7 & $(0.5)$ & 18.6 & $(0.6)$ & 34.4 & $(0.7)$ & 28.3 & $(0.7)$ \\
\hline & United Kingdom & 13.1 & $(0.5)$ & 54.7 & $(0.7)$ & 23.9 & $(0.6)$ & 8.3 & $(0.3)$ & 5.0 & $(0.3)$ & 14.8 & (0.5) & 49.5 & $(0.7)$ & 30.6 & $(0.6)$ \\
\hline & United States & 19.2 & $(0.6)$ & 55.0 & $(0.7)$ & 20.0 & $(0.6)$ & 5.9 & $(0.3)$ & 5.9 & $(0.3)$ & 17.2 & $(0.6)$ & 49.8 & $(0.7)$ & 27.2 & $(0.7)$ \\
\hline & OECD average & 19.6 & $(0.1)$ & 53.4 & $(0.1)$ & 19.3 & $(0.1)$ & 7.7 & $(0.1)$ & 6.7 & $(0.1)$ & 12.4 & $(0.1)$ & 43.0 & $(0.1)$ & 37.9 & $(0.1)$ \\
\hline & Albania & 47.6 & $(0.9)$ & 45.6 & (0.9) & 4.7 & $(0.4)$ & 2.2 & $(0.3)$ & 3.6 & $(0.3)$ & 7.2 & $(0.5)$ & 36.6 & $(0.7)$ & 52.6 & $(0.9)$ \\
\hline ఏ & Algeria & 37.1 & $(0.9)$ & 50.3 & (0.9) & 8.4 & (0.5) & 4.3 & $(0.3)$ & 12.1 & $(0.6)$ & 22.3 & (0.9) & 39.0 & $(0.7)$ & 26.6 & $(0.8)$ \\
\hline 0 & Brazil & 19.9 & $(0.4)$ & 56.2 & $(0.5)$ & 17.4 & $(0.4)$ & 6.5 & $(0.2)$ & 7.2 & $(0.3)$ & 11.0 & $(0.3)$ & 48.7 & $(0.5)$ & 33.2 & $(0.5)$ \\
\hline & B-S-J-G (China) & 9.4 & $(0.5)$ & 55.3 & (0.8) & 30.7 & $(0.7)$ & 4.7 & $(0.4)$ & 4.1 & $(0.3)$ & 15.3 & (0.5) & 56.5 & $(0.7)$ & 24.1 & $(0.7)$ \\
\hline & Bulgaria & 14.4 & $(0.5)$ & 53.6 & $(0.7)$ & 22.7 & $(0.5)$ & 9.3 & $(0.4)$ & 14.6 & $(0.5)$ & 13.5 & $(0.6)$ & 44.3 & $(0.8)$ & 27.6 & $(0.7)$ \\
\hline & CABA (Argentina) & 34.5 & (2.0) & 54.2 & (1.7) & 8.8 & $(0.9)$ & 2.5 & $(0.4)$ & 2.0 & $(0.3)$ & 5.6 & $(0.7)$ & 42.6 & (1.4) & 49.8 & (1.6) \\
\hline & Colombia & 27.0 & $(0.7)$ & 47.2 & $(0.7)$ & 14.3 & $(0.5)$ & 11.5 & $(0.5)$ & 11.9 & $(0.4)$ & 15.2 & $(0.4)$ & 46.8 & $(0.7)$ & 26.1 & $(0.6)$ \\
\hline & Costa Rica & 28.8 & $(0.7)$ & 45.9 & $(0.7)$ & 13.6 & $(0.4)$ & 11.7 & $(0.5)$ & 13.3 & $(0.6)$ & 12.0 & $(0.5)$ & 40.6 & $(0.8)$ & 34.1 & $(0.8)$ \\
\hline & Croatia & 19.1 & $(0.6)$ & 62.1 & (0.6) & 13.8 & (0.5) & 4.9 & $(0.3)$ & 5.3 & $(0.3)$ & 9.7 & (0.4) & 43.3 & $(0.8)$ & 41.6 & $(0.8)$ \\
\hline & Cyprus* & 26.8 & (0.6) & 53.4 & $(0.7)$ & 13.9 & $(0.5)$ & 5.9 & $(0.4)$ & 5.1 & $(0.3)$ & 11.7 & $(0.4)$ & 43.9 & $(0.6)$ & 39.3 & $(0.7)$ \\
\hline & Dominican Republic & 30.6 & (1.0) & 36.2 & (1.0) & 13.0 & (0.6) & 20.1 & $(0.6)$ & 17.1 & $(0.8)$ & 17.8 & $(0.6)$ & 38.7 & $(0.9)$ & 26.4 & $(0.7)$ \\
\hline & FYROM & 41.8 & $(0.7)$ & 50.3 & $(0.7)$ & 5.2 & $(0.4)$ & 2.6 & $(0.2)$ & 4.5 & $(0.3)$ & 6.8 & $(0.4)$ & 36.7 & $(0.7)$ & 52.1 & $(0.8)$ \\
\hline & Georgia & 19.9 & $(0.6)$ & 45.0 & $(0.8)$ & 28.4 & $(0.7)$ & 6.8 & $(0.4)$ & 2.4 & $(0.3)$ & 3.4 & $(0.3)$ & 53.3 & $(0.7)$ & 41.0 & $(0.7)$ \\
\hline & Hong Kong (China) & 10.0 & (0.5) & 61.1 & $(0.9)$ & 22.1 & $(0.7)$ & 6.8 & $(0.4)$ & 3.6 & $(0.2)$ & 17.3 & $(0.6)$ & 61.1 & $(0.9)$ & 17.9 & $(0.8)$ \\
\hline & Indonesia & 29.5 & $(0.9)$ & 62.8 & $(0.9)$ & 6.1 & $(0.4)$ & 1.6 & $(0.2)$ & 1.6 & $(0.2)$ & 14.3 & $(0.7)$ & 62.8 & $(0.8)$ & 21.3 & $(0.6)$ \\
\hline & Jordan & 44.0 & $(0.9)$ & 42.0 & $(0.7)$ & 8.4 & (0.4) & 5.7 & $(0.3)$ & 10.0 & $(0.4)$ & 14.2 & $(0.5)$ & 33.5 & $(0.7)$ & 42.3 & $(0.8)$ \\
\hline & Kosovo & 52.1 & (1.1) & 40.5 & (1.0) & 5.1 & $(0.4)$ & 2.4 & $(0.3)$ & 5.0 & $(0.4)$ & 9.6 & $(0.5)$ & 41.0 & $(0.9)$ & 44.4 & $(0.9)$ \\
\hline & Lebanon & 28.5 & $(1.1)$ & 46.4 & (1.0) & 17.4 & (1.0) & 7.7 & $(0.5)$ & 8.4 & $(0.6)$ & 16.2 & (0.9) & 42.5 & (1.0) & 32.9 & (1.2) \\
\hline & Lithuania & 22.1 & (0.6) & 32.4 & $(0.7)$ & 24.2 & $(0.7)$ & 21.3 & $(0.6)$ & 19.3 & (0.6) & 14.5 & $(0.5)$ & 26.3 & $(0.6)$ & 39.9 & $(0.8)$ \\
\hline & Macao (China) & 6.5 & (0.4) & 53.4 & $(0.7)$ & 32.6 & (0.8) & 7.4 & $(0.4)$ & 3.0 & $(0.3)$ & 19.3 & (0.6) & 61.6 & $(0.8)$ & 16.1 & $(0.6)$ \\
\hline & Malta & 16.1 & $(0.6)$ & 53.7 & $(0.8)$ & 21.5 & $(0.6)$ & 8.7 & $(0.5)$ & 4.6 & $(0.3)$ & 13.2 & $(0.6)$ & 49.7 & $(0.8)$ & 32.5 & $(0.7)$ \\
\hline & Moldova & 18.2 & $(0.7)$ & 49.5 & $(0.9)$ & 26.6 & $(0.8)$ & 5.7 & $(0.4)$ & 3.1 & $(0.3)$ & 7.6 & (0.3) & 55.7 & $(0.7)$ & 33.5 & $(0.8)$ \\
\hline & Montenegro & 14.4 & (0.6) & 39.4 & $(0.7)$ & 33.9 & $(0.7)$ & 12.3 & $(0.5)$ & 8.0 & $(0.4)$ & 9.5 & $(0.5)$ & 48.8 & $(0.7)$ & 33.7 & $(0.6)$ \\
\hline & Peru & 15.9 & (0.5) & 55.5 & $(0.6)$ & 22.6 & $(0.6)$ & 6.1 & $(0.3)$ & 6.7 & $(0.3)$ & 17.3 & $(0.6)$ & 54.6 & $(0.8)$ & 21.4 & $(0.7)$ \\
\hline & Qatar & 21.0 & $(0.4)$ & 49.7 & $(0.4)$ & 20.0 & $(0.4)$ & 9.3 & $(0.3)$ & 8.9 & $(0.2)$ & 15.0 & $(0.4)$ & 43.7 & $(0.5)$ & 32.4 & $(0.5)$ \\
\hline & Romania & 13.6 & $(0.6)$ & 38.9 & (0.9) & 34.9 & $(0.9)$ & 12.6 & $(0.8)$ & 5.4 & $(0.7)$ & 10.2 & $(0.5)$ & 49.8 & $(0.9)$ & 34.6 & $(0.8)$ \\
\hline & Russia & 11.3 & $(0.6)$ & 63.3 & $(0.7)$ & 21.1 & $(0.7)$ & 4.3 & $(0.4)$ & 6.0 & $(0.5)$ & 21.1 & $(0.6)$ & 56.3 & $(0.7)$ & 16.6 & $(0.6)$ \\
\hline & Singapore & 16.6 & $(0.5)$ & 59.4 & $(0.7)$ & 17.8 & $(0.5)$ & 6.2 & $(0.3)$ & 5.3 & $(0.3)$ & 18.1 & $(0.5)$ & 52.7 & $(0.6)$ & 23.8 & $(0.5)$ \\
\hline & Chinese Taipei & 23.8 & $(0.6)$ & 66.1 & $(0.6)$ & 7.3 & $(0.3)$ & 2.8 & $(0.2)$ & 3.9 & $(0.2)$ & 13.0 & $(0.5)$ & 52.5 & $(0.6)$ & 30.5 & $(0.6)$ \\
\hline & Thailand & 12.9 & $(0.5)$ & 65.5 & $(0.7)$ & 18.9 & $(0.5)$ & 2.8 & $(0.3)$ & 5.2 & $(0.3)$ & 27.2 & $(0.8)$ & 54.8 & $(0.9)$ & 12.8 & $(0.5)$ \\
\hline & Trinidad and Tobago & 28.7 & $(0.7)$ & 51.0 & $(0.8)$ & 14.1 & $(0.5)$ & 6.1 & $(0.4)$ & 5.2 & $(0.3)$ & 12.7 & $(0.6)$ & 46.0 & $(0.7)$ & 36.1 & $(0.7)$ \\
\hline & Tunisia & 21.6 & (0.6) & 35.9 & $(0.8)$ & 29.9 & $(0.6)$ & 12.6 & $(0.5)$ & 10.7 & $(0.5)$ & 26.3 & $(0.7)$ & 45.5 & $(0.9)$ & 17.5 & $(0.6)$ \\
\hline & United Arab Emirates & 22.2 & $(0.5)$ & 51.6 & $(0.6)$ & 17.5 & $(0.5)$ & 8.6 & $(0.3)$ & 8.2 & $(0.3)$ & 16.5 & $(0.5)$ & 44.5 & $(0.6)$ & 30.8 & $(0.5)$ \\
\hline & Uruguay & 23.6 & $(0.6)$ & 54.3 & $(0.7)$ & 13.8 & $(0.5)$ & 8.3 & $(0.4)$ & 9.2 & (0.4) & 11.5 & $(0.4)$ & 46.5 & $(0.7)$ & 32.8 & $(0.7)$ \\
\hline & Viet Nam & 15.4 & (0.6) & 65.4 & (0.8) & 16.1 & $(0.7)$ & 3.1 & $(0.3)$ & 2.1 & $(0.2)$ & 15.2 & $(0.5)$ & 58.6 & $(0.7)$ & 24.1 & $(0.7)$ \\
\hline & Argentina** & 35.5 & $(0.9)$ & 54.0 & (0.9) & 7.7 & (0.5) & 2.8 & $(0.3)$ & 4.2 & $(0.3)$ & 7.1 & $(0.4)$ & 44.9 & $(0.9)$ & 43.8 & (1.0) \\
\hline & Kazakhstan** & 29.0 & $(0.8)$ & 55.9 & $(0.7)$ & 10.6 & (0.5) & 4.4 & $(0.4)$ & 2.6 & $(0.2)$ & 4.8 & (0.4) & 45.3 & $(0.8)$ & 47.3 & (1.0) \\
\hline & Malaysia** & 11.5 & (0.6) & 65.6 & $(0.7)$ & 20.0 & $(0.7)$ & 2.9 & $(0.3)$ & 3.0 & $(0.2)$ & 14.3 & $(0.7)$ & 55.0 & $(0.9)$ & 27.7 & $(1.0)$ \\
\hline
\end{tabular}

* See note at the beginning of this Annex.

* Coverage is too small to ensure comparability (see Annex A4).

StatLink न्ना St http://dx.doi.org/10.1787/888933471259 
[Part 3/3]

Table III.7.1 Students' sense of belonging

Results based on students' self-reports

\begin{tabular}{|c|c|c|c|c|c|c|c|c|c|c|c|c|c|c|c|c|c|}
\hline & \multicolumn{16}{|c|}{ Percentage of students who reported the following statements } \\
\hline & & & & Othe & tuden & eem to & e me & & & & & & el lon & at sch & & & \\
\hline & & Stron & agree & & & & & Strongl & lisagree & Stron & agree & & & & & Strongl & lisagree \\
\hline & & $\%$ & S.E. & $\%$ & S.E. & $\%$ & S.E. & $\%$ & S.E. & $\%$ & S.E. & $\%$ & S.E. & $\%$ & S.E. & $\%$ & S.E. \\
\hline 0 & Australia & 14.3 & $(0.3)$ & 73.3 & $(0.4)$ & 9.3 & $(0.3)$ & 3.1 & $(0.2)$ & 5.0 & $(0.2)$ & 11.5 & $(0.3)$ & 44.9 & $(0.5)$ & 38.7 & $(0.6)$ \\
\hline 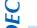 & Austria & 35.2 & $(0.6)$ & 48.6 & $(0.7)$ & 10.0 & $(0.4)$ & 6.2 & $(0.3)$ & 9.7 & $(0.4)$ & 5.7 & $(0.4)$ & 17.5 & $(0.5)$ & 67.1 & $(0.6)$ \\
\hline & Belgium & 13.7 & $(0.4)$ & 74.5 & $(0.5)$ & 9.4 & $(0.4)$ & 2.5 & $(0.2)$ & 3.9 & $(0.2)$ & 5.6 & $(0.3)$ & 38.3 & $(0.7)$ & 52.2 & $(0.7)$ \\
\hline & Canada & 17.0 & $(0.4)$ & 70.3 & $(0.5)$ & 9.3 & $(0.3)$ & 3.4 & $(0.2)$ & 6.3 & $(0.2)$ & 12.1 & $(0.3)$ & 44.3 & $(0.5)$ & 37.3 & $(0.5)$ \\
\hline & Chile & 15.9 & $(0.6)$ & 60.1 & $(0.7)$ & 18.3 & $(0.5)$ & 5.7 & $(0.4)$ & 7.9 & $(0.4)$ & 9.0 & $(0.4)$ & 34.3 & $(0.8)$ & 48.8 & $(0.9)$ \\
\hline & Czech Republic & 11.6 & $(0.5)$ & 69.6 & $(0.6)$ & 15.0 & $(0.5)$ & 3.8 & $(0.3)$ & 6.3 & $(0.3)$ & 11.8 & $(0.5)$ & 47.6 & $(0.7)$ & 34.3 & $(0.7)$ \\
\hline & Denmark & 21.3 & (0.6) & 64.1 & $(0.6)$ & 9.9 & $(0.5)$ & 4.7 & $(0.3)$ & 5.3 & $(0.4)$ & 7.6 & $(0.4)$ & 36.0 & $(0.7)$ & 51.1 & $(0.7)$ \\
\hline & Estonia & 9.9 & $(0.5)$ & 66.6 & $(0.7)$ & 19.3 & $(0.6)$ & 4.3 & $(0.3)$ & 4.6 & $(0.3)$ & 10.1 & $(0.5)$ & 42.6 & $(0.8)$ & 42.7 & $(0.9)$ \\
\hline & Finland & 11.8 & $(0.5)$ & 70.2 & $(0.6)$ & 14.3 & $(0.5)$ & 3.7 & $(0.3)$ & 4.1 & $(0.3)$ & 7.7 & $(0.4)$ & 38.8 & $(0.7)$ & 49.4 & $(0.8)$ \\
\hline & France & 18.2 & $(0.5)$ & 71.5 & $(0.7)$ & 7.5 & (0.4) & 2.8 & $(0.2)$ & 3.3 & $(0.2)$ & 6.0 & (0.4) & 33.7 & $(0.7)$ & 56.9 & $(0.8)$ \\
\hline & Germany & 27.3 & $(0.7)$ & 57.7 & $(0.7)$ & 10.8 & $(0.5)$ & 4.2 & $(0.3)$ & 6.9 & $(0.4)$ & 5.7 & $(0.3)$ & 19.0 & $(0.6)$ & 68.3 & $(0.8)$ \\
\hline & Greece & 18.7 & (0.6) & 68.7 & $(0.8)$ & 9.8 & (0.4) & 2.8 & $(0.2)$ & 4.5 & $(0.3)$ & 7.6 & (0.4) & 37.9 & $(0.8)$ & 50.1 & $(0.8)$ \\
\hline & Hungary & 15.2 & $(0.5)$ & 67.5 & $(0.8)$ & 13.2 & $(0.5)$ & 4.1 & $(0.3)$ & 6.3 & $(0.4)$ & 8.3 & $(0.4)$ & 35.7 & $(0.7)$ & 49.8 & $(0.8)$ \\
\hline & Iceland & 21.6 & $(0.7)$ & 61.3 & $(0.8)$ & 11.3 & (0.5) & 5.8 & $(0.4)$ & 8.2 & $(0.5)$ & 8.1 & (0.5) & 30.7 & $(0.8)$ & 53.0 & (0.9) \\
\hline & Ireland & 12.6 & $(0.4)$ & 78.0 & $(0.6)$ & 7.3 & $(0.4)$ & 2.2 & $(0.2)$ & 4.0 & $(0.2)$ & 8.3 & $(0.4)$ & 43.7 & $(0.7)$ & 44.1 & $(0.8)$ \\
\hline & Israel & $\mathrm{m}$ & $\mathrm{m}$ & $\mathrm{m}$ & $\mathrm{m}$ & $\mathrm{m}$ & $\mathrm{m}$ & $\mathrm{m}$ & $\mathrm{m}$ & $\mathrm{m}$ & $\mathrm{m}$ & $\mathrm{m}$ & $\mathrm{m}$ & $\mathrm{m}$ & $\mathrm{m}$ & $\mathrm{m}$ & $\mathrm{m}$ \\
\hline & Italy & 9.2 & $(0.4)$ & 67.5 & $(0.6)$ & 19.0 & $(0.5)$ & 4.3 & (0.3) & 4.1 & $(0.3)$ & 6.4 & $(0.3)$ & 34.3 & $(0.8)$ & 55.2 & $(0.8)$ \\
\hline & Japan & 10.4 & $(0.4)$ & 63.4 & $(0.7)$ & 22.0 & (0.5) & 4.2 & $(0.3)$ & 3.9 & $(0.3)$ & 7.6 & $(0.3)$ & 44.4 & $(0.7)$ & 44.1 & $(0.7)$ \\
\hline & Korea & 12.2 & $(0.5)$ & 69.8 & $(0.7)$ & 15.9 & $(0.6)$ & 2.2 & $(0.2)$ & 1.2 & $(0.2)$ & 7.1 & $(0.4)$ & 41.2 & $(0.8)$ & 50.4 & $(0.8)$ \\
\hline & Latvia & 8.5 & $(0.4)$ & 59.7 & $(0.7)$ & 25.9 & $(0.6)$ & 5.9 & $(0.4)$ & 6.8 & $(0.4)$ & 10.4 & $(0.5)$ & 45.4 & (0.8) & 37.4 & $(0.7)$ \\
\hline & Luxembourg & 21.2 & (0.6) & 60.1 & $(0.7)$ & 13.6 & $(0.5)$ & 5.1 & $(0.3)$ & 7.9 & $(0.3)$ & 7.0 & $(0.4)$ & 24.4 & $(0.6)$ & 60.6 & (0.6) \\
\hline & Mexico & 15.3 & $(0.5)$ & 56.7 & $(0.8)$ & 21.2 & $(0.5)$ & 6.8 & $(0.4)$ & 11.4 & $(0.4)$ & 9.3 & (0.4) & 36.6 & $(0.7)$ & 42.7 & $(0.8)$ \\
\hline & Netherlands & 12.8 & $(0.5)$ & 79.2 & $(0.7)$ & 6.6 & $(0.4)$ & 1.5 & $(0.2)$ & 3.5 & $(0.3)$ & 4.1 & $(0.3)$ & 36.5 & $(0.8)$ & 55.9 & $(0.8)$ \\
\hline & New Zealand & 11.7 & (0.6) & 76.5 & $(0.6)$ & 9.3 & $(0.4)$ & 2.5 & $(0.3)$ & 3.9 & $(0.3)$ & 13.0 & $(0.6)$ & 49.6 & $(0.8)$ & 33.6 & $(0.8)$ \\
\hline & Norway & 20.9 & (0.5) & 62.0 & $(0.7)$ & 11.8 & (0.5) & 5.3 & $(0.3)$ & 5.4 & $(0.3)$ & 8.9 & (0.4) & 31.9 & (0.6) & 53.7 & $(0.8)$ \\
\hline & Poland & 11.8 & (0.6) & 61.5 & $(0.8)$ & 19.2 & (0.5) & 7.5 & (0.5) & 10.4 & $(0.5)$ & 9.8 & (0.5) & 41.3 & (0.9) & 38.5 & $(0.7)$ \\
\hline & Portugal & 17.6 & $(0.6)$ & 70.1 & $(0.8)$ & 9.3 & $(0.4)$ & 3.1 & $(0.3)$ & 4.5 & $(0.3)$ & 6.6 & (0.4) & 33.8 & (0.6) & 55.0 & $(0.7)$ \\
\hline & Slovak Republic & 10.7 & $(0.4)$ & 66.0 & $(0.6)$ & 18.8 & $(0.5)$ & 4.5 & $(0.3)$ & 7.5 & $(0.4)$ & 11.9 & $(0.5)$ & 48.0 & $(0.7)$ & 32.6 & $(0.7)$ \\
\hline & Slovenia & 9.2 & $(0.4)$ & 69.3 & $(0.6)$ & 17.3 & $(0.6)$ & 4.2 & $(0.3)$ & 7.5 & $(0.4)$ & 7.1 & $(0.4)$ & 39.5 & $(1.0)$ & 45.9 & $(0.9)$ \\
\hline & Spain & 24.7 & $(0.6)$ & 61.3 & $(0.7)$ & 10.4 & $(0.5)$ & 3.6 & $(0.2)$ & 5.4 & $(0.3)$ & 3.9 & $(0.3)$ & 23.4 & $(0.6)$ & 67.3 & $(0.6)$ \\
\hline & Sweden & 19.2 & $(0.6)$ & 59.2 & $(0.8)$ & 14.9 & $(0.4)$ & 6.7 & $(0.4)$ & 10.3 & $(0.5)$ & 8.7 & $(0.4)$ & 32.2 & $(0.7)$ & 48.8 & $(0.8)$ \\
\hline & Switzerland & 27.5 & $(0.7)$ & 60.0 & $(0.7)$ & 8.5 & $(0.4)$ & 4.0 & $(0.3)$ & 5.2 & $(0.3)$ & 4.7 & $(0.3)$ & 21.8 & $(0.8)$ & 68.4 & $(0.8)$ \\
\hline & Turkey & 14.7 & $(0.5)$ & 49.0 & $(0.8)$ & 26.2 & $(0.7)$ & 10.1 & $(0.5)$ & 18.4 & $(0.6)$ & 16.6 & $(0.6)$ & 33.9 & $(0.8)$ & 31.1 & $(0.6)$ \\
\hline & United Kingdom & 13.2 & $(0.5)$ & 74.5 & $(0.6)$ & 9.3 & $(0.4)$ & 3.1 & $(0.2)$ & 4.5 & $(0.3)$ & 9.1 & $(0.4)$ & 42.6 & $(0.7)$ & 43.8 & $(0.7)$ \\
\hline & United States & 20.7 & $(0.7)$ & 68.0 & $(0.7)$ & 8.9 & $(0.4)$ & 2.4 & $(0.2)$ & 5.8 & $(0.3)$ & 12.4 & $(0.5)$ & 44.3 & $(0.8)$ & 37.5 & $(0.8)$ \\
\hline & OECD average & 16.3 & $(0.1)$ & 65.8 & $(0.1)$ & 13.6 & $(0.1)$ & 4.3 & $(0.1)$ & 6.3 & $(0.1)$ & 8.5 & $(0.1)$ & 36.8 & $(0.1)$ & 48.4 & $(0.1)$ \\
\hline in & Albania & 16.0 & $(0.6)$ & 66.6 & $(0.8)$ & 13.9 & $(0.6)$ & 3.5 & $(0.3)$ & 2.4 & $(0.3)$ & 2.5 & $(0.2)$ & 24.2 & $(0.7)$ & 70.8 & $(0.8)$ \\
\hline$\Xi$ & Algeria & 26.6 & $(0.8)$ & 56.2 & $(0.9)$ & 11.4 & $(0.5)$ & 5.8 & $(0.4)$ & 16.0 & $(0.9)$ & 12.7 & $(0.6)$ & 37.6 & $(0.7)$ & 33.8 & $(0.9)$ \\
\hline$=$ & Brazil & 15.1 & $(0.3)$ & 65.9 & $(0.5)$ & 13.4 & $(0.3)$ & 5.5 & $(0.2)$ & 7.6 & $(0.3)$ & 12.2 & $(0.3)$ & 45.6 & $(0.5)$ & 34.5 & $(0.5)$ \\
\hline & B-S-J-G (China) & 7.7 & $(0.4)$ & 51.9 & (0.6) & 36.5 & $(0.6)$ & 3.9 & $(0.3)$ & 5.5 & $(0.3)$ & 16.0 & (0.6) & 54.1 & $(0.6)$ & 24.4 & $(0.7)$ \\
\hline & Bulgaria & 11.4 & $(0.5)$ & 60.5 & $(0.8)$ & 20.3 & $(0.7)$ & 7.8 & $(0.4)$ & 14.8 & $(0.5)$ & 10.1 & $(0.5)$ & 40.2 & $(0.8)$ & 34.9 & $(0.7)$ \\
\hline & CABA (Argentina) & 24.6 & (1.7) & 67.1 & (1.6) & 6.9 & (0.9) & 1.5 & $(0.3)$ & 2.7 & $(0.4)$ & 3.5 & $(0.4)$ & 29.1 & (1.6) & 64.7 & (1.8) \\
\hline & Colombia & 14.2 & $(0.4)$ & 54.5 & $(0.7)$ & 22.1 & $(0.5)$ & 9.1 & $(0.4)$ & 13.5 & $(0.4)$ & 11.6 & $(0.4)$ & 39.7 & $(0.6)$ & 35.2 & $(0.7)$ \\
\hline & Costa Rica & 18.0 & $(0.5)$ & 54.1 & $(0.7)$ & 18.7 & $(0.5)$ & 9.1 & $(0.5)$ & 14.2 & $(0.5)$ & 8.4 & $(0.4)$ & 36.4 & $(0.7)$ & 41.0 & $(0.7)$ \\
\hline & Croatia & 10.2 & $(0.5)$ & 71.4 & $(0.7)$ & 14.5 & $(0.5)$ & 3.9 & $(0.3)$ & 5.3 & $(0.3)$ & 7.1 & $(0.4)$ & 41.4 & $(0.7)$ & 46.2 & $(0.7)$ \\
\hline & Cyprus* & 19.1 & $(0.5)$ & 66.3 & $(0.6)$ & 10.8 & $(0.4)$ & 3.8 & $(0.3)$ & 5.4 & $(0.3)$ & 8.2 & $(0.4)$ & 35.7 & $(0.7)$ & 50.7 & $(0.7)$ \\
\hline & Dominican Republic & 25.4 & $(0.9)$ & 40.8 & $(1.0)$ & 15.3 & $(0.6)$ & 18.5 & $(0.8)$ & 17.9 & $(0.8)$ & 13.0 & $(0.6)$ & 36.1 & (1.0) & 33.0 & $(0.8)$ \\
\hline & FYROM & 22.2 & $(0.6)$ & 64.3 & $(0.8)$ & 9.4 & $(0.4)$ & 4.1 & $(0.3)$ & 3.9 & $(0.3)$ & 3.7 & $(0.3)$ & 33.2 & $(0.8)$ & 59.1 & $(0.8)$ \\
\hline & Georgia & 16.4 & $(0.6)$ & 59.2 & $(0.8)$ & 19.9 & $(0.7)$ & 4.5 & $(0.3)$ & 2.6 & $(0.3)$ & 2.4 & $(0.2)$ & 41.6 & $(0.9)$ & 53.3 & $(0.9)$ \\
\hline & Hong Kong (China) & 9.3 & $(0.4)$ & 68.6 & $(0.8)$ & 18.4 & $(0.6)$ & 3.8 & $(0.3)$ & 4.4 & $(0.3)$ & 14.9 & $(0.5)$ & 58.8 & $(0.9)$ & 21.9 & $(0.7)$ \\
\hline & Indonesia & 11.9 & $(0.6)$ & 72.4 & $(0.7)$ & 13.3 & $(0.6)$ & 2.4 & $(0.2)$ & 1.7 & $(0.2)$ & 4.4 & $(0.3)$ & 51.5 & $(0.9)$ & 42.5 & $(0.9)$ \\
\hline & Jordan & 38.4 & $(0.8)$ & 52.5 & $(0.9)$ & 5.9 & $(0.3)$ & 3.2 & $(0.3)$ & 6.1 & $(0.4)$ & 6.9 & $(0.3)$ & 28.9 & $(0.6)$ & 58.0 & $(0.7)$ \\
\hline & Kosovo & 18.4 & $(0.6)$ & 67.1 & $(0.9)$ & 10.9 & $(0.6)$ & 3.6 & $(0.3)$ & 3.5 & $(0.4)$ & 3.6 & $(0.3)$ & 28.1 & $(0.8)$ & 64.8 & $(0.9)$ \\
\hline & Lebanon & 24.7 & $(0.8)$ & 52.9 & $(1.2)$ & 15.0 & $(0.8)$ & 7.4 & $(0.6)$ & 6.8 & $(0.5)$ & 8.5 & $(0.8)$ & 29.5 & (1.0) & 55.2 & $(1.4)$ \\
\hline & Lithuania & 14.0 & (0.6) & 48.6 & $(0.7)$ & 27.7 & $(0.7)$ & 9.7 & (0.4) & 20.1 & $(0.6)$ & 10.9 & $(0.5)$ & 20.5 & $(0.5)$ & 48.5 & $(0.7)$ \\
\hline & Macao (China) & 5.1 & $(0.4)$ & 60.8 & $(0.7)$ & 29.6 & $(0.7)$ & 4.5 & $(0.3)$ & 4.2 & $(0.3)$ & 15.8 & (0.6) & 58.1 & $(0.8)$ & 21.9 & $(0.6)$ \\
\hline & Malta & 16.4 & $(0.6)$ & 71.7 & $(0.7)$ & 9.7 & $(0.5)$ & 2.1 & $(0.3)$ & 3.5 & $(0.3)$ & 7.8 & $(0.4)$ & 37.4 & $(0.8)$ & 51.3 & $(0.9)$ \\
\hline & Moldova & 13.4 & $(0.5)$ & 71.0 & $(0.7)$ & 12.9 & $(0.5)$ & 2.7 & $(0.2)$ & 4.3 & $(0.3)$ & 7.2 & $(0.4)$ & 44.9 & (0.8) & 43.6 & $(0.8)$ \\
\hline & Montenegro & 14.8 & $(0.6)$ & 64.9 & $(0.7)$ & 15.4 & $(0.5)$ & 4.9 & $(0.3)$ & 7.2 & $(0.4)$ & 6.6 & $(0.3)$ & 42.6 & $(0.7)$ & 43.6 & $(0.7)$ \\
\hline & Peru & 12.8 & $(0.4)$ & 64.4 & $(0.7)$ & 18.6 & (0.6) & 4.1 & $(0.2)$ & 7.9 & $(0.4)$ & 9.6 & $(0.4)$ & 43.7 & $(0.7)$ & 38.8 & $(0.8)$ \\
\hline & Qatar & 23.5 & $(0.4)$ & 59.4 & $(0.4)$ & 11.3 & $(0.3)$ & 5.8 & $(0.2)$ & 8.5 & $(0.2)$ & 11.0 & $(0.3)$ & 37.1 & $(0.4)$ & 43.4 & $(0.5)$ \\
\hline & Romania & 19.3 & $(0.6)$ & 67.5 & (1.0) & 9.8 & $(0.6)$ & 3.4 & $(0.4)$ & 5.0 & $(0.5)$ & 9.1 & $(0.6)$ & 39.9 & $(0.8)$ & 46.0 & (1.1) \\
\hline & Russia & 8.3 & $(0.5)$ & 56.0 & $(0.7)$ & 30.0 & (0.8) & 5.8 & $(0.4)$ & 6.4 & $(0.5)$ & 14.5 & $(0.5)$ & 56.9 & $(0.7)$ & 22.2 & $(0.7)$ \\
\hline & Singapore & 10.4 & (0.4) & 70.8 & $(0.7)$ & 14.9 & $(0.5)$ & 4.0 & $(0.3)$ & 5.0 & $(0.3)$ & 12.9 & $(0.4)$ & 51.2 & $(0.7)$ & 30.9 & $(0.6)$ \\
\hline & Chinese Taipei & 8.9 & $(0.4)$ & 63.3 & $(0.5)$ & 24.6 & $(0.6)$ & 3.3 & $(0.2)$ & 3.6 & $(0.2)$ & 8.7 & $(0.4)$ & 48.8 & $(0.6)$ & 38.9 & $(0.5)$ \\
\hline & Thailand & 5.0 & $(0.3)$ & 56.6 & $(0.8)$ & 33.9 & (0.8) & 4.6 & $(0.3)$ & 5.0 & $(0.3)$ & 13.3 & (0.6) & 52.6 & (0.8) & 29.1 & $(0.8)$ \\
\hline & Trinidad and Tobago & 23.4 & $(0.7)$ & 62.0 & $(0.7)$ & 10.2 & $(0.4)$ & 4.5 & $(0.3)$ & 5.4 & $(0.4)$ & 8.9 & $(0.5)$ & 36.9 & $(0.8)$ & 48.9 & $(0.8)$ \\
\hline & Tunisia & 25.5 & $(0.7)$ & 54.9 & $(0.7)$ & 15.0 & $(0.5)$ & 4.7 & $(0.3)$ & 6.0 & $(0.4)$ & 8.9 & $(0.4)$ & 38.4 & $(0.7)$ & 46.6 & $(0.8)$ \\
\hline & United Arab Emirates & 20.7 & $(0.5)$ & 58.4 & $(0.6)$ & 14.3 & $(0.4)$ & 6.5 & $(0.3)$ & 6.6 & $(0.3)$ & 10.8 & $(0.3)$ & 37.0 & $(0.6)$ & 45.7 & $(0.6)$ \\
\hline & Uruguay & 27.9 & $(0.6)$ & 57.6 & $(0.7)$ & 7.4 & $(0.3)$ & 7.1 & $(0.4)$ & 10.3 & $(0.4)$ & 10.3 & $(0.4)$ & 39.4 & $(0.7)$ & 40.0 & $(0.8)$ \\
\hline & Viet Nam & 4.3 & $(0.4)$ & 38.3 & $(0.9)$ & 46.9 & $(0.8)$ & 10.5 & $(0.5)$ & 2.2 & $(0.3)$ & 5.3 & $(0.4)$ & 42.5 & $(0.7)$ & 50.0 & $(0.9)$ \\
\hline & Argentina** & 24.0 & $(0.7)$ & 63.3 & $(0.8)$ & 9.9 & $(0.5)$ & 2.8 & $(0.3)$ & 4.0 & $(0.3)$ & 4.7 & $(0.3)$ & 33.6 & $(0.8)$ & 57.8 & $(0.9)$ \\
\hline & Kazakhstan** & 16.4 & $(0.7)$ & 70.7 & $(0.7)$ & 10.0 & $(0.4)$ & 2.9 & $(0.3)$ & 2.9 & $(0.2)$ & 4.2 & $(0.3)$ & 35.5 & $(0.8)$ & 57.4 & $(0.9)$ \\
\hline & Malaysia** & 9.0 & $(0.5)$ & 67.7 & $(0.6)$ & 20.5 & $(0.6)$ & 2.8 & $(0.3)$ & 3.7 & $(0.2)$ & 13.2 & $(0.6)$ & 48.4 & $(0.8)$ & 34.7 & $(0.9)$ \\
\hline
\end{tabular}

* See note at the beginning of this Annex.

** Coverage is too small to ensure comparability (see Annex A4).

StatLink न्ना st http://dx.doi.org/10.1787/888933471259 
Percentage of students who reported "agree" or "strongly agree" (a) or who reported "disagree" or "strongly disagree" (d)

\begin{tabular}{|c|c|c|c|c|c|c|c|c|c|c|c|c|c|c|c|c|c|c|c|c|c|}
\hline & & Perc & entage & of bo & ys whe & o agree & $\mathrm{ed} / \mathrm{disa}$ & agreed & with th & he foll & owing & staten & nents & Perc & centage & e of gir & fls whe & agree & ed/disa & agreed & with \\
\hline & & $\begin{array}{l}\text { I fee } \\
\text { an ou } \\
\text { (or le } \\
\text { of th } \\
\text { at sc }\end{array}$ & $\begin{array}{l}\text { like } \\
\text { tssider } \\
\text { ft out } \\
\text { ings) } \\
\text { hooold }^{\text {d }}\end{array}$ & $\begin{array}{r}I \mathrm{~m} \\
\text { frie } \\
\text { ea } \\
\text { at sc }\end{array}$ & $\begin{array}{l}\text { lake } \\
\text { ends } \\
\text { sily } \\
\text { hool }^{\text {a }}\end{array}$ & $\begin{array}{l}\text { I fee } \\
\text { I be } \\
\text { at sc }\end{array}$ & $\begin{array}{l}\text { like } \\
\text { long } \\
\text { hoola }\end{array}$ & $\begin{array}{c}\text { If } \\
\text { awk } \\
\text { and } \\
\text { pla } \\
\text { my s }\end{array}$ & $\begin{array}{l}\text { feel } \\
\text { ward } \\
\text { out of } \\
\text { ce in } \\
\text { choold }\end{array}$ & $\begin{array}{r}\text { Ott } \\
\text { stud } \\
\text { see } \\
\text { to lik } \\
\end{array}$ & $\begin{array}{l}\text { her } \\
\text { lents } \\
\text { em } \\
\text { e } \mathrm{me}^{\mathrm{a}}\end{array}$ & & $\begin{array}{l}\text { eel } \\
\text { nely } \\
\text { hoold }\end{array}$ & & $\begin{array}{l}\text { like } \\
\text { sider } \\
\text { tout } \\
\text { ngs) } \\
\text { oold } \\
\end{array}$ & & $\begin{array}{l}\text { lake } \\
\text { ends } \\
\text { sily } \\
\text { hool }\end{array}$ & $\begin{array}{l}\text { I be } \\
\text { at sc }\end{array}$ & $\begin{array}{l}\text { el like } \\
\text { elong } \\
\text { choola }\end{array}$ & $\begin{array}{l}\text { If } \mathrm{f} \\
\text { awk } \\
\text { and o } \\
\text { plac } \\
\text { my sc }\end{array}$ & $\begin{array}{l}\text { eel } \\
\text { ward } \\
\text { out of } \\
\text { ce in } \\
\text { choold }\end{array}$ \\
\hline & & $\%$ & S.E. & $\%$ & S.E. & $\%$ & S.E. & $\%$ & S.E. & $\%$ & S.E. & $\%$ & S.E. & $\%$ & S.E. & $\%$ & S.E. & $\%$ & S.E. & $\%$ & S.E. \\
\hline & Australia & \begin{tabular}{|l|l|}
80.3 \\
\end{tabular} & $(0.4)$ & \begin{tabular}{|l|}
81.6 \\
\end{tabular} & $(0.6)$ & 74.0 & $(0.7)$ & \begin{tabular}{|l|l|}
81.1 \\
\end{tabular} & (0.5) & 87.5 & (0.5) & \begin{tabular}{|l|l|}
86.7 \\
\end{tabular} & $(0.4)$ & 72.7 & (0.6) & 77.1 & $(0.7)$ & 69.8 & $(0.7)$ & 75.1 & $(0.6)$ \\
\hline & Austria & 85.5 & $(0.6)$ & 77.5 & $(0.8)$ & 74.4 & $(0.7)$ & 81.5 & (0.8) & 82.6 & (0.6) & 83.7 & $(0.8)$ & 86.7 & (0.6) & 78.3 & $(0.8)$ & 77.6 & $(0.8)$ & 84.0 & $(0.6)$ \\
\hline & Belgium & 87.6 & $(0.6)$ & 83.7 & (0.6) & 60.8 & $(0.8)$ & 84.3 & $(0.7)$ & 89.0 & $(0.6)$ & 91.8 & $(0.5)$ & 86.7 & $(0.6)$ & 79.9 & (0.6) & 63.3 & $(0.9)$ & 84.1 & $(0.6)$ \\
\hline & Canada & 79.7 & (0.6) & 80.0 & $(0.6)$ & 73.0 & $(0.6)$ & 78.4 & $(0.6)$ & 87.1 & $(0.4)$ & 84.3 & (0.5) & 75.3 & (0.6) & 76.7 & $(0.6)$ & 70.2 & $(0.7)$ & 74.3 & $(0.7)$ \\
\hline & Chile & 79.0 & (0.9) & 75.6 & $(0.8)$ & 76.8 & $(0.8)$ & 78.5 & $(0.8)$ & 78.5 & (0.9) & 83.1 & $(0.8)$ & 80.8 & $(0.8)$ & 70.7 & (1.0) & 77.7 & $(0.9)$ & 81.6 & $(0.8)$ \\
\hline & Czech Republic & 77.2 & $(0.8)$ & 76.4 & (0.9) & 69.7 & $(0.9)$ & 81.3 & $(0.7)$ & 81.3 & $(0.8)$ & 82.7 & $(0.7)$ & 82.4 & $(0.7)$ & 74.1 & (0.9) & 72.2 & $(1.2)$ & 81.2 & $(0.7)$ \\
\hline & Denmark & 87.8 & $(0.7)$ & 82.2 & $(0.7)$ & 71.2 & $(0.9)$ & 85.8 & (0.8) & 85.4 & $(0.8)$ & 88.4 & $(0.6)$ & 87.4 & $(0.7)$ & 76.3 & (0.9) & 69.4 & $(0.9)$ & 83.9 & $(0.7)$ \\
\hline & Estonia & 87.2 & $(0.7)$ & 79.0 & $(0.8)$ & 77.5 & $(0.8)$ & 84.1 & $(0.8)$ & 77.0 & (0.9) & 87.8 & $(0.7)$ & 87.1 & (0.6) & 72.9 & (1.0) & 78.5 & $(0.8)$ & 82.7 & $(0.8)$ \\
\hline & Finland & $\mid 89.8$ & (0.6) & 84.3 & $(0.6)$ & 82.2 & $(0.8)$ & 84.1 & $(0.7)$ & 86.0 & (0.6) & 91.2 & $(0.6)$ & 85.4 & $(0.6)$ & 75.1 & $(0.9)$ & 78.3 & $(0.9)$ & 81.1 & $(0.8)$ \\
\hline & France & 74.5 & $(0.8)$ & 88.1 & $(0.7)$ & 37.7 & (1.2) & 83.9 & $(0.7)$ & 90.1 & (0.6) & 91.6 & $(0.5)$ & 79.0 & $(0.8)$ & 84.6 & (0.6) & 44.0 & (1.0) & 83.6 & $(0.7)$ \\
\hline & Germany & 85.8 & $(0.7)$ & 75.1 & (1.0) & 75.7 & $(0.9)$ & 82.6 & $(0.8)$ & 84.2 & (0.9) & 87.8 & $(0.7)$ & 85.2 & $(0.8)$ & 71.5 & $(0.8)$ & 74.0 & (0.9) & 82.2 & $(0.8)$ \\
\hline & Greece & 83.2 & $(0.7)$ & 81.9 & $(0.7)$ & 83.1 & $(0.7)$ & 84.0 & (0.7) & 87.0 & $(0.7)$ & 88.4 & $(0.7)$ & 85.7 & (0.7) & 78.4 & (0.9) & 82.9 & (0.6) & 85.0 & (0.6) \\
\hline & Hungary & 82.1 & $(0.8)$ & 81.8 & $(0.8)$ & 75.6 & $(0.9)$ & 82.5 & (0.8) & 83.1 & $(0.7)$ & 85.5 & $(0.7)$ & 82.2 & (0.9) & 80.3 & $(0.8)$ & 73.5 & (1.1) & 82.5 & (0.9) \\
\hline & Iceland & 80.5 & (0.9) & 76.5 & $(0.9)$ & 78.0 & (1.0) & 80.0 & (1.0) & 82.3 & (0.9) & 83.2 & $(0.8)$ & 85.1 & $(0.8)$ & 75.8 & (1.0) & 79.0 & $(0.9)$ & 81.0 & $(0.9)$ \\
\hline & Ireland & 85.3 & $(0.8)$ & 84.2 & $(0.7)$ & 73.5 & (1.0) & 85.4 & $(0.8)$ & 91.3 & (0.6) & 90.7 & $(0.7)$ & 81.2 & $(0.8)$ & 77.9 & $(0.8)$ & 73.1 & (1.0) & 79.9 & $(0.8)$ \\
\hline & Israel & $\mathrm{m}$ & $\mathrm{m}$ & $\mathrm{m}$ & $\mathrm{m}$ & $\mathrm{m}$ & $\mathrm{m}$ & $\mathrm{m}$ & $\mathrm{m}$ & $\mathrm{m}$ & $\mathrm{m}$ & $\mathrm{m}$ & $\mathrm{m}$ & $\mathrm{m}$ & $\mathrm{m}$ & $\mathrm{m}$ & $\mathrm{m}$ & $\mathrm{m}$ & $\mathrm{m}$ & $\mathrm{m}$ & $\mathrm{m}$ \\
\hline & Italy & 89.0 & (0.6) & $\mid 85.1$ & $(0.6)$ & 63.6 & $(0.8)$ & 84.7 & $(0.7)$ & 78.6 & $(0.7)$ & 89.6 & $(0.6)$ & 88.8 & (0.6) & 81.0 & $(0.7)$ & 70.9 & (1.1) & 87.8 & $(0.7)$ \\
\hline & Japan & 86.9 & $(0.7)$ & 69.3 & $(0.8)$ & 80.4 & $(0.8)$ & 79.9 & (0.9) & 72.1 & (0.9) & 89.3 & $(0.6)$ & 89.2 & $(0.5)$ & 68.2 & (1.0) & 83.3 & $(0.7)$ & 81.2 & (0.9) \\
\hline & Korea & 92.5 & $(0.5)$ & 81.2 & $(0.7)$ & 76.4 & $(1.2)$ & 89.8 & (0.6) & 81.5 & $(0.8)$ & 93.2 & $(0.5)$ & 90.1 & $(0.6)$ & 77.1 & $(0.9)$ & 82.9 & $(0.9)$ & 90.0 & (0.6) \\
\hline & Latvia & 83.5 & $(0.8)$ & 77.1 & (1.0) & 79.5 & (1.0) & 75.0 & (0.9) & 68.3 & (1.0) & 82.3 & $(0.9)$ & 84.9 & $(0.7)$ & 74.2 & $(1.0)$ & 77.7 & $(0.8)$ & 76.1 & $(0.9)$ \\
\hline & Luxembourg & 82.5 & $(0.7)$ & 77.1 & $(0.8)$ & 65.2 & $(0.9)$ & 79.3 & $(0.9)$ & 80.8 & $(0.7)$ & 84.8 & $(0.6)$ & 83.8 & $(0.7)$ & 74.6 & $(0.8)$ & 66.8 & $(0.8)$ & 80.6 & $(0.8)$ \\
\hline & Mexico & 72.4 & (0.9) & 71.9 & $(0.8)$ & 73.6 & $(0.9)$ & 73.3 & (0.9) & 72.0 & (1.0) & 76.5 & $(0.8)$ & 78.0 & (0.8) & 73.5 & $(0.8)$ & 78.7 & $(0.8)$ & 79.0 & $(0.8)$ \\
\hline & Netherland & 90.4 & (0.6) & 85.7 & $(0.7)$ & 77.5 & (1.0) & 87.5 & $(0.8)$ & 91.6 & (0.6) & 92.5 & $(0.6)$ & 91.6 & (0.6) & 84.6 & (0.8) & 84.2 & $(0.7)$ & 90.0 & $(0.7)$ \\
\hline & New Zealand & 79.9 & $(0.9)$ & 81.5 & (1.0) & 75.7 & (1.0) & 80.4 & $(0.9)$ & 89.0 & (0.6) & 86.4 & $(0.8)$ & 75.5 & (1.0) & 76.4 & $(0.9)$ & 71.7 & (1.0) & 75.4 & (0.9) \\
\hline & Norway & 88.4 & $(0.7)$ & 83.2 & $(0.8)$ & 76.3 & $(0.9)$ & 83.3 & $(0.8)$ & 83.6 & $(0.7)$ & 87.5 & $(0.8)$ & 87.4 & (0.6) & 76.7 & $(0.7)$ & 75.2 & $(0.9)$ & 81.8 & $(0.8)$ \\
\hline & Poland & 78.2 & $(0.9)$ & 73.6 & $(0.9)$ & 59.9 & (1.0) & 76.0 & $(0.8)$ & 74.1 & $(0.8)$ & 79.9 & $(0.9)$ & 78.9 & (1.0) & 73.4 & (1.0) & 65.0 & (1.0) & 78.0 & $(0.9)$ \\
\hline & Portugal & 87.4 & $(0.7)$ & 81.7 & $(0.8)$ & 81.4 & $(0.8)$ & 75.2 & $(0.8)$ & 87.4 & $(0.7)$ & 89.5 & $(0.7)$ & 86.8 & $(0.6)$ & 73.8 & (1.0) & 83.1 & $(0.7)$ & 76.4 & $(0.9)$ \\
\hline & Slovak Republic & 74.2 & $(0.9)$ & 76.6 & $(0.7)$ & 68.0 & (1.1) & 75.1 & $(0.8)$ & 76.7 & $(0.8)$ & 79.5 & $(0.9)$ & 80.5 & $(0.8)$ & 77.3 & $(0.8)$ & 71.5 & (0.9) & 80.0 & $(0.8)$ \\
\hline & Slovenia & 81.4 & $(0.9)$ & 78.0 & $(0.9)$ & 71.6 & (1.1) & 80.7 & (1.0) & 76.0 & $(0.9)$ & 84.1 & $(0.9)$ & 83.6 & $(0.8)$ & 75.7 & $(1.2)$ & 77.5 & (1.0) & 84.5 & $(0.8)$ \\
\hline & Spain & 88.6 & $(0.5)$ & 83.9 & $(0.7)$ & 85.7 & $(0.7)$ & 84.2 & $(0.7)$ & 85.8 & $(0.7)$ & 89.6 & $(0.6)$ & 91.2 & $(0.5)$ & 82.5 & $(0.7)$ & 88.8 & $(0.6)$ & 87.7 & $(0.6)$ \\
\hline & Sweden & 78.6 & $(0.8)$ & 76.2 & $(0.9)$ & 70.5 & $(1.0)$ & 79.2 & $(0.8)$ & 77.5 & $(0.9)$ & 81.2 & $(0.8)$ & 80.2 & $(0.8)$ & 73.6 & $(0.9)$ & 68.1 & (1.0) & 80.0 & $(0.8)$ \\
\hline & Switzerland & 89.1 & $(0.7)$ & 81.4 & $(0.8)$ & 69.9 & $(1.0)$ & 85.5 & $(0.7)$ & 87.2 & $(0.7)$ & 91.0 & $(0.5)$ & 87.5 & $(0.7)$ & 79.8 & $(0.9)$ & 71.8 & (1.0) & 84.7 & $(0.8)$ \\
\hline & Turkey & 59.5 & (1.2) & 59.0 & $(1.2)$ & 56.2 & (1.1) & 57.3 & (1.1) & 58.9 & $(1.2)$ & 61.3 & (1.1) & 69.1 & (1.0) & 65.5 & (1.1) & 66.5 & $(0.8)$ & 67.9 & (1.1) \\
\hline & United Kingdom & 83.2 & $(0.7)$ & 81.9 & $(0.8)$ & 68.4 & $(0.9)$ & 83.2 & (0.7) & 88.6 & $(0.6)$ & 89.8 & $(0.6)$ & 76.5 & $(0.9)$ & 75.4 & $(0.9)$ & 67.2 & (1.0) & 77.0 & $(0.7)$ \\
\hline & United States & 78.8 & $(0.8)$ & 81.3 & $(0.8)$ & 74.8 & $(0.9)$ & 79.8 & $(0.9)$ & 88.5 & $(0.7)$ & 84.3 & $(0.7)$ & 73.5 & $(0.9)$ & 75.9 & $(0.9)$ & 73.6 & $(0.9)$ & 74.1 & $(0.8)$ \\
\hline & OECD average & 82.7 & $(0.1)$ & 79.2 & $(0.1)$ & 72.3 & $(0.2)$ & 80.8 & $(0.1)$ & 82.1 & $(0.1)$ & 85.8 & $(0.1)$ & 82.9 & $(0.1)$ & $\mid 76.1$ & $(0.1)$ & 73.8 & $(0.2)$ & 81.0 & $(0.1)$ \\
\hline & Albania & 94.4 & \begin{tabular}{l|}
$(0.6)$ \\
\end{tabular} & 90.1 & $(0.7)$ & 93.2 & $(0.7)$ & 89.1 & $(0.7)$ & 83.0 & (0.9) & 94.8 & $(0.5)$ & 94.6 & (0.6) & 90.4 & $(0.8)$ & 93.0 & $(0.5)$ & 89.2 & \begin{tabular}{l|}
$(0.8)$ \\
\end{tabular} \\
\hline & Algeria & 69.9 & (1.3) & 87.1 & $(0.6)$ & 87.0 & $(0.8)$ & 64.4 & (1.2) & 82.6 & $(0.8)$ & 70.5 & $(1.2)$ & 75.0 & $(1.2)$ & 85.6 & $(0.9)$ & 87.8 & $(0.8)$ & 66.8 & (1.1) \\
\hline & Brazil & 76.9 & (0.6) & 76.0 & $(0.6)$ & 76.4 & $(0.7)$ & 80.1 & (0.6) & 80.0 & $(0.6)$ & 77.5 & $(0.7)$ & 81.3 & (0.5) & 72.0 & $(0.7)$ & 75.8 & $(0.6)$ & 83.5 & (0.5) \\
\hline & B-S-J-G (China) & 76.7 & $(0.7)$ & 79.1 & $(0.7)$ & 64.3 & (1.1) & 77.1 & (0.7) & 59.1 & $(0.9)$ & 78.5 & $(0.8)$ & 79.6 & $(0.7)$ & 77.2 & $(0.8)$ & 65.0 & (1.0) & 84.6 & $(0.8)$ \\
\hline & Bulgaria & 66.5 & (1.1) & 73.2 & $(0.8)$ & 65.0 & $(0.8)$ & 68.3 & (1.1) & 69.7 & $(0.8)$ & 71.9 & (1.0) & 74.4 & (1.0) & 76.8 & $(0.9)$ & 71.3 & $(0.9)$ & 75.9 & $(0.9)$ \\
\hline & CABA (Arge & 89.4 & (0.9) & 91.4 & $(1.2)$ & 88.1 & (1.6) & 92.6 & (1.2) & 93.9 & (1.1) & 95.1 & $(0.7)$ & 85.9 & (1.3) & 87.5 & (1.4) & 89.2 & (1.2) & 92.3 & (1.0) \\
\hline & Colombia & 68.1 & (1.0) & 69.4 & $(0.8)$ & 70.6 & (1.0) & 69.5 & $(1.0)$ & 68.5 & $(0.9)$ & 71.9 & $(0.8)$ & 73.7 & $(0.8)$ & 71.0 & (0.9) & 77.5 & $(0.8)$ & 75.9 & $(0.7)$ \\
\hline & Costa Rica & 71.1 & $(0.8)$ & 71.1 & (1.0) & 71.6 & $(0.9)$ & 72.1 & $(0.9)$ & 71.7 & (1.0) & 74.9 & $(0.8)$ & 75.3 & $(0.8)$ & 72.2 & (1.0) & 77.7 & $(0.8)$ & 77.2 & $(0.8)$ \\
\hline & Croatia & 83.7 & $(0.7)$ & 84.3 & $(0.7)$ & 81.9 & $(0.8)$ & 82.8 & $(0.8)$ & 80.7 & $(0.8)$ & 85.9 & $(0.7)$ & 88.1 & (0.6) & 83.4 & $(0.8)$ & 80.6 & $(0.9)$ & 86.9 & $(0.5)$ \\
\hline & Cyprus* & 80.1 & $(0.8)$ & 81.2 & $(0.7)$ & 78.1 & $(0.8)$ & 79.4 & $(0.7)$ & 83.6 & $(0.7)$ & 84.2 & $(0.7)$ & 85.5 & (0.7) & 79.9 & $(0.8)$ & 82.3 & $(0.7)$ & 86.9 & $(0.7)$ \\
\hline & Dominican Republic & 56.8 & (1.2) & 64.0 & (1.3) & 64.4 & $(1.2)$ & 61.8 & (1.2) & 63.9 & (1.1) & 66.0 & (1.1) & 63.7 & (1.0) & 68.0 & (1.1) & 69.2 & (1.0) & 68.2 & (1.0) \\
\hline & FYROM & 85.1 & $(0.7)$ & 93.4 & $(0.5)$ & 90.6 & $(0.7)$ & 86.0 & $(0.7)$ & 86.1 & $(0.7)$ & 91.3 & $(0.5)$ & 90.9 & $(0.5)$ & 93.5 & $(0.5)$ & 93.8 & $(0.5)$ & 91.7 & $(0.6)$ \\
\hline & Georgia & 2 & $(0.6)$ & 93.8 & $(0.6)$ & 62.3 & (1.1) & 93.4 & $(0.5)$ & 77.3 & (1.0) & 94.6 & $(0.5)$ & 96.1 & $(0.4)$ & 94.8 & $(0.4)$ & 67.6 & (0.9) & 95.2 & $(0.4)$ \\
\hline & Hong Kong (China) & 72.3 & (1.0) & 80.5 & $(0.9)$ & 68.4 & (1.1) & 76.1 & (1.1) & 75.2 & $(0.7)$ & 79.5 & $(1.0)$ & 78.4 & (1.0) & 81.6 & $(0.9)$ & 73.9 & (1.2) & 82.0 & $(0.9)$ \\
\hline & Indonesia & 96.6 & $(0.4)$ & 96.9 & $(0.4)$ & 91.8 & $(0.7)$ & 82.9 & $(0.9)$ & 84.6 & (0.9) & 94.6 & $(0.5)$ & 96.0 & $(0.4)$ & 96.0 & $(0.3)$ & 92.8 & $(0.5)$ & 85.2 & $(0.8)$ \\
\hline & Jordan & 2.6 & (1.1) & 89.7 & $(0.6)$ & 84.5 & $(0.7)$ & 70.7 & (1.0) & 87.4 & (0.9) & 82.8 & $(0.9)$ & 80.8 & (1.0) & 92.0 & $(0.7)$ & 87.3 & (1.0) & 80.5 & $(0.8)$ \\
\hline & Kosovo & 5.1 & (1.0) & 93.0 & $(0.6)$ & 92.6 & $(0.6)$ & 83.0 & $(0.8)$ & 86.3 & $(0.8)$ & 92.7 & $(0.6)$ & 88.6 & $(0.8)$ & 89.9 & $(0.7)$ & 92.5 & $(0.7)$ & 87.9 & $(0.9)$ \\
\hline & Lebanon & 72.0 & (2.0) & 90.1 & $(0.9)$ & 74.4 & (1.4) & 73.6 & (1.4) & 78.9 & (1.4) & 83.3 & $(1.2)$ & 77.3 & (1.4) & 89.4 & $(0.8)$ & 75.5 & (1.4) & 77.0 & (1.3) \\
\hline & Lithuania & 67.3 & $(0.9)$ & 63.6 & (1.0) & 51.7 & (1.1) & 64.2 & (1.0) & 60.3 & (1.1) & 67.9 & $(0.9)$ & 71.2 & (1.0) & 65.3 & (1.1) & 57.3 & (1.1) & 68.1 & (1.0) \\
\hline & Maca & 7.8 & (0.9) & 78.8 & $(0.8)$ & 60.2 & (1.1) & 75.9 & $(0 \mathrm{c}$ & 64.2 & (1.2) & 80.9 & $(1.0)$ & 80. & (0.9) & 73.4 & $(0.9)$ & 59.7 & (1.0) & 79.5 & (0.9) \\
\hline & Malta & 81.4 & (1.0) & 85.3 & $(0.8)$ & 68.2 & (1.1) & 83.4 & (1.0) & 88.4 & $(0.7)$ & 91.0 & $(0.8)$ & 77.7 & (0.9) & 78.5 & (1.1) & 71.5 & (1.2) & 81.1 & (1.1) \\
\hline & Moldova & 90.7 & $(0.7)$ & 91.0 & $(0.7)$ & 67.0 & (1.1) & 88.2 & $(0.7)$ & 84.7 & (0.6) & 88.3 & $(0.7)$ & 91.5 & $(0.6)$ & 90.2 & (0.6) & 68.4 & (1.1) & 90.3 & (0.6) \\
\hline & Monteneg & 803 & $(0.7)$ & 82.7 & $(0.7)$ & 52.7 & (1.0) & 79.0 & (0.8) & 79.3 & (0.8) & 83.8 & $(0.6)$ & 85.2 & (0.6) & 84.0 & $(0.7)$ & 54.9 & (1.0) & 86.1 & $(0.7)$ \\
\hline & Peru & 77.2 & (1.0) & 75.8 & (0.9) & 69.1 & (0.9) & 73.8 & (1.0) & 76.6 & (0.9) & 80.3 & $(0.9)$ & 81.7 & $(0.8)$ & 76.0 & $(0.8)$ & 73.7 & $(0.8)$ & 78.3 & $(0.8)$ \\
\hline & Qatar & 71.6 & (0.6) & 77.8 & $(0.5)$ & 69.3 & $(0.7)$ & 72.0 & $(0.6)$ & 78.5 & (0.6) & 76.8 & (0.5) & 79.4 & (0.5) & 77.7 & $(0.5)$ & 72.0 & $(0.6)$ & 79.9 & $(0.5)$ \\
\hline & Romania & 87.3 & (1.1) & 93.1 & $(0.7)$ & 51.3 & (1.3) & 83.2 & $(0.9)$ & 87.1 & (0.9) & 85.6 & $(1.2)$ & 88.3 & (1.2) & 91.7 & $(0.6)$ & 53.7 & (1.3) & 85.6 & (1.0) \\
\hline & Russia & 0.3 & $(0.8)$ & 75.5 & (1.1) & 75.3 & $(0.8)$ & 72.7 & (0.8) & 65.2 & (1.1) & 79.4 & $(0.9)$ & 80.5 & (1.2) & 70.8 & (1.3) & 74.0 & (1.0) & 73.0 & $(1.2)$ \\
\hline & Singapore & 6.4 & $(0.8)$ & 82.2 & $(0.9)$ & 74.9 & $(0.8)$ & 76.5 & $(0.7)$ & 80.4 & $(0.7)$ & 82.0 & $(0.7)$ & 76.5 & (0.9) & 78.1 & $(0.7)$ & 77.0 & $(0.8)$ & 76.6 & (0.9) \\
\hline & Chinese Tai & 87.2 & $(0.5)$ & 85.0 & $(0.6)$ & 88.3 & $(0.5)$ & 81.3 & $(0.8)$ & 71.7 & $(0.8)$ & 87.3 & $(0.6)$ & 90.2 & $(0.5)$ & 85.2 & $(0.6)$ & 91.5 & $(0.4)$ & 84.8 & $(0.6)$ \\
\hline & Thailand & 75.5 & $(1.0)$ & 79.2 & $(0.8)$ & 72.7 & $(0.9)$ & 62.5 & (1.1) & 58.3 & (1.4) & 76.9 & (1.0) & 83.0 & $(0.8)$ & 85.0 & $(0.7)$ & 82.7 & $(0.8)$ & 71.4 & $(1.2)$ \\
\hline & Trinidad and Tobago & 80.9 & $(0.8)$ & 87.9 & $(0.8)$ & 80.5 & $(0.9)$ & 80.4 & (1.0) & 85.9 & $(0.7)$ & 86.3 & $(0.8)$ & 82.9 & $(0.8)$ & 84.1 & $(0.9)$ & 79.0 & $(0.8)$ & 83.7 & $(0.8)$ \\
\hline & Tunisia & 76.2 & (1.2) & 85.5 & $(0.8)$ & 56.0 & (1.1) & 61.0 & (1.1) & 79.9 & $(0.8)$ & 84.4 & $(0.8)$ & 83.5 & $(0.7)$ & 81.7 & $(0.8)$ & 58.9 & (1.0) & 64.7 & (1.0) \\
\hline & United A & 76.5 & (0.9) & 81.0 & $(0.7)$ & 73.9 & $(0.8)$ & 71.6 & $(0.9)$ & 78.2 & $(0.7)$ & 80.4 & $(0.6)$ & 80.9 & $(0.6)$ & 78.6 & $(0.8)$ & 73.8 & $(0.9)$ & 78.7 & $(0.7)$ \\
\hline & Uruguay & 73.7 & $(0.9)$ & 74.4 & $(0.8)$ & 76.5 & $(0.8)$ & 76.8 & $(0.9)$ & 81.6 & $(0.8)$ & 77.6 & $(1.0)$ & 78.4 & $(0.8)$ & 71.9 & $(0.9)$ & 79.1 & $(0.7)$ & 81.4 & $(0.8)$ \\
\hline & Viet Nam & 95.2 & $(0.6)$ & 93.2 & $(0.5)$ & 81.1 & (1.0) & 80.8 & $(0.7)$ & 46.7 & (1.3) & 92.9 & $(0.7)$ & 95.5 & $(0.5)$ & 90.1 & (0.8) & 80.4 & $(0.9)$ & 84.5 & $(0.8)$ \\
\hline & Argentina* & $\mid 75.4$ & $(1.2)$ & 91.2 & $(0.7)$ & 88.1 & $(0.9)$ & 88.3 & $(0.8)$ & 90.3 & $(0.7)$ & 91.3 & $(0.7)$ & 75.4 & (1.2) & 86.9 & $(0.8)$ & 90.8 & $(0.8)$ & 89.0 & $(0.7)$ \\
\hline & Kaz & 92.8 & $(0.6)$ & 91.8 & $(0.8)$ & 82.8 & $(0.8)$ & 91.1 & (0.6) & 86.2 & (0.8) & 92.2 & $(0.5)$ & 95.6 & (0.4) & 92.3 & (0.6) & 87.3 & $(0.7)$ & 94.3 & (0.6) \\
\hline & Malaysia** & 82.1 & (1.0) & 87.3 & $(0.8)$ & 75.5 & (0.9) & 80.3 & (1.1) & 76.2 & (1.0) & 81.5 & (1.0) & 85.3 & $(0.8)$ & 87.7 & (0.6) & 78.6 & (0.9) & 84.9 & $(0.8)$ \\
\hline
\end{tabular}

1. A socio-economically disadvantaged student is a student in the bottom quarter of the PISA index of economic, social and cultural status (ESCS) within his or her own country/economy. 2. A socio-economically advantaged student is a student in the top quarter of the PISA index of economic, social and cultural status (ESCS) within his or her own country/economy. Note: Values that are statistically significant are indicated in bold (see Annex A3).

* See note at the beginning of this Annex.

** Coverage is too small to ensure comparability (see Annex A4).

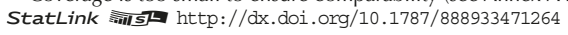


[Part 2/4]

Table III.7.2 Students' sense of belonging, by gender and socio-economic status

Percentage of students who reported "agree" or "strongly agree" (a) or who reported "disagree" or "strongly disagree" (d)

\begin{tabular}{|c|c|c|c|c|c|c|c|c|c|c|c|c|c|}
\hline & \multicolumn{12}{|c|}{ Gender difference in the percentage of students who agreed/disagreed with the following statements (B - G) } \\
\hline & & \multicolumn{2}{|c|}{$\begin{array}{c}\text { I feel like an outsider } \\
\text { (or left out of things) } \\
\text { at schoold }\end{array}$} & \multicolumn{2}{|c|}{$\begin{array}{c}\text { I make friends easily } \\
\text { at school }{ }^{\text {a }}\end{array}$} & $\begin{array}{r}\text { I feel I } \\
\text { at }\end{array}$ & $\begin{array}{l}\text { belong } \\
\text { ol }^{\mathbf{a}}\end{array}$ & $\begin{array}{l}\text { I feel } \\
\text { and o } \\
\text { in } \mathrm{m}\end{array}$ & $\begin{array}{l}\text { ward } \\
\text { place } \\
\text { ooold }\end{array}$ & $\begin{array}{c}\text { Other s } \\
\text { to }\end{array}$ & $\begin{array}{l}\text { nts seem } \\
\text { me }^{\mathrm{a}}\end{array}$ & $\begin{array}{l}\text { I fe } \\
\text { at }\end{array}$ & $\begin{array}{l}\text { nely } \\
\text { old }\end{array}$ \\
\hline & & $\%$ dif. & S.E. & $\%$ dif. & S.E. & $\%$ dif. & S.E. & $\%$ dif. & S.E. & $\%$ dif. & S.E. & $\%$ dif. & S.E. \\
\hline 0 & Australia & 7.7 & $(0.7)$ & 4.6 & $(0.9)$ & 4.3 & $(1.0)$ & 6.0 & $(0.7)$ & -0.1 & $(0.7)$ & 6.3 & $(0.7)$ \\
\hline & Austria & -1.3 & $(0.8)$ & -0.8 & $(1.1)$ & -3.3 & $(1.0)$ & -2.6 & $(0.9)$ & -2.3 & $(0.9)$ & -1.7 & $(1.0)$ \\
\hline 5 & Belgium & 0.9 & $(0.8)$ & 3.7 & $(0.9)$ & -2.5 & $(1.3)$ & 0.2 & $(0.9)$ & 1.6 & $(0.7)$ & 2.6 & $(0.7)$ \\
\hline & Canada & 4.3 & $(0.9)$ & 3.4 & $(0.7)$ & 2.8 & $(1.0)$ & 4.1 & $(1.0)$ & -0.4 & $(0.6)$ & 5.4 & $(0.8)$ \\
\hline & Chile & -1.8 & $(1.2)$ & 5.0 & $(1.3)$ & -0.9 & $(1.1)$ & -3.1 & $(1.2)$ & 5.0 & $(1.2)$ & 0.0 & $(1.1)$ \\
\hline & Czech Republic & -5.2 & $(1.0)$ & 2.3 & $(1.2)$ & -2.5 & (1.5) & 0.1 & $(0.9)$ & 0.0 & $(1.3)$ & 1.5 & $(1.0)$ \\
\hline & Denmark & 0.4 & $(1.0)$ & 5.9 & $(1.2)$ & 1.9 & $(1.4)$ & 1.9 & $(1.1)$ & 0.0 & $(0.9)$ & 2.5 & $(0.9)$ \\
\hline & Estonia & 0.1 & $(0.9)$ & 6.0 & $(1.2)$ & -1.0 & $(1.1)$ & 1.3 & $(1.1)$ & 1.1 & (1.3) & 5.1 & $(1.0)$ \\
\hline & Finland & 4.4 & $(0.9)$ & 9.2 & (1.1) & 3.9 & $(1.1)$ & 3.0 & $(1.0)$ & 8.2 & $(0.9)$ & 6.1 & $(0.9)$ \\
\hline & France & -4.5 & (1.1) & 3.5 & $(0.9)$ & -6.3 & (1.6) & 0.3 & $(1.0)$ & 0.8 & $(0.9)$ & 2.0 & $(0.7)$ \\
\hline & Germany & 0.6 & $(0.9)$ & 3.5 & $(1.2)$ & 1.7 & $(1.2)$ & 0.4 & $(1.0)$ & -1.6 & $(1.0)$ & 0.8 & $(0.9)$ \\
\hline & Greece & -2.5 & (1.0) & 3.5 & $(1.2)$ & 0.2 & $(0.9)$ & -1.0 & $(0.9)$ & -0.9 & $(0.9)$ & 0.7 & $(0.9)$ \\
\hline & Hungary & 0.0 & $(1.2)$ & 1.4 & (1.1) & 2.1 & $(1.3)$ & 0.0 & $(1.2)$ & 0.8 & (1.1) & 0.0 & (1.1) \\
\hline & Iceland & -4.6 & $(1.3)$ & 0.7 & (1.4) & -1.0 & $(1.3)$ & -0.9 & (1.3) & -1.1 & $(1.3)$ & -1.0 & $(1.2)$ \\
\hline & Ireland & 4.1 & (1.0) & 6.3 & $(1.0)$ & 0.4 & $(1.2)$ & 5.5 & (1.0) & 1.5 & $(0.9)$ & 5.9 & $(0.9)$ \\
\hline & Israel & $\mathrm{m}$ & $\mathrm{m}$ & $\mathrm{m}$ & $\mathrm{m}$ & $\mathrm{m}$ & $\mathrm{m}$ & $\mathrm{m}$ & $\mathrm{m}$ & $\mathrm{m}$ & $\mathrm{m}$ & $\mathrm{m}$ & $\mathrm{m}$ \\
\hline & Italy & 0.2 & $(0.9)$ & 4.1 & $(1.0)$ & -7.3 & $(1.4)$ & -3.1 & $(0.9)$ & 3.9 & $(1.0)$ & 0.3 & $(0.9)$ \\
\hline & Japan & -2.3 & $(0.9)$ & 1.1 & $(1.1)$ & -2.9 & $(1.0)$ & -1.3 & (1.3) & -3.4 & $(1.4)$ & 1.5 & $(0.8)$ \\
\hline & Korea & 2.4 & $(0.7)$ & 4.1 & $(1.1)$ & -6.5 & (1.4) & -0.2 & $(0.8)$ & -1.0 & $(1.0)$ & 3.1 & $(0.7)$ \\
\hline & Latvia & -1.4 & $(1.1)$ & 2.9 & (1.5) & 1.8 & (1.4) & -1.0 & (1.4) & 0.3 & (1.4) & -1.0 & $(1.2)$ \\
\hline & Luxembourg & -1.4 & $(1.1)$ & 2.5 & (1.1) & -1.6 & $(1.2)$ & -1.3 & $(1.2)$ & -1.0 & (1.1) & -0.6 & $(1.0)$ \\
\hline & Mexico & -5.6 & $(1.2)$ & -1.5 & $(1.2)$ & -5.1 & $(1.0)$ & -5.7 & $(1.1)$ & -0.1 & (1.1) & -5.7 & $(1.0)$ \\
\hline & Netherlands & -1.1 & $(0.8)$ & 1.1 & (1.1) & -6.7 & $(1.2)$ & -2.5 & $(0.9)$ & -0.6 & $(0.8)$ & 0.2 & $(0.8)$ \\
\hline & New Zealand & 4.5 & (1.4) & 5.0 & (1.4) & 4.0 & (1.5) & 5.0 & $(1.2)$ & 1.4 & $(1.0)$ & 6.5 & $(1.1)$ \\
\hline & Norway & 1.0 & $(0.8)$ & 6.5 & (1.1) & 1.1 & $(1.1)$ & 1.5 & (1.0) & 1.2 & $(1.0)$ & 3.8 & (1.1) \\
\hline & Poland & -0.6 & $(1.3)$ & 0.2 & (1.3) & -5.1 & $(1.3)$ & -2.0 & $(1.1)$ & 1.7 & $(1.2)$ & 0.3 & $(1.2)$ \\
\hline & Portugal & 0.6 & (1.0) & 7.9 & $(1.3)$ & -1.7 & $(1.2)$ & -1.1 & (1.3) & -0.4 & $(0.9)$ & 1.2 & $(0.9)$ \\
\hline & Slovak Republic & -6.4 & $(1.2)$ & -0.7 & $(1.2)$ & -3.5 & (1.4) & -4.9 & $(1.2)$ & -0.2 & (1.1) & -2.3 & $(1.2)$ \\
\hline & Slovenia & -2.2 & $(1.3)$ & 2.3 & $(1.4)$ & -5.9 & (1.4) & -3.8 & (1.4) & -5.1 & $(1.1)$ & -2.7 & $(1.2)$ \\
\hline & Spain & -2.7 & $(0.7)$ & 1.4 & $(1.0)$ & -3.1 & $(0.8)$ & -3.5 & $(0.8)$ & -0.3 & $(0.9)$ & -2.2 & $(0.7)$ \\
\hline & Sweden & -1.6 & $(1.2)$ & 2.6 & $(1.3)$ & 2.4 & (1.4) & -0.8 & (1.3) & -1.9 & $(1.2)$ & 0.4 & (1.1) \\
\hline & Switzerland & 1.6 & $(0.9)$ & 1.6 & $(1.2)$ & -1.8 & (1.4) & 0.8 & $(0.9)$ & -0.6 & $(1.0)$ & 1.7 & $(0.8)$ \\
\hline & Turkey & -9.6 & $(1.3)$ & -6.4 & $(1.7)$ & -10.3 & (1.4) & -10.6 & (1.5) & -9.5 & $(1.5)$ & -7.4 & (1.6) \\
\hline & United Kingdom & 6.7 & (1.1) & 6.5 & $(1.3)$ & 1.2 & $(1.3)$ & 6.2 & $(0.9)$ & 1.9 & $(0.9)$ & 6.9 & $(0.9)$ \\
\hline & United States & 5.3 & $(1.2)$ & 5.3 & $(1.3)$ & 1.3 & $(1.1)$ & 5.7 & $(1.2)$ & -0.3 & $(1.0)$ & 5.0 & (1.1) \\
\hline & OECD average & -0.3 & $(0.2)$ & 3.1 & $(0.2)$ & -1.5 & $(0.2)$ & -0.2 & $(0.2)$ & 0.0 & $(0.2)$ & 1.3 & $(0.2)$ \\
\hline 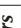 & Albania & -0.2 & $(0.7)$ & -0.3 & $(1.0)$ & 0.2 & $(0.8)$ & -0.1 & $(0.9)$ & 0.8 & $(1.3)$ & -0.4 & $(0.7)$ \\
\hline § & Algeria & -5.0 & (1.6) & 1.5 & $(1.3)$ & -0.8 & $(1.1)$ & -2.4 & (1.5) & -0.6 & (1.3) & -1.8 & (1.5) \\
\hline ไँ & Brazil & -4.4 & $(0.8)$ & 3.9 & $(0.8)$ & 0.6 & $(0.8)$ & -3.3 & $(0.8)$ & -2.0 & $(0.8)$ & -5.0 & $(0.9)$ \\
\hline & B-S-J-G (China) & -2.9 & $(1.0)$ & 1.9 & $(1.2)$ & -0.7 & $(1.5)$ & -7.5 & $(1.0)$ & -1.2 & $(1.3)$ & 0.0 & $(1.2)$ \\
\hline & Bulgaria & -7.9 & (1.4) & -3.6 & $(1.2)$ & -6.3 & $(1.2)$ & -7.6 & $(1.1)$ & -4.5 & $(1.1)$ & -6.6 & $(1.2)$ \\
\hline & CABA (Argentina) & 3.5 & $(1.2)$ & 3.9 & $(1.6)$ & -1.1 & $(1.8)$ & 0.3 & (1.8) & 4.2 & (1.4) & 2.4 & $(1.1)$ \\
\hline & Colombia & -5.6 & $(1.3)$ & -1.7 & $(1.2)$ & -6.8 & $(1.3)$ & -6.4 & (1.1) & -0.5 & $(1.3)$ & -5.5 & $(0.9)$ \\
\hline & Costa Rica & -4.3 & $(1.0)$ & -1.0 & (1.4) & -6.1 & $(1.1)$ & -5.1 & $(1.1)$ & -1.0 & (1.4) & -4.8 & (1.1) \\
\hline & Croatia & -4.3 & $(0.9)$ & 0.9 & $(1.1)$ & 1.3 & $(1.2)$ & -4.1 & $(0.9)$ & -1.8 & $(1.2)$ & -3.3 & $(1.0)$ \\
\hline & Cyprus* & -5.5 & $(1.1)$ & 1.3 & (1.1) & -4.1 & $(1.1)$ & -7.5 & $(0.9)$ & -3.4 & $(1.1)$ & -4.4 & $(1.0)$ \\
\hline & Dominican Republic & -6.9 & (1.5) & -4.0 & $(1.7)$ & -4.7 & $(1.6)$ & -6.4 & (1.5) & -4.4 & (1.6) & -6.1 & (1.4) \\
\hline & FYROM & -5.7 & $(0.9)$ & -0.1 & $(0.7)$ & -3.1 & $(0.8)$ & -5.7 & (1.0) & -0.8 & $(1.1)$ & -2.3 & $(0.8)$ \\
\hline & Georgia & -1.8 & $(0.6)$ & -1.1 & $(0.7)$ & -5.3 & $(1.2)$ & -1.8 & $(0.6)$ & 3.4 & (1.4) & -0.8 & $(0.6)$ \\
\hline & Hong Kong (China) & -6.1 & $(1.3)$ & -1.1 & $(1.2)$ & -5.5 & (1.4) & -6.0 & (1.6) & -5.3 & $(1.3)$ & -2.2 & $(1.2)$ \\
\hline & Indonesia & 0.6 & $(0.5)$ & 0.9 & $(0.5)$ & -1.0 & $(0.8)$ & -2.3 & $(1.0)$ & 0.4 & $(1.2)$ & 1.2 & $(0.7)$ \\
\hline & Jordan & -8.2 & (1.5) & -2.3 & $(0.9)$ & -2.8 & $(1.3)$ & -9.8 & $(1.2)$ & -6.8 & $(1.0)$ & -8.1 & $(1.0)$ \\
\hline & Kosovo & -3.4 & (1.3) & 3.0 & $(0.9)$ & 0.1 & $(1.0)$ & -4.9 & $(1.2)$ & 1.7 & (1.3) & -0.2 & $(0.9)$ \\
\hline & Lebanon & -5.3 & (1.6) & 0.7 & $(1.2)$ & -1.1 & (1.5) & -3.5 & (1.6) & 2.4 & $(1.5)$ & -2.7 & (1.1) \\
\hline & Lithuania & -3.8 & $(1.4)$ & -1.7 & $(1.5)$ & -5.6 & $(1.3)$ & -3.9 & $(1.2)$ & -4.6 & $(1.4)$ & -2.2 & $(1.2)$ \\
\hline & Macao (China) & -3.0 & (1.1) & 5.4 & $(1.2)$ & 0.5 & $(1.3)$ & -3.7 & (1.3) & -3.5 & (1.5) & 1.8 & (1.5) \\
\hline & Malta & 3.7 & $(1.3)$ & 6.8 & (1.3) & -3.3 & $(1.7)$ & 2.3 & (1.5) & 0.5 & (1.1) & 4.6 & $(1.2)$ \\
\hline & Moldova & -0.9 & $(0.8)$ & 0.8 & $(0.8)$ & -1.4 & $(1.2)$ & -2.1 & $(0.9)$ & 0.7 & $(1.0)$ & -0.4 & $(0.9)$ \\
\hline & Montenegro & -4.9 & $(0.9)$ & -1.4 & $(1.0)$ & -2.3 & $(1.2)$ & -7.1 & (1.1) & -0.9 & (1.1) & -5.0 & $(0.9)$ \\
\hline & Peru & -4.4 & (1.1) & -0.2 & $(1.0)$ & -4.6 & $(1.3)$ & -4.5 & (1.2) & -1.3 & $(1.0)$ & -4.4 & (1.2) \\
\hline & Qatar & -7.8 & $(0.8)$ & 0.1 & $(0.7)$ & -2.7 & $(1.0)$ & -7.9 & $(0.9)$ & -8.6 & $(0.7)$ & -7.2 & $(0.7)$ \\
\hline & Romania & -1.0 & $(1.0)$ & 1.4 & $(0.7)$ & -2.3 & (1.5) & -2.4 & $(1.0)$ & 0.5 & $(1.0)$ & -0.7 & $(1.0)$ \\
\hline & Russia & -0.2 & (1.5) & 4.7 & (1.9) & 1.3 & (1.4) & -0.3 & (1.8) & 1.7 & (1.7) & 0.6 & (1.5) \\
\hline & Singapore & -0.1 & $(1.2)$ & 4.1 & (1.1) & -2.1 & $(1.0)$ & 0.0 & $(1.0)$ & -1.7 & $(1.0)$ & -0.3 & $(1.0)$ \\
\hline & Chinese Taipei & -3.1 & $(0.9)$ & -0.2 & $(0.9)$ & -3.2 & $(0.8)$ & -3.5 & (1.0) & -0.9 & (1.1) & -0.8 & (1.0) \\
\hline & Thailand & -7.5 & $(1.1)$ & -5.7 & $(1.2)$ & -10.0 & $(1.2)$ & -8.9 & (1.5) & -5.7 & (1.6) & -8.2 & (1.1) \\
\hline & Trinidad and Tobago & -2.0 & (1.1) & 3.8 & $(1.1)$ & 1.4 & $(1.3)$ & -3.3 & (1.3) & 1.0 & $(1.1)$ & 1.0 & $(1.0)$ \\
\hline & Tunisia & -7.2 & $(1.2)$ & 3.7 & $(1.1)$ & -2.9 & (1.6) & -3.7 & (1.4) & -0.7 & (1.3) & -1.2 & $(1.0)$ \\
\hline & United Arab Emirates & -4.4 & $(1.2)$ & 2.4 & $(1.1)$ & 0.1 & $(1.2)$ & -7.1 & $(1.2)$ & -1.8 & $(0.9)$ & -4.4 & $(0.8)$ \\
\hline & Uruguay & -4.7 & (1.3) & 2.5 & $(1.2)$ & -2.7 & $(1.0)$ & -4.6 & $(1.2)$ & -7.5 & $(1.1)$ & -3.4 & (1.3) \\
\hline & Viet Nam & -0.3 & $(0.7)$ & 3.1 & $(0.9)$ & 0.7 & $(1.2)$ & -3.7 & (1.0) & 8.0 & (1.6) & 0.7 & $(0.8)$ \\
\hline & Argentina** & 0.1 & $(1.3)$ & 4.3 & $(1.1)$ & -2.7 & $(1.3)$ & -0.7 & $(1.1)$ & 5.8 & $(1.0)$ & 0.0 & $(0.9)$ \\
\hline & Kazakhstan** & -2.8 & $(0.6)$ & -0.5 & $(1.0)$ & -4.5 & $(1.1)$ & -3.2 & $(0.9)$ & -1.8 & (1.1) & -1.6 & $(0.7)$ \\
\hline & Malaysia** & -3.2 & $(1.0)$ & -0.4 & $(0.8)$ & -3.1 & $(1.0)$ & -4.6 & $(1.2)$ & -1.0 & $(1.2)$ & -3.1 & $(1.2)$ \\
\hline
\end{tabular}

1. A socio-economically disadvantaged student is a student in the bottom quarter of the PISA index of economic, social and cultural status (ESCS) within his or her own country/economy. 2. A socio-economically advantaged student is a student in the top quarter of the PISA index of economic, social and cultural status (ESCS) within his or her own country/economy. Note: Values that are statistically significant are indicated in bold (see Annex A3).

** See note at the beginning of this Annex.

Coverage is too small to ensure comparability (see Annex A4). 
Percentage of students who reported "agree" or "strongly agree" (a) or who reported "disagree" or "strongly disagree" (d)

\begin{tabular}{|c|c|c|c|c|c|c|c|c|c|c|c|c|c|c|c|c|c|c|c|c|c|}
\hline & & & & & $\begin{array}{l}\text { of } s \\
\text { ed }\end{array}$ & ci & nor & ical & $\begin{array}{l}\text { adva } \\
\text { lowi }\end{array}$ & an & $d^{1} s$ & dents & & & & $\mathrm{ce}$ & se of & 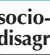 & con & mic & d \\
\hline & & $\begin{array}{l}\text { I fee } \\
\text { an ou } \\
\text { (or le } \\
\text { of th } \\
\text { at sc }\end{array}$ & $\begin{array}{l}\text { l like } \\
\text { utsider } \\
\text { eft out } \\
\text { ings) } \\
\text { hoold }\end{array}$ & $\begin{array}{r}1 \mathrm{~m} \\
\text { frie } \\
\text { ea } \\
\text { at sc }\end{array}$ & $\begin{array}{l}\text { lake } \\
\text { ends } \\
\text { sily } \\
\text { hoola }\end{array}$ & & $\begin{array}{l}\text { like } \\
\text { long } \\
\text { hoola }\end{array}$ & $\begin{array}{l}\text { If } \\
\text { awk } \\
\text { and } \\
\text { pla } \\
\text { my s }\end{array}$ & $\begin{array}{l}\text { eel } \\
\text { ward } \\
\text { put of } \\
\text { ce in } \\
\text { choold }\end{array}$ & $\begin{array}{r}\text { Ot } \\
\text { stud } \\
\text { see } \\
\text { to lik }\end{array}$ & $\begin{array}{l}\text { her } \\
\text { lents } \\
\text { em } \\
\text { e me }\end{array}$ & & $\begin{array}{l}\text { feel } \\
\text { nely } \\
\text { hool }^{\text {d }}\end{array}$ & $\begin{array}{l}\text { I fee } \\
\text { an ot } \\
\text { (or I } \\
\text { of th } \\
\text { at sc }\end{array}$ & $\begin{array}{l}\text { I like } \\
\text { tsider } \\
\text { ft out } \\
\text { ings) } \\
\text { hoold }\end{array}$ & & $\begin{array}{l}\text { ake } \\
\text { nds } \\
\text { ily } \\
\text { hool }\end{array}$ & & $\begin{array}{l}\text { el like } \\
\text { elong } \\
\text { choola }\end{array}$ & $\begin{array}{r}\text { If } \\
\text { awk } \\
\text { and o } \\
\text { plac } \\
\text { my sc }\end{array}$ & $\begin{array}{l}\text { eel } \\
\text { ward } \\
\text { out of } \\
\text { ce in } \\
\text { choold }\end{array}$ \\
\hline & & $\%$ & S.E. & $\%$ & S.E. & $\%$ & S.E. & $\%$ & S.E. & $\%$ & S.E. & $\%$ & S.E. & $\%$ & S.E. & $\%$ & S.E. & $\%$ & S.E. & $\%$ & S.E. \\
\hline & Australia & 71.8 & $(0.9)$ & 74.3 & $(0.9)$ & 65.1 & $(1.0)$ & 73.2 & $(1.0)$ & 83.2 & $(0.7)$ & 80.7 & $(0.8)$ & 80.5 & $(0.7)$ & 82.1 & $(0.7)$ & 78.2 & $(0.9)$ & 81.6 & $(0.8)$ \\
\hline & Austria & 84.5 & $(1.0)$ & 74.8 & (1.1) & 71.9 & (1.3) & 81.1 & (1.1) & 81.0 & (1.0) & 83.1 & $(1.0)$ & 86.9 & (0.9) & 79.8 & (1.0) & 79.4 & $+(1.1)$ & 84.3 & $(0.9)$ \\
\hline & Belgium & 84.3 & $(1.2)$ & 78.7 & $(1.2)$ & 56.2 & $(1.2)$ & 81.1 & $(1.0)$ & 85.4 & (1.0) & 87.9 & $(0.9)$ & 89.1 & $(0.8)$ & 84.1 & (0.8) & 69.3 & (1.0) & 86.5 & $(0.8)$ \\
\hline & Canada & 73.2 & $(0.9)$ & 74.2 & $(1.0)$ & 64.7 & (1.0) & 72.3 & $(0.8)$ & 83.0 & $(0.8)$ & 78.7 & $(0.8)$ & 81.9 & $(0.8)$ & 81.4 & (0.9) & 79.7 & $(0.9)$ & 81.2 & $(0.8)$ \\
\hline & Chile & 76.3 & (1.6) & 73.8 & (1.6) & 74.6 & (1.5) & 77.6 & (1.4) & 70.0 & (1.4) & 80.1 & (1.3) & 83.4 & (1.0) & 72.9 & (1.4) & 78.4 & (1.1) & 82.1 & $(0.8)$ \\
\hline & Czech Republic & 76.4 & $(1.3)$ & 74.1 & (1.4) & 64.9 & (1.5) & 77.4 & (1.1) & 77.5 & (1.3) & 79.7 & $(1.2)$ & 83.5 & (1.0) & 76.3 & (1.3) & 75.1 & (1.3) & 86.1 & (1.0) \\
\hline & Denmark & 85.0 & (1.0) & 74.1 & (1.4) & 63.8 & (1.4) & 82.0 & (1.1) & 83.9 & (1.3) & 84.6 & $(0.9)$ & 88.4 & (1.1) & 81.7 & (1.2) & 77.5 & (1.2) & 87.3 & (1.1) \\
\hline & Estonia & 85.3 & $(1.0)$ & 74.2 & (1.7) & 73.1 & (1.6) & 81.5 & (1.3) & 71.5 & (1.4) & 85.2 & $(1.0)$ & 90.0 & (0.8) & 79.2 & (1.1) & 82.4 & (1.3) & 86.1 & (0.9) \\
\hline & Finland & 86.2 & (1.1) & 79.0 & (1.3) & 77.9 & (1.1) & 79.8 & (1.1) & 80.1 & (1.3) & 87.6 & (0.9) & 90.3 & (0.7) & 82.9 & (0.9) & 85.1 & (1.0) & 86.0 & (1.0) \\
\hline & France & 70.9 & (1.3) & 84.0 & (1.1) & 36.0 & (1.5) & 80.1 & (1.0) & 86.0 & (1.1) & 89.3 & $(0.8)$ & 84.0 & (1.1) & 89.1 & $(0.8)$ & 48.9 & (1.6) & 87.7 & (1.1) \\
\hline & Germany & 84.7 & $(1.0)$ & 72.1 & (1.1) & 71.6 & (1.5) & 79.7 & (1.4) & 82.6 & (1.0) & 85.7 & $(0.9)$ & 87.6 & $(0.9)$ & 76.3 & (1.1) & 77.3 & (1.3) & 85.9 & (1.0) \\
\hline & Greece & 83.2 & $(1.0)$ & 78.5 & (1.3) & 81.2 & (1.2) & 82.1 & (1.1) & 85.4 & (1.2) & 87.7 & (1.1) & 86.7 & (0.9) & 82.5 & (1.1) & 84.1 & $(1.2)$ & 87.4 & $(0.8)$ \\
\hline & Hungary & 79.5 & (1.1) & 80.5 & (1.4) & 70.8 & (1.5) & 79.4 & (1.4) & 80.1 & (1.4) & 83.8 & (1.1) & 85.5 & (1.1) & 81.5 & (1.1) & 79.3 & $(1.1)$ & 86.3 & (1.0) \\
\hline & Iceland & \begin{tabular}{|l|}
81.7 \\
\end{tabular} & (1.3) & 72.4 & (1.6) & 74.9 & (1.6) & 79.1 & (1.5) & 80.9 & (1.5) & 82.4 & (1.5) & 83.1 & (1.4) & 80.3 & (1.6) & 82.2 & (1.5) & 79.9 & (1.4) \\
\hline & Ireland & 82.4 & $(0.9)$ & 80.2 & $(1.2)$ & 69.4 & (1.4) & 81.4 & (0.9) & 89.7 & $(0.7)$ & 87.6 & $(0.9)$ & 83.6 & (1.0) & 82.3 & $(0.9)$ & 77.6 & (1.3) & 84.3 & $(1.2)$ \\
\hline & Israel & $\mathrm{m}$ & & $\mathrm{m}$ & $\mathrm{m}$ & $\mathrm{m}$ & $\mathrm{m}$ & $\mathrm{m}$ & $\mathrm{m}$ & $\mathrm{m}$ & $\mathrm{m}$ & $\mathrm{m}$ & $\mathrm{m}$ & $\mathrm{m}$ & $\mathrm{m}$ & $\mathrm{m}$ & $\mathrm{m}$ & $\mathrm{m}$ & $\mathrm{m}$ & $\mathrm{m}$ & $\mathrm{m}$ \\
\hline & Italy & 88.5 & $(0.7)$ & 82.2 & (1.1) & 64.3 & (1.3) & 83.8 & (1.0) & 70.7 & (1.5) & 88.9 & $(1.0)$ & 89.2 & $(0.9)$ & 82.9 & (0.9) & 68.5 & (1.3) & 87.5 & $(0.8)$ \\
\hline & Japan & 86.1 & $(0.8)$ & 66.8 & (1.3) & 78.4 & (1.1) & 78.7 & (1.1) & 69.3 & (1.3) & 86.9 & $(1.0)$ & 89.3 & $(0.9)$ & 71.9 & (1.2) & 84.5 & (1.0) & 81.0 & (1.0) \\
\hline & Korea & 88.4 & (1.0) & 74.4 & (1.3) & 72.8 & (1.5) & 86.4 & (0.9) & 76.2 & (1.3) & 90.0 & $(0.9)$ & 91.8 & (0.7) & 82.8 & (1.1) & 85.6 & (1.1) & 92.4 & $(0.8)$ \\
\hline & Latvia & 83.7 & (1.1) & 74.9 & (1.4) & 77.0 & (1.4) & 74.1 & (1.3) & 64.4 & (1.6) & 81.3 & $(1.4)$ & 84.8 & (1.1) & 76.4 & (1.2) & 80.2 & (1.2) & 77.1 & (1.5) \\
\hline & Luxembourg & 80.1 & (1.1) & 74.4 & (1.2) & 57.2 & (1.2) & 74.4 & (1.2) & 75.5 & (1.2) & 83.1 & $(1.0)$ & 87.7 & (1.0) & 78.3 & (1.2) & 74.7 & $(1.2)$ & 85.5 & (1.1) \\
\hline & Mexico & 72.5 & (1.3) & 71.4 & (1.4) & 74.9 & (1.4) & 73.7 & (1.3) & 67.7 & (1.2) & 78.5 & (1.1) & 77.6 & (1.3) & 74.3 & (1.1) & 76.5 & (1.5) & 77.0 & (1.3) \\
\hline & Netherlanc & 90.9 & $(0.7)$ & 84.9 & (1.0) & 78.2 & $(1.2)$ & 87.4 & (0.9) & 90.1 & $(0.8)$ & 92.0 & $(0.6)$ & 91.5 & (0.7) & 86.5 & $(0.9)$ & 83.5 & (1.0) & 90.6 & $(0.7)$ \\
\hline & New Zealand & 74.8 & (1.4) & 75.3 & (1.3) & 65.9 & (1.7) & 76.5 & (1.4) & 85.2 & (1.2) & 81.4 & (1.5) & 80.7 & (1.0) & 83.4 & $(1.0)$ & 78.9 & (1.3) & 80.8 & $(1.2)$ \\
\hline & Norway & 85.5 & (1.2) & 75.7 & (1.4) & 70.6 & (1.7) & 79.2 & (1.4) & 79.4 & (1.4) & 83.0 & (1.2) & 88.8 & $(0.9)$ & 82.9 & (1.0) & 79.3 & (1.2) & 85.0 & $(1.2)$ \\
\hline & Poland & 78.9 & (1.4) & 75.3 & (1.4) & 58.3 & (1.5) & 76.7 & $(1.2)$ & 74.8 & (1.3) & 80.0 & $(1.2)$ & 78.9 & (1.3) & 70.9 & (1.4) & 65.5 & (1.5) & 77.0 & (1.2) \\
\hline & Portugal & 86.1 & (1.1) & 74.9 & (1.2) & 81.1 & (1.1) & 72.2 & (1.3) & 86.5 & $(0.8)$ & 88.4 & $(0.9)$ & 89.8 & (1.0) & 80.4 & (1.3) & 82.8 & (1.1) & 78.9 & (1.2) \\
\hline & Slovak Republic & 72.7 & (1.3) & 76.4 & (1.1) & 65.7 & (1.3) & 73.2 & (1.4) & 73.3 & (1.3) & 77.6 & (1.2) & 81.4 & (1.1) & 76.5 & $(1.0)$ & 73.3 & (1.3) & 79.8 & (1.0) \\
\hline & Slovenia & 81.2 & (1.1) & 78.4 & (1.3) & 73.4 & (1.4) & 82.6 & (1.1) & 77.4 & $(1.2)$ & 86.1 & $(1.0)$ & 83.5 & (1.2) & 74.7 & (1.9) & 74.2 & (1.6) & 83.3 & $(1.2)$ \\
\hline & Spain & 89.7 & $(0.8)$ & 83.5 & (1.1) & 86.3 & (1.1) & 85.5 & (1.0) & 84.8 & (1.1) & 90.9 & $(0.7)$ & 90.9 & $(0.7)$ & 83.9 & (1.1) & 88.4 & $(0.8)$ & 87.6 & $(0.8)$ \\
\hline & Sweden & 78.2 & (1.3) & 71.2 & (1.4) & 65.5 & (1.5) & 76.5 & (1.1) & 74.5 & (1.3) & 78.7 & (1.1) & 80.4 & (0.9) & 76.3 & (1.1) & 73.8 & (1.4) & 80.8 & $(0.9)$ \\
\hline & Switzerland & 84.3 & (1.1) & 78.7 & (1.3) & 68.3 & (1.6) & 82.6 & $(1.2)$ & 85.4 & (1.1) & 88.0 & $(0.9)$ & 90.0 & $(0.8)$ & 81.1 & $(1.2)$ & 72.4 & (1.7) & 87.4 & $(1.0)$ \\
\hline & Turkey & 61.8 & (1.5) & 59.4 & (1.5) & 61.3 & (1.5) & 59.3 & (1.7) & 61.4 & (1.4) & 62.2 & (1.6) & 68.2 & (1.3) & 65.7 & (1.4) & 62.9 & (1.2) & 65.5 & (1.5) \\
\hline & United Kingdom & 74.5 & $(1.3)$ & 74.0 & $(1.2)$ & 63.6 & (1.3) & 76.1 & (1.1) & 83.7 & (1.1) & 84.7 & $(0.9)$ & 82.6 & (1.0) & 80.3 & (1.2) & 72.9 & (1.0) & 82.6 & (1.0) \\
\hline & United States & 72.6 & (1.3) & 73.2 & (1.3) & 71.1 & (1.3) & 74.4 & (1.4) & 84.9 & (1.0) & 80.9 & (1.1) & 80.3 & (1.3) & 83.6 & (1.1) & 79.4 & (1.3) & 82.9 & $(1.2)$ \\
\hline & OECD average & 80.5 & $(0.2)$ & 75.6 & $(0.2)$ & 69.1 & $(0.2)$ & 78.3 & $(0.2)$ & 79.0 & $(0.2)$ & 83.7 & $(0.2)$ & 85.1 & $(0.2)$ & 79.6 & $(0.2)$ & 76.8 & $(0.2)$ & 83.4 & $(0.2)$ \\
\hline & Albania & 4.9 & $(0.8)$ & \begin{tabular}{|l|}
88.7 \\
\end{tabular} & (1.1) & 93.7 & $(0.8)$ & 89.1 & (1.1) & 79.4 & (1.6) & 94.3 & $(1.0)$ & 93.8 & $(0.8)$ & 91.4 & $(0.9)$ & 91. & $(1.2)$ & 89.4 & \begin{tabular}{l|}
$(1.1)$ \\
\end{tabular} \\
\hline & Algeria & 73.5 & $(1.7)$ & 85.2 & (1.1) & 86.1 & $(1.1)$ & 64.5 & (1.5) & 77.8 & (1.2) & 69.0 & (1.7) & 75.6 & (1.4) & 86.0 & (1.3) & 85.7 & (1.2) & 71.0 & (1.5) \\
\hline & Brazil & 77.3 & $(0.8)$ & 73.0 & $(0.7)$ & 73.0 & $(0.9)$ & 80.0 & $(0.7)$ & 79.0 & (0.8) & 78.8 & $(0.9)$ & 81.0 & $(0.8)$ & 74.4 & (1.0) & 79.9 & $(0.8)$ & 83.4 & $(0.7)$ \\
\hline & B-S-J-G (China) & 73.4 & $(1.3)$ & 72.3 & (1.3) & 63.8 & (1.4) & 77.1 & (1.2) & 47.7 & (1.4) & 74.7 & (1.4) & 81.3 & (1.0) & 83.0 & (1.3) & 65.9 & $(1.6)$ & 83.4 & (1.1) \\
\hline & Bulgaria & 64.0 & (1.6) & 74.7 & (1.3) & 68.7 & (1.4) & 67.0 & (1.5) & 71.1 & (1.4) & 71.6 & (1.3) & 75.6 & (1.2) & 73.4 & (1.3) & 67.7 & $(1.2)$ & 75.1 & (1.2) \\
\hline & CABA (Argentina) & 79.5 & (1.7) & 86.2 & $(2.2)$ & 88.2 & (1.5) & 91.2 & (1.8) & 85.2 & (2.0) & 91.7 & (1.4) & 90.8 & (1.7) & 90.7 & (1.5) & 91.8 & (1.9) & 93.1 & (1.5) \\
\hline & Colombia & 70.2 & (1.1) & 70.3 & $(1.2)$ & 75.3 & (1.4) & 71.2 & $(1.2)$ & 65.9 & (1.3) & 74.4 & $(1.0)$ & 74.4 & (0.9) & 72.7 & (1.0) & 74.7 & (1.2) & 75.5 & (1.1) \\
\hline & Costa Rica & 72.1 & $(1.2)$ & 69.8 & (1.5) & 73.9 & (1.4) & 72.7 & (1.4) & 69.9 & (1.5) & 77.0 & (1.2) & 75.2 & (1.2) & 73.0 & (1.6) & 75.5 & (1.4) & 75.8 & (1.1) \\
\hline & Croatia & 86.6 & $(1.0)$ & 86.2 & $(0.9)$ & 81.7 & (1.1) & 85.4 & $(0.9)$ & 80.3 & (1.1) & 88.6 & $(0.7)$ & 87.8 & $(0.9)$ & 82.6 & $(0.9)$ & 82.2 & $(1.2)$ & 86.3 & $(1.0)$ \\
\hline & Cyprus* & 83.1 & $(1.0)$ & 80.1 & $(1.0)$ & 81.0 & (1.0) & 83.9 & $(0.9)$ & 83.7 & (1.0) & 87.8 & $(0.8)$ & 80.9 & (1.3) & 80.4 & (1.1) & 77.9 & $(1.2)$ & 84.0 & (1.3) \\
\hline & Dominican Republic & 58.2 & (1.6) & 62.5 & (1.7) & 62.8 & (1.7) & 60.9 & (1.9) & 63.4 & (1.5) & 65.2 & (1.9) & 66.5 & (1.6) & 71.0 & (1.6) & 73.0 & $(1.5)$ & 70.2 & (1.7) \\
\hline & FYROM & 85.9 & (1.0) & 92.5 & $(0.8)$ & 92.7 & $(0.8)$ & 85.2 & (1.0) & 85.1 & (1.1) & 90.9 & (0.9) & 89.7 & (0.8) & 94.8 & (0.6) & 92.6 & $(0.8)$ & 90.5 & $(0.9)$ \\
\hline & Georgia & 94.6 & $(0.7)$ & 94.5 & $(0.6)$ & 71.2 & (1.6) & 94.4 & $(0.7)$ & 67.4 & (1.7) & 93.5 & $(0.8)$ & 96.3 & (0.6) & 94.5 & (0.7) & 60.7 & (1.6) & 94.9 & $(0.6)$ \\
\hline & Hong Kong & 70.2 & (1.7) & 77.2 & (1.4) & 66.6 & (1.7) & 76.7 & (1.4) & 73.2 & (1.6) & 76 & (1.4) & 80.5 & (1.1) & 82 & $(1.2)$ & 74.0 & (1.5) & 83.5 & $(1.2)$ \\
\hline & Indonesia & 95.7 & $(0.7)$ & 96.2 & $(0.5)$ & 91.3 & $(0.7)$ & 80.9 & (1.5) & 82.3 & (1.3) & 94.3 & $(0.7)$ & 96.5 & $(0.5)$ & 95.5 & $(0.6)$ & 93.0 & $(0.7)$ & 86.6 & (1.1) \\
\hline & Jordan & 8.9 & (1.6) & 87.1 & (1.1) & 84.7 & (1.3) & 70.5 & (1.4) & 86.8 & (1.1) & 82.2 & (1.1) & 83.3 & (1.1) & 92.2 & $(0.9)$ & 84.2 & (1.1) & 80.5 & (1.1) \\
\hline & Kosovo & 3.6 & (1.2) & 91.5 & $(0.9)$ & 92.4 & $(0.9)$ & 83.9 & (1.3) & 83.0 & (1.3) & 92.4 & $(0.9)$ & 91.1 & (1.0) & 91.4 & (1.1) & 92.1 & (0.9) & 89.8 & (1.0) \\
\hline & Lebanon & 75.3 & $(2.2)$ & 88.7 & (1.1) & 73.5 & $(2.2)$ & 72.8 & (2.3) & 74.7 & (2.3) & 82.8 & (2.0) & 78.8 & (2.5) & 90.5 & (1.0) & 76.6 & (1.9) & 80.4 & (1.7) \\
\hline & Lithuania & 65.7 & (1.3) & 61.6 & (1.3) & 47.7 & (1.3) & 64.7 & (1.4) & 58.3 & (1.3) & 68.4 & (1.4) & 73.1 & (1.4) & 68.5 & (1.5) & 61.3 & (1.7) & 70.0 & (1.3) \\
\hline & Macao (China) & 81.2 & (1.3) & 74.7 & (1.3) & 52.4 & (1.9) & 79.6 & $(1.2)$ & 59.2 & (1.5) & 79.1 & (1.3) & 75.5 & (1.4) & 76.8 & (1.4) & 67.3 & (1.4) & 74.5 & (1.3) \\
\hline & Malta & 77.6 & (1.5) & 80.1 & (1.3) & 66.5 & (1.7) & 81.2 & (1.3) & 86.6 & (1.2) & 87.6 & (1.1) & 82.1 & (1.3) & 82.3 & (1.3) & 72.9 & (1.5) & 84.3 & (1.2) \\
\hline & Moldova & 88.7 & (1.1) & 89.8 & (1.0) & 70.4 & (1.7) & 87.3 & (1.0) & 81.8 & (1.3) & 85.9 & (1.2) & 93.3 & $(0.8)$ & 90.4 & (1.1) & 61.9 & (1.7) & 90.2 & (0.9) \\
\hline & Montenegro & 4.1 & (1.1) & 83.6 & (1.0) & 56.2 & (1.4) & 84.3 & (1.0) & 77.8 & (1.0) & 87.7 & $(0.9)$ & 80.9 & (1.2) & 82.0 & (1.0) & 50.7 & (1.3) & 80.9 & (1.1) \\
\hline & Peru & 73.0 & (1.6) & 74.1 & (1.2) & 77.1 & (1.3) & 64.9 & (1.6) & 71.5 & (1.3) & 78.7 & (1.3) & 84.6 & (1.0) & 78.7 & (1.2) & 64.6 & $(1.2)$ & 83.5 & (1.1) \\
\hline & Qatar & 71.6 & $(0.9)$ & 74.6 & $(0.8)$ & 68.3 & $(1.0)$ & 72.4 & $(1.0)$ & 77.9 & $(0.8)$ & 75.9 & $(0.8)$ & 76.8 & $(0.7)$ & 80.5 & $(0.8)$ & 71.6 & $(0.8)$ & 76.7 & $(0.8)$ \\
\hline & Romania & 6.9 & (1.1) & 92.9 & $(0.9)$ & 55.9 & (1.8) & 83.5 & (1.1) & 85.8 & (1.1) & 85.2 & $(1.2)$ & 89.3 & (1.7) & 91.4 & (1.0) & 49.0 & $(2.0)$ & 87.2 & $(1.2)$ \\
\hline & Russia & 78.3 & (1.8) & 72.9 & (1.7) & 73.0 & (1.1) & 69.9 & (1.6) & 59.2 & (1.6) & 78.6 & (1.5) & 80.8 & (1.2) & 73.4 & (1.5) & 74.5 & $(1.1)$ & 75.4 & $(1.2)$ \\
\hline & Singapore & 70.7 & (1.1) & 77.2 & $(1.0)$ & 70.3 & $(1.2)$ & 71.4 & $(1.2)$ & 72.4 & (1.1) & 79.5 & (1.1) & 79.6 & (1.4) & 83.9 & $(1.1)$ & 80.7 & $(1.3)$ & 80.3 & (1.5) \\
\hline & Chinese Tai & 86.7 & $(0.9)$ & 84.2 & (1.0) & 88.2 & $(0.8)$ & 81.1 & (0.9) & 67.7 & (1.2) & 85.6 & $(0.9)$ & 90.0 & $(0.8)$ & 85.2 & $(0.9)$ & 90.3 & $(0.7)$ & 84.5 & (1.1) \\
\hline & Thailand & 80.0 & $(1.2)$ & $\mid 81.1$ & (1.1) & 77.5 & (1.3) & 68.0 & (1.5) & 56.5 & (1.4) & 80.5 & (1.4) & 81.5 & (1.2) & 84.6 & (1.1) & 79.9 & $(1.3)$ & 70.6 & (1.6) \\
\hline & Trinidad and T & 77.5 & (1.4) & 83.2 & (1.3) & 79.5 & (1.3) & 78.0 & (1.4) & 80.0 & (1.4) & 81.0 & (1.4) & 85.9 & (1.2) & 88.3 & (1.0) & 80.9 & (1.3) & 84.1 & $(1.2)$ \\
\hline & Tunisia & 79.7 & (1.3) & 82.5 & (1.3) & 56.6 & (1.4) & 59.4 & (1.6) & 77.1 & $(1.2)$ & 82.8 & (1.2) & 78.9 & (1.3) & 83.7 & (1.1) & 57.2 & (1.3) & 68.3 & (1.5) \\
\hline & United Arab Emirates & 77.3 & $(0.9)$ & 77.9 & $(0.9)$ & 74.3 & (1.0) & 72.0 & $(0.9)$ & 72.4 & (1.0) & 79.3 & $(0.7)$ & 79.7 & $(0.8)$ & 81.8 & $(0.9)$ & 73.9 & $(1.3)$ & 77.1 & (1.1) \\
\hline & Uruguay & 72.3 & $(1.2)$ & 71.1 & (1.4) & 74.8 & $(1.2)$ & 75.9 & (1.2) & 84.5 & (1.2) & 78.3 & $(1.2)$ & 81.3 & (1.1) & 76.2 & (1.4) & 80.6 & $(1.3)$ & 83.4 & $(1.2)$ \\
\hline & Viet Nam & 94.9 & (1.0) & 90.5 & (1.3) & 79.9 & (1.6) & 81.1 & (1.3) & 40.7 & (1.5) & 88.6 & (1.7) & 95.3 & $(0.7)$ & 91.8 & $(0.9)$ & 78.9 & (1.5) & 83.0 & (1.0) \\
\hline & $\mathrm{A}_{\mathbf{l}}$ & 64.7 & $(2.3$ & o & j & 87.1 & (I.1) & 00.0 & $(1 .)$. & (5). & (13) & 88.7 & $1 \mathrm{I}$ & & & & 10 & 90.7 & (U) & 92.1 & $(0.7)$ \\
\hline & Kazak & 3.6 & $(0.7)$ & 90.4 & (1.0) & 82.2 & (1.3) & 91.7 & $(0.8)$ & 84.2 & (1.1) & 92.7 & $(0.8)$ & 94.9 & $(0.7)$ & 93.2 & $(0.9)$ & 88.1 & $(0.9)$ & 94.1 & $(0.8)$ \\
\hline & Malaysia** & 83.6 & (1.3) & 87.3 & $(1.0)$ & 78.2 & (1.4) & 82.5 & (1.4) & 73.9 & (1.2) & 82.0 & (1.4) & 82.8 & (1.2) & 86.0 & $(1.0)$ & 73.4 & (1.5) & 81.6 & (1.3) \\
\hline
\end{tabular}

1. A socio-economically disadvantaged student is a student in the bottom quarter of the PISA index of economic, social and cultural status (ESCS) within his or her own country/economy. 2. A socio-economically advantaged student is a student in the top quarter of the PISA index of economic, social and cultural status (ESCS) within his or her own country/economy. Note: Values that are statistically significant are indicated in bold (see Annex A3).

* See note at the beginning of this Annex.

** Coverage is too small to ensure comparability (see Annex A4).

StatLink त्राजा http://dx.doi.org/10.1787/888933471264 
[Part 4/4]

Table III.7.2 Students' sense of belonging, by gender and socio-economic status

Percentage of students who reported "agree" or "strongly agree" (a) or who reported "disagree" or "strongly disagree" (d)

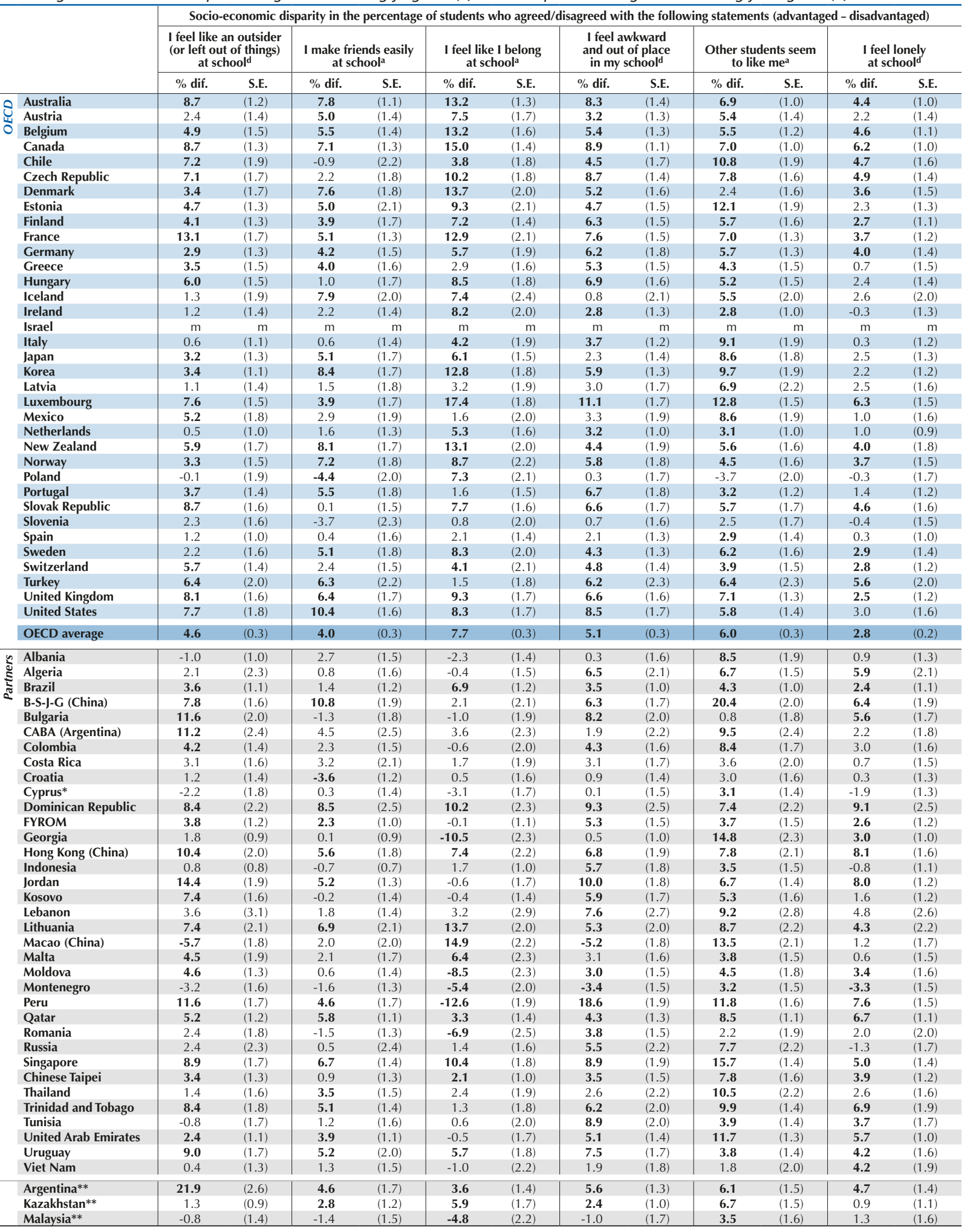

1. A socio-economically disadvantaged student is a student in the bottom quarter of the PISA index of economic, social and cultural status (ESCS) within his or her own country/economy. 2. A socio-economically advantaged student is a student in the top quarter of the PISA index of economic, social and cultural status (ESCS) within his or her own country/economy. Note: Values that are statistically significant are indicated in bold (see Annex A3).

** See note at the beginning of this Annex.

Coverage is too small to ensure comparability (see Annex A4).

StatLink 完正可 http://dx.doi.org/10.1787/888933471264 
Percentage of students who reported "agree" or "strongly agree" (a) or who reported "disagree" or "strongly disagree" (d)

\begin{tabular}{|c|c|c|c|c|c|c|c|c|c|c|c|c|c|c|c|c|c|c|c|c|c|}
\hline & & & Perce & entag & of nor & & rat & stud & & $\begin{array}{l}\text { agree } \\
\text { nts }\end{array}$ & d/disa & & & & cen & se of & st & & $\begin{array}{l}\text { nig } \\
\text { ou }\end{array}$ & $\begin{array}{l}\text { igran } \\
\text { wing }\end{array}$ & $\begin{array}{l}\text { stud } \\
\text { taten }\end{array}$ \\
\hline & & $\begin{array}{l}\text { I fee } \\
\text { an ou } \\
\text { (or le } \\
\text { of th } \\
\text { at sc }\end{array}$ & $\begin{array}{l}\text { like } \\
\text { tsider } \\
\text { ft out } \\
\text { ings) } \\
\text { hoold }^{d}\end{array}$ & $\begin{array}{r}I \mathrm{~m} \\
\text { frie } \\
\text { ea } \\
\text { at sc }\end{array}$ & $\begin{array}{l}\text { lake } \\
\text { ends } \\
\text { sily } \\
\text { hoola }\end{array}$ & & $\begin{array}{l}\text { el like } \\
\text { elong } \\
\text { choola }\end{array}$ & $\begin{array}{c}\text { If } \\
\text { awk } \\
\text { and } \\
\text { pla } \\
\text { my s }\end{array}$ & $\begin{array}{l}\text { eel } \\
\text { ward } \\
\text { put of } \\
\text { ce in } \\
\text { choold }\end{array}$ & $\begin{array}{r}\text { Ot } \\
\text { stud } \\
\text { see } \\
\text { to lik }\end{array}$ & $\begin{array}{l}\text { her } \\
\text { lents } \\
\text { em } \\
\text { e me }\end{array}$ & $\begin{array}{r}\text { If } \\
\text { lon } \\
\text { at sc }\end{array}$ & $\begin{array}{l}\text { feel } \\
\text { nely } \\
\text { choold }\end{array}$ & $\begin{array}{l}\text { I fee } \\
\text { an ot } \\
\text { (or I } \\
\text { of th } \\
\text { at sc }\end{array}$ & $\begin{array}{l}\text { el like } \\
\text { utsider } \\
\text { eft out } \\
\text { hings) } \\
\text { choold }\end{array}$ & $\begin{array}{r}\mathbf{r} \mathrm{m} \\
\mathbf{t} \\
\text { frie } \\
\text { ea } \\
\text { at sc }\end{array}$ & $\begin{array}{l}\text { nake } \\
\text { ends } \\
\text { sily } \\
\text { choola }\end{array}$ & $\begin{array}{l}\text { I be } \\
\text { at sc }\end{array}$ & $\begin{array}{l}\text { el like } \\
\text { elong } \\
\text { choola }\end{array}$ & $\begin{array}{r}\text { If } \\
\text { awk } \\
\text { and o } \\
\text { plac } \\
\text { my sc }\end{array}$ & $\begin{array}{l}\text { feel } \\
\text { kward } \\
\text { out of } \\
\text { ice in } \\
\text { choold }^{d}\end{array}$ \\
\hline & & $\%$ & S.E. & $\%$ & S.E. & $\%$ & S.E. & $\%$ & S.E. & $\%$ & S.E. & $\%$ & S.E. & $\%$ & S.E. & $\%$ & S.E. & $\%$ & S.E. & $\%$ & S.E. \\
\hline & Australia & 75.3 & $(0.5)$ & \begin{tabular}{|l|}
79.0 \\
\end{tabular} & $(0.5)$ & 69.6 & $(0.5)$ & 77.4 & $(0.5)$ & 87.2 & $(0.4)$ & \begin{tabular}{|l|l|}
82.8 \\
\end{tabular} & $(0.4)$ & 80.0 & $(1.3)$ & 79.8 & (1.3) & 77.9 & $(1.4)$ & 78.2 & (1.4) \\
\hline & Austria & 86.1 & $(0.5)$ & 78.4 & $(0.7)$ & 77.1 & $(0.6)$ & 83.5 & $(0.6)$ & 84.5 & $(0.6)$ & 85.1 & $(0.5)$ & 81.3 & (1.9) & 70.6 & $(2.4)$ & 67.4 & $(2.5)$ & 76.2 & $(2.4)$ \\
\hline & Belgium & 88.0 & $(0.5)$ & 81.5 & $(0.5)$ & 63.6 & $(0.6)$ & 85.2 & $(0.4)$ & 88.4 & $(0.5)$ & 90.8 & $(0.4)$ & 80.4 & (1.5) & 80.3 & (2.0) & 53.5 & $(2.1)$ & 77.8 & (1.6) \\
\hline & Canada & 77.2 & $(0.5)$ & 78.0 & $(0.6)$ & 70.4 & $(0.6)$ & 75.9 & $(0.5)$ & 87.2 & $(0.5)$ & 81.2 & $(0.5)$ & 80.0 & $(1.1)$ & 79.1 & $(1.0)$ & 75.8 & (1.4) & 78.4 & (1.1) \\
\hline & Chile & 80.1 & $(0.6)$ & 73.3 & $(0.6)$ & 77.4 & $(0.7)$ & 80.2 & $(0.6)$ & 76.4 & $(0.6)$ & 83.4 & $(0.6)$ & 85.1 & $(4.1)$ & 66.8 & (5.5) & 74.0 & $(6.0)$ & 76.7 & (4.8) \\
\hline & Czech Republic & 80.1 & $(0.5)$ & 75.4 & $(0.7)$ & 71.0 & $(0.7)$ & 81.5 & $(0.5)$ & 81.5 & $(0.6)$ & 82.3 & $(0.6)$ & 72.5 & (4.1) & 65.0 & (4.8) & 64.8 & (4.9) & 71.6 & $(4.7)$ \\
\hline & Denmark & 87.9 & $(0.5)$ & 79.4 & $(0.6)$ & 71.3 & $(0.7)$ & 84.9 & $(0.6)$ & 85.7 & (0.6) & 87.3 & $(0.5)$ & 82.7 & (3.1) & 72.5 & (3.9) & 60.8 & (3.8) & 78.7 & $(4.0)$ \\
\hline & Estonia & 88.1 & $(0.5)$ & 76.7 & $(0.7)$ & 78.6 & $(0.7)$ & 84.1 & (0.6) & 77.4 & $(0.7)$ & 85.9 & $(0.6)$ & c & c & 84.2 & (5.4) & c & C & $\mathrm{C}$ & c \\
\hline & Finland & 87.8 & $(0.4)$ & 79.7 & $(0.6)$ & 80.3 & $(0.6)$ & 82.7 & $(0.6)$ & 82.2 & $(0.5)$ & 88.3 & $(0.5)$ & 80.6 & (3.6) & 79.8 & (4.1) & 78.6 & (3.8) & \begin{tabular}{|l|l|}
78.8 \\
\end{tabular} & (4.4) \\
\hline & France & 77.3 & $(0.7)$ & 86.6 & $(0.5)$ & 41.4 & $(0.8)$ & 84.4 & (0.5) & 90.3 & (0.4) & 90.8 & $(0.4)$ & 71.7 & (3.1) & 85.8 & $(2.2)$ & 38.7 & (3.5) & 74.5 & (2.5) \\
\hline & Germany & 85.3 & $(0.6)$ & 73.0 & $(0.8)$ & 75.8 & $(0.7)$ & 83.3 & $(0.6)$ & 85.5 & (0.6) & 87.8 & $(0.5)$ & 84.3 & (3.0) & 70.6 & (3.1) & 67.6 & (3.9) & 76.7 & (3.6) \\
\hline & Greece & 85.4 & (0.6) & 80.6 & $(0.6)$ & 83.6 & $(0.5)$ & 84.9 & (0.5) & 87.9 & (0.5) & 88.5 & $(0.5)$ & 74.7 & $(2.8)$ & 76.5 & (3.8) & 77.1 & (3.2) & 81.4 & (3.1) \\
\hline & Hungary & 82.3 & (0.6) & 81.3 & $(0.6)$ & 74.5 & $(0.8)$ & 82.6 & $(0.6)$ & 82.9 & $(0.7)$ & 85.5 & $(0.5)$ & 77.0 & (7.7) & 72.6 & (6.5) & 79.1 & (5.6) & 76.9 & (6.3) \\
\hline & Iceland & 83.3 & $(0.6)$ & 76.8 & $(0.7)$ & 79.2 & $(0.7)$ & 80.7 & $(0.7)$ & 83.5 & $(0.6)$ & 83.9 & $(0.6)$ & 74.7 & (4.5) & 63.1 & (5.1) & 66.5 & (4.5) & 74.3 & (4.1) \\
\hline & Ireland & 84.1 & (0.6) & 81.8 & $(0.5)$ & 74.3 & $(0.8)$ & 83.3 & $(0.7)$ & 91.0 & (0.4) & 88.2 & $(0.5)$ & 79.9 & (2.1) & 78.4 & (1.6) & 69.0 & $(2.2)$ & 81.1 & (1.7) \\
\hline & Israel & $\mathrm{m}$ & & $\mathrm{m}$ & $\mathrm{m}$ & $\mathrm{m}$ & $\mathrm{m}$ & $\mathrm{m}$ & $\mathrm{m}$ & $\mathrm{m}$ & $\mathrm{m}$ & $\mathrm{m}$ & $\mathrm{m}$ & $\mathrm{m}$ & $\mathrm{m}$ & $\mathrm{m}$ & $\mathrm{m}$ & $\mathrm{m}$ & $\mathrm{m}$ & $\mathrm{m}$ & $\mathrm{m}$ \\
\hline & Italy & 89.6 & (0.4) & 83.2 & $(0.5)$ & 67.8 & $(0.6)$ & 86.8 & $(0.5)$ & 77.3 & (0.6) & 90.1 & $(0.5)$ & 82.1 & (2.3) & 81.1 & (2.5) & 63.2 & (3.0) & 82.6 & $(2.8)$ \\
\hline & Japan & 88.1 & (0.5) & 68.9 & $(0.7)$ & 82.0 & $(0.6)$ & 80.6 & (0.6) & 73.9 & (0.6) & 88.6 & $(0.5)$ & C & c & c & c & C & c & C & c \\
\hline & Korea & 91.4 & (0.4) & 79.3 & $(0.6)$ & 79.5 & $(0.8)$ & 89.9 & $(0.4)$ & 82.0 & (0.6) & 91.7 & $(0.4)$ & C & c & c & 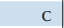 & C & c & c & C \\
\hline & Latvia & 84.7 & $(0.5)$ & 76.1 & $(0.7)$ & 79.0 & $(0.6)$ & 75.6 & (0.6) & 68.4 & $(0.7)$ & 83.2 & $(0.6)$ & c & c & c & c & c & c & 73.5 & $(6.7)$ \\
\hline & Luxembourg & 85.6 & $(0.7)$ & 75.5 & $(0.8)$ & 72.3 & $(1.0)$ & 82.4 & $(0.8)$ & 84.0 & $(0.8)$ & 85.9 & $(0.7)$ & 77.4 & (1.4) & 74.6 & (1.3) & 55.9 & (1.6) & 75.5 & (1.5) \\
\hline & Mexico & 75.3 & (0.6) & 72.8 & $(0.6)$ & 76.3 & $(0.7)$ & 76.4 & $(0.6)$ & 72.5 & $(0.7)$ & 79.5 & $(0.5)$ & 73.4 & (5.6) & 68.0 & (6.9) & 66.4 & (6.9) & 55.2 & (8.1) \\
\hline & Netherlands & 91.3 & $(0.4)$ & 84.9 & $(0.5)$ & 81.3 & $(0.6)$ & 88.7 & $(0.5)$ & 91.9 & $(0.5)$ & 92.4 & $(0.4)$ & 87.5 & (3.4) & 82.7 & (4.1) & 80.2 & $(3.1)$ & 88.8 & (3.2) \\
\hline & New Zealand & 77.5 & $(0.8)$ & 79.0 & $(0.7)$ & 72.2 & $(0.8)$ & 78.0 & $(0.7)$ & 88.2 & (0.6) & 83.0 & $(0.8)$ & 76.8 & $(1.8)$ & 77.2 & (1.8) & 76.3 & (1.8) & 75.8 & (1.9) \\
\hline & Norway & 88.5 & $(0.5)$ & 80.1 & $(0.6)$ & 75.6 & $(0.7)$ & 83.2 & $(0.6)$ & 83.2 & $(0.7)$ & 85.9 & $(0.6)$ & 81.8 & (2.7) & 75.3 & (2.6) & 73.2 & $(2.9)$ & 74.3 & (2.9) \\
\hline & Poland & 78.6 & $(0.6)$ & 73.5 & $(0.7)$ & 62.5 & $(0.7)$ & 77.0 & (0.6) & 73.3 & $(0.7)$ & 79.8 & $(0.7)$ & c & c & c & c & C & $\mathrm{C}$ & C & c \\
\hline & Portugal & 87.5 & $(0.5)$ & 78.1 & $(0.7)$ & 82.8 & $(0.5)$ & 76.5 & $(0.6)$ & 88.2 & $(0.4)$ & 89.2 & $(0.5)$ & 78.3 & (2.6) & 70.0 & (3.4) & 72.4 & (3.2) & 65.8 & (3.7) \\
\hline & Slovak Republic & 77.9 & $(0.6)$ & 77.2 & $(0.5)$ & 69.9 & $(0.7)$ & 77.9 & $(0.5)$ & 77.0 & (0.6) & 81.1 & $(0.6)$ & c & c & c & C & c & C & c & c \\
\hline & Slovenia & 82.8 & $(0.6)$ & 76.9 & $(0.8)$ & 74.7 & $(0.9)$ & 82.7 & $(0.6)$ & 78.9 & $(0.6)$ & 85.7 & $(0.6)$ & 78.6 & (3.5) & 76.2 & (3.4) & 74.1 & $(4.0)$ & 82.4 & $(2.7)$ \\
\hline & Spain & 90.8 & $(0.4)$ & $\mid 84.1$ & $(0.6)$ & 88.0 & $(0.5)$ & 86.6 & $(0.5)$ & 86.6 & (0.6) & 91.3 & $(0.4)$ & 82.9 & (1.7) & 75.5 & (2.3) & 80.1 & $(2.2)$ & 81.6 & $(1.6)$ \\
\hline & Sweden & 80.0 & $(0.6)$ & 75.5 & $(0.7)$ & 70.3 & $(0.8)$ & 80.7 & $(0.6)$ & 79.4 & $(0.6)$ & 81.9 & $(0.6)$ & 70.7 & (2.3) & 68.3 & $(2.2)$ & 63.7 & (2.4) & 72.3 & (2.3) \\
\hline & Switzerland & 89.8 & (0.6) & 81.0 & $(0.7)$ & 73.0 & $(0.8)$ & 86.7 & $(0.7)$ & 89.0 & $(0.5)$ & 91.0 & $(0.5)$ & 80.9 & (1.5) & 75.9 & (2.2) & 61.5 & $(2.3)$ & 79.5 & $(2.0)$ \\
\hline & Turkey & 64.6 & $(0.9)$ & 62.3 & $(0.8)$ & 61.4 & $(0.7)$ & 62.9 & $(0.8)$ & 63.6 & $(0.9)$ & 65.3 & $(0.8)$ & $\mathrm{c}$ & & C & $\mathrm{C}$ & $\mathrm{C}$ & $\mathrm{C}$ & c & $\mathrm{C}$ \\
\hline & United Kingdom & 80.3 & $(0.7)$ & 78.2 & $(0.7)$ & 67.1 & $(0.7)$ & 80.4 & $(0.6)$ & 88.0 & $(0.5)$ & 87.1 & $(0.5)$ & 77.5 & (1.7) & 78.5 & $(2.2)$ & 68.1 & $(2.2)$ & 76.8 & $(2.3)$ \\
\hline & United States & 77.1 & $(0.7)$ & 79.8 & $(0.7)$ & 73.6 & $(0.8)$ & 77.4 & $(0.7)$ & 89.7 & (0.5) & 81.8 & $(0.7)$ & 76.0 & (1.9) & 71.5 & (2.8) & 74.0 & $(2.7)$ & 74.9 & (2.5) \\
\hline & OECD average & 83.2 & $(0.1)$ & 77.9 & $(0.1)$ & 73.5 & $(0.1)$ & 81.3 & $(0.1)$ & 82.5 & $(0.1)$ & 85.5 & $(0.1)$ & 78.8 & (0.6) & 75.0 & $(0.7)$ & 68.9 & $0.7)$ & 76.4 & $(0.7)$ \\
\hline & Albania & 4.9 & $(0.4)$ & 90.3 & $(0.5)$ & 93.1 & $(0.4)$ & 89.7 & (0.6) & 82.7 & $(0.7)$ & 95.4 & $(0$. & C & C & C & & C & $\mathrm{c}$ & c & $c$ \\
\hline & Algeria & 72.4 & $(1.0)$ & 86.4 & $(0.4)$ & 87.3 & $(0.5)$ & 65.5 & $(0.9)$ & 82.9 & (0.6) & 71.5 & $(1.0)$ & $\mathrm{m}$ & & $\mathrm{m}$ & $\mathrm{m}$ & $\mathrm{m}$ & $\mathrm{m}$ & $\mathrm{m}$ & $\mathrm{m}$ \\
\hline ปั & Brazil & 79.7 & $(0.4)$ & 74.0 & $(0.5)$ & 76.4 & $(0.5)$ & 82.3 & $(0.3)$ & 81.3 & $(0.4)$ & 80.6 & $(0.4)$ & c & c & c & c & c & c & c & c \\
\hline & B-S-J-G (China) & 78.2 & $(0.6)$ & 78.2 & $(0.5)$ & 64.7 & $(0.8)$ & 80.8 & $(0.6)$ & 59.6 & $(0.7)$ & 78.7 & $(0.6)$ & c & $\mathrm{c}$ & c & c & c & c & c & c \\
\hline & Bulgaria & 70.7 & $(0.8)$ & 74.9 & $(0.7)$ & 68.1 & $(0.6)$ & 72.2 & $(0.9)$ & 72.1 & $(0.7)$ & 75.1 & $(0.8)$ & c & c & c & c & c & c & c & c \\
\hline & CABA (Argentina) & 89.3 & (1.0) & 89.8 & $(1.0)$ & 89.0 & $(1.2)$ & 92.5 & $(0.7)$ & 92.4 & $(0.9)$ & 94.1 & $(0.6)$ & 74.7 & $(4.2)$ & 89.5 & (3.7) & 89.1 & (3.3) & 95.6 & (2.0) \\
\hline & Colombia & 71.6 & $(0.7)$ & 70.3 & $(0.6)$ & 74.6 & $(0.6)$ & 73.2 & (0.6) & 68.7 & (0.6) & 75.2 & $(0.5)$ & c & c & c & c & c & c & c & c \\
\hline & Costa Rica & 73.4 & $(0.6)$ & 72.1 & $(0.8)$ & 74.7 & $(0.7)$ & 74.7 & $(0.7)$ & 72.3 & $(0.7)$ & 77.4 & $(0.6)$ & 71.6 & (5.3) & 67.2 & (4.5) & 74.0 & (4.1) & 80.9 & (3.5) \\
\hline & Croatia & 3 & $(0.5)$ & 83.6 & $(0.6)$ & 81.4 & $(0.7)$ & 85.3 & $(0.5)$ & 81.6 & $(0.6)$ & 87.9 & $(0.5)$ & 82.2 & (3.7) & 80.9 & (3.5) & 78.8 & (4.6) & 82.9 & $(3.7)$ \\
\hline & Cyprus* & 4.3 & $(0.6)$ & 81.5 & $(0.6)$ & 81.2 & (0.6) & 84.0 & (0.5) & 86.2 & $(0.5)$ & 87.4 & $(0.4)$ & 70.5 & (2.2) & 74.9 & (2.0) & 71.2 & (1.8) & 76.2 & $(2.1)$ \\
\hline & Dominican Republic & 61.2 & $(0.8)$ & 66.4 & $(0.9)$ & 67.3 & $(0.8)$ & 65.7 & $(0.8)$ & 66.9 & $(0.9)$ & 69.7 & $(0.9)$ & c & c & c & c & c & c & $\mathrm{c}$ & c \\
\hline & FYROM & 88.9 & $(0.4)$ & 94.0 & $(0.4)$ & 92.6 & $(0.4)$ & 89.9 & $(0.4)$ & 86.8 & $(0.6)$ & 93.4 & $(0.3)$ & c & c & c & 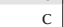 & c & c & c & c \\
\hline & Georgia & 6 & $(0.4)$ & 94.5 & $(0.4)$ & 64.7 & $(0.8)$ & 94.7 & $(0.3)$ & 75.9 & $(0.8)$ & 95.5 & $(0.3)$ & C & C & c & c & C & C & c & C \\
\hline & Hong Kong (China) & 76.2 & $(0.9)$ & 81.3 & $(0.7)$ & 71.4 & $(1.0)$ & 79.1 & $(0.8)$ & 78.0 & $(0.8)$ & 80.9 & $(0.9)$ & 77.4 & (1.5) & 81.6 & (1.5) & 71.7 & $(2.1)$ & 80.5 & $(1.4)$ \\
\hline & Indonesia & 96.5 & $(0.3)$ & 96.6 & $(0.3)$ & 92.4 & $(0.4)$ & 84.2 & $(0.7)$ & 84.3 & $(0.7)$ & 94.2 & $(0.4)$ & c & c & c & c & c & c & c & c \\
\hline & Jordan & 8.3 & $(0.8)$ & 91.2 & $(0.5)$ & 86.8 & $(0.6)$ & 76.6 & $(0.7)$ & 91.6 & $(0.5)$ & 88.2 & $(0.5)$ & 68.3 & (3.2) & 83.0 & (2.9) & 76.6 & (3.6) & 69.1 & (3.2) \\
\hline & Kosovo & 7.4 & $(0.6)$ & 91.5 & $(0.5)$ & 92.6 & $(0.5)$ & 86.1 & $(0.6)$ & 85.5 & $(0.7)$ & 93.3 & $(0.5)$ & 87.4 & (5.2) & 86.6 & (6.3) & 95.1 & $(2.9)$ & c & $\mathrm{c}$ \\
\hline & Lebanon & 7.5 & (1.5) & 90.2 & $(0.6)$ & 75.5 & (1.3) & 77.1 & (1.1) & 79.0 & (1.3) & 86.0 & $(1.0)$ & 76.6 & (7.6) & 92.6 & (2.9) & 91.1 & (3.6) & 81.5 & (5.3) \\
\hline & Lithuania & 69.2 & $(0.7)$ & 64.4 & $(0.7)$ & 54.3 & $(0.8)$ & 66.2 & $(0.8)$ & 62.6 & $(0.8)$ & 68.9 & $(0.7)$ & c & c & c & c & c & c & c & c \\
\hline & Macao (Ch & 5.4 & (1.0) & 76.3 & (1.1) & 62.2 & $(1.2)$ & 75.8 & (1.0) & 67.2 & (1.1) & 78.9 & (1.1) & 80.5 & (1.5) & 77.4 & (1.4) & 59.6 & (1.7) & 80.2 & $(1.2)$ \\
\hline & Malta & 0.6 & $(0.8)$ & 82.3 & $(0.7)$ & 70.7 & (0.8) & 83.1 & $(0.6)$ & 88.4 & (0.5) & 89.2 & $(0.5)$ & 72.5 & (3.9) & 74.9 & (4.4) & 51.5 & (4.1) & $\mid 71.4$ & (4.2) \\
\hline & Moldova & .3 & (0.4) & 90.7 & (0.5) & 67.7 & $(0.9)$ & 89.7 & (0.4) & 84.5 & (0.6) & 88.5 & $(0.5)$ & c & c & c & c & C & c & c & c \\
\hline & Montenegro & 3.3 & (0.5) & 83.9 & $(0.5)$ & 54.3 & $(0.9)$ & 82.9 & $(0.6)$ & 80.0 & $(0.5)$ & 86.8 & $(0.5)$ & 70.7 & (4.6) & 66.4 & (4.3) & 50.8 & (4.9) & 79.8 & $(4.0)$ \\
\hline & Peru & 9.6 & $(0.7)$ & 75.8 & (0.6) & 71.4 & (0.6) & 76.1 & $(0.7)$ & 77.4 & (0.6) & 82.7 & $(0.6)$ & C & c & C & c & c & C & C & c \\
\hline & Qatar & 3.3 & $(0.6)$ & 75.2 & $(0.6)$ & 66.9 & $(0.7)$ & 74.1 & $(0.7)$ & 81.6 & $(0.6)$ & 78.1 & $(0.6)$ & 78.7 & (0.6) & 80.8 & (0.6) & 74.5 & (0.6) & 78.8 & $(0.6)$ \\
\hline & Romania & 7.8 & (1.1) & 92.3 & $(0.5)$ & 52.4 & (1.1) & 84.3 & $(0.8)$ & 86.8 & $(0.8)$ & 85.8 & (1.1) & C & & c & c & C & c & C & c \\
\hline & Russia & 0.9 & $(0.7)$ & 73.2 & $(0.6)$ & 74.9 & $(0.5)$ & 73.5 & $(0.5)$ & 64.5 & $(0.8)$ & 79.7 & $(0.6)$ & 71.1 & (4.6) & 71.1 & (4.6) & 70.1 & (5.3) & 65.7 & (4.5) \\
\hline & Singapo & 6.2 & (0.6) & 80.3 & $(0.6)$ & 75.7 & $(0.7)$ & 75.7 & (0.6) & 80.6 & $(0.6)$ & 81.9 & $(0.6)$ & 77.6 & (1.7) & 78.6 & $(2.2)$ & 76.9 & $(1.7)$ & 79.3 & $(2.0)$ \\
\hline & Chinese Taipei & 8.7 & $(0.3)$ & 85.1 & $(0.4)$ & 90.0 & $(0.3)$ & 83.1 & $(0.5)$ & 72.2 & $(0.5)$ & 87.7 & $(0.4)$ & c & c & $\mathrm{c}$ & c & c & c & $\mathrm{c}$ & c \\
\hline & Thailand & 0.4 & $(0.7)$ & 82.7 & $(0.5)$ & 78.6 & (0.6) & 67.9 & $(0.9)$ & 61.5 & $(0.8)$ & 82.3 & $(0.7)$ & c & c & c & c & c & c & c & c \\
\hline & Trinidad and Tobago & 83.3 & $(0.6)$ & 86.2 & $(0.6)$ & 80.4 & $(0.6)$ & 83.0 & $(0.6)$ & 86.0 & $(0.5)$ & 86.5 & $(0.6)$ & 66.6 & $(7.1)$ & 83.8 & $(5.2)$ & 76.5 & $(6.3)$ & 71.7 & $(6.4)$ \\
\hline & Tunisia & 80.8 & $(0.7)$ & 83.7 & $(0.6)$ & 57.5 & $(0.7)$ & 63.3 & $(0.8)$ & 80.7 & $(0.5)$ & 85.6 & $(0.6)$ & c & c & $\mathrm{c}$ & c & c & c & c & $\mathrm{c}$ \\
\hline & United Arab Em & 79.3 & $(0.8)$ & 79.3 & $(0.8)$ & 73.2 & $(0.9)$ & 73.3 & $(0.8)$ & 73.6 & (0.9) & 82.1 & $(0.6)$ & 79.1 & $(0.7)$ & 79.9 & $(0.8)$ & 75.1 & $(0.8)$ & 77.7 & $(0.9)$ \\
\hline & Uruguay & 76.3 & $(0.6)$ & 73.2 & $(0.6)$ & 78.3 & $(0.6)$ & 79.4 & $(0.6)$ & 85.9 & $(0.5)$ & 79.4 & $(0.6)$ & C & c & c & c & C & c & C & c \\
\hline & Viet Nam & 95.6 & $(0.4)$ & 91.7 & (0.5) & 80.8 & $(0.7)$ & 82.7 & (0.6) & 42.5 & (0.9) & 92.7 & $(0.6)$ & C & c & c & C & C & c & c & c \\
\hline & Argentina** & 5.7 & $(1.0)$ & 89.2 & $(0.5)$ & |89.7 & $(0.5)$ & 89.0 & (0.5) & 87.6 & (0.6) & 91.5 & $(0.4)$ & 61.9 & (6.5) & 91.1 & (3.3) & 86.7 & (4.4) & 83.5 & (4.5) \\
\hline & Kaz & 4.3 & $(0.4)$ & 92.2 & (0.6) & 84.8 & (0.6) & 92.6 & (0.4) & 87.1 & (0.6) & 93.1 & (0.4) & 95.6 & (1.3) & 91.6 & (1.9) & 87.6 & (2.3) & 95.3 & (1.1) \\
\hline & Malaysia** & 84.2 & $(0.7)$ & 87.7 & $(0.5)$ & 77.4 & $(0.7)$ & 83.1 & $(0.7)$ & 77.1 & $(0.7)$ & 83.4 & (0.6) & c & c & c & c & c & c & C & r \\
\hline
\end{tabular}

Note: Values that are statistically significant are indicated in bold (see Annex A3).

* See note at the beginning of this Annex.

* Coverage is too small to ensure comparability (see Annex A4).

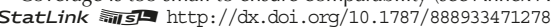


[Part 2/2]

Table III.7.3 Students' sense of belonging, by immigrant background

Percentage of students who reported "agree" or "strongly agree" (a) or who reported "disagree" or "strongly disagree" (d)

\begin{tabular}{|c|c|c|c|c|c|c|c|c|c|c|c|c|c|c|c|c|c|c|c|c|c|}
\hline & & & & ercer & gec & secon & $\begin{array}{l}\text { d-gene } \\
\text { ed with }\end{array}$ & $\begin{array}{l}\text { erati } \\
\text { th th }\end{array}$ & $\mathrm{nn}$ & $\begin{array}{l}\text { gran } \\
\text { ing s }\end{array}$ & $\begin{array}{l}\text { tuden } \\
\text { tement }\end{array}$ & & & & & in th & arcen & $\begin{array}{l}\text { age of } \\
h \text { the }\end{array}$ & $\begin{array}{l}\text { roun } \\
\text { tude } \\
\text { tulow }\end{array}$ & $\begin{array}{l}\text { ld (non } \\
\text { ents wh } \\
\text { ving sta }\end{array}$ & ag \\
\hline & & $\begin{array}{l}\text { I fee } \\
\text { an ou } \\
\text { (or le } \\
\text { of th } \\
\text { at sc }\end{array}$ & $\begin{array}{l}\text { like } \\
\text { tsider } \\
\text { eft out } \\
\text { ings) } \\
\text { hool }^{\text {d }}\end{array}$ & $\begin{array}{r}\mathrm{Im} \\
\text { frie } \\
\text { ea } \\
\text { at sc }\end{array}$ & $\begin{array}{l}\text { lake } \\
\text { ends } \\
\text { sily } \\
\text { hool }^{\text {a }}\end{array}$ & $\begin{array}{l}\text { I feel } \\
\text { I bel } \\
\text { at scl }\end{array}$ & $\begin{array}{l}\text { I like } \\
\text { long } \\
\text { hool }^{\mathrm{a}}\end{array}$ & $\begin{array}{l}\text { If } \\
\text { awk } \\
\text { and } \\
\text { plac } \\
\text { my sc }\end{array}$ & $\begin{array}{l}\text { eel } \\
\text { ward } \\
\text { out of } \\
\text { e in } \\
\text { choold }\end{array}$ & $\begin{array}{r}\text { Ot } \\
\text { stud } \\
\text { se } \\
\text { to lik }\end{array}$ & $\begin{array}{l}\text { her } \\
\text { ents } \\
\text { em } \\
\text { e me }\end{array}$ & $\begin{array}{r}\text { If } \\
\text { lon } \\
\text { at sc }\end{array}$ & $\begin{array}{l}\text { eel } \\
\text { cely } \\
\text { hoold }^{\text {d }}\end{array}$ & $\begin{array}{l}\text { I feel } \\
\text { an out } \\
\text { (or lef } \\
\text { of thi } \\
\text { at sch }\end{array}$ & \begin{tabular}{|l|} 
like \\
tsider \\
ft out \\
ings) \\
nool
\end{tabular} & $\begin{array}{l}\text { I ma } \\
\text { frier } \\
\text { eas } \\
\text { at sch }\end{array}$ & $\begin{array}{l}\text { lake } \\
\text { nds } \\
\text { sily } \\
\text { hool }^{\text {a }}\end{array}$ & $\begin{array}{l}\text { I feel } \\
\text { I bel } \\
\text { at sch }\end{array}$ & $\begin{array}{l}\text { I like } \\
\text { long } \\
\text { hool }^{\mathrm{a}}\end{array}$ & $\begin{array}{r}\text { I fe } \\
\text { awkv } \\
\text { and o } \\
\text { plac } \\
\text { my sc }\end{array}$ & $\begin{array}{l}\text { eel } \\
\text { ward } \\
\text { out of } \\
\text { ce in } \\
\text { chool }\end{array}$ \\
\hline & & $\%$ & S.E. & $\%$ & S.E. & $\%$ & S.E. & $\%$ & S.E. & $\%$ & S.E. & $\%$ & S.E. & $\%$ dif. & S.E. & $\%$ dif. & S.E. & $\%$ dif. & S.E. & $\%$ dif. & S.E. \\
\hline & Australia & \begin{tabular}{|l|}
79.9 \\
\end{tabular} & (1.1) & 80.3 & $(1.2)$ & 79.4 & (1.2) & \begin{tabular}{|l|}
81.5 \\
\end{tabular} & $(1.1)$ & \begin{tabular}{|l|}
90.9 \\
\end{tabular} & (0.8) & 84.6 & (1.1) & -4.7 & (1.5) & -0.8 & (1.4) & -8.3 & (1.5) & -0.8 & (1.5) \\
\hline 过 & Austria & 88.9 & (1.1) & 79.9 & (1.7) & 75.8 & (1.5) & 82.6 & (1.3) & 83.2 & (1.3) & 85.8 & (1.1) & 4.8 & (1.9) & 7.8 & (2.5) & 9.7 & (2.5) & 7.3 & (2.5) \\
\hline & Belgium & 86.3 & (1.6) & 87.4 & (1.4) & 56.7 & (2.3) & 81.6 & (1.5) & 89.7 & (1.4) & 91.0 & $(1.3)$ & 7.7 & (1.6) & 1.2 & $(2.2)$ & 10.1 & $(2.2)$ & 7.5 & (1.6) \\
\hline & Canada & 77.1 & (1.2) & 79.0 & (1.2) & 73.9 & (1.2) & 77.0 & (1.1) & 89.0 & $(0.7)$ & 81.9 & (0.9) & -2.9 & (1.2) & -1.1 & (1.2) & -5.4 & (1.5) & -2.5 & (1.2) \\
\hline & Chile & c & c & c & c & 91.6 & (4.8) & 90.9 & (5.9) & 85.0 & (5.9) & c & c & -5.0 & (4.2) & 6.5 & (5.5) & 3.5 & (6.2) & 3.5 & $(4.8)$ \\
\hline & Czech Republic & 72.8 & (5.6) & 80.0 & (4.9) & 70.6 & (6.4) & 79.5 & (4.6) & 76.7 & (5.9) & 76.4 & $(5.3)$ & 7.5 & (4.1) & 10.4 & (5.0) & 6.2 & (4.9) & 9.9 & $(4.7)$ \\
\hline & Denmark & 86.6 & (1.5) & 79.8 & (1.7) & 62.7 & (1.8) & 85.8 & (1.3) & 84.0 & (1.6) & 86.7 & $(1.5)$ & 5.2 & (3.3) & 6.9 & $(4.0)$ & 10.5 & (3.9) & 6.2 & $(4.2)$ \\
\hline & Estonia & 79.2 & (1.6) & 68.3 & (2.3) & 73.0 & (1.9) & 76.7 & (1.8) & 67.8 & (1.9) & 79.4 & (1.7) & C & c & -7.6 & (5.5) & C & c & C & c \\
\hline & Finland & 87.8 & (3.6) & 81.1 & (3.7) & 84.4 & (3.1) & 83.7 & (3.5) & 81.9 & (4.0) & 83.9 & (3.8) & 7.3 & (3.6) & -0.1 & $(4.0)$ & 1.7 & (3.9) & 3.9 & $(4.3)$ \\
\hline & France & 75.9 & $(2.0)$ & 83.8 & (1.7) & 36.4 & (2.5) & 82.1 & $(2.2)$ & 87.5 & (2.0) & 91.6 & (1.4) & 5.6 & (3.3) & 0.8 & $(2.2)$ & 2.7 & (3.7) & 9.9 & (2.6) \\
\hline & Germany & 86.8 & (1.5) & 75.7 & (1.7) & 71.7 & (1.7) & 78.6 & (1.8) & 83.6 & (1.8) & 86.4 & (1.8) & 1.0 & (2.9) & 2.4 & (3.1) & 8.1 & (3.9) & 6.7 & (3.6) \\
\hline & Greece & 79.7 & (2.5) & 77.7 & (2.7) & 79.0 & (2.1) & 82.1 & (2.0) & 84.3 & (2.1) & 86.0 & (2.0) & 10.7 & (3.0) & 4.0 & (3.8) & 6.5 & (3.3) & 3.5 & (3.2) \\
\hline & Hungary & 84.9 & (3.6) & 80.1 & $(4.2)$ & 77.8 & (4.8) & 85.7 & (3.5) & 77.5 & (4.6) & 87.0 & (3.4) & 5.3 & (7.7) & 8.7 & (6.4) & -4.6 & (5.7) & 5.7 & (6.4) \\
\hline & Iceland & 84.1 & $(6.1)$ & C & C & c & c & 80.0 & (7.4) & C & c & 84.2 & (5.7) & 8.6 & (4.5) & 13.7 & (5.0) & 12.7 & (4.5) & 6.4 & (4.3) \\
\hline & Ireland & 75.5 & (3.7) & 71.9 & $(4.4)$ & 68.9 & (3.9) & 77.0 & (3.4) & 87.4 & (3.9) & 81.3 & (3.5) & 4.2 & (2.0) & 3.4 & (1.7) & 5.3 & (2.3) & 2.2 & (1.7) \\
\hline & Israel & $\mathrm{m}$ & & $\mathrm{m}$ & $\mathrm{m}$ & $\mathrm{m}$ & $\mathrm{m}$ & $\mathrm{m}$ & $\mathrm{m}$ & $\mathrm{m}$ & $\mathrm{m}$ & $\mathrm{m}$ & $\mathrm{m}$ & $\mathrm{m}$ & $\mathrm{m}$ & $\mathrm{m}$ & $\mathrm{m}$ & $\mathrm{m}$ & $\mathrm{m}$ & $\mathrm{m}$ & $\mathrm{m}$ \\
\hline & Italy & \begin{tabular}{|l|}
78.8 \\
\end{tabular} & (3.4) & 79.6 & (3.9) & 61.5 & (4.7) & 77.9 & (3.4) & 71.3 & $(4.1)$ & 83.5 & (2.9) & 7.5 & (2.4) & 2.1 & $(2.7)$ & 4.6 & (3.0) & 4.2 & (2.8) \\
\hline & Japan & c & c & c & c & c & c & C & c & C & c & c & c & c & c & c & C & C & c & C & c \\
\hline & Korea & $\mathrm{m}$ & & $\mathrm{m}$ & $\mathrm{m}$ & $\mathrm{m}$ & $\mathrm{m}$ & $\mathrm{m}$ & $\mathrm{m}$ & $\mathrm{m}$ & $\mathrm{m}$ & $\mathrm{m}$ & $\mathrm{m}$ & c & c & C & c & c & c & C & c \\
\hline & Latvia & 81.0 & (2.8) & 69.4 & (3.3) & 73.5 & (2.7) & 75.9 & (3.3) & 66.4 & (3.4) & 77.1 & (3.4) & c & c & C & C & C & c & 2.1 & (6.7) \\
\hline & Luxembo & 83.9 & $(0.9)$ & 77.5 & (1.1) & 63.1 & (1.1) & 79.5 & $(1.0)$ & 79.7 & (1.1) & 85.0 & $(0.9)$ & 8.2 & (1.5) & 0.9 & (1.6) & 16.4 & (1.8) & 6.9 & (1.7) \\
\hline & Mexico & c & & C & c & c & c & C & c & c & c & c & c & 1.9 & (5.6) & 4.8 & (7.0) & 10.0 & (6.9) & 21.2 & (8.3) \\
\hline & Netherlands & 90.2 & (1.6) & 88.8 & (1.5) & 78.1 & (2.2) & 90.9 & (1.6) & 94.5 & (1.3) & 93.2 & (1.4) & 3.7 & (3.4) & 2.2 & $(4.2)$ & 1.1 & (3.2) & -0.2 & (3.2) \\
\hline & New Zealand & 81.7 & (1.7) & 81.1 & (1.8) & 80.7 & (2.0) & 83.3 & (1.7) & 90.8 & (1.3) & 88.3 & (1.7) & 0.7 & (1.8) & 1.7 & (2.0) & -4.1 & (2.1) & 2.2 & (2.1) \\
\hline & Norway & 88.3 & (1.8) & 82.9 & (2.7) & 82.0 & (2.6) & 82.8 & (2.5) & 85.1 & (2.0) & 89.6 & (1.8) & 6.7 & (2.7) & 4.8 & $(2.7)$ & 2.4 & (3.0) & 8.9 & (2.9) \\
\hline & Poland & c & & c & & c & c & c & c & c & c & c & c & C & c & c & c & C & c & C & c \\
\hline & Portugal & 89.0 & (2.6) & 79.6 & (3.3) & 80.6 & (3.0) & 73.4 & $(4.0)$ & 87.0 & (2.8) & 90.7 & $(2.1)$ & 9.2 & (2.7) & 8.2 & (3.5) & 10.4 & (3.3) & 10.7 & (3.8) \\
\hline & Slovak Rep & C & & c & C & c & c & C & c & C & c & C & c & C & C & C & C & C & C & C & \\
\hline & Slovenia & \begin{tabular}{|l|}
79.2 \\
\end{tabular} & (2.7) & 78.4 & (3.0) & 72.1 & (3.1) & 80.8 & (2.6) & 73.0 & (3.5) & 84.2 & (2.5) & 4.2 & (3.6) & 0.6 & (3.3) & 0.7 & $(4.2)$ & 0.3 & (2.8) \\
\hline & Spain & 87.9 & (3.7) & 81.3 & $(4.2)$ & 88.9 & (2.7) & 84.4 & (3.9) & 85.0 & (4.4) & 90.6 & (3.6) & 7.9 & (1.8) & 8.6 & (2.5) & 8.0 & (2.3) & 5.0 & (1.7) \\
\hline & Sweden & 80.9 & (1.6) & 75.6 & $(2.0)$ & 66.0 & (2.1) & 76.6 & (1.8) & 75.8 & $(2.2)$ & 79.1 & (1.7) & 9.3 & (2.3) & 7.2 & $(2.4)$ & 6.6 & (2.5) & 8.4 & (2.3) \\
\hline & Switzerland & 87.7 & $(1.0)$ & 82.3 & (1.5) & 68.4 & (1.6) & 83.0 & (1.3) & 86.3 & (1.1) & 90.1 & $(1.0)$ & 8.9 & (1.6) & 5.1 & $(2.4)$ & 11.5 & (2.5) & 7.1 & $(2.2)$ \\
\hline & Turkey & & & c & & c & & c & & c & & c & & c & & c & c & c & c & c & c \\
\hline & United Kingdom & 82.0 & (2.6) & 85.1 & (1.9) & 74.6 & (2.6) & 84.1 & (1.8) & 90.1 & (1.7) & 86.5 & $(2.1)$ & 2.8 & (1.9) & -0.3 & (2.3) & -1.0 & (2.1) & 3.6 & $(2.3)$ \\
\hline & United States & 73.6 & $(1.7)$ & 76.7 & (1.5) & 76.4 & (1.7) & 77.7 & (1.7) & 86.7 & (1.1) & 84.2 & (1.4) & 1.1 & (2.1) & 8.3 & $(3.0)$ & -0.4 & (2.7) & 2.5 & (2.5) \\
\hline & OECD average & 82.6 & $(0.5)$ & 79.4 & $(0.5)$ & 72.9 & (0.6) & 81.3 & (0.6) & 83.0 & (0.6) & 85.5 & $(0.5)$ & 4.7 & (0.6) & 3.9 & $(0.7)$ & 4.6 & $(0.7)$ & 5.4 & $(0.7)$ \\
\hline & Albania & C & & c & & C & c & C & c & C & 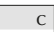 & C & & c & 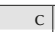 & $c$ & $c$ & C & & $c$ & \\
\hline 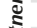 & Algeria & c & & 87.7 & $(5.9)$ & 87.6 & (8.3) & c & & 83.7 & (6.5) & 70.5 & $(8.9)$ & $\mathrm{m}$ & $\mathrm{m}$ & $\mathrm{m}$ & $\mathrm{m}$ & $\mathrm{m}$ & $\mathrm{m}$ & $\mathrm{m}$ & $\mathrm{m}$ \\
\hline & Brazil & 67.9 & (6.3) & 50.3 & (6.9) & 56.8 & (6.9) & 76.8 & (5.6) & 68.0 & $(7.2)$ & 63.2 & (6.9) & $\mathrm{c}$ & c & $\mathrm{C}$ & c & c & c & $\mathrm{c}$ & c \\
\hline & B-S-J-G (China) & c & c & c & c & c & c & c & c & c & c & c & c & c & c & c & c & c & c & c & \\
\hline & Bulgaria & c & & c & & c & c & c & c & c & c & c & c & c & c & c & c & c & c & c & $\mathrm{C}$ \\
\hline & CABA (Argentina) & 80.4 & $(3.0)$ & 85.0 & (3.5) & 85.2 & (2.8) & 89.2 & (2.6) & 85.6 & (2.4) & 90.3 & (2.1) & 14.6 & (4.3) & 0.3 & (3.4) & 0.0 & (3.6) & -3.1 & $(2.2)$ \\
\hline & Colombia & c & & c & & c & c & c & & 85.4 & (6.8) & c & c & c & c & c & c & c & c & c & \\
\hline & Costa Rica & 4.6 & $(2.7)$ & 66.9 & (2.8) & 75.7 & (2.4) & 74.6 & (2.7) & 72.5 & (2.4) & 77.2 & (2.5) & 1.8 & (5.3) & 4.9 & (4.5) & 0.7 & (4.1) & -6.2 & (3.5) \\
\hline & Croatia & 85.0 & (1.9) & 86.3 & (1.3) & 80.5 & (1.9) & 84.1 & (1.6) & 82.5 & (1.7) & 86.8 & (1.5) & 4.1 & (3.8) & 2.7 & (3.6) & 2.6 & (4.5) & 2.3 & (3.9) \\
\hline & Cyprus* & 82.3 & (3.2) & 73.2 & (3.7) & 80.3 & (3.0) & 85.8 & (3.0) & 85.9 & (2.9) & 86.3 & (3.1) & 13.8 & (2.3) & 6.6 & (2.1) & 10.0 & (2.0) & 7.8 & (2.2) \\
\hline & Dominicar & C & & C & & c & & C & & C & $\mathrm{C}$ & C & & C & C & C & C & $\mathrm{C}$ & C & c & 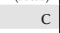 \\
\hline & FYROM & 74.4 & (5.8) & 85.1 & $(4.7)$ & 85.0 & (4.6) & 83.3 & $(4.7)$ & \begin{tabular}{|l|}
77.2 \\
\end{tabular} & (5.8) & 79.7 & (5.4) & c & c & c & c & C & c & c & c \\
\hline & Georgia & 8.1 & (4.5) & 90.2 & (4.5) & 66.5 & (6.7) & 88.0 & (5.0) & 76.2 & (4.7) & 87.6 & (4.5) & c & & c & c & C & c & c & C \\
\hline & Hong & 2.1 & (1.5) & 79.9 & (1.5) & 70.2 & (1.4) & \begin{tabular}{|l|}
78.4 \\
\end{tabular} & (1.3) & 78.7 & (1.3) & 81.2 & (1.2) & -1.2 & (1.7) & -0.3 & (1.5) & -0.2 & $(2.2)$ & 1.4 & (1.6) \\
\hline & Indonesia & c & & c & & c & & c & & c & c & c & c & c & c & C & c & C & c & c & c \\
\hline & Jordan & 77.3 & (1.8) & 91.6 & (1.1) & 84.3 & (1.6) & 76.7 & (1.7) & 92.2 & (1.4) & 87.6 & (1.3) & 10.0 & (3.2) & 8.2 & $(2.7)$ & 10.2 & (3.6) & 7.6 & (3.3) \\
\hline & Kosovo & 2.8 & (9.3) & 86.6 & (5.4) & 85.5 & (6.2) & 69.1 & (7.5) & 87.6 & (4.9) & 75.4 & $(8.2)$ & 0.0 & (5.1) & 4.9 & (6.3) & -2.5 & (3.0) & C & c \\
\hline & Lebanon & c & & 89.5 & $(4.0)$ & 75.4 & (6.2) & 43.6 & (8.1) & 74.8 & (5.3) & 58.8 & (6.7) & 0.9 & (7.6) & -2.4 & $(2.9)$ & -15.6 & (3.8) & -4.4 & (5.5) \\
\hline & Lithuania & 75.9 & (3.6) & 69.7 & (5.0) & 60.9 & (4.0) & 70.6 & (3.8) & 64.7 & (4.2) & 74.9 & $(4.1)$ & c & c & c & c & c & c & c & c \\
\hline & Macao (Ch & 1.3 & $(1.0)$ & 75.6 & $(0.9)$ & 58.3 & (1.2) & 78.2 & (1.0) & 64.9 & (1.2) & 80.9 & $(0.9)$ & -4.1 & (1.8) & -1.1 & (1.9) & 2.6 & (2.0) & -4.5 & (1.8) \\
\hline & Malta & .8 & $(6.0)$ & 85.6 & (4.3) & 75.3 & (5.9) & 78.0 & (5.1) & 93.4 & (3.4) & 87.2 & $(5.0)$ & 8.0 & (4.1) & 7.4 & (4.6) & 19.1 & (4.1) & 11.7 & $(4.2)$ \\
\hline & Moldov & 3.6 & (3.5) & 81.2 & (5.2) & 60.4 & (10.4) & 82.1 & (5.4) & 82.6 & (5.2) & 80.8 & (8.6) & c & c & c & c & c & c & c & c \\
\hline & Montenegrc & 8.5 & $(2.7)$ & 84.0 & $(2.9)$ & 44.9 & (4.0) & 79.3 & (2.7) & 78.9 & (3.1) & 81.5 & $(2.7)$ & 12.6 & (4.7) & 17.5 & (4.4) & 3.6 & (5.1) & 3.1 & (4.0) \\
\hline & Peru & c & & c & & c & c & c & & c & c & c & c & C & c & c & c & C & 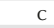 & c & $\mathrm{C}$ \\
\hline & Qatar & 7.1 & $(1.0)$ & 77.8 & (1.1) & 71.9 & (1.2) & 76.2 & (1.1) & 83.9 & (1.0) & 81.9 & (1.1) & -5.4 & (0.9) & -5.7 & $(0.8)$ & -7.5 & (1.0) & -4.8 & $(1.0)$ \\
\hline & Romania & c & & c & & c & & c & & c & & C & c & c & c & c & c & C & c & c & c \\
\hline & Russia & 0.4 & $(2.7)$ & 75.1 & (3.6) & 75.5 & (3.1) & 70.5 & (3.1) & 61.9 & (3.6) & 74.8 & (3.1) & 9.8 & (4.5) & 2.0 & (4.6) & 4.8 & (5.2) & 7.8 & (4.4) \\
\hline & Singapc & 8.4 & $(2.3)$ & 82.1 & (2.1) & 77.3 & (2.5) & 81.2 & (2.4) & 84.1 & (2.0) & 85.1 & $(2.0)$ & -1.4 & (1.8) & 1.6 & $(2.2)$ & -1.2 & (1.7) & -3.6 & $(2.2)$ \\
\hline & Chinese Taipe & c & & c & & c & & c & & c & c & c & c & c & c & c & c & c & c & c & c \\
\hline & Thailand & c & & 70.0 & $(6.4)$ & 79.3 & (5.6) & c & c & c & c & 60.1 & $(8.4)$ & c & c & c & c & c & c & c & c \\
\hline & Trin & 9.8 & $(7.0)$ & 74.6 & $(6.2)$ & 70.7 & (6.0) & 69.3 & 6.9) & 66.5 & (6.7) & 68.8 & $(6.4)$ & 16.7 & (7.2) & 2.4 & (5.3) & 3.8 & (6.2) & 11.2 & (6.3) \\
\hline & Tunisia & c & & 80.1 & $(4.6)$ & c & & c & & 73.8 & (7.1) & 75.8 & (6.3) & $\mathrm{c}$ & c & c & c & c & c & c & c \\
\hline & United Arab Emirates & 79.4 & $(0.9)$ & 80.8 & $(1.0)$ & 73.9 & (1.1) & 76.9 & (1.0) & 82.0 & $(0.9)$ & 82.7 & $(0.9)$ & 0.2 & (1.1) & -0.6 & (1.1) & -1.9 & (1.0) & -4.4 & (1.1) \\
\hline & Urug & c & $\mathrm{C}$ & c & c & c & c & c & c & c & c & c & c & c & c & c & c & c & c & c & c \\
\hline & Viet Nam & c & $\mathrm{C}$ & c & c & c & c & c & c & c & C & C & c & c & c & c & c & c & c & c & C \\
\hline & $\operatorname{Ar}$ & 5.4 & $(4.1)$ & 79.7 & (3.6) & \begin{tabular}{|l|}
86.8 \\
\end{tabular} & (2.9) & 83.7 & (2.8) & 78.8 & (3.0) & 89.0 & $(2.2)$ & 13.8 & (6.5) & -1.9 & (3.2) & 3.0 & (4.3) & 5.5 & (4.4) \\
\hline & & 2.5 & (1.3) & 91.4 & (1.4) & 85.5 & (1.7) & \begin{tabular}{|l|}
91.9 \\
\end{tabular} & (1.3) & 86.3 & (1.6) & 91.3 & (1.3) & -1.4 & (1.4) & 0.6 & (2.1) & -2.9 & (2.4) & -2.7 & (1.2) \\
\hline & Malaysia** & 78.7 & (8.0) & 86.5 & (4.9) & 77.4 & (8.2) & 78.2 & (7.8) & 63.5 & (8.8) & 82.9 & (6.1) & c & c & c & c & c & c & c & 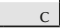 \\
\hline
\end{tabular}

Note: Values that are statistically significant are indicated in bold (see Annex A3).

* See note at the beginning of this Annex.

** Coverage is too small to ensure comparability (see Annex A4).

StatLink ints/ http://dx.doi.org/10.1787/888933471278 
Percentage of students who reported "agree" or "strongly agree" (a) or who reported "disagree" or "strongly disagree" (d)

\begin{tabular}{|c|c|c|c|c|c|c|c|c|c|c|c|c|c|c|c|c|c|c|c|c|c|c|c|}
\hline & \multicolumn{11}{|c|}{$\begin{array}{l}\text { Percentage of students who agreed/disagreed } \\
\text { with the following statements (PISA 2003) }\end{array}$} & \multicolumn{12}{|c|}{$\begin{array}{l}\text { Percentage of students who agreed/disagreed } \\
\text { with the following statements (PISA 2015) }\end{array}$} \\
\hline & \begin{tabular}{|c|} 
I feel like \\
an outsider \\
(or left out \\
of things) \\
at schoold
\end{tabular} & \multicolumn{2}{|c|}{$\begin{array}{c}\text { I make } \\
\text { friends } \\
\text { easily } \\
\text { at schoola }\end{array}$} & \multicolumn{2}{|c|}{$\begin{array}{l}\text { I feel like } \\
\text { I belong } \\
\text { at schoola }\end{array}$} & \multicolumn{2}{|c|}{$\begin{array}{c}\text { I feel } \\
\text { awkward } \\
\text { and out of } \\
\text { place in } \\
\text { my schoold }\end{array}$} & \multicolumn{2}{|c|}{$\begin{array}{l}\text { Other } \\
\text { students } \\
\text { seem } \\
\text { to like me }{ }^{a}\end{array}$} & \multicolumn{2}{|c|}{$\begin{array}{c}\text { I feel } \\
\text { lonely } \\
\text { at schoold }\end{array}$} & \multicolumn{2}{|c|}{\begin{tabular}{|} 
I feel like \\
an outsider \\
(or left out \\
of things) \\
at schoold
\end{tabular}} & \multicolumn{2}{|c|}{$\begin{array}{c}\text { I make } \\
\text { friends } \\
\text { easily } \\
\text { at schoola }\end{array}$} & \multicolumn{2}{|c|}{$\begin{array}{l}\text { I feel like } \\
\text { I belong } \\
\text { at schoola }\end{array}$} & \multicolumn{2}{|c|}{$\begin{array}{c}\text { I feel } \\
\text { awkward } \\
\text { and out of } \\
\text { place in } \\
\text { my schoold }\end{array}$} & \multicolumn{2}{|c|}{$\begin{array}{c}\text { Other } \\
\text { students } \\
\text { seem } \\
\text { to like me } \text { ma }^{\mathrm{a}}\end{array}$} & \multicolumn{2}{|c|}{$\begin{array}{c}\text { I feel } \\
\text { lonely } \\
\text { at schoold }\end{array}$} \\
\hline & $\begin{array}{ll}\% & \text { S.E. }\end{array}$ & $\%$ & S.E. & $\%$ & S.E. & $\%$ & S.E. & $\%$ & S.E. & $\%$ & S.E. & $\%$ & S.E. & $\%$ & S.E. & $\%$ & S.E. & $\%$ & S.E. & $\%$ & S.E. & $\%$ & S.E. \\
\hline Australia & $92.4 \quad(0.3)$ & 91.4 & $(0.3)$ & \begin{tabular}{|l|}
88.1 \\
\end{tabular} & $(0.4)$ & 91.2 & $(0.3)$ & 95.1 & $(0.2)$ & 93.5 & $(0.3)$ & 76.5 & (0.4) & 79.4 & $(0.5)$ & 71.9 & $(0.5)$ & \begin{tabular}{|l|}
78.1 \\
\end{tabular} & $(0.4)$ & \begin{tabular}{|l|}
87.6 \\
\end{tabular} & $(0.3)$ & 83.5 & $(0.4)$ \\
\hline Austria & $94.0(0.5)$ & 90.1 & $(0.4)$ & 88.7 & $(0.6)$ & 91.3 & $(0.6)$ & 78.2 & $(0.8)$ & 92.6 & $(0.4)$ & 86.1 & $(0.5)$ & 77.9 & $(0.6)$ & 76.0 & $(0.5)$ & 82.8 & $(0.5)$ & 83.8 & $(0.5)$ & 84.6 & $(0.5)$ \\
\hline Belgium & $92.3(0.4)$ & 89.3 & $(0.5)$ & 56.1 & $(0.8)$ & 84.5 & $(0.4)$ & 92.0 & $(0.3)$ & 93.9 & $(0.3)$ & 87.1 & $(0.5)$ & 81.8 & $(0.4)$ & 62.0 & $(0.5)$ & 84.2 & $(0.4)$ & 88.2 & $(0.5)$ & 90.5 & $(0.4)$ \\
\hline Canada & $91.3 \quad(0.3)$ & 89.9 & $(0.3)$ & 81.2 & $(0.5)$ & 89.3 & $(0.3)$ & 94.3 & $(0.3)$ & 92.1 & $(0.3)$ & 77.5 & $(0.5)$ & 78.3 & $(0.5)$ & 71.6 & $(0.5)$ & 76.3 & $(0.4)$ & 87.3 & (0.4) & 81.6 & $(0.4)$ \\
\hline Chile & $\mathrm{m} \quad \mathrm{m}$ & $\mathrm{m}$ & $\mathrm{m}$ & $\mathrm{m}$ & $\mathrm{m}$ & $\mathrm{m}$ & $\mathrm{m}$ & $\mathrm{m}$ & $\mathrm{m}$ & $\mathrm{m}$ & $\mathrm{m}$ & 79.9 & $(0.6)$ & 73.2 & $(0.6)$ & 77.3 & $(0.7)$ & 80.0 & $(0.6)$ & 76.0 & $(0.6)$ & 83.1 & $(0.6)$ \\
\hline Czech Republic & $\begin{array}{ll}89.7 & (0.6) \\
\end{array}$ & 89.1 & $(0.5)$ & 77.5 & $(0.7)$ & 93.5 & (0.5) & 87.3 & $(0.5)$ & 92.6 & $(0.4)$ & 79.8 & $(0.5)$ & 75.3 & $(0.7)$ & 70.9 & $(0.7)$ & 81.3 & $(0.5)$ & 81.2 & $(0.6)$ & 81.9 & $(0.6)$ \\
\hline Denmark & $94.8 \quad(0.4)$ & 88.2 & $(0.5)$ & 69.6 & $(0.9)$ & 88.3 & $(0.6)$ & 91.9 & $(0.5)$ & 93.7 & $(0.5)$ & 87.6 & $(0.5)$ & 79.2 & $(0.5)$ & 70.3 & $(0.6)$ & 84.8 & $(0.5)$ & 85.4 & $(0.6)$ & 87.1 & $(0.5)$ \\
\hline Estonia & $\mathrm{m} \quad \mathrm{m}$ & $\mathrm{m}$ & $\mathrm{m}$ & $\mathrm{m}$ & $\mathrm{m}$ & $\mathrm{m}$ & $\mathrm{m}$ & $\mathrm{m}$ & $\mathrm{m}$ & $\mathrm{m}$ & $\mathrm{m}$ & 87.2 & $(0.4)$ & 76.0 & $(0.7)$ & 78.0 & $(0.6)$ & 83.4 & $(0.5)$ & 76.5 & $(0.7)$ & 85.3 & $(0.6)$ \\
\hline Finland & $94.5 \quad(0.3)$ & 87.7 & $(0.5)$ & 88.8 & $(0.5)$ & 91.3 & (0.4) & 87.0 & $(0.5)$ & 93.7 & $(0.4)$ & 87.7 & (0.4) & 79.8 & $(0.5)$ & 80.3 & $(0.6)$ & 82.6 & (0.6) & 82.0 & $(0.5)$ & 88.2 & (0.5) \\
\hline France & $92.1(0.5)$ & 91.7 & $(0.4)$ & 45.5 & (1.0) & 87.7 & (0.6) & 92.6 & (0.5) & 93.8 & $(0.5)$ & 76.8 & $(0.6)$ & 86.3 & (0.5) & 40.9 & $(0.8)$ & 83.7 & (0.5) & 89.7 & $(0.4)$ & 90.6 & $(0.4)$ \\
\hline Germany & $93.8(0.5)$ & 86.4 & $(0.5)$ & 87.1 & $(0.6)$ & 88.4 & (0.5) & 69.9 & (0.8) & 93.8 & $(0.3)$ & 85.5 & $(0.6)$ & 73.3 & $(0.7)$ & 74.9 & $(0.7)$ & 82.4 & (0.6) & 85.0 & $(0.5)$ & 87.3 & $(0.5)$ \\
\hline Greece & $93.6(0.4)$ & 90.6 & $(0.4)$ & 90.9 & (0.5) & 91.8 & (0.4) & 92.2 & (0.4) & 93.4 & $(0.3)$ & 84.4 & (0.6) & 80.2 & $(0.5)$ & 83.0 & $(0.5)$ & 84.5 & (0.5) & 87.4 & $(0.5)$ & 88.0 & $(0.5)$ \\
\hline Hungary & $90.7(0.4)$ & 88.4 & $(0.5)$ & 90.8 & $(0.5)$ & 92.6 & $(0.4)$ & 88.9 & $(0.5)$ & 92.8 & $(0.4)$ & 82.1 & (0.6) & 81.1 & $(0.6)$ & 74.5 & $(0.8)$ & 82.5 & $(0.6)$ & 82.7 & $(0.7)$ & 85.5 & $(0.5)$ \\
\hline Iceland & $90.1(0.5)$ & 84.9 & (0.6) & 88.6 & $(0.5)$ & 89.1 & (0.5) & 89.6 & $(0.5)$ & 89.6 & $(0.5)$ & 82.9 & $(0.6)$ & 76.1 & $(0.7)$ & 78.5 & $(0.7)$ & 80.5 & $(0.7)$ & 82.9 & $(0.6)$ & 83.6 & $(0.6)$ \\
\hline Ireland & $94.3(0.4)$ & 91.5 & $(0.5)$ & 87.9 & $(0.6)$ & 92.2 & (0.4) & 95.4 & $(0.4)$ & 95.4 & $(0.4)$ & 83.3 & (0.6) & \begin{tabular}{|l|}
81.1 \\
\end{tabular} & $(0.5)$ & 73.3 & $(0.8)$ & 82.7 & $(0.6)$ & 90.5 & $(0.5)$ & 87.8 & $(0.5)$ \\
\hline Israel & $\mathrm{m}$ & $\mathrm{m}$ & $\mathrm{m}$ & $\mathrm{m}$ & $\mathrm{m}$ & $\mathrm{m}$ & $\mathrm{m}$ & $\mathrm{m}$ & $\mathrm{m}$ & $\mathrm{m}$ & $\mathrm{m}$ & $\mathrm{m}$ & $\mathrm{m}$ & $\mathrm{m}$ & $\mathrm{m}$ & $\mathrm{m}$ & $\mathrm{m}$ & $\mathrm{m}$ & $\mathrm{m}$ & $\mathrm{m}$ & $\mathrm{m}$ & $\mathrm{m}$ & $\mathrm{m}$ \\
\hline Italy & $95.3 \quad(0.3)$ & 92.2 & $(0.4)$ & 85.5 & $(0.6)$ & 93.9 & (0.4) & 91.6 & $(0.4)$ & 94.2 & $(0.4)$ & 88.9 & $(0.4)$ & 83.0 & $(0.5)$ & 67.3 & $(0.6)$ & 86.3 & $(0.5)$ & 76.6 & (0.6) & 89.5 & $(0.5)$ \\
\hline Japan & $94.2(0.3)$ & 76.9 & $(0.7)$ & 80.4 & $(0.7)$ & 82.2 & $(0.7)$ & 68.7 & $(0.8)$ & 70.6 & $(0.9)$ & 88.1 & $(0.5)$ & 68.8 & $(0.7)$ & 81.9 & $(0.6)$ & 80.5 & $(0.6)$ & 73.8 & (0.6) & 88.5 & $(0.5)$ \\
\hline Korea & $91.5(0.3)$ & 78.7 & $(0.7)$ & 75.8 & $(0.8)$ & 91.4 & $(0.4)$ & 44.8 & $(0.9)$ & 92.9 & $(0.4)$ & 91.3 & $(0.4)$ & 79.3 & $(0.6)$ & 79.5 & $(0.8)$ & 89.9 & $(0.4)$ & 81.9 & (0.6) & 91.7 & $(0.4)$ \\
\hline Latvia & $94.9(0.4)$ & 89.2 & $(0.6)$ & 92.0 & $(0.5)$ & 90.7 & $(0.7)$ & 72.4 & (1.7) & 91.2 & $(0.5)$ & 84.2 & (0.5) & 75.7 & $(0.7)$ & 78.6 & $(0.6)$ & 75.6 & $(0.6)$ & 68.2 & $(0.7)$ & 82.8 & $(0.6)$ \\
\hline Luxembourg & $92.2(0.4)$ & 89.4 & $(0.5)$ & 73.4 & $(0.7)$ & 90.0 & (0.5) & 90.9 & $(0.4)$ & 92.9 & $(0.4)$ & 83.2 & (0.5) & 75.9 & $(0.6)$ & 66.0 & $(0.6)$ & 80.0 & $(0.5)$ & 81.3 & $(0.6)$ & 85.1 & $(0.4)$ \\
\hline Mexico & $90.5(0.6)$ & 87.6 & $(0.6)$ & 92.0 & $(0.5)$ & 89.9 & (0.6) & 89.2 & $(0.6)$ & 89.4 & $(0.5)$ & 75.2 & (0.6) & 72.7 & $(0.5)$ & 76.1 & $(0.7)$ & 76.1 & $(0.6)$ & 72.0 & $(0.7)$ & 79.3 & $(0.5)$ \\
\hline Netherlands & $96.0(0.3)$ & 91.6 & $(0.6)$ & 77.2 & (1.0) & 92.3 & (0.6) & 92.6 & (0.5) & 97.1 & $(0.3)$ & 91.0 & (0.4) & 85.2 & $(0.5)$ & 80.9 & $(0.6)$ & 88.8 & (0.5) & 91.9 & $(0.5)$ & 92.4 & (0.4) \\
\hline New Zeal & $92.1(0.4)$ & 90.9 & $(0.5)$ & 86.0 & $(0.6)$ & 89.4 & (0.5) & 93.8 & $(0.3)$ & 93.4 & $(0.4)$ & 77.7 & $(0.7)$ & 78.9 & $(0.6)$ & 73.7 & $(0.7)$ & 77.9 & $(0.7)$ & 88.2 & $(0.5)$ & 83.1 & $(0.7)$ \\
\hline Norway & $94.5 \quad(0.4)$ & 90.1 & $(0.5)$ & 85.3 & $(0.7)$ & 91.0 & (0.5) & 90.7 & $(0.4)$ & 92.9 & $(0.4)$ & 87.9 & (0.5) & 80.0 & $(0.5)$ & 75.7 & $(0.7)$ & 82.6 & (0.6) & 83.0 & $(0.6)$ & 85.6 & (0.5) \\
\hline Poland & $91.8(0.5)$ & 88.1 & $(0.5)$ & 76.4 & $(0.7)$ & 90.2 & (0.5) & 92.8 & (0.4) & 91.7 & $(0.5)$ & 78.5 & (0.6) & 73.5 & $(0.7)$ & 62.4 & $(0.8)$ & 77.0 & (0.6) & 73.3 & $(0.7)$ & 79.8 & (0.7) \\
\hline Portugal & $94.1(0.6)$ & 93.4 & (0.5) & 93.6 & $(0.5)$ & 88.8 & (0.6) & 90.9 & (0.5) & 95.4 & $(0.4)$ & 87.1 & $(0.4)$ & 77.8 & $(0.6)$ & 82.3 & $(0.5)$ & 75.8 & (0.6) & 87.6 & $(0.5)$ & 88.8 & (0.5) \\
\hline Slovak Republic & $91.9(0.5)$ & 91.7 & $(0.4)$ & 85.2 & $(0.5)$ & 88.6 & $(0.5)$ & 91.0 & $(0.4)$ & 93.1 & $(0.4)$ & 77.3 & $(0.6)$ & 77.0 & $(0.5)$ & 69.7 & $(0.7)$ & 77.5 & $(0.5)$ & 76.7 & $(0.6)$ & 80.6 & $(0.6)$ \\
\hline Slovenia & $\mathrm{m}$ & $\mathrm{m}$ & $\mathrm{m}$ & $\mathrm{m}$ & $\mathrm{m}$ & $\mathrm{m}$ & & $\mathrm{m}$ & $\mathrm{m}$ & $\mathrm{m}$ & $\mathrm{m}$ & 82.4 & $(0.6)$ & 76.8 & $(0.8)$ & 74.5 & $(0.8)$ & 82.5 & $(0.6)$ & 78.5 & $(0.6)$ & 85.4 & $(0.6)$ \\
\hline Spain & $96.3 \quad(0.3)$ & 91.1 & $(0.4)$ & 85.0 & $(0.6)$ & 91.0 & $(0.5)$ & 91.9 & $(0.4)$ & 95.0 & $(0.5)$ & 89.9 & $(0.4)$ & 83.2 & $(0.5)$ & 87.2 & $(0.5)$ & 86.0 & $(0.5)$ & 86.0 & $(0.6)$ & 90.7 & $(0.4)$ \\
\hline Sweden & $94.7 \quad(0.4)$ & 88.5 & (0.6) & 81.1 & $(0.7)$ & 95.0 & $(0.3)$ & 90.8 & $(0.5)$ & 93.3 & $(0.4)$ & 79.4 & $(0.5)$ & 74.9 & $(0.6)$ & 69.3 & $(0.8)$ & 79.6 & $(0.5)$ & 78.4 & $(0.6)$ & 81.0 & $(0.6)$ \\
\hline Switzerla & $92.7 \quad(0.4)$ & 88.3 & $(0.5)$ & 81.8 & (1.5) & 88.3 & $(0.6)$ & 78.5 & $(0.9)$ & 93.6 & $(0.3)$ & 88.3 & $(0.5)$ & 80.6 & $(0.6)$ & 70.8 & $(0.7)$ & 85.1 & (0.6) & 87.5 & (0.5) & 90.1 & $(0.4)$ \\
\hline Turkey & $86.2(0.8)$ & 87.9 & $(0.5)$ & 75.1 & (0.9) & 88.9 & $(0.8)$ & 41.4 & $(0.9)$ & 74.9 & $(0.8)$ & 64.3 & (0.9) & 62.3 & $(0.8)$ & 61.4 & $(0.7)$ & 62.7 & $(0.8)$ & 63.6 & $(0.8)$ & 65.0 & $(0.8)$ \\
\hline United Kit & $93.1 \quad(0.4)$ & 91.5 & (0.5) & 84.6 & $(0.5)$ & 91.4 & $(0.4)$ & 95.2 & $(0.3)$ & 94.5 & $(0.3)$ & 79.9 & $(0.6)$ & 78.7 & $(0.6)$ & 67.8 & $(0.7)$ & 80.1 & (0.6) & 87.7 & $(0.5)$ & 86.4 & $(0.4)$ \\
\hline United States & $\mathrm{m}$ & $\mathrm{m}$ & $\mathrm{m}$ & $\mathrm{m}$ & $\mathrm{m}$ & $\mathrm{m}$ & $\mathrm{m}$ & $\mathrm{m}$ & $\mathrm{m}$ & $\mathrm{m}$ & $\mathrm{m}$ & 76.2 & $(0.6)$ & 78.6 & $(0.6)$ & 74.2 & $(0.7)$ & 77.0 & (0.6) & 88.7 & (0.5) & 81.8 & $(0.6)$ \\
\hline OECD a & $92.9 \quad(0.1)$ & 88.9 & $(0.1)$ & $\mid 81.7$ & $(0.1)$ & 90.1 & $(0.1)$ & 85.4 & $(0.1)$ & 91.9 & $(0.1)$ & 83.0 & $(0.1)$ & 77.9 & $(0.1)$ & 72.6 & $(0.1)$ & 80.9 & $(0.1)$ & 82.4 & (0.1) & 85.4 & $(0.1)$ \\
\hline OECD a & $\mathrm{m}$ & $\mathrm{m}$ & $\mathrm{m}$ & $\mathrm{m}$ & & $\mathrm{m}$ & $\mathrm{m}$ & $\mathrm{m}$ & $\mathrm{m}$ & $\mathrm{m}$ & & 82.8 & $(0.1)$ & 77.7 & $(0.1)$ & 73.0 & $(0.1)$ & 80.9 & $(0.1)$ & 82.1 & $(0.1)$ & 85.2 & $(0.1)$ \\
\hline
\end{tabular}

\begin{tabular}{|c|c|c|c|c|c|c|c|c|c|c|c|c|c|c|c|c|c|c|c|c|c|c|c|c|c|}
\hline \multirow{4}{*}{ 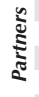 } & Albania & $\mathrm{m}$ & $\mathrm{m}$ & $\mathrm{m}$ & $\mathrm{m}$ & $\mathrm{m}$ & $\mathrm{m}$ & $\mathrm{m}$ & $\mathrm{m}$ & $\mathrm{m}$ & $\mathrm{m}$ & $\mathrm{m}$ & $\mathrm{m}$ & 94.5 & $(0.4)$ & \begin{tabular}{|l|l}
90.2 \\
\end{tabular} & $(0.5)$ & 93.1 & $(0.4)$ & \begin{tabular}{|l|l}
89.2 \\
\end{tabular} & $(0.6)$ & 82.6 & $(0.7)$ & 95.0 & $(0.4)$ \\
\hline & Algeria & $\mathrm{m}$ & $\mathrm{m}$ & $\mathrm{m}$ & $\mathrm{m}$ & $\mathrm{m}$ & $\mathrm{m}$ & $\mathrm{m}$ & $\mathrm{m}$ & $\mathrm{m}$ & $\mathrm{m}$ & $\mathrm{m}$ & $\mathrm{m}$ & 72.3 & $(1.0)$ & 86.4 & $(0.5)$ & 87.4 & $(0.6)$ & 65.5 & $(0.9)$ & 82.8 & $(0.6)$ & 71.4 & $(1.0)$ \\
\hline & Brazil & 93.4 & $(0.5)$ & 91.4 & $(0.5)$ & 92.2 & $(0.5)$ & 89.4 & $(0.5)$ & 92.3 & $(0.5)$ & 92.7 & $(0.5)$ & 79.2 & $(0.4)$ & 73.9 & $(0.5)$ & 76.1 & $(0.5)$ & 81.9 & $(0.4)$ & 81.0 & $(0.4)$ & 80.1 & $(0.4)$ \\
\hline & B-S-J-G (China) & $\mathrm{m}$ & $\mathrm{m}$ & $\mathrm{m}$ & $\mathrm{m}$ & $\mathrm{m}$ & $\mathrm{m}$ & $\mathrm{m}$ & $\mathrm{m}$ & $\mathrm{m}$ & $\mathrm{m}$ & $\mathrm{m}$ & $\mathrm{m}$ & 78.0 & $(0.6)$ & 78.2 & $(0.5)$ & 64.6 & $(0.8)$ & 80.6 & $(0.6)$ & 59.6 & $(0.7)$ & 78.5 & $(0.6)$ \\
\hline & Bulgaria & $\mathrm{m}$ & $\mathrm{m}$ & $\mathrm{m}$ & $\mathrm{m}$ & $\mathrm{m}$ & $\mathrm{m}$ & $\mathrm{m}$ & $\mathrm{m}$ & $\mathrm{m}$ & $\mathrm{m}$ & $\mathrm{m}$ & $\mathrm{m}$ & 70.3 & $(0.8)$ & 74.9 & (0.6) & 68.0 & $(0.6)$ & 72.0 & $(0.9)$ & 71.9 & $(0.7)$ & 75.1 & $(0.8)$ \\
\hline & CABA (Argentina) & $\mathrm{m}$ & $\mathrm{m}$ & $\mathrm{m}$ & $\mathrm{m}$ & $\mathrm{m}$ & $\mathrm{m}$ & $\mathrm{m}$ & $\mathrm{m}$ & $\mathrm{m}$ & $\mathrm{m}$ & $\mathrm{m}$ & $\mathrm{m}$ & 87.5 & (1.0) & 89.3 & (1.1) & 88.7 & (1.1) & 92.4 & $(0.7)$ & 91.7 & (1.0) & 93.8 & (0.6) \\
\hline & Colombia & $\mathrm{m}$ & $\mathrm{m}$ & $\mathrm{m}$ & $\mathrm{m}$ & $\mathrm{m}$ & $\mathrm{m}$ & $\mathrm{m}$ & $\mathrm{m}$ & $\mathrm{m}$ & $\mathrm{m}$ & $\mathrm{m}$ & $\mathrm{m}$ & 71.1 & $(0.7)$ & 70.3 & $(0.6)$ & 74.3 & $(0.6)$ & 72.9 & $(0.6)$ & 68.7 & $(0.5)$ & 74.9 & $(0.6)$ \\
\hline & Costa Rica & $\mathrm{m}$ & $\mathrm{m}$ & $\mathrm{m}$ & $\mathrm{m}$ & $\mathrm{m}$ & $\mathrm{m}$ & $\mathrm{m}$ & $\mathrm{m}$ & $\mathrm{m}$ & $\mathrm{m}$ & $\mathrm{m}$ & $\mathrm{m}$ & 73.2 & $(0.6)$ & 71.7 & $(0.7)$ & 74.7 & $(0.6)$ & 74.7 & $(0.7)$ & 72.2 & $(0.7)$ & 77.4 & $(0.5)$ \\
\hline & Croatia & $\mathrm{m}$ & $\mathrm{m}$ & $\mathrm{m}$ & $\mathrm{m}$ & $\mathrm{m}$ & $\mathrm{m}$ & $\mathrm{m}$ & $\mathrm{m}$ & $\mathrm{m}$ & $\mathrm{m}$ & $\mathrm{m}$ & $\mathrm{m}$ & 86.0 & $(0.5)$ & 83.8 & $(0.5)$ & 81.2 & $(0.6)$ & 85.0 & $(0.5)$ & 81.6 & $(0.6)$ & 87.6 & $(0.5)$ \\
\hline & Cyprus* & $\mathrm{m}$ & $\mathrm{m}$ & $\mathrm{m}$ & $\mathrm{m}$ & $\mathrm{m}$ & $\mathrm{m}$ & $\mathrm{m}$ & $\mathrm{m}$ & $\mathrm{m}$ & $\mathrm{m}$ & $\mathrm{m}$ & $\mathrm{m}$ & 82.9 & $(0.5)$ & 80.6 & $(0.5)$ & 80.2 & $(0.5)$ & 83.2 & $(0.5)$ & 85.4 & $(0.5)$ & 86.5 & $(0.4)$ \\
\hline & Dominican Republic & $\mathrm{m}$ & $\mathrm{m}$ & $\mathrm{m}$ & $\mathrm{m}$ & $\mathrm{m}$ & $\mathrm{m}$ & $\mathrm{m}$ & $\mathrm{m}$ & $\mathrm{m}$ & $\mathrm{m}$ & $\mathrm{m}$ & $\mathrm{m}$ & 60.4 & $(0.8)$ & 66.1 & $(0.9)$ & 66.9 & $(0.8)$ & 65.1 & $(0.8)$ & 66.2 & $(0.8)$ & 69.1 & $(0.9)$ \\
\hline & FYROM & $\mathrm{m}$ & $\mathrm{m}$ & $\mathrm{m}$ & $\mathrm{m}$ & $\mathrm{m}$ & $\mathrm{m}$ & $\mathrm{m}$ & $\mathrm{m}$ & $\mathrm{m}$ & $\mathrm{m}$ & $\mathrm{m}$ & $\mathrm{m}$ & 87.9 & $(0.4)$ & 93.5 & $(0.3)$ & 92.1 & $(0.4)$ & 88.8 & $(0.4)$ & 86.5 & $(0.6)$ & 92.4 & $(0.3)$ \\
\hline & Georgia & $\mathrm{m}$ & $\mathrm{m}$ & $\mathrm{m}$ & $\mathrm{m}$ & $\mathrm{m}$ & $\mathrm{m}$ & $\mathrm{m}$ & $\mathrm{m}$ & $\mathrm{m}$ & $\mathrm{m}$ & $\mathrm{m}$ & $\mathrm{m}$ & 95.1 & $(0.4)$ & 94.3 & $(0.4)$ & 64.8 & $(0.8)$ & 94.3 & $(0.3)$ & 75.6 & $(0.8)$ & 95.0 & $(0.4)$ \\
\hline & Hong Kong (China) & 82.3 & (0.6) & 87.7 & $(0.5)$ & 68.1 & $(0.9)$ & 89.6 & (0.6) & 76.6 & $(0.7)$ & 88.5 & $(0.6)$ & 75.3 & $(0.7)$ & 81.0 & $(0.7)$ & 71.1 & $(0.9)$ & 79.0 & (0.6) & 77.9 & $(0.7)$ & 80.7 & $(0.7)$ \\
\hline & Indonesia & 96.1 & $(0.3)$ & 97.7 & $(0.2)$ & 68.1 & (1.3) & 88.7 & $(0.7)$ & 83.3 & $(0.6)$ & 92.7 & $(0.3)$ & 96.3 & $(0.3)$ & 96.4 & $(0.3)$ & 92.3 & $(0.4)$ & 84.1 & $(0.7)$ & 84.3 & $(0.7)$ & 94.0 & $(0.4)$ \\
\hline & Jordan & $\mathrm{m}$ & $\mathrm{m}$ & $\mathrm{m}$ & $\mathrm{m}$ & $\mathrm{m}$ & $\mathrm{m}$ & $\mathrm{m}$ & $\mathrm{m}$ & $\mathrm{m}$ & $\mathrm{m}$ & $\mathrm{m}$ & $\mathrm{m}$ & 76.8 & $(0.7)$ & 90.9 & $(0.5)$ & 85.9 & $(0.6)$ & 75.7 & (0.6) & 90.9 & $(0.5)$ & 87.0 & $(0.5)$ \\
\hline & Kosovo & $\mathrm{m}$ & $\mathrm{m}$ & $\mathrm{m}$ & $\mathrm{m}$ & $\mathrm{m}$ & $\mathrm{m}$ & $\mathrm{m}$ & $\mathrm{m}$ & $\mathrm{m}$ & $\mathrm{m}$ & $\mathrm{m}$ & $\mathrm{m}$ & 86.8 & (0.6) & 91.4 & $(0.5)$ & 92.5 & $(0.5)$ & 85.4 & (0.6) & 85.4 & $(0.6)$ & 92.9 & $(0.4)$ \\
\hline & Lebanon & $\mathrm{m}$ & $\mathrm{m}$ & $\mathrm{m}$ & $\mathrm{m}$ & $\mathrm{m}$ & $\mathrm{m}$ & $\mathrm{m}$ & $\mathrm{m}$ & $\mathrm{m}$ & $\mathrm{m}$ & $\mathrm{m}$ & $\mathrm{m}$ & 74.9 & (1.4) & 89.7 & (0.6) & 74.9 & (1.2) & 75.4 & (1.1) & 77.6 & $(1.2)$ & 84.7 & (1.0) \\
\hline & Lithu & $\mathrm{m}$ & & $\mathrm{m}$ & $\mathrm{m}$ & $\mathrm{m}$ & $\mathrm{m}$ & $\mathrm{m}$ & $\mathrm{m}$ & $\mathrm{m}$ & $\mathrm{m}$ & $\mathrm{m}$ & $\mathrm{m}$ & 69.3 & $(0.7)$ & 64.5 & $(0.7)$ & 54.5 & $(0.8)$ & 66.2 & (0.8) & 62.6 & $(0.8)$ & 69.0 & $(0.7)$ \\
\hline & Macao (Chin & 84.3 & (1.1) & 83.6 & (1.1) & 65.1 & (1.7) & 86.2 & $(1.2)$ & 72.4 & (1.3) & 84.8 & (1.3) & 79.3 & (0.6) & 76.1 & (0.6) & 59.9 & $(0.8)$ & 77.7 & (0.6) & 65.9 & $(0.7)$ & 80.0 & $(0.7)$ \\
\hline & Malta & $\mathrm{m}$ & $\mathrm{m}$ & $\mathrm{m}$ & $\mathrm{m}$ & $\mathrm{m}$ & $\mathrm{m}$ & $\mathrm{m}$ & $\mathrm{m}$ & $\mathrm{m}$ & $\mathrm{m}$ & $\mathrm{m}$ & $\mathrm{m}$ & 79.6 & $(0.7)$ & 81.9 & $(0.7)$ & 69.8 & $(0.8)$ & 82.3 & $(0.7)$ & 88.1 & $(0.5)$ & 88.7 & (0.5) \\
\hline & Moldova & $\mathrm{m}$ & $\mathrm{m}$ & $\mathrm{m}$ & $\mathrm{m}$ & $\mathrm{m}$ & $\mathrm{m}$ & $\mathrm{m}$ & $\mathrm{m}$ & $\mathrm{m}$ & $\mathrm{m}$ & $\mathrm{m}$ & $\mathrm{m}$ & 91.1 & $(0.5)$ & 90.6 & $(0.5)$ & 67.7 & $(0.9)$ & 89.3 & (0.4) & 84.3 & (0.6) & 88.5 & (0.4) \\
\hline & Montenegro & $\mathrm{m}$ & $\mathrm{m}$ & $\mathrm{m}$ & $\mathrm{m}$ & $\mathrm{m}$ & $\mathrm{m}$ & $\mathrm{m}$ & $\mathrm{m}$ & $\mathrm{m}$ & $\mathrm{m}$ & $\mathrm{m}$ & $\mathrm{m}$ & 82.8 & (0.5) & 83.3 & $(0.5)$ & 53.8 & $(0.8)$ & 82.5 & (0.6) & 79.7 & $(0.5)$ & 86.3 & $(0.4)$ \\
\hline & Peru & $\mathrm{m}$ & $\mathrm{m}$ & $\mathrm{m}$ & $\mathrm{m}$ & $\mathrm{m}$ & $\mathrm{m}$ & $\mathrm{m}$ & $\mathrm{m}$ & $\mathrm{m}$ & $\mathrm{m}$ & $\mathrm{m}$ & $\mathrm{m}$ & 79.4 & $(0.7)$ & 75.9 & $(0.6)$ & 71.4 & $(0.6)$ & 76.0 & $(0.7)$ & 77.2 & $(0.6)$ & 82.5 & $(0.6)$ \\
\hline & Qatar & $\mathrm{m}$ & $\mathrm{m}$ & $\mathrm{m}$ & $\mathrm{m}$ & $\mathrm{m}$ & $\mathrm{m}$ & $\mathrm{m}$ & $\mathrm{m}$ & $\mathrm{m}$ & $\mathrm{m}$ & $\mathrm{m}$ & $\mathrm{m}$ & 75.6 & $(0.4)$ & 77.8 & (0.4) & 70.7 & $(0.4)$ & 76.1 & $(0.4)$ & 82.9 & $(0.4)$ & 80.5 & (0.4) \\
\hline & Romania & $\mathrm{m}$ & $\mathrm{m}$ & $\mathrm{m}$ & $\mathrm{m}$ & $\mathrm{m}$ & $\mathrm{m}$ & $\mathrm{m}$ & $\mathrm{m}$ & $\mathrm{m}$ & $\mathrm{m}$ & $\mathrm{m}$ & $\mathrm{m}$ & 87.8 & (1.1) & 92.4 & $(0.5)$ & 52.5 & (1.1) & 84.4 & $(0.8)$ & 86.8 & $(0.8)$ & 85.9 & (1.0) \\
\hline & Russia & 93.8 & (0.4) & 87.6 & $(0.5)$ & 92.1 & $(0.6)$ & 85.2 & $(0.6)$ & 50.8 & $(1.0)$ & 91.1 & $(0.5)$ & 80.4 & $(0.7)$ & 73.1 & $(0.7)$ & 74.6 & $(0.6)$ & 72.9 & $(0.6)$ & 64.3 & $(0.7)$ & 79.1 & $(0.6)$ \\
\hline & Singapore & $\mathrm{m}$ & $\mathrm{m}$ & $\mathrm{m}$ & $\mathrm{m}$ & $\mathrm{m}$ & $\mathrm{m}$ & $\mathrm{m}$ & $\mathrm{m}$ & $\mathrm{m}$ & $\mathrm{m}$ & $\mathrm{m}$ & $\mathrm{m}$ & 76.5 & (0.6) & 80.2 & $(0.6)$ & 76.0 & $(0.6)$ & 76.5 & (0.6) & 81.2 & $(0.5)$ & 82.1 & (0.6) \\
\hline & Chinese Ta & $\mathrm{m}$ & $\mathrm{m}$ & $\mathrm{m}$ & $\mathrm{m}$ & $\mathrm{m}$ & $\mathrm{m}$ & $\mathrm{m}$ & $\mathrm{m}$ & $\mathrm{m}$ & $\mathrm{m}$ & $\mathrm{m}$ & $\mathrm{m}$ & 88.7 & $(0.3)$ & 85.1 & $(0.4)$ & 89.9 & $(0.3)$ & 83.0 & $(0.5)$ & 72.2 & $(0.5)$ & 87.7 & $(0.4)$ \\
\hline & Thailand & 93.6 & (0.5) & 94.7 & $(0.4)$ & 95.4 & $(0.4)$ & 84.9 & $(0.6)$ & 79.7 & $(0.7)$ & 88.9 & $(0.6)$ & 79.7 & $(0$. & 82.5 & $(0.5)$ & 78.4 & $(0.6)$ & 67.6 & (0.9) & 61.6 & $(0.8)$ & 81.7 & $(0.7)$ \\
\hline & Trinidad and Tobago & $\mathrm{m}$ & $\mathrm{m}$ & $\mathrm{m}$ & $\mathrm{m}$ & $\mathrm{m}$ & $\mathrm{m}$ & $\mathrm{m}$ & $\mathrm{m}$ & $\mathrm{m}$ & $\mathrm{m}$ & $\mathrm{m}$ & $\mathrm{m}$ & 81.9 & $(0.6)$ & 85.9 & $(0.6)$ & 79.7 & $(0.6)$ & 82.1 & $(0.6)$ & 85.3 & $(0.5)$ & 85.8 & $(0.6)$ \\
\hline & Tunisia & 90.5 & (0.6) & 88.2 & $(0.5)$ & 58.2 & $(1.2)$ & 82.7 & $(0.8)$ & 89.1 & $(0.5)$ & 89.2 & $(0.6)$ & 80.1 & $(0.8)$ & 83.4 & (0.6) & 57.6 & $(0.7)$ & 63.0 & $(0.8)$ & 80.3 & $(0.5)$ & 85.0 & (0.6) \\
\hline & Unite & $\mathrm{m}$ & $\mathrm{m}$ & $\mathrm{m}$ & $\mathrm{m}$ & $\mathrm{m}$ & $\mathrm{m}$ & $\mathrm{m}$ & $\mathrm{m}$ & $\mathrm{m}$ & $\mathrm{m}$ & $\mathrm{m}$ & $\mathrm{m}$ & 78.7 & $(0.5)$ & 79.8 & $(0.5)$ & 73.9 & $(0.6)$ & 75.3 & $(0.6)$ & 79.1 & $(0.5)$ & 82.6 & $(0.4)$ \\
\hline & Uruge & 92.7 & $(0.4)$ & 89.9 & $(0.5)$ & 92.8 & $(0.4)$ & 92.8 & $(0.5)$ & 92.8 & $(0.5)$ & 93.5 & $(0.4)$ & 76.2 & $(0.6)$ & 73.1 & $(0.6)$ & 77.9 & $(0.6)$ & 79.3 & $(0.6)$ & 85.6 & $(0.5)$ & 79.4 & $(0.6)$ \\
\hline & Viet Nam & $\mathrm{m}$ & $\mathrm{m}$ & $\mathrm{m}$ & $\mathrm{m}$ & $\mathrm{m}$ & $\mathrm{m}$ & $\mathrm{m}$ & $\mathrm{m}$ & $\mathrm{m}$ & $\mathrm{m}$ & $\mathrm{m}$ & $\mathrm{m}$ & 95.3 & $(0.4)$ & 91.6 & $(0.5)$ & 80.8 & $(0.7)$ & 82.7 & (0.6) & 42.6 & $(0.9)$ & 92.5 & $(0.6)$ \\
\hline & Arger & $\mathrm{m}$ & $\mathrm{m}$ & $\mathrm{m}$ & $\mathrm{m}$ & $\mathrm{m}$ & $\mathrm{m}$ & $\mathrm{m}$ & $\mathrm{m}$ & $\mathrm{m}$ & $\mathrm{m}$ & $\mathrm{n}$ & $\mathrm{m}$ & 75.4 & (1.0) & 89.0 & $(0.5)$ & 89.5 & $(0.5)$ & 88.7 & $(0.5)$ & 87.3 & $(0.6)$ & 91.3 & $(0.4)$ \\
\hline & Kazakhstan** & $\mathrm{m}$ & $\mathrm{m}$ & $\mathrm{m}$ & $\mathrm{m}$ & $\mathrm{m}$ & $\mathrm{m}$ & $\mathrm{m}$ & $\mathrm{m}$ & $\mathrm{m}$ & $\mathrm{m}$ & $\mathrm{m}$ & $\mathrm{m}$ & 94.2 & $(0.4)$ & 92.0 & $(0.5)$ & 85.0 & (0.6) & 92.6 & $(0.4)$ & 87.1 & (0.6) & 92.9 & $(0.4)$ \\
\hline & Malaysia** & $\mathrm{m}$ & $\mathrm{m}$ & $\mathrm{m}$ & $\mathrm{m}$ & $\mathrm{m}$ & $\mathrm{m}$ & $\mathrm{m}$ & $\mathrm{m}$ & $\mathrm{m}$ & $\mathrm{m}$ & $\mathrm{m}$ & $\mathrm{m}$ & 83.8 & $(0.7)$ & 87.5 & (0.6) & 77.1 & $(0.7)$ & 82.8 & $(0.8)$ & 76.7 & $(0.7)$ & 83.1 & (0.6) \\
\hline
\end{tabular}

1. "OECD average-30" includes all OECD countries with available data for both years.

Note: Values that are statistically significant are indicated in bold (see Annex A3).

* See note at the beginning of this Annex.

** Coverage is too small to ensure comparability (see Annex A4).

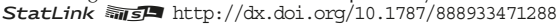


[Part 2/2]

Table III.7.4 Change between 2003 and 2015 in students' sense of belonging

Percentage of students who reported "agree" or "strongly agree" (a) or who reported "disagree" or "strongly disagree" (d)

\begin{tabular}{|c|c|c|c|c|c|c|c|c|c|c|c|c|c|}
\hline & \multicolumn{12}{|c|}{ Change between 2003 and 2015 in the percentage of students who agreed/disagreed with the following statements (PISA 2015 - PISA 2003) } \\
\hline & & \multicolumn{2}{|c|}{$\begin{array}{c}\text { I feel like an outsider } \\
\text { (or left out of things) } \\
\text { at schoold }^{\mathbf{d}}\end{array}$} & \multicolumn{2}{|c|}{$\begin{array}{l}\text { I make friends easily } \\
\text { at school }\end{array}$} & $\begin{array}{r}\text { I feel lil } \\
\text { at } s\end{array}$ & $\begin{array}{l}\text { belong } \\
\text { ola }^{\mathbf{a}}\end{array}$ & $\begin{array}{l}\text { I feel } \\
\text { and o } \\
\text { in } \mathrm{m}\end{array}$ & $\begin{array}{l}\text { ward } \\
\text { place } \\
\text { oold }^{\mathrm{d}}\end{array}$ & $\begin{array}{l}\text { Other st } \\
\text { to I }\end{array}$ & $\begin{array}{l}\text { its seem } \\
\text { ne }^{\mathrm{a}}\end{array}$ & $\begin{array}{l}\text { I fee } \\
\text { at s }\end{array}$ & $\begin{array}{l}\text { eely } \\
\text { old }^{d}\end{array}$ \\
\hline & & $\%$ dif. & S.E. & $\%$ dif. & S.E. & $\%$ dif. & S.E. & $\%$ dif. & S.E. & $\%$ dif. & S.E. & $\%$ dif. & S.E. \\
\hline 0 & Australia & -15.9 & $(0.5)$ & -12.1 & $(0.5)$ & -16.2 & $(0.6)$ & -13.1 & $(0.5)$ & -7.6 & $(0.4)$ & -10.0 & $(0.5)$ \\
\hline ర్తు & Austria & -7.9 & $(0.7)$ & -12.1 & $(0.7)$ & -12.7 & $(0.8)$ & -8.5 & $(0.8)$ & 5.6 & $(0.9)$ & -8.0 & $(0.7)$ \\
\hline పే & Belgium & -5.2 & $(0.6)$ & -7.5 & $(0.6)$ & 5.9 & $(0.9)$ & -0.3 & $(0.6)$ & -3.9 & $(0.6)$ & -3.4 & $(0.5)$ \\
\hline & Canada & -13.9 & $(0.6)$ & -11.6 & $(0.6)$ & -9.6 & $(0.7)$ & -13.0 & $(0.5)$ & -6.9 & $(0.4)$ & -10.5 & $(0.5)$ \\
\hline & Chile & $\mathrm{m}$ & $\mathrm{m}$ & $\mathrm{m}$ & $\mathrm{m}$ & $\mathrm{m}$ & $\mathrm{m}$ & $\mathrm{m}$ & $\mathrm{m}$ & $\mathrm{m}$ & $\mathrm{m}$ & $\mathrm{m}$ & $\mathrm{m}$ \\
\hline & Czech Republic & -10.0 & $(0.8)$ & -13.8 & $(0.9)$ & -6.6 & (1.0) & -12.2 & $(0.7)$ & -6.1 & $(0.8)$ & -10.7 & $(0.7)$ \\
\hline & Denmark & -7.2 & (0.6) & -9.0 & $(0.8)$ & 0.7 & (1.1) & -3.4 & $(0.7)$ & -6.5 & $(0.8)$ & -6.6 & $(0.7)$ \\
\hline & Estonia & $\mathrm{m}$ & $\mathrm{m}$ & $\mathrm{m}$ & $\mathrm{m}$ & $\mathrm{m}$ & $\mathrm{m}$ & $\mathrm{m}$ & $\mathrm{m}$ & $\mathrm{m}$ & $\mathrm{m}$ & $\mathrm{m}$ & $\mathrm{m}$ \\
\hline & Finland & -6.9 & $(0.5)$ & -7.9 & $(0.7)$ & -8.6 & $(0.8)$ & -8.7 & $(0.7)$ & -5.0 & $(0.8)$ & -5.5 & $(0.6)$ \\
\hline & France & -15.2 & $(0.8)$ & -5.4 & $(0.6)$ & -4.6 & (1.3) & -4.0 & $(0.8)$ & -2.8 & $(0.6)$ & -3.1 & $(0.6)$ \\
\hline & Germany & -8.4 & $(0.8)$ & -13.1 & $(0.9)$ & -12.3 & (0.9) & -6.0 & $(0.8)$ & 15.1 & (0.9) & -6.4 & $(0.6)$ \\
\hline & Greece & -9.2 & $(0.7)$ & -10.4 & $(0.7)$ & -7.9 & $(0.7)$ & -7.3 & $(0.7)$ & -4.8 & $(0.6)$ & -5.4 & $(0.6)$ \\
\hline & Hungary & -8.6 & $(0.7)$ & -7.3 & $(0.7)$ & -16.3 & $(0.9)$ & -10.1 & $(0.7)$ & -6.2 & $(0.9)$ & -7.3 & $(0.6)$ \\
\hline & Iceland & -7.2 & $(0.8)$ & -8.8 & $(0.9)$ & -10.1 & $(0.8)$ & -8.6 & (0.9) & -6.7 & $(0.8)$ & -6.0 & $(0.8)$ \\
\hline & Ireland & -11.0 & $(0.7)$ & -10.3 & $(0.7)$ & -14.6 & $(1.0)$ & -9.5 & $(0.8)$ & -4.8 & $(0.6)$ & -7.6 & $(0.6)$ \\
\hline & Israel & $\mathrm{m}$ & $\mathrm{m}$ & $\mathrm{m}$ & $\mathrm{m}$ & $\mathrm{m}$ & $\mathrm{m}$ & $\mathrm{m}$ & $\mathrm{m}$ & $\mathrm{m}$ & $\mathrm{m}$ & $\mathrm{m}$ & $\mathrm{m}$ \\
\hline & Italy & -6.4 & $(0.5)$ & -9.2 & $(0.6)$ & -18.1 & $(0.9)$ & -7.6 & $(0.7)$ & -14.9 & $(0.7)$ & -4.7 & $(0.6)$ \\
\hline & Japan & -6.2 & (0.6) & -8.1 & $(1.0)$ & 1.5 & $(0.9)$ & -1.7 & $(0.9)$ & 5.1 & (1.0) & 17.9 & (1.0) \\
\hline & Korea & -0.2 & $(0.5)$ & 0.5 & $(0.9)$ & 3.7 & (1.1) & -1.6 & $(0.5)$ & 37.2 & (1.1) & -1.2 & $(0.5)$ \\
\hline & Latvia & -10.7 & (0.6) & -13.5 & $(0.9)$ & -13.4 & $(0.8)$ & -15.2 & $(0.9)$ & -4.2 & (1.8) & -8.4 & $(0.8)$ \\
\hline & Luxembourg & -9.0 & $(0.6)$ & -13.5 & $(0.8)$ & -7.4 & $(0.9)$ & -10.1 & $(0.7)$ & -9.6 & $(0.7)$ & -7.9 & $(0.6)$ \\
\hline & Mexico & -15.4 & (0.9) & -14.9 & $(0.8)$ & -15.9 & $(0.9)$ & -13.8 & $(0.9)$ & -17.2 & (0.9) & -10.1 & $(0.7)$ \\
\hline & Netherlands & -5.0 & $(0.5)$ & -6.4 & $(0.8)$ & 3.8 & (1.1) & -3.5 & $(0.8)$ & -0.7 & $(0.7)$ & -4.7 & $(0.5)$ \\
\hline & New Zealand & -14.5 & $(0.8)$ & -11.9 & $(0.8)$ & -12.3 & (0.9) & -11.5 & $(0.9)$ & -5.5 & $(0.6)$ & -10.3 & $(0.8)$ \\
\hline & Norway & -6.6 & $(0.7)$ & -10.1 & $(0.7)$ & -9.5 & $(1.0)$ & -8.5 & $(0.8)$ & -7.8 & $(0.7)$ & -7.3 & $(0.7)$ \\
\hline & Poland & -13.3 & $(0.8)$ & -14.6 & $(0.9)$ & -14.0 & (1.0) & -13.2 & $(0.8)$ & -19.5 & $(0.8)$ & -11.9 & $(0.8)$ \\
\hline & Portugal & -7.0 & $(0.7)$ & -15.6 & $(0.8)$ & -11.3 & $(0.7)$ & -13.0 & $(0.8)$ & -3.3 & $(0.7)$ & -6.5 & $(0.6)$ \\
\hline & Slovak Republic & -14.6 & $(0.8)$ & -14.7 & $(0.7)$ & -15.5 & (0.9) & -11.1 & $(0.7)$ & -14.3 & $(0.7)$ & -12.5 & $(0.7)$ \\
\hline & Slovenia & $\mathrm{m}$ & $\mathrm{m}$ & $\mathrm{m}$ & $\mathrm{m}$ & $\mathrm{m}$ & $\mathrm{m}$ & $\mathrm{m}$ & $\mathrm{m}$ & m & $\mathrm{m}$ & $\mathrm{m}$ & m \\
\hline & Spain & -6.4 & (0.5) & -7.8 & $(0.7)$ & 2.2 & $(0.8)$ & -5.0 & $(0.7)$ & -5.9 & $(0.7)$ & -4.3 & $(0.6)$ \\
\hline & Sweden & -15.3 & $(0.7)$ & -13.6 & $(0.8)$ & -11.8 & (1.0) & -15.4 & $(0.6)$ & -12.4 & $(0.8)$ & -12.3 & $(0.7)$ \\
\hline & Switzerland & -4.4 & $(0.6)$ & -7.7 & $(0.8)$ & -11.0 & (1.6) & -3.1 & $(0.8)$ & 8.9 & (1.0) & -3.5 & $(0.5)$ \\
\hline & Turkey & -21.9 & (1.2) & -25.7 & (1.0) & -13.8 & (1.1) & -26.2 & (1.1) & 22.2 & $(1.2)$ & -9.9 & (1.1) \\
\hline & United Kingdom & -13.1 & $(0.7)$ & -12.8 & $(0.7)$ & -16.8 & $(0.9)$ & -11.2 & $(0.7)$ & -7.5 & $(0.6)$ & -8.1 & $(0.6)$ \\
\hline & United States & $\mathrm{m}$ & $\mathrm{m}$ & $\mathrm{m}$ & $\mathrm{m}$ & $\mathrm{m}$ & $\mathrm{m}$ & $\mathrm{m}$ & $\mathrm{m}$ & $\mathrm{m}$ & $\mathrm{m}$ & $\mathrm{m}$ & $\mathrm{m}$ \\
\hline & OECD average- $30^{1}$ & -9.9 & $(0.1)$ & -11.0 & $(0.1)$ & -9.1 & $(0.2)$ & -9.2 & $(0.1)$ & -3.0 & $(0.2)$ & -6.5 & $(0.1)$ \\
\hline & OECD average-35 & $\mathrm{m}$ & $\mathrm{m}$ & $\mathrm{m}$ & $\mathrm{m}$ & $\mathrm{m}$ & $\mathrm{m}$ & $\mathrm{m}$ & $\mathrm{m}$ & $\mathrm{m}$ & $\mathrm{m}$ & $\mathrm{m}$ & $\mathrm{m}$ \\
\hline$n$ & Albania & $\mathrm{m}$ & $\mathrm{m}$ & $\mathrm{m}$ & $\mathrm{m}$ & $\mathrm{m}$ & $\mathrm{m}$ & $\mathrm{m}$ & $\mathrm{m}$ & $\mathrm{m}$ & $\mathrm{m}$ & $\mathrm{m}$ & $\mathrm{m}$ \\
\hline ఏ & Algeria & $\mathrm{m}$ & $\mathrm{m}$ & $\mathrm{m}$ & $\mathrm{m}$ & $\mathrm{m}$ & $\mathrm{m}$ & $\mathrm{m}$ & $\mathrm{m}$ & $\mathrm{m}$ & $\mathrm{m}$ & $\mathrm{m}$ & $\mathrm{m}$ \\
\hline$\frac{\pi}{\pi}$ & Brazil & -14.2 & $(0.7)$ & -17.4 & $(0.7)$ & -16.1 & $(0.7)$ & -7.5 & $(0.6)$ & -11.3 & $(0.6)$ & -12.5 & $(0.6)$ \\
\hline & B-S-J-G (China) & $\mathrm{m}$ & $\mathrm{m}$ & $\mathrm{m}$ & $\mathrm{m}$ & $\mathrm{m}$ & $\mathrm{m}$ & $\mathrm{m}$ & $\mathrm{m}$ & $\mathrm{m}$ & $\mathrm{m}$ & $\mathrm{m}$ & $\mathrm{m}$ \\
\hline & Bulgaria & $\mathrm{m}$ & $\mathrm{m}$ & $\mathrm{m}$ & $\mathrm{m}$ & $\mathrm{m}$ & $\mathrm{m}$ & $\mathrm{m}$ & $\mathrm{m}$ & $\mathrm{m}$ & $\mathrm{m}$ & $\mathrm{m}$ & $\mathrm{m}$ \\
\hline & CABA (Argentina) & $\mathrm{m}$ & $\mathrm{m}$ & $\mathrm{m}$ & $\mathrm{m}$ & $\mathrm{m}$ & $\mathrm{m}$ & $\mathrm{m}$ & $\mathrm{m}$ & $\mathrm{m}$ & $\mathrm{m}$ & $\mathrm{m}$ & $\mathrm{m}$ \\
\hline & Colombia & $\mathrm{m}$ & $\mathrm{m}$ & $\mathrm{m}$ & $\mathrm{m}$ & $\mathrm{m}$ & $\mathrm{m}$ & $\mathrm{m}$ & $\mathrm{m}$ & $\mathrm{m}$ & $\mathrm{m}$ & $\mathrm{m}$ & $\mathrm{m}$ \\
\hline & Costa Rica & $\mathrm{m}$ & $\mathrm{m}$ & $\mathrm{m}$ & $\mathrm{m}$ & $\mathrm{m}$ & $\mathrm{m}$ & $\mathrm{m}$ & $\mathrm{m}$ & $\mathrm{m}$ & $\mathrm{m}$ & $\mathrm{m}$ & $\mathrm{m}$ \\
\hline & Croatia & $\mathrm{m}$ & $\mathrm{m}$ & $\mathrm{m}$ & $\mathrm{m}$ & $\mathrm{m}$ & $\mathrm{m}$ & $\mathrm{m}$ & $\mathrm{m}$ & $\mathrm{m}$ & $\mathrm{m}$ & $\mathrm{m}$ & $\mathrm{m}$ \\
\hline & Cyprus* & $\mathrm{m}$ & $\mathrm{m}$ & $\mathrm{m}$ & $\mathrm{m}$ & $\mathrm{m}$ & $\mathrm{m}$ & $\mathrm{m}$ & $\mathrm{m}$ & $\mathrm{m}$ & $\mathrm{m}$ & $\mathrm{m}$ & $\mathrm{m}$ \\
\hline & Dominican Republic & $\mathrm{m}$ & $\mathrm{m}$ & $\mathrm{m}$ & $\mathrm{m}$ & $\mathrm{m}$ & $\mathrm{m}$ & $\mathrm{m}$ & $\mathrm{m}$ & $\mathrm{m}$ & $\mathrm{m}$ & $\mathrm{m}$ & $\mathrm{m}$ \\
\hline & FYROM & $\mathrm{m}$ & $\mathrm{m}$ & $\mathrm{m}$ & $\mathrm{m}$ & $\mathrm{m}$ & $\mathrm{m}$ & $\mathrm{m}$ & $\mathrm{m}$ & $\mathrm{m}$ & $\mathrm{m}$ & $\mathrm{m}$ & $\mathrm{m}$ \\
\hline & Georgia & $\mathrm{m}$ & $\mathrm{m}$ & $\mathrm{m}$ & $\mathrm{m}$ & $\mathrm{m}$ & $\mathrm{m}$ & $\mathrm{m}$ & $\mathrm{m}$ & $\mathrm{m}$ & $\mathrm{m}$ & $\mathrm{m}$ & $\mathrm{m}$ \\
\hline & Hong Kong (China) & -7.0 & (0.9) & -6.6 & $(0.9)$ & 3.0 & (1.3) & -10.6 & $(0.8)$ & 1.2 & $(1.0)$ & -7.9 & $(0.9)$ \\
\hline & Indonesia & 0.2 & $(0.4)$ & -1.3 & $(0.3)$ & 24.2 & (1.4) & -4.7 & (1.0) & 1.0 & $(0.9)$ & 1.2 & $(0.5)$ \\
\hline & Jordan & $\mathrm{m}$ & $\mathrm{m}$ & $\mathrm{m}$ & $\mathrm{m}$ & $\mathrm{m}$ & $\mathrm{m}$ & $\mathrm{m}$ & $\mathrm{m}$ & $\mathrm{m}$ & $\mathrm{m}$ & $\mathrm{m}$ & $\mathrm{m}$ \\
\hline & Kosovo & $\mathrm{m}$ & $\mathrm{m}$ & $\mathrm{m}$ & $\mathrm{m}$ & $\mathrm{m}$ & $\mathrm{m}$ & $\mathrm{m}$ & $\mathrm{m}$ & $\mathrm{m}$ & $\mathrm{m}$ & $\mathrm{m}$ & $\mathrm{m}$ \\
\hline & Lebanon & $\mathrm{m}$ & $\mathrm{m}$ & $\mathrm{m}$ & $\mathrm{m}$ & $\mathrm{m}$ & $\mathrm{m}$ & $\mathrm{m}$ & $\mathrm{m}$ & $\mathrm{m}$ & $\mathrm{m}$ & $\mathrm{m}$ & $\mathrm{m}$ \\
\hline & Lithuania & $\mathrm{m}$ & $\mathrm{m}$ & $\mathrm{m}$ & $\mathrm{m}$ & $\mathrm{m}$ & $\mathrm{m}$ & $\mathrm{m}$ & $\mathrm{m}$ & $\mathrm{m}$ & $\mathrm{m}$ & $\mathrm{m}$ & $\mathrm{m}$ \\
\hline & Macao (China) & -5.1 & $(1.3)$ & -7.5 & $(1.3)$ & -5.2 & (1.9) & -8.5 & $(1.3)$ & -6.5 & (1.5) & -4.8 & (1.4) \\
\hline & Malta & $\mathrm{m}$ & $\mathrm{m}$ & $\mathrm{m}$ & $\mathrm{m}$ & $\mathrm{m}$ & $\mathrm{m}$ & $\mathrm{m}$ & $\mathrm{m}$ & $\mathrm{m}$ & $\mathrm{m}$ & $\mathrm{m}$ & $\mathrm{m}$ \\
\hline & Moldova & $\mathrm{m}$ & $\mathrm{m}$ & $\mathrm{m}$ & $\mathrm{m}$ & $\mathrm{m}$ & $\mathrm{m}$ & $\mathrm{m}$ & $\mathrm{m}$ & $\mathrm{m}$ & $\mathrm{m}$ & $\mathrm{m}$ & $\mathrm{m}$ \\
\hline & Montenegro & $\mathrm{m}$ & $\mathrm{m}$ & $\mathrm{m}$ & $\mathrm{m}$ & $\mathrm{m}$ & $\mathrm{m}$ & $\mathrm{m}$ & $\mathrm{m}$ & $\mathrm{m}$ & $\mathrm{m}$ & $\mathrm{m}$ & $\mathrm{m}$ \\
\hline & Peru & $\mathrm{m}$ & $\mathrm{m}$ & $\mathrm{m}$ & $\mathrm{m}$ & $\mathrm{m}$ & $\mathrm{m}$ & $\mathrm{m}$ & $\mathrm{m}$ & $\mathrm{m}$ & $\mathrm{m}$ & $\mathrm{m}$ & $\mathrm{m}$ \\
\hline & Qatar & $\mathrm{m}$ & $\mathrm{m}$ & $\mathrm{m}$ & $\mathrm{m}$ & $\mathrm{m}$ & $\mathrm{m}$ & $\mathrm{m}$ & $\mathrm{m}$ & $\mathrm{m}$ & $\mathrm{m}$ & $\mathrm{m}$ & $\mathrm{m}$ \\
\hline & Romania & $\mathrm{m}$ & $\mathrm{m}$ & $\mathrm{m}$ & $\mathrm{m}$ & $\mathrm{m}$ & $\mathrm{m}$ & $\mathrm{m}$ & $\mathrm{m}$ & $\mathrm{m}$ & $\mathrm{m}$ & $\mathrm{m}$ & $\mathrm{m}$ \\
\hline & Russia & -13.3 & $(0.9)$ & -14.5 & $(0.9)$ & -17.5 & $(0.8)$ & -12.4 & $(0.9)$ & 13.5 & $(1.2)$ & -12.1 & $(0.8)$ \\
\hline & Singapore & $\mathrm{m}$ & $\mathrm{m}$ & $\mathrm{m}$ & $\mathrm{m}$ & $\mathrm{m}$ & $\mathrm{m}$ & $\mathrm{m}$ & $\mathrm{m}$ & $\mathrm{m}$ & $\mathrm{m}$ & $\mathrm{m}$ & $\mathrm{m}$ \\
\hline & Chinese Taipei & $\mathrm{m}$ & $\mathrm{m}$ & $\mathrm{m}$ & $\mathrm{m}$ & $\mathrm{m}$ & $\mathrm{m}$ & $\mathrm{m}$ & $\mathrm{m}$ & $\mathrm{m}$ & $\mathrm{m}$ & $\mathrm{m}$ & $\mathrm{m}$ \\
\hline & Thailand & -13.9 & $(0.8)$ & -12.2 & $(0.6)$ & -17.0 & $(0.7)$ & -17.3 & (1.1) & -18.1 & $(1.1)$ & -7.3 & $(0.9)$ \\
\hline & Trinidad and Tobago & $\mathrm{m}$ & $\mathrm{m}$ & $\mathrm{m}$ & $\mathrm{m}$ & $\mathrm{m}$ & $\mathrm{m}$ & $\mathrm{m}$ & $\mathrm{m}$ & $\mathrm{m}$ & $\mathrm{m}$ & $\mathrm{m}$ & $\mathrm{m}$ \\
\hline & Tunisia & -10.3 & (1.0) & -4.8 & $(0.8)$ & -0.6 & (1.4) & -19.7 & (1.1) & -8.7 & $(0.7)$ & -4.2 & $(0.9)$ \\
\hline & United Arab Emirates & $\mathrm{m}$ & $\mathrm{m}$ & $\mathrm{m}$ & $\mathrm{m}$ & $\mathrm{m}$ & $\mathrm{m}$ & $\mathrm{m}$ & $\mathrm{m}$ & $\mathrm{m}$ & $\mathrm{m}$ & $\mathrm{m}$ & $\mathrm{m}$ \\
\hline & Uruguay & -16.5 & $(0.7)$ & -16.8 & $(0.8)$ & -14.9 & $(0.7)$ & -13.6 & $(0.7)$ & -7.2 & $(0.7)$ & -14.0 & $(0.7)$ \\
\hline & Viet Nam & $\mathrm{m}$ & $\mathrm{m}$ & $\mathrm{m}$ & $\mathrm{m}$ & $\mathrm{m}$ & $\mathrm{m}$ & $\mathrm{m}$ & $\mathrm{m}$ & $\mathrm{m}$ & $\mathrm{m}$ & $\mathrm{m}$ & $\mathrm{m}$ \\
\hline & Argentina** & $\mathrm{m}$ & $\mathrm{m}$ & $\mathrm{m}$ & $\mathrm{m}$ & $\mathrm{m}$ & $\mathrm{m}$ & $\mathrm{m}$ & $\mathrm{m}$ & $\mathrm{m}$ & $\mathrm{m}$ & $\mathrm{m}$ & $\mathrm{m}$ \\
\hline & Kazakhstan** & $\mathrm{m}$ & $\mathrm{m}$ & $\mathrm{m}$ & $\mathrm{m}$ & $\mathrm{m}$ & $\mathrm{m}$ & $\mathrm{m}$ & $\mathrm{m}$ & $\mathrm{m}$ & $\mathrm{m}$ & $\mathrm{m}$ & $\mathrm{m}$ \\
\hline & Malaysia** & $\mathrm{m}$ & $\mathrm{m}$ & $\mathrm{m}$ & $\mathrm{m}$ & $\mathrm{m}$ & $\mathrm{m}$ & $\mathrm{m}$ & $\mathrm{m}$ & $\mathrm{m}$ & $\mathrm{m}$ & $\mathrm{m}$ & $\mathrm{m}$ \\
\hline
\end{tabular}

1. "OECD average-30" includes all OECD countries with available data for both years.

Note: Values that are statistically significant are indicated in bold (see Annex A3).

* See note at the beginning of this Annex.

.

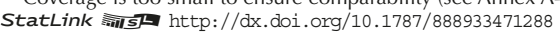


Percentage of students who reported "agree" or "strongly agree" (a) or who reported "disagree" or "strongly disagree" (d)

\begin{tabular}{|c|c|c|c|c|c|c|c|c|c|c|c|c|c|c|c|c|c|c|c|c|}
\hline & & & & & nt & e o & dents & wh & agreed/ & $/ / d$ & & & & & & & centag & of st & ts & swh \\
\hline & & $\begin{array}{l}\text { I fee } \\
\text { an ou } \\
\text { (or le } \\
\text { of th } \\
\text { at sc } \\
\end{array}$ & $\begin{array}{l}\text { llike } \\
\text { utsider } \\
\text { eft out } \\
\text { hings) } \\
\text { hooold }\end{array}$ & & $\begin{array}{l}\text { lake } \\
\text { ends } \\
\text { sily } \\
\text { hoola }\end{array}$ & & $\begin{array}{l}\text { like } \\
\text { ong } \\
\text { oola }\end{array}$ & $\begin{array}{c}\text { If } \\
\text { awk } \\
\text { and } \\
\text { pla } \\
\text { my s }\end{array}$ & $\begin{array}{l}\text { feel } \\
\text { ward } \\
\text { out of } \\
\text { ce in } \\
\text { choold }^{\text {d }}\end{array}$ & $\begin{array}{r}\text { O } \\
\text { stu } \\
\text { to } \mathrm{S}\end{array}$ & $\begin{array}{l}\text { er } \\
\text { ents } \\
m \\
\text { me }^{a}\end{array}$ & & $\begin{array}{c}\text { eel } \\
\text { nely } \\
\text { hoold }\end{array}$ & $\begin{array}{l}\text { I fe } \\
\text { an o } \\
\text { (or } \\
\text { of } t \\
\text { at s }\end{array}$ & $\begin{array}{l}\text { like } \\
\text { sider } \\
\text { t out } \\
\text { ngs) } \\
\text { oold } \\
\end{array}$ & $\begin{array}{r}1 \mathrm{~m} \\
\text { frie } \\
\text { ea } \\
\text { at sc }\end{array}$ & $\begin{array}{l}\text { nake } \\
\text { ends } \\
\text { sily } \\
\text { choola }\end{array}$ & $\begin{array}{l}\text { I fee } \\
\text { I be } \\
\text { at sc }\end{array}$ & $\begin{array}{c}\text { ll like } \\
\text { clong } \\
\text { chooo }\end{array}$ & $\begin{array}{r}\text { I } \\
\text { awl } \\
\text { and } \\
\text { pla } \\
\text { my s }\end{array}$ \\
\hline & & $\%$ & S.E. & $\%$ & S.E. & $\%$ & S.E. & $\%$ & S.E. & $\%$ & S.E. & $\%$ & S.E. & $\%$ & S.E. & $\%$ & S.E. & $\%$ & S.E. & $\%$ \\
\hline & Australia & 85.2 & $(0.5)$ & 85.5 & $(0.4)$ & 78.1 & $(0.5)$ & \begin{tabular}{|l|}
84.9 \\
\end{tabular} & $(0.4)$ & 91.5 & $(0.4)$ & \begin{tabular}{|l|}
88.3 \\
\end{tabular} & $(0.4)$ & 76.5 & $(0.4)$ & 79.4 & $(0.5)$ & 71.9 & $(0.5)$ & 78.1 \\
\hline & Austria & 92.8 & $(0.6)$ & 90.1 & $(0.6)$ & 86.0 & $(0.8)$ & 91.3 & (0.6) & 93.7 & $(0.4)$ & 94.2 & $(0.5)$ & 86.1 & $(0.5)$ & 77.9 & $(0.6)$ & 76.0 & $(0.5)$ & 82.8 \\
\hline & Belgium & 90.4 & $(0.5)$ & 87.8 & $(0.5)$ & 68.4 & $(0.8)$ & 87.8 & $(0.5)$ & 91.6 & $(0.3)$ & 92.7 & $(0.3)$ & 87.1 & $(0.5)$ & 81.8 & $(0.4)$ & 62.0 & $(0.5)$ & 84.2 \\
\hline & Canada & 86.7 & $(0.5)$ & 87.0 & $(0.5)$ & 78.4 & $(0.5)$ & 85.3 & (0.4) & 93.3 & $(0.3)$ & 88.8 & $(0.4)$ & 77.5 & $(0.5)$ & 78.3 & $(0.5)$ & 71.6 & $(0.5)$ & 76.3 \\
\hline & Chile & 86.2 & $(0.7)$ & 85.6 & $(0.6)$ & 87.5 & $(0.6)$ & 85.3 & $(0.8)$ & 88.0 & $(0.6)$ & 91.5 & $(0.5)$ & 79.9 & $(0.6)$ & 73.2 & $(0.6)$ & 77.3 & $(0.7)$ & 80.0 \\
\hline & Czech Republic & 84.7 & $(0.8)$ & 87.5 & $(0.8)$ & 78.1 & (1.1) & 89.9 & $(0.7)$ & 88.6 & $(0.7)$ & 90.2 & $(0.7)$ & 79.8 & $(0.5)$ & 75.3 & $(0.7)$ & 70.9 & $(0.7)$ & 81.3 \\
\hline & Denmark & 93.0 & $(0.5)$ & 84.4 & $(0.6)$ & 77.4 & $(0.8)$ & 90.5 & (0.5) & 87.7 & (0.5) & 92.7 & $(0.5)$ & 87.6 & $(0.5)$ & 79.2 & $(0.5)$ & 70.3 & $(0.6)$ & 84.8 \\
\hline & Estonia & 90.9 & $(0.6)$ & 82.4 & $(0.8)$ & 81.0 & $(0.9)$ & 88.5 & $(0.7)$ & 80.8 & $(0.8)$ & 90.9 & $(0.6)$ & 87.2 & $(0.4)$ & 76.0 & $(0.7)$ & 78.0 & $(0.6)$ & 83.4 \\
\hline & Finland & 90.9 & $(0.5)$ & 85.5 & $(0.5)$ & 84.3 & $(0.7)$ & 85.5 & $(0.7)$ & 87.6 & $(0.6)$ & 91.3 & $(0.5)$ & 87.7 & $(0.4)$ & 79.8 & $(0.5)$ & 80.3 & $(0.6)$ & 82.6 \\
\hline & France & 79.0 & $(0.8)$ & 92.1 & $(0.5)$ & 47.4 & (1.0) & 86.9 & $(0.6)$ & 92.5 & $(0.5)$ & 93.0 & $(0.5)$ & 76.8 & (0.6) & 86.3 & $(0.5)$ & 40.9 & $(0.8)$ & 83.7 \\
\hline & Germany & 91.5 & $(0.6)$ & 82.1 & $(0.7)$ & 83.6 & $(0.8)$ & 89.5 & (0.6) & 92.5 & $(0.5)$ & 93.9 & $(0.5)$ & 85.5 & (0.6) & 73.3 & $(0.7)$ & 74.9 & $(0.7)$ & 82.4 \\
\hline & Greece & 85.5 & $(0.8)$ & 86.8 & $(0.6)$ & 88.9 & (0.6) & 88.4 & $(0.7)$ & 90.3 & $(0.5)$ & 89.8 & $(0.7)$ & 84.4 & (0.6) & 80.2 & (0.5) & 83.0 & $(0.5)$ & 84.5 \\
\hline & Hungary & 88.6 & $(0.6)$ & 89.5 & $(0.5)$ & 84.9 & $(0.7)$ & 88.1 & $(0.7)$ & 90.8 & $(0.5)$ & 91.4 & $(0.5)$ & 82.1 & (0.6) & 81.1 & $(0.6)$ & 74.5 & $(0.8)$ & 82.5 \\
\hline & Iceland & 90.4 & $(0.6)$ & 85.6 & $(0.7)$ & 88.2 & $(0.6)$ & 89.0 & (0.6) & 91.2 & $(0.6)$ & 91.8 & (0.6) & 82.9 & $(0.6)$ & 76.1 & $(0.7)$ & 78.5 & $(0.7)$ & 80.5 \\
\hline & Ireland & 90.9 & $(0.5)$ & 89.5 & $(0.5)$ & 79.7 & $(0.9)$ & 89.8 & $(0.6)$ & 94.1 & $(0.4)$ & 93.3 & $(0.5)$ & 83.3 & (0.6) & 81.1 & $(0.5)$ & 73.3 & $(0.8)$ & \begin{tabular}{|l|}
82.7 \\
\end{tabular} \\
\hline & Israel & 88.4 & (0.6) & 89.6 & $(0.5)$ & 90.6 & $(0.6)$ & 91.1 & $(0.6)$ & 89.7 & $(0.6)$ & 92.0 & $(0.5)$ & $\mathrm{m}$ & $\mathrm{m}$ & $\mathrm{m}$ & $\mathrm{m}$ & $\mathrm{m}$ & $\mathrm{m}$ & $\mathrm{m}$ \\
\hline & Italy & 91.2 & $(0.3)$ & 89.6 & $(0.3)$ & 77.2 & $(0.4)$ & 88.6 & $(0.4)$ & 85.8 & $(0.3)$ & 92.7 & $(0.3)$ & 88.9 & $(0.4)$ & 83.0 & $(0.5)$ & 67.3 & $(0.6)$ & 86.3 \\
\hline & Japan & 91.5 & $(0.5)$ & 79.0 & $(0.6)$ & 83.9 & $(0.6)$ & 83.3 & $(0.8)$ & 77.4 & $(0.8)$ & 89.8 & $(0.5)$ & 88.1 & $(0.5)$ & 68.8 & $(0.7)$ & 81.9 & $(0.6)$ & 80.5 \\
\hline & Korea & 91.8 & $(0.5)$ & 78.8 & $(0.7)$ & 76.3 & (1.0) & 89.3 & $(0.5)$ & 77.7 & $(0.8)$ & 91.1 & $(0.5)$ & 91.3 & $(0.4)$ & 79.3 & (0.6) & 79.5 & $(0.8)$ & 89.9 \\
\hline & Latvia & 91.4 & $(0.7)$ & 87.1 & $(0.7)$ & 90.1 & $(0.6)$ & 85.7 & $(0.7)$ & 80.0 & $(0.9)$ & 90.1 & $(0.8)$ & 84.2 & $(0.5)$ & 75.7 & $(0.7)$ & 78.6 & $(0.6)$ & 75.6 \\
\hline & Luxembc & 88.3 & $(0.6)$ & 86.8 & $(0.6)$ & 76.0 & $(0.7)$ & 83.8 & $(0.5)$ & 88.4 & $(0.5)$ & 90.7 & $(0.5)$ & 83.2 & $(0.5)$ & 75.9 & $(0.6)$ & 66.0 & $(0.6)$ & 80.0 \\
\hline & Mexico & 85.6 & $(0.4)$ & 89.0 & $(0.4)$ & 91.5 & $(0.3)$ & 86.4 & $(0.3)$ & 88.9 & $(0.3)$ & 88.9 & $(0.3)$ & 75.2 & (0.6) & 72.7 & $(0.5)$ & 76.1 & $(0.7)$ & 76.1 \\
\hline & Netherlands & 92.8 & $(0.6)$ & 89.6 & $(0.6)$ & 84.5 & (1.0) & 91.0 & $(0.7)$ & 94.0 & $(0.5)$ & 94.6 & $(0.5)$ & 91.0 & $(0.4)$ & 85.2 & $(0.5)$ & 80.9 & $(0.6)$ & 88.8 \\
\hline & New Zealand & 86.1 & $(0.7)$ & 86.8 & $(0.7)$ & 78.4 & $(0.9)$ & 85.5 & $(0.7)$ & 91.4 & $(0.5)$ & 88.0 & $(0.5)$ & 77.7 & $(0.7)$ & 78.9 & $(0.6)$ & 73.7 & $(0.7)$ & 77.9 \\
\hline & Norway & 91.6 & $(0.5)$ & 85.6 & $(0.6)$ & 87.1 & $(0.6)$ & 87.7 & $(0.6)$ & 88.7 & $(0.6)$ & 90.5 & $(0.5)$ & 87.9 & $(0.5)$ & 80.0 & $(0.5)$ & 75.7 & $(0.7)$ & 82.6 \\
\hline & Poland & 89.8 & $(0.8)$ & 86.7 & $(0.7)$ & 76.0 & $(0.8)$ & 88.9 & $(0.7)$ & 83.7 & $(0.7)$ & 91.2 & $(0.6)$ & 78.5 & (0.6) & 73.5 & $(0.7)$ & 62.4 & $(0.8)$ & 77.0 \\
\hline & Portugal & 91.1 & $(0.6)$ & 86.9 & $(0.7)$ & 91.1 & $(0.6)$ & 83.9 & $(0.8)$ & 93.6 & $(0.5)$ & 92.5 & $(0.6)$ & 87.1 & $(0.4)$ & 77.8 & $(0.6)$ & 82.3 & $(0.5)$ & 75.8 \\
\hline & Slovak Republic & 82.3 & $(1.0)$ & 86.5 & $(0.6)$ & 77.7 & $(0.9)$ & 83.3 & $(0.9)$ & 84.5 & $(0.8)$ & 86.3 & $(0.7)$ & 77.3 & $(0.6)$ & 77.0 & $(0.5)$ & 69.7 & $(0.7)$ & 77.5 \\
\hline & Slovenia & 89.8 & $(0.6)$ & 91.4 & $(0.6)$ & 83.4 & $(0.7)$ & 89.4 & $(0.6)$ & 88.5 & $(0.6)$ & 92.1 & $(0.5)$ & 82.4 & $(0.6)$ & 76.8 & $(0.8)$ & 74.5 & $(0.8)$ & 82.5 \\
\hline & Spain & 92.1 & $(0.4)$ & 90.8 & $(0.3)$ & 93.1 & $(0.4)$ & 91.1 & $(0.4)$ & 91.7 & $(0.3)$ & 94.2 & $(0.3)$ & 89.9 & $(0.4)$ & 83.2 & $(0.5)$ & 87.2 & $(0.5)$ & 86.0 \\
\hline & Sweden & 89.5 & $(0.6)$ & 86.8 & $(0.7)$ & 78.6 & $(0.9)$ & 90.2 & $(0.6)$ & 88.8 & $(0.7)$ & 90.5 & $(0.6)$ & 79.4 & $(0.5)$ & 74.9 & $(0.6)$ & 69.3 & $(0.8)$ & 79.6 \\
\hline & Switzerl & 92.6 & $(0.5)$ & 87.9 & $(0.5)$ & 82.5 & $(0.9)$ & 90.3 & $(0.6)$ & 94.2 & $(0.4)$ & 94.6 & $(0.4)$ & 88.3 & $(0.5)$ & 80.6 & $(0.6)$ & 70.8 & $(0.7)$ & 85.1 \\
\hline & Turkey & 82.7 & $(0.7)$ & 85.5 & $(0.6)$ & 84.2 & $(0.7)$ & 81.6 & $(0.8)$ & 85.9 & $(0.7)$ & 82.9 & $(0.9)$ & 64.3 & $(0.9)$ & 62.3 & $(0.8)$ & 61.4 & $(0.7)$ & 62.7 \\
\hline & United Kingdom & 88.6 & $(0.6)$ & 88.0 & $(0.6)$ & 79.4 & $(0.8)$ & 87.8 & $(0.5)$ & 92.6 & $(0.4)$ & 92.5 & $(0.5)$ & 79.9 & $(0.6)$ & 78.7 & (0.6) & 67.8 & $(0.7)$ & 80.1 \\
\hline & United States & 85.6 & $(0.7)$ & 87.9 & $(0.6)$ & 80.6 & (0.8) & 83.4 & $(0.7)$ & 93.5 & $(0.5)$ & 88.1 & $(0.7)$ & 76.2 & (0.6) & 78.6 & (0.6) & 74.2 & $(0.7)$ & 77.0 \\
\hline & OECD avera & 88.9 & $(0.1)$ & 86.8 & $(0.1)$ & 81.0 & $(0.1)$ & 87.5 & $(0.1)$ & 89.1 & $(0.1)$ & 91.1 & $(0.1)$ & 83.0 & $(0.1)$ & 77.9 & $(0.1)$ & 72.6 & $(0.1)$ & 80.9 \\
\hline & OECD av & 88.8 & (0.1) & 86.9 & $(0.1)$ & 81.6 & (0.1) & 87.5 & $(0.1)$ & 88.9 & $(0.1)$ & 91.1 & (0.1) & 82.8 & $(0.1)$ & |77.7 & $(0.1)$ & | 73.0 & $(0.1)$ & 80.9 \\
\hline & Albania & 89.2 & (0.9) & 86.1 & $(0.8)$ & 93.8 & (0.6) & 81.6 & (1.1) & 81.3 & (0.9) & 89.2 & $(0.7)$ & 94.5 & (0.4) & 90.2 & (0.5) & 93.1 & $(0.4)$ & 89.2 \\
\hline 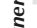 & Algeria & $\mathrm{m}$ & & $\mathrm{m}$ & $\mathrm{m}$ & $\mathrm{m}$ & $\mathrm{m}$ & $\mathrm{m}$ & $\mathrm{m}$ & $\mathrm{m}$ & $\mathrm{m}$ & $\mathrm{m}$ & $\mathrm{m}$ & 72.3 & (1.0) & 86.4 & $(0.5)$ & 87.4 & $(0.6)$ & 65.5 \\
\hline & Brazil & 83.8 & $(0.5)$ & 86.3 & $(0.5)$ & 86.3 & $(0.4)$ & 86.2 & $(0.5)$ & 88.1 & $(0.5)$ & 80.1 & $(0.6)$ & 79.2 & $(0.4)$ & 73.9 & $(0.5)$ & 76.1 & $(0.5)$ & 81.9 \\
\hline & B-S-J-G (C & $\mathrm{m}$ & $\mathrm{m}$ & $\mathrm{m}$ & $\mathrm{m}$ & $\mathrm{m}$ & $\mathrm{m}$ & $\mathrm{m}$ & $\mathrm{m}$ & $\mathrm{m}$ & $\mathrm{m}$ & $\mathrm{m}$ & $\mathrm{m}$ & 78.0 & (0.6) & 78.2 & $(0.5)$ & 64.6 & $(0.8)$ & 80.6 \\
\hline & Bulgaria & 76.2 & $(1.2)$ & 90.4 & $(0.5)$ & 82.0 & $(0.8)$ & 79.0 & $(1.1)$ & 83.5 & $(0.7)$ & 81.0 & (1.1) & 70.3 & $(0.8)$ & 74.9 & $(0.6)$ & 68.0 & $(0.6)$ & 72.0 \\
\hline & CABA (Arge & $\mathrm{m}$ & $\mathrm{m}$ & $\mathrm{m}$ & $\mathrm{m}$ & $\mathrm{m}$ & $\mathrm{m}$ & $\mathrm{m}$ & $\mathrm{m}$ & $\mathrm{m}$ & $\mathrm{m}$ & $\mathrm{m}$ & $\mathrm{m}$ & 87.5 & (1.0) & 89.3 & (1.1) & 88.7 & (1.1) & 92.4 \\
\hline & Colombia & 85.5 & $(0.8)$ & 90.2 & $(0.5)$ & 94.1 & $(0.5)$ & 83.5 & $(0.8)$ & 86.6 & $(0.7)$ & 87.5 & $(0.7)$ & 71.1 & $(0.7)$ & 70.3 & $(0.6)$ & 74.3 & $(0.6)$ & 72.9 \\
\hline & Costa Rica & 87.3 & $(0.8)$ & 90.6 & $(0.6)$ & 90.7 & $(0.7)$ & 89.2 & $(0.7)$ & 90.1 & $(0.6)$ & 89.8 & $(0.8)$ & 73.2 & $(0.6)$ & 71.7 & $(0.7)$ & 74.7 & $(0.6)$ & 74.7 \\
\hline & Croatia & 91.7 & $(0.5)$ & 91.2 & $(0.5)$ & 88.1 & $(0.6)$ & 90.9 & $(0.5)$ & 87.8 & $(0.7)$ & 93.1 & $(0.4)$ & 86.0 & $(0.5)$ & 83.8 & $(0.5)$ & 81.2 & $(0.6)$ & 85.0 \\
\hline & Cyprus* & $\mathrm{m}$ & & $\mathrm{m}$ & $\mathrm{m}$ & $\mathrm{m}$ & $\mathrm{m}$ & $\mathrm{m}$ & $\mathrm{m}$ & $\mathrm{m}$ & $\mathrm{m}$ & $\mathrm{m}$ & $\mathrm{m}$ & 82.9 & $(0.5)$ & 80.6 & $(0.5)$ & 80.2 & $(0.5)$ & 83.2 \\
\hline & Dominican Republic & $\mathrm{m}$ & & $\mathrm{m}$ & $\mathrm{m}$ & $\mathrm{m}$ & & $\mathrm{m}$ & $\mathrm{m}$ & $\mathrm{m}$ & $\mathrm{m}$ & $\mathrm{m}$ & $\mathrm{m}$ & 60.4 & $(0.8)$ & 66.1 & $(0.9)$ & 66.9 & $(0.8)$ & 65.1 \\
\hline & FYROM & $\mathrm{m}$ & $\mathrm{m}$ & $\mathrm{m}$ & $\mathrm{m}$ & $\mathrm{m}$ & $\mathrm{m}$ & $\mathrm{m}$ & $\mathrm{m}$ & $\mathrm{m}$ & $\mathrm{m}$ & $\mathrm{m}$ & $\mathrm{m}$ & 87.9 & $(0.4)$ & 93.5 & $(0.3)$ & 92.1 & $(0.4)$ & 88.8 \\
\hline & Georgia & $\mathrm{m}$ & & $\mathrm{m}$ & $\mathrm{m}$ & $\mathrm{m}$ & $\mathrm{m}$ & $\mathrm{m}$ & $\mathrm{m}$ & $\mathrm{m}$ & $\mathrm{m}$ & $\mathrm{m}$ & $\mathrm{m}$ & 95.1 & $(0.4)$ & 94.3 & $(0.4)$ & 64.8 & $(0.8)$ & 94.3 \\
\hline & Hong & 2.0 & $(0.9)$ & 86.3 & $(0.6)$ & 73.0 & $(1.0)$ & 87.3 & $(0.7)$ & 80.1 & $(0.7)$ & 86.0 & $(0.6)$ & 75.3 & $(0.7)$ & 81.0 & $(0.7)$ & 71.1 & $(0.9)$ & 79.0 \\
\hline & Indonesia & 87.7 & $(0.7)$ & 96.1 & $(0.4)$ & 92.7 & $(0.5)$ & 74.8 & (1.0) & 86.1 & $(0.7)$ & 87.2 & $(0.6)$ & 96.3 & $(0.3)$ & 96.4 & $(0.3)$ & 92.3 & $(0.4)$ & 84.1 \\
\hline & Jordan & 73.2 & $(1.0)$ & 86.6 & $(0.6)$ & 86.4 & $(0.7)$ & 65.6 & $(0.9)$ & 87.8 & $(0.6)$ & 76.0 & (1.0) & 76.8 & $(0.7)$ & 90.9 & $(0.5)$ & 85.9 & $(0.6)$ & 75.7 \\
\hline & Kosovo & $\mathrm{m}$ & & $\mathrm{m}$ & $\mathrm{m}$ & $\mathrm{m}$ & $\mathrm{m}$ & $\mathrm{m}$ & $\mathrm{m}$ & $\mathrm{m}$ & $\mathrm{m}$ & $\mathrm{m}$ & $\mathrm{m}$ & 86.8 & (0.6) & 91.4 & $(0.5)$ & 92.5 & $(0.5)$ & 85.4 \\
\hline & Lebanon & $\mathrm{m}$ & $\mathrm{m}$ & $\mathrm{m}$ & $\mathrm{m}$ & $\mathrm{m}$ & $\mathrm{m}$ & $\mathrm{m}$ & $\mathrm{m}$ & $\mathrm{m}$ & $\mathrm{m}$ & $\mathrm{m}$ & $\mathrm{m}$ & 74.9 & (1.4) & 89.7 & $(0.6)$ & 74.9 & $(1.2)$ & 75.4 \\
\hline & Lithuania & 84.0 & $(0.9)$ & 87.6 & $(0.5)$ & 66.6 & $(0.9)$ & 83.7 & (0.8) & 81.9 & $(0.8)$ & 86.8 & $(0.7)$ & 69.3 & $(0.7)$ & 64.5 & $(0.7)$ & 54.5 & $(0.8)$ & 66.2 \\
\hline & Macao (Ch & 84.3 & $(0.7)$ & 81.9 & $(0.6)$ & 65.5 & $(0.9)$ & 83.4 & (0.6) & 72.8 & $(0.7)$ & 82.6 & $(0.7)$ & 79.3 & (0.6) & 76.1 & (0.6) & 59.9 & $(0.8)$ & 77.7 \\
\hline & Malta & $\mathrm{m}$ & $\mathrm{m}$ & $\mathrm{m}$ & $\mathrm{m}$ & $\mathrm{m}$ & $\mathrm{m}$ & $\mathrm{m}$ & $\mathrm{m}$ & $\mathrm{m}$ & $\mathrm{m}$ & $\mathrm{m}$ & $\mathrm{m}$ & 79.6 & $(0.7)$ & 81.9 & $(0.7)$ & 69.8 & $(0.8)$ & 82.3 \\
\hline & Moldova & $\mathrm{m}$ & $\mathrm{m}$ & $\mathrm{m}$ & $\mathrm{m}$ & $\mathrm{m}$ & $\mathrm{m}$ & $\mathrm{m}$ & $\mathrm{m}$ & $\mathrm{m}$ & $\mathrm{m}$ & $\mathrm{m}$ & $\mathrm{m}$ & 91.1 & (0.5) & 90.6 & $(0.5)$ & 67.7 & $(0.9)$ & 89.3 \\
\hline & Monteneg & 8.7 & $(0.6)$ & 92.0 & $(0.6)$ & 67.7 & $(0.9)$ & 88.3 & (0.6) & 88.7 & $(0.6)$ & 91.7 & $(0.6)$ & 82.8 & $(0.5)$ & 83.3 & $(0.5)$ & 53.8 & $(0.8)$ & 82.5 \\
\hline & Peru & 4.8 & (1.1) & 86.5 & $(0.6)$ & 86.4 & $(0.8)$ & 75.1 & (1.1) & 86.6 & $(0.8)$ & 86.3 & $(1.0)$ & 79.4 & $(0.7)$ & 75.9 & $(0.6)$ & 71.4 & $(0.6)$ & 76.0 \\
\hline & Qatar & 66.8 & $(0.5)$ & 85.1 & $(0.5)$ & 78.2 & $(0.5)$ & 68.3 & $(0.5)$ & 85.9 & $(0.4)$ & 72.1 & $(0.5)$ & 75.6 & $(0.4)$ & 77.8 & $(0.4)$ & 70.7 & $(0.4)$ & 76.1 \\
\hline & Romaniz & 77.4 & (1.4) & 85.9 & $(0.9)$ & 66.8 & $(0.9)$ & 73.5 & (1.3) & 83.0 & $(0.8)$ & 72.8 & (1.4) & 87.8 & (1.1) & 92.4 & $(0.5)$ & 52.5 & (1.1) & 84.4 \\
\hline & Russia & 1.2 & $(0.6)$ & 85.3 & $(0.7)$ & 81.2 & $(0.8)$ & 82.0 & $(0.7)$ & 79.3 & $(0.8)$ & 89.3 & $(0.6)$ & 80.4 & $(0.7)$ & 73.1 & $(0.7)$ & 74.6 & $(0.6)$ & 72.9 \\
\hline & Singapore & 83.7 & $(0.7)$ & 88.4 & $(0.4)$ & 83.8 & $(0.7)$ & 83.3 & $(0.6)$ & 86.4 & $(0.5)$ & 84.4 & $(0.6)$ & 76.5 & $(0.6)$ & 80.2 & $(0.6)$ & 76.0 & $(0.6)$ & 76.5 \\
\hline & Chinese Taipei & $\mathrm{m}$ & & $\mathrm{m}$ & $\mathrm{m}$ & $\mathrm{m}$ & $\mathrm{m}$ & $\mathrm{m}$ & & $\mathrm{m}$ & $\mathrm{m}$ & $\mathrm{m}$ & $\mathrm{m}$ & 88.7 & $(0.3)$ & 85.1 & $(0.4)$ & 89.9 & $(0.3)$ & 83.0 \\
\hline & Thailand & 78.5 & $(0.9)$ & 91.7 & $(0.5)$ & 91.2 & $(0.5)$ & 67.4 & (1.1) & 71.7 & $(0.8)$ & 79.2 & (1.0) & 79.7 & $(0.7)$ & 82.5 & $(0.5)$ & 78.4 & $(0.6)$ & 67.6 \\
\hline & Trinidad a & $\mathrm{m}$ & $\mathrm{m}$ & $\mathrm{m}$ & $\mathrm{m}$ & $\mathrm{m}$ & $\mathrm{m}$ & $\mathrm{m}$ & $m$ & $\mathrm{~m}$ & $\mathrm{~m}$ & $\mathrm{~m}$ & $\mathrm{~m}$ & 81.9 & (0.6) & 85.9 & $(0.6)$ & 79.7 & $(0.6)$ & 82.1 \\
\hline & Tunisia & 74.7 & $(1.0)$ & 86.9 & $(0.7)$ & 65.9 & (1.1) & 63.8 & (1.1) & 85.1 & $(0.7)$ & 81.0 & $(0.9)$ & 80.1 & $(0.8)$ & 83.4 & $(0.6)$ & 57.6 & $(0.7)$ & 63.0 \\
\hline & United Arab E & 77.5 & $(0.8)$ & 87.6 & $(0.5)$ & 83.6 & $(0.5)$ & 76.4 & $(0.6)$ & 84.1 & $(0.7)$ & 83.2 & $(0.7)$ & 78.7 & $(0.5)$ & 79.8 & $(0.5)$ & 73.9 & $(0.6)$ & 75.3 \\
\hline & & 85.0 & $(0.8)$ & 88.0 & $(0.6)$ & 92.5 & $(0.5)$ & 86.7 & $(0.8)$ & 96.9 & $(0.4)$ & 82.3 & $(0.8)$ & 76.2 & $(0.6)$ & 73.1 & $(0.6)$ & 77.9 & (0.6) & 79.3 \\
\hline & Viet Nam & 94.5 & (0.5) & 91.9 & (0.5) & 82.7 & (0.8) & 88.7 & $(0.6)$ & 40.8 & (1.1) & 93.9 & $(0.5)$ & 95.3 & (0.4) & 91.6 & $(0.5)$ & 80.8 & $(0.7)$ & 82.7 \\
\hline & Argentina** & 7.4 & (1.3) & 87.1 & $(0.6)$ & 89.9 & $(0.6)$ & 81.3 & (0.9) & 83.3 & $(0.7)$ & 83.9 & $(0.8)$ & 75.4 & (1.0) & 89.0 & $(0.5)$ & 89.5 & $(0.5)$ & 88.7 \\
\hline & Kazakhstan** & 91.0 & $(0.7)$ & 93.2 & $(0.4)$ & 88.7 & $(0.7)$ & 91.8 & (0.6) & 89.1 & $(0.7)$ & 91.4 & $(0.6)$ & 94.2 & (0.4) & 92.0 & $(0.5)$ & 85.0 & $(0.6)$ & 92.6 \\
\hline & Malaysia** & 79.9 & $(1.0)$ & 90.7 & $(0.6)$ & 81.5 & $(0.8)$ & 77.4 & (1.1) & 80.3 & $(0.7)$ & 80.1 & $(1.0)$ & 83.8 & $(0.7)$ & 87.5 & $(0.6)$ & 77.1 & $(0.7)$ & 82.8 \\
\hline
\end{tabular}

1. "OECD average-30" includes all OECD countries, with the exception of Chile, Estonia, Israel and the United States.

Note: Values that are statistically significant are indicated in bold (see Annex A3).

* See note at the beginning of this Annex.

** Coverage is too small to ensure comparability (see Annex A4).

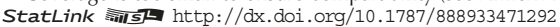


[Part 2/2]

Table III.7.5 Change between 2012 and 2015 in students' sense of belonging

Percentage of students who reported "agree" or "strongly agree" (a) or who reported "disagree" or "strongly disagree" (d)

\begin{tabular}{|c|c|c|c|c|c|c|c|c|c|c|c|c|c|}
\hline & \multicolumn{12}{|c|}{ Change between 2012 and 2015 in the percentage of students who agreed/disagreed with the following statements (PISA 2015 - PISA 2012) } \\
\hline & & \multicolumn{2}{|c|}{$\begin{array}{c}\text { I feel like an outsider } \\
\text { (or left out of things) } \\
\text { at schoold }\end{array}$} & \multicolumn{2}{|c|}{$\begin{array}{l}\text { I make friends easily } \\
\text { at schoola }\end{array}$} & $\begin{array}{r}\text { I feel lil } \\
\text { at s }\end{array}$ & $\begin{array}{l}\text { belong } \\
\text { ola }^{\mathbf{a}}\end{array}$ & $\begin{array}{c}\text { I feel } \\
\text { and o } \\
\text { in } \mathrm{m}\end{array}$ & $\begin{array}{l}\text { ward } \\
\text { place } \\
\text { oold }\end{array}$ & $\begin{array}{r}\text { Other s } \\
\text { to }\end{array}$ & $\begin{array}{l}\text { ths seem } \\
\text { ne }^{\mathrm{a}}\end{array}$ & $\begin{array}{l}\text { I fee } \\
\text { at s }\end{array}$ & $\begin{array}{l}\text { nely } \\
\text { old }\end{array}$ \\
\hline & & $\%$ dif. & S.E. & $\%$ dif. & S.E. & $\%$ dif. & S.E. & $\%$ dif. & S.E. & $\%$ dif. & S.E. & $\%$ dif. & S.E. \\
\hline$\sqrt{2}$ & Australia & -8.6 & $(0.7)$ & -6.1 & $(0.6)$ & -6.2 & $(0.7)$ & -6.8 & $(0.6)$ & -3.9 & $(0.5)$ & -4.8 & $(0.5)$ \\
\hline U & Austria & -6.7 & $(0.7)$ & -12.1 & $(0.8)$ & -10.0 & $(0.9)$ & -8.5 & $(0.8)$ & -10.0 & $(0.7)$ & -9.6 & $(0.8)$ \\
\hline పే & Belgium & -3.3 & (0.6) & -6.0 & $(0.7)$ & -6.4 & (1.0) & -3.6 & $(0.7)$ & -3.5 & $(0.6)$ & -2.3 & $(0.5)$ \\
\hline & Canada & -9.2 & $(0.7)$ & -8.7 & $(0.7)$ & -6.8 & $(0.7)$ & -9.0 & $(0.6)$ & -6.0 & $(0.5)$ & -7.2 & $(0.6)$ \\
\hline & Chile & -6.3 & $(0.9)$ & -12.5 & $(0.8)$ & -10.3 & $(0.9)$ & -5.3 & (1.0) & -12.0 & $(0.9)$ & -8.4 & $(0.8)$ \\
\hline & Czech Republic & -4.9 & $(0.9)$ & -12.2 & (1.1) & -7.2 & (1.4) & -8.6 & $(0.9)$ & -7.3 & $(0.9)$ & -8.3 & $(0.9)$ \\
\hline & Denmark & -5.3 & $(0.7)$ & -5.2 & $(0.8)$ & -7.1 & (1.0) & -5.7 & $(0.7)$ & -2.3 & $(0.8)$ & -5.6 & $(0.7)$ \\
\hline & Estonia & -3.7 & $(0.7)$ & -6.4 & (1.0) & -3.0 & (1.1) & -5.1 & $(0.9)$ & -4.3 & (1.1) & -5.6 & $(0.8)$ \\
\hline & Finland & -3.2 & $(0.7)$ & -5.7 & $(0.8)$ & -4.0 & $(0.9)$ & -2.8 & $(0.9)$ & -5.6 & $(0.8)$ & -3.2 & $(0.7)$ \\
\hline & France & -2.2 & (1.0) & -5.8 & $(0.7)$ & -6.5 & (1.2) & -3.2 & $(0.8)$ & -2.8 & $(0.6)$ & -2.4 & $(0.6)$ \\
\hline & Germany & -6.0 & $(0.8)$ & -8.8 & (1.0) & -8.8 & (1.1) & -7.1 & $(0.9)$ & -7.5 & $(0.8)$ & -6.6 & $(0.7)$ \\
\hline & Greece & -1.1 & $(0.9)$ & -6.6 & $(0.8)$ & -5.9 & $(0.8)$ & -3.9 & $(0.8)$ & -2.9 & $(0.7)$ & -1.8 & $(0.8)$ \\
\hline & Hungary & -6.5 & $(0.8)$ & -8.5 & $(0.8)$ & -10.4 & (1.0) & -5.6 & (1.0) & -8.1 & (0.9) & -5.9 & $(0.7)$ \\
\hline & Iceland & -7.5 & $(0.8)$ & -9.5 & (1.0) & -9.7 & (0.9) & -8.5 & $(0.9)$ & -8.3 & $(0.8)$ & -8.2 & $(0.8)$ \\
\hline & Ireland & -7.6 & $(0.8)$ & -8.3 & $(0.8)$ & -6.3 & (1.2) & -7.1 & $(0.9)$ & -3.6 & $(0.6)$ & -5.5 & $(0.7)$ \\
\hline & Israel & $\mathrm{m}$ & $\mathrm{m}$ & $\mathrm{m}$ & $\mathrm{m}$ & $\mathrm{m}$ & $\mathrm{m}$ & $\mathrm{m}$ & $\mathrm{m}$ & $\mathrm{m}$ & $\mathrm{m}$ & $\mathrm{m}$ & $\mathrm{m}$ \\
\hline & Italy & -2.3 & $(0.5)$ & -6.6 & $(0.6)$ & -9.9 & $(0.8)$ & -2.3 & $(0.7)$ & -9.2 & $(0.7)$ & -3.2 & $(0.6)$ \\
\hline & Japan & -3.5 & $(0.7)$ & -10.3 & $(0.9)$ & -2.1 & $(0.8)$ & -2.8 & (1.0) & -3.6 & (1.0) & -1.3 & $(0.7)$ \\
\hline & Korea & -0.5 & $(0.6)$ & 0.4 & $(0.9)$ & 3.2 & (1.3) & 0.6 & $(0.7)$ & 4.2 & (1.0) & 0.6 & $(0.6)$ \\
\hline & Latvia & -7.2 & $(0.8)$ & -11.4 & (1.0) & -11.5 & $(0.9)$ & -10.2 & (1.0) & -11.8 & $(1.1)$ & -7.4 & (1.0) \\
\hline & Luxembourg & -5.1 & $(0.8)$ & -11.0 & $(0.8)$ & -10.0 & $(0.9)$ & -3.8 & $(0.8)$ & -7.1 & $(0.7)$ & -5.6 & $(0.6)$ \\
\hline & Mexico & -10.4 & $(0.7)$ & -16.3 & $(0.7)$ & -15.4 & $(0.8)$ & -10.3 & $(0.7)$ & -16.9 & $(0.7)$ & -9.6 & $(0.6)$ \\
\hline & Netherlands & -1.8 & $(0.8)$ & -4.4 & $(0.8)$ & -3.6 & (1.1) & -2.2 & $(0.9)$ & -2.1 & $(0.7)$ & -2.2 & $(0.6)$ \\
\hline & New Zealand & -8.4 & (1.0) & -7.9 & $(0.9)$ & -4.7 & (1.1) & -7.6 & $(0.9)$ & -3.2 & $(0.7)$ & -4.8 & $(0.9)$ \\
\hline & Norway & -3.7 & $(0.7)$ & -5.6 & $(0.8)$ & -11.4 & $(0.9)$ & -5.1 & $(0.9)$ & -5.8 & $(0.9)$ & -4.9 & $(0.7)$ \\
\hline & Poland & -11.2 & (1.0) & -13.2 & (1.0) & -13.6 & (1.1) & -11.9 & $(0.9)$ & -10.4 & (1.0) & -11.4 & $(0.9)$ \\
\hline & Portugal & -4.0 & $(0.8)$ & -9.1 & (1.0) & -8.9 & $(0.8)$ & -8.2 & (1.0) & -5.9 & $(0.7)$ & -3.6 & $(0.7)$ \\
\hline & Slovak Republic & -5.0 & $(1.2)$ & -9.5 & $(0.8)$ & -8.0 & (1.1) & -5.8 & (1.1) & -7.7 & $(1.0)$ & -5.7 & $(0.9)$ \\
\hline & Slovenia & -7.4 & $(0.8)$ & -14.6 & $(0.9)$ & -9.0 & (1.1) & -6.8 & $(0.9)$ & -10.1 & $(0.9)$ & -6.6 & $(0.8)$ \\
\hline & Spain & -2.3 & $(0.5)$ & -7.5 & (0.6) & -5.9 & $(0.6)$ & -5.2 & $(0.7)$ & -5.7 & $(0.6)$ & -3.5 & $(0.5)$ \\
\hline & Sweden & -10.1 & $(0.8)$ & -11.9 & $(0.9)$ & -9.3 & $(1.2)$ & -10.6 & $(0.8)$ & -10.4 & $(0.9)$ & -9.5 & $(0.9)$ \\
\hline & Switzerland & -4.3 & $(0.7)$ & -7.3 & $(0.8)$ & -11.7 & (1.1) & -5.2 & $(0.8)$ & -6.7 & $(0.7)$ & -4.4 & $(0.5)$ \\
\hline & Turkey & -18.4 & (1.1) & -23.3 & (1.0) & -22.8 & (1.0) & -18.9 & $(1.2)$ & -22.2 & (1.1) & -17.9 & $(1.2)$ \\
\hline & United Kingdom & -8.7 & $(0.8)$ & -9.2 & $(0.8)$ & -11.6 & (1.1) & -7.7 & $(0.8)$ & -4.9 & $(0.7)$ & -6.1 & $(0.7)$ \\
\hline & United States & -9.4 & (1.0) & -9.3 & $(0.8)$ & -6.4 & (1.1) & -6.4 & (0.9) & -4.8 & $(0.7)$ & -6.3 & (1.0) \\
\hline & OECD average- $30^{1}$ & -6.0 & $(0.1)$ & -8.9 & $(0.2)$ & -8.4 & $(0.2)$ & -6.6 & $(0.2)$ & -6.7 & $(0.1)$ & -5.7 & $(0.1)$ \\
\hline & OECD average-35 & -6.1 & $(0.1)$ & -9.1 & $(0.1)$ & -8.3 & $(0.2)$ & -6.5 & $(0.1)$ & -6.8 & $(0.1)$ & -5.8 & $(0.1)$ \\
\hline 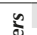 & Albania & 5.3 & (1.0) & 4.2 & $(1.0)$ & -0.7 & $(0.8)$ & 7.5 & $(1.2)$ & 1.2 & (1.1) & 5.9 & $(0.8)$ \\
\hline$\Xi$ & Algeria & $\mathrm{m}$ & $\mathrm{m}$ & $\mathrm{m}$ & $\mathrm{m}$ & $\mathrm{m}$ & $\mathrm{m}$ & $\mathrm{m}$ & $\mathrm{m}$ & $\mathrm{m}$ & $\mathrm{m}$ & $\mathrm{m}$ & $\mathrm{m}$ \\
\hline$\frac{1}{\pi}$ & Brazil & -4.6 & $(0.7)$ & -12.4 & $(0.7)$ & -10.2 & $(0.7)$ & -4.3 & $(0.6)$ & -7.1 & $(0.6)$ & 0.1 & $(0.8)$ \\
\hline 2 & B-S-J-G (China) & $\mathrm{m}$ & $\mathrm{m}$ & $\mathrm{m}$ & $\mathrm{m}$ & $\mathrm{m}$ & $\mathrm{m}$ & $\mathrm{m}$ & $\mathrm{m}$ & $\mathrm{m}$ & $\mathrm{m}$ & $\mathrm{m}$ & $\mathrm{m}$ \\
\hline & Bulgaria & -5.9 & (1.4) & -15.5 & $(0.8)$ & -14.0 & (1.0) & -7.0 & (1.4) & -11.6 & $(1.0)$ & -5.9 & $(1.3)$ \\
\hline & CABA (Argentina) & $\mathrm{m}$ & $\mathrm{m}$ & $\mathrm{m}$ & $\mathrm{m}$ & $\mathrm{m}$ & $\mathrm{m}$ & $\mathrm{m}$ & $\mathrm{m}$ & $\mathrm{m}$ & $\mathrm{m}$ & $\mathrm{m}$ & $\mathrm{m}$ \\
\hline & Colombia & -14.4 & (1.1) & -19.9 & $(0.8)$ & -19.8 & $(0.8)$ & -10.6 & (1.0) & -17.8 & $(0.9)$ & -12.6 & $(0.9)$ \\
\hline & Costa Rica & -14.0 & (1.0) & -19.0 & (1.0) & -16.1 & (1.0) & -14.5 & (1.0) & -17.9 & $(0.9)$ & -12.5 & (1.0) \\
\hline & Croatia & -5.7 & $(0.7)$ & -7.4 & $(0.8)$ & -6.9 & $(0.9)$ & -5.9 & $(0.7)$ & -6.2 & $(0.9)$ & -5.5 & $(0.6)$ \\
\hline & Cyprus* & $\mathrm{m}$ & $\mathrm{m}$ & $\mathrm{m}$ & $\mathrm{m}$ & $\mathrm{m}$ & $\mathrm{m}$ & $\mathrm{m}$ & $\mathrm{m}$ & $\mathrm{m}$ & $\mathrm{m}$ & $\mathrm{m}$ & $\mathrm{m}$ \\
\hline & Dominican Republic & $\mathrm{m}$ & $\mathrm{m}$ & $\mathrm{m}$ & $\mathrm{m}$ & $\mathrm{m}$ & $\mathrm{m}$ & $\mathrm{m}$ & $\mathrm{m}$ & $\mathrm{m}$ & $\mathrm{m}$ & $\mathrm{m}$ & $\mathrm{m}$ \\
\hline & FYROM & $\mathrm{m}$ & $\mathrm{m}$ & $\mathrm{m}$ & $\mathrm{m}$ & $\mathrm{m}$ & $\mathrm{m}$ & $\mathrm{m}$ & $\mathrm{m}$ & $\mathrm{m}$ & $\mathrm{m}$ & $\mathrm{m}$ & $\mathrm{m}$ \\
\hline & Georgia & $\mathrm{m}$ & $\mathrm{m}$ & $\mathrm{m}$ & $\mathrm{m}$ & $\mathrm{m}$ & $\mathrm{m}$ & $\mathrm{m}$ & $\mathrm{m}$ & $\mathrm{m}$ & $\mathrm{m}$ & $\mathrm{m}$ & $\mathrm{m}$ \\
\hline & Hong Kong (China) & -6.7 & (1.1) & -5.3 & $(0.9)$ & -1.9 & (1.4) & -8.3 & $(0.9)$ & -2.3 & $(1.0)$ & -5.4 & $(0.9)$ \\
\hline & Indonesia & 8.6 & $(0.8)$ & 0.3 & $(0.5)$ & -0.4 & $(0.7)$ & 9.3 & $(1.2)$ & -1.7 & $(1.0)$ & 6.8 & $(0.7)$ \\
\hline & Jordan & 3.6 & $(1.3)$ & 4.2 & $(0.7)$ & -0.5 & $(0.9)$ & 10.2 & (1.1) & 3.1 & $(0.8)$ & 11.0 & (1.1) \\
\hline & Kosovo & $\mathrm{m}$ & $\mathrm{m}$ & $\mathrm{m}$ & $\mathrm{m}$ & $\mathrm{m}$ & $\mathrm{m}$ & $\mathrm{m}$ & $\mathrm{m}$ & $\mathrm{m}$ & $\mathrm{m}$ & $\mathrm{m}$ & $\mathrm{m}$ \\
\hline & Lebanon & $\mathrm{m}$ & $\mathrm{m}$ & $\mathrm{m}$ & $\mathrm{m}$ & $\mathrm{m}$ & $\mathrm{m}$ & $\mathrm{m}$ & $\mathrm{m}$ & $\mathrm{m}$ & $\mathrm{m}$ & $\mathrm{m}$ & $\mathrm{m}$ \\
\hline & Lithuania & -14.8 & (1.1) & -23.1 & $(0.9)$ & -12.1 & $(1.2)$ & -17.5 & (1.1) & -19.4 & (1.1) & -17.9 & (1.0) \\
\hline & Macao (China) & -5.0 & $(0.9)$ & -5.8 & $(0.8)$ & -5.6 & $(1.2)$ & -5.7 & $(0.8)$ & -6.9 & $(1.0)$ & -2.6 & (1.0) \\
\hline & Malta & $\mathrm{m}$ & $\mathrm{m}$ & $\mathrm{m}$ & $\mathrm{m}$ & $\mathrm{m}$ & $\mathrm{m}$ & $\mathrm{m}$ & $\mathrm{m}$ & $\mathrm{m}$ & $\mathrm{m}$ & $\mathrm{m}$ & $\mathrm{m}$ \\
\hline & Moldova & $\mathrm{m}$ & $\mathrm{m}$ & $\mathrm{m}$ & $\mathrm{m}$ & $\mathrm{m}$ & $\mathrm{m}$ & $\mathrm{m}$ & $\mathrm{m}$ & $\mathrm{m}$ & $\mathrm{m}$ & $\mathrm{m}$ & $\mathrm{m}$ \\
\hline & Montenegro & -5.9 & $(0.7)$ & -8.7 & $(0.8)$ & -13.9 & $(1.2)$ & -5.8 & $(0.8)$ & -9.0 & $(0.8)$ & -5.4 & $(0.7)$ \\
\hline & Peru & -5.4 & (1.3) & -10.7 & $(0.9)$ & -15.0 & $(1.0)$ & 1.0 & $(1.3)$ & -9.4 & (1.0) & -3.8 & (1.1) \\
\hline & Qatar & 8.8 & $(0.7)$ & -7.3 & $(0.6)$ & -7.5 & $(0.7)$ & 7.8 & $(0.7)$ & -3.0 & $(0.5)$ & 8.3 & $(0.6)$ \\
\hline & Romania & 10.5 & (1.7) & 6.5 & $(1.0)$ & -14.3 & (1.4) & 10.9 & (1.6) & 3.9 & (1.1) & 13.1 & (1.7) \\
\hline & Russia & -10.7 & (1.0) & -12.2 & $(1.0)$ & -6.6 & (1.0) & -9.1 & (1.0) & -15.0 & (1.1) & -10.2 & $(0.8)$ \\
\hline & Singapore & -7.2 & $(0.9)$ & -8.2 & $(0.8)$ & -7.8 & $(0.9)$ & -6.8 & $(0.8)$ & -5.2 & $(0.8)$ & -2.3 & $(0.8)$ \\
\hline & Chinese Taipei & $\mathrm{m}$ & $\mathrm{m}$ & $\mathrm{m}$ & $\mathrm{m}$ & $\mathrm{m}$ & $\mathrm{m}$ & $\mathrm{m}$ & $\mathrm{m}$ & $\mathrm{m}$ & $\mathrm{m}$ & $\mathrm{m}$ & $\mathrm{m}$ \\
\hline & Thailand & 1.3 & (1.1) & -9.2 & $(0.7)$ & -12.8 & $(0.7)$ & 0.2 & (1.4) & -10.1 & $(1.1)$ & 2.5 & (1.2) \\
\hline & Trinidad and Tobago & $\mathrm{m}$ & $\mathrm{m}$ & $\mathrm{m}$ & $\mathrm{m}$ & $\mathrm{m}$ & $\mathrm{m}$ & $\mathrm{m}$ & $\mathrm{m}$ & $\mathrm{m}$ & $\mathrm{m}$ & $\mathrm{m}$ & $\mathrm{m}$ \\
\hline & Tunisia & 5.5 & (1.3) & -3.5 & $(0.9)$ & -8.4 & (1.3) & -0.8 & (1.3) & -4.8 & (0.9) & 4.0 & (1.1) \\
\hline & United Arab Emirates & 1.2 & $(0.9)$ & -7.8 & $(0.7)$ & -9.8 & $(0.8)$ & -1.1 & $(0.8)$ & -5.0 & $(0.8)$ & -0.5 & $(0.8)$ \\
\hline & Uruguay & -8.8 & (1.0) & -14.9 & $(0.9)$ & -14.6 & $(0.8)$ & -7.4 & (1.0) & -11.3 & $(0.6)$ & -2.9 & (1.0) \\
\hline & Viet Nam & 0.9 & $(0.7)$ & -0.3 & $(0.7)$ & -2.0 & (1.1) & -6.0 & $(0.8)$ & 1.8 & (1.4) & -1.4 & $(0.8)$ \\
\hline & Argentina** & 8.0 & (1.7) & 1.8 & $(0.8)$ & -0.4 & $(0.8)$ & 7.4 & (1.0) & 4.0 & $(0.9)$ & 7.4 & $(0.9)$ \\
\hline & Kazakhstan** & 3.2 & $(0.8)$ & -1.2 & $(0.7)$ & -3.7 & $(0.9)$ & 0.8 & $(0.7)$ & -2.0 & $(0.9)$ & 1.5 & $(0.7)$ \\
\hline & Malaysia** & 3.9 & $(1.2)$ & -3.2 & $(0.8)$ & -4.4 & $(1.1)$ & 5.4 & (1.3) & -3.6 & $(1.0)$ & 3.0 & $(1.2)$ \\
\hline
\end{tabular}

1. "OECD average-30" includes all OECD countries, with the exception of Chile, Estonia, Israel and the United States.

Note: Values that are statistically significant are indicated in bold (see Annex A3).

* See note at the beginning of this Annex.

** Coverage is too small to ensure comparability (see Annex A4).

StatLink त्ञाIs http://dx.doi.org/10.1787/888933471292 


\begin{tabular}{|c|c|c|c|c|c|c|c|c|c|c|c|c|c|}
\hline & \multicolumn{12}{|c|}{ Index of sense of belonging, by: } \\
\hline & & \multicolumn{4}{|c|}{ All students } & \multicolumn{8}{|c|}{ National quarters of the index of sense of belonging } \\
\hline & & Aver & & $\begin{array}{c}\mathrm{Va} \\
\text { of } t\end{array}$ & & Bottom & sarter & Second & arter & Third o & irter & Top q & ter \\
\hline & & Mean index & S.E. & S.D. & S.E. & Mean index & S.E. & Mean index & S.E. & Mean index & S.E. & Mean index & S.E. \\
\hline 0 & Australia & -0.12 & $(0.01)$ & 0.95 & $(0.01)$ & -1.14 & $(0.01)$ & -0.45 & $(0.00)$ & -0.04 & $(0.00)$ & 1.13 & $(0.02)$ \\
\hline 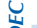 & Austria & 0.44 & $(0.02)$ & 1.26 & $(0.01)$ & -1.16 & $(0.02)$ & 0.09 & $(0.01)$ & 0.77 & $(0.00)$ & 2.07 & $(0.02)$ \\
\hline & Belgium & 0.01 & $(0.01)$ & 0.85 & $(0.01)$ & -0.93 & $(0.01)$ & -0.31 & $(0.00)$ & 0.20 & $(0.00)$ & 1.10 & $(0.01)$ \\
\hline & Canada & -0.11 & $(0.01)$ & 1.01 & $(0.01)$ & -1.18 & $(0.01)$ & -0.46 & $(0.00)$ & -0.05 & $(0.00)$ & 1.24 & $(0.02)$ \\
\hline & Chile & -0.04 & $(0.02)$ & 1.02 & $(0.01)$ & -1.19 & $(0.02)$ & -0.40 & $(0.00)$ & 0.16 & $(0.01)$ & 1.29 & $(0.02)$ \\
\hline & Czech Republic & -0.25 & $(0.01)$ & 0.79 & $(0.01)$ & -1.11 & $(0.01)$ & -0.47 & $(0.00)$ & -0.16 & $(0.00)$ & 0.76 & $(0.02)$ \\
\hline & Denmark & 0.14 & $(0.01)$ & 1.05 & $(0.01)$ & -1.07 & $(0.02)$ & -0.24 & $(0.00)$ & 0.41 & $(0.01)$ & 1.46 & $(0.02)$ \\
\hline & Estonia & -0.06 & $(0.01)$ & 0.86 & $(0.01)$ & -1.02 & $(0.01)$ & -0.39 & $(0.00)$ & 0.11 & $(0.01)$ & 1.05 & $(0.02)$ \\
\hline & Finland & 0.09 & $(0.02)$ & 0.98 & $(0.01)$ & -1.01 & $(0.01)$ & -0.28 & $(0.00)$ & 0.32 & $(0.01)$ & 1.34 & $(0.02)$ \\
\hline & France & -0.06 & $(0.01)$ & 0.78 & $(0.01)$ & -0.93 & $(0.01)$ & -0.36 & $(0.00)$ & 0.11 & $(0.00)$ & 0.94 & $(0.02)$ \\
\hline & Germany & 0.29 & $(0.02)$ & 1.07 & $(0.01)$ & -1.04 & $(0.02)$ & 0.00 & $(0.01)$ & 0.56 & $(0.00)$ & 1.63 & $(0.02)$ \\
\hline & Greece & 0.10 & $(0.01)$ & 0.96 & $(0.01)$ & -0.95 & $(0.01)$ & -0.28 & $(0.00)$ & 0.27 & $(0.01)$ & 1.37 & $(0.02)$ \\
\hline & Hungary & 0.06 & $(0.02)$ & 1.01 & $(0.01)$ & -1.09 & $(0.02)$ & -0.33 & $(0.00)$ & 0.30 & $(0.01)$ & 1.37 & $(0.02)$ \\
\hline & Iceland & 0.19 & $(0.02)$ & 1.29 & $(0.01)$ & -1.31 & $(0.03)$ & -0.28 & $(0.01)$ & 0.47 & $(0.01)$ & 1.90 & $(0.02)$ \\
\hline & Ireland & -0.02 & $(0.01)$ & 0.94 & $(0.01)$ & -1.03 & $(0.01)$ & -0.38 & $(0.00)$ & 0.13 & $(0.01)$ & 1.21 & $(0.02)$ \\
\hline & Israel & $\mathrm{m}$ & $\mathrm{m}$ & $\mathrm{m}$ & $\mathrm{m}$ & $\mathrm{m}$ & $\mathrm{m}$ & $\mathrm{m}$ & $\mathrm{m}$ & $\mathrm{m}$ & $\mathrm{m}$ & $\mathrm{m}$ & $\mathrm{m}$ \\
\hline & Italy & 0.05 & $(0.01)$ & 0.86 & $(0.01)$ & -0.93 & $(0.01)$ & -0.28 & $(0.00)$ & 0.27 & $(0.00)$ & 1.15 & $(0.02)$ \\
\hline & Japan & -0.03 & $(0.01)$ & 0.90 & $(0.01)$ & -0.97 & $(0.01)$ & -0.41 & $(0.00)$ & 0.07 & $(0.00)$ & 1.18 & $(0.02)$ \\
\hline & Korea & 0.16 & $(0.02)$ & 0.89 & $(0.01)$ & -0.78 & $(0.01)$ & -0.27 & $(0.00)$ & 0.35 & $(0.01)$ & 1.33 & $(0.03)$ \\
\hline & Latvia & -0.20 & $(0.01)$ & 0.86 & $(0.01)$ & -1.17 & $(0.02)$ & -0.46 & $(0.00)$ & -0.06 & $(0.01)$ & 0.89 & $(0.02)$ \\
\hline & Luxembourg & 0.14 & $(0.01)$ & 1.06 & $(0.01)$ & -1.13 & $(0.01)$ & -0.22 & $(0.00)$ & 0.43 & $(0.00)$ & 1.47 & $(0.02)$ \\
\hline & Mexico & -0.14 & $(0.02)$ & 1.08 & $(0.01)$ & -1.41 & $(0.02)$ & -0.47 & $(0.00)$ & 0.06 & $(0.01)$ & 1.24 & $(0.02)$ \\
\hline & Netherlands & 0.17 & $(0.01)$ & 0.89 & $(0.01)$ & -0.82 & $(0.02)$ & -0.18 & $(0.00)$ & 0.43 & $(0.01)$ & 1.24 & $(0.02)$ \\
\hline & New Zealand & -0.17 & $(0.01)$ & 0.87 & $(0.01)$ & -1.09 & $(0.01)$ & -0.45 & $(0.00)$ & -0.12 & $(0.01)$ & 0.99 & $(0.02)$ \\
\hline & Norway & 0.21 & $(0.02)$ & 1.13 & $(0.01)$ & -1.07 & $(0.02)$ & -0.23 & $(0.01)$ & 0.45 & $(0.01)$ & 1.70 & $(0.02)$ \\
\hline & Poland & -0.25 & $(0.01)$ & 0.95 & $(0.02)$ & -1.37 & $(0.02)$ & -0.50 & $(0.00)$ & -0.08 & $(0.01)$ & 0.93 & $(0.02)$ \\
\hline & Portugal & 0.10 & $(0.01)$ & 0.99 & $(0.01)$ & -0.99 & $(0.01)$ & -0.27 & $(0.00)$ & 0.29 & $(0.01)$ & 1.39 & $(0.02)$ \\
\hline & Slovak Republic & -0.28 & $(0.01)$ & 0.83 & $(0.01)$ & -1.21 & $(0.01)$ & -0.51 & $(0.00)$ & -0.17 & $(0.00)$ & 0.79 & $(0.02)$ \\
\hline & Slovenia & -0.10 & $(0.02)$ & 0.89 & $(0.01)$ & -1.17 & $(0.02)$ & -0.37 & $(0.00)$ & 0.14 & $(0.01)$ & 1.00 & $(0.02)$ \\
\hline & Spain & 0.47 & $(0.02)$ & 1.16 & $(0.01)$ & -0.92 & $(0.02)$ & 0.09 & $(0.01)$ & 0.73 & $(0.00)$ & 1.98 & $(0.01)$ \\
\hline & Sweden & 0.04 & $(0.02)$ & 1.22 & $(0.02)$ & -1.42 & $(0.03)$ & -0.35 & $(0.01)$ & 0.34 & $(0.01)$ & 1.59 & $(0.03)$ \\
\hline & Switzerland & 0.36 & $(0.02)$ & 1.07 & $(0.01)$ & -0.92 & $(0.02)$ & 0.01 & $(0.01)$ & 0.61 & $(0.01)$ & 1.72 & $(0.02)$ \\
\hline & Turkey & -0.44 & $(0.02)$ & 1.12 & $(0.02)$ & -1.70 & $(0.02)$ & -0.80 & $(0.00)$ & -0.27 & $(0.01)$ & 1.02 & $(0.03)$ \\
\hline & United Kingdom & -0.09 & $(0.01)$ & 0.90 & $(0.01)$ & -1.07 & $(0.01)$ & -0.42 & $(0.00)$ & 0.03 & $(0.01)$ & 1.10 & $(0.02)$ \\
\hline & United States & -0.09 & $(0.02)$ & 1.02 & $(0.01)$ & -1.15 & $(0.01)$ & -0.45 & $(0.00)$ & -0.05 & $(0.01)$ & 1.30 & $(0.02)$ \\
\hline & OECD average & 0.02 & $(0.00)$ & 0.99 & $(0.00)$ & -1.10 & $(0.00)$ & -0.33 & $(0.00)$ & 0.21 & $(0.00)$ & 1.29 & $(0.00)$ \\
\hline$n$ & Albania & 0.40 & $(0.01)$ & 0.78 & $(0.01)$ & -0.50 & $(0.01)$ & 0.13 & $(0.00)$ & 0.56 & $(0.00)$ & 1.42 & $(0.02)$ \\
\hline 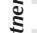 & Algeria & -0.21 & $(0.02)$ & 0.80 & $(0.01)$ & -1.11 & $(0.01)$ & -0.55 & $(0.01)$ & -0.04 & $(0.00)$ & 0.85 & $(0.02)$ \\
\hline$\Sigma$ & Brazil & -0.15 & $(0.01)$ & 0.98 & $(0.01)$ & -1.18 & $(0.01)$ & -0.46 & $(0.00)$ & -0.09 & $(0.00)$ & 1.15 & $(0.01)$ \\
\hline & B-S-J-G (China) & -0.33 & $(0.01)$ & 0.76 & $(0.01)$ & -1.11 & $(0.01)$ & -0.59 & $(0.00)$ & -0.28 & $(0.00)$ & 0.65 & $(0.02)$ \\
\hline & Bulgaria & -0.34 & $(0.02)$ & 0.94 & $(0.01)$ & -1.46 & $(0.02)$ & -0.60 & $(0.00)$ & -0.15 & $(0.00)$ & 0.84 & $(0.02)$ \\
\hline & CABA (Argentina) & 0.38 & $(0.04)$ & 0.91 & $(0.02)$ & -0.63 & $(0.01)$ & 0.00 & $(0.01)$ & 0.54 & $(0.01)$ & 1.60 & $(0.03)$ \\
\hline & Colombia & -0.31 & $(0.01)$ & 1.02 & $(0.01)$ & -1.50 & $(0.01)$ & -0.57 & $(0.00)$ & -0.14 & $(0.00)$ & 0.97 & $(0.02)$ \\
\hline & Costa Rica & -0.16 & $(0.02)$ & 1.21 & $(0.01)$ & -1.62 & $(0.02)$ & -0.48 & $(0.00)$ & 0.08 & $(0.01)$ & 1.39 & $(0.02)$ \\
\hline & Croatia & 0.05 & $(0.02)$ & 0.96 & $(0.01)$ & -1.04 & $(0.02)$ & -0.31 & $(0.00)$ & 0.28 & $(0.01)$ & 1.25 & $(0.02)$ \\
\hline & Cyprus* & 0.10 & $(0.02)$ & 1.03 & $(0.01)$ & -1.01 & $(0.02)$ & -0.32 & $(0.00)$ & 0.26 & $(0.01)$ & 1.48 & $(0.02)$ \\
\hline & Dominican Republic & -0.40 & $(0.02)$ & 1.21 & $(0.02)$ & -1.77 & $(0.02)$ & -0.77 & $(0.01)$ & -0.21 & $(0.01)$ & 1.14 & $(0.03)$ \\
\hline & FYROM & 0.35 & $(0.01)$ & 0.93 & $(0.01)$ & -0.68 & $(0.01)$ & -0.04 & $(0.01)$ & 0.49 & $(0.01)$ & 1.61 & $(0.02)$ \\
\hline & Georgia & 0.20 & $(0.02)$ & 0.78 & $(0.01)$ & -0.64 & $(0.01)$ & -0.15 & $(0.00)$ & 0.34 & $(0.01)$ & 1.24 & $(0.02)$ \\
\hline & Hong Kong (China) & -0.35 & $(0.01)$ & 0.69 & $(0.02)$ & -1.08 & $(0.01)$ & -0.54 & $(0.00)$ & -0.30 & $(0.00)$ & 0.53 & $(0.02)$ \\
\hline & Indonesia & 0.10 & $(0.01)$ & 0.65 & $(0.01)$ & -0.58 & $(0.01)$ & -0.16 & $(0.00)$ & 0.20 & $(0.00)$ & 0.96 & $(0.02)$ \\
\hline & Jordan & 0.19 & $(0.02)$ & 0.96 & $(0.01)$ & -0.88 & $(0.01)$ & -0.19 & $(0.00)$ & 0.35 & $(0.00)$ & 1.48 & $(0.02)$ \\
\hline & Kosovo & 0.29 & $(0.01)$ & 0.80 & $(0.01)$ & -0.65 & $(0.01)$ & 0.00 & $(0.01)$ & 0.47 & $(0.01)$ & 1.31 & $(0.02)$ \\
\hline & Lebanon & 0.02 & $(0.03)$ & 0.90 & $(0.02)$ & -0.96 & $(0.01)$ & -0.36 & $(0.01)$ & 0.17 & $(0.01)$ & 1.22 & $(0.03)$ \\
\hline & Lithuania & -0.27 & $(0.02)$ & 1.13 & $(0.01)$ & -1.71 & $(0.02)$ & -0.64 & $(0.01)$ & 0.15 & $(0.01)$ & 1.13 & $(0.02)$ \\
\hline & Macao (China) & -0.40 & $(0.01)$ & 0.62 & $(0.01)$ & -1.09 & $(0.01)$ & -0.59 & $(0.00)$ & -0.33 & $(0.00)$ & 0.40 & $(0.01)$ \\
\hline & Malta & -0.02 & $(0.02)$ & 0.81 & $(0.01)$ & -0.94 & $(0.01)$ & -0.34 & $(0.00)$ & 0.15 & $(0.00)$ & 1.05 & $(0.02)$ \\
\hline & Moldova & 0.04 & $(0.01)$ & 0.74 & $(0.01)$ & -0.79 & $(0.01)$ & -0.24 & $(0.00)$ & 0.19 & $(0.00)$ & 0.99 & $(0.02)$ \\
\hline & Montenegro & -0.10 & $(0.01)$ & 0.91 & $(0.01)$ & -1.10 & $(0.02)$ & -0.43 & $(0.00)$ & 0.04 & $(0.01)$ & 1.08 & $(0.02)$ \\
\hline & Peru & -0.22 & $(0.01)$ & 0.80 & $(0.01)$ & -1.13 & $(0.01)$ & -0.48 & $(0.00)$ & -0.08 & $(0.00)$ & 0.82 & $(0.01)$ \\
\hline & Qatar & -0.10 & $(0.01)$ & 0.99 & $(0.01)$ & -1.17 & $(0.01)$ & -0.47 & $(0.00)$ & 0.01 & $(0.00)$ & 1.22 & $(0.01)$ \\
\hline & Romania & 0.00 & $(0.02)$ & 0.77 & $(0.01)$ & -0.89 & $(0.02)$ & -0.29 & $(0.00)$ & 0.18 & $(0.00)$ & 1.00 & $(0.02)$ \\
\hline & Russia & -0.37 & $(0.01)$ & 0.80 & $(0.02)$ & -1.22 & $(0.02)$ & -0.59 & $(0.00)$ & -0.30 & $(0.00)$ & 0.61 & $(0.03)$ \\
\hline & Singapore & -0.21 & $(0.01)$ & 0.88 & $(0.01)$ & -1.14 & $(0.01)$ & -0.48 & $(0.00)$ & -0.18 & $(0.00)$ & 0.95 & $(0.02)$ \\
\hline & Chinese Taipei & 0.02 & $(0.01)$ & 0.95 & $(0.01)$ & -0.97 & $(0.01)$ & -0.36 & $(0.00)$ & 0.12 & $(0.00)$ & 1.30 & $(0.02)$ \\
\hline & Thailand & -0.35 & $(0.01)$ & 0.65 & $(0.01)$ & -1.05 & $(0.01)$ & -0.58 & $(0.00)$ & -0.28 & $(0.00)$ & 0.49 & $(0.01)$ \\
\hline & Trinidad and Tobago & 0.05 & $(0.01)$ & 0.89 & $(0.01)$ & -0.94 & $(0.01)$ & -0.31 & $(0.00)$ & 0.20 & $(0.00)$ & 1.24 & $(0.02)$ \\
\hline & Tunisia & -0.20 & $(0.01)$ & 0.73 & $(0.01)$ & -0.99 & $(0.01)$ & -0.48 & $(0.00)$ & -0.07 & $(0.00)$ & 0.74 & $(0.02)$ \\
\hline & United Arab Emirates & -0.10 & $(0.01)$ & 0.88 & $(0.01)$ & -1.04 & $(0.01)$ & -0.44 & $(0.00)$ & 0.02 & $(0.00)$ & 1.07 & $(0.02)$ \\
\hline & Uruguay & -0.09 & $(0.02)$ & 1.10 & $(0.01)$ & -1.31 & $(0.02)$ & -0.44 & $(0.00)$ & 0.03 & $(0.01)$ & 1.35 & $(0.02)$ \\
\hline & Viet Nam & -0.06 & $(0.01)$ & 0.60 & $(0.01)$ & -0.75 & $(0.01)$ & -0.30 & $(0.00)$ & 0.09 & $(0.00)$ & 0.71 & $(0.02)$ \\
\hline & Argentina** $^{* *}$ & 0.21 & $(0.02)$ & 0.92 & $(0.01)$ & -0.78 & $(0.01)$ & -0.19 & $(0.00)$ & 0.35 & $(0.01)$ & 1.45 & $(0.02)$ \\
\hline & Kazakhstan** & 0.34 & $(0.02)$ & 0.87 & $(0.01)$ & -0.63 & $(0.01)$ & -0.05 & $(0.00)$ & 0.50 & $(0.00)$ & 1.52 & $(0.02)$ \\
\hline & Malaysia** & -0.13 & $(0.02)$ & 0.75 & $(0.01)$ & -0.94 & $(0.01)$ & -0.42 & $(0.00)$ & -0.04 & $(0.00)$ & 0.87 & $(0.02)$ \\
\hline
\end{tabular}

1. ESCS refers to the the PISA index of economic, social and cultural status.

Note: Values that are statistically significant are indicated in bold (see Annex A3).

* See note at the beginning of this Annex.

** Coverage is too small to ensure comparability (see Annex A4).

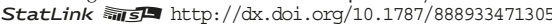


[Part 2/3]

Table III.7.6 Index of sense of belonging, by student characteristics

Results based on students' self-reports

\begin{tabular}{|c|c|c|c|c|c|c|c|c|c|c|c|c|c|c|c|c|}
\hline & \multicolumn{16}{|c|}{ Index of sense of belonging, by: } \\
\hline & \multicolumn{10}{|c|}{ National quarters of the ESCS ${ }^{1}$ index } & \multicolumn{6}{|c|}{ Gender } \\
\hline & \multicolumn{2}{|c|}{ Bottom quarter } & \multicolumn{2}{|c|}{ Second quarter } & \multicolumn{2}{|c|}{ Third quarter } & \multicolumn{2}{|c|}{ Top quarter } & \multicolumn{2}{|c|}{$\begin{array}{l}\text { Top - bottom } \\
\text { quarter }\end{array}$} & \multicolumn{2}{|c|}{ Boys } & \multicolumn{2}{|c|}{ Girls } & \multicolumn{2}{|c|}{$\begin{array}{c}\text { Gender } \\
\text { difference }(B-G)\end{array}$} \\
\hline & $\begin{array}{l}\text { Mean } \\
\text { index }\end{array}$ & S.E. & $\begin{array}{l}\text { Mean } \\
\text { index }\end{array}$ & S.E. & $\begin{array}{l}\text { Mean } \\
\text { index }\end{array}$ & S.E. & $\begin{array}{l}\text { Mean } \\
\text { index }\end{array}$ & S.E. & Dif. & S.E. & $\begin{array}{l}\text { Mean } \\
\text { index }\end{array}$ & S.E. & $\begin{array}{l}\text { Mean } \\
\text { index }\end{array}$ & S.E. & Dif. & S.E. \\
\hline Australia & -0.29 & $(0.02)$ & -0.13 & $(0.02)$ & -0.08 & $(0.02)$ & 0.00 & $(0.02)$ & 0.29 & $(0.03)$ & -0.03 & $(0.02)$ & -0.22 & $(0.01)$ & 0.18 & $(0.02)$ \\
\hline Austria & 0.32 & $(0.03)$ & 0.39 & $(0.04)$ & 0.54 & $(0.04)$ & 0.54 & $(0.04)$ & 0.22 & $(0.05)$ & 0.43 & $(0.02)$ & 0.46 & $(0.02)$ & -0.03 & $(0.03)$ \\
\hline Belgium & -0.07 & $(0.03)$ & -0.02 & $(0.02)$ & 0.07 & $(0.02)$ & 0.08 & $(0.02)$ & 0.15 & $(0.03)$ & 0.06 & $(0.02)$ & -0.03 & $(0.02)$ & 0.08 & $(0.02)$ \\
\hline Canada & -0.24 & $(0.02)$ & -0.14 & $(0.02)$ & -0.07 & $(0.02)$ & 0.01 & $(0.02)$ & 0.25 & $(0.03)$ & -0.04 & $(0.01)$ & -0.19 & $(0.02)$ & 0.15 & $(0.02)$ \\
\hline Chile & -0.17 & $(0.03)$ & -0.01 & $(0.04)$ & -0.07 & $(0.03)$ & 0.10 & $(0.03)$ & 0.28 & $(0.04)$ & 0.00 & $(0.03)$ & -0.07 & $(0.02)$ & 0.06 & $(0.03)$ \\
\hline Czech Republic & -0.36 & $(0.02)$ & -0.29 & $(0.02)$ & -0.20 & $(0.02)$ & -0.14 & $(0.02)$ & 0.23 & $(0.03)$ & -0.22 & $(0.02)$ & -0.27 & $(0.02)$ & 0.05 & $(0.02)$ \\
\hline Denmark & 0.02 & $(0.03)$ & 0.13 & $(0.03)$ & 0.17 & $(0.03)$ & 0.26 & $(0.03)$ & 0.24 & $(0.05)$ & 0.24 & $(0.02)$ & 0.04 & $(0.02)$ & 0.20 & $(0.03)$ \\
\hline Estonia & -0.15 & $(0.03)$ & -0.10 & $(0.03)$ & -0.07 & $(0.02)$ & 0.07 & $(0.03)$ & 0.22 & $(0.04)$ & -0.02 & $(0.02)$ & -0.11 & $(0.02)$ & 0.09 & $(0.03)$ \\
\hline Finland & 0.00 & $(0.03)$ & 0.02 & $(0.03)$ & 0.12 & $(0.03)$ & 0.22 & $(0.03)$ & 0.23 & $(0.04)$ & 0.19 & $(0.02)$ & -0.02 & $(0.02)$ & 0.21 & $(0.03)$ \\
\hline France & -0.17 & $(0.02)$ & -0.10 & $(0.02)$ & -0.06 & $(0.02)$ & 0.10 & $(0.02)$ & 0.27 & $(0.03)$ & -0.05 & $(0.02)$ & -0.07 & $(0.02)$ & 0.02 & $(0.02)$ \\
\hline Germany & 0.22 & $(0.03)$ & 0.24 & $(0.03)$ & 0.31 & $(0.03)$ & 0.40 & $(0.03)$ & 0.18 & $(0.04)$ & 0.34 & $(0.03)$ & 0.24 & $(0.02)$ & 0.10 & $(0.03)$ \\
\hline Greece & 0.01 & $(0.03)$ & 0.09 & $(0.03)$ & 0.12 & $(0.03)$ & 0.18 & $(0.03)$ & 0.16 & $(0.04)$ & 0.13 & $(0.02)$ & 0.06 & $(0.02)$ & 0.07 & $(0.03)$ \\
\hline Hungary & -0.09 & $(0.03)$ & 0.03 & $(0.03)$ & 0.09 & $(0.04)$ & 0.21 & $(0.03)$ & 0.30 & $(0.04)$ & 0.11 & $(0.02)$ & 0.01 & $(0.02)$ & 0.11 & $(0.03)$ \\
\hline Iceland & 0.09 & $(0.04)$ & 0.15 & $(0.04)$ & 0.27 & $(0.04)$ & 0.28 & $(0.05)$ & 0.19 & $(0.06)$ & 0.23 & $(0.03)$ & 0.16 & $(0.03)$ & 0.07 & $(0.04)$ \\
\hline Ireland & -0.08 & $(0.03)$ & -0.04 & $(0.03)$ & 0.00 & $(0.03)$ & 0.07 & $(0.03)$ & 0.15 & $(0.04)$ & 0.07 & $(0.02)$ & -0.10 & $(0.02)$ & 0.18 & $(0.02)$ \\
\hline Israel & $\mathrm{m}$ & $\mathrm{m}$ & $\mathrm{m}$ & $\mathrm{m}$ & $\mathrm{m}$ & $\mathrm{m}$ & $\mathrm{m}$ & $\mathrm{m}$ & $\mathrm{m}$ & $\mathrm{m}$ & $\mathrm{m}$ & $\mathrm{m}$ & $\mathrm{m}$ & $\mathrm{m}$ & $\mathrm{m}$ & $\mathrm{m}$ \\
\hline Italy & -0.02 & $(0.02)$ & 0.07 & $(0.02)$ & 0.09 & $(0.03)$ & 0.07 & $(0.02)$ & 0.09 & $(0.03)$ & 0.08 & $(0.02)$ & 0.03 & $(0.02)$ & 0.05 & $(0.03)$ \\
\hline Japan & -0.11 & $(0.02)$ & -0.05 & $(0.03)$ & -0.02 & $(0.02)$ & 0.07 & $(0.03)$ & 0.18 & $(0.03)$ & -0.02 & $(0.02)$ & -0.05 & $(0.02)$ & 0.02 & $(0.03)$ \\
\hline Korea & 0.00 & $(0.02)$ & 0.16 & $(0.03)$ & 0.16 & $(0.03)$ & 0.32 & $(0.03)$ & 0.33 & $(0.04)$ & 0.22 & $(0.02)$ & 0.09 & $(0.02)$ & 0.13 & $(0.03)$ \\
\hline Latvia & -0.28 & $(0.03)$ & -0.23 & $(0.02)$ & -0.18 & $(0.03)$ & -0.12 & $(0.03)$ & 0.16 & $(0.04)$ & -0.18 & $(0.02)$ & -0.22 & $(0.02)$ & 0.04 & $(0.03)$ \\
\hline Luxembourg & -0.05 & $(0.02)$ & 0.08 & $(0.03)$ & 0.16 & $(0.03)$ & 0.36 & $(0.03)$ & 0.42 & $(0.04)$ & 0.18 & $(0.02)$ & 0.09 & $(0.02)$ & 0.09 & $(0.03)$ \\
\hline Mexico & -0.24 & $(0.03)$ & -0.22 & $(0.03)$ & -0.10 & $(0.03)$ & -0.02 & $(0.04)$ & 0.21 & (0.05) & -0.20 & $(0.02)$ & -0.09 & $(0.02)$ & -0.11 & $(0.03)$ \\
\hline Netherlands & 0.14 & $(0.02)$ & 0.15 & $(0.03)$ & 0.18 & $(0.03)$ & 0.20 & $(0.03)$ & 0.06 & $(0.03)$ & 0.19 & $(0.02)$ & 0.14 & $(0.02)$ & 0.04 & $(0.03)$ \\
\hline New Zealand & -0.29 & $(0.03)$ & -0.18 & $(0.03)$ & -0.17 & $(0.03)$ & -0.04 & $(0.03)$ & 0.25 & $(0.04)$ & -0.10 & $(0.02)$ & -0.23 & $(0.02)$ & 0.13 & $(0.03)$ \\
\hline Norway & 0.04 & $(0.04)$ & 0.26 & $(0.03)$ & 0.21 & $(0.03)$ & 0.33 & $(0.03)$ & 0.29 & $(0.05)$ & 0.31 & $(0.02)$ & 0.11 & $(0.02)$ & 0.19 & $(0.03)$ \\
\hline Poland & -0.30 & $(0.03)$ & -0.27 & $(0.03)$ & -0.20 & $(0.03)$ & -0.23 & $(0.03)$ & 0.07 & $(0.04)$ & -0.25 & $(0.02)$ & -0.26 & $(0.02)$ & 0.01 & $(0.03)$ \\
\hline Portugal & -0.02 & $(0.03)$ & 0.10 & $(0.03)$ & 0.09 & $(0.02)$ & 0.24 & $(0.03)$ & 0.27 & $(0.04)$ & 0.17 & $(0.02)$ & 0.03 & $(0.02)$ & 0.14 & $(0.03)$ \\
\hline Slovak Republic & -0.43 & $(0.02)$ & -0.29 & $(0.02)$ & -0.23 & $(0.02)$ & -0.17 & $(0.02)$ & 0.26 & $(0.03)$ & -0.30 & $(0.02)$ & -0.25 & $(0.02)$ & -0.05 & $(0.03)$ \\
\hline Slovenia & -0.15 & $(0.03)$ & -0.11 & $(0.02)$ & -0.08 & $(0.03)$ & -0.05 & $(0.03)$ & 0.09 & $(0.04)$ & -0.12 & $(0.02)$ & -0.07 & $(0.02)$ & -0.05 & $(0.03)$ \\
\hline Spain & 0.41 & $(0.03)$ & 0.40 & $(0.03)$ & 0.50 & $(0.04)$ & 0.58 & $(0.03)$ & 0.17 & $(0.05)$ & 0.47 & $(0.02)$ & 0.47 & $(0.02)$ & -0.01 & $(0.03)$ \\
\hline Sweden & -0.11 & $(0.04)$ & 0.02 & $(0.03)$ & 0.11 & $(0.03)$ & 0.13 & $(0.04)$ & 0.23 & $(0.05)$ & 0.10 & $(0.03)$ & -0.02 & $(0.02)$ & 0.11 & $(0.04)$ \\
\hline Switzerland & 0.28 & $(0.03)$ & 0.37 & $(0.04)$ & 0.39 & $(0.03)$ & 0.38 & $(0.03)$ & 0.10 & $(0.04)$ & 0.43 & $(0.02)$ & 0.28 & $(0.02)$ & 0.14 & $(0.03)$ \\
\hline Turkey & -0.50 & $(0.03)$ & -0.47 & $(0.03)$ & -0.45 & $(0.03)$ & -0.33 & $(0.04)$ & 0.17 & $(0.05)$ & -0.56 & $(0.03)$ & -0.32 & $(0.03)$ & -0.24 & $(0.04)$ \\
\hline United Kingdom & -0.21 & $(0.02)$ & -0.11 & $(0.03)$ & -0.07 & $(0.02)$ & 0.01 & $(0.02)$ & 0.22 & $(0.03)$ & 0.03 & $(0.02)$ & -0.21 & $(0.02)$ & 0.24 & $(0.02)$ \\
\hline United States & -0.22 & $(0.03)$ & -0.17 & $(0.02)$ & -0.04 & $(0.03)$ & 0.09 & $(0.03)$ & 0.30 & $(0.04)$ & 0.00 & $(0.02)$ & -0.18 & $(0.02)$ & 0.18 & $(0.03)$ \\
\hline OECD average & -0.09 & $(0.00)$ & -0.01 & $(0.00)$ & 0.04 & $(0.01)$ & 0.12 & $(0.01)$ & 0.21 & $(0.01)$ & 0.05 & $(0.00)$ & -0.02 & $(0.00)$ & 0.08 & $(0.00)$ \\
\hline
\end{tabular}

\begin{tabular}{|c|c|c|c|c|c|c|c|c|c|c|c|c|c|c|c|c|}
\hline Albania & 0.33 & $(0.02)$ & 0.39 & $(0.03)$ & 0.40 & $(0.02)$ & 0.50 & $(0.03)$ & 0.17 & $(0.03)$ & 0.43 & $(0.02)$ & 0.38 & $(0.02)$ & 0.05 & $(0.03)$ \\
\hline Algeria & -0.26 & $(0.03)$ & -0.26 & $(0.03)$ & -0.21 & $(0.03)$ & -0.13 & $(0.03)$ & 0.12 & $(0.04)$ & -0.23 & $(0.02)$ & -0.20 & $(0.02)$ & -0.03 & $(0.03)$ \\
\hline Brazil & -0.25 & $(0.02)$ & -0.18 & $(0.02)$ & -0.16 & $(0.03)$ & 0.00 & $(0.02)$ & 0.26 & $(0.03)$ & -0.15 & $(0.02)$ & -0.15 & $(0.01)$ & 0.00 & $(0.02)$ \\
\hline B-S-J-G (China) & -0.49 & $(0.02)$ & -0.37 & $(0.03)$ & -0.29 & $(0.02)$ & -0.18 & $(0.03)$ & 0.31 & $(0.03)$ & -0.32 & $(0.02)$ & -0.35 & $(0.02)$ & 0.03 & $(0.02)$ \\
\hline Bulgaria & -0.49 & $(0.02)$ & -0.36 & $(0.03)$ & -0.28 & $(0.03)$ & -0.25 & $(0.03)$ & 0.24 & $(0.04)$ & -0.39 & $(0.02)$ & -0.29 & $(0.02)$ & -0.11 & $(0.02)$ \\
\hline CABA (Argentina) & 0.16 & $(0.03)$ & 0.27 & $(0.06)$ & 0.50 & $(0.06)$ & 0.57 & $(0.08)$ & 0.41 & $(0.07)$ & 0.45 & $(0.05)$ & 0.31 & $(0.05)$ & 0.13 & $(0.05)$ \\
\hline Colombia & -0.34 & $(0.03)$ & -0.38 & $(0.03)$ & -0.31 & $(0.02)$ & -0.21 & $(0.03)$ & 0.14 & $(0.04)$ & -0.36 & $(0.02)$ & -0.26 & $(0.02)$ & -0.10 & $(0.03)$ \\
\hline Costa Rica & -0.24 & $(0.03)$ & -0.18 & $(0.03)$ & -0.16 & $(0.04)$ & -0.06 & $(0.04)$ & 0.18 & $(0.04)$ & -0.18 & $(0.03)$ & -0.14 & $(0.02)$ & -0.04 & $(0.03)$ \\
\hline Croatia & 0.01 & $(0.03)$ & 0.00 & $(0.03)$ & 0.03 & $(0.03)$ & 0.15 & $(0.03)$ & 0.14 & $(0.04)$ & 0.04 & $(0.02)$ & 0.06 & $(0.02)$ & -0.02 & $(0.03)$ \\
\hline Cyprus* & 0.04 & $(0.02)$ & 0.16 & $(0.03)$ & 0.09 & $(0.03)$ & 0.12 & $(0.03)$ & 0.08 & $(0.04)$ & 0.06 & $(0.02)$ & 0.14 & $(0.02)$ & -0.08 & $(0.03)$ \\
\hline Dominican Republic & -0.54 & $(0.04)$ & -0.45 & $(0.04)$ & -0.42 & $(0.05)$ & -0.21 & $(0.04)$ & 0.32 & $(0.06)$ & -0.47 & $(0.03)$ & -0.34 & $(0.03)$ & -0.13 & $(0.04)$ \\
\hline FYROM & 0.15 & $(0.03)$ & 0.31 & $(0.03)$ & 0.42 & $(0.03)$ & 0.50 & $(0.04)$ & 0.36 & $(0.05)$ & 0.31 & $(0.02)$ & 0.38 & $(0.02)$ & -0.07 & $(0.03)$ \\
\hline Georgia & 0.10 & $(0.03)$ & 0.13 & $(0.03)$ & 0.19 & $(0.03)$ & 0.38 & $(0.03)$ & 0.28 & $(0.04)$ & 0.20 & $(0.02)$ & 0.20 & $(0.02)$ & 0.00 & $(0.03)$ \\
\hline Hong Kong (China) & -0.45 & $(0.02)$ & -0.35 & $(0.02)$ & -0.35 & $(0.02)$ & -0.24 & $(0.03)$ & 0.21 & $(0.03)$ & -0.35 & $(0.02)$ & -0.35 & $(0.02)$ & 0.00 & $(0.02)$ \\
\hline Indonesia & 0.05 & $(0.02)$ & 0.10 & $(0.02)$ & 0.15 & $(0.02)$ & 0.12 & $(0.02)$ & 0.06 & $(0.03)$ & 0.11 & $(0.02)$ & 0.10 & $(0.01)$ & 0.01 & $(0.02)$ \\
\hline Jordan & 0.01 & $(0.04)$ & 0.17 & $(0.03)$ & 0.29 & $(0.04)$ & 0.31 & $(0.03)$ & 0.30 & $(0.05)$ & 0.08 & $(0.03)$ & 0.30 & $(0.03)$ & -0.22 & $(0.04)$ \\
\hline Kosovo & 0.22 & $(0.03)$ & 0.20 & $(0.03)$ & 0.31 & $(0.03)$ & 0.40 & $(0.03)$ & 0.18 & $(0.04)$ & 0.29 & $(0.02)$ & 0.28 & $(0.02)$ & 0.00 & $(0.03)$ \\
\hline Lebanon & -0.07 & $(0.05)$ & -0.01 & $(0.04)$ & -0.05 & $(0.05)$ & 0.19 & $(0.05)$ & 0.26 & $(0.07)$ & 0.00 & $(0.03)$ & 0.03 & $(0.03)$ & -0.03 & $(0.03)$ \\
\hline Lithuania & -0.39 & $(0.03)$ & -0.29 & $(0.04)$ & -0.29 & $(0.04)$ & -0.10 & $(0.04)$ & 0.29 & $(0.05)$ & -0.31 & $(0.03)$ & -0.23 & $(0.02)$ & -0.08 & $(0.03)$ \\
\hline Macao (China) & -0.42 & $(0.02)$ & -0.38 & $(0.02)$ & -0.42 & $(0.02)$ & -0.40 & $(0.02)$ & 0.02 & $(0.03)$ & -0.38 & $(0.02)$ & -0.43 & $(0.01)$ & 0.05 & $(0.02)$ \\
\hline Malta & -0.09 & $(0.02)$ & -0.06 & $(0.03)$ & 0.04 & $(0.03)$ & 0.03 & $(0.03)$ & 0.12 & $(0.04)$ & 0.06 & $(0.02)$ & -0.10 & $(0.02)$ & 0.16 & $(0.03)$ \\
\hline Moldov & -0.06 & $(0.03)$ & 0.03 & $(0.02)$ & 0.07 & $(0.02)$ & 0.12 & $(0.03)$ & 0.17 & $(0.03)$ & 0.05 & $(0.02)$ & 0.03 & $(0.02)$ & 0.02 & $(0.02)$ \\
\hline Montenegro & -0.13 & $(0.03)$ & -0.10 & $(0.02)$ & -0.09 & $(0.03)$ & -0.08 & $(0.03)$ & 0.04 & $(0.04)$ & -0.15 & $(0.02)$ & -0.05 & $(0.02)$ & -0.09 & $(0.03)$ \\
\hline Peru & -0.40 & $(0.02)$ & -0.23 & $(0.02)$ & -0.19 & $(0.03)$ & -0.07 & $(0.03)$ & 0.34 & $(0.03)$ & -0.27 & $(0.02)$ & -0.17 & $(0.02)$ & -0.11 & $(0.02)$ \\
\hline Qatar & -0.21 & $(0.02)$ & -0.13 & $(0.02)$ & -0.04 & $(0.02)$ & -0.03 & $(0.02)$ & 0.19 & $(0.03)$ & -0.18 & $(0.01)$ & -0.03 & $(0.01)$ & -0.16 & $(0.02)$ \\
\hline Romania & -0.05 & $(0.02)$ & -0.02 & $(0.03)$ & -0.01 & $(0.03)$ & 0.08 & $(0.03)$ & 0.13 & $(0.04)$ & 0.00 & $(0.02)$ & 0.00 & $(0.02)$ & -0.01 & $(0.02)$ \\
\hline Russia & -0.47 & $(0.03)$ & -0.40 & $(0.03)$ & -0.34 & $(0.03)$ & -0.29 & $(0.03)$ & 0.17 & $(0.04)$ & -0.35 & $(0.02)$ & -0.40 & $(0.02)$ & 0.05 & $(0.02)$ \\
\hline Singapore & -0.34 & $(0.02)$ & -0.22 & $(0.02)$ & -0.16 & $(0.03)$ & -0.14 & $(0.03)$ & 0.20 & $(0.04)$ & -0.16 & $(0.01)$ & -0.27 & $(0.02)$ & 0.10 & $(0.02)$ \\
\hline Chinese Taipei & -0.10 & $(0.02)$ & 0.03 & $(0.02)$ & 0.05 & $(0.02)$ & 0.11 & $(0.03)$ & 0.22 & $(0.04)$ & 0.04 & $(0.02)$ & 0.00 & $(0.01)$ & 0.05 & $(0.02)$ \\
\hline Thailand & -0.40 & $(0.02)$ & -0.38 & $(0.02)$ & -0.38 & $(0.02)$ & -0.26 & $(0.0$ & 0.14 & $(0.03)$ & -0.42 & $(0.02)$ & -0.31 & $(0$. & -0.11 & $(0.02)$ \\
\hline Trinidad and Tobago & -0.10 & $(0.03)$ & 0.03 & $(0.03)$ & 0.10 & $(0.03)$ & 0.18 & $(0.03)$ & 0.28 & $(0.04)$ & 0.08 & $(0.02)$ & 0.02 & $(0.02)$ & 0.06 & $(0.03)$ \\
\hline Tunisia & -0.25 & $(0.02)$ & -0.19 & $(0.02)$ & -0.20 & $(0.02)$ & -0.16 & $(0.02)$ & 0.10 & $(0.03)$ & -0.23 & $(0.02)$ & -0.18 & $(0.02)$ & -0.05 & $(0.02)$ \\
\hline United A & -0.22 & $(0.02)$ & -0.11 & $(0.02)$ & -0.06 & $(0.02)$ & -0.01 & $(0.02)$ & 0.21 & $(0.02)$ & -0.11 & $(0.01)$ & -0.09 & $(0.02)$ & -0.02 & $(0.02)$ \\
\hline Uruge & -0.23 & $(0.03)$ & -0.19 & $(0.03)$ & -0.0 & $(0.03)$ & 0.14 & $(0.04)$ & 0.37 & $(0.0$ & -0.07 & $(0.03)$ & -0.12 & $(0.02)$ & 0.05 & $(0.03)$ \\
\hline Viet Nam & -0.15 & $(0.02)$ & -0.07 & $(0.02)$ & 0.00 & $(0.02)$ & -0.03 & $(0.02)$ & 0.12 & $(0.03)$ & -0.02 & $(0.02)$ & -0.10 & $(0.01)$ & 0.08 & $(0.02)$ \\
\hline Argentina** & 0.02 & $(0.04)$ & 0.13 & $(0.03)$ & 0.25 & $(0.03)$ & 0.43 & $(0.03)$ & 0.40 & $(0.05)$ & 0.28 & $(0.02)$ & 0.14 & $(0.02)$ & 0.14 & $(0.03)$ \\
\hline Kazakhstan** & 0.22 & $(0.03)$ & 0.31 & $(0.03)$ & 0.30 & $(0.03)$ & 0.52 & $(0.04)$ & 0.30 & $(0.05)$ & 0.27 & $(0.02)$ & 0.40 & $(0.03)$ & -0.13 & $(0.03)$ \\
\hline Malaysia** & -0.17 & $(0.03)$ & -0.13 & $(0.03)$ & -0.13 & $(0.02)$ & -0.11 & $(0.02)$ & 0.06 & $(0.03)$ & -0.17 & $(0.02)$ & -0.10 & $(0.02)$ & -0.07 & $(0.02)$ \\
\hline
\end{tabular}

. ESCS refers to the the PISA index of economic, social and cultural status.

Note: Values that are statistically significant are indicated in bold (see Annex A3).

* See note at the beginning of this Annex.

** Coverage is too small to ensure comparability (see Annex A4).

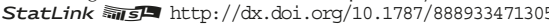




\begin{tabular}{|c|c|c|c|c|c|c|c|c|c|c|c|c|c|c|c|c|c|}
\hline & \multicolumn{16}{|c|}{ Index of sense of belonging, by: } \\
\hline & & & & & & & Imn & igrant b & kground & & & & & & $\begin{array}{r}\text { Diffe } \\
\text { immigran } \\
\text {-immigra }\end{array}$ & $\begin{array}{l}\text { ence } \\
\text { backgro } \\
\text { - immig }\end{array}$ & \\
\hline & & $\begin{array}{r}\mathrm{No} \\
\text { immi }\end{array}$ & $\begin{array}{l}\text { on- } \\
\text { grant }\end{array}$ & $\begin{array}{r}\text { Fir } \\
\text { gener }\end{array}$ & $\begin{array}{l}\text { st- } \\
\text { ration }\end{array}$ & $\begin{array}{r}\text { Secc } \\
\text { gener }\end{array}$ & $\begin{array}{l}\text { ond- } \\
\text { ration }\end{array}$ & $\begin{array}{r}\text { Dif } \\
\text { by in } \\
\text { bac } \\
\text { (non-ir } \\
\text { first-g }\end{array}$ & $\begin{array}{l}\text { ence } \\
\text { igrant } \\
\text { ound } \\
\text { igrant - } \\
\text { eration) }\end{array}$ & $\begin{array}{r}\text { Diff } \\
\text { by im } \\
\text { back } \\
\text { (non-im } \\
\text { second-g }\end{array}$ & $\begin{array}{l}\text { ence } \\
\text { igrant } \\
\text { ound } \\
\text { igrant - } \\
\text { neration) }\end{array}$ & $\begin{array}{r}\text { Diff } \\
\text { by im } \\
\text { back } \\
\text { (second- } \\
\text { first-ge }\end{array}$ & $\begin{array}{l}\text { ence } \\
\text { igrant } \\
\text { ound } \\
\text { ceration - } \\
\text { ration) }\end{array}$ & $\begin{array}{r}\text { Before } \\
\text { for s } \\
\text { socio- } \\
\end{array}$ & $\begin{array}{l}\text { counting } \\
\text { dents' } \\
\text { onomic } \\
\text { us }\end{array}$ & $\begin{array}{r}\text { After ac } \\
\text { for st } \\
\text { socio-e } \\
\text { st }\end{array}$ & $\begin{array}{l}\text { ounting } \\
\text { lents' } \\
\text { onomic } \\
\text { us }\end{array}$ \\
\hline & & $\begin{array}{l}\text { Mean } \\
\text { index }\end{array}$ & S.E. & $\begin{array}{l}\text { Mean } \\
\text { index }\end{array}$ & S.E. & $\begin{array}{l}\text { Mean } \\
\text { index }\end{array}$ & S.E. & Dif. & S.E. & Dif. & S.E. & Dif. & S.E. & Dif. & S.E. & Dif. & S.E. \\
\hline & Australia & -0.15 & $(0.01)$ & -0.06 & $(0.03)$ & -0.07 & $(0.03)$ & -0.09 & $(0.04)$ & -0.08 & $(0.03)$ & -0.01 & $(0.04)$ & -0.08 & $(0.03)$ & -0.09 & $(0.03)$ \\
\hline & Austria & 0.47 & $(0.02)$ & 0.15 & $(0.06)$ & 0.47 & $(0.05)$ & 0.32 & $(0.07)$ & 0.00 & $(0.05)$ & 0.32 & $(0.09)$ & 0.12 & $(0.04)$ & 0.05 & $(0.04)$ \\
\hline & Belgium & 0.02 & $(0.01)$ & -0.07 & $(0.04)$ & 0.10 & $(0.04)$ & 0.08 & $(0.04)$ & -0.09 & $(0.05)$ & 0.17 & $(0.06)$ & 0.00 & $(0.03)$ & -0.04 & $(0.03)$ \\
\hline & Canada & -0.11 & $(0.01)$ & -0.08 & $(0.03)$ & -0.12 & $(0.03)$ & -0.03 & $(0.03)$ & 0.01 & $(0.03)$ & -0.04 & $(0.04)$ & -0.01 & $(0.02)$ & -0.01 & $(0.02)$ \\
\hline & Chile & -0.03 & $(0.02)$ & -0.34 & $(0.10)$ & 0.13 & $(0.17)$ & 0.31 & $(0.10)$ & -0.15 & $(0.17)$ & 0.46 & $(0.22)$ & 0.19 & $(0.08)$ & 0.17 & $(0.08)$ \\
\hline & Czech Republic & -0.24 & $(0.01)$ & -0.35 & $(0.08)$ & -0.20 & $(0.11)$ & 0.11 & $(0.08)$ & -0.04 & $(0.11)$ & 0.15 & $(0.13)$ & 0.04 & $(0.07)$ & 0.03 & $(0.07)$ \\
\hline & Denmark & 0.15 & $(0.02)$ & -0.09 & $(0.09)$ & 0.14 & $(0.04)$ & 0.24 & $(0.10)$ & 0.01 & $(0.05)$ & 0.23 & $(0.10)$ & 0.06 & $(0.05)$ & 0.00 & $(0.05)$ \\
\hline & Estonia & -0.05 & $(0.01)$ & 0.04 & $(0.30)$ & -0.25 & $(0.03)$ & -0.08 & $(0.30)$ & 0.20 & $(0.03)$ & -0.28 & $(0.30)$ & 0.18 & $(0.04)$ & 0.18 & $(0.04)$ \\
\hline & Finland & 0.09 & $(0.02)$ & 0.00 & $(0.12)$ & 0.22 & $(0.10)$ & 0.09 & $(0.12)$ & -0.13 & $(0.11)$ & 0.21 & $(0.17)$ & -0.01 & $(0.08)$ & -0.06 & $(0.08)$ \\
\hline & France & -0.05 & $(0.01)$ & -0.19 & $(0.05)$ & -0.05 & $(0.04)$ & 0.14 & $(0.05)$ & 0.00 & $(0.04)$ & 0.13 & $(0.06)$ & 0.05 & $(0.03)$ & -0.02 & $(0.04)$ \\
\hline & Germany & 0.30 & $(0.02)$ & 0.18 & $(0.09)$ & 0.27 & $(0.05)$ & 0.11 & $(0.09)$ & 0.02 & $(0.06)$ & 0.09 & $(0.09)$ & 0.05 & $(0.05)$ & 0.00 & $(0.06)$ \\
\hline & Greece & 0.12 & $(0.02)$ & -0.15 & $(0.08)$ & 0.05 & $(0.06)$ & 0.27 & $(0.08)$ & 0.07 & $(0.06)$ & 0.20 & $(0.10)$ & 0.14 & $(0.05)$ & 0.10 & $(0.05)$ \\
\hline & Hungary & 0.06 & $(0.02)$ & -0.09 & (0.13) & 0.21 & $(0.12)$ & 0.15 & $(0.13)$ & -0.15 & $(0.12)$ & 0.30 & $(0.19)$ & -0.02 & $(0.08)$ & 0.01 & $(0.08)$ \\
\hline & Iceland & 0.21 & $(0.02)$ & -0.14 & $(0.11)$ & -0.21 & $(0.17)$ & 0.36 & $(0.10)$ & 0.42 & $(0.17)$ & -0.06 & $(0.20)$ & 0.38 & (0.09) & 0.31 & (0.09) \\
\hline & Ireland & 0.01 & $(0.01)$ & -0.17 & $(0.04)$ & -0.18 & $(0.09)$ & 0.18 & $(0.04)$ & 0.19 & $(0.09)$ & -0.01 & (0.09) & 0.18 & $(0.04)$ & 0.19 & $(0.04)$ \\
\hline & Israel & m & $\mathrm{m}$ & $\mathrm{m}$ & $\mathrm{m}$ & $\mathrm{m}$ & $\mathrm{m}$ & $\mathrm{m}$ & m & $\mathrm{m}$ & $\mathrm{m}$ & $\mathrm{m}$ & $\mathrm{m}$ & $\mathrm{m}$ & $\mathrm{m}$ & $\mathrm{m}$ & $\mathrm{m}$ \\
\hline & Italy & 0.07 & $(0.01)$ & -0.22 & $(0.05)$ & -0.08 & $(0.10)$ & 0.29 & $(0.05)$ & 0.15 & $(0.10)$ & 0.14 & $(0.11)$ & 0.23 & $(0.05)$ & 0.22 & (0.05) \\
\hline & Japan & -0.03 & $(0.01)$ & C & $\mathrm{C}$ & C & $\mathrm{C}$ & C & $\mathrm{C}$ & C & C & C & C & 0.18 & $(0.23)$ & 0.16 & $(0.23)$ \\
\hline & Korea & 0.16 & $(0.02)$ & c & & $\mathrm{m}$ & $\mathrm{m}$ & C & C & $\mathrm{m}$ & $\mathrm{m}$ & $\mathrm{m}$ & $\mathrm{m}$ & C & c & C & c \\
\hline & Latvia & -0.19 & $(0.01)$ & -0.52 & (0.16) & -0.31 & $(0.06)$ & 0.33 & $(0.16)$ & 0.11 & $(0.06)$ & 0.22 & $(0.17)$ & 0.16 & $(0.06)$ & 0.17 & $(0.06)$ \\
\hline & Luxembourg & 0.29 & $(0.02)$ & -0.09 & $(0.03)$ & 0.07 & $(0.03)$ & 0.38 & $(0.04)$ & 0.22 & $(0.04)$ & 0.16 & $(0.04)$ & 0.29 & $(0.03)$ & 0.21 & $(0.03)$ \\
\hline & Mexico & -0.14 & $(0.02)$ & -0.44 & $(0.12)$ & C & C & 0.31 & $(0.12)$ & C & C & C & C & 0.35 & $(0.09)$ & 0.30 & (0.09) \\
\hline & Netherlands & 0.16 & $(0.01)$ & 0.09 & $(0.09)$ & 0.26 & $(0.04)$ & 0.07 & $(0.09)$ & -0.10 & $(0.05)$ & 0.18 & $(0.11)$ & -0.07 & $(0.04)$ & -0.10 & $(0.04)$ \\
\hline & New Zealand & -0.18 & $(0.02)$ & -0.19 & $(0.04)$ & -0.04 & $(0.05)$ & 0.01 & $(0.04)$ & -0.14 & $(0.05)$ & 0.15 & $(0.06)$ & -0.04 & $(0.03)$ & -0.04 & $(0.03)$ \\
\hline & Norway & 0.22 & $(0.02)$ & -0.13 & $(0.08)$ & 0.37 & $(0.07)$ & 0.36 & $(0.08)$ & -0.14 & $(0.07)$ & 0.50 & $(0.09)$ & 0.10 & $(0.06)$ & 0.03 & $(0.06)$ \\
\hline & Poland & -0.25 & $(0.01)$ & C & & C & c & c & C & C & C & C & C & c & c & c & c \\
\hline & Portugal & 0.12 & $(0.01)$ & -0.11 & $(0.09)$ & 0.08 & $(0.07)$ & 0.23 & $(0.09)$ & 0.04 & $(0.07)$ & 0.19 & $(0.11)$ & 0.14 & $(0.06)$ & 0.14 & $(0.06)$ \\
\hline & Slovak Republic & -0.27 & $(0.01)$ & c & $\mathrm{c}$ & -0.80 & $(0.19)$ & c & $\mathrm{C}$ & 0.53 & $(0.19)$ & C & C & 0.54 & $(0.12)$ & 0.54 & $(0.12)$ \\
\hline & Slovenia & -0.09 & $(0.02)$ & -0.21 & $(0.06)$ & -0.17 & $(0.07)$ & 0.12 & $(0.06)$ & 0.08 & $(0.07)$ & 0.04 & $(0.10)$ & 0.10 & $(0.05)$ & 0.07 & $(0.05)$ \\
\hline & Spain & 0.51 & $(0.02)$ & 0.09 & $(0.05)$ & 0.48 & $(0.15)$ & 0.42 & $(0.06)$ & 0.03 & $(0.15)$ & 0.39 & $(0.16)$ & 0.35 & $(0.05)$ & 0.32 & $(0.05)$ \\
\hline & Sweden & 0.07 & $(0.02)$ & -0.28 & $(0.06)$ & 0.08 & $(0.06)$ & 0.34 & $(0.06)$ & -0.02 & $(0.06)$ & 0.36 & $(0.09)$ & 0.13 & $(0.04)$ & 0.07 & $(0.04)$ \\
\hline & Switzerland & 0.40 & $(0.02)$ & 0.04 & $(0.04)$ & 0.38 & $(0.04)$ & 0.36 & $(0.05)$ & 0.02 & $(0.05)$ & 0.34 & $(0.06)$ & 0.13 & $(0.04)$ & 0.11 & $(0.04)$ \\
\hline & Turkey & -0.43 & $(0.02)$ & c & c & -0.29 & $(0.19)$ & c & c & -0.14 & $(0.18)$ & c & c & 0.08 & $(0.13)$ & 0.12 & $(0.13)$ \\
\hline & United Kingdom & -0.09 & $(0.01)$ & -0.23 & $(0.04)$ & 0.06 & $(0.05)$ & 0.14 & $(0.04)$ & -0.15 & $(0.05)$ & 0.29 & $(0.07)$ & 0.01 & $(0.03)$ & -0.01 & $(0.04)$ \\
\hline & United States & -0.04 & $(0.02)$ & -0.23 & $(0.05)$ & -0.18 & $(0.04)$ & 0.18 & $(0.04)$ & 0.14 & $(0.04)$ & 0.04 & $(0.06)$ & 0.16 & $(0.03)$ & 0.07 & $(0.04)$ \\
\hline & OECD average & 0.03 & $(0.00)$ & -0.13 & $(0.02)$ & 0.01 & $(0.02)$ & 0.20 & $(0.02)$ & 0.03 & $(0.02)$ & 0.17 & $(0.02)$ & 0.13 & $(0.01)$ & 0.10 & $(0.01)$ \\
\hline & Albania & 0.41 & $(0.01)$ & c & C & c & c & C & C & C & C & C & C & C & C & C & c \\
\hline 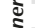 & Algeria & -0.21 & $(0.02)$ & $\mathrm{m}$ & $\mathrm{m}$ & -0.38 & $(0.11)$ & $\mathrm{m}$ & $\mathrm{m}$ & 0.17 & $(0.11)$ & $\mathrm{m}$ & $\mathrm{m}$ & 0.18 & $(0.11)$ & 0.19 & $(0.11)$ \\
\hline & Brazil & -0.14 & $(0.01)$ & -0.52 & $(0.18)$ & -0.41 & $(0.12)$ & 0.38 & $(0.18)$ & 0.27 & $(0.12)$ & 0.11 & $(0.23)$ & 0.30 & $(0.10)$ & 0.29 & $(0.10)$ \\
\hline$=$ & B-S-J-G (China) & -0.33 & $(0.01)$ & c & c & c & c & c & C & C & c & C & c & 0.00 & $(0.22)$ & -0.01 & $(0.23)$ \\
\hline & Bulgaria & -0.34 & $(0.02)$ & c & & c & c & c & c & c & c & c & c & 0.08 & $(0.10)$ & 0.08 & $(0.11)$ \\
\hline & CABA (Argentina) & 0.41 & $(0.04)$ & 0.35 & $(0.11)$ & 0.10 & $(0.06)$ & 0.06 & $(0.11)$ & 0.31 & $(0.07)$ & -0.25 & $(0.10)$ & 0.22 & $(0.07)$ & 0.03 & $(0.07)$ \\
\hline & Colombia & -0.30 & $(0.01)$ & c & & -0.54 & $(0.17)$ & c & c & 0.24 & $(0.17)$ & c & C & 0.17 & $(0.15)$ & 0.18 & $(0.14)$ \\
\hline & Costa Rica & -0.15 & $(0.02)$ & -0.15 & $(0.09)$ & -0.22 & $(0.07)$ & -0.01 & $(0.09)$ & 0.06 & $(0.08)$ & -0.07 & $(0.11)$ & 0.04 & $(0.07)$ & 0.01 & $(0.07)$ \\
\hline & Croatia & 0.05 & $(0.02)$ & -0.10 & $(0.09)$ & 0.05 & $(0.05)$ & 0.15 & $(0.09)$ & 0.00 & $(0.05)$ & 0.15 & $(0.10)$ & 0.03 & $(0.05)$ & 0.01 & $(0.05)$ \\
\hline & Cyprus* & 0.14 & $(0.02)$ & -0.19 & $(0.05)$ & 0.03 & $(0.07)$ & 0.34 & $(0.05)$ & 0.11 & $(0.07)$ & 0.22 & $(0.08)$ & 0.28 & $(0.04)$ & 0.27 & $(0.04)$ \\
\hline & Dominican Republic & -0.38 & $(0.02)$ & -0.71 & $(0.18)$ & -0.95 & $(0.15)$ & 0.33 & $(0.18)$ & 0.57 & $(0.15)$ & -0.24 & $(0.21)$ & 0.48 & $(0.13)$ & 0.43 & $(0.12)$ \\
\hline & FYROM & 0.37 & $(0.01)$ & -0.57 & $(0.09)$ & 0.01 & $(0.12)$ & 0.94 & $(0.09)$ & 0.37 & $(0.12)$ & 0.58 & $(0.15)$ & 0.53 & $(0.09)$ & 0.54 & $(0.09)$ \\
\hline & Georgia & 0.21 & $(0.02)$ & C & c & 0.04 & $(0.11)$ & c & c & 0.17 & $(0.12)$ & c & c & 0.13 & $(0.12)$ & 0.14 & $(0.12)$ \\
\hline & Hong Kong (China) & -0.34 & $(0.01)$ & -0.34 & $(0.03)$ & -0.36 & $(0.02)$ & -0.01 & $(0.03)$ & 0.01 & $(0.03)$ & -0.02 & $(0.03)$ & 0.01 & $(0.02)$ & -0.05 & $(0.02)$ \\
\hline & Indonesia & 0.11 & $(0.01)$ & c & c & c & c & c & c & c & c & c & C & c & c & c & c \\
\hline & Jordan & 0.22 & $(0.02)$ & -0.09 & $(0.06)$ & 0.22 & $(0.04)$ & 0.32 & $(0.06)$ & 0.00 & $(0.04)$ & 0.31 & $(0.08)$ & 0.09 & $(0.03)$ & 0.10 & $(0.03)$ \\
\hline & Kosovo & 0.30 & $(0.01)$ & 0.11 & $(0.15)$ & -0.01 & $(0.16)$ & 0.19 & $(0.15)$ & 0.30 & $(0.16)$ & -0.12 & $(0.21)$ & 0.23 & $(0.12)$ & 0.24 & $(0.12)$ \\
\hline & Lebanon & 0.07 & $(0.03)$ & 0.05 & $(0.12)$ & -0.54 & $(0.10)$ & 0.02 & $(0.13)$ & 0.60 & $(0.10)$ & -0.58 & $(0.17)$ & 0.29 & $(0.08)$ & 0.30 & $(0.09)$ \\
\hline & Lithuania & -0.27 & $(0.02)$ & -0.43 & $(0.25)$ & -0.28 & $(0.11)$ & 0.16 & $(0.25)$ & 0.01 & $(0.11)$ & 0.15 & $(0.28)$ & 0.05 & $(0.10)$ & 0.06 & $(0.10)$ \\
\hline & Macao (China) & -0.42 & $(0.02)$ & -0.38 & $(0.02)$ & -0.40 & $(0.02)$ & -0.05 & $(0.03)$ & -0.02 & $(0.02)$ & -0.03 & $(0.02)$ & -0.03 & $(0.02)$ & -0.03 & $(0.02)$ \\
\hline & Malta & 0.00 & $(0.02)$ & -0.21 & $(0.07)$ & -0.12 & $(0.11)$ & 0.21 & $(0.07)$ & 0.11 & $(0.11)$ & 0.09 & $(0.12)$ & 0.17 & $(0.07)$ & 0.20 & $(0.07)$ \\
\hline & Moldova & 0.04 & $(0.01)$ & $\mathrm{C}$ & c & -0.19 & $(0.12)$ & c & C & 0.24 & $(0.12)$ & c & C & 0.12 & $(0.10)$ & 0.15 & $(0.10)$ \\
\hline & Montenegro & -0.09 & $(0.01)$ & -0.31 & $(0.08)$ & -0.16 & $(0.06)$ & 0.22 & $(0.08)$ & 0.07 & $(0.06)$ & 0.15 & $(0.11)$ & 0.12 & $(0.05)$ & 0.13 & $(0.05)$ \\
\hline & Peru & -0.21 & $(0.01)$ & c & & c & c & c & C & C & c & c & c & 0.18 & $(0.14)$ & 0.20 & $(0.15)$ \\
\hline & Qatar & -0.14 & $(0.02)$ & -0.07 & $(0.01)$ & -0.05 & $(0.03)$ & -0.07 & $(0.02)$ & -0.09 & $(0.03)$ & 0.02 & $(0.04)$ & -0.08 & $(0.02)$ & -0.08 & $(0.02)$ \\
\hline & Romania & 0.00 & $(0.02)$ & c & c & c & c & c & C & c & C & c & c & c & c & C & c \\
\hline & Russia & -0.37 & $(0.01)$ & -0.44 & $(0.08)$ & -0.42 & $(0.04)$ & 0.08 & $(0.07)$ & 0.05 & $(0.04)$ & 0.03 & $(0.10)$ & 0.06 & $(0.03)$ & 0.05 & $(0.03)$ \\
\hline & Singapore & -0.22 & $(0.01)$ & -0.18 & $(0.04)$ & -0.19 & $(0.04)$ & -0.04 & $(0.04)$ & -0.03 & $(0.04)$ & -0.02 & $(0.05)$ & -0.04 & $(0.03)$ & 0.01 & $(0.03)$ \\
\hline & Chinese Taipei & 0.02 & $(0.01)$ & c & c & c & c & c & c & c & c & c & c & c & c & c & c \\
\hline & Thailand & -0.35 & $(0.01)$ & c & C & -0.60 & $(0.11)$ & c & $\mathrm{C}$ & 0.26 & $(0.11)$ & c & c & 0.23 & $(0.10)$ & 0.19 & $(0.10)$ \\
\hline & Trinidad and Tobago & 0.07 & $(0.01)$ & -0.24 & $(0.13)$ & -0.32 & $(0.14)$ & 0.31 & $(0.13)$ & 0.39 & $(0.14)$ & -0.08 & $(0.19)$ & 0.36 & $(0.09)$ & 0.35 & $(0.09)$ \\
\hline & Tunisia & -0.19 & $(0.01)$ & c & c & -0.53 & $(0.09)$ & c & c & 0.34 & $(0.09)$ & $\mathrm{c}$ & c & 0.33 & $(0.07)$ & 0.34 & $(0.08)$ \\
\hline & United Arab Emirates & -0.12 & $(0.02)$ & -0.06 & $(0.02)$ & -0.07 & $(0.02)$ & -0.06 & $(0.02)$ & -0.06 & $(0.03)$ & -0.01 & $(0.02)$ & -0.06 & $(0.02)$ & -0.05 & $(0.02)$ \\
\hline & Uruguay & -0.09 & $(0.02)$ & c & c & c & c & c & c & c & c & c & c & 0.20 & $(0.18)$ & 0.26 & $(0.19)$ \\
\hline & Viet Nam & -0.06 & $(0.01)$ & c & c & c & c & c & c & c & c & c & c & c & c & c & c \\
\hline & Argentina** & 0.22 & $(0.02)$ & 0.04 & $(0.12)$ & -0.06 & $(0.06)$ & 0.18 & $(0.12)$ & 0.28 & $(0.06)$ & -0.10 & $(0.12)$ & 0.25 & $(0.06)$ & 0.18 & $(0.06)$ \\
\hline & Kazakhstan** & 0.33 & $(0.02)$ & 0.40 & $(0.07)$ & 0.38 & $(0.05)$ & -0.07 & $(0.07)$ & -0.05 & $(0.06)$ & -0.02 & $(0.08)$ & -0.06 & $(0.05)$ & -0.07 & $(0.05)$ \\
\hline & Malaysia** & -0.13 & $(0.02)$ & C & c & -0.16 & $(0.13)$ & C & C & 0.03 & $(0.13)$ & C & C & 0.09 & $(0.11)$ & 0.08 & $(0.11)$ \\
\hline
\end{tabular}

1. ESCS refers to the the PISA index of economic, social and cultural status.

Note: Values that are statistically significant are indicated in bold (see Annex A3)

* See note at the beginning of this Annex.

** Coverage is too small to ensure comparability (see Annex A4).

StatLink *inst http://dx.doi.org/10.1787/888933471305 
[Part 1/1]

Table III.7.8a Index of sense of belonging, by student performance in science

Results based on students' self-reports

\begin{tabular}{|c|c|c|c|c|c|c|c|c|c|c|c|c|c|c|c|c|c|}
\hline & \multicolumn{10}{|c|}{$\begin{array}{l}\text { Science performance, by national quarters } \\
\text { of the index of sense of belonging }\end{array}$} & Before a & $\begin{array}{l}\text { nting for } \\
\text { io-econo }\end{array}$ & $\begin{array}{l}\text { tudents' } \\
\text { iic profi }\end{array}$ & chools' & $\begin{array}{r}\text { After ac } \\
\text { students } \\
\text { socio-eco }\end{array}$ & $\begin{array}{l}\text { ting for } \\
\text { schoools' } \\
\text { c profile } \\
\end{array}$ \\
\hline & & $\begin{array}{l}\text { Bott } \\
\text { qua }\end{array}$ & & $\begin{array}{l}\text { Sec } \\
\text { qua }\end{array}$ & & & & $\begin{array}{r}\text { To } \\
\text { qua }\end{array}$ & & $\begin{array}{r}\text { Top - } \\
\text { qua }\end{array}$ & $\begin{array}{l}\text { ottom } \\
\text { ter }\end{array}$ & $\begin{array}{l}\text { Change } \\
\text { score p } \\
\text { change } \\
\text { of sense }\end{array}$ & $\begin{array}{l}\text { cience } \\
\text { e-unit } \\
\text { eindex } \\
\text { longing } \\
\end{array}$ & $\begin{array}{r}\text { Explain } \\
\text { in } \\
\text { perf } \\
(\mathrm{r}-\mathrm{squ}\end{array}$ & $\begin{array}{l}\text { riance } \\
\text { nt } \\
\text { nce } \\
\text { 100) }\end{array}$ & $\begin{array}{r}\text { Change in } \\
\text { per one } \\
\text { in the in } \\
\text { of } b\end{array}$ & $\begin{array}{l}\text { ce score } \\
\text { change } \\
\text { of sense } \\
\text { ing } \\
\end{array}$ \\
\hline & & $\begin{array}{l}\text { Mean } \\
\text { score }\end{array}$ & S.E. & $\begin{array}{l}\text { Mean } \\
\text { score }\end{array}$ & S.E. & $\begin{array}{l}\text { Mean } \\
\text { score }\end{array}$ & S.E. & $\begin{array}{l}\text { Mean } \\
\text { score }\end{array}$ & S.E. & $\begin{array}{l}\text { Score } \\
\text { dif. }\end{array}$ & S.E. & $\begin{array}{l}\text { Score } \\
\text { dif. }\end{array}$ & S.E. & $\%$ & S.E. & $\begin{array}{c}\text { Score } \\
\text { dif. }\end{array}$ & S.E. \\
\hline 0 & Australia & 498 & (2.6) & 514 & $(2.7)$ & 518 & $(2.7)$ & 522 & $(2.3)$ & 24 & $(3.1)$ & 9 & (1.1) & 0.6 & $(0.2)$ & 3 & (1.1) \\
\hline ডي & Austria & 482 & (3.6) & 503 & (3.6) & 501 & (3.6) & 504 & (3.4) & 22 & $(4.2)$ & 6 & (1.1) & 0.6 & $(0.2)$ & 2 & $(0.9)$ \\
\hline ప & Belgium & 497 & (3.6) & 512 & (2.9) & 512 & (2.9) & 515 & (3.1) & 18 & $(4.1)$ & 6 & (1.7) & 0.3 & $(0.2)$ & 1 & $(1.2)$ \\
\hline & Canada & 517 & (3.0) & 533 & (3.2) & 534 & (2.8) & 534 & (3.1) & 17 & (3.5) & 5 & $(1.2)$ & 0.3 & $(0.1)$ & 2 & (1.1) \\
\hline & Chile & 432 & (3.7) & 445 & (3.5) & 454 & (3.5) & 463 & (3.6) & 31 & (4.4) & 9 & (1.4) & 1.2 & $(0.3)$ & 4 & $(1.2)$ \\
\hline & Czech Republic & 483 & (3.5) & 493 & (3.5) & 503 & (3.1) & 513 & (2.9) & 31 & (4.0) & 13 & (1.8) & 1.1 & $(0.3)$ & 6 & (1.5) \\
\hline & Denmark & 495 & (3.8) & 509 & (3.7) & 512 & (3.2) & 511 & (3.3) & 16 & (3.9) & 5 & $(1.2)$ & 0.4 & $(0.2)$ & 3 & $(1.2)$ \\
\hline & Estonia & 519 & (3.3) & 535 & (3.8) & 539 & (3.3) & 549 & (3.2) & 29 & (4.1) & 10 & (1.7) & 1.0 & $(0.3)$ & 8 & (1.7) \\
\hline & Finland & 526 & $(4.2)$ & 534 & (3.4) & 536 & (3.3) & 537 & (3.3) & 10 & $(4.7)$ & 4 & (1.5) & 0.2 & $(0.1)$ & 1 & (1.5) \\
\hline & France & 477 & (3.8) & 500 & (2.6) & 508 & (3.3) & 520 & (3.1) & 42 & (4.6) & 18 & $(2.2)$ & 2.1 & $(0.5)$ & 6 & (1.6) \\
\hline & Germany & 508 & (3.9) & 524 & (3.8) & 522 & (3.5) & 528 & (3.2) & 20 & (4.4) & 6 & (1.5) & 0.4 & $(0.2)$ & 1 & (1.1) \\
\hline & Greece & 444 & $(4.7)$ & 455 & (5.0) & 461 & (4.3) & 467 & (4.3) & 23 & (4.5) & 7 & (1.6) & 0.6 & $(0.2)$ & 4 & (1.3) \\
\hline & Hungary & 458 & (3.8) & 476 & (4.4) & 487 & (4.1) & 492 & (3.5) & 34 & (4.8) & 11 & (1.7) & 1.4 & $(0.4)$ & 4 & (1.3) \\
\hline & Iceland & 456 & (3.6) & 474 & (3.8) & 486 & (3.5) & 486 & (3.6) & 30 & (5.2) & 8 & (1.3) & 1.2 & $(0.4)$ & 6 & (1.3) \\
\hline & Ireland & 503 & (3.6) & 507 & (3.6) & 502 & (3.1) & 501 & (3.2) & -2 & (3.9) & -1 & (1.3) & 0.0 & $(0.0)$ & -3 & (1.3) \\
\hline & Israel & $\mathrm{m}$ & $\mathrm{m}$ & $\mathrm{m}$ & $\mathrm{m}$ & $\mathrm{m}$ & $\mathrm{m}$ & m & $\mathrm{m}$ & $\mathrm{m}$ & $\mathrm{m}$ & $\mathrm{m}$ & $\mathrm{m}$ & $\mathrm{m}$ & $\mathrm{m}$ & $\mathrm{m}$ & $\mathrm{m}$ \\
\hline & Italy & 473 & (3.4) & 486 & (3.6) & 485 & (3.2) & 486 & (4.1) & 13 & (4.5) & 2 & (1.9) & 0.0 & $(0.1)$ & 1 & (1.6) \\
\hline & Japan & 527 & (4.0) & 541 & (4.1) & 541 & $(4.2)$ & 549 & (3.4) & 21 & (3.9) & 8 & (1.5) & 0.5 & $(0.2)$ & 1 & (1.4) \\
\hline & Korea & 510 & (4.1) & 516 & (4.5) & 514 & (4.3) & 526 & (3.9) & 16 & (4.8) & 6 & (1.7) & 0.4 & $(0.2)$ & 0 & (1.4) \\
\hline & Latvia & 486 & (3.2) & 489 & (3.1) & 489 & (2.7) & 501 & (3.0) & 15 & (4.6) & 6 & (1.8) & 0.4 & $(0.2)$ & 4 & (1.7) \\
\hline & Luxembourg & 465 & (3.2) & 481 & (3.0) & 488 & (2.7) & 507 & (2.7) & 43 & (4.4) & 13 & (1.3) & 1.9 & $(0.4)$ & 6 & (1.1) \\
\hline & Mexico & 401 & (2.9) & 411 & (3.0) & 422 & (2.8) & 432 & (2.7) & 30 & (3.0) & 8 & (0.9) & 1.6 & $(0.3)$ & 5 & $(0.7)$ \\
\hline & Netherlands & 504 & (4.1) & 523 & (4.0) & 514 & (3.1) & 515 & (3.9) & 11 & (5.8) & 1 & $(2.2)$ & 0.0 & $(0.0)$ & -1 & (1.7) \\
\hline & New Zealand & 506 & $(4.0)$ & 524 & (3.7) & 521 & (4.0) & 519 & (3.8) & 13 & (5.4) & 4 & (1.9) & 0.1 & $(0.1)$ & 0 & (1.9) \\
\hline & Norway & 485 & (3.3) & 505 & (3.2) & 510 & (3.1) & 506 & (3.6) & 22 & $(4.2)$ & 6 & (1.3) & 0.5 & $(0.2)$ & 4 & $(1.2)$ \\
\hline & Poland & 499 & (3.8) & 503 & (3.9) & 502 & (3.5) & 506 & (3.2) & 7 & (4.0) & 2 & (1.4) & 0.0 & $(0.1)$ & 1 & (1.3) \\
\hline & Portugal & 491 & (3.7) & 505 & (3.8) & 497 & (3.3) & 516 & (2.7) & 25 & (3.5) & 7 & $(1.2)$ & 0.6 & $(0.2)$ & 3 & (1.0) \\
\hline & Slovak Republic & 448 & (3.6) & 461 & (3.7) & 476 & (3.2) & 490 & (3.3) & 42 & (4.0) & 15 & (1.6) & 1.8 & $(0.4)$ & 8 & (1.5) \\
\hline & Slovenia & 499 & (2.8) & 513 & (3.1) & 523 & (3.1) & 528 & (3.2) & 29 & (4.4) & 11 & (1.8) & 1.1 & $(0.4)$ & 7 & (1.6) \\
\hline & Spain & 490 & (3.2) & 496 & (3.1) & 498 & $(3.2)$ & 494 & (3.0) & 4 & $(4.0)$ & 2 & $(1.2)$ & 0.1 & $(0.1)$ & 0 & $(1.1)$ \\
\hline & Sweden & 482 & (4.6) & 499 & (4.4) & 501 & $(4.2)$ & 510 & (4.4) & 29 & (4.7) & 7 & (1.3) & 0.8 & $(0.3)$ & 5 & $(1.2)$ \\
\hline & Switzerland & 493 & (4.3) & 511 & (4.1) & 520 & (3.6) & 507 & (3.8) & 14 & (4.5) & 5 & (1.5) & 0.3 & $(0.2)$ & 3 & (1.3) \\
\hline & Turkey & 419 & (4.6) & 414 & $(5.2)$ & 431 & (4.6) & 442 & (4.4) & 23 & (4.5) & 7 & (1.3) & 0.9 & $(0.3)$ & 4 & $(1.0)$ \\
\hline & United Kingdom & 509 & (3.7) & 516 & (3.5) & 510 & (3.5) & 516 & (3.5) & 7 & (4.0) & 2 & (1.6) & 0.0 & $(0.1)$ & -1 & (1.5) \\
\hline & United States & 491 & (4.3) & 504 & (3.9) & 501 & $(4.0)$ & 501 & (3.6) & 10 & (4.4) & 2 & (1.3) & 0.1 & $(0.1)$ & -1 & $(1.2)$ \\
\hline & OECD average & 484 & $(0.6)$ & 497 & $(0.6)$ & 501 & $(0.6)$ & 506 & (0.6) & 21 & $(0.7)$ & 7 & $(0.3)$ & 0.7 & $(0.0)$ & 3 & $(0.2)$ \\
\hline 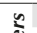 & Albania & 430 & $(4.0)$ & 426 & $(4.1)$ & 428 & $(4.7)$ & 429 & (4.3) & -1 & $(4.0)$ & 0 & (1.8) & 0.0 & $(0.0)$ & 0 & (1.8) \\
\hline & Algeria & 370 & (3.3) & 372 & (3.5) & 380 & (3.5) & 394 & (3.9) & 24 & (3.7) & 10 & (1.8) & 1.3 & $(0.5)$ & 8 & (1.6) \\
\hline ปั & Brazil & 384 & (3.2) & 401 & (2.9) & 413 & (2.9) & 434 & (2.9) & 50 & (3.0) & 15 & (1.0) & 2.7 & $(0.4)$ & 10 & $(0.9)$ \\
\hline 2 & B-S-J-G (China) & 505 & (5.9) & 510 & (5.9) & 518 & (4.9) & 540 & (5.2) & 35 & (5.0) & 19 & $(2.1)$ & 1.9 & $(0.4)$ & 7 & (1.6) \\
\hline & Bulgaria & 428 & (5.3) & 438 & (5.5) & 466 & (5.2) & 485 & (4.0) & 57 & (5.6) & 19 & (1.9) & 3.4 & $(0.6)$ & 10 & (1.5) \\
\hline & CABA (Argentina) & 461 & (6.1) & 472 & (8.0) & 486 & (7.5) & 487 & (9.6) & 26 & (8.7) & 12 & (3.3) & 1.6 & $(0.9)$ & 1 & (2.6) \\
\hline & Colombia & 399 & (3.3) & 406 & (3.3) & 423 & (2.5) & 439 & (3.0) & 40 & (3.5) & 11 & (1.1) & 2.1 & $(0.4)$ & 8 & $(0.9)$ \\
\hline & Costa Rica & 414 & (3.2) & 417 & (3.3) & 422 & (2.7) & 433 & (2.9) & 19 & (3.6) & 5 & $(0.9)$ & 0.7 & $(0.3)$ & 3 & $(0.8)$ \\
\hline & Croatia & 464 & (3.6) & 474 & (3.5) & 483 & (3.2) & 485 & (3.6) & 21 & $(4.2)$ & 7 & (1.4) & 0.6 & $(0.2)$ & 4 & $(1.2)$ \\
\hline & Cyprus* & 418 & (2.6) & 441 & (3.0) & 442 & (2.9) & 441 & (2.6) & 24 & (3.6) & 6 & (1.3) & 0.4 & $(0.2)$ & 6 & $(1.2)$ \\
\hline & Dominican Republic & 320 & (3.4) & 317 & (4.1) & 345 & (3.2) & 365 & (3.7) & 45 & $(4.2)$ & 12 & (1.3) & 4.2 & $(0.8)$ & 8 & (1.1) \\
\hline & FYROM & 362 & (3.1) & 383 & $(2.8)$ & 399 & (2.9) & 411 & (3.3) & 49 & (4.9) & 18 & (1.9) & 3.9 & $(0.8)$ & 12 & $(1.7)$ \\
\hline & Georgia & 399 & (3.7) & 401 & (3.4) & 422 & $(4.0)$ & 435 & (3.4) & 36 & (4.8) & 17 & $(2.0)$ & 2.2 & $(0.5)$ & 12 & (1.9) \\
\hline & Hong Kong (China) & 514 & (3.5) & 524 & (3.5) & 530 & (3.2) & 529 & (3.7) & 15 & (3.9) & 4 & (1.8) & 0.1 & $(0.1)$ & 1 & (1.7) \\
\hline & Indonesia & 400 & (3.7) & 402 & (3.5) & 404 & (3.0) & 409 & (3.2) & 9 & (3.8) & 5 & (2.2) & 0.2 & $(0.2)$ & 4 & (1.8) \\
\hline & Jordan & 373 & (3.7) & 411 & (3.6) & 430 & (3.4) & 437 & (3.0) & 63 & $(4.0)$ & 22 & (1.6) & 6.3 & $(0.8)$ & 19 & (1.6) \\
\hline & Kosovo & 357 & (3.2) & 380 & (3.1) & 393 & (3.0) & 396 & (3.4) & 38 & (4.2) & 17 & (1.9) & 3.5 & $(0.8)$ & 14 & (1.8) \\
\hline & Lebanon & 335 & (6.0) & 390 & (4.5) & 402 & (5.1) & 428 & (4.5) & 93 & (7.0) & 34 & (2.9) & 11.4 & (1.6) & 28 & (2.9) \\
\hline & Lithuania & 466 & (3.1) & 465 & (4.3) & 485 & (3.5) & 495 & (3.7) & 30 & $(4.2)$ & 10 & (1.2) & 1.4 & $(0.3)$ & 5 & (1.1) \\
\hline & Macao (China) & 517 & (2.9) & 528 & $(2.2)$ & 535 & (2.5) & 535 & (2.4) & 18 & (4.0) & 8 & (2.0) & 0.4 & $(0.2)$ & 8 & (2.0) \\
\hline & Malta & 445 & (3.9) & 475 & (3.9) & 473 & (3.9) & 478 & (3.5) & 34 & (5.8) & 12 & (2.5) & 0.7 & $(0.3)$ & 5 & (2.1) \\
\hline & Moldova & 426 & (3.3) & 425 & (2.7) & 432 & (2.6) & 446 & (3.1) & 20 & (3.9) & 11 & $(2.0)$ & 0.9 & $(0.3)$ & 9 & (1.7) \\
\hline & Montenegro & 407 & (2.6) & 406 & (2.4) & 422 & (2.3) & 427 & (2.7) & 20 & (3.9) & 6 & (1.5) & 0.5 & $(0.2)$ & 6 & (1.4) \\
\hline & Peru & 370 & (2.7) & 389 & (3.3) & 410 & (3.3) & 429 & (3.3) & 58 & (4.0) & 24 & (1.7) & 6.3 & $(0.8)$ & 15 & (1.4) \\
\hline & Qatar & 391 & (2.3) & 428 & (2.1) & 432 & (2.0) & 446 & (2.2) & 55 & (3.6) & 15 & (1.1) & 2.4 & $(0.3)$ & 13 & (1.0) \\
\hline & Romania & 422 & (4.7) & 434 & $(4.2)$ & 439 & (3.5) & 448 & (3.7) & 25 & (4.6) & 11 & (2.1) & 1.2 & $(0.4)$ & 8 & $(1.8)$ \\
\hline & Russia & 482 & (4.1) & 483 & (3.5) & 486 & (3.5) & 508 & (3.3) & 27 & (4.1) & 11 & (1.6) & 1.2 & $(0.3)$ & 9 & (1.5) \\
\hline & Singapore & 539 & (3.1) & 556 & (3.5) & 566 & (3.0) & 563 & (3.1) & 24 & (4.3) & 11 & (1.7) & 0.8 & $(0.3)$ & 4 & (1.7) \\
\hline & Chinese Taipei & 524 & (3.5) & 529 & (3.7) & 537 & (3.4) & 540 & (3.8) & 16 & (4.0) & 7 & (1.4) & 0.4 & $(0.2)$ & 3 & $(1.2)$ \\
\hline & Thailand & 401 & (3.4) & 415 & (3.9) & 429 & (3.5) & 444 & (3.9) & 43 & (4.2) & 22 & $(2.2)$ & 3.2 & $(0.6)$ & 17 & $(2.0)$ \\
\hline & Trinidad and Tobago & 415 & (2.9) & 431 & (3.4) & 428 & (3.6) & 443 & (3.0) & 28 & (4.4) & 9 & (1.5) & 0.8 & $(0.3)$ & 4 & (1.4) \\
\hline & Tunisia & 381 & (3.4) & 387 & (2.8) & 392 & (2.9) & 396 & (2.6) & 16 & (3.7) & 6 & (1.7) & 0.5 & $(0.3)$ & 5 & (1.6) \\
\hline & United Arab Emirates & 420 & (3.2) & 437 & (3.3) & 443 & (3.1) & 459 & (2.9) & 39 & (3.4) & 15 & (1.4) & 1.7 & $(0.3)$ & 14 & (1.3) \\
\hline & Uruguay & 423 & (3.2) & 434 & (2.8) & 443 & (2.8) & 461 & (3.7) & 37 & (4.6) & 11 & (1.4) & 2.0 & $(0.5)$ & 5 & (1.1) \\
\hline & Viet Nam & 522 & (5.5) & 522 & (3.9) & 527 & (4.3) & 529 & (4.7) & 7 & (4.4) & 2 & $(2.4)$ & 0.0 & $(0.1)$ & 0 & $(2.2)$ \\
\hline & Argentina** & 408 & (4.0) & 432 & (3.6) & 440 & (3.6) & 456 & (3.6) & 48 & (4.3) & 16 & (1.7) & 3.5 & $(0.7)$ & 9 & $(1.4)$ \\
\hline & Kazakhstan** & 443 & (4.6) & 452 & (4.4) & 464 & (4.1) & 467 & (4.5) & 23 & (4.7) & 10 & $(2.0)$ & 1.4 & $(0.5)$ & 8 & $(1.8)$ \\
\hline & Malaysia** & 427 & (4.5) & 442 & (3.8) & 444 & (3.4) & 460 & (3.3) & 33 & (4.3) & 13 & $(2.1)$ & 1.7 & $(0.5)$ & 14 & $(1.7)$ \\
\hline
\end{tabular}

1. The socio-economic profile is measured by the PISA index of economic, social and cultural status (ESCS).

Note: Values that are statistically significant are indicated in bold (see Annex A3).

* See note at the beginning of this Annex.

Coverall to ensure comparability (see Annex A4).

StatLink 釉 
Difference in science scores between students who feel like outsiders and students who do not feel like outsiders at school

\begin{tabular}{|c|c|c|c|c|c|c|c|c|c|}
\hline & \multicolumn{8}{|c|}{ All students } \\
\hline & & \multirow{2}{*}{\multicolumn{2}{|c|}{$\begin{array}{l}\text { I do not feel like an outsider } \\
\text { (or left out of things) at school }\end{array}$}} & \multirow{2}{*}{\multicolumn{2}{|c|}{$\begin{array}{l}\text { I feel like an outsider } \\
\text { (or left out of things) at school }\end{array}$}} & \multicolumn{4}{|c|}{$\begin{array}{l}\text { Difference between students who feel like an outsider } \\
\text { (or left out of things) at school and those who do not }\end{array}$} \\
\hline & & & & & & \multicolumn{2}{|c|}{$\begin{array}{c}\text { Before accounting for students' } \\
\text { and schools' socio-economic profile }{ }^{1}\end{array}$} & $\begin{array}{r}\text { After accou } \\
\text { and schools'sc }\end{array}$ & $\begin{array}{l}\text { students' }^{\prime} \\
\text { omic profile }\end{array}$ \\
\hline & & Mean score & S.E. & Mean score & S.E. & Score dif. & S.E. & Score dif. & S.E. \\
\hline 0 & Australia & 518 & (1.6) & 496 & (4.4) & -22 & (2.8) & -13 & $(2.7)$ \\
\hline ডي & Austria & 499 & $(2.5)$ & 489 & $(6.8)$ & -10 & (4.3) & -2 & (3.5) \\
\hline$\overline{0}$ & Belgium & 513 & (2.3) & 485 & $(7.0)$ & -28 & $(4.7)$ & -15 & (3.4) \\
\hline & Canada & 534 & $(2.2)$ & 517 & $(5.0)$ & -17 & $(2.8)$ & -12 & (2.6) \\
\hline & Chile & 453 & (2.5) & 432 & (6.4) & -21 & $(4.0)$ & -14 & $(3.2)$ \\
\hline & Czech Republic & 503 & $(2.0)$ & 483 & (5.7) & -20 & (3.6) & -10 & $(3.2)$ \\
\hline & Denmark & 510 & $(2.3)$ & 488 & (6.5) & -22 & $(4.2)$ & -19 & (4.0) \\
\hline & Estonia & 540 & $(2.2)$ & 507 & (5.8) & -33 & (3.6) & -29 & (3.5) \\
\hline & Finland & 535 & $(2.3)$ & 520 & $(7.3)$ & -15 & $(5.0)$ & -12 & $(4.8)$ \\
\hline & France & 514 & $(2.0)$ & 465 & $(5.8)$ & -49 & (3.7) & -26 & $(3.1)$ \\
\hline & Germany & 522 & (2.6) & 511 & (6.5) & -11 & (3.9) & -4 & (3.3) \\
\hline & Greece & 461 & (3.7) & 431 & (7.6) & -30 & (3.9) & -22 & (3.5) \\
\hline & Hungary & 483 & (2.6) & 456 & $(7.1)$ & -26 & $(4.6)$ & -13 & (3.6) \\
\hline & Iceland & 480 & (1.8) & 454 & (6.1) & -26 & (4.3) & -24 & $(4.2)$ \\
\hline & Ireland & 504 & (2.3) & 501 & (6.0) & -3 & (3.7) & -2 & (3.6) \\
\hline & Israel & $\mathrm{m}$ & $\mathrm{m}$ & $\mathrm{m}$ & $\mathrm{m}$ & $\mathrm{m}$ & $\mathrm{m}$ & $\mathrm{m}$ & $\mathrm{m}$ \\
\hline & Italy & 485 & (2.6) & 464 & $(7.1)$ & -20 & (4.5) & -15 & (3.9) \\
\hline & Japan & 543 & (2.9) & 518 & (8.1) & -25 & $(5.2)$ & -14 & $(4.7)$ \\
\hline & Korea & 516 & $(3.1)$ & 518 & (8.4) & 2 & (5.3) & 6 & $(4.7)$ \\
\hline & Latvia & 494 & $(1.7)$ & 476 & (6.0) & -18 & (4.3) & -17 & $(4.2)$ \\
\hline & Luxembourg & 491 & $(1.2)$ & 455 & $(4.8)$ & -36 & (3.6) & -22 & (3.0) \\
\hline & Mexico & 421 & $(2.1)$ & 401 & (4.5) & -20 & (2.4) & -14 & $(2.2)$ \\
\hline & Netherlands & 516 & (2.3) & 496 & (8.1) & -19 & (5.8) & -12 & (5.1) \\
\hline & New Zealand & 522 & $(2.7)$ & 500 & (7.4) & -22 & $(4.7)$ & -17 & $(4.0)$ \\
\hline & Norway & 507 & $(2.2)$ & 464 & (6.5) & -43 & $(4.3)$ & -39 & $(4.3)$ \\
\hline & Poland & 504 & (2.5) & 499 & $(6.2)$ & -5 & (3.7) & -5 & (3.5) \\
\hline & Portugal & 506 & (2.4) & 477 & (6.3) & -29 & (3.8) & -23 & (3.3) \\
\hline & Slovak Republic & 476 & (2.4) & 444 & (5.8) & -31 & (3.4) & -20 & (2.8) \\
\hline & Slovenia & 522 & $(1.7)$ & 489 & (6.2) & -33 & (4.5) & -23 & (3.5) \\
\hline & Spain & 497 & $(2.1)$ & 470 & (6.4) & -27 & (4.3) & -24 & $(4.0)$ \\
\hline & Sweden & 502 & (3.4) & 484 & $(7.1)$ & -18 & (3.7) & -16 & (3.4) \\
\hline & Switzerland & 511 & (2.9) & 484 & (7.5) & -27 & (4.6) & -18 & $(4.2)$ \\
\hline & Turkey & 433 & $(4.1)$ & 415 & $(7.2)$ & -18 & (3.1) & -10 & (2.5) \\
\hline & United Kingdom & 514 & (2.6) & 507 & $(6.2)$ & -7 & (3.6) & -2 & (3.4) \\
\hline & United States & 501 & (3.0) & 494 & (6.6) & -7 & (3.6) & -2 & (3.4) \\
\hline & OECD average & 501 & $(0.4)$ & 479 & (1.1) & -22 & $(0.7)$ & -15 & $(0.6)$ \\
\hline$n$ & Albania & 429 & (3.4) & 417 & $(8.2)$ & -11 & $(4.8)$ & -11 & $(4.8)$ \\
\hline ฐ & Algeria & 384 & (3.0) & 368 & $(6.2)$ & -16 & (3.3) & -12 & (3.3) \\
\hline ปัต & Brazil & 416 & (2.4) & 381 & $(4.8)$ & -35 & $(2.5)$ & -28 & $(2.2)$ \\
\hline & B-S-J-G (China) & 521 & (4.6) & 509 & $(8.2)$ & -12 & (3.5) & -5 & $(2.7)$ \\
\hline & Bulgaria & 468 & (3.9) & 423 & $(8.1)$ & -45 & $(4.2)$ & -24 & (3.3) \\
\hline & CABA (Argentina) & 485 & (6.4) & 433 & (13.4) & -52 & $(7.0)$ & -25 & (5.8) \\
\hline & Colombia & 424 & $(2.2)$ & 401 & $(5.0)$ & -23 & $(2.8)$ & -19 & (2.4) \\
\hline & Costa Rica & 425 & $(2.1)$ & 413 & $(4.7)$ & -12 & (2.5) & -9 & $(2.3)$ \\
\hline & Croatia & 480 & (2.5) & 453 & $(6.2)$ & -28 & (3.7) & -23 & (3.1) \\
\hline & Cyprus* & 440 & (1.6) & 412 & (5.3) & -28 & (3.7) & -31 & (3.6) \\
\hline & Dominican Republic & 349 & $(2.8)$ & 319 & (5.8) & -30 & $(3.1)$ & -21 & $(2.8)$ \\
\hline & FYROM & 395 & (1.4) & 346 & (6.3) & -49 & (4.9) & -39 & $(4.8)$ \\
\hline & Georgia & 417 & $(2.3)$ & 368 & (9.9) & -49 & (7.5) & -40 & $(6.8)$ \\
\hline & Hong Kong (China) & 526 & $(2.7)$ & 520 & (5.9) & -6 & $(3.2)$ & -1 & $(2.7)$ \\
\hline & Indonesia & 405 & (2.5) & 378 & (8.3) & -26 & (5.8) & -18 & $(5.0)$ \\
\hline & Jordan & 425 & (2.5) & 373 & (5.6) & -53 & (3.1) & -44 & (3.0) \\
\hline & Kosovo & 389 & $(1.7)$ & 335 & (5.6) & -54 & (3.8) & -45 & $(3.8)$ \\
\hline & Lebanon & 408 & (3.3) & 334 & $(8.7)$ & -74 & (5.4) & -67 & $(6.0)$ \\
\hline & Lithuania & 484 & (2.9) & 463 & $(5.8)$ & -21 & (2.9) & -13 & (2.5) \\
\hline & Macao (China) & 533 & (1.1) & 514 & $(4.2)$ & -19 & (3.1) & -21 & (3.1) \\
\hline & Malta & 478 & $(2.2)$ & 433 & $(7.8)$ & -45 & $(5.7)$ & -32 & (4.9) \\
\hline & Moldova & 437 & (2.0) & 397 & $(7.2)$ & -40 & $(5.2)$ & -36 & (4.6) \\
\hline & Montenegro & 419 & $(1.2)$ & 401 & (4.4) & -18 & (3.1) & -18 & (2.9) \\
\hline & Peru & 407 & (2.5) & 370 & (5.6) & -37 & (3.1) & -23 & (2.5) \\
\hline & Qatar & 434 & $(1.3)$ & 394 & (3.8) & -41 & (2.5) & -35 & (2.4) \\
\hline & Romania & 440 & (3.1) & 409 & (9.4) & -30 & (6.3) & -25 & $(5.2)$ \\
\hline & Russia & 493 & $(2.7)$ & 476 & (6.5) & -17 & (3.8) & -16 & (3.4) \\
\hline & Singapore & 561 & $(1.3)$ & 540 & (4.9) & -21 & (3.6) & -9 & (3.7) \\
\hline & Chinese Taipei & 534 & $(2.8)$ & 520 & (7.5) & -14 & $(4.7)$ & -7 & $(4.0)$ \\
\hline & Thailand & 427 & (2.9) & 403 & (5.9) & -24 & (3.0) & -22 & (2.8) \\
\hline & Trinidad and Tobago & 434 & $(1.7)$ & 409 & $(6.0)$ & -25 & $(4.3)$ & -16 & (3.5) \\
\hline & Tunisia & 392 & $(2.1)$ & 377 & (5.1) & -15 & (3.0) & -13 & (3.0) \\
\hline & United Arab Emirates & 445 & (2.4) & 421 & (5.4) & -24 & (3.0) & -26 & (3.0) \\
\hline & Uruguay & 446 & $(2.3)$ & 422 & (5.6) & -24 & (3.3) & -14 & (2.9) \\
\hline & Viet Nam & 526 & (3.9) & 508 & $(13.7)$ & -18 & (9.9) & -14 & $(9.2)$ \\
\hline & Argentina** & 448 & $(2.8)$ & 396 & (6.6) & -52 & (3.8) & -33 & (3.0) \\
\hline & Kazakhstan** & 458 & (3.7) & 431 & (10.4) & -27 & (6.7) & -24 & (6.7) \\
\hline & Malaysia** & 447 & (2.8) & 424 & (6.6) & -24 & (3.8) & -26 & (3.4) \\
\hline
\end{tabular}

1. The socio-economic profile is measured by the PISA index of economic, social and cultural status (ESCS).

Note: Values that are statistically significant are indicated in bold (see Annex A3).

* See note at the beginning of this Annex.

** Coverage is too small to ensure comparability (see Annex A4).

StatLink 䣓四 http://dx.doi.org/10.1787/888933471353 
[Part 1/1]

Table III.7.11 Index of sense of belonging and life satisfaction

Results based on students' self-reports

\begin{tabular}{|c|c|c|c|c|c|c|c|c|c|c|c|c|c|c|}
\hline & \multicolumn{10}{|c|}{ Average life satisfaction, by national quarters of the index of sense belonging } & \multirow{2}{*}{\multicolumn{2}{|c|}{$\begin{array}{l}\text { Change in life } \\
\text { satisfaction } \\
\text { associated with } \\
\text { a one-unit change } \\
\text { in the index of } \\
\text { sense of belonging }\end{array}$}} & \multirow{2}{*}{\multicolumn{2}{|c|}{$\begin{array}{c}\text { Explained variance } \\
\text { in life satisfaction } \\
\text { ( } r \text {-squared } \times 100)\end{array}$}} \\
\hline & \multicolumn{2}{|c|}{ Bottom quarter } & \multicolumn{2}{|c|}{ Second quarter } & \multicolumn{2}{|c|}{ Third quarter } & \multicolumn{2}{|c|}{ Top quarter } & \multicolumn{2}{|c|}{ Top - bottom quarter } & & & & \\
\hline & Mean & S.E. & Mean & S.E. & Mean & S.E. & Mean & S.E. & Dif. & S.E. & $\begin{array}{c}\text { Index } \\
\text { change }\end{array}$ & S.E. & $\%$ & S.E. \\
\hline A Australia & $\mathrm{m}$ & $\mathrm{m}$ & $\mathrm{m}$ & $\mathrm{m}$ & $\mathrm{m}$ & $\mathrm{m}$ & $\mathrm{m}$ & $\mathrm{m}$ & $\mathrm{m}$ & $\mathrm{m}$ & $\mathrm{m}$ & $\mathrm{m}$ & $\mathrm{m}$ & $\mathrm{m}$ \\
\hline Austria & 6.71 & $(0.07)$ & 7.28 & $(0.05)$ & 7.84 & $(0.05)$ & 8.26 & $(0.05)$ & 1.55 & $(0.08)$ & 0.39 & $(0.02)$ & 5.0 & $(0.5)$ \\
\hline Belgium (excl. Flemish) & 6.51 & $(0.10)$ & 7.43 & $(0.07)$ & 7.79 & $(0.08)$ & 8.20 & $(0.06)$ & 1.68 & $(0.11)$ & 0.70 & $(0.04)$ & 9.1 & (1.1) \\
\hline Canada & $\mathrm{m}$ & $\mathrm{m}$ & $\mathrm{m}$ & $\mathrm{m}$ & $\mathrm{m}$ & $\mathrm{m}$ & $\mathrm{m}$ & $\mathrm{m}$ & $\mathrm{m}$ & $\mathrm{m}$ & $\mathrm{m}$ & $\mathrm{m}$ & $\mathrm{m}$ & $\mathrm{m}$ \\
\hline Chile & 6.49 & $(0.08)$ & 7.19 & $(0.07)$ & 7.60 & $(0.07)$ & 8.16 & $(0.05)$ & 1.66 & $(0.09)$ & 0.50 & $(0.03)$ & 5.0 & $(0.6)$ \\
\hline Czech Republic & 6.13 & $(0.08)$ & 6.90 & $(0.07)$ & 7.27 & $(0.06)$ & 7.91 & $(0.06)$ & 1.79 & $(0.10)$ & 0.71 & $(0.04)$ & 5.9 & $(0.6)$ \\
\hline Denmark & $\mathrm{m}$ & $\mathrm{m}$ & $\mathrm{m}$ & $\mathrm{m}$ & $\mathrm{m}$ & $\mathrm{m}$ & $\mathrm{m}$ & $\mathrm{m}$ & $\mathrm{m}$ & $\mathrm{m}$ & $\mathrm{m}$ & $\mathrm{m}$ & $\mathrm{m}$ & $\mathrm{m}$ \\
\hline Estonia & 6.35 & $(0.07)$ & 7.36 & $(0.06)$ & 7.84 & $(0.06)$ & 8.46 & $(0.05)$ & 2.11 & $(0.09)$ & 0.83 & $(0.04)$ & 11.5 & (0.8) \\
\hline Finland & 6.74 & $(0.07)$ & 7.83 & $(0.05)$ & 8.25 & $(0.04)$ & 8.73 & $(0.04)$ & 1.99 & $(0.07)$ & 0.70 & $(0.03)$ & 13.7 & (0.9) \\
\hline France & 6.70 & $(0.07)$ & 7.57 & $(0.06)$ & 7.90 & $(0.04)$ & 8.33 & $(0.04)$ & 1.63 & $(0.08)$ & 0.71 & $(0.04)$ & 8.2 & $(0.8)$ \\
\hline Germany & 6.41 & $(0.08)$ & 7.10 & $(0.07)$ & 7.74 & $(0.05)$ & 8.14 & $(0.06)$ & 1.73 & $(0.10)$ & 0.56 & $(0.03)$ & 7.7 & $(0.8)$ \\
\hline Greece & 5.99 & $(0.08)$ & 6.70 & $(0.07)$ & 7.16 & $(0.05)$ & 7.79 & $(0.06)$ & 1.81 & $(0.09)$ & 0.64 & $(0.04)$ & 7.3 & (0.8) \\
\hline Hungary & 6.21 & $(0.07)$ & 7.03 & $(0.08)$ & 7.42 & $(0.08)$ & 8.00 & $(0.05)$ & 1.79 & (0.09) & 0.62 & $(0.03)$ & 7.5 & $(0.7)$ \\
\hline Iceland & 6.57 & $(0.10)$ & 7.42 & $(0.08)$ & 8.24 & $(0.06)$ & 8.96 & $(0.04)$ & 2.39 & $(0.11)$ & 0.54 & $(0.03)$ & 10.1 & (0.9) \\
\hline Ireland & 5.89 & $(0.09)$ & 7.19 & (0.05) & 7.76 & $(0.06)$ & 8.35 & $(0.04)$ & 2.46 & $(0.10)$ & 0.89 & $(0.04)$ & 14.9 & (1.1) \\
\hline Israel & $\mathrm{m}$ & $\mathrm{m}$ & $\mathrm{m}$ & $\mathrm{m}$ & $\mathrm{m}$ & $\mathrm{m}$ & $\mathrm{m}$ & $\mathrm{m}$ & $\mathrm{m}$ & $\mathrm{m}$ & $\mathrm{m}$ & $\mathrm{m}$ & $\mathrm{m}$ & $\mathrm{m}$ \\
\hline Italy & 5.97 & $(0.07)$ & 6.72 & $(0.08)$ & 7.15 & $(0.05)$ & 7.71 & $(0.05)$ & 1.74 & $(0.08)$ & 0.71 & $(0.03)$ & 7.4 & $(0.6)$ \\
\hline Japan & 5.57 & $(0.06)$ & 6.61 & $(0.07)$ & 7.12 & $(0.06)$ & 7.92 & $(0.06)$ & 2.35 & $(0.08)$ & 0.90 & $(0.04)$ & 12.6 & (0.9) \\
\hline Korea & 5.13 & $(0.07)$ & 6.06 & $(0.06)$ & 6.88 & $(0.06)$ & 7.39 & $(0.06)$ & 2.26 & $(0.09)$ & 0.94 & $(0.04)$ & 12.6 & (0.9) \\
\hline Latvia & 6.44 & $(0.07)$ & 7.27 & $(0.06)$ & 7.55 & $(0.06)$ & 8.20 & $(0.06)$ & 1.76 & $(0.08)$ & 0.64 & $(0.03)$ & 7.6 & $(0.7)$ \\
\hline Luxembourg & 6.61 & $(0.07)$ & 7.13 & $(0.07)$ & 7.60 & $(0.06)$ & 8.17 & $(0.06)$ & 1.55 & $(0.09)$ & 0.50 & $(0.03)$ & 5.7 & (0.6) \\
\hline Mexico & 7.83 & $(0.07)$ & 8.04 & $(0.06)$ & 8.33 & $(0.06)$ & 8.87 & $(0.05)$ & 1.04 & (0.09) & 0.28 & $(0.02)$ & 2.2 & (0.4) \\
\hline Netherlands & 7.22 & $(0.05)$ & 7.58 & $(0.05)$ & 8.02 & $(0.04)$ & 8.47 & $(0.04)$ & 1.25 & $(0.06)$ & 0.49 & $(0.03)$ & 8.0 & (0.8) \\
\hline New Zealand & $\mathrm{m}$ & $\mathrm{m}$ & $\mathrm{m}$ & $\mathrm{m}$ & $\mathrm{m}$ & $\mathrm{m}$ & $\mathrm{m}$ & $\mathrm{m}$ & $\mathrm{m}$ & $\mathrm{m}$ & $\mathrm{m}$ & $\mathrm{m}$ & $\mathrm{m}$ & $\mathrm{m}$ \\
\hline Norway & $\mathrm{m}$ & $\mathrm{m}$ & $\mathrm{m}$ & $\mathrm{m}$ & $\mathrm{m}$ & $\mathrm{m}$ & $\mathrm{m}$ & $\mathrm{m}$ & $\mathrm{m}$ & $\mathrm{m}$ & $\mathrm{m}$ & $\mathrm{m}$ & $\mathrm{m}$ & $\mathrm{m}$ \\
\hline Poland & 6.31 & $(0.08)$ & 7.03 & $(0.07)$ & 7.39 & $(0.07)$ & 8.01 & $(0.06)$ & 1.70 & $(0.10)$ & 0.50 & $(0.04)$ & 4.2 & $(0.7)$ \\
\hline Portugal & 6.52 & $(0.06)$ & 7.23 & $(0.06)$ & 7.64 & $(0.06)$ & 8.07 & $(0.04)$ & 1.55 & $(0.07)$ & 0.48 & $(0.03)$ & 5.9 & $(0.6)$ \\
\hline Slovak Republic & 6.76 & $(0.08)$ & 7.26 & $(0.06)$ & 7.67 & $(0.06)$ & 8.16 & $(0.05)$ & 1.40 & $(0.09)$ & 0.50 & $(0.04)$ & 3.4 & $(0.6)$ \\
\hline Slovenia & 6.28 & $(0.08)$ & 6.91 & $(0.07)$ & 7.50 & $(0.07)$ & 8.01 & $(0.06)$ & 1.73 & $(0.09)$ & 0.56 & $(0.04)$ & 4.7 & $(0.7)$ \\
\hline Spain & 6.50 & $(0.06)$ & 7.30 & $(0.05)$ & 7.76 & $(0.05)$ & 8.15 & $(0.05)$ & 1.65 & $(0.07)$ & 0.46 & $(0.03)$ & 6.6 & $(0.7)$ \\
\hline Sweden & $\mathrm{m}$ & $\mathrm{m}$ & $\mathrm{m}$ & $\mathrm{m}$ & $\mathrm{m}$ & $\mathrm{m}$ & $\mathrm{m}$ & $\mathrm{m}$ & $\mathrm{m}$ & $\mathrm{m}$ & $\mathrm{m}$ & $\mathrm{m}$ & $\mathrm{m}$ & $\mathrm{m}$ \\
\hline Switzerland & 6.87 & $(0.09)$ & 7.53 & $(0.07)$ & 8.05 & $(0.05)$ & 8.43 & $(0.05)$ & 1.56 & $(0.10)$ & 0.51 & $(0.04)$ & 7.9 & (1.0) \\
\hline Turkey & 6.19 & $(0.12)$ & 5.49 & $(0.11)$ & 5.91 & $(0.10)$ & 6.88 & $(0.10)$ & 0.70 & $(0.15)$ & 0.21 & $(0.04)$ & 0.7 & $(0.3)$ \\
\hline United Kingdom & 5.48 & $(0.07)$ & 6.97 & $(0.06)$ & 7.39 & $(0.06)$ & 8.11 & $(0.05)$ & 2.63 & $(0.09)$ & 0.98 & $(0.03)$ & 14.9 & $(0.9)$ \\
\hline United States & 6.07 & $(0.08)$ & 7.25 & $(0.08)$ & 7.70 & $(0.05)$ & 8.40 & $(0.05)$ & 2.33 & $(0.10)$ & 0.76 & $(0.03)$ & 12.1 & $(0.9)$ \\
\hline OECD average & 6.37 & $(0.01)$ & 7.12 & $(0.01)$ & 7.59 & $(0.01)$ & 8.15 & $(0.01)$ & 1.78 & $(0.02)$ & 0.61 & $(0.01)$ & 7.9 & $(0.1)$ \\
\hline
\end{tabular}

\begin{tabular}{|c|c|c|c|c|c|c|c|c|c|c|c|c|c|c|c|}
\hline 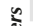 & Albania & $\mathrm{m}$ & $\mathrm{m}$ & $\mathrm{m}$ & $\mathrm{m}$ & $\mathrm{m}$ & $\mathrm{m}$ & $\mathrm{m}$ & $\mathrm{m}$ & $\mathrm{m}$ & $\mathrm{m}$ & $\mathrm{m}$ & $\mathrm{m}$ & $\mathrm{m}$ & $\mathrm{m}$ \\
\hline 0 & Algeria & $\mathrm{m}$ & $\mathrm{m}$ & $\mathrm{m}$ & $\mathrm{m}$ & $\mathrm{m}$ & $\mathrm{m}$ & $\mathrm{m}$ & $\mathrm{m}$ & $\mathrm{m}$ & $\mathrm{m}$ & $\mathrm{m}$ & $\mathrm{m}$ & $\mathrm{m}$ & $\mathrm{m}$ \\
\hline ปั & Brazil & 7.03 & $(0.06)$ & 7.53 & $(0.05)$ & 7.72 & $(0.04)$ & 8.06 & $(0.04)$ & 1.04 & $(0.07)$ & 0.32 & $(0.02)$ & 1.8 & $(0.3)$ \\
\hline & B-S-J-G (China) & 5.87 & $(0.08)$ & 6.61 & $(0.07)$ & 7.15 & $(0.07)$ & 7.71 & $(0.07)$ & 1.84 & $(0.10)$ & 0.85 & $(0.04)$ & 7.6 & $(0.7)$ \\
\hline & Bulgaria & 7.08 & $(0.07)$ & 6.97 & $(0.10)$ & 7.38 & $(0.07)$ & 8.24 & $(0.07)$ & 1.15 & $(0.10)$ & 0.34 & $(0.03)$ & 1.7 & $(0.3)$ \\
\hline & CABA (Argentina) & $\mathrm{m}$ & $\mathrm{m}$ & $\mathrm{m}$ & $\mathrm{m}$ & $\mathrm{m}$ & $\mathrm{m}$ & $\mathrm{m}$ & $\mathrm{m}$ & $\mathrm{m}$ & $\mathrm{m}$ & $\mathrm{m}$ & $\mathrm{m}$ & $\mathrm{m}$ & $\mathrm{m}$ \\
\hline & Colombia & 7.72 & $(0.07)$ & 7.50 & $(0.07)$ & 7.97 & $(0.06)$ & 8.35 & $(0.06)$ & 0.63 & $(0.09)$ & 0.20 & $(0.03)$ & 0.7 & $(0.2)$ \\
\hline & Costa Rica & 7.70 & $(0.07)$ & 7.93 & $(0.06)$ & 8.37 & $(0.05)$ & 8.82 & $(0.05)$ & 1.11 & $(0.08)$ & 0.25 & $(0.02)$ & 2.1 & $(0.4)$ \\
\hline & Croatia & 7.04 & $(0.08)$ & 7.74 & $(0.06)$ & 8.17 & $(0.05)$ & 8.64 & $(0.04)$ & 1.60 & $(0.10)$ & 0.55 & $(0.04)$ & 6.5 & $(0.8)$ \\
\hline & Cyprus* & 6.11 & $(0.08)$ & 6.80 & $(0.06)$ & 7.35 & $(0.06)$ & 7.98 & $(0.05)$ & 1.87 & $(0.09)$ & 0.62 & $(0.03)$ & 7.8 & $(0.8)$ \\
\hline & Dominican Republic & 8.65 & $(0.09)$ & 8.13 & $(0.10)$ & 8.47 & $(0.09)$ & 8.79 & $(0.06)$ & 0.14 & $(0.11)$ & 0.06 & $(0.02)$ & 0.1 & $(0.1)$ \\
\hline & FYROM & $\mathrm{m}$ & $\mathrm{m}$ & $\mathrm{m}$ & $\mathrm{m}$ & $\mathrm{m}$ & $\mathrm{m}$ & $\mathrm{m}$ & $\mathrm{m}$ & $\mathrm{m}$ & $\mathrm{m}$ & $\mathrm{m}$ & $\mathrm{m}$ & $\mathrm{m}$ & $\mathrm{m}$ \\
\hline & Georgia & $\mathrm{m}$ & $\mathrm{m}$ & $\mathrm{m}$ & $\mathrm{m}$ & $\mathrm{m}$ & $\mathrm{m}$ & $\mathrm{m}$ & $\mathrm{m}$ & $\mathrm{m}$ & $\mathrm{m}$ & $\mathrm{m}$ & $\mathrm{m}$ & $\mathrm{m}$ & $\mathrm{m}$ \\
\hline & Hong Kong (China) & 5.47 & $(0.09)$ & 6.25 & $(0.06)$ & 6.89 & $(0.06)$ & 7.33 & $(0.05)$ & 1.86 & $(0.09)$ & 0.90 & $(0.05)$ & 9.4 & $(0.8)$ \\
\hline & Indonesia & $\mathrm{m}$ & $\mathrm{m}$ & $\mathrm{m}$ & $\mathrm{m}$ & $\mathrm{m}$ & $\mathrm{m}$ & $\mathrm{m}$ & $\mathrm{m}$ & $\mathrm{m}$ & $\mathrm{m}$ & $\mathrm{m}$ & $\mathrm{m}$ & $\mathrm{m}$ & $\mathrm{m}$ \\
\hline & Jordan & $\mathrm{m}$ & $\mathrm{m}$ & $\mathrm{m}$ & $\mathrm{m}$ & $\mathrm{m}$ & $\mathrm{m}$ & $\mathrm{m}$ & $\mathrm{m}$ & $\mathrm{m}$ & $\mathrm{m}$ & $\mathrm{m}$ & $\mathrm{m}$ & $\mathrm{m}$ & $\mathrm{m}$ \\
\hline & Kosovo & $\mathrm{m}$ & $\mathrm{m}$ & $\mathrm{m}$ & $\mathrm{m}$ & $\mathrm{m}$ & $\mathrm{m}$ & $\mathrm{m}$ & $\mathrm{m}$ & $\mathrm{m}$ & $\mathrm{m}$ & $\mathrm{m}$ & $\mathrm{m}$ & $\mathrm{m}$ & $\mathrm{m}$ \\
\hline & Lebanon & $\mathrm{m}$ & $\mathrm{m}$ & $\mathrm{m}$ & $\mathrm{m}$ & $\mathrm{m}$ & $\mathrm{m}$ & $\mathrm{m}$ & $\mathrm{m}$ & $\mathrm{m}$ & $\mathrm{m}$ & $\mathrm{m}$ & $\mathrm{m}$ & $\mathrm{m}$ & $\mathrm{m}$ \\
\hline & Lithuania & 7.73 & $(0.07)$ & 7.30 & $(0.07)$ & 7.84 & $(0.06)$ & 8.59 & $(0.04)$ & 0.86 & $(0.09)$ & 0.25 & $(0.03)$ & 1.7 & $(0.4)$ \\
\hline & Macao (China) & 5.65 & $(0.06)$ & 6.52 & $(0.06)$ & 6.85 & $(0.06)$ & 7.34 & $(0.06)$ & 1.69 & $(0.09)$ & 0.96 & $(0.06)$ & 8.0 & $(0.8)$ \\
\hline & Malta & $\mathrm{m}$ & $\mathrm{m}$ & $\mathrm{m}$ & $\mathrm{m}$ & $\mathrm{m}$ & $\mathrm{m}$ & $\mathrm{m}$ & $\mathrm{m}$ & $\mathrm{m}$ & $\mathrm{m}$ & $\mathrm{m}$ & $\mathrm{m}$ & $\mathrm{m}$ & $\mathrm{m}$ \\
\hline & Moldova & $\mathrm{m}$ & $\mathrm{m}$ & $\mathrm{m}$ & $\mathrm{m}$ & $\mathrm{m}$ & $\mathrm{m}$ & $\mathrm{m}$ & $\mathrm{m}$ & $\mathrm{m}$ & $\mathrm{m}$ & $\mathrm{m}$ & $\mathrm{m}$ & $\mathrm{m}$ & $\mathrm{m}$ \\
\hline & Montenegro & 7.00 & $(0.08)$ & 7.59 & $(0.07)$ & 7.95 & $(0.06)$ & 8.43 & $(0.06)$ & 1.43 & $(0.10)$ & 0.49 & $(0.04)$ & 3.3 & $(0.5)$ \\
\hline & Peru & 6.87 & $(0.09)$ & 7.29 & $(0.07)$ & 7.70 & $(0.07)$ & 8.15 & $(0.06)$ & 1.28 & $(0.10)$ & 0.50 & $(0.04)$ & 2.8 & $(0.4)$ \\
\hline & Qatar & 6.63 & $(0.06)$ & 7.14 & $(0.04)$ & 7.54 & $(0.04)$ & 8.21 & $(0.05)$ & 1.58 & $(0.08)$ & 0.53 & $(0.03)$ & 4.3 & (0.5) \\
\hline & Romania & $\mathrm{m}$ & $\mathrm{m}$ & $\mathrm{m}$ & $\mathrm{m}$ & $\mathrm{m}$ & $\mathrm{m}$ & $\mathrm{m}$ & $\mathrm{m}$ & $\mathrm{m}$ & $\mathrm{m}$ & $\mathrm{m}$ & $\mathrm{m}$ & $\mathrm{m}$ & $\mathrm{m}$ \\
\hline & Russia & 6.97 & $(0.08)$ & 7.60 & $(0.08)$ & 7.96 & $(0.07)$ & 8.50 & $(0.08)$ & 1.54 & $(0.11)$ & 0.60 & $(0.04)$ & 4.5 & $(0.7)$ \\
\hline & Singapore & $\mathrm{m}$ & $\mathrm{m}$ & $\mathrm{m}$ & $\mathrm{m}$ & $\mathrm{m}$ & $\mathrm{m}$ & $\mathrm{m}$ & $\mathrm{m}$ & $\mathrm{m}$ & $\mathrm{m}$ & $\mathrm{m}$ & $\mathrm{m}$ & $\mathrm{m}$ & $\mathrm{m}$ \\
\hline & Chinese Taipei & 5.72 & $(0.07)$ & 6.45 & $(0.04)$ & 6.76 & $(0.05)$ & 7.43 & $(0.06)$ & 1.71 & $(0.07)$ & 0.58 & $(0.03)$ & 6.7 & $(0.6)$ \\
\hline & Thailand & 7.17 & $(0.07)$ & 7.60 & $(0.06)$ & 7.80 & $(0.06)$ & 8.27 & $(0.05)$ & 1.11 & $(0.08)$ & 0.63 & $(0.04)$ & 3.7 & $(0.5)$ \\
\hline & Trinidad and Tobago & $\mathrm{m}$ & $\mathrm{m}$ & $\mathrm{m}$ & $\mathrm{m}$ & $\mathrm{m}$ & $\mathrm{m}$ & $\mathrm{m}$ & $\mathrm{m}$ & $\mathrm{m}$ & $\mathrm{m}$ & $\mathrm{m}$ & $\mathrm{m}$ & $\mathrm{m}$ & $\mathrm{m}$ \\
\hline & Tunisia & 5.74 & $(0.10)$ & 6.93 & $(0.09)$ & 7.22 & $(0.09)$ & 7.69 & $(0.08)$ & 1.95 & $(0.13)$ & 0.87 & $(0.06)$ & 4.9 & $(0.7)$ \\
\hline & United Arab Emirates & 6.36 & $(0.07)$ & 7.17 & $(0.06)$ & 7.61 & $(0.05)$ & 8.01 & $(0.05)$ & 1.65 & $(0.08)$ & 0.62 & $(0.03)$ & 4.9 & $(0.5)$ \\
\hline & Uruguay & 6.99 & $(0.07)$ & 7.54 & $(0.07)$ & 7.83 & $(0.06)$ & 8.42 & $(0.05)$ & 1.43 & $(0.09)$ & 0.40 & $(0.02)$ & 3.9 & $(0.5)$ \\
\hline & Viet Nam & $\mathrm{m}$ & $\mathrm{m}$ & $\mathrm{m}$ & $\mathrm{m}$ & $\mathrm{m}$ & $\mathrm{m}$ & $\mathrm{m}$ & $\mathrm{m}$ & $\mathrm{m}$ & $\mathrm{m}$ & $\mathrm{m}$ & $\mathrm{m}$ & $\mathrm{m}$ & $\mathrm{m}$ \\
\hline & Argentina** & $\mathrm{m}$ & $\mathrm{m}$ & $\mathrm{m}$ & $\mathrm{m}$ & $\mathrm{m}$ & $\mathrm{m}$ & $\mathrm{m}$ & $\mathrm{m}$ & $\mathrm{m}$ & $\mathrm{m}$ & $\mathrm{m}$ & $\mathrm{m}$ & $\mathrm{m}$ & $\mathrm{m}$ \\
\hline & Kazakhstan** & $\mathrm{m}$ & $\mathrm{m}$ & $\mathrm{m}$ & $\mathrm{m}$ & $\mathrm{m}$ & $\mathrm{m}$ & $\mathrm{m}$ & $\mathrm{m}$ & $\mathrm{m}$ & $\mathrm{m}$ & $\mathrm{m}$ & $\mathrm{m}$ & $\mathrm{m}$ & $\mathrm{m}$ \\
\hline & Malaysia** $^{* *}$ & 6.27 & $(0.07)$ & 7.06 & $(0.07)$ & 7.29 & $(0.06)$ & 7.66 & $(0.06)$ & 1.39 & $(0.08)$ & 0.63 & $(0.04)$ & 5.0 & $(0.6)$ \\
\hline
\end{tabular}

Note: Values that are statistically significant are indicated in bold (see Annex A3).

* See note at the beginning of this Annex.

** Coverage is too small to ensure comparability (see Annex A4).

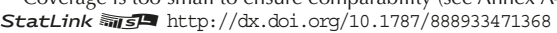


Likelihood that a student is not satisfied with his/her life if he/she "feels like an outsider at school", "feels awkward at school" and "feels lonely at school"

\begin{tabular}{|c|c|c|c|c|c|c|c|c|c|c|c|c|c|}
\hline & \multicolumn{12}{|c|}{ Likelihood that a student is "not satisfied" with his or her life" } \\
\hline & & \multicolumn{4}{|c|}{ "I feel like an outsider at school" } & \multicolumn{4}{|c|}{ "I feel awkward and out of place in my school" } & & "I feel lonely & y at school" & \\
\hline & & $\begin{array}{l}\text { Before acco } \\
\text { students' an } \\
\text { socio-econo }\end{array}$ & $\begin{array}{l}\text { unting for } \\
\text { d schools } \\
\text { nic profile }{ }^{2}\end{array}$ & $\begin{array}{l}\text { After acco } \\
\text { students' ar } \\
\text { socio-econo }\end{array}$ & $\begin{array}{l}\text { nting for } \\
\text { d schools' } \\
\text { nic profile }\end{array}$ & $\begin{array}{l}\text { Before acco } \\
\text { students' an } \\
\text { socio-econo }\end{array}$ & $\begin{array}{l}\text { unting for } \\
\text { d schools' } \\
\text { mic profile }\end{array}$ & $\begin{array}{l}\text { After acco } \\
\text { students' an } \\
\text { socio-econo }\end{array}$ & $\begin{array}{l}\text { unting for } \\
\text { d schools' } \\
\text { mic profile }\end{array}$ & $\begin{array}{l}\text { Before acco } \\
\text { students' ar } \\
\text { socio-econo }\end{array}$ & $\begin{array}{l}\text { ounting for } \\
\text { d schools' } \\
\text { mic profile }\end{array}$ & $\begin{array}{l}\text { After acco } \\
\text { students' an } \\
\text { socio-econo }\end{array}$ & $\begin{array}{l}\text { unting for } \\
\text { d schools' } \\
\text { mic profile }\end{array}$ \\
\hline & & Odds ratio & S.E. & Odds ratio & S.E. & Odds ratio & S.E. & Odds ratio & S.E. & Odds ratio & S.E. & Odds ratio & S.E. \\
\hline 0 & Australia & $\mathrm{m}$ & $\mathrm{m}$ & $\mathrm{m}$ & $\mathrm{m}$ & $\mathrm{m}$ & $\mathrm{m}$ & $\mathrm{m}$ & $\mathrm{m}$ & $\mathrm{m}$ & $\mathrm{m}$ & $\mathrm{m}$ & $\mathrm{m}$ \\
\hline ర్త & Austria & 2.16 & $(0.19)$ & 2.12 & $(0.20)$ & 2.29 & $(0.23)$ & 2.23 & $(0.22)$ & 2.24 & $(0.21)$ & 2.21 & $(0.22)$ \\
\hline & Belgium (excl. Flemish) & 3.43 & $(0.51)$ & 3.29 & $(0.49)$ & 3.34 & $(0.51)$ & 3.17 & $(0.50)$ & 4.67 & $(0.74)$ & 4.40 & $(0.76)$ \\
\hline & Canada & $\mathrm{m}$ & $\mathrm{m}$ & $\mathrm{m}$ & $\mathrm{m}$ & $\mathrm{m}$ & $\mathrm{m}$ & $\mathrm{m}$ & $\mathrm{m}$ & $\mathrm{m}$ & $\mathrm{m}$ & $\mathrm{m}$ & $\mathrm{m}$ \\
\hline & Chile & 2.31 & $(0.23)$ & 2.27 & $(0.22)$ & 2.20 & $(0.21)$ & 2.18 & $(0.21)$ & 2.49 & $(0.26)$ & 2.47 & $(0.26)$ \\
\hline & Czech Republic & 2.41 & $(0.23)$ & 2.35 & $(0.22)$ & 3.16 & $(0.33)$ & 3.05 & $(0.32)$ & 3.27 & $(0.28)$ & 3.19 & $(0.27)$ \\
\hline & Denmark & $\mathrm{m}$ & $\mathrm{m}$ & $\mathrm{m}$ & $\mathrm{m}$ & $\mathrm{m}$ & $\mathrm{m}$ & $\mathrm{m}$ & $\mathrm{m}$ & $\mathrm{m}$ & $\mathrm{m}$ & $\mathrm{m}$ & $\mathrm{m}$ \\
\hline & Estonia & 4.02 & $(0.46)$ & 3.95 & $(0.45)$ & 5.03 & $(0.53)$ & 4.92 & $(0.52)$ & 4.84 & $(0.44)$ & 4.84 & $(0.44)$ \\
\hline & Finland & 5.95 & $(0.72)$ & 5.81 & $(0.71)$ & 5.55 & $(0.59)$ & 5.37 & $(0.56)$ & 5.90 & $(0.85)$ & 5.83 & $(0.85)$ \\
\hline & France & 3.13 & $(0.35)$ & 2.85 & $(0.33)$ & 3.59 & $(0.43)$ & 3.35 & $(0.43)$ & 5.24 & $(0.72)$ & 5.04 & $(0.72)$ \\
\hline & Germany & 2.91 & $(0.30)$ & 2.85 & $(0.30)$ & 2.79 & $(0.33)$ & 2.68 & $(0.31)$ & 3.36 & $(0.40)$ & 3.25 & $(0.39)$ \\
\hline & Greece & 2.69 & $(0.24)$ & 2.66 & $(0.23)$ & 2.95 & $(0.31)$ & 2.91 & $(0.30)$ & 3.08 & $(0.35)$ & 3.08 & $(0.35)$ \\
\hline & Hungary & 3.03 & $(0.26)$ & 2.93 & $(0.25)$ & 2.41 & $(0.22)$ & 2.30 & $(0.21)$ & 3.11 & $(0.35)$ & 3.04 & $(0.35)$ \\
\hline & Iceland & 3.40 & $(0.45)$ & 3.39 & $(0.45)$ & 4.08 & $(0.54)$ & 4.12 & $(0.55)$ & 3.92 & $(0.49)$ & 3.89 & $(0.49)$ \\
\hline & Ireland & 5.00 & $(0.47)$ & 5.01 & $(0.46)$ & 4.87 & $(0.53)$ & 4.82 & $(0.53)$ & 6.57 & $(0.83)$ & 6.63 & $(0.82)$ \\
\hline & Israel & $\mathrm{m}$ & $\mathrm{m}$ & $\mathrm{m}$ & $\mathrm{m}$ & $\mathrm{m}$ & $\mathrm{m}$ & $\mathrm{m}$ & $\mathrm{m}$ & $\mathrm{m}$ & $\mathrm{m}$ & $\mathrm{m}$ & $\mathrm{m}$ \\
\hline & Italy & 3.12 & $(0.30)$ & 3.12 & $(0.31)$ & 2.53 & $(0.22)$ & 2.50 & $(0.22)$ & 3.66 & $(0.30)$ & 3.71 & $(0.31)$ \\
\hline & Japan & 3.45 & $(0.28)$ & 3.35 & $(0.27)$ & 3.74 & $(0.30)$ & 3.67 & $(0.29)$ & 4.16 & $(0.43)$ & 4.05 & $(0.41)$ \\
\hline & Korea & 4.13 & $(0.48)$ & 4.07 & $(0.48)$ & 3.39 & $(0.35)$ & 3.31 & $(0.34)$ & 4.53 & $(0.45)$ & 4.51 & $(0.46)$ \\
\hline & Latvia & 2.99 & $(0.30)$ & 2.95 & $(0.30)$ & 3.01 & $(0.35)$ & 2.96 & $(0.35)$ & 3.45 & $(0.37)$ & 3.40 & $(0.37)$ \\
\hline & Luxembourg & 2.35 & $(0.24)$ & 2.28 & $(0.24)$ & 2.25 & $(0.24)$ & 2.18 & $(0.24)$ & 2.59 & $(0.26)$ & 2.52 & $(0.27)$ \\
\hline & Mexico & 1.77 & $(0.22)$ & 1.72 & $(0.22)$ & 1.94 & $(0.24)$ & 1.91 & $(0.24)$ & 1.91 & $(0.25)$ & 1.89 & $(0.25)$ \\
\hline & Netherlands & 4.16 & $(0.67)$ & 4.21 & $(0.69)$ & 4.01 & $(0.54)$ & 4.08 & $(0.57)$ & 5.16 & $(1.01)$ & 5.24 & (1.04) \\
\hline & New Zealand & $\mathrm{m}$ & $\mathrm{m}$ & $\mathrm{m}$ & $\mathrm{m}$ & $\mathrm{m}$ & $\mathrm{m}$ & $\mathrm{m}$ & $\mathrm{m}$ & $\mathrm{m}$ & $\mathrm{m}$ & $\mathrm{m}$ & $\mathrm{m}$ \\
\hline & Norway & $\mathrm{m}$ & $\mathrm{m}$ & $\mathrm{m}$ & $\mathrm{m}$ & $\mathrm{m}$ & $\mathrm{m}$ & $\mathrm{m}$ & $\mathrm{m}$ & $\mathrm{m}$ & $\mathrm{m}$ & $\mathrm{m}$ & $\mathrm{m}$ \\
\hline & Poland & 2.37 & $(0.21)$ & 2.38 & $(0.21)$ & 2.35 & $(0.26)$ & 2.35 & $(0.26)$ & 2.59 & $(0.24)$ & 2.59 & $(0.24)$ \\
\hline & Portugal & 3.30 & $(0.39)$ & 3.29 & $(0.40)$ & 2.21 & $(0.21)$ & 2.21 & $(0.22)$ & 4.00 & $(0.45)$ & 4.01 & $(0.46)$ \\
\hline & Slovak Republic & 2.37 & $(0.24)$ & 2.29 & $(0.23)$ & 2.42 & $(0.22)$ & 2.35 & $(0.21)$ & 2.82 & $(0.25)$ & 2.76 & $(0.25)$ \\
\hline & Slovenia & 2.44 & $(0.26)$ & 2.47 & $(0.27)$ & 2.73 & $(0.25)$ & 2.77 & $(0.26)$ & 2.54 & $(0.23)$ & 2.57 & $(0.24)$ \\
\hline & Spain & 3.24 & $(0.39)$ & 3.17 & $(0.38)$ & 2.98 & $(0.34)$ & 2.93 & $(0.34)$ & 3.27 & $(0.38)$ & 3.24 & $(0.38)$ \\
\hline & Sweden & $\mathrm{m}$ & $\mathrm{m}$ & $\mathrm{m}$ & $\mathrm{m}$ & $\mathrm{m}$ & $\mathrm{m}$ & $\mathrm{m}$ & $\mathrm{m}$ & $\mathrm{m}$ & $\mathrm{m}$ & $\mathrm{m}$ & $\mathrm{m}$ \\
\hline & Switzerland & 3.43 & $(0.50)$ & 3.31 & $(0.49)$ & 3.17 & $(0.44)$ & 3.08 & $(0.43)$ & 4.29 & $(0.70)$ & 4.19 & $(0.70)$ \\
\hline & Turkey & 1.21 & $(0.09)$ & 1.20 & $(0.09)$ & 1.12 & $(0.07)$ & 1.11 & $(0.07)$ & 1.18 & $(0.08)$ & 1.17 & $(0.08)$ \\
\hline & United Kingdom & 5.06 & $(0.41)$ & 4.96 & $(0.41)$ & 4.77 & $(0.42)$ & 4.68 & $(0.41)$ & 6.18 & $(0.55)$ & 6.17 & $(0.55)$ \\
\hline & United States & 4.27 & $(0.39)$ & 4.17 & $(0.38)$ & 3.53 & $(0.29)$ & 3.44 & $(0.29)$ & 4.69 & $(0.41)$ & 4.65 & $(0.42)$ \\
\hline & OECD average & 3.22 & $(0.07)$ & 3.16 & $(0.07)$ & 3.16 & $(0.07)$ & 3.09 & $(0.07)$ & 3.77 & $(0.09)$ & 3.73 & $(0.09)$ \\
\hline$n$ & Albania & $\mathrm{m}$ & $\mathrm{m}$ & $\mathrm{m}$ & $\mathrm{m}$ & $\mathrm{m}$ & $\mathrm{m}$ & $\mathrm{m}$ & $\mathrm{m}$ & $\mathrm{m}$ & $\mathrm{m}$ & $\mathrm{m}$ & $\mathrm{m}$ \\
\hline$\Xi$ & Algeria & $\mathrm{m}$ & $\mathrm{m}$ & $\mathrm{m}$ & $\mathrm{m}$ & $\mathrm{m}$ & $\mathrm{m}$ & $\mathrm{m}$ & $\mathrm{m}$ & $\mathrm{m}$ & $\mathrm{m}$ & $\mathrm{m}$ & $\mathrm{m}$ \\
\hline$=$ & Brazil & 1.85 & $(0.13)$ & 1.85 & $(0.13)$ & 2.02 & $(0.15)$ & 2.03 & $(0.14)$ & 2.07 & $(0.14)$ & 2.07 & $(0.14)$ \\
\hline & B-S-J-G (China) & 2.53 & $(0.19)$ & 2.48 & $(0.19)$ & 2.84 & $(0.24)$ & 2.78 & $(0.23)$ & 2.74 & $(0.23)$ & 2.69 & $(0.23)$ \\
\hline & Bulgaria & 1.70 & $(0.15)$ & 1.62 & $(0.14)$ & 1.58 & $(0.13)$ & 1.53 & $(0.13)$ & 1.97 & $(0.17)$ & 1.92 & $(0.16)$ \\
\hline & CABA (Argentina) & $\mathrm{m}$ & $\mathrm{m}$ & $\mathrm{m}$ & $\mathrm{m}$ & $\mathrm{m}$ & $\mathrm{m}$ & $\mathrm{m}$ & $\mathrm{m}$ & $\mathrm{m}$ & $\mathrm{m}$ & $\mathrm{m}$ & $\mathrm{m}$ \\
\hline & Colombia & 1.43 & $(0.12)$ & 1.44 & $(0.12)$ & 1.43 & $(0.10)$ & 1.44 & $(0.10)$ & 1.68 & $(0.16)$ & 1.70 & $(0.17)$ \\
\hline & Costa Rica & 2.66 & $(0.27)$ & 2.66 & $(0.27)$ & 2.61 & $(0.25)$ & 2.60 & $(0.25)$ & 2.93 & $(0.30)$ & 2.94 & $(0.31)$ \\
\hline & Croatia & 3.05 & $(0.35)$ & 3.10 & $(0.36)$ & 3.71 & $(0.41)$ & 3.79 & $(0.42)$ & 4.17 & $(0.55)$ & 4.24 & $(0.56)$ \\
\hline & Cyprus* & 3.06 & $(0.31)$ & 3.12 & $(0.32)$ & 2.69 & $(0.25)$ & 2.73 & $(0.27)$ & 3.18 & $(0.31)$ & 3.26 & $(0.32)$ \\
\hline & Dominican Republic & 1.45 & $(0.20)$ & 1.42 & $(0.21)$ & 1.31 & $(0.16)$ & 1.27 & $(0.16)$ & 1.41 & $(0.20)$ & 1.38 & $(0.20)$ \\
\hline & FYROM & $\mathrm{m}$ & $\mathrm{m}$ & $\mathrm{m}$ & $\mathrm{m}$ & $\mathrm{m}$ & $\mathrm{m}$ & $\mathrm{m}$ & $\mathrm{m}$ & $\mathrm{m}$ & $\mathrm{m}$ & $\mathrm{m}$ & $\mathrm{m}$ \\
\hline & Georgia & $\mathrm{m}$ & $\mathrm{m}$ & $\mathrm{m}$ & $\mathrm{m}$ & $\mathrm{m}$ & $\mathrm{m}$ & $\mathrm{m}$ & $\mathrm{m}$ & $\mathrm{m}$ & $\mathrm{m}$ & $\mathrm{m}$ & $\mathrm{m}$ \\
\hline & Hong Kong (China) & 3.76 & $(0.31)$ & 3.66 & $(0.31)$ & 2.56 & $(0.24)$ & 2.51 & $(0.24)$ & 3.62 & $(0.29)$ & 3.52 & $(0.30)$ \\
\hline & Indonesia & $\mathrm{m}$ & $\mathrm{m}$ & $\mathrm{m}$ & $\mathrm{m}$ & $\mathrm{m}$ & $\mathrm{m}$ & $\mathrm{m}$ & $\mathrm{m}$ & $\mathrm{m}$ & $\mathrm{m}$ & $\mathrm{m}$ & $\mathrm{m}$ \\
\hline & Jordan & $\mathrm{m}$ & $\mathrm{m}$ & $\mathrm{m}$ & $\mathrm{m}$ & $\mathrm{m}$ & $\mathrm{m}$ & $\mathrm{m}$ & $\mathrm{m}$ & $\mathrm{m}$ & $\mathrm{m}$ & $\mathrm{m}$ & $\mathrm{m}$ \\
\hline & Kosovo & $\mathrm{m}$ & $\mathrm{m}$ & $\mathrm{m}$ & $\mathrm{m}$ & $\mathrm{m}$ & $\mathrm{m}$ & $\mathrm{m}$ & $\mathrm{m}$ & $\mathrm{m}$ & $\mathrm{m}$ & $\mathrm{m}$ & $\mathrm{m}$ \\
\hline & Lebanon & $\mathrm{m}$ & $\mathrm{m}$ & $\mathrm{m}$ & $\mathrm{m}$ & $\mathrm{m}$ & $\mathrm{m}$ & $\mathrm{m}$ & $\mathrm{m}$ & $\mathrm{m}$ & $\mathrm{m}$ & $\mathrm{m}$ & $\mathrm{m}$ \\
\hline & Lithuania & 1.52 & $(0.14)$ & 1.50 & $(0.14)$ & 1.73 & $(0.19)$ & 1.72 & $(0.19)$ & 1.59 & $(0.16)$ & 1.58 & $(0.16)$ \\
\hline & Macao (China) & 2.81 & $(0.22)$ & 2.88 & $(0.24)$ & 2.45 & $(0.22)$ & 2.51 & $(0.23)$ & 2.96 & $(0.24)$ & 2.96 & $(0.24)$ \\
\hline & Malta & $\mathrm{m}$ & $\mathrm{m}$ & $\mathrm{m}$ & $\mathrm{m}$ & $\mathrm{m}$ & $\mathrm{m}$ & $\mathrm{m}$ & $\mathrm{m}$ & $\mathrm{m}$ & $\mathrm{m}$ & $\mathrm{m}$ & $\mathrm{m}$ \\
\hline & Moldova & $\mathrm{m}$ & $\mathrm{m}$ & $\mathrm{m}$ & $\mathrm{m}$ & $\mathrm{m}$ & $\mathrm{m}$ & $\mathrm{m}$ & $\mathrm{m}$ & $\mathrm{m}$ & $\mathrm{m}$ & $\mathrm{m}$ & $\mathrm{m}$ \\
\hline & Montenegro & 2.75 & $(0.26)$ & 2.81 & $(0.26)$ & 2.60 & $(0.24)$ & 2.66 & $(0.25)$ & 2.98 & $(0.28)$ & 3.04 & $(0.29)$ \\
\hline & Peru & 2.33 & $(0.18)$ & 2.29 & $(0.18)$ & 1.99 & $(0.15)$ & 1.93 & $(0.15)$ & 2.41 & $(0.19)$ & 2.36 & $(0.18)$ \\
\hline & Qatar & 2.43 & $(0.14)$ & 2.41 & $(0.14)$ & 2.20 & $(0.12)$ & 2.19 & $(0.13)$ & 2.39 & $(0.17)$ & 2.35 & $(0.17)$ \\
\hline & Romania & $\mathrm{m}$ & $\mathrm{m}$ & $\mathrm{m}$ & $\mathrm{m}$ & $\mathrm{m}$ & $\mathrm{m}$ & $\mathrm{m}$ & $\mathrm{m}$ & $\mathrm{m}$ & $\mathrm{m}$ & $\mathrm{m}$ & $\mathrm{m}$ \\
\hline & Russia & 2.85 & $(0.33)$ & 2.85 & $(0.33)$ & 2.60 & $(0.23)$ & 2.59 & $(0.23)$ & 3.56 & $(0.38)$ & 3.58 & $(0.38)$ \\
\hline & Singapore & $\mathrm{m}$ & $\mathrm{m}$ & $\mathrm{m}$ & $\mathrm{m}$ & $\mathrm{m}$ & $\mathrm{m}$ & $\mathrm{m}$ & $\mathrm{m}$ & $\mathrm{m}$ & $\mathrm{m}$ & $\mathrm{m}$ & $\mathrm{m}$ \\
\hline & Chinese Taipei & 3.35 & $(0.30)$ & 3.31 & $(0.29)$ & 2.46 & $(0.20)$ & 2.44 & $(0.19)$ & 3.35 & $(0.32)$ & 3.31 & $(0.32)$ \\
\hline & Thailand & 2.96 & $(0.33)$ & 2.96 & $(0.33)$ & 1.78 & $(0.21)$ & 1.78 & $(0.21)$ & 2.37 & $(0.29)$ & 2.38 & $(0.29)$ \\
\hline & Trinidad and Tobago & $\mathrm{m}$ & $\mathrm{m}$ & $\mathrm{m}$ & $\mathrm{m}$ & $\mathrm{m}$ & $\mathrm{m}$ & $\mathrm{m}$ & $\mathrm{m}$ & $\mathrm{m}$ & $\mathrm{m}$ & $\mathrm{m}$ & $\mathrm{m}$ \\
\hline & Tunisia & 2.22 & $(0.22)$ & 2.31 & $(0.24)$ & 1.60 & $(0.12)$ & 1.55 & $(0.12)$ & 2.66 & $(0.28)$ & 2.64 & $(0.27)$ \\
\hline & United Arab Emirates & 2.60 & $(0.16)$ & 2.57 & $(0.16)$ & 2.15 & $(0.14)$ & 2.13 & $(0.14)$ & 2.54 & $(0.17)$ & 2.49 & $(0.16)$ \\
\hline & Uruguay & 3.16 & $(0.28)$ & 2.98 & $(0.26)$ & 2.73 & $(0.27)$ & 2.61 & $(0.26)$ & 2.29 & $(0.21)$ & 2.20 & $(0.20)$ \\
\hline & Viet Nam & $\mathrm{m}$ & $\mathrm{m}$ & $\mathrm{m}$ & $\mathrm{m}$ & $\mathrm{m}$ & $\mathrm{m}$ & $\mathrm{m}$ & $\mathrm{m}$ & $\mathrm{m}$ & $\mathrm{m}$ & $\mathrm{m}$ & $\mathrm{m}$ \\
\hline & Argentina** & $\mathrm{m}$ & $\mathrm{m}$ & $\mathrm{m}$ & $\mathrm{m}$ & $\mathrm{m}$ & $\mathrm{m}$ & $\mathrm{m}$ & $\mathrm{m}$ & $\mathrm{m}$ & $\mathrm{m}$ & $\mathrm{m}$ & $\mathrm{m}$ \\
\hline & Kazakhstan** & $\mathrm{m}$ & $\mathrm{m}$ & $\mathrm{m}$ & $\mathrm{m}$ & $\mathrm{m}$ & $\mathrm{m}$ & $\mathrm{m}$ & $\mathrm{m}$ & $\mathrm{m}$ & $\mathrm{m}$ & $\mathrm{m}$ & $\mathrm{m}$ \\
\hline & Malaysia** & 2.40 & $(0.23)$ & 2.39 & $(0.23)$ & 2.64 & $(0.26)$ & 2.64 & $(0.26)$ & 2.86 & $(0.25)$ & 2.85 & $(0.25)$ \\
\hline
\end{tabular}

1. A student is classified as «not satisfied» with life if he or she reported between 0 and 4 on the life-satisfaction scale. The life-satisfaction scale ranges from 0 to 10 . 2. The socio-economic profile is measured by the PISA index of economic, social and cultural status (ESCS).

Note: Values that are statistically significant are indicated in bold (see Annex A3).

** See note at the beginning of this Annex.

Coverage is too small to ensure comparability (see Annex A4). 
Table III.7.14 Index of sense of belonging and disciplinary climate at school

\begin{tabular}{|c|c|c|c|c|c|c|c|c|c|}
\hline & \multirow{2}{*}{\multicolumn{2}{|c|}{$\begin{array}{l}\text { Schools with negative } \\
\text { disciplinary climate }^{1}\end{array}$}} & \multirow{2}{*}{\multicolumn{2}{|c|}{$\begin{array}{l}\text { Schools with positive } \\
\text { disciplinary climate }\end{array}$}} & \multicolumn{4}{|c|}{\begin{tabular}{|c|} 
Difference between schools with positive and negative disciplinary climates \\
(positive - negative)
\end{tabular}} \\
\hline & & & & & & \multicolumn{2}{|c|}{\begin{tabular}{|c|} 
Before accounting for students' \\
and schools' socio-economic profile
\end{tabular}} & \multicolumn{2}{|c|}{$\begin{array}{l}\text { After accounting for students' } \\
\text { and schools' socio-economic profile }\end{array}$} \\
\hline & & Mean index & S.E. & Mean index & S.E. & Index change & S.E. & Index change & S.E. \\
\hline & Australia & -0.26 & $(0.03)$ & 0.00 & $(0.07)$ & 0.26 & $(0.04)$ & 0.15 & $(0.04)$ \\
\hline 岙 & Austria & 0.35 & $(0.05)$ & 0.59 & $(0.11)$ & 0.23 & $(0.06)$ & 0.18 & $(0.06)$ \\
\hline & Belgium & -0.07 & $(0.03)$ & 0.04 & $(0.06)$ & 0.11 & $(0.03)$ & 0.07 & $(0.03)$ \\
\hline & Canada & -0.10 & $(0.03)$ & -0.04 & $(0.09)$ & 0.05 & $(0.06)$ & 0.01 & $(0.06)$ \\
\hline & Chile & -0.17 & $(0.03)$ & 0.05 & $(0.09)$ & 0.22 & $(0.06)$ & 0.13 & $(0.06)$ \\
\hline & Czech Republic & -0.33 & $(0.02)$ & -0.17 & $(0.06)$ & 0.16 & $(0.04)$ & 0.10 & $(0.04)$ \\
\hline & Denmark & 0.06 & $(0.04)$ & 0.19 & $(0.10)$ & 0.13 & $(0.06)$ & 0.08 & $(0.07)$ \\
\hline & Estonia & -0.11 & $(0.02)$ & 0.03 & $(0.06)$ & 0.14 & $(0.04)$ & 0.14 & $(0.04)$ \\
\hline & Finland & 0.00 & $(0.03)$ & 0.18 & $(0.06)$ & 0.18 & $(0.04)$ & 0.16 & $(0.04)$ \\
\hline & France & -0.24 & $(0.04)$ & 0.07 & $(0.09)$ & 0.30 & $(0.05)$ & 0.16 & $(0.06)$ \\
\hline & Germany & 0.16 & $(0.06)$ & 0.36 & $(0.13)$ & 0.20 & $(0.07)$ & 0.16 & $(0.10)$ \\
\hline & Greece & 0.03 & $(0.03)$ & 0.19 & $(0.08)$ & 0.16 & $(0.05)$ & 0.12 & $(0.05)$ \\
\hline & Hungary & -0.03 & $(0.05)$ & 0.14 & $(0.11)$ & 0.17 & $(0.06)$ & 0.03 & $(0.08)$ \\
\hline & Iceland & 0.20 & $(0.06)$ & 0.29 & $(0.13)$ & 0.09 & $(0.08)$ & 0.05 & $(0.08)$ \\
\hline & Ireland & -0.13 & $(0.04)$ & 0.03 & $(0.09)$ & 0.16 & $(0.05)$ & 0.15 & $(0.05)$ \\
\hline & Israel & $\mathrm{m}$ & $\mathrm{m}$ & $\mathrm{m}$ & $\mathrm{m}$ & $\mathrm{m}$ & $\mathrm{m}$ & $\mathrm{m}$ & $\mathrm{m}$ \\
\hline & Italy & -0.02 & $(0.03)$ & 0.15 & $(0.06)$ & 0.17 & $(0.04)$ & 0.16 & $(0.05)$ \\
\hline & Japan & -0.21 & $(0.03)$ & 0.07 & $(0.07)$ & 0.28 & $(0.04)$ & 0.19 & $(0.04)$ \\
\hline & Korea & 0.08 & $(0.04)$ & 0.23 & $(0.09)$ & 0.14 & $(0.06)$ & 0.07 & $(0.06)$ \\
\hline & Latvia & -0.16 & $(0.04)$ & -0.19 & $(0.09)$ & -0.02 & $(0.05)$ & -0.02 & $(0.05)$ \\
\hline & Luxembourg & -0.02 & $(0.03)$ & 0.19 & $(0.07)$ & 0.21 & $(0.04)$ & 0.17 & $(0.06)$ \\
\hline & Mexico & -0.16 & $(0.05)$ & -0.05 & $(0.11)$ & 0.11 & $(0.06)$ & 0.14 & $(0.06)$ \\
\hline & Netherlands & 0.10 & $(0.05)$ & 0.26 & $(0.11)$ & 0.16 & $(0.07)$ & 0.15 & $(0.06)$ \\
\hline & New Zealand & -0.18 & $(0.06)$ & -0.15 & $(0.13)$ & 0.03 & $(0.07)$ & 0.00 & $(0.08)$ \\
\hline & Norway & 0.18 & $(0.04)$ & 0.28 & $(0.10)$ & 0.11 & $(0.06)$ & 0.10 & $(0.06)$ \\
\hline & Poland & -0.28 & $(0.04)$ & -0.16 & $(0.10)$ & 0.12 & $(0.06)$ & 0.12 & $(0.06)$ \\
\hline & Portugal & 0.08 & $(0.06)$ & 0.13 & $(0.13)$ & 0.05 & $(0.07)$ & 0.04 & $(0.07)$ \\
\hline & Slovak Republic & -0.39 & $(0.04)$ & -0.18 & $(0.08)$ & 0.21 & $(0.05)$ & 0.10 & $(0.07)$ \\
\hline & Slovenia & -0.11 & $(0.03)$ & 0.01 & $(0.07)$ & 0.12 & $(0.04)$ & 0.10 & $(0.06)$ \\
\hline & Spain & 0.36 & $(0.05)$ & 0.55 & $(0.14)$ & 0.19 & $(0.09)$ & 0.18 & $(0.09)$ \\
\hline & Sweden & -0.10 & $(0.04)$ & 0.12 & $(0.11)$ & 0.21 & $(0.06)$ & 0.23 & $(0.07)$ \\
\hline & Switzerland & 0.25 & $(0.05)$ & 0.53 & $(0.11)$ & 0.29 & $(0.06)$ & 0.32 & $(0.07)$ \\
\hline & Turkey & -0.54 & $(0.03)$ & -0.33 & $(0.09)$ & 0.22 & $(0.05)$ & 0.20 & $(0.05)$ \\
\hline & United Kingdom & -0.14 & $(0.04)$ & -0.02 & $(0.08)$ & 0.12 & $(0.05)$ & 0.13 & $(0.04)$ \\
\hline & United States & -0.06 & $(0.05)$ & -0.07 & $(0.13)$ & 0.00 & $(0.08)$ & -0.05 & $(0.08)$ \\
\hline & OECD average & -0.06 & $(0.01)$ & 0.10 & $(0.02)$ & 0.15 & $(0.01)$ & 0.12 & $(0.01)$ \\
\hline$=$ & Albania & 0.27 & $(0.03)$ & 0.47 & $(0.09)$ & 0.20 & $(0.06)$ & 0.20 & $(0.05)$ \\
\hline § & Algeria & -0.25 & $(0.03)$ & -0.22 & $(0.11)$ & 0.03 & $(0.07)$ & 0.05 & $(0.07)$ \\
\hline T) & Brazil & -0.25 & $(0.02)$ & 0.04 & $(0.06)$ & 0.29 & $(0.03)$ & 0.21 & $(0.03)$ \\
\hline & B-S-J-G (China) & -0.48 & $(0.02)$ & -0.17 & $(0.07)$ & 0.32 & $(0.05)$ & 0.21 & $(0.05)$ \\
\hline & Bulgaria & -0.48 & $(0.04)$ & -0.18 & $(0.11)$ & 0.30 & $(0.07)$ & 0.17 & $(0.07)$ \\
\hline & CABA (Argentina) & 0.29 & $(0.05)$ & 0.48 & $(0.17)$ & 0.19 & $(0.12)$ & 0.15 & $(0.10)$ \\
\hline & Colombia & -0.37 & $(0.05)$ & -0.25 & $(0.13)$ & 0.12 & $(0.07)$ & 0.12 & $(0.06)$ \\
\hline & Costa Rica & -0.13 & $(0.05)$ & -0.18 & $(0.12)$ & -0.05 & $(0.08)$ & -0.04 & $(0.06)$ \\
\hline & Croatia & -0.07 & $(0.03)$ & 0.13 & $(0.08)$ & 0.20 & $(0.04)$ & 0.24 & $(0.05)$ \\
\hline & Cyprus* & 0.01 & $(0.03)$ & 0.16 & $(0.07)$ & 0.16 & $(0.04)$ & 0.27 & $(0.05)$ \\
\hline & Dominican Republic & -0.53 & $(0.09)$ & -0.24 & $(0.21)$ & 0.29 & $(0.12)$ & 0.22 & $(0.11)$ \\
\hline & FYROM & 0.06 & $(0.03)$ & 0.55 & $(0.08)$ & 0.49 & $(0.05)$ & 0.37 & $(0.06)$ \\
\hline & Georgia & 0.12 & $(0.03)$ & 0.37 & $(0.09)$ & 0.25 & $(0.05)$ & 0.23 & $(0.05)$ \\
\hline & Hong Kong (China) & -0.36 & $(0.04)$ & -0.30 & $(0.09)$ & 0.06 & $(0.05)$ & 0.03 & $(0.06)$ \\
\hline & Indonesia & 0.09 & $(0.03)$ & 0.19 & $(0.08)$ & 0.09 & $(0.04)$ & 0.10 & $(0.05)$ \\
\hline & Jordan & 0.03 & $(0.05)$ & 0.37 & $(0.12)$ & 0.34 & $(0.07)$ & 0.35 & $(0.07)$ \\
\hline & Kosovo & 0.20 & $(0.03)$ & 0.37 & $(0.08)$ & 0.16 & $(0.05)$ & 0.16 & $(0.05)$ \\
\hline & Lebanon & -0.17 & $(0.09)$ & 0.16 & $(0.21)$ & 0.33 & $(0.11)$ & 0.33 & $(0.12)$ \\
\hline & Lithuania & -0.35 & $(0.04)$ & -0.06 & $(0.10)$ & 0.29 & $(0.05)$ & 0.19 & $(0.06)$ \\
\hline & Macao (China) & -0.43 & $(0.02)$ & -0.40 & $(0.05)$ & 0.02 & $(0.03)$ & 0.02 & $(0.03)$ \\
\hline & Malta & -0.05 & $(0.03)$ & -0.03 & $(0.06)$ & 0.02 & $(0.03)$ & -0.05 & $(0.03)$ \\
\hline & Moldova & -0.04 & $(0.02)$ & 0.17 & $(0.06)$ & 0.22 & $(0.04)$ & 0.21 & $(0.04)$ \\
\hline & Montenegro & -0.15 & $(0.02)$ & -0.03 & $(0.06)$ & 0.12 & $(0.04)$ & 0.11 & $(0.04)$ \\
\hline & Peru & -0.25 & $(0.04)$ & -0.06 & $(0.11)$ & 0.20 & $(0.07)$ & 0.17 & $(0.06)$ \\
\hline & Qatar & -0.17 & $(0.02)$ & -0.02 & $(0.04)$ & 0.15 & $(0.02)$ & 0.12 & $(0.02)$ \\
\hline & Romania & -0.21 & $(0.05)$ & 0.18 & $(0.10)$ & 0.39 & $(0.06)$ & 0.42 & $(0.07)$ \\
\hline & Russia & -0.42 & $(0.02)$ & -0.28 & $(0.07)$ & 0.15 & $(0.05)$ & 0.16 & $(0.05)$ \\
\hline & Singapore & -0.26 & $(0.02)$ & -0.13 & $(0.06)$ & 0.13 & $(0.04)$ & -0.01 & $(0.05)$ \\
\hline & Chinese Taipei & -0.06 & $(0.03)$ & 0.06 & $(0.07)$ & 0.12 & $(0.04)$ & 0.10 & $(0.05)$ \\
\hline & Thailand & -0.40 & $(0.02)$ & -0.31 & $(0.06)$ & 0.09 & $(0.04)$ & 0.16 & $(0.04)$ \\
\hline & Trinidad and Tobago & -0.03 & $(0.03)$ & 0.14 & $(0.08)$ & 0.16 & $(0.05)$ & 0.12 & $(0.06)$ \\
\hline & Tunisia & -0.25 & $(0.03)$ & -0.13 & $(0.06)$ & 0.12 & $(0.04)$ & 0.17 & $(0.05)$ \\
\hline & United Arab Emirates & -0.23 & $(0.03)$ & 0.02 & $(0.07)$ & 0.25 & $(0.04)$ & 0.25 & $(0.04)$ \\
\hline & Uruguay & -0.22 & $(0.04)$ & 0.08 & $(0.11)$ & 0.30 & $(0.07)$ & 0.11 & $(0.06)$ \\
\hline & Viet Nam & -0.11 & $(0.03)$ & 0.01 & $(0.08)$ & 0.12 & $(0.05)$ & 0.13 & $(0.05)$ \\
\hline & Argentina** & 0.15 & $(0.05)$ & 0.34 & $(0.12)$ & 0.18 & $(0.07)$ & 0.16 & $(0.06)$ \\
\hline & Kazakhstan** & 0.14 & $(0.03)$ & 0.63 & $(0.08)$ & 0.49 & $(0.05)$ & 0.47 & $(0.05)$ \\
\hline & Malaysia** & -0.20 & $(0.03)$ & 0.08 & $(0.08)$ & 0.28 & $(0.05)$ & 0.32 & $(0.07)$ \\
\hline
\end{tabular}

1. Schools with positive (negative) disciplinary climate are those whose average index of disciplinary climate is statistically higher (lower) than the average level in the country/economy. 2. The socio-economic profile is measured by the PISA index of economic, social and cultural status (ESCS),

Note: Values that are statistically significant are indicated in bold (see Annex A3).

** See note at the beginning of this Annex.

** Coverage is too small to ensure comparability (see Annex A4).

StatLink त्ना15 $\mathrm{http}: / / \mathrm{dx} . \mathrm{doi} . \mathrm{org} / 10.1787 / 888933471399$ 


\begin{tabular}{|c|c|c|c|c|c|c|c|c|c|c|c|c|c|c|c|c|c|}
\hline & \multicolumn{8}{|c|}{ Teachers called on me less often than they called on other students } & \multicolumn{8}{|c|}{ Teachers graded me harder than they graded other students } \\
\hline & & \multicolumn{2}{|c|}{ Never } & \multicolumn{2}{|c|}{$\begin{array}{l}\text { A few times } \\
\text { a year }\end{array}$} & \multicolumn{2}{|c|}{$\begin{array}{l}\text { A few times } \\
\text { a month }\end{array}$} & \multicolumn{2}{|c|}{$\begin{array}{c}\text { Once a week } \\
\text { or more }\end{array}$} & \multicolumn{2}{|c|}{ Never } & \multicolumn{2}{|c|}{$\begin{array}{l}\text { A few times } \\
\text { a year }\end{array}$} & \multicolumn{2}{|c|}{$\begin{array}{l}\text { A few times } \\
\text { a month }\end{array}$} & \multicolumn{2}{|c|}{$\begin{array}{c}\text { Once a week } \\
\text { or more }\end{array}$} \\
\hline & & $\%$ & S.E. & $\%$ & S.E. & $\%$ & S.E. & $\%$ & S.E. & $\%$ & S.E. & $\%$ & S.E. & $\%$ & S.E. & $\%$ & S.E. \\
\hline \multirow{36}{*}{ 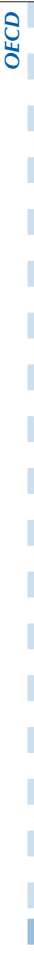 } & Australia & 34.4 & $(0.5)$ & 31.0 & $(0.5)$ & 20.5 & $(0.4)$ & 14.1 & $(0.3)$ & 56.9 & $(0.6)$ & 27.5 & $(0.4)$ & 11.0 & $(0.3)$ & 4.6 & $(0.2)$ \\
\hline & Austria & 33.2 & $(0.7)$ & 27.6 & (0.6) & 23.0 & (0.5) & 16.2 & (0.5) & 57.6 & (0.9) & 25.1 & (0.8) & 11.3 & (0.4) & 6.1 & (0.4) \\
\hline & Belgium & 44.2 & $(0.6)$ & 22.2 & $(0.5)$ & 17.3 & $(0.4)$ & 16.3 & $(0.5)$ & 56.0 & $(0.7)$ & 22.9 & $(0.6)$ & 13.3 & $(0.4)$ & 7.9 & $(0.4)$ \\
\hline & Canada & $\mathrm{m}$ & $\mathrm{m}$ & $\mathrm{m}$ & $\mathrm{m}$ & $\mathrm{m}$ & $\mathrm{m}$ & $\mathrm{m}$ & $\mathrm{m}$ & $\mathrm{m}$ & $\mathrm{m}$ & $\mathrm{m}$ & $\mathrm{m}$ & $\mathrm{m}$ & $\mathrm{m}$ & $\mathrm{m}$ & $\mathrm{m}$ \\
\hline & Chile & 39.6 & $(0.9)$ & 26.6 & (0.6) & 22.5 & $(0.6)$ & 11.2 & $(0.5)$ & 64.2 & $(0.8)$ & 18.0 & $(0.5)$ & 13.2 & $(0.6)$ & 4.7 & $(0.3)$ \\
\hline & Czech Republic & 35.4 & (0.9) & 26.4 & $(0.6)$ & 23.4 & $(0.7)$ & 14.8 & $(0.6)$ & 65.8 & $(0.7)$ & 20.3 & $(0.6)$ & 9.0 & $(0.4)$ & 4.9 & $(0.3)$ \\
\hline & Denmark & 34.5 & $(0.7)$ & 34.4 & $(0.7)$ & 18.5 & (0.6) & 12.6 & $(0.5)$ & 50.0 & $(0.7)$ & 30.0 & $(0.7)$ & 13.2 & $(0.6)$ & 6.8 & $(0.3)$ \\
\hline & Estonia & 27.9 & $(0.7)$ & 23.9 & (0.6) & 26.9 & (0.5) & 21.3 & (0.6) & 39.9 & $(0.8)$ & 30.5 & $(0.7)$ & 21.2 & (0.6) & 8.5 & $(0.4)$ \\
\hline & Finland & 46.4 & $(0.8)$ & 30.7 & $(0.7)$ & 15.8 & (0.4) & 7.1 & $(0.3)$ & 57.4 & $(0.8)$ & 27.3 & (0.6) & 10.9 & $(0.5)$ & 4.4 & $(0.3)$ \\
\hline & France & 34.1 & (0.6) & 21.0 & (0.5) & 27.7 & (0.5) & 17.1 & (0.5) & 56.0 & $(0.8)$ & 22.5 & (0.6) & 15.7 & (0.5) & 5.7 & (0.4) \\
\hline & Germany & 30.1 & $(0.7)$ & 31.5 & $(0.7)$ & 22.1 & $(0.6)$ & 16.3 & $(0.5)$ & 51.5 & $(0.8)$ & 30.2 & $(0.8)$ & 13.1 & $(0.5)$ & 5.2 & $(0.3)$ \\
\hline & Greece & 25.9 & (0.6) & 29.1 & $(0.6)$ & 26.2 & $(0.7)$ & 18.7 & $(0.7)$ & 49.6 & $(0.7)$ & 29.2 & $(0.7)$ & 14.7 & $(0.5)$ & 6.5 & $(0.4)$ \\
\hline & Hungary & 23.1 & $(0.7)$ & 19.9 & (0.6) & 31.3 & (0.8) & 25.7 & $(0.8)$ & 58.3 & (0.8) & 19.9 & $(0.7)$ & 14.2 & (0.6) & 7.6 & (0.4) \\
\hline & Iceland & 57.9 & $(0.8)$ & 20.7 & $(0.7)$ & 12.4 & (0.6) & 9.0 & (0.4) & 69.4 & $(0.8)$ & 20.2 & $(0.7)$ & 6.8 & $(0.4)$ & 3.5 & $(0.3)$ \\
\hline & Ireland & 36.8 & $(0.7)$ & 34.2 & $(0.7)$ & 16.9 & $(0.5)$ & 12.1 & $(0.4)$ & 60.9 & $(0.9)$ & 25.8 & $(0.6)$ & 9.4 & $(0.5)$ & 3.9 & $(0.3)$ \\
\hline & Israel & $\mathrm{m}$ & $\mathrm{m}$ & $\mathrm{m}$ & $\mathrm{m}$ & $\mathrm{m}$ & $\mathrm{m}$ & $\mathrm{m}$ & $\mathrm{m}$ & $\mathrm{m}$ & $\mathrm{m}$ & $\mathrm{m}$ & $\mathrm{m}$ & $\mathrm{m}$ & $\mathrm{m}$ & $\mathrm{m}$ & $\mathrm{m}$ \\
\hline & Italy & $\mathrm{m}$ & $\mathrm{m}$ & $\mathrm{m}$ & $\mathrm{m}$ & $\mathrm{m}$ & $\mathrm{m}$ & $\mathrm{m}$ & $\mathrm{m}$ & $\mathrm{m}$ & $\mathrm{m}$ & $\mathrm{m}$ & $\mathrm{m}$ & $\mathrm{m}$ & $\mathrm{m}$ & $\mathrm{m}$ & $\mathrm{m}$ \\
\hline & Japan & 55.8 & $(0.7)$ & 9.7 & $(0.4)$ & 13.1 & (0.4) & 21.3 & $(0.7)$ & 84.0 & (0.6) & 10.4 & (0.4) & 3.4 & (0.3) & 2.2 & $(0.2)$ \\
\hline & Korea & 54.3 & $(0.7)$ & 13.9 & $(0.5)$ & 15.8 & (0.6) & 16.0 & (0.6) & 82.6 & (0.6) & 9.7 & (0.4) & 6.0 & (0.4) & 1.7 & $(0.2)$ \\
\hline & Latvia & 28.0 & $(0.8)$ & 30.2 & $(0.7)$ & 24.2 & $(0.7)$ & 17.6 & $(0.8)$ & 40.7 & (0.9) & 32.3 & $(0.8)$ & 18.8 & $(0.7)$ & 8.1 & $(0.4)$ \\
\hline & Luxembourg & 33.0 & $(0.7)$ & 24.5 & $(0.7)$ & 19.6 & $(0.5)$ & 22.9 & $(0.6)$ & 56.6 & $(0.7)$ & 24.8 & $(0.6)$ & 11.9 & $(0.4)$ & 6.7 & (0.3) \\
\hline & Mexico & 66.5 & $(0.7)$ & 17.6 & $(0.5)$ & 9.0 & (0.4) & 6.9 & (0.3) & 66.9 & (0.6) & 17.8 & (0.5) & 10.4 & (0.5) & 4.9 & (0.3) \\
\hline & Netherlands & 57.9 & (0.8) & 20.5 & (0.6) & 12.5 & (0.5) & 9.0 & (0.4) & 70.0 & (0.6) & 16.6 & (0.5) & 7.7 & (0.4) & 5.8 & $(0.3)$ \\
\hline & New Zealand & 32.0 & $(0.7)$ & 33.0 & $(0.6)$ & 20.2 & $(0.7)$ & 14.9 & (0.6) & 59.4 & $(0.8)$ & 25.9 & (0.6) & 10.6 & $(0.5)$ & 4.2 & $(0.3)$ \\
\hline & Norway & 46.8 & $(0.8)$ & 26.6 & $(0.7)$ & 16.8 & $(0.6)$ & 9.9 & $(0.5)$ & 39.7 & $(0.8)$ & 34.2 & $(0.8)$ & 18.0 & $(0.6)$ & 8.1 & (0.4) \\
\hline & Poland & 39.6 & $(0.8)$ & 27.2 & $(0.7)$ & 15.5 & (0.6) & 17.8 & (0.6) & 52.0 & $(0.9)$ & 27.9 & (0.6) & 11.5 & (0.5) & 8.6 & (0.4) \\
\hline & Portugal & 37.7 & $(0.7)$ & 23.4 & $(0.6)$ & 21.8 & (0.6) & 17.1 & (0.6) & 58.8 & (0.6) & 22.8 & $(0.5)$ & 12.5 & $(0.4)$ & 5.9 & $(0.3)$ \\
\hline & Slovak Republic & 22.9 & $(0.7)$ & 35.4 & $(0.7)$ & 26.6 & $(0.7)$ & 15.1 & (0.6) & 55.5 & $(0.8)$ & 25.1 & (0.6) & 12.4 & $(0.4)$ & 7.1 & $(0.4)$ \\
\hline & Slovenia & 26.8 & $(0.8)$ & 21.7 & $(0.6)$ & 31.6 & $(0.8)$ & 19.8 & $(0.6)$ & 47.9 & $(0.8)$ & 32.8 & $(0.8)$ & 14.1 & $(0.5)$ & 5.2 & $(0.3)$ \\
\hline & Spain & 46.8 & $(0.8)$ & 27.4 & (0.6) & 15.9 & $(0.5)$ & 10.0 & (0.5) & 53.5 & $(0.7)$ & 24.9 & (0.6) & 14.0 & (0.5) & 7.6 & (0.4) \\
\hline & Sweden & 54.3 & $(0.8)$ & 23.6 & (0.6) & 14.2 & (0.6) & 8.0 & $(0.5)$ & 55.1 & $(0.8)$ & 27.0 & (0.6) & 12.2 & $(0.5)$ & 5.6 & (0.4) \\
\hline & Switzerland & 38.5 & $(0.9)$ & 24.7 & $(0.7)$ & 19.2 & (0.6) & 17.6 & (0.6) & 66.1 & $(0.8)$ & 20.9 & $(0.7)$ & 8.8 & (0.5) & 4.1 & $(0.3)$ \\
\hline & Turkey & 34.8 & $(0.8)$ & 20.2 & $(0.7)$ & 20.5 & $(0.7)$ & 24.5 & $(0.7)$ & 55.4 & (1.0) & 21.5 & $(0.7)$ & 15.1 & $(0.6)$ & 8.0 & $(0.4)$ \\
\hline & United Kingdom & 34.8 & $(0.6)$ & 29.9 & $(0.6)$ & 20.3 & $(0.5)$ & 15.0 & (0.5) & 58.6 & $(0.7)$ & 25.7 & $(0.5)$ & 11.1 & (0.5) & 4.6 & (0.3) \\
\hline & United States & 39.9 & $(0.7)$ & 24.7 & $(0.5)$ & 17.5 & $(0.5)$ & 17.9 & $(0.5)$ & 63.5 & (0.9) & 20.3 & (0.6) & 10.8 & (0.5) & 5.4 & $(0.4)$ \\
\hline & OECD average & 39.2 & $(0.1)$ & 25.4 & $(0.1)$ & 20.0 & $(0.1)$ & 15.4 & $(0.1)$ & 58.1 & $(0.1)$ & 24.1 & $(0.1)$ & 12.1 & $(0.1)$ & 5.8 & (0.1) \\
\hline
\end{tabular}

\begin{tabular}{|c|c|c|c|c|c|c|c|c|c|c|c|c|c|c|c|c|c|}
\hline \multirow{4}{*}{ 离 } & Albania & $\mathrm{m}$ & $\mathrm{m}$ & $\mathrm{m}$ & $\mathrm{m}$ & $\mathrm{m}$ & $\mathrm{m}$ & $\mathrm{m}$ & $\mathrm{m}$ & $\mathrm{m}$ & $\mathrm{m}$ & $\mathrm{m}$ & $\mathrm{m}$ & $\mathrm{m}$ & $\mathrm{m}$ & $\mathrm{m}$ & $\mathrm{m}$ \\
\hline & Algeria & $\mathrm{m}$ & $\mathrm{m}$ & $\mathrm{m}$ & $\mathrm{m}$ & $\mathrm{m}$ & $\mathrm{m}$ & $\mathrm{m}$ & $\mathrm{m}$ & $\mathrm{m}$ & $\mathrm{m}$ & $\mathrm{m}$ & $\mathrm{m}$ & $\mathrm{m}$ & $\mathrm{m}$ & $\mathrm{m}$ & $\mathrm{m}$ \\
\hline & Brazil & 41.5 & $(0.6)$ & 32.0 & $(0.5)$ & 15.7 & $(0.4)$ & 10.8 & $(0.3)$ & 56.8 & $(0.5)$ & 25.4 & $(0.4)$ & 12.5 & $(0.3)$ & 5.3 & $(0.2)$ \\
\hline & B-S-J-G (China) & 36.5 & $(0.9)$ & 13.7 & $(0.6)$ & 20.2 & $(0.7)$ & 29.6 & $(1.0)$ & 57.8 & (1.0) & 14.3 & $(0.5)$ & 15.1 & $(0.5)$ & 12.8 & $(0.6)$ \\
\hline & Bulgaria & 39.1 & $(0.7)$ & 24.9 & (0.6) & 19.5 & $(0.5)$ & 16.5 & $(0.5)$ & 38.0 & $(0.7)$ & 26.0 & (0.6) & 20.9 & $(0.6)$ & 15.1 & (0.6) \\
\hline & CABA (Argentina) & $\mathrm{m}$ & $\mathrm{m}$ & $\mathrm{m}$ & $\mathrm{m}$ & $\mathrm{m}$ & $\mathrm{m}$ & $\mathrm{m}$ & $\mathrm{m}$ & $\mathrm{m}$ & $\mathrm{m}$ & $\mathrm{m}$ & $\mathrm{m}$ & $\mathrm{m}$ & $\mathrm{m}$ & $\mathrm{m}$ & $\mathrm{m}$ \\
\hline & Colombia & 43.3 & $(0.7)$ & 28.0 & $(0.6)$ & 16.4 & $(0.4)$ & 12.4 & $(0.4)$ & 61.8 & $(0.8)$ & 20.8 & $(0.6)$ & 11.0 & $(0.4)$ & 6.5 & $(0.3)$ \\
\hline & Costa Rica & 53.4 & $(0.7)$ & 24.8 & $(0.5)$ & 13.6 & $(0.5)$ & 8.2 & $(0.4)$ & 63.2 & $(0.7)$ & 20.2 & $(0.6)$ & 10.4 & $(0.6)$ & 6.2 & $(0.4)$ \\
\hline & Croatia & 29.9 & $(0.7)$ & 29.0 & $(0.7)$ & 26.7 & $(0.7)$ & 14.4 & $(0.5)$ & 49.1 & $(0.7)$ & 30.6 & $(0.6)$ & 13.9 & $(0.4)$ & 6.5 & $(0.4)$ \\
\hline & Cyprus* & 32.4 & $(0.7)$ & 31.2 & $(0.7)$ & 21.7 & $(0.6)$ & 14.7 & $(0.5)$ & 42.1 & $(0.7)$ & 32.1 & $(0.7)$ & 16.9 & $(0.6)$ & 8.8 & (0.4) \\
\hline & Dominican Republic & 53.6 & $(1.0)$ & 16.6 & $(0.7)$ & 15.6 & $(0.6)$ & 14.3 & $(0.7)$ & 53.2 & $(0.9)$ & 17.2 & $(0.6)$ & 18.5 & $(0.7)$ & 11.1 & $(0.6)$ \\
\hline & FYROM & $\mathrm{m}$ & $\mathrm{m}$ & $\mathrm{m}$ & $\mathrm{m}$ & $\mathrm{m}$ & $\mathrm{m}$ & $\mathrm{m}$ & $\mathrm{m}$ & $\mathrm{m}$ & $\mathrm{m}$ & $\mathrm{m}$ & $\mathrm{m}$ & $\mathrm{m}$ & $\mathrm{m}$ & $\mathrm{m}$ & $\mathrm{m}$ \\
\hline & Georgia & $\mathrm{m}$ & $\mathrm{m}$ & $\mathrm{m}$ & $\mathrm{m}$ & $\mathrm{m}$ & $\mathrm{m}$ & $\mathrm{m}$ & $\mathrm{m}$ & $\mathrm{m}$ & $\mathrm{m}$ & $\mathrm{m}$ & $\mathrm{m}$ & $\mathrm{m}$ & $\mathrm{m}$ & $\mathrm{m}$ & $\mathrm{m}$ \\
\hline & Hong Kong (China) & 23.0 & $(0.6)$ & 16.2 & $(0.6)$ & 28.7 & $(0.7)$ & 32.1 & $(0.7)$ & 51.9 & (1.0) & 19.5 & $(0.6)$ & 18.5 & $(0.6)$ & 10.2 & $(0.5)$ \\
\hline & Indonesia & $\mathrm{m}$ & $\mathrm{m}$ & $\mathrm{m}$ & $\mathrm{m}$ & $\mathrm{m}$ & $\mathrm{m}$ & $\mathrm{m}$ & $\mathrm{m}$ & $\mathrm{m}$ & $\mathrm{m}$ & $\mathrm{m}$ & $\mathrm{m}$ & $\mathrm{m}$ & $\mathrm{m}$ & $\mathrm{m}$ & $\mathrm{m}$ \\
\hline & Jordan & $\mathrm{m}$ & $\mathrm{m}$ & $\mathrm{m}$ & $\mathrm{m}$ & $\mathrm{m}$ & $\mathrm{m}$ & $\mathrm{m}$ & $\mathrm{m}$ & $\mathrm{m}$ & $\mathrm{m}$ & $\mathrm{m}$ & $\mathrm{m}$ & $\mathrm{m}$ & $\mathrm{m}$ & $\mathrm{m}$ & $\mathrm{m}$ \\
\hline & Kosovo & $\mathrm{m}$ & $\mathrm{m}$ & $\mathrm{m}$ & $\mathrm{m}$ & $\mathrm{m}$ & $\mathrm{m}$ & $\mathrm{m}$ & $\mathrm{m}$ & $\mathrm{m}$ & $\mathrm{m}$ & $\mathrm{m}$ & $\mathrm{m}$ & $\mathrm{m}$ & $\mathrm{m}$ & $\mathrm{m}$ & $\mathrm{m}$ \\
\hline & Lebanon & $\mathrm{m}$ & $\mathrm{m}$ & $\mathrm{m}$ & $\mathrm{m}$ & $\mathrm{m}$ & $\mathrm{m}$ & $\mathrm{m}$ & $\mathrm{m}$ & $\mathrm{m}$ & $\mathrm{m}$ & $\mathrm{m}$ & $\mathrm{m}$ & $\mathrm{m}$ & $\mathrm{m}$ & $\mathrm{m}$ & $\mathrm{m}$ \\
\hline & Lithuania & 29.6 & $(0.6)$ & 26.6 & $(0.7)$ & 28.6 & $(0.7)$ & 15.3 & $(0.5)$ & 51.3 & $(0.8)$ & 25.4 & $(0.7)$ & 15.7 & $(0.5)$ & 7.6 & $(0.4)$ \\
\hline & Macao (China) & 19.4 & $(0.6)$ & 16.5 & $(0.6)$ & 28.5 & $(0.6)$ & 35.5 & $(0.7)$ & 64.2 & $(0.7)$ & 16.9 & $(0.6)$ & 12.2 & $(0.5)$ & 6.6 & $(0.4)$ \\
\hline & Malta & $\mathrm{m}$ & $\mathrm{m}$ & $\mathrm{m}$ & $\mathrm{m}$ & $\mathrm{m}$ & $\mathrm{m}$ & $\mathrm{m}$ & $\mathrm{m}$ & $\mathrm{m}$ & $\mathrm{m}$ & $\mathrm{m}$ & $\mathrm{m}$ & $\mathrm{m}$ & $\mathrm{m}$ & $\mathrm{m}$ & $\mathrm{m}$ \\
\hline & Moldova & $\mathrm{m}$ & $\mathrm{m}$ & $\mathrm{m}$ & $\mathrm{m}$ & $\mathrm{m}$ & $\mathrm{m}$ & $\mathrm{m}$ & $\mathrm{m}$ & $\mathrm{m}$ & $\mathrm{m}$ & $\mathrm{m}$ & $\mathrm{m}$ & $\mathrm{m}$ & $\mathrm{m}$ & $\mathrm{m}$ & $\mathrm{m}$ \\
\hline & Montenegro & 40.8 & $(0.6)$ & 19.8 & $(0.6)$ & 22.4 & $(0.6)$ & 17.0 & $(0.5)$ & 56.3 & $(0.8)$ & 24.5 & $(0.6)$ & 13.2 & $(0.4)$ & 6.0 & $(0.3)$ \\
\hline & Peru & 47.0 & $(0.8)$ & 26.5 & $(0.6)$ & 14.4 & $(0.5)$ & 12.1 & $(0.4)$ & 44.6 & $(0.6)$ & 24.7 & $(0.5)$ & 18.5 & $(0.5)$ & 12.2 & $(0.4)$ \\
\hline & Qatar & 35.9 & $(0.4)$ & 32.2 & $(0.5)$ & 18.0 & $(0.4)$ & 13.9 & $(0.3)$ & 46.1 & $(0.5)$ & 28.1 & $(0.5)$ & 16.7 & $(0.4)$ & 9.1 & $(0.2)$ \\
\hline & Romania & $\mathrm{m}$ & $\mathrm{m}$ & $\mathrm{m}$ & $\mathrm{m}$ & $\mathrm{m}$ & $\mathrm{m}$ & $\mathrm{m}$ & $\mathrm{m}$ & $\mathrm{m}$ & $\mathrm{m}$ & $\mathrm{m}$ & $\mathrm{m}$ & $\mathrm{m}$ & $\mathrm{m}$ & $\mathrm{m}$ & $\mathrm{m}$ \\
\hline & Russia & 21.7 & $(0.7)$ & 17.5 & $(0.5)$ & 30.1 & $(0.6)$ & 30.7 & $(0.7)$ & 44.4 & $(0.9)$ & 22.8 & (0.6) & 20.5 & $(0.8)$ & 12.4 & (0.6) \\
\hline & Singapore & 31.6 & $(0.6)$ & 25.9 & $(0.7)$ & 24.7 & $(0.6)$ & 17.8 & $(0.5)$ & 62.8 & $(0.7)$ & 20.0 & $(0.5)$ & 12.8 & $(0.5)$ & 4.4 & $(0.3)$ \\
\hline & Chinese Taipei & 48.8 & $(0.7)$ & 13.4 & $(0.5)$ & 21.8 & $(0.6)$ & 16.0 & $(0.5)$ & 85.4 & $(0.4)$ & 7.4 & $(0.3)$ & 4.6 & $(0.3)$ & 2.7 & $(0.2)$ \\
\hline & Thailand & 33.4 & $(0.7)$ & 13.5 & $(0.6)$ & 16.9 & $(0.6)$ & 36.3 & $(0.9)$ & 62.1 & (1.0) & 14.1 & (0.6) & 13.2 & $(0.5)$ & 10.6 & $(0.5)$ \\
\hline & Trinidad and Tobago & $\mathrm{m}$ & $\mathrm{m}$ & $\mathrm{m}$ & $\mathrm{m}$ & $\mathrm{m}$ & $\mathrm{m}$ & $\mathrm{m}$ & $\mathrm{m}$ & $\mathrm{m}$ & $\mathrm{m}$ & $\mathrm{m}$ & $\mathrm{m}$ & $\mathrm{m}$ & $\mathrm{m}$ & $\mathrm{m}$ & $\mathrm{m}$ \\
\hline & Tunisia & 37.1 & $(0.7)$ & 33.5 & $(0.7)$ & 13.4 & $(0.5)$ & 16.0 & $(0.5)$ & 54.3 & $(0.8)$ & 26.1 & $(0.7)$ & 13.3 & $(0.5)$ & 6.3 & $(0.4)$ \\
\hline & United Arab Emirates & 34.5 & $(0.5)$ & 32.1 & $(0.5)$ & 18.6 & $(0.5)$ & 14.8 & $(0.5)$ & 50.1 & $(0.7)$ & 26.6 & $(0.5)$ & 14.9 & $(0.4)$ & 8.3 & $(0.4)$ \\
\hline & Uruguay & 38.0 & $(0.9)$ & 27.3 & $(0.6)$ & 18.9 & $(0.7)$ & 15.9 & $(0.5)$ & 51.0 & $(0.7)$ & 23.1 & $(0.6)$ & 16.8 & $(0.5)$ & 9.1 & $(0.4)$ \\
\hline & Viet Nam & $\mathrm{m}$ & $\mathrm{m}$ & $\mathrm{m}$ & $\mathrm{m}$ & $\mathrm{m}$ & $\mathrm{m}$ & $\mathrm{m}$ & $\mathrm{m}$ & $\mathrm{m}$ & $\mathrm{m}$ & $\mathrm{m}$ & $\mathrm{m}$ & $\mathrm{m}$ & $\mathrm{m}$ & $\mathrm{m}$ & $\mathrm{m}$ \\
\hline & Argentina** & $\mathrm{m}$ & $\mathrm{m}$ & $\mathrm{m}$ & $\mathrm{m}$ & $\mathrm{m}$ & $\mathrm{m}$ & $\mathrm{m}$ & $\mathrm{m}$ & $\mathrm{m}$ & $\mathrm{m}$ & $\mathrm{m}$ & $\mathrm{m}$ & $\mathrm{m}$ & $\mathrm{m}$ & $\mathrm{m}$ & $\mathrm{m}$ \\
\hline & Kazakhstan** & $\mathrm{m}$ & $\mathrm{m}$ & $\mathrm{m}$ & $\mathrm{m}$ & $\mathrm{m}$ & $\mathrm{m}$ & $\mathrm{m}$ & $\mathrm{m}$ & $\mathrm{m}$ & $\mathrm{m}$ & $\mathrm{m}$ & $\mathrm{m}$ & $\mathrm{m}$ & $\mathrm{m}$ & $\mathrm{m}$ & $\mathrm{m}$ \\
\hline & Malaysia** & 12.7 & $(0.5)$ & 20.0 & $(0.6)$ & 31.9 & $(0.7)$ & 35.4 & $(0.9)$ & 35.7 & $(0.8)$ & 28.9 & $(0.6)$ & 26.3 & $(0.7)$ & 9.2 & $(0.5)$ \\
\hline
\end{tabular}

* See note at the beginning of this Annex.

** Coverage is too small to ensure comparability (see Annex A4).

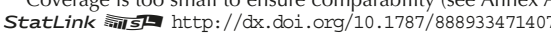


[Part 2/3]

Table III.7.15 Students' perception of teacher unfairness

Results based on students' self-reports

\begin{tabular}{|c|c|c|c|c|c|c|c|c|c|c|c|c|c|c|c|c|}
\hline & & & $\begin{array}{l}\text { s gav } \\
\text { lat I a }\end{array}$ & $\begin{array}{l}\text { ne the i } \\
\text { less sm }\end{array}$ & $\begin{array}{l}\text { essio } \\
\text { than }\end{array}$ & $\begin{array}{l}\text { at the } \\
\text { lly an }\end{array}$ & hink & & & achers & sciplin & me mo & harsh & han ot & stude & \\
\hline & & & $\begin{array}{r}\text { A fe } \\
\mathrm{a}\end{array}$ & $\begin{array}{l}\text { times } \\
\text { ar }\end{array}$ & $\begin{array}{c}\mathrm{A} \mathrm{fe} \\
\mathrm{at}\end{array}$ & $\begin{array}{l}\text { imes } \\
\text { th }\end{array}$ & $\begin{array}{r}\text { Onc } \\
\text { or }\end{array}$ & $\begin{array}{l}\text { week } \\
\text { pre }\end{array}$ & & & $\begin{array}{r}\text { A fe } \\
\mathrm{a}\end{array}$ & $\begin{array}{l}\text { imes } \\
\text { ar }\end{array}$ & A fe & $\begin{array}{l}\text { imes } \\
\text { nth }\end{array}$ & $\begin{array}{r}\text { Once } \\
\text { or }\end{array}$ & $\begin{array}{l}\text { week } \\
\text { ore }\end{array}$ \\
\hline & $\%$ & S.E. & $\%$ & S.E. & $\%$ & S.E. & $\%$ & S.E. & $\%$ & S.E. & $\%$ & S.E. & $\%$ & S.E. & $\%$ & S.E. \\
\hline Australia & 51.0 & $(0.5)$ & 25.9 & $(0.5)$ & 13.8 & (0.4) & 9.3 & (0.3) & 63.5 & (0.6) & 19.2 & (0.4) & 9.9 & (0.3) & 7.4 & $(0.3)$ \\
\hline Austria & 51.3 & $(0.8)$ & 24.4 & $(0.6)$ & 14.0 & $(0.4)$ & 10.3 & $(0.4)$ & 58.0 & $(0.7)$ & 22.7 & (0.6) & 11.6 & $(0.4)$ & 7.8 & $(0.4)$ \\
\hline 0 Belgium & 56.9 & $(0.7)$ & 21.8 & $(0.5)$ & 12.8 & $(0.4)$ & 8.5 & $(0.4)$ & 66.4 & $(0.6)$ & 17.7 & $(0.5)$ & 9.6 & $(0.3)$ & 6.3 & $(0.3)$ \\
\hline Canada & $\mathrm{m}$ & $\mathrm{m}$ & $\mathrm{m}$ & $\mathrm{m}$ & $\mathrm{m}$ & $\mathrm{m}$ & $\mathrm{m}$ & $\mathrm{m}$ & $\mathrm{m}$ & $\mathrm{m}$ & $\mathrm{m}$ & $\mathrm{m}$ & $\mathrm{m}$ & $\mathrm{m}$ & $\mathrm{m}$ & $\mathrm{m}$ \\
\hline Chile & 69.8 & $(0.7)$ & 15.7 & $(0.5)$ & 9.7 & $(0.4)$ & 4.8 & $(0.3)$ & 66.8 & $(0.6)$ & 18.3 & $(0.5)$ & 9.8 & $(0.4)$ & 5.1 & $(0.3)$ \\
\hline Czech Republic & 60.3 & (0.6) & 20.9 & $(0.5)$ & 10.9 & $(0.5)$ & 8.0 & $(0.5)$ & 76.8 & $(0.7)$ & 13.5 & $(0.5)$ & 5.3 & $(0.4)$ & 4.4 & $(0.3)$ \\
\hline Denmark & 60.5 & $(0.6)$ & 23.6 & $(0.6)$ & 10.7 & $(0.5)$ & 5.3 & $(0.3)$ & 71.2 & $(0.6)$ & 15.8 & $(0.5)$ & 8.2 & $(0.4)$ & 4.8 & $(0.3)$ \\
\hline Estonia & 46.9 & $(0.9)$ & 26.6 & $(0.7)$ & 16.6 & $(0.5)$ & 9.9 & $(0.5)$ & 68.6 & $(0.8)$ & 18.6 & (0.6) & 8.3 & $(0.4)$ & 4.5 & $(0.4)$ \\
\hline Finland & 58.8 & $(0.7)$ & 23.3 & $(0.5)$ & 11.6 & $(0.5)$ & 6.3 & $(0.3)$ & 63.5 & $(0.8)$ & 19.2 & $(0.6)$ & 9.8 & $(0.4)$ & 7.5 & $(0.4)$ \\
\hline France & 51.9 & $(0.7)$ & 21.0 & $(0.5)$ & 15.5 & $(0.5)$ & 11.7 & $(0.5)$ & 72.2 & $(0.7)$ & 14.6 & $(0.5)$ & 7.5 & $(0.4)$ & 5.7 & $(0.3)$ \\
\hline Germany & 53.2 & $(0.7)$ & 25.2 & $(0.5)$ & 13.3 & $(0.5)$ & 8.3 & (0.4) & 59.5 & $(0.8)$ & 23.2 & (0.6) & 10.8 & (0.5) & 6.5 & $(0.3)$ \\
\hline Greece & 62.9 & $(0.8)$ & 18.3 & $(0.5)$ & 10.9 & (0.4) & 7.9 & $(0.5)$ & 76.9 & $(0.8)$ & 12.5 & (0.5) & 6.1 & $(0.5)$ & 4.5 & $(0.3)$ \\
\hline Hungary & 45.3 & $(0.7)$ & 23.3 & $(0.6)$ & 19.0 & $(0.6)$ & 12.4 & $(0.5)$ & 62.6 & $(0.8)$ & 17.2 & $(0.5)$ & 11.2 & $(0.5)$ & 9.1 & $(0.4)$ \\
\hline Iceland & 73.8 & (0.8) & 15.8 & $(0.5)$ & 6.4 & (0.4) & 3.9 & (0.4) & 74.8 & $(0.8)$ & 13.7 & (0.6) & 7.2 & (0.5) & 4.4 & $(0.4)$ \\
\hline Ireland & 53.1 & (0.8) & 27.1 & $(0.6)$ & 11.2 & (0.6) & 8.7 & $(0.4)$ & 63.3 & $(0.8)$ & 20.5 & (0.6) & 8.5 & (0.4) & 7.7 & $(0.4)$ \\
\hline Israel & $\mathrm{m}$ & $\mathrm{m}$ & $\mathrm{m}$ & $\mathrm{m}$ & $\mathrm{m}$ & $\mathrm{m}$ & $\mathrm{m}$ & $\mathrm{m}$ & $\mathrm{m}$ & $\mathrm{m}$ & $\mathrm{m}$ & $\mathrm{m}$ & $\mathrm{m}$ & $\mathrm{m}$ & $\mathrm{m}$ & $\mathrm{m}$ \\
\hline Italy & $\mathrm{m}$ & $\mathrm{m}$ & $\mathrm{m}$ & $\mathrm{m}$ & $\mathrm{m}$ & $\mathrm{m}$ & $\mathrm{m}$ & $\mathrm{m}$ & $\mathrm{m}$ & $\mathrm{m}$ & $\mathrm{m}$ & $\mathrm{m}$ & $\mathrm{m}$ & $\mathrm{m}$ & $\mathrm{m}$ & $\mathrm{m}$ \\
\hline Japan & 79.1 & (0.6) & 12.9 & $(0.4)$ & 4.8 & (0.3) & 3.2 & (0.3) & 82.6 & $(0.5)$ & 8.8 & (0.3) & 4.7 & (0.3) & 3.8 & $(0.2)$ \\
\hline Korea & 69.3 & (0.6) & 17.2 & $(0.5)$ & 9.7 & $(0.4)$ & 3.8 & $(0.3)$ & 80.9 & $(0.6)$ & 11.4 & $(0.4)$ & 5.1 & $(0.3)$ & 2.6 & $(0.2)$ \\
\hline Latvia & 51.9 & $(0.7)$ & 23.8 & $(0.6)$ & 14.4 & (0.6) & 9.8 & $(0.5)$ & 68.3 & $(0.7)$ & 18.2 & (0.6) & 8.1 & $(0.4)$ & 5.4 & $(0.4)$ \\
\hline Luxembourg & 51.3 & (0.6) & 24.2 & $(0.6)$ & 13.2 & (0.4) & 11.3 & $(0.4)$ & 63.0 & (0.6) & 19.4 & (0.5) & 9.8 & $(0.4)$ & 7.8 & $(0.4)$ \\
\hline Mexico & 61.1 & $(0.7)$ & 20.9 & (0.6) & 11.6 & (0.4) & 6.4 & $(0.3)$ & 82.8 & $(0.6)$ & 10.4 & (0.4) & 4.4 & $(0.3)$ & 2.4 & $(0.2)$ \\
\hline Netherlands & 68.1 & $(0.7)$ & 20.1 & $(0.6)$ & 8.3 & $(0.4)$ & 3.5 & $(0.3)$ & 71.4 & $(0.7)$ & 16.2 & $(0.5)$ & 7.6 & $(0.4)$ & 4.8 & $(0.3)$ \\
\hline New Zealand & 50.1 & (1.0) & 26.9 & $(0.8)$ & 14.5 & $(0.5)$ & 8.5 & (0.4) & 62.4 & $(0.8)$ & 20.2 & $(0.6)$ & 10.3 & $(0.4)$ & 7.1 & $(0.4)$ \\
\hline Norway & 53.1 & $(0.7)$ & 25.0 & $(0.7)$ & 13.7 & $(0.5)$ & 8.3 & $(0.4)$ & 68.4 & $(0.7)$ & 16.3 & $(0.5)$ & 8.7 & (0.4) & 6.6 & $(0.4)$ \\
\hline Poland & 49.8 & (0.9) & 27.5 & $(0.8)$ & 12.1 & (0.5) & 10.7 & (0.5) & 65.8 & $(0.9)$ & 18.9 & (0.6) & 8.9 & (0.4) & 6.4 & $(0.4)$ \\
\hline Portugal & 47.0 & $(0.8)$ & 26.9 & $(0.7)$ & 15.7 & $(0.6)$ & 10.4 & $(0.4)$ & 55.2 & $(0.6)$ & 23.6 & $(0.6)$ & 13.6 & $(0.5)$ & 7.6 & $(0.3)$ \\
\hline Slovak Republic & 46.0 & $(0.7)$ & 26.0 & $(0.6)$ & 15.1 & (0.6) & 12.9 & $(0.5)$ & 73.0 & $(0.7)$ & 14.5 & $(0.5)$ & 6.8 & $(0.4)$ & 5.7 & $(0.4)$ \\
\hline Slovenia & 55.1 & $(0.7)$ & 25.5 & $(0.6)$ & 12.7 & (0.5) & 6.7 & (0.3) & 74.1 & $(0.7)$ & 15.8 & (0.6) & 5.7 & (0.4) & 4.5 & $(0.3)$ \\
\hline Spain & 63.6 & $(0.7)$ & 17.6 & $(0.5)$ & 10.3 & (0.4) & 8.5 & $(0.3)$ & 73.8 & $(0.7)$ & 13.4 & (0.5) & 6.8 & $(0.3)$ & 6.1 & $(0.4)$ \\
\hline Sweden & 58.4 & $(0.8)$ & 23.6 & $(0.7)$ & 11.2 & $(0.5)$ & 6.8 & $(0.4)$ & 74.7 & $(0.7)$ & 13.9 & $(0.5)$ & 6.6 & $(0.3)$ & 4.7 & $(0.3)$ \\
\hline Switzerland & 56.5 & $(0.8)$ & 25.0 & $(0.7)$ & 11.0 & (0.5) & 7.5 & $(0.4)$ & 62.9 & $(0.7)$ & 19.5 & (0.6) & 10.2 & $(0.5)$ & 7.5 & $(0.4)$ \\
\hline Turkey & 58.3 & $(0.8)$ & 16.8 & $(0.5)$ & 14.1 & (0.5) & 10.9 & $(0.5)$ & 67.9 & $(0.8)$ & 15.9 & (0.6) & 8.7 & (0.4) & 7.5 & $(0.4)$ \\
\hline United Kingdom & 47.8 & $(0.7)$ & 26.2 & $(0.5)$ & 15.9 & $(0.5)$ & 10.1 & $(0.4)$ & 59.5 & $(0.9)$ & 19.3 & $(0.5)$ & 12.2 & $(0.5)$ & 9.0 & $(0.4)$ \\
\hline United States & 62.7 & (0.8) & 20.4 & $(0.6)$ & 10.1 & $(0.4)$ & 6.8 & $(0.4)$ & 73.9 & $(0.8)$ & 14.1 & $(0.5)$ & 7.3 & $(0.4)$ & 4.7 & $(0.3)$ \\
\hline OECD average & 57.0 & $(0.1)$ & 22.5 & $(0.1)$ & 12.3 & $(0.1)$ & 8.2 & $(0.1)$ & 68.9 & $(0.1)$ & 16.8 & (0.1) & 8.4 & $(0.1)$ & 5.9 & $(0.1)$ \\
\hline
\end{tabular}

\begin{tabular}{|c|c|c|c|c|c|c|c|c|c|c|c|c|c|c|c|c|}
\hline Albania & $\mathrm{m}$ & $\mathrm{m}$ & $\mathrm{m}$ & $\mathrm{m}$ & $\mathrm{m}$ & $\mathrm{m}$ & $\mathrm{m}$ & $\mathrm{m}$ & $\mathrm{m}$ & $\mathrm{m}$ & $\mathrm{m}$ & $\mathrm{m}$ & $\mathrm{m}$ & $\mathrm{m}$ & $\mathrm{m}$ & $\mathrm{m}$ \\
\hline Algeria & $\mathrm{m}$ & $\mathrm{m}$ & $\mathrm{m}$ & $\mathrm{m}$ & $\mathrm{m}$ & $\mathrm{m}$ & $\mathrm{m}$ & $\mathrm{m}$ & $\mathrm{m}$ & $\mathrm{m}$ & $\mathrm{m}$ & $\mathrm{m}$ & $\mathrm{m}$ & $\mathrm{m}$ & $\mathrm{m}$ & $\mathrm{m}$ \\
\hline Brazil & 64.1 & $(0.5)$ & 19.3 & $(0.4)$ & 9.7 & $(0.3)$ & 6.9 & $(0.3)$ & 69.6 & $(0.5)$ & 17.2 & $(0.4)$ & 8.3 & $(0.2)$ & 4.9 & $(0.2)$ \\
\hline B-S-J-G (China) & 65.4 & (0.6) & 13.7 & $(0.5)$ & 11.5 & $(0.4)$ & 9.5 & $(0.4)$ & 67.1 & $(1.0)$ & 13.9 & $(0.5)$ & 11.0 & (0.5) & 8.0 & $(0.4)$ \\
\hline Bulgaria & 48.8 & $(0.7)$ & 22.5 & (0.6) & 15.0 & $(0.5)$ & 13.6 & $(0.5)$ & 67.1 & $(0.8)$ & 16.5 & (0.6) & 8.9 & $(0.4)$ & 7.5 & (0.4) \\
\hline CABA (Argentina) & $\mathrm{m}$ & $\mathrm{m}$ & $\mathrm{m}$ & $\mathrm{m}$ & $\mathrm{m}$ & $\mathrm{m}$ & $\mathrm{m}$ & $\mathrm{m}$ & $\mathrm{m}$ & $\mathrm{m}$ & $\mathrm{m}$ & $\mathrm{m}$ & $\mathrm{m}$ & $\mathrm{m}$ & $\mathrm{m}$ & $\mathrm{m}$ \\
\hline Colombia & 76.7 & $(0.7)$ & 12.3 & $(0.4)$ & 6.4 & $(0.3)$ & 4.6 & $(0.4)$ & 74.0 & $(0.7)$ & 14.5 & $(0.5)$ & 7.1 & $(0.4)$ & 4.4 & $(0.3)$ \\
\hline Costa Rica & 81.8 & (0.6) & 9.7 & $(0.4)$ & 5.3 & $(0.3)$ & 3.2 & $(0.3)$ & 65.1 & $(0.7)$ & 20.8 & (0.6) & 9.0 & $(0.5)$ & 5.1 & $(0.3)$ \\
\hline Croatia & 53.6 & $(0.8)$ & 23.9 & (0.6) & 13.8 & $(0.5)$ & 8.8 & $(0.4)$ & 73.2 & $(0.7)$ & 15.6 & (0.5) & 6.9 & $(0.4)$ & 4.4 & $(0.3)$ \\
\hline Cyprus* & 48.7 & $(0.8)$ & 25.1 & $(0.6)$ & 15.3 & $(0.5)$ & 10.8 & $(0.4)$ & 68.0 & $(0.6)$ & 16.6 & $(0.5)$ & 8.8 & $(0.4)$ & 6.7 & $(0.4)$ \\
\hline Dominican Republic & 65.6 & $(0.9)$ & 12.3 & $(0.6)$ & 11.6 & $(0.6)$ & 10.5 & $(0.5)$ & 83.7 & $(0.6)$ & 7.1 & $(0.4)$ & 5.2 & $(0.3)$ & 4.0 & $(0.3)$ \\
\hline FYROM & $\mathrm{m}$ & $\mathrm{m}$ & $\mathrm{m}$ & $\mathrm{m}$ & $\mathrm{m}$ & $\mathrm{m}$ & $\mathrm{m}$ & $\mathrm{m}$ & $\mathrm{m}$ & $\mathrm{m}$ & $\mathrm{m}$ & $\mathrm{m}$ & $\mathrm{m}$ & $\mathrm{m}$ & $\mathrm{m}$ & $\mathrm{m}$ \\
\hline Georgia & $\mathrm{m}$ & $\mathrm{m}$ & $\mathrm{m}$ & $\mathrm{m}$ & $\mathrm{m}$ & $\mathrm{m}$ & $\mathrm{m}$ & $\mathrm{m}$ & $\mathrm{m}$ & $\mathrm{m}$ & $\mathrm{m}$ & $\mathrm{m}$ & $\mathrm{m}$ & $\mathrm{m}$ & $\mathrm{m}$ & $\mathrm{m}$ \\
\hline Hong Kong (China) & 49.5 & (1.0) & 23.1 & $(0.6)$ & 18.4 & $(0.7)$ & 9.0 & $(0.4)$ & 70.4 & $(0.8)$ & 14.4 & $(0.5)$ & 9.9 & $(0.5)$ & 5.3 & $(0.4)$ \\
\hline Indonesia & $\mathrm{m}$ & $\mathrm{m}$ & $\mathrm{m}$ & $\mathrm{m}$ & $\mathrm{m}$ & $\mathrm{m}$ & $\mathrm{m}$ & $\mathrm{m}$ & $\mathrm{m}$ & $\mathrm{m}$ & $\mathrm{m}$ & $\mathrm{m}$ & $\mathrm{m}$ & $\mathrm{m}$ & $\mathrm{m}$ & $\mathrm{m}$ \\
\hline Jordan & $\mathrm{m}$ & $\mathrm{m}$ & $\mathrm{m}$ & $\mathrm{m}$ & $\mathrm{m}$ & $\mathrm{m}$ & $\mathrm{m}$ & $\mathrm{m}$ & $\mathrm{m}$ & $\mathrm{m}$ & $\mathrm{m}$ & $\mathrm{m}$ & $\mathrm{m}$ & $\mathrm{m}$ & $\mathrm{m}$ & $\mathrm{m}$ \\
\hline Kosovo & $\mathrm{m}$ & $\mathrm{m}$ & $\mathrm{m}$ & $\mathrm{m}$ & $\mathrm{m}$ & $\mathrm{m}$ & $\mathrm{m}$ & $\mathrm{m}$ & $\mathrm{m}$ & $\mathrm{m}$ & $\mathrm{m}$ & $\mathrm{m}$ & $\mathrm{m}$ & $\mathrm{m}$ & $\mathrm{m}$ & $\mathrm{m}$ \\
\hline Lebanon & $\mathrm{m}$ & $\mathrm{m}$ & $\mathrm{m}$ & $\mathrm{m}$ & $\mathrm{m}$ & $\mathrm{m}$ & $\mathrm{m}$ & $\mathrm{m}$ & $\mathrm{m}$ & $\mathrm{m}$ & $\mathrm{m}$ & $\mathrm{m}$ & $\mathrm{m}$ & $\mathrm{m}$ & $\mathrm{m}$ & $\mathrm{m}$ \\
\hline Lithuania & 52.7 & $(0.8)$ & 24.7 & $(0.6)$ & 14.3 & $(0.5)$ & 8.3 & $(0.5)$ & 60.5 & $(0.7)$ & 19.4 & $(0.5)$ & 12.3 & $(0.5)$ & 7.8 & $(0.4)$ \\
\hline Macao (China) & 56.7 & $(0.7)$ & 20.1 & $(0.6)$ & 14.1 & $(0.5)$ & 9.0 & $(0.4)$ & 64.9 & $(0.6)$ & 17.4 & $(0.4)$ & 11.5 & $(0.4)$ & 6.1 & $(0.4)$ \\
\hline Malta & $\mathrm{m}$ & $\mathrm{m}$ & $\mathrm{m}$ & $\mathrm{m}$ & $\mathrm{m}$ & $\mathrm{m}$ & $\mathrm{m}$ & $\mathrm{m}$ & $\mathrm{m}$ & $\mathrm{m}$ & $\mathrm{m}$ & $\mathrm{m}$ & $\mathrm{m}$ & $\mathrm{m}$ & $\mathrm{m}$ & $\mathrm{m}$ \\
\hline Moldova & $\mathrm{m}$ & $\mathrm{m}$ & $\mathrm{m}$ & $\mathrm{m}$ & $\mathrm{m}$ & $\mathrm{m}$ & $\mathrm{m}$ & $\mathrm{m}$ & $\mathrm{m}$ & $\mathrm{m}$ & $\mathrm{m}$ & $\mathrm{m}$ & $\mathrm{m}$ & $\mathrm{m}$ & $\mathrm{m}$ & $\mathrm{m}$ \\
\hline Montenegro & 64.4 & (0.6) & 18.1 & $(0.5)$ & 11.0 & $(0.5)$ & 6.5 & $(0.3)$ & 75.9 & $(0.6)$ & 12.9 & $(0.5)$ & 6.6 & $(0.4)$ & 4.6 & $(0.3)$ \\
\hline Peru & 54.8 & $(0.7)$ & 20.9 & $(0.6)$ & 14.6 & $(0.4)$ & 9.6 & $(0.4)$ & 56.1 & $(0.6)$ & 21.8 & $(0.5)$ & 13.4 & $(0.4)$ & 8.7 & $(0.4)$ \\
\hline Qatar & 51.2 & $(0.5)$ & 23.5 & $(0.5)$ & 15.4 & $(0.3)$ & 10.0 & $(0.3)$ & 60.4 & $(0.4)$ & 19.9 & $(0.4)$ & 11.2 & $(0.3)$ & 8.4 & $(0.3)$ \\
\hline Romania & $\mathrm{m}$ & $\mathrm{m}$ & $\mathrm{m}$ & $\mathrm{m}$ & $\mathrm{m}$ & $\mathrm{m}$ & $\mathrm{m}$ & $\mathrm{m}$ & $\mathrm{m}$ & $\mathrm{m}$ & $\mathrm{m}$ & $\mathrm{m}$ & $\mathrm{m}$ & $\mathrm{m}$ & $\mathrm{m}$ & $\mathrm{m}$ \\
\hline Russia & 44.0 & (1.0) & 23.8 & $(0.7)$ & 19.7 & $(0.5)$ & 12.5 & $(0.6)$ & 71.2 & $(1.0)$ & 14.9 & $(0.6)$ & 8.6 & $(0.5)$ & 5.3 & $(0.5)$ \\
\hline Singapore & 58.8 & $(0.6)$ & 22.5 & $(0.5)$ & 11.9 & $(0.4)$ & 6.8 & $(0.3)$ & 68.6 & $(0.7)$ & 17.2 & $(0.5)$ & 8.9 & $(0.4)$ & 5.4 & $(0.3)$ \\
\hline Chinese Taipei & 75.0 & $(0.6)$ & 11.4 & $(0.4)$ & 8.4 & $(0.4)$ & 5.2 & $(0.3)$ & 82.7 & $(0.6)$ & 8.4 & $(0.3)$ & 5.6 & $(0.3)$ & 3.3 & $(0.2)$ \\
\hline Thailand & 59.6 & $(0.9)$ & 17.8 & $(0.6)$ & 13.5 & $(0.5)$ & 9.1 & $(0.4)$ & 67.6 & $(0.9)$ & 15.5 & $(0.6)$ & 10.0 & $(0.5)$ & 7.0 & $(0.4)$ \\
\hline Trinidad and Tobago & $\mathrm{m}$ & $\mathrm{m}$ & $\mathrm{m}$ & $\mathrm{m}$ & $\mathrm{m}$ & $\mathrm{m}$ & $\mathrm{m}$ & $\mathrm{m}$ & $\mathrm{m}$ & $\mathrm{m}$ & $\mathrm{m}$ & $\mathrm{m}$ & $\mathrm{m}$ & $\mathrm{m}$ & $\mathrm{m}$ & $\mathrm{m}$ \\
\hline Tunisia & 44.8 & $(0.9)$ & 27.9 & $(0.7)$ & 15.2 & $(0.6)$ & 12.1 & $(0.5)$ & 69.3 & $(0.7)$ & 16.8 & $(0.6)$ & 8.0 & $(0.4)$ & 5.8 & $(0.4)$ \\
\hline United Arab Emirates & 52.0 & $(0.5)$ & 22.5 & $(0.5)$ & 15.1 & $(0.3)$ & 10.3 & $(0.4)$ & 59.9 & $(0.7)$ & 20.1 & $(0.4)$ & 11.2 & $(0.4)$ & 8.8 & (0.4) \\
\hline Uruguay & 72.7 & $(0.6)$ & 13.0 & $(0.5)$ & 8.0 & $(0.3)$ & 6.3 & $(0.4)$ & 78.0 & $(0.7)$ & 12.5 & $(0.5)$ & 5.1 & $(0.3)$ & 4.4 & $(0.3)$ \\
\hline Viet Nam & $\mathrm{m}$ & $\mathrm{m}$ & $\mathrm{m}$ & $\mathrm{m}$ & $\mathrm{m}$ & $\mathrm{m}$ & $\mathrm{m}$ & $\mathrm{m}$ & $\mathrm{m}$ & $\mathrm{m}$ & $\mathrm{m}$ & $\mathrm{m}$ & $\mathrm{m}$ & $\mathrm{m}$ & $\mathrm{m}$ & $\mathrm{m}$ \\
\hline Argentina** & $\mathrm{m}$ & $\mathrm{m}$ & $\mathrm{m}$ & $\mathrm{m}$ & $\mathrm{m}$ & $\mathrm{m}$ & $\mathrm{m}$ & $\mathrm{m}$ & $\mathrm{m}$ & $\mathrm{m}$ & $\mathrm{m}$ & $\mathrm{m}$ & $\mathrm{m}$ & $\mathrm{m}$ & $\mathrm{m}$ & $\mathrm{m}$ \\
\hline Kazakhstan** & $\mathrm{m}$ & $\mathrm{m}$ & $\mathrm{m}$ & $\mathrm{m}$ & $\mathrm{m}$ & $\mathrm{m}$ & $\mathrm{m}$ & $\mathrm{m}$ & $\mathrm{m}$ & $\mathrm{m}$ & $\mathrm{m}$ & $\mathrm{m}$ & $\mathrm{m}$ & $\mathrm{m}$ & $\mathrm{m}$ & $\mathrm{m}$ \\
\hline Malaysia** & 50.4 & (0.9) & 23.6 & $(0.6)$ & 17.4 & $(0.6)$ & 8.6 & $(0.4)$ & 43.8 & $(0.9)$ & 26.8 & $(0.6)$ & 18.6 & $(0.6)$ & 10.8 & $(0.5)$ \\
\hline
\end{tabular}

* See note at the beginning of this Annex.

** Coverage is too small to ensure comparability (see Annex A4).

StatLink *ins 


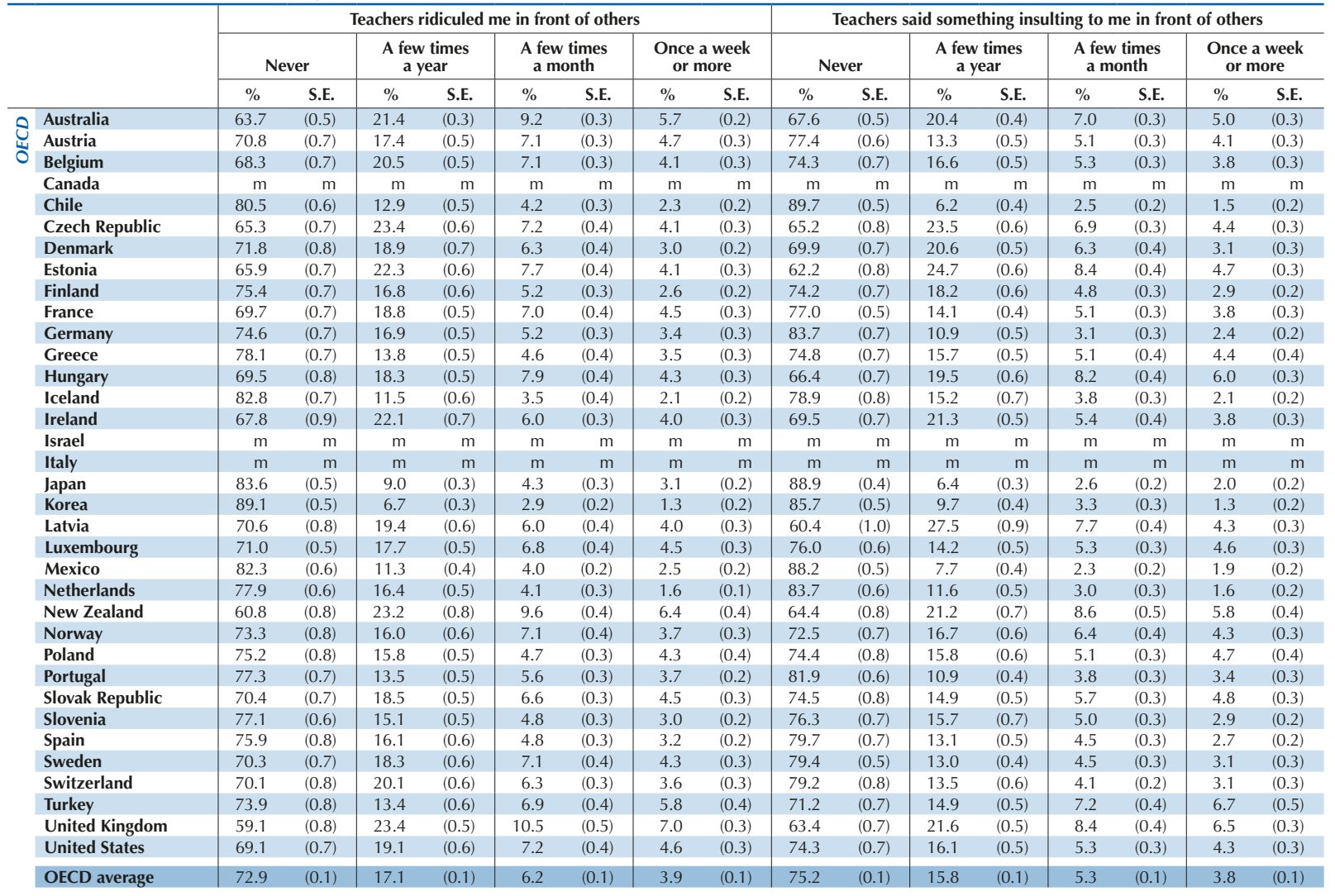

\begin{tabular}{|c|c|c|c|c|c|c|c|c|c|c|c|c|c|c|c|c|c|}
\hline \multirow{4}{*}{ 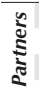 } & Albania & $\mathrm{m}$ & $\mathrm{m}$ & $\mathrm{m}$ & $\mathrm{m}$ & $\mathrm{m}$ & $\mathrm{m}$ & $\mathrm{m}$ & $\mathrm{m}$ & $\mathrm{m}$ & $\mathrm{m}$ & $\mathrm{m}$ & $\mathrm{m}$ & $\mathrm{m}$ & $\mathrm{m}$ & $\mathrm{m}$ & $\mathrm{m}$ \\
\hline & Algeria & $\mathrm{m}$ & $\mathrm{m}$ & $\mathrm{m}$ & $\mathrm{m}$ & $\mathrm{m}$ & $\mathrm{m}$ & $\mathrm{m}$ & $\mathrm{m}$ & $\mathrm{m}$ & $\mathrm{m}$ & $\mathrm{m}$ & $\mathrm{m}$ & $\mathrm{m}$ & $\mathrm{m}$ & $\mathrm{m}$ & $\mathrm{m}$ \\
\hline & Brazil & 82.2 & $(0.4)$ & 10.1 & $(0.3)$ & 4.5 & $(0.2)$ & 3.1 & $(0.2)$ & 78.8 & $(0.5)$ & 12.3 & $(0.3)$ & 5.0 & $(0.3)$ & 3.8 & $(0.2)$ \\
\hline & B-S-J-G (China) & 84.8 & $(0.5)$ & 8.3 & $(0.3)$ & 3.8 & $(0.3)$ & 3.1 & $(0.2)$ & 86.6 & $(0.5)$ & 7.2 & $(0.3)$ & 3.0 & $(0.2)$ & 3.2 & $(0.2)$ \\
\hline & Bulgaria & 67.6 & $(0.8)$ & 18.1 & $(0.5)$ & 7.9 & $(0.5)$ & 6.4 & $(0.4)$ & 69.9 & $(0.9)$ & 17.1 & $(0.6)$ & 6.8 & $(0.4)$ & 6.2 & $(0.4)$ \\
\hline & CABA (Argentina) & $\mathrm{m}$ & $\mathrm{m}$ & $\mathrm{m}$ & $\mathrm{m}$ & $\mathrm{m}$ & $\mathrm{m}$ & $\mathrm{m}$ & $\mathrm{m}$ & $\mathrm{m}$ & $\mathrm{m}$ & $\mathrm{m}$ & $\mathrm{m}$ & $\mathrm{m}$ & $\mathrm{m}$ & $\mathrm{m}$ & $\mathrm{m}$ \\
\hline & Colombia & 75.5 & $(0.7)$ & 15.6 & $(0.5)$ & 5.3 & $(0.3)$ & 3.6 & $(0.2)$ & 75.5 & $(0.8)$ & 15.1 & $(0.5)$ & 5.2 & $(0.3)$ & 4.2 & $(0.3)$ \\
\hline & Costa Rica & 81.2 & $(0.6)$ & 12.3 & $(0.5)$ & 3.7 & $(0.3)$ & 2.8 & $(0.2)$ & 91.1 & $(0.5)$ & 5.6 & $(0.4)$ & 1.8 & $(0.2)$ & 1.5 & $(0.2)$ \\
\hline & Croatia & 79.7 & $(0.7)$ & 13.7 & $(0.5)$ & 4.0 & $(0.3)$ & 2.6 & $(0.3)$ & 77.7 & $(0.7)$ & 15.2 & $(0.5)$ & 4.0 & $(0.3)$ & 3.1 & $(0.3)$ \\
\hline & Cyprus* & 66.8 & $(0.7)$ & 19.9 & $(0.6)$ & 7.7 & $(0.4)$ & 5.6 & $(0.3)$ & 64.7 & (0.6) & 21.1 & $(0.6)$ & 7.7 & (0.4) & 6.5 & $(0.3)$ \\
\hline & Dominican Republic & 79.2 & $(0.8)$ & 10.3 & $(0.6)$ & 4.8 & $(0.4)$ & 5.7 & $(0.4)$ & 76.6 & $(0.8)$ & 10.8 & $(0.6)$ & 6.2 & $(0.4)$ & 6.4 & (0.4) \\
\hline & FYROM & $\mathrm{m}$ & $\mathrm{m}$ & $\mathrm{m}$ & $\mathrm{m}$ & $\mathrm{m}$ & $\mathrm{m}$ & $\mathrm{m}$ & $\mathrm{m}$ & $\mathrm{m}$ & $\mathrm{m}$ & $\mathrm{m}$ & $\mathrm{m}$ & $\mathrm{m}$ & $\mathrm{m}$ & $\mathrm{m}$ & $\mathrm{m}$ \\
\hline & Georgia & $\mathrm{m}$ & $\mathrm{m}$ & $\mathrm{m}$ & $\mathrm{m}$ & $\mathrm{m}$ & $\mathrm{m}$ & $\mathrm{m}$ & $\mathrm{m}$ & $\mathrm{m}$ & $\mathrm{m}$ & $\mathrm{m}$ & $\mathrm{m}$ & $\mathrm{m}$ & $\mathrm{m}$ & $\mathrm{m}$ & $\mathrm{m}$ \\
\hline & Hong Kong (China) & 68.1 & $(0.9)$ & 17.1 & $(0.6)$ & 8.5 & $(0.5)$ & 6.4 & $(0.4)$ & 79.5 & $(0.8)$ & 11.6 & $(0.4)$ & 4.9 & $(0.4)$ & 4.0 & $(0.3)$ \\
\hline & Indonesia & $\mathrm{m}$ & $\mathrm{m}$ & $\mathrm{m}$ & $\mathrm{m}$ & $\mathrm{m}$ & $\mathrm{m}$ & $\mathrm{m}$ & $\mathrm{m}$ & $\mathrm{m}$ & $\mathrm{m}$ & $\mathrm{m}$ & $\mathrm{m}$ & $\mathrm{m}$ & $\mathrm{m}$ & $\mathrm{m}$ & $\mathrm{m}$ \\
\hline & Jordan & $\mathrm{m}$ & $\mathrm{m}$ & $\mathrm{m}$ & $\mathrm{m}$ & $\mathrm{m}$ & $\mathrm{m}$ & $\mathrm{m}$ & $\mathrm{m}$ & $\mathrm{m}$ & $\mathrm{m}$ & $\mathrm{m}$ & $\mathrm{m}$ & $\mathrm{m}$ & $\mathrm{m}$ & $\mathrm{m}$ & $\mathrm{m}$ \\
\hline & Kosovo & $\mathrm{m}$ & $\mathrm{m}$ & $\mathrm{m}$ & $\mathrm{m}$ & $\mathrm{m}$ & $\mathrm{m}$ & $\mathrm{m}$ & $\mathrm{m}$ & $\mathrm{m}$ & $\mathrm{m}$ & $\mathrm{m}$ & $\mathrm{m}$ & $\mathrm{m}$ & $\mathrm{m}$ & $\mathrm{m}$ & $\mathrm{m}$ \\
\hline & Lebanon & $\mathrm{m}$ & $\mathrm{m}$ & $\mathrm{m}$ & $\mathrm{m}$ & $\mathrm{m}$ & $\mathrm{m}$ & $\mathrm{m}$ & $\mathrm{m}$ & $\mathrm{m}$ & $\mathrm{m}$ & $\mathrm{m}$ & $\mathrm{m}$ & $\mathrm{m}$ & $\mathrm{m}$ & $\mathrm{m}$ & $\mathrm{m}$ \\
\hline & Lithuania & 65.1 & $(0.8)$ & 21.5 & $(0.7)$ & 9.1 & $(0.4)$ & 4.2 & $(0.3)$ & 68.0 & $(0.8)$ & 19.6 & $(0.6)$ & 7.7 & $(0.4)$ & 4.8 & $(0.3)$ \\
\hline & Macao (China) & 72.0 & $(0.7)$ & 17.3 & $(0.5)$ & 6.9 & $(0.4)$ & 3.8 & $(0.3)$ & 76.8 & $(0.6)$ & 15.7 & $(0.6)$ & 4.6 & $(0.3)$ & 2.9 & $(0.2)$ \\
\hline & Malta & $\mathrm{m}$ & $\mathrm{m}$ & $\mathrm{m}$ & $\mathrm{m}$ & $\mathrm{m}$ & $\mathrm{m}$ & $\mathrm{m}$ & $\mathrm{m}$ & $\mathrm{m}$ & $\mathrm{m}$ & $\mathrm{m}$ & $\mathrm{m}$ & $\mathrm{m}$ & $\mathrm{m}$ & $\mathrm{m}$ & $\mathrm{m}$ \\
\hline & Moldova & $\mathrm{m}$ & $\mathrm{m}$ & $\mathrm{m}$ & $\mathrm{m}$ & $\mathrm{m}$ & $\mathrm{m}$ & $\mathrm{m}$ & $\mathrm{m}$ & $\mathrm{m}$ & $\mathrm{m}$ & $\mathrm{m}$ & $\mathrm{m}$ & $\mathrm{m}$ & $\mathrm{m}$ & $\mathrm{m}$ & $\mathrm{m}$ \\
\hline & Montenegro & 82.7 & $(0.5)$ & 9.7 & $(0.4)$ & 4.2 & $(0.3)$ & 3.4 & $(0.3)$ & 81.1 & $(0.6)$ & 11.1 & $(0.5)$ & 4.3 & $(0.3)$ & 3.6 & $(0.2)$ \\
\hline & Peru & 83.8 & $(0.5)$ & 9.7 & $(0.4)$ & 3.8 & $(0.3)$ & 2.7 & $(0.2)$ & 89.0 & $(0.5)$ & 6.1 & $(0.3)$ & 2.7 & $(0.2)$ & 2.2 & $(0.2)$ \\
\hline & Qatar & 62.0 & $(0.5)$ & 20.9 & $(0.4)$ & 10.4 & $(0.3)$ & 6.7 & $(0.2)$ & 62.2 & $(0.4)$ & 20.3 & $(0.4)$ & 9.4 & $(0.3)$ & 8.1 & $(0.3)$ \\
\hline & Romania & $\mathrm{m}$ & $\mathrm{m}$ & $\mathrm{m}$ & $\mathrm{m}$ & $\mathrm{m}$ & $\mathrm{m}$ & $\mathrm{m}$ & $\mathrm{m}$ & $\mathrm{m}$ & $\mathrm{m}$ & $\mathrm{m}$ & $\mathrm{m}$ & $\mathrm{m}$ & $\mathrm{m}$ & $\mathrm{m}$ & $\mathrm{m}$ \\
\hline & Russia & 75.2 & $(0.9)$ & 13.5 & $(0.6)$ & 6.6 & $(0.4)$ & 4.7 & $(0.4)$ & 73.1 & (1.0) & 15.0 & $(0.5)$ & 7.0 & $(0.5)$ & 4.9 & $(0.4)$ \\
\hline & Singapore & 67.1 & $(0.6)$ & 21.1 & $(0.5)$ & 7.6 & $(0.3)$ & 4.1 & $(0.3)$ & 72.0 & $(0.6)$ & 18.8 & $(0.6)$ & 5.4 & $(0.3)$ & 3.8 & $(0.3)$ \\
\hline & Chinese Taipei & 89.2 & $(0.5)$ & 6.0 & $(0.3)$ & 2.8 & $(0.2)$ & 1.9 & $(0.2)$ & 90.6 & $(0.4)$ & 5.6 & $(0.3)$ & 2.3 & $(0.2)$ & 1.5 & $(0.2)$ \\
\hline & Thailand & 68.7 & $(0.8)$ & 14.9 & $(0.6)$ & 8.8 & $(0.5)$ & 7.6 & $(0.4)$ & 70.2 & $(0.8)$ & 14.4 & $(0.5)$ & 8.5 & $(0.4)$ & 6.9 & $(0.4)$ \\
\hline & Trinidad and Tobago & $\mathrm{m}$ & $\mathrm{m}$ & $\mathrm{m}$ & $\mathrm{m}$ & $\mathrm{m}$ & $\mathrm{m}$ & $\mathrm{m}$ & $\mathrm{m}$ & $\mathrm{m}$ & $\mathrm{m}$ & $\mathrm{m}$ & $\mathrm{m}$ & $\mathrm{m}$ & $\mathrm{m}$ & $\mathrm{m}$ & $\mathrm{m}$ \\
\hline & Tunisia & 66.6 & $(0.8)$ & 19.0 & $(0.6)$ & 7.6 & $(0.4)$ & 6.9 & $(0.4)$ & 68.4 & $(0.8)$ & 17.2 & $(0.6)$ & 7.1 & $(0.5)$ & 7.2 & $(0.4)$ \\
\hline & United Arab Emirates & 63.5 & $(0.6)$ & 20.0 & $(0.4)$ & 9.5 & $(0.3)$ & 7.0 & $(0.4)$ & 63.4 & $(0.6)$ & 19.9 & $(0.4)$ & 9.0 & $(0.3)$ & 7.7 & $(0.4)$ \\
\hline & Uruguay & 81.1 & $(0.6)$ & 11.7 & $(0.5)$ & 4.4 & $(0.4)$ & 2.8 & $(0.2)$ & 90.7 & $(0.4)$ & 5.1 & $(0.3)$ & 2.3 & $(0.2)$ & 2.0 & $(0.2)$ \\
\hline & Viet Nam & $\mathrm{m}$ & $\mathrm{m}$ & $\mathrm{m}$ & $\mathrm{m}$ & $\mathrm{m}$ & $\mathrm{m}$ & $\mathrm{m}$ & $\mathrm{m}$ & $\mathrm{m}$ & $\mathrm{m}$ & $\mathrm{m}$ & $\mathrm{m}$ & $\mathrm{m}$ & $\mathrm{m}$ & $\mathrm{m}$ & $\mathrm{m}$ \\
\hline & Argentina** & $\mathrm{m}$ & $\mathrm{m}$ & $\mathrm{m}$ & $\mathrm{m}$ & $\mathrm{m}$ & $\mathrm{m}$ & $\mathrm{m}$ & $\mathrm{m}$ & $\mathrm{m}$ & $\mathrm{m}$ & $\mathrm{m}$ & $\mathrm{m}$ & $\mathrm{m}$ & $\mathrm{m}$ & $\mathrm{m}$ & $\mathrm{m}$ \\
\hline & Kazakhstan** & $\mathrm{m}$ & $\mathrm{m}$ & $\mathrm{m}$ & $\mathrm{m}$ & $\mathrm{m}$ & $\mathrm{m}$ & $\mathrm{m}$ & $\mathrm{m}$ & $\mathrm{m}$ & $\mathrm{m}$ & $\mathrm{m}$ & $\mathrm{m}$ & $\mathrm{m}$ & $\mathrm{m}$ & $\mathrm{m}$ & $\mathrm{m}$ \\
\hline & Malaysia** & 59.0 & $(0.8)$ & 24.1 & $(0.6)$ & 11.0 & $(0.5)$ & 5.8 & $(0.4)$ & 71.9 & $(0.9)$ & 16.7 & $(0.6)$ & 7.2 & $(0.4)$ & 4.2 & $(0.3)$ \\
\hline
\end{tabular}

* See note at the beginning of this Annex.

** Coverage is too small to ensure comparability (see Annex A4).

StatLink त्ना15 http://dx.doi.org/10.1787/888933471407 
[Part 1/6]

Table III.7.16 Students' perception of teacher unfairness, by gender and socio-economic status

Percentage of students who reported "once a week or more" or "a few times a month"

\begin{tabular}{|c|c|c|c|c|c|c|c|c|c|c|c|c|c|c|}
\hline & \multicolumn{14}{|c|}{ Percentage of boys who reported being treated unfairly by their teachers a few times a month or more frequently } \\
\hline & \multicolumn{2}{|c|}{$\begin{array}{l}\text { Any unfair } \\
\text { treatment }\end{array}$} & \multicolumn{2}{|c|}{$\begin{array}{l}\text { Teachers called } \\
\text { on me less often } \\
\text { than they called } \\
\text { on other students }\end{array}$} & \multicolumn{2}{|c|}{\begin{tabular}{|c|}
$\begin{array}{c}\text { Teachers graded me } \\
\text { harder than } \\
\text { they graded } \\
\text { other students }\end{array}$ \\
\end{tabular}} & \multicolumn{2}{|c|}{$\begin{array}{c}\text { Teachers gave me } \\
\text { the impression } \\
\text { that I am less smart } \\
\text { than I really am }\end{array}$} & \multicolumn{2}{|c|}{$\begin{array}{l}\text { Teachers disciplined } \\
\text { me more harshly } \\
\text { than other students }\end{array}$} & \multicolumn{2}{|c|}{$\begin{array}{c}\text { Teachers ridiculed } \\
\text { me in front } \\
\text { of others }\end{array}$} & \multicolumn{2}{|c|}{$\begin{array}{c}\text { Teachers said } \\
\text { something insulting } \\
\text { to me in front } \\
\text { of others }\end{array}$} \\
\hline & $\%$ & S.E. & $\%$ & S.E. & $\%$ & S.E. & $\%$ & S.E. & $\%$ & S.E. & $\%$ & S.E. & $\%$ & S.E. \\
\hline Australia & 54.0 & $(0.8)$ & 36.2 & $(0.7)$ & 18.8 & $(0.6)$ & 24.8 & $(0.7)$ & 22.3 & $(0.5)$ & 18.2 & $(0.5)$ & 14.3 & $(0.5)$ \\
\hline Austria & 61.1 & $(1.0)$ & 40.5 & (1.0) & 21.2 & $(0.9)$ & 26.6 & $(1.0)$ & 24.3 & $(0.9)$ & 15.3 & $(0.8)$ & 12.1 & $(0.7)$ \\
\hline$\widehat{\widehat{\partial}}$ Belgium & 55.8 & $(0.9)$ & 35.8 & $(0.9)$ & 26.8 & $(0.7)$ & 24.7 & $(0.9)$ & 22.1 & $(0.7)$ & 14.1 & $(0.6)$ & 11.7 & $(0.6)$ \\
\hline Canada & $\mathrm{m}$ & $\mathrm{m}$ & $\mathrm{m}$ & $\mathrm{m}$ & $\mathrm{m}$ & $\mathrm{m}$ & $\mathrm{m}$ & $\mathrm{m}$ & $\mathrm{m}$ & $\mathrm{m}$ & $\mathrm{m}$ & $\mathrm{m}$ & $\mathrm{m}$ & $\mathrm{m}$ \\
\hline Chile & 52.7 & $(1.0)$ & 35.9 & $(1.0)$ & 20.3 & $(0.9)$ & 15.7 & $(0.8)$ & 18.9 & $(0.8)$ & 8.4 & $(0.6)$ & 5.3 & $(0.6)$ \\
\hline Czech Republic & 56.1 & $(1.1)$ & 39.0 & $(1.1)$ & 16.9 & $(0.7)$ & 21.9 & $(0.8)$ & 13.8 & $(0.9)$ & 13.4 & $(0.8)$ & 13.5 & $(0.8)$ \\
\hline Denmark & 52.5 & $(1.1)$ & 32.6 & $(1.0)$ & 25.4 & (1.1) & 18.9 & $(0.7)$ & 18.3 & $(0.9)$ & 11.8 & $(0.6)$ & 11.4 & $(0.7)$ \\
\hline Estonia & 65.3 & $(0.9)$ & 48.3 & $(1.0)$ & 32.5 & $(0.9)$ & 27.8 & (1.0) & 17.8 & $(0.8)$ & 13.5 & $(0.7)$ & 15.1 & $(0.8)$ \\
\hline Finland & 42.7 & $(1.1)$ & 23.7 & $(0.8)$ & 18.2 & $(0.8)$ & 19.2 & $(0.7)$ & 22.6 & $(0.9)$ & 10.2 & $(0.7)$ & 9.6 & $(0.7)$ \\
\hline France & 64.9 & $(0.8)$ & 46.1 & $(1.0)$ & 25.5 & $(0.9)$ & 28.7 & $(0.8)$ & 19.4 & $(0.8)$ & 14.0 & $(0.8)$ & 11.5 & $(0.7)$ \\
\hline Germany & 58.7 & $(1.0)$ & 39.8 & $(1.0)$ & 21.4 & $(0.9)$ & 23.9 & $(0.8)$ & 22.7 & $(0.8)$ & 10.0 & $(0.5)$ & 6.9 & $(0.5)$ \\
\hline Greece & 64.0 & $(1.1)$ & 44.3 & $(1.2)$ & 24.2 & $(0.8)$ & 20.9 & (0.9) & 16.5 & $(0.9)$ & 11.0 & $(0.8)$ & 12.9 & $(0.9)$ \\
\hline Hungary & 74.2 & $(0.9)$ & 57.5 & $(1.1)$ & 24.9 & $(0.8)$ & 32.2 & (1.0) & 25.0 & $(0.9)$ & 14.1 & $(0.8)$ & 15.9 & $(0.9)$ \\
\hline Iceland & 32.9 & (1.4) & 20.7 & $(1.1)$ & 11.3 & $(0.9)$ & 11.2 & (0.9) & 14.8 & $(1.1)$ & 6.8 & $(0.6)$ & 6.4 & $(0.6)$ \\
\hline Ireland & 51.1 & (1.1) & 31.5 & $(0.9)$ & 17.3 & $(0.9)$ & 21.8 & $(0.9)$ & 21.9 & $(0.9)$ & 13.1 & $(0.7)$ & 11.4 & $(0.7)$ \\
\hline Israel & $\mathrm{m}$ & $\mathrm{m}$ & $\mathrm{m}$ & $\mathrm{m}$ & $\mathrm{m}$ & $\mathrm{m}$ & $\mathrm{m}$ & $\mathrm{m}$ & $\mathrm{m}$ & $\mathrm{m}$ & $\mathrm{m}$ & $\mathrm{m}$ & $\mathrm{m}$ & $\mathrm{m}$ \\
\hline Italy & $\mathrm{m}$ & $\mathrm{m}$ & $\mathrm{m}$ & $\mathrm{m}$ & $\mathrm{m}$ & $\mathrm{m}$ & $\mathrm{m}$ & $\mathrm{m}$ & $\mathrm{m}$ & $\mathrm{m}$ & $\mathrm{m}$ & $\mathrm{m}$ & $\mathrm{m}$ & $\mathrm{m}$ \\
\hline Japan & 43.4 & $(1.0)$ & 35.9 & $(1.0)$ & 7.7 & $(0.5)$ & 10.6 & $(0.6)$ & 11.2 & $(0.6)$ & 9.1 & $(0.5)$ & 6.1 & $(0.4)$ \\
\hline Korea & 40.7 & $(1.0)$ & 33.8 & $(1.0)$ & 10.3 & $(0.7)$ & 15.8 & $(0.7)$ & 10.1 & $(0.6)$ & 5.5 & $(0.5)$ & 5.7 & $(0.5)$ \\
\hline Latvia & 63.8 & $(1.3)$ & 42.1 & $(1.5)$ & 31.4 & (1.3) & 27.4 & (1.0) & 19.1 & $(0.8)$ & 13.3 & $(0.8)$ & 14.8 & $(0.8)$ \\
\hline Luxembourg & 62.6 & $(0.9)$ & 45.5 & $(1.1)$ & 25.0 & $(0.8)$ & 28.3 & $(0.7)$ & 25.2 & $(0.7)$ & 15.2 & $(0.6)$ & 13.9 & $(0.6)$ \\
\hline Mexico & 38.1 & $(1.0)$ & 18.5 & $(0.7)$ & 19.2 & $(0.9)$ & 21.9 & $(0.7)$ & 9.3 & $(0.6)$ & 8.3 & $(0.5)$ & 5.4 & $(0.4)$ \\
\hline Netherlands & 39.7 & $(1.1)$ & 21.9 & (1.0) & 17.9 & $(0.8)$ & 13.2 & $(0.7)$ & 16.7 & $(0.8)$ & 7.6 & $(0.6)$ & 6.1 & $(0.6)$ \\
\hline New Zealand & 56.6 & $(1.2)$ & 37.9 & $(1.2)$ & 17.5 & $(0.8)$ & 24.1 & (1.1) & 21.9 & $(0.8)$ & 19.5 & $(0.9)$ & 17.1 & $(0.8)$ \\
\hline Norway & 47.5 & $(1.2)$ & 27.8 & $(1.0)$ & 29.1 & (1.1) & 22.2 & $(1.0)$ & 20.7 & $(1.0)$ & 12.9 & $(0.7)$ & 12.3 & $(0.7)$ \\
\hline Poland & 55.7 & $(1.1)$ & 35.5 & $(1.0)$ & 25.3 & $(1.0)$ & 25.8 & (1.0) & 20.5 & $(1.0)$ & 11.9 & $(0.8)$ & 12.9 & $(0.8)$ \\
\hline Portugal & 59.7 & (1.1) & 41.8 & $(0.9)$ & 22.6 & $(0.8)$ & 28.1 & $(0.9)$ & 27.7 & $(0.9)$ & 11.7 & $(0.7)$ & 9.2 & $(0.7)$ \\
\hline Slovak Republic & 61.5 & $(0.9)$ & 41.1 & $(1.0)$ & 22.6 & $(0.9)$ & 31.0 & $(0.9)$ & 17.1 & (1.0) & 13.4 & $(0.7)$ & 12.6 & $(0.6)$ \\
\hline Slovenia & 63.3 & $(1.1)$ & 51.4 & $(1.2)$ & 22.6 & $(0.8)$ & 20.3 & $(0.8)$ & 14.5 & $(0.9)$ & 10.2 & $(0.6)$ & 10.1 & $(0.5)$ \\
\hline Spain & 53.6 & $(1.1)$ & 30.0 & $(0.8)$ & 28.2 & $(0.8)$ & 22.0 & $(0.8)$ & 19.3 & $(0.8)$ & 10.3 & $(0.6)$ & 9.7 & $(0.6)$ \\
\hline Sweden & 43.1 & $(1.1)$ & 24.7 & $(1.0)$ & 19.9 & $(0.9)$ & 19.2 & (1.0) & 15.7 & $(0.9)$ & 13.9 & $(0.7)$ & 9.3 & $(0.6)$ \\
\hline Switzerland & 56.4 & $(1.1)$ & 39.2 & $(1.0)$ & 17.5 & $(1.0)$ & 21.3 & $(0.9)$ & 24.9 & (1.1) & 12.6 & $(0.8)$ & 9.4 & $(0.6)$ \\
\hline Turkey & 65.5 & $(1.0)$ & 45.2 & $(1.3)$ & 27.9 & $(0.9)$ & 27.7 & (1.0) & 20.8 & $(0.8)$ & 17.3 & $(0.9)$ & 17.9 & $(1.0)$ \\
\hline United Kingdom & 57.6 & $(1.0)$ & 36.3 & $(0.9)$ & 18.8 & $(0.9)$ & 27.5 & $(0.9)$ & 26.5 & $(0.9)$ & 19.8 & $(0.8)$ & 17.4 & $(0.8)$ \\
\hline United States & 52.0 & $(1.0)$ & 35.7 & (1.0) & 19.1 & $(0.9)$ & 17.7 & $(0.8)$ & 16.1 & $(0.8)$ & 14.4 & $(0.7)$ & 11.8 & $(0.7)$ \\
\hline OECD average & 54.6 & $(0.2)$ & 36.7 & $(0.2)$ & 21.5 & $(0.2)$ & 22.6 & $(0.2)$ & 19.3 & $(0.1)$ & 12.5 & $(0.1)$ & 11.2 & $(0.1)$ \\
\hline
\end{tabular}

\begin{tabular}{|c|c|c|c|c|c|c|c|c|c|c|c|c|c|c|}
\hline Albania & $\mathrm{m}$ & $\mathrm{m}$ & $\mathrm{m}$ & $\mathrm{m}$ & $\mathrm{m}$ & $\mathrm{m}$ & $\mathrm{m}$ & $\mathrm{m}$ & $\mathrm{m}$ & $\mathrm{m}$ & $\mathrm{m}$ & $\mathrm{m}$ & $\mathrm{m}$ & $\mathrm{m}$ \\
\hline Algeria & $\mathrm{m}$ & $\mathrm{m}$ & $\mathrm{m}$ & $\mathrm{m}$ & $\mathrm{m}$ & $\mathrm{m}$ & $\mathrm{m}$ & $\mathrm{m}$ & $\mathrm{m}$ & $\mathrm{m}$ & $\mathrm{m}$ & $\mathrm{m}$ & $\mathrm{m}$ & $\mathrm{m}$ \\
\hline Brazil & 50.6 & $(0.7)$ & 30.0 & $(0.6)$ & 22.1 & $(0.6)$ & 20.2 & $(0.6)$ & 17.0 & $(0.6)$ & 10.5 & $(0.5)$ & 11.9 & $(0.6)$ \\
\hline B-S-J-G (China) & 65.3 & (1.1) & 50.1 & (1.1) & 32.1 & $(1.2)$ & 23.5 & $(0.9)$ & 24.3 & $(1.0)$ & 9.9 & $(0.6)$ & 8.9 & $(0.4)$ \\
\hline Bulgaria & 65.0 & $(0.9)$ & 37.3 & $(0.9)$ & 37.9 & $(1.0)$ & 31.4 & $(0.9)$ & 21.1 & $(0.9)$ & 18.6 & $(0.9)$ & 15.4 & $(0.8)$ \\
\hline CABA (Argentina) & $\mathrm{m}$ & $\mathrm{m}$ & $\mathrm{m}$ & $\mathrm{m}$ & $\mathrm{m}$ & $\mathrm{m}$ & $\mathrm{m}$ & $\mathrm{m}$ & $\mathrm{m}$ & $\mathrm{m}$ & $\mathrm{m}$ & $\mathrm{m}$ & $\mathrm{m}$ & $\mathrm{m}$ \\
\hline Colombia & 51.2 & $(0.9)$ & 33.0 & $(1.0)$ & 22.4 & $(0.8)$ & 13.2 & $(0.8)$ & 15.6 & $(0.8)$ & 11.9 & $(0.7)$ & 11.8 & $(0.7)$ \\
\hline Costa Rica & 41.7 & (1.1) & 25.1 & $(1.0)$ & 21.0 & $(1.0)$ & 10.6 & $(0.7)$ & 18.2 & $(0.9)$ & 8.5 & $(0.6)$ & 4.5 & $(0.5)$ \\
\hline Croatia & 58.4 & (1.2) & 42.2 & (1.0) & 23.6 & $(1.0)$ & 23.3 & (1.0) & 15.5 & $(0.9)$ & 9.0 & $(0.7)$ & 9.5 & $(0.7)$ \\
\hline Cyprus* & 61.2 & (1.0) & 37.1 & $(0.9)$ & 30.9 & $(0.9)$ & 29.4 & $(0.8)$ & 23.2 & $(1.0)$ & 18.0 & $(0.8)$ & 19.1 & $(0.8)$ \\
\hline Dominican Republic & 56.6 & (1.0) & 31.5 & (1.0) & 33.9 & (1.1) & 25.4 & (1.0) & 12.4 & $(0.7)$ & 12.7 & $(0.8)$ & 15.1 & $(0.9)$ \\
\hline FYROM & $\mathrm{m}$ & $\mathrm{m}$ & $\mathrm{m}$ & $\mathrm{m}$ & $\mathrm{m}$ & $\mathrm{m}$ & $\mathrm{m}$ & $\mathrm{m}$ & $\mathrm{m}$ & $\mathrm{m}$ & $\mathrm{m}$ & $\mathrm{m}$ & $\mathrm{m}$ & $\mathrm{m}$ \\
\hline Georgia & $\mathrm{m}$ & $\mathrm{m}$ & $\mathrm{m}$ & $\mathrm{m}$ & $\mathrm{m}$ & $\mathrm{m}$ & $\mathrm{m}$ & $\mathrm{m}$ & $\mathrm{m}$ & $\mathrm{m}$ & $\mathrm{m}$ & $\mathrm{m}$ & $\mathrm{m}$ & $\mathrm{m}$ \\
\hline Hong Kong (China) & 73.7 & $(0.9)$ & 61.4 & $(1.0)$ & 34.9 & $(1.1)$ & 34.1 & $(1.2)$ & 20.5 & $(1.0)$ & 21.2 & $(1.0)$ & 13.6 & $(0.9)$ \\
\hline Indonesia & $\mathrm{m}$ & $\mathrm{m}$ & $\mathrm{m}$ & $\mathrm{m}$ & $\mathrm{m}$ & $\mathrm{m}$ & $\mathrm{m}$ & $\mathrm{m}$ & $\mathrm{m}$ & $\mathrm{m}$ & $\mathrm{m}$ & $\mathrm{m}$ & $\mathrm{m}$ & $\mathrm{m}$ \\
\hline Jordan & $\mathrm{m}$ & $\mathrm{m}$ & $\mathrm{m}$ & $\mathrm{m}$ & $\mathrm{m}$ & $\mathrm{m}$ & $\mathrm{m}$ & $\mathrm{m}$ & $\mathrm{m}$ & $\mathrm{m}$ & $\mathrm{m}$ & $\mathrm{m}$ & $\mathrm{m}$ & $\mathrm{m}$ \\
\hline Kosovo & $\mathrm{m}$ & $\mathrm{m}$ & $\mathrm{m}$ & $\mathrm{m}$ & $\mathrm{m}$ & $\mathrm{m}$ & $\mathrm{m}$ & $\mathrm{m}$ & $\mathrm{m}$ & $\mathrm{m}$ & $\mathrm{m}$ & $\mathrm{m}$ & $\mathrm{m}$ & $\mathrm{m}$ \\
\hline Lebanon & $\mathrm{m}$ & $\mathrm{m}$ & $\mathrm{m}$ & $\mathrm{m}$ & $\mathrm{m}$ & $\mathrm{m}$ & $\mathrm{m}$ & $\mathrm{m}$ & $\mathrm{m}$ & $\mathrm{m}$ & $\mathrm{m}$ & $\mathrm{m}$ & $\mathrm{m}$ & $\mathrm{m}$ \\
\hline Lithuania & 65.1 & $(1.0)$ & 46.2 & $(0.9)$ & 27.8 & $(0.9)$ & 26.8 & $(0.9)$ & 28.1 & $(0.9)$ & 18.4 & $(0.8)$ & 16.6 & $(0.8)$ \\
\hline Macao (China) & 75.2 & $(0.8)$ & 65.9 & (1.1) & 23.0 & $(0.9)$ & 26.9 & $(0.9)$ & 21.8 & $(0.9)$ & 14.7 & $(0.7)$ & 10.2 & $(0.6)$ \\
\hline Malta & $\mathrm{m}$ & $\mathrm{m}$ & $\mathrm{m}$ & $\mathrm{m}$ & $\mathrm{m}$ & $\mathrm{m}$ & $\mathrm{m}$ & $\mathrm{m}$ & $\mathrm{m}$ & $\mathrm{m}$ & $\mathrm{m}$ & $\mathrm{m}$ & $\mathrm{m}$ & $\mathrm{m}$ \\
\hline Moldova & $\mathrm{m}$ & $\mathrm{m}$ & $\mathrm{m}$ & $\mathrm{m}$ & $\mathrm{m}$ & $\mathrm{m}$ & $\mathrm{m}$ & $\mathrm{m}$ & $\mathrm{m}$ & $\mathrm{m}$ & $\mathrm{m}$ & $\mathrm{m}$ & $\mathrm{m}$ & $\mathrm{m}$ \\
\hline Montenegro & 54.5 & $(0.9)$ & 39.9 & $(1.0)$ & 20.4 & $(0.7)$ & 20.0 & $(0.7)$ & 15.2 & $(0.7)$ & 10.0 & $(0.6)$ & 10.3 & $(0.6)$ \\
\hline Peru & 60.9 & (1.0) & 29.7 & $(0.8)$ & 35.2 & $(0.8)$ & 27.9 & $(0.9)$ & 27.1 & $(0.9)$ & 8.8 & $(0.6)$ & 6.6 & $(0.6)$ \\
\hline Qatar & 59.0 & $(0.8)$ & 35.3 & $(0.7)$ & 29.8 & $(0.6)$ & 29.4 & $(0.6)$ & 26.1 & $(0.6)$ & 22.8 & $(0.6)$ & 22.3 & $(0.6)$ \\
\hline Romania & $\mathrm{m}$ & $\mathrm{m}$ & $\mathrm{m}$ & $\mathrm{m}$ & $\mathrm{m}$ & $\mathrm{m}$ & $\mathrm{m}$ & $\mathrm{m}$ & $\mathrm{m}$ & $\mathrm{m}$ & $\mathrm{m}$ & $\mathrm{m}$ & $\mathrm{m}$ & $\mathrm{m}$ \\
\hline Russia & 73.9 & (1.1) & 60.7 & (1.1) & 36.4 & $(1.2)$ & 34.3 & $(1.3)$ & 18.4 & $(1.0)$ & 14.5 & $(0.8)$ & 14.0 & $(0.9)$ \\
\hline Singapore & 58.3 & $(0.8)$ & 44.8 & $(0.8)$ & 22.0 & $(0.8)$ & 20.8 & $(0.8)$ & 19.4 & $(0.8)$ & 16.6 & $(0.8)$ & 13.0 & $(0.7)$ \\
\hline Chinese Taipei & 48.5 & (1.0) & 39.2 & (1.0) & 9.1 & $(0.5)$ & 17.1 & $(0.7)$ & 11.7 & $(0.7)$ & 7.0 & (0.5) & 5.7 & $(0.5)$ \\
\hline Thailand & 64.9 & $(0.9)$ & 54.4 & $(0.9)$ & 28.9 & $(1.0)$ & 28.8 & $(0.8)$ & 23.9 & $(1.0)$ & 22.3 & $(1.0)$ & 21.2 & $(0.9)$ \\
\hline Trinidad and Tobago & $\mathrm{m}$ & $\mathrm{m}$ & $\mathrm{m}$ & $\mathrm{m}$ & $\mathrm{m}$ & $\mathrm{m}$ & $\mathrm{m}$ & $\mathrm{m}$ & $\mathrm{m}$ & $\mathrm{m}$ & $\mathrm{m}$ & $\mathrm{m}$ & $\mathrm{m}$ & $\mathrm{m}$ \\
\hline Tunisia & 63.1 & $(1.2)$ & 33.2 & $(1.0)$ & 22.7 & $(0.8)$ & 31.9 & (1.1) & 20.9 & $(0.8)$ & 20.9 & $(0.9)$ & 20.3 & $(1.0)$ \\
\hline United Arab Emirates & 59.6 & $(0.8)$ & 35.4 & $(0.8)$ & 28.1 & $(0.8)$ & 30.1 & $(0.7)$ & 25.9 & $(0.8)$ & 22.2 & $(0.7)$ & 21.4 & $(0.8)$ \\
\hline Uruguay & 56.3 & (1.1) & 38.0 & (1.1) & 30.2 & $(0.9)$ & 17.4 & $(0.7)$ & 14.3 & $(0.6)$ & 9.8 & $(0.7)$ & 6.1 & $(0.5)$ \\
\hline Viet Nam & $\mathrm{m}$ & $\mathrm{m}$ & $\mathrm{m}$ & $\mathrm{m}$ & $\mathrm{m}$ & $\mathrm{m}$ & $\mathrm{m}$ & $\mathrm{m}$ & $\mathrm{m}$ & $\mathrm{m}$ & $\mathrm{m}$ & $\mathrm{m}$ & $\mathrm{m}$ & $\mathrm{m}$ \\
\hline Argentina** & $\mathrm{m}$ & $\mathrm{m}$ & $\mathrm{m}$ & $\mathrm{m}$ & $\mathrm{m}$ & $\mathrm{m}$ & $\mathrm{m}$ & $\mathrm{m}$ & $\mathrm{m}$ & $\mathrm{m}$ & $\mathrm{m}$ & $\mathrm{m}$ & $\mathrm{m}$ & $\mathrm{m}$ \\
\hline Kazakhstan** & $\mathrm{m}$ & $\mathrm{m}$ & $\mathrm{m}$ & $\mathrm{m}$ & $\mathrm{m}$ & $\mathrm{m}$ & $\mathrm{m}$ & $\mathrm{m}$ & $\mathrm{m}$ & $\mathrm{m}$ & $\mathrm{m}$ & $\mathrm{m}$ & $\mathrm{m}$ & $\mathrm{m}$ \\
\hline Malaysia** & 82.3 & (1.0) & 70.5 & $(1.1)$ & 42.4 & $(1.2)$ & 33.9 & $(1.1)$ & 38.7 & $(1.1)$ & 23.4 & (1.0) & 16.1 & $(0.9)$ \\
\hline
\end{tabular}

A socio-economically disadvantaged student is a student in the bottom quarter of the PISA index of economic, social and cultural status (ESCS) within his or her own country/economy. 2. A socio-economically advantaged student is a student in the top quarter of the PISA index of economic, social and cultural status (ESCS) within his or her own country/economy. Note: Values that are statistically significant are indicated in bold (see Annex A3).

* See note at the beginning of this Annex.

** Coverage is too small to ensure comparability (see Annex A4).

StatLink 需政 http://dx.doi.org/10.1787/888933471410 
Percentage of students who reported "once a week or more" or "a few times a month"

\begin{tabular}{|c|c|c|c|c|c|c|c|c|c|c|c|c|c|c|c|}
\hline & & \multicolumn{14}{|c|}{ Percentage of girls who reported being treated unfairly by their teachers a few times a month or more frequently } \\
\hline & & \multicolumn{2}{|c|}{$\begin{array}{l}\text { Any unfair } \\
\text { treatment }\end{array}$} & \multicolumn{2}{|c|}{$\begin{array}{l}\text { Teachers called } \\
\text { on me less often } \\
\text { than they called } \\
\text { on other students }\end{array}$} & \multicolumn{2}{|c|}{$\begin{array}{c}\text { Teachers graded me } \\
\text { harder than } \\
\text { they graded } \\
\text { other students }\end{array}$} & \multicolumn{2}{|c|}{$\begin{array}{l}\text { Teachers gave me } \\
\text { the impression } \\
\text { that I am less smart } \\
\text { than I really am }\end{array}$} & \multicolumn{2}{|c|}{\begin{tabular}{|c|}
$\begin{array}{c}\text { Teachers disciplined } \\
\text { me more harshly } \\
\text { than other students }\end{array}$ \\
\end{tabular}} & \multicolumn{2}{|c|}{$\begin{array}{c}\text { Teachers ridiculed } \\
\text { me in front } \\
\text { of others }\end{array}$} & \multicolumn{2}{|c|}{$\begin{array}{c}\text { Teachers said } \\
\text { something insulting } \\
\text { to me in front } \\
\text { of others }\end{array}$} \\
\hline & & $\%$ & S.E. & $\%$ & S.E. & $\%$ & S.E. & $\%$ & S.E. & $\%$ & S.E. & $\%$ & S.E. & $\%$ & S.E. \\
\hline$\sigma$ & Australia & 47.3 & $(0.8)$ & 33.0 & $(0.7)$ & 12.4 & $(0.5)$ & 21.4 & $(0.6)$ & 12.3 & $(0.6)$ & 11.7 & $(0.5)$ & 9.6 & $(0.5)$ \\
\hline & Austria & 52.3 & (1.0) & 37.9 & $(0.8)$ & 13.5 & $(0.6)$ & 22.1 & $(0.8)$ & 14.4 & $(0.5)$ & 8.4 & $(0.5)$ & 6.4 & $(0.4)$ \\
\hline & Belgium & 45.2 & $(0.8)$ & 31.4 & $(0.8)$ & 15.6 & $(0.5)$ & 18.0 & $(0.6)$ & 9.7 & $(0.5)$ & 8.3 & $(0.4)$ & 6.4 & $(0.5)$ \\
\hline & Canada & $\mathrm{m}$ & $\mathrm{m}$ & $\mathrm{m}$ & $\mathrm{m}$ & $\mathrm{m}$ & $\mathrm{m}$ & $\mathrm{m}$ & $\mathrm{m}$ & $\mathrm{m}$ & $\mathrm{m}$ & $\mathrm{m}$ & $\mathrm{m}$ & $\mathrm{m}$ & $\mathrm{m}$ \\
\hline & Chile & 43.8 & $(1.3)$ & 31.6 & $(1.3)$ & 15.4 & $(0.9)$ & 13.3 & $(0.7)$ & 11.0 & $(0.7)$ & 4.7 & $(0.5)$ & 2.8 & $(0.3)$ \\
\hline & Czech Republic & 51.3 & $(1.3)$ & 37.4 & $(1.3)$ & 10.9 & $(0.7)$ & 15.7 & $(0.8)$ & 5.4 & $(0.4)$ & 9.2 & $(0.6)$ & 9.0 & $(0.5)$ \\
\hline & Denmark & 42.1 & (1.2) & 29.7 & (1.1) & 14.7 & $(0.8)$ & 13.0 & $(0.7)$ & 7.8 & $(0.6)$ & 6.8 & $(0.5)$ & 7.5 & $(0.6)$ \\
\hline & Estonia & 63.2 & $(1.2)$ & 48.2 & (1.1) & 26.8 & $(1.0)$ & 25.2 & $(1.0)$ & 7.7 & $(0.6)$ & 9.9 & $(0.6)$ & 11.1 & $(0.7)$ \\
\hline & Finland & 36.1 & $(1.2)$ & 22.0 & $(0.9)$ & 12.4 & $(0.8)$ & 16.6 & $(0.9)$ & 11.8 & $(0.7)$ & 5.4 & $(0.4)$ & 5.5 & $(0.4)$ \\
\hline & France & 57.8 & $(0.8)$ & 43.6 & $(0.9)$ & 17.6 & $(0.8)$ & 25.8 & $(0.7)$ & 7.3 & $(0.5)$ & 9.3 & $(0.5)$ & 6.5 & $(0.4)$ \\
\hline & Germany & 50.7 & (1.1) & 37.0 & (1.1) & 15.3 & $(0.7)$ & 19.4 & $(0.8)$ & 12.0 & $(0.8)$ & 7.1 & $(0.5)$ & 4.1 & $(0.5)$ \\
\hline & Greece & 58.8 & $(0.9)$ & 45.6 & $(0.9)$ & 18.0 & $(0.8)$ & 16.6 & $(0.8)$ & 4.5 & $(0.5)$ & 5.0 & $(0.5)$ & 6.0 & $(0.5)$ \\
\hline & Hungary & 69.5 & $(0.9)$ & 56.5 & $(1.0)$ & 18.7 & $(0.8)$ & 30.7 & $(0.9)$ & 15.5 & $(0.8)$ & 10.3 & $(0.7)$ & 12.4 & $(0.7)$ \\
\hline & Iceland & 29.6 & (1.1) & 22.1 & (1.0) & 9.5 & $(0.7)$ & 9.6 & $(0.7)$ & 8.6 & $(0.8)$ & 4.6 & $(0.5)$ & 5.6 & $(0.6)$ \\
\hline & Ireland & 40.7 & $(1.0)$ & 26.4 & $(0.8)$ & 9.2 & $(0.6)$ & 17.9 & $(0.8)$ & 10.2 & $(0.6)$ & 6.8 & $(0.5)$ & 6.9 & $(0.5)$ \\
\hline & Israel & $\mathrm{m}$ & $\mathrm{m}$ & $\mathrm{m}$ & $\mathrm{m}$ & $\mathrm{m}$ & $\mathrm{m}$ & $\mathrm{m}$ & $\mathrm{m}$ & $\mathrm{m}$ & $\mathrm{m}$ & $\mathrm{m}$ & $\mathrm{m}$ & $\mathrm{m}$ & $\mathrm{m}$ \\
\hline & Italy & $\mathrm{m}$ & $\mathrm{m}$ & $\mathrm{m}$ & $\mathrm{m}$ & $\mathrm{m}$ & $\mathrm{m}$ & $\mathrm{m}$ & $\mathrm{m}$ & $\mathrm{m}$ & $\mathrm{m}$ & $\mathrm{m}$ & $\mathrm{m}$ & $\mathrm{m}$ & $\mathrm{m}$ \\
\hline & Japan & 37.9 & $(0.8)$ & 32.9 & $(0.8)$ & 3.5 & $(0.4)$ & 5.4 & $(0.4)$ & 5.9 & $(0.5)$ & 5.6 & $(0.4)$ & 3.1 & $(0.3)$ \\
\hline & Korea & 35.1 & (1.1) & 29.7 & $(1.0)$ & 4.9 & $(0.5)$ & 11.0 & $(0.7)$ & 5.0 & $(0.4)$ & 2.8 & $(0.3)$ & 3.4 & $(0.4)$ \\
\hline & Latvia & 58.6 & (1.2) & 41.6 & (1.1) & 22.6 & $(0.9)$ & 21.1 & $(1.0)$ & 7.9 & $(0.7)$ & 6.7 & $(0.4)$ & 9.3 & $(0.6)$ \\
\hline & Luxembourg & 52.8 & $(0.9)$ & 39.5 & $(0.9)$ & 12.4 & $(0.7)$ & 20.7 & $(0.8)$ & 10.2 & $(0.6)$ & 7.5 & $(0.5)$ & 5.9 & $(0.4)$ \\
\hline & Mexico & 25.7 & $(0.8)$ & 13.2 & $(0.7)$ & 11.3 & $(0.6)$ & 14.1 & $(0.6)$ & 4.4 & $(0.4)$ & 4.6 & $(0.3)$ & 2.9 & $(0.3)$ \\
\hline & Netherlands & 32.9 & $(0.8)$ & 21.3 & $(0.8)$ & 9.2 & $(0.5)$ & 10.5 & $(0.6)$ & 8.2 & (0.6) & 3.8 & $(0.3)$ & 3.2 & $(0.3)$ \\
\hline & New Zealand & 48.8 & (1.1) & 32.2 & $(0.9)$ & 12.0 & $(0.8)$ & 22.0 & $(0.9)$ & 12.9 & $(0.7)$ & 12.5 & $(0.7)$ & 11.7 & $(0.9)$ \\
\hline & Norway & 41.9 & (1.0) & 25.5 & (1.0) & 23.1 & $(0.8)$ & 21.6 & $(0.9)$ & 9.8 & $(0.6)$ & 8.6 & $(0.6)$ & 9.3 & $(0.7)$ \\
\hline & Poland & 45.4 & $(1.0)$ & 30.9 & $(1.0)$ & 14.7 & $(0.9)$ & 19.6 & $(0.8)$ & 10.0 & $(0.8)$ & 5.8 & $(0.6)$ & 6.6 & $(0.6)$ \\
\hline & Portugal & 50.8 & $(0.9)$ & 36.0 & $(0.9)$ & 14.1 & $(0.7)$ & 24.0 & $(0.8)$ & 14.7 & $(0.7)$ & 6.9 & $(0.4)$ & 5.2 & $(0.4)$ \\
\hline & Slovak Republic & 57.8 & (1.1) & 42.3 & (1.1) & 16.1 & $(0.8)$ & 24.7 & $(1.0)$ & 7.8 & $(0.5)$ & 8.6 & $(0.6)$ & 8.3 & $(0.6)$ \\
\hline & Slovenia & 60.8 & (1.3) & 51.4 & $(1.2)$ & 15.8 & $(0.7)$ & 18.5 & $(0.8)$ & 5.6 & $(0.6)$ & 5.3 & $(0.5)$ & 5.7 & $(0.6)$ \\
\hline & Spain & 37.8 & $(0.9)$ & 21.8 & $(0.7)$ & 15.0 & $(0.7)$ & 15.6 & $(0.6)$ & 6.5 & $(0.5)$ & 5.8 & $(0.5)$ & 4.8 & $(0.4)$ \\
\hline & Sweden & 36.7 & (1.0) & 19.6 & $(0.9)$ & 15.8 & $(0.7)$ & 16.9 & $(0.7)$ & 7.1 & $(0.5)$ & 8.9 & $(0.6)$ & 6.0 & $(0.4)$ \\
\hline & Switzerland & 45.4 & $(1.0)$ & 34.1 & $(0.9)$ & 8.2 & $(0.6)$ & 15.6 & $(0.8)$ & 9.8 & $(0.6)$ & 6.9 & $(0.5)$ & 5.0 & $(0.5)$ \\
\hline & Turkey & 58.5 & (1.1) & 44.9 & (1.0) & 18.4 & $(0.8)$ & 22.3 & $(0.7)$ & 11.6 & $(0.8)$ & 8.0 & $(0.6)$ & 10.0 & $(0.6)$ \\
\hline & United Kingdom & 52.6 & $(1.0)$ & 34.2 & $(0.9)$ & 12.5 & $(0.7)$ & 24.4 & $(0.9)$ & 16.0 & $(0.8)$ & 15.0 & $(0.9)$ & 12.5 & $(0.6)$ \\
\hline & United States & 46.8 & (1.1) & 35.1 & (1.0) & 13.4 & $(0.7)$ & 16.0 & $(0.9)$ & 8.0 & $(0.7)$ & 9.3 & $(0.7)$ & 7.5 & $(0.6)$ \\
\hline & OECD average & 47.3 & $(0.2)$ & 34.0 & $(0.2)$ & 14.2 & $(0.1)$ & 18.4 & $(0.1)$ & 9.4 & $(0.1)$ & 7.5 & $(0.1)$ & 6.9 & $(0.1)$ \\
\hline
\end{tabular}

\begin{tabular}{|c|c|c|c|c|c|c|c|c|c|c|c|c|c|c|c|}
\hline 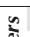 & Albania & $\mathrm{m}$ & $\mathrm{m}$ & $\mathrm{m}$ & $\mathrm{m}$ & $\mathrm{m}$ & $\mathrm{m}$ & $\mathrm{m}$ & $\mathrm{m}$ & $\mathrm{m}$ & $\mathrm{m}$ & $\mathrm{m}$ & $\mathrm{m}$ & $\mathrm{m}$ & $\mathrm{m}$ \\
\hline ¿ & Algeria & $\mathrm{m}$ & $\mathrm{m}$ & $\mathrm{m}$ & $\mathrm{m}$ & $\mathrm{m}$ & $\mathrm{m}$ & $\mathrm{m}$ & $\mathrm{m}$ & $\mathrm{m}$ & $\mathrm{m}$ & $\mathrm{m}$ & $\mathrm{m}$ & $\mathrm{m}$ & $\mathrm{m}$ \\
\hline & Brazil & 39.5 & $(0.7)$ & 23.3 & $(0.6)$ & 13.7 & $(0.5)$ & 13.3 & $(0.5)$ & 9.8 & $(0.4)$ & 5.0 & $(0.3)$ & 6.1 & $(0.3)$ \\
\hline & B-S-J-G (China) & 60.1 & (1.3) & 49.3 & $(1.5)$ & 22.9 & (1.0) & 18.1 & $(0.7)$ & 12.8 & $(0.8)$ & 3.5 & $(0.4)$ & 3.1 & $(0.3)$ \\
\hline & Bulgaria & 60.8 & $(0.9)$ & 34.6 & $(1.0)$ & 34.0 & $(0.9)$ & 25.8 & (1.0) & 11.3 & $(0.7)$ & 9.7 & $(0.7)$ & 10.4 & $(0.7)$ \\
\hline & CABA (Argentina) & $\mathrm{m}$ & $\mathrm{m}$ & $\mathrm{m}$ & $\mathrm{m}$ & $\mathrm{m}$ & $\mathrm{m}$ & $\mathrm{m}$ & $\mathrm{m}$ & $\mathrm{m}$ & $\mathrm{m}$ & $\mathrm{m}$ & $\mathrm{m}$ & $\mathrm{m}$ & $\mathrm{m}$ \\
\hline & Colombia & 37.9 & $(0.9)$ & 25.1 & $(0.8)$ & 13.0 & $(0.6)$ & 9.0 & $(0.5)$ & 7.8 & $(0.5)$ & 6.3 & $(0.4)$ & 7.3 & $(0.5)$ \\
\hline & Costa Rica & 30.3 & (1.0) & 18.7 & $(0.8)$ & 12.4 & $(0.7)$ & 6.4 & $(0.5)$ & 10.1 & $(0.6)$ & 4.7 & $(0.4)$ & 2.2 & $(0.3)$ \\
\hline & Croatia & 54.7 & $(0.9)$ & 40.1 & $(1.0)$ & 17.5 & $(0.8)$ & 21.9 & $(0.8)$ & 7.4 & $(0.6)$ & 4.5 & $(0.3)$ & 4.9 & $(0.4)$ \\
\hline & Cyprus* & 51.9 & $(1.0)$ & 35.9 & $(0.8)$ & 20.8 & $(0.8)$ & 23.0 & $(0.9)$ & 8.1 & $(0.6)$ & 8.9 & $(0.6)$ & 9.6 & $(0.6)$ \\
\hline & Dominican Republic & 48.0 & (1.3) & 28.3 & $(1.1)$ & 25.5 & (1.1) & 18.9 & $(0.9)$ & 6.2 & $(0.6)$ & 8.4 & $(0.7)$ & 10.2 & $(0.7)$ \\
\hline & FYROM & $\mathrm{m}$ & $\mathrm{m}$ & $\mathrm{m}$ & $\mathrm{m}$ & $\mathrm{m}$ & $\mathrm{m}$ & $\mathrm{m}$ & $\mathrm{m}$ & $\mathrm{m}$ & $\mathrm{m}$ & $\mathrm{m}$ & $\mathrm{m}$ & $\mathrm{m}$ & $\mathrm{m}$ \\
\hline & Georgia & $\mathrm{m}$ & $\mathrm{m}$ & $\mathrm{m}$ & $\mathrm{m}$ & $\mathrm{m}$ & $\mathrm{m}$ & $\mathrm{m}$ & $\mathrm{m}$ & $\mathrm{m}$ & $\mathrm{m}$ & $\mathrm{m}$ & $\mathrm{m}$ & $\mathrm{m}$ & $\mathrm{m}$ \\
\hline & Hong Kong (China) & 66.8 & (1.1) & 60.1 & $(1.3)$ & 22.3 & (0.9) & 20.6 & $(0.9)$ & 9.9 & $(0.6)$ & 8.3 & $(0.6)$ & 4.2 & $(0.5)$ \\
\hline & Indonesia & $\mathrm{m}$ & $\mathrm{m}$ & $\mathrm{m}$ & $\mathrm{m}$ & $\mathrm{m}$ & $\mathrm{m}$ & $\mathrm{m}$ & $\mathrm{m}$ & $\mathrm{m}$ & $\mathrm{m}$ & $\mathrm{m}$ & $\mathrm{m}$ & $\mathrm{m}$ & $\mathrm{m}$ \\
\hline & Jordan & $\mathrm{m}$ & $\mathrm{m}$ & $\mathrm{m}$ & $\mathrm{m}$ & $\mathrm{m}$ & $\mathrm{m}$ & $\mathrm{m}$ & $\mathrm{m}$ & $\mathrm{m}$ & $\mathrm{m}$ & $\mathrm{m}$ & $\mathrm{m}$ & $\mathrm{m}$ & $\mathrm{m}$ \\
\hline & Kosovo & $\mathrm{m}$ & $\mathrm{m}$ & $\mathrm{m}$ & $\mathrm{m}$ & $\mathrm{m}$ & $\mathrm{m}$ & $\mathrm{m}$ & $\mathrm{m}$ & $\mathrm{m}$ & $\mathrm{m}$ & $\mathrm{m}$ & $\mathrm{m}$ & $\mathrm{m}$ & $\mathrm{m}$ \\
\hline & Lebanon & $\mathrm{m}$ & $\mathrm{m}$ & $\mathrm{m}$ & $\mathrm{m}$ & $\mathrm{m}$ & $\mathrm{m}$ & $\mathrm{m}$ & $\mathrm{m}$ & $\mathrm{m}$ & $\mathrm{m}$ & $\mathrm{m}$ & $\mathrm{m}$ & $\mathrm{m}$ & $\mathrm{m}$ \\
\hline & Lithuania & 56.1 & $(1.0)$ & 41.4 & $(0.9)$ & 18.9 & $(0.8)$ & 18.4 & $(0.7)$ & 12.1 & $(0.7)$ & 8.3 & $(0.5)$ & 8.2 & $(0.6)$ \\
\hline & Macao (China) & 68.9 & $(0.9)$ & 62.2 & $(1.0)$ & 14.8 & $(0.8)$ & 19.3 & $(0.9)$ & 13.5 & $(0.7)$ & 6.7 & $(0.5)$ & 4.6 & $(0.4)$ \\
\hline & Malta & $\mathrm{m}$ & $\mathrm{m}$ & $\mathrm{m}$ & $\mathrm{m}$ & $\mathrm{m}$ & $\mathrm{m}$ & $\mathrm{m}$ & $\mathrm{m}$ & $\mathrm{m}$ & $\mathrm{m}$ & $\mathrm{m}$ & $\mathrm{m}$ & $\mathrm{m}$ & $\mathrm{m}$ \\
\hline & Moldova & $\mathrm{m}$ & $\mathrm{m}$ & $\mathrm{m}$ & $\mathrm{m}$ & $\mathrm{m}$ & $\mathrm{m}$ & $\mathrm{m}$ & $\mathrm{m}$ & $\mathrm{m}$ & $\mathrm{m}$ & $\mathrm{m}$ & $\mathrm{m}$ & $\mathrm{m}$ & $\mathrm{m}$ \\
\hline & Montenegro & 50.2 & $(0.8)$ & 39.0 & $(1.0)$ & 18.0 & $(0.6)$ & 15.0 & $(0.7)$ & 7.3 & $(0.5)$ & 5.3 & $(0.4)$ & 5.5 & $(0.4)$ \\
\hline & Peru & 48.1 & $(1.0)$ & 23.3 & $(0.8)$ & 26.1 & $(0.8)$ & 20.6 & $(0.8)$ & 17.0 & $(0.7)$ & 4.2 & $(0.3)$ & 3.1 & $(0.4)$ \\
\hline & Qatar & 48.6 & $(0.6)$ & 28.6 & $(0.6)$ & 22.1 & $(0.6)$ & 21.6 & $(0.5)$ & 13.6 & $(0.4)$ & 11.8 & $(0.5)$ & 13.0 & $(0.5)$ \\
\hline & Romania & $\mathrm{m}$ & $\mathrm{m}$ & $\mathrm{m}$ & $\mathrm{m}$ & $\mathrm{m}$ & $\mathrm{m}$ & $\mathrm{m}$ & $\mathrm{m}$ & $\mathrm{m}$ & $\mathrm{m}$ & $\mathrm{m}$ & $\mathrm{m}$ & $\mathrm{m}$ & $\mathrm{m}$ \\
\hline & Russia & 72.4 & (1.1) & 60.9 & $(1.2)$ & 29.5 & (1.1) & 30.2 & $(1.0)$ & 9.7 & $(0.6)$ & 8.3 & $(0.6)$ & 9.9 & $(0.7)$ \\
\hline & Singapore & 49.7 & $(0.8)$ & 40.1 & $(0.9)$ & 12.1 & $(0.6)$ & 16.5 & $(0.7)$ & 8.6 & $(0.6)$ & 6.5 & $(0.4)$ & 5.2 & $(0.3)$ \\
\hline & Chinese Taipei & 41.9 & $(1.0)$ & 36.3 & $(0.8)$ & 5.3 & $(0.4)$ & 10.0 & $(0.5)$ & 6.2 & $(0.4)$ & 2.4 & $(0.3)$ & 1.9 & $(0.2)$ \\
\hline & Thailand & 59.1 & (1.1) & 52.3 & $(1.1)$ & 20.0 & $(0.8)$ & 17.9 & $(0.8)$ & 11.7 & $(0.6)$ & 12.0 & $(0.6)$ & 11.0 & $(0.5)$ \\
\hline & Trinidad and Tobago & $\mathrm{m}$ & $\mathrm{m}$ & $\mathrm{m}$ & $\mathrm{m}$ & $\mathrm{m}$ & $\mathrm{m}$ & $\mathrm{m}$ & $\mathrm{m}$ & $\mathrm{m}$ & $\mathrm{m}$ & $\mathrm{m}$ & $\mathrm{m}$ & $\mathrm{m}$ & $\mathrm{m}$ \\
\hline & Tunisia & 50.1 & $(0.9)$ & 26.2 & $(0.9)$ & 17.0 & $(0.8)$ & 23.5 & $(1.0)$ & 8.0 & $(0.6)$ & 9.0 & $(0.6)$ & 9.5 & $(0.6)$ \\
\hline & United Arab Emirates & 48.9 & $(0.8)$ & 31.5 & $(0.8)$ & 18.7 & $(0.7)$ & 21.2 & $(0.5)$ & 14.7 & $(0.6)$ & 11.2 & $(0.6)$ & 12.4 & $(0.5)$ \\
\hline & Uruguay & 46.5 & $(1.0)$ & 31.9 & $(1.0)$ & 22.2 & $(0.7)$ & 11.6 & $(0.6)$ & 5.2 & $(0.4)$ & 5.0 & $(0.4)$ & 2.6 & $(0.3)$ \\
\hline & Viet Nam & $\mathrm{m}$ & $\mathrm{m}$ & $\mathrm{m}$ & $\mathrm{m}$ & $\mathrm{m}$ & $\mathrm{m}$ & $\mathrm{m}$ & $\mathrm{m}$ & $\mathrm{m}$ & $\mathrm{m}$ & $\mathrm{m}$ & $\mathrm{m}$ & $\mathrm{m}$ & $\mathrm{m}$ \\
\hline & Argentina** $^{* *}$ & $\mathrm{~m}$ & $\mathrm{~m}$ & $\mathrm{~m}$ & $\mathrm{~m}$ & $\mathrm{~m}$ & $\mathrm{~m}$ & $\mathrm{~m}$ & $\mathrm{~m}$ & $\mathrm{~m}$ & $\mathrm{~m}$ & $\mathrm{~m}$ & $\mathrm{~m}$ & $\mathrm{~m}$ & $\mathrm{~m}$ \\
\hline & Kazakhstan** & $\mathrm{m}$ & $\mathrm{m}$ & $\mathrm{m}$ & $\mathrm{m}$ & $\mathrm{m}$ & $\mathrm{m}$ & $\mathrm{m}$ & $\mathrm{m}$ & $\mathrm{m}$ & $\mathrm{m}$ & $\mathrm{m}$ & $\mathrm{m}$ & $\mathrm{m}$ & $\mathrm{m}$ \\
\hline & Malaysia** & 72.5 & $(0.9)$ & 64.4 & $(0.9)$ & 29.2 & (1.0) & 19.0 & $(0.8)$ & 21.2 & $(0.8)$ & 10.9 & $(0.7)$ & 7.2 & (0.6) \\
\hline
\end{tabular}

. A socio-economically disadvantaged student is a student in the bottom quarter of the PISA index of economic, social and cultural status (ESCS) within his or her own country/economy. 2. A socio-economically advantaged student is a student in the top quarter of the PISA index of economic, social and cultural status (ESCS) within his or her own country/economy. Note: Values that are statistically significant are indicated in bold (see Annex A3).

* See note at the beginning of this Annex.

** Coverage is too small to ensure comparability (see Annex A4).

StatLink 需四 http://dx.doi.org/10.1787/888933471410 
[Part 3/6]

Table III.7.16 Students' perception of teacher unfairness, by gender and socio-economic status

Percentage of students who reported "once a week or more" or "a few times a month"

\begin{tabular}{|c|c|c|c|c|c|c|c|c|c|c|c|c|c|c|}
\hline & \multicolumn{14}{|c|}{ Gender difference in the percentage of students who reported being treated unfairly by their teachers (B - G) } \\
\hline & \multicolumn{2}{|c|}{$\begin{array}{l}\text { Any unfair } \\
\text { treatment }\end{array}$} & \multicolumn{2}{|c|}{$\begin{array}{l}\text { Teachers called } \\
\text { on me less often } \\
\text { than they called } \\
\text { on other students }\end{array}$} & \multicolumn{2}{|c|}{$\begin{array}{c}\text { Teachers graded me } \\
\text { harder than } \\
\text { they graded } \\
\text { other students }\end{array}$} & \multicolumn{2}{|c|}{$\begin{array}{c}\text { Teachers gave me } \\
\text { the impression } \\
\text { that I am less smart } \\
\text { than I really am }\end{array}$} & \multicolumn{2}{|c|}{$\begin{array}{l}\text { Teachers disciplined } \\
\text { me more harshly } \\
\text { than other students }\end{array}$} & \multicolumn{2}{|c|}{$\begin{array}{c}\text { Teachers ridiculed } \\
\text { me in front } \\
\text { of others }\end{array}$} & \multicolumn{2}{|c|}{$\begin{array}{l}\text { Teachers said } \\
\text { something insulting } \\
\text { to me in front } \\
\text { of others }\end{array}$} \\
\hline & $\%$ dif. & S.E. & $\%$ dif. & S.E. & $\%$ dif. & S.E. & $\%$ dif. & S.E. & $\%$ dif. & S.E. & $\%$ dif. & S.E. & $\%$ dif. & S.E. \\
\hline Australia & 6.7 & $(1.0)$ & 3.2 & $(1.0)$ & 6.5 & $(0.7)$ & 3.4 & $(0.9)$ & 9.9 & $(0.7)$ & 6.5 & $(0.7)$ & 4.7 & $(0.7)$ \\
\hline Austria & 8.8 & (1.4) & 2.6 & (1.3) & 7.7 & (1.1) & 4.6 & $(1.2)$ & 10.0 & $(1.1)$ & 6.9 & $(1.0)$ & 5.7 & $(0.8)$ \\
\hline 0 Belgium & 10.7 & $(1.2)$ & 4.3 & $(1.2)$ & 11.3 & $(0.9)$ & 6.7 & (1.1) & 12.4 & $(0.7)$ & 5.8 & $(0.7)$ & 5.3 & $(0.7)$ \\
\hline Canada & $\mathrm{m}$ & $\mathrm{m}$ & $\mathrm{m}$ & $\mathrm{m}$ & $\mathrm{m}$ & $\mathrm{m}$ & $\mathrm{m}$ & $\mathrm{m}$ & $\mathrm{m}$ & $\mathrm{m}$ & $\mathrm{m}$ & $\mathrm{m}$ & $\mathrm{m}$ & $\mathrm{m}$ \\
\hline Chile & 8.9 & (1.5) & 4.3 & (1.6) & 4.8 & (1.3) & 2.4 & $(1.0)$ & 8.0 & (1.0) & 3.7 & $(0.8)$ & 2.5 & $(0.7)$ \\
\hline Czech Republic & 4.9 & (1.6) & 1.6 & (1.6) & 6.1 & (1.0) & 6.3 & (1.1) & 8.4 & (1.0) & 4.2 & (1.0) & 4.5 & (1.0) \\
\hline Denmark & 10.4 & $(1.7)$ & 2.9 & (1.5) & 10.7 & $(1.3)$ & 5.9 & $(1.0)$ & 10.5 & (1.1) & 5.0 & $(0.8)$ & 3.8 & $(1.0)$ \\
\hline Estonia & 2.1 & (1.5) & 0.1 & (1.5) & 5.7 & (1.4) & 2.6 & (1.4) & 10.0 & (1.0) & 3.6 & (1.0) & 4.0 & (1.1) \\
\hline Finland & 6.6 & (1.5) & 1.7 & $(1.2)$ & 5.7 & $(1.0)$ & 2.6 & $(1.0)$ & 10.8 & (1.0) & 4.8 & $(0.8)$ & 4.1 & $(0.8)$ \\
\hline France & 7.0 & (1.1) & 2.5 & (1.4) & 7.8 & (1.1) & 2.9 & $(1.0)$ & 12.0 & $(0.9)$ & 4.7 & $(0.9)$ & 5.0 & $(0.8)$ \\
\hline Germany & 7.9 & (1.4) & 2.8 & (1.4) & 6.1 & (1.1) & 4.5 & (1.1) & 10.7 & (1.0) & 2.9 & $(0.8)$ & 2.7 & $(0.6)$ \\
\hline Greece & 5.2 & (1.4) & -1.3 & (1.6) & 6.2 & $(1.2)$ & 4.3 & $(1.2)$ & 12.0 & (0.9) & 6.0 & (0.9) & 6.9 & (1.0) \\
\hline Hungary & 4.7 & (1.3) & 1.0 & (1.5) & 6.2 & (1.1) & 1.5 & $(1.2)$ & 9.5 & (1.3) & 3.8 & (1.1) & 3.5 & $(1.2)$ \\
\hline Iceland & 3.3 & (1.8) & -1.4 & (1.6) & 1.8 & (1.1) & 1.6 & (1.1) & 6.2 & (1.3) & 2.2 & $(0.8)$ & 0.8 & $(0.8)$ \\
\hline Ireland & 10.3 & (1.4) & 5.2 & (1.1) & 8.1 & (1.0) & 3.9 & (1.0) & 11.7 & (0.9) & 6.3 & $(0.8)$ & 4.4 & $(0.7)$ \\
\hline Israel & $\mathrm{m}$ & $\mathrm{m}$ & $\mathrm{m}$ & $\mathrm{m}$ & $\mathrm{m}$ & $\mathrm{m}$ & $\mathrm{m}$ & $\mathrm{m}$ & $\mathrm{m}$ & $\mathrm{m}$ & $\mathrm{m}$ & $\mathrm{m}$ & $\mathrm{m}$ & $\mathrm{m}$ \\
\hline Italy & $\mathrm{m}$ & $\mathrm{m}$ & $\mathrm{m}$ & $\mathrm{m}$ & $\mathrm{m}$ & $\mathrm{m}$ & $\mathrm{m}$ & $\mathrm{m}$ & $\mathrm{m}$ & $\mathrm{m}$ & $\mathrm{m}$ & $\mathrm{m}$ & $\mathrm{m}$ & $\mathrm{m}$ \\
\hline Japan & 5.5 & (1.3) & 3.0 & $(1.2)$ & 4.2 & $(0.5)$ & 5.2 & $(0.6)$ & 5.3 & (0.8) & 3.5 & (0.6) & 3.0 & $(0.6)$ \\
\hline Korea & 5.6 & (1.4) & 4.1 & (1.4) & 5.5 & $(0.8)$ & 4.9 & (1.0) & 5.1 & $(0.7)$ & 2.7 & (0.6) & 2.2 & (0.6) \\
\hline Latvia & 5.2 & (1.6) & 0.5 & (1.8) & 8.8 & (1.6) & 6.3 & (1.4) & 11.1 & (1.0) & 6.6 & (0.9) & 5.4 & $(0.9)$ \\
\hline Luxembourg & 9.8 & (1.4) & 5.9 & (1.4) & 12.6 & (1.1) & 7.6 & (1.2) & 15.0 & (0.9) & 7.7 & (0.8) & 8.0 & $(0.7)$ \\
\hline Mexico & 12.4 & (1.3) & 5.4 & (0.9) & 7.9 & (1.0) & 7.8 & (0.9) & 4.9 & $(0.7)$ & 3.7 & $(0.6)$ & 2.5 & (0.5) \\
\hline Netherlands & 6.8 & (1.5) & 0.6 & (1.2) & 8.7 & (1.0) & 2.7 & (1.0) & 8.5 & (1.1) & 3.8 & $(0.7)$ & 2.9 & $(0.7)$ \\
\hline New Zealand & 7.8 & (1.5) & 5.6 & (1.5) & 5.6 & $(1.0)$ & 2.2 & $(1.3)$ & 9.0 & $(1.0)$ & 7.0 & $(1.1)$ & 5.5 & $(1.1)$ \\
\hline Norway & 5.7 & (1.5) & 2.2 & $(1.2)$ & 5.9 & (1.4) & 0.6 & (1.3) & 10.9 & $(1.2)$ & 4.3 & $(0.9)$ & 3.0 & (1.0) \\
\hline Poland & 10.3 & (1.4) & 4.6 & (1.5) & 10.6 & (1.4) & 6.2 & $(1.3)$ & 10.5 & $(1.2)$ & 6.2 & $(0.9)$ & 6.4 & $(1.0)$ \\
\hline Portugal & 8.9 & (1.3) & 5.7 & $(1.2)$ & 8.5 & (1.1) & 4.1 & (1.1) & 13.0 & (1.1) & 4.8 & $(0.8)$ & 4.0 & $(0.9)$ \\
\hline Slovak Republic & 3.7 & (1.3) & -1.2 & (1.4) & 6.6 & $(1.1)$ & 6.2 & (1.3) & 9.2 & (1.1) & 4.8 & $(0.9)$ & 4.3 & $(0.9)$ \\
\hline Slovenia & 2.5 & $(1.7)$ & 0.0 & $(1.7)$ & 6.8 & $(1.1)$ & 1.8 & $(1.1)$ & 8.9 & (1.1) & 4.9 & $(0.8)$ & 4.3 & $(0.8)$ \\
\hline Spain & 15.7 & (1.4) & 8.1 & $(1.0)$ & 13.2 & (1.0) & 6.4 & (1.1) & 12.9 & (1.0) & 4.5 & $(0.8)$ & 4.9 & $(0.8)$ \\
\hline Sweden & 6.4 & (1.4) & 5.0 & (1.3) & 4.1 & (1.1) & 2.4 & (1.0) & 8.6 & (1.0) & 5.1 & (1.0) & 3.4 & $(0.8)$ \\
\hline Switzerland & 11.1 & (1.5) & 5.1 & (1.3) & 9.3 & $(1.2)$ & 5.7 & (1.3) & 15.1 & $(1.2)$ & 5.7 & $(0.8)$ & 4.4 & $(0.8)$ \\
\hline Turkey & 7.0 & $(1.2)$ & 0.4 & (1.4) & 9.5 & (1.1) & 5.4 & (1.1) & 9.2 & (1.1) & 9.3 & $(1.0)$ & 7.9 & (1.1) \\
\hline United Kingdom & 5.0 & $(1.2)$ & 2.2 & (1.3) & 6.3 & $(1.1)$ & 3.1 & $(1.2)$ & 10.5 & (1.0) & 4.8 & $(1.2)$ & 4.9 & (1.1) \\
\hline United States & 5.3 & (1.4) & 0.6 & (1.5) & 5.7 & $(1.0)$ & 1.6 & (1.1) & 8.1 & $(0.9)$ & 5.0 & (1.0) & 4.3 & $(0.9)$ \\
\hline OECD average & 7.3 & $(0.2)$ & 2.7 & $(0.2)$ & 7.3 & $(0.2)$ & 4.2 & $(0.2)$ & 9.9 & $(0.2)$ & 5.0 & $(0.2)$ & 4.4 & $(0.2)$ \\
\hline
\end{tabular}

\begin{tabular}{|c|c|c|c|c|c|c|c|c|c|c|c|c|c|c|}
\hline Albania & $\mathrm{m}$ & $\mathrm{m}$ & $\mathrm{m}$ & $\mathrm{m}$ & $\mathrm{m}$ & $\mathrm{m}$ & $\mathrm{m}$ & $\mathrm{m}$ & $\mathrm{m}$ & $\mathrm{m}$ & $\mathrm{m}$ & $\mathrm{m}$ & $\mathrm{m}$ & $\mathrm{m}$ \\
\hline Algeria & $\mathrm{m}$ & $\mathrm{m}$ & $\mathrm{m}$ & $\mathrm{m}$ & $\mathrm{m}$ & $\mathrm{m}$ & $\mathrm{m}$ & $\mathrm{m}$ & $\mathrm{m}$ & $\mathrm{m}$ & $\mathrm{m}$ & $\mathrm{m}$ & $\mathrm{m}$ & $\mathrm{m}$ \\
\hline Brazil & 11.1 & $(1.0)$ & 6.7 & $(0.8)$ & 8.4 & $(0.8)$ & 6.9 & $(0.8)$ & 7.1 & $(0.7)$ & 5.5 & $(0.6)$ & 5.7 & $(0.6$ \\
\hline B-S-J-G (China) & 5.2 & $(1.2)$ & 0.8 & (1.3) & 9.3 & $(1.3)$ & 5.4 & $(1.0)$ & 11.5 & $(1.2)$ & 6.5 & $(0.6)$ & 5.8 & $(0.5)$ \\
\hline Bulgaria & 4.3 & (1.4) & 2.6 & (1.3) & 3.8 & (1.5) & 5.6 & (1.4) & 9.8 & (1.1) & 8.9 & $(0.9)$ & 5.0 & $(1.0)$ \\
\hline CABA (Argentina) & $\mathrm{m}$ & $\mathrm{m}$ & $\mathrm{m}$ & $\mathrm{m}$ & $\mathrm{m}$ & $\mathrm{m}$ & $\mathrm{m}$ & $\mathrm{m}$ & $\mathrm{m}$ & $\mathrm{m}$ & $\mathrm{m}$ & $\mathrm{m}$ & $\mathrm{m}$ & $\mathrm{m}$ \\
\hline Colombia & 13.3 & (1.3) & 7.9 & $(1.2)$ & 9.5 & $(0.9)$ & 4.3 & $(0.8)$ & 7.7 & $(0.9)$ & 5.6 & $(0.7)$ & 4.5 & $(0.8)$ \\
\hline Costa Rica & 11.5 & (1.3) & 6.5 & (1.2) & 8.6 & (1.1) & 4.2 & $(0.9)$ & 8.1 & $(1.0)$ & 3.7 & $(0.8)$ & 2.3 & $(0.6)$ \\
\hline Croatia & 3.7 & (1.4) & 2.1 & (1.2) & 6.1 & (1.3) & 1.4 & (1.2) & 8.1 & (1.1) & 4.5 & $(0.8)$ & 4.6 & $(0.8)$ \\
\hline Cyprus* & 9.3 & (1.4) & 1.2 & $(1.2)$ & 10.1 & $(1.2)$ & 6.5 & $(1.2)$ & 15.1 & (1.1) & 9.1 & $(1.0)$ & 9.5 & $(1.0)$ \\
\hline Dominican Republic & 8.6 & (1.7) & 3.3 & (1.4) & 8.4 & $(1.6)$ & 6.5 & (1.3) & 6.2 & $(0.9)$ & 4.3 & $(1.0)$ & 4.9 & $(1.1)$ \\
\hline FYROM & $\mathrm{m}$ & $\mathrm{m}$ & $\mathrm{m}$ & $\mathrm{m}$ & $\mathrm{m}$ & $\mathrm{m}$ & $\mathrm{m}$ & $\mathrm{m}$ & $\mathrm{m}$ & $\mathrm{m}$ & $\mathrm{m}$ & $\mathrm{m}$ & $\mathrm{m}$ & $\mathrm{m}$ \\
\hline Georgia & $\mathrm{m}$ & $\mathrm{m}$ & $\mathrm{m}$ & $\mathrm{m}$ & $\mathrm{m}$ & $\mathrm{m}$ & $\mathrm{m}$ & $\mathrm{m}$ & $\mathrm{m}$ & $\mathrm{m}$ & $\mathrm{m}$ & $\mathrm{m}$ & $\mathrm{m}$ & $\mathrm{m}$ \\
\hline Hong Kong (China) & 6.8 & (1.5) & 1.2 & (1.6) & 12.6 & $(1.3)$ & 13.5 & (1.4) & 10.6 & $(1.0)$ & 12.9 & (1.1) & 9.4 & $(0.9)$ \\
\hline Indonesia & $\mathrm{m}$ & $\mathrm{m}$ & $\mathrm{m}$ & $\mathrm{m}$ & $\mathrm{m}$ & $\mathrm{m}$ & $\mathrm{m}$ & $\mathrm{m}$ & $\mathrm{m}$ & $\mathrm{m}$ & $\mathrm{m}$ & $\mathrm{m}$ & $\mathrm{m}$ & $\mathrm{m}$ \\
\hline Jordan & $\mathrm{m}$ & $\mathrm{m}$ & $\mathrm{m}$ & $\mathrm{m}$ & $\mathrm{m}$ & $\mathrm{m}$ & $\mathrm{m}$ & $\mathrm{m}$ & $\mathrm{m}$ & $\mathrm{m}$ & $\mathrm{m}$ & $\mathrm{m}$ & $\mathrm{m}$ & $\mathrm{m}$ \\
\hline Kosovo & $\mathrm{m}$ & $\mathrm{m}$ & $\mathrm{m}$ & $\mathrm{m}$ & $\mathrm{m}$ & $\mathrm{m}$ & $\mathrm{m}$ & $\mathrm{m}$ & $\mathrm{m}$ & $\mathrm{m}$ & $\mathrm{m}$ & $\mathrm{m}$ & $\mathrm{m}$ & $\mathrm{m}$ \\
\hline Lebanon & $\mathrm{m}$ & $\mathrm{m}$ & $\mathrm{m}$ & $\mathrm{m}$ & $\mathrm{m}$ & $\mathrm{m}$ & $\mathrm{m}$ & $\mathrm{m}$ & $\mathrm{m}$ & $\mathrm{m}$ & $\mathrm{m}$ & $\mathrm{m}$ & $\mathrm{m}$ & $\mathrm{m}$ \\
\hline Lithuania & 9.1 & (1.2) & 4.8 & $(1.2)$ & 8.9 & $(1.2)$ & 8.4 & $(1.1)$ & 15.9 & (1.1) & 10.1 & $(0.9)$ & 8.5 & $(1.0)$ \\
\hline Macao (China) & 6.3 & (1.2) & 3.7 & (1.5) & 8.2 & $(1.2)$ & 7.6 & (1.3) & 8.4 & (1.2) & 8.0 & $(0.9)$ & 5.6 & $(0.6)$ \\
\hline Malta & $\mathrm{m}$ & $\mathrm{m}$ & $\mathrm{m}$ & $\mathrm{m}$ & $\mathrm{m}$ & $\mathrm{m}$ & $\mathrm{m}$ & $\mathrm{m}$ & $\mathrm{m}$ & $\mathrm{m}$ & $\mathrm{m}$ & $\mathrm{m}$ & $\mathrm{m}$ & $\mathrm{m}$ \\
\hline Moldova & $\mathrm{m}$ & $\mathrm{m}$ & $\mathrm{m}$ & $\mathrm{m}$ & $\mathrm{m}$ & $\mathrm{m}$ & $\mathrm{m}$ & $\mathrm{m}$ & $\mathrm{m}$ & $\mathrm{m}$ & $\mathrm{m}$ & $\mathrm{m}$ & $\mathrm{m}$ & $\mathrm{m}$ \\
\hline Montenegro & 4.3 & (1.2) & 0.9 & (1.4) & 2.5 & $(0.9)$ & 5.0 & $(0.9)$ & 7.9 & $(0.8)$ & 4.7 & $(0.7)$ & 4.8 & $(0.7)$ \\
\hline Peru & 12.8 & (1.4) & 6.3 & (1.2) & 9.2 & (1.1) & 7.3 & (1.1) & 10.1 & (1.0) & 4.6 & $(0.6)$ & 3.5 & $(0.7)$ \\
\hline Qatar & 10.3 & $(1.0)$ & 6.7 & $(0.9)$ & 7.7 & $(0.9)$ & 7.8 & $(0.8)$ & 12.5 & $(0.8)$ & 11.0 & $(0.8)$ & 9.3 & $(0.8)$ \\
\hline Romania & $\mathrm{m}$ & $\mathrm{m}$ & $\mathrm{m}$ & $\mathrm{m}$ & $\mathrm{m}$ & $\mathrm{m}$ & $\mathrm{m}$ & $\mathrm{m}$ & $\mathrm{m}$ & $\mathrm{m}$ & $\mathrm{m}$ & $\mathrm{m}$ & $\mathrm{m}$ & $\mathrm{m}$ \\
\hline Russia & 1.5 & (1.6) & -0.2 & (1.6) & 6.9 & (1.4) & 4.1 & (1.7) & 8.7 & (1.1) & 6.3 & $(0.9)$ & 4.1 & $(0.8)$ \\
\hline Singapore & 8.6 & (1.1) & 4.7 & (1.2) & 9.9 & $(1.0)$ & 4.3 & $(1.2)$ & 10.8 & (1.1) & 10.2 & $(0.8)$ & 7.7 & $(0.7)$ \\
\hline Chinese Taipei & 6.6 & (1.3) & 2.9 & $(1.2)$ & 3.8 & $(0.6)$ & 7.2 & $(0.8)$ & 5.5 & $(0.8)$ & 4.6 & $(0.6)$ & 3.8 & $(0.5)$ \\
\hline Thailand & 5.8 & (1.3) & 2.1 & (1.4) & 9.0 & $(1.0)$ & 10.9 & $(1.0)$ & 12.2 & (1.1) & 10.3 & (1.2) & 10.2 & $(0.9)$ \\
\hline Trinidad and Tobago & $\mathrm{m}$ & $\mathrm{m}$ & $\mathrm{m}$ & $\mathrm{m}$ & $\mathrm{m}$ & $\mathrm{m}$ & $\mathrm{m}$ & $\mathrm{m}$ & $\mathrm{m}$ & $\mathrm{m}$ & $\mathrm{m}$ & $\mathrm{m}$ & $\mathrm{m}$ & $\mathrm{m}$ \\
\hline Tunisia & 13.0 & (1.3) & 7.0 & $(1.2)$ & 5.7 & (1.1) & 8.4 & (1.4) & 12.9 & (1.1) & 11.9 & (1.1) & 10.8 & (1.1) \\
\hline United Arab Emirates & 10.6 & (1.1) & 3.9 & $(1.2)$ & 9.4 & $(0.9)$ & 8.9 & $(0.9)$ & 11.2 & (1.0) & 10.9 & $(0.9)$ & 9.0 & $(0.9)$ \\
\hline Uruguay & 9.8 & (1.3) & 6.1 & (1.3) & 8.0 & (1.1) & 5.8 & (1.0) & 9.1 & $(0.7)$ & 4.8 & $(0.8)$ & 3.5 & $(0.5)$ \\
\hline Viet Nam & $\mathrm{m}$ & $\mathrm{m}$ & $\mathrm{m}$ & $\mathrm{m}$ & $\mathrm{m}$ & $\mathrm{m}$ & $\mathrm{m}$ & $\mathrm{m}$ & $\mathrm{m}$ & $\mathrm{m}$ & $\mathrm{m}$ & $\mathrm{m}$ & $\mathrm{m}$ & $\mathrm{m}$ \\
\hline Argentina** & $\mathrm{m}$ & $\mathrm{m}$ & $\mathrm{m}$ & $\mathrm{m}$ & $\mathrm{m}$ & $\mathrm{m}$ & $\mathrm{m}$ & $\mathrm{m}$ & $\mathrm{m}$ & $\mathrm{m}$ & $\mathrm{m}$ & $\mathrm{m}$ & $\mathrm{m}$ & $\mathrm{m}$ \\
\hline Kazakhstan** & $\mathrm{m}$ & $\mathrm{m}$ & $\mathrm{m}$ & $\mathrm{m}$ & $\mathrm{m}$ & $\mathrm{m}$ & $\mathrm{m}$ & $\mathrm{m}$ & $\mathrm{m}$ & $\mathrm{m}$ & $\mathrm{m}$ & $\mathrm{m}$ & $\mathrm{m}$ & $\mathrm{m}$ \\
\hline Malaysia** & 9.8 & $(1.2)$ & 6.0 & (1.3) & 13.2 & (1.3) & 14.9 & (1.2) & 17.4 & $(1.2)$ & 12.6 & $(1.0)$ & 8.8 & $(0.9)$ \\
\hline
\end{tabular}

A socio-economically disadvantaged student is a student in the bottom quarter of the PISA index of economic, social and cultural status (ESCS) within his or her own country/economy. 2. A socio-economically advantaged student is a student in the top quarter of the PISA index of economic, social and cultural status (ESCS) within his or her own country/economy. Note: Values that are statistically significant are indicated in bold (see Annex A3).

** See note at the beginning of this Annex.

Coverage is too small to ensure comparability (see Annex A4). 
Percentage of students who reported "once a week or more" or "a few times a month"

\begin{tabular}{|c|c|c|c|c|c|c|c|c|c|c|c|c|c|c|}
\hline & \multicolumn{14}{|c|}{$\begin{array}{l}\text { Percentage of socio-economically disadvantaged }{ }^{1} \text { students who reported being treated unfairly } \\
\text { by their teachers a few times a month or more frequently }\end{array}$} \\
\hline & \multicolumn{2}{|c|}{$\begin{array}{l}\text { Any unfair } \\
\text { treatment }\end{array}$} & \multicolumn{2}{|c|}{$\begin{array}{l}\text { Teachers called } \\
\text { on me less often } \\
\text { than they called } \\
\text { on other students }\end{array}$} & \multicolumn{2}{|c|}{\begin{tabular}{|c|} 
Teachers graded me \\
harder than \\
they graded \\
other students
\end{tabular}} & \multicolumn{2}{|c|}{\begin{tabular}{|c|} 
Teachers gave me \\
the impression \\
that I am less smart \\
than I really am
\end{tabular}} & \multicolumn{2}{|c|}{$\begin{array}{l}\text { Teachers disciplined } \\
\text { me more harshly } \\
\text { than other students }\end{array}$} & \multicolumn{2}{|c|}{$\begin{array}{c}\text { Teachers ridiculed } \\
\text { me in front } \\
\text { of others }\end{array}$} & \multicolumn{2}{|c|}{$\begin{array}{c}\text { Teachers said } \\
\text { something insulting } \\
\text { to me in front } \\
\text { of others }\end{array}$} \\
\hline & $\%$ & S.E. & $\%$ & S.E. & $\%$ & S.E. & $\%$ & S.E. & $\%$ & S.E. & $\%$ & S.E. & $\%$ & S.E. \\
\hline Australia & 54.0 & $(0.9)$ & 14.5 & $(0.8)$ & 17.6 & $(0.8)$ & 19.5 & $(0.9)$ & 27.0 & $(1.0)$ & 16.8 & $(0.8)$ & 37.4 & $(0.8)$ \\
\hline Austria & 60.0 & $(1.3)$ & 9.7 & $(0.9)$ & 13.3 & $(1.0)$ & 21.0 & (1.1) & 26.1 & $(1.3)$ & 18.0 & $(1.2)$ & 44.0 & $(1.3)$ \\
\hline Belgium & 53.2 & $(1.1)$ & 9.3 & $(0.9)$ & 11.3 & $(0.8)$ & 15.8 & $(1.1)$ & 21.9 & $(1.0)$ & 21.7 & $(1.0)$ & 37.3 & (1.1) \\
\hline Canada & $\mathrm{m}$ & $\mathrm{m}$ & $\mathrm{m}$ & $\mathrm{m}$ & $\mathrm{m}$ & $\mathrm{m}$ & $\mathrm{m}$ & $\mathrm{m}$ & $\mathrm{m}$ & $\mathrm{m}$ & $\mathrm{m}$ & $\mathrm{m}$ & $\mathrm{m}$ & $\mathrm{m}$ \\
\hline Chile & 47.9 & (1.6) & 4.5 & $(0.6)$ & 7.2 & $(1.0)$ & 15.5 & $(1.2)$ & 15.6 & $(1.0)$ & 21.8 & $(1.3)$ & 32.5 & $(1.4)$ \\
\hline Czech Republic & 58.0 & (1.6) & 11.6 & $(0.9)$ & 12.0 & $(1.2)$ & 10.3 & $(0.9)$ & 22.8 & $(1.3)$ & 14.6 & (1.0) & 41.2 & (1.5) \\
\hline Denmark & 49.9 & $(1.7)$ & 10.4 & $(0.9)$ & 10.1 & $(0.8)$ & 13.5 & (1.0) & 16.6 & $(1.3)$ & 19.1 & $(1.2)$ & 34.9 & (1.7) \\
\hline Estonia & 64.1 & (1.6) & 13.0 & (1.1) & 12.5 & $(1.0)$ & 11.0 & $(1.0)$ & 27.0 & (1.4) & 30.1 & (1.5) & 48.0 & (1.5) \\
\hline Finland & 42.4 & (1.4) & 7.6 & $(0.8)$ & 7.7 & $(0.7)$ & 17.8 & (1.0) & 20.4 & $(1.2)$ & 18.4 & (1.1) & 25.5 & (1.1) \\
\hline France & 64.4 & (1.4) & 10.0 & $(1.0)$ & 13.4 & $(1.1)$ & 15.4 & (1.0) & 31.3 & (1.6) & 21.6 & (1.3) & 48.6 & $(1.2)$ \\
\hline Germany & 54.8 & $(1.8)$ & 5.4 & $(0.8)$ & 8.2 & $(0.8)$ & 16.9 & (1.1) & 21.5 & $(1.5)$ & 16.3 & (1.1) & 38.7 & (1.7) \\
\hline Greece & 62.7 & (1.5) & 9.0 & $(1.1)$ & 7.7 & $(0.8)$ & 11.7 & (1.1) & 19.9 & (1.1) & 24.5 & (1.4) & 44.4 & (1.6) \\
\hline Hungary & 77.8 & (1.1) & 16.0 & (1.3) & 13.4 & $(1.2)$ & 20.3 & (1.0) & 33.4 & (1.4) & 20.8 & $(1.2)$ & 64.5 & (1.4) \\
\hline Iceland & 29.8 & (1.9) & 5.6 & $(0.9)$ & 5.1 & $(0.9)$ & 11.1 & (1.3) & 10.5 & (1.3) & 8.7 & (1.3) & 21.0 & (1.7) \\
\hline Ireland & 44.9 & (1.3) & 9.2 & $(0.8)$ & 9.3 & $(0.8)$ & 15.6 & (1.0) & 20.0 & (1.1) & 11.5 & (1.0) & 29.4 & (1.3) \\
\hline Israel & $\mathrm{m}$ & $\mathrm{m}$ & $\mathrm{m}$ & $\mathrm{m}$ & $\mathrm{m}$ & $\mathrm{m}$ & $\mathrm{m}$ & $\mathrm{m}$ & $\mathrm{m}$ & $\mathrm{m}$ & $\mathrm{m}$ & $\mathrm{m}$ & $\mathrm{m}$ & $\mathrm{m}$ \\
\hline Italy & $\mathrm{m}$ & $\mathrm{m}$ & $\mathrm{m}$ & $\mathrm{m}$ & $\mathrm{m}$ & $\mathrm{m}$ & $\mathrm{m}$ & $\mathrm{m}$ & $\mathrm{m}$ & $\mathrm{m}$ & $\mathrm{m}$ & $\mathrm{m}$ & $\mathrm{m}$ & $\mathrm{m}$ \\
\hline Japan & 42.6 & (1.3) & 4.6 & $(0.5)$ & 6.3 & $(0.7)$ & 8.5 & $(0.8)$ & 8.4 & $(0.7)$ & 6.0 & (0.6) & 37.5 & $(1.2)$ \\
\hline Korea & 39.6 & (1.4) & 4.7 & $(0.6)$ & 4.7 & $(0.6)$ & 8.3 & $(0.8)$ & 13.6 & $(1.0)$ & 8.3 & $(0.8)$ & 35.1 & (1.4) \\
\hline Latvia & 61.9 & (1.6) & 12.4 & $(1.3)$ & 8.9 & $(1.0)$ & 13.3 & (1.3) & 26.4 & $(1.2)$ & 25.0 & (1.4) & 41.9 & (1.7) \\
\hline Luxembourg & 58.2 & (1.4) & 8.7 & $(0.9)$ & 9.6 & $(0.8)$ & 15.6 & (0.8) & 24.6 & (1.3) & 16.3 & (0.9) & 45.4 & (1.3) \\
\hline Mexico & 28.8 & (1.3) & 4.1 & $(0.6)$ & 4.7 & $(0.7)$ & 5.7 & $(0.7)$ & 15.7 & (1.0) & 15.3 & (1.1) & 16.1 & (1.1) \\
\hline Netherlands & 36.4 & (1.4) & 4.8 & $(0.7)$ & 6.4 & $(0.8)$ & 13.0 & $(1.0)$ & 11.0 & $(0.8)$ & 14.3 & (0.9) & 21.4 & (1.4) \\
\hline New Zealand & 52.5 & (1.5) & 17.7 & (1.4) & 16.1 & $(1.2)$ & 20.2 & $(1.2)$ & 24.4 & (1.3) & 17.1 & $(1.2)$ & 36.0 & (1.4) \\
\hline Norway & 43.1 & $(1.5)$ & 10.9 & $(0.9)$ & 10.1 & $(0.9)$ & 14.4 & $(1.1)$ & 22.9 & (1.3) & 24.8 & $(1.3)$ & 26.0 & $(1.3)$ \\
\hline Poland & 54.6 & (1.6) & 9.9 & $(1.0)$ & 8.2 & $(0.9)$ & 14.7 & $(1.1)$ & 23.4 & $(1.3)$ & 21.5 & (1.3) & 39.4 & (1.6) \\
\hline Portugal & 56.5 & (1.5) & 8.5 & $(0.9)$ & 9.8 & $(0.9)$ & 20.7 & $(1.2)$ & 26.2 & (1.4) & 19.7 & $(1.2)$ & 41.2 & (1.4) \\
\hline Slovak Republic & 63.3 & (1.7) & 9.3 & $(0.9)$ & 9.6 & $(0.9)$ & 11.4 & $(1.0)$ & 31.3 & (1.5) & 17.5 & $(1.1)$ & 45.6 & (1.8) \\
\hline Slovenia & 63.5 & (1.6) & 9.1 & $(0.9)$ & 7.9 & $(0.7)$ & 10.7 & $(0.9)$ & 20.8 & (1.4) & 20.6 & $(1.2)$ & 52.5 & (1.5) \\
\hline Spain & 45.9 & (1.6) & 6.9 & $(0.9)$ & 7.1 & $(0.7)$ & 13.0 & $(0.9)$ & 19.3 & $(1.1)$ & 20.4 & $(1.1)$ & 25.6 & (1.3) \\
\hline Sweden & 40.7 & (1.5) & 8.1 & $(0.8)$ & 12.3 & $(0.9)$ & 11.7 & $(0.9)$ & 19.9 & $(1.2)$ & 18.1 & (1.1) & 23.0 & $(1.2)$ \\
\hline Switzerland & 53.6 & $(1.3)$ & 8.7 & $(0.9)$ & 11.0 & $(0.9)$ & 16.7 & $(1.1)$ & 18.7 & $(1.2)$ & 12.7 & (1.1) & 41.0 & (1.6) \\
\hline Turkey & 60.8 & (1.5) & 12.5 & (1.1) & 10.0 & $(0.9)$ & 14.8 & $(1.1)$ & 24.3 & $(1.3)$ & 20.0 & (1.4) & 44.2 & (1.7) \\
\hline United Kingdom & 56.5 & (1.5) & 15.1 & $(1.1)$ & 17.8 & $(1.3)$ & 21.5 & $(1.2)$ & 27.4 & (1.3) & 14.9 & $(0.9)$ & 37.4 & $(1.3)$ \\
\hline United States & 52.1 & (1.5) & 10.6 & (1.1) & 13.2 & (1.1) & 13.9 & $(1.2)$ & 20.2 & (1.4) & 16.5 & (1.4) & 38.6 & (1.6) \\
\hline OECD average & 52.3 & $(0.3)$ & 9.5 & $(0.2)$ & 10.1 & $(0.2)$ & 14.5 & $(0.2)$ & 21.6 & $(0.2)$ & 17.9 & $(0.2)$ & 37.3 & $(0.3)$ \\
\hline
\end{tabular}

\begin{tabular}{|c|c|c|c|c|c|c|c|c|c|c|c|c|c|c|}
\hline Albania & $\mathrm{m}$ & $\mathrm{m}$ & $\mathrm{m}$ & $\mathrm{m}$ & $\mathrm{m}$ & $\mathrm{m}$ & $\mathrm{m}$ & $\mathrm{m}$ & $\mathrm{m}$ & $\mathrm{m}$ & $\mathrm{m}$ & $\mathrm{m}$ & $\mathrm{m}$ & $\mathrm{m}$ \\
\hline Algeria & $\mathrm{m}$ & $\mathrm{m}$ & $\mathrm{m}$ & $\mathrm{m}$ & $\mathrm{m}$ & $\mathrm{m}$ & $\mathrm{m}$ & $\mathrm{m}$ & $\mathrm{m}$ & $\mathrm{m}$ & $\mathrm{m}$ & $\mathrm{m}$ & $\mathrm{m}$ & $\mathrm{m}$ \\
\hline Brazil & 42.9 & $(0.9)$ & 9.0 & $(0.6)$ & 7.5 & $(0.5)$ & 12.0 & $(0.6)$ & 15.9 & $(0.8)$ & 17.3 & $(0.7)$ & 24.9 & $(0.8)$ \\
\hline B-S-J-G (China) & 61.3 & $(1.4)$ & 6.3 & $(0.6)$ & 6.5 & $(0.7)$ & 18.2 & $(1.5)$ & 19.0 & (1.3) & 26.0 & (1.7) & 49.3 & (1.4) \\
\hline Bulgaria & 58.5 & (1.4) & 14.3 & $(1.0)$ & 15.8 & (1.1) & 16.5 & (1.2) & 25.5 & (1.1) & 33.4 & (1.5) & 35.1 & $(1.2)$ \\
\hline CABA (Argentina) & $\mathrm{m}$ & $\mathrm{m}$ & $\mathrm{m}$ & $\mathrm{m}$ & $\mathrm{m}$ & $\mathrm{m}$ & $\mathrm{m}$ & $\mathrm{m}$ & $\mathrm{m}$ & $\mathrm{m}$ & $\mathrm{m}$ & $\mathrm{m}$ & $\mathrm{m}$ & $\mathrm{m}$ \\
\hline Colombia & 40.1 & $(1.4)$ & 7.9 & $(0.8)$ & 7.4 & $(0.7)$ & 9.4 & $(0.9)$ & 9.7 & $(0.9)$ & 13.9 & $(1.0)$ & 27.8 & (1.6) \\
\hline Costa Rica & 32.4 & $(1.5)$ & 2.9 & $(0.5)$ & 5.9 & $(0.7)$ & 11.9 & (1.1) & 7.4 & $(0.8)$ & 13.7 & $(1.2)$ & 21.6 & (1.4) \\
\hline Croatia & 55.3 & (1.4) & 4.8 & $(0.5)$ & 5.7 & $(0.6)$ & 8.5 & $(0.9)$ & 20.6 & (1.1) & 17.1 & (1.0) & 43.6 & (1.5) \\
\hline Cyprus* & 55.6 & (1.4) & 13.5 & $(0.9)$ & 12.9 & (1.1) & 14.6 & $(1.0)$ & 26.0 & (1.4) & 25.1 & (1.3) & 35.9 & $(1.2)$ \\
\hline Dominican Republic & 47.9 & (1.9) & 11.8 & (1.1) & 9.5 & (1.1) & 8.0 & $(0.9)$ & 20.2 & (1.4) & 25.2 & (1.4) & 27.3 & (1.7) \\
\hline FYROM & $\mathrm{m}$ & $\mathrm{m}$ & $\mathrm{m}$ & $\mathrm{m}$ & $\mathrm{m}$ & $\mathrm{m}$ & $\mathrm{m}$ & $\mathrm{m}$ & $\mathrm{m}$ & $\mathrm{m}$ & $\mathrm{m}$ & $\mathrm{m}$ & $\mathrm{m}$ & $\mathrm{m}$ \\
\hline Georgia & $\mathrm{m}$ & $\mathrm{m}$ & $\mathrm{m}$ & $\mathrm{m}$ & $\mathrm{m}$ & $\mathrm{m}$ & $\mathrm{m}$ & $\mathrm{m}$ & $\mathrm{m}$ & $\mathrm{m}$ & $\mathrm{m}$ & $\mathrm{m}$ & $\mathrm{m}$ & $\mathrm{m}$ \\
\hline Hong Kong (China) & 71.3 & $(1.4)$ & 9.0 & $(0.9)$ & 14.4 & $(1.2)$ & 15.0 & $(1.3)$ & 26.9 & $(1.2)$ & 27.5 & (1.3) & 62.0 & (1.4) \\
\hline Indonesia & $\mathrm{m}$ & $\mathrm{m}$ & $\mathrm{m}$ & $\mathrm{m}$ & $\mathrm{m}$ & $\mathrm{m}$ & $\mathrm{m}$ & $\mathrm{m}$ & $\mathrm{m}$ & $\mathrm{m}$ & $\mathrm{m}$ & $\mathrm{m}$ & $\mathrm{m}$ & $\mathrm{m}$ \\
\hline Jordan & $\mathrm{m}$ & $\mathrm{m}$ & $\mathrm{m}$ & $\mathrm{m}$ & $\mathrm{m}$ & $\mathrm{m}$ & $\mathrm{m}$ & $\mathrm{m}$ & $\mathrm{m}$ & $\mathrm{m}$ & $\mathrm{m}$ & $\mathrm{m}$ & $\mathrm{m}$ & $\mathrm{m}$ \\
\hline Kosovo & $\mathrm{m}$ & $\mathrm{m}$ & $\mathrm{m}$ & $\mathrm{m}$ & $\mathrm{m}$ & $\mathrm{m}$ & $\mathrm{m}$ & $\mathrm{m}$ & $\mathrm{m}$ & $\mathrm{m}$ & $\mathrm{m}$ & $\mathrm{m}$ & $\mathrm{m}$ & $\mathrm{m}$ \\
\hline Lebanon & $\mathrm{m}$ & $\mathrm{m}$ & $\mathrm{m}$ & $\mathrm{m}$ & $\mathrm{m}$ & $\mathrm{m}$ & $\mathrm{m}$ & $\mathrm{m}$ & $\mathrm{m}$ & $\mathrm{m}$ & $\mathrm{m}$ & $\mathrm{m}$ & $\mathrm{m}$ & $\mathrm{m}$ \\
\hline Lithuania & 61.6 & $(1.4)$ & 12.7 & $(1.0)$ & 13.6 & $(1.1)$ & 19.2 & $(1.3)$ & 23.0 & (1.4) & 22.2 & (1.3) & 42.8 & $(1.7)$ \\
\hline Macao (China) & 77.1 & $(1.2)$ & 6.6 & $(0.7)$ & 9.3 & $(0.9)$ & 17.1 & (1.1) & 22.1 & (1.1) & 17.0 & (1.1) & 71.2 & (1.4) \\
\hline Malta & $\mathrm{m}$ & $\mathrm{m}$ & $\mathrm{m}$ & $\mathrm{m}$ & $\mathrm{m}$ & $\mathrm{m}$ & $\mathrm{m}$ & $\mathrm{m}$ & $\mathrm{m}$ & $\mathrm{m}$ & $\mathrm{m}$ & $\mathrm{m}$ & $\mathrm{m}$ & $\mathrm{m}$ \\
\hline Moldova & $\mathrm{m}$ & $\mathrm{m}$ & $\mathrm{m}$ & $\mathrm{m}$ & $\mathrm{m}$ & $\mathrm{m}$ & $\mathrm{m}$ & $\mathrm{m}$ & $\mathrm{m}$ & $\mathrm{m}$ & $\mathrm{m}$ & $\mathrm{m}$ & $\mathrm{m}$ & $\mathrm{m}$ \\
\hline Montenegro & 49.0 & $(1.2)$ & 6.0 & $(0.8)$ & 5.7 & $(0.8)$ & 8.6 & $(0.8)$ & 13.1 & $(0.9)$ & 14.6 & $(0.9)$ & 39.5 & (1.4) \\
\hline Peru & 55.6 & (1.5) & 5.8 & $(0.8)$ & 5.9 & $(0.7)$ & 22.4 & $(1.3)$ & 21.7 & $(1.2)$ & 30.7 & (1.6) & 29.2 & (1.3) \\
\hline Qatar & 55.2 & $(1.0)$ & 20.3 & $(0.8)$ & 19.5 & $(0.8)$ & 21.0 & $(0.7)$ & 27.2 & $(0.8)$ & 27.5 & $(0.8)$ & 30.8 & $(0.9)$ \\
\hline Romania & $\mathrm{m}$ & $\mathrm{m}$ & $\mathrm{m}$ & $\mathrm{m}$ & $\mathrm{m}$ & $\mathrm{m}$ & $\mathrm{m}$ & $\mathrm{m}$ & $\mathrm{m}$ & $\mathrm{m}$ & $\mathrm{m}$ & $\mathrm{m}$ & $\mathrm{m}$ & $\mathrm{m}$ \\
\hline Russia & 73.7 & $(1.5)$ & 11.1 & $(1.2)$ & 9.4 & $(0.9)$ & 12.1 & $(1.0)$ & 31.1 & (1.6) & 29.8 & (1.5) & 64.2 & (1.7) \\
\hline Singapore & 57.2 & $(1.2)$ & 10.5 & $(0.9)$ & 12.9 & $(1.0)$ & 17.1 & (1.1) & 19.9 & $(1.2)$ & 22.0 & $(1.0)$ & 45.5 & (1.1) \\
\hline Chinese Taipei & 45.4 & (1.5) & 3.5 & $(0.5)$ & 4.7 & $(0.5)$ & 8.2 & $(0.7)$ & 14.7 & $(0.8)$ & 6.0 & $(0.6)$ & 39.1 & (1.3) \\
\hline Thailand & 62.3 & (1.6) & 16.4 & (1.1) & 17.3 & (1.1) & 16.4 & $(0.9)$ & 22.6 & (1.4) & 24.0 & (1.1) & 53.9 & (1.5) \\
\hline Trinidad and Tobago & $\mathrm{m}$ & $\mathrm{m}$ & $\mathrm{m}$ & $\mathrm{m}$ & $\mathrm{m}$ & $\mathrm{m}$ & $\mathrm{m}$ & $\mathrm{m}$ & $\mathrm{m}$ & $\mathrm{m}$ & $\mathrm{m}$ & $\mathrm{m}$ & $\mathrm{m}$ & $\mathrm{m}$ \\
\hline Tunisia & 59.9 & $(1.7)$ & 16.8 & $(1.2)$ & 16.0 & $(1.2)$ & 15.1 & $(1.3)$ & 29.2 & (1.5) & 21.6 & (1.1) & 32.2 & (1.4) \\
\hline United Arab Emirates & 55.1 & $(1.0)$ & 17.7 & $(0.7)$ & 16.9 & $(0.8)$ & 21.0 & $(1.0)$ & 26.5 & $(0.9)$ & 24.0 & (1.0) & 33.6 & (1.0) \\
\hline Uruguay & 46.1 & (1.3) & 3.8 & $(0.5)$ & 5.9 & $(0.6)$ & 9.4 & $(0.9)$ & 13.4 & $(0.9)$ & 22.9 & (1.2) & 31.1 & (1.3) \\
\hline Viet Nam & $\mathrm{m}$ & $\mathrm{m}$ & $\mathrm{m}$ & $\mathrm{m}$ & $\mathrm{m}$ & $\mathrm{m}$ & $\mathrm{m}$ & $\mathrm{m}$ & $\mathrm{m}$ & $\mathrm{m}$ & $\mathrm{m}$ & $\mathrm{m}$ & $\mathrm{m}$ & $\mathrm{m}$ \\
\hline Argentina** & $\mathrm{m}$ & $\mathrm{m}$ & $\mathrm{m}$ & $\mathrm{m}$ & $\mathrm{m}$ & $\mathrm{m}$ & $\mathrm{m}$ & $\mathrm{m}$ & $\mathrm{m}$ & $\mathrm{m}$ & $\mathrm{m}$ & $\mathrm{m}$ & $\mathrm{m}$ & $\mathrm{m}$ \\
\hline Kazakhstan** & $\mathrm{m}$ & $\mathrm{m}$ & $\mathrm{m}$ & $\mathrm{m}$ & $\mathrm{m}$ & $\mathrm{m}$ & $\mathrm{m}$ & $\mathrm{m}$ & $\mathrm{m}$ & $\mathrm{m}$ & $\mathrm{m}$ & $\mathrm{m}$ & $\mathrm{m}$ & $\mathrm{m}$ \\
\hline Malaysia** & 79.5 & (1.3) & 12.5 & $(1.0)$ & 19.2 & $(1.3)$ & 33.9 & $(1.7)$ & 30.0 & (1.4) & 39.2 & (1.5) & 70.6 & (1.3) \\
\hline
\end{tabular}

1. A socio-economically disadvantaged student is a student in the bottom quarter of the PISA index of economic, social and cultural status (ESCS) within his or her own country/economy. 2. A socio-economically advantaged student is a student in the top quarter of the PISA index of economic, social and cultural status (ESCS) within his or her own country/economy. Note: Values that are statistically significant are indicated in bold (see Annex A3).

* See note at the beginning of this Annex.

** Coverage is too small to ensure comparability (see Annex A4).

StatLink 需四 $\mathrm{http}: / / \mathrm{dx} . \mathrm{doi} . \mathrm{org} / 10.1787 / 888933471410$ 
[Part 5/6]

Table III.7.16 Students' perception of teacher unfairness, by gender and socio-economic status

Percentage of students who reported "once a week or more" or "a few times a month"

Percentage of socio-economically advantaged ${ }^{2}$ students who reported being treated unfairly

\begin{tabular}{|c|c|c|c|c|c|c|c|c|c|c|c|c|c|c|}
\hline & \multicolumn{14}{|c|}{$\begin{array}{l}\text { Percentage of socio-economically advantaged }{ }^{2} \text { students who reported being treated unfairly } \\
\text { by their teachers a few times a month or more frequently }\end{array}$} \\
\hline & \multicolumn{2}{|c|}{$\begin{array}{l}\text { Any unfair } \\
\text { treatment }\end{array}$} & \multicolumn{2}{|c|}{$\begin{array}{l}\text { Teachers called } \\
\text { on me less often } \\
\text { than they called } \\
\text { on other students }\end{array}$} & \multicolumn{2}{|c|}{$\begin{array}{c}\text { Teachers graded me } \\
\text { harder than } \\
\text { they graded } \\
\text { other students }\end{array}$} & \multicolumn{2}{|c|}{$\begin{array}{l}\text { Teachers gave me } \\
\text { the impression } \\
\text { that I am less smart } \\
\text { than I really am }\end{array}$} & \multicolumn{2}{|c|}{$\begin{array}{l}\text { Teachers disciplined } \\
\text { me more harshly } \\
\text { than other students }\end{array}$} & \multicolumn{2}{|c|}{$\begin{array}{c}\text { Teachers ridiculed } \\
\text { me in front } \\
\text { of others }\end{array}$} & \multicolumn{2}{|c|}{$\begin{array}{c}\text { Teachers said } \\
\text { something insulting } \\
\text { to me in front } \\
\text { of others }\end{array}$} \\
\hline & $\%$ & S.E. & $\%$ & S.E. & $\%$ & S.E. & $\%$ & S.E. & $\%$ & S.E. & $\%$ & S.E. & $\%$ & S.E. \\
\hline Australia & 47.8 & $(1.1)$ & 10.4 & $(0.7)$ & 13.1 & $(0.7)$ & 16.0 & $(0.8)$ & 20.3 & $(0.9)$ & 14.2 & $(0.7)$ & 31.9 & $(1.0)$ \\
\hline Austria & 54.8 & $(1.2)$ & 9.8 & $(0.8)$ & 12.3 & $(1.0)$ & 19.2 & $(1.0)$ & 22.4 & $(1.1)$ & 17.3 & (1.1) & 36.6 & (1.1) \\
\hline$\widehat{\widehat{O}}$ Belgium & 46.4 & (1.5) & 7.7 & $(0.8)$ & 10.0 & $(0.6)$ & 15.5 & $(0.9)$ & 18.8 & $(1.0)$ & 20.1 & $(0.8)$ & 28.4 & (1.3) \\
\hline Canada & $\mathrm{m}$ & $\mathrm{m}$ & $\mathrm{m}$ & $\mathrm{m}$ & $\mathrm{m}$ & $\mathrm{m}$ & $\mathrm{m}$ & $\mathrm{m}$ & $\mathrm{m}$ & $\mathrm{m}$ & $\mathrm{m}$ & $\mathrm{m}$ & $\mathrm{m}$ & $\mathrm{m}$ \\
\hline Chile & 49.9 & (1.6) & 4.7 & $(0.7)$ & 7.6 & $(0.7)$ & 15.0 & $(0.8)$ & 14.1 & $(0.9)$ & 14.1 & (1.1) & 35.3 & (1.5) \\
\hline Czech Republic & 49.6 & (1.5) & 9.5 & $(0.9)$ & 11.0 & (1.0) & 8.0 & $(0.9)$ & 15.2 & $(0.9)$ & 13.3 & $(0.9)$ & 35.3 & (1.4) \\
\hline Denmark & 43.6 & (1.5) & 9.2 & $(0.9)$ & 9.0 & $(0.9)$ & 11.4 & (1.1) & 13.4 & $(1.1)$ & 18.8 & $(1.2)$ & 27.5 & (1.5) \\
\hline Estonia & 61.7 & (1.3) & 11.9 & $(0.9)$ & 10.0 & $(0.8)$ & 12.1 & $(1.0)$ & 22.4 & $(1.2)$ & 27.9 & (1.1) & 46.1 & (1.5) \\
\hline Finland & 34.2 & (1.6) & 7.1 & $(0.7)$ & 7.9 & $(0.8)$ & 16.0 & $(1.2)$ & 15.0 & $(0.9)$ & 10.8 & $(0.9)$ & 18.9 & (1.1) \\
\hline France & 55.1 & $(1.2)$ & 6.3 & $(0.7)$ & 10.0 & $(0.8)$ & 10.6 & $(0.8)$ & 20.6 & $(1.0)$ & 20.0 & $(1.2)$ & 39.6 & $(1.3)$ \\
\hline Germany & 53.0 & (1.4) & 4.6 & $(0.6)$ & 7.5 & $(0.7)$ & 16.1 & $(1.2)$ & 18.0 & $(1.2)$ & 20.5 & $(1.2)$ & 37.6 & (1.4) \\
\hline Greece & 58.3 & (1.6) & 8.5 & $(0.9)$ & 7.7 & (0.9) & 8.1 & $(0.9)$ & 16.6 & $(0.9)$ & 18.9 & $(1.2)$ & 44.8 & (1.5) \\
\hline Hungary & 66.1 & (1.4) & 12.1 & $(0.9)$ & 10.8 & (0.9) & 20.2 & (1.1) & 29.0 & (1.3) & 21.8 & (1.3) & 48.8 & (1.4) \\
\hline Iceland & 33.1 & (1.7) & 6.7 & (1.0) & 6.9 & (0.9) & 12.9 & (1.4) & 9.9 & (1.1) & 11.9 & (1.3) & 21.8 & (1.5) \\
\hline Ireland & 46.4 & (1.3) & 8.4 & $(0.8)$ & 9.4 & $(0.7)$ & 15.9 & (1.0) & 19.1 & (1.3) & 14.8 & (1.0) & 27.9 & (1.1) \\
\hline Israel & $\mathrm{m}$ & $\mathrm{m}$ & $\mathrm{m}$ & $\mathrm{m}$ & $\mathrm{m}$ & $\mathrm{m}$ & $\mathrm{m}$ & $\mathrm{m}$ & $\mathrm{m}$ & $\mathrm{m}$ & $\mathrm{m}$ & $\mathrm{m}$ & $\mathrm{m}$ & $\mathrm{m}$ \\
\hline Italy & $\mathrm{m}$ & $\mathrm{m}$ & $\mathrm{m}$ & $\mathrm{m}$ & $\mathrm{m}$ & $\mathrm{m}$ & $\mathrm{m}$ & $\mathrm{m}$ & $\mathrm{m}$ & $\mathrm{m}$ & $\mathrm{m}$ & $\mathrm{m}$ & $\mathrm{m}$ & $\mathrm{m}$ \\
\hline Japan & 36.5 & (1.1) & 5.0 & (0.5) & 8.9 & $(0.7)$ & 8.7 & $(0.7)$ & 7.7 & $(0.8)$ & 5.2 & (0.6) & 28.8 & $(1.1)$ \\
\hline Korea & 34.8 & (1.8) & 4.6 & $(0.6)$ & 3.9 & (0.6) & 7.0 & $(0.7)$ & 13.4 & (1.1) & 6.3 & $(0.7)$ & 27.4 & (1.5) \\
\hline Latvia & 59.3 & (1.4) & 12.2 & (1.0) & 11.1 & (1.1) & 13.9 & (1.1) & 21.3 & (1.3) & 26.7 & (1.4) & 39.1 & (1.6) \\
\hline Luxembourg & 53.7 & $(1.2)$ & 8.3 & $(0.8)$ & 10.3 & (0.9) & 16.6 & (1.1) & 21.1 & (1.1) & 18.7 & (1.1) & 37.4 & (1.3) \\
\hline Mexico & 36.1 & (1.3) & 5.4 & $(0.6)$ & 8.2 & $(0.7)$ & 9.0 & $(0.7)$ & 21.0 & (1.1) & 17.6 & $(1.2)$ & 17.5 & (1.0) \\
\hline Netherlands & 33.2 & (1.3) & 4.3 & $(0.7)$ & 5.4 & $(0.7)$ & 10.8 & (0.9) & 10.9 & $(1.0)$ & 10.6 & (1.0) & 20.0 & $(1.1)$ \\
\hline New Zealand & 52.1 & (1.3) & 12.4 & $(1.1)$ & 16.7 & $(1.2)$ & 16.4 & $(1.2)$ & 22.6 & (1.3) & 13.4 & $(1.2)$ & 33.1 & (1.3) \\
\hline Norway & 45.2 & $(1.3)$ & 10.8 & $(0.8)$ & 12.1 & $(0.9)$ & 15.6 & $(1.2)$ & 19.7 & (1.4) & 26.6 & (1.4) & 26.0 & $(1.2)$ \\
\hline Poland & 47.2 & (1.7) & 9.0 & $(0.8)$ & 8.6 & $(0.8)$ & 15.5 & (1.4) & 20.9 & (1.3) & 19.2 & (1.3) & 28.5 & $(1.3)$ \\
\hline Portugal & 54.0 & (1.5) & 4.6 & $(0.7)$ & 6.8 & $(0.7)$ & 20.7 & $(1.2)$ & 25.9 & (1.5) & 17.9 & (1.0) & 36.3 & (1.5) \\
\hline Slovak Republic & 56.1 & (1.4) & 10.6 & $(0.9)$ & 12.7 & $(1.0)$ & 12.9 & $(1.1)$ & 24.4 & (1.1) & 19.6 & (1.3) & 37.2 & (1.6) \\
\hline Slovenia & 58.5 & (1.7) & 6.9 & $(0.8)$ & 8.4 & (1.0) & 10.1 & (1.0) & 18.5 & $(1.2)$ & 19.1 & (1.3) & 48.1 & $(1.7)$ \\
\hline Spain & 42.3 & (1.3) & 5.6 & $(0.5)$ & 7.3 & $(0.7)$ & 12.2 & $(0.7)$ & 13.9 & $(0.8)$ & 22.1 & (1.1) & 23.8 & $(1.2)$ \\
\hline Sweden & 37.5 & (1.3) & 6.8 & $(0.8)$ & 10.7 & $(0.8)$ & 10.6 & $(0.8)$ & 15.0 & $(1.0)$ & 16.2 & $(1.0)$ & 21.4 & $(1.2)$ \\
\hline Switzerland & 48.2 & (1.5) & 6.2 & $(0.7)$ & 8.8 & $(0.8)$ & 16.7 & $(1.2)$ & 15.3 & $(1.1)$ & 11.8 & (1.0) & 33.2 & (1.4) \\
\hline Turkey & 62.2 & (1.6) & 16.0 & $(1.3)$ & 14.4 & (1.4) & 19.2 & $(1.3)$ & 24.9 & (1.3) & 27.4 & (1.6) & 43.9 & $(1.2)$ \\
\hline United Kingdom & 52.7 & $(1.3)$ & 13.5 & $(0.9)$ & 16.4 & $(0.9)$ & 18.6 & $(1.2)$ & 24.4 & $(1.2)$ & 15.8 & (1.1) & 33.9 & $(1.2)$ \\
\hline United States & 43.0 & $(1.2)$ & 9.2 & $(1.0)$ & 10.3 & (1.0) & 10.6 & $(0.7)$ & 14.8 & $(1.0)$ & 15.7 & (0.9) & 28.2 & $(1.2)$ \\
\hline OECD average & 48.5 & $(0.3)$ & 8.4 & $(0.1)$ & 9.8 & $(0.2)$ & 13.8 & $(0.2)$ & 18.5 & $(0.2)$ & 17.3 & $(0.2)$ & 32.6 & $(0.2)$ \\
\hline
\end{tabular}

\begin{tabular}{|c|c|c|c|c|c|c|c|c|c|c|c|c|c|c|}
\hline Albania & $\mathrm{m}$ & $\mathrm{m}$ & $\mathrm{m}$ & $\mathrm{m}$ & $\mathrm{m}$ & $\mathrm{m}$ & $\mathrm{m}$ & $\mathrm{m}$ & $\mathrm{m}$ & $\mathrm{m}$ & $\mathrm{m}$ & $\mathrm{m}$ & $\mathrm{m}$ & $\mathrm{m}$ \\
\hline Algeria & $\mathrm{m}$ & $\mathrm{m}$ & $\mathrm{m}$ & $\mathrm{m}$ & $\mathrm{m}$ & $\mathrm{m}$ & $\mathrm{m}$ & $\mathrm{m}$ & $\mathrm{m}$ & $\mathrm{m}$ & $\mathrm{m}$ & $\mathrm{m}$ & $\mathrm{m}$ & $\mathrm{m}$ \\
\hline Brazil & 46.5 & $(0.9)$ & 9.5 & $(0.7)$ & 8.1 & $(0.6)$ & 13.9 & $(0.6)$ & 17.1 & $(0.8)$ & 17.6 & $(0.6)$ & 28.1 & $(1.0)$ \\
\hline B-S-J-G (China) & 59.4 & $(2.1)$ & 7.0 & $(0.7)$ & 8.0 & $(0.8)$ & 19.1 & (1.6) & 21.1 & (1.3) & 27.6 & $(2.2)$ & 43.4 & (1.9) \\
\hline Bulgaria & 67.6 & $(1.2)$ & 11.1 & $(0.8)$ & 12.6 & (1.0) & 16.7 & (1.0) & 31.1 & $(1.0)$ & 39.8 & (1.3) & 37.7 & $(1.2)$ \\
\hline CABA (Argentina) & $\mathrm{m}$ & $\mathrm{m}$ & $\mathrm{m}$ & $\mathrm{m}$ & $\mathrm{m}$ & $\mathrm{m}$ & $\mathrm{m}$ & $\mathrm{m}$ & $\mathrm{m}$ & $\mathrm{m}$ & $\mathrm{m}$ & $\mathrm{m}$ & $\mathrm{m}$ & $\mathrm{m}$ \\
\hline Colombia & 46.0 & (1.5) & 10.4 & $(0.9)$ & 9.7 & $(0.8)$ & 13.8 & (1.1) & 11.0 & $(0.8)$ & 20.9 & $(1.0)$ & 29.6 & (1.4) \\
\hline Costa Rica & 38.3 & $(2.0)$ & 3.5 & $(0.7)$ & 7.7 & $(0.8)$ & 16.8 & (1.1) & 7.9 & $(0.9)$ & 19.6 & (1.6) & 23.5 & (1.4) \\
\hline Croatia & 55.1 & (1.3) & 7.2 & $(0.8)$ & 6.5 & $(0.7)$ & 11.1 & (0.9) & 24.1 & (1.4) & 20.3 & (1.1) & 36.1 & $(1.2)$ \\
\hline Cyprus* & 55.4 & (1.6) & 15.5 & (1.1) & 14.5 & (1.1) & 16.1 & (1.0) & 24.7 & $(1.2)$ & 23.7 & $(1.2)$ & 35.1 & (1.4) \\
\hline Dominican Republic & 51.3 & $(1.6)$ & 12.9 & (1.4) & 11.1 & $(1.3)$ & 10.1 & (1.1) & 22.5 & (1.4) & 30.9 & (1.8) & 29.7 & (1.7) \\
\hline FYROM & $\mathrm{m}$ & $\mathrm{m}$ & $\mathrm{m}$ & $\mathrm{m}$ & $\mathrm{m}$ & $\mathrm{m}$ & $\mathrm{m}$ & $\mathrm{m}$ & $\mathrm{m}$ & $\mathrm{m}$ & $\mathrm{m}$ & $\mathrm{m}$ & $\mathrm{m}$ & $\mathrm{m}$ \\
\hline Georgia & $\mathrm{m}$ & $\mathrm{m}$ & $\mathrm{m}$ & $\mathrm{m}$ & $\mathrm{m}$ & $\mathrm{m}$ & $\mathrm{m}$ & $\mathrm{m}$ & $\mathrm{m}$ & $\mathrm{m}$ & $\mathrm{m}$ & $\mathrm{m}$ & $\mathrm{m}$ & $\mathrm{m}$ \\
\hline Hong Kong (China) & 67.1 & (1.9) & 9.2 & $(1.0)$ & 16.2 & (1.3) & 16.0 & (1.5) & 28.7 & $(1.8)$ & 30.2 & $(2.0)$ & 56.2 & $(2.1)$ \\
\hline Indonesia & $\mathrm{m}$ & $\mathrm{m}$ & $\mathrm{m}$ & $\mathrm{m}$ & $\mathrm{m}$ & $\mathrm{m}$ & $\mathrm{m}$ & $\mathrm{m}$ & $\mathrm{m}$ & $\mathrm{m}$ & $\mathrm{m}$ & $\mathrm{m}$ & $\mathrm{m}$ & $\mathrm{m}$ \\
\hline Jordan & $\mathrm{m}$ & $\mathrm{m}$ & $\mathrm{m}$ & $\mathrm{m}$ & $\mathrm{m}$ & $\mathrm{m}$ & $\mathrm{m}$ & $\mathrm{m}$ & $\mathrm{m}$ & $\mathrm{m}$ & $\mathrm{m}$ & $\mathrm{m}$ & $\mathrm{m}$ & $\mathrm{m}$ \\
\hline Kosovo & $\mathrm{m}$ & $\mathrm{m}$ & $\mathrm{m}$ & $\mathrm{m}$ & $\mathrm{m}$ & $\mathrm{m}$ & $\mathrm{m}$ & $\mathrm{m}$ & $\mathrm{m}$ & $\mathrm{m}$ & $\mathrm{m}$ & $\mathrm{m}$ & $\mathrm{m}$ & $\mathrm{m}$ \\
\hline Lebanon & $\mathrm{m}$ & $\mathrm{m}$ & $\mathrm{m}$ & $\mathrm{m}$ & $\mathrm{m}$ & $\mathrm{m}$ & $\mathrm{m}$ & $\mathrm{m}$ & $\mathrm{m}$ & $\mathrm{m}$ & $\mathrm{m}$ & $\mathrm{m}$ & $\mathrm{m}$ & $\mathrm{m}$ \\
\hline Lithuania & 59.0 & $(1.8)$ & 11.8 & $(1.2)$ & 12.7 & $(0.9)$ & 19.7 & (1.1) & 21.2 & $(1.2)$ & 23.7 & (1.1) & 42.8 & (1.7) \\
\hline Macao (China) & 66.0 & (1.5) & 9.0 & $(0.9)$ & 12.3 & (1.0) & 18.1 & (1.2) & 23.5 & (1.3) & 20.7 & (1.3) & 55.0 & (1.6) \\
\hline Malta & $\mathrm{m}$ & $\mathrm{m}$ & $\mathrm{m}$ & $\mathrm{m}$ & $\mathrm{m}$ & $\mathrm{m}$ & $\mathrm{m}$ & $\mathrm{m}$ & $\mathrm{m}$ & $\mathrm{m}$ & $\mathrm{m}$ & $\mathrm{m}$ & $\mathrm{m}$ & $\mathrm{m}$ \\
\hline Moldova & $\mathrm{m}$ & $\mathrm{m}$ & $\mathrm{m}$ & $\mathrm{m}$ & $\mathrm{m}$ & $\mathrm{m}$ & $\mathrm{m}$ & $\mathrm{m}$ & $\mathrm{m}$ & $\mathrm{m}$ & $\mathrm{m}$ & $\mathrm{m}$ & $\mathrm{m}$ & $\mathrm{m}$ \\
\hline Montenegro & 56.5 & (1.6) & 9.9 & $(0.7)$ & 10.3 & (0.9) & 16.0 & (1.1) & 21.4 & (1.3) & 25.6 & (1.3) & 40.2 & (1.5) \\
\hline Peru & 53.2 & (1.5) & 4.1 & $(0.5)$ & 6.9 & $(0.7)$ & 21.2 & (1.2) & 25.1 & (1.1) & 30.0 & (1.0) & 23.5 & $(1.2)$ \\
\hline Qatar & 51.6 & $(1.2)$ & 16.6 & $(0.8)$ & 17.2 & (0.8) & 19.1 & (0.8) & 24.5 & $(0.9)$ & 25.6 & (1.0) & 32.5 & (1.0) \\
\hline Romania & $\mathrm{m}$ & $\mathrm{m}$ & $\mathrm{m}$ & $\mathrm{m}$ & $\mathrm{m}$ & $\mathrm{m}$ & $\mathrm{m}$ & $\mathrm{m}$ & $\mathrm{m}$ & $\mathrm{m}$ & $\mathrm{m}$ & $\mathrm{m}$ & $\mathrm{m}$ & $\mathrm{m}$ \\
\hline Russia & 71.4 & (1.3) & 10.3 & (1.1) & 11.7 & $(1.3)$ & 14.0 & (1.0) & 33.3 & (1.7) & 34.1 & (1.5) & 56.1 & (1.5) \\
\hline Singapore & 51.3 & (1.6) & 8.1 & $(0.7)$ & 10.9 & $(0.8)$ & 12.1 & (0.9) & 16.7 & (1.1) & 13.9 & (1.1) & 39.0 & (1.6) \\
\hline Chinese Taipei & 42.3 & (1.5) & 3.9 & (0.5) & 4.8 & $(0.5)$ & 9.5 & $(0.8)$ & 11.9 & $(0.8)$ & 7.6 & $(0.7)$ & 33.8 & (1.4) \\
\hline Thailand & 61.0 & $(1.5)$ & 14.6 & (1.5) & 15.4 & $(1.3)$ & 15.8 & (1.5) & 21.5 & (1.3) & 21.2 & (1.7) & 52.5 & (1.5) \\
\hline Trinidad and Tobago & $\mathrm{m}$ & $\mathrm{m}$ & $\mathrm{m}$ & $\mathrm{m}$ & $\mathrm{m}$ & $\mathrm{m}$ & $\mathrm{m}$ & $\mathrm{m}$ & $\mathrm{m}$ & $\mathrm{m}$ & $\mathrm{m}$ & $\mathrm{m}$ & $\mathrm{m}$ & $\mathrm{m}$ \\
\hline Tunisia & 50.9 & $(1.6)$ & 12.7 & $(1.0)$ & 14.0 & (1.0) & 13.6 & (1.1) & 25.1 & (1.4) & 17.2 & (1.1) & 24.6 & (1.3) \\
\hline United Arab Emirates & 53.6 & $(1.1)$ & 17.5 & $(0.8)$ & 18.1 & $(0.8)$ & 20.5 & (0.9) & 26.7 & (1.1) & 24.1 & (1.0) & 33.1 & (1.2) \\
\hline Uruguay & 56.7 & $(1.6)$ & 4.5 & $(0.6)$ & 8.4 & $(1.0)$ & 10.3 & (0.9) & 13.4 & $(0.9)$ & 31.0 & $(1.2)$ & 39.8 & (1.7) \\
\hline Viet Nam & $\mathrm{m}$ & $\mathrm{m}$ & $\mathrm{m}$ & $\mathrm{m}$ & $\mathrm{m}$ & $\mathrm{m}$ & $\mathrm{m}$ & $\mathrm{m}$ & $\mathrm{m}$ & $\mathrm{m}$ & $\mathrm{m}$ & $\mathrm{m}$ & $\mathrm{m}$ & $\mathrm{m}$ \\
\hline Argentina** & $\mathrm{m}$ & $\mathrm{m}$ & $\mathrm{m}$ & $\mathrm{m}$ & $\mathrm{m}$ & $\mathrm{m}$ & $\mathrm{m}$ & $\mathrm{m}$ & $\mathrm{m}$ & $\mathrm{m}$ & $\mathrm{m}$ & $\mathrm{m}$ & $\mathrm{m}$ & $\mathrm{m}$ \\
\hline Kazakhstan** & $\mathrm{m}$ & $\mathrm{m}$ & $\mathrm{m}$ & $\mathrm{m}$ & $\mathrm{m}$ & $\mathrm{m}$ & $\mathrm{m}$ & $\mathrm{m}$ & $\mathrm{m}$ & $\mathrm{m}$ & $\mathrm{m}$ & $\mathrm{m}$ & $\mathrm{m}$ & $\mathrm{m}$ \\
\hline Malaysia** & 73.1 & (1.4) & 10.3 & $(0.9)$ & 15.2 & $(1.0)$ & 24.3 & (1.4) & 23.4 & $(1.2)$ & 31.8 & (1.6) & 63.1 & (1.5) \\
\hline
\end{tabular}

1. A socio-economically disadvantaged student is a student in the bottom quarter of the PISA index of economic, social and cultural status (ESCS) within his or her own country/economy. 2. A socio-economically advantaged student is a student in the top quarter of the PISA index of economic, social and cultural status (ESCS) within his or her own country/economy. Note: Values that are statistically significant are indicated in bold (see Annex A3).

* See note at the beginning of this Annex.

** Coverage is too small to ensure comparability (see Annex A4).

StatLink 需四 http://dx.doi.org/10.1787/888933471410 
[Part 6/6]

Table III.7.16 Students' perception of teacher unfairness, by gender and socio-economic status

Percentage of students who reported "once a week or more" or "a few times a month"

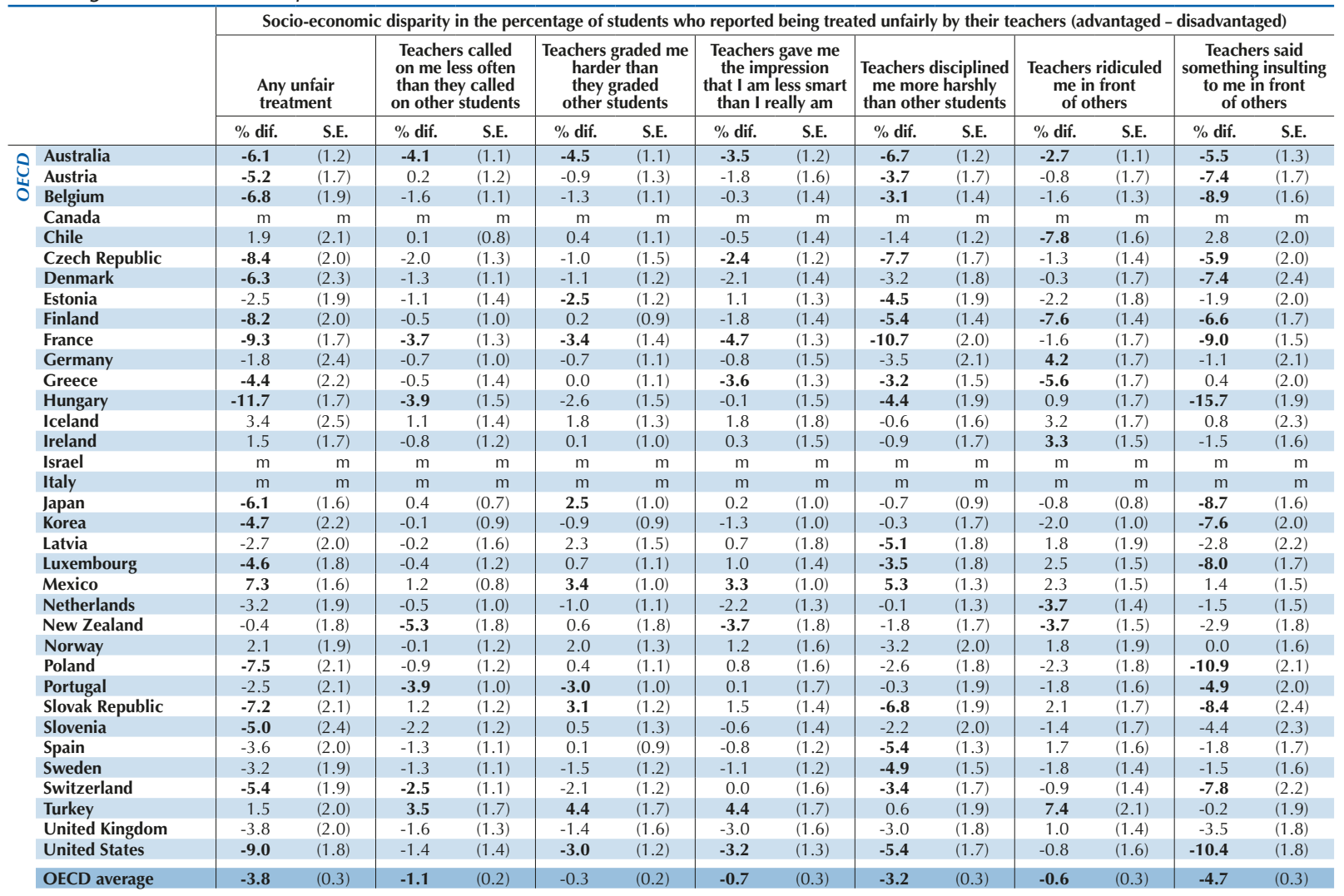

\begin{tabular}{|c|c|c|c|c|c|c|c|c|c|c|c|c|c|c|c|}
\hline$\approx$ & Albania & $\mathrm{m}$ & $\mathrm{m}$ & $\mathrm{m}$ & $\mathrm{m}$ & $\mathrm{m}$ & $\mathrm{m}$ & $\mathrm{m}$ & $\mathrm{m}$ & $\mathrm{m}$ & $\mathrm{m}$ & $\mathrm{m}$ & $\mathrm{m}$ & $\mathrm{m}$ & $\mathrm{m}$ \\
\hline$\Xi$ & Algeria & $\mathrm{m}$ & $\mathrm{m}$ & $\mathrm{m}$ & $\mathrm{m}$ & $\mathrm{m}$ & $\mathrm{m}$ & $\mathrm{m}$ & $\mathrm{m}$ & $\mathrm{m}$ & $\mathrm{m}$ & $\mathrm{m}$ & $\mathrm{m}$ & $\mathrm{m}$ & $\mathrm{m}$ \\
\hline & Brazil & 3.5 & $(1.3)$ & 0.5 & $(0.8)$ & 0.6 & $(0.8)$ & 1.9 & $(0.8)$ & 1.2 & $(1.2)$ & 0.3 & $(1.0)$ & 3.1 & $(1.2)$ \\
\hline & B-S-J-G (China) & -1.9 & $(2.6)$ & 0.6 & $(0.8)$ & 1.5 & (1.1) & 0.9 & $(2.1)$ & 2.2 & $(1.7)$ & 1.5 & $(3.0)$ & -5.9 & (2.3) \\
\hline & Bulgaria & 9.0 & $(2.0)$ & -3.2 & (1.4) & -3.1 & (1.5) & 0.2 & (1.7) & 5.6 & (1.7) & 6.4 & $(2.1)$ & 2.6 & (1.8) \\
\hline & CABA (Argentina) & $\mathrm{m}$ & $\mathrm{m}$ & $\mathrm{m}$ & $\mathrm{m}$ & $\mathrm{m}$ & $\mathrm{m}$ & $\mathrm{m}$ & $\mathrm{m}$ & $\mathrm{m}$ & $\mathrm{m}$ & $\mathrm{m}$ & $\mathrm{m}$ & $\mathrm{m}$ & $\mathrm{m}$ \\
\hline & Colombia & 5.8 & (1.9) & 2.4 & (1.1) & 2.4 & (1.0) & 4.3 & (1.5) & 1.3 & (1.2) & 7.1 & (1.2) & 1.8 & (2.1) \\
\hline & Costa Rica & 5.8 & $(2.6)$ & 0.6 & $(0.9)$ & 1.8 & (1.0) & 5.0 & (1.4) & 0.5 & (1.1) & 5.9 & (1.8) & 2.0 & (2.1) \\
\hline & Croatia & -0.2 & $(1.9)$ & 2.3 & $(0.9)$ & 0.9 & $(0.9)$ & 2.6 & (1.2) & 3.6 & (1.7) & 3.2 & (1.5) & -7.5 & $(2.0)$ \\
\hline & Cyprus* & -0.1 & (1.9) & 2.0 & (1.4) & 1.5 & (1.5) & 1.4 & (1.3) & -1.4 & (1.8) & -1.4 & (1.7) & -0.7 & $(1.8)$ \\
\hline & Dominican Republic & 3.4 & $(2.6)$ & 1.0 & (1.9) & 1.6 & (1.6) & 2.0 & (1.4) & 2.2 & (1.8) & 5.7 & $(2.1)$ & 2.5 & (2.5) \\
\hline & FYROM & $\mathrm{m}$ & $\mathrm{m}$ & $\mathrm{m}$ & $\mathrm{m}$ & $\mathrm{m}$ & $\mathrm{m}$ & $\mathrm{m}$ & $\mathrm{m}$ & $\mathrm{m}$ & $\mathrm{m}$ & $\mathrm{m}$ & $\mathrm{m}$ & $\mathrm{m}$ & $\mathrm{m}$ \\
\hline & Georgia & $\mathrm{m}$ & $\mathrm{m}$ & $\mathrm{m}$ & $\mathrm{m}$ & $\mathrm{m}$ & $\mathrm{m}$ & $\mathrm{m}$ & $\mathrm{m}$ & $\mathrm{m}$ & $\mathrm{m}$ & $\mathrm{m}$ & $\mathrm{m}$ & $\mathrm{m}$ & $\mathrm{m}$ \\
\hline & Hong Kong (China) & -4.2 & $(2.2)$ & 0.2 & (1.3) & 1.8 & (1.9) & 1.0 & $(2.2)$ & 1.8 & $(2.0)$ & 2.7 & $(2.5)$ & -5.8 & (2.3) \\
\hline & Indonesia & $\mathrm{m}$ & $\mathrm{m}$ & $\mathrm{m}$ & $\mathrm{m}$ & $\mathrm{m}$ & $\mathrm{m}$ & $\mathrm{m}$ & $\mathrm{m}$ & $\mathrm{m}$ & $\mathrm{m}$ & $\mathrm{m}$ & $\mathrm{m}$ & $\mathrm{m}$ & $\mathrm{m}$ \\
\hline & Jordan & $\mathrm{m}$ & $\mathrm{m}$ & $\mathrm{m}$ & $\mathrm{m}$ & $\mathrm{m}$ & $\mathrm{m}$ & $\mathrm{m}$ & $\mathrm{m}$ & $\mathrm{m}$ & $\mathrm{m}$ & $\mathrm{m}$ & $\mathrm{m}$ & $\mathrm{m}$ & $\mathrm{m}$ \\
\hline & Kosovo & $\mathrm{m}$ & $\mathrm{m}$ & $\mathrm{m}$ & $\mathrm{m}$ & $\mathrm{m}$ & $\mathrm{m}$ & $\mathrm{m}$ & $\mathrm{m}$ & $\mathrm{m}$ & $\mathrm{m}$ & $\mathrm{m}$ & $\mathrm{m}$ & $\mathrm{m}$ & $\mathrm{m}$ \\
\hline & Lebanon & $\mathrm{m}$ & $\mathrm{m}$ & $\mathrm{m}$ & $\mathrm{m}$ & $\mathrm{m}$ & $\mathrm{m}$ & $\mathrm{m}$ & $\mathrm{m}$ & $\mathrm{m}$ & $\mathrm{m}$ & $\mathrm{m}$ & $\mathrm{m}$ & $\mathrm{m}$ & $\mathrm{m}$ \\
\hline & Lithuania & -2.6 & $(2.2)$ & -0.9 & (1.6) & -1.0 & (1.5) & 0.5 & $(1.7)$ & -1.8 & $(1.7)$ & 1.6 & (1.7) & 0.0 & (2.7) \\
\hline & Macao (China) & -11.0 & $(1.9)$ & 2.4 & (1.0) & 2.9 & (1.3) & 1.1 & (1.6) & 1.4 & (1.6) & 3.8 & (1.6) & -16.2 & (2.0) \\
\hline & Malta & $\mathrm{m}$ & $\mathrm{m}$ & $\mathrm{m}$ & $\mathrm{m}$ & $\mathrm{m}$ & $\mathrm{m}$ & $\mathrm{m}$ & $\mathrm{m}$ & $\mathrm{m}$ & $\mathrm{m}$ & $\mathrm{m}$ & $\mathrm{m}$ & $\mathrm{m}$ & $\mathrm{m}$ \\
\hline & Moldova & $\mathrm{m}$ & $\mathrm{m}$ & $\mathrm{m}$ & $\mathrm{m}$ & $\mathrm{m}$ & $\mathrm{m}$ & $\mathrm{m}$ & $\mathrm{m}$ & $\mathrm{m}$ & $\mathrm{m}$ & $\mathrm{m}$ & $\mathrm{m}$ & $\mathrm{m}$ & $\mathrm{m}$ \\
\hline & Montenegro & 7.5 & $(2.2)$ & 3.9 & $(1.1)$ & 4.6 & $(1.2)$ & 7.3 & (1.3) & 8.3 & (1.6) & 11.0 & (1.7) & 0.7 & $(2.2)$ \\
\hline & Peru & -2.4 & $(2.0)$ & -1.7 & (1.0) & 1.0 & (1.0) & -1.2 & (1.6) & 3.4 & (1.7) & -0.6 & (1.8) & -5.7 & (1.7) \\
\hline & Qatar & -3.6 & $(1.5)$ & -3.7 & (1.3) & -2.4 & (1.1) & -1.9 & $(1.0)$ & -2.7 & $(1.2)$ & -1.9 & (1.4) & 1.7 & (1.4) \\
\hline & Romania & $\mathrm{m}$ & $\mathrm{m}$ & $\mathrm{m}$ & $\mathrm{m}$ & $\mathrm{m}$ & $\mathrm{m}$ & $\mathrm{m}$ & $\mathrm{m}$ & $\mathrm{m}$ & $\mathrm{m}$ & $\mathrm{m}$ & $\mathrm{m}$ & $\mathrm{m}$ & $\mathrm{m}$ \\
\hline & Russia & -2.3 & (1.9) & -0.7 & (1.5) & 2.3 & (1.6) & 1.9 & (1.4) & 2.2 & (2.6) & 4.3 & (1.9) & -8.1 & $(2.0)$ \\
\hline & Singapore & -5.9 & $(2.0)$ & -2.3 & (1.1) & -2.0 & (1.3) & -5.0 & (1.5) & -3.2 & (1.7) & -8.1 & (1.5) & -6.5 & $(2.0)$ \\
\hline & Chinese Taipei & -3.1 & (1.9) & 0.4 & (0.6) & 0.1 & $(0.7)$ & 1.3 & $(0.9)$ & -2.8 & (1.0) & 1.6 & $(0.9)$ & -5.3 & (1.8) \\
\hline & Thailand & -1.3 & $(2.2)$ & -1.8 & (1.7) & -1.8 & (1.6) & -0.6 & (1.6) & -1.1 & (1.8) & -2.9 & $(2.0)$ & -1.4 & (2.1) \\
\hline & Trinidad and Tobago & $\mathrm{m}$ & $\mathrm{m}$ & $\mathrm{m}$ & $\mathrm{m}$ & $\mathrm{m}$ & $\mathrm{m}$ & $\mathrm{m}$ & $\mathrm{m}$ & $\mathrm{m}$ & $\mathrm{m}$ & $\mathrm{m}$ & $\mathrm{m}$ & $\mathrm{m}$ & $\mathrm{m}$ \\
\hline & Tunisia & -9.0 & $(2.2)$ & -4.2 & (1.4) & -2.0 & (1.5) & -1.6 & (1.7) & -4.1 & (1.9) & -4.5 & (1.6) & -7.6 & (1.9) \\
\hline & United Arab Emirates & -1.5 & $(1.4)$ & -0.2 & (1.0) & 1.2 & (1.1) & -0.5 & (1.3) & 0.2 & (1.4) & 0.1 & (1.2) & -0.6 & (1.6) \\
\hline & Uruguay & 10.6 & $(2.0)$ & 0.6 & $(0.7)$ & 2.5 & (1.1) & 0.9 & (1.2) & 0.1 & (1.2) & 8.1 & (1.8) & 8.7 & (2.2) \\
\hline & Viet Nam & $\mathrm{m}$ & $\mathrm{m}$ & $\mathrm{m}$ & $\mathrm{m}$ & $\mathrm{m}$ & $\mathrm{m}$ & $\mathrm{m}$ & $\mathrm{m}$ & $\mathrm{m}$ & $\mathrm{m}$ & $\mathrm{m}$ & $\mathrm{m}$ & $\mathrm{m}$ & $\mathrm{m}$ \\
\hline & Argentina** $^{* *}$ & $\mathrm{~m}$ & $\mathrm{~m}$ & $\mathrm{~m}$ & $\mathrm{~m}$ & $\mathrm{~m}$ & $\mathrm{~m}$ & $\mathrm{~m}$ & $\mathrm{~m}$ & $\mathrm{~m}$ & $\mathrm{~m}$ & $\mathrm{~m}$ & $\mathrm{~m}$ & $\mathrm{~m}$ & $\mathrm{~m}$ \\
\hline & Kazakhstan** & $\mathrm{m}$ & $\mathrm{m}$ & $\mathrm{m}$ & $\mathrm{m}$ & $\mathrm{m}$ & $\mathrm{m}$ & $\mathrm{m}$ & $\mathrm{m}$ & $\mathrm{m}$ & $\mathrm{m}$ & $\mathrm{m}$ & $\mathrm{m}$ & $\mathrm{m}$ & $\mathrm{m}$ \\
\hline & Malaysia** & -6.5 & $(1.8)$ & -2.1 & (1.3) & -4.1 & (1.6) & -9.6 & $(2.2)$ & -6.6 & (1.9) & -7.4 & $(2.2)$ & -7.4 & (1.9) \\
\hline
\end{tabular}

. A socio-economically disadvantaged student is a student in the bottom quarter of the PISA index of economic, social and cultural status (ESCS) within his or her own country/economy. 2. A socio-economically advantaged student is a student in the top quarter of the PISA index of economic, social and cultural status (ESCS) within his or her own country/economy. Note: Values that are statistically significant are indicated in bold (see Annex A3).

** See note at the beginning of this Annex.

Coverage is too small to ensure comparability (see Annex A4). 
[Part 1/1]

Table III.7.17 Students' perception of teacher unfairness, by immigrant background

Percentage of students who reported "once a week or more" or "a few times a month"

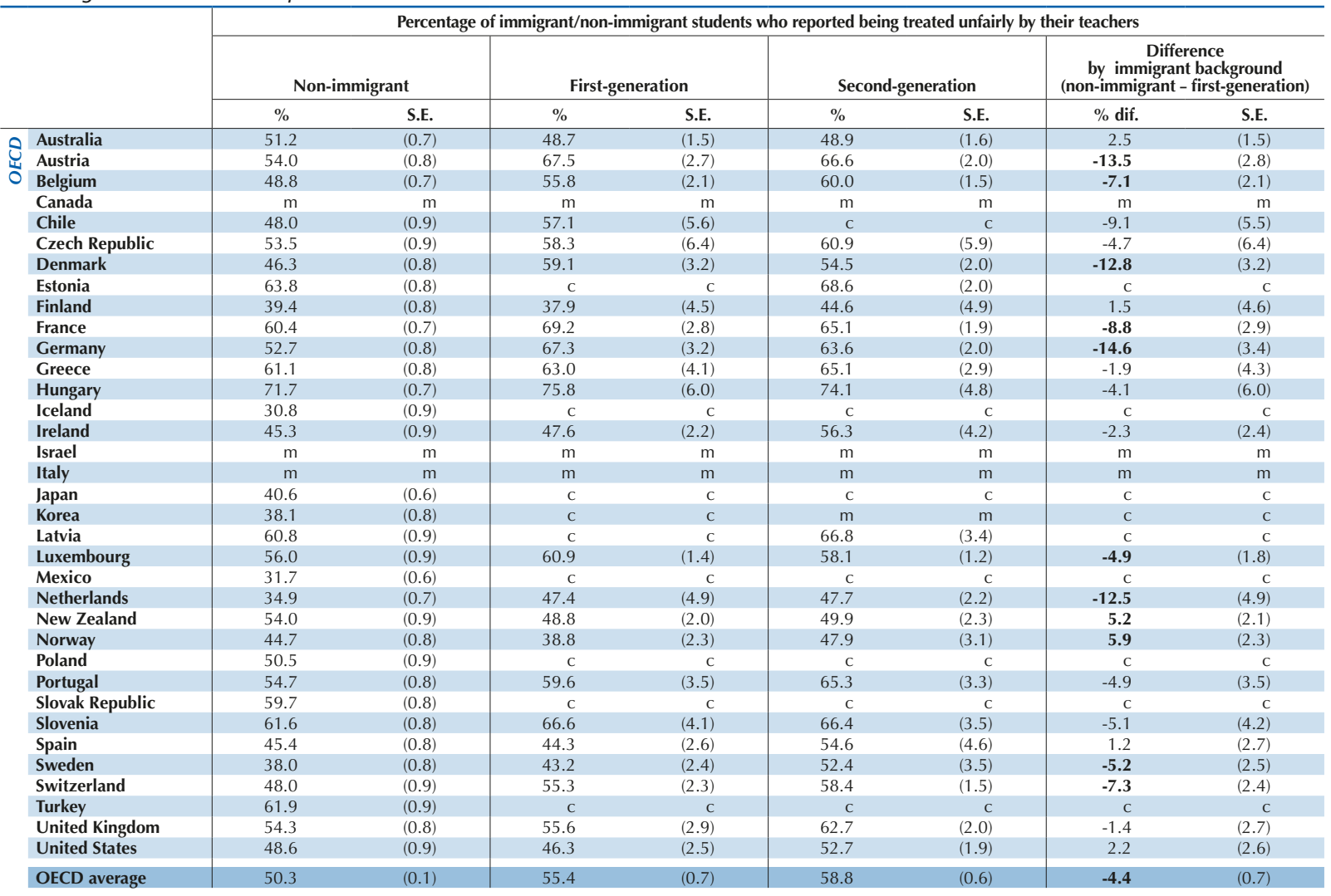

\begin{tabular}{|c|c|c|c|c|c|c|c|c|}
\hline Albania & $\mathrm{m}$ & $\mathrm{m}$ & $\mathrm{m}$ & $\mathrm{m}$ & $\mathrm{m}$ & $\mathrm{m}$ & $\mathrm{m}$ & $\mathrm{m}$ \\
\hline § Algeria & $\mathrm{m}$ & $\mathrm{m}$ & $\mathrm{m}$ & $\mathrm{m}$ & $\mathrm{m}$ & $\mathrm{m}$ & $\mathrm{m}$ & $\mathrm{m}$ \\
\hline ‡ Brazil & 44.4 & $(0.5)$ & c & c & 66.6 & (6.6) & c & c \\
\hline B-S-J-G (China) & 62.9 & (1.1) & c & c & c & c & c & c \\
\hline Bulgaria & 63.2 & $(0.6)$ & c & c & c & c & c & c \\
\hline CABA (Argentina) & $\mathrm{m}$ & $\mathrm{m}$ & $\mathrm{m}$ & $\mathrm{m}$ & $\mathrm{m}$ & $\mathrm{m}$ & $\mathrm{m}$ & $\mathrm{m}$ \\
\hline Colombia & 43.7 & $(0.7)$ & c & c & c & c & c & c \\
\hline Costa Rica & 35.6 & $(0.8)$ & 36.0 & (4.1) & 36.1 & (3.2) & -0.4 & $(4.2)$ \\
\hline Croatia & 55.8 & $(0.8)$ & 64.0 & $(4.7)$ & 61.2 & $(2.1)$ & -8.3 & $(4.7)$ \\
\hline Cyprus* & 55.9 & $(0.7)$ & 60.4 & $(2.0)$ & 54.2 & $(4.0)$ & -4.5 & $(2.1)$ \\
\hline Dominican Republic & 52.1 & $(0.9)$ & c & c & c & c & c & c \\
\hline FYROM & $\mathrm{m}$ & $\mathrm{m}$ & $\mathrm{m}$ & $\mathrm{m}$ & $\mathrm{m}$ & $\mathrm{m}$ & $\mathrm{m}$ & $\mathrm{m}$ \\
\hline Georgia & $\mathrm{m}$ & $\mathrm{m}$ & $\mathrm{m}$ & $\mathrm{m}$ & $\mathrm{m}$ & $\mathrm{m}$ & $\mathrm{m}$ & $\mathrm{m}$ \\
\hline Hong Kong (China) & 70.1 & $(0.8)$ & 68.7 & $(1.8)$ & 71.6 & $(1.2)$ & 1.3 & $(1.8)$ \\
\hline Indonesia & $\mathrm{m}$ & $\mathrm{m}$ & $\mathrm{m}$ & $\mathrm{m}$ & $\mathrm{m}$ & $\mathrm{m}$ & $\mathrm{m}$ & $\mathrm{m}$ \\
\hline Jordan & $\mathrm{m}$ & $\mathrm{m}$ & $\mathrm{m}$ & $\mathrm{m}$ & $\mathrm{m}$ & $\mathrm{m}$ & $\mathrm{m}$ & $\mathrm{m}$ \\
\hline Kosovo & $\mathrm{m}$ & $\mathrm{m}$ & $\mathrm{m}$ & $\mathrm{m}$ & $\mathrm{m}$ & $\mathrm{m}$ & $\mathrm{m}$ & $\mathrm{m}$ \\
\hline Lebanon & $\mathrm{m}$ & $\mathrm{m}$ & $\mathrm{m}$ & $\mathrm{m}$ & $\mathrm{m}$ & $\mathrm{m}$ & $\mathrm{m}$ & $\mathrm{m}$ \\
\hline Lithuania & 60.6 & $(0.8)$ & c & c & 63.6 & $(4.7)$ & c & $\mathrm{c}$ \\
\hline Macao (China) & 71.7 & (1.1) & 69.8 & (1.6) & 73.5 & $(0.9)$ & 1.8 & $(2.0)$ \\
\hline Malta & $\mathrm{m}$ & $\mathrm{m}$ & $\mathrm{m}$ & $\mathrm{m}$ & $\mathrm{m}$ & $\mathrm{m}$ & $\mathrm{m}$ & $\mathrm{m}$ \\
\hline Moldova & $\mathrm{m}$ & $\mathrm{m}$ & $\mathrm{m}$ & $\mathrm{m}$ & $\mathrm{m}$ & $\mathrm{m}$ & $\mathrm{m}$ & $\mathrm{m}$ \\
\hline Montenegro & 52.2 & $(0.7)$ & 55.7 & $(4.7)$ & 53.4 & (3.7) & -3.5 & $(4.8)$ \\
\hline Peru & 54.4 & $(0.7)$ & C & c & c & c & c & c \\
\hline Qatar & 55.6 & $(0.8)$ & 51.5 & $(0.7)$ & 52.6 & (1.3) & 4.1 & (1.1) \\
\hline Romania & $\mathrm{m}$ & $\mathrm{m}$ & $\mathrm{m}$ & $\mathrm{m}$ & $\mathrm{m}$ & $\mathrm{m}$ & $\mathrm{m}$ & $\mathrm{m}$ \\
\hline Russia & 73.2 & $(0.9)$ & 68.3 & (3.5) & 76.3 & $(4.3)$ & 4.9 & $(3.8)$ \\
\hline Singapore & 54.7 & $(0.7)$ & 53.3 & (1.6) & 47.3 & $(2.7)$ & 1.4 & $(1.6)$ \\
\hline Chinese Taipei & 45.2 & $(0.8)$ & c & c & c & c & c & c \\
\hline Thailand & 61.4 & $(0.8)$ & C & C & c & C & c & c \\
\hline Trinidad and Tobago & $\mathrm{m}$ & $\mathrm{m}$ & $\mathrm{m}$ & $\mathrm{m}$ & $\mathrm{m}$ & $\mathrm{m}$ & $\mathrm{m}$ & $\mathrm{m}$ \\
\hline Tunisia & 55.5 & $(0.9)$ & c & c & 75.8 & (6.3) & c & $\mathrm{c}$ \\
\hline United Arab Emirates & 54.2 & $(0.9)$ & 53.9 & $(1.0)$ & 53.3 & (1.3) & 0.2 & (1.3) \\
\hline Uruguay & 50.8 & $(0.8)$ & c & c & c & c & c & c \\
\hline Viet Nam & $\mathrm{m}$ & $\mathrm{m}$ & $\mathrm{m}$ & $\mathrm{m}$ & $\mathrm{m}$ & $\mathrm{m}$ & $\mathrm{m}$ & $\mathrm{m}$ \\
\hline Argentina** & $\mathrm{m}$ & $\mathrm{m}$ & $\mathrm{m}$ & $\mathrm{m}$ & $\mathrm{m}$ & $\mathrm{m}$ & $\mathrm{m}$ & $\mathrm{m}$ \\
\hline Kazakhstan** & $\mathrm{m}$ & $\mathrm{m}$ & $\mathrm{m}$ & $\mathrm{m}$ & $\mathrm{m}$ & $\mathrm{m}$ & $\mathrm{m}$ & $\mathrm{m}$ \\
\hline Malaysia** & 73 & 7) & & & 3 & .3) & & \\
\hline
\end{tabular}

Note: Values that are statistically significant are indicated in bold (see Annex A3).

* See note at the beginning of this Annex.

** Coverage is too small to ensure comparability (see Annex A4)

StatLink 完正目 http://dx.doi.org/10.1787/888933471423 


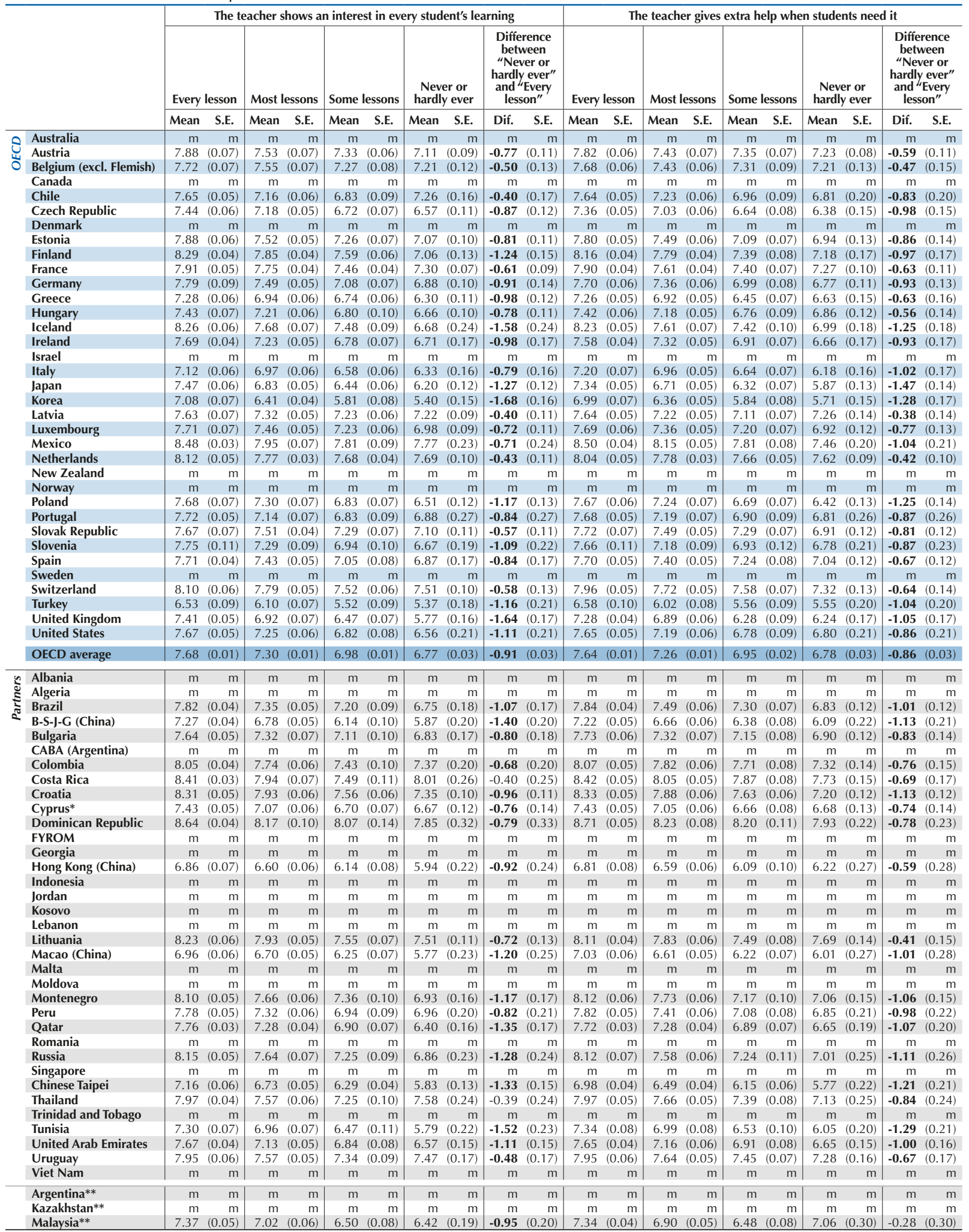

Note: Values that are statistically significant are indicated in bold (see Annex A3).

* See note at the beginning of this Annex.

** Coverage is too small to ensure comparability (see Annex A4).

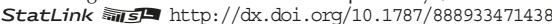


[Part 2/3]

Table III.7.18 Life satisfaction, by teacher support in science class

Results based on students' self-reports

\begin{tabular}{|c|c|c|c|c|c|c|c|c|c|c|c|c|c|c|c|c|c|c|c|c|c|}
\hline & & & & The tea & cher hel & Ips stud & lents wit & th their & learnin & & & & The teac & her con & ntinues $t$ & teachin & ng until $t$ & he stud & dents unc & derstan & \\
\hline & & Every & lesson & Most & lessons & Some & lessons & $\begin{array}{r}\text { Nev } \\
\text { hardl }\end{array}$ & $\begin{array}{l}\text { er or } \\
\text { ly ever }\end{array}$ & $\begin{array}{r}\text { Diffe } \\
\text { bety } \\
\text { "Nev } \\
\text { hardly } \\
\text { and" } \\
\text { less }\end{array}$ & $\begin{array}{l}\text { rence } \\
\text { ween } \\
\text { ver or } \\
\text { yever" } \\
\text { Every } \\
\text { son" }\end{array}$ & Every & lesson & Most I & lessons & Some & lessons & $\begin{array}{c}\text { Nev } \\
\text { hardl }\end{array}$ & $\begin{array}{l}\text { ver or } \\
\text { lly ever }\end{array}$ & $\begin{array}{l}\text { Diffe } \\
\text { betv } \\
\text { "Ney } \\
\text { hardly } \\
\text { and } \\
\text { less }\end{array}$ & $\begin{array}{l}\text { erence } \\
\text { ween } \\
\text { ver or } \\
\text { y ever" } \\
\text { "Every } \\
\text { son" }\end{array}$ \\
\hline & & Mean & S.E. & Mean & S.E. & Mean & S.E. & Mean & S.E. & Dif. & S.E. & Mean & S.E. & Mean & S.E. & Mean & S.E. & Mean & S.E. & Dif. & S.E. \\
\hline & Australia & $\mathrm{m}$ & $\mathrm{m}$ & $\mathrm{m}$ & $\mathrm{m}$ & $\mathrm{m}$ & $\mathrm{m}$ & $\mathrm{m}$ & $\mathrm{m}$ & $\mathrm{m}$ & $\mathrm{m}$ & $\mathrm{m}$ & $\mathrm{m}$ & $\mathrm{m}$ & $\mathrm{m}$ & $\mathrm{m}$ & $\mathrm{m}$ & $\mathrm{m}$ & $\mathrm{m}$ & $\mathrm{m}$ & $\mathrm{m}$ \\
\hline & Austria & 7.88 & $(0.09)$ & 7.56 & $(0.08)$ & 7.50 & $(0.07)$ & 7.24 & $(0.05)$ & -0.63 & $(0.11)$ & 7.78 & $(0.07)$ & 7.53 & $(0.07)$ & 7.34 & $(0.08)$ & 7.21 & $(0.09)$ & -0.58 & $(0.11)$ \\
\hline & Belgium (excl. Flemish) & 7.68 & $(0.06)$ & 7.44 & $(0.07)$ & 7.33 & $(0.09)$ & 6.99 & $(0.15)$ & -0.68 & $(0.16)$ & 7.69 & $(0.06)$ & 7.38 & $(0.07)$ & 7.34 & $(0.08)$ & 7.29 & $(0.15)$ & -0.41 & $(0.15)$ \\
\hline & Canada & $\mathrm{m}$ & & $\mathrm{m}$ & $\mathrm{m}$ & $\mathrm{m}$ & $\mathrm{m}$ & $\mathrm{m}$ & $\mathrm{m}$ & $\mathrm{m}$ & $\mathrm{m}$ & $\mathrm{m}$ & $\mathrm{m}$ & $\mathrm{m}$ & $\mathrm{m}$ & $\mathrm{m}$ & $\mathrm{m}$ & $\mathrm{m}$ & $\mathrm{m}$ & $\mathrm{m}$ & $\mathrm{m}$ \\
\hline & Chile & 7.64 & $(0.05)$ & 7.18 & $(0.06)$ & 6.78 & $(0.09)$ & 6.57 & $(0.28)$ & -1.07 & $(0.28)$ & 7.68 & $(0.05)$ & 7.22 & $(0.06)$ & 6.83 & $(0.08)$ & 6.88 & $(0.16)$ & -0.80 & $(0.16)$ \\
\hline & Czech Republic & 7.49 & $(0.07)$ & 7.26 & $(0.05)$ & 6.85 & $(0.07)$ & 6.65 & $(0.08)$ & -0.84 & $(0.10)$ & 7.43 & $(0.06)$ & 7.14 & $(0.06)$ & 6.93 & $(0.06)$ & 6.66 & $(0.09)$ & $\mid-0.77$ & $(0.10)$ \\
\hline & Denmark & $\mathrm{m}$ & & $\mathrm{m}$ & & $\mathrm{m}$ & $\mathrm{m}$ & $\mathrm{m}$ & $\mathrm{m}$ & $\mathrm{m}$ & $\mathrm{m}$ & $\mathrm{m}$ & $\mathrm{m}$ & $\mathrm{m}$ & $\mathrm{m}$ & $\mathrm{m}$ & $\mathrm{m}$ & $\mathrm{m}$ & $\mathrm{m}$ & $\mathrm{m}$ & $\mathrm{m}$ \\
\hline & Estonia & 7.82 & $(0.06)$ & 7.50 & $(0.06)$ & 7.06 & $(0.07)$ & 7.02 & $(0.13)$ & -0.80 & $(0.15)$ & 7.89 & $(0.06)$ & 7.55 & $(0.05)$ & 7.17 & $(0.07)$ & 6.99 & $(0.11)$ & -0.91 & $(0.14)$ \\
\hline & Finland & 8.17 & $(0.04)$ & 7.73 & $(0.04)$ & 7.37 & $(0.09)$ & 6.92 & $(0.22)$ & -1.25 & $(0.23)$ & 8.17 & $(0.05)$ & 7.91 & $(0.04)$ & 7.55 & $(0.06)$ & 7.22 & $(0.14)$ & -0.95 & $(0.15)$ \\
\hline & France & 7.92 & $(0.05)$ & 7.62 & $(0.04)$ & 7.44 & $(0.06)$ & 7.15 & $(0.09)$ & -0.76 & $(0.11)$ & 7.88 & $(0.04)$ & 7.64 & $(0.04)$ & 7.43 & $(0.05)$ & 7.24 & $(0.09)$ & -0.64 & $(0.10)$ \\
\hline & Germany & 7.76 & $(0.09)$ & 7.51 & $(0.06)$ & 7.17 & $(0.06)$ & 6.88 & $(0.08)$ & -0.88 & $(0.12)$ & 7.71 & $(0.06)$ & 7.40 & $(0.06)$ & 7.07 & $(0.07)$ & 6.75 & $(0.12)$ & -0.96 & $(0.14)$ \\
\hline & Greece & 7.17 & $(0.05)$ & 6.87 & $(0.06)$ & 6.51 & $(0.09)$ & 6.43 & $(0.19)$ & -0.74 & $(0.19)$ & 7.21 & $(0.06)$ & 6.99 & $(0.05)$ & 6.64 & $(0.08)$ & 6.40 & $(0.13)$ & -0.82 & $(0.15)$ \\
\hline & Hungary & 7.44 & $(0.08)$ & 7.22 & $(0.06)$ & 6.95 & $(0.08)$ & 6.77 & $(0.08)$ & -0.67 & $(0.10)$ & 7.49 & $(0.07)$ & 7.21 & $(0.06)$ & 6.94 & $(0.06)$ & 6.72 & $(0.11)$ & -0.77 & (0.13) \\
\hline & Iceland & 8.16 & $(0.05)$ & 7.50 & $(0.08)$ & 7.27 & $(0.12)$ & 7.26 & $(0.28)$ & -0.89 & $(0.28)$ & 8.16 & $(0.05)$ & 7.60 & $(0.07)$ & 7.39 & $(0.10)$ & 6.74 & $(0.28)$ & -1.42 & $(0.28)$ \\
\hline & Ireland & 7.59 & $(0.04)$ & 7.23 & $(0.05)$ & 6.93 & $(0.07)$ & 6.59 & $(0.18)$ & -1.00 & $(0.18)$ & 7.61 & $(0.04)$ & 7.29 & $(0.05)$ & 6.94 & $(0.07)$ & 6.60 & $(0.13)$ & $\mid-1.01$ & $(0.14)$ \\
\hline & Israel & $\mathrm{m}$ & & $\mathrm{m}$ & $\mathrm{m}$ & $\mathrm{m}$ & $\mathrm{m}$ & $\mathrm{m}$ & $\mathrm{m}$ & $\mathrm{m}$ & $\mathrm{m}$ & $\mathrm{m}$ & $\mathrm{m}$ & $\mathrm{m}$ & $\mathrm{m}$ & $\mathrm{m}$ & $\mathrm{m}$ & $\mathrm{m}$ & $\mathrm{m}$ & $\mathrm{m}$ & $\mathrm{m}$ \\
\hline & Italy & 7.19 & $(0.07)$ & 6.89 & $(0.05)$ & 6.61 & $(0.07)$ & 6.21 & $(0.19)$ & $-0.98 \mid$ & $(0.20)$ & 7.15 & $(0.06)$ & 6.95 & $(0.06)$ & 6.63 & $(0.06)$ & 6.51 & $(0.12)$ & $|-0.64|$ & $(0.14)$ \\
\hline & Japan & 7.34 & $(0.05)$ & 6.68 & $(0.05)$ & 6.32 & $(0.07)$ & 6.06 & $(0.12)$ & $\mid-1.27$ & $(0.13)$ & 7.33 & $(0.05)$ & 6.81 & $(0.04)$ & 6.30 & $(0.06)$ & 6.25 & $(0.11)$ & \begin{tabular}{|l|}
-1.08 \\
\end{tabular} & $(0.12)$ \\
\hline & Korea & 6.98 & $(0.06)$ & 6.26 & $(0.05)$ & 5.71 & $(0.09)$ & 5.48 & $(0.21)$ & -1.50 & $(0.21)$ & 7.08 & $(0.06)$ & 6.37 & $(0.05)$ & 5.86 & $(0.07)$ & 5.41 & $(0.18)$ & -1.67 & (0.19) \\
\hline & Latvia & 7.63 & $(0.05)$ & 7.23 & $(0.06)$ & 7.10 & $(0.07)$ & 7.20 & (0.15) & -0.44 & (0.15) & 7.66 & $(0.06)$ & 7.39 & $(0.06)$ & 6.98 & $(0.07)$ & 7.11 & $(0.11)$ & -0.55 & $(0.13)$ \\
\hline & Luxembourg & 7.61 & $(0.06)$ & 7.50 & $(0.06)$ & 7.38 & $(0.06)$ & 7.08 & $(0.07)$ & -0.53 & $(0.09)$ & 7.59 & $(0.05)$ & 7.46 & $(0.06)$ & 7.18 & $(0.06)$ & 7.06 & $(0.10)$ & $\mid-0.53$ & $(0.12)$ \\
\hline & Mexico & 8.51 & $(0.04)$ & 8.05 & $(0.06)$ & 7.76 & $(0.09)$ & 7.56 & $(0.22)$ & -0.95 & $(0.22)$ & 8.48 & $(0.04)$ & 8.18 & $(0.05)$ & 7.90 & $(0.07)$ & 7.50 & $(0.15)$ & $|-0.98|$ & (0.15) \\
\hline & Netherlands & 8.14 & $(0.06)$ & 7.82 & $(0.04)$ & 7.82 & $(0.04)$ & 7.54 & $(0.05)$ & -0.59 & $(0.07)$ & 8.05 & $(0.05)$ & 7.82 & $(0.04)$ & 7.70 & $(0.04)$ & 7.57 & $(0.09)$ & -0.49 & $(0.10)$ \\
\hline & New Zealand & $\mathrm{m}$ & $\mathrm{m}$ & $\mathrm{m}$ & $\mathrm{m}$ & $\mathrm{m}$ & $\mathrm{m}$ & $\mathrm{m}$ & $\mathrm{m}$ & $\mathrm{m}$ & $\mathrm{m}$ & $\mathrm{m}$ & $\mathrm{m}$ & $\mathrm{m}$ & $\mathrm{m}$ & $\mathrm{m}$ & $\mathrm{m}$ & $\mathrm{m}$ & $\mathrm{m}$ & $\mathrm{m}$ & $\mathrm{m}$ \\
\hline & Norway & $\mathrm{m}$ & & $\mathrm{m}$ & $\mathrm{m}$ & $\mathrm{m}$ & $\mathrm{m}$ & $\mathrm{m}$ & $\mathrm{m}$ & $\mathrm{m}$ & $\mathrm{m}$ & $\mathrm{m}$ & $\mathrm{m}$ & $\mathrm{m}$ & $\mathrm{m}$ & $\mathrm{m}$ & $\mathrm{m}$ & $\mathrm{m}$ & $\mathrm{m}$ & $\mathrm{m}$ & $\mathrm{m}$ \\
\hline & Poland & 7.66 & $(0.06)$ & 7.21 & $(0.06)$ & 6.83 & $(0.07)$ & 6.36 & $(0.16)$ & -1.31 & $(0.17)$ & 7.62 & $(0.07)$ & 7.23 & $(0.06)$ & 6.86 & $(0.07)$ & 6.58 & $(0.11)$ & -1.04 & $(0.14)$ \\
\hline & Portugal & 7.68 & $(0.05)$ & 7.05 & $(0.08)$ & 6.90 & $(0.09)$ & 7.13 & $(0.30)$ & -0.55 & $(0.30)$ & 7.64 & $(0.05)$ & 7.27 & $(0.06)$ & 6.85 & $(0.08)$ & 6.78 & $(0.23)$ & -0.87 & $(0.23)$ \\
\hline & Slovak Republic & 7.85 & $(0.07)$ & 7.57 & $(0.06)$ & 7.39 & $(0.05)$ & 6.98 & $(0.09)$ & -0.87 & $(0.11)$ & 7.78 & $(0.07)$ & 7.54 & $(0.06)$ & 7.36 & $(0.06)$ & 7.03 & $(0.10)$ & -0.76 & $(0.12)$ \\
\hline & Slovenia & 7.87 & $(0.11)$ & 7.37 & $(0.09)$ & 6.97 & $(0.10)$ & 6.74 & $(0.16)$ & -1.13 & $(0.21)$ & 7.53 & $(0.14)$ & 7.45 & $(0.09)$ & 7.02 & $(0.10)$ & 6.73 & $(0.18)$ & -0.80 & $(0.21)$ \\
\hline & Spain & 7.71 & $(0.04)$ & 7.33 & $(0.05)$ & 7.17 & $(0.10)$ & 6.77 & $(0.16)$ & -0.95 & $(0.16)$ & 7.71 & $(0.04)$ & 7.42 & $(0.06)$ & 7.18 & $(0.08)$ & 6.84 & $(0.13)$ & -0.86 & $(0.14)$ \\
\hline & Sweden & $\mathrm{m}$ & & $\mathrm{m}$ & & $\mathrm{m}$ & & $\mathrm{m}$ & $\mathrm{m}$ & $\mathrm{m}$ & $\mathrm{m}$ & $\mathrm{m}$ & $\mathrm{m}$ & $\mathrm{m}$ & $\mathrm{m}$ & $\mathrm{m}$ & $\mathrm{m}$ & $\mathrm{m}$ & $\mathrm{m}$ & $\mathrm{m}$ & $\mathrm{m}$ \\
\hline & Switzerland & 7.95 & $(0.06)$ & 7.80 & $(0.06)$ & 7.72 & $(0.06)$ & 7.34 & $(0.09)$ & -0.61 & $(0.12)$ & 7.93 & $(0.05)$ & 7.73 & $(0.07)$ & 7.59 & $(0.06)$ & 7.53 & $(0.11)$ & -0.41 & $(0.12)$ \\
\hline & Turkey & 6.53 & $(0.09)$ & 5.87 & $(0.07)$ & 5.44 & $(0.09)$ & 5.56 & $(0.23)$ & -0.97 & $(0.24)$ & 6.54 & $(0.10)$ & 6.01 & $(0.08)$ & 5.59 & $(0.10)$ & 5.40 & $(0.18)$ & -1.14 & $(0.18)$ \\
\hline & United Kingdom & 7.29 & $(0.04)$ & 6.78 & $(0.06)$ & 6.24 & $(0.11)$ & 6.21 & $(0.18)$ & -1.07 & $(0.18)$ & 7.27 & $(0.04)$ & 7.10 & $(0.06)$ & 6.38 & $(0.08)$ & 6.14 & $(0.15)$ & -1.13 & $(0.16)$ \\
\hline & United States & 7.64 & $(0.04)$ & 7.15 & $(0.07)$ & 6.76 & $(0.10)$ & 6.50 & $(0.28)$ & -1.14 & $(0.27)$ & 7.67 & $(0.05)$ & 7.26 & $(0.06)$ & 7.01 & $(0.07)$ & 6.57 & $(0.15)$ & -1.10 & $(0.15)$ \\
\hline & OECD average & 7.65 & $(0.01)$ & 7.26 & $(0.01)$ & 6.97 & $(0.02)$ & 6.76 & $(0.03)$ & -0.90 & $(0.03)$ & 7.63 & $(0.01)$ & 7.32 & $(0.01)$ & 7.00 & $(0.01)$ & 6.77 & $(0.03)$ & -0.86 & $(0.03$ \\
\hline & Albania & $\mathrm{m}$ & $\mathrm{m}$ & $\mathrm{m}$ & $\mathrm{m}$ & $\mathrm{m}$ & $\mathrm{m}$ & $\mathrm{m}$ & $\mathrm{m}$ & $\mathrm{m}$ & $\mathrm{m}$ & $\mathrm{m}$ & $\mathrm{m}$ & $\mathrm{m}$ & & $\mathrm{m}$ & $\mathrm{m}$ & $\mathrm{m}$ & $\mathrm{m}$ & $\mathrm{m}$ & $\mathrm{m}$ \\
\hline$\overline{0}$ & Algeria & $\mathrm{m}$ & & $\mathrm{m}$ & $\mathrm{m}$ & $\mathrm{m}$ & $\mathrm{m}$ & $\mathrm{m}$ & $\mathrm{m}$ & $\mathrm{m}$ & $\mathrm{m}$ & $\mathrm{m}$ & $\mathrm{m}$ & $\mathrm{m}$ & $\mathrm{m}$ & $\mathrm{m}$ & $\mathrm{m}$ & $\mathrm{m}$ & $\mathrm{m}$ & $\mathrm{m}$ & $\mathrm{m}$ \\
\hline & Brazil & 7.81 & $(0.04)$ & 7.36 & $(0.05)$ & 7.23 & $(0.10)$ & 6.56 & $(0.23)$ & -1.25 & $(0.23)$ & 7.83 & $(0.04)$ & 7.40 & $(0.05)$ & 7.11 & $(0.08)$ & 7.09 & $(0.15)$ & -0.74 & $(0.16)$ \\
\hline & B-S-J-G (China) & 7.18 & $(0.05)$ & 6.66 & $(0.06)$ & 6.26 & $(0.09)$ & 6.16 & $(0.23)$ & -1.02 & $(0.23)$ & 7.31 & $(0.06)$ & 6.89 & $(0.05)$ & 6.28 & $(0.07)$ & 6.13 & $(0.13)$ & -1.18 & $(0.14)$ \\
\hline & Bulgaria & 7.77 & $(0.06)$ & 7.32 & $(0.07)$ & 7.16 & $(0.08)$ & 7.02 & $(0.12)$ & -0.76 & $(0.14)$ & 7.73 & $(0.06)$ & 7.23 & $(0.06)$ & 7.14 & $(0.08)$ & 6.79 & $(0.13)$ & -0.94 & $(0.16)$ \\
\hline & CABA (Arge & $\mathrm{m}$ & & $\mathrm{m}$ & & $\mathrm{m}$ & & $\mathrm{m}$ & & $\mathrm{m}$ & & $\mathrm{m}$ & & $\mathrm{m}$ & & $\mathrm{m}$ & $\mathrm{m}$ & $\mathrm{m}$ & $\mathrm{m}$ & $\mathrm{m}$ & $\mathrm{m}$ \\
\hline & Colombia & 8.09 & $(0.04)$ & 7.76 & $(0.07)$ & 7.47 & $(0.09)$ & 7.09 & $(0.26)$ & -1.00 & $(0.25)$ & 8.06 & $(0.05)$ & 7.86 & $(0.06)$ & 7.60 & $(0.08)$ & 7.20 & $(0.17)$ & -0.86 & $(0.18)$ \\
\hline & Costa Rica & 8.41 & $(0.04)$ & 8.03 & $(0.06)$ & 7.68 & $(0.09)$ & 7.77 & $(0.24)$ & -0.64 & $(0.24)$ & 8.40 & $(0.05)$ & 8.09 & $(0.06)$ & 7.78 & $(0.08)$ & 7.83 & $(0.14)$ & -0.57 & $(0.15)$ \\
\hline & Croatia & 8.36 & $(0.06)$ & 8.07 & $(0.06)$ & 7.75 & $(0.06)$ & 7.31 & $(0.08)$ & -1.06 & $(0.10)$ & 8.29 & $(0.06)$ & 7.93 & $(0.07)$ & 7.73 & $(0.06)$ & 7.57 & $(0.08)$ & -0.72 & $(0.10)$ \\
\hline & Cyprus* & 7.41 & $(0.05)$ & 6.96 & $(0.05)$ & 6.62 & $(0.08)$ & 6.64 & $(0.16)$ & -0.77 & $(0.17)$ & 7.44 & $(0.05)$ & 7.11 & $(0.05)$ & 6.63 & $(0.07)$ & 6.71 & $(0.13)$ & -0.72 & $(0.15)$ \\
\hline & Dominican Republic & 8.68 & $(0.05)$ & 8.22 & $(0.09)$ & 7.84 & $(0.15)$ & 7.78 & $(0.33)$ & -0.90 & $(0.33)$ & 8.67 & $(0.05)$ & 8.39 & $(0.09)$ & 7.89 & $(0.10)$ & 7.87 & $(0.26)$ & -0.80 & $(0.27)$ \\
\hline & FYROM & $\mathrm{m}$ & $\mathrm{m}$ & $\mathrm{m}$ & $\mathrm{m}$ & $\mathrm{m}$ & $\mathrm{m}$ & $\mathrm{m}$ & $\mathrm{m}$ & $\mathrm{m}$ & $\mathrm{m}$ & $\mathrm{m}$ & $\mathrm{m}$ & $\mathrm{m}$ & $\mathrm{m}$ & $\mathrm{m}$ & $\mathrm{m}$ & $\mathrm{m}$ & $\mathrm{m}$ & $\mathrm{m}$ & $\mathrm{m}$ \\
\hline & Georgia & $\mathrm{m}$ & & $\mathrm{m}$ & $\mathrm{m}$ & $\mathrm{m}$ & $\mathrm{m}$ & $\mathrm{m}$ & $\mathrm{m}$ & $\mathrm{m}$ & $\mathrm{m}$ & $\mathrm{m}$ & $\mathrm{m}$ & $\mathrm{m}$ & $\mathrm{m}$ & $\mathrm{m}$ & $\mathrm{m}$ & $\mathrm{m}$ & $\mathrm{m}$ & $\mathrm{m}$ & $\mathrm{n}$ \\
\hline & Hong Kong (China) & 6.83 & $(0.08)$ & 6.56 & $(0.06)$ & 6.11 & $(0.10)$ & 5.78 & $(0.25)$ & -1.05 & $(0.27)$ & 6.85 & $(0.07)$ & 6.65 & $(0.06)$ & 6.06 & $(0.09)$ & 5.99 & $(0.21)$ & -0.87 & $(0.22)$ \\
\hline & Indonesia & $\mathrm{m}$ & $\mathrm{m}$ & $\mathrm{m}$ & $\mathrm{m}$ & $\mathrm{m}$ & $\mathrm{m}$ & $\mathrm{m}$ & $\mathrm{m}$ & $\mathrm{m}$ & $\mathrm{m}$ & $\mathrm{m}$ & $\mathrm{m}$ & $\mathrm{m}$ & $\mathrm{m}$ & $\mathrm{m}$ & $\mathrm{m}$ & $\mathrm{m}$ & $\mathrm{m}$ & $\mathrm{m}$ & $\mathrm{m}$ \\
\hline & Jordan & $\mathrm{m}$ & & $\mathrm{m}$ & $\mathrm{m}$ & $\mathrm{m}$ & $\mathrm{m}$ & $\mathrm{m}$ & $\mathrm{m}$ & $\mathrm{m}$ & $\mathrm{m}$ & $\mathrm{m}$ & $\mathrm{m}$ & $\mathrm{m}$ & & $\mathrm{m}$ & 111 & $\mathrm{~m}$ & $\mathrm{~m}$ & $\mathrm{~m}$ & $\mathrm{n}$ \\
\hline & Kosovo & $\mathrm{m}$ & & $\mathrm{m}$ & & $\mathrm{m}$ & & $\mathrm{m}$ & $\mathrm{m}$ & $\mathrm{m}$ & $\mathrm{m}$ & $\mathrm{m}$ & $\mathrm{m}$ & $\mathrm{m}$ & & $\mathrm{m}$ & $\mathrm{m}$ & $\mathrm{m}$ & $\mathrm{m}$ & $\mathrm{m}$ & $n$ \\
\hline & Lebanon & $\mathrm{m}$ & & $\mathrm{m}$ & $\mathrm{m}$ & $\mathrm{m}$ & $\mathrm{m}$ & $\mathrm{m}$ & $\mathrm{m}$ & $\mathrm{m}$ & $\mathrm{m}$ & $\mathrm{m}$ & $\mathrm{m}$ & $\mathrm{m}$ & $\mathrm{m}$ & $\mathrm{m}$ & $\mathrm{m}$ & $\mathrm{m}$ & $\mathrm{m}$ & $\mathrm{m}$ & $\mathrm{m}$ \\
\hline & Lithuania & 8.10 & $(0.04)$ & 7.77 & $(0.06)$ & 7.54 & $(0.08)$ & 7.43 & $(0.18)$ & -0.68 & $(0.18)$ & 8.20 & $(0.04)$ & 7.84 & $(0.06)$ & 7.45 & $(0.08)$ & 7.54 & $(0.12)$ & -0.66 & $(0.13)$ \\
\hline & Macao (China) & 6.99 & $(0.06)$ & 6.66 & $(0.05)$ & 6.14 & $(0.07)$ & 5.80 & $(0.27)$ & -1.19 & $(0.29)$ & 7.05 & $(0.06)$ & 6.69 & $(0.05)$ & 6.21 & $(0.07)$ & 5.56 & $(0.22)$ & -1.49 & $(0.23)$ \\
\hline & Malta & $\mathrm{m}$ & $\mathrm{m}$ & $\mathrm{m}$ & $\mathrm{m}$ & $\mathrm{m}$ & $\mathrm{m}$ & $\mathrm{m}$ & & $\mathrm{m}$ & & $\mathrm{m}$ & & $\mathrm{m}$ & & $\mathrm{m}$ & $\mathrm{m}$ & $\mathrm{m}$ & $\mathrm{m}$ & $\mathrm{m}$ & $\mathrm{m}$ \\
\hline & Moldova & $\mathrm{m}$ & & $\mathrm{m}$ & $\mathrm{m}$ & $\mathrm{m}$ & $\mathrm{m}$ & $\mathrm{m}$ & $\mathrm{m}$ & $\mathrm{m}$ & $\mathrm{m}$ & $\mathrm{m}$ & $\mathrm{m}$ & $\mathrm{m}$ & $\mathrm{m}$ & $\mathrm{m}$ & $\mathrm{m}$ & $\mathrm{m}$ & $\mathrm{m}$ & $\mathrm{m}$ & $\mathrm{m}$ \\
\hline & Montenegro & 8.20 & $(0.06)$ & 7.73 & $(0.06)$ & 7.35 & $(0.09)$ & 7.06 & $(0.12)$ & -1.15 & $(0.13)$ & 8.15 & $(0.05)$ & 7.72 & $(0.05)$ & 7.29 & $(0.09)$ & 7.02 & $(0.16)$ & -1.13 & $(0.15)$ \\
\hline & Peru & 7.80 & $(0.04)$ & 7.41 & $(0.06)$ & 6.96 & $(0.09)$ & 6.38 & $(0.27)$ & -1.43 & $(0.28)$ & 7.86 & $(0.05)$ & 7.38 & $(0.06)$ & 7.07 & $(0.07)$ & 6.85 & $(0.16)$ & -1.01 & $(0.16)$ \\
\hline & Qatar & 7.70 & $(0.03)$ & 7.27 & $(0.04)$ & 6.84 & $(0.07)$ & 6.41 & $(0.22)$ & -1.29 & $(0.22)$ & 7.74 & $(0.03)$ & 7.27 & $(0.05)$ & 6.93 & $(0.06)$ & 6.50 & $(0.14)$ & -1.23 & $(0.14)$ \\
\hline & Romani & $\mathrm{m}$ & & $\mathrm{m}$ & & $\mathrm{m}$ & & $\mathrm{m}$ & & $\mathrm{m}$ & & $\mathrm{m}$ & & $\mathrm{m}$ & & $\mathrm{m}$ & $\mathrm{m}$ & $\mathrm{m}$ & $\mathrm{m}$ & $\mathrm{m}$ & \\
\hline & Russia & 8.10 & $(0.07)$ & 7.57 & $(0.06)$ & 7.28 & $(0.09)$ & 7.15 & $(0.25)$ & -0.95 & $(0.24)$ & 8.13 & $(0.05)$ & 7.72 & $(0.08)$ & 7.22 & $(0.07)$ & 6.91 & $(0.16)$ & -1.21 & $(0.17)$ \\
\hline & Singapore & $\mathrm{m}$ & & $\mathrm{m}$ & & $\mathrm{m}$ & & $\mathrm{m}$ & $\mathrm{m}$ & $\mathrm{m}$ & $\mathrm{m}$ & $\mathrm{m}$ & $\mathrm{m}$ & $\mathrm{m}$ & $\mathrm{m}$ & $\mathrm{m}$ & $\mathrm{m}$ & $\mathrm{m}$ & $\mathrm{m}$ & $\mathrm{m}$ & $\mathrm{m}$ \\
\hline & Chinese Taipei & 6.98 & $(0.04)$ & 6.45 & $(0.05)$ & 6.09 & $(0.07)$ & 5.66 & $(0.23)$ & -1.32 & $(0.22)$ & 7.03 & $(0.05)$ & 6.62 & $(0.05)$ & 6.26 & $(0.05)$ & 5.74 & $(0.15)$ & -1.29 & $0.15)$ \\
\hline & Thailand & 7.96 & $(0.04)$ & 7.59 & $(0.05)$ & 7.38 & $(0.08)$ & 7.46 & $(0.21)$ & -0.50 & $(0.21)$ & 7.98 & $(0.04)$ & 7.63 & $(0.07)$ & 7.37 & $(0.09)$ & 6.99 & $(0.18)$ & -0.99 & $(0.18)$ \\
\hline & Trinidad and Tobago & $\mathrm{m}$ & & $\mathrm{m}$ & & $\mathrm{m}$ & $\mathrm{m}$ & $\mathrm{m}$ & $\mathrm{m}$ & $\mathrm{m}$ & $\mathrm{m}$ & $\mathrm{m}$ & $\mathrm{m}$ & $\mathrm{m}$ & $\mathrm{m}$ & $\mathrm{m}$ & $\mathrm{m}$ & $\mathrm{m}$ & $\mathrm{m}$ & $\mathrm{m}$ & $\mathrm{m}$ \\
\hline & Tunisia & 7.32 & $(0.06)$ & 6.84 & $(0.08)$ & 6.53 & $(0.10)$ & 5.58 & $(0.24)$ & -1.73 & $(0.25)$ & 7.22 & $(0.07)$ & 7.10 & $(0.07)$ & 6.56 & $(0.10)$ & 5.89 & $(0.17)$ & -1.33 & $(0.19)$ \\
\hline & Uni & 7.63 & $(0.04)$ & 7.10 & $(0.07)$ & 6.72 & $(0.08)$ & 6.76 & $(0.20)$ & -0.87 & $(0.21)$ & 7.62 & $(0.04)$ & 7.14 & $(0.06)$ & 6.89 & $(0.07)$ & 6.67 & $(0.12)$ & -0.95 & $(0.13)$ \\
\hline & Uruguay & 7.98 & $(0.05)$ & 7.53 & $(0.06)$ & 7.40 & $(0.08)$ & 7.26 & $(0.18)$ & -0.72 & $(0.18)$ & 7.93 & $(0.05)$ & 7.63 & $(0.05)$ & 7.40 & $(0.08)$ & 7.29 & $(0.17)$ & -0.64 & $(0.17)$ \\
\hline & Viet Nam & $\mathrm{m}$ & $\mathrm{m}$ & $\mathrm{m}$ & $\mathrm{m}$ & $\mathrm{m}$ & $\mathrm{m}$ & $\mathrm{m}$ & $\mathrm{m}$ & $\mathrm{m}$ & $\mathrm{m}$ & $\mathrm{m}$ & $\mathrm{m}$ & $\mathrm{m}$ & $\mathrm{m}$ & $\mathrm{m}$ & $\mathrm{m}$ & m & $\mathrm{m}$ & $\mathrm{m}$ & $\mathrm{m}$ \\
\hline & Argentina** & $\mathrm{m}$ & & $\mathrm{m}$ & $\mathrm{m}$ & $\mathrm{m}$ & $\mathrm{m}$ & $\mathrm{m}$ & $\mathrm{m}$ & $\mathrm{m}$ & $\mathrm{m}$ & $\mathrm{m}$ & $\mathrm{m}$ & $\mathrm{m}$ & & $\mathrm{m}$ & $\mathrm{m}$ & $\mathrm{m}$ & $\mathrm{m}$ & $\mathrm{m}$ & $m$ \\
\hline & nstan** & $\mathrm{m}$ & & $\mathrm{m}$ & & $\mathrm{m}$ & & $\mathrm{m}$ & $\mathrm{m}$ & $\mathrm{m}$ & $\mathrm{m}$ & $\mathrm{m}$ & $\mathrm{m}$ & $\mathrm{m}$ & & $\mathrm{m}$ & $\mathrm{m}$ & $\mathrm{m}$ & $\mathrm{m}$ & $\mathrm{m}$ & \\
\hline & Malaysia** & 7.33 & $(0.04)$ & 6.81 & $(0.06)$ & 6.42 & $(0.11)$ & 6.57 & $(0.46)$ & -0.76 & $(0.45)$ & 7.37 & $(0.04)$ & 6.91 & $(0.06)$ & 6.49 & $(0.08)$ & 6.20 & $(0.27)$ & -1.18 & $(0.27)$ \\
\hline
\end{tabular}

Note: Values that are statistically significant are indicated in bold (see Annex A3).

* See note at the beginning of this Annex.

** Coverage is too small to ensure comparability (see Annex A4).

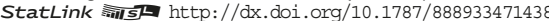




\begin{tabular}{|c|c|c|c|c|c|c|c|c|c|c|c|}
\hline & \multicolumn{10}{|c|}{ The teacher gives students an opportunity to express opinions } \\
\hline & & \multicolumn{2}{|c|}{ Every lesson } & \multicolumn{2}{|c|}{ Most lessons } & \multicolumn{2}{|c|}{ Some lessons } & Never & lly ever & $\begin{array}{l}\text { Differe } \\
\text { "Never } \\
\text { and " }\end{array}$ & $\begin{array}{l}\text { tween } \\
\text { lly ever" } \\
\text { esson" }\end{array}$ \\
\hline & & Mean & S.E. & Mean & S.E. & Mean & S.E. & Mean & S.E. & Dif. & S.E. \\
\hline 0 & Australia & $\mathrm{m}$ & $\mathrm{m}$ & $\mathrm{m}$ & $\mathrm{m}$ & $\mathrm{m}$ & $\mathrm{m}$ & $\mathrm{m}$ & $\mathrm{m}$ & $\mathrm{m}$ & $\mathrm{m}$ \\
\hline تِ & Austria & 7.79 & $(0.05)$ & 7.44 & $(0.07)$ & 7.34 & $(0.06)$ & 7.14 & $(0.11)$ & -0.65 & $(0.12)$ \\
\hline & Belgium (excl. Flemish) & 7.75 & $(0.06)$ & 7.50 & $(0.07)$ & 7.25 & $(0.07)$ & 7.22 & $(0.14)$ & -0.53 & $(0.15)$ \\
\hline & Canada & $\mathrm{m}$ & $\mathrm{m}$ & $\mathrm{m}$ & $\mathrm{m}$ & $\mathrm{m}$ & $\mathrm{m}$ & $\mathrm{m}$ & $\mathrm{m}$ & $\mathrm{m}$ & $\mathrm{m}$ \\
\hline & Chile & 7.67 & $(0.05)$ & 7.25 & $(0.05)$ & 6.98 & $(0.08)$ & 6.78 & $(0.16)$ & -0.89 & $(0.17)$ \\
\hline & Czech Republic & 7.40 & $(0.05)$ & 7.09 & $(0.05)$ & 6.84 & $(0.08)$ & 6.49 & $(0.10)$ & -0.91 & $(0.11)$ \\
\hline & Denmark & $\mathrm{m}$ & $\mathrm{m}$ & $\mathrm{m}$ & $\mathrm{m}$ & $\mathrm{m}$ & $\mathrm{m}$ & $\mathrm{m}$ & $\mathrm{m}$ & $\mathrm{m}$ & $\mathrm{m}$ \\
\hline & Estonia & 7.79 & $(0.06)$ & 7.52 & $(0.06)$ & 7.19 & $(0.07)$ & 6.90 & $(0.11)$ & -0.89 & $(0.13)$ \\
\hline & Finland & 8.18 & $(0.04)$ & 7.84 & $(0.04)$ & 7.57 & $(0.06)$ & 7.21 & $(0.13)$ & -0.97 & $(0.13)$ \\
\hline & France & 7.94 & $(0.04)$ & 7.63 & $(0.05)$ & 7.39 & $(0.05)$ & 7.38 & $(0.08)$ & -0.56 & $(0.09)$ \\
\hline & Germany & 7.68 & $(0.06)$ & 7.36 & $(0.06)$ & 7.02 & $(0.07)$ & 6.91 & $(0.11)$ & -0.77 & $(0.13)$ \\
\hline & Greece & 7.21 & $(0.05)$ & 6.88 & $(0.06)$ & 6.63 & $(0.07)$ & 6.28 & $(0.14)$ & -0.93 & $(0.15)$ \\
\hline & Hungary & 7.44 & $(0.07)$ & 7.17 & $(0.05)$ & 6.89 & $(0.09)$ & 6.78 & $(0.11)$ & -0.66 & $(0.13)$ \\
\hline & Iceland & 8.18 & $(0.05)$ & 7.65 & $(0.07)$ & 7.35 & $(0.12)$ & 6.79 & $(0.21)$ & -1.38 & $(0.22)$ \\
\hline & Ireland & 7.65 & $(0.06)$ & 7.37 & $(0.05)$ & 7.09 & $(0.06)$ & 6.68 & $(0.12)$ & -0.97 & $(0.13)$ \\
\hline & Israel & $\mathrm{m}$ & $\mathrm{m}$ & $\mathrm{m}$ & $\mathrm{m}$ & $\mathrm{m}$ & $\mathrm{m}$ & $\mathrm{m}$ & $\mathrm{m}$ & $\mathrm{m}$ & $\mathrm{m}$ \\
\hline & Italy & 7.20 & $(0.06)$ & 6.94 & $(0.06)$ & 6.59 & $(0.07)$ & 6.34 & $(0.13)$ & -0.85 & $(0.13)$ \\
\hline & Japan & 7.25 & $(0.06)$ & 6.88 & $(0.06)$ & 6.60 & $(0.06)$ & 6.46 & $(0.08)$ & -0.79 & $(0.10)$ \\
\hline & Korea & 7.17 & $(0.07)$ & 6.36 & $(0.06)$ & 6.02 & $(0.07)$ & 5.63 & $(0.11)$ & -1.54 & $(0.12)$ \\
\hline & Latvia & 7.64 & $(0.06)$ & 7.33 & $(0.05)$ & 7.08 & $(0.07)$ & 6.97 & $(0.13)$ & -0.67 & $(0.15)$ \\
\hline & Luxembourg & 7.63 & $(0.05)$ & 7.41 & $(0.05)$ & 7.22 & $(0.07)$ & 6.92 & $(0.11)$ & -0.71 & $(0.13)$ \\
\hline & Mexico & 8.48 & $(0.04)$ & 8.13 & $(0.05)$ & 7.87 & $(0.08)$ & 7.53 & $(0.21)$ & -0.95 & $(0.22)$ \\
\hline & Netherlands & 8.09 & $(0.05)$ & 7.80 & $(0.04)$ & 7.72 & $(0.04)$ & 7.63 & $(0.07)$ & -0.46 & $(0.08)$ \\
\hline & New Zealand & $\mathrm{m}$ & $\mathrm{m}$ & $\mathrm{m}$ & $\mathrm{m}$ & $\mathrm{m}$ & $\mathrm{m}$ & $\mathrm{m}$ & $\mathrm{m}$ & $\mathrm{m}$ & $\mathrm{m}$ \\
\hline & Norway & $\mathrm{m}$ & $\mathrm{m}$ & $\mathrm{m}$ & $\mathrm{m}$ & $\mathrm{m}$ & $\mathrm{m}$ & $\mathrm{m}$ & $\mathrm{m}$ & $\mathrm{m}$ & $\mathrm{m}$ \\
\hline & Poland & 7.63 & $(0.06)$ & 7.32 & $(0.06)$ & 6.84 & $(0.06)$ & 6.43 & $(0.12)$ & -1.20 & $(0.13)$ \\
\hline & Portugal & 7.73 & $(0.05)$ & 7.23 & $(0.06)$ & 6.86 & $(0.08)$ & 6.71 & $(0.23)$ & -1.01 & $(0.23)$ \\
\hline & Slovak Republic & 7.72 & $(0.06)$ & 7.51 & $(0.06)$ & 7.28 & $(0.06)$ & 7.04 & $(0.11)$ & -0.68 & $(0.12)$ \\
\hline & Slovenia & 7.63 & $(0.09)$ & 7.21 & $(0.10)$ & 6.85 & $(0.12)$ & 6.83 & $(0.25)$ & -0.80 & $(0.26)$ \\
\hline & Spain & 7.73 & $(0.05)$ & 7.48 & $(0.06)$ & 7.24 & $(0.06)$ & 6.89 & $(0.11)$ & -0.84 & $(0.13)$ \\
\hline & Sweden & $\mathrm{m}$ & $\mathrm{m}$ & $\mathrm{m}$ & $\mathrm{m}$ & $\mathrm{m}$ & $\mathrm{m}$ & $\mathrm{m}$ & $\mathrm{m}$ & $\mathrm{m}$ & $\mathrm{m}$ \\
\hline & Switzerland & 7.95 & $(0.05)$ & 7.71 & $(0.05)$ & 7.49 & $(0.08)$ & 7.52 & $(0.13)$ & -0.43 & $(0.13)$ \\
\hline & Turkey & 6.60 & $(0.10)$ & 5.92 & $(0.08)$ & 5.53 & $(0.10)$ & 5.28 & $(0.15)$ & -1.32 & $(0.17)$ \\
\hline & United Kingdom & 7.34 & $(0.06)$ & 7.09 & $(0.06)$ & 6.71 & $(0.07)$ & 6.09 & $(0.11)$ & -1.25 & $(0.13)$ \\
\hline & United States & 7.71 & $(0.06)$ & 7.28 & $(0.06)$ & 6.99 & $(0.06)$ & 6.80 & $(0.14)$ & -0.91 & $(0.14)$ \\
\hline & OECD average & 7.65 & $(0.01)$ & 7.30 & $(0.01)$ & 7.02 & $(0.01)$ & 6.77 & $(0.03)$ & -0.88 & $(0.03)$ \\
\hline$\stackrel{2}{2}$ & Albania & $\mathrm{m}$ & $\mathrm{m}$ & $\mathrm{m}$ & $\mathrm{m}$ & $\mathrm{m}$ & $\mathrm{m}$ & $\mathrm{m}$ & $\mathrm{m}$ & $\mathrm{m}$ & $\mathrm{m}$ \\
\hline$\stackrel{\Xi}{\Xi}$ & Algeria & $\mathrm{m}$ & $\mathrm{m}$ & $\mathrm{m}$ & $\mathrm{m}$ & $\mathrm{m}$ & $\mathrm{m}$ & $\mathrm{m}$ & $\mathrm{m}$ & $\mathrm{m}$ & $\mathrm{m}$ \\
\hline ฮั & Brazil & 7.86 & $(0.04)$ & 7.44 & $(0.06)$ & 7.23 & $(0.07)$ & 6.82 & $(0.10)$ & -1.04 & $(0.11)$ \\
\hline & B-S-J-G (China) & 7.28 & $(0.06)$ & 6.85 & $(0.04)$ & 6.24 & $(0.07)$ & 6.12 & $(0.15)$ & -1.16 & $(0.16)$ \\
\hline & Bulgaria & 7.79 & $(0.06)$ & 7.23 & $(0.07)$ & 7.07 & $(0.08)$ & 6.77 & $(0.15)$ & -1.02 & $(0.17)$ \\
\hline & CABA (Argentina) & $\mathrm{m}$ & $\mathrm{m}$ & $\mathrm{m}$ & $\mathrm{m}$ & $\mathrm{m}$ & $\mathrm{m}$ & $\mathrm{m}$ & $\mathrm{m}$ & $\mathrm{m}$ & $\mathrm{m}$ \\
\hline & Colombia & 8.06 & $(0.04)$ & 7.85 & $(0.06)$ & 7.58 & $(0.08)$ & 7.02 & $(0.18)$ & -1.05 & $(0.19)$ \\
\hline & Costa Rica & 8.47 & $(0.04)$ & 8.06 & $(0.05)$ & 7.85 & $(0.08)$ & 7.76 & $(0.16)$ & -0.71 & $(0.16)$ \\
\hline & Croatia & 8.25 & $(0.05)$ & 7.95 & $(0.06)$ & 7.51 & $(0.06)$ & 7.39 & $(0.11)$ & -0.87 & $(0.12)$ \\
\hline & Cyprus* & 7.40 & $(0.05)$ & 7.08 & $(0.05)$ & 6.66 & $(0.07)$ & 6.80 & $(0.15)$ & -0.60 & $(0.17)$ \\
\hline & Dominican Republic & 8.68 & $(0.04)$ & 8.26 & $(0.08)$ & 8.15 & $(0.12)$ & 7.63 & $(0.38)$ & -1.05 & $(0.38)$ \\
\hline & FYROM & $\mathrm{m}$ & $\mathrm{m}$ & $\mathrm{m}$ & $\mathrm{m}$ & $\mathrm{m}$ & $\mathrm{m}$ & $\mathrm{m}$ & $\mathrm{m}$ & $\mathrm{m}$ & $\mathrm{m}$ \\
\hline & Georgia & $\mathrm{m}$ & $\mathrm{m}$ & $\mathrm{m}$ & $\mathrm{m}$ & $\mathrm{m}$ & $\mathrm{m}$ & $\mathrm{m}$ & $\mathrm{m}$ & $\mathrm{m}$ & $\mathrm{m}$ \\
\hline & Hong Kong (China) & 6.87 & $(0.08)$ & 6.61 & $(0.06)$ & 6.13 & $(0.08)$ & 6.03 & $(0.21)$ & -0.84 & $(0.23)$ \\
\hline & Indonesia & $\mathrm{m}$ & $\mathrm{m}$ & $\mathrm{m}$ & $\mathrm{m}$ & $\mathrm{m}$ & $\mathrm{m}$ & $\mathrm{m}$ & $\mathrm{m}$ & $\mathrm{m}$ & $\mathrm{m}$ \\
\hline & Jordan & $\mathrm{m}$ & $\mathrm{m}$ & $\mathrm{m}$ & $\mathrm{m}$ & $\mathrm{m}$ & $\mathrm{m}$ & $\mathrm{m}$ & $\mathrm{m}$ & $\mathrm{m}$ & $\mathrm{m}$ \\
\hline & Kosovo & $\mathrm{m}$ & $\mathrm{m}$ & $\mathrm{m}$ & $\mathrm{m}$ & $\mathrm{m}$ & $\mathrm{m}$ & $\mathrm{m}$ & $\mathrm{m}$ & $\mathrm{m}$ & $\mathrm{m}$ \\
\hline & Lebanon & $\mathrm{m}$ & $\mathrm{m}$ & $\mathrm{m}$ & $\mathrm{m}$ & $\mathrm{m}$ & $\mathrm{m}$ & $\mathrm{m}$ & $\mathrm{m}$ & $\mathrm{m}$ & $\mathrm{m}$ \\
\hline & Lithuania & 8.21 & $(0.05)$ & 7.82 & $(0.05)$ & 7.57 & $(0.07)$ & 7.31 & $(0.13)$ & -0.90 & $(0.14)$ \\
\hline & Macao (China) & 7.00 & $(0.06)$ & 6.73 & $(0.06)$ & 6.24 & $(0.07)$ & 5.73 & $(0.18)$ & -1.27 & $(0.19)$ \\
\hline & Malta & $\mathrm{m}$ & $\mathrm{m}$ & $\mathrm{m}$ & $\mathrm{m}$ & $\mathrm{m}$ & $\mathrm{m}$ & $\mathrm{m}$ & $\mathrm{m}$ & $\mathrm{m}$ & $\mathrm{m}$ \\
\hline & Moldova & $\mathrm{m}$ & $\mathrm{m}$ & $\mathrm{m}$ & $\mathrm{m}$ & $\mathrm{m}$ & $\mathrm{m}$ & $\mathrm{m}$ & $\mathrm{m}$ & $\mathrm{m}$ & $\mathrm{m}$ \\
\hline & Montenegro & 8.19 & $(0.05)$ & 7.69 & $(0.06)$ & 7.26 & $(0.10)$ & 6.87 & $(0.16)$ & -1.32 & $(0.16)$ \\
\hline & Peru & 7.84 & $(0.04)$ & 7.32 & $(0.06)$ & 6.95 & $(0.08)$ & 6.47 & $(0.27)$ & -1.36 & $(0.26)$ \\
\hline & Qatar & 7.81 & $(0.04)$ & 7.34 & $(0.04)$ & 7.06 & $(0.05)$ & 6.61 & $(0.10)$ & -1.20 & $(0.11)$ \\
\hline & Romania & $\mathrm{m}$ & $\mathrm{m}$ & $\mathrm{m}$ & $\mathrm{m}$ & $\mathrm{m}$ & $\mathrm{m}$ & $\mathrm{m}$ & $\mathrm{m}$ & $\mathrm{m}$ & $\mathrm{m}$ \\
\hline & Russia & 8.12 & $(0.05)$ & 7.72 & $(0.07)$ & 7.32 & $(0.06)$ & 6.81 & $(0.15)$ & -1.31 & $(0.17)$ \\
\hline & Singapore & $\mathrm{m}$ & $\mathrm{m}$ & $\mathrm{m}$ & $\mathrm{m}$ & $\mathrm{m}$ & $\mathrm{m}$ & $\mathrm{m}$ & $\mathrm{m}$ & $\mathrm{m}$ & $\mathrm{m}$ \\
\hline & Chinese Taipei & 6.98 & $(0.04)$ & 6.56 & $(0.04)$ & 6.16 & $(0.06)$ & 5.91 & $(0.16)$ & -1.07 & $(0.15)$ \\
\hline & Thailand & 7.94 & $(0.04)$ & 7.68 & $(0.05)$ & 7.35 & $(0.09)$ & 7.12 & $(0.22)$ & -0.82 & $(0.22)$ \\
\hline & Trinidad and Tobago & $\mathrm{m}$ & $\mathrm{m}$ & $\mathrm{m}$ & $\mathrm{m}$ & $\mathrm{m}$ & $\mathrm{m}$ & $\mathrm{m}$ & $\mathrm{m}$ & $\mathrm{m}$ & $\mathrm{m}$ \\
\hline & Tunisia & 7.30 & $(0.07)$ & 7.04 & $(0.08)$ & 6.58 & $(0.10)$ & 6.10 & $(0.18)$ & -1.20 & $(0.20)$ \\
\hline & United Arab Emirates & 7.71 & $(0.04)$ & 7.27 & $(0.05)$ & 6.90 & $(0.07)$ & 6.62 & $(0.11)$ & -1.09 & $(0.13)$ \\
\hline & Uruguay & 7.99 & $(0.06)$ & 7.65 & $(0.05)$ & 7.34 & $(0.08)$ & 7.16 & $(0.15)$ & -0.83 & $(0.14)$ \\
\hline & Viet Nam & $\mathrm{m}$ & $\mathrm{m}$ & $\mathrm{m}$ & $\mathrm{m}$ & $\mathrm{m}$ & $\mathrm{m}$ & $\mathrm{m}$ & $\mathrm{m}$ & m & $\mathrm{m}$ \\
\hline & Argentina $^{* *}$ & $\mathrm{~m}$ & $\mathrm{~m}$ & $\mathrm{~m}$ & $\mathrm{~m}$ & $\mathrm{~m}$ & $\mathrm{~m}$ & $\mathrm{~m}$ & $\mathrm{~m}$ & $\mathrm{~m}$ & $\mathrm{~m}$ \\
\hline & Kazakhstan** & $\mathrm{m}$ & $\mathrm{m}$ & $\mathrm{m}$ & $\mathrm{m}$ & $\mathrm{m}$ & $\mathrm{m}$ & $\mathrm{m}$ & $\mathrm{m}$ & $\mathrm{m}$ & $\mathrm{m}$ \\
\hline & Malaysia** & 7.43 & $(0.05)$ & 6.94 & $(0.06)$ & 6.46 & $(0.08)$ & 6.68 & $(0.21)$ & -0.75 & $(0.23)$ \\
\hline
\end{tabular}

Note: Values that are statistically significant are indicated in bold (see Annex A3).

* See note at the beginning of this Annex.

** Coverage is too small to ensure comparability (see Annex A4).

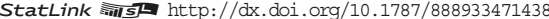


[Part 1/4]

Table III.8.1 Students' exposure to bullying

Based on students' self-reports

\begin{tabular}{|c|c|c|c|c|c|c|c|c|c|c|c|c|}
\hline & & & Per & & & & & y type & bullying ac & & & \\
\hline & $\begin{array}{r}\text { Index ore } \\
\text { to bul }\end{array}$ & $\begin{array}{l}\text { osure } \\
\text { ng }\end{array}$ & & pumled & Never or & st never & A few $t$ & a year & A few tim & month & Once a v & or more \\
\hline & Mean index & S.E. & $\%$ & S.E. & $\%$ & S.E. & $\%$ & S.E. & $\%$ & S.E. & $\%$ & S.E. \\
\hline Australia & 0.45 & $(0.01)$ & 14.8 & $(0.4)$ & 43.3 & $(0.6)$ & 32.5 & $(0.4)$ & 13.5 & $(0.3)$ & 10.7 & $(0.3)$ \\
\hline Austria & 0.10 & $(0.01)$ & 7.9 & $(0.5)$ & 49.9 & $(0.8)$ & 30.9 & $(0.7)$ & 11.3 & $(0.4)$ & 7.9 & $(0.4)$ \\
\hline ర̄ Belgium & 0.18 & $(0.01)$ & 7.2 & $(0.3)$ & 48.0 & $(0.8)$ & 33.5 & $(0.7)$ & 11.0 & $(0.3)$ & 7.6 & $(0.3)$ \\
\hline Canada & 0.39 & $(0.01)$ & 12.9 & $(0.4)$ & 46.2 & $(0.5)$ & 33.5 & $(0.5)$ & 11.3 & $(0.4)$ & 9.0 & $(0.4)$ \\
\hline Chile & 0.15 & $(0.01)$ & 7.9 & $(0.4)$ & 47.3 & $(0.8)$ & 34.7 & $(0.7)$ & 11.0 & $(0.4)$ & 7.0 & $(0.4)$ \\
\hline Czech Republic & 0.15 & $(0.02)$ & 11.7 & $(0.5)$ & 44.8 & (1.0) & 29.7 & $(0.7)$ & 12.6 & $(0.5)$ & 12.8 & (0.5) \\
\hline Denmark & 0.22 & $(0.01)$ & 6.4 & $(0.3)$ & 43.9 & $(0.8)$ & 36.0 & $(0.7)$ & 12.8 & $(0.5)$ & 7.4 & $(0.3)$ \\
\hline Estonia & 0.24 & $(0.01)$ & 9.5 & $(0.5)$ & 46.7 & $(0.7)$ & 33.1 & $(0.6)$ & 11.2 & $(0.4)$ & 9.0 & $(0.5)$ \\
\hline Finland & 0.23 & $(0.02)$ & 9.5 & $(0.4)$ & 51.4 & $(0.9)$ & 31.7 & $(0.7)$ & 9.9 & $(0.4)$ & 7.0 & $(0.4)$ \\
\hline France & -0.08 & $(0.02)$ & 6.7 & $(0.4)$ & 54.2 & $(0.7)$ & 27.8 & $(0.6)$ & 10.2 & $(0.4)$ & 7.7 & $(0.3)$ \\
\hline Germany & 0.17 & $(0.01)$ & 6.1 & (0.4) & 48.6 & $(0.8)$ & 35.7 & (0.6) & 10.0 & $(0.4)$ & 5.7 & $(0.4)$ \\
\hline Greece & -0.55 & $(0.02)$ & 6.7 & (0.5) & 59.0 & $(0.8)$ & 24.3 & $(0.7)$ & 8.1 & $(0.4)$ & 8.6 & $(0.5)$ \\
\hline Hungary & -0.06 & $(0.02)$ & 9.3 & (0.5) & 52.6 & $(0.8)$ & 27.1 & (0.6) & 11.6 & $(0.4)$ & 8.7 & $(0.4)$ \\
\hline Iceland & -0.43 & $(0.02)$ & 5.1 & (0.4) & 65.2 & $(0.8)$ & 22.9 & $(0.7)$ & 6.8 & (0.4) & 5.1 & $(0.3)$ \\
\hline Ireland & 0.10 & $(0.02)$ & 6.8 & $(0.4)$ & 52.9 & (0.9) & 32.4 & $(0.7)$ & 8.8 & $(0.4)$ & 5.9 & $(0.4)$ \\
\hline Israel & $\mathrm{m}$ & $\mathrm{m}$ & $\mathrm{m}$ & $\mathrm{m}$ & $\mathrm{m}$ & $\mathrm{m}$ & $\mathrm{m}$ & $\mathrm{m}$ & $\mathrm{m}$ & $\mathrm{m}$ & $\mathrm{m}$ & $\mathrm{m}$ \\
\hline Italy & $\mathrm{m}$ & $\mathrm{m}$ & $\mathrm{m}$ & $\mathrm{m}$ & $\mathrm{m}$ & $\mathrm{m}$ & $\mathrm{m}$ & $\mathrm{m}$ & $\mathrm{m}$ & $\mathrm{m}$ & $\mathrm{m}$ & $\mathrm{m}$ \\
\hline Japan & -0.21 & $(0.02)$ & 5.1 & $(0.3)$ & 54.5 & $(0.7)$ & 23.6 & $(0.5)$ & 11.2 & (0.4) & 10.7 & $(0.5)$ \\
\hline Korea & -1.44 & $(0.02)$ & 2.1 & $(0.2)$ & 73.2 & $(0.7)$ & 14.9 & $(0.5)$ & 5.9 & $(0.4)$ & 6.0 & $(0.4)$ \\
\hline Latvia & 0.65 & $(0.01)$ & 17.5 & (0.6) & 30.7 & $(0.7)$ & 38.8 & $(0.8)$ & 16.6 & (0.6) & 13.9 & (0.6) \\
\hline Luxembourg & -0.15 & $(0.01)$ & 7.9 & $(0.4)$ & 56.0 & (0.6) & 28.3 & (0.6) & 9.0 & $(0.4)$ & 6.7 & $(0.4)$ \\
\hline Mexico & 0.13 & $(0.01)$ & 10.1 & $(0.4)$ & 48.4 & $(0.7)$ & 31.4 & $(0.7)$ & 10.7 & $(0.4)$ & 9.5 & $(0.3)$ \\
\hline Netherlands & -0.33 & $(0.01)$ & 3.3 & $(0.4)$ & 62.3 & $(0.7)$ & 28.4 & $(0.7)$ & 6.1 & $(0.4)$ & 3.2 & $(0.3)$ \\
\hline New Zealand & 0.61 & $(0.02)$ & 18.3 & $(0.6)$ & 39.1 & $(0.8)$ & 34.9 & $(0.8)$ & 14.9 & $(0.5)$ & 11.2 & $(0.5)$ \\
\hline Norway & -0.01 & $(0.02)$ & 9.6 & $(0.4)$ & 52.6 & $(0.8)$ & 29.7 & $(0.6)$ & 11.1 & $(0.5)$ & 6.6 & $(0.4)$ \\
\hline Poland & 0.27 & $(0.02)$ & 10.7 & $(0.4)$ & 45.5 & $(0.8)$ & 33.4 & $(0.7)$ & 11.2 & $(0.5)$ & 9.9 & $(0.5)$ \\
\hline Portugal & -0.52 & $(0.02)$ & 5.7 & $(0.3)$ & 64.5 & $(0.7)$ & 23.7 & $(0.6)$ & 6.9 & $(0.3)$ & 5.0 & $(0.3)$ \\
\hline Slovak Republic & 0.10 & $(0.02)$ & 11.5 & $(0.5)$ & 48.5 & $(0.9)$ & 29.0 & $(0.6)$ & 12.1 & (0.6) & 10.4 & (0.5) \\
\hline Slovenia & 0.01 & $(0.01)$ & 7.3 & $(0.4)$ & 52.6 & $(0.8)$ & 31.0 & $(0.8)$ & 9.9 & $(0.5)$ & 6.5 & $(0.4)$ \\
\hline Spain & -0.09 & $(0.01)$ & 6.0 & $(0.4)$ & 55.6 & $(0.7)$ & 30.4 & $(0.5)$ & 8.1 & $(0.3)$ & 5.9 & $(0.3)$ \\
\hline Sweden & -0.11 & $(0.02)$ & 8.4 & (0.4) & 50.0 & $(0.9)$ & 32.0 & $(0.6)$ & 10.7 & $(0.5)$ & 7.2 & $(0.4)$ \\
\hline Switzerland & 0.24 & $(0.02)$ & 7.3 & $(0.5)$ & 47.3 & $(0.8)$ & 35.9 & $(0.7)$ & 10.2 & $(0.5)$ & 6.6 & $(0.4)$ \\
\hline Turkey & -0.97 & $(0.03)$ & 8.8 & $(0.5)$ & 64.0 & $(0.9)$ & 17.4 & (0.6) & 9.4 & $(0.5)$ & 9.2 & $(0.5)$ \\
\hline United Kingdom & 0.40 & $(0.02)$ & 14.2 & (0.5) & 44.7 & $(0.8)$ & 31.4 & $(0.7)$ & 12.8 & $(0.5)$ & 11.1 & $(0.5)$ \\
\hline United States & 0.16 & $(0.02)$ & 10.0 & $(0.5)$ & 51.7 & $(1.0)$ & 29.3 & $(0.7)$ & 10.6 & $(0.6)$ & 8.4 & $(0.4)$ \\
\hline OECD average & 0.00 & $(0.00)$ & 8.9 & $(0.1)$ & 51.4 & $(0.1)$ & 30.0 & $(0.1)$ & 10.5 & $(0.1)$ & 8.1 & $(0.1)$ \\
\hline
\end{tabular}

\begin{tabular}{|c|c|c|c|c|c|c|c|c|c|c|c|c|}
\hline Albania & $\mathrm{m}$ & $\mathrm{m}$ & $\mathrm{m}$ & $\mathrm{m}$ & $\mathrm{m}$ & $\mathrm{m}$ & $\mathrm{m}$ & $\mathrm{m}$ & $\mathrm{m}$ & $\mathrm{m}$ & $\mathrm{m}$ & $\mathrm{m}$ \\
\hline Algeria & $\mathrm{m}$ & $\mathrm{m}$ & $\mathrm{m}$ & $\mathrm{m}$ & $\mathrm{m}$ & $\mathrm{m}$ & $\mathrm{m}$ & $\mathrm{m}$ & $\mathrm{m}$ & $\mathrm{m}$ & $\mathrm{m}$ & $\mathrm{m}$ \\
\hline Brazil & -0.23 & $(0.01)$ & 9.0 & $(0.3)$ & 56.9 & $(0.5)$ & 25.7 & $(0.5)$ & 8.4 & $(0.3)$ & 9.0 & $(0.3)$ \\
\hline B-S-J-G (China) & 0.10 & $(0.02)$ & 10.5 & $(0.5)$ & 46.5 & $(1.2)$ & 31.0 & $(0.7)$ & 12.2 & $(0.5)$ & 10.3 & $(0.5)$ \\
\hline Bulgaria & 0.14 & $(0.02)$ & 13.8 & $(0.7)$ & 46.6 & $(0.8)$ & 28.7 & $(0.8)$ & 12.6 & $(0.4)$ & 12.2 & $(0.5)$ \\
\hline CABA (Argentina) & $\mathrm{m}$ & $\mathrm{m}$ & $\mathrm{m}$ & $\mathrm{m}$ & $\mathrm{m}$ & $\mathrm{m}$ & $\mathrm{m}$ & $\mathrm{m}$ & $\mathrm{m}$ & $\mathrm{m}$ & $\mathrm{m}$ & $\mathrm{m}$ \\
\hline Colombia & 0.16 & $(0.01)$ & 7.6 & $(0.4)$ & 45.5 & $(0.8)$ & 32.4 & $(0.7)$ & 11.4 & $(0.4)$ & 10.7 & $(0.5)$ \\
\hline Costa Rica & 0.10 & $(0.01)$ & 10.9 & $(0.5)$ & 50.4 & $(0.7)$ & 28.8 & $(0.6)$ & 10.4 & $(0.4)$ & 10.3 & $(0.5)$ \\
\hline Croatia & -0.12 & $(0.02)$ & 6.7 & $(0.4)$ & 55.7 & $(0.7)$ & 27.2 & $(0.5)$ & 9.1 & $(0.4)$ & 8.0 & $(0.4)$ \\
\hline Cyprus* & $\mathrm{m}$ & $\mathrm{m}$ & $\mathrm{m}$ & $\mathrm{m}$ & 53.9 & $(0.6)$ & 28.0 & $(0.6)$ & 9.4 & $(0.4)$ & 8.7 & $(0.4)$ \\
\hline Dominican Republic & -0.29 & $(0.03)$ & 12.2 & $(0.6)$ & 47.3 & (1.0) & 22.6 & $(0.8)$ & 12.9 & $(0.6)$ & 17.2 & $(0.6)$ \\
\hline FYROM & $\mathrm{m}$ & $\mathrm{m}$ & $\mathrm{m}$ & $\mathrm{m}$ & $\mathrm{m}$ & $\mathrm{m}$ & $\mathrm{m}$ & $\mathrm{m}$ & $\mathrm{m}$ & $\mathrm{m}$ & $\mathrm{m}$ & $\mathrm{m}$ \\
\hline Georgia & $\mathrm{m}$ & $\mathrm{m}$ & $\mathrm{m}$ & $\mathrm{m}$ & $\mathrm{m}$ & $\mathrm{m}$ & $\mathrm{m}$ & $\mathrm{m}$ & $\mathrm{m}$ & $\mathrm{m}$ & $\mathrm{m}$ & $\mathrm{m}$ \\
\hline Hong Kong (China) & 0.21 & $(0.03)$ & 15.4 & $(0.7)$ & 43.2 & (1.0) & 24.5 & $(0.7)$ & 16.9 & $(0.6)$ & 15.5 & $(0.6)$ \\
\hline Indonesia & $\mathrm{m}$ & $\mathrm{m}$ & $\mathrm{m}$ & $\mathrm{m}$ & $\mathrm{m}$ & $\mathrm{m}$ & $\mathrm{m}$ & $\mathrm{m}$ & $\mathrm{m}$ & $\mathrm{m}$ & $\mathrm{m}$ & $\mathrm{m}$ \\
\hline Jordan & $\mathrm{m}$ & $\mathrm{m}$ & $\mathrm{m}$ & $\mathrm{m}$ & $\mathrm{m}$ & $\mathrm{m}$ & $\mathrm{m}$ & $\mathrm{m}$ & $\mathrm{m}$ & $\mathrm{m}$ & $\mathrm{m}$ & $\mathrm{m}$ \\
\hline Kosovo & $\mathrm{m}$ & $\mathrm{m}$ & $\mathrm{m}$ & $\mathrm{m}$ & $\mathrm{m}$ & $\mathrm{m}$ & $\mathrm{m}$ & $\mathrm{m}$ & $\mathrm{m}$ & $\mathrm{m}$ & $\mathrm{m}$ & $\mathrm{m}$ \\
\hline Lebanon & $\mathrm{m}$ & $\mathrm{m}$ & $\mathrm{m}$ & $\mathrm{m}$ & $\mathrm{m}$ & $\mathrm{m}$ & $\mathrm{m}$ & $\mathrm{m}$ & $\mathrm{m}$ & $\mathrm{m}$ & $\mathrm{m}$ & $\mathrm{m}$ \\
\hline Lithuania & -0.10 & $(0.02)$ & 9.6 & $(0.4)$ & 56.3 & $(0.8)$ & 27.3 & $(0.7)$ & 9.8 & $(0.5)$ & 6.6 & $(0.4)$ \\
\hline Macao (China) & 0.49 & $(0.01)$ & 14.4 & $(0.5)$ & 40.3 & $(0.7)$ & 32.4 & $(0.7)$ & 14.7 & $(0.6)$ & 12.6 & $(0.5)$ \\
\hline Malta & $\mathrm{m}$ & $\mathrm{m}$ & $\mathrm{m}$ & $\mathrm{m}$ & $\mathrm{m}$ & $\mathrm{m}$ & $\mathrm{m}$ & $\mathrm{m}$ & $\mathrm{m}$ & $\mathrm{m}$ & $\mathrm{m}$ & $\mathrm{m}$ \\
\hline Moldova & $\mathrm{m}$ & $\mathrm{m}$ & $\mathrm{m}$ & $\mathrm{m}$ & $\mathrm{m}$ & $\mathrm{m}$ & $\mathrm{m}$ & $\mathrm{m}$ & $\mathrm{m}$ & $\mathrm{m}$ & $\mathrm{m}$ & $\mathrm{m}$ \\
\hline Montenegro & -0.91 & $(0.02)$ & 7.0 & $(0.4)$ & 63.2 & $(0.7)$ & 20.5 & $(0.6)$ & 7.1 & $(0.3)$ & 9.3 & $(0.4)$ \\
\hline Peru & -0.23 & $(0.02)$ & 6.1 & $(0.4)$ & 51.3 & $(0.9)$ & 30.3 & $(0.6)$ & 9.4 & $(0.4)$ & 9.0 & $(0.4)$ \\
\hline Qatar & 0.36 & $(0.01)$ & 19.1 & $(0.3)$ & 45.4 & $(0.4)$ & 29.6 & $(0.4)$ & 13.0 & $(0.3)$ & 12.0 & $(0.3)$ \\
\hline Romania & $\mathrm{m}$ & $\mathrm{m}$ & $\mathrm{m}$ & $\mathrm{m}$ & $\mathrm{m}$ & $\mathrm{m}$ & $\mathrm{m}$ & $\mathrm{m}$ & $\mathrm{m}$ & $\mathrm{m}$ & $\mathrm{m}$ & $\mathrm{m}$ \\
\hline Russia & -0.01 & $(0.03)$ & 9.5 & $(0.7)$ & 44.4 & (1.5) & 28.1 & $(0.7)$ & 14.5 & $(0.6)$ & 13.0 & $(0.8)$ \\
\hline Singapore & 0.51 & $(0.01)$ & 14.5 & $(0.5)$ & 42.1 & $(0.7)$ & 32.8 & (0.6) & 13.3 & $(0.4)$ & 11.7 & $(0.4)$ \\
\hline Chinese Taipei & -0.57 & $(0.01)$ & 3.1 & $(0.2)$ & 70.4 & $(0.7)$ & 18.9 & $(0.6)$ & 6.9 & $(0.3)$ & 3.8 & $(0.2)$ \\
\hline Thailand & 0.11 & $(0.03)$ & 17.5 & $(0.8)$ & 51.7 & $(0.9)$ & 21.1 & $(0.6)$ & 13.4 & $(0.6)$ & 13.8 & $(0.6)$ \\
\hline Trinidad and Tobago & $\mathrm{m}$ & $\mathrm{m}$ & $\mathrm{m}$ & $\mathrm{m}$ & $\mathrm{m}$ & $\mathrm{m}$ & $\mathrm{m}$ & $\mathrm{m}$ & $\mathrm{m}$ & $\mathrm{m}$ & $\mathrm{m}$ & $\mathrm{m}$ \\
\hline Tunisia & 0.32 & $(0.02)$ & 16.2 & $(0.7)$ & 38.5 & $(0.9)$ & 33.3 & $(0.8)$ & 14.3 & $(0.5)$ & 13.9 & $(0.5)$ \\
\hline United Arab Emirates & 0.30 & $(0.02)$ & 17.8 & $(0.6)$ & 44.1 & $(0.6)$ & 28.8 & $(0.5)$ & 13.2 & $(0.4)$ & 13.8 & $(0.4)$ \\
\hline Uruguay & -0.05 & $(0.01)$ & 9.5 & $(0.4)$ & 55.7 & $(0.7)$ & 27.4 & $(0.6)$ & 8.6 & $(0.3)$ & 8.3 & $(0.4)$ \\
\hline Viet Nam & $\mathrm{m}$ & $\mathrm{m}$ & $\mathrm{m}$ & $\mathrm{m}$ & $\mathrm{m}$ & $\mathrm{m}$ & $\mathrm{m}$ & $\mathrm{m}$ & $\mathrm{m}$ & $\mathrm{m}$ & $\mathrm{m}$ & $\mathrm{m}$ \\
\hline Argentina** & $\mathrm{m}$ & $\mathrm{m}$ & $\mathrm{m}$ & $\mathrm{m}$ & $\mathrm{m}$ & $\mathrm{m}$ & $\mathrm{m}$ & $\mathrm{m}$ & $\mathrm{m}$ & $\mathrm{m}$ & $\mathrm{m}$ & $\mathrm{m}$ \\
\hline Kazakhstan** & $\mathrm{m}$ & $\mathrm{m}$ & $\mathrm{m}$ & $\mathrm{m}$ & $\mathrm{m}$ & $\mathrm{m}$ & $\mathrm{m}$ & $\mathrm{m}$ & $\mathrm{m}$ & $\mathrm{m}$ & $\mathrm{m}$ & $\mathrm{m}$ \\
\hline Malaysia** & 0.65 & $(0.02)$ & 17.9 & $(0.8)$ & 35.3 & $(0.9)$ & 34.1 & $(0.7)$ & 17.7 & (0.6) & 12.9 & (0.6) \\
\hline
\end{tabular}

1. A student is frequently bullied if he or she is in the top $10 \%$ of the index of exposure to bullying among all countries/economies. See Annex A1 for information on the index of exposure to bullying.

* See note at the beginning of this Annex.

** Coverage is too small to ensure comparability (see Annex A4)

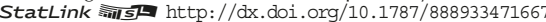




\begin{tabular}{|c|c|c|c|c|c|c|c|c|c|c|c|c|c|c|c|c|}
\hline & & & & & & Perce & ge of & dents & o repo & $d$ the fol & owing & & & & & \\
\hline & & Oth & studer & left me & it of th & s on $p$ & ose & & & & Othe & tudent & ade fu & of me & & \\
\hline & $\begin{array}{r}\text { Never } \\
n\end{array}$ & almost & $\begin{array}{r}\text { A fe } \\
\mathrm{a}\end{array}$ & times & $\begin{array}{c}\text { A fe } \\
\text { a n }\end{array}$ & $\begin{array}{l}\text { imes } \\
\text { nth }\end{array}$ & $\begin{array}{l}\text { Once } \\
\text { or }\end{array}$ & $\begin{array}{l}\text { week } \\
\text { ore }\end{array}$ & Never & $\begin{array}{l}\text { almost } \\
\text { er }\end{array}$ & $\begin{array}{r}\text { A fe } \\
a\end{array}$ & times & $\begin{array}{r}\text { A fev } \\
\text { a n }\end{array}$ & times & $\begin{array}{r}\text { Once } \\
\text { or }\end{array}$ & $\begin{array}{l}\text { week } \\
\text { ore }\end{array}$ \\
\hline & $\%$ & S.E. & $\%$ & S.E. & $\%$ & S.E. & $\%$ & S.E. & $\%$ & S.E. & $\%$ & S.E. & $\%$ & S.E. & $\%$ & S.E. \\
\hline Australia & 64.8 & $(0.6)$ & 22.4 & $(0.4)$ & 8.1 & $(0.3)$ & 4.7 & $(0.2)$ & 61.4 & $(0.5)$ & 23.5 & $(0.4)$ & 8.5 & $(0.3)$ & 6.6 & $(0.3)$ \\
\hline Austria & 82.4 & $(0.5)$ & 11.9 & $(0.4)$ & 3.3 & $(0.2)$ & 2.3 & $(0.2)$ & 64.5 & $(0.7)$ & 23.6 & $(0.6)$ & 7.0 & $(0.4)$ & 4.9 & $(0.3)$ \\
\hline Belgium & 81.6 & $(0.4)$ & 12.5 & $(0.4)$ & 3.9 & $(0.2)$ & 2.1 & $(0.2)$ & 66.4 & $(0.6)$ & 22.5 & $(0.6)$ & 6.8 & $(0.3)$ & 4.3 & $(0.2)$ \\
\hline Canada & 69.5 & $(0.5)$ & 20.9 & $(0.4)$ & 6.2 & $(0.3)$ & 3.4 & $(0.2)$ & 63.0 & $(0.5)$ & 23.6 & $(0.5)$ & 7.6 & $(0.3)$ & 5.8 & $(0.3)$ \\
\hline Chile & 76.9 & $(0.6)$ & 15.7 & $(0.5)$ & 5.1 & $(0.4)$ & 2.3 & $(0.2)$ & 70.6 & $(0.6)$ & 19.9 & $(0.5)$ & 5.9 & $(0.4)$ & 3.6 & $(0.3)$ \\
\hline Czech Republic & 73.3 & $(0.8)$ & 16.8 & $(0.6)$ & 5.8 & $(0.3)$ & 4.0 & $(0.3)$ & 71.1 & $(0.8)$ & 17.8 & $(0.6)$ & 5.9 & $(0.3)$ & 5.2 & $(0.3)$ \\
\hline Denmark & 78.4 & $(0.6)$ & 15.6 & $(0.6)$ & 4.3 & $(0.3)$ & 1.7 & $(0.2)$ & 67.4 & $(0.7)$ & 21.3 & $(0.6)$ & 7.0 & $(0.3)$ & 4.2 & $(0.3)$ \\
\hline Estonia & 78.2 & $(0.6)$ & 15.2 & $(0.5)$ & 4.1 & $(0.3)$ & 2.5 & $(0.2)$ & 62.1 & $(0.7)$ & 24.2 & $(0.6)$ & 8.2 & $(0.4)$ & 5.5 & $(0.3)$ \\
\hline Finland & 76.0 & $(0.7)$ & 16.9 & $(0.6)$ & 4.5 & $(0.3)$ & 2.7 & $(0.2)$ & 68.9 & $(0.8)$ & 20.6 & $(0.6)$ & 6.5 & $(0.4)$ & 4.0 & $(0.3)$ \\
\hline France & 81.5 & $(0.6)$ & 11.8 & $(0.4)$ & 4.1 & $(0.2)$ & 2.6 & $(0.2)$ & 69.2 & $(0.6)$ & 19.1 & $(0.5)$ & 6.8 & $(0.3)$ & 4.9 & $(0.3)$ \\
\hline Germany & 81.0 & $(0.7)$ & 13.5 & $(0.4)$ & 3.6 & $(0.3)$ & 1.9 & $(0.2)$ & 66.5 & $(0.8)$ & 24.2 & $(0.6)$ & 5.8 & $(0.3)$ & 3.4 & $(0.3)$ \\
\hline Greece & 88.4 & $(0.5)$ & 6.7 & $(0.4)$ & 2.8 & $(0.3)$ & 2.1 & $(0.2)$ & 71.8 & $(0.8)$ & 18.2 & $(0.6)$ & 5.6 & $(0.3)$ & 4.4 & $(0.3)$ \\
\hline Hungary & 74.6 & $(0.7)$ & 16.1 & $(0.6)$ & 6.1 & $(0.3)$ & 3.2 & $(0.3)$ & 75.3 & $(0.7)$ & 15.0 & $(0.5)$ & 5.6 & $(0.3)$ & 4.0 & $(0.3)$ \\
\hline Iceland & 85.7 & $(0.7)$ & 9.7 & $(0.5)$ & 2.8 & $(0.3)$ & 1.8 & $(0.2)$ & 77.8 & $(0.8)$ & 15.5 & $(0.6)$ & 3.9 & $(0.3)$ & 2.8 & $(0.3)$ \\
\hline Ireland & 77.7 & $(0.6)$ & 16.4 & $(0.6)$ & 3.6 & $(0.2)$ & 2.3 & $(0.2)$ & 71.2 & $(0.7)$ & 20.3 & $(0.5)$ & 5.1 & $(0.4)$ & 3.4 & $(0.2)$ \\
\hline Israel & $\mathrm{m}$ & $\mathrm{m}$ & $\mathrm{m}$ & $\mathrm{m}$ & $\mathrm{m}$ & $\mathrm{m}$ & $\mathrm{m}$ & $\mathrm{m}$ & $\mathrm{m}$ & $\mathrm{m}$ & $\mathrm{m}$ & $\mathrm{m}$ & $\mathrm{m}$ & $\mathrm{m}$ & $\mathrm{m}$ & $\mathrm{m}$ \\
\hline Italy & $\mathrm{m}$ & $\mathrm{m}$ & $\mathrm{m}$ & $\mathrm{m}$ & $\mathrm{m}$ & $\mathrm{m}$ & $\mathrm{m}$ & $\mathrm{m}$ & $\mathrm{m}$ & $\mathrm{m}$ & $\mathrm{m}$ & $\mathrm{m}$ & $\mathrm{m}$ & $\mathrm{m}$ & $\mathrm{m}$ & $\mathrm{m}$ \\
\hline Japan & 85.0 & $(0.5)$ & 10.2 & $(0.4)$ & 2.6 & $(0.2)$ & 2.1 & $(0.2)$ & 67.2 & $(0.7)$ & 15.9 & $(0.4)$ & 8.5 & $(0.4)$ & 8.5 & $(0.4)$ \\
\hline Korea & 95.6 & $(0.3)$ & 3.0 & $(0.2)$ & 0.9 & $(0.1)$ & 0.5 & $(0.1)$ & 80.6 & $(0.7)$ & 9.2 & $(0.4)$ & 5.1 & $(0.4)$ & 5.1 & $(0.4)$ \\
\hline Latvia & 61.7 & $(0.8)$ & 25.6 & $(0.7)$ & 8.7 & $(0.5)$ & 4.1 & $(0.3)$ & 58.9 & $(0.8)$ & 26.1 & $(0.7)$ & 8.9 & $(0.4)$ & 6.1 & $(0.4)$ \\
\hline Luxembourg & 82.8 & $(0.5)$ & 11.5 & $(0.4)$ & 3.4 & $(0.3)$ & 2.3 & $(0.2)$ & 73.2 & $(0.6)$ & 18.3 & $(0.6)$ & 4.7 & $(0.2)$ & 3.9 & $(0.2)$ \\
\hline Mexico & 77.2 & $(0.6)$ & 13.8 & $(0.5)$ & 5.6 & $(0.3)$ & 3.4 & $(0.2)$ & 66.0 & $(0.6)$ & 21.1 & $(0.5)$ & 7.1 & $(0.3)$ & 5.9 & $(0.3)$ \\
\hline Netherlands & 91.0 & $(0.5)$ & 6.5 & $(0.4)$ & 1.6 & $(0.2)$ & 0.9 & $(0.1)$ & 80.7 & $(0.6)$ & 14.9 & $(0.5)$ & 2.9 & $(0.3)$ & 1.5 & $(0.2)$ \\
\hline New Zealand & 63.6 & $(0.8)$ & 23.6 & $(0.7)$ & 8.4 & $(0.5)$ & 4.4 & $(0.3)$ & 57.6 & $(0.7)$ & 25.0 & $(0.7)$ & 9.6 & $(0.5)$ & 7.8 & $(0.4)$ \\
\hline Norway & 79.3 & $(0.6)$ & 13.6 & $(0.5)$ & 4.5 & $(0.3)$ & 2.6 & $(0.2)$ & 74.6 & $(0.7)$ & 16.0 & $(0.5)$ & 5.8 & $(0.3)$ & 3.7 & $(0.3)$ \\
\hline Poland & 75.6 & $(0.6)$ & 16.1 & $(0.6)$ & 4.7 & $(0.3)$ & 3.6 & $(0.2)$ & 67.8 & $(0.8)$ & 20.5 & $(0.7)$ & 6.5 & $(0.4)$ & 5.2 & $(0.4)$ \\
\hline Portugal & 86.8 & $(0.5)$ & 8.6 & $(0.4)$ & 2.9 & $(0.2)$ & 1.7 & $(0.2)$ & 80.4 & $(0.6)$ & 12.9 & $(0.6)$ & 3.7 & $(0.2)$ & 3.0 & $(0.2)$ \\
\hline Slovak Republic & 71.9 & $(0.8)$ & 17.7 & $(0.6)$ & 6.6 & $(0.4)$ & 3.7 & $(0.3)$ & 71.9 & $(0.8)$ & 17.7 & $(0.7)$ & 5.5 & $(0.3)$ & 4.9 & $(0.3)$ \\
\hline Slovenia & 80.2 & $(0.6)$ & 14.4 & $(0.6)$ & 3.5 & $(0.3)$ & 1.9 & $(0.2)$ & 73.4 & $(0.7)$ & 17.8 & $(0.6)$ & 5.5 & $(0.4)$ & 3.3 & $(0.3)$ \\
\hline Spain & 85.0 & $(0.5)$ & 10.5 & $(0.4)$ & 2.5 & $(0.2)$ & 2.1 & $(0.2)$ & 73.9 & $(0.6)$ & 18.1 & $(0.5)$ & 4.9 & $(0.3)$ & 3.1 & $(0.3)$ \\
\hline Sweden & 79.8 & $(0.6)$ & 13.7 & $(0.4)$ & 4.0 & $(0.3)$ & 2.4 & $(0.2)$ & 70.9 & $(0.9)$ & 19.7 & $(0.7)$ & 5.9 & $(0.4)$ & 3.5 & $(0.3)$ \\
\hline Switzerland & 82.2 & $(0.7)$ & 12.2 & $(0.6)$ & 3.5 & $(0.3)$ & 2.1 & $(0.2)$ & 63.4 & $(0.8)$ & 25.8 & $(0.7)$ & 6.7 & $(0.4)$ & 4.1 & $(0.3)$ \\
\hline Turkey & 81.3 & $(0.7)$ & 10.1 & $(0.4)$ & 5.2 & $(0.4)$ & 3.4 & $(0.3)$ & 80.2 & $(0.8)$ & 10.7 & $(0.5)$ & 4.8 & $(0.3)$ & 4.3 & $(0.4)$ \\
\hline United Kingdom & 69.3 & $(0.6)$ & 19.2 & $(0.5)$ & 6.9 & $(0.4)$ & 4.5 & $(0.3)$ & 62.3 & $(0.7)$ & 22.5 & $(0.6)$ & 8.2 & $(0.4)$ & 6.9 & $(0.4)$ \\
\hline United States & 71.7 & $(0.8)$ & 18.3 & $(0.6)$ & 6.3 & $(0.4)$ & 3.7 & $(0.3)$ & 68.8 & $(0.9)$ & 19.8 & $(0.6)$ & 6.6 & $(0.4)$ & 4.8 & $(0.3)$ \\
\hline OECD average & 78.5 & $(0.1)$ & 14.3 & $(0.1)$ & 4.5 & $(0.1)$ & 2.7 & $(0.0)$ & 69.7 & $(0.1)$ & 19.4 & $(0.1)$ & 6.3 & $(0.1)$ & 4.6 & $(0.1)$ \\
\hline
\end{tabular}

\begin{tabular}{|c|c|c|c|c|c|c|c|c|c|c|c|c|c|c|c|c|c|}
\hline ( & Albania & $\mathrm{m}$ & $\mathrm{m}$ & $\mathrm{m}$ & $\mathrm{m}$ & $\mathrm{m}$ & $\mathrm{m}$ & $\mathrm{m}$ & $\mathrm{m}$ & $\mathrm{m}$ & $\mathrm{m}$ & $\mathrm{m}$ & $\mathrm{m}$ & $\mathrm{m}$ & $\mathrm{m}$ & $\mathrm{m}$ & $\mathrm{m}$ \\
\hline & Algeria & $\mathrm{m}$ & $\mathrm{m}$ & $\mathrm{m}$ & $\mathrm{m}$ & $\mathrm{m}$ & $\mathrm{m}$ & $\mathrm{m}$ & $\mathrm{m}$ & $\mathrm{m}$ & $\mathrm{m}$ & $\mathrm{m}$ & $\mathrm{m}$ & $\mathrm{m}$ & $\mathrm{m}$ & $\mathrm{m}$ & $\mathrm{m}$ \\
\hline & Brazil & 78.1 & $(0.3)$ & 14.1 & $(0.3)$ & 4.4 & $(0.2)$ & 3.4 & $(0.2)$ & 75.5 & $(0.5)$ & 15.2 & $(0.4)$ & 4.6 & $(0.2)$ & 4.7 & $(0.2)$ \\
\hline & B-S-J-G (China) & 77.4 & $(0.7)$ & 14.7 & $(0.6)$ & 4.6 & $(0.3)$ & 3.3 & $(0.3)$ & 69.2 & $(0.9)$ & 18.5 & $(0.6)$ & 6.7 & $(0.4)$ & 5.6 & $(0.4)$ \\
\hline & Bulgaria & 77.4 & $(0.7)$ & 14.5 & $(0.5)$ & 4.6 & $(0.3)$ & 3.5 & $(0.3)$ & 69.1 & $(0.8)$ & 18.5 & $(0.6)$ & 6.8 & $(0.4)$ & 5.6 & $(0.4)$ \\
\hline & CABA (Argentina) & $\mathrm{m}$ & $\mathrm{m}$ & $\mathrm{m}$ & $\mathrm{m}$ & $\mathrm{m}$ & $\mathrm{m}$ & $\mathrm{m}$ & $\mathrm{m}$ & $\mathrm{m}$ & $\mathrm{m}$ & $\mathrm{m}$ & $\mathrm{m}$ & $\mathrm{m}$ & $\mathrm{m}$ & $\mathrm{m}$ & $\mathrm{m}$ \\
\hline & Colombia & 75.4 & $(0.6)$ & 16.3 & $(0.5)$ & 5.1 & $(0.3)$ & 3.2 & $(0.2)$ & 68.2 & $(0.7)$ & 20.3 & $(0.6)$ & 6.2 & $(0.3)$ & 5.3 & $(0.3)$ \\
\hline & Costa Rica & 77.1 & $(0.7)$ & 14.8 & $(0.5)$ & 5.0 & $(0.3)$ & 3.1 & $(0.3)$ & 69.8 & $(0.6)$ & 18.5 & (0.5) & 6.1 & $(0.3)$ & 5.7 & $(0.4)$ \\
\hline & Croatia & 83.5 & $(0.6)$ & 11.5 & $(0.4)$ & 3.2 & $(0.3)$ & 1.9 & $(0.2)$ & 75.8 & $(0.7)$ & 16.2 & (0.5) & 4.8 & $(0.3)$ & 3.2 & $(0.2)$ \\
\hline & Cyprus* & 77.7 & $(0.5)$ & 14.4 & $(0.5)$ & 5.1 & $(0.3)$ & 2.8 & $(0.2)$ & 69.0 & $(0.6)$ & 19.8 & $(0.5)$ & 6.7 & $(0.4)$ & 4.5 & $(0.3)$ \\
\hline & Dominican Republic & 70.7 & $(0.9)$ & 13.2 & $(0.6)$ & 8.5 & $(0.5)$ & 7.7 & $(0.5)$ & 71.0 & $(0.8)$ & 13.7 & $(0.6)$ & 6.8 & $(0.5)$ & 8.5 & $(0.5)$ \\
\hline & FYROM & $\mathrm{m}$ & $\mathrm{m}$ & $\mathrm{m}$ & $\mathrm{m}$ & $\mathrm{m}$ & $\mathrm{m}$ & $\mathrm{m}$ & $\mathrm{m}$ & $\mathrm{m}$ & $\mathrm{m}$ & $\mathrm{m}$ & $\mathrm{m}$ & $\mathrm{m}$ & $\mathrm{m}$ & $\mathrm{m}$ & $\mathrm{m}$ \\
\hline & Georgia & $\mathrm{m}$ & $\mathrm{m}$ & $\mathrm{m}$ & $\mathrm{m}$ & $\mathrm{m}$ & $\mathrm{m}$ & $\mathrm{m}$ & $\mathrm{m}$ & $\mathrm{m}$ & $\mathrm{m}$ & $\mathrm{m}$ & $\mathrm{m}$ & $\mathrm{m}$ & $\mathrm{m}$ & $\mathrm{m}$ & $\mathrm{m}$ \\
\hline & Hong Kong (China) & 77.4 & $(0.7)$ & 14.1 & $(0.5)$ & 4.4 & $(0.4)$ & 4.1 & $(0.3)$ & 53.3 & (1.0) & 20.6 & $(0.6)$ & 14.6 & $(0.6)$ & 11.5 & $(0.6)$ \\
\hline & Indonesia & $\mathrm{m}$ & $\mathrm{m}$ & $\mathrm{m}$ & $\mathrm{m}$ & $\mathrm{m}$ & $\mathrm{m}$ & $\mathrm{m}$ & $\mathrm{m}$ & $\mathrm{m}$ & $\mathrm{m}$ & $\mathrm{m}$ & $\mathrm{m}$ & $\mathrm{m}$ & $\mathrm{m}$ & $\mathrm{m}$ & $\mathrm{m}$ \\
\hline & Jordan & $\mathrm{m}$ & $\mathrm{m}$ & $\mathrm{m}$ & $\mathrm{m}$ & $\mathrm{m}$ & $\mathrm{m}$ & $\mathrm{m}$ & $\mathrm{m}$ & $\mathrm{m}$ & $\mathrm{m}$ & $\mathrm{m}$ & $\mathrm{m}$ & $\mathrm{m}$ & $\mathrm{m}$ & $\mathrm{m}$ & $\mathrm{m}$ \\
\hline & Kosovo & $\mathrm{m}$ & $\mathrm{m}$ & $\mathrm{m}$ & $\mathrm{m}$ & $\mathrm{m}$ & $\mathrm{m}$ & $\mathrm{m}$ & $\mathrm{m}$ & $\mathrm{m}$ & $\mathrm{m}$ & $\mathrm{m}$ & $\mathrm{m}$ & $\mathrm{m}$ & $\mathrm{m}$ & $\mathrm{m}$ & $\mathrm{m}$ \\
\hline & Lebanon & $\mathrm{m}$ & $\mathrm{m}$ & $\mathrm{m}$ & $\mathrm{m}$ & $\mathrm{m}$ & $\mathrm{m}$ & $\mathrm{m}$ & $\mathrm{m}$ & $\mathrm{m}$ & $\mathrm{m}$ & $\mathrm{m}$ & $\mathrm{m}$ & $\mathrm{m}$ & $\mathrm{m}$ & $\mathrm{m}$ & $\mathrm{m}$ \\
\hline & Lithuania & 79.6 & $(0.6)$ & 13.6 & $(0.5)$ & 4.5 & $(0.3)$ & 2.3 & $(0.3)$ & 74.3 & $(0.6)$ & 16.5 & $(0.5)$ & 5.9 & $(0.4)$ & 3.3 & $(0.3)$ \\
\hline & Macao (China) & 69.3 & $(0.7)$ & 21.2 & $(0.6)$ & 5.9 & $(0.4)$ & 3.6 & $(0.3)$ & 55.5 & $(0.7)$ & 24.6 & (0.6) & 11.1 & $(0.5)$ & 8.8 & $(0.4)$ \\
\hline & Malta & $\mathrm{m}$ & $\mathrm{m}$ & $\mathrm{m}$ & $\mathrm{m}$ & $\mathrm{m}$ & $\mathrm{m}$ & $\mathrm{m}$ & $\mathrm{m}$ & $\mathrm{m}$ & $\mathrm{m}$ & $\mathrm{m}$ & $\mathrm{m}$ & $\mathrm{m}$ & $\mathrm{m}$ & $\mathrm{m}$ & $\mathrm{m}$ \\
\hline & Moldova & $\mathrm{m}$ & $\mathrm{m}$ & $\mathrm{m}$ & $\mathrm{m}$ & $\mathrm{m}$ & $\mathrm{m}$ & $\mathrm{m}$ & $\mathrm{m}$ & $\mathrm{m}$ & $\mathrm{m}$ & $\mathrm{m}$ & $\mathrm{m}$ & $\mathrm{m}$ & $\mathrm{m}$ & $\mathrm{m}$ & $\mathrm{m}$ \\
\hline & Montenegro & 86.6 & $(0.5)$ & 8.5 & $(0.4)$ & 2.6 & $(0.3)$ & 2.3 & $(0.2)$ & 82.9 & $(0.5)$ & 10.3 & $(0.4)$ & 3.5 & $(0.3)$ & 3.3 & $(0.3)$ \\
\hline & Peru & 81.8 & $(0.6)$ & 12.0 & $(0.5)$ & 3.8 & $(0.2)$ & 2.4 & $(0.2)$ & 77.8 & $(0.6)$ & 14.5 & $(0.5)$ & 4.0 & $(0.3)$ & 3.7 & $(0.3)$ \\
\hline & Qatar & 68.9 & $(0.4)$ & 18.9 & $(0.4)$ & 8.3 & $(0.2)$ & 3.9 & $(0.2)$ & 63.7 & $(0.4)$ & 21.6 & $(0.4)$ & 8.4 & $(0.2)$ & 6.2 & $(0.2)$ \\
\hline & Romania & $\mathrm{m}$ & $\mathrm{m}$ & $\mathrm{m}$ & $\mathrm{m}$ & $\mathrm{m}$ & $\mathrm{m}$ & $\mathrm{m}$ & $\mathrm{m}$ & $\mathrm{m}$ & $\mathrm{m}$ & $\mathrm{m}$ & $\mathrm{m}$ & $\mathrm{m}$ & $\mathrm{m}$ & $\mathrm{m}$ & $\mathrm{m}$ \\
\hline & Russia & 60.5 & $(1.2)$ & 21.4 & $(0.6)$ & 10.6 & $(0.8)$ & 7.5 & $(0.5)$ & 71.7 & (1.1) & 16.5 & $(0.5)$ & 6.6 & $(0.4)$ & 5.2 & (0.6) \\
\hline & Singapore & 65.1 & $(0.6)$ & 23.0 & $(0.5)$ & 7.8 & $(0.3)$ & 4.2 & $(0.3)$ & 57.0 & $(0.6)$ & 24.6 & $(0.6)$ & 9.5 & $(0.4)$ & 8.8 & $(0.4)$ \\
\hline & Chinese Taipei & 88.0 & $(0.4)$ & 8.6 & $(0.3)$ & 2.3 & $(0.2)$ & 1.0 & $(0.1)$ & 82.6 & $(0.5)$ & 10.6 & $(0.4)$ & 4.2 & $(0.3)$ & 2.6 & $(0.1)$ \\
\hline & Thailand & 73.6 & $(0.9)$ & 14.1 & $(0.6)$ & 7.4 & $(0.4)$ & 5.0 & $(0.3)$ & 61.8 & $(0.8)$ & 18.3 & $(0.6)$ & 10.5 & $(0.4)$ & 9.4 & $(0.5)$ \\
\hline & Trinidad and Tobago & $\mathrm{m}$ & $\mathrm{m}$ & $\mathrm{m}$ & $\mathrm{m}$ & $\mathrm{m}$ & $\mathrm{m}$ & $\mathrm{m}$ & $\mathrm{m}$ & $\mathrm{m}$ & $\mathrm{m}$ & $\mathrm{m}$ & $\mathrm{m}$ & $\mathrm{m}$ & $\mathrm{m}$ & $\mathrm{m}$ & $\mathrm{m}$ \\
\hline & Tunisia & 70.7 & $(0.8)$ & 17.6 & $(0.6)$ & 7.0 & $(0.4)$ & 4.7 & $(0.3)$ & 65.9 & $(0.7)$ & 21.0 & $(0.6)$ & 7.6 & $(0.4)$ & 5.5 & $(0.3)$ \\
\hline & United Arab Emirates & 69.3 & $(0.6)$ & 18.3 & $(0.5)$ & 7.5 & $(0.3)$ & 4.9 & $(0.2)$ & 62.9 & $(0.6)$ & 21.2 & $(0.4)$ & 8.1 & $(0.3)$ & 7.8 & (0.3) \\
\hline & Uruguay & 76.9 & $(0.6)$ & 14.3 & $(0.5)$ & 4.7 & $(0.2)$ & 4.1 & $(0.3)$ & 72.1 & $(0.6)$ & 17.6 & $(0.5)$ & 5.1 & $(0.3)$ & 5.2 & $(0.3)$ \\
\hline & Viet Nam & $\mathrm{m}$ & $\mathrm{m}$ & $\mathrm{m}$ & $\mathrm{m}$ & $\mathrm{m}$ & $\mathrm{m}$ & $\mathrm{m}$ & $\mathrm{m}$ & $\mathrm{m}$ & $\mathrm{m}$ & $\mathrm{m}$ & $\mathrm{m}$ & $\mathrm{m}$ & $\mathrm{m}$ & $\mathrm{m}$ & $\mathrm{m}$ \\
\hline & Argentina** & $\mathrm{m}$ & $\mathrm{m}$ & $\mathrm{m}$ & $\mathrm{m}$ & $\mathrm{m}$ & $\mathrm{m}$ & $\mathrm{m}$ & $\mathrm{m}$ & $\mathrm{m}$ & $\mathrm{m}$ & $\mathrm{m}$ & $\mathrm{m}$ & $\mathrm{m}$ & $\mathrm{m}$ & $\mathrm{m}$ & $\mathrm{m}$ \\
\hline & Kazakhstan** & $\mathrm{m}$ & $\mathrm{m}$ & $\mathrm{m}$ & $\mathrm{m}$ & $\mathrm{m}$ & $\mathrm{m}$ & $\mathrm{m}$ & $\mathrm{m}$ & $\mathrm{m}$ & $\mathrm{m}$ & $\mathrm{m}$ & $\mathrm{m}$ & $\mathrm{m}$ & $\mathrm{m}$ & $\mathrm{m}$ & $\mathrm{m}$ \\
\hline & Malaysia** & 64.8 & (1.0) & 21.5 & $(0.6)$ & 9.4 & $(0.5)$ & 4.4 & $(0.3)$ & 56.4 & $(0.9)$ & 24.4 & $(0.7)$ & 11.2 & $(0.5)$ & 8.1 & $(0.5)$ \\
\hline
\end{tabular}

1. A student is frequently bullied if he or she is in the top $10 \%$ of the index of exposure to bullying among all countries/economies. See Annex A1 for information on the index of exposure to bullying.

* See note at the beginning of this Annex.

** Coverage is too small to ensure comparability (see Annex A4).

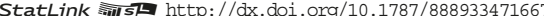


[Part 3/4]

Table III.8.1 Students' exposure to bullying

Based on students' self-reports

\begin{tabular}{|c|c|c|c|c|c|c|c|c|c|c|c|c|c|c|c|c|}
\hline & \multicolumn{16}{|c|}{ Percentage of students who reported the following } \\
\hline & \multicolumn{8}{|c|}{ I was threatened by other students } & \multicolumn{8}{|c|}{ Other students took away or destroyed things that belong to me } \\
\hline & \multicolumn{2}{|c|}{$\begin{array}{c}\text { Never or almost } \\
\text { never }\end{array}$} & \multicolumn{2}{|c|}{$\begin{array}{l}\text { A few times } \\
\text { a year }\end{array}$} & \multicolumn{2}{|c|}{$\begin{array}{l}\text { A few times } \\
\text { a month }\end{array}$} & \multicolumn{2}{|c|}{$\begin{array}{l}\text { Once a week } \\
\text { or more }\end{array}$} & \multicolumn{2}{|c|}{$\begin{array}{c}\text { Never or almost } \\
\text { never }\end{array}$} & \multicolumn{2}{|c|}{$\begin{array}{l}\text { A few times } \\
\text { a year }\end{array}$} & \multicolumn{2}{|c|}{$\begin{array}{l}\text { A few times } \\
\text { a month }\end{array}$} & \multicolumn{2}{|c|}{$\begin{array}{c}\text { Once a week } \\
\text { or more }\end{array}$} \\
\hline & $\%$ & S.E. & $\%$ & S.E. & $\%$ & S.E. & $\%$ & S.E. & $\%$ & S.E. & $\%$ & S.E. & $\%$ & S.E. & $\%$ & S.E. \\
\hline Australia & 79.8 & $(0.5)$ & 13.0 & $(0.4)$ & 4.1 & $(0.2)$ & 3.0 & $(0.2)$ & 82.2 & $(0.5)$ & 12.0 & $(0.4)$ & 3.2 & $(0.2)$ & 2.5 & $(0.2)$ \\
\hline Austria & 92.1 & $(0.5)$ & 4.9 & $(0.4)$ & 1.6 & $(0.2)$ & 1.3 & $(0.2)$ & 82.1 & $(0.6)$ & 12.6 & $(0.5)$ & 3.4 & $(0.3)$ & 1.9 & $(0.2)$ \\
\hline Belgium & 91.0 & $(0.3)$ & 6.3 & $(0.3)$ & 1.6 & $(0.2)$ & 1.1 & $(0.1)$ & 89.4 & $(0.4)$ & 7.6 & $(0.4)$ & 1.9 & $(0.2)$ & 1.0 & $(0.1)$ \\
\hline Canada & 85.3 & $(0.4)$ & 10.0 & $(0.4)$ & 2.5 & $(0.2)$ & 2.2 & $(0.2)$ & 86.0 & $(0.4)$ & 10.1 & (0.4) & 2.4 & $(0.2)$ & 1.6 & $(0.1)$ \\
\hline Chile & 90.2 & $(0.5)$ & 6.9 & $(0.4)$ & 1.9 & $(0.2)$ & 1.0 & $(0.2)$ & 83.8 & $(0.6)$ & 11.6 & $(0.5)$ & 3.1 & $(0.3)$ & 1.4 & $(0.2)$ \\
\hline Czech Republic & 89.6 & $(0.5)$ & 6.0 & $(0.4)$ & 2.3 & $(0.2)$ & 2.2 & $(0.2)$ & 78.1 & $(0.8)$ & 14.6 & $(0.7)$ & 4.1 & $(0.3)$ & 3.2 & $(0.3)$ \\
\hline Denmark & 92.6 & $(0.4)$ & 5.5 & $(0.3)$ & 1.0 & $(0.1)$ & 0.9 & $(0.1)$ & 79.1 & $(0.6)$ & 16.7 & $(0.5)$ & 3.1 & $(0.3)$ & 1.1 & $(0.1)$ \\
\hline Estonia & 90.0 & $(0.5)$ & 7.0 & $(0.4)$ & 1.6 & $(0.2)$ & 1.4 & $(0.2)$ & 84.7 & $(0.7)$ & 11.4 & $(0.6)$ & 2.2 & $(0.2)$ & 1.7 & $(0.2)$ \\
\hline Finland & 88.6 & $(0.5)$ & 8.3 & $(0.4)$ & 1.8 & $(0.2)$ & 1.3 & $(0.2)$ & 86.7 & $(0.6)$ & 10.6 & $(0.5)$ & 1.8 & $(0.1)$ & 1.0 & $(0.2)$ \\
\hline France & 91.5 & $(0.4)$ & 5.4 & $(0.3)$ & 1.7 & $(0.2)$ & 1.3 & $(0.2)$ & 90.0 & $(0.5)$ & 7.1 & $(0.4)$ & 1.8 & $(0.2)$ & 1.2 & $(0.2)$ \\
\hline Germany & 94.1 & $(0.4)$ & 4.2 & $(0.3)$ & 0.9 & $(0.2)$ & 0.8 & $(0.1)$ & 83.6 & $(0.6)$ & 12.6 & $(0.5)$ & 2.7 & $(0.2)$ & 1.1 & $(0.1)$ \\
\hline Greece & 93.3 & $(0.6)$ & 3.5 & $(0.3)$ & 1.7 & $(0.3)$ & 1.5 & $(0.2)$ & 88.8 & $(0.6)$ & 6.6 & $(0.4)$ & 2.5 & $(0.3)$ & 2.0 & $(0.2)$ \\
\hline Hungary & 91.6 & $(0.5)$ & 4.6 & $(0.3)$ & 2.2 & $(0.2)$ & 1.6 & $(0.2)$ & 86.2 & $(0.6)$ & 8.9 & $(0.4)$ & 3.0 & $(0.3)$ & 2.0 & $(0.2)$ \\
\hline Iceland & 90.0 & $(0.5)$ & 7.1 & $(0.4)$ & 1.8 & $(0.2)$ & 1.1 & $(0.1)$ & 91.8 & $(0.5)$ & 6.4 & $(0.4)$ & 1.1 & $(0.2)$ & 0.7 & $(0.1)$ \\
\hline Ireland & 88.7 & $(0.5)$ & 8.4 & $(0.4)$ & 1.9 & $(0.2)$ & 1.0 & $(0.1)$ & 84.1 & $(0.6)$ & 12.5 & $(0.5)$ & 2.3 & $(0.2)$ & 1.1 & $(0.2)$ \\
\hline Israel & $\mathrm{m}$ & $\mathrm{m}$ & $\mathrm{m}$ & $\mathrm{m}$ & $\mathrm{m}$ & $\mathrm{m}$ & $\mathrm{m}$ & $\mathrm{m}$ & $\mathrm{m}$ & $\mathrm{m}$ & $\mathrm{m}$ & $\mathrm{m}$ & $\mathrm{m}$ & $\mathrm{m}$ & $\mathrm{m}$ & $\mathrm{m}$ \\
\hline Italy & $\mathrm{m}$ & $\mathrm{m}$ & $\mathrm{m}$ & $\mathrm{m}$ & $\mathrm{m}$ & $\mathrm{m}$ & $\mathrm{m}$ & $\mathrm{m}$ & $\mathrm{m}$ & $\mathrm{m}$ & $\mathrm{m}$ & $\mathrm{m}$ & $\mathrm{m}$ & $\mathrm{m}$ & $\mathrm{m}$ & $\mathrm{m}$ \\
\hline Japan & 93.5 & $(0.4)$ & 3.9 & $(0.3)$ & 1.3 & $(0.1)$ & 1.3 & $(0.2)$ & 86.3 & $(0.5)$ & 10.9 & $(0.4)$ & 1.8 & $(0.2)$ & 1.0 & $(0.1)$ \\
\hline Korea & 97.1 & $(0.2)$ & 2.0 & $(0.2)$ & 0.6 & $(0.1)$ & 0.3 & $(0.1)$ & 94.1 & $(0.4)$ & 4.3 & $(0.3)$ & 1.2 & $(0.2)$ & 0.5 & $(0.1)$ \\
\hline Latvia & 80.8 & $(0.6)$ & 12.7 & $(0.5)$ & 3.5 & $(0.3)$ & 3.0 & $(0.3)$ & 75.1 & $(0.8)$ & 17.7 & $(0.6)$ & 4.6 & $(0.4)$ & 2.6 & $(0.3)$ \\
\hline Luxembourg & 91.1 & $(0.4)$ & 5.5 & $(0.3)$ & 1.8 & $(0.2)$ & 1.5 & $(0.2)$ & 87.3 & $(0.5)$ & 8.5 & $(0.4)$ & 2.5 & $(0.2)$ & 1.7 & $(0.2)$ \\
\hline Mexico & 89.4 & $(0.4)$ & 6.5 & $(0.3)$ & 2.5 & $(0.2)$ & 1.7 & $(0.2)$ & 87.0 & $(0.5)$ & 8.4 & $(0.4)$ & 2.8 & $(0.2)$ & 1.7 & $(0.2)$ \\
\hline Netherlands & 94.7 & $(0.4)$ & 4.1 & $(0.3)$ & 0.7 & $(0.1)$ & 0.6 & $(0.1)$ & 88.2 & $(0.5)$ & 9.5 & $(0.5)$ & 1.6 & $(0.2)$ & 0.7 & $(0.1)$ \\
\hline New Zealand & 78.4 & $(0.6)$ & 13.4 & $(0.5)$ & 4.8 & $(0.3)$ & 3.5 & $(0.3)$ & 79.9 & $(0.6)$ & 13.8 & $(0.5)$ & 3.8 & $(0.3)$ & 2.5 & $(0.2)$ \\
\hline Norway & 89.2 & $(0.5)$ & 7.0 & $(0.3)$ & 2.3 & $(0.2)$ & 1.6 & $(0.2)$ & 80.6 & $(0.6)$ & 14.4 & $(0.5)$ & 3.3 & $(0.3)$ & 1.7 & $(0.2)$ \\
\hline Poland & 90.0 & $(0.5)$ & 6.1 & $(0.4)$ & 2.1 & $(0.2)$ & 1.8 & $(0.2)$ & 86.2 & (0.6) & 9.6 & $(0.5)$ & 2.1 & $(0.2)$ & 2.1 & $(0.2)$ \\
\hline Portugal & 88.2 & $(0.5)$ & 8.6 & $(0.5)$ & 1.8 & $(0.2)$ & 1.4 & $(0.2)$ & 89.6 & $(0.4)$ & 7.4 & $(0.4)$ & 1.9 & $(0.2)$ & 1.0 & $(0.1)$ \\
\hline Slovak Republic & 88.1 & $(0.5)$ & 7.0 & $(0.4)$ & 2.5 & $(0.2)$ & 2.4 & $(0.2)$ & 81.6 & $(0.7)$ & 12.2 & $(0.5)$ & 3.6 & $(0.3)$ & 2.6 & $(0.3)$ \\
\hline Slovenia & 92.0 & $(0.4)$ & 5.3 & $(0.3)$ & 1.7 & $(0.2)$ & 1.0 & $(0.1)$ & 86.6 & $(0.5)$ & 10.0 & $(0.5)$ & 2.2 & $(0.2)$ & 1.2 & $(0.1)$ \\
\hline Spain & 92.2 & $(0.4)$ & 5.2 & $(0.3)$ & 1.3 & $(0.2)$ & 1.2 & $(0.1)$ & 84.1 & $(0.6)$ & 12.1 & $(0.4)$ & 2.4 & $(0.2)$ & 1.4 & $(0.1)$ \\
\hline Sweden & 88.2 & (0.6) & 7.9 & $(0.5)$ & 2.4 & $(0.2)$ & 1.6 & $(0.1)$ & 81.6 & $(0.8)$ & 13.8 & (0.6) & 2.9 & $(0.3)$ & 1.6 & $(0.2)$ \\
\hline Switzerland & 92.3 & $(0.5)$ & 5.2 & $(0.4)$ & 1.6 & $(0.2)$ & 0.8 & $(0.1)$ & 81.5 & $(0.7)$ & 13.9 & $(0.6)$ & 3.1 & $(0.3)$ & 1.4 & $(0.2)$ \\
\hline Turkey & 86.6 & $(0.6)$ & 7.4 & $(0.4)$ & 3.6 & $(0.3)$ & 2.4 & $(0.3)$ & 89.1 & $(0.5)$ & 5.5 & $(0.3)$ & 3.2 & $(0.3)$ & 2.3 & $(0.3)$ \\
\hline United Kingdom & 81.8 & $(0.6)$ & 11.7 & $(0.5)$ & 3.7 & $(0.2)$ & 2.8 & $(0.2)$ & 85.3 & $(0.5)$ & 9.9 & $(0.4)$ & 2.6 & $(0.2)$ & 2.1 & $(0.2)$ \\
\hline United States & 85.4 & $(0.6)$ & 9.7 & $(0.5)$ & 2.7 & $(0.3)$ & 2.2 & $(0.2)$ & 88.1 & $(0.4)$ & 8.4 & $(0.4)$ & 2.2 & $(0.3)$ & 1.3 & $(0.2)$ \\
\hline OECD average & 89.3 & $(0.1)$ & 7.0 & $(0.1)$ & 2.1 & $(0.0)$ & 1.6 & $(0.0)$ & 85.1 & $(0.1)$ & 10.7 & $(0.1)$ & 2.6 & $(0.0)$ & 1.6 & $(0.0)$ \\
\hline
\end{tabular}

\begin{tabular}{|c|c|c|c|c|c|c|c|c|c|c|c|c|c|c|c|c|}
\hline Albania & $\mathrm{m}$ & $\mathrm{m}$ & $\mathrm{m}$ & $\mathrm{m}$ & $\mathrm{m}$ & $\mathrm{m}$ & $\mathrm{m}$ & $\mathrm{m}$ & $\mathrm{m}$ & $\mathrm{m}$ & $\mathrm{m}$ & $\mathrm{m}$ & $\mathrm{m}$ & $\mathrm{m}$ & $\mathrm{m}$ & $\mathrm{m}$ \\
\hline ¿ Algeria & $\mathrm{m}$ & $\mathrm{m}$ & $\mathrm{m}$ & $\mathrm{m}$ & $\mathrm{m}$ & $\mathrm{m}$ & $\mathrm{m}$ & $\mathrm{m}$ & $\mathrm{m}$ & $\mathrm{m}$ & $\mathrm{m}$ & $\mathrm{m}$ & $\mathrm{m}$ & $\mathrm{m}$ & $\mathrm{m}$ & $\mathrm{m}$ \\
\hline Brazil & 88.6 & $(0.3)$ & 7.3 & $(0.3)$ & 2.0 & $(0.1)$ & 2.1 & $(0.2)$ & 86.2 & $(0.4)$ & 8.5 & $(0.3)$ & 2.8 & $(0.1)$ & 2.6 & $(0.2)$ \\
\hline B-S-J-G (China) & 89.6 & $(0.5)$ & 6.9 & $(0.4)$ & 1.9 & $(0.2)$ & 1.6 & $(0.2)$ & 62.0 & (1.1) & 25.5 & $(0.7)$ & 8.2 & $(0.5)$ & 4.3 & $(0.3)$ \\
\hline Bulgaria & 84.2 & $(0.7)$ & 9.9 & $(0.5)$ & 3.3 & $(0.3)$ & 2.6 & $(0.3)$ & 77.7 & $(0.8)$ & 14.9 & $(0.6)$ & 4.4 & $(0.4)$ & 3.0 & $(0.3)$ \\
\hline CABA (Argentina) & $\mathrm{m}$ & $\mathrm{m}$ & $\mathrm{m}$ & $\mathrm{m}$ & $\mathrm{m}$ & $\mathrm{m}$ & $\mathrm{m}$ & $\mathrm{m}$ & $\mathrm{m}$ & $\mathrm{m}$ & $\mathrm{m}$ & $\mathrm{m}$ & $\mathrm{m}$ & $\mathrm{m}$ & $\mathrm{m}$ & $\mathrm{m}$ \\
\hline Colombia & 91.1 & $(0.4)$ & 5.6 & $(0.3)$ & 2.0 & $(0.2)$ & 1.3 & $(0.1)$ & 86.7 & $(0.5)$ & 8.8 & $(0.4)$ & 2.5 & $(0.2)$ & 2.0 & $(0.2)$ \\
\hline Costa Rica & 86.1 & $(0.5)$ & 9.3 & $(0.4)$ & 2.8 & $(0.3)$ & 1.8 & $(0.2)$ & 92.9 & $(0.4)$ & 5.1 & $(0.4)$ & 1.0 & $(0.1)$ & 1.0 & $(0.2)$ \\
\hline Croatia & 88.8 & $(0.6)$ & 7.3 & $(0.4)$ & 2.0 & $(0.2)$ & 2.0 & $(0.2)$ & 87.4 & $(0.6)$ & 9.1 & $(0.4)$ & 2.0 & $(0.2)$ & 1.5 & $(0.2)$ \\
\hline Cyprus* & 85.3 & $(0.4)$ & 8.6 & $(0.4)$ & 3.8 & $(0.3)$ & 2.4 & $(0.2)$ & 84.3 & $(0.5)$ & 10.4 & $(0.4)$ & 3.0 & $(0.2)$ & 2.3 & $(0.2)$ \\
\hline Dominican Republic & 82.5 & $(0.7)$ & 9.2 & $(0.5)$ & 4.3 & $(0.4)$ & 4.0 & $(0.3)$ & 77.7 & $(0.8)$ & 10.9 & $(0.5)$ & 5.4 & (0.4) & 6.0 & (0.4) \\
\hline FYROM & $\mathrm{m}$ & $\mathrm{m}$ & $\mathrm{m}$ & $\mathrm{m}$ & $\mathrm{m}$ & $\mathrm{m}$ & $\mathrm{m}$ & $\mathrm{m}$ & $\mathrm{m}$ & $\mathrm{m}$ & $\mathrm{m}$ & $\mathrm{m}$ & $\mathrm{m}$ & $\mathrm{m}$ & $\mathrm{m}$ & $\mathrm{m}$ \\
\hline Georgia & $\mathrm{m}$ & $\mathrm{m}$ & $\mathrm{m}$ & $\mathrm{m}$ & $\mathrm{m}$ & $\mathrm{m}$ & $\mathrm{m}$ & $\mathrm{m}$ & $\mathrm{m}$ & $\mathrm{m}$ & $\mathrm{m}$ & $\mathrm{m}$ & $\mathrm{m}$ & $\mathrm{m}$ & $\mathrm{m}$ & $\mathrm{m}$ \\
\hline Hong Kong (China) & 84.8 & $(0.6)$ & 8.0 & $(0.4)$ & 3.1 & $(0.3)$ & 4.0 & $(0.4)$ & 75.5 & $(0.9)$ & 14.0 & $(0.7)$ & 5.5 & $(0.3)$ & 4.9 & $(0.4)$ \\
\hline Indonesia & $\mathrm{m}$ & $\mathrm{m}$ & $\mathrm{m}$ & $\mathrm{m}$ & $\mathrm{m}$ & $\mathrm{m}$ & $\mathrm{m}$ & $\mathrm{m}$ & $\mathrm{m}$ & $\mathrm{m}$ & $\mathrm{m}$ & $\mathrm{m}$ & $\mathrm{m}$ & $\mathrm{m}$ & $\mathrm{m}$ & $\mathrm{m}$ \\
\hline Jordan & $\mathrm{m}$ & $\mathrm{m}$ & $\mathrm{m}$ & $\mathrm{m}$ & $\mathrm{m}$ & $\mathrm{m}$ & $\mathrm{m}$ & $\mathrm{m}$ & $\mathrm{m}$ & $\mathrm{m}$ & $\mathrm{m}$ & $\mathrm{m}$ & $\mathrm{m}$ & $\mathrm{m}$ & $\mathrm{m}$ & $\mathrm{m}$ \\
\hline Kosovo & $\mathrm{m}$ & $\mathrm{m}$ & $\mathrm{m}$ & $\mathrm{m}$ & $\mathrm{m}$ & $\mathrm{m}$ & $\mathrm{m}$ & $\mathrm{m}$ & $\mathrm{m}$ & $\mathrm{m}$ & $\mathrm{m}$ & $\mathrm{m}$ & $\mathrm{m}$ & $\mathrm{m}$ & $\mathrm{m}$ & $\mathrm{m}$ \\
\hline Lebanon & $\mathrm{m}$ & $\mathrm{m}$ & $\mathrm{m}$ & $\mathrm{m}$ & $\mathrm{m}$ & $\mathrm{m}$ & $\mathrm{m}$ & $\mathrm{m}$ & $\mathrm{m}$ & $\mathrm{m}$ & $\mathrm{m}$ & $\mathrm{m}$ & $\mathrm{m}$ & $\mathrm{m}$ & $\mathrm{m}$ & $\mathrm{m}$ \\
\hline Lithuania & 86.4 & $(0.5)$ & 8.8 & $(0.4)$ & 2.9 & $(0.3)$ & 1.9 & $(0.2)$ & 86.9 & $(0.6)$ & 8.9 & $(0.4)$ & 2.5 & $(0.2)$ & 1.7 & $(0.2)$ \\
\hline Macao (China) & 83.3 & $(0.5)$ & 10.5 & $(0.4)$ & 3.6 & $(0.2)$ & 2.6 & $(0.3)$ & 74.0 & (0.6) & 17.5 & $(0.5)$ & 5.1 & $(0.3)$ & 3.4 & $(0.3)$ \\
\hline Malta & $\mathrm{m}$ & $\mathrm{m}$ & $\mathrm{m}$ & $\mathrm{m}$ & $\mathrm{m}$ & $\mathrm{m}$ & $\mathrm{m}$ & $\mathrm{m}$ & $\mathrm{m}$ & $\mathrm{m}$ & $\mathrm{m}$ & $\mathrm{m}$ & $\mathrm{m}$ & $\mathrm{m}$ & $\mathrm{m}$ & $\mathrm{m}$ \\
\hline Moldova & $\mathrm{m}$ & $\mathrm{m}$ & $\mathrm{m}$ & $\mathrm{m}$ & $\mathrm{m}$ & $\mathrm{m}$ & $\mathrm{m}$ & $\mathrm{m}$ & $\mathrm{m}$ & $\mathrm{m}$ & $\mathrm{m}$ & $\mathrm{m}$ & $\mathrm{m}$ & $\mathrm{m}$ & $\mathrm{m}$ & $\mathrm{m}$ \\
\hline Montenegro & 87.0 & $(0.4)$ & 6.8 & $(0.4)$ & 2.8 & $(0.2)$ & 3.4 & $(0.3)$ & 89.9 & $(0.5)$ & 6.1 & $(0.3)$ & 2.1 & $(0.2)$ & 2.0 & $(0.2)$ \\
\hline Peru & 92.8 & (0.4) & 4.5 & $(0.3)$ & 1.7 & $(0.2)$ & 1.0 & $(0.1)$ & 83.3 & (0.6) & 11.3 & (0.4) & 3.1 & $(0.2)$ & 2.2 & $(0.2)$ \\
\hline Qatar & 79.9 & $(0.4)$ & 11.3 & $(0.3)$ & 5.2 & $(0.2)$ & 3.5 & $(0.2)$ & 76.7 & $(0.4)$ & 14.2 & $(0.3)$ & 5.4 & $(0.2)$ & 3.7 & $(0.2)$ \\
\hline Romania & $\mathrm{m}$ & $\mathrm{m}$ & $\mathrm{m}$ & $\mathrm{m}$ & $\mathrm{m}$ & $\mathrm{m}$ & $\mathrm{m}$ & $\mathrm{m}$ & $\mathrm{m}$ & $\mathrm{m}$ & $\mathrm{m}$ & $\mathrm{m}$ & $\mathrm{m}$ & $\mathrm{m}$ & $\mathrm{m}$ & $\mathrm{m}$ \\
\hline Russia & 87.2 & $(0.8)$ & 7.8 & $(0.5)$ & 2.7 & $(0.4)$ & 2.3 & $(0.2)$ & 83.6 & (1.0) & 10.8 & $(0.5)$ & 3.2 & $(0.4)$ & 2.4 & (0.4) \\
\hline Singapore & 86.7 & $(0.4)$ & 9.0 & (0.4) & 2.4 & $(0.2)$ & 2.0 & $(0.2)$ & 82.5 & (0.5) & 12.4 & $(0.5)$ & 3.2 & $(0.2)$ & 1.9 & $(0.2)$ \\
\hline Chinese Taipei & 96.4 & $(0.2)$ & 2.6 & $(0.2)$ & 0.5 & $(0.1)$ & 0.5 & $(0.1)$ & 85.5 & $(0.6)$ & 11.1 & $(0.5)$ & 2.5 & $(0.2)$ & 1.0 & $(0.1)$ \\
\hline Thailand & 81.1 & $(0.8)$ & 10.4 & $(0.5)$ & 5.1 & $(0.3)$ & 3.5 & $(0.3)$ & 78.8 & $(0.9)$ & 11.6 & $(0.6)$ & 5.7 & $(0.3)$ & 3.9 & $(0.3)$ \\
\hline Trinidad and Tobago & $\mathrm{m}$ & $\mathrm{m}$ & $\mathrm{m}$ & $\mathrm{m}$ & $\mathrm{m}$ & $\mathrm{m}$ & $\mathrm{m}$ & $\mathrm{m}$ & $\mathrm{m}$ & $\mathrm{m}$ & $\mathrm{m}$ & $\mathrm{m}$ & $\mathrm{m}$ & $\mathrm{m}$ & $\mathrm{m}$ & $\mathrm{m}$ \\
\hline Tunisia & 73.2 & $(0.8)$ & 17.3 & $(0.6)$ & 5.6 & $(0.4)$ & 3.8 & $(0.3)$ & 79.2 & $(0.8)$ & 13.5 & $(0.6)$ & 4.4 & $(0.4)$ & 2.9 & $(0.3)$ \\
\hline United Arab Emirates & 80.9 & $(0.5)$ & 10.9 & $(0.4)$ & 4.8 & $(0.3)$ & 3.4 & $(0.2)$ & 77.5 & $(0.6)$ & 13.1 & $(0.4)$ & 5.5 & $(0.3)$ & 4.0 & $(0.2)$ \\
\hline Uruguay & 89.7 & $(0.4)$ & 6.1 & $(0.3)$ & 2.2 & $(0.2)$ & 2.0 & $(0.2)$ & 86.5 & (0.6) & 9.4 & $(0.5)$ & 2.2 & $(0.2)$ & 1.9 & $(0.2)$ \\
\hline Viet Nam & $\mathrm{m}$ & $\mathrm{m}$ & $\mathrm{m}$ & $\mathrm{m}$ & $\mathrm{m}$ & $\mathrm{m}$ & $\mathrm{m}$ & $\mathrm{m}$ & $\mathrm{m}$ & $\mathrm{m}$ & $\mathrm{m}$ & $\mathrm{m}$ & $\mathrm{m}$ & $\mathrm{m}$ & $\mathrm{m}$ & $\mathrm{m}$ \\
\hline Argentina** & $\mathrm{m}$ & $\mathrm{m}$ & $\mathrm{m}$ & $\mathrm{m}$ & $\mathrm{m}$ & $\mathrm{m}$ & $\mathrm{m}$ & $\mathrm{m}$ & $\mathrm{m}$ & $\mathrm{m}$ & $\mathrm{m}$ & $\mathrm{m}$ & $\mathrm{m}$ & $\mathrm{m}$ & $\mathrm{m}$ & $\mathrm{m}$ \\
\hline Kazakhstan** & $\mathrm{m}$ & $\mathrm{m}$ & $\mathrm{m}$ & $\mathrm{m}$ & $\mathrm{m}$ & $\mathrm{m}$ & $\mathrm{m}$ & $\mathrm{m}$ & $\mathrm{m}$ & $\mathrm{m}$ & $\mathrm{m}$ & $\mathrm{m}$ & $\mathrm{m}$ & $\mathrm{m}$ & $\mathrm{m}$ & $\mathrm{m}$ \\
\hline Malaysia** & 84.4 & $(0.8)$ & 9.4 & $(0.5)$ & 3.9 & $(0.4)$ & 2.3 & $(0.2)$ & 74.0 & $(0.8)$ & 17.4 & $(0.6)$ & 5.5 & $(0.3)$ & 3.1 & $(0.3)$ \\
\hline
\end{tabular}

1. A student is frequently bullied if he or she is in the top $10 \%$ of the index of exposure to bullying among all countries/economies. See Annex A1 for information on the index of exposure to bullying.

* See note at the beginning of this Annex.

** Coverage is too small to ensure comparability (see Annex A4).

StatLink *iाlst http://dx.doi.org/10.1787/888933471667 


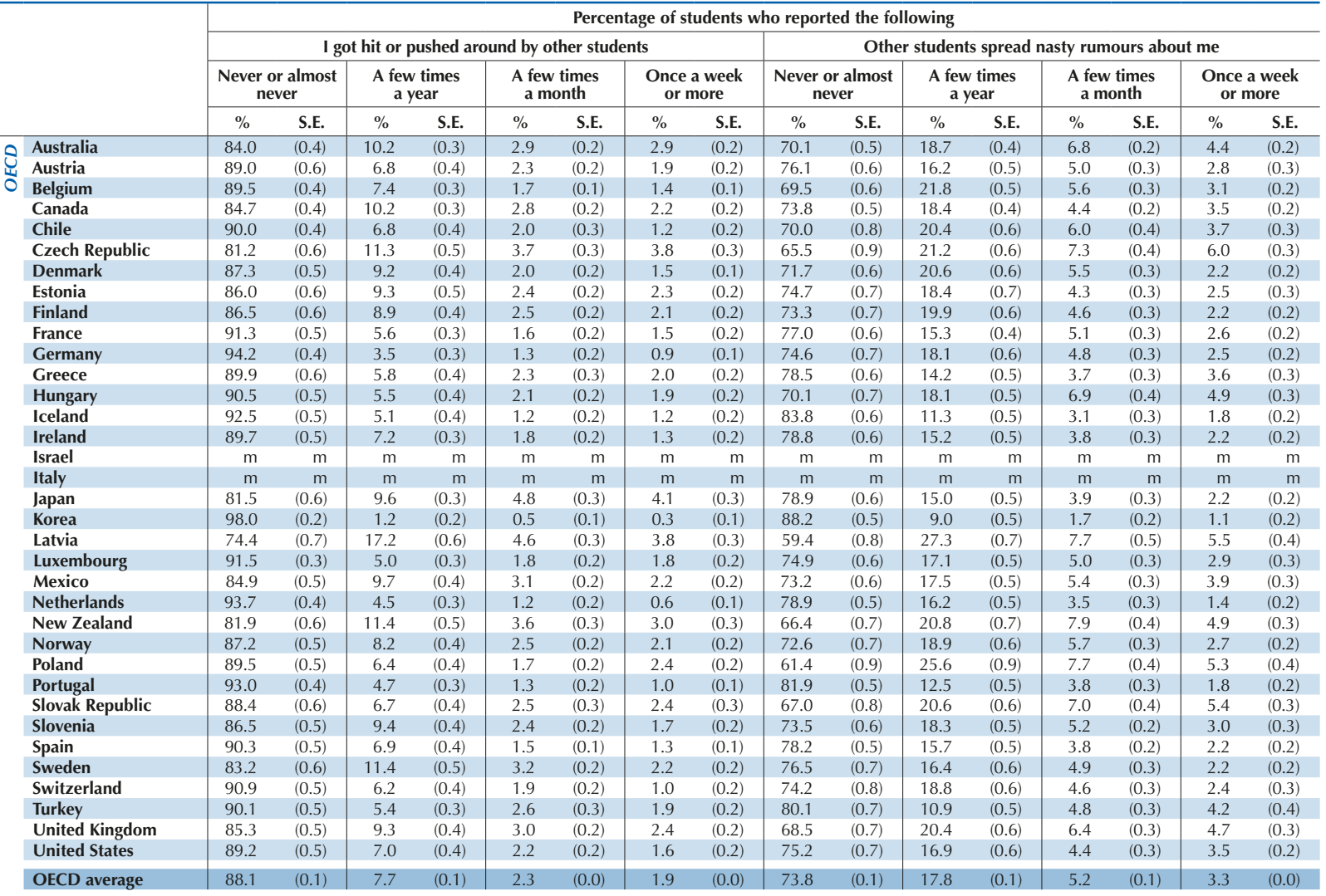

\begin{tabular}{|c|c|c|c|c|c|c|c|c|c|c|c|c|c|c|c|c|c|}
\hline ( & Albania & $\mathrm{m}$ & $\mathrm{m}$ & $\mathrm{m}$ & $\mathrm{m}$ & $\mathrm{m}$ & $\mathrm{m}$ & $\mathrm{m}$ & $\mathrm{m}$ & $\mathrm{m}$ & $\mathrm{m}$ & $\mathrm{m}$ & $\mathrm{m}$ & $\mathrm{m}$ & $\mathrm{m}$ & $\mathrm{m}$ & $\mathrm{m}$ \\
\hline & Algeria & $\mathrm{m}$ & $\mathrm{m}$ & $\mathrm{m}$ & $\mathrm{m}$ & $\mathrm{m}$ & $\mathrm{m}$ & $\mathrm{m}$ & $\mathrm{m}$ & $\mathrm{m}$ & $\mathrm{m}$ & $\mathrm{m}$ & $\mathrm{m}$ & $\mathrm{m}$ & $\mathrm{m}$ & $\mathrm{m}$ & $\mathrm{m}$ \\
\hline & Brazil & 91.7 & $(0.3)$ & 5.0 & $(0.2)$ & 1.5 & $(0.1)$ & 1.7 & $(0.1)$ & 77.7 & $(0.5)$ & 14.3 & $(0.4)$ & 4.0 & $(0.2)$ & 3.9 & $(0.2)$ \\
\hline & B-S-J-G (China) & 89.3 & $(0.5)$ & 6.6 & $(0.4)$ & 2.2 & $(0.2)$ & 2.0 & $(0.2)$ & 80.8 & $(0.6)$ & 12.9 & $(0.5)$ & 3.2 & $(0.3)$ & 3.1 & $(0.2)$ \\
\hline & Bulgaria & 76.6 & $(0.8)$ & 14.3 & $(0.6)$ & 4.7 & $(0.3)$ & 4.4 & $(0.3)$ & 67.8 & $(0.7)$ & 19.7 & $(0.6)$ & 6.8 & $(0.4)$ & 5.7 & $(0.4)$ \\
\hline & CABA (Argentina) & $\mathrm{m}$ & $\mathrm{m}$ & $\mathrm{m}$ & $\mathrm{m}$ & $\mathrm{m}$ & $\mathrm{m}$ & $\mathrm{m}$ & $\mathrm{m}$ & $\mathrm{m}$ & $\mathrm{m}$ & $\mathrm{m}$ & $\mathrm{m}$ & $\mathrm{m}$ & $\mathrm{m}$ & $\mathrm{m}$ & $\mathrm{m}$ \\
\hline & Colombia & 87.3 & $(0.4)$ & 8.7 & $(0.3)$ & 2.0 & $(0.2)$ & 2.0 & $(0.2)$ & 67.1 & $(0.7)$ & 22.0 & (0.5) & 6.2 & $(0.3)$ & 4.7 & $(0.2)$ \\
\hline & Costa Rica & 91.4 & $(0.4)$ & 5.9 & $(0.3)$ & 1.2 & $(0.2)$ & 1.5 & $(0.2)$ & 68.5 & $(0.7)$ & 19.3 & (0.5) & 6.2 & $(0.3)$ & 6.0 & $(0.4)$ \\
\hline & Croatia & 89.0 & $(0.5)$ & 7.2 & $(0.3)$ & 2.1 & $(0.2)$ & 1.8 & $(0.2)$ & 72.6 & $(0.6)$ & 17.9 & $(0.4)$ & 5.5 & $(0.3)$ & 4.0 & $(0.3)$ \\
\hline & Cyprus* & 84.7 & $(0.5)$ & 8.8 & $(0.4)$ & 3.8 & $(0.3)$ & 2.8 & $(0.2)$ & 73.9 & $(0.6)$ & 16.8 & $(0.6)$ & 5.2 & $(0.3)$ & 4.2 & $(0.3)$ \\
\hline & Dominican Republic & 90.8 & $(0.5)$ & 4.4 & $(0.4)$ & 2.5 & $(0.3)$ & 2.3 & $(0.3)$ & 73.5 & $(0.7)$ & 13.4 & $(0.6)$ & 6.3 & $(0.4)$ & 6.8 & $(0.5)$ \\
\hline & FYROM & $\mathrm{m}$ & $\mathrm{m}$ & $\mathrm{m}$ & $\mathrm{m}$ & $\mathrm{m}$ & $\mathrm{m}$ & $\mathrm{m}$ & $\mathrm{m}$ & $\mathrm{m}$ & $\mathrm{m}$ & $\mathrm{m}$ & $\mathrm{m}$ & $\mathrm{m}$ & $\mathrm{m}$ & $\mathrm{m}$ & $\mathrm{m}$ \\
\hline & Georgia & $\mathrm{m}$ & $\mathrm{m}$ & $\mathrm{m}$ & $\mathrm{m}$ & $\mathrm{m}$ & $\mathrm{m}$ & $\mathrm{m}$ & $\mathrm{m}$ & $\mathrm{m}$ & $\mathrm{m}$ & $\mathrm{m}$ & $\mathrm{m}$ & $\mathrm{m}$ & $\mathrm{m}$ & $\mathrm{m}$ & $\mathrm{m}$ \\
\hline & Hong Kong (China) & 79.8 & $(0.7)$ & 10.7 & $(0.4)$ & 4.3 & $(0.3)$ & 5.2 & $(0.4)$ & 73.9 & $(0.8)$ & 16.7 & $(0.7)$ & 5.0 & $(0.4)$ & 4.3 & $(0.3)$ \\
\hline & Indonesia & $\mathrm{m}$ & $\mathrm{m}$ & $\mathrm{m}$ & $\mathrm{m}$ & $\mathrm{m}$ & $\mathrm{m}$ & $\mathrm{m}$ & $\mathrm{m}$ & $\mathrm{m}$ & $\mathrm{m}$ & $\mathrm{m}$ & $\mathrm{m}$ & $\mathrm{m}$ & $\mathrm{m}$ & $\mathrm{m}$ & $\mathrm{m}$ \\
\hline & Jordan & $\mathrm{m}$ & $\mathrm{m}$ & $\mathrm{m}$ & $\mathrm{m}$ & $\mathrm{m}$ & $\mathrm{m}$ & $\mathrm{m}$ & $\mathrm{m}$ & $\mathrm{m}$ & $\mathrm{m}$ & $\mathrm{m}$ & $\mathrm{m}$ & $\mathrm{m}$ & $\mathrm{m}$ & $\mathrm{m}$ & $\mathrm{m}$ \\
\hline & Kosovo & $\mathrm{m}$ & $\mathrm{m}$ & $\mathrm{m}$ & $\mathrm{m}$ & $\mathrm{m}$ & $\mathrm{m}$ & $\mathrm{m}$ & $\mathrm{m}$ & $\mathrm{m}$ & $\mathrm{m}$ & $\mathrm{m}$ & $\mathrm{m}$ & $\mathrm{m}$ & $\mathrm{m}$ & $\mathrm{m}$ & $\mathrm{m}$ \\
\hline & Lebanon & $\mathrm{m}$ & $\mathrm{m}$ & $\mathrm{m}$ & $\mathrm{m}$ & $\mathrm{m}$ & $\mathrm{m}$ & $\mathrm{m}$ & $\mathrm{m}$ & $\mathrm{m}$ & $\mathrm{m}$ & $\mathrm{m}$ & $\mathrm{m}$ & $\mathrm{m}$ & $\mathrm{m}$ & $\mathrm{m}$ & $\mathrm{m}$ \\
\hline & Lithuania & 87.3 & $(0.5)$ & 8.3 & $(0.4)$ & 2.4 & $(0.2)$ & 2.1 & $(0.2)$ & 75.3 & $(0.6)$ & 16.8 & $(0.5)$ & 4.8 & $(0.3)$ & 3.1 & $(0.3)$ \\
\hline & Macao (China) & 88.4 & $(0.5)$ & 7.4 & $(0.4)$ & 1.9 & $(0.2)$ & 2.3 & $(0.2)$ & 71.6 & $(0.7)$ & 19.1 & (0.6) & 5.7 & $(0.4)$ & 3.6 & $(0.3)$ \\
\hline & Malta & $\mathrm{m}$ & $\mathrm{m}$ & $\mathrm{m}$ & $\mathrm{m}$ & $\mathrm{m}$ & $\mathrm{m}$ & $\mathrm{m}$ & $\mathrm{m}$ & $\mathrm{m}$ & $\mathrm{m}$ & $\mathrm{m}$ & $\mathrm{m}$ & $\mathrm{m}$ & $\mathrm{m}$ & $\mathrm{m}$ & $\mathrm{m}$ \\
\hline & Moldova & $\mathrm{m}$ & $\mathrm{m}$ & $\mathrm{m}$ & $\mathrm{m}$ & $\mathrm{m}$ & $\mathrm{m}$ & $\mathrm{m}$ & $\mathrm{m}$ & $\mathrm{m}$ & $\mathrm{m}$ & $\mathrm{m}$ & $\mathrm{m}$ & $\mathrm{m}$ & $\mathrm{m}$ & $\mathrm{m}$ & $\mathrm{m}$ \\
\hline & Montenegro & 93.1 & $(0.4)$ & 3.3 & $(0.2)$ & 1.8 & $(0.2)$ & 1.7 & $(0.2)$ & 75.1 & $(0.6)$ & 14.9 & $(0.5)$ & 5.1 & $(0.3)$ & 4.8 & $(0.3)$ \\
\hline & Peru & 88.5 & $(0.5)$ & 7.9 & $(0.4)$ & 2.1 & $(0.2)$ & 1.5 & $(0.2)$ & 70.0 & $(0.6)$ & 20.5 & (0.6) & 5.1 & $(0.3)$ & 4.5 & $(0.3)$ \\
\hline & Qatar & 78.9 & $(0.4)$ & 12.3 & $(0.3)$ & 5.2 & $(0.2)$ & 3.5 & $(0.2)$ & 69.4 & $(0.4)$ & 18.3 & $(0.4)$ & 6.8 & $(0.3)$ & 5.5 & $(0.2)$ \\
\hline & Romania & $\mathrm{m}$ & $\mathrm{m}$ & $\mathrm{m}$ & $\mathrm{m}$ & $\mathrm{m}$ & $\mathrm{m}$ & $\mathrm{m}$ & $\mathrm{m}$ & $\mathrm{m}$ & $\mathrm{m}$ & $\mathrm{m}$ & $\mathrm{m}$ & $\mathrm{m}$ & $\mathrm{m}$ & $\mathrm{m}$ & $\mathrm{m}$ \\
\hline & Russia & 92.6 & $(0.6)$ & 4.3 & $(0.4)$ & 1.5 & $(0.2)$ & 1.6 & $(0.2)$ & 75.5 & $(0.9)$ & 15.5 & (0.6) & 5.7 & $(0.5)$ & 3.3 & $(0.2)$ \\
\hline & Singapore & 85.1 & $(0.4)$ & 9.8 & $(0.4)$ & 2.7 & $(0.2)$ & 2.4 & $(0.2)$ & 71.6 & $(0.7)$ & 19.6 & $(0.6)$ & 5.7 & $(0.3)$ & 3.0 & $(0.2)$ \\
\hline & Chinese Taipei & 97.7 & $(0.2)$ & 1.4 & $(0.1)$ & 0.4 & $(0.1)$ & 0.4 & $(0.1)$ & 86.9 & $(0.4)$ & 9.6 & $(0.4)$ & 2.4 & $(0.2)$ & 1.1 & $(0.1)$ \\
\hline & Thailand & 85.1 & $(0.8)$ & 7.8 & $(0.5)$ & 4.2 & $(0.3)$ & 2.9 & $(0.3)$ & 75.2 & $(0.8)$ & 13.7 & $(0.6)$ & 6.4 & $(0.3)$ & 4.8 & $(0.4)$ \\
\hline & Trinidad and Tobago & $\mathrm{m}$ & $\mathrm{m}$ & $\mathrm{m}$ & $\mathrm{m}$ & $\mathrm{m}$ & $\mathrm{m}$ & $\mathrm{m}$ & $\mathrm{m}$ & $\mathrm{m}$ & $\mathrm{m}$ & $\mathrm{m}$ & $\mathrm{m}$ & $\mathrm{m}$ & $\mathrm{m}$ & $\mathrm{m}$ & $\mathrm{m}$ \\
\hline & Tunisia & 75.5 & $(0.8)$ & 15.9 & $(0.6)$ & 4.9 & $(0.3)$ & 3.6 & $(0.3)$ & 65.0 & $(0.8)$ & 22.4 & $(0.6)$ & 6.6 & $(0.3)$ & 6.0 & $(0.4)$ \\
\hline & United Arab Emirates & 80.6 & $(0.6)$ & 11.3 & $(0.4)$ & 4.3 & $(0.3)$ & 3.8 & $(0.2)$ & 69.5 & $(0.5)$ & 17.8 & $(0.5)$ & 7.2 & $(0.3)$ & 5.5 & $(0.3)$ \\
\hline & Uruguay & 89.6 & $(0.4)$ & 6.4 & $(0.3)$ & 2.2 & $(0.2)$ & 1.8 & $(0.2)$ & 77.6 & $(0.6)$ & 14.6 & (0.5) & 4.1 & $(0.3)$ & 3.7 & $(0.2)$ \\
\hline & Viet Nam & $\mathrm{m}$ & $\mathrm{m}$ & $\mathrm{m}$ & $\mathrm{m}$ & $\mathrm{m}$ & $\mathrm{m}$ & $\mathrm{m}$ & $\mathrm{m}$ & $\mathrm{m}$ & $\mathrm{m}$ & $\mathrm{m}$ & $\mathrm{m}$ & $\mathrm{m}$ & $\mathrm{m}$ & $\mathrm{m}$ & $\mathrm{m}$ \\
\hline & Argentina** & $\mathrm{m}$ & $\mathrm{m}$ & $\mathrm{m}$ & $\mathrm{m}$ & $\mathrm{m}$ & $\mathrm{m}$ & $\mathrm{m}$ & $\mathrm{m}$ & $\mathrm{m}$ & $\mathrm{m}$ & $\mathrm{m}$ & $\mathrm{m}$ & $\mathrm{m}$ & $\mathrm{m}$ & $\mathrm{m}$ & $\mathrm{m}$ \\
\hline & Kazakhstan** & $\mathrm{m}$ & $\mathrm{m}$ & $\mathrm{m}$ & $\mathrm{m}$ & $\mathrm{m}$ & $\mathrm{m}$ & $\mathrm{m}$ & $\mathrm{m}$ & $\mathrm{m}$ & $\mathrm{m}$ & $\mathrm{m}$ & $\mathrm{m}$ & $\mathrm{m}$ & $\mathrm{m}$ & $\mathrm{m}$ & $\mathrm{m}$ \\
\hline & Malaysia** & 84.6 & $(0.6)$ & 9.2 & $(0.4)$ & 3.8 & $(0.3)$ & 2.5 & $(0.3)$ & 58.9 & $(0.8)$ & 27.5 & (0.6) & 8.7 & $(0.4)$ & 4.9 & $(0.3)$ \\
\hline
\end{tabular}

1. A student is frequently bullied if he or she is in the top $10 \%$ of the index of exposure to bullying among all countries/economies. See Annex A1 for information on the index of exposure to bullying.

* See note at the beginning of this Annex.

** Coverage is too small to ensure comparability (see Annex A4).

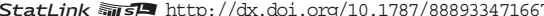


A corrigendum has been issued for this page. See: http://www.oecd.org/about/publishing/Corrigenda_PISA2015IR_VolumellI.pdf ANNEX B1: RESULTS FOR COUNTRIES AND ECONOMIES

[Part 1/6]

Table III.8.2 Students' exposure to different types of bullying, by gender and socio-economic status

Percentage of students who reported being bullied "a few times a month" or "once a week or more" Percentage of boys who reported being bullied at least a few times a month

\begin{tabular}{|c|c|c|c|c|c|c|c|c|c|c|c|c|c|c|c|}
\hline & of $b$ & $\begin{array}{l}\text { pe } \\
\text { g act }\end{array}$ & $\begin{array}{r}\text { Other } \\
\text { left me } \\
\text { on }\end{array}$ & $\begin{array}{l}\text { Idents } \\
\text { of things } \\
\text { oose }\end{array}$ & $\begin{array}{c}\text { Othe } \\
\text { made }\end{array}$ & $\begin{array}{l}\text { dents } \\
\text { of me }\end{array}$ & $\begin{array}{l}\text { I was } t \\
\text { by oth }\end{array}$ & $\begin{array}{l}\text { atened } \\
\text { udents }\end{array}$ & $\begin{array}{r}\text { Other } \\
\text { took } \\
\text { destro } \\
\text { that be }\end{array}$ & $\begin{array}{l}\text { Idents } \\
\text { ay or } \\
\text { things } \\
\text { g to me }\end{array}$ & $\begin{array}{l}\text { I } \\
\text { or pus } \\
\text { by oth }\end{array}$ & $\begin{array}{l}\text { it } \\
\text { around } \\
\text { udents }\end{array}$ & $\begin{array}{l}\text { Othe } \\
\text { spre } \\
\text { rumou }\end{array}$ & $\begin{array}{l}\text { dents } \\
\text { lasty } \\
\text { out me }\end{array}$ \\
\hline & & $\%$ & S.E. & $\%$ & S.E. & $\%$ & S.E. & $\%$ & S.E. & $\%$ & S.E. & $\%$ & S.E. & $\%$ & S.E. \\
\hline$\theta$ & Australia & 25.4 & $(0.7)$ & 12.2 & $(0.5)$ & 17.8 & $(0.6)$ & 8.7 & $(0.5)$ & 7.6 & $(0.4)$ & 8.1 & $(0.5)$ & 9.9 & $(0.5)$ \\
\hline ర్山 & Austria & 22.9 & $(0.7)$ & 6.3 & $(0.5)$ & 14.9 & (0.6) & 4.4 & $(0.4)$ & 7.5 & $(0.5)$ & 6.7 & $(0.5)$ & 7.3 & (0.5) \\
\hline & Belgium & 18.5 & $(0.7)$ & 5.9 & $(0.4)$ & 12.1 & $(0.6)$ & 3.4 & $(0.4)$ & 4.2 & $(0.3)$ & 4.7 & $(0.3)$ & 6.9 & $(0.5)$ \\
\hline & Canada & 21.5 & $(0.6)$ & 9.5 & $(0.4)$ & 15.5 & $(0.6)$ & 5.9 & $(0.4)$ & 5.4 & $(0.4)$ & 7.3 & $(0.5)$ & 6.8 & $(0.4)$ \\
\hline & Chile & 19.4 & $(0.8)$ & 8.8 & $(0.7)$ & 11.4 & $(0.6)$ & 3.7 & $(0.5)$ & 5.6 & $(0.6)$ & 3.6 & $(0.5)$ & 8.5 & $(0.7)$ \\
\hline & Czech Republic & 26.9 & (1.0) & 10.4 & $(0.6)$ & 13.2 & $(0.7)$ & 6.3 & $(0.5)$ & 9.3 & $(0.5)$ & 10.5 & $(0.6)$ & 11.8 & $(0.7)$ \\
\hline & Denmark & 21.8 & $(0.8)$ & 5.2 & $(0.4)$ & 13.0 & $(0.6)$ & 3.2 & $(0.4)$ & 5.4 & $(0.5)$ & 5.7 & $(0.4)$ & 7.4 & $(0.6)$ \\
\hline & Estonia & 22.4 & (0.9) & 7.3 & $(0.6)$ & 16.3 & $(0.7)$ & 4.4 & $(0.5)$ & 5.5 & $(0.5)$ & 7.0 & $(0.5)$ & 6.5 & (0.4) \\
\hline & Finland & 17.9 & $(0.8)$ & 6.3 & $(0.5)$ & 11.9 & $(0.7)$ & 4.9 & $(0.5)$ & 4.1 & $(0.4)$ & 7.4 & $(0.6)$ & 5.8 & $(0.4)$ \\
\hline & France & 17.8 & $(0.8)$ & 6.1 & $(0.5)$ & 12.6 & $(0.7)$ & 3.6 & $(0.4)$ & 4.0 & $(0.5)$ & 3.8 & $(0.4)$ & 6.8 & $(0.5)$ \\
\hline & Germany & 16.8 & $(0.7)$ & 5.3 & $(0.4)$ & 10.7 & $(0.6)$ & 2.4 & $(0.3)$ & 5.5 & $(0.4)$ & 3.6 & $(0.4)$ & 6.3 & $(0.5)$ \\
\hline & Greece & 19.1 & $(0.8)$ & 5.6 & $(0.4)$ & 12.3 & $(0.7)$ & 4.8 & $(0.5)$ & 6.5 & $(0.5)$ & 6.5 & $(0.5)$ & 7.8 & $(0.5)$ \\
\hline & Hungary & 20.6 & $(0.8)$ & 9.6 & $(0.6)$ & 10.7 & $(0.7)$ & 5.3 & $(0.4)$ & 6.4 & $(0.6)$ & 6.0 & $(0.5)$ & 10.0 & $(0.7)$ \\
\hline & Iceland & 11.6 & $(0.9)$ & 3.9 & $(0.5)$ & 7.8 & $(0.8)$ & 3.3 & $(0.5)$ & 2.5 & $(0.4)$ & 3.7 & $(0.5)$ & 3.9 & $(0.5)$ \\
\hline & Ireland & 16.1 & $(0.9)$ & 5.0 & $(0.4)$ & 10.5 & $(0.7)$ & 3.7 & $(0.4)$ & 4.4 & $(0.4)$ & 4.6 & $(0.5)$ & 5.4 & $(0.5)$ \\
\hline & Israel & $\mathrm{m}$ & $\mathrm{m}$ & $\mathrm{m}$ & $\mathrm{m}$ & $\mathrm{m}$ & $\mathrm{m}$ & $\mathrm{m}$ & $\mathrm{m}$ & $\mathrm{m}$ & $\mathrm{m}$ & $\mathrm{m}$ & $\mathrm{m}$ & $\mathrm{m}$ & $\mathrm{m}$ \\
\hline & Italy & $\mathrm{m}$ & $\mathrm{m}$ & $\mathrm{m}$ & $\mathrm{m}$ & $\mathrm{m}$ & $\mathrm{m}$ & $\mathrm{m}$ & $\mathrm{m}$ & $\mathrm{m}$ & $\mathrm{m}$ & $\mathrm{m}$ & $\mathrm{m}$ & $\mathrm{m}$ & $\mathrm{m}$ \\
\hline & Japan & 25.4 & $(0.7)$ & 4.6 & $(0.4)$ & 20.0 & $(0.7)$ & 3.3 & $(0.4)$ & 4.1 & $(0.4)$ & 12.6 & $(0.5)$ & 6.5 & $(0.5)$ \\
\hline & Korea & 15.4 & $(0.9)$ & 1.9 & $(0.3)$ & 13.7 & $(0.9)$ & 1.5 & $(0.2)$ & 2.7 & $(0.3)$ & 1.5 & $(0.2)$ & 3.3 & $(0.4)$ \\
\hline & Latvia & 32.5 & (1.0) & 14.2 & $(0.8)$ & 17.7 & $(0.9)$ & 9.5 & $(0.7)$ & 7.9 & $(0.7)$ & 10.9 & $(0.9)$ & 12.0 & $(0.8)$ \\
\hline & Luxembourg & 16.8 & $(0.7)$ & 6.2 & $(0.5)$ & 9.7 & $(0.5)$ & 4.9 & $(0.4)$ & 6.3 & $(0.4)$ & 5.4 & $(0.4)$ & 7.3 & $(0.6)$ \\
\hline & Mexico & 22.7 & $(0.8)$ & 10.5 & $(0.6)$ & 15.6 & $(0.7)$ & 5.9 & $(0.4)$ & 5.9 & $(0.4)$ & 7.4 & $(0.5)$ & 9.2 & $(0.5)$ \\
\hline & Netherlands & 9.6 & $(0.7)$ & 2.7 & $(0.4)$ & 5.4 & $(0.5)$ & 1.8 & $(0.3)$ & 3.1 & $(0.4)$ & 2.9 & $(0.4)$ & 3.8 & $(0.4)$ \\
\hline & New Zealand & 28.8 & (1.0) & 12.4 & $(0.8)$ & 21.4 & (1.0) & 10.5 & $(0.6)$ & 8.3 & $(0.6)$ & 9.4 & $(0.7)$ & 11.1 & $(0.8)$ \\
\hline & Norway & 17.8 & $(0.7)$ & 6.7 & $(0.6)$ & 10.8 & $(0.7)$ & 5.3 & $(0.5)$ & 6.4 & $(0.5)$ & 6.8 & $(0.5)$ & 7.5 & $(0.6)$ \\
\hline & Poland & 22.1 & $(0.9)$ & 9.6 & $(0.6)$ & 14.0 & $(0.8)$ & 5.1 & $(0.5)$ & 5.4 & $(0.5)$ & 5.7 & $(0.5)$ & 11.4 & $(0.6)$ \\
\hline & Portugal & 12.5 & (0.6) & 4.9 & $(0.5)$ & 7.5 & $(0.5)$ & 3.9 & $(0.4)$ & 3.8 & $(0.3)$ & 3.1 & $(0.3)$ & 5.4 & $(0.5)$ \\
\hline & Slovak Republic & 22.0 & (1.0) & 10.9 & $(0.7)$ & 11.8 & $(0.7)$ & 6.0 & $(0.5)$ & 7.0 & $(0.5)$ & 5.9 & $(0.5)$ & 11.1 & $(0.7)$ \\
\hline & Slovenia & 17.7 & $(0.8)$ & 5.3 & $(0.5)$ & 10.9 & $(0.6)$ & 3.8 & $(0.4)$ & 4.8 & $(0.5)$ & 6.5 & $(0.5)$ & 6.8 & $(0.5)$ \\
\hline & Spain & 15.2 & $(0.7)$ & 4.9 & $(0.4)$ & 9.1 & $(0.5)$ & 3.7 & $(0.3)$ & 4.5 & $(0.4)$ & 3.9 & $(0.3)$ & 6.1 & $(0.4)$ \\
\hline & Sweden & 17.8 & $(0.8)$ & 4.8 & $(0.4)$ & 10.7 & $(0.6)$ & 4.8 & $(0.4)$ & 5.4 & $(0.5)$ & 7.3 & $(0.5)$ & 5.7 & $(0.4)$ \\
\hline & Switzerland & 17.4 & $(0.8)$ & 5.4 & $(0.6)$ & 11.4 & $(0.6)$ & 3.4 & $(0.4)$ & 6.3 & $(0.5)$ & 4.3 & $(0.4)$ & 6.4 & $(0.5)$ \\
\hline & Turkey & 22.1 & $(1.2)$ & 10.3 & (1.0) & 13.0 & (1.0) & 8.4 & $(0.8)$ & 8.4 & $(0.7)$ & 7.3 & $(0.7)$ & 10.5 & $(0.8)$ \\
\hline & United Kingdom & 24.3 & (1.0) & 10.5 & $(0.6)$ & 16.6 & $(0.8)$ & 7.4 & $(0.5)$ & 5.8 & $(0.4)$ & 6.9 & $(0.5)$ & 9.3 & $(0.6)$ \\
\hline & United States & 18.4 & $(0.7)$ & 9.6 & $(0.6)$ & 12.1 & $(0.7)$ & 5.6 & $(0.6)$ & 4.3 & $(0.5)$ & 4.9 & $(0.5)$ & 5.9 & $(0.5)$ \\
\hline & OECD average & 19.9 & $(0.1)$ & 7.3 & $(0.1)$ & 12.8 & $(0.1)$ & 4.9 & $(0.1)$ & 5.6 & $(0.1)$ & 6.1 & $(0.1)$ & 7.6 & $(0.1)$ \\
\hline 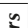 & Albania & $\mathrm{m}$ & $\mathrm{m}$ & $\mathrm{m}$ & $\mathrm{m}$ & $\mathrm{m}$ & $\mathrm{m}$ & $\mathrm{m}$ & $\mathrm{m}$ & $\mathrm{m}$ & $\mathrm{m}$ & $\mathrm{m}$ & $\mathrm{m}$ & $\mathrm{m}$ & $\mathrm{m}$ \\
\hline$\Xi$ & Algeria & $\mathrm{m}$ & $\mathrm{m}$ & $\mathrm{m}$ & $\mathrm{m}$ & $\mathrm{m}$ & $\mathrm{m}$ & $\mathrm{m}$ & $\mathrm{m}$ & $\mathrm{m}$ & $\mathrm{m}$ & $\mathrm{m}$ & $\mathrm{m}$ & $\mathrm{m}$ & $\mathrm{m}$ \\
\hline ไั้ & Brazil & 20.6 & $(0.7)$ & 9.3 & $(0.4)$ & 12.1 & $(0.6)$ & 5.2 & $(0.3)$ & 6.8 & $(0.4)$ & 4.7 & $(0.3)$ & 9.2 & $(0.4)$ \\
\hline & B-S-J-G (China) & 27.9 & (1.1) & 10.1 & $(0.5)$ & 16.8 & $(0.7)$ & 4.4 & $(0.4)$ & 15.5 & $(0.9)$ & 5.9 & $(0.4)$ & 7.9 & $(0.4)$ \\
\hline & Bulgaria & 27.0 & $(0.9)$ & 8.5 & $(0.6)$ & 14.2 & $(0.7)$ & 7.8 & $(0.5)$ & 9.2 & $(0.7)$ & 11.7 & $(0.7)$ & 12.9 & $(0.7)$ \\
\hline & CABA (Argentina) & $\mathrm{m}$ & $\mathrm{m}$ & $\mathrm{m}$ & $\mathrm{m}$ & $\mathrm{m}$ & $\mathrm{m}$ & $\mathrm{m}$ & $\mathrm{m}$ & $\mathrm{m}$ & $\mathrm{m}$ & $\mathrm{m}$ & $\mathrm{m}$ & $\mathrm{m}$ & $\mathrm{m}$ \\
\hline & Colombia & 24.9 & $(0.9)$ & 10.0 & $(0.7)$ & 14.7 & $(0.7)$ & 4.7 & $(0.4)$ & 6.1 & $(0.4)$ & 6.1 & $(0.5)$ & 10.4 & $(0.6)$ \\
\hline & Costa Rica & 20.4 & $(0.8)$ & 8.8 & $(0.6)$ & 12.9 & $(0.7)$ & 4.9 & $(0.5)$ & 2.4 & $(0.3)$ & 3.8 & $(0.4)$ & 9.7 & $(0.5)$ \\
\hline & Croatia & 17.1 & $(0.9)$ & 4.8 & $(0.5)$ & 9.2 & $(0.6)$ & 5.4 & $(0.5)$ & 4.7 & $(0.5)$ & 5.9 & $(0.5)$ & 7.8 & $(0.6)$ \\
\hline & Cyprus* & 23.3 & $(0.7)$ & 10.7 & $(0.5)$ & 15.2 & $(0.7)$ & 9.4 & $(0.5)$ & 8.0 & $(0.4)$ & 9.9 & $(0.6)$ & 11.4 & $(0.6)$ \\
\hline & Dominican Republic & 31.7 & (1.1) & 18.2 & $(0.9)$ & 16.9 & (1.1) & 10.6 & $(0.8)$ & 12.6 & $(0.8)$ & 6.9 & $(0.7)$ & 12.5 & $(0.9)$ \\
\hline & FYROM & $\mathrm{m}$ & $\mathrm{m}$ & $\mathrm{m}$ & $\mathrm{m}$ & $\mathrm{m}$ & $\mathrm{m}$ & $\mathrm{m}$ & $\mathrm{m}$ & $\mathrm{m}$ & $\mathrm{m}$ & $\mathrm{m}$ & $\mathrm{m}$ & $\mathrm{m}$ & $\mathrm{m}$ \\
\hline & Georgia & $\mathrm{m}$ & $\mathrm{m}$ & $\mathrm{m}$ & $\mathrm{m}$ & $\mathrm{m}$ & $\mathrm{m}$ & $\mathrm{m}$ & $\mathrm{m}$ & $\mathrm{m}$ & $\mathrm{m}$ & $\mathrm{m}$ & $\mathrm{m}$ & $\mathrm{m}$ & $\mathrm{m}$ \\
\hline & Hong Kong (China) & 40.1 & (1.1) & 12.9 & $(0.8)$ & 32.8 & (1.1) & 10.5 & $(0.8)$ & 14.4 & $(0.8)$ & 13.9 & $(0.9)$ & 13.0 & $(0.7)$ \\
\hline & Indonesia & $\mathrm{m}$ & $\mathrm{m}$ & $\mathrm{m}$ & $\mathrm{m}$ & $\mathrm{m}$ & $\mathrm{m}$ & $\mathrm{m}$ & $\mathrm{m}$ & $\mathrm{m}$ & $\mathrm{m}$ & $\mathrm{m}$ & $\mathrm{m}$ & $\mathrm{m}$ & $\mathrm{m}$ \\
\hline & Jordan & $\mathrm{m}$ & $\mathrm{m}$ & $\mathrm{m}$ & $\mathrm{m}$ & $\mathrm{m}$ & $\mathrm{m}$ & $\mathrm{m}$ & $\mathrm{m}$ & $\mathrm{m}$ & $\mathrm{m}$ & $\mathrm{m}$ & $\mathrm{m}$ & $\mathrm{m}$ & $\mathrm{m}$ \\
\hline & Kosovo & $\mathrm{m}$ & $\mathrm{m}$ & $\mathrm{m}$ & $\mathrm{m}$ & $\mathrm{m}$ & $\mathrm{m}$ & $\mathrm{m}$ & $\mathrm{m}$ & $\mathrm{m}$ & $\mathrm{m}$ & $\mathrm{m}$ & $\mathrm{m}$ & $\mathrm{m}$ & $\mathrm{m}$ \\
\hline & Lebanon & $\mathrm{m}$ & $\mathrm{m}$ & $\mathrm{m}$ & $\mathrm{m}$ & $\mathrm{m}$ & $\mathrm{m}$ & $\mathrm{m}$ & $\mathrm{m}$ & $\mathrm{m}$ & $\mathrm{m}$ & $\mathrm{m}$ & $\mathrm{m}$ & $\mathrm{m}$ & $\mathrm{m}$ \\
\hline & Lithuania & 16.8 & $(0.8)$ & 7.6 & $(0.6)$ & 10.6 & $(0.6)$ & 6.4 & $(0.5)$ & 5.8 & $(0.5)$ & 6.5 & $(0.5)$ & 7.2 & $(0.5)$ \\
\hline & Macao (China) & 34.0 & (1.0) & 13.2 & $(0.7)$ & 25.7 & $(0.8)$ & 9.6 & $(0.7)$ & 12.2 & $(0.7)$ & 6.9 & $(0.5)$ & 11.8 & $(0.7)$ \\
\hline & Malta & $\mathrm{m}$ & $\mathrm{m}$ & $\mathrm{m}$ & $\mathrm{m}$ & $\mathrm{m}$ & $\mathrm{m}$ & $\mathrm{m}$ & $\mathrm{m}$ & $\mathrm{m}$ & $\mathrm{m}$ & $\mathrm{m}$ & $\mathrm{m}$ & $\mathrm{m}$ & $\mathrm{m}$ \\
\hline & Moldova & $\mathrm{m}$ & $\mathrm{m}$ & $\mathrm{m}$ & $\mathrm{m}$ & $\mathrm{m}$ & $\mathrm{m}$ & $\mathrm{m}$ & $\mathrm{m}$ & $\mathrm{m}$ & $\mathrm{m}$ & $\mathrm{m}$ & $\mathrm{m}$ & $\mathrm{m}$ & $\mathrm{m}$ \\
\hline & Montenegro & 18.1 & $(0.8)$ & 6.1 & $(0.5)$ & 8.4 & $(0.5)$ & 9.2 & $(0.6)$ & 5.2 & $(0.5)$ & 5.4 & $(0.4)$ & 9.9 & $(0.6)$ \\
\hline & Peru & 21.0 & $(0.8)$ & 7.5 & $(0.5)$ & 10.2 & $(0.5)$ & 3.8 & (0.4) & 7.2 & $(0.5)$ & 5.4 & $(0.4)$ & 9.5 & $(0.5)$ \\
\hline & Qatar & 32.9 & $(0.5)$ & 17.6 & $(0.4)$ & 21.8 & $(0.5)$ & 14.1 & $(0.5)$ & 13.5 & $(0.5)$ & 13.8 & $(0.5)$ & 16.4 & (0.4) \\
\hline & Romania & $\mathrm{m}$ & $\mathrm{m}$ & $\mathrm{m}$ & $\mathrm{m}$ & $\mathrm{m}$ & $\mathrm{m}$ & $\mathrm{m}$ & $\mathrm{m}$ & $\mathrm{m}$ & $\mathrm{m}$ & $\mathrm{m}$ & $\mathrm{m}$ & $\mathrm{m}$ & $\mathrm{m}$ \\
\hline & Russia & 27.6 & (1.4) & 18.9 & (1.0) & 12.4 & $(0.9)$ & 6.0 & $(0.5)$ & 6.6 & $(0.6)$ & 3.8 & $(0.4)$ & 8.1 & $(0.5)$ \\
\hline & Singapore & 31.5 & (1.0) & 14.2 & $(0.7)$ & 25.0 & $(0.9)$ & 6.5 & $(0.5)$ & 7.3 & $(0.5)$ & 8.0 & $(0.6)$ & 10.4 & $(0.5)$ \\
\hline & Chinese Taipei & 13.9 & $(0.6)$ & 4.5 & $(0.3)$ & 9.2 & $(0.5)$ & 1.5 & $(0.2)$ & 5.2 & $(0.4)$ & 1.4 & $(0.2)$ & 4.2 & $(0.4)$ \\
\hline & Thailand & 33.7 & (1.1) & 16.2 & $(0.9)$ & 24.4 & $(0.9)$ & 12.3 & $(0.8)$ & 12.9 & $(0.8)$ & 10.9 & $(0.8)$ & 14.8 & $(0.8)$ \\
\hline & Trinidad and Tobago & $\mathrm{m}$ & $\mathrm{m}$ & $\mathrm{m}$ & $\mathrm{m}$ & $\mathrm{m}$ & $\mathrm{m}$ & $\mathrm{m}$ & $\mathrm{m}$ & $\mathrm{m}$ & $\mathrm{m}$ & $\mathrm{m}$ & $\mathrm{m}$ & $\mathrm{m}$ & $\mathrm{m}$ \\
\hline & Tunisia & 34.4 & (1.1) & 15.5 & $(0.9)$ & 17.0 & $(0.8)$ & 13.4 & $(0.8)$ & 10.3 & $(0.8)$ & 12.6 & $(0.8)$ & 15.4 & $(0.8)$ \\
\hline & United Arab Emirates & 34.3 & $(0.7)$ & 16.2 & $(0.6)$ & 22.3 & $(0.7)$ & 12.9 & $(0.7)$ & 14.0 & $(0.6)$ & 12.7 & $(0.6)$ & 16.8 & $(0.6)$ \\
\hline & Uruguay & 18.0 & $(0.8)$ & 8.9 & $(0.5)$ & 10.9 & $(0.6)$ & 5.3 & $(0.5)$ & 4.7 & $(0.5)$ & 4.9 & $(0.5)$ & 7.1 & $(0.5)$ \\
\hline & Viet Nam & $\mathrm{m}$ & $\mathrm{m}$ & $\mathrm{m}$ & $\mathrm{m}$ & $\mathrm{m}$ & $\mathrm{m}$ & $\mathrm{m}$ & $\mathrm{m}$ & $\mathrm{m}$ & $\mathrm{m}$ & $\mathrm{m}$ & $\mathrm{m}$ & $\mathrm{m}$ & $\mathrm{m}$ \\
\hline & Argentina** & $\mathrm{m}$ & $\mathrm{m}$ & $\mathrm{m}$ & $\mathrm{m}$ & $\mathrm{m}$ & $\mathrm{m}$ & $\mathrm{m}$ & $\mathrm{m}$ & $\mathrm{m}$ & $\mathrm{m}$ & $\mathrm{m}$ & $\mathrm{m}$ & $\mathrm{m}$ & $\mathrm{m}$ \\
\hline & Kazakhstan** & $\mathrm{m}$ & $\mathrm{m}$ & $\mathrm{m}$ & $\mathrm{m}$ & $\mathrm{m}$ & $\mathrm{m}$ & $\mathrm{m}$ & $\mathrm{m}$ & $\mathrm{m}$ & $\mathrm{m}$ & $\mathrm{m}$ & $\mathrm{m}$ & $\mathrm{m}$ & $\mathrm{m}$ \\
\hline & Malaysia** & 37.4 & (1.3) & 17.9 & $(0.9)$ & 25.2 & $(1.2)$ & 9.0 & $(0.8)$ & 11.5 & $(0.6)$ & 8.8 & $(0.6)$ & 15.8 & $(0.7)$ \\
\hline
\end{tabular}

1. A socio-economically disadvantaged student is a student in the bottom quarter of the PISA index of economic, social and cultural status (ESCS) within his or her own country/economy. 2. A socio-economically advantaged student is a student in the top quarter of the PISA index of economic, social and cultural status (ESCS) within his or her own country/economy. Note: Values that are statistically significant are indicated in bold (see Annex A3).

* See note at the beginning of this Annex.

** Coverage is too small to ensure comparability (see Annex A4).

StatLink 部 SD http://dx.doi.org/10.1787/888933471672 
Percentage of students who reported being bullied "a few times a month" or "once a week or more"

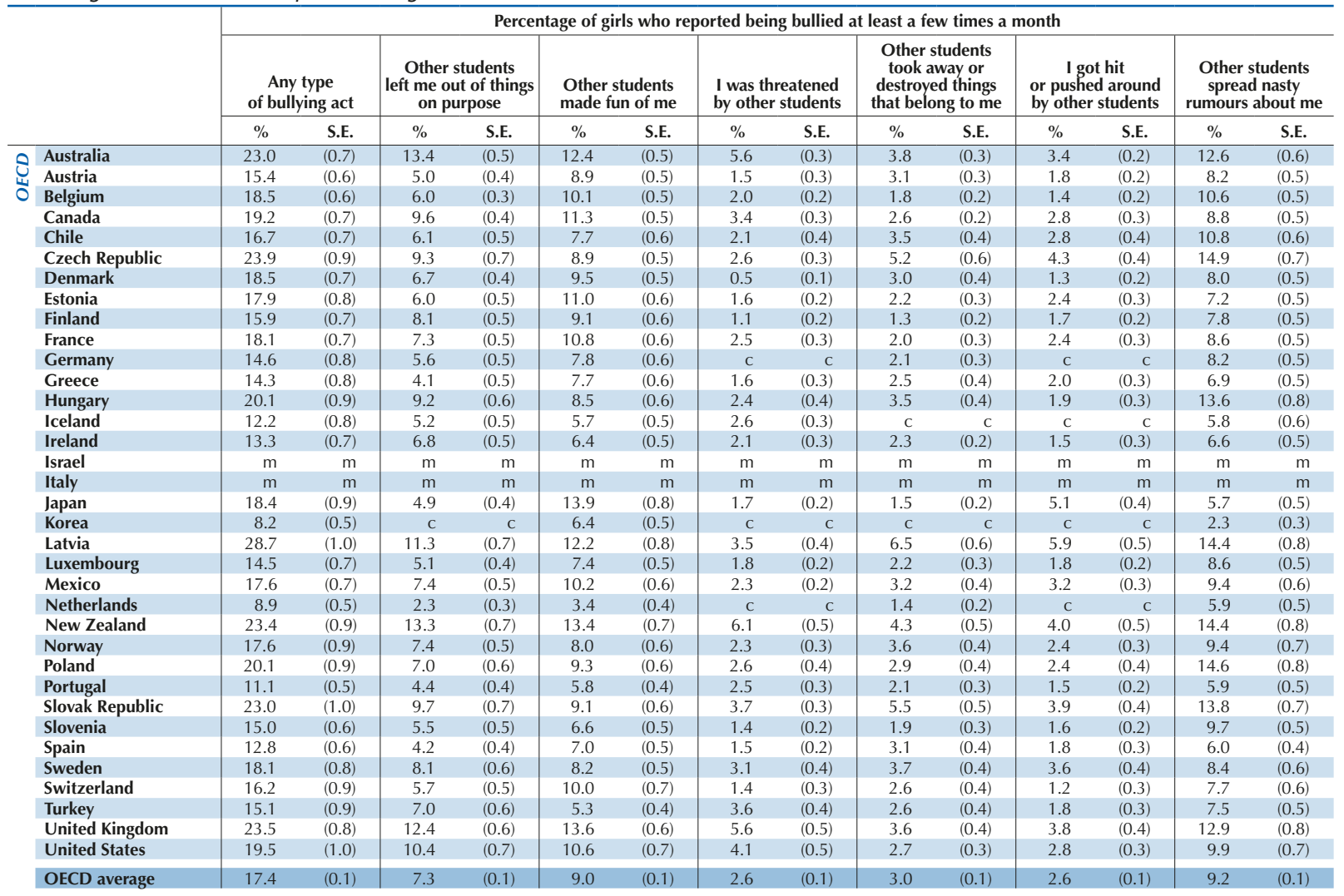

\begin{tabular}{|c|c|c|c|c|c|c|c|c|c|c|c|c|c|c|c|}
\hline$\approx$ & Albania & $\mathrm{m}$ & $\mathrm{m}$ & $\mathrm{m}$ & $\mathrm{m}$ & $\mathrm{m}$ & $\mathrm{m}$ & $\mathrm{m}$ & $\mathrm{m}$ & $\mathrm{m}$ & $\mathrm{m}$ & $\mathrm{m}$ & $\mathrm{m}$ & $\mathrm{m}$ & $\mathrm{m}$ \\
\hline 0 & Algeria & $\mathrm{m}$ & $\mathrm{m}$ & $\mathrm{m}$ & $\mathrm{m}$ & $\mathrm{m}$ & $\mathrm{m}$ & $\mathrm{m}$ & $\mathrm{m}$ & $\mathrm{m}$ & $\mathrm{m}$ & $\mathrm{m}$ & $\mathrm{m}$ & $\mathrm{m}$ & $\mathrm{m}$ \\
\hline I & Brazil & 14.6 & $(0.5)$ & 6.4 & $(0.3)$ & 6.8 & $(0.3)$ & 3.0 & $(0.2)$ & 4.0 & $(0.3)$ & 1.9 & $(0.2)$ & 6.8 & $(0.3)$ \\
\hline & B-S-J-G (China) & 16.3 & $(0.9)$ & 5.3 & $(0.6)$ & 7.3 & $(0.5)$ & 2.4 & $(0.3)$ & 9.1 & $(0.7)$ & 2.2 & $(0.3)$ & 4.5 & $(0.4)$ \\
\hline & Bulgaria & 22.3 & $(0.9)$ & 7.7 & $(0.6)$ & 10.4 & $(0.5)$ & 3.9 & (0.5) & 5.5 & (0.6) & 6.3 & $(0.6)$ & 11.9 & $(0.7)$ \\
\hline & CABA (Argentina) & $\mathrm{m}$ & $\mathrm{m}$ & $\mathrm{m}$ & $\mathrm{m}$ & $\mathrm{m}$ & $\mathrm{m}$ & $\mathrm{m}$ & $\mathrm{m}$ & $\mathrm{m}$ & $\mathrm{m}$ & $\mathrm{m}$ & $\mathrm{m}$ & $\mathrm{m}$ & $\mathrm{m}$ \\
\hline & Colombia & 19.6 & $(0.7)$ & 6.8 & $(0.4)$ & 8.7 & $(0.5)$ & 2.1 & $(0.2)$ & 3.1 & $(0.4)$ & 2.3 & $(0.3)$ & 11.3 & $(0.5)$ \\
\hline & Costa Rica & 21.1 & $(0.8)$ & 7.5 & $(0.6)$ & 10.6 & $(0.7)$ & 4.3 & $(0.5)$ & 1.7 & $(0.3)$ & 1.7 & $(0.3)$ & 14.5 & $(0.7)$ \\
\hline & Croatia & 17.0 & $(0.7)$ & 5.3 & $(0.4)$ & 6.9 & $(0.5)$ & 2.5 & $(0.3)$ & 2.5 & $(0.3)$ & 2.0 & $(0.2)$ & 11.1 & $(0.6)$ \\
\hline & Cyprus* & 13.1 & $(0.7)$ & 5.2 & $(0.5)$ & 7.4 & $(0.6)$ & 3.0 & $(0.4)$ & 2.8 & $(0.3)$ & 3.2 & $(0.4)$ & 7.4 & $(0.5)$ \\
\hline & Dominican Republic & 28.6 & $(1.1)$ & 14.3 & $(0.9)$ & 13.8 & $(0.9)$ & 6.2 & $(0.6)$ & 10.3 & $(0.8)$ & 2.8 & $(0.4)$ & 13.7 & $(0.8)$ \\
\hline & FYROM & $\mathrm{m}$ & $\mathrm{m}$ & $\mathrm{m}$ & $\mathrm{m}$ & $\mathrm{m}$ & $\mathrm{m}$ & $\mathrm{m}$ & $\mathrm{m}$ & $\mathrm{m}$ & $\mathrm{m}$ & $\mathrm{m}$ & $\mathrm{m}$ & $\mathrm{m}$ & $\mathrm{m}$ \\
\hline & Georgia & $\mathrm{m}$ & $\mathrm{m}$ & $\mathrm{m}$ & $\mathrm{m}$ & $\mathrm{m}$ & $\mathrm{m}$ & $\mathrm{m}$ & $\mathrm{m}$ & $\mathrm{m}$ & $\mathrm{m}$ & $\mathrm{m}$ & $\mathrm{m}$ & $\mathrm{m}$ & $\mathrm{m}$ \\
\hline & Hong Kong (China) & 24.5 & $(0.9)$ & 4.1 & $(0.4)$ & 19.2 & $(1.0)$ & 3.7 & $(0.4)$ & 6.4 & $(0.5)$ & 5.0 & $(0.5)$ & 5.8 & $(0.5)$ \\
\hline & Indonesia & $\mathrm{m}$ & $\mathrm{m}$ & $\mathrm{m}$ & $\mathrm{m}$ & $\mathrm{m}$ & $\mathrm{m}$ & $\mathrm{m}$ & $\mathrm{m}$ & $\mathrm{m}$ & $\mathrm{m}$ & $\mathrm{m}$ & $\mathrm{m}$ & $\mathrm{m}$ & $\mathrm{m}$ \\
\hline & Jordan & $\mathrm{m}$ & $\mathrm{m}$ & $\mathrm{m}$ & $\mathrm{m}$ & $\mathrm{m}$ & $\mathrm{m}$ & $\mathrm{m}$ & $\mathrm{m}$ & $\mathrm{m}$ & $\mathrm{m}$ & $\mathrm{m}$ & $\mathrm{m}$ & $\mathrm{m}$ & $\mathrm{m}$ \\
\hline & Kosovo & $\mathrm{m}$ & $\mathrm{m}$ & $\mathrm{m}$ & $\mathrm{m}$ & $\mathrm{m}$ & $\mathrm{m}$ & $\mathrm{m}$ & $\mathrm{m}$ & $\mathrm{m}$ & $\mathrm{m}$ & $\mathrm{m}$ & $\mathrm{m}$ & $\mathrm{m}$ & $\mathrm{m}$ \\
\hline & Lebanon & $\mathrm{m}$ & $\mathrm{m}$ & $\mathrm{m}$ & $\mathrm{m}$ & $\mathrm{m}$ & $\mathrm{m}$ & $\mathrm{m}$ & $\mathrm{m}$ & $\mathrm{m}$ & $\mathrm{m}$ & $\mathrm{m}$ & $\mathrm{m}$ & $\mathrm{m}$ & $\mathrm{m}$ \\
\hline & Lithuania & 16.0 & $(0.9)$ & 6.0 & $(0.5)$ & 7.8 & $(0.6)$ & 3.1 & $(0.5)$ & 2.6 & $(0.3)$ & 2.4 & $(0.3)$ & 8.6 & $(0.7)$ \\
\hline & Macao (China) & 20.5 & $(0.8)$ & 5.8 & $(0.5)$ & 14.1 & $(0.7)$ & 2.8 & $(0.4)$ & 4.8 & (0.5) & 1.5 & $(0.3)$ & 6.8 & $(0.5)$ \\
\hline & Malta & $\mathrm{m}$ & $\mathrm{m}$ & $\mathrm{m}$ & $\mathrm{m}$ & $\mathrm{m}$ & $\mathrm{m}$ & $\mathrm{m}$ & $\mathrm{m}$ & $\mathrm{m}$ & $\mathrm{m}$ & $\mathrm{m}$ & $\mathrm{m}$ & $\mathrm{m}$ & $\mathrm{m}$ \\
\hline & Moldova & $\mathrm{m}$ & $\mathrm{m}$ & $\mathrm{m}$ & $\mathrm{m}$ & $\mathrm{m}$ & $\mathrm{m}$ & $\mathrm{m}$ & $\mathrm{m}$ & $\mathrm{m}$ & $\mathrm{m}$ & $\mathrm{m}$ & $\mathrm{m}$ & $\mathrm{m}$ & $\mathrm{m}$ \\
\hline & Montenegro & 14.6 & $(0.7)$ & 3.7 & $(0.4)$ & 5.3 & $(0.4)$ & 3.1 & $(0.3)$ & 2.9 & $(0.4)$ & 1.7 & $(0.3)$ & 9.9 & $(0.6)$ \\
\hline & Peru & 15.8 & $(0.8)$ & 4.9 & $(0.4)$ & 5.2 & $(0.4)$ & 1.5 & $(0.3)$ & 3.4 & $(0.4)$ & 1.7 & $(0.2)$ & 9.7 & $(0.5)$ \\
\hline & Qatar & 17.7 & $(0.5)$ & 7.1 & $(0.4)$ & 8.1 & $(0.4)$ & 3.8 & $(0.3)$ & 5.1 & $(0.3)$ & 4.1 & $(0.3)$ & 8.5 & $(0.4)$ \\
\hline & Romania & $\mathrm{m}$ & $\mathrm{m}$ & $\mathrm{m}$ & $\mathrm{m}$ & $\mathrm{m}$ & $\mathrm{m}$ & $\mathrm{m}$ & $\mathrm{m}$ & $\mathrm{m}$ & $\mathrm{m}$ & $\mathrm{m}$ & $\mathrm{m}$ & $\mathrm{m}$ & $\mathrm{m}$ \\
\hline & Russia & 27.3 & (1.6) & 17.4 & (1.4) & 11.2 & (1.0) & 4.0 & $(0.7)$ & 4.6 & $(0.8)$ & 2.5 & $(0.5)$ & 9.8 & $(0.7)$ \\
\hline & Singapore & 18.3 & $(0.7)$ & 9.5 & $(0.5)$ & 11.3 & $(0.7)$ & 2.1 & $(0.3)$ & 2.6 & $(0.3)$ & 2.0 & $(0.2)$ & 7.0 & $(0.5)$ \\
\hline & Chinese Taipei & 7.4 & $(0.5)$ & 2.1 & $(0.2)$ & 4.4 & $(0.3)$ & $\mathrm{m}$ & $\mathrm{m}$ & 1.7 & $(0.2)$ & $\mathrm{m}$ & $\mathrm{m}$ & 2.8 & $(0.2)$ \\
\hline & Thailand & 22.3 & $(0.9)$ & 9.4 & $(0.6)$ & 16.5 & $(0.8)$ & 5.7 & $(0.5)$ & 7.1 & $(0.6)$ & 4.3 & $(0.5)$ & 8.4 & $(0.6)$ \\
\hline & Trinidad and Tobago & $\mathrm{m}$ & $\mathrm{m}$ & $\mathrm{m}$ & $\mathrm{m}$ & $\mathrm{m}$ & $\mathrm{m}$ & $\mathrm{m}$ & $\mathrm{m}$ & $\mathrm{m}$ & $\mathrm{m}$ & $\mathrm{m}$ & $\mathrm{m}$ & $\mathrm{m}$ & $\mathrm{m}$ \\
\hline & Tunisia & 23.0 & $(0.8)$ & 8.5 & $(0.6)$ & 9.8 & $(0.5)$ & 6.1 & $(0.5)$ & 4.9 & $(0.5)$ & 5.2 & $(0.5)$ & 10.1 & $(0.6)$ \\
\hline & United Arab Emirates & 20.4 & $(0.6)$ & 8.9 & $(0.4)$ & 10.0 & $(0.4)$ & 3.8 & $(0.3)$ & 5.3 & $(0.4)$ & 3.8 & $(0.3)$ & 9.0 & $(0.5)$ \\
\hline & Uruguay & 16.0 & $(0.6)$ & 8.7 & $(0.5)$ & 9.7 & $(0.5)$ & 3.2 & $(0.4)$ & 3.5 & $(0.3)$ & 3.1 & $(0.3)$ & 8.4 & $(0.5)$ \\
\hline & Viet Nam & $\mathrm{m}$ & $\mathrm{m}$ & $\mathrm{m}$ & $\mathrm{m}$ & $\mathrm{m}$ & $\mathrm{m}$ & $\mathrm{m}$ & $\mathrm{m}$ & $\mathrm{m}$ & $\mathrm{m}$ & $\mathrm{m}$ & $\mathrm{m}$ & $\mathrm{m}$ & $\mathrm{m}$ \\
\hline & Argentina** $^{* *}$ & $\mathrm{~m}$ & $\mathrm{~m}$ & $\mathrm{~m}$ & $\mathrm{~m}$ & $\mathrm{~m}$ & $\mathrm{~m}$ & $\mathrm{~m}$ & $\mathrm{~m}$ & $\mathrm{~m}$ & $\mathrm{~m}$ & $\mathrm{~m}$ & $\mathrm{~m}$ & $\mathrm{~m}$ & $\mathrm{~m}$ \\
\hline & Kazakhstan** & $\mathrm{m}$ & $\mathrm{m}$ & $\mathrm{m}$ & $\mathrm{m}$ & $\mathrm{m}$ & $\mathrm{m}$ & $\mathrm{m}$ & $\mathrm{m}$ & $\mathrm{m}$ & $\mathrm{m}$ & $\mathrm{m}$ & $\mathrm{m}$ & $\mathrm{m}$ & $\mathrm{m}$ \\
\hline & Malaysia** & 24.6 & $(0.8)$ & 10.1 & $(0.6)$ & 13.9 & $(0.8)$ & 3.7 & $(0.4)$ & 6.0 & $(0.5)$ & 4.0 & $(0.4)$ & 11.5 & $(0.6)$ \\
\hline
\end{tabular}

1. A socio-economically disadvantaged student is a student in the bottom quarter of the PISA index of economic, social and cultural status (ESCS) within his or her own country/economy. 2. A socio-economically advantaged student is a student in the top quarter of the PISA index of economic, social and cultural status (ESCS) within his or her own country/economy. Note: Values that are statistically significant are indicated in bold (see Annex A3).

* See note at the beginning of this Annex.

** Coverage is too small to ensure comparability (see Annex A4).

StatLink त्ञाज http://dx.doi.org/10.1787/888933471672 
[Part 3/6]

Table III.8.2 Students' exposure to different types of bullying, by gender and socio-economic status

Percentage of students who reported being bullied "a few times a month" or "once a week or more"

\begin{tabular}{|c|c|c|c|c|c|c|c|c|c|c|c|c|c|c|}
\hline & \multicolumn{14}{|c|}{ Gender difference in the percentage of students who reported being bullied at least a few times a month (B - G) } \\
\hline & \multicolumn{2}{|c|}{$\begin{array}{c}\text { Any type } \\
\text { of bullying act }\end{array}$} & \multicolumn{2}{|c|}{$\begin{array}{c}\text { Other students } \\
\text { left me out of things } \\
\text { on purpose }\end{array}$} & \multicolumn{2}{|c|}{$\begin{array}{l}\text { Other students } \\
\text { made fun of me }\end{array}$} & \multicolumn{2}{|c|}{$\begin{array}{l}\text { I was threatened } \\
\text { by other students }\end{array}$} & \multicolumn{2}{|c|}{$\begin{array}{l}\text { Other students } \\
\text { took away or } \\
\text { destroyed things } \\
\text { that belong to me }\end{array}$} & \multicolumn{2}{|c|}{$\begin{array}{l}\text { I got hit } \\
\text { or pushed around } \\
\text { by other students }\end{array}$} & \multicolumn{2}{|c|}{$\begin{array}{l}\text { Other students } \\
\text { spread nasty } \\
\text { rumours about me }\end{array}$} \\
\hline & $\%$ dif. & S.E. & $\%$ dif. & S.E. & $\%$ dif. & S.E. & $\%$ dif. & S.E. & $\%$ dif. & S.E. & $\%$ dif. & S.E. & $\%$ dif. & S.E. \\
\hline Australia & 2.4 & $(0.9)$ & -1.2 & $(0.7)$ & 5.4 & $(0.9)$ & 3.1 & (0.6) & 3.8 & (0.5) & 4.7 & $(0.5)$ & -2.8 & $(0.7)$ \\
\hline Austria & 7.4 & $(0.9)$ & 1.3 & $(0.5)$ & 6.0 & $(0.8)$ & 2.9 & $(0.5)$ & 4.4 & $(0.6)$ & 4.9 & $(0.5)$ & -0.9 & (0.8) \\
\hline$\widehat{\widehat{O}}$ Belgium & -0.1 & (1.0) & -0.1 & $(0.5)$ & 2.0 & $(0.8)$ & 1.5 & $(0.5)$ & 2.4 & $(0.4)$ & 3.3 & $(0.4)$ & -3.8 & $(0.7)$ \\
\hline Canada & 2.3 & $(0.9)$ & -0.1 & $(0.6)$ & 4.2 & (0.9) & 2.5 & $(0.5)$ & 2.8 & (0.5) & 4.5 & $(0.5)$ & -2.0 & (0.5) \\
\hline Chile & 2.7 & $(1.2)$ & 2.7 & $(0.8)$ & 3.7 & (0.9) & 1.6 & $(0.7)$ & 2.0 & $(0.7)$ & 0.8 & $(0.6)$ & -2.3 & $(1.0)$ \\
\hline Czech Republic & 2.9 & (1.3) & 1.1 & $(0.9)$ & 4.3 & (0.9) & 3.7 & $(0.6)$ & 4.1 & $(0.8)$ & 6.2 & $(0.7)$ & -3.1 & (0.9) \\
\hline Denmark & 3.3 & (1.0) & -1.5 & $(0.6)$ & 3.5 & $(0.8)$ & 2.7 & $(0.4)$ & 2.3 & $(0.6)$ & 4.4 & $(0.5)$ & -0.6 & $(0.8)$ \\
\hline Estonia & 4.5 & (1.1) & 1.3 & $(0.8)$ & 5.3 & $(0.9)$ & 2.8 & $(0.6)$ & 3.3 & $(0.6)$ & 4.6 & $(0.6)$ & -0.7 & (0.6) \\
\hline Finland & 2.0 & (1.0) & -1.8 & $(0.7)$ & 2.8 & $(0.9)$ & 3.8 & $(0.6)$ & 2.9 & $(0.5)$ & 5.8 & $(0.7)$ & -2.0 & $(0.6)$ \\
\hline France & -0.3 & $(1.0)$ & -1.2 & $(0.8)$ & 1.8 & $(0.9)$ & 1.1 & $(0.5)$ & 2.0 & $(0.5)$ & 1.4 & $(0.5)$ & -1.8 & $(0.7)$ \\
\hline Germany & 2.2 & $(1.0)$ & -0.3 & $(0.6)$ & 2.9 & $(0.8)$ & c & c & 3.4 & $(0.5)$ & C & c & -1.8 & (0.7) \\
\hline Greece & 4.8 & $(1.0)$ & 1.6 & $(0.6)$ & 4.5 & $(0.9)$ & 3.2 & $(0.5)$ & 4.0 & $(0.6)$ & 4.5 & $(0.5)$ & 0.9 & $(0.7)$ \\
\hline Hungary & 0.4 & $(1.2)$ & 0.4 & $(0.8)$ & 2.2 & $(0.9)$ & 2.9 & $(0.5)$ & 2.8 & $(0.7)$ & 4.1 & $(0.6)$ & -3.6 & $(1.0)$ \\
\hline Iceland & -0.6 & $(1.2)$ & -1.4 & $(0.8)$ & 2.0 & $(0.9)$ & 0.8 & $(0.6)$ & C & c & c & c & -1.9 & $(0.8)$ \\
\hline Ireland & 2.8 & (1.1) & -1.8 & $(0.6)$ & 4.2 & $(0.8)$ & 1.6 & $(0.5)$ & 2.2 & $(0.5)$ & 3.1 & $(0.5)$ & -1.2 & $(0.7)$ \\
\hline Israel & $\mathrm{m}$ & $\mathrm{m}$ & $\mathrm{m}$ & $\mathrm{m}$ & $\mathrm{m}$ & $\mathrm{m}$ & $\mathrm{m}$ & $\mathrm{m}$ & $\mathrm{m}$ & $\mathrm{m}$ & $\mathrm{m}$ & $\mathrm{m}$ & $\mathrm{m}$ & $\mathrm{m}$ \\
\hline Italy & $\mathrm{m}$ & $\mathrm{m}$ & $\mathrm{m}$ & $\mathrm{m}$ & $\mathrm{m}$ & $\mathrm{m}$ & $\mathrm{m}$ & $\mathrm{m}$ & $\mathrm{m}$ & $\mathrm{m}$ & $\mathrm{m}$ & $\mathrm{m}$ & $\mathrm{m}$ & $\mathrm{m}$ \\
\hline Japan & 7.0 & $(1.0)$ & -0.2 & $(0.5)$ & 6.0 & (1.0) & 1.6 & $(0.4)$ & 2.7 & $(0.5)$ & 7.5 & $(0.7)$ & 0.8 & $(0.7)$ \\
\hline Korea & 7.2 & $(1.1)$ & c & c & 7.3 & $(1.0)$ & c & $\mathrm{C}$ & c & c & C & c & 0.9 & (0.5) \\
\hline Latvia & 3.9 & (1.3) & 2.9 & (1.1) & 5.5 & $(1.1)$ & 6.0 & $(0.8)$ & 1.4 & $(0.8)$ & 5.0 & $(1.0)$ & -2.4 & (1.0) \\
\hline Luxembourg & 2.3 & $(1.0)$ & 1.0 & $(0.6)$ & 2.3 & $(0.7)$ & 3.1 & $(0.5)$ & 4.0 & $(0.5)$ & 3.6 & $(0.5)$ & -1.4 & $(0.8)$ \\
\hline Mexico & 5.1 & $(1.1)$ & 3.0 & $(0.7)$ & 5.4 & $(1.0)$ & 3.7 & $(0.4)$ & 2.7 & $(0.6)$ & 4.3 & $(0.6)$ & -0.3 & $(0.7)$ \\
\hline Netherlands & 0.6 & $(0.8)$ & 0.4 & $(0.4)$ & 2.0 & $(0.6)$ & c & c & 1.8 & $(0.5)$ & c & c & -2.1 & (0.6) \\
\hline New Zealand & 5.4 & (1.4) & -0.9 & $(1.1)$ & 8.1 & $(1.2)$ & 4.5 & $(0.8)$ & 3.9 & $(0.8)$ & 5.4 & $(0.8)$ & -3.3 & $(1.2)$ \\
\hline Norway & 0.2 & (1.1) & -0.7 & $(0.7)$ & 2.8 & $(0.9)$ & 3.0 & $(0.6)$ & 2.8 & $(0.6)$ & 4.5 & $(0.6)$ & -1.9 & $(0.9)$ \\
\hline Poland & 2.0 & (1.3) & 2.6 & (0.9) & 4.7 & $(0.9)$ & 2.5 & (0.6) & 2.5 & $(0.6)$ & 3.3 & $(0.6)$ & -3.2 & $(0.9)$ \\
\hline Portugal & 1.4 & $(0.8)$ & 0.4 & $(0.6)$ & 1.7 & $(0.7)$ & 1.5 & $(0.5)$ & 1.8 & $(0.5)$ & 1.6 & $(0.3)$ & -0.5 & $(0.7)$ \\
\hline Slovak Republic & -1.0 & (1.3) & 1.2 & (1.0) & 2.7 & $(0.9)$ & 2.3 & $(0.6)$ & 1.5 & $(0.6)$ & 2.1 & $(0.6)$ & -2.7 & (1.0) \\
\hline Slovenia & 2.7 & (1.1) & -0.2 & $(0.7)$ & 4.3 & $(0.8)$ & 2.4 & $(0.4)$ & 2.9 & $(0.5)$ & 4.8 & $(0.6)$ & -2.8 & $(0.8)$ \\
\hline Spain & 2.4 & (1.0) & 0.7 & $(0.5)$ & 2.1 & $(0.7)$ & 2.2 & $(0.3)$ & 1.4 & $(0.5)$ & 2.1 & $(0.4)$ & 0.1 & (0.6) \\
\hline Sweden & -0.3 & (1.1) & -3.3 & $(0.7)$ & 2.6 & $(0.7)$ & 1.7 & $(0.5)$ & 1.7 & $(0.5)$ & 3.7 & $(0.6)$ & -2.6 & $(0.7)$ \\
\hline Switzerland & 1.2 & $(1.1)$ & -0.3 & $(0.6)$ & 1.4 & $(0.8)$ & 2.1 & $(0.5)$ & 3.7 & $(0.6)$ & 3.1 & $(0.5)$ & -1.3 & $(0.7)$ \\
\hline Turkey & 6.9 & (1.4) & 3.3 & (1.1) & 7.7 & (1.1) & 4.8 & (0.9) & 5.8 & $(0.8)$ & 5.4 & $(0.7)$ & 3.0 & $(0.8)$ \\
\hline United Kingdom & 0.8 & $(1.2)$ & -1.9 & $(0.9)$ & 3.0 & $(1.0)$ & 1.8 & $(0.7)$ & 2.2 & $(0.6)$ & 3.1 & $(0.6)$ & -3.5 & $(0.9)$ \\
\hline United States & -1.2 & (1.1) & -0.8 & (0.9) & 1.5 & (1.0) & 1.5 & $(0.7)$ & 1.6 & $(0.6)$ & 2.1 & $(0.6)$ & -4.0 & $(0.9)$ \\
\hline OECD average & 2.5 & $(0.2)$ & 0.2 & $(0.1)$ & 3.8 & $(0.2)$ & 2.6 & $(0.1)$ & 2.8 & $(0.1)$ & 3.9 & $(0.1)$ & -1.7 & $(0.1)$ \\
\hline
\end{tabular}

\begin{tabular}{|c|c|c|c|c|c|c|c|c|c|c|c|c|c|c|}
\hline Albania & $\mathrm{m}$ & $\mathrm{m}$ & $\mathrm{m}$ & $\mathrm{m}$ & $\mathrm{m}$ & $\mathrm{m}$ & $\mathrm{m}$ & $\mathrm{m}$ & $\mathrm{m}$ & $\mathrm{m}$ & $\mathrm{m}$ & $\mathrm{m}$ & $\mathrm{m}$ & $\mathrm{m}$ \\
\hline Algeria & $\mathrm{m}$ & $\mathrm{m}$ & $\mathrm{m}$ & $\mathrm{m}$ & $\mathrm{m}$ & $\mathrm{m}$ & $\mathrm{m}$ & $\mathrm{m}$ & $\mathrm{m}$ & $\mathrm{m}$ & $\mathrm{m}$ & $\mathrm{m}$ & $\mathrm{m}$ & $\mathrm{m}$ \\
\hline Brazil & 6.0 & $(0.8)$ & 2.8 & $(0.6)$ & 5.4 & $(0.7)$ & 2.2 & $(0.4)$ & 2.8 & $(0.5)$ & 2.7 & $(0.4)$ & 2.4 & $(0.5)$ \\
\hline B-S-J-G (China) & 11.6 & (1.1) & 4.8 & $(0.8)$ & 9.5 & $(0.7)$ & 2.0 & $(0.5)$ & 6.5 & $(0.8)$ & 3.6 & (0.5) & 3.4 & $(0.6)$ \\
\hline Bulgaria & 4.7 & $(1.2)$ & 0.8 & $(0.8)$ & 3.8 & $(0.7)$ & 3.8 & $(0.6)$ & 3.8 & $(0.8)$ & 5.4 & $(0.8)$ & 0.9 & $(0.9)$ \\
\hline CABA (Argentina) & $\mathrm{m}$ & $\mathrm{m}$ & $\mathrm{m}$ & $\mathrm{m}$ & $\mathrm{m}$ & $\mathrm{m}$ & $\mathrm{m}$ & $\mathrm{m}$ & $\mathrm{m}$ & $\mathrm{m}$ & $\mathrm{m}$ & $\mathrm{m}$ & $\mathrm{m}$ & $\mathrm{m}$ \\
\hline Colombia & 5.4 & (1.1) & 3.1 & $(0.8)$ & 6.0 & $(0.9)$ & 2.6 & $(0.5)$ & 3.0 & $(0.5)$ & 3.8 & (0.6) & -0.9 & (0.9) \\
\hline Costa Rica & -0.7 & (1.1) & 1.3 & $(0.7)$ & 2.3 & $(1.0)$ & 0.6 & $(0.8)$ & 0.7 & $(0.4)$ & 2.1 & $(0.5)$ & -4.8 & $(0.8)$ \\
\hline Croatia & 0.0 & (1.1) & -0.5 & $(0.6)$ & 2.2 & $(0.8)$ & 2.9 & (0.6) & 2.2 & (0.6) & 3.8 & (0.6) & -3.3 & $(0.9)$ \\
\hline Cyprus* & 10.2 & (1.2) & 5.6 & $(0.7)$ & 7.8 & $(0.9)$ & 6.3 & $(0.6)$ & 5.2 & $(0.5)$ & 6.7 & $(0.8)$ & 4.1 & $(0.9)$ \\
\hline Dominican Republic & 3.1 & (1.5) & 3.9 & (1.1) & 3.0 & (1.3) & 4.4 & $(0.9)$ & 2.3 & (1.1) & 4.1 & $(0.8)$ & -1.2 & (1.2) \\
\hline FYROM & $\mathrm{m}$ & $\mathrm{m}$ & $\mathrm{m}$ & $\mathrm{m}$ & $\mathrm{m}$ & $\mathrm{m}$ & $\mathrm{m}$ & $\mathrm{m}$ & $\mathrm{m}$ & $\mathrm{m}$ & $\mathrm{m}$ & $\mathrm{m}$ & $\mathrm{m}$ & $\mathrm{m}$ \\
\hline Georgia & $\mathrm{m}$ & $\mathrm{m}$ & $\mathrm{m}$ & $\mathrm{m}$ & $\mathrm{m}$ & $\mathrm{m}$ & $\mathrm{m}$ & $\mathrm{m}$ & $\mathrm{m}$ & $\mathrm{m}$ & $\mathrm{m}$ & $\mathrm{m}$ & $\mathrm{m}$ & $\mathrm{m}$ \\
\hline Hong Kong (China) & 15.6 & (1.3) & 8.8 & $(0.9)$ & 13.6 & (1.4) & 6.9 & $(0.9)$ & 8.0 & $(1.0)$ & 9.0 & (1.1) & 7.2 & $(0.9)$ \\
\hline Indonesia & $\mathrm{m}$ & $\mathrm{m}$ & $\mathrm{m}$ & $\mathrm{m}$ & $\mathrm{m}$ & $\mathrm{m}$ & $\mathrm{m}$ & $\mathrm{m}$ & $\mathrm{m}$ & $\mathrm{m}$ & $\mathrm{m}$ & $\mathrm{m}$ & $\mathrm{m}$ & $\mathrm{m}$ \\
\hline Jordan & $\mathrm{m}$ & $\mathrm{m}$ & $\mathrm{m}$ & $\mathrm{m}$ & $\mathrm{m}$ & $\mathrm{m}$ & $\mathrm{m}$ & $\mathrm{m}$ & $\mathrm{m}$ & $\mathrm{m}$ & $\mathrm{m}$ & $\mathrm{m}$ & $\mathrm{m}$ & $\mathrm{m}$ \\
\hline Kosovo & $\mathrm{m}$ & $\mathrm{m}$ & $\mathrm{m}$ & $\mathrm{m}$ & $\mathrm{m}$ & $\mathrm{m}$ & $\mathrm{m}$ & $\mathrm{m}$ & $\mathrm{m}$ & $\mathrm{m}$ & $\mathrm{m}$ & $\mathrm{m}$ & $\mathrm{m}$ & $\mathrm{m}$ \\
\hline Lebanon & $\mathrm{m}$ & $\mathrm{m}$ & $\mathrm{m}$ & $\mathrm{m}$ & $\mathrm{m}$ & $\mathrm{m}$ & $\mathrm{m}$ & $\mathrm{m}$ & $\mathrm{m}$ & $\mathrm{m}$ & $\mathrm{m}$ & $\mathrm{m}$ & $\mathrm{m}$ & $\mathrm{m}$ \\
\hline Lithuania & 0.8 & (1.0) & 1.6 & $(0.7)$ & 2.8 & $(0.8)$ & 3.3 & $(0.6)$ & 3.3 & $(0.6)$ & 4.0 & $(0.5)$ & -1.4 & $(0.8)$ \\
\hline Macao (China) & 13.5 & (1.3) & 7.5 & $(0.9)$ & 11.6 & $(1.1)$ & 6.7 & $(0.8)$ & 7.4 & $(0.9)$ & 5.4 & (0.6) & 5.0 & $(0.9)$ \\
\hline Malta & $\mathrm{m}$ & $\mathrm{m}$ & $\mathrm{m}$ & $\mathrm{m}$ & $\mathrm{m}$ & $\mathrm{m}$ & $\mathrm{m}$ & $\mathrm{m}$ & $\mathrm{m}$ & $\mathrm{m}$ & $\mathrm{m}$ & $\mathrm{m}$ & $\mathrm{m}$ & $\mathrm{m}$ \\
\hline Moldova & $\mathrm{m}$ & $\mathrm{m}$ & $\mathrm{m}$ & $\mathrm{m}$ & $\mathrm{m}$ & $\mathrm{m}$ & $\mathrm{m}$ & $\mathrm{m}$ & $\mathrm{m}$ & $\mathrm{m}$ & $\mathrm{m}$ & $\mathrm{m}$ & $\mathrm{m}$ & $\mathrm{m}$ \\
\hline Montenegro & 3.5 & (1.0) & 2.5 & $(0.6)$ & 3.1 & $(0.6)$ & 6.1 & $(0.7)$ & 2.3 & $(0.5)$ & 3.8 & $(0.5)$ & -0.1 & $(0.8)$ \\
\hline Peru & 5.3 & $(0.9)$ & 2.7 & $(0.5)$ & 5.0 & $(0.7)$ & 2.4 & $(0.5)$ & 3.8 & $(0.6)$ & 3.7 & (0.5) & -0.2 & $(0.7)$ \\
\hline Qatar & 15.2 & $(0.8)$ & 10.5 & $(0.6)$ & 13.7 & $(0.8)$ & 10.4 & (0.5) & 8.3 & $(0.6)$ & 9.7 & (0.6) & 7.9 & (0.6) \\
\hline Romania & $\mathrm{m}$ & $\mathrm{m}$ & $\mathrm{m}$ & $\mathrm{m}$ & $\mathrm{m}$ & $\mathrm{m}$ & $\mathrm{m}$ & $\mathrm{m}$ & $\mathrm{m}$ & $\mathrm{m}$ & $\mathrm{m}$ & $\mathrm{m}$ & $\mathrm{m}$ & $\mathrm{m}$ \\
\hline Russia & 0.3 & (1.6) & 1.6 & $(1.3)$ & 1.2 & $(0.8)$ & 2.0 & $(0.8)$ & 2.0 & $(0.7)$ & 1.3 & $(0.5)$ & -1.7 & $(0.7)$ \\
\hline Singapore & 13.2 & (1.3) & 4.7 & $(0.9)$ & 13.7 & $(1.2)$ & 4.3 & $(0.6)$ & 4.7 & $(0.6)$ & 6.1 & (0.6) & 3.4 & $(0.8)$ \\
\hline Chinese Taipei & 6.5 & $(0.8)$ & 2.4 & $(0.4)$ & 4.9 & $(0.7)$ & $\mathrm{m}$ & m & 3.5 & $(0.4)$ & $\mathrm{m}$ & $\mathrm{m}$ & 1.4 & $(0.5)$ \\
\hline Thailand & 11.4 & $(1.2)$ & 6.8 & $(1.0)$ & 7.8 & (1.0) & 6.6 & $(0.9)$ & 5.8 & (1.0) & 6.6 & $(1.0)$ & 6.4 & $(0.9)$ \\
\hline Trinidad and Tobago & $\mathrm{m}$ & $\mathrm{m}$ & $\mathrm{m}$ & $\mathrm{m}$ & $\mathrm{m}$ & $\mathrm{m}$ & $\mathrm{m}$ & $\mathrm{m}$ & $\mathrm{m}$ & $\mathrm{m}$ & $\mathrm{m}$ & $\mathrm{m}$ & $\mathrm{m}$ & $\mathrm{m}$ \\
\hline Tunisia & 11.4 & $(1.2)$ & 7.1 & $(1.0)$ & 7.1 & $(0.9)$ & 7.3 & $(0.9)$ & 5.4 & $(0.7)$ & 7.4 & $(0.9)$ & 5.3 & (1.0) \\
\hline United Arab Emirates & 13.9 & $(0.9)$ & 7.3 & $(0.7)$ & 12.3 & $(0.9)$ & 9.1 & $(0.7)$ & 8.7 & $(0.7)$ & 8.9 & (0.7) & 7.7 & $(0.8)$ \\
\hline Uruguay & 2.0 & (1.0) & 0.2 & $(0.8)$ & 1.2 & $(0.9)$ & 2.1 & $(0.6)$ & 1.2 & $(0.5)$ & 1.8 & (0.5) & -1.3 & $(0.7)$ \\
\hline Viet Nam & $\mathrm{m}$ & $\mathrm{m}$ & $\mathrm{m}$ & $\mathrm{m}$ & $\mathrm{m}$ & $\mathrm{m}$ & $\mathrm{m}$ & $\mathrm{m}$ & $\mathrm{m}$ & $\mathrm{m}$ & $\mathrm{m}$ & $\mathrm{m}$ & $\mathrm{m}$ & $\mathrm{m}$ \\
\hline Argentina** & $\mathrm{m}$ & $\mathrm{m}$ & $\mathrm{m}$ & $\mathrm{m}$ & $\mathrm{m}$ & $\mathrm{m}$ & $\mathrm{m}$ & $\mathrm{m}$ & $\mathrm{m}$ & $\mathrm{m}$ & $\mathrm{m}$ & $\mathrm{m}$ & $\mathrm{m}$ & $\mathrm{m}$ \\
\hline Kazakhstan** & $\mathrm{m}$ & $\mathrm{m}$ & $\mathrm{m}$ & $\mathrm{m}$ & $\mathrm{m}$ & $\mathrm{m}$ & $\mathrm{m}$ & $\mathrm{m}$ & $\mathrm{m}$ & $\mathrm{m}$ & $\mathrm{m}$ & $\mathrm{m}$ & $\mathrm{m}$ & $\mathrm{m}$ \\
\hline Malaysia** & 12.8 & (1.4) & 7.8 & $(0.9)$ & 11.3 & $(1.1)$ & 5.3 & $(0.7)$ & 5.5 & $(0.8)$ & 4.8 & $(0.7)$ & 4.3 & $(0.9)$ \\
\hline
\end{tabular}

1. A socio-economically disadvantaged student is a student in the bottom quarter of the PISA index of economic, social and cultural status (ESCS) within his or her own country/economy. 2. A socio-economically advantaged student is a student in the top quarter of the PISA index of economic, social and cultural status (ESCS) within his or her own country/economy. Note: Values that are statistically significant are indicated in bold (see Annex A3).

* See note at the beginning of this Annex.

** Coverage is too small to ensure comparability (see Annex A4).

StatLink 弃正四 http://dx.doi.org/10.1787/888933471672 
Percentage of students who reported being bullied "a few times a month" or "once a week or more"

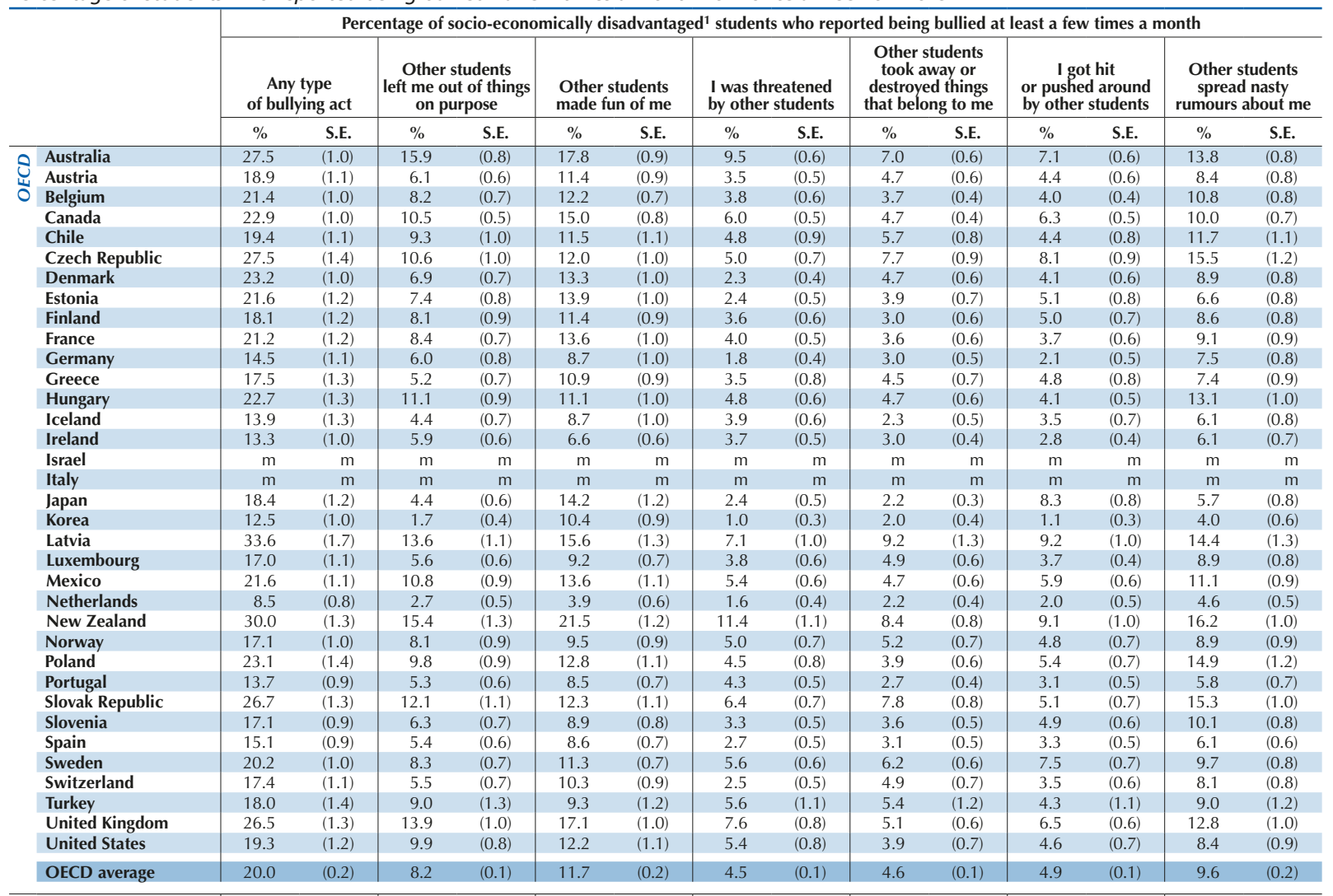

\begin{tabular}{|c|c|c|c|c|c|c|c|c|c|c|c|c|c|c|c|}
\hline$\approx$ & Albania & $\mathrm{m}$ & $\mathrm{m}$ & $\mathrm{m}$ & $\mathrm{m}$ & $\mathrm{m}$ & $\mathrm{m}$ & $\mathrm{m}$ & $\mathrm{m}$ & $\mathrm{m}$ & $\mathrm{m}$ & $\mathrm{m}$ & $\mathrm{m}$ & $\mathrm{m}$ & $\mathrm{m}$ \\
\hline 0 & Algeria & $\mathrm{m}$ & $\mathrm{m}$ & $\mathrm{m}$ & $\mathrm{m}$ & $\mathrm{m}$ & $\mathrm{m}$ & $\mathrm{m}$ & $\mathrm{m}$ & $\mathrm{m}$ & $\mathrm{m}$ & $\mathrm{m}$ & $\mathrm{m}$ & $\mathrm{m}$ & $\mathrm{m}$ \\
\hline I & Brazil & 16.8 & $(0.8)$ & 7.8 & $(0.6)$ & 8.2 & $(0.5)$ & 3.9 & $(0.4)$ & 5.1 & $(0.5)$ & 3.6 & $(0.4)$ & 7.8 & $(0.5)$ \\
\hline & B-S-J-G (China) & 25.0 & (1.6) & 9.7 & $(0.9)$ & 15.3 & $(1.2)$ & 4.4 & $(0.6)$ & 12.8 & $(1.2)$ & 4.3 & $(0.5)$ & 6.8 & $(0.6)$ \\
\hline & Bulgaria & 24.5 & $(1.2)$ & 8.7 & $(0.8)$ & 12.6 & (0.9) & 7.3 & $(0.9)$ & 6.9 & (0.9) & 9.9 & $(0.8)$ & 12.7 & (1.0) \\
\hline & CABA (Argentina) & $\mathrm{m}$ & $\mathrm{m}$ & $\mathrm{m}$ & $\mathrm{m}$ & $\mathrm{m}$ & $\mathrm{m}$ & $\mathrm{m}$ & $\mathrm{m}$ & $\mathrm{m}$ & $\mathrm{m}$ & $\mathrm{m}$ & $\mathrm{m}$ & $\mathrm{m}$ & $\mathrm{m}$ \\
\hline & Colombia & 20.9 & $(1.0)$ & 6.9 & $(0.6)$ & 11.4 & $(0.8)$ & 2.9 & $(0.4)$ & 3.5 & $(0.5)$ & 3.8 & $(0.6)$ & 9.4 & $(0.8)$ \\
\hline & Costa Rica & 22.8 & $(1.2)$ & 10.1 & (1.0) & 12.8 & (1.1) & 4.8 & $(0.7)$ & 1.5 & $(0.3)$ & 2.9 & $(0.5)$ & 13.4 & $(1.0)$ \\
\hline & Croatia & 17.4 & (1.1) & 5.6 & $(0.7)$ & 9.0 & $(0.8)$ & 4.2 & $(0.6)$ & 4.2 & $(0.6)$ & 4.5 & $(0.7)$ & 10.4 & $(0.9)$ \\
\hline & Cyprus* & 18.5 & $(1.1)$ & 7.0 & $(0.7)$ & 11.7 & $(0.9)$ & 5.2 & $(0.6)$ & 4.5 & $(0.5)$ & 6.5 & $(0.7)$ & 8.2 & $(0.7)$ \\
\hline & Dominican Republic & 29.9 & (1.6) & 15.3 & (1.2) & 17.2 & (1.4) & 7.4 & (1.2) & 11.8 & (1.4) & 5.2 & (1.0) & 13.6 & (1.1) \\
\hline & FYROM & $\mathrm{m}$ & $\mathrm{m}$ & $\mathrm{m}$ & $\mathrm{m}$ & $\mathrm{m}$ & $\mathrm{m}$ & $\mathrm{m}$ & $\mathrm{m}$ & $\mathrm{m}$ & $\mathrm{m}$ & $\mathrm{m}$ & $\mathrm{m}$ & $\mathrm{m}$ & $\mathrm{m}$ \\
\hline & Georgia & $\mathrm{m}$ & $\mathrm{m}$ & $\mathrm{m}$ & $\mathrm{m}$ & $\mathrm{m}$ & $\mathrm{m}$ & $\mathrm{m}$ & $\mathrm{m}$ & $\mathrm{m}$ & $\mathrm{m}$ & $\mathrm{m}$ & $\mathrm{m}$ & $\mathrm{m}$ & $\mathrm{m}$ \\
\hline & Hong Kong (China) & 31.8 & $(1.3)$ & 9.6 & $(0.8)$ & 25.5 & (1.3) & 7.1 & $(0.8)$ & 9.6 & $(0.9)$ & 9.0 & $(0.9)$ & 9.9 & $(0.9)$ \\
\hline & Indonesia & $\mathrm{m}$ & $\mathrm{m}$ & $\mathrm{m}$ & $\mathrm{m}$ & $\mathrm{m}$ & $\mathrm{m}$ & $\mathrm{m}$ & $\mathrm{m}$ & $\mathrm{m}$ & $\mathrm{m}$ & $\mathrm{m}$ & $\mathrm{m}$ & $\mathrm{m}$ & $\mathrm{m}$ \\
\hline & Jordan & $\mathrm{m}$ & $\mathrm{m}$ & $\mathrm{m}$ & $\mathrm{m}$ & $\mathrm{m}$ & $\mathrm{m}$ & $\mathrm{m}$ & $\mathrm{m}$ & $\mathrm{m}$ & $\mathrm{m}$ & $\mathrm{m}$ & $\mathrm{m}$ & $\mathrm{m}$ & $\mathrm{m}$ \\
\hline & Kosovo & $\mathrm{m}$ & $\mathrm{m}$ & $\mathrm{m}$ & $\mathrm{m}$ & $\mathrm{m}$ & $\mathrm{m}$ & $\mathrm{m}$ & $\mathrm{m}$ & $\mathrm{m}$ & $\mathrm{m}$ & $\mathrm{m}$ & $\mathrm{m}$ & $\mathrm{m}$ & $\mathrm{m}$ \\
\hline & Lebanon & $\mathrm{m}$ & $\mathrm{m}$ & $\mathrm{m}$ & $\mathrm{m}$ & $\mathrm{m}$ & $\mathrm{m}$ & $\mathrm{m}$ & $\mathrm{m}$ & $\mathrm{m}$ & $\mathrm{m}$ & $\mathrm{m}$ & $\mathrm{m}$ & $\mathrm{m}$ & $\mathrm{m}$ \\
\hline & Lithuania & 19.1 & $(1.3)$ & 7.5 & $(0.8)$ & 10.5 & $(0.9)$ & 6.0 & $(0.8)$ & 4.1 & $(0.6)$ & 5.0 & $(0.8)$ & 9.4 & $(1.0)$ \\
\hline & Macao (China) & 25.2 & $(1.2)$ & 9.3 & (1.0) & 17.8 & (1.1) & 5.9 & $(0.8)$ & 8.9 & (0.9) & 3.6 & (0.5) & 9.1 & $(0.8)$ \\
\hline & Malta & $\mathrm{m}$ & $\mathrm{m}$ & $\mathrm{m}$ & $\mathrm{m}$ & $\mathrm{m}$ & $\mathrm{m}$ & $\mathrm{m}$ & $\mathrm{m}$ & $\mathrm{m}$ & $\mathrm{m}$ & $\mathrm{m}$ & $\mathrm{m}$ & $\mathrm{m}$ & $\mathrm{m}$ \\
\hline & Moldova & $\mathrm{m}$ & $\mathrm{m}$ & $\mathrm{m}$ & $\mathrm{m}$ & $\mathrm{m}$ & $\mathrm{m}$ & $\mathrm{m}$ & $\mathrm{m}$ & $\mathrm{m}$ & $\mathrm{m}$ & $\mathrm{m}$ & $\mathrm{m}$ & $\mathrm{m}$ & $\mathrm{m}$ \\
\hline & Montenegro & 17.2 & $(1.1)$ & 5.5 & $(0.7)$ & 8.3 & $(0.8)$ & 6.0 & $(0.8)$ & 4.1 & $(0.7)$ & 3.5 & $(0.7)$ & 10.3 & $(0.9)$ \\
\hline & Peru & 18.9 & (1.3) & 7.2 & $(0.9)$ & 7.4 & $(0.8)$ & 4.0 & $(0.6)$ & 6.3 & $(0.7)$ & 4.5 & $(0.6)$ & 8.4 & $(0.8)$ \\
\hline & Qatar & 28.1 & $(0.8)$ & 14.3 & $(0.7)$ & 16.4 & $(0.7)$ & 11.1 & $(0.6)$ & 11.6 & $(0.6)$ & 10.7 & $(0.6)$ & 13.9 & $(0.6)$ \\
\hline & Romania & $\mathrm{m}$ & $\mathrm{m}$ & $\mathrm{m}$ & $\mathrm{m}$ & $\mathrm{m}$ & $\mathrm{m}$ & $\mathrm{m}$ & $\mathrm{m}$ & $\mathrm{m}$ & $\mathrm{m}$ & $\mathrm{m}$ & $\mathrm{m}$ & $\mathrm{m}$ & $\mathrm{m}$ \\
\hline & Russia & 29.2 & (1.9) & 19.3 & (1.3) & 12.4 & (1.3) & 5.2 & $(0.7)$ & 6.0 & $(0.9)$ & 3.8 & $(0.6)$ & 8.8 & $(0.9)$ \\
\hline & Singapore & 29.0 & (1.1) & 16.1 & $(0.9)$ & 21.0 & (1.0) & 5.4 & $(0.5)$ & 6.2 & $(0.7)$ & 6.2 & $(0.7)$ & 10.7 & $(0.8)$ \\
\hline & Chinese Taipei & 10.9 & $(0.9)$ & 3.6 & $(0.5)$ & 7.1 & $(0.7)$ & 1.0 & $(0.2)$ & 3.8 & $(0.5)$ & 0.9 & $(0.2)$ & 3.1 & $(0.4)$ \\
\hline & Thailand & 28.1 & (1.5) & 13.4 & (1.1) & 21.8 & $(1.2)$ & 10.3 & $(0.9)$ & 10.7 & $(0.9)$ & 8.7 & $(0.7)$ & 11.5 & $(0.9)$ \\
\hline & Trinidad and Tobago & $\mathrm{m}$ & $\mathrm{m}$ & $\mathrm{m}$ & $\mathrm{m}$ & $\mathrm{m}$ & $\mathrm{m}$ & $\mathrm{m}$ & $\mathrm{m}$ & $\mathrm{m}$ & $\mathrm{m}$ & $\mathrm{m}$ & $\mathrm{m}$ & $\mathrm{m}$ & $\mathrm{m}$ \\
\hline & Tunisia & 32.0 & (1.4) & 13.7 & (1.1) & 14.7 & $(1.2)$ & 10.9 & $(1.0)$ & 8.4 & $(1.0)$ & 10.4 & (1.0) & 14.1 & $(0.9)$ \\
\hline & United Arab Emirates & 30.6 & (1.1) & 14.3 & $(0.8)$ & 17.5 & $(0.9)$ & 10.2 & $(0.7)$ & 10.7 & $(0.8)$ & 9.5 & $(0.6)$ & 13.8 & $(0.9)$ \\
\hline & Uruguay & 17.8 & $(1.0)$ & 9.1 & $(0.7)$ & 10.3 & $(0.8)$ & 4.7 & $(0.7)$ & 3.8 & $(0.5)$ & 4.0 & $(0.7)$ & 9.0 & $(0.8)$ \\
\hline & Viet Nam & $\mathrm{m}$ & $\mathrm{m}$ & $\mathrm{m}$ & $\mathrm{m}$ & $\mathrm{m}$ & $\mathrm{m}$ & $\mathrm{m}$ & $\mathrm{m}$ & $\mathrm{m}$ & $\mathrm{m}$ & $\mathrm{m}$ & $\mathrm{m}$ & $\mathrm{m}$ & $\mathrm{m}$ \\
\hline & Argentina** $^{* *}$ & $\mathrm{~m}$ & $\mathrm{~m}$ & $\mathrm{~m}$ & $\mathrm{~m}$ & $\mathrm{~m}$ & $\mathrm{~m}$ & $\mathrm{~m}$ & $\mathrm{~m}$ & $\mathrm{~m}$ & $\mathrm{~m}$ & $\mathrm{~m}$ & $\mathrm{~m}$ & $\mathrm{~m}$ & $\mathrm{~m}$ \\
\hline & Kazakhstan** & $\mathrm{m}$ & $\mathrm{m}$ & $\mathrm{m}$ & $\mathrm{m}$ & $\mathrm{m}$ & $\mathrm{m}$ & $\mathrm{m}$ & $\mathrm{m}$ & $\mathrm{m}$ & $\mathrm{m}$ & $\mathrm{m}$ & $\mathrm{m}$ & $\mathrm{m}$ & $\mathrm{m}$ \\
\hline & Malaysia** & 30.0 & (1.4) & 14.1 & $(1.0)$ & 18.2 & $(1.3)$ & 6.0 & $(0.8)$ & 9.4 & $(1.0)$ & 5.8 & $(0.7)$ & 13.8 & $(0.8)$ \\
\hline
\end{tabular}

1. A socio-economically disadvantaged student is a student in the bottom quarter of the PISA index of economic, social and cultural status (ESCS) within his or her own country/economy. 2. A socio-economically advantaged student is a student in the top quarter of the PISA index of economic, social and cultural status (ESCS) within his or her own country/economy. Note: Values that are statistically significant are indicated in bold (see Annex A3).

* See note at the beginning of this Annex.

** Coverage is too small to ensure comparability (see Annex A4).

StatLink त्ञाज http://dx.doi.org/10.1787/888933471672 
[Part 5/6]

Table III.8.2 Students' exposure to different types of bullying, by gender and socio-economic status

Percentage of students who reported being bullied "a few times a month" or "once a week or more"

Percentage of socio-economically advantaged ${ }^{2}$ students who reported being bullied at least a few times a month

\begin{tabular}{|c|c|c|c|c|c|c|c|c|c|c|c|c|c|c|}
\hline & \multicolumn{14}{|c|}{ Percentage of socio-economically advantaged ${ }^{2}$ students who reported being bullied at least a few times a month } \\
\hline & \multicolumn{2}{|c|}{$\begin{array}{c}\text { Any type } \\
\text { of bullying act }\end{array}$} & \multicolumn{2}{|c|}{$\begin{array}{c}\text { Other students } \\
\text { left me out of things } \\
\text { on purpose }\end{array}$} & \multicolumn{2}{|c|}{$\begin{array}{l}\text { Other students } \\
\text { made fun of me }\end{array}$} & \multicolumn{2}{|c|}{$\begin{array}{l}\text { I was threatened } \\
\text { by other students }\end{array}$} & \multicolumn{2}{|c|}{$\begin{array}{l}\text { Other students } \\
\text { took away or } \\
\text { destroyed things } \\
\text { that belong to me }\end{array}$} & \multicolumn{2}{|c|}{$\begin{array}{l}\text { I got hit } \\
\text { or pushed around } \\
\text { by other students }\end{array}$} & \multicolumn{2}{|c|}{$\begin{array}{l}\text { Other students } \\
\text { spread nasty } \\
\text { rumours about me }\end{array}$} \\
\hline & $\%$ & S.E. & $\%$ & S.E. & $\%$ & S.E. & $\%$ & S.E. & $\%$ & S.E. & $\%$ & S.E. & $\%$ & S.E. \\
\hline Australia & 21.9 & $(1.0)$ & 11.0 & $(0.6)$ & 13.0 & $(0.8)$ & 5.7 & $(0.4)$ & 5.3 & $(0.6)$ & 4.4 & $(0.4)$ & 8.6 & $(0.6)$ \\
\hline Austria & 20.5 & (1.1) & 5.6 & $(0.7)$ & 13.4 & (1.0) & 2.9 & $(0.5)$ & 5.9 & $(0.6)$ & 4.1 & $(0.6)$ & 7.5 & $(0.7)$ \\
\hline Belgium & 15.3 & $(0.7)$ & 3.9 & $(0.4)$ & 9.0 & $(0.6)$ & 1.7 & $(0.3)$ & 2.4 & $(0.3)$ & 2.3 & $(0.3)$ & 6.8 & $(0.5)$ \\
\hline Canada & 16.8 & $(0.8)$ & 8.1 & $(0.6)$ & 11.3 & $(0.5)$ & 3.0 & $(0.3)$ & 2.8 & $(0.3)$ & 4.1 & $(0.3)$ & 5.8 & $(0.5)$ \\
\hline Chile & 17.7 & $(0.9)$ & 7.1 & $(0.6)$ & 9.4 & $(0.7)$ & 2.0 & $(0.5)$ & 3.8 & $(0.5)$ & 3.0 & $(0.6)$ & 8.4 & $(0.7)$ \\
\hline Czech Republic & 22.7 & $(1.2)$ & 7.6 & $(0.9)$ & 9.5 & $(0.7)$ & 3.5 & $(0.5)$ & 5.4 & $(0.6)$ & 6.2 & $(0.7)$ & 11.0 & $(0.9)$ \\
\hline Denmark & 18.0 & $(1.2)$ & 5.6 & $(0.7)$ & 10.4 & $(0.9)$ & 1.6 & $(0.3)$ & 3.1 & $(0.4)$ & 3.4 & $(0.5)$ & 6.7 & $(0.8)$ \\
\hline Estonia & 19.9 & (1.3) & 5.5 & $(0.7)$ & 13.6 & $(1.2)$ & 2.3 & $(0.4)$ & 3.4 & $(0.5)$ & 3.7 & $(0.6)$ & 6.5 & $(0.8)$ \\
\hline Finland & 15.0 & (1.0) & 6.5 & $(0.8)$ & 9.2 & $(0.8)$ & 3.2 & $(0.5)$ & 2.8 & $(0.7)$ & 4.7 & $(0.7)$ & 5.4 & $(0.6)$ \\
\hline France & 13.3 & $(1.0)$ & 4.2 & $(0.6)$ & 9.2 & $(0.8)$ & 1.5 & $(0.3)$ & 2.7 & $(0.5)$ & 2.0 & $(0.4)$ & 5.8 & $(0.7)$ \\
\hline Germany & 14.9 & (1.0) & 4.3 & $(0.6)$ & 8.1 & $(0.8)$ & 1.1 & $(0.4)$ & 3.8 & $(0.5)$ & 1.4 & $(0.4)$ & 6.5 & $(0.7)$ \\
\hline Greece & 15.2 & $(0.9)$ & 3.8 & $(0.6)$ & 9.0 & $(0.8)$ & 2.2 & $(0.4)$ & 4.8 & $(0.6)$ & 3.8 & $(0.6)$ & 6.8 & $(0.8)$ \\
\hline Hungary & 17.7 & (1.1) & 7.1 & $(0.7)$ & 8.3 & $(0.8)$ & 3.5 & $(0.5)$ & 4.2 & $(0.7)$ & 3.6 & $(0.5)$ & 11.0 & $(0.9)$ \\
\hline Iceland & 10.3 & (1.1) & 3.9 & $(0.7)$ & 6.1 & $(0.9)$ & 2.5 & $(0.6)$ & 1.7 & $(0.5)$ & 2.7 & $(0.6)$ & 4.4 & $(0.8)$ \\
\hline Ireland & 15.4 & $(0.9)$ & 6.0 & $(0.7)$ & 8.7 & $(0.7)$ & 2.2 & $(0.4)$ & 3.9 & $(0.5)$ & 3.2 & $(0.6)$ & 5.6 & $(0.6)$ \\
\hline Israel & $\mathrm{m}$ & $\mathrm{m}$ & $\mathrm{m}$ & $\mathrm{m}$ & $\mathrm{m}$ & $\mathrm{m}$ & $\mathrm{m}$ & $\mathrm{m}$ & $\mathrm{m}$ & $\mathrm{m}$ & $\mathrm{m}$ & $\mathrm{m}$ & $\mathrm{m}$ & $\mathrm{m}$ \\
\hline Italy & $\mathrm{m}$ & $\mathrm{m}$ & $\mathrm{m}$ & $\mathrm{m}$ & $\mathrm{m}$ & $\mathrm{m}$ & $\mathrm{m}$ & $\mathrm{m}$ & $\mathrm{m}$ & $\mathrm{m}$ & $\mathrm{m}$ & $\mathrm{m}$ & $\mathrm{m}$ & $\mathrm{m}$ \\
\hline Japan & 25.6 & $(1.2)$ & 5.2 & $(0.6)$ & 20.3 & (1.1) & 2.6 & $(0.5)$ & 3.0 & $(0.4)$ & 10.0 & $(0.8)$ & 6.8 & $(0.7)$ \\
\hline Korea & 12.5 & $(0.9)$ & 1.3 & $(0.3)$ & 11.1 & (1.0) & 1.2 & $(0.3)$ & 1.7 & (0.4) & 0.8 & $(0.2)$ & 2.2 & $(0.4)$ \\
\hline Latvia & 27.9 & (1.4) & 12.1 & $(1.0)$ & 15.2 & $(1.2)$ & 6.3 & $(0.6)$ & 6.2 & $(0.8)$ & 7.0 & $(0.7)$ & 11.4 & $(1.1)$ \\
\hline Luxembourg & 13.3 & $(0.9)$ & 4.5 & $(0.6)$ & 7.3 & $(0.6)$ & 2.0 & $(0.4)$ & 3.0 & $(0.5)$ & 2.6 & $(0.5)$ & 6.3 & $(0.6)$ \\
\hline Mexico & 21.3 & $(1.0)$ & 9.0 & $(0.7)$ & 13.2 & $(0.8)$ & 3.7 & $(0.5)$ & 4.7 & $(0.5)$ & 5.2 & $(0.7)$ & 8.8 & $(0.8)$ \\
\hline Netherlands & 9.7 & $(0.8)$ & 2.2 & $(0.4)$ & 4.8 & $(0.6)$ & 1.4 & $(0.4)$ & 2.0 & $(0.4)$ & 1.4 & $(0.3)$ & 4.9 & $(0.6)$ \\
\hline New Zealand & 24.2 & (1.4) & 11.5 & $(1.2)$ & 15.1 & (1.3) & 6.8 & $(0.9)$ & 5.5 & $(0.8)$ & 6.3 & $(0.8)$ & 12.0 & $(0.9)$ \\
\hline Norway & 17.8 & $(1.2)$ & 7.4 & $(0.7)$ & 10.0 & $(0.9)$ & 4.1 & $(0.6)$ & 5.6 & $(0.6)$ & 5.5 & $(0.7)$ & 8.9 & $(0.9)$ \\
\hline Poland & 20.8 & $(1.2)$ & 7.8 & $(0.9)$ & 10.8 & $(0.9)$ & 3.4 & $(0.6)$ & 4.4 & $(0.7)$ & 2.8 & $(0.7)$ & 12.0 & (1.0) \\
\hline Portugal & 10.1 & $(0.9)$ & 3.3 & $(0.5)$ & 5.2 & (0.7) & 2.1 & $(0.4)$ & 2.6 & $(0.5)$ & 1.6 & $(0.3)$ & 4.5 & $(0.6)$ \\
\hline Slovak Republic & 20.7 & $(1.2)$ & 10.1 & $(0.8)$ & 10.0 & $(0.9)$ & 4.1 & $(0.6)$ & 4.7 & $(0.5)$ & 4.8 & $(0.7)$ & 11.7 & $(0.9)$ \\
\hline Slovenia & 16.3 & (1.3) & 4.9 & $(0.8)$ & 8.2 & $(1.0)$ & 2.2 & $(0.4)$ & 3.2 & $(0.6)$ & 3.7 & $(0.7)$ & 7.6 & $(0.9)$ \\
\hline Spain & 11.6 & $(0.8)$ & 3.4 & $(0.5)$ & 6.1 & $(0.7)$ & 2.3 & $(0.4)$ & 3.4 & $(0.5)$ & 2.4 & $(0.4)$ & 5.2 & $(0.6)$ \\
\hline Sweden & 16.0 & (1.1) & 5.4 & $(0.7)$ & 8.4 & $(0.8)$ & 2.7 & $(0.5)$ & 3.4 & $(0.5)$ & 5.1 & $(0.6)$ & 5.5 & $(0.5)$ \\
\hline Switzerland & 15.2 & $(0.9)$ & 4.9 & $(0.6)$ & 10.3 & $(0.9)$ & 1.7 & $(0.4)$ & 3.7 & (0.6) & 2.0 & $(0.4)$ & 5.8 & $(0.7)$ \\
\hline Turkey & 20.5 & (1.5) & 8.6 & $(0.9)$ & 10.1 & (1.1) & 6.2 & $(0.9)$ & 5.6 & $(0.8)$ & 4.8 & $(0.7)$ & 10.9 & $(1.2)$ \\
\hline United Kingdom & 23.7 & (1.1) & 10.2 & $(0.8)$ & 15.4 & $(0.9)$ & 5.9 & $(0.7)$ & 4.0 & $(0.5)$ & 4.7 & (0.6) & 10.2 & $(0.8)$ \\
\hline United States & 17.5 & (1.2) & 9.9 & (1.0) & 10.9 & $(0.9)$ & 4.5 & $(0.6)$ & 3.7 & $(0.5)$ & 3.3 & $(0.5)$ & 6.8 & $(0.7)$ \\
\hline OECD average & 17.6 & $(0.2)$ & 6.4 & $(0.1)$ & 10.3 & $(0.2)$ & 3.1 & $(0.1)$ & 3.8 & $(0.1)$ & 3.8 & $(0.1)$ & 7.5 & $(0.1)$ \\
\hline
\end{tabular}

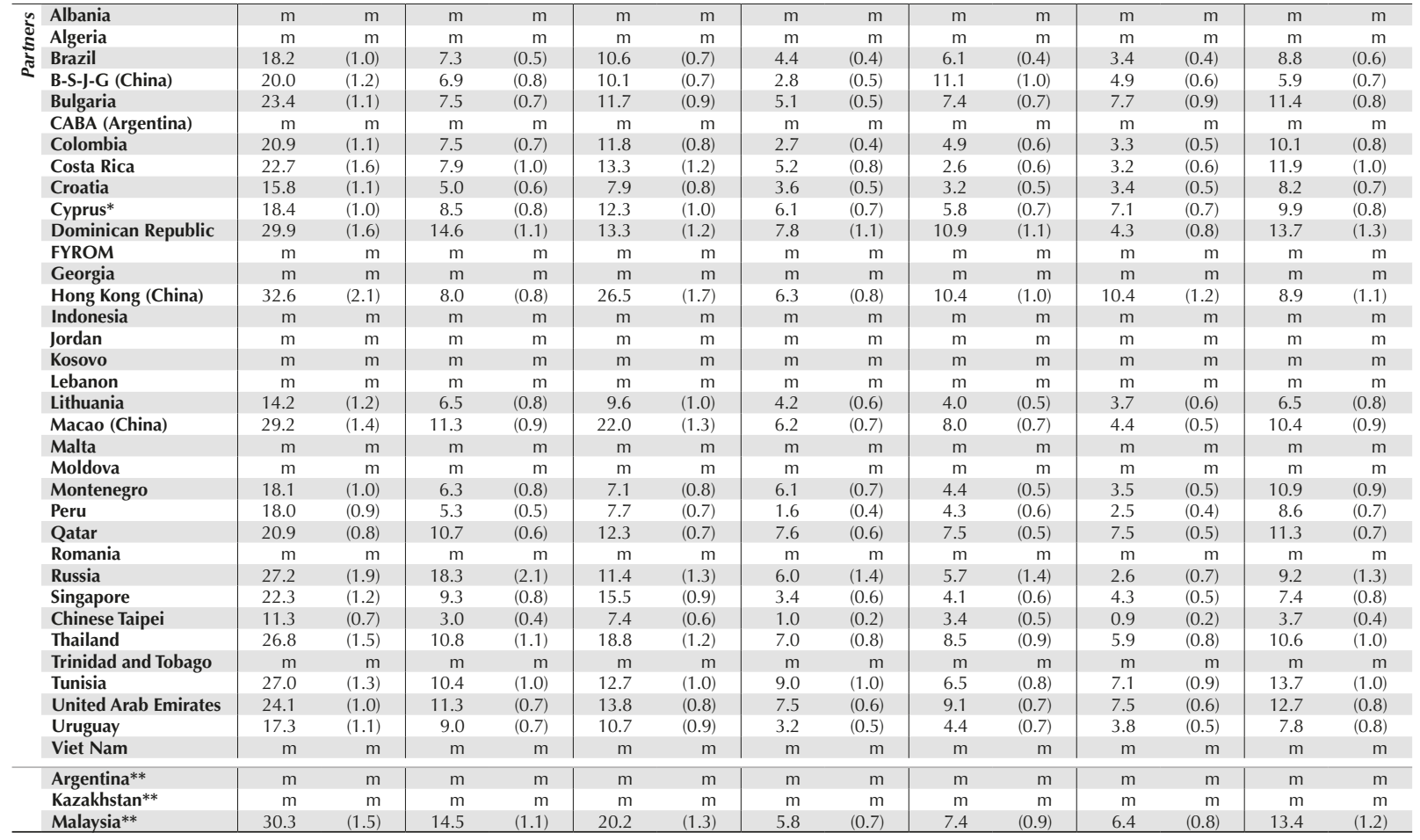

1. A socio-economically disadvantaged student is a student in the bottom quarter of the PISA index of economic, social and cultural status (ESCS) within his or her own country/economy. 2. A socio-economically advantaged student is a student in the top quarter of the PISA index of economic, social and cultural status (ESCS) within his or her own country/economy. Note: Values that are statistically significant are indicated in bold (see Annex A3).

* See note at the beginning of this Annex.

** Coverage is too small to ensure comparability (see Annex A4).

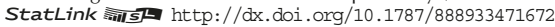


Percentage of students who reported being bullied "a few times a month" or "once a week or more"

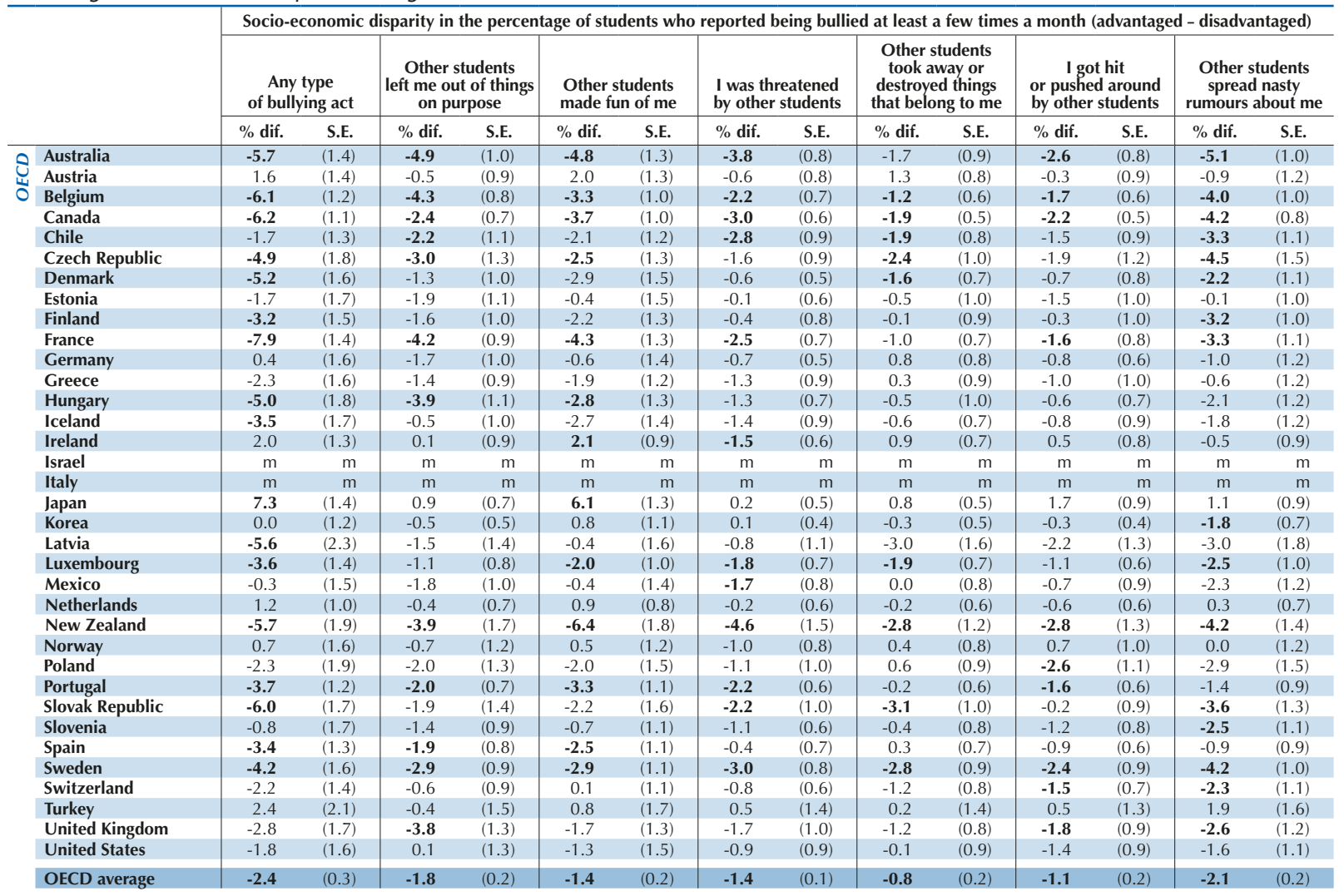

\begin{tabular}{|c|c|c|c|c|c|c|c|c|c|c|c|c|c|c|c|}
\hline \multirow{4}{*}{ 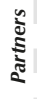 } & Albania & $\mathrm{m}$ & $\mathrm{m}$ & $\mathrm{m}$ & $\mathrm{m}$ & $\mathrm{m}$ & $\mathrm{m}$ & $\mathrm{m}$ & $\mathrm{m}$ & $\mathrm{m}$ & $\mathrm{m}$ & $\mathrm{m}$ & $\mathrm{m}$ & $\mathrm{m}$ & $\mathrm{m}$ \\
\hline & Algeria & $\mathrm{m}$ & $\mathrm{m}$ & $\mathrm{m}$ & $\mathrm{m}$ & $\mathrm{m}$ & $\mathrm{m}$ & $\mathrm{m}$ & $\mathrm{m}$ & $\mathrm{m}$ & $\mathrm{m}$ & $\mathrm{m}$ & $\mathrm{m}$ & $\mathrm{m}$ & $\mathrm{m}$ \\
\hline & Brazil & 1.4 & (1.3) & -0.5 & $(0.8)$ & 2.5 & $(0.9)$ & 0.5 & $(0.5)$ & 1.0 & $(0.6)$ & -0.2 & $(0.5)$ & 1.0 & $(0.8)$ \\
\hline & B-S-J-G (China) & -4.9 & $(1.7)$ & -2.8 & (1.3) & -5.2 & $(1.3)$ & -1.6 & $(0.7)$ & -1.7 & (1.3) & 0.6 & $(0.7)$ & -0.9 & $(0.9)$ \\
\hline & Bulgaria & -1.1 & (1.6) & -1.1 & (1.1) & -1.0 & $(1.2)$ & -2.1 & $(1.0)$ & 0.5 & $(1.2)$ & -2.3 & $(1.2)$ & -1.2 & (1.3) \\
\hline & CABA (Argentina) & $\mathrm{m}$ & $\mathrm{m}$ & $\mathrm{m}$ & $\mathrm{m}$ & $\mathrm{m}$ & $\mathrm{m}$ & $\mathrm{m}$ & $\mathrm{m}$ & $\mathrm{m}$ & $\mathrm{m}$ & $\mathrm{m}$ & $\mathrm{m}$ & $\mathrm{m}$ & $\mathrm{m}$ \\
\hline & Colombia & 0.0 & $(1.5)$ & 0.6 & $(0.9)$ & 0.5 & (1.1) & -0.2 & $(0.6)$ & 1.5 & $(0.7)$ & -0.5 & $(0.7)$ & 0.7 & (1.1) \\
\hline & Costa Rica & -0.2 & (1.9) & -2.2 & (1.4) & 0.5 & (1.5) & 0.4 & $(1.0)$ & 1.1 & $(0.7)$ & 0.3 & $(0.7)$ & -1.6 & (1.4) \\
\hline & Croatia & -1.6 & (1.5) & -0.6 & $(0.8)$ & -1.0 & $(1.0)$ & -0.6 & $(0.7)$ & -1.0 & $(0.8)$ & -1.0 & $(0.9)$ & -2.2 & (1.1) \\
\hline & Cyprus* & -0.1 & (1.5) & 1.5 & (1.1) & 0.6 & (1.4) & 0.9 & $(1.0)$ & 1.3 & (1.0) & 0.7 & (1.0) & 1.7 & $(1.0)$ \\
\hline & Dominican Republic & 0.0 & $(2.4)$ & -0.7 & (1.6) & -3.9 & (1.8) & 0.4 & (1.7) & -1.0 & (1.9) & -0.9 & (1.3) & 0.1 & (1.9) \\
\hline & FYROM & $\mathrm{m}$ & $\mathrm{m}$ & $\mathrm{m}$ & $\mathrm{m}$ & $\mathrm{m}$ & $\mathrm{m}$ & $\mathrm{m}$ & $\mathrm{m}$ & $\mathrm{m}$ & $\mathrm{m}$ & $\mathrm{m}$ & $\mathrm{m}$ & $\mathrm{m}$ & $\mathrm{m}$ \\
\hline & Georgia & $\mathrm{m}$ & $\mathrm{m}$ & $\mathrm{m}$ & $\mathrm{m}$ & $\mathrm{m}$ & $\mathrm{m}$ & $\mathrm{m}$ & $\mathrm{m}$ & $\mathrm{m}$ & $\mathrm{m}$ & $\mathrm{m}$ & $\mathrm{m}$ & $\mathrm{m}$ & $\mathrm{m}$ \\
\hline & Hong Kong (China) & 0.7 & $(2.5)$ & -1.6 & (1.1) & 1.0 & $(2.2)$ & -0.8 & (1.1) & 0.8 & (1.4) & 1.4 & (1.6) & -1.1 & (1.5) \\
\hline & Indonesia & $\mathrm{m}$ & $\mathrm{m}$ & $\mathrm{m}$ & $\mathrm{m}$ & $\mathrm{m}$ & $\mathrm{m}$ & $\mathrm{m}$ & $\mathrm{m}$ & $\mathrm{m}$ & $\mathrm{m}$ & $\mathrm{m}$ & $\mathrm{m}$ & $\mathrm{m}$ & $\mathrm{m}$ \\
\hline & Jordan & $\mathrm{m}$ & $\mathrm{m}$ & $\mathrm{m}$ & $\mathrm{m}$ & $\mathrm{m}$ & $\mathrm{m}$ & $\mathrm{m}$ & $\mathrm{m}$ & $\mathrm{m}$ & $\mathrm{m}$ & $\mathrm{m}$ & $\mathrm{m}$ & $\mathrm{m}$ & $\mathrm{m}$ \\
\hline & Kosovo & $\mathrm{m}$ & $\mathrm{m}$ & $\mathrm{m}$ & $\mathrm{m}$ & $\mathrm{m}$ & $\mathrm{m}$ & $\mathrm{m}$ & $\mathrm{m}$ & $\mathrm{m}$ & $\mathrm{m}$ & $\mathrm{m}$ & $\mathrm{m}$ & $\mathrm{m}$ & $\mathrm{m}$ \\
\hline & Lebanon & $\mathrm{m}$ & $\mathrm{m}$ & $\mathrm{m}$ & $\mathrm{m}$ & $\mathrm{m}$ & $\mathrm{m}$ & $\mathrm{m}$ & $\mathrm{m}$ & $\mathrm{m}$ & $\mathrm{m}$ & $\mathrm{m}$ & $\mathrm{m}$ & $\mathrm{m}$ & $\mathrm{m}$ \\
\hline & Lithuania & -4.8 & (1.8) & -1.1 & $(1.0)$ & -0.9 & (1.4) & -1.8 & (1.0) & -0.1 & $(0.8)$ & -1.3 & (1.0) & -2.9 & (1.3) \\
\hline & Macao (China) & 4.1 & $(1.8)$ & 1.9 & (1.3) & 4.2 & (1.6) & 0.3 & (1.1) & -0.8 & $(1.2)$ & 0.8 & $(0.8)$ & 1.3 & $(1.2)$ \\
\hline & Malta & $\mathrm{m}$ & $\mathrm{m}$ & $\mathrm{m}$ & $\mathrm{m}$ & $\mathrm{m}$ & $\mathrm{m}$ & $\mathrm{m}$ & $\mathrm{m}$ & $\mathrm{m}$ & $\mathrm{m}$ & $\mathrm{m}$ & $\mathrm{m}$ & $\mathrm{m}$ & $\mathrm{m}$ \\
\hline & Moldova & $\mathrm{m}$ & $\mathrm{m}$ & $\mathrm{m}$ & $\mathrm{m}$ & $\mathrm{m}$ & $\mathrm{m}$ & $\mathrm{m}$ & $\mathrm{m}$ & $\mathrm{m}$ & $\mathrm{m}$ & $\mathrm{m}$ & $\mathrm{m}$ & $\mathrm{m}$ & $\mathrm{m}$ \\
\hline & Montenegro & 0.9 & (1.5) & 0.8 & $(1.0)$ & -1.2 & (1.1) & 0.1 & $(1.0)$ & 0.4 & $(0.8)$ & 0.0 & $(0.8)$ & 0.6 & $(1.2)$ \\
\hline & Peru & -0.9 & $(1.7)$ & -1.9 & (1.1) & 0.3 & $(1.0)$ & -2.4 & $(0.7)$ & -2.0 & $(0.9)$ & -2.0 & $(0.7)$ & 0.2 & (1.1) \\
\hline & Qatar & -7.3 & $(1.3)$ & -3.6 & $(1.0)$ & -4.1 & (1.1) & -3.4 & $(0.9)$ & -4.1 & $(0.9)$ & -3.2 & $(0.8)$ & -2.6 & $(1.0)$ \\
\hline & Romania & $\mathrm{m}$ & $\mathrm{m}$ & $\mathrm{m}$ & $\mathrm{m}$ & $\mathrm{m}$ & $\mathrm{m}$ & $\mathrm{m}$ & $\mathrm{m}$ & $\mathrm{m}$ & $\mathrm{m}$ & $\mathrm{m}$ & $\mathrm{m}$ & $\mathrm{m}$ & $\mathrm{m}$ \\
\hline & Russia & -2.0 & (2.4) & -1.0 & $(2.3)$ & -1.0 & (1.8) & 0.8 & (1.7) & -0.3 & (1.5) & -1.2 & (1.0) & 0.4 & (1.6) \\
\hline & Singapore & -6.7 & $(1.8)$ & -6.8 & (1.4) & -5.5 & (1.4) & -2.0 & $(0.8)$ & -2.1 & $(0.9)$ & -1.9 & $(0.9)$ & -3.4 & $(1.2)$ \\
\hline & Chinese Taipei & 0.4 & $(1.2)$ & -0.6 & $(0.6)$ & 0.2 & $(1.0)$ & 0.0 & $(0.3)$ & -0.4 & $(0.8)$ & 0.1 & $(0.3)$ & 0.6 & $(0.6)$ \\
\hline & Thailand & -1.3 & $(2.0)$ & -2.6 & (1.4) & -3.0 & (1.6) & -3.3 & (1.1) & -2.3 & $(1.2)$ & -2.8 & (1.1) & -0.9 & (1.3) \\
\hline & Trinidad and Tobago & $\mathrm{m}$ & $\mathrm{m}$ & $\mathrm{m}$ & $\mathrm{m}$ & $\mathrm{m}$ & $\mathrm{m}$ & $\mathrm{m}$ & $\mathrm{m}$ & $\mathrm{m}$ & $\mathrm{m}$ & $\mathrm{m}$ & $\mathrm{m}$ & $\mathrm{m}$ & $\mathrm{m}$ \\
\hline & Tunisia & -5.0 & (1.9) & -3.4 & (1.4) & -2.1 & (1.6) & -2.0 & (1.4) & -1.9 & (1.2) & -3.3 & (1.3) & -0.4 & (1.3) \\
\hline & United Arab Emirates & -6.4 & $(1.6)$ & -3.0 & $(1.0)$ & -3.7 & $(1.3)$ & -2.6 & $(0.9)$ & -1.6 & $(1.0)$ & -2.1 & $(0.9)$ & -1.1 & $(1.2)$ \\
\hline & Uruguay & -0.5 & $(1.5)$ & -0.1 & $(1.0)$ & 0.4 & $(1.2)$ & -1.4 & $(0.8)$ & 0.6 & $(0.8)$ & -0.2 & $(0.8)$ & -1.2 & $(1.0)$ \\
\hline & Viet Nam & $\mathrm{m}$ & $\mathrm{m}$ & $\mathrm{m}$ & $\mathrm{m}$ & $\mathrm{m}$ & $\mathrm{m}$ & $\mathrm{m}$ & $\mathrm{m}$ & $\mathrm{m}$ & $\mathrm{m}$ & $\mathrm{m}$ & $\mathrm{m}$ & $\mathrm{m}$ & $\mathrm{m}$ \\
\hline & Argentina** & $\mathrm{m}$ & $\mathrm{m}$ & $\mathrm{m}$ & $\mathrm{m}$ & $\mathrm{m}$ & $\mathrm{m}$ & $\mathrm{m}$ & $\mathrm{m}$ & $\mathrm{m}$ & $\mathrm{m}$ & $\mathrm{m}$ & $\mathrm{m}$ & $\mathrm{m}$ & $\mathrm{m}$ \\
\hline & Kazakhstan** & $\mathrm{m}$ & $\mathrm{m}$ & $\mathrm{m}$ & $\mathrm{m}$ & $\mathrm{m}$ & $\mathrm{m}$ & $\mathrm{m}$ & $\mathrm{m}$ & $\mathrm{m}$ & $\mathrm{m}$ & $\mathrm{m}$ & $\mathrm{m}$ & $\mathrm{m}$ & $\mathrm{m}$ \\
\hline & Malaysia** & 0.3 & $(2.0)$ & 0.4 & (1.3) & 1.9 & (1.6) & -0.2 & $(1.0)$ & -1.9 & (1.4) & 0.6 & $(1.0)$ & -0.3 & (1.6) \\
\hline
\end{tabular}

1. A socio-economically disadvantaged student is a student in the bottom quarter of the PISA index of economic, social and cultural status (ESCS) within his or her own country/economy. 2. A socio-economically advantaged student is a student in the top quarter of the PISA index of economic, social and cultural status (ESCS) within his or her own country/economy. Note: Values that are statistically significant are indicated in bold (see Annex A3).

* See note at the beginning of this Annex.

** Coverage is too small to ensure comparability (see Annex A4).

StatLink 需政 http://dx.doi.org/10.1787/888933471672 
[Part 1/3]

Table III.8.4 Students' exposure to bullying, by deciles of science performance

Percentage of students who reported being bullied "a few times a month" or "once a week or more"

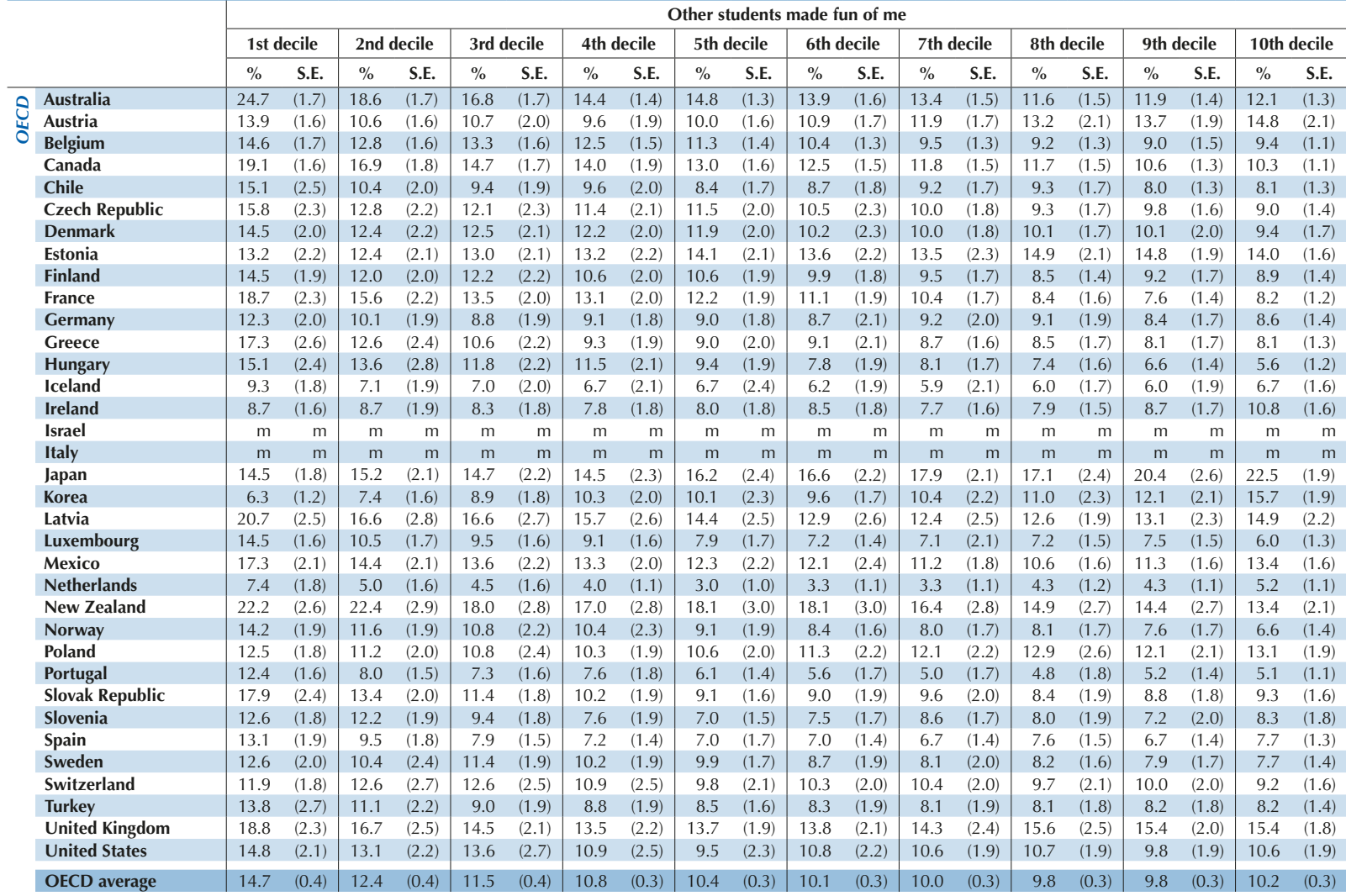

\begin{tabular}{|c|c|c|c|c|c|c|c|c|c|c|c|c|c|c|c|c|c|c|c|c|}
\hline Albania & $\mathrm{m}$ & $\mathrm{m}$ & $\mathrm{m}$ & $\mathrm{m}$ & $\mathrm{m}$ & $\mathrm{m}$ & $\mathrm{m}$ & $\mathrm{m}$ & $\mathrm{m}$ & $\mathrm{m}$ & $\mathrm{m}$ & $\mathrm{m}$ & $\mathrm{m}$ & $\mathrm{m}$ & $\mathrm{m}$ & $\mathrm{m}$ & $\mathrm{m}$ & $\mathrm{m}$ & $\mathrm{m}$ & $\mathrm{m}$ \\
\hline Algeria & $\mathrm{m}$ & $\mathrm{m}$ & $\mathrm{m}$ & $\mathrm{m}$ & $\mathrm{m}$ & $\mathrm{m}$ & $\mathrm{m}$ & $\mathrm{m}$ & $\mathrm{m}$ & $\mathrm{m}$ & $\mathrm{m}$ & $\mathrm{m}$ & $\mathrm{m}$ & $\mathrm{m}$ & $\mathrm{m}$ & $\mathrm{m}$ & $\mathrm{m}$ & $\mathrm{m}$ & $\mathrm{m}$ & $\mathrm{m}$ \\
\hline Brazil & 13.7 & (1.8) & 10.5 & $(1.2)$ & 10.1 & (1.3) & 8.4 & $(1.2)$ & 8.1 & (1.1) & 7.7 & $(1.2)$ & 7.8 & (1.1) & 8.4 & $(1.2)$ & 9.2 & (1.2) & 10.3 & (1.3) \\
\hline B-S-J-G (China) & 19.8 & (2.0) & 14.3 & $(2.2)$ & 12.8 & (1.7) & 12.5 & $(1.7)$ & 12.3 & $(2.3)$ & 11.1 & $(2.2)$ & 10.6 & (1.7) & 10.1 & (1.9) & 10.1 & (1.9) & 10.0 & (1.6) \\
\hline Bulgaria & 17.2 & $(2.8)$ & 12.4 & (2.4) & 12.7 & $(2.3)$ & 12.9 & $(2.8)$ & 13.6 & (2.3) & 12.3 & $(2.0)$ & 13.1 & (2.0) & 11.4 & $(2.2)$ & 10.5 & (1.9) & 9.7 & (1.4) \\
\hline CABA (Argentina) & $\mathrm{m}$ & $\mathrm{m}$ & $\mathrm{m}$ & $\mathrm{m}$ & $\mathrm{m}$ & $\mathrm{m}$ & $\mathrm{m}$ & $\mathrm{m}$ & $\mathrm{m}$ & $\mathrm{m}$ & $\mathrm{m}$ & $\mathrm{m}$ & $\mathrm{m}$ & $\mathrm{m}$ & $\mathrm{m}$ & $\mathrm{m}$ & $\mathrm{m}$ & $\mathrm{m}$ & $\mathrm{m}$ & $\mathrm{m}$ \\
\hline Colombia & 17.9 & (2.3) & 13.7 & (2.3) & 11.2 & (1.9) & 10.7 & (1.9) & 9.4 & $(2.0)$ & 9.5 & $(1.7)$ & 9.5 & (1.7) & 10.6 & (1.6) & 10.8 & (1.6) & 12.1 & (1.5) \\
\hline Costa Rica & 11.2 & (1.7) & 11.5 & $(2.0)$ & 11.5 & (1.8) & 10.3 & $(2.0)$ & 10.6 & $(2.0)$ & 10.7 & $(2.0)$ & 11.5 & $(2.3)$ & 12.1 & (1.8) & 12.1 & (2.0) & 15.7 & (1.8) \\
\hline Croatia & 9.8 & (1.9) & 9.8 & $(2.0)$ & 9.7 & $(2.1)$ & 8.1 & $(1.7)$ & 7.7 & (1.9) & 7.1 & $(1.5)$ & 7.0 & (1.6) & 6.9 & (1.4) & 7.0 & (1.4) & 6.9 & $(1.2)$ \\
\hline Cyprus* & 21.6 & $(2.2)$ & 14.9 & $(2.0)$ & 12.3 & (2.5) & 11.3 & (2.4) & 10.9 & $(1.8)$ & 10.1 & (1.5) & 9.3 & (1.7) & 8.7 & (2.0) & 6.5 & (1.6) & 7.9 & (1.4) \\
\hline Dominican Republic & 16.5 & (2.9) & 17.1 & (3.5) & 16.7 & (2.9) & 15.4 & $(2.9)$ & 15.6 & (2.5) & 14.9 & (2.6) & 16.0 & (3.3) & 14.8 & (2.4) & 13.6 & (2.5) & 13.3 & (2.8) \\
\hline FYROM & $\mathrm{m}$ & $\mathrm{m}$ & $\mathrm{m}$ & $\mathrm{m}$ & $\mathrm{m}$ & $\mathrm{m}$ & $\mathrm{m}$ & $\mathrm{m}$ & $\mathrm{m}$ & $\mathrm{m}$ & $\mathrm{m}$ & $\mathrm{m}$ & $\mathrm{m}$ & $\mathrm{m}$ & $\mathrm{m}$ & $\mathrm{m}$ & $\mathrm{m}$ & $\mathrm{m}$ & $\mathrm{m}$ & $\mathrm{m}$ \\
\hline Georgia & $\mathrm{m}$ & $\mathrm{m}$ & $\mathrm{m}$ & $\mathrm{m}$ & $\mathrm{m}$ & $\mathrm{m}$ & $\mathrm{m}$ & $\mathrm{m}$ & $\mathrm{m}$ & $\mathrm{m}$ & $\mathrm{m}$ & $\mathrm{m}$ & $\mathrm{m}$ & $\mathrm{m}$ & $\mathrm{m}$ & $\mathrm{m}$ & $\mathrm{m}$ & $\mathrm{m}$ & $\mathrm{m}$ & $\mathrm{m}$ \\
\hline Hong Kong (China) & 25.9 & (2.5) & 27.4 & (3.0) & 26.8 & (2.8) & 26.6 & $(2.7)$ & 25.2 & $(2.8)$ & 25.6 & (3.0) & 25.2 & $(2.8)$ & 25.3 & (3.1) & 26.0 & (2.9) & 26.8 & (2.1) \\
\hline Indonesia & $\mathrm{m}$ & $\mathrm{m}$ & $\mathrm{m}$ & $\mathrm{m}$ & $\mathrm{m}$ & $\mathrm{m}$ & $\mathrm{m}$ & $\mathrm{m}$ & $\mathrm{m}$ & $\mathrm{m}$ & $\mathrm{m}$ & $\mathrm{m}$ & $\mathrm{m}$ & $\mathrm{m}$ & $\mathrm{m}$ & $\mathrm{m}$ & $\mathrm{m}$ & $\mathrm{m}$ & $\mathrm{m}$ & $\mathrm{m}$ \\
\hline Jordan & $\mathrm{m}$ & $\mathrm{m}$ & $\mathrm{m}$ & $\mathrm{m}$ & $\mathrm{m}$ & $\mathrm{m}$ & $\mathrm{m}$ & $\mathrm{m}$ & $\mathrm{m}$ & $\mathrm{m}$ & $\mathrm{m}$ & $\mathrm{m}$ & $\mathrm{m}$ & $\mathrm{m}$ & $\mathrm{m}$ & $\mathrm{m}$ & $\mathrm{m}$ & $\mathrm{m}$ & $\mathrm{m}$ & $\mathrm{m}$ \\
\hline Kosovo & $\mathrm{m}$ & $\mathrm{m}$ & $\mathrm{m}$ & $\mathrm{m}$ & $\mathrm{m}$ & $\mathrm{m}$ & $\mathrm{m}$ & $\mathrm{m}$ & $\mathrm{m}$ & $\mathrm{m}$ & $\mathrm{m}$ & $\mathrm{m}$ & $\mathrm{m}$ & $\mathrm{m}$ & $\mathrm{m}$ & $\mathrm{m}$ & $\mathrm{m}$ & $\mathrm{m}$ & $\mathrm{m}$ & $\mathrm{m}$ \\
\hline Lebanon & $\mathrm{m}$ & $\mathrm{m}$ & $\mathrm{m}$ & $\mathrm{m}$ & $\mathrm{m}$ & $\mathrm{m}$ & $\mathrm{m}$ & $\mathrm{m}$ & $\mathrm{m}$ & $\mathrm{m}$ & $\mathrm{m}$ & $\mathrm{m}$ & $\mathrm{m}$ & $\mathrm{m}$ & $\mathrm{m}$ & $\mathrm{m}$ & $\mathrm{m}$ & $\mathrm{m}$ & $\mathrm{m}$ & $\mathrm{m}$ \\
\hline Lithuania & 16.7 & $(2.2)$ & 10.7 & (2.4) & 7.8 & (1.5) & 7.9 & (1.5) & 8.2 & $(2.0)$ & 8.6 & (1.7) & 7.0 & (1.6) & 7.0 & (1.8) & 9.3 & (1.8) & 9.5 & (1.5) \\
\hline Macao (China) & 31.9 & (2.6) & 24.0 & $(2.8)$ & 21.9 & (2.6) & 21.0 & (3.4) & 19.2 & (2.4) & 17.5 & (2.6) & 17.0 & $(2.1)$ & 15.3 & (2.5) & 14.7 & (2.5) & 17.2 & (2.0) \\
\hline Malta & $\mathrm{m}$ & $\mathrm{m}$ & $\mathrm{m}$ & $\mathrm{m}$ & $\mathrm{m}$ & $\mathrm{m}$ & $\mathrm{m}$ & $\mathrm{m}$ & $\mathrm{m}$ & $\mathrm{m}$ & $\mathrm{m}$ & $\mathrm{m}$ & $\mathrm{m}$ & $\mathrm{m}$ & $\mathrm{m}$ & $\mathrm{m}$ & $\mathrm{m}$ & $\mathrm{m}$ & $\mathrm{m}$ & $\mathrm{m}$ \\
\hline Moldova & $\mathrm{m}$ & $\mathrm{m}$ & $\mathrm{m}$ & $\mathrm{m}$ & $\mathrm{m}$ & $\mathrm{m}$ & $\mathrm{m}$ & $\mathrm{m}$ & $\mathrm{m}$ & $\mathrm{m}$ & $\mathrm{m}$ & $\mathrm{m}$ & $\mathrm{m}$ & $\mathrm{m}$ & $\mathrm{m}$ & $\mathrm{m}$ & $\mathrm{m}$ & $\mathrm{m}$ & $\mathrm{m}$ & $\mathrm{m}$ \\
\hline Montenegro & 10.6 & (1.7) & 9.4 & (1.9) & 8.0 & (1.8) & 7.5 & (1.7) & 6.2 & (1.6) & 6.2 & (1.6) & 5.2 & (1.6) & 5.0 & (1.3) & 5.0 & (1.3) & 6.1 & (1.2) \\
\hline Peru & 10.0 & (1.5) & 8.8 & (1.7) & 8.5 & (1.9) & 8.0 & $(1.8)$ & 8.2 & (1.8) & 7.3 & (1.4) & 6.5 & (1.4) & 6.5 & (1.4) & 6.3 & (1.4) & 7.7 & (1.3) \\
\hline Qatar & 27.5 & (1.8) & 21.4 & (1.5) & 17.6 & $(2.2)$ & 15.5 & $(1.5)$ & 13.2 & (1.4) & 12.2 & (1.4) & 12.0 & (1.3) & 10.9 & $(1.2)$ & 10.9 & (1.3) & 10.0 & (1.0) \\
\hline Romania & $\mathrm{m}$ & $\mathrm{m}$ & $\mathrm{m}$ & $\mathrm{m}$ & $\mathrm{m}$ & $\mathrm{m}$ & $\mathrm{m}$ & $\mathrm{m}$ & $\mathrm{m}$ & $\mathrm{m}$ & $\mathrm{m}$ & $\mathrm{m}$ & $\mathrm{m}$ & $\mathrm{m}$ & $\mathrm{m}$ & $\mathrm{m}$ & $\mathrm{m}$ & $\mathrm{m}$ & $\mathrm{m}$ & $\mathrm{m}$ \\
\hline Russia & 13.5 & (2.5) & 11.8 & (2.4) & 12.1 & $(2.8)$ & 11.2 & $(2.8)$ & 11.1 & $(2.1)$ & 10.6 & (1.9) & 10.8 & $(2.1)$ & 11.5 & $(2.2)$ & 12.0 & (2.5) & 13.6 & (2.0) \\
\hline Singapor & 28.8 & $(2.0)$ & 20.1 & $(2.2)$ & 19.4 & (1.9) & 17.8 & (2.0) & 17.4 & $(2.3)$ & 16.3 & $(2.3)$ & 15.9 & $(2.3)$ & 16.0 & $(2.1)$ & 15.3 & (2.0) & 16.5 & (1.9) \\
\hline Chinese Taipei & 7.0 & (1.0) & 6.7 & $(1.2)$ & 6.6 & (1.4) & 6.3 & (1.4) & 6.8 & (1.3) & 6.7 & $(1.2)$ & 7.3 & $(1.7)$ & 7.0 & (1.4) & 7.1 & (1.3) & 6.7 & (1.0) \\
\hline Thailand & 29.4 & (3.0) & 26.2 & (3.3) & 22.6 & $(2.8)$ & 20.7 & (2.4) & 19.6 & $(2.4)$ & 18.9 & (2.5) & 18.4 & (3.1) & 17.1 & (2.5) & 14.4 & (2.1) & 12.3 & (1.6) \\
\hline Trinidad and Tobago & $\mathrm{m}$ & $\mathrm{m}$ & $\mathrm{m}$ & $\mathrm{m}$ & $\mathrm{m}$ & $\mathrm{m}$ & $\mathrm{m}$ & $\mathrm{m}$ & $\mathrm{m}$ & $\mathrm{m}$ & $\mathrm{m}$ & $\mathrm{m}$ & $\mathrm{m}$ & $\mathrm{m}$ & $\mathrm{m}$ & $\mathrm{m}$ & $\mathrm{m}$ & $\mathrm{m}$ & $\mathrm{m}$ & $\mathrm{m}$ \\
\hline Tunisia & 19.4 & (2.4) & 14.1 & $(2.2)$ & 12.9 & (2.6) & 12.8 & $(2.7)$ & 11.6 & $(2.2)$ & 10.8 & (2.4) & 12.2 & $(2.2)$ & 11.2 & $(2.2)$ & 12.1 & (2.3) & 14.6 & (1.9) \\
\hline United Arab Emirates & 24.3 & (1.9) & 19.9 & (1.8) & 18.4 & (1.9) & 16.3 & $(2.1)$ & 15.1 & (2.1) & 14.9 & (1.6) & 13.3 & (1.7) & 12.9 & (1.6) & 12.7 & (1.4) & 12.5 & (1.2) \\
\hline Uruguay & 11.9 & (1.8) & 10.0 & (1.7) & 9.9 & (1.7) & 9.2 & (1.6) & 10.1 & (1.8) & 10.4 & (1.8) & 10.0 & $(1.8)$ & 10.7 & (1.7) & 9.9 & (2.4) & 11.0 & (1.6) \\
\hline Viet Nam & $\mathrm{m}$ & $\mathrm{m}$ & $\mathrm{m}$ & $\mathrm{m}$ & $\mathrm{m}$ & $\mathrm{m}$ & $\mathrm{m}$ & $\mathrm{m}$ & $\mathrm{m}$ & $\mathrm{m}$ & $\mathrm{m}$ & $\mathrm{m}$ & $\mathrm{m}$ & $\mathrm{m}$ & $\mathrm{m}$ & $\mathrm{m}$ & $\mathrm{m}$ & $\mathrm{m}$ & $\mathrm{m}$ & $\mathrm{m}$ \\
\hline Argentina** & $\mathrm{m}$ & $\mathrm{m}$ & $\mathrm{m}$ & $\mathrm{m}$ & $\mathrm{m}$ & $\mathrm{m}$ & $\mathrm{m}$ & $\mathrm{m}$ & $\mathrm{m}$ & $\mathrm{m}$ & $\mathrm{m}$ & $\mathrm{m}$ & $\mathrm{m}$ & $\mathrm{m}$ & $\mathrm{m}$ & $\mathrm{m}$ & $\mathrm{m}$ & $\mathrm{m}$ & $\mathrm{m}$ & $\mathrm{m}$ \\
\hline Kazakhstan** & $\mathrm{m}$ & $\mathrm{m}$ & $\mathrm{m}$ & $\mathrm{m}$ & $\mathrm{m}$ & $\mathrm{m}$ & $\mathrm{m}$ & $\mathrm{m}$ & $\mathrm{m}$ & $\mathrm{m}$ & $\mathrm{m}$ & $\mathrm{m}$ & $\mathrm{m}$ & $\mathrm{m}$ & $\mathrm{m}$ & $\mathrm{m}$ & $\mathrm{m}$ & $\mathrm{m}$ & $\mathrm{m}$ & $\mathrm{m}$ \\
\hline Malaysia** & 28.5 & (2.6) & 24.3 & (2.8) & 22.0 & (2.8) & 19.8 & (2.6) & 17.2 & (2.2) & 15.2 & (2.1) & 16.5 & $(2.3)$ & 15.9 & (2.6) & 16.5 & (2.7) & 16.7 & (2.1) \\
\hline
\end{tabular}

* See note at the beginning of this Annex.

** Coverage is too small to ensure comparability (see Annex A4).

StatLink 完政L http://dx.doi.org/10.1787/888933471694 
Percentage of students who reported being bullied "a few times a month" or "once a week or more"

\begin{tabular}{|c|c|c|c|c|c|c|c|c|c|c|c|c|c|c|c|c|c|c|c|c|}
\hline & \multicolumn{20}{|c|}{ I got hit or pushed around by other students } \\
\hline & \multicolumn{2}{|c|}{ 1st decile } & \multicolumn{2}{|c|}{ 2nd decile } & \multicolumn{2}{|c|}{ 3rd decile } & \multicolumn{2}{|c|}{ 4th decile } & \multicolumn{2}{|c|}{ 5th decile } & \multicolumn{2}{|c|}{ 6th decile } & \multicolumn{2}{|c|}{ 7th decile } & \multicolumn{2}{|c|}{ 8th decile } & \multicolumn{2}{|c|}{ 9th decile } & \multicolumn{2}{|c|}{ 10th decile } \\
\hline & $\%$ & S.E. & $\%$ & S.E. & $\%$ & S.E. & $\%$ & S.E. & $\%$ & S.E. & $\%$ & S.E. & $\%$ & S.E. & $\%$ & S.E. & $\%$ & S.E. & $\%$ & S.E. \\
\hline Australia & 13.1 & (1.3) & 8.1 & $(1.3)$ & 6.4 & (1.0) & 5.7 & (1.1) & 5.0 & $(1.0)$ & 4.7 & (1.1) & 4.7 & $(0.8)$ & 3.8 & $(0.8)$ & 3.5 & $(0.9)$ & 3.2 & $(0.7)$ \\
\hline Austria & 9.4 & (1.5) & 5.4 & (1.3) & 4.0 & $(1.1)$ & 4.2 & (1.4) & 3.7 & $(1.0)$ & 4.2 & (1.3) & 2.9 & $(1.1)$ & 2.7 & $(0.8)$ & 3.0 & (1.0) & 3.2 & (0.9) \\
\hline 0 Belgium & 8.4 & (1.6) & 4.4 & $(1.0)$ & 3.4 & (1.0) & 2.8 & $(0.8)$ & 2.8 & $(0.8)$ & 2.4 & $(0.8)$ & 2.4 & $(0.7)$ & 2.3 & $(0.6)$ & 1.6 & $(0.6)$ & 1.5 & $(0.5)$ \\
\hline Canada & 11.5 & (1.4) & 8.1 & (1.4) & 5.6 & (1.1) & 5.2 & (1.1) & 4.7 & $(0.9)$ & 4.1 & $(0.9)$ & 3.6 & $(0.8)$ & 3.4 & $(0.9)$ & 2.7 & $(0.7)$ & 2.1 & $(0.6)$ \\
\hline Chile & 10.4 & (2.5) & 5.4 & (1.8) & 3.3 & (1.0) & 2.6 & (1.0) & 2.1 & (1.0) & 1.8 & (1.0) & 1.8 & (0.8) & 1.7 & (0.9) & 1.7 & $(0.8)$ & 1.8 & (0.6) \\
\hline Czech Republic & 12.8 & $(2.0)$ & 10.2 & (1.9) & 9.0 & (1.8) & 8.0 & (1.8) & 7.9 & (1.9) & 6.5 & (1.6) & 4.8 & (1.3) & 5.5 & (1.3) & 5.6 & $(1.2)$ & 5.7 & $(1.0)$ \\
\hline Denmark & 6.2 & (1.5) & 4.8 & (1.3) & 4.2 & (1.4) & 3.4 & $(1.2)$ & 3.4 & (1.2) & 3.5 & (1.1) & 2.7 & (1.1) & 2.6 & $(0.9)$ & 2.3 & $(0.8)$ & 2.3 & $(0.8$ \\
\hline Estonia & 7.1 & (1.6) & 4.9 & $(1.7)$ & 4.4 & (1.4) & 4.2 & (1.3) & 4.2 & $(1.4)$ & 4.6 & (1.6) & 4.9 & (1.5) & 4.4 & $(1.2)$ & 4.7 & (1.4) & 3.7 & $(1.1)$ \\
\hline Finland & 9.3 & (1.7) & 5.8 & (1.4) & 5.3 & (1.5) & 4.2 & (1.2) & 3.6 & (1.3) & 3.6 & (1.1) & 3.8 & (1.2) & 3.9 & (1.0) & 3.9 & (1.2) & 3.6 & (1.2) \\
\hline France & 9.3 & (1.9) & 6.0 & (1.4) & 4.4 & (1.5) & 3.0 & (1.1) & 2.2 & $(0.7)$ & 2.1 & (0.8) & 1.8 & $(0.7)$ & 1.5 & (0.8) & 1.2 & $(0.7)$ & 0.8 & $(0.5)$ \\
\hline Germany & 6.6 & (1.3) & 4.7 & (1.4) & 3.0 & (1.1) & 2.1 & (0.9) & 2.1 & $(0.9)$ & 1.4 & $(0.8)$ & 1.5 & $(0.6)$ & 1.2 & $(0.5)$ & 1.0 & $(0.5)$ & 1.1 & $(0.6)$ \\
\hline Greece & 13.8 & (2.6) & 7.1 & (2.4) & 5.0 & (1.8) & 3.0 & (1.3) & 3.4 & (1.2) & 3.5 & (1.1) & 3.1 & (1.3) & 2.2 & (0.8) & 1.6 & (0.6) & 1.3 & $(0.5$ \\
\hline Hungary & 9.4 & (1.9) & 7.5 & (1.9) & 5.5 & (1.4) & 4.1 & (1.4) & 3.2 & (1.3) & 2.1 & $(0.8)$ & 1.9 & $(0.9)$ & 2.0 & (1.0) & 2.0 & $(0.8)$ & 2.3 & $(0.8$ \\
\hline Iceland & 4.7 & (1.4) & 3.2 & (1.3) & 2.6 & (1.3) & 2.5 & (1.2) & 2.1 & (1.2) & 1.7 & (1.1) & 1.6 & (0.9) & 2.3 & $(1.2)$ & 2.3 & (1.2) & 1.8 & (1.1) \\
\hline Ireland & 4.4 & (1.0) & 3.4 & (1.0) & 2.9 & (0.8) & 2.9 & (0.9) & 3.0 & (1.0) & 2.7 & (1.1) & 2.6 & (1.1) & 2.5 & (0.9) & 2.7 & $(0.9)$ & 3.9 & $(1.0$ \\
\hline Israel & $\mathrm{m}$ & $\mathrm{m}$ & $\mathrm{m}$ & $\mathrm{m}$ & $\mathrm{m}$ & $\mathrm{m}$ & $\mathrm{m}$ & $\mathrm{m}$ & $\mathrm{m}$ & $\mathrm{m}$ & $\mathrm{m}$ & $\mathrm{m}$ & $\mathrm{m}$ & $\mathrm{m}$ & $\mathrm{m}$ & $\mathrm{m}$ & $\mathrm{m}$ & $\mathrm{m}$ & $\mathrm{m}$ & $\mathrm{m}$ \\
\hline Italy & $\mathrm{m}$ & $\mathrm{m}$ & $\mathrm{m}$ & $\mathrm{m}$ & $\mathrm{m}$ & $\mathrm{m}$ & $\mathrm{m}$ & $\mathrm{m}$ & $\mathrm{m}$ & $\mathrm{m}$ & $\mathrm{m}$ & $\mathrm{m}$ & $\mathrm{m}$ & $\mathrm{m}$ & $\mathrm{m}$ & $\mathrm{m}$ & $\mathrm{m}$ & $\mathrm{m}$ & $\mathrm{m}$ & $\mathrm{m}$ \\
\hline Japan & 9.8 & (1.4) & 9.1 & $(1.7)$ & 9.2 & (1.6) & 8.4 & $(1.7)$ & 8.3 & $(1.8)$ & 7.9 & (1.6) & 8.7 & (1.7) & 7.3 & (1.5) & 9.1 & (1.7) & 11.4 & (1.6) \\
\hline Korea & 1.6 & $(0.6)$ & 1.4 & $(0.7)$ & 1.2 & $(0.8)$ & 0.8 & $(0.6)$ & 0.9 & $(0.6)$ & 0.6 & $(0.5)$ & 0.5 & $(0.5)$ & 0.3 & $(0.3)$ & 0.5 & $(0.4)$ & 0.6 & $(0.4)$ \\
\hline Latvia & 17.5 & $(2.3)$ & 11.9 & $(2.3)$ & 10.0 & (2.1) & 7.8 & (1.9) & 7.3 & (2.1) & 6.6 & (1.8) & 5.8 & (1.5) & 5.3 & (1.7) & 5.3 & (1.3) & 6.7 & $(1.4)$ \\
\hline Luxembourg & 10.2 & (1.7) & 5.6 & (1.4) & 4.5 & (1.4) & 4.1 & (1.1) & 3.2 & (1.2) & 1.9 & $(0.8)$ & 1.5 & $(0.7)$ & 1.7 & (0.9) & 2.1 & $(0.8)$ & 1.7 & $(0.7)$ \\
\hline Mexico & 9.5 & (1.8) & 6.8 & (1.9) & 6.4 & (1.6) & 6.1 & (1.7) & 5.0 & $(1.5)$ & 3.9 & $(1.2)$ & 3.6 & (1.1) & 3.6 & (1.0) & 3.7 & (1.1) & 5.0 & $(0.9)$ \\
\hline Netherlands & 5.6 & (1.6) & 3.4 & (1.3) & 2.7 & $(1.0)$ & 1.3 & $(0.7)$ & 1.2 & $(0.7)$ & 1.1 & $(0.6)$ & 0.9 & $(0.6)$ & 0.7 & $(0.5)$ & 0.9 & $(0.5)$ & 1.0 & $(0.6)$ \\
\hline New Zealand & 13.2 & (1.9) & 9.7 & $(2.1)$ & 6.6 & (1.8) & 7.1 & (1.7) & 7.0 & (1.9) & 5.4 & (1.5) & 5.0 & (1.3) & 4.1 & (1.5) & 4.1 & (1.3) & 5.3 & $(1.3)$ \\
\hline Norway & 10.8 & (1.8) & 7.4 & (1.9) & 5.1 & (1.5) & 4.2 & $(1.2)$ & 3.5 & (1.1) & 3.6 & (1.1) & 3.8 & $(1.2)$ & 3.2 & (1.0) & 3.2 & $(1.0)$ & 1.9 & $(0.7)$ \\
\hline Poland & 8.0 & (1.6) & 5.2 & (1.5) & 4.3 & (1.6) & 3.5 & (1.4) & 4.3 & $(1.3)$ & 3.5 & (1.1) & 3.7 & (1.3) & 3.4 & $(1.2)$ & 2.5 & (1.1) & 2.7 & $(1.0)$ \\
\hline Portugal & 8.7 & (1.4) & 3.7 & $(1.0)$ & 2.7 & $(1.0)$ & 2.3 & $(1.0)$ & 1.7 & $(1.0)$ & 1.3 & $(0.7)$ & 0.9 & $(0.6)$ & 0.8 & $(0.5)$ & 0.9 & $(0.5)$ & 0.6 & $(0.4)$ \\
\hline Slovak Republic & 11.5 & (2.1) & 7.7 & (1.7) & 6.5 & (1.5) & 5.3 & (1.5) & 4.3 & (1.1) & 4.2 & (1.4) & 4.1 & (1.3) & 3.6 & (1.3) & 2.5 & (1.0) & 2.0 & $(0.7)$ \\
\hline Slovenia & 9.5 & (1.6) & 7.2 & (1.4) & 5.1 & (1.3) & 3.4 & (1.2) & 4.0 & (1.5) & 2.9 & (1.3) & 3.3 & (1.5) & 2.8 & (1.2) & 2.0 & $(0.9)$ & 1.7 & $(0.8$ \\
\hline Spain & 6.2 & (1.4) & 3.7 & $(1.2)$ & 3.1 & (1.0) & 2.8 & $(1.0)$ & 2.0 & $(0.7)$ & 2.0 & $(0.8)$ & 1.8 & $(0.7)$ & 2.3 & (1.0) & 2.4 & $(0.8)$ & 2.3 & $(0.7)$ \\
\hline Sweden & 11.5 & (1.8) & 7.8 & (1.9) & 7.0 & (1.8) & 5.9 & (1.4) & 4.6 & (1.3) & 3.9 & (1.4) & 4.0 & (1.6) & 3.5 & (1.3) & 3.4 & (1.0) & 3.7 & $(1.0$ \\
\hline Switzerland & 5.6 & (1.5) & 5.5 & (1.6) & 3.8 & (1.4) & 3.4 & (1.3) & 2.3 & $(1.0)$ & 2.1 & (1.1) & 1.5 & $(0.8)$ & 1.5 & $(0.8)$ & 1.5 & $(0.7)$ & 1.5 & $(0.6$ \\
\hline Turkey & 9.2 & (2.7) & 7.3 & $(2.1)$ & 5.9 & (1.8) & 5.2 & (1.6) & 4.2 & (1.4) & 3.5 & $(1.2)$ & 3.3 & (1.1) & 2.9 & (1.1) & 2.5 & (1.1) & 1.7 & $(0.7$ \\
\hline United Ki & 9.3 & (1.5) & 8.3 & (1.8) & 6.5 & (1.5) & 5.3 & (1.3) & 4.2 & (1.3) & 4.8 & (1.6) & 4.4 & (1.6) & 4.0 & (1.4) & 4.3 & (1.1) & 3.3 & $(0.8$ \\
\hline United States & 8.2 & (1.5) & 5.2 & (1.6) & 6.0 & (1.7) & 4.1 & (1.5) & 2.5 & (1.2) & 2.7 & $(0.9)$ & 2.5 & (1.1) & 2.7 & (1.0) & 3.0 & (1.0) & 2.2 & $(0.8$ \\
\hline OECD average & 9.1 & $(0.3)$ & 6.2 & $(0.3)$ & 5.0 & $(0.2)$ & 4.2 & $(0.2)$ & 3.8 & $(0.2)$ & 3.4 & $(0.2)$ & 3.1 & $(0.2)$ & 2.9 & $(0.2)$ & 2.8 & $(0.2)$ & 2.8 & (0.1) \\
\hline
\end{tabular}

\begin{tabular}{|c|c|c|c|c|c|c|c|c|c|c|c|c|c|c|c|c|c|c|c|c|c|}
\hline \multirow{3}{*}{ 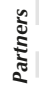 } & Albania & $\mathrm{m}$ & $\mathrm{m}$ & $\mathrm{m}$ & $\mathrm{m}$ & $\mathrm{m}$ & $\mathrm{m}$ & $\mathrm{m}$ & $\mathrm{m}$ & $\mathrm{m}$ & $\mathrm{m}$ & $\mathrm{m}$ & $\mathrm{m}$ & $\mathrm{m}$ & $\mathrm{m}$ & $\mathrm{m}$ & $\mathrm{m}$ & $\mathrm{m}$ & $\mathrm{m}$ & $\mathrm{m}$ & $\mathrm{m}$ \\
\hline & Algeria & $\mathrm{m}$ & $\mathrm{m}$ & $\mathrm{m}$ & $\mathrm{m}$ & $\mathrm{m}$ & $\mathrm{m}$ & $\mathrm{m}$ & $\mathrm{m}$ & $\mathrm{m}$ & $\mathrm{m}$ & $\mathrm{m}$ & $\mathrm{m}$ & $\mathrm{m}$ & $\mathrm{m}$ & $\mathrm{m}$ & $\mathrm{m}$ & $\mathrm{m}$ & $\mathrm{m}$ & $\mathrm{m}$ & $\mathrm{m}$ \\
\hline & Brazil & 8.3 & (1.2) & 5.4 & (1.1) & 4.7 & (1.1) & 3.6 & $(0.8)$ & 3.0 & $(0.7)$ & 2.3 & $(0.7)$ & 2.0 & $(0.7)$ & 2.1 & (0.6) & 1.6 & $(0.6)$ & 1.5 & $(0.5)$ \\
\hline & B-S-J-G (China) & 8.9 & (1.6) & 5.9 & (1.4) & 3.8 & (1.1) & 3.0 & (1.0) & 3.5 & (1.2) & 4.0 & (1.3) & 3.5 & $(1.2)$ & 3.1 & (1.3) & 2.9 & (1.1) & 3.2 & $(1.2)$ \\
\hline & Bulgaria & 18.7 & (3.4) & 11.5 & $(2.2)$ & 11.0 & (1.8) & 10.8 & (1.9) & 10.4 & (2.2) & 8.7 & (1.9) & 7.5 & (1.9) & 6.3 & (1.3) & 5.9 & (1.3) & 4.3 & (1.1) \\
\hline & CABA (Argentina) & $\mathrm{m}$ & $\mathrm{m}$ & $\mathrm{m}$ & $\mathrm{m}$ & $\mathrm{m}$ & $\mathrm{m}$ & $\mathrm{m}$ & $\mathrm{m}$ & $\mathrm{m}$ & $\mathrm{m}$ & $\mathrm{m}$ & $\mathrm{m}$ & $\mathrm{m}$ & $\mathrm{m}$ & $\mathrm{m}$ & $\mathrm{m}$ & $\mathrm{m}$ & $\mathrm{m}$ & $\mathrm{m}$ & $\mathrm{m}$ \\
\hline & Colombia & 9.7 & (1.8) & 7.2 & (1.7) & 5.2 & (1.5) & 4.1 & (1.3) & 2.7 & (0.9) & 2.5 & $(0.8)$ & 2.6 & $(0.8)$ & 2.5 & $(0.8)$ & 2.1 & $(0.7)$ & 2.3 & $(0.7)$ \\
\hline & Costa Rica & 4.9 & (1.3) & 3.6 & (1.3) & 2.7 & (1.3) & 2.3 & (1.2) & 1.8 & $(0.8)$ & 2.3 & (1.0) & 2.2 & $(1.0)$ & 2.6 & (1.2) & 2.5 & (1.0) & 2.1 & $(0.8)$ \\
\hline & Croatia & 6.3 & (1.5) & 5.8 & (1.4) & 4.2 & (1.4) & 4.0 & (1.3) & 4.1 & (1.2) & 3.2 & (1.1) & 3.2 & (1.1) & 2.8 & (1.0) & 2.2 & (1.0) & 3.1 & (0.9) \\
\hline & Cyprus* & 16.2 & $(2.0)$ & 10.5 & (1.7) & 8.0 & (1.7) & 6.6 & (1.5) & 6.9 & (1.9) & 6.1 & (1.4) & 5.0 & (1.3) & 3.5 & (1.1) & 2.2 & $(0.9)$ & 1.6 & $(0.7)$ \\
\hline & Dominican Republic & 8.7 & (2.6) & 8.2 & (2.8) & 7.3 & $(2.2)$ & 5.5 & $(2.2)$ & 4.7 & (1.8) & 4.0 & (1.6) & 3.7 & (1.6) & 3.3 & (1.4) & 2.4 & (1.1) & 2.3 & $(0.8)$ \\
\hline & FYROM & $\mathrm{m}$ & $\mathrm{m}$ & $\mathrm{m}$ & $\mathrm{m}$ & $\mathrm{m}$ & $\mathrm{m}$ & $\mathrm{m}$ & $\mathrm{m}$ & $\mathrm{m}$ & $\mathrm{m}$ & $\mathrm{m}$ & $\mathrm{m}$ & $\mathrm{m}$ & $\mathrm{m}$ & $\mathrm{m}$ & $\mathrm{m}$ & $\mathrm{m}$ & $\mathrm{m}$ & $\mathrm{m}$ & $\mathrm{m}$ \\
\hline & Georgia & $\mathrm{m}$ & $\mathrm{m}$ & $\mathrm{m}$ & $\mathrm{m}$ & $\mathrm{m}$ & $\mathrm{m}$ & $\mathrm{m}$ & $\mathrm{m}$ & $\mathrm{m}$ & $\mathrm{m}$ & $\mathrm{m}$ & $\mathrm{m}$ & $\mathrm{m}$ & $\mathrm{m}$ & $\mathrm{m}$ & $\mathrm{m}$ & $\mathrm{m}$ & $\mathrm{m}$ & $\mathrm{m}$ & $\mathrm{m}$ \\
\hline & Hong Kong (China) & 14.5 & $(2.2)$ & 11.7 & (2.4) & 10.0 & $(2.0)$ & 10.4 & (1.9) & 9.2 & (2.0) & 8.4 & (1.9) & 8.3 & (1.7) & 7.8 & (1.8) & 7.0 & (1.6) & 7.5 & (1.7) \\
\hline & Indonesia & $\mathrm{m}$ & $\mathrm{m}$ & $\mathrm{m}$ & $\mathrm{m}$ & $\mathrm{m}$ & $\mathrm{m}$ & $\mathrm{m}$ & $\mathrm{m}$ & $\mathrm{m}$ & $\mathrm{m}$ & $\mathrm{m}$ & $\mathrm{m}$ & $\mathrm{m}$ & $\mathrm{m}$ & $\mathrm{m}$ & $\mathrm{m}$ & $\mathrm{m}$ & $\mathrm{m}$ & $\mathrm{m}$ & $\mathrm{m}$ \\
\hline & Jordan & $\mathrm{m}$ & $\mathrm{m}$ & $\mathrm{m}$ & $\mathrm{m}$ & $\mathrm{m}$ & $\mathrm{m}$ & $\mathrm{m}$ & $\mathrm{m}$ & $\mathrm{m}$ & $\mathrm{m}$ & $\mathrm{m}$ & $\mathrm{m}$ & $\mathrm{m}$ & $\mathrm{m}$ & $\mathrm{m}$ & $\mathrm{m}$ & $\mathrm{m}$ & $\mathrm{m}$ & $\mathrm{m}$ & $\mathrm{m}$ \\
\hline & Kosovo & $\mathrm{m}$ & $\mathrm{m}$ & $\mathrm{m}$ & $\mathrm{m}$ & $\mathrm{m}$ & $\mathrm{m}$ & $\mathrm{m}$ & $\mathrm{m}$ & $\mathrm{m}$ & $\mathrm{m}$ & $\mathrm{m}$ & $\mathrm{m}$ & $\mathrm{m}$ & $\mathrm{m}$ & $\mathrm{m}$ & $\mathrm{m}$ & $\mathrm{m}$ & $\mathrm{m}$ & $\mathrm{m}$ & $\mathrm{m}$ \\
\hline & Lebanon & $\mathrm{m}$ & $\mathrm{m}$ & $\mathrm{m}$ & $\mathrm{m}$ & $\mathrm{m}$ & $\mathrm{m}$ & $\mathrm{m}$ & $\mathrm{m}$ & $\mathrm{m}$ & $\mathrm{m}$ & $\mathrm{m}$ & $\mathrm{m}$ & $\mathrm{m}$ & $\mathrm{m}$ & $\mathrm{m}$ & $\mathrm{m}$ & $\mathrm{m}$ & $\mathrm{m}$ & $\mathrm{m}$ & $\mathrm{m}$ \\
\hline & Lithuania & 13.2 & $(2.0)$ & 7.7 & $(2.0)$ & 4.8 & (1.4) & 4.2 & (1.4) & 3.4 & (1.1) & 3.0 & (1.0) & 2.5 & (1.1) & 2.0 & $(0.9)$ & 2.1 & $(0.8)$ & 2.6 & $(0.9)$ \\
\hline & Macao (China) & 10.9 & (1.6) & 5.8 & (1.5) & 4.5 & (1.3) & 4.6 & (1.4) & 4.0 & (1.3) & 3.3 & (1.2) & 3.0 & (1.1) & 2.2 & (1.0) & 2.0 & $(0.9)$ & 2.1 & $(0.8)$ \\
\hline & Malta & $\mathrm{m}$ & $\mathrm{m}$ & $\mathrm{m}$ & $\mathrm{m}$ & $\mathrm{m}$ & $\mathrm{m}$ & $\mathrm{m}$ & $\mathrm{m}$ & $\mathrm{m}$ & $\mathrm{m}$ & $\mathrm{m}$ & $\mathrm{m}$ & $\mathrm{m}$ & $\mathrm{m}$ & $\mathrm{m}$ & $\mathrm{m}$ & $\mathrm{m}$ & $\mathrm{m}$ & $\mathrm{m}$ & $\mathrm{m}$ \\
\hline & Moldova & $\mathrm{m}$ & $\mathrm{m}$ & $\mathrm{m}$ & $\mathrm{m}$ & $\mathrm{m}$ & $\mathrm{m}$ & $\mathrm{m}$ & $\mathrm{m}$ & $\mathrm{m}$ & $\mathrm{m}$ & $\mathrm{m}$ & $\mathrm{m}$ & $\mathrm{m}$ & $\mathrm{m}$ & $\mathrm{m}$ & $\mathrm{m}$ & $\mathrm{m}$ & $\mathrm{m}$ & $\mathrm{m}$ & $\mathrm{m}$ \\
\hline & Montenegro & 7.4 & (1.6) & 5.3 & (1.5) & 3.7 & (1.2) & 3.6 & (1.1) & 3.2 & (1.2) & 2.9 & $(0.9)$ & 2.8 & $(0.9)$ & 2.9 & (1.0) & 2.4 & $(0.9)$ & 2.1 & $(0.8)$ \\
\hline & Peru & 7.1 & (1.4) & 5.1 & (1.6) & 4.9 & (1.2) & 4.2 & $(1.2)$ & 3.3 & (1.1) & 2.8 & $(0.8)$ & 2.4 & (0.8) & 2.3 & $(0.9)$ & 2.2 & $(0.8)$ & 2.1 & $(0.7)$ \\
\hline & Qatar & 23.4 & (1.9) & 18.2 & (1.7) & 13.6 & (1.7) & 9.5 & (1.2) & 7.3 & (1.2) & 5.7 & $(0.9)$ & 5.1 & (1.0) & 4.4 & (1.0) & 3.6 & $(0.8)$ & 2.9 & $(0.6)$ \\
\hline & Romania & $\mathrm{m}$ & $\mathrm{m}$ & $\mathrm{m}$ & $\mathrm{m}$ & $\mathrm{m}$ & $\mathrm{m}$ & $\mathrm{m}$ & $\mathrm{m}$ & $\mathrm{m}$ & $\mathrm{m}$ & $\mathrm{m}$ & $\mathrm{m}$ & $\mathrm{m}$ & $\mathrm{m}$ & $\mathrm{m}$ & $\mathrm{m}$ & $\mathrm{m}$ & $\mathrm{m}$ & $\mathrm{m}$ & $\mathrm{m}$ \\
\hline & Russia & 6.8 & (1.7) & 4.7 & (1.6) & 3.9 & (1.5) & 2.8 & (1.3) & 2.9 & (1.1) & 2.6 & (1.0) & 2.3 & (0.9) & 2.2 & (1.1) & 2.6 & (1.1) & 0.9 & $(0.6)$ \\
\hline & Singapore & 12.6 & (1.6) & 6.2 & (1.5) & 5.1 & (1.1) & 4.3 & (1.1) & 4.3 & (1.2) & 4.1 & (1.1) & 4.4 & $(1.2)$ & 3.8 & (1.3) & 3.6 & (1.0) & 2.8 & $(0.8)$ \\
\hline & Chinese Taipei & 2.3 & $(0.5)$ & 0.6 & $(0.3)$ & 0.5 & $(0.3)$ & 0.4 & $(0.4)$ & 0.6 & (0.4) & 0.9 & $(0.4)$ & 1.0 & $(0.5)$ & 0.6 & $(0.4)$ & 0.7 & $(0.5)$ & 0.4 & $(0.4)$ \\
\hline & Thailand & 17.1 & (2.6) & 13.2 & (2.4) & 10.3 & (1.9) & 8.5 & (1.6) & 6.6 & (1.4) & 5.0 & (1.5) & 4.6 & (1.5) & 3.5 & (1.2) & 2.1 & (1.0) & 1.1 & $(0.6)$ \\
\hline & Trinidad and Tobago & $\mathrm{m}$ & $\mathrm{m}$ & $\mathrm{m}$ & $\mathrm{m}$ & $\mathrm{m}$ & $\mathrm{m}$ & $\mathrm{m}$ & $\mathrm{m}$ & $\mathrm{m}$ & $\mathrm{m}$ & $\mathrm{m}$ & $\mathrm{m}$ & $\mathrm{m}$ & $\mathrm{m}$ & $\mathrm{m}$ & $\mathrm{m}$ & $\mathrm{m}$ & $\mathrm{m}$ & $\mathrm{m}$ & $\mathrm{m}$ \\
\hline & Tunisia & 15.9 & (2.5) & 12.3 & $(2.2)$ & 10.7 & $(2.3)$ & 8.7 & $(2.0)$ & 8.3 & (2.3) & 6.7 & (1.6) & 7.0 & (1.8) & 6.3 & (2.1) & 5.8 & (1.6) & 5.8 & (1.4) \\
\hline & United Arab Emirates & 20.4 & (1.9) & 13.9 & (1.6) & 10.2 & (1.5) & 8.5 & (1.5) & 7.3 & (1.5) & 6.3 & (1.3) & 5.0 & (1.1) & 4.5 & (1.1) & 3.8 & $(0.8)$ & 3.0 & $(0.8)$ \\
\hline & Uruguay & 7.4 & (1.7) & 5.9 & (1.5) & 5.3 & (1.4) & 4.8 & (1.3) & 4.2 & (1.3) & 3.5 & (1.1) & 2.7 & (1.0) & 2.5 & $(0.9)$ & 2.2 & $(0.8)$ & 2.6 & $(0.8)$ \\
\hline & Viet Nam & $\mathrm{m}$ & $\mathrm{m}$ & $\mathrm{m}$ & $\mathrm{m}$ & $\mathrm{m}$ & $\mathrm{m}$ & $\mathrm{m}$ & $\mathrm{m}$ & $\mathrm{m}$ & $\mathrm{m}$ & $\mathrm{m}$ & $\mathrm{m}$ & $\mathrm{m}$ & $\mathrm{m}$ & $\mathrm{m}$ & $\mathrm{m}$ & $\mathrm{m}$ & $\mathrm{m}$ & $\mathrm{m}$ & $\mathrm{m}$ \\
\hline & Argentina** & $\mathrm{m}$ & $\mathrm{m}$ & $\mathrm{m}$ & $\mathrm{m}$ & $\mathrm{m}$ & $\mathrm{m}$ & $\mathrm{m}$ & $\mathrm{m}$ & $\mathrm{m}$ & $\mathrm{m}$ & $\mathrm{m}$ & $\mathrm{m}$ & $\mathrm{m}$ & $\mathrm{m}$ & $\mathrm{m}$ & $\mathrm{m}$ & $\mathrm{m}$ & $\mathrm{m}$ & $\mathrm{m}$ & $\mathrm{m}$ \\
\hline & Kazakhstan** & $\mathrm{m}$ & $\mathrm{m}$ & $\mathrm{m}$ & $\mathrm{m}$ & $\mathrm{m}$ & $\mathrm{m}$ & $\mathrm{m}$ & $\mathrm{m}$ & $\mathrm{m}$ & $\mathrm{m}$ & $\mathrm{m}$ & $\mathrm{m}$ & $\mathrm{m}$ & $\mathrm{m}$ & $\mathrm{m}$ & $\mathrm{m}$ & $\mathrm{m}$ & $\mathrm{m}$ & $\mathrm{m}$ & $\mathrm{m}$ \\
\hline & Malaysia** & 17.9 & (1.9) & 9.2 & $(1.8)$ & 7.5 & $(1.8)$ & 5.5 & $(1.7)$ & 4.6 & $(1.2)$ & 3.5 & $(1.2)$ & 3.6 & $(1.1)$ & 3.5 & (1.1) & 3.9 & (1.2) & 3.6 & $(0.8)$ \\
\hline
\end{tabular}

* See note at the beginning of this Annex.

** Coverage is too small to ensure comparability (see Annex A4).

StatLink त्गाड़् http://dx.doi.org/10.1787/888933471694 
[Part 3/3]

Table III.8.4 Students' exposure to bullying, by deciles of science performance

Percentage of students who reported being bullied "a few times a month" or "once a week or more"

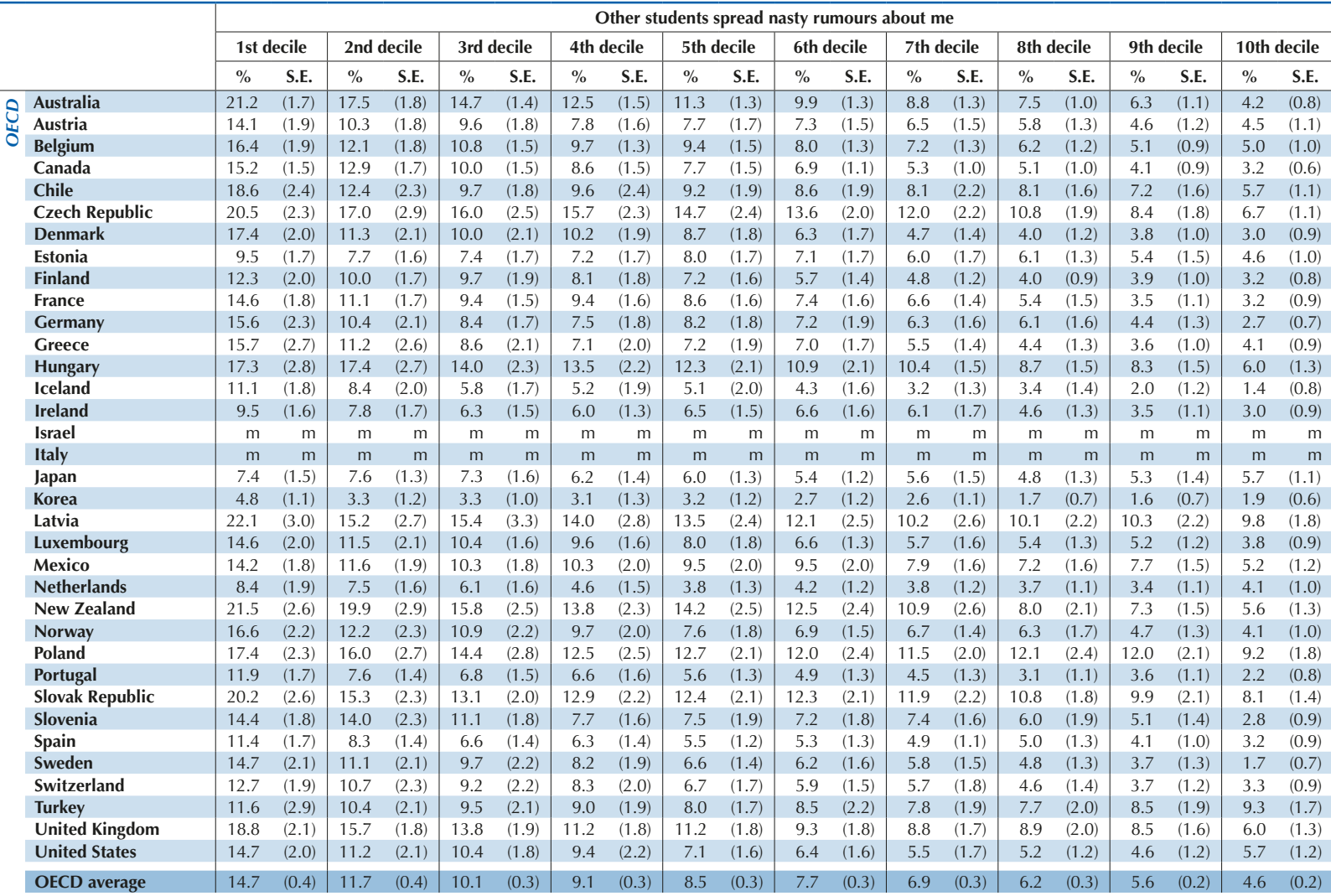

\begin{tabular}{|c|c|c|c|c|c|c|c|c|c|c|c|c|c|c|c|c|c|c|c|c|}
\hline Albania & $\mathrm{m}$ & $\mathrm{m}$ & $\mathrm{m}$ & $\mathrm{m}$ & $\mathrm{m}$ & $\mathrm{m}$ & $\mathrm{m}$ & $\mathrm{m}$ & $\mathrm{m}$ & $\mathrm{m}$ & $\mathrm{m}$ & $\mathrm{m}$ & $\mathrm{m}$ & $\mathrm{m}$ & $\mathrm{m}$ & $\mathrm{m}$ & $\mathrm{m}$ & $\mathrm{m}$ & $\mathrm{m}$ & $\mathrm{m}$ \\
\hline Algeria & $\mathrm{m}$ & $\mathrm{m}$ & $\mathrm{m}$ & $\mathrm{m}$ & $\mathrm{m}$ & $\mathrm{m}$ & $\mathrm{m}$ & $\mathrm{m}$ & $\mathrm{m}$ & $\mathrm{m}$ & $\mathrm{m}$ & $\mathrm{m}$ & $\mathrm{m}$ & $\mathrm{m}$ & $\mathrm{m}$ & $\mathrm{m}$ & $\mathrm{m}$ & $\mathrm{m}$ & $\mathrm{m}$ & $\mathrm{m}$ \\
\hline Brazil & 14.2 & (1.8) & 10.4 & $(1.2)$ & 9.0 & (1.4) & 8.5 & (1.3) & 7.6 & (1.1) & 6.8 & (1.1) & 6.9 & $(1.0)$ & 6.3 & (0.9) & 6.1 & $(1.0)$ & 6.0 & (1.0) \\
\hline B-S-J-G (China) & 10.5 & (1.4) & 8.3 & (1.7) & 7.6 & (1.6) & 7.1 & $(1.5)$ & 7.2 & (1.7) & 6.5 & $(1.8)$ & 5.4 & (1.7) & 4.3 & (1.1) & 3.8 & $(0.9)$ & 2.7 & $(0.8)$ \\
\hline Bulgaria & 20.8 & (3.0) & 15.7 & (2.4) & 14.6 & (2.4) & 13.6 & $(2.2)$ & 13.3 & (2.1) & 10.7 & $(2.0)$ & 11.0 & $(2.1)$ & 10.1 & (1.9) & 10.3 & (1.7) & 7.8 & (1.7) \\
\hline CABA (Argentina) & $\mathrm{m}$ & $\mathrm{m}$ & $\mathrm{m}$ & $\mathrm{m}$ & $\mathrm{m}$ & $\mathrm{m}$ & $\mathrm{m}$ & $\mathrm{m}$ & $\mathrm{m}$ & $\mathrm{m}$ & $\mathrm{m}$ & $\mathrm{m}$ & $\mathrm{m}$ & $\mathrm{m}$ & $\mathrm{m}$ & $\mathrm{m}$ & $\mathrm{m}$ & $\mathrm{m}$ & $\mathrm{m}$ & $\mathrm{m}$ \\
\hline Colombia & 15.7 & (1.9) & 13.0 & (1.9) & 11.9 & $(2.0)$ & 12.0 & $(2.0)$ & 10.4 & $(2.0)$ & 10.4 & (1.6) & 9.6 & (1.5) & 9.5 & (1.5) & 9.2 & (1.4) & 7.7 & (1.2) \\
\hline Costa Rica & 12.7 & (1.8) & 14.1 & (1.8) & 14.0 & $(2.0)$ & 12.9 & $(2.2)$ & 11.8 & $(1.8)$ & 12.1 & (2.4) & 12.0 & (3.0) & 11.5 & (2.6) & 11.0 & (2.4) & 9.9 & (1.7) \\
\hline Croatia & 15.1 & $(1.8)$ & 13.8 & (2.3) & 13.0 & $(2.3)$ & 11.3 & (2.0) & 9.0 & (1.9) & 8.1 & $(1.8)$ & 7.0 & (1.5) & 6.5 & (1.2) & 6.2 & (1.4) & 5.4 & (1.0) \\
\hline Cyprus* & 17.9 & $(2.0)$ & 13.3 & (1.7) & 11.1 & (1.9) & 9.1 & $(2.0)$ & 9.9 & $(2.0)$ & 9.2 & (1.9) & 8.3 & (1.7) & 6.6 & (1.5) & 5.1 & (1.3) & 4.6 & (1.2) \\
\hline Dominican Republic & 14.5 & (3.1) & 14.5 & (3.2) & 13.1 & $(2.7)$ & 13.0 & $(2.9)$ & 13.0 & $(2.3)$ & 13.4 & (2.5) & 13.4 & (2.5) & 13.1 & (2.3) & 12.8 & (2.4) & 11.3 & (1.7) \\
\hline FYROM & $\mathrm{m}$ & $\mathrm{m}$ & $\mathrm{m}$ & $\mathrm{m}$ & $\mathrm{m}$ & $\mathrm{m}$ & $\mathrm{m}$ & $\mathrm{m}$ & $\mathrm{m}$ & $\mathrm{m}$ & $\mathrm{m}$ & $\mathrm{m}$ & $\mathrm{m}$ & $\mathrm{m}$ & $\mathrm{m}$ & $\mathrm{m}$ & $\mathrm{m}$ & $\mathrm{m}$ & $\mathrm{m}$ & $\mathrm{m}$ \\
\hline Georgia & $\mathrm{m}$ & $\mathrm{m}$ & $\mathrm{m}$ & $\mathrm{m}$ & $\mathrm{m}$ & $\mathrm{m}$ & $\mathrm{m}$ & $\mathrm{m}$ & $\mathrm{m}$ & $\mathrm{m}$ & $\mathrm{m}$ & $\mathrm{m}$ & $\mathrm{m}$ & $\mathrm{m}$ & $\mathrm{m}$ & $\mathrm{m}$ & $\mathrm{m}$ & $\mathrm{m}$ & $\mathrm{m}$ & $\mathrm{m}$ \\
\hline Hong Kong (China) & 17.6 & $(2.1)$ & 14.0 & (2.7) & 10.4 & (2.0) & 10.2 & $(2.2)$ & 8.5 & $(2.0)$ & 8.7 & $(2.1)$ & 7.3 & (1.5) & 6.6 & (1.8) & 5.5 & (1.3) & 5.2 & (1.4) \\
\hline Indonesia & $\mathrm{m}$ & $\mathrm{m}$ & $\mathrm{m}$ & $\mathrm{m}$ & $\mathrm{m}$ & $\mathrm{m}$ & $\mathrm{m}$ & $\mathrm{m}$ & $\mathrm{m}$ & $\mathrm{m}$ & $\mathrm{m}$ & $\mathrm{m}$ & $\mathrm{m}$ & $\mathrm{m}$ & $\mathrm{m}$ & $\mathrm{m}$ & $\mathrm{m}$ & $\mathrm{m}$ & $\mathrm{m}$ & $\mathrm{m}$ \\
\hline Jordan & $\mathrm{m}$ & $\mathrm{m}$ & $\mathrm{m}$ & $\mathrm{m}$ & $\mathrm{m}$ & $\mathrm{m}$ & $\mathrm{m}$ & $\mathrm{m}$ & $\mathrm{m}$ & $\mathrm{m}$ & $\mathrm{m}$ & $\mathrm{m}$ & $\mathrm{m}$ & $\mathrm{m}$ & $\mathrm{m}$ & $\mathrm{m}$ & $\mathrm{m}$ & $\mathrm{m}$ & $\mathrm{m}$ & $\mathrm{m}$ \\
\hline Kosovo & $\mathrm{m}$ & $\mathrm{m}$ & $\mathrm{m}$ & $\mathrm{m}$ & $\mathrm{m}$ & $\mathrm{m}$ & $\mathrm{m}$ & $\mathrm{m}$ & $\mathrm{m}$ & $\mathrm{m}$ & $\mathrm{m}$ & $\mathrm{m}$ & $\mathrm{m}$ & $\mathrm{m}$ & $\mathrm{m}$ & $\mathrm{m}$ & $\mathrm{m}$ & $\mathrm{m}$ & $\mathrm{m}$ & $\mathrm{m}$ \\
\hline Lebanon & $\mathrm{m}$ & $\mathrm{m}$ & $\mathrm{m}$ & $\mathrm{m}$ & $\mathrm{m}$ & $\mathrm{m}$ & $\mathrm{m}$ & $\mathrm{m}$ & $\mathrm{m}$ & $\mathrm{m}$ & $\mathrm{m}$ & $\mathrm{m}$ & $\mathrm{m}$ & $\mathrm{m}$ & $\mathrm{m}$ & $\mathrm{m}$ & $\mathrm{m}$ & $\mathrm{m}$ & $\mathrm{m}$ & $\mathrm{m}$ \\
\hline Lithuania & 18.2 & (2.3) & 11.7 & (2.1) & 8.5 & (1.9) & 7.9 & (1.9) & 7.7 & $(2.2)$ & 7.0 & (1.8) & 5.6 & (1.6) & 5.2 & (1.4) & 4.6 & $(1.2)$ & 4.1 & (1.4) \\
\hline Macao (China) & 17.7 & $(2.3)$ & 14.0 & (2.4) & 10.8 & $(2.0)$ & 9.2 & $(2.0)$ & 8.7 & $(1.5)$ & 7.5 & (1.8) & 7.6 & (1.8) & 6.4 & (1.7) & 5.8 & (1.6) & 5.4 & (1.3) \\
\hline Malta & $\mathrm{m}$ & $\mathrm{m}$ & $\mathrm{m}$ & $\mathrm{m}$ & $\mathrm{m}$ & $\mathrm{m}$ & $\mathrm{m}$ & $\mathrm{m}$ & $\mathrm{m}$ & $\mathrm{m}$ & $\mathrm{m}$ & $\mathrm{m}$ & $\mathrm{m}$ & $\mathrm{m}$ & $\mathrm{m}$ & $\mathrm{m}$ & $\mathrm{m}$ & $\mathrm{m}$ & $\mathrm{m}$ & $\mathrm{m}$ \\
\hline Moldova & $\mathrm{m}$ & $\mathrm{m}$ & $\mathrm{m}$ & $\mathrm{m}$ & $\mathrm{m}$ & $\mathrm{m}$ & $\mathrm{m}$ & $\mathrm{m}$ & $\mathrm{m}$ & $\mathrm{m}$ & $\mathrm{m}$ & $\mathrm{m}$ & $\mathrm{m}$ & $\mathrm{m}$ & $\mathrm{m}$ & $\mathrm{m}$ & $\mathrm{m}$ & $\mathrm{m}$ & $\mathrm{m}$ & $\mathrm{m}$ \\
\hline Montenegro & 13.1 & (2.0) & 11.3 & (1.8) & 10.5 & (2.0) & 10.6 & $(2.0)$ & 9.9 & (1.8) & 9.2 & (1.9) & 9.0 & (1.7) & 9.1 & (1.8) & 9.1 & (1.5) & 8.3 & (1.6) \\
\hline Peru & 11.3 & (1.9) & 11.6 & (1.8) & 11.0 & (1.9) & 10.0 & (1.5) & 10.7 & (1.6) & 10.0 & (1.8) & 8.9 & (1.7) & 8.8 & (1.5) & 8.7 & (1.5) & 5.3 & (1.2) \\
\hline Qatar & 27.1 & (1.8) & 20.9 & (1.7) & 16.9 & (1.8) & 14.1 & (1.4) & 11.8 & $(1.3)$ & 10.1 & $(1.2)$ & 9.5 & $(1.0)$ & 7.6 & $(0.9)$ & 6.6 & $(0.9)$ & 5.0 & $(0.7)$ \\
\hline Romania & $\mathrm{m}$ & $\mathrm{m}$ & $\mathrm{m}$ & $\mathrm{m}$ & $\mathrm{m}$ & $\mathrm{m}$ & $\mathrm{m}$ & $\mathrm{m}$ & $\mathrm{m}$ & $\mathrm{m}$ & $\mathrm{m}$ & $\mathrm{m}$ & $\mathrm{m}$ & $\mathrm{m}$ & $\mathrm{m}$ & $\mathrm{m}$ & $\mathrm{m}$ & $\mathrm{m}$ & $\mathrm{m}$ & $\mathrm{m}$ \\
\hline Russia & 13.6 & $(2.1)$ & 10.7 & (2.3) & 9.3 & (2.4) & 8.1 & $(2.0)$ & 7.4 & (1.9) & 8.4 & (1.9) & 8.4 & (1.8) & 8.3 & (1.8) & 8.1 & $(2.0)$ & 7.9 & (1.5) \\
\hline Singapor & 20.1 & (1.9) & 12.5 & (1.9) & 10.3 & (1.3) & 8.8 & $(1.5)$ & 8.0 & (1.7) & 7.0 & (1.6) & 6.9 & (1.4) & 5.1 & (1.2) & 4.2 & (1.1) & 4.5 & (1.2) \\
\hline Chinese Taipei & 5.1 & (1.0) & 4.6 & (1.1) & 4.2 & (1.1) & 4.0 & $(1.0)$ & 3.7 & $(1.0)$ & 3.1 & $(0.9)$ & 3.0 & $(0.9)$ & 2.8 & $(0.8)$ & 2.9 & $(0.9)$ & 1.4 & $(0.6)$ \\
\hline Thailand & 20.3 & $(2.7)$ & 17.1 & (2.2) & 14.4 & $(2.2)$ & 12.1 & $(1.8)$ & 10.4 & (1.9) & 9.0 & $(2.1)$ & 8.4 & (1.9) & 7.1 & (2.1) & 6.5 & (1.4) & 6.9 & (1.2) \\
\hline Trinidad and Tobago & $\mathrm{m}$ & $\mathrm{m}$ & $\mathrm{m}$ & $\mathrm{m}$ & $\mathrm{m}$ & $\mathrm{m}$ & $\mathrm{m}$ & $\mathrm{m}$ & $\mathrm{m}$ & $\mathrm{m}$ & $\mathrm{m}$ & $\mathrm{m}$ & $\mathrm{m}$ & $\mathrm{m}$ & $\mathrm{m}$ & $\mathrm{m}$ & $\mathrm{m}$ & $\mathrm{m}$ & $\mathrm{m}$ & $\mathrm{m}$ \\
\hline Tunisia & 18.3 & (2.5) & 16.3 & (2.3) & 14.5 & (2.5) & 13.4 & $(2.5)$ & 11.0 & $(2.2)$ & 10.8 & $(2.2)$ & 9.6 & (1.9) & 10.1 & (2.3) & 11.8 & (2.4) & 11.2 & (1.8) \\
\hline United Arab Emirates & 24.7 & $(2.2)$ & 17.7 & (1.8) & 15.5 & (1.8) & 13.4 & $(1.5)$ & 11.7 & (1.7) & 11.4 & (1.5) & 10.1 & (1.4) & 9.9 & (1.6) & 8.7 & (1.3) & 6.8 & (1.0) \\
\hline Uruguay & 10.5 & (1.6) & 9.2 & (1.9) & 8.5 & (1.5) & 8.5 & (1.7) & 7.8 & (1.8) & 7.5 & (1.5) & 7.1 & (1.4) & 6.7 & (1.3) & 6.9 & $(1.8)$ & 6.2 & $(1.3)$ \\
\hline Viet Nam & $\mathrm{m}$ & $\mathrm{m}$ & $\mathrm{m}$ & $\mathrm{m}$ & $\mathrm{m}$ & $\mathrm{m}$ & $\mathrm{m}$ & $\mathrm{m}$ & $\mathrm{m}$ & $\mathrm{m}$ & $\mathrm{m}$ & $\mathrm{m}$ & $\mathrm{m}$ & $\mathrm{m}$ & $\mathrm{m}$ & $\mathrm{m}$ & $\mathrm{m}$ & $\mathrm{m}$ & $\mathrm{m}$ & $\mathrm{m}$ \\
\hline Argentina** & $\mathrm{m}$ & $\mathrm{m}$ & $\mathrm{m}$ & $\mathrm{m}$ & $\mathrm{m}$ & $\mathrm{m}$ & $\mathrm{m}$ & $\mathrm{m}$ & $\mathrm{m}$ & $\mathrm{m}$ & $\mathrm{m}$ & $\mathrm{m}$ & $\mathrm{m}$ & $\mathrm{m}$ & $\mathrm{m}$ & $\mathrm{m}$ & $\mathrm{m}$ & $\mathrm{m}$ & $\mathrm{m}$ & $\mathrm{m}$ \\
\hline Kazakhstan** & $\mathrm{m}$ & $\mathrm{m}$ & $\mathrm{m}$ & $\mathrm{m}$ & $\mathrm{m}$ & $\mathrm{m}$ & $\mathrm{m}$ & $\mathrm{m}$ & $\mathrm{m}$ & $\mathrm{m}$ & $\mathrm{m}$ & $\mathrm{m}$ & $\mathrm{m}$ & $\mathrm{m}$ & $\mathrm{m}$ & $\mathrm{m}$ & $\mathrm{m}$ & $\mathrm{m}$ & $\mathrm{m}$ & $\mathrm{m}$ \\
\hline Malaysia** & 26.4 & (2.3) & 18.7 & (2.5) & 16.5 & (2.0) & 15.1 & (2.1) & 11.7 & (1.8) & 10.8 & (2.1) & 10.6 & (1.9) & 10.3 & (1.7) & 9.3 & (1.5) & 6.0 & (1.1) \\
\hline
\end{tabular}

* See note at the beginning of this Annex.

** Coverage is too small to ensure comparability (see Annex A4).

StatLink 睭L http://dx.doi.org/10.1787/888933471694 
Index of exposure to bullying, by:

\begin{tabular}{|c|c|c|c|c|c|c|c|c|c|c|c|c|c|c|}
\hline & \multicolumn{13}{|c|}{ Index of exposure to bullying, by: } \\
\hline & & \multicolumn{2}{|c|}{ All students } & of th & $\begin{array}{r}\text { Nat } \\
\text { le index }\end{array}$ & $\begin{array}{l}\text { ational } \\
x \text { of exp }\end{array}$ & $\begin{array}{l}\text { quarters } \\
\text { posure to bull }\end{array}$ & lying & & National qu & tarters & of the $E$ & ESCS $^{1}$ index & \\
\hline & & Average & $\begin{array}{c}\text { Variation } \\
\text { in this index }\end{array}$ & $\begin{array}{l}\text { Bottom } \\
\text { quarter }\end{array}$ & $\begin{array}{l}\text { Secor } \\
\text { quart }\end{array}$ & $\begin{array}{l}\text { ond } \\
\text { rter }\end{array}$ & $\begin{array}{l}\text { Third } \\
\text { quarter }\end{array}$ & $\begin{array}{c}\text { Top } \\
\text { quarter }\end{array}$ & $\begin{array}{l}\text { Bottom } \\
\text { quarter }\end{array}$ & $\begin{array}{l}\text { Second } \\
\text { quarter }\end{array}$ & $\begin{array}{l}\text { Thi } \\
\text { quat }\end{array}$ & $\begin{array}{l}\text { ird } \\
\text { rter }\end{array}$ & $\begin{array}{c}\text { Top } \\
\text { quarter }\end{array}$ & $\begin{array}{c}\text { Top - bottom } \\
\text { quarter }\end{array}$ \\
\hline & & $\begin{array}{ll}\text { Mean } & \\
\text { index } & \text { S.E. }\end{array}$ & S.D. S.E. & $\begin{array}{l}\text { Mean } \\
\text { index }\end{array}$ & $\begin{array}{l}\text { Mean } \\
\text { index }\end{array}$ & S.E. & $\begin{array}{ll}\text { Mean } & \\
\text { index } & \text { S.E. }\end{array}$ & $\begin{array}{l}\text { Mean } \\
\text { index }\end{array}$ & $\begin{array}{l}\text { Mean } \\
\text { index S.E. }\end{array}$ & $\begin{array}{l}\text { Mean } \\
\text { index S.E. }\end{array}$ & $\begin{array}{l}\text { Mean } \\
\text { index }\end{array}$ & S.E. & $\begin{array}{l}\text { Mean } \\
\text { index S.E. }\end{array}$ & Dif. \\
\hline & Australia & $0.45(0.01)$ & $1.02(0.01)$ & $-0.50(0.00)$ & -0.29 & (0.01) & $0.71(0.00)$ & $1.90(0.01)$ & $0.56(0.03)$ & $0.47(0.02)$ & 0.40 & $(0.03)$ & $0.38(0.02)$ & \begin{tabular}{|l|l|}
$\mathbf{- 0 . 1 8}(0.04)$ \\
\end{tabular} \\
\hline & Austria & $.10(0.01)$ & $0.95(0.01)$ & $-0.69(0.00)$ & -0.69 & $(0.00)$ & $0.32(0.00)$ & $1.45(0.02)$ & $0.07(0.03)$ & $0.09(0.03)$ & 0.06 & $(0.03)$ & $0.15(0.03)$ & $0.07(0.04)$ \\
\hline & Belgium & $0.18(0.01)$ & $0.86(0.01)$ & $-0.55(0.00)$ & -0.50 & $(0.00)$ & $0.36(0.00)$ & $1.41(0.02)$ & $0.22(0.02)$ & $0.20(0.02)$ & 0.17 & $(0.02)$ & $0.15(0.02)$ & $-\mathbf{- 0 . 0 7}(0.03)$ \\
\hline & Canada & $39(0.01)$ & $0.99(0.01)$ & $-0.49(0.00)$ & -0.37 & $(0.01)$ & $0.63(0.00)$ & $1.77(0.02)$ & $0.47(0.02)$ & $0.42(0.02)$ & 0.37 & $(0.02)$ & $0.29(0.02)$ & \begin{tabular}{|c|c|}
$\mathbf{0 . 1 9}$ & $(0.03)$ \\
\end{tabular} \\
\hline & Chile & $15(0.01)$ & $.91(0.01)$ & $-0.63(0.00)$ & -0.56 & $(0.01)$ & $0.35(0.01)$ & $1.43(0.02)$ & $0.19(0.03)$ & $0.10(0.03)$ & 0.15 & $(0.02)$ & $0.15(0.02)$ & $-0.05(0.03)$ \\
\hline & Czech Rep & $0.15(0.02)$ & $1.08(0.01)$ & $-0.83(0.00)$ & -0.67 & $(0.01)$ & $0.40(0.01)$ & $1.69(0.02)$ & $0.16(0.04)$ & $0.18(0.04)$ & 0.15 & $(0.03)$ & $0.10(0.03)$ & $-0.06(0.05)$ \\
\hline & Denmark & $0.22(0.01)$ & $0.79(0.01)$ & $-0.50(0.00)$ & -0.35 & $(0.01)$ & $0.40(0.01)$ & $1.34(0.01)$ & $0.24(0.02)$ & $0.23(0.02)$ & 0.22 & $(0.02)$ & $0.21(0.02)$ & $-0.03(0$ \\
\hline & Estonia & $24(0.01)$ & $0.90(0.01)$ & $-0.55(0.00)$ & -0.45 & $(0.01)$ & $0.45(0.01)$ & $1.52(0.02)$ & $0.25(0.03)$ & $0.26(0.03)$ & 0.26 & $(0.03)$ & $0.21(0.03)$ & $-0.04(0.04)$ \\
\hline & Finland & $0.23(0.02)$ & $0.91(0.01)$ & $-0.52(0.00)$ & -0.52 & $(0.00)$ & $0.42(0.01)$ & $1.54(0.02)$ & $0.25(0.03)$ & $0.27(0.03)$ & 0.21 & $(0.02)$ & $0.20(0.03)$ & -0.05 \\
\hline & France & $-0.08(0.02)$ & $0.97(0.01)$ & $-0.85(0.00)$ & -0.85 & $(0.00)$ & $0.03(0.01)$ & $1.33(0.02)$ & $-0.07(0.03)$ & $-0.06(0.03)$ & -0.08 & $(0.02)$ & $-0.12(0.03)$ & $-0.06(0.04)$ \\
\hline & Germ & $0.17(0.01)$ & $0.81(0.01)$ & $-0.52(0$ & -0.47 & $(0.00)$ & $0.36(0.00)$ & $1.32(0.02)$ & $0.15(0.03)$ & $0.18(0.03)$ & 0.19 & & 015 & 0.00 \\
\hline & Greece & $-0.55(0.02)$ & $1.22(0.02)$ & $-1.43(0.00)$ & -1.43 & $(0.00)$ & $-0.60(0.02)$ & $1.26(0.04)$ & $-0.54(0.04)$ & $-0.53(0$ & -0.53 & & -0.60 & $-0.06(0$ \\
\hline & Hungary & $-0.06(0.02)$ & $1.10(0.02)$ & $-0.94(0.00)$ & -0.94 & $(0.00)$ & $0.10(0.01)$ & $1.53(0.02)$ & $-0.04(0.04)$ & $-0.09(0.04)$ & -0.06 & $(0.03)$ & $-0.06(0.03)$ & $-0.01(0.05)$ \\
\hline & Icelan & $\begin{array}{ll}.43 & (0.02)\end{array}$ & $1.02(0.01)$ & $-1.10(0.00)$ & -1.10 & $(0.00)$ & $-0.64(0.02)$ & $1.10(0.03)$ & -0.38 (0.04) & $\begin{array}{|ll|}-0.39 & (0.04) \\
\end{array}$ & -0.50 & & $-0.48(0.04)$ & $-0.10(0$ \\
\hline & Ireland & $10(0.02)$ & $0.88(0.01)$ & $-0.61(0.00)$ & -0.61 & $(0.00)$ & $0.24(0.01)$ & $1.37(0.02)$ & $0.02(0.02)$ & $0.11(0.03)$ & 0.15 & $(0.03)$ & $0.12(0.02)$ & 0.10 \\
\hline & Israel & $\mathrm{m}$ & $\mathrm{m}$ & $\mathrm{m}$ & $\mathrm{m}$ & & $\mathrm{m}$ & $\mathrm{m}$ & $\mathrm{m}$ & $\mathrm{m}$ & $\mathrm{m}$ & & $\mathrm{m}$ & $\mathrm{m}$ \\
\hline & Italy & $\mathrm{m}$ & $\mathrm{m}$ & $\mathrm{m}$ & $\mathrm{m}$ & & $\mathrm{m}$ & $\mathrm{m}$ & & $\mathrm{m}$ & $\mathrm{m}$ & $\mathrm{m}$ & $\mathrm{m}$ & $\mathrm{m}$ \\
\hline & Japz & $.21(0.02)$ & $.98(0.01)$ & $-0.98(0.00)$ & -0.98 & $(0.00)$ & $-0.08(0.01)$ & $1.21(0.02)$ & $-0.31(0.03)$ & $-0.23(0.03)$ & -0.19 & $(0.02)$ & $-0.10(0.03)$ & $\mathbf{0 . 2 1}(0.03)$ \\
\hline & Korea & $-1.44(0.02)$ & $1.08(0.02)$ & $-2.03(0.00)$ & -2.03 & $(0.00)$ & $-1.94(0.01)$ & $0.25(0.03)$ & $-1.45(0.03)$ & $-1.50(0.03)$ & -1.43 & & $-1.38(0.03)$ & $0.07(0.04)$ \\
\hline & Latvia & $0.65(0.01)$ & $0.93(0.01)$ & $-0.38(0.00)$ & 0.16 & $(0.01)$ & $0.90(0.01)$ & $1.93(0.02)$ & $0.73(0.03)$ & $0.66(0.03)$ & 0.63 & $(0.03)$ & $0.60(0.03)$ & \begin{tabular}{|l|l|}
$\mathbf{0 . 1 3}$ & $(0.04)$ \\
\end{tabular} \\
\hline & Lux & $-0.15(0.01)$ & $1.05(0.01)$ & $-0.95(0.00)$ & -0.95 & & $-0.10(0.01)$ & $1.37(0.02)$ & $-0.14(0.03)$ & $-0.13(0.03)$ & & & $-0.22(0.03)$ & $-0.09(0)$ \\
\hline & & $0.13(0.01)$ & $1.03(0.01)$ & 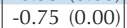 & -0.70 & & $0.37(0.01)$ & $1.58(0.02)$ & $0.14(0.03)$ & $0.12(0$ & 0.08 & & $0.16(0.03)$ & $0.01(0$ \\
\hline & $\mathrm{Ne}$ & $-0.33(0.01)$ & $0.82(0.02)$ & $-0.88(0.00)$ & -0.88 & 0) & $-0.43(0.01)$ & $0.89(0.02)$ & $-0.37(0$ & $-0.30(0.03)$ & -0.35 & & $-0.29(0.02)$ & $0.07(0$ \\
\hline & New Zeal & $0.61(0.02)$ & $1.04(0.01)$ & $-0.41(0.00)$ & -0.07 & $(0.01)$ & $0.87(0.01)$ & $2.07(0.02)$ & $0.74(0.04)$ & \begin{tabular}{|l|l|}
0.59 & $(0.03)$ \\
\end{tabular} & 0.60 & & $0.55(0.03)$ & $-0.19(0)$ \\
\hline & Norway & $-0.01(0.02)$ & $1.07(0.01)$ & $-0.86(0$ & -0.86 & & $0.15(0$ & $1.54(0$. & $-0.01(0$ & $-0.02(0$ & -0.01 & & $.00(C$ & 0.01 \\
\hline & & $0.27(0.02)$ & $0.95(0.01)$ & $-0.56(0.00)$ & -0.45 & & $0.46(0$ & $1.63(0$. & $0.31(0$ & $0.28(0$ & 0.23 & & $0.25(C$ & -0.06 \\
\hline & Portugal & $-0.52(0.02)$ & $1.10(0.01)$ & $-1.24(0.00)$ & -1.24 & $(0.00)$ & $-0.71(0.02)$ & $1.12(0.02)$ & $-0.45(0.03)$ & $-0.56(0.03)$ & -0.50 & $(0.03)$ & $-0.56(0.03)$ & $-0.11(0$ \\
\hline & Slov & $\mid 0.10(0.02)$ & $1.13(0.01)$ & $-0.86(0.00)$ & -0.80 & & $0.36(0.01)$ & $1.72(0$. & $0.22(0$ & 0.05 & & & 0.06 & -0.16 \\
\hline & & $01(0.01)$ & $0.94(0.01)$ & $-0.73(0.00)$ & -0.73 & & $0.16(0$. & $1.36(0$. & $0.05(0$ & $0.01(0$ & 0.00 & & $0.01(0.03)$ & $-0.04(C$ \\
\hline & $\mathrm{Sp}$ & $-0.09(0.01)$ & $91(0.01)$ & $-0.78(0.00)$ & -0.78 & 0) & $-0.04(0.01)$ & $.23(0$. & $-0.12(0.03)$ & $-0.07(0.02)$ & -0.08 & 5) & $-0.11(0.03)$ & $0.01(0$ \\
\hline & Sweden & $-0.11(0.02)$ & $1.11(0.01)$ & $-1.05(0.00)$ & -1.05 & $(0.00)$ & $0.19(0.01)$ & $1.46(0.02)$ & $-0.04(0.03)$ & $-0.12(0.04)$ & -0.13 & $(0.04)$ & $-0.17(0.03)$ & $-0.13(0$ \\
\hline & Swi & $0.24(0.02)$ & $0.82(0.01)$ & $7(0$. & 0( & & $0.42(0$ & $1.40(0$ & $0.22(0$ & $0.24(0$ & 5 & & $0.24(C$ & 0.02 \\
\hline & Tur & $.97(0.03)$ & $1.60(0.03)$ & $5(0$. & 5 & & -1.24 & $.44(0$ & $-0.96(0$ & $-1.10(0$ & 7 & & $-0.87(C$ & $0.09(0$ \\
\hline & United I & $0.40(0.02)$ & $1.03(0.01)$ & $-0.54(0.00)$ & -0.38 & $(0.01)$ & $0.66(0.01)$ & $1.86(0.02)$ & $0.44(0.03)$ & 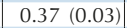 & 0.39 & $(0.03)$ & $0.40(0.03)$ & $-0.04(0.05)$ \\
\hline & United States & $0.16(0.02)$ & $1.00(0.01)$ & $-0.66(0.00)$ & -0.66 & $(0.00)$ & $0.37(0.01)$ & $1.60(0.02)$ & $0.17(0.03)$ & $0.17(0.03)$ & 0.17 & $(0.03)$ & $0.15(0.03)$ & $-0.02(0.05)$ \\
\hline & OECD average & $0.00(0.00)$ & $1.00(0.00)$ & $|-0.82(0.00)|$ & -0.75 & $(0.00)$ & $0.12(0.00)$ & $1.44(0.00)$ & $0.02(0.01)$ & $0.00(0.01)$ & 0.00 & $(0.01)$ & $-0.01(0.01)$ & \begin{tabular}{|l|l|}
$\mathbf{- 0 . 0 4}(0.0$ \\
\end{tabular} \\
\hline & Albar & $\mathrm{m}$ & $\mathrm{m}$ & $\mathrm{m}$ & $\mathrm{m}$ & & $\mathrm{m}$ & $\mathrm{m}$ & $\mathrm{m}$ & $\mathrm{m}$ & $\mathrm{m}$ & & $\mathrm{m}$ & $\mathrm{m}$ \\
\hline & Alger & & $\mathrm{m}$ & $\mathrm{m}$ & $\mathrm{m}$ & & $\mathrm{m}$ & $\mathrm{m}$ & $\mathrm{m}$ & $\mathrm{m}$ & $\mathrm{m}$ & $\mathrm{m}$ & $\mathrm{m}$ & $\mathrm{m}$ \\
\hline & Brazil & $.23(0.01)$ & $.18(0.01)$ & $.12(0.00)$ & -1.12 & $(0.00)$ & $-0.16(0.01)$ & $.49(0.02)$ & $-0.26(0.02)$ & $-0.26(0.03)$ & -0.23 & $(0.02)$ & $-0.16(0.02)$ & $\mathbf{0 . 1 0}(0.03)$ \\
\hline & B-S-J-C & $0.10(0.02)$ & $1.04(0.01)$ & $-0.80(0.00)$ & -0.70 & $(0.01)$ & $0.30(0.01)$ & $1.60(0.02)$ & $0.23(0.04)$ & $0.12(0.03)$ & 0.05 & $(0.04)$ & $0.00(0.04)$ & $-0.23(0.04)$ \\
\hline & Bulga & $0.14(0.02)$ & $1.19(0.02)$ & $-0.92(0.00)$ & -0.78 & $(0.01)$ & $0.43(0.01)$ & $1.85(0.03)$ & $0.14(0.04)$ & $0.16(0.04)$ & 0.16 & $(0.03)$ & $0.11(0.03)$ & $-0.03(0.05)$ \\
\hline & CA & $\mathrm{m}$ & & $\mathrm{m}$ & $\mathrm{m}$ & & $\mathrm{m}$ & $\mathrm{m}$ & $\mathrm{m}$ & $\mathrm{m}$ & $\mathrm{m}$ & & $\mathrm{m}$ & $\mathrm{m}$ \\
\hline & Col & $16(0.01)$ & $.92(0.01)$ & $.66(0.00)$ & -0.54 & $(0.01)$ & $0.39(0.01)$ & $.46(0.02)$ & $0.10(0.03)$ & $0.20(0.03)$ & 0.20 & $(0.02)$ & $0.15(0.02)$ & $0.05(0.03)$ \\
\hline & Costa & $10(0.01)$ & $1.06(0.01)$ & $-0.77(0.00)$ & -0.77 & $(0.00)$ & $0.31(0.01)$ & $.64(0.02)$ & $0.14(0.03)$ & $0.04(0.03)$ & 0.05 & $(0.03)$ & $0.18(0.04)$ & $0.04(0.05)$ \\
\hline & & $.12(0.02)$ & $0.97(0.01)$ & $-0.86(0.00)$ & -0.86 & $(0.00)$ & $-0.05(0.01)$ & $1.31(0.02)$ & $-0.08(0.03)$ & $-0.12(0.03)$ & -0.13 & $(0.03)$ & $-0.14(0.03)$ & $-0.06(0$ \\
\hline & & $\mathrm{m}$ & $\mathrm{m}$ & $\mathrm{m}$ & $\mathrm{m}$ & & $\mathrm{m}$ & $\mathrm{m}$ & $\mathrm{m}$ & $\mathrm{m}$ & $\mathrm{m}$ & & $\mathrm{m}$ & $\mathrm{m}$ \\
\hline & Domi & $.29(0.03)$ & $1.45(0.02)$ & $-1.59(0.00)$ & -1.44 & $(0.01)$ & $0.10(0.01)$ & $1.78(0.03)$ & $-0.32(0.06)$ & $-0.31(0.06)$ & -0.24 & $(0.05)$ & $-0.27(0.05)$ & $0.05(0.08)$ \\
\hline & FYROM & $\mathrm{m}$ & $\mathrm{m}$ & $\mathrm{m}$ & $\mathrm{m}$ & & $\mathrm{m}$ & $\mathrm{m}$ & $\mathrm{m}$ & $\mathrm{m}$ & $\mathrm{m}$ & & $\mathrm{m}$ & $\mathrm{m}$ \\
\hline & Geo & & & $\mathrm{m}$ & $\mathrm{m}$ & & $\mathrm{m}$ & $\mathrm{m}$ & $\mathrm{m}$ & $\mathrm{m}$ & $\mathrm{m}$ & & $\mathrm{m}$ & $\mathrm{m}$ \\
\hline & Ho & $0.21(0.03)$ & $.26(0.02)$ & $-0.95(0.00)$ & -0.72 & $(0.01)$ & $0.52(0.01)$ & $.00(0.03)$ & $.20(0.04)$ & $0.20(0.05)$ & .22 & $(0.04)$ & $0.22(0.06)$ & $0.02(0.07)$ \\
\hline & Indonesi & $\mathrm{m}$ & $\mathrm{m}$ & $\mathrm{m}$ & $\mathrm{m}$ & & $\mathrm{m}$ & $\mathrm{m}$ & $\mathrm{m}$ & $\mathrm{m}$ & $\mathrm{m}$ & & $\mathrm{m}$ & $\mathrm{m}$ \\
\hline & Jordan & $\mathrm{m}$ & $\mathrm{m}$ & $\mathrm{m}$ & $\mathrm{m}$ & & $\mathrm{m}$ & $\mathrm{m}$ & $\mathrm{m}$ & $\mathrm{m}$ & $\mathrm{m}$ & $\mathrm{m}$ & $\mathrm{m}$ & $\mathrm{m}$ \\
\hline & & 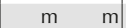 & $\mathrm{m}$ & $\mathrm{m}$ & $\mathrm{m}$ & & $\mathrm{m}$ & $\mathrm{m}$ & $\mathrm{m}$ & $\mathrm{m}$ & $\mathrm{m}$ & & $\mathrm{m}$ & $m$ \\
\hline & & $\mathrm{m}$ & $\mathrm{m}$ & $\mathrm{m}$ & $\mathrm{m}$ & & $\mathrm{m}$ & $\mathrm{m}$ & $\mathrm{m}$ & $\mathrm{m}$ & $\mathrm{m}$ & $\mathrm{n}$ & $\mathrm{m}$ & $\mathrm{m}$ \\
\hline & & $10(0.02)$ & $1.12(0.01)$ & $-0.95(0.00)$ & -0.95 & $(0.00)$ & $-0.03(0.02)$ & $1.54(0.02)$ & $-0.03(0.04)$ & $-0.09(0.03)$ & -0.13 & $(0.04)$ & $-0.15(0.04)$ & $-\mathbf{0 . 1 2}(0.06)$ \\
\hline & & $0.49(0.01)$ & $0.98(0.01)$ & $-0.47(0.00)$ & -0.17 & $(0.01)$ & $0.75(0.01)$ & $1.86(0.02)$ & $0.43(0.03)$ & $\begin{array}{|ll|}0.43 & (0.03) \\
\end{array}$ & 0.54 & $(0.03)$ & $0.56(0.03)$ & $0.13(0.04)$ \\
\hline & & $\mathrm{m}$ & $\mathrm{m}$ & $\mathrm{m}$ & $\mathrm{m}$ & & $\mathrm{m}$ & $\mathrm{m}$ & $\mathrm{m}$ & $\mathrm{m}$ & $\mathrm{m}$ & & $\mathrm{m}$ & $\mathrm{m}$ \\
\hline & Mol & $\mathrm{m}$ & $\mathrm{m}$ & $\mathrm{m}$ & $\mathrm{m}$ & & $\mathrm{m}$ & $\mathrm{m}$ & $\mathrm{m}$ & $\mathrm{m}$ & $\mathrm{m}$ & 1 & $\mathrm{~m}$ & $\mathrm{~m}$ \\
\hline & & $91(0$ & $40(0$ & $85(0.00)$ & 85( & $0)$ & .13 & $20(C$ & $-0.90(($ & .98 & 88 & & -0.87 & 0.04 \\
\hline & & $23(0.02)$ & 22( & 60 & 66( & & -0.06 & $1.25(0.02)$ & $-0.19(C$ & -0.24 & -0.21 & & $-0.29(0.03)$ & -0.10 \\
\hline & Qatar & $0.36(0.01)$ & $1.30(0.01)$ & $-0.82(0.00)$ & -0.64 & $(0.01)$ & $0.66(0.01)$ & $2.22(0.02)$ & $0.45(0.03)$ & $\begin{array}{|ll|}0.43 & (0.02) \\
\end{array}$ & 0.30 & $(0.02)$ & $0.24(0.03)$ & $-0.21(0.04)$ \\
\hline & Rom & $\mathrm{m}$ & $\mathrm{m}$ & $\mathrm{m}$ & $\mathrm{m}$ & & $\mathrm{m}$ & $\mathrm{m}$ & $\mathrm{m}$ & $\mathrm{m}$ & $\mathrm{m}$ & & $\mathrm{m}$ & $\mathrm{m}$ \\
\hline & & 01 & .02) & 00) & -0.83 & & .01) & .56 & -0.01 & 05) & .02 & & -0.03 & -0.02 \\
\hline & & $1(0.01)$ & $0.95(0$. & $8(0$ & & & $0.75(0$ & $1.84(0$. & $0.63(0$ & $0.54(0$ & 0.47 & & $0.41(0.02)$ & -0.22 $(0.04)$ \\
\hline & Chir & $0.57(0.01)$ & $0.91(0.01)$ & $-1.12(0.00)$ & -1.12 & $(0.00)$ & $-0.91(0.01)$ & $0.84(0.01)$ & $-0.62(0.02)$ & $-0.57(0.02)$ & -0.59 & $(0.03)$ & $-0.52(0.03)$ & $\mathbf{0 . 1 0}(0.04)$ \\
\hline & & $0.11(0.03)$ & $1.43(0.02)$ & $-1.07(0.00)$ & -1.07 & $(0.00)$ & $0.37(0.01)$ & $2.20(0.03)$ & $0.14(0.05)$ & $0.12(0.05)$ & 0.10 & $(0.05)$ & $0.08(0.05)$ & $-0.06(0.07)$ \\
\hline & & $\mathrm{m}$ & & $\mathrm{m}$ & $\mathrm{m}$ & & $\mathrm{m}$ & $\mathrm{m}$ & $\mathrm{m}$ & $\mathrm{m}$ & $\mathrm{m}$ & & $\mathrm{m}$ & $\mathrm{m}$ \\
\hline & Tunis & $0.32(0.02)$ & $1.20(0.01)$ & $-0.89(0.00)$ & -0.47 & $(0.01)$ & $0.64(0.01)$ & $1.99(0.02)$ & $0.40(0.04)$ & $0.27(0.03)$ & 0.29 & (0.04) & $0.29(0.04)$ & \begin{tabular}{|c|c|}
$\mathbf{0 . 1 1}$ & $(0.05)$
\end{tabular} \\
\hline & Uni & $0.30(0.02)$ & $1.29(0.01)$ & $-0.90(0.00)$ & -0.66 & $(0.01)$ & $0.60(0.01)$ & $2.14(0.02)$ & $0.38(0.03)$ & $0.32(0.04)$ & 0.27 & $(0.03)$ & $0.21(0.03)$ & $-0.17(0.04)$ \\
\hline & & $-0.05(0.01)$ & $1.09(0.01)$ & $-0.88(0.00)$ & -0.88 & $(0.00)$ & $0.05(0.01)$ & $1.52(0.02)$ & $-0.08(0.03)$ & $-0.10(0.03)$ & -0.01 & $(0.03)$ & $\mid-0.01(0.03)$ & $0.08(0.05)$ \\
\hline & Viet Nam & $\mathrm{m}$ & $\mathrm{m}$ & $\mathrm{m}$ & $\mathrm{m}$ & & $\mathrm{m}$ & $\mathrm{m}$ & $\mathrm{m}$ & $\mathrm{m}$ & $\mathrm{m}$ & & $\mathrm{m}$ & $\mathrm{m}$ \\
\hline & & $\mathrm{m}$ & $\mathrm{m}$ & $\mathrm{m}$ & $\mathrm{m}$ & & $\mathrm{m}$ & $\mathrm{m}$ & $\mathrm{m}$ & $\mathrm{m}$ & $\mathrm{m}$ & & $\mathrm{m}$ & $\mathrm{m}$ \\
\hline & & & $\mathrm{m}$ & $\mathrm{m}$ & $\mathrm{m}$ & & $\mathrm{m}$ & $\mathrm{m}$ & $\mathrm{m}$ & $\mathrm{m}$ & $\mathrm{m}$ & & $\mathrm{m}$ & $\mathrm{m}$ \\
\hline & Malay & $65(0.02)$ & $.98(0.01)$ & $36(0.00)$ & 0.05 & $(0$ & $0.92(0.01)$ & .00 & 0.63 & $0.63(0.03)$ & 0.68 & & $0.66(0.04)$ & $0.02(0.05)$ \\
\hline
\end{tabular}

1. ESCS refers to the PISA index of economic, social and cultural status.

Note: Values that are statistically significant are indicated in bold (see Annex A3).

* See note at the beginning of this Annex.

** Coverage is too small to ensure comparability (see Annex A4).

StatLink न्ताइ http://dx.doi.org/10.1787/888933471703 
[Part 2/2]

Table III.8.5 Index of exposure to bullying, by student characteristics

Results based on students' self-reports

\begin{tabular}{|c|c|c|c|c|c|c|c|c|c|c|c|c|c|c|}
\hline & \multicolumn{14}{|c|}{ Index of exposure to bullying, by: } \\
\hline & \multicolumn{6}{|c|}{ Gender } & \multicolumn{8}{|c|}{ Immigrant background } \\
\hline & \multicolumn{2}{|c|}{ Boys } & \multicolumn{2}{|c|}{ Girls } & \multicolumn{2}{|c|}{$\begin{array}{c}\text { Gender difference } \\
(B-G)\end{array}$} & \multicolumn{2}{|c|}{ Non-immigrant } & \multicolumn{2}{|c|}{ First-generation } & \multicolumn{2}{|c|}{ Second-generation } & \multicolumn{2}{|c|}{$\begin{array}{l}\text { Difference by immigrant } \\
\text { background (non-immigrant - } \\
\text { first-generation immigrant) }\end{array}$} \\
\hline & $\begin{array}{l}\text { Mean } \\
\text { index }\end{array}$ & S.E. & $\begin{array}{l}\text { Mean } \\
\text { index }\end{array}$ & S.E. & Dif. & S.E. & $\begin{array}{l}\text { Mean } \\
\text { index }\end{array}$ & S.E. & $\begin{array}{l}\text { Mean } \\
\text { index }\end{array}$ & S.E. & $\begin{array}{l}\text { Mean } \\
\text { index }\end{array}$ & S.E. & Dif. & S.E. \\
\hline Australia & 0.51 & $(0.02)$ & 0.39 & $(0.02)$ & 0.12 & $(0.02)$ & 0.50 & $(0.01)$ & 0.33 & $(0.03)$ & 0.32 & $(0.03)$ & 0.17 & $(0.03)$ \\
\hline Austria & 0.21 & $(0.02)$ & -0.01 & $(0.02)$ & 0.22 & $(0.02)$ & 0.10 & $(0.02)$ & 0.20 & $(0.07)$ & -0.01 & $(0.03)$ & -0.10 & $(0.08)$ \\
\hline Belgium & 0.20 & $(0.02)$ & 0.16 & $(0.01)$ & 0.04 & $(0.02)$ & 0.19 & $(0.01)$ & 0.23 & $(0.05)$ & 0.07 & $(0.03)$ & -0.05 & $(0.05)$ \\
\hline Canada & 0.43 & $(0.02)$ & 0.35 & $(0.02)$ & 0.08 & $(0.02)$ & 0.41 & $(0.01)$ & 0.29 & $(0.03)$ & 0.32 & $(0.03)$ & 0.12 & $(0.03)$ \\
\hline Chile & 0.21 & $(0.02)$ & 0.09 & $(0.02)$ & 0.12 & $(0.03)$ & 0.14 & $(0.01)$ & 0.46 & $(0.15)$ & -0.02 & $(0.16)$ & -0.31 & $(0.15)$ \\
\hline Czech Republic & 0.24 & $(0.03)$ & 0.05 & $(0.02)$ & 0.20 & $(0.03)$ & 0.14 & $(0.02)$ & 0.52 & $(0.15)$ & 0.53 & $(0.15)$ & -0.39 & $(0.15)$ \\
\hline Denmark & 0.25 & $(0.02)$ & 0.20 & $(0.01)$ & 0.05 & $(0.02)$ & 0.23 & $(0.01)$ & 0.36 & $(0.07)$ & 0.14 & $(0.03)$ & -0.14 & $(0.08)$ \\
\hline Estonia & 0.31 & $(0.02)$ & 0.17 & $(0.02)$ & 0.14 & $(0.02)$ & 0.22 & $(0.02)$ & 0.28 & $(0.14)$ & 0.44 & $(0.04)$ & -0.06 & $(0.14)$ \\
\hline Finland & 0.29 & $(0.02)$ & 0.17 & $(0.02)$ & 0.12 & $(0.03)$ & 0.23 & $(0.02)$ & 0.32 & $(0.13)$ & 0.09 & $(0.08)$ & -0.09 & $(0.13)$ \\
\hline France & -0.10 & $(0.02)$ & -0.07 & $(0.02)$ & -0.03 & $(0.03)$ & -0.08 & $(0.01)$ & -0.07 & $(0.07)$ & -0.17 & $(0.05)$ & -0.01 & $(0.07)$ \\
\hline Germany & 0.20 & $(0.02)$ & 0.15 & $(0.02)$ & 0.05 & $(0.03)$ & 0.17 & $(0.02)$ & 0.30 & $(0.07)$ & 0.15 & $(0.03)$ & -0.14 & $(0.08)$ \\
\hline Greece & -0.43 & $(0.03)$ & -0.68 & $(0.02)$ & 0.26 & $(0.03)$ & -0.58 & $(0.02)$ & -0.15 & $(0.13)$ & -0.48 & $(0.07)$ & -0.43 & $(0.13)$ \\
\hline Hungary & -0.01 & $(0.03)$ & -0.12 & $(0.02)$ & 0.10 & $(0.03)$ & -0.07 & $(0.02)$ & 0.04 & $(0.16)$ & -0.02 & $(0.14)$ & -0.10 & $(0.16)$ \\
\hline Iceland & -0.44 & $(0.03)$ & -0.43 & $(0.02)$ & -0.01 & $(0.04)$ & -0.45 & $(0.02)$ & -0.15 & $(0.12)$ & -0.14 & $(0.19)$ & -0.30 & $(0.12)$ \\
\hline Ireland & 0.14 & $(0.02)$ & 0.06 & $(0.02)$ & 0.08 & $(0.03)$ & 0.08 & $(0.02)$ & 0.17 & $(0.04)$ & 0.31 & $(0.09)$ & -0.09 & $(0.04)$ \\
\hline Israel & $\mathrm{m}$ & $\mathrm{m}$ & $\mathrm{m}$ & $\mathrm{m}$ & $\mathrm{m}$ & $\mathrm{m}$ & $\mathrm{m}$ & $\mathrm{m}$ & $\mathrm{m}$ & $\mathrm{m}$ & $\mathrm{m}$ & $\mathrm{m}$ & $\mathrm{m}$ & $\mathrm{m}$ \\
\hline Italy & $\mathrm{m}$ & $\mathrm{m}$ & $\mathrm{m}$ & $\mathrm{m}$ & $\mathrm{m}$ & $\mathrm{m}$ & $\mathrm{m}$ & $\mathrm{m}$ & $\mathrm{m}$ & $\mathrm{m}$ & $\mathrm{m}$ & $\mathrm{m}$ & $\mathrm{m}$ & $\mathrm{m}$ \\
\hline Japan & -0.13 & $(0.02)$ & -0.28 & $(0.02)$ & 0.15 & $(0.02)$ & -0.21 & $(0.02)$ & C & C & c & C & C & C \\
\hline Korea & -1.38 & $(0.02)$ & -1.50 & $(0.02)$ & 0.12 & $(0.03)$ & -1.44 & $(0.02)$ & $\mathrm{c}$ & c & $\mathrm{m}$ & $\mathrm{m}$ & c & c \\
\hline Latvia & 0.74 & $(0.02)$ & 0.57 & $(0.02)$ & 0.16 & $(0.03)$ & 0.65 & $(0.02)$ & 0.66 & $(0.18)$ & 0.71 & $(0.06)$ & -0.02 & $(0.18)$ \\
\hline Luxembourg & -0.09 & $(0.02)$ & -0.21 & $(0.02)$ & 0.12 & $(0.03)$ & -0.22 & $(0.02)$ & 0.05 & $(0.04)$ & -0.19 & $(0.03)$ & -0.27 & $(0.04)$ \\
\hline Mexico & 0.22 & $(0.02)$ & 0.03 & $(0.02)$ & 0.19 & $(0.03)$ & 0.12 & $(0.01)$ & 0.36 & $(0.15)$ & C & c & -0.24 & $(0.16)$ \\
\hline Netherlands & -0.32 & $(0.02)$ & -0.33 & $(0.02)$ & 0.01 & $(0.03)$ & -0.32 & $(0.01)$ & -0.26 & $(0.07)$ & -0.37 & $(0.03)$ & -0.06 & $(0.07)$ \\
\hline New Zealand & 0.71 & $(0.02)$ & 0.52 & $(0.02)$ & 0.19 & $(0.03)$ & 0.65 & $(0.02)$ & 0.56 & $(0.04)$ & 0.37 & $(0.05)$ & 0.09 & $(0.05)$ \\
\hline Norway & 0.02 & $(0.02)$ & -0.04 & $(0.02)$ & 0.06 & $(0.03)$ & -0.01 & $(0.02)$ & 0.12 & $(0.08)$ & -0.09 & $(0.06)$ & -0.13 & $(0.08)$ \\
\hline Poland & 0.33 & $(0.02)$ & 0.21 & $(0.02)$ & 0.12 & $(0.03)$ & 0.27 & $(0.02)$ & $\mathrm{C}$ & $\mathrm{C}$ & C & $\mathrm{C}$ & $\mathrm{C}$ & $\mathrm{C}$ \\
\hline Portugal & -0.49 & $(0.02)$ & -0.55 & $(0.02)$ & 0.06 & $(0.03)$ & -0.53 & $(0.02)$ & -0.34 & $(0.08)$ & -0.49 & $(0.09)$ & -0.19 & $(0.08)$ \\
\hline Slovak Republic & 0.18 & $(0.03)$ & 0.03 & $(0.03)$ & 0.15 & $(0.03)$ & 0.09 & $(0.02)$ & c & c & 0.74 & $(0.32)$ & c & c \\
\hline Slovenia & 0.09 & $(0.02)$ & -0.06 & $(0.02)$ & 0.15 & $(0.03)$ & 0.01 & $(0.01)$ & 0.15 & $(0.10)$ & -0.05 & $(0.06)$ & -0.14 & $(0.10)$ \\
\hline Spain & -0.05 & $(0.02)$ & -0.14 & $(0.02)$ & 0.09 & $(0.02)$ & -0.11 & $(0.02)$ & 0.04 & $(0.04)$ & 0.06 & $(0.09)$ & -0.15 & $(0.05)$ \\
\hline Sweden & -0.12 & $(0.03)$ & -0.11 & $(0.03)$ & -0.01 & $(0.03)$ & -0.12 & $(0.02)$ & -0.08 & $(0.06)$ & -0.13 & $(0.05)$ & -0.04 & $(0.06)$ \\
\hline Switzerland & 0.25 & $(0.02)$ & 0.22 & $(0.02)$ & 0.03 & $(0.02)$ & 0.23 & $(0.02)$ & 0.36 & $(0.05)$ & 0.20 & $(0.03)$ & -0.13 & $(0.05)$ \\
\hline Turkey & -0.74 & $(0.05)$ & -1.21 & $(0.03)$ & 0.47 & $(0.05)$ & -0.99 & $(0.03)$ & c & c & -0.71 & $(0.44)$ & c & c \\
\hline United Kingdom & 0.42 & $(0.02)$ & 0.39 & $(0.02)$ & 0.03 & $(0.03)$ & 0.40 & $(0.01)$ & 0.46 & $(0.06)$ & 0.29 & $(0.06)$ & -0.06 & $(0.06)$ \\
\hline United States & 0.15 & $(0.02)$ & 0.18 & $(0.02)$ & -0.02 & $(0.03)$ & 0.19 & $(0.02)$ & 0.16 & $(0.07)$ & 0.04 & $(0.03)$ & 0.03 & $(0.07)$ \\
\hline OECD average & 0.05 & $(0.00)$ & -0.05 & $(0.00)$ & 0.11 & $(0.01)$ & 0.00 & $(0.00)$ & 0.19 & $(0.02)$ & 0.07 & $(0.02)$ & -0.12 & $(0.02)$ \\
\hline
\end{tabular}

\begin{tabular}{|c|c|c|c|c|c|c|c|c|c|c|c|c|c|c|}
\hline Albania & $\mathrm{m}$ & $\mathrm{m}$ & $\mathrm{m}$ & $\mathrm{m}$ & $\mathrm{m}$ & $\mathrm{m}$ & $\mathrm{m}$ & $\mathrm{m}$ & $\mathrm{m}$ & $\mathrm{m}$ & $\mathrm{m}$ & $\mathrm{m}$ & $\mathrm{m}$ & $\mathrm{m}$ \\
\hline Algeria & $\mathrm{m}$ & $\mathrm{m}$ & $\mathrm{m}$ & $\mathrm{m}$ & $\mathrm{m}$ & $\mathrm{m}$ & $\mathrm{m}$ & $\mathrm{m}$ & $\mathrm{m}$ & $\mathrm{m}$ & $\mathrm{m}$ & $\mathrm{m}$ & $\mathrm{m}$ & $\mathrm{m}$ \\
\hline Brazil & -0.11 & $(0.02)$ & -0.34 & $(0.01)$ & 0.23 & $(0.03)$ & -0.24 & $(0.01)$ & 0.09 & $(0.30)$ & 0.46 & $(0.26)$ & -0.33 & $(0.30)$ \\
\hline B-S-J-G (China) & 0.26 & $(0.03)$ & -0.08 & $(0.02)$ & 0.34 & $(0.03)$ & 0.10 & $(0.02)$ & C & C & C & C & C & c \\
\hline Bulgaria & 0.21 & $(0.03)$ & 0.07 & $(0.03)$ & 0.14 & $(0.03)$ & 0.13 & $(0.02)$ & c & c & c & c & c & c \\
\hline CABA (Argentina) & $\mathrm{m}$ & $\mathrm{m}$ & $\mathrm{m}$ & $\mathrm{m}$ & $\mathrm{m}$ & $\mathrm{m}$ & $\mathrm{m}$ & $\mathrm{m}$ & $\mathrm{m}$ & $\mathrm{m}$ & $\mathrm{m}$ & $\mathrm{m}$ & $\mathrm{m}$ & $\mathrm{m}$ \\
\hline Colombia & 0.28 & $(0.02)$ & 0.06 & $(0.02)$ & 0.22 & $(0.02)$ & 0.15 & $(0.01)$ & c & c & 0.64 & $(0.16)$ & c & c \\
\hline Costa Rica & 0.13 & $(0.02)$ & 0.08 & $(0.02)$ & 0.05 & $(0.03)$ & 0.11 & $(0.02)$ & 0.11 & $(0.09)$ & -0.05 & $(0.06)$ & 0.00 & $(0.09)$ \\
\hline Croatia & -0.08 & $(0.03)$ & -0.15 & $(0.02)$ & 0.07 & $(0.03)$ & -0.12 & $(0.02)$ & 0.01 & $(0.11)$ & -0.09 & $(0.04)$ & -0.13 & $(0.11)$ \\
\hline Cyprus* & $\mathrm{m}$ & $\mathrm{m}$ & $\mathrm{m}$ & $\mathrm{m}$ & $\mathrm{m}$ & $\mathrm{m}$ & $\mathrm{m}$ & $\mathrm{m}$ & $\mathrm{m}$ & $\mathrm{m}$ & $\mathrm{m}$ & $\mathrm{m}$ & $\mathrm{m}$ & $\mathrm{m}$ \\
\hline Dominican Republic & -0.13 & $(0.04)$ & -0.43 & $(0.03)$ & 0.30 & $(0.05)$ & -0.31 & $(0.03)$ & 0.21 & $(0.30)$ & 0.14 & $(0.32)$ & -0.52 & $(0.31)$ \\
\hline FYROM & $\mathrm{m}$ & $\mathrm{m}$ & $\mathrm{m}$ & $\mathrm{m}$ & $\mathrm{m}$ & $\mathrm{m}$ & $\mathrm{m}$ & $\mathrm{m}$ & $\mathrm{m}$ & $\mathrm{m}$ & $\mathrm{m}$ & $\mathrm{m}$ & $\mathrm{m}$ & $\mathrm{m}$ \\
\hline Georgia & $\mathrm{m}$ & $\mathrm{m}$ & $\mathrm{m}$ & $\mathrm{m}$ & $\mathrm{m}$ & $\mathrm{m}$ & $\mathrm{m}$ & $\mathrm{m}$ & $\mathrm{m}$ & $\mathrm{m}$ & $\mathrm{m}$ & $\mathrm{m}$ & $\mathrm{m}$ & $\mathrm{m}$ \\
\hline Hong Kong (China) & 0.46 & $(0.03)$ & -0.04 & $(0.02)$ & 0.49 & $(0.04)$ & 0.22 & $(0.03)$ & 0.14 & $(0.05)$ & 0.22 & $(0.04)$ & 0.08 & $(0.06)$ \\
\hline Indonesia & $\mathrm{m}$ & $\mathrm{m}$ & $\mathrm{m}$ & $\mathrm{m}$ & $\mathrm{m}$ & $\mathrm{m}$ & $\mathrm{m}$ & $\mathrm{m}$ & $\mathrm{m}$ & $\mathrm{m}$ & $\mathrm{m}$ & $\mathrm{m}$ & $\mathrm{m}$ & $\mathrm{m}$ \\
\hline Jordan & $\mathrm{m}$ & $\mathrm{m}$ & $\mathrm{m}$ & $\mathrm{m}$ & $\mathrm{m}$ & $\mathrm{m}$ & $\mathrm{m}$ & $\mathrm{m}$ & $\mathrm{m}$ & $\mathrm{m}$ & $\mathrm{m}$ & $\mathrm{m}$ & $\mathrm{m}$ & $\mathrm{m}$ \\
\hline Kosovo & $\mathrm{m}$ & $\mathrm{m}$ & $\mathrm{m}$ & $\mathrm{m}$ & $\mathrm{m}$ & $\mathrm{m}$ & $\mathrm{m}$ & $\mathrm{m}$ & $\mathrm{m}$ & $\mathrm{m}$ & $\mathrm{m}$ & $\mathrm{m}$ & $\mathrm{m}$ & $\mathrm{m}$ \\
\hline Lebanon & $\mathrm{m}$ & $\mathrm{m}$ & $\mathrm{m}$ & $\mathrm{m}$ & $\mathrm{m}$ & $\mathrm{m}$ & $\mathrm{m}$ & $\mathrm{m}$ & $\mathrm{m}$ & $\mathrm{m}$ & $\mathrm{m}$ & $\mathrm{m}$ & $\mathrm{m}$ & $\mathrm{m}$ \\
\hline Lithuania & -0.07 & $(0.02)$ & -0.13 & $(0.02)$ & 0.06 & $(0.03)$ & -0.11 & $(0.02)$ & 0.34 & $(0.37)$ & -0.09 & $(0.09)$ & -0.45 & $(0.37)$ \\
\hline Macao (China) & 0.68 & $(0.02)$ & 0.30 & $(0.01)$ & 0.37 & $(0.03)$ & 0.56 & $(0.02)$ & 0.35 & $(0.03)$ & 0.49 & $(0.02)$ & 0.21 & $(0.04)$ \\
\hline Malta & $\mathrm{m}$ & $\mathrm{m}$ & $\mathrm{m}$ & $\mathrm{m}$ & $\mathrm{m}$ & $\mathrm{m}$ & $\mathrm{m}$ & $\mathrm{m}$ & $\mathrm{m}$ & $\mathrm{m}$ & $\mathrm{m}$ & $\mathrm{m}$ & $\mathrm{m}$ & $\mathrm{m}$ \\
\hline Moldova & $\mathrm{m}$ & $\mathrm{m}$ & $\mathrm{m}$ & $\mathrm{m}$ & $\mathrm{m}$ & $\mathrm{m}$ & $\mathrm{m}$ & $\mathrm{m}$ & $\mathrm{m}$ & $\mathrm{m}$ & $\mathrm{m}$ & $\mathrm{m}$ & $\mathrm{m}$ & $\mathrm{m}$ \\
\hline Montenegro & -0.79 & $(0.03)$ & -1.03 & $(0.02)$ & 0.24 & $(0.04)$ & -0.92 & $(0.02)$ & -0.46 & $(0.17)$ & -0.75 & $(0.10)$ & -0.46 & $(0.17)$ \\
\hline Peru & -0.09 & $(0.02)$ & -0.38 & $(0.02)$ & 0.29 & $(0.03)$ & -0.23 & $(0.02)$ & $\mathrm{C}$ & c & c & c & c & c \\
\hline Qatar & 0.70 & $(0.02)$ & 0.03 & $(0.01)$ & 0.67 & $(0.02)$ & 0.32 & $(0.02)$ & 0.36 & $(0.01)$ & 0.36 & $(0.03)$ & -0.04 & $(0.03)$ \\
\hline Romania & $\mathrm{m}$ & $\mathrm{m}$ & $\mathrm{m}$ & $\mathrm{m}$ & $\mathrm{m}$ & $\mathrm{m}$ & $\mathrm{m}$ & $\mathrm{m}$ & $\mathrm{m}$ & $\mathrm{m}$ & $\mathrm{m}$ & $\mathrm{m}$ & $\mathrm{m}$ & $\mathrm{m}$ \\
\hline Russia & 0.00 & $(0.04)$ & -0.02 & $(0.04)$ & 0.01 & $(0.03)$ & -0.01 & $(0.03)$ & 0.08 & $(0.17)$ & -0.09 & $(0.07)$ & -0.09 & $(0.15)$ \\
\hline Singapore & 0.70 & $(0.02)$ & 0.32 & $(0.02)$ & 0.38 & $(0.03)$ & 0.52 & $(0.01)$ & 0.48 & $(0.03)$ & 0.49 & $(0.05)$ & 0.04 & $(0.04)$ \\
\hline Chinese Taipei & -0.47 & $(0.02)$ & -0.69 & $(0.01)$ & 0.22 & $(0.03)$ & -0.57 & $(0.01)$ & c & c & c & c & c & c \\
\hline Thailand & 0.41 & $(0.04)$ & -0.12 & $(0.04)$ & 0.52 & $(0.05)$ & 0.09 & $(0.03)$ & c & c & 0.49 & $(0.20)$ & c & c \\
\hline Trinidad and Tobago & $\mathrm{m}$ & $\mathrm{m}$ & $\mathrm{m}$ & $\mathrm{m}$ & $\mathrm{m}$ & $\mathrm{m}$ & $\mathrm{m}$ & $\mathrm{m}$ & $\mathrm{m}$ & $\mathrm{m}$ & $\mathrm{m}$ & $\mathrm{m}$ & $\mathrm{m}$ & $\mathrm{m}$ \\
\hline Tunisia & 0.58 & $(0.04)$ & 0.10 & $(0.02)$ & 0.48 & $(0.04)$ & 0.29 & $(0.02)$ & c & c & 1.03 & $(0.21)$ & c & c \\
\hline United Arab Emirates & 0.60 & $(0.02)$ & 0.02 & $(0.02)$ & 0.58 & $(0.03)$ & 0.26 & $(0.03)$ & 0.28 & $(0.02)$ & 0.32 & $(0.03)$ & -0.02 & $(0.04)$ \\
\hline Uruguay & -0.01 & $(0.02)$ & -0.08 & $(0.02)$ & 0.08 & $(0.03)$ & -0.05 & $(0.01)$ & c & C & c & c & c & c \\
\hline Viet Nam & $\mathrm{m}$ & $\mathrm{m}$ & $\mathrm{m}$ & $\mathrm{m}$ & $\mathrm{m}$ & $\mathrm{m}$ & $\mathrm{m}$ & $\mathrm{m}$ & $\mathrm{m}$ & $\mathrm{m}$ & $\mathrm{m}$ & $\mathrm{m}$ & $\mathrm{m}$ & $\mathrm{m}$ \\
\hline Argentina** & $\mathrm{m}$ & $\mathrm{m}$ & $\mathrm{m}$ & $\mathrm{m}$ & $\mathrm{m}$ & $\mathrm{m}$ & $\mathrm{m}$ & $\mathrm{m}$ & $\mathrm{m}$ & $\mathrm{m}$ & $\mathrm{m}$ & $\mathrm{m}$ & $\mathrm{m}$ & $\mathrm{m}$ \\
\hline Kazakhstan** & $\mathrm{m}$ & $\mathrm{m}$ & $\mathrm{m}$ & $\mathrm{m}$ & $\mathrm{m}$ & $\mathrm{m}$ & $\mathrm{m}$ & $\mathrm{m}$ & $\mathrm{m}$ & $\mathrm{m}$ & $\mathrm{m}$ & $\mathrm{m}$ & $\mathrm{m}$ & $\mathrm{m}$ \\
\hline Malaysia** & 0.84 & $(0.03)$ & 0.48 & $(0.02)$ & 0.36 & $(0.03)$ & 0.64 & $(0.02)$ & c & C & 1.11 & $(0.18)$ & C & C \\
\hline
\end{tabular}

1. ESCS refers to the PISA index of economic, social and cultural status.

Note: Values that are statistically significant are indicated in bold (see Annex A3).

* See note at the beginning of this Annex.

.

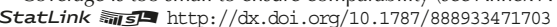




\begin{tabular}{|c|c|c|c|c|c|c|c|c|c|c|c|c|c|c|c|c|c|c|}
\hline & & & & & & & & & & & Index of & exposur & e to bul & ying, by: & & & \\
\hline & & & Variat & tion in th & e index $c$ & of exposu & ire to bu & ullying & & & & School & socio-ec & onomic & profile $^{1}$ & & & \\
\hline & & $\begin{array}{r}\text { Tote } \\
\text { variat }\end{array}$ & $\begin{array}{l}\text { tal } \\
\text { tion }\end{array}$ & $\begin{array}{l}\text { Varia } \\
\text { betw } \\
\text { scho }\end{array}$ & $\begin{array}{l}\text { tion } \\
\text { eeen } \\
\text { ols }^{3}\end{array}$ & $\begin{array}{r}\text { Variat } \\
\text { within }\end{array}$ & $\begin{array}{l}\text { tion } \\
\text { chools }\end{array}$ & 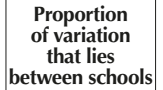 & & & & & $\begin{array}{l}\text { Th } \\
\text { qua }\end{array}$ & & $\begin{array}{r}\text { To } \\
\text { qua }\end{array}$ & & $\begin{array}{r}\text { Top - b } \\
\text { qua }\end{array}$ & $\begin{array}{l}\text { ottom } \\
\text { rter }\end{array}$ \\
\hline & & Coefficient & S.E. & Coefficient & S.E. & Coefficient & S.E. & $\%$ & Mean & S.E. & Mean & S.E. & Mean & S.E. & Mean & S.E. & Dif. & S.E. \\
\hline & Australia & 1.07 & (0.03) & 0.07 & $(0.01)$ & 1.00 & $(0.02)$ & 6.1 & 0.62 & $(0.03)$ & 0.51 & $(0.03)$ & 0.42 & $(0.02)$ & 0.27 & $(0.02)$ & -0.35 & $(0.04)$ \\
\hline ड & Austria & 0.88 & $(0.03)$ & 0.02 & $(0.01)$ & 0.86 & $(0.03)$ & 2.0 & 0.10 & $(0.04)$ & 0.09 & $(0.04)$ & 0.08 & $(0.04)$ & 0.12 & $(0.03)$ & 0.02 & $(0.05)$ \\
\hline ప & Belgium & 0.73 & $(0.02)$ & 0.02 & $(0.00)$ & 0.71 & $(0.02)$ & 2.1 & 0.25 & $(0.03)$ & 0.23 & $(0.03)$ & 0.17 & $(0.03)$ & 0.09 & $(0.02)$ & -0.16 & $(0.03)$ \\
\hline & Canada & 0.95 & $(0.02)$ & 0.02 & $(0.00)$ & 0.93 & $(0.02)$ & 2.3 & 0.46 & $(0.02)$ & 0.39 & $(0.03)$ & 0.39 & $(0.03)$ & 0.30 & $(0.03)$ & -0.16 & $(0.03)$ \\
\hline & Chile & 0.79 & $(0.03)$ & 0.01 & $(0.00)$ & 0.77 & $(0.02)$ & 1.3 & 0.20 & $(0.05)$ & 0.14 & $(0.04)$ & 0.12 & $(0.04)$ & 0.13 & $(0.02)$ & -0.06 & $(0.06)$ \\
\hline & Czech Republic & 1.11 & $(0.04)$ & 0.06 & $(0.01)$ & 1.04 & $(0.03)$ & 5.5 & 0.20 & $(0.03)$ & 0.21 & $(0.05)$ & 0.11 & $(0.04)$ & 0.09 & $(0.04)$ & -0.11 & $(0.05)$ \\
\hline & Denmark & 0.63 & $(0.02)$ & 0.01 & $(0.00)$ & 0.62 & $(0.01)$ & 1.4 & 0.26 & $(0.03)$ & 0.21 & $(0.02)$ & 0.21 & $(0.03)$ & 0.21 & $(0.03)$ & -0.05 & $(0.04)$ \\
\hline & Estonia & 0.79 & $(0.02)$ & 0.01 & $(0.00)$ & 0.78 & $(0.02)$ & 1.3 & 0.28 & $(0.04)$ & 0.23 & $(0.03)$ & 0.25 & $(0.03)$ & 0.21 & $(0.03)$ & -0.07 & $(0.04)$ \\
\hline & Finland & 0.82 & $(0.02)$ & 0.01 & $(0.00)$ & 0.81 & $(0.02)$ & 1.7 & 0.29 & $(0.04)$ & 0.19 & $(0.04)$ & 0.23 & $(0.04)$ & 0.21 & $(0.04)$ & -0.09 & (0.05) \\
\hline & France & 0.92 & $(0.03)$ & 0.03 & $(0.01)$ & 0.89 & $(0.03)$ & 3.0 & 0.10 & $(0.03)$ & -0.03 & $(0.03)$ & -0.21 & $(0.02)$ & -0.18 & $(0.03)$ & -0.27 & $(0.05)$ \\
\hline & Germany & 0.65 & $(0.02)$ & 0.02 & $(0.00)$ & 0.63 & $(0.02)$ & 3.0 & 0.21 & $(0.04)$ & 0.22 & $(0.04)$ & 0.15 & $(0.03)$ & 0.12 & $(0.03)$ & -0.09 & $(0.05)$ \\
\hline & Greece & 1.44 & $(0.07)$ & 0.05 & $(0.01)$ & 1.40 & $(0.05)$ & 3.2 & -0.41 & $(0.07)$ & -0.57 & $(0.04)$ & -0.66 & $(0.04)$ & -0.56 & $(0.04)$ & -0.15 & $(0.08)$ \\
\hline & Hungary & 1.18 & $(0.05)$ & 0.03 & $(0.01)$ & 1.15 & $(0.04)$ & 2.5 & 0.07 & $(0.05)$ & -0.11 & $(0.04)$ & -0.11 & $(0.04)$ & -0.11 & $(0.03)$ & -0.17 & $(0.06)$ \\
\hline & Iceland & 0.95 & $(0.05)$ & 0.02 & $(0.01)$ & 0.93 & (0.05) & 2.3 & -0.32 & $(0.04)$ & -0.47 & $(0.03)$ & -0.42 & $(0.04)$ & -0.53 & $(0.03)$ & -0.21 & $(0.05)$ \\
\hline & Ireland & 0.77 & $(0.02)$ & 0.02 & $(0.00)$ & 0.76 & $(0.02)$ & 2.1 & 0.08 & $(0.03)$ & 0.14 & $(0.04)$ & 0.07 & $(0.04)$ & 0.11 & $(0.03)$ & 0.03 & $(0.04)$ \\
\hline & Israel & $\mathrm{m}$ & $\mathrm{m}$ & $\mathrm{m}$ & $\mathrm{m}$ & $\mathrm{m}$ & $\mathrm{m}$ & $\mathrm{m}$ & $\mathrm{m}$ & $\mathrm{m}$ & $\mathrm{m}$ & $\mathrm{m}$ & $\mathrm{m}$ & $\mathrm{m}$ & $\mathrm{m}$ & $\mathrm{m}$ & $\mathrm{m}$ & $\mathrm{m}$ \\
\hline & Italy & $\mathrm{m}$ & & $\mathrm{m}$ & $\mathrm{m}$ & $\mathrm{m}$ & $\mathrm{m}$ & $\mathrm{m}$ & $\mathrm{m}$ & $\mathrm{m}$ & $\mathrm{m}$ & $\mathrm{m}$ & $\mathrm{m}$ & $\mathrm{m}$ & $\mathrm{m}$ & $\mathrm{m}$ & $\mathrm{m}$ & $\mathrm{m}$ \\
\hline & Japan & 0.95 & $(0.03)$ & 0.03 & $(0.01)$ & 0.92 & $(0.03)$ & 3.6 & -0.27 & $(0.04)$ & -0.27 & $(0.04)$ & -0.19 & $(0.04)$ & -0.10 & $(0.03)$ & 0.17 & $(0.05)$ \\
\hline & Korea & 1.18 & $(0.04)$ & 0.02 & $(0.01)$ & 1.16 & $(0.04)$ & 1.4 & -1.48 & $(0.03)$ & -1.44 & $(0.04)$ & -1.49 & $(0.04)$ & -1.36 & $(0.04)$ & 0.12 & $(0.05)$ \\
\hline & Latvia & 0.84 & $(0.03)$ & 0.03 & $(0.01)$ & 0.81 & $(0.02)$ & 3.5 & 0.70 & $(0.05)$ & 0.70 & $(0.05)$ & 0.65 & $(0.05)$ & 0.56 & $(0.03)$ & -0.14 & $(0.06)$ \\
\hline & Luxembourg & 1.10 & $(0.06)$ & 0.01 & $(0.01)$ & 1.08 & $(0.05)$ & 1.2 & -0.07 & $(0.03)$ & -0.22 & $(0.03)$ & -0.15 & $(0.02)$ & -0.17 & $(0.03)$ & -0.10 & $(0.04)$ \\
\hline & Mexico & 1.03 & $(0.03)$ & 0.04 & $(0.01)$ & 0.99 & $(0.02)$ & 3.9 & 0.21 & $(0.03)$ & 0.15 & $(0.03)$ & 0.08 & $(0.04)$ & 0.06 & $(0.04)$ & -0.14 & $(0.06)$ \\
\hline & Netherlands & 0.67 & $(0.03)$ & 0.01 & $(0.00)$ & 0.66 & $(0.03)$ & 1.5 & -0.26 & $(0.04)$ & -0.33 & $(0.02)$ & -0.36 & $(0.02)$ & -0.34 & $(0.03)$ & -0.08 & $(0.05)$ \\
\hline & New Zealand & 1.06 & $(0.04)$ & 0.03 & $(0.01)$ & 1.03 & $(0.03)$ & 2.9 & 0.77 & $(0.04)$ & 0.61 & $(0.05)$ & 0.56 & $(0.04)$ & 0.52 & $(0.03)$ & -0.25 & $(0.05)$ \\
\hline & Norway & 1.14 & $(0.03)$ & 0.01 & $(0.01)$ & 1.13 & $(0.03)$ & 1.2 & 0.01 & $(0.05)$ & 0.03 & $(0.04)$ & -0.03 & $(0.03)$ & -0.05 & $(0.04)$ & -0.06 & $(0.07)$ \\
\hline & Poland & 0.91 & $(0.03)$ & 0.01 & $(0.00)$ & 0.91 & $(0.02)$ & 0.7 & 0.27 & $(0.04)$ & 0.31 & $(0.04)$ & 0.26 & $(0.04)$ & 0.25 & $(0.03)$ & -0.03 & $(0.05)$ \\
\hline & Portugal & 1.18 & $(0.04)$ & 0.01 & $(0.01)$ & 1.17 & $(0.03)$ & 1.2 & -0.47 & $(0.03)$ & -0.50 & $(0.05)$ & -0.52 & $(0.05)$ & -0.58 & $(0.03)$ & -0.11 & $(0.04)$ \\
\hline & Slovak Republic & 1.22 & $(0.05)$ & 0.07 & $(0.01)$ & 1.16 & $(0.04)$ & 5.4 & 0.25 & $(0.04)$ & 0.09 & $(0.06)$ & 0.11 & $(0.06)$ & -0.03 & $(0.05)$ & -0.28 & $(0.07)$ \\
\hline & Slovenia & 0.86 & $(0.03)$ & 0.03 & $(0.01)$ & 0.83 & $(0.03)$ & 3.1 & 0.10 & $(0.03)$ & 0.03 & $(0.03)$ & -0.02 & $(0.02)$ & -0.04 & $(0.03)$ & -0.14 & $(0.04)$ \\
\hline & Spain & 0.83 & $(0.03)$ & 0.02 & $(0.00)$ & 0.80 & $(0.02)$ & 2.5 & -0.06 & $(0.03)$ & -0.09 & $(0.03)$ & -0.15 & $(0.03)$ & -0.07 & $(0.04)$ & -0.01 & $(0.05)$ \\
\hline & Sweden & 1.24 & $(0.04)$ & 0.04 & $(0.01)$ & 1.20 & $(0.03)$ & 3.5 & -0.02 & $(0.04)$ & -0.10 & $(0.04)$ & -0.14 & $(0.06)$ & -0.20 & $(0.05)$ & -0.18 & $(0.07)$ \\
\hline & Switzerland & 0.68 & $(0.03)$ & 0.03 & $(0.00)$ & 0.65 & $(0.02)$ & 3.8 & 0.27 & $(0.04)$ & 0.23 & $(0.04)$ & 0.28 & $(0.04)$ & 0.17 & $(0.03)$ & -0.11 & $(0.04)$ \\
\hline & Turkey & 2.46 & $(0.10)$ & 0.06 & $(0.02)$ & 2.40 & $(0.08)$ & 2.4 & -0.82 & $(0.09)$ & -1.05 & $(0.07)$ & -1.11 & $(0.05)$ & -0.91 & $(0.08)$ & -0.09 & $(0.13)$ \\
\hline & United Kingdom & 1.07 & $(0.03)$ & 0.03 & $(0.01)$ & 1.04 & $(0.02)$ & 2.5 & 0.39 & $(0.04)$ & 0.41 & $(0.03)$ & 0.45 & $(0.03)$ & 0.35 & $(0.03)$ & -0.04 & $(0.05)$ \\
\hline & United States & 1.00 & $(0.03)$ & 0.02 & $(0.01)$ & 0.98 & $(0.02)$ & 2.3 & 0.13 & $(0.05)$ & 0.15 & $(0.04)$ & 0.19 & $(0.04)$ & 0.18 & $(0.04)$ & 0.05 & $(0.06)$ \\
\hline & OECD average & 1.00 & $(0.01)$ & 0.03 & $(0.00)$ & 0.98 & $(0.01)$ & 2.6 & 0.06 & $(0.01)$ & 0.00 & $(0.01)$ & -0.02 & $(0.01)$ & -0.04 & $(0.01)$ & -0.10 & $(0.01)$ \\
\hline & Albania & $\mathrm{m}$ & $\mathrm{m}$ & $\mathrm{m}$ & $\mathrm{m}$ & $\mathrm{m}$ & $\mathrm{m}$ & $\mathrm{m}$ & $\mathrm{m}$ & $\mathrm{m}$ & $\mathrm{m}$ & $\mathrm{m}$ & $\mathrm{m}$ & $\mathrm{m}$ & $\mathrm{m}$ & $\mathrm{m}$ & $\mathrm{m}$ & $\mathrm{n}$ \\
\hline ఏ & Algeria & $\mathrm{m}$ & $\mathrm{m}$ & $\mathrm{m}$ & $\mathrm{m}$ & $\mathrm{m}$ & $\mathrm{m}$ & $\mathrm{m}$ & $\mathrm{m}$ & $\mathrm{m}$ & $\mathrm{m}$ & $\mathrm{m}$ & $\mathrm{m}$ & $\mathrm{m}$ & $\mathrm{m}$ & $\mathrm{m}$ & $\mathrm{m}$ & $\mathrm{m}$ \\
\hline$\Sigma$ & Brazil & 1.36 & $(0.03)$ & 0.03 & $(0.01)$ & 1.33 & $(0.03)$ & 2.2 & -0.20 & $(0.03)$ & -0.25 & $(0.02)$ & -0.26 & $(0.03)$ & -0.20 & $(0.03)$ & 0.00 & $(0.04)$ \\
\hline$\pi$ & B-S-J-G (China) & 1.07 & $(0.04)$ & 0.05 & $(0.01)$ & 1.02 & $(0.03)$ & 4.6 & 0.25 & $(0.04)$ & 0.15 & $(0.05)$ & 0.03 & $(0.06)$ & -0.05 & $(0.02)$ & -0.30 & $(0.05)$ \\
\hline & Bulgaria & 1.38 & $(0.04)$ & 0.04 & $(0.01)$ & 1.35 & $(0.04)$ & 2.6 & 0.23 & $(0.06)$ & 0.20 & $(0.06)$ & 0.10 & $(0.05)$ & 0.06 & $(0.03)$ & -0.17 & $(0.07)$ \\
\hline & CABA (Argentina) & $\mathrm{m}$ & $\mathrm{m}$ & $\mathrm{m}$ & $\mathrm{m}$ & $\mathrm{m}$ & $\mathrm{m}$ & $\mathrm{m}$ & $\mathrm{m}$ & $\mathrm{m}$ & $\mathrm{m}$ & $\mathrm{m}$ & $\mathrm{m}$ & $\mathrm{m}$ & $\mathrm{m}$ & $\mathrm{m}$ & $\mathrm{m}$ & $\mathrm{m}$ \\
\hline & Colombia & 0.83 & $(0.02)$ & 0.01 & $(0.00)$ & 0.82 & $(0.02)$ & 1.8 & 0.17 & $(0.04)$ & 0.23 & $(0.03)$ & 0.13 & $(0.03)$ & 0.11 & $(0.03)$ & -0.06 & $(0.05)$ \\
\hline & Costa Rica & 1.11 & $(0.03)$ & 0.02 & $(0.01)$ & 1.09 & $(0.03)$ & 1.5 & 0.14 & $(0.04)$ & 0.06 & $(0.04)$ & 0.04 & $(0.03)$ & 0.17 & $(0.04)$ & 0.03 & $(0.05)$ \\
\hline & Croatia & 0.94 & $(0.03)$ & 0.03 & $(0.01)$ & 0.91 & $(0.03)$ & 3.6 & -0.02 & $(0.04)$ & -0.09 & $(0.05)$ & -0.14 & $(0.04)$ & -0.21 & $(0.03)$ & -0.19 & $(0.05)$ \\
\hline & Cyprus* & $\mathrm{m}$ & & $\mathrm{m}$ & $\mathrm{m}$ & $\mathrm{m}$ & $\mathrm{m}$ & $\mathrm{m}$ & $\mathrm{m}$ & $\mathrm{m}$ & $\mathrm{m}$ & $\mathrm{m}$ & $\mathrm{m}$ & $\mathrm{m}$ & $\mathrm{m}$ & $\mathrm{m}$ & $\mathrm{m}$ & $\mathrm{m}$ \\
\hline & Dominican Republic & 2.03 & $(0.07)$ & 0.05 & $(0.02)$ & 1.98 & $(0.05)$ & 2.6 & -0.25 & $(0.06)$ & -0.37 & $(0.08)$ & -0.26 & $(0.07)$ & -0.27 & $(0.06)$ & -0.02 & $(0.08)$ \\
\hline & FYROM & $\mathrm{m}$ & $\mathrm{m}$ & $\mathrm{m}$ & $\mathrm{m}$ & $\mathrm{m}$ & $\mathrm{m}$ & $\mathrm{m}$ & $\mathrm{m}$ & $\mathrm{m}$ & $\mathrm{m}$ & $\mathrm{m}$ & $\mathrm{m}$ & $\mathrm{m}$ & $\mathrm{m}$ & $\mathrm{m}$ & $\mathrm{m}$ & $\mathrm{m}$ \\
\hline & Georgia & $\mathrm{m}$ & & $\mathrm{m}$ & $\mathrm{m}$ & $\mathrm{m}$ & $\mathrm{m}$ & $\mathrm{m}$ & $\mathrm{m}$ & $\mathrm{m}$ & $\mathrm{m}$ & $\mathrm{m}$ & $\mathrm{m}$ & $\mathrm{m}$ & $\mathrm{m}$ & $\mathrm{m}$ & $\mathrm{m}$ & $\mathrm{m}$ \\
\hline & Hong Kong (China) & 1.59 & $(0.06)$ & 0.05 & $(0.01)$ & 1.53 & $(0.05)$ & 3.4 & 0.29 & $(0.06)$ & 0.12 & $(0.05)$ & 0.20 & $(0.06)$ & 0.23 & $(0.08)$ & -0.06 & $(0.09)$ \\
\hline & Indonesia & $\mathrm{m}$ & $\mathrm{m}$ & $\mathrm{m}$ & $\mathrm{m}$ & $\mathrm{m}$ & $\mathrm{m}$ & $\mathrm{m}$ & $\mathrm{m}$ & $\mathrm{m}$ & $\mathrm{m}$ & $\mathrm{m}$ & $\mathrm{m}$ & $\mathrm{m}$ & $\mathrm{m}$ & $\mathrm{m}$ & $\mathrm{m}$ & $\mathrm{m}$ \\
\hline & Jordan & $\mathrm{m}$ & $\mathrm{m}$ & $\mathrm{m}$ & $\mathrm{m}$ & $\mathrm{m}$ & $\mathrm{m}$ & $\mathrm{m}$ & $\mathrm{m}$ & $\mathrm{m}$ & $\mathrm{m}$ & $\mathrm{m}$ & $\mathrm{m}$ & $\mathrm{m}$ & $\mathrm{m}$ & $\mathrm{m}$ & $\mathrm{m}$ & $\mathrm{m}$ \\
\hline & Kosovo & $\mathrm{m}$ & $\mathrm{m}$ & $\mathrm{m}$ & $\mathrm{m}$ & $\mathrm{m}$ & $\mathrm{m}$ & $\mathrm{m}$ & $\mathrm{m}$ & $\mathrm{m}$ & $\mathrm{m}$ & $\mathrm{m}$ & $\mathrm{m}$ & $\mathrm{m}$ & $\mathrm{m}$ & $\mathrm{m}$ & $\mathrm{m}$ & $\mathrm{m}$ \\
\hline & Lebanon & $\mathrm{m}$ & $\mathrm{m}$ & $\mathrm{m}$ & $\mathrm{m}$ & $\mathrm{m}$ & $\mathrm{m}$ & $\mathrm{m}$ & $\mathrm{m}$ & $\mathrm{m}$ & $\mathrm{m}$ & $\mathrm{m}$ & $\mathrm{m}$ & $\mathrm{m}$ & $\mathrm{m}$ & $\mathrm{m}$ & $\mathrm{m}$ & $\mathrm{m}$ \\
\hline & Lithuania & 1.22 & $(0.05)$ & 0.05 & $(0.01)$ & .18 & $(0.04)$ & 3.7 & 0.07 & $(0.05)$ & -0.10 & $(0.04)$ & -0.16 & $(0.05)$ & -0.21 & $(0.04)$ & -0.28 & $(0.05)$ \\
\hline & Macao (China) & 0.96 & $(0.08)$ & 0.07 & $(0.03)$ & 0.89 & $(0.05)$ & 6.9 & 0.42 & $(0.03)$ & 0.36 & $(0.03)$ & 0.53 & $(0.03)$ & 0.67 & $(0.03)$ & 0.24 & $(0.04)$ \\
\hline & Malta & $\mathrm{m}$ & $\mathrm{m}$ & $\mathrm{m}$ & $\mathrm{m}$ & $\mathrm{m}$ & $\mathrm{m}$ & $\mathrm{m}$ & $\mathrm{m}$ & $\mathrm{m}$ & $\mathrm{m}$ & $\mathrm{m}$ & $\mathrm{m}$ & $\mathrm{m}$ & $\mathrm{m}$ & $\mathrm{m}$ & $\mathrm{m}$ & $\mathrm{m}$ \\
\hline & Moldova & $\mathrm{m}$ & & $\mathrm{m}$ & $\mathrm{m}$ & $\mathrm{m}$ & $\mathrm{m}$ & $\mathrm{m}$ & $\mathrm{m}$ & $\mathrm{m}$ & $\mathrm{m}$ & $\mathrm{m}$ & $\mathrm{m}$ & $\mathrm{m}$ & $\mathrm{m}$ & $\mathrm{m}$ & $\mathrm{m}$ & $\mathrm{m}$ \\
\hline & Montenegro & 1.91 & $(0.10)$ & 0.02 & $(0.01)$ & 1.89 & $(0.09)$ & 1.1 & -0.89 & $(0.04)$ & -0.93 & $(0.03)$ & -0.92 & $(0.07)$ & -0.88 & $(0.07)$ & 0.00 & $(0.08)$ \\
\hline & Peru & 1.02 & $(0.03)$ & 0.04 & $(0.01)$ & 0.97 & $(0.03)$ & 4.1 & -0.16 & $(0.04)$ & -0.20 & $(0.05)$ & -0.22 & $(0.04)$ & -0.34 & $(0.03)$ & -0.18 & $(0.06)$ \\
\hline & Qatar & 1.58 & $(0.09)$ & 0.17 & $(0.02)$ & 1.40 & $(0.07)$ & 11.1 & 0.53 & $(0.02)$ & 0.39 & $(0.03)$ & 0.27 & $(0.02)$ & 0.20 & $(0.02)$ & -0.33 & $(0.03)$ \\
\hline & Romania & $\mathrm{m}$ & $\mathrm{m}$ & $\mathrm{m}$ & $\mathrm{m}$ & $\mathrm{m}$ & $\mathrm{m}$ & $\mathrm{m}$ & $\mathrm{m}$ & $\mathrm{m}$ & $\mathrm{m}$ & $\mathrm{m}$ & $\mathrm{m}$ & $\mathrm{m}$ & $\mathrm{m}$ & $\mathrm{m}$ & $\mathrm{m}$ & $\mathrm{m}$ \\
\hline & Russia & 21 & $(0.04)$ & 0.05 & $(0.01)$ & 1.16 & $(0.03)$ & 3.7 & -0.11 & $(0.07)$ & 0.03 & $(0.06)$ & -0.01 & $(0.09)$ & 0.06 & $(0.09)$ & 0.17 & $(0.11)$ \\
\hline & Singapore & 0.89 & $(0.03)$ & 0.04 & $(0.01)$ & 0.85 & $(0.02)$ & 4.6 & 0.66 & $(0.02)$ & 0.60 & $(0.02)$ & 0.48 & $(0.03)$ & 0.31 & $(0.02)$ & -0.35 & $(0.03)$ \\
\hline & Chinese Taipei & 0.83 & $(0.03)$ & 0.03 & $(0.00)$ & 0.80 & $(0.02)$ & 3.1 & -0.60 & $(0.03)$ & -0.58 & $(0.03)$ & -0.59 & $(0.03)$ & -0.53 & $(0.03)$ & 0.06 & $(0.04)$ \\
\hline & Thailand & 2.01 & $(0.08)$ & 0.11 & $(0.02)$ & 1.90 & $(0.06)$ & 5.4 & 0.29 & $(0.06)$ & 0.16 & $(0.09)$ & 0.06 & $(0.06)$ & -0.07 & $(0.06)$ & -0.36 & $(0.08)$ \\
\hline & Trinidad and Tobago & $\mathrm{m}$ & $\mathrm{m}$ & $\mathrm{m}$ & $\mathrm{m}$ & $\mathrm{m}$ & $\mathrm{m}$ & $\mathrm{m}$ & $\mathrm{m}$ & $\mathrm{m}$ & $\mathrm{m}$ & $\mathrm{m}$ & $\mathrm{m}$ & $\mathrm{m}$ & $\mathrm{m}$ & $\mathrm{m}$ & $\mathrm{m}$ & $\mathrm{m}$ \\
\hline & Tunisia & 1.41 & $(0.04)$ & 0.04 & $(0.01)$ & 1.37 & $(0.04)$ & 2.9 & 0.45 & $(0.06)$ & 0.34 & $(0.05)$ & 0.18 & $(0.05)$ & 0.31 & $(0.04)$ & -0.14 & $(0.07)$ \\
\hline & United Arab Emirates & 1.65 & $(0.05)$ & 0.12 & $(0.01)$ & 1.53 & $(0.04)$ & 7.2 & 0.43 & $(0.06)$ & 0.24 & $(0.04)$ & 0.29 & $(0.05)$ & 0.23 & $(0.03)$ & -0.20 & $(0.07)$ \\
\hline & Uruguay & 1.18 & $(0.04)$ & 0.01 & $(0.01)$ & 1.16 & $(0.03)$ & 1.2 & -0.03 & $(0.03)$ & -0.02 & $(0.03)$ & -0.15 & $(0.04)$ & 0.00 & $(0.03)$ & 0.03 & $(0.04)$ \\
\hline & Viet Nam & $\mathrm{m}$ & $\mathrm{m}$ & $\mathrm{m}$ & $\mathrm{m}$ & $\mathrm{m}$ & $\mathrm{m}$ & $\mathrm{m}$ & $\mathrm{m}$ & $\mathrm{m}$ & $\mathrm{m}$ & $\mathrm{m}$ & $\mathrm{m}$ & $\mathrm{m}$ & $\mathrm{m}$ & $\mathrm{m}$ & $\mathrm{m}$ & $\mathrm{m}$ \\
\hline & Argentina** & $\mathrm{m}$ & $\mathrm{m}$ & $\mathrm{m}$ & $\mathrm{m}$ & $\mathrm{m}$ & $\mathrm{m}$ & $\mathrm{m}$ & $\mathrm{m}$ & $\mathrm{m}$ & $\mathrm{m}$ & $\mathrm{m}$ & $\mathrm{m}$ & $\mathrm{m}$ & $\mathrm{m}$ & $\mathrm{m}$ & $\mathrm{m}$ & $\mathrm{m}$ \\
\hline & Kazakhstan** & $\mathrm{m}$ & $\mathrm{m}$ & $\mathrm{m}$ & $\mathrm{m}$ & $\mathrm{m}$ & $\mathrm{m}$ & $\mathrm{m}$ & $\mathrm{m}$ & $\mathrm{m}$ & $\mathrm{m}$ & $\mathrm{m}$ & $\mathrm{m}$ & $\mathrm{m}$ & $\mathrm{m}$ & $\mathrm{m}$ & $\mathrm{m}$ & $\mathrm{m}$ \\
\hline & Malaysia** & 0.95 & $(0.03)$ & 0.05 & $(0.01)$ & 0.90 & $(0.02)$ & 5.7 & 0.65 & $(0.05)$ & 0.67 & $(0.05)$ & 0.66 & $(0.06)$ & 0.64 & $(0.06)$ & -0.01 & $(0.08)$ \\
\hline
\end{tabular}

1. The socio-economic profile is measured by the PISA index of economic, social and cultural status (ESCS).

2. The total variation in student ESCS is equal to the square of the standard deviation of the index of exposure to bullying within each country/economy. Due to the unbalanced, clustered nature of the data, the sum of the between- and within-school variation components, as an estimate from a sample, does not necessarily add up to the total.

3. In some countries/economies, sub-units within schools were sampled instead of schools; this may affect the estimation of between-school variation components (see Annex A3). Note: Values that are statistically significant are indicated in bold (see Annex A3).

* See note at the beginning of this Annex.

Coverage is too small to ensure comparability (see Annex A4).

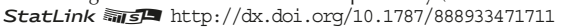


[Part 2/2]

Table III.8.6 Index of exposure to bullying, by school characteristics

Results based on students' self-reports

\begin{tabular}{|c|c|c|c|c|c|c|c|c|c|c|c|c|c|c|c|c|c|c|c|c|}
\hline & \multicolumn{20}{|c|}{ Index of exposure to bullying, by: } \\
\hline & \multicolumn{8}{|c|}{ School location } & \multicolumn{6}{|c|}{ Type of school } & \multicolumn{6}{|c|}{ Education level } \\
\hline & \multicolumn{2}{|c|}{\begin{tabular}{|c|}
$\begin{array}{c}\text { Rural area } \\
\text { or village } \\
\text { (fewer than } \\
3000 \text { people) }\end{array}$ \\
\end{tabular}} & \multicolumn{2}{|c|}{\begin{tabular}{|c|} 
Town \\
$(3000$ \\
to 100000 \\
people) \\
\end{tabular}} & \multicolumn{2}{|c|}{$\begin{array}{c}\text { City } \\
\text { (over } 100000 \\
\text { people) }\end{array}$} & \multicolumn{2}{|c|}{$\begin{array}{c}\text { City - } \\
\text { rural area }\end{array}$} & \multicolumn{2}{|c|}{ Public } & \multicolumn{2}{|c|}{ Private } & \multicolumn{2}{|c|}{$\begin{array}{l}\text { Private - } \\
\text { public }\end{array}$} & \multicolumn{2}{|c|}{$\begin{array}{l}\text { Lower } \\
\text { secondary } \\
\text { (ISCED 2) }\end{array}$} & \multicolumn{2}{|c|}{$\begin{array}{l}\text { Upper } \\
\text { secondary } \\
\text { (ISCED 3) }\end{array}$} & \multicolumn{2}{|c|}{$\begin{array}{l}\text { ISCED } 3 \text { - } \\
\text { ISCED } 2\end{array}$} \\
\hline & Mean & S.E. & Mean & S.E. & Mean & S.E. & Dif. & S.E. & Mean & S.E. & Mean & S.E. & Dif. & S.E. & Mean & S.E. & Mean & S.E. & Dif. & S.E. \\
\hline Australia & 0.63 & $(0.09)$ & 0.60 & $(0.03)$ & 0.38 & $(0.02)$ & \begin{tabular}{|l|}
-0.25 \\
\end{tabular} & $(0.09)$ & 0.51 & $(0.02)$ & 0.36 & $(0.02)$ & \begin{tabular}{|l|}
-0.15 \\
\end{tabular} & $(0.03)$ & 0.46 & $(0.01)$ & 0.41 & $(0.03)$ & -0.05 & $(0.03)$ \\
\hline Austria & 0.27 & $(0.08)$ & 0.07 & $(0.01)$ & 0.10 & $(0.03)$ & \begin{tabular}{|l|}
-0.17 \\
\end{tabular} & $(0.08)$ & 0.09 & $(0.02)$ & 0.12 & $(0.06)$ & 0.02 & $(0.06)$ & 0.17 & $(0.22)$ & 0.10 & $(0.01)$ & -0.07 & $(0.22)$ \\
\hline Belgium & 0.12 & $(0.05)$ & 0.18 & $(0.01)$ & 0.18 & $(0.03)$ & 0.06 & $(0.07)$ & w & w & w & w & w & w & 0.34 & $(0.06)$ & 0.17 & $(0.01)$ & -0.17 & $(0.06)$ \\
\hline Canada & 0.50 & $(0.06)$ & 0.44 & $(0.02)$ & 0.32 & $(0.02)$ & \begin{tabular}{|l|}
-0.18 \\
\end{tabular} & $(0.07)$ & 0.39 & $(0.01)$ & 0.34 & $(0.03)$ & -0.04 & $(0.03)$ & 0.43 & $(0.03)$ & 0.38 & $(0.01)$ & -0.05 & $(0.03)$ \\
\hline Chile & 0.51 & $(0.15)$ & 0.17 & $(0.03)$ & 0.13 & $(0.01)$ & -0.38 & $(0.15)$ & 0.17 & $(0.03)$ & 0.14 & $(0.02)$ & -0.04 & $(0.03)$ & 0.49 & $(0.10)$ & 0.13 & $(0.01)$ & -0.37 & $(0.10)$ \\
\hline Czech R & 0.42 & $(0.06)$ & 0.10 & $(0.02)$ & 0.14 & $(0.04)$ & \begin{tabular}{|l|}
-0.28 \\
\end{tabular} & $(0.07)$ & 0.16 & $(0.02)$ & 0.07 & $(0.05)$ & -0.09 & $(0.06)$ & 0.31 & $(0.03)$ & -0.03 & $(0.02)$ & -0.33 & $(0.03)$ \\
\hline Denmark & 0.24 & $(0.03)$ & 0.22 & $(0.01)$ & 0.24 & $(0.04)$ & 0.00 & $(0.04)$ & 0.23 & $(0.01)$ & 0.21 & $(0.03)$ & -0.02 & $(0.04)$ & 0.22 & $(0.01)$ & -0.08 & $(0.16)$ & -0.31 & \\
\hline Estonia & 0.22 & $(0.04)$ & 0.24 & $(0.02)$ & 0.28 & $(0.02)$ & 0.06 & $(0.04)$ & 0.24 & $(0.01)$ & 0.31 & $(0.08)$ & 0.07 & $(0.08)$ & 0.24 & $(0.01)$ & 0.28 & $(0.07)$ & 0.03 & $(0.08)$ \\
\hline Finland & 0.28 & $(0.06)$ & 0.24 & $(0.02)$ & 0.19 & $(0.03)$ & -0.09 & $(0.07)$ & 0.23 & $(0.02)$ & 0.22 & $(0.09)$ & -0.01 & $(0.09)$ & 0.23 & $(0.02)$ & C & C & C & C \\
\hline France & 0.03 & $(0.07)$ & -0.07 & $(0.02)$ & -0.14 & $(0.03)$ & -0.16 & $(0.08)$ & -0.09 & $(0.02)$ & -0.09 & $(0.04)$ & 0.00 & $(0.04)$ & 0.16 & $(0.04)$ & -0.15 & $(0.02)$ & \begin{tabular}{|l|}
-0.32 \\
\end{tabular} & $(0.04)$ \\
\hline Germany & 0.20 & $(0.04)$ & 0.17 & $(0.02)$ & 0.21 & $(0.03)$ & 0.02 & $(0.06)$ & 0.19 & $(0.02)$ & 0.09 & $(0.04)$ & -0.10 & $(0.05)$ & 0.18 & $(0.01)$ & -0.04 & $(0.06)$ & -0.22 & $(0.06)$ \\
\hline Greece & -0.45 & $(0.15)$ & -0.53 & $(0.03)$ & -0.62 & $(0.03)$ & -0.17 & $(0.15)$ & -0.55 & $(0.02)$ & -0.48 & $(0.06)$ & \begin{tabular}{|l|}
0.07 \\
\end{tabular} & $(0.07)$ & -0.13 & & -0.57 & $(0.02)$ & -0.44 & \\
\hline Hungary & 0.12 & $(0.11)$ & -0.06 & $(0.03)$ & -0.10 & $(0.02)$ & -0.23 & $(0.12)$ & -0.08 & $(0.02)$ & -0.06 & $(0.04)$ & 0.01 & $(0.04)$ & 0.07 & (0.08) & -0.08 & $(0.02)$ & -0.15 & $(0.09)$ \\
\hline Iceland & -0.30 & $(0.05)$ & -0.45 & $(0.02)$ & -0.49 & $(0.03)$ & -0.20 & $(0.06)$ & -0.44 & $(0.02)$ & c & c & C & C & -0.43 & $(0.02)$ & $\mathrm{m}$ & $\mathrm{m}$ & $\mathrm{m}$ & \\
\hline Ireland & 0.13 & $(0.05)$ & 0.11 & $(0.02)$ & 0.06 & $(0.02)$ & -0.08 & $(0.06)$ & 0.14 & $(0.02)$ & 0.07 & $0.02)$ & -0.08 & $(0.03)$ & 0.12 & $(0.02)$ & .06 & $(0.02)$ & -0.06 & $(0.02)$ \\
\hline Israel & $\mathrm{m}$ & $\mathrm{m}$ & $\mathrm{m}$ & $\mathrm{m}$ & $\mathrm{m}$ & $\mathrm{m}$ & $\mathrm{m}$ & $\mathrm{m}$ & $\mathrm{m}$ & $\mathrm{m}$ & $\mathrm{m}$ & $\mathrm{m}$ & $\mathrm{m}$ & $\mathrm{m}$ & $\mathrm{m}$ & $\mathrm{m}$ & $\mathrm{m}$ & $\mathrm{m}$ & $\mathrm{m}$ & $\mathrm{m}$ \\
\hline Italy & $\mathrm{m}$ & & $\mathrm{m}$ & $\mathrm{m}$ & $\mathrm{m}$ & $\mathrm{m}$ & $\mathrm{m}$ & $\mathrm{m}$ & $\mathrm{m}$ & $\mathrm{m}$ & $\mathrm{m}$ & $\mathrm{m}$ & $\mathrm{m}$ & $\mathrm{m}$ & $\mathrm{m}$ & $\mathrm{m}$ & $\mathrm{m}$ & $\mathrm{m}$ & $\mathrm{m}$ & \\
\hline Japan & c & c & -0.27 & $(0.03)$ & -0.18 & $(0.02)$ & c & C & -0.25 & $(0.02)$ & -0.11 & $(0.03)$ & 0.14 & (0.03) & $\mathrm{m}$ & $\mathrm{m}$ & -0.21 & $(0.02)$ & $\mathrm{m}$ & $\mathrm{m}$ \\
\hline Korea & c & & -1.41 & $(0.04)$ & -1.44 & $(0.02)$ & c & c & -1.42 & $(0.02)$ & -1.47 & $(0.03)$ & -0.05 & $(0.04)$ & -1.44 & $(0.07)$ & -1.44 & & 0.00 & $(0.07)$ \\
\hline Latvia & 0.81 & $(0.05)$ & 0.62 & $(0.02)$ & 0.59 & $(0.03)$ & \begin{tabular}{|l|}
-0.22 \\
\end{tabular} & $(0.06)$ & 0.65 & $(0.02)$ & 0.73 & $(0.11)$ & 0.08 & $(0.11)$ & 0.67 & $(0.02)$ & 0.34 & $(0.06)$ & -0.32 & $(0.06)$ \\
\hline Luxembourg & $\mathrm{m}$ & & -0.11 & $(0.02)$ & -0.20 & $(0.02)$ & $\mathrm{m}$ & $\mathrm{m}$ & -0.17 & $(0.01)$ & -0.09 & $(0.03)$ & 0.08 & $(0.04)$ & -0.08 & $(0.02)$ & -0.25 & $(0.02)$ & -0.17 & $(0.03)$ \\
\hline Mexi & 0.23 & $(0.03)$ & 0.15 & $(0.03)$ & 0.08 & $(0.03)$ & -0.15 & $(0.04)$ & 0.12 & $(0.01)$ & 0.14 & $(0.07)$ & 0.02 & $(0.08)$ & 0.30 & $(0.03)$ & 0.01 & $(0.02)$ & -0.29 & $(0.03)$ \\
\hline Net! & c & & -0.32 & $(0.02)$ & -0.34 & $(0.02)$ & $\mathrm{c}$ & $\mathrm{C}$ & -0.26 & $(0.03)$ & -0.37 & $(0.02)$ & -0.11 & $(0.04)$ & -0.30 & $(0.02)$ & -0.38 & $(0.02)$ & -0.08 & $(0.02)$ \\
\hline New Zeal & 0.75 & $(0.10)$ & 0.67 & $(0.03)$ & 0.54 & $(0.02)$ & -0.21 & $(0.10)$ & 0.61 & $(0.02)$ & 0.52 & $(0.08)$ & -0.09 & $(0.09)$ & 0.76 & $(0.08)$ & 0.60 & $(0.02)$ & -0.15 & $(0.08)$ \\
\hline Norway & 0.03 & $(0.05)$ & -0.01 & $(0.02)$ & -0.06 & $(0.04)$ & -0.09 & $(0.07)$ & -0.02 & $(0.02)$ & -0.09 & $(0.18)$ & $\mid-0.07$ & $(0.18)$ & -0.01 & $(0.02)$ & $\mathrm{c}$ & c & c & \\
\hline Poland & 0.27 & $(0.03)$ & 0.25 & $(0.03)$ & 0.31 & $(0.02)$ & 0.04 & $(0.04)$ & 0.27 & $(0.02)$ & 0.27 & $(0.11)$ & 0.00 & $(0.11)$ & 0.27 & $(0.02)$ & c & c & c & \\
\hline Port & -0.17 & $(0.11)$ & -0.53 & $(0.02)$ & -0.52 & $(0.05)$ & -0.35 & $(0.12)$ & -0.52 & $(0.02)$ & -0.49 & $(0.10)$ & 0.03 & $(0.10)$ & -0.32 & $(0.03)$ & -0.62 & $(0.02)$ & -0.30 & $(0.03)$ \\
\hline Slovak Re & 0.28 & $(0.05)$ & 0.08 & $(0.02)$ & 0.03 & $(0.07)$ & \begin{tabular}{|l|}
-0.25 \\
\end{tabular} & $(0.08)$ & 0.10 & $(0.02)$ & 0.13 & $(0.06)$ & 0.03 & $(0.06)$ & 0.29 & $(0.03)$ & -0.05 & $(0.02)$ & -0.34 & $(0.04)$ \\
\hline Slovenia & 0.08 & $(0.06)$ & 0.01 & $(0.02)$ & 0.03 & $(0.03)$ & -0.05 & $(0.07)$ & 0.01 & $(0.01)$ & 0.12 & $(0.09)$ & 0.11 & $(0.09)$ & 0.20 & (0.09) & 0.00 & $(0.01)$ & -0.20 & $(0.09)$ \\
\hline Spain & -0.06 & $(0.07)$ & -0.10 & $(0.02)$ & -0.08 & $(0.03)$ & -0.02 & $(0.08)$ & -0.12 & $(0.02)$ & -0.03 & $(0.02)$ & 0.09 & $(0.03)$ & -0.10 & $(0.01)$ & C & c & C & \\
\hline Swede & -0.11 & $(0.06)$ & -0.11 & $(0.03)$ & -0.12 & $(0.04)$ & -0.02 & $(0.08)$ & -0.12 & $(0.02)$ & -0.09 & $(0.05)$ & 0.02 & $(0.06)$ & -0.11 & $(0.02)$ & -0.53 & $(0.17)$ & -0.42 & $(0.17)$ \\
\hline Switzerland & 0.38 & $(0.06)$ & 0.25 & $(0.02)$ & 0.14 & $(0.02)$ & \begin{tabular}{|l|}
-0.23 \\
\end{tabular} & $(0.07)$ & 0.23 & $(0.02)$ & 0.29 & $(0.07)$ & 0.05 & $(0.08)$ & 0.30 & $(0.02)$ & 0.05 & $(0.02)$ & -0.25 & $(0.03)$ \\
\hline Turkey & -0.59 & $(0.18)$ & -0.99 & $(0.04)$ & -0.97 & $(0.05)$ & -0.38 & $(0.18)$ & -1.00 & $(0.03)$ & -0.46 & $(0.16)$ & 0.54 & $(0.16)$ & -0.26 & $(0.39)$ & -0.99 & $(0.03)$ & -0.73 & (0.39) \\
\hline United Kingdom & 0.38 & $(0.05)$ & 0.42 & $(0.02)$ & 0.32 & $(0.04)$ & -0.06 & $(0.07)$ & 0.40 & $(0.02)$ & 0.29 & $(0.09)$ & -0.11 & $(0.09)$ & 0.55 & $(0.09)$ & 0.40 & $(0.02)$ & -0.15 & $(0.09)$ \\
\hline United States & 0.28 & $(0.06)$ & 0.16 & $(0.03)$ & 0.14 & $(0.03)$ & -0.15 & $(0.06)$ & 0.16 & $(0.02)$ & 0.24 & $(0.08)$ & 0.08 & $(0.08)$ & 0.41 & $(0.06)$ & 0.14 & $(0.02)$ & -0.27 & $(0.07)$ \\
\hline OECD average & 0.19 & $(0.01)$ & 0.00 & $(0.00)$ & -0.03 & $(0.01)$ & -0.14 & $(0.02)$ & 0.00 & $(0.00)$ & 0.03 & $(0.01)$ & 0.01 & $(0.01)$ & 0.13 & $(0.02)$ & -0.08 & $(0.01)$ & -0.23 & $(0.02)$ \\
\hline
\end{tabular}

\begin{tabular}{|c|c|c|c|c|c|c|c|c|c|c|c|c|c|c|c|c|c|c|c|c|}
\hline Albania & $\mathrm{m}$ & $\mathrm{m}$ & $\mathrm{m}$ & $\mathrm{m}$ & $\mathrm{m}$ & $\mathrm{m}$ & $\mathrm{m}$ & $\mathrm{m}$ & $\mathrm{m}$ & $\mathrm{m}$ & $\mathrm{m}$ & $\mathrm{m}$ & $\mathrm{m}$ & $\mathrm{m}$ & $\mathrm{m}$ & $\mathrm{m}$ & $\mathrm{m}$ & $\mathrm{m}$ & $\mathrm{m}$ & $\mathrm{m}$ \\
\hline Algeria & $\mathrm{m}$ & $\mathrm{m}$ & $\mathrm{m}$ & $\mathrm{m}$ & $\mathrm{m}$ & $\mathrm{m}$ & $\mathrm{m}$ & $\mathrm{m}$ & $\mathrm{m}$ & $\mathrm{m}$ & $\mathrm{m}$ & $\mathrm{m}$ & $\mathrm{m}$ & $\mathrm{m}$ & $\mathrm{m}$ & $\mathrm{m}$ & $\mathrm{m}$ & $\mathrm{m}$ & $\mathrm{m}$ & $\mathrm{m}$ \\
\hline Brazil & .17 & $(0.10)$ & 0.23 & $(0.02)$ & -0.26 & $(0.02)$ & 0.09 & $(0.11)$ & -0.25 & $(0.02)$ & -0.21 & $(0.03)$ & 0.05 & $(0.03)$ & 0.01 & $(0.04)$ & -0.29 & $(0.01)$ & -0.30 & $(0.04)$ \\
\hline B-S-J-G (China) & 0.28 & $(0.08)$ & 0.10 & $(0.03)$ & 0.04 & $(0.03)$ & -0.24 & $(0.08)$ & 0.08 & $(0.02)$ & 0.22 & $(0.08)$ & 0.14 & $(0.08)$ & 0.15 & $(0.03)$ & 0.01 & $(0.03)$ & -0.15 & $(0.04)$ \\
\hline Bulgaria & 0.33 & $(0.19)$ & 0.13 & $(0.03)$ & 0.14 & $(0.03)$ & -0.18 & (0.19) & 0.14 & $(0.02)$ & c & c & c & c & 0.72 & $(0.24)$ & 0.13 & $(0.02)$ & -0.59 & $(0.24)$ \\
\hline $\mathrm{CAB}$ & $\mathrm{m}$ & & c & & c & c & $\mathrm{m}$ & $\mathrm{m}$ & c & c & c & c & c & c & c & c & c & c & c & c \\
\hline Colombia & 0.25 & $(0.04)$ & 0.21 & $(0.03)$ & 0.11 & $(0.02)$ & -0.14 & $(0.04)$ & 0.18 & $(0.02)$ & 0.10 & $(0.03)$ & -0.08 & $(0.04)$ & 0.25 & $(0.02)$ & 0.10 & $(0.02)$ & -0.15 & $(0.03)$ \\
\hline Costa Rica & 0.10 & $(0.03)$ & 0.09 & $(0.02)$ & 0.17 & $(0.05)$ & 0.07 & $(0.06)$ & 0.10 & $(0.02)$ & 0.08 & $(0.04)$ & -0.02 & $(0.05)$ & 0.11 & $(0.02)$ & 0.10 & $(0.02)$ & -0.01 & $(0.03)$ \\
\hline Croatia & c & c & -0.12 & $(0.02)$ & -0.13 & $(0.03)$ & C & c & -0.12 & $(0.02)$ & 0.06 & $(0.15)$ & 0.18 & $(0.15)$ & c & c & -0.12 & $(0.02)$ & c & c \\
\hline Cyprus* & $\mathrm{m}$ & $\mathrm{m}$ & $\mathrm{m}$ & $\mathrm{m}$ & $\mathrm{m}$ & $\mathrm{m}$ & $\mathrm{m}$ & $\mathrm{m}$ & $\mathrm{m}$ & $\mathrm{m}$ & $\mathrm{m}$ & $\mathrm{m}$ & $\mathrm{m}$ & $\mathrm{m}$ & $\mathrm{m}$ & $\mathrm{m}$ & $\mathrm{m}$ & $\mathrm{m}$ & $\mathrm{m}$ & $\mathrm{m}$ \\
\hline public & .32 & $(0.10)$ & .27 & $(0.04)$ & -0.30 & $(0.05)$ & 0.02 & $(0.11)$ & -0.31 & $(0.03)$ & -0.21 & $(0.06)$ & 0.10 & $(0.07)$ & -0.02 & $(0.08)$ & -0.35 & $(0.03)$ & -0.32 & $(0.08)$ \\
\hline FYROM & c & c & c & c & C & C & C & c & c & $c$ & c & $c$ & c & c & c & c & C & c & c & C \\
\hline Geor & C & c & c & $\mathrm{C}$ & C & C & C & C & C & 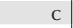 & c & 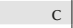 & c & C & C & c & c & c & c & c \\
\hline Hon & $\mathrm{m}$ & $\mathrm{m}$ & $\mathrm{m}$ & $\mathrm{m}$ & 0.21 & $(0.03)$ & $\mathrm{m}$ & $\mathrm{m}$ & 0.16 & $(0.11)$ & 0.22 & $(0.03)$ & 0.05 & $(0.12)$ & 0.23 & (0.04) & 0.20 & 0.03) & -0.03 & $0.04)$ \\
\hline Indo & $\mathrm{m}$ & $\mathrm{m}$ & $\mathrm{m}$ & $\mathrm{m}$ & $\mathrm{m}$ & $\mathrm{m}$ & $\mathrm{m}$ & $\mathrm{m}$ & $\mathrm{m}$ & $\mathrm{m}$ & $\mathrm{m}$ & $\mathrm{m}$ & $\mathrm{m}$ & $\mathrm{m}$ & $\mathrm{m}$ & $\mathrm{m}$ & $\mathrm{m}$ & $\mathrm{m}$ & $\mathrm{m}$ & $\mathrm{m}$ \\
\hline Jordan & $\mathrm{m}$ & $\mathrm{m}$ & $\mathrm{m}$ & $\mathrm{m}$ & $\mathrm{m}$ & $\mathrm{m}$ & $\mathrm{m}$ & $\mathrm{m}$ & $\mathrm{m}$ & $\mathrm{m}$ & $\mathrm{m}$ & $\mathrm{m}$ & $\mathrm{m}$ & $\mathrm{m}$ & $\mathrm{m}$ & $\mathrm{m}$ & $\mathrm{m}$ & $\mathrm{m}$ & $\mathrm{m}$ & $\mathrm{m}$ \\
\hline Koso & $\mathrm{m}$ & $\mathrm{m}$ & $\mathrm{m}$ & $\mathrm{m}$ & $\mathrm{m}$ & $\mathrm{m}$ & $\mathrm{m}$ & $\mathrm{m}$ & $\mathrm{m}$ & $\mathrm{m}$ & $\mathrm{m}$ & $\mathrm{m}$ & $\mathrm{m}$ & $\mathrm{m}$ & $\mathrm{m}$ & $\mathrm{m}$ & $\mathrm{m}$ & $\mathrm{m}$ & $\mathrm{m}$ & $\mathrm{m}$ \\
\hline Leb & $\mathrm{m}$ & $\mathrm{m}$ & $\mathrm{m}$ & $\mathrm{m}$ & $\mathrm{m}$ & $\mathrm{m}$ & $\mathrm{m}$ & $\mathrm{m}$ & $\mathrm{m}$ & $\mathrm{m}$ & $\mathrm{m}$ & $\mathrm{m}$ & $\mathrm{m}$ & $\mathrm{m}$ & $\mathrm{m}$ & . & $\mathrm{m}$ & $\mathrm{m}$ & $\mathrm{m}$ & $\mathrm{m}$ \\
\hline Lith & 0.07 & $(0.04)$ & 0.11 & $(0.02)$ & -0.18 & $(0.03)$ & .25 & $(0.05)$ & 0.10 & $(0.02)$ & -0.05 & $(0.12)$ & 0.05 & .12) & 0.10 & $0.02)$ & c & c & c & C \\
\hline Maca & c & c & c & C & 0.49 & $(0.01)$ & c & c & c & c & 0.49 & $(0.01)$ & c & c & 0.54 & $(0.02)$ & 0.45 & $(0.02)$ & -0.09 & $(0.03)$ \\
\hline Malt & $\mathrm{m}$ & $\mathrm{m}$ & $\mathrm{m}$ & $\mathrm{m}$ & $\mathrm{m}$ & $\mathrm{m}$ & $\mathrm{m}$ & $\mathrm{m}$ & $\mathrm{m}$ & $\mathrm{m}$ & $\mathrm{m}$ & $\mathrm{m}$ & $\mathrm{m}$ & $\mathrm{m}$ & $\mathrm{m}$ & $\mathrm{m}$ & $\mathrm{m}$ & $\mathrm{m}$ & $\mathrm{m}$ & $\mathrm{m}$ \\
\hline Mo & C & C & c & C & C & 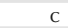 & C & 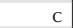 & C & , & C & & C & C & C & C & C & C & C & C \\
\hline M & c & & .91 & $(0.02)$ & .91 & $(0.04)$ & C & c & -0.91 & $(0.02)$ & c & $c$ & C & c & -0.70 & $(0.20)$ & -0.91 & 2) & -0.21 & $(0.20)$ \\
\hline $\mathrm{Pe}$ & .18 & $(0.04)$ & -0.25 & $(0.02)$ & -0.29 & (0. & -0.12 & $(0.06)$ & -0.20 & 2) & -0.31 & $(0.03)$ & -0.12 & $(0.04)$ & -0.13 & & -0.26 & & -0.14 & .03) \\
\hline Qata & 0.18 & $(0.05)$ & 0.44 & $(0.02)$ & 0.30 & $(0.02)$ & 0.12 & $(0.05)$ & 0.33 & $(0.01)$ & 0.38 & $(0.02)$ & 0.05 & $(0.02)$ & 0.67 & $(0.03)$ & 0.28 & $(0.01)$ & -0.39 & $(0.03)$ \\
\hline & $\mathrm{m}$ & & $\mathrm{m}$ & & $\mathrm{m}$ & $\mathrm{m}$ & $\mathrm{m}$ & $\mathrm{m}$ & $\mathrm{m}$ & $\mathrm{m}$ & $\mathrm{m}$ & $\mathrm{m}$ & $\mathrm{m}$ & $\mathrm{m}$ & $\mathrm{m}$ & $\mathrm{m}$ & $\mathrm{m}$ & $\mathrm{m}$ & $\mathrm{m}$ & $\mathrm{m}$ \\
\hline Rus & 0.00 & $(0.06)$ & .06 & $(0.05)$ & 0.01 & $(0.04)$ & 0.01 & $(0.07)$ & -0.01 & $(0.04)$ & c & & C & 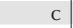 & 0.03 & & -0.25 & & -0.27 & $(0.05)$ \\
\hline $\mathrm{Si}$ & $\mathrm{m}$ & $\mathrm{m}$ & $\mathrm{m}$ & & 0.53 & & $\mathrm{~m}$ & $\mathrm{~m}$ & 0.53 & (0. & 0.37 & $(0.04)$ & -0.16 & $(0.05)$ & 0.63 & 0) & 0.51 & 1) & -0.11 & $(0.10)$ \\
\hline & c & c & -0.59 & $(0.02)$ & -0.56 & & C & c & -0.55 & & -0.62 & & -0.07 & & -0.44 & & -0.65 & & -0.20 & $(0.03)$ \\
\hline & 0.30 & $(0.07)$ & 0.10 & $(0.05)$ & -0.04 & $(0.07)$ & 0.34 & $(0.10)$ & 0.07 & $(0.03)$ & 0.35 & $(0.13)$ & 0.28 & $(0.13)$ & 0.28 & $(0.05)$ & 0.05 & $(0.03)$ & -0.23 & $(0.06)$ \\
\hline go & $\mathrm{m}$ & & $\mathrm{m}$ & & $\mathrm{m}$ & & $\mathrm{m}$ & $\mathrm{m}$ & $\mathrm{m}$ & $\mathrm{m}$ & $\mathrm{m}$ & $\mathrm{m}$ & $\mathrm{m}$ & $\mathrm{m}$ & $\mathrm{m}$ & $\mathrm{m}$ & $\mathrm{m}$ & $\mathrm{m}$ & $\mathrm{m}$ & $\mathrm{m}$ \\
\hline & 0.54 & $(0.12)$ & 31 & 3) & 0.25 & )3) & 30 & 2) & 0.29 & 3) & 52 & (C & .23 & 21) & .54 & 74) & 0.21 & D2) & 0.33 & $(0.05)$ \\
\hline irates & 0.37 & $(0.12)$ & 0.28 & $(0.05)$ & 0.30 & $(0.02)$ & -0.07 & $(0.12)$ & 0.28 & $(0.03)$ & 0.31 & $(0.03)$ & 0.03 & $(0.05)$ & 0.56 & $(0.05)$ & 0.26 & $(0.02)$ & -0.30 & $(0.05)$ \\
\hline Uru & .08 & $(0.06)$ & -0.04 & $(0.02)$ & -0.05 & $(0.02)$ & 0.03 & $(0.06)$ & -0.07 & $(0.01)$ & 0.09 & $(0.04)$ & 0.16 & $(0.04)$ & 0.04 & $(0.03)$ & -0.10 & $(0.02)$ & -0.14 & $(0.03)$ \\
\hline Viet Nam & $\mathrm{m}$ & $\mathrm{m}$ & $\mathrm{m}$ & $\mathrm{m}$ & $\mathrm{m}$ & $\mathrm{m}$ & $\mathrm{m}$ & $\mathrm{m}$ & $\mathrm{m}$ & $\mathrm{m}$ & $\mathrm{m}$ & $\mathrm{m}$ & $\mathrm{m}$ & $\mathrm{m}$ & $\mathrm{m}$ & $\mathrm{m}$ & $\mathrm{m}$ & $\mathrm{m}$ & $\mathrm{m}$ & $\mathrm{m}$ \\
\hline Arge & $\mathrm{m}$ & & $\mathrm{m}$ & $\mathrm{m}$ & $\mathrm{m}$ & $\mathrm{m}$ & $\mathrm{m}$ & $\mathrm{m}$ & $\mathrm{m}$ & $\mathrm{m}$ & $\mathrm{m}$ & $\mathrm{m}$ & $\mathrm{m}$ & $\mathrm{m}$ & $\mathrm{m}$ & $\mathrm{m}$ & $\mathrm{m}$ & $\mathrm{m}$ & $\mathrm{m}$ & $\mathrm{m}$ \\
\hline & $\mathrm{m}$ & & $\mathrm{m}$ & $\mathrm{m}$ & $\mathrm{m}$ & $\mathrm{m}$ & $\mathrm{m}$ & $\mathrm{m}$ & $\mathrm{m}$ & $\mathrm{m}$ & $\mathrm{m}$ & $\mathrm{m}$ & $\mathrm{m}$ & $\mathrm{m}$ & $\mathrm{m}$ & $\mathrm{m}$ & $\mathrm{m}$ & $\mathrm{m}$ & $\mathrm{m}$ & $\mathrm{m}$ \\
\hline Malaysia* & 0.63 & $(0.04)$ & 0.62 & $(0.03)$ & 0.69 & $(0.04)$ & 0.06 & $(0.06)$ & 0.65 & $(0.02)$ & 0.73 & (0.13) & 0.08 & $(0.13)$ & 1.41 & (0.16) & 0.63 & $(0.02)$ & -0.79 & $0.16)$ \\
\hline
\end{tabular}

1. The socio-economic profile is measured by the PISA index of economic, social and cultural status (ESCS).

2. The total variation in student ESCS is equal to the square of the standard deviation of the index of exposure to bullying within each country/economy. Due to the unbalanced, clustered nature of the data, the sum of the between- and within-school variation components, as an estimate from a sample, does not necessarily add up to the total.

3. In some countries/economies, sub-units within schools were sampled instead of schools; this may affect the estimation of between-school variation components (see Annex A3). Note: Values that are statistically significant are indicated in bold (see Annex A3).

* See note at the beginning of this Annex.

** Coverage is too small to ensure comparability (see Annex A4).

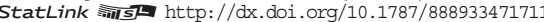


Results based on students' self-reports

\begin{tabular}{|c|c|c|c|c|c|c|c|c|c|c|c|c|c|c|c|c|c|}
\hline & \multicolumn{10}{|c|}{$\begin{array}{l}\text { Science performance, by national quarters } \\
\text { of the index of exposure to bullying }\end{array}$} & \multicolumn{4}{|c|}{$\begin{array}{l}\text { Before accounting for students' and schools' } \\
\text { socio-economic profile }\end{array}$} & \multirow{2}{*}{\multicolumn{2}{|c|}{ 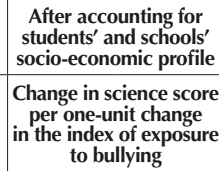 }} \\
\hline & & \multicolumn{2}{|c|}{$\begin{array}{l}\text { Bottom } \\
\text { quarter }\end{array}$} & \multicolumn{2}{|c|}{$\begin{array}{l}\text { Second } \\
\text { quarter }\end{array}$} & \multicolumn{2}{|c|}{$\begin{array}{c}\text { Third } \\
\text { quarter }\end{array}$} & \multicolumn{2}{|c|}{$\begin{array}{c}\text { Top } \\
\text { quarter }\end{array}$} & \multicolumn{2}{|c|}{$\begin{array}{c}\text { Top - } \\
\text { bottom quarter }\end{array}$} & \multicolumn{2}{|c|}{$\begin{array}{l}\text { Change in science } \\
\text { score per one-unit } \\
\text { change in the index of } \\
\text { exposure to bullying }\end{array}$} & \multicolumn{2}{|c|}{$\begin{array}{c}\text { Explained variance } \\
\text { in student } \\
\text { performance } \\
(r \text {-squared } x \text { 100) }\end{array}$} & & \\
\hline & & $\begin{array}{l}\text { Mean } \\
\text { score }\end{array}$ & S.E. & $\begin{array}{l}\text { Mean } \\
\text { score }\end{array}$ & S.E. & $\begin{array}{l}\text { Mean } \\
\text { score }\end{array}$ & S.E. & $\begin{array}{l}\text { Mean } \\
\text { score }\end{array}$ & S.E. & $\begin{array}{l}\text { Score } \\
\text { dif. }\end{array}$ & S.E. & $\begin{array}{l}\text { Score } \\
\text { dif. }\end{array}$ & S.E. & $\%$ & S.E. & $\begin{array}{c}\text { Score } \\
\text { dif. }\end{array}$ & S.E. \\
\hline & Australia & 521 & $(2.4)$ & 519 & (2.5) & 526 & (2.3) & 488 & (2.9) & -33 & (3.7) & -14 & $(1.2)$ & 1.9 & $(0.3)$ & -10 & (1.0) \\
\hline ¿ & Austria & 489 & (3.2) & 488 & (3.6) & 518 & $(4.2)$ & 497 & (3.5) & 8 & (4.0) & 1 & (1.6) & 0.0 & $(0.0)$ & 0 & (1.3) \\
\hline & Belgium & 511 & (3.1) & 508 & (3.1) & 522 & (3.1) & 498 & (3.0) & -13 & (3.7) & -9 & (1.5) & 0.6 & $(0.2)$ & -4 & $(1.2)$ \\
\hline & Canada & 534 & (2.6) & 530 & (2.6) & 543 & (2.4) & 512 & $(3.0)$ & -23 & (2.7) & -11 & (1.0) & 1.4 & $(0.3)$ & -9 & $(0.9)$ \\
\hline & Chile & 446 & (3.6) & 450 & (3.1) & 460 & (3.4) & 441 & $(4.0)$ & -5 & $(4.6)$ & -6 & $(2.1)$ & 0.4 & $(0.3)$ & -5 & (1.8) \\
\hline & Czech Republic & 497 & (3.1) & 498 & $(2.7)$ & 506 & (3.2) & 492 & (3.3) & -6 & (3.6) & -4 & $(1.2)$ & 0.3 & $(0.2)$ & -3 & (1.1) \\
\hline & Denmark & 510 & $(3.0)$ & 506 & (3.5) & 519 & (3.4) & 494 & (3.3) & -17 & (3.4) & -9 & (1.6) & 0.6 & $(0.2)$ & -8 & (1.6) \\
\hline & Estonia & 535 & (3.1) & 529 & (3.4) & 548 & $(2.7)$ & 530 & (3.6) & -5 & (4.1) & -2 & (1.8) & 0.1 & $(0.1)$ & -2 & $(1.8)$ \\
\hline & Finland & 534 & (3.1) & 536 & (3.0) & 545 & (3.7) & 520 & (3.7) & -14 & (4.6) & -8 & (1.7) & 0.6 & $(0.2)$ & -7 & (1.6) \\
\hline & France & 503 & (3.0) & 505 & (3.3) & 510 & (3.4) & 488 & (3.4) & -15 & (4.5) & -10 & (1.7) & 1.0 & $(0.3)$ & -4 & (1.4) \\
\hline & Germany & 519 & $(3.8)$ & 515 & (3.9) & 533 & (3.9) & 519 & $(4.2)$ & 0 & (4.4) & -4 & (2.0) & 0.1 & $(0.1)$ & -2 & (1.7) \\
\hline & Greece & 458 & $(4.0)$ & 458 & (4.8) & 467 & (4.1) & 446 & $(5.8)$ & -12 & $(5.2)$ & -7 & (1.4) & 1.0 & $(0.4)$ & -6 & (1.1) \\
\hline & Hungary & 476 & (3.6) & 477 & (4.1) & 492 & (3.0) & 469 & (3.8) & -7 & (4.1) & -6 & (1.4) & 0.4 & $(0.2)$ & -3 & (1.2) \\
\hline & Iceland & 476 & (3.2) & 481 & (3.3) & 477 & (3.4) & 468 & $(4.0)$ & -9 & (4.9) & -6 & (1.8) & 0.5 & $(0.3)$ & -5 & (1.8) \\
\hline & Ireland & 499 & (3.7) & 503 & (3.1) & 509 & (3.0) & 503 & (3.4) & 4 & (3.4) & 1 & (1.3) & 0.0 & $(0.0)$ & -1 & (1.3) \\
\hline & Israel & $\mathrm{m}$ & $\mathrm{m}$ & $\mathrm{m}$ & $\mathrm{m}$ & $\mathrm{m}$ & $\mathrm{m}$ & $\mathrm{m}$ & $\mathrm{m}$ & $\mathrm{m}$ & $\mathrm{m}$ & $\mathrm{m}$ & $\mathrm{m}$ & $\mathrm{m}$ & $\mathrm{m}$ & $\mathrm{m}$ & $\mathrm{m}$ \\
\hline & Italy & $\mathrm{m}$ & $\mathrm{m}$ & $\mathrm{m}$ & $\mathrm{m}$ & $\mathrm{m}$ & $\mathrm{m}$ & $\mathrm{m}$ & $\mathrm{m}$ & $\mathrm{m}$ & $\mathrm{m}$ & $\mathrm{m}$ & $\mathrm{m}$ & $\mathrm{m}$ & $\mathrm{m}$ & $\mathrm{m}$ & $\mathrm{m}$ \\
\hline & Japan & 531 & (3.7) & 529 & (3.3) & 551 & (3.4) & 547 & $(4.5)$ & 16 & (4.4) & 5 & (1.7) & 0.3 & $(0.2)$ & 2 & (1.4) \\
\hline & Korea & 508 & $(4.1)$ & 511 & (4.0) & 514 & (3.7) & 532 & (3.6) & 24 & (3.7) & 6 & (1.2) & 0.4 & $(0.2)$ & 4 & $(1.2)$ \\
\hline & Latvia & 490 & (3.1) & 502 & (2.4) & 501 & (3.2) & 473 & (3.0) & -17 & (4.2) & -10 & (1.5) & 1.2 & $(0.4)$ & -7 & (1.4) \\
\hline & Luxembourg & 489 & (2.6) & 487 & (2.9) & 498 & (2.7) & 472 & (2.9) & -17 & (4.1) & -10 & (1.4) & 1.0 & $(0.3)$ & -8 & (1.1) \\
\hline & Mexico & 414 & (2.6) & 416 & (2.9) & 425 & (3.0) & 411 & (2.9) & -2 & (3.1) & -2 & $(1.2)$ & 0.1 & $(0.1)$ & -1 & $(1.0)$ \\
\hline & Netherlands & 513 & (3.1) & 512 & (3.8) & 516 & (2.9) & 516 & (3.7) & 3 & $(4.1)$ & -2 & (2.4) & 0.0 & $(0.1)$ & -1 & (1.9) \\
\hline & New Zealand & 523 & (3.9) & 525 & $(4.1)$ & 536 & $(4.3)$ & 488 & (3.7) & -35 & (5.6) & -13 & (2.0) & 1.6 & $(0.5)$ & -9 & $(1.8)$ \\
\hline & Norway & 501 & $(3.4)$ & 508 & (3.7) & 508 & (3.6) & 490 & (3.8) & -11 & (4.9) & -9 & (1.6) & 0.9 & $(0.4)$ & -8 & (1.5) \\
\hline & Poland & 498 & (3.8) & 496 & (3.4) & 511 & (3.9) & 505 & (3.7) & 7 & $(4.3)$ & 2 & (1.6) & 0.0 & $(0.1)$ & 3 & $(1.5)$ \\
\hline & Portugal & 508 & (3.5) & 505 & (3.4) & 507 & (3.3) & 490 & (3.8) & -18 & (4.3) & -9 & (1.3) & 1.1 & $(0.3)$ & -7 & (1.3) \\
\hline & Slovak Republic & 472 & (3.6) & 469 & (3.5) & 480 & $(3.2)$ & 451 & (3.4) & -21 & (3.9) & -9 & $(1.3)$ & 1.0 & $(0.3)$ & -5 & $(1.2)$ \\
\hline & Slovenia & 518 & $(3.4)$ & 514 & (3.1) & 522 & (3.3) & 509 & (3.1) & -9 & (4.9) & -7 & (1.7) & 0.5 & $(0.3)$ & -4 & (1.4) \\
\hline & Spain & 494 & $(2.8)$ & 495 & (3.0) & 496 & (3.2) & 491 & (3.8) & -2 & (4.1) & -3 & (1.8) & 0.1 & $(0.1)$ & -3 & (1.6) \\
\hline & Sweden & 499 & $(4.5)$ & 498 & $(4.7)$ & 515 & $(4.2)$ & 484 & $(4.1)$ & -14 & (5.0) & -7 & (1.4) & 0.6 & $(0.2)$ & -5 & (1.3) \\
\hline & Switzerland & 510 & (3.7) & 505 & (4.3) & 518 & (3.6) & 500 & $(4.1)$ & -11 & (4.3) & -6 & (1.9) & 0.3 & $(0.2)$ & -5 & (1.8) \\
\hline & Turkey & 424 & $(4.3)$ & 427 & (4.5) & 430 & $(4.6)$ & 425 & $(4.8)$ & 1 & (3.7) & -1 & (1.0) & 0.1 & $(0.1)$ & -1 & $(0.8)$ \\
\hline & United Kingdom & 510 & (3.7) & 513 & (3.5) & 528 & (3.8) & 504 & (3.5) & -6 & (4.3) & -4 & (1.5) & 0.2 & $(0.1)$ & -3 & (1.4) \\
\hline & United States & 496 & (3.7) & 500 & (4.6) & 512 & (4.0) & 490 & (3.8) & -6 & (4.1) & -5 & (1.4) & 0.3 & $(0.2)$ & -6 & (1.2) \\
\hline & OECD average & 497 & $(0.6)$ & 497 & $(0.6)$ & 507 & $(0.6)$ & 489 & $(0.6)$ & -8 & $(0.7)$ & -5 & $(0.3)$ & 0.6 & $(0.0)$ & -4 & $(0.2)$ \\
\hline
\end{tabular}

\begin{tabular}{|c|c|c|c|c|c|c|c|c|c|c|c|c|c|c|c|c|}
\hline Albania & $\mathrm{m}$ & $\mathrm{m}$ & $\mathrm{m}$ & $\mathrm{m}$ & $\mathrm{m}$ & $\mathrm{m}$ & $\mathrm{m}$ & $\mathrm{m}$ & $\mathrm{m}$ & $\mathrm{m}$ & $\mathrm{m}$ & $\mathrm{m}$ & $\mathrm{m}$ & $\mathrm{m}$ & $\mathrm{m}$ & $\mathrm{m}$ \\
\hline Algeria & $\mathrm{m}$ & $\mathrm{m}$ & $\mathrm{m}$ & $\mathrm{m}$ & $\mathrm{m}$ & $\mathrm{m}$ & $\mathrm{m}$ & $\mathrm{m}$ & $\mathrm{m}$ & $\mathrm{m}$ & $\mathrm{m}$ & $\mathrm{m}$ & $\mathrm{m}$ & $\mathrm{m}$ & $\mathrm{m}$ & $\mathrm{m}$ \\
\hline Brazil & 410 & (3.0) & 411 & (2.9) & 416 & (2.7) & 401 & (3.2) & -9 & (3.0) & -5 & (1.0) & 0.4 & $(0.2)$ & -5 & $(0.9)$ \\
\hline B-S-J-G (China) & 519 & $(5.0)$ & 528 & (5.1) & 529 & (6.4) & 496 & (5.9) & -23 & $(5.3)$ & -11 & (1.8) & 1.2 & $(0.4)$ & -5 & (1.5) \\
\hline Bulgaria & 452 & $(4.7)$ & 454 & (5.1) & 469 & (4.4) & 440 & (5.8) & -12 & (5.3) & -7 & (1.7) & 0.6 & $(0.3)$ & -4 & (1.3) \\
\hline CABA (Argentina) & $\mathrm{m}$ & $\mathrm{m}$ & $\mathrm{m}$ & $\mathrm{m}$ & $\mathrm{m}$ & $\mathrm{m}$ & $\mathrm{m}$ & $\mathrm{m}$ & $\mathrm{m}$ & $\mathrm{m}$ & $\mathrm{m}$ & $\mathrm{m}$ & $\mathrm{m}$ & $\mathrm{m}$ & $\mathrm{m}$ & $\mathrm{m}$ \\
\hline Colombia & 416 & (2.6) & 417 & (3.3) & 425 & (3.0) & 409 & (3.2) & -7 & (3.0) & -5 & (1.4) & 0.3 & $(0.2)$ & -4 & (1.3) \\
\hline Costa Rica & 417 & $(2.7)$ & 414 & (2.4) & 427 & (3.4) & 429 & (3.3) & 12 & (3.2) & 4 & (1.2) & 0.4 & $(0.2)$ & 4 & (1.1) \\
\hline Croatia & 475 & (3.2) & 479 & (3.5) & 482 & (3.4) & 471 & (3.6) & -4 & (3.7) & -5 & (1.6) & 0.3 & $(0.2)$ & -1 & (1.3) \\
\hline Cyprus* & $\mathrm{m}$ & $\mathrm{m}$ & $\mathrm{m}$ & $\mathrm{m}$ & $\mathrm{m}$ & $\mathrm{m}$ & $\mathrm{m}$ & $\mathrm{m}$ & $\mathrm{m}$ & $\mathrm{m}$ & $\mathrm{m}$ & $\mathrm{m}$ & $\mathrm{m}$ & $\mathrm{m}$ & $\mathrm{m}$ & $\mathrm{m}$ \\
\hline Dominican Republic & 334 & $(3.2)$ & 330 & (3.4) & 352 & (3.6) & 330 & $(4.0)$ & -3 & (3.7) & -1 & $(0.9)$ & 0.0 & $(0.1)$ & -1 & $(0.9)$ \\
\hline FYROM & $\mathrm{m}$ & $\mathrm{m}$ & $\mathrm{m}$ & $\mathrm{m}$ & $\mathrm{m}$ & $\mathrm{m}$ & $\mathrm{m}$ & $\mathrm{m}$ & $\mathrm{m}$ & $\mathrm{m}$ & $\mathrm{m}$ & $\mathrm{m}$ & $\mathrm{m}$ & $\mathrm{m}$ & $\mathrm{m}$ & $\mathrm{m}$ \\
\hline Georgia & $\mathrm{m}$ & $\mathrm{m}$ & $\mathrm{m}$ & $\mathrm{m}$ & $\mathrm{m}$ & $\mathrm{m}$ & $\mathrm{m}$ & $\mathrm{m}$ & $\mathrm{m}$ & $\mathrm{m}$ & $\mathrm{m}$ & $\mathrm{m}$ & $\mathrm{m}$ & $\mathrm{m}$ & $\mathrm{m}$ & $\mathrm{m}$ \\
\hline Hong Kong (China) & 522 & $(3.2)$ & 526 & (3.9) & 536 & (3.1) & 513 & (3.6) & -9 & $(4.3)$ & -4 & (1.3) & 0.4 & $(0.3)$ & -4 & $(1.2)$ \\
\hline Indonesia & $\mathrm{m}$ & $\mathrm{m}$ & $\mathrm{m}$ & $\mathrm{m}$ & $\mathrm{m}$ & $\mathrm{m}$ & $\mathrm{m}$ & $\mathrm{m}$ & $\mathrm{m}$ & $\mathrm{m}$ & $\mathrm{m}$ & $\mathrm{m}$ & $\mathrm{m}$ & $\mathrm{m}$ & $\mathrm{m}$ & $\mathrm{m}$ \\
\hline Jordan & $\mathrm{m}$ & $\mathrm{m}$ & $\mathrm{m}$ & $\mathrm{m}$ & $\mathrm{m}$ & $\mathrm{m}$ & $\mathrm{m}$ & $\mathrm{m}$ & $\mathrm{m}$ & $\mathrm{m}$ & $\mathrm{m}$ & $\mathrm{m}$ & $\mathrm{m}$ & $\mathrm{m}$ & $\mathrm{m}$ & $\mathrm{m}$ \\
\hline Kosovo & $\mathrm{m}$ & $\mathrm{m}$ & $\mathrm{m}$ & $\mathrm{m}$ & $\mathrm{m}$ & $\mathrm{m}$ & $\mathrm{m}$ & $\mathrm{m}$ & $\mathrm{m}$ & $\mathrm{m}$ & $\mathrm{m}$ & $\mathrm{m}$ & $\mathrm{m}$ & $\mathrm{m}$ & $\mathrm{m}$ & $\mathrm{m}$ \\
\hline Lebanon & $\mathrm{m}$ & $\mathrm{m}$ & $\mathrm{m}$ & $\mathrm{m}$ & $\mathrm{m}$ & $\mathrm{m}$ & $\mathrm{m}$ & $\mathrm{m}$ & $\mathrm{m}$ & $\mathrm{m}$ & $\mathrm{m}$ & $\mathrm{m}$ & $\mathrm{m}$ & $\mathrm{m}$ & $\mathrm{m}$ & $\mathrm{m}$ \\
\hline Lithuania & 477 & (3.3) & 478 & (3.5) & 487 & (3.3) & 469 & (3.6) & -8 & $(4.0)$ & -6 & (1.4) & 0.6 & $(0.3)$ & -3 & $(1.2)$ \\
\hline Macao (China) & 534 & $(2.3)$ & 536 & (2.4) & 536 & (2.8) & 509 & $(2.9)$ & -25 & (3.8) & -12 & (1.5) & 2.0 & $(0.5)$ & -13 & (1.5) \\
\hline Malta & $\mathrm{m}$ & $\mathrm{m}$ & $\mathrm{m}$ & $\mathrm{m}$ & $\mathrm{m}$ & $\mathrm{m}$ & $\mathrm{m}$ & $\mathrm{m}$ & $\mathrm{m}$ & $\mathrm{m}$ & $\mathrm{m}$ & $\mathrm{m}$ & $\mathrm{m}$ & $\mathrm{m}$ & $\mathrm{m}$ & $\mathrm{m}$ \\
\hline Moldova & $\mathrm{m}$ & $\mathrm{m}$ & $\mathrm{m}$ & $\mathrm{m}$ & $\mathrm{m}$ & $\mathrm{m}$ & $\mathrm{m}$ & $\mathrm{m}$ & $\mathrm{m}$ & $\mathrm{m}$ & $\mathrm{m}$ & $\mathrm{m}$ & $\mathrm{m}$ & $\mathrm{m}$ & $\mathrm{m}$ & $\mathrm{m}$ \\
\hline Montenegro & 415 & $(2.4)$ & 413 & $(2.8)$ & 419 & (2.3) & 415 & $(2.9)$ & 0 & $(4.0)$ & -1 & (1.0) & 0.0 & $(0.1)$ & -1 & $(0.9)$ \\
\hline Peru & 400 & (3.2) & 399 & (3.1) & 406 & (3.3) & 395 & (3.2) & -6 & (3.7) & -4 & (1.3) & 0.3 & $(0.2)$ & -1 & (1.0) \\
\hline Qatar & 430 & (1.9) & 432 & (2.0) & 451 & (2.1) & 387 & (2.1) & -42 & $(2.8)$ & -14 & $(0.7)$ & 3.3 & $(0.3)$ & -11 & $(0.7)$ \\
\hline Romania & $\mathrm{m}$ & $\mathrm{m}$ & $\mathrm{m}$ & $\mathrm{m}$ & $\mathrm{m}$ & $\mathrm{m}$ & $\mathrm{m}$ & $\mathrm{m}$ & $\mathrm{m}$ & $\mathrm{m}$ & $\mathrm{m}$ & $\mathrm{m}$ & $\mathrm{m}$ & $\mathrm{m}$ & $\mathrm{m}$ & $\mathrm{m}$ \\
\hline Russia & 483 & (3.8) & 484 & (3.9) & 500 & (3.1) & 488 & $(4.8)$ & 5 & $(4.5)$ & 1 & (1.6) & 0.0 & $(0.1)$ & 0 & $(1.4)$ \\
\hline Singapore & 563 & $(2.9)$ & 568 & $(2.8)$ & 566 & (3.1) & 527 & (3.1) & -36 & $(4.2)$ & -17 & (1.5) & 2.4 & $(0.4)$ & -9 & (1.4) \\
\hline Chinese Taipei & 530 & (3.6) & 526 & (3.7) & 533 & (3.6) & 542 & (3.6) & 12 & $(4.1)$ & 4 & (1.6) & 0.1 & $(0.1)$ & 2 & (1.3) \\
\hline Thailand & 430 & (3.9) & 428 & (3.3) & 429 & (3.4) & 403 & $(4.0)$ & -27 & (3.8) & -9 & $(0.9)$ & 2.8 & $(0.5)$ & -7 & $(0.8)$ \\
\hline Trinidad and Tobago & $\mathrm{m}$ & $\mathrm{m}$ & $\mathrm{m}$ & $\mathrm{m}$ & $\mathrm{m}$ & $\mathrm{m}$ & $\mathrm{m}$ & $\mathrm{m}$ & $\mathrm{m}$ & $\mathrm{m}$ & $\mathrm{m}$ & $\mathrm{m}$ & $\mathrm{m}$ & $\mathrm{m}$ & $\mathrm{m}$ & $\mathrm{m}$ \\
\hline Tunisia & 389 & $(2.7)$ & 394 & (3.0) & 395 & (2.9) & 380 & (3.4) & -9 & (3.8) & -3 & (1.2) & 0.3 & $(0.3)$ & -2 & (1.1) \\
\hline United Arab Emirates & 447 & $(2.8)$ & 446 & (2.9) & 460 & (3.3) & 408 & (3.5) & -39 & (3.4) & -12 & (1.0) & 2.5 & $(0.4)$ & -10 & (1.0) \\
\hline Uruguay & 438 & (2.9) & 438 & (2.7) & 447 & (3.3) & 437 & (2.9) & -1 & (3.2) & -1 & (1.0) & 0.0 & $(0.0)$ & -2 & (0.9) \\
\hline Viet Nam & $\mathrm{m}$ & $\mathrm{m}$ & $\mathrm{m}$ & $\mathrm{m}$ & $\mathrm{m}$ & $\mathrm{m}$ & $\mathrm{m}$ & $\mathrm{m}$ & $\mathrm{m}$ & $\mathrm{m}$ & $\mathrm{m}$ & $\mathrm{m}$ & $\mathrm{m}$ & $\mathrm{m}$ & $\mathrm{m}$ & $\mathrm{m}$ \\
\hline Argentina** & $\mathrm{m}$ & $\mathrm{m}$ & $\mathrm{m}$ & $\mathrm{m}$ & $\mathrm{m}$ & $\mathrm{m}$ & $\mathrm{m}$ & $\mathrm{m}$ & $\mathrm{m}$ & $\mathrm{m}$ & $\mathrm{m}$ & $\mathrm{m}$ & $\mathrm{m}$ & $\mathrm{m}$ & $\mathrm{m}$ & $\mathrm{m}$ \\
\hline Kazakhstan** & $\mathrm{m}$ & $\mathrm{m}$ & $\mathrm{m}$ & $\mathrm{m}$ & $\mathrm{m}$ & $\mathrm{m}$ & $\mathrm{m}$ & $\mathrm{m}$ & $\mathrm{m}$ & $\mathrm{m}$ & $\mathrm{m}$ & $\mathrm{m}$ & $\mathrm{m}$ & $\mathrm{m}$ & $\mathrm{m}$ & $\mathrm{m}$ \\
\hline Malaysia** & 446 & (3.4) & 452 & (3.6) & 451 & $(4.0)$ & 424 & $(4.2)$ & -22 & $(4.0)$ & -12 & (1.3) & 2.2 & (0.5) & -12 & $(1.2)$ \\
\hline
\end{tabular}

1. The socio-economic profile is measured by the PISA index of economic, social and cultural status (ESCS).

Note: Values that are statistically significant are indicated in bold (see Annex A3).

* See note at the beginning of this Annex.

** Coverage is too small to ensure comparability (see Annex A4).

StatLink ints 
[Part 1/1]

Table III.8.9 Index of exposure to bullying and life satisfaction

Results based on students' self-reports

\begin{tabular}{|c|c|c|c|c|c|c|c|c|c|c|c|c|c|c|c|}
\hline & \multicolumn{10}{|c|}{ Average life satisfaction, by national quarters of the index of exposure to bullying } & \multirow{2}{*}{\multicolumn{2}{|c|}{$\begin{array}{l}\text { Change in life satisfaction } \\
\text { associated with a one-unit } \\
\text { change in the index } \\
\text { of exposure to bullying }\end{array}$}} & & \\
\hline & & Bottom & quarter & Second & quarter & $\begin{array}{r}\text { Th } \\
\text { qua }\end{array}$ & & $\begin{array}{r}\text { To } \\
\text { qua }\end{array}$ & & $\begin{array}{r}\text { Top - b } \\
\text { qua }\end{array}$ & $\begin{array}{l}\text { ttom } \\
\text { ter }\end{array}$ & & & in stud & $\begin{array}{l}\text { mance } \\
\text { 100) }\end{array}$ \\
\hline & & Mean & S.E. & Mean & S.E. & Mean & S.E. & Mean & S.E. & Dif. & S.E. & Index change & S.E. & $\%$ & S.E. \\
\hline 0 & Australia & $\mathrm{m}$ & $\mathrm{m}$ & $\mathrm{m}$ & $\mathrm{m}$ & $\mathrm{m}$ & $\mathrm{m}$ & $\mathrm{m}$ & $\mathrm{m}$ & $\mathrm{m}$ & $\mathrm{m}$ & $\mathrm{m}$ & $\mathrm{m}$ & $\mathrm{m}$ & $\mathrm{m}$ \\
\hline 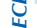 & Austria & 7.92 & $(0.06)$ & 7.92 & $(0.06)$ & 7.46 & $(0.06)$ & 6.81 & $(0.07)$ & -1.11 & $(0.09)$ & -0.47 & $(0.04)$ & 4.1 & $(0.6)$ \\
\hline o & Belgium (excl. Flemish) & 7.90 & $(0.07)$ & 7.94 & $(0.08)$ & 7.40 & $(0.07)$ & 6.68 & $(0.09)$ & -1.23 & $(0.09)$ & -0.62 & $(0.04)$ & 7.5 & $(0.8)$ \\
\hline & Canada & $\mathrm{m}$ & $\mathrm{m}$ & $\mathrm{m}$ & $\mathrm{m}$ & $\mathrm{m}$ & $\mathrm{m}$ & $\mathrm{m}$ & $\mathrm{m}$ & $\mathrm{m}$ & $\mathrm{m}$ & $\mathrm{m}$ & $\mathrm{m}$ & $\mathrm{m}$ & $\mathrm{m}$ \\
\hline & Chile & 7.77 & $(0.07)$ & 7.73 & $(0.07)$ & 7.27 & $(0.06)$ & 6.68 & $(0.08)$ & -1.09 & $(0.10)$ & -0.52 & $(0.05)$ & 4.1 & $(0.7)$ \\
\hline & Czech Republic & 7.54 & $(0.06)$ & 7.37 & $(0.06)$ & 6.98 & $(0.07)$ & 6.35 & $(0.07)$ & -1.19 & $(0.09)$ & -0.44 & $(0.03)$ & 4.3 & $(0.7)$ \\
\hline & Denmark & $\mathrm{m}$ & $\mathrm{m}$ & $\mathrm{m}$ & $\mathrm{m}$ & $\mathrm{m}$ & $\mathrm{m}$ & $\mathrm{m}$ & $\mathrm{m}$ & $\mathrm{m}$ & $\mathrm{m}$ & $\mathrm{m}$ & $\mathrm{m}$ & $\mathrm{m}$ & $\mathrm{m}$ \\
\hline & Estonia & 7.84 & $(0.06)$ & 7.80 & $(0.05)$ & 7.47 & $(0.05)$ & 6.89 & $(0.08)$ & -0.95 & $(0.10)$ & -0.47 & $(0.04)$ & 4.0 & $(0.7)$ \\
\hline & Finland & 8.31 & $(0.04)$ & 8.28 & $(0.04)$ & 7.68 & $(0.06)$ & 7.30 & $(0.06)$ & -1.01 & $(0.07)$ & -0.49 & $(0.03)$ & 5.7 & $(0.7)$ \\
\hline & France & 8.05 & $(0.04)$ & 7.93 & $(0.05)$ & 7.55 & $(0.05)$ & 7.02 & $(0.06)$ & -1.03 & $(0.08)$ & -0.45 & $(0.03)$ & 5.1 & $(0.6)$ \\
\hline & Germany & 7.93 & $(0.05)$ & 7.71 & $(0.08)$ & 7.22 & $(0.07)$ & 6.52 & $(0.09)$ & -1.41 & $(0.09)$ & -0.71 & $(0.04)$ & 7.0 & $(0.7)$ \\
\hline & Greece & 7.11 & $(0.06)$ & 7.41 & $(0.06)$ & 6.92 & $(0.08)$ & 6.20 & $(0.08)$ & -0.91 & $(0.11)$ & -0.35 & $(0.04)$ & 3.4 & $(0.7)$ \\
\hline & Hungary & 7.53 & $(0.07)$ & 7.59 & $(0.06)$ & 7.15 & $(0.07)$ & 6.40 & $(0.09)$ & -1.13 & $(0.11)$ & -0.42 & $(0.03)$ & 4.1 & $(0.6)$ \\
\hline & Iceland & 8.26 & $(0.07)$ & 8.24 & $(0.06)$ & 7.90 & $(0.08)$ & 6.78 & $(0.09)$ & -1.48 & $(0.12)$ & -0.62 & $(0.04)$ & 8.1 & (1.1) \\
\hline & Ireland & 7.84 & $(0.06)$ & 7.81 & $(0.05)$ & 7.18 & $(0.06)$ & 6.40 & $(0.07)$ & -1.44 & $(0.09)$ & -0.74 & $(0.04)$ & 9.1 & (1.0) \\
\hline & Israel & $\mathrm{m}$ & $\mathrm{m}$ & $\mathrm{m}$ & $\mathrm{m}$ & $\mathrm{m}$ & $\mathrm{m}$ & $\mathrm{m}$ & $\mathrm{m}$ & $\mathrm{m}$ & $\mathrm{m}$ & $\mathrm{m}$ & $\mathrm{m}$ & $\mathrm{m}$ & $\mathrm{m}$ \\
\hline & Italy & $\mathrm{m}$ & $\mathrm{m}$ & $\mathrm{m}$ & $\mathrm{m}$ & $\mathrm{m}$ & $\mathrm{m}$ & $\mathrm{m}$ & $\mathrm{m}$ & $\mathrm{m}$ & $\mathrm{m}$ & $\mathrm{m}$ & $\mathrm{m}$ & $\mathrm{m}$ & $\mathrm{m}$ \\
\hline & Japan & 7.11 & $(0.05)$ & 7.14 & $(0.06)$ & 6.74 & $(0.06)$ & 6.26 & $(0.07)$ & -0.85 & $(0.07)$ & -0.41 & $(0.03)$ & 3.0 & $(0.4)$ \\
\hline & Korea & 6.55 & $(0.06)$ & 6.64 & $(0.07)$ & 6.47 & $(0.07)$ & 5.81 & $(0.07)$ & -0.75 & (0.09) & -0.30 & $(0.03)$ & 1.9 & $(0.4)$ \\
\hline & Latvia & 7.84 & $(0.07)$ & 7.53 & $(0.07)$ & 7.27 & $(0.06)$ & 6.83 & $(0.07)$ & -1.01 & $(0.09)$ & -0.44 & $(0.03)$ & 4.1 & $(0.7)$ \\
\hline & Luxembourg & 7.78 & $(0.06)$ & 7.74 & $(0.05)$ & 7.28 & $(0.06)$ & 6.72 & $(0.06)$ & -1.07 & $(0.08)$ & -0.42 & $(0.03)$ & 3.9 & $(0.6)$ \\
\hline & Mexico & 8.75 & $(0.05)$ & 8.57 & $(0.04)$ & 8.11 & $(0.06)$ & 7.64 & $(0.06)$ & -1.11 & $(0.09)$ & -0.44 & $(0.03)$ & 5.0 & $(0.7)$ \\
\hline & Netherlands & 8.07 & $(0.04)$ & 8.13 & $(0.04)$ & 7.87 & $(0.05)$ & 7.22 & $(0.06)$ & -0.85 & $(0.06)$ & -0.48 & $(0.04)$ & 6.5 & $(0.9)$ \\
\hline & New Zealand & $\mathrm{m}$ & $\mathrm{m}$ & $\mathrm{m}$ & $\mathrm{m}$ & $\mathrm{m}$ & $\mathrm{m}$ & $\mathrm{m}$ & $\mathrm{m}$ & $\mathrm{m}$ & $\mathrm{m}$ & $\mathrm{m}$ & $\mathrm{m}$ & $\mathrm{m}$ & $\mathrm{m}$ \\
\hline & Norway & $\mathrm{m}$ & $\mathrm{m}$ & $\mathrm{m}$ & $\mathrm{m}$ & $\mathrm{m}$ & $\mathrm{m}$ & $\mathrm{m}$ & $\mathrm{m}$ & $\mathrm{m}$ & $\mathrm{m}$ & $\mathrm{m}$ & $\mathrm{m}$ & $\mathrm{m}$ & $\mathrm{m}$ \\
\hline & Poland & 7.77 & $(0.06)$ & 7.62 & $(0.07)$ & 7.00 & $(0.07)$ & 6.36 & $(0.08)$ & -1.41 & $(0.08)$ & -0.58 & $(0.04)$ & 5.7 & $(0.7)$ \\
\hline & Portugal & 7.65 & $(0.06)$ & 7.68 & $(0.06)$ & 7.47 & $(0.06)$ & 6.66 & $(0.06)$ & -0.99 & $(0.08)$ & -0.39 & $(0.03)$ & 4.5 & $(0.6)$ \\
\hline & Slovak Republic & 8.02 & $(0.05)$ & 7.82 & $(0.06)$ & 7.31 & $(0.06)$ & 6.71 & $(0.08)$ & -1.31 & $(0.09)$ & -0.44 & $(0.03)$ & 4.6 & $(0.7)$ \\
\hline & Slovenia & 7.63 & $(0.06)$ & 7.49 & $(0.07)$ & 7.00 & $(0.08)$ & 6.58 & $(0.07)$ & -1.05 & $(0.09)$ & -0.47 & $(0.04)$ & 3.7 & $(0.6)$ \\
\hline & Spain & 7.72 & $(0.05)$ & 7.80 & $(0.05)$ & 7.47 & $(0.05)$ & 6.70 & $(0.06)$ & -1.01 & $(0.08)$ & -0.53 & $(0.03)$ & 5.3 & $(0.6)$ \\
\hline & Sweden & $\mathrm{m}$ & $\mathrm{m}$ & $\mathrm{m}$ & $\mathrm{m}$ & $\mathrm{m}$ & $\mathrm{m}$ & $\mathrm{m}$ & $\mathrm{m}$ & $\mathrm{m}$ & $\mathrm{m}$ & $\mathrm{m}$ & $\mathrm{m}$ & $\mathrm{m}$ & $\mathrm{m}$ \\
\hline & Switzerland & 8.10 & $(0.05)$ & 8.10 & $(0.04)$ & 7.63 & $(0.07)$ & 7.00 & $(0.08)$ & -1.11 & (0.09) & -0.60 & $(0.05)$ & 6.3 & $(1.0)$ \\
\hline & Turkey & 6.49 & $(0.09)$ & 6.48 & $(0.11)$ & 6.19 & $(0.10)$ & 5.30 & $(0.09)$ & -1.19 & $(0.13)$ & -0.32 & $(0.03)$ & 3.0 & $(0.6)$ \\
\hline & United Kingdom & 7.62 & $(0.07)$ & 7.51 & $(0.06)$ & 6.87 & $(0.07)$ & 5.97 & $(0.08)$ & -1.66 & $(0.10)$ & -0.67 & $(0.04)$ & 9.1 & $(0.9)$ \\
\hline & United States & 7.82 & $(0.07)$ & 7.79 & $(0.07)$ & 7.27 & $(0.06)$ & 6.56 & $(0.08)$ & -1.26 & $(0.10)$ & -0.52 & $(0.04)$ & 5.6 & $(0.8)$ \\
\hline & OECD average & 7.74 & $(0.01)$ & 7.69 & $(0.01)$ & 7.26 & $(0.01)$ & 6.61 & $(0.01)$ & -1.13 & $(0.02)$ & -0.49 & $(0.01)$ & 5.1 & $(0.1)$ \\
\hline 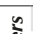 & Albania & $\mathrm{m}$ & $\mathrm{m}$ & $\mathrm{m}$ & $\mathrm{m}$ & $\mathrm{m}$ & $\mathrm{m}$ & $\mathrm{m}$ & $\mathrm{m}$ & $\mathrm{m}$ & $\mathrm{m}$ & $\mathrm{m}$ & $\mathrm{m}$ & $\mathrm{m}$ & $\mathrm{m}$ \\
\hline $\bar{a}$ & Algeria & $\mathrm{m}$ & $\mathrm{m}$ & $\mathrm{m}$ & $\mathrm{m}$ & $\mathrm{m}$ & $\mathrm{m}$ & $\mathrm{m}$ & $\mathrm{m}$ & $\mathrm{m}$ & $\mathrm{m}$ & $\mathrm{m}$ & $\mathrm{m}$ & $\mathrm{m}$ & $\mathrm{m}$ \\
\hline ปั้ & Brazil & 7.86 & $(0.04)$ & 8.00 & $(0.05)$ & 7.50 & $(0.04)$ & 6.98 & $(0.06)$ & -0.89 & $(0.07)$ & -0.35 & $(0.03)$ & 2.9 & $(0.4)$ \\
\hline & B-S-J-G (China) & 7.26 & $(0.07)$ & 7.17 & $(0.06)$ & 6.75 & $(0.07)$ & 6.16 & $(0.06)$ & -1.10 & (0.09) & -0.44 & $(0.03)$ & 3.9 & $(0.5)$ \\
\hline & Bulgaria & 7.91 & $(0.06)$ & 7.86 & $(0.08)$ & 7.13 & $(0.07)$ & 6.80 & $(0.08)$ & -1.11 & $(0.10)$ & -0.40 & $(0.03)$ & 3.6 & $(0.6)$ \\
\hline & CABA (Argentina) & $\mathrm{m}$ & $\mathrm{m}$ & $\mathrm{m}$ & $\mathrm{m}$ & $\mathrm{m}$ & $\mathrm{m}$ & $\mathrm{m}$ & $\mathrm{m}$ & $\mathrm{m}$ & $\mathrm{m}$ & $\mathrm{m}$ & $\mathrm{m}$ & $\mathrm{m}$ & $\mathrm{m}$ \\
\hline & Colombia & 8.29 & $(0.06)$ & 8.20 & $(0.06)$ & 7.77 & $(0.06)$ & 7.27 & $(0.07)$ & -1.02 & $(0.09)$ & -0.46 & $(0.03)$ & 3.2 & $(0.5)$ \\
\hline & Costa Rica & 8.65 & $(0.05)$ & 8.69 & $(0.05)$ & 8.06 & $(0.06)$ & 7.41 & $(0.08)$ & -1.24 & $(0.09)$ & -0.54 & $(0.03)$ & 7.2 & $(0.9)$ \\
\hline & Croatia & 8.26 & $(0.04)$ & 8.35 & $(0.05)$ & 7.88 & $(0.07)$ & 7.11 & $(0.08)$ & -1.15 & $(0.08)$ & -0.54 & $(0.04)$ & 6.7 & $(0.8)$ \\
\hline & Cyprus* & $\mathrm{m}$ & $\mathrm{m}$ & $\mathrm{m}$ & $\mathrm{m}$ & $\mathrm{m}$ & $\mathrm{m}$ & $\mathrm{m}$ & $\mathrm{m}$ & $\mathrm{m}$ & $\mathrm{m}$ & $\mathrm{m}$ & $\mathrm{m}$ & $\mathrm{m}$ & $\mathrm{m}$ \\
\hline & Dominican Republic & 8.91 & $(0.07)$ & 8.84 & $(0.08)$ & 8.44 & $(0.08)$ & 7.86 & $(0.09)$ & -1.06 & $(0.12)$ & -0.28 & $(0.03)$ & 3.2 & $(0.7)$ \\
\hline & FYROM & $\mathrm{m}$ & $\mathrm{m}$ & $\mathrm{m}$ & $\mathrm{m}$ & $\mathrm{m}$ & $\mathrm{m}$ & $\mathrm{m}$ & $\mathrm{m}$ & $\mathrm{m}$ & $\mathrm{m}$ & $\mathrm{m}$ & $\mathrm{m}$ & $\mathrm{m}$ & $\mathrm{m}$ \\
\hline & Georgia & $\mathrm{m}$ & $\mathrm{m}$ & $\mathrm{m}$ & $\mathrm{m}$ & $\mathrm{m}$ & $\mathrm{m}$ & $\mathrm{m}$ & $\mathrm{m}$ & $\mathrm{m}$ & $\mathrm{m}$ & $\mathrm{m}$ & $\mathrm{m}$ & $\mathrm{m}$ & $\mathrm{m}$ \\
\hline & Hong Kong (China) & 6.69 & $(0.06)$ & 6.83 & $(0.05)$ & 6.54 & $(0.06)$ & 5.87 & $(0.07)$ & -0.82 & $(0.08)$ & -0.30 & $(0.02)$ & 3.3 & $(0.5)$ \\
\hline & Indonesia & $\mathrm{m}$ & $\mathrm{m}$ & $\mathrm{m}$ & $\mathrm{m}$ & $\mathrm{m}$ & $\mathrm{m}$ & $\mathrm{m}$ & $\mathrm{m}$ & $\mathrm{m}$ & $\mathrm{m}$ & $\mathrm{m}$ & $\mathrm{m}$ & $\mathrm{m}$ & $\mathrm{m}$ \\
\hline & Jordan & $\mathrm{m}$ & $\mathrm{m}$ & $\mathrm{m}$ & $\mathrm{m}$ & $\mathrm{m}$ & $\mathrm{m}$ & $\mathrm{m}$ & $\mathrm{m}$ & $\mathrm{m}$ & $\mathrm{m}$ & $\mathrm{m}$ & $\mathrm{m}$ & $\mathrm{m}$ & $\mathrm{m}$ \\
\hline & Kosovo & $\mathrm{m}$ & $\mathrm{m}$ & $\mathrm{m}$ & $\mathrm{m}$ & $\mathrm{m}$ & $\mathrm{m}$ & $\mathrm{m}$ & $\mathrm{m}$ & $\mathrm{m}$ & $\mathrm{m}$ & $\mathrm{m}$ & $\mathrm{m}$ & $\mathrm{m}$ & $\mathrm{m}$ \\
\hline & Lebanon & $\mathrm{m}$ & $\mathrm{m}$ & $\mathrm{m}$ & $\mathrm{m}$ & $\mathrm{m}$ & $\mathrm{m}$ & $\mathrm{m}$ & $\mathrm{m}$ & $\mathrm{m}$ & $\mathrm{m}$ & $\mathrm{m}$ & $\mathrm{m}$ & $\mathrm{m}$ & $\mathrm{m}$ \\
\hline & Lithuania & 8.24 & $(0.05)$ & 8.30 & $(0.06)$ & 7.78 & $(0.07)$ & 7.15 & $(0.08)$ & -1.09 & $(0.10)$ & -0.43 & $(0.04)$ & 4.9 & $(0.8)$ \\
\hline & Macao (China) & 6.95 & $(0.07)$ & 6.78 & $(0.05)$ & 6.56 & $(0.06)$ & 6.08 & $(0.08)$ & -0.87 & $(0.11)$ & -0.33 & $(0.04)$ & 2.4 & $(0.6)$ \\
\hline & Malta & $\mathrm{m}$ & $\mathrm{m}$ & $\mathrm{m}$ & $\mathrm{m}$ & $\mathrm{m}$ & $\mathrm{m}$ & $\mathrm{m}$ & $\mathrm{m}$ & $\mathrm{m}$ & $\mathrm{m}$ & $\mathrm{m}$ & $\mathrm{m}$ & $\mathrm{m}$ & $\mathrm{m}$ \\
\hline & Moldova & $\mathrm{m}$ & $\mathrm{m}$ & $\mathrm{m}$ & $\mathrm{m}$ & $\mathrm{m}$ & $\mathrm{m}$ & $\mathrm{m}$ & $\mathrm{m}$ & $\mathrm{m}$ & $\mathrm{m}$ & $\mathrm{m}$ & $\mathrm{m}$ & $\mathrm{m}$ & $\mathrm{m}$ \\
\hline & Montenegro & 8.16 & $(0.06)$ & 8.13 & $(0.07)$ & 7.71 & $(0.06)$ & 6.97 & $(0.09)$ & -1.19 & $(0.11)$ & -0.37 & $(0.03)$ & 4.3 & $(0.6)$ \\
\hline & Peru & 7.89 & $(0.06)$ & 7.95 & $(0.06)$ & 7.33 & $(0.07)$ & 6.89 & $(0.07)$ & -1.00 & $(0.09)$ & -0.44 & $(0.04)$ & 3.5 & $(0.6)$ \\
\hline & Qatar & 7.94 & $(0.04)$ & 7.77 & $(0.04)$ & 7.08 & $(0.04)$ & 6.75 & $(0.06)$ & -1.19 & $(0.07)$ & -0.36 & $(0.02)$ & 3.4 & $(0.4)$ \\
\hline & Romania & $\mathrm{m}$ & $\mathrm{m}$ & $\mathrm{m}$ & $\mathrm{m}$ & $\mathrm{m}$ & $\mathrm{m}$ & $\mathrm{m}$ & $\mathrm{m}$ & $\mathrm{m}$ & $\mathrm{m}$ & $\mathrm{m}$ & $\mathrm{m}$ & $\mathrm{m}$ & $\mathrm{m}$ \\
\hline & Russia & 8.39 & $(0.08)$ & 8.07 & $(0.07)$ & 7.66 & $(0.07)$ & 6.93 & $(0.07)$ & -1.47 & $(0.10)$ & -0.51 & $(0.04)$ & 6.0 & $(0.8)$ \\
\hline & Singapore & $\mathrm{m}$ & $\mathrm{m}$ & $\mathrm{m}$ & $\mathrm{m}$ & $\mathrm{m}$ & $\mathrm{m}$ & $\mathrm{m}$ & $\mathrm{m}$ & $\mathrm{m}$ & $\mathrm{m}$ & $\mathrm{m}$ & $\mathrm{m}$ & $\mathrm{m}$ & $\mathrm{m}$ \\
\hline & Chinese Taipei & 6.75 & $(0.06)$ & 6.85 & $(0.06)$ & 6.77 & $(0.06)$ & 6.01 & $(0.05)$ & -0.74 & $(0.07)$ & -0.40 & $(0.03)$ & 2.9 & $(0.4)$ \\
\hline & Thailand & 7.97 & $(0.06)$ & 7.95 & $(0.05)$ & 7.66 & $(0.07)$ & 7.27 & $(0.07)$ & -0.70 & $(0.08)$ & -0.20 & $(0.02)$ & 1.7 & $(0.4)$ \\
\hline & Trinidad and Tobago & $\mathrm{m}$ & $\mathrm{m}$ & $\mathrm{m}$ & $\mathrm{m}$ & $\mathrm{m}$ & $\mathrm{m}$ & $\mathrm{m}$ & $\mathrm{m}$ & $\mathrm{m}$ & $\mathrm{m}$ & $\mathrm{m}$ & $\mathrm{m}$ & $\mathrm{m}$ & $\mathrm{m}$ \\
\hline & Tunisia & 7.46 & $(0.09)$ & 7.18 & $(0.09)$ & 6.66 & $(0.11)$ & 6.29 & $(0.10)$ & -1.17 & $(0.13)$ & -0.41 & $(0.04)$ & 2.8 & $(0.5)$ \\
\hline & United Arab Emirates & 7.73 & $(0.06)$ & 7.69 & $(0.06)$ & 7.09 & $(0.07)$ & 6.65 & $(0.07)$ & -1.08 & $(0.08)$ & -0.34 & $(0.02)$ & 3.0 & $(0.4)$ \\
\hline & Uruguay & 8.19 & $(0.06)$ & 8.17 & $(0.06)$ & 7.49 & $(0.06)$ & 6.95 & $(0.07)$ & -1.24 & $(0.08)$ & -0.50 & $(0.03)$ & 5.9 & $(0.7)$ \\
\hline & Viet Nam & $\mathrm{m}$ & $\mathrm{m}$ & $\mathrm{m}$ & $\mathrm{m}$ & $\mathrm{m}$ & $\mathrm{m}$ & $\mathrm{m}$ & $\mathrm{m}$ & $\mathrm{m}$ & $\mathrm{m}$ & $\mathrm{m}$ & $\mathrm{m}$ & $\mathrm{m}$ & $\mathrm{m}$ \\
\hline & Argentina** & $\mathrm{m}$ & $\mathrm{m}$ & $\mathrm{m}$ & $\mathrm{m}$ & $\mathrm{m}$ & $\mathrm{m}$ & $\mathrm{m}$ & $\mathrm{m}$ & $\mathrm{m}$ & $\mathrm{m}$ & $\mathrm{m}$ & $\mathrm{m}$ & $\mathrm{m}$ & $\mathrm{m}$ \\
\hline & Kazakhstan** & $\mathrm{m}$ & $\mathrm{m}$ & $\mathrm{m}$ & $\mathrm{m}$ & $\mathrm{m}$ & $\mathrm{m}$ & $\mathrm{m}$ & $\mathrm{m}$ & $\mathrm{m}$ & $\mathrm{m}$ & $\mathrm{m}$ & $\mathrm{m}$ & $\mathrm{m}$ & $\mathrm{m}$ \\
\hline & Malaysia** & 7.50 & $(0.06)$ & 7.32 & $(0.06)$ & 6.90 & $(0.07)$ & 6.55 & $(0.07)$ & -0.95 & $(0.08)$ & -0.37 & $(0.03)$ & 2.9 & $(0.5)$ \\
\hline
\end{tabular}

Note: Values that are statistically significant are indicated in bold (see Annex A3).

* See note at the beginning of this Annex.

** Coverage is too small to ensure comparability (see Annex A4).

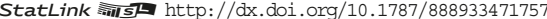




\begin{tabular}{|c|c|c|c|c|c|c|c|c|c|}
\hline & \multicolumn{8}{|c|}{ Science performance, by prevalence of bullying at school } \\
\hline & & \multirow{2}{*}{\multicolumn{2}{|c|}{$\begin{array}{l}\text { Schools with low prevalence } \\
\text { of bullying }{ }^{1}\end{array}$}} & \multirow{2}{*}{\multicolumn{2}{|c|}{$\begin{array}{l}\text { Schools with high prevalence } \\
\text { of bullying }{ }^{2}\end{array}$}} & \multicolumn{4}{|c|}{ Difference between schools with high and low prevalence of bullying } \\
\hline & & & & & & \multicolumn{2}{|c|}{$\begin{array}{l}\text { Before accounting for schools' } \\
\text { socio-economic profile }\end{array}$} & $\begin{array}{l}\text { After accol } \\
\text { socio-ec }\end{array}$ & $\begin{array}{l}\text { or schools' } \\
\text { profile }\end{array}$ \\
\hline & & Mean score & S.E. & Mean score & S.E. & Score dif. & S.E. & Score dif. & S.E. \\
\hline 0 & Australia & 546 & $(5.2)$ & 500 & $(10.8)$ & -46 & $(5.6)$ & -21 & $(4.6)$ \\
\hline 岙 & Austria & 510 & (5.6) & 459 & (15.1) & -51 & (9.5) & -25 & (5.5) \\
\hline ర & Belgium & 541 & (4.9) & 459 & (12.8) & -82 & (7.9) & -33 & (5.6) \\
\hline & Canada & 551 & (4.4) & 518 & (9.1) & -33 & $(4.8)$ & -20 & (3.4) \\
\hline & Chile & 466 & (4.9) & 418 & (13.5) & -48 & (8.6) & -24 & (5.6) \\
\hline & Czech Republic & 525 & (6.5) & 477 & $(15.1)$ & -48 & (8.6) & -27 & (5.4) \\
\hline & Denmark & 513 & (3.3) & 485 & (8.6) & -28 & $(5.3)$ & -15 & $(4.2)$ \\
\hline & Estonia & 551 & $(4.2)$ & 523 & $(9.0)$ & -29 & $(4.8)$ & -26 & (3.9) \\
\hline & Finland & 548 & $(6.2)$ & 526 & (13.8) & -22 & (7.6) & -15 & (5.5) \\
\hline & France & 533 & (3.7) & 420 & $(12.2)$ & -113 & (8.5) & -49 & $(8.2)$ \\
\hline & Germany & 537 & $(4.0)$ & 476 & (14.9) & -61 & (10.9) & -27 & (6.4) \\
\hline & Greece & 479 & (3.8) & 396 & (14.6) & -83 & $(10.8)$ & -60 & $(7.0)$ \\
\hline & Hungary & 502 & $(6.2)$ & 428 & $(16.7)$ & -75 & (10.5) & -26 & (6.3) \\
\hline & Iceland & 479 & $(2.2)$ & 462 & (6.9) & -17 & $(4.7)$ & -12 & $(4.8)$ \\
\hline & Ireland & 505 & (3.9) & 501 & $(10.7)$ & -4 & $(6.7)$ & -6 & $(4.6)$ \\
\hline & Israel & $\mathrm{m}$ & $\mathrm{m}$ & $\mathrm{m}$ & $\mathrm{m}$ & $\mathrm{m}$ & $\mathrm{m}$ & $\mathrm{m}$ & $\mathrm{m}$ \\
\hline & Italy & $\mathrm{m}$ & $\mathrm{m}$ & $\mathrm{m}$ & $\mathrm{m}$ & $\mathrm{m}$ & $\mathrm{m}$ & $\mathrm{m}$ & $\mathrm{m}$ \\
\hline & Japan & 549 & $(4.1)$ & 502 & (16.8) & -47 & (12.7) & -32 & $(7.9)$ \\
\hline & Korea & 520 & (3.9) & $\mathrm{m}$ & $\mathrm{m}$ & c & c & c & c \\
\hline & Latvia & 505 & $(6.0)$ & 485 & (12.4) & -20 & (6.4) & -12 & $(5.2)$ \\
\hline & Luxembourg & 556 & $(2.2)$ & 465 & (5.3) & -91 & (3.2) & -45 & (3.9) \\
\hline & Mexico & 435 & (4.5) & 401 & (10.9) & -34 & (6.4) & -22 & (4.9) \\
\hline & Netherlands & 528 & $(4.1)$ & 441 & $(20.1)$ & -88 & (16.0) & -45 & $(13.2)$ \\
\hline & New Zealand & 543 & $(10.3)$ & 511 & $(21.2)$ & -32 & (10.9) & -5 & $(6.1)$ \\
\hline & Norway & 510 & $(4.0)$ & 495 & $(10.1)$ & -15 & $(6.1)$ & -12 & (5.0) \\
\hline & Poland & 513 & (7.5) & 496 & (16.5) & -17 & $(9.0)$ & -8 & (6.0) \\
\hline & Portugal & 519 & (3.5) & 455 & (11.9) & -64 & (8.4) & -40 & (6.6) \\
\hline & Slovak Republic & 499 & (5.8) & 434 & (14.0) & -65 & $(8.2)$ & -32 & (6.5) \\
\hline & Slovenia & 536 & $(2.1)$ & 473 & (5.3) & -63 & (3.3) & -22 & (3.2) \\
\hline & Spain & 501 & (3.0) & 480 & (10.6) & -21 & (7.6) & -17 & (5.0) \\
\hline & Sweden & 514 & (5.9) & 477 & (13.7) & -36 & $(7.8)$ & -7 & (6.5) \\
\hline & Switzerland & 525 & (6.9) & 481 & (18.9) & -44 & (12.0) & -39 & $(8.1)$ \\
\hline & Turkey & 456 & (7.1) & 389 & (16.4) & -67 & $(9.2)$ & -45 & $(7.2)$ \\
\hline & United Kingdom & 541 & $(7.2)$ & 503 & $(15.4)$ & -38 & $(8.1)$ & -12 & $(5.1)$ \\
\hline & United States & 510 & (6.5) & 500 & $(16.6)$ & -10 & $(10.1)$ & -9 & $(7.1)$ \\
\hline & OECD average & 517 & $(0.9)$ & 470 & $(2.4)$ & -47 & (1.5) & -25 & (1.1) \\
\hline$\infty$ & Albania & $\mathrm{m}$ & $\mathrm{m}$ & $\mathrm{m}$ & $\mathrm{m}$ & $\mathrm{m}$ & $\mathrm{m}$ & $\mathrm{m}$ & $\mathrm{m}$ \\
\hline$\Xi$ & Algeria & $\mathrm{m}$ & $\mathrm{m}$ & $\mathrm{m}$ & $\mathrm{m}$ & $\mathrm{m}$ & $\mathrm{m}$ & $\mathrm{m}$ & $\mathrm{m}$ \\
\hline 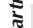 & Brazil & 411 & $(4.9)$ & 384 & $(12.1)$ & -26 & $(7.2)$ & -21 & $(5.1)$ \\
\hline 2 & B-S-J-G (China) & 568 & $(10.8)$ & 475 & (23.8) & -92 & $(13.0)$ & -42 & $(10.1)$ \\
\hline & Bulgaria & 500 & (15.4) & 420 & (32.6) & -81 & $(17.2)$ & -38 & $(10.2)$ \\
\hline & CABA (Argentina) & $\mathrm{m}$ & $\mathrm{m}$ & $\mathrm{m}$ & $\mathrm{m}$ & $\mathrm{m}$ & $\mathrm{m}$ & $\mathrm{m}$ & $\mathrm{m}$ \\
\hline & Colombia & 429 & $(4.2)$ & 400 & (12.9) & -29 & (8.7) & -15 & (5.9) \\
\hline & Costa Rica & 422 & (6.8) & 420 & (15.3) & -2 & (8.5) & -2 & $(4.7)$ \\
\hline & Croatia & 495 & (6.1) & 442 & $(14.7)$ & -53 & (8.6) & -26 & (6.6) \\
\hline & Cyprus* & $\mathrm{m}$ & $\mathrm{m}$ & $\mathrm{m}$ & $\mathrm{m}$ & $\mathrm{m}$ & $\mathrm{m}$ & $\mathrm{m}$ & $\mathrm{m}$ \\
\hline & Dominican Republic & 333 & (8.5) & 320 & $(17.9)$ & -13 & $(9.4)$ & -1 & $(6.7)$ \\
\hline & FYROM & $\mathrm{m}$ & $\mathrm{m}$ & $\mathrm{m}$ & $\mathrm{m}$ & $\mathrm{m}$ & $\mathrm{m}$ & $\mathrm{m}$ & $\mathrm{m}$ \\
\hline & Georgia & $\mathrm{m}$ & $\mathrm{m}$ & $\mathrm{m}$ & $\mathrm{m}$ & $\mathrm{m}$ & $\mathrm{m}$ & $\mathrm{m}$ & $\mathrm{m}$ \\
\hline & Hong Kong (China) & 560 & $(8.2)$ & 517 & $(17.0)$ & -42 & (8.8) & -24 & (7.5) \\
\hline & Indonesia & $\mathrm{m}$ & $\mathrm{m}$ & $\mathrm{m}$ & $\mathrm{m}$ & $\mathrm{m}$ & $\mathrm{m}$ & $\mathrm{m}$ & $\mathrm{m}$ \\
\hline & Jordan & $\mathrm{m}$ & $\mathrm{m}$ & $\mathrm{m}$ & $\mathrm{m}$ & $\mathrm{m}$ & $\mathrm{m}$ & $\mathrm{m}$ & $\mathrm{m}$ \\
\hline & Kosovo & $\mathrm{m}$ & $\mathrm{m}$ & $\mathrm{m}$ & $\mathrm{m}$ & $\mathrm{m}$ & $\mathrm{m}$ & $\mathrm{m}$ & $\mathrm{m}$ \\
\hline & Lebanon & $\mathrm{m}$ & $\mathrm{m}$ & $\mathrm{m}$ & $\mathrm{m}$ & $\mathrm{m}$ & $\mathrm{m}$ & $\mathrm{m}$ & $\mathrm{m}$ \\
\hline & Lithuania & 505 & (4.5) & 450 & $(10.2)$ & -55 & (5.7) & -33 & (4.4) \\
\hline & Macao (China) & 534 & $(5.2)$ & $\mathrm{m}$ & $\mathrm{m}$ & $\mathrm{C}$ & c & c & c \\
\hline & Malta & $\mathrm{m}$ & $\mathrm{m}$ & $\mathrm{m}$ & $\mathrm{m}$ & $\mathrm{m}$ & $\mathrm{m}$ & $\mathrm{m}$ & $\mathrm{m}$ \\
\hline & Moldova & $\mathrm{m}$ & $\mathrm{m}$ & $\mathrm{m}$ & $\mathrm{m}$ & $\mathrm{m}$ & $\mathrm{m}$ & $\mathrm{m}$ & $\mathrm{m}$ \\
\hline & Montenegro & 423 & $(1.8)$ & 365 & $(4.8)$ & -58 & (3.0) & -37 & (3.5) \\
\hline & Peru & 406 & $(4.1)$ & 369 & $(11.4)$ & -37 & $(7.2)$ & -12 & $(4.2)$ \\
\hline & Qatar & 471 & $(2.8)$ & 409 & $(5.6)$ & -61 & $(2.8)$ & -37 & (2.8) \\
\hline & Romania & $\mathrm{m}$ & $\mathrm{m}$ & $\mathrm{m}$ & $\mathrm{m}$ & $\mathrm{m}$ & $\mathrm{m}$ & $\mathrm{m}$ & $\mathrm{m}$ \\
\hline & Russia & 497 & (5.6) & 479 & $(12.7)$ & -18 & $(7.1)$ & -22 & (5.5) \\
\hline & Singapore & 633 & (3.1) & 538 & (6.5) & -96 & (3.4) & -15 & (5.4) \\
\hline & Chinese Taipei & 539 & (3.5) & 497 & (18.4) & -42 & (14.9) & 1 & (9.8) \\
\hline & Thailand & 465 & (7.7) & 409 & (15.9) & -56 & $(8.2)$ & -34 & (5.0) \\
\hline & Trinidad and Tobago & $\mathrm{m}$ & $\mathrm{m}$ & $\mathrm{m}$ & $\mathrm{m}$ & $\mathrm{m}$ & $\mathrm{m}$ & $\mathrm{m}$ & $\mathrm{m}$ \\
\hline & Tunisia & 417 & $(14.8)$ & 378 & $(30.1)$ & -39 & (15.3) & -30 & (8.9) \\
\hline & United Arab Emirates & 477 & $(5.8)$ & 418 & (12.6) & -59 & (6.8) & -48 & (5.6) \\
\hline & Uruguay & 448 & (5.8) & 420 & (13.7) & -28 & (7.9) & -12 & (5.0) \\
\hline & Viet Nam & $\mathrm{m}$ & $\mathrm{m}$ & $\mathrm{m}$ & $\mathrm{m}$ & $\mathrm{m}$ & $\mathrm{m}$ & $\mathrm{m}$ & $\mathrm{m}$ \\
\hline & Argentina** $^{* *}$ & $\mathrm{~m}$ & $\mathrm{~m}$ & $\mathrm{~m}$ & $\mathrm{~m}$ & $\mathrm{~m}$ & $\mathrm{~m}$ & $\mathrm{~m}$ & $\mathrm{~m}$ \\
\hline & Kazakhstan** & $\mathrm{m}$ & $\mathrm{m}$ & $\mathrm{m}$ & $\mathrm{m}$ & $\mathrm{m}$ & $\mathrm{m}$ & $\mathrm{m}$ & $\mathrm{m}$ \\
\hline & Malaysia** & 469 & (8.9) & 441 & (18.3) & -29 & (9.4) & -5.3 & (6.9) \\
\hline
\end{tabular}

1. A school with a low prevalence of bullying is one where $5 \%$ of students or less are frequently bullied. A student is frequently bullied if he or she is in the top $10 \%$ of the index of exposure to bullying among all countries/economies.

2. A school with a high prevalence of bullying is one where more than $10 \%$ of the students are frequently bullied. A student is frequently bullied if he or she is in the top $10 \%$ of the index of exposure to bullying among all countries/economies.

3. The socio-economic profile is measured by the PISA index of economic, social and cultural status (ESCS).

Note: Values that are statistically significant are indicated in bold (see Annex A3).

* See note at the beginning of this Annex.

** Coverage is too small to ensure comparability (see Annex A4).

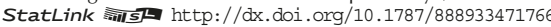


[Part 1/3]

Table III.8.15 Being frequently bullied and students' well-being

Based on students self-reports

\begin{tabular}{|c|c|c|c|c|c|c|c|c|c|c|c|c|c|c|c|c|}
\hline & \multicolumn{8}{|c|}{$\begin{array}{l}\text { Expect to end education } \\
\text { at the end of their secondary degree school }\end{array}$} & \multicolumn{8}{|c|}{ Feel like an outsider } \\
\hline & \multirow{2}{*}{\multicolumn{2}{|c|}{$\begin{array}{c}\text { Not frequently } \\
\text { bullied }^{1}\end{array}$}} & \multirow{2}{*}{\multicolumn{2}{|c|}{$\begin{array}{c}\text { Frequently } \\
\text { bullied }\end{array}$}} & \multicolumn{4}{|c|}{$\begin{array}{l}\text { Difference between frequently } \\
\text { and not frequently bullied students }\end{array}$} & \multirow{2}{*}{\multicolumn{2}{|c|}{$\begin{array}{l}\text { Not frequently } \\
\text { bullied }\end{array}$}} & \multirow{2}{*}{\multicolumn{2}{|c|}{$\begin{array}{l}\text { Frequently } \\
\text { bullied }\end{array}$}} & \multicolumn{4}{|c|}{$\begin{array}{l}\text { Difference between frequently } \\
\text { and not frequently bullied }\end{array}$} \\
\hline & & & & & \multicolumn{2}{|c|}{$\begin{array}{c}\text { Before accounting } \\
\text { for student } \\
\text { and school } \\
\text { characteristics }\end{array}$} & \multicolumn{2}{|c|}{$\begin{array}{l}\text { After accounting } \\
\text { for student } \\
\text { and school } \\
\text { characteristics }\end{array}$} & & & & & \multicolumn{2}{|c|}{\begin{tabular}{|} 
Before accounting \\
for student \\
and school \\
characteristics
\end{tabular}} & \multicolumn{2}{|c|}{$\begin{array}{l}\text { After accounting } \\
\text { for student } \\
\text { and school } \\
\text { characteristics }\end{array}$} \\
\hline & $\%$ & S.E. & $\%$ & S.E. & $\%$ dif. & S.E. & $\%$ dif. & S.E. & $\%$ & S.E. & $\%$ & S.E. & $\%$ dif. & S.E. & $\%$ dif. & S.E. \\
\hline Australia & 36.4 & $(0.6)$ & 45.5 & $(1.4)$ & 9.2 & $(1.6)$ & -0.4 & $(1.4)$ & 18.3 & $(0.4)$ & 52.6 & $(1.4)$ & 34.3 & $(1.5)$ & 35.2 & $(1.6)$ \\
\hline Austria & 63.2 & (1.0) & 66.1 & (2.9) & 2.8 & $(2.8)$ & -3.9 & (3.0) & 12.2 & $(0.5)$ & 33.7 & $(2.3)$ & 21.5 & $(2.3)$ & 20.7 & $(2.2)$ \\
\hline Belgium ${ }^{4}$ & 25.5 & $(0.7)$ & 35.0 & (2.0) & 9.5 & (1.9) & 1.7 & $(1.8)$ & 10.3 & $(0.4)$ & 42.8 & $(2.1)$ & 32.5 & $(2.1)$ & 30.6 & $(2.0)$ \\
\hline Canada & 11.9 & $(0.4)$ & 19.3 & (1.0) & 7.4 & $(1.0)$ & 2.5 & $(0.9)$ & 18.5 & $(0.4)$ & 49.7 & (1.6) & 31.3 & (1.6) & 31.0 & (1.6) \\
\hline Chile & 17.0 & $(0.8)$ & 23.9 & (3.0) & 6.9 & $(3.0)$ & -0.6 & $(1.8)$ & 18.1 & $(0.6)$ & 43.1 & (2.5) & 25.1 & $(2.5)$ & 22.7 & (2.5) \\
\hline Czech Republic & 34.6 & (1.0) & 48.1 & (1.9) & 13.5 & (1.9) & 3.5 & $(2.1)$ & 17.4 & $(0.6)$ & 40.9 & (1.8) & 23.5 & $(2.0)$ & 21.5 & $(2.1)$ \\
\hline Denmark & 58.6 & $(1.1)$ & 64.9 & (3.0) & 6.2 & $(3.1)$ & -2.9 & (3.5) & 10.6 & $(0.5)$ & 37.5 & (2.8) & 26.9 & $(2.8)$ & 25.7 & (2.9) \\
\hline Estonia & 23.9 & $(0.8)$ & 32.4 & (2.4) & 8.5 & $(2.3)$ & 3.1 & $(2.4)$ & 10.3 & $(0.4)$ & 36.3 & $(2.1)$ & 26.0 & $(2.2)$ & 24.9 & $(2.3)$ \\
\hline Finland & 54.6 & $(1.0)$ & 53.0 & (2.4) & -1.5 & $(2.3)$ & -6.7 & $(2.5)$ & 10.2 & $(0.4)$ & 32.3 & $(2.3)$ & 22.1 & $(2.3)$ & 23.6 & (2.4) \\
\hline France & 54.8 & (1.0) & 67.2 & (2.7) & 12.4 & $(2.8)$ & -1.4 & (3.2) & 21.4 & $(0.6)$ & 44.5 & (2.7) & 23.0 & $(2.8)$ & 15.7 & (2.8) \\
\hline Germany & 75.9 & $(0.9)$ & 82.0 & (2.4) & 6.1 & $(2.3)$ & -0.7 & $(2.8)$ & 12.5 & $(0.6)$ & 43.4 & (2.6) & 30.9 & $(2.8)$ & 30.9 & (2.9) \\
\hline Greece & 14.3 & $(0.9)$ & 34.1 & (3.4) & 19.8 & $(3.1)$ & 1.9 & (1.4) & 13.7 & $(0.5)$ & 41.1 & $(2.7)$ & 27.4 & $(2.8)$ & 22.7 & (2.9) \\
\hline Hungary & 44.8 & $(1.2)$ & 60.8 & (2.6) & 15.9 & (2.6) & 3.7 & (2.8) & 14.8 & $(0.5)$ & 46.5 & (2.3) & 31.8 & $(2.5)$ & 29.9 & $(2.7)$ \\
\hline Iceland & 34.1 & $(0.7)$ & 44.3 & (3.9) & 10.2 & $(4.1)$ & 1.9 & $(4.2)$ & 15.4 & $(0.6)$ & 45.1 & (4.4) & 29.7 & (4.6) & 26.1 & (4.7) \\
\hline Ireland & 30.9 & $(0.8)$ & 33.0 & (2.8) & 2.2 & (2.8) & 0.9 & $(2.7)$ & 14.0 & $(0.6)$ & 53.3 & (2.9) & 39.3 & (3.0) & 40.4 & (3.1) \\
\hline Israel & $\mathrm{m}$ & $\mathrm{m}$ & $\mathrm{m}$ & $\mathrm{m}$ & $\mathrm{m}$ & $\mathrm{m}$ & $\mathrm{m}$ & $\mathrm{m}$ & $\mathrm{m}$ & $\mathrm{m}$ & $\mathrm{m}$ & $\mathrm{m}$ & $\mathrm{m}$ & $\mathrm{m}$ & $\mathrm{m}$ & $\mathrm{m}$ \\
\hline Italy & $\mathrm{m}$ & $\mathrm{m}$ & $\mathrm{m}$ & $\mathrm{m}$ & $\mathrm{m}$ & $\mathrm{m}$ & $\mathrm{m}$ & $\mathrm{m}$ & $\mathrm{m}$ & $\mathrm{m}$ & $\mathrm{m}$ & $\mathrm{m}$ & $\mathrm{m}$ & $\mathrm{m}$ & $\mathrm{m}$ & $\mathrm{m}$ \\
\hline Japan & 22.4 & $(1.0)$ & 24.8 & $(2.3)$ & 2.3 & $(2.4)$ & -0.5 & (1.8) & 10.5 & $(0.4)$ & 37.4 & $(2.8)$ & 26.9 & $(2.8)$ & 25.2 & $(2.7)$ \\
\hline Korea & 10.2 & $(0.5)$ & 15.6 & (2.7) & 5.4 & $(2.7)$ & 1.0 & (1.9) & 8.0 & $(0.4)$ & 41.8 & (4.5) & 33.8 & (4.6) & 37.9 & (4.9) \\
\hline Latvia & 25.3 & $(0.9)$ & 36.4 & $(2.1)$ & 11.1 & $(2.1)$ & 3.1 & (1.8) & 12.6 & $(0.5)$ & 30.2 & (1.6) & 17.6 & (1.8) & 16.7 & (1.8) \\
\hline Luxembourg & 40.0 & (0.6) & 53.6 & (2.5) & 13.6 & (2.6) & 0.6 & (3.2) & 14.3 & $(0.5)$ & 46.3 & (2.6) & 32.0 & (2.6) & 28.4 & (2.7) \\
\hline Mexico & 23.9 & $(0.9)$ & 32.7 & (1.9) & 8.8 & $(2.0)$ & 3.0 & (1.9) & 23.0 & $(0.7)$ & 41.2 & (1.9) & 18.2 & $(2.1)$ & 15.6 & $(2.1)$ \\
\hline Netherlands & 26.3 & $(0.6)$ & 27.4 & $(4.1)$ & 1.1 & $(4.1)$ & 0.5 & (3.9) & 7.8 & $(0.4)$ & 43.3 & $(3.7)$ & 35.5 & (3.8) & 33.7 & $(4.0)$ \\
\hline New Zealand & 37.6 & $(1.1)$ & 51.5 & (1.8) & 14.0 & (1.9) & 3.9 & $(2.2)$ & 16.3 & $(0.7)$ & 48.1 & (1.9) & 31.8 & $(2.0)$ & 32.4 & $(2.1)$ \\
\hline Norway & 26.3 & $(0.8)$ & 34.7 & (2.3) & 8.4 & $(2.4)$ & 2.6 & $(2.2)$ & 9.2 & $(0.5)$ & 37.7 & $(2.3)$ & 28.5 & $(2.4)$ & 26.0 & (2.4) \\
\hline Poland & 33.7 & (1.1) & 48.0 & (2.5) & 14.4 & $(2.4)$ & 9.0 & (3.1) & 19.6 & $(0.6)$ & 36.5 & $(2.1)$ & 16.9 & $(2.1)$ & 16.9 & $(2.2)$ \\
\hline Portugal & 34.2 & $(1.1)$ & 55.1 & (3.1) & 20.8 & $(2.9)$ & 5.5 & (3.6) & 11.0 & $(0.4)$ & 44.1 & $(2.5)$ & 33.1 & $(2.5)$ & 30.3 & $(2.7)$ \\
\hline Slovak Republic & $\mathrm{C}$ & c & C & c & $\mathrm{C}$ & c & $\mathrm{m}$ & $\mathrm{m}$ & 19.4 & $(0.7)$ & 47.1 & (1.9) & 27.8 & $(2.1)$ & 24.5 & $(2.1)$ \\
\hline Slovenia & 42.6 & $(0.8)$ & 56.8 & (2.8) & 14.2 & $(2.9)$ & 1.1 & $(3.2)$ & 15.5 & $(0.6)$ & 42.6 & (2.8) & 27.1 & $(2.8)$ & 23.5 & (2.8) \\
\hline Spain & 35.3 & (1.0) & 45.0 & (3.3) & 9.7 & (3.2) & 1.5 & $(3.1)$ & 8.5 & $(0.4)$ & 34.9 & $(2.8)$ & 26.4 & (3.0) & 24.0 & $(2.9)$ \\
\hline Sweden & 39.0 & (1.1) & 51.2 & (2.6) & 12.2 & $(2.7)$ & 2.1 & (2.9) & 19.1 & $(0.6)$ & 33.4 & $(2.0)$ & 14.3 & $(2.0)$ & 13.0 & $(2.0)$ \\
\hline Switzerland & 57.8 & $(0.9)$ & 65.4 & (2.5) & 7.5 & $(2.4)$ & 2.8 & $(2.9)$ & 9.5 & $(0.4)$ & 35.7 & (3.0) & 26.2 & (3.0) & 25.6 & (3.1) \\
\hline Turkey & 22.4 & $(0.9)$ & 39.6 & (2.6) & 17.2 & $(2.5)$ & 7.9 & $(3.0)$ & 34.4 & $(0.9)$ & 48.6 & $(2.1)$ & 14.2 & $(2.2)$ & 10.0 & $(2.3)$ \\
\hline United Kingdom & 45.6 & $(0.9)$ & 51.7 & (2.0) & 6.1 & $(2.0)$ & 2.2 & $(2.2)$ & 14.7 & $(0.5)$ & 53.2 & (1.8) & 38.5 & (1.9) & 39.6 & $(1.8)$ \\
\hline United States & 11.2 & $(0.6)$ & 23.6 & (1.8) & 12.4 & $(1.7)$ & 6.2 & (1.5) & 20.4 & $(0.6)$ & 54.2 & $(2.1)$ & 33.8 & $(2.1)$ & 34.5 & $(2.1)$ \\
\hline OECD average & 34.8 & $(0.2)$ & 44.5 & $(0.5)$ & 9.6 & $(0.5)$ & 1.7 & $(0.5)$ & 14.9 & $(0.1)$ & 42.4 & $(0.4)$ & 27.5 & $(0.5)$ & 26.0 & $(0.5)$ \\
\hline
\end{tabular}

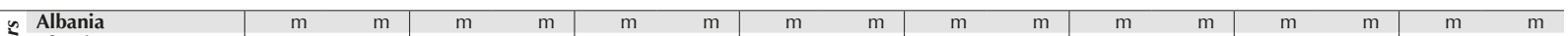

\begin{tabular}{|c|c|c|c|c|c|c|c|c|c|c|c|c|c|c|c|c|}
\hline & III & & IIII & & III & & III & & min & & mi & & & & iit & \\
\hline Brazil & 32.8 & $(0.7)$ & 40.8 & (1.6) & 7.9 & $(1.7)$ & -0.9 & $(1.8)$ & 18.4 & $(0.4)$ & 41.6 & (1.3) & 23.2 & (1.4) & 19.2 & (1.4) \\
\hline B-S-J-G (China) & 38.3 & (1.6) & 51.8 & (2.8) & 13.5 & (2.2) & 0.7 & $(2.5)$ & 19.4 & (0.6) & 43.4 & (2.1) & 23.9 & $(2.2)$ & 23.2 & (2.5) \\
\hline Bulgaria & 21.8 & (1.1) & 29.9 & (1.9) & 8.0 & (1.6) & -1.2 & (1.1) & 26.4 & (0.8) & 47.7 & (2.0) & 21.3 & $(2.1)$ & 16.7 & $(2.2)$ \\
\hline CABA (Argentina) & $\mathrm{m}$ & $\mathrm{m}$ & $\mathrm{m}$ & $\mathrm{m}$ & $\mathrm{m}$ & $\mathrm{m}$ & $\mathrm{m}$ & $\mathrm{m}$ & $\mathrm{m}$ & $\mathrm{m}$ & $\mathrm{m}$ & $\mathrm{m}$ & $\mathrm{m}$ & $\mathrm{m}$ & $\mathrm{m}$ & $\mathrm{m}$ \\
\hline Colombia & 14.7 & $(0.7)$ & 23.5 & $(2.2)$ & 8.8 & (2.1) & 1.4 & (1.3) & 27.7 & $(0.7)$ & 43.5 & (2.6) & 15.8 & $(2.6)$ & 12.2 & (2.5) \\
\hline Costa Rica & 17.1 & $(0.7)$ & 20.2 & (1.8) & 3.1 & (1.9) & 2.4 & (1.6) & 24.6 & (0.6) & 44.2 & $(2.0)$ & 19.6 & $(2.2)$ & 19.6 & (2.2) \\
\hline Croatia & 31.2 & (1.1) & 46.4 & (2.8) & 15.1 & (2.9) & 5.9 & (3.0) & 11.9 & $(0.4)$ & 42.1 & (2.6) & 30.1 & (2.6) & 27.6 & (2.6) \\
\hline Cyprus* & $\mathrm{m}$ & $\mathrm{m}$ & $\mathrm{m}$ & $\mathrm{m}$ & $\mathrm{m}$ & $\mathrm{m}$ & $\mathrm{m}$ & $\mathrm{m}$ & $\mathrm{m}$ & $\mathrm{m}$ & $\mathrm{m}$ & $\mathrm{m}$ & $\mathrm{m}$ & $\mathrm{m}$ & $\mathrm{m}$ & $\mathrm{m}$ \\
\hline Dominican Republic & 29.8 & (1.0) & 45.7 & (2.4) & 15.9 & (2.4) & 13.0 & $(2.3)$ & 37.9 & $(0.9)$ & 48.7 & (2.3) & 10.8 & (2.5) & 8.1 & (2.7) \\
\hline FYROM & $\mathrm{m}$ & $\mathrm{m}$ & $\mathrm{m}$ & $\mathrm{m}$ & $\mathrm{m}$ & $\mathrm{m}$ & $\mathrm{m}$ & $\mathrm{m}$ & $\mathrm{m}$ & $\mathrm{m}$ & $\mathrm{m}$ & $\mathrm{m}$ & $\mathrm{m}$ & $\mathrm{m}$ & $\mathrm{m}$ & $\mathrm{m}$ \\
\hline Georgia & $\mathrm{m}$ & $\mathrm{m}$ & $\mathrm{m}$ & $\mathrm{m}$ & $\mathrm{m}$ & $\mathrm{m}$ & $\mathrm{m}$ & $\mathrm{m}$ & $\mathrm{m}$ & $\mathrm{m}$ & $\mathrm{m}$ & $\mathrm{m}$ & $\mathrm{m}$ & $\mathrm{m}$ & $\mathrm{m}$ & $\mathrm{m}$ \\
\hline Hong Kong (China) & 17.0 & $(0.8)$ & 21.2 & (1.5) & 4.1 & (1.4) & -1.3 & $(1.0)$ & 21.7 & $(0.8)$ & 40.5 & (2.1) & 18.8 & (2.4) & 17.7 & (2.4) \\
\hline Indonesia & $\mathrm{m}$ & $\mathrm{m}$ & $\mathrm{m}$ & $\mathrm{m}$ & $\mathrm{m}$ & $\mathrm{m}$ & $\mathrm{m}$ & $\mathrm{m}$ & $\mathrm{m}$ & $\mathrm{m}$ & $\mathrm{m}$ & $\mathrm{m}$ & $\mathrm{m}$ & $\mathrm{m}$ & $\mathrm{m}$ & $\mathrm{m}$ \\
\hline Jordan & $\mathrm{m}$ & $\mathrm{m}$ & $\mathrm{m}$ & $\mathrm{m}$ & $\mathrm{m}$ & $\mathrm{m}$ & $\mathrm{m}$ & $\mathrm{m}$ & $\mathrm{m}$ & $\mathrm{m}$ & $\mathrm{m}$ & $\mathrm{m}$ & $\mathrm{m}$ & $\mathrm{m}$ & $\mathrm{m}$ & $\mathrm{m}$ \\
\hline Kosovo & $\mathrm{m}$ & $\mathrm{m}$ & $\mathrm{m}$ & $\mathrm{m}$ & $\mathrm{m}$ & $\mathrm{m}$ & $\mathrm{m}$ & $\mathrm{m}$ & $\mathrm{m}$ & $\mathrm{m}$ & $\mathrm{m}$ & $\mathrm{m}$ & $\mathrm{m}$ & $\mathrm{m}$ & $\mathrm{m}$ & $\mathrm{m}$ \\
\hline Lebanon & $\mathrm{m}$ & $\mathrm{m}$ & $\mathrm{m}$ & $\mathrm{m}$ & $\mathrm{m}$ & $\mathrm{m}$ & $\mathrm{m}$ & $\mathrm{m}$ & $\mathrm{m}$ & $\mathrm{m}$ & $\mathrm{m}$ & $\mathrm{m}$ & $\mathrm{m}$ & $\mathrm{m}$ & $\mathrm{m}$ & $\mathrm{m}$ \\
\hline Lithuania & 17.5 & $(0.8)$ & 33.4 & (2.4) & 15.9 & (2.3) & 3.5 & (1.5) & 28.8 & $(0.7)$ & 47.2 & $(2.1)$ & 18.4 & $(2.1)$ & 15.5 & $(2.2)$ \\
\hline Macao (China) & 13.7 & (0.5) & 20.8 & (1.7) & 7.1 & (1.7) & -0.1 & (1.1) & 16.3 & (0.6) & 47.2 & (2.0) & 30.9 & $(2.0)$ & 29.1 & (2.2) \\
\hline Malta & $\mathrm{m}$ & $\mathrm{m}$ & $\mathrm{m}$ & $\mathrm{m}$ & $\mathrm{m}$ & $\mathrm{m}$ & $\mathrm{m}$ & $\mathrm{m}$ & $\mathrm{m}$ & $\mathrm{m}$ & $\mathrm{m}$ & $\mathrm{m}$ & $\mathrm{m}$ & $\mathrm{m}$ & $\mathrm{m}$ & $\mathrm{m}$ \\
\hline Moldova & $\mathrm{m}$ & $\mathrm{m}$ & $\mathrm{m}$ & $\mathrm{m}$ & $\mathrm{m}$ & $\mathrm{m}$ & $\mathrm{m}$ & $\mathrm{m}$ & $\mathrm{m}$ & $\mathrm{m}$ & $\mathrm{m}$ & $\mathrm{m}$ & $\mathrm{m}$ & $\mathrm{m}$ & $\mathrm{m}$ & $\mathrm{m}$ \\
\hline Montenegro & 13.5 & $(0.4)$ & 25.4 & (2.6) & 11.9 & (2.7) & 3.3 & (1.7) & 15.0 & $(0.5)$ & 45.0 & (2.6) & 30.1 & $(2.7)$ & 27.6 & (2.8) \\
\hline Peru & 15.8 & $(0.5)$ & 19.8 & (2.0) & 4.0 & (2.1) & 0.9 & (1.9) & 18.6 & $(0.7)$ & 44.9 & (2.6) & 26.3 & $(2.7)$ & 21.3 & (2.9) \\
\hline Qatar & 11.1 & $(0.3)$ & 24.9 & $(0.9)$ & 13.7 & (0.9) & 4.4 & $(0.8)$ & 19.7 & $(0.4)$ & 43.7 & (1.1) & 24.0 & $(1.2)$ & 18.6 & (1.3) \\
\hline Romania & $\mathrm{m}$ & $\mathrm{m}$ & $\mathrm{m}$ & $\mathrm{m}$ & $\mathrm{m}$ & $\mathrm{m}$ & $\mathrm{m}$ & $\mathrm{m}$ & $\mathrm{m}$ & $\mathrm{m}$ & $\mathrm{m}$ & $\mathrm{m}$ & $\mathrm{m}$ & $\mathrm{m}$ & $\mathrm{m}$ & $\mathrm{m}$ \\
\hline Russia & 44.6 & (1.3) & 58.4 & $(3.0)$ & 13.8 & (2.9) & 9.4 & $(2.9)$ & 17.1 & $(0.7)$ & 43.7 & $(2.2)$ & 26.6 & $(2.3)$ & 25.6 & $(2.2)$ \\
\hline Singapore & 2.8 & $(0.2)$ & 4.2 & $(0.7)$ & 1.3 & $(0.8)$ & -0.1 & $(0.4)$ & 19.3 & (0.6) & 48.4 & (1.5) & 29.1 & (1.5) & 28.7 & (1.7) \\
\hline Chinese Taipei & 28.3 & $(0.8)$ & 46.2 & (3.8) & 17.9 & (3.7) & 11.3 & (3.3) & 10.2 & (0.4) & 47.0 & (3.1) & 36.8 & (3.3) & 34.5 & (3.3) \\
\hline Thailand & 13.7 & $(0.8)$ & 24.9 & (1.7) & 11.2 & (1.6) & 1.8 & $(1.0)$ & 15.9 & $(0.6)$ & 40.6 & (1.9) & 24.6 & $(2.0)$ & 21.3 & (2.1) \\
\hline Trinidad and Tobago & $\mathrm{m}$ & $\mathrm{m}$ & $\mathrm{m}$ & $\mathrm{m}$ & $\mathrm{m}$ & $\mathrm{m}$ & $\mathrm{m}$ & $\mathrm{m}$ & $\mathrm{m}$ & $\mathrm{m}$ & $\mathrm{m}$ & $\mathrm{m}$ & $\mathrm{m}$ & $\mathrm{m}$ & $\mathrm{m}$ & $\mathrm{m}$ \\
\hline Tunisia & 31.1 & (1.0) & 44.6 & (2.0) & 13.5 & (2.3) & 5.7 & (2.4) & 16.8 & $(0.8)$ & 34.2 & (1.6) & 17.4 & (1.7) & 14.7 & (1.8) \\
\hline United Arab Emirates & 15.8 & (0.4) & 31.5 & (1.4) & 15.7 & (1.3) & 6.9 & (1.0) & 16.7 & $(0.5)$ & 41.5 & (1.1) & 24.7 & (1.2) & 23.4 & (1.4) \\
\hline Uruguay & 46.5 & (1.0) & 51.4 & (2.4) & 4.8 & (2.7) & -0.8 & (3.1) & 21.3 & (0.6) & 44.2 & (2.4) & 22.9 & (2.5) & 21.6 & (2.6) \\
\hline Viet Nam & $\mathrm{m}$ & $\mathrm{m}$ & $\mathrm{m}$ & $\mathrm{m}$ & $\mathrm{m}$ & $\mathrm{m}$ & $\mathrm{m}$ & $\mathrm{m}$ & $\mathrm{m}$ & $\mathrm{m}$ & $\mathrm{m}$ & $\mathrm{m}$ & $\mathrm{m}$ & $\mathrm{m}$ & $\mathrm{m}$ & $\mathrm{m}$ \\
\hline Argentina** & $\mathrm{m}$ & $\mathrm{m}$ & $\mathrm{m}$ & $\mathrm{m}$ & $\mathrm{m}$ & $\mathrm{m}$ & $\mathrm{m}$ & $\mathrm{m}$ & $\mathrm{m}$ & $\mathrm{m}$ & $\mathrm{m}$ & $\mathrm{m}$ & $\mathrm{m}$ & $\mathrm{m}$ & $\mathrm{m}$ & $\mathrm{m}$ \\
\hline Kazakhstan** & $\mathrm{m}$ & $\mathrm{m}$ & $\mathrm{m}$ & $\mathrm{m}$ & $\mathrm{m}$ & $\mathrm{m}$ & $\mathrm{m}$ & $\mathrm{m}$ & $\mathrm{m}$ & $\mathrm{m}$ & $\mathrm{m}$ & $\mathrm{m}$ & $\mathrm{m}$ & $\mathrm{m}$ & $\mathrm{m}$ & $\mathrm{m}$ \\
\hline Malaysia** & 13.1 & $(0.7)$ & 27.1 & $(1.7)$ & 14.0 & (1.6) & 5.3 & (1.3) & 12.3 & $(0.6)$ & 33.7 & (1.7) & 21.4 & (1.6) & 18.7 & (1.6) \\
\hline
\end{tabular}

1. A student is frequently bullied if he or she is in the top $10 \%$ of the index of exposure to bullying among all countries/economies.

2. Student and school characteristics include the PISA index of economic, social and cultural status (ESCS) at the student and school levels, gender and science performance. 3. A student is classified as «not satisfied» with life if he or she reported between 0 and 4 on the life-satisfaction scale. The life-satisfaction scale ranges from 0 to 10 .

4. Data on life satisfaction are not available for the Flemish region of Belgium.

Note: Values that are statistically significant are indicated in bold (see Annex A3).

* See note at the beginning of this Annex.

(see Annex A4)

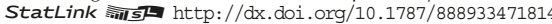




\begin{tabular}{|c|c|c|c|c|c|c|c|c|c|c|c|c|c|c|c|c|c|}
\hline & \multicolumn{8}{|c|}{ Not satisfied with life ${ }^{3}$} & & Skipp & Ischoo & least 3 & 4 days in & revious 2 & weeks & \\
\hline & & & & & & $\begin{array}{l}\text { Diffe } \\
\text { and no }\end{array}$ & $\begin{array}{l}\text { ence betw } \\
\text { frequently }\end{array}$ & $\begin{array}{l}\text { veen frec } \\
\text { y bullied }\end{array}$ & $\begin{array}{l}\text { ently } \\
\text { udents }\end{array}$ & & & & & $\begin{array}{c}\text { Diffe } \\
\text { an }\end{array}$ & $\begin{array}{l}\text { ence betw } \\
\text { not frequ }\end{array}$ & $\begin{array}{l}\text { Neen freq } \\
\text { uently bu }\end{array}$ & $\begin{array}{l}\text { ently } \\
\text { ed }\end{array}$ \\
\hline & & $\begin{array}{r}\text { Not fr } \\
\text { bu }\end{array}$ & $\begin{array}{l}\text { uently } \\
\mathrm{ed}^{1}\end{array}$ & $\begin{array}{r}\text { Frec } \\
\text { bu }\end{array}$ & $\begin{array}{l}\text { ently } \\
\text { ed }\end{array}$ & $\begin{array}{c}\text { Before a } \\
\text { for } 5 \\
\text { and } \\
\text { charac }\end{array}$ & $\begin{array}{l}\text { counting } \\
\text { dent } \\
\text { chool } \\
\text { ristics }\end{array}$ & $\begin{array}{r}\text { After a } \\
\text { for s } \\
\text { and } \\
\text { chara }\end{array}$ & $\begin{array}{l}\text { ounting } \\
\text { dent } \\
\text { hool } \\
\text { ristics }\end{array}$ & $\begin{array}{r}\text { Not fr } \\
\text { bu }\end{array}$ & $\begin{array}{l}\text { Juently } \\
\text { ed }\end{array}$ & $\begin{array}{r}\text { Fre } \\
\text { b }\end{array}$ & $\begin{array}{l}\text { ently } \\
\text { ied }\end{array}$ & $\begin{array}{r}\text { Before a } \\
\text { for } 5 \\
\text { and } \\
\text { charac }\end{array}$ & $\begin{array}{l}\text { counting } \\
\text { Ident } \\
\text { chool } \\
\text { eristics }\end{array}$ & $\begin{array}{l}\text { After ac } \\
\text { for } \\
\text { and } \\
\text { charac }\end{array}$ & $\begin{array}{l}\text { ounting } \\
\text { dent } \\
\text { hool } \\
\text { eristics }\end{array}$ \\
\hline & & $\%$ & S.E. & $\%$ & S.E. & $\%$ dif. & S.E. & $\%$ dif. & S.E. & $\%$ & S.E. & $\%$ & S.E. & $\%$ dif. & S.E. & $\%$ dif. & S.E. \\
\hline & Australia & $\mathrm{m}$ & $\mathrm{m}$ & $\mathrm{m}$ & $\mathrm{m}$ & $\mathrm{m}$ & $\mathrm{m}$ & $\mathrm{m}$ & $\mathrm{m}$ & 5.6 & $(0.3)$ & 11.4 & $(0.8)$ & 5.8 & $(0.9)$ & 3.4 & $(0.8)$ \\
\hline 5 & Austria & 10.0 & $(0.4)$ & 23.1 & $(2.1)$ & 13.1 & $(2.0)$ & 14.7 & $(2.1)$ & 2.7 & $(0.2)$ & 8.4 & (1.4) & 5.7 & (1.5) & 3.4 & $(1.0)$ \\
\hline 0 & Belgium ${ }^{4}$ & 7.0 & $(0.6)$ & 23.6 & (2.8) & 16.6 & $(2.7)$ & 14.9 & $(2.7)$ & 1.6 & $(0.2)$ & 6.2 & $(1.2)$ & 4.6 & $(1.2)$ & 1.8 & $(0.7)$ \\
\hline & Canada & $\mathrm{m}$ & $\mathrm{m}$ & $\mathrm{m}$ & $\mathrm{m}$ & $\mathrm{m}$ & $\mathrm{m}$ & $\mathrm{m}$ & $\mathrm{m}$ & 2.8 & $(0.2)$ & 8.4 & $(0.8)$ & 5.6 & $(0.8)$ & 3.3 & $(0.6)$ \\
\hline & Chile & 10.9 & $(0.5)$ & 26.6 & $(2.7)$ & 15.8 & $(2.7)$ & 16.0 & $(2.7)$ & 2.0 & $(0.3)$ & 3.7 & $(1.0)$ & 1.7 & $(1.0)$ & 0.9 & $(0.7)$ \\
\hline & Czech Republic & 11.9 & $(0.5)$ & 27.1 & $(2.0)$ & 15.2 & $(2.0)$ & 16.6 & $(2.2)$ & 1.5 & $(0.2)$ & 5.8 & $(1.0)$ & 4.3 & $(1.0)$ & 2.6 & $(0.8)$ \\
\hline & Denmark & $\mathrm{m}$ & $\mathrm{m}$ & $\mathrm{m}$ & $\mathrm{m}$ & $\mathrm{m}$ & $\mathrm{m}$ & $\mathrm{m}$ & $\mathrm{m}$ & 3.6 & $(0.3)$ & 12.2 & $(2.1)$ & 8.5 & $(2.0)$ & 4.2 & $(1.3)$ \\
\hline & Estonia & 8.2 & $(0.5)$ & 19.1 & $(2.0)$ & 10.9 & $(2.1)$ & 12.2 & $(2.1)$ & 5.2 & $(0.3)$ & 7.8 & $(1.2)$ & 2.6 & (1.3) & 1.3 & $(1.0)$ \\
\hline & Finland & 5.7 & $(0.3)$ & 14.8 & (1.5) & 9.0 & (1.7) & 9.8 & (1.6) & 8.8 & $(0.4)$ & 14.8 & $(1.6)$ & 6.0 & (1.7) & 5.4 & (1.7) \\
\hline & France & 6.2 & $(0.3)$ & 21.5 & $(2.5)$ & 15.3 & (2.5) & 12.8 & (2.4) & 3.1 & $(0.3)$ & 8.5 & (1.6) & 5.4 & (1.6) & 1.0 & $(0.8)$ \\
\hline & Germany & 9.8 & $(0.4)$ & 32.7 & (2.3) & 22.9 & $(2.4)$ & 23.6 & $(2.5)$ & 1.7 & $(0.2)$ & 6.9 & $(1.7)$ & 5.2 & $(1.7)$ & 2.6 & $(1.2)$ \\
\hline & Greece & 13.9 & $(0.5)$ & 25.7 & (2.6) & 11.7 & (2.6) & 13.3 & (3.0) & 3.7 & $(0.4)$ & 17.6 & $(2.7)$ & 13.9 & $(2.7)$ & 4.8 & (1.7) \\
\hline & Hungary & 11.5 & $(0.5)$ & 28.7 & $(2.2)$ & 17.2 & $(2.2)$ & 17.2 & (2.3) & 1.5 & $(0.3)$ & 5.2 & $(1.0)$ & 3.7 & (1.1) & 1.7 & $(0.8)$ \\
\hline & Iceland & 8.4 & $(0.5)$ & 27.8 & (3.3) & 19.3 & (3.4) & 17.1 & (3.3) & 1.3 & $(0.2)$ & 2.6 & $(1.3)$ & 1.4 & (1.3) & 0.1 & $(0.4)$ \\
\hline & Ireland & 10.4 & $(0.4)$ & 32.9 & (3.1) & 22.5 & (3.1) & 23.8 & $(3.2)$ & 3.6 & $(0.3)$ & 7.9 & (1.4) & 4.3 & (1.4) & 3.9 & $(1.2)$ \\
\hline & Israel & $\mathrm{m}$ & $\mathrm{m}$ & $\mathrm{m}$ & $\mathrm{m}$ & $\mathrm{m}$ & $\mathrm{m}$ & $\mathrm{m}$ & $\mathrm{m}$ & $\mathrm{m}$ & $\mathrm{m}$ & $\mathrm{m}$ & $\mathrm{m}$ & $\mathrm{m}$ & $\mathrm{m}$ & $\mathrm{m}$ & $\mathrm{m}$ \\
\hline & Italy & $\mathrm{m}$ & $\mathrm{m}$ & $\mathrm{m}$ & $\mathrm{m}$ & $\mathrm{m}$ & $\mathrm{m}$ & $\mathrm{m}$ & $\mathrm{m}$ & $\mathrm{m}$ & $\mathrm{m}$ & $\mathrm{m}$ & $\mathrm{m}$ & $\mathrm{m}$ & $\mathrm{m}$ & $\mathrm{m}$ & $\mathrm{m}$ \\
\hline & Japan & 15.1 & $(0.5)$ & 30.7 & $(2.9)$ & 15.6 & (2.9) & 14.6 & $(2.8)$ & 0.4 & $(0.1)$ & 2.8 & $(0.8)$ & 2.5 & $(0.8)$ & 1.4 & $(0.6)$ \\
\hline & Korea & 21.2 & $(0.6)$ & 36.9 & $(4.4)$ & 15.6 & $(4.3)$ & 17.9 & (4.5) & 0.5 & $(0.1)$ & 1.7 & $(1.2)$ & 1.2 & $(1.2)$ & 0.6 & $(0.7)$ \\
\hline & Latvia & 7.3 & $(0.5)$ & 16.1 & (1.3) & 8.8 & (1.3) & 8.3 & (1.4) & 4.3 & $(0.4)$ & 8.5 & $(1.1)$ & 4.2 & $(1.2)$ & 2.2 & $(1.0)$ \\
\hline & Luxembourg & 9.5 & $(0.5)$ & 27.9 & $(2.1)$ & 18.4 & $(2.0)$ & 20.0 & $(2.2)$ & 3.0 & $(0.2)$ & 12.8 & $(1.8)$ & 9.8 & (1.8) & 5.7 & (1.5) \\
\hline & Mexico & 5.5 & $(0.3)$ & 14.4 & (1.6) & 8.9 & (1.7) & 8.3 & (1.7) & 3.4 & $(0.3)$ & 7.9 & $(1.1)$ & 4.5 & (1.1) & 3.5 & (1.0) \\
\hline & Netherlands & 3.2 & $(0.2)$ & 19.2 & (3.9) & 16.1 & (3.9) & 16.3 & (3.9) & 0.8 & $(0.1)$ & 5.9 & $(2.2)$ & 5.1 & $(2.2)$ & 1.8 & $(1.0)$ \\
\hline & New Zealand & C & $\mathrm{C}$ & $\mathrm{C}$ & C & C & $\mathrm{c}$ & $\mathrm{m}$ & $\mathrm{m}$ & 5.5 & $(0.4)$ & 8.4 & $(1.0)$ & 2.9 & $(1.1)$ & 1.1 & $(0.8)$ \\
\hline & Norway & $\mathrm{C}$ & c & $\mathrm{C}$ & c & c & c & $\mathrm{m}$ & $\mathrm{m}$ & 2.8 & $(0.3)$ & 10.2 & (1.3) & 7.3 & (1.4) & 4.8 & $(1.1)$ \\
\hline & Poland & 11.1 & $(0.5)$ & 25.4 & (1.9) & 14.3 & $(2.0)$ & 16.5 & (2.4) & 6.4 & $(0.4)$ & 9.8 & $(1.6)$ & 3.4 & (1.6) & 1.6 & (1.3) \\
\hline & Portugal & 7.8 & $(0.4)$ & 25.5 & $(2.7)$ & 17.7 & $(2.7)$ & 17.9 & (2.9) & 3.6 & $(0.3)$ & 8.4 & $(1.6)$ & 4.8 & (1.6) & 2.4 & $(1.2)$ \\
\hline & Slovak Republic & 9.6 & $(0.4)$ & 24.1 & (1.9) & 14.6 & (1.9) & 15.2 & (2.0) & 18.5 & $(0.5)$ & 24.5 & (1.6) & 6.0 & (1.6) & 2.2 & (1.5) \\
\hline & Slovenia & 12.1 & $(0.6)$ & 30.1 & $(2.7)$ & 18.0 & (2.8) & 21.2 & (3.1) & 2.6 & $(0.2)$ & 8.9 & $(1.5)$ & 6.3 & (1.6) & 2.1 & $(0.9)$ \\
\hline & Spain & 8.2 & $(0.4)$ & 28.4 & (2.9) & 20.2 & $(2.9)$ & 19.4 & (3.0) & 4.1 & $(0.3)$ & 6.1 & $(1.4)$ & 1.9 & (1.4) & 0.8 & $(1.0)$ \\
\hline & Sweden & C & C & c & C & C & C & $\mathrm{m}$ & $\mathrm{m}$ & 1.8 & $(0.2)$ & 7.2 & (1.4) & 5.5 & (1.4) & 2.8 & $(1.0)$ \\
\hline & Switzerland & 6.3 & $(0.4)$ & 21.5 & $(2.4)$ & 15.2 & $(2.4)$ & 15.2 & $(2.5)$ & 3.1 & $(0.4)$ & 9.7 & $(2.1)$ & 6.6 & $(2.0)$ & 3.3 & (1.3) \\
\hline & Turkey & 27.1 & $(0.8)$ & 42.4 & (3.0) & 15.2 & (3.3) & 19.2 & (3.3) & 16.5 & $(0.6)$ & 23.4 & $(2.3)$ & 6.9 & $(2.2)$ & 5.2 & $(2.1)$ \\
\hline & United Kingdom & 12.5 & $(0.5)$ & 34.2 & (1.8) & 21.7 & (1.8) & 22.0 & (1.8) & 3.7 & $(0.3)$ & 8.1 & $(0.9)$ & 4.4 & $(0.9)$ & 3.0 & $(0.8)$ \\
\hline & United States & 10.2 & $(0.4)$ & 26.1 & $(2.2)$ & 15.9 & $(2.2)$ & 16.6 & $(2.2)$ & 5.6 & $(0.3)$ & 12.5 & $(1.4)$ & 7.0 & (1.3) & 4.0 & (1.0) \\
\hline & OECD average & 10.4 & $(0.1)$ & 26.2 & $(0.5)$ & 15.8 & $(0.5)$ & 16.3 & $(0.5)$ & 4.1 & $(0.1)$ & 9.2 & $(0.3)$ & 5.1 & $(0.3)$ & 2.7 & $(0.2)$ \\
\hline$n$ & Albania & $\mathrm{m}$ & $\mathrm{m}$ & $\mathrm{m}$ & $\mathrm{m}$ & $\mathrm{m}$ & $\mathrm{m}$ & $\mathrm{m}$ & $\mathrm{m}$ & $\mathrm{m}$ & $\mathrm{m}$ & $\mathrm{m}$ & $\mathrm{m}$ & $\mathrm{m}$ & $\mathrm{m}$ & $\mathrm{m}$ & $\mathrm{m}$ \\
\hline ¿ & Algeria & $\mathrm{m}$ & $\mathrm{m}$ & $\mathrm{m}$ & $\mathrm{m}$ & $\mathrm{m}$ & $\mathrm{m}$ & $\mathrm{m}$ & $\mathrm{m}$ & $\mathrm{m}$ & $\mathrm{m}$ & $\mathrm{m}$ & $\mathrm{m}$ & $\mathrm{m}$ & $\mathrm{m}$ & $\mathrm{m}$ & $\mathrm{m}$ \\
\hline & Brazil & 10.3 & $(0.3)$ & 22.8 & (1.4) & 12.5 & (1.4) & 12.9 & (1.5) & 9.6 & $(0.3)$ & 14.2 & $(1.3)$ & 4.7 & $(1.3)$ & 3.0 & $(1.2)$ \\
\hline & B-S-J-G (China) & 14.1 & $(0.5)$ & 28.0 & (1.7) & 13.9 & (1.8) & 14.2 & $(1.8)$ & 0.5 & $(0.1)$ & 1.9 & $(0.5)$ & 1.4 & $(0.6)$ & 0.1 & $(0.1)$ \\
\hline & Bulgaria & 12.3 & $(0.6)$ & 21.9 & (1.5) & 9.5 & (1.6) & 9.4 & (1.6) & 12.3 & $(0.6)$ & 20.4 & $(1.8)$ & 8.2 & (1.7) & 5.5 & (1.5) \\
\hline & CABA (Argentina) & $\mathrm{m}$ & $\mathrm{m}$ & $\mathrm{m}$ & $\mathrm{m}$ & $\mathrm{m}$ & $\mathrm{m}$ & $\mathrm{m}$ & $\mathrm{m}$ & $\mathrm{m}$ & $\mathrm{m}$ & $\mathrm{m}$ & $\mathrm{m}$ & $\mathrm{m}$ & $\mathrm{m}$ & $\mathrm{m}$ & $\mathrm{m}$ \\
\hline & Colombia & 9.2 & $(0.4)$ & 21.5 & (1.9) & 12.3 & (1.9) & 13.9 & $(2.1)$ & 6.0 & $(0.3)$ & 10.1 & $(1.3)$ & 4.1 & $(1.3)$ & 2.8 & $(1.2)$ \\
\hline & Costa Rica & 5.7 & $(0.4)$ & 19.1 & (1.7) & 13.4 & (1.7) & 13.8 & (1.8) & 6.7 & $(0.4)$ & 9.8 & $(1.2)$ & 3.1 & (1.3) & 3.1 & (1.3) \\
\hline & Croatia & 6.3 & $(0.4)$ & 21.8 & $(2.5)$ & 15.6 & (2.4) & 17.2 & (2.6) & 3.3 & $(0.3)$ & 7.0 & (1.5) & 3.7 & (1.5) & 1.5 & $(0.9)$ \\
\hline & Cyprus* & $\mathrm{m}$ & $\mathrm{m}$ & $\mathrm{m}$ & $\mathrm{m}$ & $\mathrm{m}$ & $\mathrm{m}$ & $\mathrm{m}$ & $\mathrm{m}$ & $\mathrm{m}$ & $\mathrm{m}$ & $\mathrm{m}$ & $\mathrm{m}$ & $\mathrm{m}$ & $\mathrm{m}$ & $\mathrm{m}$ & $\mathrm{m}$ \\
\hline & Dominican Republic & 6.7 & $(0.4)$ & 17.5 & $(2.2)$ & 10.8 & $(2.2)$ & 10.2 & (2.3) & 9.9 & $(0.7)$ & 14.8 & $(1.8)$ & 4.9 & (1.9) & 3.8 & $(1.8)$ \\
\hline & FYROM & $\mathrm{m}$ & $\mathrm{m}$ & $\mathrm{m}$ & $\mathrm{m}$ & $\mathrm{m}$ & $\mathrm{m}$ & $\mathrm{m}$ & $\mathrm{m}$ & $\mathrm{m}$ & $\mathrm{m}$ & $\mathrm{m}$ & $\mathrm{m}$ & $\mathrm{m}$ & $\mathrm{m}$ & $\mathrm{m}$ & $\mathrm{m}$ \\
\hline & Georgia & $\mathrm{m}$ & $\mathrm{m}$ & $\mathrm{m}$ & $\mathrm{m}$ & $\mathrm{m}$ & $\mathrm{m}$ & $\mathrm{m}$ & $\mathrm{m}$ & $\mathrm{m}$ & $\mathrm{m}$ & $\mathrm{m}$ & $\mathrm{m}$ & $\mathrm{m}$ & $\mathrm{m}$ & $\mathrm{m}$ & $\mathrm{m}$ \\
\hline & Hong Kong (China) & 13.3 & $(0.6)$ & 28.0 & (1.9) & 14.8 & (1.9) & 14.1 & (1.9) & 0.9 & $(0.2)$ & 3.1 & $(0.7)$ & 2.2 & $(0.7)$ & 0.9 & $(0.4)$ \\
\hline & Indonesia & $\mathrm{m}$ & $\mathrm{m}$ & $\mathrm{m}$ & $\mathrm{m}$ & $\mathrm{m}$ & $\mathrm{m}$ & $\mathrm{m}$ & $\mathrm{m}$ & $\mathrm{m}$ & $\mathrm{m}$ & $\mathrm{m}$ & $\mathrm{m}$ & $\mathrm{m}$ & $\mathrm{m}$ & $\mathrm{m}$ & $\mathrm{m}$ \\
\hline & Jordan & $\mathrm{m}$ & $\mathrm{m}$ & $\mathrm{m}$ & $\mathrm{m}$ & $\mathrm{m}$ & $\mathrm{m}$ & $\mathrm{m}$ & $\mathrm{m}$ & $\mathrm{m}$ & $\mathrm{m}$ & $\mathrm{m}$ & $\mathrm{m}$ & $\mathrm{m}$ & $\mathrm{m}$ & $\mathrm{m}$ & $\mathrm{m}$ \\
\hline & Kosovo & $\mathrm{m}$ & $\mathrm{m}$ & $\mathrm{m}$ & $\mathrm{m}$ & $\mathrm{m}$ & $\mathrm{m}$ & $\mathrm{m}$ & $\mathrm{m}$ & $\mathrm{m}$ & $\mathrm{m}$ & $\mathrm{m}$ & $\mathrm{m}$ & $\mathrm{m}$ & $\mathrm{m}$ & $\mathrm{m}$ & $\mathrm{m}$ \\
\hline & Lebanon & $\mathrm{m}$ & $\mathrm{m}$ & $\mathrm{m}$ & $\mathrm{m}$ & $\mathrm{m}$ & $\mathrm{m}$ & $\mathrm{m}$ & $\mathrm{m}$ & $\mathrm{m}$ & $\mathrm{m}$ & $\mathrm{m}$ & $\mathrm{m}$ & $\mathrm{m}$ & $\mathrm{m}$ & $\mathrm{m}$ & $\mathrm{m}$ \\
\hline & Lithuania & 7.0 & $(0.4)$ & 17.7 & (1.5) & 10.8 & (1.6) & 10.6 & (1.6) & 4.7 & $(0.4)$ & 12.6 & (1.5) & 7.9 & $(1.5)$ & 3.0 & (1.0) \\
\hline & Macao (China) & 13.6 & $(0.6)$ & 26.2 & (1.8) & 12.6 & (1.9) & 12.0 & (1.9) & 1.2 & $(0.2)$ & 2.0 & $(0.6)$ & 0.8 & $(0.6)$ & 0.2 & $(0.4)$ \\
\hline & Malta & $\mathrm{m}$ & $\mathrm{m}$ & $\mathrm{m}$ & $\mathrm{m}$ & $\mathrm{m}$ & $\mathrm{m}$ & m & $\mathrm{m}$ & $\mathrm{m}$ & $\mathrm{m}$ & $\mathrm{m}$ & $\mathrm{m}$ & $\mathrm{m}$ & $\mathrm{m}$ & $\mathrm{m}$ & $\mathrm{m}$ \\
\hline & Moldova & $\mathrm{m}$ & $\mathrm{m}$ & $\mathrm{m}$ & $\mathrm{m}$ & $\mathrm{m}$ & $\mathrm{m}$ & $\mathrm{m}$ & $\mathrm{m}$ & $\mathrm{m}$ & $\mathrm{m}$ & $\mathrm{m}$ & $\mathrm{m}$ & $\mathrm{m}$ & $\mathrm{m}$ & $\mathrm{m}$ & $\mathrm{m}$ \\
\hline & Montenegro & 10.0 & $(0.5)$ & 26.2 & $(2.4)$ & 16.2 & $(2.5)$ & 18.3 & $(2.8)$ & 20.7 & $(0.6)$ & 29.3 & $(2.3)$ & 8.6 & $(2.3)$ & 5.6 & $(2.1)$ \\
\hline & Peru & 11.7 & $(0.5)$ & 25.9 & $(2.6)$ & 14.2 & $(2.6)$ & 13.4 & $(2.6)$ & 7.5 & $(0.4)$ & 13.6 & $(2.3)$ & 6.1 & $(2.3)$ & 6.7 & $(2.4)$ \\
\hline & Qatar & 11.9 & $(0.3)$ & 22.1 & $(0.9)$ & 10.2 & $(1.0)$ & 11.9 & (1.1) & 10.8 & $(0.3)$ & 18.2 & $(0.9)$ & 7.4 & $(0.9)$ & 3.7 & $(0.9)$ \\
\hline & Romania & $\mathrm{m}$ & $\mathrm{m}$ & $\mathrm{m}$ & $\mathrm{m}$ & $\mathrm{m}$ & $\mathrm{m}$ & $\mathrm{m}$ & $\mathrm{m}$ & $\mathrm{m}$ & $\mathrm{m}$ & $\mathrm{m}$ & $\mathrm{m}$ & $\mathrm{m}$ & $\mathrm{m}$ & $\mathrm{m}$ & $\mathrm{m}$ \\
\hline & Russia & 9.3 & $(0.5)$ & 19.5 & $(1.7)$ & 10.2 & (1.9) & 11.0 & $(2.0)$ & 5.5 & $(0.4)$ & 11.3 & $(1.8)$ & 5.8 & $(2.0)$ & 4.7 & (1.9) \\
\hline & Singapore & $\mathrm{C}$ & $\mathrm{C}$ & C & c & $\mathrm{c}$ & C & $\mathrm{m}$ & $\mathrm{m}$ & 2.1 & $(0.2)$ & 3.7 & $(0.6)$ & 1.5 & $(0.6)$ & 0.9 & $(0.6)$ \\
\hline & Chinese Taipei & 15.5 & $(0.5)$ & 30.4 & $(2.8)$ & 14.9 & $(2.9)$ & 15.7 & (2.9) & 0.9 & $(0.1)$ & 4.8 & (1.1) & 3.8 & $(1.1)$ & 1.1 & $(0.4)$ \\
\hline & Thailand & 6.4 & $(0.5)$ & 14.2 & (1.1) & 7.9 & $(1.1)$ & 7.5 & $(1.2)$ & 4.5 & $(0.4)$ & 10.3 & $(0.9)$ & 5.8 & $(0.9)$ & 3.7 & $(0.8)$ \\
\hline & Trinidad and Tobago & $\mathrm{m}$ & $\mathrm{m}$ & $\mathrm{m}$ & $\mathrm{m}$ & $\mathrm{m}$ & $\mathrm{m}$ & $\mathrm{m}$ & $\mathrm{m}$ & $\mathrm{m}$ & $\mathrm{m}$ & $\mathrm{m}$ & $\mathrm{m}$ & $\mathrm{m}$ & $\mathrm{m}$ & $\mathrm{m}$ & $\mathrm{m}$ \\
\hline & Tunisia & 17.7 & $(0.6)$ & 27.5 & $(1.8)$ & 9.8 & (1.9) & 10.2 & (1.8) & 7.9 & $(0.6)$ & 15.4 & (1.4) & 7.5 & $(1.4)$ & 3.0 & $(1.2)$ \\
\hline & United Arab Emirates & 12.9 & $(0.4)$ & 22.7 & $(1.2)$ & 9.7 & $(1.2)$ & 10.9 & $(1.2)$ & 4.0 & $(0.3)$ & 11.8 & $(0.8)$ & 7.8 & $(0.9)$ & 6.4 & $(0.9)$ \\
\hline & Uruguay & 8.0 & $(0.3)$ & 24.5 & $(2.0)$ & 16.4 & $(2.0)$ & 15.7 & (2.0) & 10.9 & $(0.5)$ & 15.0 & $(1.8)$ & 4.1 & (1.9) & 3.2 & $(1.7)$ \\
\hline & Viet Nam & $\mathrm{m}$ & $\mathrm{m}$ & $\mathrm{m}$ & $\mathrm{m}$ & $\mathrm{m}$ & $\mathrm{m}$ & $\mathrm{m}$ & $\mathrm{m}$ & $\mathrm{m}$ & $\mathrm{m}$ & $\mathrm{m}$ & $\mathrm{m}$ & $\mathrm{m}$ & $\mathrm{m}$ & $\mathrm{m}$ & $\mathrm{m}$ \\
\hline & Argentina** $^{* *}$ & $\mathrm{~m}$ & $\mathrm{~m}$ & $\mathrm{~m}$ & $\mathrm{~m}$ & $\mathrm{~m}$ & $\mathrm{~m}$ & $\mathrm{~m}$ & $\mathrm{~m}$ & $\mathrm{~m}$ & $\mathrm{~m}$ & $\mathrm{~m}$ & $\mathrm{~m}$ & $\mathrm{~m}$ & $\mathrm{~m}$ & $\mathrm{~m}$ & $\mathrm{~m}$ \\
\hline & Kazakhstan** & $\mathrm{m}$ & $\mathrm{m}$ & $\mathrm{m}$ & $\mathrm{m}$ & $\mathrm{m}$ & $\mathrm{m}$ & $\mathrm{m}$ & $\mathrm{m}$ & $\mathrm{m}$ & $\mathrm{m}$ & $\mathrm{m}$ & $\mathrm{m}$ & $\mathrm{m}$ & $\mathrm{m}$ & $\mathrm{m}$ & $\mathrm{m}$ \\
\hline & Malaysia** & 9.5 & $(0.5)$ & 18.1 & $(1.3)$ & 8.6 & $(1.3)$ & 8.4 & (1.3) & 1.7 & $(0.2)$ & 5.0 & $(0.8)$ & 3.3 & $(0.8)$ & 2.7 & $(0.9)$ \\
\hline
\end{tabular}

1. A student is frequently bullied if he or she is in the top $10 \%$ of the index of exposure to bullying among all countries/economies.

2. Student and school characteristics include the PISA index of economic, social and cultural status (ESCS) at the student and school levels, gender and science performance.

3. A student is classified as «not satisfied» with life if he or she reported between 0 and 4 on the life-satisfaction scale. The life-satisfaction scale ranges from 0 to 10 .

4. Data on life satisfaction are not available for the Flemish community of Belgium.

Note: Values that are statistically significant are indicated in bold (see Annex A3).

* See note at the beginning of this Annex.

** Coverage is too small to ensure comparability (see Annex A4).

StatLink त्नाls $\mathrm{http} / / / \mathrm{dx}$.doi.org/10.1787/888933471814 
[Part 3/3]

Table III.8.15 Being frequently bullied and students' well-being

Based on students self-reports

\begin{tabular}{|c|c|c|c|c|c|c|c|c|c|}
\hline & \multicolumn{8}{|c|}{ "Feel anxious for a test even if well prepared" } \\
\hline & & \multirow{2}{*}{\multicolumn{2}{|c|}{ Not frequently bullied ${ }^{1}$}} & \multirow{2}{*}{\multicolumn{2}{|c|}{ Frequently bullied }} & \multicolumn{4}{|c|}{$\begin{array}{l}\text { Difference between frequently } \\
\text { and not frequently bullied }\end{array}$} \\
\hline & & & & & & \multicolumn{2}{|c|}{$\begin{array}{l}\text { Before accounting for student } \\
\text { and school characteristics }{ }^{2}\end{array}$} & $\begin{array}{l}\text { After acc } \\
\text { and sch }\end{array}$ & $\begin{array}{l}\text { student } \\
\text { eristics }\end{array}$ \\
\hline & & $\%$ & S.E. & $\%$ & S.E. & $\%$ dif. & S.E. & $\%$ dif. & S.E. \\
\hline 0 & Australia & 66.3 & $(0.6)$ & 74.8 & (1.3) & 8.5 & $(1.4)$ & 9.3 & (1.4) \\
\hline ర్屯 & Austria & 50.0 & $(0.8)$ & 61.3 & $(2.5)$ & 11.3 & (2.4) & 10.9 & (2.5) \\
\hline 0 & Belgium $^{4}$ & 41.4 & $(0.6)$ & 55.0 & $(2.0)$ & 13.6 & $(2.1)$ & 13.2 & (2.2) \\
\hline & Canada & 63.0 & $(0.4)$ & 70.5 & (1.3) & 7.5 & $(1.3)$ & 6.9 & (1.3) \\
\hline & Chile & 54.9 & $(0.8)$ & 67.6 & $(2.7)$ & 12.7 & (3.0) & 10.3 & (3.1) \\
\hline & Czech Republic & 39.1 & $(0.8)$ & 48.3 & $(2.2)$ & 9.2 & $(2.3)$ & 10.8 & $(2.2)$ \\
\hline & Denmark & 64.1 & $(0.8)$ & 72.1 & $(2.7)$ & 8.0 & $(2.9)$ & 8.4 & (3.0) \\
\hline & Estonia & 52.1 & $(0.8)$ & 61.0 & $(2.1)$ & 8.9 & $(2.3)$ & 10.4 & (2.4) \\
\hline & Finland & 48.3 & $(0.8)$ & 52.1 & $(2.0)$ & 3.8 & $(2.0)$ & 5.1 & (2.2) \\
\hline & France & 46.1 & $(0.7)$ & 62.5 & $(2.6)$ & 16.4 & $(2.6)$ & 15.5 & (2.9) \\
\hline & Germany & 40.6 & $(0.7)$ & 56.2 & (3.1) & 15.6 & (3.2) & 14.8 & (3.2) \\
\hline & Greece & 59.0 & $(0.7)$ & 61.5 & (3.1) & 2.5 & $(3.2)$ & 2.9 & (3.2) \\
\hline & Hungary & 54.0 & $(0.8)$ & 60.9 & $(2.5)$ & 6.9 & $(2.5)$ & 6.1 & $(2.7)$ \\
\hline & Iceland & 49.8 & $(0.9)$ & 73.0 & $(3.2)$ & 23.2 & (3.3) & 22.8 & (3.5) \\
\hline & Ireland & 62.5 & $(0.8)$ & 73.7 & $(2.3)$ & 11.2 & (2.5) & 12.0 & (2.5) \\
\hline & Israel & $\mathrm{m}$ & $\mathrm{m}$ & $\mathrm{m}$ & $\mathrm{m}$ & $\mathrm{m}$ & $\mathrm{m}$ & $\mathrm{m}$ & $\mathrm{m}$ \\
\hline & Italy & $\mathrm{m}$ & $\mathrm{m}$ & $\mathrm{m}$ & $\mathrm{m}$ & $\mathrm{m}$ & $\mathrm{m}$ & $\mathrm{m}$ & $\mathrm{m}$ \\
\hline & Japan & 62.2 & $(0.8)$ & 60.6 & (2.9) & -1.6 & $(3.1)$ & -0.8 & (3.1) \\
\hline & Korea & 55.0 & $(0.8)$ & 70.3 & $(4.3)$ & 15.3 & $(4.4)$ & 17.0 & $(4.2)$ \\
\hline & Latvia & 41.7 & (1.0) & 50.8 & $(1.9)$ & 9.0 & $(2.2)$ & 8.6 & $(2.2)$ \\
\hline & Luxembourg & 47.0 & $(0.7)$ & 56.5 & (2.4) & 9.5 & $(2.4)$ & 8.2 & (2.6) \\
\hline & Mexico & 59.6 & $(0.8)$ & 64.2 & $(2.1)$ & 4.7 & $(2.0)$ & 4.1 & (2.1) \\
\hline & Netherlands & 38.6 & $(0.8)$ & 51.4 & (3.8) & 12.8 & (3.8) & 15.3 & (3.8) \\
\hline & New Zealand & 70.1 & $(0.9)$ & 81.8 & (1.3) & 11.7 & $(1.7)$ & 11.7 & (1.7) \\
\hline & Norway & 60.6 & $(0.8)$ & 65.1 & (2.3) & 4.5 & $(2.7)$ & 5.8 & (2.7) \\
\hline & Poland & 43.7 & (1.0) & 56.5 & $(2.4)$ & 12.8 & $(2.5)$ & 15.7 & $(2.7)$ \\
\hline & Portugal & 68.3 & $(0.7)$ & 82.5 & (1.9) & 14.2 & $(2.0)$ & 13.1 & (2.1) \\
\hline & Slovak Republic & 46.7 & $(0.9)$ & 49.8 & $(2.2)$ & 3.1 & $(2.4)$ & 3.9 & (2.5) \\
\hline & Slovenia & 61.7 & $(0.7)$ & 65.6 & (2.5) & 3.9 & $(2.6)$ & 4.6 & (2.8) \\
\hline & Spain & 66.5 & $(0.7)$ & 76.6 & (2.5) & 10.1 & $(2.3)$ & 10.2 & (2.2) \\
\hline & Sweden & 60.6 & $(0.8)$ & 69.5 & $(2.7)$ & 9.0 & (2.8) & 9.4 & (2.8) \\
\hline & Switzerland & 32.5 & $(0.7)$ & 46.3 & (2.9) & 13.8 & $(2.8)$ & 13.9 & (2.9) \\
\hline & Turkey & 58.8 & $(0.8)$ & 59.5 & $(2.2)$ & 0.7 & $(2.3)$ & 2.0 & (2.5) \\
\hline & United Kingdom & 70.5 & $(0.8)$ & 79.6 & (1.5) & 9.1 & $(1.6)$ & 9.3 & (1.6) \\
\hline & United States & 67.2 & $(0.7)$ & 72.9 & (2.1) & 5.7 & $(2.4)$ & 4.9 & (2.4) \\
\hline & OECD average & 54.6 & $(0.1)$ & 63.9 & $(0.4)$ & 9.3 & $(0.5)$ & 9.6 & $(0.5)$ \\
\hline n & Albania & $\mathrm{m}$ & $\mathrm{m}$ & $\mathrm{m}$ & $\mathrm{m}$ & $\mathrm{m}$ & $\mathrm{m}$ & $\mathrm{m}$ & $\mathrm{m}$ \\
\hline ఏ & Algeria & $\mathrm{m}$ & $\mathrm{m}$ & $\mathrm{m}$ & $\mathrm{m}$ & $\mathrm{m}$ & $\mathrm{m}$ & $\mathrm{m}$ & $\mathrm{m}$ \\
\hline ฟั้ & Brazil & 80.8 & $(0.4)$ & 81.3 & (1.4) & 0.5 & (1.4) & 0.9 & (1.4) \\
\hline 2 & B-S-J-G (China) & 60.7 & $(0.8)$ & 71.1 & (1.9) & 10.3 & $(1.9)$ & 8.5 & (2.0) \\
\hline & Bulgaria & 54.1 & $(0.8)$ & 64.0 & $(2.1)$ & 9.9 & $(2.3)$ & 10.8 & (2.4) \\
\hline & CABA (Argentina) & $\mathrm{m}$ & $\mathrm{m}$ & $\mathrm{m}$ & $\mathrm{m}$ & $\mathrm{m}$ & $\mathrm{m}$ & $\mathrm{m}$ & $\mathrm{m}$ \\
\hline & Colombia & 78.9 & $(0.6)$ & 79.1 & $(1.8)$ & 0.2 & $(2.0)$ & 0.6 & (2.0) \\
\hline & Costa Rica & 80.9 & $(0.5)$ & 82.4 & (1.6) & 1.5 & $(1.8)$ & 2.1 & (1.7) \\
\hline & Croatia & 46.1 & (0.9) & 60.1 & (2.6) & 13.9 & $(2.6)$ & 16.2 & (2.6) \\
\hline & Cyprus* & $\mathrm{m}$ & $\mathrm{m}$ & $\mathrm{m}$ & $\mathrm{m}$ & $\mathrm{m}$ & $\mathrm{m}$ & $\mathrm{m}$ & $\mathrm{m}$ \\
\hline & Dominican Republic & 79.9 & $(0.8)$ & 80.3 & (2.5) & 0.4 & $(2.5)$ & 0.2 & (2.5) \\
\hline & FYROM & $\mathrm{m}$ & $\mathrm{m}$ & $\mathrm{m}$ & $\mathrm{m}$ & $\mathrm{m}$ & $\mathrm{m}$ & $\mathrm{m}$ & $\mathrm{m}$ \\
\hline & Georgia & $\mathrm{m}$ & $\mathrm{m}$ & $\mathrm{m}$ & $\mathrm{m}$ & $\mathrm{m}$ & $\mathrm{m}$ & $\mathrm{m}$ & $\mathrm{m}$ \\
\hline & Hong Kong (China) & 66.0 & $(0.8)$ & 73.8 & (1.6) & 7.8 & $(2.0)$ & 8.6 & (2.0) \\
\hline & Indonesia & $\mathrm{m}$ & $\mathrm{m}$ & $\mathrm{m}$ & $\mathrm{m}$ & $\mathrm{m}$ & $\mathrm{m}$ & $\mathrm{m}$ & $\mathrm{m}$ \\
\hline & Jordan & $\mathrm{m}$ & $\mathrm{m}$ & $\mathrm{m}$ & $\mathrm{m}$ & $\mathrm{m}$ & $\mathrm{m}$ & $\mathrm{m}$ & $\mathrm{m}$ \\
\hline & Kosovo & $\mathrm{m}$ & $\mathrm{m}$ & $\mathrm{m}$ & $\mathrm{m}$ & $\mathrm{m}$ & $\mathrm{m}$ & $\mathrm{m}$ & $\mathrm{m}$ \\
\hline & Lebanon & $\mathrm{m}$ & $\mathrm{m}$ & $\mathrm{m}$ & $\mathrm{m}$ & $\mathrm{m}$ & $\mathrm{m}$ & $\mathrm{m}$ & $\mathrm{m}$ \\
\hline & Lithuania & 55.4 & $(0.7)$ & 59.7 & $(2.6)$ & 4.2 & $(2.7)$ & 5.6 & (2.6) \\
\hline & Macao (China) & 64.0 & $(0.9)$ & 75.3 & (1.7) & 11.4 & $(2.0)$ & 11.5 & (2.1) \\
\hline & Malta & $\mathrm{m}$ & $\mathrm{m}$ & $\mathrm{m}$ & $\mathrm{m}$ & $\mathrm{m}$ & $\mathrm{m}$ & $\mathrm{m}$ & $\mathrm{m}$ \\
\hline & Moldova & $\mathrm{m}$ & $\mathrm{m}$ & $\mathrm{m}$ & $\mathrm{m}$ & $\mathrm{m}$ & $\mathrm{m}$ & $\mathrm{m}$ & $\mathrm{m}$ \\
\hline & Montenegro & 65.3 & $(0.8)$ & 66.7 & $(2.6)$ & 1.5 & $(2.6)$ & 4.8 & (2.5) \\
\hline & Peru & 71.4 & $(0.6)$ & 73.6 & $(2.3)$ & 2.2 & (2.5) & 0.4 & (2.6) \\
\hline & Qatar & 64.7 & $(0.5)$ & 69.4 & $(1.0)$ & 4.7 & $(1.1)$ & 7.0 & $(1.2)$ \\
\hline & Romania & $\mathrm{m}$ & $\mathrm{m}$ & $\mathrm{m}$ & $\mathrm{m}$ & $\mathrm{m}$ & $\mathrm{m}$ & $\mathrm{m}$ & $\mathrm{m}$ \\
\hline & Russia & 50.9 & $(0.9)$ & 54.0 & $(2.8)$ & 3.2 & $(2.9)$ & 2.7 & (3.0) \\
\hline & Singapore & 75.1 & $(0.7)$ & 83.0 & (1.3) & 7.9 & $(1.5)$ & 7.3 & (1.5) \\
\hline & Chinese Taipei & 66.4 & $(0.6)$ & 73.8 & $(3.1)$ & 7.4 & (3.0) & 9.4 & (2.9) \\
\hline & Thailand & 61.3 & $(0.9)$ & 72.7 & (1.1) & 11.4 & $(1.5)$ & 12.0 & (1.6) \\
\hline & Trinidad and Tobago & $\mathrm{m}$ & $\mathrm{m}$ & $\mathrm{m}$ & $\mathrm{m}$ & $\mathrm{m}$ & $\mathrm{m}$ & $\mathrm{m}$ & $\mathrm{m}$ \\
\hline & Tunisia & 58.4 & (1.0) & 66.3 & $(2.0)$ & 8.0 & $(2.2)$ & 10.1 & $(2.2)$ \\
\hline & United Arab Emirates & 60.2 & $(0.7)$ & 69.5 & $(1.2)$ & 9.3 & (1.4) & 9.9 & (1.4) \\
\hline & Uruguay & 72.8 & $(0.7)$ & 75.6 & (1.9) & 2.8 & $(2.0)$ & 2.9 & (2.0) \\
\hline & Viet Nam & $\mathrm{m}$ & $\mathrm{m}$ & $\mathrm{m}$ & $\mathrm{m}$ & $\mathrm{m}$ & $\mathrm{m}$ & $\mathrm{m}$ & $\mathrm{m}$ \\
\hline & Argentina** & $\mathrm{m}$ & $\mathrm{m}$ & $\mathrm{m}$ & $\mathrm{m}$ & $\mathrm{m}$ & $\mathrm{m}$ & $\mathrm{m}$ & $\mathrm{m}$ \\
\hline & Kazakhstan** & $\mathrm{m}$ & $\mathrm{m}$ & $\mathrm{m}$ & $\mathrm{m}$ & $\mathrm{m}$ & $\mathrm{m}$ & $\mathrm{m}$ & $\mathrm{m}$ \\
\hline & Malaysia** & 81.4 & $(0.6)$ & 83.2 & $(1.3)$ & 1.8 & (1.3) & 2.7 & $(1.2)$ \\
\hline
\end{tabular}

1. A student is frequently bullied if he or she is in the top $10 \%$ of the index of exposure to bullying among all countries/economies.

2. Student and school characteristics include the PISA index of economic, social and cultural status (ESCS) at the student and school levels, gender and science performance.

3. A student is classified as «not satisfied» with life if he or she reported between 0 and 4 on the life-satisfaction scale. The life-satisfaction scale ranges from 0 to 10 .

4. Data on life satisfaction are not available for the Flemish community of Belgium.

Note: Values that are statistically significant are indicated in bold (see Annex A3).

* See note at the beginning of this Annex.

** Coverage is too small to ensure comparability (see Annex A4).

StatLink त्ना15 $\mathrm{http}: / / \mathrm{dx}$.doi.org/10.1787/888933471814 


\begin{tabular}{|c|c|c|c|c|c|c|c|c|c|}
\hline & \multicolumn{8}{|c|}{ Percentage of students who are frequently bullied ${ }^{1}$ in: } \\
\hline & & \multirow{2}{*}{\multicolumn{2}{|c|}{$\begin{array}{l}\text { Schools with a negative } \\
\text { disciplinary climate }^{2}\end{array}$}} & \multirow{2}{*}{\multicolumn{2}{|c|}{$\begin{array}{l}\text { Schools with a positive } \\
\text { disciplinary climate }\end{array}$}} & \multicolumn{4}{|c|}{ Difference between positive and negative disciplinary climate $(P-N)$} \\
\hline & & & & & & \multicolumn{2}{|c|}{$\begin{array}{c}\text { Before accounting for students' and } \\
\text { schools' socio-economic profile }^{3}\end{array}$} & $\begin{array}{l}\text { After accout } \\
\text { schools' so }\end{array}$ & $\begin{array}{l}\text { udents' and } \\
\text { mic profile }\end{array}$ \\
\hline & & $\%$ & S.E. & $\%$ & S.E. & $\%$ dif. & S.E. & $\%$ dif. & S.E. \\
\hline 0 & Australia & 22.3 & $(2.2)$ & 8.4 & $(0.7)$ & -13.9 & $(1.4)$ & -11.4 & $(1.6)$ \\
\hline 岙 & Austria & 9.4 & $(2.5)$ & 5.7 & $(0.8)$ & -3.7 & (1.6) & -3.2 & $(1.5)$ \\
\hline$\tilde{0}$ & Belgium & 9.4 & (1.6) & 3.6 & $(0.6)$ & -5.8 & $(1.0)$ & -4.5 & $(1.0)$ \\
\hline & Canada & 15.1 & $(2.6)$ & 9.0 & $(0.9)$ & -6.1 & (1.6) & -4.7 & $(1.7)$ \\
\hline & Chile & 11.2 & (1.9) & 5.0 & $(0.6)$ & -6.3 & $(1.2)$ & -5.3 & $(1.2)$ \\
\hline & Czech Republic & 17.0 & $(2.3)$ & 5.6 & $(0.7)$ & -11.4 & (1.5) & -11.0 & $(1.7)$ \\
\hline & Denmark & 6.5 & $(1.7)$ & 4.5 & $(0.6)$ & -2.0 & (1.1) & -1.0 & (1.1) \\
\hline & Estonia & 9.4 & (3.1) & 8.2 & (1.4) & -1.2 & (1.7) & -1.3 & $(2.1)$ \\
\hline & Finland & 13.6 & $(2.3)$ & 6.6 & $(1.0)$ & -7.0 & (1.4) & -6.8 & $(1.4)$ \\
\hline & France & 14.1 & (2.4) & 3.1 & $(0.7)$ & -11.0 & (1.7) & -6.6 & $(1.7)$ \\
\hline & Germany & 10.3 & (1.9) & 2.5 & $(0.5)$ & -7.7 & (1.4) & -6.4 & $(1.9)$ \\
\hline & Greece & 13.6 & $(2.3)$ & 3.2 & $(0.7)$ & -10.3 & (1.6) & -9.7 & $(1.9)$ \\
\hline & Hungary & 15.5 & $(2.8)$ & 4.8 & $(0.9)$ & -10.7 & (1.9) & -8.6 & $(2.2)$ \\
\hline & Iceland & 6.2 & $(2.0)$ & 3.4 & $(0.7)$ & -2.8 & $(1.2)$ & -1.4 & $(1.5)$ \\
\hline & Ireland & 10.1 & $(2.0)$ & 4.8 & $(0.8)$ & -5.2 & (1.3) & -5.1 & $(1.2)$ \\
\hline & Israel & $\mathrm{m}$ & $\mathrm{m}$ & $\mathrm{m}$ & $\mathrm{m}$ & $\mathrm{m}$ & $\mathrm{m}$ & $\mathrm{m}$ & $\mathrm{m}$ \\
\hline & Italy & $\mathrm{m}$ & $\mathrm{m}$ & $\mathrm{m}$ & $\mathrm{m}$ & $\mathrm{m}$ & $\mathrm{m}$ & $\mathrm{m}$ & $\mathrm{m}$ \\
\hline & Japan & 6.8 & $(1.4)$ & 3.7 & $(0.5)$ & -3.1 & $(1.0)$ & -2.8 & $(1.0)$ \\
\hline & Korea & 3.1 & $(0.8)$ & 0.8 & $(0.3)$ & -2.2 & $(0.6)$ & -2.4 & $(0.6)$ \\
\hline & Latvia & 21.4 & (3.3) & 12.9 & $(1.3)$ & -8.4 & $(2.0)$ & -9.0 & (1.9) \\
\hline & Luxembourg & 9.6 & $(1.7)$ & 6.4 & $(0.7)$ & -3.2 & $(1.0)$ & -2.0 & (1.4) \\
\hline & Mexico & 14.7 & $(3.1)$ & 6.7 & $(1.0)$ & -8.0 & $(2.1)$ & -8.5 & $(2.1)$ \\
\hline & Netherlands & 5.8 & (3.1) & 3.0 & $(1.0)$ & -2.8 & $(2.1)$ & -1.8 & $(2.0)$ \\
\hline & New Zealand & 23.6 & (4.6) & 11.8 & (1.4) & -11.8 & $(3.2)$ & -9.5 & (3.9) \\
\hline & Norway & 11.2 & (2.4) & 8.0 & $(0.9)$ & -3.1 & (1.4) & -3.0 & (1.4) \\
\hline & Poland & 12.9 & $(2.7)$ & 7.8 & $(1.2)$ & -5.1 & (1.5) & -5.0 & (1.4) \\
\hline & Portugal & 7.4 & $(2.2)$ & 2.9 & $(0.8)$ & -4.6 & (1.4) & -4.5 & (1.4) \\
\hline & Slovak Republic & 20.1 & $(2.6)$ & 4.6 & $(0.8)$ & -15.5 & (1.7) & -13.7 & $(2.2)$ \\
\hline & Slovenia & 11.4 & (2.3) & 4.0 & $(0.7)$ & -7.4 & (1.6) & -3.8 & (1.6) \\
\hline & Spain & 8.4 & $(1.7)$ & 4.2 & $(0.7)$ & -4.2 & $(1.0)$ & -4.2 & $(1.0)$ \\
\hline & Sweden & 11.1 & $(2.2)$ & 5.4 & $(0.8)$ & -5.7 & (1.5) & -5.1 & $(2.0)$ \\
\hline & Switzerland & 9.8 & $(1.8)$ & 3.4 & $(0.7)$ & -6.4 & $(1.2)$ & -6.0 & $(1.2)$ \\
\hline & Turkey & 11.6 & $(2.8)$ & 5.3 & $(0.8)$ & -6.3 & $(2.0)$ & -6.2 & $(2.1)$ \\
\hline & United Kingdom & 19.4 & $(2.5)$ & 10.5 & $(0.8)$ & -8.9 & (1.7) & -8.5 & (1.6) \\
\hline & United States & 13.4 & $(2.7)$ & 9.3 & $(1.1)$ & -4.1 & $(1.7)$ & -4.7 & (1.8) \\
\hline & OECD average & 12.3 & $(0.4)$ & 5.7 & $(0.1)$ & -6.5 & $(0.3)$ & -5.7 & $(0.3)$ \\
\hline a & Albania & $\mathrm{m}$ & $\mathrm{m}$ & $\mathrm{m}$ & $\mathrm{m}$ & $\mathrm{m}$ & $\mathrm{m}$ & $\mathrm{m}$ & $\mathrm{m}$ \\
\hline$\Xi$ & Algeria & $\mathrm{m}$ & $\mathrm{m}$ & $\mathrm{m}$ & $\mathrm{m}$ & $\mathrm{m}$ & $\mathrm{m}$ & $\mathrm{m}$ & $\mathrm{m}$ \\
\hline รับ & Brazil & 11.0 & $(2.1)$ & 6.0 & $(0.8)$ & -5.0 & $(1.3)$ & -6.3 & $(1.3)$ \\
\hline & B-S-J-G (China) & 14.8 & $(2.0)$ & 5.6 & $(0.5)$ & -9.2 & (1.5) & -8.5 & (1.6) \\
\hline & Bulgaria & 16.5 & $(3.2)$ & 7.8 & $(0.9)$ & -8.6 & $(2.4)$ & -6.2 & $(2.2)$ \\
\hline & CABA (Argentina) & $\mathrm{m}$ & $\mathrm{m}$ & $\mathrm{m}$ & $\mathrm{m}$ & $\mathrm{m}$ & $\mathrm{m}$ & $\mathrm{m}$ & $\mathrm{m}$ \\
\hline & Colombia & 9.1 & $(2.3)$ & 3.3 & $(0.8)$ & -5.8 & $(1.5)$ & -5.8 & $(1.4)$ \\
\hline & Costa Rica & 13.3 & $(4.2)$ & 11.4 & (1.9) & -1.9 & $(2.3)$ & -1.9 & $(2.4)$ \\
\hline & Croatia & 10.6 & (1.6) & 3.3 & $(0.5)$ & -7.4 & (1.1) & -5.7 & $(1.2)$ \\
\hline & Cyprus* & $\mathrm{m}$ & $\mathrm{m}$ & $\mathrm{m}$ & $\mathrm{m}$ & $\mathrm{m}$ & $\mathrm{m}$ & $\mathrm{m}$ & $\mathrm{m}$ \\
\hline & Dominican Republic & 14.8 & (3.5) & 8.7 & $(1.0)$ & -6.1 & $(2.5)$ & -4.9 & $(2.2)$ \\
\hline & FYROM & $\mathrm{m}$ & $\mathrm{m}$ & $\mathrm{m}$ & $\mathrm{m}$ & $\mathrm{m}$ & $\mathrm{m}$ & $\mathrm{m}$ & $\mathrm{m}$ \\
\hline & Georgia & $\mathrm{m}$ & $\mathrm{m}$ & $\mathrm{m}$ & $\mathrm{m}$ & $\mathrm{m}$ & $\mathrm{m}$ & $\mathrm{m}$ & $\mathrm{m}$ \\
\hline & Hong Kong (China) & 21.7 & (3.5) & 9.6 & (1.3) & -12.1 & $(2.2)$ & -11.7 & $(2.2)$ \\
\hline & Indonesia & $\mathrm{m}$ & $\mathrm{m}$ & $\mathrm{m}$ & $\mathrm{m}$ & $\mathrm{m}$ & $\mathrm{m}$ & $\mathrm{m}$ & $\mathrm{m}$ \\
\hline & Jordan & $\mathrm{m}$ & $\mathrm{m}$ & $\mathrm{m}$ & $\mathrm{m}$ & $\mathrm{m}$ & $\mathrm{m}$ & $\mathrm{m}$ & $\mathrm{m}$ \\
\hline & Kosovo & $\mathrm{m}$ & $\mathrm{m}$ & $\mathrm{m}$ & $\mathrm{m}$ & $\mathrm{m}$ & $\mathrm{m}$ & $\mathrm{m}$ & $\mathrm{m}$ \\
\hline & Lebanon & $\mathrm{m}$ & $\mathrm{m}$ & $\mathrm{m}$ & $\mathrm{m}$ & $\mathrm{m}$ & $\mathrm{m}$ & $\mathrm{m}$ & $\mathrm{m}$ \\
\hline & Lithuania & 15.7 & $(2.6)$ & 3.9 & $(0.9)$ & -11.8 & $(1.7)$ & -9.4 & $(1.7)$ \\
\hline & Macao (China) & 25.8 & $(2.5)$ & 8.6 & $(0.8)$ & -17.2 & (1.7) & -16.2 & (1.7) \\
\hline & Malta & $\mathrm{m}$ & $\mathrm{m}$ & $\mathrm{m}$ & $\mathrm{m}$ & $\mathrm{m}$ & $\mathrm{m}$ & $\mathrm{m}$ & $\mathrm{m}$ \\
\hline & Moldova & $\mathrm{m}$ & $\mathrm{m}$ & $\mathrm{m}$ & $\mathrm{m}$ & $\mathrm{m}$ & $\mathrm{m}$ & $\mathrm{m}$ & $\mathrm{m}$ \\
\hline & Montenegro & 9.2 & $(1.6)$ & 4.3 & $(0.5)$ & -4.9 & $(1.0)$ & -4.5 & $(1.0)$ \\
\hline & Peru & 7.7 & $(2.3)$ & 3.0 & $(0.7)$ & -4.7 & (1.6) & -4.4 & (1.6) \\
\hline & Qatar & 25.6 & $(1.4)$ & 12.6 & $(0.5)$ & -13.0 & $(0.9)$ & -10.4 & $(1.0)$ \\
\hline & Romania & $\mathrm{m}$ & $\mathrm{m}$ & $\mathrm{m}$ & $\mathrm{m}$ & $\mathrm{m}$ & $\mathrm{m}$ & $\mathrm{m}$ & $\mathrm{m}$ \\
\hline & Russia & 12.2 & $(1.8)$ & 4.8 & $(0.7)$ & -7.3 & $(1.2)$ & -7.3 & $(1.2)$ \\
\hline & Singapore & 19.2 & (1.8) & 6.5 & $(0.5)$ & -12.7 & $(1.3)$ & -9.4 & (1.6) \\
\hline & Chinese Taipei & 4.8 & $(1.2)$ & 1.4 & $(0.5)$ & -3.4 & $(0.8)$ & -3.7 & (1.0) \\
\hline & Thailand & 18.4 & (3.8) & 12.8 & (1.6) & -5.5 & $(2.2)$ & -8.9 & (2.4) \\
\hline & Trinidad and Tobago & $\mathrm{m}$ & $\mathrm{m}$ & $\mathrm{m}$ & $\mathrm{m}$ & $\mathrm{m}$ & $\mathrm{m}$ & $\mathrm{m}$ & $\mathrm{m}$ \\
\hline & Tunisia & 15.2 & $(4.1)$ & 13.7 & (1.8) & -1.4 & $(2.3)$ & -3.9 & $(2.7)$ \\
\hline & United Arab Emirates & 24.9 & (3.0) & 9.7 & $(1.0)$ & -15.2 & $(2.1)$ & -15.2 & (1.9) \\
\hline & Uruguay & 10.3 & $(2.7)$ & 6.9 & $(1.1)$ & -3.4 & (1.6) & -3.5 & (1.5) \\
\hline & Viet Nam & $\mathrm{m}$ & $\mathrm{m}$ & $\mathrm{m}$ & $\mathrm{m}$ & $\mathrm{m}$ & $\mathrm{m}$ & $\mathrm{m}$ & $\mathrm{m}$ \\
\hline & Argentina** & $\mathrm{m}$ & $\mathrm{m}$ & $\mathrm{m}$ & $\mathrm{m}$ & $\mathrm{m}$ & $\mathrm{m}$ & $\mathrm{m}$ & $\mathrm{m}$ \\
\hline & Kazakhstan** & $\mathrm{m}$ & $\mathrm{m}$ & $\mathrm{m}$ & $\mathrm{m}$ & $\mathrm{m}$ & $\mathrm{m}$ & $\mathrm{m}$ & $\mathrm{m}$ \\
\hline & Malaysia** & 22.0 & (3.4) & 11.2 & (1.4) & -10.8 & (1.9) & -10.8 & $(2.2)$ \\
\hline
\end{tabular}

1. A student is frequently bullied if he or she is in the top $10 \%$ of the index of exposure to bullying among all countries/economies.

2. A school with positive (negative) disciplinary climate is one where the average index of disciplinary climate is statistically higher (lower) than the average level in the country/economy. 3. The socio-economic profile is measured by the PISA index of economic, social and cultural status (ESCS).

Note: Values that are statistically significant a

.

** Coverage is too small to ensure comparability (see Annex A4).

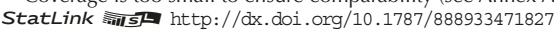


[Part 1/1]

Table III.8.23 Relationship between talking with friends and life satisfaction

Results based on students' self-reports

\begin{tabular}{|c|c|c|c|c|c|c|c|c|c|c|c|c|c|c|c|c|}
\hline & \multicolumn{4}{|c|}{ Average life satisfaction, by: } & \multicolumn{4}{|c|}{$\begin{array}{l}\text { Difference between students } \\
\text { whot talk and who do not talk } \\
\text { with their friends before school }\end{array}$} & \multicolumn{4}{|c|}{ Average life satisfaction, by: } & \multicolumn{4}{|c|}{$\begin{array}{l}\text { Difference between students } \\
\text { who talk and who do not talk } \\
\text { with their friends after school }\end{array}$} \\
\hline & \multicolumn{2}{|c|}{$\begin{array}{l}\text { Students who } \\
\text { do not talk with } \\
\text { their friends } \\
\text { before school }\end{array}$} & \multicolumn{2}{|c|}{$\begin{array}{c}\text { Students } \\
\text { who talk with } \\
\text { their friends } \\
\text { before school }\end{array}$} & \multicolumn{2}{|c|}{$\begin{array}{c}\text { Before accounting } \\
\text { for student } \\
\text { characteristics }\end{array}$} & \multicolumn{2}{|c|}{$\begin{array}{l}\text { After accounting } \\
\text { for student } \\
\text { characteristics }\end{array}$} & \multicolumn{2}{|c|}{$\begin{array}{l}\text { Students who } \\
\text { do not talk with } \\
\text { their friends } \\
\text { after school }\end{array}$} & \multicolumn{2}{|c|}{$\begin{array}{l}\text { Students } \\
\text { who talk with } \\
\text { their friends } \\
\text { after school }\end{array}$} & \multicolumn{2}{|c|}{$\begin{array}{c}\text { Before accounting } \\
\text { for student } \\
\text { characteristics }\end{array}$} & \multicolumn{2}{|c|}{$\begin{array}{l}\text { After accounting } \\
\text { for student } \\
\text { characteristics }\end{array}$} \\
\hline & Mean & S.E. & Mean & S.E. & Dif. & S.E. & Dif. & S.E. & Mean & S.E. & Mean & S.E. & Dif. & S.E. & Dif. & S.E. \\
\hline Australia & $\mathrm{m}$ & $\mathrm{m}$ & $\mathrm{m}$ & $\mathrm{m}$ & $\mathrm{m}$ & $\mathrm{m}$ & $\mathrm{m}$ & $\mathrm{m}$ & $\mathrm{m}$ & $\mathrm{m}$ & $\mathrm{m}$ & $\mathrm{m}$ & $\mathrm{m}$ & $\mathrm{m}$ & $\mathrm{m}$ & $\mathrm{m}$ \\
\hline Austria & 7.42 & $(0.05)$ & 7.60 & $(0.05)$ & 0.17 & $(0.06)$ & 0.20 & $(0.06)$ & 7.30 & $(0.06)$ & 7.59 & $(0.04)$ & 0.29 & $(0.07)$ & 0.28 & $(0.07)$ \\
\hline Belgium (excl. Flemish) & 7.53 & $(0.06)$ & 7.42 & $(0.06)$ & -0.12 & $(0.07)$ & -0.09 & $(0.07)$ & 7.49 & $(0.08)$ & 7.47 & $(0.06)$ & -0.03 & $(0.10)$ & -0.03 & $(0.10)$ \\
\hline Canada & . & $\mathrm{m}$ & . & $\mathrm{m}$ & $\mathrm{m}$ & & $\mathrm{m}$ & & $\mathrm{m}$ & & $\mathrm{m}$ & $m$ & $\mathrm{~m}$ & & $\mathrm{~m}$ & \\
\hline Chile & .24 & $(0.06)$ & 7.42 & $(0.05)$ & 0.18 & $(0.08)$ & 0.18 & $(0.0$ & 7.14 & $(0.0$ & & $(0$. & 0.29 & $(0$. & & $(0.09)$ \\
\hline Cze & 7.07 & $(0.05)$ & 7.04 & $(0.04)$ & -0.02 & $(0.06)$ & 0.01 & $(0.06)$ & 6.85 & $(0.08)$ & 7.10 & $(0.04)$ & 0.25 & $(0.09)$ & 0.25 & $(0.09)$ \\
\hline Denm & $\mathrm{m}$ & & $\mathrm{m}$ & $\mathrm{m}$ & $\mathrm{m}$ & $\mathrm{m}$ & $\mathrm{m}$ & $\mathrm{m}$ & $\mathrm{m}$ & $\mathrm{m}$ & $\mathrm{m}$ & $\mathrm{m}$ & $\mathrm{m}$ & & $\mathrm{m}$ & $\mathrm{m}$ \\
\hline Estonia & 7.43 & $(0.05)$ & 7.57 & $(0.05)$ & 0.13 & $(0.07)$ & 0.14 & $(0.07)$ & 7.36 & $(0.07)$ & 7.55 & $(0.04)$ & 0.18 & $(0.08)$ & 0.16 & $(0.08)$ \\
\hline Finland & 7.83 & $(0.04)$ & 7.94 & $(0.04)$ & 0.10 & $(0.05)$ & 0.11 & $(0.05)$ & 7.57 & $(0.07)$ & 7.96 & $(0.03)$ & 0.39 & $(0.07)$ & 0.39 & $(0.07)$ \\
\hline Fran & 7.56 & & 7.68 & & & & & & 7.46 & & & & & & & \\
\hline & & & & & & & & & & & & & & & & \\
\hline Gree & 6.83 & $(0.8$ & 6.9 & $(0$. & 0.13 & $(0$. & 0.15 & $(0$. & 6. & $(0$ & 6.98 & $(0$. & 36 & $(0$. & 36 & $(0.08)$ \\
\hline Hun & 7.10 & $(0.0$ & 7.1 & $(0$. & & $(0$. & 0.14 & $(0$. & 6.93 & $(0$. & 7.21 & (0. & & & 28 & $(0.11)$ \\
\hline Icela & 7.77 & $(0.0$ & 7.81 & $(0$. & & $(0.0$ & & $(0.0$ & 7.47 & & 7.87 & & 0.41 & $(0.11)$ & 37 & $(0.11)$ \\
\hline & 7.25 & $(0.04)$ & 7.32 & $(0.0$ & 0.07 & $(0.0$ & 0.08 & $(0.0$ & 7.10 & $(0.0$ & 7.34 & $(0.0$ & 0.24 & $(0.08)$ & 0.24 & $(0.08)$ \\
\hline & & & & & & & & & & & & & & & & \\
\hline It: & 6.80 & $(0$. & 6.92 & $(0.0$ & 0.1 & $(0$ & 0.13 & $(C$ & 34 & $(0$. & 6.94 & & & & & (0.12) \\
\hline & & $(0$. & & & & & & & & & & & & & 3 & $(0.06)$ \\
\hline & & $(0$. & & & & & & & & & & & & & & $(0.08)$ \\
\hline & & & & & & & & & & & & & & & & $(0.09)$ \\
\hline & & & & & & & & & & & & & & & & \\
\hline & & & & & & & & & & & & & & & & \\
\hline & .73 & $(0.0$ & 7.89 & $(0$. & 0.16 & $(0$ & 0.13 & $(0$ & 4 & $(0.0$ & 7.87 & $(0.03)$ & 0.23 & $(0.07)$ & 0.21 & $(0.07)$ \\
\hline & $\mathrm{m}$ & & $\mathrm{m}$ & & $\mathrm{m}$ & $\mathrm{m}$ & $\mathrm{m}$ & $\mathrm{m}$ & $\mathrm{m}$ & $\mathrm{m}$ & $\mathrm{m}$ & $\mathrm{m}$ & $\mathrm{m}$ & $\mathrm{m}$ & $\mathrm{m}$ & $\mathrm{m}$ \\
\hline & m & & $\mathrm{m}$ & & $m$ & & $\mathrm{~m}$ & & m & & m & & $\mathrm{m}$ & $m$ & $\mathrm{~m}$ & $\mathrm{~m}$ \\
\hline & 7.17 & $(0.06)$ & 7.19 & $(0.0$ & 0.02 & $(0.0$ & 0.04 & $(0.0$ & 6.75 & $(0.1$ & 7.26 & $(0$. & 0.50 & $(0.11)$ & 49 & $(0.11)$ \\
\hline & & & & & & & & & & & & & & & & \\
\hline & 7. & & & & & & & & & & & & & & & \\
\hline & & & & & & & & & & & & & & & & \\
\hline & 7.40 & $(0.04)$ & 7.46 & $(0.05)$ & 0.06 & $(0.06)$ & 0.11 & $(0.06)$ & 7.31 & $(0.06)$ & 7.47 & $(0.03)$ & 0.17 & $(0.06)$ & .22 & $(0.07)$ \\
\hline & & & & & & & & & & & & & & & & \\
\hline & 7.70 & $(0.05)$ & 7.67 & $(0.0$ & -0.03 & $(0.0$ & -0.04 & $(0$. & 7 & $(0$. & 7. & $(0$ & 0. & $(0$. & 6 & $(0.07)$ \\
\hline & & & & & & & & & & & & & & & & \\
\hline & & & & & & & & & & & & & & & & $(0.06)$ \\
\hline United State & 7.19 & $(0.05)$ & 7.45 & $(0.04)$ & 0.27 & $(0.05)$ & 0.28 & $(0.05)$ & 6.98 & $(0.07)$ & 7.44 & $(0.04)$ & 0.47 & $(0.07)$ & 0.44 & $(0.07)$ \\
\hline ECD av & 7.24 & $(0.01)$ & 7.35 & $(0.01)$ & 0.11 & $(0.01)$ & 0.13 & $(0.01)$ & 7.10 & $(0.01)$ & 7.36 & $(0.01$ & 0.26 & $(0.02)$ & 0.26 & $(0.02)$ \\
\hline
\end{tabular}

\begin{tabular}{|c|c|c|c|c|c|c|c|c|c|c|c|c|c|c|c|c|}
\hline Albania & $\mathrm{m}$ & $\mathrm{m}$ & $\mathrm{m}$ & $\mathrm{m}$ & $\mathrm{m}$ & $\mathrm{m}$ & $\mathrm{m}$ & $\mathrm{m}$ & $\mathrm{m}$ & $\mathrm{m}$ & $\mathrm{m}$ & $\mathrm{m}$ & $\mathrm{m}$ & $\mathrm{m}$ & $\mathrm{m}$ & $\mathrm{m}$ \\
\hline Algeria & $\mathrm{m}$ & $\mathrm{m}$ & $\mathrm{m}$ & $\mathrm{m}$ & $\mathrm{m}$ & $\mathrm{m}$ & $\mathrm{m}$ & $\mathrm{m}$ & $\mathrm{m}$ & $\mathrm{m}$ & $\mathrm{m}$ & $\mathrm{m}$ & $\mathrm{m}$ & $\mathrm{m}$ & $\mathrm{m}$ & $\mathrm{m}$ \\
\hline Brazil & 7.37 & $(0.06)$ & 7.63 & $(0.04)$ & 0.26 & $(0.06)$ & 0.23 & $(0.06)$ & 7.25 & $(0.07)$ & 7.64 & $(0.04)$ & 0.38 & $(0.07)$ & 0.39 & $(0.07)$ \\
\hline B-S-J-G (China) & 6.77 & $(0.06)$ & 6.87 & $(0.05)$ & 0.10 & $(0.07)$ & 0.11 & $(0.07)$ & 6.72 & $(0.06)$ & 6.91 & $(0.04)$ & 0.19 & $(0.07)$ & 0.20 & $(0.07)$ \\
\hline Bulgaria & 7.01 & $(0.10)$ & 7.49 & $(0.04)$ & 0.48 & $(0.11)$ & 0.49 & $(0.11)$ & 6.73 & $(0.12)$ & 7.52 & $(0.04)$ & 0.79 & $(0.13)$ & 0.76 & $(0.13)$ \\
\hline CABA (Argentina) & $\mathrm{m}$ & $\mathrm{m}$ & . & 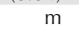 & $\mathrm{m}$ & 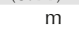 & $\mathrm{m}$ & 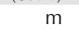 & $\mathrm{m}$ & $\mathrm{m}$ & $\mathrm{m}$ & $\mathrm{m}$ & $\mathrm{m}$ & $f^{2}$ & $\mathrm{~m}$ & \\
\hline Colombia & 7.81 & $(0.05)$ & 7.91 & $(0.05)$ & 0.10 & $(0.06)$ & 0.08 & $(0.06)$ & 7.74 & $0.05)$ & 7.93 & $(0.04)$ & 0.19 & $(0.06)$ & 0.19 & $(0.06)$ \\
\hline Costa & 8.00 & $(0.07)$ & 8.25 & $(0.03)$ & 0.25 & $(0.07)$ & 0.23 & $(0.07)$ & 7.86 & $(0.08$ & 8.27 & $(0.03)$ & 0.41 & $(0.08)$ & 0.39 & $(0.08)$ \\
\hline Croatia & 7.71 & $(0.05)$ & 7.99 & $(0.05)$ & 0.27 & $(0.06)$ & 0.25 & $(0.06)$ & 7.62 & $(0.06)$ & 7.97 & $(0.04)$ & 0.35 & $(0.07)$ & 0.34 & $(0.07)$ \\
\hline Cyprus* & 6.99 & $(0.07)$ & 7.11 & $(0.04)$ & 0.12 & $(0.08)$ & 0.12 & $(0.08)$ & 6.67 & $(0.11)$ & 7.15 & $(0.04)$ & 0.48 & $(0.12)$ & 0.43 & $(0.12)$ \\
\hline Dominican Republic & 8.33 & $(0.06)$ & 8.59 & $(0.05)$ & 0.27 & $(0.08)$ & 0.21 & $(0.08)$ & 8.27 & $(0.10)$ & 8.55 & $0.05)$ & 0.29 & $(0.11)$ & 0.27 & $(0.11)$ \\
\hline FYROI & $\mathrm{m}$ & $\mathrm{m}$ & $\mathrm{m}$ & $\mathrm{m}$ & $\mathrm{m}$ & $\mathrm{m}$ & $\mathrm{m}$ & $\mathrm{m}$ & $\mathrm{m}$ & $\mathrm{m}$ & $\mathrm{m}$ & $\mathrm{m}$ & $\mathrm{m}$ & $\mathrm{m}$ & $\mathrm{m}$ & $\mathrm{m}$ \\
\hline Georg & $\mathrm{m}$ & $\mathrm{m}$ & $\mathrm{m}$ & $\mathrm{m}$ & $\mathrm{m}$ & $\mathrm{m}$ & $\mathrm{m}$ & $\mathrm{m}$ & $\mathrm{m}$ & $\mathrm{m}$ & $\mathrm{m}$ & $\mathrm{m}$ & $\mathrm{m}$ & $\mathrm{m}$ & $\mathrm{m}$ & \\
\hline Hong Kong (China) & 6.38 & $(0.05)$ & 6.54 & $(0.05)$ & 0.16 & $(0.06)$ & 0.16 & $(0.05)$ & 6.30 & $(0.07)$ & 6.53 & $(0.05)$ & 0.23 & $(0.08)$ & 0.22 & $(0.08)$ \\
\hline Indonesia & $\mathrm{m}$ & $\mathrm{m}$ & $\mathrm{m}$ & $\mathrm{m}$ & $\mathrm{m}$ & $\mathrm{m}$ & $\mathrm{m}$ & $\mathrm{m}$ & $\mathrm{m}$ & $m$ & $\mathrm{~m}$ & $\mathrm{~m}$ & $\mathrm{~m}$ & $\mathrm{~m}$ & $\mathrm{~m}$ & $\mathrm{~m}$ \\
\hline Jordar & $\mathrm{m}$ & $\mathrm{m}$ & $\mathrm{m}$ & $\mathrm{m}$ & $\mathrm{m}$ & $\mathrm{m}$ & $\mathrm{m}$ & $\mathrm{m}$ & $\mathrm{m}$ & & $\mathrm{m}$ & $\mathrm{m}$ & & $\mathrm{m}$ & & m \\
\hline & $\mathrm{m}$ & $\mathrm{m}$ & $\mathrm{m}$ & $\mathrm{m}$ & $\mathrm{m}$ & $\mathrm{m}$ & $\mathrm{m}$ & & $\mathrm{m}$ & & & & & ... & & \\
\hline Lebanc & $\mathrm{m}$ & $\mathrm{m}$ & $\mathrm{m}$ & $\mathrm{m}$ & $\mathrm{m}$ & $\mathrm{m}$ & $\mathrm{m}$ & $\mathrm{m}$ & $\mathrm{m}$ & $\mathrm{m}$ & $\mathrm{m}$ & $\mathrm{m}$ & $\mathrm{m}$ & $\mathrm{m}$ & $\mathrm{m}$ & $\mathrm{m}$ \\
\hline Lithua & 7.77 & $(0.06)$ & 7.89 & $(0.04)$ & 0.12 & $(0.07)$ & 0.13 & $(0.07)$ & 7.53 & $0.08)$ & 7.93 & $0.03)$ & 0.40 & $(0.08)$ & 0.38 & $(0.08)$ \\
\hline Macao & 6.50 & $(0.06)$ & 6.64 & $(0.04)$ & 0.13 & $(0.07)$ & 0.13 & $(0.07)$ & 6.32 & $(0.09)$ & 6.65 & $(0.04)$ & 0.33 & $(0.11)$ & 0.30 & $(0.11)$ \\
\hline Malta & $\mathrm{m}$ & & $\mathrm{m}$ & & $\mathrm{m}$ & & $\mathrm{m}$ & & $\mathrm{m}$ & & 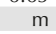 & $\mathrm{m}$ & 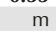 & $\mathrm{m}$ & $\mathrm{m}$ & $\mathrm{m}$ \\
\hline & $\mathrm{m}$ & & $\mathrm{m}$ & & 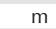 & & & & 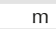 & & & & & & & $\mathrm{m}$ \\
\hline & 7.54 & .05 & 7.75 & 0.04 & 0.21 & 0.1 & $0.2 C$ & 0.1 & 7.49 & 0.1 & 7.7 & 0.0 & 0.2 & 0. & 0.2 & $(0.11)$ \\
\hline Peru & 7.39 & $(0.0$ & 7.55 & $(0.0$ & 0.15 & $(0.07)$ & 0.1 & $(0$. & 7.22 & $0 . c^{0}$ & 7.60 & 0.0 & 0.38 & $(0.07)$ & ? & $(0.07)$ \\
\hline & 7.14 & $(0.04)$ & 7.47 & $(0.03)$ & 0.33 & $(0.05)$ & 0.30 & $(0.05)$ & 6.90 & $(0.06)$ & 7.47 & $(0.02)$ & 0.57 & $(0.07)$ & 0.54 & $(0.07)$ \\
\hline & $\mathrm{m}$ & & $\mathrm{m}$ & & $\mathrm{m}$ & & $\mathrm{m}$ & & $\mathrm{m}$ & $\mathrm{m}$ & $\mathrm{m}$ & $\mathrm{m}$ & $\mathrm{m}$ & $\mathrm{m}$ & $\mathrm{m}$ & $\mathrm{m}$ \\
\hline Russ & 7.41 & $(0.07)$ & 7.89 & $(0.05)$ & 0.48 & $(0.08)$ & 0.46 & $(0.08)$ & 7.08 & $(0.10)$ & 7.88 & $(0.04)$ & 0.80 & $(0.10)$ & 0.77 & $(0.10)$ \\
\hline & $\mathrm{m}$ & & $\mathrm{m}$ & & $\mathrm{m}$ & & $\mathrm{m}$ & & $\mathrm{m}$ & & 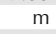 & & & & & $\mathrm{m}$ \\
\hline Chi & 6.53 & $(0.04)$ & 6.65 & $(0.04$ & 0.12 & $(0.05$ & 0.15 & $(0.05)$ & 6.48 & $(0.0$ & 6.64 & $(0.03)$ & 0.1 & $(0.05)$ & 0.1 & $(0.05)$ \\
\hline & 7.50 & $(0 . c$ & 7.80 & $(0$. & 0.29 & $(0$. & 0.28 & $(0$. & 7.45 & $(0$. & 7.78 & $(0.03)$ & 0.33 & $(0.07)$ & 0.32 & $(0.07)$ \\
\hline Tobago & $\mathrm{m}$ & & $\mathrm{m}$ & & $\mathrm{m}$ & & $\mathrm{m}$ & & $\mathrm{m}$ & & $\mathrm{m}$ & 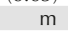 & $m$ & $\mathrm{~m}$ & $\mathrm{~m}$ & . \\
\hline Tu & 6.41 & $(0.11$ & 7.00 & $(0.05)$ & 0.59 & $(0.12)$ & 0.50 & $(0.12)$ & 6.45 & $(0.1$ & 7.03 & $(0.05)$ & 0.5 & $(0.11)$ & 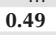 & $(0.11)$ \\
\hline mirates & 6.99 & $(0.0$ & 7.45 & & & $(0$ & & & 6. & & 7.43 & & & & 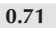 & $(0.08)$ \\
\hline & 7.36 & $(0.07)$ & 7.80 & $(0.04)$ & 0.44 & $(0.08)$ & 0.43 & $(0.08)$ & 7.16 & .09) & 7.81 & 05) & 0.65 & $(0.11)$ & 0.59 & $(0.11)$ \\
\hline Viet Nam & $\mathrm{m}$ & $\mathrm{m}$ & $\mathrm{m}$ & $\mathrm{m}$ & $\mathrm{m}$ & $\mathrm{m}$ & $\mathrm{m}$ & $\mathrm{m}$ & $\mathrm{m}$ & $\mathrm{m}$ & $\mathrm{m}$ & $\mathrm{m}$ & $\mathrm{m}$ & $\mathrm{m}$ & $\mathrm{m}$ & $\mathrm{m}$ \\
\hline & $\mathrm{m}$ & $\mathrm{m}$ & $\mathrm{m}$ & $\mathrm{m}$ & $\mathrm{m}$ & & $\mathrm{m}$ & & $\mathrm{m}$ & & $\mathrm{n}$ & $\mathrm{m}$ & & $\mathrm{m}$ & $\mathrm{m}$ & $\mathrm{m}$ \\
\hline & $\mathrm{m}$ & $\mathrm{m}$ & $\mathrm{m}$ & min & $\mathrm{m}$ & m & $\mathrm{m}$ & $\mathrm{m}$ & mit & 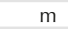 & min & $\mathrm{m}$ & $\mathrm{m}$ & $\mathrm{m}$ & 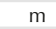 & $\mathrm{m}$ \\
\hline Malaysia** & 6.99 & $(0.06)$ & 7.11 & $(0.05)$ & 0.12 & $(0.07)$ & 0.12 & $(0.07)$ & 6.87 & $(0.07)$ & 7.13 & $(0.04)$ & 0.26 & $(0.08)$ & 0.25 & $(0.08)$ \\
\hline
\end{tabular}

1. Student characteristics include the PISA index of economic, social and cultural status (ESCS) and gender.

Note: Values that are statistically significant are indicated in bold (see Annex A3).

* See note at the beginning of this Annex.

* Coverage is too small to ensure comparability (see Annex A4).

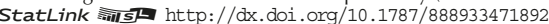




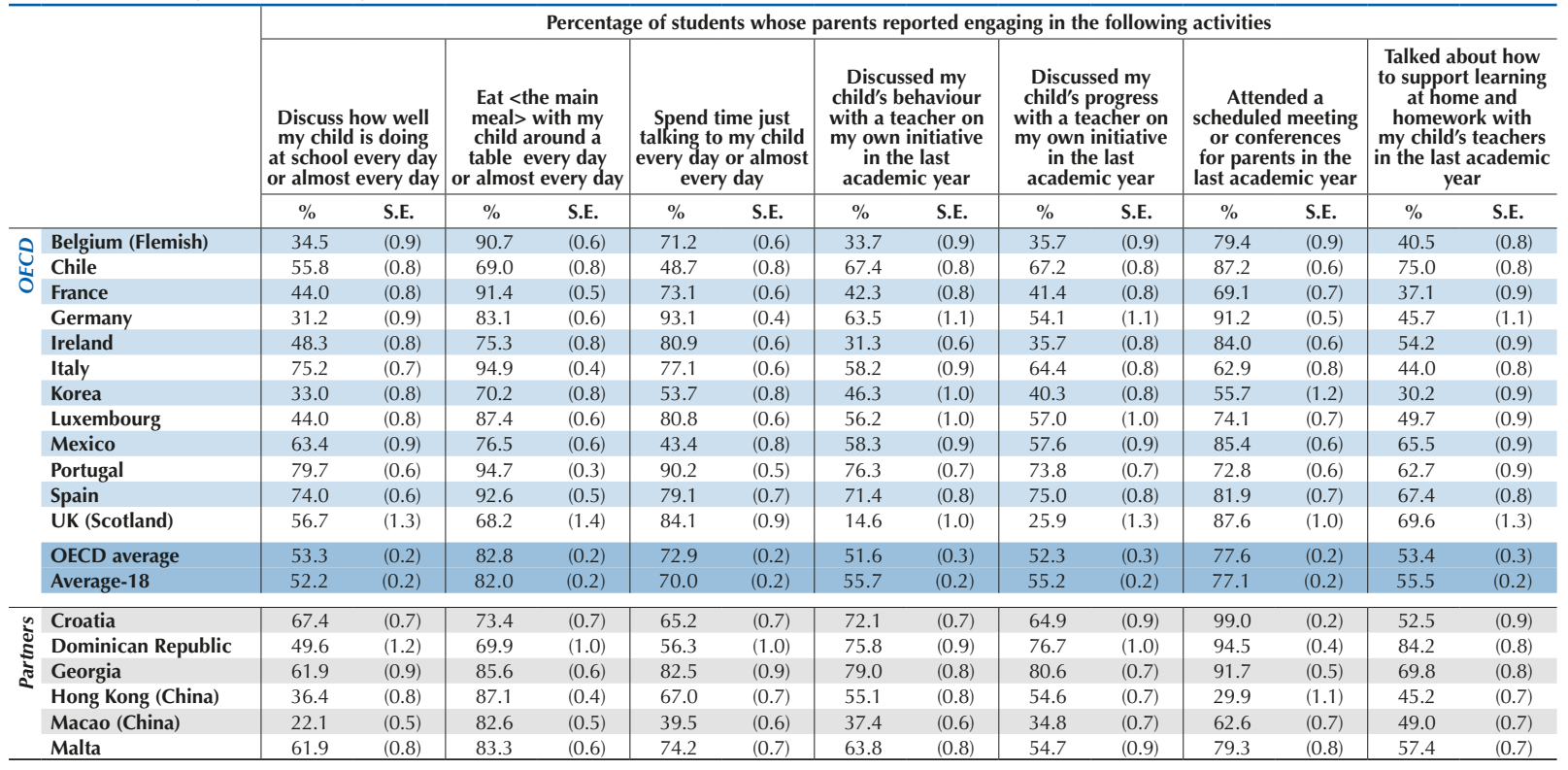

\begin{tabular}{|c|c|c|c|c|c|c|c|c|c|c|c|c|c|}
\hline & \multicolumn{12}{|c|}{ Percentage of students whose parents reported engaging in the following activities } \\
\hline & & \multicolumn{2}{|c|}{$\begin{array}{l}\text { Exchanged ideas on } \\
\text { parenting, family } \\
\text { support, or the } \\
\text { child's development } \\
\text { with my child's } \\
\text { teachers in the last } \\
\text { academic year }\end{array}$} & \multicolumn{2}{|c|}{$\begin{array}{c}\text { Discussed } \\
\text { my child's } \\
\text { behaviour on } \\
\text { the initiative of one } \\
\text { of his/her teachers }\end{array}$} & \multicolumn{2}{|c|}{$\begin{array}{c}\text { Discussed } \\
\text { my child's progress } \\
\text { on the initiative } \\
\text { of one of their } \\
\text { teachers }\end{array}$} & \multicolumn{2}{|c|}{$\begin{array}{l}\text { Participated } \\
\text { in local school } \\
\text { government, } \\
\text { e.g. parent } \\
\text { council or school } \\
\text { management } \\
\text { committee }\end{array}$} & \multicolumn{2}{|c|}{$\begin{array}{l}\text { Volunteered in physical } \\
\text { or extra-curricular activities } \\
\text { (e.g. building maintenance, } \\
\text { carpentry, gardening or yard } \\
\text { work, school play, sports, } \\
\text { field trip) }\end{array}$} & \multicolumn{2}{|c|}{$\begin{array}{l}\text { Volunteered to support school } \\
\text { activities (e.g. volunteered } \\
\text { in the school library, media } \\
\text { centre, or canteen, assisted } \\
\text { a teacher, appeared } \\
\text { as a guest speaker) }\end{array}$} \\
\hline & & $\%$ & S.E. & $\%$ & S.E. & $\%$ & S.E. & $\%$ & S.E. & $\%$ & S.E. & $\%$ & S.E. \\
\hline \multirow{14}{*}{ రి } & Belgium (Flemish) & 25.5 & $(0.7)$ & 37.2 & $(1.0)$ & 47.3 & $(1.0)$ & 5.3 & $(0.4)$ & 4.4 & $(0.4)$ & 3.7 & $(0.3)$ \\
\hline & Chile & 58.5 & $(0.9)$ & 65.6 & $(0.9)$ & 64.6 & $(0.9)$ & 27.3 & $(0.9)$ & 20.2 & $(0.8)$ & 15.4 & $(0.7)$ \\
\hline & France & 20.0 & $(0.7)$ & 29.0 & $(0.7)$ & 31.1 & (0.9) & 8.0 & $(0.4)$ & 3.6 & $(0.3)$ & 3.5 & $(0.3)$ \\
\hline & Germany & 28.8 & (1.0) & 38.6 & (1.3) & 29.5 & (1.3) & 17.6 & $(0.8)$ & 18.2 & $(0.8)$ & 11.8 & $(0.7)$ \\
\hline & Ireland & 26.7 & $(0.8)$ & 19.4 & $(1.0)$ & 29.1 & $(0.9)$ & 9.5 & $(0.5)$ & 7.8 & $(0.5)$ & 7.2 & $(0.4)$ \\
\hline & Italy & 35.9 & $(0.9)$ & 37.5 & (0.9) & 41.3 & $(0.8)$ & 17.3 & $(0.6)$ & 15.4 & $(0.6)$ & 8.3 & $(0.5)$ \\
\hline & Korea & 42.3 & (1.1) & 72.0 & $(0.7)$ & 66.4 & $(0.8)$ & 14.9 & $(0.5)$ & 28.9 & $(1.0)$ & 14.8 & $(0.6)$ \\
\hline & Luxembourg & 28.1 & $(0.8)$ & 36.1 & $(0.8)$ & 41.7 & $(0.8)$ & 9.2 & $(0.5)$ & 9.0 & $(0.5)$ & 7.1 & $(0.5)$ \\
\hline & Mexico & 39.2 & $(0.9)$ & 45.9 & (1.0) & 46.3 & (1.0) & 48.5 & $(1.0)$ & 20.9 & (1.0) & 13.9 & $(0.6)$ \\
\hline & Portugal & 60.4 & $(0.8)$ & 52.6 & $(0.8)$ & 58.1 & (1.0) & 11.4 & $(0.5)$ & 8.5 & $(0.4)$ & 6.4 & $(0.4)$ \\
\hline & Spain & 58.3 & $(0.9)$ & 55.7 & (1.2) & 60.2 & (1.3) & 17.6 & $(0.7)$ & 11.4 & $(0.7)$ & 9.3 & $(0.6)$ \\
\hline & UK (Scotland) & 20.4 & $(1.0)$ & 11.6 & $(1.0)$ & 27.0 & (1.5) & 7.0 & $(0.7)$ & 6.8 & (1.1) & 6.6 & $(0.6)$ \\
\hline & OECD average & 37.0 & $(0.3)$ & 41.8 & $(0.3)$ & 45.2 & $(0.3)$ & 16.1 & $(0.2)$ & 12.9 & $(0.2)$ & 9.0 & $(0.2)$ \\
\hline & Average-18 & 41.6 & $(0.2)$ & 46.8 & $(0.2)$ & 49.4 & $(0.2)$ & 19.3 & $(0.2)$ & 14.6 & $(0.2)$ & 11.6 & $(0.1)$ \\
\hline \multirow{6}{*}{ ఏँ } & Croatia & 48.1 & (0.7) & 28.4 & $(0.8)$ & 30.3 & $(0.8)$ & 19.3 & $(0.6)$ & 15.2 & (0.5) & 10.6 & (0.5) \\
\hline & Dominican Republic & 71.9 & (1.1) & 66.5 & $(1.0)$ & 67.7 & (1.0) & 58.5 & (1.3) & 36.1 & $(1.2)$ & 39.7 & (1.2) \\
\hline & Georgia & 52.8 & (1.0) & 72.0 & $(1.0)$ & 78.4 & $(0.8)$ & 24.3 & $(0.9)$ & 19.1 & $(0.8)$ & 13.6 & $(0.7)$ \\
\hline & Hong Kong (China) & 41.9 & $(0.8)$ & 66.5 & $(0.9)$ & 66.7 & $(0.8)$ & 9.4 & $(0.4)$ & 8.6 & $(0.5)$ & 8.9 & $(0.5)$ \\
\hline & Macao (China) & 47.3 & $(0.8)$ & 60.3 & $(0.7)$ & 56.6 & $(0.8)$ & 37.4 & $(0.7)$ & 21.4 & $(0.7)$ & 20.4 & $(0.7)$ \\
\hline & Malta & 42.3 & $(0.8)$ & 47.0 & $(0.7)$ & 47.6 & $(0.9)$ & 5.2 & $(0.4)$ & 7.6 & $(0.5)$ & 7.3 & (0.5) \\
\hline
\end{tabular}

StatLink 羿 SL http://dx.doi.org/10.1787/888933471912 
[Part 1/2]

Table III.9.3 Change between 2012 and 2015 in parents' activities with their child and at their child's school

Percentage of students whose parents reported that they routinely engage in home-based activities and that they had participated in school-related activities during the previous academic year

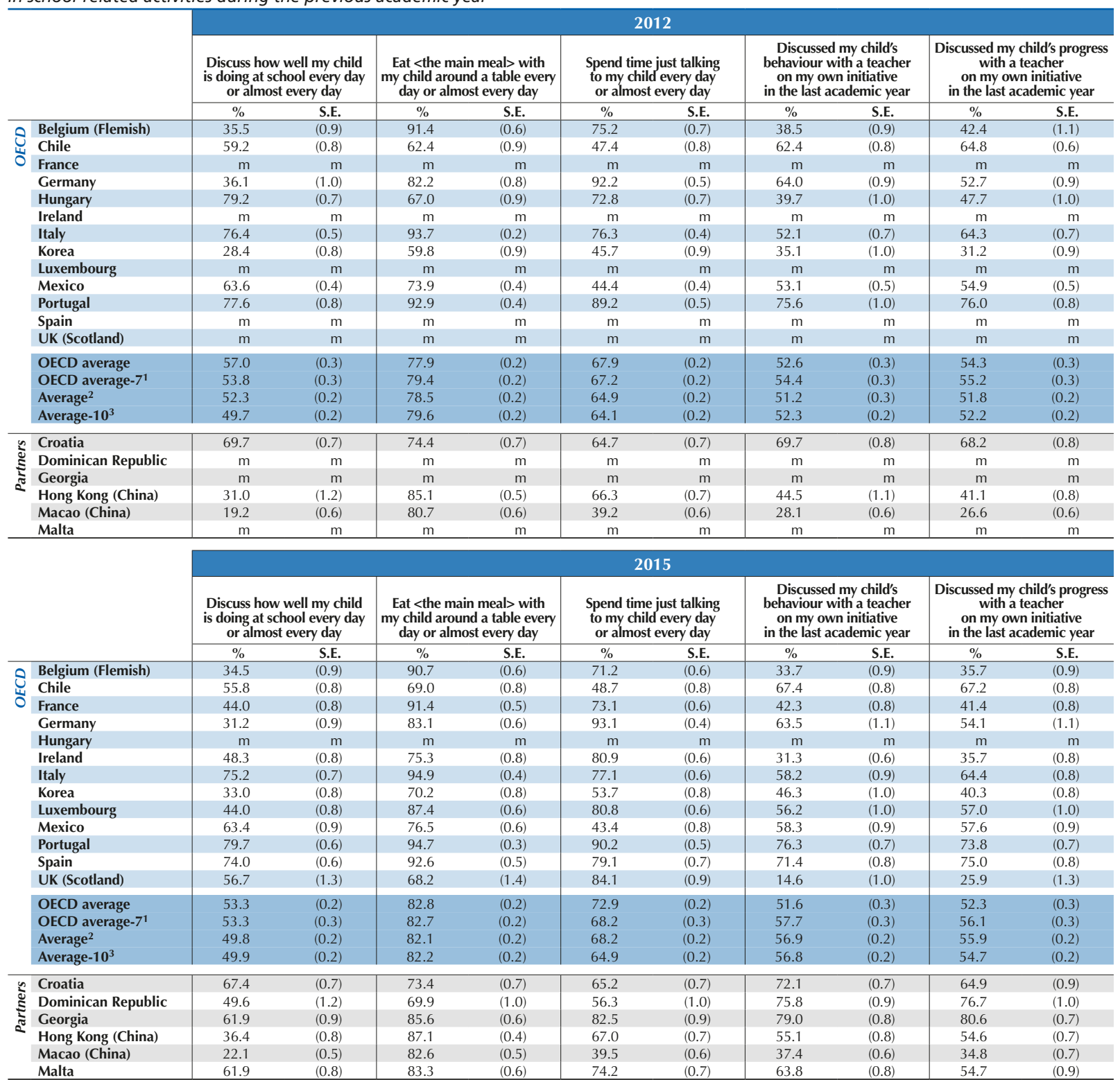

1. "OECD average-7" includes all OECD countries/economies with available data for both years.

2. "Average" includes all countries/economies with available data.

3. "Average-10" includes all countries/economies with available data for both years.

Note: Values that are statistically significant are indicated in bold (see Annex A3).

StatLink क्गाडs http://dx.doi.org/10.1787/888933471934 


\section{Table III.9.3 Change between 2012 and 2015 in parents' activities with their child and at their child's school}

Percentage of students whose parents reported that they routinely engage in home-based activities and that they had participated in school-related activities during the previous academic year

\begin{tabular}{|c|c|c|c|c|c|c|c|c|c|c|c|}
\hline & & \multicolumn{10}{|c|}{ Change between 2012 and $2015(2015$ - 2012) } \\
\hline & & \multicolumn{2}{|c|}{$\begin{array}{l}\text { Discuss how well my child } \\
\text { is doing at school every day } \\
\text { or almost every day }\end{array}$} & \multicolumn{2}{|c|}{$\begin{array}{l}\text { Eat < the main meal> with } \\
\text { my child around a table every } \\
\text { day or almost every day }\end{array}$} & \multicolumn{2}{|c|}{$\begin{array}{l}\text { Spend time just talking } \\
\text { to my child every day } \\
\text { or almost every day }\end{array}$} & \multicolumn{2}{|c|}{$\begin{array}{l}\text { Discussed my child's } \\
\text { behaviour with a teacher } \\
\text { on my own initiative } \\
\text { in the last academic year }\end{array}$} & \multicolumn{2}{|c|}{$\begin{array}{c}\text { Discussed my child's progress } \\
\text { with a teacher } \\
\text { on my own initiative } \\
\text { in the last academic year }\end{array}$} \\
\hline & & $\%$ & S.E. & $\%$ & S.E. & $\%$ & S.E. & $\%$ & S.E. & $\%$ & S.E. \\
\hline \multirow{17}{*}{ త్రి } & Belgium (Flemish) & -1.0 & (1.3) & -0.7 & $(0.8)$ & -4.0 & $(0.9)$ & -4.8 & (1.3) & -6.7 & (1.4) \\
\hline & Chile & -3.4 & (1.1) & 6.7 & $(1.2)$ & 1.3 & $(1.2)$ & 5.0 & (1.1) & 2.3 & $(1.0)$ \\
\hline & France & $\mathrm{m}$ & $\mathrm{m}$ & $\mathrm{m}$ & $\mathrm{m}$ & $\mathrm{m}$ & $\mathrm{m}$ & $\mathrm{m}$ & $\mathrm{m}$ & $\mathrm{m}$ & $\mathrm{m}$ \\
\hline & Germany & -4.9 & $(1.3)$ & 0.9 & $(1.0)$ & 0.9 & $(0.7)$ & -0.5 & (1.4) & 1.3 & (1.4) \\
\hline & Hungary & $\mathrm{m}$ & $\mathrm{m}$ & $\mathrm{m}$ & $\mathrm{m}$ & $\mathrm{m}$ & $\mathrm{m}$ & $\mathrm{m}$ & $\mathrm{m}$ & $\mathrm{m}$ & $\mathrm{m}$ \\
\hline & Ireland & $\mathrm{m}$ & $\mathrm{m}$ & $\mathrm{m}$ & $\mathrm{m}$ & $\mathrm{m}$ & $\mathrm{m}$ & $\mathrm{m}$ & $\mathrm{m}$ & $\mathrm{m}$ & $\mathrm{m}$ \\
\hline & Italy & -1.1 & $(0.9)$ & 1.2 & $(0.5)$ & 0.8 & $(0.7)$ & 6.2 & (1.1) & 0.0 & $(1.0)$ \\
\hline & Korea & 4.7 & (1.1) & 10.4 & $(1.2)$ & 8.1 & $(1.2)$ & 11.2 & (1.4) & 9.1 & $(1.2)$ \\
\hline & Luxembourg & $\mathrm{m}$ & $\mathrm{m}$ & $\mathrm{m}$ & $\mathrm{m}$ & $\mathrm{m}$ & $\mathrm{m}$ & $\mathrm{m}$ & $\mathrm{m}$ & $\mathrm{m}$ & $\mathrm{m}$ \\
\hline & Mexico & -0.2 & (1.0) & 2.7 & $(0.8)$ & -1.0 & $(0.9)$ & 5.2 & (1.0) & 2.7 & (1.1) \\
\hline & Portugal & 2.1 & $(1.0)$ & 1.8 & $(0.5)$ & 0.9 & $(0.7)$ & 0.7 & $(1.2)$ & -2.3 & $(1.1)$ \\
\hline & Spain & $\mathrm{m}$ & $\mathrm{m}$ & $\mathrm{m}$ & $\mathrm{m}$ & $\mathrm{m}$ & $\mathrm{m}$ & $\mathrm{m}$ & $\mathrm{m}$ & $\mathrm{m}$ & $\mathrm{m}$ \\
\hline & UK (Scotland) & $\mathrm{m}$ & $\mathrm{m}$ & $\mathrm{m}$ & $\mathrm{m}$ & $\mathrm{m}$ & $\mathrm{m}$ & $\mathrm{m}$ & $\mathrm{m}$ & $\mathrm{m}$ & $\mathrm{m}$ \\
\hline & OECD average & $\mathrm{m}$ & $\mathrm{m}$ & $\mathrm{m}$ & $\mathrm{m}$ & $\mathrm{m}$ & $\mathrm{m}$ & $\mathrm{m}$ & $\mathrm{m}$ & $\mathrm{m}$ & $\mathrm{m}$ \\
\hline & OECD average- $7^{1}$ & -0.6 & $(0.4)$ & 3.3 & $(0.3)$ & 1.0 & $(0.3)$ & 3.3 & $(0.5)$ & 0.9 & $(0.5)$ \\
\hline & Average $^{2}$ & $\mathrm{~m}$ & $\mathrm{~m}$ & $\mathrm{~m}$ & $\mathrm{~m}$ & $\mathrm{~m}$ & $\mathrm{~m}$ & $\mathrm{~m}$ & $\mathrm{~m}$ & $\mathrm{~m}$ & $\mathrm{~m}$ \\
\hline & Average- $10^{3}$ & 0.2 & $(0.3)$ & 2.6 & $(0.2)$ & 0.8 & $(0.3)$ & 4.5 & $(0.3)$ & 2.5 & $(0.3)$ \\
\hline \multirow{6}{*}{ 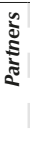 } & Croatia & -2.3 & $(1.0)$ & -1.0 & (1.0) & 0.5 & (1.0) & 2.4 & (1.1) & -3.3 & (1.2) \\
\hline & Dominican Republic & $\mathrm{m}$ & $\mathrm{m}$ & $\mathrm{m}$ & $\mathrm{m}$ & $\mathrm{m}$ & $\mathrm{m}$ & $\mathrm{m}$ & $\mathrm{m}$ & $\mathrm{m}$ & $\mathrm{m}$ \\
\hline & Georgia & $\mathrm{m}$ & $\mathrm{m}$ & $\mathrm{m}$ & $\mathrm{m}$ & $\mathrm{m}$ & $\mathrm{m}$ & $\mathrm{m}$ & $\mathrm{m}$ & $\mathrm{m}$ & $\mathrm{m}$ \\
\hline & Hong Kong (China) & 5.4 & (1.4) & 2.1 & $(0.7)$ & 0.8 & $(1.0)$ & 10.5 & (1.4) & 13.5 & $(1.1)$ \\
\hline & Macao (China) & 2.9 & $(0.8)$ & 1.9 & $(0.8)$ & 0.3 & $(0.9)$ & 9.3 & $(0.9)$ & 8.2 & $(0.9)$ \\
\hline & Malta & $\mathrm{m}$ & $\mathrm{m}$ & $\mathrm{m}$ & $\mathrm{m}$ & $\mathrm{m}$ & $\mathrm{m}$ & $\mathrm{m}$ & $\mathrm{m}$ & $\mathrm{m}$ & $\mathrm{m}$ \\
\hline
\end{tabular}

1. "OECD average-7" includes all OECD countries/economies with available data for both years.

. "Average" includes all countries/economies with available data.

. "Average-10" includes all countries/economies with available data for both years.

Note: Values that are statistically significant are indicated in bold (see Annex A3).

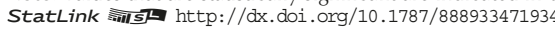


[Part 1/2]

Table III.9.4 Parents' activities and student science performance

Results based on parents' self-reports

\begin{tabular}{|c|c|c|c|c|c|c|c|c|c|c|c|c|c|c|c|}
\hline & & \multicolumn{14}{|c|}{$\begin{array}{c}\text { Difference in science performance between students whose parents engage in these activities at least once a week } \\
\text { and those whose parents engage in such activities less frequently }\end{array}$} \\
\hline & & \multicolumn{14}{|c|}{ Before accounting for students' socio-economic status } \\
\hline & & \multicolumn{2}{|c|}{$\begin{array}{l}\text { Discuss how well } \\
\text { my child is doing } \\
\text { at school at least } \\
\text { once a week }\end{array}$} & \multicolumn{2}{|c|}{$\begin{array}{c}\text { Eat } \\
\text { <the main meal } \\
\text { with my child } \\
\text { around a table } \\
\text { at least } \\
\text { once a week }\end{array}$} & \multicolumn{2}{|c|}{$\begin{array}{c}\text { Spend time } \\
\text { just talking } \\
\text { to my child at least } \\
\text { once a week }\end{array}$} & \multicolumn{2}{|c|}{$\begin{array}{c}\text { Help my child with } \\
\text { his/her science } \\
\text { homework at least } \\
\text { once a week }\end{array}$} & \multicolumn{2}{|c|}{$\begin{array}{l}\text { Ask how my child } \\
\text { is performing in } \\
\text { science class at } \\
\text { least once a week }\end{array}$} & \multicolumn{2}{|c|}{\begin{tabular}{|c|} 
Obtain science- \\
related materials \\
(e.g., applications, \\
software, study \\
guides etc.) \\
for my child \\
at least once a week \\
\end{tabular}} & \multicolumn{2}{|c|}{$\begin{array}{c}\text { Discuss with } \\
\text { my child } \\
\text { how science is used } \\
\text { in everyday life } \\
\text { at least } \\
\text { once a week }\end{array}$} \\
\hline & & Score dif. & S.E. & Score dif. & S.E. & Score dif. & S.E. & Score dif. & S.E. & Score dif. & S.E. & Score dif. & S.E. & Score dif. & S.E. \\
\hline \multirow{14}{*}{ తి } & Belgium (Flemish) & 2 & (3.7) & 40 & (9.5) & 11 & (7.1) & -45 & $(4.2)$ & 6 & (3.8) & -68 & $(8.5)$ & 6 & $(5.7)$ \\
\hline & Chile & 13 & (3.9) & 6 & (5.4) & 1 & (3.9) & -28 & $(3.1)$ & -13 & (2.7) & -30 & (2.9) & -12 & (3.4) \\
\hline & France & -4 & $(4.3)$ & 34 & $(13.4)$ & 12 & (6.7) & -38 & $(2.9)$ & 14 & (3.1) & -30 & $(6.3)$ & 9 & (4.4) \\
\hline & Germany & -27 & (3.6) & 43 & (14.1) & 54 & $(23.8)$ & -55 & $(5.0)$ & -12 & (4.0) & -62 & (6.7) & 0 & (5.0) \\
\hline & Ireland & 4 & (3.4) & 16 & (5.6) & 15 & (8.5) & -29 & $(3.7)$ & -4 & (2.7) & -8 & (5.9) & 24 & $(4.1)$ \\
\hline & Italy & 13 & (5.8) & 24 & (15.1) & 15 & (9.1) & -41 & (3.9) & -16 & (2.8) & -38 & $(4.8)$ & -9 & (3.4) \\
\hline & Korea & 27 & (3.6) & 24 & (9.4) & 17 & (4.9) & 4 & $(4.2)$ & 20 & $(4.5)$ & 7 & (5.3) & 14 & $(5.7)$ \\
\hline & Luxembourg & -6 & (4.8) & 50 & $(12.0)$ & 37 & $(10.0)$ & -26 & $(4.5)$ & -9 & (3.6) & -52 & $(5.9)$ & -10 & $(4.4)$ \\
\hline & Mexico & 16 & (3.6) & 18 & (4.4) & 8 & (3.2) & -13 & $(2.4)$ & 0 & (2.2) & -5 & (2.4) & -10 & (2.5) \\
\hline & Portugal & 17 & (7.1) & 33 & (13.1) & 45 & (13.1) & -30 & $(2.7)$ & 11 & (2.3) & -17 & (4.0) & 6 & (3.5) \\
\hline & Spain & 13 & (5.7) & 29 & $(12.7)$ & 18 & (9.4) & -18 & $(2.7)$ & 9 & (3.0) & -18 & $(4.0)$ & 5 & (3.5) \\
\hline & UK (Scotland) & 4 & (8.3) & 18 & (9.1) & c & c & 0 & (5.5) & 28 & (5.1) & -18 & (9.5) & 20 & $(6.1)$ \\
\hline & OECD average & 6 & (1.5) & 28 & (3.2) & 21 & (3.2) & -26 & $(1.1)$ & 3 & (1.0) & -28 & $(1.7)$ & 4 & $(1.3)$ \\
\hline & Average-18 & 10 & (1.2) & 22 & (2.3) & 19 & (2.3) & -24 & (0.9) & 6 & $(0.8)$ & -24 & (1.3) & 1 & (1.0) \\
\hline \multirow{6}{*}{ ఏँౖ } & Croatia & 15 & (5.6) & -21 & (6.0) & 1 & (4.9) & -42 & $(2.7)$ & 16 & $(2.7)$ & -28 & (3.4) & -13 & $(3.1)$ \\
\hline & Dominican Republic & 20 & (3.7) & 11 & (4.2) & 5 & (4.6) & -13 & (3.1) & 0 & (2.5) & -6 & (2.4) & -12 & $(2.7)$ \\
\hline & Georgia & 43 & (4.8) & 24 & (7.9) & 46 & (7.7) & -24 & (3.3) & 21 & (4.4) & -15 & (3.4) & -7 & (3.1) \\
\hline & Hong Kong (China) & 19 & (2.8) & 23 & (6.4) & 20 & (4.3) & -7 & (2.9) & 3 & (3.2) & -9 & $(4.2)$ & -4 & $(4.0)$ \\
\hline & Macao (China) & 4 & $(2.7)$ & 34 & (6.6) & 8 & (3.1) & -9 & (3.1) & -5 & (3.1) & -11 & (3.8) & -5 & (3.1) \\
\hline & Malta & 5 & $(7.2)$ & -9 & (11.1) & 15 & $(11.1)$ & -11 & (5.9) & 39 & $(4.2)$ & -21 & $(7.4)$ & 13 & $(4.8)$ \\
\hline
\end{tabular}

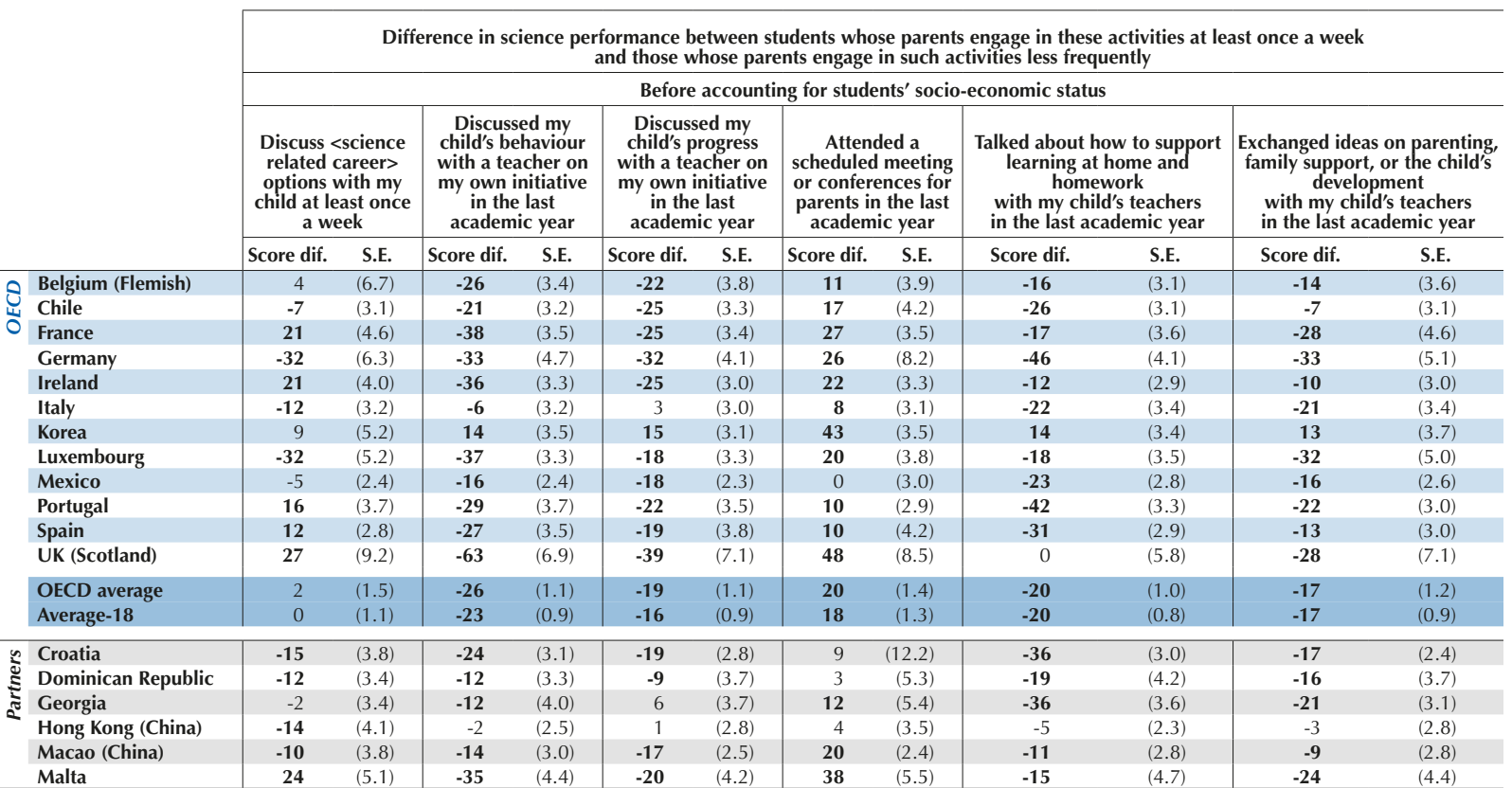

1. Parents who reported that they engage in these activities "once or twice a week" or "every day or almost every day".

Note: Values that are statistically significant are indicated in bold (see Annex A3)

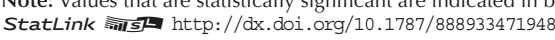




\begin{tabular}{|c|c|c|c|c|c|c|c|c|c|c|c|c|c|c|c|}
\hline & \multicolumn{14}{|c|}{$\begin{array}{c}\text { Difference in science performance between students whose parents engage in these activities at least once a week } \\
\text { and those whose parents engage in such activities less frequently }\end{array}$} \\
\hline & & \multicolumn{14}{|c|}{ After accounting for students' socio-economic status } \\
\hline & & \multicolumn{2}{|c|}{$\begin{array}{l}\text { Discuss how well } \\
\text { my child is doing } \\
\text { at school at least } \\
\text { once a week }\end{array}$} & \multicolumn{2}{|c|}{$\begin{array}{c}\text { Eat }<\text { the main } \\
\text { meal> with my } \\
\text { child around } \\
\text { a table at least } \\
\text { once a week }\end{array}$} & \multicolumn{2}{|c|}{$\begin{array}{c}\text { Spend time just } \\
\text { talking to my child } \\
\text { at least } \\
\text { once a week }\end{array}$} & \multicolumn{2}{|c|}{$\begin{array}{c}\text { Help my child with } \\
\text { his/her science } \\
\text { homework at least } \\
\text { once a week }\end{array}$} & \multicolumn{2}{|c|}{$\begin{array}{l}\text { Ask how my child } \\
\text { is performing in } \\
\text { science class at } \\
\text { least once a week }\end{array}$} & \multicolumn{2}{|c|}{\begin{tabular}{|c|} 
Obtain science- \\
related materials \\
(e.g., applications, \\
software, study \\
guides etc.) \\
for my child \\
at least once a week \\
\end{tabular}} & \multicolumn{2}{|c|}{$\begin{array}{c}\text { Discuss with my } \\
\text { child how science } \\
\text { is used in everyday } \\
\text { life at least } \\
\text { once a week }\end{array}$} \\
\hline & & Score dif. & S.E. & Score dif. & S.E. & Score dif. & S.E. & Score dif. & S.E. & Score dif. & S.E. & Score dif. & S.E. & Score dif. & S.E. \\
\hline \multirow{14}{*}{$\underset{ٍ ̆}{0}$} & Belgium (Flemish) & -4 & (3.4) & 19 & (8.9) & -2 & $(6.9)$ & -43 & (3.7) & 2 & (3.3) & -58 & $(7.5)$ & 0 & $(5.1)$ \\
\hline & Chile & 4 & (3.9) & -1 & (4.8) & -6 & (3.9) & -25 & $(2.8)$ & -12 & (2.6) & -25 & $(2.8)$ & -13 & (3.1) \\
\hline & France & -13 & $(4.0)$ & 6 & $(13.3)$ & 2 & (6.1) & -39 & $(2.5)$ & 3 & (2.6) & -29 & (5.6) & 2 & (3.9) \\
\hline & Germany & -20 & (3.3) & 22 & (14.3) & 41 & $(21.3)$ & -47 & $(4.6)$ & -11 & (3.3) & -43 & (6.1) & -3 & $(4.9)$ \\
\hline & Ireland & 2 & $(3.2)$ & 4 & (5.8) & 5 & (8.3) & -28 & (3.3) & -3 & (2.6) & -7 & (5.5) & 16 & (3.8) \\
\hline & Italy & 4 & $(6.2)$ & 13 & $(12.7)$ & 6 & (8.6) & -42 & (3.9) & -18 & (2.5) & -37 & $(4.5)$ & -13 & (3.3) \\
\hline & Korea & 17 & $(3.2)$ & 15 & (8.9) & 10 & $(4.6)$ & -1 & (3.8) & 14 & $(4.0)$ & 0 & $(5.1)$ & 7 & $(4.9)$ \\
\hline & Luxembourg & -7 & $(4.5)$ & 22 & $(12.0)$ & 2 & $(10.0)$ & -28 & $(4.1)$ & -9 & (3.4) & -37 & (5.4) & -9 & $(4.0)$ \\
\hline & Mexico & 9 & (3.5) & 11 & (3.9) & 2 & $(3.2)$ & -16 & $(2.3)$ & -3 & $(2.1)$ & -11 & $(2.3)$ & -10 & $(2.2)$ \\
\hline & Portugal & -1 & (7.1) & 23 & (11.9) & 41 & (12.6) & -31 & (2.5) & 4 & $(2.2)$ & -22 & (3.3) & -1 & (3.1) \\
\hline & Spain & 6 & $(5.0)$ & 24 & $(10.4)$ & 6 & (7.9) & -23 & $(2.8)$ & 3 & (2.8) & -18 & $(3.8)$ & 1 & (3.2) \\
\hline & UK (Scotland) & 3 & $(8.1)$ & 1 & (8.4) & $\mathrm{m}$ & $\mathrm{m}$ & -2 & $(5.3)$ & 25 & $(4.9)$ & -18 & $(8.2)$ & 13 & (5.9) \\
\hline & OECD average & 0 & $(1.4)$ & 13 & (2.9) & 10 & (2.9) & -27 & $(1.0)$ & 0 & $(0.9)$ & -25 & $(1.5)$ & -1 & $(1.2)$ \\
\hline & Average-18 & 4 & $(1.1)$ & 12 & (2.2) & 10 & (2.1) & -25 & $(0.8)$ & 2 & $(0.7)$ & -23 & $(1.2)$ & -3 & $(0.9)$ \\
\hline \multirow[t]{6}{*}{ a } & Croatia & 7 & $(5.3)$ & -16 & (6.2) & -4 & (4.9) & -41 & $(2.6)$ & 7 & (2.6) & -29 & $(3.2)$ & -14 & $(2.9)$ \\
\hline & Dominican Republic & 15 & (3.3) & 9 & $(4.2)$ & 4 & (4.5) & -15 & $(2.9)$ & -2 & (2.5) & -9 & $(2.2)$ & -12 & (2.6) \\
\hline & Georgia & 32 & $(4.6)$ & 19 & $(7.2)$ & 35 & (7.6) & -22 & (3.0) & 15 & $(4.0)$ & -16 & (3.3) & -6 & $(2.9)$ \\
\hline & Hong Kong (China) & 11 & (2.6) & 18 & (6.5) & 14 & (4.4) & -12 & $(2.7)$ & -2 & $(3.1)$ & -13 & (3.9) & -9 & $(3.9)$ \\
\hline & Macao (China) & 0 & $(2.7)$ & 30 & (6.6) & 4 & (3.1) & -13 & (3.1) & -9 & (3.0) & -14 & (3.9) & -8 & (3.2) \\
\hline & Malta & -2 & (6.9) & -10 & $(11.5)$ & 9 & (10.1) & -24 & (5.6) & 27 & $(4.1)$ & -28 & (6.4) & 1 & $(4.6)$ \\
\hline
\end{tabular}

\begin{tabular}{|c|c|c|c|c|c|c|c|c|c|c|c|c|c|}
\hline & \multicolumn{12}{|c|}{$\begin{array}{c}\text { Difference in science performance between students whose parents engage in these activities at least once a week } \\
\text { and those whose parents engage in such activities less frequently }\end{array}$} \\
\hline & & \multicolumn{12}{|c|}{ After accounting for students' socio-economic status } \\
\hline & & \multicolumn{2}{|c|}{$\begin{array}{c}\text { Discuss <science } \\
\text { related career> } \\
\text { options with my } \\
\text { child at least once } \\
\text { a week }\end{array}$} & \multicolumn{2}{|c|}{$\begin{array}{l}\text { Discussed my } \\
\text { child's behaviour } \\
\text { with a teacher on } \\
\text { my own initiative } \\
\text { in the last } \\
\text { academic year }\end{array}$} & \multicolumn{2}{|c|}{$\begin{array}{c}\text { Discussed my } \\
\text { child's progress } \\
\text { with a teacher } \\
\text { on my own } \\
\text { initiative } \\
\text { in the last } \\
\text { academic year }\end{array}$} & \multicolumn{2}{|c|}{$\begin{array}{c}\text { Attended a } \\
\text { scheduled meeting } \\
\text { or conferences for } \\
\text { parents in the last } \\
\text { academic year }\end{array}$} & \multicolumn{2}{|c|}{$\begin{array}{l}\text { Talked about how to support } \\
\text { learning at home } \\
\text { and homework } \\
\text { with my child's teachers } \\
\text { in the last academic year }\end{array}$} & \multicolumn{2}{|c|}{$\begin{array}{c}\text { Exchanged ideas on parenting, } \\
\text { family support, or the child's } \\
\text { development } \\
\text { with my child's teachers } \\
\text { in the last academic year }\end{array}$} \\
\hline & & Score dif. & S.E. & Score dif. & S.E. & Score dif. & S.E. & Score dif. & S.E. & Score dif. & S.E. & Score dif. & S.E. \\
\hline \multirow{14}{*}{ ర্ডি } & Belgium (Flemish) & -2 & $(6.3)$ & -27 & (3.1) & -24 & (3.3) & 3 & (3.4) & -19 & $(2.8)$ & -16 & $(3.5)$ \\
\hline & Chile & -7 & (2.9) & -18 & (3.0) & -20 & (3.1) & 12 & (3.8) & -20 & $(2.7)$ & -7 & (2.8) \\
\hline & France & 16 & $(4.2)$ & -36 & (2.8) & -30 & $(2.8)$ & 10 & (3.4) & -22 & $(3.1)$ & -26 & (3.6) \\
\hline & Germany & -26 & (6.0) & -32 & (4.0) & -31 & (3.6) & 13 & (7.0) & -38 & (3.7) & -30 & (4.6) \\
\hline & Ireland & 17 & (3.6) & -30 & (3.1) & -24 & $(2.7)$ & 12 & (3.0) & -15 & (2.6) & -12 & $(2.7)$ \\
\hline & Italy & -14 & $(3.2)$ & -12 & (2.9) & -4 & $(2.7)$ & 4 & (2.7) & -22 & $(3.2)$ & -21 & (3.4) \\
\hline & Korea & 4 & (4.9) & 2 & (3.2) & 5 & $(2.7)$ & 28 & (3.1) & 4 & (2.9) & 5 & (3.3) \\
\hline & Luxembourg & -21 & (4.6) & -32 & (2.9) & -22 & $(2.9)$ & 6 & (3.7) & -20 & (3.1) & -26 & $(4.1)$ \\
\hline & Mexico & -6 & $(2.2)$ & -14 & (2.0) & -15 & $(2.1)$ & 4 & (2.9) & -20 & (2.4) & -14 & (2.2) \\
\hline & Portugal & 12 & (3.0) & -28 & (3.2) & -22 & (2.8) & 8 & (2.7) & -37 & (2.9) & -22 & (2.7) \\
\hline & Spain & 10 & (2.8) & -27 & (3.2) & -19 & $(3.6)$ & 10 & (4.0) & -30 & (2.6) & -17 & (3.0) \\
\hline & UK (Scotland) & 27 & (8.7) & -55 & (6.6) & -39 & $(7.1)$ & 30 & (8.8) & -7 & (5.8) & -26 & (6.7) \\
\hline & OECD average & 1 & (1.4) & -26 & (1.0) & -20 & $(1.0)$ & 12 & (1.3) & -21 & $(0.9)$ & -18 & (1.1) \\
\hline & Average-18 & -1 & (1.0) & -22 & (0.8) & -17 & $(0.8)$ & 11 & $(1.2)$ & -20 & $(0.8)$ & -16 & $(0.8)$ \\
\hline \multirow{6}{*}{ 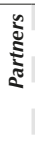 } & Croatia & -14 & (3.6) & -19 & (2.8) & -18 & $(2.6)$ & 15 & (11.8) & -29 & (2.9) & -12 & (2.4) \\
\hline & Dominican Republic & -11 & (3.3) & -11 & (3.0) & -9 & $(3.2)$ & -1 & $(5.0)$ & -17 & (3.5) & -15 & (3.3) \\
\hline & Georgia & -1 & (3.0) & -9 & (3.9) & 4 & (3.3) & 12 & (5.0) & -28 & (3.3) & -16 & (2.8) \\
\hline & Hong Kong (China) & -16 & $(4.1)$ & -3 & (2.4) & 0 & $(2.6)$ & 0 & (3.3) & -6 & $(2.2)$ & -5 & $(2.7)$ \\
\hline & Macao (China) & -12 & (3.8) & -16 & $(2.9)$ & -18 & $(2.5)$ & 19 & (2.5) & -12 & $(2.7)$ & -9 & (2.8) \\
\hline & Malta & 19 & (4.6) & -28 & $(4.0)$ & -25 & (3.9) & 22 & (5.3) & -20 & (4.4) & -26 & $(4.0)$ \\
\hline
\end{tabular}

1. Parents who reported that they engage in these activities "once or twice a week" or "every day or almost every day".

Note: Values that are statistically significant are indicated in bold (see Annex A3).

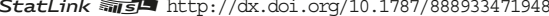


[Part 1/1]

Table III.9.6 Students' early science-related activities

Results based on parents' self-reports

\begin{tabular}{|c|c|c|c|c|c|c|c|c|c|c|c|c|c|}
\hline & \multicolumn{12}{|c|}{ Percentage of students who engaged in the following activities "regularly" or "very often" at age 10} \\
\hline & & \multicolumn{2}{|c|}{$\begin{array}{c}\text { Watched TV } \\
\text { programmes } \\
\text { about science }\end{array}$} & \multicolumn{2}{|c|}{$\begin{array}{l}\text { Read books on } \\
\text { scientific discoveries }\end{array}$} & \multicolumn{2}{|c|}{$\begin{array}{c}\text { Visited websites } \\
\text { about science topics }\end{array}$} & \multicolumn{2}{|c|}{$\begin{array}{c}\text { Attended } \\
\text { a science club }\end{array}$} & \multicolumn{2}{|c|}{$\begin{array}{l}\text { Construction play, } \\
\text { e.g. }<\text { bricks }>\end{array}$} & \multicolumn{2}{|c|}{$\begin{array}{l}\text { Experimented with } \\
\text { a science kit, } \\
\text { electronics kit, } \\
\text { or chemistry set, } \\
\text { used a microscope } \\
\text { or telescope }\end{array}$} \\
\hline & & $\%$ & S.E. & $\%$ & S.E. & $\%$ & S.E. & $\%$ & S.E. & $\%$ & S.E. & $\%$ & S.E. \\
\hline \multirow{14}{*}{ Uิ } & Belgium (Flemish) & 19.7 & $(0.7)$ & 10.1 & $(0.4)$ & 7.0 & $(0.4)$ & 0.5 & $(0.1)$ & 51.2 & $(0.8)$ & 12.7 & $(0.5)$ \\
\hline & Chile & 26.3 & $(0.7)$ & 13.7 & $(0.5)$ & 15.1 & $(0.5)$ & 1.9 & $(0.2)$ & 51.5 & $(0.7)$ & 12.1 & $(0.5)$ \\
\hline & France & 16.3 & $(0.6)$ & 11.5 & $(0.5)$ & 4.2 & $(0.3)$ & 0.8 & $(0.1)$ & 45.2 & $(0.8)$ & 13.3 & $(0.5)$ \\
\hline & Germany & 27.6 & $(0.8)$ & 13.3 & $(0.7)$ & 5.8 & $(0.5)$ & 3.4 & $(0.4)$ & 60.6 & $(0.8)$ & 10.0 & $(0.5)$ \\
\hline & Ireland & 22.3 & $(0.6)$ & 12.8 & $(0.5)$ & 8.4 & $(0.4)$ & 1.8 & $(0.2)$ & 58.1 & $(0.7)$ & 13.6 & $(0.5)$ \\
\hline & Italy & 28.2 & $(1.0)$ & 14.5 & $(0.6)$ & 13.3 & $(0.6)$ & 3.1 & $(0.3)$ & 54.5 & $(0.9)$ & 16.3 & $(0.5)$ \\
\hline & Korea & 9.4 & $(0.5)$ & 24.5 & $(0.8)$ & 4.4 & $(0.3)$ & 11.7 & $(0.5)$ & 44.8 & $(0.8)$ & 14.9 & $(0.6)$ \\
\hline & Luxembourg & 29.0 & $(0.9)$ & 15.7 & $(0.5)$ & 8.3 & $(0.5)$ & 4.4 & $(0.3)$ & 57.4 & $(0.9)$ & 10.5 & $(0.6)$ \\
\hline & Mexico & 23.3 & $(0.6)$ & 15.5 & $(0.6)$ & 19.6 & $(0.6)$ & 2.8 & $(0.2)$ & 29.2 & $(0.8)$ & 11.5 & $(0.4)$ \\
\hline & Portugal & 23.5 & $(0.6)$ & 12.6 & $(0.6)$ & 12.6 & $(0.5)$ & 3.9 & $(0.4)$ & 67.4 & $(0.6)$ & 15.0 & $(0.5)$ \\
\hline & Spain & 17.2 & $(0.7)$ & 9.3 & $(0.4)$ & 9.6 & $(0.5)$ & 1.7 & $(0.2)$ & 44.1 & $(0.8)$ & 12.2 & $(0.5)$ \\
\hline & UK (Scotland) & 24.3 & (1.1) & 11.7 & $(0.9)$ & 11.9 & $(0.8)$ & 2.6 & $(0.4)$ & 54.3 & (1.4) & 14.8 & (1.1) \\
\hline & OECD average & 22.3 & $(0.2)$ & 13.8 & $(0.2)$ & 10.0 & $(0.1)$ & 3.2 & $(0.1)$ & 51.5 & $(0.2)$ & 13.1 & $(0.2)$ \\
\hline & Average-18 & 21.8 & $(0.2)$ & 13.7 & $(0.1)$ & 10.8 & $(0.1)$ & 3.3 & $(0.1)$ & 46.7 & $(0.2)$ & 11.3 & $(0.1)$ \\
\hline \multirow{6}{*}{ ఏँ } & Croatia & 18.9 & $(0.6)$ & 8.7 & $(0.4)$ & 6.9 & $(0.5)$ & 2.3 & $(0.2)$ & 60.5 & $(0.6)$ & 9.0 & $(0.5)$ \\
\hline & Dominican Republic & 25.6 & $(1.0)$ & 18.6 & $(0.7)$ & 18.0 & $(0.7)$ & 3.4 & $(0.4)$ & 40.9 & $(1.2)$ & 8.1 & $(0.5)$ \\
\hline & Georgia & 31.8 & $(0.8)$ & 20.7 & $(0.6)$ & 21.0 & $(0.8)$ & 3.0 & $(0.3)$ & 23.1 & $(0.8)$ & 8.8 & $(0.3)$ \\
\hline & Hong Kong (China) & 14.2 & $(0.5)$ & 13.7 & $(0.5)$ & 6.7 & $(0.4)$ & 5.7 & $(0.3)$ & 29.7 & $(0.8)$ & 6.2 & $(0.4)$ \\
\hline & Macao (China) & 10.5 & $(0.5)$ & 8.9 & $(0.4)$ & 6.8 & $(0.3)$ & 3.3 & $(0.2)$ & 24.6 & $(0.6)$ & 4.4 & $(0.3)$ \\
\hline & Malta & 23.7 & $(0.8)$ & 10.8 & $(0.6)$ & 15.0 & $(0.6)$ & 2.5 & $(0.3)$ & 44.0 & $(0.8)$ & 10.7 & $(0.5)$ \\
\hline
\end{tabular}

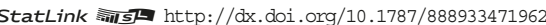




\begin{tabular}{|c|c|c|c|c|c|c|c|c|c|c|c|c|c|}
\hline & & \multicolumn{12}{|c|}{$\begin{array}{l}\text { Increased likelihood of expecting a science-related career }{ }^{1} \text { if the child reported engaging } \\
\text { in the following activity "regularly" or "very often" at age } 10\end{array}$} \\
\hline & & \multicolumn{4}{|c|}{ Watched TV programmes about science } & \multicolumn{4}{|c|}{ Read books on scientific discoveries } & \multicolumn{4}{|c|}{ Visited websites about science topics } \\
\hline & & \multicolumn{2}{|c|}{$\begin{array}{l}\text { Before accounting for } \\
\text { student characteristics }\end{array}$} & \multicolumn{2}{|c|}{$\begin{array}{c}\text { After accounting for } \\
\text { student characteristics }\end{array}$} & \multicolumn{2}{|c|}{$\begin{array}{l}\text { Before accounting for } \\
\text { student characteristics }\end{array}$} & \multicolumn{2}{|c|}{$\begin{array}{c}\text { After accounting for } \\
\text { student characteristics }\end{array}$} & \multicolumn{2}{|c|}{$\begin{array}{l}\text { Before accounting for } \\
\text { student characteristics }\end{array}$} & \multicolumn{2}{|c|}{$\begin{array}{c}\text { After accounting for } \\
\text { student characteristics }\end{array}$} \\
\hline & & Odds ratios & S.E. & Odds ratios & S.E. & Odds ratios & S.E. & Odds ratios & S.E. & Odds ratios & S.E. & Odds ratios & S.E. \\
\hline \multirow[t]{14}{*}{0} & Belgium (Flemish) & $\mathrm{m}$ & $\mathrm{m}$ & $\mathrm{m}$ & $\mathrm{m}$ & $\mathrm{m}$ & $\mathrm{m}$ & $\mathrm{m}$ & $\mathrm{m}$ & $\mathrm{m}$ & $\mathrm{m}$ & $\mathrm{m}$ & $\mathrm{m}$ \\
\hline & Chile & 1.27 & $(0.09)$ & 1.18 & $(0.09)$ & 1.47 & $(0.12)$ & 1.36 & $(0.12)$ & 1.39 & $(0.11)$ & 1.25 & $(0.10)$ \\
\hline & France & 2.14 & $(0.18)$ & 1.56 & $(0.13)$ & 2.09 & $(0.18)$ & 1.41 & $(0.13)$ & 1.91 & $(0.26)$ & 1.84 & $(0.29)$ \\
\hline & Germany & 1.79 & $(0.21)$ & 1.45 & $(0.17)$ & 1.89 & $(0.21)$ & 1.50 & $(0.17)$ & 1.86 & $(0.41)$ & 1.79 & $(0.42)$ \\
\hline & Ireland & 1.68 & $(0.12)$ & 1.33 & $(0.09)$ & 1.86 & $(0.18)$ & 1.40 & $(0.14)$ & 2.26 & $(0.22)$ & 1.82 & $(0.18)$ \\
\hline & Italy & 1.47 & $(0.12)$ & 1.30 & $(0.10)$ & 1.55 & $(0.14)$ & 1.26 & $(0.12)$ & 1.58 & $(0.15)$ & 1.53 & $(0.14)$ \\
\hline & Korea & 1.70 & $(0.19)$ & 1.41 & $(0.16)$ & 1.66 & $(0.13)$ & 1.22 & $(0.09)$ & 1.80 & $(0.22)$ & 1.45 & $(0.18)$ \\
\hline & Luxembourg & 1.77 & $(0.17)$ & 1.32 & $(0.14)$ & 1.70 & $(0.18)$ & 1.26 & $(0.15)$ & 1.36 & $(0.21)$ & 1.21 & $(0.20)$ \\
\hline & Mexico & 1.39 & $(0.09)$ & 1.27 & $(0.08)$ & 1.19 & $(0.08)$ & 1.16 & $(0.08)$ & 1.23 & $(0.08)$ & 1.14 & $(0.08)$ \\
\hline & Portugal & 1.72 & $(0.13)$ & 1.15 & $(0.10)$ & 1.60 & $(0.15)$ & 1.15 & $(0.11)$ & 1.80 & $(0.17)$ & 1.40 & $(0.14)$ \\
\hline & Spain & 1.44 & $(0.15)$ & 1.24 & $(0.14)$ & 1.36 & $(0.16)$ & 1.12 & $(0.14)$ & 1.60 & $(0.18)$ & 1.41 & $(0.16)$ \\
\hline & UK (Scotland) & 1.51 & $(0.18)$ & 1.19 & $(0.15)$ & 1.54 & $(0.30)$ & 1.06 & $(0.25)$ & 1.23 & $(0.27)$ & 0.91 & $(0.22$ \\
\hline & OECD average & 1.62 & $(0.05)$ & 1.31 & $(0.04)$ & 1.63 & $(0.05)$ & 1.26 & $(0.04)$ & 1.64 & $(0.07)$ & 1.43 & $(0.06)$ \\
\hline & Average $^{3}$ & 1.57 & $(0.04)$ & 1.28 & $(0.03)$ & 1.61 & $(0.04)$ & 1.24 & $(0.03)$ & 1.57 & $(0.05)$ & 1.36 & $(0.05)$ \\
\hline \multirow{6}{*}{ 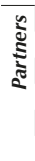 } & Croatia & 1.50 & $(0.12)$ & 1.11 & $(0.09)$ & 1.83 & $(0.22)$ & 1.13 & $(0.14)$ & 1.46 & $(0.20)$ & 1.21 & $(0.18)$ \\
\hline & Dominican Republic & 1.01 & $(0.07)$ & 0.96 & $(0.07)$ & 0.99 & $(0.09)$ & 0.99 & $(0.09)$ & 1.15 & $(0.08)$ & 1.11 & $(0.08)$ \\
\hline & Georgia & 1.38 & $(0.13)$ & 1.31 & $(0.13)$ & 1.14 & $(0.11)$ & 1.06 & $(0.10)$ & 1.17 & $(0.10)$ & 1.10 & $(0.10)$ \\
\hline & Hong Kong (China) & 1.62 & $(0.15)$ & 1.38 & $(0.13)$ & 1.56 & $(0.14)$ & 1.22 & $(0.12)$ & 1.34 & $(0.16)$ & 1.23 & $(0.16)$ \\
\hline & Macao (China) & 1.28 & $(0.16)$ & 1.12 & $(0.14)$ & 1.68 & $(0.22)$ & 1.33 & $(0.18)$ & 1.29 & $(0.19)$ & 1.19 & $(0.17)$ \\
\hline & Malta & 2.12 & $(0.19)$ & 1.47 & $(0.14)$ & 2.26 & $(0.27)$ & 1.42 & $(0.19)$ & 2.20 & $(0.22)$ & 1.54 & $(0.18)$ \\
\hline
\end{tabular}

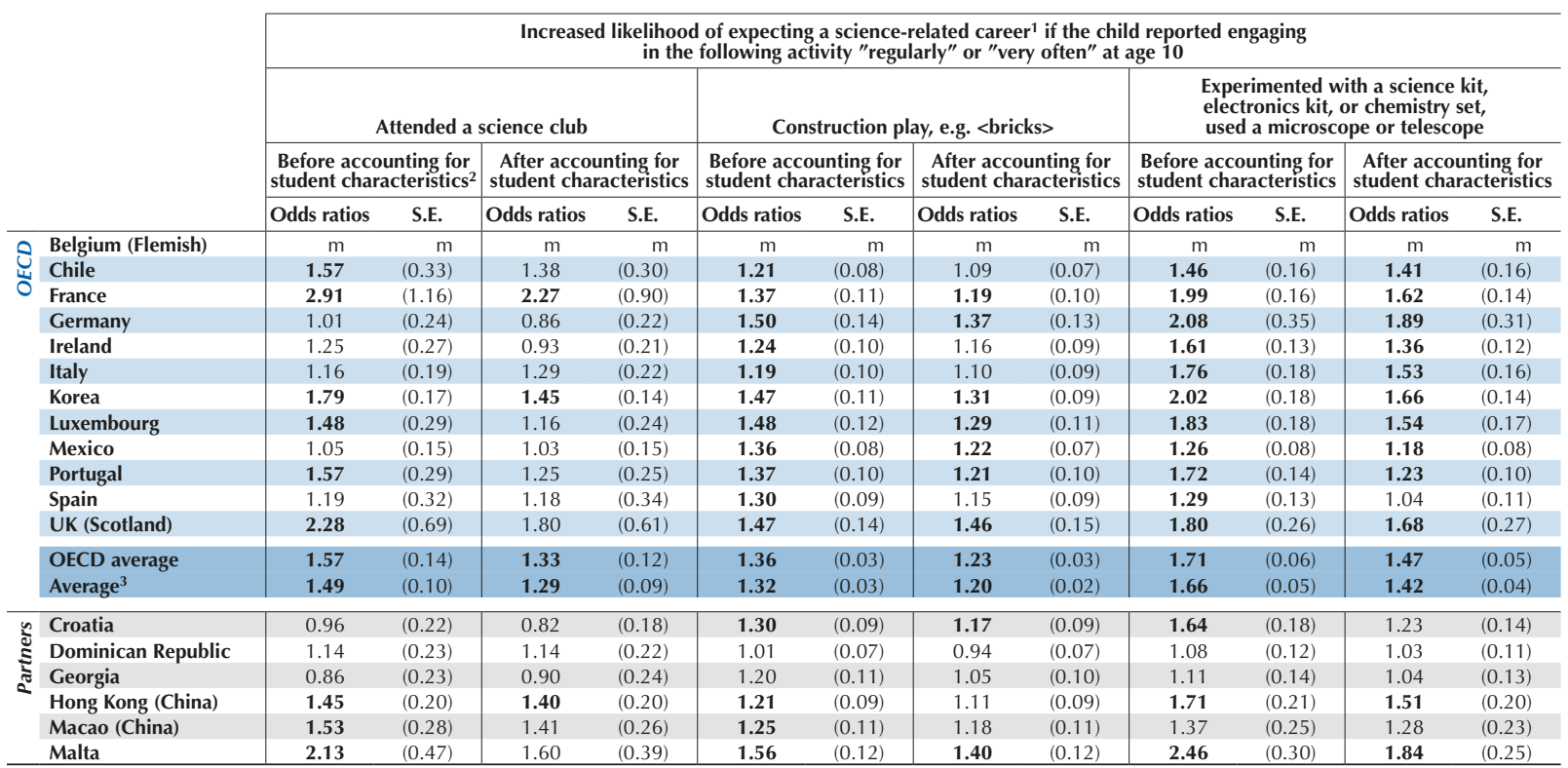

1. Students who have science-related career expectations are those who expect a career that requires the study of science beyond compulsory education, typically in formal tertiary education.

2. Student characteristics include the PISA index of economic, social and cultural status (ESCS) and science performance.

3. "Average" includes all countries/economies with available data.

Note: Values that are statistically significant are indicated in bold (see Annex A3).

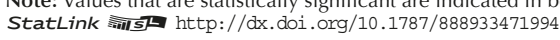


[Part 1/1]

Table III.9.11 Students' early science-related activities and self-efficacy in science

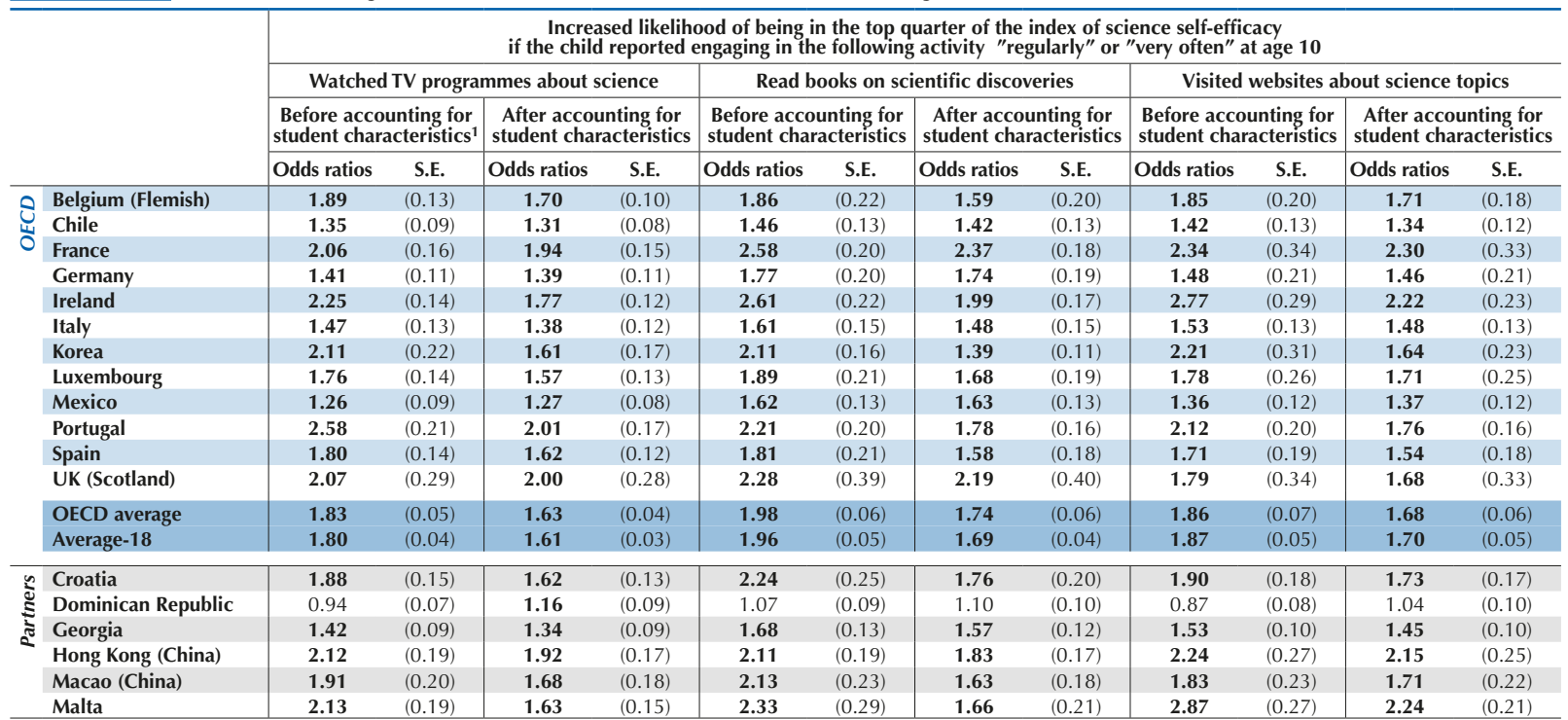

\begin{tabular}{|c|c|c|c|c|c|c|c|c|c|c|c|c|c|}
\hline & \multicolumn{12}{|c|}{$\begin{array}{l}\text { Increased likelihood of being in the top quarter of the index of science self-efficacy } \\
\text { if the child reported engaging in the following activity "regularly" or "very often" at age } 10\end{array}$} \\
\hline & & \multicolumn{4}{|c|}{ Attended a science club } & \multicolumn{4}{|c|}{ Construction play, e.g. <bricks > } & \multicolumn{4}{|c|}{$\begin{array}{l}\text { Experimented with a science kit, } \\
\text { electronics kit, or chemistry set, } \\
\text { used a microscope or telescope }\end{array}$} \\
\hline & & \multicolumn{2}{|c|}{$\begin{array}{l}\text { Before accounting for } \\
\text { student characteristics }\end{array}$} & \multicolumn{2}{|c|}{$\begin{array}{l}\text { After accounting for } \\
\text { student characteristics }\end{array}$} & \multicolumn{2}{|c|}{$\begin{array}{l}\text { Before accounting for } \\
\text { student characteristics }\end{array}$} & \multicolumn{2}{|c|}{$\begin{array}{l}\text { After accounting for } \\
\text { student characteristics }\end{array}$} & \multicolumn{2}{|c|}{$\begin{array}{l}\text { Before accounting for } \\
\text { student characteristics }\end{array}$} & \multicolumn{2}{|c|}{$\begin{array}{l}\text { After accounting for } \\
\text { student characteristics }\end{array}$} \\
\hline & & Odds ratios & S.E. & Odds ratios & S.E. & Odds ratios & S.E. & Odds ratios & S.E. & Odds ratios & S.E. & Odds ratios & S.E. \\
\hline \multirow{14}{*}{ క్షుㅇ } & Belgium (Flemish) & c & $\mathrm{c}$ & c & $\mathrm{c}$ & 1.26 & $(0.08)$ & 1.20 & $(0.07)$ & 1.45 & $(0.15)$ & 1.32 & $(0.14)$ \\
\hline & Chile & 1.87 & $(0.33)$ & 1.77 & $(0.31)$ & 1.07 & $(0.07)$ & 1.00 & $(0.06)$ & 1.63 & $(0.16)$ & 1.60 & $(0.15)$ \\
\hline & France & 2.86 & $(0.91)$ & 2.64 & $(0.86)$ & 1.25 & $(0.07)$ & 1.20 & $(0.07)$ & 1.51 & $(0.15)$ & 1.42 & $(0.14)$ \\
\hline & Germany & 1.07 & $(0.23)$ & 1.03 & $(0.22)$ & 1.38 & $(0.09)$ & 1.37 & $(0.09)$ & 1.58 & $(0.20)$ & 1.55 & $(0.20)$ \\
\hline & Ireland & 2.26 & $(0.47)$ & 1.70 & $(0.40)$ & 1.21 & $(0.07)$ & 1.13 & $(0.07)$ & 2.47 & $(0.22)$ & 2.11 & $(0.19)$ \\
\hline & Italy & 1.55 & $(0.31)$ & 1.57 & $(0.32)$ & 1.23 & $(0.08)$ & 1.19 & $(0.07)$ & 1.74 & $(0.14)$ & 1.61 & $(0.13)$ \\
\hline & Korea & 2.35 & $(0.18)$ & 1.77 & $(0.15)$ & 1.45 & $(0.08)$ & 1.21 & $(0.07)$ & 2.05 & $(0.18)$ & 1.52 & $(0.14)$ \\
\hline & Luxembourg & 1.96 & $(0.35)$ & 1.76 & $(0.32)$ & 1.15 & $(0.09)$ & 1.09 & $(0.08)$ & 1.82 & $(0.21)$ & 1.67 & $(0.20)$ \\
\hline & Mexico & 1.25 & $(0.18)$ & 1.25 & $(0.18)$ & 0.99 & $(0.07)$ & 0.99 & $(0.06)$ & 1.18 & $(0.11)$ & 1.18 & $(0.11)$ \\
\hline & Portugal & 1.78 & $(0.32)$ & 1.48 & $(0.27)$ & 1.08 & $(0.07)$ & 0.95 & $(0.06)$ & 2.12 & $(0.17)$ & 1.62 & $(0.14)$ \\
\hline & Spain & 1.42 & $(0.32)$ & 1.41 & $(0.36)$ & 1.14 & $(0.08)$ & 1.02 & $(0.08)$ & 1.79 & $(0.17)$ & 1.52 & $(0.15)$ \\
\hline & UK (Scotland) & 2.06 & $(0.63)$ & 1.94 & $(0.62)$ & 1.10 & $(0.13)$ & 1.12 & $(0.13)$ & 1.67 & $(0.25)$ & 1.68 & $(0.25)$ \\
\hline & OECD average & 1.86 & $(0.13)$ & 1.67 & $(0.12)$ & 1.19 & $(0.02)$ & 1.12 & $(0.02)$ & 1.75 & $(0.05)$ & 1.57 & $(0.05)$ \\
\hline & Average-18 & 1.80 & $(0.10)$ & 1.64 & $(0.09)$ & 1.21 & $(0.02)$ & 1.14 & $(0.02)$ & 1.79 & $(0.05)$ & 1.60 & $(0.04)$ \\
\hline \multirow{6}{*}{ 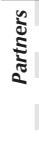 } & Croatia & 1.42 & $(0.32)$ & 1.29 & $(0.28)$ & 1.14 & $(0.08)$ & 1.06 & $(0.07)$ & 1.94 & $(0.20)$ & 1.63 & $(0.17)$ \\
\hline & Dominican Republic & 0.87 & $(0.16)$ & 0.91 & $(0.18)$ & 0.78 & $(0.06)$ & 1.04 & $(0.08)$ & 0.80 & $(0.11)$ & 0.97 & $(0.14)$ \\
\hline & Georgia & 2.36 & $(0.47)$ & 2.53 & $(0.52)$ & 1.26 & $(0.11)$ & 1.10 & $(0.10)$ & 1.50 & $(0.14)$ & 1.41 & $(0.14)$ \\
\hline & Hong Kong (China) & 1.82 & $(0.23)$ & 1.78 & $(0.23)$ & 1.38 & $(0.09)$ & 1.28 & $(0.09)$ & 2.02 & $(0.23)$ & 1.81 & $(0.22)$ \\
\hline & Macao (China) & 1.98 & $(0.34)$ & 1.81 & $(0.33)$ & 1.40 & $(0.10)$ & 1.28 & $(0.10)$ & 2.11 & $(0.29)$ & 1.92 & $(0.26)$ \\
\hline & Malta & 1.71 & $(0.44)$ & 1.26 & $(0.32)$ & 1.49 & $(0.13)$ & 1.33 & $(0.11)$ & 2.87 & $(0.30)$ & 2.21 & $(0.24)$ \\
\hline
\end{tabular}

1. Student characteristics include the PISA index of economic, social and cultural status (ESCS) and science performance.

Note: Values that are statistically significant are indicated in bold (see Annex A3).

StatLink तiाst http://dx.doi.org/10.1787/888933472017 


\begin{tabular}{|c|c|c|c|c|c|c|c|c|c|c|c|c|c|}
\hline & & \multicolumn{12}{|c|}{$\begin{array}{l}\text { Increased likelihood of being in the top quarter of the index of enjoyment of science } \\
\text { if the child reported engaging in the following activity "regularly" or "very often" at age } 10\end{array}$} \\
\hline & & \multicolumn{4}{|c|}{ Watched TV programmes about science } & \multicolumn{4}{|c|}{ Read books on scientific discoveries } & \multicolumn{4}{|c|}{ Visited websites about science topics } \\
\hline & & \multicolumn{2}{|c|}{$\begin{array}{l}\text { Before accounting for } \\
\text { student characteristics }\end{array}$} & \multicolumn{2}{|c|}{$\begin{array}{l}\text { After accounting for } \\
\text { student characteristics }\end{array}$} & \multicolumn{2}{|c|}{$\begin{array}{l}\text { Before accounting for } \\
\text { student characteristics }\end{array}$} & \multicolumn{2}{|c|}{$\begin{array}{c}\text { After accounting for } \\
\text { student characteristics }\end{array}$} & \multicolumn{2}{|c|}{$\begin{array}{l}\text { Before accounting for } \\
\text { student characteristics }\end{array}$} & \multicolumn{2}{|c|}{$\begin{array}{c}\text { After accounting for } \\
\text { student characteristics }\end{array}$} \\
\hline & & Odds ratios & S.E. & Odds ratios & S.E. & Odds ratios & S.E. & Odds ratios & S.E. & Odds ratios & S.E. & Odds ratios & S.E. \\
\hline \multirow{14}{*}{ 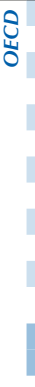 } & Belgium (Flemish) & 2.02 & $(0.14)$ & 1.77 & $(0.13)$ & 2.38 & $(0.24)$ & 1.97 & $(0.21)$ & 2.33 & $(0.24)$ & 2.14 & $(0.23)$ \\
\hline & Chile & 1.50 & $(0.10)$ & 1.46 & $(0.10)$ & 1.63 & $(0.14)$ & 1.58 & $(0.14)$ & 1.48 & $(0.12)$ & 1.40 & $(0.11)$ \\
\hline & France & 2.34 & $(0.17)$ & 2.06 & $(0.15)$ & 2.53 & $(0.21)$ & 2.15 & $(0.19)$ & 2.21 & $(0.30)$ & 2.18 & $(0.29)$ \\
\hline & Germany & 1.63 & $(0.14)$ & 1.50 & $(0.13)$ & 1.81 & $(0.20)$ & 1.65 & $(0.18)$ & 1.73 & $(0.23)$ & 1.70 & $(0.23)$ \\
\hline & Ireland & 2.60 & $(0.16)$ & 2.01 & $(0.13)$ & 3.17 & $(0.31)$ & 2.34 & $(0.22)$ & 3.19 & $(0.41)$ & 2.51 & $(0.32)$ \\
\hline & Italy & 1.85 & $(0.13)$ & 1.73 & $(0.12)$ & 2.01 & $(0.20)$ & 1.80 & $(0.18)$ & 1.74 & $(0.14)$ & 1.70 & $(0.13)$ \\
\hline & Korea & 2.11 & $(0.18)$ & 1.68 & $(0.16)$ & 2.22 & $(0.17)$ & 1.55 & $(0.12)$ & 2.63 & $(0.44)$ & 2.09 & $(0.36)$ \\
\hline & Luxembourg & 1.74 & $(0.14)$ & 1.50 & $(0.13)$ & 2.02 & $(0.18)$ & 1.75 & $(0.16)$ & 1.57 & $(0.23)$ & 1.49 & $(0.22)$ \\
\hline & Mexico & 1.32 & $(0.09)$ & 1.33 & $(0.09)$ & 1.80 & $(0.13)$ & 1.78 & $(0.13)$ & 1.32 & $(0.10)$ & 1.35 & $(0.11)$ \\
\hline & Portugal & 2.51 & $(0.18)$ & 1.99 & $(0.14)$ & 2.38 & $(0.23)$ & 1.95 & $(0.19)$ & 2.51 & $(0.23)$ & 2.14 & $(0.20)$ \\
\hline & Spain & 1.74 & $(0.16)$ & 1.53 & $(0.15)$ & 1.84 & $(0.21)$ & 1.54 & $(0.17)$ & 2.00 & $(0.20)$ & 1.81 & $(0.17)$ \\
\hline & UK (Scotland) & 1.77 & $(0.24)$ & 1.48 & $(0.21)$ & 2.83 & $(0.53)$ & 2.21 & $(0.44)$ & 2.15 & $(0.40)$ & 1.78 & $(0.31)$ \\
\hline & OECD average & 1.93 & $(0.05)$ & 1.67 & $(0.04)$ & 2.22 & $(0.07)$ & 1.86 & $(0.06)$ & 2.07 & $(0.08)$ & 1.86 & $(0.07)$ \\
\hline & Average-18 & 1.89 & $(0.04)$ & 1.66 & $(0.03)$ & 2.15 & $(0.06)$ & 1.80 & $(0.05)$ & 1.97 & $(0.06)$ & 1.78 & $(0.05)$ \\
\hline \multirow{6}{*}{$\frac{\grave{d}}{\vdots}$} & Croatia & 1.73 & $(0.13)$ & 1.53 & $(0.12)$ & 2.07 & $(0.23)$ & 1.70 & $(0.18)$ & 1.60 & $(0.17)$ & 1.48 & $(0.16)$ \\
\hline & Dominican Republic & 0.95 & $(0.07)$ & 1.11 & $(0.09)$ & 1.10 & $(0.09)$ & 1.14 & $(0.10)$ & 0.83 & $(0.07)$ & 0.97 & $(0.09)$ \\
\hline & Georgia & 1.54 & $(0.11)$ & 1.43 & $(0.10)$ & 1.80 & $(0.13)$ & 1.65 & $(0.12)$ & 1.44 & $(0.11)$ & 1.36 & $(0.10)$ \\
\hline & Hong Kong (China) & 2.44 & $(0.16)$ & 2.23 & $(0.15)$ & 2.10 & $(0.16)$ & 1.84 & $(0.15)$ & 2.11 & $(0.23)$ & 2.03 & $(0.24)$ \\
\hline & Macao (China) & 1.97 & $(0.20)$ & 1.81 & $(0.19)$ & 2.28 & $(0.25)$ & 1.94 & $(0.21)$ & 1.83 & $(0.23)$ & 1.76 & $(0.22)$ \\
\hline & Malta & 2.30 & $(0.21)$ & 1.68 & $(0.17)$ & 2.74 & $(0.33)$ & 1.87 & $(0.25)$ & 2.87 & $(0.25)$ & 2.14 & $(0.21)$ \\
\hline
\end{tabular}

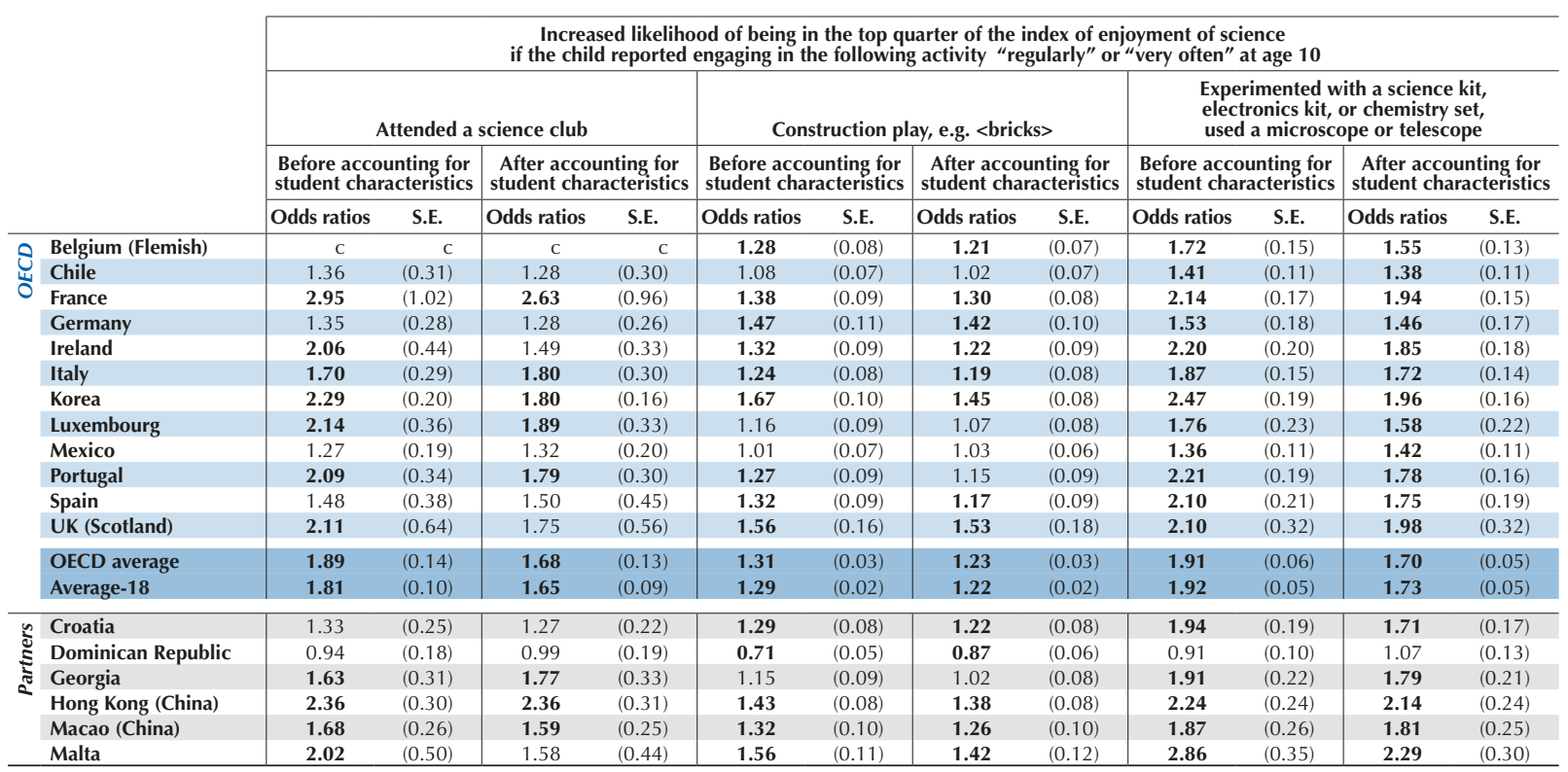

1. Student characteristics include the PISA index of economic, social and cultural status (ESCS) and science performance.

Note: Values that are statistically significant are indicated in bold (see Annex A3).

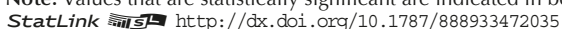


[Part 1/1]

Table III.9.15 Students' early science-related activities and performance in science

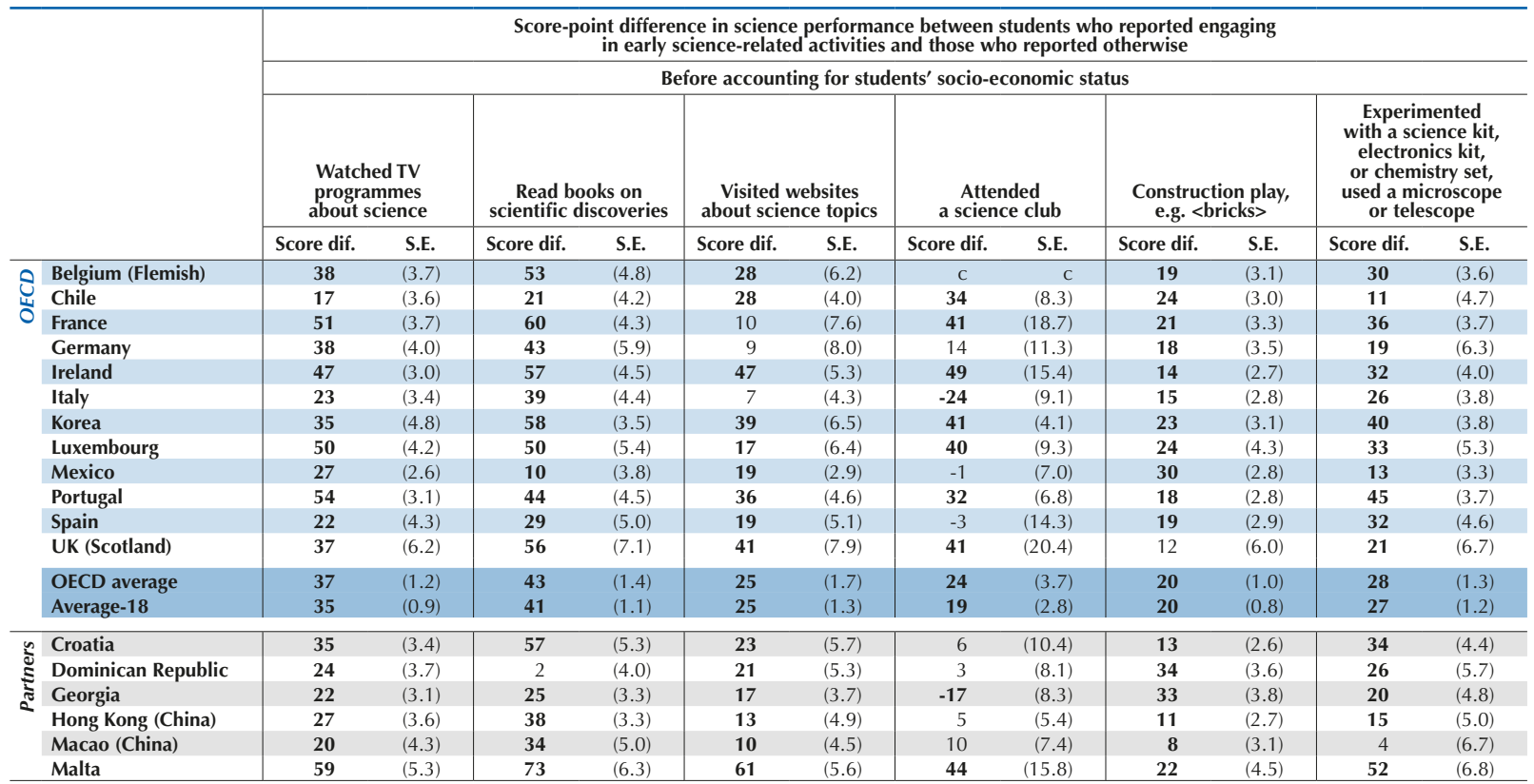

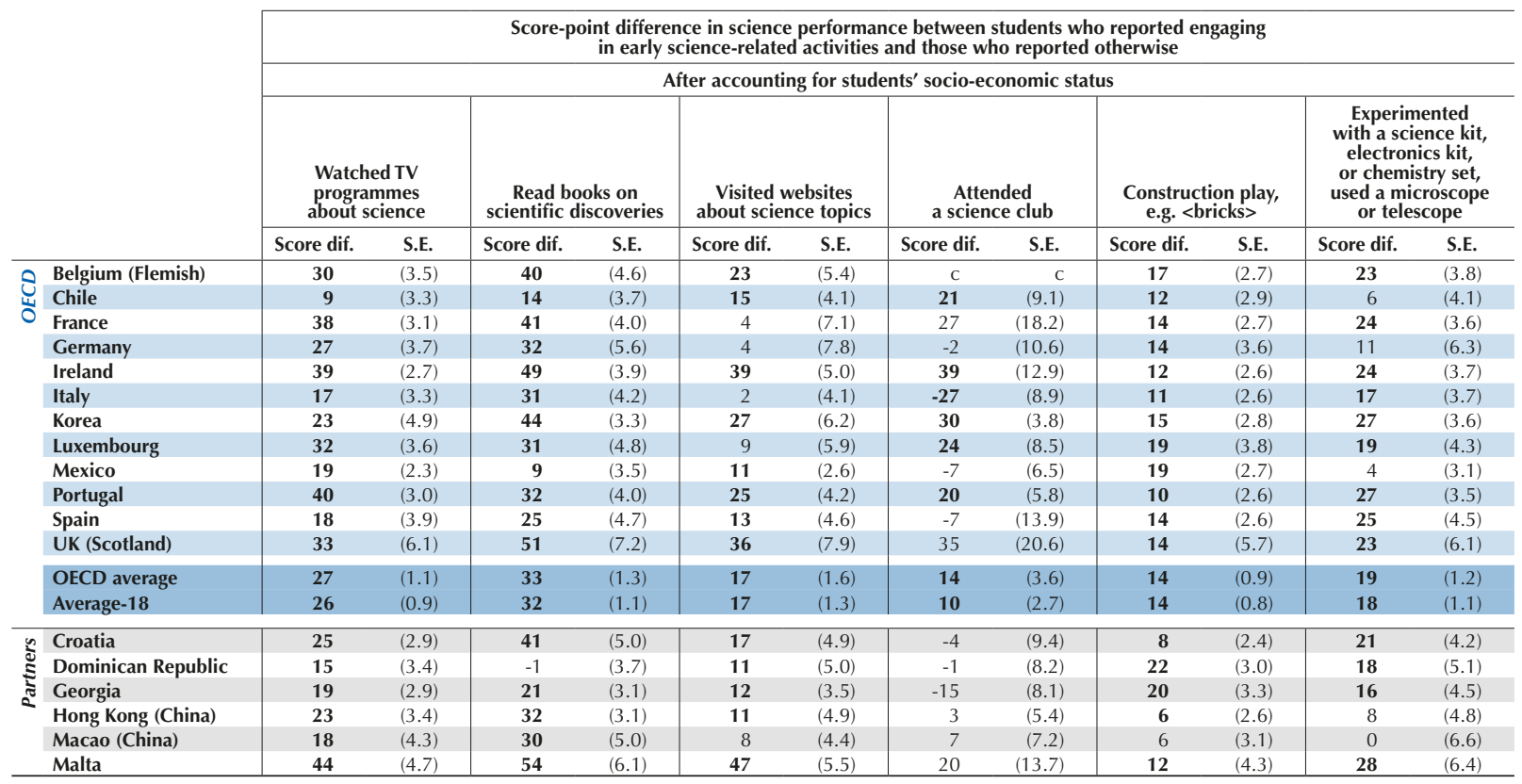

Note: Values that are statistically significant are indicated in bold (see Annex A3).

StatLink तiाs] http://dx.doi.org/10.1787/888933472054 
Table III.9.16 Students who talk to their parents before or after school

Percentage of students who reported that they talked to their parents before or after school on the most recent day they attended school

\begin{tabular}{|c|c|c|c|c|c|c|c|c|c|}
\hline & \multicolumn{8}{|c|}{ Percentage of students who reported talking to their parents } \\
\hline & & \multicolumn{2}{|c|}{ Before school } & \multicolumn{2}{|c|}{ After school } & \multicolumn{2}{|c|}{ Either before or after school } & \multicolumn{2}{|c|}{ Before and after school } \\
\hline & & $\%$ & S.E. & $\%$ & S.E. & $\%$ & S.E. & $\%$ & S.E. \\
\hline$\theta$ & Australia & 95.7 & $(0.2)$ & 90.1 & $(0.4)$ & 96.7 & $(0.2)$ & 87.0 & $(0.4)$ \\
\hline 氙 & Austria & 91.7 & $(0.5)$ & 84.1 & $(0.7)$ & 94.4 & $(0.4)$ & 78.4 & $(0.8)$ \\
\hline$\overline{0}$ & Belgium & 93.2 & $(0.3)$ & 85.4 & $(0.5)$ & 95.1 & $(0.3)$ & 81.1 & $(0.6)$ \\
\hline & Canada & 95.0 & $(0.2)$ & 88.2 & $(0.4)$ & 96.5 & $(0.2)$ & 84.6 & (0.4) \\
\hline & Chile & 86.4 & $(0.5)$ & 81.2 & (0.5) & 90.0 & $(0.4)$ & 75.4 & (0.6) \\
\hline & Czech Republic & 93.5 & $(0.4)$ & 85.6 & $(0.6)$ & 96.4 & $(0.2)$ & 80.4 & $(0.7)$ \\
\hline & Denmark & 94.3 & (0.6) & 87.2 & $(0.6)$ & 95.8 & $(0.4)$ & 83.8 & $(0.7)$ \\
\hline & Estonia & 88.8 & (0.5) & 87.9 & $(0.5)$ & 95.4 & $(0.3)$ & 79.8 & $(0.7)$ \\
\hline & Finland & 94.5 & $(0.4)$ & 82.8 & (0.6) & 96.6 & $(0.3)$ & 78.4 & $(0.7)$ \\
\hline & France & 91.4 & (0.4) & 80.8 & $(0.5)$ & 93.9 & $(0.3)$ & 75.8 & $(0.7)$ \\
\hline & Germany & 94.5 & $(0.4)$ & 86.9 & (0.6) & 96.4 & $(0.3)$ & 79.1 & $(0.8)$ \\
\hline & Greece & 92.0 & (0.5) & 88.5 & (0.5) & 96.2 & $(0.3)$ & 82.0 & $(0.7)$ \\
\hline & Hungary & 93.5 & (0.4) & 89.4 & $(0.5)$ & 96.0 & $(0.4)$ & 84.3 & (0.6) \\
\hline & Iceland & 97.4 & $(0.3)$ & 90.2 & (0.5) & 98.5 & $(0.2)$ & 87.2 & (0.6) \\
\hline & Ireland & 96.7 & $(0.3)$ & 92.1 & (0.5) & 97.8 & $(0.2)$ & 89.2 & $(0.5)$ \\
\hline & Israel & 91.1 & (0.6) & 88.0 & $(0.8)$ & 95.5 & $(0.4)$ & 80.4 & $(0.8)$ \\
\hline & Italy & 93.6 & $(0.4)$ & 89.3 & $(0.4)$ & 96.9 & $(0.2)$ & 83.9 & $(0.5)$ \\
\hline & Japan & 93.9 & (0.4) & 90.2 & (0.5) & 95.5 & $(0.4)$ & 87.9 & $(0.5)$ \\
\hline & Korea & 85.5 & $(0.7)$ & 79.4 & (0.9) & 90.3 & $(0.7)$ & 73.6 & $(0.9)$ \\
\hline & Latvia & 93.5 & (0.4) & 89.4 & (0.5) & 96.6 & $(0.2)$ & 84.6 & $(0.6)$ \\
\hline & Luxembourg & 91.6 & $(0.4)$ & 82.4 & $(0.6)$ & 94.1 & $(0.3)$ & 77.4 & (0.6) \\
\hline & Mexico & 84.4 & (0.5) & 79.7 & $(0.7)$ & 89.9 & $(0.4)$ & 72.0 & $(0.8)$ \\
\hline & Netherlands & 96.6 & $(0.2)$ & 89.0 & $(0.5)$ & 97.8 & $(0.2)$ & 86.8 & $(0.5)$ \\
\hline & New Zealand & 95.0 & $(0.4)$ & 88.8 & $(0.4)$ & 96.2 & $(0.3)$ & 85.3 & $(0.5)$ \\
\hline & Norway & 96.0 & $(0.3)$ & 87.6 & $(0.4)$ & 97.6 & $(0.3)$ & 83.6 & (0.5) \\
\hline & Poland & 90.5 & (0.4) & 83.4 & (0.6) & 94.5 & $(0.3)$ & 78.1 & $(0.6)$ \\
\hline & Portugal & 96.0 & $(0.3)$ & 92.0 & $(0.4)$ & 97.5 & $(0.2)$ & 89.0 & $(0.4)$ \\
\hline & Slovak Republic & 88.7 & (0.5) & 81.8 & (0.6) & 93.5 & $(0.4)$ & 74.2 & $(0.7)$ \\
\hline & Slovenia & 83.1 & $(0.6)$ & 79.8 & $(0.7)$ & 89.6 & $(0.6)$ & 70.0 & $(0.7)$ \\
\hline & Spain & 92.1 & $(0.4)$ & 84.0 & (0.4) & 94.8 & $(0.3)$ & 79.4 & (0.6) \\
\hline & Sweden & 94.8 & (0.4) & 87.4 & $(0.5)$ & 97.2 & $(0.2)$ & 82.0 & (0.6) \\
\hline & Switzerland & 93.7 & $(0.5)$ & 82.7 & $(0.6)$ & 95.9 & $(0.4)$ & 76.5 & $(0.7)$ \\
\hline & Turkey & 84.0 & $(0.8)$ & 80.0 & $(0.8)$ & 88.5 & $(0.6)$ & 73.7 & (1.1) \\
\hline & United Kingdom & 94.9 & $(0.3)$ & 88.7 & $(0.5)$ & 96.5 & $(0.2)$ & 84.6 & (0.6) \\
\hline & United States & 94.3 & $(0.4)$ & 88.2 & $(0.5)$ & 96.0 & $(0.3)$ & 84.8 & (0.6) \\
\hline & OECD average & 92.3 & $(0.1)$ & 86.1 & $(0.1)$ & 95.1 & $(0.1)$ & 81.0 & $(0.1)$ \\
\hline 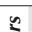 & Albania & $\mathrm{m}$ & $\mathrm{m}$ & $\mathrm{m}$ & $\mathrm{m}$ & $\mathrm{m}$ & $\mathrm{m}$ & $\mathrm{m}$ & $\mathrm{m}$ \\
\hline ఏ & Algeria & $\mathrm{m}$ & $\mathrm{m}$ & $\mathrm{m}$ & $\mathrm{m}$ & $\mathrm{m}$ & $\mathrm{m}$ & $\mathrm{m}$ & $\mathrm{m}$ \\
\hline ปั้ & Brazil & 89.5 & $(0.5)$ & 85.2 & $(0.4)$ & 93.5 & $(0.3)$ & 75.0 & $(0.5)$ \\
\hline 2 & B-S-J-G (China) & 75.0 & (1.0) & 72.1 & (0.8) & 81.2 & $(0.8)$ & 65.2 & (1.1) \\
\hline & Bulgaria & 91.0 & (0.6) & 84.1 & $(0.6)$ & 95.2 & $(0.4)$ & 75.3 & $(0.7)$ \\
\hline & CABA (Argentina) & $\mathrm{m}$ & $\mathrm{m}$ & $\mathrm{m}$ & $\mathrm{m}$ & $\mathrm{m}$ & $\mathrm{m}$ & $\mathrm{m}$ & $\mathrm{m}$ \\
\hline & Colombia & 85.3 & $(0.5)$ & 82.5 & (0.5) & 89.4 & $(0.4)$ & 75.9 & (0.6) \\
\hline & Costa Rica & 87.0 & (0.6) & 83.5 & $(0.6)$ & 91.3 & $(0.4)$ & 76.8 & $(0.7)$ \\
\hline & Croatia & 93.9 & $(0.4)$ & 85.8 & (0.5) & 96.6 & $(0.3)$ & 81.7 & $(0.6)$ \\
\hline & Cyprus* & 88.0 & $(0.5)$ & 86.1 & (0.4) & 94.1 & $(0.3)$ & 77.0 & $(0.6)$ \\
\hline & Dominican Republic & 89.8 & $(0.6)$ & 86.6 & $(0.7)$ & 94.4 & $(0.4)$ & 76.0 & $(0.8)$ \\
\hline & FYROM & $\mathrm{m}$ & $\mathrm{m}$ & $\mathrm{m}$ & $\mathrm{m}$ & $\mathrm{m}$ & $\mathrm{m}$ & $\mathrm{m}$ & $\mathrm{m}$ \\
\hline & Georgia & $\mathrm{m}$ & $\mathrm{m}$ & $\mathrm{m}$ & $\mathrm{m}$ & $\mathrm{m}$ & $\mathrm{m}$ & $\mathrm{m}$ & $\mathrm{m}$ \\
\hline & Hong Kong (China) & 89.0 & $(0.5)$ & 76.8 & $(0.6)$ & 90.8 & $(0.4)$ & 74.1 & $(0.6)$ \\
\hline & Indonesia & $\mathrm{m}$ & $\mathrm{m}$ & $\mathrm{m}$ & $\mathrm{m}$ & $\mathrm{m}$ & $\mathrm{m}$ & $\mathrm{m}$ & $\mathrm{m}$ \\
\hline & Jordan & $\mathrm{m}$ & $\mathrm{m}$ & $\mathrm{m}$ & $\mathrm{m}$ & $\mathrm{m}$ & $\mathrm{m}$ & $\mathrm{m}$ & $\mathrm{m}$ \\
\hline & Kosovo & $\mathrm{m}$ & $\mathrm{m}$ & $\mathrm{m}$ & $\mathrm{m}$ & $\mathrm{m}$ & $\mathrm{m}$ & $\mathrm{m}$ & $\mathrm{m}$ \\
\hline & Lebanon & $\mathrm{m}$ & $\mathrm{m}$ & $\mathrm{m}$ & $\mathrm{m}$ & $\mathrm{m}$ & $\mathrm{m}$ & $\mathrm{m}$ & $\mathrm{m}$ \\
\hline & Lithuania & 92.8 & $(0.4)$ & 89.7 & $(0.4)$ & 96.5 & $(0.3)$ & 83.9 & (0.6) \\
\hline & Macao (China) & 83.3 & (0.5) & 72.5 & $(0.6)$ & 85.5 & $(0.5)$ & 69.6 & $(0.6)$ \\
\hline & Malta & $\mathrm{m}$ & $\mathrm{m}$ & $\mathrm{m}$ & $\mathrm{m}$ & $\mathrm{m}$ & $\mathrm{m}$ & $\mathrm{m}$ & $\mathrm{m}$ \\
\hline & Moldova & $\mathrm{m}$ & $\mathrm{m}$ & $\mathrm{m}$ & $\mathrm{m}$ & $\mathrm{m}$ & $\mathrm{m}$ & $\mathrm{m}$ & $\mathrm{m}$ \\
\hline & Montenegro & 86.9 & $(0.5)$ & 79.8 & (0.6) & 92.7 & $(0.4)$ & 69.2 & $(0.7)$ \\
\hline & Peru & 84.1 & $(0.6)$ & 81.7 & $(0.6)$ & 88.5 & $(0.5)$ & 74.2 & $(0.7)$ \\
\hline & Qatar & 91.0 & $(0.3)$ & 88.6 & $(0.4)$ & 95.3 & $(0.2)$ & 79.8 & $(0.4)$ \\
\hline & Romania & $\mathrm{m}$ & $\mathrm{m}$ & $\mathrm{m}$ & $\mathrm{m}$ & $\mathrm{m}$ & $\mathrm{m}$ & $\mathrm{m}$ & $\mathrm{m}$ \\
\hline & Russia & 92.8 & $(0.4)$ & 92.6 & $(0.4)$ & 97.4 & $(0.2)$ & 85.1 & (0.6) \\
\hline & Singapore & 89.6 & $(0.4)$ & 77.2 & $(0.5)$ & 91.6 & $(0.4)$ & 74.4 & $(0.6)$ \\
\hline & Chinese Taipei & 81.0 & $(0.6)$ & 56.3 & $(0.7)$ & 82.8 & $(0.5)$ & 54.1 & $(0.7)$ \\
\hline & Thailand & 94.5 & $(0.3)$ & 92.6 & $(0.4)$ & 97.2 & $(0.2)$ & 88.8 & $(0.5)$ \\
\hline & Trinidad and Tobago & $\mathrm{m}$ & $\mathrm{m}$ & $\mathrm{m}$ & $\mathrm{m}$ & $\mathrm{m}$ & $\mathrm{m}$ & $\mathrm{m}$ & $\mathrm{m}$ \\
\hline & Tunisia & 90.3 & $(0.6)$ & 90.6 & $(0.5)$ & 95.9 & $(0.4)$ & 77.8 & $(0.8)$ \\
\hline & United Arab Emirates & 93.3 & $(0.3)$ & 90.5 & $(0.4)$ & 96.6 & $(0.2)$ & 84.5 & $(0.4)$ \\
\hline & Uruguay & 87.7 & $(0.6)$ & 81.2 & $(0.7)$ & 91.0 & $(0.6)$ & 70.9 & $(0.8)$ \\
\hline & Viet Nam & $\mathrm{m}$ & $\mathrm{m}$ & m & $\mathrm{m}$ & $\mathrm{m}$ & $\mathrm{m}$ & $\mathrm{m}$ & $\mathrm{m}$ \\
\hline & Argentina** & $\mathrm{m}$ & $\mathrm{m}$ & $\mathrm{m}$ & $\mathrm{m}$ & $\mathrm{m}$ & $\mathrm{m}$ & $\mathrm{m}$ & $\mathrm{m}$ \\
\hline & Kazakhstan** & $\mathrm{m}$ & $\mathrm{m}$ & $\mathrm{m}$ & $\mathrm{m}$ & $\mathrm{m}$ & $\mathrm{m}$ & $\mathrm{m}$ & $\mathrm{m}$ \\
\hline & Malaysia** & 93.1 & (0.4) & 90.0 & (0.6) & 95.7 & $(0.3)$ & 86.2 & (0.6) \\
\hline
\end{tabular}

* See note at the beginning of this Annex.

** Coverage is too small to ensure comparability (see Annex A4).

StatLink anils http://dx.doi.org/10.1787/888933472060 
[Part 1/1]

Table III.9.18 Parents who give their child emotional support

Results based on students' self-reports

\begin{tabular}{|c|c|c|c|c|c|c|c|c|}
\hline & & & ercentage of $s t$ & agreed/stron & gly agreed wi & ving stateme & & \\
\hline & $\begin{array}{r}\text { My par } \\
\text { in my }\end{array}$ & $\begin{array}{l}\text { erested } \\
\text { vities }\end{array}$ & $\begin{array}{r}\text { My parents } \\
\text { efforts }\end{array}$ & $\begin{array}{l}\text { educational } \\
\text { ements }\end{array}$ & $\begin{array}{l}\text { My parents } \\
\text { facing }\end{array}$ & $\begin{array}{l}\text { when I am } \\
\text { t school }\end{array}$ & $\begin{array}{r}\text { My par } \\
\text { to }\end{array}$ & $\begin{array}{l}\text { age me } \\
\text { nt }\end{array}$ \\
\hline & $\%$ & S.E. & $\%$ & S.E. & $\%$ & S.E. & $\%$ & S.E. \\
\hline Australia & 94.1 & $(0.2)$ & 96.4 & $(0.2)$ & 91.2 & $(0.2)$ & 93.7 & $(0.2)$ \\
\hline Austria & 95.8 & $(0.3)$ & 91.7 & $(0.3)$ & 91.6 & $(0.4)$ & 90.0 & $(0.4)$ \\
\hline Belgium & 93.9 & $(0.3)$ & 94.9 & $(0.3)$ & 91.6 & $(0.3)$ & 90.0 & $(0.3)$ \\
\hline Canada & 92.5 & $(0.3)$ & 95.9 & $(0.2)$ & 90.1 & $(0.3)$ & 92.5 & $(0.2)$ \\
\hline Chile & 91.1 & $(0.5)$ & 91.4 & $(0.4)$ & 88.8 & $(0.5)$ & 87.1 & $(0.5)$ \\
\hline Czech Republic & 91.0 & $(0.4)$ & 93.6 & $(0.3)$ & 88.6 & $(0.5)$ & 83.4 & $(0.6)$ \\
\hline Denmark & 94.5 & $(0.4)$ & 96.0 & $(0.4)$ & 94.3 & $(0.3)$ & 90.2 & $(0.4)$ \\
\hline Estonia & 91.7 & $(0.4)$ & 91.0 & $(0.5)$ & 86.9 & $(0.5)$ & 85.1 & $(0.5)$ \\
\hline Finland & 96.4 & $(0.3)$ & 93.7 & $(0.4)$ & 90.9 & $(0.5)$ & 90.9 & $(0.5)$ \\
\hline France & 95.3 & $(0.3)$ & 96.1 & $(0.2)$ & 89.9 & $(0.4)$ & 91.0 & $(0.4)$ \\
\hline Germany & 95.6 & $(0.3)$ & 92.2 & $(0.4)$ & 91.3 & $(0.4)$ & 88.4 & $(0.5)$ \\
\hline Greece & 94.6 & $(0.3)$ & 92.8 & $(0.5)$ & 90.2 & $(0.4)$ & 93.1 & $(0.3)$ \\
\hline Hungary & 96.0 & $(0.3)$ & 94.8 & $(0.4)$ & 93.1 & $(0.4)$ & 92.4 & $(0.4)$ \\
\hline Iceland & 93.5 & $(0.5)$ & 95.9 & $(0.4)$ & 93.0 & $(0.4)$ & 93.0 & $(0.5)$ \\
\hline Ireland & 96.5 & $(0.3)$ & 96.3 & $(0.2)$ & 94.1 & $(0.3)$ & 95.0 & $(0.3)$ \\
\hline Israel & $\mathrm{m}$ & $\mathrm{m}$ & $\mathrm{m}$ & $\mathrm{m}$ & $\mathrm{m}$ & $\mathrm{m}$ & $\mathrm{m}$ & $\mathrm{m}$ \\
\hline Italy & 96.1 & $(0.3)$ & 91.9 & $(0.3)$ & 89.3 & $(0.5)$ & 90.5 & $(0.4)$ \\
\hline Japan & 85.9 & $(0.5)$ & 90.7 & $(0.4)$ & 87.1 & $(0.4)$ & 79.8 & $(0.6)$ \\
\hline Korea & 96.5 & $(0.3)$ & 96.1 & $(0.3)$ & 92.9 & $(0.3)$ & 90.8 & $(0.5)$ \\
\hline Latvia & 92.5 & $(0.4)$ & 89.5 & $(0.5)$ & 86.2 & $(0.5)$ & 81.7 & $(0.6)$ \\
\hline Luxembourg & 95.3 & $(0.3)$ & 93.0 & $(0.3)$ & 88.5 & $(0.4)$ & 87.4 & $(0.5)$ \\
\hline Mexico & 91.1 & $(0.4)$ & 90.0 & $(0.5)$ & 87.6 & $(0.4)$ & 87.2 & $(0.5)$ \\
\hline Netherlands & 97.2 & $(0.2)$ & 96.5 & $(0.3)$ & 96.6 & $(0.3)$ & 95.4 & $(0.3)$ \\
\hline New Zealand & 92.3 & $(0.4)$ & 95.2 & $(0.3)$ & 88.8 & $(0.5)$ & 91.7 & $(0.4)$ \\
\hline Norway & 93.3 & $(0.4)$ & 95.0 & $(0.3)$ & 93.0 & $(0.4)$ & 92.8 & $(0.3)$ \\
\hline Poland & 94.5 & $(0.4)$ & 88.9 & (0.5) & 88.4 & $(0.6)$ & 85.9 & $(0.6)$ \\
\hline Portugal & 97.6 & $(0.3)$ & 96.2 & $(0.2)$ & 94.6 & $(0.3)$ & 94.7 & $(0.4)$ \\
\hline Slovak Republic & 91.8 & $(0.4)$ & 93.2 & $(0.4)$ & 88.1 & $(0.4)$ & 87.0 & $(0.4)$ \\
\hline Slovenia & 95.3 & $(0.3)$ & 97.2 & $(0.2)$ & 90.1 & $(0.5)$ & 93.4 & $(0.3)$ \\
\hline Spain & 95.2 & $(0.2)$ & 92.2 & $(0.3)$ & 90.5 & $(0.4)$ & 89.8 & $(0.4)$ \\
\hline Sweden & 92.6 & $(0.4)$ & 94.4 & $(0.4)$ & 92.2 & $(0.4)$ & 92.0 & $(0.4)$ \\
\hline Switzerland & 96.5 & $(0.3)$ & 95.2 & $(0.3)$ & 91.8 & $(0.5)$ & 91.6 & $(0.4)$ \\
\hline Turkey & 77.8 & $(0.7)$ & 90.3 & $(0.5)$ & 86.6 & $(0.6)$ & 83.2 & $(0.6)$ \\
\hline United Kingdom & 93.7 & $(0.3)$ & 95.6 & $(0.3)$ & 91.5 & $(0.4)$ & 92.9 & $(0.4)$ \\
\hline United States & 91.7 & $(0.4)$ & 96.4 & $(0.3)$ & 91.1 & $(0.4)$ & 93.2 & $(0.3)$ \\
\hline OECD average & 93.5 & $(0.1)$ & 93.8 & $(0.1)$ & 90.6 & $(0.1)$ & 89.9 & $(0.1)$ \\
\hline
\end{tabular}

\begin{tabular}{|c|c|c|c|c|c|c|c|c|}
\hline Albania & $\mathrm{m}$ & $\mathrm{m}$ & $\mathrm{m}$ & $\mathrm{m}$ & $\mathrm{m}$ & $\mathrm{m}$ & $\mathrm{m}$ & $\mathrm{m}$ \\
\hline$\Xi$ Algeria & $\mathrm{m}$ & $\mathrm{m}$ & $\mathrm{m}$ & $\mathrm{m}$ & $\mathrm{m}$ & $\mathrm{m}$ & $\mathrm{m}$ & $\mathrm{m}$ \\
\hline Brazil & 93.4 & $(0.3)$ & 95.1 & $(0.2)$ & 88.0 & $(0.3)$ & 91.2 & $(0.3)$ \\
\hline B-S-J-G (China) & 93.1 & $(0.5)$ & 92.8 & $(0.4)$ & 91.7 & $(0.4)$ & 93.2 & (0.4) \\
\hline Bulgaria & 83.8 & $(0.5)$ & 95.4 & $(0.3)$ & 93.7 & $(0.4)$ & 94.5 & $(0.3)$ \\
\hline CABA (Argentina) & $\mathrm{m}$ & $\mathrm{m}$ & $\mathrm{m}$ & $\mathrm{m}$ & $\mathrm{m}$ & $\mathrm{m}$ & $\mathrm{m}$ & $\mathrm{m}$ \\
\hline Colombia & 93.0 & $(0.4)$ & 93.6 & $(0.3)$ & 87.6 & $(0.4)$ & 88.3 & $(0.4)$ \\
\hline Costa Rica & 95.4 & $(0.3)$ & 95.5 & $(0.3)$ & 94.7 & $(0.3)$ & 91.6 & $(0.5)$ \\
\hline Croatia & 95.6 & $(0.3)$ & 96.7 & $(0.3)$ & 95.0 & $(0.3)$ & 92.8 & $(0.4)$ \\
\hline Cyprus* & 94.7 & $(0.3)$ & 93.8 & $(0.3)$ & 90.4 & (0.4) & 91.5 & (0.4) \\
\hline Dominican Republic & 88.3 & $(0.5)$ & 88.3 & (0.5) & 75.3 & $(0.7)$ & 84.3 & (0.5) \\
\hline FYROM & $\mathrm{m}$ & $\mathrm{m}$ & $\mathrm{m}$ & $\mathrm{m}$ & $\mathrm{m}$ & $\mathrm{m}$ & $\mathrm{m}$ & $\mathrm{m}$ \\
\hline Georgia & $\mathrm{m}$ & $\mathrm{m}$ & $\mathrm{m}$ & $\mathrm{m}$ & $\mathrm{m}$ & $\mathrm{m}$ & $\mathrm{m}$ & $\mathrm{m}$ \\
\hline Hong Kong (China) & 70.2 & $(0.8)$ & 93.0 & (0.4) & 88.5 & $(0.5)$ & 89.1 & (0.4) \\
\hline Indonesia & $\mathrm{m}$ & $\mathrm{m}$ & $\mathrm{m}$ & $\mathrm{m}$ & $\mathrm{m}$ & $\mathrm{m}$ & $\mathrm{m}$ & $\mathrm{m}$ \\
\hline Jordan & $\mathrm{m}$ & $\mathrm{m}$ & $\mathrm{m}$ & $\mathrm{m}$ & $\mathrm{m}$ & $\mathrm{m}$ & $\mathrm{m}$ & $\mathrm{m}$ \\
\hline Kosovo & $\mathrm{m}$ & $\mathrm{m}$ & $\mathrm{m}$ & $\mathrm{m}$ & $\mathrm{m}$ & $\mathrm{m}$ & $\mathrm{m}$ & $\mathrm{m}$ \\
\hline Lebanon & $\mathrm{m}$ & $\mathrm{m}$ & $\mathrm{m}$ & $\mathrm{m}$ & $\mathrm{m}$ & $\mathrm{m}$ & $\mathrm{m}$ & $\mathrm{m}$ \\
\hline Lithuania & 93.8 & $(0.3)$ & 90.9 & (0.4) & 88.0 & $(0.5)$ & 89.9 & (0.4) \\
\hline Macao (China) & 72.0 & $(0.7)$ & 91.9 & (0.4) & 83.2 & $(0.5)$ & 85.5 & $(0.6)$ \\
\hline Malta & $\mathrm{m}$ & $\mathrm{m}$ & $\mathrm{m}$ & $\mathrm{m}$ & $\mathrm{m}$ & $\mathrm{m}$ & $\mathrm{m}$ & $\mathrm{m}$ \\
\hline Moldova & $\mathrm{m}$ & $\mathrm{m}$ & $\mathrm{m}$ & $\mathrm{m}$ & $\mathrm{m}$ & $\mathrm{m}$ & $\mathrm{m}$ & $\mathrm{m}$ \\
\hline Montenegro & 91.8 & $(0.4)$ & 94.5 & $(0.3)$ & 91.8 & $(0.4)$ & 94.8 & $(0.3)$ \\
\hline Peru & 92.9 & $(0.3)$ & 92.4 & $(0.3)$ & 85.1 & $(0.5)$ & 88.4 & $(0.4)$ \\
\hline Qatar & 86.5 & $(0.3)$ & 91.6 & $(0.2)$ & 89.4 & $(0.3)$ & 91.6 & $(0.3)$ \\
\hline Romania & 0.0 & c & 0.0 & C & 0.0 & c & 0.0 & c \\
\hline Russia & 94.6 & $(0.4)$ & 93.0 & $(0.4)$ & 90.5 & $(0.5)$ & 81.8 & $(0.8)$ \\
\hline Singapore & 85.9 & $(0.5)$ & 94.8 & $(0.3)$ & 86.6 & $(0.4)$ & 89.6 & (0.4) \\
\hline Chinese Taipei & 84.2 & $(0.5)$ & 92.9 & $(0.3)$ & 92.1 & $(0.3)$ & 89.4 & (0.4) \\
\hline Thailand & 94.5 & (0.4) & 97.7 & $(0.2)$ & 95.7 & $(0.3)$ & 96.3 & (0.3) \\
\hline Trinidad and Tobago & $\mathrm{m}$ & $\mathrm{m}$ & $\mathrm{m}$ & $\mathrm{m}$ & $\mathrm{m}$ & $\mathrm{m}$ & $\mathrm{m}$ & $\mathrm{m}$ \\
\hline Tunisia & 86.5 & (0.5) & 94.1 & $(0.4)$ & 85.5 & $(0.6)$ & 94.2 & $(0.4)$ \\
\hline United Arab Emirates & 85.6 & $(0.5)$ & 93.7 & $(0.3)$ & 91.4 & $(0.3)$ & 93.9 & $(0.2)$ \\
\hline Uruguay & 94.9 & $(0.3)$ & 93.7 & $(0.3)$ & 89.8 & $(0.3)$ & 89.5 & $(0.5)$ \\
\hline Viet Nam & $\mathrm{m}$ & $\mathrm{m}$ & $\mathrm{m}$ & $\mathrm{m}$ & $\mathrm{m}$ & $\mathrm{m}$ & $\mathrm{m}$ & $\mathrm{m}$ \\
\hline Argentina** & $\mathrm{m}$ & $\mathrm{m}$ & $\mathrm{m}$ & $\mathrm{m}$ & $\mathrm{m}$ & $\mathrm{m}$ & $\mathrm{m}$ & $\mathrm{m}$ \\
\hline Kazakhstan** & $\mathrm{m}$ & $\mathrm{m}$ & $\mathrm{m}$ & $\mathrm{m}$ & $\mathrm{m}$ & $\mathrm{m}$ & $\mathrm{m}$ & $\mathrm{m}$ \\
\hline Malaysia** & 87.8 & $(0.5)$ & 96.3 & $(0.3)$ & 88.5 & $(0.5)$ & 94.4 & (0.4) \\
\hline
\end{tabular}

* See note at the beginning of this Annex.

** Coverage is too small to ensure comparability (see Annex A4).

StatLink त्राजा http://dx.doi.org/10.1787/888933472083 
[Part 1/1]

Table III.9.20 Students' perception of their parents' interest in their school activities

Percentage of students who reported that they "agree" or "strongly agree" with the statement "My parents are interested in my school activities"

\begin{tabular}{|c|c|c|c|c|c|c|c|c|c|c|}
\hline & \multicolumn{10}{|c|}{ Percentage of students who reported that their parents are interested in their school activities, by ESCS ${ }^{1}$} \\
\hline & \multicolumn{2}{|c|}{ Bottom quarter } & \multicolumn{2}{|c|}{ Second quarter } & \multicolumn{2}{|c|}{ Third quarter } & \multicolumn{2}{|c|}{ Top quarter } & \multicolumn{2}{|c|}{ Top - bottom quarter } \\
\hline & $\%$ & S.E. & $\%$ & S.E. & $\%$ & S.E. & $\%$ & S.E. & $\%$ dif. & S.E. \\
\hline Australia & 89.9 & $(0.6)$ & 94.0 & $(0.5)$ & 95.8 & $(0.4)$ & 96.9 & $(0.3)$ & 6.9 & $(0.7)$ \\
\hline Austria & 94.1 & $(0.7)$ & 96.3 & (0.6) & 96.1 & $(0.5)$ & 96.9 & $(0.4)$ & 2.8 & $(0.7)$ \\
\hline ठ Belgium & 91.6 & $(0.6)$ & 92.6 & $(0.6)$ & 95.2 & $(0.5)$ & 96.4 & (0.5) & 4.8 & $(0.7)$ \\
\hline Canada & 88.2 & (0.6) & 91.8 & $(0.5)$ & 93.8 & (0.5) & 96.1 & $(0.3)$ & 7.9 & $(0.7)$ \\
\hline Chile & 89.3 & (1.0) & 91.0 & (0.9) & 90.9 & (1.0) & 93.5 & $(0.8)$ & 4.2 & (1.2) \\
\hline Czech Republic & 86.3 & (1.0) & 90.8 & $(0.9)$ & 93.0 & (0.8) & 93.4 & (0.8) & 7.0 & (1.3) \\
\hline Denmark & 91.7 & $(0.7)$ & 94.4 & (0.6) & 95.3 & (0.6) & 96.3 & (0.6) & 4.6 & (0.8) \\
\hline Estonia & 88.7 & (1.0) & 91.4 & $(0.8)$ & 92.5 & (0.9) & 93.9 & (0.7) & 5.2 & $(1.2)$ \\
\hline Finland & 94.5 & $(0.8)$ & 96.2 & $(0.5)$ & 96.9 & (0.6) & 98.1 & (0.4) & 3.7 & $(0.9)$ \\
\hline France & 91.9 & $(0.8)$ & 95.7 & $(0.7)$ & 95.9 & $(0.5)$ & 97.9 & $(0.4)$ & 6.0 & $(0.8)$ \\
\hline Germany & 92.9 & $(0.8)$ & 96.3 & (0.6) & 95.5 & (0.6) & 97.3 & (0.4) & 4.3 & (0.9) \\
\hline Greece & 92.4 & (0.8) & 93.9 & $(0.7)$ & 95.3 & (0.6) & 97.0 & (0.4) & 4.6 & $(0.8)$ \\
\hline Hungary & 94.5 & $(0.8)$ & 95.4 & (0.6) & 96.2 & (0.6) & 97.9 & $(0.4)$ & 3.4 & (1.0) \\
\hline Iceland & 89.4 & (1.1) & 92.8 & $(0.9)$ & 95.3 & $(0.8)$ & 96.6 & (0.6) & 7.2 & (1.2) \\
\hline Ireland & 95.0 & $(0.7)$ & 96.4 & $(0.5)$ & 96.9 & $(0.4)$ & 97.5 & $(0.5)$ & 2.4 & $(0.9)$ \\
\hline Israel & $\mathrm{m}$ & $\mathrm{m}$ & $\mathrm{m}$ & $\mathrm{m}$ & $\mathrm{m}$ & $\mathrm{m}$ & $\mathrm{m}$ & $\mathrm{m}$ & $\mathrm{m}$ & $\mathrm{m}$ \\
\hline Italy & 94.9 & $(0.6)$ & 95.8 & $(0.6)$ & 96.7 & $(0.4)$ & 97.0 & $(0.4)$ & 2.1 & $(0.7)$ \\
\hline Japan & 80.5 & (0.9) & 87.5 & (1.0) & 86.4 & (1.0) & 90.5 & (0.8) & 10.0 & (1.3) \\
\hline Korea & 94.6 & (0.6) & 96.1 & $(0.7)$ & 97.0 & (0.5) & 98.5 & (0.3) & 4.0 & (0.6) \\
\hline Latvia & 91.9 & $(0.8)$ & 91.4 & $(0.9)$ & 93.4 & (0.7) & 93.5 & (0.7) & 1.6 & (1.2) \\
\hline Luxembourg & 93.0 & $(0.8)$ & 94.4 & $(0.7)$ & 96.4 & $(0.5)$ & 97.4 & (0.4) & 4.4 & $(0.9)$ \\
\hline Mexico & 88.0 & (0.9) & 91.5 & $(0.8)$ & 92.1 & $(0.7)$ & 92.8 & (0.7) & 4.7 & (1.1) \\
\hline Netherlands & 96.0 & $(0.5)$ & 96.6 & $(0.6)$ & 97.4 & $(0.5)$ & 98.7 & $(0.3)$ & 2.7 & $(0.5)$ \\
\hline New Zealand & 86.8 & $(1.2)$ & 91.4 & $(0.8)$ & 95.4 & $(0.7)$ & 95.8 & $(0.6)$ & 9.1 & $(1.2)$ \\
\hline Norway & 89.6 & $(0.9)$ & 92.1 & $(0.7)$ & 95.1 & (0.6) & 96.9 & $(0.5)$ & 7.3 & $(0.9)$ \\
\hline Poland & 92.0 & $(0.8)$ & 94.8 & $(0.8)$ & 95.6 & $(0.8)$ & 95.6 & (0.6) & 3.6 & $(1.0)$ \\
\hline Portugal & 96.3 & $(0.5)$ & 97.8 & $(0.5)$ & 97.5 & $(0.5)$ & 98.9 & $(0.3)$ & 2.6 & $(0.6)$ \\
\hline Slovak Republic & 87.0 & $(1.2)$ & 92.1 & $(0.7)$ & 93.4 & $(0.7)$ & 94.6 & $(0.6)$ & 7.6 & (1.4) \\
\hline Slovenia & 93.6 & $(0.7)$ & 95.5 & $(0.6)$ & 95.6 & $(0.6)$ & 96.7 & $(0.6)$ & 3.1 & $(0.9)$ \\
\hline Spain & 92.6 & $(0.6)$ & 95.6 & $(0.5)$ & 95.5 & (0.6) & 97.1 & $(0.5)$ & 4.4 & $(0.8)$ \\
\hline Sweden & 88.6 & $(1.0)$ & 92.1 & $(0.8)$ & 93.3 & $(0.7)$ & 96.3 & $(0.5)$ & 7.7 & (1.1) \\
\hline Switzerland & 95.5 & (0.6) & 96.9 & $(0.6)$ & 96.2 & (0.6) & 97.2 & $(0.5)$ & 1.7 & $(0.8)$ \\
\hline Turkey & 71.5 & (1.3) & 75.1 & (1.3) & 79.3 & (1.5) & 85.4 & (1.1) & 13.9 & (1.8) \\
\hline United Kingdom & 90.0 & $(0.8)$ & 93.2 & $(0.9)$ & 95.5 & $(0.5)$ & 96.8 & $(0.5)$ & 6.8 & $(1.0)$ \\
\hline United States & 86.6 & (1.0) & 90.8 & (0.8) & 93.1 & $(0.8)$ & 96.3 & $(0.5)$ & 9.6 & (1.2) \\
\hline OECD average & 90.6 & $(0.1)$ & 93.2 & $(0.1)$ & 94.4 & $(0.1)$ & 95.9 & $(0.1)$ & 5.3 & $(0.2)$ \\
\hline
\end{tabular}

\begin{tabular}{|c|c|c|c|c|c|c|c|c|c|c|}
\hline Albania & $\mathrm{m}$ & $\mathrm{m}$ & $\mathrm{m}$ & $\mathrm{m}$ & $\mathrm{m}$ & $\mathrm{m}$ & $\mathrm{m}$ & $\mathrm{m}$ & $\mathrm{m}$ & $\mathrm{m}$ \\
\hline Algeria & $\mathrm{m}$ & $\mathrm{m}$ & $\mathrm{m}$ & $\mathrm{m}$ & $\mathrm{m}$ & $\mathrm{m}$ & $\mathrm{m}$ & $\mathrm{m}$ & $\mathrm{m}$ & $\mathrm{m}$ \\
\hline Brazil & 91.4 & $(0.5)$ & 93.0 & $(0.5)$ & 94.3 & $(0.5)$ & 95.4 & $(0.4)$ & 4.0 & $(0.6)$ \\
\hline B-S-J-G (China) & 91.5 & (0.8) & 92.0 & (0.9) & 93.8 & (0.8) & 95.5 & $(0.5)$ & 4.0 & $(0.9)$ \\
\hline Bulgaria & 81.6 & (1.1) & 83.5 & (1.2) & 83.4 & (1.1) & 86.7 & $(0.9)$ & 5.2 & (1.5) \\
\hline CABA (Argentina) & $\mathrm{m}$ & $\mathrm{m}$ & $\mathrm{m}$ & $\mathrm{m}$ & $\mathrm{m}$ & $\mathrm{m}$ & $\mathrm{m}$ & $\mathrm{m}$ & $\mathrm{m}$ & $\mathrm{m}$ \\
\hline Colombia & 91.8 & $(0.8)$ & 91.9 & $(0.8)$ & 93.8 & $(0.6)$ & 94.7 & $(0.6)$ & 2.9 & $(1.0)$ \\
\hline Costa Rica & 94.2 & (0.6) & 95.3 & (0.6) & 95.5 & $(0.7)$ & 96.7 & $(0.5)$ & 2.5 & $(0.8)$ \\
\hline Croatia & 95.0 & $(0.6)$ & 95.1 & $(0.7)$ & 95.6 & (0.6) & 96.6 & $(0.4)$ & 1.6 & $(0.7)$ \\
\hline Cyprus* & $\mathrm{m}$ & $\mathrm{m}$ & $\mathrm{m}$ & $\mathrm{m}$ & $\mathrm{m}$ & $\mathrm{m}$ & $\mathrm{m}$ & $\mathrm{m}$ & $\mathrm{m}$ & $\mathrm{m}$ \\
\hline Dominican Republic & 85.1 & (1.3) & 87.4 & (1.1) & 88.4 & (1.1) & 92.2 & (1.0) & 7.1 & $(1.7)$ \\
\hline FYROM & $\mathrm{m}$ & $\mathrm{m}$ & $\mathrm{m}$ & $\mathrm{m}$ & $\mathrm{m}$ & $\mathrm{m}$ & $\mathrm{m}$ & $\mathrm{m}$ & $\mathrm{m}$ & $\mathrm{m}$ \\
\hline Georgia & $\mathrm{m}$ & $\mathrm{m}$ & $\mathrm{m}$ & $\mathrm{m}$ & $\mathrm{m}$ & $\mathrm{m}$ & $\mathrm{m}$ & $\mathrm{m}$ & $\mathrm{m}$ & $\mathrm{m}$ \\
\hline Hong Kong (China) & 59.0 & (1.5) & 68.1 & (1.4) & 73.2 & (1.3) & 80.6 & (1.3) & 21.7 & $(2.0)$ \\
\hline Indonesia & $\mathrm{m}$ & $\mathrm{m}$ & $\mathrm{m}$ & $\mathrm{m}$ & $\mathrm{m}$ & $\mathrm{m}$ & $\mathrm{m}$ & $\mathrm{m}$ & $\mathrm{m}$ & $\mathrm{m}$ \\
\hline Jordan & $\mathrm{m}$ & $\mathrm{m}$ & $\mathrm{m}$ & $\mathrm{m}$ & $\mathrm{m}$ & $\mathrm{m}$ & $\mathrm{m}$ & $\mathrm{m}$ & $\mathrm{m}$ & $\mathrm{m}$ \\
\hline Kosovo & $\mathrm{m}$ & $\mathrm{m}$ & $\mathrm{m}$ & $\mathrm{m}$ & $\mathrm{m}$ & $\mathrm{m}$ & $\mathrm{m}$ & $\mathrm{m}$ & $\mathrm{m}$ & $\mathrm{m}$ \\
\hline Lebanon & $\mathrm{m}$ & $\mathrm{m}$ & $\mathrm{m}$ & $\mathrm{m}$ & $\mathrm{m}$ & $\mathrm{m}$ & $\mathrm{m}$ & $\mathrm{m}$ & $\mathrm{m}$ & $\mathrm{m}$ \\
\hline Lithuania & 91.7 & $(0.7)$ & 94.0 & $(0.6)$ & 94.0 & $(0.8)$ & 95.3 & $(0.6)$ & 3.6 & $(0.9)$ \\
\hline Macao (China) & 63.4 & (1.5) & 69.0 & (1.4) & 74.5 & (1.5) & 81.0 & $(1.2)$ & 17.6 & $(2.1)$ \\
\hline Malta & $\mathrm{m}$ & $\mathrm{m}$ & $\mathrm{m}$ & $\mathrm{m}$ & $\mathrm{m}$ & $\mathrm{m}$ & $\mathrm{m}$ & $\mathrm{m}$ & $\mathrm{m}$ & $\mathrm{m}$ \\
\hline Moldova & $\mathrm{m}$ & $\mathrm{m}$ & $\mathrm{m}$ & $\mathrm{m}$ & $\mathrm{m}$ & $\mathrm{m}$ & $\mathrm{m}$ & $\mathrm{m}$ & $\mathrm{m}$ & $\mathrm{m}$ \\
\hline Montenegro & 89.5 & (0.9) & 91.5 & $(0.7)$ & 91.9 & $(0.8)$ & 94.3 & $(0.6)$ & 4.8 & $(1.2)$ \\
\hline Peru & 92.6 & $(0.7)$ & 92.8 & $(0.7)$ & 92.7 & $(0.7)$ & 93.5 & $(0.7)$ & 0.9 & $(0.9)$ \\
\hline Qatar & 81.3 & $(0.8)$ & 85.8 & $(0.7)$ & 89.1 & $(0.4)$ & 89.9 & $(0.6)$ & 8.6 & $(1.0)$ \\
\hline Romania & $\mathrm{m}$ & $\mathrm{m}$ & $\mathrm{m}$ & $\mathrm{m}$ & $\mathrm{m}$ & $\mathrm{m}$ & $\mathrm{m}$ & $\mathrm{m}$ & $\mathrm{m}$ & $\mathrm{m}$ \\
\hline Russia & 92.4 & $(0.9)$ & 94.8 & $(0.9)$ & 94.5 & $(0.7)$ & 96.6 & $(0.5)$ & 4.2 & (1.2) \\
\hline Singapore & 75.6 & $(1.2)$ & 84.6 & (1.0) & 89.3 & $(0.8)$ & 94.2 & $(0.5)$ & 18.6 & $(1.2)$ \\
\hline Chinese Taipei & 76.5 & (1.0) & 83.4 & $(0.9)$ & 86.4 & $(0.7)$ & 90.5 & $(0.7)$ & 13.9 & (1.3) \\
\hline Thailand & 94.0 & $(0.8)$ & 95.3 & $(0.6)$ & 94.6 & $(0.7)$ & 94.2 & $(0.5)$ & 0.3 & $(0.8)$ \\
\hline Trinidad and Tobago & $\mathrm{m}$ & $\mathrm{m}$ & $\mathrm{m}$ & $\mathrm{m}$ & $\mathrm{m}$ & $\mathrm{m}$ & $\mathrm{m}$ & $\mathrm{m}$ & $\mathrm{m}$ & $\mathrm{m}$ \\
\hline Tunisia & 82.0 & (1.1) & 86.7 & (1.1) & 87.8 & (0.9) & 89.5 & $(0.9)$ & 7.5 & (1.4) \\
\hline United Arab Emirates & 81.1 & (0.9) & 85.6 & $(0.9)$ & 86.8 & $(0.8)$ & 89.3 & (1.1) & 8.2 & (1.3) \\
\hline Uruguay & 92.5 & $(0.7)$ & 94.3 & (0.6) & 95.5 & $(0.6)$ & 97.2 & $(0.4)$ & 4.8 & $(0.9)$ \\
\hline Viet Nam & $\mathrm{m}$ & $\mathrm{m}$ & $\mathrm{m}$ & $\mathrm{m}$ & $\mathrm{m}$ & $\mathrm{m}$ & $\mathrm{m}$ & $\mathrm{m}$ & $\mathrm{m}$ & $\mathrm{m}$ \\
\hline Argentina** & $\mathrm{m}$ & $\mathrm{m}$ & $\mathrm{m}$ & $\mathrm{m}$ & $\mathrm{m}$ & $\mathrm{m}$ & $\mathrm{m}$ & $\mathrm{m}$ & $\mathrm{m}$ & $\mathrm{m}$ \\
\hline Kazakhstan** & $\mathrm{m}$ & $\mathrm{m}$ & $\mathrm{m}$ & $\mathrm{m}$ & $\mathrm{m}$ & $\mathrm{m}$ & $\mathrm{m}$ & $\mathrm{m}$ & $\mathrm{m}$ & $\mathrm{m}$ \\
\hline Malaysia** & 84.8 & (1.3) & 87.3 & $(1.2)$ & 88.7 & $(0.8)$ & 90.6 & $(0.7)$ & 5.8 & $(1.4)$ \\
\hline
\end{tabular}

1. ESCS refers to the PISA index of economic, social and cultural status.

Note: Values that are statistically significant are indicated in bold (see Annex A3).

* See note at the beginning of this Annex.

is too small to ensure comparability (see Annex A4).

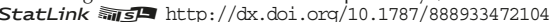


Table III.9.22 Parents' interest in their child's activities at school and student science performance

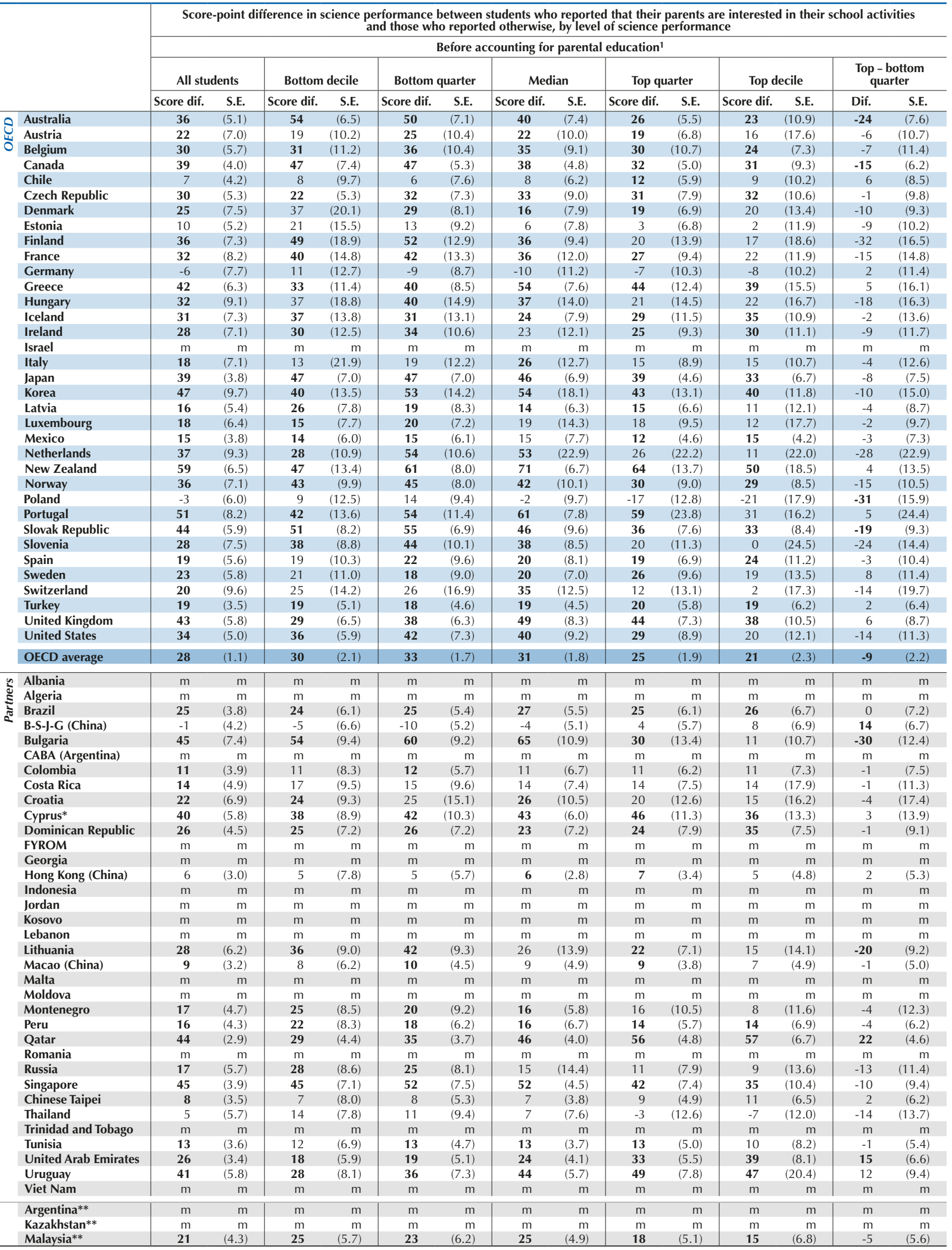

1. This model includes the number of years of completed education of the most educated parent and its squared value.

* See: Values that are statistically significant

** Coverage is too small to ensure comparability (see Annex A4).

StatLink न्ना S1 http://dx.doi.org/10.1787/888933472125 
Table III.9.22 Students' exposure to different types of bullying, by gender and socio-economic status

\begin{tabular}{|c|c|c|c|c|c|c|c|c|c|c|c|c|c|c|c|}
\hline & \multicolumn{14}{|c|}{$\begin{array}{c}\begin{array}{c}\text { Score-point difference in science performance between students who reported that their parents are interested in their school activities } \\
\text { and those who reported otherwise, by level of science performance }\end{array} \\
\end{array}$} \\
\hline & & \multicolumn{14}{|c|}{ After accounting for parental education 1} \\
\hline & & \multicolumn{2}{|c|}{ All students } & \multicolumn{2}{|c|}{ Bottom decile } & \multicolumn{2}{|c|}{ Bottom quarter } & \multicolumn{2}{|c|}{ Median } & \multicolumn{2}{|c|}{ Top quarter } & \multicolumn{2}{|c|}{ Top decile } & \multicolumn{2}{|c|}{$\begin{array}{l}\text { Top - bottom } \\
\text { quarter }\end{array}$} \\
\hline & & Score dif. & S.E. & Score dif. & S.E. & Score dif. & S.E. & Score dif. & S.E. & Score dif. & S.E. & Score dif. & S.E. & Score dif. & S.E. \\
\hline 0 & Australia & 28 & $(5.2)$ & 49 & $(9.2)$ & 34 & $(8.5)$ & 24 & $(7.9)$ & 20 & $(6.2)$ & 12 & $(7.2)$ & -15 & $(8.8)$ \\
\hline 0 & Austria & 17 & $(6.7)$ & 22 & (12.9) & 25 & $(12.1)$ & 13 & $(12.3)$ & 13 & (10.4) & 13 & $(12.4)$ & -13 & $(14.3)$ \\
\hline & Belgium & 24 & (5.5) & 30 & $(8.4)$ & 29 & $(6.5)$ & 25 & $(7.0)$ & 22 & (5.3) & 20 & $(7.7)$ & -6 & $(6.9)$ \\
\hline & Canada & 35 & (3.9) & 44 & (7.6) & 42 & $(4.1)$ & 34 & $(4.7)$ & 28 & (6.4) & 24 & (8.3) & -14 & (7.3) \\
\hline & Chile & 4 & $(4.2)$ & 5 & (10.1) & 5 & $(6.7)$ & 4 & (5.0) & 5 & (9.0) & 1 & (7.8) & 0 & $(9.9)$ \\
\hline & Czech Republic & 27 & (5.4) & 24 & $(5.9)$ & 31 & $(10.4)$ & 31 & (7.5) & 25 & (4.8) & 24 & (7.3) & -6 & $(10.8)$ \\
\hline & Denmark & 21 & $(7.6)$ & 34 & $(23.3)$ & 25 & (9.6) & 12 & (9.3) & 12 & $(6.0)$ & 17 & $(8.2)$ & -14 & (9.5) \\
\hline & Estonia & 9 & (5.1) & 24 & (12.6) & 10 & (6.7) & 7 & (6.4) & -1 & (7.5) & -2 & (9.6) & -11 & $(8.6)$ \\
\hline & Finland & 32 & $(7.0)$ & 48 & $(10.7)$ & 46 & $(12.3)$ & 31 & $(10.3)$ & 16 & (9.5) & 13 & $(14.9)$ & -30 & $(14.1)$ \\
\hline & France & 20 & (8.3) & 32 & $(20.2)$ & 26 & (16.7) & 19 & (15.9) & 15 & $(11.2)$ & 5 & (14.3) & -11 & (15.6) \\
\hline & Germany & -10 & $(7.9)$ & 3 & (27.6) & -12 & (11.7) & -16 & (10.7) & -12 & (11.5) & -14 & (18.2) & 0 & $(12.9)$ \\
\hline & Greece & 38 & (6.4) & 36 & (13.4) & 41 & (9.6) & 42 & (16.4) & 39 & (10.4) & 30 & (11.5) & -2 & $(12.7)$ \\
\hline & Hungary & 27 & $(8.9)$ & 43 & (14.6) & 39 & $(17.6)$ & 24 & (11.3) & 8 & (8.5) & 12 & $(8.3)$ & -31 & $(17.1)$ \\
\hline & Iceland & 23 & $(7.4)$ & 32 & $(12.0)$ & 21 & $(12.3)$ & 17 & (11.8) & 22 & (9.4) & 27 & $(14.2)$ & 0 & $(14.6)$ \\
\hline & Ireland & 25 & $(7.5)$ & 25 & (15.7) & 29 & $(10.8)$ & 22 & $(14.0)$ & 20 & $(12.2)$ & 26 & (16.6) & -9 & $(12.3)$ \\
\hline & Israel & $\mathrm{m}$ & $\mathrm{m}$ & $\mathrm{m}$ & $\mathrm{m}$ & $\mathrm{m}$ & $\mathrm{m}$ & $\mathrm{m}$ & $\mathrm{m}$ & $\mathrm{m}$ & $\mathrm{m}$ & $\mathrm{m}$ & $\mathrm{m}$ & $\mathrm{m}$ & $\mathrm{m}$ \\
\hline & Italy & 15 & $(7.2)$ & 12 & $(18.7)$ & 17 & $(12.3)$ & 24 & (9.4) & 14 & (7.5) & 15 & $(18.7)$ & -3 & $(12.7)$ \\
\hline & Japan & 31 & $(3.7)$ & 34 & $(8.4)$ & 35 & $(4.8)$ & 33 & (5.0) & 28 & (5.4) & 26 & $(10.2)$ & -7 & (6.0) \\
\hline & Korea & 42 & (9.7) & 41 & $(24.5)$ & 47 & $(13.0)$ & 51 & (18.9) & 31 & $(10.3)$ & 32 & (20.9) & -16 & (14.4) \\
\hline & Latvia & 16 & $(5.3)$ & 25 & (7.9) & 21 & (6.5) & 14 & (9.8) & 12 & $(7.5)$ & 13 & (9.1) & -9 & (8.7) \\
\hline & Luxembourg & 11 & $(6.2)$ & 19 & (11.6) & 20 & $(10.2)$ & 15 & (12.4) & 3 & (8.9) & -10 & (20.0) & -17 & $(12.0)$ \\
\hline & Mexico & 12 & (3.5) & 16 & (7.4) & 14 & $(6.2)$ & 11 & (6.1) & 9 & (5.6) & 11 & $(7.2)$ & -5 & $(8.1)$ \\
\hline & Netherlands & 32 & $(9.0)$ & 31 & (15.4) & 48 & (11.6) & 40 & (12.9) & 17 & $(14.7)$ & 7 & (13.4) & -31 & $(17.8)$ \\
\hline & New Zealand & 53 & $(6.5)$ & 46 & (16.0) & 56 & (10.7) & 65 & $(9.3)$ & 51 & $(12.3)$ & 40 & (17.6) & -5 & $(14.7)$ \\
\hline & Norway & 30 & $(7.3)$ & 40 & (12.9) & 41 & $(10.2)$ & 34 & (9.8) & 19 & $(9.2)$ & 18 & $(9.7)$ & -22 & (12.5) \\
\hline & Poland & -6 & (5.4) & 1 & $(8.8)$ & 3 & (7.9) & -3 & (9.9) & -12 & $(7.8)$ & -19 & $(12.1)$ & -15 & $(10.1)$ \\
\hline & Portugal & 49 & (9.6) & 57 & (19.6) & 58 & $(19.2)$ & 53 & $(17.0)$ & 38 & (18.8) & 20 & (10.5) & -20 & (24.9) \\
\hline & Slovak Republic & 34 & (5.4) & 44 & $(12.2)$ & 44 & $(6.2)$ & 37 & (10.5) & 26 & $(10.0)$ & 23 & $(9.7)$ & -17 & (10.5) \\
\hline & Slovenia & 26 & $(7.3)$ & 42 & $(8.3)$ & 42 & (10.4) & 31 & (11.4) & 15 & (18.9) & -3 & $(10.3)$ & -27 & (19.6) \\
\hline & Spain & 15 & $(5.8)$ & 17 & $(12.6)$ & 16 & $(11.4)$ & 10 & $(7.9)$ & 15 & $(6.4)$ & 17 & $(13.2)$ & 0 & (11.6) \\
\hline & Sweden & 17 & (5.7) & 23 & $(10.5)$ & 21 & (8.1) & 14 & $(8.0)$ & 17 & (9.6) & 12 & (8.8) & -4 & (10.7) \\
\hline & Switzerland & 20 & (9.5) & 23 & (11.6) & 28 & $(15.2)$ & 27 & $(14.2)$ & 7 & $(13.2)$ & 0 & $(14.0)$ & -22 & (20.0) \\
\hline & Turkey & 16 & (3.4) & 19 & $(7.1)$ & 18 & $(4.2)$ & 17 & $(4.9)$ & 15 & $(5.1)$ & 12 & (5.3) & -3 & (5.5) \\
\hline & United Kingdom & 40 & (5.7) & 35 & (7.4) & 39 & (6.3) & 43 & $(11.0)$ & 37 & $(7.2)$ & 36 & (8.3) & -2 & (8.8) \\
\hline & United States & 28 & $(4.8)$ & 38 & (10.9) & 38 & (6.0) & 33 & $(8.3)$ & 19 & (5.3) & 12 & (8.9) & -18 & (6.5) \\
\hline & OECD average & 24 & $(1.1)$ & 30 & (2.4) & 29 & (1.8) & 25 & (1.9) & 17 & (1.7) & 14 & $(2.1)$ & -12 & (2.2) \\
\hline
\end{tabular}

\begin{tabular}{|c|c|c|c|c|c|c|c|c|c|c|c|c|c|c|c|}
\hline 2 & Albania & $\mathrm{m}$ & $\mathrm{m}$ & $\mathrm{m}$ & $\mathrm{m}$ & $\mathrm{m}$ & $\mathrm{m}$ & $\mathrm{m}$ & $\mathrm{m}$ & $\mathrm{m}$ & $\mathrm{m}$ & $\mathrm{m}$ & $\mathrm{m}$ & $\mathrm{m}$ & $\mathrm{m}$ \\
\hline$\cong$ & Algeria & $\mathrm{m}$ & $\mathrm{m}$ & $\mathrm{m}$ & $\mathrm{m}$ & $\mathrm{m}$ & $\mathrm{m}$ & $\mathrm{m}$ & $\mathrm{m}$ & $\mathrm{m}$ & $\mathrm{m}$ & $\mathrm{m}$ & $\mathrm{m}$ & $\mathrm{m}$ & $\mathrm{m}$ \\
\hline ฐ & Brazil & 23 & (3.9) & 26 & (5.8) & 26 & (4.6) & 23 & (5.5) & 14 & (6.8) & 12 & (5.6) & -12 & (7.2) \\
\hline & B-S-J-G (China) & -4 & (3.8) & -5 & (7.0) & -9 & (6.6) & -6 & (5.6) & 0 & (5.3) & 2 & (6.9) & 9 & (7.2) \\
\hline & Bulgaria & 40 & (7.6) & 56 & $(8.2)$ & 54 & (9.9) & 51 & (9.5) & 24 & $(8.7)$ & 8 & (10.3) & -31 & (10.5) \\
\hline & CABA (Argentina) & $\mathrm{m}$ & $\mathrm{m}$ & $\mathrm{m}$ & $\mathrm{m}$ & $\mathrm{m}$ & $\mathrm{m}$ & $\mathrm{m}$ & $\mathrm{m}$ & $\mathrm{m}$ & $\mathrm{m}$ & $\mathrm{m}$ & $\mathrm{m}$ & $\mathrm{m}$ & $\mathrm{m}$ \\
\hline & Colombia & 10 & (3.6) & 11 & (8.0) & 11 & (4.3) & 12 & (8.1) & 9 & (6.6) & 4 & $(6.7)$ & -2 & (7.9) \\
\hline & Costa Rica & 11 & $(4.7)$ & 12 & $(8.2)$ & 12 & (4.9) & 11 & $(4.7)$ & 13 & (5.4) & 10 & (13.6) & 1 & (6.0) \\
\hline & Croatia & 20 & $(7.0)$ & 19 & (15.4) & 22 & (10.1) & 25 & (13.9) & 19 & (17.9) & 11 & (9.8) & -4 & (18.8) \\
\hline & Cyprus* & 41 & (5.9) & 42 & $(11.2)$ & 47 & (8.6) & 45 & $(9.8)$ & 42 & $(10.2)$ & 32 & $(18.2)$ & -5 & (11.9) \\
\hline & Dominican Republic & 24 & (4.4) & 25 & $(7.8)$ & 24 & (6.0) & 21 & (5.1) & 19 & (6.9) & 25 & $(7.2)$ & -5 & (8.1) \\
\hline & FYROM & $\mathrm{m}$ & $\mathrm{m}$ & $\mathrm{m}$ & $\mathrm{m}$ & $\mathrm{m}$ & $\mathrm{m}$ & $\mathrm{m}$ & $\mathrm{m}$ & $\mathrm{m}$ & $\mathrm{m}$ & $\mathrm{m}$ & $\mathrm{m}$ & $\mathrm{m}$ & $\mathrm{m}$ \\
\hline & Georgia & $\mathrm{m}$ & $\mathrm{m}$ & $\mathrm{m}$ & $\mathrm{m}$ & $\mathrm{m}$ & $\mathrm{m}$ & $\mathrm{m}$ & $\mathrm{m}$ & $\mathrm{m}$ & $\mathrm{m}$ & $\mathrm{m}$ & $\mathrm{m}$ & $\mathrm{m}$ & $\mathrm{m}$ \\
\hline & Hong Kong (China) & 1 & (2.9) & 1 & (7.7) & -1 & (5.6) & 1 & (3.3) & 3 & (3.0) & 1 & (4.5) & 3 & (5.8) \\
\hline & Indonesia & $\mathrm{m}$ & $\mathrm{m}$ & $\mathrm{m}$ & $\mathrm{m}$ & $\mathrm{m}$ & $\mathrm{m}$ & $\mathrm{m}$ & $\mathrm{m}$ & $\mathrm{m}$ & $\mathrm{m}$ & $\mathrm{m}$ & $\mathrm{m}$ & $\mathrm{m}$ & $\mathrm{m}$ \\
\hline & Jordan & $\mathrm{m}$ & $\mathrm{m}$ & $\mathrm{m}$ & $\mathrm{m}$ & $\mathrm{m}$ & $\mathrm{m}$ & $\mathrm{m}$ & $\mathrm{m}$ & $\mathrm{m}$ & $\mathrm{m}$ & $\mathrm{m}$ & $\mathrm{m}$ & $\mathrm{m}$ & $\mathrm{m}$ \\
\hline & Kosovo & $\mathrm{m}$ & $\mathrm{m}$ & $\mathrm{m}$ & $\mathrm{m}$ & $\mathrm{m}$ & $\mathrm{m}$ & $\mathrm{m}$ & $\mathrm{m}$ & $\mathrm{m}$ & $\mathrm{m}$ & $\mathrm{m}$ & $\mathrm{m}$ & $\mathrm{m}$ & $\mathrm{m}$ \\
\hline & Lebanon & $\mathrm{m}$ & $\mathrm{m}$ & $\mathrm{m}$ & $\mathrm{m}$ & $\mathrm{m}$ & $\mathrm{m}$ & $\mathrm{m}$ & $\mathrm{m}$ & $\mathrm{m}$ & $\mathrm{m}$ & $\mathrm{m}$ & $\mathrm{m}$ & $\mathrm{m}$ & $\mathrm{m}$ \\
\hline & Lithuania & 25 & (6.6) & 39 & (8.5) & 38 & (8.9) & 21 & (9.3) & 16 & (9.6) & 7 & (14.4) & -21 & (11.6) \\
\hline & Macao (China) & 7 & (3.3) & 6 & (8.1) & 7 & (4.9) & 8 & (5.6) & 6 & (4.1) & 5 & (6.4) & -2 & (5.7) \\
\hline & Malta & $\mathrm{m}$ & $\mathrm{m}$ & $\mathrm{m}$ & $\mathrm{m}$ & $\mathrm{m}$ & $\mathrm{m}$ & $\mathrm{m}$ & $\mathrm{m}$ & $\mathrm{m}$ & $\mathrm{m}$ & $\mathrm{m}$ & $\mathrm{m}$ & $\mathrm{m}$ & $\mathrm{m}$ \\
\hline & Moldova & $\mathrm{m}$ & $\mathrm{m}$ & $\mathrm{m}$ & $\mathrm{m}$ & $\mathrm{m}$ & $\mathrm{m}$ & $\mathrm{m}$ & $\mathrm{m}$ & $\mathrm{m}$ & $\mathrm{m}$ & $\mathrm{m}$ & $\mathrm{m}$ & $\mathrm{m}$ & $\mathrm{m}$ \\
\hline & Montenegro & 16 & $(4.8)$ & 23 & (9.2) & 19 & (7.3) & 14 & (6.2) & 14 & (11.1) & 5 & (8.9) & -5 & (12.1) \\
\hline & Peru & 16 & $(4.3)$ & 20 & (8.8) & 20 & (7.0) & 16 & (6.8) & 12 & (5.5) & 10 & (8.5) & -8 & $(7.2)$ \\
\hline & Qatar & 42 & (2.9) & 29 & (5.3) & 35 & (3.7) & 42 & (3.6) & 47 & (4.6) & 47 & (6.9) & 12 & (4.3) \\
\hline & Romania & $\mathrm{m}$ & $\mathrm{m}$ & $\mathrm{m}$ & $\mathrm{m}$ & $\mathrm{m}$ & $\mathrm{m}$ & $\mathrm{m}$ & $\mathrm{m}$ & $\mathrm{m}$ & $\mathrm{m}$ & $\mathrm{m}$ & $\mathrm{m}$ & $\mathrm{m}$ & $\mathrm{m}$ \\
\hline & Russia & 13 & (5.6) & 28 & (8.4) & 22 & (6.8) & 9 & (9.1) & 4 & $(8.7)$ & 3 & (7.8) & -19 & $(10.0)$ \\
\hline & Singapore & 33 & (3.9) & 42 & (8.6) & 41 & $(6.0)$ & 35 & (4.9) & 28 & (6.4) & 19 & (8.6) & -12 & (8.4) \\
\hline & Chinese Taipei & 0 & (3.4) & 1 & (5.7) & -4 & (5.1) & -1 & (5.1) & 0 & $(6.2)$ & -1 & (5.1) & 3 & $(7.2)$ \\
\hline & Thailand & 7 & (5.8) & 14 & (10.3) & 9 & (7.1) & 6 & (7.3) & 0 & (9.3) & -1 & (7.3) & -10 & (10.3) \\
\hline & Trinidad and Tobago & $\mathrm{m}$ & $\mathrm{m}$ & $\mathrm{m}$ & $\mathrm{m}$ & $\mathrm{m}$ & $\mathrm{m}$ & $\mathrm{m}$ & $\mathrm{m}$ & $\mathrm{m}$ & $\mathrm{m}$ & $\mathrm{m}$ & $\mathrm{m}$ & $\mathrm{m}$ & $\mathrm{m}$ \\
\hline & Tunisia & 12 & (3.7) & 13 & (7.5) & 13 & $(4.8)$ & 11 & $(5.2)$ & 10 & $(4.8)$ & 6 & $(8.0)$ & -3 & (6.2) \\
\hline & United Arab Emirates & 23 & (3.3) & 19 & $(4.9)$ & 18 & $(5.0)$ & 22 & (5.5) & 27 & $(5.0)$ & 27 & (6.4) & 9 & $(6.2)$ \\
\hline & Uruguay & 35 & (5.4) & 30 & $(9.7)$ & 37 & (6.5) & 38 & $(5.8)$ & 33 & (6.9) & 30 & (11.1) & -4 & (7.9) \\
\hline & Viet Nam & $\mathrm{m}$ & $\mathrm{m}$ & $\mathrm{m}$ & $\mathrm{m}$ & $\mathrm{m}$ & $\mathrm{m}$ & $\mathrm{m}$ & $\mathrm{m}$ & $\mathrm{m}$ & $\mathrm{m}$ & $\mathrm{m}$ & $\mathrm{m}$ & $\mathrm{m}$ & $\mathrm{m}$ \\
\hline & Argentina** & $\mathrm{m}$ & $\mathrm{m}$ & $\mathrm{m}$ & $\mathrm{m}$ & $\mathrm{m}$ & $\mathrm{m}$ & $\mathrm{m}$ & $\mathrm{m}$ & $\mathrm{m}$ & $\mathrm{m}$ & $\mathrm{m}$ & $\mathrm{m}$ & $\mathrm{m}$ & $\mathrm{m}$ \\
\hline & Kazakhstan** & $\mathrm{m}$ & $\mathrm{m}$ & $\mathrm{m}$ & $\mathrm{m}$ & $\mathrm{m}$ & $\mathrm{m}$ & $\mathrm{m}$ & $\mathrm{m}$ & $\mathrm{m}$ & $\mathrm{m}$ & $\mathrm{m}$ & $\mathrm{m}$ & $\mathrm{m}$ & $\mathrm{m}$ \\
\hline & Malaysia** & 20 & $(4.3)$ & 26 & (5.8) & 23 & $(7.0)$ & 21 & $(6.3)$ & 16 & $(4.1)$ & 14 & $(10.2)$ & -7 & (6.9) \\
\hline
\end{tabular}

1. This model includes the number of years of completed education of the most educated parent and its squared value.

Note: Values that are statistically significant are indicated in bold (see Annex A3).

* See note at the beginning of this Annex.

** Coverage is too small to ensure comparability (see Annex A4).

StatLink त्गाड़ http://dx.doj.org/10.1787/888933472125 
[Part 1/1]

Table III.9.23 Parents who initiate talks with their child's teacher, by parents' socio-economic status gender and immigrant background

Based on parents' self-reports

\begin{tabular}{|c|c|c|c|c|c|c|c|c|c|c|c|}
\hline & & \multicolumn{10}{|c|}{ Likelihood that parents discussed their child's progress with the teacher on their own initiative, by parents' characteristics } \\
\hline & & \multicolumn{10}{|c|}{ Before accounting for student science performance } \\
\hline & & \multicolumn{2}{|c|}{$\begin{array}{l}\text { Respondent is the mother } \\
\text { or female guardian }\end{array}$} & \multicolumn{2}{|c|}{$\begin{array}{c}\text { Respondent } \\
\text { is foreign born }\end{array}$} & \multicolumn{2}{|c|}{$\begin{array}{l}\text { Respondent has } \\
\text { a university degree }\end{array}$} & \multicolumn{2}{|c|}{$\begin{array}{l}\text { Respondent is in the top } \\
\text { two income categories }\end{array}$} & \multicolumn{2}{|c|}{$\begin{array}{c}\text { Respondent is } \\
\text { in the top two classes } \\
\text { of education expenditure }\end{array}$} \\
\hline & & Odds ratio & S.E. & Odds ratio & S.E. & Odds ratio & S.E. & Odds ratio & S.E. & Odds ratio & S.E. \\
\hline \multirow{14}{*}{ త్ర } & Belgium (Flemish) & 1.01 & $(0.1)$ & 1.32 & $(0.1)$ & 1.01 & $(0.1)$ & 1.02 & $(0.1)$ & 1.25 & $(0.1)$ \\
\hline & Chile & 1.13 & $(0.1)$ & 1.21 & $(0.3)$ & 0.82 & $(0.1)$ & 0.76 & $(0.0)$ & 0.73 & $(0.1)$ \\
\hline & France & 1.08 & $(0.1)$ & 1.22 & $(0.1)$ & 1.29 & $(0.1)$ & 1.10 & $(0.1)$ & 1.40 & $(0.1)$ \\
\hline & Germany & 1.18 & $(0.1)$ & 0.91 & $(0.1)$ & 0.97 & $(0.1)$ & 0.82 & $(0.1)$ & 1.33 & $(0.1)$ \\
\hline & Ireland & 0.95 & $(0.1)$ & 1.02 & $(0.1)$ & 1.05 & $(0.1)$ & $\mathrm{m}$ & $\mathrm{m}$ & 1.41 & $(0.2)$ \\
\hline & Italy & 0.97 & $(0.1)$ & 1.12 & $(0.1)$ & 1.52 & $(0.1)$ & $\mathrm{m}$ & $\mathrm{m}$ & 1.68 & $(0.1)$ \\
\hline & Korea & 1.57 & $(0.1)$ & 0.45 & $(0.6)$ & 1.81 & $(0.2)$ & 1.71 & $(0.1)$ & 1.77 & $(0.1)$ \\
\hline & Luxembourg & 1.04 & $(0.1)$ & 0.81 & $(0.1)$ & 1.12 & $(0.1)$ & 1.19 & $(0.1)$ & 1.20 & $(0.1)$ \\
\hline & Mexico & 0.95 & $(0.1)$ & 1.34 & $(0.4)$ & 0.83 & $(0.1)$ & 0.92 & $(0.1)$ & 1.05 & $(0.3)$ \\
\hline & Portugal & 1.43 & $(0.1)$ & 0.89 & $(0.1)$ & 1.04 & $(0.1)$ & 0.99 & $(0.1)$ & 1.81 & $(0.7)$ \\
\hline & Spain & 1.24 & $(0.1)$ & 0.86 & $(0.1)$ & 0.98 & $(0.1)$ & 0.95 & $(0.1)$ & 1.31 & $(0.2)$ \\
\hline & UK (Scotland) & 0.73 & $(0.1)$ & 1.02 & $(0.2)$ & 1.15 & $(0.2)$ & 0.87 & $(0.1)$ & 0.75 & $(0.4)$ \\
\hline & OECD average & 1.11 & $(0.0)$ & 1.01 & $(0.1)$ & 1.13 & $(0.0)$ & 1.03 & $(0.0)$ & 1.31 & $(0.1)$ \\
\hline & Average-18 & 1.14 & $(0.0)$ & 0.98 & $(0.1)$ & 1.11 & $(0.0)$ & 0.98 & $(0.0)$ & 1.25 & $(0.1)$ \\
\hline \multirow{6}{*}{ 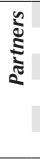 } & Croatia & 1.03 & $(0.1)$ & 1.08 & $(0.1)$ & 1.01 & $(0.1)$ & 1.06 & $(0.1)$ & 1.40 & $(0.1)$ \\
\hline & Dominican Republic & 1.20 & $(0.1)$ & 0.51 & $(0.2)$ & 0.92 & $(0.1)$ & 0.84 & $(0.1)$ & 0.79 & $(0.1)$ \\
\hline & Georgia & 1.53 & $(0.2)$ & 0.81 & $(0.3)$ & 0.94 & $(0.1)$ & 0.69 & $(0.1)$ & 1.00 & $(0.1)$ \\
\hline & Hong Kong (China) & 1.23 & $(0.1)$ & 1.06 & $(0.1)$ & 0.98 & $(0.1)$ & 0.97 & $(0.1)$ & 1.11 & $(0.1)$ \\
\hline & Macao (China) & 1.18 & $(0.1)$ & 1.03 & $(0.1)$ & 1.26 & $(0.1)$ & 0.91 & $(0.1)$ & 1.36 & $(0.1)$ \\
\hline & Malta & 1.09 & $(0.1)$ & 0.95 & $(0.1)$ & 1.22 & $(0.1)$ & 0.88 & $(0.1)$ & 1.17 & $(0.1)$ \\
\hline
\end{tabular}

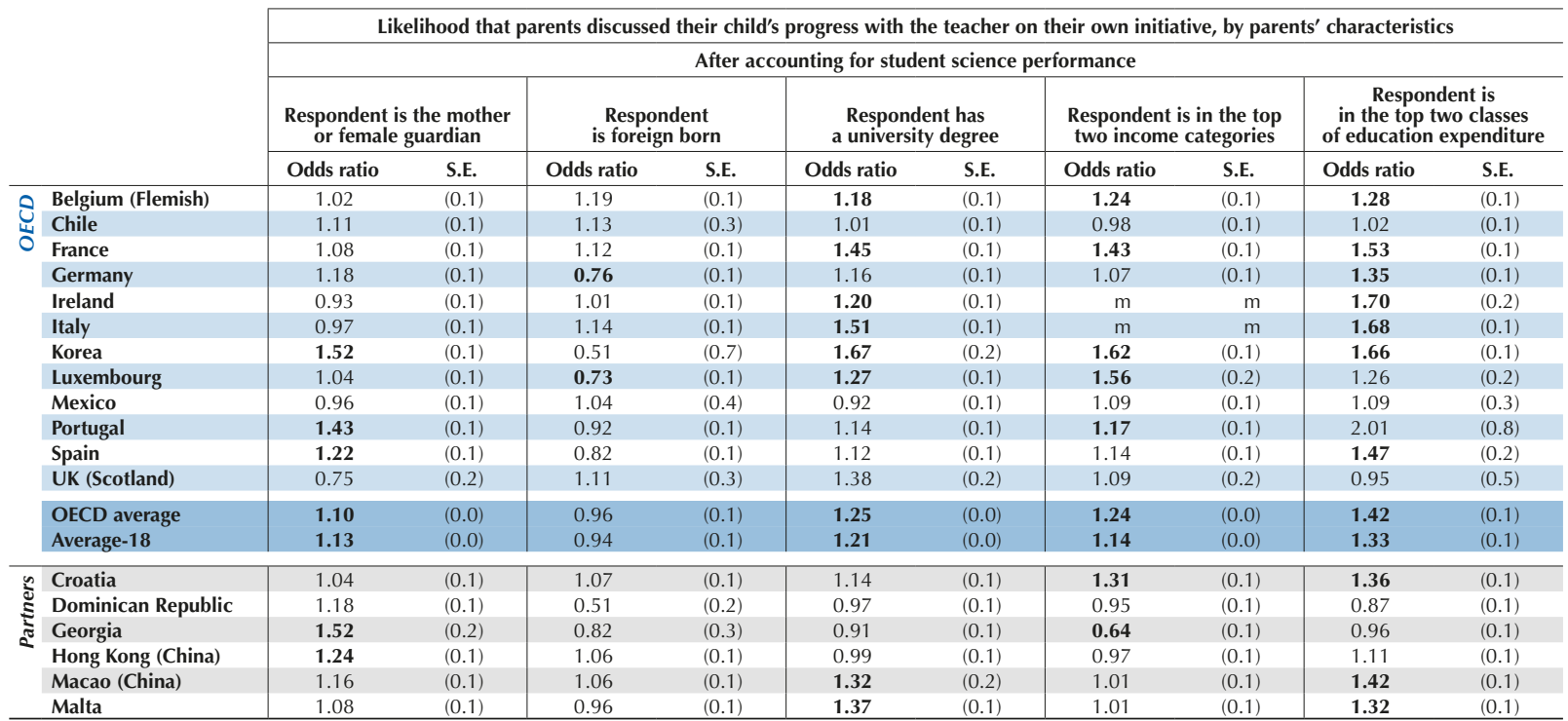

Notes: Students' parents were asked to report their family income before taxes and their total expenditures in education. Their answers were coded in six income classes, defined independently by each country. Low(high)-income students are students in the bottom(top) two categories of family income. The same classification was applied to expenditure in education.

Values that are statistically significant are indicated in bold (see Annex A3).

StatLink त्राIst http://dx.doi.org/10.1787/888933472130 
Table III.9.24 Parents' interest in their child's activities at school and student well-being outcomes

\begin{tabular}{|c|c|c|c|c|c|c|c|c|c|c|c|c|c|c|c|c|}
\hline & \multicolumn{16}{|c|}{ Increased likelihood of students reporting the following well-being outcomes if their parents are interested in their school activities } \\
\hline & \multicolumn{8}{|c|}{ Before accounting for students' socio-economic status } & \multicolumn{8}{|c|}{ After accounting for students' socio-economic status } \\
\hline & \multicolumn{2}{|c|}{\begin{tabular}{|c|} 
Not satisfied \\
(Students who \\
reported 0 to \\
4 on the life \\
satisfaction scale) \\
\end{tabular}} & \multicolumn{2}{|c|}{$\begin{array}{c}\text { Very satisfied } \\
\text { (Students who } \\
\text { reported 9 or } \\
10 \text { on the life } \\
\text { satisfaction scale) }\end{array}$} & \multicolumn{2}{|c|}{$\begin{array}{l}\text { I feel lonely } \\
\text { at school }\end{array}$} & \multicolumn{2}{|c|}{$\begin{array}{l}\text { I want top grades } \\
\text { in most or all } \\
\text { of my courses }\end{array}$} & \multicolumn{2}{|c|}{$\begin{array}{c}\text { Not satisfied } \\
\text { (Students who } \\
\text { reported 0 to } \\
4 \text { on the life } \\
\text { satisfaction scale) }\end{array}$} & \multicolumn{2}{|c|}{\begin{tabular}{|c|} 
Very satisfied \\
(Students who \\
reported 9 or \\
10 on the life \\
satisfaction scale) \\
\end{tabular}} & \multicolumn{2}{|c|}{$\begin{array}{l}\text { I feel lonely } \\
\text { at school }\end{array}$} & \multicolumn{2}{|c|}{$\begin{array}{c}\text { I want top grades } \\
\text { in most or all } \\
\text { of my courses }\end{array}$} \\
\hline & $\begin{array}{l}\text { Odds } \\
\text { ratio }\end{array}$ & S.E. & $\begin{array}{l}\text { Odds } \\
\text { ratio }\end{array}$ & S.E. & $\begin{array}{l}\text { Odds } \\
\text { ratio }\end{array}$ & S.E. & $\begin{array}{l}\text { Odds } \\
\text { ratio }\end{array}$ & S.E. & $\begin{array}{l}\text { Odds } \\
\text { ratio }\end{array}$ & S.E. & $\begin{array}{l}\text { Odds } \\
\text { ratio }\end{array}$ & S.E. & $\begin{array}{l}\text { Odds } \\
\text { ratio }\end{array}$ & S.E. & $\begin{array}{l}\text { Odds } \\
\text { ratio }\end{array}$ & S.E. \\
\hline Australia & $\mathrm{m}$ & $\mathrm{m}$ & $\mathrm{m}$ & $\mathrm{m}$ & 0.45 & $(0.05)$ & 2.52 & $(0.25)$ & $\mathrm{m}$ & $\mathrm{m}$ & $\mathrm{m}$ & $\mathrm{m}$ & 0.49 & $(0.05)$ & 2.20 & $(0.22)$ \\
\hline Austria & 0.22 & $(0.04)$ & 2.84 & $(0.44)$ & 0.54 & $(0.09)$ & 1.51 & $(0.22)$ & 0.24 & $(0.04)$ & 2.78 & $(0.42)$ & 0.56 & $(0.09)$ & 1.58 & $(0.23)$ \\
\hline$\widehat{\widehat{O}}$ Belgium ${ }^{1}$ & 0.17 & $(0.03)$ & 3.57 & $(0.84)$ & 0.46 & $(0.06)$ & 1.34 & $(0.13)$ & 0.18 & $(0.04)$ & 3.54 & $(0.82)$ & 0.51 & $(0.07)$ & 1.42 & $(0.14)$ \\
\hline Canada & $\mathrm{m}$ & $\mathrm{m}$ & $\mathrm{m}$ & $\mathrm{m}$ & 0.39 & $(0.03)$ & 2.39 & $(0.19)$ & $\mathrm{m}$ & $\mathrm{m}$ & $\mathrm{m}$ & $\mathrm{m}$ & 0.42 & $(0.04)$ & 1.96 & $(0.16)$ \\
\hline Chile & 0.56 & $(0.07)$ & 1.16 & $(0.12)$ & 0.75 & $(0.10)$ & 2.81 & $(0.42)$ & 0.58 & $(0.08)$ & 1.15 & $(0.12)$ & 0.76 & $(0.10)$ & 2.79 & $(0.42)$ \\
\hline Czech Republic & 0.33 & $(0.03)$ & 1.69 & $(0.22)$ & 0.54 & $(0.07)$ & 1.95 & $(0.18)$ & 0.35 & $(0.04)$ & 1.71 & $(0.22)$ & 0.58 & $(0.07)$ & 1.91 & $(0.18)$ \\
\hline Denmark & $\mathrm{m}$ & $\mathrm{m}$ & $\mathrm{m}$ & $\mathrm{m}$ & 0.53 & $(0.08)$ & 1.97 & $(0.28)$ & $\mathrm{m}$ & $\mathrm{m}$ & $\mathrm{m}$ & $\mathrm{m}$ & 0.56 & $(0.09)$ & 1.75 & $(0.26)$ \\
\hline Estonia & 0.29 & $(0.04)$ & 1.99 & $(0.24)$ & 0.49 & $(0.05)$ & 2.74 & $(0.47)$ & 0.31 & $(0.04)$ & 1.89 & $(0.23)$ & 0.50 & $(0.05)$ & 2.62 & $(0.46)$ \\
\hline Finland & 0.20 & $(0.03)$ & 2.50 & $(0.44)$ & 0.33 & $(0.05)$ & 1.79 & $(0.26)$ & 0.22 & $(0.03)$ & 2.43 & $(0.42)$ & 0.35 & $(0.05)$ & 1.57 & $(0.23)$ \\
\hline France & 0.19 & $(0.03)$ & 2.22 & $(0.38)$ & 0.41 & $(0.06)$ & 2.29 & $(0.32)$ & 0.22 & $(0.04)$ & 2.16 & $(0.36)$ & 0.44 & $(0.07)$ & 2.13 & $(0.31)$ \\
\hline Germany & 0.21 & $(0.03)$ & 2.55 & $(0.49)$ & 0.48 & $(0.08)$ & 2.16 & $(0.34)$ & 0.21 & $(0.03)$ & 2.47 & $(0.48)$ & 0.47 & $(0.08)$ & 2.18 & $(0.35)$ \\
\hline Greece & 0.30 & (0.04) & 1.87 & $(0.31)$ & 0.34 & $(0.05)$ & 2.28 & $(0.34)$ & 0.33 & $(0.05)$ & 1.98 & $(0.33)$ & 0.35 & $(0.06)$ & 2.02 & $(0.29)$ \\
\hline Hungary & 0.20 & $(0.03)$ & 1.49 & $(0.32)$ & 0.43 & $(0.06)$ & 2.62 & $(0.44)$ & 0.22 & $(0.04)$ & 1.46 & $(0.32)$ & 0.44 & $(0.06)$ & 2.50 & $(0.42)$ \\
\hline Iceland & 0.24 & $(0.04)$ & 1.74 & $(0.28)$ & 0.61 & $(0.12)$ & 3.66 & (1.00) & 0.30 & $(0.05)$ & 1.61 & $(0.27)$ & 0.68 & $(0.13)$ & 2.85 & $(0.81)$ \\
\hline Ireland & 0.30 & $(0.05)$ & 1.45 & $(0.25)$ & 0.49 & $(0.09)$ & 2.38 & $(0.48)$ & 0.32 & $(0.05)$ & 1.51 & $(0.27)$ & 0.49 & $(0.09)$ & 2.15 & $(0.44)$ \\
\hline Israel & $\mathrm{m}$ & $\mathrm{m}$ & $\mathrm{m}$ & $\mathrm{m}$ & $\mathrm{m}$ & $\mathrm{m}$ & $\mathrm{m}$ & $\mathrm{m}$ & $\mathrm{m}$ & $\mathrm{m}$ & $\mathrm{m}$ & $\mathrm{m}$ & $\mathrm{m}$ & $\mathrm{m}$ & $\mathrm{m}$ & $\mathrm{m}$ \\
\hline Italy & 0.29 & $(0.05)$ & 1.42 & $(0.24)$ & 0.54 & $(0.10)$ & 2.17 & $(0.39)$ & 0.31 & $(0.05)$ & 1.44 & $(0.24)$ & 0.55 & $(0.10)$ & 2.17 & $(0.38)$ \\
\hline Japan & 0.36 & $(0.03)$ & 1.71 & $(0.16)$ & 0.46 & $(0.05)$ & 1.75 & $(0.13)$ & 0.38 & $(0.03)$ & 1.75 & $(0.17)$ & 0.50 & $(0.05)$ & 1.52 & $(0.12)$ \\
\hline Korea & 0.21 & $(0.03)$ & 1.96 & $(0.49)$ & 0.34 & $(0.07)$ & 1.94 & $(0.31)$ & 0.23 & $(0.04)$ & 2.07 & $(0.48)$ & 0.35 & $(0.07)$ & 1.43 & $(0.25)$ \\
\hline Latvia & 0.39 & $(0.06)$ & 1.10 & $(0.15)$ & 0.58 & $(0.08)$ & 4.02 & $(0.58)$ & 0.40 & $(0.06)$ & 1.10 & $(0.15)$ & 0.59 & $(0.08)$ & 3.87 & $(0.57)$ \\
\hline Luxembourg & 0.21 & $(0.03)$ & 2.10 & $(0.39)$ & 0.46 & $(0.06)$ & 3.18 & $(0.39)$ & 0.22 & $(0.03)$ & 2.00 & $(0.37)$ & 0.48 & $(0.06)$ & 3.24 & $(0.41)$ \\
\hline Mexico & 0.49 & $(0.07)$ & 1.11 & $(0.10)$ & 0.89 & $(0.14)$ & 11.24 & (1.73) & 0.53 & $(0.08)$ & 1.13 & $(0.10)$ & 0.92 & $(0.14)$ & 10.70 & (1.59) \\
\hline Netherlands & 0.23 & $(0.06)$ & 1.37 & $(0.30)$ & 0.37 & $(0.09)$ & 3.29 & $(0.68)$ & 0.26 & $(0.06)$ & 1.56 & $(0.35)$ & 0.40 & $(0.09)$ & 3.20 & $(0.65)$ \\
\hline New Zealand & $\mathrm{m}$ & $\mathrm{m}$ & $\mathrm{m}$ & $\mathrm{m}$ & 0.48 & $(0.05)$ & 2.69 & $(0.42)$ & $\mathrm{m}$ & $\mathrm{m}$ & $\mathrm{m}$ & $\mathrm{m}$ & 0.50 & $(0.06)$ & 2.20 & $(0.35)$ \\
\hline Norway & $\mathrm{m}$ & $\mathrm{m}$ & $\mathrm{m}$ & $\mathrm{m}$ & 0.42 & $(0.06)$ & 2.76 & $(0.34)$ & $\mathrm{m}$ & $\mathrm{m}$ & $\mathrm{m}$ & $\mathrm{m}$ & 0.45 & $(0.07)$ & 2.27 & $(0.31)$ \\
\hline Poland & 0.25 & $(0.03)$ & 2.41 & $(0.43)$ & 0.62 & $(0.11)$ & 1.50 & $(0.20)$ & 0.26 & $(0.04)$ & 2.30 & $(0.42)$ & 0.62 & $(0.11)$ & 1.47 & $(0.20)$ \\
\hline Portugal & 0.18 & $(0.04)$ & 1.86 & $(0.43)$ & 0.39 & $(0.10)$ & 4.84 & $(1.18)$ & 0.19 & $(0.04)$ & 2.06 & $(0.47)$ & 0.42 & $(0.11)$ & 4.06 & $(0.98)$ \\
\hline Slovak Republic & 0.30 & $(0.04)$ & 1.47 & $(0.17)$ & 0.48 & $(0.06)$ & 2.09 & $(0.23)$ & 0.33 & $(0.04)$ & 1.46 & $(0.17)$ & 0.52 & $(0.07)$ & 1.79 & $(0.20)$ \\
\hline Slovenia & 0.31 & $(0.05)$ & 1.21 & $(0.16)$ & 0.55 & $(0.08)$ & 1.75 & $(0.25)$ & 0.32 & $(0.05)$ & 1.25 & $(0.17)$ & 0.58 & $(0.09)$ & 1.70 & $(0.25)$ \\
\hline Spain & 0.24 & $(0.04)$ & 2.09 & $(0.33)$ & 0.47 & $(0.08)$ & 2.30 & $(0.34)$ & 0.26 & $(0.04)$ & 2.05 & $(0.32)$ & 0.48 & $(0.08)$ & 2.17 & $(0.32)$ \\
\hline Sweden & $\mathrm{m}$ & $\mathrm{m}$ & $\mathrm{m}$ & $\mathrm{m}$ & 0.85 & $(0.12)$ & 1.53 & $(0.20)$ & $\mathrm{m}$ & $\mathrm{m}$ & $\mathrm{m}$ & $\mathrm{m}$ & 0.88 & $(0.13)$ & 1.39 & $(0.18)$ \\
\hline Switzerland & 0.15 & $(0.03)$ & 1.62 & $(0.31)$ & 0.40 & $(0.09)$ & 2.24 & $(0.53)$ & 0.16 & $(0.04)$ & 1.63 & $(0.31)$ & 0.42 & $(0.10)$ & 2.27 & $(0.54)$ \\
\hline Turkey & 0.45 & $(0.04)$ & 2.14 & $(0.26)$ & 0.96 & $(0.07)$ & 2.92 & $(0.36)$ & 0.46 & $(0.04)$ & 2.26 & $(0.28)$ & 1.01 & $(0.07)$ & 2.80 & $(0.35)$ \\
\hline United Kingdom & 0.26 & $(0.03)$ & 1.74 & $(0.28)$ & 0.42 & $(0.06)$ & 3.70 & $(0.74)$ & 0.28 & $(0.03)$ & 1.74 & $(0.28)$ & 0.43 & $(0.06)$ & 3.08 & $(0.63)$ \\
\hline United States & 0.27 & $(0.03)$ & 2.03 & $(0.27)$ & 0.44 & $(0.04)$ & 2.52 & $(0.49)$ & 0.29 & $(0.04)$ & 2.06 & $(0.28)$ & 0.45 & $(0.05)$ & 2.41 & $(0.49)$ \\
\hline OECD average & 0.28 & $(0.01)$ & 1.87 & $(0.07)$ & 0.51 & $(0.01)$ & 2.73 & $(0.09)$ & 0.30 & $(0.01)$ & 1.88 & $(0.07)$ & 0.53 & $(0.01)$ & 2.51 & $(0.08)$ \\
\hline
\end{tabular}

\begin{tabular}{|c|c|c|c|c|c|c|c|c|c|c|c|c|c|c|c|c|c|}
\hline$\approx$ & Albania & $\mathrm{m}$ & $\mathrm{m}$ & $\mathrm{m}$ & $\mathrm{m}$ & $\mathrm{m}$ & $\mathrm{m}$ & $\mathrm{m}$ & $\mathrm{m}$ & $\mathrm{m}$ & $\mathrm{m}$ & $\mathrm{m}$ & $\mathrm{m}$ & $\mathrm{m}$ & $\mathrm{m}$ & $\mathrm{m}$ & $\mathrm{m}$ \\
\hline & Algeria & $\mathrm{m}$ & $\mathrm{m}$ & $\mathrm{m}$ & $\mathrm{m}$ & $\mathrm{m}$ & $\mathrm{m}$ & $\mathrm{m}$ & $\mathrm{m}$ & $\mathrm{m}$ & $\mathrm{m}$ & $\mathrm{m}$ & $\mathrm{m}$ & $\mathrm{m}$ & $\mathrm{m}$ & $\mathrm{m}$ & $\mathrm{m}$ \\
\hline & Brazil & 0.24 & $(0.02)$ & 1.82 & $(0.14)$ & 0.55 & $(0.05)$ & 4.73 & $(0.49)$ & 0.24 & $(0.02)$ & 1.97 & $(0.15)$ & 0.58 & $(0.06)$ & 4.40 & $(0.48)$ \\
\hline & B-S-J-G (China) & 0.40 & $(0.04)$ & 2.55 & $(0.24)$ & 0.55 & $(0.05)$ & 1.53 & $(0.13)$ & 0.40 & $(0.04)$ & 2.49 & $(0.23)$ & 0.56 & $(0.05)$ & 1.50 & $(0.13)$ \\
\hline & Bulgaria & 0.38 & $(0.05)$ & 1.24 & $(0.18)$ & 0.56 & $(0.09)$ & 2.95 & $(0.33)$ & 0.41 & $(0.06)$ & 1.26 & $(0.18)$ & 0.62 & $(0.10)$ & 2.82 & $(0.31)$ \\
\hline & CABA (Argentina) & $\mathrm{m}$ & $\mathrm{m}$ & $\mathrm{m}$ & $\mathrm{m}$ & $\mathrm{m}$ & $\mathrm{m}$ & $\mathrm{m}$ & $\mathrm{m}$ & $\mathrm{m}$ & $\mathrm{m}$ & $\mathrm{m}$ & $\mathrm{m}$ & $\mathrm{m}$ & $\mathrm{m}$ & $\mathrm{m}$ & $\mathrm{m}$ \\
\hline & Colombia & 0.29 & $(0.03)$ & 2.11 & $(0.23)$ & 0.70 & $(0.08)$ & 4.36 & $(0.77)$ & 0.29 & $(0.03)$ & 2.21 & $(0.23)$ & 0.71 & $(0.08)$ & 4.57 & $(0.82)$ \\
\hline & Costa Rica & 0.18 & $(0.03)$ & 2.45 & $(0.37)$ & 0.61 & $(0.08)$ & 7.14 & $(1.53)$ & 0.18 & $(0.03)$ & 2.54 & $(0.38)$ & 0.61 & $(0.08)$ & 7.29 & (1.56) \\
\hline & Croatia & 0.24 & $(0.04)$ & 2.54 & $(0.38)$ & 0.44 & $(0.07)$ & 1.60 & $(0.22)$ & 0.24 & $(0.04)$ & 2.64 & $(0.40)$ & 0.46 & $(0.08)$ & 1.53 & $(0.21)$ \\
\hline & Cyprus* & 0.24 & $(0.03)$ & 1.39 & $(0.22)$ & 0.26 & $(0.04)$ & 3.23 & $(0.36)$ & 0.26 & $(0.03)$ & 1.42 & $(0.22)$ & 0.28 & $(0.04)$ & 2.74 & $(0.34)$ \\
\hline & Dominican Republic & 0.58 & $(0.09)$ & 1.14 & $(0.13)$ & 0.95 & $(0.11)$ & 10.65 & $(1.36)$ & 0.66 & $(0.10)$ & 1.26 & $(0.14)$ & 1.06 & $(0.12)$ & 10.19 & $(1.32)$ \\
\hline & FYROM & $\mathrm{m}$ & $\mathrm{m}$ & $\mathrm{m}$ & $\mathrm{m}$ & $\mathrm{m}$ & $\mathrm{m}$ & $\mathrm{m}$ & $\mathrm{m}$ & $\mathrm{m}$ & $\mathrm{m}$ & $\mathrm{m}$ & $\mathrm{m}$ & $\mathrm{m}$ & $\mathrm{m}$ & $\mathrm{m}$ & $\mathrm{m}$ \\
\hline & Georgia & $\mathrm{m}$ & $\mathrm{m}$ & $\mathrm{m}$ & $\mathrm{m}$ & $\mathrm{m}$ & $\mathrm{m}$ & $\mathrm{m}$ & $\mathrm{m}$ & $\mathrm{m}$ & $\mathrm{m}$ & $\mathrm{m}$ & $\mathrm{m}$ & $\mathrm{m}$ & $\mathrm{m}$ & $\mathrm{m}$ & $\mathrm{m}$ \\
\hline & Hong Kong (China) & 0.41 & $(0.03)$ & 1.94 & $(0.20)$ & 0.60 & $(0.04)$ & 1.90 & $(0.22)$ & 0.43 & $(0.03)$ & 1.85 & $(0.20)$ & 0.64 & $(0.04)$ & 1.80 & $(0.20)$ \\
\hline & Indonesia & $\mathrm{m}$ & $\mathrm{m}$ & $\mathrm{m}$ & $\mathrm{m}$ & $\mathrm{m}$ & $\mathrm{m}$ & $\mathrm{m}$ & $\mathrm{m}$ & $\mathrm{m}$ & $\mathrm{m}$ & $\mathrm{m}$ & $\mathrm{m}$ & $\mathrm{m}$ & $\mathrm{m}$ & $\mathrm{m}$ & $\mathrm{m}$ \\
\hline & Jordan & $\mathrm{m}$ & $\mathrm{m}$ & $\mathrm{m}$ & $\mathrm{m}$ & $\mathrm{m}$ & $\mathrm{m}$ & $\mathrm{m}$ & $\mathrm{m}$ & $\mathrm{m}$ & $\mathrm{m}$ & $\mathrm{m}$ & $\mathrm{m}$ & $\mathrm{m}$ & $\mathrm{m}$ & $\mathrm{m}$ & $\mathrm{m}$ \\
\hline & Kosovo & $\mathrm{m}$ & $\mathrm{m}$ & $\mathrm{m}$ & $\mathrm{m}$ & $\mathrm{m}$ & $\mathrm{m}$ & $\mathrm{m}$ & $\mathrm{m}$ & $\mathrm{m}$ & $\mathrm{m}$ & $\mathrm{m}$ & $\mathrm{m}$ & $\mathrm{m}$ & $\mathrm{m}$ & $\mathrm{m}$ & $\mathrm{m}$ \\
\hline & Lebanon & $\mathrm{m}$ & $\mathrm{m}$ & $\mathrm{m}$ & $\mathrm{m}$ & $\mathrm{m}$ & $\mathrm{m}$ & $\mathrm{m}$ & $\mathrm{m}$ & $\mathrm{m}$ & $\mathrm{m}$ & $\mathrm{m}$ & $\mathrm{m}$ & $\mathrm{m}$ & $\mathrm{m}$ & $\mathrm{m}$ & $\mathrm{m}$ \\
\hline & Lithuania & 0.34 & $(0.05)$ & 1.55 & $(0.17)$ & 0.84 & $(0.11)$ & 2.87 & $(0.37)$ & 0.36 & $(0.05)$ & 1.54 & $(0.17)$ & 0.88 & $(0.11)$ & 2.57 & $(0.34)$ \\
\hline & Macao (China) & 0.37 & $(0.03)$ & 2.21 & $(0.27)$ & 0.65 & $(0.05)$ & 1.74 & $(0.11)$ & 0.39 & $(0.03)$ & 2.16 & $(0.26)$ & 0.65 & $(0.06)$ & 1.61 & $(0.11)$ \\
\hline & Malta & $\mathrm{m}$ & $\mathrm{m}$ & $\mathrm{m}$ & $\mathrm{m}$ & $\mathrm{m}$ & $\mathrm{m}$ & $\mathrm{m}$ & $\mathrm{m}$ & $\mathrm{m}$ & $\mathrm{m}$ & $\mathrm{m}$ & $\mathrm{m}$ & $\mathrm{m}$ & $\mathrm{m}$ & $\mathrm{m}$ & $\mathrm{m}$ \\
\hline & Moldova & $\mathrm{m}$ & $\mathrm{m}$ & $\mathrm{m}$ & $\mathrm{m}$ & $\mathrm{m}$ & $\mathrm{m}$ & $\mathrm{m}$ & $\mathrm{m}$ & $\mathrm{m}$ & $\mathrm{m}$ & $\mathrm{m}$ & $\mathrm{m}$ & $\mathrm{m}$ & $\mathrm{m}$ & $\mathrm{m}$ & $\mathrm{m}$ \\
\hline & Montenegro & 0.51 & $(0.08)$ & 1.43 & $(0.16)$ & 0.51 & $(0.06)$ & 1.88 & $(0.21)$ & 0.51 & $(0.08)$ & 1.46 & $(0.15)$ & 0.51 & $(0.06)$ & 1.81 & $(0.20)$ \\
\hline & Peru & 0.35 & $(0.04)$ & 2.18 & $(0.27)$ & 0.47 & $(0.05)$ & 3.90 & $(0.71)$ & 0.36 & $(0.05)$ & 2.31 & $(0.29)$ & 0.50 & $(0.06)$ & 3.79 & $(0.68)$ \\
\hline & Qatar & 0.34 & $(0.02)$ & 1.69 & $(0.10)$ & 0.47 & $(0.03)$ & 4.74 & $(0.40)$ & 0.36 & $(0.03)$ & 1.88 & $(0.12)$ & 0.55 & $(0.03)$ & 3.80 & $(0.31)$ \\
\hline & Romania & $\mathrm{m}$ & $\mathrm{m}$ & $\mathrm{m}$ & $\mathrm{m}$ & $\mathrm{m}$ & $\mathrm{m}$ & $\mathrm{m}$ & $\mathrm{m}$ & $\mathrm{m}$ & $\mathrm{m}$ & $\mathrm{m}$ & $\mathrm{m}$ & $\mathrm{m}$ & $\mathrm{m}$ & $\mathrm{m}$ & $\mathrm{m}$ \\
\hline & Russia & 0.28 & $(0.05)$ & 2.57 & $(0.41)$ & 0.43 & $(0.06)$ & 1.95 & $(0.30)$ & 0.28 & $(0.05)$ & 2.58 & $(0.40)$ & 0.42 & $(0.06)$ & 1.83 & $(0.28)$ \\
\hline & Singapore & $\mathrm{m}$ & $\mathrm{m}$ & $\mathrm{m}$ & $\mathrm{m}$ & 0.54 & $(0.04)$ & 1.49 & $(0.15)$ & $\mathrm{m}$ & $\mathrm{m}$ & $\mathrm{m}$ & $\mathrm{m}$ & 0.59 & $(0.05)$ & 1.44 & $(0.15)$ \\
\hline & Chinese Taipei & 0.31 & $(0.02)$ & 2.87 & $(0.32)$ & 0.48 & $(0.03)$ & 1.82 & $(0.13)$ & 0.32 & $(0.03)$ & 2.74 & $(0.31)$ & 0.49 & $(0.04)$ & 1.68 & $(0.13)$ \\
\hline & Thailand & 0.26 & $(0.03)$ & 2.17 & $(0.36)$ & 0.60 & $(0.08)$ & 2.59 & $(0.43)$ & 0.27 & $(0.04)$ & 2.23 & $(0.38)$ & 0.61 & $(0.08)$ & 2.57 & $(0.42)$ \\
\hline & Trinidad and Tobago & $\mathrm{m}$ & $\mathrm{m}$ & $\mathrm{m}$ & $\mathrm{m}$ & $\mathrm{m}$ & $\mathrm{m}$ & $\mathrm{m}$ & $\mathrm{m}$ & $\mathrm{m}$ & $\mathrm{m}$ & $\mathrm{m}$ & $\mathrm{m}$ & $\mathrm{m}$ & $\mathrm{m}$ & $\mathrm{m}$ & $\mathrm{m}$ \\
\hline & Tunisia & 0.36 & $(0.04)$ & 2.20 & $(0.28)$ & 0.52 & $(0.06)$ & 4.72 & $(0.84)$ & 0.38 & $(0.04)$ & 2.25 & $(0.28)$ & 0.53 & $(0.06)$ & 4.57 & $(0.83)$ \\
\hline & United Arab Emirates & 0.36 & $(0.03)$ & 1.66 & $(0.13)$ & 0.58 & $(0.05)$ & 2.58 & $(0.29)$ & 0.37 & $(0.03)$ & 1.72 & $(0.14)$ & 0.62 & $(0.05)$ & 2.30 & $(0.25)$ \\
\hline & Uruguay & 0.21 & $(0.03)$ & 1.95 & $(0.25)$ & 0.53 & $(0.07)$ & 3.29 & $(0.50)$ & 0.24 & $(0.03)$ & 2.05 & $(0.26)$ & 0.58 & $(0.08)$ & 3.29 & $(0.51)$ \\
\hline & Viet Nam & $\mathrm{m}$ & $\mathrm{m}$ & $\mathrm{m}$ & $\mathrm{m}$ & $\mathrm{m}$ & $\mathrm{m}$ & $\mathrm{m}$ & $\mathrm{m}$ & $\mathrm{m}$ & $\mathrm{m}$ & $\mathrm{m}$ & $\mathrm{m}$ & $\mathrm{m}$ & $\mathrm{m}$ & $\mathrm{m}$ & $\mathrm{m}$ \\
\hline & Argentina** & $\mathrm{m}$ & $\mathrm{m}$ & $\mathrm{m}$ & $\mathrm{m}$ & $\mathrm{m}$ & $\mathrm{m}$ & $\mathrm{m}$ & $\mathrm{m}$ & $\mathrm{m}$ & $\mathrm{m}$ & $\mathrm{m}$ & $\mathrm{m}$ & $\mathrm{m}$ & $\mathrm{m}$ & $\mathrm{m}$ & $\mathrm{m}$ \\
\hline & Kazakhstan** & $\mathrm{m}$ & $\mathrm{m}$ & $\mathrm{m}$ & $\mathrm{m}$ & $\mathrm{m}$ & $\mathrm{m}$ & $\mathrm{m}$ & $\mathrm{m}$ & $\mathrm{m}$ & $\mathrm{m}$ & $\mathrm{m}$ & $\mathrm{m}$ & $\mathrm{m}$ & $\mathrm{m}$ & $\mathrm{m}$ & $\mathrm{m}$ \\
\hline & Malaysia** & 0.37 & $(0.03)$ & 1.79 & $(0.21)$ & 0.47 & $(0.04)$ & 3.32 & $(0.51)$ & 0.38 & $(0.04)$ & 1.86 & $(0.22)$ & 0.50 & $(0.04)$ & 3.26 & $(0.52)$ \\
\hline
\end{tabular}

1. Data on life satisfaction are not available for the Flemish community of Belgium.

Note: Values that are statistically significant are indicated in bold (see Annex A3).

* See note at the beginning of this Annex.

Coverage is too small to ensure comparability (see Annex A4). 
[Part 1/1]

Table III.9.25 Parents' participation in school activities and language skills, by immigrant background

Results based on parents' and students' self-reports

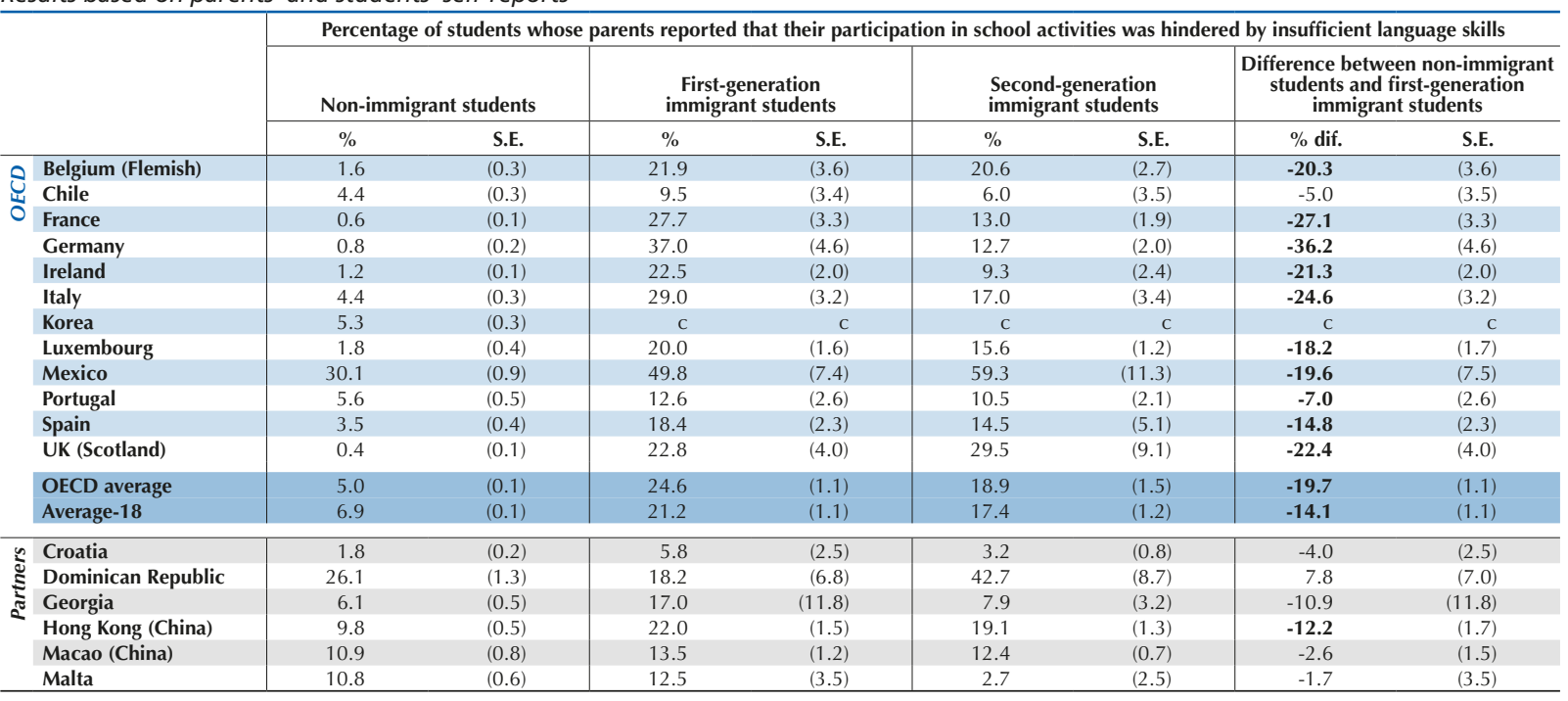

Note: Values that are statistically significant are indicated in bold (see Annex A3).

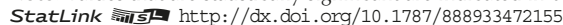

\section{Table III.9.26 Obstacles to parents' participation in their child's school activities}

Results based on parents' self-reports

\begin{tabular}{|c|c|c|c|c|c|c|c|c|c|c|c|c|c|c|c|c|c|}
\hline & & \multicolumn{16}{|c|}{ Percentage of students whose parents reported that participation in school activities was hindered by the following factors } \\
\hline & & \multicolumn{2}{|c|}{$\begin{array}{l}\text { The meeting } \\
\text { times were } \\
\text { inconvenient }\end{array}$} & \multicolumn{2}{|c|}{$\begin{array}{l}\text { I was not able } \\
\text { to get off } \\
\text { from work }\end{array}$} & \multicolumn{2}{|c|}{$\begin{array}{l}\text { I had no one to } \\
\text { take care of my } \\
\text { child/children }\end{array}$} & \multicolumn{2}{|c|}{$\begin{array}{l}\text { I had } \\
\text { problems with } \\
\text { transportation }\end{array}$} & \multicolumn{2}{|c|}{\begin{tabular}{|c|} 
My \\
<language skills> \\
were not \\
sufficient
\end{tabular}} & \multicolumn{2}{|c|}{$\begin{array}{l}\text { I think } \\
\text { participation } \\
\text { is not relevant } \\
\text { for my child's } \\
\text { development }\end{array}$} & \multicolumn{2}{|c|}{$\begin{array}{l}\text { I do not know } \\
\text { how I could } \\
\text { participate in } \\
\text { school activities }\end{array}$} & \multicolumn{2}{|c|}{$\begin{array}{c}\text { My child does } \\
\text { not want me } \\
\text { to participate }\end{array}$} \\
\hline & & $\%$ & S.E. & $\%$ & S.E. & $\%$ & S.E. & $\%$ & S.E. & $\%$ & S.E. & $\%$ & S.E. & $\%$ & S.E. & $\%$ & S.E. \\
\hline \multirow{14}{*}{$\begin{array}{l}\text { O̦ } \\
\text { O }\end{array}$} & Belgium (Flemish) & 19.6 & $(0.7)$ & 16.6 & $(0.6)$ & 5.2 & $(0.4)$ & 3.6 & $(0.4)$ & 3.9 & $(0.4)$ & 11.7 & $(0.5)$ & 7.0 & $(0.5)$ & 4.9 & $(0.3)$ \\
\hline & Chile & 24.9 & $(0.8)$ & 30.9 & $(0.8)$ & 18.2 & (0.6) & 15.1 & $(0.8)$ & 4.6 & $(0.3)$ & 21.2 & $(0.7)$ & 19.0 & $(0.6)$ & 22.9 & $(0.7)$ \\
\hline & France & 39.1 & $(0.8)$ & 41.5 & $(0.8)$ & 11.1 & $(0.4)$ & 5.8 & $(0.4)$ & 2.6 & $(0.3)$ & 4.1 & $(0.3)$ & 14.9 & $(0.5)$ & 3.6 & $(0.3)$ \\
\hline & Germany & 35.0 & $(0.8)$ & 35.7 & $(0.9)$ & 7.5 & $(0.6)$ & 2.7 & $(0.3)$ & 2.6 & $(0.3)$ & 14.8 & $(0.6)$ & 6.5 & $(0.5)$ & 6.8 & $(0.5)$ \\
\hline & Ireland & 16.7 & $(0.6)$ & 19.0 & $(0.6)$ & 8.5 & $(0.4)$ & 3.4 & $(0.3)$ & 3.6 & $(0.3)$ & 5.7 & $(0.3)$ & 16.1 & $(0.5)$ & 8.9 & $(0.4)$ \\
\hline & Italy & 31.9 & $(0.9)$ & 31.1 & $(0.9)$ & 8.9 & $(0.4)$ & 9.0 & $(0.5)$ & 6.0 & $(0.3)$ & 11.2 & $(0.5)$ & 17.5 & $(0.6)$ & 7.7 & $(0.5)$ \\
\hline & Korea & 66.3 & $(0.9)$ & 59.2 & $(1.0)$ & 12.4 & $(0.6)$ & 5.1 & $(0.3)$ & 5.3 & $(0.3)$ & 16.4 & $(0.5)$ & 15.4 & $(0.6)$ & 11.8 & $(0.5)$ \\
\hline & Luxembourg & 26.2 & $(0.8)$ & 27.4 & $(0.8)$ & 8.7 & $(0.5)$ & 3.2 & $(0.3)$ & 9.3 & $(0.5)$ & 9.8 & $(0.5)$ & 13.0 & $(0.6)$ & 6.7 & $(0.5)$ \\
\hline & Mexico & 45.9 & $(0.7)$ & 45.5 & $(0.7)$ & 32.7 & $(0.8)$ & 14.8 & $(0.6)$ & 30.5 & $(0.9)$ & 28.8 & $(0.7)$ & 32.3 & $(0.7)$ & 32.3 & $(0.9)$ \\
\hline & Portugal & 29.8 & $(0.7)$ & 37.2 & $(0.7)$ & 10.7 & $(0.6)$ & 7.7 & $(0.4)$ & 6.1 & $(0.5)$ & 7.6 & $(0.4)$ & 13.4 & $(0.5)$ & 5.7 & $(0.3)$ \\
\hline & Spain & 24.7 & $(0.7)$ & 34.5 & $(0.8)$ & 10.8 & $(0.5)$ & 3.4 & $(0.3)$ & 4.8 & $(0.4)$ & 12.1 & $(0.5)$ & 14.8 & $(0.6)$ & 8.8 & $(0.5)$ \\
\hline & UK (Scotland) & 18.5 & $(1.2)$ & 20.5 & (1.1) & 8.0 & $(0.7)$ & 3.7 & $(0.5)$ & 1.5 & $(0.2)$ & 5.7 & $(0.6)$ & 12.5 & (0.9) & 11.2 & (1.0) \\
\hline & OECD average & 31.5 & $(0.2)$ & 33.3 & $(0.2)$ & 11.9 & $(0.2)$ & 6.5 & $(0.1)$ & 6.7 & $(0.1)$ & 12.4 & $(0.2)$ & 15.2 & $(0.2)$ & 10.9 & $(0.2)$ \\
\hline & Average-18 & 32.8 & $(0.2)$ & 35.7 & $(0.2)$ & 12.8 & $(0.1)$ & 6.9 & $(0.1)$ & 8.4 & $(0.1)$ & 13.0 & $(0.1)$ & 16.8 & $(0.2)$ & 12.6 & $(0.1)$ \\
\hline \multirow{6}{*}{ ఏ } & Croatia & 20.2 & $(0.5)$ & 22.9 & $(0.7)$ & 6.0 & $(0.3)$ & 8.7 & $(0.4)$ & 1.9 & $(0.2)$ & 4.8 & $(0.3)$ & 19.7 & $(0.6)$ & 5.6 & $(0.3)$ \\
\hline & Dominican Republic & 29.5 & $(1.0)$ & 44.4 & $(1.1)$ & 33.2 & $(1.2)$ & 9.7 & $(0.5)$ & 26.2 & $(1.2)$ & 36.5 & $(1.4)$ & 40.7 & $(1.2)$ & 45.5 & (1.4) \\
\hline & Georgia & 19.8 & $(0.7)$ & 29.1 & $(0.8)$ & 8.7 & $(0.5)$ & 4.4 & $(0.4)$ & 6.4 & $(0.5)$ & 14.1 & $(0.6)$ & 13.5 & $(0.6)$ & 12.9 & $(0.6)$ \\
\hline & Hong Kong (China) & 66.1 & $(0.9)$ & 68.3 & $(0.7)$ & 15.5 & $(0.5)$ & 4.7 & $(0.3)$ & 13.4 & $(0.6)$ & 10.0 & $(0.4)$ & 10.5 & $(0.5)$ & 11.1 & $(0.4)$ \\
\hline & Macao (China) & 39.3 & $(0.6)$ & 44.2 & $(0.6)$ & 13.0 & $(0.5)$ & 6.8 & $(0.4)$ & 12.0 & $(0.5)$ & 10.5 & $(0.5)$ & 20.0 & $(0.6)$ & 11.3 & $(0.5)$ \\
\hline & Malta & 36.9 & $(1.0)$ & 35.1 & $(0.9)$ & 11.1 & $(0.5)$ & 11.8 & $(0.6)$ & 11.1 & $(0.6)$ & 10.0 & $(0.6)$ & 15.5 & $(0.6)$ & 8.8 & $(0.6)$ \\
\hline
\end{tabular}

StatLink तiा Sम http://dx.doi.org/10.1787/888933472167 


\begin{tabular}{|c|c|c|c|c|c|c|c|c|c|c|c|c|c|c|c|}
\hline & \multicolumn{14}{|c|}{ Percentage of students who reported that they have the following things at home } \\
\hline & & \multicolumn{2}{|c|}{ A desk to study at } & A qu & $\begin{array}{l}\text { lace } \\
\text { dy }\end{array}$ & $\begin{array}{l}\text { A comp } \\
\text { use for }\end{array}$ & $\begin{array}{l}\text { you can } \\
\text { ol work }\end{array}$ & & $\begin{array}{l}\text { onal } \\
\text { ire }\end{array}$ & $\begin{array}{l}\text { Books } t \\
\text { your sc }\end{array}$ & $\begin{array}{l}\text { lp with } \\
\text { ll work }\end{array}$ & $\begin{array}{r}\mathrm{Te} \\
\text { refere }\end{array}$ & $\begin{array}{l}\text { cal } \\
\text { books }\end{array}$ & A d & nary \\
\hline & & $\%$ & S.E. & $\%$ & S.E. & $\%$ & S.E. & $\%$ & S.E. & $\%$ & S.E. & $\%$ & S.E. & $\%$ & S.E. \\
\hline 0 & Australia & 89.7 & $(0.4)$ & 87.8 & $(0.3)$ & 95.0 & $(0.2)$ & 79.9 & $(0.5)$ & 79.4 & $(0.5)$ & 51.4 & $(0.5)$ & 93.1 & $(0.2)$ \\
\hline ư & Austria & 96.0 & $(0.3)$ & 96.2 & $(0.2)$ & 96.8 & $(0.2)$ & 47.6 & $(0.7)$ & 75.9 & $(0.7)$ & 71.9 & $(0.8)$ & 97.3 & (0.3) \\
\hline 0 & Belgium & 95.2 & $(0.3)$ & 93.5 & $(0.3)$ & 95.1 & $(0.3)$ & 60.8 & $(0.7)$ & 78.0 & $(0.6)$ & 62.1 & $(0.6)$ & 95.0 & $(0.2)$ \\
\hline & Canada & 86.9 & $(0.5)$ & 91.7 & $(0.3)$ & 94.8 & $(0.3)$ & 69.4 & $(0.6)$ & 73.8 & $(0.6)$ & 57.4 & $(0.7)$ & 91.8 & $(0.3)$ \\
\hline & Chile & 75.2 & $(0.7)$ & 86.1 & $(0.5)$ & 83.5 & (0.6) & 32.4 & $(0.8)$ & 86.0 & $(0.5)$ & 55.6 & $(0.7)$ & 97.2 & $(0.3)$ \\
\hline & Czech Republic & 98.0 & $(0.2)$ & 91.1 & $(0.5)$ & 96.2 & $(0.3)$ & 47.1 & $(0.8)$ & 88.9 & $(0.5)$ & 87.3 & $(0.5)$ & 91.7 & $(0.5)$ \\
\hline & Denmark & 90.6 & $(0.5)$ & 94.8 & $(0.3)$ & 98.6 & $(0.2)$ & 90.5 & $(0.5)$ & 86.5 & (0.6) & 71.2 & $(0.7)$ & 92.6 & (0.4) \\
\hline & Estonia & 96.9 & $(0.2)$ & 93.0 & $(0.4)$ & 87.6 & (0.6) & 74.9 & $(0.9)$ & 87.3 & (0.6) & 74.0 & (0.8) & 89.3 & (0.5) \\
\hline & Finland & 93.2 & $(0.3)$ & 95.4 & $(0.3)$ & 95.8 & $(0.3)$ & 40.0 & $(1.0)$ & 77.4 & $(0.8)$ & 41.4 & $(0.8)$ & 84.1 & $(0.5)$ \\
\hline & France & 97.2 & $(0.3)$ & 94.4 & $(0.4)$ & 94.0 & $(0.3)$ & 36.3 & $(0.9)$ & 83.5 & (0.6) & 44.8 & $(0.8)$ & 97.0 & $(0.2)$ \\
\hline & Germany & 95.1 & $(0.3)$ & 96.3 & $(0.3)$ & 95.5 & $(0.3)$ & 44.7 & $(0.8)$ & 88.0 & $(0.5)$ & 74.8 & $(0.7)$ & 94.9 & $(0.4)$ \\
\hline & Greece & 97.5 & $(0.2)$ & 87.1 & $(0.5)$ & 92.2 & (0.5) & 44.2 & $(1.2)$ & 83.3 & $(0.7)$ & 54.9 & $(0.8)$ & 96.6 & (0.3) \\
\hline & Hungary & 96.8 & $(0.3)$ & 93.0 & $(0.4)$ & 93.1 & (0.4) & 47.3 & $(0.9)$ & 89.4 & $(0.7)$ & 57.4 & $(0.9)$ & 91.1 & (0.6) \\
\hline & Iceland & 94.5 & $(0.4)$ & 95.5 & $(0.4)$ & 98.1 & $(0.2)$ & 82.4 & $(0.7)$ & 89.8 & $(0.6)$ & 83.8 & $(0.8)$ & 93.0 & (0.4) \\
\hline & Ireland & 90.4 & $(0.5)$ & 91.2 & $(0.5)$ & 89.4 & $(0.5)$ & 58.5 & $(0.8)$ & 86.1 & $(0.5)$ & 42.7 & $(0.9)$ & 96.8 & $(0.2)$ \\
\hline & Israel & 95.3 & $(0.3)$ & 93.5 & $(0.4)$ & 93.3 & (0.6) & 56.7 & $(0.8)$ & 83.1 & $(0.6)$ & 62.3 & (0.9) & 96.1 & $(0.3)$ \\
\hline & Italy & 96.2 & $(0.3)$ & 92.7 & $(0.4)$ & 92.7 & (0.4) & 57.9 & (0.9) & 88.2 & $(0.6)$ & 87.0 & $(0.5)$ & 98.7 & $(0.2)$ \\
\hline & Japan & 94.5 & $(0.3)$ & 87.2 & $(0.4)$ & 62.3 & $(0.7)$ & 13.4 & $(0.4)$ & 84.7 & $(0.6)$ & 49.6 & $(0.9)$ & 97.6 & $(0.2)$ \\
\hline & Korea & 94.9 & $(0.4)$ & 84.5 & $(0.5)$ & 91.1 & $(0.4)$ & 51.3 & (1.1) & 89.2 & $(0.5)$ & 54.1 & (1.1) & 94.2 & (0.4) \\
\hline & Latvia & 98.1 & $(0.2)$ & 92.2 & $(0.5)$ & 96.1 & $(0.3)$ & 73.6 & $(0.8)$ & 92.3 & $(0.4)$ & 65.4 & $(0.9)$ & 89.8 & (0.6) \\
\hline & Luxembourg & 95.6 & $(0.3)$ & 94.8 & $(0.3)$ & 94.4 & $(0.3)$ & 50.2 & $(0.7)$ & 84.6 & $(0.4)$ & 70.7 & $(0.6)$ & 96.8 & $(0.2)$ \\
\hline & Mexico & 76.7 & $(0.8)$ & 73.0 & $(0.9)$ & 56.5 & (1.4) & 24.2 & $(0.9)$ & 65.6 & $(0.9)$ & 29.9 & $(0.8)$ & 97.2 & $(0.2)$ \\
\hline & Netherlands & 94.1 & $(0.3)$ & 97.3 & $(0.2)$ & 96.5 & $(0.3)$ & 63.8 & $(0.7)$ & 80.1 & $(0.8)$ & 88.8 & $(0.5)$ & 94.7 & $(0.4)$ \\
\hline & New Zealand & 86.5 & $(0.6)$ & 89.6 & $(0.6)$ & 92.5 & $(0.5)$ & 73.1 & $(0.7)$ & 83.8 & $(0.7)$ & 51.9 & $(0.9)$ & 92.3 & (0.5) \\
\hline & Norway & 95.5 & $(0.3)$ & 94.0 & $(0.4)$ & 96.7 & $(0.3)$ & 68.7 & $(0.7)$ & 86.2 & $(0.5)$ & 75.7 & $(0.7)$ & 88.6 & (0.5) \\
\hline & Poland & 95.9 & $(0.3)$ & 96.2 & $(0.3)$ & 97.1 & $(0.3)$ & 60.1 & $(0.8)$ & 95.3 & $(0.3)$ & 79.5 & $(0.7)$ & 97.3 & $(0.3)$ \\
\hline & Portugal & 95.6 & $(0.3)$ & 96.3 & $(0.3)$ & 95.9 & $(0.3)$ & 45.3 & $(0.9)$ & 89.1 & $(0.5)$ & 49.9 & $(0.9)$ & 97.0 & $(0.2)$ \\
\hline & Slovak Republic & 91.2 & $(0.6)$ & 86.6 & $(0.6)$ & 92.3 & $(0.5)$ & 60.6 & $(1.0)$ & 86.6 & $(0.6)$ & 75.9 & $(0.8)$ & 90.3 & $(0.6)$ \\
\hline & Slovenia & 98.5 & $(0.2)$ & 93.5 & $(0.4)$ & 97.0 & $(0.2)$ & 67.6 & $(0.7)$ & 88.1 & $(0.5)$ & 81.6 & $(0.6)$ & 86.8 & $(0.5)$ \\
\hline & Spain & 97.6 & $(0.2)$ & 94.1 & $(0.3)$ & 91.9 & $(0.5)$ & 44.7 & (1.0) & 81.6 & $(0.5)$ & 62.1 & $(0.9)$ & 98.1 & $(0.2)$ \\
\hline & Sweden & 89.8 & $(0.5)$ & 93.3 & $(0.4)$ & 95.8 & $(0.4)$ & 67.5 & $(1.0)$ & 74.3 & $(0.8)$ & 56.9 & $(0.9)$ & 82.2 & $(0.8)$ \\
\hline & Switzerland & 96.6 & $(0.3)$ & 95.7 & $(0.4)$ & 95.9 & $(0.3)$ & 43.7 & $(0.8)$ & 78.9 & $(0.7)$ & 74.0 & $(0.7)$ & 93.3 & $(0.4)$ \\
\hline & Turkey & 84.4 & $(0.9)$ & 83.5 & $(0.6)$ & 67.8 & (1.4) & 42.5 & (1.1) & 82.9 & $(0.9)$ & 42.0 & (1.0) & 94.3 & $(0.4)$ \\
\hline & United Kingdom & 85.1 & $(0.6)$ & 88.4 & $(0.4)$ & 93.2 & $(0.4)$ & 74.3 & $(0.9)$ & 92.4 & $(0.5)$ & 52.0 & $(0.9)$ & 86.9 & $(0.7)$ \\
\hline & United States & 78.3 & $(0.9)$ & 89.7 & $(0.5)$ & 87.5 & $(0.8)$ & 68.2 & $(0.8)$ & 74.1 & $(0.9)$ & 64.9 & $(0.9)$ & 86.1 & (0.6) \\
\hline & OECD average & 92.4 & $(0.1)$ & 91.5 & $(0.1)$ & 91.2 & $(0.1)$ & 56.1 & $(0.1)$ & 83.8 & $(0.1)$ & 63.0 & $(0.1)$ & 93.1 & (0.1) \\
\hline$n$ & Albania & 91.3 & $(0.5)$ & 91.1 & $(0.5)$ & 71.0 & $(0.9)$ & 47.8 & $(0.9)$ & 76.5 & $(0.8)$ & 31.8 & $(0.8)$ & 74.3 & $(1.0)$ \\
\hline$\approx$ & Algeria & 78.0 & $(0.9)$ & 76.2 & $(0.8)$ & 57.6 & (1.4) & 39.7 & (1.3) & 71.5 & $(1.0)$ & 44.9 & $(1.0)$ & 79.6 & $(0.9)$ \\
\hline$\approx$ & Brazil & 63.8 & $(0.7)$ & 79.1 & $(0.5)$ & 69.4 & $(0.8)$ & 30.4 & $(0.6)$ & 84.8 & $(0.5)$ & 41.8 & $(0.6)$ & 89.2 & $(0.4)$ \\
\hline & Bulgaria & 93.8 & $(0.5)$ & 78.8 & $(0.6)$ & 95.7 & $(0.4)$ & 58.0 & $(0.8)$ & 84.4 & $(0.6)$ & 56.9 & $(0.9)$ & 88.2 & $(0.9)$ \\
\hline & B-S-J-G (China) & 92.8 & $(0.5)$ & 85.2 & $(0.8)$ & 59.8 & (1.5) & 41.3 & (1.3) & 80.6 & $(1.0)$ & 59.1 & (1.1) & 97.1 & $(0.3)$ \\
\hline & CABA (Argentina) & 83.9 & (1.5) & 86.2 & $(1.2)$ & 91.3 & $(0.9)$ & 46.0 & (2.5) & 72.5 & (1.3) & 55.7 & (1.9) & 98.0 & $(0.4)$ \\
\hline & Colombia & 64.2 & $(0.9)$ & 69.8 & $(0.7)$ & 62.6 & $(1.3)$ & 27.5 & $(0.7)$ & 79.4 & (0.6) & 37.7 & $(0.7)$ & 97.1 & $(0.2)$ \\
\hline & Costa Rica & 83.0 & $(0.6)$ & 82.4 & $(0.7)$ & 74.1 & $(1.2)$ & 34.4 & $(0.9)$ & 60.2 & $(0.9)$ & 32.4 & (1.0) & 95.9 & $(0.3)$ \\
\hline & Croatia & 96.6 & $(0.2)$ & 86.2 & $(0.6)$ & 92.8 & $(0.4)$ & 61.8 & $(0.9)$ & 88.4 & $(0.5)$ & 64.6 & $(0.7)$ & 94.9 & $(0.3)$ \\
\hline & Cyprus* & 97.6 & $(0.2)$ & 89.5 & $(0.4)$ & 92.1 & $(0.3)$ & 57.4 & $(0.7)$ & 82.2 & $(0.5)$ & 65.9 & $(0.6)$ & 95.8 & $(0.2)$ \\
\hline & Dominican Republic & 53.9 & (1.0) & 84.2 & $(0.6)$ & 57.9 & (1.3) & 29.5 & $(1.0)$ & 90.6 & $(0.5)$ & 44.8 & (1.0) & 88.2 & $(0.7)$ \\
\hline & FYROM & 93.2 & $(0.4)$ & 93.7 & $(0.3)$ & 93.1 & $(0.4)$ & 57.7 & $(0.7)$ & 85.7 & $(0.6)$ & 47.2 & $(0.8)$ & 85.2 & (0.6) \\
\hline & Georgia & 94.9 & $(0.3)$ & 90.4 & $(0.5)$ & 79.2 & $(0.8)$ & 35.8 & (0.9) & 89.0 & $(0.5)$ & 53.3 & (0.8) & 84.0 & (0.7) \\
\hline & Hong Kong (China) & 89.8 & $(0.5)$ & 80.6 & $(0.7)$ & 93.9 & $(0.4)$ & 49.3 & $(0.9)$ & 79.9 & $(0.7)$ & 59.0 & $(0.8)$ & 97.3 & $(0.3)$ \\
\hline & Indonesia & 64.9 & $(1.2)$ & 56.4 & $(0.9)$ & 28.3 & (1.4) & 21.7 & (1.1) & 87.6 & $(0.7)$ & 17.6 & $(0.8)$ & 91.3 & (0.6) \\
\hline & Jordan & 62.6 & $(1.2)$ & 83.0 & (0.6) & 78.4 & $(0.9)$ & 50.7 & (1.1) & 66.8 & $(0.7)$ & 34.9 & $(0.9)$ & 84.8 & $(0.7)$ \\
\hline & Kosovo & 76.2 & $(0.7)$ & 95.2 & $(0.4)$ & 90.5 & $(0.6)$ & 67.4 & $(0.8)$ & 82.3 & $(0.7)$ & 43.8 & (1.0) & 81.9 & (0.6) \\
\hline & Lebanon & 84.3 & $(0.9)$ & 81.6 & $(0.8)$ & 76.8 & $(0.9)$ & 55.7 & (1.4) & 79.5 & $(0.9)$ & 51.4 & (1.3) & 92.4 & $(0.6)$ \\
\hline & Lithuania & 98.7 & $(0.2)$ & 93.1 & $(0.4)$ & 96.3 & $(0.3)$ & 73.2 & $(0.8)$ & 90.6 & $(0.4)$ & 67.6 & $(0.7)$ & 88.6 & $(0.5)$ \\
\hline & Macao (China) & 88.6 & $(0.5)$ & 81.5 & $(0.5)$ & 95.0 & $(0.3)$ & 59.4 & $(0.7)$ & 70.5 & $(0.6)$ & 57.7 & $(0.8)$ & 96.6 & $(0.3)$ \\
\hline & Malta & 92.1 & $(0.4)$ & 84.3 & $(0.6)$ & 94.8 & $(0.3)$ & 75.2 & $(0.7)$ & 91.0 & $(0.4)$ & 64.1 & $(0.8)$ & 95.2 & (0.3) \\
\hline & Moldova & 90.2 & $(0.6)$ & 89.2 & $(0.5)$ & 82.3 & $(0.8)$ & 47.8 & $(1.1)$ & 88.2 & $(0.6)$ & 71.6 & $(0.8)$ & 89.5 & $(0.7)$ \\
\hline & Montenegro & 97.4 & $(0.2)$ & 89.5 & $(0.4)$ & 90.7 & $(0.4)$ & 64.4 & $(0.6)$ & 65.4 & $(0.6)$ & 57.6 & $(0.7)$ & 91.7 & $(0.4)$ \\
\hline & Peru & 77.6 & $(0.9)$ & 77.7 & $(0.7)$ & 54.6 & $(1.2)$ & 29.7 & (0.9) & 74.5 & $(0.7)$ & 62.4 & (1.1) & 97.5 & $(0.2)$ \\
\hline & Qatar & 82.0 & $(0.3)$ & 88.8 & $(0.3)$ & 88.3 & $(0.3)$ & 63.3 & $(0.4)$ & 77.8 & $(0.4)$ & 64.6 & $(0.5)$ & 83.5 & $(0.4)$ \\
\hline & Romania & 96.7 & $(0.3)$ & 93.6 & $(0.4)$ & 87.7 & $(0.8)$ & 56.8 & (1.4) & 85.1 & (0.9) & 74.5 & (1.0) & 87.6 & (0.7) \\
\hline & Russia & 97.3 & $(0.2)$ & 89.9 & $(0.5)$ & 95.9 & $(0.4)$ & 67.3 & $(0.6)$ & 94.5 & $(0.3)$ & 87.6 & $(0.6)$ & 92.3 & (0.5) \\
\hline & Singapore & 91.7 & $(0.4)$ & 78.2 & $(0.6)$ & 89.8 & $(0.5)$ & 72.9 & $(0.7)$ & 93.6 & $(0.3)$ & 66.7 & $(0.7)$ & 96.2 & $(0.2)$ \\
\hline & Chinese Taipei & 93.9 & $(0.3)$ & 84.3 & $(0.5)$ & 87.1 & $(0.5)$ & 41.9 & $(0.9)$ & 74.5 & $(0.7)$ & 63.9 & $(0.9)$ & 95.1 & (0.3) \\
\hline & Thailand & 87.3 & $(0.6)$ & 74.5 & $(0.8)$ & 62.2 & (1.3) & 40.6 & $(1.2)$ & 85.7 & $(0.7)$ & 53.6 & $(1.2)$ & 83.9 & (0.9) \\
\hline & Trinidad and Tobago & 76.8 & $(0.7)$ & 73.1 & $(0.7)$ & 85.9 & $(0.5)$ & 70.6 & $(0.7)$ & 94.4 & $(0.4)$ & 65.3 & $(0.9)$ & 95.3 & $(0.4)$ \\
\hline & Tunisia & 91.3 & $(0.6)$ & 82.7 & $(0.7)$ & 65.2 & $(1.2)$ & 48.6 & (1.0) & 75.3 & $(0.9)$ & 43.0 & $(0.9)$ & 83.5 & $(0.8)$ \\
\hline & United Arab Emirates & 84.9 & $(0.5)$ & 85.9 & $(0.4)$ & 90.1 & $(0.4)$ & 64.2 & $(0.7)$ & 78.3 & $(0.4)$ & 57.0 & $(0.7)$ & 87.5 & $(0.4)$ \\
\hline & Uruguay & 83.2 & $(0.6)$ & 87.5 & $(0.5)$ & 88.7 & $(0.5)$ & 43.2 & $(0.9)$ & 80.6 & $(0.6)$ & 61.2 & $(0.8)$ & 97.1 & $(0.3)$ \\
\hline & Viet Nam & 90.9 & $(0.8)$ & 83.3 & $(0.9)$ & 44.2 & (1.5) & 19.0 & (1.1) & 79.2 & (1.1) & 35.6 & (1.1) & 70.2 & (1.5) \\
\hline & Argentina** & 70.3 & (1.0) & 79.3 & $(0.9)$ & 84.4 & (0.9) & 49.1 & $(1.2)$ & 72.9 & $(0.8)$ & 54.5 & (1.0) & 96.2 & (0.4) \\
\hline & Kazakhstan** & 94.9 & $(0.5)$ & 90.6 & $(0.6)$ & 81.9 & $(0.9)$ & 69.5 & (1.1) & 87.4 & (0.6) & 66.0 & (0.9) & 90.0 & $(0.6)$ \\
\hline & Malaysia** & 89.3 & $(0.5)$ & 73.5 & $(0.9)$ & 62.3 & $(1.2)$ & 39.4 & $(0.9)$ & 94.2 & $(0.4)$ & 61.5 & $(0.8)$ & 96.6 & $(0.3)$ \\
\hline
\end{tabular}

* See note at the beginning of this Annex.

** Coverage is too small to ensure comparability (see Annex A4).

StatLink न्ता 
[Part 1/1]

Table III.10.2 Availability of a quiet place to study and science performance

Results are based on students' self-reports

\begin{tabular}{|c|c|c|c|c|c|}
\hline & \multicolumn{4}{|c|}{ Change in science performance associated with students who reported having a quiet place to study } \\
\hline & & \multicolumn{2}{|c|}{ Before accounting for parental education } & \multicolumn{2}{|c|}{ After accounting for parental education ${ }^{1}$} \\
\hline & & Score dif. & S.E. & Score dif. & S.E. \\
\hline \multirow{36}{*}{ 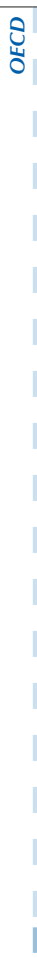 } & Australia & 39 & (2.9) & 31 & $(2.8)$ \\
\hline & Austria & 44 & $(8.1)$ & 39 & (7.5) \\
\hline & Belgium & 52 & $(5.2)$ & 44 & (5.5) \\
\hline & Canada & 26 & $(4.2)$ & 22 & (4.0) \\
\hline & Chile & 14 & (3.9) & 7 & (3.9) \\
\hline & Czech Republic & 22 & (4.3) & 17 & (4.3) \\
\hline & Denmark & 38 & (5.3) & 34 & (5.7) \\
\hline & Estonia & 16 & (5.2) & 13 & (5.2) \\
\hline & Finland & 17 & $(7.8)$ & 12 & (7.6) \\
\hline & France & 61 & (7.4) & 52 & (7.2) \\
\hline & Germany & 46 & (8.1) & 36 & (8.2) \\
\hline & Greece & 22 & (4.3) & 16 & $(4.2)$ \\
\hline & Hungary & 36 & (6.1) & 25 & (6.6) \\
\hline & Iceland & 26 & (8.3) & 21 & (8.1) \\
\hline & Ireland & 28 & (4.3) & 25 & (4.3) \\
\hline & Israel & 28 & (7.4) & 20 & (6.9) \\
\hline & Italy & 27 & (5.0) & 24 & (5.0) \\
\hline & Japan & 10 & (3.9) & 4 & (3.8) \\
\hline & Korea & 15 & (3.9) & 8 & (3.5) \\
\hline & Latvia & 12 & (4.9) & 9 & $(5.0)$ \\
\hline & Luxembourg & 51 & (6.6) & 44 & (6.7) \\
\hline & Mexico & 9 & $(2.7)$ & 5 & (2.6) \\
\hline & Netherlands & 42 & (8.5) & 36 & (9.0) \\
\hline & New Zealand & 41 & (6.1) & 38 & (6.1) \\
\hline & Norway & 44 & (6.0) & 40 & (6.1) \\
\hline & Poland & 4 & (8.0) & 0 & (7.3) \\
\hline & Portugal & 10 & (8.2) & 7 & (7.8) \\
\hline & Slovak Republic & 44 & (5.0) & 33 & (4.7) \\
\hline & Slovenia & 35 & (5.0) & 31 & (4.9) \\
\hline & Spain & 34 & (5.0) & 28 & $(4.7)$ \\
\hline & Sweden & 32 & (4.9) & 27 & (4.7) \\
\hline & Switzerland & 24 & (7.5) & 15 & (7.0) \\
\hline & Turkey & 25 & (3.7) & 20 & (3.3) \\
\hline & United Kingdom & 34 & (4.0) & 31 & $(4.0)$ \\
\hline & United States & 18 & $(4.3)$ & 9 & $(4.2$ \\
\hline & OECD average & 29 & (1.0) & 24 & (1.0) \\
\hline \multirow{38}{*}{ 苋 } & Albania & $\mathrm{m}$ & $\mathrm{m}$ & $\mathrm{m}$ & $\mathrm{m}$ \\
\hline & Algeria & 11 & (3.8) & 10 & (3.8) \\
\hline & Brazil & 21 & $(2.7)$ & 17 & (2.5) \\
\hline & Bulgaria & 72 & (6.3) & 62 & (6.4) \\
\hline & B-S-J-G (China) & 10 & $(4.2)$ & 8 & $(4.1)$ \\
\hline & CABA (Argentina) & 41 & (8.6) & 22 & (7.3) \\
\hline & Colombia & 12 & (3.0) & 8 & (2.6) \\
\hline & Costa Rica & 15 & (3.0) & 9 & (2.8) \\
\hline & Croatia & 19 & $(4.2)$ & 19 & $(4.0)$ \\
\hline & Cyprus* & 38 & (4.8) & 33 & (4.8) \\
\hline & Dominican Republic & 5 & $(4.0)$ & 2 & (3.9) \\
\hline & FYROM & 35 & (6.1) & 33 & (6.0) \\
\hline & Georgia & 27 & (5.6) & 23 & (5.6) \\
\hline & Hong Kong (China) & 4 & (3.4) & 0 & (3.4) \\
\hline & Indonesia & 18 & $(2.5)$ & 12 & $(2.3)$ \\
\hline & Jordan & 30 & (3.6) & 23 & (3.3) \\
\hline & Kosovo & 16 & (8.5) & 16 & (8.4) \\
\hline & Lebanon & 34 & (5.5) & 31 & (5.7) \\
\hline & Lithuania & 32 & (6.7) & 28 & (6.9) \\
\hline & Macao (China) & 6 & (3.3) & 3 & (3.3) \\
\hline & Malta & 40 & (5.1) & 34 & (5.3) \\
\hline & Moldova & 29 & (5.0) & 23 & (5.1) \\
\hline & Montenegro & 10 & $(4.1)$ & 10 & $(4.2)$ \\
\hline & Peru & 11 & (3.2) & 6 & $(2.9)$ \\
\hline & Qatar & 35 & $(2.7)$ & 31 & (2.5) \\
\hline & Romania & 23 & (4.8) & 21 & (5.0) \\
\hline & Russia & 0 & $(4.2)$ & -2 & (3.9) \\
\hline & Singapore & 39 & (3.5) & 27 & (3.5) \\
\hline & Chinese Taipei & 24 & (3.8) & 14 & (3.6) \\
\hline & Thailand & 21 & (3.1) & 18 & (2.9) \\
\hline & Trinidad and Tobago & 37 & (3.3) & 33 & (3.4) \\
\hline & Tunisia & 16 & (3.2) & 13 & (3.1) \\
\hline & United Arab Emirates & 16 & (3.0) & 14 & $(2.9)$ \\
\hline & Uruguay & 17 & (3.9) & 10 & (3.6) \\
\hline & Viet Nam & 27 & $(4.0)$ & 21 & (3.8) \\
\hline & Argentina** $^{* *}$ & 26 & (3.6) & 20 & (3.3) \\
\hline & Kazakhstan** & 17 & (4.6) & 15 & (4.5) \\
\hline & Malaysia** & 26 & $(3.2)$ & 23 & $(2.9)$ \\
\hline
\end{tabular}

1. This model includes the number of years of completed education of the most educated parent and its squared value.

Note: Values that are statistically significant are indicated in bold (see Annex A3).

* See note at the beginning of this Annex.

* Coverage is too small to ensure comparability (see Annex A4).

StatLink त्ञाड $\mathrm{http}: / / \mathrm{dx}$. doi.org/10.1787/888933472296 


\begin{tabular}{|c|c|c|c|c|c|c|c|c|c|c|c|c|c|c|c|}
\hline & \multicolumn{14}{|c|}{ Index of family wealth } \\
\hline & & \multicolumn{4}{|c|}{ All students } & & & & tional qu & ters of $t$ & index o & amily we & & & \\
\hline & & & & $\begin{array}{c}\text { Var } \\
\text { of } t h\end{array}$ & $\begin{array}{l}\text { ility } \\
\text { index }\end{array}$ & Bottor & quarter & Secon & juarter & Thirc & uarter & Top & arter & $\begin{array}{r}\text { Top } \\
\text { qu }\end{array}$ & $\begin{array}{l}\text { ottom } \\
\text { ter }\end{array}$ \\
\hline & & $\begin{array}{l}\text { Mean } \\
\text { index }\end{array}$ & S.E. & S.D. & S.E. & $\begin{array}{l}\text { Mean } \\
\text { index }\end{array}$ & S.E. & $\begin{array}{l}\text { Mean } \\
\text { index }\end{array}$ & S.E. & $\begin{array}{l}\text { Mean } \\
\text { index }\end{array}$ & S.E. & $\begin{array}{l}\text { Mean } \\
\text { index }\end{array}$ & S.E. & Dif. & S.E. \\
\hline 0 & Australia & 0.65 & $(0.01)$ & 0.87 & $(0.01)$ & -0.42 & $(0.02)$ & 0.40 & $(0.01)$ & 0.89 & $(0.01)$ & 1.73 & $(0.02)$ & 2.15 & $(0.02)$ \\
\hline 岙 & Austria & 0.13 & $(0.02)$ & 0.82 & $(0.01)$ & -0.84 & $(0.02)$ & -0.14 & $(0.02)$ & 0.34 & $(0.02)$ & 1.16 & $(0.03)$ & 2.01 & $(0.03)$ \\
\hline 0 & Belgium & 0.12 & $(0.02)$ & 0.81 & $(0.01)$ & -0.87 & $(0.02)$ & -0.12 & $(0.01)$ & 0.35 & $(0.02)$ & 1.13 & $(0.03)$ & 2.00 & $(0.03)$ \\
\hline & Canada & 0.55 & $(0.02)$ & 1.00 & $(0.01)$ & -0.63 & $(0.02)$ & 0.22 & $(0.02)$ & 0.80 & $(0.02)$ & 1.82 & $(0.03)$ & 2.45 & $(0.03)$ \\
\hline & Chile & -0.65 & $(0.02)$ & 1.00 & $(0.02)$ & -1.89 & $(0.03)$ & -0.95 & $(0.03)$ & -0.35 & $(0.02)$ & 0.61 & $(0.03)$ & 2.50 & $(0.04)$ \\
\hline & Czech Republic & -0.18 & $(0.01)$ & 0.84 & $(0.02)$ & -1.20 & $(0.03)$ & -0.43 & $(0.01)$ & 0.04 & $(0.01)$ & 0.85 & $(0.02)$ & 2.06 & $(0.03)$ \\
\hline & Denmark & 0.53 & $(0.02)$ & 0.70 & $(0.02)$ & -0.31 & $(0.02)$ & 0.32 & $(0.01)$ & 0.74 & $(0.02)$ & 1.37 & $(0.03)$ & 1.68 & $(0.03)$ \\
\hline & Estonia & -0.19 & $(0.01)$ & 0.76 & $(0.01)$ & -1.09 & $(0.02)$ & -0.42 & $(0.01)$ & 0.01 & $(0.01)$ & 0.76 & $(0.02)$ & 1.85 & $(0.03)$ \\
\hline & Finland & 0.16 & $(0.01)$ & 0.73 & $(0.01)$ & -0.68 & $(0.02)$ & -0.07 & $(0.01)$ & 0.34 & $(0.01)$ & 1.07 & $(0.02)$ & 1.76 & $(0.02)$ \\
\hline & France & 0.00 & $(0.02)$ & 0.77 & $(0.01)$ & -0.96 & $(0.02)$ & -0.23 & $(0.02)$ & 0.24 & $(0.01)$ & 0.94 & $(0.02)$ & 1.90 & $(0.03)$ \\
\hline & Germany & 0.13 & $(0.02)$ & 0.83 & $(0.01)$ & -0.86 & $(0.02)$ & -0.13 & $(0.02)$ & 0.35 & $(0.02)$ & 1.16 & $(0.02)$ & 2.02 & $(0.03)$ \\
\hline & Greece & -0.31 & $(0.02)$ & 0.87 & $(0.03)$ & -1.29 & $(0.03)$ & -0.59 & $(0.02)$ & -0.12 & $(0.02)$ & 0.76 & $(0.04)$ & 2.05 & $(0.04)$ \\
\hline & Hungary & -0.34 & $(0.02)$ & 0.81 & $(0.01)$ & -1.29 & $(0.02)$ & -0.60 & $(0.01)$ & -0.13 & $(0.02)$ & 0.68 & $(0.03)$ & 1.98 & $(0.03)$ \\
\hline & Iceland & 0.27 & $(0.01)$ & 0.67 & $(0.01)$ & -0.52 & $(0.01)$ & 0.07 & $(0.01)$ & 0.44 & $(0.01)$ & 1.10 & $(0.02)$ & 1.62 & $(0.03)$ \\
\hline & Ireland & 0.43 & $(0.02)$ & 0.86 & $(0.01)$ & -0.57 & $(0.02)$ & 0.11 & $(0.01)$ & 0.62 & $(0.02)$ & 1.55 & $(0.03)$ & 2.12 & $(0.03)$ \\
\hline & Israel & 0.03 & $(0.03)$ & 0.99 & $(0.02)$ & -1.16 & $(0.05)$ & -0.22 & $(0.03)$ & 0.29 & $(0.02)$ & 1.20 & $(0.03)$ & 2.36 & $(0.05)$ \\
\hline & Italy & -0.01 & $(0.01)$ & 0.74 & $(0.01)$ & -0.88 & $(0.02)$ & -0.25 & $(0.01)$ & 0.16 & $(0.01)$ & 0.91 & $(0.02)$ & 1.79 & $(0.03)$ \\
\hline & Japan & -0.50 & $(0.01)$ & 0.68 & $(0.01)$ & -1.33 & $(0.02)$ & -0.72 & $(0.01)$ & -0.32 & $(0.01)$ & 0.35 & $(0.02)$ & 1.68 & $(0.02)$ \\
\hline & Korea & -0.59 & $(0.01)$ & 0.53 & $(0.01)$ & -1.22 & $(0.02)$ & -0.73 & $(0.01)$ & -0.44 & $(0.01)$ & 0.04 & $(0.02)$ & 1.26 & $(0.02)$ \\
\hline & Latvia & -0.45 & $(0.02)$ & 0.79 & $(0.02)$ & -1.40 & $(0.02)$ & -0.70 & $(0.02)$ & -0.24 & $(0.02)$ & 0.54 & $(0.03)$ & 1.93 & $(0.03)$ \\
\hline & Luxembourg & 0.31 & $(0.01)$ & 0.99 & $(0.02)$ & -0.85 & $(0.02)$ & 0.01 & $(0.01)$ & 0.55 & $(0.01)$ & 1.53 & $(0.03)$ & 2.38 & $(0.03)$ \\
\hline & Mexico & -1.49 & $(0.05)$ & 1.38 & $(0.03)$ & -3.21 & $(0.07)$ & -1.95 & $(0.05)$ & -1.04 & $(0.05)$ & 0.23 & $(0.06)$ & 3.44 & $(0.07)$ \\
\hline & Netherlands & 0.31 & $(0.01)$ & 0.64 & $(0.01)$ & -0.47 & $(0.02)$ & 0.12 & $(0.01)$ & 0.50 & $(0.01)$ & 1.11 & $(0.02)$ & 1.58 & $(0.02)$ \\
\hline & New Zealand & 0.38 & $(0.02)$ & 0.93 & $(0.02)$ & -0.76 & $(0.03)$ & 0.12 & $(0.02)$ & 0.65 & $(0.02)$ & 1.52 & $(0.03)$ & 2.28 & $(0.03)$ \\
\hline & Norway & 0.60 & $(0.01)$ & 0.80 & $(0.02)$ & -0.32 & $(0.02)$ & 0.34 & $(0.01)$ & 0.80 & $(0.01)$ & 1.59 & $(0.02)$ & 1.91 & $(0.03)$ \\
\hline & Poland & -0.30 & $(0.02)$ & 0.77 & $(0.02)$ & -1.19 & $(0.02)$ & -0.56 & $(0.02)$ & -0.11 & $(0.02)$ & 0.66 & $(0.03)$ & 1.86 & $(0.03)$ \\
\hline & Portugal & 0.01 & $(0.02)$ & 0.86 & $(0.01)$ & -1.06 & $(0.02)$ & -0.25 & $(0.01)$ & 0.26 & $(0.02)$ & 1.08 & $(0.03)$ & 2.14 & $(0.03)$ \\
\hline & Slovak Republic & -0.32 & $(0.02)$ & 0.88 & $(0.02)$ & -1.37 & $(0.04)$ & -0.55 & $(0.01)$ & -0.09 & $(0.01)$ & 0.72 & $(0.02)$ & 2.08 & $(0.04)$ \\
\hline & Slovenia & 0.04 & $(0.01)$ & 0.69 & $(0.01)$ & -0.77 & $(0.01)$ & -0.20 & $(0.01)$ & 0.20 & $(0.01)$ & 0.93 & $(0.02)$ & 1.71 & $(0.02)$ \\
\hline & Spain & 0.10 & $(0.02)$ & 0.84 & $(0.01)$ & -0.91 & $(0.03)$ & -0.16 & $(0.02)$ & 0.33 & $(0.02)$ & 1.15 & $(0.03)$ & 2.06 & $(0.03)$ \\
\hline & Sweden & 0.48 & $(0.02)$ & 0.90 & $(0.02)$ & -0.58 & $(0.03)$ & 0.23 & $(0.02)$ & 0.71 & $(0.02)$ & 1.55 & $(0.03)$ & 2.14 & $(0.04)$ \\
\hline & Switzerland & 0.13 & $(0.01)$ & 0.84 & $(0.01)$ & -0.84 & $(0.02)$ & -0.14 & $(0.02)$ & 0.32 & $(0.02)$ & 1.18 & $(0.03)$ & 2.02 & $(0.03)$ \\
\hline & Turkey & -1.47 & $(0.04)$ & 1.02 & $(0.03)$ & -2.77 & $(0.04)$ & -1.75 & $(0.04)$ & -1.13 & $(0.03)$ & -0.24 & $(0.05)$ & 2.53 & $(0.06)$ \\
\hline & United Kingdom & 0.49 & $(0.02)$ & 0.98 & $(0.02)$ & -0.65 & $(0.02)$ & 0.16 & $(0.02)$ & 0.72 & $(0.02)$ & 1.75 & $(0.03)$ & 2.40 & $(0.03)$ \\
\hline & United States & 0.48 & $(0.03)$ & 1.08 & $(0.02)$ & -0.81 & $(0.03)$ & 0.13 & $(0.03)$ & 0.75 & $(0.03)$ & 1.85 & $(0.04)$ & 2.66 & $(0.04)$ \\
\hline & OECD average & -0.01 & $(0.00)$ & 0.85 & $(0.00)$ & -1.03 & $(0.00)$ & -0.28 & $(0.00)$ & 0.21 & $(0.00)$ & 1.04 & $(0.00)$ & 2.07 & $(0.01)$ \\
\hline 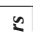 & Albania & -1.35 & $(0.03)$ & 1.06 & $(0.02)$ & -2.66 & $(0.03)$ & -1.69 & $(0.03)$ & -1.04 & $(0.03)$ & -0.02 & $(0.04)$ & 2.64 & $(0.03)$ \\
\hline 9 & Algeria & -1.93 & $(0.03)$ & 1.19 & $(0.02)$ & -3.35 & $(0.04)$ & -2.28 & $(0.03)$ & -1.59 & $(0.04)$ & -0.49 & $(0.05)$ & 2.86 & $(0.05)$ \\
\hline స & Brazil & -1.13 & $(0.02)$ & 1.08 & $(0.01)$ & -2.46 & $(0.03)$ & -1.45 & $(0.02)$ & -0.80 & $(0.02)$ & 0.21 & $(0.03)$ & 2.67 & $(0.03)$ \\
\hline & B-S-J-G (China) & -1.27 & $(0.04)$ & 1.08 & $(0.03)$ & -2.59 & $(0.05)$ & -1.61 & $(0.04)$ & -0.97 & $(0.04)$ & 0.08 & $(0.06)$ & 2.67 & $(0.07)$ \\
\hline & Bulgaria & -0.31 & $(0.02)$ & 0.94 & $(0.03)$ & -1.38 & $(0.04)$ & -0.57 & $(0.02)$ & -0.09 & $(0.02)$ & 0.78 & $(0.04)$ & 2.17 & $(0.05)$ \\
\hline & CABA (Argentina) & -0.44 & $(0.07)$ & 0.96 & $(0.03)$ & -1.66 & $(0.06)$ & -0.71 & $(0.07)$ & -0.12 & $(0.07)$ & 0.73 & $(0.09)$ & 2.39 & $(0.07)$ \\
\hline & Colombia & -1.65 & $(0.04)$ & 1.38 & $(0.03)$ & -3.41 & $(0.06)$ & -2.05 & $(0.05)$ & -1.19 & $(0.05)$ & 0.05 & $(0.05)$ & 3.46 & $(0.07)$ \\
\hline & Costa Rica & -1.17 & $(0.04)$ & 1.16 & $(0.02)$ & -2.60 & $(0.04)$ & -1.57 & $(0.04)$ & -0.81 & $(0.04)$ & 0.30 & $(0.05)$ & 2.91 & $(0.06)$ \\
\hline & Croatia & -0.43 & $(0.01)$ & 0.68 & $(0.01)$ & -1.21 & $(0.02)$ & -0.64 & $(0.01)$ & -0.26 & $(0.01)$ & 0.42 & $(0.02)$ & 1.63 & $(0.02)$ \\
\hline & Cyprus* & 0.30 & $(0.01)$ & 1.04 & $(0.01)$ & -0.92 & $(0.02)$ & 0.00 & $(0.01)$ & 0.54 & $(0.01)$ & 1.59 & $(0.03)$ & 2.51 & $(0.03)$ \\
\hline & Dominican Republic & -1.58 & $(0.04)$ & 1.28 & $(0.03)$ & -3.19 & $(0.05)$ & -1.95 & $(0.04)$ & -1.19 & $(0.04)$ & 0.00 & $(0.05)$ & 3.19 & $(0.06)$ \\
\hline & FYROM & -0.69 & $(0.01)$ & 0.93 & $(0.02)$ & -1.81 & $(0.02)$ & -0.95 & $(0.02)$ & -0.43 & $(0.01)$ & 0.42 & $(0.02)$ & 2.23 & $(0.03)$ \\
\hline & Georgia & -1.17 & $(0.02)$ & 0.91 & $(0.02)$ & -2.28 & $(0.03)$ & -1.42 & $(0.02)$ & -0.91 & $(0.02)$ & -0.07 & $(0.03)$ & 2.21 & $(0.04)$ \\
\hline & Hong Kong (China) & -0.76 & $(0.02)$ & 0.79 & $(0.02)$ & -1.64 & $(0.02)$ & -1.04 & $(0.02)$ & -0.58 & $(0.02)$ & 0.23 & $(0.03)$ & 1.87 & $(0.03)$ \\
\hline & Indonesia & -2.67 & $(0.05)$ & 1.34 & $(0.03)$ & -4.38 & $(0.08)$ & -3.01 & $(0.05)$ & -2.27 & $(0.04)$ & -1.03 & $(0.06)$ & 3.35 & $(0.08)$ \\
\hline & Jordan & -0.91 & $(0.04)$ & 1.27 & $(0.02)$ & -2.47 & $(0.05)$ & -1.26 & $(0.04)$ & -0.53 & $(0.04)$ & 0.62 & $(0.05)$ & 3.09 & $(0.05)$ \\
\hline & Kosovo & -0.79 & $(0.02)$ & 0.96 & $(0.02)$ & -1.92 & $(0.03)$ & -1.10 & $(0.02)$ & -0.54 & $(0.02)$ & 0.41 & $(0.03)$ & 2.33 & $(0.04)$ \\
\hline & Lebanon & -0.63 & $(0.04)$ & 1.22 & $(0.04)$ & -2.07 & $(0.04)$ & -1.06 & $(0.04)$ & -0.34 & $(0.04)$ & 0.94 & $(0.09)$ & 3.01 & $(0.08)$ \\
\hline & Lithuania & -0.41 & $(0.02)$ & 0.79 & $(0.02)$ & -1.31 & $(0.03)$ & -0.63 & $(0.01)$ & -0.22 & $(0.01)$ & 0.53 & $(0.03)$ & 1.84 & $(0.04)$ \\
\hline & Macao (China) & -0.39 & $(0.01)$ & 0.81 & $(0.02)$ & -1.32 & $(0.01)$ & -0.68 & $(0.01)$ & -0.22 & $(0.01)$ & 0.66 & $(0.02)$ & 1.98 & $(0.02)$ \\
\hline & Malta & 0.29 & $(0.01)$ & 0.84 & $(0.02)$ & -0.73 & $(0.02)$ & 0.04 & $(0.02)$ & 0.52 & $(0.01)$ & 1.33 & $(0.02)$ & 2.06 & $(0.03)$ \\
\hline & Moldova & -1.40 & $(0.02)$ & 1.06 & $(0.02)$ & -2.74 & $(0.05)$ & -1.59 & $(0.02)$ & -1.07 & $(0.02)$ & -0.20 & $(0.03)$ & 2.54 & $(0.05)$ \\
\hline & Montenegro & -0.57 & $(0.01)$ & 0.93 & $(0.02)$ & -1.60 & $(0.02)$ & -0.87 & $(0.01)$ & -0.40 & $(0.01)$ & 0.57 & $(0.03)$ & 2.17 & $(0.03)$ \\
\hline & Peru & -1.92 & $(0.04)$ & 1.43 & $(0.03)$ & -3.71 & $(0.06)$ & -2.38 & $(0.04)$ & -1.44 & $(0.05)$ & -0.15 & $(0.06)$ & 3.57 & $(0.07)$ \\
\hline & Qatar & 0.91 & $(0.01)$ & 1.48 & $(0.01)$ & -0.89 & $(0.02)$ & 0.41 & $(0.01)$ & 1.34 & $(0.01)$ & 2.81 & $(0.02)$ & 3.70 & $(0.02)$ \\
\hline & Romania & -0.94 & $(0.03)$ & 0.98 & $(0.02)$ & -2.16 & $(0.05)$ & -1.19 & $(0.03)$ & -0.64 & $(0.03)$ & 0.23 & $(0.04)$ & 2.39 & $(0.05)$ \\
\hline & Russia & -0.54 & $(0.02)$ & 0.80 & $(0.02)$ & -1.49 & $(0.03)$ & -0.78 & $(0.02)$ & -0.34 & $(0.02)$ & 0.43 & $(0.03)$ & 1.92 & $(0.03)$ \\
\hline & Singapore & -0.18 & $(0.02)$ & 0.85 & $(0.01)$ & -1.23 & $(0.02)$ & -0.42 & $(0.02)$ & 0.08 & $(0.02)$ & 0.87 & $(0.02)$ & 2.09 & $(0.02)$ \\
\hline & Chinese Taipei & -0.41 & $(0.01)$ & 0.86 & $(0.01)$ & -1.43 & $(0.02)$ & -0.69 & $(0.01)$ & -0.18 & $(0.01)$ & 0.68 & $(0.02)$ & 2.11 & $(0.03)$ \\
\hline & Thailand & -1.18 & $(0.04)$ & 1.14 & $(0.02)$ & -2.55 & $(0.04)$ & -1.57 & $(0.03)$ & -0.87 & $(0.04)$ & 0.28 & $(0.06)$ & 2.82 & $(0.06)$ \\
\hline & Trinidad and Tobago & -0.32 & $(0.02)$ & 1.27 & $(0.02)$ & -1.87 & $(0.03)$ & -0.71 & $(0.02)$ & 0.04 & $(0.02)$ & 1.27 & $(0.03)$ & 3.14 & $(0.04)$ \\
\hline & Tunisia & -1.49 & $(0.03)$ & 1.20 & $(0.02)$ & -2.99 & $(0.04)$ & -1.86 & $(0.03)$ & -1.13 & $(0.03)$ & 0.01 & $(0.04)$ & 3.00 & $(0.05)$ \\
\hline & United Arab Emirates & 0.67 & $(0.02)$ & 1.42 & $(0.01)$ & -1.04 & $(0.03)$ & 0.14 & $(0.03)$ & 1.06 & $(0.03)$ & 2.53 & $(0.03)$ & 3.58 & $(0.03)$ \\
\hline & Uruguay & -0.84 & $(0.02)$ & 0.96 & $(0.02)$ & -2.04 & $(0.03)$ & -1.12 & $(0.02)$ & -0.54 & $(0.02)$ & 0.34 & $(0.04)$ & 2.38 & $(0.04)$ \\
\hline & Viet Nam & -2.25 & $(0.05)$ & 1.19 & $(0.03)$ & -3.77 & $(0.07)$ & -2.54 & $(0.04)$ & -1.87 & $(0.04)$ & -0.84 & $(0.06)$ & 2.92 & $(0.07)$ \\
\hline & Argentina** & -1.00 & $(0.03)$ & 0.99 & $(0.03)$ & -2.27 & $(0.05)$ & -1.26 & $(0.03)$ & -0.65 & $(0.03)$ & 0.17 & $(0.03)$ & 2.44 & $(0.05)$ \\
\hline & Kazakhstan** & -1.22 & $(0.02)$ & 0.86 & $(0.03)$ & -2.24 & $(0.03)$ & -1.47 & $(0.02)$ & -0.99 & $(0.02)$ & -0.17 & $(0.04)$ & 2.08 & $(0.05)$ \\
\hline & Malaysia** & -0.79 & $(0.04)$ & 1.20 & $(0.02)$ & -2.28 & $(0.04)$ & -1.20 & $(0.05)$ & -0.41 & $(0.05)$ & 0.74 & $(0.05)$ & 3.02 & $(0.05)$ \\
\hline
\end{tabular}

Note: Values that are statistically significant are indicated in bold (see Annex A3).

* See note at the beginning of this Annex.

is too small to ensure comparability (see Annex A4).

StatLink न्ताइ http://dx.doi.org/10.1787/888933472334 
[Part 2/2]

Table III.10.6 Index of family wealth, by student characteristics

Results based on students' self-reports

\begin{tabular}{|c|c|c|c|c|c|c|c|c|c|}
\hline & \multicolumn{8}{|c|}{ Index of family wealth } \\
\hline & & \multicolumn{8}{|c|}{ By immigration background } \\
\hline & & \multicolumn{2}{|c|}{ Non-immigrant } & \multicolumn{2}{|c|}{ Second-generation } & \multicolumn{2}{|c|}{ First-generation } & $\begin{array}{l}\text { Difference b } \\
\text { (non-imm }\end{array}$ & $\begin{array}{l}\text { background } \\
\text { eneration) }\end{array}$ \\
\hline & & Mean index & S.E. & Mean index & S.E. & Mean index & S.E. & Dif. & S.E. \\
\hline 0 & Australia & 0.69 & $(0.01)$ & 0.60 & $(0.03)$ & 0.45 & $(0.03)$ & 0.24 & $(0.03)$ \\
\hline ডي山ّ山 & Austria & 0.24 & $(0.01)$ & -0.24 & $(0.03)$ & -0.37 & $(0.07)$ & 0.61 & $(0.07)$ \\
\hline$\overline{0}$ & Belgium & 0.18 & $(0.02)$ & -0.04 & $(0.03)$ & -0.21 & $(0.05)$ & 0.39 & $(0.05)$ \\
\hline & Canada & 0.62 & $(0.02)$ & 0.51 & $(0.03)$ & 0.30 & $(0.03)$ & 0.32 & $(0.03)$ \\
\hline & Chile & -0.64 & $(0.02)$ & -0.67 & $(0.16)$ & -1.09 & $(0.13)$ & 0.46 & $(0.14)$ \\
\hline & Czech Republic & -0.18 & $(0.01)$ & -0.29 & $(0.11)$ & -0.38 & $(0.13)$ & 0.20 & $(0.13)$ \\
\hline & Denmark & 0.57 & $(0.02)$ & 0.20 & $(0.03)$ & 0.26 & $(0.08)$ & 0.31 & $(0.08)$ \\
\hline & Estonia & -0.18 & $(0.01)$ & -0.23 & $(0.05)$ & -0.07 & $(0.14)$ & -0.11 & $(0.14)$ \\
\hline & Finland & 0.18 & $(0.01)$ & -0.19 & $(0.05)$ & -0.19 & $(0.11)$ & 0.37 & $(0.11)$ \\
\hline & France & 0.05 & $(0.01)$ & -0.22 & $(0.05)$ & -0.53 & $(0.08)$ & 0.59 & $(0.08)$ \\
\hline & Germany & 0.20 & $(0.02)$ & -0.21 & $(0.03)$ & -0.20 & $(0.08)$ & 0.40 & $(0.08)$ \\
\hline & Greece & -0.25 & $(0.02)$ & -0.72 & $(0.06)$ & -0.80 & $(0.10)$ & 0.54 & $(0.10)$ \\
\hline & Hungary & -0.33 & $(0.02)$ & -0.08 & $(0.13)$ & -0.60 & $(0.15)$ & 0.27 & $(0.15)$ \\
\hline & Iceland & 0.28 & $(0.01)$ & 0.08 & $(0.10)$ & 0.16 & $(0.08)$ & 0.12 & $(0.08)$ \\
\hline & Ireland & 0.45 & $(0.02)$ & 0.26 & $(0.07)$ & 0.30 & $(0.06)$ & 0.15 & $(0.06)$ \\
\hline & Israel & 0.09 & $(0.03)$ & -0.17 & $(0.04)$ & -0.43 & $(0.17)$ & 0.52 & $(0.17)$ \\
\hline & Italy & 0.03 & $(0.01)$ & -0.35 & $(0.06)$ & -0.58 & $(0.04)$ & 0.61 & $(0.04)$ \\
\hline & Japan & -0.50 & $(0.01)$ & c & C & c & $\mathrm{C}$ & c & C \\
\hline & Korea & -0.59 & $(0.01)$ & $\mathrm{m}$ & $\mathrm{m}$ & c & c & c & $\mathrm{c}$ \\
\hline & Latvia & -0.45 & $(0.02)$ & -0.40 & $(0.07)$ & -0.06 & $(0.33)$ & -0.39 & $(0.33)$ \\
\hline & Luxembourg & 0.50 & $(0.02)$ & 0.20 & $(0.02)$ & 0.05 & $(0.03)$ & 0.45 & $(0.03)$ \\
\hline & Mexico & -1.48 & $(0.05)$ & c & C & -2.55 & $(0.17)$ & 1.07 & $(0.17)$ \\
\hline & Netherlands & 0.36 & $(0.01)$ & -0.05 & $(0.03)$ & -0.04 & $(0.07)$ & 0.40 & $(0.06)$ \\
\hline & New Zealand & 0.43 & $(0.02)$ & 0.23 & $(0.05)$ & 0.32 & $(0.04)$ & 0.11 & $(0.04)$ \\
\hline & Norway & 0.66 & $(0.01)$ & 0.33 & $(0.04)$ & 0.12 & $(0.06)$ & 0.54 & $(0.06)$ \\
\hline & Poland & -0.30 & $(0.02)$ & C & C & C & C & C & $\mathrm{C}$ \\
\hline & Portugal & 0.02 & $(0.02)$ & 0.02 & $(0.07)$ & -0.22 & $(0.06)$ & 0.24 & $(0.06)$ \\
\hline & Slovak Republic & -0.31 & $(0.02)$ & -0.43 & $(0.22)$ & -0.09 & $(0.27)$ & -0.22 & $(0.28)$ \\
\hline & Slovenia & 0.06 & $(0.01)$ & -0.20 & $(0.04)$ & -0.20 & $(0.06)$ & 0.26 & $(0.06)$ \\
\hline & Spain & 0.16 & $(0.02)$ & -0.23 & $(0.12)$ & -0.40 & $(0.04)$ & 0.56 & $(0.04)$ \\
\hline & Sweden & 0.56 & $(0.02)$ & 0.24 & $(0.04)$ & -0.10 & $(0.06)$ & 0.66 & $(0.07)$ \\
\hline & Switzerland & 0.19 & $(0.01)$ & 0.01 & $(0.03)$ & -0.02 & $(0.06)$ & 0.21 & $(0.06)$ \\
\hline & Turkey & -1.47 & $(0.04)$ & -0.83 & $(0.18)$ & C & $\mathrm{C}$ & c & $\mathrm{C}$ \\
\hline & United Kingdom & 0.57 & $(0.02)$ & 0.25 & $(0.06)$ & 0.03 & $(0.05)$ & 0.55 & $(0.05)$ \\
\hline & United States & 0.57 & $(0.03)$ & 0.30 & $(0.05)$ & 0.02 & $(0.07)$ & 0.55 & $(0.07)$ \\
\hline & OECD average & 0.03 & $(0.00)$ & -0.13 & $(0.03)$ & -0.26 & $(0.03)$ & 0.29 & $(0.03)$ \\
\hline$\approx$ & Albania & -1.35 & $(0.03)$ & c & $\mathrm{C}$ & c & c & C & $\mathrm{c}$ \\
\hline$\Xi$ & Algeria & -1.92 & $(0.03)$ & -1.49 & $(0.25)$ & $\mathrm{m}$ & $\mathrm{m}$ & $\mathrm{m}$ & $\mathrm{m}$ \\
\hline ปั้ & Brazil & -1.12 & $(0.02)$ & -1.28 & $(0.16)$ & -0.87 & $(0.36)$ & -0.25 & $(0.36)$ \\
\hline & B-S-J-G (China) & -1.26 & $(0.04)$ & c & C & c & C & c & C \\
\hline & Bulgaria & -0.31 & $(0.02)$ & c & c & c & c & c & c \\
\hline & CABA (Argentina) & -0.30 & $(0.07)$ & -1.06 & $(0.07)$ & -1.26 & $(0.11)$ & 0.97 & $(0.13)$ \\
\hline & Colombia & -1.64 & $(0.04)$ & -1.80 & $(0.27)$ & c & c & c & c \\
\hline & Costa Rica & -1.13 & $(0.04)$ & -1.67 & $(0.08)$ & -1.57 & $(0.16)$ & 0.44 & $(0.16)$ \\
\hline & Croatia & -0.42 & $(0.01)$ & -0.48 & $(0.03)$ & -0.57 & $(0.10)$ & 0.15 & $(0.10)$ \\
\hline & Cyprus* & 0.35 & $(0.01)$ & 0.05 & $(0.09)$ & -0.15 & $(0.07)$ & 0.49 & $(0.07)$ \\
\hline & Dominican Republic & -1.56 & $(0.04)$ & -2.34 & $(0.26)$ & -1.98 & $(0.39)$ & 0.42 & $(0.39)$ \\
\hline & FYROM & -0.69 & $(0.01)$ & -0.60 & $(0.14)$ & -0.66 & $(0.39)$ & -0.02 & $(0.39)$ \\
\hline & Georgia & -1.16 & $(0.02)$ & -1.07 & $(0.09)$ & c & $\mathrm{c}$ & c & c \\
\hline & Hong Kong (China) & -0.64 & $(0.02)$ & -0.89 & $(0.02)$ & -1.10 & $(0.03)$ & 0.46 & $(0.04)$ \\
\hline & Indonesia & -2.66 & $(0.05)$ & C & $\mathrm{C}$ & c & C & c & $\mathrm{C}$ \\
\hline & Jordan & -0.91 & $(0.04)$ & -0.74 & $(0.06)$ & -1.01 & $(0.15)$ & 0.10 & $(0.14)$ \\
\hline & Kosovo & -0.79 & $(0.02)$ & -0.79 & $(0.20)$ & -0.50 & $(0.16)$ & -0.29 & $(0.16)$ \\
\hline & Lebanon & -0.59 & $(0.05)$ & -0.78 & $(0.17)$ & -0.94 & $(0.22)$ & 0.35 & $(0.21)$ \\
\hline & Lithuania & -0.41 & $(0.01)$ & -0.24 & $(0.09)$ & -1.04 & $(0.88)$ & 0.63 & $(0.88)$ \\
\hline & Macao (China) & -0.23 & $(0.02)$ & -0.43 & $(0.02)$ & -0.62 & $(0.03)$ & 0.38 & $(0.03)$ \\
\hline & Malta & 0.29 & $(0.01)$ & 0.29 & $(0.10)$ & 0.26 & $(0.13)$ & 0.03 & $(0.13)$ \\
\hline & Moldova & -1.39 & $(0.02)$ & -1.21 & $(0.14)$ & c & C & c & C \\
\hline & Montenegro & -0.59 & $(0.01)$ & -0.39 & $(0.06)$ & -0.51 & $(0.12)$ & -0.08 & $(0.13)$ \\
\hline & Peru & -1.92 & $(0.04)$ & c & $\mathrm{C}$ & C & $\mathrm{C}$ & C & $\mathrm{C}$ \\
\hline & Qatar & 1.58 & $(0.02)$ & 0.53 & $(0.03)$ & 0.33 & $(0.02)$ & 1.25 & $(0.03)$ \\
\hline & Romania & -0.93 & $(0.03)$ & c & c & c & c & c & c \\
\hline & Russia & -0.55 & $(0.02)$ & -0.44 & $(0.06)$ & -0.50 & $(0.10)$ & -0.05 & $(0.09)$ \\
\hline & Singapore & -0.21 & $(0.02)$ & -0.11 & $(0.05)$ & -0.01 & $(0.05)$ & -0.20 & $(0.05)$ \\
\hline & Chinese Taipei & -0.41 & $(0.01)$ & c & c & c & c & c & c \\
\hline & Thailand & -1.17 & $(0.04)$ & -1.84 & $(0.23)$ & c & c & c & c \\
\hline & Trinidad and Tobago & -0.31 & $(0.02)$ & -0.60 & $(0.17)$ & -0.61 & $(0.26)$ & 0.30 & $(0.26)$ \\
\hline & Tunisia & -1.48 & $(0.03)$ & -1.52 & $(0.20)$ & c & $\mathrm{C}$ & c & C \\
\hline & United Arab Emirates & 1.32 & $(0.03)$ & 0.32 & $(0.04)$ & 0.18 & $(0.03)$ & 1.14 & $(0.04)$ \\
\hline & Uruguay & -0.84 & $(0.02)$ & c & C & C & C & C & C \\
\hline & Viet Nam & -2.25 & $(0.05)$ & c & c & c & c & c & c \\
\hline & Argentina** $^{* *}$ & -0.98 & $(0.03)$ & -1.25 & $(0.09)$ & -1.54 & $(0.10)$ & 0.56 & $(0.10)$ \\
\hline & Kazakhstan** & -1.21 & $(0.02)$ & -1.25 & $(0.06)$ & -1.38 & $(0.06)$ & 0.17 & $(0.06)$ \\
\hline & Malaysia** & -0.78 & $(0.04)$ & -1.44 & $(0.17)$ & C & C & C & c \\
\hline
\end{tabular}

Note: Values that are statistically significant are indicated in bold (see Annex A3).

* See note at the beginning of this Annex.

** Coverage is too small to ensure comparability (see Annex A4).

StatLink 감ㄴ http://dx.doi.org/10.1787/888933472334 


\begin{tabular}{|c|c|c|c|c|c|c|c|c|c|c|c|c|c|c|c|c|c|c|}
\hline & \multicolumn{10}{|c|}{ Science performance, by national quarters of the index of family wealth } & Befo & $\begin{array}{l}\text { account } \\
\text { educ }\end{array}$ & $\begin{array}{l}\text { ting for } \\
\text { cation }\end{array}$ & ents' & $\begin{array}{r}\text { After a } \\
\text { for } \\
\text { edu }\end{array}$ & $\begin{array}{l}\text { ounting } \\
\text { rents' } \\
\text { tion }{ }^{\prime}\end{array}$ & \\
\hline & & $\begin{array}{l}\text { Bot } \\
\text { qua }\end{array}$ & $\begin{array}{l}\text { tom } \\
\text { rter }\end{array}$ & & $\begin{array}{l}\text { ond } \\
\text { rter }\end{array}$ & & & $\begin{array}{r}\text { Tc } \\
\text { qua }\end{array}$ & & $\begin{array}{r}\text { Top - } \\
\text { qua }\end{array}$ & $\begin{array}{l}\text { bottom } \\
\text { rter }\end{array}$ & $\begin{array}{c}\text { Change } \\
\text { score pe } \\
\text { change i } \\
\text { of fam }\end{array}$ & $\begin{array}{l}\text { science } \\
\text { one-unit } \\
\text { the index } \\
\text { wealth } \\
\end{array}$ & $\begin{array}{c}\begin{array}{c}\text { Explain } \\
\text { in } \\
\text { perf } \\
(\mathrm{r}-\mathrm{squ}\end{array} \\
\end{array}$ & $\begin{array}{l}\text { variance } \\
\text { dent } \\
\text { nance } \\
\text { d x 100) }\end{array}$ & $\begin{array}{c}\text { Change } \\
\text { score p } \\
\text { change i } \\
\text { of fam }\end{array}$ & $\begin{array}{l}\text { science } \\
\text { one-unit } \\
\text { the index } \\
\text { wealth }\end{array}$ & $\begin{array}{c}\text { Gini index } \\
\text { of income } \\
\text { inequality }{ }^{2} \\
(2014)\end{array}$ \\
\hline & & $\begin{array}{l}\text { Mean } \\
\text { score }\end{array}$ & S.E. & $\begin{array}{l}\text { Mean } \\
\text { score }\end{array}$ & S.E. & $\begin{array}{l}\text { Mean } \\
\text { score }\end{array}$ & S.E. & $\begin{array}{l}\text { Mean } \\
\text { score }\end{array}$ & S.E. & $\begin{array}{c}\text { Score } \\
\text { dif. }\end{array}$ & S.E. & $\begin{array}{c}\text { Score } \\
\text { dif. }\end{array}$ & S.E. & $\%$ & S.E. & $\begin{array}{c}\text { Score } \\
\text { dif. }\end{array}$ & S.E. & $\begin{array}{l}\text { Mean } \\
\text { index }\end{array}$ \\
\hline & Australia & 493 & (2.9) & 517 & $(2.6)$ & 522 & $(2.4)$ & 515 & $(2.6)$ & 23 & $(3.8)$ & 9 & $(1.5)$ & 0.6 & $(0.2)$ & 4 & $(1.4)$ & $\mathrm{m}$ \\
\hline ডي & Austria & 474 & (4.4) & 500 & (3.9) & 506 & (3.4) & 500 & (3.7) & 26 & $(5.7)$ & 11 & $(2.3)$ & 0.9 & $(0.4)$ & 5 & $(2.0)$ & 30.48 \\
\hline & Belgium & 477 & (3.7) & 503 & (3.2) & 514 & (2.8) & 515 & (3.2) & 38 & $(4.1)$ & 16 & (2.3) & 1.7 & $(0.5)$ & 9 & $(2.1)$ & 27.59 \\
\hline & Canada & 518 & (3.3) & 532 & $(2.8)$ & 534 & $(2.6)$ & 530 & $(2.7)$ & 11 & $(3.2)$ & 3 & $(1.1)$ & 0.1 & $(0.1)$ & 1 & (1.1) & $\mathrm{m}$ \\
\hline & Chile & 416 & (3.5) & 440 & (3.4) & 455 & (3.9) & 478 & $(3.2)$ & 62 & $(4.4)$ & 24 & (1.5) & 7.9 & $(0.9)$ & 15 & (1.6) & 50.45 \\
\hline & Czech Republic & 476 & $(4.0)$ & 492 & (3.4) & 500 & $(3.2)$ & 504 & $(2.7)$ & 28 & $(4.4)$ & 13 & (1.9) & 1.3 & $(0.4)$ & 7 & $(2.0)$ & 26.13 \\
\hline & Denmark & 498 & (3.5) & 505 & (3.3) & 510 & (3.6) & 497 & $(4.3)$ & -2 & $(4.9)$ & 1 & $(2.7)$ & 0.0 & $(0.1)$ & -3 & $(2.5)$ & 29.08 \\
\hline & Estonia & 527 & (3.3) & 533 & (3.0) & 540 & (3.3) & 540 & (3.1) & 13 & $(4.3)$ & 4 & $(2.2)$ & 0.1 & $(0.1)$ & 1 & $(2.1)$ & 33.15 \\
\hline & Finland & 521 & $(4.9)$ & 538 & (3.0) & 537 & (3.5) & 528 & (3.5) & 7 & (5.6) & 2 & $(2.9)$ & 0.0 & $(0.1)$ & -2 & $(2.7)$ & 27.12 \\
\hline & France & 475 & (4.6) & 501 & (3.3) & 507 & (3.1) & 503 & (3.3) & 28 & (5.9) & 12 & $(2.8)$ & 0.8 & $(0.4)$ & 5 & $(2.8)$ & 33.10 \\
\hline & Germany & 487 & $(4.3)$ & 516 & (3.9) & 529 & $(4.0)$ & 527 & (3.5) & 40 & $(4.3)$ & 16 & $(2.1)$ & 1.7 & $(0.4)$ & 10 & $(2.0)$ & $\mathrm{m}$ \\
\hline & Greece & 439 & (5.6) & 458 & $(4.7)$ & 463 & $(4.0)$ & 461 & (4.7) & 22 & (4.9) & 8 & $(2.1)$ & 0.6 & $(0.3)$ & 1 & $(2.0)$ & 36.68 \\
\hline & Hungary & 453 & $(4.1)$ & 478 & (3.6) & 484 & (3.6) & 492 & (3.6) & 40 & $(5.2)$ & 17 & (2.6) & 2.0 & $(0.6)$ & 6 & $(2.6)$ & 30.55 \\
\hline & Iceland & 488 & (3.6) & 478 & (3.8) & 473 & (3.4) & 458 & (2.9) & -30 & (4.6) & -15 & $(2.2)$ & 1.3 & $(0.4)$ & -19 & $(2.2)$ & 26.94 \\
\hline & Ireland & 492 & (3.4) & 503 & (3.4) & 509 & (3.0) & 507 & (3.4) & 15 & $(4.1)$ & 6 & $(1.7)$ & 0.4 & $(0.2)$ & 1 & (1.7) & 32.52 \\
\hline & Israel & 450 & (8.6) & 476 & (4.5) & 488 & (4.8) & 468 & (4.5) & 18 & $(9.2)$ & 7 & (3.7) & 0.4 & $(0.4)$ & 0 & (3.1) & $\mathrm{m}$ \\
\hline & Italy & 463 & (3.3) & 481 & (3.9) & 487 & (3.6) & 495 & (3.7) & 32 & $(4.2)$ & 14 & $(2.1)$ & 1.3 & $(0.4)$ & 9 & $(2.1)$ & 35.16 \\
\hline & Japan & 527 & $(4.0)$ & 543 & (3.8) & 542 & (3.8) & 541 & (3.8) & 14 & $(4.3)$ & 7 & $(2.2)$ & 0.2 & $(0.2)$ & 2 & $(2.0)$ & $\mathrm{m}$ \\
\hline & Korea & 501 & (3.9) & 521 & (3.7) & 523 & $(4.0)$ & 520 & (5.1) & 20 & (5.1) & 16 & (3.8) & 0.8 & $(0.4)$ & 3 & (3.3) & $\mathrm{m}$ \\
\hline & Latvia & 479 & (3.2) & 496 & $(2.9)$ & 491 & $(2.7)$ & 497 & (2.6) & 18 & (4.1) & 7 & $(2.1)$ & 0.4 & $(0.3)$ & 2 & $(2.2)$ & 35.48 \\
\hline & Luxembourg & 459 & (3.1) & 480 & $(2.6)$ & 493 & (3.0) & 499 & $(2.7)$ & 40 & $(4.4)$ & 15 & (1.6) & 2.1 & $(0.4)$ & 7 & $(1.7)$ & 34.79 \\
\hline & Mexico & 391 & (3.1) & 409 & $(3.1)$ & 426 & (3.1) & 440 & (3.7) & 49 & $(4.8)$ & 14 & $(1.2)$ & 7.4 & $(1.2)$ & 10 & $(1.2)$ & 48.21 \\
\hline & Netherlands & 494 & $(4.3)$ & 511 & (3.2) & 519 & (3.7) & 511 & (3.7) & 17 & (5.1) & 10 & $(3.0)$ & 0.4 & $(0.2)$ & 1 & $(2.7)$ & 27.99 \\
\hline & New Zealand & 491 & (3.6) & 519 & $(4.1)$ & 528 & (3.8) & 521 & $(4.1)$ & 30 & $(5.2)$ & 11 & $(2.1)$ & 1.0 & $(0.4)$ & 8 & $(2.0)$ & $\mathrm{m}$ \\
\hline & Norway & 487 & (3.5) & 512 & (3.0) & 509 & (3.3) & 491 & (4.1) & 4 & $(5.0)$ & -1 & (2.4) & 0.0 & $(0.1)$ & -5 & (2.4) & 25.90 \\
\hline & Poland & 480 & (3.6) & 499 & (3.8) & 513 & (3.5) & 516 & $(4.0)$ & 36 & $(5.0)$ & 17 & (2.5) & 2.1 & $(0.6)$ & 9 & $(2.2)$ & 32.08 \\
\hline & Portugal & 475 & (3.8) & 504 & (3.5) & 512 & $(2.7)$ & 515 & (3.1) & 40 & $(4.2)$ & 17 & $(1.8)$ & 2.6 & $(0.5)$ & 8 & $(2.0)$ & 36.04 \\
\hline & Slovak Republic & 430 & (5.1) & 466 & (3.4) & 477 & (3.3) & 477 & (3.3) & 47 & (5.5) & 23 & $(2.2)$ & 4.3 & $(0.8)$ & 14 & $(2.2)$ & 26.12 \\
\hline & Slovenia & 503 & $(3.2)$ & 511 & (3.1) & 526 & $(2.7)$ & 514 & $(2.7)$ & 11 & $(4.5)$ & 4 & $(2.2)$ & 0.1 & $(0.1)$ & -5 & $(2.2)$ & 25.59 \\
\hline & Spain & 466 & (3.4) & 493 & (3.4) & 506 & (2.9) & 508 & (3.1) & 42 & $(4.4)$ & 20 & (1.9) & 3.5 & $(0.7)$ & 12 & (1.9) & 35.89 \\
\hline & Sweden & 477 & (5.0) & 505 & (5.8) & 510 & $(3.7)$ & 486 & $(4.0)$ & 9 & $(4.6)$ & 2 & (1.9) & 0.0 & $(0.1)$ & -2 & (1.9) & 27.32 \\
\hline & Switzerland & 486 & $(4.5)$ & 509 & $(4.3)$ & 519 & $(4.4)$ & 511 & (4.4) & 25 & $(5.1)$ & 8 & (2.1) & 0.5 & $(0.2)$ & 2 & $(2.0)$ & 31.64 \\
\hline & Turkey & 391 & $(4.2)$ & 420 & $(4.6)$ & 438 & $(4.8)$ & 455 & $(5.2)$ & 64 & (5.9) & 23 & (2.0) & 8.8 & (1.4) & 21 & (1.8) & 40.18 \\
\hline & United Kingdom & 501 & $(4.1)$ & 507 & (3.5) & 511 & (3.5) & 523 & (3.8) & 22 & $(4.6)$ & 8 & (1.4) & 0.6 & $(0.2)$ & 5 & (1.4) & 32.57 \\
\hline & United States & 466 & $(4.0)$ & 496 & (4.9) & 508 & (3.6) & 518 & (3.7) & 52 & $(4.8)$ & 18 & (1.6) & 3.9 & $(0.7)$ & 12 & (1.5) & 41.06 \\
\hline & OECD average & 476 & $(0.7)$ & 496 & $(0.6)$ & 503 & $(0.6)$ & 502 & $(0.6)$ & 26 & $(0.8)$ & 10 & $(0.4)$ & 1.7 & $(0.1)$ & 4 & $(0.4)$ & 32.85 \\
\hline & Albania & 427 & $(4.1)$ & 428 & $(4.2)$ & 428 & (3.7) & 430 & (3.8) & 3 & $(4.0)$ & 1 & (1.5) & 0.0 & $(0.0)$ & 1 & $(1.6)$ & 28.96 \\
\hline ఏ & Algeria & 368 & $(2.9)$ & 375 & (3.4) & 378 & $(3.1)$ & 386 & (5.2) & 18 & (5.5) & 6 & $(1.7)$ & 1.0 & $(0.6)$ & 6 & (1.5) & $\mathrm{m}$ \\
\hline & Brazil & 363 & $(2.1)$ & 395 & $(2.7)$ & 413 & $(2.6)$ & 439 & $(4.8)$ & 77 & $(5.0)$ & 27 & (1.6) & 10.4 & $(1.1)$ & 23 & (1.4) & 51.48 \\
\hline & B-S-J-G (China) & 453 & (6.1) & 509 & $(7.5)$ & 537 & $(4.6)$ & 573 & $(7.7)$ & 120 & $(9.5)$ & 40 & $(2.7)$ & 17.2 & $(2.0)$ & 35 & $(2.6)$ & 42.16 \\
\hline & Bulgaria & 421 & $(6.2)$ & 453 & (5.3) & 466 & $(4.3)$ & 455 & (4.9) & 35 & $(5.8)$ & 14 & $(2.4)$ & 1.7 & $(0.6)$ & 6 & $(2.2)$ & 36.01 \\
\hline & CABA (Argentina) & 425 & $(6.3)$ & 471 & (9.8) & 491 & $(8.6)$ & 513 & (7.7) & 88 & $(9.1)$ & 32 & $(2.8)$ & 12.7 & $(2.3)$ & 19 & $(2.8)$ & $\mathrm{m}$ \\
\hline & Colombia & 381 & $(4.0)$ & 401 & (3.3) & 424 & (3.0) & 460 & $(4.2)$ & 79 & (5.9) & 21 & (1.4) & 13.8 & (1.8) & 20 & (1.3) & 53.50 \\
\hline & Costa Rica & 388 & (3.0) & 408 & $(2.4)$ & 428 & $(3.2)$ & 456 & (3.6) & 68 & $(5.0)$ & 23 & (1.5) & 13.9 & (1.7) & 19 & (1.6) & 48.53 \\
\hline & Croatia & 460 & (3.6) & 477 & (3.3) & 482 & (3.4) & 484 & (3.9) & 25 & $(4.2)$ & 13 & (2.4) & 0.9 & $(0.3)$ & 7 & $(2.3)$ & 32.51 \\
\hline & Cyprus* & 413 & (2.9) & 438 & $(2.9)$ & 447 & $(2.7)$ & 435 & (3.0) & 21 & $(4.2)$ & 7 & $(1.3)$ & 0.7 & $(0.2)$ & 2 & (1.3) & 34.31 \\
\hline & Dominican Republic & 306 & (3.1) & 320 & $(2.8)$ & 337 & (3.9) & 370 & $(6.0)$ & 64 & $(6.7)$ & 18 & $(1.7)$ & 10.7 & $(1.7)$ & 16 & (1.6) & 47.07 \\
\hline & FYROM & 357 & $(2.8)$ & 385 & $(2.9)$ & 402 & $(2.8)$ & 397 & $(2.7)$ & 40 & (3.8) & 16 & (1.5) & 3.0 & $(0.5)$ & 12 & (1.7) & $\mathrm{m}$ \\
\hline & Georgia & 387 & (3.4) & 412 & (3.7) & 421 & (3.4) & 426 & (3.8) & 39 & (4.9) & 16 & (1.8) & 2.6 & $(0.6)$ & 10 & (1.8) & 40.09 \\
\hline & Hong Kong (China) & 510 & (3.3) & 521 & (3.3) & 525 & (3.7) & 537 & $(4.0)$ & 27 & $(4.7)$ & 12 & $(2.0)$ & 1.5 & $(0.5)$ & 7 & $(2.0)$ & $\mathrm{m}$ \\
\hline & Indonesia & 377 & (3.5) & 395 & $(3.2)$ & 406 & (3.1) & 436 & (4.9) & 60 & $(5.9)$ & 18 & $(1.3)$ & 12.2 & (1.9) & 14 & $(1.2)$ & 39.47 \\
\hline & Jordan & 378 & $(4.2)$ & 407 & $(3.7)$ & 425 & (3.4) & 432 & (3.6) & 54 & $(5.5)$ & 15 & (1.6) & 5.5 & $(1.0)$ & 11 & (1.6) & $\mathrm{m}$ \\
\hline & Kosovo & 364 & (2.9) & 379 & $(3.2)$ & 386 & $(2.7)$ & 389 & $(2.9)$ & 24 & $(4.1)$ & 10 & (1.4) & 1.9 & $(0.5)$ & 9 & (1.5) & $\mathrm{m}$ \\
\hline & Lebanon & 348 & $(4.0)$ & 371 & (5.4) & 396 & $(4.0)$ & 433 & (6.1) & 86 & $(6.9)$ & 26 & $(1.7)$ & 12.6 & (1.7) & 26 & (1.7) & $\mathrm{m}$ \\
\hline & Lithuania & 457 & (3.4) & 479 & (3.4) & 483 & (3.9) & 485 & $(4.0)$ & 28 & $(4.6)$ & 13 & (2.3) & 1.3 & $(0.4)$ & 6 & $(2.3)$ & 35.15 \\
\hline & Macao (China) & 526 & $(2.7)$ & 529 & (3.0) & 531 & (2.6) & 529 & (2.6) & 3 & $(3.8)$ & 0 & $(1.7)$ & 0.0 & $(0.0)$ & -2 & $(1.7)$ & $\mathrm{m}$ \\
\hline & Malta & 446 & $(4.1)$ & 467 & $(4.0)$ & 471 & $(4.4)$ & 478 & (3.9) & 32 & $(6.1)$ & 14 & (2.4) & 1.1 & $(0.3)$ & 7 & (2.4) & $\mathrm{m}$ \\
\hline & Moldova & 396 & (3.4) & 431 & $(2.9)$ & 439 & $(2.8)$ & 450 & (3.7) & 54 & $(4.9)$ & 19 & $(1.7)$ & 5.6 & $(1.0)$ & 16 & (1.6) & 26.83 \\
\hline & Montenegro & 406 & $(2.1)$ & 414 & $(2.8)$ & 418 & $(2.2)$ & 412 & (2.6) & 7 & $(3.1)$ & 2 & $(1.3)$ & 0.1 & $(0.1)$ & -1 & $(1.3)$ & 31.93 \\
\hline & Peru & 354 & $(2.3)$ & 383 & (3.9) & 413 & $(3.2)$ & 441 & $(4.5)$ & 86 & $(5.0)$ & 22 & $(1.2)$ & 17.4 & $(1.7)$ & 19 & $(1.2)$ & 44.14 \\
\hline & Qatar & 418 & $(2.2)$ & 441 & $(2.3)$ & 426 & (1.8) & 393 & (1.9) & -26 & (2.8) & -6 & $(0.7)$ & 0.8 & $(0.2)$ & -6 & $(0.7)$ & $\mathrm{m}$ \\
\hline & Romania & 406 & $(4.4)$ & 430 & (3.9) & 444 & (3.9) & 461 & $(5.0)$ & 55 & $(6.0)$ & 21 & $(2.1)$ & 6.7 & $(1.2)$ & 17 & $(2.0)$ & 27.45 \\
\hline & Russia & 478 & (3.8) & 493 & $(3.2)$ & 491 & (3.4) & 491 & $(4.4)$ & 13 & $(4.4)$ & 4 & $(2.0)$ & 0.2 & $(0.2)$ & -2 & (1.9) & 41.59 \\
\hline & Singapore & 506 & $(2.8)$ & 555 & $(3.1)$ & 577 & $(2.6)$ & 585 & (3.7) & 78 & $(4.9)$ & 36 & $(2.1)$ & 8.6 & $(0.9)$ & 26 & $(2.1)$ & $\mathrm{m}$ \\
\hline & Chinese Taipei & 509 & (3.6) & 531 & (3.5) & 544 & (3.7) & 546 & (3.5) & 37 & $(4.6)$ & 15 & $(2.2)$ & 1.8 & $(0.5)$ & 6 & $(2.0)$ & $\mathrm{m}$ \\
\hline & Thailand & 398 & (3.3) & 412 & $(3.0)$ & 423 & (3.6) & 455 & $(7.0)$ & 56 & $(7.4)$ & 18 & $(2.1)$ & 7.0 & (1.6) & 15 & $(1.7)$ & 37.85 \\
\hline & Trinidad and Tobago & 400 & (3.1) & 420 & (3.3) & 438 & (3.4) & 448 & (3.3) & 48 & $(4.6)$ & 14 & (1.3) & 3.6 & $(0.7)$ & 12 & (1.4) & $\mathrm{m}$ \\
\hline & Tunisia & 367 & (2.6) & 381 & $(2.9)$ & 390 & (3.2) & 411 & $(4.2)$ & 44 & $(4.8)$ & 13 & (1.5) & 6.2 & $(1.2)$ & 11 & (1.4) & $\mathrm{m}$ \\
\hline & United Arab Emirates & 429 & $(4.3)$ & 455 & $(3.1)$ & 446 & (3.3) & 422 & (3.3) & -8 & $(4.8)$ & -3 & $(1.2)$ & 0.1 & $(0.1)$ & -3 & (1.1) & $\mathrm{m}$ \\
\hline & Uruguay & 407 & (3.3) & 426 & $(3.1)$ & 444 & (3.3) & 468 & (3.6) & 61 & $(4.6)$ & 25 & (1.6) & 7.7 & $(0.9)$ & 17 & (1.5) & 41.60 \\
\hline & Viet Nam & 501 & (4.6) & 515 & $(3.7)$ & 532 & (4.3) & 551 & (7.4) & 49 & $(7.7)$ & 16 & $(2.2)$ & 6.2 & (1.4) & 11 & (1.7) & 37.59 \\
\hline & Argentina** & 400 & (3.9) & 423 & $(4.3)$ & 444 & (3.8) & 463 & $(3.9)$ & 63 & $(5.3)$ & 23 & $(2.2)$ & 8.1 & $(1.4)$ & 18 & $(2.3)$ & 42.67 \\
\hline & Kazakhstan** & 433 & (3.9) & 449 & $(4.4)$ & 465 & $(4.8)$ & 479 & $(4.7)$ & 46 & $(5.3)$ & 20 & $(2.1)$ & 5.2 & $(1.0)$ & 19 & $(2.1)$ & 26.33 \\
\hline & Malaysia** & 409 & (3.5) & 436 & $(3.4)$ & 455 & (3.9) & 472 & $(5.3)$ & 63 & $(6.0)$ & 19 & (1.6) & 9.3 & (1.5) & 17 & (1.7) & $\mathrm{m}$ \\
\hline
\end{tabular}

1. This model includes the number of years of completed education of the most educated parent and its squared value.

2. Source: World Bank World Development Indicator (http://data.worldbank.org/data-catalog/world-development-indicators). The data on the Gini index are for 2014 Note: Values that are statistically significant are indicated in bold (see Annex A3).

* See note at the beginning of this Annex.

** Coverage is too small to ensure comparability (see Annex A4).

StatLink 年15 http://dx.doi.org/10.1787/888933472348 


\begin{tabular}{|c|c|c|c|c|c|c|c|c|c|c|c|c|c|c|c|c|c|c|c|c|c|}
\hline & & & Percen & e of & der & no ar & "no & sfiec & witl & ir life, & & & rcen & & & & & isf & & eir & \\
\hline & & & & & & & & & & $\begin{array}{r}\text { Top - b } \\
\text { qua }\end{array}$ & $\begin{array}{l}\text { ottom } \\
\text { ter }\end{array}$ & & & & & & & & & & $\begin{array}{l}\text { ttom } \\
\text { er }\end{array}$ \\
\hline & & $\%$ & S.E. & $\%$ & S.E. & $\%$ & S.E. & $\%$ & S.E. & $\%$ dif. & S.E. & $\%$ & S.E. & $\%$ & S.E. & $\%$ & S.E. & $\%$ & S.E. & $\%$ dif. & S.E. \\
\hline 0 & Australia & $\mathrm{m}$ & $\mathrm{m}$ & $\mathrm{m}$ & $\mathrm{m}$ & $\mathrm{m}$ & $\mathrm{m}$ & $\mathrm{m}$ & $\mathrm{m}$ & $\mathrm{m}$ & $\mathrm{m}$ & $\mathrm{m}$ & $\mathrm{m}$ & $\mathrm{m}$ & $\mathrm{m}$ & $\mathrm{m}$ & $\mathrm{m}$ & $\mathrm{m}$ & $\mathrm{m}$ & $\mathrm{m}$ & $\mathrm{m}$ \\
\hline & Austria & 15.3 & (1.1) & 12.5 & $(1.0)$ & 8.2 & $(0.7)$ & 8.4 & $(0.7)$ & -6.9 & (1.4) & 33.4 & (1.3) & 38.2 & (1.5) & 40.3 & (1.5) & 46.7 & (1.6) & 13.3 & (2.1) \\
\hline & Belgium (excl. Flemish) & 13.0 & (1.3) & 8.4 & $(1.0)$ & 6.8 & $(0.9)$ & 5.4 & $(0.7)$ & -7.6 & (1.3) & 30.1 & (1.8) & 29.8 & (1.9) & 31.5 & (1.8) & 39.7 & (2.1) & 9.6 & (2.4) \\
\hline & Canada & $\mathrm{m}$ & $\mathrm{m}$ & $\mathrm{m}$ & $\mathrm{m}$ & $\mathrm{m}$ & $\mathrm{m}$ & $\mathrm{m}$ & $\mathrm{m}$ & $\mathrm{m}$ & $\mathrm{m}$ & $\mathrm{m}$ & $\mathrm{m}$ & $\mathrm{m}$ & $\mathrm{m}$ & $\mathrm{m}$ & $\mathrm{m}$ & $\mathrm{m}$ & $\mathrm{m}$ & $\mathrm{m}$ & $\mathrm{m}$ \\
\hline & Chile & 17.7 & (1.3) & 11.4 & $(0.8)$ & 9.9 & $(1.0)$ & 9.3 & $(0.7)$ & -8.4 & (1.5) & 34.2 & (1.5) & 35.7 & (1.6) & 39.4 & (1.4) & 43.0 & (1.4) & 8.8 & $(2.0)$ \\
\hline & Czech Republic & 17.9 & $(1.2)$ & 14.1 & (1.0) & 12.4 & $(0.9)$ & 10.9 & $(0.8)$ & -7.0 & (1.3) & 27.1 & (1.3) & 29.0 & (1.3) & 29.3 & (1.1) & 37.0 & (1.3) & 9.9 & (1.8) \\
\hline & Denmark & $\mathrm{m}$ & $\mathrm{m}$ & $\mathrm{m}$ & $\mathrm{m}$ & $\mathrm{m}$ & $\mathrm{m}$ & $\mathrm{m}$ & $\mathrm{m}$ & $\mathrm{m}$ & $\mathrm{m}$ & $\mathrm{m}$ & $\mathrm{m}$ & $\mathrm{m}$ & $\mathrm{m}$ & $\mathrm{m}$ & $\mathrm{m}$ & $\mathrm{m}$ & $\mathrm{m}$ & $\mathrm{m}$ & $\mathrm{m}$ \\
\hline & Estonia & 15.8 & (1.2) & 8.0 & $(0.8)$ & 7.1 & $(0.8)$ & 6.3 & $(0.6)$ & -9.5 & $(1.2)$ & 25.5 & (1.5) & 34.5 & (1.5) & 40.0 & (1.7) & 47.8 & (1.6) & 22.3 & (2.1) \\
\hline & Finland & 8.3 & $(0.7)$ & 6.0 & $(0.6)$ & 6.6 & $(0.8)$ & 5.8 & $(0.6)$ & -2.5 & (0.9) & 39.8 & (1.5) & 42.7 & (1.5) & 44.6 & (1.4) & 50.3 & $(1.2)$ & 10.5 & (1.8) \\
\hline & France & 11.5 & (1.1) & 8.0 & $(0.8)$ & 5.6 & $(0.6)$ & 4.3 & $(0.6)$ & -7.1 & (1.1) & 29.5 & (1.6) & 35.8 & (1.1) & 37.8 & (1.3) & 43.0 & $(1.2)$ & 13.6 & (1.9) \\
\hline & Germany & 13.4 & (1.0) & 10.3 & $(1.0)$ & 10.9 & $(0.9)$ & 9.6 & $(0.8)$ & -3.8 & (1.3) & 30.1 & (1.1) & 33.7 & (1.4) & 33.0 & (1.4) & 38.9 & (1.5) & 8.8 & (1.7) \\
\hline & Greece & 19.2 & (1.4) & 14.3 & (1.1) & 13.8 & (1.0) & 11.4 & $(1.0)$ & -7.7 & (1.8) & 20.6 & (1.3) & 25.7 & (1.4) & 26.0 & (1.4) & 32.6 & (1.5) & 12.0 & (1.9) \\
\hline & Hungary & 19.3 & (1.3) & 12.9 & (1.1) & 11.7 & $(0.9)$ & 8.8 & (0.8) & -10.5 & (1.4) & 26.1 & (1.3) & 30.5 & (1.3) & 32.1 & (1.5) & 37.9 & $(1.3)$ & 11.7 & (1.8) \\
\hline & Iceland & 13.5 & (1.2) & 10.0 & (1.0) & 8.3 & (1.0) & 6.2 & $(0.7)$ & -7.3 & (1.5) & 37.9 & (1.7) & 45.5 & (1.6) & 48.7 & (1.6) & 54.4 & $(1.7)$ & 16.5 & (2.7) \\
\hline & Ireland & 16.6 & (1.1) & 10.3 & $(0.8)$ & 10.9 & $(0.9)$ & 9.7 & $(0.8)$ & -6.9 & (1.4) & 28.2 & $(1.2)$ & 33.6 & (1.4) & 33.1 & (1.3) & 34.8 & (1.3) & 6.6 & (1.7) \\
\hline & Israel & $\mathrm{m}$ & $\mathrm{m}$ & $\mathrm{m}$ & $\mathrm{m}$ & $\mathrm{m}$ & $\mathrm{m}$ & $\mathrm{m}$ & $\mathrm{m}$ & $\mathrm{m}$ & $\mathrm{m}$ & $\mathrm{m}$ & $\mathrm{m}$ & $\mathrm{m}$ & $\mathrm{m}$ & $\mathrm{m}$ & $\mathrm{m}$ & $\mathrm{m}$ & $\mathrm{m}$ & $\mathrm{m}$ & $\mathrm{m}$ \\
\hline & Italy & 20.4 & (1.3) & 14.0 & (1.0) & 12.9 & (1.0) & 11.4 & (0.9) & -9.0 & (1.5) & 20.3 & (1.2) & 22.9 & $(1.2)$ & 24.4 & (1.4) & 29.2 & $(1.3)$ & 8.8 & (1.8) \\
\hline & Japan & 19.4 & (1.1) & 14.2 & (1.0) & 14.9 & $(0.9)$ & 15.8 & (1.0) & -3.6 & (1.6) & 21.7 & (1.0) & 22.8 & (1.1) & 24.4 & (1.0) & 26.1 & (1.1) & 4.4 & (1.5) \\
\hline & Korea & 25.9 & $(1.2)$ & 23.7 & (1.3) & 19.8 & $(1.2)$ & 17.0 & (1.1) & -8.9 & (1.6) & 14.5 & (1.0) & 16.7 & (1.1) & 19.3 & (1.3) & 24.0 & (1.2) & 9.5 & (1.7) \\
\hline & Latvia & 13.1 & (1.1) & 8.1 & (1.0) & 8.1 & $(0.9)$ & 6.4 & $(0.8)$ & -6.7 & (1.5) & 23.8 & (1.5) & 29.4 & (1.4) & 32.1 & (1.4) & 40.1 & (1.7) & 16.3 & (2.1) \\
\hline & Luxembour & 14.0 & (1.0) & 11.2 & $(0.9)$ & 10.2 & $(1.0)$ & 9.2 & $(0.9)$ & -4.8 & (1.3) & 30.9 & (1.4) & 35.1 & (1.5) & 36.0 & (1.3) & 42.2 & (1.4) & 11.3 & (2.0) \\
\hline & Mexico & 8.3 & $(0.8)$ & 6.8 & $(0.7)$ & 5.4 & (0.6) & 5.1 & (0.6) & -3.2 & (1.0) & 58.2 & (1.6) & 57.1 & (1.5) & 58.0 & (1.2) & 60.5 & (1.4) & 2.3 & (2.2) \\
\hline & Netherlands & 5.6 & $(0.6)$ & 3.4 & (0.6) & 3.4 & (0.6) & 2.4 & (0.5) & -3.2 & (0.8) & 29.9 & (1.5) & 29.8 & (1.3) & 31.6 & (1.3) & 38.3 & (1.3) & 8.4 & (2.0) \\
\hline & New Zealand & $\mathrm{m}$ & $\mathrm{m}$ & $\mathrm{m}$ & $\mathrm{m}$ & $\mathrm{m}$ & $\mathrm{m}$ & $\mathrm{m}$ & $\mathrm{m}$ & $\mathrm{m}$ & $\mathrm{m}$ & $\mathrm{m}$ & $\mathrm{m}$ & $\mathrm{m}$ & $\mathrm{m}$ & $\mathrm{m}$ & $\mathrm{m}$ & $\mathrm{m}$ & $\mathrm{m}$ & $\mathrm{m}$ & $\mathrm{m}$ \\
\hline & Norway & $\mathrm{m}$ & $\mathrm{m}$ & $\mathrm{m}$ & $\mathrm{m}$ & $\mathrm{m}$ & $\mathrm{m}$ & $\mathrm{m}$ & $\mathrm{m}$ & $\mathrm{m}$ & $\mathrm{m}$ & $\mathrm{m}$ & $\mathrm{m}$ & $\mathrm{m}$ & $\mathrm{m}$ & $\mathrm{m}$ & $\mathrm{m}$ & $\mathrm{m}$ & $\mathrm{m}$ & $\mathrm{m}$ & $\mathrm{m}$ \\
\hline & Poland & 17.5 & (1.2) & 13.3 & $(1.2)$ & 9.6 & $(1.0)$ & 10.0 & $(0.9)$ & -7.5 & (1.4) & 25.2 & (1.4) & 31.5 & (1.6) & 33.8 & (1.7) & 38.8 & (1.6) & 13.6 & (2.0) \\
\hline & Portugal & 12.6 & (1.0) & 9.4 & $(0.8)$ & 7.2 & $(0.7)$ & 6.2 & $(0.8)$ & -6.4 & (1.4) & 26.4 & (1.4) & 29.4 & (1.3) & 31.8 & (1.4) & 36.3 & (1.5) & 9.8 & (2.1) \\
\hline & Slovak Rep & 15.3 & (1.1) & 10.1 & $(0.9)$ & 11.0 & $(0.8)$ & 9.0 & (0.8) & -6.2 & (1.5) & 35.2 & (1.5) & 36.3 & (1.5) & 40.0 & (1.2) & 45.6 & $(1.2)$ & 10.4 & $(2.1)$ \\
\hline & Slovenia & 15.7 & (1.2) & 13.7 & (1.1) & 13.3 & (1.1) & 11.3 & (1.1) & -4.4 & (1.7) & 29.8 & (1.5) & 31.2 & (1.5) & 33.6 & (1.6) & 35.4 & (1.4) & 5.6 & (1.9) \\
\hline & Spain & 13.8 & $(0.8)$ & 9.7 & $(0.9)$ & 7.2 & $(0.7)$ & 7.3 & $(0.7)$ & -6.5 & (1.1) & 27.8 & (1.3) & 32.0 & (1.6) & 33.9 & (1.3) & 38.3 & (1.3) & 10.6 & (1.6) \\
\hline & Sweden & $\mathrm{m}$ & $\mathrm{m}$ & $\mathrm{m}$ & $\mathrm{m}$ & $\mathrm{m}$ & $\mathrm{m}$ & $\mathrm{m}$ & $\mathrm{m}$ & $\mathrm{m}$ & $\mathrm{m}$ & $\mathrm{m}$ & $\mathrm{m}$ & $\mathrm{m}$ & $\mathrm{m}$ & $\mathrm{m}$ & $\mathrm{m}$ & $\mathrm{m}$ & $\mathrm{m}$ & $\mathrm{m}$ & $\mathrm{m}$ \\
\hline & Switzerland & 8.0 & $(0.8)$ & 8.5 & $(0.8)$ & 6.3 & $(0.7)$ & 6.8 & $(0.8)$ & -1.2 & (1.0) & 36.2 & (1.6) & 38.1 & (1.6) & 39.3 & (1.5) & 44.4 & (1.4) & 8.2 & (2.0) \\
\hline & Turkey & 34.5 & (1.7) & 29.8 & (1.6) & 25.3 & (1.3) & 24.5 & (1.4) & -10.1 & $(2.3)$ & 25.2 & (1.8) & 26.1 & (1.4) & 25.4 & (1.5) & 28.3 & (1.4) & 3.1 & $(2.1)$ \\
\hline & United Kingdom & 19.6 & (1.0) & 16.0 & $(0.9)$ & 14.0 & $(0.8)$ & 12.8 & $(1.0)$ & -6.8 & (1.4) & 20.5 & $(1.2)$ & 28.3 & (1.3) & 30.2 & (1.4) & 34.0 & (1.4) & 13.5 & (1.9) \\
\hline & United States & 17.0 & $(0.9)$ & 12.9 & (1.1) & 9.7 & $(0.8)$ & 7.6 & $(0.8)$ & -9.4 & (1.2) & 29.7 & (1.4) & 31.7 & (1.5) & 39.4 & (1.5) & 42.5 & (1.8) & 12.8 & $(2.2)$ \\
\hline & OECD average & 15.8 & $(0.2)$ & 11.8 & $(0.2)$ & 10.4 & $(0.2)$ & 9.2 & $(0.2)$ & -6.5 & $(0.3)$ & 29.2 & $(0.3)$ & 32.6 & $(0.3)$ & 34.6 & $(0.3)$ & 39.6 & $(0.3)$ & 10.4 & $(0.4)$ \\
\hline & Albania & $\mathrm{m}$ & $\mathrm{m}$ & $\mathrm{m}$ & $\mathrm{m}$ & $\mathrm{m}$ & $\mathrm{m}$ & $\mathrm{m}$ & $\mathrm{m}$ & $\mathrm{m}$ & $\mathrm{m}$ & $\mathrm{m}$ & $\mathrm{m}$ & $\mathrm{m}$ & III & $\mathrm{m}$ & 7 & $\mathrm{~m}$ & $\mathrm{~m}$ & $\mathrm{~m}$ & $\mathrm{~m}$ \\
\hline & Algeria & $\mathrm{m}$ & $\mathrm{m}$ & $\mathrm{m}$ & $\mathrm{m}$ & $\mathrm{m}$ & $\mathrm{m}$ & $\mathrm{m}$ & $\mathrm{m}$ & $\mathrm{m}$ & $\mathrm{m}$ & $\mathrm{m}$ & $\mathrm{m}$ & $\mathrm{m}$ & $\mathrm{m}$ & $\mathrm{m}$ & $\mathrm{m}$ & $\mathrm{m}$ & $\mathrm{m}$ & $\mathrm{m}$ & $\mathrm{m}$ \\
\hline 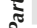 & Brazil & 14.9 & $(0.7)$ & 11.2 & $(0.6)$ & 11.4 & $(0.6)$ & 9.8 & $(0.7)$ & -5.1 & (1.0) & 46.9 & (1.0) & 44.2 & (1.0) & 43.9 & (1.0) & 3.0 & (1.1) & -3.9 & (1.5) \\
\hline & B-S-J-G & 19.0 & (1.1) & 17.4 & (1.2) & 14.4 & (1.0) & 11.5 & $(1.2)$ & -7.5 & $(1$ & 1 & (1 & 26.5 & & 26.6 & & 3 & & 6.2 & (2.4) \\
\hline & Bulgaria & 18.7 & (1.3) & 14.8 & (1.1) & 11.9 & (1.0) & 9.9 & $(0.8)$ & -8.9 & (1.6) & 36.5 & (1.6) & 38.6 & (1.3) & 43.6 & (1.4) & 51.9 & (1.7) & 15.4 & (2.4) \\
\hline & CABA (Arg & $\mathrm{m}$ & $\mathrm{m}$ & $\mathrm{m}$ & $\mathrm{m}$ & $\mathrm{m}$ & $\mathrm{m}$ & $\mathrm{m}$ & $\mathrm{m}$ & $\mathrm{m}$ & $\mathrm{m}$ & $\mathrm{m}$ & $\mathrm{m}$ & $\mathrm{m}$ & $\mathrm{m}$ & $\mathrm{m}$ & $\mathrm{m}$ & $\mathrm{m}$ & $\mathrm{m}$ & $\mathrm{m}$ & $\mathrm{m}$ \\
\hline & Colombia & 10.4 & $(0.8)$ & 10.9 & $(0.8)$ & 9.6 & $(0.7)$ & 9.4 & $(0.7)$ & -1.1 & $(0.9)$ & 55.8 & (1.8) & 51.7 & (1.5) & 49.0 & (1.3) & 46.9 & (1.5) & -8.9 & $(2.3)$ \\
\hline & Costa Rica & 9.0 & $(0.9)$ & 7.1 & $(0.7)$ & 6.0 & $(0.6)$ & 6.1 & $(0.8)$ & -2.8 & $(1.2)$ & 57.6 & (1.6) & 58.5 & (1.5) & 55.9 & (1.6) & 61.6 & (1.8) & 3.9 & $(2.2)$ \\
\hline & Croatia & 10.3 & $(0.9)$ & 7.3 & $(0.6)$ & 6.9 & $(0.9)$ & 4.7 & $(0.5)$ & -5.6 & $(1$ & 40.5 & $(1$ & 46.9 & & 48.5 & & 5.2 & 5) & 14.7 & $(2.2)$ \\
\hline & Cyprus* & 19.3 & (1.0) & 12.6 & $(1.0)$ & 10.9 & $(0.9)$ & 11.9 & $(1.0)$ & -7.4 & $(1$. & 24.9 & $(1.2)$ & 27.4 & $(1$ & 29.3 & $(1$ & 38.5 & (1.5) & 13.5 & (1.9) \\
\hline & Dominican Republic & 11.6 & (1.0) & 8.6 & $(0.9)$ & 7.1 & (1.1) & 5.5 & $(0.9)$ & -6.1 & (1.4) & 67.3 & (1.6) & 69.9 & (1.7) & 70.1 & (1.8) & 63.6 & (1.4) & -3.7 & $(2.2)$ \\
\hline & FYROM & $\mathrm{m}$ & $\mathrm{m}$ & $\mathrm{m}$ & $\mathrm{m}$ & $\mathrm{m}$ & $\mathrm{m}$ & $\mathrm{m}$ & $\mathrm{m}$ & $\mathrm{m}$ & $\mathrm{m}$ & $\mathrm{m}$ & $\mathrm{m}$ & $\mathrm{m}$ & $\mathrm{m}$ & $\mathrm{m}$ & $\mathrm{m}$ & $\mathrm{m}$ & $\mathrm{m}$ & $\mathrm{m}$ & $\mathrm{m}$ \\
\hline & Georgia & $\mathrm{m}$ & $\mathrm{m}$ & $\mathrm{m}$ & $\mathrm{m}$ & $\mathrm{m}$ & $\mathrm{m}$ & $\mathrm{m}$ & $\mathrm{m}$ & $\mathrm{m}$ & $\mathrm{m}$ & $\mathrm{m}$ & $\mathrm{m}$ & $\mathrm{m}$ & $\mathrm{m}$ & $\mathrm{m}$ & $\mathrm{m}$ & $\mathrm{m}$ & $\mathrm{m}$ & $\mathrm{m}$ & $\mathrm{m}$ \\
\hline & Hong Kor & 19.5 & (1.1) & 15.5 & $(1.2)$ & 15.2 & $(1.2)$ & 12.4 & $(1.0)$ & -7.1 & (1.3) & 11.7 & $(1.0)$ & 12.5 & $(1.0)$ & 12.5 & (1.0) & 18.6 & $(1.2)$ & 6.9 & (1.6) \\
\hline & Indonesia & $\mathrm{m}$ & $\mathrm{m}$ & $\mathrm{m}$ & $\mathrm{m}$ & $\mathrm{m}$ & $\mathrm{m}$ & $\mathrm{m}$ & $\mathrm{m}$ & $\mathrm{m}$ & $\mathrm{m}$ & $\mathrm{m}$ & $\mathrm{m}$ & $\mathrm{m}$ & 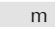 & $\mathrm{m}$ & 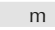 & $\mathrm{m}$ & $\mathrm{m}$ & $\mathrm{m}$ & $\mathrm{m}$ \\
\hline & Jordan & $\mathrm{m}$ & $\mathrm{m}$ & $\mathrm{m}$ & $\mathrm{m}$ & $\mathrm{m}$ & $\mathrm{m}$ & $\mathrm{m}$ & $\mathrm{m}$ & $\mathrm{m}$ & $\mathrm{m}$ & $\mathrm{m}$ & $\mathrm{m}$ & $\mathrm{m}$ & $\mathrm{m}$ & $\mathrm{m}$ & $\mathrm{n}$ & $\mathrm{m}$ & $\mathrm{m}$ & $\mathrm{m}$ & $\mathrm{m}$ \\
\hline & Kosovo & $\mathrm{m}$ & $\mathrm{m}$ & $\mathrm{m}$ & $\mathrm{m}$ & $\mathrm{m}$ & $\mathrm{m}$ & $\mathrm{m}$ & $\mathrm{m}$ & $\mathrm{m}$ & $\mathrm{m}$ & $\mathrm{m}$ & $\mathrm{m}$ & $\mathrm{m}$ & $\mathrm{m}$ & $\mathrm{m}$ & $\mathrm{m}$ & $\mathrm{m}$ & $\mathrm{m}$ & $\mathrm{m}$ & $\mathrm{m}$ \\
\hline & Lebanon & $\mathrm{m}$ & $\mathrm{m}$ & $\mathrm{m}$ & $\mathrm{m}$ & $\mathrm{m}$ & $\mathrm{m}$ & $\mathrm{m}$ & $\mathrm{m}$ & $\mathrm{m}$ & $\mathrm{m}$ & $\mathrm{m}$ & $\mathrm{m}$ & $\mathrm{m}$ & $\mathrm{m}$ & $\mathrm{m}$ & $\mathrm{m}$ & $\mathrm{m}$ & $\mathrm{m}$ & $\mathrm{m}$ & $\mathrm{m}$ \\
\hline & Lithuania & 12.0 & $(1.0)$ & 8.1 & $(0.8)$ & 6.4 & $(0.8)$ & 5.8 & $(0.8)$ & -6.2 & $(1.2)$ & 34.4 & (1.3) & 47.2 & (1.3) & 50.6 & (1.7) & 58.0 & $(1.2)$ & 23.6 & (1.5) \\
\hline & Macao (China) & 20.0 & (1.1) & 16.0 & (1.1) & 13.7 & (1.1) & 12.0 & $(0.8)$ & -7.9 & (1.5) & 12.6 & (1.0) & 15.1 & (1.1) & 16.8 & $(1.2)$ & 21.5 & $(1.2)$ & 8.9 & (1.6) \\
\hline & Malta & $\mathrm{m}$ & $\mathrm{m}$ & $\mathrm{m}$ & $\mathrm{m}$ & $\mathrm{m}$ & $\mathrm{m}$ & $\mathrm{m}$ & $\mathrm{m}$ & $\mathrm{m}$ & $\mathrm{m}$ & $\mathrm{m}$ & $\mathrm{m}$ & $\mathrm{m}$ & $\mathrm{m}$ & $\mathrm{m}$ & $\mathrm{m}$ & $\mathrm{m}$ & $\mathrm{m}$ & $\mathrm{m}$ & $\mathrm{m}$ \\
\hline & Moldova & $\mathrm{m}$ & $\mathrm{m}$ & $\mathrm{m}$ & $\mathrm{m}$ & $\mathrm{m}$ & $\mathrm{m}$ & $\mathrm{m}$ & $\mathrm{m}$ & $\mathrm{m}$ & $\mathrm{m}$ & $\mathrm{m}$ & $\mathrm{m}$ & $\mathrm{m}$ & $\mathrm{m}$ & $\mathrm{m}$ & $\mathrm{m}$ & $\mathrm{m}$ & $\mathrm{m}$ & $\mathrm{m}$ & $\mathrm{m}$ \\
\hline & Montenegro & 14.3 & $(1.0)$ & 11.5 & $(1.0)$ & 9.7 & $(0.9)$ & 8.8 & $(0.9)$ & -5.4 & (1.4) & 42.6 & (1.5) & 47.8 & (1.4) & 51.7 & (1.3) & 7.8 & (1.5) & 15.2 & $(2.2)$ \\
\hline & Peru & 14.9 & $(0.9)$ & 13.7 & $(0.9)$ & 11.8 & $(0.9)$ & 10.8 & $(0.8)$ & -4.1 & (1.1) & 47.8 & (1.4) & 45.8 & (1.6) & 39.4 & (1.5) & 38.3 & (1.5) & -9.5 & (2.0) \\
\hline & Qatar & 19.0 & $(0.7)$ & 13.7 & $(0.8)$ & 12.3 & $(0.7)$ & 10.1 & $(0.6)$ & -8.9 & (1.0) & 33.7 & (0.9) & 37.7 & (1.1) & 44.0 & (0.9) & 54.9 & (0.9) & 21.2 & (1.3) \\
\hline & Romani & $\mathrm{m}$ & & $\mathrm{m}$ & 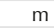 & $\mathrm{m}$ & 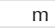 & $\mathrm{m}$ & $\mathrm{m}$ & $\mathrm{m}$ & 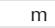 & $\mathrm{m}$ & $\mathrm{m}$ & $\mathrm{m}$ & $\mathrm{m}$ & $\mathrm{m}$ & $\mathrm{m}$ & $\mathrm{m}$ & $\mathrm{m}$ & $\mathrm{m}$ & $\mathrm{m}$ \\
\hline & Russia & 13.0 & $(0.9)$ & 10.1 & $(0.9)$ & 9.9 & $(0.9)$ & 8.0 & $(0.7)$ & -4.9 & (1.2) & 41.4 & (1.3) & 43.1 & (1.8) & 46.2 & (1.6) & 56.1 & (1.3) & 14.8 & (1.8) \\
\hline & Singapore & $\mathrm{m}$ & $\mathrm{m}$ & $\mathrm{m}$ & $\mathrm{m}$ & $\mathrm{m}$ & $\mathrm{m}$ & $\mathrm{m}$ & $\mathrm{m}$ & $\mathrm{m}$ & $\mathrm{m}$ & $\mathrm{m}$ & $\mathrm{m}$ & $\mathrm{m}$ & $\mathrm{m}$ & $\mathrm{m}$ & $\mathrm{m}$ & $\mathrm{m}$ & $\mathrm{m}$ & $\mathrm{m}$ & $\mathrm{m}$ \\
\hline & Chinese Tai & 21.5 & (1.2) & 13.3 & $(0.9)$ & 14.7 & $(0.9)$ & 14.3 & (0.8) & -7.2 & (1.5) & 14.2 & $(0.7)$ & 19.1 & (0.9) & 17.9 & (1.0) & 22.5 & (0.9) & 8.3 & $(1.0)$ \\
\hline & Thail & 9.6 & (1.0) & 6.6 & $(0.8)$ & 8.6 & $(0.9)$ & 6.2 & $(0.7)$ & -3.4 & $(1.2)$ & 43.6 & (1.6) & 45.0 & (1.4) & 43.6 & (1.6) & 38.6 & (1.5) & -5.0 & (2.3) \\
\hline & & $\mathrm{m}$ & & $\mathrm{m}$ & & $m$ & & $\mathrm{~m}$ & $\mathrm{~m}$ & $\mathrm{~m}$ & & $\mathrm{~m}$ & & $\mathrm{~m}$ & 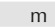 & $\mathrm{m}$ & & $\mathrm{m}$ & $\mathrm{m}$ & $\mathrm{m}$ & $\mathrm{m}$ \\
\hline & Tunisia & 28.0 & (1.4) & 22.6 & (1.3) & 14.5 & $(1.2)$ & 12.3 & (0.9) & -15.7 & (1.7) & 31.9 & (1.5) & 36.6 & (1.4) & 41.9 & (1.8) & 43.5 & (1.6) & 11.6 & (2.1) \\
\hline & United Arab Emirates & 20.7 & $(1.0)$ & 15.2 & $(0.8)$ & 12.5 & $(0.6)$ & 9.7 & $(0.8)$ & -11.0 & (1.3) & 33.4 & (1.1) & 35.0 & (1.1) & 39.1 & $(1.2)$ & 51.4 & (1.5) & 18.0 & (1.7) \\
\hline & Uruguay & 15.1 & $(0.8)$ & 9.7 & $(0.9)$ & 8.4 & $(0.9)$ & 5.7 & $(0.7)$ & -9.4 & (1.1) & 39.0 & (1.3) & 42.0 & (1.5) & 45.1 & (1.4) & 50.3 & (1.6) & 11.3 & $(2.2)$ \\
\hline & Viet Nam & $\mathrm{m}$ & $\mathrm{m}$ & $\mathrm{m}$ & $\mathrm{m}$ & $\mathrm{m}$ & $\mathrm{m}$ & $\mathrm{m}$ & $\mathrm{m}$ & $\mathrm{m}$ & $\mathrm{m}$ & $\mathrm{m}$ & $\mathrm{m}$ & $\mathrm{m}$ & $\mathrm{m}$ & $\mathrm{m}$ & $\mathrm{m}$ & $\mathrm{m}$ & $\mathrm{m}$ & $\mathrm{m}$ & $\mathrm{m}$ \\
\hline & & $\mathrm{m}$ & $\mathrm{m}$ & $\mathrm{m}$ & $\mathrm{m}$ & $\mathrm{m}$ & $\mathrm{m}$ & $\mathrm{m}$ & $\mathrm{m}$ & $\mathrm{m}$ & $\mathrm{m}$ & $\mathrm{m}$ & $\mathrm{m}$ & $\mathrm{m}$ & $\mathrm{m}$ & m & $\mathrm{m}$ & $\mathrm{m}$ & $\mathrm{m}$ & $\mathrm{m}$ & $\mathrm{m}$ \\
\hline & & $\mathrm{m}$ & & II & & III & & $\mathrm{m}$ & $\mathrm{m}$ & m & & $\mathrm{m}$ & III & $\mathrm{m}$ & 11 & $\mathrm{~m}$ & $\mathrm{n}$ & $\mathrm{m}$ & & $\mathrm{m}$ & $\mathrm{m}$ \\
\hline & Malaysia** & 12.9 & (1.1) & 10.4 & $(0.9)$ & 10.4 & $(0.8)$ & 10.4 & $(0.8)$ & -2.5 & $(1.2)$ & 29.4 & (1.3) & 31.0 & (1.4) & 28.9 & (1.4) & 29.9 & (1.5) & 0.5 & (1.9) \\
\hline
\end{tabular}

1. A student is classified as «not satisfied» with life if he or she reported between 0 and 4 on the life-satisfaction scale. The life-satisfaction scale ranges from 0 to 10

2. A student is classified as "very satisfied» with life if he or she reported 9 or 10 on the life-satisfaction scale. The life-satisfaction scale ranges from 0 to 10.

Note: Values that are statistically significant are indicated in bold (see Annex A3).

* See note at the beginning of this Annex.

* Coverage is too small to ensure comparability (see Annex A4)

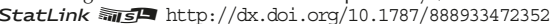




\begin{tabular}{|c|c|c|c|c|c|c|c|c|c|c|c|c|c|c|c|}
\hline & \multirow{2}{*}{\multicolumn{10}{|c|}{ Average life satisfaction, by national quarters of the index of family wealth }} & \multirow{2}{*}{\multicolumn{4}{|c|}{$\begin{array}{c}\text { School wealth }{ }^{1} \text { and life satisfaction } \\
\begin{array}{c}\text { Change in the index of life satisfaction associated } \\
\text { with a one-unit change in school wealth }\end{array}\end{array}$}} \\
\hline & & & & & & & & & & & & & & & \\
\hline & & Botton & quarter & Seconc & quarter & Third & quarter & Top & uarter & $\begin{array}{r}\text { Top } \\
\mathrm{q}\end{array}$ & $\begin{array}{l}\text { ottom } \\
\text { rter }\end{array}$ & $\begin{array}{l}\text { Before } \\
\text { for stud } \\
\text { of fam }\end{array}$ & $\begin{array}{l}\text { counting } \\
\text { ts }^{\prime} \text { index } \\
\text { wealth }\end{array}$ & $\begin{array}{l}\text { After a } \\
\text { for stuo } \\
\text { of fam }\end{array}$ & $\begin{array}{l}\text { ounting } \\
\text { ts' index } \\
\text { wealth }\end{array}$ \\
\hline & & Mean & S.E. & Mean & S.E. & Mean & S.E. & Mean & S.E. & Dif. & S.E. & $\begin{array}{l}\text { Index } \\
\text { change }\end{array}$ & S.E. & $\begin{array}{c}\text { Index } \\
\text { change }\end{array}$ & S.E. \\
\hline 0 & Australia & $\mathrm{m}$ & $\mathrm{m}$ & $\mathrm{m}$ & $\mathrm{m}$ & $\mathrm{m}$ & $\mathrm{m}$ & $\mathrm{m}$ & $\mathrm{m}$ & $\mathrm{m}$ & $\mathrm{m}$ & $\mathrm{m}$ & $\mathrm{m}$ & $\mathrm{m}$ & $\mathrm{m}$ \\
\hline & Austria & 7.11 & $(0.08)$ & 7.43 & $(0.07)$ & 7.68 & $(0.06)$ & 7.87 & $(0.06)$ & 0.75 & $(0.10)$ & 0.56 & $(0.13)$ & 0.31 & $(0.13)$ \\
\hline & Belgium (excl. Flemish) & 7.11 & $(0.08)$ & 7.43 & $(0.07)$ & 7.55 & $(0.07)$ & 7.83 & $(0.07)$ & 0.71 & $(0.09)$ & 0.24 & $(0.12)$ & -0.03 & $(0.12)$ \\
\hline & Canada & $\mathrm{m}$ & $\mathrm{m}$ & $\mathrm{m}$ & $\mathrm{m}$ & $\mathrm{m}$ & $\mathrm{m}$ & $\mathrm{m}$ & $\mathrm{m}$ & $\mathrm{m}$ & $\mathrm{m}$ & $\mathrm{m}$ & $\mathrm{m}$ & $\mathrm{m}$ & $\mathrm{m}$ \\
\hline & Chile & 6.97 & $(0.09)$ & 7.29 & $(0.07)$ & 7.53 & $(0.07)$ & 7.68 & $(0.06)$ & 0.72 & $(0.10)$ & 0.12 & $(0.06)$ & -0.21 & $(0.07)$ \\
\hline & Czech Republic & 6.69 & $(0.07)$ & 6.96 & $(0.06)$ & 7.14 & $(0.06)$ & 7.41 & $(0.06)$ & 0.71 & $(0.08)$ & 0.10 & $(0.11)$ & -0.07 & $(0.11)$ \\
\hline & Denmark & $\mathrm{m}$ & $\mathrm{m}$ & $\mathrm{m}$ & $\mathrm{m}$ & $\mathrm{m}$ & $\mathrm{m}$ & $\mathrm{m}$ & $\mathrm{m}$ & $\mathrm{m}$ & $\mathrm{m}$ & $\mathrm{m}$ & $\mathrm{m}$ & $\mathrm{m}$ & $\mathrm{m}$ \\
\hline & Estonia & 6.90 & $(0.07)$ & 7.48 & $(0.05)$ & 7.65 & $(0.06)$ & 7.98 & $(0.06)$ & 1.08 & $(0.07)$ & 0.28 & $(0.13)$ & -0.06 & $(0.14)$ \\
\hline & Finland & 7.68 & $(0.06)$ & 7.89 & $(0.05)$ & 7.92 & $(0.06)$ & 8.07 & $(0.04)$ & 0.39 & $(0.07)$ & 0.03 & $(0.15)$ & -0.09 & $(0.15)$ \\
\hline & France & 7.21 & $(0.08)$ & 7.59 & $(0.05)$ & 7.75 & $(0.05)$ & 7.97 & $(0.04)$ & 0.76 & $(0.09)$ & 0.41 & $(0.12)$ & 0.15 & $(0.11)$ \\
\hline & Germany & 7.07 & $(0.07)$ & 7.40 & $(0.07)$ & 7.36 & $(0.07)$ & 7.58 & $(0.05)$ & 0.51 & $(0.08)$ & 0.28 & $(0.15)$ & 0.16 & (0.15) \\
\hline & Greece & 6.47 & $(0.08)$ & 6.92 & $(0.08)$ & 7.01 & $(0.07)$ & 7.26 & $(0.07)$ & 0.79 & $(0.11)$ & 0.05 & $(0.09)$ & -0.19 & $(0.10)$ \\
\hline & Hungary & 6.67 & $(0.08)$ & 7.17 & $(0.08)$ & 7.26 & $(0.06)$ & 7.58 & $(0.06)$ & 0.92 & $(0.10)$ & 0.24 & $(0.13)$ & -0.05 & $(0.13)$ \\
\hline & Iceland & 7.34 & $(0.08)$ & 7.73 & (0.08) & 7.92 & $(0.08)$ & 8.18 & $(0.07)$ & 0.84 & $(0.12)$ & 0.47 & $(0.20)$ & 0.21 & $(0.20)$ \\
\hline & Ireland & 6.92 & $(0.06)$ & 7.41 & $(0.06)$ & 7.37 & $(0.06)$ & 7.52 & $(0.05)$ & 0.60 & $(0.08)$ & 0.10 & $(0.11)$ & -0.08 & $(0.12)$ \\
\hline & Israel & m & $\mathrm{m}$ & $\mathrm{m}$ & $\mathrm{m}$ & $\mathrm{m}$ & $\mathrm{m}$ & $\mathrm{m}$ & m & $\mathrm{m}$ & m & $\mathrm{m}$ & $\mathrm{m}$ & $\mathrm{m}$ & $\mathrm{m}$ \\
\hline & Italy & 6.45 & $(0.08)$ & 6.91 & $(0.06)$ & 7.02 & $(0.07)$ & 7.19 & $(0.07)$ & 0.74 & $(0.10)$ & 0.21 & $(0.16)$ & -0.02 & $(0.17)$ \\
\hline & Japan & 6.58 & $(0.06)$ & 6.84 & $(0.07)$ & 6.88 & $(0.05)$ & 6.89 & $(0.06)$ & 0.31 & $(0.08)$ & 0.42 & $(0.20)$ & 0.32 & $(0.20)$ \\
\hline & Korea & 6.01 & $(0.07)$ & 6.22 & $(0.08)$ & 6.51 & $(0.07)$ & 6.71 & $(0.07)$ & 0.70 & $(0.10)$ & -0.03 & $(0.22)$ & -0.45 & $(0.23)$ \\
\hline & Latvia & 6.97 & $(0.08)$ & 7.32 & $(0.07)$ & 7.45 & $(0.07)$ & 7.74 & $(0.07)$ & 0.78 & $(0.10)$ & 0.06 & $(0.12)$ & -0.17 & $(0.12)$ \\
\hline & Luxembourg & 7.08 & $(0.07)$ & 7.38 & $(0.06)$ & 7.42 & $(0.06)$ & 7.62 & $(0.06)$ & 0.54 & $(0.09)$ & 0.11 & $(0.12)$ & -0.07 & $(0.13)$ \\
\hline & Mexico & 8.17 & $(0.08)$ & 8.18 & $(0.06)$ & 8.32 & $(0.05)$ & 8.40 & $(0.05)$ & 0.22 & $(0.09)$ & 0.02 & $(0.03)$ & -0.09 & $(0.04)$ \\
\hline & Netherlands & 7.64 & $(0.05)$ & 7.77 & $(0.05)$ & 7.84 & $(0.04)$ & 8.05 & $(0.04)$ & 0.40 & $(0.07)$ & -0.30 & $(0.11)$ & -0.48 & $(0.11)$ \\
\hline & New Zealand & $\mathrm{m}$ & $\mathrm{m}$ & $\mathrm{m}$ & $\mathrm{m}$ & $\mathrm{m}$ & $\mathrm{m}$ & $\mathrm{m}$ & $\mathrm{m}$ & $\mathrm{m}$ & $\mathrm{m}$ & $\mathrm{m}$ & $\mathrm{m}$ & $\mathrm{m}$ & $\mathrm{m}$ \\
\hline & Norway & $\mathrm{m}$ & $\mathrm{m}$ & $\mathrm{m}$ & $\mathrm{m}$ & $\mathrm{m}$ & $\mathrm{m}$ & $\mathrm{m}$ & $\mathrm{m}$ & $\mathrm{m}$ & $\mathrm{m}$ & $\mathrm{m}$ & $\mathrm{m}$ & $\mathrm{m}$ & $\mathrm{m}$ \\
\hline & Poland & 6.68 & $(0.09)$ & 7.16 & $(0.07)$ & 7.38 & $(0.07)$ & 7.51 & $(0.07)$ & 0.83 & $(0.11)$ & -0.06 & $(0.18)$ & -0.28 & $(0.17)$ \\
\hline & Portugal & 7.00 & $(0.07)$ & 7.30 & $(0.05)$ & 7.51 & $(0.05)$ & 7.65 & $(0.06)$ & 0.65 & $(0.10)$ & 0.01 & $(0.14)$ & -0.23 & $(0.13)$ \\
\hline & Slovak Republic & 7.12 & $(0.08)$ & 7.44 & $(0.07)$ & 7.52 & $(0.05)$ & 7.78 & $(0.05)$ & 0.67 & $(0.10)$ & 0.23 & $(0.14)$ & 0.00 & $(0.13)$ \\
\hline & Slovenia & 6.97 & $(0.08)$ & 7.12 & $(0.06)$ & 7.24 & $(0.07)$ & 7.37 & $(0.07)$ & 0.41 & $(0.11)$ & 0.03 & $(0.16)$ & -0.14 & $(0.16)$ \\
\hline & Spain & 6.99 & $(0.05)$ & 7.38 & $(0.07)$ & 7.59 & $(0.05)$ & 7.71 & $(0.05)$ & 0.72 & $(0.07)$ & 0.46 & $(0.08)$ & 0.17 & $(0.10)$ \\
\hline & Sweden & m & $\mathrm{m}$ & $\mathrm{m}$ & $\mathrm{m}$ & $\mathrm{m}$ & m & $\mathrm{m}$ & $\mathrm{m}$ & $\mathrm{m}$ & $\mathrm{m}$ & $\mathrm{m}$ & $\mathrm{m}$ & $\mathrm{m}$ & $\mathrm{m}$ \\
\hline & Switzerland & 7.60 & $(0.05)$ & 7.68 & $(0.06)$ & 7.75 & $(0.05)$ & 7.83 & $(0.07)$ & 0.24 & $(0.08)$ & -0.01 & $(0.12)$ & -0.09 & $(0.13)$ \\
\hline & Turkey & 5.71 & $(0.12)$ & 6.06 & $(0.10)$ & 6.26 & $(0.09)$ & 6.44 & $(0.09)$ & 0.73 & $(0.15)$ & 0.00 & $(0.12)$ & -0.37 & $(0.12)$ \\
\hline & United Kingdom & 6.50 & $(0.06)$ & 6.97 & $(0.06)$ & 7.11 & $(0.07)$ & 7.33 & $(0.06)$ & 0.83 & $(0.09)$ & 0.26 & $(0.12)$ & 0.04 & $(0.12)$ \\
\hline & United States & 6.88 & $(0.07)$ & 7.16 & $(0.08)$ & 7.63 & $(0.07)$ & 7.76 & $(0.06)$ & 0.89 & $(0.09)$ & 0.15 & $(0.09)$ & -0.14 & $(0.10)$ \\
\hline & OECD average & 6.95 & $(0.01)$ & 7.27 & $(0.01)$ & 7.41 & $(0.01)$ & 7.60 & $(0.01)$ & 0.66 & $(0.02)$ & 0.16 & $(0.03)$ & -0.07 & $(0.03)$ \\
\hline & Albania & $\mathrm{m}$ & $\mathrm{m}$ & $\mathrm{m}$ & $\mathrm{m}$ & $\mathrm{m}$ & $\mathrm{m}$ & $\mathrm{m}$ & $\mathrm{m}$ & $\mathrm{m}$ & $\mathrm{m}$ & $\mathrm{m}$ & $\mathrm{m}$ & $\mathrm{m}$ & $\mathrm{m}$ \\
\hline$\Xi$ & Algeria & $\mathrm{m}$ & $\mathrm{m}$ & $\mathrm{m}$ & $\mathrm{m}$ & $\mathrm{m}$ & $\mathrm{m}$ & $\mathrm{m}$ & $\mathrm{m}$ & $\mathrm{m}$ & $\mathrm{m}$ & $\mathrm{m}$ & $\mathrm{m}$ & $\mathrm{m}$ & $\mathrm{m}$ \\
\hline & Brazil & 7.49 & $(0.05)$ & 7.62 & $(0.05)$ & 7.58 & $(0.05)$ & 7.65 & $(0.05)$ & 0.16 & $(0.07)$ & -0.24 & $(0.05)$ & -0.42 & $(0.05)$ \\
\hline 2 & B-S-J-G (China) & 6.53 & $(0.08)$ & 6.70 & $(0.08)$ & 6.92 & $(0.06)$ & 7.19 & $(0.09)$ & 0.66 & $(0.12)$ & 0.14 & $(0.06)$ & -0.14 & $(0.07)$ \\
\hline & Bulgaria & 6.93 & $(0.09)$ & 7.28 & $(0.08)$ & 7.54 & $(0.07)$ & 7.92 & $(0.08)$ & 0.99 & $(0.12)$ & 0.29 & $(0.13)$ & 0.00 & $(0.12)$ \\
\hline & CABA (Argentina) & m & $\mathrm{m}$ & $\mathrm{m}$ & $\mathrm{m}$ & $\mathrm{m}$ & $\mathrm{m}$ & $\mathrm{m}$ & $\mathrm{m}$ & $\mathrm{m}$ & $\mathrm{m}$ & $\mathrm{m}$ & $\mathrm{m}$ & $\mathrm{m}$ & $\mathrm{m}$ \\
\hline & Colombia & 8.00 & $(0.08)$ & 7.85 & $(0.07)$ & 7.89 & $(0.06)$ & 7.80 & $(0.06)$ & -0.20 & $(0.10)$ & -0.25 & $(0.04)$ & -0.39 & $(0.05)$ \\
\hline & Costa Rica & 8.10 & $(0.07)$ & 8.19 & $(0.07)$ & 8.21 & $(0.06)$ & 8.34 & $(0.06)$ & 0.24 & $(0.09)$ & -0.14 & $(0.05)$ & -0.33 & $(0.06)$ \\
\hline & Croatia & 7.52 & $(0.07)$ & 7.87 & $(0.06)$ & 7.99 & $(0.06)$ & 8.23 & $(0.06)$ & 0.71 & $(0.09)$ & -0.49 & $(0.18)$ & -0.78 & $(0.18)$ \\
\hline & Cyprus* & 6.65 & $(0.06)$ & 7.05 & $(0.06)$ & 7.18 & $(0.06)$ & 7.37 & $(0.07)$ & 0.72 & $(0.10)$ & 0.09 & $(0.10)$ & -0.15 & $(0.10)$ \\
\hline & Dominican Republic & 8.38 & $(0.08)$ & 8.51 & $(0.08)$ & 8.61 & $(0.08)$ & 8.53 & $(0.08)$ & 0.16 & $(0.12)$ & -0.20 & $(0.06)$ & -0.33 & $(0.07)$ \\
\hline & FYROM & $\mathrm{m}$ & $\mathrm{m}$ & $\mathrm{m}$ & $\mathrm{m}$ & $\mathrm{m}$ & $\mathrm{m}$ & $\mathrm{m}$ & $\mathrm{m}$ & $\mathrm{m}$ & $\mathrm{m}$ & $\mathrm{m}$ & $\mathrm{m}$ & $\mathrm{m}$ & $\mathrm{m}$ \\
\hline & Georgia & $\mathrm{m}$ & $\mathrm{m}$ & $\mathrm{m}$ & $\mathrm{m}$ & $\mathrm{m}$ & $\mathrm{m}$ & $\mathrm{m}$ & $\mathrm{m}$ & $\mathrm{m}$ & $\mathrm{m}$ & $\mathrm{m}$ & $\mathrm{m}$ & $\mathrm{m}$ & $\mathrm{m}$ \\
\hline & Hong Kong (China) & 6.15 & $(0.06)$ & 6.43 & $(0.07)$ & 6.53 & $(0.07)$ & 6.80 & $(0.05)$ & 0.65 & $(0.07)$ & 0.44 & $(0.12)$ & 0.20 & $(0.12)$ \\
\hline & Indonesia & $\mathrm{m}$ & $\mathrm{m}$ & $\mathrm{m}$ & $\mathrm{m}$ & $\mathrm{m}$ & m & $\mathrm{m}$ & $\mathrm{m}$ & $\mathrm{m}$ & $\mathrm{m}$ & $\mathrm{m}$ & $\mathrm{m}$ & $\mathrm{m}$ & $\mathrm{m}$ \\
\hline & Jordan & $\mathrm{m}$ & $\mathrm{m}$ & $\mathrm{m}$ & $\mathrm{m}$ & $\mathrm{m}$ & $\mathrm{m}$ & $\mathrm{m}$ & $\mathrm{m}$ & $\mathrm{m}$ & $\mathrm{m}$ & $\mathrm{m}$ & $\mathrm{m}$ & $\mathrm{m}$ & $\mathrm{m}$ \\
\hline & Kosovo & $\mathrm{m}$ & $\mathrm{m}$ & $\mathrm{m}$ & $\mathrm{m}$ & $\mathrm{m}$ & $\mathrm{m}$ & $\mathrm{m}$ & $\mathrm{m}$ & $\mathrm{m}$ & $\mathrm{m}$ & $\mathrm{m}$ & $\mathrm{m}$ & $\mathrm{m}$ & $\mathrm{m}$ \\
\hline & Lebanon & $\mathrm{m}$ & $\mathrm{m}$ & $\mathrm{m}$ & $\mathrm{m}$ & $\mathrm{m}$ & $\mathrm{m}$ & $\mathrm{m}$ & $\mathrm{m}$ & $\mathrm{m}$ & $\mathrm{m}$ & $\mathrm{m}$ & $\mathrm{m}$ & $\mathrm{m}$ & $\mathrm{m}$ \\
\hline & Lithuania & 7.24 & $(0.06)$ & 7.89 & $(0.06)$ & 8.06 & $(0.07)$ & 8.27 & $(0.06)$ & 1.03 & $(0.08)$ & 0.18 & $(0.12)$ & -0.12 & $(0.12)$ \\
\hline & Macao (China) & 6.17 & $(0.07)$ & 6.44 & $(0.06)$ & 6.75 & $(0.06)$ & 7.01 & $(0.05)$ & 0.84 & $(0.09)$ & 0.20 & $(0.09)$ & -0.19 & $(0.10)$ \\
\hline & Malta & $\mathrm{m}$ & $\mathrm{m}$ & $\mathrm{m}$ & m & $\mathrm{m}$ & $\mathrm{m}$ & $\mathrm{m}$ & $\mathrm{m}$ & $\mathrm{m}$ & $\mathrm{m}$ & $\mathrm{m}$ & $\mathrm{m}$ & $\mathrm{m}$ & $\mathrm{m}$ \\
\hline & Moldova & $\mathrm{m}$ & $\mathrm{m}$ & $\mathrm{m}$ & $\mathrm{m}$ & $\mathrm{m}$ & $\mathrm{m}$ & $\mathrm{m}$ & $\mathrm{m}$ & $\mathrm{m}$ & $\mathrm{m}$ & $\mathrm{m}$ & $\mathrm{m}$ & $\mathrm{m}$ & $\mathrm{m}$ \\
\hline & Montenegro & 7.35 & $(0.08)$ & 7.69 & $(0.07)$ & 7.86 & $(0.07)$ & 8.09 & $(0.07)$ & 0.74 & $(0.11)$ & -0.51 & $(0.15)$ & -0.80 & $(0.15)$ \\
\hline & Peru & 7.52 & $(0.08)$ & 7.54 & $(0.07)$ & 7.48 & $(0.07)$ & 7.47 & $(0.07)$ & -0.06 & $(0.10)$ & -0.12 & $(0.04)$ & -0.25 & $(0.05)$ \\
\hline & Qatar & 6.89 & $(0.05)$ & 7.24 & $(0.05)$ & 7.54 & $(0.05)$ & 7.95 & $(0.05)$ & 1.07 & $(0.07)$ & 0.29 & $(0.03)$ & 0.01 & $(0.03)$ \\
\hline & Romania & C & c & $\mathrm{m}$ & $\mathrm{m}$ & $\mathrm{m}$ & $\mathrm{m}$ & $\mathrm{m}$ & $\mathrm{m}$ & $\mathrm{m}$ & $\mathrm{m}$ & $\mathrm{m}$ & $\mathrm{m}$ & $\mathrm{m}$ & $\mathrm{m}$ \\
\hline & Russia & 7.46 & $(0.06)$ & 7.63 & $(0.08)$ & 7.78 & $(0.08)$ & 8.15 & $(0.06)$ & 0.69 & $(0.08)$ & -0.36 & $(0.09)$ & -0.66 & $(0.10)$ \\
\hline & Singapore & $\mathrm{m}$ & $\mathrm{m}$ & $\mathrm{m}$ & $\mathrm{m}$ & $\mathrm{m}$ & $\mathrm{m}$ & $\mathrm{m}$ & $\mathrm{m}$ & $\mathrm{m}$ & $\mathrm{m}$ & $\mathrm{m}$ & $\mathrm{m}$ & $\mathrm{m}$ & $\mathrm{m}$ \\
\hline & Chinese Taipei & 6.18 & $(0.06)$ & 6.69 & $(0.05)$ & 6.64 & $(0.06)$ & 6.86 & $(0.05)$ & 0.68 & $(0.07)$ & 0.09 & $(0.10)$ & -0.14 & $(0.10)$ \\
\hline & Thailand & 7.61 & $(0.07)$ & 7.85 & $(0.06)$ & 7.71 & $(0.07)$ & 7.67 & $(0.07)$ & 0.06 & $(0.10)$ & -0.25 & $(0.06)$ & -0.40 & $(0.06)$ \\
\hline & Trinidad and Tobago & $\mathrm{m}$ & $\mathrm{m}$ & $\mathrm{m}$ & $\mathrm{m}$ & $\mathrm{m}$ & $\mathrm{m}$ & $\mathrm{m}$ & $\mathrm{m}$ & $\mathrm{m}$ & $\mathrm{m}$ & $\mathrm{m}$ & $\mathrm{m}$ & $\mathrm{m}$ & $\mathrm{m}$ \\
\hline & Tunisia & 6.18 & $(0.10)$ & 6.69 & $(0.09)$ & 7.25 & $(0.09)$ & 7.46 & $(0.08)$ & 1.29 & $(0.13)$ & 0.07 & $(0.06)$ & -0.44 & $(0.06)$ \\
\hline & United Arab Emirates & 6.80 & $(0.06)$ & 7.12 & $(0.06)$ & 7.37 & $(0.05)$ & 7.91 & $(0.07)$ & 1.10 & $(0.10)$ & 0.19 & $(0.05)$ & -0.12 & $(0.06)$ \\
\hline & Uruguay & 7.29 & $(0.06)$ & 7.60 & $(0.07)$ & 7.79 & $(0.07)$ & 8.11 & $(0.07)$ & 0.82 & $(0.10)$ & 0.14 & $(0.07)$ & -0.19 & $(0.08)$ \\
\hline & Viet Nam & $\mathrm{m}$ & $\mathrm{m}$ & $\mathrm{m}$ & $\mathrm{m}$ & $\mathrm{m}$ & $\mathrm{m}$ & $\mathrm{m}$ & $\mathrm{m}$ & $\mathrm{m}$ & $\mathrm{m}$ & $\mathrm{m}$ & $\mathrm{m}$ & $\mathrm{m}$ & $\mathrm{m}$ \\
\hline & Argentina** & $\mathrm{m}$ & $\mathrm{m}$ & $\mathrm{m}$ & $\mathrm{m}$ & $\mathrm{m}$ & $\mathrm{m}$ & $\mathrm{m}$ & $\mathrm{m}$ & $\mathrm{m}$ & $\mathrm{m}$ & $\mathrm{m}$ & $\mathrm{m}$ & $\mathrm{m}$ & $\mathrm{m}$ \\
\hline & Kazakhstan** & $\mathrm{m}$ & $\mathrm{m}$ & $\mathrm{m}$ & $\mathrm{m}$ & $\mathrm{m}$ & $\mathrm{m}$ & $\mathrm{m}$ & $\mathrm{m}$ & $\mathrm{m}$ & $\mathrm{m}$ & $\mathrm{m}$ & $\mathrm{m}$ & $\mathrm{m}$ & $\mathrm{m}$ \\
\hline & Malaysia** & 6.91 & $(0.07)$ & 7.12 & $(0.06)$ & 7.11 & $(0.07)$ & 7.13 & $(0.07)$ & 0.22 & $(0.09)$ & -0.17 & $(0.06)$ & -0.31 & $(0.06)$ \\
\hline
\end{tabular}

1. School wealth is calculated, for each student, as the average value of the index of family wealth of all the other students in the school.

Note: Values that are statistically significant are indicated in bold (see Annex A3).

* See note at the beginning of this Annex.

** Coverage is too small to ensure comparability (see Annex A4).

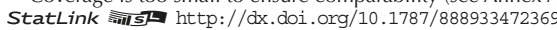


[Part 1/1]

Table III.10.10 Distribution of students, by family income

Results are based on parents' self-reports

\begin{tabular}{|c|c|c|c|c|c|c|c|c|c|c|c|c|c|}
\hline & & \multicolumn{4}{|c|}{ Family income } & \multicolumn{8}{|c|}{ Percentage of students, by family income } \\
\hline & & \multicolumn{2}{|c|}{$\begin{array}{c}\text { Maximum value } \\
\text { for low-income students }\end{array}$} & \multicolumn{2}{|c|}{$\begin{array}{c}\text { Minimum value } \\
\text { for high-income students }\end{array}$} & \multicolumn{2}{|c|}{$\begin{array}{l}\text { Low-income } \\
\text { students }\end{array}$} & \multicolumn{2}{|c|}{$\begin{array}{l}\text { Middle-income } \\
\text { students }\end{array}$} & \multicolumn{2}{|c|}{$\begin{array}{l}\text { High-income } \\
\text { students }\end{array}$} & \multicolumn{2}{|c|}{$\begin{array}{c}\text { Difference } \\
\text { between high- } \\
\text { and low-income } \\
\text { students }\end{array}$} \\
\hline & & $\begin{array}{l}\text { National } \\
\text { currency }\end{array}$ & $\begin{array}{l}\text { USD } \\
\text { in PPP }\end{array}$ & $\begin{array}{l}\text { National } \\
\text { currency }\end{array}$ & $\begin{array}{l}\text { USD } \\
\text { in PPP }\end{array}$ & $\%$ & S.E. & $\%$ & S.E. & $\%$ & S.E. & $\%$ dif. & S.E. \\
\hline \multirow{14}{*}{ త্ } & Belgium (Flemish) & 30000 & 36786 & 50000 & 61311 & 28.7 & $(1.1)$ & 30.4 & (0.9) & 40.9 & (1.3) & 12.1 & $(2.2)$ \\
\hline & Chile & 280000 & 769 & 580000 & 1593 & 31.3 & $(1.2)$ & 29.3 & (1.0) & 39.3 & $(1.2)$ & 8.0 & $(2.3)$ \\
\hline & France & 22500 & 27479 & 37500 & 45798 & 29.9 & (1.0) & 27.3 & $(0.8)$ & 42.8 & $(1.1)$ & 12.9 & (2.0) \\
\hline & Germany & 30000 & 38595 & 50000 & 64325 & 25.8 & (1.2) & 28.8 & (1.1) & 45.4 & (1.5) & 19.7 & (2.4) \\
\hline & Italy & $\mathrm{m}$ & $\mathrm{m}$ & $\mathrm{m}$ & $\mathrm{m}$ & $\mathrm{m}$ & $\mathrm{m}$ & $\mathrm{m}$ & $\mathrm{m}$ & $\mathrm{m}$ & $\mathrm{m}$ & $\mathrm{m}$ & $\mathrm{m}$ \\
\hline & Ireland & $\mathrm{m}$ & $\mathrm{m}$ & $\mathrm{m}$ & $\mathrm{m}$ & $\mathrm{m}$ & $\mathrm{m}$ & $\mathrm{m}$ & $\mathrm{m}$ & $\mathrm{m}$ & $\mathrm{m}$ & $\mathrm{m}$ & $\mathrm{m}$ \\
\hline & Korea & 33000000 & 37870 & 55000000 & 63116 & 25.4 & (1.0) & 30.3 & (0.9) & 44.3 & (1.5) & 19.0 & (2.4) \\
\hline & Luxembourg & 35000 & 39198 & 65000 & 72797 & 30.5 & (0.8) & 29.4 & $(0.7)$ & 40.1 & (0.9) & 9.6 & (1.6) \\
\hline & Mexico & 75000 & 9357 & 187500 & 23392 & 86.0 & $(0.8)$ & 8.1 & $(0.5)$ & 5.9 & $(0.6)$ & -80.2 & (1.3) \\
\hline & Portugal & 11249 & 19296 & 18750 & 32163 & 52.9 & (1.2) & 19.6 & (0.6) & 27.4 & (1.0) & -25.5 & (2.1) \\
\hline & Spain & 20000 & 29694 & 30000 & 44541 & 53.8 & (1.6) & 27.7 & (1.0) & 18.5 & $(1.2)$ & -35.3 & (2.7) \\
\hline & UK (Scotland) & 27000 & 39033 & 45000 & 65054 & 33.5 & (1.6) & 22.4 & (1.2) & 44.0 & (1.8) & 10.5 & (3.1) \\
\hline & OECD average & $\mathrm{m}$ & 27808 & $\mathrm{~m}$ & 47409 & 39.8 & $(0.4)$ & 25.3 & $(0.3)$ & 34.9 & $(0.4)$ & -4.9 & $(0.7)$ \\
\hline & Average $^{1}$ & $\mathrm{~m}$ & 20658 & $\mathrm{~m}$ & 38056 & 41.5 & $(0.3)$ & 27.1 & $(0.2)$ & 31.4 & $(0.3)$ & -10.0 & $(0.5)$ \\
\hline \multirow{6}{*}{ ఏँ } & Croatia & 6000 & 1635 & 12000 & 3271 & 45.3 & (1.0) & 40.9 & (0.8) & 13.8 & $(0.7)$ & -31.5 & (1.6) \\
\hline & Dominican Republic & 22500 & 1114 & 37500 & 1857 & 73.5 & $(1.2)$ & 14.8 & $(0.8)$ & 11.7 & $(0.9)$ & -61.9 & (2.0) \\
\hline & Georgia & 3000 & 3590 & 9001 & 10771 & 51.5 & (1.4) & 32.2 & (1.0) & 16.3 & (1.0) & -35.3 & (2.2) \\
\hline & Hong Kong (China) & 120000 & 21544 & 540000 & 96948 & 24.8 & $(0.8)$ & 26.0 & $(0.7)$ & 49.2 & (1.3) & 24.3 & (2.0) \\
\hline & Macao (China) & 144000 & 26238 & 288000 & 52477 & 35.4 & $(0.8)$ & 25.6 & $(0.7)$ & 39.0 & (0.8) & 3.5 & (1.4) \\
\hline & Malta & 10500 & 18073 & 33900 & 58349 & 35.0 & $(0.9)$ & 40.4 & (1.0) & 24.6 & $(0.8)$ & -10.4 & (1.4) \\
\hline
\end{tabular}

1. "Average" includes all countries and economies with available data.

Notes: Students' parents were asked to report their family income before taxes. Their answers were coded in six income categories, defined independently by each country.

Low(high)-income students are students in the bottom(top) two categories of family income. Middle-income students are students in the third and fourth categories of family income.

Values that are statistically significant are indicated in bold (see Annex A3).

StatLink त्राज़ http://dx.doi.org/10.1787/888933472378 


\begin{tabular}{|c|c|c|c|c|c|c|c|c|c|c|c|}
\hline & \multicolumn{4}{|c|}{ Percentage of students by parental occupation ${ }^{1}$} & \multicolumn{6}{|c|}{ Performance in science by parental occupation } \\
\hline & & \multicolumn{2}{|c|}{$\begin{array}{c}\text { Children } \\
\text { of blue-collar workers }\end{array}$} & \multicolumn{2}{|c|}{$\begin{array}{c}\text { Children } \\
\text { of white-collar workers }\end{array}$} & $\begin{array}{r}\text { Performan } \\
\text { among } \\
\text { of blue-co }\end{array}$ & $\begin{array}{l}\text { science } \\
\text { dren } \\
\text { vorkers }\end{array}$ & $\begin{array}{c}\text { Performanc } \\
\text { among } \\
\text { of white-co }\end{array}$ & $\begin{array}{l}\text { science } \\
\text { dren } \\
\text { workers }\end{array}$ & $\begin{array}{c}\text { Differen } \\
\text { performa } \\
\text { children o } \\
\text { workers } \\
\text { of blue-c }\end{array}$ & $\begin{array}{l}\text { science } \\
\text { etween } \\
\text { te-collar } \\
\text { hildren } \\
\text { workers }\end{array}$ \\
\hline & & $\%$ & S.E. & $\%$ & S.E. & Mean score & S.E. & Mean score & S.E. & Score dif. & S.E. \\
\hline & Australia & 12.2 & $(0.4)$ & 66.5 & $(0.6)$ & 472 & $(3.4)$ & 533 & $(1.7)$ & 61 & $(3.6)$ \\
\hline ర & Austria & 17.0 & $(0.7)$ & 55.7 & $(1.0)$ & 454 & $(3.8)$ & 526 & $(2.6)$ & 71 & $(4.2)$ \\
\hline ప & Belgium & 17.5 & $(0.7)$ & 58.6 & $(1.0)$ & 450 & (3.3) & 540 & $(2.2)$ & 90 & $(4.1)$ \\
\hline & Canada & 10.7 & $(0.5)$ & 71.3 & $(0.8)$ & 495 & (3.6) & 547 & $(2.0)$ & 52 & (3.6) \\
\hline & Chile & 30.4 & $(1.0)$ & 38.9 & $(1.0)$ & 419 & (3.2) & 484 & $(2.9)$ & 65 & (3.5) \\
\hline & Czech Republic & 20.3 & $(0.6)$ & 47.0 & $(0.9)$ & 452 & (3.5) & 529 & $(2.8)$ & 77 & $(4.2)$ \\
\hline & Denmark & 13.9 & $(0.6)$ & 62.6 & $(1.0)$ & 468 & $(4.1)$ & 526 & $(2.4)$ & 58 & $(4.2)$ \\
\hline & Estonia & 18.7 & $(0.6)$ & 60.5 & $(0.9)$ & 503 & (3.6) & 555 & $(2.2)$ & 52 & (3.7) \\
\hline & Finland & 11.2 & $(0.5)$ & 58.5 & $(1.1)$ & 494 & $(5.1)$ & 553 & $(2.5)$ & 58 & (5.2) \\
\hline & France & 14.6 & $(0.7)$ & 57.8 & $(1.0)$ & 448 & (3.8) & 534 & $(2.3)$ & 85 & $(4.8)$ \\
\hline & Germany & 14.0 & $(0.6)$ & 55.5 & $(0.9)$ & 464 & (4.9) & 546 & $(2.6)$ & 82 & $(4.8)$ \\
\hline & Greece & 24.5 & $(1.1)$ & 49.1 & (1.3) & 418 & (5.1) & 489 & (3.4) & 71 & (5.0) \\
\hline & Hungary & 25.1 & $(0.9)$ & 48.8 & $(1.1)$ & 427 & (3.6) & 520 & $(2.9)$ & 93 & $(4.3)$ \\
\hline & Iceland & 9.0 & $(0.5)$ & 76.3 & $(0.8)$ & 454 & $(6.2)$ & 485 & $(2.2)$ & 30 & (6.9) \\
\hline & Ireland & 13.9 & $(0.7)$ & 57.9 & $(1.2)$ & 467 & $(4.5)$ & 525 & (2.3) & 58 & $(4.4)$ \\
\hline & Israel & 12.2 & $(0.8)$ & 72.8 & (1.1) & 409 & (5.1) & 495 & (3.2) & 85 & (5.6) \\
\hline & Italy & 22.3 & $(0.6)$ & 48.6 & $(0.8)$ & 445 & (3.8) & 509 & (3.0) & 65 & $(4.3)$ \\
\hline & Japan & 13.2 & $(0.6)$ & 52.2 & $(0.8)$ & 508 & $(4.0)$ & 558 & (3.1) & 50 & $(4.1)$ \\
\hline & Korea & 13.1 & $(0.6)$ & 52.2 & $(1.1)$ & 492 & (4.1) & 538 & (3.6) & 46 & $(4.8)$ \\
\hline & Latvia & 19.5 & $(0.8)$ & 52.4 & (1.0) & 458 & (3.6) & 514 & (1.9) & 56 & $(4.1)$ \\
\hline & Luxembourg & 23.8 & $(0.5)$ & 47.9 & $(0.5)$ & 428 & $(2.7)$ & 532 & (1.7) & 104 & (3.3) \\
\hline & Mexico & 41.9 & (1.1) & 31.7 & $(1.0)$ & 399 & (2.5) & 443 & $(3.0)$ & 43 & $(3.4)$ \\
\hline & Netherlands & 9.9 & $(0.6)$ & 63.4 & $(0.9)$ & 456 & (5.6) & 535 & $(2.6)$ & 79 & $(6.2)$ \\
\hline & New Zealand & 13.1 & $(0.5)$ & 71.1 & $(0.8)$ & 463 & $(5.2)$ & 538 & $(2.5)$ & 75 & (5.4) \\
\hline & Norway & 5.6 & $(0.4)$ & 77.0 & $(0.9)$ & 453 & (5.0) & 514 & $(2.4)$ & 62 & (5.0) \\
\hline & Poland & 29.0 & $(1.0)$ & 44.6 & $(1.0)$ & 478 & (3.5) & 532 & (3.0) & 54 & $(4.1)$ \\
\hline & Portugal & 25.3 & $(1.0)$ & 50.0 & $(1.1)$ & 461 & (3.3) & 535 & $(2.5)$ & 74 & (3.9) \\
\hline & Slovak Republic & 24.0 & $(0.8)$ & 49.0 & (1.1) & 427 & $(3.7)$ & 501 & (3.0) & 73 & $(4.3)$ \\
\hline & Slovenia & 18.5 & $(0.5)$ & 58.5 & $(0.7)$ & 468 & (3.5) & 540 & (1.7) & 73 & (3.9) \\
\hline & Spain & 26.0 & $(0.9)$ & 46.2 & $(1.3)$ & 463 & $(2.6)$ & 521 & $(2.2)$ & 58 & (3.1) \\
\hline & Sweden & 7.3 & $(0.4)$ & 70.4 & (1.1) & 444 & (5.5) & 519 & (3.6) & 75 & (6.1) \\
\hline & Switzerland & 15.2 & $(0.7)$ & 59.2 & (1.1) & 460 & $(4.2)$ & 538 & $(2.9)$ & 78 & $(4.5)$ \\
\hline & Turkey & 54.3 & (1.5) & 25.4 & (1.4) & 415 & (4.3) & 461 & (5.7) & 45 & (6.1) \\
\hline & United Kingdom & 12.0 & $(0.5)$ & 65.9 & $(0.9)$ & 472 & (4.4) & 534 & $(2.8)$ & 62 & $(4.9)$ \\
\hline & United States & 16.0 & $(0.9)$ & 63.4 & $(1.2)$ & 460 & $(4.6)$ & 520 & $(2.8)$ & 60 & $(4.8)$ \\
\hline & OECD average & 18.7 & $(0.1)$ & 56.2 & $(0.2)$ & 456 & $(0.7)$ & 522 & $(0.5)$ & 66 & $(0.8)$ \\
\hline$n$ & Albania & 383 & $(1.3)$ & 397 & $(1,2)$ & 427 & 42 & 428 & 39 & 1 & 4.3 \\
\hline ఏ & Algeria & 25.2 & $(1.1)$ & 37.3 & (1.4) & 372 & (2.9) & 390 & $(4.6)$ & 19 & $(4.9)$ \\
\hline & Brazil & 30.6 & $(0.7)$ & 35.2 & $(0.9)$ & 381 & $(2.2)$ & 441 & (3.8) & 60 & (3.9) \\
\hline$a^{2}+3 x-10$ & B-S-J-G (China) & 36.8 & (1.3) & 37.0 & (1.4) & 491 & (4.9) & 566 & (5.8) & 75 & $(6.7)$ \\
\hline & Bulgaria & 23.5 & $(1.1)$ & 51.4 & (1.4) & 402 & (5.3) & 493 & (3.9) & 92 & (6.0) \\
\hline & CABA (Argentina) & 15.9 & (1.7) & 60.7 & (3.1) & 420 & (6.3) & 504 & (6.5) & 84 & $(7.9)$ \\
\hline & Colombia & 39.5 & $(1.2)$ & 39.5 & (1.2) & 392 & (2.9) & 445 & (3.4) & 53 & (4.3) \\
\hline & Costa Rica & 11.2 & $(0.5)$ & 34.2 & (1.1) & 404 & $(3.0)$ & 450 & $(2.7)$ & 46 & (3.4) \\
\hline & Croatia & 19.2 & $(0.7)$ & 43.4 & $(0.8)$ & 442 & (3.7) & 508 & $(2.9)$ & 66 & (3.9) \\
\hline & Cyprus* & 14.3 & $(0.5)$ & 55.1 & $(0.7)$ & 398 & $(3.2)$ & 460 & (1.9) & 62 & (3.5) \\
\hline & Dominican Republic & 32.1 & $(1.1)$ & 36.7 & (1.0) & 314 & (2.6) & 359 & (4.3) & 45 & $(4.7)$ \\
\hline & FYROM & 28.4 & $(0.6)$ & 51.3 & $(0.7)$ & 375 & $(3.2)$ & 403 & $(2.0)$ & 28 & $(4.0)$ \\
\hline & Georgia & 21.3 & $(0.9)$ & 56.3 & (1.1) & 393 & $(4.2)$ & 441 & $(2.9)$ & 48 & $(4.6)$ \\
\hline & Hong Kong (China) & 19.9 & $(0.9)$ & 49.3 & $(1.2)$ & 507 & (3.5) & 539 & (3.1) & 32 & $(4.1)$ \\
\hline & Indonesia & 49.8 & (1.7) & 17.8 & $(0.9)$ & 390 & (2.6) & 437 & $(4.6)$ & 47 & $(4.8)$ \\
\hline & Jordan & 18.9 & $(0.8)$ & 57.7 & (1.1) & 397 & (3.7) & 433 & (2.9) & 36 & $(4.3)$ \\
\hline & Kosovo & 7.8 & $(0.4)$ & 50.5 & $(0.8)$ & 362 & (4.5) & 390 & $(2.2)$ & 28 & $(5.1)$ \\
\hline & Lebanon & 18.0 & $(0.9)$ & 70.5 & $(1.1)$ & 366 & (3.9) & 402 & (3.9) & 36 & $(4.7)$ \\
\hline & Lithuania & 23.7 & $(0.8)$ & 55.5 & (1.1) & 445 & $(3.1)$ & 506 & (3.4) & 61 & $(4.3)$ \\
\hline & Macao (China) & 10.0 & $(0.5)$ & 36.3 & $(0.6)$ & 519 & $(4.1)$ & 539 & $(2.2)$ & 20 & $(4.8)$ \\
\hline & Malta & 22.0 & $(0.6)$ & 51.1 & $(0.7)$ & 426 & (4.3) & 500 & $(2.6)$ & 74 & (5.0) \\
\hline & Moldova & 33.3 & (1.1) & 40.1 & $(1.2)$ & 409 & (2.8) & 458 & (3.1) & 50 & $(4.1)$ \\
\hline & Montenegro & 20.1 & $(0.6)$ & 49.5 & $(0.7)$ & 391 & $(2.9)$ & 440 & (1.7) & 49 & (3.5) \\
\hline & Peru & 47.7 & (1.3) & 28.9 & $(1.2)$ & 367 & $(2.0)$ & 441 & (3.8) & 74 & $(4.2)$ \\
\hline & Qatar & 1.9 & $(0.1)$ & 90.5 & $(0.3)$ & 409 & $(8.0)$ & 434 & $(1.2)$ & 25 & $(8.2)$ \\
\hline & Romania & 42.3 & (1.5) & 29.2 & $(1.7)$ & 418 & $(3.0)$ & 475 & $(4.2)$ & 57 & $(4.9)$ \\
\hline & Russia & 12.1 & $(0.8)$ & 64.2 & (1.2) & 458 & (3.9) & 504 & (2.9) & 46 & (4.1) \\
\hline & Singapore & 8.3 & $(0.4)$ & 76.6 & $(0.6)$ & 492 & (4.5) & 575 & (1.5) & 83 & $(4.6)$ \\
\hline & Chinese Taipei & 18.8 & $(0.7)$ & 57.3 & (1.0) & 501 & $(4.0)$ & 558 & (3.2) & 57 & (5.0) \\
\hline & Thailand & 53.8 & (1.3) & 22.8 & $(1.2)$ & 408 & $(2.4)$ & 459 & (5.5) & 52 & (5.8) \\
\hline & Trinidad and Tobago & 13.9 & $(0.6)$ & 56.7 & $(0.9)$ & 392 & $(4.4)$ & 450 & $(2.1)$ & 58 & (5.0) \\
\hline & Tunisia & 44.3 & $(1.2)$ & 34.0 & $(1.2)$ & 375 & (2.4) & 419 & (3.8) & 44 & $(4.3)$ \\
\hline & United Arab Emirates & 2.6 & $(0.2)$ & 88.2 & $(0.4)$ & 417 & (7.4) & 453 & $(2.6)$ & 36 & $(7.2)$ \\
\hline & Uruguay & 32.2 & $(0.8)$ & 36.4 & $(0.9)$ & 407 & (2.5) & 472 & (3.1) & 64 & (3.6) \\
\hline & Viet Nam & 61.0 & (1.6) & 18.7 & (1.1) & 512 & (3.4) & 559 & (7.9) & 47 & (7.3) \\
\hline & Argentina** & 36.6 & (1.5) & 34.7 & (1.4) & 411 & $(3.2)$ & 465 & (3.4) & 54 & $(3.7)$ \\
\hline & Kazakhstan** & 16.5 & $(0.8)$ & 67.3 & (1.1) & 444 & $(4.6)$ & 462 & (4.2) & 18 & (4.4) \\
\hline & Malaysia** & 30.3 & (1.4) & 48.0 & (1.5) & 417 & (3.1) & 467 & (3.6) & 50 & (4.1) \\
\hline
\end{tabular}

1. Workers in white-collar occupations are defined as managers (ISCO-08 category 1), professionals (ISCO-08 category 2), and technicians and associate professionals (ISCO-08 category 3). Workers in blue-collar occupations are defined as skilled agricultural, forestry and fishery workers (ISCO-08 category 6 ), craft and related trades workers (ISCO-08 category 7), plant and machine operators and assemblers (ISCO-08 category 8), and workers in elementary occupations (ISCO-08 category 9),

2. Schools that are directly or indirectly managed by a non-government organisation, such as a church, trade union, business, or other private institution.

3. The index of social segregation at school measures the concentration of students in schools according to their parents' occupation (Jenkins et al., 2006; Hutchens, 2001 and 2004). It has values between 0 and 100, with values closer to 100 indicating that children of blue-collar and white-collar workers are distributed unevenly across schools. The index can be split into two components: a part that is related to differences in the social composition of private and public schools (a "between" component, called "Segregation between public and private schools" in the table), and a part that is explained by differences across schools within the public and the private sector (a "within" component).

Note: Values that are statistically significant are indicated in bold (see Annex A3).

* See note at the beginning of this Annex.

Coverage is too small to ensure comparability (see Annex A4).

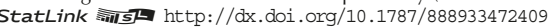


[Part 2/2]

Table III.10.13 Parental occupation, private schools and segregation at school

Results based on students' and school principals' self-reports

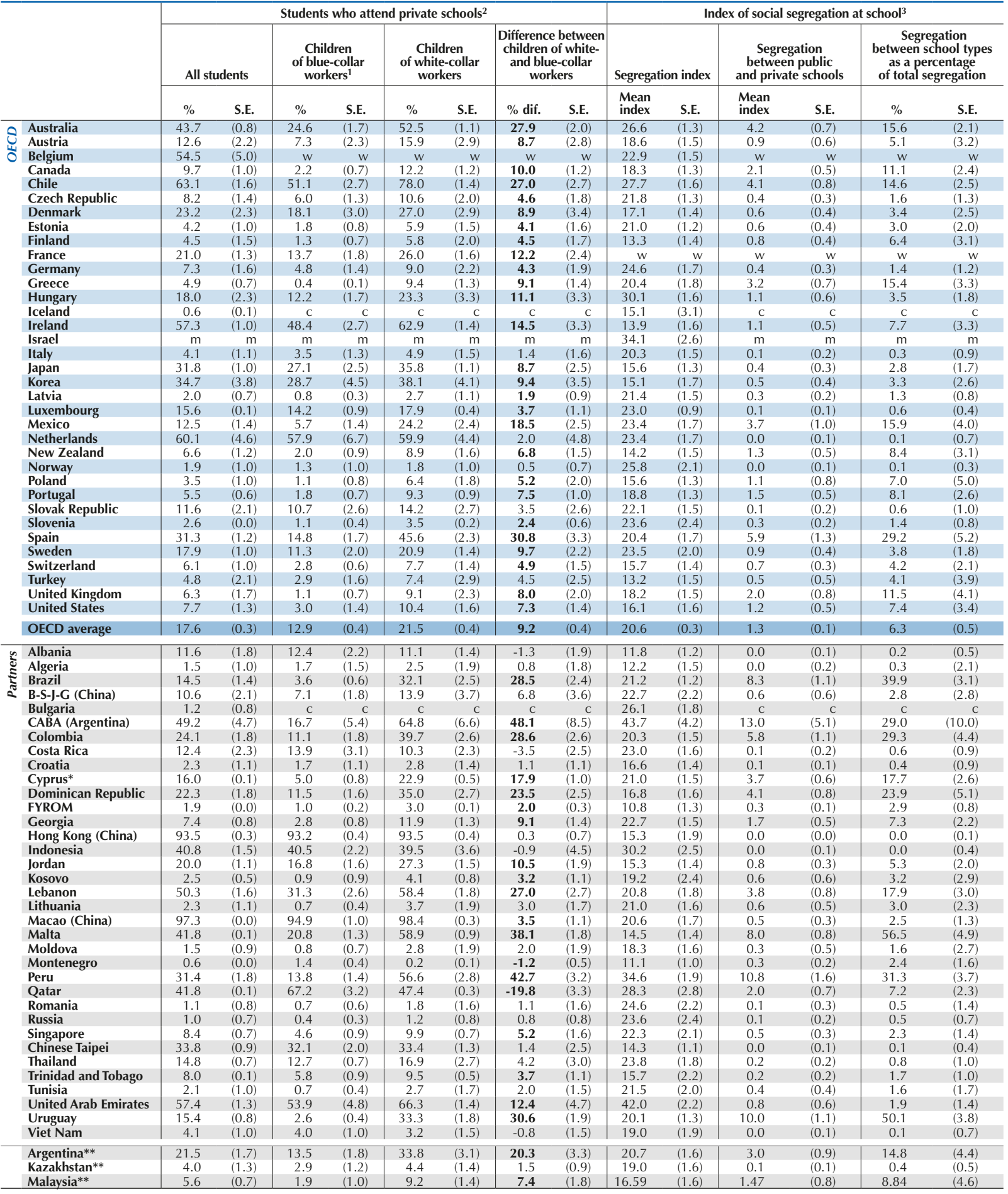

1. Workers in white-collar occupations are defined as managers (ISCO-08 category 1), professionals (ISCO-08 category 2), and technicians and associate professionals (ISCO-08 category 3). Workers in blue-collar occupations are defined as skilled agricultural, forestry and fishery workers (ISCO-08 category 6), craft and related trades workers (ISCO-08 category 7), plant and machine operators and assemblers (ISCO-08 category 8), and workers in elementary occupations (ISCO-08 category 9).

2. Schools that are directly or indirectly managed by a non-government organisation, such as a church, trade union, business, or other private institution.

3. The index of social segregation at school measures the concentration of students in schools according to their parents' occupation (Jenkins et al., 2006; Hutchens, 2001 and 2004). It has values between 0 and 100, with values closer to 100 indicating that children of blue-collar and white-collar workers are distributed unevenly across schools. The index can be split into two components: a part that is related to differences in the social composition of private and public schools (a "between" component, called "Segregation between public and private schools" in the table), and a part that is explained by differences across schools within the public and the private sector (a "within" component).

Note: Values that are statistically significant are indicated in bold (see Annex A3).

* See note at the beginning of this Annex.

Coverage is too small to ensure comparability (see Annex A4).

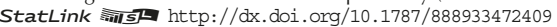




\begin{tabular}{|c|c|c|c|c|c|c|c|c|c|c|c|c|c|c|c|}
\hline & \multicolumn{8}{|c|}{ Students who attend pre-vocational or vocational schools } & \multicolumn{6}{|c|}{ Index of social segregation at school $^{2}$} \\
\hline & & All s & dents & $\begin{array}{r}\mathrm{Cl} \\
\text { of bl } \\
\mathrm{wc}\end{array}$ & $\begin{array}{l}\text { ren } \\
\text { collar } \\
\mathrm{ers}^{1}\end{array}$ & $\begin{array}{r}\mathrm{Cl} \\
\text { of wh} \\
w\end{array}$ & $\begin{array}{l}\text { en } \\
\text { collar } \\
\text { ers }\end{array}$ & $\begin{array}{c}\text { Differen } \\
\text { childre } \\
\text { and b } \\
\text { wC }\end{array}$ & $\begin{array}{l}\text { between } \\
\text { f white- } \\
\text {-collar } \\
\text { ers }\end{array}$ & Segrega & n Index & $\begin{array}{r}\text { Seg } \\
\text { betwe } \\
\text { and voca }\end{array}$ & $\begin{array}{l}\text { ion } \\
\text { ioneral } \\
\text { I schools }\end{array}$ & $\begin{array}{r}\text { Se } \\
\text { betv } \\
\text { tracks } \\
\text { of seg }\end{array}$ & $\begin{array}{l}\text { tion } \\
\text { chool } \\
\text { rcentage } \\
\text { on index }\end{array}$ \\
\hline & & $\%$ & S.E. & $\%$ & S.E. & $\%$ & S.E. & $\%$ dif. & S.E. & $\begin{array}{l}\text { Mean } \\
\text { index }\end{array}$ & S.E. & $\begin{array}{l}\text { Mean } \\
\text { index }\end{array}$ & S.E. & $\%$ & S.E. \\
\hline 0 & Australia & 13.0 & $(0.8)$ & 16.4 & $(1.4)$ & 11.2 & $(0.8)$ & -5.2 & $(1.3)$ & 26.6 & $(1.3)$ & 0.3 & $(0.1)$ & 1.1 & $(0.5)$ \\
\hline & Austria & 71.4 & $(0.9)$ & 85.3 & (1.9) & 62.1 & (1.2) & -23.2 & $(2.3)$ & 18.6 & (1.5) & 3.6 & $(0.8)$ & 19.4 & $(4.1)$ \\
\hline & Belgium & 41.4 & $(1.3)$ & 59.2 & $(2.2)$ & 28.0 & (1.2) & -31.2 & (2.4) & 22.9 & (1.5) & 5.1 & $(0.8)$ & 22.2 & (3.4) \\
\hline & Canada & $a$ & $a$ & $\mathrm{a}$ & $\mathrm{a}$ & $\mathrm{a}$ & $\mathrm{a}$ & a & $\mathrm{a}$ & 18.3 & (1.3) & $\mathrm{a}$ & $\mathrm{a}$ & $\mathrm{a}$ & $\mathrm{a}$ \\
\hline & Chile & 0.6 & $(0.1)$ & 1.1 & $(0.3)$ & 0.3 & $(0.1)$ & -0.9 & $(0.2)$ & 27.7 & (1.6) & 0.1 & $(0.1)$ & 0.5 & $(0.2)$ \\
\hline & Czech Republic & 33.3 & (1.3) & 37.3 & $(2.0)$ & 30.1 & (1.7) & -7.1 & $(2.3)$ & 21.8 & $(1.3)$ & 0.3 & $(0.2)$ & 1.3 & $(0.8)$ \\
\hline & Denmark & $\mathrm{a}$ & $a$ & $\mathrm{a}$ & $a$ & $\mathrm{a}$ & $a$ & $\mathrm{a}$ & $a$ & 17.1 & (1.4) & $\mathrm{a}$ & $\mathrm{a}$ & a & $a$ \\
\hline & Estonia & 0.3 & $(0.1)$ & 0.4 & $(0.3)$ & 0.1 & $(0.1)$ & -0.3 & $(0.3)$ & 21.0 & $(1.2)$ & 0.1 & $(0.1)$ & 0.2 & $(0.4)$ \\
\hline & Finland & $\mathrm{a}$ & $a$ & $a$ & $a$ & $\mathrm{a}$ & $a$ & a & $a$ & 13.3 & (1.4) & $\mathrm{a}$ & $\mathrm{a}$ & a & $a$ \\
\hline & France & 18.7 & $(0.9)$ & 29.8 & $(2.0)$ & 9.4 & $(0.7)$ & -20.4 & $(2.2)$ & w & w & w & w & w & w \\
\hline & Germany & 2.7 & $(0.7)$ & 3.8 & (1.8) & 1.6 & $(0.5)$ & -2.2 & (1.7) & 24.6 & (1.7) & 0.2 & $(0.3)$ & 1.0 & $(1.2)$ \\
\hline & Greece & 16.4 & (2.6) & 28.3 & $(4.5)$ & 7.8 & (1.3) & -20.5 & (3.6) & 20.4 & (1.8) & 3.8 & (1.0) & 18.7 & $(4.3)$ \\
\hline & Hungary & 15.9 & $(0.6)$ & 29.9 & (1.8) & 5.4 & $(0.6)$ & -24.5 & (1.8) & 30.1 & (1.6) & 5.9 & $(0.7)$ & 19.5 & $(2.5)$ \\
\hline & Iceland & $\mathrm{a}$ & $\mathrm{a}$ & $\mathrm{a}$ & $\mathrm{a}$ & a & $\mathrm{a}$ & $\mathrm{a}$ & $\mathrm{a}$ & 15.1 & (3.1) & $\mathrm{a}$ & $\mathrm{a}$ & a & $\mathrm{a}$ \\
\hline & Ireland & 0.8 & $(0.2)$ & 1.6 & $(0.8)$ & 0.4 & $(0.1)$ & -1.2 & $(0.8)$ & 13.9 & (1.6) & 0.2 & $(0.2)$ & 1.5 & (1.3) \\
\hline & Israel & $\mathrm{a}$ & $a$ & $\mathrm{a}$ & $a$ & $\mathrm{a}$ & a & a & $a$ & 34.1 & (2.6) & $\mathrm{a}$ & $\mathrm{a}$ & $\mathrm{a}$ & $\mathrm{a}$ \\
\hline & Italy & 49.7 & $(1.2)$ & 68.5 & (1.8) & 33.7 & (1.6) & -34.9 & $(2.0)$ & 20.3 & $(1.5)$ & 6.3 & $(0.7)$ & 31.0 & $(2.6)$ \\
\hline & Japan & 24.4 & $(0.9)$ & 34.2 & (2.5) & 17.9 & $(0.7)$ & -16.3 & (2.6) & 15.6 & (1.3) & 1.8 & $(0.5)$ & 11.2 & (3.1) \\
\hline & Korea & 16.1 & $(0.4)$ & 23.8 & $(2.0)$ & 11.3 & (1.0) & -12.5 & (2.6) & 15.1 & (1.7) & 1.4 & $(0.6)$ & 9.2 & (3.5) \\
\hline & Latvia & 0.8 & $(0.4)$ & 0.9 & $(0.8)$ & 1.0 & $(0.5)$ & 0.1 & $(0.8)$ & 21.4 & (1.5) & 0.0 & $(0.1)$ & 0.0 & $(0.3)$ \\
\hline & Luxembourg & 15.0 & $(0.1)$ & 17.9 & $(0.9)$ & 12.5 & $(0.5)$ & -5.4 & $(1.2)$ & 23.0 & $(0.9)$ & 0.3 & $(0.1)$ & 1.2 & $(0.5)$ \\
\hline & Mexico & 25.3 & (1.1) & 24.4 & (1.6) & 24.4 & (1.6) & 0.0 & $(2.2)$ & 23.4 & (1.7) & 0.0 & $(0.0)$ & 0.0 & $(0.1)$ \\
\hline & Netherlands & 26.1 & $(0.9)$ & 48.5 & $(2.8)$ & 16.1 & $(0.9)$ & -32.4 & $(2.8)$ & 23.4 & (1.7) & 6.3 & (1.0) & 27.0 & $(3.7)$ \\
\hline & New Zealand & $\mathrm{a}$ & $\mathrm{a}$ & $\mathrm{a}$ & a & $\mathrm{a}$ & $\mathrm{a}$ & $\mathrm{a}$ & $a$ & 14.2 & (1.5) & $\mathrm{a}$ & $\mathrm{a}$ & a & $\mathrm{a}$ \\
\hline & Norway & $\mathrm{a}$ & $\mathrm{a}$ & $\mathrm{a}$ & a & $\mathrm{a}$ & $\mathrm{a}$ & $\mathrm{a}$ & a & 25.8 & (2.1) & $\mathrm{a}$ & $\mathrm{a}$ & $\mathrm{a}$ & a \\
\hline & Poland & 0.1 & $(0.1)$ & 0.1 & $(0.1)$ & 0.1 & $(0.1)$ & 0.0 & $(0.2)$ & 15.6 & $(1.3)$ & 0.0 & $(0.0)$ & 0.0 & $(0.1)$ \\
\hline & Portugal & 13.1 & (1.1) & 21.2 & (1.4) & 7.4 & (1.3) & -13.7 & (1.4) & 18.8 & (1.3) & 2.0 & $(0.4)$ & 10.8 & $(2.3)$ \\
\hline & Slovak Republic & 5.7 & $(0.7)$ & 9.0 & $(1.2)$ & 2.5 & $(0.4)$ & -6.4 & (1.1) & 22.1 & (1.5) & 1.0 & $(0.3)$ & 4.7 & (1.1) \\
\hline & Slovenia & 57.4 & $(0.2)$ & 79.1 & (1.8) & 44.0 & $(0.7)$ & -35.1 & $(2.2)$ & 23.6 & (2.4) & 6.8 & $(0.9)$ & 28.9 & $(4.0)$ \\
\hline & Spain & 0.9 & $(0.1)$ & 1.8 & $(0.4)$ & 0.3 & $(0.1)$ & -1.4 & $(0.4)$ & 20.4 & (1.7) & 0.3 & $(0.1)$ & 1.4 & $(0.6)$ \\
\hline & Sweden & 0.1 & $(0.1)$ & c & c & 0.2 & $(0.2)$ & 0.2 & $(0.2)$ & 23.5 & $(2.0)$ & 0.1 & $(0.1)$ & 0.5 & $(0.3)$ \\
\hline & Switzerland & 9.2 & (1.1) & 10.4 & $(2.4)$ & 8.7 & (1.0) & -1.7 & $(2.1)$ & 15.7 & (1.4) & 0.0 & $(0.1)$ & 0.3 & $(0.6)$ \\
\hline & Turkey & 41.0 & (1.9) & 43.8 & (2.5) & 28.9 & (2.8) & -14.9 & (3.2) & 13.2 & (1.5) & 1.2 & $(0.5)$ & 9.2 & (3.8) \\
\hline & United Kingdom & 0.8 & $(0.2)$ & 0.9 & $(0.3)$ & 0.7 & $(0.3)$ & -0.1 & $(0.3)$ & 18.2 & (1.5) & 0.0 & $(0.0)$ & 0.0 & $(0.1)$ \\
\hline & United States & $\mathrm{a}$ & a & a & a & a & a & a & a & 16.1 & (1.6) & a & a & a & a \\
\hline & OECD average & 18.5 & $(0.2)$ & 26.1 & $(0.4)$ & 13.6 & $(0.2)$ & -11.5 & $(0.4)$ & 20.6 & $(0.3)$ & 1.9 & $(0.1)$ & 8.7 & $(0.4)$ \\
\hline 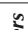 & Albania & 6.4 & (1.5) & 6.9 & (1.6) & 5.7 & (1.5) & -1.2 & $(0.9)$ & 11.8 & $(1.2)$ & 0.0 & $(0.0)$ & 0.2 & $(0.4)$ \\
\hline 5 & Algeria & 0.6 & $(0.6)$ & 1.2 & (1.2) & 0.1 & $(0.2)$ & -1.1 & $(1.2)$ & 12.2 & (1.5) & 0.3 & $(0.3)$ & 2.2 & $(2.8)$ \\
\hline ปั & Brazil & 4.7 & $(1.0)$ & 4.2 & $(0.9)$ & 6.3 & (1.4) & 2.2 & $(0.8)$ & 21.2 & (1.2) & 0.1 & $(0.1)$ & 0.6 & $(0.4)$ \\
\hline & B-S-J-G (China) & 6.2 & (1.1) & 5.2 & $(1.2)$ & 6.7 & $(0.9)$ & 1.5 & $(1.0)$ & 22.7 & $(2.2)$ & 0.0 & $(0.1)$ & 0.2 & $(0.3)$ \\
\hline & Bulgaria & 46.2 & $(2.0)$ & 59.4 & $(2.8)$ & 33.0 & (2.8) & -26.4 & (3.8) & 26.1 & (1.8) & 3.6 & (1.0) & 13.6 & $(4.0)$ \\
\hline & CABA (Argentina) & 13.0 & (4.3) & 19.2 & $(7.7)$ & 9.0 & (3.2) & -10.2 & (5.9) & 43.7 & $(4.2)$ & 1.1 & (1.0) & 2.5 & $(2.3)$ \\
\hline & Colombia & 20.8 & (1.6) & 21.0 & $(2.2)$ & 19.3 & $(1.7)$ & -1.7 & $(2.0)$ & 20.3 & (1.5) & 0.0 & $(0.1)$ & 0.1 & $(0.3)$ \\
\hline & Costa Rica & 12.3 & (1.4) & 11.1 & (1.8) & 12.6 & (1.6) & 1.5 & (1.8) & 23.0 & (1.6) & 0.0 & $(0.1)$ & 0.1 & $(0.4)$ \\
\hline & Croatia & 67.3 & $(0.8)$ & 85.0 & (1.5) & 49.7 & $(1.2)$ & -35.3 & (1.9) & 16.6 & (1.4) & 7.5 & $(0.9)$ & 45.3 & $(4.7)$ \\
\hline & Cyprus* & 11.9 & $(0.1)$ & 24.1 & $(1.2)$ & 5.2 & $(0.4)$ & -18.9 & (1.4) & 21.0 & (1.5) & 4.0 & $(0.5)$ & 19.0 & $(2.4)$ \\
\hline & Dominican Republic & 4.8 & $(0.5)$ & 2.4 & $(0.5)$ & 8.0 & (1.1) & 5.6 & (1.1) & 16.8 & (1.6) & 0.9 & $(0.3)$ & 5.1 & (1.7) \\
\hline & FYROM & 55.1 & $(0.3)$ & 63.7 & $(1.2)$ & 45.7 & $(0.8)$ & -18.0 & $(1.7)$ & 10.8 & (1.3) & 1.7 & $(0.3)$ & 15.2 & $(2.9)$ \\
\hline & Georgia & 1.7 & $(0.8)$ & 3.2 & (1.5) & 0.7 & $(0.4)$ & -2.4 & (1.1) & 22.7 & (1.5) & 0.4 & $(0.2)$ & 1.9 & $(0.9)$ \\
\hline & Hong Kong (China) & $\mathrm{a}$ & $\mathrm{a}$ & $\mathrm{a}$ & $a$ & $\mathrm{a}$ & $\mathrm{a}$ & $\mathrm{a}$ & $\mathrm{a}$ & 15.3 & (1.9) & $\mathrm{a}$ & a & $\mathrm{a}$ & $\mathrm{a}$ \\
\hline & Indonesia & 16.0 & (1.3) & 16.3 & (1.9) & 12.8 & $(2.0)$ & -3.5 & $(2.7)$ & 30.2 & (2.5) & 0.1 & $(0.2)$ & 0.4 & $(0.6)$ \\
\hline & Jordan & $\mathrm{a}$ & $\mathrm{a}$ & $\mathrm{a}$ & $\mathrm{a}$ & $\mathrm{a}$ & $\mathrm{a}$ & a & $a$ & 15.3 & (1.4) & $\mathrm{a}$ & $\mathrm{a}$ & $\mathrm{a}$ & $\mathrm{a}$ \\
\hline & Kosovo & 35.3 & $(0.7)$ & 46.3 & (3.2) & 32.2 & $(1.0)$ & -14.1 & (3.3) & 19.2 & (2.4) & 1.0 & $(0.5)$ & 5.5 & $(2.2)$ \\
\hline & Lebanon & $\mathrm{a}$ & $a$ & $\mathrm{a}$ & $\mathrm{a}$ & $\mathrm{a}$ & $\mathrm{a}$ & a & $\mathrm{a}$ & 20.8 & (1.8) & $\mathrm{a}$ & $\mathrm{a}$ & $\mathrm{a}$ & $\mathrm{a}$ \\
\hline & Lithuania & 1.5 & $(0.6)$ & 2.3 & $(0.7)$ & 0.8 & $(0.4)$ & -1.5 & $(0.4)$ & 21.0 & (1.6) & 0.2 & $(0.1)$ & 0.9 & $(0.3)$ \\
\hline & Macao (China) & 1.2 & $(0.1)$ & 1.2 & $(0.6)$ & 0.7 & $(0.2)$ & -0.5 & $(0.7)$ & 20.6 & (1.7) & 0.0 & $(0.1)$ & 0.2 & $(0.5)$ \\
\hline & Malta & $a$ & $\mathrm{a}$ & a & a & a & $\mathrm{a}$ & a & a & 14.5 & (1.4) & $\mathrm{a}$ & $\mathrm{a}$ & $\mathrm{a}$ & a \\
\hline & Moldova & $\mathrm{a}$ & a & a & a & $\mathrm{a}$ & $\mathrm{a}$ & a & a & 18.3 & (1.6) & $\mathrm{a}$ & a & a & a \\
\hline & Montenegro & 66.0 & $(0.3)$ & 78.7 & (1.1) & 53.5 & $(0.7)$ & -25.3 & (1.4) & 11.1 & $(1.0)$ & 3.7 & $(0.4)$ & 33.0 & (3.9) \\
\hline & Peru & $\mathrm{a}$ & a & $\mathrm{a}$ & $\mathrm{a}$ & $\mathrm{a}$ & $\mathrm{a}$ & a & $\mathrm{a}$ & 34.6 & (1.9) & $\mathrm{a}$ & a & $\mathrm{a}$ & $\mathrm{a}$ \\
\hline & Qatar & a & a & a & a & $\mathrm{a}$ & a & a & a & 28.3 & (2.8) & $\mathrm{a}$ & $\mathrm{a}$ & $\mathrm{a}$ & $\mathrm{a}$ \\
\hline & Romania & $\mathrm{a}$ & a & $\mathrm{a}$ & $\mathrm{a}$ & $\mathrm{a}$ & a & a & $\mathrm{a}$ & 24.6 & $(2.2)$ & $\mathrm{a}$ & $\mathrm{a}$ & a & a \\
\hline & Russia & 4.5 & (1.5) & 9.4 & (3.4) & 3.5 & (1.3) & -5.8 & $(2.5)$ & 23.6 & (2.4) & 0.7 & $(0.5)$ & 3.1 & (2.0) \\
\hline & Singapore & $\mathrm{a}$ & $\mathrm{a}$ & $\mathrm{a}$ & $a$ & a & a & a & $\mathrm{a}$ & 22.3 & $(2.1)$ & $\mathrm{a}$ & $\mathrm{a}$ & $\mathrm{a}$ & $\mathrm{a}$ \\
\hline & Chinese Taipei & 36.3 & (1.3) & 44.6 & $(2.2)$ & 29.4 & (1.4) & -15.2 & (2.4) & 14.3 & (1.1) & 1.2 & $(0.4)$ & 8.7 & (2.6) \\
\hline & Thailand & 17.7 & $(0.8)$ & 19.2 & $(1.2)$ & 12.9 & (1.6) & -6.3 & $(2.2)$ & 23.8 & (1.8) & 0.4 & $(0.3)$ & 1.6 & $(1.1)$ \\
\hline & Trinidad and Tobago & $\mathrm{a}$ & $a$ & $\mathrm{a}$ & $\mathrm{a}$ & $\mathrm{a}$ & a & $\mathrm{a}$ & $\mathrm{a}$ & 15.7 & $(2.2)$ & $\mathrm{a}$ & $\mathrm{a}$ & $\mathrm{a}$ & $\mathrm{a}$ \\
\hline & Tunisia & $\mathrm{a}$ & $\mathrm{a}$ & $\mathrm{a}$ & $\mathrm{a}$ & $\mathrm{a}$ & $\mathrm{a}$ & $\mathrm{a}$ & $\mathrm{a}$ & 21.5 & $(2.0)$ & $\mathrm{a}$ & $\mathrm{a}$ & $\mathrm{a}$ & $\mathrm{a}$ \\
\hline & United Arab Emirates & 3.9 & $(0.4)$ & 1.9 & (2.5) & 3.5 & $(0.4)$ & 1.6 & $(2.2)$ & 42.0 & $(2.2)$ & 0.1 & $(0.6)$ & 0.3 & (1.5) \\
\hline & Uruguay & 1.7 & $(0.3)$ & 2.3 & $(0.5)$ & 1.3 & $(0.3)$ & -0.9 & $(0.5)$ & 20.1 & (1.3) & 0.1 & $(0.1)$ & 0.3 & $(0.3)$ \\
\hline & Viet Nam & a & $a$ & a & a & a & a & a & a & 19.0 & (1.9) & $a$ & a & a & a \\
\hline & Argentina** & 16.6 & $(2.6)$ & 18.1 & $(3.1)$ & 14.2 & (2.4) & -3.8 & $(2.4)$ & 20.7 & $(1.6)$ & 0.1 & $(0.2)$ & 0.7 & $(0.8)$ \\
\hline & Kazakhstan** & 14.0 & $(2.1)$ & 13.0 & $(2.5)$ & 14.5 & $(2.2)$ & 1.6 & $(2.2)$ & 19.0 & (1.6) & 0.0 & $(0.1)$ & 0.1 & $(0.5)$ \\
\hline & Malaysia** & 10.5 & $(1.2)$ & 11.7 & (1.6) & 8.2 & (1.1) & -3.5 & (1.4) & 16.6 & (1.6) & 0.2 & $(0.1)$ & 1.0 & $(0.7)$ \\
\hline
\end{tabular}

1. Workers in white-collar occupations are defined as managers (ISCO-08 category 1), professionals (ISCO-08 category 2), and technicians and associate professionals (ISCO-08 category 3). Workers in blue-collar occupations are defined as skilled agricultural, forestry and fishery workers (ISCO-08 category 6), craft and related trades workers (ISCO-08 category 7), plant and machine operators and assemblers (ISCO-08 category 8), and workers in elementary occupations (ISCO-08 category 9 ).

2. The index of social segregation at school measures the concentration of students in schools according to their parents' occupation (Jenkins et al., 2006; Hutchens, 2001 and 2004). It has values between 0 and 100, with values closer to 100 indicating that children of blue-collar and white-collar workers are distributed unevenly across schools. The index can be split into two components: a part that is related to differences in the social composition of general and vocational schools (a "between" component, called «Segregation between general and vocational schools» in the table), and a part that is explained by differences across schools within the two different tracks (a "within" component).

Note: Values that are statistically significant are indicated in bold (see Annex A3).

* See note at the beginning of this Annex.

Coverage is too small to ensure comparability (see Annex A4).

StatLink त्नाइ http://dx.doi.org/10.1787/888933472410 
[Part 1/2]

Table III.10.15 Students' expectations and parental occupation

Results based on students' and school principals' self-reports

\begin{tabular}{|c|c|c|c|c|c|c|c|c|c|c|c|c|c|}
\hline & \multicolumn{6}{|c|}{ Students who expect to work in a high-status occupation ${ }^{1}$ by the age of 30} & \multicolumn{6}{|c|}{ Students who expect to complete tertiary education } \\
\hline & & \multicolumn{2}{|c|}{\begin{tabular}{|c|} 
Children \\
of blue-collar workers
\end{tabular}} & of white & en workers & $\begin{array}{c}\text { Differer } \\
\text { children } \\
\text { blue-co }\end{array}$ & $\begin{array}{l}\text { etween } \\
\text { hite- and } \\
\text { vorkers }\end{array}$ & of blue- & $\begin{array}{l}\text { en } \\
\text { workers }\end{array}$ & of white- & r workers & $\begin{array}{c}\text { Differen } \\
\text { children } \\
\text { blue-co }\end{array}$ & $\begin{array}{l}\text { etween } \\
\text { hite- and } \\
\text { Norkers }\end{array}$ \\
\hline & & $\%$ & S.E. & $\%$ & S.E. & $\%$ dif. & S.E. & $\%$ & S.E. & $\%$ & S.E. & $\%$ dif. & S.E. \\
\hline 0 & Australia & 51.5 & $(1.5)$ & 68.8 & $(0.7)$ & 17.3 & (1.6) & 37.4 & (1.5) & 63.1 & $(0.7)$ & 25.7 & (1.6) \\
\hline & Austria & 39.3 & $(2.1)$ & 65.1 & $(1.2)$ & 25.8 & $(2.2)$ & 12.3 & $(1.2)$ & 38.1 & $(1.2)$ & 25.8 & (1.8) \\
\hline ప & Belgium & 44.7 & (3.2) & 69.6 & (1.7) & 24.9 & (3.2) & 19.9 & (1.7) & 42.7 & (1.1) & 22.8 & (2.0) \\
\hline & Canada & 58.7 & $(1.8)$ & 76.5 & $(0.7)$ & 17.8 & $(2.0)$ & 44.0 & (1.8) & 71.4 & $(0.8)$ & 27.4 & (1.9) \\
\hline & Chile & 64.9 & (1.7) & 80.3 & (1.1) & 15.4 & (2.0) & 53.7 & (1.6) & 80.9 & (1.0) & 27.2 & (1.7) \\
\hline & Czech Republic & 29.1 & $(2.2)$ & 58.0 & (1.6) & 28.9 & $(2.3)$ & 35.1 & (1.8) & 71.4 & (1.0) & 36.3 & (1.9) \\
\hline & Denmark & 48.2 & $(2.7)$ & 70.2 & (1.3) & 21.9 & (2.8) & 25.4 & (1.9) & 45.8 & $(1.2)$ & 20.4 & (2.1) \\
\hline & Estonia & 50.1 & $(2.1)$ & 72.5 & $(1.0)$ & 22.5 & $(2.3)$ & 22.2 & (1.6) & 55.0 & $(1.0)$ & 32.8 & (1.9) \\
\hline & Finland & 27.7 & $(2.2)$ & 56.9 & $(1.2)$ & 29.2 & $(2.3)$ & 12.2 & (1.4) & 36.3 & $(1.3)$ & 24.1 & $(1.7)$ \\
\hline & France & 36.2 & $(2.1)$ & 63.4 & $(1.2)$ & 27.3 & (2.4) & 16.4 & (1.3) & 44.1 & $(1.2)$ & 27.8 & (1.8) \\
\hline & Germany & 26.2 & (1.9) & 55.4 & $(1.2)$ & 29.2 & (2.1) & 8.0 & $(1.2)$ & 25.2 & $(1.2)$ & 17.2 & (1.4) \\
\hline & Greece & 51.7 & $(2.2)$ & 73.3 & (1.1) & 21.6 & $(2.3)$ & 48.8 & (2.9) & 80.8 & (1.3) & 32.0 & (2.6) \\
\hline & Hungary & 28.1 & $(1.4)$ & 62.1 & (1.4) & 34.0 & $(1.9)$ & 13.9 & $(1.3)$ & 53.3 & $(1.4)$ & 39.5 & $(1.6)$ \\
\hline & Iceland' & 53.7 & (3.4) & 66.1 & (1.1) & 12.5 & (3.6) & 24.3 & (2.8) & 43.1 & (1.0) & 18.8 & (3.1) \\
\hline & Ireland & 57.6 & $(2.2)$ & 74.8 & (1.0) & 17.2 & (2.5) & 31.1 & (1.7) & 55.2 & (0.9) & 24.2 & (1.9) \\
\hline & Israel & 72.6 & $(2.3)$ & 77.0 & $(0.9)$ & 4.4 & (2.4) & 37.5 & $(2.2)$ & 65.2 & (1.1) & 27.7 & $(2.1)$ \\
\hline & Italy & 43.6 & (1.9) & 67.8 & $(1.1)$ & 24.2 & $(2.0)$ & 23.7 & (1.6) & 50.7 & (1.4) & 27.0 & (1.8) \\
\hline & Japan & 37.6 & $(2.2)$ & 52.5 & $(1.2)$ & 15.0 & $(2.5)$ & 40.5 & $(2.2)$ & 68.9 & $(1.2)$ & 28.5 & $(2.3)$ \\
\hline & Korea & 53.4 & $(2.0)$ & 64.6 & (1.3) & 11.3 & (2.3) & 62.4 & (2.3) & 82.2 & (1.0) & 19.8 & $(2.4)$ \\
\hline & Latvia & 44.9 & $(2.1)$ & 68.5 & (1.1) & 23.6 & $(2.3)$ & 11.5 & $(1.2)$ & 34.0 & $(1.2)$ & 22.5 & (1.6) \\
\hline & Luxembourg & 37.9 & (1.6) & 70.5 & (1.0) & 32.7 & (1.9) & 23.0 & $(1.2)$ & 57.6 & $(0.9)$ & 34.6 & (1.5) \\
\hline & Mexico & 77.1 & (1.0) & 84.8 & $(1.0)$ & 7.7 & (1.4) & 49.4 & (1.3) & 70.6 & $(1.2)$ & 21.2 & (1.5) \\
\hline & Netherlands & 36.1 & $(2.3)$ & 58.0 & $(1.2)$ & 21.9 & (2.4) & 6.4 & $(1.1)$ & 22.8 & $(0.9)$ & 16.4 & (1.5) \\
\hline & New Zealand & 55.1 & $(2.8)$ & 70.8 & $(0.9)$ & 15.7 & (2.9) & 30.5 & $(2.0)$ & 52.0 & (1.1) & 21.5 & (2.4) \\
\hline & Norway & 41.8 & (3.2) & 61.9 & $(1.1)$ & 20.2 & (3.2) & 15.9 & $(2.3)$ & 27.1 & $(0.7)$ & 11.3 & $(2.4)$ \\
\hline & Poland & 31.8 & (1.6) & 60.2 & (1.4) & 28.5 & (1.9) & 31.0 & (1.6) & 66.0 & (1.3) & 35.0 & (1.8) \\
\hline & Portugal & 54.0 & (1.7) & 77.9 & $(1.0)$ & 23.8 & (1.7) & 22.4 & $(1.2)$ & 55.1 & (1.3) & 32.8 & (1.6) \\
\hline & Slovak Republic & 36.1 & (1.9) & 64.9 & (1.3) & 28.8 & (2.0) & $\mathrm{m}$ & $\mathrm{m}$ & $\mathrm{m}$ & $\mathrm{m}$ & $\mathrm{m}$ & $\mathrm{m}$ \\
\hline & Slovenia & 33.5 & (1.9) & 63.9 & $(0.9)$ & 30.4 & (2.2) & 10.9 & (1.1) & 34.8 & $(1.0)$ & 23.8 & $(1.6)$ \\
\hline & Spain & 59.1 & (1.4) & 78.9 & $(0.8)$ & 19.8 & (1.4) & 33.4 & (1.1) & 67.1 & (1.0) & 33.7 & (1.4) \\
\hline & Sweden & 39.9 & (3.1) & 57.5 & (1.1) & 17.7 & (3.2) & 20.2 & (1.8) & 45.7 & $(1.2)$ & 25.5 & (2.1) \\
\hline & Switzerland & 29.5 & $(2.3)$ & 56.8 & (1.5) & 27.4 & $(2.5)$ & 12.9 & $(1.2)$ & 36.5 & (1.4) & 23.6 & (1.6) \\
\hline & Turkey & 66.7 & $(1.3)$ & 76.7 & (1.9) & 10.0 & (1.9) & 66.8 & (1.4) & 82.3 & (1.7) & 15.4 & $(2.2)$ \\
\hline & United Kingdom & 60.7 & (2.3) & 77.1 & $(0.9)$ & 16.5 & $(2.2)$ & 27.0 & (1.7) & 49.5 & (1.1) & 22.5 & (2.0) \\
\hline & United States & 64.9 & (1.8) & 74.7 & (1.0) & 9.8 & (2.1) & 62.8 & (1.4) & 83.4 & $(0.8)$ & 20.7 & $(1.6)$ \\
\hline & OECD average & 47.0 & $(0.4)$ & 68.0 & $(0.2)$ & 21.0 & $(0.4)$ & 29.2 & $(0.3)$ & 54.7 & $(0.2)$ & 25.5 & $(0.3)$ \\
\hline$n$ & Albania & 67.9 & (1.5) & 83.5 & $(1.3)$ & 15.6 & $(2.0)$ & $\mathrm{m}$ & $\mathrm{m}$ & $\mathrm{m}$ & $\mathrm{m}$ & $\mathrm{m}$ & $\mathrm{m}$ \\
\hline ఏ & Algeria & 63.4 & $(2.0)$ & 68.7 & (1.5) & 5.2 & (2.4) & $\mathrm{m}$ & $\mathrm{m}$ & $\mathrm{m}$ & $\mathrm{m}$ & $\mathrm{m}$ & $\mathrm{m}$ \\
\hline $\mathbf{s}$ & Brazil & 74.3 & $(0.9)$ & 82.6 & $(0.9)$ & 8.3 & (1.1) & 37.6 & $(1.0)$ & 59.9 & $(1.0)$ & 22.3 & $(1.3)$ \\
\hline ฮ & B-S-J-G (China) & 61.6 & (1.6) & 70.0 & $(1.2)$ & 8.3 & (2.0) & 26.0 & $(1.7)$ & 58.6 & $(2.3)$ & 32.6 & (2.5) \\
\hline & Bulgaria & 47.0 & $(2.4)$ & 76.5 & (1.1) & 29.5 & (2.6) & 24.4 & (1.5) & 52.8 & $(1.2)$ & 28.4 & (1.9) \\
\hline & CABA (Argentina) & 76.2 & (3.7) & 87.0 & $(1.3)$ & 10.8 & (3.8) & $\mathrm{m}$ & $\mathrm{m}$ & $\mathrm{m}$ & $\mathrm{m}$ & $\mathrm{m}$ & $\mathrm{m}$ \\
\hline & Colombia & 72.8 & $(1.0)$ & 81.4 & (1.0) & 8.6 & (1.4) & 68.5 & $(1.3)$ & 85.2 & (1.0) & 16.7 & $(1.5)$ \\
\hline & Costa Rica & 72.2 & (1.8) & 79.7 & $(0.9)$ & 7.5 & (2.0) & 50.2 & $(2.1)$ & 57.6 & (1.6) & 7.4 & $(2.7)$ \\
\hline & Croatia & 32.6 & (1.9) & 64.6 & $(1.2)$ & 32.0 & $(2.1)$ & 19.9 & (1.4) & 50.9 & (1.3) & 31.0 & (1.8) \\
\hline & Cyprus* & 54.9 & $(1.7)$ & 73.9 & $(0.8)$ & 19.0 & $(2.0)$ & 60.5 & (1.6) & 87.4 & $(0.6)$ & 27.0 & $(1.8)$ \\
\hline & Dominican Republic & 80.5 & $(1.3)$ & 82.7 & $(1.0)$ & 2.3 & (1.6) & 61.3 & (1.8) & 68.1 & (1.5) & 6.9 & $(2.1)$ \\
\hline & FYROM & 55.3 & (1.5) & 73.3 & $(1.2)$ & 18.0 & (2.0) & $\mathrm{m}$ & $\mathrm{m}$ & $\mathrm{m}$ & $\mathrm{m}$ & $\mathrm{m}$ & $\mathrm{m}$ \\
\hline & Georgia & 66.4 & $(2.3)$ & 80.4 & $(1.1)$ & 14.1 & $(2.3)$ & $\mathrm{m}$ & $\mathrm{m}$ & $\mathrm{m}$ & $\mathrm{m}$ & $\mathrm{m}$ & $\mathrm{m}$ \\
\hline & Hong Kong (China) & 67.7 & (1.6) & 77.4 & (1.3) & 9.7 & $(2.0)$ & 43.3 & (1.9) & 64.9 & $(1.3)$ & 21.6 & $(2.1)$ \\
\hline & Indonesia & 59.5 & (1.6) & 66.9 & $(2.0)$ & 7.3 & $(2.4)$ & $\mathrm{m}$ & $\mathrm{m}$ & $\mathrm{m}$ & $\mathrm{m}$ & $\mathrm{m}$ & $\mathrm{m}$ \\
\hline & Jordan & 61.3 & $(2.0)$ & 76.2 & $(1.0)$ & 14.9 & $(2.1)$ & $\mathrm{m}$ & $\mathrm{m}$ & $\mathrm{m}$ & $\mathrm{m}$ & $\mathrm{m}$ & $\mathrm{m}$ \\
\hline & Kosovo & 65.2 & $(2.8)$ & 76.7 & (1.0) & 11.5 & (3.0) & $\mathrm{m}$ & $\mathrm{m}$ & $\mathrm{m}$ & $\mathrm{m}$ & $\mathrm{m}$ & $\mathrm{m}$ \\
\hline & Lebanon & 79.6 & $(2.4)$ & 83.0 & $(1.1)$ & 3.4 & $(2.7)$ & $\mathrm{m}$ & $\mathrm{m}$ & $\mathrm{m}$ & $\mathrm{m}$ & $\mathrm{m}$ & $\mathrm{m}$ \\
\hline & Lithuania & 44.8 & $(1.8)$ & 74.3 & $(0.9)$ & 29.5 & (1.9) & 31.8 & $(1.6)$ & 71.3 & $(1.5)$ & 39.4 & (1.9) \\
\hline & Macao (China) & 54.3 & $(2.3)$ & 63.0 & (1.1) & 8.7 & (2.3) & 41.5 & (2.4) & 53.5 & $(1.2)$ & 12.0 & (2.7) \\
\hline & Malta & 52.6 & $(2.0)$ & 74.8 & $(0.9)$ & 22.3 & $(2.2)$ & $\mathrm{m}$ & $\mathrm{m}$ & $\mathrm{m}$ & $\mathrm{m}$ & $\mathrm{m}$ & $\mathrm{m}$ \\
\hline & Moldova & 42.6 & (1.4) & 69.9 & $(1.2)$ & 27.3 & $(1.8)$ & $\mathrm{m}$ & $\mathrm{m}$ & $\mathrm{m}$ & $\mathrm{m}$ & $\mathrm{m}$ & $\mathrm{m}$ \\
\hline & Montenegro & 50.1 & (1.6) & 69.3 & $(0.9)$ & 19.2 & (1.9) & 52.1 & (1.9) & 78.0 & $(0.9)$ & 25.9 & $(2.2)$ \\
\hline & Peru & 69.8 & $(1.0)$ & 86.9 & $(0.9)$ & 17.1 & $(1.2)$ & 55.2 & (1.0) & 78.6 & (1.1) & 23.3 & (1.3) \\
\hline & Qatar & 72.6 & (3.6) & 75.2 & $(0.5)$ & 2.6 & (3.6) & 69.9 & (3.4) & 80.0 & $(0.5)$ & 10.1 & (3.4) \\
\hline & Romania & 47.5 & $(2.0)$ & 78.7 & (1.4) & 31.2 & (2.4) & $\mathrm{m}$ & $\mathrm{m}$ & $\mathrm{m}$ & $\mathrm{m}$ & $\mathrm{m}$ & $\mathrm{m}$ \\
\hline & Russia & 53.9 & (3.2) & 75.3 & (1.0) & 21.4 & (3.1) & 8.3 & $(1.3)$ & 21.4 & $(0.9)$ & 13.1 & (1.4) \\
\hline & Singapore & 72.7 & $(2.1)$ & 84.2 & $(0.7)$ & 11.5 & $(2.1)$ & 34.1 & (1.8) & 70.4 & $(0.7)$ & 36.3 & (1.9) \\
\hline & Chinese Taipei & 44.3 & (1.6) & 64.4 & (1.0) & 20.1 & (1.8) & 29.7 & (1.5) & 58.7 & $(1.1)$ & 28.9 & (2.0) \\
\hline & Thailand & 58.0 & (1.4) & 71.7 & (1.7) & 13.7 & (2.4) & 62.7 & (1.4) & 83.7 & (1.6) & 20.9 & (1.9) \\
\hline & Trinidad and Tobago & 58.1 & $(2.2)$ & 72.1 & (1.1) & 14.0 & $(2.7)$ & $\mathrm{m}$ & $\mathrm{m}$ & $\mathrm{m}$ & $\mathrm{m}$ & $\mathrm{m}$ & $\mathrm{m}$ \\
\hline & Tunisia & 69.3 & (1.3) & 77.6 & $(1.2)$ & 8.3 & (1.9) & 45.8 & (1.4) & 66.0 & (1.4) & 20.3 & $(2.0)$ \\
\hline & United Arab Emirates & 71.1 & $(3.1)$ & 77.2 & $(0.6)$ & 6.1 & (3.1) & 63.3 & (3.6) & 75.7 & (0.6) & 12.4 & (3.6) \\
\hline & Uruguay & 56.9 & (1.6) & 75.0 & $(1.1)$ & 18.2 & (1.9) & 30.1 & (1.5) & 59.6 & (1.4) & 29.5 & (2.0) \\
\hline & Viet Nam & 56.3 & $(1.2)$ & 60.0 & (2.4) & 3.6 & (2.5) & $\mathrm{m}$ & $\mathrm{m}$ & $\mathrm{m}$ & $\mathrm{m}$ & $\mathrm{m}$ & $\mathrm{m}$ \\
\hline & Argentina** & 63.6 & (1.4) & 77.3 & (1.1) & 13.7 & (1.6) & $\mathrm{m}$ & $\mathrm{m}$ & $\mathrm{m}$ & $\mathrm{m}$ & $\mathrm{m}$ & $\mathrm{m}$ \\
\hline & Kazakhstan** & 71.7 & $(2.0)$ & 77.1 & (1.0) & 5.4 & $(2.1)$ & $\mathrm{m}$ & $\mathrm{m}$ & $\mathrm{m}$ & $\mathrm{m}$ & $\mathrm{m}$ & $\mathrm{m}$ \\
\hline & Malaysia** & 67.3 & (1.6) & 79.0 & $(0.9)$ & 11.7 & (1.6) & 61.0 & $(1.8)$ & 75.3 & $(1.2)$ & 14.3 & (1.9) \\
\hline
\end{tabular}

1. Blue-collar occupations include skilled agricultural, forestry and fishery workers (ISCO-08 category 6), craft and related trades workers (ISCO-08 category 7), plant and machine operators and assemblers (ISCO-08 category 8) and elementary occupations (ISCO-08 category 9).

White-collar occupations include managers (ISCO-08 category 1), professionals (ISCO-08 category 2) and technicians and associate professionals (ISCO-08 category 3 )

High-status occupations include managers (ISCO-08 category 1 ) or professionals (ISCO-08 category 2).

2. Schools with students mostly from a white-collar background are schools where the percentage of children of white-collar workers is statistically significantly above the country/economy average.

Notes: In order to increase international comparability, odd-ratios are reported only for countries with at least fifty children of blue-collar workers in white-collar schools.

Values that are statistically significant are indicated in bold (see Annex A3).

* See note at the beginning of this Annex.

Corage is too small to ensure comparability (see Annex A4).

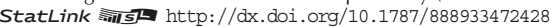


Results based on students' and school principals' self-reports

\begin{tabular}{|c|c|c|c|c|c|c|c|c|c|c|c|c|c|c|c|}
\hline & \multicolumn{6}{|c|}{$\begin{array}{l}\text { Students whose schoolmates are predominantly } \\
\text { from white-collar backgrounds }{ }^{2}\end{array}$} & \multicolumn{4}{|c|}{$\begin{array}{l}\text { Increased likelihood of children } \\
\text { of blue-collar workers to expect } \\
\text { to complete university when } \\
\text { their schoolmates are predominantly } \\
\text { from white-collar backgrounds }\end{array}$} & $\begin{array}{l}\text { Inc } \\
\text { of } b \\
a h \\
\text { their s } \\
\text { fro }\end{array}$ & $\begin{array}{l}\text { ed likelih } \\
\text { collar wc } \\
\text { status oc } \\
\text { olmates } \\
\text { hite-coll }\end{array}$ & $\begin{array}{l}\text { od of } \mathrm{ch} \\
\text { rkers to } \\
\text { upation } \\
\text { re predo } \\
r \text { backgr }\end{array}$ & $\begin{array}{l}\text { ren } \\
\text { ect } \\
\text { een } \\
\text { nantly } \\
\text { dis }\end{array}$ \\
\hline & & $\begin{array}{r}C \\
\text { of } b \\
w\end{array}$ & $\begin{array}{l}\text { ren } \\
\text { collar } \\
\text { ers }\end{array}$ & of $\begin{array}{r}C \\
u\end{array}$ & $\begin{array}{l}\text { en } \\
\text { collar } \\
\text { ers }\end{array}$ & $\begin{array}{r}\text { Diff } \\
\text { betwee } \\
\text { of white } \\
\text { collar }\end{array}$ & $\begin{array}{l}\text { nce } \\
\text { hildren } \\
\text { nd blue- } \\
\text { orkers }\end{array}$ & $\begin{array}{r}\text { Before } \\
\text { for } \\
\text { perf }\end{array}$ & $\begin{array}{l}\text { ounting } \\
\text { nce } \\
\text { ance }\end{array}$ & $\begin{array}{c}\text { After } \\
\text { for } \\
\text { perf }\end{array}$ & $\begin{array}{l}\text { unting } \\
\text { ance } \\
\text { ance }\end{array}$ & $\begin{array}{c}\text { Before } \\
\text { for } \\
\text { perfo }\end{array}$ & $\begin{array}{l}\text { unting } \\
\text { nce } \\
\text { ance }\end{array}$ & $\begin{array}{c}\text { After a } \\
\text { for } \\
\text { perfo }\end{array}$ & $\begin{array}{l}\text { unting } \\
\text { nce } \\
\text { ance }\end{array}$ \\
\hline & & $\%$ & S.E. & $\%$ & S.E. & $\%$ dif. & S.E. & $\begin{array}{l}\text { Odds } \\
\text { ratios }\end{array}$ & S.E. & $\begin{array}{c}\text { Odds } \\
\text { ratios }\end{array}$ & S.E. & $\begin{array}{l}\text { Odds } \\
\text { ratios }\end{array}$ & S.E. & $\begin{array}{l}\text { Odds } \\
\text { ratios }\end{array}$ & S.E. \\
\hline 0 & Australia & 0.7 & $(0.2)$ & 35.4 & $(2.1)$ & 34.7 & $(2.0)$ & $\mathrm{C}$ & C & $\mathrm{C}$ & C & C & C & C & C \\
\hline 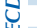 & Austria & 5.5 & $(0.8)$ & 35.2 & $(2.8)$ & 29.7 & $(2.4)$ & 6.4 & $(2.5)$ & 4.5 & $(2.1)$ & 6.2 & (3.1) & 4.6 & $(2.6)$ \\
\hline & Belgium & 7.8 & $(1.0)$ & 49.7 & $(2.6)$ & 41.9 & (2.2) & 2.7 & $(0.7)$ & 1.4 & $(0.4)$ & $\begin{array}{l}.02 \\
1.5\end{array}$ & $(0.5)$ & $\begin{array}{l}\mathbf{7 . 0} \\
1.0\end{array}$ & $(0.3)$ \\
\hline & Canada & 3.0 & $(0.6)$ & 31.2 & $(2.6)$ & 28.2 & $(2.2)$ & 1.5 & $(0.6)$ & 1.4 & $(0.6)$ & 0.9 & $(0.3)$ & 0.8 & $(0.3)$ \\
\hline & Chile & 7.4 & (1.3) & 55.1 & (3.7) & 47.6 & $(2.8)$ & 3.3 & $(0.8)$ & 2.2 & $(0.4)$ & 1.8 & $(0.4)$ & 1.4 & $(0.3)$ \\
\hline & Czech Republic & 5.9 & $(0.8)$ & 44.4 & (2.8) & 38.5 & $(2.3)$ & 4.9 & (1.5) & 2.3 & $(0.7)$ & 3.0 & $(0.8)$ & 1.4 & $(0.4)$ \\
\hline & Denmark & 4.1 & $(0.7)$ & 31.0 & (2.8) & 26.9 & $(2.4)$ & $\mathrm{C}$ & $\mathrm{C}$ & $\mathrm{C}$ & C & $\mathrm{c}$ & $\mathrm{C}$ & C & $\mathrm{C}$ \\
\hline & Estonia & 6.2 & $(0.9)$ & 42.2 & (2.3) & 36.0 & (1.9) & 2.4 & $(0.8)$ & 1.7 & $(0.6)$ & 1.3 & $(0.3)$ & 1.0 & $(0.2)$ \\
\hline & Finland & 5.7 & (1.1) & 32.8 & (3.8) & 27.1 & (3.0) & $\mathrm{C}$ & $\mathrm{C}$ & C & $\mathrm{C}$ & $\mathrm{C}$ & C & C & C \\
\hline & France & 5.4 & $(0.9)$ & 45.2 & (3.3) & 39.8 & $(2.8)$ & c & c & C & C & c & $\mathrm{c}$ & c & c \\
\hline & Germany & 4.0 & $(0.8)$ & 40.4 & (3.1) & 36.4 & $(2.8)$ & $\mathrm{c}$ & c & $\mathrm{c}$ & c & c & c & c & c \\
\hline & Greece & 7.5 & $(1.3)$ & 41.5 & (3.7) & 34.1 & (3.0) & 2.6 & $(0.6)$ & 1.4 & $(0.3)$ & 1.5 & $(0.3)$ & 1.0 & $(0.2)$ \\
\hline & Hungary & 8.3 & $(1.2)$ & 56.8 & (3.1) & 48.4 & (2.4) & 8.4 & (1.7) & 2.9 & $(0.7)$ & 5.1 & (1.0) & 2.4 & $(0.5)$ \\
\hline & Iceland & 7.1 & (1.4) & 34.9 & (0.5) & 27.8 & (1.6) & $\mathrm{C}$ & $\mathrm{C}$ & $\mathrm{C}$ & C & $\mathrm{C}$ & $\mathrm{C}$ & C & C \\
\hline & Ireland & 5.4 & $(1.2)$ & 33.5 & (4.3) & 28.0 & (3.4) & c & c & c & C & C & c & c & c \\
\hline & Israel & 5.5 & (1.0) & 59.6 & (3.3) & 54.1 & (3.1) & $\mathrm{C}$ & C & c & C & C & c & c & c \\
\hline & Italy & 6.6 & (0.9) & 40.6 & (3.0) & 34.0 & (2.4) & 4.6 & $(1.0)$ & 3.1 & $(0.8)$ & 3.1 & $(0.6)$ & 2.2 & $(0.4)$ \\
\hline & Japan & 6.0 & (1.0) & 34.6 & (3.4) & 28.6 & (2.8) & $\mathrm{C}$ & $\mathrm{C}$ & $\mathrm{C}$ & C & $\mathrm{C}$ & C & $\mathrm{C}$ & $\mathrm{C}$ \\
\hline & Korea & 4.1 & $(0.8)$ & 31.9 & (4.3) & 27.8 & (3.7) & C & c & C & C & c & c & c & c \\
\hline & Latvia & 4.7 & (0.8) & 38.4 & (2.7) & 33.8 & (2.3) & C & C & C & C & C & C & C & C \\
\hline & Luxembourg & 7.9 & $(0.7)$ & 56.3 & (0.6) & 48.4 & (1.0) & 4.0 & $(0.8)$ & 2.4 & $(0.5)$ & 4.1 & $(0.8)$ & 2.6 & $(0.5)$ \\
\hline & Mexico & 7.2 & (1.1) & 45.3 & (3.4) & 38.1 & (2.8) & 2.8 & $(0.6)$ & 2.1 & $(0.4)$ & 1.4 & $(0.2)$ & 1.1 & $(0.2)$ \\
\hline & Netherlands & 3.7 & $(0.8)$ & 38.2 & (3.2) & 34.5 & (2.9) & $\mathrm{C}$ & C & $\mathrm{C}$ & $\mathrm{C}$ & C & C & C & C \\
\hline & New Zealand & 4.2 & $(0.9)$ & 28.7 & (2.7) & 24.5 & $(2.6)$ & c & c & $\mathrm{C}$ & C & C & c & C & c \\
\hline & Norway & 0.0 & $(0.0)$ & 37.7 & (3.4) & 37.7 & (3.4) & c & c & c & C & C & c & c & c \\
\hline & Poland & 7.5 & $(1.3)$ & 39.1 & (3.6) & 31.5 & $(2.7)$ & 1.7 & $(0.4)$ & 1.3 & $(0.3)$ & 1.7 & $(0.4)$ & 1.4 & $(0.3)$ \\
\hline & Portugal & 7.7 & (1.6) & 44.8 & (3.7) & 37.1 & (2.5) & 1.6 & $(0.4)$ & 1.3 & $(0.4)$ & 1.5 & $(0.3)$ & 1.3 & $(0.3)$ \\
\hline & Slovak Republic & 6.6 & $(0.9)$ & 44.5 & (3.4) & 37.9 & (2.8) & $\mathrm{m}$ & $\mathrm{m}$ & $\mathrm{m}$ & $\mathrm{m}$ & $\mathrm{C}$ & $\mathrm{C}$ & $\mathrm{C}$ & C \\
\hline & Slovenia & 6.3 & (1.1) & 44.9 & $(0.7)$ & 38.6 & (1.5) & $\mathrm{C}$ & $\mathrm{c}$ & $\mathrm{c}$ & $\mathrm{C}$ & $\mathrm{c}$ & $\mathrm{c}$ & $\mathrm{C}$ & c \\
\hline & Spain & 5.3 & (1.0) & 43.8 & (3.6) & 38.5 & (3.1) & 2.1 & $(0.5)$ & 2.0 & $(0.5)$ & 1.9 & $(0.5)$ & 1.7 & $(0.4)$ \\
\hline & Sweden & 0.0 & $(0.0)$ & 33.2 & (3.3) & 33.2 & (3.3) & C & C & $\mathrm{C}$ & C & $\mathrm{C}$ & C & $\mathrm{C}$ & C \\
\hline & Switzerland & 5.8 & $(1.1)$ & 36.4 & (3.3) & 30.7 & (2.6) & $\mathrm{C}$ & c & $\mathrm{C}$ & C & C & c & C & c \\
\hline & Turkey & 8.1 & (1.8) & 34.5 & (5.7) & 26.4 & $(4.2)$ & 6.0 & $(1.6)$ & 2.5 & $(0.6)$ & 5.5 & $(1.7)$ & 3.6 & $(1.1)$ \\
\hline & United Kingdom & 3.3 & $(0.7)$ & 32.7 & (3.1) & 29.3 & (2.7) & $\mathrm{C}$ & $\mathrm{C}$ & $\mathrm{C}$ & C & $\mathrm{C}$ & $\mathrm{C}$ & $\mathrm{C}$ & $\mathrm{C}$ \\
\hline & United States & 6.4 & $(1.2)$ & 35.4 & (4.3) & 29.0 & (3.4) & c & c & c & c & c & c & c & c \\
\hline & OECD average & 5.5 & $(0.2)$ & 40.3 & $(0.5)$ & 34.8 & $(0.5)$ & 3.7 & $(0.3)$ & 2.2 & $(0.2)$ & 2.8 & $(0.3)$ & 1.9 & $(0.2)$ \\
\hline & Albania & 6.4 & $(1.3)$ & 26.6 & $(4.2)$ & 20.2 & (3.1) & $\mathrm{m}$ & $\mathrm{m}$ & $\mathrm{m}$ & $\mathrm{m}$ & C & C & $\mathrm{C}$ & C \\
\hline ๘ँ & Algeria & 6.0 & $(1.2)$ & 33.5 & (5.1) & 27.5 & $(4.2)$ & $\mathrm{m}$ & $\mathrm{m}$ & $\mathrm{m}$ & $\mathrm{m}$ & c & c & C & c \\
\hline & Brazil & 5.5 & $(0.6)$ & 42.7 & $(2.2)$ & 37.2 & (1.9) & 2.7 & $(0.5)$ & 1.7 & $(0.3)$ & 2.2 & $(0.4)$ & 1.6 & $(0.3)$ \\
\hline & B-S-J-G (China) & 6.2 & $(1.2)$ & 47.2 & $(4.7)$ & 41.0 & $(4.0)$ & 4.8 & $(1.2)$ & 1.8 & $(0.5)$ & 1.3 & $(0.3)$ & 0.9 & $(0.2)$ \\
\hline & Bulgaria & 11.1 & (1.6) & 59.8 & (3.4) & 48.6 & (2.6) & 3.8 & $(0.7)$ & 1.9 & $(0.5)$ & 4.3 & $(0.9)$ & 2.1 & $(0.5)$ \\
\hline & CABA (Argentina) & 4.4 & (1.6) & 73.0 & (6.0) & 68.6 & $(5.2)$ & $\mathrm{m}$ & $\mathrm{m}$ & $\mathrm{m}$ & $\mathrm{m}$ & $\mathrm{C}$ & C & $\mathrm{C}$ & $\mathrm{C}$ \\
\hline & Colombia & 5.3 & $(0.9)$ & 43.0 & (3.2) & 37.7 & $(2.7)$ & 3.1 & $(0.8)$ & 2.0 & $(0.5)$ & 1.3 & $(0.2)$ & 1.0 & $(0.2)$ \\
\hline & Costa Rica & 4.2 & $(0.9)$ & 43.5 & (3.0) & 39.3 & $(2.7)$ & C & $\mathrm{C}$ & $\mathrm{C}$ & $\mathrm{C}$ & C & $\mathrm{c}$ & $\mathrm{C}$ & $\mathrm{C}$ \\
\hline & Croatia & 5.5 & (1.0) & 38.8 & (3.0) & 33.3 & $(2.4)$ & 7.5 & $(2.6)$ & 4.9 & $(1.7)$ & 8.0 & $(2.8)$ & 5.3 & $(2.3)$ \\
\hline & Cyprus* & 8.2 & $(0.9)$ & 49.9 & $(0.7)$ & 41.7 & (1.3) & 3.0 & (1.3) & 2.9 & (1.6) & 1.7 & $(0.5)$ & 1.5 & $(0.5)$ \\
\hline & Dominican Republic & 7.7 & (1.5) & 40.9 & (4.4) & 33.2 & (3.3) & 0.9 & $(0.2)$ & 0.7 & $(0.1)$ & 1.4 & $(0.3)$ & 1.1 & $(0.2)$ \\
\hline & FYROM & 10.6 & $(0.9)$ & 37.8 & $(0.8)$ & 27.3 & (1.4) & $\mathrm{m}$ & $\mathrm{m}$ & $\mathrm{m}$ & $\mathrm{m}$ & $\mathrm{c}$ & $\mathrm{C}$ & $\mathrm{C}$ & C \\
\hline & Georgia & 3.1 & $(0.6)$ & 37.3 & (2.9) & 34.2 & (2.5) & $\mathrm{m}$ & $\mathrm{m}$ & $\mathrm{m}$ & $\mathrm{m}$ & c & c & c & c \\
\hline & Hong Kong (China) & 5.6 & (1.1) & 38.9 & (4.3) & 33.4 & (3.6) & $\mathrm{C}$ & $\mathrm{C}$ & $\mathrm{C}$ & $\mathrm{C}$ & c & $\mathrm{c}$ & c & c \\
\hline & Indonesia & 3.4 & $(0.8)$ & 47.1 & (4.6) & 43.8 & $(4.2)$ & $\mathrm{m}$ & $\mathrm{m}$ & $\mathrm{m}$ & $\mathrm{m}$ & c & c & c & c \\
\hline & Jordan & 4.2 & $(0.8)$ & 33.0 & (3.4) & 28.7 & $(2.8)$ & $\mathrm{m}$ & $\mathrm{m}$ & $\mathrm{m}$ & $\mathrm{m}$ & C & c & C & c \\
\hline & Kosovo & 1.2 & $(0.6)$ & 27.1 & (1.4) & 25.9 & (1.5) & $\mathrm{m}$ & $\mathrm{m}$ & $\mathrm{m}$ & $\mathrm{m}$ & $\mathrm{c}$ & $\mathrm{c}$ & c & $\mathrm{c}$ \\
\hline & Lebanon & 3.1 & $(0.6)$ & 33.6 & (3.4) & 30.4 & (3.2) & $\mathrm{m}$ & $\mathrm{m}$ & $\mathrm{m}$ & $\mathrm{m}$ & c & c & c & c \\
\hline & Lithuania & 5.8 & $(1.0)$ & 40.4 & (3.7) & 34.5 & (3.1) & 2.5 & $(0.6)$ & 1.4 & $(0.4)$ & 2.8 & $(0.8)$ & 2.0 & $(0.6)$ \\
\hline & Macao (China) & 7.4 & (1.0) & 54.2 & (1.0) & 46.8 & (1.4) & $\mathrm{C}$ & $\mathrm{C}$ & $\mathrm{C}$ & $\mathrm{C}$ & $\mathrm{C}$ & $\mathrm{C}$ & $\mathrm{C}$ & $\mathrm{c}$ \\
\hline & Malta & 10.2 & (1.0) & 48.7 & $(0.8)$ & 38.5 & (1.6) & $\mathrm{m}$ & $\mathrm{m}$ & $\mathrm{m}$ & $\mathrm{m}$ & $\mathrm{c}$ & c & c & c \\
\hline & Moldova & 9.5 & (1.4) & 45.0 & $(4.1)$ & 35.5 & (3.2) & $\mathrm{m}$ & $\mathrm{m}$ & $\mathrm{m}$ & $\mathrm{m}$ & c & c & c & c \\
\hline & Montenegro & 14.8 & (1.3) & 47.5 & $(0.7)$ & 32.7 & (1.6) & 4.9 & (1.4) & 3.6 & $(1.1)$ & 3.0 & $(0.6)$ & 2.4 & $(0.5)$ \\
\hline & Peru & 7.5 & (1.0) & 59.2 & (3.0) & 51.7 & $(2.7)$ & 2.0 & $(0.4)$ & 1.3 & $(0.3)$ & 2.4 & $(0.5)$ & 1.8 & $(0.3)$ \\
\hline & Qatar & 1.0 & $(0.7)$ & 39.5 & $(0.3)$ & 38.6 & $(0.8)$ & C & C & $\mathrm{C}$ & C & C & c & C & C \\
\hline & Romania & 8.9 & (1.4) & 53.3 & (5.0) & 44.4 & $(4.2)$ & $\mathrm{m}$ & $\mathrm{m}$ & $\mathrm{m}$ & $\mathrm{m}$ & c & $\mathrm{c}$ & c & c \\
\hline & Russia & 4.2 & $(0.9)$ & 39.1 & $(4.2)$ & 34.9 & (3.7) & $\mathrm{c}$ & $\mathrm{c}$ & $\mathrm{C}$ & $\mathrm{C}$ & c & $\mathrm{c}$ & c & c \\
\hline & Singapore & 2.7 & $(0.7)$ & 39.4 & $(0.9)$ & 36.7 & (1.1) & $\mathrm{C}$ & c & $\mathrm{C}$ & $\mathrm{C}$ & $\mathrm{C}$ & $\mathrm{C}$ & C & c \\
\hline & Chinese Taipei & 8.3 & (1.3) & 39.7 & (3.2) & 31.4 & $(2.3)$ & 1.6 & $(0.3)$ & 1.0 & $(0.3)$ & 2.5 & $(0.5)$ & 1.7 & $(0.3)$ \\
\hline & Thailand & 7.2 & (1.2) & 49.5 & (4.8) & 42.3 & (4.0) & 5.4 & (1.1) & 3.2 & $(0.6)$ & 1.8 & $(0.4)$ & 1.3 & $(0.3)$ \\
\hline & Trinidad and Tobago & 4.6 & $(0.9)$ & 35.0 & $(0.6)$ & 30.5 & $(1.2)$ & $\mathrm{m}$ & $\mathrm{m}$ & $\mathrm{m}$ & $\mathrm{m}$ & $\mathrm{C}$ & C & $\mathrm{c}$ & C \\
\hline & Tunisia & 5.4 & $(0.9)$ & 41.0 & (4.4) & 35.6 & (3.9) & 2.4 & $(0.6)$ & 1.8 & $(0.4)$ & 1.1 & $(0.2)$ & 0.9 & $(0.2)$ \\
\hline & United Arab Emirates & 0.0 & $(0.0)$ & 60.2 & (2.6) & 60.2 & (2.6) & $\mathrm{C}$ & $\mathrm{C}$ & $\mathrm{c}$ & $\mathrm{C}$ & $\mathrm{C}$ & $\mathrm{C}$ & $\mathrm{C}$ & $\mathrm{C}$ \\
\hline & Uruguay & 4.5 & $(0.7)$ & 41.4 & (2.4) & 36.9 & $(2.2)$ & 3.5 & (0.9) & 2.3 & $(0.6)$ & 1.7 & $(0.4)$ & 1.2 & $(0.3)$ \\
\hline & Viet Nam & 7.4 & (1.3) & 42.2 & (5.4) & 34.7 & (4.5) & $\mathrm{m}$ & $\mathrm{m}$ & $\mathrm{m}$ & $\mathrm{m}$ & c & $\mathrm{c}$ & $\mathrm{c}$ & c \\
\hline & Argentina** & 6.2 & $(1.3)$ & 42.1 & $(4.6)$ & 35.9 & (3.6) & $\mathrm{m}$ & $\mathrm{m}$ & $\mathrm{m}$ & $\mathrm{m}$ & C & c & C & C \\
\hline & Kazakhstan** & 3.9 & $(0.9)$ & 34.5 & (3.1) & 30.6 & (2.6) & $\mathrm{m}$ & $\mathrm{m}$ & $\mathrm{m}$ & $\mathrm{m}$ & c & $\mathrm{C}$ & c & c \\
\hline & Malaysia** & 9.4 & (1.6) & 47.8 & $(4.2)$ & 38.4 & (3.2) & 1.9 & $(0.5)$ & 1.3 & $(0.3)$ & 2.7 & $(0.6)$ & 2.2 & $(0.5)$ \\
\hline
\end{tabular}

1. Blue-collar occupations include skilled agricultural, forestry and fishery workers (ISCO-08 category 6), craft and related trades workers (ISCO-08 category 7), plant and machine operators and assemblers (ISCO-08 category 8) and elementary occupations (ISCO-08 category 9).

White-collar occupations include managers (ISCO-08 category 1), professionals (ISCO-08 category 2) and technicians and associate professionals (ISCO-08 category 3 )

High-status occupations include managers (ISCO-08 category 1) or professionals (ISCO-08 category 2).

2. Schools with students mostly from a white-collar background are schools where the percentage of children of white-collar workers is statistically significantly above the country/economy average.

Notes: In order to increase international comparability, odd-ratios are reported only for countries with at least fifty children of blue-collar workers in white-collar schools.

Values that are statistically significant are indicated in bold (see Annex A3).

* See note at the beginning of this Annex.

** Coverage is too small to ensure comparability (see Annex A4).

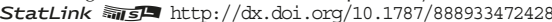


[Part 1/1]

Table III.10.16 Students expecting the same career as their parents

Results based on students' self-reports

\begin{tabular}{|c|c|c|c|c|c|c|c|c|c|c|c|c|c|c|c|c|c|c|c|c|c|}
\hline & & All ste & ents & & & & & & & & & & & & & & $\begin{array}{l}\text { nce b } \\
\text { d girl }\end{array}$ & $\begin{array}{l}\text { etwe } \\
\text { s (B }\end{array}$ & & $\begin{array}{r}\text { Dif } \\
\text { betw }\end{array}$ & $\begin{array}{l}\text { ice } \\
\text { boys }\end{array}$ \\
\hline & & $\begin{array}{c}\text { Studen } \\
\text { expe } \\
\text { same } \\
\text { one o } \\
\text { par }\end{array}$ & $\begin{array}{l}\text { ts who } \\
\text { t the } \\
\text { ob as } \\
\text { their } \\
\text { nts }\end{array}$ & $\begin{array}{l}\text { Expec } \\
\text { of th } \\
\text { most p } \\
\text { occup } \\
\text { for I } \\
\text { stude } \\
\text { their c }\end{array}$ & $\begin{array}{l}\text { tone } \\
\text { five } \\
\text { opular } \\
\text { ations } \\
\text { nale } \\
\text { nts in } \\
\text { ountry }\end{array}$ & $\begin{array}{r}\text { Ex } \\
\text { the } \\
\text { occup } \\
\text { their }\end{array}$ & $\begin{array}{l}\text { ct } \\
\text { me } \\
\text { ion as } \\
\text { ther }\end{array}$ & $\begin{array}{r}\text { Ex } \\
\text { the } \\
\text { occup } \\
\text { their }\end{array}$ & $\begin{array}{l}\text { ct } \\
\text { me } \\
\text { ion as } \\
\text { other }\end{array}$ & $\begin{array}{c}\text { Expe } \\
\text { of th } \\
\text { most } \\
\text { occu } \\
\text { for } \\
\text { stud } \\
\text { their }\end{array}$ & $\begin{array}{l}\text { one } \\
\text { five } \\
\text { pular } \\
\text { tions } \\
\text { nale } \\
\text { ts in } \\
\text { untry }\end{array}$ & $\begin{array}{l}\text { the } \\
\text { occup } \\
\text { their }\end{array}$ & $\begin{array}{l}\text { ct } \\
\text { me } \\
\text { on as } \\
\text { ther }\end{array}$ & $\begin{array}{l}\text { Exp } \\
\text { the } \\
\text { occup } \\
\text { their }\end{array}$ & $\begin{array}{l}\text { ct } \\
\text { me } \\
\text { on as } \\
\text { ther }\end{array}$ & $\begin{array}{r}\text { Exp } \\
\text { the } \mathrm{s} \\
\text { occupa } \\
\text { their } \mathrm{f}\end{array}$ & $\begin{array}{l}\text { ct } \\
\text { me } \\
\text { on as } \\
\text { ther }\end{array}$ & $\begin{array}{r}\text { Exp } \\
\text { the } \\
\text { occupa } \\
\text { their } m\end{array}$ & $\begin{array}{l}\text { ct } \\
\text { me } \\
\text { on as } \\
\text { ther }\end{array}$ & \begin{tabular}{|} 
as their \\
and girl \\
expec \\
same $j$ \\
their m \\
(B-
\end{tabular} & $\begin{array}{l}\text { fother } \\
\text { who } \\
\text { the } \\
\text { b as } \\
\text { thers } \\
\text { s) }\end{array}$ \\
\hline & & $\%$ & S.E. & $\%$ & S.E. & $\%$ & S.E. & $\%$ & S.E. & $\%$ & S.E. & $\%$ & S.E. & $\%$ & S.E. & $\%$ dif. & S.E. & $\%$ dif. & S.E. & \% dif. & S.E. \\
\hline & Australia & 6.3 & $(0.3)$ & 31.1 & $(0.8)$ & 5.8 & $(0.4)$ & 2.0 & $(0.2)$ & 33.7 & $(0.8)$ & 2.3 & $(0.3)$ & 3.2 & $(0.3)$ & 3.5 & $(0.4)$ & -1.1 & $(0.4)$ & 2.7 & $(0.5)$ \\
\hline & Austria & 1.1 & $(0.2)$ & 28.2 & (1.7) & 1.3 & $(0.2)$ & 0.6 & $(0.2)$ & 32.3 & (1.4) & 0.7 & $(0.2)$ & 0.3 & $(0.1)$ & 0.6 & $(0.3)$ & 0.3 & $(0.2)$ & 1.0 & $(0.2)$ \\
\hline & Belgium & 6.6 & $(0.6)$ & 30.2 & (1.3) & 7.5 & $(1.0)$ & 1.5 & $(0.3)$ & 32.7 & (1.6) & 2.2 & $(0.4)$ & 3.4 & $(0.5)$ & 5.3 & (1.1) & -1.9 & $(0.6)$ & 4.0 & $(1.2)$ \\
\hline & Canada & 7.8 & $(0.3)$ & 38.5 & $(0.7)$ & 8.1 & $(0.5)$ & 2.6 & $(0.3)$ & 48.2 & (0.9) & 2.8 & $(0.3)$ & 3.5 & $(0.3)$ & 5.2 & $(0.6)$ & -0.9 & (0.5) & 4.6 & $(0.7)$ \\
\hline & Chile & 4.6 & (0.4) & 40.8 & (1.3) & 4.9 & (0.5) & 1.3 & $(0.2)$ & 43.7 & $(1.2)$ & 1.9 & $(0.4)$ & 1.6 & $(0.3)$ & 3.0 & (0.6) & -0.3 & $(0.4)$ & 3.3 & $(0.5)$ \\
\hline & Czech Repu & 7.3 & $(0.5)$ & 33.5 & (1.0) & 8.0 & $(0.6)$ & 2.3 & $(0.3)$ & 32.4 & (1.4) & 1.3 & $(0.2)$ & 4.3 & $(0.5)$ & 6.7 & $(0.7)$ & -2.0 & $(0.5)$ & 3.8 & $(0.8)$ \\
\hline & Denmark & 9.7 & $(0.8)$ & 54.3 & $(1.2)$ & 9.5 & (1.0) & 2.6 & $(0.5)$ & 55.2 & $(1.1)$ & 3.9 & $(0.6)$ & 4.3 & (0.6) & 5.6 & (1.1) & -1.7 & $(0.7)$ & 5.2 & (1.1) \\
\hline & Estonia & 6.9 & $(0.4)$ & 33.6 & (1.0) & 8.7 & $(0.6)$ & 2.4 & $(0.4)$ & 43.2 & (1.3) & 2.7 & $(0.4)$ & 2.6 & $(0.3)$ & 6.0 & $(0.7)$ & -0.2 & $(0.5)$ & 6.2 & $(0.6)$ \\
\hline & Finland & 8.3 & $(0.4)$ & 34.6 & (1.0) & 8.2 & $(0.6)$ & 2.8 & $(0.4)$ & 37.7 & (1.3) & 2.5 & $(0.4)$ & 4.6 & $(0.4)$ & 5.8 & $(0.7)$ & -1.8 & $(0.6)$ & 3.6 & $(0.8)$ \\
\hline & France & 5.8 & (0.4) & 26.5 & (1.0) & 5.2 & $(0.5)$ & 2.0 & $(0.3)$ & 30.2 & $(1.0)$ & 2.3 & $(0.3)$ & 3.0 & $(0.4)$ & 2.9 & $(0.5)$ & -1.0 & (0.5) & 2.2 & $(0.7)$ \\
\hline & Germany & 9.1 & $(0.5)$ & 31.1 & $(0.9)$ & 8.1 & $(0.8)$ & 2.6 & $(0.4)$ & 32.7 & (1.0) & 3.7 & $(0.5)$ & 5.2 & $(0.5)$ & 4.4 & (0.9) & -2.6 & $(0.6)$ & 2.8 & (0.9) \\
\hline & Greece & 7.6 & $(0.5)$ & 29.7 & (1.1) & 8.8 & $(0.6)$ & 2.5 & (0.4) & 44.4 & $(1.2)$ & 2.9 & $(0.4)$ & 3.1 & $(0.4)$ & 5.9 & $(0.6)$ & -0.6 & $(0.6)$ & 5.6 & $(0.7)$ \\
\hline & Hungary & 8.7 & (0.5) & 33.6 & (1.6) & 8.9 & $(0.6)$ & 2.5 & (0.4) & 27.9 & $(1.1)$ & 3.9 & (0.6) & 3.8 & (0.5) & 5.0 & $(0.8)$ & -1.3 & $(0.7)$ & 5.2 & $(0.8)$ \\
\hline & Iceland & 81 & (0.6) & 45.5 & (1.4) & 7.5 & $(0.8)$ & 2.5 & $(0.5)$ & 44.6 & (1.3) & 3.0 & $(0.5)$ & 4.0 & $(0.6)$ & 4.5 & (0.9) & -1.5 & $(0.7)$ & 3.5 & (1.1) \\
\hline & Ireland & 5.8 & $(0.4)$ & 25.0 & (0.9) & 6.2 & $(0.6)$ & 1.8 & $(0.3)$ & 33.7 & $(1.1)$ & 1.7 & $(0.3)$ & 3.0 & $(0.4)$ & 4.4 & $(0.6)$ & -1.2 & $(0.4)$ & 3.2 & $(0.6)$ \\
\hline & Israel & 7.6 & $(0.5)$ & 43.1 & (1.3) & 7.7 & $(0.7)$ & 2.5 & (0.4) & 45.7 & (1.1) & 2.2 & $(0.4)$ & 3.5 & $(0.4)$ & 5.6 & & -1.1 & $(0.6)$ & 4.2 & $(0.8)$ \\
\hline & Italy & 7.4 & $(0.5)$ & 27.9 & (1.1) & 8.3 & (0.6) & 2.7 & $(0.4$ & 34.0 & (1.0) & 3.4 & $(0.5)$ & 2.6 & $(0.4)$ & 4.9 & $(0.7)$ & 0.1 & $(0.6)$ & 5.7 & $(0.7)$ \\
\hline & Japan & 9.8 & $(0.5)$ & 36.9 & (1.2) & 9.0 & $(0.6)$ & 4.2 & $(0.4)$ & 35.3 & $(1.2)$ & 3.4 & $(0.4)$ & 6.5 & $(0.4)$ & 5.6 & $(0.8)$ & -2.3 & $(0.6)$ & 2.5 & $(0.8)$ \\
\hline & Korea & 9.0 & $(0.4)$ & 38.1 & (1.2) & 7.8 & (0.6) & 4.1 & $(0.4)$ & 38.0 & $(1.2)$ & 4.3 & $(0.5)$ & 3.8 & $(0.5)$ & 3.5 & & 0.3 & & .0 & $(0.8)$ \\
\hline & Latvia & 7.2 & $(0.5)$ & 34.7 & (1.1) & 7.9 & $(0.8)$ & 1.8 & $(0.3)$ & 37.5 & $(1.0)$ & 2.2 & $(0.4)$ & 3.6 & $(0.4)$ & 5.7 & $(0.9)$ & -1.8 & $(0.5)$ & 4.2 & (0.9) \\
\hline & Luxembo & 6.8 & $(0.4)$ & 28.5 & (1.0) & 5.9 & (0.5) & 2.8 & (0.4) & 38.7 & (1.0) & 2.4 & $(0.3)$ & 4.8 & $(0.5)$ & 3.5 & $(0.7)$ & -1.9 & (0.6) & 1.1 & $(0.8)$ \\
\hline & Mexico & 3.4 & $(0.3)$ & 39.0 & (1.0) & 3.8 & $(0.4)$ & 1.1 & $(0.2)$ & 39.0 & (1.0) & 1.7 & $(0.2)$ & 1.1 & $(0.2)$ & 2. & $(0.4)$ & 0.1 & $(0.3)$ & 2.8 & $(0.4)$ \\
\hline & Netherlands & 8.0 & (0.5) & 31.6 & (1.0) & 7.6 & $(0.7)$ & 1.9 & $(0.3)$ & 29.2 & (1.0) & 2.9 & $(0.4)$ & 4.6 & $(0.5)$ & 4.8 & $(0.8)$ & -2.7 & $(0.6)$ & 3.1 & $(0.9)$ \\
\hline & New Zealand & 5.8 & (0.4) & 35.1 & (1.1) & 6.9 & (0.6) & 1.3 & $(0.3$ & 32.1 & $(1.1)$ & 1.6 & $(0.3)$ & 2.4 & $(0.3)$ & 3. & $(0.7)$ & 10 & $(0.4)$ & .6 & $(0.6)$ \\
\hline & Norway & 9.5 & $(0.5)$ & 38.2 & (1.1) & 8.3 & $(0.6)$ & 2.3 & $(0.3)$ & 40.3 & $(1.0)$ & 4.6 & $(0.4)$ & 5.0 & $(0.5)$ & 3.7 & $(0.8)$ & -2.7 & $(0.6)$ & 3 & $(0.7)$ \\
\hline & Poland & 8.0 & $(0.5)$ & 35.2 & (1.3) & 9.8 & $(0.7)$ & 3.0 & $(0.5)$ & 36.9 & (1.1) & 2.0 & $(0.5)$ & 3.2 & $(0.4)$ & 7.8 & $(0.8)$ & -0.1 & $(0.6)$ & .7 & $(0.8)$ \\
\hline & Portuga & 5.1 & $(0.5)$ & 38.1 & (1.1) & 6.2 & $(0.6)$ & 1.6 & $(0.3$ & 37.3 & $(1.1)$ & 1.7 & $(0.3)$ & 20 & $(0.3)$ & 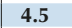 & $(0.7)$ & -0.4 & $(0.5)$ & 4.2 & $(0.6)$ \\
\hline & Slovak Republic & 5.8 & $(0.4)$ & 33.2 & (1.0) & 6.5 & $(0.6)$ & .6 & $(0.3)$ & 36.4 & $(1.2)$ & .4 & $(0.3)$ & 3.2 & $(0.4)$ & 5.1 & $(0.6)$ & -1.6 & $(0.5)$ & 3.3 & $(0.7)$ \\
\hline & Slovenia & 6.6 & $(0.5)$ & 35.0 & (1.0) & 7.3 & $(0.6)$ & 2.7 & $(0.4)$ & 33.9 & $(1.0)$ & 1.0 & $(0.2)$ & 3.0 & $(0.5)$ & 6.3 & $(0.7)$ & -0.3 & $(0.6)$ & 4.4 & $(0.8)$ \\
\hline & Spain & 5.5 & (0.4) & 34.3 & $(1.1)$ & 5.7 & $(0.6)$ & 2.3 & $(0.3)$ & 36.0 & $(0.9)$ & 2.3 & $(0.4)$ & 2.1 & $(0.3)$ & 3.4 & $(0.6)$ & 0.2 & $(0.4)$ & 3.6 & (0.6) \\
\hline & Sweden & 7.6 & (0.5) & 28.6 & $(0.8)$ & 7.0 & $(0.6)$ & 2.7 & $(0.4$ & 37.8 & $(1.2)$ & 3.5 & $(0.5)$ & 3.5 & $(0.4)$ & 3.5 & $(0.8)$ & -0.8 & $(0.6)$ & .5 & $(0.8)$ \\
\hline & Switzerla & 8.5 & (0.4) & 25.2 & (1.1) & 7.9 & $(0.7)$ & 2.9 & $(0.5)$ & 34.6 & $(1.2)$ & 2.7 & $(0.5)$ & 4.9 & $(0.5)$ & 5.2 & $(0.9)$ & -2.0 & $(0.8)$ & 3.0 & $(0.8)$ \\
\hline & Turkey & 41 & (0.4) & 43.2 & (1.3) & 3.4 & $(0.5)$ & 2.5 & $(0.5)$ & 45.3 & (1.3) & 1.2 & $(02)$ & 1.5 & $(0.2)$ & 2.2 & $(05)$ & 0.9 & $(0.4)$ & 1.8 & $(0.5)$ \\
\hline & United K & 7.0 & (0.5) & 31.8 & (0.9) & 2.7 & $(0.4$ & 6.7 & $(0$. & 34.1 & $(0.9)$ & 3.5 & $(0$. & 2.2 & $(0.3)$ & -0.7 & $(0.5)$ & 4.5 & $(0.6)$ & 0.5 & $(0.5)$ \\
\hline & United States & 5.5 & $(0.4)$ & 33.3 & (0.9) & 6.1 & (0.5) & 1.5 & $(0.3)$ & 45.1 & $(1.2)$ & 1.5 & $(0.2)$ & 2.4 & $(0.4)$ & 4.6 & $(0.6)$ & -0.9 & $(0.5)$ & 3.7 & $(0.7)$ \\
\hline & OECD average & 6.9 & $(0.1)$ & 34.5 & $(0.2)$ & 6.9 & $(0.1)$ & 2.4 & $(0.1)$ & 37.7 & $(0.2)$ & 2.5 & $(0.1)$ & 3.3 & $(0.1)$ & 4.4 & $(0.1)$ & -0.9 & $(0.1)$ & 3.6 & $(0.1)$ \\
\hline$n$ & Albania & 9.4 & $(0.9)$ & 50.8 & (1.5) & 6.4 & $(0.8)$ & 3.2 & $(0.5$ & 53.4 & (1. & 6.8 & $(0$ & 4.4 & $(0.8)$ & -0.4 & (1 & -1.2 & $(0.9)$ & 2.0 & $(1.0)$ \\
\hline & Algeria & 14.4 & (1.5) & 47.9 & (1.6) & 9 & $(0.7)$ & 3 & (1. & & (1. & 5.9 & & 85 & & 3.0 & & -3.1 & & 5 & \\
\hline & Brazil & 2.9 & $(0.2)$ & 45.8 & $(0.7)$ & 3.4 & $(0.3)$ & 0.8 & $(0.2$ & 51.1 & $(0.7$ & 1.3 & $(0.2)$ & 0.6 & $(0$. & 2.1 & $(0.3)$ & 0.2 & $(0.2)$ & 2.0 & $(0.3)$ \\
\hline & B-S-J-G (China) & 7.2 & $(0.4)$ & 47.7 & (1.1) & 6.4 & $(0.6)$ & 3.9 & $(0.4)$ & 51.6 & $(1.1)$ & 3.5 & $(0.5)$ & 3.5 & $(0.4)$ & 2.9 & $(0.8)$ & 0.4 & $(0.6)$ & 2.9 & $(0.8)$ \\
\hline & Bulgaria & 7.0 & $(0.5)$ & 42.7 & (1.5) & 7.2 & $(0.7$ & 2 & $(0$. & 41.6 & (1. & 2.8 & $(0.4)$ & 4.0 & $(0.4)$ & 4.4 & $(0.8)$ & -1.8 & $(0$ & 1 & $(0.8)$ \\
\hline & $\mathrm{CAB}$ & 9.0 & $(1.3$ & 40.5 & $(2.3$ & 9.8 & $(1.8$ & 3.8 & $(0$. & 49.2 & $(2.1)$ & 3.5 & $(0 . c)$ & 4.1 & $(0$. & 6.3 & (1.8) & -0.3 & (1.1) & .7 & (1.6) \\
\hline & Color & 31 & $(0.3)$ & 40.8 & $(1.0$ & .7 & $(0.4$ & 0 & (0. & 45.7 & $(0$. & 2.1 & $(0$. & 1.0 & $(0.2)$ & 0.6 & $(0.5)$ & 0.0 & $(0.3)$ & 1.7 & $(0.4)$ \\
\hline & Costa & & $(0.3$ & 36.8 & (1.1 & 3.6 & $(0$. & & (0. & 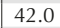 & (1) & 1.5 & (0. & 0.7 & $(0$. & 2. & $(0$. & 0.2 & $(0.3)$ & 2.9 & (0.4) \\
\hline & Croat & 6.1 & $(0.4)$ & 27.5 & (1.1 & 6.1 & $(0.6)$ & .7 & (0. & 3.2 & (1.2) & 1.7 & $(0$. & 2.9 & $(0$. & 4.4 & $(0.7)$ & -0.2 & $(0.5)$ & 3.2 & $(0.8)$ \\
\hline & Cyprus* & 63 & (0.4) & 34.4 & (0.9) & .8 & $(0.5$ & 3 & $(0$. & & (1. & 2.2 & $(0.4)$ & 2.8 & $(0.3)$ & 4.6 & $(0.7)$ & -0.5 & $(0.4)$ & 4.0 & $(0.6)$ \\
\hline & Dominica & 5 & $(0.5$ & 50.2 & $(1.1$ & 4.5 & $(0.5$ & 2.1 & (0. & 52.0 & (1. & 2.2 & $(0$. & 2.0 & (0. & 2. & $(0.6)$ & 0.1 & $(0.6)$ & 2.6 & $(0.7)$ \\
\hline & FYRC & & $(0)$. & & $(1.0$ & 9.9 & $(0$. & & (0. & & & & & & & & & & & & \\
\hline & Georgia & & $(0.5$ & 43.9 & $(1.3$ & 5.6 & $(0$. & 1.5 & (0. & 5 & (1. & ? & $(0$ & 2 & $(0$ & 2.6 & $(0$. & -1.4 & $(0$ & $\mathbf{0}$ & $(0.7)$ \\
\hline & Hong & 5.8 & (0.4) & 32.8 & (1.1) & 5.2 & $(0.5)$ & 2.8 & $(0.4$ & 32.8 & $(0.9)$ & 1.8 & $(0$. & 3.0 & $(0$. & 3.5 & $(0.7)$ & -0.2 & $(0.6)$ & 2.3 & $(0.7)$ \\
\hline & Indor & & $(0.3)$ & 47.8 & (12) & 4.3 & (0.5 & & $(0$. & & (1 & 2.1 & & 2.4 & & 21 & & 0.1 & & 19 & $(06)$ \\
\hline & Jordan & 0 & $(0.5$ & 54.9 & $(1.2$ & 7.4 & $(0.6$ & 3.4 & $(0$. & 55.2 & (1. & 3.5 & $(0$. & 6.0 & $(0$. & 3.9 & $(0.7)$ & -2.6 & $(0.7)$ & 1.4 & (0.9) \\
\hline & Koso & & $(0.5$ & & (1. & & $(0$. & & (0. & & & 3.0 & & & & 2 & & & & 3.2 & \\
\hline & Leb & 13.0 & $(0.8$ & & 1 & & 0 & & & & & & & 9 & & 5 & & -6.3 & & -0.4 & 2) \\
\hline & Lithuania & 7.0 & $(0.4)$ & 35.4 & (1.1) & 8.6 & $(0.7)$ & 2.6 & $(0.3)$ & 34.1 & $(1.1$ & 2.5 & $(0.4)$ & 2.3 & $(0.3)$ & 6.1 & $(0.8)$ & 0.4 & $(0.5)$ & 6.3 & $(0.9)$ \\
\hline & Mac & & (0. & & & & ( & & & & & & & & & 1.9 & & 03 & & 16 & \\
\hline & Malta & & (0. & & (1.2 & 5.8 & (O & 2 & ( & 3 & (1. & 2.2 & (0 & 2.0 & & 3. & $(0$ & -0.7 & $(0$ & 3.8 & $(0.7)$ \\
\hline & Moldo & & $(0.3$ & 37.7 & 1.2 & 5.7 & (0. & 1.6 & (0. & 46.6 & (1. & 1.0 & (0. & 2.5 & (0. & 4. & & -0.9 & & 3.3 & $(0.6)$ \\
\hline & Mon & & (0. & & (0- & & 0 & & & & & & & 27 & & & & 15 & & b & $(0.7)$ \\
\hline & Peru & 3.0 & $(0.3)$ & 46.6 & (1.0) & 3.6 & $(0.4$ & 0.5 & (0. & 43.5 & $1 .($ & 1.7 & $(0.3)$ & 0.6 & $(0.2)$ & 1.9 & $(0.5)$ & -0.2 & $(0.2)$ & 3.0 & $(0.4)$ \\
\hline & Qatar & & $(03$ & 55.5 & (0.8) & 11.4 & $(0$ & & $(0$ & 50.7 & 0 & 4.6 & & 2.9 & & 6.8 & & -1.0 & & 8.5 & \\
\hline & Rom & & (0. & \begin{tabular}{|l|}
37.1 \\
\end{tabular} & 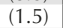 & 8.3 & (0. & 3.2 & (0. & 36.4 & (1. & 3.9 & (0. & 4.0 & (0. & 4. & (1.1) & -0.9 & $(0.7)$ & 4.3 & (1.0) \\
\hline & Russ & & $(0.5$ & 30.2 & (1.0 & 7.5 & (0. & 2.9 & (0. & 36 & (0. & 3.3 & (0. & 3.4 & (0. & 4. & & -0.5 & & 4.1 & $(0.7)$ \\
\hline & & & $(0$. & & 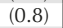 & & 0 & & & & & & & 3. & & 2 & & 0.0 & & 9 & $(0.7)$ \\
\hline & Chine & 6.5 & $(0.5$ & 29.7 & (0.9) & 5.3 & (0. & 3.0 & (0. & 32.4 & (1. & 1.9 & (0. & 3.6 & (0. & 3.4 & $(0.5)$ & -0.6 & (0.6) & 1.7 & $(0.7)$ \\
\hline & & & (0.4 & 53.4 & . & 5.8 & $(0$. & 3.2 & (0. & 54 & . & 1.5 & & 1.0 & (0. & 4. & & 2.2 & & 4.8 & $(0.9)$ \\
\hline & Trin & 7. & (0.4 & 43.4 & 12 & 7.5 & $(0$. & 3.1 & (0. & 43.4 & (1. & 3.1 & (0. & 2.4 & (0. & 4.4 & (0. & 0.8 & $(0.7)$ & 5.1 & $(0.8)$ \\
\hline & Tunis & 6.6 & $(0.7$ & 54.4 & (1.2 & 5.3 & $(0.6$ & 3.0 & $(0$. & 58.0 & (1. & 2.4 & (0. & 2.5 & (0. & 2. & (0. & 0.5 & (1. & 2.8 & (0.8) \\
\hline & & 10.0 & (0. & & 1 & 11.2 & & & & & & & & 3.8 & & & & -1.3 & & .5 & \\
\hline & Urug & 4.8 & (0.4) & 36.5 & (1.1) & 5.5 & $(0.6)$ & 1.2 & $(0.3)$ & 40.1 & $(1.0)$ & 2.2 & $(0.3)$ & 1.8 & $(0.3)$ & 3.3 & $(0.7)$ & -0.6 & $(0.4)$ & 3.7 & $(0.7)$ \\
\hline & Viet Nam & 3.5 & $(0.3)$ & 50.6 & (1.3) & 3.9 & $(0.5)$ & 1.7 & $(0.3)$ & 52.4 & (1.3) & 1.6 & $(0.3)$ & 1.7 & $(0.3)$ & 2.2 & $(0.5)$ & 0.0 & $(0.4)$ & 2.1 & $(0.6)$ \\
\hline & & & $(0.4$ & & & & & & & & & ) & & 1.4 & & 4. & & -0.1 & & .4 & \\
\hline & & 12.1 & $(0.7)$ & \begin{tabular}{|l|}
41.2 \\
\end{tabular} & $(1.2)$ & 11.2 & (0.7 & 3.9 & (0. & 46.4 & (1. & 4.5 & (0. & 6.7 & $(0$. & 6.7 & $(0.9)$ & -2.8 & $(0.8)$ & 4.5 & $(0.9)$ \\
\hline & Malaysia** & 3.2 & $(0.3)$ & 42.4 & (1.1) & 3.1 & $(0.4)$ & 0.7 & $(0.2)$ & 46.0 & $(1.0)$ & 1.6 & $(0.2)$ & 1.4 & $(0.2)$ & 1.4 & $(0.4)$ & -0.7 & $(0.3)$ & 1.7 & $(0.4)$ \\
\hline
\end{tabular}

Notes: Students reported their expected occupation when they are 30 years old Students' expected occupation and parents' current occupation are coded according to the International Standard Classification of Occupations 2008 edition (ISCO-08), at the 3 digit level (e.g. 111 ISCO code: Senior officials and legislators.

Values that are statistically significant are indicated in bold (see Annex A3).

* See note at the beginning of this Annex.

** Coverage is too small to ensure comparability (see Annex A4).

StatLink त्ञाज ht htp://dx.doi.org/10.1787/888933472430 


\begin{tabular}{|c|c|c|c|c|c|c|c|c|c|c|c|c|c|c|}
\hline & \multicolumn{14}{|c|}{ Number of days per week students reported that they attend physical education classes } \\
\hline & \multicolumn{2}{|c|}{$\mathbf{0}$} & \multicolumn{2}{|c|}{1} & \multicolumn{2}{|c|}{2} & \multicolumn{2}{|c|}{3} & \multicolumn{2}{|c|}{4} & \multicolumn{2}{|c|}{5} & \multicolumn{2}{|c|}{6 or 7 days } \\
\hline & $\%$ & S.E. & $\%$ & S.E. & $\%$ & S.E. & $\%$ & S.E. & $\%$ & S.E. & $\%$ & S.E. & $\%$ & S.E. \\
\hline Australia & 15.5 & $(0.5)$ & 17.2 & $(0.7)$ & 28.3 & $(0.7)$ & 21.4 & $(0.6)$ & 9.4 & $(0.4)$ & 8.2 & $(0.3)$ & 0.0 & c \\
\hline Austria & 11.0 & $(0.7)$ & 65.4 & (1.9) & 15.3 & (1.6) & 3.2 & $(0.5)$ & 1.3 & $(0.4)$ & 2.0 & $(0.2)$ & 1.7 & $(0.3)$ \\
\hline 0 Belgium & 1.4 & $(0.2)$ & 52.8 & (2.3) & 38.4 & $(2.1)$ & 2.6 & $(0.3)$ & 1.9 & $(0.3)$ & 2.1 & $(0.3)$ & 0.6 & $(0.1)$ \\
\hline Canada & 24.3 & $(0.6)$ & 11.4 & $(0.6)$ & 9.4 & $(0.6)$ & 13.7 & $(0.7)$ & 4.4 & $(0.4)$ & 36.8 & (0.9) & 0.0 & C \\
\hline Chile & 1.0 & $(0.1)$ & 53.9 & (2.9) & 32.3 & (2.8) & 2.0 & $(0.3)$ & 1.8 & $(0.2)$ & 9.0 & $(0.5)$ & 0.0 & c \\
\hline Czech Republic & 3.3 & $(0.3)$ & 39.3 & (2.3) & 46.7 & $(2.2)$ & 5.1 & $(0.9)$ & 2.3 & $(0.4)$ & 3.3 & $(0.4)$ & 0.0 & c \\
\hline Denmark & 2.9 & $(0.5)$ & 72.7 & (1.7) & 13.7 & (1.3) & 4.1 & $(0.6)$ & 2.4 & $(0.5)$ & 4.2 & $(0.8)$ & 0.0 & c \\
\hline Estonia & 3.1 & $(0.3)$ & 32.1 & (1.9) & 60.5 & (1.9) & 1.5 & $(0.2)$ & 0.4 & $(0.1)$ & 2.4 & $(0.3)$ & 0.0 & c \\
\hline Finland & 1.2 & $(0.2)$ & 47.5 & $(1.3)$ & 34.6 & (1.1) & 8.5 & $(0.8)$ & 2.6 & $(0.3)$ & 5.6 & $(0.3)$ & 0.0 & C \\
\hline France & 3.5 & $(0.2)$ & 69.7 & $(0.9)$ & 17.8 & $(0.7)$ & 3.7 & $(0.4)$ & 1.2 & $(0.1)$ & 4.0 & $(0.3)$ & 0.0 & c \\
\hline Germany & 2.0 & $(0.4)$ & 66.3 & $(1.7)$ & 25.3 & (1.7) & 3.0 & $(0.5)$ & 1.0 & $(0.2)$ & 1.4 & $(0.2)$ & 1.0 & $(0.2)$ \\
\hline Greece & 3.0 & $(0.3)$ & 6.5 & $(0.9)$ & 72.5 & $(1.2)$ & 5.5 & $(0.4)$ & 1.9 & $(0.2)$ & 2.2 & $(0.2)$ & 8.3 & (0.5) \\
\hline Hungary & 1.1 & $(0.2)$ & 1.9 & $(0.5)$ & 9.4 & (1.1) & 31.2 & (1.9) & 21.4 & (1.3) & 33.3 & (1.9) & 1.7 & $(0.2)$ \\
\hline Iceland & 3.0 & $(0.3)$ & 12.6 & $(0.5)$ & 51.3 & $(0.8)$ & 17.3 & $(0.6)$ & 6.7 & $(0.4)$ & 2.9 & $(0.3)$ & 6.3 & $(0.5)$ \\
\hline Ireland & 9.1 & $(1.2)$ & 76.8 & (1.8) & 10.1 & (1.5) & 1.0 & $(0.2)$ & 0.6 & $(0.1)$ & 2.5 & $(0.3)$ & 0.0 & c \\
\hline Israel & 9.4 & $(1.2)$ & 26.2 & $(1.7)$ & 47.4 & (1.7) & 3.7 & $(0.3)$ & 2.3 & $(0.2)$ & 2.6 & $(0.3)$ & 8.3 & $(0.5)$ \\
\hline Italy & $\mathrm{m}$ & $\mathrm{m}$ & $\mathrm{m}$ & $\mathrm{m}$ & $\mathrm{m}$ & $\mathrm{m}$ & $\mathrm{m}$ & $\mathrm{m}$ & $\mathrm{m}$ & $\mathrm{m}$ & $\mathrm{m}$ & $\mathrm{m}$ & $\mathrm{m}$ & $\mathrm{m}$ \\
\hline Japan & 0.1 & $(0.0)$ & 5.1 & (1.3) & 40.3 & (2.5) & 51.4 & (2.4) & 2.5 & $(0.5)$ & 0.4 & $(0.1)$ & 0.3 & $(0.1)$ \\
\hline Korea & 0.5 & $(0.1)$ & 7.3 & (1.7) & 73.1 & (2.1) & 13.2 & $(1.2)$ & 3.7 & $(0.7)$ & 2.1 & $(0.5)$ & 0.0 & c \\
\hline Latvia & 5.3 & $(0.4)$ & 14.4 & (1.5) & 65.2 & (1.6) & 6.9 & $(0.7)$ & 1.8 & $(0.2)$ & 6.4 & $(0.4)$ & 0.0 & c \\
\hline Luxembourg & 2.4 & $(0.2)$ & 58.2 & $(0.5)$ & 27.7 & $(0.4)$ & 5.1 & $(0.3)$ & 2.2 & $(0.2)$ & 4.3 & $(0.2)$ & 0.0 & C \\
\hline Mexico & 22.9 & $(2.2)$ & 27.3 & (1.9) & 34.1 & $(2.2)$ & 5.9 & (1.1) & 2.1 & $(0.3)$ & 2.5 & $(0.2)$ & 5.1 & $(0.3)$ \\
\hline Netherlands & 3.7 & $(0.5)$ & 61.6 & (2.1) & 27.6 & (2.0) & 4.7 & $(0.6)$ & 1.4 & $(0.4)$ & 1.0 & $(0.2)$ & 0.0 & c \\
\hline New Zealand & 40.4 & (1.6) & 6.9 & (1.1) & 11.9 & (1.2) & 10.1 & (1.0) & 18.6 & $(1.0)$ & 9.6 & $(0.7)$ & 2.5 & $(0.3)$ \\
\hline Norway & 0.7 & $(0.1)$ & 36.1 & (2.3) & 50.2 & (2.0) & 9.7 & $(0.9)$ & 1.4 & $(0.4)$ & 1.0 & $(0.3)$ & 1.0 & $(0.2)$ \\
\hline Poland & 0.7 & $(0.1)$ & 1.0 & $(0.4)$ & 22.7 & (2.9) & 30.4 & $(2.3)$ & 39.8 & $(2.9)$ & 5.4 & $(0.8)$ & 0.0 & c \\
\hline Portugal & 0.6 & $(0.2)$ & 9.2 & (1.1) & 81.0 & (1.7) & 5.4 & (1.3) & 1.0 & $(0.1)$ & 0.5 & $(0.1)$ & 2.3 & $(0.2)$ \\
\hline Slovak Republic & 4.0 & $(0.4)$ & 14.3 & (1.7) & 65.4 & (1.9) & 10.5 & (1.3) & 2.3 & $(0.4)$ & 3.4 & $(0.3)$ & 0.0 & c \\
\hline Slovenia & 1.1 & $(0.2)$ & 19.1 & $(0.3)$ & 54.6 & $(0.5)$ & 20.8 & $(0.5)$ & 1.8 & $(0.2)$ & 2.6 & $(0.2)$ & 0.0 & c \\
\hline Spain & 1.7 & $(0.2)$ & 9.4 & (1.8) & 86.4 & (1.9) & 1.0 & $(0.2)$ & 0.4 & $(0.1)$ & 1.1 & $(0.2)$ & 0.0 & c \\
\hline Sweden & 2.1 & $(0.3)$ & 16.2 & (1.6) & 64.0 & $(2.0)$ & 5.6 & (1.0) & 2.2 & $(0.5)$ & 1.8 & $(0.2)$ & 8.1 & $(0.5)$ \\
\hline Switzerland & 4.0 & (0.5) & 22.3 & (1.6) & 58.0 & (1.8) & 10.1 & (1.1) & 1.8 & $(0.2)$ & 2.0 & $(0.2)$ & 1.9 & $(0.2)$ \\
\hline Turkey & 5.0 & (1.4) & 46.6 & (1.7) & 23.7 & (1.3) & 2.4 & $(0.2)$ & 4.1 & $(0.5)$ & 18.3 & $(0.9)$ & 0.0 & C \\
\hline United Kingdom & 4.4 & (0.4) & 38.1 & $(2.1)$ & 34.7 & (1.9) & 11.5 & $(0.7)$ & 6.2 & (0.4) & 5.1 & $(0.3)$ & 0.0 & C \\
\hline United States & 41.0 & (1.4) & 2.6 & $(0.4)$ & 6.2 & $(1.2)$ & 12.0 & (1.5) & 5.2 & $(0.9)$ & 33.0 & $(2.1)$ & 0.0 & C \\
\hline OECD average & 6.9 & $(0.1)$ & 30.8 & $(0.3)$ & 39.4 & $(0.3)$ & 10.1 & $(0.2)$ & 4.7 & $(0.1)$ & 6.6 & $(0.1)$ & 1.4 & $(0.0)$ \\
\hline
\end{tabular}

\begin{tabular}{|c|c|c|c|c|c|c|c|c|c|c|c|c|c|c|}
\hline Albania & $\mathrm{m}$ & $\mathrm{m}$ & $\mathrm{m}$ & $\mathrm{m}$ & $\mathrm{m}$ & $\mathrm{m}$ & $\mathrm{m}$ & $\mathrm{m}$ & $\mathrm{m}$ & $\mathrm{m}$ & $\mathrm{m}$ & $\mathrm{m}$ & $\mathrm{m}$ & $\mathrm{m}$ \\
\hline Algeria & $\mathrm{m}$ & $\mathrm{m}$ & $\mathrm{m}$ & $\mathrm{m}$ & $\mathrm{m}$ & $\mathrm{m}$ & $\mathrm{m}$ & $\mathrm{m}$ & $\mathrm{m}$ & $\mathrm{m}$ & $\mathrm{m}$ & $\mathrm{m}$ & $\mathrm{m}$ & $\mathrm{m}$ \\
\hline Brazil & 11.5 & $(0.8)$ & 37.9 & $(1.3)$ & 35.4 & $(1.2)$ & 3.5 & $(0.2)$ & 1.7 & $(0.1)$ & 3.1 & $(0.2)$ & 7.0 & $(0.3)$ \\
\hline B-S-J-G (China) & 1.0 & $(0.2)$ & 14.2 & (2.0) & 50.8 & (2.5) & 24.6 & (2.0) & 4.9 & $(0.8)$ & 3.5 & $(0.4)$ & 1.1 & $(0.1)$ \\
\hline Bulgaria & 2.3 & $(0.2)$ & 5.6 & (1.1) & 50.0 & (1.9) & 25.5 & (1.6) & 3.8 & $(0.3)$ & 4.0 & $(0.5)$ & 8.9 & $(0.5)$ \\
\hline CABA (Argentina) & $\mathrm{m}$ & $\mathrm{m}$ & $\mathrm{m}$ & $\mathrm{m}$ & $\mathrm{m}$ & $\mathrm{m}$ & $\mathrm{m}$ & $\mathrm{m}$ & $\mathrm{m}$ & $\mathrm{m}$ & $\mathrm{m}$ & $\mathrm{m}$ & $\mathrm{m}$ & $\mathrm{m}$ \\
\hline Colombia & 3.0 & $(0.6)$ & 65.2 & $(2.0)$ & 18.6 & $(1.7)$ & 1.5 & $(0.2)$ & 1.2 & $(0.2)$ & 4.6 & $(0.3)$ & 6.0 & $(0.4)$ \\
\hline Costa Rica & 8.0 & (1.5) & 88.8 & $(1.7)$ & 2.0 & $(0.6)$ & 0.2 & $(0.1)$ & 0.1 & $(0.0)$ & 0.9 & $(0.1)$ & 0.0 & c \\
\hline Croatia & 1.1 & $(0.2)$ & 35.3 & (2.6) & 61.2 & (2.6) & 1.1 & $(0.2)$ & 0.5 & $(0.1)$ & 0.4 & $(0.1)$ & 0.5 & $(0.1)$ \\
\hline Cyprus* & 2.8 & $(0.2)$ & 20.6 & $(0.4)$ & 54.4 & $(0.5)$ & 10.6 & $(0.4)$ & 2.9 & $(0.2)$ & 8.7 & $(0.4)$ & 0.0 & c \\
\hline Dominican Republic & 7.9 & $(0.7)$ & 25.1 & $(2.2)$ & 32.6 & $(2.3)$ & 6.1 & $(0.9)$ & 3.1 & $(0.4)$ & 25.3 & (1.1) & 0.0 & c \\
\hline FYROM & $\mathrm{m}$ & $\mathrm{m}$ & $\mathrm{m}$ & $\mathrm{m}$ & $\mathrm{m}$ & $\mathrm{m}$ & $\mathrm{m}$ & $\mathrm{m}$ & $\mathrm{m}$ & $\mathrm{m}$ & $\mathrm{m}$ & $\mathrm{m}$ & $\mathrm{m}$ & $\mathrm{m}$ \\
\hline Georgia & $\mathrm{m}$ & $\mathrm{m}$ & $\mathrm{m}$ & $\mathrm{m}$ & $\mathrm{m}$ & $\mathrm{m}$ & $\mathrm{m}$ & $\mathrm{m}$ & $\mathrm{m}$ & $\mathrm{m}$ & $\mathrm{m}$ & $\mathrm{m}$ & $\mathrm{m}$ & $\mathrm{m}$ \\
\hline Hong Kong (China) & 1.3 & $(0.2)$ & 89.8 & (1.4) & 7.0 & (1.3) & 0.6 & $(0.1)$ & 0.4 & $(0.1)$ & 0.9 & $(0.1)$ & 0.0 & c \\
\hline Indonesia & $\mathrm{m}$ & $\mathrm{m}$ & $\mathrm{m}$ & $\mathrm{m}$ & $\mathrm{m}$ & $\mathrm{m}$ & $\mathrm{m}$ & $\mathrm{m}$ & $\mathrm{m}$ & $\mathrm{m}$ & $\mathrm{m}$ & $\mathrm{m}$ & $\mathrm{m}$ & $\mathrm{m}$ \\
\hline Jordan & $\mathrm{m}$ & $\mathrm{m}$ & $\mathrm{m}$ & $\mathrm{m}$ & $\mathrm{m}$ & $\mathrm{m}$ & $\mathrm{m}$ & $\mathrm{m}$ & $\mathrm{m}$ & $\mathrm{m}$ & $\mathrm{m}$ & $\mathrm{m}$ & $\mathrm{m}$ & $\mathrm{m}$ \\
\hline Kosovo & $\mathrm{m}$ & $\mathrm{m}$ & $\mathrm{m}$ & $\mathrm{m}$ & $\mathrm{m}$ & $\mathrm{m}$ & $\mathrm{m}$ & $\mathrm{m}$ & $\mathrm{m}$ & $\mathrm{m}$ & $\mathrm{m}$ & $\mathrm{m}$ & $\mathrm{m}$ & $\mathrm{m}$ \\
\hline Lebanon & $\mathrm{m}$ & $\mathrm{m}$ & $\mathrm{m}$ & $\mathrm{m}$ & $\mathrm{m}$ & $\mathrm{m}$ & $\mathrm{m}$ & $\mathrm{m}$ & $\mathrm{m}$ & $\mathrm{m}$ & $\mathrm{m}$ & $\mathrm{m}$ & $\mathrm{m}$ & $\mathrm{m}$ \\
\hline Lithuania & 7.1 & $(0.4)$ & 6.0 & $(0.6)$ & 75.2 & (1.1) & 4.3 & $(0.7)$ & 1.6 & $(0.1)$ & 5.6 & $(0.4)$ & 0.0 & c \\
\hline Macao (China) & 1.2 & $(0.1)$ & 45.4 & $(0.3)$ & 46.1 & $(0.3)$ & 3.7 & $(0.2)$ & 1.1 & $(0.1)$ & 2.0 & $(0.2)$ & 0.6 & $(0.1)$ \\
\hline Malta & $\mathrm{m}$ & $\mathrm{m}$ & $\mathrm{m}$ & $\mathrm{m}$ & $\mathrm{m}$ & $\mathrm{m}$ & $\mathrm{m}$ & $\mathrm{m}$ & $\mathrm{m}$ & $\mathrm{m}$ & $\mathrm{m}$ & $\mathrm{m}$ & $\mathrm{m}$ & $\mathrm{m}$ \\
\hline Moldova & $\mathrm{m}$ & $\mathrm{m}$ & $\mathrm{m}$ & $\mathrm{m}$ & $\mathrm{m}$ & $\mathrm{m}$ & $\mathrm{m}$ & $\mathrm{m}$ & $\mathrm{m}$ & $\mathrm{m}$ & $\mathrm{m}$ & $\mathrm{m}$ & $\mathrm{m}$ & $\mathrm{m}$ \\
\hline Montenegro & 3.3 & $(0.3)$ & 5.8 & $(0.3)$ & 53.6 & $(0.7)$ & 8.7 & $(0.4)$ & 3.3 & $(0.3)$ & 4.7 & $(0.3)$ & 20.7 & $(0.6)$ \\
\hline Peru & 3.0 & $(0.5)$ & 64.1 & $(2.0)$ & 17.0 & (1.8) & 1.7 & $(0.4)$ & 1.2 & $(0.2)$ & 13.1 & $(0.5)$ & 0.0 & c \\
\hline Qatar & 13.0 & $(0.3)$ & 42.0 & $(0.4)$ & 17.3 & $(0.3)$ & 8.3 & $(0.3)$ & 4.5 & $(0.2)$ & 15.0 & $(0.3)$ & 0.0 & c \\
\hline Romania & $\mathrm{m}$ & $\mathrm{m}$ & $\mathrm{m}$ & $\mathrm{m}$ & $\mathrm{m}$ & $\mathrm{m}$ & $\mathrm{m}$ & $\mathrm{m}$ & $\mathrm{m}$ & $\mathrm{m}$ & $\mathrm{m}$ & $\mathrm{m}$ & $\mathrm{m}$ & $\mathrm{m}$ \\
\hline Russia & 3.8 & $(0.8)$ & 3.8 & $(0.8)$ & 17.6 & (1.5) & 61.9 & $(2.0)$ & 3.8 & $(0.4)$ & 1.8 & $(0.2)$ & 7.3 & $(0.5)$ \\
\hline Singapore & 2.5 & (0.5) & 38.8 & (1.0) & 49.4 & $(0.4)$ & 6.9 & $(0.6)$ & 1.0 & $(0.1)$ & 1.4 & $(0.2)$ & 0.0 & c \\
\hline Chinese Taipei & 0.9 & $(0.2)$ & 22.5 & $(2.1)$ & 71.4 & $(2.2)$ & 3.0 & $(0.5)$ & 0.5 & $(0.1)$ & 1.8 & $(0.2)$ & 0.0 & c \\
\hline Thailand & 8.2 & $(0.9)$ & 74.5 & (1.4) & 9.1 & $(0.9)$ & 2.0 & $(0.2)$ & 0.9 & $(0.1)$ & 5.3 & $(0.4)$ & 0.0 & c \\
\hline Trinidad and Tobago & $\mathrm{m}$ & $\mathrm{m}$ & $\mathrm{m}$ & $\mathrm{m}$ & $\mathrm{m}$ & $\mathrm{m}$ & $\mathrm{m}$ & $\mathrm{m}$ & $\mathrm{m}$ & $\mathrm{m}$ & $\mathrm{m}$ & $\mathrm{m}$ & $\mathrm{m}$ & $\mathrm{m}$ \\
\hline Tunisia & 9.1 & $(0.9)$ & 35.6 & $(2.0)$ & 34.6 & (1.8) & 8.7 & $(0.8)$ & 2.7 & $(0.3)$ & 9.3 & $(0.5)$ & 0.0 & c \\
\hline United Arab Emirates & 8.3 & $(0.7)$ & 40.7 & $(1.2)$ & 32.4 & $(1.2)$ & 5.1 & $(0.3)$ & 2.3 & $(0.1)$ & 11.1 & $(0.4)$ & 0.0 & c \\
\hline Uruguay & 19.2 & $(0.9)$ & 11.3 & (1.1) & 52.8 & (1.3) & 4.9 & $(0.4)$ & 1.6 & $(0.2)$ & 3.9 & $(0.3)$ & 6.3 & $(0.4)$ \\
\hline Viet Nam & $\mathrm{m}$ & $\mathrm{m}$ & $\mathrm{m}$ & $\mathrm{m}$ & $\mathrm{m}$ & $\mathrm{m}$ & $\mathrm{m}$ & $\mathrm{m}$ & $\mathrm{m}$ & $\mathrm{m}$ & $\mathrm{m}$ & $\mathrm{m}$ & $\mathrm{m}$ & $\mathrm{m}$ \\
\hline Argentina** & $\mathrm{m}$ & $\mathrm{m}$ & $\mathrm{m}$ & $\mathrm{m}$ & $\mathrm{m}$ & $\mathrm{m}$ & $\mathrm{m}$ & $\mathrm{m}$ & $\mathrm{m}$ & $\mathrm{m}$ & $\mathrm{m}$ & $\mathrm{m}$ & $\mathrm{m}$ & $\mathrm{m}$ \\
\hline Kazakhstan** & $\mathrm{m}$ & $\mathrm{m}$ & $\mathrm{m}$ & $\mathrm{m}$ & $\mathrm{m}$ & $\mathrm{m}$ & $\mathrm{m}$ & $\mathrm{m}$ & $\mathrm{m}$ & $\mathrm{m}$ & $\mathrm{m}$ & $\mathrm{m}$ & $\mathrm{m}$ & $\mathrm{m}$ \\
\hline Malaysia** & 2.2 & $(0.4)$ & 50.3 & (2.6) & 34.3 & $(2.7)$ & 3.5 & $(0.3)$ & 2.0 & $(0.2)$ & 7.7 & $(0.5)$ & 0.0 & c \\
\hline
\end{tabular}

* See note at the beginning of this Annex.

** Coverage is too small to ensure comparability (see Annex A4).

StatLink त्ना15L http://dx.doi.org/10.1787/888933472525 
[Part 1/1]

Table III.11.4a Physical activity at school, by student performance in science

Results based on students' self-reports

\begin{tabular}{|c|c|c|c|c|c|c|c|c|c|c|c|c|c|}
\hline & \multicolumn{12}{|c|}{ Science performance } \\
\hline & & \multicolumn{6}{|c|}{$\begin{array}{l}\text { Average number of days students attend physical education class } \\
\text { in school, by science performance }\end{array}$} & \multicolumn{6}{|c|}{$\begin{array}{c}\text { Change in science score associated with one additional day } \\
\text { of physical education }\end{array}$} \\
\hline & & $\begin{array}{l}\text { Bottom } \\
\text { science }\end{array}$ & $\begin{array}{l}\text { arter of } \\
\text { ormance }\end{array}$ & $\begin{array}{r}\text { Top quar } \\
\text { perf }\end{array}$ & $\begin{array}{l}\text { of science } \\
\text { lance }\end{array}$ & $\begin{array}{r}\text { Differe } \\
\text { top a } \\
\text { quarte } \\
\text { per } \\
\text { (top }\end{array}$ & $\begin{array}{l}\text { between } \\
\text { pottom } \\
\text { science } \\
\text { pance } \\
\text { ttom) }\end{array}$ & $\begin{array}{r}\text { Before ac } \\
\text { for student } \\
\text { socio-ec } \\
\text { pro }\end{array}$ & $\begin{array}{l}\text { unting } \\
\text { d school } \\
\text { omic } \\
1\end{array}$ & $\begin{array}{r}\text { Explair } \\
\text { in studen } \\
(r-s q u\end{array}$ & $\begin{array}{l}\text { ariance } \\
\text { formance } \\
x \mathbf{1 0 0} \text { ) }\end{array}$ & $\begin{array}{l}\text { After acc } \\
\text { students' a } \\
\text { socio-econ }\end{array}$ & $\begin{array}{l}\text { ting for } \\
\text { schools' } \\
\text { ic profile }\end{array}$ \\
\hline & & Mean & S.E. & Mean & S.E. & Dif. & S.E. & Score dif. & S.E. & $\%$ & S.E. & Score dif. & S.E. \\
\hline 0 & Australia & 2.60 & $(0.04)$ & 1.81 & $(0.04)$ & -0.79 & $(0.06)$ & -15 & (0.9) & 4.5 & $(0.6)$ & -13 & $(0.8)$ \\
\hline & Austria & 1.48 & $(0.05)$ & 1.20 & $(0.04)$ & -0.28 & $(0.06)$ & -9 & (1.9) & 0.9 & $(0.4)$ & -11 & (1.6) \\
\hline$\overline{0}$ & Belgium & 1.65 & $(0.04)$ & 1.55 & $(0.04)$ & -0.10 & $(0.05)$ & -5 & (2.3) & 0.2 & $(0.2)$ & -8 & (1.6) \\
\hline & Canada & 3.19 & $(0.05)$ & 2.25 & $(0.06)$ & -0.94 & $(0.08)$ & -8 & $(0.5)$ & 3.1 & $(0.4)$ & -7 & $(0.5)$ \\
\hline & Chile & 2.17 & $(0.06)$ & 1.54 & $(0.05)$ & -0.62 & $(0.08)$ & -14 & (1.4) & 4.0 & $(0.8)$ & -11 & $(1.2)$ \\
\hline & Czech Republic & 1.93 & $(0.05)$ & 1.62 & $(0.05)$ & -0.31 & $(0.06)$ & -12 & (2.0) & 1.5 & $(0.5)$ & -9 & $(1.8)$ \\
\hline & Denmark & 1.58 & $(0.06)$ & 1.30 & $(0.04)$ & -0.28 & $(0.06)$ & -10 & (1.8) & 1.3 & $(0.4)$ & -9 & (1.5) \\
\hline & Estonia & 1.88 & $(0.03)$ & 1.59 & $(0.03)$ & -0.29 & $(0.04)$ & -17 & (2.1) & 2.4 & $(0.6)$ & -13 & $(2.2)$ \\
\hline & Finland & 2.19 & $(0.04)$ & 1.52 & $(0.03)$ & -0.68 & $(0.05)$ & -21 & (1.4) & 5.8 & $(0.8)$ & -20 & (1.4) \\
\hline & France & 1.86 & $(0.05)$ & 1.12 & $(0.02)$ & -0.74 & $(0.05)$ & -30 & (1.8) & 8.6 & $(0.9)$ & -16 & (1.4) \\
\hline & Germany & 1.66 & $(0.05)$ & 1.29 & $(0.03)$ & -0.36 & $(0.07)$ & -19 & (2.7) & 2.9 & $(0.9)$ & -13 & (1.9) \\
\hline & Greece & 2.85 & $(0.07)$ & 2.07 & $(0.03)$ & -0.78 & $(0.07)$ & -12 & $(0.9)$ & 3.8 & $(0.5)$ & -8 & $(0.8)$ \\
\hline & Hungary & 3.55 & $(0.08)$ & 3.77 & $(0.08)$ & 0.22 & $(0.12)$ & 5 & (2.9) & 0.5 & $(0.5)$ & 1 & (1.6) \\
\hline & Iceland & 2.72 & $(0.07)$ & 2.28 & $(0.04)$ & -0.44 & $(0.08)$ & -8 & (1.1) & 1.5 & $(0.4)$ & -7 & $(1.1)$ \\
\hline & Ireland & 1.31 & $(0.04)$ & 1.06 & $(0.04)$ & -0.25 & $(0.04)$ & -13 & $(2.2)$ & 1.5 & $(0.4)$ & -12 & (1.5) \\
\hline & Israel & 2.61 & $(0.08)$ & 1.72 & $(0.06)$ & -0.89 & $(0.09)$ & -12 & (1.1) & 4.1 & $(0.8)$ & -8 & $(1.0)$ \\
\hline & Italy & $\mathrm{m}$ & $\mathrm{m}$ & $\mathrm{m}$ & $\mathrm{m}$ & $\mathrm{m}$ & $\mathrm{m}$ & $\mathrm{m}$ & $\mathrm{m}$ & $\mathrm{m}$ & $\mathrm{m}$ & $\mathrm{m}$ & $\mathrm{m}$ \\
\hline & Japan & 2.65 & $(0.04)$ & 2.44 & $(0.05)$ & -0.21 & $(0.06)$ & -16 & $(4.8)$ & 1.5 & $(0.8)$ & -7 & (3.4) \\
\hline & Korea & 2.26 & $(0.05)$ & 2.16 & $(0.04)$ & -0.10 & $(0.05)$ & -7 & (3.3) & 0.3 & $(0.3)$ & -9 & $(2.3)$ \\
\hline & Latvia & 2.30 & $(0.06)$ & 1.91 & $(0.03)$ & -0.39 & $(0.06)$ & -11 & (1.5) & 2.0 & $(0.6)$ & -9 & (1.3) \\
\hline & Luxembourg & 1.82 & $(0.03)$ & 1.48 & $(0.03)$ & -0.34 & $(0.05)$ & -12 & (1.4) & 1.5 & $(0.3)$ & -14 & (1.2) \\
\hline & Mexico & 1.98 & $(0.07)$ & 1.39 & $(0.08)$ & -0.59 & $(0.08)$ & -7 & $(0.9)$ & 2.3 & $(0.6)$ & -6 & $(0.8)$ \\
\hline & Netherlands & 1.61 & $(0.05)$ & 1.23 & $(0.03)$ & -0.38 & $(0.05)$ & -22 & $(3.0)$ & 3.1 & $(0.8)$ & -9 & $(2.3)$ \\
\hline & New Zealand & 2.56 & $(0.08)$ & 1.37 & $(0.07)$ & -1.19 & $(0.11)$ & -12 & $(0.9)$ & 5.5 & $(0.8)$ & -11 & $(0.9)$ \\
\hline & Norway & 1.90 & $(0.06)$ & 1.75 & $(0.04)$ & -0.15 & $(0.05)$ & -8 & $(2.1)$ & 0.5 & $(0.3)$ & -8 & $(2.1)$ \\
\hline & Poland & 3.34 & $(0.07)$ & 3.13 & $(0.07)$ & -0.21 & $(0.08)$ & -9 & $(2.9)$ & 0.9 & $(0.6)$ & -4 & $(2.1)$ \\
\hline & Portugal & 2.28 & $(0.04)$ & 2.04 & $(0.03)$ & -0.24 & $(0.05)$ & -11 & (1.7) & 1.1 & $(0.3)$ & -11 & (1.5) \\
\hline & Slovak Republic & 2.12 & $(0.05)$ & 1.94 & $(0.05)$ & -0.18 & $(0.06)$ & -9 & (2.5) & 0.7 & $(0.4)$ & -6 & (1.9) \\
\hline & Slovenia & 2.00 & $(0.03)$ & 2.20 & $(0.02)$ & 0.20 & $(0.04)$ & 10 & (1.7) & 0.9 & $(0.3)$ & 0 & (1.4) \\
\hline & Spain & 1.95 & $(0.02)$ & 1.91 & $(0.03)$ & -0.05 & $(0.03)$ & -7 & (2.9) & 0.2 & $(0.2)$ & -2 & (2.8) \\
\hline & Sweden & 2.68 & $(0.07)$ & 2.03 & $(0.05)$ & -0.65 & $(0.08)$ & -10 & (1.1) & 2.5 & $(0.5)$ & -8 & (1.0) \\
\hline & Switzerland & 2.19 & $(0.05)$ & 1.84 & $(0.04)$ & -0.35 & $(0.06)$ & -13 & $(2.2)$ & 1.7 & $(0.6)$ & -11 & (1.9) \\
\hline & Turkey & 2.37 & $(0.06)$ & 1.80 & $(0.06)$ & -0.58 & $(0.09)$ & -7 & (0.9) & 2.0 & $(0.5)$ & -6 & (1.0) \\
\hline & United Kingdom & 2.16 & $(0.05)$ & 1.76 & $(0.04)$ & -0.40 & $(0.06)$ & -12 & (1.4) & 2.0 & $(0.5)$ & -13 & $(1.2)$ \\
\hline & United States & 2.70 & $(0.10)$ & 1.94 & $(0.12)$ & -0.75 & $(0.15)$ & -6 & $(1.1)$ & 1.8 & $(0.6)$ & -5 & $(0.9)$ \\
\hline & OECD average & 2.24 & $(0.01)$ & 1.82 & $(0.01)$ & -0.41 & $(0.01)$ & -11 & $(0.4)$ & 2.3 & $(0.1)$ & -9 & $(0.3)$ \\
\hline$n$ & Albania & $\mathrm{m}$ & $\mathrm{m}$ & $\mathrm{m}$ & $\mathrm{m}$ & $\mathrm{m}$ & $\mathrm{m}$ & $\mathrm{m}$ & $\mathrm{m}$ & $\mathrm{m}$ & $\mathrm{m}$ & $\mathrm{m}$ & $\mathrm{m}$ \\
\hline$\Xi$ & Algeria & $\mathrm{m}$ & $\mathrm{m}$ & $\mathrm{m}$ & $\mathrm{m}$ & $\mathrm{m}$ & $\mathrm{m}$ & $\mathrm{m}$ & $\mathrm{m}$ & $\mathrm{m}$ & $\mathrm{m}$ & $\mathrm{m}$ & $\mathrm{m}$ \\
\hline ปั & Brazil & 2.42 & $(0.06)$ & 1.45 & $(0.04)$ & -0.97 & $(0.07)$ & -12 & $(0.8)$ & 4.9 & $(0.6)$ & -9 & $(0.7)$ \\
\hline$\alpha$ & B-S-J-G (China) & 2.23 & $(0.06)$ & 2.54 & $(0.07)$ & 0.31 & $(0.09)$ & 11 & (3.0) & 1.1 & $(0.7)$ & -2 & (2.1) \\
\hline & Bulgaria & 3.00 & $(0.07)$ & 2.45 & $(0.06)$ & -0.55 & $(0.09)$ & -10 & (1.3) & 2.2 & $(0.6)$ & -5 & (1.0) \\
\hline & CABA (Argentina) & $\mathrm{m}$ & $\mathrm{m}$ & $\mathrm{m}$ & $\mathrm{m}$ & $\mathrm{m}$ & $\mathrm{m}$ & $\mathrm{m}$ & $\mathrm{m}$ & $\mathrm{m}$ & $\mathrm{m}$ & $\mathrm{m}$ & $\mathrm{m}$ \\
\hline & Colombia & 2.17 & $(0.08)$ & 1.39 & $(0.04)$ & -0.78 & $(0.09)$ & -11 & (1.0) & 4.2 & $(0.7)$ & -9 & $(0.8)$ \\
\hline & Costa Rica & 1.01 & $(0.03)$ & 0.98 & $(0.01)$ & -0.03 & $(0.03)$ & -3 & (3.3) & 0.0 & $(0.1)$ & -5 & $(2.1)$ \\
\hline & Croatia & 1.69 & $(0.04)$ & 1.69 & $(0.04)$ & -0.01 & $(0.05)$ & -1 & (3.8) & 0.0 & $(0.1)$ & -3 & (2.8) \\
\hline & Cyprus* & 2.36 & $(0.04)$ & 1.94 & $(0.03)$ & -0.42 & $(0.05)$ & -12 & $(1.2)$ & 2.1 & $(0.4)$ & -8 & (1.1) \\
\hline & Dominican Republic & 2.95 & $(0.10)$ & 1.90 & $(0.07)$ & -1.05 & $(0.12)$ & -10 & (1.1) & 5.8 & (1.0) & -7 & $(0.8)$ \\
\hline & FYROM & $\mathrm{m}$ & $\mathrm{m}$ & $\mathrm{m}$ & $\mathrm{m}$ & $\mathrm{m}$ & $\mathrm{m}$ & $\mathrm{m}$ & $\mathrm{m}$ & $\mathrm{m}$ & $\mathrm{m}$ & $\mathrm{m}$ & $\mathrm{m}$ \\
\hline & Georgia & $\mathrm{m}$ & $\mathrm{m}$ & $\mathrm{m}$ & $\mathrm{m}$ & $\mathrm{m}$ & $\mathrm{m}$ & $\mathrm{m}$ & $\mathrm{m}$ & $\mathrm{m}$ & $\mathrm{m}$ & $\mathrm{m}$ & $\mathrm{m}$ \\
\hline & Hong Kong (China) & 1.21 & $(0.03)$ & 1.08 & $(0.03)$ & -0.13 & $(0.04)$ & -16 & (4.3) & 1.0 & $(0.5)$ & -17 & (3.3) \\
\hline & Indonesia & $\mathrm{m}$ & $\mathrm{m}$ & $\mathrm{m}$ & $\mathrm{m}$ & $\mathrm{m}$ & $\mathrm{m}$ & $\mathrm{m}$ & $\mathrm{m}$ & $\mathrm{m}$ & $\mathrm{m}$ & $\mathrm{m}$ & $\mathrm{m}$ \\
\hline & Jordan & $\mathrm{m}$ & $\mathrm{m}$ & $\mathrm{m}$ & $\mathrm{m}$ & $\mathrm{m}$ & $\mathrm{m}$ & $\mathrm{m}$ & $\mathrm{m}$ & $\mathrm{m}$ & $\mathrm{m}$ & $\mathrm{m}$ & $\mathrm{m}$ \\
\hline & Kosovo & $\mathrm{m}$ & $\mathrm{m}$ & $\mathrm{m}$ & $\mathrm{m}$ & $\mathrm{m}$ & $\mathrm{m}$ & $\mathrm{m}$ & $\mathrm{m}$ & $\mathrm{m}$ & $\mathrm{m}$ & $\mathrm{m}$ & $\mathrm{m}$ \\
\hline & Lebanon & $\mathrm{m}$ & $\mathrm{m}$ & $\mathrm{m}$ & $\mathrm{m}$ & $\mathrm{m}$ & $\mathrm{m}$ & $\mathrm{m}$ & $\mathrm{m}$ & $\mathrm{m}$ & $\mathrm{m}$ & $\mathrm{m}$ & $\mathrm{m}$ \\
\hline & Lithuania & 2.16 & $(0.04)$ & 1.93 & $(0.03)$ & -0.22 & $(0.05)$ & -8 & (1.4) & 0.8 & $(0.3)$ & -6 & $(1.2)$ \\
\hline & Macao (China) & 1.80 & $(0.04)$ & 1.57 & $(0.02)$ & -0.23 & $(0.05)$ & -10 & (1.7) & 1.2 & $(0.4)$ & -10 & (1.7) \\
\hline & Malta & $\mathrm{m}$ & $\mathrm{m}$ & $\mathrm{m}$ & $\mathrm{m}$ & $\mathrm{m}$ & $\mathrm{m}$ & $\mathrm{m}$ & $\mathrm{m}$ & $\mathrm{m}$ & $\mathrm{m}$ & $\mathrm{m}$ & $\mathrm{m}$ \\
\hline & Moldova & $\mathrm{m}$ & $\mathrm{m}$ & $\mathrm{m}$ & $\mathrm{m}$ & $\mathrm{m}$ & $\mathrm{m}$ & $\mathrm{m}$ & $\mathrm{m}$ & $\mathrm{m}$ & $\mathrm{m}$ & $\mathrm{m}$ & $\mathrm{m}$ \\
\hline & Montenegro & 3.68 & $(0.09)$ & 2.65 & $(0.05)$ & -1.04 & $(0.10)$ & -8 & (0.6) & 3.6 & $(0.6)$ & -7 & $(0.6)$ \\
\hline & Peru & 2.25 & $(0.06)$ & 1.33 & $(0.04)$ & -0.92 & $(0.07)$ & -14 & (0.9) & 6.3 & $(0.8)$ & -9 & $(0.7)$ \\
\hline & Qatar & 2.30 & $(0.05)$ & 1.56 & $(0.02)$ & -0.75 & $(0.05)$ & -11 & $(0.6)$ & 3.1 & $(0.3)$ & -8 & $(0.6)$ \\
\hline & Romania & $\mathrm{m}$ & $\mathrm{m}$ & $\mathrm{m}$ & $\mathrm{m}$ & $\mathrm{m}$ & $\mathrm{m}$ & $\mathrm{m}$ & $\mathrm{m}$ & $\mathrm{m}$ & $\mathrm{m}$ & $\mathrm{m}$ & $\mathrm{m}$ \\
\hline & Russia & 3.31 & $(0.09)$ & 2.71 & $(0.05)$ & -0.60 & $(0.10)$ & -10 & (1.6) & 3.0 & $(0.9)$ & -9 & (1.5) \\
\hline & Singapore & 1.89 & $(0.03)$ & 1.58 & $(0.03)$ & -0.32 & $(0.03)$ & -21 & (1.8) & 2.7 & $(0.5)$ & -19 & $(2.2)$ \\
\hline & Chinese Taipei & 1.84 & $(0.03)$ & 1.86 & $(0.04)$ & 0.02 & $(0.05)$ & 1 & (3.7) & 0.0 & $(0.1)$ & 3 & (2.5) \\
\hline & Thailand & 1.65 & $(0.06)$ & 1.07 & $(0.02)$ & -0.58 & $(0.06)$ & -16 & $(1.2)$ & 4.4 & $(0.7)$ & -13 & (1.1) \\
\hline & Trinidad and Tobago & $\mathrm{m}$ & $\mathrm{m}$ & $\mathrm{m}$ & $\mathrm{m}$ & $\mathrm{m}$ & $\mathrm{m}$ & $\mathrm{m}$ & $\mathrm{m}$ & $\mathrm{m}$ & $\mathrm{m}$ & $\mathrm{m}$ & $\mathrm{m}$ \\
\hline & Tunisia & 2.27 & $(0.07)$ & 1.54 & $(0.05)$ & -0.73 & $(0.08)$ & -10 & $(1.0)$ & 4.4 & $(0.9)$ & -7 & $(1.0)$ \\
\hline & United Arab Emirates & 2.35 & $(0.04)$ & 1.47 & $(0.04)$ & -0.88 & $(0.06)$ & -17 & (1.1) & 5.9 & $(0.7)$ & -16 & (1.1) \\
\hline & Uruguay & 2.31 & $(0.07)$ & 1.67 & $(0.05)$ & -0.64 & $(0.09)$ & -9 & (1.1) & 2.5 & $(0.6)$ & -8 & $(0.8)$ \\
\hline & Viet Nam & $\mathrm{m}$ & $\mathrm{m}$ & $\mathrm{m}$ & $\mathrm{m}$ & $\mathrm{m}$ & $\mathrm{m}$ & $\mathrm{m}$ & $\mathrm{m}$ & $\mathrm{m}$ & $\mathrm{m}$ & $\mathrm{m}$ & $\mathrm{m}$ \\
\hline & Argentina** & $\mathrm{m}$ & $\mathrm{m}$ & $\mathrm{m}$ & $\mathrm{m}$ & $\mathrm{m}$ & $\mathrm{m}$ & $\mathrm{m}$ & $\mathrm{m}$ & $\mathrm{m}$ & $\mathrm{m}$ & $\mathrm{m}$ & $\mathrm{m}$ \\
\hline & Kazakhstan** & $\mathrm{m}$ & $\mathrm{m}$ & $\mathrm{m}$ & $\mathrm{m}$ & $\mathrm{m}$ & $\mathrm{m}$ & $\mathrm{m}$ & $\mathrm{m}$ & $\mathrm{m}$ & $\mathrm{m}$ & $\mathrm{m}$ & $\mathrm{m}$ \\
\hline & Malaysia** & 2.10 & $(0.06)$ & 1.55 & $(0.04)$ & -0.55 & $(0.06)$ & -12 & (1.3) & 3.5 & $(0.7)$ & -11 & $(1.1)$ \\
\hline
\end{tabular}

1. The socio-economic profile is measured by the PISA index of economic, social and cultural status.

Note: Values that are statistically significant are indicated in bold (see Annex A3).

* See note at the beginning of this Annex.

Coverage is too small to ensure comparability (see Annex A4).

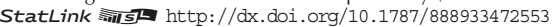


Results based on students' self-reports

\begin{tabular}{|c|c|c|c|c|c|c|c|c|c|}
\hline & \multicolumn{4}{|c|}{ Average life satisfaction, by: } & \multicolumn{4}{|c|}{$\begin{array}{c}\text { Difference in life satisfaction between students who reported attending } \\
3 \text { days or more and students who reported attending } 2 \text { days } \\
\text { or less of physical education at school }\end{array}$} \\
\hline & & \multicolumn{2}{|c|}{$\begin{array}{l}\text { Students who reported attending } \\
2 \text { days or less of physical } \\
\text { education at school }\end{array}$} & \multicolumn{2}{|c|}{$\begin{array}{l}\text { Students who reported attending } \\
3 \text { days or more of physical } \\
\text { education at school }\end{array}$} & \multicolumn{2}{|c|}{$\begin{array}{l}\text { Before accounting for students' } \\
\text { and schools' socio-economic } \\
\text { profile }^{1}\end{array}$} & $\begin{array}{l}\text { After accou } \\
\text { schools's }\end{array}$ & $\begin{array}{l}\text { students' and } \\
\text { omic profile }\end{array}$ \\
\hline & & Mean & S.E. & Mean & S.E. & Dif. & S.E. & Dif. & S.E. \\
\hline 0 & Australia & $\mathrm{m}$ & $\mathrm{m}$ & $\mathrm{m}$ & $\mathrm{m}$ & $\mathrm{m}$ & $\mathrm{m}$ & $\mathrm{m}$ & $\mathrm{m}$ \\
\hline 氙 & Austria & 7.53 & $(0.04)$ & 7.48 & $(0.08)$ & -0.05 & $(0.09)$ & -0.05 & $(0.08)$ \\
\hline 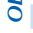 & Belgium (excl. Flemish) & 7.50 & $(0.06)$ & 7.45 & $(0.07)$ & -0.05 & $(0.09)$ & -0.06 & $(0.08)$ \\
\hline & Canada & $\mathrm{m}$ & $\mathrm{m}$ & $\mathrm{m}$ & $\mathrm{m}$ & $\mathrm{m}$ & m & $\mathrm{m}$ & $\mathrm{m}$ \\
\hline & Chile & 7.36 & $(0.05)$ & 7.37 & $(0.05)$ & 0.01 & $(0.07)$ & 0.01 & $(0.07)$ \\
\hline & Czech Republic & 6.96 & $(0.05)$ & 7.15 & $(0.05)$ & 0.19 & $(0.07)$ & 0.18 & $(0.07)$ \\
\hline & Denmark & $\mathrm{m}$ & $\mathrm{m}$ & $\mathrm{m}$ & $\mathrm{m}$ & $\mathrm{m}$ & $\mathrm{m}$ & $\mathrm{m}$ & $\mathrm{m}$ \\
\hline & Estonia & 7.41 & $(0.05)$ & 7.56 & $(0.04)$ & 0.16 & $(0.06)$ & 0.17 & $(0.06)$ \\
\hline & Finland & 7.74 & $(0.04)$ & 8.05 & $(0.04)$ & 0.31 & $(0.06)$ & 0.31 & $(0.06)$ \\
\hline & France & 7.70 & $(0.03)$ & 7.49 & $(0.06)$ & -0.21 & $(0.07)$ & -0.16 & $(0.08)$ \\
\hline & Germany & 7.34 & $(0.04)$ & 7.34 & $(0.07)$ & 0.01 & $(0.08)$ & 0.01 & $(0.08)$ \\
\hline & Greece & 6.23 & $(0.11)$ & 6.98 & $(0.03)$ & 0.75 & $(0.11)$ & 0.76 & $(0.11)$ \\
\hline & Hungary & 7.14 & $(0.28)$ & 7.17 & $(0.04)$ & 0.03 & $(0.29)$ & -0.07 & $(0.30)$ \\
\hline & Iceland & 7.48 & $(0.12)$ & 7.86 & $(0.04)$ & 0.38 & $(0.13)$ & 0.41 & $(0.13)$ \\
\hline & Ireland & 7.30 & $(0.04)$ & 7.32 & $(0.10)$ & 0.03 & $(0.11)$ & 0.03 & $(0.11)$ \\
\hline & Israel & m & $\mathrm{m}$ & $\mathrm{m}$ & $\mathrm{m}$ & $\mathrm{m}$ & $\mathrm{m}$ & $\mathrm{m}$ & $\mathrm{m}$ \\
\hline & Italy & $\mathrm{m}$ & $\mathrm{m}$ & $\mathrm{m}$ & $\mathrm{m}$ & $\mathrm{m}$ & $\mathrm{m}$ & $\mathrm{m}$ & $\mathrm{m}$ \\
\hline & Japan & 6.75 & $(0.18)$ & 6.82 & $(0.04)$ & 0.08 & $(0.19)$ & 0.14 & $(0.19)$ \\
\hline & Korea & 6.08 & $(0.12)$ & 6.39 & $(0.04)$ & 0.31 & $(0.14)$ & 0.30 & $(0.14)$ \\
\hline & Latvia & 7.11 & $(0.08)$ & 7.42 & $(0.04)$ & 0.31 & $(0.09)$ & 0.32 & $(0.09)$ \\
\hline & Luxembourg & 7.32 & $(0.04)$ & 7.46 & $(0.05)$ & 0.14 & $(0.06)$ & 0.16 & $(0.07)$ \\
\hline & Mexico & 8.27 & $(0.04)$ & 8.28 & $(0.04)$ & 0.00 & $(0.05)$ & 0.00 & $(0.05)$ \\
\hline & Netherlands & 7.82 & $(0.03)$ & 7.84 & $(0.04)$ & 0.02 & $(0.05)$ & -0.04 & $(0.05)$ \\
\hline & New Zealand & $\mathrm{m}$ & $\mathrm{m}$ & $\mathrm{m}$ & $\mathrm{m}$ & $\mathrm{m}$ & $\mathrm{m}$ & $\mathrm{m}$ & $\mathrm{m}$ \\
\hline & Norway & $\mathrm{m}$ & $\mathrm{m}$ & $\mathrm{m}$ & $\mathrm{m}$ & $\mathrm{m}$ & $\mathrm{m}$ & $\mathrm{m}$ & $\mathrm{m}$ \\
\hline & Poland & 6.97 & $(0.22)$ & 7.19 & $(0.04)$ & 0.22 & $(0.22)$ & 0.13 & $(0.20)$ \\
\hline & Portugal & 7.43 & $(0.12)$ & 7.36 & $(0.03)$ & -0.06 & $(0.12)$ & -0.10 & $(0.12)$ \\
\hline & Slovak Republic & 7.24 & $(0.08)$ & 7.53 & $(0.04)$ & 0.28 & $(0.10)$ & 0.28 & $(0.10)$ \\
\hline & Slovenia & 7.13 & $(0.07)$ & 7.18 & $(0.05)$ & 0.05 & $(0.09)$ & 0.12 & $(0.10)$ \\
\hline & Spain & 7.58 & $(0.09)$ & 7.40 & $(0.04)$ & -0.18 & $(0.10)$ & -0.13 & $(0.10)$ \\
\hline & Sweden & $\mathrm{m}$ & $\mathrm{m}$ & $\mathrm{m}$ & $\mathrm{m}$ & $\mathrm{m}$ & $\mathrm{m}$ & $\mathrm{m}$ & $\mathrm{m}$ \\
\hline & Switzerland & 7.65 & $(0.06)$ & 7.75 & $(0.04)$ & 0.10 & $(0.08)$ & 0.09 & $(0.08)$ \\
\hline & Turkey & 6.17 & $(0.08)$ & 6.08 & $(0.07)$ & -0.09 & $(0.08)$ & -0.09 & $(0.08)$ \\
\hline & United Kingdom & 6.78 & $(0.05)$ & 7.14 & $(0.05)$ & 0.36 & $(0.06)$ & 0.34 & $(0.06)$ \\
\hline & United States & 7.19 & $(0.06)$ & 7.50 & $(0.04)$ & 0.31 & $(0.07)$ & 0.31 & $(0.07)$ \\
\hline & OECD average & 7.23 & $(0.02)$ & 7.35 & $(0.01)$ & 0.13 & $(0.02)$ & 0.13 & $(0.02)$ \\
\hline 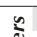 & Albania & $\mathrm{m}$ & $\mathrm{m}$ & $\mathrm{m}$ & $\mathrm{m}$ & $\mathrm{m}$ & $\mathrm{m}$ & $\mathrm{m}$ & $\mathrm{m}$ \\
\hline$\Xi$ & Algeria & $\mathrm{m}$ & $\mathrm{m}$ & $\mathrm{m}$ & $\mathrm{m}$ & $\mathrm{m}$ & $\mathrm{m}$ & $\mathrm{m}$ & $\mathrm{m}$ \\
\hline อั้ & Brazil & 7.50 & $(0.04)$ & 7.64 & $(0.04)$ & 0.13 & $(0.05)$ & 0.09 & $(0.05)$ \\
\hline & B-S-J-G (China) & 6.61 & $(0.11)$ & 6.88 & $(0.04)$ & 0.27 & $(0.12)$ & 0.22 & $(0.12)$ \\
\hline & Bulgaria & 7.23 & $(0.14)$ & 7.42 & $(0.04)$ & 0.19 & $(0.14)$ & 0.25 & $(0.14)$ \\
\hline & CABA (Argentina) & m & $\mathrm{m}$ & $\mathrm{m}$ & $\mathrm{m}$ & $\mathrm{m}$ & $\mathrm{m}$ & $\mathrm{m}$ & $\mathrm{m}$ \\
\hline & Colombia & 7.88 & $(0.04)$ & 7.86 & $(0.07)$ & -0.02 & $(0.08)$ & -0.05 & $(0.07)$ \\
\hline & Costa Rica & 8.20 & $(0.03)$ & 8.27 & $(0.22)$ & 0.07 & $(0.23)$ & 0.03 & $(0.22)$ \\
\hline & Croatia & 7.88 & $(0.07)$ & 7.90 & $(0.04)$ & 0.02 & $(0.08)$ & 0.02 & $(0.08)$ \\
\hline & Cyprus* & 6.99 & $(0.07)$ & 7.09 & $(0.04)$ & 0.10 & $(0.08)$ & 0.10 & $(0.08)$ \\
\hline & Dominican Republic & 8.46 & $(0.06)$ & 8.49 & $(0.05)$ & 0.03 & $(0.08)$ & -0.01 & $(0.08)$ \\
\hline & FYROM & $\mathrm{m}$ & $\mathrm{m}$ & $\mathrm{m}$ & $\mathrm{m}$ & $\mathrm{m}$ & m & $\mathrm{m}$ & m \\
\hline & Georgia & $\mathrm{m}$ & $\mathrm{m}$ & $\mathrm{m}$ & $\mathrm{m}$ & $\mathrm{m}$ & $\mathrm{m}$ & $\mathrm{m}$ & $\mathrm{m}$ \\
\hline & Hong Kong (China) & 6.46 & $(0.04)$ & 6.71 & $(0.09)$ & 0.24 & $(0.09)$ & 0.21 & $(0.09)$ \\
\hline & Indonesia & $\mathrm{m}$ & $\mathrm{m}$ & $\mathrm{m}$ & $\mathrm{m}$ & $\mathrm{m}$ & $\mathrm{m}$ & $\mathrm{m}$ & $\mathrm{m}$ \\
\hline & Jordan & $\mathrm{m}$ & $\mathrm{m}$ & $\mathrm{m}$ & $\mathrm{m}$ & $\mathrm{m}$ & $\mathrm{m}$ & $\mathrm{m}$ & $\mathrm{m}$ \\
\hline & Kosovo & $\mathrm{m}$ & $\mathrm{m}$ & $\mathrm{m}$ & $\mathrm{m}$ & $\mathrm{m}$ & $\mathrm{m}$ & $\mathrm{m}$ & $\mathrm{m}$ \\
\hline & Lebanon & $\mathrm{m}$ & $\mathrm{m}$ & $\mathrm{m}$ & $\mathrm{m}$ & $\mathrm{m}$ & $\mathrm{m}$ & $\mathrm{m}$ & $\mathrm{m}$ \\
\hline & Lithuania & 7.51 & $(0.11)$ & 7.92 & $(0.03)$ & 0.41 & $(0.11)$ & 0.41 & $(0.11)$ \\
\hline & Macao (China) & 6.63 & $(0.05)$ & 6.57 & $(0.04)$ & -0.06 & $(0.08)$ & -0.05 & $(0.08)$ \\
\hline & Malta & $\mathrm{m}$ & $\mathrm{m}$ & $\mathrm{m}$ & $\mathrm{m}$ & m & $\mathrm{m}$ & m & $\mathrm{m}$ \\
\hline & Moldova & $\mathrm{m}$ & $\mathrm{m}$ & $\mathrm{m}$ & $\mathrm{m}$ & $\mathrm{m}$ & $\mathrm{m}$ & $\mathrm{m}$ & $\mathrm{m}$ \\
\hline & Montenegro & 7.37 & $(0.13)$ & 7.77 & $(0.04)$ & 0.41 & $(0.13)$ & 0.43 & $(0.13)$ \\
\hline & Peru & 7.50 & $(0.04)$ & 7.52 & $(0.05)$ & 0.02 & $(0.06)$ & -0.02 & $(0.06)$ \\
\hline & Qatar & 7.29 & $(0.03)$ & 7.51 & $(0.03)$ & 0.22 & $(0.05)$ & 0.20 & $(0.05)$ \\
\hline & Romania & $\mathrm{m}$ & $\mathrm{m}$ & $\mathrm{m}$ & $\mathrm{m}$ & $\mathrm{m}$ & $\mathrm{m}$ & $\mathrm{m}$ & $\mathrm{m}$ \\
\hline & Russia & 7.34 & $(0.15)$ & 7.79 & $(0.04)$ & 0.45 & $(0.16)$ & 0.42 & $(0.16)$ \\
\hline & Singapore & $\mathrm{m}$ & $\mathrm{m}$ & $\mathrm{m}$ & $\mathrm{m}$ & $\mathrm{m}$ & $\mathrm{m}$ & $\mathrm{m}$ & $\mathrm{m}$ \\
\hline & Chinese Taipei & 6.54 & $(0.06)$ & 6.61 & $(0.04)$ & 0.07 & $(0.07)$ & 0.06 & $(0.07)$ \\
\hline & Thailand & 7.72 & $(0.04)$ & 7.75 & $(0.07)$ & 0.03 & $(0.08)$ & -0.03 & $(0.08)$ \\
\hline & Trinidad and Tobago & m & $\mathrm{m}$ & $\mathrm{m}$ & $\mathrm{m}$ & $\mathrm{m}$ & $\mathrm{m}$ & $\mathrm{m}$ & $\mathrm{m}$ \\
\hline & Tunisia & 6.84 & $(0.06)$ & 6.96 & $(0.06)$ & 0.12 & $(0.08)$ & 0.15 & $(0.08)$ \\
\hline & United Arab Emirates & 7.15 & $(0.05)$ & 7.44 & $(0.05)$ & 0.28 & $(0.07)$ & 0.28 & $(0.07)$ \\
\hline & Uruguay & 7.60 & $(0.06)$ & 7.72 & $(0.04)$ & 0.12 & $(0.07)$ & 0.11 & $(0.07)$ \\
\hline & Viet Nam & $\mathrm{m}$ & m & $\mathrm{m}$ & m & $\mathrm{m}$ & m & $\mathrm{m}$ & $\mathrm{m}$ \\
\hline & Argentina** $^{* *}$ & $\mathrm{~m}$ & $\mathrm{~m}$ & $\mathrm{~m}$ & $\mathrm{~m}$ & $\mathrm{~m}$ & $\mathrm{~m}$ & $\mathrm{~m}$ & $\mathrm{~m}$ \\
\hline & Kazakhstan** & $\mathrm{m}$ & $\mathrm{m}$ & $\mathrm{m}$ & $\mathrm{m}$ & $\mathrm{m}$ & $\mathrm{m}$ & $\mathrm{m}$ & $\mathrm{m}$ \\
\hline & Malaysia** & 7.11 & $(0.05)$ & 7.02 & $(0.06)$ & -0.08 & $(0.07)$ & -0.10 & $(0.07)$ \\
\hline
\end{tabular}

1. The socio-economic profile is measured by the PISA index of economic, social and cultural status.

Note: Values that are statistically significant are indicated in bold (see Annex A3).

* See note at the beginning of this Annex.

** Coverage is too small to ensure comparability (see Annex A4).

StatLink त्ना15 ht htp://dx.doi.org/10.1787/888933472571 
[Part 1/1]

Table III.11.6 Students practicing sports

Based on students' self-reports

\begin{tabular}{|c|c|c|c|c|c|c|c|}
\hline & \multicolumn{6}{|c|}{ Percentage of students who reported the followings } \\
\hline & & \multicolumn{2}{|c|}{$\begin{array}{l}\text { Exercise or practice sports } \\
\text { before school }\end{array}$} & \multicolumn{2}{|c|}{$\begin{array}{l}\text { Exercise or practice sports } \\
\text { after school }\end{array}$} & \multicolumn{2}{|c|}{$\begin{array}{c}\text { Exercise or practice sports before } \\
\text { or after school }\end{array}$} \\
\hline & & $\%$ & S.E. & $\%$ & S.E. & $\%$ & S.E. \\
\hline \multirow{36}{*}{ ర్ } & Australia & 44.4 & (0.6) & 68.7 & $(0.6)$ & 71.7 & $(0.5)$ \\
\hline & Austria & 38.3 & $(1.0)$ & 57.4 & $(0.8)$ & 61.4 & $(0.8)$ \\
\hline & Belgium & 43.6 & $(0.7)$ & 70.6 & $(0.6)$ & 73.1 & $(0.6)$ \\
\hline & Canada & 47.7 & $(0.6)$ & 71.7 & $(0.5)$ & 74.2 & $(0.5)$ \\
\hline & Chile & 49.6 & $(0.9)$ & 61.4 & $(0.8)$ & 65.6 & $(0.8)$ \\
\hline & Czech Republic & 46.7 & $(0.7)$ & 63.1 & $(0.7)$ & 68.1 & $(0.7)$ \\
\hline & Denmark & 34.9 & $(1.1)$ & 62.7 & $(0.9)$ & 65.4 & $(0.9)$ \\
\hline & Estonia & 45.7 & $(0.7)$ & 67.4 & (0.6) & 72.1 & $(0.6)$ \\
\hline & Finland & 35.1 & $(0.8)$ & 67.1 & $(0.8)$ & 69.6 & $(0.8)$ \\
\hline & France & 37.9 & $(0.7)$ & 59.0 & $(0.7)$ & 62.9 & $(0.7)$ \\
\hline & Germany & 38.1 & (1.1) & 68.6 & $(0.8)$ & 70.0 & $(0.9)$ \\
\hline & Greece & 40.1 & (1.0) & 58.8 & $(0.7)$ & 63.0 & $(0.8)$ \\
\hline & Hungary & 62.3 & $(0.9)$ & 74.1 & (0.6) & 80.2 & $(0.7)$ \\
\hline & Iceland & 30.1 & $(0.9)$ & 70.7 & $(0.8)$ & 71.6 & $(0.8)$ \\
\hline & Ireland & 34.9 & $(0.7)$ & 77.6 & $(0.7)$ & 78.6 & $(0.7)$ \\
\hline & Israel & 49.1 & (1.0) & 62.9 & (0.9) & 67.4 & $(0.9)$ \\
\hline & Italy & 34.0 & $(0.8)$ & 65.0 & $(0.7)$ & 68.2 & $(0.7)$ \\
\hline & Japan & 41.5 & $(0.9)$ & 49.8 & (0.9) & 57.7 & $(0.9)$ \\
\hline & Korea & 24.2 & $(0.9)$ & 42.9 & $(0.8)$ & 46.3 & $(0.9)$ \\
\hline & Latvia & 57.5 & $(0.9)$ & 70.7 & $(0.7)$ & 76.3 & $(0.6)$ \\
\hline & Luxembourg & 42.7 & $(0.7)$ & 72.9 & $(0.7)$ & 75.4 & $(0.6)$ \\
\hline & Mexico & 56.2 & $(0.9)$ & 68.7 & (0.9) & 76.1 & $(0.7)$ \\
\hline & Netherlands & 40.9 & $(0.9)$ & 76.1 & $(0.8)$ & 78.0 & $(0.7)$ \\
\hline & New Zealand & 44.4 & (1.0) & 70.7 & $(0.8)$ & 73.0 & $(0.8)$ \\
\hline & Norway & 31.4 & $(0.8)$ & 70.1 & $(0.8)$ & 71.5 & $(0.8)$ \\
\hline & Poland & 52.2 & $(0.8)$ & 74.8 & $(0.7)$ & 79.0 & $(0.7)$ \\
\hline & Portugal & 50.8 & (1.0) & 65.0 & $(0.9)$ & 70.9 & $(0.9)$ \\
\hline & Slovak Republic & 54.6 & $(0.8)$ & 75.1 & $(0.6)$ & 79.3 & $(0.6)$ \\
\hline & Slovenia & 36.0 & $(0.7)$ & 51.3 & $(0.8)$ & 55.9 & $(0.8)$ \\
\hline & Spain & 43.8 & $(0.7)$ & 70.3 & $(0.6)$ & 73.8 & $(0.6)$ \\
\hline & Sweden & 30.9 & $(0.8)$ & 64.9 & $(0.9)$ & 66.6 & $(0.8)$ \\
\hline & Switzerland & 41.9 & $(0.8)$ & 70.7 & $(0.7)$ & 73.1 & $(0.7)$ \\
\hline & Turkey & 61.0 & $(0.9)$ & 63.4 & (1.0) & 70.7 & $(0.9)$ \\
\hline & United Kingdom & 34.6 & $(0.7)$ & 60.7 & $(0.7)$ & 63.4 & (0.6) \\
\hline & United States & 48.4 & $(0.9)$ & 71.0 & $(0.8)$ & 73.4 & $(0.8)$ \\
\hline & OECD average & 43.0 & $(0.1)$ & 66.2 & $(0.1)$ & 69.8 & $(0.1)$ \\
\hline \multirow{38}{*}{ 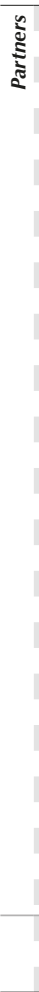 } & Albania & $\mathrm{m}$ & $\mathrm{m}$ & $\mathrm{m}$ & $\mathrm{m}$ & $\mathrm{m}$ & $\mathrm{m}$ \\
\hline & Algeria & $\mathrm{m}$ & $\mathrm{m}$ & $\mathrm{m}$ & $\mathrm{m}$ & $\mathrm{m}$ & $\mathrm{m}$ \\
\hline & Brazil & 49.0 & $(0.8)$ & 59.9 & $(0.7)$ & 66.0 & $(0.6)$ \\
\hline & B-S-J-G (China) & 68.7 & $(0.9)$ & 63.6 & (0.9) & 75.6 & $(0.8)$ \\
\hline & Bulgaria & 65.8 & $(0.9)$ & 69.1 & $(0.9)$ & 78.3 & $(0.6)$ \\
\hline & CABA (Argentina) & $\mathrm{m}$ & $\mathrm{m}$ & $\mathrm{m}$ & $\mathrm{m}$ & $\mathrm{m}$ & $\mathrm{m}$ \\
\hline & Colombia & 61.4 & $(0.7)$ & 67.7 & $(0.6)$ & 73.9 & $(0.6)$ \\
\hline & Costa Rica & 50.8 & $(0.8)$ & 61.6 & $(0.8)$ & 67.4 & $(0.8)$ \\
\hline & Croatia & 46.3 & $(0.9)$ & 59.9 & $(0.8)$ & 65.4 & $(0.8)$ \\
\hline & Cyprus* & 50.6 & $(0.8)$ & 67.4 & $(0.8)$ & 72.8 & $(0.7)$ \\
\hline & Dominican Republic & 61.4 & (1.1) & 72.1 & (1.0) & 76.0 & $(0.9)$ \\
\hline & FYROM & $\mathrm{m}$ & $\mathrm{m}$ & $\mathrm{m}$ & $\mathrm{m}$ & $\mathrm{m}$ & $\mathrm{m}$ \\
\hline & Georgia & $\mathrm{m}$ & $\mathrm{m}$ & $\mathrm{m}$ & $\mathrm{m}$ & $\mathrm{m}$ & $\mathrm{m}$ \\
\hline & Hong Kong (China) & 48.3 & $(0.8)$ & 58.4 & $(0.7)$ & 64.7 & $(0.7)$ \\
\hline & Indonesia & $\mathrm{m}$ & $\mathrm{m}$ & $\mathrm{m}$ & $\mathrm{m}$ & $\mathrm{m}$ & $\mathrm{m}$ \\
\hline & Jordan & $\mathrm{m}$ & $\mathrm{m}$ & $\mathrm{m}$ & $\mathrm{m}$ & $\mathrm{m}$ & $\mathrm{m}$ \\
\hline & Kosovo & $\mathrm{m}$ & $\mathrm{m}$ & $\mathrm{m}$ & $\mathrm{m}$ & $\mathrm{m}$ & $\mathrm{m}$ \\
\hline & Lebanon & $\mathrm{m}$ & $\mathrm{m}$ & $\mathrm{m}$ & $\mathrm{m}$ & $\mathrm{m}$ & $\mathrm{m}$ \\
\hline & Lithuania & 63.4 & $(0.8)$ & 74.0 & $(0.6)$ & 80.2 & $(0.6)$ \\
\hline & Macao (China) & 49.8 & $(0.8)$ & 62.2 & $(0.7)$ & 67.8 & $(0.7)$ \\
\hline & Malta & $\mathrm{m}$ & $\mathrm{m}$ & $\mathrm{m}$ & $\mathrm{m}$ & $\mathrm{m}$ & $\mathrm{m}$ \\
\hline & Moldova & $\mathrm{m}$ & $\mathrm{m}$ & $\mathrm{m}$ & $\mathrm{m}$ & $\mathrm{m}$ & $\mathrm{m}$ \\
\hline & Montenegro & 77.2 & $(0.6)$ & 78.1 & $(0.6)$ & 85.2 & $(0.5)$ \\
\hline & Peru & 63.3 & $(0.8)$ & 68.8 & $(0.7)$ & 75.1 & (0.6) \\
\hline & Qatar & 59.9 & $(0.4)$ & 73.6 & $(0.5)$ & 78.6 & $(0.4)$ \\
\hline & Romania & $\mathrm{m}$ & $\mathrm{m}$ & $\mathrm{m}$ & $\mathrm{m}$ & $\mathrm{m}$ & $\mathrm{m}$ \\
\hline & Russia & 68.3 & $(0.8)$ & 71.1 & $(0.7)$ & 79.8 & $(0.7)$ \\
\hline & Singapore & 34.5 & $(0.5)$ & 54.2 & (0.6) & 58.7 & $(0.6)$ \\
\hline & Chinese Taipei & 36.5 & $(0.7)$ & 59.1 & $(0.8)$ & 63.6 & $(0.7)$ \\
\hline & Thailand & 56.0 & (1.1) & 71.9 & (0.9) & 76.5 & $(0.8)$ \\
\hline & Trinidad and Tobago & $\mathrm{m}$ & $\mathrm{m}$ & $\mathrm{m}$ & $\mathrm{m}$ & $\mathrm{m}$ & $\mathrm{m}$ \\
\hline & Tunisia & 66.5 & $(0.8)$ & 64.9 & $(0.8)$ & 74.3 & $(0.7)$ \\
\hline & United Arab Emirates & 61.3 & (0.9) & 73.7 & $(0.7)$ & 79.1 & $(0.7)$ \\
\hline & Uruguay & 55.7 & $(0.9)$ & 64.1 & $(0.8)$ & 70.3 & $(0.8)$ \\
\hline & Viet Nam & $\mathrm{m}$ & $\mathrm{m}$ & $\mathrm{m}$ & $\mathrm{m}$ & $\mathrm{m}$ & $\mathrm{m}$ \\
\hline & Argentina** & $\mathrm{m}$ & $\mathrm{m}$ & $\mathrm{m}$ & $\mathrm{m}$ & $\mathrm{m}$ & $\mathrm{m}$ \\
\hline & Kazakhstan** & $\mathrm{m}$ & $\mathrm{m}$ & $\mathrm{m}$ & $\mathrm{m}$ & $\mathrm{m}$ & $\mathrm{m}$ \\
\hline & Malaysia** & 57.2 & $(1.0)$ & 66.5 & $(0.9)$ & 73.3 & $(0.8)$ \\
\hline
\end{tabular}

* See note at the beginning of this Annex.

** Coverage is too small to ensure comparability (see Annex A4).

StatLink 需四 http://dx.doi.org/10.1787/888933472583 


\begin{tabular}{|c|c|c|c|c|c|c|c|c|c|c|}
\hline & & & Percent & udents & orted & g or pr & sports & nool, b & & \\
\hline & & & & & al quar & he ESCS & & & & \\
\hline & Bott & arter & Sec & iter & & & & & Top - b & quarter \\
\hline & $\%$ & S.E. & $\%$ & S.E. & $\%$ & S.E. & $\%$ & S.E. & $\%$ dif. & S.E. \\
\hline Australia & 62.4 & $(1.2)$ & 69.1 & (1.0) & 70.7 & $(1.0)$ & 72.8 & (0.9) & 10.4 & (1.5) \\
\hline Austria & 52.3 & (1.4) & 54.0 & (1.5) & 57.1 & (1.6) & 66.1 & $(1.7)$ & 13.8 & $(2.1)$ \\
\hline $\bar{\partial}$ Belgium & 60.9 & (1.4) & 69.3 & $(1.0)$ & 72.9 & (1.1) & 78.7 & $(0.9)$ & 17.8 & (1.4) \\
\hline Canada & 64.6 & $(1.0)$ & 70.1 & (1.0) & 72.6 & (1.1) & 79.3 & (0.9) & 14.7 & $(1.3)$ \\
\hline Chile & 62.0 & (1.7) & 60.2 & (1.5) & 61.2 & (1.4) & 62.1 & (1.4) & 0.1 & $(2.3)$ \\
\hline Czech Republic & 58.2 & (1.7) & 63.1 & (1.4) & 65.1 & (1.4) & 65.9 & (1.3) & 7.7 & $(2.2)$ \\
\hline Denmark & 54.7 & $(1.4)$ & 63.2 & (1.5) & 66.2 & $(1.8)$ & 66.4 & (1.6) & 11.7 & $(2.1)$ \\
\hline Estonia & 60.3 & (1.6) & 65.8 & (1.4) & 69.6 & (1.6) & 73.8 & $(1.2)$ & 13.5 & $(2.0)$ \\
\hline Finland & 58.8 & $(1.4)$ & 65.4 & (1.4) & 69.9 & $(1.5)$ & 73.8 & (1.6) & 15.1 & $(2.1)$ \\
\hline France & 54.5 & (1.5) & 58.8 & (1.5) & 58.9 & $(1.3)$ & 63.6 & (1.3) & 9.1 & $(2.1)$ \\
\hline Germany & 63.1 & (1.9) & 63.9 & (2.4) & 73.8 & (1.9) & 73.7 & $(1.8)$ & 10.6 & $(2.6)$ \\
\hline Greece & 53.2 & (1.6) & 57.9 & (1.4) & 61.9 & (1.6) & 62.1 & $(1.8)$ & 8.9 & $(2.6)$ \\
\hline Hungary & 67.2 & $(1.7)$ & 74.8 & $(1.8)$ & 75.5 & $(1.3)$ & 78.3 & $(1.3)$ & 11.1 & $(2.2)$ \\
\hline Iceland & 63.9 & (1.8) & 70.3 & (2.0) & 71.8 & (1.5) & 76.1 & (1.7) & 12.2 & $(2.6)$ \\
\hline Ireland & 74.6 & (1.4) & 75.4 & (1.4) & 79.6 & (1.0) & 80.9 & (1.1) & 6.2 & $(1.7)$ \\
\hline Israel & 61.8 & (1.4) & 59.8 & (1.3) & 62.4 & $(1.8)$ & 67.6 & (1.4) & 5.8 & $(1.7)$ \\
\hline Italy & 53.2 & (1.4) & 66.7 & (1.6) & 68.7 & $(1.2)$ & 71.3 & $(1.2)$ & 18.1 & $(2.1)$ \\
\hline Japan & 51.4 & (1.6) & 49.2 & (1.4) & 50.3 & (1.4) & 48.7 & (1.4) & -2.7 & $(1.8)$ \\
\hline Korea & 41.9 & $(1.3)$ & 43.2 & $(1.7)$ & 42.9 & $(1.7)$ & 43.5 & (1.6) & 1.6 & $(2.0)$ \\
\hline Latvia & 65.1 & (1.4) & 71.2 & (1.5) & 69.5 & (1.5) & 76.9 & (1.4) & 11.8 & $(2.0)$ \\
\hline Luxembourg & 67.7 & $(1.3)$ & 70.1 & (1.6) & 73.5 & (1.3) & 79.9 & $(0.9)$ & 12.2 & (1.6) \\
\hline Mexico & 66.6 & $(1.8)$ & 69.4 & (1.4) & 67.3 & (1.5) & 71.3 & (1.4) & 4.8 & $(2.2)$ \\
\hline Netherlands & 72.0 & (1.6) & 74.6 & (1.6) & 81.0 & $(1.3)$ & 76.8 & (1.4) & 4.8 & $(2.0)$ \\
\hline New Zealand & 65.7 & (1.4) & 71.1 & (1.6) & 71.8 & (1.6) & 74.5 & (1.4) & 8.7 & (1.9) \\
\hline Norway & 59.2 & (1.6) & 70.5 & (1.6) & 72.4 & (1.4) & 78.2 & $(1.2)$ & 19.0 & (1.8) \\
\hline Poland & 72.5 & (1.5) & 75.2 & (1.5) & 75.7 & (1.5) & 76.0 & (1.3) & 3.4 & $(2.0)$ \\
\hline Portugal & 62.1 & (1.5) & 66.2 & (1.3) & 66.5 & $(1.7)$ & 65.4 & (1.5) & 3.3 & $(2.1)$ \\
\hline Slovak Republic & 69.8 & (1.3) & 74.5 & $(1.3)$ & 77.1 & $(1.1)$ & 78.4 & $(1.0)$ & 8.6 & $(1.8)$ \\
\hline Slovenia & 48.5 & $(1.7)$ & 50.4 & (1.6) & 48.9 & (1.9) & 57.5 & $(1.7)$ & 9.0 & $(2.3)$ \\
\hline Spain & 67.8 & (1.3) & 68.7 & (1.4) & 72.1 & $(1.3)$ & 72.6 & (1.3) & 4.8 & $(1.8)$ \\
\hline Sweden & 55.4 & $(1.7)$ & 65.7 & (1.4) & 68.2 & (1.6) & 70.0 & $(1.8)$ & 14.5 & $(2.7)$ \\
\hline Switzerland & 67.2 & (1.6) & 69.3 & (1.6) & 74.2 & (1.5) & 72.4 & $(1.2)$ & 5.2 & $(1.8)$ \\
\hline Turkey & 56.9 & (1.7) & 62.1 & $(1.5)$ & 66.1 & $(1.7)$ & 68.5 & $(1.7)$ & 11.6 & $(2.3)$ \\
\hline United Kingdom & 53.2 & (1.4) & 59.6 & (1.6) & 63.2 & (1.5) & 67.0 & (1.3) & 13.8 & (1.9) \\
\hline United States & 66.4 & (1.3) & 68.4 & (1.4) & 71.8 & (1.5) & 77.2 & (1.4) & 10.8 & (1.8) \\
\hline OECD average & 61.0 & $(0.3)$ & 65.3 & $(0.3)$ & 67.7 & $(0.2)$ & 70.5 & $(0.2)$ & 9.5 & $(0.3)$ \\
\hline
\end{tabular}

\begin{tabular}{|c|c|c|c|c|c|c|c|c|c|c|c|}
\hline \multirow{38}{*}{ 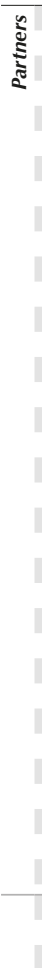 } & Albania & $\mathrm{m}$ & $\mathrm{m}$ & $\mathrm{m}$ & $\mathrm{m}$ & $\mathrm{m}$ & $\mathrm{m}$ & $\mathrm{m}$ & $\mathrm{m}$ & $\mathrm{m}$ & $\mathrm{m}$ \\
\hline & Algeria & $\mathrm{m}$ & $\mathrm{m}$ & $\mathrm{m}$ & $\mathrm{m}$ & $\mathrm{m}$ & $\mathrm{m}$ & $\mathrm{m}$ & $\mathrm{m}$ & $\mathrm{m}$ & $\mathrm{m}$ \\
\hline & Brazil & 54.8 & (1.4) & 55.6 & (1.5) & 60.9 & (1.3) & 66.1 & (1.3) & 11.2 & (1.9) \\
\hline & B-S-J-G (China) & 62.4 & (1.4) & 63.7 & (1.6) & 63.8 & (1.6) & 64.4 & (1.5) & 2.0 & $(2.0)$ \\
\hline & Bulgaria & 66.0 & (1.9) & 71.5 & (1.4) & 71.8 & (1.4) & 67.1 & (1.7) & 1.1 & (2.5) \\
\hline & CABA (Argentina) & $\mathrm{m}$ & $\mathrm{m}$ & $\mathrm{m}$ & $\mathrm{m}$ & $\mathrm{m}$ & $\mathrm{m}$ & $\mathrm{m}$ & $\mathrm{m}$ & $\mathrm{m}$ & $\mathrm{m}$ \\
\hline & Colombia & 65.5 & (1.3) & 68.8 & (1.2) & 67.1 & $(1.2)$ & 69.2 & (1.4) & 3.8 & (1.8) \\
\hline & Costa Rica & 55.7 & (1.5) & 61.1 & (1.6) & 63.3 & (1.4) & 65.8 & (1.5) & 10.1 & (2.2) \\
\hline & Croatia & 56.2 & (1.5) & 59.2 & (1.5) & 63.8 & (1.5) & 60.6 & (1.5) & 4.4 & $(2.0)$ \\
\hline & Cyprus* & 58.6 & (1.7) & 66.2 & (1.3) & 70.4 & (1.3) & 73.8 & (1.4) & 15.2 & $(2.2)$ \\
\hline & Dominican Republic & 64.2 & $(2.2)$ & 74.6 & (1.9) & 73.2 & (2.1) & 74.9 & (1.8) & 10.7 & (2.5) \\
\hline & FYROM & $\mathrm{m}$ & $\mathrm{m}$ & $\mathrm{m}$ & $\mathrm{m}$ & $\mathrm{m}$ & $\mathrm{m}$ & $\mathrm{m}$ & $\mathrm{m}$ & $\mathrm{m}$ & $\mathrm{m}$ \\
\hline & Georgia & $\mathrm{m}$ & $\mathrm{m}$ & $\mathrm{m}$ & $\mathrm{m}$ & $\mathrm{m}$ & $\mathrm{m}$ & $\mathrm{m}$ & $\mathrm{m}$ & $\mathrm{m}$ & $\mathrm{m}$ \\
\hline & Hong Kong (China) & 54.8 & $(1.3)$ & 58.3 & (1.5) & 60.7 & (1.6) & 59.8 & (1.4) & 5.0 & $(2.1)$ \\
\hline & Indonesia & $\mathrm{m}$ & $\mathrm{m}$ & $\mathrm{m}$ & $\mathrm{m}$ & $\mathrm{m}$ & $\mathrm{m}$ & $\mathrm{m}$ & $\mathrm{m}$ & $\mathrm{m}$ & $\mathrm{m}$ \\
\hline & Jordan & $\mathrm{m}$ & $\mathrm{m}$ & $\mathrm{m}$ & $\mathrm{m}$ & $\mathrm{m}$ & $\mathrm{m}$ & $\mathrm{m}$ & $\mathrm{m}$ & $\mathrm{m}$ & $\mathrm{m}$ \\
\hline & Kosovo & $\mathrm{m}$ & $\mathrm{m}$ & $\mathrm{m}$ & $\mathrm{m}$ & $\mathrm{m}$ & $\mathrm{m}$ & $\mathrm{m}$ & $\mathrm{m}$ & $\mathrm{m}$ & $\mathrm{m}$ \\
\hline & Lebanon & $\mathrm{m}$ & $\mathrm{m}$ & $\mathrm{m}$ & $\mathrm{m}$ & $\mathrm{m}$ & $\mathrm{m}$ & $\mathrm{m}$ & $\mathrm{m}$ & $\mathrm{m}$ & $\mathrm{m}$ \\
\hline & Lithuania & 70.9 & (1.5) & 75.6 & (1.3) & 75.0 & $(1.2)$ & 75.0 & $(1.2)$ & 4.1 & $(1.7)$ \\
\hline & Macao (China) & 58.7 & (1.6) & 61.7 & (1.4) & 62.8 & (1.5) & 65.9 & (1.3) & 7.2 & (2.1) \\
\hline & Malta & $\mathrm{m}$ & $\mathrm{m}$ & m & $\mathrm{m}$ & $\mathrm{m}$ & $\mathrm{m}$ & $\mathrm{m}$ & $\mathrm{m}$ & $\mathrm{m}$ & $\mathrm{m}$ \\
\hline & Moldova & $\mathrm{m}$ & $\mathrm{m}$ & $\mathrm{m}$ & $\mathrm{m}$ & $\mathrm{m}$ & $\mathrm{m}$ & $\mathrm{m}$ & $\mathrm{m}$ & $\mathrm{m}$ & $\mathrm{m}$ \\
\hline & Montenegro & 74.4 & (1.4) & 79.9 & (1.3) & 79.1 & (1.1) & 78.8 & (1.3) & 4.5 & (1.9) \\
\hline & Peru & 72.3 & (1.5) & 67.2 & (1.6) & 68.4 & (1.2) & 68.3 & (1.6) & -4.0 & $(2.2)$ \\
\hline & Qatar & 70.9 & $(0.9)$ & 73.0 & (0.9) & 73.8 & (1.0) & 76.7 & $(0.9)$ & 5.8 & (1.1) \\
\hline & Romania & $\mathrm{m}$ & $\mathrm{m}$ & $\mathrm{m}$ & $\mathrm{m}$ & $\mathrm{m}$ & $\mathrm{m}$ & $\mathrm{m}$ & $\mathrm{m}$ & $\mathrm{m}$ & $\mathrm{m}$ \\
\hline & Russia & 69.8 & (1.6) & 71.4 & (1.5) & 69.8 & (1.4) & 73.2 & (1.5) & 3.3 & (2.4) \\
\hline & Singapore & 54.5 & (1.2) & 52.1 & (1.3) & 52.9 & (1.4) & 57.4 & (1.4) & 3.0 & (1.9) \\
\hline & Chinese Taipei & 56.0 & (1.5) & 59.3 & (1.5) & 58.6 & (1.3) & 62.3 & (1.3) & 6.2 & (1.9) \\
\hline & Thailand & 71.6 & (1.6) & 74.9 & (1.3) & 71.5 & (1.5) & 69.4 & (1.7) & -2.1 & (2.1) \\
\hline & Trinidad and Tobago & $\mathrm{m}$ & $\mathrm{m}$ & $\mathrm{m}$ & $\mathrm{m}$ & $\mathrm{m}$ & $\mathrm{m}$ & $\mathrm{m}$ & $\mathrm{m}$ & $\mathrm{m}$ & $\mathrm{m}$ \\
\hline & Tunisia & 61.6 & (1.6) & 65.8 & (1.6) & 66.9 & (1.8) & 64.8 & (1.6) & 3.3 & $(2.1)$ \\
\hline & United Arab Emirates & 70.9 & (1.3) & 71.9 & (1.5) & 74.5 & (1.3) & 77.3 & $(0.9)$ & 6.4 & (1.3) \\
\hline & Uruguay & 55.7 & (1.6) & 64.2 & (1.6) & 65.5 & (1.5) & 70.0 & (1.5) & 14.3 & (2.2) \\
\hline & Viet Nam & $\mathrm{m}$ & $\mathrm{m}$ & $\mathrm{m}$ & $\mathrm{m}$ & $\mathrm{m}$ & $\mathrm{m}$ & $\mathrm{m}$ & $\mathrm{m}$ & $\mathrm{m}$ & $\mathrm{m}$ \\
\hline & Argentina** & $\mathrm{m}$ & $\mathrm{m}$ & $\mathrm{m}$ & $\mathrm{m}$ & $\mathrm{m}$ & $\mathrm{m}$ & $\mathrm{m}$ & $\mathrm{m}$ & $\mathrm{m}$ & $\mathrm{m}$ \\
\hline & Kazakhstan** & $\mathrm{m}$ & $\mathrm{m}$ & $\mathrm{m}$ & $\mathrm{m}$ & $\mathrm{m}$ & $\mathrm{m}$ & $\mathrm{m}$ & $\mathrm{m}$ & $\mathrm{m}$ & $\mathrm{m}$ \\
\hline & Malaysia** & 67.2 & (1.5) & 67.0 & (1.5) & 65.9 & (1.4) & 65.8 & (1.6) & -1.4 & (2.1) \\
\hline
\end{tabular}

1. ESCS refers to the PISA index of economic, social and cultural status.

Note: Values that are statistically significant are indicated in bold (see Annex A3).

* See note at the beginning of this Annex.

** Coverage is too small to ensure comparability (see Annex A4).

StatLink त्राड़ी http://dx.doi.org/10.1787/888933472608 
[Part 2/2]

Table III.11.7b Students practicing sports after school, by student characteristics

Results based on students' self-reports

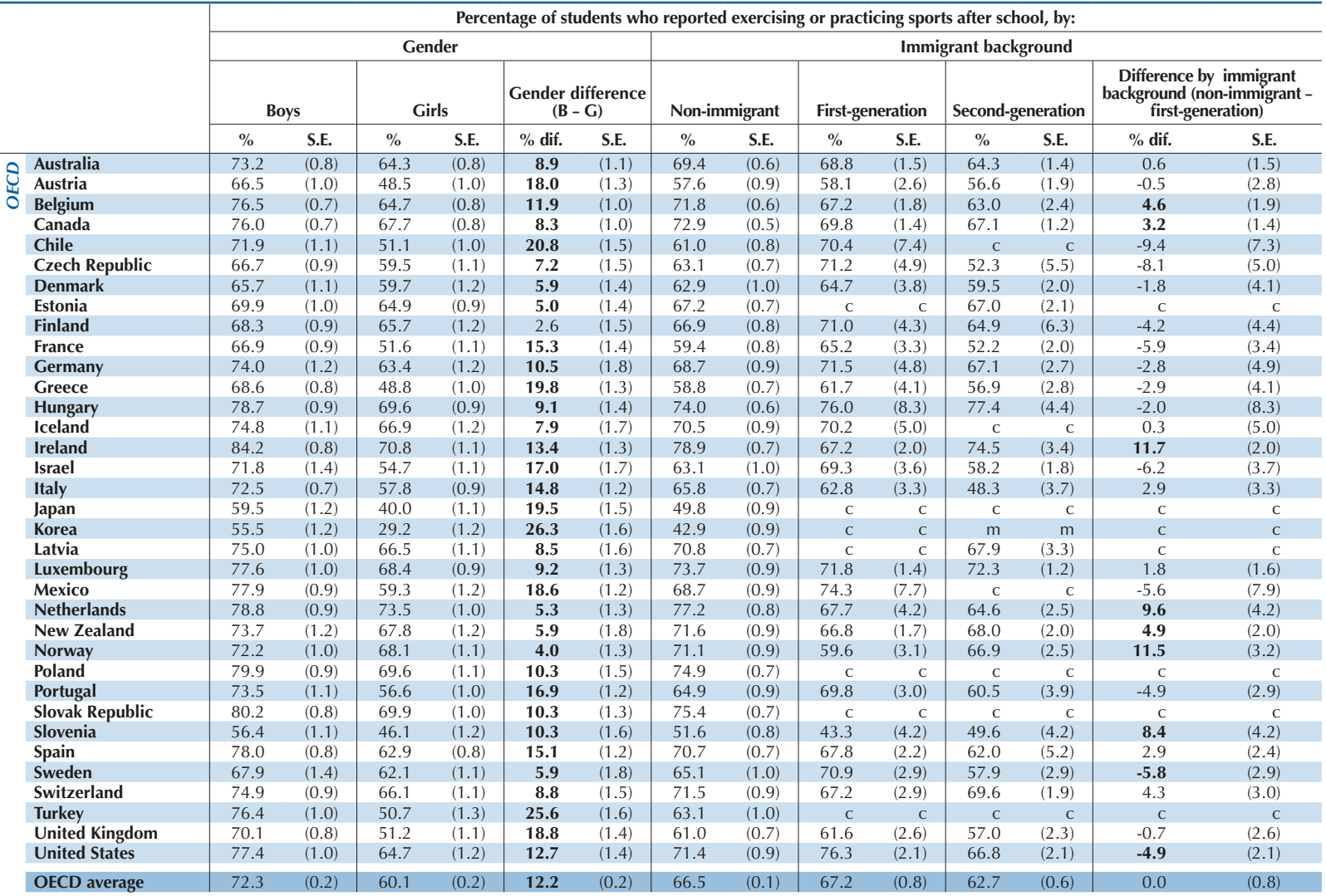

\begin{tabular}{|c|c|c|c|c|c|c|c|c|c|c|c|c|c|c|}
\hline Albania & $\mathrm{m}$ & $\mathrm{m}$ & $\mathrm{m}$ & $\mathrm{m}$ & $\mathrm{m}$ & $\mathrm{m}$ & $\mathrm{m}$ & $\mathrm{m}$ & $\mathrm{m}$ & $\mathrm{m}$ & $\mathrm{m}$ & $\mathrm{m}$ & $\mathrm{m}$ & $\mathrm{m}$ \\
\hline Algeria & $\mathrm{m}$ & $\mathrm{m}$ & $\mathrm{m}$ & $\mathrm{m}$ & $\mathrm{m}$ & $\mathrm{m}$ & $\mathrm{m}$ & $\mathrm{m}$ & $\mathrm{m}$ & $\mathrm{m}$ & $\mathrm{m}$ & $\mathrm{m}$ & $\mathrm{m}$ & $\mathrm{m}$ \\
\hline Brazil & 72.4 & $(0.8)$ & 48.4 & $(0.8)$ & 24.1 & $(0.9)$ & 59.6 & $(0.7)$ & c & c & 69.5 & (11.1) & c & c \\
\hline B-S-J-G (China) & 71.7 & (1.1) & 54.3 & (1.3) & 17.5 & (1.5) & 63.5 & $(0.9)$ & c & c & c & c & c & c \\
\hline Bulgaria & 75.5 & (1.1) & 62.6 & (1.1) & 12.9 & (1.5) & 69.0 & $(0.9)$ & C & C & C & c & c & c \\
\hline CABA (Argentina) & $\mathrm{m}$ & $\mathrm{m}$ & $\mathrm{m}$ & $\mathrm{m}$ & $\mathrm{m}$ & $\mathrm{m}$ & $\mathrm{m}$ & $\mathrm{m}$ & $\mathrm{m}$ & $\mathrm{m}$ & $\mathrm{m}$ & $\mathrm{m}$ & $\mathrm{m}$ & $\mathrm{m}$ \\
\hline Colombia & 79.7 & $(0.7)$ & 57.1 & $(0.8)$ & 22.6 & (1.1) & 67.5 & $(0.6)$ & c & c & c & c & c & c \\
\hline Costa Rica & 74.9 & $(1.0)$ & 48.7 & (1.3) & 26.2 & (1.6) & 61.6 & $(0.9)$ & 55.5 & (4.4) & 62.6 & (3.1) & 6.1 & (4.4) \\
\hline Croatia & 71.2 & $(1.0)$ & 49.8 & (1.1) & 21.5 & (1.4) & 59.5 & $(0.9)$ & 53.7 & (5.6) & 63.4 & (2.4) & 5.8 & (5.5) \\
\hline Cyprus* & 76.2 & $(0.9)$ & 59.4 & (1.1) & 16.7 & (1.3) & 67.5 & $(0.8)$ & 64.7 & (2.4) & 67.5 & (3.6) & 2.7 & (2.5) \\
\hline Dominican Republic & 82.4 & (1.0) & 62.2 & (1.5) & 20.2 & (1.7) & 71.7 & $(1.0)$ & c & c & c & c & c & c \\
\hline FYROM & $\mathrm{m}$ & $\mathrm{m}$ & $\mathrm{m}$ & $\mathrm{m}$ & $\mathrm{m}$ & $\mathrm{m}$ & $\mathrm{m}$ & $\mathrm{m}$ & $\mathrm{m}$ & $\mathrm{m}$ & $\mathrm{m}$ & $\mathrm{m}$ & $\mathrm{m}$ & $\mathrm{m}$ \\
\hline Georgia & $\mathrm{m}$ & $\mathrm{m}$ & $\mathrm{m}$ & $\mathrm{m}$ & $\mathrm{m}$ & $\mathrm{m}$ & $\mathrm{m}$ & $\mathrm{m}$ & $\mathrm{m}$ & $\mathrm{m}$ & $\mathrm{m}$ & $\mathrm{m}$ & $\mathrm{m}$ & $\mathrm{m}$ \\
\hline Hong Kong (China) & 67.0 & $(0.8)$ & 49.7 & (1.0) & 17.4 & (1.3) & 58.4 & $(0.9)$ & 61.1 & (2.1) & 56.3 & (1.5) & -2.7 & (2.4) \\
\hline Indonesia & $\mathrm{m}$ & $\mathrm{m}$ & $\mathrm{m}$ & $\mathrm{m}$ & $\mathrm{m}$ & $\mathrm{m}$ & $\mathrm{m}$ & $\mathrm{m}$ & $\mathrm{m}$ & $\mathrm{m}$ & $\mathrm{m}$ & $\mathrm{m}$ & $\mathrm{m}$ & $\mathrm{m}$ \\
\hline Jordan & $\mathrm{m}$ & $\mathrm{m}$ & $\mathrm{m}$ & $\mathrm{m}$ & $\mathrm{m}$ & $\mathrm{m}$ & $\mathrm{m}$ & $\mathrm{m}$ & $\mathrm{m}$ & $\mathrm{m}$ & $\mathrm{m}$ & $\mathrm{m}$ & $\mathrm{m}$ & $\mathrm{m}$ \\
\hline Kosovo & $\mathrm{m}$ & $\mathrm{m}$ & $\mathrm{m}$ & $\mathrm{m}$ & $\mathrm{m}$ & $\mathrm{m}$ & $\mathrm{m}$ & $\mathrm{m}$ & $\mathrm{m}$ & $\mathrm{m}$ & $\mathrm{m}$ & $\mathrm{m}$ & $\mathrm{m}$ & $\mathrm{m}$ \\
\hline Lebanon & $\mathrm{m}$ & $\mathrm{m}$ & $\mathrm{m}$ & $\mathrm{m}$ & $\mathrm{m}$ & $\mathrm{m}$ & $\mathrm{m}$ & $\mathrm{m}$ & $\mathrm{m}$ & $\mathrm{m}$ & $\mathrm{m}$ & $\mathrm{m}$ & $\mathrm{m}$ & $\mathrm{m}$ \\
\hline Lithuania & 80.9 & $(0.8)$ & 67.3 & (1.0) & 13.7 & (1.3) & 74.0 & $(0.7)$ & c & c & 74.4 & $(4.2)$ & c & c \\
\hline Macao (China) & 72.6 & $(0.9)$ & 51.8 & (1.1) & 20.8 & (1.4) & 63.7 & (1.1) & 65.3 & (1.5) & 59.7 & $(1.2)$ & -1.6 & (1.8) \\
\hline Malta & $\mathrm{m}$ & $\mathrm{m}$ & $\mathrm{m}$ & $\mathrm{m}$ & $\mathrm{m}$ & $\mathrm{m}$ & $\mathrm{m}$ & $\mathrm{m}$ & $\mathrm{m}$ & $\mathrm{m}$ & $\mathrm{m}$ & $\mathrm{m}$ & $\mathrm{m}$ & $\mathrm{m}$ \\
\hline Moldova & $\mathrm{m}$ & $\mathrm{m}$ & $\mathrm{m}$ & $\mathrm{m}$ & $\mathrm{m}$ & $\mathrm{m}$ & $\mathrm{m}$ & $\mathrm{m}$ & $\mathrm{m}$ & $\mathrm{m}$ & $\mathrm{m}$ & $\mathrm{m}$ & $\mathrm{m}$ & $\mathrm{m}$ \\
\hline Montenegro & 84.6 & $(0.8)$ & 71.9 & (0.9) & 12.7 & $(1.2)$ & 78.2 & $(0.6)$ & 75.0 & (4.5) & 75.4 & (3.3) & 3.2 & (4.6) \\
\hline Peru & 79.3 & $(0.8)$ & 57.4 & (1.0) & 21.9 & (1.3) & 68.7 & $(0.7)$ & c & c & c & c & C & c \\
\hline Qatar & 80.4 & $(0.6)$ & 67.9 & $(0.7)$ & 12.5 & $(0.8)$ & 73.6 & $(0.7)$ & 73.5 & $(0.7)$ & 72.9 & (1.1) & 0.1 & (1.0) \\
\hline Romania & $\mathrm{m}$ & $\mathrm{m}$ & $\mathrm{m}$ & $\mathrm{m}$ & $\mathrm{m}$ & $\mathrm{m}$ & $\mathrm{m}$ & $\mathrm{m}$ & $\mathrm{m}$ & $\mathrm{m}$ & $\mathrm{m}$ & $\mathrm{m}$ & $\mathrm{m}$ & $\mathrm{m}$ \\
\hline Russia & 77.4 & (1.0) & 65.1 & (1.0) & 12.3 & (1.4) & 71.1 & $(0.7)$ & 77.5 & (2.9) & 64.1 & (2.8) & -6.4 & (3.1) \\
\hline Singapore & 63.6 & $(0.9)$ & 44.2 & $(0.9)$ & 19.4 & (1.3) & 53.2 & $(0.7)$ & 59.7 & (1.9) & 54.3 & (2.5) & -6.4 & (2.0) \\
\hline Chinese Taipei & 68.6 & $(0.9)$ & 49.4 & (1.0) & 19.1 & $(1.2)$ & 59.1 & $(0.8)$ & c & c & c & c & c & c \\
\hline Thailand & 81.2 & $(0.9)$ & 64.9 & $(1.2)$ & 16.3 & (1.4) & 71.7 & $(0.9)$ & c & c & 72.5 & (7.1) & c & c \\
\hline Trinidad and Tobago & $\mathrm{m}$ & $\mathrm{m}$ & $\mathrm{m}$ & $\mathrm{m}$ & $\mathrm{m}$ & $\mathrm{m}$ & $\mathrm{m}$ & $\mathrm{m}$ & $\mathrm{m}$ & $\mathrm{m}$ & $\mathrm{m}$ & $\mathrm{m}$ & $\mathrm{m}$ & $\mathrm{m}$ \\
\hline Tunisia & 77.5 & $(1.0)$ & 54.2 & (1.1) & 23.3 & (1.4) & 64.4 & $(0.8)$ & c & c & c & c & c & c \\
\hline United Arab Emirates & 81.1 & $(0.6)$ & 67.0 & $(0.8)$ & 14.1 & (1.0) & 76.4 & $(0.8)$ & 72.9 & (1.1) & 69.9 & (1.3) & 3.5 & (1.3) \\
\hline Uruguay & 77.0 & $(1.0)$ & 53.0 & $(1.2)$ & 23.9 & (1.6) & 63.9 & $(0.8)$ & c & c & c & c & c & c \\
\hline Viet Nam & $\mathrm{m}$ & $\mathrm{m}$ & $\mathrm{m}$ & $\mathrm{m}$ & $\mathrm{m}$ & $\mathrm{m}$ & $\mathrm{m}$ & $\mathrm{m}$ & $\mathrm{m}$ & $\mathrm{m}$ & $\mathrm{m}$ & $\mathrm{m}$ & $\mathrm{m}$ & $\mathrm{m}$ \\
\hline Argentina** & $\mathrm{m}$ & $\mathrm{m}$ & $\mathrm{m}$ & $\mathrm{m}$ & $\mathrm{m}$ & $\mathrm{m}$ & $\mathrm{m}$ & $\mathrm{m}$ & $\mathrm{m}$ & $\mathrm{m}$ & $\mathrm{m}$ & $\mathrm{m}$ & $\mathrm{m}$ & $\mathrm{m}$ \\
\hline Kazakhstan** & $\mathrm{m}$ & $\mathrm{m}$ & $\mathrm{m}$ & $\mathrm{m}$ & $\mathrm{m}$ & $\mathrm{m}$ & $\mathrm{m}$ & $\mathrm{m}$ & $\mathrm{m}$ & $\mathrm{m}$ & $\mathrm{m}$ & $\mathrm{m}$ & $\mathrm{m}$ & $\mathrm{m}$ \\
\hline Malaysia** & 79.6 & $(0.8)$ & 54.8 & $(1.2)$ & 24.7 & $(1.2)$ & 66.1 & $(0.9)$ & c & c & 74.6 & (5.8) & $\mathrm{C}$ & c \\
\hline
\end{tabular}

1. ESCS refers to the PISA index of economic, social and cultural status.

Note: Values that are statistically significant are indicated in bold (see Annex A3).

* See note at the beginning of this Annex.

Coverage is too small to ensure comparability (see Annex A4).

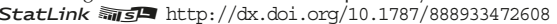




\begin{tabular}{|c|c|c|c|c|c|c|c|c|c|c|c|c|c|c|c|c|c|}
\hline & \multicolumn{4}{|c|}{ Average life satisfaction, by: } & \multicolumn{4}{|c|}{$\begin{array}{c}\text { Difference between students } \\
\text { who reported practicing and those } \\
\text { who reported not practicing sports } \\
\text { before school }\end{array}$} & \multicolumn{4}{|c|}{ Average life satisfaction, by: } & \multicolumn{4}{|c|}{$\begin{array}{c}\text { Difference between students } \\
\text { who reported practicing and those } \\
\text { who reported not practicing sports } \\
\text { after school }\end{array}$} \\
\hline & & \multicolumn{2}{|c|}{\begin{tabular}{|c|}
$\begin{array}{c}\text { Students who } \\
\text { reported not } \\
\text { practicing sports } \\
\text { before school }\end{array}$ \\
\end{tabular}} & \multicolumn{2}{|c|}{\begin{tabular}{|c|}
$\begin{array}{c}\text { Students who } \\
\text { reported } \\
\text { practicing sports } \\
\text { before school }\end{array}$ \\
\end{tabular}} & \multicolumn{2}{|c|}{\begin{tabular}{|c|} 
Before \\
accounting for \\
students' socio- \\
economic status \\
\end{tabular}} & \multicolumn{2}{|c|}{$\begin{array}{c}\text { After accounting } \\
\text { for students' } \\
\text { socio-economic } \\
\text { status }\end{array}$} & \multicolumn{2}{|c|}{$\begin{array}{c}\text { Students who } \\
\text { reported not } \\
\text { practicing sports } \\
\text { after school }\end{array}$} & \multicolumn{2}{|c|}{\begin{tabular}{|c|}
$\begin{array}{c}\text { Students who } \\
\text { reported } \\
\text { practicing sports } \\
\text { after school }\end{array}$ \\
\end{tabular}} & \multicolumn{2}{|c|}{$\begin{array}{c}\text { Before } \\
\text { accounting for } \\
\text { students' socio- } \\
\text { economic status }\end{array}$} & \multicolumn{2}{|c|}{$\begin{array}{c}\text { After accounting } \\
\text { for students' } \\
\text { socio-economic } \\
\text { status }\end{array}$} \\
\hline & & Mean & S.E. & Mean & S.E. & Dif. & S.E. & Dif. & S.E. & Mean & S.E. & Mean & S.E. & Dif. & S.E. & Dif. & S.E. \\
\hline$\theta$ & Australia & $\mathrm{m}$ & $\mathrm{m}$ & $\mathrm{m}$ & $\mathrm{m}$ & $\mathrm{m}$ & $\mathrm{m}$ & $\mathrm{m}$ & $\mathrm{m}$ & $\mathrm{m}$ & $\mathrm{m}$ & $\mathrm{m}$ & $\mathrm{m}$ & $\mathrm{m}$ & $\mathrm{m}$ & $\mathrm{m}$ & $\mathrm{m}$ \\
\hline & Austria & 7.41 & $(0.04)$ & 7.70 & $(0.05)$ & 0.29 & $(0.06)$ & 0.29 & $(0.06)$ & 7.23 & $(0.06)$ & 7.73 & $(0.05)$ & 0.50 & $(0.07)$ & 0.45 & $(0.07)$ \\
\hline & Belgium (excl. Flemish) & 7.40 & $(0.05)$ & 7.56 & $(0.07)$ & 0.16 & $(0.07)$ & 0.16 & $(0.07)$ & 7.23 & $(0.08)$ & 7.60 & $(0.05)$ & 0.37 & $(0.09)$ & 0.29 & $(0.09)$ \\
\hline & Canada & $\mathrm{m}$ & $\mathrm{m}$ & $\mathrm{m}$ & $\mathrm{m}$ & $\mathrm{m}$ & $\mathrm{m}$ & $\mathrm{m}$ & $\mathrm{m}$ & $\mathrm{m}$ & $\mathrm{m}$ & $\mathrm{m}$ & $\mathrm{m}$ & $\mathrm{m}$ & $\mathrm{m}$ & $\mathrm{m}$ & $\mathrm{m}$ \\
\hline & Chile & 7.18 & $(0.06)$ & 7.51 & $(0.06)$ & 0.34 & $(0.08)$ & 0.36 & $(0.08)$ & 7.06 & $(0.07)$ & 7.55 & $(0.05)$ & 0.50 & $(0.08)$ & 0.49 & $(0.08)$ \\
\hline & Czech Republic & 6.91 & $(0.05)$ & 7.21 & $(0.05)$ & 0.30 & $(0.07)$ & 0.31 & $(0.06)$ & 6.74 & $(0.06)$ & 7.23 & $(0.05)$ & 0.49 & $(0.07)$ & 0.45 & $(0.07)$ \\
\hline & Denmark & $\mathrm{m}$ & $\mathrm{m}$ & $\mathrm{m}$ & $\mathrm{m}$ & $\mathrm{m}$ & $\mathrm{m}$ & $\mathrm{m}$ & $\mathrm{m}$ & $\mathrm{m}$ & $\mathrm{m}$ & $\mathrm{m}$ & $\mathrm{m}$ & $\mathrm{m}$ & $\mathrm{m}$ & $\mathrm{m}$ & $\mathrm{m}$ \\
\hline & Estonia & 7.37 & (0.05) & 7.68 & $(0.05)$ & 0.31 & $(0.07)$ & 0.30 & $(0.07)$ & 7.14 & $(0.06)$ & 7.68 & $(0.04)$ & 0.54 & $(0.07)$ & 0.47 & $(0.07)$ \\
\hline & Finland & 7.78 & $(0.03)$ & 8.09 & $(0.05)$ & 0.31 & $(0.06)$ & 0.30 & $(0.06)$ & 7.50 & $(0.05)$ & 8.07 & $(0.03)$ & 0.57 & $(0.05)$ & 0.53 & $(0.05)$ \\
\hline & France & 7.59 & $(0.03)$ & 7.72 & $(0.04)$ & 0.13 & $(0.06)$ & 0.14 & $(0.06)$ & 7.44 & $(0.04)$ & 7.78 & $(0.04)$ & 0.34 & $(0.06)$ & 0.32 & $(0.06)$ \\
\hline & Germany & 7.20 & $(0.04)$ & 7.40 & $(0.08)$ & 0.20 & $(0.09)$ & 0.21 & $(0.08)$ & 6.91 & $(0.08)$ & 7.44 & $(0.05)$ & 0.53 & $(0.10)$ & 0.49 & $(0.10)$ \\
\hline & Greece & 6.74 & $(0.04)$ & 7.19 & $(0.06)$ & 0.45 & $(0.07)$ & 0.45 & $(0.07)$ & 6.62 & $(0.06)$ & 7.13 & $(0.04)$ & 0.51 & $(0.08)$ & 0.49 & $(0.08)$ \\
\hline & Hungary & 6.98 & $(0.07)$ & 7.27 & $(0.04)$ & 0.29 & $(0.08)$ & 0.28 & $(0.07)$ & 6.76 & $(0.08)$ & 7.30 & $(0.04)$ & 0.54 & $(0.08)$ & 0.49 & $(0.08)$ \\
\hline & Iceland & 7.64 & $(0.05)$ & 8.15 & $(0.06)$ & 0.51 & $(0.08)$ & 0.48 & $(0.08)$ & 7.10 & $(0.08)$ & 8.08 & $(0.04)$ & 0.98 & $(0.09)$ & 0.92 & $(0.09)$ \\
\hline & Ireland & 7.15 & $(0.04)$ & 7.55 & $(0.05)$ & 0.40 & $(0.07)$ & 0.40 & $(0.07)$ & 6.70 & $(0.08)$ & 7.46 & $(0.03)$ & 0.76 & $(0.08)$ & 0.75 & $(0.08)$ \\
\hline & Israel & $\mathrm{m}$ & $\mathrm{m}$ & $\mathrm{m}$ & $\mathrm{m}$ & $\mathrm{m}$ & $\mathrm{m}$ & $\mathrm{m}$ & $\mathrm{m}$ & $\mathrm{m}$ & $\mathrm{m}$ & $\mathrm{m}$ & $\mathrm{m}$ & $\mathrm{m}$ & $\mathrm{m}$ & $\mathrm{m}$ & $\mathrm{m}$ \\
\hline & Italy & 6.75 & (0.05) & 7.16 & $(0.04)$ & 0.40 & $(0.05)$ & 0.40 & $(0.05)$ & 6.60 & $(0.06)$ & 7.06 & $(0.05)$ & 0.46 & $(0.06)$ & 0.42 & $(0.06)$ \\
\hline & Japan & 6.75 & $(0.04)$ & 6.91 & $(0.05)$ & 0.16 & $(0.06)$ & 0.18 & $(0.06)$ & 6.66 & $(0.04)$ & 6.99 & $(0.05)$ & 0.32 & $(0.06)$ & 0.33 & $(0.06)$ \\
\hline & Korea & 6.25 & $(0.04)$ & 6.74 & $(0.08)$ & 0.49 & $(0.08)$ & 0.50 & $(0.08)$ & 6.14 & $(0.05)$ & 6.67 & $(0.06)$ & 0.53 & $(0.07)$ & 0.53 & $(0.07)$ \\
\hline & Latvia & 7.19 & $(0.05)$ & 7.51 & $(0.04)$ & 0.31 & $(0.06)$ & 0.31 & $(0.06)$ & 7.11 & $(0.06)$ & 7.48 & $(0.04)$ & 0.37 & $(0.07)$ & 0.33 & $(0.07)$ \\
\hline & Luxembourg & 7.31 & $(0.05)$ & 7.50 & $(0.06)$ & 0.18 & $(0.07)$ & 0.21 & $(0.07)$ & 6.96 & $(0.07)$ & 7.55 & $(0.04)$ & 0.58 & $(0.08)$ & 0.54 & $(0.08)$ \\
\hline & Mexico & 8.16 & $(0.04)$ & 8.36 & $(0.04)$ & 0.21 & $(0.05)$ & 0.21 & $(0.05)$ & 8.05 & $(0.05)$ & 8.38 & $(0.03)$ & 0.33 & $(0.05)$ & 0.32 & $(0.05)$ \\
\hline & Netherlands & 7.73 & $(0.03)$ & 7.95 & $(0.04)$ & 0.22 & $(0.05)$ & 0.23 & $(0.05)$ & 7.63 & $(0.05)$ & 7.89 & $(0.03)$ & 0.26 & $(0.05)$ & 0.26 & $(0.05)$ \\
\hline & New Zealand & $\mathrm{m}$ & $\mathrm{m}$ & $\mathrm{m}$ & $\mathrm{m}$ & $\mathrm{m}$ & $\mathrm{m}$ & $\mathrm{m}$ & $\mathrm{m}$ & $\mathrm{m}$ & $\mathrm{m}$ & $\mathrm{m}$ & $\mathrm{m}$ & $\mathrm{m}$ & $\mathrm{m}$ & $\mathrm{m}$ & $\mathrm{m}$ \\
\hline & Norway & $\mathrm{m}$ & $\mathrm{m}$ & $\mathrm{m}$ & $\mathrm{m}$ & $\mathrm{m}$ & $\mathrm{m}$ & $\mathrm{m}$ & $\mathrm{m}$ & $\mathrm{m}$ & $\mathrm{m}$ & $\mathrm{m}$ & $\mathrm{m}$ & $\mathrm{m}$ & $\mathrm{m}$ & $\mathrm{m}$ & $\mathrm{m}$ \\
\hline & Poland & 6.98 & $(0.06)$ & 7.36 & $(0.05)$ & 0.37 & $(0.07)$ & 0.40 & $(0.07)$ & 6.75 & $(0.07)$ & 7.33 & $(0.04)$ & 0.57 & $(0.07)$ & 0.56 & $(0.07)$ \\
\hline & Portugal & 7.23 & $(0.04)$ & 7.50 & $(0.04)$ & 0.27 & $(0.06)$ & 0.28 & $(0.06)$ & 7.13 & $(0.06)$ & 7.50 & $(0.04)$ & 0.37 & $(0.07)$ & 0.36 & $(0.07)$ \\
\hline & Slovak Republic & 7.33 & $(0.05)$ & 7.56 & $(0.04)$ & 0.23 & $(0.06)$ & 0.24 & $(0.06)$ & 7.18 & $(0.06)$ & 7.57 & $(0.04)$ & 0.39 & $(0.08)$ & 0.35 & $(0.07)$ \\
\hline & Slovenia & 7.06 & $(0.05)$ & 7.35 & $(0.05)$ & 0.29 & $(0.07)$ & 0.29 & $(0.07)$ & 7.01 & $(0.06)$ & 7.32 & $(0.04)$ & 0.31 & $(0.06)$ & 0.31 & $(0.06)$ \\
\hline & Spain & 7.35 & $(0.04)$ & 7.55 & $(0.05)$ & 0.20 & $(0.06)$ & 0.21 & $(0.06)$ & 7.11 & $(0.06)$ & 7.57 & $(0.04)$ & 0.46 & $(0.07)$ & 0.44 & $(0.07)$ \\
\hline & Sweden & $\mathrm{m}$ & $\mathrm{m}$ & $\mathrm{m}$ & & $\mathrm{m}$ & $\mathrm{m}$ & $\mathrm{m}$ & $\mathrm{m}$ & $\mathrm{m}$ & $\mathrm{m}$ & $\mathrm{m}$ & $\mathrm{m}$ & $\mathrm{m}$ & $\mathrm{m}$ & $\mathrm{m}$ & $\mathrm{m}$ \\
\hline & Switzerland & 7.57 & $(0.04)$ & 7.84 & $(0.06)$ & 0.28 & $(0.06)$ & 0.29 & $(0.06)$ & 7.32 & $(0.06)$ & 7.84 & $(0.04)$ & 0.53 & $(0.07)$ & 0.52 & $(0.07)$ \\
\hline & Turkey & 5.75 & $(0.08)$ & 6.36 & $(0.06)$ & 0.61 & $(0.08)$ & 0.59 & $(0.08)$ & 5.72 & $(0.08)$ & 6.36 & $(0.06)$ & 0.65 & $(0.08)$ & 0.62 & $(0.08)$ \\
\hline & United Kingdom & 6.85 & $(0.05)$ & 7.26 & $(0.06)$ & 0.41 & $(0.07)$ & 0.40 & $(0.07)$ & 6.62 & $(0.07)$ & 7.22 & $(0.05)$ & 0.60 & $(0.08)$ & 0.56 & $(0.08)$ \\
\hline & United States & 7.11 & $(0.05)$ & 7.62 & $(0.05)$ & 0.51 & $(0.07)$ & 0.52 & $(0.07)$ & 6.80 & $(0.06)$ & 7.60 & $(0.04)$ & 0.80 & $(0.07)$ & 0.76 & $(0.07)$ \\
\hline & OECD average & 7.17 & $(0.01)$ & 7.48 & $(0.01)$ & 0.31 & $(0.01)$ & 0.32 & $(0.01)$ & 6.97 & $(0.01)$ & 7.48 & $(0.01)$ & 0.51 & $(0.01)$ & 0.48 & $(0.01)$ \\
\hline
\end{tabular}

\begin{tabular}{|c|c|c|c|c|c|c|c|c|c|c|c|c|c|c|c|c|}
\hline Albania & $\mathrm{m}$ & $\mathrm{m}$ & $\mathrm{m}$ & $\mathrm{m}$ & $\mathrm{m}$ & $\mathrm{m}$ & $\mathrm{m}$ & $\mathrm{m}$ & $\mathrm{m}$ & $\mathrm{m}$ & $\mathrm{m}$ & $\mathrm{m}$ & $\mathrm{m}$ & $\mathrm{m}$ & $\mathrm{m}$ & $\mathrm{m}$ \\
\hline Algeria & $\mathrm{m}$ & $\mathrm{m}$ & $\mathrm{m}$ & $\mathrm{m}$ & $\mathrm{m}$ & $\mathrm{m}$ & $\mathrm{m}$ & $\mathrm{m}$ & $\mathrm{m}$ & $\mathrm{m}$ & $\mathrm{m}$ & $\mathrm{m}$ & $\mathrm{m}$ & $\mathrm{m}$ & $\mathrm{m}$ & $\mathrm{m}$ \\
\hline Brazil & 7.31 & $(0.05)$ & 7.80 & $(0.04)$ & 0.49 & $(0.06)$ & 0.49 & $(0.06)$ & 7.25 & $(0.05)$ & 7.77 & $(0.04)$ & 0.52 & $(0.06)$ & 0.53 & $(0.06)$ \\
\hline B-S-J-G (China) & 6.46 & $(0.06)$ & 7.01 & $(0.04)$ & 0.54 & $(0.06)$ & 0.55 & $(0.06)$ & 6.46 & $(0.06)$ & 7.05 & $(0.04)$ & 0.59 & $(0.07)$ & 0.58 & $(0.07)$ \\
\hline Bulgaria & 7.05 & $(0.07)$ & 7.57 & $(0.05)$ & 0.52 & $(0.09)$ & 0.51 & $(0.09)$ & 7.02 & $(0.08)$ & 7.57 & $(0.05)$ & 0.55 & $(0.09)$ & 0.55 & $(0.09)$ \\
\hline CABA (Argentina) & $\mathrm{m}$ & $\mathrm{m}$ & $\mathrm{m}$ & $\mathrm{m}$ & $\mathrm{m}$ & $\mathrm{m}$ & $\mathrm{m}$ & $\mathrm{m}$ & $\mathrm{m}$ & $\mathrm{m}$ & $\mathrm{m}$ & $\mathrm{m}$ & $\mathrm{m}$ & $\mathrm{m}$ & $\mathrm{m}$ & $\mathrm{m}$ \\
\hline Colombia & 7.60 & $(0.05)$ & 8.03 & $(0.04)$ & 0.42 & $(0.05)$ & 0.43 & $(0.05)$ & 7.56 & $(0.05)$ & 8.00 & $(0.04)$ & 0.44 & $(0.06)$ & 0.45 & $(0.06)$ \\
\hline Costa Rica & 7.97 & $(0.05)$ & 8.39 & $(0.04)$ & 0.42 & $(0.06)$ & 0.42 & $(0.06)$ & 7.89 & $(0.06)$ & 8.36 & $(0.04)$ & 0.47 & $(0.07)$ & 0.47 & $(0.08)$ \\
\hline Croatia & 7.62 & $(0.05)$ & 8.20 & $(0.05)$ & 0.57 & $(0.06)$ & 0.57 & $(0.06)$ & 7.58 & $(0.05)$ & 8.09 & $(0.04)$ & 0.51 & $(0.05)$ & 0.50 & $(0.05)$ \\
\hline Cyprus* & 6.96 & $(0.04)$ & 7.18 & $(0.05)$ & 0.22 & $(0.06)$ & 0.21 & $(0.06)$ & 6.74 & $(0.06)$ & 7.26 & $(0.04)$ & 0.51 & $(0.07)$ & 0.45 & $(0.07)$ \\
\hline Dominican Republic & 8.25 & $(0.07)$ & 8.67 & $(0.06)$ & 0.42 & $(0.10)$ & 0.42 & $(0.10)$ & 8.19 & $(0.08)$ & 8.63 & $(0.06)$ & 0.43 & $(0.10)$ & 0.44 & $(0.10)$ \\
\hline FYROM & $\mathrm{m}$ & $\mathrm{m}$ & $\mathrm{m}$ & $\mathrm{m}$ & $\mathrm{m}$ & $\mathrm{m}$ & $\mathrm{m}$ & $\mathrm{m}$ & $\mathrm{m}$ & $\mathrm{m}$ & $\mathrm{m}$ & $\mathrm{m}$ & $\mathrm{m}$ & $\mathrm{m}$ & $\mathrm{m}$ & $\mathrm{m}$ \\
\hline Georgia & $\mathrm{m}$ & $\mathrm{m}$ & $\mathrm{m}$ & $\mathrm{m}$ & $\mathrm{m}$ & $\mathrm{m}$ & $\mathrm{m}$ & $\mathrm{m}$ & $\mathrm{m}$ & $\mathrm{m}$ & $\mathrm{m}$ & $\mathrm{m}$ & $\mathrm{m}$ & $\mathrm{m}$ & $\mathrm{m}$ & $\mathrm{m}$ \\
\hline Hong Kong (China) & 6.35 & $(0.04)$ & 6.64 & $(0.06)$ & 0.29 & $(0.06)$ & 0.29 & $(0.06)$ & 6.23 & $(0.05)$ & 6.66 & $(0.05)$ & 0.42 & $(0.06)$ & 0.41 & $(0.06)$ \\
\hline Indonesia & $\mathrm{m}$ & $\mathrm{m}$ & $\mathrm{m}$ & $\mathrm{m}$ & $\mathrm{m}$ & $\mathrm{m}$ & $\mathrm{m}$ & $\mathrm{m}$ & $\mathrm{m}$ & $\mathrm{m}$ & $\mathrm{m}$ & $\mathrm{m}$ & $\mathrm{m}$ & $\mathrm{m}$ & $\mathrm{m}$ & $\mathrm{m}$ \\
\hline Jordan & $\mathrm{m}$ & $\mathrm{m}$ & $\mathrm{m}$ & $\mathrm{m}$ & $\mathrm{m}$ & $\mathrm{m}$ & $\mathrm{m}$ & $\mathrm{m}$ & $\mathrm{m}$ & $\mathrm{m}$ & $\mathrm{m}$ & $\mathrm{m}$ & $\mathrm{m}$ & $\mathrm{m}$ & $\mathrm{m}$ & $\mathrm{m}$ \\
\hline Kosovo & $\mathrm{m}$ & $\mathrm{m}$ & $\mathrm{m}$ & $\mathrm{m}$ & $\mathrm{m}$ & $\mathrm{m}$ & $\mathrm{m}$ & $\mathrm{m}$ & $\mathrm{m}$ & $\mathrm{m}$ & $\mathrm{m}$ & $\mathrm{m}$ & $\mathrm{m}$ & $\mathrm{m}$ & $\mathrm{m}$ & $\mathrm{m}$ \\
\hline Lebanon & $\mathrm{m}$ & $\mathrm{m}$ & $\mathrm{m}$ & $\mathrm{m}$ & $\mathrm{m}$ & $\mathrm{m}$ & $\mathrm{m}$ & $\mathrm{m}$ & $\mathrm{m}$ & $\mathrm{m}$ & $\mathrm{m}$ & $\mathrm{m}$ & $\mathrm{m}$ & $\mathrm{m}$ & $\mathrm{m}$ & $\mathrm{m}$ \\
\hline Lithuania & 7.59 & $(0.06)$ & 8.03 & $(0.03)$ & 0.43 & $(0.06)$ & 0.43 & $(0.06)$ & 7.45 & $(0.07)$ & 8.02 & $(0.03)$ & 0.57 & $(0.07)$ & 0.55 & $(0.07)$ \\
\hline Macao (China) & 6.52 & $(0.04)$ & 6.66 & $(0.04)$ & 0.14 & $(0.06)$ & 0.16 & $(0.06)$ & 6.36 & $(0.05)$ & 6.73 & $(0.04)$ & 0.37 & $(0.06)$ & 0.34 & $(0.06)$ \\
\hline Malta & $\mathrm{m}$ & $\mathrm{m}$ & $\mathrm{m}$ & $\mathrm{m}$ & $\mathrm{m}$ & $\mathrm{m}$ & $\mathrm{m}$ & $\mathrm{m}$ & $\mathrm{m}$ & $\mathrm{m}$ & $\mathrm{m}$ & $\mathrm{m}$ & $\mathrm{m}$ & $\mathrm{m}$ & $\mathrm{m}$ & $\mathrm{m}$ \\
\hline Moldova & $\mathrm{m}$ & $\mathrm{m}$ & $\mathrm{m}$ & $\mathrm{m}$ & $\mathrm{m}$ & $\mathrm{m}$ & $\mathrm{m}$ & $\mathrm{m}$ & $\mathrm{m}$ & $\mathrm{m}$ & $\mathrm{m}$ & $\mathrm{m}$ & $\mathrm{m}$ & $\mathrm{m}$ & $\mathrm{m}$ & $\mathrm{m}$ \\
\hline Montenegro & 7.24 & $(0.09)$ & 7.84 & $(0.04)$ & 0.59 & $(0.11)$ & 0.59 & $(0.11)$ & 7.32 & $(0.08)$ & 7.84 & $(0.04)$ & 0.52 & $(0.09)$ & 0.51 & $(0.09)$ \\
\hline Peru & 7.23 & $(0.06)$ & 7.62 & $(0.04)$ & 0.39 & $(0.06)$ & 0.39 & $(0.06)$ & 7.10 & $(0.06)$ & 7.62 & $(0.05)$ & 0.52 & $(0.08)$ & 0.52 & $(0.08)$ \\
\hline Qatar & 7.08 & $(0.04)$ & 7.56 & $(0.03)$ & 0.48 & $(0.05)$ & 0.49 & $(0.05)$ & 6.90 & $(0.05)$ & 7.56 & $(0.02)$ & 0.66 & $(0.06)$ & 0.64 & $(0.06)$ \\
\hline Romania & $\mathrm{m}$ & $\mathrm{m}$ & $\mathrm{m}$ & $\mathrm{m}$ & $\mathrm{m}$ & $\mathrm{m}$ & $\mathrm{m}$ & $\mathrm{m}$ & $\mathrm{m}$ & $\mathrm{m}$ & $\mathrm{m}$ & $\mathrm{m}$ & $\mathrm{m}$ & $\mathrm{m}$ & $\mathrm{m}$ & $\mathrm{m}$ \\
\hline Russia & 7.40 & $(0.07)$ & 7.93 & $(0.05)$ & 0.53 & $(0.08)$ & 0.53 & $(0.08)$ & 7.49 & $(0.08)$ & 7.89 & $(0.05)$ & 0.40 & $(0.09)$ & 0.40 & (0.09) \\
\hline Singapore & $\mathrm{m}$ & $\mathrm{m}$ & $\mathrm{m}$ & $\mathrm{m}$ & $\mathrm{m}$ & $\mathrm{m}$ & $\mathrm{m}$ & $\mathrm{m}$ & $\mathrm{m}$ & $\mathrm{m}$ & $\mathrm{m}$ & $\mathrm{m}$ & $\mathrm{m}$ & $\mathrm{m}$ & $\mathrm{m}$ & $\mathrm{m}$ \\
\hline Chinese Taipei & 6.46 & $(0.03)$ & 6.84 & $(0.04)$ & 0.38 & $(0.05)$ & 0.39 & $(0.05)$ & 6.34 & $(0.05)$ & 6.77 & $(0.03)$ & 0.44 & $(0.05)$ & 0.42 & $(0.05)$ \\
\hline Thailand & 7.54 & $(0.05)$ & 7.85 & $(0.04)$ & 0.31 & $(0.05)$ & 0.30 & $(0.05)$ & 7.35 & $(0.06)$ & 7.85 & $(0.04)$ & 0.50 & $(0.06)$ & 0.49 & $(0.06)$ \\
\hline Trinidad and Tobago & $\mathrm{m}$ & $\mathrm{m}$ & $\mathrm{m}$ & $\mathrm{m}$ & $\mathrm{m}$ & $\mathrm{m}$ & $\mathrm{m}$ & $\mathrm{m}$ & $\mathrm{m}$ & $\mathrm{m}$ & $\mathrm{m}$ & $\mathrm{m}$ & $\mathrm{m}$ & $\mathrm{m}$ & $\mathrm{m}$ & $\mathrm{m}$ \\
\hline Tunisia & 6.73 & $(0.07)$ & 7.00 & $(0.06)$ & 0.27 & $(0.09)$ & 0.27 & $(0.09)$ & 6.70 & $(0.08)$ & 7.06 & $(0.06)$ & 0.36 & $(0.09)$ & 0.35 & $(0.09)$ \\
\hline United Arab Emirates & 7.01 & $(0.05)$ & 7.50 & $(0.04)$ & 0.49 & $(0.07)$ & 0.50 & $(0.07)$ & 6.91 & $(0.07)$ & 7.45 & $(0.04)$ & 0.54 & $(0.07)$ & 0.52 & $(0.08)$ \\
\hline Uruguay & 7.41 & $(0.06)$ & 7.92 & $(0.05)$ & 0.51 & $(0.08)$ & 0.51 & $(0.08)$ & 7.29 & $(0.06)$ & 7.92 & $(0.05)$ & 0.63 & $(0.08)$ & 0.59 & $(0.08)$ \\
\hline Viet Nam & $\mathrm{m}$ & $\mathrm{m}$ & $\mathrm{m}$ & $\mathrm{m}$ & $\mathrm{m}$ & $\mathrm{m}$ & $\mathrm{m}$ & $\mathrm{m}$ & $\mathrm{m}$ & $\mathrm{m}$ & $\mathrm{m}$ & $\mathrm{m}$ & $\mathrm{m}$ & $\mathrm{m}$ & $\mathrm{m}$ & $\mathrm{m}$ \\
\hline Argentina** & $\mathrm{m}$ & $\mathrm{m}$ & $\mathrm{m}$ & $\mathrm{m}$ & $\mathrm{m}$ & $\mathrm{m}$ & $\mathrm{m}$ & $\mathrm{m}$ & $\mathrm{m}$ & $\mathrm{m}$ & $\mathrm{m}$ & $\mathrm{m}$ & $\mathrm{m}$ & $\mathrm{m}$ & $\mathrm{m}$ & $\mathrm{m}$ \\
\hline Kazakhstan** & $\mathrm{m}$ & $\mathrm{m}$ & $\mathrm{m}$ & $\mathrm{m}$ & $\mathrm{m}$ & $\mathrm{m}$ & $\mathrm{m}$ & $\mathrm{m}$ & $\mathrm{m}$ & $\mathrm{m}$ & $\mathrm{m}$ & $\mathrm{m}$ & $\mathrm{m}$ & $\mathrm{m}$ & $\mathrm{m}$ & $\mathrm{m}$ \\
\hline Malaysia** & 6.94 & $(0.05)$ & 7.16 & $(0.05)$ & 0.23 & $(0.06)$ & 0.24 & $(0.06)$ & 6.85 & $(0.05)$ & 7.19 & $(0.05)$ & 0.34 & $(0.05)$ & 0.34 & $(0.05)$ \\
\hline
\end{tabular}

Note: Values that are statistically significant are indicated in bold (see Annex A3).

* See note at the beginning of this Annex.

** Coverage is too small to ensure comparability (see Annex A4).

StatLink i्गाडs http://dx.doi.org/10.1787/888933472612 
[Part 1/2]

Table III.11.9 Frequency of students' physical activity outside of school

Results based on students' self-reports

\begin{tabular}{|c|c|c|c|c|c|c|c|c|c|c|c|c|c|c|c|c|}
\hline & & & & & rcentag & of stud & ts whe & ported & he follo & ing acti & ty outsi & of sch & & & & \\
\hline & & & umber & days $p$ & week s & dents e & age in & oderate & hysical & ctivity $f$ & a tota & $f$ at lea & $60 \mathrm{~min}$ & es per & & \\
\hline & & & & & & & & & & & & & & & & \\
\hline & $\%$ & S.E. & $\%$ & S.E. & $\%$ & S.E. & $\%$ & S.E. & $\%$ & S.E. & $\%$ & S.E. & $\%$ & S.E. & $\%$ & S.E. \\
\hline Australia & 11.5 & $(0.3)$ & 11.5 & $(0.3)$ & 14.0 & $(0.4)$ & 14.4 & $(0.4)$ & 10.2 & $(0.3)$ & 14.5 & $(0.4)$ & 5.4 & $(0.3)$ & 18.5 & $(0.4)$ \\
\hline Austria & 9.9 & $(0.5)$ & 12.0 & $(0.4)$ & 10.9 & $(0.5)$ & 9.7 & $(0.3)$ & 6.9 & $(0.4)$ & 11.7 & $(0.5)$ & 4.6 & $(0.3)$ & 34.2 & $(0.7)$ \\
\hline Belgium & 12.8 & $(0.4)$ & 15.9 & $(0.4)$ & 12.8 & $(0.4)$ & 10.5 & $(0.3)$ & 6.9 & $(0.3)$ & 13.3 & $(0.4)$ & 4.7 & $(0.2)$ & 23.2 & $(0.4)$ \\
\hline Canada & 7.1 & $(0.3)$ & 7.1 & $(0.2)$ & 10.6 & $(0.3)$ & 13.9 & $(0.4)$ & 10.9 & $(0.3)$ & 16.6 & $(0.4)$ & 6.2 & $(0.2)$ & 27.6 & $(0.5)$ \\
\hline Chile & 12.3 & $(0.5)$ & 15.4 & $(0.5)$ & 15.1 & $(0.4)$ & 14.2 & $(0.5)$ & 7.3 & $(0.3)$ & 11.6 & $(0.4)$ & 3.5 & $(0.3)$ & 20.7 & $(0.5)$ \\
\hline Czech Republic & 6.7 & $(0.4)$ & 12.1 & $(0.4)$ & 12.1 & $(0.4)$ & 12.5 & $(0.4)$ & 8.9 & $(0.4)$ & 10.7 & $(0.5)$ & 4.6 & $(0.2)$ & 32.4 & $(0.7)$ \\
\hline Denmark & 6.6 & $(0.4)$ & 7.8 & $(0.5)$ & 8.9 & $(0.4)$ & 9.8 & $(0.4)$ & 8.3 & $(0.4)$ & 17.2 & $(0.5)$ & 8.2 & $(0.4)$ & 33.1 & $(0.7)$ \\
\hline Estonia & 9.7 & $(0.4)$ & 9.3 & $(0.4)$ & 15.5 & $(0.5)$ & 15.3 & $(0.5)$ & 10.9 & $(0.4)$ & 13.2 & $(0.5)$ & 5.5 & $(0.3)$ & 20.7 & $(0.7)$ \\
\hline Finland & 5.6 & $(0.3)$ & 8.8 & $(0.4)$ & 11.1 & $(0.5)$ & 13.5 & $(0.5)$ & 11.4 & $(0.4)$ & 15.6 & $(0.5)$ & 9.1 & $(0.4)$ & 25.0 & $(0.7)$ \\
\hline France & 13.0 & $(0.5)$ & 14.3 & $(0.5)$ & 13.6 & $(0.5)$ & 10.9 & $(0.4)$ & 8.5 & $(0.4)$ & 8.7 & $(0.3)$ & 4.4 & $(0.3)$ & 26.5 & $(0.7)$ \\
\hline Germany & 5.7 & $(0.3)$ & 8.6 & $(0.4)$ & 10.3 & $(0.5)$ & 10.6 & $(0.4)$ & 8.3 & $(0.4)$ & 13.6 & $(0.5)$ & 6.0 & $(0.3)$ & 36.9 & $(0.7)$ \\
\hline Greece & 13.4 & $(0.5)$ & 13.4 & $(0.5)$ & 16.3 & $(0.5)$ & 15.4 & $(0.5)$ & 9.4 & $(0.4)$ & 9.7 & $(0.4)$ & 4.4 & $(0.3)$ & 18.1 & (0.6) \\
\hline Hungary & 8.5 & $(0.4)$ & 8.8 & $(0.4)$ & 11.9 & $(0.6)$ & 12.5 & $(0.4)$ & 7.6 & $(0.3)$ & 14.4 & $(0.5)$ & 5.0 & $(0.3)$ & 31.2 & $(0.7)$ \\
\hline Iceland & 8.6 & $(0.5)$ & 8.8 & $(0.6)$ & 10.3 & $(0.6)$ & 11.1 & $(0.6)$ & 10.6 & $(0.5)$ & 13.1 & $(0.7)$ & 10.6 & $(0.5)$ & 26.9 & $(0.9)$ \\
\hline Ireland & 9.6 & $(0.4)$ & 13.7 & $(0.6)$ & 15.9 & $(0.5)$ & 14.2 & $(0.5)$ & 9.8 & $(0.4)$ & 12.6 & $(0.5)$ & 6.5 & $(0.4)$ & 17.6 & $(0.7)$ \\
\hline Israel & 19.1 & $(0.8)$ & 13.8 & $(0.5)$ & 13.5 & $(0.5)$ & 11.9 & $(0.5)$ & 7.7 & $(0.4)$ & 6.7 & $(0.3)$ & 14.7 & (1.3) & 12.6 & $(0.5)$ \\
\hline Italy & $\mathrm{m}$ & $\mathrm{m}$ & $\mathrm{m}$ & $\mathrm{m}$ & $\mathrm{m}$ & $\mathrm{m}$ & $\mathrm{m}$ & $\mathrm{m}$ & $\mathrm{m}$ & $\mathrm{m}$ & $\mathrm{m}$ & $\mathrm{m}$ & $\mathrm{m}$ & $\mathrm{m}$ & $\mathrm{m}$ & $\mathrm{m}$ \\
\hline Japan & 26.9 & $(0.8)$ & 6.9 & $(0.4)$ & 5.7 & $(0.3)$ & 5.7 & $(0.3)$ & 3.1 & $(0.2)$ & 14.9 & $(0.5)$ & 10.7 & $(0.5)$ & 26.1 & $(0.8)$ \\
\hline Korea & 19.8 & $(0.7)$ & 12.3 & $(0.5)$ & 13.6 & $(0.5)$ & 10.6 & $(0.4)$ & 5.0 & $(0.3)$ & 14.6 & $(0.5)$ & 4.0 & $(0.4)$ & 20.1 & $(0.7)$ \\
\hline Latvia & 7.2 & $(0.4)$ & 9.2 & $(0.5)$ & 12.6 & $(0.4)$ & 13.8 & $(0.5)$ & 9.8 & $(0.4)$ & 12.7 & $(0.5)$ & 5.9 & $(0.3)$ & 28.8 & $(0.7)$ \\
\hline Luxembourg & 12.4 & $(0.5)$ & 15.9 & $(0.6)$ & 14.9 & $(0.4)$ & 12.2 & $(0.5)$ & 9.5 & $(0.4)$ & 9.7 & $(0.4)$ & 4.5 & $(0.3)$ & 20.9 & (0.6) \\
\hline Mexico & 10.0 & $(0.4)$ & 16.4 & $(0.5)$ & 17.3 & $(0.5)$ & 14.5 & $(0.5)$ & 7.9 & $(0.4)$ & 12.9 & $(0.4)$ & 3.8 & $(0.3)$ & 17.1 & (0.6) \\
\hline Netherlands & 6.1 & $(0.4)$ & 7.0 & $(0.4)$ & 8.3 & $(0.4)$ & 8.1 & $(0.4)$ & 5.3 & $(0.4)$ & 24.9 & $(0.7)$ & 11.6 & $(0.5)$ & 28.7 & $(0.8)$ \\
\hline New Zealand & 10.5 & $(0.6)$ & 10.3 & $(0.4)$ & 12.3 & $(0.5)$ & 12.6 & $(0.5)$ & 10.2 & $(0.5)$ & 15.7 & $(0.5)$ & 7.0 & $(0.4)$ & 21.3 & $(0.7)$ \\
\hline Norway & 7.0 & $(0.4)$ & 7.4 & $(0.4)$ & 9.2 & $(0.4)$ & 9.7 & $(0.4)$ & 7.8 & $(0.4)$ & 16.6 & $(0.6)$ & 7.8 & $(0.4)$ & 34.4 & $(0.8)$ \\
\hline Poland & 7.0 & $(0.4)$ & 8.1 & $(0.4)$ & 9.5 & $(0.5)$ & 10.6 & $(0.5)$ & 9.2 & $(0.5)$ & 11.0 & $(0.5)$ & 6.9 & $(0.4)$ & 37.6 & $(0.8)$ \\
\hline Portugal & 15.3 & $(0.6)$ & 12.9 & $(0.6)$ & 17.3 & $(0.6)$ & 12.0 & $(0.4)$ & 6.8 & $(0.4)$ & 9.7 & $(0.3)$ & 3.1 & $(0.2)$ & 23.0 & $(0.7)$ \\
\hline Slovak Republic & 8.1 & $(0.4)$ & 11.0 & $(0.5)$ & 13.1 & $(0.5)$ & 11.7 & $(0.4)$ & 8.9 & $(0.4)$ & 12.2 & $(0.4)$ & 4.1 & $(0.3)$ & 30.9 & $(0.7)$ \\
\hline Slovenia & 6.3 & $(0.4)$ & 12.8 & $(0.6)$ & 14.4 & $(0.6)$ & 14.7 & $(0.6)$ & 9.4 & $(0.5)$ & 12.6 & $(0.5)$ & 5.7 & $(0.4)$ & 24.2 & $(0.8)$ \\
\hline Spain & 16.5 & $(0.5)$ & 11.8 & $(0.5)$ & 16.7 & $(0.5)$ & 13.4 & $(0.5)$ & 8.9 & $(0.4)$ & 10.7 & $(0.4)$ & 3.8 & $(0.3)$ & 18.2 & $(0.5)$ \\
\hline Sweden & 8.9 & $(0.5)$ & 9.4 & $(0.4)$ & 10.3 & $(0.5)$ & 11.0 & $(0.5)$ & 8.8 & $(0.4)$ & 15.0 & $(0.6)$ & 7.1 & $(0.3)$ & 29.4 & $(0.8)$ \\
\hline Switzerland & 7.4 & $(0.4)$ & 11.6 & $(0.7)$ & 11.5 & $(0.6)$ & 10.5 & $(0.4)$ & 7.3 & $(0.4)$ & 13.0 & $(0.5)$ & 6.5 & $(0.4)$ & 32.2 & $(0.8)$ \\
\hline Turkey & 17.8 & $(0.6)$ & 19.7 & $(0.6)$ & 15.7 & $(0.6)$ & 10.8 & $(0.5)$ & 6.1 & $(0.4)$ & 8.8 & $(0.4)$ & 1.6 & $(0.2)$ & 19.5 & $(0.8)$ \\
\hline United Kingdom & 11.4 & $(0.4)$ & 14.4 & $(0.6)$ & 13.0 & $(0.5)$ & 11.4 & $(0.4)$ & 8.0 & $(0.4)$ & 13.5 & $(0.4)$ & 4.9 & $(0.3)$ & 23.5 & $(0.7)$ \\
\hline United States & 10.7 & $(0.5)$ & 7.2 & $(0.4)$ & 10.1 & $(0.4)$ & 11.6 & $(0.5)$ & 8.4 & $(0.4)$ & 16.5 & (0.6) & 7.0 & $(0.4)$ & 28.5 & $(0.7)$ \\
\hline OECD average & 10.9 & $(0.1)$ & 11.3 & $(0.1)$ & 12.6 & $(0.1)$ & 11.9 & $(0.1)$ & 8.4 & $(0.1)$ & 13.2 & $(0.1)$ & 6.2 & $(0.1)$ & 25.6 & $(0.1)$ \\
\hline
\end{tabular}

\begin{tabular}{|c|c|c|c|c|c|c|c|c|c|c|c|c|c|c|c|c|}
\hline Albania & $\mathrm{m}$ & $\mathrm{m}$ & $\mathrm{m}$ & $\mathrm{m}$ & $\mathrm{m}$ & $\mathrm{m}$ & $\mathrm{m}$ & $\mathrm{m}$ & $\mathrm{m}$ & $\mathrm{m}$ & $\mathrm{m}$ & $\mathrm{m}$ & $\mathrm{m}$ & $\mathrm{m}$ & $\mathrm{m}$ & $\mathrm{m}$ \\
\hline Algeria & $\mathrm{m}$ & $\mathrm{m}$ & $\mathrm{m}$ & $\mathrm{m}$ & $\mathrm{m}$ & $\mathrm{m}$ & $\mathrm{m}$ & $\mathrm{m}$ & $\mathrm{m}$ & $\mathrm{m}$ & $\mathrm{m}$ & $\mathrm{m}$ & $\mathrm{m}$ & $\mathrm{m}$ & $\mathrm{m}$ & $\mathrm{m}$ \\
\hline Brazil & 22.5 & $(0.5)$ & 17.6 & $(0.4)$ & 16.2 & $(0.4)$ & 11.4 & $(0.3)$ & 5.9 & $(0.2)$ & 8.9 & $(0.3)$ & 2.7 & $(0.1)$ & 14.7 & $(0.4)$ \\
\hline B-S-J-G (China) & 17.2 & (0.6) & 15.3 & $(0.8)$ & 15.7 & $(0.7)$ & 9.4 & $(0.4)$ & 4.2 & $(0.3)$ & 18.1 & $(0.8)$ & 3.5 & $(0.4)$ & 16.6 & $(0.6)$ \\
\hline Bulgaria & 10.8 & $(0.5)$ & 12.4 & $(0.6)$ & 17.1 & $(0.6)$ & 14.4 & $(0.5)$ & 9.1 & $(0.4)$ & 10.1 & $(0.4)$ & 4.8 & $(0.3)$ & 21.2 & $(0.7)$ \\
\hline CABA (Argentina) & $\mathrm{m}$ & $\mathrm{m}$ & $\mathrm{m}$ & $\mathrm{m}$ & $\mathrm{m}$ & $\mathrm{m}$ & $\mathrm{m}$ & $\mathrm{m}$ & $\mathrm{m}$ & $\mathrm{m}$ & $\mathrm{m}$ & $\mathrm{m}$ & $\mathrm{m}$ & $\mathrm{m}$ & $\mathrm{m}$ & $\mathrm{m}$ \\
\hline Colombia & 23.9 & $(0.7)$ & 21.0 & $(0.5)$ & 14.0 & $(0.4)$ & 10.0 & $(0.4)$ & 5.0 & $(0.3)$ & 9.6 & $(0.4)$ & 2.6 & $(0.2)$ & 13.9 & $(0.5)$ \\
\hline Costa Rica & 14.4 & (0.5) & 20.4 & (0.6) & 17.3 & (0.5) & 13.4 & $(0.5)$ & 7.3 & $(0.5)$ & 10.3 & $(0.5)$ & 3.0 & $(0.3)$ & 14.0 & $(0.5)$ \\
\hline Croatia & 12.0 & $(0.5)$ & 13.5 & (0.6) & 14.4 & $(0.5)$ & 11.4 & $(0.4)$ & 7.2 & $(0.3)$ & 11.2 & $(0.5)$ & 4.7 & $(0.3)$ & 25.6 & $(0.7)$ \\
\hline Cyprus* & 11.7 & $(0.5)$ & 14.2 & $(0.5)$ & 18.0 & $(0.5)$ & 15.1 & $(0.5)$ & 10.4 & $(0.5)$ & 9.2 & $(0.5)$ & 4.7 & $(0.3)$ & 16.7 & $(0.5)$ \\
\hline Dominican Republic & 13.7 & $(0.7)$ & 17.3 & $(0.8)$ & 17.8 & $(0.7)$ & 10.5 & $(0.5)$ & 7.1 & $(0.4)$ & 13.4 & $(0.6)$ & 3.6 & $(0.3)$ & 16.6 & (0.6) \\
\hline FYROM & $\mathrm{m}$ & $\mathrm{m}$ & $\mathrm{m}$ & $\mathrm{m}$ & $\mathrm{m}$ & $\mathrm{m}$ & $\mathrm{m}$ & $\mathrm{m}$ & $\mathrm{m}$ & $\mathrm{m}$ & $\mathrm{m}$ & $\mathrm{m}$ & $\mathrm{m}$ & $\mathrm{m}$ & $\mathrm{m}$ & $\mathrm{m}$ \\
\hline Georgia & $\mathrm{m}$ & $\mathrm{m}$ & $\mathrm{m}$ & $\mathrm{m}$ & $\mathrm{m}$ & $\mathrm{m}$ & $\mathrm{m}$ & $\mathrm{m}$ & $\mathrm{m}$ & $\mathrm{m}$ & $\mathrm{m}$ & $\mathrm{m}$ & $\mathrm{m}$ & $\mathrm{m}$ & $\mathrm{m}$ & $\mathrm{m}$ \\
\hline Hong Kong (China) & 17.6 & $(0.6)$ & 15.0 & $(0.5)$ & 12.8 & $(0.5)$ & 10.7 & $(0.4)$ & 5.2 & $(0.3)$ & 12.1 & $(0.6)$ & 3.5 & $(0.3)$ & 23.1 & $(0.7)$ \\
\hline Indonesia & $\mathrm{m}$ & $\mathrm{m}$ & $\mathrm{m}$ & $\mathrm{m}$ & $\mathrm{m}$ & $\mathrm{m}$ & $\mathrm{m}$ & $\mathrm{m}$ & $\mathrm{m}$ & $\mathrm{m}$ & $\mathrm{m}$ & $\mathrm{m}$ & $\mathrm{m}$ & $\mathrm{m}$ & $\mathrm{m}$ & $\mathrm{m}$ \\
\hline Jordan & $\mathrm{m}$ & $\mathrm{m}$ & $\mathrm{m}$ & $\mathrm{m}$ & $\mathrm{m}$ & $\mathrm{m}$ & $\mathrm{m}$ & $\mathrm{m}$ & $\mathrm{m}$ & $\mathrm{m}$ & $\mathrm{m}$ & $\mathrm{m}$ & $\mathrm{m}$ & $\mathrm{m}$ & $\mathrm{m}$ & $\mathrm{m}$ \\
\hline Kosovo & $\mathrm{m}$ & $\mathrm{m}$ & $\mathrm{m}$ & $\mathrm{m}$ & $\mathrm{m}$ & $\mathrm{m}$ & $\mathrm{m}$ & $\mathrm{m}$ & $\mathrm{m}$ & $\mathrm{m}$ & $\mathrm{m}$ & $\mathrm{m}$ & $\mathrm{m}$ & $\mathrm{m}$ & $\mathrm{m}$ & $\mathrm{m}$ \\
\hline Lebanon & $\mathrm{m}$ & $\mathrm{m}$ & $\mathrm{m}$ & $\mathrm{m}$ & $\mathrm{m}$ & $\mathrm{m}$ & $\mathrm{m}$ & $\mathrm{m}$ & $\mathrm{m}$ & $\mathrm{m}$ & $\mathrm{m}$ & $\mathrm{m}$ & $\mathrm{m}$ & $\mathrm{m}$ & $\mathrm{m}$ & $\mathrm{m}$ \\
\hline Lithuania & 9.0 & $(0.4)$ & 10.1 & $(0.4)$ & 12.3 & $(0.5)$ & 12.9 & $(0.5)$ & 8.6 & $(0.4)$ & 12.6 & $(0.5)$ & 4.9 & $(0.3)$ & 29.7 & $(0.7)$ \\
\hline Macao (China) & 16.8 & $(0.5)$ & 19.1 & (0.6) & 14.9 & $(0.6)$ & 9.3 & $(0.4)$ & 4.5 & $(0.3)$ & 10.5 & $(0.5)$ & 4.6 & $(0.3)$ & 20.2 & $(0.6)$ \\
\hline Malta & $\mathrm{m}$ & $\mathrm{m}$ & $\mathrm{m}$ & $\mathrm{m}$ & $\mathrm{m}$ & $\mathrm{m}$ & $\mathrm{m}$ & $\mathrm{m}$ & $\mathrm{m}$ & $\mathrm{m}$ & $\mathrm{m}$ & $\mathrm{m}$ & $\mathrm{m}$ & $\mathrm{m}$ & $\mathrm{m}$ & $\mathrm{m}$ \\
\hline Moldova & $\mathrm{m}$ & $\mathrm{m}$ & $\mathrm{m}$ & $\mathrm{m}$ & $\mathrm{m}$ & $\mathrm{m}$ & $\mathrm{m}$ & $\mathrm{m}$ & $\mathrm{m}$ & $\mathrm{m}$ & $\mathrm{m}$ & $\mathrm{m}$ & $\mathrm{m}$ & $\mathrm{m}$ & $\mathrm{m}$ & $\mathrm{m}$ \\
\hline Montenegro & 5.9 & (0.4) & 9.7 & (0.4) & 14.3 & $(0.4)$ & 14.7 & $(0.4)$ & 10.7 & $(0.4)$ & 12.7 & $(0.4)$ & 4.9 & $(0.3)$ & 27.2 & $(0.6)$ \\
\hline Peru & 8.7 & $(0.4)$ & 21.2 & $(0.5)$ & 17.5 & $(0.5)$ & 14.0 & $(0.5)$ & 7.2 & $(0.3)$ & 10.9 & $(0.4)$ & 2.9 & $(0.2)$ & 17.5 & $(0.6)$ \\
\hline Qatar & 23.0 & (0.4) & 16.9 & (0.4) & 14.7 & $(0.3)$ & 13.1 & $(0.3)$ & 8.1 & $(0.3)$ & 7.9 & $(0.3)$ & 2.8 & $(0.2)$ & 13.4 & $(0.3)$ \\
\hline Romania & $\mathrm{m}$ & $\mathrm{m}$ & $\mathrm{m}$ & $\mathrm{m}$ & $\mathrm{m}$ & $\mathrm{m}$ & $\mathrm{m}$ & $\mathrm{m}$ & $\mathrm{m}$ & $\mathrm{m}$ & $\mathrm{m}$ & $\mathrm{m}$ & $\mathrm{m}$ & $\mathrm{m}$ & $\mathrm{m}$ & $\mathrm{m}$ \\
\hline Russia & 6.4 & $(0.5)$ & 8.6 & (0.4) & 12.8 & $(0.6)$ & 16.7 & $(0.6)$ & 10.3 & $(0.4)$ & 8.8 & $(0.5)$ & 7.6 & $(0.4)$ & 28.8 & $(0.8)$ \\
\hline Singapore & 15.2 & $(0.5)$ & 14.9 & $(0.5)$ & 14.4 & $(0.5)$ & 10.0 & $(0.4)$ & 5.0 & $(0.3)$ & 11.5 & $(0.4)$ & 3.0 & $(0.2)$ & 25.9 & $(0.5)$ \\
\hline Chinese Taipei & 15.8 & $(0.5)$ & 11.1 & (0.4) & 13.2 & $(0.5)$ & 8.7 & $(0.4)$ & 3.8 & $(0.2)$ & 16.4 & $(0.4)$ & 3.8 & $(0.2)$ & 27.1 & $(0.5)$ \\
\hline Thailand & 4.7 & $(0.3)$ & 15.8 & $(0.5)$ & 16.1 & $(0.6)$ & 15.6 & $(0.5)$ & 6.6 & $(0.3)$ & 14.9 & $(0.5)$ & 1.8 & $(0.2)$ & 24.5 & $(0.7)$ \\
\hline Trinidad and Tobago & $\mathrm{m}$ & $\mathrm{m}$ & $\mathrm{m}$ & $\mathrm{m}$ & $\mathrm{m}$ & $\mathrm{m}$ & $\mathrm{m}$ & $\mathrm{m}$ & $\mathrm{m}$ & $\mathrm{m}$ & $\mathrm{m}$ & $\mathrm{m}$ & $\mathrm{m}$ & $\mathrm{m}$ & $\mathrm{m}$ & $\mathrm{m}$ \\
\hline Tunisia & 20.5 & $(0.7)$ & 20.8 & $(0.7)$ & 17.6 & $(0.7)$ & 13.6 & $(0.5)$ & 7.3 & $(0.4)$ & 4.9 & $(0.3)$ & 4.0 & $(0.3)$ & 11.2 & $(0.5)$ \\
\hline United Arab Emirates & 27.1 & $(0.7)$ & 16.8 & $(0.4)$ & 14.5 & $(0.4)$ & 10.9 & $(0.4)$ & 6.9 & $(0.3)$ & 7.7 & $(0.3)$ & 2.5 & $(0.2)$ & 13.5 & $(0.4)$ \\
\hline Uruguay & 15.6 & $(0.5)$ & 12.3 & $(0.5)$ & 16.5 & $(0.5)$ & 12.1 & $(0.4)$ & 7.6 & $(0.4)$ & 12.3 & $(0.5)$ & 5.8 & $(0.4)$ & 17.8 & $(0.6)$ \\
\hline Viet Nam & $\mathrm{m}$ & $\mathrm{m}$ & $\mathrm{m}$ & $\mathrm{m}$ & $\mathrm{m}$ & $\mathrm{m}$ & $\mathrm{m}$ & $\mathrm{m}$ & $\mathrm{m}$ & $\mathrm{m}$ & $\mathrm{m}$ & $\mathrm{m}$ & $\mathrm{m}$ & $\mathrm{m}$ & $\mathrm{m}$ & $\mathrm{m}$ \\
\hline Argentina** & $\mathrm{m}$ & $\mathrm{m}$ & $\mathrm{m}$ & $\mathrm{m}$ & $\mathrm{m}$ & $\mathrm{m}$ & $\mathrm{m}$ & $\mathrm{m}$ & $\mathrm{m}$ & $\mathrm{m}$ & $\mathrm{m}$ & $\mathrm{m}$ & $\mathrm{m}$ & $\mathrm{m}$ & $\mathrm{m}$ & $\mathrm{m}$ \\
\hline Kazakhstan** & $\mathrm{m}$ & $\mathrm{m}$ & $\mathrm{m}$ & $\mathrm{m}$ & $\mathrm{m}$ & $\mathrm{m}$ & $\mathrm{m}$ & $\mathrm{m}$ & $\mathrm{m}$ & $\mathrm{m}$ & $\mathrm{m}$ & $\mathrm{m}$ & $\mathrm{m}$ & $\mathrm{m}$ & $\mathrm{m}$ & $\mathrm{m}$ \\
\hline Malaysia** & 6.0 & $(0.4)$ & 12.0 & (0.6) & 13.8 & $(0.4)$ & 11.8 & $(0.4)$ & 5.9 & $(0.3)$ & 16.7 & $(0.7)$ & 3.2 & $(0.2)$ & 30.4 & (1.0) \\
\hline
\end{tabular}

* See note at the beginning of this Annex.

** Coverage is too small to ensure comparability (see Annex A4).

StatLink 年政 http://dx.doi.org/10.1787/888933472624 
Percentage of students who reported the following activity outside of school

\begin{tabular}{|c|c|c|c|c|c|c|c|c|c|c|c|c|c|c|c|c|}
\hline & \multicolumn{16}{|c|}{ Percentage of students who reported the following activity outside of school } \\
\hline & \multicolumn{16}{|c|}{$\begin{array}{c}\text { Number of days per week students engage in vigorous physical activity (activity that made students sweat and breathe hard) } \\
\text { for a total of at least } 20 \text { minutes per day }\end{array}$} \\
\hline & \multicolumn{2}{|c|}{$\mathbf{0}$} & \multicolumn{2}{|c|}{1} & \multicolumn{2}{|c|}{2} & \multicolumn{2}{|c|}{3} & \multicolumn{2}{|c|}{4} & \multicolumn{2}{|c|}{5} & \multicolumn{2}{|c|}{6} & \multicolumn{2}{|c|}{7} \\
\hline & $\%$ & S.E. & $\%$ & S.E. & $\%$ & S.E. & $\%$ & S.E. & $\%$ & S.E. & $\%$ & S.E. & $\%$ & S.E. & $\%$ & S.E. \\
\hline Australia & 16.7 & $(0.4)$ & 13.9 & $(0.4)$ & 16.9 & $(0.4)$ & 16.0 & $(0.4)$ & 11.7 & $(0.3)$ & 9.8 & $(0.3)$ & 4.7 & $(0.2)$ & 10.3 & $(0.3)$ \\
\hline Austria & 20.6 & $(0.7)$ & 19.0 & $(0.5)$ & 17.8 & $(0.5)$ & 14.8 & $(0.6)$ & 10.4 & $(0.4)$ & 7.3 & $(0.3)$ & 3.5 & $(0.4)$ & 6.7 & $(0.5)$ \\
\hline Belgium & 18.6 & $(0.6)$ & 18.9 & $(0.4)$ & 17.5 & $(0.4)$ & 15.9 & $(0.4)$ & 10.4 & $(0.4)$ & 8.1 & $(0.3)$ & 3.7 & $(0.3)$ & 6.9 & $(0.3)$ \\
\hline Canada & 15.1 & (0.4) & 11.7 & $(0.3)$ & 14.6 & (0.4) & 14.6 & $(0.3)$ & 11.7 & (0.4) & 13.3 & $(0.3)$ & 5.8 & $(0.3)$ & 13.3 & $(0.4)$ \\
\hline Chile & 21.4 & $(0.7)$ & 19.7 & $(0.6)$ & 17.7 & $(0.5)$ & 14.3 & $(0.4)$ & 8.9 & $(0.4)$ & 6.5 & $(0.4)$ & 2.9 & $(0.3)$ & 8.6 & (0.5) \\
\hline Czech Republic & 11.5 & $(0.5)$ & 15.9 & $(0.7)$ & 16.1 & (0.6) & 16.9 & $(0.5)$ & 12.6 & $(0.4)$ & 9.9 & $(0.4)$ & 5.5 & $(0.3)$ & 11.4 & $(0.5)$ \\
\hline Denmark & 11.1 & $(0.5)$ & 11.5 & $(0.6)$ & 14.7 & $(0.4)$ & 17.5 & $(0.6)$ & 13.1 & $(0.5)$ & 12.5 & $(0.6)$ & 6.3 & $(0.4)$ & 13.2 & $(0.5)$ \\
\hline Estonia & 13.0 & $(0.5)$ & 13.2 & $(0.5)$ & 18.0 & $(0.6)$ & 16.9 & $(0.5)$ & 12.4 & $(0.6)$ & 11.3 & $(0.4)$ & 4.9 & $(0.3)$ & 10.4 & (0.5) \\
\hline Finland & 12.1 & $(0.5)$ & 15.2 & $(0.6)$ & 18.3 & $(0.5)$ & 16.9 & $(0.5)$ & 11.8 & $(0.4)$ & 11.4 & $(0.4)$ & 7.4 & $(0.5)$ & 6.8 & $(0.3)$ \\
\hline France & 22.7 & (0.6) & 21.1 & $(0.6)$ & 19.2 & $(0.5)$ & 14.4 & $(0.5)$ & 8.4 & (0.4) & 5.3 & $(0.3)$ & 2.7 & $(0.2)$ & 6.2 & $(0.3)$ \\
\hline Germany & 11.5 & $(0.5)$ & 14.0 & (0.5) & 19.9 & $(0.6)$ & 19.3 & $(0.7)$ & 13.7 & $(0.4)$ & 9.8 & (0.4) & 3.9 & $(0.3)$ & 7.8 & $(0.4)$ \\
\hline Greece & 18.3 & $(0.6)$ & 14.5 & $(0.4)$ & 16.4 & $(0.5)$ & 15.2 & $(0.5)$ & 10.3 & $(0.5)$ & 9.9 & $(0.4)$ & 4.9 & $(0.3)$ & 10.4 & $(0.5)$ \\
\hline Hungary & 13.6 & (0.6) & 11.5 & $(0.4)$ & 16.7 & $(0.5)$ & 16.6 & $(0.5)$ & 11.2 & $(0.4)$ & 11.6 & (0.5) & 5.1 & $(0.3)$ & 13.5 & (0.6) \\
\hline Iceland & 9.8 & $(0.5)$ & 8.6 & $(0.5)$ & 11.3 & $(0.4)$ & 11.8 & $(0.6)$ & 12.1 & $(0.6)$ & 14.6 & $(0.6)$ & 11.3 & $(0.6)$ & 20.3 & $(0.6)$ \\
\hline Ireland & 14.1 & $(0.5)$ & 12.9 & $(0.5)$ & 16.1 & $(0.5)$ & 15.6 & $(0.6)$ & 12.7 & $(0.4)$ & 11.4 & $(0.4)$ & 6.6 & $(0.4)$ & 10.6 & $(0.5)$ \\
\hline Israel & 20.0 & $(0.7)$ & 14.9 & $(0.5)$ & 15.3 & $(0.6)$ & 12.5 & $(0.5)$ & 8.9 & $(0.5)$ & 6.7 & $(0.4)$ & 14.4 & (1.3) & 7.4 & $(0.4)$ \\
\hline Italy & $\mathrm{m}$ & $\mathrm{m}$ & $\mathrm{m}$ & $\mathrm{m}$ & $\mathrm{m}$ & $\mathrm{m}$ & $\mathrm{m}$ & $\mathrm{m}$ & $\mathrm{m}$ & $\mathrm{m}$ & $\mathrm{m}$ & $\mathrm{m}$ & $\mathrm{m}$ & $\mathrm{m}$ & $\mathrm{m}$ & $\mathrm{m}$ \\
\hline Japan & 33.3 & $(0.8)$ & 11.0 & $(0.4)$ & 8.9 & $(0.4)$ & 8.1 & $(0.4)$ & 3.8 & $(0.3)$ & 6.8 & $(0.4)$ & 10.9 & $(0.5)$ & 17.2 & $(0.8)$ \\
\hline Korea & 27.7 & $(0.8)$ & 16.3 & $(0.6)$ & 20.0 & $(0.7)$ & 12.5 & $(0.5)$ & 5.8 & $(0.3)$ & 7.2 & $(0.4)$ & 2.5 & $(0.4)$ & 8.0 & $(0.4)$ \\
\hline Latvia & 12.4 & $(0.5)$ & 13.0 & $(0.6)$ & 17.0 & $(0.6)$ & 17.1 & $(0.6)$ & 12.0 & $(0.6)$ & 12.3 & $(0.6)$ & 5.3 & $(0.4)$ & 10.8 & $(0.5)$ \\
\hline Luxembourg & 16.3 & $(0.5)$ & 15.7 & $(0.5)$ & 16.8 & $(0.5)$ & 15.5 & $(0.5)$ & 11.5 & $(0.4)$ & 8.8 & $(0.4)$ & 4.7 & $(0.3)$ & 10.7 & $(0.4)$ \\
\hline Mexico & 14.9 & $(0.5)$ & 18.5 & $(0.6)$ & 18.9 & $(0.5)$ & 13.5 & $(0.4)$ & 8.4 & $(0.4)$ & 11.4 & $(0.4)$ & 4.5 & $(0.3)$ & 10.1 & $(0.4)$ \\
\hline Netherlands & 16.0 & $(0.6)$ & 14.5 & $(0.5)$ & 16.1 & $(0.5)$ & 23.0 & $(0.7)$ & 13.4 & $(0.5)$ & 8.0 & $(0.4)$ & 4.3 & $(0.3)$ & 4.6 & $(0.3)$ \\
\hline New Zealand & 19.1 & $(0.8)$ & 11.8 & $(0.6)$ & 16.8 & (0.6) & 14.2 & $(0.5)$ & 12.1 & $(0.6)$ & 10.7 & $(0.5)$ & 6.0 & $(0.4)$ & 9.3 & $(0.5)$ \\
\hline Norway & 10.9 & $(0.6)$ & 11.9 & $(0.5)$ & 14.9 & $(0.5)$ & 17.0 & $(0.6)$ & 13.3 & $(0.4)$ & 12.8 & $(0.5)$ & 7.2 & $(0.4)$ & 12.0 & $(0.5)$ \\
\hline Poland & 11.5 & $(0.5)$ & 11.7 & $(0.5)$ & 13.0 & $(0.6)$ & 15.4 & $(0.6)$ & 11.8 & $(0.5)$ & 10.8 & (0.5) & 6.6 & $(0.4)$ & 19.3 & $(0.6)$ \\
\hline Portugal & 21.1 & $(0.6)$ & 14.6 & (0.5) & 19.5 & $(0.5)$ & 14.3 & $(0.4)$ & 10.7 & $(0.5)$ & 7.8 & $(0.4)$ & 3.3 & $(0.3)$ & 8.7 & (0.5) \\
\hline Slovak Republic & 12.4 & $(0.5)$ & 15.3 & $(0.6)$ & 16.7 & $(0.5)$ & 16.4 & $(0.6)$ & 10.2 & $(0.5)$ & 9.7 & $(0.4)$ & 4.8 & $(0.3)$ & 14.4 & $(0.6)$ \\
\hline Slovenia & 11.2 & $(0.4)$ & 14.6 & $(0.6)$ & 15.8 & $(0.6)$ & 15.1 & $(0.6)$ & 11.5 & $(0.5)$ & 10.6 & $(0.5)$ & 6.6 & $(0.4)$ & 14.5 & (0.6) \\
\hline Spain & 21.4 & $(0.7)$ & 13.1 & $(0.5)$ & 19.8 & $(0.5)$ & 14.9 & $(0.4)$ & 12.8 & $(0.5)$ & 7.8 & $(0.3)$ & 3.8 & $(0.3)$ & 6.4 & $(0.4)$ \\
\hline Sweden & 12.3 & $(0.6)$ & 12.3 & $(0.5)$ & 15.2 & $(0.5)$ & 15.3 & $(0.5)$ & 13.5 & $(0.5)$ & 12.4 & $(0.5)$ & 7.6 & $(0.4)$ & 11.4 & $(0.6)$ \\
\hline Switzerland & 12.0 & $(0.5)$ & 15.5 & $(0.6)$ & 18.3 & $(0.7)$ & 18.6 & $(0.6)$ & 12.6 & $(0.6)$ & 10.4 & $(0.5)$ & 4.7 & $(0.3)$ & 7.8 & (0.5) \\
\hline Turkey & 21.8 & $(0.6)$ & 21.4 & $(0.6)$ & 18.7 & $(0.6)$ & 13.1 & $(0.4)$ & 6.7 & $(0.3)$ & 6.4 & $(0.4)$ & 2.2 & $(0.2)$ & 9.8 & $(0.5)$ \\
\hline United Kingdom & 21.3 & $(0.5)$ & 19.3 & $(0.7)$ & 17.6 & $(0.4)$ & 14.2 & $(0.5)$ & 9.1 & $(0.5)$ & 8.0 & $(0.4)$ & 3.6 & $(0.3)$ & 6.8 & $(0.4)$ \\
\hline United States & 16.6 & $(0.6)$ & 9.8 & $(0.4)$ & 11.8 & $(0.5)$ & 12.3 & $(0.5)$ & 8.6 & $(0.4)$ & 16.6 & $(0.6)$ & 7.6 & $(0.4)$ & 16.8 & $(0.5)$ \\
\hline OECD average & 16.5 & $(0.1)$ & 14.6 & $(0.1)$ & 16.5 & $(0.1)$ & 15.3 & $(0.1)$ & 10.8 & $(0.1)$ & 9.9 & $(0.1)$ & 5.6 & $(0.1)$ & 10.7 & $(0.1)$ \\
\hline
\end{tabular}

\begin{tabular}{|c|c|c|c|c|c|c|c|c|c|c|c|c|c|c|c|c|}
\hline Albania & $\mathrm{m}$ & $\mathrm{m}$ & $\mathrm{m}$ & $\mathrm{m}$ & $\mathrm{m}$ & $\mathrm{m}$ & $\mathrm{m}$ & $\mathrm{m}$ & $\mathrm{m}$ & $\mathrm{m}$ & $\mathrm{m}$ & $\mathrm{m}$ & $\mathrm{m}$ & $\mathrm{m}$ & $\mathrm{m}$ & $\mathrm{m}$ \\
\hline Algeria & $\mathrm{m}$ & $\mathrm{m}$ & $\mathrm{m}$ & $\mathrm{m}$ & $\mathrm{m}$ & $\mathrm{m}$ & $\mathrm{m}$ & $\mathrm{m}$ & $\mathrm{m}$ & $\mathrm{m}$ & $\mathrm{m}$ & $\mathrm{m}$ & $\mathrm{m}$ & $\mathrm{m}$ & $\mathrm{m}$ & $\mathrm{m}$ \\
\hline ฐ Brazil & 34.7 & $(0.5)$ & 16.3 & $(0.3)$ & 13.6 & $(0.3)$ & 10.0 & $(0.3)$ & 5.8 & $(0.2)$ & 7.7 & $(0.3)$ & 3.0 & $(0.2)$ & 8.9 & $(0.3)$ \\
\hline B-S-J-G (China) & 13.7 & $(0.5)$ & 14.6 & $(0.8)$ & 21.0 & $(0.7)$ & 13.9 & $(0.7)$ & 7.1 & $(0.5)$ & 16.1 & $(0.8)$ & 3.0 & $(0.3)$ & 10.7 & $(0.6)$ \\
\hline Bulgaria & 17.2 & $(0.6)$ & 16.3 & $(0.5)$ & 17.1 & $(0.5)$ & 14.6 & $(0.5)$ & 8.5 & $(0.4)$ & 9.2 & $(0.4)$ & 4.8 & $(0.4)$ & 12.3 & $(0.5)$ \\
\hline CABA (Argentina) & $\mathrm{m}$ & $\mathrm{m}$ & $\mathrm{m}$ & $\mathrm{m}$ & $\mathrm{m}$ & $\mathrm{m}$ & $\mathrm{m}$ & $\mathrm{m}$ & $\mathrm{m}$ & $\mathrm{m}$ & $\mathrm{m}$ & $\mathrm{m}$ & $\mathrm{m}$ & $\mathrm{m}$ & $\mathrm{m}$ & $\mathrm{m}$ \\
\hline Colombia & 19.3 & $(0.6)$ & 24.4 & $(0.5)$ & 16.8 & $(0.5)$ & 11.7 & $(0.4)$ & 7.6 & $(0.4)$ & 8.1 & $(0.3)$ & 3.6 & $(0.2)$ & 8.5 & $(0.4)$ \\
\hline Costa Rica & 27.5 & $(0.7)$ & 20.2 & $(0.6)$ & 15.2 & $(0.5)$ & 13.4 & $(0.5)$ & 7.0 & $(0.3)$ & 6.2 & $(0.3)$ & 3.1 & $(0.2)$ & 7.6 & $(0.4)$ \\
\hline Croatia & 19.3 & $(0.6)$ & 15.9 & $(0.5)$ & 16.9 & $(0.5)$ & 13.1 & $(0.5)$ & 8.8 & $(0.4)$ & 9.0 & $(0.4)$ & 5.0 & $(0.3)$ & 12.1 & $(0.5)$ \\
\hline Cyprus* & 16.5 & $(0.5)$ & 16.7 & $(0.5)$ & 16.0 & $(0.6)$ & 13.2 & $(0.5)$ & 10.3 & $(0.5)$ & 9.3 & $(0.5)$ & 6.3 & $(0.4)$ & 11.8 & $(0.5)$ \\
\hline Dominican Republic & 16.4 & $(0.8)$ & 18.0 & $(0.8)$ & 17.3 & $(0.7)$ & 12.7 & $(0.6)$ & 8.3 & $(0.4)$ & 10.8 & $(0.5)$ & 4.5 & $(0.4)$ & 12.0 & (0.6) \\
\hline FYROM & $\mathrm{m}$ & $\mathrm{m}$ & $\mathrm{m}$ & $\mathrm{m}$ & $\mathrm{m}$ & $\mathrm{m}$ & $\mathrm{m}$ & $\mathrm{m}$ & $\mathrm{m}$ & $\mathrm{m}$ & $\mathrm{m}$ & $\mathrm{m}$ & $\mathrm{m}$ & $\mathrm{m}$ & $\mathrm{m}$ & $\mathrm{m}$ \\
\hline Georgia & $\mathrm{m}$ & $\mathrm{m}$ & $\mathrm{m}$ & $\mathrm{m}$ & $\mathrm{m}$ & $\mathrm{m}$ & $\mathrm{m}$ & $\mathrm{m}$ & $\mathrm{m}$ & $\mathrm{m}$ & $\mathrm{m}$ & $\mathrm{m}$ & $\mathrm{m}$ & $\mathrm{m}$ & $\mathrm{m}$ & $\mathrm{m}$ \\
\hline Hong Kong (China) & 22.6 & $(0.7)$ & 23.3 & $(0.7)$ & 17.3 & $(0.6)$ & 13.0 & $(0.5)$ & 6.1 & $(0.3)$ & 7.1 & $(0.4)$ & 2.4 & $(0.2)$ & 8.1 & $(0.5)$ \\
\hline Indonesia & $\mathrm{m}$ & $\mathrm{m}$ & $\mathrm{m}$ & $\mathrm{m}$ & $\mathrm{m}$ & $\mathrm{m}$ & $\mathrm{m}$ & $\mathrm{m}$ & $\mathrm{m}$ & $\mathrm{m}$ & $\mathrm{m}$ & $\mathrm{m}$ & $\mathrm{m}$ & $\mathrm{m}$ & $\mathrm{m}$ & $\mathrm{m}$ \\
\hline Jordan & $\mathrm{m}$ & $\mathrm{m}$ & $\mathrm{m}$ & $\mathrm{m}$ & $\mathrm{m}$ & $\mathrm{m}$ & $\mathrm{m}$ & $\mathrm{m}$ & $\mathrm{m}$ & $\mathrm{m}$ & $\mathrm{m}$ & $\mathrm{m}$ & $\mathrm{m}$ & $\mathrm{m}$ & $\mathrm{m}$ & $\mathrm{m}$ \\
\hline Kosovo & $\mathrm{m}$ & $\mathrm{m}$ & $\mathrm{m}$ & $\mathrm{m}$ & $\mathrm{m}$ & $\mathrm{m}$ & $\mathrm{m}$ & $\mathrm{m}$ & $\mathrm{m}$ & $\mathrm{m}$ & $\mathrm{m}$ & $\mathrm{m}$ & $\mathrm{m}$ & $\mathrm{m}$ & $\mathrm{m}$ & $\mathrm{m}$ \\
\hline Lebanon & $\mathrm{m}$ & $\mathrm{m}$ & $\mathrm{m}$ & $\mathrm{m}$ & $\mathrm{m}$ & $\mathrm{m}$ & $\mathrm{m}$ & $\mathrm{m}$ & $\mathrm{m}$ & $\mathrm{m}$ & $\mathrm{m}$ & $\mathrm{m}$ & $\mathrm{m}$ & $\mathrm{m}$ & $\mathrm{m}$ & $\mathrm{m}$ \\
\hline Lithuania & 14.1 & $(0.4)$ & 12.6 & $(0.4)$ & 17.6 & $(0.7)$ & 16.6 & $(0.6)$ & 11.3 & $(0.4)$ & 11.7 & $(0.5)$ & 5.2 & $(0.3)$ & 11.0 & $(0.5)$ \\
\hline Macao (China) & 24.1 & $(0.6)$ & 25.9 & $(0.7)$ & 20.4 & $(0.7)$ & 10.1 & $(0.4)$ & 5.7 & $(0.3)$ & 5.8 & $(0.4)$ & 2.8 & $(0.3)$ & 5.2 & $(0.3)$ \\
\hline Malta & $\mathrm{m}$ & $\mathrm{m}$ & $\mathrm{m}$ & $\mathrm{m}$ & $\mathrm{m}$ & $\mathrm{m}$ & $\mathrm{m}$ & $\mathrm{m}$ & $\mathrm{m}$ & $\mathrm{m}$ & $\mathrm{m}$ & $\mathrm{m}$ & $\mathrm{m}$ & $\mathrm{m}$ & $\mathrm{m}$ & $\mathrm{m}$ \\
\hline Moldova & $\mathrm{m}$ & $\mathrm{m}$ & $\mathrm{m}$ & $\mathrm{m}$ & $\mathrm{m}$ & $\mathrm{m}$ & $\mathrm{m}$ & $\mathrm{m}$ & $\mathrm{m}$ & $\mathrm{m}$ & $\mathrm{m}$ & $\mathrm{m}$ & $\mathrm{m}$ & $\mathrm{m}$ & $\mathrm{m}$ & $\mathrm{m}$ \\
\hline Montenegro & 14.5 & $(0.6)$ & 13.7 & $(0.5)$ & 15.1 & $(0.4)$ & 14.1 & $(0.6)$ & 9.0 & $(0.4)$ & 10.6 & $(0.4)$ & 5.5 & $(0.4)$ & 17.5 & (0.6) \\
\hline Peru & 14.5 & $(0.5)$ & 24.0 & $(0.6)$ & 19.7 & $(0.6)$ & 14.4 & $(0.5)$ & 8.2 & $(0.4)$ & 7.3 & $(0.4)$ & 3.4 & $(0.2)$ & 8.5 & $(0.4)$ \\
\hline Qatar & 25.1 & $(0.4)$ & 18.0 & $(0.4)$ & 16.0 & $(0.4)$ & 12.1 & $(0.3)$ & 8.1 & $(0.3)$ & 7.7 & $(0.3)$ & 3.8 & $(0.2)$ & 9.2 & $(0.3)$ \\
\hline Romania & $\mathrm{m}$ & $\mathrm{m}$ & $\mathrm{m}$ & $\mathrm{m}$ & $\mathrm{m}$ & $\mathrm{m}$ & $\mathrm{m}$ & $\mathrm{m}$ & $\mathrm{m}$ & $\mathrm{m}$ & $\mathrm{m}$ & $\mathrm{m}$ & $\mathrm{m}$ & $\mathrm{m}$ & $\mathrm{m}$ & $\mathrm{m}$ \\
\hline Russia & 12.3 & $(0.6)$ & 12.5 & $(0.5)$ & 15.3 & $(0.5)$ & 21.5 & $(0.6)$ & 11.2 & $(0.4)$ & 8.7 & $(0.4)$ & 6.0 & $(0.3)$ & 12.5 & $(0.6)$ \\
\hline Singapore & 18.7 & $(0.5)$ & 23.3 & $(0.6)$ & 22.0 & $(0.7)$ & 15.0 & $(0.5)$ & 7.8 & $(0.4)$ & 6.2 & $(0.3)$ & 2.0 & $(0.2)$ & 4.9 & $(0.3)$ \\
\hline Chinese Taipei & 18.4 & $(0.6)$ & 15.5 & $(0.6)$ & 25.4 & $(0.6)$ & 12.3 & $(0.4)$ & 6.3 & $(0.3)$ & 8.4 & $(0.4)$ & 2.9 & $(0.2)$ & 10.9 & $(0.4)$ \\
\hline Thailand & 11.5 & $(0.5)$ & 23.9 & $(0.6)$ & 20.9 & $(0.5)$ & 15.9 & $(0.5)$ & 6.4 & $(0.3)$ & 9.4 & $(0.4)$ & 1.8 & $(0.2)$ & 10.2 & $(0.5)$ \\
\hline Trinidad and Tobago & $\mathrm{m}$ & $\mathrm{m}$ & $\mathrm{m}$ & $\mathrm{m}$ & $\mathrm{m}$ & $\mathrm{m}$ & $\mathrm{m}$ & $\mathrm{m}$ & $\mathrm{m}$ & $\mathrm{m}$ & $\mathrm{m}$ & $\mathrm{m}$ & $\mathrm{m}$ & $\mathrm{m}$ & $\mathrm{m}$ & $\mathrm{m}$ \\
\hline Tunisia & 25.2 & $(0.7)$ & 20.4 & $(0.6)$ & 17.2 & $(0.6)$ & 13.0 & $(0.6)$ & 8.1 & $(0.5)$ & 5.0 & $(0.3)$ & 3.1 & $(0.3)$ & 8.0 & $(0.4)$ \\
\hline United Arab Emirates & 26.1 & $(0.7)$ & 19.6 & $(0.5)$ & 15.6 & $(0.5)$ & 11.4 & $(0.4)$ & 7.3 & $(0.3)$ & 7.5 & $(0.4)$ & 3.0 & $(0.2)$ & 9.6 & $(0.3)$ \\
\hline Uruguay & 23.7 & $(0.7)$ & 12.4 & $(0.5)$ & 17.4 & $(0.6)$ & 14.6 & $(0.5)$ & 8.0 & $(0.4)$ & 9.4 & $(0.4)$ & 5.8 & $(0.3)$ & 8.6 & $(0.4)$ \\
\hline Viet Nam & $\mathrm{m}$ & $\mathrm{m}$ & $\mathrm{m}$ & $\mathrm{m}$ & $\mathrm{m}$ & $\mathrm{m}$ & $\mathrm{m}$ & $\mathrm{m}$ & $\mathrm{m}$ & $\mathrm{m}$ & $\mathrm{m}$ & $\mathrm{m}$ & $\mathrm{m}$ & $\mathrm{m}$ & $\mathrm{m}$ & $\mathrm{m}$ \\
\hline Argentina** & $\mathrm{m}$ & $\mathrm{m}$ & $\mathrm{m}$ & $\mathrm{m}$ & $\mathrm{m}$ & $\mathrm{m}$ & $\mathrm{m}$ & $\mathrm{m}$ & $\mathrm{m}$ & $\mathrm{m}$ & $\mathrm{m}$ & $\mathrm{m}$ & $\mathrm{m}$ & $\mathrm{m}$ & $\mathrm{m}$ & $\mathrm{m}$ \\
\hline Kazakhstan** & $\mathrm{m}$ & $\mathrm{m}$ & $\mathrm{m}$ & $\mathrm{m}$ & $\mathrm{m}$ & $\mathrm{m}$ & $\mathrm{m}$ & $\mathrm{m}$ & $\mathrm{m}$ & $\mathrm{m}$ & $\mathrm{m}$ & $\mathrm{m}$ & $\mathrm{m}$ & $\mathrm{m}$ & $\mathrm{m}$ & $\mathrm{m}$ \\
\hline Malaysia** & 8.8 & $(0.5)$ & 19.1 & $(0.7)$ & 21.4 & $(0.6)$ & 16.7 & $(0.6)$ & 8.8 & $(0.4)$ & 10.0 & $(0.4)$ & 2.7 & $(0.2)$ & 12.5 & (0.5) \\
\hline
\end{tabular}

* See note at the beginning of this Annex.

** Coverage is too small to ensure comparability (see Annex A4).

StatLink iना St http://dx. doi.org/10.1787/888933472624 
[Part 1/2]

Table III.11.10 Students who do not engage in physical activity outside of school, by student characteristics Results based on students' self-reports

Percentage of students who do NOT engage in neither moderate (for at least 60 minutes per day) nor vigorous physical activity

\begin{tabular}{|c|c|c|c|c|c|c|c|c|c|c|c|c|c|}
\hline & \multicolumn{12}{|c|}{$\begin{array}{l}\text { Percentage of students who do NOT engage in neither moderate (for at least } 60 \text { minutes per day) nor vigorous physical activity } \\
\text { (for at least } 20 \text { minutes per day) }\end{array}$} \\
\hline & & \multirow{2}{*}{\multicolumn{2}{|c|}{ All students }} & \multicolumn{10}{|c|}{ National quarters of the ESCS ${ }^{1}$ index } \\
\hline & & & & Bott & Iarter & Secc & Iarter & & irter & & rter & Top - bo & quarter \\
\hline & & $\%$ & S.E. & $\%$ & S.E. & $\%$ & S.E. & $\%$ & S.E. & $\%$ & S.E. & $\%$ dif. & S.E. \\
\hline 0 & Australia & 6.5 & $(0.2)$ & 8.9 & $(0.6)$ & 6.8 & $(0.6)$ & 5.7 & $(0.5)$ & 4.1 & $(0.4)$ & -4.8 & $(0.7)$ \\
\hline 氙 & Austria & 6.1 & $(0.4)$ & 8.2 & $(0.9)$ & 6.1 & $(0.7)$ & 6.0 & $(0.6)$ & 4.1 & $(0.5)$ & -4.1 & (1.0) \\
\hline 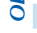 & Belgium & 7.2 & $(0.4)$ & 12.2 & $(0.9)$ & 7.8 & $(0.6)$ & 5.7 & $(0.6)$ & 3.6 & $(0.4)$ & -8.6 & (0.9) \\
\hline & Canada & 4.8 & $(0.2)$ & 7.6 & $(0.6)$ & 5.4 & $(0.4)$ & 4.2 & $(0.4)$ & 1.9 & $(0.3)$ & -5.7 & $(0.6)$ \\
\hline & Chile & 8.0 & $(0.4)$ & 7.6 & $(0.8)$ & 8.5 & $(0.9)$ & 8.6 & (1.0) & 7.3 & $(0.6)$ & -0.3 & (1.0) \\
\hline & Czech Republic & 3.3 & $(0.3)$ & 5.5 & $(0.8)$ & 3.3 & $(0.6)$ & 2.1 & $(0.4)$ & 2.5 & $(0.4)$ & -2.9 & $(0.9)$ \\
\hline & Denmark & 4.0 & $(0.3)$ & 6.1 & $(0.8)$ & 4.3 & $(0.7)$ & 2.9 & $(0.4)$ & 3.0 & $(0.6)$ & -3.2 & $(0.9)$ \\
\hline & Estonia & 5.4 & $(0.3)$ & 7.1 & $(0.8)$ & 5.4 & $(0.7)$ & 5.2 & $(0.8)$ & 3.6 & $(0.6)$ & -3.5 & $(1.0)$ \\
\hline & Finland & 3.8 & $(0.3)$ & 5.9 & $(0.7)$ & 4.5 & $(0.5)$ & 3.2 & $(0.5)$ & 1.8 & $(0.4)$ & -4.0 & $(0.9)$ \\
\hline & France & 8.8 & $(0.4)$ & 14.0 & $(1.0)$ & 10.2 & $(0.8)$ & 7.4 & $(0.8)$ & 3.9 & $(0.6)$ & -10.1 & (1.1) \\
\hline & Germany & 3.1 & $(0.2)$ & 4.6 & $(0.6)$ & 3.0 & $(0.6)$ & 2.8 & $(0.4)$ & 1.6 & $(0.4)$ & -3.0 & $(0.7)$ \\
\hline & Greece & 7.9 & $(0.4)$ & 10.2 & $(0.9)$ & 7.9 & $(0.8)$ & 7.2 & $(0.7)$ & 6.2 & $(0.7)$ & -4.0 & $(1.2)$ \\
\hline & Hungary & 4.7 & $(0.3)$ & 7.5 & $(0.8)$ & 5.3 & $(0.9)$ & 4.0 & $(0.6)$ & 1.8 & $(0.4)$ & -5.7 & (1.0) \\
\hline & Iceland & 5.0 & $(0.4)$ & 7.0 & $(0.9)$ & 5.5 & $(0.8)$ & 4.5 & $(0.8)$ & 2.7 & $(0.7)$ & -4.2 & (1.1) \\
\hline & Ireland & 5.0 & $(0.3)$ & 6.9 & $(0.8)$ & 4.9 & $(0.5)$ & 4.1 & $(0.6)$ & 4.2 & $(0.6)$ & -2.7 & $(1.0)$ \\
\hline & Israel & 11.8 & $(0.6)$ & 17.0 & (1.0) & 12.3 & $(0.8)$ & 9.6 & $(0.9)$ & 8.6 & $(0.7)$ & -8.4 & (1.1) \\
\hline & Italy & $\mathrm{m}$ & $\mathrm{m}$ & m & $\mathrm{m}$ & $\mathrm{m}$ & $\mathrm{m}$ & $\mathrm{m}$ & $\mathrm{m}$ & $\mathrm{m}$ & $\mathrm{m}$ & $\mathrm{m}$ & $\mathrm{m}$ \\
\hline & Japan & 18.0 & $(0.7)$ & 19.6 & $(1.0)$ & 18.1 & $(1.3)$ & 17.1 & $(1.3)$ & 16.7 & (1.0) & -2.9 & $(1.2)$ \\
\hline & Korea & 13.8 & (0.6) & 14.4 & $(0.9)$ & 14.0 & $(1.3)$ & 14.5 & (1.3) & 12.2 & (1.1) & -2.3 & (1.5) \\
\hline & Latvia & 3.9 & $(0.3)$ & 4.2 & $(0.7)$ & 4.1 & $(0.7)$ & 4.1 & $(0.6)$ & 3.1 & $(0.5)$ & -1.2 & $(0.8)$ \\
\hline & Luxembourg & 7.1 & $(0.4)$ & 11.2 & $(0.9)$ & 7.5 & $(0.7)$ & 5.8 & $(0.7)$ & 3.9 & $(0.5)$ & -7.3 & $(0.8)$ \\
\hline & Mexico & 6.2 & $(0.4)$ & 6.3 & $(0.9)$ & 6.9 & $(0.7)$ & 6.0 & $(0.6)$ & 5.7 & $(0.6)$ & -0.6 & (1.1) \\
\hline & Netherlands & 3.1 & $(0.3)$ & 5.4 & $(0.6)$ & 3.3 & $(0.5)$ & 2.7 & $(0.4)$ & 1.3 & $(0.3)$ & -4.1 & $(0.6)$ \\
\hline & New Zealand & 6.7 & $(0.5)$ & 9.7 & $(1.1)$ & 6.7 & $(0.8)$ & 5.3 & $(0.7)$ & 4.3 & $(0.7)$ & -5.4 & (1.3) \\
\hline & Norway & 4.1 & $(0.3)$ & 5.7 & $(0.7)$ & 4.7 & $(0.8)$ & 3.9 & $(0.6)$ & 2.1 & $(0.5)$ & -3.5 & $(0.8)$ \\
\hline & Poland & 3.5 & $(0.3)$ & 4.1 & $(0.6)$ & 3.2 & $(0.6)$ & 3.6 & (0.6) & 2.9 & $(0.5)$ & -1.1 & $(0.9)$ \\
\hline & Portugal & 9.5 & $(0.4)$ & 12.5 & $(0.9)$ & 9.9 & $(0.8)$ & 8.0 & $(0.8)$ & 7.5 & $(0.8)$ & -5.1 & $(1.2)$ \\
\hline & Slovak Republic & 4.2 & $(0.3)$ & 5.9 & $(0.9)$ & 4.8 & (0.6) & 3.6 & $(0.5)$ & 2.8 & $(0.5)$ & -3.0 & $(1.0)$ \\
\hline & Slovenia & 3.6 & $(0.3)$ & 5.1 & $(0.6)$ & 3.6 & $(0.5)$ & 3.3 & $(0.8)$ & 2.4 & $(0.5)$ & -2.7 & $(0.8)$ \\
\hline & Spain & 9.5 & $(0.4)$ & 14.4 & (1.1) & 9.1 & $(0.8)$ & 7.8 & $(0.8)$ & 6.5 & $(0.8)$ & -8.0 & (1.3) \\
\hline & Sweden & 5.3 & $(0.3)$ & 9.1 & $(0.8)$ & 5.9 & $(0.7)$ & 3.7 & $(0.6)$ & 2.5 & $(0.5)$ & -6.6 & $(1.0)$ \\
\hline & Switzerland & 3.6 & $(0.3)$ & 4.9 & $(0.7)$ & 3.9 & $(0.7)$ & 2.7 & $(0.5)$ & 3.0 & $(0.6)$ & -1.8 & (0.8) \\
\hline & Turkey & 11.5 & $(0.5)$ & 15.4 & $(1.1)$ & 10.9 & $(0.9)$ & 11.7 & (1.1) & 8.0 & $(0.9)$ & -7.4 & (1.3) \\
\hline & United Kingdom & 7.4 & $(0.4)$ & 10.6 & (0.9) & 8.2 & $(0.7)$ & 6.4 & $(0.8)$ & 3.8 & $(0.5)$ & -6.7 & $(1.0)$ \\
\hline & United States & 6.6 & (0.4) & 10.0 & $(0.8)$ & 7.6 & $(0.9)$ & 5.0 & (0.8) & 3.6 & $(0.4)$ & -6.4 & $(0.9)$ \\
\hline & OECD average & 6.6 & $(0.1)$ & 9.0 & $(0.1)$ & 6.9 & $(0.1)$ & 5.8 & $(0.1)$ & 4.5 & $(0.1)$ & -4.5 & $(0.2)$ \\
\hline$=$ & Albania & $\mathrm{m}$ & $\mathrm{m}$ & $\mathrm{m}$ & $\mathrm{m}$ & $\mathrm{m}$ & $\mathrm{m}$ & $\mathrm{m}$ & $\mathrm{m}$ & $\mathrm{m}$ & $\mathrm{m}$ & $\mathrm{m}$ & $\mathrm{m}$ \\
\hline 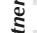 & Algeria & $\mathrm{m}$ & $\mathrm{m}$ & $\mathrm{m}$ & $\mathrm{m}$ & $\mathrm{m}$ & $\mathrm{m}$ & $\mathrm{m}$ & $\mathrm{m}$ & $\mathrm{m}$ & $\mathrm{m}$ & $\mathrm{m}$ & $\mathrm{m}$ \\
\hline$\stackrel{2}{5}$ & Brazil & 16.4 & $(0.4)$ & 17.5 & $(0.8)$ & 18.9 & $(0.9)$ & 15.7 & $(0.9)$ & 13.7 & $(0.9)$ & -3.8 & $(1.2)$ \\
\hline & B-S-J-G (China) & 7.4 & $(0.4)$ & 7.4 & $(0.8)$ & 7.9 & $(0.7)$ & 7.4 & $(0.9)$ & 6.8 & $(0.7)$ & -0.6 & (1.0) \\
\hline & Bulgaria & 7.4 & $(0.4)$ & 10.7 & $(0.8)$ & 8.0 & $(0.9)$ & 6.7 & $(0.7)$ & 4.6 & $(0.6)$ & -6.0 & $(1.0)$ \\
\hline & CABA (Argentina) & $\mathrm{m}$ & $\mathrm{m}$ & $\mathrm{m}$ & $\mathrm{m}$ & $\mathrm{m}$ & $\mathrm{m}$ & $\mathrm{m}$ & $\mathrm{m}$ & $\mathrm{m}$ & $\mathrm{m}$ & $\mathrm{m}$ & $\mathrm{m}$ \\
\hline & Colombia & 12.6 & $(0.5)$ & 15.5 & $(1.0)$ & 13.1 & $(0.9)$ & 12.2 & $(0.7)$ & 9.5 & $(1.0)$ & -6.0 & $(1.3)$ \\
\hline & Costa Rica & 10.1 & $(0.4)$ & 11.0 & $(0.9)$ & 10.8 & $(0.9)$ & 9.7 & (1.0) & 9.1 & $(0.9)$ & -1.8 & $(1.2)$ \\
\hline & Croatia & 6.9 & $(0.4)$ & 8.1 & $(0.9)$ & 7.8 & $(0.8)$ & 6.3 & $(0.7)$ & 5.5 & $(0.6)$ & -2.6 & $(1.0)$ \\
\hline & Cyprus* & 7.2 & $(0.4)$ & 10.1 & $(0.8)$ & 7.2 & $(0.8)$ & 5.8 & $(0.7)$ & 5.7 & $(0.7)$ & -4.4 & $(1.0)$ \\
\hline & Dominican Republic & 8.1 & $(0.6)$ & 9.9 & $(1.2)$ & 8.5 & (1.3) & 8.2 & $(1.2)$ & 5.8 & $(0.7)$ & -4.0 & (1.3) \\
\hline & FYROM & $\mathrm{m}$ & $\mathrm{m}$ & $\mathrm{m}$ & $\mathrm{m}$ & $\mathrm{m}$ & $\mathrm{m}$ & $\mathrm{m}$ & $\mathrm{m}$ & $\mathrm{m}$ & $\mathrm{m}$ & $\mathrm{m}$ & $\mathrm{m}$ \\
\hline & Georgia & $\mathrm{m}$ & $\mathrm{m}$ & $\mathrm{m}$ & $\mathrm{m}$ & $\mathrm{m}$ & $\mathrm{m}$ & $\mathrm{m}$ & $\mathrm{m}$ & $\mathrm{m}$ & $\mathrm{m}$ & $\mathrm{m}$ & $\mathrm{m}$ \\
\hline & Hong Kong (China) & 11.0 & (0.5) & 13.7 & $(0.9)$ & 11.2 & $(1.0)$ & 10.5 & $(0.9)$ & 8.3 & $(0.9)$ & -5.4 & (1.3) \\
\hline & Indonesia & $\mathrm{m}$ & $\mathrm{m}$ & $\mathrm{m}$ & $\mathrm{m}$ & $\mathrm{m}$ & $\mathrm{m}$ & $\mathrm{m}$ & $\mathrm{m}$ & $\mathrm{m}$ & $\mathrm{m}$ & $\mathrm{m}$ & $\mathrm{m}$ \\
\hline & Jordan & $\mathrm{m}$ & $\mathrm{m}$ & $\mathrm{m}$ & $\mathrm{m}$ & $\mathrm{m}$ & $\mathrm{m}$ & $\mathrm{m}$ & $\mathrm{m}$ & $\mathrm{m}$ & $\mathrm{m}$ & $\mathrm{m}$ & $\mathrm{m}$ \\
\hline & Kosovo & $\mathrm{m}$ & $\mathrm{m}$ & $\mathrm{m}$ & $\mathrm{m}$ & $\mathrm{m}$ & $\mathrm{m}$ & $\mathrm{m}$ & $\mathrm{m}$ & $\mathrm{m}$ & $\mathrm{m}$ & $\mathrm{m}$ & $\mathrm{m}$ \\
\hline & Lebanon & $\mathrm{m}$ & $\mathrm{m}$ & $\mathrm{m}$ & $\mathrm{m}$ & $\mathrm{m}$ & $\mathrm{m}$ & $\mathrm{m}$ & $\mathrm{m}$ & $\mathrm{m}$ & $\mathrm{m}$ & $\mathrm{m}$ & $\mathrm{m}$ \\
\hline & Lithuania & 4.7 & $(0.3)$ & 6.8 & $(0.8)$ & 4.0 & $(0.6)$ & 4.5 & $(0.6)$ & 3.4 & $(0.5)$ & -3.3 & (0.9) \\
\hline & Macao (China) & 11.2 & $(0.5)$ & 13.5 & (1.1) & 11.5 & $(0.9)$ & 10.4 & (0.9) & 9.2 & $(0.9)$ & -4.3 & (1.5) \\
\hline & Malta & $\mathrm{m}$ & $\mathrm{m}$ & $\mathrm{m}$ & $\mathrm{m}$ & $\mathrm{m}$ & $\mathrm{m}$ & $\mathrm{m}$ & $\mathrm{m}$ & $\mathrm{m}$ & $\mathrm{m}$ & $\mathrm{m}$ & $\mathrm{m}$ \\
\hline & Moldova & $\mathrm{m}$ & $\mathrm{m}$ & $\mathrm{m}$ & $\mathrm{m}$ & $\mathrm{m}$ & $\mathrm{m}$ & $\mathrm{m}$ & $\mathrm{m}$ & $\mathrm{m}$ & $\mathrm{m}$ & $\mathrm{m}$ & $\mathrm{m}$ \\
\hline & Montenegro & 3.8 & $(0.3)$ & 5.0 & $(0.6)$ & 3.5 & $(0.6)$ & 4.0 & $(0.6)$ & 2.6 & $(0.5)$ & -2.4 & $(0.8)$ \\
\hline & Peru & 4.4 & $(0.3)$ & 4.3 & $(0.6)$ & 4.5 & $(0.6)$ & 3.6 & $(0.5)$ & 5.0 & $(0.6)$ & 0.8 & $(0.9)$ \\
\hline & Qatar & 14.7 & $(0.3)$ & 17.8 & $(0.8)$ & 15.1 & $(0.9)$ & 13.1 & (0.6) & 12.7 & $(0.7)$ & -5.1 & $(1.0)$ \\
\hline & Romania & $\mathrm{m}$ & $\mathrm{m}$ & $\mathrm{m}$ & $\mathrm{m}$ & $\mathrm{m}$ & $\mathrm{m}$ & $\mathrm{m}$ & $\mathrm{m}$ & $\mathrm{m}$ & $\mathrm{m}$ & $\mathrm{m}$ & $\mathrm{m}$ \\
\hline & Russia & 3.6 & $(0.3)$ & 3.6 & $(0.5)$ & 3.6 & $(0.6)$ & 4.0 & $(0.5)$ & 3.1 & $(0.5)$ & -0.5 & $(0.7)$ \\
\hline & Singapore & 8.4 & $(0.4)$ & 9.0 & $(0.8)$ & 9.1 & $(0.7)$ & 7.8 & $(0.8)$ & 7.7 & $(0.7)$ & -1.2 & $(1.1)$ \\
\hline & Chinese Taipei & 8.8 & $(0.4)$ & 10.4 & $(0.8)$ & 7.9 & $(0.7)$ & 8.8 & $(0.8)$ & 8.0 & $(0.8)$ & -2.4 & $(1.1)$ \\
\hline & Thailand & 3.1 & $(0.3)$ & 3.6 & $(0.6)$ & 2.9 & $(0.5)$ & 2.4 & $(0.5)$ & 3.5 & $(0.6)$ & -0.1 & $(0.8)$ \\
\hline & Trinidad and Tobago & $\mathrm{m}$ & $\mathrm{m}$ & $\mathrm{m}$ & $\mathrm{m}$ & $\mathrm{m}$ & $\mathrm{m}$ & $\mathrm{m}$ & $\mathrm{m}$ & $\mathrm{m}$ & $\mathrm{m}$ & m & $\mathrm{m}$ \\
\hline & Tunisia & 13.3 & $(0.6)$ & 14.9 & $(1.1)$ & 12.6 & $(1.1)$ & 12.5 & $(1.2)$ & 13.3 & $(1.0)$ & -1.6 & (1.5) \\
\hline & United Arab Emirates & 17.6 & $(0.6)$ & 23.5 & (1.1) & 18.9 & $(1.1)$ & 14.4 & $(0.9)$ & 13.7 & $(0.8)$ & -9.7 & $(1.1)$ \\
\hline & Uruguay & 11.0 & (0.5) & 16.9 & $(1.1)$ & 11.3 & (1.1) & 9.0 & $(0.8)$ & 7.4 & $(0.7)$ & -9.5 & (1.3) \\
\hline & Viet Nam & $\mathrm{m}$ & $\mathrm{m}$ & $\mathrm{m}$ & $\mathrm{m}$ & $\mathrm{m}$ & $\mathrm{m}$ & $\mathrm{m}$ & $\mathrm{m}$ & $\mathrm{m}$ & $\mathrm{m}$ & $\mathrm{m}$ & $\mathrm{m}$ \\
\hline & Argentina** $^{* *}$ & $\mathrm{~m}$ & $\mathrm{~m}$ & $\mathrm{~m}$ & $\mathrm{~m}$ & $\mathrm{~m}$ & $\mathrm{~m}$ & $\mathrm{~m}$ & $\mathrm{~m}$ & $\mathrm{~m}$ & $\mathrm{~m}$ & $\mathrm{~m}$ & $\mathrm{~m}$ \\
\hline & Kazakhstan** & $\mathrm{m}$ & $\mathrm{m}$ & $\mathrm{m}$ & $\mathrm{m}$ & $\mathrm{m}$ & $\mathrm{m}$ & $\mathrm{m}$ & $\mathrm{m}$ & $\mathrm{m}$ & $\mathrm{m}$ & $\mathrm{m}$ & $\mathrm{m}$ \\
\hline & Malaysia** & 2.7 & $(0.3)$ & 2.9 & $(0.4)$ & 2.8 & $(0.6)$ & 3.0 & $(0.5)$ & 2.2 & $(0.5)$ & -0.7 & $(0.7)$ \\
\hline
\end{tabular}

1. ESCS refers to the PISA index of economic, social and cultural status.

Note: Values that are statistically significant are indicated in bold (see Annex A3).

* See note at the beginning of this Annex.

** Coverage is too small to ensure comparability (see Annex A4).

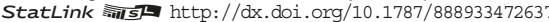




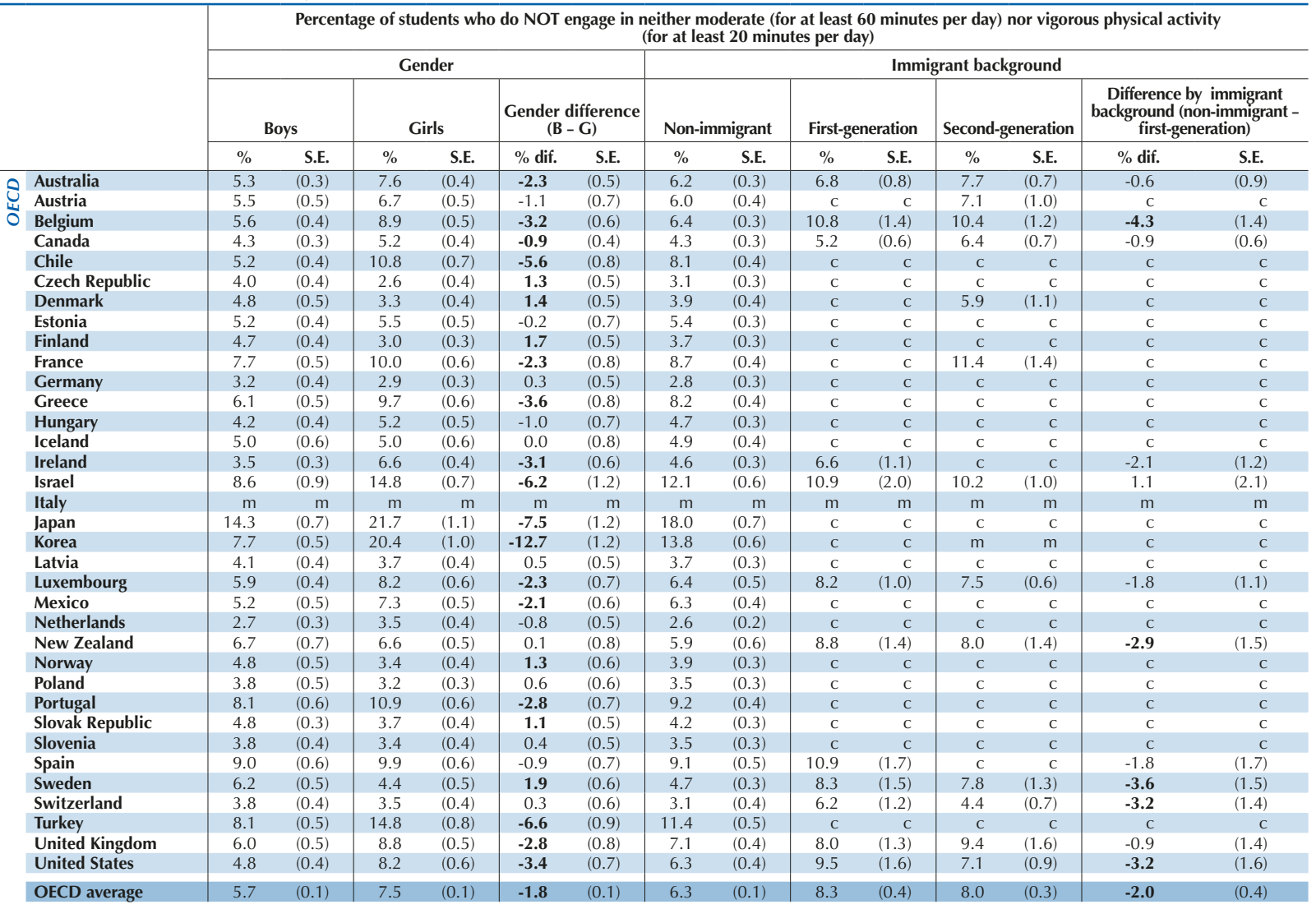

\begin{tabular}{|c|c|c|c|c|c|c|c|c|c|c|c|c|c|c|}
\hline Albania & $\mathrm{m}$ & $\mathrm{m}$ & $\mathrm{m}$ & $\mathrm{m}$ & $\mathrm{m}$ & $\mathrm{m}$ & $\mathrm{m}$ & $\mathrm{m}$ & $\mathrm{m}$ & $\mathrm{m}$ & $\mathrm{m}$ & $\mathrm{m}$ & $\mathrm{m}$ & $\mathrm{m}$ \\
\hline Algeria & $\mathrm{m}$ & $\mathrm{m}$ & $\mathrm{m}$ & $\mathrm{m}$ & $\mathrm{m}$ & $\mathrm{m}$ & $\mathrm{m}$ & $\mathrm{m}$ & $\mathrm{m}$ & $\mathrm{m}$ & $\mathrm{m}$ & $\mathrm{m}$ & $\mathrm{m}$ & $\mathrm{m}$ \\
\hline Brazil & 11.0 & $(0.5)$ & 21.4 & $(0.7)$ & -10.3 & $(0.8)$ & 16.7 & $(0.5)$ & c & c & c & c & c & $\mathrm{c}$ \\
\hline B-S-J-G (China) & 6.8 & $(0.5)$ & 8.1 & $(0.7)$ & -1.3 & (0.9) & 7.3 & $(0.4)$ & c & c & c & C & c & c \\
\hline Bulgaria & 6.7 & $(0.5)$ & 8.3 & $(0.6)$ & -1.6 & $(0.8)$ & 7.2 & $(0.4)$ & c & c & c & c & c & c \\
\hline CABA (Argentina) & $\mathrm{m}$ & $\mathrm{m}$ & $\mathrm{m}$ & $\mathrm{m}$ & $\mathrm{m}$ & $\mathrm{m}$ & $\mathrm{m}$ & $\mathrm{m}$ & $\mathrm{m}$ & $\mathrm{m}$ & $\mathrm{m}$ & $\mathrm{m}$ & $\mathrm{m}$ & $\mathrm{m}$ \\
\hline Colombia & 10.2 & $(0.7)$ & 14.6 & $(0.6)$ & -4.4 & $(0.8)$ & 12.6 & $(0.5)$ & c & c & c & c & c & c \\
\hline Costa Rica & 6.4 & $(0.5)$ & 13.7 & $(0.7)$ & -7.3 & $(0.9)$ & 10.1 & $(0.5)$ & c & c & 11.4 & (1.8) & c & c \\
\hline Croatia & 5.9 & $(0.5)$ & 7.9 & $(0.6)$ & -2.0 & $(0.7)$ & 7.2 & $(0.4)$ & c & c & 5.7 & (1.1) & c & c \\
\hline Cyprus* & 6.2 & $(0.6)$ & 8.1 & $(0.6)$ & -1.9 & $(0.9)$ & 7.1 & $(0.4)$ & 9.3 & (1.5) & c & c & -2.2 & (1.5) \\
\hline Dominican Republic & 6.8 & $(0.7)$ & 9.3 & $(0.8)$ & -2.5 & $(0.9)$ & 7.9 & $(0.6)$ & c & c & c & c & c & c \\
\hline FYROM & $\mathrm{m}$ & $\mathrm{m}$ & $\mathrm{m}$ & $\mathrm{m}$ & $\mathrm{m}$ & $\mathrm{m}$ & $\mathrm{m}$ & $\mathrm{m}$ & $\mathrm{m}$ & $\mathrm{m}$ & $\mathrm{m}$ & $\mathrm{m}$ & $\mathrm{m}$ & $\mathrm{m}$ \\
\hline Georgia & $\mathrm{m}$ & $\mathrm{m}$ & $\mathrm{m}$ & $\mathrm{m}$ & $\mathrm{m}$ & $\mathrm{m}$ & $\mathrm{m}$ & $\mathrm{m}$ & $\mathrm{m}$ & $\mathrm{m}$ & $\mathrm{m}$ & $\mathrm{m}$ & $\mathrm{m}$ & $\mathrm{m}$ \\
\hline Hong Kong (China) & 9.4 & $(0.6)$ & 12.6 & $(0.7)$ & -3.2 & $(0.9)$ & 10.7 & $(0.6)$ & 12.6 & (1.3) & 11.0 & $(0.9)$ & -1.9 & (1.4) \\
\hline Indonesia & $\mathrm{m}$ & $\mathrm{m}$ & $\mathrm{m}$ & $\mathrm{m}$ & $\mathrm{m}$ & $\mathrm{m}$ & $\mathrm{m}$ & $\mathrm{m}$ & $\mathrm{m}$ & $\mathrm{m}$ & $\mathrm{m}$ & $\mathrm{m}$ & $\mathrm{m}$ & $\mathrm{m}$ \\
\hline Jordan & $\mathrm{m}$ & $\mathrm{m}$ & $\mathrm{m}$ & $\mathrm{m}$ & $\mathrm{m}$ & $\mathrm{m}$ & $\mathrm{m}$ & $\mathrm{m}$ & $\mathrm{m}$ & $\mathrm{m}$ & $\mathrm{m}$ & $\mathrm{m}$ & $\mathrm{m}$ & $\mathrm{m}$ \\
\hline Kosovo & $\mathrm{m}$ & $\mathrm{m}$ & $\mathrm{m}$ & $\mathrm{m}$ & $\mathrm{m}$ & $\mathrm{m}$ & $\mathrm{m}$ & $\mathrm{m}$ & $\mathrm{m}$ & $\mathrm{m}$ & $\mathrm{m}$ & $\mathrm{m}$ & $\mathrm{m}$ & $\mathrm{m}$ \\
\hline Lebanon & $\mathrm{m}$ & $\mathrm{m}$ & $\mathrm{m}$ & $\mathrm{m}$ & $\mathrm{m}$ & $\mathrm{m}$ & $\mathrm{m}$ & $\mathrm{m}$ & $\mathrm{m}$ & $\mathrm{m}$ & $\mathrm{m}$ & $\mathrm{m}$ & $\mathrm{m}$ & $\mathrm{m}$ \\
\hline Lithuania & 5.0 & $(0.4)$ & 4.4 & $(0.4)$ & 0.5 & $(0.5)$ & 4.6 & $(0.3)$ & c & c & $\mathrm{c}$ & $\mathrm{c}$ & c & $\mathrm{c}$ \\
\hline Macao (China) & 9.1 & $(0.6)$ & 13.3 & $(0.7)$ & -4.2 & $(0.9)$ & 10.9 & $(0.8)$ & 11.4 & (1.0) & 11.3 & $(0.7)$ & -0.5 & (1.3) \\
\hline Malta & $\mathrm{m}$ & $\mathrm{m}$ & $\mathrm{m}$ & $\mathrm{m}$ & $\mathrm{m}$ & $\mathrm{m}$ & $\mathrm{m}$ & $\mathrm{m}$ & $\mathrm{m}$ & $\mathrm{m}$ & $\mathrm{m}$ & $\mathrm{m}$ & $\mathrm{m}$ & $\mathrm{m}$ \\
\hline Moldova & $\mathrm{m}$ & $\mathrm{m}$ & $\mathrm{m}$ & $\mathrm{m}$ & $\mathrm{m}$ & $\mathrm{m}$ & $\mathrm{m}$ & $\mathrm{m}$ & $\mathrm{m}$ & $\mathrm{m}$ & $\mathrm{m}$ & $\mathrm{m}$ & $\mathrm{m}$ & $\mathrm{m}$ \\
\hline Montenegro & 2.7 & $(0.3)$ & 4.9 & $(0.5)$ & -2.2 & $(0.5)$ & 3.9 & $(0.3)$ & c & c & c & c & c & c \\
\hline Peru & 3.0 & $(0.3)$ & 5.8 & $(0.5)$ & -2.8 & $(0.6)$ & 4.4 & $(0.3)$ & c & c & c & c & c & c \\
\hline Qatar & 10.4 & $(0.4)$ & 18.6 & $(0.5)$ & -8.3 & $(0.6)$ & 19.0 & $(0.6)$ & 10.9 & $(0.5)$ & 13.6 & $(0.8)$ & 8.1 & $(0.7)$ \\
\hline Romania & $\mathrm{m}$ & $\mathrm{m}$ & $\mathrm{m}$ & $\mathrm{m}$ & $\mathrm{m}$ & $\mathrm{m}$ & $\mathrm{m}$ & $\mathrm{m}$ & $\mathrm{m}$ & $\mathrm{m}$ & $\mathrm{m}$ & $\mathrm{m}$ & $\mathrm{m}$ & $\mathrm{m}$ \\
\hline Russia & 3.5 & $(0.4)$ & 3.6 & $(0.4)$ & -0.1 & $(0.5)$ & 3.4 & $(0.3)$ & c & c & c & c & c & c \\
\hline Singapore & 7.3 & $(0.5)$ & 9.6 & $(0.6)$ & -2.3 & $(0.8)$ & 8.5 & $(0.4)$ & 7.2 & (1.4) & 10.3 & (1.6) & 1.2 & (1.5) \\
\hline Chinese Taipei & 6.8 & $(0.5)$ & 10.8 & $(0.6)$ & -4.1 & $(0.8)$ & 8.7 & $(0.4)$ & c & C & C & c & C & $\mathrm{c}$ \\
\hline Thailand & 3.2 & $(0.5)$ & 3.0 & $(0.3)$ & 0.3 & $(0.6)$ & 3.2 & $(0.3)$ & c & c & c & c & c & c \\
\hline Trinidad and Tobago & $\mathrm{m}$ & $\mathrm{m}$ & $\mathrm{m}$ & $\mathrm{m}$ & $\mathrm{m}$ & $\mathrm{m}$ & $\mathrm{m}$ & $\mathrm{m}$ & $\mathrm{m}$ & $\mathrm{m}$ & $\mathrm{m}$ & $\mathrm{m}$ & $\mathrm{m}$ & $\mathrm{m}$ \\
\hline Tunisia & 7.0 & $(0.6)$ & 18.6 & (1.0) & -11.6 & (1.0) & 13.5 & $(0.6)$ & c & c & c & c & c & $\mathrm{c}$ \\
\hline United Arab Emirates & 12.0 & $(0.6)$ & 22.8 & (0.9) & -10.8 & (1.1) & 22.7 & (1.0) & 12.3 & $(0.7)$ & 17.3 & $(0.8)$ & 10.4 & $(1.2)$ \\
\hline Uruguay & 7.6 & $(0.6)$ & 14.0 & $(0.8)$ & -6.3 & (1.0) & 10.9 & $(0.5)$ & c & c & c & c & c & c \\
\hline Viet Nam & $\mathrm{m}$ & $\mathrm{m}$ & $\mathrm{m}$ & $\mathrm{m}$ & $\mathrm{m}$ & $\mathrm{m}$ & $\mathrm{m}$ & $\mathrm{m}$ & $\mathrm{m}$ & $\mathrm{m}$ & $\mathrm{m}$ & $\mathrm{m}$ & $\mathrm{m}$ & $\mathrm{m}$ \\
\hline Argentina** & $\mathrm{m}$ & $\mathrm{m}$ & $\mathrm{m}$ & $\mathrm{m}$ & $\mathrm{m}$ & $\mathrm{m}$ & $\mathrm{m}$ & $\mathrm{m}$ & $\mathrm{m}$ & $\mathrm{m}$ & $\mathrm{m}$ & $\mathrm{m}$ & $\mathrm{m}$ & $\mathrm{m}$ \\
\hline Kazakhstan** & $\mathrm{m}$ & $\mathrm{m}$ & $\mathrm{m}$ & $\mathrm{m}$ & $\mathrm{m}$ & $\mathrm{m}$ & $\mathrm{m}$ & $\mathrm{m}$ & $\mathrm{m}$ & $\mathrm{m}$ & $\mathrm{m}$ & $\mathrm{m}$ & $\mathrm{m}$ & $\mathrm{m}$ \\
\hline Malaysia** & 2.4 & $(0.3)$ & 3.0 & $(0.3)$ & -0.6 & $(0.4)$ & 2.7 & $(0.3)$ & c & C & C & c & C & c \\
\hline
\end{tabular}

1. ESCS refers to the PISA index of economic, social and cultural status.

Note: Values that are statistically significant are indicated in bold (see Annex A3).

* See note at the beginning of this Annex.

* Coverage is too small to ensure comparability (see Annex A4).

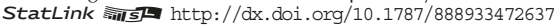


[Part 1/1]

Table III.11.11a Engaging in moderate physical activity outside of school and student science performance

Results based on students' self-reports

\begin{tabular}{|c|c|c|c|c|c|c|c|c|c|c|c|}
\hline & \multicolumn{10}{|c|}{ Science performance } \\
\hline & & \multicolumn{6}{|c|}{$\begin{array}{l}\text { Average number of days students engage in moderate physical activity } \\
\text { for at least } 60 \text { minutes per day, by science performance }\end{array}$} & \multicolumn{4}{|c|}{$\begin{array}{c}\text { Change in science score associated } \\
\text { with one additional day of moderate physical activity }\end{array}$} \\
\hline & & \multicolumn{2}{|c|}{$\begin{array}{l}\text { Bottom quarter } \\
\text { of science performance }\end{array}$} & $\begin{array}{r}\text { Top } \\
\text { of scienc }\end{array}$ & $\begin{array}{l}\text { ter } \\
\text { ormance }\end{array}$ & $\begin{array}{l}\text { Differe } \\
\text { top and } \\
\text { of scien } \\
\text { (top }\end{array}$ & $\begin{array}{l}\text { etween } \\
\text { i quarter } \\
\text { ormance } \\
\text { om) }\end{array}$ & $\begin{array}{r}\text { Before a } \\
\text { for student }\end{array}$ & $\begin{array}{l}\text { unting } \\
\text { acteristics }{ }^{1}\end{array}$ & $\begin{array}{r}\text { After a } \\
\text { for student }\end{array}$ & $\begin{array}{l}\text { Inting } \\
\text { acteristics }\end{array}$ \\
\hline & & Mean & S.E. & Mean & S.E. & Dif. & S.E. & Score dif. & S.E. & Score dif. & S.E. \\
\hline 0 & Australia & 4.47 & $(0.06)$ & 4.57 & $(0.06)$ & 0.10 & $(0.08)$ & 1 & $(0.5)$ & -1 & $(0.5)$ \\
\hline ¿ & Austria & 4.72 & $(0.10)$ & 5.48 & $(0.08)$ & 0.76 & $(0.13)$ & 4 & $(0.6)$ & 2 & $(0.5)$ \\
\hline 0 & Belgium & 3.81 & $(0.08)$ & 5.16 & $(0.07)$ & 1.34 & $(0.11)$ & 8 & $(0.6)$ & 5 & $(0.5)$ \\
\hline & Canada & 5.13 & $(0.05)$ & 5.30 & $(0.07)$ & 0.16 & $(0.10)$ & 1 & $(0.6)$ & -1 & $(0.5)$ \\
\hline & Chile & 4.32 & $(0.09)$ & 4.44 & $(0.07)$ & 0.12 & $(0.12)$ & 1 & $(0.6)$ & -1 & $(0.5)$ \\
\hline & Czech Republic & 4.65 & $(0.09)$ & 5.45 & $(0.07)$ & 0.80 & $(0.13)$ & 5 & $(0.6)$ & 3 & $(0.6)$ \\
\hline & Denmark & 5.24 & $(0.10)$ & 5.67 & $(0.08)$ & 0.42 & $(0.12)$ & 3 & $(0.6)$ & 1 & $(0.6)$ \\
\hline & Estonia & 4.72 & $(0.08)$ & 4.75 & $(0.07)$ & 0.03 & $(0.10)$ & 0 & $(0.6)$ & -1 & $(0.6)$ \\
\hline & Finland & 4.98 & $(0.07)$ & 5.38 & $(0.08)$ & 0.40 & $(0.10)$ & 3 & $(0.6)$ & 1 & $(0.6)$ \\
\hline & France & 4.12 & $(0.09)$ & 5.02 & $(0.07)$ & 0.90 & $(0.11)$ & 5 & $(0.6)$ & 3 & $(0.5)$ \\
\hline & Germany & 5.13 & $(0.09)$ & 5.86 & $(0.08)$ & 0.72 & $(0.12)$ & 5 & $(0.7)$ & 3 & $(0.6)$ \\
\hline & Greece & 4.19 & $(0.09)$ & 4.46 & $(0.08)$ & 0.27 & $(0.12)$ & 2 & $(0.6)$ & 1 & $(0.6)$ \\
\hline & Hungary & 4.62 & $(0.11)$ & 5.54 & $(0.07)$ & 0.92 & $(0.13)$ & 6 & $(0.8)$ & 3 & $(0.7)$ \\
\hline & Iceland & 5.10 & $(0.10)$ & 5.30 & $(0.10)$ & 0.20 & $(0.15)$ & 1 & $(0.8)$ & 0 & $(0.9)$ \\
\hline & Ireland & 4.53 & $(0.08)$ & 4.54 & $(0.09)$ & 0.01 & $(0.10)$ & 0 & $(0.5)$ & -1 & $(0.5)$ \\
\hline & Israel & 3.95 & $(0.11)$ & 4.20 & $(0.07)$ & 0.25 & $(0.13)$ & 2 & $(0.8)$ & 0 & $(0.7)$ \\
\hline & Italy & $\mathrm{m}$ & $\mathrm{m}$ & $\mathrm{m}$ & $\mathrm{m}$ & $\mathrm{m}$ & $\mathrm{m}$ & $\mathrm{m}$ & $\mathrm{m}$ & $\mathrm{m}$ & $\mathrm{m}$ \\
\hline & Japan & 4.79 & $(0.10)$ & 4.55 & $(0.10)$ & -0.24 & $(0.13)$ & -1 & $(0.5)$ & -1 & $(0.4)$ \\
\hline & Korea & 4.59 & $(0.09)$ & 4.12 & $(0.09)$ & -0.47 & $(0.14)$ & -3 & $(0.7)$ & -3 & $(0.6)$ \\
\hline & Latvia & 4.76 & $(0.09)$ & 5.41 & $(0.07)$ & 0.65 & $(0.11)$ & 4 & $(0.5)$ & 3 & $(0.5)$ \\
\hline & Luxembourg & 4.09 & $(0.08)$ & 4.75 & $(0.08)$ & 0.66 & $(0.10)$ & 4 & $(0.6)$ & 1 & $(0.6)$ \\
\hline & Mexico & 3.86 & $(0.07)$ & 4.71 & $(0.07)$ & 0.86 & $(0.09)$ & 4 & $(0.4)$ & 3 & $(0.4)$ \\
\hline & Netherlands & 5.06 & $(0.10)$ & 5.99 & $(0.07)$ & 0.93 & $(0.13)$ & 7 & $(0.9)$ & 6 & $(0.8)$ \\
\hline & New Zealand & 4.59 & $(0.09)$ & 5.06 & $(0.09)$ & 0.47 & $(0.13)$ & 3 & $(0.8)$ & 1 & $(0.7)$ \\
\hline & Norway & 5.03 & $(0.10)$ & 5.82 & $(0.09)$ & 0.79 & $(0.13)$ & 5 & $(0.7)$ & 3 & $(0.7)$ \\
\hline & Poland & 5.27 & $(0.10)$ & 5.66 & $(0.09)$ & 0.39 & $(0.13)$ & 3 & $(0.7)$ & 1 & $(0.6)$ \\
\hline & Portugal & 4.13 & $(0.08)$ & 4.51 & $(0.09)$ & 0.38 & $(0.12)$ & 2 & $(0.6)$ & 1 & $(0.5)$ \\
\hline & Slovak Republic & 4.26 & $(0.10)$ & 5.48 & $(0.06)$ & 1.21 & $(0.11)$ & 7 & $(0.6)$ & 5 & $(0.5)$ \\
\hline & Slovenia & 4.43 & $(0.08)$ & 5.23 & $(0.09)$ & 0.80 & $(0.12)$ & 5 & $(0.7)$ & 3 & $(0.7)$ \\
\hline & Spain & 3.90 & $(0.07)$ & 4.46 & $(0.07)$ & 0.56 & $(0.10)$ & 3 & $(0.5)$ & 2 & $(0.5)$ \\
\hline & Sweden & 4.65 & $(0.09)$ & 5.61 & $(0.10)$ & 0.96 & $(0.12)$ & 6 & $(0.7)$ & 4 & $(0.7)$ \\
\hline & Switzerland & 4.64 & $(0.09)$ & 5.72 & $(0.09)$ & 1.08 & $(0.12)$ & 7 & $(0.7)$ & 5 & $(0.6)$ \\
\hline & Turkey & 3.44 & $(0.09)$ & 4.61 & $(0.10)$ & 1.17 & $(0.13)$ & 6 & $(0.7)$ & 4 & $(0.5)$ \\
\hline & United Kingdom & 4.30 & $(0.08)$ & 4.89 & $(0.08)$ & 0.60 & $(0.12)$ & 4 & $(0.6)$ & 2 & $(0.6)$ \\
\hline & United States & 4.78 & $(0.09)$ & 5.39 & $(0.08)$ & 0.61 & $(0.13)$ & 4 & $(0.7)$ & 2 & $(0.7)$ \\
\hline & OECD average & 4.54 & $(0.02)$ & 5.09 & $(0.01)$ & 0.55 & $(0.02)$ & 3 & $(0.1)$ & 2 & $(0.1)$ \\
\hline$\approx$ & Albania & $\mathrm{m}$ & $\mathrm{m}$ & $\mathrm{m}$ & $\mathrm{m}$ & $\mathrm{m}$ & $\mathrm{m}$ & $\mathrm{m}$ & $\mathrm{m}$ & $\mathrm{m}$ & $\mathrm{m}$ \\
\hline ఏ & Algeria & $\mathrm{m}$ & $\mathrm{m}$ & $\mathrm{m}$ & $\mathrm{m}$ & $\mathrm{m}$ & $\mathrm{m}$ & $\mathrm{m}$ & $\mathrm{m}$ & $\mathrm{m}$ & $\mathrm{m}$ \\
\hline & Brazil & 3.47 & $(0.07)$ & 3.90 & $(0.05)$ & 0.44 & $(0.08)$ & 2 & $(0.4)$ & 1 & $(0.4)$ \\
\hline$\approx$ & B-S-J-G (China) & 3.90 & $(0.09)$ & 4.33 & $(0.09)$ & 0.43 & $(0.13)$ & 3 & $(0.8)$ & 2 & $(0.7)$ \\
\hline & Bulgaria & 3.80 & $(0.09)$ & 5.14 & $(0.07)$ & 1.35 & $(0.12)$ & 9 & $(0.7)$ & 6 & $(0.6)$ \\
\hline & CABA (Argentina) & $\mathrm{m}$ & $\mathrm{m}$ & $\mathrm{m}$ & $\mathrm{m}$ & $\mathrm{m}$ & $\mathrm{m}$ & $\mathrm{m}$ & $\mathrm{m}$ & $\mathrm{m}$ & $\mathrm{m}$ \\
\hline & Colombia & 3.03 & $(0.07)$ & 4.13 & $(0.08)$ & 1.10 & $(0.11)$ & 6 & $(0.6)$ & 4 & $(0.5)$ \\
\hline & Costa Rica & 3.70 & $(0.09)$ & 4.04 & $(0.07)$ & 0.34 & $(0.11)$ & 2 & $(0.5)$ & 0 & $(0.5)$ \\
\hline & Croatia & 4.16 & $(0.09)$ & 5.13 & $(0.08)$ & 0.97 & $(0.11)$ & 5 & $(0.5)$ & 4 & $(0.4)$ \\
\hline & Cyprus* & 4.07 & $(0.07)$ & 4.44 & $(0.08)$ & 0.37 & $(0.11)$ & 2 & $(0.6)$ & 2 & $(0.6)$ \\
\hline & Dominican Republic & 3.88 & $(0.10)$ & 4.59 & $(0.09)$ & 0.71 & $(0.13)$ & 4 & $(0.5)$ & 2 & $(0.5)$ \\
\hline & FYROM & $\mathrm{m}$ & $\mathrm{m}$ & $\mathrm{m}$ & $\mathrm{m}$ & $\mathrm{m}$ & $\mathrm{m}$ & $\mathrm{m}$ & $\mathrm{m}$ & $\mathrm{m}$ & $\mathrm{m}$ \\
\hline & Georgia & $\mathrm{m}$ & $\mathrm{m}$ & $\mathrm{m}$ & $\mathrm{m}$ & $\mathrm{m}$ & $\mathrm{m}$ & $\mathrm{m}$ & $\mathrm{m}$ & $\mathrm{m}$ & $\mathrm{m}$ \\
\hline & Hong Kong (China) & 4.48 & $(0.08)$ & 4.22 & $(0.10)$ & -0.26 & $(0.12)$ & -1 & $(0.5)$ & -1 & $(0.4)$ \\
\hline & Indonesia & $\mathrm{m}$ & $\mathrm{m}$ & $\mathrm{m}$ & $\mathrm{m}$ & $\mathrm{m}$ & $\mathrm{m}$ & $\mathrm{m}$ & $\mathrm{m}$ & $\mathrm{m}$ & $\mathrm{m}$ \\
\hline & Jordan & $\mathrm{m}$ & $\mathrm{m}$ & $\mathrm{m}$ & $\mathrm{m}$ & $\mathrm{m}$ & $\mathrm{m}$ & $\mathrm{m}$ & $\mathrm{m}$ & $\mathrm{m}$ & $\mathrm{m}$ \\
\hline & Kosovo & $\mathrm{m}$ & $\mathrm{m}$ & $\mathrm{m}$ & $\mathrm{m}$ & $\mathrm{m}$ & $\mathrm{m}$ & $\mathrm{m}$ & $\mathrm{m}$ & $\mathrm{m}$ & $\mathrm{m}$ \\
\hline & Lebanon & $\mathrm{m}$ & $\mathrm{m}$ & $\mathrm{m}$ & $\mathrm{m}$ & $\mathrm{m}$ & $\mathrm{m}$ & $\mathrm{m}$ & $\mathrm{m}$ & $\mathrm{m}$ & $\mathrm{m}$ \\
\hline & Lithuania & 4.42 & $(0.10)$ & 5.39 & $(0.08)$ & 0.96 & $(0.12)$ & 5 & $(0.6)$ & 4 & $(0.6)$ \\
\hline & Macao (China) & 3.99 & $(0.08)$ & 4.41 & $(0.09)$ & 0.42 & $(0.12)$ & 2 & $(0.5)$ & 2 & $(0.5)$ \\
\hline & Malta & $\mathrm{m}$ & $\mathrm{m}$ & $\mathrm{m}$ & $\mathrm{m}$ & $\mathrm{m}$ & $\mathrm{m}$ & $\mathrm{m}$ & $\mathrm{m}$ & $\bar{m}$ & $\mathrm{~m}$ \\
\hline & Moldova & $\mathrm{m}$ & $\mathrm{m}$ & $\mathrm{m}$ & $\mathrm{m}$ & $\mathrm{m}$ & $\mathrm{m}$ & $\mathrm{m}$ & $\mathrm{m}$ & $\mathrm{m}$ & $\mathrm{m}$ \\
\hline & Montenegro & 4.52 & $(0.08)$ & 5.50 & $(0.07)$ & 0.98 & $(0.11)$ & 6 & $(0.6)$ & 5 & $(0.6)$ \\
\hline & Peru & 3.59 & $(0.08)$ & 4.71 & $(0.07)$ & 1.12 & $(0.10)$ & 6 & $(0.5)$ & 4 & $(0.5)$ \\
\hline & Qatar & 3.38 & $(0.05)$ & 4.19 & $(0.06)$ & 0.81 & $(0.08)$ & 6 & $(0.4)$ & 5 & $(0.4)$ \\
\hline & Romania & $\mathrm{m}$ & $\mathrm{m}$ & $\mathrm{m}$ & $\mathrm{m}$ & $\mathrm{m}$ & $\mathrm{m}$ & $\mathrm{m}$ & $\mathrm{m}$ & $\mathrm{m}$ & $\mathrm{m}$ \\
\hline & Russia & 4.85 & $(0.09)$ & 5.48 & $(0.10)$ & 0.63 & $(0.14)$ & 4 & $(0.6)$ & 3 & $(0.6)$ \\
\hline & Singapore & 4.26 & $(0.07)$ & 4.52 & $(0.08)$ & 0.27 & $(0.10)$ & 2 & $(0.5)$ & 1 & $(0.5)$ \\
\hline & Chinese Taipei & 4.63 & $(0.07)$ & 4.69 & $(0.08)$ & 0.05 & $(0.10)$ & 0 & $(0.5)$ & 0 & $(0.5)$ \\
\hline & Thailand & 4.29 & $(0.08)$ & 5.23 & $(0.07)$ & 0.95 & $(0.10)$ & 5 & $(0.5)$ & 4 & $(0.5)$ \\
\hline & Trinidad and Tobago & $\mathrm{m}$ & $\mathrm{m}$ & $\mathrm{m}$ & $\mathrm{m}$ & $\mathrm{m}$ & $\mathrm{m}$ & $\mathrm{m}$ & $\mathrm{m}$ & $\mathrm{m}$ & $\mathrm{m}$ \\
\hline & Tunisia & 3.59 & $(0.08)$ & 3.51 & $(0.09)$ & -0.08 & $(0.12)$ & -1 & $(0.5)$ & -1 & $(0.5)$ \\
\hline & United Arab Emirates & 3.38 & $(0.06)$ & 4.05 & $(0.07)$ & 0.67 & $(0.10)$ & 5 & $(0.6)$ & 4 & $(0.5)$ \\
\hline & Uruguay & 3.96 & $(0.08)$ & 4.62 & $(0.09)$ & 0.65 & $(0.12)$ & 3 & $(0.6)$ & 2 & $(0.6)$ \\
\hline & Viet Nam & $\mathrm{m}$ & $\mathrm{m}$ & $\mathrm{m}$ & $\mathrm{m}$ & $\mathrm{m}$ & $\mathrm{m}$ & $\mathrm{m}$ & $\mathrm{m}$ & $\mathrm{m}$ & $\mathrm{m}$ \\
\hline & Argentina** & $\mathrm{m}$ & $\mathrm{m}$ & $\mathrm{m}$ & $\mathrm{m}$ & $\mathrm{m}$ & $\mathrm{m}$ & $\mathrm{m}$ & $\mathrm{m}$ & $\mathrm{m}$ & $\mathrm{m}$ \\
\hline & Kazakhstan** & $\mathrm{m}$ & $\mathrm{m}$ & $\mathrm{m}$ & $\mathrm{m}$ & $\mathrm{m}$ & $\mathrm{m}$ & $\mathrm{m}$ & $\mathrm{m}$ & $\mathrm{m}$ & $\mathrm{m}$ \\
\hline & Malaysia** & 4.36 & $(0.08)$ & 5.56 & $(0.09)$ & 1.20 & $(0.12)$ & 6 & $(0.6)$ & 5 & $(0.6)$ \\
\hline
\end{tabular}

1. Student characteristics include the PISA index of economic, social and cultural status and gender.

Note: Values that are statistically significant are indicated in bold (see Annex A3).

* See note at the beginning of this Annex.

** Coverage is too small to ensure comparability (see Annex A4).

StatLink त्राज ht htp://dx.doi.org/10.1787/888933472649 
[Part 1/1]

Table III.11.12a Engaging in vigorous physical activity outside of school and student performance in science

Results based on students' self-reports

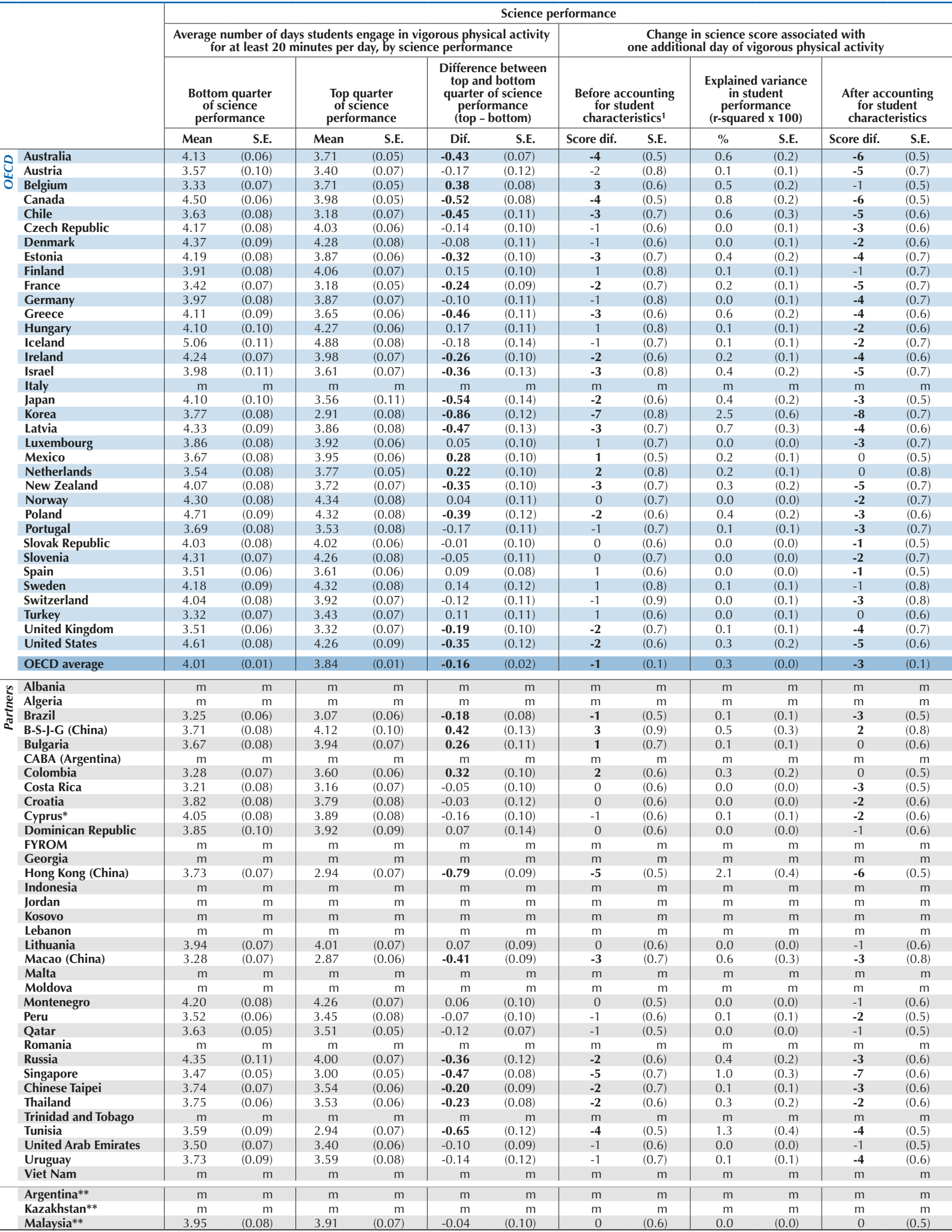

1. Student characteristics include the PISA index of economic, social and cultural status and gender.

Note: Values that are statistically significant are indicated in bold (see Annex A3).

* See note at the beginning of this Annex.

to small to ensure comparability (see Annex A4).

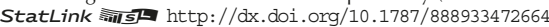


[Part 1/4]

Table III.11.13 Frequency of students' physical activity outside of school, by student characteristics

Results based on students' self-reports

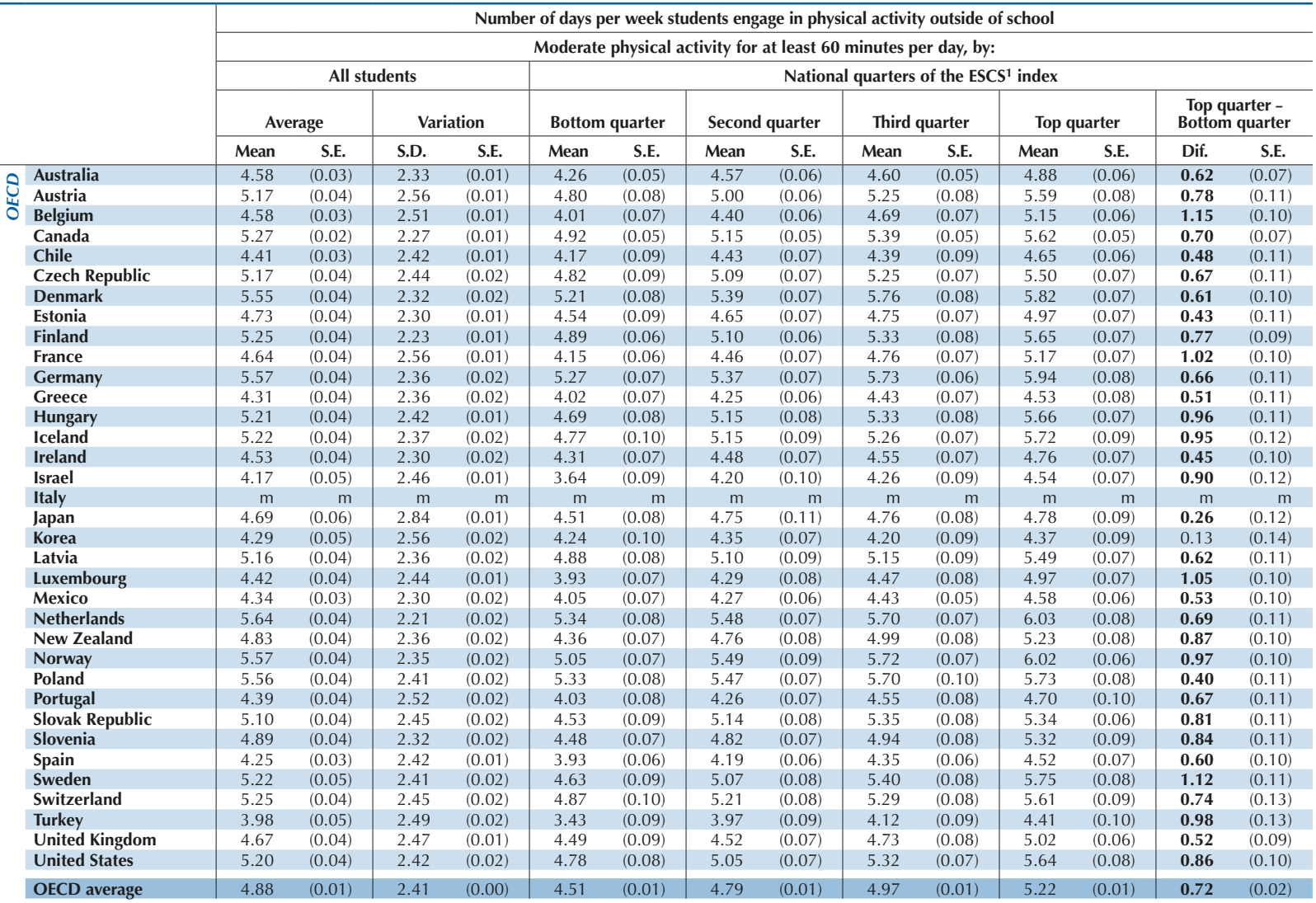

\begin{tabular}{|c|c|c|c|c|c|c|c|c|c|c|c|c|c|c|}
\hline Albania & $\mathrm{m}$ & $\mathrm{m}$ & $\mathrm{m}$ & $\mathrm{m}$ & $\mathrm{m}$ & $\mathrm{m}$ & $\mathrm{m}$ & $\mathrm{m}$ & $\mathrm{m}$ & $\mathrm{m}$ & $\mathrm{m}$ & $\mathrm{m}$ & $\mathrm{m}$ & $\mathrm{m}$ \\
\hline Algeria & $\mathrm{m}$ & $\mathrm{m}$ & $\mathrm{m}$ & $\mathrm{m}$ & $\mathrm{m}$ & $\mathrm{m}$ & $\mathrm{m}$ & $\mathrm{m}$ & $\mathrm{m}$ & $\mathrm{m}$ & $\mathrm{m}$ & $\mathrm{m}$ & $\mathrm{m}$ & $\mathrm{m}$ \\
\hline Brazil & 3.72 & $(0.03)$ & 2.41 & $(0.01)$ & 3.44 & $(0.05)$ & 3.52 & $(0.06)$ & 3.82 & $(0.05)$ & 4.06 & $(0.05)$ & 0.62 & $(0.07)$ \\
\hline B-S-J-G (China) & 4.19 & $(0.05)$ & 2.45 & $(0.02)$ & 3.96 & $(0.08)$ & 4.23 & $(0.09)$ & 4.29 & $(0.09)$ & 4.28 & $(0.07)$ & 0.32 & $(0.09)$ \\
\hline Bulgaria & 4.54 & $(0.04)$ & 2.38 & $(0.02)$ & 3.97 & $(0.09)$ & 4.48 & $(0.07)$ & 4.67 & $(0.08)$ & 4.98 & $(0.07)$ & 1.01 & $(0.12)$ \\
\hline CABA (Argentina) & $\mathrm{m}$ & $\mathrm{m}$ & $\mathrm{m}$ & $\mathrm{m}$ & $\mathrm{m}$ & $\mathrm{m}$ & $\mathrm{m}$ & $\mathrm{m}$ & $\mathrm{m}$ & $\mathrm{m}$ & $\mathrm{m}$ & $\mathrm{m}$ & $\mathrm{m}$ & $\mathrm{m}$ \\
\hline Colombia & 3.60 & $(0.04)$ & 2.42 & $(0.02)$ & 3.27 & $(0.08)$ & 3.47 & $(0.07)$ & 3.64 & $(0.06)$ & 4.01 & $(0.08)$ & 0.74 & $(0.12)$ \\
\hline Costa Rica & 3.91 & $(0.04)$ & 2.30 & $(0.02)$ & 3.68 & $(0.07)$ & 3.67 & $(0.06)$ & 4.12 & $(0.08)$ & 4.19 & $(0.08)$ & 0.52 & $(0.11)$ \\
\hline Croatia & 4.68 & $(0.04)$ & 2.52 & $(0.01)$ & 4.27 & $(0.08)$ & 4.52 & $(0.08)$ & 4.79 & $(0.09)$ & 5.15 & $(0.07)$ & 0.88 & $(0.11)$ \\
\hline Cyprus* & 4.28 & $(0.03)$ & 2.30 & $(0.01)$ & 3.98 & $(0.06)$ & 4.23 & $(0.07)$ & 4.47 & $(0.07)$ & 4.44 & $(0.06)$ & 0.46 & $(0.09)$ \\
\hline Dominican Republic & 4.17 & $(0.04)$ & 2.38 & $(0.02)$ & 3.82 & $(0.10)$ & 3.98 & $(0.10)$ & 4.37 & $(0.11)$ & 4.49 & $(0.08)$ & 0.67 & $(0.13)$ \\
\hline FYROM & $\mathrm{m}$ & $\mathrm{m}$ & $\mathrm{m}$ & $\mathrm{m}$ & $\mathrm{m}$ & $\mathrm{m}$ & $\mathrm{m}$ & $\mathrm{m}$ & $\mathrm{m}$ & $\mathrm{m}$ & $\mathrm{m}$ & $\mathrm{m}$ & $\mathrm{m}$ & $\mathrm{m}$ \\
\hline Georgia & $\mathrm{m}$ & $\mathrm{m}$ & $\mathrm{m}$ & $\mathrm{m}$ & $\mathrm{m}$ & $\mathrm{m}$ & $\mathrm{m}$ & $\mathrm{m}$ & $\mathrm{m}$ & $\mathrm{m}$ & $\mathrm{m}$ & $\mathrm{m}$ & $\mathrm{m}$ & $\mathrm{m}$ \\
\hline Hong Kong (China) & 4.37 & $(0.05)$ & 2.59 & $(0.01)$ & 4.11 & $(0.08)$ & 4.38 & $(0.09)$ & 4.56 & $(0.09)$ & 4.40 & $(0.11)$ & 0.29 & $(0.13)$ \\
\hline Indonesia & $\mathrm{m}$ & $\mathrm{m}$ & $\mathrm{m}$ & $\mathrm{m}$ & $\mathrm{m}$ & $\mathrm{m}$ & $\mathrm{m}$ & $\mathrm{m}$ & $\mathrm{m}$ & $\mathrm{m}$ & $\mathrm{m}$ & $\mathrm{m}$ & $\mathrm{m}$ & $\mathrm{m}$ \\
\hline Jordan & $\mathrm{m}$ & $\mathrm{m}$ & $\mathrm{m}$ & $\mathrm{m}$ & $\mathrm{m}$ & $\mathrm{m}$ & $\mathrm{m}$ & $\mathrm{m}$ & $\mathrm{m}$ & $\mathrm{m}$ & $\mathrm{m}$ & $\mathrm{m}$ & $\mathrm{m}$ & $\mathrm{m}$ \\
\hline Kosovo & $\mathrm{m}$ & $\mathrm{m}$ & $\mathrm{m}$ & $\mathrm{m}$ & $\mathrm{m}$ & $\mathrm{m}$ & $\mathrm{m}$ & $\mathrm{m}$ & $\mathrm{m}$ & $\mathrm{m}$ & $\mathrm{m}$ & $\mathrm{m}$ & $\mathrm{m}$ & $\mathrm{m}$ \\
\hline Lebanon & $\mathrm{m}$ & $\mathrm{m}$ & $\mathrm{m}$ & $\mathrm{m}$ & $\mathrm{m}$ & $\mathrm{m}$ & $\mathrm{m}$ & $\mathrm{m}$ & $\mathrm{m}$ & $\mathrm{m}$ & $\mathrm{m}$ & $\mathrm{m}$ & $\mathrm{m}$ & $\mathrm{m}$ \\
\hline Lithuania & 5.08 & $(0.04)$ & 2.44 & $(0.01)$ & 4.63 & $(0.07)$ & 5.12 & $(0.07)$ & 5.10 & $(0.07)$ & 5.43 & $(0.06)$ & 0.80 & $(0.10)$ \\
\hline Macao (China) & 4.17 & $(0.04)$ & 2.55 & $(0.01)$ & 4.07 & $(0.08)$ & 4.19 & $(0.09)$ & 4.11 & $(0.09)$ & 4.31 & $(0.07)$ & 0.24 & $(0.11)$ \\
\hline Malta & $\mathrm{m}$ & $\mathrm{m}$ & $\mathrm{m}$ & $\mathrm{m}$ & $\mathrm{m}$ & $\mathrm{m}$ & $\mathrm{m}$ & $\mathrm{m}$ & $\mathrm{m}$ & $\mathrm{m}$ & $\mathrm{m}$ & $\mathrm{m}$ & $\mathrm{m}$ & $\mathrm{m}$ \\
\hline Moldova & $\mathrm{m}$ & $\mathrm{m}$ & $\mathrm{m}$ & $\mathrm{m}$ & $\mathrm{m}$ & $\mathrm{m}$ & $\mathrm{m}$ & $\mathrm{m}$ & $\mathrm{m}$ & $\mathrm{m}$ & $\mathrm{m}$ & $\mathrm{m}$ & $\mathrm{m}$ & $\mathrm{m}$ \\
\hline Montenegro & 5.08 & $(0.04)$ & 2.30 & $(0.01)$ & 4.76 & $(0.07)$ & 4.97 & $(0.07)$ & 5.17 & $(0.07)$ & 5.42 & $(0.07)$ & 0.65 & $(0.09)$ \\
\hline Peru & 4.21 & $(0.04)$ & 2.31 & $(0.02)$ & 3.67 & $(0.08)$ & 4.12 & $(0.06)$ & 4.39 & $(0.07)$ & 4.61 & $(0.07)$ & 0.93 & $(0.10)$ \\
\hline Qatar & 3.68 & $(0.02)$ & 2.36 & $(0.01)$ & 3.34 & $(0.04)$ & 3.57 & $(0.05)$ & 3.81 & $(0.05)$ & 4.01 & $(0.05)$ & 0.67 & $(0.06)$ \\
\hline Romania & $\mathrm{m}$ & $\mathrm{m}$ & $\mathrm{m}$ & $\mathrm{m}$ & $\mathrm{m}$ & $\mathrm{m}$ & $\mathrm{m}$ & $\mathrm{m}$ & $\mathrm{m}$ & $\mathrm{m}$ & $\mathrm{m}$ & $\mathrm{m}$ & $\mathrm{m}$ & $\mathrm{m}$ \\
\hline Russia & 5.17 & $(0.04)$ & 2.33 & $(0.02)$ & 4.91 & $(0.09)$ & 5.13 & $(0.09)$ & 5.24 & $(0.07)$ & 5.39 & $(0.07)$ & 0.48 & $(0.11)$ \\
\hline Singapore & 4.51 & $(0.03)$ & 2.60 & $(0.01)$ & 4.39 & $(0.06)$ & 4.51 & $(0.07)$ & 4.49 & $(0.06)$ & 4.65 & $(0.07)$ & 0.26 & $(0.10)$ \\
\hline Chinese Taipei & 4.74 & $(0.03)$ & 2.61 & $(0.01)$ & 4.57 & $(0.06)$ & 4.82 & $(0.07)$ & 4.74 & $(0.07)$ & 4.81 & $(0.08)$ & 0.25 & $(0.09)$ \\
\hline Thailand & 4.78 & $(0.04)$ & 2.31 & $(0.01)$ & 4.53 & $(0.07)$ & 4.67 & $(0.07)$ & 4.88 & $(0.08)$ & 5.04 & $(0.07)$ & 0.52 & $(0.10)$ \\
\hline Trinidad and Tobago & $\mathrm{m}$ & $\mathrm{m}$ & $\mathrm{m}$ & $\mathrm{m}$ & $\mathrm{m}$ & $\mathrm{m}$ & $\mathrm{m}$ & $\mathrm{m}$ & $\mathrm{m}$ & $\mathrm{m}$ & $\mathrm{m}$ & $\mathrm{m}$ & $\mathrm{m}$ & $\mathrm{m}$ \\
\hline Tunisia & 3.53 & $(0.04)$ & 2.25 & $(0.02)$ & 3.40 & $(0.06)$ & 3.41 & $(0.07)$ & 3.67 & $(0.07)$ & 3.63 & $(0.08)$ & 0.22 & $(0.10)$ \\
\hline United Arab Emirates & 3.54 & $(0.03)$ & 2.41 & $(0.01)$ & 3.12 & $(0.05)$ & 3.34 & $(0.07)$ & 3.73 & $(0.06)$ & 3.97 & $(0.05)$ & 0.86 & $(0.07)$ \\
\hline Uruguay & 4.33 & $(0.04)$ & 2.43 & $(0.01)$ & 3.94 & $(0.07)$ & 4.16 & $(0.08)$ & 4.47 & $(0.08)$ & 4.71 & $(0.08)$ & 0.77 & $(0.10)$ \\
\hline Viet Nam & $\mathrm{m}$ & $\mathrm{m}$ & $\mathrm{m}$ & $\mathrm{m}$ & $\mathrm{m}$ & $\mathrm{m}$ & $\mathrm{m}$ & $\mathrm{m}$ & $\mathrm{m}$ & $\mathrm{m}$ & $\mathrm{m}$ & $\mathrm{m}$ & $\mathrm{m}$ & $\mathrm{m}$ \\
\hline Argentina** $^{* *}$ & $\mathrm{~m}$ & $\mathrm{~m}$ & $\mathrm{~m}$ & $\mathrm{~m}$ & $\mathrm{~m}$ & $\mathrm{~m}$ & $\mathrm{~m}$ & $\mathrm{~m}$ & $\mathrm{~m}$ & $\mathrm{~m}$ & $\mathrm{~m}$ & $\mathrm{~m}$ & $\mathrm{~m}$ & $\mathrm{~m}$ \\
\hline Kazakhstan** & $\mathrm{m}$ & $\mathrm{m}$ & $\mathrm{m}$ & $\mathrm{m}$ & $\mathrm{m}$ & $\mathrm{m}$ & $\mathrm{m}$ & $\mathrm{m}$ & $\mathrm{m}$ & $\mathrm{m}$ & $\mathrm{m}$ & $\mathrm{m}$ & $\mathrm{m}$ & $\mathrm{m}$ \\
\hline Malaysia** & 5.15 & $(0.05)$ & 2.39 & $(0.01)$ & 4.76 & $(0.08)$ & 5.16 & $(0.09)$ & 5.25 & $(0.08)$ & 5.43 & $(0.09)$ & 0.68 & $(0.10)$ \\
\hline
\end{tabular}

1. ESCS refers to the PISA index of economic, social and cultural status.

Note: Values that are statistically significant are indicated in bold (see Annex A3).

* See note at the beginning of this Annex.

** Coverage is too small to ensure comparability (see Annex A4).

StatLink त्ञाता $\mathrm{http}: / / \mathrm{dx}$. doi.org/10.1787/888933472688 


\begin{tabular}{|c|c|c|c|c|c|c|c|c|c|c|c|c|c|c|}
\hline & \multicolumn{14}{|c|}{ Number of days per week students engage in physical activity outside of school } \\
\hline & \multicolumn{14}{|c|}{ Moderate physical activity for at least 60 minutes per day, by: } \\
\hline & \multicolumn{6}{|c|}{ Gender } & \multicolumn{8}{|c|}{ Immigrant background } \\
\hline & \multicolumn{2}{|c|}{ Boys } & \multicolumn{2}{|c|}{ Girls } & \multicolumn{2}{|c|}{$\begin{array}{c}\text { Gender difference } \\
(B-G)\end{array}$} & \multicolumn{2}{|c|}{ Non-immigrant } & \multicolumn{2}{|c|}{ First-generation } & \multicolumn{2}{|c|}{ Second-generation } & \multicolumn{2}{|c|}{$\begin{array}{c}\text { Difference by immigrant } \\
\text { background (non-immigrant - } \\
\text { first-generation) }\end{array}$} \\
\hline & Mean & S.E. & Mean & S.E. & Dif. & S.E. & Mean & S.E. & Mean & S.E. & Mean & S.E. & Dif. & S.E. \\
\hline Australia & 4.88 & $(0.04)$ & 4.27 & $(0.03)$ & 0.61 & $(0.05)$ & 4.63 & $(0.03)$ & 4.56 & $(0.08)$ & 4.34 & $(0.07)$ & 0.07 & $(0.08)$ \\
\hline Austria & 5.23 & $(0.06)$ & 5.10 & $(0.05)$ & 0.13 & $(0.07)$ & 5.22 & $(0.04)$ & 4.85 & $(0.13)$ & 5.01 & $(0.11)$ & 0.37 & $(0.13)$ \\
\hline $\bar{\partial}$ Belgium & 4.75 & $(0.04)$ & 4.40 & $(0.05)$ & 0.35 & $(0.06)$ & 4.68 & $(0.04)$ & 4.01 & $(0.11)$ & 4.18 & $(0.11)$ & 0.67 & $(0.11)$ \\
\hline Canada & 5.56 & $(0.04)$ & 5.00 & $(0.03)$ & 0.56 & $(0.05)$ & 5.36 & $(0.03)$ & 5.07 & $(0.07)$ & 5.06 & $(0.07)$ & 0.29 & $(0.08)$ \\
\hline Chile & 4.68 & $(0.05)$ & 4.14 & $(0.05)$ & 0.55 & $(0.08)$ & 4.41 & $(0.03)$ & 4.04 & $(0.30)$ & 4.53 & $(0.45)$ & 0.37 & $(0.31)$ \\
\hline Czech Republic & 4.99 & $(0.06)$ & 5.36 & $(0.05)$ & -0.37 & $(0.08)$ & 5.18 & $(0.04)$ & 4.63 & $(0.32)$ & 5.06 & $(0.28)$ & 0.55 & $(0.32)$ \\
\hline Denmark & 5.65 & $(0.06)$ & 5.45 & $(0.05)$ & 0.20 & $(0.08)$ & 5.59 & $(0.05)$ & 5.11 & $(0.20)$ & 5.23 & $(0.11)$ & 0.48 & $(0.20)$ \\
\hline Estonia & 4.74 & $(0.05)$ & 4.72 & $(0.05)$ & 0.02 & $(0.07)$ & 4.73 & $(0.04)$ & 4.68 & $(0.45)$ & 4.77 & $(0.12)$ & 0.05 & $(0.45)$ \\
\hline Finland & 5.22 & $(0.05)$ & 5.27 & $(0.06)$ & -0.05 & $(0.06)$ & 5.24 & $(0.04)$ & 4.96 & $(0.20)$ & 5.69 & $(0.23)$ & 0.29 & $(0.20)$ \\
\hline France & 4.72 & $(0.05)$ & 4.56 & $(0.05)$ & 0.16 & $(0.06)$ & 4.65 & $(0.04)$ & 4.58 & $(0.19)$ & 4.54 & $(0.13)$ & 0.07 & $(0.20)$ \\
\hline Germany & 5.59 & $(0.05)$ & 5.54 & $(0.05)$ & 0.05 & $(0.07)$ & 5.63 & $(0.04)$ & 4.74 & $(0.19)$ & 5.48 & $(0.09)$ & 0.88 & $(0.20)$ \\
\hline Greece & 4.50 & (0.05) & 4.10 & $(0.04)$ & 0.40 & $(0.06)$ & 4.28 & $(0.04)$ & 4.63 & $(0.15)$ & 4.57 & $(0.13)$ & -0.35 & $(0.17)$ \\
\hline Hungary & 5.26 & (0.05) & 5.17 & $(0.05)$ & 0.09 & $(0.07)$ & 5.21 & $(0.04)$ & 5.31 & $(0.44)$ & 5.65 & $(0.22)$ & -0.10 & $(0.44)$ \\
\hline Iceland & 5.30 & (0.05) & 5.15 & $(0.06)$ & 0.15 & $(0.07)$ & 5.23 & (0.05) & 4.86 & $(0.32)$ & 5.51 & $(0.29)$ & 0.37 & $(0.33)$ \\
\hline Ireland & 4.89 & (0.05) & 4.15 & $(0.05)$ & 0.74 & $(0.06)$ & 4.55 & $(0.05)$ & 4.42 & $(0.10)$ & 4.39 & $(0.19)$ & 0.13 & $(0.11)$ \\
\hline Israel & 4.36 & (0.10) & 3.99 & $(0.05)$ & 0.38 & $(0.11)$ & 4.13 & (0.05) & 4.30 & $(0.23)$ & 4.35 & $(0.10)$ & -0.17 & $(0.22)$ \\
\hline Italy & $\mathrm{m}$ & $\mathrm{m}$ & $\mathrm{m}$ & $\mathrm{m}$ & $\mathrm{m}$ & $\mathrm{m}$ & $\mathrm{m}$ & $\mathrm{m}$ & $\mathrm{m}$ & $\mathrm{m}$ & $\mathrm{m}$ & $\mathrm{m}$ & $\mathrm{m}$ & $\mathrm{m}$ \\
\hline Japan & 5.03 & (0.07) & 4.35 & $(0.07)$ & 0.67 & $(0.09)$ & 4.69 & $(0.06)$ & C & C & c & C & c & C \\
\hline Korea & 4.81 & $(0.06)$ & 3.72 & $(0.07)$ & 1.09 & $(0.08)$ & 4.29 & $(0.05)$ & c & C & $\mathrm{m}$ & $\mathrm{m}$ & c & c \\
\hline Latvia & 5.03 & (0.06) & 5.28 & $(0.05)$ & -0.26 & $(0.07)$ & 5.18 & $(0.04)$ & 5.12 & $(0.47)$ & 4.79 & $(0.18)$ & 0.06 & $(0.48)$ \\
\hline Luxembourg & 4.64 & (0.05) & 4.20 & $(0.05)$ & 0.44 & $(0.06)$ & 4.55 & $(0.05)$ & 4.31 & $(0.08)$ & 4.28 & $(0.06)$ & 0.24 & $(0.10)$ \\
\hline Mexico & 4.42 & (0.05) & 4.25 & $(0.04)$ & 0.17 & $(0.06)$ & 4.35 & $(0.03)$ & 3.53 & $(0.33)$ & c & c & 0.82 & $(0.33)$ \\
\hline Netherlands & 5.66 & (0.05) & 5.62 & $(0.04)$ & 0.03 & $(0.06)$ & 5.74 & $(0.04)$ & 4.81 & $(0.23)$ & 4.94 & $(0.14)$ & 0.93 & $(0.23)$ \\
\hline New Zealand & 5.05 & $(0.05)$ & 4.62 & $(0.06)$ & 0.44 & $(0.07)$ & 4.92 & $(0.05)$ & 4.54 & $(0.10)$ & 4.58 & $(0.11)$ & 0.38 & $(0.11)$ \\
\hline Norway & 5.53 & $(0.06)$ & 5.61 & $(0.05)$ & -0.08 & $(0.06)$ & 5.62 & $(0.05)$ & 5.04 & $(0.16)$ & 5.42 & $(0.13)$ & 0.58 & $(0.16)$ \\
\hline Poland & 5.61 & $(0.06)$ & 5.50 & $(0.06)$ & 0.11 & $(0.08)$ & 5.55 & $(0.04)$ & C & c & c & c & c & c \\
\hline Portugal & 4.60 & $(0.07)$ & 4.17 & $(0.05)$ & 0.44 & $(0.08)$ & 4.39 & $(0.04)$ & 4.31 & $(0.20)$ & 4.50 & $(0.24)$ & 0.08 & $(0.20)$ \\
\hline Slovak Republic & 5.09 & $(0.05)$ & 5.10 & $(0.05)$ & -0.01 & $(0.07)$ & 5.12 & $(0.04)$ & C & c & 4.22 & $(0.48)$ & c & c \\
\hline Slovenia & 5.00 & $(0.06)$ & 4.78 & $(0.05)$ & 0.21 & $(0.07)$ & 4.94 & $(0.04)$ & 3.90 & $(0.19)$ & 4.71 & $(0.17)$ & 1.04 & $(0.20)$ \\
\hline Spain & 4.40 & $(0.04)$ & 4.10 & $(0.05)$ & 0.30 & $(0.06)$ & 4.28 & $(0.03)$ & 4.12 & $(0.11)$ & 3.69 & $(0.24)$ & 0.15 & $(0.12)$ \\
\hline Sweden & 5.14 & $(0.07)$ & 5.30 & $(0.05)$ & -0.16 & $(0.08)$ & 5.34 & $(0.05)$ & 4.38 & $(0.12)$ & 4.92 & $(0.14)$ & 0.96 & $(0.14)$ \\
\hline Switzerland & 5.29 & $(0.06)$ & 5.20 & $(0.05)$ & 0.09 & $(0.07)$ & 5.42 & $(0.05)$ & 4.75 & $(0.13)$ & 4.90 & $(0.09)$ & 0.67 & $(0.13)$ \\
\hline Turkey & 4.05 & $(0.06)$ & 3.91 & $(0.06)$ & 0.14 & $(0.07)$ & 3.99 & $(0.05)$ & c & c & c & c & c & c \\
\hline United Kingdom & 4.86 & $(0.05)$ & 4.48 & $(0.05)$ & 0.38 & $(0.07)$ & 4.73 & $(0.04)$ & 4.47 & $(0.12)$ & 4.45 & $(0.11)$ & 0.26 & $(0.12)$ \\
\hline United States & 5.60 & $(0.05)$ & 4.80 & $(0.05)$ & 0.79 & $(0.07)$ & 5.33 & $(0.04)$ & 4.78 & $(0.14)$ & 4.79 & $(0.09)$ & 0.55 & $(0.14)$ \\
\hline OECD average & 5.00 & $(0.01)$ & 4.75 & $(0.01)$ & 0.26 & $(0.01)$ & 4.92 & $(0.01)$ & 4.58 & $(0.04)$ & 4.78 & $(0.04)$ & 0.37 & $(0.04)$ \\
\hline
\end{tabular}

\begin{tabular}{|c|c|c|c|c|c|c|c|c|c|c|c|c|c|c|}
\hline Albania & $\mathrm{m}$ & $\mathrm{m}$ & $\mathrm{m}$ & $\mathrm{m}$ & $\mathrm{m}$ & $\mathrm{m}$ & $\mathrm{m}$ & $\mathrm{m}$ & $\mathrm{m}$ & $\mathrm{m}$ & $\mathrm{m}$ & $\mathrm{m}$ & $\mathrm{m}$ & $\mathrm{m}$ \\
\hline Algeria & $\mathrm{m}$ & $\mathrm{m}$ & $\mathrm{m}$ & $\mathrm{m}$ & $\mathrm{m}$ & $\mathrm{m}$ & $\mathrm{m}$ & $\mathrm{m}$ & $\mathrm{m}$ & $\mathrm{m}$ & $\mathrm{m}$ & $\mathrm{m}$ & $\mathrm{m}$ & $\mathrm{m}$ \\
\hline Brazil & 3.97 & $(0.04)$ & 3.49 & $(0.04)$ & 0.48 & $(0.06)$ & 3.71 & $(0.03)$ & c & c & 4.82 & $(0.39)$ & c & c \\
\hline B-S-J-G (China) & 4.28 & $(0.06)$ & 4.09 & $(0.07)$ & 0.19 & $(0.07)$ & 4.20 & $(0.05)$ & c & c & c & c & c & c \\
\hline Bulgaria & 4.52 & $(0.05)$ & 4.56 & $(0.06)$ & -0.04 & $(0.07)$ & 4.56 & $(0.04)$ & c & c & c & c & c & c \\
\hline CABA (Argentina) & $\mathrm{m}$ & $\mathrm{m}$ & $\mathrm{m}$ & $\mathrm{m}$ & $\mathrm{m}$ & $\mathrm{m}$ & $\mathrm{m}$ & $\mathrm{m}$ & $\mathrm{m}$ & $\mathrm{m}$ & $\mathrm{m}$ & $\mathrm{m}$ & $\mathrm{m}$ & $\mathrm{m}$ \\
\hline Colombia & 3.71 & $(0.05)$ & 3.50 & $(0.05)$ & 0.21 & $(0.06)$ & 3.61 & $(0.04)$ & c & $\mathrm{c}$ & 3.76 & $(0.46)$ & c & $\mathrm{c}$ \\
\hline Costa Rica & 4.16 & $(0.05)$ & 3.67 & $(0.05)$ & 0.49 & $(0.06)$ & 3.91 & $(0.04)$ & 3.66 & $(0.18)$ & 4.06 & $(0.15)$ & 0.25 & $(0.18)$ \\
\hline Croatia & 4.84 & $(0.05)$ & 4.54 & $(0.06)$ & 0.30 & $(0.08)$ & 4.69 & $(0.04)$ & 4.90 & $(0.25)$ & 4.61 & $(0.11)$ & -0.21 & $(0.25)$ \\
\hline Cyprus* & 4.46 & $(0.05)$ & 4.12 & $(0.04)$ & 0.34 & $(0.07)$ & 4.25 & $(0.03)$ & 4.54 & $(0.12)$ & 4.55 & $(0.19)$ & -0.29 & $(0.12)$ \\
\hline Dominican Republic & 4.32 & $(0.06)$ & 4.03 & $(0.06)$ & 0.29 & $(0.08)$ & 4.18 & $(0.05)$ & c & c & 3.87 & $(0.45)$ & c & c \\
\hline FYROM & $\mathrm{m}$ & $\mathrm{m}$ & $\mathrm{m}$ & $\mathrm{m}$ & $\mathrm{m}$ & $\mathrm{m}$ & $\mathrm{m}$ & $\mathrm{m}$ & $\mathrm{m}$ & $\mathrm{m}$ & $\mathrm{m}$ & $\mathrm{m}$ & $\mathrm{m}$ & $\mathrm{m}$ \\
\hline Georgia & $\mathrm{m}$ & $\mathrm{m}$ & $\mathrm{m}$ & $\mathrm{m}$ & $\mathrm{m}$ & $\mathrm{m}$ & $\mathrm{m}$ & $\mathrm{m}$ & $\mathrm{m}$ & $\mathrm{m}$ & $\mathrm{m}$ & $\mathrm{m}$ & $\mathrm{m}$ & $\mathrm{m}$ \\
\hline Hong Kong (China) & 4.65 & $(0.06)$ & 4.07 & $(0.06)$ & 0.58 & $(0.08)$ & 4.38 & $(0.05)$ & 4.30 & $(0.12)$ & 4.39 & $(0.08)$ & 0.08 & $(0.12)$ \\
\hline Indonesia & $\mathrm{m}$ & $\mathrm{m}$ & $\mathrm{m}$ & $\mathrm{m}$ & $\mathrm{m}$ & $\mathrm{m}$ & $\mathrm{m}$ & $\mathrm{m}$ & $\mathrm{m}$ & $\mathrm{m}$ & $\mathrm{m}$ & $\mathrm{m}$ & $\mathrm{m}$ & $\mathrm{m}$ \\
\hline Jordan & $\mathrm{m}$ & $\mathrm{m}$ & $\mathrm{m}$ & $\mathrm{m}$ & $\mathrm{m}$ & $\mathrm{m}$ & $\mathrm{m}$ & $\mathrm{m}$ & $\mathrm{m}$ & $\mathrm{m}$ & $\mathrm{m}$ & $\mathrm{m}$ & $\mathrm{m}$ & $\mathrm{m}$ \\
\hline Kosovo & $\mathrm{m}$ & $\mathrm{m}$ & $\mathrm{m}$ & $\mathrm{m}$ & $\mathrm{m}$ & $\mathrm{m}$ & $\mathrm{m}$ & $\mathrm{m}$ & $\mathrm{m}$ & $\mathrm{m}$ & $\mathrm{m}$ & $\mathrm{m}$ & $\mathrm{m}$ & $\mathrm{m}$ \\
\hline Lebanon & $\mathrm{m}$ & $\mathrm{m}$ & $\mathrm{m}$ & $\mathrm{m}$ & $\mathrm{m}$ & $\mathrm{m}$ & $\mathrm{m}$ & $\mathrm{m}$ & $\mathrm{m}$ & $\mathrm{m}$ & $\mathrm{m}$ & $\mathrm{m}$ & $\mathrm{m}$ & $\mathrm{m}$ \\
\hline Lithuania & 5.05 & $(0.05)$ & 5.11 & $(0.04)$ & -0.06 & $(0.05)$ & 5.08 & $(0.04)$ & 3.87 & $(0.61)$ & 5.27 & $(0.26)$ & 1.21 & $(0.61)$ \\
\hline Macao (China) & 4.43 & $(0.05)$ & 3.90 & $(0.05)$ & 0.53 & $(0.07)$ & 4.16 & $(0.06)$ & 4.12 & $(0.09)$ & 4.21 & $(0.06)$ & 0.05 & $(0.10)$ \\
\hline Malta & $\mathrm{m}$ & $\mathrm{m}$ & $\mathrm{m}$ & $\mathrm{m}$ & $\mathrm{m}$ & $\mathrm{m}$ & $\mathrm{m}$ & $\mathrm{m}$ & $\mathrm{m}$ & $\mathrm{m}$ & $\mathrm{m}$ & $\mathrm{m}$ & $\mathrm{m}$ & $\mathrm{m}$ \\
\hline Moldova & $\mathrm{m}$ & $\mathrm{m}$ & $\mathrm{m}$ & $\mathrm{m}$ & $\mathrm{m}$ & $\mathrm{m}$ & $\mathrm{m}$ & $\mathrm{m}$ & $\mathrm{m}$ & $\mathrm{m}$ & $\mathrm{m}$ & $\mathrm{m}$ & $\mathrm{m}$ & $\mathrm{m}$ \\
\hline Montenegro & 5.28 & $(0.04)$ & 4.89 & $(0.05)$ & 0.39 & $(0.06)$ & 5.09 & $(0.04)$ & 4.69 & $(0.24)$ & 5.13 & $(0.14)$ & 0.40 & $(0.24)$ \\
\hline Peru & 4.34 & $(0.05)$ & 4.09 & $(0.05)$ & 0.25 & $(0.07)$ & 4.21 & $(0.03)$ & c & c & c & c & c & $\mathrm{c}$ \\
\hline Qatar & 3.96 & $(0.03)$ & 3.43 & $(0.03)$ & 0.53 & $(0.05)$ & 3.36 & $(0.03)$ & 3.98 & $(0.04)$ & 3.77 & $(0.06)$ & -0.62 & $(0.05)$ \\
\hline Romania & $\mathrm{m}$ & $\mathrm{m}$ & $\mathrm{m}$ & $\mathrm{m}$ & $\mathrm{m}$ & $\mathrm{m}$ & $\mathrm{m}$ & $\mathrm{m}$ & $\mathrm{m}$ & $\mathrm{m}$ & $\mathrm{m}$ & $\mathrm{m}$ & $\mathrm{m}$ & $\mathrm{m}$ \\
\hline Russia & 5.20 & $(0.06)$ & 5.14 & $(0.05)$ & 0.06 & $(0.07)$ & 5.19 & $(0.05)$ & 5.05 & $(0.20)$ & 4.75 & $(0.20)$ & 0.14 & $(0.19)$ \\
\hline Singapore & 4.69 & $(0.05)$ & 4.31 & $(0.05)$ & 0.38 & $(0.07)$ & 4.50 & $(0.04)$ & 4.58 & $(0.10)$ & 4.48 & $(0.14)$ & -0.09 & $(0.11)$ \\
\hline Chinese Taipei & 5.17 & $(0.04)$ & 4.29 & $(0.04)$ & 0.87 & $(0.05)$ & 4.74 & $(0.03)$ & c & c & c & c & c & c \\
\hline Thailand & 4.80 & $(0.06)$ & 4.77 & $(0.05)$ & 0.04 & $(0.07)$ & 4.79 & $(0.04)$ & c & c & 4.84 & $(0.42)$ & c & c \\
\hline Trinidad and Tobago & $\mathrm{m}$ & $\mathrm{m}$ & $\mathrm{m}$ & $\mathrm{m}$ & $\mathrm{m}$ & $\mathrm{m}$ & $\mathrm{m}$ & $\mathrm{m}$ & $\mathrm{m}$ & $\mathrm{m}$ & $\mathrm{m}$ & $\mathrm{m}$ & $\mathrm{m}$ & $\mathrm{m}$ \\
\hline Tunisia & 3.86 & $(0.05)$ & 3.26 & $(0.05)$ & 0.60 & $(0.06)$ & 3.52 & $(0.04)$ & c & c & 3.88 & $(0.30)$ & $\mathrm{c}$ & $\mathrm{c}$ \\
\hline United Arab Emirates & 3.85 & $(0.04)$ & 3.26 & $(0.05)$ & 0.59 & $(0.06)$ & 3.18 & $(0.05)$ & 3.90 & $(0.04)$ & 3.62 & $(0.06)$ & -0.72 & $(0.06)$ \\
\hline Uruguay & 4.67 & $(0.06)$ & 4.03 & $(0.06)$ & 0.64 & $(0.08)$ & 4.33 & $(0.04)$ & $\mathrm{C}$ & $\begin{array}{r}\text { C } \\
\mathrm{C}\end{array}$ & $\mathrm{C}$ & $\begin{array}{r}\text { C } \\
\text { (0.00) }\end{array}$ & $\mathrm{C}$ & 10.00 \\
\hline Viet Nam & $\mathrm{m}$ & $\mathrm{m}$ & $\mathrm{m}$ & $\mathrm{m}$ & $\mathrm{m}$ & $\mathrm{m}$ & $\mathrm{m}$ & $\mathrm{m}$ & $\mathrm{m}$ & $\mathrm{m}$ & $\mathrm{m}$ & $\mathrm{m}$ & $\mathrm{m}$ & $\mathrm{m}$ \\
\hline Argentina** & $\mathrm{m}$ & $\mathrm{m}$ & $\mathrm{m}$ & $\mathrm{m}$ & $\mathrm{m}$ & $\mathrm{m}$ & $\mathrm{m}$ & $\mathrm{m}$ & $\mathrm{m}$ & $\mathrm{m}$ & $\mathrm{m}$ & $\mathrm{m}$ & $\mathrm{m}$ & $\mathrm{m}$ \\
\hline Kazakhstan** & $\mathrm{m}$ & $\mathrm{m}$ & $\mathrm{m}$ & $\mathrm{m}$ & $\mathrm{m}$ & $\mathrm{m}$ & $\mathrm{m}$ & $\mathrm{m}$ & $\mathrm{m}$ & $\mathrm{m}$ & $\mathrm{m}$ & $\mathrm{m}$ & $\mathrm{m}$ & $\mathrm{m}$ \\
\hline Malaysia** & 4.99 & $(0.06)$ & 5.29 & $(0.06)$ & -0.30 & $(0.06)$ & 5.17 & $(0.05)$ & C & C & 4.95 & $(0.30)$ & c & c \\
\hline
\end{tabular}

1. ESCS refers to the PISA index of economic, social and cultural status.

Note: Values that are statistically significant are indicated in bold (see Annex A3).

* See note at the beginning of this Annex.

** Coverage is too small to ensure comparability (see Annex A4).

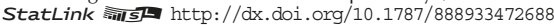


[Part 3/4]

Table III.11.13 Frequency of students' physical activity outside of school, by student characteristics

Results based on students' self-reports

\begin{tabular}{|c|c|c|c|c|c|c|c|c|c|c|c|c|c|c|c|}
\hline & \multicolumn{14}{|c|}{ Number of days per week students engage in physical activity outside of school } \\
\hline & & & Vig & us phy & al activit & activity & at make & Idents s & eat and $b$ & the har & for at le & $20 \mathrm{~min}$ & tes per $d$ & & \\
\hline & & & All $s$ & ents & & & & & Nation & quarters & ff the ES & index & & & \\
\hline & & & & & tion & Bottom & quarter & Seconc & quarter & Third & uarter & Top & iarter & $\begin{array}{r}\text { Top } \\
\text { Bottor }\end{array}$ & $\begin{array}{l}\text { arter - } \\
\text { quarter }\end{array}$ \\
\hline & & Mean & S.E. & S.D. & S.E. & Mean & S.E. & Mean & S.E. & Mean & S.E. & Mean & S.E. & Dif. & S.E. \\
\hline$\theta$ & Australia & 3.92 & $(0.03)$ & 2.19 & $(0.01)$ & 3.62 & $(0.06)$ & 3.81 & $(0.05)$ & 4.01 & $(0.05)$ & 4.21 & $(0.05)$ & 0.59 & $(0.07)$ \\
\hline & Austria & 3.45 & $(0.05)$ & 2.06 & $(0.03)$ & 3.14 & $(0.06)$ & 3.33 & $(0.07)$ & 3.46 & $(0.08)$ & 3.84 & $(0.10)$ & 0.70 & $(0.11)$ \\
\hline J & Belgium & 3.55 & $(0.03)$ & 2.07 & $(0.01)$ & 3.06 & $(0.05)$ & 3.48 & $(0.05)$ & 3.68 & $(0.06)$ & 3.91 & $(0.04)$ & 0.85 & $(0.06)$ \\
\hline & Canada & 4.26 & $(0.03)$ & 2.28 & $(0.01)$ & 3.90 & $(0.04)$ & 4.14 & $(0.05)$ & 4.30 & $(0.06)$ & 4.66 & $(0.06)$ & 0.76 & $(0.08)$ \\
\hline & Chile & 3.44 & $(0.03)$ & 2.13 & $(0.02)$ & 3.34 & $(0.06)$ & 3.41 & $(0.07)$ & 3.37 & $(0.07)$ & 3.62 & $(0.07)$ & 0.28 & $(0.10)$ \\
\hline & Czech Republic & 4.12 & $(0.04)$ & 2.16 & $(0.02)$ & 3.78 & $(0.08)$ & 4.13 & $(0.07)$ & 4.16 & $(0.07)$ & 4.40 & $(0.07)$ & 0.61 & $(0.09)$ \\
\hline & Denmark & 4.39 & $(0.05)$ & 2.18 & $(0.02)$ & 4.01 & $(0.07)$ & 4.37 & $(0.08)$ & 4.59 & $(0.07)$ & 4.58 & $(0.07)$ & 0.57 & $(0.11)$ \\
\hline & Estonia & 4.07 & $(0.03)$ & 2.13 & $(0.02)$ & 3.80 & $(0.07)$ & 4.04 & $(0.07)$ & 4.10 & $(0.07)$ & 4.36 & $(0.06)$ & 0.56 & $(0.10)$ \\
\hline & Finland & 3.99 & $(0.04)$ & 2.05 & $(0.02)$ & 3.49 & $(0.06)$ & 3.86 & $(0.07)$ & 4.15 & $(0.06)$ & 4.44 & $(0.06)$ & 0.95 & $(0.09)$ \\
\hline & France & 3.22 & $(0.03)$ & 2.00 & $(0.02)$ & 2.98 & $(0.05)$ & 3.17 & $(0.06)$ & 3.29 & $(0.06)$ & 3.45 & $(0.05)$ & 0.48 & $(0.07)$ \\
\hline & Germany & 3.94 & $(0.03)$ & 1.98 & $(0.02)$ & 3.73 & $(0.06)$ & 3.77 & $(0.06)$ & 4.02 & $(0.06)$ & 4.22 & $(0.06)$ & 0.49 & $(0.08)$ \\
\hline & Greece & 3.86 & $(0.03)$ & 2.23 & $(0.02)$ & 3.69 & $(0.06)$ & 3.77 & $(0.08)$ & 4.00 & $(0.08)$ & 3.99 & $(0.07)$ & 0.30 & $(0.09)$ \\
\hline & Hungary & 4.23 & $(0.05)$ & 2.24 & $(0.02)$ & 3.76 & $(0.08)$ & 4.14 & $(0.09)$ & 4.34 & $(0.07)$ & 4.67 & $(0.07)$ & 0.91 & $(0.11)$ \\
\hline & Iceland & 4.99 & $(0.04)$ & 2.31 & $(0.02)$ & 4.53 & $(0.08)$ & 5.01 & $(0.10)$ & 5.05 & $(0.07)$ & 5.36 & $(0.08)$ & 0.83 & $(0.11)$ \\
\hline & Ireland & 4.13 & $(0.03)$ & 2.19 & $(0.02)$ & 3.95 & $(0.07)$ & 4.05 & $(0.07)$ & 4.17 & $(0.06)$ & 4.35 & $(0.05)$ & 0.40 & $(0.08)$ \\
\hline & Israel & 3.90 & $(0.05)$ & 2.32 & $(0.02)$ & 3.45 & $(0.08)$ & 3.95 & $(0.10)$ & 4.01 & $(0.08)$ & 4.15 & $(0.07)$ & 0.70 & $(0.11)$ \\
\hline & Italy & $\mathrm{m}$ & $\mathrm{m}$ & $\mathrm{m}$ & $\mathrm{m}$ & $\mathrm{m}$ & $\mathrm{m}$ & $\mathrm{m}$ & $\mathrm{m}$ & $\mathrm{m}$ & $\mathrm{m}$ & $\mathrm{m}$ & $\mathrm{m}$ & $\mathrm{m}$ & $\mathrm{m}$ \\
\hline & Japan & 3.88 & $(0.06)$ & 2.75 & $(0.02)$ & 3.77 & $(0.08)$ & 3.91 & $(0.10)$ & 4.00 & $(0.09)$ & 3.89 & $(0.08)$ & 0.12 & $(0.11)$ \\
\hline & Korea & 3.24 & $(0.04)$ & 2.15 & $(0.03)$ & 3.23 & $(0.09)$ & 3.17 & $(0.07)$ & 3.18 & $(0.08)$ & 3.39 & $(0.06)$ & 0.16 & $(0.10)$ \\
\hline & Latvia & 4.16 & $(0.04)$ & 2.15 & $(0.02)$ & 3.98 & $(0.08)$ & 4.14 & $(0.07)$ & 4.16 & $(0.08)$ & 4.34 & $(0.06)$ & 0.36 & $(0.10)$ \\
\hline & Luxembourg & 3.89 & $(0.03)$ & 2.20 & $(0.02)$ & 3.51 & $(0.07)$ & 3.76 & $(0.07)$ & 4.00 & $(0.06)$ & 4.26 & $(0.06)$ & 0.74 & $(0.10)$ \\
\hline & Mexico & 3.84 & $(0.03)$ & 2.19 & $(0.02)$ & 3.57 & $(0.06)$ & 3.73 & $(0.06)$ & 3.90 & $(0.05)$ & 4.16 & $(0.06)$ & 0.58 & $(0.08)$ \\
\hline & Netherlands & 3.67 & $(0.03)$ & 1.91 & $(0.02)$ & 3.33 & $(0.05)$ & 3.60 & $(0.06)$ & 3.82 & $(0.05)$ & 3.92 & $(0.06)$ & 0.60 & $(0.08)$ \\
\hline & New Zealand & 3.91 & $(0.04)$ & 2.22 & $(0.02)$ & 3.57 & $(0.08)$ & 3.78 & $(0.09)$ & 4.01 & $(0.08)$ & 4.25 & $(0.06)$ & 0.69 & $(0.10)$ \\
\hline & Norway & 4.37 & $(0.04)$ & 2.16 & $(0.02)$ & 3.89 & $(0.06)$ & 4.32 & $(0.07)$ & 4.51 & $(0.06)$ & 4.75 & $(0.06)$ & 0.86 & $(0.09)$ \\
\hline & Poland & 4.60 & $(0.04)$ & 2.35 & $(0.02)$ & 4.49 & $(0.08)$ & 4.68 & $(0.07)$ & 4.61 & $(0.08)$ & 4.61 & $(0.08)$ & 0.13 & $(0.11)$ \\
\hline & Portugal & 3.59 & $(0.04)$ & 2.15 & $(0.02)$ & 3.28 & $(0.07)$ & 3.54 & $(0.05)$ & 3.73 & $(0.07)$ & 3.79 & $(0.07)$ & 0.51 & $(0.10)$ \\
\hline & Slovak Republic & 4.17 & $(0.04)$ & 2.26 & $(0.02)$ & 3.88 & $(0.07)$ & 4.20 & $(0.07)$ & 4.35 & $(0.09)$ & 4.24 & $(0.05)$ & 0.36 & $(0.08)$ \\
\hline & Slovenia & 4.32 & $(0.04)$ & 2.26 & $(0.02)$ & 3.95 & $(0.06)$ & 4.26 & $(0.07)$ & 4.36 & $(0.07)$ & 4.71 & $(0.08)$ & 0.76 & $(0.10)$ \\
\hline & Spain & 3.55 & $(0.03)$ & 2.06 & $(0.02)$ & 3.29 & $(0.06)$ & 3.48 & $(0.06)$ & 3.71 & $(0.06)$ & 3.72 & $(0.06)$ & 0.42 & $(0.08)$ \\
\hline & Sweden & 4.30 & $(0.04)$ & 2.19 & $(0.02)$ & 3.85 & $(0.07)$ & 4.23 & $(0.07)$ & 4.46 & $(0.07)$ & 4.63 & $(0.07)$ & 0.78 & $(0.09)$ \\
\hline & Switzerland & 3.93 & $(0.03)$ & 2.02 & $(0.02)$ & 3.76 & $(0.07)$ & 3.87 & $(0.06)$ & 3.96 & $(0.08)$ & 4.15 & $(0.05)$ & 0.40 & $(0.09)$ \\
\hline & Turkey & 3.38 & $(0.04)$ & 2.17 & $(0.02)$ & 3.02 & $(0.06)$ & 3.41 & $(0.05)$ & 3.50 & $(0.08)$ & 3.59 & $(0.07)$ & 0.57 & (0.09) \\
\hline & United Kingdom & 3.43 & $(0.03)$ & 2.09 & $(0.02)$ & 3.09 & $(0.07)$ & 3.34 & $(0.07)$ & 3.52 & $(0.07)$ & 3.78 & $(0.05)$ & 0.69 & $(0.09)$ \\
\hline & United States & 4.50 & $(0.04)$ & 2.42 & $(0.01)$ & 4.18 & $(0.07)$ & 4.25 & $(0.08)$ & 4.62 & $(0.07)$ & 4.95 & $(0.08)$ & 0.77 & $(0.10)$ \\
\hline & OECD average & 3.95 & $(0.01)$ & 2.18 & $(0.00)$ & 3.64 & $(0.01)$ & 3.88 & $(0.01)$ & 4.03 & $(0.01)$ & 4.22 & $(0.01)$ & 0.57 & $(0.02)$ \\
\hline$\infty$ & Albania & $\mathrm{m}$ & $\mathrm{m}$ & $\mathrm{m}$ & $\mathrm{m}$ & $\mathrm{m}$ & $\mathrm{m}$ & $\mathrm{m}$ & $\mathrm{m}$ & $\mathrm{m}$ & $\mathrm{m}$ & $\mathrm{m}$ & $\mathrm{m}$ & $\mathrm{m}$ & $\mathrm{m}$ \\
\hline 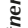 & Algeria & $\mathrm{m}$ & $\mathrm{m}$ & $\mathrm{m}$ & $\mathrm{m}$ & $\mathrm{m}$ & $\mathrm{m}$ & $\mathrm{m}$ & $\mathrm{m}$ & $\mathrm{m}$ & $\mathrm{m}$ & $\mathrm{m}$ & $\mathrm{m}$ & $\mathrm{m}$ & $\mathrm{m}$ \\
\hline & Brazil & 3.15 & $(0.03)$ & 2.29 & $(0.02)$ & 2.86 & $(0.04)$ & 3.02 & $(0.05)$ & 3.17 & $(0.05)$ & 3.49 & $(0.05)$ & 0.63 & $(0.06)$ \\
\hline & B-S-J-G (China) & 3.99 & $(0.05)$ & 2.17 & $(0.02)$ & 3.74 & $(0.08)$ & 4.03 & $(0.08)$ & 4.02 & $(0.08)$ & 4.19 & $(0.07)$ & 0.45 & $(0.10)$ \\
\hline & Bulgaria & 3.89 & $(0.04)$ & 2.29 & $(0.02)$ & 3.55 & $(0.07)$ & 3.92 & $(0.08)$ & 3.99 & $(0.08)$ & 4.09 & $(0.07)$ & 0.54 & $(0.09)$ \\
\hline & CABA (Argentina) & $\mathrm{m}$ & $\mathrm{m}$ & $\mathrm{m}$ & $\mathrm{m}$ & $\mathrm{m}$ & $\mathrm{m}$ & $\mathrm{m}$ & $\mathrm{m}$ & $\mathrm{m}$ & $\mathrm{m}$ & $\mathrm{m}$ & $\mathrm{m}$ & $\mathrm{m}$ & $\mathrm{m}$ \\
\hline & Colombia & 3.45 & $(0.03)$ & 2.16 & $(0.02)$ & 3.24 & $(0.07)$ & 3.38 & $(0.06)$ & 3.47 & $(0.06)$ & 3.72 & $(0.06)$ & 0.47 & $(0.09)$ \\
\hline & Costa Rica & 3.21 & $(0.04)$ & 2.15 & $(0.02)$ & 2.97 & $(0.07)$ & 3.14 & $(0.07)$ & 3.35 & $(0.07)$ & 3.36 & $(0.07)$ & 0.39 & $(0.09)$ \\
\hline & Croatia & 3.83 & $(0.04)$ & 2.31 & $(0.02)$ & 3.63 & $(0.08)$ & 3.73 & $(0.07)$ & 3.94 & $(0.09)$ & 4.03 & $(0.09)$ & 0.41 & $(0.11)$ \\
\hline & Cyprus* & 3.96 & $(0.03)$ & 2.29 & $(0.02)$ & 3.62 & $(0.06)$ & 3.92 & $(0.07)$ & 4.06 & $(0.07)$ & 4.24 & $(0.06)$ & 0.62 & $(0.08)$ \\
\hline & Dominican Republic & 3.89 & $(0.05)$ & 2.28 & $(0.02)$ & 3.70 & $(0.11)$ & 3.76 & $(0.10)$ & 4.00 & $(0.10)$ & 4.07 & $(0.10)$ & 0.37 & $(0.16)$ \\
\hline & FYROM & $\mathrm{m}$ & $\mathrm{m}$ & $\mathrm{m}$ & $\mathrm{m}$ & $\mathrm{m}$ & $\mathrm{m}$ & $\mathrm{m}$ & $\mathrm{m}$ & $\mathrm{m}$ & $\mathrm{m}$ & $\mathrm{m}$ & $\mathrm{m}$ & $\mathrm{m}$ & $\mathrm{m}$ \\
\hline & Georgia & $\mathrm{m}$ & $\mathrm{m}$ & $\mathrm{m}$ & $\mathrm{m}$ & $\mathrm{m}$ & $\mathrm{m}$ & $\mathrm{m}$ & $\mathrm{m}$ & $\mathrm{m}$ & $\mathrm{m}$ & $\mathrm{m}$ & $\mathrm{m}$ & $\mathrm{m}$ & $\mathrm{m}$ \\
\hline & Hong Kong (China) & 3.28 & $(0.04)$ & 2.12 & $(0.02)$ & 3.13 & $(0.07)$ & 3.26 & $(0.08)$ & 3.29 & $(0.07)$ & 3.44 & $(0.07)$ & 0.31 & $(0.09)$ \\
\hline & Indonesia & $\mathrm{m}$ & $\mathrm{m}$ & $\mathrm{m}$ & $\mathrm{m}$ & $\mathrm{m}$ & $\mathrm{m}$ & $\mathrm{m}$ & $\mathrm{m}$ & $\mathrm{m}$ & $\mathrm{m}$ & $\mathrm{m}$ & $\mathrm{m}$ & $\mathrm{m}$ & $\mathrm{m}$ \\
\hline & Jordan & $\mathrm{m}$ & $\mathrm{m}$ & $\mathrm{m}$ & $\mathrm{m}$ & $\mathrm{m}$ & $\mathrm{m}$ & $\mathrm{m}$ & $\mathrm{m}$ & $\mathrm{m}$ & $\mathrm{m}$ & $\mathrm{m}$ & $\mathrm{m}$ & $\mathrm{m}$ & $\mathrm{m}$ \\
\hline & Kosovo & $\mathrm{m}$ & $\mathrm{m}$ & $\mathrm{m}$ & $\mathrm{m}$ & $\mathrm{m}$ & $\mathrm{m}$ & $\mathrm{m}$ & $\mathrm{m}$ & $\mathrm{m}$ & $\mathrm{m}$ & $\mathrm{m}$ & $\mathrm{m}$ & $\mathrm{m}$ & $\mathrm{m}$ \\
\hline & Lebanon & $\mathrm{m}$ & $\mathrm{m}$ & $\mathrm{m}$ & $\mathrm{m}$ & $\mathrm{m}$ & $\mathrm{m}$ & $\mathrm{m}$ & $\mathrm{m}$ & $\mathrm{m}$ & $\mathrm{m}$ & $\mathrm{m}$ & $\mathrm{m}$ & $\mathrm{m}$ & $\mathrm{m}$ \\
\hline & Lithuania & 4.09 & $(0.03)$ & 2.18 & $(0.02)$ & 3.77 & $(0.06)$ & 4.16 & $(0.07)$ & 4.18 & $(0.07)$ & 4.23 & $(0.08)$ & 0.46 & $(0.09)$ \\
\hline & Macao (China) & 3.02 & $(0.03)$ & 1.96 & $(0.03)$ & 2.89 & $(0.06)$ & 3.01 & $(0.06)$ & 2.98 & $(0.06)$ & 3.22 & $(0.06)$ & 0.33 & $(0.09)$ \\
\hline & Malta & $\mathrm{m}$ & $\mathrm{m}$ & $\mathrm{m}$ & $\mathrm{m}$ & $\mathrm{m}$ & $\mathrm{m}$ & $\mathrm{m}$ & $\mathrm{m}$ & $\mathrm{m}$ & $\mathrm{m}$ & $\mathrm{m}$ & $\mathrm{m}$ & $\mathrm{m}$ & $\mathrm{m}$ \\
\hline & Moldova & $\mathrm{m}$ & $\mathrm{m}$ & $\mathrm{m}$ & $\mathrm{m}$ & $\mathrm{m}$ & $\mathrm{m}$ & $\mathrm{m}$ & $\mathrm{m}$ & $\mathrm{m}$ & $\mathrm{m}$ & $\mathrm{m}$ & $\mathrm{m}$ & $\mathrm{m}$ & $\mathrm{m}$ \\
\hline & Montenegro & 4.31 & $(0.03)$ & 2.39 & $(0.02)$ & 4.00 & $(0.07)$ & 4.17 & $(0.07)$ & 4.49 & $(0.06)$ & 4.55 & $(0.07)$ & 0.55 & $(0.10)$ \\
\hline & Peru & 3.56 & $(0.03)$ & 2.08 & $(0.02)$ & 3.48 & $(0.06)$ & 3.51 & $(0.06)$ & 3.58 & $(0.05)$ & 3.67 & $(0.06)$ & 0.19 & $(0.09)$ \\
\hline & Qatar & 3.44 & $(0.02)$ & 2.24 & $(0.01)$ & 3.24 & $(0.04)$ & 3.32 & $(0.04)$ & 3.48 & $(0.04)$ & 3.74 & $(0.04)$ & 0.50 & $(0.06)$ \\
\hline & Romania & $\mathrm{m}$ & $\mathrm{m}$ & $\mathrm{m}$ & $\mathrm{m}$ & $\mathrm{m}$ & $\mathrm{m}$ & $\mathrm{m}$ & $\mathrm{m}$ & $\mathrm{m}$ & $\mathrm{m}$ & $\mathrm{m}$ & $\mathrm{m}$ & $\mathrm{m}$ & $\mathrm{m}$ \\
\hline & Russia & 4.19 & $(0.04)$ & 2.17 & $(0.02)$ & 4.00 & $(0.09)$ & 4.15 & $(0.08)$ & 4.23 & $(0.08)$ & 4.38 & $(0.08)$ & 0.37 & $(0.10)$ \\
\hline & Singapore & 3.21 & $(0.02)$ & 1.87 & $(0.02)$ & 3.22 & $(0.05)$ & 3.08 & $(0.04)$ & 3.13 & $(0.05)$ & 3.42 & $(0.05)$ & 0.20 & $(0.08)$ \\
\hline & Chinese Taipei & 3.64 & $(0.03)$ & 2.19 & $(0.02)$ & 3.56 & $(0.06)$ & 3.68 & $(0.06)$ & 3.55 & $(0.06)$ & 3.77 & $(0.08)$ & 0.21 & $(0.10)$ \\
\hline & Thailand & 3.68 & $(0.03)$ & 2.08 & $(0.02)$ & 3.59 & $(0.05)$ & 3.67 & $(0.06)$ & 3.69 & $(0.07)$ & 3.76 & $(0.08)$ & 0.17 & $(0.09)$ \\
\hline & Trinidad and Tobago & $\mathrm{m}$ & $\mathrm{m}$ & $\mathrm{m}$ & $\mathrm{m}$ & $\mathrm{m}$ & $\mathrm{m}$ & $\mathrm{m}$ & $\mathrm{m}$ & $\mathrm{m}$ & $\mathrm{m}$ & $\mathrm{m}$ & $\mathrm{m}$ & $\mathrm{m}$ & $\mathrm{m}$ \\
\hline & Tunisia & 3.26 & $(0.03)$ & 2.13 & $(0.02)$ & 3.22 & $(0.07)$ & 3.15 & $(0.07)$ & 3.35 & $(0.07)$ & 3.30 & $(0.07)$ & 0.08 & $(0.10)$ \\
\hline & United Arab Emirates & 3.36 & $(0.03)$ & 2.25 & $(0.02)$ & 3.12 & $(0.05)$ & 3.22 & $(0.06)$ & 3.43 & $(0.05)$ & 3.68 & $(0.06)$ & 0.56 & $(0.08)$ \\
\hline & Uruguay & 3.65 & $(0.04)$ & 2.25 & $(0.02)$ & 3.27 & $(0.07)$ & 3.57 & $(0.06)$ & 3.79 & $(0.08)$ & 3.94 & $(0.08)$ & 0.67 & $(0.10)$ \\
\hline & Viet Nam & $\mathrm{m}$ & $\mathrm{m}$ & $\mathrm{m}$ & $\mathrm{m}$ & $\mathrm{m}$ & $\mathrm{m}$ & $\mathrm{m}$ & $\mathrm{m}$ & $\mathrm{m}$ & $\mathrm{m}$ & $\mathrm{m}$ & $\mathrm{m}$ & $\mathrm{m}$ & $\mathrm{m}$ \\
\hline & Argentina** & $\mathrm{m}$ & $\mathrm{m}$ & $\mathrm{m}$ & $\mathrm{m}$ & $\mathrm{m}$ & $\mathrm{m}$ & $\mathrm{m}$ & $\mathrm{m}$ & $\mathrm{m}$ & $\mathrm{m}$ & $\mathrm{m}$ & $\mathrm{m}$ & $\mathrm{m}$ & $\mathrm{m}$ \\
\hline & Kazakhstan** & $\mathrm{m}$ & $\mathrm{m}$ & $\mathrm{m}$ & $\mathrm{m}$ & $\mathrm{m}$ & $\mathrm{m}$ & $\mathrm{m}$ & $\mathrm{m}$ & $\mathrm{m}$ & $\mathrm{m}$ & $\mathrm{m}$ & $\mathrm{m}$ & $\mathrm{m}$ & $\mathrm{m}$ \\
\hline & Malaysia** & 4.01 & $(0.04)$ & 2.12 & $(0.02)$ & 3.94 & $(0.06)$ & 4.01 & $(0.07)$ & 4.09 & $(0.07)$ & 3.99 & $(0.06)$ & 0.05 & $(0.08)$ \\
\hline
\end{tabular}

1. ESCS refers to the PISA index of economic, social and cultural status.

Note: Values that are statistically significant are indicated in bold (see Annex A3).

* See note at the beginning of this Annex.

** Coverage is too small to ensure comparability (see Annex A4).

StatLink त्ञाता $\mathrm{http}: / / \mathrm{dx}$. doi.org/10.1787/888933472688 


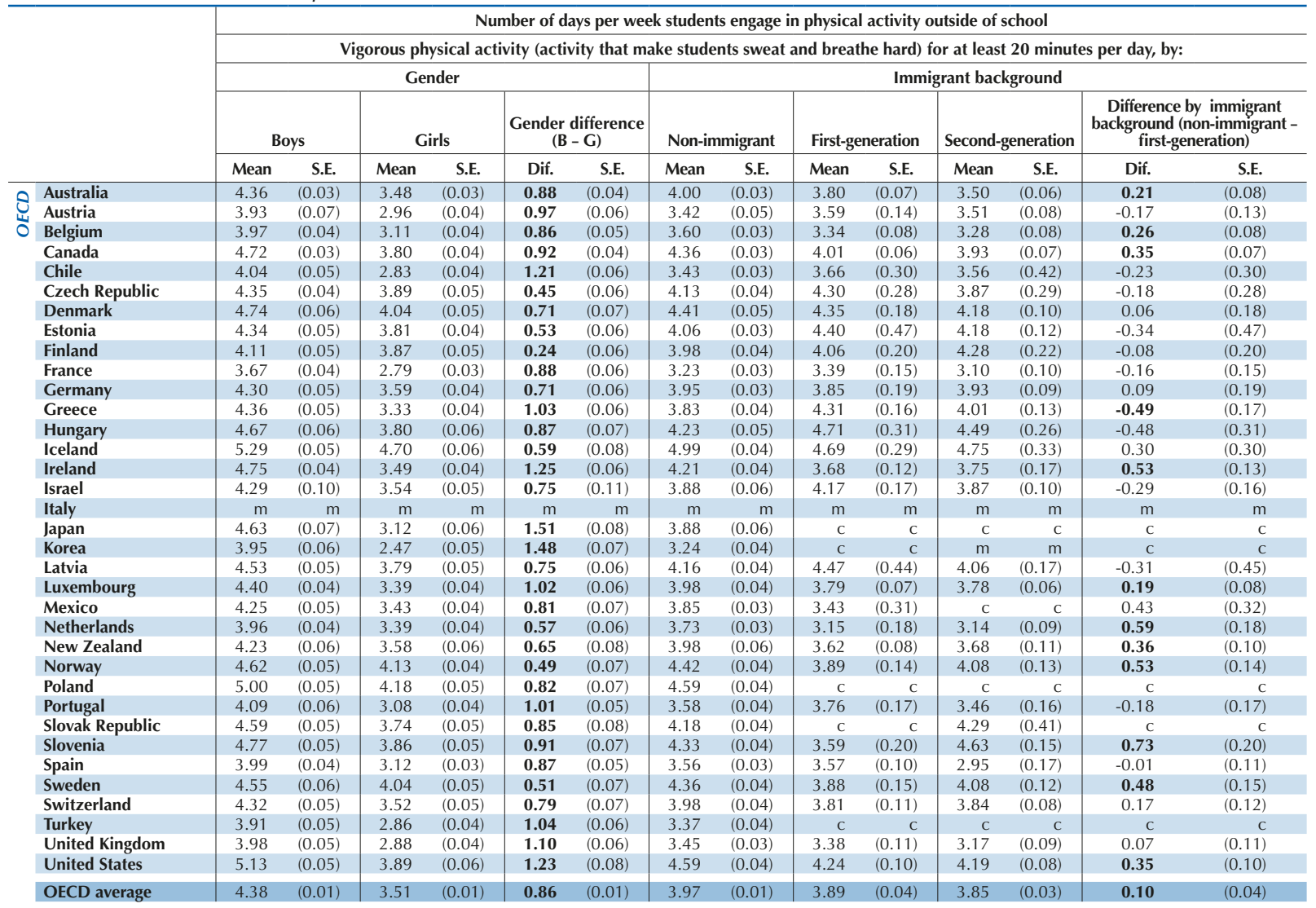

\begin{tabular}{|c|c|c|c|c|c|c|c|c|c|c|c|c|c|c|}
\hline Albania & $\mathrm{m}$ & $\mathrm{m}$ & $\mathrm{m}$ & $\mathrm{m}$ & $\mathrm{m}$ & $\mathrm{m}$ & $\mathrm{m}$ & $\mathrm{m}$ & $\mathrm{m}$ & $\mathrm{m}$ & $\mathrm{m}$ & $\mathrm{m}$ & $\mathrm{m}$ & $\mathrm{m}$ \\
\hline Algeria & $\mathrm{m}$ & $\mathrm{m}$ & $\mathrm{m}$ & $\mathrm{m}$ & $\mathrm{m}$ & $\mathrm{m}$ & $\mathrm{m}$ & $\mathrm{m}$ & $\mathrm{m}$ & $\mathrm{m}$ & $\mathrm{m}$ & $\mathrm{m}$ & $\mathrm{m}$ & $\mathrm{m}$ \\
\hline Brazil & 3.74 & $(0.04)$ & 2.61 & $(0.03)$ & 1.13 & $(0.05)$ & 3.14 & $(0.03)$ & c & c & 4.54 & $(0.40)$ & c & c \\
\hline B-S-J-G (China) & 4.27 & $(0.06)$ & 3.68 & $(0.06)$ & 0.60 & $(0.07)$ & 4.00 & $(0.05)$ & c & c & c & c & c & c \\
\hline Bulgaria & 4.30 & $(0.06)$ & 3.45 & $(0.05)$ & 0.85 & $(0.06)$ & 3.90 & $(0.04)$ & c & c & c & c & c & c \\
\hline CABA (Argentina) & $\mathrm{m}$ & $\mathrm{m}$ & $\mathrm{m}$ & $\mathrm{m}$ & $\mathrm{m}$ & $\mathrm{m}$ & $\mathrm{m}$ & $\mathrm{m}$ & $\mathrm{m}$ & $\mathrm{m}$ & $\mathrm{m}$ & $\mathrm{m}$ & $\mathrm{m}$ & $\mathrm{m}$ \\
\hline Colombia & 3.86 & $(0.05)$ & 3.09 & $(0.04)$ & 0.77 & $(0.06)$ & 3.44 & $(0.03)$ & $\mathrm{c}$ & $\mathrm{c}$ & 3.64 & $(0.42)$ & c & c \\
\hline Costa Rica & 3.92 & $(0.06)$ & 2.52 & $(0.04)$ & 1.40 & $(0.06)$ & 3.21 & $(0.04)$ & 3.25 & $(0.20)$ & 3.13 & $(0.15)$ & -0.04 & $(0.19)$ \\
\hline Croatia & 4.44 & $(0.06)$ & 3.27 & $(0.05)$ & 1.17 & $(0.07)$ & 3.82 & $(0.04)$ & 3.85 & $(0.22)$ & 3.96 & $(0.13)$ & -0.03 & $(0.22)$ \\
\hline Cyprus* & 4.46 & $(0.05)$ & 3.49 & $(0.04)$ & 0.97 & $(0.06)$ & 3.95 & $(0.03)$ & 4.08 & $(0.14)$ & 4.10 & $(0.19)$ & -0.13 & $(0.14)$ \\
\hline Dominican Republic & 4.37 & $(0.06)$ & 3.43 & $(0.06)$ & 0.94 & $(0.09)$ & 3.87 & $(0.05)$ & c & c & 4.40 & $(0.42)$ & c & c \\
\hline FYROM & $\mathrm{m}$ & $\mathrm{m}$ & $\mathrm{m}$ & $\mathrm{m}$ & $\mathrm{m}$ & $\mathrm{m}$ & $\mathrm{m}$ & $\mathrm{m}$ & $\mathrm{m}$ & $\mathrm{m}$ & $\mathrm{m}$ & $\mathrm{m}$ & $\mathrm{m}$ & $\mathrm{m}$ \\
\hline Georgia & $\mathrm{m}$ & $\mathrm{m}$ & $\mathrm{m}$ & $\mathrm{m}$ & $\mathrm{m}$ & $\mathrm{m}$ & $\mathrm{m}$ & $\mathrm{m}$ & $\mathrm{m}$ & $\mathrm{m}$ & $\mathrm{m}$ & $\mathrm{m}$ & $\mathrm{m}$ & $\mathrm{m}$ \\
\hline Hong Kong (China) & 3.76 & $(0.05)$ & 2.80 & $(0.04)$ & 0.95 & $(0.06)$ & 3.30 & $(0.04)$ & 3.31 & $(0.09)$ & 3.16 & $(0.06)$ & -0.01 & $(0.10)$ \\
\hline Indonesia & $\mathrm{m}$ & $\mathrm{m}$ & $\mathrm{m}$ & $\mathrm{m}$ & $\mathrm{m}$ & $\mathrm{m}$ & $\mathrm{m}$ & $\mathrm{m}$ & $\mathrm{m}$ & $\mathrm{m}$ & $\mathrm{m}$ & $\mathrm{m}$ & $\mathrm{m}$ & $\mathrm{m}$ \\
\hline Jordan & $\mathrm{m}$ & $\mathrm{m}$ & $\mathrm{m}$ & $\mathrm{m}$ & $\mathrm{m}$ & $\mathrm{m}$ & $\mathrm{m}$ & $\mathrm{m}$ & $\mathrm{m}$ & $\mathrm{m}$ & $\mathrm{m}$ & $\mathrm{m}$ & $\mathrm{m}$ & $\mathrm{m}$ \\
\hline Kosovo & $\mathrm{m}$ & $\mathrm{m}$ & $\mathrm{m}$ & $\mathrm{m}$ & $\mathrm{m}$ & $\mathrm{m}$ & $\mathrm{m}$ & $\mathrm{m}$ & $\mathrm{m}$ & $\mathrm{m}$ & $\mathrm{m}$ & $\mathrm{m}$ & $\mathrm{m}$ & $\mathrm{m}$ \\
\hline Lebanon & $\mathrm{m}$ & $\mathrm{m}$ & $\mathrm{m}$ & $\mathrm{m}$ & $\mathrm{m}$ & $\mathrm{m}$ & $\mathrm{m}$ & $\mathrm{m}$ & $\mathrm{m}$ & $\mathrm{m}$ & $\mathrm{m}$ & $\mathrm{m}$ & $\mathrm{m}$ & $\mathrm{m}$ \\
\hline Lithuania & 4.59 & $(0.05)$ & 3.59 & $(0.04)$ & 1.00 & $(0.06)$ & 4.09 & $(0.03)$ & 3.73 & $(0.54)$ & 4.33 & $(0.21)$ & 0.35 & $(0.54)$ \\
\hline Macao (China) & 3.53 & $(0.05)$ & 2.51 & $(0.03)$ & 1.01 & $(0.06)$ & 3.03 & $(0.05)$ & 3.09 & $(0.08)$ & 3.00 & $(0.04)$ & -0.06 & $(0.09)$ \\
\hline Malta & $\mathrm{m}$ & $\mathrm{m}$ & $\mathrm{m}$ & $\mathrm{m}$ & $\mathrm{m}$ & $\mathrm{m}$ & $\mathrm{m}$ & $\mathrm{m}$ & $\mathrm{m}$ & $\mathrm{m}$ & $\mathrm{m}$ & $\mathrm{m}$ & $\mathrm{m}$ & $\mathrm{m}$ \\
\hline Moldova & $\mathrm{m}$ & $\mathrm{m}$ & $\mathrm{m}$ & $\mathrm{m}$ & $\mathrm{m}$ & $\mathrm{m}$ & $\mathrm{m}$ & $\mathrm{m}$ & $\mathrm{m}$ & $\mathrm{m}$ & $\mathrm{m}$ & $\mathrm{m}$ & $\mathrm{m}$ & $\mathrm{m}$ \\
\hline Montenegro & 4.95 & $(0.04)$ & 3.67 & $(0.05)$ & 1.27 & $(0.06)$ & 4.30 & $(0.04)$ & 4.19 & $(0.24)$ & 4.49 & $(0.16)$ & 0.11 & $(0.25)$ \\
\hline Peru & 4.12 & $(0.04)$ & 2.98 & $(0.04)$ & 1.15 & $(0.05)$ & 3.56 & $(0.03)$ & c & c & c & c & c & c \\
\hline Qatar & 4.01 & $(0.03)$ & 2.93 & $(0.03)$ & 1.09 & $(0.04)$ & 3.26 & $(0.03)$ & 3.61 & $(0.03)$ & 3.44 & $(0.05)$ & -0.36 & $(0.04)$ \\
\hline Romania & $\mathrm{m}$ & $\mathrm{m}$ & $\mathrm{m}$ & $\mathrm{m}$ & $\mathrm{m}$ & $\mathrm{m}$ & $\mathrm{m}$ & $\mathrm{m}$ & $\mathrm{m}$ & $\mathrm{m}$ & $\mathrm{m}$ & $\mathrm{m}$ & $\mathrm{m}$ & $\mathrm{m}$ \\
\hline Russia & 4.59 & $(0.06)$ & 3.82 & $(0.05)$ & 0.77 & $(0.07)$ & 4.19 & $(0.04)$ & 4.23 & $(0.18)$ & 4.24 & $(0.18)$ & -0.04 & $(0.18)$ \\
\hline Singapore & 3.64 & $(0.04)$ & 2.76 & $(0.03)$ & 0.88 & $(0.05)$ & 3.16 & $(0.02)$ & 3.54 & $(0.09)$ & 3.11 & $(0.10)$ & -0.37 & $(0.10)$ \\
\hline Chinese Taipei & 4.24 & $(0.04)$ & 3.03 & $(0.05)$ & 1.21 & $(0.06)$ & 3.64 & $(0.03)$ & c & c & c & c & c & c \\
\hline Thailand & 4.27 & $(0.06)$ & 3.24 & $(0.03)$ & 1.03 & $(0.07)$ & 3.68 & $(0.03)$ & c & c & 3.34 & $(0.33)$ & c & c \\
\hline Trinidad and Tobago & $\mathrm{m}$ & $\mathrm{m}$ & $\mathrm{m}$ & $\mathrm{m}$ & $\mathrm{m}$ & $\mathrm{m}$ & $\mathrm{m}$ & $\mathrm{m}$ & $\mathrm{m}$ & $\mathrm{m}$ & $\mathrm{m}$ & $\mathrm{m}$ & $\mathrm{m}$ & $\mathrm{m}$ \\
\hline Tunisia & 3.93 & $(0.05)$ & 2.69 & $(0.04)$ & 1.24 & $(0.06)$ & 3.24 & $(0.03)$ & c & c & 3.31 & $(0.35)$ & c & c \\
\hline United Arab Emirates & 3.93 & $(0.04)$ & 2.84 & $(0.04)$ & 1.09 & $(0.06)$ & 3.17 & $(0.05)$ & 3.55 & $(0.05)$ & 3.37 & $(0.06)$ & -0.38 & $(0.07)$ \\
\hline Uruguay & 4.41 & $(0.05)$ & 2.99 & $(0.04)$ & 1.42 & $(0.07)$ & 3.64 & $(0.04)$ & $\mathrm{C}$ & C & $\mathrm{C}$ & $\begin{array}{r}\text { C } \\
\text { (0.00) }\end{array}$ & C & $\mathrm{C}$ \\
\hline Viet Nam & $\mathrm{m}$ & $\mathrm{m}$ & $\mathrm{m}$ & $\mathrm{m}$ & $\mathrm{m}$ & $\mathrm{m}$ & $\mathrm{m}$ & $\mathrm{m}$ & $\mathrm{m}$ & $\mathrm{m}$ & $\mathrm{m}$ & $\mathrm{m}$ & $\mathrm{m}$ & $\mathrm{m}$ \\
\hline Argentina** & $\mathrm{m}$ & $\mathrm{m}$ & $\mathrm{m}$ & $\mathrm{m}$ & $\mathrm{m}$ & $\mathrm{m}$ & $\mathrm{m}$ & $\mathrm{m}$ & $\mathrm{m}$ & $\mathrm{m}$ & $\mathrm{m}$ & $\mathrm{m}$ & $\mathrm{m}$ & $\mathrm{m}$ \\
\hline Kazakhstan** & $\mathrm{m}$ & $\mathrm{m}$ & $\mathrm{m}$ & $\mathrm{m}$ & $\mathrm{m}$ & $\mathrm{m}$ & $\mathrm{m}$ & $\mathrm{m}$ & $\mathrm{m}$ & $\mathrm{m}$ & $\mathrm{m}$ & $\mathrm{m}$ & $\mathrm{m}$ & $\mathrm{m}$ \\
\hline Malaysia** & 4.65 & $(0.06)$ & 3.43 & $(0.04)$ & 1.21 & $(0.07)$ & 4.00 & $(0.04)$ & C & C & 4.27 & $(0.32)$ & c & $\mathrm{c}$ \\
\hline
\end{tabular}

1. ESCS refers to the PISA index of economic, social and cultural status.

Note: Values that are statistically significant are indicated in bold (see Annex A3).

* See note at the beginning of this Annex.

.

StatLink त्नाईs $\mathrm{http}: / / \mathrm{dx}$.doi.org/10.1787/888933472688 
[Part 1/2]

Table III.11.15 Frequency of students' physical activity outside of school and science performance

Results based on students' self-reports

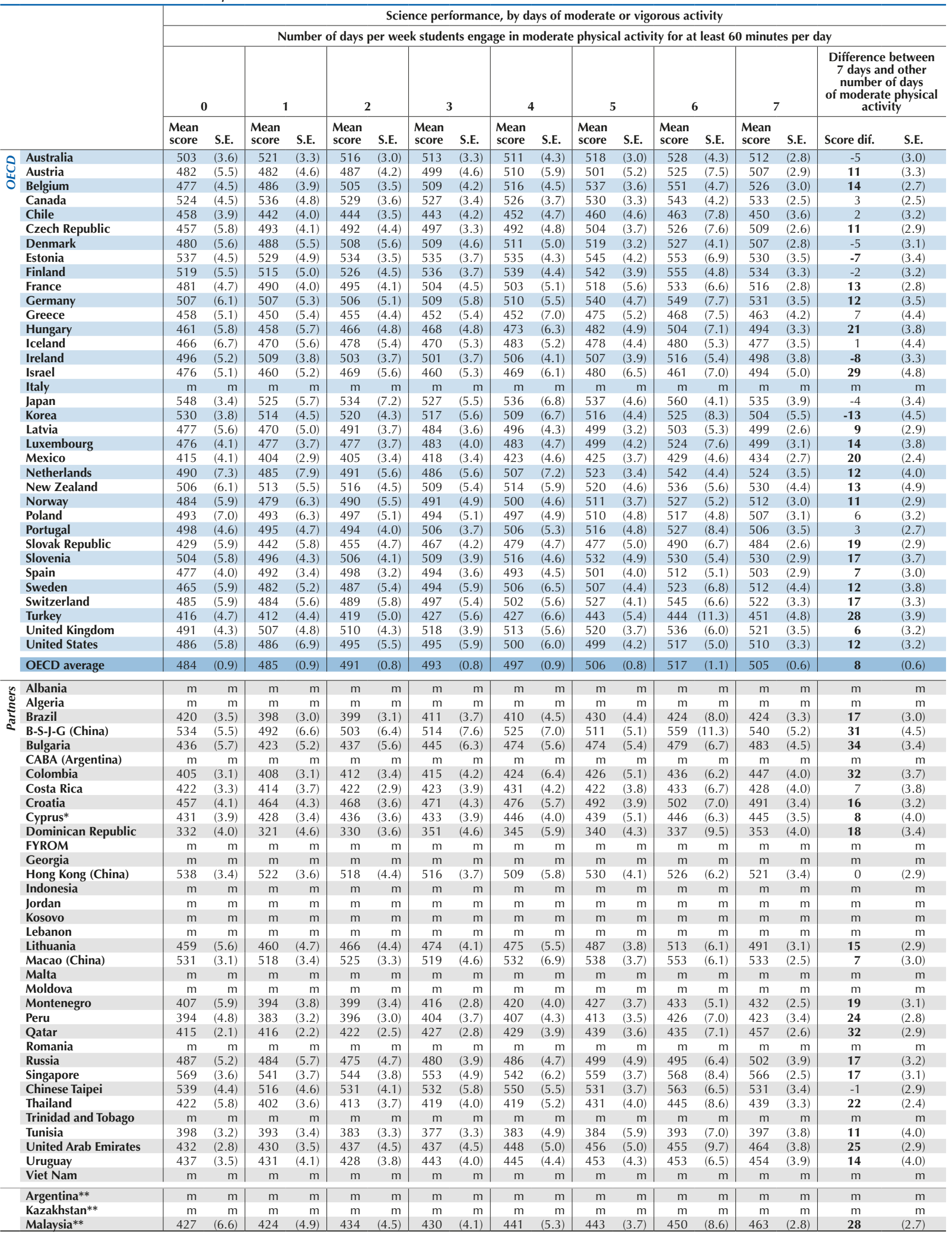

Note: Values that are statistically significant are indicated in bold (see Annex A3).

* See note at the beginning of this Annex.

** Coverage is too small to ensure comparability (see Annex A4).

StatLink 尚ils $\mathrm{http}: / / \mathrm{dx} . \mathrm{doi}$. org $/ 10.1787 / 888933472704$ 


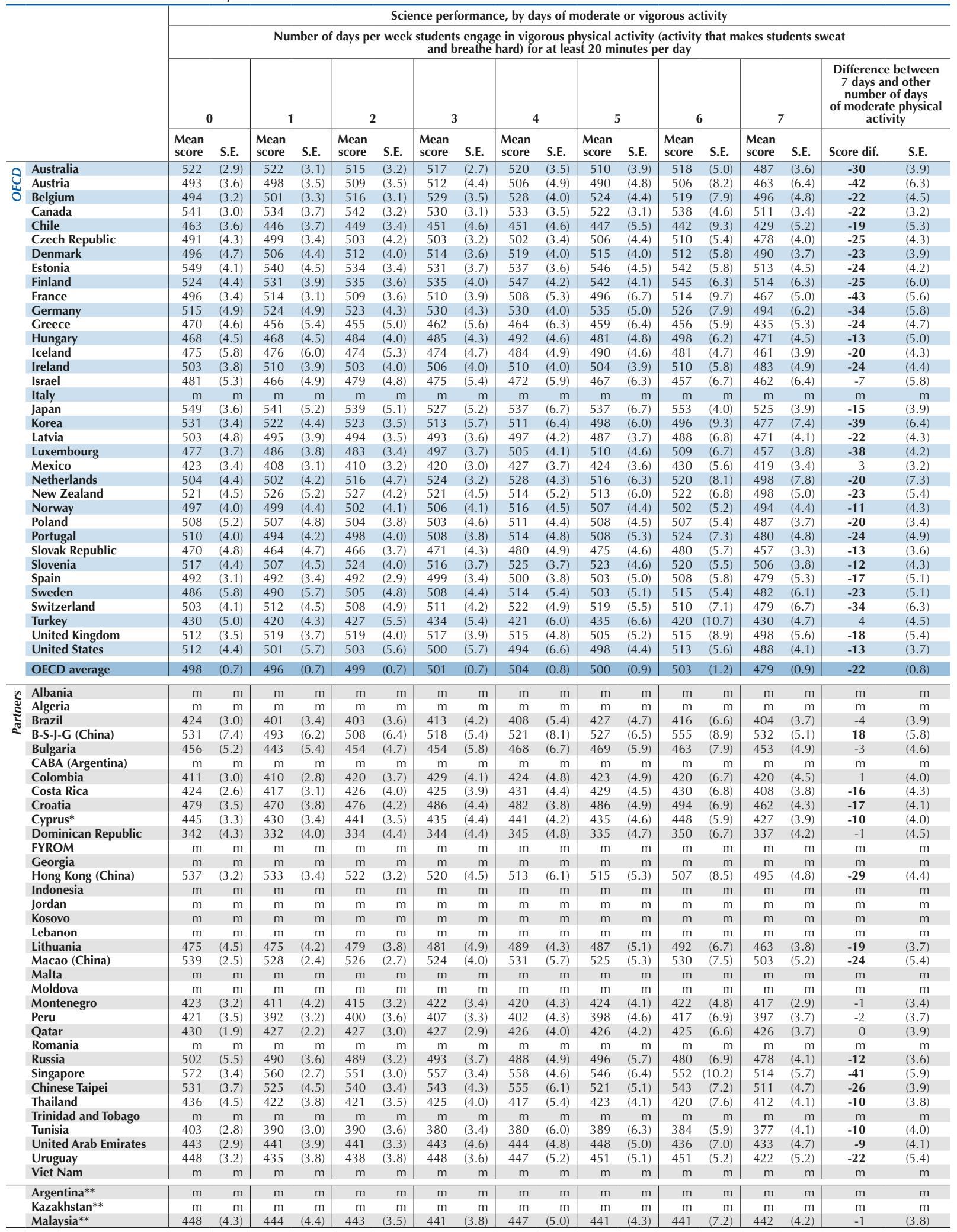

Note: Values that are statistically significant are indicated in bold (see Annex A3).

* See note at the beginning of this Annex.

** Coverage is too small to ensure comparability (see Annex A4).

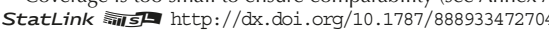


[Part 1/2]

Table III.11.16 Physical activity outside of school and students' satisfaction with life

Results based on students' self-reports

Average life satisfaction by:

\begin{tabular}{|c|c|c|c|c|c|c|c|c|c|c|c|c|c|c|}
\hline & \multicolumn{13}{|c|}{ Average life satisfaction by: } \\
\hline & & \multicolumn{13}{|c|}{ Number of days per week students engage in moderate physical activity for at least 60 minutes per day } \\
\hline & & & All stu & ents & & & & Bo & bys & & & Gi & irls & \\
\hline & & 0 day & 1-2 days & $\begin{array}{c}3 \text { days } \\
\text { or more }\end{array}$ & $\begin{array}{r}3 d \\
\text { or } m \\
0 d\end{array}$ & $\begin{array}{l}\text { ays } \\
\text { ore - } \\
\text { lay }\end{array}$ & 0 day & 1-2 days & $\begin{array}{c}3 \text { days } \\
\text { or more }\end{array}$ & $\begin{array}{l}3 \text { days - } \\
0 \text { day }\end{array}$ & 0 day & 1-2 days & $\begin{array}{c}3 \text { days } \\
\text { or more }\end{array}$ & $\begin{array}{c}3 \text { days } \\
\text { or more - } \\
0 \text { day }\end{array}$ \\
\hline & & Mean S.E. & Mean S.E. & Mean S.E. & Dif. & S.E. & Mean S.E. & Mean S.E. & Mean S.E. & Dif. S.E. & Mean S.E. & Mean S.E. & Mean S.E. & Dif. $\quad$ S.E. \\
\hline & Australia & & $\mathrm{m}$ & $\mathrm{m}$ & $\mathrm{m}$ & $\mathrm{m}$ & $\mathrm{m}$ & $\mathrm{m}$ & $\mathrm{m}$ & $\mathrm{m}$ & $\mathrm{m}$ & $\mathrm{m}$ & $\mathrm{m}$ & $\mathrm{m}$ \\
\hline & Austria & $7.13(0.11)$ & $7.41(0.06)$ & $7.62(0.04)$ & 0.48 & $(0.1)$ & $7.82(0.16)$ & $7.76(0.09)$ & $8.05(0.04)$ & $0.23(0.16)$ & $6.38(0.15)$ & $7.11(0.08)$ & $7.17(0.07)$ & $\mathbf{0 . 8 0}(0.15)$ \\
\hline & Belgium (excl. Flemish) & $7.04(0.11)$ & $7.49(0.07)$ & $7.60(0.06)$ & 0.57 & $(0.1)$ & $7.50(0.16)$ & $7.84(0.09)$ & $7.82(0.07)$ & $0.31(0.18)$ & $6.66(0.16)$ & $7.17(0.10)$ & $7.37(0.07)$ & $0.71(0.16)$ \\
\hline & Canada & & & $\mathrm{m}$ & $\mathrm{m}$ & $\mathrm{m}$ & $\mathrm{m}$ & $\mathrm{m}$ & $\mathrm{m}$ & $\mathrm{m}$ & $\mathrm{m}$ & $\mathrm{m}$ & $\mathrm{m}$ & $\mathrm{m}$ \\
\hline & Chile & $7.03(0.11)$ & $7.30(0.07)$ & $7.47(0.04)$ & 0.45 & $(0.1)$ & $6.97(0.14)$ & $7.59(0.09)$ & $7.70(0.05)$ & $\mathbf{0 . 7 3}(0.15)$ & $7.07(0.15)$ & $7.06(0.10)$ & $7.21(0.07)$ & $0.14(0.18)$ \\
\hline & Czech Rep & $6.90(0.14)$ & $6.97(0.07)$ & $7.10(0.04)$ & 0.21 & $(0.1)$ & $7.28(0.19)$ & $7.30(0.07)$ & $7.42(0.05)$ & $0.14(0.19)$ & $6.26(0.27)$ & $6.55(0.10)$ & $6.81(0.05)$ & $\mathbf{0 . 5 5}(0.26)$ \\
\hline & Denm & $\mathrm{m} \quad \mathrm{m}$ & $\mathrm{m} \quad \mathrm{m}$ & $\mathrm{m} \quad \mathrm{m}$ & $\mathrm{m}$ & $\mathrm{m}$ & $\mathrm{m} \quad \mathrm{m}$ & $\mathrm{m} \quad \mathrm{m}$ & $\mathrm{m} \quad \mathrm{m}$ & $\mathrm{m} \quad \mathrm{m}$ & $\mathrm{m} \quad \mathrm{m}$ & $\mathrm{m} \quad \mathrm{m}$ & $\mathrm{m} \quad \mathrm{m}$ & $\mathrm{m} \quad \mathrm{m}$ \\
\hline & Estonia & $6.99(0.13)$ & $.51(0.06)$ & $7.58(0.04)$ & 0.59 & $(0.1)$ & $7.09(0.18)$ & $7.70(0.08)$ & $7.85(0.06)$ & $\mathbf{0 . 7 6}(0.20)$ & $6.89(0.18)$ & $7.30(0.09)$ & $7.31(0.06)$ & $\mathbf{0 . 4 3}(0.20)$ \\
\hline & Finland & $7.23(0.10)$ & $7.66(0.06)$ & $8.00(0.03)$ & 0.77 & $(0.1)$ & $7.62(0.15)$ & $8.15(0.07)$ & $8.35(0.04)$ & $\mathbf{0 . 7 3}(0.14)$ & $6.56(0.20)$ & $7.14(0.10)$ & $7.64(0.04)$ & $\mathbf{1 . 0 9}(0.21)$ \\
\hline & France & $7.42(0.08)$ & $7.63(0.05)$ & $7.69(0.03)$ & 0.28 & $(0.1)$ & $7.48(0.13)$ & $7.81(0.07)$ & $7.94(0.05)$ & $\mathbf{0 . 4 6}(0.13)$ & $7.37(0.11)$ & $7.48(0.07)$ & $7.43(0.05)$ & $0.07(0.12)$ \\
\hline & Gern & $6.99(0.17)$ & $7.14(0.07)$ & $7.40(0.04)$ & 0.40 & $(0.2)$ & $7.47(0.20)$ & $7.50(0.10)$ & $7.80(0.05)$ & $0.33(0.20)$ & $6.40(0.24)$ & $6.86(0.09)$ & $7.01(0.05)$ & 0.62 \\
\hline & Gree & $6.51(0.10)$ & $6.88(0.06)$ & $7.01(0.04)$ & 0.50 & $(0.1)$ & $7.00(0.14)$ & $7.18(0.08)$ & 7.28 & $0.28(0.15)$ & $6.10(0.14)$ & $6.62(0.09)$ & $6.69(0.07)$ & 0.59 \\
\hline & Hung & $6.83(0.13)$ & $7.11(0.08)$ & $7.22(0.04)$ & 0.38 & $(0.1)$ & $7.12(0.18)$ & $7.49(0.11)$ & $7.61(0.06)$ & $\mathbf{0 . 4 9}(0.19)$ & $6.53(0.21)$ & $6.76(0.11)$ & $6.82(0.06)$ & $0.28(0.21)$ \\
\hline & Icela & $6.74(0.19)$ & $7.55(0.10)$ & $8.00(0.04)$ & 1.26 & $(0.2)$ & $7.42(0.26)$ & $8.05(0.12)$ & $8.48(0.05)$ & $\mathbf{1 . 0 6}(0.26)$ & $6.12(0.25)$ & $7.09(0.14)$ & $7.57(0.07)$ & $1.45(0.26)$ \\
\hline & Irela & $6.58(0.10)$ & $7.36(0.06)$ & $7.38(0.04)$ & 0.80 & $(0.1)$ & $7.08(0.12)$ & $7.59(0.07)$ & $7.63(0.05)$ & $\mathbf{0 . 5 5}(0.13)$ & $6.17(0.16)$ & $7.19(0.08)$ & $7.07(0.06)$ & 0.91 \\
\hline & Israel & & $\mathrm{m}$ & $\mathrm{m}$ & $\mathrm{m}$ & $\mathrm{m}$ & $\mathrm{m}$ & $\mathrm{m}$ & $\mathrm{m}$ & $\mathrm{m}$ & $\mathrm{m}$ & $\mathrm{m}$ & $\mathrm{m}$ & $\mathrm{m}$ \\
\hline & Italy & & & $\mathrm{m}$ & $\mathrm{m}$ & $\mathrm{m}$ & $\mathrm{m}$ & $\mathrm{m}$ & $\mathrm{m}$ & $\mathrm{m}$ & $\mathrm{m}$ & $\mathrm{m}$ & $\mathrm{m}$ & $\mathrm{m}$ \\
\hline & Japan & $6.57(0.05)$ & $6.76(0.08)$ & $6.92(0.04)$ & 0.35 & $(0.1)$ & $6.45(0.09)$ & $6.63(0.11)$ & $6.88(0.06)$ & $\mathbf{0 . 4 3}(0.10)$ & $6.67(0.07)$ & $6.87(0.11)$ & $6.97(0.06)$ & 0.31 \\
\hline & Kor & $5.85(0.07)$ & $6.43(0.07)$ & $6.52(0.05)$ & 0.67 & $(0.1)$ & $5.99(0.14)$ & $6.63(0.11)$ & $6.70(0.06)$ & $\mathbf{0 . 7 1}(0.15)$ & $5.77(0.09)$ & $6.25(0.07)$ & $6.24(0.08)$ & 0.46 \\
\hline & Latv & $6.88(0.12)$ & $7.27(0.07)$ & $7.45(0.04)$ & 0.57 & $(0.1)$ & $6.99(0.16)$ & $7.32(0.09)$ & $7.56(0.06)$ & $\mathbf{0 . 5 7}(0.16)$ & $6.72(0.16)$ & $7.22(0.09)$ & $7.35(0.05)$ & 0.63 \\
\hline & Lu & $6.96(0.10)$ & $7.31(0.06)$ & $7.49(0.04)$ & 0.53 & $(0.1)$ & $7.26(0.15)$ & $7.74(0.08)$ & $7.88(0.05)$ & $\mathbf{0 . 6 2}(0.16)$ & $6.72(0.12)$ & $6.98(0.08)$ & $7.04(0.05)$ & 0.32 \\
\hline & & $7.95(0.10)$ & $8.26(0.05)$ & $8.35(0.03)$ & 0.40 & $(0.1)$ & $8.20(0.14)$ & $8.29(0.07)$ & 8.4 & 0.20 & 7.76 & $8.22(0.07)$ & 8.30 & 0.53 \\
\hline & Neth & $7.56(0.10)$ & $7.91(0.06)$ & $7.83(0.03)$ & 0.27 & $(0.1)$ & $7.97(0.14)$ & $8.07(0.09)$ & $8.13(0.04)$ & $0.16(0.14)$ & $7.17(0.15)$ & $7.76(0.07)$ & $7.55(0.04)$ & 0.38 \\
\hline & New & & $\mathrm{m}$ & $\mathrm{m}$ & $\mathrm{m}$ & $\mathrm{m}$ & $\mathrm{m}$ & $\mathrm{m}$ & $\mathrm{m}$ & $\mathrm{m}$ & $\mathrm{m}$ & $\mathrm{m}$ & $\mathrm{m}$ & $\mathrm{m}$ \\
\hline & Norway & $\mathrm{m}$ & & $\mathrm{m}$ & $\mathrm{m}$ & $\mathrm{m}$ & $\mathrm{m}$ & $\mathrm{m}$ & $\mathrm{m}$ & $\mathrm{m}$ & $\mathrm{m}$ & $\mathrm{m}$ & $\mathrm{m}$ & $\mathrm{m}$ \\
\hline & & $02(0.15)$ & $.02(0.09)$ & $7.24(0.04)$ & .22 & $(0.1)$ & $.37(0.19)$ & $.48(0.10)$ & $.56(0.05)$ & 0.19 & $.52(0.21)$ & 13) & 06) & 21) \\
\hline & Po & $7.11(0.08)$ & $7.37(0.05)$ & $7.43(0.04)$ & 0.32 & $(0.1)$ & $7.34(0.11)$ & $7.68(0.07)$ & $7.66(0.05)$ & $\mathbf{0 . 3 2}(0.10)$ & $6.91(0.11)$ & $7.12(0.08)$ & $7.16(0.06)$ & 0.25 \\
\hline & Slo & $4(0.12)$ & $7.38(0.06)$ & $7.54(0.04)$ & 0.40 & $(0.1)$ & $7.30(0.17)$ & $7.72(0.09)$ & $7.84(0.06)$ & $\mathbf{0 . 5 4}(0.18)$ & $6.89(0.16)$ & $7.06(0.10)$ & $7.24(0.06)$ & 0.35 \\
\hline & Slov & $4(0.15)$ & $7.04(0.06)$ & $7.26(0.05)$ & 0.42 & $(0.2)$ & 7.23 & 7.46 & 7.73 & 0.50 & 6.37 & 6.67 & 6.75 & 0.38 \\
\hline & Spai & 7.16 & $7.46(0.06)$ & 7.49 & 0.33 & $(0.1)$ & 7.41 & 7.56 & 7.68 & 0.27 & 6.88 & $7.37(0.07)$ & $7.28(0.06)$ & 0.40 \\
\hline & Swede & & $\mathrm{m}$ & $\mathrm{m}$ & $\mathrm{m}$ & $\mathrm{m}$ & $\mathrm{m}$ & $\mathrm{m}$ & $\mathrm{m}$ & $\mathrm{m}$ & $\mathrm{m}$ & $\mathrm{m}$ & $\mathrm{m}$ & $\mathrm{m}$ \\
\hline & & $7.51(0.14)$ & $7.55(0.06)$ & $7.80(0.04)$ & 0.29 & (0.1) & $7.85(0.22)$ & $7.94(0.08)$ & 8.09 (0.05) & $0.24(0.23)$ & $7.13(0.16)$ & 7.19 (0.09) & $7.47(0.05)$ & 0.35 \\
\hline & Tu & $70(0.12)$ & $6.16(0.09)$ & $6.24(0.08)$ & 0.54 & $(0.2)$ & $5.93(0.17)$ & $6.43(0.11)$ & & 0.63 & 5.52 & 5.9 & 5.90 & 0.38 \\
\hline & Uni & $6.47(0.12)$ & $6.96(0.06)$ & $7.08(0.05)$ & 0.62 & $(0.1)$ & $6.88(0.16)$ & $7.29(0.08)$ & $(0.06)$ & $\mathbf{0 . 5 1}(0.16)$ & $6.12(0.14)$ & 6.69 & 6.73 & 0.62 \\
\hline & United States & $6.88(0.09)$ & $7.09(0.08)$ & $7.50(0.04)$ & 0.62 & $(0.1)$ & $7.13(0.16)$ & $7.38(0.12)$ & $7.78(0.06)$ & $\mathbf{0 . 6 4}(0.17)$ & $6.69(0.12)$ & $6.91(0.11)$ & $7.17(0.05)$ & $0.48(0.14)$ \\
\hline & OECD average & $\mid 6.93(0.02)$ & $7.26(0.01)$ & $|7.42(0.01)|$ & 0.49 & $(0.0)$ & $\mid 7.23(0.03)$ & $7.54(0.02)$ & $|7.69(0.01)|$ & $|\mathbf{0 . 4 7}(0.03)|$ & $6.60(0.03)$ & $7.01(0.02)$ & $|7.12(0.01)|$ & $0.51(0.03)$ \\
\hline & Albania & & & & $\mathrm{m}$ & & 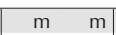 & & $\mathrm{m}$ & & . & & 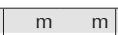 & $m$ \\
\hline & Alg & $\mathrm{m}$ & $\mathrm{m}$ & $\mathrm{m}$ & $\mathrm{m}$ & $\mathrm{m}$ & $\mathrm{m}$ & $\mathrm{m}$ & $\mathrm{m}$ & $\mathrm{m}$ & $\mathrm{m}$ & $\mathrm{m}$ & $\mathrm{m}$ & $\mathrm{m}$ \\
\hline & Bra & $.24(0.06)$ & $7.65(0.04)$ & $7.68(0.04)$ & 0.44 & (0.1) & $7.31(0.09)$ & $7.73(0.06)$ & $7.87(0.05)$ & $\mathbf{0 . 5 6}(0.09)$ & $7.20(0.07)$ & $7.57(0.06)$ & $7.47(0.06)$ & 0.27 \\
\hline & B-S- & $38(0.09)$ & $6.80(0.06)$ & $7.01(0.04)$ & 0.63 & $(0.1)$ & $6.45(0.11)$ & $6.77(0.07)$ & $7.07(0.05)$ & $\mathbf{0 . 6 2}(0.11)$ & $(0.11)$ & 6.83 & $6.93(0.06)$ & 0.63 \\
\hline & Bul & $.07(0.11)$ & $7.28(0.07)$ & $7.53(0.05)$ & 0.46 & $(0.1)$ & $7.31(0.17)$ & $7.43(0.09)$ & $7.77(0.07)$ & $\mathbf{0 . 4 6}(0.19)$ & $6.81(0.17)$ & $7.11(0.12)$ & $7.28(0.06)$ & $\mathbf{0 . 4 7}(0.19)$ \\
\hline & & & $\mathrm{m}$ & $\mathrm{m}$ & $\mathrm{m}$ & $\mathrm{m}$ & $\mathrm{m} \quad \mathrm{m}$ & $\mathrm{m} \quad \mathrm{m}$ & $\mathrm{m} \quad \mathrm{m}$ & $\mathrm{m} \quad \mathrm{m}$ & $\mathrm{m} \quad \mathrm{m}$ & $\mathrm{m} \quad \mathrm{m}$ & $\mathrm{m} \quad \mathrm{m}$ & $\mathrm{m}$ \\
\hline & $\mathrm{Co}$ & $96(0.07)$ & $7.86(0.06)$ & $7.87(0.05)$ & -0.09 & $(0.1)$ & $8.26(0.09)$ & $8.06(0.07)$ & $8.01(0.06)$ & $-0.25(0.11)$ & $7.73(0.08)$ & $7.69(0.08)$ & $7.73(0.07)$ & -0.01 \\
\hline & & $(0.09)$ & $8.29(0.04)$ & $8.26(0.05)$ & 0.46 & $(0.1)$ & $(0.14)$ & $8.48(0.06)$ & $8.36(0.06)$ & 0.29 & & 8.12 & 8.14 & 0.50 \\
\hline & & $(0.10)$ & $7.86(0.06)$ & $(0.05)$ & 0.43 & $(0.1)$ & $7.66(0.15)$ & $8.27(0.07)$ & $9(0.06)$ & $\mathbf{0 . 6 3}(0.15)$ & $7.47(0.13)$ & $7.54(0.08)$ & $7.69(0.06)$ & 0.22 \\
\hline & Сур & $76(0.12)$ & $7.10(0.06)$ & $7.10(0.04)$ & 0.34 & $(0.1)$ & $6.82(0.18)$ & $7.29(0.08)$ & $7.34(0.06)$ & $\mathbf{0 . 5 1}(0.19)$ & $6.70(0.14)$ & $6.96(0.08)$ & $6.86(0.06)$ & $0.16(0.16)$ \\
\hline & & $8.25(0.11)$ & $8.47(0.07)$ & $8.56(0.05)$ & 0.32 & $(0.1)$ & $8.21(0.22)$ & $8.50(0.11)$ & $8.64(0.08)$ & $0.43(0.23)$ & $8.27(0.13)$ & $8.45(0.09)$ & $8.48(0.07)$ & $0.21(0.14)$ \\
\hline & FYR & & $m$ & $m$ & $\mathrm{~m}$ & & $\mathrm{~m}$ & $\mathrm{~m}$ & $\mathrm{~m}$ & $\mathrm{~m}$ & $\mathrm{~m}$ & $\mathrm{~m}$ & $m$ & $\mathrm{~m}$ \\
\hline & & & & & $\mathrm{m}$ & $\mathrm{m}$ & & & & & & & & \\
\hline & Hong & $6.19(0.09)$ & $6.50(0.06)$ & $6.56(0.05)$ & 0.38 & $(0.1)$ & $6.09(0.15)$ & $6.50(0.10)$ & $6.63(0.06)$ & $\mathbf{0 . 5 4}(0.16)$ & $6.26(0.09)$ & $6.49(0.06)$ & $6.49(0.06)$ & $\mathbf{0 . 2 3}(0.09)$ \\
\hline & Indor & & $\mathrm{m}$ & $\mathrm{m}$ & $\mathrm{m}$ & $\mathrm{m}$ & $\mathrm{m}$ & $\mathrm{m}$ & $\mathrm{m}$ & $\mathrm{m}$ & $\mathrm{m}$ & $\mathrm{m}$ & $\mathrm{m}$ & $\mathrm{m}$ \\
\hline & Jord & & $m$ & & $\mathrm{~m}$ & $\mathrm{~m}$ & 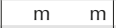 & $\mathrm{m}$ & $m$ & $\mathrm{~m}$ & $\mathrm{~m}$ & $\mathrm{~m}$ & $\mathrm{~m}$ & $\mathrm{~m}$ \\
\hline & & & $\mathrm{m}$ & & $\mathrm{m}$ & & & & & & & & & $\mathrm{m}$ \\
\hline & & $\mathrm{m}$ & $\mathrm{m}$ & $\mathrm{m}$ & $\mathrm{m}$ & $\mathrm{m}$ & $\mathrm{m}$ & $\mathrm{m}$ & $\mathrm{m}$ & $\mathrm{m}$ & $\mathrm{m}$ & $\mathrm{m}$ & $\mathrm{m}$ & $\mathrm{m}$ \\
\hline & & $3(0.13)$ & $7.77(0.06)$ & $7.93(0.04)$ & 0.29 & $(0.1)$ & $7.96(0.15)$ & 08) & $8.17(0.04)$ & 0.21 & 7.22 & $7.47(0.09)$ & 7.69 & 48 \\
\hline & $M$ & $.13(0.08)$ & $6.62(0.05)$ & $6.73(0.04)$ & 0.61 & $(0.1)$ & $6.08(0.13)$ & $6.58(0.10)$ & $6.74(0.06)$ & $\mathbf{0 . 6 6}(0.15)$ & $6.16(0.11)$ & $6.65(0.07)$ & $6.73(0.06)$ & 0.57 \\
\hline & & & & & $\mathrm{m}$ & & $\mathrm{m}$ & & & & & & & $\mathrm{m}$ \\
\hline & Mo & & & $\mathrm{m}$ & $\mathrm{m}$ & $\mathrm{m}$ & $\mathrm{m}$ & $\mathrm{m}$ & $\mathrm{m}$ & $\mathrm{m}$ & $\mathrm{m}$ & $\mathrm{m}$ & $\mathrm{m}$ & $\mathrm{m}$ \\
\hline & & & $.65(0.08)$ & $.80(0.04)$ & 0.42 & $(0.2)$ & $8.07(0.21)$ & $7.93(0.11)$ & $7.98(0.06)$ & $-0.09(0.22)$ & .23) & $7.40(0.12)$ & $7.60(0.06)$ & 2) \\
\hline & & & $7.52(0.06)$ & $7.58(0.04)$ & & $(0.1)$ & & $7.61(0.06)$ & & & & 7.43 & 7.51 & . \\
\hline & & $.17(0.05)$ & $7.34(0.04)$ & $7.52(0.04)$ & 0.35 & $(0.1)$ & $7.17(0.10)$ & $7.42(0.06)$ & $7.65(0.05)$ & $\mathbf{0 . 4 8}(0.11)$ & $7.17(0.06)$ & $7.28(0.06)$ & $7.39(0.06)$ & 0.22 \\
\hline & & & $\mathrm{m}$ & $\mathrm{m}$ & $\mathrm{m}$ & $\mathrm{m}$ & & & $\mathrm{m}$ & $\mathrm{m}$ & & $\mathrm{m}$ & $\mathrm{m}$ & $\mathrm{m}$ \\
\hline & & $63(0.16)$ & $7.62(0.07)$ & $7.81(0.05)$ & 0.18 & $(0.2)$ & $8.05(0.18)$ & $7.79(0.11)$ & $7.95(0.06)$ & $-0.10(0.19)$ & $7.20(0.25)$ & $7.48(0.08)$ & $7.68(0.07)$ & .48 \\
\hline & & & & & $\mathrm{m}$ & & & & & & & $\mathrm{m}$ & $\mathrm{m}$ & $\mathrm{m}$ \\
\hline & & $3(0.07)$ & $6.54(0.05)$ & $6.71(0.04)$ & 0.47 & $(0.1)$ & $6.17(0.10)$ & $6.72(0.07)$ & $6.85(0.05)$ & $\mathbf{0 . 6 7}(0.10)$ & $6.27(0.08)$ & $6.42(0.06)$ & $6.52(0.05)$ & $\mathbf{0 . 2 5}(0.09)$ \\
\hline & Tha & $7.24(0.16)$ & $7.66(0.05)$ & $7.78(0.04)$ & 0.54 & $(0.2)$ & $7.27(0.24)$ & $7.56(0.09)$ & $7.88(0.06)$ & $\mathbf{0 . 6 1}(0.23)$ & $7.22(0.21)$ & $7.74(0.07)$ & $7.71(0.05)$ & $\mathbf{0 . 4 9}(0.22)$ \\
\hline & & & $\mathrm{m}$ & $\mathrm{m}$ & $\mathrm{m}$ & $\mathrm{m}$ & $\mathrm{m}$ & & $\mathrm{m}$ & $\mathrm{m}$ & & $\mathrm{m}$ & & $\mathrm{m}$ \\
\hline & & .09) & $6.97(0.08)$ & 7.02 & .43 & $(0.1)$ & & & 08) & & 12) & 6.89 & 08) & 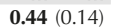 \\
\hline & & $18(0.07)$ & $7.31(0.05)$ & $7.38(0.05)$ & 0.19 & $(0.1)$ & $7.36(0.09)$ & $7.42(0.09)$ & $7.53(0.06)$ & $0.17(0.09)$ & $7.08(0.08)$ & $7.22(0.07)$ & $7.20(0.06)$ & $0.12(0.11)$ \\
\hline & Urug & $7.24(0.09)$ & $7.59(0.06)$ & $7.87(0.03)$ & 0.63 & $(0.1)$ & $7.41(0.15)$ & $7.78(0.10)$ & $8.11(0.05)$ & $\mathbf{0 . 6 9}(0.16)$ & $7.14(0.12)$ & $7.46(0.08)$ & $7.63(0.06)$ & $\mathbf{0 . 4 9}(0.13)$ \\
\hline & Viet Nam & $\mathrm{m}$ & $\mathrm{m}$ & $\mathrm{m}$ & $\mathrm{m}$ & $\mathrm{m}$ & $\mathrm{m}$ & $\mathrm{m}$ & $\mathrm{m}$ & $\mathrm{m}$ & $\mathrm{m}$ & $\mathrm{m}$ & $\mathrm{m}$ & $\mathrm{m}$ \\
\hline & & & & & III & & & & & & & & & III \\
\hline & & & & & $\mathrm{m}$ & & & & III & Int & $\mathrm{m}$ & $\mathrm{m}$ & $\mathrm{m}$ & $\mathrm{m}$ \\
\hline & Malaysia** & $6.63(0.13)$ & $6.97(0.06)$ & $7.14(0.04)$ & 0.51 & $(0.1)$ & $6.69(0.19)$ & $7.08(0.10)$ & $7.18(0.05)$ & $\mathbf{0 . 4 8}(0.19)$ & $6.58(0.15)$ & $6.86(0.08)$ & $7.11(0.06)$ & $0.53(0$. \\
\hline
\end{tabular}

Note: Values that are statistically significant are indicated in bold (see Annex A3).

* See note at the beginning of this Annex.

** Coverage is too small to ensure comparability (see Annex A4).

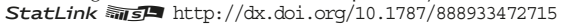


Number of days per week students engage in vigorous physical activity (activity that makes students sweat and breathe hard)

\begin{tabular}{|c|c|c|c|c|c|c|c|c|c|c|c|c|c|}
\hline & \multicolumn{12}{|c|}{ Average life satisfaction by: } \\
\hline & & \multicolumn{12}{|c|}{$\begin{array}{c}\text { Number of days per week students engage in vigorous physical activity (activity that makes students sweat and breathe hard) } \\
\text { for at least } 20 \text { minutes per day }\end{array}$} \\
\hline & & & All stu & udents & & & & oys & & & Gi & irls & \\
\hline & & 0 day & 1-2 days & $\begin{array}{l}3 \text { days } \\
\text { or more }\end{array}$ & \begin{tabular}{|c|}
3 days \\
or more - \\
0 day
\end{tabular} & 0 day & 1-2 days & $\begin{array}{l}3 \text { days } \\
\text { or more }\end{array}$ & $\begin{array}{l}3 \text { days - } \\
0 \text { day }\end{array}$ & 0 day & 1-2 days & $\begin{array}{l}3 \text { days } \\
\text { or more }\end{array}$ & $\begin{array}{c}3 \text { days } \\
\text { or more - } \\
0 \text { day }\end{array}$ \\
\hline & & Mean S.E. & Mean S.E. & Mean S.E. & Dif. S.E. & Mean S.E. & Mean S.E. & Mean S.E. & Dif. S.E. & Mean S.E. & Mean S.E. & Mean S.E. & Dif. S.E. \\
\hline & Australia & & & $\mathrm{m}$ & & $\mathrm{m}$ & $\mathrm{m}$ & $\mathrm{m}$ & $\mathrm{m}$ & $\mathrm{m}$ & $\mathrm{m}$ & $\mathrm{m}$ & $\mathrm{m}$ \\
\hline & Austria & $7.15(0.08)$ & $7.49(0.05)$ & $7.74(0.04)$ & $\mathbf{0 . 5 8}(0.08)$ & $7.79(0.11)$ & $7.91(0.06)$ & $8.05(0.06)$ & $\mathbf{0 . 2 6}(0.11)$ & $6.78(0.10)$ & $7.17(0.07)$ & $7.22(0.07)$ & $\mathbf{0 . 4 4}(0.11)$ \\
\hline & Belgium (excl. Flemish) & $7.09(0.10)$ & $7.51(0.06)$ & $7.68(0.05)$ & $\mathbf{0 . 5 9}(0.12)$ & $7.20(0.15)$ & $7.83(0.08)$ & $7.90(0.06)$ & $\mathbf{0 . 7 0}(0.16)$ & $7.04(0.13)$ & $7.24(0.09)$ & $7.33(0.09)$ & $0.29(0.16)$ \\
\hline & Canada & & $\mathrm{m}$ & $\mathrm{m}$ & $\mathrm{m}$ & $\mathrm{m}$ & $\mathrm{m}$ & $\mathrm{m}$ & $\mathrm{m}$ & $\mathrm{m}$ & $\mathrm{m}$ & $\mathrm{m}$ & $\mathrm{m}$ \\
\hline & Chile & $6.94(0.06)$ & $7.34(0.05)$ & $7.62(0.06)$ & $\mathbf{0 . 6 8}(0.08)$ & $6.96(0.11)$ & $7.45(0.09)$ & $7.83(0.06)$ & $\mathbf{0 . 8 8}(0.13)$ & $6.93(0.08)$ & $7.24(0.08)$ & $7.21(0.11)$ & $\mathbf{0 . 2 8}(0.12)$ \\
\hline & Czech Rep & $6.77(0.11)$ & $6.88(0.06)$ & $7.22(0.04)$ & $\mathbf{0 . 4 4}(0.12)$ & $7.10(0.16)$ & $7.25(0.09)$ & $7.49(0.06)$ & $\mathbf{0 . 3 9}(0.17)$ & $6.48(0.14)$ & $6.57(0.07)$ & $6.89(0.07)$ & $\mathbf{0 . 4 1}(0.14)$ \\
\hline & Denmark & & & $\mathrm{m} \quad \mathrm{m}$ & $\mathrm{m}$ & $\mathrm{m}$ & $\mathrm{m}$ & $\mathrm{m}$ & $\mathrm{m}$ & $\mathrm{m}$ & $\mathrm{m}$ & $\mathrm{m}$ & $\mathrm{m}$ \\
\hline & Estonia & $6.91(0.11)$ & $7.47(0.06)$ & $7.66(0.04)$ & $\mathbf{0 . 7 5}(0.13)$ & $7.07(0.16)$ & $7.65(0.07)$ & $7.89(0.06)$ & $\mathbf{0 . 8 2}(0.19)$ & $6.81(0.14)$ & $7.31(0.08)$ & $7.39(0.06)$ & $\mathbf{0 . 5 8}(0.15)$ \\
\hline & Finland & $7.38(0.08)$ & $7.71(0.05)$ & $8.12(0.03)$ & $\mathbf{0 . 7 4}(0.08)$ & $7.89(0.10)$ & $8.08(0.07)$ & $8.44(0.04)$ & $\mathbf{0 . 5 5}(0.10)$ & $6.77(0.13)$ & $7.38(0.06)$ & $7.76(0.05)$ & $\mathbf{0 . 9 8}(0.13)$ \\
\hline & France & $7.29(0.06)$ & $7.62(0.04)$ & $7.86(0.04)$ & $\mathbf{0 . 5 7}(0.07)$ & $7.44(0.10)$ & $7.83(0.06)$ & $8.01(0.06)$ & $\mathbf{0 . 5 8}(0.12)$ & $7.21(0.08)$ & $7.45(0.05)$ & $7.60(0.06)$ & 0.3 \\
\hline & Germany & $6.84(0.12)$ & $7.21(0.05)$ & $7.52(0.05)$ & $\mathbf{0 . 6 8}(0.14)$ & $7.37(0.19)$ & $7.62(0.08)$ & $7.84(0.05)$ & $\mathbf{0 . 4 7}(0.20)$ & $6.46(0.14)$ & $6.94(0.07)$ & $7.11(0.07)$ & 0.65 \\
\hline & Gre & $40(0.08)$ & $6.84(0$ & $7.13(0.04)$ & $\mathbf{0 . 7 3}(0.09)$ & $6.87(0.15)$ & $7.16(0.09)$ & & $\mathbf{0 . 4 3}(0.15)$ & & $6.59(0.09)$ & & 070 \\
\hline & & 6.57 & 7.04 & $7.35(0$ & 0.78 & $6.92(0.20)$ & 7.43 & 7.68 & 0.7 & 6.36 & 6.78 & $6.92(0.08)$ & \\
\hline & Iceland & $6.81(0.16)$ & $7.33(0.10)$ & $8.09(0.04)$ & $\mathbf{1 . 2 8}(0.16)$ & $7.50(0.21)$ & $7.83(0.14)$ & $8.50(0.05)$ & $\mathbf{1 . 0 0}(0.21)$ & $6.35(0.20)$ & $6.98(0.12)$ & \begin{tabular}{|l|}
7.66 \\
$(0.06)$
\end{tabular} & 1.31 \\
\hline & Ireland & $6.49(0.10)$ & $7.15(0.06)$ & $7.60(0.04)$ & $1.11(0.11)$ & $6.82(0.16)$ & $7.38(0.08)$ & $7.74(0.05)$ & $0.92(0.17)$ & $6.36(0.12)$ & $6.99(0.07)$ & $7.37(0.06)$ & 1.01 \\
\hline & Israel & & $\mathrm{m}$ & & $\mathrm{m}$ & $\mathrm{m} \quad \mathrm{m}$ & $\mathrm{m}$ & $\mathrm{m}$ & $\mathrm{m}$ & $\mathrm{m}$ & $\mathrm{m}$ & $\mathrm{m}$ & $\mathrm{m}$ \\
\hline & Italy & & & $\mathrm{m}$ & $\mathrm{m}$ & $\mathrm{m}$ & $\mathrm{m}$ & $\mathrm{m}$ & $\mathrm{m}$ & $\mathrm{m}$ & $\mathrm{m}$ & $\mathrm{m}$ & $\mathrm{m}$ \\
\hline & & .05) & $79(0.07)$ & .04) & $26(0.06)$ & $51(0.09)$ & $.64(0.10)$ & $.87(0.06)$ & $.36(0.10)$ & $74(0.06)$ & $6.89(0.08)$ & $.00(0.07)$ & 09) \\
\hline & Ко & $5.85(0.07)$ & $6.45(0.06)$ & $6.66(0.06)$ & $\mathbf{0 . 8 1}(0.08)$ & $5.88(0.13)$ & $6.63(0.08)$ & $6.77(0.07)$ & $\mathbf{0 . 8 9}(0.14)$ & $5.84(0.07)$ & $6.27(0.07)$ & $6.39(0.10)$ & 0. \\
\hline & Latvia & $04(0.08)$ & $7.21(0$ & $7.52(0.04)$ & $\mathbf{0 . 4 8}(0.09)$ & $7.06(0.15)$ & $7.23(0.09)$ & $7.59(0.05)$ & $\mathbf{0 . 5 3}(0.15)$ & & $7.20(0.08)$ & $7.43(0.06)$ & \\
\hline & & & 7.31 & .05) & 066 & 7.1 & 7.77 & 7.9 & & & 6.98 & & \\
\hline & & 77) & 8.23 & $8.37(0$ & $0.27(0$ & $8.25(0.11)$ & $8.26(0.06)$ & $8.41(0.04)$ & $0.17(0.12)$ & 8.01 & 8.20 & $8.31(0.06)$ & 0.30 \\
\hline & $\mathrm{Ne}$ & $7.61(0.05)$ & $7.71(0.04)$ & $7.97(0.03)$ & $\mathbf{0 . 3 6}(0.05)$ & $7.86(0.10)$ & $8.00(0.06)$ & $8.21(0.04)$ & $\mathbf{0 . 3 5}(0.10)$ & $7.44(0.07)$ & $7.49(0.06)$ & $7.66(0.04)$ & 0.22 \\
\hline & $\mathrm{Nev}$ & $\mathrm{m}$ & $\mathrm{m}$ & & $\mathrm{m}$ & & $\mathrm{m}$ & $\mathrm{m}$ & $\mathrm{m}$ & $\mathrm{m}$ & $\mathrm{m}$ & $\mathrm{m}$ & $\mathrm{m}$ \\
\hline & Nor & & & & & $\mathrm{m}$ & & $\mathrm{m}$ & & $\mathrm{m}$ & $\mathrm{m}$ & $\mathrm{m}$ & $\mathrm{m}$ \\
\hline & Pola & $79(0.11)$ & $7.03(0.07)$ & $7.32(0.04)$ & $\mathbf{0 . 5 3}(0.12)$ & $7.20(0.18)$ & $7.31(0.10)$ & $7.64(0.05)$ & $\mathbf{0 . 4 4}(0.20)$ & $6.52(0.13)$ & $6.83(0.10)$ & $6.90(0.07)$ & 0.38 \\
\hline & & $05(0.05)$ & $7.38(0.05)$ & $7.51(0.04)$ & $\mathbf{0 . 4 6}(0.05)$ & $7.33(0.11)$ & $7.59(0.07)$ & $7.71(0.05)$ & $\mathbf{0 . 3 8}(0.10)$ & $6.89(0.07)$ & $7.21(0.07)$ & & \\
\hline & Slo & $94(0.10)$ & $7.37(0.05)$ & $7.65(0.04)$ & $\mathbf{0 . 7 1}(0.10)$ & $7.13(0.14)$ & $7.68(0.08)$ & $7.89(0.05)$ & 0.76 & $6.80(0.13)$ & $7.14(0.08)$ & $7.32(0.07)$ & 0.52 \\
\hline & Slo & 12) & 7.08 & $7.35(0.05)$ & $\mathbf{0 . 7 8}(0.12)$ & $6.80(0.20)$ & 7.60 & $+(0.05)$ & 0.9 & & 6.71 & $6.79(0.09)$ & \\
\hline & Spa & $06(C$ & 7.37 & $7.64(0.04)$ & $\mathbf{0 . 5 8}(0.08)$ & $7.14(0.11)$ & $7.48(0.07)$ & $7.81(0.05)$ & $\mathbf{0 . 6 7}(0.11)$ & $7.01(0.09)$ & $7.29(0.05)$ & $7.38(0.07)$ & 0.38 \\
\hline & Sw & & $\mathrm{m}$ & $\mathrm{m}$ & $\mathrm{m}$ & $\mathrm{m}$ & $\mathrm{m}$ & $\mathrm{m}$ & $\mathrm{m}$ & $\mathrm{m}$ & $\mathrm{m}$ & $\mathrm{m}$ & $\mathrm{m}$ \\
\hline & Sw & $.34(0.10)$ & $7.59(0.05)$ & $7.87(0.05)$ & $\mathbf{0 . 5 4}(0.11)$ & $7.75(0.18)$ & $7.95(0.06)$ & $8.11(0.06)$ & $\mathbf{0 . 3 6}(0.18)$ & $7.05(0.11)$ & $7.32(0.07)$ & $7.51(0.07)$ & 0.46 \\
\hline & Turke & & $6.19(0.08)$ & $6.31(0.08)$ & $\mathbf{0 . 6 3}(0.13)$ & $6.06(0.16)$ & $6.33(0.10)$ & $6.59(0.09)$ & $\mathbf{0 . 5 3}(0.18)$ & $5.52(0.16)$ & $6.05(0.11)$ & $5.83(0.11)$ & 0.3 \\
\hline & United I & $3(0.09)$ & $6.95(0.05)$ & $7.29(0.05)$ & $\mathbf{0 . 8 5}(0.11)$ & $6.85(0.12)$ & $7.14(0$ & $7.55(0.06)$ & $\mathbf{0 . 7 0}(0.15)$ & $6.21(0.11)$ & $6.81(0.07)$ & $6.82(0.08)$ & 0.60 \\
\hline & United & $6.77(0.08)$ & $7.03(0.08)$ & $7.64(0.04)$ & $\mathbf{0 . 8 6}(0.09)$ & $7.04(0.13)$ & $7.26(0.11)$ & $7.86(0.05)$ & $\mathbf{0 . 8 1}(0.14)$ & $6.64(0.10)$ & $6.89(0.11)$ & $7.33(0.05)$ & $0.70(0.11)$ \\
\hline & OECD av & $6.87(0.02)$ & $7.23(0.01)$ & $7.52(0.01)$ & $\mathbf{0 . 6 6}(0.02)$ & $7.15(0.03)$ & $7.49(0.02)$ & $7.75(0.01)$ & $|0.61(0.03)|$ & $6.69(0.02)$ & $7.03(0.02)$ & $7.19(0.01)$ & 0.51 ( \\
\hline & Alban & & & & & $\mathrm{m}$ & & $\mathrm{m}$ & $n$ & $\mathrm{~m}$ & $n$ & $\mathrm{~m}$ & $\mathrm{~m}$ \\
\hline & & & & & & $\mathrm{m}$ & & $\mathrm{m}$ & $\mathrm{m}$ & $\mathrm{m}$ & $\mathrm{m}$ & $\mathrm{m}$ & $\mathrm{m}$ \\
\hline & Brazi & .04) & $71(0.04)$ & $.04)$ & $41(0.05)$ & $39(0.09)$ & $7.79(0.07)$ & $.87(0.04)$ & $\mathbf{0 . 4 8}(0.10)$ & $7.27(0.05)$ & $7.63(0.06)$ & $7.47(0.07)$ & $\mathbf{0 . 2 0}(0.08)$ \\
\hline & B-S-J-G (China) & $6.28(0.09)$ & $6.80(0.05)$ & $7.01(0.04)$ & $\mathbf{0 . 7 3}(0.08)$ & $6.25(0.14)$ & $6.79(0.06)$ & $7.05(0.05)$ & $\mathbf{0 . 8 0}(0.15)$ & $6.31(0.10)$ & $6.80(0.08)$ & $6.96(0.07)$ & $\mathbf{0 . 6 5}(0.11)$ \\
\hline & & $6.89(0.09)$ & 7.35 (0.06) & $7.64(0.05)$ & $\mathbf{0 . 7 6}(0.10)$ & $7.06(0.15)$ & $7.59(0.09)$ & $7.78(0.07)$ & $\mathbf{0 . 7 2}(0.16)$ & $6.78(0.12)$ & $7.13(0.08)$ & $7.45(0.07)$ & $\mathbf{0 . 6 7}(0.13)$ \\
\hline & & & & & & & & & $\mathrm{m}$ & & $\mathrm{m}$ & $\mathrm{m}$ & $\mathrm{m}$ \\
\hline & Col & $6(0.08)$ & $7.86(0.05)$ & $7.97(0.05)$ & $\mathbf{0 . 2 1}(0.09)$ & $7.98(0.12)$ & $8.11(0.05)$ & $8.08(0.07)$ & $0.10(0.13)$ & $7.64(0.09)$ & $7.67(0.07)$ & $7.82(0.08)$ & $0.18(0.12)$ \\
\hline & Costa & $7.88(0.06)$ & $8.26(0.05)$ & $8.37(0.05)$ & $\mathbf{0 . 4 9}(0.07)$ & $7.90(0.12)$ & $8.45(0.07)$ & $8.44(0.06)$ & $\mathbf{0 . 5 4}(0.13)$ & $7.88(0.06)$ & $8.09(0.07)$ & $8.23(0.07)$ & $\mathbf{0 . 3 6}(0.09)$ \\
\hline & & & 7 & 8. & 8) & $0.16)$ & 8. & & 0. & & 7.6 & $(0.07)$ & \\
\hline & & $(0.09)$ & 7.03 & 7.19 & 0.43 & $6.93(0.16)$ & 7.18 & $7.37(0.05)$ & 0.44 & 6.67 & 6.92 & $6.94(0.08)$ & 0.27 \\
\hline & Dominica & $8.30(0.11)$ & $8.46(0.06)$ & $8.60(0.05)$ & $\mathbf{0 . 3 0}(0.12)$ & $8.33(0.21)$ & $8.39(0.12)$ & $8.68(0.06)$ & $0.35(0.21)$ & $8.28(0.13)$ & $8.52(0.10)$ & $8.48(0.08)$ & $0.20(0.16)$ \\
\hline & FYRO & & & & & $\mathrm{m}$ & $\mathrm{m}$ & $\mathrm{m}$ & $\mathrm{m}$ & $\mathrm{m}$ & $\mathrm{m}$ & $\mathrm{m}$ & $\mathrm{m}$ \\
\hline & & & & & & & & & & & & & \\
\hline & Hong & $6.17(0.07)$ & $6.47(0.05)$ & $6.68(0.06)$ & $\mathbf{0 . 5 1}(0.09)$ & $6.13(0.12)$ & $6.47(0.08)$ & $6.70(0.08)$ & $\mathbf{0 . 5 7}(0.14)$ & $6.19(0.08)$ & $6.48(0.06)$ & $6.64(0.08)$ & $\mathbf{0 . 4 5}(0.11)$ \\
\hline & Indonesia & & $\mathrm{m}$ & $\mathrm{m}$ & $\mathrm{m}$ & $\mathrm{m}$ & $\mathrm{m}$ & $\mathrm{m}$ & $\mathrm{m}$ & $\mathrm{m}$ & $\mathrm{m}$ & $\mathrm{m}$ & $\mathrm{m}$ \\
\hline & & & $\mathrm{m}$ & & $\mathrm{m}$ & $\mathrm{m}$ & $\mathrm{m}$ & $\mathrm{m}$ & $\mathrm{m}$ & $\mathrm{m}$ & $\mathrm{m}$ & $\mathrm{m}$ & $\mathrm{m}$ \\
\hline & & & & & $m$ & & $m$ & & $m$ & & $n$ & & $\mathrm{~m}$ \\
\hline & & & $\mathrm{m}$ & $\mathrm{m}$ & $\mathrm{m}$ & $\mathrm{m}$ & $\mathrm{m}$ & $\mathrm{m}$ & $\mathrm{m}$ & $\mathrm{m}$ & $\mathrm{m}$ & $\mathrm{m}$ & $\mathrm{m}$ \\
\hline & & 09) & 7.82 & $7.99(0.04)$ & $\mathbf{0 . 4 9}(0.09)$ & $7.74(0.14)$ & $8.08(0.08)$ & $8.21(0.05)$ & $\mathbf{0 . 4 7}(0.15)$ & $7.37(0.12)$ & $7.63(0.07)$ & $7.67(0.06)$ & 0.30 \\
\hline & $M$ & $29(0.06)$ & $6.60(0.04)$ & $6.83(0.05)$ & $\mathbf{0 . 5 5}(0.07)$ & $6.22(0.10)$ & $6.53(0.07)$ & $6.83(0.07)$ & $\mathbf{0 . 6 1}(0.12)$ & $6.32(0.09)$ & $6.67(0.06)$ & $6.84(0.09)$ & 0.52 \\
\hline & & & & & $\mathrm{m}$ & & & $\mathrm{m}$ & & $\mathrm{m}$ & $\mathrm{m}$ & $\mathrm{m}$ & $\mathrm{m}$ \\
\hline & & & & $\mathrm{m}$ & & $\mathrm{m}$ & $\mathrm{m}$ & $\mathrm{m}$ & $\mathrm{m}$ & $\mathrm{m}$ & $\mathrm{m}$ & $\mathrm{m}$ & $\mathrm{m}$ \\
\hline & & 10) & $1(0.06)$ & $.82(0.05)$ & $.40(0.11)$ & $7.87(0.19)$ & $7.92(0.10)$ & $8.00(0.06)$ & $0.14(0.19)$ & $7.25(0.12)$ & $7.56(0.08)$ & $7.56(0.08)$ & $\mathbf{0 . 3 1}(0.14)$ \\
\hline & Peru & 09) & 33( & 7.66 & )) & 18) & 7.52 & 5) & 0.8 & 1) & 7.55 & $7.53(0.09)$ & 13) \\
\hline & Qatar & $.15(0.05)$ & $7.36(0.04)$ & $7.54(0.04)$ & $\mathbf{0 . 4 0}(0.07)$ & $7.04(0.09)$ & $7.47(0.07)$ & $7.63(0.05)$ & $\mathbf{0 . 5 9}(0.11)$ & $7.19(0.06)$ & $7.27(0.05)$ & $7.42(0.06)$ & $\mathbf{0 . 2 3}(0.09)$ \\
\hline & & & $\mathrm{m}$ & & & & & $\mathrm{m}$ & & $\mathrm{m}$ & $\mathrm{m}$ & $\mathrm{m}$ & $\mathrm{m}$ \\
\hline & & $30(0.08)$ & $7.69(0.06)$ & $7.88(0.05)$ & $\mathbf{0 . 5 8}(0.10)$ & $7.91(0.18)$ & $7.82(0.08)$ & $7.96(0.06)$ & $0.06(0.19)$ & $6.98(0.10)$ & $7.60(0.09)$ & $7.79(0.08)$ & $\mathbf{0 . 8 1}(0.13)$ \\
\hline & & & $\mathrm{m}$ & & & $\mathrm{m}$ & $\mathrm{m}$ & $\mathrm{m}$ & $\mathrm{m}$ & $\mathrm{m}$ & $\mathrm{m}$ & $\mathrm{m}$ & $\mathrm{m}$ \\
\hline & & $7(0.06)$ & $6.59(0.04)$ & $6.84(0.04)$ & $\mathbf{0 . 7 7}(0.07)$ & $5.97(0.11)$ & $6.67(0.07)$ & $6.96(0.06)$ & $\mathbf{0 . 9 9}(0.12)$ & $6.12(0.07)$ & $6.52(0.05)$ & $6.60(0.06)$ & $\mathbf{0 . 4 8}(0.09)$ \\
\hline & & $.33(0.10)$ & $7.64(0.04)$ & $7.90(0.04)$ & $\mathbf{0 . 5 7}(0.10)$ & $7.30(0.18)$ & $7.52(0.09)$ & $7.97(0.07)$ & $\mathbf{0 . 6 6}(0.19)$ & $7.34(0.12)$ & $7.71(0.05)$ & $7.81(0.06)$ & $\mathbf{0 . 4 8}(0.12)$ \\
\hline & & & & & $\mathrm{m}$ & 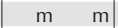 & $\mathrm{m}$ & $\mathrm{m}$ & $\mathrm{m}$ & $\mathrm{m}$ & $\mathrm{m}$ & $\mathrm{m}$ & $\mathrm{m}$ \\
\hline & Tunisia & $.67(0.07)$ & $6.99(0.07)$ & $7.00(0.08)$ & $\mathbf{0 . 3 4}(0.09)$ & $6.90(0.19)$ & $7.04(0.10)$ & $7.01(0.09)$ & $0.11(0.20)$ & $6.60(0.08)$ & $6.95(0.09)$ & $7.00(0.13)$ & $\mathbf{0 . 4 0}(0.13)$ \\
\hline & & $12(0.07)$ & $7.35(0.05)$ & $7.38(0.05)$ & $\mathbf{0 . 2 6}(0.09)$ & $7.26(0.11)$ & $7.46(0.08)$ & $7.52(0.07)$ & $\mathbf{0 . 2 6}(0.11)$ & $7.07(0.09)$ & $7.26(0.07)$ & $7.18(0.06)$ & $0.12(0.11)$ \\
\hline & & $7.29(0.06)$ & $7.73(0.05)$ & $7.87(0.05)$ & $\mathbf{0 . 5 9}(0.07)$ & $7.34(0.13)$ & $7.86(0.08)$ & $8.11(0.05)$ & $\mathbf{0 . 7 7}(0.14)$ & $7.27(0.07)$ & $7.64(0.09)$ & $7.50(0.08)$ & $\mathbf{0 . 2 4}(0.11)$ \\
\hline & Viet Nam & $\mathrm{m}$ & $\mathrm{m}$ & $\mathrm{m}$ & $\mathrm{m}$ & $\mathrm{m}$ & $\mathrm{m}$ & $\mathrm{m}$ & $\mathrm{m}$ & $\mathrm{m}$ & $\mathrm{m}$ & $\mathrm{m}$ & $\mathrm{m}$ \\
\hline & Arg & $\mathrm{m}$ & $\mathrm{m}$ & $\mathrm{m}$ & $\mathrm{m}$ & $\mathrm{m}$ & $\mathrm{m}$ & $\mathrm{m}$ & $\mathrm{m}$ & $\mathrm{m}$ & $\mathrm{m}$ & $\mathrm{m}$ & $\mathrm{m}$ \\
\hline & & & $\mathrm{m}$ & $\mathrm{m}$ & $\mathrm{m}$ & $\mathrm{m}$ & $\mathrm{m}$ & $\mathrm{m}$ & $\mathrm{m}$ & $\mathrm{m}$ & $\mathrm{m}$ & $\mathrm{m}$ & $\mathrm{m}$ \\
\hline & Malaysia** & $51(0.11)$ & $7.00(0.05)$ & $7.21(0.05)$ & $\mathbf{0 . 7 0}(0.11)$ & $6.43(0.20)$ & $6.95(0.10)$ & $7.26(0.06)$ & $\mathbf{0 . 8 3}(0.21)$ & $6.55(0.12)$ & $7.02(0.06)$ & $7.14(0.08)$ & $\mathbf{0 . 6 0}(0.13)$ \\
\hline
\end{tabular}

Note: Values that are statistically significant are indicated in bold (see Annex A3).

* See note at the beginning of this Annex.

** Coverage is too small to ensure comparability (see Annex A4).

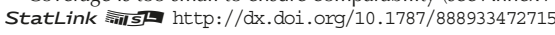


[Part 1/1]

Table III.11.17 Relationship between students' physical activity in school and outside of school

Results based on students' self-reports

\begin{tabular}{|c|c|c|c|c|c|c|c|c|c|c|c|c|}
\hline & Number & $\begin{array}{l}\text { ays per w } \\
\text { for at le }\end{array}$ & $\begin{array}{l}\text { ek studen } \\
\text { ist } 20 \mathrm{~min}\end{array}$ & $\begin{array}{l}\text { ngage in v } \\
\text { s outside }\end{array}$ & $\begin{array}{l}\text { gorous ph } \\
\text { f school }\end{array}$ & al activity & Nun & $\begin{array}{l}\text { of days pe } \\
\text { ctivity for }\end{array}$ & $\begin{array}{l}\text { week stuc } \\
\text { t least } 60\end{array}$ & $\begin{array}{l}\text { ts engage } \\
\text { nutes outs }\end{array}$ & $\begin{array}{l}n \text { modera } \\
\text { de of sch }\end{array}$ & hysical \\
\hline & $\begin{array}{c}\text { Students } \\
\text { at most, } \\
\text { week } \\
\text { educati }\end{array}$ & $\begin{array}{l}\text { o attend, } \\
\text { day per } \\
\text { hysical } \\
\text { t school }\end{array}$ & $\begin{array}{l}\text { Students } \\
\text { more th } \\
\text { per wee } \\
\text { educati }\end{array}$ & $\begin{array}{l}\text { o attend } \\
\text { two days } \\
\text { physical } \\
\text { at school }\end{array}$ & $\begin{array}{r}\text { Differen } \\
\text { of day } \\
\text { ed }\end{array}$ & $\begin{array}{l}\text { y number } \\
\text { physical } \\
\text { tion }\end{array}$ & $\begin{array}{l}\text { Students } \\
\text { at most, } \\
\text { week } \\
\text { educati }\end{array}$ & $\begin{array}{l}\text { o attend, } \\
\text { day per } \\
\text { hysical } \\
\text { t school }\end{array}$ & $\begin{array}{l}\text { Students } \\
\text { more th } \\
\text { per wee } \\
\text { educati }\end{array}$ & $\begin{array}{l}\text { o attend } \\
\text { two days } \\
\text { physical } \\
\text { t school }\end{array}$ & $\begin{array}{r}\text { Differen } \\
\text { of day } \\
\text { ed }\end{array}$ & $\begin{array}{l}\text { y number } \\
\text { physical } \\
\text { tion }\end{array}$ \\
\hline & Mean & S.E. & Mean & S.E. & Dif. & S.E. & Mean & S.E. & Mean & S.E. & Dif. & S.E. \\
\hline Australia & 4.27 & $(0.05)$ & 4.73 & $(0.03)$ & 0.46 & $(0.06)$ & 3.37 & $(0.04)$ & 4.18 & $(0.03)$ & 0.81 & $(0.04)$ \\
\hline Austria & 5.15 & $(0.04)$ & 5.26 & $(0.08)$ & 0.12 & $(0.08)$ & 3.34 & $(0.05)$ & 3.79 & $(0.08)$ & 0.45 & $(0.08)$ \\
\hline Belgium & 4.53 & $(0.05)$ & 4.65 & $(0.05)$ & 0.12 & $(0.08)$ & 3.40 & $(0.03)$ & 3.70 & $(0.05)$ & 0.30 & $(0.06)$ \\
\hline Canada & 4.86 & $(0.04)$ & 5.50 & $(0.03)$ & 0.64 & $(0.05)$ & 3.51 & $(0.05)$ & 4.67 & $(0.03)$ & 1.16 & $(0.06)$ \\
\hline Chile & 4.31 & $(0.05)$ & 4.52 & $(0.06)$ & 0.21 & $(0.08)$ & 3.29 & $(0.05)$ & 3.59 & $(0.06)$ & 0.29 & $(0.08)$ \\
\hline Czech Republic & 5.17 & $(0.06)$ & 5.19 & $(0.04)$ & 0.02 & $(0.07)$ & 3.94 & $(0.05)$ & 4.26 & $(0.05)$ & 0.32 & $(0.07)$ \\
\hline Denmark & 5.52 & $(0.04)$ & 5.64 & $(0.08)$ & 0.12 & $(0.09)$ & 4.30 & $(0.04)$ & 4.66 & $(0.10)$ & 0.36 & $(0.10)$ \\
\hline Estonia & 4.75 & $(0.07)$ & 4.72 & $(0.04)$ & -0.03 & $(0.08)$ & 3.93 & $(0.05)$ & 4.15 & $(0.04)$ & 0.22 & $(0.06)$ \\
\hline Finland & 4.94 & $(0.06)$ & 5.54 & $(0.05)$ & 0.60 & $(0.07)$ & 3.50 & $(0.04)$ & 4.45 & $(0.05)$ & 0.95 & $(0.06)$ \\
\hline France & 4.67 & $(0.05)$ & 4.58 & $(0.07)$ & -0.08 & $(0.08)$ & 3.11 & $(0.03)$ & 3.51 & $(0.06)$ & 0.40 & $(0.07)$ \\
\hline Germany & 5.60 & $(0.05)$ & 5.48 & $(0.08)$ & -0.12 & $(0.10)$ & 3.91 & $(0.04)$ & 3.98 & $(0.07)$ & 0.07 & $(0.08)$ \\
\hline Greece & 3.96 & $(0.11)$ & 4.33 & $(0.04)$ & 0.36 & $(0.11)$ & 3.30 & $(0.10)$ & 3.90 & $(0.04)$ & 0.61 & $(0.10)$ \\
\hline Hungary & 4.61 & $(0.29)$ & 5.23 & $(0.04)$ & 0.62 & $(0.29)$ & 3.96 & $(0.16)$ & 4.24 & $(0.05)$ & 0.29 & $(0.17)$ \\
\hline Iceland & 4.85 & $(0.11)$ & 5.29 & $(0.05)$ & 0.44 & $(0.12)$ & 4.49 & $(0.10)$ & 5.09 & $(0.04)$ & 0.59 & $(0.11)$ \\
\hline Ireland & 4.51 & $(0.04)$ & 4.63 & $(0.10)$ & 0.12 & $(0.11)$ & 4.09 & $(0.03)$ & 4.38 & $(0.12)$ & 0.29 & $(0.12)$ \\
\hline Israel & 4.33 & $(0.10)$ & 4.06 & $(0.05)$ & -0.27 & $(0.10)$ & 4.08 & $(0.11)$ & 3.78 & $(0.05)$ & -0.30 & $(0.11)$ \\
\hline Italy & $\mathrm{m}$ & $\mathrm{m}$ & $\mathrm{m}$ & $\mathrm{m}$ & $\mathrm{m}$ & $\mathrm{m}$ & $\mathrm{m}$ & $\mathrm{m}$ & $\mathrm{m}$ & $\mathrm{m}$ & $\mathrm{m}$ & $\mathrm{m}$ \\
\hline Japan & 4.22 & $(0.19)$ & 4.72 & $(0.06)$ & 0.49 & $(0.20)$ & 3.45 & $(0.24)$ & 3.90 & $(0.06)$ & 0.45 & $(0.25)$ \\
\hline Korea & 4.34 & $(0.18)$ & 4.28 & $(0.05)$ & -0.05 & $(0.19)$ & 3.12 & $(0.15)$ & 3.25 & $(0.04)$ & 0.13 & $(0.15)$ \\
\hline Latvia & 5.12 & $(0.09)$ & 5.17 & $(0.04)$ & 0.05 & $(0.10)$ & 3.75 & $(0.08)$ & 4.26 & $(0.04)$ & 0.51 & $(0.09)$ \\
\hline Luxembourg & 4.28 & $(0.05)$ & 4.61 & $(0.06)$ & 0.33 & $(0.07)$ & 3.65 & $(0.04)$ & 4.23 & $(0.04)$ & 0.58 & $(0.05)$ \\
\hline Mexico & 4.31 & $(0.05)$ & 4.38 & $(0.05)$ & 0.08 & $(0.08)$ & 3.73 & $(0.05)$ & 3.98 & $(0.04)$ & 0.26 & $(0.07)$ \\
\hline Netherlands & 5.71 & $(0.05)$ & 5.50 & $(0.07)$ & -0.21 & $(0.09)$ & 3.62 & $(0.04)$ & 3.77 & $(0.06)$ & 0.16 & $(0.07)$ \\
\hline New Zealand & 4.56 & $(0.07)$ & 5.07 & $(0.05)$ & 0.51 & $(0.08)$ & 3.28 & $(0.06)$ & 4.46 & $(0.05)$ & 1.18 & $(0.07)$ \\
\hline Norway & 5.49 & $(0.07)$ & 5.62 & $(0.05)$ & 0.13 & $(0.08)$ & 4.11 & $(0.06)$ & 4.52 & $(0.04)$ & 0.41 & $(0.07)$ \\
\hline Poland & 4.34 & $(0.28)$ & 5.58 & $(0.04)$ & 1.25 & $(0.28)$ & 3.89 & $(0.26)$ & 4.61 & $(0.04)$ & 0.72 & $(0.26)$ \\
\hline Portugal & 4.06 & $(0.18)$ & 4.43 & $(0.04)$ & 0.36 & $(0.18)$ & 3.15 & $(0.11)$ & 3.63 & $(0.04)$ & 0.47 & $(0.11)$ \\
\hline Slovak Republic & 4.91 & $(0.10)$ & 5.14 & $(0.04)$ & 0.23 & $(0.11)$ & 3.79 & $(0.08)$ & 4.25 & $(0.04)$ & 0.46 & $(0.08)$ \\
\hline Slovenia & 4.61 & $(0.08)$ & 4.97 & $(0.05)$ & 0.36 & $(0.08)$ & 4.13 & $(0.08)$ & 4.37 & $(0.04)$ & 0.24 & $(0.09)$ \\
\hline Spain & 4.33 & $(0.13)$ & 4.23 & $(0.03)$ & -0.10 & $(0.13)$ & 3.58 & $(0.11)$ & 3.54 & $(0.03)$ & -0.04 & $(0.12)$ \\
\hline Sweden & 5.03 & $(0.11)$ & 5.28 & $(0.05)$ & 0.26 & $(0.12)$ & 3.73 & $(0.09)$ & 4.43 & $(0.04)$ & 0.70 & $(0.09)$ \\
\hline Switzerland & 5.04 & $(0.08)$ & 5.33 & $(0.05)$ & 0.29 & $(0.09)$ & 3.77 & $(0.08)$ & 4.00 & $(0.04)$ & 0.23 & $(0.08)$ \\
\hline Turkey & 3.88 & $(0.06)$ & 4.11 & $(0.07)$ & 0.24 & $(0.08)$ & 3.16 & $(0.05)$ & 3.62 & $(0.05)$ & 0.47 & $(0.07)$ \\
\hline United Kingdom & 4.41 & $(0.06)$ & 4.86 & $(0.05)$ & 0.44 & $(0.08)$ & 2.95 & $(0.06)$ & 3.77 & $(0.04)$ & 0.82 & $(0.07)$ \\
\hline United States & 4.88 & $(0.06)$ & 5.45 & $(0.06)$ & 0.57 & $(0.09)$ & 3.94 & $(0.05)$ & 4.93 & $(0.04)$ & 0.99 & $(0.06)$ \\
\hline OECD average & 4.69 & $(0.02)$ & 4.94 & $(0.01)$ & 0.25 & $(0.02)$ & 3.66 & $(0.02)$ & 4.11 & $(0.01)$ & 0.46 & $(0.02)$ \\
\hline
\end{tabular}

\begin{tabular}{|c|c|c|c|c|c|c|c|c|c|c|c|c|}
\hline Albania & $\mathrm{m}$ & $\mathrm{m}$ & $\mathrm{m}$ & $\mathrm{m}$ & $\mathrm{m}$ & $\mathrm{m}$ & $\mathrm{m}$ & $\mathrm{m}$ & $\mathrm{m}$ & $\mathrm{m}$ & $\mathrm{m}$ & $\mathrm{m}$ \\
\hline Algeria & $\mathrm{m}$ & $\mathrm{m}$ & $\mathrm{m}$ & $\mathrm{m}$ & $\mathrm{m}$ & $\mathrm{m}$ & $\mathrm{m}$ & $\mathrm{m}$ & $\mathrm{m}$ & $\mathrm{m}$ & $\mathrm{m}$ & $\mathrm{m}$ \\
\hline Brazil & 3.58 & $(0.04)$ & 3.88 & $(0.04)$ & 0.29 & $(0.06)$ & 2.97 & $(0.04)$ & 3.34 & $(0.03)$ & 0.37 & $(0.05)$ \\
\hline B-S-J-G (China) & 3.67 & $(0.07)$ & 4.29 & $(0.06)$ & 0.61 & $(0.08)$ & 3.28 & $(0.11)$ & 4.13 & $(0.05)$ & 0.85 & $(0.12)$ \\
\hline Bulgaria & 4.11 & $(0.17)$ & 4.58 & $(0.05)$ & 0.48 & $(0.18)$ & 3.31 & $(0.13)$ & 3.94 & $(0.04)$ & 0.63 & $(0.12)$ \\
\hline CABA (Argentina) & $\mathrm{m}$ & $\mathrm{m}$ & $\mathrm{m}$ & $\mathrm{m}$ & $\mathrm{m}$ & $\mathrm{m}$ & $\mathrm{m}$ & $\mathrm{m}$ & $\mathrm{m}$ & $\mathrm{m}$ & $\mathrm{m}$ & $\mathrm{m}$ \\
\hline Colombia & 3.60 & $(0.05)$ & 3.62 & $(0.08)$ & 0.02 & $(0.09)$ & 3.35 & $(0.04)$ & 3.64 & $(0.06)$ & 0.29 & $(0.07)$ \\
\hline Costa Rica & 3.90 & $(0.04)$ & 4.14 & $(0.22)$ & 0.25 & $(0.23)$ & 3.18 & $(0.04)$ & 3.53 & $(0.22)$ & 0.34 & $(0.22)$ \\
\hline Croatia & 4.65 & $(0.07)$ & 4.71 & $(0.06)$ & 0.06 & $(0.09)$ & 3.79 & $(0.07)$ & 3.86 & $(0.06)$ & 0.06 & $(0.09)$ \\
\hline Cyprus* & 3.92 & $(0.06)$ & 4.40 & $(0.04)$ & 0.48 & $(0.07)$ & 3.68 & $(0.06)$ & 4.04 & $(0.04)$ & 0.36 & $(0.07)$ \\
\hline Dominican Republic & 3.99 & $(0.08)$ & 4.25 & $(0.05)$ & 0.26 & $(0.08)$ & 3.58 & $(0.08)$ & 4.03 & $(0.05)$ & 0.45 & $(0.08)$ \\
\hline FYROM & $\mathrm{m}$ & $\mathrm{m}$ & $\mathrm{m}$ & $\mathrm{m}$ & $\mathrm{m}$ & $\mathrm{m}$ & $\mathrm{m}$ & $\mathrm{m}$ & $\mathrm{m}$ & $\mathrm{m}$ & $\mathrm{m}$ & $\mathrm{m}$ \\
\hline Georgia & $\mathrm{m}$ & $\mathrm{m}$ & $\mathrm{m}$ & $\mathrm{m}$ & $\mathrm{m}$ & $\mathrm{m}$ & $\mathrm{m}$ & $\mathrm{m}$ & $\mathrm{m}$ & $\mathrm{m}$ & $\mathrm{m}$ & $\mathrm{m}$ \\
\hline Hong Kong (China) & 4.33 & $(0.05)$ & 4.74 & $(0.24)$ & 0.41 & $(0.24)$ & 3.22 & $(0.04)$ & 3.98 & $(0.14)$ & 0.76 & $(0.14)$ \\
\hline Indonesia & $\mathrm{m}$ & $\mathrm{m}$ & $\mathrm{m}$ & $\mathrm{m}$ & $\mathrm{m}$ & $\mathrm{m}$ & $\mathrm{m}$ & $\mathrm{m}$ & $\mathrm{m}$ & $\mathrm{m}$ & $\mathrm{m}$ & $\mathrm{m}$ \\
\hline Jordan & $\mathrm{m}$ & $\mathrm{m}$ & $\mathrm{m}$ & $\mathrm{m}$ & $\mathrm{m}$ & $\mathrm{m}$ & $\mathrm{m}$ & $\mathrm{m}$ & $\mathrm{m}$ & $\mathrm{m}$ & $\mathrm{m}$ & $\mathrm{m}$ \\
\hline Kosovo & $\mathrm{m}$ & $\mathrm{m}$ & $\mathrm{m}$ & $\mathrm{m}$ & $\mathrm{m}$ & $\mathrm{m}$ & $\mathrm{m}$ & $\mathrm{m}$ & $\mathrm{m}$ & $\mathrm{m}$ & $\mathrm{m}$ & $\mathrm{m}$ \\
\hline Lebanon & $\mathrm{m}$ & $\mathrm{m}$ & $\mathrm{m}$ & $\mathrm{m}$ & $\mathrm{m}$ & $\mathrm{m}$ & $\mathrm{m}$ & $\mathrm{m}$ & $\mathrm{m}$ & $\mathrm{m}$ & $\mathrm{m}$ & $\mathrm{m}$ \\
\hline Lithuania & 4.88 & $(0.10)$ & 5.12 & $(0.04)$ & 0.24 & $(0.10)$ & 3.81 & $(0.10)$ & 4.13 & $(0.03)$ & 0.33 & $(0.10)$ \\
\hline Macao (China) & 4.04 & $(0.06)$ & 4.28 & $(0.04)$ & 0.24 & $(0.07)$ & 2.83 & $(0.04)$ & 3.20 & $(0.04)$ & 0.37 & $(0.06)$ \\
\hline Malta & $\mathrm{m}$ & $\mathrm{m}$ & $\mathrm{m}$ & $\mathrm{m}$ & $\mathrm{m}$ & $\mathrm{m}$ & $\mathrm{m}$ & $\mathrm{m}$ & $\mathrm{m}$ & $\mathrm{m}$ & $\mathrm{m}$ & $\mathrm{m}$ \\
\hline Moldova & $\mathrm{m}$ & $\mathrm{m}$ & $\mathrm{m}$ & $\mathrm{m}$ & $\mathrm{m}$ & $\mathrm{m}$ & $\mathrm{m}$ & $\mathrm{m}$ & $\mathrm{m}$ & $\mathrm{m}$ & $\mathrm{m}$ & $\mathrm{m}$ \\
\hline Montenegro & 4.85 & $(0.13)$ & 5.13 & $(0.04)$ & 0.28 & $(0.14)$ & 4.04 & $(0.12)$ & 4.34 & $(0.04)$ & 0.29 & $(0.13)$ \\
\hline Peru & 4.24 & $(0.04)$ & 4.18 & $(0.06)$ & -0.07 & $(0.07)$ & 3.44 & $(0.04)$ & 3.82 & $(0.05)$ & 0.38 & $(0.06)$ \\
\hline Qatar & 3.46 & $(0.03)$ & 3.96 & $(0.03)$ & 0.50 & $(0.05)$ & 3.10 & $(0.03)$ & 3.85 & $(0.03)$ & 0.75 & $(0.04)$ \\
\hline Romania & $\mathrm{m}$ & $\mathrm{m}$ & $\mathrm{m}$ & $\mathrm{m}$ & $\mathrm{m}$ & $\mathrm{m}$ & $\mathrm{m}$ & $\mathrm{m}$ & $\mathrm{m}$ & $\mathrm{m}$ & $\mathrm{m}$ & $\mathrm{m}$ \\
\hline Russia & 4.95 & $(0.15)$ & 5.19 & $(0.04)$ & 0.24 & $(0.15)$ & 3.59 & $(0.15)$ & 4.24 & $(0.04)$ & 0.65 & $(0.15)$ \\
\hline Singapore & 4.48 & $(0.06)$ & 4.53 & $(0.05)$ & 0.05 & $(0.08)$ & 2.99 & $(0.04)$ & 3.37 & $(0.03)$ & 0.38 & $(0.05)$ \\
\hline Chinese Taipei & 4.69 & $(0.08)$ & 4.74 & $(0.04)$ & 0.05 & $(0.09)$ & 3.44 & $(0.08)$ & 3.70 & $(0.04)$ & 0.25 & $(0.08)$ \\
\hline Thailand & 4.78 & $(0.05)$ & 4.75 & $(0.08)$ & -0.03 & $(0.09)$ & 3.59 & $(0.03)$ & 4.05 & $(0.08)$ & 0.46 & $(0.08)$ \\
\hline Trinidad and Tobago & $\mathrm{m}$ & $\mathrm{m}$ & $\mathrm{m}$ & $\mathrm{m}$ & $\mathrm{m}$ & $\mathrm{m}$ & $\mathrm{m}$ & $\mathrm{m}$ & $\mathrm{m}$ & $\mathrm{m}$ & $\mathrm{m}$ & $\mathrm{m}$ \\
\hline Tunisia & 3.28 & $(0.06)$ & 3.70 & $(0.05)$ & 0.43 & $(0.07)$ & 2.86 & $(0.05)$ & 3.55 & $(0.05)$ & 0.69 & $(0.08)$ \\
\hline United Arab Emirates & 3.48 & $(0.05)$ & 3.60 & $(0.05)$ & 0.12 & $(0.07)$ & 3.15 & $(0.04)$ & 3.56 & $(0.05)$ & 0.42 & $(0.06)$ \\
\hline Uruguay & 4.11 & $(0.07)$ & 4.41 & $(0.04)$ & 0.31 & $(0.07)$ & 3.35 & $(0.07)$ & 3.76 & $(0.04)$ & 0.41 & $(0.08)$ \\
\hline Viet Nam & $\mathrm{m}$ & $\mathrm{m}$ & $\mathrm{m}$ & $\mathrm{m}$ & $\mathrm{m}$ & $\mathrm{m}$ & $\mathrm{m}$ & $\mathrm{m}$ & $\mathrm{m}$ & $\mathrm{m}$ & $\mathrm{m}$ & $\mathrm{m}$ \\
\hline Argentina** & $\mathrm{m}$ & $\mathrm{m}$ & $\mathrm{m}$ & $\mathrm{m}$ & $\mathrm{m}$ & $\mathrm{m}$ & $\mathrm{m}$ & $\mathrm{m}$ & $\mathrm{m}$ & $\mathrm{m}$ & $\mathrm{m}$ & $\mathrm{m}$ \\
\hline Kazakhstan** & $\mathrm{m}$ & $\mathrm{m}$ & $\mathrm{m}$ & $\mathrm{m}$ & $\mathrm{m}$ & $\mathrm{m}$ & $\mathrm{m}$ & $\mathrm{m}$ & $\mathrm{m}$ & $\mathrm{m}$ & $\mathrm{m}$ & $\mathrm{m}$ \\
\hline Malaysia** & 5.25 & $(0.07)$ & 5.04 & $(0.06)$ & -0.22 & $(0.07)$ & 3.93 & $(0.05)$ & 4.09 & $(0.05)$ & 0.16 & $(0.06)$ \\
\hline
\end{tabular}

Note: Values that are statistically significant are indicated in bold (see Annex A3).

* See note at the beginning of this Annex.

** Coverage is too small to ensure comparability (see Annex A4).

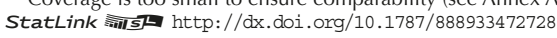


[Part 1/2]

Table III.11.18 Physical activity outside of school and well-being outcomes

Results based on students' self-reports

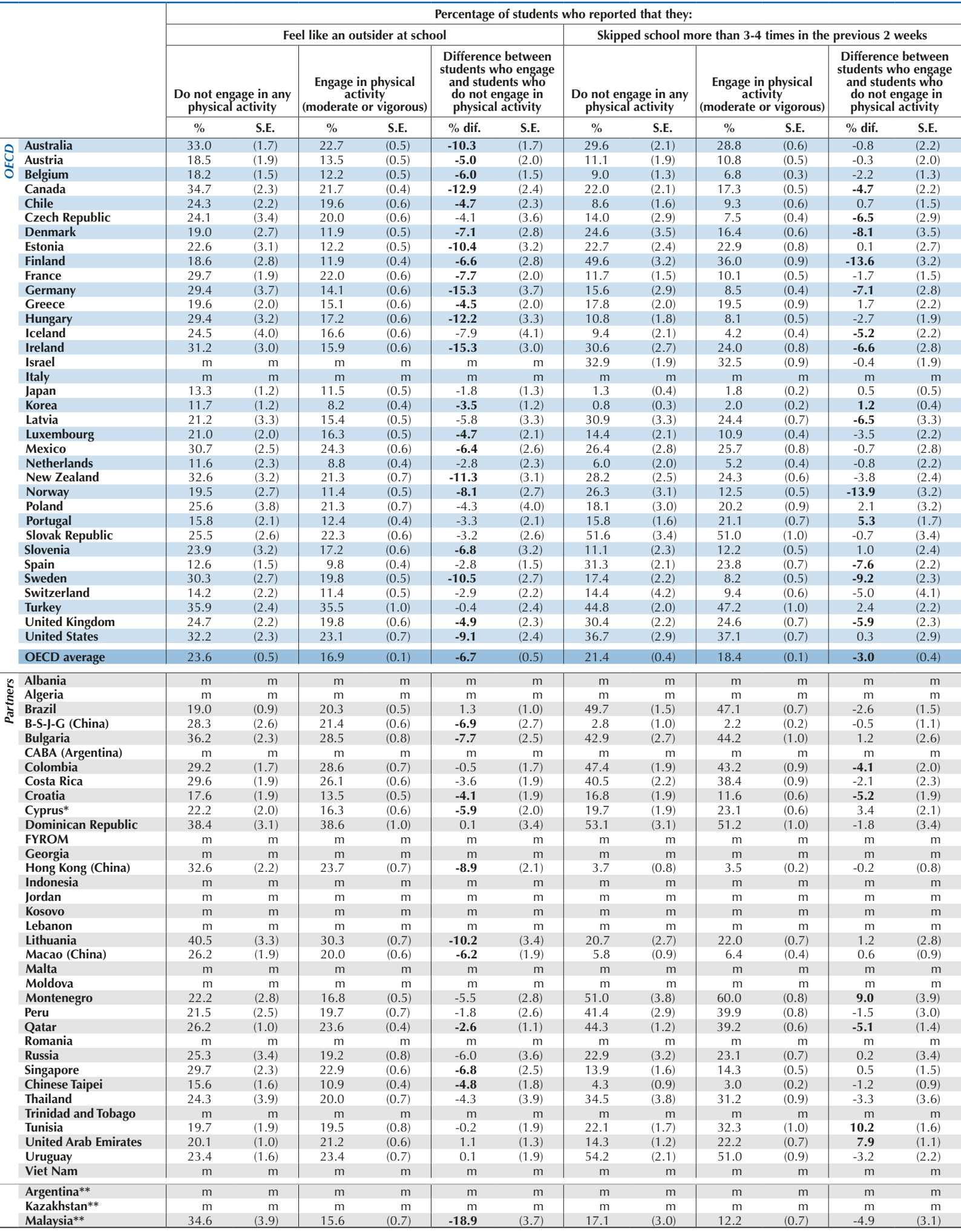

1. A student is frequently bullied if he or she is in the top $10 \%$ of the index of exposure to bullying among all countries/economies. See Annex A1 for information on the index of exposure to bullying.

Note: Values that are statistically significant are indicated in bold (see Annex A3).

* See note at the beginning of this Annex.

** Coverage is too small to ensure comparability (see Annex A4).

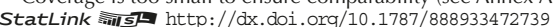


[Part 2/2]

Table III.11.18 Physical activity outside of school and well-being outcomes

Results based on students' self-reports

\begin{tabular}{|c|c|c|c|c|c|c|c|c|c|c|c|c|c|}
\hline & \multicolumn{12}{|c|}{ Percentage of students who reported that they: } \\
\hline & & \multicolumn{6}{|c|}{ Feel very anxious even if they are well-prepared for a test } & \multicolumn{6}{|c|}{ Are frequently bullied ${ }^{1}$} \\
\hline & & $\begin{array}{l}\text { Do not e } \\
\text { physic }\end{array}$ & $\begin{array}{l}\text { ge in any } \\
\text { ctivity }\end{array}$ & $\begin{array}{r}\text { Engage } \\
\text { a } \\
\text { (moderat }\end{array}$ & $\begin{array}{l}\text { hysical } \\
\text { y } \\
\text { vigorous) }\end{array}$ & $\begin{array}{r}\text { Differen } \\
\text { students } \\
\text { and stu } \\
\text { do not } \\
\text { physic }\end{array}$ & $\begin{array}{l}\text { etween } \\
\text { engage } \\
\text { ts who } \\
\text { age in } \\
\text { ctivity }\end{array}$ & $\begin{array}{l}\text { Do not } \\
\text { physi }\end{array}$ & $\begin{array}{l}\text { se in any } \\
\text { tivity }\end{array}$ & $\begin{array}{r}\text { Engag } \\
\text { (modera }\end{array}$ & $\begin{array}{l}\text { hysical } \\
\text { y } \\
\text { vigorous) }\end{array}$ & $\begin{array}{r}\text { Differen } \\
\text { students } \\
\text { and stu } \\
\text { do not } \\
\text { physic }\end{array}$ & $\begin{array}{l}\text { etween } \\
\text { engage } \\
\text { s who } \\
\text { age in } \\
\text { tivity }\end{array}$ \\
\hline & & $\%$ & S.E. & $\%$ & S.E. & $\%$ dif. & S.E. & $\%$ & S.E. & $\%$ & S.E. & $\%$ dif. & S.E. \\
\hline 0 & Australia & 70.4 & $(1.9)$ & 67.2 & $(0.6)$ & -3.2 & $(1.9)$ & 16.4 & $(1.4)$ & 14.5 & $(0.4)$ & -1.9 & $(1.4)$ \\
\hline ర్త & Austria & 57.2 & (2.4) & 50.2 & $(0.9)$ & -7.0 & (2.4) & 8.3 & (1.6) & 7.7 & $(0.5)$ & -0.6 & (1.6) \\
\hline 0 & Belgium & 49.9 & (1.9) & 41.8 & $(0.6)$ & -8.1 & $(2.0)$ & 9.1 & (1.3) & 6.8 & $(0.3)$ & -2.3 & $(1.3)$ \\
\hline & Canada & 64.5 & $(2.0)$ & 63.9 & $(0.4)$ & -0.6 & $(2.1)$ & 15.3 & (1.8) & 12.4 & $(0.4)$ & -2.9 & (1.7) \\
\hline & Chile & 62.9 & $(2.3)$ & 55.2 & $(0.8)$ & -7.7 & $(2.5)$ & 7.0 & $(1.2)$ & 7.8 & $(0.5)$ & 0.8 & $(1.3)$ \\
\hline & Czech Republic & 35.0 & (4.3) & 40.3 & $(0.7)$ & 5.3 & $(4.4)$ & 17.5 & (3.0) & 11.3 & $(0.5)$ & -6.2 & (3.1) \\
\hline & Denmark & 63.1 & $(3.7)$ & 64.5 & $(0.8)$ & 1.4 & $(3.8)$ & 10.9 & $(2.3)$ & 6.1 & $(0.3)$ & -4.8 & (2.4) \\
\hline & Estonia & 53.4 & (3.2) & 53.0 & $(0.8)$ & -0.5 & $(3.2)$ & 10.2 & $(2.0)$ & 9.5 & $(0.5)$ & -0.7 & $(2.2)$ \\
\hline & Finland & 45.8 & (3.6) & 48.9 & $(0.8)$ & 3.1 & (3.6) & 12.3 & $(2.3)$ & 9.2 & $(0.4)$ & -3.1 & $(2.3)$ \\
\hline & France & 51.3 & $(2.2)$ & 46.5 & $(0.8)$ & -4.9 & $(2.4)$ & 7.5 & $(1.0)$ & 6.4 & $(0.4)$ & -1.1 & (1.1) \\
\hline & Germany & 43.1 & $(4.2)$ & 41.1 & $(0.8)$ & -2.0 & $(4.4)$ & 14.6 & (3.0) & 5.7 & $(0.5)$ & -8.9 & (3.0) \\
\hline & Greece & 65.5 & $(2.5)$ & 58.5 & $(0.7)$ & -7.0 & $(2.5)$ & 5.2 & $(1.1)$ & 6.6 & $(0.5)$ & 1.3 & $(1.1)$ \\
\hline & Hungary & 61.5 & $(3.1)$ & 54.2 & $(0.8)$ & -7.3 & $(3.0)$ & 14.8 & $(2.0)$ & 8.8 & $(0.5)$ & -6.0 & $(2.1)$ \\
\hline & Iceland & 54.5 & (3.8) & 50.9 & $(0.9)$ & -3.6 & $(4.1)$ & 8.0 & $(2.1)$ & 4.9 & $(0.4)$ & -3.0 & $(2.1)$ \\
\hline & Ireland & 67.2 & $(2.8)$ & 63.1 & $(0.8)$ & -4.1 & $(3.0)$ & 11.3 & $(2.1)$ & 6.5 & $(0.4)$ & -4.8 & $(2.2)$ \\
\hline & Israel & 52.2 & $(2.5)$ & 43.5 & $(0.7)$ & -8.8 & $(2.6)$ & $\mathrm{m}$ & $\mathrm{m}$ & $\mathrm{m}$ & $\mathrm{m}$ & $\mathrm{m}$ & $\mathrm{m}$ \\
\hline & Italy & $\mathrm{m}$ & $\mathrm{m}$ & $\mathrm{m}$ & $\mathrm{m}$ & $\mathrm{m}$ & $\mathrm{m}$ & $\mathrm{m}$ & $\mathrm{m}$ & $\mathrm{m}$ & $\mathrm{m}$ & $\mathrm{m}$ & $\mathrm{m}$ \\
\hline & Japan & 63.4 & (1.6) & 62.0 & $(0.8)$ & -1.4 & (1.7) & 5.1 & $(0.7)$ & 5.1 & $(0.3)$ & -0.1 & $(0.8)$ \\
\hline & Korea & 59.4 & (1.9) & 54.7 & $(0.8)$ & -4.7 & (1.9) & 1.1 & $(0.4)$ & 2.3 & $(0.2)$ & 1.2 & $(0.4)$ \\
\hline & Latvia & 39.8 & (3.7) & 43.4 & $(0.9)$ & 3.5 & (3.7) & 22.7 & (3.1) & 17.3 & $(0.6)$ & -5.4 & $(3.2)$ \\
\hline & Luxembourg & 51.6 & (2.6) & 47.3 & $(0.7)$ & -4.4 & $(2.6)$ & 9.3 & (1.4) & 7.6 & $(0.4)$ & -1.6 & (1.5) \\
\hline & Mexico & 66.1 & $(2.8)$ & 59.4 & $(0.8)$ & -6.7 & $(2.9)$ & 8.9 & (1.3) & 10.2 & $(0.4)$ & 1.3 & (1.4) \\
\hline & Netherlands & 44.0 & (3.9) & 39.0 & $(0.8)$ & -5.1 & $(3.9)$ & 4.7 & (1.9) & 3.2 & $(0.4)$ & -1.5 & (1.9) \\
\hline & New Zealand & 73.9 & $(2.8)$ & 71.8 & $(0.8)$ & -2.1 & $(2.8)$ & 23.9 & $(2.8)$ & 17.8 & $(0.7)$ & -6.1 & (3.0) \\
\hline & Norway & 59.1 & $(2.8)$ & 61.2 & $(0.7)$ & 2.1 & $(2.9)$ & 10.9 & $(2.3)$ & 9.0 & $(0.4)$ & -1.9 & (2.4) \\
\hline & Poland & 51.2 & $(3.7)$ & 45.0 & $(0.9)$ & -6.2 & $(3.7)$ & 15.7 & $(2.9)$ & 10.4 & $(0.5)$ & -5.3 & (3.0) \\
\hline & Portugal & 66.9 & $(2.0)$ & 69.3 & $(0.7)$ & 2.3 & $(2.2)$ & 6.5 & $(1.2)$ & 5.4 & $(0.3)$ & -1.0 & $(1.2)$ \\
\hline & Slovak Republic & 42.5 & $(3.0)$ & 47.3 & $(0.8)$ & 4.8 & (3.0) & 14.6 & $(2.3)$ & 11.1 & $(0.5)$ & -3.6 & $(2.2)$ \\
\hline & Slovenia & 67.0 & (3.6) & 61.7 & $(0.7)$ & -5.2 & (3.7) & 7.8 & $(2.1)$ & 7.2 & $(0.4)$ & -0.7 & $(2.1)$ \\
\hline & Spain & 68.9 & $(1.8)$ & 66.9 & $(0.8)$ & -2.0 & $(2.0)$ & 8.6 & $(1.3)$ & 5.7 & $(0.4)$ & -2.9 & $(1.3)$ \\
\hline & Sweden & 55.6 & (3.4) & 61.6 & $(0.8)$ & 6.0 & $(3.2)$ & 8.6 & $(1.8)$ & 8.2 & $(0.4)$ & -0.4 & (1.9) \\
\hline & Switzerland & 38.9 & $(4.1)$ & 33.2 & $(0.8)$ & -5.8 & $(4.3)$ & 8.9 & $(2.4)$ & 7.2 & $(0.5)$ & -1.7 & $(2.4)$ \\
\hline & Turkey & 63.2 & $(2.3)$ & 58.1 & $(0.9)$ & -5.1 & $(2.5)$ & 7.0 & $(1.2)$ & 8.8 & $(0.6)$ & 1.9 & (1.3) \\
\hline & United Kingdom & 75.5 & $(2.1)$ & 71.6 & $(0.7)$ & -3.8 & $(2.3)$ & 17.8 & (1.9) & 13.9 & $(0.6)$ & -3.9 & $(2.1)$ \\
\hline & United States & 75.7 & $(2.4)$ & 67.1 & $(0.7)$ & -8.6 & $(2.4)$ & 7.5 & (1.3) & 10.1 & $(0.5)$ & 2.6 & (1.4) \\
\hline & OECD average & 57.7 & $(0.5)$ & 54.8 & $(0.1)$ & -2.9 & $(0.5)$ & 10.8 & $(0.3)$ & 8.6 & $(0.1)$ & -2.2 & $(0.3)$ \\
\hline$n$ & Albania & $\mathrm{m}$ & $\mathrm{m}$ & $\mathrm{m}$ & $\mathrm{m}$ & $\mathrm{m}$ & $\mathrm{m}$ & $\mathrm{m}$ & $\mathrm{m}$ & $\mathrm{m}$ & $\mathrm{m}$ & $\mathrm{m}$ & $\mathrm{m}$ \\
\hline ఏ & Algeria & $\mathrm{m}$ & $\mathrm{m}$ & $\mathrm{m}$ & $\mathrm{m}$ & $\mathrm{m}$ & $\mathrm{m}$ & $\mathrm{m}$ & $\mathrm{m}$ & $\mathrm{m}$ & $\mathrm{m}$ & $\mathrm{m}$ & $\mathrm{m}$ \\
\hline ปั & Brazil & 81.7 & $(1.0)$ & 80.6 & $(0.5)$ & -1.1 & $(1.0)$ & 6.9 & $(0.5)$ & 9.1 & $(0.3)$ & 2.2 & $(0.7)$ \\
\hline$=$ & B-S-J-G (China) & 59.7 & $(2.5)$ & 61.9 & $(0.8)$ & 2.3 & $(2.7)$ & 9.0 & $(1.2)$ & 10.6 & $(0.5)$ & 1.6 & (1.3) \\
\hline & Bulgaria & 56.6 & $(2.5)$ & 54.9 & $(0.8)$ & -1.7 & $(2.6)$ & 13.2 & (1.7) & 13.2 & $(0.7)$ & 0.0 & (1.8) \\
\hline & CABA (Argentina) & $\mathrm{m}$ & $\mathrm{m}$ & $\mathrm{m}$ & $\mathrm{m}$ & $\mathrm{m}$ & $\mathrm{m}$ & $\mathrm{m}$ & $\mathrm{m}$ & $\mathrm{m}$ & $\mathrm{m}$ & $\mathrm{m}$ & $\mathrm{m}$ \\
\hline & Colombia & 76.7 & $(1.5)$ & 79.2 & $(0.5)$ & 2.5 & $(1.5)$ & 6.2 & $(1.0)$ & 7.6 & $(0.4)$ & 1.4 & $(1.1)$ \\
\hline & Costa Rica & 79.4 & $(1.8)$ & 81.2 & $(0.6)$ & 1.8 & $(2.0)$ & 13.5 & (1.4) & 10.6 & $(0.5)$ & -3.0 & (1.5) \\
\hline & Croatia & 55.9 & $(2.8)$ & 46.5 & $(0.9)$ & -9.4 & $(2.7)$ & 9.3 & (1.4) & 6.4 & $(0.4)$ & -2.8 & (1.4) \\
\hline & Cyprus* & 61.0 & $(2.8)$ & 57.4 & $(0.7)$ & -3.6 & $(2.9)$ & C & $\mathrm{C}$ & c & $\mathrm{C}$ & $\mathrm{C}$ & $\mathrm{C}$ \\
\hline & Dominican Republic & 81.2 & (2.6) & 80.1 & $(0.8)$ & -1.1 & $(2.4)$ & 10.5 & $(2.1)$ & 12.2 & $(0.7)$ & 1.8 & $(2.3)$ \\
\hline & FYROM & $\mathrm{m}$ & $\mathrm{m}$ & $\mathrm{m}$ & $\mathrm{m}$ & $\mathrm{m}$ & $\mathrm{m}$ & $\mathrm{m}$ & $\mathrm{m}$ & $\mathrm{m}$ & $\mathrm{m}$ & $\mathrm{m}$ & $\mathrm{m}$ \\
\hline & Georgia & $\mathrm{m}$ & $\mathrm{m}$ & $\mathrm{m}$ & $\mathrm{m}$ & $\mathrm{m}$ & $\mathrm{m}$ & $\mathrm{m}$ & $\mathrm{m}$ & $\mathrm{m}$ & $\mathrm{m}$ & $\mathrm{m}$ & $\mathrm{m}$ \\
\hline & Hong Kong (China) & 65.2 & $(2.1)$ & 67.3 & $(0.7)$ & 2.2 & $(2.0)$ & 14.4 & (1.5) & 15.5 & $(0.7)$ & 1.1 & $(1.7)$ \\
\hline & Indonesia & $\mathrm{m}$ & $\mathrm{m}$ & $\mathrm{m}$ & $\mathrm{m}$ & $\mathrm{m}$ & $\mathrm{m}$ & $\mathrm{m}$ & $\mathrm{m}$ & $\mathrm{m}$ & $\mathrm{m}$ & $\mathrm{m}$ & $\mathrm{m}$ \\
\hline & Jordan & $\mathrm{m}$ & $\mathrm{m}$ & $\mathrm{m}$ & $\mathrm{m}$ & $\mathrm{m}$ & $\mathrm{m}$ & $\mathrm{m}$ & $\mathrm{m}$ & $\mathrm{m}$ & $\mathrm{m}$ & $\mathrm{m}$ & $\mathrm{m}$ \\
\hline & Kosovo & $\mathrm{m}$ & $\mathrm{m}$ & $\mathrm{m}$ & $\mathrm{m}$ & $\mathrm{m}$ & $\mathrm{m}$ & $\mathrm{m}$ & $\mathrm{m}$ & $\mathrm{m}$ & $\mathrm{m}$ & $\mathrm{m}$ & $\mathrm{m}$ \\
\hline & Lebanon & $\mathrm{m}$ & $\mathrm{m}$ & $\mathrm{m}$ & $\mathrm{m}$ & $\mathrm{m}$ & $\mathrm{m}$ & $\mathrm{m}$ & $\mathrm{m}$ & $\mathrm{m}$ & $\mathrm{m}$ & $\mathrm{m}$ & $\mathrm{m}$ \\
\hline & Lithuania & 51.6 & (3.4) & 55.9 & $(0.7)$ & 4.2 & (3.5) & 14.6 & $(2.5)$ & 9.1 & $(0.4)$ & -5.5 & $(2.5)$ \\
\hline & Macao (China) & 66.6 & $(2.1)$ & 65.5 & $(0.8)$ & -1.2 & $(2.3)$ & 13.0 & $(1.5)$ & 14.6 & $(0.6)$ & 1.5 & $(1.6)$ \\
\hline & Malta & $\mathrm{m}$ & $\mathrm{m}$ & $\mathrm{m}$ & $\mathrm{m}$ & $\mathrm{m}$ & $\mathrm{m}$ & $\mathrm{m}$ & $\mathrm{m}$ & $\mathrm{m}$ & $\mathrm{m}$ & $\mathrm{m}$ & $\mathrm{m}$ \\
\hline & Moldova & $\mathrm{m}$ & $\mathrm{m}$ & $\mathrm{m}$ & $\mathrm{m}$ & $\mathrm{m}$ & $\mathrm{m}$ & $\mathrm{m}$ & $\mathrm{m}$ & $\mathrm{m}$ & $\mathrm{m}$ & $\mathrm{m}$ & $\mathrm{m}$ \\
\hline & Montenegro & 68.6 & (3.6) & 65.2 & $(0.9)$ & -3.4 & $(3.7)$ & 7.0 & $(2.1)$ & 6.5 & $(0.4)$ & -0.4 & $(2.2)$ \\
\hline & Peru & 67.3 & $(2.9)$ & 71.5 & $(0.6)$ & 4.2 & $(3.0)$ & 5.6 & (1.4) & 6.0 & $(0.4)$ & 0.4 & $(1.4)$ \\
\hline & Qatar & 65.5 & $(1.2)$ & 65.4 & $(0.5)$ & -0.1 & $(1.2)$ & 13.6 & $(0.9)$ & 18.9 & $(0.4)$ & 5.3 & $(1.0)$ \\
\hline & Romania & $\mathrm{m}$ & $\mathrm{m}$ & $\mathrm{m}$ & $\mathrm{m}$ & $\mathrm{m}$ & $\mathrm{m}$ & $\mathrm{m}$ & $\mathrm{m}$ & $\mathrm{m}$ & $\mathrm{m}$ & $\mathrm{m}$ & $\mathrm{m}$ \\
\hline & Russia & 40.6 & $(4.4)$ & 51.5 & $(0.8)$ & 10.9 & $(4.2)$ & 8.4 & $(2.8)$ & 9.2 & $(0.7)$ & 0.8 & (2.9) \\
\hline & Singapore & 76.8 & (1.9) & 76.2 & $(0.7)$ & -0.6 & (1.9) & 16.1 & $(1.7)$ & 14.3 & $(0.5)$ & -1.8 & $(1.8)$ \\
\hline & Chinese Taipei & 68.9 & $(1.6)$ & 66.3 & $(0.6)$ & -2.6 & $(1.7)$ & 4.0 & $(0.9)$ & 3.0 & $(0.2)$ & -1.0 & (1.0) \\
\hline & Thailand & 63.5 & $(4.1)$ & 63.3 & $(0.8)$ & -0.2 & $(4.4)$ & 16.9 & $(3.2)$ & 17.3 & $(0.8)$ & 0.4 & $(3.2)$ \\
\hline & Trinidad and Tobago & $\mathrm{m}$ & $\mathrm{m}$ & $\mathrm{m}$ & $\mathrm{m}$ & $\mathrm{m}$ & $\mathrm{m}$ & $\mathrm{m}$ & $\mathrm{m}$ & $\mathrm{m}$ & $\mathrm{m}$ & $\mathrm{m}$ & $\mathrm{m}$ \\
\hline & Tunisia & 61.4 & $(2.1)$ & 59.2 & $(1.0)$ & -2.2 & $(2.3)$ & 12.9 & (1.5) & 16.6 & $(0.7)$ & 3.7 & (1.6) \\
\hline & United Arab Emirates & 58.2 & $(1.2)$ & 62.7 & $(0.7)$ & 4.5 & $(1.3)$ & 12.8 & $(0.9)$ & 18.3 & $(0.6)$ & 5.5 & $(0.9)$ \\
\hline & Uruguay & 69.7 & (1.9) & 73.4 & $(0.8)$ & 3.6 & $(2.0)$ & 8.4 & (1.3) & 9.2 & $(0.4)$ & 0.8 & (1.4) \\
\hline & Viet Nam & $\mathrm{m}$ & $\mathrm{m}$ & $\mathrm{m}$ & $\mathrm{m}$ & $\mathrm{m}$ & $\mathrm{m}$ & $\mathrm{m}$ & $\mathrm{m}$ & $\mathrm{m}$ & $\mathrm{m}$ & $\mathrm{m}$ & $\mathrm{m}$ \\
\hline & Argentina** $^{* *}$ & $\mathrm{~m}$ & $\mathrm{~m}$ & $\mathrm{~m}$ & $\mathrm{~m}$ & $\mathrm{~m}$ & $\mathrm{~m}$ & $\mathrm{~m}$ & $\mathrm{~m}$ & $\mathrm{~m}$ & $\mathrm{~m}$ & $\mathrm{~m}$ & $\mathrm{~m}$ \\
\hline & Kazakhstan** & $\mathrm{m}$ & $\mathrm{m}$ & $\mathrm{m}$ & $\mathrm{m}$ & $\mathrm{m}$ & $\mathrm{m}$ & $\mathrm{m}$ & $\mathrm{m}$ & $\mathrm{m}$ & $\mathrm{m}$ & $\mathrm{m}$ & $\mathrm{m}$ \\
\hline & Malaysia** & 77.2 & (3.5) & 81.8 & $(0.6)$ & 4.6 & (3.6) & 31.3 & (3.9) & 17.5 & $(0.7)$ & -13.8 & (3.9) \\
\hline
\end{tabular}

1. A student is frequently bullied if he or she is in the top $10 \%$ of the index of exposure to bullying among all countries/economies. See Annex A1 for information on the index of exposure to bullying.

Note: Values that are statistically significant are indicated in bold (see Annex A3).

* See note at the beginning of this Annex.

* Coverage is too small to ensure comparability (see Annex A4).

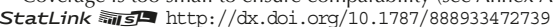


[Part 1/1]

Table III.11.21 Students' eating habits before and after school

Based on students' self-reports

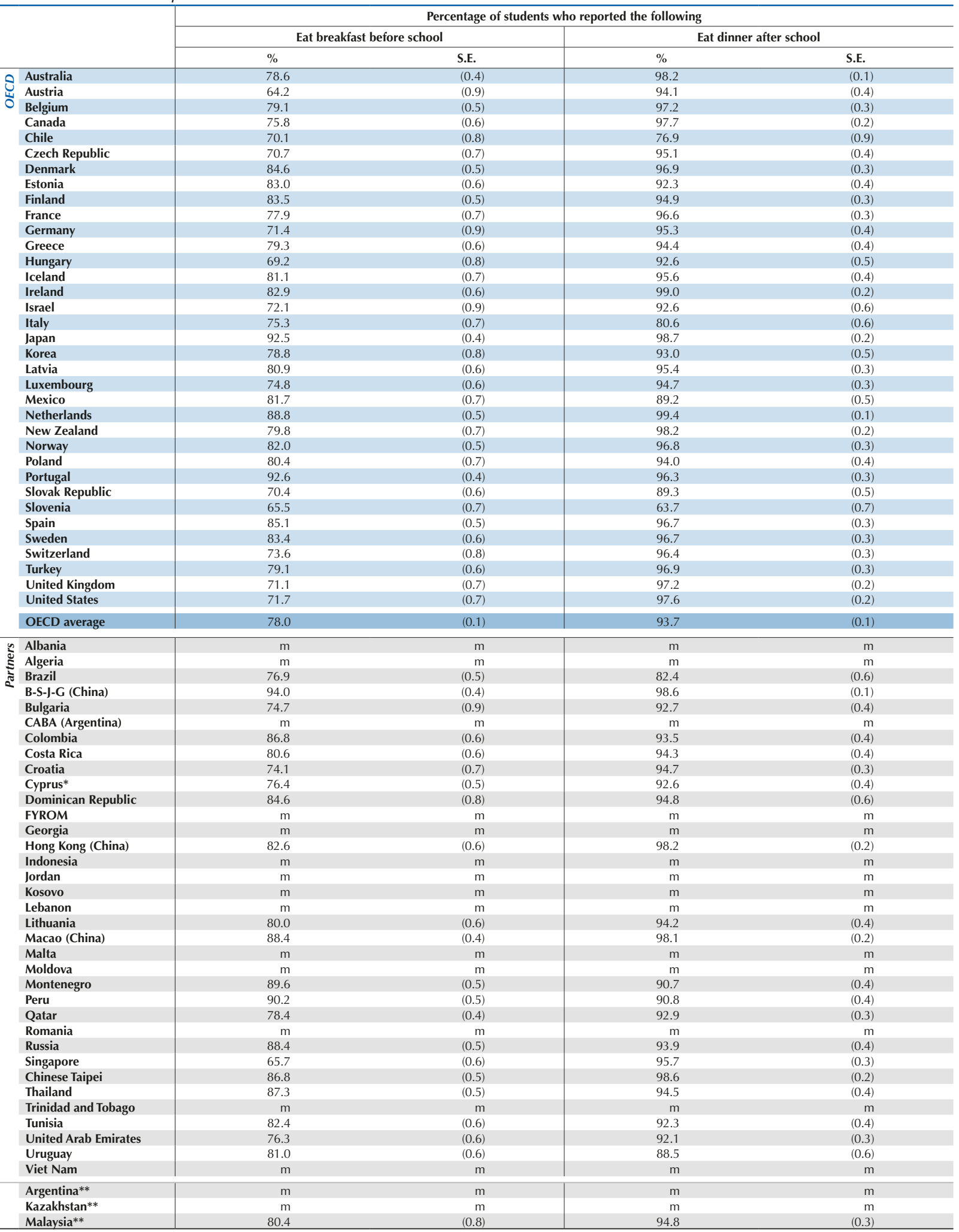

* See note at the beginning of this Annex.

** Coverage is too small to ensure comparability (see Annex A4).

StatLink न्नाओs http://dx.doi.org/10.1787/888933472760 
[Part 1/4]

Table III.11.22 Students' eating habits, by student characteristics

Percentage of students who reported "yes"

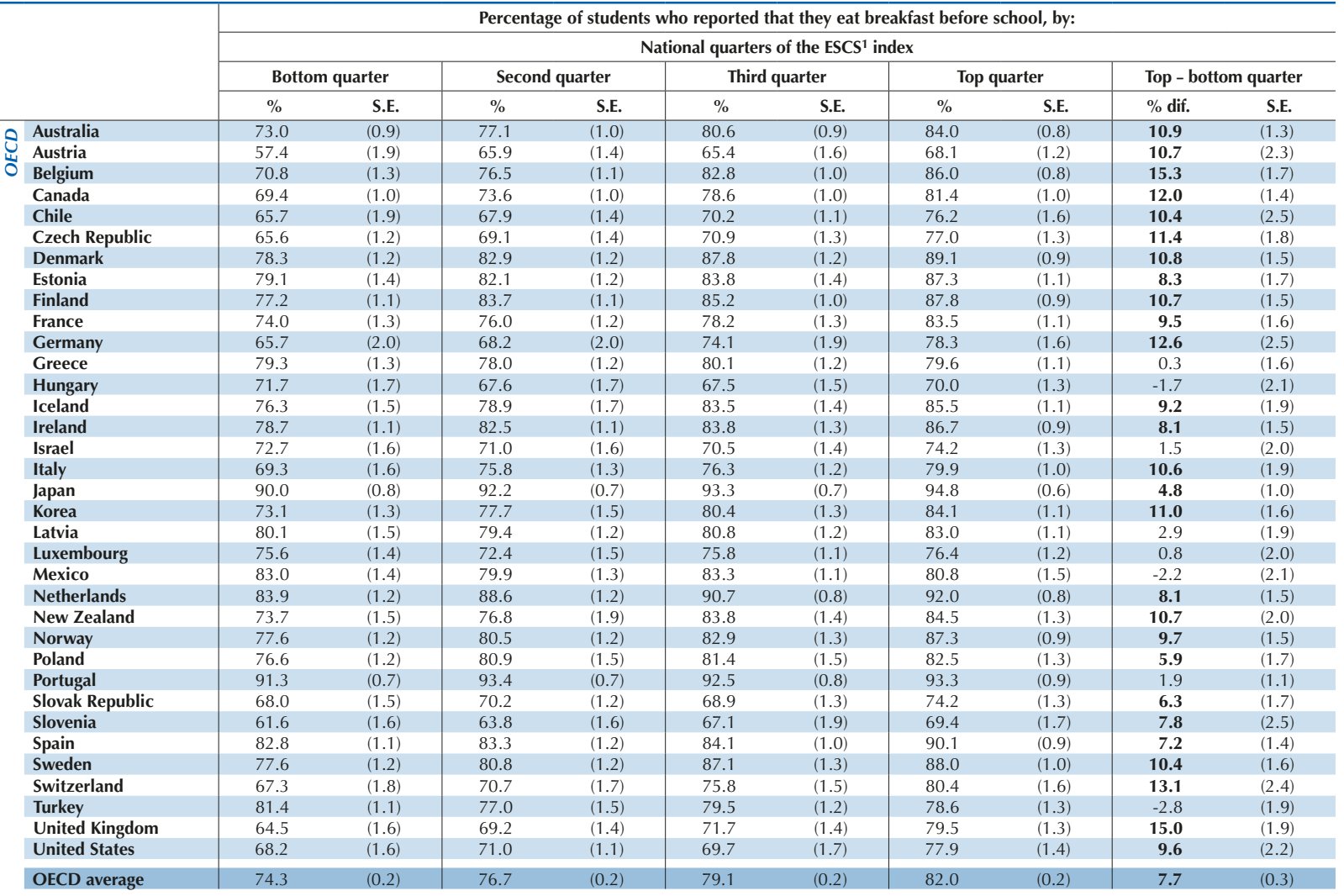

\begin{tabular}{|c|c|c|c|c|c|c|c|c|c|c|c|}
\hline \multirow{4}{*}{ ఏँ๊ } & Albania & $\mathrm{m}$ & $\mathrm{m}$ & $\mathrm{m}$ & $\mathrm{m}$ & $\mathrm{m}$ & $\mathrm{m}$ & $\mathrm{m}$ & $\mathrm{m}$ & $\mathrm{m}$ & $\mathrm{m}$ \\
\hline & Algeria & $\mathrm{m}$ & $\mathrm{m}$ & $\mathrm{m}$ & $\mathrm{m}$ & $\mathrm{m}$ & $\mathrm{m}$ & $\mathrm{m}$ & $\mathrm{m}$ & $\mathrm{m}$ & $\mathrm{m}$ \\
\hline & Brazil & 76.2 & (1.0) & 76.0 & (1.0) & 77.3 & $(0.9)$ & 77.8 & $(0.8)$ & 1.6 & (1.3) \\
\hline & B-S-J-G (China) & 92.8 & $(0.8)$ & 94.2 & $(0.8)$ & 94.2 & $(0.8)$ & 95.0 & $(0.6)$ & 2.2 & $(1.0)$ \\
\hline & Bulgaria & 75.4 & (1.7) & 75.2 & (1.5) & 74.8 & (1.5) & 73.4 & (1.6) & -2.0 & $(2.1)$ \\
\hline & CABA (Argentina) & $\mathrm{m}$ & $\mathrm{m}$ & $\mathrm{m}$ & $\mathrm{m}$ & $\mathrm{m}$ & $\mathrm{m}$ & $\mathrm{m}$ & $\mathrm{m}$ & $\mathrm{m}$ & $\mathrm{m}$ \\
\hline & Colombia & 84.7 & (1.3) & 87.1 & (1.1) & 85.9 & (1.1) & 89.3 & $(0.9)$ & 4.6 & (1.6) \\
\hline & Costa Rica & 79.4 & (1.2) & 80.4 & (1.3) & 80.2 & (1.4) & 82.2 & (1.1) & 2.8 & (1.7) \\
\hline & Croatia & 73.0 & (1.3) & 74.3 & (1.5) & 74.0 & (1.4) & 74.9 & (1.3) & 1.9 & (1.8) \\
\hline & Cyprus* & 74.5 & (1.2) & 75.5 & $(1.2)$ & 78.1 & $(1.2)$ & 77.6 & (1.3) & 3.1 & (1.9) \\
\hline & Dominican Republic & 82.6 & (1.8) & 84.9 & (1.4) & 85.8 & (1.4) & 84.7 & (1.3) & 2.1 & (2.1) \\
\hline & FYROM & $\mathrm{m}$ & $\mathrm{m}$ & $\mathrm{m}$ & $\mathrm{m}$ & $\mathrm{m}$ & $\mathrm{m}$ & $\mathrm{m}$ & $\mathrm{m}$ & $\mathrm{m}$ & $\mathrm{m}$ \\
\hline & Georgia & $\mathrm{m}$ & $\mathrm{m}$ & $\mathrm{m}$ & $\mathrm{m}$ & $\mathrm{m}$ & $\mathrm{m}$ & $\mathrm{m}$ & $\mathrm{m}$ & $\mathrm{m}$ & $\mathrm{m}$ \\
\hline & Hong Kong (China) & 81.1 & (1.0) & 82.3 & $(1.0)$ & 83.5 & (1.4) & 84.0 & $(1.2)$ & 2.8 & (1.5) \\
\hline & Indonesia & $\mathrm{m}$ & $\mathrm{m}$ & $\mathrm{m}$ & $\mathrm{m}$ & $\mathrm{m}$ & $\mathrm{m}$ & $\mathrm{m}$ & $\mathrm{m}$ & $\mathrm{m}$ & $\mathrm{m}$ \\
\hline & Jordan & $\mathrm{m}$ & $\mathrm{m}$ & $\mathrm{m}$ & $\mathrm{m}$ & $\mathrm{m}$ & $\mathrm{m}$ & $\mathrm{m}$ & $\mathrm{m}$ & $\mathrm{m}$ & $\mathrm{m}$ \\
\hline & Kosovo & $\mathrm{m}$ & $\mathrm{m}$ & $\mathrm{m}$ & $\mathrm{m}$ & $\mathrm{m}$ & $\mathrm{m}$ & $\mathrm{m}$ & $\mathrm{m}$ & $\mathrm{m}$ & $\mathrm{m}$ \\
\hline & Lebanon & $\mathrm{m}$ & $\mathrm{m}$ & $\mathrm{m}$ & $\mathrm{m}$ & $\mathrm{m}$ & $\mathrm{m}$ & $\mathrm{m}$ & $\mathrm{m}$ & $\mathrm{m}$ & $\mathrm{m}$ \\
\hline & Lithuania & 76.6 & (1.2) & 78.4 & $(1.2)$ & 81.4 & (1.3) & 84.2 & $(1.0)$ & 7.6 & (1.4) \\
\hline & Macao (China) & 87.1 & (1.0) & 89.3 & $(0.9)$ & 88.2 & $(0.9)$ & 89.1 & $(0.9)$ & 2.1 & (1.4) \\
\hline & Malta & $\mathrm{m}$ & $\mathrm{m}$ & $\mathrm{m}$ & $\mathrm{m}$ & $\mathrm{m}$ & $\mathrm{m}$ & $\mathrm{m}$ & $\mathrm{m}$ & $\mathrm{m}$ & $\mathrm{m}$ \\
\hline & Moldova & $\mathrm{m}$ & $\mathrm{m}$ & $\mathrm{m}$ & $\mathrm{m}$ & $\mathrm{m}$ & $\mathrm{m}$ & $\mathrm{m}$ & $\mathrm{m}$ & $\mathrm{m}$ & $\mathrm{m}$ \\
\hline & Montenegro & 87.7 & (1.0) & 90.4 & (1.1) & 90.8 & $(0.9)$ & 89.6 & $(0.9)$ & 1.8 & (1.3) \\
\hline & Peru & 92.0 & (0.9) & 90.6 & (1.0) & 89.4 & (1.1) & 89.4 & (1.1) & -2.5 & (1.4) \\
\hline & Qatar & 77.9 & (0.9) & 79.1 & $(0.8)$ & 79.6 & $(0.8)$ & 77.2 & $(0.8)$ & -0.7 & $(1.2)$ \\
\hline & Romania & $\mathrm{m}$ & $\mathrm{m}$ & $\mathrm{m}$ & $\mathrm{m}$ & $\mathrm{m}$ & $\mathrm{m}$ & $\mathrm{m}$ & $\mathrm{m}$ & $\mathrm{m}$ & $\mathrm{m}$ \\
\hline & Russia & 88.5 & $(0.9)$ & 88.7 & (1.3) & 87.4 & $(0.9)$ & 89.1 & (1.3) & 0.6 & (1.8) \\
\hline & Singapore & 55.5 & (1.1) & 62.4 & (1.3) & 68.6 & $(1.2)$ & 76.0 & (1.3) & 20.5 & (1.7) \\
\hline & Chinese Taipei & 88.2 & (0.9) & 87.6 & $(0.8)$ & 86.3 & (1.1) & 85.2 & $(0.9)$ & -2.9 & $(1.2)$ \\
\hline & Thailand & 87.6 & (0.9) & 88.2 & $(0.9)$ & 86.6 & $(0.9)$ & 86.8 & (1.0) & -0.8 & $(1.3)$ \\
\hline & Trinidad and Tobago & $\mathrm{m}$ & $\mathrm{m}$ & $\mathrm{m}$ & $\mathrm{m}$ & $\mathrm{m}$ & $\mathrm{m}$ & $\mathrm{m}$ & $\mathrm{m}$ & $\mathrm{m}$ & $\mathrm{m}$ \\
\hline & Tunisia & 81.0 & (1.4) & 82.6 & (1.1) & 82.5 & $(1.2)$ & 83.1 & $(0.9)$ & 2.1 & $(1.7)$ \\
\hline & United Arab Emirates & 76.2 & $(0.9)$ & 73.9 & (1.0) & 78.1 & $(0.9)$ & 77.2 & (1.0) & 1.0 & (1.3) \\
\hline & Uruguay & 78.5 & (1.5) & 80.4 & (1.4) & 80.9 & $(1.0)$ & 84.0 & (1.1) & 5.5 & (1.7) \\
\hline & Viet Nam & $\mathrm{m}$ & $\mathrm{m}$ & $\mathrm{m}$ & $\mathrm{m}$ & $\mathrm{m}$ & $\mathrm{m}$ & $\mathrm{m}$ & $\mathrm{m}$ & $\mathrm{m}$ & $\mathrm{m}$ \\
\hline & Argentina** & $\mathrm{m}$ & $\mathrm{m}$ & $\mathrm{m}$ & $\mathrm{m}$ & $\mathrm{m}$ & $\mathrm{m}$ & $\mathrm{m}$ & $\mathrm{m}$ & $\mathrm{m}$ & $\mathrm{m}$ \\
\hline & Kazakhstan** & $\mathrm{m}$ & $\mathrm{m}$ & $\mathrm{m}$ & $\mathrm{m}$ & $\mathrm{m}$ & $\mathrm{m}$ & $\mathrm{m}$ & $\mathrm{m}$ & $\mathrm{m}$ & $\mathrm{m}$ \\
\hline & Malaysia** & 77.3 & (1.4) & 80.2 & $(1.2)$ & 80.3 & $(1.2)$ & 83.9 & $(1.2)$ & 6.6 & (1.6) \\
\hline
\end{tabular}

1. ESCS refers to the PISA index of economic, social and cultural status.

Note: Values that are statistically significant are indicated in bold (see Annex A3).

* See note at the beginning of this Annex.

** Coverage is too small to ensure comparability (see Annex A4).

StatLink त्नाls $\mathrm{http}: / / \mathrm{dx}$.doi.org/10.1787/888933472777 


\section{Table III.11.22 Students' eating habits, by student characteristics}

Percentage of students who reported "yes"

\begin{tabular}{|c|c|c|c|c|c|c|c|c|c|c|c|c|c|c|c|}
\hline & \multicolumn{14}{|c|}{ Percentage of students who reported that they eat breakfast before school, by: } \\
\hline & & \multicolumn{6}{|c|}{ Gender } & & & & Imm & grant bac & round & & \\
\hline & & & & & & Gender & $\begin{array}{l}\text { fiference } \\
\text { G) }\end{array}$ & Non-i & nigrant & First-ge & ration & Second- & neration & $\begin{array}{r}\text { Differer } \\
\text { backgrour } \\
\text { firs }\end{array}$ & $\begin{array}{l}\text { Imigrant } \\
\text { nmigrant - } \\
\text { ion) }\end{array}$ \\
\hline & & Mean & S.E. & Mean & S.E. & Dif. & S.E. & Mean & S.E. & Mean & S.E. & Mean & S.E. & Dif. & S.E. \\
\hline 0 & Australia & 84.3 & $(0.5)$ & 73.0 & $(0.7)$ & 11.2 & $(0.9)$ & 78.4 & $(0.5)$ & 81.6 & (1.3) & 77.3 & (1.6) & -3.2 & (1.4) \\
\hline 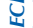 & Austria & 69.8 & (1.1) & 58.6 & $(1.2)$ & 11.3 & (1.5) & 65.6 & $(1.0)$ & 62.5 & (2.2) & 56.7 & (1.9) & 3.0 & (2.5) \\
\hline 0 & Belgium & 82.7 & $(0.6)$ & 75.5 & $(0.7)$ & 7.1 & (1.0) & 79.7 & $(0.6)$ & 77.5 & (1.8) & 75.0 & (1.5) & 2.2 & (1.9) \\
\hline & Canada & 80.2 & $(0.7)$ & 71.5 & $(0.8)$ & 8.7 & $(0.9)$ & 75.3 & $(0.7)$ & 79.6 & $(1.2)$ & 74.7 & $(1.0)$ & -4.3 & $(1.2)$ \\
\hline & Chile & 76.1 & $(0.9)$ & 64.2 & $(1.2)$ & 11.9 & (1.4) & 70.1 & $(0.8)$ & 65.4 & (5.0) & c & $\mathrm{C}$ & 4.8 & $(5.1)$ \\
\hline & Czech Republic & 72.8 & (1.1) & 68.5 & (1.1) & 4.2 & (1.7) & 70.8 & $(0.8)$ & 66.1 & (6.5) & 64.7 & $(4.9)$ & 4.7 & (6.7) \\
\hline & Denmark & 87.8 & $(0.7)$ & 81.4 & $(0.8)$ & 6.3 & $(1.1)$ & 85.3 & $(0.6)$ & 80.0 & (2.9) & 77.5 & (1.7) & 5.3 & $(2.8)$ \\
\hline & Estonia & 84.9 & $(0.8)$ & 81.1 & (1.0) & 3.9 & (1.3) & 83.3 & $(0.7)$ & 86.9 & (5.2) & 80.2 & (1.9) & -3.6 & (5.1) \\
\hline & Finland & 85.1 & $(0.8)$ & 81.8 & $(0.7)$ & 3.3 & $(1.0)$ & 83.7 & $(0.5)$ & 78.7 & (3.9) & 80.2 & $(4.6)$ & 5.0 & (3.9) \\
\hline & France & 84.1 & $(0.8)$ & 72.1 & $(0.9)$ & 12.0 & $(0.9)$ & 79.2 & $(0.7)$ & 71.3 & (3.5) & 67.7 & $(2.3)$ & 7.9 & (3.5) \\
\hline & Germany & 74.8 & $(1.2)$ & 68.2 & $(1.2)$ & 6.7 & (1.5) & 73.3 & $(1.0)$ & 61.6 & (5.1) & 62.6 & (2.6) & 11.8 & $(5.2)$ \\
\hline & Greece & 82.6 & $(0.8)$ & 75.9 & (1.0) & 6.7 & (1.3) & 78.9 & $(0.6)$ & 83.8 & (3.5) & 82.7 & $(2.0)$ & -5.0 & (3.5) \\
\hline & Hungary & 75.6 & (1.0) & 63.0 & (1.0) & 12.6 & (1.3) & 69.4 & $(0.9)$ & 57.9 & (8.3) & 69.0 & $(4.7)$ & 11.4 & (8.4) \\
\hline & Iceland & 86.3 & $(0.9)$ & 76.4 & (1.1) & 9.9 & (1.4) & 81.1 & $(0.8)$ & 84.8 & (4.1) & C & c & -3.6 & $(4.1)$ \\
\hline & Ireland & 87.3 & $(0.6)$ & 78.4 & (1.0) & 8.9 & $(1.1)$ & 83.5 & $(0.7)$ & 81.1 & (1.4) & 73.7 & $(2.9)$ & 2.4 & (1.5) \\
\hline & Israel & 77.1 & (1.4) & 67.5 & $(0.9)$ & 9.6 & (1.6) & 72.1 & $(1.0)$ & 79.2 & (3.5) & 69.6 & $(2.0)$ & -7.1 & (3.7) \\
\hline & Italy & 81.0 & $(0.9)$ & 69.9 & $(0.9)$ & 11.0 & $(1.1)$ & 75.5 & $(0.8)$ & 72.8 & (2.7) & 73.3 & (2.6) & 2.7 & $(2.8)$ \\
\hline & Japan & 91.7 & $(0.6)$ & 93.2 & $(0.5)$ & -1.5 & $(0.8)$ & 92.5 & $(0.4)$ & C & c & C & c & c & c \\
\hline & Korea & 81.2 & $(1.0)$ & 76.2 & $(1.2)$ & 5.0 & (1.5) & 78.8 & $(0.8)$ & c & C & $\mathrm{m}$ & $\mathrm{m}$ & c & c \\
\hline & Latvia & 83.0 & $(0.7)$ & 78.9 & (1.0) & 4.1 & $(1.2)$ & 80.7 & $(0.6)$ & 73.5 & (7.5) & 86.7 & (2.5) & 7.2 & $(7.5)$ \\
\hline & Luxembourg & 77.6 & $(0.9)$ & 72.2 & $(0.9)$ & 5.4 & $(1.2)$ & 74.1 & $(0.9)$ & 78.3 & (1.1) & 73.6 & (1.1) & -4.3 & (1.4) \\
\hline & Mexico & 84.4 & $(0.8)$ & 78.9 & (1.0) & 5.5 & $(1.1)$ & 81.7 & $(0.8)$ & 84.9 & (5.3) & C & C & -3.2 & $(5.2)$ \\
\hline & Netherlands & 91.3 & $(0.6)$ & 86.4 & $(0.8)$ & 4.9 & (1.0) & 90.1 & $(0.6)$ & 73.6 & $(4.8)$ & 80.1 & (1.8) & 16.5 & (4.9) \\
\hline & New Zealand & 85.2 & $(0.7)$ & 74.4 & $(1.2)$ & 10.8 & (1.4) & 79.4 & $(0.8)$ & 83.4 & (1.8) & 78.2 & $(2.0)$ & -4.0 & $(1.8)$ \\
\hline & Norway & 84.8 & $(0.8)$ & 79.4 & $(0.9)$ & 5.4 & $(1.3)$ & 82.6 & $(0.5)$ & 78.5 & (2.5) & 78.1 & $(2.7)$ & 4.0 & (2.5) \\
\hline & Poland & 84.5 & $(0.9)$ & 76.2 & (1.0) & 8.3 & $(1.2)$ & 80.3 & $(0.8)$ & C & C & C & c & c & c \\
\hline & Portugal & 95.4 & $(0.4)$ & 89.8 & $(0.6)$ & 5.6 & $(0.7)$ & 93.2 & $(0.3)$ & 82.8 & (3.5) & 88.3 & $(2.8)$ & 10.4 & (3.4) \\
\hline & Slovak Republic & 73.7 & $(0.8)$ & 67.1 & (1.1) & 6.6 & (1.3) & 70.2 & $(0.7)$ & c & C & C & c & c & c \\
\hline & Slovenia & 69.3 & $(1.0)$ & 61.5 & (1.0) & 7.9 & (1.4) & 66.6 & $(0.7)$ & 51.6 & $(4.7)$ & 52.4 & $(4.1)$ & 15.0 & $(4.7)$ \\
\hline & Spain & 88.8 & $(0.6)$ & 81.4 & $(0.7)$ & 7.4 & (1.0) & 85.7 & $(0.5)$ & 80.2 & (1.7) & 80.6 & $(4.9)$ & 5.5 & (1.9) \\
\hline & Sweden & 85.9 & $(0.8)$ & 80.9 & $(0.8)$ & 5.0 & (1.1) & 85.2 & $(0.7)$ & 78.3 & $(2.2)$ & 71.9 & (3.0) & 6.8 & $(2.3)$ \\
\hline & Switzerland & 75.7 & $(1.0)$ & 71.3 & $(1.2)$ & 4.3 & (1.4) & 74.8 & $(0.9)$ & 75.7 & (2.8) & 69.6 & (1.7) & -0.9 & $(2.8)$ \\
\hline & Turkey & 84.1 & $(0.8)$ & 74.2 & $(0.9)$ & 9.8 & $(1.2)$ & 79.2 & $(0.6)$ & c & c & c & c & c & c \\
\hline & United Kingdom & 78.0 & $(0.8)$ & 64.0 & (1.1) & 14.0 & (1.3) & 70.0 & $(0.7)$ & 77.6 & (2.0) & 76.1 & (2.4) & -7.6 & $(2.0)$ \\
\hline & United States & 75.5 & (1.0) & 68.0 & $(0.9)$ & 7.5 & (1.4) & 71.6 & $(0.8)$ & 72.7 & $(2.3)$ & 71.4 & $(1.7)$ & -1.2 & (2.5) \\
\hline & OECD average & 81.8 & $(0.1)$ & 74.3 & $(0.2)$ & 7.5 & $(0.2)$ & 78.3 & $(0.1)$ & 75.4 & $(0.7)$ & 73.8 & $(0.5)$ & 2.6 & $(0.7)$ \\
\hline 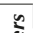 & Albania & $\mathrm{m}$ & $\mathrm{m}$ & $\mathrm{m}$ & $\mathrm{m}$ & $\mathrm{m}$ & $\mathrm{m}$ & $\mathrm{m}$ & $\mathrm{m}$ & $\mathrm{m}$ & $\mathrm{m}$ & $\mathrm{m}$ & $\mathrm{m}$ & $\mathrm{m}$ & $\mathrm{m}$ \\
\hline$\Xi$ & Algeria & $\mathrm{m}$ & $\mathrm{m}$ & $\mathrm{m}$ & $\mathrm{m}$ & $\mathrm{m}$ & $\mathrm{m}$ & $\mathrm{m}$ & $\mathrm{m}$ & $\mathrm{m}$ & $\mathrm{m}$ & $\mathrm{m}$ & $\mathrm{m}$ & $\mathrm{m}$ & $\mathrm{m}$ \\
\hline ฝั & Brazil & 79.1 & $(0.7)$ & 74.8 & $(0.7)$ & 4.3 & (1.0) & 76.7 & $(0.5)$ & C & c & 79.7 & (6.9) & c & c \\
\hline & B-S-J-G (China) & 93.5 & $(0.5)$ & 94.6 & $(0.5)$ & -1.0 & $(0.6)$ & 94.1 & $(0.4)$ & C & C & C & c & c & c \\
\hline & Bulgaria & 80.4 & (1.0) & 68.7 & (1.1) & 11.7 & $(1.3)$ & 74.5 & $(0.9)$ & c & C & c & c & c & c \\
\hline & CABA (Argentina) & $\mathrm{m}$ & $\mathrm{m}$ & $\mathrm{m}$ & $\mathrm{m}$ & $\mathrm{m}$ & $\mathrm{m}$ & $\mathrm{m}$ & $\mathrm{m}$ & $\mathrm{m}$ & $\mathrm{m}$ & $\mathrm{m}$ & $\mathrm{m}$ & $\mathrm{m}$ & $\mathrm{m}$ \\
\hline & Colombia & 90.0 & $(0.7)$ & 83.9 & $(0.8)$ & 6.1 & $(0.9)$ & 86.8 & $(0.6)$ & $\mathrm{C}$ & c & $\mathrm{c}$ & c & $\mathrm{c}$ & c \\
\hline & Costa Rica & 85.0 & $(0.9)$ & 76.4 & $(0.8)$ & 8.5 & $(1.2)$ & 80.8 & $(0.7)$ & 78.3 & (4.5) & 78.4 & $(2.2)$ & 2.4 & (4.6) \\
\hline & Croatia & 79.2 & $(0.9)$ & 69.4 & (1.1) & 9.8 & (1.4) & 73.9 & $(0.8)$ & 79.7 & (4.1) & 73.7 & (2.4) & -5.8 & $(4.0)$ \\
\hline & Cyprus* & 79.5 & $(0.8)$ & 73.6 & (0.8) & 5.9 & $(1.2)$ & 76.7 & $(0.5)$ & 75.1 & $(2.0)$ & 71.8 & (3.9) & 1.5 & (2.1) \\
\hline & Dominican Republic & 88.9 & $(0.9)$ & 80.5 & (1.3) & 8.4 & (1.5) & 84.2 & $(0.9)$ & $\mathrm{c}$ & c & 93.3 & $(4.0)$ & c & c \\
\hline & FYROM & $\mathrm{m}$ & $\mathrm{m}$ & $\mathrm{m}$ & $\mathrm{m}$ & $\mathrm{m}$ & $\mathrm{m}$ & $\mathrm{m}$ & $\mathrm{m}$ & $\mathrm{m}$ & $\mathrm{m}$ & $\mathrm{m}$ & $\mathrm{m}$ & $\mathrm{m}$ & $\mathrm{m}$ \\
\hline & Georgia & $\mathrm{m}$ & $\mathrm{m}$ & $\mathrm{m}$ & $\mathrm{m}$ & $\mathrm{m}$ & $\mathrm{m}$ & $\mathrm{m}$ & $\mathrm{m}$ & $\mathrm{m}$ & $\mathrm{m}$ & $\mathrm{m}$ & $\mathrm{m}$ & $\mathrm{m}$ & $\mathrm{m}$ \\
\hline & Hong Kong (China) & 82.2 & $(0.9)$ & 83.1 & $(0.8)$ & -0.8 & $(1.3)$ & 81.3 & $(0.8)$ & 86.6 & (1.3) & 84.3 & $(1.1)$ & -5.3 & (1.4) \\
\hline & Indonesia & $\mathrm{m}$ & $\mathrm{m}$ & $\mathrm{m}$ & $\mathrm{m}$ & $\mathrm{m}$ & $\mathrm{m}$ & $\mathrm{m}$ & $\mathrm{m}$ & $\mathrm{m}$ & $\mathrm{m}$ & $\mathrm{m}$ & $\mathrm{m}$ & $\mathrm{m}$ & $\mathrm{m}$ \\
\hline & Jordan & $\mathrm{m}$ & $\mathrm{m}$ & $\mathrm{m}$ & $\mathrm{m}$ & $\mathrm{m}$ & $\mathrm{m}$ & $\mathrm{m}$ & $\mathrm{m}$ & $\mathrm{m}$ & $\mathrm{m}$ & $\mathrm{m}$ & $\mathrm{m}$ & $\mathrm{m}$ & $\mathrm{m}$ \\
\hline & Kosovo & $\mathrm{m}$ & $\mathrm{m}$ & $\mathrm{m}$ & $\mathrm{m}$ & $\mathrm{m}$ & $\mathrm{m}$ & $\mathrm{m}$ & $\mathrm{m}$ & $\mathrm{m}$ & $\mathrm{m}$ & $\mathrm{m}$ & $\mathrm{m}$ & $\mathrm{m}$ & $\mathrm{m}$ \\
\hline & Lebanon & $\mathrm{m}$ & $\mathrm{m}$ & $\mathrm{m}$ & $\mathrm{m}$ & $\mathrm{m}$ & $\mathrm{m}$ & $\mathrm{m}$ & $\mathrm{m}$ & $\mathrm{m}$ & $\mathrm{m}$ & $\mathrm{m}$ & $\mathrm{m}$ & $\mathrm{m}$ & $\mathrm{m}$ \\
\hline & Lithuania & 84.1 & $(0.8)$ & 76.1 & $(0.9)$ & 8.0 & $(1.2)$ & 80.0 & $(0.6)$ & $\mathrm{c}$ & c & 85.4 & (3.0) & c & c \\
\hline & Macao (China) & 88.7 & $(0.6)$ & 88.1 & $(0.7)$ & 0.6 & $(1.0)$ & 87.1 & $(0.7)$ & 90.0 & (1.0) & 88.9 & $(0.7)$ & -2.9 & $(1.2)$ \\
\hline & Malta & $\mathrm{m}$ & $\mathrm{m}$ & $\mathrm{m}$ & $\mathrm{m}$ & $\mathrm{m}$ & $\mathrm{m}$ & $\mathrm{m}$ & $\mathrm{m}$ & $\mathrm{m}$ & $\mathrm{m}$ & $\mathrm{m}$ & $\mathrm{m}$ & $\mathrm{m}$ & $\mathrm{m}$ \\
\hline & Moldova & $\mathrm{m}$ & $\mathrm{m}$ & $\mathrm{m}$ & $\mathrm{m}$ & $\mathrm{m}$ & $\mathrm{m}$ & $\mathrm{m}$ & $\mathrm{m}$ & $\mathrm{m}$ & $\mathrm{m}$ & $\mathrm{m}$ & $\mathrm{m}$ & $\mathrm{m}$ & $\mathrm{m}$ \\
\hline & Montenegro & 90.5 & $(0.6)$ & 88.8 & $(0.7)$ & 1.7 & $(0.9)$ & 90.0 & $(0.5)$ & 80.5 & $(4.2)$ & 84.3 & (2.5) & 9.5 & $(4.2)$ \\
\hline & Peru & 92.1 & $(0.7)$ & 88.1 & $(0.7)$ & 4.1 & $(0.9)$ & 90.1 & $(0.6)$ & C & C & C & c & c & c \\
\hline & Qatar & 83.3 & $(0.6)$ & 74.3 & $(0.6)$ & 9.0 & $(0.9)$ & 76.2 & $(0.7)$ & 80.2 & $(0.6)$ & 79.6 & $(1.0)$ & -3.9 & $(0.9)$ \\
\hline & Romania & $\mathrm{m}$ & $\mathrm{m}$ & $\mathrm{m}$ & $\mathrm{m}$ & $\mathrm{m}$ & $\mathrm{m}$ & $\mathrm{m}$ & $\mathrm{m}$ & $\mathrm{m}$ & $\mathrm{m}$ & $\mathrm{m}$ & $\mathrm{m}$ & $\mathrm{m}$ & $\mathrm{m}$ \\
\hline & Russia & 90.4 & $(0.7)$ & 86.6 & $(0.7)$ & 3.8 & $(1.0)$ & 88.5 & $(0.5)$ & 90.8 & (2.3) & 85.0 & $(2.8)$ & -2.3 & $(2.3)$ \\
\hline & Singapore & 69.0 & $(0.9)$ & 62.1 & $(0.9)$ & 6.9 & (1.3) & 63.2 & $(0.7)$ & 76.8 & (1.9) & 72.0 & $(2.3)$ & -13.6 & $(2.1)$ \\
\hline & Chinese Taipei & 88.8 & $(0.6)$ & 84.9 & $(0.7)$ & 3.9 & $(1.0)$ & 86.8 & $(0.5)$ & $\mathrm{c}$ & C & c & c & c & c \\
\hline & Thailand & 87.9 & $(0.7)$ & 86.9 & $(0.7)$ & 1.0 & $(1.0)$ & 87.3 & $(0.5)$ & c & C & 84.0 & (5.4) & c & c \\
\hline & Trinidad and Tobago & $\mathrm{m}$ & $\mathrm{m}$ & $\mathrm{m}$ & $\mathrm{m}$ & $\mathrm{m}$ & $\mathrm{m}$ & $\mathrm{m}$ & $\mathrm{m}$ & $\mathrm{m}$ & $\mathrm{m}$ & $\mathrm{m}$ & $\mathrm{m}$ & $\mathrm{m}$ & $\mathrm{m}$ \\
\hline & Tunisia & 88.3 & $(0.8)$ & 77.4 & $(0.9)$ & 10.9 & (1.1) & 82.4 & $(0.6)$ & c & C & 74.6 & $(6.0)$ & c & c \\
\hline & United Arab Emirates & 82.7 & $(0.7)$ & 70.6 & $(0.8)$ & 12.2 & (1.1) & 75.5 & $(0.7)$ & 77.1 & $(0.8)$ & 76.7 & $(1.0)$ & -1.6 & (1.1) \\
\hline & Uruguay & 84.7 & $(0.9)$ & 77.9 & (1.0) & 6.9 & $(1.3)$ & 81.0 & $(0.6)$ & $\mathrm{C}$ & $\mathrm{C}$ & c & c & $\mathrm{c}$ & c \\
\hline & Viet Nam & $\mathrm{m}$ & $\mathrm{m}$ & $\mathrm{m}$ & $\mathrm{m}$ & $\mathrm{m}$ & $\mathrm{m}$ & $\mathrm{m}$ & $\mathrm{m}$ & $\mathrm{m}$ & $\mathrm{m}$ & $\mathrm{m}$ & $\mathrm{m}$ & $\mathrm{m}$ & $\mathrm{m}$ \\
\hline & Argentina** & $\mathrm{m}$ & $\mathrm{m}$ & $\mathrm{m}$ & $\mathrm{m}$ & $\mathrm{m}$ & $\mathrm{m}$ & $\mathrm{m}$ & $\mathrm{m}$ & $\mathrm{m}$ & $\mathrm{m}$ & $\mathrm{m}$ & $\mathrm{m}$ & $\mathrm{m}$ & $\mathrm{m}$ \\
\hline & Kazakhstan** & $\mathrm{m}$ & $\mathrm{m}$ & $\mathrm{m}$ & $\mathrm{m}$ & $\mathrm{m}$ & $\mathrm{m}$ & $\mathrm{m}$ & $\mathrm{m}$ & $\mathrm{m}$ & $\mathrm{m}$ & $\mathrm{m}$ & $\mathrm{m}$ & $\mathrm{m}$ & $\mathrm{m}$ \\
\hline & Malaysia** & 82.4 & $(0.9)$ & 78.7 & $(1.0)$ & 3.7 & $(1.1)$ & 80.5 & $(0.8)$ & $\mathrm{C}$ & $\mathrm{C}$ & 75.1 & $(6.7)$ & C & c \\
\hline
\end{tabular}

1. ESCS refers to the PISA index of economic, social and cultural status.

Note: Values that are statistically significant are indicated in bold (see Annex A3).

* See note at the beginning of this Annex.

** Coverage is too small to ensure comparability (see Annex A4).

StatLink 규넨 $\mathrm{http}: / / \mathrm{dx}$.doi.org/10.1787/888933472777 
[Part 3/4]

Table III.11.22 Students' eating habits, by student characteristics

Percentage of students who reported "yes"

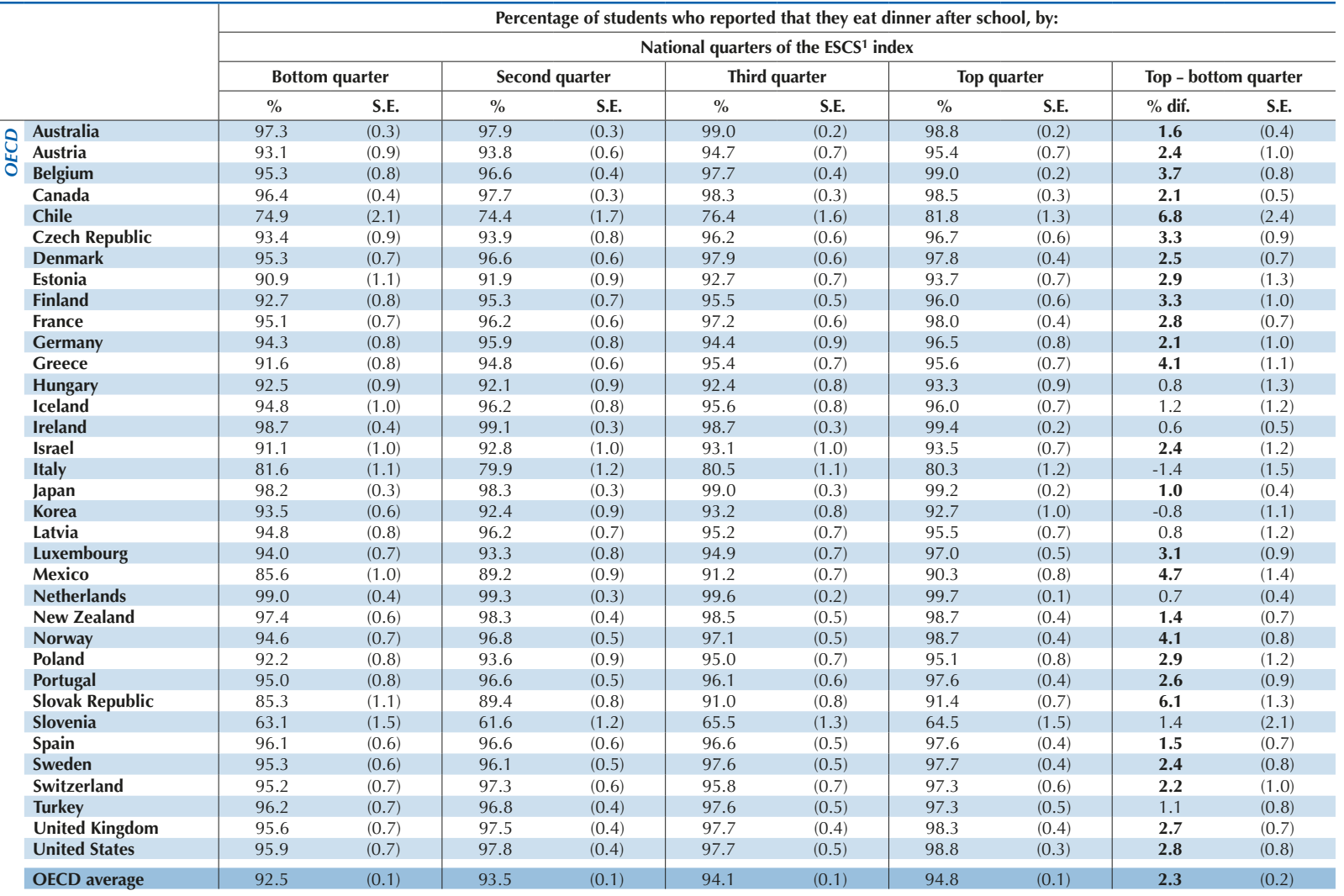

\begin{tabular}{|c|c|c|c|c|c|c|c|c|c|c|c|}
\hline \multirow{4}{*}{ 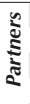 } & Albania & $\mathrm{m}$ & $\mathrm{m}$ & $\mathrm{m}$ & $\mathrm{m}$ & $\mathrm{m}$ & $\mathrm{m}$ & $\mathrm{m}$ & $\mathrm{m}$ & $\mathrm{m}$ & $\mathrm{m}$ \\
\hline & Algeria & $\mathrm{m}$ & $\mathrm{m}$ & $\mathrm{m}$ & $\mathrm{m}$ & $\mathrm{m}$ & $\mathrm{m}$ & $\mathrm{m}$ & $\mathrm{m}$ & $\mathrm{m}$ & $\mathrm{m}$ \\
\hline & Brazil & 81.9 & $(0.9)$ & 82.6 & $(1.0)$ & 81.8 & $(1.0)$ & 83.2 & (1.1) & 1.2 & $(1.4)$ \\
\hline & B-S-J-G (China) & 98.5 & $(0.4)$ & 98.6 & $(0.5)$ & 98.5 & $(0.4)$ & 98.6 & $(0.3)$ & 0.2 & $(0.5)$ \\
\hline & Bulgaria & 90.7 & $(0.9)$ & 92.6 & $(0.9)$ & 93.2 & $(0.8)$ & 94.0 & $(0.8)$ & 3.3 & (1.3) \\
\hline & CABA (Argentina) & $\mathrm{m}$ & $\mathrm{m}$ & $\mathrm{m}$ & $\mathrm{m}$ & $\mathrm{m}$ & $\mathrm{m}$ & $\mathrm{m}$ & $\mathrm{m}$ & $\mathrm{m}$ & $\mathrm{m}$ \\
\hline & Colombia & 93.4 & $(0.7)$ & 93.0 & $(0.7)$ & 93.1 & $(0.8)$ & 94.5 & $(0.7)$ & 1.0 & $(0.9)$ \\
\hline & Costa Rica & 94.2 & $(0.8)$ & 93.7 & $(0.7)$ & 94.4 & $(0.7)$ & 95.1 & $(0.7)$ & 0.9 & $(1.1)$ \\
\hline & Croatia & 94.0 & $(0.6)$ & 94.8 & $(0.6)$ & 95.4 & $(0.6)$ & 94.7 & $(0.6)$ & 0.6 & $(0.9)$ \\
\hline & Cyprus* & 90.2 & $(0.8)$ & 92.2 & $(0.7)$ & 94.0 & $(0.8)$ & 93.9 & $(0.7)$ & 3.7 & $(1.0)$ \\
\hline & Dominican Republic & 92.1 & (1.4) & 94.4 & (1.0) & 94.8 & $(0.9)$ & 96.8 & $(0.7)$ & 4.7 & (1.6) \\
\hline & FYROM & $\mathrm{m}$ & $\mathrm{m}$ & $\mathrm{m}$ & $\mathrm{m}$ & $\mathrm{m}$ & $\mathrm{m}$ & $\mathrm{m}$ & $\mathrm{m}$ & $\mathrm{m}$ & $\mathrm{m}$ \\
\hline & Georgia & $\mathrm{m}$ & $\mathrm{m}$ & $\mathrm{m}$ & $\mathrm{m}$ & $\mathrm{m}$ & $\mathrm{m}$ & $\mathrm{m}$ & $\mathrm{m}$ & $\mathrm{m}$ & $\mathrm{m}$ \\
\hline & Hong Kong (China) & 98.1 & $(0.4)$ & 97.6 & $(0.5)$ & 98.8 & $(0.3)$ & 98.4 & (0.4) & 0.2 & $(0.6)$ \\
\hline & Indonesia & $\mathrm{m}$ & $\mathrm{m}$ & $\mathrm{m}$ & $\mathrm{m}$ & $\mathrm{m}$ & $\mathrm{m}$ & $\mathrm{m}$ & $\mathrm{m}$ & $\mathrm{m}$ & $\mathrm{m}$ \\
\hline & Jordan & $\mathrm{m}$ & $\mathrm{m}$ & $\mathrm{m}$ & $\mathrm{m}$ & $\mathrm{m}$ & $\mathrm{m}$ & $\mathrm{m}$ & $\mathrm{m}$ & $\mathrm{m}$ & $\mathrm{m}$ \\
\hline & Kosovo & $\mathrm{m}$ & $\mathrm{m}$ & $\mathrm{m}$ & $\mathrm{m}$ & $\mathrm{m}$ & $\mathrm{m}$ & $\mathrm{m}$ & $\mathrm{m}$ & $\mathrm{m}$ & $\mathrm{m}$ \\
\hline & Lebanon & $\mathrm{m}$ & $\mathrm{m}$ & $\mathrm{m}$ & $\mathrm{m}$ & $\mathrm{m}$ & $\mathrm{m}$ & $\mathrm{m}$ & $\mathrm{m}$ & $\mathrm{m}$ & $\mathrm{m}$ \\
\hline & Lithuania & 93.1 & $(0.7)$ & 95.1 & $(0.7)$ & 93.8 & $(0.7)$ & 94.8 & $(0.6)$ & 1.7 & $(0.9)$ \\
\hline & Macao (China) & 97.4 & $(0.4)$ & 98.8 & $(0.3)$ & 97.8 & $(0.5)$ & 98.4 & $(0.4)$ & 1.0 & $(0.6)$ \\
\hline & Malta & $\mathrm{m}$ & $\mathrm{m}$ & $\mathrm{m}$ & $\mathrm{m}$ & $\mathrm{m}$ & $\mathrm{m}$ & $\mathrm{m}$ & $\mathrm{m}$ & $\mathrm{m}$ & $\mathrm{m}$ \\
\hline & Moldova & $\mathrm{m}$ & $\mathrm{m}$ & $\mathrm{m}$ & $\mathrm{m}$ & $\mathrm{m}$ & $\mathrm{m}$ & $\mathrm{m}$ & $\mathrm{m}$ & $\mathrm{m}$ & $\mathrm{m}$ \\
\hline & Montenegro & 87.2 & $(1.0)$ & 92.0 & $(0.8)$ & 91.6 & $(0.7)$ & 91.9 & $(0.7)$ & 4.7 & $(1.1)$ \\
\hline & Peru & 89.1 & (1.1) & 90.3 & $(1.0)$ & 91.4 & $(0.9)$ & 91.6 & $(0.8)$ & 2.5 & $(1.3)$ \\
\hline & Qatar & 90.4 & $(0.7)$ & 93.6 & $(0.5)$ & 94.3 & $(0.5)$ & 93.3 & $(0.4)$ & 2.9 & $(0.8)$ \\
\hline & Romania & $\mathrm{m}$ & $\mathrm{m}$ & $\mathrm{m}$ & $\mathrm{m}$ & $\mathrm{m}$ & $\mathrm{m}$ & $\mathrm{m}$ & $\mathrm{m}$ & $\mathrm{m}$ & $\mathrm{m}$ \\
\hline & Russia & 92.5 & $(1.0)$ & 93.2 & $(0.8)$ & 94.7 & $(0.7)$ & 95.2 & $(0.7)$ & 2.7 & $(1.3)$ \\
\hline & Singapore & 93.1 & $(0.9)$ & 95.2 & $(0.6)$ & 97.0 & $(0.5)$ & 97.4 & (0.4) & 4.3 & $(1.0)$ \\
\hline & Chinese Taipei & 98.1 & $(0.3)$ & 98.6 & $(0.3)$ & 98.7 & $(0.3)$ & 99.0 & $(0.2)$ & 0.9 & $(0.4)$ \\
\hline & Thailand & 94.2 & $(0.7)$ & 94.5 & $(0.7)$ & 95.0 & $(0.6)$ & 94.4 & $(0.7)$ & 0.2 & $(0.8)$ \\
\hline & Trinidad and Tobago & $\mathrm{m}$ & $\mathrm{m}$ & $\mathrm{m}$ & $\mathrm{m}$ & $\mathrm{m}$ & $\mathrm{m}$ & $\mathrm{m}$ & $\mathrm{m}$ & $\mathrm{m}$ & $\mathrm{m}$ \\
\hline & Tunisia & 92.1 & (1.0) & 91.9 & $(0.9)$ & 91.8 & $(0.9)$ & 93.4 & (0.8) & 1.4 & $(1.2)$ \\
\hline & United Arab Emirates & 90.4 & $(0.7)$ & 91.5 & $(0.7)$ & 93.3 & $(0.6)$ & 93.0 & $(0.6)$ & 2.6 & $(1.0)$ \\
\hline & Uruguay & 87.0 & (1.0) & 87.6 & (1.3) & 88.1 & (1.1) & 90.9 & (1.0) & 4.0 & $(1.5)$ \\
\hline & Viet Nam & $\mathrm{m}$ & $\mathrm{m}$ & $\mathrm{m}$ & $\mathrm{m}$ & $\mathrm{m}$ & $\mathrm{m}$ & $\mathrm{m}$ & $\mathrm{m}$ & $\mathrm{m}$ & $\mathrm{m}$ \\
\hline & Argentina $^{* *}$ & $\mathrm{~m}$ & $\mathrm{~m}$ & $\mathrm{~m}$ & $\mathrm{~m}$ & $\mathrm{~m}$ & $\mathrm{~m}$ & $\mathrm{~m}$ & $\mathrm{~m}$ & $\mathrm{~m}$ & $\mathrm{~m}$ \\
\hline & Kazakhstan** & $\mathrm{m}$ & $\mathrm{m}$ & $\mathrm{m}$ & $\mathrm{m}$ & $\mathrm{m}$ & $\mathrm{m}$ & $\mathrm{m}$ & $\mathrm{m}$ & $\mathrm{m}$ & $\mathrm{m}$ \\
\hline & Malaysia** & 93.6 & $(0.6)$ & 94.3 & $(0.6)$ & 94.9 & $(0.6)$ & 96.2 & $(0.5)$ & 2.6 & $(0.8)$ \\
\hline
\end{tabular}

1. ESCS refers to the PISA index of economic, social and cultural status.

Note: Values that are statistically significant are indicated in bold (see Annex A3).

* See note at the beginning of this Annex.

** Coverage is too small to ensure comparability (see Annex A4).

StatLink त्नाls $\mathrm{http}: / / \mathrm{dx}$.doi.org/10.1787/888933472777 


\section{Table III.11.22 Students' eating habits, by student characteristics}

Percentage of students who reported "yes"

\begin{tabular}{|c|c|c|c|c|c|c|c|c|c|c|c|c|c|c|c|}
\hline & \multicolumn{14}{|c|}{ Percentage of students who reported that they eat dinner after school, by: } \\
\hline & & \multicolumn{6}{|c|}{ Gender } & & & & Imm & grant bac & round & & \\
\hline & & & & & & Gender & $\begin{array}{l}\text { ference } \\
\text { G) }\end{array}$ & Non-i & nigrant & First-g & neration & Second- & neration & $\begin{array}{r}\text { Differer } \\
\text { backgrour } \\
\text { firs }\end{array}$ & $\begin{array}{l}\text { mmigrant } \\
\text { immigrant - } \\
\text { tion) }\end{array}$ \\
\hline & & Mean & S.E. & Mean & S.E. & Dif. & S.E. & Mean & S.E. & Mean & S.E. & Mean & S.E. & Dif. & S.E. \\
\hline 0 & Australia & 98.7 & $(0.2)$ & 97.8 & $(0.2)$ & 0.9 & $(0.3)$ & 98.4 & $(0.1)$ & 97.3 & $(0.5)$ & 98.5 & $(0.4)$ & 1.0 & $(0.5)$ \\
\hline 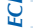 & Austria & 95.5 & $(0.4)$ & 92.9 & $(0.6)$ & 2.6 & $(0.7)$ & 94.6 & $(0.4)$ & 90.4 & $(2.2)$ & 94.0 & $(0.8)$ & 4.2 & (2.2) \\
\hline ठ̄ & Belgium & 97.0 & $(0.4)$ & 97.4 & $(0.3)$ & -0.4 & $(0.4)$ & 98.3 & $(0.2)$ & 90.0 & (1.5) & 93.6 & $(1.0)$ & 8.3 & (1.5) \\
\hline & Canada & 97.9 & $(0.2)$ & 97.5 & $(0.2)$ & 0.4 & $(0.3)$ & 97.9 & $(0.2)$ & 97.8 & $(0.4)$ & 97.0 & $(0.4)$ & 0.1 & $(0.4)$ \\
\hline & Chile & 79.9 & (1.1) & 74.0 & $(1.2)$ & 5.9 & (1.5) & 76.8 & $(0.9)$ & 79.3 & $(5.1)$ & c & $\mathrm{C}$ & -2.5 & $(5.1)$ \\
\hline & Czech Republic & 96.5 & $(0.4)$ & 93.5 & $(0.6)$ & 3.0 & $(0.7)$ & 95.1 & $(0.4)$ & 94.3 & (2.0) & 92.7 & $(2.8)$ & 0.8 & (2.0) \\
\hline & Denmark & 97.3 & $(0.3)$ & 96.5 & $(0.4)$ & 0.8 & $(0.5)$ & 97.1 & $(0.3)$ & 92.8 & $(2.2)$ & 96.0 & $(0.7)$ & 4.3 & $(2.1)$ \\
\hline & Estonia & 93.2 & $(0.6)$ & 91.3 & $(0.6)$ & 2.0 & $(0.9)$ & 92.2 & $(0.5)$ & 92.2 & (3.9) & 93.3 & (1.3) & 0.0 & (3.9) \\
\hline & Finland & 95.9 & $(0.4)$ & 93.8 & $(0.5)$ & 2.1 & $(0.6)$ & 95.0 & $(0.3)$ & 92.6 & $(3.2)$ & 90.7 & $(3.2)$ & 2.4 & (3.3) \\
\hline & France & 96.9 & $(0.4)$ & 96.3 & $(0.4)$ & 0.7 & $(0.4)$ & 96.7 & $(0.3)$ & 94.1 & $(1.8)$ & 96.1 & $(0.9)$ & 2.6 & $(1.7)$ \\
\hline & Germany & 96.0 & $(0.6)$ & 94.5 & $(0.6)$ & 1.5 & $(0.9)$ & 95.5 & $(0.4)$ & 94.8 & (2.1) & 93.9 & (1.3) & 0.6 & (2.1) \\
\hline & Greece & 94.6 & $(0.6)$ & 94.2 & $(0.5)$ & 0.4 & $(0.7)$ & 94.8 & $(0.4)$ & 86.3 & (3.5) & 93.1 & (1.5) & 8.5 & (3.5) \\
\hline & Hungary & 95.0 & $(0.6)$ & 90.1 & $(0.7)$ & 4.9 & $(0.8)$ & 92.7 & $(0.4)$ & 79.3 & (8.1) & 92.1 & (3.0) & 13.5 & $(8.1)$ \\
\hline & Iceland & 96.9 & $(0.5)$ & 94.5 & $(0.6)$ & 2.4 & $(0.7)$ & 95.6 & $(0.4)$ & 97.7 & (1.6) & 94.8 & (3.6) & -2.1 & (1.7) \\
\hline & Ireland & 99.1 & $(0.2)$ & 98.8 & $(0.2)$ & 0.3 & $(0.3)$ & 99.0 & $(0.2)$ & 98.3 & $(0.6)$ & 100.0 & c & 0.6 & $(0.6)$ \\
\hline & Israel & 91.8 & $(0.8)$ & 93.4 & $(0.8)$ & -1.6 & (1.1) & 93.1 & $(0.6)$ & 84.7 & (2.9) & 92.4 & $(1.2)$ & 8.3 & $(2.8)$ \\
\hline & Italy & 82.0 & $(0.8)$ & 79.3 & $(0.8)$ & 2.7 & $(1.0)$ & 80.5 & $(0.6)$ & 80.8 & (2.9) & 82.5 & (3.5) & -0.3 & (2.9) \\
\hline & Japan & 99.1 & $(0.2)$ & 98.3 & $(0.2)$ & 0.8 & $(0.3)$ & 98.7 & $(0.2)$ & C & c & C & c & c & c \\
\hline & Korea & 94.1 & $(0.6)$ & 91.8 & $(0.7)$ & 2.3 & $(0.8)$ & 93.0 & $(0.5)$ & c & c & $\mathrm{m}$ & $\mathrm{m}$ & c & c \\
\hline & Latvia & 96.1 & $(0.4)$ & 94.8 & $(0.4)$ & 1.3 & $(0.6)$ & 95.6 & $(0.3)$ & 95.6 & $(3.2)$ & 94.1 & (1.5) & 0.0 & (3.2) \\
\hline & Luxembourg & 94.2 & $(0.5)$ & 95.2 & $(0.4)$ & -1.0 & $(0.6)$ & 94.8 & $(0.5)$ & 94.9 & $(0.8)$ & 94.8 & $(0.6)$ & -0.1 & $(1.0)$ \\
\hline & Mexico & 91.6 & $(0.6)$ & 86.7 & $(0.7)$ & 5.0 & $(1.0)$ & 89.2 & $(0.5)$ & 94.2 & (3.1) & C & C & -5.0 & (3.1) \\
\hline & Netherlands & 99.1 & $(0.2)$ & 99.7 & $(0.1)$ & -0.6 & $(0.2)$ & 99.6 & $(0.1)$ & 96.7 & $(1.7)$ & 98.3 & $(0.6)$ & 2.9 & $(1.7)$ \\
\hline & New Zealand & 98.6 & $(0.3)$ & 97.8 & $(0.3)$ & 0.9 & $(0.4)$ & 98.5 & $(0.2)$ & 96.7 & $(0.8)$ & 98.2 & $(0.6)$ & 1.8 & $(0.8)$ \\
\hline & Norway & 97.5 & $(0.4)$ & 96.2 & $(0.4)$ & 1.3 & $(0.5)$ & 96.9 & $(0.3)$ & 95.4 & $(1.2)$ & 96.3 & $(0.9)$ & 1.5 & $(1.1)$ \\
\hline & Poland & 93.3 & $(0.5)$ & 94.6 & $(0.4)$ & -1.3 & $(0.7)$ & 94.0 & $(0.4)$ & C & c & C & c & c & c \\
\hline & Portugal & 96.5 & $(0.4)$ & 96.1 & $(0.5)$ & 0.4 & $(0.6)$ & 96.5 & $(0.3)$ & 91.5 & $(2.0)$ & 96.4 & $(1.2)$ & 5.0 & $(2.0)$ \\
\hline & Slovak Republic & 89.7 & $(0.5)$ & 88.9 & $(0.7)$ & 0.8 & $(0.8)$ & 89.5 & $(0.4)$ & C & c & C & c & c & c \\
\hline & Slovenia & 65.5 & (1.1) & 61.9 & (1.1) & 3.6 & (1.6) & 64.0 & $(0.7)$ & 57.0 & (4.9) & 60.1 & $(3.7)$ & 7.0 & (5.0) \\
\hline & Spain & 96.7 & $(0.4)$ & 96.7 & (0.4) & 0.0 & $(0.5)$ & 96.9 & $(0.3)$ & 95.9 & $(0.9)$ & 91.5 & $(4.0)$ & 1.0 & $(0.9)$ \\
\hline & Sweden & 96.9 & $(0.3)$ & 96.4 & $(0.4)$ & 0.5 & $(0.5)$ & 96.7 & $(0.3)$ & 96.6 & $(0.8)$ & 96.8 & $(0.9)$ & 0.1 & $(0.8)$ \\
\hline & Switzerland & 96.3 & $(0.4)$ & 96.5 & $(0.4)$ & -0.1 & $(0.6)$ & 97.2 & $(0.3)$ & 93.7 & $(1.3)$ & 95.2 & $(0.7)$ & 3.6 & $(1.3)$ \\
\hline & Turkey & 96.8 & $(0.4)$ & 97.0 & $(0.4)$ & -0.2 & $(0.5)$ & 97.0 & $(0.3)$ & C & c & 100.0 & $(0.0)$ & c & c \\
\hline & United Kingdom & 98.0 & $(0.2)$ & 96.4 & $(0.4)$ & 1.6 & $(0.5)$ & 97.6 & $(0.2)$ & 97.0 & $(0.8)$ & 95.2 & $(1.3)$ & 0.5 & $(0.9)$ \\
\hline & United States & 98.1 & $(0.3)$ & 97.1 & $(0.3)$ & 1.0 & $(0.4)$ & 98.0 & $(0.2)$ & 94.9 & (1.5) & 97.1 & $(0.8)$ & 3.1 & (1.6) \\
\hline & OECD average & 94.4 & $(0.1)$ & 93.1 & $(0.1)$ & 1.3 & $(0.1)$ & 93.9 & $(0.1)$ & 91.4 & $(0.5)$ & 93.6 & $(0.3)$ & 2.4 & $(0.5)$ \\
\hline 2 & Albania & $\mathrm{m}$ & $\mathrm{m}$ & $\mathrm{m}$ & $\mathrm{m}$ & $\mathrm{m}$ & $\mathrm{m}$ & $\mathrm{m}$ & $\mathrm{m}$ & $\mathrm{m}$ & $\mathrm{m}$ & $\mathrm{m}$ & $\mathrm{m}$ & $\mathrm{m}$ & $\mathrm{m}$ \\
\hline ఏ & Algeria & $\mathrm{m}$ & $\mathrm{m}$ & $\mathrm{m}$ & $\mathrm{m}$ & $\mathrm{m}$ & $\mathrm{m}$ & $\mathrm{m}$ & $\mathrm{m}$ & $\mathrm{m}$ & $\mathrm{m}$ & $\mathrm{m}$ & $\mathrm{m}$ & $\mathrm{m}$ & $\mathrm{m}$ \\
\hline$=$ & Brazil & 84.0 & $(0.7)$ & 80.9 & $(0.8)$ & 3.0 & $(0.9)$ & 82.5 & $(0.6)$ & C & c & 80.5 & (7.6) & c & c \\
\hline & B-S-J-G (China) & 98.7 & $(0.2)$ & 98.4 & $(0.3)$ & 0.2 & $(0.3)$ & 98.6 & $(0.1)$ & C & c & $\mathrm{C}$ & c & c & c \\
\hline & Bulgaria & 92.7 & $(0.5)$ & 92.6 & $(0.6)$ & 0.0 & $(0.8)$ & 92.8 & $(0.4)$ & C & c & c & c & c & c \\
\hline & CABA (Argentina) & $\mathrm{m}$ & $\mathrm{m}$ & $\mathrm{m}$ & $\mathrm{m}$ & $\mathrm{m}$ & $\mathrm{m}$ & $\mathrm{m}$ & $\mathrm{m}$ & $\mathrm{m}$ & $\mathrm{m}$ & $\mathrm{m}$ & $\mathrm{m}$ & $\mathrm{m}$ & $\mathrm{m}$ \\
\hline & Colombia & 95.3 & $(0.4)$ & 91.9 & $(0.5)$ & 3.4 & $(0.6)$ & 93.6 & $(0.4)$ & c & c & 94.7 & $(5.2)$ & $\mathrm{c}$ & c \\
\hline & Costa Rica & 95.1 & $(0.5)$ & 93.5 & $(0.5)$ & 1.6 & $(0.7)$ & 94.4 & $(0.4)$ & 92.7 & (2.6) & 96.3 & $(1.2)$ & 1.7 & (2.6) \\
\hline & Croatia & 94.9 & $(0.5)$ & 94.5 & $(0.4)$ & 0.5 & $(0.7)$ & 94.6 & $(0.3)$ & 94.7 & $(2.4)$ & 96.2 & $(0.7)$ & -0.1 & (2.5) \\
\hline & Cyprus* & 93.0 & $(0.5)$ & 92.2 & $(0.5)$ & 0.8 & $(0.7)$ & 92.7 & $(0.4)$ & 91.1 & (1.6) & 92.3 & $(2.3)$ & 1.6 & $(1.7)$ \\
\hline & Dominican Republic & 95.1 & $(0.9)$ & 94.4 & $(0.6)$ & 0.7 & $(1.0)$ & 94.8 & $(0.6)$ & c & c & c & c & c & c \\
\hline & FYROM & $\mathrm{m}$ & $\mathrm{m}$ & $\mathrm{m}$ & $\mathrm{m}$ & $\mathrm{m}$ & $\mathrm{m}$ & $\mathrm{m}$ & $\mathrm{m}$ & $\mathrm{m}$ & $\mathrm{m}$ & $\mathrm{m}$ & $\mathrm{m}$ & $\mathrm{m}$ & $\mathrm{m}$ \\
\hline & Georgia & $\mathrm{m}$ & $\mathrm{m}$ & $\mathrm{m}$ & $\mathrm{m}$ & $\mathrm{m}$ & $\mathrm{m}$ & $\mathrm{m}$ & $\mathrm{m}$ & $\mathrm{m}$ & $\mathrm{m}$ & $\mathrm{m}$ & $\mathrm{m}$ & $\mathrm{m}$ & $\mathrm{m}$ \\
\hline & Hong Kong (China) & 98.4 & $(0.3)$ & 98.1 & $(0.3)$ & 0.3 & $(0.4)$ & 98.4 & $(0.2)$ & 97.8 & $(0.7)$ & 98.2 & $(0.4)$ & 0.6 & $(0.7)$ \\
\hline & Indonesia & $\mathrm{m}$ & $\mathrm{m}$ & $\mathrm{m}$ & $\mathrm{m}$ & $\mathrm{m}$ & $\mathrm{m}$ & $\mathrm{m}$ & $\mathrm{m}$ & $\mathrm{m}$ & $\mathrm{m}$ & $\mathrm{m}$ & $\mathrm{m}$ & $\mathrm{m}$ & $\mathrm{m}$ \\
\hline & Jordan & $\mathrm{m}$ & $\mathrm{m}$ & $\mathrm{m}$ & $\mathrm{m}$ & $\mathrm{m}$ & $\mathrm{m}$ & $\mathrm{m}$ & $\mathrm{m}$ & $\mathrm{m}$ & $\mathrm{m}$ & $\mathrm{m}$ & $\mathrm{m}$ & $\mathrm{m}$ & $\mathrm{m}$ \\
\hline & Kosovo & $\mathrm{m}$ & $\mathrm{m}$ & $\mathrm{m}$ & $\mathrm{m}$ & $\mathrm{m}$ & $\mathrm{m}$ & $\mathrm{m}$ & $\mathrm{m}$ & $\mathrm{m}$ & $\mathrm{m}$ & $\mathrm{m}$ & $\mathrm{m}$ & $\mathrm{m}$ & $\mathrm{m}$ \\
\hline & Lebanon & $\mathrm{m}$ & $\mathrm{m}$ & $\mathrm{m}$ & $\mathrm{m}$ & $\mathrm{m}$ & $\mathrm{m}$ & $\mathrm{m}$ & $\mathrm{m}$ & $\mathrm{m}$ & $\mathrm{m}$ & $\mathrm{m}$ & $\mathrm{m}$ & $\mathrm{m}$ & $\mathrm{m}$ \\
\hline & Lithuania & 94.8 & $(0.5)$ & 93.5 & $(0.6)$ & 1.3 & $(0.7)$ & 94.3 & $(0.4)$ & 77.4 & (12.6) & 91.4 & $(2.3)$ & 16.9 & (12.6) \\
\hline & Macao (China) & 98.7 & $(0.2)$ & 97.5 & $(0.3)$ & 1.2 & $(0.4)$ & 98.0 & $(0.4)$ & 97.9 & $(0.5)$ & 98.3 & $(0.3)$ & 0.0 & $(0.7)$ \\
\hline & Malta & $\mathrm{m}$ & $\mathrm{m}$ & $\mathrm{m}$ & $\mathrm{m}$ & $\mathrm{m}$ & $\mathrm{m}$ & $\mathrm{m}$ & $\mathrm{m}$ & $\mathrm{m}$ & $\mathrm{m}$ & $\mathrm{m}$ & $\mathrm{m}$ & $\mathrm{m}$ & $\mathrm{m}$ \\
\hline & Moldova & $\mathrm{m}$ & $\mathrm{m}$ & $\mathrm{m}$ & $\mathrm{m}$ & $\mathrm{m}$ & $\mathrm{m}$ & $\mathrm{m}$ & $\mathrm{m}$ & $\mathrm{m}$ & $\mathrm{m}$ & $\mathrm{m}$ & $\mathrm{m}$ & $\mathrm{m}$ & $\mathrm{m}$ \\
\hline & Montenegro & 91.6 & $(0.5)$ & 89.8 & $(0.6)$ & 1.8 & $(0.8)$ & 90.8 & $(0.5)$ & 84.5 & (3.9) & 89.0 & $(2.2)$ & 6.3 & $(4.0)$ \\
\hline & Peru & 91.7 & $(0.5)$ & 89.8 & $(0.6)$ & 1.9 & $(0.8)$ & 90.7 & $(0.4)$ & C & c & C & c & c & c \\
\hline & Qatar & 93.5 & $(0.4)$ & 92.4 & $(0.4)$ & 1.1 & $(0.5)$ & 90.8 & $(0.4)$ & 95.1 & $(0.4)$ & 93.0 & $(0.6)$ & -4.3 & $(0.5)$ \\
\hline & Romania & $\mathrm{m}$ & $\mathrm{m}$ & $\mathrm{m}$ & $\mathrm{m}$ & $\mathrm{m}$ & $\mathrm{m}$ & $\mathrm{m}$ & $\mathrm{m}$ & $\mathrm{m}$ & $\mathrm{m}$ & $\mathrm{m}$ & $\mathrm{m}$ & $\mathrm{m}$ & $\mathrm{m}$ \\
\hline & Russia & 94.7 & $(0.5)$ & 93.1 & $(0.6)$ & 1.6 & $(0.7)$ & 93.8 & $(0.5)$ & 94.1 & $(2.2)$ & 95.7 & (1.4) & -0.3 & $(2.2)$ \\
\hline & Singapore & 96.1 & $(0.3)$ & 95.2 & $(0.4)$ & 0.9 & $(0.4)$ & 95.2 & $(0.3)$ & 97.8 & $(0.6)$ & 96.6 & $(1.1)$ & -2.6 & $(0.7)$ \\
\hline & Chinese Taipei & 98.9 & $(0.2)$ & 98.3 & $(0.2)$ & 0.6 & $(0.3)$ & 98.6 & $(0.2)$ & c & c & c & c & c & c \\
\hline & Thailand & 94.7 & $(0.5)$ & 94.3 & $(0.5)$ & 0.4 & $(0.6)$ & 94.5 & $(0.4)$ & c & c & 99.9 & $(0.1)$ & c & c \\
\hline & Trinidad and Tobago & $\mathrm{m}$ & $\mathrm{m}$ & $\mathrm{m}$ & $\mathrm{m}$ & $\mathrm{m}$ & $\mathrm{m}$ & $\mathrm{m}$ & $\mathrm{m}$ & $\mathrm{m}$ & $\mathrm{m}$ & $\mathrm{m}$ & $\mathrm{m}$ & $\mathrm{m}$ & $\mathrm{m}$ \\
\hline & Tunisia & 94.6 & $(0.5)$ & 90.3 & $(0.6)$ & 4.2 & $(0.8)$ & 92.5 & $(0.4)$ & C & c & 76.1 & (6.4) & c & c \\
\hline & United Arab Emirates & 93.7 & $(0.3)$ & 90.6 & $(0.5)$ & 3.1 & $(0.6)$ & 91.4 & $(0.5)$ & 93.6 & $(0.5)$ & 91.2 & $(0.7)$ & -2.2 & $(0.6)$ \\
\hline & Uruguay & 90.8 & $(0.7)$ & 86.6 & $(0.8)$ & 4.2 & $(1.0)$ & 88.4 & $(0.6)$ & C & c & c & c & $\mathrm{c}$ & c \\
\hline & Viet Nam & $\mathrm{m}$ & $\mathrm{m}$ & $\mathrm{m}$ & $\mathrm{m}$ & $\mathrm{m}$ & $\mathrm{m}$ & $\mathrm{m}$ & $\mathrm{m}$ & $\mathrm{m}$ & $\mathrm{m}$ & $\mathrm{m}$ & $\mathrm{m}$ & $\mathrm{m}$ & $\mathrm{m}$ \\
\hline & Argentina** & $\mathrm{m}$ & $\mathrm{m}$ & $\mathrm{m}$ & $\mathrm{m}$ & $\mathrm{m}$ & $\mathrm{m}$ & $\mathrm{m}$ & $\mathrm{m}$ & $\mathrm{m}$ & $\mathrm{m}$ & $\mathrm{m}$ & $\mathrm{m}$ & $\mathrm{m}$ & $\mathrm{m}$ \\
\hline & Kazakhstan** & $\mathrm{m}$ & $\mathrm{m}$ & $\mathrm{m}$ & $\mathrm{m}$ & $\mathrm{m}$ & $\mathrm{m}$ & $\mathrm{m}$ & $\mathrm{m}$ & $\mathrm{m}$ & $\mathrm{m}$ & $\mathrm{m}$ & $\mathrm{m}$ & $\mathrm{m}$ & $\mathrm{m}$ \\
\hline & Malaysia** & 95.6 & $(0.4)$ & 94.0 & $(0.5)$ & 1.7 & $(0.7)$ & 95.0 & $(0.3)$ & $\mathrm{C}$ & $\mathrm{c}$ & 89.3 & (4.4) & $\mathrm{C}$ & $\mathrm{C}$ \\
\hline
\end{tabular}

1. ESCS refers to the PISA index of economic, social and cultural status.

Note: Values that are statistically significant are indicated in bold (see Annex A3).

* See note at the beginning of this Annex.

** Coverage is too small to ensure comparability (see Annex A4).

StatLink 규넨 $\mathrm{http}: / / \mathrm{dx}$.doi.org/10.1787/888933472777 
[Part 1/1]

Table III.11.24a Eating breakfast and student performance in science

Results based on students' self-reports

\begin{tabular}{|c|c|c|c|c|c|c|c|c|c|c|c|}
\hline & \multicolumn{10}{|c|}{ Science performance } \\
\hline & & \multicolumn{6}{|c|}{$\begin{array}{l}\text { Percentage of students who reported that they eat breakfast before school, } \\
\text { by science performance }\end{array}$} & \multicolumn{4}{|c|}{$\begin{array}{l}\text { Change in science score associated } \\
\text { with eating breakfast before school }\end{array}$} \\
\hline & & \multicolumn{2}{|c|}{$\begin{array}{l}\text { Bottom quarter of science } \\
\text { performance }\end{array}$} & $\begin{array}{r}\text { Top qua } \\
\text { per }\end{array}$ & $\begin{array}{l}\text { cience } \\
\text { ce }\end{array}$ & $\begin{array}{r}\text { Differen } \\
\text { and bo } \\
\text { of scienc } \\
\text { (top }\end{array}$ & $\begin{array}{l}\text { een top } \\
\text { uarter } \\
\text { rmance } \\
\text { m) }\end{array}$ & $\begin{array}{r}\text { Before } \\
\text { for } s \\
\text { socio-eco }\end{array}$ & $\begin{array}{l}\text { unting } \\
\text { nts }^{\prime} \\
\text { ic status }\end{array}$ & $\begin{array}{r}\text { After a } \\
\text { for st } \\
\text { socio-eco }\end{array}$ & $\begin{array}{l}\text { Inting } \\
\text { nts' }^{\prime} \\
\text { ic status }\end{array}$ \\
\hline & & $\%$ & S.E. & $\%$ & S.E. & $\%$ dif. & S.E. & Score dif. & S.E. & Score dif. & S.E. \\
\hline 0 & Australia & 74.6 & (1.0) & 83.8 & $(0.9)$ & 9.1 & (1.5) & 21 & (2.9) & 13 & (2.8) \\
\hline 巡 & Austria & 64.0 & $(1.8)$ & 68.0 & $(1.7)$ & 4.0 & $(2.5)$ & 7 & (3.7) & 0 & (3.3) \\
\hline & Belgium & 71.5 & $(1.2)$ & 88.3 & $(0.9)$ & 16.8 & $(1.5)$ & 36 & (3.1) & 21 & $(2.8)$ \\
\hline & Canada & 72.2 & (1.1) & 80.3 & $(1.0)$ & 8.2 & $(1.4)$ & 15 & $(2.4)$ & 8 & $(2.3)$ \\
\hline & Chile & 74.0 & (1.9) & 72.6 & $(1.5)$ & -1.4 & $(2.4)$ & -1 & (3.0) & -7 & (2.6) \\
\hline & Czech Republic & 68.9 & (1.5) & 76.2 & $(1.6)$ & 7.3 & $(2.2)$ & 14 & (3.5) & 6 & $(3.1)$ \\
\hline & Denmark & 78.3 & (1.4) & 91.1 & $(1.0)$ & 12.8 & (1.7) & 31 & (3.9) & 22 & (3.8) \\
\hline & Estonia & 80.6 & (1.5) & 86.6 & $(1.2)$ & 6.0 & $(2.0)$ & 14 & $(4.0)$ & 8 & (3.9) \\
\hline & Finland & 79.8 & $(1.3)$ & 88.7 & $(1.1)$ & 8.9 & (1.6) & 24 & (3.3) & 16 & $(3.2)$ \\
\hline & France & 73.4 & (1.6) & 84.2 & $(1.2)$ & 10.8 & $(1.8)$ & 23 & (3.5) & 14 & (3.0) \\
\hline & Germany & 66.1 & (1.9) & 76.2 & (1.9) & 10.0 & $(2.7)$ & 19 & $(4.1)$ & 9 & $(4.0)$ \\
\hline & Greece & 82.9 & (1.3) & 77.3 & $(1.4)$ & -5.5 & (1.9) & -11 & (3.4) & -12 & (3.3) \\
\hline & Hungary & 79.3 & (1.8) & 65.3 & $(1.4)$ & -13.9 & (2.4) & -23 & (3.7) & -21 & (3.3) \\
\hline & Iceland & 76.7 & (1.8) & 85.8 & $(1.4)$ & 9.1 & $(2.5)$ & 20 & (4.5) & 15 & $(4.4)$ \\
\hline & Ireland & 77.6 & (1.5) & 88.3 & $(1.0)$ & 10.7 & $(1.7)$ & 25 & (3.6) & 19 & (3.5) \\
\hline & Israel & 79.3 & (1.5) & 65.4 & $(1.5)$ & -14.0 & $(2.2)$ & -26 & (3.9) & -27 & (3.3) \\
\hline & Italy & 71.7 & (1.7) & 81.4 & $(1.2)$ & 9.8 & (1.9) & 18 & (3.3) & 12 & $(3.2)$ \\
\hline & Japan & 88.2 & $(0.9)$ & 95.2 & $(0.6)$ & 7.0 & $(1.0)$ & 35 & (4.9) & 27 & $(4.7)$ \\
\hline & Korea & 71.1 & (1.7) & 86.6 & $(1.1)$ & 15.5 & $(2.1)$ & 34 & $(4.1)$ & 27 & (3.5) \\
\hline & Latvia & 81.2 & (1.4) & 81.9 & $(1.3)$ & 0.7 & (2.0) & 2 & (3.3) & 1 & (3.3) \\
\hline & Luxembourg & 74.2 & (1.6) & 79.2 & $(1.4)$ & 4.9 & $(2.1)$ & 11 & (3.4) & 8 & $(3.1)$ \\
\hline & Mexico & 84.3 & (1.4) & 80.2 & $(1.2)$ & -4.1 & $(1.8)$ & -7 & $(3.2)$ & -6 & (3.0) \\
\hline & Netherlands & 85.0 & (1.1) & 93.1 & $(0.8)$ & 8.1 & $(1.4)$ & 31 & $(4.4)$ & 21 & $(4.0)$ \\
\hline & New Zealand & 74.6 & (1.5) & 86.0 & $(1.2)$ & 11.4 & $(2.0)$ & 27 & (4.5) & 16 & (4.4) \\
\hline & Norway & 76.1 & (1.4) & 87.9 & $(1.1)$ & 11.8 & (1.8) & 31 & (3.4) & 24 & (3.3) \\
\hline & Poland & 79.9 & (1.5) & 82.3 & $(1.5)$ & 2.4 & $(2.1)$ & 6 & $(4.0)$ & 2 & (3.6) \\
\hline & Portugal & 91.3 & $(0.9)$ & 93.9 & $(0.7)$ & 2.6 & $(1.1)$ & 13 & (4.5) & 9 & $(4.1)$ \\
\hline & Slovak Republic & 73.0 & (1.6) & 71.2 & (1.5) & -1.8 & (2.4) & -3 & (2.9) & -6 & (2.9) \\
\hline & Slovenia & 58.7 & (1.6) & 73.0 & (1.6) & 14.3 & $(2.3)$ & 22 & $(3.2)$ & 17 & $(2.8)$ \\
\hline & Spain & 81.6 & $(1.1)$ & 88.9 & $(0.9)$ & 7.3 & (1.5) & 19 & $(3.2)$ & 12 & $(3.2)$ \\
\hline & Sweden & 76.0 & (1.5) & 89.5 & (1.0) & 13.5 & $(1.8)$ & 37 & (3.9) & 26 & $(4.0)$ \\
\hline & Switzerland & 68.6 & (1.7) & 80.8 & (1.6) & 12.3 & (2.4) & 24 & (3.9) & 14 & (3.6) \\
\hline & Turkey & 83.3 & $(1.2)$ & 76.1 & (1.8) & -7.2 & $(2.3)$ & -13 & (3.9) & -12 & (3.4) \\
\hline & United Kingdom & 65.0 & (1.5) & 77.5 & $(1.3)$ & 12.5 & $(2.0)$ & 23 & $(3.2)$ & 15 & (3.0) \\
\hline & United States & 75.4 & (1.4) & 70.9 & $(1.5)$ & -4.5 & $(2.0)$ & -8 & $(2.9)$ & -14 & $(2.7)$ \\
\hline & OECD average & 76.0 & $(0.3)$ & 81.5 & $(0.2)$ & 5.6 & $(0.3)$ & 14 & $(0.6)$ & 8 & $(0.6)$ \\
\hline in & Albania & $\mathrm{m}$ & $\mathrm{m}$ & $\mathrm{m}$ & $\mathrm{m}$ & $\mathrm{m}$ & $\mathrm{m}$ & $\mathrm{m}$ & $\mathrm{m}$ & $\mathrm{m}$ & $\mathrm{m}$ \\
\hline 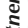 & Algeria & $\mathrm{m}$ & $\mathrm{m}$ & $\mathrm{m}$ & $\mathrm{m}$ & $\mathrm{m}$ & $\mathrm{m}$ & $\mathrm{m}$ & $\mathrm{m}$ & $\mathrm{m}$ & $\mathrm{m}$ \\
\hline ปั & Brazil & 78.7 & $(1.2)$ & 76.9 & $(1.0)$ & -1.8 & $(1.7)$ & -2 & (2.9) & -3 & $(2.8)$ \\
\hline & B-S-J-G (China) & 92.2 & (1.1) & 95.4 & $(0.6)$ & 3.1 & $(1.3)$ & 25 & $(8.1)$ & 20 & (7.9) \\
\hline & Bulgaria & 80.9 & (1.6) & 71.8 & (1.9) & -9.1 & $(2.5)$ & -17 & $(4.3)$ & -15 & (3.8) \\
\hline & CABA (Argentina) & $\mathrm{m}$ & $\mathrm{m}$ & $\mathrm{m}$ & $\mathrm{m}$ & $\mathrm{m}$ & $\mathrm{m}$ & $\mathrm{m}$ & $\mathrm{m}$ & $\mathrm{m}$ & $\mathrm{m}$ \\
\hline & Colombia & 86.1 & $(1.2)$ & 87.4 & $(0.9)$ & 1.4 & $(1.3)$ & 4 & $(3.1)$ & 0 & (3.0) \\
\hline & Costa Rica & 80.1 & (1.6) & 82.9 & $(1.5)$ & 2.8 & $(2.2)$ & 7 & (3.1) & 5 & $(2.8)$ \\
\hline & Croatia & 79.9 & (1.5) & 69.1 & (1.5) & -10.8 & $(2.2)$ & -19 & (3.4) & -20 & (3.1) \\
\hline & Cyprus* & 78.2 & (1.5) & 75.9 & (1.4) & -2.3 & $(2.0)$ & -5 & (3.3) & -8 & $(3.1)$ \\
\hline & Dominican Republic & 89.1 & (1.9) & 79.3 & $(1.4)$ & -9.8 & $(2.3)$ & -22 & $(4.5)$ & -23 & $(4.0)$ \\
\hline & FYROM & $\mathrm{m}$ & $\mathrm{m}$ & $\mathrm{m}$ & $\mathrm{m}$ & $\mathrm{m}$ & $\mathrm{m}$ & $\mathrm{m}$ & $\mathrm{m}$ & $\mathrm{m}$ & $\mathrm{m}$ \\
\hline & Georgia & $\mathrm{m}$ & $\mathrm{m}$ & $\mathrm{m}$ & $\mathrm{m}$ & $\mathrm{m}$ & $\mathrm{m}$ & $\mathrm{m}$ & $\mathrm{m}$ & $\mathrm{m}$ & $\mathrm{m}$ \\
\hline & Hong Kong (China) & 81.5 & (1.1) & 83.0 & $(1.3)$ & 1.5 & $(1.7)$ & 4 & $(3.2)$ & 3 & $(3.2)$ \\
\hline & Indonesia & $\mathrm{m}$ & $\mathrm{m}$ & $\mathrm{m}$ & $\mathrm{m}$ & $\mathrm{m}$ & $\mathrm{m}$ & $\mathrm{m}$ & $\mathrm{m}$ & $\mathrm{m}$ & $\mathrm{m}$ \\
\hline & Jordan & $\mathrm{m}$ & $\mathrm{m}$ & $\mathrm{m}$ & $\mathrm{m}$ & $\mathrm{m}$ & $\mathrm{m}$ & $\mathrm{m}$ & $\mathrm{m}$ & $\mathrm{m}$ & $\mathrm{m}$ \\
\hline & Kosovo & $\mathrm{m}$ & $\mathrm{m}$ & $\mathrm{m}$ & $\mathrm{m}$ & $\mathrm{m}$ & $\mathrm{m}$ & $\mathrm{m}$ & $\mathrm{m}$ & $\mathrm{m}$ & $\mathrm{m}$ \\
\hline & Lebanon & $\mathrm{m}$ & $\mathrm{m}$ & $\mathrm{m}$ & $\mathrm{m}$ & $\mathrm{m}$ & $\mathrm{m}$ & $\mathrm{m}$ & $\mathrm{m}$ & $\mathrm{m}$ & $\mathrm{m}$ \\
\hline & Lithuania & 78.8 & $(1.2)$ & 83.7 & $(1.4)$ & 4.9 & $(1.8)$ & 12 & (3.1) & 6 & (2.9) \\
\hline & Macao (China) & 88.4 & $(0.9)$ & 88.7 & $(1.0)$ & 0.3 & (1.4) & 1 & (3.6) & 0 & (3.6) \\
\hline & Malta & $\mathrm{m}$ & $\mathrm{m}$ & $\mathrm{m}$ & $\mathrm{m}$ & $\mathrm{m}$ & $\mathrm{m}$ & $\mathrm{m}$ & $\mathrm{m}$ & $\mathrm{m}$ & $\mathrm{m}$ \\
\hline & Moldova & $\mathrm{m}$ & $\mathrm{m}$ & $\mathrm{m}$ & $\mathrm{m}$ & $\mathrm{m}$ & $\mathrm{m}$ & $\mathrm{m}$ & $\mathrm{m}$ & $\mathrm{m}$ & $\mathrm{m}$ \\
\hline & Montenegro & 90.6 & (1.0) & 88.2 & $(1.1)$ & -2.4 & (1.6) & -8 & $(5.3)$ & -10 & $(5.2)$ \\
\hline & Peru & 92.4 & (1.0) & 89.1 & $(1.1)$ & -3.3 & (1.6) & -9 & $(4.0)$ & -6 & (3.6) \\
\hline & Qatar & 81.4 & $(1.2)$ & 76.6 & $(0.8)$ & -4.9 & (1.4) & -9 & (2.5) & -9 & (2.4) \\
\hline & Romania & $\mathrm{m}$ & $\mathrm{m}$ & $\mathrm{m}$ & $\mathrm{m}$ & $\mathrm{m}$ & $\mathrm{m}$ & $\mathrm{m}$ & $\mathrm{m}$ & $\mathrm{m}$ & $\mathrm{m}$ \\
\hline & Russia & 89.2 & (1.1) & 88.1 & (1.3) & -1.1 & $(1.8)$ & -3 & $(5.0)$ & -3 & (4.9) \\
\hline & Singapore & 57.2 & $(1.3)$ & 75.1 & $(1.4)$ & 17.9 & $(2.0)$ & 32 & (2.9) & 17 & (2.9) \\
\hline & Chinese Taipei & 89.3 & $(0.9)$ & 85.4 & $(0.9)$ & -3.9 & $(1.3)$ & -14 & (3.4) & -11 & (3.2) \\
\hline & Thailand & 88.4 & $(1.2)$ & 84.8 & $(1.2)$ & -3.6 & (1.7) & -10 & $(4.3)$ & -9 & $(4.1)$ \\
\hline & Trinidad and Tobago & $\mathrm{m}$ & $\mathrm{m}$ & $\mathrm{m}$ & $\mathrm{m}$ & $\mathrm{m}$ & $\mathrm{m}$ & $\mathrm{m}$ & $\mathrm{m}$ & $\mathrm{m}$ & $\mathrm{m}$ \\
\hline & Tunisia & 83.0 & (1.4) & 82.5 & $(1.2)$ & -0.5 & $(1.8)$ & 0 & $(2.9)$ & -1 & $(2.8)$ \\
\hline & United Arab Emirates & 80.2 & (1.1) & 75.0 & $(1.2)$ & -5.3 & (1.6) & -10 & (3.0) & -10 & (2.9) \\
\hline & Uruguay & 82.5 & (1.7) & 82.6 & $(1.2)$ & 0.1 & $(2.3)$ & 3 & $(4.2)$ & -3 & (3.6) \\
\hline & Viet Nam & $\mathrm{m}$ & $\mathrm{m}$ & $\mathrm{m}$ & $\mathrm{m}$ & $\mathrm{m}$ & $\mathrm{m}$ & $\mathrm{m}$ & $\mathrm{m}$ & $\mathrm{m}$ & $\mathrm{m}$ \\
\hline & Argentina** & $\mathrm{m}$ & $\mathrm{m}$ & $\mathrm{m}$ & $\mathrm{m}$ & $\mathrm{m}$ & $\mathrm{m}$ & $\mathrm{m}$ & $\mathrm{m}$ & $\mathrm{m}$ & $\mathrm{m}$ \\
\hline & Kazakhstan** & $\mathrm{m}$ & $\mathrm{m}$ & $\mathrm{m}$ & $\mathrm{m}$ & $\mathrm{m}$ & $\mathrm{m}$ & $\mathrm{m}$ & $\mathrm{m}$ & $\mathrm{m}$ & $\mathrm{m}$ \\
\hline & Malaysia** & 79.1 & (1.4) & 82.3 & $(1.4)$ & 3.1 & (1.9) & 6 & (3.0) & 2 & $(2.7)$ \\
\hline
\end{tabular}

Note: Values that are statistically significant are indicated in bold (see Annex A3).

* See note at the beginning of this Annex.

* Coverage is too small to ensure comparability (see Annex A4).

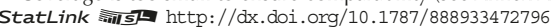


[Part 1/1]

Table III.11.26a Eating dinner and student performance in science

Results based on students' self-reports

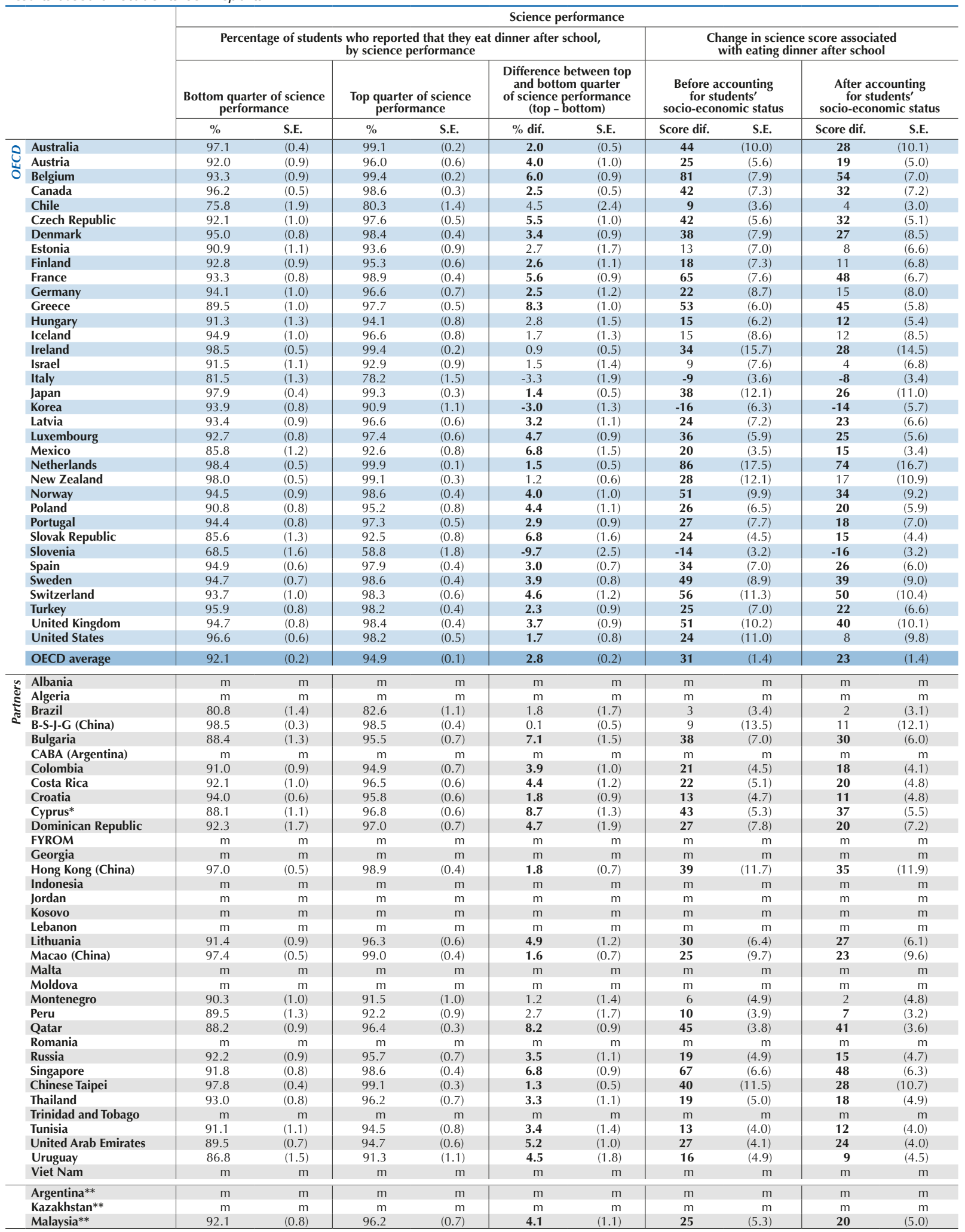

Note: Values that are statistically significant are indicated in bold (see Annex A3).

** See note at the beginning of this Annex.

Coverage is too small to ensure comparability (see Annex A4).

StatLink त्तiाs $\mathrm{http}: / / \mathrm{dx}$.doi.org/10.1787/888933472820 
[Part 1/1]

Table III.11.27 Eating habits and life satisfaction

Results based on students' self-reports

\begin{tabular}{|c|c|c|c|c|c|c|c|c|c|c|c|c|c|c|c|c|c|}
\hline & \multicolumn{4}{|c|}{ Average life satisfaction, by: } & Diffe & $\begin{array}{l}\text { ence in It } \\
\text { oy eating }\end{array}$ & $\begin{array}{l}\text { ife satisf } \\
\text { breakfa }\end{array}$ & ction & Aver & ge life sa & tisfactio & , by: & Diff & $\begin{array}{l}\text { ence in I } \\
\text { by eatin }\end{array}$ & $\begin{array}{l}\text { ife satisf } \\
\text { g dinner }\end{array}$ & ction \\
\hline & & \begin{tabular}{|r} 
Student \\
report \\
breakfa \\
sch
\end{tabular} & $\begin{array}{l}\text { does not } \\
\text { eating } \\
\text { t before } \\
\text { ool }\end{array}$ & $\begin{array}{l}\text { Studen } \\
\text { eating } \\
\text { before }\end{array}$ & $\begin{array}{l}\text { reports } \\
\text { reakfast } \\
\text { school }\end{array}$ & $\begin{array}{l}\text { Be } \\
\text { accou } \\
\text { studen } \\
\text { econon }\end{array}$ & $\begin{array}{l}\text { ore } \\
\text { ting for } \\
\text { ic socio- } \\
\text { ic status }\end{array}$ & $\begin{array}{r}\text { After ac } \\
\text { for st } \\
\text { socio-e } \\
\text { st }\end{array}$ & $\begin{array}{l}\text { ounting } \\
\text { dents }^{\prime} \\
\text { onomic } \\
\text { us }\end{array}$ & $\begin{array}{l}\text { Stude } \\
\text { not rep }\end{array}$ & $\begin{array}{l}t \text { does } \\
\text { t eating } \\
\text { er }\end{array}$ & $\begin{array}{c}\text { Studen } \\
\text { eating }\end{array}$ & $\begin{array}{l}\text { reports } \\
\text { dinner }\end{array}$ & $\begin{array}{r}B \\
\text { accou } \\
\text { studen } \\
\text { econon }\end{array}$ & $\begin{array}{l}\text { ore } \\
\text { ing for } \\
\text { 'socio- } \\
\text { c status }\end{array}$ & $\begin{array}{r}\text { After a } \\
\text { for st } \\
\text { socio-e } \\
\text { st }\end{array}$ & $\begin{array}{l}\text { ounting } \\
\text { dents } \\
\text { onomic } \\
\text { us }\end{array}$ \\
\hline & & Mean & S.E. & Mean & S.E. & Dif. & S.E. & Dif. & S.E. & Mean & S.E. & Mean & S.E. & Dif. & S.E. & Dif. & S.E. \\
\hline & Australia & $\mathrm{m}$ & $\mathrm{m}$ & $\mathrm{m}$ & $\mathrm{m}$ & $\mathrm{m}$ & $\mathrm{m}$ & $\mathrm{m}$ & $\mathrm{m}$ & $\mathrm{m}$ & $\mathrm{m}$ & $\mathrm{m}$ & $\mathrm{m}$ & $\mathrm{m}$ & $\mathrm{m}$ & $\mathrm{m}$ & $\mathrm{m}$ \\
\hline$\sqrt{-1}$ & Austria & 7.12 & $(0.05)$ & 7.76 & $(0.04)$ & 0.64 & $(0.07)$ & 0.61 & $(0.07)$ & 6.45 & $(0.16)$ & 7.59 & $(0.03)$ & 1.14 & $(0.16)$ & 1.10 & $(0.15)$ \\
\hline & Belgium (excl. Flemish) & 7.03 & $(0.08)$ & 7.62 & $(0.05)$ & 0.59 & $(0.08)$ & 0.52 & $(0.08)$ & 7.29 & $(0.25)$ & 7.48 & $(0.05)$ & 0.19 & $(0.25)$ & 0.03 & $(0.26)$ \\
\hline & Canada & $\mathrm{m}$ & $\mathrm{m}$ & $\mathrm{m}$ & $\mathrm{m}$ & $\mathrm{m}$ & $\mathrm{m}$ & $\mathrm{m}$ & $\mathrm{m}$ & $\mathrm{m}$ & $\mathrm{m}$ & m & m & $\mathrm{m}$ & $\mathrm{m}$ & $\mathrm{m}$ & $\mathrm{m}$ \\
\hline & Chile & 6.90 & $(0.06)$ & 7.54 & $(0.05)$ & 0.64 & $(0.06)$ & 0.61 & $(0.06)$ & 7.01 & $(0.08)$ & 7.45 & $(0.04)$ & 0.44 & $(0.08)$ & 0.41 & $(0.08)$ \\
\hline & Czech Republic & 6.69 & $(0.07)$ & 7.20 & $(0.04)$ & 0.51 & $(0.07)$ & 0.46 & $(0.07)$ & 6.11 & $(0.18)$ & 7.10 & $(0.04)$ & 0.99 & $(0.18)$ & 0.92 & $(0.18)$ \\
\hline & Denmark & $\mathrm{m}$ & $\mathrm{m}$ & $\mathrm{m}$ & $\mathrm{m}$ & $\mathrm{m}$ & $\mathrm{m}$ & $\mathrm{m}$ & $\mathrm{m}$ & $\mathrm{m}$ & $\mathrm{m}$ & $\mathrm{m}$ & m & $\mathrm{m}$ & $\mathrm{m}$ & $\mathrm{m}$ & $\mathrm{m}$ \\
\hline & Estonia & 6.92 & $(0.10)$ & 7.62 & $(0.04)$ & 0.70 & $(0.11)$ & 0.64 & $(0.11)$ & 6.73 & $(0.15)$ & 7.57 & $(0.03)$ & 0.84 & $(0.15)$ & 0.79 & $(0.15)$ \\
\hline & Finland & 7.26 & $(0.08)$ & 8.01 & $(0.03)$ & 0.75 & $(0.08)$ & 0.71 & $(0.08)$ & 6.87 & $(0.16)$ & 7.94 & $(0.03)$ & 1.07 & $(0.16)$ & 1.03 & $(0.16)$ \\
\hline & France & 7.17 & $(0.07)$ & 7.77 & $(0.03)$ & 0.60 & $(0.07)$ & 0.56 & $(0.07)$ & 6.80 & $(0.16)$ & 7.67 & $(0.03)$ & 0.87 & $(0.17)$ & 0.80 & $(0.17)$ \\
\hline & Germany & 6.70 & $(0.09)$ & 7.50 & $(0.04)$ & 0.80 & $(0.09)$ & 0.77 & $(0.09)$ & 5.72 & $(0.26)$ & 7.36 & $(0.04)$ & 1.64 & $(0.26)$ & 1.61 & $(0.26)$ \\
\hline & Greece & 6.40 & (0.09) & 7.05 & $(0.04)$ & 0.65 & $(0.10)$ & 0.64 & $(0.10)$ & 6.34 & $(0.18)$ & 6.95 & $(0.04)$ & 0.61 & $(0.19)$ & 0.56 & $(0.20)$ \\
\hline & Hungary & 6.68 & $(0.06)$ & 7.38 & $(0.04)$ & 0.71 & $(0.07)$ & 0.72 & $(0.08)$ & 6.35 & $(0.14)$ & 7.23 & $(0.04)$ & 0.88 & $(0.14)$ & 0.86 & $(0.14)$ \\
\hline & Iceland & 6.76 & $(0.10)$ & 8.03 & $(0.04)$ & 1.27 & $(0.10)$ & 1.20 & $(0.10)$ & 6.24 & $(0.25)$ & 7.86 & $(0.04)$ & 1.62 & $(0.25)$ & 1.57 & $(0.24)$ \\
\hline & Ireland & 6.33 & $(0.10)$ & 7.49 & $(0.03)$ & 1.17 & $(0.10)$ & 1.15 & $(0.11)$ & 4.75 & $(0.40)$ & 7.32 & $(0.03)$ & 2.57 & $(0.40)$ & 2.55 & $(0.40)$ \\
\hline & Israel & $\mathrm{m}$ & $\mathrm{m}$ & $\mathrm{m}$ & $\mathrm{m}$ & $\mathrm{m}$ & $\mathrm{m}$ & $\mathrm{m}$ & $\mathrm{m}$ & $\mathrm{m}$ & $\mathrm{m}$ & $\mathrm{m}$ & $\mathrm{m}$ & $\mathrm{m}$ & $\mathrm{m}$ & $\mathrm{m}$ & $\mathrm{m}$ \\
\hline & Italy & 6.25 & $(0.09)$ & 7.09 & $(0.04)$ & 0.84 & $(0.09)$ & 0.81 & $(0.09)$ & 6.76 & $(0.09)$ & 6.92 & $(0.04)$ & 0.16 & $(0.09)$ & 0.17 & $(0.10)$ \\
\hline & Japan & 5.98 & $(0.11)$ & 6.88 & $(0.04)$ & 0.91 & $(0.11)$ & 0.87 & $(0.11)$ & 6.04 & $(0.29)$ & 6.83 & $(0.04)$ & 0.79 & $(0.30)$ & 0.73 & $(0.31)$ \\
\hline & Korea & 5.88 & $(0.07)$ & 6.49 & $(0.04)$ & 0.61 & $(0.08)$ & 0.56 & $(0.08)$ & 5.75 & $(0.16)$ & 6.41 & $(0.04)$ & 0.66 & $(0.16)$ & 0.67 & $(0.16)$ \\
\hline & Latvia & 6.86 & $(0.07)$ & 7.50 & (0.04) & 0.64 & $(0.08)$ & 0.63 & $(0.07)$ & 6.60 & $(0.16)$ & 7.41 & $(0.04)$ & 0.81 & $(0.17)$ & 0.80 & $(0.17)$ \\
\hline & Luxembourg & 6.96 & $(0.06)$ & 7.53 & $(0.04)$ & 0.56 & $(0.07)$ & 0.55 & $(0.07)$ & 6.88 & $(0.17)$ & 7.41 & $(0.03)$ & 0.53 & $(0.18)$ & 0.49 & $(0.18)$ \\
\hline & Mexico & 7.72 & $(0.06)$ & 8.40 & $(0.03)$ & 0.68 & $(0.07)$ & 0.68 & $(0.07)$ & 7.80 & $(0.10)$ & 8.33 & $(0.03)$ & 0.52 & $(0.11)$ & 0.51 & $(0.11)$ \\
\hline & Netherlands & 7.28 & $(0.08)$ & 7.89 & $(0.03)$ & 0.60 & $(0.08)$ & 0.61 & $(0.08)$ & $\mathrm{m}$ & $\mathrm{m}$ & 7.82 & $(0.02)$ & $\mathrm{m}$ & $\mathrm{m}$ & $\mathrm{m}$ & $\mathrm{m}$ \\
\hline & New Zealand & $\mathrm{m}$ & $\mathrm{m}$ & $\mathrm{m}$ & $\mathrm{m}$ & $\mathrm{m}$ & $\mathrm{m}$ & $\mathrm{m}$ & $\mathrm{m}$ & $\mathrm{m}$ & $\mathrm{m}$ & $\mathrm{m}$ & $\mathrm{m}$ & $\mathrm{m}$ & $\mathrm{m}$ & $\mathrm{m}$ & $\mathrm{m}$ \\
\hline & Norway & $\mathrm{m}$ & $\mathrm{m}$ & $\mathrm{m}$ & $\mathrm{m}$ & $\mathrm{m}$ & $\mathrm{m}$ & $\mathrm{m}$ & $\mathrm{m}$ & $\mathrm{m}$ & $\mathrm{m}$ & $\mathrm{m}$ & $\mathrm{m}$ & $\mathrm{m}$ & $\mathrm{m}$ & $\mathrm{m}$ & $\mathrm{m}$ \\
\hline & Poland & 6.37 & $(0.08)$ & 7.38 & $(0.04)$ & 1.01 & $(0.09)$ & 0.99 & $(0.09)$ & 6.36 & $(0.20)$ & 7.24 & $(0.04)$ & 0.88 & $(0.21)$ & 0.85 & $0.21)$ \\
\hline & Portugal & 6.49 & $(0.12)$ & 7.44 & $(0.03)$ & 0.95 & $(0.13)$ & 0.94 & $(0.13)$ & 7.20 & $(0.17)$ & 7.38 & $(0.03)$ & 0.17 & $(0.18)$ & 0.15 & $(0.18)$ \\
\hline & Slovak Republic & 7.13 & $(0.07)$ & 7.58 & $(0.04)$ & 0.45 & $(0.08)$ & 0.43 & $(0.08)$ & 7.13 & $(0.10)$ & 7.49 & $(0.03)$ & 0.36 & $(0.10)$ & 0.31 & $(0.10)$ \\
\hline & Slovenia & 6.77 & $(0.07)$ & 7.38 & $(0.04)$ & 0.60 & $(0.07)$ & 0.60 & $(0.07)$ & 7.11 & $(0.07)$ & 7.19 & $(0.04)$ & 0.08 & $(0.08)$ & 0.08 & $(0.08)$ \\
\hline & Spain & 6.59 & $(0.09)$ & 7.58 & $(0.04)$ & 0.99 & $(0.09)$ & 0.94 & $(0.09)$ & 6.34 & $(0.21)$ & 7.46 & $(0.03)$ & 1.12 & $(0.21)$ & 1.07 & $(0.20)$ \\
\hline & Sweden & $\mathrm{m}$ & $\mathrm{m}$ & $\mathrm{m}$ & m & $\mathrm{m}$ & $\mathrm{m}$ & $\mathrm{m}$ & $\mathrm{m}$ & $\mathrm{m}$ & $\mathrm{m}$ & $\mathrm{m}$ & $\mathrm{m}$ & $\mathrm{m}$ & $\mathrm{m}$ & $\mathrm{m}$ & $\mathrm{m}$ \\
\hline & Switzerland & 7.32 & $(0.08)$ & 7.82 & $(0.04)$ & 0.50 & $(0.09)$ & 0.48 & $(0.09)$ & 6.97 & $(0.30)$ & 7.71 & $(0.03)$ & 0.74 & $(0.30)$ & 0.73 & $(0.30)$ \\
\hline & Turkey & 5.09 & $(0.11)$ & 6.39 & $(0.07)$ & 1.30 & $(0.12)$ & 1.31 & $(0.11)$ & 5.35 & $(0.24)$ & 6.14 & $(0.06)$ & 0.79 & $(0.24)$ & 0.77 & $(0.24)$ \\
\hline & United Kingdom & 6.18 & $(0.07)$ & 7.32 & $(0.04)$ & 1.14 & $(0.07)$ & 1.09 & $(0.07)$ & 5.04 & $(0.24)$ & 7.04 & $(0.04)$ & 2.00 & $(0.25)$ & 1.91 & $(0.25)$ \\
\hline & United States & 6.64 & $(0.06)$ & 7.64 & $(0.04)$ & 1.00 & $(0.08)$ & 0.96 & $(0.07)$ & 5.98 & $(0.28)$ & 7.39 & $(0.03)$ & 1.41 & $(0.27)$ & 1.29 & $(0.27)$ \\
\hline & OECD average & 6.70 & $(0.02)$ & 7.47 & $(0.01)$ & 0.78 & $(0.02)$ & 0.75 & $(0.02)$ & 6.44 & $(0.04)$ & 7.35 & $(0.01)$ & 0.88 & $(0.04)$ & 0.84 & $(0.04)$ \\
\hline 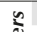 & Albania & $\mathrm{m}$ & $\mathrm{m}$ & $\mathrm{m}$ & $\mathrm{m}$ & $\mathrm{m}$ & $\mathrm{m}$ & $\mathrm{m}$ & $\mathrm{m}$ & $\mathrm{m}$ & $\mathrm{m}$ & $\mathrm{m}$ & $\mathrm{m}$ & $\mathrm{m}$ & $\mathrm{m}$ & $\mathrm{m}$ & $\mathrm{m}$ \\
\hline & Algeria & $\mathrm{m}$ & $\mathrm{m}$ & $\mathrm{m}$ & $\mathrm{m}$ & $\mathrm{m}$ & $\mathrm{m}$ & $\mathrm{m}$ & $\mathrm{m}$ & $\mathrm{m}$ & $\mathrm{m}$ & $\mathrm{m}$ & $\mathrm{m}$ & $\mathrm{m}$ & $\mathrm{m}$ & $\mathrm{m}$ & $\mathrm{m}$ \\
\hline & Brazil & 6.98 & $(0.07)$ & 7.71 & $(0.03)$ & 0.72 & $(0.07)$ & 0.73 & $(0.07)$ & 7.25 & $(0.08)$ & 7.62 & $(0.04)$ & 0.37 & $(0.09)$ & 0.37 & $(0.09)$ \\
\hline 2 & B-S-J-G (China) & 6.01 & $(0.13)$ & 6.89 & $(0.04)$ & 0.88 & $(0.14)$ & 0.86 & $(0.14)$ & 6.08 & $(0.24)$ & 6.84 & $(0.04)$ & 0.76 & $(0.24)$ & 0.77 & $(0.25)$ \\
\hline & Bulgaria & 7.13 & $(0.08)$ & 7.49 & $(0.04)$ & 0.37 & $(0.09)$ & 0.37 & $(0.09)$ & 6.90 & $(0.14)$ & 7.44 & $(0.04)$ & 0.54 & $(0.15)$ & 0.50 & $(0.15)$ \\
\hline & CABA (Argentina) & $\mathrm{m}$ & $\mathrm{m}$ & $\mathrm{m}$ & $\mathrm{m}$ & $\mathrm{m}$ & $\mathrm{m}$ & $\mathrm{m}$ & $\mathrm{m}$ & $\mathrm{m}$ & $\mathrm{m}$ & $\mathrm{m}$ & $\mathrm{m}$ & $\mathrm{m}$ & $\mathrm{m}$ & $\mathrm{m}$ & $\mathrm{m}$ \\
\hline & Colombia & 7.09 & $(0.11)$ & 7.98 & $(0.04)$ & 0.89 & $(0.11)$ & 0.90 & $(0.11)$ & 7.07 & $(0.14)$ & 7.91 & $(0.04)$ & 0.83 & $(0.13)$ & 0.84 & $(0.13)$ \\
\hline & Costa Rica & 7.47 & $(0.09)$ & 8.34 & $(0.03)$ & 0.87 & $(0.09)$ & 0.87 & $(0.09)$ & 7.56 & $(0.18)$ & 8.21 & $(0.03)$ & 0.65 & $(0.18)$ & 0.65 & $(0.18)$ \\
\hline & Croatia & 7.35 & $(0.07)$ & 8.07 & $(0.04)$ & 0.72 & $(0.07)$ & 0.72 & $(0.07)$ & 7.55 & $(0.15)$ & 7.91 & $(0.04)$ & 0.35 & $(0.15)$ & 0.35 & $(0.15)$ \\
\hline & Cyprus* & 6.58 & $(0.07)$ & 7.23 & $(0.04)$ & 0.65 & $(0.08)$ & 0.62 & $(0.08)$ & 6.57 & $(0.17)$ & 7.12 & $(0.03)$ & 0.56 & $(0.17)$ & 0.49 & $(0.16)$ \\
\hline & Dominican Republic & 8.04 & $(0.13)$ & 8.60 & $(0.05)$ & 0.56 & $(0.14)$ & 0.56 & $(0.14)$ & 8.32 & $(0.25)$ & 8.49 & $(0.04)$ & 0.17 & $(0.25)$ & 0.18 & $(0.25)$ \\
\hline & FYROM & $\mathrm{m}$ & $\mathrm{m}$ & $\mathrm{m}$ & $\mathrm{m}$ & $\mathrm{m}$ & $\mathrm{m}$ & $\mathrm{m}$ & $\mathrm{m}$ & $\mathrm{m}$ & $\mathrm{m}$ & $\mathrm{m}$ & $\mathrm{m}$ & $\mathrm{m}$ & $\mathrm{m}$ & $\mathrm{m}$ & $\mathrm{m}$ \\
\hline & Georgia & $\mathrm{m}$ & $\mathrm{m}$ & $\mathrm{m}$ & $\mathrm{m}$ & $\mathrm{m}$ & $\mathrm{m}$ & $\mathrm{m}$ & $\mathrm{m}$ & $\mathrm{m}$ & $\mathrm{m}$ & $\mathrm{m}$ & $\mathrm{m}$ & $\mathrm{m}$ & $\mathrm{m}$ & $\mathrm{m}$ & $\mathrm{m}$ \\
\hline & Hong Kong (China) & 6.05 & $(0.09)$ & 6.58 & $(0.04)$ & 0.52 & $(0.09)$ & 0.51 & $(0.09)$ & 5.47 & $(0.26)$ & 6.50 & $(0.04)$ & 1.03 & $(0.26)$ & 0.99 & $(0.25)$ \\
\hline & Indonesia & $\mathrm{m}$ & $\mathrm{m}$ & $\mathrm{m}$ & $\mathrm{m}$ & $\mathrm{m}$ & $\mathrm{m}$ & $\mathrm{m}$ & $\mathrm{m}$ & $\mathrm{m}$ & $\mathrm{m}$ & $\mathrm{m}$ & $\mathrm{m}$ & $\mathrm{m}$ & $\mathrm{m}$ & $\mathrm{m}$ & $\mathrm{m}$ \\
\hline & Jordan & $\mathrm{m}$ & $\mathrm{m}$ & $\mathrm{m}$ & $\mathrm{m}$ & $\mathrm{m}$ & $\mathrm{m}$ & $\mathrm{m}$ & $\mathrm{m}$ & $\mathrm{m}$ & $\mathrm{m}$ & $\mathrm{m}$ & $\mathrm{m}$ & $\mathrm{m}$ & $\mathrm{m}$ & $\mathrm{m}$ & $\mathrm{m}$ \\
\hline & Kosovo & $\mathrm{m}$ & $\mathrm{m}$ & $\mathrm{m}$ & $\mathrm{m}$ & $\mathrm{m}$ & $\mathrm{m}$ & $\mathrm{m}$ & $\mathrm{m}$ & $\mathrm{m}$ & $\mathrm{m}$ & $\mathrm{m}$ & $\mathrm{m}$ & $\mathrm{m}$ & $\mathrm{m}$ & $\mathrm{m}$ & $\mathrm{m}$ \\
\hline & Lebanon & $\mathrm{m}$ & $\mathrm{m}$ & $\mathrm{m}$ & $\mathrm{m}$ & $\mathrm{m}$ & $\mathrm{m}$ & $\mathrm{m}$ & $\mathrm{m}$ & $\mathrm{m}$ & $\mathrm{m}$ & $\mathrm{m}$ & $\mathrm{m}$ & $\mathrm{m}$ & $\mathrm{m}$ & $\mathrm{m}$ & $\mathrm{m}$ \\
\hline & Lithuania & 7.29 & $(0.07)$ & 8.01 & $(0.03)$ & 0.71 & $(0.08)$ & 0.68 & $(0.08)$ & 7.16 & $(0.17)$ & 7.91 & $(0.03)$ & 0.75 & $(0.17)$ & 0.74 & $(0.16)$ \\
\hline & Macao (China) & 6.19 & $(0.10)$ & 6.65 & $(0.03)$ & 0.45 & $(0.10)$ & 0.44 & $(0.10)$ & 5.88 & $(0.31)$ & 6.61 & $(0.03)$ & 0.73 & $(0.31)$ & 0.69 & $(0.32)$ \\
\hline & Malta & $\mathrm{m}$ & $\mathrm{m}$ & $\mathrm{m}$ & $\mathrm{m}$ & $\mathrm{m}$ & $\mathrm{m}$ & $\mathrm{m}$ & $\mathrm{m}$ & $\mathrm{m}$ & $\mathrm{m}$ & $\mathrm{m}$ & $\mathrm{m}$ & $\mathrm{m}$ & $\mathrm{m}$ & $\mathrm{m}$ & $\mathrm{m}$ \\
\hline & Moldo & $\mathrm{m}$ & $\mathrm{m}$ & $\mathrm{m}$ & $\mathrm{m}$ & $\mathrm{m}$ & $\mathrm{m}$ & $\mathrm{m}$ & $m$ & $\mathrm{~m}$ & $\mathrm{~m}$ & $\mathrm{~m}$ & $\mathrm{~m}$ & $\mathrm{~m}$ & $\mathrm{~m}$ & $\mathrm{~m}$ & $\mathrm{~m}$ \\
\hline & Montenegro & 6.97 & $(0.13)$ & 7.80 & $(0.04)$ & 0.83 & $(0.14)$ & 0.83 & $(0.14)$ & 7.37 & $(0.15)$ & 7.75 & $(0.04)$ & 0.39 & $(0.16)$ & 0.37 & $(0.16)$ \\
\hline & Peru & 6.54 & $(0.13)$ & 7.58 & $(0.04)$ & 1.03 & $(0.14)$ & 1.03 & $(0.14)$ & 6.98 & $(0.12)$ & 7.51 & $(0.04)$ & 0.53 & $(0.13)$ & 0.53 & $(0.13)$ \\
\hline & Qatar & 6.71 & $(0.06)$ & 7.55 & $(0.02)$ & 0.84 & $(0.06)$ & 0.84 & $(0.06)$ & 6.66 & $(0.10)$ & 7.42 & $(0.02)$ & 0.76 & $(0.11)$ & 0.73 & $(0.11)$ \\
\hline & Romania & $\mathrm{m}$ & $\mathrm{m}$ & $\mathrm{m}$ & $\mathrm{m}$ & $\mathrm{m}$ & $\mathrm{m}$ & $\mathrm{m}$ & $\mathrm{m}$ & $\mathrm{m}$ & $\mathrm{m}$ & $\mathrm{m}$ & $\mathrm{m}$ & $\mathrm{m}$ & $\mathrm{m}$ & $\mathrm{m}$ & $\mathrm{m}$ \\
\hline & Russia & 6.97 & $(0.13)$ & 7.87 & $(0.04)$ & 0.90 & $(0.13)$ & 0.90 & $(0.13)$ & 7.20 & $(0.17)$ & 7.80 & $(0.04)$ & 0.60 & $(0.17)$ & 0.58 & $(0.17)$ \\
\hline & Singapore & $\mathrm{m}$ & $\mathrm{m}$ & $\mathrm{m}$ & $\mathrm{m}$ & $\mathrm{m}$ & $\mathrm{m}$ & $\mathrm{m}$ & $\mathrm{m}$ & $\mathrm{m}$ & $\mathrm{m}$ & $\mathrm{m}$ & $\mathrm{m}$ & $\mathrm{m}$ & $\mathrm{m}$ & $\mathrm{m}$ & $\mathrm{m}$ \\
\hline & Chinese Taipei & 6.10 & $(0.08)$ & 6.67 & $(0.03)$ & 0.57 & $(0.08)$ & 0.59 & $(0.08)$ & 6.03 & $(0.21)$ & 6.60 & $(0.03)$ & 0.57 & $(0.21)$ & 0.51 & $(0.22)$ \\
\hline & Thailand & 6.98 & $(0.09)$ & 7.82 & $(0.03)$ & 0.83 & $(0.09)$ & 0.83 & $(0.09)$ & 7.18 & $(0.15)$ & 7.74 & $(0.03)$ & 0.56 & $(0.15)$ & 0.56 & $(0.15)$ \\
\hline & Trinidad and Tobago & $\mathrm{m}$ & $\mathrm{m}$ & $\mathrm{m}$ & $\mathrm{m}$ & $\mathrm{m}$ & $\mathrm{m}$ & $\mathrm{m}$ & $\mathrm{m}$ & $\mathrm{m}$ & $\mathrm{m}$ & $\mathrm{m}$ & $\mathrm{m}$ & $\mathrm{m}$ & $\mathrm{m}$ & $\mathrm{m}$ & $\mathrm{m}$ \\
\hline & Tunisia & 6.11 & $(0.13)$ & 7.06 & $(0.05)$ & 0.96 & $(0.14)$ & 0.94 & $(0.14)$ & 6.13 & $(0.20)$ & 6.96 & $(0.05)$ & 0.83 & $(0.21)$ & 0.82 & $(0.21)$ \\
\hline & United Arab Emirates & 6.77 & $(0.06)$ & 7.47 & $(0.03)$ & 0.70 & $(0.06)$ & 0.69 & $(0.06)$ & 6.65 & $(0.12)$ & 7.37 & $(0.04)$ & 0.72 & $(0.13)$ & 0.69 & $(0.13)$ \\
\hline & Uruguay & 6.98 & $(0.08)$ & 7.85 & $(0.04)$ & 0.87 & $(0.08)$ & 0.84 & $(0.08)$ & 7.23 & $(0.11)$ & 7.74 & $(0.04)$ & 0.51 & $(0.11)$ & 0.47 & $(0.11)$ \\
\hline & Viet Nam & $\mathrm{m}$ & $\mathrm{m}$ & $\mathrm{m}$ & $\mathrm{m}$ & $\mathrm{m}$ & $\mathrm{m}$ & $\mathrm{m}$ & $\mathrm{m}$ & $\mathrm{m}$ & $\mathrm{m}$ & $\mathrm{m}$ & $\mathrm{m}$ & $\mathrm{m}$ & $\mathrm{m}$ & $\mathrm{m}$ & $\mathrm{m}$ \\
\hline & Arge & $\mathrm{m}$ & $\mathrm{m}$ & $\mathrm{m}$ & $\mathrm{m}$ & $\mathrm{m}$ & $\mathrm{m}$ & $\mathrm{m}$ & $\mathrm{m}$ & $\mathrm{m}$ & $\mathrm{m}$ & $\mathrm{m}$ & $\mathrm{m}$ & $\mathrm{m}$ & $\mathrm{m}$ & $\mathrm{m}$ & $\mathrm{m}$ \\
\hline & Kazakhstan** & $\mathrm{m}$ & $\mathrm{m}$ & $\mathrm{m}$ & $\mathrm{m}$ & $\mathrm{m}$ & $\mathrm{m}$ & $\mathrm{m}$ & $\mathrm{m}$ & $\mathrm{m}$ & $\mathrm{m}$ & $\mathrm{m}$ & $\mathrm{m}$ & $\mathrm{m}$ & $\mathrm{m}$ & $\mathrm{m}$ & $\mathrm{m}$ \\
\hline & Malaysia** & 6.70 & $(0.07)$ & 7.16 & $(0.04)$ & 0.46 & $(0.07)$ & 0.45 & $(0.07)$ & 6.77 & $(0.13)$ & 7.09 & $(0.04)$ & 0.32 & $(0.13)$ & 0.30 & $(0.13)$ \\
\hline
\end{tabular}

Note: Values that are statistically significant are indicated in bold (see Annex A3).

* See note at the beginning of this Annex.

** Coverage is too small to ensure comparability (see Annex A4).

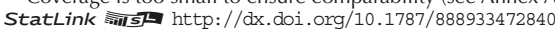


[Part 1/1]

Table III.12.1 Students who work in the household and work for pay

Based on students' self-reports

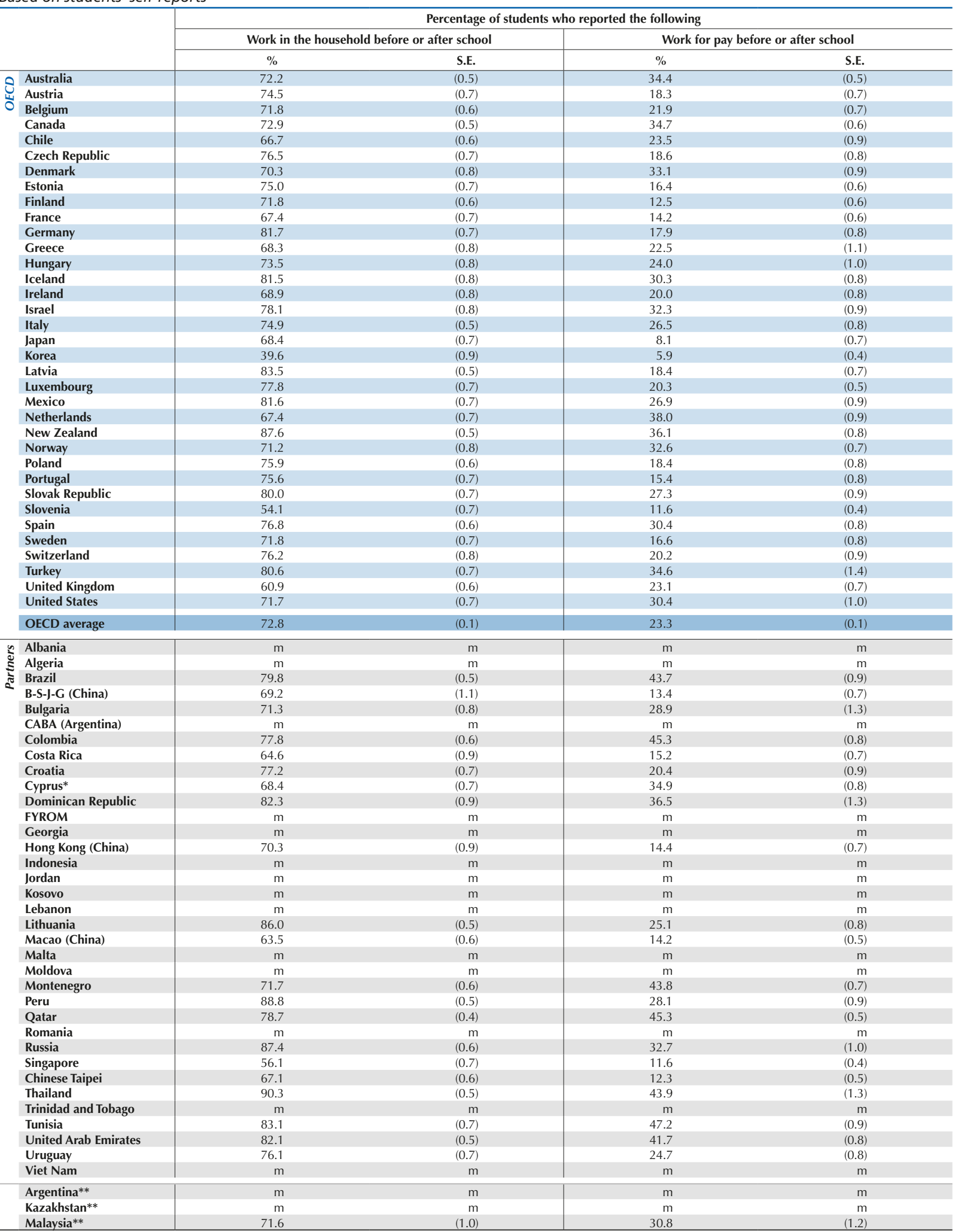

* See note at the beginning of this Annex.

** Coverage is too small to ensure comparability (see Annex A4).

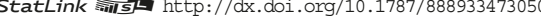


[Part 1/2]

Table III.12.2 Students who work in the household, by student characteristics

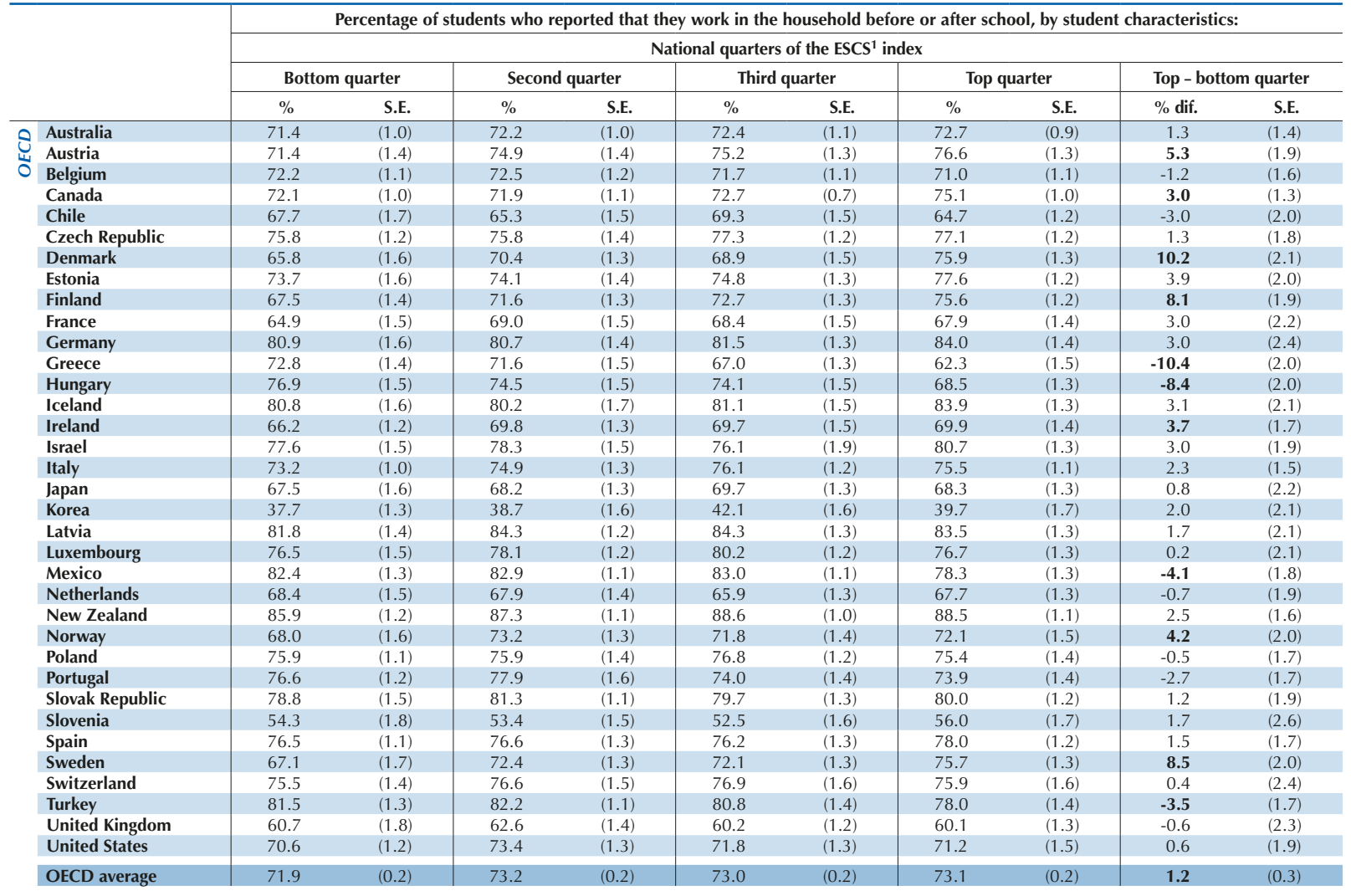

\begin{tabular}{|c|c|c|c|c|c|c|c|c|c|c|c|}
\hline \multirow{4}{*}{ 范 } & Albania & $\mathrm{m}$ & $\mathrm{m}$ & $\mathrm{m}$ & $\mathrm{m}$ & $\mathrm{m}$ & $\mathrm{m}$ & $\mathrm{m}$ & $\mathrm{m}$ & $\mathrm{m}$ & $\mathrm{m}$ \\
\hline & Algeria & $\mathrm{m}$ & $\mathrm{m}$ & $\mathrm{m}$ & $\mathrm{m}$ & $\mathrm{m}$ & $\mathrm{m}$ & $\mathrm{m}$ & $\mathrm{m}$ & $\mathrm{m}$ & $\mathrm{m}$ \\
\hline & Brazil & 82.3 & (1.1) & 80.8 & $(0.9)$ & 79.6 & $(0.9)$ & 77.5 & (1.1) & -4.8 & (1.4) \\
\hline & B-S-J-G (China) & 79.2 & (1.4) & 72.7 & (1.4) & 66.2 & $(2.0)$ & 58.7 & (2.1) & -20.5 & (2.5) \\
\hline & Bulgaria & 70.0 & (1.5) & 73.3 & (1.4) & 73.0 & $(1.2)$ & 68.8 & (1.5) & -1.2 & (2.0) \\
\hline & CABA (Argentina) & $\mathrm{m}$ & $\mathrm{m}$ & $\mathrm{m}$ & $\mathrm{m}$ & $\mathrm{m}$ & $\mathrm{m}$ & $\mathrm{m}$ & $\mathrm{m}$ & $\mathrm{m}$ & $\mathrm{m}$ \\
\hline & Colombia & 83.8 & (1.1) & 82.1 & $(1.2)$ & 78.3 & $(1.0)$ & 67.6 & (1.9) & -16.2 & $(2.2)$ \\
\hline & Costa Rica & 68.8 & (1.6) & 66.5 & (1.4) & 64.1 & (1.6) & 59.1 & (1.5) & -9.8 & $(2.1)$ \\
\hline & Croatia & 75.7 & (1.3) & 76.9 & $(1.2)$ & 79.0 & $(1.2)$ & 77.2 & (1.3) & 1.4 & (1.9) \\
\hline & Cyprus* & 70.0 & (1.3) & 72.1 & (1.3) & 68.3 & (1.6) & 63.4 & (1.7) & -6.6 & $(2.1)$ \\
\hline & Dominican Republic & 84.1 & (1.8) & 87.0 & (1.7) & 82.4 & (1.6) & 76.9 & (1.6) & -7.1 & (2.5) \\
\hline & FYROM & $\mathrm{m}$ & $\mathrm{m}$ & $\mathrm{m}$ & $\mathrm{m}$ & $\mathrm{m}$ & $\mathrm{m}$ & $\mathrm{m}$ & $\mathrm{m}$ & $\mathrm{m}$ & $\mathrm{m}$ \\
\hline & Georgia & $\mathrm{m}$ & $\mathrm{m}$ & $\mathrm{m}$ & $\mathrm{m}$ & $\mathrm{m}$ & $\mathrm{m}$ & $\mathrm{m}$ & $\mathrm{m}$ & $\mathrm{m}$ & $\mathrm{m}$ \\
\hline & Hong Kong (China) & 69.9 & (1.1) & 71.8 & (1.5) & 72.3 & $(1.8)$ & 67.0 & (1.7) & -2.9 & (1.8) \\
\hline & Indonesia & $\mathrm{m}$ & $\mathrm{m}$ & $\mathrm{m}$ & $\mathrm{m}$ & $\mathrm{m}$ & $\mathrm{m}$ & $\mathrm{m}$ & $\mathrm{m}$ & $\mathrm{m}$ & $\mathrm{m}$ \\
\hline & Jordan & $\mathrm{m}$ & $\mathrm{m}$ & $\mathrm{m}$ & $\mathrm{m}$ & $\mathrm{m}$ & $\mathrm{m}$ & $\mathrm{m}$ & $\mathrm{m}$ & $\mathrm{m}$ & $\mathrm{m}$ \\
\hline & Kosovo & $\mathrm{m}$ & $\mathrm{m}$ & $\mathrm{m}$ & $\mathrm{m}$ & $\mathrm{m}$ & $\mathrm{m}$ & $\mathrm{m}$ & $\mathrm{m}$ & $\mathrm{m}$ & $\mathrm{m}$ \\
\hline & Lebanon & $\mathrm{m}$ & $\mathrm{m}$ & $\mathrm{m}$ & $\mathrm{m}$ & $\mathrm{m}$ & $\mathrm{m}$ & $\mathrm{m}$ & $\mathrm{m}$ & $\mathrm{m}$ & $\mathrm{m}$ \\
\hline & Lithuania & 85.8 & (1.1) & 85.8 & (1.1) & 85.9 & (1.0) & 86.6 & (1.0) & 0.7 & (1.5) \\
\hline & Macao (China) & 60.6 & (1.6) & 66.0 & (1.5) & 63.4 & (1.6) & 64.2 & (1.4) & 3.6 & $(2.2)$ \\
\hline & Malta & $\mathrm{m}$ & $\mathrm{m}$ & $\mathrm{m}$ & $\mathrm{m}$ & $\mathrm{m}$ & $\mathrm{m}$ & $\mathrm{m}$ & $\mathrm{m}$ & $\mathrm{m}$ & $\mathrm{m}$ \\
\hline & Moldova & $\mathrm{m}$ & $\mathrm{m}$ & $\mathrm{m}$ & $\mathrm{m}$ & $\mathrm{m}$ & $\mathrm{m}$ & $\mathrm{m}$ & $\mathrm{m}$ & $\mathrm{m}$ & $\mathrm{m}$ \\
\hline & Montenegro & 71.6 & (1.3) & 71.9 & (1.3) & 72.3 & (1.3) & 71.0 & (1.3) & -0.5 & $(2.0)$ \\
\hline & Peru & 91.2 & (1.1) & 91.7 & $(0.8)$ & 89.5 & $(0.9)$ & 84.3 & (1.3) & -6.8 & (1.8) \\
\hline & Qatar & 81.7 & $(0.8)$ & 81.9 & $(0.8)$ & 76.9 & $(0.9)$ & 74.7 & (1.0) & -7.0 & (1.3) \\
\hline & Romania & $\mathrm{m}$ & $\mathrm{m}$ & $\mathrm{m}$ & $\mathrm{m}$ & $\mathrm{m}$ & $\mathrm{m}$ & $\mathrm{m}$ & $\mathrm{m}$ & $\mathrm{m}$ & $\mathrm{m}$ \\
\hline & Russia & 88.3 & $(1.0)$ & 87.9 & (1.4) & 86.1 & $(1.0)$ & 87.5 & $(1.2)$ & -0.8 & $(1.3)$ \\
\hline & Singapore & 58.6 & $(1.2)$ & 57.1 & (1.3) & 55.7 & (1.4) & 53.1 & (1.5) & -5.5 & $(1.8)$ \\
\hline & Chinese Taipei & 67.4 & (1.1) & 68.8 & $(1.3)$ & 66.0 & $(1.3)$ & 66.2 & (1.2) & -1.2 & (1.5) \\
\hline & Thailand & 91.7 & $(0.8)$ & 91.8 & $(0.8)$ & 90.2 & (1.1) & 87.5 & (1.0) & -4.2 & $(1.2)$ \\
\hline & Trinidad and Tobago & $\mathrm{m}$ & $\mathrm{m}$ & $\mathrm{m}$ & $\mathrm{m}$ & $\mathrm{m}$ & $\mathrm{m}$ & $\mathrm{m}$ & $\mathrm{m}$ & $\mathrm{m}$ & $\mathrm{m}$ \\
\hline & Tunisia & 85.6 & (1.3) & 85.4 & (1.3) & 82.7 & (1.5) & 78.9 & (1.4) & -6.7 & (1.8) \\
\hline & United Arab Emirates & 86.2 & $(0.8)$ & 83.4 & $(0.9)$ & 81.8 & $(0.8)$ & 77.2 & (1.1) & -9.0 & (1.3) \\
\hline & Uruguay & 77.2 & (1.5) & 75.6 & $(1.2)$ & 77.0 & $(1.3)$ & 74.5 & (1.5) & -2.6 & $(2.0)$ \\
\hline & Viet Nam & $\mathrm{m}$ & $\mathrm{m}$ & $\mathrm{m}$ & $\mathrm{m}$ & $\mathrm{m}$ & $\mathrm{m}$ & $\mathrm{m}$ & $\mathrm{m}$ & $\mathrm{m}$ & $\mathrm{m}$ \\
\hline & Argentina** $^{* *}$ & $\mathrm{~m}$ & $\mathrm{~m}$ & $\mathrm{~m}$ & $\mathrm{~m}$ & $\mathrm{~m}$ & $\mathrm{~m}$ & $\mathrm{~m}$ & $\mathrm{~m}$ & $\mathrm{~m}$ & $\mathrm{~m}$ \\
\hline & Kazakhstan** & $\mathrm{m}$ & $\mathrm{m}$ & $\mathrm{m}$ & $\mathrm{m}$ & $\mathrm{m}$ & $\mathrm{m}$ & $\mathrm{m}$ & $\mathrm{m}$ & $\mathrm{m}$ & $\mathrm{m}$ \\
\hline & Malaysia** & 76.2 & (1.4) & 72.6 & $(1.7)$ & 72.0 & (1.5) & 65.8 & (1.8) & -10.3 & $(2.2)$ \\
\hline
\end{tabular}

1. ESCS refers to the PISA index of economic, social and cultural status.

Note: Values that are statistically significant are indicated in bold (see Annex A3).

* See note at the beginning of this Annex.

** Coverage is too small to ensure comparability (see Annex A4).

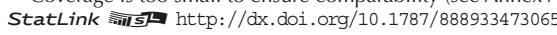


Table III.12.2 Students who work in the household, by student characteristics

\begin{tabular}{|c|c|c|c|c|c|c|c|c|c|c|c|c|c|c|c|}
\hline & \multicolumn{14}{|c|}{ Percentage of students who reported that they work in the household before or after school, by student characteristics } \\
\hline & & \multicolumn{6}{|c|}{ Gender } & & & & Imm & grant ba & round & & \\
\hline & & & & & & $\begin{array}{r}\text { Gender } \\
\text { (B }\end{array}$ & $\begin{array}{l}\text { ference } \\
\text { G) }\end{array}$ & Non-i & nigrant & First- & ration & Second & neration & $\begin{array}{r}\text { Differen } \\
\text { backgroun } \\
\text { firs }\end{array}$ & $\begin{array}{l}\text { migrant } \\
\text { nmigrant - } \\
\text { ion) }\end{array}$ \\
\hline & & $\%$ & S.E. & $\%$ & S.E. & $\%$ dif. & S.E. & $\%$ & S.E. & $\%$ & S.E. & $\%$ & S.E. & $\%$ dif. & S.E. \\
\hline 0 & Australia & 70.6 & $(0.8)$ & 73.7 & $(0.7)$ & -3.1 & $(1.1)$ & 71.1 & $(0.5)$ & 77.6 & $(1.6)$ & 73.0 & $(1.3)$ & -6.4 & $(1.6)$ \\
\hline ర్ & Austria & 69.1 & (1.1) & 79.8 & (1.0) & -10.7 & (1.4) & 72.9 & $(0.8)$ & 79.5 & (2.6) & 81.9 & (1.5) & -6.6 & $(2.6)$ \\
\hline 0 & Belgium & 67.9 & $(0.8)$ & 75.6 & $(0.8)$ & -7.8 & (1.1) & 70.8 & $(0.6)$ & 75.4 & $(2.0)$ & 77.6 & (1.6) & -4.6 & $(2.0)$ \\
\hline & Canada & 70.9 & $(0.6)$ & 74.8 & $(0.7)$ & -3.9 & $(0.9)$ & 70.9 & $(0.5)$ & 78.2 & (1.0) & 76.0 & $(1.2)$ & -7.3 & $(1.0)$ \\
\hline & Chile & 65.2 & $(1.0)$ & 68.1 & $(0.8)$ & -2.9 & $(1.3)$ & 66.4 & $(0.6)$ & 66.4 & (5.4) & c & C & 0.1 & (5.4) \\
\hline & Czech Republic & 74.1 & $(0.9)$ & 78.9 & $(1.0)$ & -4.8 & (1.4) & 76.6 & $(0.7)$ & 74.1 & (5.7) & 73.4 & $(4.3)$ & 2.5 & (5.6) \\
\hline & Denmark & 70.4 & (1.1) & 70.1 & (1.1) & 0.3 & $(1.6)$ & 70.1 & $(0.8)$ & 71.5 & (4.3) & 71.8 & (1.8) & -1.4 & $(4.4)$ \\
\hline & Estonia & 72.4 & $(1.0)$ & 77.7 & $(0.9)$ & -5.3 & (1.3) & 74.9 & $(0.7)$ & 83.7 & (6.2) & 75.8 & $(2.0)$ & -8.8 & (6.3) \\
\hline & Finland & 67.5 & $(1.0)$ & 76.3 & $(0.8)$ & -8.8 & $(1.4)$ & 71.4 & $(0.7)$ & 79.8 & (3.4) & 81.3 & (3.7) & -8.4 & (3.5) \\
\hline & France & 61.9 & $(0.9)$ & 72.6 & $(0.8)$ & -10.7 & (1.0) & 66.3 & $(0.8)$ & 73.7 & (2.5) & 75.7 & $(2.0)$ & -7.4 & $(2.7)$ \\
\hline & Germany & 78.9 & $(0.9)$ & 84.4 & $(0.8)$ & -5.5 & $(1.2)$ & 81.3 & $(0.8)$ & 84.8 & (3.7) & 82.6 & $(2.0)$ & -3.4 & (3.8) \\
\hline & Greece & 66.3 & (1.1) & 70.4 & (1.0) & -4.2 & $(1.3)$ & 67.2 & $(0.8)$ & 80.9 & (3.0) & 76.7 & (2.6) & -13.7 & (2.9) \\
\hline & Hungary & 71.5 & $(1.0)$ & 75.5 & (1.0) & -4.1 & (1.3) & 73.5 & $(0.8)$ & 64.1 & (9.5) & 71.4 & (5.8) & 9.4 & $(9.7)$ \\
\hline & Iceland & 80.3 & (1.1) & 82.7 & $(0.9)$ & -2.3 & (1.4) & 81.6 & $(0.8)$ & 78.5 & (4.6) & 85.9 & (6.1) & 3.1 & $(4.7)$ \\
\hline & Ireland & 66.8 & (1.1) & 71.1 & $(0.9)$ & -4.4 & (1.3) & 68.6 & $(0.9)$ & 70.8 & (2.1) & 67.7 & (3.5) & -2.2 & $(2.2)$ \\
\hline & Israel & 72.9 & (1.3) & 82.8 & $(0.9)$ & -9.8 & (1.5) & 78.4 & $(0.9)$ & 80.4 & $(2.6)$ & 75.5 & $(2.0)$ & -2.1 & $(2.6)$ \\
\hline & Italy & 72.6 & $(0.8)$ & 77.2 & $(0.8)$ & -4.6 & $(1.1)$ & 74.4 & $(0.6)$ & 80.2 & $(2.7)$ & 80.8 & $(2.7)$ & -5.7 & $(2.9)$ \\
\hline & Japan & 64.8 & $(0.9)$ & 72.0 & $(0.9)$ & -7.1 & $(1.2)$ & 68.3 & $(0.7)$ & C & $\mathrm{C}$ & C & c & c & c \\
\hline & Korea & 39.4 & $(1.0)$ & 39.8 & (1.3) & -0.3 & (1.5) & 39.6 & $(0.9)$ & C & C & $\mathrm{m}$ & $\mathrm{m}$ & c & $\mathrm{c}$ \\
\hline & Latvia & 82.0 & $(0.9)$ & 84.9 & $(0.8)$ & -3.0 & $(1.2)$ & 83.9 & $(0.6)$ & 75.8 & (7.6) & 78.4 & $(2.9)$ & 8.1 & (7.6) \\
\hline & Luxembourg & 75.0 & $(1.0)$ & 80.6 & $(0.9)$ & -5.5 & $(1.2)$ & 78.8 & $(1.0)$ & 74.1 & $(1.7)$ & 78.9 & $(1.2)$ & 4.7 & (1.8) \\
\hline & Mexico & 79.2 & $(0.9)$ & 83.9 & $(0.8)$ & -4.7 & $(1.0)$ & 81.7 & $(0.7)$ & 69.8 & $(7.2)$ & C & c & 11.9 & (7.4) \\
\hline & Netherlands & 64.6 & $(1.0)$ & 70.1 & $(0.8)$ & -5.5 & (1.1) & 66.2 & $(0.8)$ & 84.0 & (3.8) & 76.5 & $(2.1)$ & -17.7 & (3.9) \\
\hline & New Zealand & 86.9 & $(0.8)$ & 88.3 & $(0.7)$ & -1.4 & $(1.0)$ & 88.0 & $(0.6)$ & 87.7 & $(1.3)$ & 84.9 & $(1.7)$ & 0.4 & (1.4) \\
\hline & Norway & 70.3 & $(0.9)$ & 72.2 & (1.0) & -1.9 & (1.1) & 70.1 & $(0.9)$ & 81.2 & $(2.3)$ & 77.0 & $(2.2)$ & -11.1 & (2.4) \\
\hline & Poland & 73.3 & $(1.0)$ & 78.6 & $(0.9)$ & -5.3 & (1.4) & 75.9 & $(0.6)$ & c & C & c & c & c & c \\
\hline & Portugal & 71.3 & $(1.0)$ & 79.9 & $(0.8)$ & -8.5 & $(1.2)$ & 75.2 & $(0.7)$ & 84.5 & $(2.7)$ & 73.5 & (3.5) & -9.3 & $(2.8)$ \\
\hline & Slovak Republic & 78.9 & $(0.9)$ & 81.1 & (1.0) & -2.2 & (1.3) & 80.0 & $(0.7)$ & $\mathrm{C}$ & C & C & C & C & $\mathrm{C}$ \\
\hline & Slovenia & 51.9 & $(1.0)$ & 56.3 & (1.0) & -4.3 & (1.5) & 54.2 & $(0.7)$ & 53.0 & (4.4) & 52.1 & $(4.0)$ & 1.2 & $(4.5)$ \\
\hline & Spain & 74.3 & $(0.8)$ & 79.3 & $(0.8)$ & -4.9 & $(1.1)$ & 76.5 & $(0.6)$ & 78.9 & (1.8) & 81.6 & $(3.1)$ & -2.4 & (1.8) \\
\hline & Sweden & 69.8 & (1.1) & 73.7 & $(0.9)$ & -3.9 & $(1.3)$ & 71.2 & $(0.7)$ & 75.9 & (2.8) & 73.6 & $(2.1)$ & -4.7 & (2.9) \\
\hline & Switzerland & 72.2 & $(1.2)$ & 80.4 & (1.1) & -8.2 & (1.6) & 75.8 & $(1.0)$ & 76.4 & (2.4) & 77.3 & $(1.7)$ & -0.6 & $(2.7)$ \\
\hline & Turkey & 79.7 & $(0.9)$ & 81.5 & (1.1) & -1.8 & (1.4) & 80.6 & $(0.7)$ & C & C & C & C & c & $\mathrm{C}$ \\
\hline & United Kingdom & 59.7 & $(0.8)$ & 62.1 & $(0.8)$ & -2.4 & (1.1) & 59.5 & $(0.8)$ & 67.2 & (2.6) & 69.5 & (2.6) & -7.7 & $(2.8)$ \\
\hline & United States & 70.3 & (1.0) & 73.1 & $(0.8)$ & -2.8 & $(1.2)$ & 70.9 & $(0.7)$ & 77.9 & (2.5) & 74.4 & (1.6) & -7.0 & $(2.5)$ \\
\hline & OECD average & 70.4 & $(0.2)$ & 75.1 & $(0.2)$ & -4.8 & $(0.2)$ & 72.4 & $(0.1)$ & 76.2 & $(0.7)$ & 75.9 & $(0.5)$ & -3.2 & $(0.8)$ \\
\hline$n$ & Albania & $\mathrm{m}$ & $\mathrm{m}$ & $\mathrm{m}$ & $\mathrm{m}$ & $\mathrm{m}$ & $\mathrm{m}$ & $\mathrm{m}$ & $\mathrm{m}$ & $\mathrm{m}$ & $\mathrm{m}$ & $\mathrm{m}$ & $\mathrm{m}$ & $\mathrm{m}$ & $\mathrm{m}$ \\
\hline & Algeria & $\mathrm{m}$ & $\mathrm{m}$ & $\mathrm{m}$ & $\mathrm{m}$ & $\mathrm{m}$ & $\mathrm{m}$ & $\mathrm{m}$ & $\mathrm{m}$ & $\mathrm{m}$ & $\mathrm{m}$ & $\mathrm{m}$ & $\mathrm{m}$ & $\mathrm{m}$ & $\mathrm{m}$ \\
\hline ปั & Brazil & 75.6 & $(0.8)$ & 83.6 & $(0.7)$ & -8.0 & (1.0) & 79.6 & $(0.6)$ & $\mathrm{m}$ & $\mathrm{m}$ & 80.7 & (7.5) & $\mathrm{m}$ & $\mathrm{m}$ \\
\hline & B-S-J-G (China) & 68.2 & (1.1) & 70.3 & (1.4) & -2.0 & $(1.1)$ & 68.9 & $(1.1)$ & $\mathrm{m}$ & $\mathrm{m}$ & $\mathrm{m}$ & $\mathrm{m}$ & $\mathrm{m}$ & $\mathrm{m}$ \\
\hline & Bulgaria & 67.1 & (1.1) & 75.6 & $(0.9)$ & -8.5 & (1.3) & 71.3 & $(0.8)$ & $\mathrm{m}$ & $\mathrm{m}$ & $\mathrm{m}$ & $\mathrm{m}$ & $\mathrm{m}$ & $\mathrm{m}$ \\
\hline & CABA (Argentina) & $\mathrm{m}$ & $\mathrm{m}$ & $\mathrm{m}$ & $\mathrm{m}$ & $\mathrm{m}$ & $\mathrm{m}$ & $\mathrm{m}$ & $\mathrm{m}$ & $\mathrm{m}$ & $\mathrm{m}$ & $\mathrm{m}$ & $\mathrm{m}$ & $\mathrm{m}$ & $\mathrm{m}$ \\
\hline & Colombia & 77.4 & $(0.9)$ & 78.2 & $(0.8)$ & -0.9 & (1.1) & 77.6 & $(0.7)$ & $\mathrm{m}$ & $\mathrm{m}$ & $\mathrm{m}$ & $\mathrm{m}$ & $\mathrm{m}$ & $\mathrm{m}$ \\
\hline & Costa Rica & 62.7 & $(1.2)$ & 66.3 & $(1.2)$ & -3.6 & (1.6) & 63.4 & $(0.9)$ & 73.1 & (4.9) & 75.9 & $(2.7)$ & -9.6 & $(5.0)$ \\
\hline & Croatia & 75.4 & $(1.0)$ & 78.9 & $(0.8)$ & -3.5 & $(1.2)$ & 77.1 & $(0.7)$ & 84.3 & (3.8) & 76.0 & $(2.0)$ & -7.2 & (3.8) \\
\hline & Cyprus* & 68.6 & $(0.9)$ & 68.2 & $(0.9)$ & 0.4 & (1.1) & 67.8 & $(0.8)$ & 71.8 & (2.6) & 76.0 & (3.6) & -4.0 & $(2.8)$ \\
\hline & Dominican Republic & 79.1 & (1.1) & 85.3 & (1.0) & -6.2 & $(1.2)$ & 82.4 & $(0.9)$ & $\mathrm{m}$ & $\mathrm{m}$ & $\mathrm{m}$ & $\mathrm{m}$ & $\mathrm{m}$ & $\mathrm{m}$ \\
\hline & FYROM & $\mathrm{m}$ & $\mathrm{m}$ & $\mathrm{m}$ & $\mathrm{m}$ & $\mathrm{m}$ & $\mathrm{m}$ & $\mathrm{m}$ & $\mathrm{m}$ & $\mathrm{m}$ & $\mathrm{m}$ & $\mathrm{m}$ & $\mathrm{m}$ & $\mathrm{m}$ & $\mathrm{m}$ \\
\hline & Georgia & $\mathrm{m}$ & $\mathrm{m}$ & $\mathrm{m}$ & $\mathrm{m}$ & $\mathrm{m}$ & $\mathrm{m}$ & $\mathrm{m}$ & $\mathrm{m}$ & $\mathrm{m}$ & $\mathrm{m}$ & $\mathrm{m}$ & $\mathrm{m}$ & $\mathrm{m}$ & $\mathrm{m}$ \\
\hline & Hong Kong (China) & 69.9 & $(1.2)$ & 70.6 & $(1.0)$ & -0.7 & (1.3) & 69.1 & $(1.1)$ & 73.8 & (1.6) & 72.0 & (1.6) & -4.8 & $(1.8)$ \\
\hline & Indonesia & $\mathrm{m}$ & $\mathrm{m}$ & $\mathrm{m}$ & $\mathrm{m}$ & $\mathrm{m}$ & $\mathrm{m}$ & $\mathrm{m}$ & $\mathrm{m}$ & $\mathrm{m}$ & $\mathrm{m}$ & $\mathrm{m}$ & $\mathrm{m}$ & $\mathrm{m}$ & $\mathrm{m}$ \\
\hline & Jordan & $\mathrm{m}$ & $\mathrm{m}$ & $\mathrm{m}$ & $\mathrm{m}$ & $\mathrm{m}$ & $\mathrm{m}$ & $\mathrm{m}$ & $\mathrm{m}$ & $\mathrm{m}$ & $\mathrm{m}$ & $\mathrm{m}$ & $\mathrm{m}$ & $\mathrm{m}$ & $\mathrm{m}$ \\
\hline & Kosovo & $\mathrm{m}$ & $\mathrm{m}$ & $\mathrm{m}$ & $\mathrm{m}$ & $\mathrm{m}$ & $\mathrm{m}$ & $\mathrm{m}$ & $\mathrm{m}$ & $\mathrm{m}$ & $\mathrm{m}$ & $\mathrm{m}$ & $\mathrm{m}$ & $\mathrm{m}$ & $\mathrm{m}$ \\
\hline & Lebanon & $\mathrm{m}$ & $\mathrm{m}$ & $\mathrm{m}$ & $\mathrm{m}$ & $\mathrm{m}$ & $\mathrm{m}$ & $\mathrm{m}$ & $\mathrm{m}$ & $\mathrm{m}$ & $\mathrm{m}$ & $\mathrm{m}$ & $\mathrm{m}$ & $\mathrm{m}$ & $\mathrm{m}$ \\
\hline & Lithuania & 83.9 & $(0.7)$ & 88.1 & $(0.7)$ & -4.2 & $(1.0)$ & 86.2 & $(0.5)$ & $\mathrm{m}$ & $\mathrm{m}$ & 79.1 & $(4.0)$ & $\mathrm{m}$ & $\mathrm{m}$ \\
\hline & Macao (China) & 62.3 & $(0.9)$ & 64.6 & (1.1) & -2.3 & (1.5) & 61.2 & $(1.1)$ & 69.3 & $(1.2)$ & 62.8 & (1.1) & -8.1 & $(1.7)$ \\
\hline & Malta & $\mathrm{m}$ & $\mathrm{m}$ & $\mathrm{m}$ & $\mathrm{m}$ & $\mathrm{m}$ & $\mathrm{m}$ & $\mathrm{m}$ & $\mathrm{m}$ & $\mathrm{m}$ & $\mathrm{m}$ & $\mathrm{m}$ & $\mathrm{m}$ & $\mathrm{m}$ & $\mathrm{m}$ \\
\hline & Moldova & $\mathrm{m}$ & $\mathrm{m}$ & $\mathrm{m}$ & $\mathrm{m}$ & $\mathrm{m}$ & $\mathrm{m}$ & $\mathrm{m}$ & $\mathrm{m}$ & $\mathrm{m}$ & $\mathrm{m}$ & $\mathrm{m}$ & $\mathrm{m}$ & $\mathrm{m}$ & $\mathrm{m}$ \\
\hline & Montenegro & 72.5 & $(1.0)$ & 70.9 & $(0.8)$ & 1.6 & $(1.3)$ & 71.8 & $(0.7)$ & 74.3 & (4.4) & 68.8 & (3.6) & -2.5 & $(4.4)$ \\
\hline & Peru & 87.9 & $(0.7)$ & 89.8 & $(0.7)$ & -1.8 & $(0.9)$ & 88.7 & $(0.5)$ & $\mathrm{m}$ & $\mathrm{m}$ & $\mathrm{m}$ & $\mathrm{m}$ & $\mathrm{m}$ & $\mathrm{m}$ \\
\hline & Qatar & 80.5 & $(0.6)$ & 77.2 & $(0.6)$ & 3.4 & (0.9) & 76.5 & $(0.6)$ & 80.0 & $(0.6)$ & 81.5 & (0.9) & -3.5 & $(0.8)$ \\
\hline & Romania & $\mathrm{m}$ & $\mathrm{m}$ & $\mathrm{m}$ & $\mathrm{m}$ & $\mathrm{m}$ & $\mathrm{m}$ & $\mathrm{m}$ & $\mathrm{m}$ & $\mathrm{m}$ & $\mathrm{m}$ & $\mathrm{m}$ & $\mathrm{m}$ & $\mathrm{m}$ & $\mathrm{m}$ \\
\hline & Russia & 86.4 & $(0.8)$ & 88.4 & $(0.8)$ & -2.0 & $(0.9)$ & 87.2 & $(0.7)$ & 90.8 & (2.3) & 88.1 & (2.8) & -3.6 & (2.4) \\
\hline & Singapore & 55.8 & $(0.9)$ & 56.4 & $(0.9)$ & -0.6 & $(1.2)$ & 56.1 & $(0.7)$ & 57.3 & (2.5) & 53.5 & (2.6) & -1.2 & (2.5) \\
\hline & Chinese Taipei & 65.1 & $(0.8)$ & 69.2 & $(0.9)$ & -4.0 & $(1.1)$ & 67.1 & $(0.6)$ & $\mathrm{m}$ & $\mathrm{m}$ & $\mathrm{m}$ & $\mathrm{m}$ & $\mathrm{m}$ & $\mathrm{m}$ \\
\hline & Thailand & 88.5 & $(0.7)$ & 91.6 & $(0.5)$ & -3.1 & $(0.7)$ & 90.3 & $(0.5)$ & $\mathrm{m}$ & $\mathrm{m}$ & 88.9 & (5.8) & $\mathrm{m}$ & $\mathrm{m}$ \\
\hline & Trinidad and Tobago & $\mathrm{m}$ & $\mathrm{m}$ & $\mathrm{m}$ & $\mathrm{m}$ & $\mathrm{m}$ & $\mathrm{m}$ & $\mathrm{m}$ & $\mathrm{m}$ & $\mathrm{m}$ & $\mathrm{m}$ & $\mathrm{m}$ & $\mathrm{m}$ & $\mathrm{m}$ & $\mathrm{m}$ \\
\hline & Tunisia & 80.1 & $(1.0)$ & 85.7 & $(0.8)$ & -5.6 & $(1.3)$ & 83.1 & $(0.7)$ & $\mathrm{m}$ & $\mathrm{m}$ & $\mathrm{m}$ & $\mathrm{m}$ & $\mathrm{m}$ & $\mathrm{m}$ \\
\hline & United Arab Emirates & 82.2 & $(0.7)$ & 82.0 & $(0.7)$ & 0.2 & (1.1) & 83.6 & $(0.8)$ & 80.8 & $(0.8)$ & 81.1 & (1.0) & 2.8 & (1.1) \\
\hline & Uruguay & 75.3 & (1.1) & 76.7 & $(0.8)$ & -1.4 & $(1.2)$ & 76.1 & $(0.7)$ & $\mathrm{m}$ & $\mathrm{m}$ & $\mathrm{m}$ & $\mathrm{m}$ & $\mathrm{m}$ & $\mathrm{m}$ \\
\hline & Viet Nam & $\mathrm{m}$ & $\mathrm{m}$ & $\mathrm{m}$ & $\mathrm{m}$ & $\mathrm{m}$ & $\mathrm{m}$ & $\mathrm{m}$ & $\mathrm{m}$ & $\mathrm{m}$ & $\mathrm{m}$ & $\mathrm{m}$ & $\mathrm{m}$ & $\mathrm{m}$ & $\mathrm{m}$ \\
\hline & Argentina** & $\mathrm{m}$ & $\mathrm{m}$ & $\mathrm{m}$ & $\mathrm{m}$ & $\mathrm{m}$ & $\mathrm{m}$ & $\mathrm{m}$ & $\mathrm{m}$ & $\mathrm{m}$ & $\mathrm{m}$ & $\mathrm{m}$ & $\mathrm{m}$ & $\mathrm{m}$ & $\mathrm{m}$ \\
\hline & Kazakhstan** & $\mathrm{m}$ & $\mathrm{m}$ & $\mathrm{m}$ & $\mathrm{m}$ & $\mathrm{m}$ & $\mathrm{m}$ & $\mathrm{m}$ & $\mathrm{m}$ & $\mathrm{m}$ & $\mathrm{m}$ & $\mathrm{m}$ & $\mathrm{m}$ & $\mathrm{m}$ & $\mathrm{m}$ \\
\hline & Malaysia** & 75.0 & $(1.0)$ & 68.6 & $(1.2)$ & 6.3 & $(1.1)$ & 71.3 & $(1.0)$ & $\mathrm{m}$ & $\mathrm{m}$ & 72.3 & (5.6) & $\mathrm{m}$ & $\mathrm{m}$ \\
\hline
\end{tabular}

1. ESCS refers to the PISA index of economic, social and cultural status.

Note: Values that are statistically significant are indicated in bold (see Annex A3).

* See note at the beginning of this Annex.

** Coverage is too small to ensure comparability (see Annex A4).

StatLink न्ता $\mathrm{http}: / / \mathrm{dx}$. doi.org/10.1787/888933473065 
[Part 1/2]

Table III.12.7 Students who work for pay, by student characteristics

Percentage of students who reported that they work for pay before or after school, by:

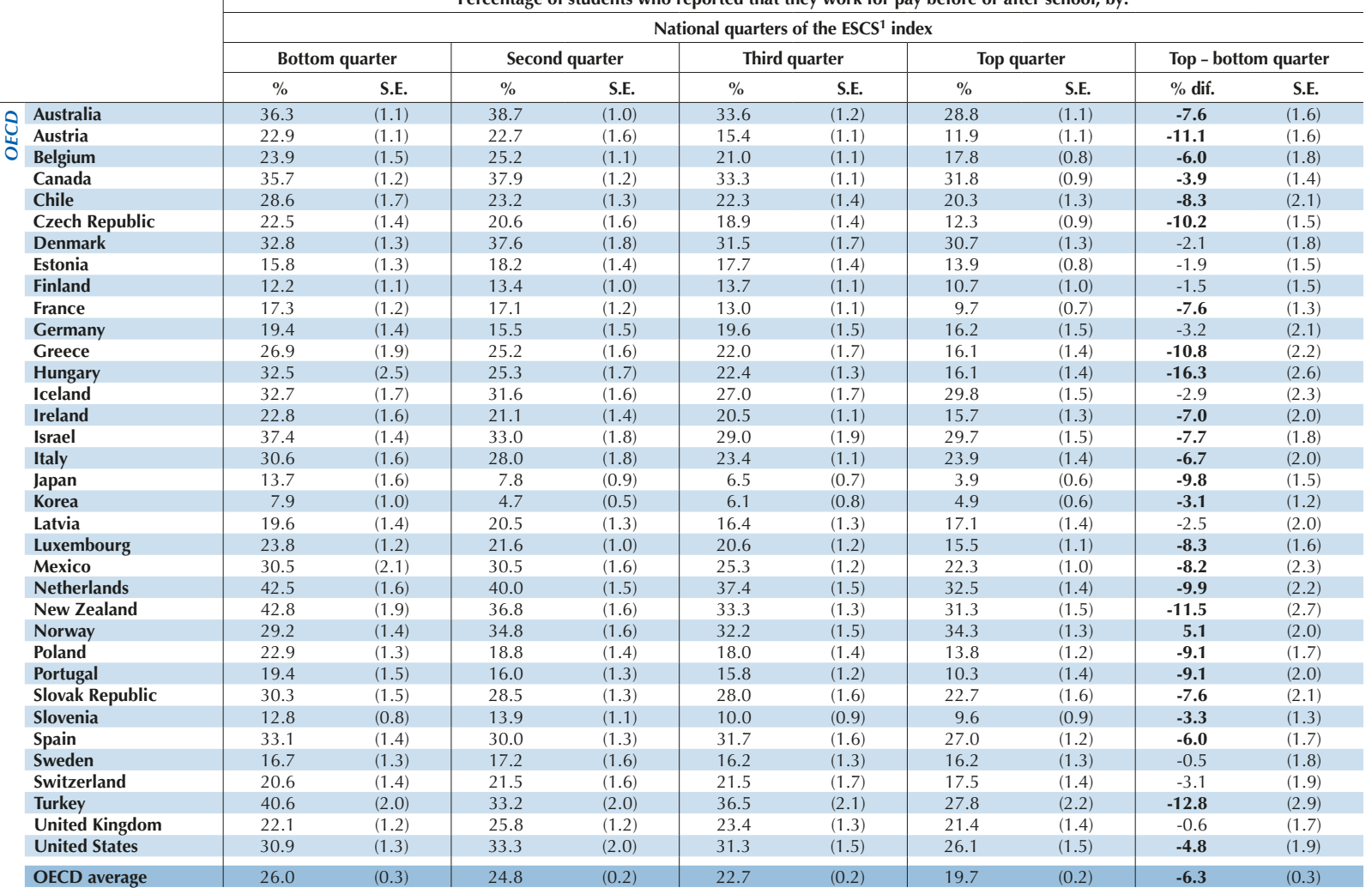

\begin{tabular}{|c|c|c|c|c|c|c|c|c|c|c|c|}
\hline \multirow{4}{*}{ 范 } & Albania & $\mathrm{m}$ & $\mathrm{m}$ & $\mathrm{m}$ & $\mathrm{m}$ & $\mathrm{m}$ & $\mathrm{m}$ & $\mathrm{m}$ & $\mathrm{m}$ & $\mathrm{m}$ & $\mathrm{m}$ \\
\hline & Algeria & $\mathrm{m}$ & $\mathrm{m}$ & $\mathrm{m}$ & $\mathrm{m}$ & $\mathrm{m}$ & $\mathrm{m}$ & $\mathrm{m}$ & $\mathrm{m}$ & $\mathrm{m}$ & $\mathrm{m}$ \\
\hline & Brazil & 47.8 & $(1.2)$ & 45.2 & (1.5) & 44.7 & (1.4) & 38.9 & (1.7) & -8.9 & $(2.0)$ \\
\hline & B-S-J-G (China) & 19.2 & (1.3) & 11.9 & $(1.2)$ & 13.6 & (1.1) & 8.8 & (1.2) & -10.5 & (1.7) \\
\hline & Bulgaria & 36.1 & $(2.2)$ & 33.1 & $(1.8)$ & 27.1 & (1.9) & 20.4 & (1.5) & -15.7 & (2.3) \\
\hline & CABA (Argentina) & $\mathrm{m}$ & $\mathrm{m}$ & $\mathrm{m}$ & $\mathrm{m}$ & $\mathrm{m}$ & $\mathrm{m}$ & $\mathrm{m}$ & $\mathrm{m}$ & $\mathrm{m}$ & $\mathrm{m}$ \\
\hline & Colombia & 49.1 & (1.4) & 48.3 & (1.5) & 45.6 & (1.4) & 38.5 & (1.6) & -10.6 & $(2.0)$ \\
\hline & Costa Rica & 18.3 & (1.8) & 17.0 & $(1.2)$ & 13.8 & (1.1) & 12.1 & (1.1) & -6.2 & $(2.1)$ \\
\hline & Croatia & 19.6 & (1.5) & 22.5 & (1.3) & 22.7 & (1.4) & 16.6 & (1.2) & -3.0 & (1.7) \\
\hline & Cyprus* & 38.7 & (1.4) & 37.8 & (1.6) & 34.3 & (1.5) & 28.8 & (1.4) & -9.9 & (1.9) \\
\hline & Dominican Republic & 39.1 & $(1.7)$ & 40.7 & (1.9) & 40.0 & $(2.1)$ & 27.7 & (2.3) & -11.4 & $(2.8)$ \\
\hline & FYROM & $\mathrm{m}$ & $\mathrm{m}$ & $\mathrm{m}$ & $\mathrm{m}$ & $\mathrm{m}$ & $\mathrm{m}$ & $\mathrm{m}$ & $\mathrm{m}$ & $\mathrm{m}$ & $\mathrm{m}$ \\
\hline & Georgia & $\mathrm{m}$ & $\mathrm{m}$ & $\mathrm{m}$ & $\mathrm{m}$ & $\mathrm{m}$ & $\mathrm{m}$ & $\mathrm{m}$ & $\mathrm{m}$ & $\mathrm{m}$ & $\mathrm{m}$ \\
\hline & Hong Kong (China) & 15.1 & (1.1) & 14.5 & (1.2) & 14.9 & (1.4) & 12.9 & (1.4) & -2.2 & (1.9) \\
\hline & Indonesia & $\mathrm{m}$ & $\mathrm{m}$ & $\mathrm{m}$ & $\mathrm{m}$ & $\mathrm{m}$ & $\mathrm{m}$ & $\mathrm{m}$ & $\mathrm{m}$ & $\mathrm{m}$ & $\mathrm{m}$ \\
\hline & Jordan & $\mathrm{m}$ & $\mathrm{m}$ & $\mathrm{m}$ & $\mathrm{m}$ & $\mathrm{m}$ & $\mathrm{m}$ & $\mathrm{m}$ & $\mathrm{m}$ & $\mathrm{m}$ & $\mathrm{m}$ \\
\hline & Kosovo & $\mathrm{m}$ & $\mathrm{m}$ & $\mathrm{m}$ & $\mathrm{m}$ & $\mathrm{m}$ & $\mathrm{m}$ & $\mathrm{m}$ & $\mathrm{m}$ & $\mathrm{m}$ & $\mathrm{m}$ \\
\hline & Lebanon & $\mathrm{m}$ & $\mathrm{m}$ & $\mathrm{m}$ & $\mathrm{m}$ & $\mathrm{m}$ & $\mathrm{m}$ & $\mathrm{m}$ & $\mathrm{m}$ & $\mathrm{m}$ & $\mathrm{m}$ \\
\hline & Lithuania & 28.2 & (1.5) & 27.0 & (1.5) & 22.0 & $(1.3)$ & 23.0 & (1.3) & -5.2 & (1.8) \\
\hline & Macao (China) & 13.9 & (1.1) & 13.1 & (1.0) & 14.1 & $(0.9)$ & 15.6 & (1.1) & 1.7 & (1.6) \\
\hline & Malta & $\mathrm{m}$ & $\mathrm{m}$ & $\mathrm{m}$ & $\mathrm{m}$ & $\mathrm{m}$ & $\mathrm{m}$ & $\mathrm{m}$ & $\mathrm{m}$ & $\mathrm{m}$ & $\mathrm{m}$ \\
\hline & Moldova & $\mathrm{m}$ & $\mathrm{m}$ & $\mathrm{m}$ & $\mathrm{m}$ & $\mathrm{m}$ & $\mathrm{m}$ & $\mathrm{m}$ & $\mathrm{m}$ & $\mathrm{m}$ & $\mathrm{m}$ \\
\hline & Montenegro & 42.3 & (1.5) & 46.1 & $(1.5)$ & 43.4 & $(1.5)$ & 43.0 & (1.4) & 0.6 & $(2.2)$ \\
\hline & Peru & 46.7 & (1.6) & 30.6 & $(2.1)$ & 25.3 & (1.4) & 17.2 & (1.5) & -29.4 & $(2.2)$ \\
\hline & Qatar & 55.7 & (0.9) & 44.5 & (1.1) & 40.7 & $(0.9)$ & 41.0 & $(0.9)$ & -14.6 & (1.3) \\
\hline & Romania & $\mathrm{m}$ & $\mathrm{m}$ & $\mathrm{m}$ & $\mathrm{m}$ & $\mathrm{m}$ & $\mathrm{m}$ & $\mathrm{m}$ & $\mathrm{m}$ & $\mathrm{m}$ & $\mathrm{m}$ \\
\hline & Russia & 34.0 & $(1.5)$ & 34.7 & (1.6) & 27.6 & (1.4) & 34.5 & (1.7) & 0.5 & $(2.3)$ \\
\hline & Singapore & 16.6 & $(0.9)$ & 12.8 & $(0.9)$ & 9.6 & $(0.8)$ & 7.2 & (0.6) & -9.4 & (1.1) \\
\hline & Chinese Taipei & 19.7 & (1.1) & 13.8 & $(0.9)$ & 9.4 & $(0.9)$ & 6.3 & $(0.6)$ & -13.4 & (1.3) \\
\hline & Thailand & 49.1 & (1.4) & 49.0 & (1.8) & 44.9 & $(2.1)$ & 32.7 & (2.2) & -16.4 & (2.4) \\
\hline & Trinidad and Tobago & $\mathrm{m}$ & $\mathrm{m}$ & $\mathrm{m}$ & $\mathrm{m}$ & $\mathrm{m}$ & $\mathrm{m}$ & $\mathrm{m}$ & $\mathrm{m}$ & $\mathrm{m}$ & $\mathrm{m}$ \\
\hline & Tunisia & 45.4 & (1.9) & 48.6 & (1.6) & 51.1 & (1.6) & 43.6 & (1.5) & -1.8 & $(2.2)$ \\
\hline & United Arab Emirates & 51.5 & (1.3) & 41.9 & (1.7) & 35.6 & $(1.2)$ & 37.7 & (1.3) & -13.8 & (1.7) \\
\hline & Uruguay & 28.5 & $(1.3)$ & 26.3 & $(1.2)$ & 25.2 & (1.5) & 19.1 & (1.3) & -9.4 & (1.8) \\
\hline & Viet Nam & $\mathrm{m}$ & $\mathrm{m}$ & $\mathrm{m}$ & $\mathrm{m}$ & $\mathrm{m}$ & $\mathrm{m}$ & $\mathrm{m}$ & $\mathrm{m}$ & $\mathrm{m}$ & $\mathrm{m}$ \\
\hline & Argentina** $^{* *}$ & $\mathrm{~m}$ & $\mathrm{~m}$ & $\mathrm{~m}$ & $\mathrm{~m}$ & $\mathrm{~m}$ & $\mathrm{~m}$ & $\mathrm{~m}$ & $\mathrm{~m}$ & $\mathrm{~m}$ & $\mathrm{~m}$ \\
\hline & Kazakhstan** & $\mathrm{m}$ & $\mathrm{m}$ & $\mathrm{m}$ & $\mathrm{m}$ & $\mathrm{m}$ & $\mathrm{m}$ & $\mathrm{m}$ & $\mathrm{m}$ & $\mathrm{m}$ & $\mathrm{m}$ \\
\hline & Malaysia** & 39.5 & $(1.7)$ & 33.5 & (1.9) & 28.7 & $(1.7)$ & 21.4 & (1.5) & -18.2 & (1.9) \\
\hline
\end{tabular}

1. ESCS refers to the PISA index of economic, social and cultural status.

Note: Values that are statistically significant are indicated in bold (see Annex A3).

* See note at the beginning of this Annex.

** Coverage is too small to ensure comparability (see Annex A4).

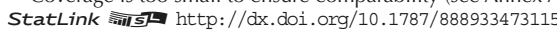


Table III.12.7 Students who work for pay, by student characteristics

\begin{tabular}{|c|c|c|c|c|c|c|c|c|c|c|c|c|c|c|c|}
\hline & \multicolumn{14}{|c|}{ Percentage of students who reported that they work for pay before or after school, by: } \\
\hline & & \multicolumn{6}{|c|}{ Gender } & & & & Imm & grant ba & ground & & \\
\hline & & & & & & $\begin{array}{r}\text { Gender } \\
\text { (B }\end{array}$ & $\begin{array}{l}\text { ference } \\
\text { G) }\end{array}$ & Non-i & igrant & First- & ration & Second & eneration & $\begin{array}{r}\text { Differen } \\
\text { backgroun } \\
\text { first }\end{array}$ & $\begin{array}{l}\text { migrant } \\
\text { nmigrant - } \\
\text { ion) }\end{array}$ \\
\hline & & $\%$ & S.E. & $\%$ & S.E. & $\%$ dif. & S.E. & $\%$ & S.E. & $\%$ & S.E. & $\%$ & S.E. & $\%$ dif. & S.E. \\
\hline 0 & Australia & 34.6 & $(0.7)$ & 34.3 & $(0.8)$ & 0.2 & $(1.0)$ & 36.2 & $(0.6)$ & 29.6 & $(1.5)$ & 26.1 & $(1.7)$ & 6.6 & $(1.7)$ \\
\hline ర్ & Austria & 24.4 & $(1.0)$ & 12.2 & $(0.9)$ & 12.2 & (1.5) & 17.4 & $(0.8)$ & 23.7 & (3.3) & 19.7 & (1.6) & -6.3 & (3.4) \\
\hline 0 & Belgium & 26.3 & (1.1) & 17.5 & $(0.7)$ & 8.8 & (1.3) & 21.0 & $(0.6)$ & 27.1 & (2.4) & 23.4 & (2.1) & -6.1 & $(2.4)$ \\
\hline & Canada & 37.4 & $(0.8)$ & 32.0 & $(0.8)$ & 5.4 & $(0.9)$ & 38.9 & $(0.6)$ & 24.9 & (1.4) & 23.8 & (1.4) & 14.0 & (1.7) \\
\hline & Chile & 29.8 & (1.4) & 17.3 & $(0.9)$ & 12.5 & (1.6) & 23.1 & $(0.9)$ & C & C & c & C & c & c \\
\hline & Czech Republic & 24.0 & (1.1) & 13.0 & $(0.9)$ & 11.0 & $(1.2)$ & 18.3 & $(0.8)$ & c & C & c & c & C & c \\
\hline & Denmark & 34.7 & $(0.9)$ & 31.5 & (1.3) & 3.2 & $(1.4)$ & 33.3 & (1.0) & 33.3 & (3.8) & 30.0 & $(2.0)$ & 0.0 & (3.9) \\
\hline & Estonia & 23.2 & $(0.9)$ & 9.5 & $(0.7)$ & 13.7 & (1.1) & 15.0 & $(0.7)$ & C & C & 27.1 & $(2.1)$ & C & C \\
\hline & Finland & 16.4 & $(0.9)$ & 8.3 & $(0.6)$ & 8.1 & $(1.1)$ & 11.9 & $(0.5)$ & 29.7 & (4.4) & c & c & -17.8 & $(4.2)$ \\
\hline & France & 18.9 & $(0.8)$ & 9.8 & $(0.6)$ & 9.1 & (1.0) & 13.3 & $(0.6)$ & 21.2 & (2.3) & 18.9 & (2.6) & -7.8 & $(2.3)$ \\
\hline & Germany & 21.8 & (1.1) & 14.2 & $(1.0)$ & 7.5 & (1.3) & 17.1 & $(0.9)$ & c & c & 18.6 & (1.9) & c & c \\
\hline & Greece & 30.9 & (1.4) & 13.8 & $(0.9)$ & 17.2 & $(1.3)$ & 21.3 & (1.1) & 34.5 & (4.5) & 28.6 & $(3.2)$ & -13.2 & (4.4) \\
\hline & Hungary & 32.1 & $(1.2)$ & 15.9 & $(1.0)$ & 16.2 & $(1.3)$ & 24.0 & $(1.0)$ & C & c & c & c & c & c \\
\hline & Iceland & 33.1 & $(1.2)$ & 27.7 & $(0.9)$ & 5.4 & (1.6) & 29.8 & $(0.8)$ & 40.2 & (5.5) & c & c & -10.4 & (5.5) \\
\hline & Ireland & 25.6 & $(1.2)$ & 14.3 & $(0.8)$ & 11.2 & (1.3) & 20.5 & $(0.9)$ & 15.3 & (1.9) & c & c & 5.2 & (1.8) \\
\hline & Israel & 36.8 & (1.5) & 28.3 & $(0.9)$ & 8.5 & (1.6) & 32.0 & (1.0) & 37.5 & (3.2) & 29.9 & $(2.0)$ & -5.5 & (3.1) \\
\hline & Italy & 34.2 & $(1.2)$ & 19.0 & $(0.8)$ & 15.2 & (1.4) & 25.1 & $(0.8)$ & 44.2 & (2.9) & 34.4 & $(4.1)$ & -19.0 & $(2.8)$ \\
\hline & Japan & 8.4 & $(0.7)$ & 7.8 & $(0.9)$ & 0.6 & $(0.8)$ & 7.9 & $(0.6)$ & c & $\mathrm{C}$ & C & c & c & c \\
\hline & Korea & 8.3 & $(0.7)$ & 3.3 & $(0.4)$ & 5.0 & $(0.8)$ & 5.9 & $(0.4)$ & C & C & $\mathrm{m}$ & $\mathrm{m}$ & c & c \\
\hline & Latvia & 27.2 & (1.1) & 9.8 & $(0.7)$ & 17.3 & $(1.2)$ & 18.0 & $(0.7)$ & c & $\mathrm{C}$ & 21.0 & (2.4) & C & c \\
\hline & Luxembourg & 25.7 & $(0.8)$ & 15.2 & $(0.7)$ & 10.5 & (1.1) & 17.8 & $(0.7)$ & 25.5 & (1.5) & 20.0 & (1.1) & -7.7 & (1.8) \\
\hline & Mexico & 36.1 & $(1.1)$ & 17.5 & $(0.9)$ & 18.6 & $(1.1)$ & 26.6 & (1.0) & C & C & C & C & C & c \\
\hline & Netherlands & 41.5 & $(1.2)$ & 34.6 & $(1.0)$ & 6.9 & (1.4) & 38.3 & (0.9) & 31.1 & (4.6) & 34.7 & $(2.0)$ & 7.2 & $(4.7)$ \\
\hline & New Zealand & 40.6 & $(0.9)$ & 31.7 & (1.3) & 8.9 & (1.6) & 36.3 & $(1.0)$ & 32.9 & (2.1) & 35.9 & $(2.3)$ & 3.4 & $(2.2)$ \\
\hline & Norway & 37.5 & $(1.0)$ & 27.9 & $(1.0)$ & 9.6 & (1.5) & 32.7 & $(0.8)$ & 36.3 & (3.1) & 27.0 & $(2.5)$ & -3.6 & (3.3) \\
\hline & Poland & 26.8 & $(1.2)$ & 9.7 & $(0.7)$ & 17.1 & (1.4) & 18.3 & $(0.8)$ & c & C & c & c & c & c \\
\hline & Portugal & 20.4 & $(1.2)$ & 10.3 & $(0.7)$ & 10.1 & (1.1) & 15.2 & $(0.8)$ & 17.8 & $(2.1)$ & c & c & -2.6 & $(2.2)$ \\
\hline & Slovak Republic & 37.3 & (1.1) & 17.0 & $(1.0)$ & 20.3 & (1.4) & 26.8 & $(0.9)$ & $\mathrm{C}$ & C & c & c & C & $\mathrm{C}$ \\
\hline & Slovenia & 16.9 & $(0.7)$ & 6.0 & $(0.5)$ & 10.9 & $(0.8)$ & 11.1 & $(0.4)$ & 20.9 & (3.5) & 11.1 & $(1.8)$ & -9.8 & (3.6) \\
\hline & Spain & 34.7 & $(1.2)$ & 26.2 & $(1.0)$ & 8.5 & $(1.5)$ & 29.5 & $(0.9)$ & 35.5 & $(2.2)$ & 37.0 & (4.4) & -6.0 & $(2.3)$ \\
\hline & Sweden & 20.9 & (1.0) & 12.4 & $(0.8)$ & 8.5 & $(1.0)$ & 15.7 & $(0.8)$ & 24.3 & (2.8) & 16.9 & $(2.3)$ & -8.6 & (2.9) \\
\hline & Switzerland & 24.7 & (1.3) & 15.4 & $(1.0)$ & 9.3 & (1.5) & 19.4 & (1.0) & 23.2 & $(2.1)$ & 20.7 & $(2.0)$ & -3.7 & $(2.2)$ \\
\hline & Turkey & 45.5 & (1.6) & 23.8 & (1.5) & 21.7 & (1.8) & 34.0 & (1.4) & $\mathrm{C}$ & $\mathrm{C}$ & $\mathrm{C}$ & $\mathrm{C}$ & c & $\mathrm{C}$ \\
\hline & United Kingdom & 27.1 & (1.0) & 19.2 & $(0.9)$ & 7.9 & $(1.2)$ & 23.9 & $(0.8)$ & 19.3 & (1.9) & 16.3 & (2.1) & 4.6 & $(2.2)$ \\
\hline & United States & 36.1 & (1.3) & 24.8 & (1.2) & 11.4 & (1.4) & 31.7 & (1.1) & 27.6 & (2.3) & 24.5 & (1.7) & 4.1 & $(2.3)$ \\
\hline & OECD average & 28.6 & $(0.2)$ & 18.0 & $(0.2)$ & 10.5 & $(0.2)$ & 23.1 & $(0.1)$ & 28.5 & $(0.6)$ & 24.8 & $(0.5)$ & -3.6 & $(0.6)$ \\
\hline$n$ & Albania & $\mathrm{m}$ & $\mathrm{m}$ & $\mathrm{m}$ & $\mathrm{m}$ & $\mathrm{m}$ & $\mathrm{m}$ & $\mathrm{m}$ & $\mathrm{m}$ & $\mathrm{m}$ & $\mathrm{m}$ & $\mathrm{m}$ & $\mathrm{m}$ & $\mathrm{m}$ & $\mathrm{m}$ \\
\hline & Algeria & $\mathrm{m}$ & $\mathrm{m}$ & $\mathrm{m}$ & $\mathrm{m}$ & $\mathrm{m}$ & $\mathrm{m}$ & $\mathrm{m}$ & $\mathrm{m}$ & $\mathrm{m}$ & $\mathrm{m}$ & $\mathrm{m}$ & $\mathrm{m}$ & $\mathrm{m}$ & $\mathrm{m}$ \\
\hline ปั & Brazil & 49.2 & (1.0) & 38.6 & $(0.9)$ & 10.6 & $(0.9)$ & 43.0 & $(0.9)$ & c & c & 69.3 & (10.4) & c & c \\
\hline & B-S-J-G (China) & 15.3 & $(0.8)$ & 11.2 & $(0.9)$ & 4.1 & $(0.9)$ & 12.9 & $(0.7)$ & c & C & c & c & c & c \\
\hline & Bulgaria & 39.0 & (1.6) & 18.4 & $(1.2)$ & 20.6 & (1.6) & 28.3 & (1.3) & $\mathrm{c}$ & C & c & c & c & c \\
\hline & CABA (Argentina) & $\mathrm{m}$ & $\mathrm{m}$ & $\mathrm{m}$ & $\mathrm{m}$ & $\mathrm{m}$ & $\mathrm{m}$ & $\mathrm{m}$ & $\mathrm{m}$ & $\mathrm{m}$ & $\mathrm{m}$ & $\mathrm{m}$ & $\mathrm{m}$ & $\mathrm{m}$ & $\mathrm{m}$ \\
\hline & Colombia & 53.7 & $(1.0)$ & 37.9 & $(1.0)$ & 15.7 & (1.3) & 44.8 & $(0.8)$ & $\mathrm{c}$ & $\mathrm{C}$ & c & c & $\mathrm{c}$ & c \\
\hline & Costa Rica & 21.3 & (1.0) & 9.4 & $(0.8)$ & 11.9 & (1.1) & 14.8 & $(0.7)$ & c & C & 18.3 & (2.5) & c & c \\
\hline & Croatia & 31.2 & (1.3) & 10.6 & $(0.8)$ & 20.6 & (1.4) & 20.0 & $(0.9)$ & c & c & 20.4 & (2.5) & c & c \\
\hline & Cyprus* & 43.9 & $(1.1)$ & 26.6 & $(0.9)$ & 17.4 & $(1.2)$ & 34.9 & $(0.9)$ & 34.8 & (2.4) & 32.0 & (3.6) & 0.1 & $(2.5)$ \\
\hline & Dominican Republic & 46.9 & (1.7) & 26.6 & $(1.2)$ & 20.3 & $(1.8)$ & 35.5 & (1.3) & c & c & c & c & c & c \\
\hline & FYROM & $\mathrm{m}$ & $\mathrm{m}$ & $\mathrm{m}$ & $\mathrm{m}$ & $\mathrm{m}$ & $\mathrm{m}$ & $\mathrm{m}$ & $\mathrm{m}$ & $\mathrm{m}$ & $\mathrm{m}$ & $\mathrm{m}$ & $\mathrm{m}$ & $\mathrm{m}$ & $\mathrm{m}$ \\
\hline & Georgia & $\mathrm{m}$ & $\mathrm{m}$ & $\mathrm{m}$ & $\mathrm{m}$ & $\mathrm{m}$ & $\mathrm{m}$ & $\mathrm{m}$ & $\mathrm{m}$ & $\mathrm{m}$ & $\mathrm{m}$ & $\mathrm{m}$ & $\mathrm{m}$ & $\mathrm{m}$ & $\mathrm{m}$ \\
\hline & Hong Kong (China) & 18.5 & $(1.0)$ & 10.2 & $(0.8)$ & 8.3 & (1.3) & 13.6 & $(0.8)$ & 15.9 & (1.5) & 15.1 & (1.3) & -2.3 & $(1.7)$ \\
\hline & Indonesia & $\mathrm{m}$ & $\mathrm{m}$ & $\mathrm{m}$ & $\mathrm{m}$ & $\mathrm{m}$ & $\mathrm{m}$ & $\mathrm{m}$ & $\mathrm{m}$ & $\mathrm{m}$ & $\mathrm{m}$ & $\mathrm{m}$ & $\mathrm{m}$ & $\mathrm{m}$ & $\mathrm{m}$ \\
\hline & Jordan & $\mathrm{m}$ & $\mathrm{m}$ & $\mathrm{m}$ & $\mathrm{m}$ & $\mathrm{m}$ & $\mathrm{m}$ & $\mathrm{m}$ & $\mathrm{m}$ & $\mathrm{m}$ & $\mathrm{m}$ & $\mathrm{m}$ & $\mathrm{m}$ & $\mathrm{m}$ & $\mathrm{m}$ \\
\hline & Kosovo & $\mathrm{m}$ & $\mathrm{m}$ & $\mathrm{m}$ & $\mathrm{m}$ & $\mathrm{m}$ & $\mathrm{m}$ & $\mathrm{m}$ & $\mathrm{m}$ & $\mathrm{m}$ & $\mathrm{m}$ & $\mathrm{m}$ & $\mathrm{m}$ & $\mathrm{m}$ & $\mathrm{m}$ \\
\hline & Lebanon & $\mathrm{m}$ & $\mathrm{m}$ & $\mathrm{m}$ & $\mathrm{m}$ & $\mathrm{m}$ & $\mathrm{m}$ & $\mathrm{m}$ & $\mathrm{m}$ & $\mathrm{m}$ & $\mathrm{m}$ & $\mathrm{m}$ & $\mathrm{m}$ & $\mathrm{m}$ & $\mathrm{m}$ \\
\hline & Lithuania & 34.7 & (1.0) & 15.6 & $(0.9)$ & 19.1 & $(1.2)$ & 24.9 & $(0.8)$ & c & c & 20.5 & (3.6) & c & c \\
\hline & Macao (China) & 12.9 & $(0.7)$ & 15.5 & $(0.7)$ & -2.6 & $(1.0)$ & 14.2 & $(0.9)$ & 12.7 & (1.1) & 14.8 & $(0.8)$ & 1.5 & (1.4) \\
\hline & Malta & $\mathrm{m}$ & $\mathrm{m}$ & $\mathrm{m}$ & $\mathrm{m}$ & $\mathrm{m}$ & $\mathrm{m}$ & $\mathrm{m}$ & $\mathrm{m}$ & $\mathrm{m}$ & $\mathrm{m}$ & $\mathrm{m}$ & $\mathrm{m}$ & $\mathrm{m}$ & $\mathrm{m}$ \\
\hline & Moldova & $\mathrm{m}$ & $\mathrm{m}$ & $\mathrm{m}$ & $\mathrm{m}$ & $\mathrm{m}$ & $\mathrm{m}$ & $\mathrm{m}$ & $\mathrm{m}$ & $\mathrm{m}$ & $\mathrm{m}$ & $\mathrm{m}$ & $\mathrm{m}$ & $\mathrm{m}$ & $\mathrm{m}$ \\
\hline & Montenegro & 52.3 & $(0.9)$ & 35.4 & $(0.9)$ & 16.9 & (1.1) & 43.3 & $(0.7)$ & 50.5 & (4.4) & 44.0 & (3.9) & -7.2 & (4.6) \\
\hline & Peru & 36.9 & (1.1) & 18.6 & $(1.0)$ & 18.3 & $(1.3)$ & 27.9 & $(0.9)$ & c & C & c & c & C & c \\
\hline & Qatar & 49.0 & $(0.7)$ & 42.1 & $(0.6)$ & 6.9 & $(0.8)$ & 59.6 & $(0.7)$ & 30.3 & $(0.7)$ & 44.5 & $(1.2)$ & 29.3 & $(1.0)$ \\
\hline & Romania & $\mathrm{m}$ & $\mathrm{m}$ & $\mathrm{m}$ & $\mathrm{m}$ & $\mathrm{m}$ & $\mathrm{m}$ & $\mathrm{m}$ & $\mathrm{m}$ & c & C & c & c & c & c \\
\hline & Russia & 42.5 & $(1.3)$ & 23.4 & $(1.0)$ & 19.2 & $(1.3)$ & 32.5 & (1.0) & 38.2 & (5.0) & 27.4 & (3.4) & -5.7 & $(4.9)$ \\
\hline & Singapore & 13.9 & $(0.7)$ & 9.1 & $(0.4)$ & 4.9 & $(0.9)$ & 11.7 & $(0.5)$ & 12.0 & (1.1) & 8.6 & (1.5) & -0.3 & (1.3) \\
\hline & Chinese Taipei & 15.4 & $(0.8)$ & 9.2 & $(0.5)$ & 6.2 & (0.9) & 12.2 & $(0.5)$ & C & C & c & c & c & c \\
\hline & Thailand & 53.5 & (1.4) & 36.7 & $(1.5)$ & 16.8 & (1.6) & 43.4 & (1.3) & c & $\mathrm{C}$ & $\mathrm{c}$ & c & $\mathrm{c}$ & c \\
\hline & Trinidad and Tobago & $\mathrm{m}$ & $\mathrm{m}$ & $\mathrm{m}$ & $\mathrm{m}$ & $\mathrm{m}$ & $\mathrm{m}$ & $\mathrm{m}$ & $\mathrm{m}$ & $\mathrm{m}$ & $\mathrm{m}$ & $\mathrm{m}$ & $\mathrm{m}$ & $\mathrm{m}$ & $\mathrm{m}$ \\
\hline & Tunisia & 56.3 & (1.3) & 39.3 & $(1.2)$ & 17.0 & $(1.7)$ & 46.6 & $(0.9)$ & c & C & c & c & c & c \\
\hline & United Arab Emirates & 47.0 & $(1.1)$ & 36.9 & (1.1) & 10.0 & $(1.7)$ & 56.7 & (1.1) & 27.4 & (1.1) & 33.6 & $(1.2)$ & 29.3 & (1.3) \\
\hline & Uruguay & 34.4 & (1.3) & 16.2 & $(0.8)$ & 18.2 & (1.6) & 24.4 & $(0.8)$ & c & C & c & c & C & c \\
\hline & Viet Nam & $\mathrm{m}$ & $\mathrm{m}$ & $\mathrm{m}$ & $\mathrm{m}$ & $\mathrm{m}$ & $\mathrm{m}$ & $\mathrm{m}$ & $\mathrm{m}$ & $\mathrm{m}$ & $\mathrm{m}$ & $\mathrm{m}$ & $\mathrm{m}$ & $\mathrm{m}$ & $\mathrm{m}$ \\
\hline & Argentina** & $\mathrm{m}$ & $\mathrm{m}$ & $\mathrm{m}$ & $\mathrm{m}$ & $\mathrm{m}$ & $\mathrm{m}$ & $\mathrm{m}$ & $\mathrm{m}$ & $\mathrm{m}$ & $\mathrm{m}$ & $\mathrm{m}$ & $\mathrm{m}$ & $\mathrm{m}$ & $\mathrm{m}$ \\
\hline & Kazakhstan** & $\mathrm{m}$ & $\mathrm{m}$ & $\mathrm{m}$ & $\mathrm{m}$ & $\mathrm{m}$ & $\mathrm{m}$ & $\mathrm{m}$ & $\mathrm{m}$ & $\mathrm{m}$ & $\mathrm{m}$ & $\mathrm{m}$ & $\mathrm{m}$ & $\mathrm{m}$ & $\mathrm{m}$ \\
\hline & Malaysia** & 42.0 & (1.4) & 20.8 & $(1.2)$ & 21.2 & $(1.2)$ & 30.0 & $(1.2)$ & c & C & c & c & c & c \\
\hline
\end{tabular}

1. ESCS refers to the PISA index of economic, social and cultural status.

Note: Values that are statistically significant are indicated in bold (see Annex A3).

* See note at the beginning of this Annex.

** Coverage is too small to ensure comparability (see Annex A4).

StatLink न्ता $\mathrm{http}: / / \mathrm{dx}$. doi.org/10.1787/888933473115 
Table III.12.8 Students who work for pay and science performance, by student characteristics

\begin{tabular}{|c|c|c|c|c|c|c|c|c|c|}
\hline & \multicolumn{8}{|c|}{ All students } \\
\hline & & \multirow{2}{*}{\multicolumn{2}{|c|}{$\begin{array}{l}\text { Science performance if student } \\
\text { does not work for pay } \\
\text { before or after school }\end{array}$}} & \multirow{2}{*}{\multicolumn{2}{|c|}{$\begin{array}{c}\text { Science performance if student } \\
\text { works for pay } \\
\text { before or after school }\end{array}$}} & \multicolumn{4}{|c|}{ Change in science score if student works for pay before or after school } \\
\hline & & & & & & \multicolumn{2}{|c|}{$\begin{array}{l}\text { Before accounting for students' } \\
\text { socio-economic status }\end{array}$} & $\begin{array}{r}\text { After accou } \\
\text { socio-ec }\end{array}$ & $\begin{array}{l}\text { students' } \\
\text { status }\end{array}$ \\
\hline & & Mean score & S.E. & Mean score & S.E. & Score dif. & S.E. & Score dif. & S.E. \\
\hline 0 & Australia & 531 & (1.8) & 481 & $(2.4)$ & -50 & $(2.8)$ & -46 & $(2.8)$ \\
\hline U్ & Austria & 512 & (2.6) & 435 & (3.3) & -77 & (3.7) & -67 & (3.4) \\
\hline 0 & Belgium & 525 & $(2.1)$ & 465 & (3.4) & -60 & (3.1) & -55 & $(2.6)$ \\
\hline & Canada & 547 & $(2.1)$ & 502 & $(2.5)$ & -44 & $(2.2)$ & -43 & $(2.1)$ \\
\hline & Chile & 465 & $(2.6)$ & 406 & (3.3) & -59 & (3.5) & -54 & (3.3) \\
\hline & Czech Republic & 511 & $(1.9)$ & 446 & (3.6) & -65 & (3.5) & -56 & $(3.2)$ \\
\hline & Denmark & 517 & $(2.4)$ & 492 & $(3.2)$ & -25 & (3.4) & -24 & $(3.2)$ \\
\hline & Estonia & 548 & (1.9) & 476 & $(4.2)$ & -71 & $(4.0)$ & -71 & (3.9) \\
\hline & Finland & 542 & $(2.3)$ & 483 & $(4.5)$ & -60 & $(4.6)$ & -59 & $(4.3)$ \\
\hline & France & 515 & $(2.0)$ & 439 & $(4.2)$ & -76 & (4.4) & -66 & $(4.1)$ \\
\hline & Germany & 527 & (3.6) & 494 & (5.4) & -34 & (5.4) & -32 & $(4.6)$ \\
\hline & Greece & 475 & (3.5) & 405 & (4.4) & -70 & $(4.3)$ & -63 & (3.8) \\
\hline & Hungary & 501 & $(2.5)$ & 421 & (3.7) & -80 & (3.9) & -66 & $(3.2)$ \\
\hline & Iceland & 487 & $(2.1)$ & 451 & $(3.0)$ & -36 & (3.8) & -35 & $(3.9)$ \\
\hline & Ireland & 515 & $(2.3)$ & 460 & (3.9) & -56 & (3.9) & -52 & (3.5) \\
\hline & Israel & 496 & (3.1) & 428 & (3.7) & -68 & $(3.2)$ & -64 & (3.1) \\
\hline & Italy & 498 & $(2.7)$ & 442 & (3.3) & -56 & (3.7) & -53 & (3.3) \\
\hline & Japan & 548 & $(2.7)$ & 462 & $(6.2)$ & -86 & $(6.2)$ & -73 & (6.1) \\
\hline & Korea & 523 & (3.1) & 419 & $(7.0)$ & -103 & $(7.2)$ & -98 & $(7.1)$ \\
\hline & Latvia & 502 & (1.6) & 445 & (3.2) & -58 & (3.3) & -56 & (3.4) \\
\hline & Luxembourg & 504 & $(1.3)$ & 436 & $(3.2)$ & -67 & (3.5) & -60 & $(3.2)$ \\
\hline & Mexico & 429 & $(2.4)$ & 396 & (3.0) & -33 & $(3.2)$ & -29 & $(3.1)$ \\
\hline & Netherlands & 532 & $(2.5)$ & 486 & $(3.2)$ & -45 & (3.6) & -41 & $(3.3)$ \\
\hline & New Zealand & 542 & $(2.6)$ & 479 & (3.5) & -64 & (3.8) & -57 & (3.5) \\
\hline & Norway & 515 & $(2.4)$ & 480 & $(2.6)$ & -34 & $(2.7)$ & -36 & $(2.5)$ \\
\hline & Poland & 515 & $(2.5)$ & 452 & (3.8) & -63 & (3.8) & -56 & (3.7) \\
\hline & Portugal & 515 & $(2.4)$ & 435 & $(4.0)$ & -80 & $(4.2)$ & -72 & (3.5) \\
\hline & Slovak Republic & 485 & (2.5) & 431 & (3.5) & -54 & $(3.7)$ & -49 & $(3.4)$ \\
\hline & Slovenia & 527 & (1.4) & 442 & (3.8) & -84 & $(4.0)$ & -79 & $(3.9)$ \\
\hline & Spain & 510 & $(2.1)$ & 465 & $(2.5)$ & -45 & $(2.4)$ & -42 & $(2.2)$ \\
\hline & Sweden & 511 & $(3.4)$ & 454 & (3.9) & -57 & $(4.0)$ & -56 & (3.9) \\
\hline & Switzerland & 519 & $(3.0)$ & 463 & $(4.3)$ & -57 & (3.8) & -55 & (3.6) \\
\hline & Turkey & 445 & $(4.2)$ & 394 & (3.6) & -51 & (3.9) & -47 & (3.5) \\
\hline & United Kingdom & 526 & $(2.6)$ & 476 & (3.4) & -51 & (3.4) & -50 & (3.1) \\
\hline & United States & 519 & $(2.9)$ & 458 & (3.7) & -62 & (3.3) & -60 & (3.2) \\
\hline & OECD average & 511 & $(0.4)$ & 451 & $(0.6)$ & -59 & $(0.7)$ & -55 & $(0.6)$ \\
\hline 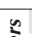 & Albania & $\mathrm{m}$ & $\mathrm{m}$ & $\mathrm{m}$ & $\mathrm{m}$ & $\mathrm{m}$ & $\mathrm{m}$ & $\mathrm{m}$ & $\mathrm{m}$ \\
\hline ¿ & Algeria & $\mathrm{m}$ & $\mathrm{m}$ & $\mathrm{m}$ & $\mathrm{m}$ & $\mathrm{m}$ & $\mathrm{m}$ & $\mathrm{m}$ & $\mathrm{m}$ \\
\hline స్ & Brazil & 437 & (3.5) & 384 & (2.5) & -53 & $(3.1)$ & -49 & $(2.7)$ \\
\hline$a^{\sigma}$ & B-S-J-G (China) & 531 & $(4.5)$ & 435 & (5.8) & -96 & $(6.0)$ & -83 & (5.0) \\
\hline & Bulgaria & 484 & $(4.0)$ & 402 & $(4.5)$ & -82 & $(4.7)$ & -72 & (3.8) \\
\hline & CABA (Argentina) & $\mathrm{m}$ & $\mathrm{m}$ & $\mathrm{m}$ & $\mathrm{m}$ & $\mathrm{m}$ & $\mathrm{m}$ & $\mathrm{m}$ & $\mathrm{m}$ \\
\hline & Colombia & 441 & $(2.5)$ & 395 & $(2.8)$ & -46 & $(2.7)$ & -41 & $(2.3)$ \\
\hline & Costa Rica & 430 & $(2.2)$ & 392 & (3.2) & -38 & (3.4) & -33 & (3.1) \\
\hline & Croatia & 490 & $(2.5)$ & 430 & (3.9) & -60 & $(4.1)$ & -57 & (3.9) \\
\hline & Cyprus* & 462 & $(1.7)$ & 396 & $(2.2)$ & -67 & $(2.8)$ & -63 & $(2.7)$ \\
\hline & Dominican Republic & 364 & (3.6) & 313 & (3.0) & -51 & $(4.5)$ & -46 & (3.8) \\
\hline & FYROM & $\mathrm{m}$ & $\mathrm{m}$ & $\mathrm{m}$ & $\mathrm{m}$ & $\mathrm{m}$ & $\mathrm{m}$ & $\mathrm{m}$ & $\mathrm{m}$ \\
\hline & Georgia & $\mathrm{m}$ & $\mathrm{m}$ & $\mathrm{m}$ & $\mathrm{m}$ & $\mathrm{m}$ & $\mathrm{m}$ & $\mathrm{m}$ & $\mathrm{m}$ \\
\hline & Hong Kong (China) & 532 & $(2.5)$ & 477 & $(4.2)$ & -55 & $(4.4)$ & -54 & $(4.2)$ \\
\hline & Indonesia & $\mathrm{m}$ & $\mathrm{m}$ & $\mathrm{m}$ & $\mathrm{m}$ & $\mathrm{m}$ & $\mathrm{m}$ & $\mathrm{m}$ & $\mathrm{m}$ \\
\hline & Jordan & $\mathrm{m}$ & $\mathrm{m}$ & $\mathrm{m}$ & $\mathrm{m}$ & $\mathrm{m}$ & $\mathrm{m}$ & $\mathrm{m}$ & $\mathrm{m}$ \\
\hline & Kosovo & $\mathrm{m}$ & $\mathrm{m}$ & $\mathrm{m}$ & $\mathrm{m}$ & $\mathrm{m}$ & $\mathrm{m}$ & $\mathrm{m}$ & $\mathrm{m}$ \\
\hline & Lebanon & $\mathrm{m}$ & $\mathrm{m}$ & $\mathrm{m}$ & $\mathrm{m}$ & $\mathrm{m}$ & $\mathrm{m}$ & $\mathrm{m}$ & $\mathrm{m}$ \\
\hline & Lithuania & 496 & $(2.5)$ & 431 & (3.1) & -65 & (3.3) & -62 & $(3.2)$ \\
\hline & Macao (China) & 534 & $(1.1)$ & 499 & (3.1) & -34 & (3.3) & -35 & (3.3) \\
\hline & Malta & $\mathrm{m}$ & $\mathrm{m}$ & $\mathrm{m}$ & $\mathrm{m}$ & $\mathrm{m}$ & $\mathrm{m}$ & $\mathrm{m}$ & $\mathrm{m}$ \\
\hline & Moldova & $\mathrm{m}$ & $\mathrm{m}$ & $\mathrm{m}$ & $\mathrm{m}$ & $\mathrm{m}$ & $\mathrm{m}$ & $\mathrm{m}$ & $\mathrm{m}$ \\
\hline & Montenegro & 438 & $(1.6)$ & 396 & (1.9) & -43 & $(2.6)$ & -43 & (2.6) \\
\hline & Peru & 427 & $(2.7)$ & 374 & (2.6) & -54 & $(3.1)$ & -39 & $(2.5)$ \\
\hline & Qatar & 470 & (1.5) & 382 & (1.4) & -88 & (1.9) & -84 & (1.9) \\
\hline & Romania & $\mathrm{m}$ & $\mathrm{m}$ & $\mathrm{m}$ & $\mathrm{m}$ & $\mathrm{m}$ & $\mathrm{m}$ & $\mathrm{m}$ & $\mathrm{m}$ \\
\hline & Russia & 507 & $(2.6)$ & 457 & $(3.2)$ & -49 & $(2.7)$ & -49 & $(2.7)$ \\
\hline & Singapore & 567 & (1.3) & 470 & (3.7) & -97 & $(4.2)$ & -83 & $(4.3)$ \\
\hline & Chinese Taipei & 544 & $(2.6)$ & 452 & (4.5) & -92 & (4.6) & -76 & $(4.1)$ \\
\hline & Thailand & 446 & $(3.2)$ & 393 & (2.5) & -53 & (3.3) & -47 & (2.8) \\
\hline & Trinidad and Tobago & $\mathrm{m}$ & $\mathrm{m}$ & $\mathrm{m}$ & $\mathrm{m}$ & $\mathrm{m}$ & $\mathrm{m}$ & $\mathrm{m}$ & $\mathrm{m}$ \\
\hline & Tunisia & 407 & $(2.7)$ & 373 & (2.4) & -34 & $(2.7)$ & -33 & $(2.5)$ \\
\hline & United Arab Emirates & 481 & (2.3) & 388 & (2.4) & -93 & $(2.7)$ & -89 & (2.5) \\
\hline & Uruguay & 458 & $(2.5)$ & 405 & (3.2) & -52 & (3.5) & -45 & $(3.2)$ \\
\hline & Viet Nam & $\mathrm{m}$ & $\mathrm{m}$ & $\mathrm{m}$ & $\mathrm{m}$ & $\mathrm{m}$ & $\mathrm{m}$ & $\mathrm{m}$ & $\mathrm{m}$ \\
\hline & Argentina** & $\mathrm{m}$ & $\mathrm{m}$ & $\mathrm{m}$ & $\mathrm{m}$ & $\mathrm{m}$ & $\mathrm{m}$ & $\mathrm{m}$ & $\mathrm{m}$ \\
\hline & Kazakhstan** & $\mathrm{m}$ & $\mathrm{m}$ & $\mathrm{m}$ & $\mathrm{m}$ & $\mathrm{m}$ & $\mathrm{m}$ & $\mathrm{m}$ & $\mathrm{m}$ \\
\hline & Malaysia** & 461 & $(2.7)$ & 406 & (3.5) & -55 & $(3.0)$ & -48 & $(2.7)$ \\
\hline
\end{tabular}

1. A socio-economically disadvantaged student is a student in the bottom quarter of the distribution of the PISA index of economic, social and cultural status (ESCS) within his or her country/economy.

2. A socio-economically advantaged student is a student in the top quarter of the distribution of the PISA index of economic, social and cultural status (ESCS) within his or her country/economy.

Note: Values that are statistically significant are indicated in bold (see Annex A3).

* See note at the beginning of this Annex.

** Coverage is too small to ensure comparability (see Annex A4).

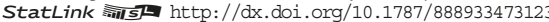




\begin{tabular}{|c|c|c|c|c|c|c|c|c|c|c|c|c|c|c|c|c|}
\hline & \multicolumn{8}{|c|}{ Boys } & \multicolumn{8}{|c|}{ Girls } \\
\hline & \multirow{2}{*}{\multicolumn{2}{|c|}{$\begin{array}{c}\text { Science } \\
\text { performance } \\
\text { if student does } \\
\text { not work for pay } \\
\text { before or } \\
\text { after school }\end{array}$}} & \multirow{2}{*}{\multicolumn{2}{|c|}{$\begin{array}{c}\text { Science } \\
\text { performance } \\
\text { if student works } \\
\text { for pay before or } \\
\text { after school }\end{array}$}} & \multicolumn{4}{|c|}{$\begin{array}{l}\text { Change in science score if student } \\
\text { works for pay before or after school }\end{array}$} & \multirow{2}{*}{\multicolumn{2}{|c|}{\begin{tabular}{|c|} 
Science \\
performance \\
if student does \\
not work for pay \\
before or \\
after school
\end{tabular}}} & \multirow{2}{*}{\multicolumn{2}{|c|}{$\begin{array}{c}\text { Science } \\
\text { performance } \\
\text { if student works } \\
\text { for pay before or } \\
\text { after school }\end{array}$}} & \multicolumn{4}{|c|}{$\begin{array}{l}\text { Change in science score if student } \\
\text { works for pay before or after school }\end{array}$} \\
\hline & & & & & \multicolumn{2}{|c|}{\begin{tabular}{|c|} 
Before \\
accounting for \\
students' socio- \\
economic status
\end{tabular}} & \multicolumn{2}{|c|}{$\begin{array}{l}\text { After accounting } \\
\text { for students' } \\
\text { socio-economic } \\
\text { status }\end{array}$} & & & & & $\begin{array}{r}\text { B } \\
\text { accou } \\
\text { studen } \\
\text { econor }\end{array}$ & $\begin{array}{l}\text { fore } \\
\text { ting for } \\
s^{\prime} \text { socio- } \\
\text { ic status }\end{array}$ & $\begin{array}{r}\text { After ac } \\
\text { for st } \\
\text { socio-e } \\
\text { st }\end{array}$ & $\begin{array}{l}\text { counting } \\
\text { Idents' } \\
\text { conomic } \\
\text { tus }\end{array}$ \\
\hline & $\begin{array}{l}\text { Mean } \\
\text { score }\end{array}$ & S.E. & $\begin{array}{l}\text { Mean } \\
\text { score }\end{array}$ & S.E. & $\begin{array}{c}\text { Score } \\
\text { dif. }\end{array}$ & S.E. & $\begin{array}{l}\text { Score } \\
\text { dif. }\end{array}$ & S.E. & $\begin{array}{l}\text { Mean } \\
\text { score }\end{array}$ & S.E. & $\begin{array}{l}\text { Mean } \\
\text { score }\end{array}$ & S.E. & $\begin{array}{l}\text { Score } \\
\text { dif. }\end{array}$ & S.E. & $\begin{array}{c}\text { Score } \\
\text { dif. }\end{array}$ & S.E. \\
\hline Australia & 538 & (2.4) & 477 & $(2.9)$ & -61 & (3.3) & -57 & $(3.2)$ & 525 & $(2.1)$ & 486 & (3.2) & -39 & (3.8) & -36 & (3.8) \\
\hline Austria & 532 & (3.5) & 438 & $(4.2)$ & -94 & (4.6) & -83 & $(4.1)$ & 496 & $(3.1)$ & 430 & (5.9) & -66 & (6.1) & -55 & (5.9) \\
\hline Belgium & 539 & (2.6) & 468 & $(4.6)$ & -72 & $(4.1)$ & -65 & (3.5) & 512 & (2.6) & 461 & $(4.7)$ & -50 & (4.5) & -47 & (3.8) \\
\hline Canada & 553 & (2.6) & 499 & $(3.2)$ & -54 & $(3.2)$ & -53 & (3.0) & 541 & (2.5) & 506 & (2.8) & -34 & (2.9) & -33 & (2.8) \\
\hline Chile & 479 & (3.4) & 415 & $(4.1)$ & -64 & $(4.6)$ & -56 & $(4.3)$ & 454 & (3.0) & 392 & (4.5) & -62 & (5.1) & -58 & (4.6) \\
\hline Czech Republic & 524 & (3.2) & 445 & $(4.4)$ & -79 & $(4.8)$ & -69 & $(4.3)$ & 500 & $(2.2)$ & 449 & (5.2) & -51 & (4.9) & -41 & (4.8) \\
\hline Denmark & 526 & (3.0) & 491 & (3.9) & -35 & $(4.8)$ & -33 & (4.6) & 508 & $(3.2)$ & 492 & (4.3) & -16 & (4.1) & -15 & $(4.0)$ \\
\hline Estonia & 556 & (2.6) & 479 & $(4.7)$ & -78 & (4.6) & -77 & $(4.6)$ & 540 & $(2.1)$ & 471 & (6.3) & -70 & (6.4) & -68 & (6.1) \\
\hline Finland & 539 & (2.5) & 471 & $(5.2)$ & -68 & (5.6) & -67 & $(5.2)$ & 546 & (2.8) & 507 & (6.1) & -39 & (6.1) & -38 & (6.5) \\
\hline France & 524 & (2.5) & 440 & $(5.2)$ & -84 & (6.0) & -74 & (5.4) & 507 & $(2.7)$ & 437 & (6.5) & -70 & (6.9) & -61 & (6.5) \\
\hline Germany & 542 & $(4.7)$ & 489 & (6.6) & -53 & (7.4) & -50 & (6.6) & 514 & (3.6) & 500 & (7.3) & -15 & (7.1) & -14 & (6.1) \\
\hline Greece & 479 & $(4.2)$ & 409 & $(4.8)$ & -70 & (4.7) & -64 & $(4.2)$ & 471 & (3.7) & 397 & (6.0) & -74 & (6.1) & -66 & (5.6) \\
\hline Hungary & 511 & (3.5) & 427 & $(4.2)$ & -83 & (4.9) & -68 & (4.4) & 494 & (3.0) & 410 & (6.3) & -84 & (6.4) & -69 & (5.5) \\
\hline Iceland & 492 & (3.2) & 448 & $(4.3)$ & -43 & (5.3) & -43 & (5.5) & 484 & (2.7) & 455 & (4.2) & -29 & (5.3) & -27 & (5.3) \\
\hline Ireland & 527 & $(3.2)$ & 462 & $(4.4)$ & -65 & $(4.8)$ & -60 & (4.5) & 505 & (2.5) & 455 & (5.5) & -50 & $(5.2)$ & -47 & (4.7) \\
\hline Israel & 514 & (3.8) & 420 & (5.0) & -94 & (4.4) & -89 & (4.4) & 481 & (3.9) & 437 & (4.7) & -44 & $(4.2)$ & -40 & $(4.0)$ \\
\hline Italy & 515 & (3.2) & 448 & (3.8) & -67 & (4.4) & -63 & $(4.0)$ & 485 & (3.6) & 431 & (5.9) & -54 & (5.5) & -49 & (5.0) \\
\hline Japan & 555 & (3.8) & 467 & $(7.1)$ & -88 & (6.9) & -77 & (6.7) & 540 & (3.0) & 456 & (8.9) & -84 & (9.4) & -69 & (8.7) \\
\hline Korea & 521 & (4.5) & 417 & $(8.7)$ & -105 & (9.0) & -103 & (8.5) & 524 & (3.2) & 427 & (10.2) & -98 & (10.3) & -87 & (11.3) \\
\hline Latvia & 503 & (2.3) & 445 & (3.6) & -58 & (4.1) & -58 & (4.1) & 502 & (2.3) & 444 & (5.6) & -58 & (5.8) & -54 & (5.9) \\
\hline Luxembourg & 515 & (2.0) & 439 & (3.9) & -76 & (4.3) & -70 & $(4.2)$ & 494 & (1.7) & 431 & (5.0) & -62 & (5.5) & -52 & (4.8) \\
\hline Mexico & 440 & (2.8) & 400 & (3.5) & -40 & (3.8) & -35 & (3.7) & 421 & (2.5) & 388 & (4.1) & -33 & $(4.0)$ & -29 & (3.9) \\
\hline Netherlands & 541 & (3.3) & 486 & $(4.1)$ & -56 & (4.5) & -51 & (4.4) & 524 & (3.0) & 487 & (3.7) & -36 & $(4.7)$ & -32 & (4.4) \\
\hline New Zealand & 555 & (3.5) & 476 & $(4.7)$ & -80 & (5.1) & -72 & (4.6) & 531 & (3.1) & 482 & (4.3) & -49 & (5.0) & -43 & (4.8) \\
\hline Norway & 525 & (3.1) & 480 & (3.4) & -45 & (3.7) & -47 & (3.6) & 506 & (2.9) & 481 & (3.3) & -25 & (3.8) & -27 & (3.5) \\
\hline Poland & 525 & (3.0) & 454 & $(4.0)$ & -71 & (4.6) & -64 & (4.5) & 506 & $(2.7)$ & 445 & (7.0) & -60 & (6.8) & -52 & (6.3) \\
\hline Portugal & 527 & (2.9) & 442 & $(4.6)$ & -85 & $(5.1)$ & -78 & $(4.3)$ & 505 & (2.5) & 423 & $(6.2)$ & -83 & (6.3) & -72 & (6.3) \\
\hline Slovak Republic & 494 & (3.2) & 433 & (3.7) & -61 & $(4.1)$ & -55 & (3.9) & 478 & (2.9) & 425 & (5.3) & -53 & (5.4) & -49 & (5.1) \\
\hline Slovenia & 530 & $(2.3)$ & 443 & $(4.5)$ & -87 & (5.0) & -82 & $(4.6)$ & 524 & (1.9) & 439 & $(8.2)$ & -84 & (8.6) & -77 & (9.1) \\
\hline Spain & 519 & (2.6) & 467 & (3.2) & -52 & (3.5) & -51 & (3.3) & 502 & (2.5) & 463 & (3.9) & -39 & (3.8) & -36 & (3.4) \\
\hline Sweden & 516 & (3.9) & 452 & $(4.3)$ & -64 & (4.9) & -62 & $(5.0)$ & 507 & $(3.7)$ & 458 & (5.8) & -50 & $(6.0)$ & -48 & (5.7) \\
\hline Switzerland & 529 & (3.3) & 461 & $(4.7)$ & -69 & $(4.7)$ & -66 & (4.6) & 510 & (3.7) & 467 & (7.3) & -43 & (6.7) & -42 & (6.0) \\
\hline Turkey & 450 & (4.9) & 396 & $(4.4)$ & -54 & $(4.6)$ & -49 & $(4.4)$ & 442 & $(4.4)$ & 392 & (4.4) & -50 & $(4.8)$ & -47 & $(4.2)$ \\
\hline United Kingdom & 532 & (3.0) & 475 & $(4.1)$ & -56 & (4.4) & -57 & $(4.2)$ & 521 & (3.6) & 476 & (4.6) & -45 & $(4.8)$ & -44 & (4.4) \\
\hline United States & 531 & (3.5) & 459 & $(4.3)$ & -72 & (4.6) & -70 & (4.3) & 510 & (3.2) & 456 & (4.5) & -54 & $(4.2)$ & -52 & (4.0) \\
\hline OECD average & 520 & $(0.6)$ & 452 & $(0.8)$ & -68 & $(0.8)$ & -63 & $(0.8)$ & 503 & $(0.5)$ & 450 & (1.0) & -53 & (1.0) & -48 & $(0.9)$ \\
\hline
\end{tabular}

\begin{tabular}{|c|c|c|c|c|c|c|c|c|c|c|c|c|c|c|c|c|c|}
\hline \multirow{4}{*}{ 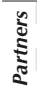 } & Albania & $\mathrm{m}$ & $\mathrm{m}$ & $\mathrm{m}$ & $\mathrm{m}$ & $\mathrm{m}$ & $\mathrm{m}$ & $\mathrm{m}$ & $\mathrm{m}$ & $\mathrm{m}$ & $\mathrm{m}$ & $\mathrm{m}$ & $\mathrm{m}$ & $\mathrm{m}$ & $\mathrm{m}$ & $\mathrm{m}$ & $\mathrm{m}$ \\
\hline & Algeria & $\mathrm{m}$ & $\mathrm{m}$ & $\mathrm{m}$ & $\mathrm{m}$ & $\mathrm{m}$ & $\mathrm{m}$ & $\mathrm{m}$ & $\mathrm{m}$ & $\mathrm{m}$ & $\mathrm{m}$ & $\mathrm{m}$ & $\mathrm{m}$ & $\mathrm{m}$ & $\mathrm{m}$ & $\mathrm{m}$ & $\mathrm{m}$ \\
\hline & Brazil & 448 & (3.9) & 387 & $(2.9)$ & -62 & (3.9) & -57 & (3.6) & 428 & $(3.7)$ & 380 & $(2.7)$ & -48 & (3.4) & -43 & (3.1) \\
\hline & B-S-J-G (China) & 537 & (4.4) & 443 & (6.8) & -95 & (6.5) & -86 & (5.5) & 525 & $(5.2)$ & 424 & (6.3) & -100 & $(7.2)$ & -81 & (6.5) \\
\hline & Bulgaria & 487 & (5.5) & 402 & $(5.0)$ & -86 & $(6.2)$ & -76 & (5.3) & 481 & $(4.3)$ & 401 & (5.5) & -79 & (5.9) & -68 & $(4.6)$ \\
\hline & CABA (Argentina) & $\mathrm{m}$ & $\mathrm{m}$ & $\mathrm{m}$ & $\mathrm{m}$ & $\mathrm{m}$ & $\mathrm{m}$ & $\mathrm{m}$ & $\mathrm{m}$ & $\mathrm{m}$ & $\mathrm{m}$ & $\mathrm{m}$ & $\mathrm{m}$ & $\mathrm{m}$ & $\mathrm{m}$ & $\mathrm{m}$ & $\mathrm{m}$ \\
\hline & Colombia & 453 & (3.6) & 401 & (3.5) & -51 & (3.5) & -45 & (3.1) & 433 & $(2.7)$ & 387 & (3.1) & -46 & (3.5) & -42 & $(2.9)$ \\
\hline & Costa Rica & 445 & $(2.8)$ & 396 & (3.8) & -49 & (4.4) & -42 & (3.9) & 417 & $(2.3)$ & 384 & $(4.7)$ & -33 & $(4.7)$ & -30 & (4.6) \\
\hline & Croatia & 504 & $(3.2)$ & 432 & $(4.2)$ & -71 & $(4.5)$ & -67 & (4.3) & 480 & (2.8) & 424 & $(6.5)$ & -56 & (6.6) & -55 & $(5.8)$ \\
\hline & Cyprus* & 465 & (2.6) & 394 & (2.6) & -71 & (3.5) & -65 & (3.4) & 460 & $(2.2)$ & 398 & (3.1) & -62 & (3.9) & -59 & (3.9) \\
\hline & Dominican Republic & 376 & $(4.8)$ & 315 & (3.7) & -60 & (5.4) & -53 & (4.7) & 356 & (3.4) & 309 & (3.7) & -47 & (4.9) & -43 & (4.2) \\
\hline & FYROM & $\mathrm{m}$ & $\mathrm{m}$ & $\mathrm{m}$ & $\mathrm{m}$ & $\mathrm{m}$ & $\mathrm{m}$ & $\mathrm{m}$ & $\mathrm{m}$ & $\mathrm{m}$ & $\mathrm{m}$ & $\mathrm{m}$ & $\mathrm{m}$ & $\mathrm{m}$ & $\mathrm{m}$ & $\mathrm{m}$ & $\mathrm{m}$ \\
\hline & Georgia & $\mathrm{m}$ & $\mathrm{m}$ & $\mathrm{m}$ & $\mathrm{m}$ & $\mathrm{m}$ & $\mathrm{m}$ & $\mathrm{m}$ & $\mathrm{m}$ & $\mathrm{m}$ & $\mathrm{m}$ & $\mathrm{m}$ & $\mathrm{m}$ & $\mathrm{m}$ & $\mathrm{m}$ & $\mathrm{m}$ & $\mathrm{m}$ \\
\hline & Hong Kong (China) & 536 & (2.8) & 474 & (5.6) & -62 & (5.6) & -62 & (5.4) & 529 & (3.4) & 483 & $(6.2)$ & -46 & (6.2) & -42 & (6.0) \\
\hline & Indonesia & $\mathrm{m}$ & $\mathrm{m}$ & $\mathrm{m}$ & $\mathrm{m}$ & $\mathrm{m}$ & $\mathrm{m}$ & $\mathrm{m}$ & $\mathrm{m}$ & $\mathrm{m}$ & $\mathrm{m}$ & $\mathrm{m}$ & $\mathrm{m}$ & $\mathrm{m}$ & $\mathrm{m}$ & $\mathrm{m}$ & $\mathrm{m}$ \\
\hline & Jordan & $\mathrm{m}$ & $\mathrm{m}$ & $\mathrm{m}$ & $\mathrm{m}$ & $\mathrm{m}$ & $\mathrm{m}$ & $\mathrm{m}$ & $\mathrm{m}$ & $\mathrm{m}$ & $\mathrm{m}$ & $\mathrm{m}$ & $\mathrm{m}$ & $\mathrm{m}$ & $\mathrm{m}$ & $\mathrm{m}$ & $\mathrm{m}$ \\
\hline & Kosovo & $\mathrm{m}$ & $\mathrm{m}$ & $\mathrm{m}$ & $\mathrm{m}$ & $\mathrm{m}$ & $\mathrm{m}$ & $\mathrm{m}$ & $\mathrm{m}$ & $\mathrm{m}$ & $\mathrm{m}$ & $\mathrm{m}$ & $\mathrm{m}$ & $\mathrm{m}$ & $\mathrm{m}$ & $\mathrm{m}$ & $\mathrm{m}$ \\
\hline & Lebanon & $\mathrm{m}$ & $\mathrm{m}$ & $\mathrm{m}$ & $\mathrm{m}$ & $\mathrm{m}$ & $\mathrm{m}$ & $\mathrm{m}$ & $\mathrm{m}$ & $\mathrm{m}$ & $\mathrm{m}$ & $\mathrm{m}$ & $\mathrm{m}$ & $\mathrm{m}$ & $\mathrm{m}$ & $\mathrm{m}$ & $\mathrm{m}$ \\
\hline & Lithuania & 502 & (3.3) & 432 & (3.3) & -70 & (3.9) & -67 & (3.7) & 491 & $(2.7)$ & 427 & $(4.4)$ & -64 & $(4.8)$ & -58 & $(4.8)$ \\
\hline & Macao (China) & 532 & (1.6) & 476 & $(4.7)$ & -56 & (5.1) & -58 & (5.1) & 535 & (1.7) & 519 & (3.9) & -16 & $(4.2)$ & -15 & $(4.2)$ \\
\hline & Malta & $\mathrm{m}$ & $\mathrm{m}$ & $\mathrm{m}$ & $\mathrm{m}$ & $\mathrm{m}$ & $\mathrm{m}$ & $\mathrm{m}$ & $\mathrm{m}$ & $\mathrm{m}$ & $\mathrm{m}$ & $\mathrm{m}$ & $\mathrm{m}$ & $\mathrm{m}$ & $\mathrm{m}$ & $\mathrm{m}$ & $\mathrm{m}$ \\
\hline & Moldova & $\mathrm{m}$ & $\mathrm{m}$ & $\mathrm{m}$ & $\mathrm{m}$ & $\mathrm{m}$ & $\mathrm{m}$ & $\mathrm{m}$ & $\mathrm{m}$ & $\mathrm{m}$ & $\mathrm{m}$ & $\mathrm{m}$ & $\mathrm{m}$ & $\mathrm{m}$ & $\mathrm{m}$ & $\mathrm{m}$ & $\mathrm{m}$ \\
\hline & Montenegro & 444 & (2.9) & 398 & $(2.5)$ & -46 & (3.7) & -47 & (3.6) & 434 & $(2.0)$ & 392 & $(2.5)$ & -42 & (3.4) & -42 & $(3.2)$ \\
\hline & Peru & 437 & (3.4) & 377 & $(3.0)$ & -61 & (3.9) & -45 & (3.3) & 419 & (3.3) & 368 & $(4.2)$ & -51 & $(4.2)$ & -37 & (3.7) \\
\hline & Qatar & 472 & (2.3) & 376 & $(2.0)$ & -96 & (2.9) & -93 & (2.9) & 468 & (1.7) & 388 & (1.9) & -81 & (2.5) & -76 & (2.6) \\
\hline & Romania & $\mathrm{m}$ & $\mathrm{m}$ & $\mathrm{m}$ & $\mathrm{m}$ & $\mathrm{m}$ & $\mathrm{m}$ & $\mathrm{m}$ & $\mathrm{m}$ & $\mathrm{m}$ & $\mathrm{m}$ & $\mathrm{m}$ & $\mathrm{m}$ & $\mathrm{m}$ & $\mathrm{m}$ & $\mathrm{m}$ & $\mathrm{m}$ \\
\hline & Russia & 518 & (3.3) & 460 & $(3.7)$ & -58 & (3.6) & -59 & (3.5) & 498 & $(2.7)$ & 451 & (4.9) & -47 & $(4.1)$ & -45 & $(3.8)$ \\
\hline & Singapore & 574 & (1.9) & 470 & $(4.5)$ & -104 & (5.0) & -92 & (5.1) & 560 & $(1.8)$ & 471 & (6.3) & -89 & (6.6) & -73 & (6.5) \\
\hline & Chinese Taipei & 549 & $(4.0)$ & 456 & (6.1) & -93 & (6.6) & -79 & (6.0) & 539 & (3.8) & 445 & (5.7) & -94 & (5.7) & -75 & (5.6) \\
\hline & Thailand & 449 & $(4.7)$ & 391 & $(2.8)$ & -58 & $(4.4)$ & -50 & (3.9) & 444 & (3.2) & 395 & (2.9) & -49 & (3.7) & -44 & (3.2) \\
\hline & Trinidad and Tobago & $\mathrm{m}$ & $\mathrm{m}$ & $\mathrm{m}$ & $\mathrm{m}$ & $\mathrm{m}$ & $\mathrm{m}$ & $\mathrm{m}$ & $\mathrm{m}$ & $\mathrm{m}$ & $\mathrm{m}$ & $\mathrm{m}$ & $\mathrm{m}$ & $\mathrm{m}$ & $\mathrm{m}$ & $\mathrm{m}$ & $\mathrm{m}$ \\
\hline & Tunisia & 414 & (3.4) & 377 & $(2.8)$ & -37 & (3.7) & -35 & (3.4) & 403 & $(2.9)$ & 369 & $(2.7)$ & -34 & (3.3) & -34 & (3.1) \\
\hline & United Arab Emirates & 478 & (3.6) & 379 & (3.4) & -99 & $(4.0)$ & -96 & (3.8) & 482 & $(3.2)$ & 398 & $(2.8)$ & -84 & (3.8) & -80 & (3.5) \\
\hline & Uruguay & 474 & (3.8) & 408 & (3.8) & -66 & $(4.8)$ & -55 & $(4.2)$ & 447 & (2.6) & 401 & (4.4) & -46 & (4.9) & -41 & (4.6) \\
\hline & Viet Nam & $\mathrm{m}$ & $\mathrm{m}$ & $\mathrm{m}$ & m & $\mathrm{m}$ & $\mathrm{m}$ & $\mathrm{m}$ & $\mathrm{m}$ & $\mathrm{m}$ & $\mathrm{m}$ & $\mathrm{m}$ & $\mathrm{m}$ & $\mathrm{m}$ & $\mathrm{m}$ & $\mathrm{m}$ & $\mathrm{m}$ \\
\hline & Argentina** & $\mathrm{m}$ & $\mathrm{m}$ & $\mathrm{m}$ & $\mathrm{m}$ & $\mathrm{m}$ & $\mathrm{m}$ & $\mathrm{m}$ & $\mathrm{m}$ & $\mathrm{m}$ & $\mathrm{m}$ & $\mathrm{m}$ & $\mathrm{m}$ & $\mathrm{m}$ & $\mathrm{m}$ & $\mathrm{m}$ & $\mathrm{m}$ \\
\hline & Kazakhstan** & $\mathrm{m}$ & $\mathrm{m}$ & $\mathrm{m}$ & $\mathrm{m}$ & $\mathrm{m}$ & $\mathrm{m}$ & $\mathrm{m}$ & $\mathrm{m}$ & $\mathrm{m}$ & $\mathrm{m}$ & $\mathrm{m}$ & $\mathrm{m}$ & $\mathrm{m}$ & $\mathrm{m}$ & $\mathrm{m}$ & $\mathrm{m}$ \\
\hline & Malaysia** & 468 & (3.3) & 407 & (3.6) & -60 & (3.4) & -52 & (3.2) & 457 & $(2.9)$ & 403 & $(4.3)$ & -54 & (3.9) & -46 & (3.5) \\
\hline
\end{tabular}

1. A socio-economically disadvantaged student is a student in the bottom quarter of the distribution of the PISA index of economic, social and cultural status (ESCS) within his

or her country/economy.
2. A socio-economically advantaged student is a student in the top quarter of the distribution of the PISA index of economic, social and cultural status (ESCS) within his or her

Note: Values that are statistically significant are indicated in bold (see Annex A3)

* See note at the beginning of this Annex.

** Coverage is too small to ensure comparability (see Annex A4).

StatLink त्राजा http://dx.doi.org/10.1787/888933473123 
[Part 3/3]

Table III.12.8 Students who work for pay and science performance, by student characteristics

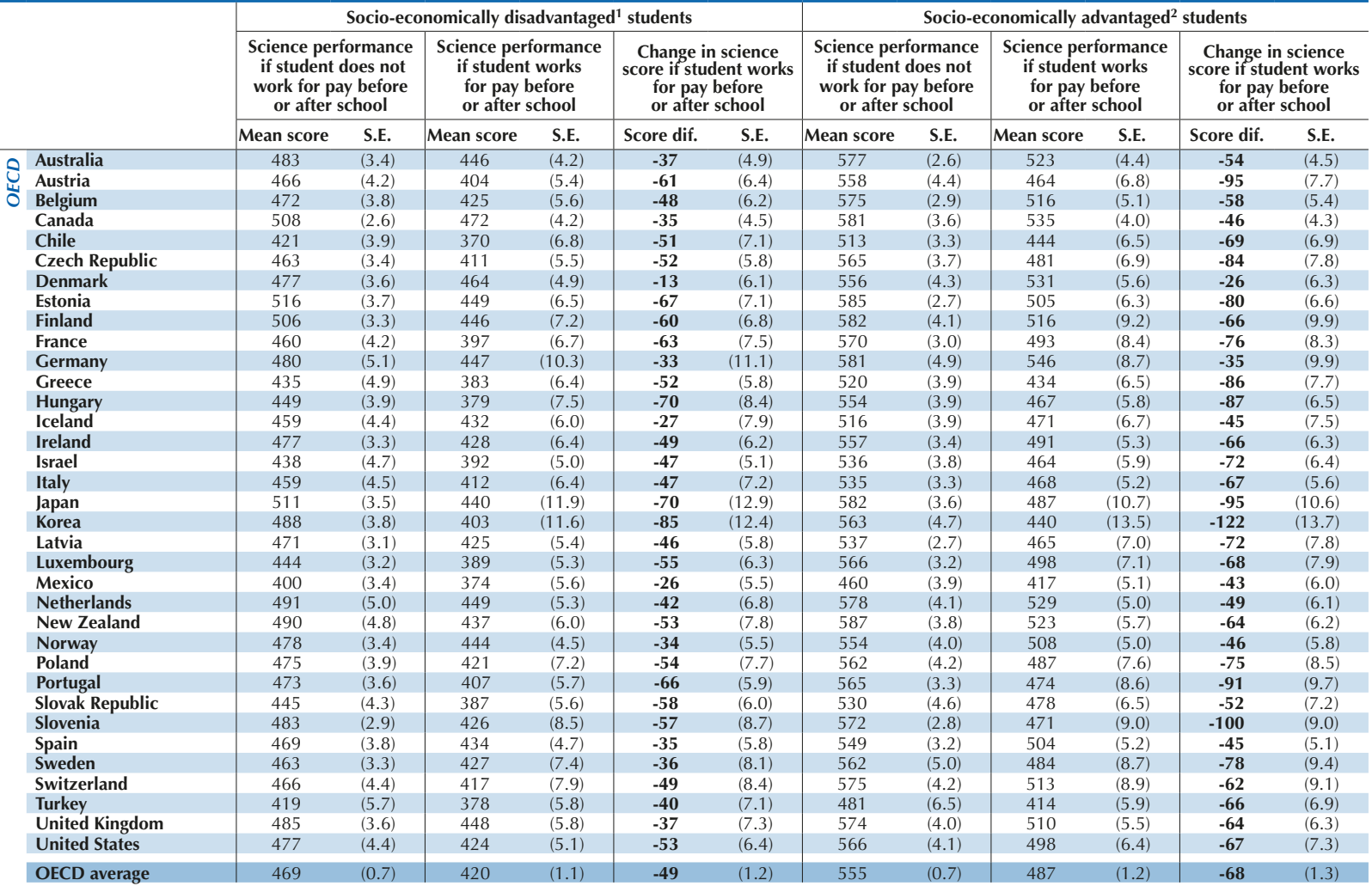

\begin{tabular}{|c|c|c|c|c|c|c|c|c|c|c|c|c|}
\hline Albania & $\mathrm{m}$ & $\mathrm{m}$ & $\mathrm{m}$ & $\mathrm{m}$ & $\mathrm{m}$ & $\mathrm{m}$ & $\mathrm{m}$ & $\mathrm{m}$ & $\mathrm{m}$ & $\mathrm{m}$ & $\mathrm{m}$ & $\mathrm{m}$ \\
\hline$\cong$ Algeria & $\mathrm{m}$ & $\mathrm{m}$ & $\mathrm{m}$ & $\mathrm{m}$ & $\mathrm{m}$ & $\mathrm{m}$ & $\mathrm{m}$ & $\mathrm{m}$ & $\mathrm{m}$ & $\mathrm{m}$ & $\mathrm{m}$ & $\mathrm{m}$ \\
\hline Brazil & 394 & (3.6) & 361 & (3.3) & -33 & (4.2) & 492 & (6.3) & 416 & (5.0) & -77 & (6.0) \\
\hline B-S-J-G (China) & 476 & (5.4) & 391 & $(8.3)$ & -85 & (7.9) & 590 & (8.8) & 471 & (9.3) & -119 & (13.2) \\
\hline Bulgaria & 437 & (5.4) & 365 & (6.5) & -72 & (6.7) & 530 & (4.9) & 442 & (7.4) & -88 & (8.6) \\
\hline CABA (Argentina) & $\mathrm{m}$ & $\mathrm{m}$ & $\mathrm{m}$ & $\mathrm{m}$ & $\mathrm{m}$ & $\mathrm{m}$ & $\mathrm{m}$ & $\mathrm{m}$ & $\mathrm{m}$ & $\mathrm{m}$ & $\mathrm{m}$ & $\mathrm{m}$ \\
\hline Colombia & 404 & $(4.0)$ & 370 & $(4.1)$ & -34 & $(4.0)$ & 488 & (6.0) & 430 & (4.7) & -58 & (6.1) \\
\hline Costa Rica & 399 & (2.7) & 375 & (6.0) & -24 & (6.4) & 472 & (3.8) & 417 & (5.8) & -55 & (7.0) \\
\hline Croatia & 456 & (3.6) & 407 & (5.3) & -49 & (6.0) & 535 & $(4.2)$ & 463 & (7.6) & -73 & $(8.0)$ \\
\hline Cyprus* & 424 & (3.1) & 375 & (3.5) & -50 & (4.5) & 502 & (3.6) & 425 & (5.2) & -76 & (6.4) \\
\hline Dominican Republic & 328 & $(4.2)$ & 301 & (4.5) & -27 & (6.0) & 410 & (6.1) & 329 & (5.6) & -81 & (8.1) \\
\hline FYROM & $\mathrm{m}$ & $\mathrm{m}$ & $\mathrm{m}$ & $\mathrm{m}$ & $\mathrm{m}$ & $\mathrm{m}$ & $\mathrm{m}$ & $\mathrm{m}$ & $\mathrm{m}$ & $\mathrm{m}$ & $\mathrm{m}$ & $\mathrm{m}$ \\
\hline Georgia & $\mathrm{m}$ & $\mathrm{m}$ & $\mathrm{m}$ & $\mathrm{m}$ & $\mathrm{m}$ & $\mathrm{m}$ & $\mathrm{m}$ & $\mathrm{m}$ & $\mathrm{m}$ & $\mathrm{m}$ & $\mathrm{m}$ & $\mathrm{m}$ \\
\hline Hong Kong (China) & 513 & (3.5) & 458 & $(7.0)$ & -55 & (7.8) & 557 & $(4.2)$ & 503 & $(8.2)$ & -55 & (8.8) \\
\hline Indonesia & $\mathrm{m}$ & $\mathrm{m}$ & $\mathrm{m}$ & $\mathrm{m}$ & $\mathrm{m}$ & $\mathrm{m}$ & $\mathrm{m}$ & $\mathrm{m}$ & $\mathrm{m}$ & $\mathrm{m}$ & $\mathrm{m}$ & $\mathrm{m}$ \\
\hline Jordan & $\mathrm{m}$ & $\mathrm{m}$ & $\mathrm{m}$ & $\mathrm{m}$ & $\mathrm{m}$ & $\mathrm{m}$ & $\mathrm{m}$ & $\mathrm{m}$ & $\mathrm{m}$ & $\mathrm{m}$ & $\mathrm{m}$ & $\mathrm{m}$ \\
\hline Kosovo & $\mathrm{m}$ & $\mathrm{m}$ & $\mathrm{m}$ & $\mathrm{m}$ & $\mathrm{m}$ & $\mathrm{m}$ & $\mathrm{m}$ & $\mathrm{m}$ & $\mathrm{m}$ & $\mathrm{m}$ & $\mathrm{m}$ & $\mathrm{m}$ \\
\hline Lebanon & $\mathrm{m}$ & $\mathrm{m}$ & $\mathrm{m}$ & $\mathrm{m}$ & $\mathrm{m}$ & $\mathrm{m}$ & $\mathrm{m}$ & $\mathrm{m}$ & $\mathrm{m}$ & $\mathrm{m}$ & $\mathrm{m}$ & $\mathrm{m}$ \\
\hline Lithuania & 455 & (3.3) & 405 & (5.5) & -51 & (6.0) & 540 & $(4.3)$ & 468 & (5.7) & -73 & $(6.2)$ \\
\hline Macao (China) & 520 & $(2.7)$ & 493 & $(7.2)$ & -27 & (7.5) & 550 & (2.7) & 507 & (7.1) & -43 & (7.6) \\
\hline Malta & $\mathrm{m}$ & $\mathrm{m}$ & $\mathrm{m}$ & $\mathrm{m}$ & $\mathrm{m}$ & $\mathrm{m}$ & $\mathrm{m}$ & $\mathrm{m}$ & $\mathrm{m}$ & $\mathrm{m}$ & $\mathrm{m}$ & $\mathrm{m}$ \\
\hline Moldova & $\mathrm{m}$ & $\mathrm{m}$ & $\mathrm{m}$ & $\mathrm{m}$ & $\mathrm{m}$ & $\mathrm{m}$ & $\mathrm{m}$ & $\mathrm{m}$ & $\mathrm{m}$ & $\mathrm{m}$ & $\mathrm{m}$ & $\mathrm{m}$ \\
\hline Montenegro & 416 & (3.0) & 376 & (3.7) & -40 & (4.7) & 466 & (4.1) & 424 & (3.7) & -42 & (5.5) \\
\hline Peru & 389 & (3.4) & 346 & $(5.2)$ & -43 & (5.5) & 468 & (5.7) & 396 & (4.6) & -71 & (6.8) \\
\hline Qatar & 435 & (2.8) & 358 & (2.6) & -77 & (3.8) & 488 & (2.8) & 397 & (2.7) & -92 & (3.7) \\
\hline Romania & $\mathrm{m}$ & $\mathrm{m}$ & $\mathrm{m}$ & $\mathrm{m}$ & $\mathrm{m}$ & $\mathrm{m}$ & $\mathrm{m}$ & $\mathrm{m}$ & $\mathrm{m}$ & $\mathrm{m}$ & $\mathrm{m}$ & $\mathrm{m}$ \\
\hline Russia & 473 & (4.6) & 439 & $(5.3)$ & -34 & (6.0) & 541 & (3.6) & 475 & (4.4) & -65 & (5.6) \\
\hline Singapore & 510 & (3.0) & 434 & (6.9) & -77 & (8.0) & 616 & (3.3) & 516 & (8.3) & -100 & (8.6) \\
\hline Chinese Taipei & 499 & (3.9) & 431 & (5.9) & -67 & (6.3) & 590 & (4.8) & 480 & (8.5) & -110 & (9.0) \\
\hline Thailand & 419 & (3.1) & 388 & (3.6) & -31 & (4.0) & 489 & (7.1) & 408 & (4.8) & -81 & (6.1) \\
\hline Trinidad and Tobago & $\mathrm{m}$ & $\mathrm{m}$ & $\mathrm{m}$ & $\mathrm{m}$ & $\mathrm{m}$ & $\mathrm{m}$ & $\mathrm{m}$ & $\mathrm{m}$ & $\mathrm{m}$ & $\mathrm{m}$ & $\mathrm{m}$ & $\mathrm{m}$ \\
\hline Tunisia & 380 & (3.6) & 358 & (3.4) & -22 & (4.4) & 447 & (7.8) & 394 & (3.9) & -53 & (6.9) \\
\hline United Arab Emirates & 442 & (3.0) & 373 & (3.2) & -70 & (3.6) & 504 & (3.6) & 403 & (3.7) & -101 & (4.4) \\
\hline Uruguay & 415 & (3.1) & 377 & (5.1) & -37 & (5.9) & 508 & (4.8) & 437 & (6.3) & -71 & (7.1) \\
\hline Viet Nam & $\mathrm{m}$ & $\mathrm{m}$ & $\mathrm{m}$ & $\mathrm{m}$ & $\mathrm{m}$ & $\mathrm{m}$ & $\mathrm{m}$ & $\mathrm{m}$ & $\mathrm{m}$ & $\mathrm{m}$ & $\mathrm{m}$ & $\mathrm{m}$ \\
\hline Argentina** & $\mathrm{m}$ & $\mathrm{m}$ & $\mathrm{m}$ & $\mathrm{m}$ & $\mathrm{m}$ & $\mathrm{m}$ & $\mathrm{m}$ & $\mathrm{m}$ & $\mathrm{m}$ & $\mathrm{m}$ & $\mathrm{m}$ & $\mathrm{m}$ \\
\hline Kazakhstan** & $\mathrm{m}$ & $\mathrm{m}$ & $\mathrm{m}$ & $\mathrm{m}$ & $\mathrm{m}$ & $\mathrm{m}$ & $\mathrm{m}$ & $\mathrm{m}$ & $\mathrm{m}$ & $\mathrm{m}$ & $\mathrm{m}$ & $\mathrm{m}$ \\
\hline Malaysia** & 431 & $(3.2)$ & 385 & $(4.6)$ & -46 & $(4.7)$ & 495 & (5.0) & 435 & (6.6) & -59 & (6.1) \\
\hline
\end{tabular}

1. A socio-economically disadvantaged student is a student in the bottom quarter of the distribution of the PISA index of economic, social and cultural status (ESCS) within his

2. A socio-economically advantaged student is a student in the top quarter of the distribution of the PISA index of economic, social and cultural status (ESCS) within his or her country/economy.

Note: Values that are statistically significant are indicated in bold (see Annex A3).

* See note at the beginning of this Annex.

** Coverage is too small to ensure comparability (see Annex A4).

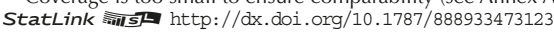




\begin{tabular}{|c|c|c|c|c|c|c|c|c|c|}
\hline & \multicolumn{4}{|c|}{ Average life satisfaction } & \multicolumn{4}{|c|}{$\begin{array}{l}\text { Difference between students who work and those } \\
\text { who do not work for pay before or after school }\end{array}$} \\
\hline & & \multicolumn{2}{|c|}{$\begin{array}{c}\text { Students who do not work } \\
\text { for pay before or after school }\end{array}$} & \multicolumn{2}{|c|}{$\begin{array}{c}\text { Students who work } \\
\text { for pay before or after school }\end{array}$} & \multicolumn{2}{|c|}{$\begin{array}{l}\text { Before accounting for students' } \\
\text { socio-economic status }\end{array}$} & $\begin{array}{r}\text { After acc } \\
\text { socio }\end{array}$ & $\begin{array}{l}r \text { students' } \\
\text { status }\end{array}$ \\
\hline & & Mean & S.E. & Mean & S.E. & Dif. & S.E. & Dif. & S.E. \\
\hline 0 & Australia & $\mathrm{m}$ & $\mathrm{m}$ & $\mathrm{m}$ & $\mathrm{m}$ & $\mathrm{m}$ & $\mathrm{m}$ & $\mathrm{m}$ & $\mathrm{m}$ \\
\hline 苾 & Austria & 7.46 & $(0.04)$ & 7.77 & $(0.08)$ & 0.31 & $(0.08)$ & 0.38 & $(0.08)$ \\
\hline$\overline{0}$ & Belgium (excl. Flemish) & 7.44 & $(0.05)$ & 7.60 & $(0.10)$ & 0.16 & $(0.10)$ & 0.18 & $(0.10)$ \\
\hline & Canada & $\mathrm{m}$ & $\mathrm{m}$ & $\mathrm{m}$ & $\mathrm{m}$ & $\mathrm{m}$ & $\mathrm{m}$ & $\mathrm{m}$ & $\mathrm{m}$ \\
\hline & Chile & 7.28 & $(0.05)$ & 7.56 & $(0.06)$ & 0.28 & $(0.07)$ & 0.32 & $(0.07)$ \\
\hline & Czech Republic & 7.01 & $(0.04)$ & 7.25 & $(0.08)$ & 0.24 & $(0.09)$ & 0.31 & $(0.09)$ \\
\hline & Denmark & $\mathrm{m}$ & $\mathrm{m}$ & $\mathrm{m}$ & $\mathrm{m}$ & $\mathrm{m}$ & $\mathrm{m}$ & $\mathrm{m}$ & $\mathrm{m}$ \\
\hline & Estonia & 7.47 & $(0.04)$ & 7.72 & $(0.08)$ & 0.25 & $(0.08)$ & 0.26 & $(0.08)$ \\
\hline & Finland & 7.86 & $(0.03)$ & 8.04 & $(0.07)$ & 0.18 & $(0.08)$ & 0.19 & $(0.08)$ \\
\hline & France & 7.59 & $(0.03)$ & 7.86 & $(0.08)$ & 0.27 & $(0.09)$ & 0.32 & $(0.08)$ \\
\hline & Germany & 7.23 & $(0.04)$ & 7.46 & $(0.11)$ & 0.22 & $(0.11)$ & 0.23 & $(0.11)$ \\
\hline & Greece & 6.87 & $(0.04)$ & 7.10 & $(0.08)$ & 0.23 & $(0.09)$ & 0.27 & $(0.09)$ \\
\hline & Hungary & 7.13 & $(0.05)$ & 7.26 & $(0.08)$ & 0.13 & $(0.09)$ & 0.23 & $(0.09)$ \\
\hline & Iceland & 7.70 & $(0.05)$ & 8.00 & $(0.07)$ & 0.31 & $(0.08)$ & 0.32 & $(0.08)$ \\
\hline & Ireland & 7.27 & $(0.03)$ & 7.37 & $(0.08)$ & 0.11 & $(0.09)$ & 0.12 & $(0.09)$ \\
\hline & Israel & $\mathrm{m}$ & $\mathrm{m}$ & $\mathrm{m}$ & $\mathrm{m}$ & $\mathrm{m}$ & $\mathrm{m}$ & $\mathrm{m}$ & $\mathrm{m}$ \\
\hline & Italy & 6.79 & $(0.05)$ & 7.18 & $(0.06)$ & 0.39 & $(0.08)$ & 0.42 & $(0.08)$ \\
\hline & Japan & 6.83 & $(0.04)$ & 6.61 & $(0.13)$ & -0.22 & $(0.13)$ & -0.15 & $(0.13)$ \\
\hline & Korea & 6.34 & $(0.04)$ & 6.67 & $(0.17)$ & 0.33 & $(0.17)$ & 0.36 & $(0.16)$ \\
\hline & Latvia & 7.35 & $(0.04)$ & 7.47 & $(0.09)$ & 0.11 & $(0.10)$ & 0.13 & $(0.10)$ \\
\hline & Luxembourg & 7.34 & $(0.04)$ & 7.57 & $(0.09)$ & 0.24 & $(0.09)$ & 0.27 & $(0.09)$ \\
\hline & Mexico & 8.27 & $(0.03)$ & 8.27 & $(0.06)$ & 0.00 & $(0.06)$ & 0.01 & $(0.06)$ \\
\hline & Netherlands & 7.75 & $(0.03)$ & 7.94 & $(0.04)$ & 0.19 & $(0.05)$ & 0.19 & $(0.05)$ \\
\hline & New Zealand & $\mathrm{m}$ & $\mathrm{m}$ & $\mathrm{m}$ & $\mathrm{m}$ & $\mathrm{m}$ & $\mathrm{m}$ & $\mathrm{m}$ & $\mathrm{m}$ \\
\hline & Norway & $\mathrm{m}$ & $\mathrm{m}$ & $\mathrm{m}$ & $\mathrm{m}$ & $\mathrm{m}$ & $\mathrm{m}$ & $\mathrm{m}$ & $\mathrm{m}$ \\
\hline & Poland & 7.14 & $(0.05)$ & 7.38 & $(0.08)$ & 0.24 & $(0.09)$ & 0.28 & $(0.08)$ \\
\hline & Portugal & 7.32 & $(0.04)$ & 7.64 & $(0.08)$ & 0.32 & $(0.10)$ & 0.34 & $(0.10)$ \\
\hline & Slovak Republic & 7.38 & $(0.04)$ & 7.67 & $(0.06)$ & 0.28 & $(0.07)$ & 0.32 & $(0.07)$ \\
\hline & Slovenia & 7.12 & $(0.04)$ & 7.58 & $(0.10)$ & 0.47 & $(0.11)$ & 0.47 & $(0.11)$ \\
\hline & Spain & 7.38 & $(0.04)$ & 7.54 & $(0.05)$ & 0.16 & $(0.06)$ & 0.18 & $(0.06)$ \\
\hline & Sweden & $\mathrm{m}$ & $\mathrm{m}$ & $\mathrm{m}$ & $\mathrm{m}$ & $\mathrm{m}$ & $\mathrm{m}$ & $\mathrm{m}$ & $\mathrm{m}$ \\
\hline & Switzerland & 7.66 & $(0.04)$ & 7.82 & $(0.08)$ & 0.15 & $(0.09)$ & 0.16 & $(0.09)$ \\
\hline & Turkey & 6.10 & $(0.07)$ & 6.19 & $(0.08)$ & 0.10 & $(0.09)$ & 0.13 & $(0.09)$ \\
\hline & United Kingdom & 6.93 & $(0.05)$ & 7.18 & $(0.06)$ & 0.25 & $(0.08)$ & 0.25 & $(0.08)$ \\
\hline & United States & 7.27 & $(0.04)$ & 7.58 & $(0.06)$ & 0.31 & $(0.06)$ & 0.33 & $(0.06)$ \\
\hline & OECD average & 7.26 & $(0.01)$ & 7.47 & $(0.02)$ & 0.21 & $(0.02)$ & 0.24 & $(0.02)$ \\
\hline$n$ & Albania & $\mathrm{m}$ & $\mathrm{m}$ & $\mathrm{m}$ & $\mathrm{m}$ & $\mathrm{m}$ & $\mathrm{m}$ & $\mathrm{m}$ & $\mathrm{m}$ \\
\hline$\stackrel{\Xi}{\Xi}$ & Algeria & $\mathrm{m}$ & $\mathrm{m}$ & $\mathrm{m}$ & $\mathrm{m}$ & $\mathrm{m}$ & $\mathrm{m}$ & $\mathrm{m}$ & $\mathrm{m}$ \\
\hline 胥 & Brazil & 7.40 & $(0.05)$ & 7.74 & $(0.04)$ & 0.33 & $(0.06)$ & 0.33 & $(0.06)$ \\
\hline & B-S-J-G (China) & 6.79 & $(0.04)$ & 7.09 & $(0.08)$ & 0.30 & $(0.09)$ & 0.36 & $(0.08)$ \\
\hline & Bulgaria & 7.36 & $(0.05)$ & 7.49 & $(0.08)$ & 0.13 & $(0.09)$ & 0.20 & $(0.09)$ \\
\hline & CABA (Argentina) & $\mathrm{m}$ & $\mathrm{m}$ & $\mathrm{m}$ & $\mathrm{m}$ & $\mathrm{m}$ & $\mathrm{m}$ & $\mathrm{m}$ & $\mathrm{m}$ \\
\hline & Colombia & 7.75 & $(0.05)$ & 8.01 & $(0.05)$ & 0.26 & $(0.05)$ & 0.25 & $(0.05)$ \\
\hline & Costa Rica & 8.17 & $(0.04)$ & 8.21 & $(0.09)$ & 0.04 & $(0.10)$ & 0.05 & $(0.10)$ \\
\hline & Croatia & 7.82 & $(0.04)$ & 8.18 & $(0.08)$ & 0.36 & $(0.08)$ & 0.37 & $(0.08)$ \\
\hline & Cyprus* & 7.05 & $(0.04)$ & 7.13 & $(0.05)$ & 0.08 & $(0.06)$ & 0.11 & $(0.06)$ \\
\hline & Dominican Republic & 8.47 & $(0.05)$ & 8.54 & $(0.09)$ & 0.06 & $(0.10)$ & 0.06 & $(0.10)$ \\
\hline & FYROM & $\mathrm{m}$ & $\mathrm{m}$ & $\mathrm{m}$ & $\mathrm{m}$ & $\mathrm{m}$ & $\mathrm{m}$ & $\mathrm{m}$ & $\mathrm{m}$ \\
\hline & Georgia & $\mathrm{m}$ & $\mathrm{m}$ & $\mathrm{m}$ & $\mathrm{m}$ & $\mathrm{m}$ & $\mathrm{m}$ & $\mathrm{m}$ & $\mathrm{m}$ \\
\hline & Hong Kong (China) & 6.48 & $(0.04)$ & 6.54 & $(0.11)$ & 0.06 & $(0.10)$ & 0.08 & $(0.10)$ \\
\hline & Indonesia & $\mathrm{m}$ & $\mathrm{m}$ & $\mathrm{m}$ & $\mathrm{m}$ & $\mathrm{m}$ & $\mathrm{m}$ & $\mathrm{m}$ & $\mathrm{m}$ \\
\hline & Jordan & $\mathrm{m}$ & $\mathrm{m}$ & $\mathrm{m}$ & $\mathrm{m}$ & $\mathrm{m}$ & $\mathrm{m}$ & $\mathrm{m}$ & $\mathrm{m}$ \\
\hline & Kosovo & $\mathrm{m}$ & $\mathrm{m}$ & $\mathrm{m}$ & $\mathrm{m}$ & $\mathrm{m}$ & $\mathrm{m}$ & $\mathrm{m}$ & $\mathrm{m}$ \\
\hline & Lebanon & $\mathrm{m}$ & $\mathrm{m}$ & $\mathrm{m}$ & $\mathrm{m}$ & $\mathrm{m}$ & $\mathrm{m}$ & $\mathrm{m}$ & $\mathrm{m}$ \\
\hline & Lithuania & 7.83 & $(0.04)$ & 7.97 & $(0.07)$ & 0.14 & $(0.08)$ & 0.17 & $(0.08)$ \\
\hline & Macao (China) & 6.62 & $(0.03)$ & 6.46 & $(0.09)$ & -0.16 & $(0.09)$ & -0.17 & $(0.09)$ \\
\hline & Malta & $\mathrm{m}$ & $\mathrm{m}$ & $\mathrm{m}$ & m & $\mathrm{m}$ & m & $\mathrm{m}$ & $\mathrm{m}$ \\
\hline & Moldova & $\mathrm{m}$ & $\mathrm{m}$ & $\mathrm{m}$ & $\mathrm{m}$ & $\mathrm{m}$ & $\mathrm{m}$ & $\mathrm{m}$ & $\mathrm{m}$ \\
\hline & Montenegro & 7.61 & $(0.05)$ & 7.86 & $(0.05)$ & 0.25 & $(0.06)$ & 0.25 & $(0.06)$ \\
\hline & Peru & 7.42 & $(0.04)$ & 7.60 & $(0.07)$ & 0.18 & $(0.08)$ & 0.17 & $(0.09)$ \\
\hline & Qatar & 7.13 & $(0.03)$ & 7.66 & $(0.04)$ & 0.53 & $(0.06)$ & 0.59 & $(0.06)$ \\
\hline & Romania & $\mathrm{m}$ & $\mathrm{m}$ & $\mathrm{m}$ & $\mathrm{m}$ & $\mathrm{m}$ & $\mathrm{m}$ & $\mathrm{m}$ & $\mathrm{m}$ \\
\hline & Russia & 7.65 & $(0.04)$ & 8.00 & $(0.07)$ & 0.35 & $(0.07)$ & 0.35 & $(0.07)$ \\
\hline & Singapore & $\mathrm{m}$ & $\mathrm{m}$ & $\mathrm{m}$ & $\mathrm{m}$ & $\mathrm{m}$ & $\mathrm{m}$ & $\mathrm{m}$ & $\mathrm{m}$ \\
\hline & Chinese Taipei & 6.60 & $(0.03)$ & 6.52 & $(0.08)$ & -0.08 & $(0.08)$ & 0.02 & $(0.08)$ \\
\hline & Thailand & 7.65 & $(0.04)$ & 7.80 & $(0.05)$ & 0.14 & $(0.06)$ & 0.13 & $(0.06)$ \\
\hline & Trinidad and Tobago & $\mathrm{m}$ & $\mathrm{m}$ & $\mathrm{m}$ & $\mathrm{m}$ & $\mathrm{m}$ & $\mathrm{m}$ & $\mathrm{m}$ & $\mathrm{m}$ \\
\hline & Tunisia & 6.91 & $(0.06)$ & 6.88 & $(0.07)$ & -0.02 & $(0.10)$ & -0.02 & $(0.09)$ \\
\hline & United Arab Emirates & 7.12 & $(0.04)$ & 7.57 & $(0.05)$ & 0.45 & $(0.06)$ & 0.50 & $(0.06)$ \\
\hline & Uruguay & 7.63 & $(0.04)$ & 7.85 & $(0.08)$ & 0.23 & $(0.09)$ & 0.27 & $(0.09)$ \\
\hline & Viet Nam & $\mathrm{m}$ & $\mathrm{m}$ & $\mathrm{m}$ & $\mathrm{m}$ & $\mathrm{m}$ & $\mathrm{m}$ & $\mathrm{m}$ & $\mathrm{m}$ \\
\hline & Argentina** $^{* *}$ & $\mathrm{~m}$ & $\mathrm{~m}$ & $\mathrm{~m}$ & $\mathrm{~m}$ & $\mathrm{~m}$ & $\mathrm{~m}$ & $\mathrm{~m}$ & $\mathrm{~m}$ \\
\hline & Kazakhstan** & $\mathrm{m}$ & $\mathrm{m}$ & $\mathrm{m}$ & $\mathrm{m}$ & $\mathrm{m}$ & $\mathrm{m}$ & $\mathrm{m}$ & $\mathrm{m}$ \\
\hline & Malaysia** & 7.03 & $(0.05)$ & 7.15 & $(0.07)$ & 0.11 & $(0.08)$ & 0.14 & $(0.08)$ \\
\hline
\end{tabular}

Note: Values that are statistically significant are indicated in bold (see Annex A3).

* See note at the beginning of this Annex.

** Coverage is too small to ensure comparability (see Annex A4).

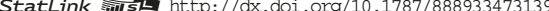


[Part 1/2]

Table III.12.10 Students who work for pay and well-being outcomes

Results based on students' self-reports

\begin{tabular}{|c|c|c|c|c|c|c|c|c|c|c|c|c|}
\hline & \multicolumn{12}{|c|}{ Percentage of students who agreed/strongly agreed with the following statements } \\
\hline & \multicolumn{6}{|c|}{ Feel like an outsider (or left out of things) at school } & \multicolumn{6}{|c|}{ Expect to end (their) education at the secondary level } \\
\hline & $\begin{array}{l}\text { Student } \\
\text { wor } \\
\text { before o }\end{array}$ & $\begin{array}{l}\text { do not } \\
\text { pay } \\
\text { r school }\end{array}$ & $\begin{array}{r}\text { Stu } \\
\text { wo } \\
\text { before }\end{array}$ & $\begin{array}{l}\text { who } \\
\text { pay } \\
\text { r school }\end{array}$ & $\begin{array}{l}\text { Differen } \\
\text { studen } \\
\text { and st } \\
\text { do not } v \\
\text { before or }\end{array}$ & $\begin{array}{l}\text { etween } \\
\text { ho do } \\
\text { ts who } \\
\text { for pay } \\
\text { er school }\end{array}$ & $\begin{array}{l}\text { Studen } \\
\text { wo } \\
\text { before }\end{array}$ & $\begin{array}{l}\text { o do not } \\
\text { pay } \\
\text { er school }\end{array}$ & $\begin{array}{r}\text { Stu } \\
\text { wo } \\
\text { before c }\end{array}$ & $\begin{array}{l}\text { who } \\
\text { pay } \\
\text { er school }\end{array}$ & $\begin{array}{r}\text { Differer } \\
\text { studer } \\
\text { and st } \\
\text { do not } \\
\text { before o }\end{array}$ & $\begin{array}{l}\text { etween } \\
\text { ho do } \\
\text { ts who } \\
\text { for pay } \\
\text { rr school }\end{array}$ \\
\hline & $\%$ & S.E. & $\%$ & S.E. & $\%$ dif. & S.E. & $\%$ & S.E. & $\%$ & S.E. & $\%$ dif. & S.E. \\
\hline Australia & 23.1 & $(0.5)$ & 24.7 & $(0.8)$ & 1.6 & $(0.9)$ & 34.9 & $(0.7)$ & 42.1 & $(0.9)$ & 7.2 & $(1.2)$ \\
\hline Austria & 12.6 & $(0.5)$ & 17.7 & $(1.2)$ & 5.1 & $(1.2)$ & 61.4 & (1.1) & 72.8 & (1.6) & 11.5 & $(1.7)$ \\
\hline Belgium & 11.8 & $(0.4)$ & 16.4 & (1.0) & 4.6 & $(1.0)$ & 24.4 & $(0.7)$ & 31.5 & (1.4) & 7.1 & (1.3) \\
\hline Canada & 22.5 & $(0.5)$ & 22.2 & $(0.8)$ & -0.3 & $(0.9)$ & 12.1 & $(0.5)$ & 14.0 & $(0.6)$ & 1.9 & $(0.7)$ \\
\hline Chile & 19.0 & $(0.7)$ & 23.4 & (1.5) & 4.4 & (1.7) & 15.0 & $(0.7)$ & 23.2 & (1.5) & 8.2 & (1.4) \\
\hline Czech Republic & 18.8 & $(0.6)$ & 25.3 & (1.5) & 6.6 & (1.7) & 31.3 & $(0.9)$ & 55.9 & (1.7) & 24.6 & (1.7) \\
\hline Denmark & 11.6 & $(0.6)$ & 13.1 & $(0.7)$ & 1.5 & (1.0) & 57.8 & (1.3) & 60.8 & (1.5) & 3.0 & (1.7) \\
\hline Estonia & 11.8 & $(0.5)$ & 17.1 & (1.3) & 5.3 & (1.4) & 22.3 & $(0.7)$ & 36.7 & $(2.1)$ & 14.4 & (2.1) \\
\hline Finland & 11.9 & $(0.5)$ & 14.5 & (1.6) & 2.7 & (1.7) & 54.5 & (1.0) & 52.9 & $(2.0)$ & -1.6 & (1.9) \\
\hline France & 21.2 & $(0.7)$ & 32.8 & (1.7) & 11.6 & (1.8) & 53.3 & (1.0) & 69.6 & (1.9) & 16.3 & (1.7) \\
\hline Germany & 14.6 & $(0.6)$ & 17.7 & (1.9) & 3.1 & $(1.9)$ & 75.8 & (1.1) & 77.2 & $(2.0)$ & 1.4 & (2.0) \\
\hline Greece & 13.7 & $(0.6)$ & 20.6 & (1.4) & 6.9 & (1.5) & 11.3 & (1.0) & 27.4 & (1.9) & 16.1 & (1.9) \\
\hline Hungary & 16.4 & $(0.7)$ & 21.8 & (1.2) & 5.4 & (1.3) & 39.2 & (1.1) & 64.0 & (1.9) & 24.8 & (1.8) \\
\hline Iceland & 16.2 & $(0.8)$ & 19.3 & (1.3) & 3.2 & (1.6) & 33.1 & $(0.9)$ & 37.1 & (1.4) & 4.0 & $(1.8)$ \\
\hline Ireland & 16.3 & $(0.7)$ & 16.9 & (1.2) & 0.6 & $(1.2)$ & 29.1 & $(0.8)$ & 37.7 & (1.7) & 8.6 & (1.8) \\
\hline Israel & C & $\mathrm{C}$ & c & $\mathrm{c}$ & $\mathrm{c}$ & $\mathrm{c}$ & 26.4 & $(1.0)$ & 39.8 & (1.6) & 13.3 & (1.4) \\
\hline Italy & 10.3 & $(0.5)$ & 12.6 & $(0.9)$ & 2.4 & $(1.0)$ & 28.0 & (1.1) & 42.2 & (1.6) & 14.2 & (1.8) \\
\hline Japan & 11.2 & $(0.5)$ & 19.7 & (1.8) & 8.5 & (1.9) & 20.7 & $(0.9)$ & 42.2 & $(2.7)$ & 21.5 & (2.8) \\
\hline Korea & 8.5 & (0.4) & 12.1 & (1.7) & 3.6 & (1.8) & 9.3 & $(0.6)$ & 25.4 & (1.8) & 16.1 & (1.9) \\
\hline Latvia & 14.4 & $(0.5)$ & 21.1 & (1.7) & 6.7 & $(1.8)$ & 25.2 & $\begin{array}{l}(0.9) \\
(0.9)\end{array}$ & 37.0 & $\begin{array}{l}(1.0) \\
\text { (1.9) }\end{array}$ & 11.8 & $\begin{array}{l}(2.0) \\
(1.0)\end{array}$ \\
\hline Luxembourg & 14.9 & (0.6) & 23.2 & (1.2) & 8.3 & (1.3) & 37.4 & $(0.7)$ & 51.1 & (1.5) & 13.7 & (1.6) \\
\hline Mexico & 21.5 & $(0.7)$ & 32.1 & (1.4) & 10.6 & (1.6) & 19.8 & $(0.9)$ & 29.5 & (1.4) & 9.7 & (1.6) \\
\hline Netherlands & 8.0 & $(0.5)$ & 10.2 & $(0.7)$ & 2.1 & $(0.8)$ & 26.5 & $(0.9)$ & 26.1 & (1.0) & -0.4 & (1.4) \\
\hline New Zealand & 21.9 & $(0.9)$ & 22.9 & (1.3) & 1.1 & (1.6) & 35.7 & $(1.2)$ & 48.1 & (1.6) & 12.4 & (1.7) \\
\hline Norway & 11.4 & $(0.7)$ & 12.4 & (0.8) & 1.0 & (1.1) & 25.0 & (0.9) & 30.5 & $(1.1)$ & 5.4 & (1.3) \\
\hline Poland & 20.5 & $(0.7)$ & 26.3 & (1.4) & 5.8 & (1.6) & 31.0 & (1.1) & 53.5 & (1.8) & 22.5 & (1.9) \\
\hline Portugal & 11.5 & $(0.5)$ & 19.2 & (1.4) & 7.7 & (1.5) & 31.6 & $(1.1)$ & 56.3 & $(2.4)$ & 24.6 & (2.3) \\
\hline Slovak Republic & 19.3 & $(0.6)$ & 29.6 & (1.2) & 10.2 & $(1.2)$ & c & c & c & c & c & c \\
\hline Slovenia & 16.1 & $(0.6)$ & 26.1 & (1.9) & 10.0 & (2.0) & 41.2 & $(0.9)$ & 60.4 & $(2.1)$ & 19.3 & (2.1) \\
\hline Spain & 8.9 & $(0.4)$ & 12.0 & $(0.8)$ & 3.0 & $(0.9)$ & 32.6 & (1.0) & 42.3 & (1.3) & 9.8 & $(1.2)$ \\
\hline Sweden & 19.7 & $(0.6)$ & 22.9 & (1.5) & 3.1 & $(1.5)$ & 38.0 & $(1.2)$ & 47.1 & (1.8) & 9.1 & (1.9) \\
\hline Switzerland & 11.3 & $(0.6)$ & 12.9 & (1.5) & 1.5 & (1.6) & 56.6 & (1.1) & 64.5 & (1.8) & 7.9 & (2.1) \\
\hline Turkey & 31.8 & (1.0) & 42.0 & (1.2) & 10.2 & (1.3) & 18.7 & $(0.8)$ & 33.8 & (1.8) & 15.1 & (1.8) \\
\hline United Kingdom & 20.1 & $(0.7)$ & 20.4 & (1.4) & 0.3 & (1.5) & 45.1 & (1.0) & 51.9 & (1.6) & 6.8 & (1.8) \\
\hline United States & 23.5 & $(0.7)$ & 24.4 & (1.1) & 0.9 & (1.4) & 10.8 & $(0.6)$ & 15.6 & $(1.0)$ & 4.8 & (1.0) \\
\hline OECD average & 16.1 & $(0.1)$ & 20.8 & $(0.2)$ & 4.7 & $(0.3)$ & 32.8 & $(0.2)$ & 44.1 & $(0.3)$ & 11.3 & $(0.3)$ \\
\hline Albania & $\mathrm{m}$ & $\mathrm{m}$ & $\mathrm{m}$ & $\mathrm{m}$ & $\mathrm{m}$ & $\mathrm{m}$ & $\mathrm{m}$ & $\mathrm{m}$ & $\mathrm{m}$ & $\mathrm{m}$ & $\mathrm{m}$ & $\mathrm{m}$ \\
\hline 气 Algeria & $\mathrm{m}$ & $\mathrm{m}$ & $\mathrm{m}$ & $\mathrm{m}$ & $\mathrm{m}$ & $\mathrm{m}$ & $\mathrm{m}$ & $\mathrm{m}$ & $\mathrm{m}$ & $\mathrm{m}$ & $\mathrm{m}$ & $\mathrm{m}$ \\
\hline Brazil & 17.0 & $(0.7)$ & 24.2 & $(0.8)$ & 7.3 & (1.0) & 26.7 & $(0.9)$ & 38.7 & (1.0) & 12.1 & (1.1) \\
\hline B-S-J-G (China) & 21.6 & $(0.6)$ & 24.6 & (1.6) & 3.0 & (1.8) & 35.7 & (1.6) & 65.6 & $(2.1)$ & 29.9 & (2.4) \\
\hline Bulgaria & 24.8 & $(0.9)$ & 39.8 & (1.6) & 15.0 & (1.8) & 16.1 & $(0.9)$ & 34.5 & (1.8) & 18.4 & (1.6) \\
\hline CABA (Argentina) & $\mathrm{m}$ & $\mathrm{m}$ & $\mathrm{m}$ & $\mathrm{m}$ & $\mathrm{m}$ & $\mathrm{m}$ & $\mathrm{m}$ & $\mathrm{m}$ & $\mathrm{m}$ & $\mathrm{m}$ & $\mathrm{m}$ & $\mathrm{m}$ \\
\hline Colombia & 24.0 & $(0.8)$ & 34.5 & $(1.0)$ & 10.5 & (1.1) & 9.9 & $(0.6)$ & 20.2 & (1.1) & 10.3 & $(1.2)$ \\
\hline Costa Rica & 25.4 & $(0.7)$ & 33.6 & (1.6) & 8.2 & $(1.8)$ & 16.1 & $(0.7)$ & 21.4 & (1.5) & 5.3 & (1.6) \\
\hline Croatia & 11.9 & $(0.5)$ & 21.5 & (1.3) & 9.6 & (1.4) & 27.4 & (1.1) & 49.1 & $(1.7)$ & 21.7 & (1.7) \\
\hline Cyprus* & 14.7 & $(0.6)$ & 20.6 & (1.0) & 6.0 & $(1.2)$ & 8.7 & $(0.4)$ & 18.2 & $(0.7)$ & 9.5 & $(0.8)$ \\
\hline Dominican Republic & 33.2 & (1.2) & 46.2 & (1.5) & 13.0 & (1.9) & 27.4 & $(1.2)$ & 38.8 & $(1.7)$ & 11.4 & (2.0) \\
\hline FYROM & $\mathrm{m}$ & $\mathrm{m}$ & $\mathrm{m}$ & $\mathrm{m}$ & $\mathrm{m}$ & $\mathrm{m}$ & $\mathrm{m}$ & $\mathrm{m}$ & $\mathrm{m}$ & $\mathrm{m}$ & $\mathrm{m}$ & $\mathrm{m}$ \\
\hline Georgia & $\mathrm{m}$ & $\mathrm{m}$ & $\mathrm{m}$ & $\mathrm{m}$ & $\mathrm{m}$ & $\mathrm{m}$ & $\mathrm{m}$ & $\mathrm{m}$ & $\mathrm{m}$ & $\mathrm{m}$ & $\mathrm{m}$ & $\mathrm{m}$ \\
\hline Hong Kong (China) & 24.4 & $(0.8)$ & 26.4 & (1.8) & 2.0 & $(1.8)$ & 16.3 & $(0.7)$ & 25.9 & $(2.3)$ & 9.5 & $(2.2)$ \\
\hline Indonesia & $\mathrm{m}$ & $\mathrm{m}$ & $\mathrm{m}$ & $\mathrm{m}$ & $\mathrm{m}$ & $\mathrm{m}$ & $\mathrm{m}$ & $\mathrm{m}$ & $\mathrm{m}$ & $\mathrm{m}$ & $\mathrm{m}$ & $\mathrm{m}$ \\
\hline Jordan & $\mathrm{m}$ & $\mathrm{m}$ & $\mathrm{m}$ & $\mathrm{m}$ & $\mathrm{m}$ & $\mathrm{m}$ & $\mathrm{m}$ & $\mathrm{m}$ & $\mathrm{m}$ & $\mathrm{m}$ & $\mathrm{m}$ & $\mathrm{m}$ \\
\hline Kosovo & $\mathrm{m}$ & $\mathrm{m}$ & $\mathrm{m}$ & $\mathrm{m}$ & $\mathrm{m}$ & $\mathrm{m}$ & $\mathrm{m}$ & $\mathrm{m}$ & $\mathrm{m}$ & $\mathrm{m}$ & $\mathrm{m}$ & $\mathrm{m}$ \\
\hline Lebanon & $\mathrm{m}$ & $\mathrm{m}$ & $\mathrm{m}$ & $\mathrm{m}$ & $\mathrm{m}$ & $\mathrm{m}$ & $\mathrm{m}$ & $\mathrm{m}$ & $\mathrm{m}$ & $\mathrm{m}$ & $\mathrm{m}$ & $\mathrm{m}$ \\
\hline Lithuania & 28.1 & $(0.8)$ & 38.1 & $(1.2)$ & 10.0 & (1.4) & 14.3 & $(0.7)$ & 31.4 & $(1.6)$ & 17.1 & (1.6) \\
\hline Macao (China) & 19.6 & $(0.7)$ & 27.0 & (1.9) & 7.4 & $(2.1)$ & 14.6 & $(0.6)$ & 15.5 & $(1.3)$ & 0.9 & (1.4) \\
\hline Malta & $\mathrm{m}$ & $\mathrm{m}$ & $\mathrm{m}$ & $\mathrm{m}$ & $\mathrm{m}$ & $\mathrm{m}$ & $\mathrm{m}$ & $\mathrm{m}$ & $\mathrm{m}$ & $\mathrm{m}$ & $\mathrm{m}$ & $\mathrm{m}$ \\
\hline Moldova & $\mathrm{m}$ & $\mathrm{m}$ & $\mathrm{m}$ & $\mathrm{m}$ & $\mathrm{m}$ & $\mathrm{m}$ & $\mathrm{m}$ & $\mathrm{m}$ & $\mathrm{m}$ & $\mathrm{m}$ & $\mathrm{m}$ & $\mathrm{m}$ \\
\hline Montenegro & 14.9 & $(0.6)$ & 19.7 & $(0.8)$ & 4.8 & $(1.0)$ & 11.3 & $(0.6)$ & 15.6 & $(0.7)$ & 4.3 & $(1.0)$ \\
\hline Peru & 15.8 & $(0.6)$ & 25.5 & $(1.5)$ & 9.7 & (1.4) & 14.5 & $(0.6)$ & 17.6 & $(0.9)$ & 3.1 & (1.1) \\
\hline Qatar & 20.6 & $(0.6)$ & 27.1 & $(0.7)$ & 6.5 & (1.0) & 9.8 & $(0.4)$ & 18.0 & $(0.6)$ & 8.1 & $(0.7)$ \\
\hline Romania & $\mathrm{m}$ & $\mathrm{m}$ & $\mathrm{m}$ & $\mathrm{m}$ & $\mathrm{m}$ & $\mathrm{m}$ & $\mathrm{m}$ & $\mathrm{m}$ & $\mathrm{m}$ & $\mathrm{m}$ & $\mathrm{m}$ & $\mathrm{m}$ \\
\hline Russ & 17.1 & $(0.8)$ & 24.7 & $(1.0)$ & 7.7 & (1.0) & 40.9 & (1.4) & 55.7 & (1.6) & 14.8 & (1.6) \\
\hline Singapore & 22.7 & $(0.6)$ & 29.3 & $(1.7)$ & 6.7 & (1.9) & 2.7 & $(0.2)$ & 5.2 & $(0.8)$ & 2.5 & $(0.8)$ \\
\hline Chinese Taipei & 10.7 & $(0.4)$ & 15.8 & (1.2) & 5.2 & (1.3) & 26.3 & $(0.7)$ & 47.1 & (1.9) & 20.9 & (1.8) \\
\hline Thailand & 16.5 & $(0.8)$ & 25.1 & (1.0) & 8.5 & $(1.3)$ & 10.8 & $(0.7)$ & 21.8 & $(1.1)$ & 11.0 & (1.0) \\
\hline Trinidad and Tobago & $\mathrm{m}$ & $\mathrm{m}$ & $\mathrm{m}$ & & $\mathrm{m}$ & & $\mathrm{m}$ & & $\mathrm{m}$ & & $\mathrm{m}$ & $\mathrm{m}$ \\
\hline Tunisia & 17.8 & $(0.9)$ & 22.7 & $(1.2)$ & 4.8 & (1.3) & 27.7 & (1.1) & 37.9 & $(1.3)$ & 10.2 & (1.3) \\
\hline rab Emirates & 20.3 & $(0.6)$ & 22.1 & $(0.8)$ & 1.8 & $(0.9)$ & 14.1 & $(0.5)$ & 24.4 & $(0.9)$ & 10.3 & (1.0) \\
\hline Uruguay & 20.9 & $(0.8)$ & 28.9 & (1.1) & 8.1 & (1.4) & 41.3 & (1.0) & 57.6 & (1.5) & 16.3 & (1.6) \\
\hline Viet Nam & $\mathrm{m}$ & $\mathrm{m}$ & $\mathrm{m}$ & $\mathrm{m}$ & $\mathrm{m}$ & $\mathrm{m}$ & $\mathrm{m}$ & $\mathrm{m}$ & $\mathrm{m}$ & $\mathrm{m}$ & $\mathrm{m}$ & $\mathrm{m}$ \\
\hline Argentin & $\mathrm{m}$ & $\mathrm{m}$ & $\mathrm{m}$ & $\mathrm{m}$ & $\mathrm{m}$ & $\mathrm{m}$ & $\mathrm{m}$ & $\mathrm{m}$ & $\mathrm{m}$ & $\mathrm{m}$ & $\mathrm{m}$ & $\mathrm{m}$ \\
\hline Kazakhstan** & $\mathrm{m}$ & $\mathrm{m}$ & $\mathrm{m}$ & $\mathrm{m}$ & $\mathrm{m}$ & $\mathrm{m}$ & $\mathrm{m}$ & $\mathrm{m}$ & $\mathrm{m}$ & $\mathrm{m}$ & $\mathrm{m}$ & $\mathrm{m}$ \\
\hline Malaysia** & 14.0 & $(0.7)$ & 20.8 & (1.3) & 6.8 & (1.4) & 11.2 & $(0.7)$ & 24.3 & (1.3) & 13.1 & $(1.3)$ \\
\hline
\end{tabular}

Note: Values that are statistically significant are indicated in bold (see Annex A3),

* See note at the beginning of this Annex.

** Coverage is too small to ensure comparability (see Annex A4).

StatLink 체제 $\mathrm{http}: / / \mathrm{dx}$.doi.org/10.1787/888933473143 


\begin{tabular}{|c|c|c|c|c|c|c|c|c|c|c|c|c|c|}
\hline & \multicolumn{12}{|c|}{ Percentage of students who agreed/strongly agreed with the following statements } \\
\hline & & \multicolumn{6}{|c|}{ Arrived late for school in the 2 weeks prior to the PISA test } & \multicolumn{6}{|c|}{ Skipped school at least 3-4 days in the previous 2 weeks } \\
\hline & & \begin{tabular}{|c} 
Studen \\
wor \\
before 0
\end{tabular} & $\begin{array}{l}\text { o do not } \\
\text { pay } \\
\text { er school }\end{array}$ & $\begin{array}{r}\text { Stud } \\
\text { wor } \\
\text { before } 0\end{array}$ & $\begin{array}{l}\text { who } \\
\text { pay } \\
\text { rs school }\end{array}$ & $\begin{array}{r}\text { Differer } \\
\text { studer } \\
\text { and ste } \\
\text { do not v } \\
\text { before or }\end{array}$ & $\begin{array}{l}\text { etween } \\
\text { ho do } \\
\text { ts who } \\
\text { for pay } \\
\text { er school }\end{array}$ & $\begin{array}{c}\text { Studen } \\
\text { wo } \\
\text { before } c\end{array}$ & $\begin{array}{l}\text { o do not } \\
\text { pay } \\
\text { r school }\end{array}$ & $\begin{array}{r}\text { Stu } \\
\text { wo } \\
\text { before } 0\end{array}$ & $\begin{array}{l}\text { who } \\
\text { pay } \\
\text { er school }\end{array}$ & $\begin{array}{r}\text { Differen } \\
\text { studen } \\
\text { and stu } \\
\text { do not v } \\
\text { before or }\end{array}$ & $\begin{array}{l}\text { etween } \\
\text { ho do } \\
\text { ts who } \\
\text { for pay } \\
\text { ar school }\end{array}$ \\
\hline & & $\%$ & S.E. & $\%$ & S.E. & $\%$ dif. & S.E. & $\%$ & S.E. & $\%$ & S.E. & $\%$ dif. & S.E. \\
\hline 0 & Australia & 37.9 & $(0.8)$ & 46.1 & $(0.7)$ & 8.2 & $(1.0)$ & 3.2 & $(0.3)$ & 5.1 & $(0.4)$ & 1.9 & $(0.5)$ \\
\hline 讪 & Austria & 33.7 & $(1.2)$ & 39.6 & (1.4) & 5.9 & (1.8) & 3.6 & $(0.3)$ & 6.2 & $(0.7)$ & 2.6 & $(0.8)$ \\
\hline ప & Belgium & 47.9 & $(0.9)$ & 61.2 & (1.4) & 13.2 & (1.3) & 2.2 & $(0.2)$ & 5.6 & $(0.6)$ & 3.4 & $(0.6)$ \\
\hline & Canada & 44.1 & $(0.9)$ & 53.7 & $(1.0)$ & 9.6 & (1.1) & 5.3 & $(0.3)$ & 8.3 & $(0.6)$ & 3.0 & $(0.6)$ \\
\hline & Chile & 65.1 & (1.1) & 72.2 & (1.5) & 7.1 & $(1.7)$ & 3.4 & $(0.4)$ & 6.3 & (1.1) & 2.8 & $(1.1)$ \\
\hline & Czech Republic & 49.7 & $(1.0)$ & 60.5 & $(1.9)$ & 10.8 & $(2.2)$ & 1.9 & $(0.2)$ & 3.5 & $(0.6)$ & 1.6 & $(0.6)$ \\
\hline & Denmark & 48.6 & (1.1) & 46.1 & (1.3) & -2.5 & (1.5) & 4.9 & $(0.5)$ & 6.0 & $(0.7)$ & 1.1 & $(0.8)$ \\
\hline & Estonia & 39.9 & $(0.9)$ & 56.2 & (1.9) & 16.3 & $(2.0)$ & 6.7 & $(0.5)$ & 14.8 & (1.3) & 8.2 & (1.3) \\
\hline & Finland & 35.5 & $(1.0)$ & 41.3 & (2.5) & 5.9 & (2.6) & 10.0 & $(0.5)$ & 10.2 & $(1.2)$ & 0.2 & (1.3) \\
\hline & France & 50.3 & $(1.0)$ & 63.4 & $(1.8)$ & 13.1 & $(1.8)$ & 6.7 & $(0.4)$ & 12.1 & $(1.1)$ & 5.3 & $(1.2)$ \\
\hline & Germany & 38.7 & (1.1) & 46.7 & $(2.5)$ & 8.0 & (2.4) & 3.3 & $(0.4)$ & 7.3 & (1.0) & 4.1 & (1.0) \\
\hline & Greece & 52.0 & $(0.8)$ & 60.6 & $(1.8)$ & 8.6 & (1.9) & 10.4 & $(0.6)$ & 21.8 & (1.5) & 11.4 & $(1.3)$ \\
\hline & Hungary & 30.6 & $(1.0)$ & 48.1 & (1.9) & 17.5 & $(2.0)$ & 2.8 & $(0.3)$ & 7.0 & $(0.7)$ & 4.1 & $(0.8)$ \\
\hline & Iceland & 48.4 & $(1.2)$ & 53.2 & $(2.0)$ & 4.8 & $(2.2)$ & 4.6 & $(0.5)$ & 5.9 & $(0.8)$ & 1.3 & $(0.9)$ \\
\hline & Ireland & 29.1 & $(1.0)$ & 38.9 & (1.5) & 9.8 & $(1.5)$ & 4.8 & $(0.4)$ & 5.8 & $(0.8)$ & 1.0 & $(0.9)$ \\
\hline & Israel & 56.1 & $(1.2)$ & 60.3 & (1.4) & 4.2 & (1.3) & 11.0 & $(0.7)$ & 15.2 & (1.1) & 4.2 & $(1.2)$ \\
\hline & Italy & 33.7 & $(0.8)$ & 42.2 & (1.7) & 8.5 & (1.7) & 7.8 & $(0.5)$ & 13.3 & (1.1) & 5.5 & $(1.2)$ \\
\hline & Japan & 10.3 & $(0.6)$ & 26.2 & (2.4) & 15.9 & $(2.4)$ & 0.5 & $(0.1)$ & 4.0 & $(0.9)$ & 3.5 & $(0.9)$ \\
\hline & Korea & 18.3 & $(0.9)$ & 34.9 & (3.6) & 16.6 & (3.5) & 0.5 & $(0.1)$ & 3.4 & $(0.9)$ & 2.9 & $(0.9)$ \\
\hline & Latvia & 52.3 & (1.1) & 57.0 & (1.8) & 4.7 & $(2.1)$ & 8.1 & $(0.5)$ & 13.4 & $(1.4)$ & 5.3 & (1.5) \\
\hline & Luxembourg & 52.6 & $(0.8)$ & 60.6 & (1.7) & 8.0 & $(2.0)$ & 3.2 & $(0.3)$ & 8.7 & $(1.0)$ & 5.5 & $(1.0)$ \\
\hline & Mexico & 47.4 & (1.1) & 52.8 & (1.7) & 5.5 & (1.8) & 3.4 & $(0.3)$ & 5.0 & $(0.6)$ & 1.6 & $(0.6)$ \\
\hline & Netherlands & 46.9 & $(1.0)$ & 57.4 & (1.4) & 10.4 & (1.7) & 3.4 & $(0.3)$ & 6.1 & $(0.7)$ & 2.7 & $(0.8)$ \\
\hline & New Zealand & 41.7 & $(1.1)$ & 51.1 & (1.3) & 9.4 & (1.5) & 5.3 & $(0.4)$ & 8.1 & $(0.8)$ & 2.8 & $(0.9)$ \\
\hline & Norway & 43.8 & $(1.0)$ & 52.6 & (1.3) & 8.8 & (1.3) & 4.4 & $(0.3)$ & 5.8 & $(0.6)$ & 1.3 & $(0.6)$ \\
\hline & Poland & 54.5 & $(1.2)$ & 64.7 & (1.8) & 10.2 & (1.8) & 11.0 & $(0.7)$ & 20.4 & (1.7) & 9.4 & $(1.7)$ \\
\hline & Portugal & 44.1 & (1.1) & 52.9 & (1.9) & 8.8 & $(2.1)$ & 5.2 & $(0.4)$ & 11.7 & $(1.2)$ & 6.5 & $(1.2)$ \\
\hline & Slovak Republic & 32.5 & $(0.9)$ & 47.6 & $(1.7)$ & 15.2 & (1.7) & 14.8 & $(0.5)$ & 20.6 & $(1.2)$ & 5.8 & $(1.3)$ \\
\hline & Slovenia & 47.6 & $(1.0)$ & 60.4 & $(2.0)$ & 12.7 & $(2.3)$ & 6.9 & $(0.4)$ & 15.7 & (1.5) & 8.8 & (1.5) \\
\hline & Spain & 40.8 & $(0.9)$ & 43.5 & (1.5) & 2.8 & (1.6) & 6.5 & $(0.4)$ & 7.7 & $(0.8)$ & 1.1 & $(0.8)$ \\
\hline & Sweden & 52.6 & $(0.9)$ & 60.7 & $(2.0)$ & 8.1 & $(2.2)$ & 3.4 & $(0.3)$ & 5.1 & $(0.8)$ & 1.7 & $(0.8)$ \\
\hline & Switzerland & 44.9 & $(1.2)$ & 50.5 & (1.6) & 5.6 & (1.6) & 4.9 & $(0.6)$ & 7.5 & $(1.0)$ & 2.6 & (1.1) \\
\hline & Turkey & 45.4 & $(1.3)$ & 53.2 & (1.5) & 7.8 & (1.7) & 13.4 & $(0.7)$ & 17.2 & $(0.9)$ & 3.8 & $(0.9)$ \\
\hline & United Kingdom & 31.1 & $(0.9)$ & 38.1 & (1.4) & 7.1 & (1.3) & 6.1 & $(0.4)$ & 8.2 & $(0.7)$ & 2.1 & $(0.8)$ \\
\hline & United States & 31.1 & $(0.9)$ & 42.6 & $(1.8)$ & 11.5 & (1.6) & 6.2 & $(0.4)$ & 8.7 & $(0.8)$ & 2.5 & $(0.8)$ \\
\hline & OECD average & 42.3 & $(0.2)$ & 51.3 & $(0.3)$ & 9.1 & $(0.3)$ & 5.7 & $(0.1)$ & 9.5 & $(0.2)$ & 3.8 & $(0.2)$ \\
\hline 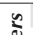 & Albania & $\mathrm{m}$ & $\mathrm{m}$ & $\mathrm{m}$ & $\mathrm{m}$ & $\mathrm{m}$ & $\mathrm{m}$ & $\mathrm{m}$ & $\mathrm{m}$ & $\mathrm{m}$ & $\mathrm{m}$ & $\mathrm{m}$ & $\mathrm{m}$ \\
\hline$\Xi$ & Algeria & $\mathrm{m}$ & $\mathrm{m}$ & $\mathrm{m}$ & $\mathrm{m}$ & $\mathrm{m}$ & $\mathrm{m}$ & $\mathrm{m}$ & $\mathrm{m}$ & $\mathrm{m}$ & $\mathrm{m}$ & $\mathrm{m}$ & $\mathrm{m}$ \\
\hline ปั้ & Brazil & 38.3 & $(0.9)$ & 41.5 & (1.0) & 3.2 & $(1.2)$ & 8.8 & $(0.6)$ & 10.8 & $(0.6)$ & 2.0 & $(0.9)$ \\
\hline 2 & B-S-J-G (China) & 38.3 & $(1.1)$ & 50.0 & $(2.0)$ & 11.6 & $(2.1)$ & 1.4 & $(0.2)$ & 4.4 & $(0.8)$ & 3.1 & $(0.8)$ \\
\hline & Bulgaria & 52.8 & $(1.2)$ & 61.8 & (1.5) & 8.9 & (1.8) & 11.9 & $(0.7)$ & 19.7 & (1.3) & 7.8 & (1.4) \\
\hline & CABA (Argentina) & $\mathrm{m}$ & $\mathrm{m}$ & $\mathrm{m}$ & $\mathrm{m}$ & $\mathrm{m}$ & $\mathrm{m}$ & $\mathrm{m}$ & $\mathrm{m}$ & $\mathrm{m}$ & $\mathrm{m}$ & $\mathrm{m}$ & $\mathrm{m}$ \\
\hline & Colombia & 40.9 & $(1.0)$ & 44.6 & $(1.2)$ & 3.6 & (1.3) & 7.1 & $(0.5)$ & 6.1 & $(0.5)$ & -1.0 & $(0.6)$ \\
\hline & Costa Rica & 52.3 & $(1.2)$ & 59.0 & $(2.0)$ & 6.7 & $(2.1)$ & 8.7 & $(0.5)$ & 11.9 & $(1.3)$ & 3.3 & (1.4) \\
\hline & Croatia & 39.3 & $(1.0)$ & 54.1 & (1.7) & 14.8 & (1.8) & 4.8 & $(0.4)$ & 11.5 & (1.2) & 6.7 & $(1.2)$ \\
\hline & Cyprus* & 54.3 & $(1.0)$ & 60.5 & $(1.3)$ & 6.2 & (1.6) & 10.9 & $(0.6)$ & 17.5 & $(0.9)$ & 6.6 & (1.1) \\
\hline & Dominican Republic & 38.6 & (1.4) & 45.6 & (1.6) & 7.0 & (1.9) & 8.2 & $(0.7)$ & 11.5 & (1.0) & 3.3 & (1.1) \\
\hline & FYROM & $\mathrm{m}$ & $\mathrm{m}$ & $\mathrm{m}$ & $\mathrm{m}$ & $\mathrm{m}$ & $\mathrm{m}$ & $\mathrm{m}$ & $\mathrm{m}$ & $\mathrm{m}$ & $\mathrm{m}$ & $\mathrm{m}$ & $\mathrm{m}$ \\
\hline & Georgia & $\mathrm{m}$ & $\mathrm{m}$ & $\mathrm{m}$ & $\mathrm{m}$ & $\mathrm{m}$ & $\mathrm{m}$ & $\mathrm{m}$ & $\mathrm{m}$ & $\mathrm{m}$ & $\mathrm{m}$ & $\mathrm{m}$ & $\mathrm{m}$ \\
\hline & Hong Kong (China) & 22.2 & $(0.8)$ & 37.5 & $(1.7)$ & 15.3 & $(2.0)$ & 0.9 & $(0.2)$ & 3.6 & $(0.8)$ & 2.8 & $(0.8)$ \\
\hline & Indonesia & $\mathrm{m}$ & $\mathrm{m}$ & $\mathrm{m}$ & $\mathrm{m}$ & $\mathrm{m}$ & $\mathrm{m}$ & $\mathrm{m}$ & $\mathrm{m}$ & $\mathrm{m}$ & $\mathrm{m}$ & $\mathrm{m}$ & $\mathrm{m}$ \\
\hline & Jordan & $\mathrm{m}$ & $\mathrm{m}$ & $\mathrm{m}$ & $\mathrm{m}$ & $\mathrm{m}$ & $\mathrm{m}$ & $\mathrm{m}$ & $\mathrm{m}$ & $\mathrm{m}$ & $\mathrm{m}$ & $\mathrm{m}$ & $\mathrm{m}$ \\
\hline & Kosovo & $\mathrm{m}$ & $\mathrm{m}$ & $\mathrm{m}$ & $\mathrm{m}$ & $\mathrm{m}$ & $\mathrm{m}$ & $\mathrm{m}$ & $\mathrm{m}$ & $\mathrm{m}$ & $\mathrm{m}$ & $\mathrm{m}$ & $\mathrm{m}$ \\
\hline & Lebanon & $\mathrm{m}$ & $\mathrm{m}$ & $\mathrm{m}$ & $\mathrm{m}$ & $\mathrm{m}$ & $\mathrm{m}$ & $\mathrm{m}$ & $\mathrm{m}$ & $\mathrm{m}$ & $\mathrm{m}$ & $\mathrm{m}$ & $\mathrm{m}$ \\
\hline & Lithuania & 45.5 & $(1.0)$ & 53.0 & (1.4) & 7.5 & (1.6) & 8.9 & $(0.6)$ & 15.0 & $(1.1)$ & 6.1 & $(1.2)$ \\
\hline & Macao (China) & 28.2 & $(0.6)$ & 34.6 & (1.8) & 6.4 & (1.9) & 1.7 & $(0.2)$ & 3.2 & $(0.7)$ & 1.5 & $(0.7)$ \\
\hline & Malta & $\mathrm{m}$ & $\mathrm{m}$ & $\mathrm{m}$ & $\mathrm{m}$ & $\mathrm{m}$ & $\mathrm{m}$ & $\mathrm{m}$ & $\mathrm{m}$ & $\mathrm{m}$ & $\mathrm{m}$ & $\mathrm{m}$ & $\mathrm{m}$ \\
\hline & Moldova & $\mathrm{m}$ & $\mathrm{m}$ & $\mathrm{m}$ & $\mathrm{m}$ & $\mathrm{m}$ & $\mathrm{m}$ & $\mathrm{m}$ & $\mathrm{m}$ & $\mathrm{m}$ & $\mathrm{m}$ & $\mathrm{m}$ & $\mathrm{m}$ \\
\hline & Montenegro & 60.8 & (1.1) & 66.6 & $(1.0)$ & 5.8 & (1.4) & 18.8 & $(0.8)$ & 23.0 & (1.0) & 4.2 & (1.2) \\
\hline & Peru & 57.5 & $(1.2)$ & 63.5 & (1.6) & 6.0 & (1.9) & 6.1 & $(0.4)$ & 6.7 & $(0.6)$ & 0.5 & $(0.7)$ \\
\hline & Qatar & 41.5 & $(0.6)$ & 51.6 & $(0.7)$ & 10.1 & $(1.0)$ & 6.8 & $(0.3)$ & 11.4 & $(0.5)$ & 4.7 & $(0.6)$ \\
\hline & Romania & $\mathrm{m}$ & $\mathrm{m}$ & $\mathrm{m}$ & $\mathrm{m}$ & $\mathrm{m}$ & $\mathrm{m}$ & $\mathrm{m}$ & $\mathrm{m}$ & $\mathrm{m}$ & $\mathrm{m}$ & $\mathrm{m}$ & $\mathrm{m}$ \\
\hline & Russia & 52.1 & $(1.5)$ & 61.6 & (1.4) & 9.5 & (1.4) & 10.0 & $(0.7)$ & 15.1 & $(1.2)$ & 5.1 & $(1.2)$ \\
\hline & Singapore & 21.6 & $(0.6)$ & 40.4 & $(2.0)$ & 18.8 & $(2.0)$ & 1.6 & $(0.2)$ & 2.8 & $(0.6)$ & 1.2 & $(0.6)$ \\
\hline & Chinese Taipei & 31.4 & $(0.8)$ & 50.4 & (1.8) & 18.9 & (1.8) & 1.7 & $(0.2)$ & 9.0 & (1.0) & 7.3 & (1.0) \\
\hline & Thailand & 33.8 & $(1.2)$ & 39.3 & $(1.0)$ & 5.4 & $(1.1)$ & 6.2 & $(0.6)$ & 5.7 & $(0.5)$ & -0.6 & $(0.7)$ \\
\hline & Trinidad and Tobago & $\mathrm{m}$ & $\mathrm{m}$ & $\mathrm{m}$ & $\mathrm{m}$ & $\mathrm{m}$ & $\mathrm{m}$ & $\mathrm{m}$ & $\mathrm{m}$ & $\mathrm{m}$ & $\mathrm{m}$ & $\mathrm{m}$ & $\mathrm{m}$ \\
\hline & Tunisia & 73.2 & $(1.1)$ & 76.1 & (1.1) & 3.0 & (1.5) & 10.8 & $(0.9)$ & 15.1 & $(0.9)$ & 4.4 & (1.1) \\
\hline & United Arab Emirates & 38.1 & $(0.9)$ & 50.6 & (1.1) & 12.5 & (1.4) & 8.2 & $(0.5)$ & 10.0 & $(0.6)$ & 1.8 & $(0.8)$ \\
\hline & Uruguay & 62.6 & $(1.0)$ & 68.7 & (1.4) & 6.1 & $(1.7)$ & 8.6 & $(0.6)$ & 11.9 & $(1.0)$ & 3.3 & $(1.2)$ \\
\hline & Viet Nam & $\mathrm{m}$ & $\mathrm{m}$ & $\mathrm{m}$ & $\mathrm{m}$ & $\mathrm{m}$ & $\mathrm{m}$ & $\mathrm{m}$ & $\mathrm{m}$ & $\mathrm{m}$ & $\mathrm{m}$ & $\mathrm{m}$ & $\mathrm{m}$ \\
\hline & Argentina** & $\mathrm{m}$ & $\mathrm{m}$ & $\mathrm{m}$ & $\mathrm{m}$ & $\mathrm{m}$ & $\mathrm{m}$ & $\mathrm{m}$ & $\mathrm{m}$ & $\mathrm{m}$ & $\mathrm{m}$ & $\mathrm{m}$ & $\mathrm{m}$ \\
\hline & Kazakhstan** & $\mathrm{m}$ & $\mathrm{m}$ & $\mathrm{m}$ & $\mathrm{m}$ & $\mathrm{m}$ & $\mathrm{m}$ & $\mathrm{m}$ & $\mathrm{m}$ & $\mathrm{m}$ & $\mathrm{m}$ & $\mathrm{m}$ & $\mathrm{m}$ \\
\hline & Malaysia** & 32.7 & $(1.0)$ & 38.9 & $(1.5)$ & 6.2 & (1.5) & 3.8 & $(0.4)$ & 5.1 & $(0.6)$ & 1.3 & $(0.6)$ \\
\hline
\end{tabular}

Note: Values that are statistically significant are indicated in bold (see Annex A3).

* See note at the beginning of this Annex.

** Coverage is too small to ensure comparability (see Annex A4)

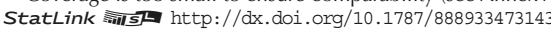


[Part 1/2]

Table III.13.6 Change between 2012 and 2015 in age at which students started using the Internet

Results based on students' self-reports

\begin{tabular}{|c|c|c|c|c|c|c|c|c|c|c|c|c|c|c|c|c|c|c|c|}
\hline & & & & & & PIS & 2012 & & & & & & & & & $\mathrm{PI}$ & 2015 & & \\
\hline & & Perc & ntage & f stude & $\begin{array}{l}\text { nts w } \\
\text { hen } t\end{array}$ & $\begin{array}{l}\text { starte } \\
\text { were. }\end{array}$ & using & e & & $\begin{array}{l}\text { Perce } \\
\text { of stu }\end{array}$ & $\begin{array}{l}\text { ntage } \\
\text { dents }\end{array}$ & Perc & ntag & f st & $\begin{array}{l}\text { nts } n \\
\text { hen } t\end{array}$ & $\begin{array}{l}\text { starte } \\
\text { were. }\end{array}$ & $\begin{array}{l}\text { using } \\
\text {.. }\end{array}$ & the & \\
\hline & & $\begin{array}{l}6 \text { yea } \\
\text { or yo }\end{array}$ & $\begin{array}{l}\text { old } \\
\text { nger }\end{array}$ & $\begin{array}{r}7.9 y \\
0\end{array}$ & & $\begin{array}{r}10-12 \\
0\end{array}$ & ears & $\begin{array}{r}13 y \\
\text { old or }\end{array}$ & $\begin{array}{l}\text { ears } \\
\text { older }\end{array}$ & $\begin{array}{l}\text { never } \\
\text { Inte }\end{array}$ & $\begin{array}{l}\text { used } \\
\text { rnet }\end{array}$ & $\begin{array}{l}6 \text { yea } \\
\text { or yo }\end{array}$ & $\begin{array}{l}\text { old } \\
\text { nger }\end{array}$ & & $\begin{array}{l}\text { ears } \\
\text { Id }\end{array}$ & $\begin{array}{r}10-12 \\
\text { ol }\end{array}$ & $\begin{array}{l}\text { years } \\
\text { d }\end{array}$ & $\begin{array}{r}13 \\
\text { old } 0\end{array}$ & $\begin{array}{l}\text { ars } \\
\text { Ider }\end{array}$ \\
\hline & & $\%$ & S.E. & $\%$ & S.E. & $\%$ & S.E. & $\%$ & S.E. & $\%$ & S.E. & $\%$ & S.E. & $\%$ & S.E. & $\%$ & S.E. & $\%$ & S.E. \\
\hline & Australia & 19.3 & $(0.4)$ & 48.1 & $(0.4)$ & 27.4 & $(0.4)$ & 5.1 & $(0.2)$ & 0.1 & $(0.0)$ & 22.0 & $(0.5)$ & 45.8 & $(0.5)$ & 27.7 & $(0.5)$ & 4.4 & $(0.2)$ \\
\hline & Austria & 8.0 & $(0.4)$ & 37.8 & $(0.7)$ & 43.9 & $(0.7)$ & 10.2 & $(0.6)$ & 0.1 & $(0.0)$ & 9.3 & $(0.5)$ & 36.1 & $(0.6)$ & 43.9 & $(0.7)$ & 10.4 & $(0.4)$ \\
\hline 0 & Belgium & 14.6 & $(0.5)$ & 41.1 & $(0.6)$ & 37.8 & $(0.7)$ & 6.4 & $(0.3)$ & 0.1 & $(0.0)$ & 13.7 & $(0.4)$ & 39.0 & $(0.6)$ & 39.7 & $(0.7)$ & 7.4 & $(0.3)$ \\
\hline & Canada & $\mathrm{m}$ & $\mathrm{m}$ & $\mathrm{m}$ & $\mathrm{m}$ & $\mathrm{m}$ & $\mathrm{m}$ & $\mathrm{m}$ & $\mathrm{m}$ & $\mathrm{m}$ & $\mathrm{m}$ & $\mathrm{m}$ & $\mathrm{m}$ & $\mathrm{m}$ & $\mathrm{m}$ & $\mathrm{m}$ & $\mathrm{m}$ & $\mathrm{m}$ & $\mathrm{m}$ \\
\hline & Chile & 12.2 & $(0.4)$ & 37.4 & $(0.8)$ & 37.2 & $(0.9)$ & 12.9 & $(0.6)$ & 0.3 & $(0.1)$ & 13.7 & $(0.5)$ & 40.8 & $(0.8)$ & 36.4 & $(0.8)$ & 9.1 & $(0.5)$ \\
\hline & Czech Republic & 7.0 & $(0.4)$ & 41.9 & $(0.9)$ & 42.8 & $(1.0)$ & 8.3 & $(0.5)$ & 0.1 & $(0.0)$ & 13.6 & $(0.5)$ & 47.5 & $(0.7)$ & 33.8 & $(0.7)$ & 4.8 & $(0.3)$ \\
\hline & Denmark & 32.6 & $(0.8)$ & 51.5 & $(0.7)$ & 14.8 & $(0.5)$ & 0.9 & $(0.1)$ & 0.1 & $(0.0)$ & 31.2 & $(0.8)$ & 50.3 & $(0.8)$ & 17.2 & $(0.6)$ & 1.1 & $(0.2)$ \\
\hline & Estonia & 24.1 & $(0.8)$ & 56.1 & $(0.9)$ & 17.2 & $(0.7)$ & 2.4 & $(0.3)$ & 0.1 & $(0.1)$ & 31.0 & $(0.6)$ & 50.4 & $(0.6)$ & 16.1 & $(0.6)$ & 2.3 & $(0.2)$ \\
\hline & Finland & 20.9 & $(0.6)$ & 60.2 & $(0.6)$ & 17.8 & $(0.5)$ & 1.1 & $(0.2)$ & 0.0 & c & 26.1 & (0.6) & 56.3 & $(0.7)$ & 16.1 & $(0.4)$ & 1.1 & $(0.1)$ \\
\hline & France & $\mathrm{m}$ & $\mathrm{m}$ & $\mathrm{m}$ & $\mathrm{m}$ & $\mathrm{m}$ & $\mathrm{m}$ & $\mathrm{m}$ & $\mathrm{m}$ & $\mathrm{m}$ & $\mathrm{m}$ & 12.8 & (0.4) & 43.7 & $(0.9)$ & 37.3 & $(0.8)$ & 5.9 & (0.4) \\
\hline & Germany & 7.1 & $(0.4)$ & 35.2 & $(0.8)$ & 46.5 & $(0.7)$ & 11.2 & $(0.5)$ & 0.1 & $(0.1)$ & $\mathrm{m}$ & $\mathrm{m}$ & $\mathrm{m}$ & $\mathrm{m}$ & $\mathrm{m}$ & $\mathrm{m}$ & $\mathrm{m}$ & $\mathrm{m}$ \\
\hline & Greece & 5.1 & $(0.3)$ & 22.7 & $(0.6)$ & 41.8 & $(0.7)$ & 29.7 & $(0.7)$ & 0.6 & $(0.1)$ & 8.7 & $(0.5)$ & 33.2 & $(0.7)$ & 42.9 & $(0.8)$ & 14.7 & $(0.7)$ \\
\hline & Hungary & 8.9 & $(0.5)$ & 38.4 & (1.0) & 42.9 & $(0.9)$ & 9.7 & (0.6) & 0.1 & $(0.1)$ & 16.4 & $(0.6)$ & 46.4 & $(0.7)$ & 32.1 & $(0.7)$ & 4.8 & $(0.4)$ \\
\hline & Iceland & 22.9 & $(0.7)$ & 52.6 & $(0.9)$ & 21.6 & $(0.7)$ & 2.8 & $(0.3)$ & 0.2 & $(0.1)$ & 30.4 & $(0.8)$ & 47.4 & $(0.9)$ & 19.7 & $(0.8)$ & 2.1 & $(0.2)$ \\
\hline & Ireland & 6.6 & $(0.4)$ & 31.9 & $(0.8)$ & 47.5 & (0.8) & 13.8 & (0.5) & 0.1 & $(0.1)$ & 8.6 & $(0.5)$ & 33.1 & $(0.7)$ & 47.0 & $(0.7)$ & 11.2 & $(0.4)$ \\
\hline & Israel & 27.9 & $(0.8)$ & 44.8 & $(0.8)$ & 20.8 & (0.8) & 5.8 & $(0.5)$ & 0.7 & $(0.1)$ & 33.8 & $(0.8)$ & 43.4 & $(0.7)$ & 17.3 & $(0.6)$ & 4.9 & (0.5) \\
\hline & Italy & 7.1 & $(0.2)$ & 27.3 & $(0.4)$ & 46.8 & $(0.5)$ & 18.6 & $(0.4)$ & 0.2 & $(0.0)$ & 8.5 & $(0.4)$ & 31.9 & $(0.7)$ & 46.2 & $(0.7)$ & 13.1 & (0.6) \\
\hline & Japan & 6.5 & $(0.4)$ & 38.9 & $(0.6)$ & 43.9 & $(0.7)$ & 10.4 & $(0.5)$ & 0.3 & $(0.1)$ & 9.4 & $(0.4)$ & 34.3 & $(0.6)$ & 42.7 & $(0.6)$ & 13.4 & $(0.5)$ \\
\hline & Korea & 11.8 & $(0.5)$ & 58.3 & $(0.7)$ & 26.5 & $(0.8)$ & 3.3 & $(0.3)$ & 0.1 & $(0.0)$ & 14.8 & $(0.6)$ & 50.2 & $(0.7)$ & 30.0 & $(0.7)$ & 4.9 & $(0.3)$ \\
\hline & Latvia & 12.1 & $(0.7)$ & 49.3 & (1.0) & 32.3 & (1.0) & 6.0 & $(0.4)$ & 0.2 & $(0.1)$ & 18.4 & $(0.7)$ & 52.2 & $(0.8)$ & 25.6 & $(0.8)$ & 3.9 & $(0.3)$ \\
\hline & Luxembourg & $\mathrm{m}$ & $\mathrm{m}$ & $\mathrm{m}$ & $\mathrm{m}$ & $\mathrm{m}$ & $\mathrm{m}$ & $\mathrm{m}$ & $\mathrm{m}$ & $\mathrm{m}$ & $\mathrm{m}$ & 9.3 & $(0.4)$ & 32.9 & $(0.7)$ & 45.3 & $(0.8)$ & 12.0 & $(0.5)$ \\
\hline & Mexico & 6.2 & $(0.3)$ & 27.3 & $(0.5)$ & 38.0 & $(0.4)$ & 24.9 & $(0.5)$ & 3.6 & $(0.3)$ & 7.2 & $(0.4)$ & 31.4 & $(0.8)$ & 39.7 & $(0.8)$ & 20.5 & (1.0) \\
\hline & Netherlands & 33.3 & (0.9) & 50.5 & $(0.9)$ & 15.3 & $(0.6)$ & 0.8 & $(0.1)$ & 0.1 & $(0.0)$ & 24.3 & $(0.8)$ & 47.4 & $(0.7)$ & 24.9 & $(0.7)$ & 3.2 & $(0.3)$ \\
\hline & New Zealand & 23.7 & $(0.8)$ & 48.3 & $(0.9)$ & 23.8 & $(0.7)$ & 4.0 & $(0.3)$ & 0.2 & $(0.1)$ & 21.0 & (0.6) & 47.0 & $(0.9)$ & 26.8 & $(0.7)$ & 5.0 & $(0.4)$ \\
\hline & Norway & 26.1 & $(0.7)$ & 50.9 & $(0.9)$ & 20.9 & $(0.6)$ & 1.9 & $(0.2)$ & 0.2 & $(0.1)$ & $\mathrm{m}$ & $\mathrm{m}$ & $\mathrm{m}$ & $\mathrm{m}$ & $\mathrm{m}$ & $\mathrm{m}$ & $\mathrm{m}$ & $\mathrm{m}$ \\
\hline & Poland & 8.3 & $(0.5)$ & 37.2 & $(0.8)$ & 41.6 & $(0.9)$ & 12.3 & $(0.6)$ & 0.6 & $(0.1)$ & 17.1 & $(0.7)$ & 46.8 & $(0.8)$ & 30.1 & $(0.7)$ & 5.7 & $(0.4)$ \\
\hline & Portugal & 11.0 & $(0.6)$ & 39.7 & $(0.7)$ & 39.5 & $(0.8)$ & 9.7 & $(0.5)$ & 0.1 & $(0.0)$ & 17.1 & $(0.7)$ & 45.0 & $(0.8)$ & 32.5 & $(0.9)$ & 5.1 & $(0.3)$ \\
\hline & Slovak Republic & 4.9 & $(0.4)$ & 26.3 & $(0.8)$ & 46.7 & $(0.9)$ & 21.5 & $(0.8)$ & 0.6 & $(0.2)$ & 8.0 & $(0.4)$ & 35.9 & $(0.7)$ & 43.8 & $(0.7)$ & 11.7 & $(0.5)$ \\
\hline & Slovenia & 12.6 & $(0.5)$ & 48.6 & $(0.8)$ & 32.6 & (0.8) & 6.1 & $(0.4)$ & 0.0 & $(0.0)$ & 15.9 & $(0.5)$ & 47.6 & $(0.9)$ & 32.1 & $(0.8)$ & 4.3 & $(0.3)$ \\
\hline & Spain & 14.8 & $(0.4)$ & 45.3 & $(0.6)$ & 34.0 & $(0.5)$ & 5.8 & $(0.3)$ & 0.1 & $(0.0)$ & 16.9 & (0.5) & 46.3 & $(0.7)$ & 31.9 & $(0.7)$ & 4.7 & $(0.3)$ \\
\hline & Sweden & 25.1 & $(0.7)$ & 53.8 & $(0.8)$ & 18.7 & $(0.6)$ & 2.1 & $(0.2)$ & 0.3 & $(0.1)$ & 26.2 & $(0.6)$ & 49.1 & $(0.7)$ & 21.7 & $(0.7)$ & 2.5 & $(0.2)$ \\
\hline & Switzerland & 8.8 & $(0.4)$ & 38.4 & $(0.7)$ & 43.1 & $(0.7)$ & 9.6 & $(0.4)$ & 0.2 & $(0.0)$ & 9.8 & $(0.5)$ & 38.4 & $(0.7)$ & 41.7 & $(0.7)$ & 9.7 & (0.6) \\
\hline & Turkey & 5.4 & $(0.4)$ & 32.9 & $(0.8)$ & 40.5 & $(0.8)$ & 20.0 & $(0.8)$ & 1.2 & $(0.3)$ & $\mathrm{m}$ & $\mathrm{m}$ & $\mathrm{m}$ & $\mathrm{m}$ & $\mathrm{m}$ & $\mathrm{m}$ & $\mathrm{m}$ & $\mathrm{m}$ \\
\hline & United Kingdom & $\mathrm{m}$ & $\mathrm{m}$ & $\mathrm{m}$ & $\mathrm{m}$ & $\mathrm{m}$ & $\mathrm{m}$ & $\mathrm{m}$ & $\mathrm{m}$ & $\mathrm{m}$ & $\mathrm{m}$ & 27.6 & $(0.7)$ & 47.6 & $(0.8)$ & 21.9 & $(0.7)$ & 2.8 & $(0.2)$ \\
\hline & United States & $\mathrm{m}$ & $\mathrm{m}$ & $\mathrm{m}$ & $\mathrm{m}$ & $\mathrm{m}$ & $\mathrm{m}$ & $\mathrm{m}$ & $\mathrm{m}$ & $\mathrm{m}$ & $\mathrm{m}$ & $\mathrm{m}$ & $\mathrm{m}$ & $\mathrm{m}$ & $\mathrm{m}$ & $\mathrm{m}$ & $\mathrm{m}$ & $\mathrm{m}$ & $\mathrm{m}$ \\
\hline & OECD average & 14.5 & $(0.1)$ & 42.4 & $(0.1)$ & 33.5 & $(0.1)$ & 9.2 & $(0.1)$ & 0.4 & $(0.0)$ & 17.4 & $(0.1)$ & 43.2 & $(0.1)$ & 32.1 & $(0.1)$ & 6.9 & $(0.1)$ \\
\hline & OECD average- $27^{1}$ & 14.7 & $(0.1)$ & 42.7 & $(0.1)$ & 33.2 & $(0.1)$ & 9.0 & $(0.1)$ & 0.3 & $(0.0)$ & 17.5 & $(0.1)$ & 43.5 & $(0.1)$ & 31.8 & $(0.1)$ & 6.9 & $(0.1)$ \\
\hline$\approx$ & Albania & $\mathrm{m}$ & $\mathrm{m}$ & $\mathrm{m}$ & $\mathrm{m}$ & $\mathrm{m}$ & $\mathrm{m}$ & $\mathrm{m}$ & $\mathrm{m}$ & $\mathrm{m}$ & $\mathrm{m}$ & $\mathrm{m}$ & $\mathrm{m}$ & $\mathrm{m}$ & $\mathrm{m}$ & $\mathrm{m}$ & $\mathrm{m}$ & $\mathrm{m}$ & $\mathrm{m}$ \\
\hline & Algeria & $\mathrm{m}$ & $\mathrm{m}$ & $\mathrm{m}$ & $\mathrm{m}$ & $\mathrm{m}$ & $\mathrm{m}$ & $\mathrm{m}$ & $\mathrm{m}$ & $\mathrm{m}$ & $\mathrm{m}$ & $\mathrm{m}$ & $\mathrm{m}$ & $\mathrm{m}$ & $\mathrm{m}$ & $\mathrm{m}$ & $\mathrm{m}$ & $\mathrm{m}$ & $\mathrm{m}$ \\
\hline ? & Brazil & $\mathrm{m}$ & $\mathrm{m}$ & $\mathrm{m}$ & $\mathrm{m}$ & $\mathrm{m}$ & $\mathrm{m}$ & $\mathrm{m}$ & $\mathrm{m}$ & $\mathrm{m}$ & $\mathrm{m}$ & 17.2 & $(0.6)$ & 36.0 & $(0.6)$ & 31.2 & $(0.5)$ & 14.4 & $(0.5)$ \\
\hline & B-S-J-G (China) & $\mathrm{m}$ & $\mathrm{m}$ & $\mathrm{m}$ & $\mathrm{m}$ & $\mathrm{m}$ & $\mathrm{m}$ & $\mathrm{m}$ & $\mathrm{m}$ & $\mathrm{m}$ & $\mathrm{m}$ & 6.7 & $(0.5)$ & 27.8 & (1.1) & 34.8 & (1.1) & 24.0 & (1.1) \\
\hline & Bulgaria & $\mathrm{m}$ & $\mathrm{m}$ & $\mathrm{m}$ & $\mathrm{m}$ & $\mathrm{m}$ & $\mathrm{m}$ & $\mathrm{m}$ & $\mathrm{m}$ & $\mathrm{m}$ & $\mathrm{m}$ & 20.4 & $(0.7)$ & 49.9 & $(0.8)$ & 23.5 & $(0.7)$ & 5.3 & $(0.5)$ \\
\hline & CABA (Argentina) & $\mathrm{m}$ & $\mathrm{m}$ & $\mathrm{m}$ & $\mathrm{m}$ & $\mathrm{m}$ & $\mathrm{m}$ & $\mathrm{m}$ & $\mathrm{m}$ & $\mathrm{m}$ & $\mathrm{m}$ & $\mathrm{m}$ & $\mathrm{m}$ & $\mathrm{m}$ & $\mathrm{m}$ & $\mathrm{m}$ & $\mathrm{m}$ & $\mathrm{m}$ & $\mathrm{m}$ \\
\hline & Colombia & $\mathrm{m}$ & $\mathrm{m}$ & $\mathrm{m}$ & $\mathrm{m}$ & $\mathrm{m}$ & $\mathrm{m}$ & $\mathrm{m}$ & $\mathrm{m}$ & $\mathrm{m}$ & $\mathrm{m}$ & 11.3 & $(0.5)$ & 36.3 & $(0.7)$ & 35.7 & $(0.7)$ & 16.2 & $(0.7)$ \\
\hline & Costa Rica & 9.1 & $(0.5)$ & 28.7 & (0.9) & 39.2 & $(0.8)$ & 22.3 & (1.1) & 0.6 & $(0.2)$ & 9.9 & $(0.5)$ & 35.5 & $(0.9)$ & 38.5 & $(0.7)$ & 15.9 & $(0.7)$ \\
\hline & Croatia & 7.2 & $(0.4)$ & 34.8 & $(0.8)$ & 44.0 & $(0.8)$ & 13.9 & (0.6) & 0.2 & $(0.1)$ & 12.9 & $(0.5)$ & 44.7 & $(0.8)$ & 36.1 & $(0.8)$ & 6.1 & $(0.3)$ \\
\hline & Cyprus* & $\mathrm{m}$ & $\mathrm{m}$ & $\mathrm{m}$ & $\mathrm{m}$ & $\mathrm{m}$ & $\mathrm{m}$ & $\mathrm{m}$ & $\mathrm{m}$ & $\mathrm{m}$ & $\mathrm{m}$ & $\mathrm{m}$ & $\mathrm{m}$ & $\mathrm{m}$ & $\mathrm{m}$ & $\mathrm{m}$ & $\mathrm{m}$ & $\mathrm{m}$ & $\mathrm{m}$ \\
\hline & Dominican Republic & $\mathrm{m}$ & $\mathrm{m}$ & $\mathrm{m}$ & $\mathrm{m}$ & $\mathrm{m}$ & $\mathrm{m}$ & $\mathrm{m}$ & $\mathrm{m}$ & $\mathrm{m}$ & $\mathrm{m}$ & 8.6 & $(0.5)$ & 23.9 & (1.0) & 36.2 & $(0.9)$ & 27.9 & (1.1) \\
\hline & FYROM & $\mathrm{m}$ & $\mathrm{m}$ & $\mathrm{m}$ & $\mathrm{m}$ & $\mathrm{m}$ & $\mathrm{m}$ & $\mathrm{m}$ & $\mathrm{m}$ & $\mathrm{m}$ & $\mathrm{m}$ & $\mathrm{m}$ & $\mathrm{m}$ & $\mathrm{m}$ & $\mathrm{m}$ & $\mathrm{m}$ & $\mathrm{m}$ & $\mathrm{m}$ & $\mathrm{m}$ \\
\hline & Georgia & $\mathrm{m}$ & $\mathrm{m}$ & $\mathrm{m}$ & $\mathrm{m}$ & $\mathrm{m}$ & $\mathrm{m}$ & $\mathrm{m}$ & $\mathrm{m}$ & $\mathrm{m}$ & $\mathrm{m}$ & $\mathrm{m}$ & $\mathrm{m}$ & $\mathrm{m}$ & $\mathrm{m}$ & $\mathrm{m}$ & $\mathrm{m}$ & $\mathrm{m}$ & $\mathrm{m}$ \\
\hline & Hong Kong (China) & 24.7 & $(1.0)$ & 51.2 & (1.0) & 21.7 & $(0.7)$ & 2.3 & $(0.3)$ & 0.1 & $(0.0)$ & 27.9 & $(0.7)$ & 50.2 & $(0.7)$ & 18.9 & $(0.5)$ & 2.7 & $(0.2)$ \\
\hline & Indonesia & $\mathrm{m}$ & $\mathrm{m}$ & $\mathrm{m}$ & $\mathrm{m}$ & $\mathrm{m}$ & $\mathrm{m}$ & $\mathrm{m}$ & $\mathrm{m}$ & $\mathrm{m}$ & $\mathrm{m}$ & $\mathrm{m}$ & $\mathrm{m}$ & $\mathrm{m}$ & $\mathrm{m}$ & $\mathrm{m}$ & $\mathrm{m}$ & m & $\mathrm{m}$ \\
\hline & Jordan & 9.1 & $(0.5)$ & 17.8 & (0.6) & 31.4 & $(0.7)$ & 35.3 & (0.8) & 6.4 & $(0.5)$ & $\mathrm{m}$ & $\mathrm{m}$ & $\mathrm{m}$ & $\mathrm{m}$ & $\mathrm{m}$ & $\mathrm{m}$ & $\mathrm{m}$ & $\mathrm{m}$ \\
\hline & Kosovo & $\mathrm{m}$ & $\mathrm{m}$ & $\mathrm{m}$ & $\mathrm{m}$ & $\mathrm{m}$ & $\mathrm{m}$ & $\mathrm{m}$ & $\mathrm{m}$ & $\mathrm{m}$ & $\mathrm{m}$ & $\mathrm{m}$ & $\mathrm{m}$ & $\mathrm{m}$ & $\mathrm{m}$ & $\mathrm{m}$ & $\mathrm{m}$ & $\mathrm{m}$ & $\mathrm{m}$ \\
\hline & Lebanon & $\mathrm{m}$ & $\mathrm{m}$ & $\mathrm{m}$ & $\mathrm{m}$ & $\mathrm{m}$ & $\mathrm{m}$ & $\mathrm{m}$ & $\mathrm{m}$ & $\mathrm{m}$ & $\mathrm{m}$ & $\mathrm{m}$ & $\mathrm{m}$ & $\mathrm{m}$ & $\mathrm{m}$ & $\mathrm{m}$ & $\mathrm{m}$ & $\mathrm{m}$ & $\mathrm{m}$ \\
\hline & Lithuania & $\mathrm{m}$ & $\mathrm{m}$ & $\mathrm{m}$ & $\mathrm{m}$ & $\mathrm{m}$ & $\mathrm{m}$ & $\mathrm{m}$ & $\mathrm{m}$ & $\mathrm{m}$ & $\mathrm{m}$ & 20.5 & (0.6) & 51.9 & $(0.7)$ & 23.4 & $(0.7)$ & 3.6 & $(0.2)$ \\
\hline & Macao (China) & 10.6 & $(0.4)$ & 42.4 & $(0.7)$ & 38.9 & $(0.7)$ & 7.9 & $(0.3)$ & 0.2 & $(0.1)$ & 17.1 & $(0.6)$ & 50.5 & $(0.7)$ & 28.3 & $(0.7)$ & 4.0 & $(0.3)$ \\
\hline & Malta & $\mathrm{m}$ & $\mathrm{m}$ & $\mathrm{m}$ & $\mathrm{m}$ & $\mathrm{m}$ & $\mathrm{m}$ & $\mathrm{m}$ & $\mathrm{m}$ & $\mathrm{m}$ & $\mathrm{m}$ & $\mathrm{m}$ & $\mathrm{m}$ & $\mathrm{m}$ & $\mathrm{m}$ & $\mathrm{m}$ & $\mathrm{m}$ & $\mathrm{m}$ & $\mathrm{m}$ \\
\hline & Moldova & $\mathrm{m}$ & $\mathrm{m}$ & $\mathrm{m}$ & $\mathrm{m}$ & $\mathrm{m}$ & $\mathrm{m}$ & $\mathrm{m}$ & $\mathrm{m}$ & $\mathrm{m}$ & $\mathrm{m}$ & $\mathrm{m}$ & $\mathrm{m}$ & $\mathrm{m}$ & $\mathrm{m}$ & $\mathrm{m}$ & $\mathrm{m}$ & $\mathrm{m}$ & $\mathrm{m}$ \\
\hline & Montenegro & $\mathrm{m}$ & $\mathrm{m}$ & $\mathrm{m}$ & $\mathrm{m}$ & $\mathrm{m}$ & $\mathrm{m}$ & $\mathrm{m}$ & $\mathrm{m}$ & $\mathrm{m}$ & $\mathrm{m}$ & $\mathrm{m}$ & $\mathrm{m}$ & $\mathrm{m}$ & $\mathrm{m}$ & $\mathrm{m}$ & $\mathrm{m}$ & $\mathrm{m}$ & 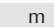 \\
\hline & Peru & $\mathrm{m}$ & $\mathrm{m}$ & $\mathrm{m}$ & $\mathrm{m}$ & $\mathrm{m}$ & $\mathrm{m}$ & $\mathrm{m}$ & $\mathrm{m}$ & $\mathrm{m}$ & $\mathrm{m}$ & 8.2 & $(0.4)$ & 24.6 & $(0.7)$ & 32.7 & $(0.6)$ & 29.9 & (0.9) \\
\hline & Qatar & $\mathrm{m}$ & $\mathrm{m}$ & $\mathrm{m}$ & $\mathrm{m}$ & $\mathrm{m}$ & $\mathrm{m}$ & $\mathrm{m}$ & $\mathrm{m}$ & $\mathrm{m}$ & $\mathrm{m}$ & $\mathrm{m}$ & $\mathrm{m}$ & $\mathrm{m}$ & $\mathrm{m}$ & $\mathrm{m}$ & $\mathrm{m}$ & $\mathrm{m}$ & $\mathrm{m}$ \\
\hline & Roman & $\mathrm{m}$ & $\mathrm{m}$ & $\mathrm{m}$ & $\mathrm{m}$ & $\mathrm{m}$ & $\mathrm{m}$ & $\mathrm{m}$ & 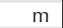 & $\mathrm{m}$ & 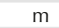 & m & $\mathrm{m}$ & $\mathrm{m}$ & $m$ & m & $\mathrm{m}$ & m & $\mathrm{n}$ \\
\hline & Russia & 2.3 & $(0.2)$ & 14.8 & (0.6) & 39.1 & $(0.9)$ & 42.8 & (1.2) & 1.0 & $(0.1)$ & 5.5 & $(0.3)$ & 30.5 & $(0.8)$ & 45.4 & $(0.6)$ & 18.2 & $(0.9)$ \\
\hline & Singapor & 16.3 & $(0.5)$ & 45.7 & (0.6) & 32.3 & $(0.7)$ & 5.7 & $(0.3)$ & 0.0 & $(0.0)$ & 17.4 & $(0.5)$ & 45.7 & $(0.6)$ & 31.2 & $(0.6)$ & 5.6 & $(0.3)$ \\
\hline & Chinese T & $\mathrm{m}$ & $\mathrm{m}$ & $\mathrm{m}$ & $\mathrm{m}$ & $\mathrm{m}$ & $\mathrm{m}$ & $\mathrm{m}$ & $\mathrm{m}$ & $\mathrm{m}$ & $\mathrm{m}$ & 13.1 & $(0.5)$ & 39.4 & $(0.6)$ & 38.8 & $(0.6)$ & 8.6 & $(0.4)$ \\
\hline & Thailand & $\mathrm{m}$ & $\mathrm{m}$ & $\mathrm{m}$ & $\mathrm{m}$ & $\mathrm{m}$ & $\mathrm{m}$ & $\mathrm{m}$ & $\mathrm{m}$ & $\mathrm{m}$ & $\mathrm{m}$ & 6.8 & $(0.4)$ & 33.5 & $(0.8)$ & 39.7 & $(0.8)$ & 19.5 & $(0.7)$ \\
\hline & Trinidad and Tobago & $\mathrm{m}$ & $\mathrm{m}$ & $\mathrm{m}$ & $\mathrm{m}$ & $\mathrm{m}$ & $\mathrm{m}$ & $\mathrm{m}$ & $\mathrm{m}$ & $\mathrm{m}$ & $\mathrm{m}$ & $\mathrm{m}$ & $\mathrm{m}$ & $\mathrm{m}$ & $\mathrm{m}$ & $\mathrm{m}$ & $\mathrm{m}$ & $\mathrm{m}$ & $\mathrm{m}$ \\
\hline & Tunisia & $\mathrm{m}$ & $\mathrm{m}$ & $\mathrm{m}$ & $\mathrm{m}$ & $\mathrm{m}$ & $\mathrm{m}$ & $\mathrm{m}$ & $\mathrm{m}$ & $\mathrm{m}$ & $\mathrm{m}$ & $\mathrm{m}$ & $\mathrm{m}$ & $\mathrm{m}$ & $\mathrm{m}$ & m & $\mathrm{m}$ & m & $\mathrm{m}$ \\
\hline & Unit & $\mathrm{m}$ & $\mathrm{m}$ & $\mathrm{m}$ & $\mathrm{m}$ & $\mathrm{m}$ & $\mathrm{m}$ & $\mathrm{m}$ & $\mathrm{m}$ & $\mathrm{m}$ & $\mathrm{m}$ & $\mathrm{m}$ & $\mathrm{m}$ & $\mathrm{m}$ & $\mathrm{m}$ & $\mathrm{m}$ & $\mathrm{m}$ & $\mathrm{m}$ & $\mathrm{m}$ \\
\hline & Uruguay & 10.5 & $(0.5)$ & 37.1 & $(0.8)$ & 38.4 & $(0.7)$ & 13.6 & $(0.6)$ & 0.4 & $(0.1)$ & 17.7 & (0.6) & 47.1 & $(0.7)$ & 28.6 & $(0.7)$ & 6.5 & (0.4) \\
\hline & Viet Nam & $\mathrm{m}$ & $\mathrm{m}$ & $\mathrm{m}$ & $\mathrm{m}$ & $\mathrm{m}$ & $\mathrm{m}$ & $\mathrm{m}$ & $\mathrm{m}$ & $\mathrm{m}$ & $\mathrm{m}$ & $\mathrm{m}$ & $\mathrm{m}$ & $\mathrm{m}$ & $\mathrm{m}$ & $\mathrm{m}$ & $\mathrm{m}$ & $\mathrm{m}$ & $\mathrm{m}$ \\
\hline & Argentina* & $\mathrm{m}$ & $\mathrm{m}$ & $\mathrm{m}$ & $\mathrm{m}$ & $\mathrm{m}$ & $\mathrm{m}$ & $\mathrm{m}$ & $\mathrm{m}$ & $\mathrm{m}$ & $\mathrm{m}$ & $\mathrm{m}$ & $\mathrm{m}$ & $\mathrm{m}$ & $\mathrm{m}$ & $\mathrm{m}$ & $\mathrm{m}$ & $\mathrm{m}$ & $\mathrm{m}$ \\
\hline & & $\mathrm{m}$ & $\mathrm{m}$ & $\mathrm{m}$ & $\mathrm{m}$ & m & $\mathrm{m}$ & $\mathrm{m}$ & $\mathrm{m}$ & $\mathrm{m}$ & $\mathrm{m}$ & $\mathrm{m}$ & $\mathrm{m}$ & $\mathrm{m}$ & $\mathrm{m}$ & $\mathrm{m}$ & $\mathrm{m}$ & $\mathrm{m}$ & $\mathrm{m}$ \\
\hline & Malaysia** & $\mathrm{m}$ & $\mathrm{m}$ & $\mathrm{m}$ & $\mathrm{m}$ & $\mathrm{m}$ & $\mathrm{m}$ & $\mathrm{m}$ & $\mathrm{m}$ & $\mathrm{m}$ & $\mathrm{m}$ & $\mathrm{m}$ & $\mathrm{m}$ & $\mathrm{m}$ & $\mathrm{m}$ & $\mathrm{m}$ & $\mathrm{m}$ & $\mathrm{m}$ & $\mathrm{m}$ \\
\hline
\end{tabular}

1. "OECD average-27" includes all OECD countries with available data for both years

Note: Values that are statistically significant are indicated in bold (see Annex A3).

* See note at the beginning of this Annex.

(s) small to ensure comparability (see Annex A4).

StatLink 部 Jl http://dx.doi.org/10.1787/888933473203 
Results based on students' self-reports

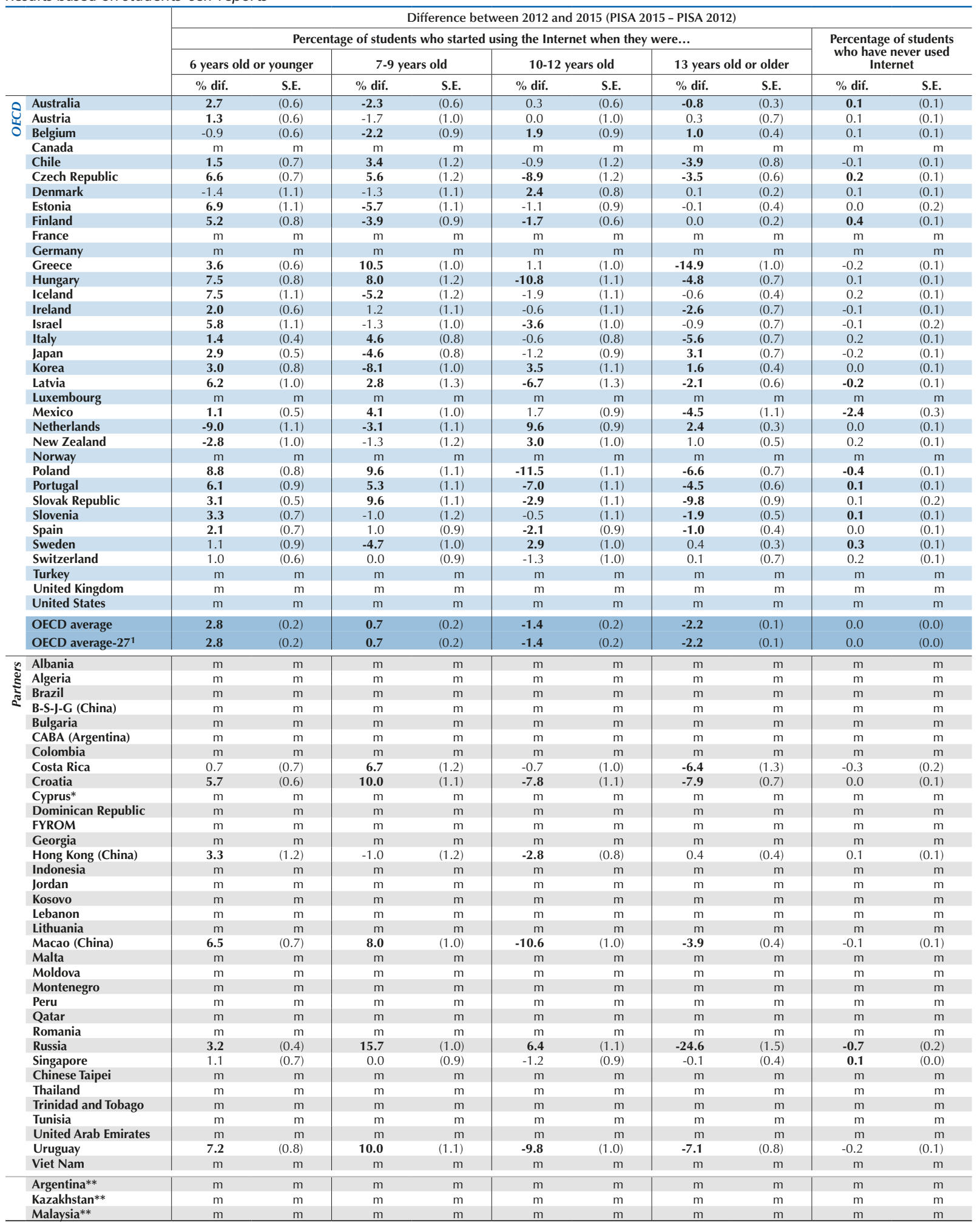

1. "OECD average-27" includes all OECD countries with available data for both years.

Note: Values that are statistically significant are indicated in bold (see Annex A3).

* See note at the beginning of this Annex.

is too small to ensure comparability (see Annex A4).

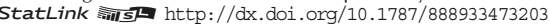


[Part 1/2]

Table III.13.7 Internet use outside of school on a typical weekday, by gender

Results based on students' self-reports

\begin{tabular}{|c|c|c|c|c|c|c|c|c|c|c|c|c|c|c|c|}
\hline & \multicolumn{14}{|c|}{ All students } \\
\hline & & \multicolumn{12}{|c|}{ Percentage of students who reported that, on a typical weekday, they use the Internet outside of school... } & & \\
\hline & & $\ldots \mathbf{n}$ & t all & ...one & r or less & $1 \ldots \mathrm{b}$ & $\begin{array}{l}\text { veen } \\
\text { hours }\end{array}$ & 2 an & $\begin{array}{l}\text { veen } \\
\text { hours }\end{array}$ & $\begin{array}{c}\ldots . \\
4 \text { an }\end{array}$ & $\begin{array}{l}\text { veen } \\
\text { hours }\end{array}$ & thä & $\begin{array}{l}\text { pre } \\
\text { hours }\end{array}$ & $\begin{array}{c}\text { Interne } \\
\text { of sc } \\
\text { on we }\end{array}$ & $\begin{array}{l}\text { utside } \\
\text { ool, } \\
\text { days }{ }^{1}\end{array}$ \\
\hline & & $\%$ & S.E. & $\%$ & S.E. & $\%$ & S.E. & $\%$ & S.E. & $\%$ & S.E. & $\%$ & S.E. & Minutes & S.E. \\
\hline 0 & Australia & 1.8 & $(0.1)$ & 10.3 & $(0.3)$ & 18.7 & $(0.4)$ & 31.2 & $(0.5)$ & 20.6 & $(0.5)$ & 17.5 & $(0.5)$ & 164 & (1.5) \\
\hline$\pi$ & Austria & 1.2 & $(0.2)$ & 18.3 & $(0.6)$ & 21.1 & $(0.5)$ & 26.5 & $(0.6)$ & 15.8 & $(0.5)$ & 17.1 & $(0.6)$ & 149 & $(2.0)$ \\
\hline 0 & Belgium & 2.4 & $(0.2)$ & 15.8 & $(0.4)$ & 22.1 & $(0.5)$ & 27.9 & $(0.6)$ & 16.4 & $(0.4)$ & 15.4 & $(0.5)$ & 146 & (1.6) \\
\hline & Canada & $\mathrm{m}$ & $\mathrm{m}$ & $\mathrm{m}$ & $\mathrm{m}$ & $\mathrm{m}$ & $\mathrm{m}$ & $\mathrm{m}$ & $\mathrm{m}$ & $\mathrm{m}$ & $\mathrm{m}$ & $\mathrm{m}$ & $\mathrm{m}$ & $\mathrm{m}$ & $\mathrm{m}$ \\
\hline & Chile & 5.6 & $(0.4)$ & 10.6 & $(0.5)$ & 12.8 & $(0.4)$ & 20.0 & $(0.7)$ & 19.2 & $(0.7)$ & 31.9 & $(0.9)$ & 195 & (2.5) \\
\hline & Czech Republic & 2.2 & $(0.2)$ & 15.0 & $(0.5)$ & 22.3 & $(0.5)$ & 28.1 & $(0.6)$ & 15.3 & $(0.6)$ & 17.1 & $(0.6)$ & 149 & $(2.1)$ \\
\hline & Denmark & 0.6 & $(0.1)$ & 9.7 & $(0.5)$ & 20.3 & $(0.8)$ & 33.9 & $(0.8)$ & 20.6 & $(0.8)$ & 14.9 & $(0.6)$ & 159 & (2.4) \\
\hline & Estonia & 1.3 & $(0.2)$ & 12.0 & $(0.5)$ & 18.9 & $(0.7)$ & 30.2 & $(0.8)$ & 19.5 & $(0.6)$ & 18.1 & $(0.6)$ & 163 & $(2.0)$ \\
\hline & Finland & 0.5 & $(0.1)$ & 15.8 & $(0.5)$ & 23.9 & $(0.6)$ & 32.1 & $(0.7)$ & 16.2 & $(0.5)$ & 11.5 & $(0.5)$ & 138 & (1.7) \\
\hline & France & 2.9 & $(0.3)$ & 20.0 & $(0.7)$ & 24.4 & $(0.7)$ & 28.0 & $(0.7)$ & 12.8 & $(0.4)$ & 12.0 & $(0.5)$ & 127 & (1.9) \\
\hline & Germany & $\mathrm{m}$ & $\mathrm{m}$ & $\mathrm{m}$ & $\mathrm{m}$ & $\mathrm{m}$ & $\mathrm{m}$ & $\mathrm{m}$ & $\mathrm{m}$ & $\mathrm{m}$ & $\mathrm{m}$ & $\mathrm{m}$ & $\mathrm{m}$ & $\mathrm{m}$ & $\mathrm{m}$ \\
\hline & Greece & 4.2 & $(0.3)$ & 20.2 & $(0.7)$ & 23.0 & $(0.6)$ & 26.6 & $(0.7)$ & 14.8 & $(0.6)$ & 11.2 & $(0.5)$ & 126 & (1.9) \\
\hline & Hungary & 2.2 & $(0.2)$ & 13.6 & $(0.6)$ & 20.9 & $(0.7)$ & 26.2 & $(0.6)$ & 16.4 & $(0.5)$ & 20.8 & $(0.7)$ & 161 & $(2.2)$ \\
\hline & Iceland & 0.7 & $(0.1)$ & 12.1 & $(0.6)$ & 24.3 & $(0.7)$ & 31.8 & $(0.9)$ & 18.9 & $(0.8)$ & 12.2 & $(0.5)$ & 145 & (1.9) \\
\hline & Ireland & 1.4 & $(0.2)$ & 15.0 & $(0.7)$ & 22.5 & $(0.6)$ & 30.3 & $(0.6)$ & 17.2 & $(0.6)$ & 13.6 & $(0.6)$ & 144 & (2.4) \\
\hline & Israel & 7.9 & $(1.2)$ & 21.5 & $(0.8)$ & 19.3 & $(0.7)$ & 20.6 & $(0.7)$ & 12.9 & $(0.7)$ & 17.8 & $(0.8)$ & 135 & (3.7) \\
\hline & Italy & 2.3 & $(0.2)$ & 15.0 & $(0.5)$ & 19.5 & $(0.5)$ & 24.8 & $(0.6)$ & 15.1 & $(0.4)$ & 23.3 & $(0.7)$ & 165 & $(2.0)$ \\
\hline & Japan & 7.7 & $(0.4)$ & 30.3 & $(0.8)$ & 25.0 & $(0.6)$ & 22.9 & $(0.6)$ & 7.7 & $(0.4)$ & 6.4 & $(0.5)$ & 90 & (2.4) \\
\hline & Korea & 19.3 & $(0.8)$ & 36.0 & $(0.8)$ & 23.0 & $(0.6)$ & 15.8 & $(0.6)$ & 4.0 & $(0.3)$ & 1.9 & $(0.2)$ & 55 & (1.3) \\
\hline & Latvia & 2.0 & $(0.3)$ & 15.5 & $(0.6)$ & 21.1 & $(0.6)$ & 29.8 & $(0.7)$ & 16.3 & $(0.6)$ & 15.4 & $(0.6)$ & 147 & (2.1) \\
\hline & Luxembourg & 2.3 & $(0.2)$ & 15.3 & $(0.5)$ & 20.1 & $(0.6)$ & 27.3 & $(0.6)$ & 16.7 & $(0.5)$ & 18.4 & $(0.6)$ & 155 & (1.8) \\
\hline & Mexico & 11.7 & $(0.5)$ & 24.8 & $(0.9)$ & 18.5 & $(0.5)$ & 16.9 & $(0.6)$ & 13.0 & $(0.5)$ & 15.2 & $(0.6)$ & 121 & (2.8) \\
\hline & Netherlands & 1.0 & $(0.1)$ & 12.4 & $(0.5)$ & 21.2 & $(0.6)$ & 29.4 & $(0.6)$ & 18.2 & $(0.6)$ & 17.8 & $(0.6)$ & 159 & (1.8) \\
\hline & New Zealand & 2.2 & $(0.2)$ & 11.1 & $(0.5)$ & 18.1 & $(0.7)$ & 30.5 & $(0.9)$ & 20.8 & $(0.8)$ & 17.3 & $(0.8)$ & 163 & (2.4) \\
\hline & Norway & $\mathrm{m}$ & $\mathrm{m}$ & $\mathrm{m}$ & $\mathrm{m}$ & $\mathrm{m}$ & $\mathrm{m}$ & $\mathrm{m}$ & $\mathrm{m}$ & $\mathrm{m}$ & $\mathrm{m}$ & $\mathrm{m}$ & $\mathrm{m}$ & $\mathrm{m}$ & $\mathrm{m}$ \\
\hline & Poland & 1.7 & $(0.2)$ & 15.0 & $(0.6)$ & 22.4 & $(0.7)$ & 29.9 & $(0.8)$ & 16.0 & $(0.5)$ & 15.1 & $(0.7)$ & 146 & $(2.1)$ \\
\hline & Portugal & 2.9 & $(0.2)$ & 18.9 & $(0.5)$ & 21.6 & $(0.6)$ & 25.9 & $(0.7)$ & 16.1 & $(0.5)$ & 14.6 & $(0.5)$ & 140 & (1.9) \\
\hline & Slovak Republic & 4.4 & $(0.4)$ & 15.9 & $(0.6)$ & 19.9 & $(0.5)$ & 25.6 & $(0.7)$ & 14.8 & $(0.5)$ & 19.4 & $(0.6)$ & 152 & $(2.0)$ \\
\hline & Slovenia & 2.1 & $(0.2)$ & 24.0 & $(0.7)$ & 25.9 & $(0.8)$ & 25.1 & $(0.7)$ & 11.6 & $(0.4)$ & 11.2 & $(0.5)$ & 120 & (1.9) \\
\hline & Spain & 2.4 & $(0.2)$ & 13.3 & $(0.5)$ & 18.5 & $(0.6)$ & 26.5 & $(0.6)$ & 17.6 & $(0.6)$ & 21.7 & $(0.7)$ & 167 & $(2.3)$ \\
\hline & Sweden & 0.6 & $(0.1)$ & 7.6 & $(0.4)$ & 14.1 & $(0.5)$ & 30.9 & $(0.7)$ & 24.8 & $(0.6)$ & 22.0 & $(0.8)$ & 187 & $(2.1)$ \\
\hline & Switzerland & 1.5 & $(0.2)$ & 21.8 & $(0.7)$ & 25.2 & $(0.7)$ & 26.3 & $(0.7)$ & 13.6 & $(0.5)$ & 11.6 & $(0.6)$ & 126 & (2.3) \\
\hline & Turkey & $\mathrm{m}$ & $\mathrm{m}$ & $\mathrm{m}$ & $\mathrm{m}$ & $\mathrm{m}$ & $\mathrm{m}$ & $\mathrm{m}$ & $\mathrm{m}$ & $\mathrm{m}$ & $\mathrm{m}$ & $\mathrm{m}$ & $\mathrm{m}$ & $\mathrm{m}$ & $\mathrm{m}$ \\
\hline & United Kingdom & 0.7 & $(0.1)$ & 7.7 & $(0.4)$ & 15.8 & $(0.7)$ & 29.4 & $(0.7)$ & 22.1 & $(0.6)$ & 24.1 & $(0.9)$ & 188 & $(2.7)$ \\
\hline & United States & $\mathrm{m}$ & $\mathrm{m}$ & $\mathrm{m}$ & $\mathrm{m}$ & $\mathrm{m}$ & $\mathrm{m}$ & $\mathrm{m}$ & $\mathrm{m}$ & $\mathrm{m}$ & $\mathrm{m}$ & $\mathrm{m}$ & $\mathrm{m}$ & $\mathrm{m}$ & $\mathrm{m}$ \\
\hline & OECD average & 3.3 & $(0.1)$ & 16.5 & $(0.1)$ & 20.8 & $(0.1)$ & 27.0 & $(0.1)$ & 16.2 & $(0.1)$ & 16.2 & $(0.1)$ & 146 & $(0.4)$ \\
\hline 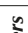 & Albania & $\mathrm{m}$ & $\mathrm{m}$ & $\mathrm{m}$ & $\mathrm{m}$ & $\mathrm{m}$ & $\mathrm{m}$ & $\mathrm{m}$ & $\mathrm{m}$ & $\mathrm{m}$ & $\mathrm{m}$ & $\mathrm{m}$ & $\mathrm{m}$ & $\mathrm{m}$ & $\mathrm{m}$ \\
\hline 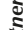 & Algeria & $\mathrm{m}$ & $\mathrm{m}$ & $\mathrm{m}$ & $\mathrm{m}$ & $\mathrm{m}$ & $\mathrm{m}$ & $\mathrm{m}$ & $\mathrm{m}$ & $\mathrm{m}$ & $\mathrm{m}$ & $\mathrm{m}$ & $\mathrm{m}$ & $\mathrm{m}$ & $\mathrm{m}$ \\
\hline ป & Brazil & 9.2 & $(0.4)$ & 14.4 & $(0.4)$ & 12.0 & $(0.4)$ & 14.5 & $(0.5)$ & 14.3 & $(0.4)$ & 35.6 & $(0.8)$ & 190 & (2.6) \\
\hline$\approx$ & B-S-J-G (China) & 44.9 & $(1.3)$ & 29.9 & $(0.9)$ & 10.2 & $(0.4)$ & 7.1 & $(0.4)$ & 3.9 & $(0.2)$ & 4.0 & $(0.4)$ & 42 & (1.6) \\
\hline & Bulgaria & 3.0 & $(0.3)$ & 11.1 & $(0.5)$ & 15.1 & $(0.5)$ & 23.9 & $(0.7)$ & 18.4 & $(0.5)$ & 28.6 & $(0.8)$ & 187 & $(2.3)$ \\
\hline & CABA (Argentina) & $\mathrm{m}$ & $\mathrm{m}$ & $\mathrm{m}$ & $\mathrm{m}$ & $\mathrm{m}$ & $\mathrm{m}$ & $\mathrm{m}$ & $\mathrm{m}$ & $\mathrm{m}$ & $\mathrm{m}$ & $\mathrm{m}$ & $\mathrm{m}$ & $\mathrm{m}$ & $\mathrm{m}$ \\
\hline & Colombia & 11.5 & $(0.6)$ & 21.5 & $(0.6)$ & 15.5 & $(0.5)$ & 16.6 & $(0.5)$ & 13.4 & $(0.5)$ & 21.6 & $(0.8)$ & 143 & (2.9) \\
\hline & Costa Rica & 7.7 & $(0.5)$ & 15.2 & $(0.6)$ & 14.1 & $(0.5)$ & 15.8 & $(0.5)$ & 14.9 & $(0.5)$ & 32.3 & $(0.8)$ & 182 & $(2.7)$ \\
\hline & Croatia & 3.1 & $(0.2)$ & 19.3 & $(0.6)$ & 21.3 & $(0.6)$ & 25.4 & $(0.6)$ & 14.7 & $(0.5)$ & 16.2 & $(0.6)$ & 141 & (2.0) \\
\hline & Cyprus* & $\mathrm{m}$ & $\mathrm{m}$ & $\mathrm{m}$ & $\mathrm{m}$ & $\mathrm{m}$ & $\mathrm{m}$ & $\mathrm{m}$ & $\mathrm{m}$ & $\mathrm{m}$ & $\mathrm{m}$ & $\mathrm{m}$ & $\mathrm{m}$ & $\mathrm{m}$ & $\mathrm{m}$ \\
\hline & Dominican Republic & 16.2 & $(0.8)$ & 22.9 & $(0.8)$ & 16.5 & $(0.5)$ & 12.6 & $(0.8)$ & 10.8 & $(0.6)$ & 21.0 & $(0.8)$ & 130 & $(2.8)$ \\
\hline & FYROM & $\mathrm{m}$ & $\mathrm{m}$ & $\mathrm{m}$ & $\mathrm{m}$ & $\mathrm{m}$ & $\mathrm{m}$ & $\mathrm{m}$ & $\mathrm{m}$ & $\mathrm{m}$ & $\mathrm{m}$ & $\mathrm{m}$ & $\mathrm{m}$ & $\mathrm{m}$ & $\mathrm{m}$ \\
\hline & Georgia & $\mathrm{m}$ & $\mathrm{m}$ & $\mathrm{m}$ & $\mathrm{m}$ & $\mathrm{m}$ & $\mathrm{m}$ & $\mathrm{m}$ & $\mathrm{m}$ & $\mathrm{m}$ & $\mathrm{m}$ & $\mathrm{m}$ & $\mathrm{m}$ & $\mathrm{m}$ & $\mathrm{m}$ \\
\hline & Hong Kong (China) & 6.4 & $(0.4)$ & 22.0 & $(0.6)$ & 20.4 & $(0.6)$ & 25.9 & $(0.6)$ & 13.2 & $(0.6)$ & 12.1 & $(0.5)$ & 123 & (2.0) \\
\hline & Indonesia & $\mathrm{m}$ & $\mathrm{m}$ & $\mathrm{m}$ & $\mathrm{m}$ & $\mathrm{m}$ & $\mathrm{m}$ & $\mathrm{m}$ & $\mathrm{m}$ & $\mathrm{m}$ & $\mathrm{m}$ & $\mathrm{m}$ & $\mathrm{m}$ & $\mathrm{m}$ & $\mathrm{m}$ \\
\hline & Jordan & $\mathrm{m}$ & $\mathrm{m}$ & $\mathrm{m}$ & $\mathrm{m}$ & $\mathrm{m}$ & $\mathrm{m}$ & $\mathrm{m}$ & $\mathrm{m}$ & $\mathrm{m}$ & $\mathrm{m}$ & $\mathrm{m}$ & $\mathrm{m}$ & $\mathrm{m}$ & $\mathrm{m}$ \\
\hline & Kosovo & $\mathrm{m}$ & $\mathrm{m}$ & $\mathrm{m}$ & $\mathrm{m}$ & $\mathrm{m}$ & $\mathrm{m}$ & $\mathrm{m}$ & $\mathrm{m}$ & $\mathrm{m}$ & $\mathrm{m}$ & $\mathrm{m}$ & $\mathrm{m}$ & $\mathrm{m}$ & $\mathrm{m}$ \\
\hline & Lebanon & $\mathrm{m}$ & $\mathrm{m}$ & $\mathrm{m}$ & $\mathrm{m}$ & $\mathrm{m}$ & $\mathrm{m}$ & $\mathrm{m}$ & $\mathrm{m}$ & $\mathrm{m}$ & $\mathrm{m}$ & $\mathrm{m}$ & $\mathrm{m}$ & $\mathrm{m}$ & $\mathrm{m}$ \\
\hline & Lithuania & 3.2 & $(0.2)$ & 15.8 & $(0.6)$ & 23.3 & $(0.5)$ & 28.9 & $(0.6)$ & 16.0 & $(0.6)$ & 12.9 & $(0.5)$ & 137 & (1.8) \\
\hline & Macao (China) & 6.4 & $(0.4)$ & 16.4 & $(0.5)$ & 20.8 & $(0.6)$ & 29.9 & $(0.7)$ & 14.9 & $(0.7)$ & 11.6 & $(0.5)$ & 130 & (1.7) \\
\hline & Malta & $\mathrm{m}$ & $\mathrm{m}$ & $\mathrm{m}$ & $\mathrm{m}$ & $\mathrm{m}$ & $\mathrm{m}$ & $\mathrm{m}$ & $\mathrm{m}$ & $\mathrm{m}$ & $\mathrm{m}$ & $\mathrm{m}$ & $\mathrm{m}$ & $\mathrm{m}$ & $\mathrm{m}$ \\
\hline & Moldova & $\mathrm{m}$ & $\mathrm{m}$ & $\mathrm{m}$ & $\mathrm{m}$ & $\mathrm{m}$ & $\mathrm{m}$ & $\mathrm{m}$ & $\mathrm{m}$ & $\mathrm{m}$ & $\mathrm{m}$ & $\mathrm{m}$ & $\mathrm{m}$ & $\mathrm{m}$ & $\mathrm{m}$ \\
\hline & Montenegro & $\mathrm{m}$ & $\mathrm{m}$ & $\mathrm{m}$ & $\mathrm{m}$ & $\mathrm{m}$ & $\mathrm{m}$ & $\mathrm{m}$ & $\mathrm{m}$ & $\mathrm{m}$ & $\mathrm{m}$ & $\mathrm{m}$ & $\mathrm{m}$ & $\mathrm{m}$ & $\mathrm{m}$ \\
\hline & Peru & 10.3 & $(0.5)$ & 33.4 & $(0.9)$ & 21.8 & $(0.6)$ & 17.1 & $(0.6)$ & 8.6 & $(0.4)$ & 8.6 & $(0.5)$ & 92 & $(2.2)$ \\
\hline & Qatar & $\mathrm{m}$ & $\mathrm{m}$ & $\mathrm{m}$ & $\mathrm{m}$ & $\mathrm{m}$ & $\mathrm{m}$ & $\mathrm{m}$ & $\mathrm{m}$ & $\mathrm{m}$ & $\mathrm{m}$ & $\mathrm{m}$ & $\mathrm{m}$ & $\mathrm{m}$ & $\mathrm{m}$ \\
\hline & Romania & $\mathrm{m}$ & $\mathrm{m}$ & $\mathrm{m}$ & $\mathrm{m}$ & $\mathrm{m}$ & $\mathrm{m}$ & $\mathrm{m}$ & $\mathrm{m}$ & $\mathrm{m}$ & $\mathrm{m}$ & $\mathrm{m}$ & $\mathrm{m}$ & $\mathrm{m}$ & $\mathrm{m}$ \\
\hline & Russia & 5.7 & $(0.3)$ & 14.2 & $(0.5)$ & 16.6 & $(0.6)$ & 25.1 & $(0.6)$ & 17.3 & $(0.7)$ & 21.2 & $(0.8)$ & 161 & (2.6) \\
\hline & Singapore & 3.6 & $(0.2)$ & 14.2 & $(0.5)$ & 20.9 & $(0.6)$ & 29.8 & $(0.6)$ & 15.5 & $(0.5)$ & 16.1 & $(0.5)$ & 147 & (1.4) \\
\hline & Chinese Taipei & 7.5 & $(0.5)$ & 24.4 & $(0.6)$ & 21.3 & $(0.6)$ & 22.2 & $(0.5)$ & 10.5 & $(0.4)$ & 14.0 & $(0.6)$ & 120 & (2.0) \\
\hline & Thailand & 10.2 & $(0.4)$ & 23.5 & $(0.7)$ & 19.4 & $(0.7)$ & 19.4 & $(0.7)$ & 13.6 & $(0.6)$ & 13.9 & $(0.6)$ & 122 & (2.4) \\
\hline & Trinidad and Tobago & $\mathrm{m}$ & $\mathrm{m}$ & $\mathrm{m}$ & $\mathrm{m}$ & $\mathrm{m}$ & $\mathrm{m}$ & $\mathrm{m}$ & $\mathrm{m}$ & $\mathrm{m}$ & $\mathrm{m}$ & $\mathrm{m}$ & $\mathrm{m}$ & $\mathrm{m}$ & $\mathrm{m}$ \\
\hline & Tunisia & $\mathrm{m}$ & $\mathrm{m}$ & $\mathrm{m}$ & $\mathrm{m}$ & $\mathrm{m}$ & $\mathrm{m}$ & $\mathrm{m}$ & $\mathrm{m}$ & $\mathrm{m}$ & $\mathrm{m}$ & $\mathrm{m}$ & $\mathrm{m}$ & $\mathrm{m}$ & $\mathrm{m}$ \\
\hline & United Arab Emirates & $\mathrm{m}$ & $\mathrm{m}$ & $\mathrm{m}$ & $\mathrm{m}$ & $\mathrm{m}$ & $\mathrm{m}$ & $\mathrm{m}$ & $\mathrm{m}$ & $\mathrm{m}$ & $\mathrm{m}$ & $\mathrm{m}$ & $\mathrm{m}$ & $\mathrm{m}$ & $\mathrm{m}$ \\
\hline & Uruguay & 8.5 & $(0.5)$ & 13.5 & $(0.5)$ & 13.2 & $(0.5)$ & 16.4 & $(0.5)$ & 16.5 & $(0.6)$ & 31.9 & $(0.7)$ & 185 & $(2.1)$ \\
\hline & Viet Nam & $\mathrm{m}$ & $\mathrm{m}$ & $\mathrm{m}$ & $\mathrm{m}$ & $\mathrm{m}$ & $\mathrm{m}$ & $\mathrm{m}$ & $\mathrm{m}$ & $\mathrm{m}$ & $\mathrm{m}$ & $\mathrm{m}$ & $\mathrm{m}$ & $\mathrm{m}$ & $\mathrm{m}$ \\
\hline & Argentina** & $\mathrm{m}$ & $\mathrm{m}$ & $\mathrm{m}$ & $\mathrm{m}$ & $\mathrm{m}$ & $\mathrm{m}$ & $\mathrm{m}$ & $\mathrm{m}$ & $\mathrm{m}$ & $\mathrm{m}$ & $\mathrm{m}$ & $\mathrm{m}$ & $\mathrm{m}$ & $\mathrm{m}$ \\
\hline & Kazakhstan** & $\mathrm{m}$ & $\mathrm{m}$ & $\mathrm{m}$ & $\mathrm{m}$ & $\mathrm{m}$ & $\mathrm{m}$ & $\mathrm{m}$ & $\mathrm{m}$ & $\mathrm{m}$ & $\mathrm{m}$ & $\mathrm{m}$ & $\mathrm{m}$ & $\mathrm{m}$ & $\mathrm{m}$ \\
\hline & Malaysia** & $\mathrm{m}$ & $\mathrm{m}$ & $\mathrm{m}$ & $\mathrm{m}$ & $\mathrm{m}$ & $\mathrm{m}$ & $\mathrm{m}$ & $\mathrm{m}$ & $\mathrm{m}$ & $\mathrm{m}$ & $\mathrm{m}$ & $\mathrm{m}$ & $\mathrm{m}$ & $\mathrm{m}$ \\
\hline
\end{tabular}

1. As answers were given on a categorical scale, it is not possible to compute exactly the average time students spend on line. The numbers in this table thus report a lower bound for the number of minutes students spend on online activities, whereby the answer "between one and two hours", for instance, is converted into " 61 minutes at least".

2. A low internet user is a student who uses the Internet for less than 1 hours per day on a typical weekday.

3. An extreme internet user is a student who uses the Internet for more than 6 hours a day on a typical weekday.

Note: Values that are statistically significant are indicated in bold (see Annex A3).

See note at the beginning of this Annex.

Coverage is too small to ensure comparability (see Annex A4).

StatLink त्रोज़ http://dx.doi.org/10.1787/888933473214 
Results based on students' self-reports

\begin{tabular}{|c|c|c|c|c|c|c|c|c|c|c|c|c|c|c|c|c|c|c|c|}
\hline & & & & Boys & & & & & & Girls & & & & & Differ & rence $(B$ & $3-G)$ & \\
\hline & & $\begin{array}{l}\text { Percer } \\
\text { are, }\end{array}$ & $\begin{array}{l}\text { tage o } \\
\text { on a typ }\end{array}$ & $\begin{array}{l}\text { studen } \\
\text { ical we }\end{array}$ & $\begin{array}{l}\text { ts who } \\
\text { ekday }\end{array}$ & $\begin{array}{r}\text { Averas } \\
\text { in minute }\end{array}$ & $\begin{array}{l}\text { time, } \\
\text { per day, }\end{array}$ & $\begin{array}{l}\text { Percen } \\
\text { are, } 0\end{array}$ & $\begin{array}{l}\text { tage of } \\
\text { on a typ }\end{array}$ & $\begin{array}{l}\text { f studen } \\
\text { ical we }\end{array}$ & $\begin{array}{l}\text { ts who } \\
\text { ekday }\end{array}$ & $\begin{array}{r}\text { Averag } \\
\text { in minute }\end{array}$ & $\begin{array}{l}\text { time, } \\
\text { per day, }\end{array}$ & $\begin{array}{c}\text { Percen } \\
\text { are, o }\end{array}$ & $\begin{array}{l}\text { tage o } \\
\text { on a typ }\end{array}$ & $\begin{array}{l}\text { studen } \\
\text { ical we }\end{array}$ & $\begin{array}{l}\text { ts who } \\
\text { ekday }\end{array}$ & $\begin{array}{c}\text { Aver } \\
\text { in mins }\end{array}$ & $\begin{array}{l}\text { time, } \\
\text { per day, }\end{array}$ \\
\hline & & $\begin{array}{r}\text { Low Ir } \\
\text { use }\end{array}$ & $\begin{array}{l}\text { ternet } \\
\mathrm{ars}^{2}\end{array}$ & & $\begin{array}{l}\text { eme } \\
\text { rnet } \\
\text { rrs }^{3}\end{array}$ & $\begin{array}{r}\text { Interne } \\
\text { of sc } \\
\text { on we }\end{array}$ & $\begin{array}{l}\text { outside } \\
\text { ool, } \\
\text { ddays }{ }^{1}\end{array}$ & $\begin{array}{r}\text { Low In } \\
\text { us }\end{array}$ & $\begin{array}{l}\text { ternet } \\
\text { ers }\end{array}$ & & $\begin{array}{l}\text { reme } \\
\text { ernet } \\
\text { sers }\end{array}$ & $\begin{array}{r}\text { Internet } \\
\text { of sc } \\
\text { on we }\end{array}$ & $\begin{array}{l}\text { outside } \\
\text { ool, } \\
\text { kdays }\end{array}$ & $\begin{array}{r}\text { Low In } \\
\text { use }\end{array}$ & $\begin{array}{l}\text { ternet } \\
\text { ers }\end{array}$ & $\begin{array}{l}\text { Extr } \\
\text { Inte } \\
\text { us }\end{array}$ & $\begin{array}{l}\text { eme } \\
\text { rnet } \\
\text { ers }\end{array}$ & $\begin{array}{r}\text { Intern } \\
\text { of } \\
\text { on } v\end{array}$ & $\begin{array}{l}\text { outside } \\
\text { ool, } \\
\text { kdays }\end{array}$ \\
\hline & & $\%$ & S.E. & $\%$ & S.E. & Minutes & S.E. & $\%$ & S.E. & $\%$ & S.E. & Minutes & S.E. & $\%$ dif. & S.E. & $\%$ dif. & S.E. & Dif. & S.E. \\
\hline & Australia & 13.3 & $(0.6)$ & \begin{tabular}{|l|}
19.2 \\
\end{tabular} & (0.6) & 165 & (1.8) & 10.9 & $(0.4)$ & 15.8 & $(0.6)$ & 163 & $(2.1)$ & 2.4 & $(0.7)$ & 3.3 & $(0.8)$ & 1.8 & (2.5) \\
\hline 5 & Austria & 19.8 & $(0.8)$ & 16.2 & $(0.9)$ & 147 & $(2.8)$ & 19.2 & $(0.8)$ & 18.0 & $(0.8)$ & 150 & $(2.3)$ & 0.6 & $(1.0)$ & -1.7 & $(1.1)$ & -3.1 & $(3.2)$ \\
\hline$a$ & Belgium & 18.2 & $(0.8)$ & 17.3 & $(0.7)$ & 149 & $(2.2)$ & 18.2 & $(0.6)$ & 13.5 & $(0.6)$ & 143 & $(2.1)$ & 0.0 & $(1.0)$ & 3.8 & $(0.9)$ & 6.4 & $(2.9)$ \\
\hline & Canada & $\mathrm{m}$ & $\mathrm{m}$ & $\mathrm{m}$ & $\mathrm{m}$ & $\mathrm{m}$ & $\mathrm{m}$ & $\mathrm{m}$ & $\mathrm{m}$ & $\mathrm{m}$ & $\mathrm{m}$ & $\mathrm{m}$ & $\mathrm{m}$ & $\mathrm{m}$ & $\mathrm{m}$ & $\mathrm{m}$ & $\mathrm{m}$ & $\mathrm{m}$ & $\mathrm{m}$ \\
\hline & Chile & 17.7 & $(1.0)$ & 31.5 & (1.1) & 189 & (3.2) & 14.6 & $(0.8)$ & 32.3 & (1.1) & 201 & $(3.2)$ & 3.2 & $(1.1)$ & -0.8 & (1.4) & -11.6 & $(4.1)$ \\
\hline & Czech Republic & 16.6 & $(0.7)$ & 18.6 & $(0.8)$ & 154 & $(2.7)$ & 17.8 & $(0.8)$ & 15.6 & $(0.9)$ & 144 & $(2.7)$ & -1.3 & (1.0) & 3.0 & $(1.2)$ & 9.3 & (3.7) \\
\hline & Denmark & 9.4 & $(0.7)$ & 18.0 & (0.9) & 172 & (3.1) & 11.0 & $(0.6)$ & 11.8 & $(0.7)$ & 146 & $(2.8)$ & -1.6 & $(0.8)$ & 6.3 & (1.1) & 26.3 & (3.5) \\
\hline & Estonia & 12.8 & $(0.7)$ & 19.7 & (0.9) & 169 & $(2.7)$ & 13.8 & $(0.8)$ & 16.5 & $(0.8)$ & 157 & $(2.6)$ & -1.0 & $(1.2)$ & 3.2 & $(1.2)$ & 11.6 & (3.6) \\
\hline & Finland & 15.4 & $(0.7)$ & 12.1 & $(0.7)$ & 141 & (2.4) & 17.3 & $(0.8)$ & 10.8 & $(0.7)$ & 134 & $(2.3)$ & -1.9 & $(1.0)$ & 1.3 & (0.9) & 7.8 & (3.3) \\
\hline & France & 23.1 & $(1.0)$ & 13.4 & $(0.7)$ & 128 & $(2.5)$ & 22.5 & $(0.9)$ & 10.6 & $(0.7)$ & 125 & $(2.5)$ & 0.6 & $(1.2)$ & 2.8 & (0.9) & 3.2 & (3.1) \\
\hline & Germany & $\mathrm{m}$ & $\mathrm{m}$ & $\mathrm{m}$ & $\mathrm{m}$ & $\mathrm{m}$ & $\mathrm{m}$ & $\mathrm{m}$ & $\mathrm{m}$ & $\mathrm{m}$ & $\mathrm{m}$ & $\mathrm{m}$ & $\mathrm{m}$ & $\mathrm{m}$ & $\mathrm{m}$ & $\mathrm{m}$ & $\mathrm{m}$ & $\mathrm{m}$ & $\mathrm{m}$ \\
\hline & Greece & 25.1 & $(1.0)$ & 11.1 & $(0.7)$ & 124 & (2.6) & 23.6 & $(0.9)$ & 11.3 & $(0.7)$ & 129 & (2.4) & 1.4 & $(1.2)$ & -0.2 & (1.0) & -5.0 & (3.4) \\
\hline & Hungary & 16.1 & $(0.9)$ & 20.2 & (0.9) & 158 & $(3.0)$ & 15.4 & $(0.9)$ & 21.3 & $(0.9)$ & 165 & (3.2) & 0.6 & $(1.1)$ & -1.0 & (1.4) & -6.4 & $(4.3)$ \\
\hline & Iceland & 12.3 & $(0.9)$ & 14.3 & $(0.8)$ & 155 & (2.9) & 13.3 & $(0.8)$ & 10.3 & $(0.7)$ & 137 & (2.6) & -1.0 & $(1.2)$ & 4.0 & $(1.2)$ & 18.4 & $(4.0)$ \\
\hline & Ireland & 16.9 & $(1.0)$ & 13.7 & $(0.9)$ & 140 & (3.2) & 15.9 & $(1.0)$ & 13.5 & $(0.8)$ & 148 & (3.1) & 1.0 & $(1.2)$ & 0.2 & $(1.2)$ & -7.6 & $(4.1)$ \\
\hline & Israel & 34.7 & $(2.6)$ & 12.9 & $(0.9)$ & 114 & (5.1) & 24.0 & $(1.2)$ & 22.6 & (1.1) & 157 & (4.1) & 10.6 & $(2.7)$ & -9.7 & $(1.2)$ & -42.5 & (5.7) \\
\hline & Italy & 18.8 & $(0.8)$ & 20.8 & (0.9) & 156 & (3.0) & 15.9 & $(0.7)$ & 25.6 & $(0.8)$ & 175 & (2.3) & 2.9 & (1.1) & -4.8 & $(1.2)$ & -18.6 & (3.9) \\
\hline & Japan & 38.7 & (1.0) & 6.3 & $(0.7)$ & 87 & (2.9) & 37.2 & (1.0) & 6.5 & $(0.6)$ & 92 & (2.8) & 1.5 & (1.3) & -0.1 & $(0.8)$ & -4.6 & (3.3) \\
\hline & Korea & 50.4 & (1.5) & 2.0 & $(0.2)$ & 59 & (1.8) & 60.8 & $(1.2)$ & 1.8 & $(0.3)$ & 50 & (1.6) & -10.4 & (1.9) & 0.3 & $(0.3)$ & 8.9 & $(2.2)$ \\
\hline & Latvia & 17.3 & $(0.9)$ & 18.2 & $(0.9)$ & 155 & $(2.7)$ & 17.6 & $(0.8)$ & 12.7 & $(0.7)$ & 139 & (2.4) & $\mid-0.3$ & $(1.2)$ & 5.5 & (1.0) & 16.8 & $(3.0)$ \\
\hline & Luxembourg & 17.2 & $(0.8)$ & 19.8 & $(0.8)$ & 159 & $(2.7)$ & 17.9 & $(0.8)$ & 17.0 & $(0.8)$ & 151 & $(2.6)$ & -0.6 & $(1.2)$ & 2.8 & $(1.1)$ & 8.7 & (3.8) \\
\hline & Mexico & 38.8 & (1.3) & 15.0 & $(0.8)$ & 116 & $(3.2)$ & 34.0 & $(1.2)$ & 15.3 & $(0.9)$ & 126 & (3.7) & 4.8 & (1.3) & -0.3 & (1.0) & -9.7 & $(4.0)$ \\
\hline & Netherlands & 13.7 & $(0.7)$ & 17.0 & (0.9) & 155 & $(2.7)$ & 13.1 & $(0.8)$ & 18.6 & $(0.7)$ & 163 & $(2.3)$ & 0.6 & $(1.0)$ & -1.6 & (1.1) & -7.3 & (3.4) \\
\hline & New Zealand & 14.6 & $(0.9)$ & 17.5 & (1.1) & 161 & (3.1) & 11.9 & $(0.8)$ & 17.0 & (1.1) & 165 & (3.4) & 2.7 & (1.4) & 0.4 & (1.5) & -3.8 & $(4.4)$ \\
\hline & Norway & $\mathrm{m}$ & $\mathrm{m}$ & $\mathrm{m}$ & $\mathrm{m}$ & $\mathrm{m}$ & $\mathrm{m}$ & $\mathrm{m}$ & m & $\mathrm{m}$ & $\mathrm{m}$ & $\mathrm{m}$ & $\mathrm{m}$ & $\mathrm{m}$ & $\mathrm{m}$ & $\mathrm{m}$ & $\mathrm{m}$ & $\mathrm{m}$ & $\mathrm{m}$ \\
\hline & Poland & 15.4 & $(0.7)$ & 16.2 & $(0.9)$ & 149 & $(2.8)$ & 18.0 & $(0.9)$ & 14.0 & $(0.9)$ & 142 & (2.6) & -2.6 & $(1.1)$ & 2.2 & (1.1) & 7.4 & (3.4) \\
\hline & Portugal & 20.4 & $(0.9)$ & 17.4 & $(0.8)$ & 149 & $(2.6)$ & 23.3 & $(0.8)$ & 11.7 & $(0.7)$ & 130 & $(2.4)$ & -2.8 & $(1.2)$ & 5.7 & $(1.0)$ & 18.4 & (3.4) \\
\hline & Slovak Republic & 20.7 & $(0.9)$ & 20.3 & $(0.8)$ & 154 & $(2.7)$ & 19.8 & $(0.8)$ & 18.6 & $(0.8)$ & 150 & (2.9) & 1.0 & $(1.0)$ & 1.7 & (1.0) & 3.3 & (3.8) \\
\hline & Slovenia & 25.5 & $(0.9)$ & 12.6 & $(0.8)$ & 124 & $(2.5)$ & 26.9 & $(1.1)$ & 9.7 & $(0.7)$ & 115 & $(2.4)$ & -1.5 & (1.3) & 2.9 & (1.0) & 8.8 & (3.3) \\
\hline & Spain & 16.3 & $(0.7)$ & 20.5 & $(0.9)$ & 160 & $(2.9)$ & 15.2 & $(0.8)$ & 22.9 & $(0.9)$ & 173 & $(3.2)$ & 1.1 & (1.1) & -2.4 & $(1.2)$ & -13.6 & $(4.1)$ \\
\hline & Sweden & 8.9 & $(0.6)$ & 23.0 & (1.1) & 189 & $(2.9)$ & 7.5 & $(0.7)$ & 21.1 & (1.1) & 185 & (3.0) & 1.3 & $(0.9)$ & 2.0 & (1.4) & 3.4 & $(4.1)$ \\
\hline & Switzerland & 22.5 & $(1.1)$ & 12.1 & $(0.8)$ & 128 & $(2.8)$ & 24.1 & (1.0) & 11.1 & $(0.7)$ & 125 & $(2.7)$ & -1.6 & (1.4) & 1.0 & $(0.9)$ & 3.0 & (3.2) \\
\hline & Turkey & $\mathrm{m}$ & $\mathrm{m}$ & $\mathrm{m}$ & $\mathrm{m}$ & $\mathrm{m}$ & $\mathrm{m}$ & $\mathrm{m}$ & $\mathrm{m}$ & $\mathrm{m}$ & $\mathrm{m}$ & $\mathrm{m}$ & $\mathrm{m}$ & $\mathrm{m}$ & $\mathrm{m}$ & $\mathrm{m}$ & $\mathrm{m}$ & $\mathrm{m}$ & $\mathrm{m}$ \\
\hline & United Kingdom & 8.2 & $(0.7)$ & 25.6 & $(1.1)$ & 191 & (3.1) & 8.6 & $(0.7)$ & 22.7 & $(1.2)$ & 184 & (3.6) & -0.4 & $(1.0)$ & 2.9 & (1.4) & 6.8 & $(4.0)$ \\
\hline & United States & $\mathrm{m}$ & $\mathrm{m}$ & $\mathrm{m}$ & $\mathrm{m}$ & $\mathrm{m}$ & $\mathrm{m}$ & $\mathrm{m}$ & $\mathrm{m}$ & $\mathrm{m}$ & $\mathrm{m}$ & $\mathrm{m}$ & $\mathrm{m}$ & $\mathrm{m}$ & $\mathrm{m}$ & $\mathrm{m}$ & $\mathrm{m}$ & $\mathrm{m}$ & $\mathrm{m}$ \\
\hline & OECD average & 20.0 & $(0.2)$ & 16.8 & $(0.2)$ & 147 & $(0.5)$ & 19.6 & $(0.2)$ & 15.7 & $(0.2)$ & 145 & $(0.5)$ & 0.3 & $(0.2)$ & 1.1 & $(0.2)$ & 1.2 & $(0.7)$ \\
\hline & Albania & $\mathrm{m}$ & $\mathrm{m}$ & $\mathrm{m}$ & $\mathrm{m}$ & $\mathrm{m}$ & $\mathrm{m}$ & $\mathrm{m}$ & $\mathrm{m}$ & $\mathrm{m}$ & $\mathrm{m}$ & $\mathrm{m}$ & $\mathrm{m}$ & $\mathrm{m}$ & $\mathrm{m}$ & $\mathrm{m}$ & $\mathrm{m}$ & $\mathrm{m}$ & $\mathrm{m}$ \\
\hline$\Xi$ & Algeria & $\mathrm{m}$ & $\mathrm{m}$ & $\mathrm{m}$ & $\mathrm{m}$ & $\mathrm{m}$ & $\mathrm{m}$ & $\mathrm{m}$ & $\mathrm{m}$ & $\mathrm{m}$ & $\mathrm{m}$ & $\mathrm{m}$ & $\mathrm{m}$ & $\mathrm{m}$ & $\mathrm{m}$ & $\mathrm{m}$ & $\mathrm{m}$ & $\mathrm{m}$ & $\mathrm{m}$ \\
\hline & Brazil & 25.0 & $(0.8)$ & 33.8 & (1.0) & 182 & (3.0) & 22.3 & $(0.8)$ & 37.3 & $(1.0)$ & 197 & (3.1) & 2.7 & $(0.8)$ & -3.5 & (1.1) & -14.8 & (3.1) \\
\hline & B-S-J-G (China) & 72.1 & $(0.8)$ & 4.7 & $(0.4)$ & 47 & (1.7) & 78.0 & $(1.2)$ & 3.2 & $(0.5)$ & 37 & $(2.1)$ & -5.9 & $(1.3)$ & 1.5 & $(0.5)$ & 10.0 & $(2.2)$ \\
\hline & Bulgaria & 17.1 & $(1.0)$ & 27.5 & $(1.0)$ & 179 & $(2.9)$ & 11.0 & $(0.7)$ & 29.6 & (1.1) & 197 & (3.1) & 6.1 & $(1.1)$ & -2.1 & (1.3) & -18.1 & (3.9) \\
\hline & CABA (Argentina) & $\mathrm{m}$ & $\mathrm{m}$ & $\mathrm{m}$ & $\mathrm{m}$ & $\mathrm{m}$ & $\mathrm{m}$ & $\mathrm{m}$ & $\mathrm{m}$ & $\mathrm{m}$ & $\mathrm{m}$ & $\mathrm{m}$ & $\mathrm{m}$ & $\mathrm{m}$ & $\mathrm{m}$ & $\mathrm{m}$ & $\mathrm{m}$ & $\mathrm{m}$ & $\mathrm{m}$ \\
\hline & Colombia & 35.9 & $(1.3)$ & 19.2 & $(0.8)$ & 132 & (3.4) & 30.5 & $(1.0)$ & 23.6 & $(1.0)$ & 152 & (3.6) & 5.4 & (1.5) & -4.4 & $(1.0)$ & -19.3 & $(4.0)$ \\
\hline & Costa Rica & 23.8 & $(1.2)$ & 31.5 & (1.1) & 178 & (3.6) & 22.0 & $(0.9)$ & 33.0 & (1.1) & 186 & (3.6) & 1.8 & (1.3) & -1.5 & (1.5) & -8.2 & $(4.7)$ \\
\hline & Croatia & 25.6 & $(0.9)$ & 15.2 & $(0.8)$ & 133 & $(2.4)$ & 19.6 & $(0.8)$ & 17.0 & $(0.8)$ & 148 & $(2.9)$ & 6.0 & $(1.2)$ & -1.8 & (1.1) & -15.7 & (3.7) \\
\hline & Cyprus* & $\mathrm{m}$ & $\mathrm{m}$ & $\mathrm{m}$ & $\mathrm{m}$ & $\mathrm{m}$ & $\mathrm{m}$ & $\mathrm{m}$ & $\mathrm{m}$ & $\mathrm{m}$ & $\mathrm{m}$ & $\mathrm{m}$ & $\mathrm{m}$ & $\mathrm{m}$ & $\mathrm{m}$ & $\mathrm{m}$ & $\mathrm{m}$ & $\mathrm{m}$ & $\mathrm{m}$ \\
\hline & Dominican Republic & 42.2 & (1.1) & 17.7 & (1.0) & 118 & $(2.9)$ & 36.1 & (1.3) & 24.2 & (1.1) & 141 & (4.1) & 6.1 & (1.6) & -6.4 & (1.4) & -23.7 & (4.5) \\
\hline & FYROM & $\mathrm{m}$ & $\mathrm{m}$ & $\mathrm{m}$ & $\mathrm{m}$ & $\mathrm{m}$ & $\mathrm{m}$ & $\mathrm{m}$ & $\mathrm{m}$ & $\mathrm{m}$ & $\mathrm{m}$ & $\mathrm{m}$ & $\mathrm{m}$ & $\mathrm{m}$ & $\mathrm{m}$ & $\mathrm{m}$ & $\mathrm{m}$ & $\mathrm{m}$ & $\mathrm{m}$ \\
\hline & Georgia & $\mathrm{m}$ & $\mathrm{m}$ & $\mathrm{m}$ & $\mathrm{m}$ & $\mathrm{m}$ & $\mathrm{m}$ & $\mathrm{m}$ & $\mathrm{m}$ & $\mathrm{m}$ & $\mathrm{m}$ & $\mathrm{m}$ & $\mathrm{m}$ & $\mathrm{m}$ & $\mathrm{m}$ & $\mathrm{m}$ & $\mathrm{m}$ & $\mathrm{m}$ & $\mathrm{m}$ \\
\hline & Hong Kong (China) & 26.3 & $(0.9)$ & 15.6 & $(0.9)$ & 133 & $(2.8)$ & 30.5 & $(1.0)$ & 8.6 & $(0.6)$ & 112 & $(2.5)$ & -4.2 & $(1.2)$ & 7.0 & $(1.1)$ & 20.9 & (3.7) \\
\hline & Indonesia & $\mathrm{m}$ & $\mathrm{m}$ & $\mathrm{m}$ & $\mathrm{m}$ & $\mathrm{m}$ & $\mathrm{m}$ & $\mathrm{m}$ & $\mathrm{m}$ & $\mathrm{m}$ & $\mathrm{m}$ & $\mathrm{m}$ & $\mathrm{m}$ & $\mathrm{m}$ & $\mathrm{m}$ & $\mathrm{m}$ & $\mathrm{m}$ & $\mathrm{m}$ & $\mathrm{m}$ \\
\hline & Jordan & $\mathrm{m}$ & $\mathrm{m}$ & $\mathrm{m}$ & $\mathrm{m}$ & $\mathrm{m}$ & $\mathrm{m}$ & $\mathrm{m}$ & $\mathrm{m}$ & $\mathrm{m}$ & $\mathrm{m}$ & $\mathrm{m}$ & $\mathrm{m}$ & $\mathrm{m}$ & $\mathrm{m}$ & $\mathrm{m}$ & $\mathrm{m}$ & $\mathrm{m}$ & $\mathrm{m}$ \\
\hline & Kosovo & $\mathrm{m}$ & $\mathrm{m}$ & $\mathrm{m}$ & $\mathrm{m}$ & $\mathrm{m}$ & $\mathrm{m}$ & $\mathrm{m}$ & $\mathrm{m}$ & $\mathrm{m}$ & $\mathrm{m}$ & $\mathrm{m}$ & $\mathrm{m}$ & $\mathrm{m}$ & $\mathrm{m}$ & $\mathrm{m}$ & $\mathrm{m}$ & $\mathrm{m}$ & $\mathrm{m}$ \\
\hline & Lebanon & $\mathrm{m}$ & $\mathrm{m}$ & $\mathrm{m}$ & $\mathrm{m}$ & $\mathrm{m}$ & $\mathrm{m}$ & $\mathrm{m}$ & $\mathrm{m}$ & $\mathrm{m}$ & $\mathrm{m}$ & $\mathrm{m}$ & $\mathrm{m}$ & $\mathrm{m}$ & $\mathrm{m}$ & $\mathrm{m}$ & $\mathrm{m}$ & $\mathrm{m}$ & $\mathrm{m}$ \\
\hline & Lithuania & 19.1 & $(0.8)$ & 14.7 & $(0.7)$ & 142 & $(2.4)$ & 18.9 & $(0.8)$ & 11.0 & $(0.7)$ & 132 & $(2.6)$ & 0.3 & $(1.1)$ & 3.7 & $(1.0)$ & 9.5 & (3.5) \\
\hline & Macao (China) & 23.9 & $(0.9)$ & 12.1 & $(0.7)$ & 129 & $(2.5)$ & 21.7 & $(0.8)$ & 11.2 & $(0.7)$ & 131 & $(2.2)$ & 2.2 & $(1.2)$ & 0.8 & $(0.9)$ & -2.1 & (3.4) \\
\hline & Malta & $\mathrm{m}$ & $\mathrm{m}$ & $\mathrm{m}$ & $\mathrm{m}$ & $\mathrm{m}$ & $\mathrm{m}$ & $\mathrm{m}$ & $\mathrm{m}$ & $\mathrm{m}$ & $\mathrm{m}$ & $\mathrm{m}$ & $\mathrm{m}$ & $\mathrm{m}$ & $\mathrm{m}$ & $\mathrm{m}$ & $\mathrm{m}$ & $\mathrm{m}$ & $\mathrm{m}$ \\
\hline & Moldova & $\mathrm{m}$ & $\mathrm{m}$ & $\mathrm{m}$ & $\mathrm{m}$ & $\mathrm{m}$ & $\mathrm{m}$ & $\mathrm{m}$ & $\mathrm{m}$ & $\mathrm{m}$ & $\mathrm{m}$ & $\mathrm{m}$ & $\mathrm{m}$ & $\mathrm{m}$ & $\mathrm{m}$ & $\mathrm{m}$ & $\mathrm{m}$ & $\mathrm{m}$ & $\mathrm{m}$ \\
\hline & Montenegro & $\mathrm{m}$ & $\mathrm{m}$ & $\mathrm{m}$ & $\mathrm{m}$ & $\mathrm{m}$ & $\mathrm{m}$ & $\mathrm{m}$ & $\mathrm{m}$ & $\mathrm{m}$ & $\mathrm{m}$ & $\mathrm{m}$ & $\mathrm{m}$ & $\mathrm{m}$ & $\mathrm{m}$ & $\mathrm{m}$ & $\mathrm{m}$ & $\mathrm{m}$ & $\mathrm{m}$ \\
\hline & Peru & 44.5 & (1.3) & 8.4 & $(0.6)$ & 89 & (2.5) & 42.9 & (1.4) & 8.9 & $(0.5)$ & 94 & (2.6) & 1.5 & (1.8) & -0.5 & $(0.6)$ & -4.6 & (2.9) \\
\hline & Qatar & $\mathrm{m}$ & $\mathrm{m}$ & $\mathrm{m}$ & $\mathrm{m}$ & $\mathrm{m}$ & $\mathrm{m}$ & $\mathrm{m}$ & $\mathrm{m}$ & $\mathrm{m}$ & $\mathrm{m}$ & $\mathrm{m}$ & $\mathrm{m}$ & $\mathrm{m}$ & $\mathrm{m}$ & $\mathrm{m}$ & $\mathrm{m}$ & $\mathrm{m}$ & $\mathrm{m}$ \\
\hline & Romania & $\mathrm{m}$ & $\mathrm{m}$ & $\mathrm{m}$ & $\mathrm{m}$ & $\mathrm{m}$ & $\mathrm{m}$ & $\mathrm{m}$ & $\mathrm{m}$ & $\mathrm{m}$ & $\mathrm{m}$ & $\mathrm{m}$ & $\mathrm{m}$ & $\mathrm{m}$ & $\mathrm{m}$ & $\mathrm{m}$ & $\mathrm{m}$ & $\mathrm{m}$ & $\mathrm{m}$ \\
\hline & Russia & 22.7 & $(0.9)$ & 20.2 & $(1.2)$ & 153 & $(4.0)$ & 17.1 & $(0.6)$ & 22.1 & $(0.9)$ & 169 & $(2.8)$ & 5.6 & $(1.1)$ & -1.9 & (1.4) & -16.5 & $(4.5)$ \\
\hline & Singapore & 18.8 & $(0.7)$ & 17.5 & $(0.7)$ & 148 & $(2.0)$ & 16.7 & $(0.7)$ & 14.6 & $(0.7)$ & 146 & $(2.1)$ & 2.0 & $(1.0)$ & 2.9 & $(1.0)$ & 2.2 & (2.9) \\
\hline & Chinese Taipei & 29.8 & $(0.9)$ & 15.0 & $(0.8)$ & 123 & $(2.7)$ & 34.0 & $(1.1)$ & 12.9 & $(0.7)$ & 117 & $(2.8)$ & -4.2 & (1.4) & 2.1 & $(0.9)$ & 6.6 & (3.8) \\
\hline & Thailand & 35.4 & $(1.2)$ & 14.2 & $(0.9)$ & 119 & (3.5) & 32.4 & (1.0) & 13.7 & $(0.8)$ & 125 & (3.0) & 3.0 & (1.6) & 0.5 & $(1.2)$ & -6.1 & $(4.1)$ \\
\hline & Trinidad and Tobago & $\mathrm{m}$ & $\mathrm{m}$ & $\mathrm{m}$ & $\mathrm{m}$ & $\mathrm{m}$ & $\mathrm{m}$ & $\mathrm{m}$ & $\mathrm{m}$ & $\mathrm{m}$ & $\mathrm{m}$ & $\mathrm{m}$ & $\mathrm{m}$ & $\mathrm{m}$ & $\mathrm{m}$ & $\mathrm{m}$ & $\mathrm{m}$ & $\mathrm{m}$ & $\mathrm{m}$ \\
\hline & Tunisia & $\mathrm{m}$ & $\mathrm{m}$ & $\mathrm{m}$ & $\mathrm{m}$ & $\mathrm{m}$ & $\mathrm{m}$ & $\mathrm{m}$ & $\mathrm{m}$ & $\mathrm{m}$ & $\mathrm{m}$ & $\mathrm{m}$ & $\mathrm{m}$ & $\mathrm{m}$ & $\mathrm{m}$ & $\mathrm{m}$ & $\mathrm{m}$ & $\mathrm{m}$ & $\mathrm{m}$ \\
\hline & United Arab Emirates & $\mathrm{m}$ & $\mathrm{m}$ & $\mathrm{m}$ & $\mathrm{m}$ & $\mathrm{m}$ & $\mathrm{m}$ & $\mathrm{m}$ & $\mathrm{m}$ & $\mathrm{m}$ & $\mathrm{m}$ & $\mathrm{m}$ & $\mathrm{m}$ & $\mathrm{m}$ & $\mathrm{m}$ & $\mathrm{m}$ & $\mathrm{m}$ & $\mathrm{m}$ & $\mathrm{m}$ \\
\hline & Uruguay & 24.3 & $(1.0)$ & 28.8 & $(1.0)$ & 173 & (3.4) & 20.1 & $(0.8)$ & 34.7 & $(1.0)$ & 195 & $(2.9)$ & 4.2 & $(1.2)$ & -5.8 & (1.4) & -22.2 & $(4.6)$ \\
\hline & Viet Nam & $\mathrm{m}$ & $\mathrm{m}$ & $\mathrm{m}$ & $\mathrm{m}$ & $\mathrm{m}$ & $\mathrm{m}$ & $\mathrm{m}$ & $\mathrm{m}$ & $\mathrm{m}$ & $\mathrm{m}$ & $\mathrm{m}$ & $\mathrm{m}$ & $\mathrm{m}$ & $\mathrm{m}$ & $\mathrm{m}$ & $\mathrm{m}$ & $\mathrm{m}$ & $\mathrm{m}$ \\
\hline & Argentina** & $\mathrm{m}$ & $\mathrm{m}$ & $\mathrm{m}$ & $\mathrm{m}$ & $\mathrm{m}$ & $\mathrm{m}$ & $\mathrm{m}$ & $\mathrm{m}$ & $\mathrm{m}$ & $\mathrm{m}$ & $\mathrm{m}$ & $\mathrm{m}$ & $\mathrm{m}$ & $\mathrm{m}$ & $\mathrm{m}$ & $\mathrm{m}$ & $\mathrm{m}$ & $\mathrm{m}$ \\
\hline & Kazakhstan** & $\mathrm{m}$ & & $\mathrm{m}$ & $\mathrm{m}$ & $\mathrm{m}$ & $\mathrm{m}$ & $\mathrm{m}$ & $\mathrm{m}$ & $\mathrm{m}$ & $\mathrm{m}$ & $\mathrm{m}$ & $\mathrm{m}$ & $\mathrm{m}$ & $\mathrm{m}$ & $\mathrm{m}$ & $\mathrm{m}$ & $\mathrm{m}$ & $\mathrm{m}$ \\
\hline & Malaysia** & $\mathrm{m}$ & $\mathrm{m}$ & $\mathrm{m}$ & $\mathrm{m}$ & $\mathrm{m}$ & $\mathrm{m}$ & $\mathrm{m}$ & $\mathrm{m}$ & $\mathrm{m}$ & $\mathrm{m}$ & $\mathrm{m}$ & $\mathrm{m}$ & $\mathrm{m}$ & $\mathrm{m}$ & $\mathrm{m}$ & $\mathrm{m}$ & $\mathrm{m}$ & $\mathrm{m}$ \\
\hline
\end{tabular}

1. As answers were given on a categorical scale, it is not possible to compute exactly the average time students spend on line. The numbers in this table thus report a lower bound for the number of minutes students spend on online activities, whereby the answer "between one and two hours", for instance, is converted into "61 minutes at least"

2. A low internet user is a student who uses the Internet for less than 1 hours per day on a typical weekday.

Note: Values that are statistically significant are indicated in bold (see Annex A3).

* See note at the beginning of this Annex.

** Coverage is too small to ensure comparability (see Annex A4).

StatLink 需四 http://dx.doi.org/10.1787/888933473214 
[Part 1/2]

Table III.13.8 Internet use outside of school on a typical weekend day, by gender

Results based on students' self-reports

All student

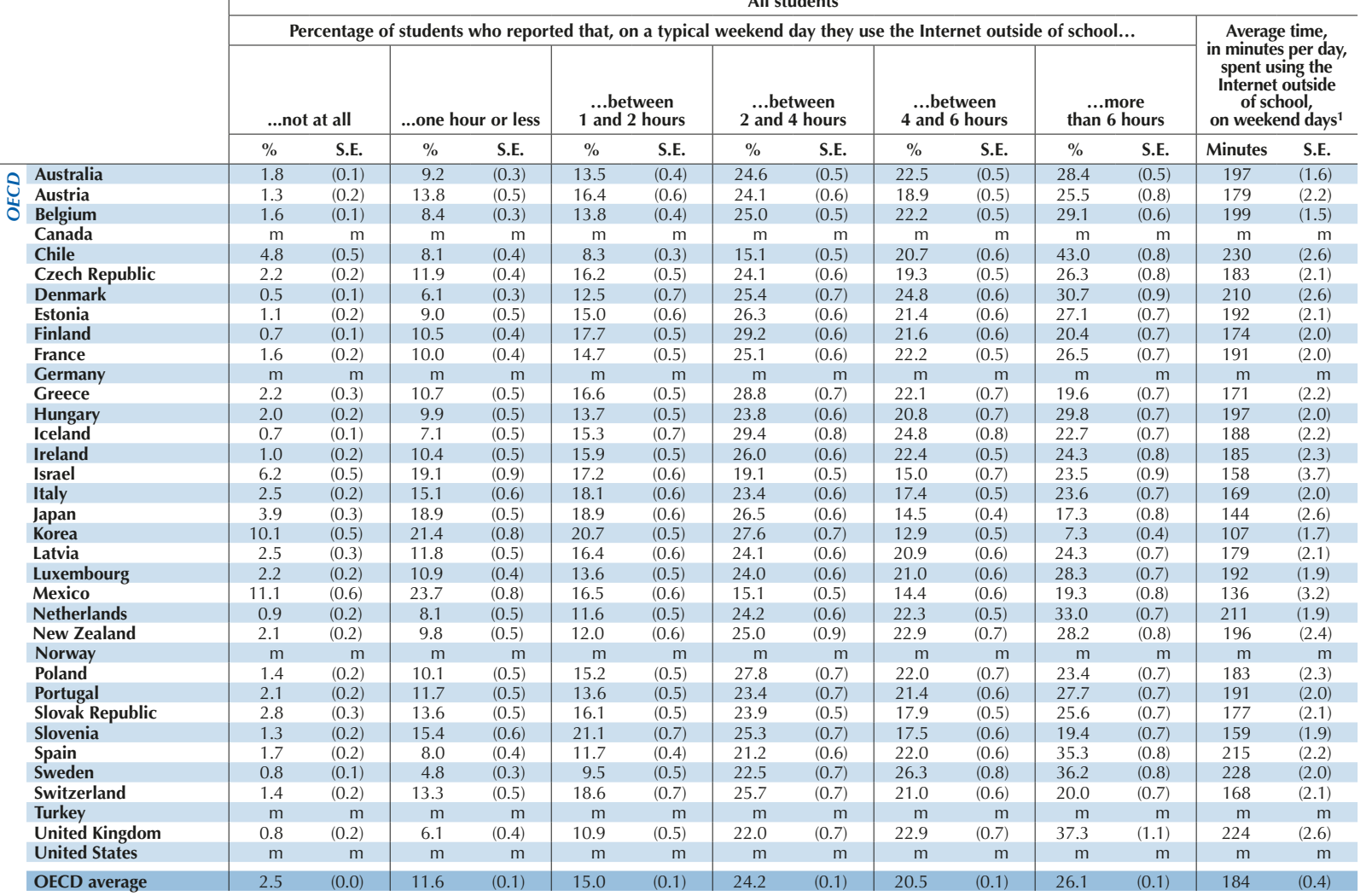

\begin{tabular}{|c|c|c|c|c|c|c|c|c|c|c|c|c|c|c|}
\hline Albania & $\mathrm{m}$ & $\mathrm{m}$ & $\mathrm{m}$ & $\mathrm{m}$ & $\mathrm{m}$ & $\mathrm{m}$ & $\mathrm{m}$ & $\mathrm{m}$ & $\mathrm{m}$ & $\mathrm{m}$ & $\mathrm{m}$ & $\mathrm{m}$ & $\mathrm{m}$ & $\mathrm{m}$ \\
\hline Algeria & $\mathrm{m}$ & $\mathrm{m}$ & $\mathrm{m}$ & $\mathrm{m}$ & $\mathrm{m}$ & $\mathrm{m}$ & $\mathrm{m}$ & $\mathrm{m}$ & $\mathrm{m}$ & $\mathrm{m}$ & $\mathrm{m}$ & $\mathrm{m}$ & $\mathrm{m}$ & $\mathrm{m}$ \\
\hline Brazil & 7.6 & $(0.3)$ & 12.4 & $(0.4)$ & 10.6 & $(0.4)$ & 13.3 & $(0.4)$ & 15.1 & $(0.3)$ & 41.1 & $(0.7)$ & 209 & (2.3) \\
\hline B-S-J-G (China) & 15.4 & $(0.8)$ & 27.0 & $(0.9)$ & 21.1 & $(0.7)$ & 15.8 & $(0.6)$ & 9.9 & $(0.5)$ & 10.7 & $(0.6)$ & 99 & (2.8) \\
\hline Bulgaria & 3.1 & $(0.3)$ & 9.4 & $(0.5)$ & 12.0 & $(0.5)$ & 19.4 & $(0.6)$ & 19.9 & $(0.6)$ & 36.2 & $(0.8)$ & 211 & (2.4) \\
\hline CABA (Argentina) & $\mathrm{m}$ & $\mathrm{m}$ & $\mathrm{m}$ & $\mathrm{m}$ & $\mathrm{m}$ & $\mathrm{m}$ & $\mathrm{m}$ & $\mathrm{m}$ & $\mathrm{m}$ & $\mathrm{m}$ & $\mathrm{m}$ & $\mathrm{m}$ & $\mathrm{m}$ & $\mathrm{m}$ \\
\hline Colombia & 11.2 & $(0.6)$ & 20.1 & $(0.6)$ & 13.7 & $(0.5)$ & 14.1 & $(0.4)$ & 14.2 & $(0.5)$ & 26.8 & $(0.8)$ & 159 & (3.2) \\
\hline Costa Rica & 6.4 & $(0.4)$ & 13.5 & $(0.6)$ & 11.4 & $(0.4)$ & 13.9 & $(0.4)$ & 15.5 & $(0.5)$ & 39.3 & $(0.7)$ & 205 & (2.6) \\
\hline Croatia & 1.7 & $(0.2)$ & 10.5 & $(0.5)$ & 14.9 & $(0.5)$ & 25.0 & $(0.7)$ & 21.8 & $(0.5)$ & 26.1 & $(0.7)$ & 188 & (2.1) \\
\hline Cyprus* & $\mathrm{m}$ & $\mathrm{m}$ & $\mathrm{m}$ & $\mathrm{m}$ & $\mathrm{m}$ & $\mathrm{m}$ & $\mathrm{m}$ & $\mathrm{m}$ & $\mathrm{m}$ & $\mathrm{m}$ & $\mathrm{m}$ & $\mathrm{m}$ & $\mathrm{m}$ & $\mathrm{m}$ \\
\hline Dominican Republic & 12.5 & $(0.8)$ & 21.5 & $(0.9)$ & 14.3 & $(0.6)$ & 12.1 & $(0.5)$ & 13.0 & $(0.7)$ & 26.6 & $(0.9)$ & 153 & (2.9) \\
\hline FYROM & $\mathrm{m}$ & $\mathrm{m}$ & $\mathrm{m}$ & $\mathrm{m}$ & $\mathrm{m}$ & $\mathrm{m}$ & $\mathrm{m}$ & $\mathrm{m}$ & $\mathrm{m}$ & $\mathrm{m}$ & $\mathrm{m}$ & $\mathrm{m}$ & $\mathrm{m}$ & $\mathrm{m}$ \\
\hline Georgia & $\mathrm{m}$ & $\mathrm{m}$ & $\mathrm{m}$ & $\mathrm{m}$ & $\mathrm{m}$ & $\mathrm{m}$ & $\mathrm{m}$ & $\mathrm{m}$ & $\mathrm{m}$ & $\mathrm{m}$ & $\mathrm{m}$ & $\mathrm{m}$ & $\mathrm{m}$ & $\mathrm{m}$ \\
\hline Hong Kong (China) & 5.6 & $(0.3)$ & 14.8 & $(0.6)$ & 13.7 & $(0.5)$ & 24.4 & $(0.7)$ & 18.8 & $(0.6)$ & 22.6 & $(0.7)$ & 167 & (2.0) \\
\hline Indonesia & $\mathrm{m}$ & $\mathrm{m}$ & $\mathrm{m}$ & $\mathrm{m}$ & $\mathrm{m}$ & $\mathrm{m}$ & $\mathrm{m}$ & $\mathrm{m}$ & $\mathrm{m}$ & $\mathrm{m}$ & $\mathrm{m}$ & $\mathrm{m}$ & $\mathrm{m}$ & $\mathrm{m}$ \\
\hline Jordan & $\mathrm{m}$ & $\mathrm{m}$ & $\mathrm{m}$ & $\mathrm{m}$ & $\mathrm{m}$ & $\mathrm{m}$ & $\mathrm{m}$ & $\mathrm{m}$ & $\mathrm{m}$ & $\mathrm{m}$ & $\mathrm{m}$ & $\mathrm{m}$ & $\mathrm{m}$ & $\mathrm{m}$ \\
\hline Kosovo & $\mathrm{m}$ & $\mathrm{m}$ & $\mathrm{m}$ & $\mathrm{m}$ & $\mathrm{m}$ & $\mathrm{m}$ & $\mathrm{m}$ & $\mathrm{m}$ & $\mathrm{m}$ & $\mathrm{m}$ & $\mathrm{m}$ & $\mathrm{m}$ & $\mathrm{m}$ & $\mathrm{m}$ \\
\hline Lebanon & $\mathrm{m}$ & $\mathrm{m}$ & $\mathrm{m}$ & $\mathrm{m}$ & $\mathrm{m}$ & $\mathrm{m}$ & $\mathrm{m}$ & $\mathrm{m}$ & $\mathrm{m}$ & $\mathrm{m}$ & $\mathrm{m}$ & $\mathrm{m}$ & $\mathrm{m}$ & $\mathrm{m}$ \\
\hline Lithuania & 3.1 & $(0.3)$ & 13.4 & $(0.6)$ & 17.8 & $(0.6)$ & 26.9 & $(0.6)$ & 20.1 & $(0.5)$ & 18.8 & $(0.6)$ & 162 & (2.0) \\
\hline Macao (China) & 5.9 & $(0.3)$ & 7.6 & $(0.4)$ & 10.1 & $(0.5)$ & 23.5 & $(0.5)$ & 22.1 & $(0.6)$ & 30.7 & $(0.7)$ & 200 & (2.0) \\
\hline Malta & $\mathrm{m}$ & $\mathrm{m}$ & $\mathrm{m}$ & $\mathrm{m}$ & $\mathrm{m}$ & $\mathrm{m}$ & $\mathrm{m}$ & $\mathrm{m}$ & $\mathrm{m}$ & $\mathrm{m}$ & $\mathrm{m}$ & $\mathrm{m}$ & $\mathrm{m}$ & $\mathrm{m}$ \\
\hline Moldova & $\mathrm{m}$ & $\mathrm{m}$ & $\mathrm{m}$ & $\mathrm{m}$ & $\mathrm{m}$ & $\mathrm{m}$ & $\mathrm{m}$ & $\mathrm{m}$ & $\mathrm{m}$ & $\mathrm{m}$ & $\mathrm{m}$ & $\mathrm{m}$ & $\mathrm{m}$ & $\mathrm{m}$ \\
\hline Montenegro & $\mathrm{m}$ & $\mathrm{m}$ & $\mathrm{m}$ & $\mathrm{m}$ & $\mathrm{m}$ & $\mathrm{m}$ & $\mathrm{m}$ & $\mathrm{m}$ & $\mathrm{m}$ & $\mathrm{m}$ & $\mathrm{m}$ & $\mathrm{m}$ & $\mathrm{m}$ & $\mathrm{m}$ \\
\hline Peru & 8.9 & $(0.5)$ & 27.3 & $(0.7)$ & 19.3 & $(0.5)$ & 18.5 & $(0.6)$ & 12.7 & $(0.5)$ & 13.3 & $(0.6)$ & 117 & (2.4) \\
\hline Qatar & $\mathrm{m}$ & $\mathrm{m}$ & $\mathrm{m}$ & $\mathrm{m}$ & $\mathrm{m}$ & $\mathrm{m}$ & $\mathrm{m}$ & $\mathrm{m}$ & $\mathrm{m}$ & $\mathrm{m}$ & $\mathrm{m}$ & $\mathrm{m}$ & $\mathrm{m}$ & $\mathrm{m}$ \\
\hline Romania & $\mathrm{m}$ & $\mathrm{m}$ & $\mathrm{m}$ & $\mathrm{m}$ & $\mathrm{m}$ & $\mathrm{m}$ & $\mathrm{m}$ & $\mathrm{m}$ & $\mathrm{m}$ & $\mathrm{m}$ & $\mathrm{m}$ & $\mathrm{m}$ & $\mathrm{m}$ & $\mathrm{m}$ \\
\hline Russia & 3.7 & $(0.3)$ & 10.0 & $(0.5)$ & 13.3 & $(0.6)$ & 23.5 & $(0.6)$ & 20.1 & $(0.7)$ & 29.5 & (1.0) & 193 & (2.7) \\
\hline Singapore & 3.4 & $(0.2)$ & 8.8 & $(0.4)$ & 12.0 & $(0.4)$ & 24.6 & $(0.5)$ & 21.1 & $(0.5)$ & 30.1 & $(0.5)$ & 198 & (1.5) \\
\hline Chinese Taipei & 3.2 & $(0.2)$ & 12.0 & $(0.4)$ & 13.6 & $(0.5)$ & 21.1 & $(0.5)$ & 17.9 & $(0.6)$ & 32.2 & $(0.7)$ & 195 & (2.2) \\
\hline Thailand & 6.5 & $(0.4)$ & 12.0 & $(0.6)$ & 12.8 & $(0.5)$ & 17.1 & $(0.6)$ & 19.5 & $(0.6)$ & 32.1 & (1.0) & 193 & (3.1) \\
\hline Trinidad and Tobago & $\mathrm{m}$ & $\mathrm{m}$ & $\mathrm{m}$ & $\mathrm{m}$ & $\mathrm{m}$ & $\mathrm{m}$ & $\mathrm{m}$ & $\mathrm{m}$ & $\mathrm{m}$ & $\mathrm{m}$ & $\mathrm{m}$ & $\mathrm{m}$ & $\mathrm{m}$ & $\mathrm{m}$ \\
\hline Tunisia & $\mathrm{m}$ & $\mathrm{m}$ & $\mathrm{m}$ & $\mathrm{m}$ & $\mathrm{m}$ & $\mathrm{m}$ & $\mathrm{m}$ & $\mathrm{m}$ & $\mathrm{m}$ & $\mathrm{m}$ & $\mathrm{m}$ & $\mathrm{m}$ & $\mathrm{m}$ & $\mathrm{m}$ \\
\hline United Arab Emirates & $\mathrm{m}$ & $\mathrm{m}$ & $\mathrm{m}$ & $\mathrm{m}$ & $\mathrm{m}$ & $\mathrm{m}$ & $\mathrm{m}$ & $\mathrm{m}$ & $\mathrm{m}$ & $\mathrm{m}$ & $\mathrm{m}$ & $\mathrm{m}$ & $\mathrm{m}$ & $\mathrm{m}$ \\
\hline Uruguay & 7.7 & $(0.4)$ & 12.8 & $(0.5)$ & 11.1 & $(0.4)$ & 15.0 & $(0.6)$ & 17.0 & $(0.6)$ & 36.3 & $(0.7)$ & 199 & (2.3) \\
\hline Viet Nam & $\mathrm{m}$ & $\mathrm{m}$ & $\mathrm{m}$ & $\mathrm{m}$ & $\mathrm{m}$ & $\mathrm{m}$ & $\mathrm{m}$ & $\mathrm{m}$ & $\mathrm{m}$ & $\mathrm{m}$ & $\mathrm{m}$ & $\mathrm{m}$ & $\mathrm{m}$ & $\mathrm{m}$ \\
\hline Argentina** & $\mathrm{m}$ & $\mathrm{m}$ & $\mathrm{m}$ & $\mathrm{m}$ & $\mathrm{m}$ & $\mathrm{m}$ & $\mathrm{m}$ & $\mathrm{m}$ & $\mathrm{m}$ & $\mathrm{m}$ & $\mathrm{m}$ & $\mathrm{m}$ & $\mathrm{m}$ & $\mathrm{m}$ \\
\hline Kazakhstan** & $\mathrm{m}$ & $\mathrm{m}$ & $\mathrm{m}$ & $\mathrm{m}$ & $\mathrm{m}$ & $\mathrm{m}$ & $\mathrm{m}$ & $\mathrm{m}$ & $\mathrm{m}$ & $\mathrm{m}$ & $\mathrm{m}$ & $\mathrm{m}$ & $\mathrm{m}$ & $\mathrm{m}$ \\
\hline Malaysia** & $\mathrm{m}$ & $\mathrm{m}$ & $\mathrm{m}$ & $\mathrm{m}$ & $\mathrm{m}$ & $\mathrm{m}$ & $\mathrm{m}$ & $\mathrm{m}$ & $\mathrm{m}$ & $\mathrm{m}$ & $\mathrm{m}$ & $\mathrm{m}$ & $\mathrm{m}$ & $\mathrm{m}$ \\
\hline
\end{tabular}

1. As answers were given on a categorical scale, it is not possible to compute exactly the average time students spend on line. The numbers in this table thus report a lower bound for the number of minutes students spend on online activities, whereby the answer "between one and two hours", for instance, is converted into " 61 minutes at least".

2. A low internet user is a student who uses the Internet for less than 1 hours per day on a typical weekend day.

3. An extreme internet user is a student who uses the Internet for more than 6 hours a day on a typical weekend day.

Note: Values that are statistically significant are indicated in bold (see Annex A3).

* See note at the beginning of this Annex.

Coverage is too small to ensure comparability (see Annex A4).

StatLink त्नाज़ http://dx.doi.org/10.1787/888933473222 
Results based on students' self-reports

\begin{tabular}{|c|c|c|c|c|c|c|c|c|c|c|c|c|c|c|c|c|c|c|}
\hline & \multicolumn{6}{|c|}{ Boys } & \multicolumn{6}{|c|}{ Girls } & \multicolumn{6}{|c|}{ Difference (B - G) } \\
\hline & \multicolumn{4}{|c|}{$\begin{array}{l}\text { Percentage of students } \\
\text { who are, on a typical } \\
\text { weekend day }\end{array}$} & \multirow{2}{*}{\multicolumn{2}{|c|}{\begin{tabular}{|c|} 
Average time, \\
in minutes per day, \\
spent using the \\
Internet outside \\
of school, \\
on weekend days ${ }^{1}$
\end{tabular}}} & \multicolumn{4}{|c|}{$\begin{array}{l}\text { Percentage of students } \\
\text { who are, on a typical } \\
\text { weekend day }\end{array}$} & \multirow{2}{*}{\multicolumn{2}{|c|}{$\begin{array}{c}\text { Average time, } \\
\text { in minutes per day, } \\
\text { spent using the } \\
\text { Internet outside } \\
\text { of school, } \\
\text { on weekend days }\end{array}$}} & \multicolumn{4}{|c|}{$\begin{array}{l}\text { Percentage of students } \\
\text { who are, on a typical } \\
\text { weekend day }\end{array}$} & \multirow{2}{*}{\multicolumn{2}{|c|}{$\begin{array}{l}\text { Average time, } \\
\text { in minutes per day, } \\
\text { spent using the } \\
\text { Internet outside } \\
\text { of school, } \\
\text { on weekend days }\end{array}$}} \\
\hline & \multicolumn{2}{|c|}{$\begin{array}{c}\text { Low Internet } \\
\text { users }^{2}\end{array}$} & \multicolumn{2}{|c|}{$\begin{array}{l}\text { Extreme } \\
\text { Internet } \\
\text { users }^{3}\end{array}$} & & & \multicolumn{2}{|c|}{$\begin{array}{c}\text { Low Internet } \\
\text { users }\end{array}$} & \multicolumn{2}{|c|}{$\begin{array}{l}\text { Extreme } \\
\text { Internet } \\
\text { users }\end{array}$} & & & \multicolumn{2}{|c|}{$\begin{array}{c}\text { Low Internet } \\
\text { users }\end{array}$} & \multicolumn{2}{|c|}{$\begin{array}{l}\text { Extreme } \\
\text { Internet } \\
\text { users }\end{array}$} & & \\
\hline & $\%$ & S.E. & $\%$ & S.E. & Minutes & S.E. & $\%$ & S.E. & $\%$ & S.E. & Minutes & S.E. & $\%$ dif. & S.E. & $\%$ dif. & S.E. & Dif. & S.E. \\
\hline Australia & 12.6 & $(0.5)$ & 30.4 & $(0.7)$ & 196 & $(2.1)$ & 9.4 & $(0.5)$ & 26.4 & $(0.7)$ & 197 & $(2.2)$ & 3.2 & $(0.6)$ & 4.0 & $(1.0)$ & -0.5 & (2.9) \\
\hline Austria & 15.2 & $(0.8)$ & 26.4 & (1.1) & 181 & (3.1) & 15.0 & $(0.6)$ & 24.5 & $(0.9)$ & 178 & (2.5) & 0.2 & (1.1) & 1.9 & $(1.2)$ & 3.0 & (3.4) \\
\hline Belgium & 10.6 & $(0.6)$ & 30.8 & $(0.8)$ & 201 & $(2.1)$ & 9.3 & $(0.5)$ & 27.4 & $(0.8)$ & 197 & $(2.2)$ & 1.3 & $(0.8)$ & 3.4 & (1.0) & 4.1 & $(2.9)$ \\
\hline Canada & $\mathrm{m}$ & $\mathrm{m}$ & $\mathrm{m}$ & $\mathrm{m}$ & $\mathrm{m}$ & $\mathrm{m}$ & $\mathrm{m}$ & $\mathrm{m}$ & $\mathrm{m}$ & $\mathrm{m}$ & $\mathrm{m}$ & $\mathrm{m}$ & $\mathrm{m}$ & $\mathrm{m}$ & $\mathrm{m}$ & $\mathrm{m}$ & $\mathrm{m}$ & $\mathrm{m}$ \\
\hline Chile & 14.7 & $(1.1)$ & 40.7 & (1.0) & 221 & (3.6) & 11.1 & $(0.8)$ & 45.2 & (1.0) & 239 & (3.0) & 3.6 & $(1.2)$ & -4.5 & (1.3) & -17.8 & $(4.3)$ \\
\hline Czech Republic & 12.7 & $(0.7)$ & 30.0 & (1.0) & 193 & $(2.8)$ & 15.5 & $(0.7)$ & 22.4 & (1.0) & 172 & $(2.6)$ & -2.9 & (1.0) & 7.6 & (1.3) & 21.3 & (3.4) \\
\hline Denmark & 6.1 & $(0.5)$ & 37.8 & (1.3) & 228 & (3.4) & \begin{tabular}{|l|}
7.1 \\
7.1
\end{tabular} & $(0.5)$ & 23.6 & (1.0) & 193 & (3.0) & -1.0 & $(0.8)$ & 14.2 & (1.5) & 34.8 & (3.8) \\
\hline Estonia & 10.0 & $(0.9)$ & 30.9 & (0.9) & 202 & (2.9) & 10.3 & $(0.7)$ & 23.2 & $(0.9)$ & 182 & $(2.8)$ & -0.3 & (1.1) & 7.8 & (1.3) & 20.1 & (3.9) \\
\hline Finland & 10.9 & $(0.7)$ & 22.5 & (1.0) & 180 & (2.9) & 11.5 & $(0.7)$ & 18.2 & $(0.8)$ & 168 & (2.5) & -0.5 & (0.9) & 4.3 & (1.2) & 11.2 & (3.6) \\
\hline France & 13.0 & $(0.8)$ & 29.2 & (1.0) & 194 & (2.9) & 10.1 & $(0.6)$ & 24.0 & (0.9) & 187 & (2.4) & 2.8 & (1.0) & 5.3 & (1.3) & 6.7 & (3.5) \\
\hline Germany & $\mathrm{m}$ & $\mathrm{m}$ & $\mathrm{m}$ & $\mathrm{m}$ & m & $\mathrm{m}$ & $\mathrm{m}$ & $\mathrm{m}$ & $\mathrm{m}$ & $\mathrm{m}$ & $\mathrm{m}$ & $\mathrm{m}$ & $\mathrm{m}$ & $\mathrm{m}$ & $\mathrm{m}$ & $\mathrm{m}$ & $\mathrm{m}$ & $\mathrm{m}$ \\
\hline Greece & 14.2 & $(0.9)$ & 19.9 & $(1.0)$ & 170 & (3.1) & 11.7 & $(0.8)$ & 19.2 & $(0.9)$ & 172 & $(2.9)$ & 2.5 & (1.1) & 0.8 & (1.3) & -2.1 & $(4.0)$ \\
\hline Hungary & 12.4 & $(0.7)$ & 30.9 & (1.0) & 198 & $(2.8)$ & 11.3 & $(0.7)$ & 28.8 & (1.1) & 196 & (2.8) & 1.1 & (0.9) & 2.1 & (1.5) & 1.3 & $(4.1)$ \\
\hline Iceland' & 7.0 & $(0.7)$ & 26.0 & (1.0) & 199 & (3.0) & 8.6 & $(0.7)$ & 19.6 & (0.9) & 178 & (2.9) & -1.6 & (0.9) & 6.4 & (1.4) & 20.3 & $(4.0)$ \\
\hline Ireland & 13.1 & $(0.8)$ & 22.9 & (1.0) & 177 & $(2.8)$ & 9.7 & (0.8) & 25.9 & (1.1) & 194 & (3.1) & 3.4 & (1.1) & -3.0 & (1.3) & -16.9 & (3.7) \\
\hline Israel & 28.0 & $(2.0)$ & 19.1 & (1.2) & 142 & (5.4) & 22.5 & (1.0) & 28.0 & (1.0) & 173 & (3.5) & 5.5 & (2.1) & -8.9 & (1.3) & -31.0 & (5.5) \\
\hline Italy & 19.3 & $(0.9)$ & 21.2 & (0.9) & 159 & (3.0) & 15.8 & $(0.7)$ & 25.9 & (0.9) & 179 & (2.5) & 3.5 & (1.1) & -4.8 & $(1.2)$ & -20.7 & $(4.1)$ \\
\hline Japan & 22.8 & $(0.8)$ & 17.1 & (1.0) & 142 & $(3.2)$ & 22.7 & $(0.8)$ & 17.6 & (1.1) & 147 & (3.4) & 0.1 & (1.0) & -0.4 & $(1.2)$ & -5.5 & $(4.0)$ \\
\hline Korea & 21.5 & (1.1) & 7.8 & (0.5) & 121 & (2.1) & 42.4 & $(1.2)$ & 6.8 & $(0.5)$ & 92 & (2.2) & -20.8 & (1.5) & 1.0 & $(0.7)$ & 29.4 & (2.8) \\
\hline Latvia & 15.6 & $(0.7)$ & 28.1 & (0.8) & 187 & $(2.7)$ & 12.9 & $(0.8)$ & 20.5 & (0.9) & 172 & (2.7) & 2.7 & (1.1) & 7.7 & (1.0) & 15.0 & (3.3) \\
\hline Luxembourg & 13.3 & $(0.7)$ & 30.0 & (1.0) & 196 & (2.6) & 13.0 & $(0.7)$ & 26.8 & (0.9) & 189 & (2.8) & 0.3 & (1.1) & 3.2 & (1.4) & 6.9 & (3.9) \\
\hline Mexico & 36.7 & $(1.3)$ & 18.0 & (0.9) & 129 & (3.5) & 32.8 & (1.3) & 20.5 & (1.0) & 142 & $(4.0)$ & 3.8 & (1.4) & -2.5 & (1.0) & -12.9 & (3.6) \\
\hline Netherlands & 8.8 & $(0.7)$ & 32.7 & (1.0) & 210 & $(2.5)$ & 9.2 & $(0.6)$ & 33.3 & $(0.9)$ & 211 & $(2.5)$ & -0.4 & $(0.8)$ & -0.6 & (1.3) & -1.5 & (3.3) \\
\hline New Zealand & 13.3 & $(0.9)$ & 28.9 & (1.1) & 194 & (3.3) & 10.5 & $(0.8)$ & 27.5 & (1.1) & 199 & (3.1) & 2.8 & (1.3) & 1.4 & (1.4) & -5.2 & (4.3) \\
\hline Norway & $\mathrm{m}$ & & $\mathrm{m}$ & & $\mathrm{m}$ & $\mathrm{m}$ & $\mathrm{m}$ & $\mathrm{m}$ & $\mathrm{m}$ & $\mathrm{m}$ & $\mathrm{m}$ & $\mathrm{m}$ & $\mathrm{m}$ & $\mathrm{m}$ & $\mathrm{m}$ & $\mathrm{m}$ & $\mathrm{m}$ & $\mathrm{m}$ \\
\hline Poland & 11.3 & $(0.6)$ & 24.8 & (1.0) & 188 & (2.9) & 11.9 & $(0.8)$ & 21.9 & $(0.9)$ & 177 & (2.9) & -0.6 & (1.0) & 2.8 & $(1.2)$ & 11.4 & (3.7) \\
\hline Portugal & 12.8 & $(0.6)$ & 32.0 & (1.1) & 201 & (2.8) & 15.0 & $(0.7)$ & 23.4 & (0.9) & 180 & (2.6) & -2.2 & (0.8) & 8.6 & (1.3) & 21.9 & (3.6) \\
\hline Slovak Republic & 17.5 & $(0.9)$ & 26.4 & (0.9) & 177 & (2.9) & 15.3 & $(0.8)$ & 24.9 & (1.0) & 177 & $(2.8)$ & 2.2 & (1.0) & 1.5 & (1.3) & 0.7 & (3.8) \\
\hline Slovenia & 17.4 & $(0.7)$ & 22.4 & (0.8) & 164 & (2.6) & 16.0 & $(0.9)$ & 16.3 & (0.9) & 154 & (2.6) & 1.4 & $(1.2)$ & 6.1 & (1.1) & 10.4 & (3.6) \\
\hline Spain & 10.7 & $(0.6)$ & 32.5 & (1.0) & 206 & $(2.8)$ & 8.9 & $(0.5)$ & 38.1 & $(1.2)$ & 223 & (3.0) & 1.8 & $(0.8)$ & -5.6 & (1.6) & -16.8 & (3.9) \\
\hline Sweden & 6.0 & $(0.5)$ & 41.4 & (1.1) & 236 & $(2.8)$ & 5.2 & $(0.4)$ & 31.1 & (1.1) & 220 & (2.6) & 0.8 & $(0.7)$ & 10.3 & (1.6) & 16.8 & (3.7) \\
\hline Switzerland & 13.9 & $(0.7)$ & 22.2 & $(0.9)$ & 174 & (2.6) & 15.5 & $(0.8)$ & 17.8 & (0.9) & 162 & (2.9) & -1.5 & (1.0) & 4.4 & $(1.2)$ & 11.4 & (3.6) \\
\hline Turkey & $\mathrm{m}$ & $\mathrm{m}$ & $\mathrm{m}$ & $\mathrm{m}$ & $\mathrm{m}$ & $\mathrm{m}$ & $\mathrm{m}$ & $\mathrm{m}$ & $\mathrm{m}$ & $\mathrm{m}$ & $\mathrm{m}$ & $\mathrm{m}$ & $\mathrm{m}$ & $\mathrm{m}$ & $\mathrm{m}$ & $\mathrm{m}$ & $\mathrm{m}$ & $\mathrm{m}$ \\
\hline United Kingdom & 6.8 & $(0.5)$ & 39.0 & (1.4) & 226 & $(3.2)$ & 7.1 & $(0.6)$ & 35.6 & (1.5) & 222 & (3.7) & -0.3 & $(0.8)$ & 3.4 & (1.9) & 4.2 & $(4.6)$ \\
\hline United States & $\mathrm{m}$ & m & $\mathrm{m}$ & $\mathrm{m}$ & $\mathrm{m}$ & m & $\mathrm{m}$ & m & m & $\mathrm{m}$ & $\mathrm{m}$ & $\mathrm{m}$ & $\mathrm{m}$ & $\mathrm{m}$ & $\mathrm{m}$ & m & $\mathrm{m}$ & m \\
\hline OECD average & 14.3 & $(0.2)$ & 27.4 & $(0.2)$ & 186 & $(0.5)$ & 13.9 & $(0.1)$ & 24.8 & $(0.2)$ & 182 & $(0.5)$ & 0.4 & $(0.2)$ & 2.6 & $(0.2)$ & 4.0 & $(0.7)$ \\
\hline
\end{tabular}

\begin{tabular}{|c|c|c|c|c|c|c|c|c|c|c|c|c|c|c|c|c|c|c|}
\hline Albania & $\mathrm{m}$ & $\mathrm{m}$ & $\mathrm{m}$ & $\mathrm{m}$ & $\mathrm{m}$ & $\mathrm{m}$ & $\mathrm{m}$ & $\mathrm{m}$ & $\mathrm{m}$ & $\mathrm{m}$ & $\mathrm{m}$ & $\mathrm{m}$ & $\mathrm{m}$ & $\mathrm{m}$ & $\mathrm{m}$ & $\mathrm{m}$ & $\mathrm{m}$ & $\mathrm{m}$ \\
\hline Algeria & $\mathrm{m}$ & $\mathrm{m}$ & $\mathrm{m}$ & $\mathrm{m}$ & $\mathrm{m}$ & $\mathrm{m}$ & $\mathrm{m}$ & $\mathrm{m}$ & $\mathrm{m}$ & $\mathrm{m}$ & $\mathrm{m}$ & $\mathrm{m}$ & $\mathrm{m}$ & $\mathrm{m}$ & $\mathrm{m}$ & $\mathrm{m}$ & $\mathrm{m}$ & $\mathrm{m}$ \\
\hline Brazil & 21.3 & $(0.8)$ & 38.5 & $(0.9)$ & 200 & (3.0) & 18.7 & $(0.6)$ & 43.5 & $(0.9)$ & 216 & $(2.9)$ & 2.6 & $(0.9)$ & -5.0 & (1.1) & -16.0 & (3.7) \\
\hline B-S-J-G (China) & 37.9 & $(1.2)$ & 13.0 & $(0.8)$ & 112 & (3.3) & 47.5 & (1.5) & 8.1 & $(0.6)$ & 85 & (3.0) & -9.6 & (1.4) & 4.9 & $(0.8)$ & 26.9 & (3.1) \\
\hline Bulgaria & 15.7 & $(0.9)$ & 34.9 & (1.1) & 202 & (3.2) & 9.1 & $(0.7)$ & 37.6 & (1.1) & 221 & (3.0) & 6.6 & $(1.0)$ & -2.7 & (1.4) & -18.9 & (4.0) \\
\hline CABA (Argentina) & $\mathrm{m}$ & $\mathrm{m}$ & $\mathrm{m}$ & $\mathrm{m}$ & $\mathrm{m}$ & $\mathrm{m}$ & $\mathrm{m}$ & $\mathrm{m}$ & $\mathrm{m}$ & $\mathrm{m}$ & $\mathrm{m}$ & $\mathrm{m}$ & $\mathrm{m}$ & $\mathrm{m}$ & $\mathrm{m}$ & $\mathrm{m}$ & $\mathrm{m}$ & $\mathrm{m}$ \\
\hline Colombia & 33.7 & (1.3) & 24.0 & $(1.0)$ & 149 & (3.8) & 29.1 & (1.1) & 29.1 & (1.1) & 168 & $(4.0)$ & 4.6 & (1.5) & -5.1 & $(1.3)$ & -19.2 & (4.7) \\
\hline Costa Rica & 21.1 & $(0.9)$ & 37.0 & $(0.9)$ & 197 & (3.4) & 18.9 & $(1.0)$ & 41.5 & (1.1) & 213 & (3.6) & 2.2 & (1.3) & -4.5 & (1.5) & -15.7 & (4.7) \\
\hline Croatia & 14.9 & $(0.9)$ & 24.7 & $(1.0)$ & 179 & (2.9) & 9.9 & $(0.6)$ & 27.3 & (1.0) & 196 & (3.1) & 5.0 & (1.0) & -2.6 & (1.4) & -16.3 & (4.2) \\
\hline Cyprus* & $\mathrm{m}$ & $\mathrm{m}$ & $\mathrm{m}$ & $\mathrm{m}$ & $\mathrm{m}$ & $\mathrm{m}$ & $\mathrm{m}$ & $\mathrm{m}$ & $\mathrm{m}$ & $\mathrm{m}$ & $\mathrm{m}$ & $\mathrm{m}$ & $\mathrm{m}$ & $\mathrm{m}$ & $\mathrm{m}$ & $\mathrm{m}$ & $\mathrm{m}$ & $\mathrm{m}$ \\
\hline Dominican Republic & 36.3 & $(1.2)$ & 22.9 & (1.1) & 142 & (3.6) & 31.8 & (1.3) & 30.2 & $(1.2)$ & 164 & $(4.2)$ & 4.5 & (1.6) & -7.3 & (1.5) & -21.9 & (5.2) \\
\hline FYROM & $\mathrm{m}$ & $\mathrm{m}$ & $\mathrm{m}$ & $\mathrm{m}$ & $\mathrm{m}$ & $\mathrm{m}$ & $\mathrm{m}$ & $\mathrm{m}$ & $\mathrm{m}$ & $\mathrm{m}$ & $\mathrm{m}$ & $\mathrm{m}$ & $\mathrm{m}$ & $\mathrm{m}$ & $\mathrm{m}$ & $\mathrm{m}$ & $\mathrm{m}$ & $\mathrm{m}$ \\
\hline Georgia & $\mathrm{m}$ & $\mathrm{m}$ & $\mathrm{m}$ & $\mathrm{m}$ & $\mathrm{m}$ & $\mathrm{m}$ & $\mathrm{m}$ & $\mathrm{m}$ & $\mathrm{m}$ & $\mathrm{m}$ & $\mathrm{m}$ & $\mathrm{m}$ & $\mathrm{m}$ & $\mathrm{m}$ & $\mathrm{m}$ & $\mathrm{m}$ & $\mathrm{m}$ & $\mathrm{m}$ \\
\hline Hong Kong (China) & 19.3 & $(0.9)$ & 26.2 & $(1.0)$ & 174 & (2.8) & 21.6 & $(0.9)$ & 19.0 & $(0.9)$ & 160 & $(2.9)$ & -2.3 & (1.3) & 7.1 & $(1.4)$ & 13.9 & (4.1) \\
\hline Indonesia & $\mathrm{m}$ & $\mathrm{m}$ & $\mathrm{m}$ & $\mathrm{m}$ & $\mathrm{m}$ & $\mathrm{m}$ & $\mathrm{m}$ & $\mathrm{m}$ & $\mathrm{m}$ & $\mathrm{m}$ & $\mathrm{m}$ & $\mathrm{m}$ & $\mathrm{m}$ & $\mathrm{m}$ & $\mathrm{m}$ & $\mathrm{m}$ & $\mathrm{m}$ & $\mathrm{m}$ \\
\hline Jordan & $\mathrm{m}$ & $\mathrm{m}$ & $\mathrm{m}$ & $\mathrm{m}$ & $\mathrm{m}$ & $\mathrm{m}$ & $\mathrm{m}$ & $\mathrm{m}$ & $\mathrm{m}$ & $\mathrm{m}$ & $\mathrm{m}$ & $\mathrm{m}$ & $\mathrm{m}$ & $\mathrm{m}$ & $\mathrm{m}$ & $\mathrm{m}$ & $\mathrm{m}$ & $\mathrm{m}$ \\
\hline Kosovo & $\mathrm{m}$ & $\mathrm{m}$ & $\mathrm{m}$ & $\mathrm{m}$ & $\mathrm{m}$ & $\mathrm{m}$ & $\mathrm{m}$ & $\mathrm{m}$ & $\mathrm{m}$ & $\mathrm{m}$ & $\mathrm{m}$ & $\mathrm{m}$ & $\mathrm{m}$ & $\mathrm{m}$ & $\mathrm{m}$ & $\mathrm{m}$ & $\mathrm{m}$ & $\mathrm{m}$ \\
\hline Lebanon & $\mathrm{m}$ & $\mathrm{m}$ & $\mathrm{m}$ & $\mathrm{m}$ & $\mathrm{m}$ & $\mathrm{m}$ & $\mathrm{m}$ & $\mathrm{m}$ & $\mathrm{m}$ & $\mathrm{m}$ & $\mathrm{m}$ & $\mathrm{m}$ & $\mathrm{m}$ & $\mathrm{m}$ & $\mathrm{m}$ & $\mathrm{m}$ & $\mathrm{m}$ & $\mathrm{m}$ \\
\hline Lithuania & 18.0 & $(0.9)$ & 21.0 & $(0.8)$ & 165 & $(2.7)$ & 15.0 & $(0.7)$ & 16.6 & $(0.9)$ & 159 & $(2.5)$ & 3.0 & $(1.0)$ & 4.4 & $(1.1)$ & 5.9 & (3.4) \\
\hline Macao (China) & 13.7 & $(0.7)$ & 31.7 & $(1.0)$ & 202 & (2.9) & 13.3 & $(0.6)$ & 29.7 & $(1.0)$ & 199 & $(2.8)$ & 0.4 & $(0.9)$ & 2.0 & $(1.4)$ & 2.7 & (4.1) \\
\hline Malta & $\mathrm{m}$ & $\mathrm{m}$ & $\mathrm{m}$ & $\mathrm{m}$ & $\mathrm{m}$ & $\mathrm{m}$ & $\mathrm{m}$ & $\mathrm{m}$ & $\mathrm{m}$ & $\mathrm{m}$ & $\mathrm{m}$ & $\mathrm{m}$ & $\mathrm{m}$ & $\mathrm{m}$ & $\mathrm{m}$ & $\mathrm{m}$ & $\mathrm{m}$ & $\mathrm{m}$ \\
\hline Moldova & $\mathrm{m}$ & $\mathrm{m}$ & $\mathrm{m}$ & $\mathrm{m}$ & $\mathrm{m}$ & $\mathrm{m}$ & $\mathrm{m}$ & $\mathrm{m}$ & $\mathrm{m}$ & $\mathrm{m}$ & $\mathrm{m}$ & $\mathrm{m}$ & $\mathrm{m}$ & $\mathrm{m}$ & $\mathrm{m}$ & $\mathrm{m}$ & $\mathrm{m}$ & $\mathrm{m}$ \\
\hline Montenegro & $\mathrm{m}$ & $\mathrm{m}$ & $\mathrm{m}$ & $\mathrm{m}$ & $\mathrm{m}$ & $\mathrm{m}$ & $\mathrm{m}$ & $\mathrm{m}$ & $\mathrm{m}$ & $\mathrm{m}$ & $\mathrm{m}$ & $\mathrm{m}$ & $\mathrm{m}$ & $\mathrm{m}$ & $\mathrm{m}$ & $\mathrm{m}$ & $\mathrm{m}$ & $\mathrm{m}$ \\
\hline Peru & 36.1 & $(1.1)$ & 12.9 & $(0.7)$ & 115 & (2.8) & 36.3 & $(1.3)$ & 13.7 & $(0.8)$ & 119 & (3.2) & -0.2 & (1.6) & -0.8 & $(0.9)$ & -4.4 & (3.6) \\
\hline Qatar & $\mathrm{m}$ & $\mathrm{m}$ & $\mathrm{m}$ & $\mathrm{m}$ & $\mathrm{m}$ & $\mathrm{m}$ & $\mathrm{m}$ & $\mathrm{m}$ & $\mathrm{m}$ & $\mathrm{m}$ & $\mathrm{m}$ & $\mathrm{m}$ & $\mathrm{m}$ & $\mathrm{m}$ & $\mathrm{m}$ & $\mathrm{m}$ & $\mathrm{m}$ & $\mathrm{m}$ \\
\hline Romania & $\mathrm{m}$ & $\mathrm{m}$ & $\mathrm{m}$ & $\mathrm{m}$ & $\mathrm{m}$ & $\mathrm{m}$ & $\mathrm{m}$ & $\mathrm{m}$ & $\mathrm{m}$ & $\mathrm{m}$ & $\mathrm{m}$ & $\mathrm{m}$ & $\mathrm{m}$ & $\mathrm{m}$ & $\mathrm{m}$ & $\mathrm{m}$ & $\mathrm{m}$ & $\mathrm{m}$ \\
\hline Russia & 15.1 & $(0.8)$ & 28.8 & (1.5) & 188 & (4.1) & 12.2 & $(0.7)$ & 30.1 & $(1.0)$ & 197 & $(2.5)$ & 2.9 & (1.1) & -1.3 & (1.6) & -9.0 & (4.1) \\
\hline Singapore & 13.8 & $(0.6)$ & 31.3 & $(0.8)$ & 198 & (2.1) & 10.6 & $(0.6)$ & 28.8 & $(0.9)$ & 198 & $(2.4)$ & 3.2 & $(0.9)$ & 2.5 & $(1.3)$ & 0.3 & (3.4) \\
\hline Chinese Taipei & 13.3 & $(0.6)$ & 34.2 & (1.1) & 203 & (3.0) & 17.2 & $(0.7)$ & 30.1 & $(1.0)$ & 187 & (3.1) & -3.9 & $(0.9)$ & 4.0 & (1.5) & 16.0 & (4.2) \\
\hline Thailand & 20.2 & $(1.1)$ & 31.7 & (1.3) & 187 & (4.1) & 17.2 & $(0.9)$ & 32.4 & $(1.2)$ & 198 & (3.5) & 3.0 & $(1.2)$ & -0.7 & (1.5) & -10.4 & (4.4) \\
\hline Trinidad and Tobago & $\mathrm{m}$ & $\mathrm{m}$ & $\mathrm{m}$ & $\mathrm{m}$ & $\mathrm{m}$ & $\mathrm{m}$ & $\mathrm{m}$ & $\mathrm{m}$ & $\mathrm{m}$ & $\mathrm{m}$ & $\mathrm{m}$ & $\mathrm{m}$ & $\mathrm{m}$ & $\mathrm{m}$ & $\mathrm{m}$ & $\mathrm{m}$ & $\mathrm{m}$ & $\mathrm{m}$ \\
\hline Tunisia & $\mathrm{m}$ & $\mathrm{m}$ & $\mathrm{m}$ & $\mathrm{m}$ & $\mathrm{m}$ & $\mathrm{m}$ & $\mathrm{m}$ & $\mathrm{m}$ & $\mathrm{m}$ & $\mathrm{m}$ & $\mathrm{m}$ & $\mathrm{m}$ & $\mathrm{m}$ & $\mathrm{m}$ & $\mathrm{m}$ & $\mathrm{m}$ & $\mathrm{m}$ & $\mathrm{m}$ \\
\hline United Arab Emirates & $\mathrm{m}$ & $\mathrm{m}$ & $\mathrm{m}$ & $\mathrm{m}$ & $\mathrm{m}$ & $\mathrm{m}$ & $\mathrm{m}$ & $\mathrm{m}$ & $\mathrm{m}$ & $\mathrm{m}$ & $\mathrm{m}$ & $\mathrm{m}$ & $\mathrm{m}$ & $\mathrm{m}$ & $\mathrm{m}$ & $\mathrm{m}$ & $\mathrm{m}$ & $\mathrm{m}$ \\
\hline Uruguay & 23.3 & $(1.1)$ & 32.5 & (1.1) & 185 & (3.5) & 18.1 & $(0.8)$ & 39.6 & $(0.9)$ & 211 & $(3.0)$ & 5.2 & $(1.3)$ & -7.1 & $(1.4)$ & -25.8 & (4.5) \\
\hline Viet Nam & $\mathrm{m}$ & $\mathrm{m}$ & $\mathrm{m}$ & $\mathrm{m}$ & $\mathrm{m}$ & $\mathrm{m}$ & $\mathrm{m}$ & $\mathrm{m}$ & $\mathrm{m}$ & $\mathrm{m}$ & $\mathrm{m}$ & $\mathrm{m}$ & $\mathrm{m}$ & $\mathrm{m}$ & $\mathrm{m}$ & $\mathrm{m}$ & $\mathrm{m}$ & $\mathrm{m}$ \\
\hline Argentina** & $\mathrm{m}$ & $\mathrm{m}$ & $\mathrm{m}$ & $\mathrm{m}$ & $\mathrm{m}$ & $\mathrm{m}$ & $\mathrm{m}$ & $\mathrm{m}$ & $\mathrm{m}$ & $\mathrm{m}$ & $\mathrm{m}$ & $\mathrm{m}$ & $\mathrm{m}$ & $\mathrm{m}$ & $\mathrm{m}$ & $\mathrm{m}$ & $\mathrm{m}$ & $\mathrm{m}$ \\
\hline Kazakhstan** & $\mathrm{m}$ & $\mathrm{m}$ & $\mathrm{m}$ & $\mathrm{m}$ & $\mathrm{m}$ & $\mathrm{m}$ & $\mathrm{m}$ & $\mathrm{m}$ & $\mathrm{m}$ & $\mathrm{m}$ & $\mathrm{m}$ & $\mathrm{m}$ & $\mathrm{m}$ & $\mathrm{m}$ & $\mathrm{m}$ & $\mathrm{m}$ & $\mathrm{m}$ & $\mathrm{m}$ \\
\hline Malaysia** & $\mathrm{m}$ & $\mathrm{m}$ & $\mathrm{m}$ & $\mathrm{m}$ & $\mathrm{m}$ & $\mathrm{m}$ & $\mathrm{m}$ & $\mathrm{m}$ & $\mathrm{m}$ & $\mathrm{m}$ & $\mathrm{m}$ & $\mathrm{m}$ & $\mathrm{m}$ & $\mathrm{m}$ & $\mathrm{m}$ & $\mathrm{m}$ & $\mathrm{m}$ & $\mathrm{m}$ \\
\hline
\end{tabular}

1. As answers were given on a categorical scale, it is not possible to compute exactly the average time students spend on line. The numbers in this table thus report a lower bound for the number of minutes students spend on online activities, whereby the answer "between one and two hours", for instance, is converted into " 61 minutes at least".

2. A low internet user is a student who uses the Internet for less than 1 hours per day on a typical weekend day

3. An extreme internet user is a student who uses the Internet for more than 6 hours a day on a typical weekend day.

Note: Values that are statistically significant are indicated in bold (see Annex A3).

* See note at the beginning of this Annex.

** Coverage is too small to ensure comparability (see Annex A4).

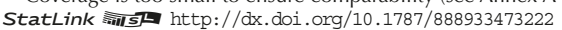


Table III.13.9 Change between 2012 and 2015 in time spent using the Internet outside of school

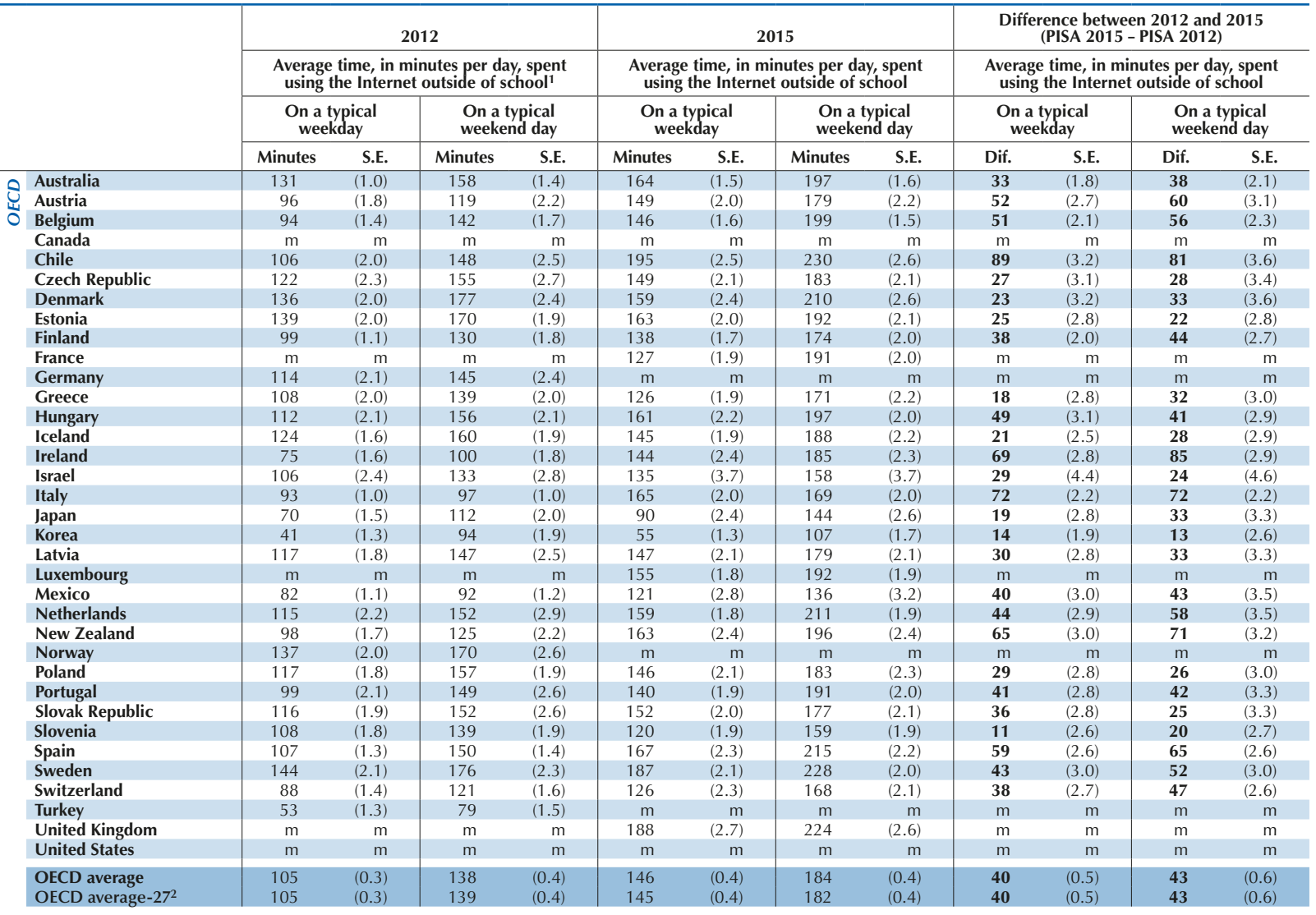

\begin{tabular}{|c|c|c|c|c|c|c|c|c|c|c|c|c|c|}
\hline 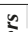 & Albania & $\mathrm{m}$ & $\mathrm{m}$ & $\mathrm{m}$ & $\mathrm{m}$ & $\mathrm{m}$ & $\mathrm{m}$ & $\mathrm{m}$ & $\mathrm{m}$ & $\mathrm{m}$ & $\mathrm{m}$ & $\mathrm{m}$ & $\mathrm{m}$ \\
\hline$\Xi$ & Algeria & $\mathrm{m}$ & $\mathrm{m}$ & $\mathrm{m}$ & $\mathrm{m}$ & $\mathrm{m}$ & $\mathrm{m}$ & $\mathrm{m}$ & $\mathrm{m}$ & $\mathrm{m}$ & $\mathrm{m}$ & $\mathrm{m}$ & $\mathrm{m}$ \\
\hline 些 & Brazil & $\mathrm{m}$ & $\mathrm{m}$ & $\mathrm{m}$ & $\mathrm{m}$ & 190 & $(2.6)$ & 209 & $(2.3)$ & $\mathrm{m}$ & $\mathrm{m}$ & $\mathrm{m}$ & $\mathrm{m}$ \\
\hline & B-S-J-G (China) & $\mathrm{m}$ & $\mathrm{m}$ & $\mathrm{m}$ & $\mathrm{m}$ & 42 & (1.6) & 99 & $(2.8)$ & $\mathrm{m}$ & $\mathrm{m}$ & $\mathrm{m}$ & $\mathrm{m}$ \\
\hline & Bulgaria & $\mathrm{m}$ & $\mathrm{m}$ & $\mathrm{m}$ & $\mathrm{m}$ & 187 & $(2.3)$ & 211 & $(2.4)$ & $\mathrm{m}$ & $\mathrm{m}$ & $\mathrm{m}$ & $\mathrm{m}$ \\
\hline & CABA (Argentina) & $\mathrm{m}$ & $\mathrm{m}$ & $\mathrm{m}$ & $\mathrm{m}$ & $\mathrm{m}$ & $\mathrm{m}$ & $\mathrm{m}$ & $\mathrm{m}$ & $\mathrm{m}$ & $\mathrm{m}$ & $\mathrm{m}$ & $\mathrm{m}$ \\
\hline & Colombia & $\mathrm{m}$ & $\mathrm{m}$ & $\mathrm{m}$ & $\mathrm{m}$ & 143 & (2.9) & 159 & $(3.2)$ & $\mathrm{m}$ & $\mathrm{m}$ & $\mathrm{m}$ & $\mathrm{m}$ \\
\hline & Costa Rica & 92 & $(2.1)$ & 114 & $(2.5)$ & 182 & $(2.7)$ & 205 & (2.6) & 91 & (3.5) & 91 & $(3.6$ \\
\hline & Croatia & 103 & (1.8) & 143 & $(1.8)$ & 141 & $(2.0)$ & 188 & $(2.1)$ & 38 & $(2.7)$ & 45 & $(2.8$ \\
\hline & Cyprus* & $\mathrm{m}$ & $\mathrm{m}$ & $\mathrm{m}$ & $\mathrm{m}$ & $\mathrm{m}$ & $\mathrm{m}$ & $\mathrm{m}$ & $\mathrm{m}$ & $\mathrm{m}$ & $\mathrm{m}$ & $\mathrm{m}$ & $\mathrm{m}$ \\
\hline & Dominican Republic & $\mathrm{m}$ & $\mathrm{m}$ & $\mathrm{m}$ & $\mathrm{m}$ & 130 & $(2.8)$ & 153 & $(2.9)$ & $\mathrm{m}$ & $\mathrm{m}$ & $\mathrm{m}$ & $\mathrm{m}$ \\
\hline & FYROM & $\mathrm{m}$ & $\mathrm{m}$ & $\mathrm{m}$ & $\mathrm{m}$ & $\mathrm{m}$ & $\mathrm{m}$ & $\mathrm{m}$ & $\mathrm{m}$ & $\mathrm{m}$ & $\mathrm{m}$ & $\mathrm{m}$ & $\mathrm{m}$ \\
\hline & Georgia & $\mathrm{m}$ & $\mathrm{m}$ & $\mathrm{m}$ & $\mathrm{m}$ & $\mathrm{m}$ & $\mathrm{m}$ & $\mathrm{m}$ & $\mathrm{m}$ & $\mathrm{m}$ & $\mathrm{m}$ & $\mathrm{m}$ & $\mathrm{m}$ \\
\hline & Hong Kong (China) & 111 & (1.6) & 165 & $(2.0)$ & 123 & $(2.0)$ & 167 & $(2.0)$ & 11 & (2.6) & 3 & $(2.8$ \\
\hline & Indonesia & $\mathrm{m}$ & $\mathrm{m}$ & $\mathrm{m}$ & $\mathrm{m}$ & $\mathrm{m}$ & $\mathrm{m}$ & $\mathrm{m}$ & $\mathrm{m}$ & $\mathrm{m}$ & $\mathrm{m}$ & $\mathrm{m}$ & $\mathrm{n}$ \\
\hline & Jordan & 70 & (1.7) & 112 & $(2.4)$ & $\mathrm{m}$ & $\mathrm{m}$ & $\mathrm{m}$ & $\mathrm{m}$ & $\mathrm{m}$ & $\mathrm{m}$ & $\mathrm{m}$ & $\mathrm{m}$ \\
\hline & Kosovo & $\mathrm{m}$ & $\mathrm{m}$ & $\mathrm{m}$ & $\mathrm{m}$ & $\mathrm{m}$ & $\mathrm{m}$ & $\mathrm{m}$ & $\mathrm{m}$ & $\mathrm{m}$ & $\mathrm{m}$ & $\mathrm{m}$ & $\mathrm{n}$ \\
\hline & Lebanon & $\mathrm{m}$ & $\mathrm{m}$ & $\mathrm{m}$ & $\mathrm{m}$ & $\mathrm{m}$ & $\mathrm{m}$ & $\mathrm{m}$ & $\mathrm{m}$ & $\mathrm{m}$ & $\mathrm{m}$ & $\mathrm{m}$ & $\mathrm{m}$ \\
\hline & Lithuania & $\mathrm{m}$ & $\mathrm{m}$ & $\mathrm{m}$ & $\mathrm{m}$ & 137 & (1.8) & 162 & $(2.0)$ & $\mathrm{m}$ & $\mathrm{m}$ & $\mathrm{m}$ & $\mathrm{n}$ \\
\hline & Macao (China) & 112 & (1.5) & 178 & $(2.0)$ & 130 & (1.7) & 200 & $(2.0)$ & 17 & $(2.3)$ & 22 & $(2.8$ \\
\hline & Malta & $\mathrm{m}$ & $\mathrm{m}$ & $\mathrm{m}$ & $\mathrm{m}$ & $\mathrm{m}$ & $\mathrm{m}$ & $\mathrm{m}$ & $\mathrm{m}$ & $\mathrm{m}$ & $\mathrm{m}$ & $\mathrm{m}$ & $\mathrm{m}$ \\
\hline & Moldova & $\mathrm{m}$ & $\mathrm{m}$ & $\mathrm{m}$ & $\mathrm{m}$ & $\mathrm{m}$ & $\mathrm{m}$ & $\mathrm{m}$ & $\mathrm{m}$ & $\mathrm{m}$ & $\mathrm{m}$ & $\mathrm{m}$ & $\mathrm{m}$ \\
\hline & Montenegro & $\mathrm{m}$ & $\mathrm{m}$ & $\mathrm{m}$ & $\mathrm{m}$ & $\mathrm{m}$ & $\mathrm{m}$ & $\mathrm{m}$ & $\mathrm{m}$ & $\mathrm{m}$ & $\mathrm{m}$ & $\mathrm{m}$ & $\mathrm{m}$ \\
\hline & Peru & $\mathrm{m}$ & $\mathrm{m}$ & $\mathrm{m}$ & $\mathrm{m}$ & 92 & $(2.2)$ & 117 & $(2.4)$ & $\mathrm{m}$ & $\mathrm{m}$ & $\mathrm{m}$ & $\mathrm{m}$ \\
\hline & Qatar & $\mathrm{m}$ & $\mathrm{m}$ & $\mathrm{m}$ & $\mathrm{m}$ & $\mathrm{m}$ & $\mathrm{m}$ & $\mathrm{m}$ & $\mathrm{m}$ & $\mathrm{m}$ & $\mathrm{m}$ & $\mathrm{m}$ & $\mathrm{m}$ \\
\hline & Romania & $\mathrm{m}$ & $\mathrm{m}$ & $\mathrm{m}$ & $\mathrm{m}$ & $\mathrm{m}$ & $\mathrm{m}$ & $\mathrm{m}$ & $\mathrm{m}$ & $\mathrm{m}$ & $\mathrm{m}$ & $\mathrm{m}$ & $\mathrm{m}$ \\
\hline & Russia & 130 & (3.0) & 162 & $(2.8)$ & 161 & (2.6) & 193 & $(2.7)$ & 31 & $(4.0)$ & 32 & $(3.8$ \\
\hline & Singapore & 102 & (1.5) & 152 & $(1.8)$ & 147 & (1.4) & 198 & $(1.5)$ & 45 & $(2.1)$ & 47 & $(2.4$ \\
\hline & Chinese Taipei & $\mathrm{m}$ & $\mathrm{m}$ & $\mathrm{m}$ & $\mathrm{m}$ & 120 & $(2.0)$ & 195 & $(2.2)$ & $\mathrm{m}$ & $\mathrm{m}$ & $\mathrm{m}$ & $\mathrm{m}$ \\
\hline & Thailand & $\mathrm{m}$ & $\mathrm{m}$ & $\mathrm{m}$ & $\mathrm{m}$ & 122 & (2.4) & 193 & $(3.1)$ & $\mathrm{m}$ & $\mathrm{m}$ & $\mathrm{m}$ & $\mathrm{m}$ \\
\hline & Trinidad and Tobago & $\mathrm{m}$ & $\mathrm{m}$ & $\mathrm{m}$ & $\mathrm{m}$ & $\mathrm{m}$ & $\mathrm{m}$ & $\mathrm{m}$ & $\mathrm{m}$ & $\mathrm{m}$ & $\mathrm{m}$ & $\mathrm{m}$ & $\mathrm{m}$ \\
\hline & Tunisia & $\mathrm{m}$ & $\mathrm{m}$ & $\mathrm{m}$ & $\mathrm{m}$ & $\mathrm{m}$ & $\mathrm{m}$ & $\mathrm{m}$ & $\mathrm{m}$ & $\mathrm{m}$ & $\mathrm{m}$ & $\mathrm{m}$ & $\mathrm{m}$ \\
\hline & United Arab Emirates & $\mathrm{m}$ & $\mathrm{m}$ & $\mathrm{m}$ & $\mathrm{m}$ & $\mathrm{m}$ & $\mathrm{m}$ & $\mathrm{m}$ & $\mathrm{m}$ & $\mathrm{m}$ & $\mathrm{m}$ & $\mathrm{m}$ & $\mathrm{m}$ \\
\hline & Uruguay & 118 & $(2.2)$ & 144 & $(2.5)$ & 185 & (2.1) & 199 & $(2.3)$ & 67 & (3.0) & 55 & $(3.4$ \\
\hline & Viet Nam & $\mathrm{m}$ & $\mathrm{m}$ & $\mathrm{m}$ & $\mathrm{m}$ & $\mathrm{m}$ & $\mathrm{m}$ & $\mathrm{m}$ & $\mathrm{m}$ & $\mathrm{m}$ & $\mathrm{m}$ & $\mathrm{m}$ & $\mathrm{m}$ \\
\hline & Argentina** & $\mathrm{m}$ & $\mathrm{m}$ & $\mathrm{m}$ & $\mathrm{m}$ & $\mathrm{m}$ & $\mathrm{m}$ & $\mathrm{m}$ & $\mathrm{m}$ & $\mathrm{m}$ & $\mathrm{m}$ & $\mathrm{m}$ & $\mathrm{m}$ \\
\hline & Kazakhstan** & $\mathrm{m}$ & $\mathrm{m}$ & $\mathrm{m}$ & $\mathrm{m}$ & $\mathrm{m}$ & $\mathrm{m}$ & $\mathrm{m}$ & $\mathrm{m}$ & $\mathrm{m}$ & $\mathrm{m}$ & $\mathrm{m}$ & $\mathrm{m}$ \\
\hline & Malaysia** & $\mathrm{m}$ & $\mathrm{m}$ & $\mathrm{m}$ & $\mathrm{m}$ & $\mathrm{m}$ & $\mathrm{m}$ & $\mathrm{m}$ & $\mathrm{m}$ & $\mathrm{m}$ & $\mathrm{m}$ & $\mathrm{m}$ & $\mathrm{m}$ \\
\hline
\end{tabular}

1. As the answers were given on a categorical scale, it is not possible to compute exactly the average time students spend on line. The numbers in this table thus report a lower bound for the number of minutes students spend on online activities, whereby the answer "between one and two hours", for instance, is converted into " 61 minutes at least". 2. "OECD average-27"includes all OECD countries with avallable data for both years.

Note: Values that are statistically significant are indicated in bold (see Annex A3).

* See note at the beginning of this Annex.

** Coverage is too small to ensure comparability (see Annex A4).

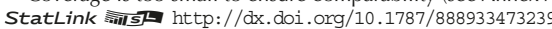


[Part 1/1]

Table III.13.10 Use of Internet/chat/social networks before and after school

Based on students' self-reports

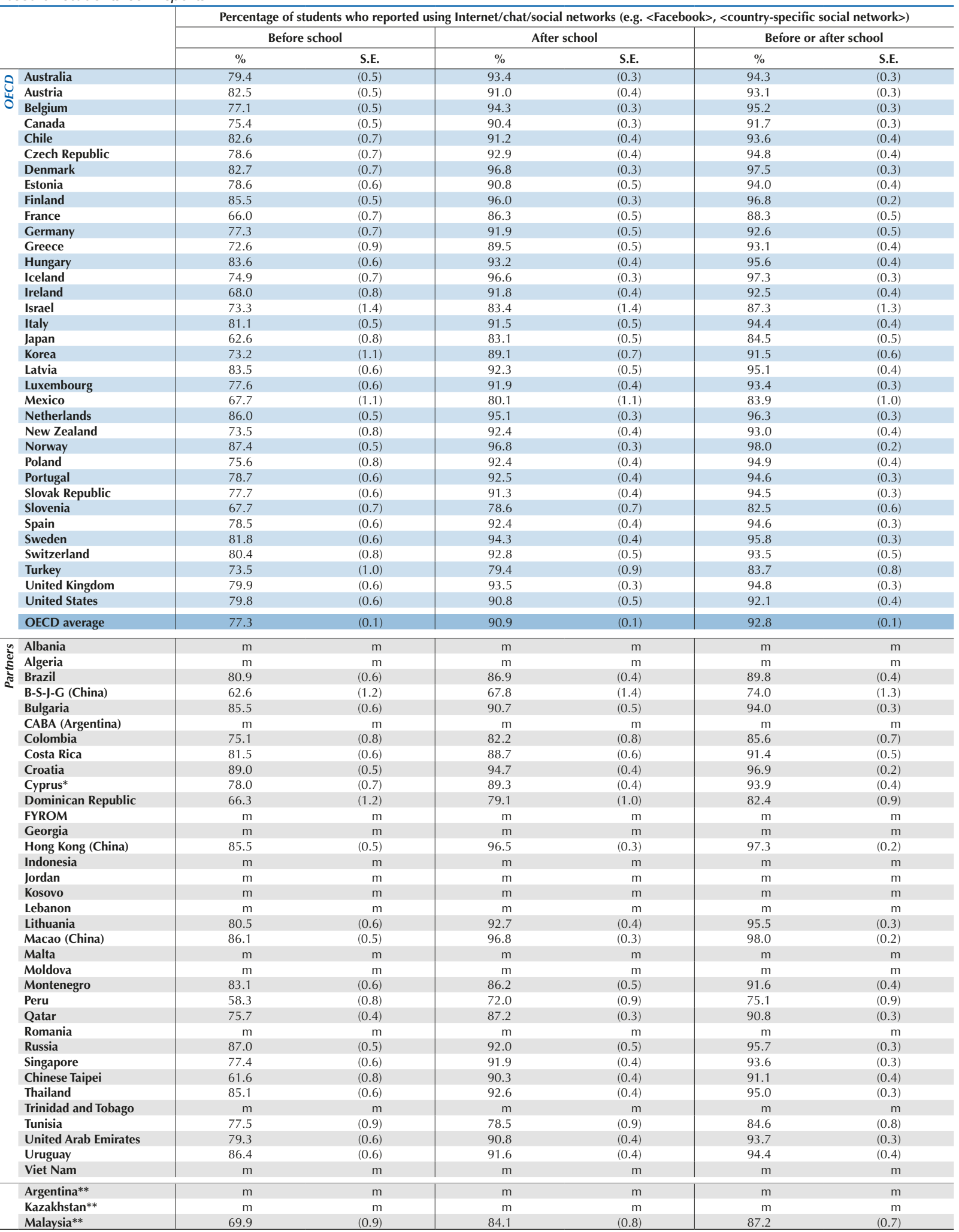

* See note at the beginning of this Annex.

** Coverage is too small to ensure comparability (see Annex A4).

StatLink तiा sL http://dx.doi.org/10.1787/888933473247 
[Part 1/4]

Table III.13.11 Use of Internet/chat/social networks before and after school, by student characteristics

\begin{tabular}{|c|c|c|c|c|c|c|c|c|c|c|c|}
\hline & \multicolumn{10}{|c|}{$\begin{array}{l}\text { Percentage of students who reported that they use the Internet/Chat/Social networks } \\
(\text { e.g. }<\text { Facebook }>,<\text { country-specific social network }>) \text { before school, by: }\end{array}$} \\
\hline & & \multicolumn{10}{|c|}{ National quarters of the ESCS ${ }^{1}$ index } \\
\hline & & \multicolumn{2}{|c|}{ Bottom quarter } & \multicolumn{2}{|c|}{ Second quarter } & & & & & Top - b & juarter \\
\hline & & $\%$ & S.E. & $\%$ & S.E. & $\%$ & S.E. & $\%$ & S.E. & $\%$ dif. & S.E. \\
\hline 0 & Australia & 80.2 & (1.0) & 81.1 & (1.0) & 79.6 & (0.9) & 76.8 & $(1.0)$ & -3.4 & (1.3) \\
\hline U్山 & Austria & 84.9 & (1.1) & 85.3 & (1.1) & 81.2 & $(1.0)$ & 78.5 & (1.3) & -6.5 & (1.6) \\
\hline 0 & Belgium & 78.5 & (1.3) & 79.1 & $(0.7)$ & 77.9 & (0.9) & 73.2 & (1.1) & -5.3 & (1.8) \\
\hline & Canada & 76.8 & (0.9) & 76.3 & (0.9) & 74.4 & $(1.2)$ & 74.2 & $(0.9)$ & -2.7 & $(1.2)$ \\
\hline & Chile & 79.7 & (1.3) & 82.5 & $(1.2)$ & 84.6 & (1.1) & 83.7 & (1.1) & 4.0 & (1.6) \\
\hline & Czech Republic & 82.3 & $(1.1)$ & 79.9 & $(1.3)$ & 77.6 & $(1.2)$ & 74.7 & (1.4) & -7.6 & (1.6) \\
\hline & Denmark & 83.3 & (1.2) & 84.0 & (1.1) & 82.9 & (1.4) & 81.0 & (1.4) & -2.2 & (1.8) \\
\hline & Estonia & 79.5 & (1.1) & 81.8 & (1.3) & 76.9 & (1.3) & 76.3 & (1.2) & -3.2 & (1.7) \\
\hline & Finland & 84.5 & $(0.9)$ & 85.7 & $(1.0)$ & 85.4 & $(1.2)$ & 86.1 & $(1.0)$ & 1.6 & (1.4) \\
\hline & France & 68.5 & (1.5) & 68.8 & (1.1) & 65.6 & (1.4) & 61.6 & (1.3) & -6.9 & (1.9) \\
\hline & Germany & 81.5 & (1.6) & 76.7 & (1.7) & 77.3 & (1.7) & 74.1 & (1.7) & -7.4 & (2.3) \\
\hline & Greece & 73.3 & $(1.7)$ & 76.9 & (1.5) & 73.4 & (1.4) & 67.2 & (1.8) & -6.1 & $(2.1)$ \\
\hline & Hungary & 83.8 & $(1.2)$ & 86.6 & $(1.2)$ & 83.3 & (1.0) & 80.8 & (1.3) & -3.0 & (2.0) \\
\hline & Iceland & 78.2 & (1.7) & 74.6 & (1.7) & 71.8 & (1.5) & 75.1 & (1.6) & -3.1 & (2.4) \\
\hline & Ireland & 69.7 & (1.5) & 69.6 & (1.3) & 67.9 & (1.5) & 65.1 & (1.5) & -4.6 & (2.3) \\
\hline & Israel & 76.3 & (1.4) & 72.5 & (2.0) & 71.8 & $(2.3)$ & 72.4 & $(2.0)$ & -3.9 & $(2.2)$ \\
\hline & Italy & 82.8 & (1.1) & 82.0 & (1.1) & 80.6 & (1.0) & 78.8 & (1.1) & -3.9 & (1.4) \\
\hline & Japan & 65.0 & (1.3) & 64.9 & (1.3) & 59.8 & (1.3) & 60.3 & (1.4) & -4.7 & (1.9) \\
\hline & Korea & 77.3 & (1.3) & 77.4 & (1.3) & 73.6 & (1.9) & 64.2 & $(2.0)$ & -13.1 & (2.1) \\
\hline & Latvia & 84.1 & (1.1) & 85.7 & $(1.1)$ & 84.4 & (1.1) & 79.9 & $(1.2)$ & -4.1 & (1.5) \\
\hline & Luxembourg & 79.9 & (1.2) & 81.3 & $(1.3)$ & 76.6 & (1.5) & 73.1 & (1.3) & -6.8 & (1.7) \\
\hline & Mexico & 44.8 & (2.6) & 66.0 & $(1.8)$ & 75.6 & $(1.2)$ & 80.8 & (1.1) & 36.0 & (2.8) \\
\hline & Netherlands & 87.2 & $(0.9)$ & 86.6 & (1.1) & 86.2 & (1.1) & 84.1 & $(1.3)$ & -3.1 & (1.7) \\
\hline & New Zealand & 78.7 & (1.5) & 74.7 & (1.6) & 71.7 & (1.5) & 68.9 & (1.5) & -9.8 & $(1.8)$ \\
\hline & Norway & 87.8 & $(1.0)$ & 87.6 & $(1.0)$ & 88.3 & $(0.9)$ & 86.2 & $(1.2)$ & -1.6 & (1.4) \\
\hline & Poland & 75.6 & (1.4) & 76.3 & (1.4) & 77.6 & (1.3) & 72.7 & (1.6) & -3.0 & (1.9) \\
\hline & Portugal & 80.6 & (1.1) & 82.0 & (1.4) & 78.6 & $(1.2)$ & 73.6 & (1.4) & -6.9 & $(1.7)$ \\
\hline & Slovak Republic & 78.6 & $(1.3)$ & 80.4 & (1.1) & 78.4 & (1.3) & 73.6 & $(1.2)$ & -5.0 & (1.7) \\
\hline & Slovenia & 73.5 & (1.4) & 68.5 & (1.4) & 63.6 & (1.5) & 65.2 & (1.7) & -8.2 & (2.1) \\
\hline & Spain & 79.7 & $(1.3)$ & 79.6 & $(1.2)$ & 79.0 & (1.1) & 75.8 & (1.4) & -3.9 & (1.9) \\
\hline & Sweden & 80.7 & $(1.2)$ & 81.3 & (1.4) & 82.5 & (1.3) & 82.6 & (1.3) & 1.8 & (1.8) \\
\hline & Switzerland & 83.7 & (1.1) & 81.3 & (1.4) & 81.6 & (1.6) & 75.3 & (1.6) & -8.3 & (2.0) \\
\hline & Turkey & 60.1 & (2.0) & 72.9 & (1.5) & 79.1 & (1.5) & 81.6 & $(1.3)$ & 21.4 & (2.4) \\
\hline & United Kingdom & 80.6 & $(1.2)$ & 83.1 & $(1.0)$ & 80.4 & (1.3) & 75.8 & (1.1) & -4.8 & (1.6) \\
\hline & United States & 81.1 & (1.1) & 82.0 & $(1.2)$ & 80.5 & (1.2) & 75.6 & (1.2) & -5.5 & (1.7) \\
\hline & OECD average & 77.8 & $(0.2)$ & 78.7 & $(0.2)$ & 77.4 & $(0.2)$ & 75.1 & $(0.2)$ & -2.7 & $(0.3)$ \\
\hline 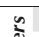 & Albania & $\mathrm{m}$ & $\mathrm{m}$ & $\mathrm{m}$ & $\mathrm{m}$ & $\mathrm{m}$ & $\mathrm{m}$ & $\mathrm{m}$ & $\mathrm{m}$ & $\mathrm{m}$ & $\mathrm{m}$ \\
\hline ఏ & Algeria & $\mathrm{m}$ & $\mathrm{m}$ & $\mathrm{m}$ & $\mathrm{m}$ & $\mathrm{m}$ & $\mathrm{m}$ & $\mathrm{m}$ & $\mathrm{m}$ & $\mathrm{m}$ & $\mathrm{m}$ \\
\hline ปั & Brazil & 67.7 & (1.3) & 81.0 & $(1.1)$ & 84.4 & (1.0) & 86.7 & $(0.8)$ & 19.0 & (1.5) \\
\hline$a^{2}$ & B-S-J-G (China) & 65.2 & (1.4) & 65.0 & (1.9) & 62.1 & (1.9) & 58.0 & $(2.2)$ & -7.2 & (2.3) \\
\hline & Bulgaria & 84.9 & (1.2) & 85.9 & (1.2) & 88.1 & (1.2) & 83.1 & (1.3) & -1.8 & (1.8) \\
\hline & CABA (Argentina) & $\mathrm{m}$ & $\mathrm{m}$ & $\mathrm{m}$ & $\mathrm{m}$ & $\mathrm{m}$ & $\mathrm{m}$ & $\mathrm{m}$ & $\mathrm{m}$ & $\mathrm{m}$ & $\mathrm{m}$ \\
\hline & Colombia & 56.2 & (1.7) & 74.7 & (1.4) & 82.0 & (1.0) & 86.4 & $(0.9)$ & 30.1 & (2.0) \\
\hline & Costa Rica & 71.4 & (1.3) & 80.0 & (1.6) & 84.7 & (1.1) & 89.2 & (1.1) & 17.8 & (1.7) \\
\hline & Croatia & 87.5 & $(0.9)$ & 89.7 & $(0.9)$ & 89.3 & $(0.9)$ & 89.3 & $(1.0)$ & 1.9 & (1.3) \\
\hline & Cyprus* & 76.5 & $(1.2)$ & 79.8 & $(1.2)$ & 79.6 & (1.3) & 76.2 & (1.4) & -0.4 & (1.7) \\
\hline & Dominican Republic & 48.9 & $(2.3)$ & 64.0 & (1.8) & 71.9 & (1.9) & 75.9 & (1.6) & 27.0 & $(2.7)$ \\
\hline & FYROM & $\mathrm{m}$ & $\mathrm{m}$ & $\mathrm{m}$ & $\mathrm{m}$ & $\mathrm{m}$ & $\mathrm{m}$ & $\mathrm{m}$ & $\mathrm{m}$ & $\mathrm{m}$ & $\mathrm{m}$ \\
\hline & Georgia & $\mathrm{m}$ & $\mathrm{m}$ & $\mathrm{m}$ & $\mathrm{m}$ & $\mathrm{m}$ & $\mathrm{m}$ & $\mathrm{m}$ & $\mathrm{m}$ & $\mathrm{m}$ & $\mathrm{m}$ \\
\hline & Hong Kong (China) & 84.6 & $(1.2)$ & 86.6 & (1.0) & 87.1 & $(0.8)$ & 83.8 & (1.4) & -0.8 & (1.9) \\
\hline & Indonesia & $\mathrm{m}$ & $\mathrm{m}$ & $\mathrm{m}$ & $\mathrm{m}$ & $\mathrm{m}$ & $\mathrm{m}$ & $\mathrm{m}$ & $\mathrm{m}$ & $\mathrm{m}$ & $\mathrm{m}$ \\
\hline & Jordan & $\mathrm{m}$ & $\mathrm{m}$ & $\mathrm{m}$ & $\mathrm{m}$ & $\mathrm{m}$ & $\mathrm{m}$ & $\mathrm{m}$ & $\mathrm{m}$ & $\mathrm{m}$ & $\mathrm{m}$ \\
\hline & Kosovo & $\mathrm{m}$ & $\mathrm{m}$ & $\mathrm{m}$ & $\mathrm{m}$ & $\mathrm{m}$ & $\mathrm{m}$ & $\mathrm{m}$ & $\mathrm{m}$ & $\mathrm{m}$ & $\mathrm{m}$ \\
\hline & Lebanon & $\mathrm{m}$ & $\mathrm{m}$ & $\mathrm{m}$ & $\mathrm{m}$ & $\mathrm{m}$ & $\mathrm{m}$ & $\mathrm{m}$ & $\mathrm{m}$ & $\mathrm{m}$ & $\mathrm{m}$ \\
\hline & Lithuania & 78.6 & $(1.2)$ & 81.1 & (1.1) & 82.9 & (1.3) & 79.8 & $(1.2)$ & 1.2 & (1.6) \\
\hline & Macao (China) & 87.2 & (1.1) & 85.8 & $(1.2)$ & 86.7 & (1.1) & 84.6 & (1.1) & -2.6 & (1.6) \\
\hline & Malta & $\mathrm{m}$ & $\mathrm{m}$ & $\mathrm{m}$ & $\mathrm{m}$ & $\mathrm{m}$ & $\mathrm{m}$ & $\mathrm{m}$ & $\mathrm{m}$ & $\mathrm{m}$ & $\mathrm{m}$ \\
\hline & Moldova & $\mathrm{m}$ & $\mathrm{m}$ & $\mathrm{m}$ & $\mathrm{m}$ & $\mathrm{m}$ & $\mathrm{m}$ & $\mathrm{m}$ & $\mathrm{m}$ & $\mathrm{m}$ & $\mathrm{m}$ \\
\hline & Montenegro & 80.2 & $(1.2)$ & 84.4 & $(1.2)$ & 83.5 & $(1.2)$ & 84.0 & $(1.0)$ & 3.8 & (1.6) \\
\hline & Peru & 34.5 & (2.1) & 57.4 & $(1.2)$ & 64.3 & (1.3) & 68.0 & (1.6) & 33.5 & (2.4) \\
\hline & Qatar & 74.5 & (1.0) & 72.5 & (0.9) & 75.9 & $(0.8)$ & 79.6 & $(0.8)$ & 5.2 & (1.4) \\
\hline & Romania & $\mathrm{m}$ & $\mathrm{m}$ & $\mathrm{m}$ & $\mathrm{m}$ & $\mathrm{m}$ & $\mathrm{m}$ & $\mathrm{m}$ & $\mathrm{m}$ & $\mathrm{m}$ & $\mathrm{m}$ \\
\hline & Russia & 84.8 & $(1.2)$ & 87.6 & (1.1) & 87.0 & $(0.8)$ & 89.0 & $(1.2)$ & 4.1 & (1.8) \\
\hline & Singapore & 81.7 & $(1.2)$ & 78.4 & $(1.0)$ & 78.0 & (1.4) & 71.4 & $(1.2)$ & -10.3 & (1.7) \\
\hline & Chinese Taipei & 70.3 & $(1.2)$ & 66.1 & (1.3) & 58.6 & (1.5) & 51.3 & (1.6) & -19.0 & $(2.1)$ \\
\hline & Thailand & 79.4 & (1.3) & 84.5 & (1.0) & 88.7 & $(0.9)$ & 87.8 & $(0.9)$ & 8.3 & (1.5) \\
\hline & Trinidad and Tobago & $\mathrm{m}$ & $\mathrm{m}$ & $\mathrm{m}$ & $\mathrm{m}$ & $\mathrm{m}$ & $\mathrm{m}$ & $\mathrm{m}$ & $\mathrm{m}$ & $\mathrm{m}$ & $\mathrm{m}$ \\
\hline & Tunisia & 61.0 & $(2.3)$ & 75.7 & (1.4) & 82.1 & (1.3) & 89.0 & (1.0) & 28.0 & (2.5) \\
\hline & United Arab Emirates & 76.8 & (1.5) & 78.9 & (1.5) & 78.8 & $(1.2)$ & 82.9 & $(0.8)$ & 6.1 & (1.7) \\
\hline & Uruguay & 81.1 & $(1.3)$ & 88.0 & $(0.9)$ & 89.5 & (1.1) & 86.8 & $(1.0)$ & 5.7 & (1.5) \\
\hline & Viet Nam & $\mathrm{m}$ & $\mathrm{m}$ & $\mathrm{m}$ & $\mathrm{m}$ & $\mathrm{m}$ & $\mathrm{m}$ & $\mathrm{m}$ & $\mathrm{m}$ & $\mathrm{m}$ & $\mathrm{m}$ \\
\hline & Argentina** $^{* *}$ & $\mathrm{~m}$ & $\mathrm{~m}$ & $\mathrm{~m}$ & $\mathrm{~m}$ & $\mathrm{~m}$ & $\mathrm{~m}$ & $\mathrm{~m}$ & $\mathrm{~m}$ & $\mathrm{~m}$ & $\mathrm{~m}$ \\
\hline & Kazakhstan** & $\mathrm{m}$ & $\mathrm{m}$ & $\mathrm{m}$ & $\mathrm{m}$ & $\mathrm{m}$ & $\mathrm{m}$ & $\mathrm{m}$ & $\mathrm{m}$ & $\mathrm{m}$ & $\mathrm{m}$ \\
\hline & Malaysia** & 64.7 & $(1.7)$ & 73.1 & $(1.3)$ & 72.9 & (1.6) & 68.9 & $(1.5)$ & 4.2 & $(2.2)$ \\
\hline
\end{tabular}

1. ESCS refers to the PISA index of economic, social and cultural status.

Note: Values that are statistically significant are indicated in bold (see Annex A3).

* See note at the beginning of this Annex.

** Coverage is too small to ensure comparability (see Annex A4).

StatLink त्ता st http://dx.doi.org/10.1787/888933473257 
Table III.13.11 Use of Internet/chat/social networks before and after school, by student characteristics

\begin{tabular}{|c|c|c|c|c|c|c|c|c|c|c|c|c|c|c|c|}
\hline & \multicolumn{14}{|c|}{$\begin{array}{l}\text { Percentage of students who reported that they use the Internet/Chat/Social networks } \\
\text { (e.g. }<\text { Facebook }>,<\text { country-specific social network }>\text { ) before school, by: }\end{array}$} \\
\hline & & \multicolumn{6}{|c|}{ Gender } & & & & Immi & rant bac & round & & \\
\hline & & & & & & $\begin{array}{r}\text { Gender } \\
\text { (B }\end{array}$ & $\begin{array}{l}\text { ference } \\
\text { J) }\end{array}$ & Non-in & igrant & First-g & eration & Second & neration & $\begin{array}{r}\text { Differen } \\
\text { backgroun } \\
\text { first }\end{array}$ & $\begin{array}{l}\text { nmigrant } \\
\text { mmigrant - } \\
\text { tion) }\end{array}$ \\
\hline & & $\%$ & S.E. & $\%$ & S.E. & $\%$ dif. & S.E. & $\%$ & S.E. & $\%$ & S.E. & $\%$ & S.E. & $\%$ dif. & S.E. \\
\hline 0 & Australia & 77.2 & $(0.7)$ & 81.6 & (0.6) & -4.5 & $(0.8)$ & 79.7 & $(0.6)$ & 79.6 & $(1.2)$ & 76.4 & (1.4) & 0.1 & (1.3) \\
\hline ¿ & Austria & 80.1 & $(0.8)$ & 84.8 & $(0.8)$ & -4.7 & (1.1) & 81.6 & (0.6) & 84.8 & (2.3) & 86.8 & (1.5) & -3.2 & (2.4) \\
\hline 0 & Belgium & 75.9 & $(0.8)$ & 78.2 & $(0.7)$ & -2.3 & (1.1) & 77.3 & $(0.6)$ & 74.9 & (1.8) & 76.2 & (1.7) & 2.4 & (1.9) \\
\hline & Canada & 71.2 & $(0.7)$ & 79.4 & $(0.6)$ & -8.2 & $(0.8)$ & 76.0 & (0.6) & 74.0 & (1.0) & 73.2 & (1.4) & 2.0 & $(1.2)$ \\
\hline & Chile & 81.5 & (0.9) & 83.6 & (0.9) & -2.1 & $(1.2)$ & 82.6 & $(0.7)$ & 84.5 & (5.1) & 80.4 & (6.8) & -2.0 & (5.1) \\
\hline & Czech Republic & 77.6 & (1.0) & 79.6 & $(0.9)$ & -2.0 & $(1.3)$ & 78.3 & $(0.7)$ & 88.1 & (3.0) & 83.6 & (4.1) & -9.8 & (3.0) \\
\hline & Denmark & 80.1 & $(0.8)$ & 85.3 & $(0.9)$ & -5.2 & (1.1) & 82.5 & $(0.7)$ & 85.3 & (2.6) & 84.0 & (1.5) & -2.8 & $(2.7)$ \\
\hline & Estonia & 75.1 & $(0.9)$ & 82.2 & (0.9) & -7.1 & $(1.3)$ & 78.2 & (0.6) & 72.1 & (7.2) & 82.2 & $(2.0)$ & 6.1 & (7.1) \\
\hline & Finland & 82.2 & $(0.7)$ & 88.8 & $(0.6)$ & -6.6 & (0.9) & 85.3 & $(0.5)$ & 86.1 & (3.4) & 94.8 & (2.3) & -0.8 & (3.4) \\
\hline & France & 64.4 & (1.0) & 67.5 & (1.0) & -3.2 & (1.4) & 65.9 & $(0.8)$ & 70.6 & (2.6) & 64.5 & (2.6) & -4.7 & (2.6) \\
\hline & Germany & 76.1 & $(1.2)$ & 78.4 & $(0.9)$ & -2.3 & (1.6) & 76.7 & (0.8) & 82.3 & (3.0) & 81.1 & (2.3) & -5.6 & (3.0) \\
\hline & Greece & 73.3 & $(0.9)$ & 72.0 & (1.2) & 1.3 & $(1.2)$ & 72.1 & (0.9) & 79.4 & (3.0) & 74.3 & (2.5) & -7.4 & (3.0) \\
\hline & Hungary & 82.6 & $(0.7)$ & 84.7 & (1.0) & -2.1 & $(1.2)$ & 83.8 & (0.6) & 78.9 & (5.9) & 81.3 & (4.3) & 4.9 & (5.8) \\
\hline & Iceland & 70.2 & (1.2) & 79.1 & (0.9) & -8.9 & (1.5) & 74.5 & (0.8) & 88.5 & (3.5) & 79.4 & (6.7) & -14.0 & (3.7) \\
\hline & Ireland & 65.9 & (1.0) & 70.2 & (1.2) & -4.2 & (1.5) & 67.9 & (0.9) & 69.0 & (2.2) & 69.2 & (3.5) & -1.1 & (2.3) \\
\hline & Israel & 71.1 & (2.4) & 75.6 & (1.1) & -4.5 & (2.5) & 73.7 & (1.4) & 72.2 & (4.7) & 71.7 & (2.5) & 1.5 & (4.7) \\
\hline & Italy & 79.6 & $(0.8)$ & 82.5 & $(0.8)$ & -2.8 & (1.1) & 80.9 & (0.6) & 82.9 & (3.7) & 83.4 & (3.4) & -2.0 & (3.8) \\
\hline & Japan & 64.2 & (1.0) & 60.9 & (1.0) & 3.4 & (1.3) & 62.4 & (0.8) & C & c & C & c & C & c \\
\hline & Korea & 72.1 & (1.5) & 74.3 & (1.3) & -2.2 & (1.8) & 73.2 & (1.1) & c & c & $\mathrm{m}$ & $\mathrm{m}$ & c & c \\
\hline & Latvia & 81.2 & $(0.9)$ & 85.8 & $(0.9)$ & -4.6 & $(1.2)$ & 83.9 & $(0.6)$ & 74.0 & $(7.4)$ & 81.4 & (3.0) & 9.8 & (7.6) \\
\hline & Luxembourg & 76.0 & (0.9) & 79.1 & $(0.8)$ & -3.1 & $(1.2)$ & 77.6 & (0.9) & 75.5 & (1.5) & 78.7 & (1.0) & 2.1 & (1.8) \\
\hline & Mexico & 68.4 & $(1.2)$ & 67.1 & (1.3) & 1.3 & (1.1) & 68.0 & (1.1) & 43.7 & (8.7) & C & C & 24.2 & (8.6) \\
\hline & Netherlands & 81.8 & (0.9) & 90.0 & (0.6) & -8.2 & (1.1) & 86.1 & (0.6) & 85.6 & (4.1) & 84.6 & (1.4) & 0.4 & (4.3) \\
\hline & New Zealand & 71.5 & (1.2) & 75.5 & (1.0) & -4.1 & (1.4) & 73.0 & (1.0) & 73.2 & (1.9) & 73.6 & (2.4) & -0.2 & $(2.1)$ \\
\hline & Norway & 84.9 & $(0.7)$ & 89.9 & $(0.7)$ & -5.0 & (1.0) & 87.8 & (0.5) & 86.7 & (1.7) & 83.7 & $(2.1)$ & 1.1 & (1.8) \\
\hline & Poland & 75.7 & $(1.0)$ & 75.4 & (1.1) & 0.4 & $(1.2)$ & 75.6 & $(0.8)$ & C & c & C & $\mathrm{C}$ & C & c \\
\hline & Portugal & 77.0 & $(0.9)$ & 80.3 & (0.8) & -3.3 & (1.0) & 78.6 & $(0.7)$ & 84.2 & $(2.2)$ & 74.0 & (3.3) & -5.6 & $(2.3)$ \\
\hline & Slovak Republic & 77.3 & $(0.8)$ & 78.1 & (0.9) & -0.9 & $(1.2)$ & 77.7 & (0.6) & C & C & c & C & C & c \\
\hline & Slovenia & 64.6 & (1.0) & 70.9 & (1.1) & -6.3 & (1.6) & 67.0 & $(0.7)$ & 81.4 & (3.7) & 72.9 & (3.7) & -14.4 & (3.8) \\
\hline & Spain & 75.9 & $(0.7)$ & 81.0 & (0.9) & -5.1 & (1.1) & 78.3 & $(0.7)$ & 78.3 & (1.8) & 84.0 & (3.4) & 0.0 & (1.8) \\
\hline & Sweden & 77.0 & $(0.9)$ & 86.4 & $(0.8)$ & -9.4 & (1.1) & 81.6 & $(0.7)$ & 82.5 & (2.4) & 82.9 & (1.6) & -0.9 & (2.4) \\
\hline & Switzerland & 78.0 & (1.2) & 83.0 & $(0.9)$ & -5.0 & (1.5) & 79.3 & (0.9) & 79.3 & (2.3) & 84.5 & (1.3) & 0.1 & (2.4) \\
\hline & Turkey & 77.2 & (1.0) & 69.8 & (1.4) & 7.4 & (1.5) & 73.6 & (1.0) & c & c & 76.1 & (10.5) & c & c \\
\hline & United Kingdom & 77.1 & $(0.8)$ & 82.8 & $(0.8)$ & -5.7 & (1.1) & 80.2 & $(0.7)$ & 78.8 & (1.8) & 75.0 & $(2.5)$ & 1.4 & (2.0) \\
\hline & United States & 75.1 & (1.0) & 84.4 & $(0.7)$ & -9.3 & (1.2) & 79.2 & (0.6) & 79.4 & (2.3) & 82.0 & (1.5) & -0.2 & (2.4) \\
\hline & OECD average & 75.4 & $(0.2)$ & 79.1 & $(0.2)$ & -3.7 & $(0.2)$ & 77.1 & $(0.1)$ & 78.5 & $(0.7)$ & 79.2 & $(0.6)$ & -0.6 & $(0.7)$ \\
\hline$n$ & Albania & $\mathrm{m}$ & $\mathrm{m}$ & $\mathrm{m}$ & $m$ & $\mathrm{~m}$ & $\mathrm{~m}$ & $\mathrm{~m}$ & $\mathrm{~m}$ & $m$ & $\mathrm{~m}$ & $\mathrm{~m}$ & $\mathrm{~m}$ & $\mathrm{~m}$ & $\mathrm{~m}$ \\
\hline$\Xi$ & Algeria & $\mathrm{m}$ & $\mathrm{m}$ & $\mathrm{m}$ & $\mathrm{m}$ & $\mathrm{m}$ & $\mathrm{m}$ & $\mathrm{m}$ & $\mathrm{m}$ & $\mathrm{m}$ & $\mathrm{m}$ & $\mathrm{m}$ & $\mathrm{m}$ & $\mathrm{m}$ & $\mathrm{m}$ \\
\hline 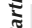 & Brazil & 80.0 & $(0.7)$ & 81.6 & $(0.7)$ & -1.6 & $(0.9)$ & 80.9 & $(0.6)$ & c & c & 78.6 & $(7.4)$ & c & c \\
\hline & B-S-J-G (China) & 65.8 & (1.3) & 58.9 & (1.6) & 6.9 & (1.4) & 62.5 & (1.3) & c & c & c & c & c & c \\
\hline & Bulgaria & 83.9 & $(0.7)$ & 87.2 & $(0.8)$ & -3.3 & $(0.9)$ & 85.6 & $(0.6)$ & c & C & c & c & C & c \\
\hline & CABA (Argentina) & $\mathrm{m}$ & $\mathrm{m}$ & $\mathrm{m}$ & $\mathrm{m}$ & $\mathrm{m}$ & $\mathrm{m}$ & $\mathrm{m}$ & $\mathrm{m}$ & $\mathrm{m}$ & $\mathrm{m}$ & $\mathrm{m}$ & $\mathrm{m}$ & $\mathrm{m}$ & $\mathrm{m}$ \\
\hline & Colombia & 75.8 & $(1.1)$ & 74.4 & $(0.9)$ & 1.4 & (1.1) & 75.1 & $(0.9)$ & c & c & 72.1 & $(10.8)$ & c & c \\
\hline & Costa Rica & 81.4 & $(0.7)$ & 81.7 & $(0.8)$ & -0.3 & (1.0) & 82.0 & (0.6) & 75.5 & $(4.0)$ & 75.8 & $(3.0)$ & 6.5 & $(4.1)$ \\
\hline & Croatia & 87.3 & $(0.7)$ & 90.4 & (0.6) & -3.1 & $(0.8)$ & 89.2 & $(0.5)$ & 88.5 & (3.2) & 87.2 & (1.6) & 0.7 & (3.3) \\
\hline & Cyprus* & 77.5 & $(0.9)$ & 78.5 & $(0.9)$ & -0.9 & $(1.2)$ & 78.1 & $(0.7)$ & 76.9 & (2.2) & 77.6 & (3.4) & 1.2 & (2.4) \\
\hline & Dominican Republic & 71.1 & (1.5) & 61.8 & (1.6) & 9.4 & (2.1) & 65.8 & (1.2) & $\mathrm{c}$ & $\mathrm{C}$ & 72.8 & (9.1) & $\mathrm{C}$ & $\mathrm{C}$ \\
\hline & FYROM & $\mathrm{m}$ & $\mathrm{m}$ & $\mathrm{m}$ & $\mathrm{m}$ & $\mathrm{m}$ & $\mathrm{m}$ & $\mathrm{m}$ & $\mathrm{m}$ & $\mathrm{m}$ & $\mathrm{m}$ & $\mathrm{m}$ & $\mathrm{m}$ & $\mathrm{m}$ & $\mathrm{m}$ \\
\hline & Georgia & $\mathrm{m}$ & $\mathrm{m}$ & $\mathrm{m}$ & $\mathrm{m}$ & $\mathrm{m}$ & $\mathrm{m}$ & $\mathrm{m}$ & $\mathrm{m}$ & $\mathrm{m}$ & $\mathrm{m}$ & $\mathrm{m}$ & $\mathrm{m}$ & $\mathrm{m}$ & $\mathrm{m}$ \\
\hline & Hong Kong (China) & 84.1 & $(0.7)$ & 87.0 & $(0.7)$ & -2.9 & $(1.0)$ & 85.5 & $(0.8)$ & 84.7 & $(1.4)$ & 85.7 & $(1.1)$ & 0.8 & (1.6) \\
\hline & Indonesia & $\mathrm{m}$ & $\mathrm{m}$ & $\mathrm{m}$ & $\mathrm{m}$ & $\mathrm{m}$ & $\mathrm{m}$ & $\mathrm{m}$ & $\mathrm{m}$ & $\mathrm{m}$ & $\mathrm{m}$ & $\mathrm{m}$ & $\mathrm{m}$ & $\mathrm{m}$ & $\mathrm{m}$ \\
\hline & Jordan & $\mathrm{m}$ & $\mathrm{m}$ & $\mathrm{m}$ & $\mathrm{m}$ & $\mathrm{m}$ & $\mathrm{m}$ & $\mathrm{m}$ & $\mathrm{m}$ & $\mathrm{m}$ & $\mathrm{m}$ & $\mathrm{m}$ & $\mathrm{m}$ & $\mathrm{m}$ & $\mathrm{m}$ \\
\hline & Kosovo & $\mathrm{m}$ & $\mathrm{m}$ & $\mathrm{m}$ & $\mathrm{m}$ & $\mathrm{m}$ & $\mathrm{m}$ & $\mathrm{m}$ & $\mathrm{m}$ & $\mathrm{m}$ & $\mathrm{m}$ & $\mathrm{m}$ & $\mathrm{m}$ & $\mathrm{m}$ & $\mathrm{m}$ \\
\hline & Lebanon & $\mathrm{m}$ & $\mathrm{m}$ & $\mathrm{m}$ & $\mathrm{m}$ & $\mathrm{m}$ & $\mathrm{m}$ & $\mathrm{m}$ & $\mathrm{m}$ & $\mathrm{m}$ & $\mathrm{m}$ & $\mathrm{m}$ & $\mathrm{m}$ & $\mathrm{m}$ & $\mathrm{m}$ \\
\hline & Lithuania & 79.1 & $(0.8)$ & 81.8 & $(0.8)$ & -2.7 & $(1.1)$ & 80.4 & $(0.6)$ & 50.6 & $(11.5)$ & 81.3 & $(4.0)$ & 29.9 & (11.6) \\
\hline & Macao (China) & 86.9 & $(0.8)$ & 85.2 & $(0.7)$ & 1.8 & (1.1) & 87.8 & $(0.6)$ & 85.3 & $(1.2)$ & 85.3 & $(0.9)$ & 2.5 & $(1.2)$ \\
\hline & Malta & $\mathrm{m}$ & $\mathrm{m}$ & $\mathrm{m}$ & $\mathrm{m}$ & $\mathrm{m}$ & $\mathrm{m}$ & $\mathrm{m}$ & $\mathrm{m}$ & $\mathrm{m}$ & $\mathrm{m}$ & $\mathrm{m}$ & $\mathrm{m}$ & $\mathrm{m}$ & $\mathrm{m}$ \\
\hline & Moldova & $\mathrm{m}$ & $\mathrm{m}$ & $\mathrm{m}$ & $\mathrm{m}$ & $\mathrm{m}$ & $\mathrm{m}$ & $\mathrm{m}$ & $\mathrm{m}$ & $\mathrm{m}$ & $\mathrm{m}$ & $\mathrm{m}$ & $\mathrm{m}$ & $\mathrm{m}$ & $\mathrm{m}$ \\
\hline & Montenegro & 83.3 & $(0.7)$ & 82.9 & $(0.8)$ & 0.3 & $(0.8)$ & 83.2 & $(0.6)$ & 75.7 & $(4.6)$ & 84.4 & (2.8) & 7.5 & $(4.8)$ \\
\hline & Peru & 58.9 & (1.0) & 57.6 & (1.3) & 1.3 & (1.6) & 58.1 & $(0.8)$ & C & c & c & c & C & c \\
\hline & Qatar & 75.8 & $(0.7)$ & 75.5 & $(0.5)$ & 0.3 & (0.9) & 82.4 & (0.6) & 69.6 & $(0.6)$ & 73.7 & (1.1) & 12.9 & $(0.8)$ \\
\hline & Romania & $\mathrm{m}$ & $\mathrm{m}$ & $\mathrm{m}$ & $\mathrm{m}$ & $\mathrm{m}$ & $\mathrm{m}$ & $\mathrm{m}$ & $\mathrm{m}$ & $\mathrm{m}$ & $\mathrm{m}$ & $\mathrm{m}$ & $\mathrm{m}$ & $\mathrm{m}$ & $\mathrm{m}$ \\
\hline & Russia & 85.7 & $(0.7)$ & 88.3 & $(0.7)$ & -2.6 & (1.0) & 87.1 & $(0.6)$ & 93.1 & (2.1) & 82.4 & (2.3) & -6.1 & $(2.2)$ \\
\hline & Singapore & 74.3 & $(0.9)$ & 80.7 & $(0.8)$ & -6.4 & (1.1) & 78.7 & $(0.7)$ & 71.4 & (1.7) & 74.0 & (2.5) & 7.4 & (1.9) \\
\hline & Chinese Taipei & 62.5 & (1.0) & 60.6 & (1.1) & 1.9 & (1.5) & 61.5 & $(0.8)$ & c & $\mathrm{C}$ & c & $\mathrm{C}$ & $\mathrm{c}$ & $\mathrm{c}$ \\
\hline & Thailand & 85.2 & $(0.8)$ & 85.0 & $(0.8)$ & 0.1 & (1.1) & 85.3 & (0.6) & c & C & 70.0 & (6.0) & C & c \\
\hline & Trinidad and Tobago & $\mathrm{m}$ & $\mathrm{m}$ & $\mathrm{m}$ & $\mathrm{m}$ & $\mathrm{m}$ & $\mathrm{m}$ & $\mathrm{c}$ & c & c & c & $\mathrm{c}$ & $\mathrm{c}$ & c & c \\
\hline & Tunisia & 79.7 & (1.1) & 75.6 & (1.1) & 4.1 & (1.3) & 77.7 & (0.9) & c & C & 80.4 & (4.3) & C & c \\
\hline & United Arab Emirates & 79.9 & $(0.8)$ & 78.8 & (1.0) & 1.1 & (1.3) & 86.8 & $(0.5)$ & 73.1 & (1.1) & 75.4 & (1.3) & 13.7 & (1.3) \\
\hline & Uruguay & 86.1 & $(0.8)$ & 86.6 & $(0.7)$ & -0.5 & (1.0) & 86.4 & (0.6) & c & c & c & c & C & c \\
\hline & Viet Nam & $\mathrm{m}$ & $\mathrm{m}$ & $\mathrm{m}$ & $\mathrm{m}$ & $\mathrm{m}$ & $\mathrm{m}$ & $\mathrm{m}$ & $\mathrm{m}$ & $\mathrm{m}$ & $\mathrm{m}$ & $\mathrm{m}$ & $\mathrm{m}$ & $\mathrm{m}$ & $\mathrm{m}$ \\
\hline & Argentina** & $\mathrm{m}$ & $\mathrm{m}$ & $\mathrm{m}$ & $\mathrm{m}$ & $\mathrm{m}$ & $\mathrm{m}$ & $\mathrm{m}$ & $\mathrm{m}$ & $\mathrm{m}$ & $\mathrm{m}$ & $\mathrm{m}$ & $\mathrm{m}$ & $\mathrm{m}$ & $\mathrm{m}$ \\
\hline & Kazakhstan** & $\mathrm{m}$ & $\mathrm{m}$ & $\mathrm{m}$ & $\mathrm{m}$ & $\mathrm{m}$ & $\mathrm{m}$ & $\mathrm{m}$ & $\mathrm{m}$ & $\mathrm{m}$ & $\mathrm{m}$ & $\mathrm{m}$ & $\mathrm{m}$ & $\mathrm{m}$ & $\mathrm{m}$ \\
\hline & Malaysia** & 73.1 & (1.0) & 67.1 & (1.2) & 6.0 & $(1.3)$ & 69.8 & $(0.9)$ & c & c & 79.7 & (5.5) & c & c \\
\hline
\end{tabular}

1. ESCS refers to the PISA index of economic, social and cultural status.

Note: Values that are statistically significant are indicated in bold (see Annex A3).

* See note at the beginning of this Annex.

** Coverage is too small to ensure comparability (see Annex A4).

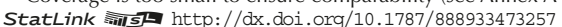


[Part 3/4]

Table III.13.11 Use of Internet/chat/social networks before and after school, by student characteristics

\begin{tabular}{|c|c|c|c|c|c|c|c|c|c|c|c|}
\hline & \multicolumn{10}{|c|}{$\begin{array}{l}\text { Percentage of students who reported that they use the Internet/Chat/Social networks } \\
\text { (e.g. }<\text { Facebook }>,<\text { country-specific social network }>\text { ) after school, by: }\end{array}$} \\
\hline & & \multicolumn{10}{|c|}{ National quarters of the ESCS ${ }^{1}$ index } \\
\hline & & \multicolumn{2}{|c|}{ Bottom quarter } & \multicolumn{2}{|c|}{ Second quarter } & & & & & Top - b & juarter \\
\hline & & $\%$ & S.E. & $\%$ & S.E. & $\%$ & S.E. & $\%$ & S.E. & $\%$ dif. & S.E. \\
\hline 0 & Australia & 91.6 & $(0.6)$ & 94.0 & $(0.6)$ & 93.8 & $(0.5)$ & 94.3 & $(0.5)$ & 2.7 & $(0.8)$ \\
\hline 氙 & Austria & 91.1 & $(0.8)$ & 91.5 & $(0.7)$ & 90.9 & $(0.8)$ & 90.6 & $(0.7)$ & -0.6 & $(1.1)$ \\
\hline$\overline{0}$ & Belgium & 93.7 & $(0.8)$ & 94.0 & $(0.5)$ & 94.6 & $(0.5)$ & 95.2 & $(0.5)$ & 1.5 & $(0.9)$ \\
\hline & Canada & 90.6 & $(0.6)$ & 90.3 & $(0.8)$ & 89.6 & $(0.7)$ & 91.2 & (0.5) & 0.6 & $(0.9)$ \\
\hline & Chile & 86.4 & $(0.9)$ & 92.1 & $(0.8)$ & 92.9 & $(0.8)$ & 93.4 & $(0.8)$ & 7.0 & (1.3) \\
\hline & Czech Republic & 91.6 & $(0.8)$ & 93.0 & $(0.9)$ & 93.5 & $(0.7)$ & 93.3 & $(0.7)$ & 1.7 & (1.0) \\
\hline & Denmark & 95.5 & $(0.6)$ & 97.3 & $(0.4)$ & 97.1 & $(0.6)$ & 97.3 & $(0.5)$ & 1.8 & $(0.8)$ \\
\hline & Estonia & 88.7 & (1.1) & 92.2 & $(0.8)$ & 90.6 & $(0.8)$ & 91.9 & (0.9) & 3.1 & (1.3) \\
\hline & Finland & 94.9 & (0.6) & 95.7 & (0.6) & 96.1 & $(0.7)$ & 97.3 & $(0.4)$ & 2.4 & $(0.7)$ \\
\hline & France & 84.4 & (1.0) & 87.4 & (1.0) & 86.4 & (1.1) & 87.1 & (1.0) & 2.7 & (1.3) \\
\hline & Germany & 93.1 & (0.9) & 92.3 & (1.1) & 91.0 & $(1.2)$ & 91.8 & (1.0) & -1.2 & (1.4) \\
\hline & Greece & 87.0 & (1.3) & 91.4 & (0.9) & 88.9 & (0.9) & 90.6 & (0.8) & 3.6 & (1.5) \\
\hline & Hungary & 89.8 & (1.1) & 93.3 & (1.0) & 93.8 & $(0.9)$ & 95.7 & $(0.5)$ & 5.9 & (1.3) \\
\hline & Iceland & 97.0 & $(0.7)$ & 95.6 & $(0.7)$ & 96.6 & $(0.7)$ & 97.2 & $(0.7)$ & 0.2 & (1.1) \\
\hline & Ireland & 90.1 & $(0.9)$ & 92.1 & $(0.7)$ & 92.2 & $(0.8)$ & 92.7 & $(0.8)$ & 2.7 & (1.0) \\
\hline & Israel & 82.1 & (1.3) & 84.4 & (1.8) & 81.3 & (2.4) & 85.8 & (1.6) & 3.8 & (2.0) \\
\hline & Italy & 90.0 & $(0.9)$ & 91.3 & $(0.7)$ & 91.9 & $(0.7)$ & 93.0 & $(0.7)$ & 3.0 & (1.0) \\
\hline & Japan & 80.2 & (1.1) & 84.4 & (1.1) & 82.4 & (1.1) & 85.6 & (0.9) & 5.4 & (1.5) \\
\hline & Korea & 89.8 & $(1.0)$ & 89.9 & $(0.9)$ & 89.7 & (1.1) & 86.9 & (1.5) & -2.9 & (1.7) \\
\hline & Latvia & 91.7 & $(1.0)$ & 91.9 & $(0.9)$ & 93.1 & $(0.8)$ & 92.3 & $(0.9)$ & 0.5 & (1.3) \\
\hline & Luxembourg & 91.6 & $(0.7)$ & 91.9 & $(0.7)$ & 91.5 & $(0.9)$ & 92.8 & $(0.8)$ & 1.2 & (1.0) \\
\hline & Mexico & 56.3 & $(2.7)$ & 79.2 & (1.6) & 87.5 & $(1.2)$ & 93.3 & $(0.8)$ & 37.0 & (2.6) \\
\hline & Netherlands & 94.9 & (0.6) & 95.0 & $(0.7)$ & 95.5 & $(0.6)$ & 95.2 & $(0.6)$ & 0.3 & $(0.9)$ \\
\hline & New Zealand & 92.5 & $(0.8)$ & 92.8 & $(0.9)$ & 93.4 & $(0.9)$ & 91.1 & $(1.0)$ & -1.4 & $(1.2)$ \\
\hline & Norway & 95.6 & $(0.7)$ & 96.9 & (0.5) & 97.0 & $(0.5)$ & 97.7 & $(0.5)$ & 2.0 & $(0.7)$ \\
\hline & Poland & 90.1 & (1.0) & 92.7 & (0.9) & 93.3 & $(0.9)$ & 93.5 & (1.0) & 3.4 & (1.3) \\
\hline & Portugal & 90.7 & $(0.8)$ & 93.3 & $(0.7)$ & 92.5 & $(0.9)$ & 93.5 & $(0.8)$ & 2.8 & (1.0) \\
\hline & Slovak Republic & 87.8 & (1.1) & 92.1 & $(0.8)$ & 91.7 & $(0.8)$ & 93.4 & $(0.7)$ & 5.6 & (1.3) \\
\hline & Slovenia & 81.8 & $(1.3)$ & 77.5 & (1.4) & 77.3 & (1.4) & 78.0 & (1.6) & -3.7 & (2.0) \\
\hline & Spain & 90.7 & $(0.7)$ & 92.6 & $(0.7)$ & 93.4 & $(0.8)$ & 92.7 & $(0.8)$ & 2.0 & $(1.2)$ \\
\hline & Sweden & 93.2 & $(0.8)$ & 93.5 & $(0.7)$ & 95.8 & $(0.8)$ & 94.9 & $(0.9)$ & 1.7 & (1.1) \\
\hline & Switzerland & 94.4 & $(0.9)$ & 92.7 & (0.9) & 92.1 & (1.3) & 92.2 & (1.2) & -2.2 & (1.6) \\
\hline & Turkey & 64.5 & (1.9) & 80.9 & (1.4) & 84.9 & (1.3) & 87.4 & (1.1) & 22.9 & $(2.1)$ \\
\hline & United Kingdom & 92.4 & $(0.9)$ & 95.3 & $(0.6)$ & 93.6 & $(0.9)$ & 93.0 & $(0.7)$ & 0.6 & (1.2) \\
\hline & United States & 88.7 & $(0.9)$ & 92.5 & $(0.7)$ & 91.0 & $(0.8)$ & 91.1 & (1.0) & 2.3 & (1.3) \\
\hline & OECD average & 88.7 & $(0.2)$ & 91.2 & $(0.2)$ & 91.3 & $(0.2)$ & 92.1 & $(0.2)$ & 3.4 & $(0.2)$ \\
\hline$=$ & Albania & $\mathrm{m}$ & $\mathrm{m}$ & $\mathrm{m}$ & $\mathrm{m}$ & $\mathrm{m}$ & $\mathrm{m}$ & $\mathrm{m}$ & $\mathrm{m}$ & $\mathrm{m}$ & $\mathrm{m}$ \\
\hline 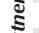 & Algeria & $\mathrm{m}$ & $\mathrm{m}$ & $\mathrm{m}$ & $\mathrm{m}$ & $\mathrm{m}$ & $\mathrm{m}$ & $\mathrm{m}$ & $\mathrm{m}$ & $\mathrm{m}$ & $\mathrm{m}$ \\
\hline సั & Brazil & 73.2 & (1.4) & 85.5 & (0.9) & 90.2 & $(0.6)$ & 94.4 & $(0.5)$ & 21.1 & (1.5) \\
\hline 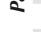 & B-S-J-G (China) & 67.8 & (1.6) & 68.9 & (2.0) & 67.2 & (2.0) & 67.1 & $(2.1)$ & -0.7 & (2.5) \\
\hline & Bulgaria & 87.9 & (1.1) & 89.5 & (1.0) & 92.7 & $(0.7)$ & 92.4 & $(0.8)$ & 4.5 & (1.5) \\
\hline & CABA (Argentina) & $\mathrm{m}$ & $\mathrm{m}$ & $\mathrm{m}$ & $\mathrm{m}$ & $\mathrm{m}$ & $\mathrm{m}$ & $\mathrm{m}$ & $\mathrm{m}$ & $\mathrm{m}$ & $\mathrm{m}$ \\
\hline & Colombia & 63.3 & (2.1) & 82.5 & (1.3) & 87.7 & $(0.9)$ & 94.5 & $(0.6)$ & 31.2 & (2.3) \\
\hline & Costa Rica & 77.9 & (1.4) & 87.5 & (1.1) & 92.6 & $(0.9)$ & 95.9 & $(0.7)$ & 17.9 & (1.5) \\
\hline & Croatia & 94.2 & $(0.7)$ & 94.4 & $(0.7)$ & 95.1 & $(0.6)$ & 94.9 & $(0.6)$ & 0.7 & (1.0) \\
\hline & Cyprus* & 85.6 & (1.0) & 88.9 & (0.9) & 90.6 & (1.0) & 91.7 & $(0.8)$ & 6.1 & (1.4) \\
\hline & Dominican Republic & 60.7 & (2.5) & 77.0 & (1.6) & 84.5 & (1.3) & 89.8 & $(1.0)$ & 29.1 & (2.5) \\
\hline & FYROM & $\mathrm{m}$ & $\mathrm{m}$ & $\mathrm{m}$ & $\mathrm{m}$ & $\mathrm{m}$ & $\mathrm{m}$ & $\mathrm{m}$ & $\mathrm{m}$ & $\mathrm{m}$ & $\mathrm{m}$ \\
\hline & Georgia & $\mathrm{m}$ & $\mathrm{m}$ & $\mathrm{m}$ & $\mathrm{m}$ & $\mathrm{m}$ & $\mathrm{m}$ & $\mathrm{m}$ & $\mathrm{m}$ & $\mathrm{m}$ & $\mathrm{m}$ \\
\hline & Hong Kong (China) & 96.4 & $(0.5)$ & 96.5 & $(0.7)$ & 96.6 & $(0.5)$ & 96.7 & $(0.5)$ & 0.2 & $(0.7)$ \\
\hline & Indonesia & $\mathrm{m}$ & $\mathrm{m}$ & $\mathrm{m}$ & $\mathrm{m}$ & $\mathrm{m}$ & $\mathrm{m}$ & $\mathrm{m}$ & $\mathrm{m}$ & $\mathrm{m}$ & $\mathrm{m}$ \\
\hline & Jordan & $\mathrm{m}$ & $\mathrm{m}$ & $\mathrm{m}$ & $\mathrm{m}$ & $\mathrm{m}$ & $\mathrm{m}$ & $\mathrm{m}$ & $\mathrm{m}$ & $\mathrm{m}$ & $\mathrm{m}$ \\
\hline & Kosovo & $\mathrm{m}$ & $\mathrm{m}$ & $\mathrm{m}$ & $\mathrm{m}$ & $\mathrm{m}$ & $\mathrm{m}$ & $\mathrm{m}$ & $\mathrm{m}$ & $\mathrm{m}$ & $\mathrm{m}$ \\
\hline & Lebanon & $\mathrm{m}$ & $\mathrm{m}$ & $\mathrm{m}$ & $\mathrm{m}$ & $\mathrm{m}$ & $\mathrm{m}$ & $\mathrm{m}$ & $\mathrm{m}$ & $\mathrm{m}$ & $\mathrm{m}$ \\
\hline & Lithuania & 91.1 & $(0.8)$ & 92.2 & $(0.8)$ & 93.5 & $(0.7)$ & 94.5 & $(0.7)$ & 3.4 & $(1.2)$ \\
\hline & Macao (China) & 95.5 & $(0.5)$ & 97.1 & $(0.6)$ & 97.2 & $(0.5)$ & 97.3 & (0.5) & 1.8 & $(0.6)$ \\
\hline & Malta & $\mathrm{m}$ & $\mathrm{m}$ & $\mathrm{m}$ & $\mathrm{m}$ & $\mathrm{m}$ & $\mathrm{m}$ & $\mathrm{m}$ & $\mathrm{m}$ & $\mathrm{m}$ & $\mathrm{m}$ \\
\hline & Moldova & $\mathrm{m}$ & $\mathrm{m}$ & $\mathrm{m}$ & $\mathrm{m}$ & $\mathrm{m}$ & $\mathrm{m}$ & $\mathrm{m}$ & $\mathrm{m}$ & $\mathrm{m}$ & $\mathrm{m}$ \\
\hline & Montenegro & 83.6 & $(1.2)$ & 86.4 & (1.1) & 87.8 & $(0.8)$ & 87.0 & (1.1) & 3.4 & (1.6) \\
\hline & Peru & 44.5 & (2.5) & 71.4 & (1.7) & 77.3 & (1.3) & 84.1 & (1.0) & 39.6 & $(2.7)$ \\
\hline & Qatar & 83.5 & $(0.8)$ & 84.8 & (0.8) & 89.0 & $(0.6)$ & 91.0 & (0.6) & 7.5 & (1.0) \\
\hline & Romania & $\mathrm{m}$ & $\mathrm{m}$ & $\mathrm{m}$ & $\mathrm{m}$ & $\mathrm{m}$ & $\mathrm{m}$ & $\mathrm{m}$ & $\mathrm{m}$ & $\mathrm{m}$ & $\mathrm{m}$ \\
\hline & Russia & 88.9 & (1.0) & 93.3 & $(0.7)$ & 92.2 & $(0.8)$ & 93.5 & (1.0) & 4.5 & (1.3) \\
\hline & Singapore & 90.8 & $(0.9)$ & 93.2 & $(0.7)$ & 92.7 & $(0.7)$ & 91.0 & $(0.8)$ & 0.1 & $(1.2)$ \\
\hline & Chinese Taipei & 93.1 & $(0.6)$ & 91.9 & $(0.7)$ & 89.1 & $(0.9)$ & 86.9 & $(0.8)$ & -6.3 & (1.1) \\
\hline & Thailand & 86.8 & (1.1) & 91.1 & $(0.7)$ & 94.9 & $(0.5)$ & 97.4 & $(0.6)$ & 10.6 & (1.2) \\
\hline & Trinidad and Tobago & $\mathrm{m}$ & m & $\mathrm{m}$ & $\mathrm{m}$ & $\mathrm{m}$ & $\mathrm{m}$ & $\mathrm{m}$ & $\mathrm{m}$ & $\mathrm{m}$ & $\mathrm{m}$ \\
\hline & Tunisia & 61.6 & $(2.7)$ & 78.5 & $(1.2)$ & 81.6 & (1.4) & 89.8 & $(1.0)$ & 28.2 & (2.8) \\
\hline & United Arab Emirates & 86.8 & $(0.9)$ & 90.3 & $(0.8)$ & 92.6 & $(0.7)$ & 93.6 & $(0.5)$ & 6.8 & (1.2) \\
\hline & Uruguay & 85.3 & (1.0) & 91.5 & $(0.8)$ & 94.3 & $(0.7)$ & 94.8 & $(0.7)$ & 9.5 & (1.3) \\
\hline & Viet Nam & $\mathrm{m}$ & $\mathrm{m}$ & $\mathrm{m}$ & $\mathrm{m}$ & $\mathrm{m}$ & $\mathrm{m}$ & $\mathrm{m}$ & $\mathrm{m}$ & $\mathrm{m}$ & $\mathrm{m}$ \\
\hline & Argentina** & $\mathrm{m}$ & $\mathrm{m}$ & $\mathrm{m}$ & $\mathrm{m}$ & $\mathrm{m}$ & $\mathrm{m}$ & $\mathrm{m}$ & $\mathrm{m}$ & $\mathrm{m}$ & $\mathrm{m}$ \\
\hline & Kazakhstan** & $\mathrm{m}$ & $\mathrm{m}$ & $\mathrm{m}$ & $\mathrm{m}$ & $\mathrm{m}$ & $\mathrm{m}$ & $\mathrm{m}$ & $\mathrm{m}$ & $\mathrm{m}$ & $\mathrm{m}$ \\
\hline & Malaysia** & 74.8 & $(1.4)$ & 85.6 & $(1.2)$ & 87.7 & $(1.2)$ & 88.3 & (1.5) & 13.5 & $(2.0)$ \\
\hline
\end{tabular}

1. ESCS refers to the PISA index of economic, social and cultural status.

Note: Values that are statistically significant are indicated in bold (see Annex A3).

* See note at the beginning of this Annex.

** Coverage is too small to ensure comparability (see Annex A4).

StatLink त्राजा http://dx.doi.org/10.1787/888933473257 
Table III.13.11 Use of Internet/chat/social networks before and after school, by student characteristics

\begin{tabular}{|c|c|c|c|c|c|c|c|c|c|c|c|c|c|c|c|}
\hline & \multicolumn{14}{|c|}{$\begin{array}{l}\text { Percentage of students who reported that they use the Internet/Chat/Social networks } \\
\text { (e.g. }<\text { Facebook }>,<\text { country-specific social network }>\text { ) after school, by: }\end{array}$} \\
\hline & & \multicolumn{6}{|c|}{ Gender } & & & & Imm & rant bac & ground & & \\
\hline & & & & & & $\underset{(B}{\text { Gender }}$ & $\begin{array}{l}\text { ference } \\
\text { )) }\end{array}$ & Non-i & igrant & First-g & eration & Second & neration & $\begin{array}{r}\text { Differen } \\
\text { backgroun } \\
\text { first }\end{array}$ & $\begin{array}{l}\text { nmigrant } \\
\text { mmigrant - } \\
\text { tion) }\end{array}$ \\
\hline & & $\%$ & S.E. & $\%$ & S.E. & $\%$ dif. & S.E. & $\%$ & S.E. & $\%$ & S.E. & $\%$ & S.E. & $\%$ dif. & S.E. \\
\hline 0 & Australia & 92.5 & $(0.4)$ & 94.3 & $(0.4)$ & -1.8 & $(0.5)$ & 93.3 & $(0.3)$ & 93.5 & $(0.8)$ & 93.6 & (0.9) & -0.2 & $(0.9)$ \\
\hline ¿ & Austria & 89.2 & $(0.7)$ & 92.7 & $(0.5)$ & -3.5 & $(0.9)$ & 90.6 & $(0.5)$ & 92.1 & (1.7) & 93.4 & $(0.9)$ & -1.5 & (1.7) \\
\hline 0 & Belgium & 93.4 & $(0.4)$ & 95.2 & $(0.4)$ & -1.7 & $(0.6)$ & 94.9 & $(0.3)$ & 89.7 & (1.3) & 92.9 & (1.6) & 5.2 & (1.4) \\
\hline & Canada & 88.0 & $(0.5)$ & 92.8 & (0.4) & -4.9 & $(0.6)$ & 90.4 & $(0.4)$ & 89.2 & (1.0) & 91.8 & (0.6) & 1.2 & (1.0) \\
\hline & Chile & 91.0 & $(0.6)$ & 91.4 & $(0.7)$ & -0.3 & (1.0) & 91.3 & (0.5) & 83.9 & (5.6) & 80.2 & $(10.3)$ & 7.4 & (5.6) \\
\hline & Czech Republic & 91.9 & $(0.6)$ & 93.9 & (0.6) & -2.0 & $(0.8)$ & 92.9 & $(0.4)$ & 95.2 & (2.0) & 92.9 & (3.3) & -2.3 & (2.0) \\
\hline & Denmark & 96.5 & $(0.4)$ & 97.1 & $(0.4)$ & -0.6 & $(0.5)$ & 96.8 & $(0.3)$ & 96.6 & (1.0) & 96.0 & $(0.7)$ & 0.3 & (1.1) \\
\hline & Estonia & 88.0 & $(0.8)$ & 93.6 & (0.6) & -5.7 & (1.1) & 91.2 & (0.5) & 92.9 & $(5.0)$ & 86.9 & (1.5) & -1.7 & (5.0) \\
\hline & Finland & 94.6 & $(0.5)$ & 97.4 & $(0.3)$ & -2.8 & $(0.5)$ & 96.1 & $(0.3)$ & 92.9 & (2.9) & 94.5 & (2.6) & 3.2 & (2.9) \\
\hline & France & 85.4 & $(0.7)$ & 87.2 & $(0.7)$ & -1.8 & $(1.0)$ & 86.7 & $(0.5)$ & 85.9 & $(2.0)$ & 83.3 & (1.8) & 0.7 & $(2.0)$ \\
\hline & Germany & 90.8 & $(0.7)$ & 92.9 & $(0.6)$ & -2.1 & $(0.8)$ & 91.9 & (0.6) & 90.0 & $(4.0)$ & 93.4 & (1.4) & 1.8 & $(4.0)$ \\
\hline & Greece & 89.1 & $(0.8)$ & 89.8 & (0.6) & -0.6 & (1.0) & 89.8 & $(0.5)$ & 80.5 & $(4.1)$ & 89.2 & (2.0) & 9.4 & $(4.0)$ \\
\hline & Hungary & 92.3 & $(0.7)$ & 94.1 & (0.6) & -1.8 & $(1.0)$ & 93.2 & $(0.4)$ & 96.8 & (2.3) & 94.6 & (3.1) & -3.6 & (2.3) \\
\hline & Iceland & 95.5 & $(0.5)$ & 97.6 & $(0.4)$ & -2.1 & $(0.6)$ & 96.6 & $(0.3)$ & 96.5 & $(2.1)$ & 97.5 & (2.5) & 0.1 & $(2.0)$ \\
\hline & Ireland & 90.4 & $(0.6)$ & 93.2 & $(0.6)$ & -2.8 & $(0.9)$ & 92.1 & $(0.4)$ & 90.0 & $(1.2)$ & 88.6 & (2.4) & 2.2 & (1.3) \\
\hline & Israel & 80.6 & (2.6) & 86.1 & $(0.8)$ & -5.5 & $(2.7)$ & 83.6 & (1.3) & 79.0 & (5.0) & 83.5 & $(2.7)$ & 4.6 & (4.8) \\
\hline & Italy & 91.1 & $(0.6)$ & 92.0 & (0.6) & -0.9 & $(0.9)$ & 91.9 & $(0.4)$ & 86.0 & (2.4) & 91.0 & (2.3) & 5.8 & (2.3) \\
\hline & Japan & 84.6 & $(0.7)$ & 81.7 & $(0.8)$ & 2.9 & $(1.0)$ & 83.1 & (0.5) & C & c & c & c & c & c \\
\hline & Korea & 88.0 & $(0.8)$ & 90.2 & (1.0) & -2.2 & (1.1) & 89.1 & $(0.7)$ & c & c & $\mathrm{m}$ & $\mathrm{m}$ & c & c \\
\hline & Latvia & 90.2 & $(0.7)$ & 94.3 & $(0.6)$ & -4.1 & $(0.8)$ & 92.4 & $(0.5)$ & 86.9 & (5.1) & 91.3 & (2.3) & 5.5 & (5.3) \\
\hline & Luxembourg & 90.6 & $(0.7)$ & 93.1 & $(0.5)$ & -2.4 & $(1.1)$ & 92.4 & $(0.5)$ & 90.4 & $(0.9)$ & 91.8 & $(0.7)$ & 2.0 & $(1.0)$ \\
\hline & Mexico & 81.0 & $(1.2)$ & 79.3 & (1.3) & 1.7 & $(1.2)$ & 80.3 & (1.1) & 64.6 & $(6.2)$ & $\mathrm{C}$ & $\mathrm{C}$ & 15.7 & (6.3) \\
\hline & Netherlands & 93.0 & $(0.5)$ & 97.2 & $(0.3)$ & -4.1 & $(0.6)$ & 95.2 & $(0.3)$ & 95.7 & $(2.2)$ & 94.0 & $(1.1)$ & -0.5 & $(2.2)$ \\
\hline & New Zealand & 91.7 & $(0.6)$ & 93.2 & (0.5) & -1.5 & $(0.8)$ & 92.2 & $(0.5)$ & 92.2 & (1.1) & 93.4 & $(1.2)$ & -0.1 & (1.1) \\
\hline & Norway & 96.7 & $(0.4)$ & 96.9 & $(0.4)$ & -0.2 & $(0.5)$ & 97.1 & (0.3) & 95.3 & (1.2) & 94.2 & (1.4) & 1.8 & (1.3) \\
\hline & Poland & 91.4 & $(0.7)$ & 93.5 & $(0.5)$ & -2.1 & $(0.8)$ & 92.5 & $(0.4)$ & C & c & c & $\mathrm{C}$ & C & c \\
\hline & Portugal & 92.3 & $(0.6)$ & 92.6 & $(0.5)$ & -0.3 & $(0.8)$ & 92.4 & $(0.4)$ & 94.7 & (1.5) & 93.2 & (1.8) & -2.3 & (1.5) \\
\hline & Slovak Republic & 90.6 & $(0.6)$ & 92.0 & $(0.6)$ & -1.4 & $(0.8)$ & 91.6 & $(0.4)$ & C & $\mathrm{c}$ & $\mathrm{C}$ & $\mathrm{C}$ & $\mathrm{C}$ & $\mathrm{C}$ \\
\hline & Slovenia & 75.8 & $(0.8)$ & 81.6 & (0.9) & -5.7 & (1.1) & 78.3 & $(0.7)$ & 79.7 & (3.8) & 86.2 & (2.6) & -1.4 & (3.8) \\
\hline & Spain & 91.4 & $(0.5)$ & 93.3 & $(0.5)$ & -2.0 & $(0.7)$ & 92.9 & $(0.4)$ & 87.2 & (1.5) & 89.1 & (3.9) & 5.7 & (1.5) \\
\hline & Sweden & 93.1 & $(0.5)$ & 95.6 & $(0.5)$ & -2.5 & $(0.7)$ & 94.7 & (0.4) & 91.2 & (1.8) & 93.5 & (1.1) & 3.5 & (1.8) \\
\hline & Switzerland & 91.3 & $(0.7)$ & 94.4 & (0.6) & -3.2 & $(0.9)$ & 92.2 & (0.6) & 91.6 & $(2.1)$ & 95.1 & $(0.9)$ & 0.6 & $(2.2)$ \\
\hline & Turkey & 83.4 & (0.9) & 75.5 & (1.2) & 8.0 & (1.3) & 79.7 & (0.9) & c & c & 71.0 & (7.7) & c & c \\
\hline & United Kingdom & 92.4 & $(0.5)$ & 94.6 & $(0.4)$ & -2.1 & $(0.8)$ & 94.2 & $(0.3)$ & 90.6 & (1.4) & 89.6 & (1.6) & 3.6 & (1.5) \\
\hline & United States & 88.3 & $(0.7)$ & 93.4 & (0.6) & -5.1 & $(0.8)$ & 90.7 & $(0.5)$ & 89.3 & (1.4) & 91.8 & (1.0) & 1.4 & (1.5) \\
\hline & OECD average & 89.9 & $(0.1)$ & 91.8 & $(0.1)$ & -1.9 & $(0.2)$ & 91.0 & $(0.1)$ & 89.3 & $(0.5)$ & 90.6 & $(0.6)$ & 2.3 & $(0.5)$ \\
\hline in & Albania & $\mathrm{m}$ & $\mathrm{m}$ & $\mathrm{m}$ & $\mathrm{m}$ & $\mathrm{m}$ & $\mathrm{m}$ & $\mathrm{m}$ & $\mathrm{m}$ & $\mathrm{m}$ & $m$ & $\mathrm{~m}$ & $\mathrm{~m}$ & $\mathrm{~m}$ & $\mathrm{~m}$ \\
\hline$\Xi$ & Algeria & $\mathrm{m}$ & $\mathrm{m}$ & $\mathrm{m}$ & $\mathrm{m}$ & $\mathrm{m}$ & $\mathrm{m}$ & $\mathrm{m}$ & $\mathrm{m}$ & $\mathrm{m}$ & $\mathrm{m}$ & $\mathrm{m}$ & $\mathrm{m}$ & $\mathrm{m}$ & $\mathrm{m}$ \\
\hline 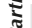 & Brazil & 87.9 & $(0.6)$ & 86.1 & $(0.6)$ & 1.8 & $(0.8)$ & 86.9 & $(0.4)$ & c & c & 82.6 & (6.4) & c & c \\
\hline & B-S-J-G (China) & 71.0 & (1.3) & 64.1 & (1.7) & 6.9 & $(1.2)$ & 67.7 & (1.4) & c & c & c & C & c & c \\
\hline & Bulgaria & 88.8 & $(0.7)$ & 92.6 & $(0.6)$ & -3.8 & $(0.9)$ & 90.9 & $(0.5)$ & c & c & c & c & $\mathrm{C}$ & c \\
\hline & CABA (Argentina) & $\mathrm{m}$ & $\mathrm{m}$ & $\mathrm{m}$ & $\mathrm{m}$ & $\mathrm{m}$ & $\mathrm{m}$ & $\mathrm{m}$ & $\mathrm{m}$ & $\mathrm{m}$ & $\mathrm{m}$ & $\mathrm{m}$ & $\mathrm{m}$ & $\mathrm{m}$ & $\mathrm{m}$ \\
\hline & Colombia & 82.5 & $(1.0)$ & 82.0 & $(0.9)$ & 0.6 & (1.1) & 82.3 & $(0.8)$ & c & c & 76.5 & $(11.8)$ & c & c \\
\hline & Costa Rica & 89.3 & $(0.8)$ & 88.2 & $(0.7)$ & 1.1 & $(0.8)$ & 89.3 & (0.6) & 81.7 & (3.7) & 83.0 & $(2.4)$ & 7.6 & (3.7) \\
\hline & Croatia & 93.4 & $(0.5)$ & 95.9 & $(0.4)$ & -2.5 & $(0.6)$ & 94.7 & $(0.4)$ & 99.1 & (0.9) & 94.4 & $(1.2)$ & -4.5 & (1.0) \\
\hline & Cyprus* & 87.4 & $(0.6)$ & 90.9 & (0.6) & -3.5 & $(0.9)$ & 89.6 & (0.4) & 85.6 & (1.8) & 88.3 & (2.8) & 4.0 & (1.8) \\
\hline & Dominican Republic & 81.7 & (1.1) & 76.7 & (1.3) & 5.0 & (1.4) & 79.2 & (1.0) & c & $\mathrm{c}$ & 64.8 & (9.4) & $\mathrm{c}$ & $\mathrm{c}$ \\
\hline & FYROM & $\mathrm{m}$ & $\mathrm{m}$ & $\mathrm{m}$ & $\mathrm{m}$ & $\mathrm{m}$ & $\mathrm{m}$ & $\mathrm{m}$ & $\mathrm{m}$ & $\mathrm{m}$ & $\mathrm{m}$ & $\mathrm{m}$ & $\mathrm{m}$ & $\mathrm{m}$ & $\mathrm{m}$ \\
\hline & Georgia & $\mathrm{m}$ & $\mathrm{m}$ & $\mathrm{m}$ & $\mathrm{m}$ & $\mathrm{m}$ & $\mathrm{m}$ & $\mathrm{m}$ & $\mathrm{m}$ & $\mathrm{m}$ & $\mathrm{m}$ & $\mathrm{m}$ & $\mathrm{m}$ & $\mathrm{m}$ & $\mathrm{m}$ \\
\hline & Hong Kong (China) & 95.0 & (0.5) & 98.1 & $(0.3)$ & -3.0 & $(0.5)$ & 96.9 & $(0.4)$ & 96.6 & $(0.7)$ & 95.2 & $(0.7)$ & 0.4 & $(0.7)$ \\
\hline & Indonesia & $\mathrm{m}$ & $\mathrm{m}$ & $\mathrm{m}$ & $\mathrm{m}$ & $\mathrm{m}$ & $\mathrm{m}$ & $\mathrm{m}$ & $\mathrm{m}$ & $\mathrm{m}$ & $\mathrm{m}$ & $\mathrm{m}$ & $\mathrm{m}$ & $\mathrm{m}$ & $\mathrm{m}$ \\
\hline & Jordan & $\mathrm{m}$ & $\mathrm{m}$ & $\mathrm{m}$ & $\mathrm{m}$ & $\mathrm{m}$ & $\mathrm{m}$ & $\mathrm{m}$ & $\mathrm{m}$ & $\mathrm{m}$ & $\mathrm{m}$ & $\mathrm{m}$ & $\mathrm{m}$ & $\mathrm{m}$ & $\mathrm{m}$ \\
\hline & Kosovo & $\mathrm{m}$ & $\mathrm{m}$ & $\mathrm{m}$ & $\mathrm{m}$ & $\mathrm{m}$ & $\mathrm{m}$ & $\mathrm{m}$ & $\mathrm{m}$ & $\mathrm{m}$ & $\mathrm{m}$ & $\mathrm{m}$ & $\mathrm{m}$ & $\mathrm{m}$ & $\mathrm{m}$ \\
\hline & Lebanon & $\mathrm{m}$ & $\mathrm{m}$ & $\mathrm{m}$ & $\mathrm{m}$ & $\mathrm{m}$ & $\mathrm{m}$ & $\mathrm{m}$ & $\mathrm{m}$ & $\mathrm{m}$ & $\mathrm{m}$ & $\mathrm{m}$ & $\mathrm{m}$ & $\mathrm{m}$ & $\mathrm{m}$ \\
\hline & Lithuania & 90.9 & $(0.6)$ & 94.6 & $(0.5)$ & -3.7 & $(0.8)$ & 92.9 & $(0.4)$ & 69.6 & (13.6) & 94.9 & $(1.2)$ & 23.3 & $(13.7)$ \\
\hline & Macao (China) & 96.3 & $(0.4)$ & 97.3 & $(0.3)$ & -1.0 & $(0.6)$ & 96.7 & $(0.4)$ & 96.0 & $(0.8)$ & 97.3 & $(0.3)$ & 0.7 & $(0.9)$ \\
\hline & Malta & $\mathrm{m}$ & $\mathrm{m}$ & $\mathrm{m}$ & $\mathrm{m}$ & $\mathrm{m}$ & $\mathrm{m}$ & $\mathrm{m}$ & $\mathrm{m}$ & $\mathrm{m}$ & $\mathrm{m}$ & $\mathrm{m}$ & $\mathrm{m}$ & $\mathrm{m}$ & $\mathrm{m}$ \\
\hline & Moldova & $\mathrm{m}$ & $\mathrm{m}$ & $\mathrm{m}$ & $\mathrm{m}$ & $\mathrm{m}$ & $\mathrm{m}$ & $\mathrm{m}$ & $\mathrm{m}$ & $\mathrm{m}$ & $\mathrm{m}$ & $\mathrm{m}$ & $\mathrm{m}$ & $\mathrm{m}$ & $\mathrm{m}$ \\
\hline & Montenegro & 86.1 & $(0.7)$ & 86.2 & $(0.7)$ & -0.1 & $(0.9)$ & 86.2 & $(0.5)$ & 80.4 & $(4.1)$ & 90.1 & $(2.1)$ & 5.8 & $(4.1)$ \\
\hline & Peru & 73.5 & (1.1) & 70.3 & (1.2) & 3.2 & (1.4) & 72.0 & (0.9) & C & c & c & c & c & c \\
\hline & Qatar & 87.1 & $(0.5)$ & 87.3 & $(0.5)$ & -0.2 & $(0.7)$ & 87.2 & $(0.5)$ & 87.2 & $(0.5)$ & 87.1 & $(0.9)$ & 0.0 & $(0.7)$ \\
\hline & Romania & $\mathrm{m}$ & $\mathrm{m}$ & $\mathrm{m}$ & $\mathrm{m}$ & $\mathrm{m}$ & $\mathrm{m}$ & $\mathrm{m}$ & $\mathrm{m}$ & $\mathrm{m}$ & $\mathrm{m}$ & $\mathrm{m}$ & $\mathrm{m}$ & $\mathrm{m}$ & $\mathrm{m}$ \\
\hline & Russia & 90.9 & $(0.8)$ & 93.0 & $(0.5)$ & -2.1 & $(0.9)$ & 92.0 & $(0.5)$ & 96.2 & (1.7) & 88.4 & (2.9) & -4.2 & (1.9) \\
\hline & Singapore & 90.2 & $(0.5)$ & 93.8 & $(0.5)$ & -3.6 & $(0.7)$ & 92.3 & $(0.4)$ & 91.5 & $(0.9)$ & 90.0 & (1.6) & 0.7 & (1.0) \\
\hline & Chinese Taipei & 91.0 & $(0.6)$ & 89.5 & $(0.6)$ & 1.6 & $(0.8)$ & 90.3 & (0.4) & c & C & c & c & c & c \\
\hline & Thailand & 92.0 & $(0.5)$ & 93.0 & $(0.6)$ & -1.0 & $(0.8)$ & 92.9 & $(0.4)$ & c & c & 78.9 & (5.7) & C & c \\
\hline & Trinidad and Tobago & $\mathrm{m}$ & $\mathrm{m}$ & $\mathrm{m}$ & $\mathrm{m}$ & $\mathrm{m}$ & $\mathrm{m}$ & $\mathrm{m}$ & $\mathrm{m}$ & $\mathrm{m}$ & $\mathrm{m}$ & $\mathrm{m}$ & $\mathrm{m}$ & $\mathrm{m}$ & $\mathrm{m}$ \\
\hline & Tunisia & 80.4 & $(1.2)$ & 76.8 & (1.1) & 3.6 & (1.4) & 78.7 & (0.9) & c & c & 70.3 & (7.5) & c & c \\
\hline & United Arab Emirates & 90.1 & $(0.4)$ & 91.5 & $(0.5)$ & -1.4 & $(0.7)$ & 92.7 & $(0.5)$ & 89.8 & $(0.8)$ & 90.0 & $(0.7)$ & 2.9 & (1.0) \\
\hline & Uruguay & 92.0 & $(0.6)$ & 91.3 & $(0.5)$ & 0.6 & $(0.7)$ & 91.6 & $(0.5)$ & c & c & c & c & C & c \\
\hline & Viet Nam & $\mathrm{m}$ & $\mathrm{m}$ & $\mathrm{m}$ & $\mathrm{m}$ & $\mathrm{m}$ & $\mathrm{m}$ & $\mathrm{m}$ & $\mathrm{m}$ & $\mathrm{m}$ & $\mathrm{m}$ & $\mathrm{m}$ & $\mathrm{m}$ & $\mathrm{m}$ & $\mathrm{m}$ \\
\hline & Argentina** & $\mathrm{m}$ & $\mathrm{m}$ & $\mathrm{m}$ & $\mathrm{m}$ & $\mathrm{m}$ & $\mathrm{m}$ & $\mathrm{m}$ & $\mathrm{m}$ & $\mathrm{m}$ & $\mathrm{m}$ & $\mathrm{m}$ & $\mathrm{m}$ & $\mathrm{m}$ & $\mathrm{m}$ \\
\hline & Kazakhstan** & $\mathrm{m}$ & $\mathrm{m}$ & $\mathrm{m}$ & $\mathrm{m}$ & $\mathrm{m}$ & $\mathrm{m}$ & $\mathrm{m}$ & $\mathrm{m}$ & $\mathrm{m}$ & $\mathrm{m}$ & $\mathrm{m}$ & $\mathrm{m}$ & $\mathrm{m}$ & $\mathrm{m}$ \\
\hline & Malaysia** & 87.2 & $(0.8)$ & 81.3 & (1.0) & 5.9 & $(1.0)$ & 84.2 & $(0.8)$ & c & c & 84.2 & (6.3) & c & c \\
\hline
\end{tabular}

1. ESCS refers to the PISA index of economic, social and cultural status.

Note: Values that are statistically significant are indicated in bold (see Annex A3).

* See note at the beginning of this Annex.

** Coverage is too small to ensure comparability (see Annex A4).

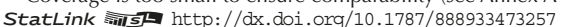


[Part 1/3]

Table III.13.13 Use of online games/chat/social networks outside of school, by gender and socio-economic status

Results based on students' self-reports

\begin{tabular}{|c|c|c|c|c|c|c|c|c|c|c|c|c|c|c|c|c|}
\hline & \multicolumn{8}{|c|}{ Percentage of boys who reported "almost every day" or "every day" } & \multicolumn{8}{|c|}{ Percentage of girls who reported "almost every day" or "every day" } \\
\hline & \multicolumn{2}{|c|}{$\begin{array}{c}\text { Play online } \\
\text { games } \\
\text { (one-player } \\
\text { or collaborative } \\
\text { online games) }\end{array}$} & \multicolumn{2}{|c|}{$\begin{array}{l}\text { Chat on line } \\
\text { (e.g. }\langle M S N>\text { ) }\end{array}$} & \multicolumn{2}{|c|}{$\begin{array}{c}\text { Participate in } \\
\text { social network } \\
\text { (e.g. }<\text { Facebook>, } \\
<\text { Myspace>) }\end{array}$} & \multicolumn{2}{|c|}{$\begin{array}{c}\text { Any type } \\
\text { of Internet/chat/ } \\
\text { social networks } \\
\text { outside of school }\end{array}$} & \multicolumn{2}{|c|}{$\begin{array}{c}\text { Play online } \\
\text { games } \\
\text { (one-player } \\
\text { or collaborative } \\
\text { online games) }\end{array}$} & \multicolumn{2}{|c|}{$\begin{array}{l}\text { Chat on line } \\
\text { (e.g. }\langle M S N>\text { ) }\end{array}$} & \multicolumn{2}{|c|}{$\begin{array}{c}\text { Participate } \\
\text { in social } \\
\text { network (e.g. } \\
<\text { Facebook> } \\
<\text { Myspace }>\text { ) }\end{array}$} & \multicolumn{2}{|c|}{$\begin{array}{c}\text { Any type } \\
\text { of Internet/chat// } \\
\text { social networks } \\
\text { outside of school }\end{array}$} \\
\hline & $\%$ & S.E. & $\%$ & S.E. & $\%$ & S.E. & $\%$ & S.E. & $\%$ & S.E. & $\%$ & S.E. & $\%$ & S.E. & $\%$ & S.E. \\
\hline Australia & 52.0 & $(0.8)$ & 58.2 & $(0.7)$ & 74.7 & $(0.8)$ & 86.9 & $(0.5)$ & 13.8 & $(0.5)$ & 57.8 & $(0.7)$ & 85.4 & $(0.5)$ & 88.7 & $(0.5)$ \\
\hline Austria & 54.6 & (1.1) & 80.0 & $(0.8)$ & 64.3 & (1.0) & 89.2 & $(0.7)$ & 9.7 & $(0.6$ & 87.0 & $(0.6)$ & 74.2 & $(0.9)$ & 92.1 & $(0.5)$ \\
\hline Belgium & 55.8 & (1.1) & 61.8 & (0.8) & 78.9 & (0.8) & 88.4 & $(0.5)$ & 13.9 & $(0.5)$ & 60.9 & (1.0) & 86.0 & $(0.6)$ & 89.1 & $(0.6)$ \\
\hline Canada & $\mathrm{m}$ & $\mathrm{m}$ & $\mathrm{m}$ & $\mathrm{m}$ & $\mathrm{m}$ & $\mathrm{m}$ & $\mathrm{m}$ & $\mathrm{m}$ & $\mathrm{m}$ & $\mathrm{m}$ & $\mathrm{m}$ & $\mathrm{m}$ & $\mathrm{m}$ & $\mathrm{m}$ & $\mathrm{m}$ & $\mathrm{m}$ \\
\hline Chile & 47.6 & $(1.2)$ & 60.6 & (1.0) & 70.5 & $(1.2)$ & 83.8 & $(0.9)$ & 16.6 & $(0.8)$ & 63.0 & (0.9) & 76.6 & $(0.9)$ & 83.7 & $(0.8)$ \\
\hline Czech Repu & 66.8 & (1.1) & 61.4 & (1.1) & 75.7 & $(0.8)$ & 87.2 & $(0.7)$ & 12.1 & $(0.7)$ & 58.3 & (1.0) & 85.6 & $(0.8)$ & 88.4 & $(0.8)$ \\
\hline Denmark & 60.0 & $(0.9)$ & 65.1 & (1.0) & 84.9 & $(0.9)$ & 92.9 & $(0.5$ & 7.4 & $(0.7$ & 61.9 & $(1.2$ & 90.7 & $(0.6)$ & 92.5 & $(0.6)$ \\
\hline Estonia & 64.9 & (1.3) & 51.8 & $(1.2$ & 74.4 & $(0.9$ & & & 13.8 & (0. & & & 87.1 & & 90.0 & $(0.6)$ \\
\hline Finla & 62 & (1. & 73 & (1. & 6 & (1. & & $(0$. & 16 & & & & 66 & & & 7) \\
\hline France & 61.8 & $(1.1)$ & 69.3 & (1.0) & 67.4 & $(0.9)$ & 84.4 & $(0.7)$ & 22.3 & $(0.8)$ & 75.3 & $(0.9$ & 77.4 & & 84.6 & $(0.7)$ \\
\hline Germany & 57.6 & (1.0) & 54.1 & (1.0) & 55.2 & $(0.9)$ & 81.1 & $(0.8)$ & 10.2 & $(0.6)$ & 44.7 & (1.2) & 58.9 & (1.0) & 68.3 & (1.1) \\
\hline Greece & 56.2 & $(1.2)$ & 56.7 & (1.1) & 70.8 & (1.2) & 81.3 & $(1.1)$ & 21.4 & $(0.7)$ & 64.0 & (0.9) & 76.2 & (1.0) & 83.6 & $(0.9)$ \\
\hline Hungary & 58.1 & (1.3) & 64.5 & (1.1) & 75.1 & (1.1) & 84.7 & $(0.8)$ & 16.2 & $(0.8)$ & 68.6 & (1.1) & 84.8 & (1.0) & 88.7 & $(0.8)$ \\
\hline Icelan & 58.4 & (1.3) & 56.3 & (1.3) & 73.1 & $(1.2$ & 88.3 & $(0.8$ & 8.9 & $(0.7$ & 57.6 & $(1$. & 85.8 & & 89.6 & $(0.7)$ \\
\hline Ireland & 48.1 & (1.3) & 80.1 & $\begin{array}{l}(0.9) \\
\text { (n) }\end{array}$ & & $(0$. & & & 8.9 & & & & 88.7 & & 92.3 & $(0.6)$ \\
\hline Israe & 38.6 & $(1.5$ & & $(1$. & & & & & & & & & & & & 2) \\
\hline Ital & & (1. & & & & & & & & & & & & & & \\
\hline Japan & 63.0 & (1.0) & 78.2 & (1.0) & 38.4 & $(1.0$ & 89.8 & $(0$. & 30.1 & $(0$. & 88 & $(0$. & & (1.0) & 91.4 & $(0.7)$ \\
\hline Korea & 35.7 & (1.3) & 36.5 & $(0.9$ & 62 & (1. & 75.7 & (1. & 8.5 & $(0$. & 38.0 & (1. & 71. & (1.1) & 78.3 & (1.1) \\
\hline Latv & 61.4 & (1. & 69. & (0. & & (1. & & & 10.7 & $(0$. & 72.7 & & 83 & $(0.8)$ & 89.1 & $(0.7)$ \\
\hline Luxe & 58.7 & (1. & 64 & (1. & & $(0$. & & & 14.2 & & & & 79.5 & & 84.2 & $(0.8)$ \\
\hline Mexi & 31.5 & (1.0 & & (1. & & & & & 7.3 & & & & 61.2 & & 72.5 & (1.2) \\
\hline Neth & 56.1 & $(1.0$ & & (1. & & & & & & & & & & & 89.4 & $(0.7)$ \\
\hline New & 55.5 & (1.3) & 76.5 & (1.1) & 73.2 & (1. & 87.7 & $(0.8$ & 14.8 & (1.) & 80.8 & (1. & 81.9 & (1.1) & 87.6 & $(0.8)$ \\
\hline & 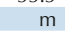 & & & & & & & & & & & & & & & $\mathrm{m}$ \\
\hline Pol & 63.6 & $(1.2$ & 40. & (1. & 77 & $(1$. & 88 & $(0.7)$ & 11. & $(0$. & 40.7 & $(1$. & 89.7 & $(0.7)$ & 91.4 & $(0.6)$ \\
\hline & 60 & (1. & & & & (0. & & & & & & & 78 & & 83.3 & $(0.8)$ \\
\hline & & (1. & & & & & & & 11.0 & & & & 84.4 & & 86.0 & $(0.7)$ \\
\hline Slove & 50.3 & $(1.0)$ & 49 & (1. & 73 & (1. & 83.3 & & 7.2 & $(0$. & 46.6 & (1. & 85.2 & & 87.3 & $(0.8)$ \\
\hline Spain & 43.2 & (1.0) & 69.2 & (1.0) & 64.8 & (1. & 85.8 & $(0$. & 10.0 & $(0.6$ & 70.4 & (1. & 77.1 & $(0.7)$ & 87.8 & $(0.7)$ \\
\hline & 70.6 & (1. & 47. & (1. & & (1) & & & 11 & (0. & & & 87.9 & (0.7) & 89.5 & 6) \\
\hline & 54.5 & (1.1 & 58. & $(1.2$ & 60. & (1. & 84 & $(0$. & 10. & $(0$. & 52.3 & (1. & 67.9 & 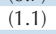 & 79.5 & (1.0) \\
\hline & & & & & & & & & $m$ & & & & & & $\mathrm{~m}$ & r \\
\hline Unit & 61.9 & $(1.2)$ & 80.3 & $(0.9)$ & 80.2 & $(0.8)$ & 92.0 & (0.6) & 13.5 & $(0.8)$ & 85.6 & (1.0) & 86.5 & (1.0) & 92.9 & (0.6) \\
\hline United State & $\mathrm{m}$ & $\mathrm{m}$ & $\mathrm{m}$ & $\mathrm{m}$ & $\mathrm{m}$ & $\mathrm{m}$ & $\mathrm{m}$ & $\mathrm{m}$ & $\mathrm{m}$ & $\mathrm{m}$ & $\mathrm{m}$ & $\mathrm{m}$ & $\mathrm{m}$ & $\mathrm{m}$ & $\mathrm{m}$ & $\mathrm{m}$ \\
\hline OECD average & 55.5 & $(0.2)$ & 61.6 & $(0.2)$ & 68.8 & $(0.2)$ & 85.1 & $(0.2)$ & 13.3 & $(0.1)$ & 61.7 & $(0.2)$ & 78.1 & $(0.2)$ & 85.8 & $(0.1)$ \\
\hline
\end{tabular}

\begin{tabular}{|l|ll|ll|ll|ll|lll|lll|ll|l}
\hline Albania & $\mathrm{m}$ & $\mathrm{m}$ & $\mathrm{m}$ & $\mathrm{m}$ & $\mathrm{m}$ & $\mathrm{m}$ & $\mathrm{m}$ & $\mathrm{m}$ & $\mathrm{m}$ & $\mathrm{m}$ & $\mathrm{m}$ & $\mathrm{m}$ & $\mathrm{m}$ & $\mathrm{m}$ & $\mathrm{m}$ & $\mathrm{m}$
\end{tabular}

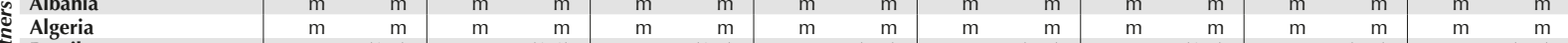

\begin{tabular}{|l|rr|rr|rr|rrrrr|rrrrrr}
\hline Brazil & 47.4 & $(1.0)$ & 52.4 & $(1.1)$ & 68.7 & $(1.0)$ & 74.7 & $(0.9)$ & 22.4 & $(0.7)$ & 47.5 & $(1.0)$ & 72.6 & $(0.8)$ & 75.9 & $(0.7)$ \\
\hline
\end{tabular}

\begin{tabular}{|l|cc|cc|cc|ccc|cc|cc|ccc|}
\hline B-S-J-G (China) & 25.9 & $(1.0)$ & 55.5 & $(1.2)$ & 45.9 & $(1.2)$ & 58.9 & $(1.2)$ & 5.9 & $(0.5)$ & 50.3 & $(1.5)$ & 41.8 & $(1.3)$ & 52.6 & $(1.5$ \\
\hline
\end{tabular}

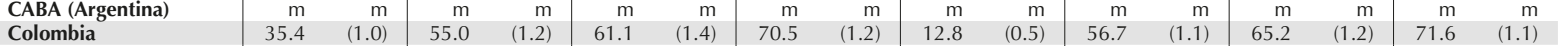

$\begin{array}{llllllllllllllllllll}\text { Colombia } & 35.4 & (1.0) & 55.0 & (1.2) & 61.1 & (1.4) & 70.5 & (1.2) & 12.8 & (0.5) & 56.7 & (1.1) & 65.2 & (1.2) & 71.6 & (1.1) \\ \text { Costa Rica } & 55.2 & (1.0) & 61.4 & (1.2) & 65.5 & (1.0) & 80.9 & (0.9) & 20.2 & (0.7) & 59.3 & (1.1) & 69.8 & (0.9) & 78.1 & (0.8)\end{array}$

\begin{tabular}{l|lllllllllllllllllll} 
Croatia & 53.4 & $(0.9)$ & 53.3 & $(1.0)$ & 77.6 & $(1.0)$ & 82.9 & $(0.9)$ & 10.3 & $(0.6)$ & 43.4 & $(0.9)$ & 87.3 & $(0.9)$ & 89.2 & $(0.7)$ \\
\hline
\end{tabular}

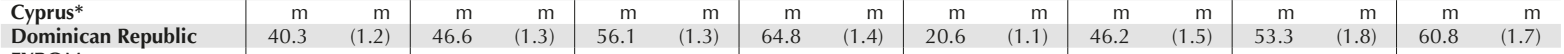

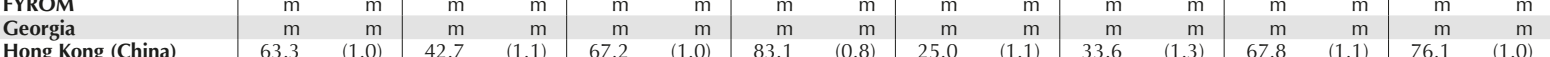

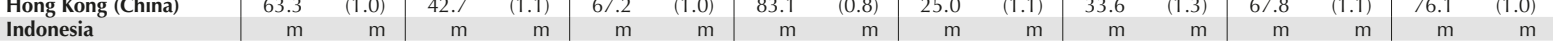

Jordan

Kosovo

Lebanon

Lithuania

Macao (China)

Montenegro

Peru

Qatar

Romania

Russia

Chinese Taipe

Thailand

Trinidad and Tobago

Tunisia

United Arab Emirates

Uruguay

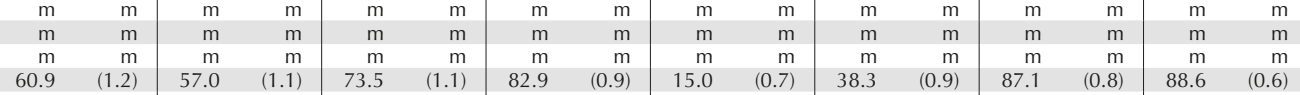
\begin{tabular}{ll|ll|ll|ll|ll|ll|llll}
60.9 & $(1.2)$ & 57.0 & $(1.1)$ & 73.5 & $(1.1)$ & 82.9 & $(0.9)$ & 15.0 & $(0.7)$ & 38.3 & $(0.9)$ & 87.1 & $(0.8)$ & 88.6 & $(0.6)$ \\
57.8 & $(0.9)$ & 55.1 & $(1.1)$ & 73.3 & $(1.0)$ & 86.0 & $(0.6)$ & 19.6 & $(0.9)$ & 56.5 & $(1.1)$ & 74.1 & $(1.0)$ & 83.0 & $(0.8)$
\end{tabular} Kazakhstan**

\begin{tabular}{|c|c|c|c|c|c|c|c|c|c|c|c|c|c|c|c|}
\hline & & & & & & & & & & & & & & & \\
\hline $\mathrm{m}$ & $\mathrm{m}$ & $\mathrm{m}$ & $\mathrm{m}$ & $\mathrm{m}$ & $\mathrm{m}$ & $\mathrm{m}$ & $\mathrm{m}$ & $\mathrm{m}$ & $\mathrm{m}$ & $\mathrm{m}$ & $\mathrm{m}$ & $\mathrm{m}$ & $\mathrm{m}$ & $\mathrm{m}$ & $\mathrm{m}$ \\
\hline $\mathrm{m}$ & $\mathrm{m}$ & $\mathrm{m}$ & $\mathrm{m}$ & $\mathrm{m}$ & $\mathrm{m}$ & $\mathrm{m}$ & $\mathrm{m}$ & $\mathrm{m}$ & $\mathrm{m}$ & $\mathrm{m}$ & $\mathrm{m}$ & $\mathrm{m}$ & $\mathrm{m}$ & $\mathrm{m}$ & $\mathrm{m}$ \\
\hline 25.2 & $(0.9)$ & 55.0 & $(1.2)$ & 45.0 & $(1.2)$ & 60.9 & $(1.2)$ & 5.0 & (0.4) & 53.8 & (1.4) & 44.1 & (1.4) & 55.8 & (1.3) \\
\hline $\mathrm{m}$ & $\mathrm{m}$ & $\mathrm{m}$ & $\mathrm{m}$ & $\mathrm{m}$ & $\mathrm{m}$ & $\mathrm{m}$ & $\mathrm{m}$ & $\mathrm{m}$ & $\mathrm{m}$ & $\mathrm{m}$ & $\mathrm{m}$ & $\mathrm{m}$ & $\mathrm{m}$ & $\mathrm{m}$ & $\mathrm{m}$ \\
\hline $\mathrm{m}$ & $\mathrm{m}$ & $\mathrm{m}$ & $\mathrm{m}$ & $\mathrm{m}$ & $\mathrm{m}$ & $\mathrm{m}$ & $\mathrm{m}$ & $\mathrm{m}$ & $\mathrm{m}$ & $\mathrm{m}$ & $\mathrm{m}$ & $\mathrm{m}$ & $\mathrm{m}$ & $\mathrm{m}$ & $\mathrm{m}$ \\
\hline 62.0 & (1.0) & 67.3 & (1.0) & 77.7 & $(0.8)$ & 83.4 & $(0.7)$ & 18.8 & (0.8) & 69.2 & $(1.0)$ & 82.4 & $(0.9)$ & 85.7 & $(0.8)$ \\
\hline 47.0 & $(1.0)$ & 43.9 & (1.0) & 59.0 & $(0.8)$ & 78.6 & $(0.7)$ & 17.0 & (0.7) & 40.9 & $(1.2)$ & 70.6 & $(1.0)$ & 78.9 & (1.0) \\
\hline 49.1 & $(0.8)$ & 55.1 & $(0.8)$ & 75.6 & $(0.7)$ & 83.2 & (0.7) & 17.4 & $(0.7)$ & 57.5 & $(1.2)$ & 76.0 & $(0.8)$ & 81.2 & $(0.7)$ \\
\hline 53.0 & (1.3) & 58.9 & (1.4) & 68.6 & (1.4) & 77.3 & (1.3) & 31.4 & (0.9) & 70.5 & $(1.2)$ & 73.8 & (1.1) & 82.5 & (1.0) \\
\hline $\mathrm{m}$ & $\mathrm{m}$ & $\mathrm{m}$ & $\mathrm{m}$ & $\mathrm{m}$ & $\mathrm{m}$ & $\mathrm{m}$ & $\mathrm{m}$ & $\mathrm{m}$ & $\mathrm{m}$ & $\mathrm{m}$ & $\mathrm{m}$ & $\mathrm{m}$ & $\mathrm{m}$ & $\mathrm{m}$ & $\mathrm{m}$ \\
\hline $\mathrm{m}$ & $\mathrm{m}$ & $\mathrm{m}$ & $\mathrm{m}$ & $\mathrm{m}$ & $\mathrm{m}$ & $\mathrm{m}$ & $\mathrm{m}$ & $\mathrm{m}$ & $\mathrm{m}$ & $\mathrm{m}$ & $\mathrm{m}$ & $\mathrm{m}$ & $\mathrm{m}$ & $\mathrm{m}$ & $\mathrm{m}$ \\
\hline $\mathrm{m}$ & $\mathrm{m}$ & $\mathrm{m}$ & $\mathrm{m}$ & $\mathrm{m}$ & $\mathrm{m}$ & $\mathrm{m}$ & $\mathrm{m}$ & $\mathrm{m}$ & $\mathrm{m}$ & $\mathrm{m}$ & $\mathrm{m}$ & $\mathrm{m}$ & $\mathrm{m}$ & $\mathrm{m}$ & $\mathrm{m}$ \\
\hline 51.3 & (1.3) & 52.9 & (1.1) & 75.3 & (1.0) & 81.8 & (1.1) & 14.9 & $(0.8)$ & 50.1 & $(1.2)$ & 81.9 & $(0.8)$ & 85.0 & (0.8) \\
\hline $\mathrm{m}$ & $\mathrm{m}$ & $\mathrm{m}$ & $\mathrm{m}$ & $\mathrm{m}$ & $\mathrm{m}$ & $\mathrm{m}$ & $\mathrm{m}$ & $\mathrm{m}$ & $\mathrm{m}$ & $\mathrm{m}$ & $\mathrm{m}$ & $\mathrm{m}$ & $\mathrm{m}$ & $\mathrm{m}$ & $\mathrm{m}$ \\
\hline $\mathrm{m}$ & $\mathrm{m}$ & $\mathrm{m}$ & $\mathrm{m}$ & $\mathrm{m}$ & $\mathrm{m}$ & $\mathrm{m}$ & $\mathrm{m}$ & $\mathrm{m}$ & $\mathrm{m}$ & $\mathrm{m}$ & $\mathrm{m}$ & $\mathrm{m}$ & $\mathrm{m}$ & $\mathrm{m}$ & $\mathrm{m}$ \\
\hline $\mathrm{m}$ & $\mathrm{m}$ & $\mathrm{m}$ & $\mathrm{m}$ & $\mathrm{m}$ & $\mathrm{m}$ & $\mathrm{m}$ & $\mathrm{m}$ & $\mathrm{m}$ & $\mathrm{m}$ & $\mathrm{m}$ & $\mathrm{m}$ & $\mathrm{m}$ & $\mathrm{m}$ & $\mathrm{m}$ & $\mathrm{m}$ \\
\hline $\mathrm{m}$ & $\mathrm{m}$ & $\mathrm{m}$ & $\mathrm{m}$ & $\mathrm{m}$ & $\mathrm{m}$ & $\mathrm{m}$ & $\mathrm{m}$ & $\mathrm{m}$ & $\mathrm{m}$ & $\mathrm{m}$ & $\mathrm{m}$ & $\mathrm{m}$ & $\mathrm{m}$ & $\mathrm{m}$ & $\mathrm{m}$ \\
\hline
\end{tabular}

1. A socio-economically disadvantaged student is a student in the bottom quarter of the distribution of the PISA index of economic, social and cultural status (ESCS) within his or her country/economy.

2. A socio-economically advantaged student is a student in the top quarter of the distribution of the PISA index of economic, social and cultural status (ESCS) within his or her country/economy.

Note: Values that are statistically significant are indicated in bold (see Annex A3).

* See note at the beginning of this Annex.

Coverage is too small to ensure comparability (see Annex A4).

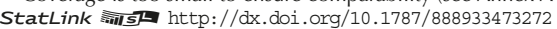




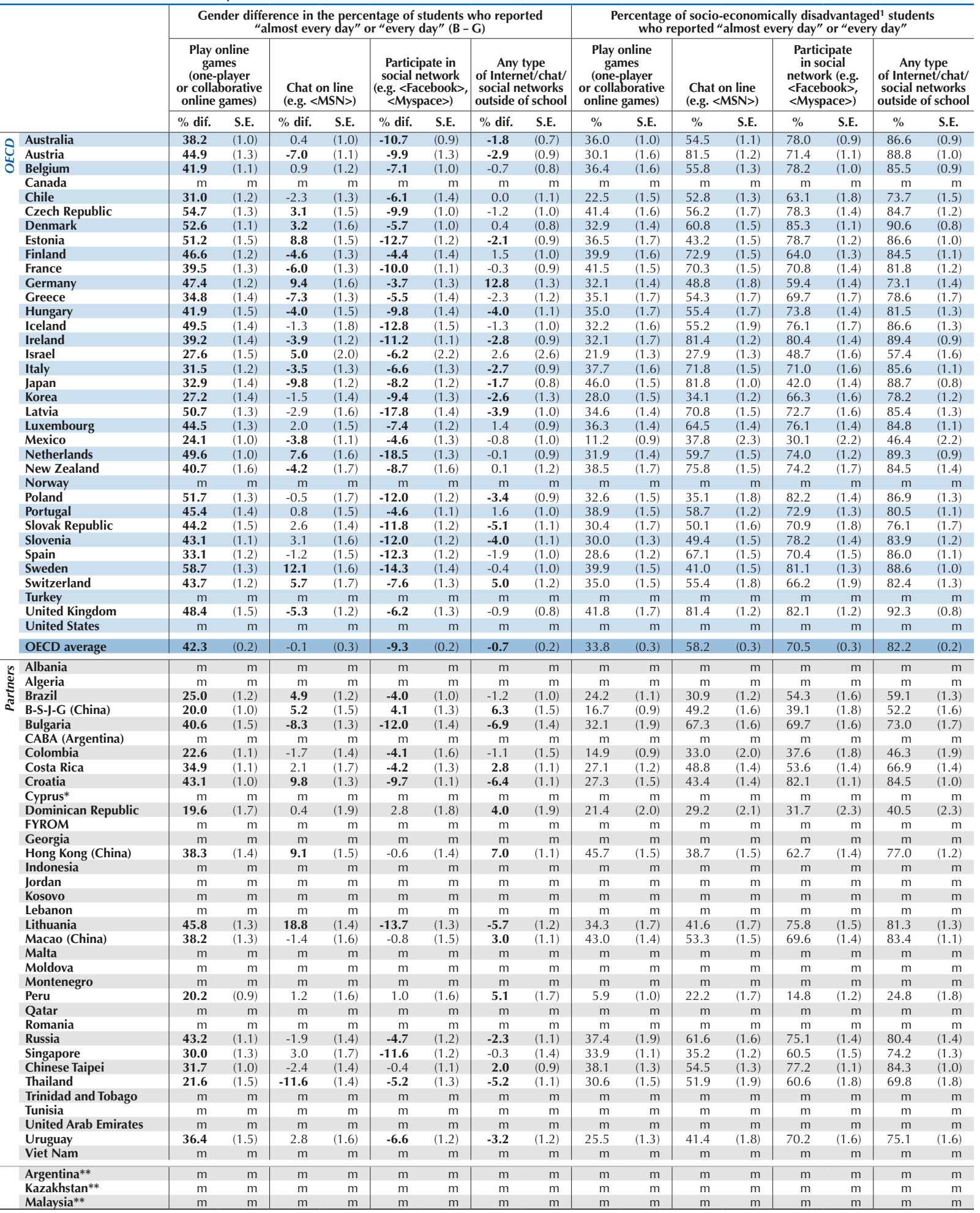

1. A socio-economically disadvantaged student is a student in the bottom quarter of the distribution of the PISA index of economic, social and cultural status (ESCS) within his

2. A socio-economically advantaged student is a student in the top quarter of the distribution of the PISA index of economic, social and cultural status (ESCS) within his or her country/economy.

Note: Values that are statistically significant are indicated in bold (see Annex A3).

* See note at the beginning of this Annex.

** Coverage is too small to ensure comparability (see Annex A4).

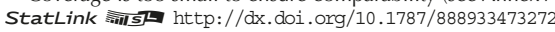


[Part 3/3]

Table III.13.13 Use of online games/chat/social networks outside of school, by gender and socio-economic status

Results based on students' self-reports

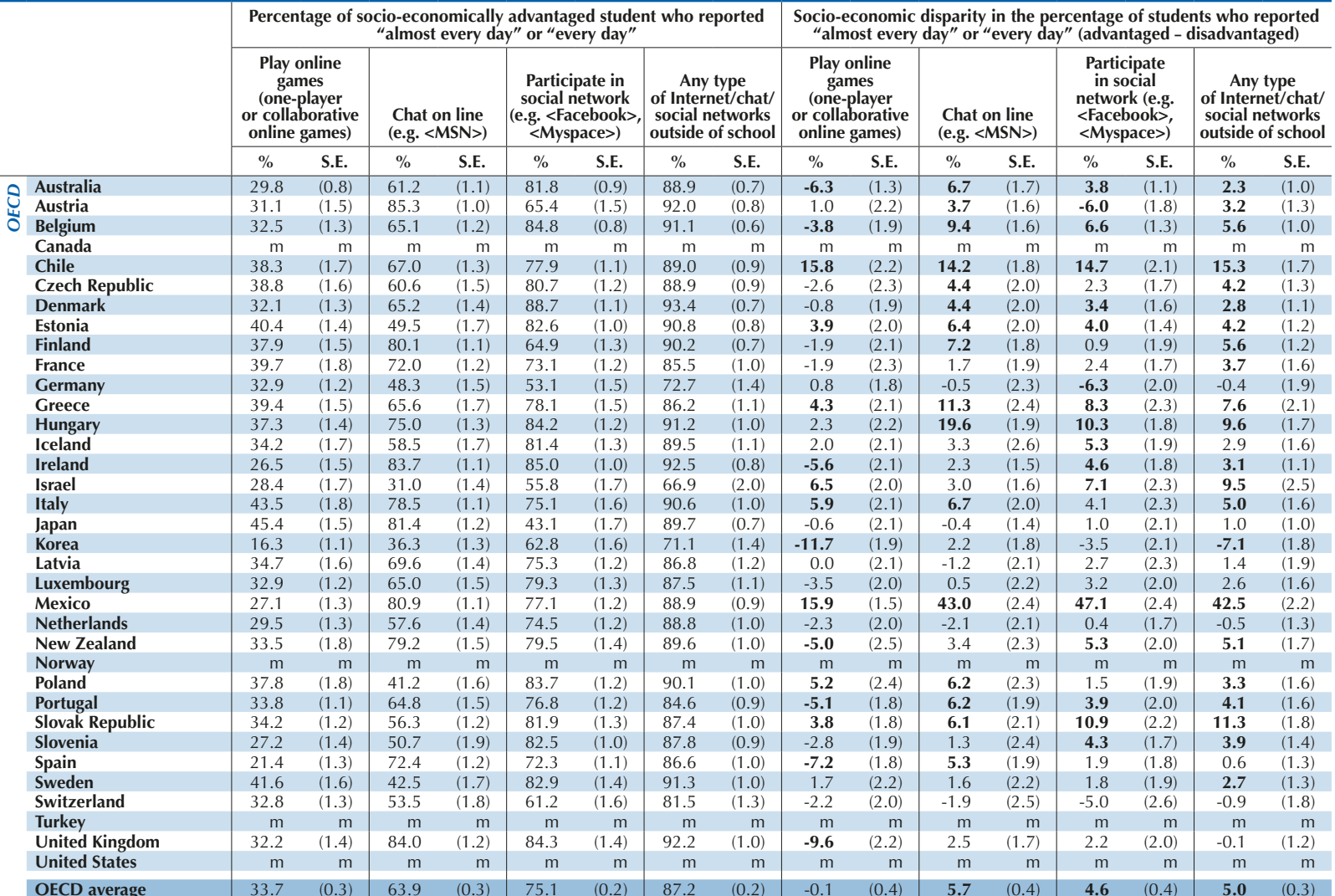

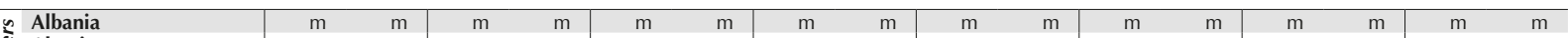

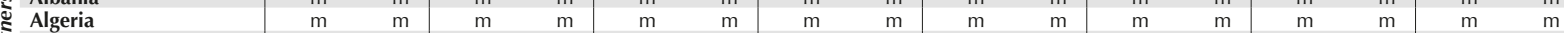

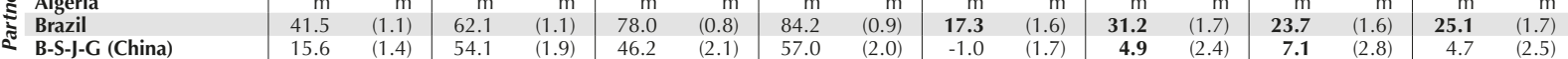

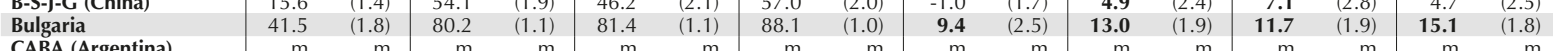

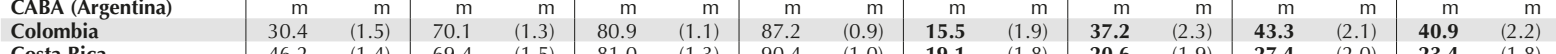
\begin{tabular}{l|cc|cc|cc|ccc|ccccccc} 
Costa Rica & 46.2 & $(1.4)$ & 69.4 & $(1.5)$ & 81.0 & $(1.3)$ & 90.4 & $(1.0)$ & $\mathbf{1 9 . 1}$ & $(1.8)$ & $\mathbf{2 0 . 6}$ & $(1.9)$ & $\mathbf{2 7 . 4}$ & $(2.0)$ & $\mathbf{2 3 . 4}$ & $(1.8)$ \\
\hline
\end{tabular}

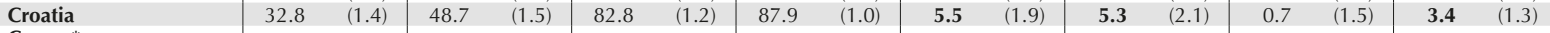

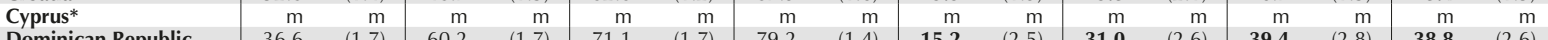
$\begin{array}{lrrrrrrrrrrrrrrrr}\text { Dominican Republic } & 36.6 & (1.7) & 60.2 & (1.7) & 71.1 & (1.7) & 79.2 & (1.4) & \mathbf{1 5 . 2} & (2.5) & \mathbf{3 1 . 0} & (2.6) & \mathbf{3 9 . 4} & (2.8) & \mathbf{3 8 . 8} & (2.6) \\ \text { FYROM } & \mathrm{m} & \mathrm{m} & \mathrm{m} & \mathrm{m} & \mathrm{m} & \mathrm{m} & \mathrm{m} & \mathrm{m} & \mathrm{m} & \mathrm{m} & \mathrm{m} & \mathrm{m} & \mathrm{m} & \mathrm{m} & \mathrm{m} & \mathrm{m}\end{array}$

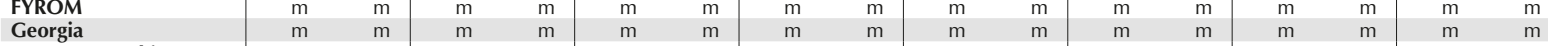

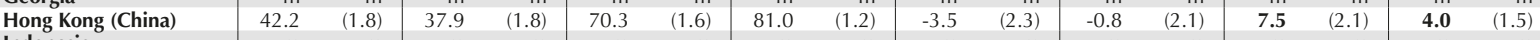

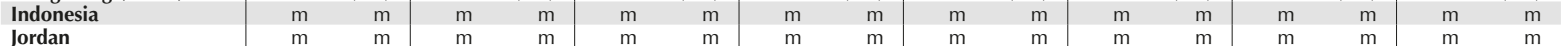
\begin{tabular}{lllllllllllllllll} 
Kosovo & $\mathrm{m}$ & $\mathrm{m}$ & $\mathrm{m}$ & $\mathrm{m}$ & $\mathrm{m}$ & $\mathrm{m}$ & $\mathrm{m}$ & $\mathrm{m}$ & $\mathrm{m}$ & $\mathrm{m}$ & $\mathrm{m}$ & $\mathrm{m}$ & $\mathrm{m}$ & $\mathrm{m}$ & $\mathrm{m}$ & $\mathrm{m}$ \\
\hline & $\mathrm{m}$ & $\mathrm{m}$ & $\mathrm{m}$ & $\mathrm{m}$ & $\mathrm{m}$ & $\mathrm{m}$ & $\mathrm{m}$ & $\mathrm{m}$ & $\mathrm{m}$ & $\mathrm{m}$ & $\mathrm{m}$ & $\mathrm{m}$ & $\mathrm{m}$ & $\mathrm{m}$ & $\mathrm{m}$ & $\mathrm{m}$
\end{tabular} Lebanon

Lithuania

Macao (China)

Malta

Moldova

Montenegro

Q

Qatar

Russia

Singapore

Chinese Taipei

Thailand

Trinidad and Tobago

Tunisia

United Arab Emirates

Uruguay

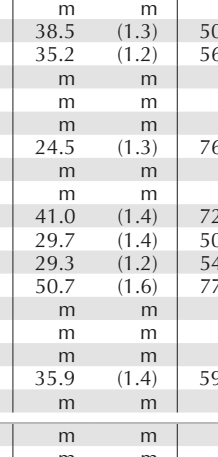

Kazakhstan*

1. A socio-economically country/economy.

Note: Values that are statistically significant are indicated in bold (see Annex A3).

* See note at the beginning of this Annex.

** Coverage is too small to ensure comparability (see Annex A4).

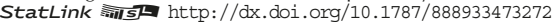




\begin{tabular}{|c|c|c|c|c|c|c|c|c|c|c|c|c|c|c|c|c|c|c|c|c|c|}
\hline & & & rcentag & ge of 1 & boys w & ho agr & $\mathrm{reed} / \mathrm{s}$ & trongl & y agree & ed wit & $h$ the $f$ & followit & & & ercenta & ge of $b$ & boys w & ho agr & $\mathrm{reed} / \mathrm{s}$ & trongly & $y$ agre \\
\hline & & 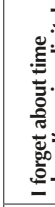 & 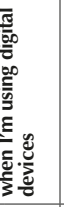 & 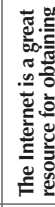 & 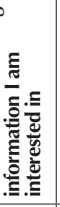 & $\begin{array}{l}2 \\
2 \\
5 \\
0\end{array}$ & 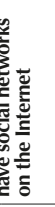 & 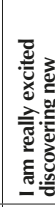 & 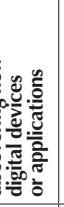 & 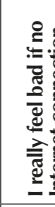 & 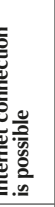 & 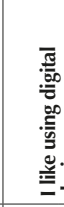 & & 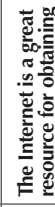 & 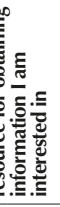 & 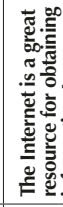 & 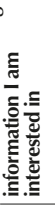 & 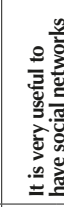 & 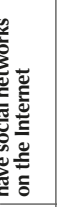 & 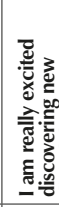 & 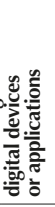 \\
\hline & & $\%$ & S.E. & $\%$ & S.E. & $\%$ & S.E. & $\%$ & S.E. & $\%$ & S.E. & $\%$ & S.E. & $\%$ & S.E. & $\%$ & S.E. & $\%$ & S.E. & $\%$ & S.E. \\
\hline & Australia & \begin{tabular}{|l}
61.0 \\
\end{tabular} & $(0.8)$ & 92.3 & $(0.4)$ & 86.3 & $(0.6)$ & \begin{tabular}{|l|}
77.2 \\
\end{tabular} & $(0.7)$ & 54.9 & $(0.8)$ & 93.3 & $(0.4)$ & \begin{tabular}{|c|}
69.4 \\
\end{tabular} & $(0.8)$ & 94.1 & $(0.4)$ & 92.8 & $(0.5)$ & 66.9 & $(0.9)$ \\
\hline & Austria & 52.2 & $(1.2)$ & 82.1 & (1.2) & 75.3 & (1.0) & 72.2 & (1.0) & 40.4 & $(0.8)$ & 88.1 & $(0.8)$ & 56.1 & (1.0) & 81.6 & $(0.7)$ & 86.5 & $(0.7)$ & 60.9 & (1.0) \\
\hline & Belgium & 71.6 & $(0.9)$ & 91.0 & (0.6) & 84.3 & $(0.6)$ & 76.8 & $(0.7)$ & 59.2 & $(0.9)$ & 92.4 & $(0.4)$ & 74.4 & $(0.8)$ & 91.3 & $(0.4)$ & 85.9 & $(0.5)$ & 66.1 & $(0.8)$ \\
\hline & Canada & $\mathrm{m}$ & $\mathrm{m}$ & $\mathrm{m}$ & $\mathrm{m}$ & $\mathrm{m}$ & $\mathrm{m}$ & $\mathrm{m}$ & $\mathrm{m}$ & $\mathrm{m}$ & $\mathrm{m}$ & $\mathrm{m}$ & $\mathrm{m}$ & $\mathrm{m}$ & $\mathrm{m}$ & $\mathrm{m}$ & $\mathrm{m}$ & m & $\mathrm{m}$ & $\mathrm{m}$ & $\mathrm{m}$ \\
\hline & Chile & 62.4 & $(1.2)$ & 88.0 & (0.8) & 87.7 & $(0.8)$ & 74.7 & $(1.0)$ & 44.4 & (1.1) & 90.0 & $(0.7)$ & 64.6 & (0.9) & 87.6 & $(0.7)$ & 88.0 & $(0.8)$ & 64.3 & (1.0) \\
\hline & Czech Republic & 55.8 & $(0.9)$ & 88.7 & $(0.7)$ & 80.6 & $(0.9)$ & \begin{tabular}{|l|l} 
& 70.9 \\
\end{tabular} & (1.0) & 46.9 & (1.1) & 89.6 & $(0.7)$ & 54.7 & (1.0) & 89.0 & $(0.7)$ & 81.5 & (1.0) & 47.3 & (1.1) \\
\hline & Denmark & 58.4 & (1.0) & 94.2 & $(0.5)$ & 91.1 & $(0.6)$ & 77.6 & (0.9) & 59.7 & (1.2) & 95.7 & $(0.4)$ & 60.1 & (1.1) & 95.4 & $(0.5)$ & 92.2 & $(0.6)$ & 56.7 & (1.1) \\
\hline & Estonia & 52.1 & (1.1) & 88.6 & $(0.7)$ & 79.0 & $(0.8)$ & 79.5 & $(0.8)$ & 38.0 & (1.2) & 89.6 & $(0.7)$ & 57.2 & (1.0) & 92.7 & $(0.6)$ & 79.8 & $(0.8)$ & 71.9 & (1.1) \\
\hline & Finland & 45.1 & (1.0) & 87.5 & $(0.7)$ & 83.3 & $(0.8)$ & 68.3 & (1.0) & 40.3 & (1.2) & 89.5 & $(0.6)$ & 56.4 & (0.9) & 92.4 & $(0.6)$ & 91.8 & $(0.6)$ & 57.3 & $(0.9)$ \\
\hline & France & 81.0 & $(0.8)$ & 91.9 & $(0.5)$ & 79.7 & $(0.8)$ & 74.9 & $(0.8)$ & 77.0 & $(0.8)$ & 93.6 & $(0.5)$ & 84.6 & $(0.7)$ & 94.1 & $(0.5)$ & 82.5 & $(0.6)$ & 59.9 & (1.0) \\
\hline & Germany & 61.7 & (1.0) & 87.5 & $(0.7)$ & 76.3 & (0.8) & \begin{tabular}{|l|}
77.2 \\
\end{tabular} & (0.9) & 40.5 & (1.0) & 92.8 & (0.5) & 61.9 & (1.0) & 86.1 & $(0.7)$ & 83.6 & $(0.7)$ & 60.9 & $(0.9)$ \\
\hline & Greece & 50.2 & (1.0) & 85.5 & (0.9) & 87.5 & $(0.8)$ & 75.2 & (0.9) & 76.3 & $(0.9)$ & 89.1 & $(0.8)$ & 55.1 & (1.0) & \begin{tabular}{|l}
91.6 \\
\end{tabular} & $(0.7)$ & 90.9 & $(0.6)$ & 66.0 & $(1.2)$ \\
\hline & Hungary & 56.4 & $(1.0)$ & 83.1 & $(0.9)$ & 74.5 & (1.0) & 48.1 & (1.1) & 61.1 & (1.0) & 85.7 & (0.9) & 58.5 & (1.1) & 87.6 & $(0.8)$ & 76.0 & $(0.9)$ & 33.5 & (1.2) \\
\hline & Iceland & 61.9 & $(1.3)$ & 91.0 & $(0.8)$ & 88.6 & $(0.8)$ & 78.4 & $(1.1)$ & 40.5 & (1.3) & 90.6 & $(0.7)$ & 74.0 & (1.1) & 94.3 & $(0.6)$ & 91.4 & (0.6) & 64.5 & (1.2) \\
\hline & Ireland & 65.4 & $(0.9)$ & 96.3 & $(0.4)$ & 92.6 & $(0.5)$ & 84.2 & $(0.9)$ & 45.4 & (1.1) & 96.5 & $(0.5)$ & 77.9 & $(0.9)$ & 98.2 & $(0.2)$ & 95.4 & $(0.3)$ & 76.6 & (0.9) \\
\hline & Israel & 60.0 & (1.1) & 81.6 & (1.0) & 73.6 & (1.6) & 53.8 & (1.9) & 51.4 & (2.1) & 82.2 & (1.2) & \begin{tabular}{|l|} 
\\
71.3 \\
\end{tabular} & (1.0) & 87.8 & $(0.7)$ & 83.7 & $(0.8)$ & 50.8 & (1.5) \\
\hline & Italy & 56.6 & (0.9) & 88.2 & $(0.7)$ & 75.2 & (1.0) & 78.3 & $(0.8)$ & 46.2 & (1.2) & 88.7 & $(0.7)$ & 63.5 & $(1.0)$ & 91.8 & $(0.6)$ & 78.2 & $(0.8)$ & 65.5 & (1.1) \\
\hline & Japan & 49.5 & (1.0) & 76.9 & (1.1) & 79.0 & $(0.9)$ & 38.6 & $(0.9)$ & 46.1 & (1.1) & 74.8 & $(0.9)$ & 54.5 & $(1.0)$ & 80.2 & $(0.9)$ & 84.8 & $(0.7)$ & 26.0 & $(0.8)$ \\
\hline & Korea & 52.9 & (1.1) & 71.4 & (1.2) & \begin{tabular}{|l|}
77.4 \\
\end{tabular} & $(0.9)$ & 62.5 & (1.1) & 56.7 & (1.1) & 84.9 & (1.0) & 66.4 & (1.0) & 75.5 & (1.1) & 84.9 & $(0.7)$ & 61.1 & (1.0) \\
\hline & Latvia & 53.2 & (1.0) & 82.0 & (0.9) & 71.8 & $(0.9)$ & \begin{tabular}{|l|}
76.8 \\
\end{tabular} & (1.1) & 42.8 & (1.1) & 85.5 & $(0.8)$ & 54.9 & (1.3) & 87.6 & $(0.8)$ & 78.6 & (1.0) & 71.4 & (1.2) \\
\hline & Luxemb & 56.8 & (1.0) & 83.8 & $(0.7)$ & 80.9 & $(0.8)$ & 70.1 & (1.1) & 44.2 & (1.0) & 87.3 & (0.6) & 61.7 & (1.1) & 85.7 & $(0.7)$ & 87.2 & $(0.7)$ & 54.5 & $(0.9)$ \\
\hline & Mexico & 47.9 & (1.1) & 79.9 & (1.1) & 81.2 & $(0.9)$ & 69.5 & $(0.9)$ & 47.4 & (1.0) & 83.4 & $(0.9)$ & 53.5 & $(0.9)$ & 83.9 & $(0.8)$ & 83.4 & $(0.9)$ & 62.8 & (1.1) \\
\hline & Netherland & 51.9 & (1.1) & 89.2 & $(0.6)$ & 87.6 & $(0.7)$ & 82.6 & $(0.8)$ & 58.3 & (1.0) & 91.3 & $(0.5)$ & 53.0 & $(0.9)$ & 89.8 & $(0.6)$ & 92.2 & $(0.5)$ & 76.0 & (1.0) \\
\hline & New Zealand & 64.8 & $(1.2)$ & 91.6 & $(0.7)$ & 86.8 & $(0.9)$ & 76.4 & (1.2) & 57.2 & (1.4) & 93.8 & $(0.6)$ & 70.6 & $(1.0)$ & 94.1 & $(0.5)$ & 91.2 & $(0.6)$ & 66.2 & $(1.2)$ \\
\hline & Norway & $\mathrm{m}$ & & $\mathrm{m}$ & $\mathrm{m}$ & $\mathrm{m}$ & $\mathrm{m}$ & $\mathrm{m}$ & $\mathrm{m}$ & $\mathrm{m}$ & $\mathrm{m}$ & $\mathrm{m}$ & $\mathrm{m}$ & $\mathrm{m}$ & $\mathrm{m}$ & $\mathrm{m}$ & $\mathrm{m}$ & $\mathrm{m}$ & $\mathrm{m}$ & $\mathrm{m}$ & $\mathrm{m}$ \\
\hline & Poland & 48.9 & (1.1) & 85.7 & $(0.7)$ & 80.8 & $(1.0)$ & 69.4 & (1.2) & 48.7 & (1.1) & 90.0 & $(0.7)$ & 53.7 & (1.0) & 88.6 & $(0.7)$ & 87.4 & $(0.8)$ & 50.8 & $(1.3)$ \\
\hline & Portugal & 73.2 & $(1.0)$ & 93.7 & $(0.6)$ & 88.6 & $(0.6)$ & 83.3 & $(0.7)$ & 79.4 & $(0.8)$ & 95.5 & $(0.4)$ & 73.4 & $(0.9)$ & 95.2 & $(0.5)$ & 91.6 & $(0.7)$ & 76.3 & $(0.8)$ \\
\hline & Slovak Re & 57.8 & $(0.9)$ & 82.6 & $(0.8)$ & 75.3 & $(0.9)$ & 70.0 & $(0.9)$ & 46.4 & $(0.9)$ & 83.7 & $(0.8)$ & 60.7 & (1.1) & \begin{tabular}{|l|l|}
87.8 \\
\end{tabular} & $(0.7)$ & 77.9 & $(0.9)$ & 54.5 & $(1.2)$ \\
\hline & Slovenia & 58.3 & $(1.0)$ & 86.8 & $(0.7)$ & 80.7 & $(0.9)$ & 78.0 & $(0.8)$ & 39.4 & (1.0) & 88.4 & $(0.6)$ & 64.8 & $(1.2)$ & 90.7 & $(0.6)$ & 84.6 & $(0.8)$ & 63.3 & (1.1) \\
\hline & Spain & 59.4 & $(0.7)$ & 90.2 & $(0.8)$ & 86.6 & $(0.8)$ & 73.6 & $(1.0)$ & 68.4 & (1.0) & 92.3 & $(0.6)$ & 62.0 & $(1.0)$ & 93.8 & $(0.5)$ & 90.5 & $(0.5)$ & 63.6 & (1.0) \\
\hline & Sweden & 52.2 & (1.0) & 87.2 & $(0.8)$ & 84.0 & $(0.9)$ & 79.4 & (1.0) & 73.3 & $(1.0)$ & 91.0 & $(0.8)$ & 58.2 & $(1.2)$ & 88.8 & $(0.7)$ & 91.0 & (0.6) & 73.4 & (1.1) \\
\hline & Switzerland & 60.2 & (1.0) & 85.9 & (1.0) & 77.2 & (1.0) & 67.5 & (1.1) & 42.5 & (1.4) & 90.0 & $(0.7)$ & 63.0 & (1.1) & 87.9 & $(0.8)$ & 83.5 & $(0.8)$ & 53.6 & $(1.2)$ \\
\hline & Turkey & $\mathrm{m}$ & $\mathrm{m}$ & $\mathrm{m}$ & & $\mathrm{m}$ & $\mathrm{m}$ & $\mathrm{m}$ & $\mathrm{m}$ & $\mathrm{m}$ & $\mathrm{m}$ & $\mathrm{m}$ & $\mathrm{m}$ & $\mathrm{m}$ & $\mathrm{m}$ & $\mathrm{m}$ & $\mathrm{m}$ & $\mathrm{m}$ & $\mathrm{m}$ & $\mathrm{m}$ & $\mathrm{m}$ \\
\hline & United Kingdom & 61.6 & (1.2) & 93.5 & (0.6) & 90.5 & $(0.6)$ & \begin{tabular}{|l|l|} 
& 76.8 \\
\end{tabular} & (0.9) & 64.1 & (1.1) & 95.1 & $(0.5)$ & 68.5 & $(1.2)$ & 91.0 & $(0.7)$ & 92.3 & $(0.5)$ & 65.1 & $(0.9)$ \\
\hline & United States & $\mathrm{m}$ & $\mathrm{m}$ & $\mathrm{m}$ & $\mathrm{m}$ & $\mathrm{m}$ & & $\mathrm{m}$ & & $\mathrm{m}$ & & $\mathrm{m}$ & & $\mathrm{m}$ & & $\mathrm{m}$ & $\mathrm{m}$ & $\mathrm{m}$ & $\mathrm{m}$ & $\mathrm{m}$ & $\mathrm{m}$ \\
\hline & OECD average & 58.1 & $(0.2)$ & 87.0 & $(0.1)$ & 82.1 & $(0.2)$ & 72.3 & $(0.2)$ & 52.8 & $(0.2)$ & 89.5 & $(0.1)$ & 63.2 & $(0.2)$ & 89.6 & $(0.1)$ & 86.5 & $(0.1)$ & 60.9 & $(0.2)$ \\
\hline & Albania & $\mathrm{m}$ & $\mathrm{m}$ & $\mathrm{m}$ & $\mathrm{m}$ & $\mathrm{m}$ & & $\mathrm{m}$ & & $\mathrm{m}$ & $\mathrm{m}$ & $\mathrm{m}$ & $\mathrm{m}$ & $\mathrm{m}$ & $\mathrm{m}$ & $\mathrm{m}$ & $\mathrm{m}$ & $\mathrm{m}$ & $\mathrm{m}$ & $\mathrm{m}$ & \\
\hline & Algeria & $\mathrm{m}$ & & $\mathrm{m}$ & & $\mathrm{m}$ & & $\mathrm{m}$ & & $\mathrm{m}$ & $\mathrm{m}$ & $\mathrm{m}$ & $\mathrm{m}$ & $\mathrm{m}$ & & $\mathrm{m}$ & & $\mathrm{m}$ & $\mathrm{m}$ & $\mathrm{m}$ & $\mathrm{m}$ \\
\hline & Brazil & 64.6 & (1.0) & 86.8 & $(0.7)$ & 82.6 & $(0.7)$ & 81.3 & $(0.8)$ & 67.1 & $(0.9)$ & 85.2 & $(0.8)$ & 67.0 & $(0.7)$ & 90.3 & $(0.5)$ & 84.0 & $(0.5)$ & 80.6 & $(0.7)$ \\
\hline & B-S-J-G (C & +3.4 & $(1.0)$ & 82.7 & $(0.8)$ & 84.4 & $(0.7)$ & 63.9 & $(0.9)$ & 55.0 & (1.0) & 85.0 & $(0.7)$ & 41.5 & (1.0) & 81.6 & $(1.2)$ & 79.3 & (0.9) & 48.6 & $(0.9)$ \\
\hline & Bulgaria & 56.9 & (1.1) & 78.6 & (1.3) & 73.6 & (1.1) & 64.0 & (1.0) & 61.6 & (1.3) & 81.8 & (1.2) & 60.5 & (1.1) & 85.9 & (1.0) & 80.1 & (1.0) & 59.9 & (1.2) \\
\hline & CABA (Argentina) & $\mathrm{m}$ & & $\mathrm{m}$ & & $\mathrm{m}$ & $\mathrm{m}$ & $\mathrm{m}$ & & $\mathrm{m}$ & $\mathrm{m}$ & $\mathrm{m}$ & $\mathrm{m}$ & $\mathrm{m}$ & $\mathrm{m}$ & $\mathrm{m}$ & $\mathrm{m}$ & $\mathrm{m}$ & $\mathrm{m}$ & $\mathrm{m}$ & $\mathrm{m}$ \\
\hline & Colombia & 71.4 & (1.2) & 82.0 & (0.9) & 81.3 & $(0.9)$ & 75.9 & (1.1) & 51.5 & (0.9) & 84.2 & $(0.9)$ & 73.3 & $(0.9)$ & 84.3 & $(0.8)$ & 84.1 & (0.8) & 72.0 & $(0.7)$ \\
\hline & Costa Rica & 58.7 & $(1.0)$ & 87.5 & $(0.7)$ & 87.1 & $(0.6)$ & 88.0 & $(0.8)$ & 54.6 & (1.0) & 91.5 & $(0.6)$ & 59.0 & (1.1) & 87.4 & $(0.9)$ & 86.2 & $(0.7)$ & 84.3 & $(0.7)$ \\
\hline & Croatia & 62.0 & (1.0) & 90.3 & $(0.7)$ & 84.3 & $(0.8)$ & 67.0 & (1.0) & 57.8 & (1.0) & 89.5 & $(0.6)$ & 67.7 & (1.1) & 93.2 & $(0.6)$ & 85.2 & $(0.7)$ & 52.2 & $(0.9)$ \\
\hline & Cyprus* & $\mathrm{m}$ & $\mathrm{m}$ & $\mathrm{m}$ & $\mathrm{m}$ & $\mathrm{m}$ & $\mathrm{m}$ & $\mathrm{m}$ & $\mathrm{m}$ & $\mathrm{m}$ & $\mathrm{m}$ & $\mathrm{m}$ & $\mathrm{m}$ & $\mathrm{m}$ & $\mathrm{m}$ & $\mathrm{m}$ & $\mathrm{m}$ & $\mathrm{m}$ & $\mathrm{m}$ & $\mathrm{m}$ & $\mathrm{m}$ \\
\hline & Dominic & 50.1 & (1.4) & 78.2 & (1.2) & 80.3 & (1.1) & 76.7 & $(1.2)$ & 54.8 & (1.4) & 84.5 & (1.0) & 46.0 & (1.6) & 81.6 & (1.1) & 83.2 & $(1.2)$ & 76.4 & (1.2) \\
\hline & FYR & $\mathrm{m}$ & & $\mathrm{m}$ & $\mathrm{m}$ & $\mathrm{m}$ & $\mathrm{m}$ & $\mathrm{m}$ & & $\mathrm{m}$ & $\mathrm{m}$ & $\mathrm{m}$ & & $\mathrm{m}$ & & $\mathrm{m}$ & & $\mathrm{m}$ & & $\mathrm{m}$ & \\
\hline & Geo & $\mathrm{m}$ & & $\mathrm{m}$ & $\mathrm{m}$ & $\mathrm{m}$ & $\mathrm{m}$ & $\mathrm{m}$ & $\mathrm{m}$ & $\mathrm{m}$ & $\mathrm{m}$ & $\mathrm{m}$ & $\mathrm{m}$ & $\mathrm{m}$ & $\mathrm{m}$ & $\mathrm{m}$ & $\mathrm{m}$ & $\mathrm{m}$ & $\mathrm{m}$ & $\mathrm{m}$ & $\mathrm{m}$ \\
\hline & Hong & 5.4 & (1.0) & 88.7 & $(0.8)$ & 87.8 & $(0.8)$ & 75.3 & $(0.8)$ & 63.9 & $(0.9)$ & 91.9 & $(0.7)$ & 66.5 & (1.1) & 92.9 & $(0.6)$ & 92.7 & $(0.5)$ & 65.1 & $(0.9)$ \\
\hline & Indonesia & $\mathrm{m}$ & & $\mathrm{m}$ & & $\mathrm{m}$ & $\mathrm{m}$ & $\mathrm{m}$ & & $\mathrm{m}$ & $\mathrm{m}$ & $\mathrm{m}$ & $\mathrm{m}$ & $\mathrm{m}$ & $\mathrm{m}$ & $\mathrm{m}$ & $\mathrm{m}$ & $\mathrm{m}$ & $\mathrm{m}$ & $\mathrm{m}$ & $\mathrm{m}$ \\
\hline & Jordan & $\mathrm{m}$ & $\mathrm{m}$ & $\mathrm{m}$ & & $\mathrm{m}$ & $\mathrm{m}$ & $\mathrm{m}$ & & $\mathrm{m}$ & $\mathrm{m}$ & $\mathrm{m}$ & $\mathrm{m}$ & $\mathrm{m}$ & $\mathrm{m}$ & $\mathrm{m}$ & $\mathrm{m}$ & $\mathrm{m}$ & $\mathrm{m}$ & $\mathrm{m}$ & $\mathrm{m}$ \\
\hline & Koso & $\mathrm{m}$ & $\mathrm{m}$ & $\mathrm{m}$ & & $\mathrm{m}$ & $\mathrm{m}$ & $\mathrm{m}$ & $\mathrm{m}$ & $\mathrm{m}$ & $\mathrm{m}$ & $\mathrm{m}$ & $\mathrm{m}$ & $\mathrm{m}$ & $\mathrm{m}$ & $\mathrm{m}$ & $\mathrm{m}$ & $\mathrm{m}$ & $\mathrm{m}$ & $\mathrm{m}$ & $\mathrm{m}$ \\
\hline & Lebanon & $\mathrm{m}$ & & $\mathrm{m}$ & $\mathrm{m}$ & $\mathrm{m}$ & $\mathrm{m}$ & $\mathrm{m}$ & $\mathrm{m}$ & $\mathrm{m}$ & $\mathrm{m}$ & $\mathrm{m}$ & $\mathrm{m}$ & $\mathrm{m}$ & $\mathrm{m}$ & $\mathrm{m}$ & $\mathrm{m}$ & $\mathrm{m}$ & $\mathrm{m}$ & $\mathrm{m}$ & $\mathrm{m}$ \\
\hline & Lithuaniz & 0.4 & $(0.9)$ & 78.1 & $(0.9)$ & 59.1 & $(0.9)$ & 69.8 & $(1.0)$ & 48.6 & (1.0) & 80.5 & $(0.8)$ & 42.4 & (1.0) & 82.7 & $(0.8)$ & 60.0 & (1.0) & 56.9 & (1.1) \\
\hline & Macao (China) & 54.8 & $(1.1)$ & 90.5 & $(0.7)$ & 92.7 & $(0.5)$ & 85.4 & $(0.7)$ & 63.4 & $(0.9)$ & 91.8 & $(0.6)$ & 62.4 & (1.1) & 94.0 & $(0.5)$ & 96.1 & $(0.4)$ & 84.1 & $(0.8)$ \\
\hline & Malta & $\mathrm{m}$ & & $\mathrm{m}$ & & $\mathrm{m}$ & & $\mathrm{m}$ & & $\mathrm{m}$ & & $\mathrm{m}$ & $\mathrm{m}$ & $\mathrm{m}$ & $\mathrm{m}$ & $\mathrm{m}$ & & $\mathrm{m}$ & & $\mathrm{m}$ & \\
\hline & Moldova & $\mathrm{m}$ & & $\mathrm{m}$ & & $\mathrm{m}$ & & $\mathrm{m}$ & $\mathrm{m}$ & $\mathrm{m}$ & & $\mathrm{m}$ & $\mathrm{m}$ & $\mathrm{m}$ & $\mathrm{m}$ & $\mathrm{m}$ & $\mathrm{m}$ & $\mathrm{m}$ & $\mathrm{m}$ & $\mathrm{m}$ & \\
\hline & Monteneg & $\mathrm{m}$ & & $\mathrm{m}$ & & $\mathrm{m}$ & & $\mathrm{m}$ & & $\mathrm{m}$ & & $\mathrm{m}$ & $\mathrm{m}$ & $\mathrm{m}$ & $\mathrm{m}$ & $\mathrm{m}$ & $\mathrm{m}$ & $\mathrm{m}$ & $\mathrm{m}$ & $\mathrm{m}$ & $\mathrm{m}$ \\
\hline & Peru & 59.1 & (1.0) & 86.2 & $(0.8)$ & 83.4 & $(0.8)$ & 81.2 & $(0.7)$ & 46.9 & (1.0) & 85.3 & $(0.6)$ & 59.4 & (1.1) & 88.2 & $(0.8)$ & 85.5 & $(0.9)$ & 77.5 & $(0.9)$ \\
\hline & Qatar & $\mathrm{m}$ & & $\mathrm{m}$ & & $\mathrm{m}$ & $\mathrm{m}$ & $\mathrm{m}$ & $\mathrm{m}$ & $\mathrm{m}$ & $\mathrm{m}$ & $\mathrm{m}$ & $\mathrm{m}$ & $\mathrm{m}$ & $\mathrm{m}$ & $\mathrm{m}$ & $\mathrm{m}$ & $\mathrm{m}$ & $\mathrm{m}$ & $\mathrm{m}$ & $\mathrm{m}$ \\
\hline & Roman & $\mathrm{m}$ & & $\mathrm{m}$ & & $\mathrm{m}$ & $\mathrm{m}$ & $\mathrm{m}$ & $\mathrm{m}$ & $\mathrm{m}$ & $\mathrm{m}$ & $\mathrm{m}$ & $\mathrm{m}$ & $\mathrm{m}$ & $\mathrm{m}$ & $\mathrm{m}$ & $\mathrm{m}$ & $\mathrm{m}$ & $\mathrm{m}$ & $\mathrm{m}$ & $\mathrm{m}$ \\
\hline & Russ & +2.0 & $(1.2)$ & 87.2 & $(0.9)$ & 74.2 & $(1.0)$ & 67.8 & $(1.2)$ & 40.6 & $(1.0)$ & 86.9 & $(1.0)$ & 46.5 & $(1.1)$ & 90.4 & $(0.7)$ & 77.2 & (1.0) & 66.6 & (1.3) \\
\hline & & 0.6 & $(0.9)$ & 93.6 & $(0.4)$ & 90.1 & $(0.5)$ & 84.6 & $(0.7)$ & 71.3 & $(0.8)$ & 94.7 & $(0.4)$ & 65.8 & $(0.9)$ & 94.7 & $(0.4)$ & 93.0 & $(0.5)$ & 75.7 & $(0.7)$ \\
\hline & Chinese Taipei & 58.9 & $(0.7)$ & 89.0 & $(0.6)$ & 90.2 & $(0.5)$ & 79.4 & $(0.7)$ & 80.2 & $(0.7)$ & 92.5 & $(0.5)$ & 64.4 & $(0.8)$ & 92.7 & $(0.5)$ & 91.2 & (0.6) & 70.7 & $(0.8)$ \\
\hline & Thai & 61.7 & (1.2) & 81.9 & $(1.2)$ & 82.9 & (1.0) & \begin{tabular}{|l|}
75.2 \\
\end{tabular} & (1.0) & 70.9 & (1.0) & 82.5 & (0.9) & 59.0 & (1.0) & \begin{tabular}{|l|}
88.2 \\
\end{tabular} & $(0.7)$ & 87.8 & $(0.7)$ & 74.8 & $(0.8)$ \\
\hline & Trin & $\mathrm{m}$ & & $\mathrm{m}$ & & $\mathrm{m}$ & & $\mathrm{m}$ & & $\mathrm{m}$ & $\mathrm{m}$ & $\mathrm{m}$ & $\mathrm{m}$ & $\mathrm{m}$ & $\mathrm{m}$ & $\mathrm{m}$ & $\mathrm{m}$ & $\mathrm{m}$ & $\mathrm{m}$ & $\mathrm{m}$ & \\
\hline & Tuni & $\mathrm{m}$ & & $\mathrm{m}$ & $\mathrm{m}$ & $\mathrm{m}$ & $\mathrm{m}$ & $\mathrm{m}$ & & $\mathrm{m}$ & $\mathrm{m}$ & $\mathrm{m}$ & $\mathrm{m}$ & $\mathrm{m}$ & $\mathrm{m}$ & $\mathrm{m}$ & $\mathrm{m}$ & $\mathrm{m}$ & $\mathrm{m}$ & $\mathrm{m}$ & $\mathrm{m}$ \\
\hline & Uni & & & $\mathrm{m}$ & & $\mathrm{m}$ & $\mathrm{m}$ & $\mathrm{m}$ & $\mathrm{m}$ & $\mathrm{m}$ & $\mathrm{m}$ & $\mathrm{m}$ & $\mathrm{m}$ & $\mathrm{m}$ & $\mathrm{m}$ & $\mathrm{m}$ & $\mathrm{m}$ & $\mathrm{m}$ & $\mathrm{m}$ & $\mathrm{m}$ & $\mathrm{m}$ \\
\hline & Uruguay & 38.8 & $(1.2)$ & 81.5 & (1.0) & 82.4 & (1.0) & \begin{tabular}{|l|}
72.2 \\
\end{tabular} & (1.1) & 57.5 & (1.2) & 85.9 & $(0.8)$ & 38.7 & (1.0) & 85.5 & $(0.8)$ & 85.6 & $(0.8)$ & 67.9 & (1.1) \\
\hline & Viet Nam & $\mathrm{m}$ & $\mathrm{m}$ & $\mathrm{m}$ & $\mathrm{m}$ & $\mathrm{m}$ & $\mathrm{m}$ & $\mathrm{m}$ & $\mathrm{m}$ & $\mathrm{m}$ & $\mathrm{m}$ & $\mathrm{m}$ & $\mathrm{m}$ & $\mathrm{m}$ & $\mathrm{m}$ & $\mathrm{m}$ & $\mathrm{m}$ & $\mathrm{m}$ & $\mathrm{m}$ & $\mathrm{m}$ & $\mathrm{m}$ \\
\hline & Ar & $\mathrm{m}$ & & $\mathrm{m}$ & & $\mathrm{m}$ & $\mathrm{n}$ & $\mathrm{m}$ & $\mathrm{m}$ & $\mathrm{m}$ & $\mathrm{m}$ & $\mathrm{m}$ & $\mathrm{m}$ & $\mathrm{m}$ & $m$ & $\mathrm{~m}$ & $\mathrm{~m}$ & $\mathrm{~m}$ & $m$ & $\mathrm{~m}$ & \\
\hline & Kaz & $\mathrm{m}$ & $\mathrm{m}$ & $\mathrm{m}$ & & $\mathrm{m}$ & & $\mathrm{m}$ & $\mathrm{m}$ & $\mathrm{m}$ & $\mathrm{m}$ & $\mathrm{m}$ & & $\mathrm{m}$ & $\mathrm{m}$ & $\mathrm{m}$ & $\mathrm{m}$ & $\mathrm{m}$ & $\mathrm{m}$ & $\mathrm{m}$ & \\
\hline & Malaysia* & $\mathrm{m}$ & $\mathrm{m}$ & $\mathrm{m}$ & $\mathrm{m}$ & $\mathrm{m}$ & $\mathrm{m}$ & $\mathrm{m}$ & & $\mathrm{m}$ & $\mathrm{m}$ & $\mathrm{m}$ & & $\mathrm{m}$ & $\mathrm{m}$ & $\mathrm{m}$ & $\mathrm{m}$ & $\mathrm{m}$ & $\mathrm{m}$ & $\mathrm{m}$ & \\
\hline
\end{tabular}

1. A socio-economically disadvantaged student is a student in the bottom quarter of the distribution of the PISA index of economic, social and cultural status (ESCS) within his or her country/economy.

2. A socio-economically advantaged student is a student in the top quarter of the distribution of the PISA index of economic, social and cultural status (ESCS) within his or her country/economy.

Note: Values that are statistically significant are indicated in bold (see Annex A3).

* See note at the beginning of this Annex.

.

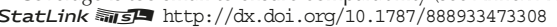




\begin{tabular}{|c|c|c|c|c|c|c|c|c|c|c|c|}
\hline \multicolumn{6}{|c|}{$\begin{array}{l}\text { Gender difference in the percentage of students who agreed/strongly } \\
\text { agreed with the following: (B-G) }\end{array}$} & \multicolumn{6}{|c|}{$\begin{array}{l}\text { Percentage of socio-economically disadvantaged } 1 \text { students } \\
\text { who agreed/strongly agreed with the following }\end{array}$} \\
\hline 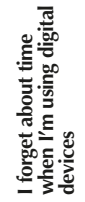 & 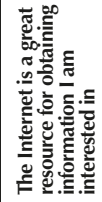 & 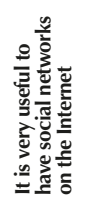 & 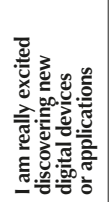 & 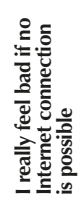 & 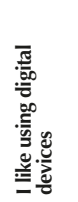 & 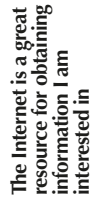 & 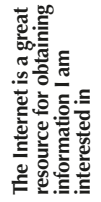 & 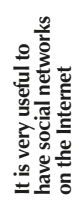 & 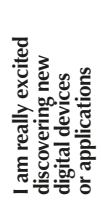 & 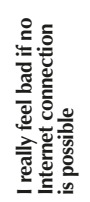 & 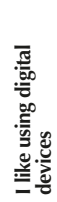 \\
\hline
\end{tabular}

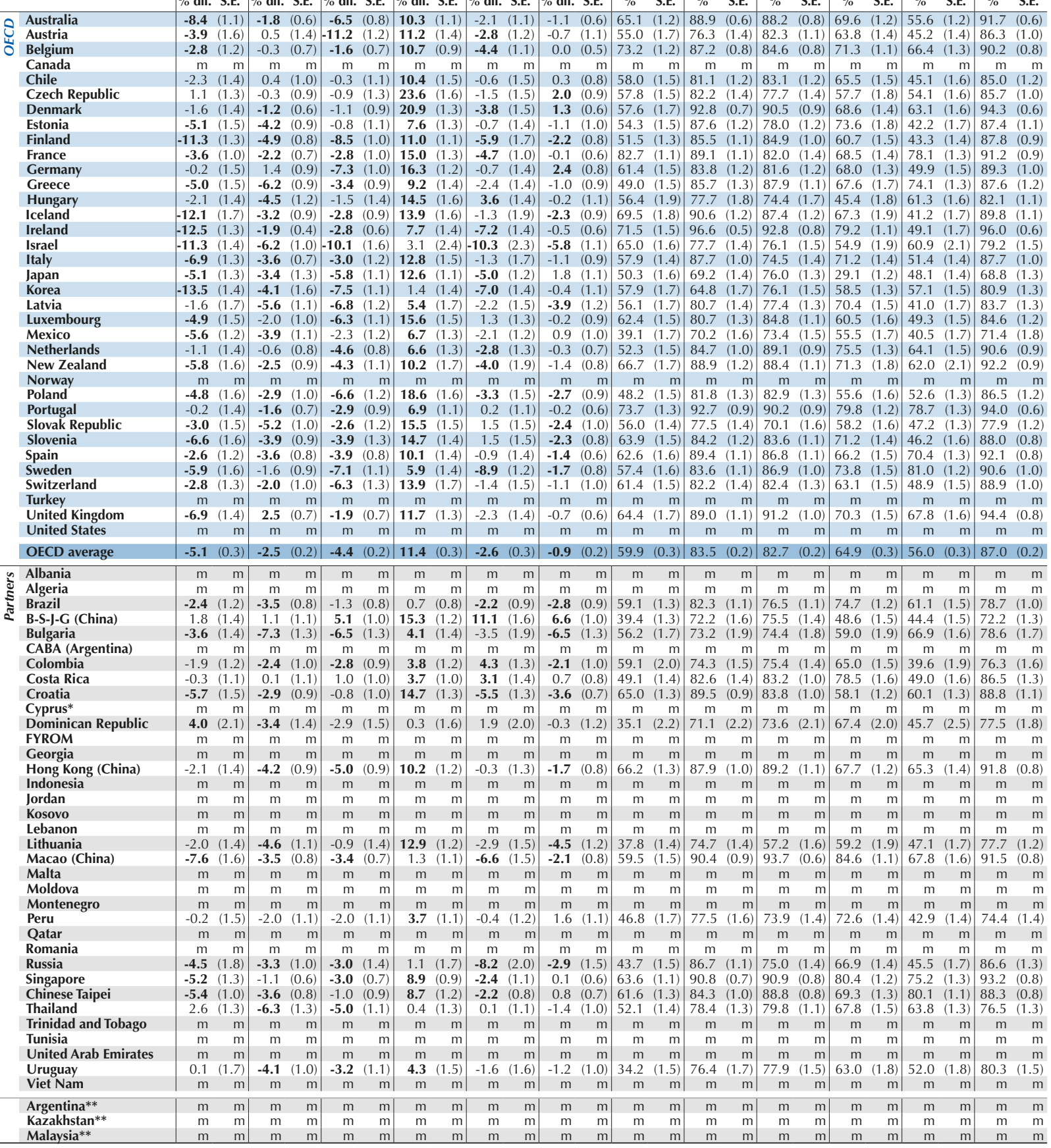

1. A socio-economically disadvantaged student is a student in the bottom quarter of the distribution of the PISA index of economic, social and cultural status (ESCS) within his or her country/economy.

2. A socio-economically advantaged student is a student in the top quarter of the distribution of the PISA index of economic, social and cultural status (ESCS) within his or her country/economy.

* See note at the beginning of this Annex.

** Coverage is too small to ensure comparability (see Annex A4).

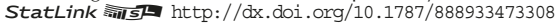




\begin{tabular}{|c|c|c|c|c|c|c|c|c|c|c|c|c|c|c|c|c|c|c|c|c|c|}
\hline & & & Per & $\begin{array}{l}\text { centa } \\
\text { who }\end{array}$ & $\begin{array}{l}\text { ge of } s \\
\text { agreec }\end{array}$ & $\begin{array}{l}\text { ocio-ee } \\
\text { d/stron }\end{array}$ & conom & $\begin{array}{l}\text { ically } \\
\text { reed w }\end{array}$ & advan & taged & $\begin{array}{l}2 \text { stud } \\
\text { owing }\end{array}$ & & & agree & $\begin{array}{r}\text { Socio } \\
\text { d/stro }\end{array}$ & $\begin{array}{l}\text {-eco } \\
\text { ongly }\end{array}$ & omic d & $\begin{array}{l}\text { disparit } \\
\text { with th }\end{array}$ & $y$ in th & $\begin{array}{l}\text { he perc } \\
\text { lowing }\end{array}$ & $\begin{array}{l}\text { rcent } \\
\mathrm{g} \mathrm{(ad}\end{array}$ \\
\hline & & 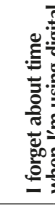 & 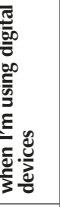 & 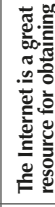 & 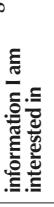 & 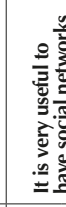 & 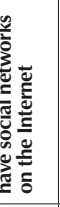 & 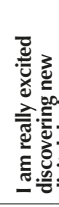 & 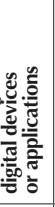 & 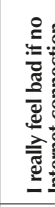 & 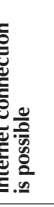 & 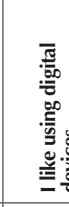 & 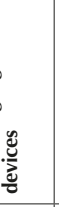 & 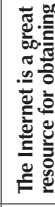 & 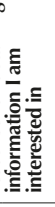 & 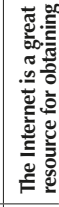 & 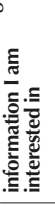 & 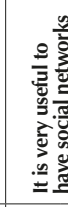 & & 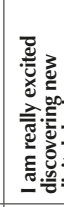 & 这 \\
\hline & & $\%$ & S.E. & $\%$ & S.E. & $\%$ & S.E. & $\%$ & S.E. & $\%$ & S.E. & $\%$ & S.E. & $\%$ dif. & S.E. & $\%$ dif. & S.E. & $\%$ dif. & S.E. & $\%$ dif. & S.E. \\
\hline$\theta$ & Australia & 66.2 & (1.0) & 97.2 & $(0.4)$ & 90.9 & $(0.7)$ & 74.8 & (1.0) & 55.9 & (1.2) & 95.6 & $(0.5)$ & 1.2 & (1.5) & 8.3 & $(0.8)$ & 2.7 & (1.0) & 5.2 & $(1.4)$ \\
\hline & Austria & 54.2 & (1.3) & 88.2 & (1.0) & 78.9 & (1.4) & 67.7 & (1.4) & 39.0 & (1.5) & 91.4 & $(0.7)$ & -0.8 & $(2.0)$ & 11.9 & (1.5) & -3.3 & (1.7) & 3.8 & (1.9) \\
\hline & Belgium & 70.6 & (1.3) & 94.5 & (0.5) & 85.6 & (1.0) & 71.0 & (1.3) & 53.5 & (1.5) & 94.6 & (0.6) & -2.5 & (1.7) & 7.4 & (0.9) & 1.0 & (1.3) & -0.3 & (1.9) \\
\hline & Canada & $\mathrm{m}$ & $\mathrm{m}$ & $\mathrm{m}$ & $\mathrm{m}$ & $\mathrm{m}$ & $\mathrm{m}$ & $\mathrm{m}$ & $\mathrm{m}$ & $\mathrm{m}$ & $\mathrm{m}$ & $\mathrm{m}$ & $\mathrm{m}$ & $\mathrm{m}$ & $\mathrm{m}$ & $\mathrm{m}$ & $\mathrm{m}$ & $\mathrm{m}$ & $\mathrm{m}$ & $\mathrm{m}$ & $\mathrm{m}$ \\
\hline & Chile & 69.2 & (1.1) & 94.8 & $(0.9)$ & 91.1 & $(0.7)$ & 71.9 & (1.3) & 45.5 & (1.3) & 94.0 & (0.7) & 11.2 & $(1.8)$ & 13.7 & (1.4) & 8.0 & (1.5) & 6.5 & $(2.0)$ \\
\hline & Czech Republic & 52.9 & (1.4) & 93.1 & $(0.8)$ & 83.1 & $(1.0)$ & 58.9 & (1.2) & 41.2 & (1.4) & 90.4 & (0.9) & -4.9 & (2.1) & 10.9 & (1.6) & 5.5 & (1.6) & 1.1 & $(2.1)$ \\
\hline & Denmark & 58.7 & (1.4) & 97.1 & (0.5) & 92.1 & $(0.8)$ & 65.1 & (1.6) & 59.4 & (1.6) & 96.1 & $(0.5)$ & 1.0 & $(2.3)$ & 4.3 & $(0.9)$ & 1.5 & (1.1) & -3.5 & $(2.1)$ \\
\hline & Estonia & 54.1 & (1.3) & 93.4 & $(0.8)$ & 81.1 & (1.3) & 77.5 & (1.1) & 32.2 & (1.4) & 91.7 & (0.9) & -0.2 & (1.9) & 5.9 & (1.4) & 3.1 & (1.8) & 3.9 & $(2.0)$ \\
\hline & Finland & 50.3 & (1.5) & 93.7 & $(0.7)$ & 88.7 & $(0.9)$ & 63.1 & (1.4) & 42.7 & (1.8) & 92.9 & (0.6) & -1.3 & (1.8) & 8.2 & (1.2) & 3.8 & (1.4) & 2.4 & $(2.0)$ \\
\hline & France & 83.0 & (1.0) & 97.2 & $(0.5)$ & 79.2 & (1.0) & 64.9 & (1.4) & 79.8 & (1.2) & 95.9 & $(0.5)$ & 0.3 & (1.5) & 8.2 & (1.2) & -2.8 & (1.8) & -3.6 & $(2.1)$ \\
\hline & Germany & 62.5 & (1.3) & 92.3 & $(0.8)$ & 79.5 & (1.1) & 71.2 & (1.1) & 32.8 & (1.2) & 93.6 & $(0.7)$ & 1.1 & (2.1) & 8.5 & (1.5) & -2.1 & (1.7) & 3.2 & (1.9) \\
\hline & Greece & 56.2 & (1.3) & 93.6 & $(0.8)$ & 90.6 & $(0.8)$ & 71.7 & (1.3) & 80.1 & (1.3) & 92.0 & (0.8) & 7.2 & (2.3) & 7.9 & (1.4) & 2.7 & (1.4) & 4.0 & $(1.9)$ \\
\hline & Hungary & 56.3 & (1.5) & 90.0 & (0.9) & 76.0 & (1.1) & 33.6 & (1.5) & 58.6 & (1.3) & 89.5 & (1.1) & -0.2 & (2.5) & 12.3 & (2.0) & 1.6 & (2.2) & -11.8 & $(2.5)$ \\
\hline & Iceland & 66.9 & (1.8) & 94.8 & (0.9) & 92.3 & (0.9) & 75.7 & (1.5) & 39.8 & (1.7) & 93.5 & (0.8) & -2.6 & $(2.3)$ & 4.2 & (1.4) & 5.0 & (1.5) & 8.4 & $(2.7)$ \\
\hline & Ireland & 0.6 & (1.3) & 97.8 & $(0.4)$ & 95.0 & (0.5) & 81.4 & (1.0) & 46.8 & (1.6) & 97.5 & (0.4) & -0.9 & (2.0) & 1.2 & $(0.7)$ & 2.2 & (1.0) & 2.2 & (1.5) \\
\hline & Israel & 65.2 & (1.3) & 89.1 & (1.0) & 80.9 & (1.4) & 52.5 & (1.9) & 54.4 & (2.1) & 87.8 & (1.0) & 0.2 & (2.1) & 11.5 & (1.6) & 4.8 & (2.0) & -2.4 & $(2.5)$ \\
\hline & Italy & 1.7 & (1.6) & 92.7 & $(0.8)$ & 78.0 & $(1.2)$ & 73.0 & (1.2) & 41.9 & (1.3) & 91.4 & (0.8) & 3.8 & (2.2) & 4.9 & (1.4) & 3.5 & (1.7) & 1.8 & (1.9) \\
\hline & Japan & 1.5 & (1.3) & 86.7 & (1.0) & 85.9 & (1.0) & 33.9 & $(1.2)$ & 49.7 & (1.4) & 77.7 & (1.2) & 1.2 & (2.1) & 17.6 & (1.3) & 9.9 & (1.6) & 4.9 & $(1.7)$ \\
\hline & Korea & 58.1 & (1.6) & 79.7 & (1.1) & 83.2 & (1.0) & 64.0 & (1.5) & 62.5 & (1.5) & 87.2 & (1.1) & 0.2 & (2.3) & 14.8 & (1.9) & 7.2 & (1.8) & 5.5 & $(1.7)$ \\
\hline & Latvia & 50.8 & (1.6) & 89.3 & (0.9) & 73.2 & (1.5) & 77.2 & (1.3) & 42.6 & (1.7) & 89.1 & $(1.2)$ & -5.3 & (2.5) & 8.6 & (1.7) & -4.2 & (2.1) & 6.8 & $(2.1)$ \\
\hline & Luxembourg & 59.4 & (1.5) & 92.3 & $(0.9)$ & 86.2 & (1.1) & 62.5 & (1.4) & 40.5 & (1.3) & 93.4 & $(0.8)$ & -3.0 & $(2.0)$ & 11.7 & (1.6) & 1.4 & (1.6) & 2.0 & $(2.1)$ \\
\hline & Mexico & 56.5 & (1.3) & 90.4 & (1.0) & 87.3 & (1.1) & 74.2 & (1.1) & 51.6 & (1.6) & 90.5 & $(0.7)$ & 17.4 & $(2.0)$ & 20.2 & (1.8) & 13.9 & (1.8) & 18.7 & $(2.0)$ \\
\hline & Netherlands & 52.9 & (1.6) & 93.1 & $(0.9)$ & 90.2 & $(0.8)$ & 79.5 & (1.3) & 56.1 & (1.8) & 92.3 & (0.9) & 0.6 & $(2.2)$ & 8.4 & (1.4) & 1.2 & (1.1) & 4.0 & $(2.0)$ \\
\hline & New Zealand & 68.5 & (1.7) & 95.2 & $(0.8)$ & 89.3 & (1.1) & 74.2 & (1.9) & 57.1 & (1.7) & 95.2 & $(0.9)$ & 1.7 & (2.6) & 6.3 & (1.5) & 0.9 & (1.6) & 2.8 & $(2.9)$ \\
\hline & Norway & $\mathrm{m}$ & $\mathrm{m}$ & $\mathrm{m}$ & & $\mathrm{m}$ & $\mathrm{m}$ & $\mathrm{m}$ & $\mathrm{m}$ & $\mathrm{m}$ & $\mathrm{m}$ & $\mathrm{m}$ & $\mathrm{m}$ & $\mathrm{m}$ & $\mathrm{m}$ & $\mathrm{m}$ & $\mathrm{m}$ & $\mathrm{m}$ & $\mathrm{m}$ & $\mathrm{m}$ & $\mathrm{m}$ \\
\hline & Poland & 51.6 & (1.6) & 91.0 & $(0.8)$ & 83.9 & $(1.4)$ & 59.9 & (1.5) & 46.1 & (1.7) & 93.5 & $(0.9)$ & 3.4 & (2.4) & 9.2 & (1.4) & 1.0 & (1.8) & 4.3 & $(2.0)$ \\
\hline & Portugal & 72.0 & (1.5) & 96.5 & $(0.6)$ & 90.0 & $(0.8)$ & 78.3 & (1.1) & 77.2 & (1.0) & 96.3 & $(0.5)$ & -1.7 & (1.8) & 3.9 & (1.1) & -0.2 & (1.3) & -1.4 & $(1.8)$ \\
\hline & Slova & 61.4 & (1.5) & 90.8 & $(0.8)$ & 80.6 & (1.1) & 63.7 & (1.4) & 42.6 & (1.4) & 89.9 & (0.9) & 5.4 & $(2.0)$ & 13.3 & (1.5) & 10.5 & (1.9) & 5.5 & $(2.0)$ \\
\hline & Sloveni & 57.4 & (1.9) & 92.4 & $(0.9)$ & 82.8 & $(1.2)$ & 69.8 & (1.6) & 32.3 & (1.8) & 90.8 & $(0.9)$ & -6.5 & (2.4) & 8.3 & (1.4) & -0.8 & (1.6) & -1.5 & $(2.0)$ \\
\hline & Spain & 0.5 & (1.4) & 94.7 & $(0.6)$ & 90.6 & $(0.7)$ & 69.6 & (1.5) & 68.3 & (1.7) & 94.4 & $(0.7)$ & -2.1 & (2.1) & 5.3 & (1.1) & 3.8 & (1.2) & 3.4 & (1.9) \\
\hline & Sweden & 7.4 & (1.7) & 92.5 & $(0.8)$ & 87.5 & (1.1) & 77.3 & (1.5) & 76.8 & (1.4) & 93.6 & (0.8) & 0.0 & $(2.3)$ & 8.9 & (1.3) & 0.6 & (1.4) & 3.5 & $(2.0)$ \\
\hline & Switzerland & 63.7 & (1.3) & 93.1 & $(0.8)$ & 79.2 & (1.1) & 58.6 & (1.5) & 42.5 & $(2.0)$ & 93.8 & $(0.8)$ & 2.3 & $(2.0)$ & 11.0 & (1.6) & -3.2 & (1.7) & -4.6 & $(2.0)$ \\
\hline & Turkey & $\mathrm{m}$ & & $\mathrm{m}$ & & $\mathrm{m}$ & $\mathrm{m}$ & $\mathrm{m}$ & & $\mathrm{m}$ & & $\mathrm{m}$ & $\mathrm{m}$ & $\mathrm{m}$ & $\mathrm{m}$ & $\mathrm{m}$ & & $\mathrm{m}$ & $\mathrm{m}$ & $\mathrm{m}$ & \\
\hline & United Kingdom & 62.9 & (1.5) & 96.1 & $(0.9)$ & 92.4 & (0.9) & 71.4 & (1.6) & 63.8 & (1.4) & 96.0 & (0.9) & -1.5 & $(2.1)$ & 7.2 & (1.4) & 1.2 & (1.2) & 1.1 & $(2.2)$ \\
\hline & United States & $\mathrm{m}$ & $\mathrm{m}$ & $\mathrm{m}$ & & $\mathrm{m}$ & $\mathrm{m}$ & $\mathrm{m}$ & & $\mathrm{m}$ & $\mathrm{m}$ & $\mathrm{m}$ & $\mathrm{m}$ & $\mathrm{m}$ & & $\mathrm{m}$ & $\mathrm{m}$ & $\mathrm{m}$ & $\mathrm{m}$ & $\mathrm{m}$ & $\mathrm{m}$ \\
\hline & OECD average & 60.7 & $(0.3)$ & 92.7 & $(0.1)$ & 85.3 & $(0.2)$ & 67.4 & $(0.3)$ & 52.0 & $(0.3)$ & 92.3 & (0.1) & 0.8 & $(0.4)$ & 9.2 & $(0.3)$ & 2.6 & $(0.3)$ & 2.5 & $(0.4)$ \\
\hline & Albania & $\mathrm{m}$ & $\mathrm{m}$ & $\mathrm{m}$ & & $\mathrm{m}$ & $\mathrm{m}$ & $\mathrm{m}$ & & $\mathrm{m}$ & $\mathrm{m}$ & $\mathrm{m}$ & & $\mathrm{m}$ & & $\mathrm{m}$ & & $\mathrm{m}$ & $\mathrm{m}$ & $\mathrm{m}$ & \\
\hline & Algeria & $\mathrm{m}$ & & $\mathrm{m}$ & & $\mathrm{m}$ & & $\mathrm{m}$ & & $\mathrm{m}$ & & $\mathrm{m}$ & & $\mathrm{m}$ & & $\mathrm{m}$ & & $\mathrm{m}$ & & $\mathrm{m}$ & \\
\hline 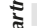 & Brazil & 70.5 & (1.1) & 91.9 & $(0.8)$ & 86.4 & $(0.7)$ & 84.8 & (0.9) & 72.6 & (1.0) & 91.0 & $(0.6)$ & 11.3 & (1.9) & 9.6 & (1.3) & 9.9 & (1.4) & 10.1 & (1.4) \\
\hline & B-S-J-G (China) & 43.3 & (1.2) & 91.6 & (1.4) & 88.6 & $(0.7)$ & 68.2 & (1.2) & 54.6 & (1.7) & 89.4 & (1.3) & 4.0 & (1.7) & 19.4 & $(2.1)$ & 13.1 & (1.7) & 19.5 & (2.0) \\
\hline & Bulgaria & 59.8 & (1.7) & 89.9 & (1.1) & 81.0 & (1.0) & 63.1 & (1.6) & 63.2 & (1.2) & 90.7 & (1.0) & 3.6 & (2.4) & 16.6 & (1.9) & 6.5 & (1.9) & 4.1 & (2.3) \\
\hline & Argentina) & $\mathrm{m}$ & & $\mathrm{m}$ & & $\mathrm{m}$ & $\mathrm{m}$ & $\mathrm{m}$ & & $\mathrm{m}$ & & $\mathrm{m}$ & $\mathrm{m}$ & $\mathrm{m}$ & & $\mathrm{m}$ & & $\mathrm{m}$ & $\mathrm{m}$ & & \\
\hline & Colo & 9.7 & (1.0) & 90.8 & $(0.8)$ & 88.4 & (1.0) & 79.1 & (1.3) & 53.5 & (1.3) & 91.4 & $(0.7)$ & 20.7 & $(2.3)$ & 16.5 & (1.7) & 13.0 & (1.7) & 14.1 & (2.0) \\
\hline & $\operatorname{Cos}$ & 3.4 & (1.4) & 93.1 & $(0.7)$ & 88.8 & (0.9) & 90.7 & (0.8) & 55.9 & (1.4) & 94.5 & (0.6) & 19.3 & (1.9) & 10.5 & (1.5) & 5.7 & (1.3) & 12.2 & $(1.8)$ \\
\hline & Croatia & 2.5 & (1.4) & 94.4 & $(0.7)$ & 84.7 & (1.0) & 58.4 & (1.4) & 61.0 & (1.7) & 93.7 & $(0.7)$ & -2.5 & (1.9) & 4.9 & (1.0) & 0.9 & (1.5) & 0.3 & (1.8) \\
\hline & Сур & $\mathrm{m}$ & & $\mathrm{m}$ & & $\mathrm{m}$ & & $\mathrm{m}$ & & $\mathrm{m}$ & & $\mathrm{m}$ & $\mathrm{m}$ & $\mathrm{m}$ & & $\mathrm{m}$ & $\mathrm{m}$ & $\mathrm{m}$ & $\mathrm{m}$ & $\mathrm{m}$ & $\mathrm{m}$ \\
\hline & Domi & 6.9 & (1.7) & 88.0 & $(1.2)$ & 88.6 & (1.3) & 84.8 & (1.5) & 56.4 & (2.0) & 91.7 & (0.9) & 21.8 & (2.6) & 16.9 & (2.5) & 15.1 & (2.4) & 17.5 & (2.4) \\
\hline & FYROM & $\mathrm{m}$ & & $\mathrm{m}$ & & $\mathrm{m}$ & $\mathrm{m}$ & $\mathrm{m}$ & & $\mathrm{m}$ & & $\mathrm{m}$ & $\mathrm{m}$ & $\mathrm{m}$ & & $\mathrm{m}$ & & $\mathrm{m}$ & $\mathrm{m}$ & $\mathrm{m}$ & \\
\hline & Georg & $\mathrm{m}$ & & $\mathrm{m}$ & & $\mathrm{m}$ & & $\mathrm{m}$ & & $\mathrm{m}$ & & $\mathrm{m}$ & $\mathrm{m}$ & $\mathrm{m}$ & & $\mathrm{m}$ & & $\mathrm{m}$ & $\mathrm{m}$ & $\mathrm{m}$ & \\
\hline & Hong Kong (China) & 63.0 & (1.8) & 93.4 & $(0.8)$ & 91.3 & $(0.9)$ & 70.3 & (1.4) & 62.5 & (1.3) & 93.4 & (0.8) & -3.1 & (2.3) & 5.5 & (1.1) & 2.0 & (1.3) & 2.6 & (1.9) \\
\hline & Indone & $\mathrm{m}$ & & $\mathrm{m}$ & $\mathrm{m}$ & $\mathrm{m}$ & $\mathrm{m}$ & $\mathrm{m}$ & & $\mathrm{m}$ & $\mathrm{m}$ & $\mathrm{m}$ & $\mathrm{m}$ & $\mathrm{m}$ & & $\mathrm{m}$ & $\mathrm{m}$ & $\mathrm{m}$ & $\mathrm{m}$ & $\mathrm{m}$ & $\mathrm{m}$ \\
\hline & Jorda & $\mathrm{m}$ & & $\mathrm{m}$ & & $\mathrm{m}$ & & $\mathrm{m}$ & & $\mathrm{m}$ & $\mathrm{m}$ & $\mathrm{m}$ & $\mathrm{m}$ & $\mathrm{m}$ & & $\mathrm{m}$ & & $\mathrm{m}$ & $\mathrm{m}$ & $\mathrm{m}$ & \\
\hline & Kos & $\mathrm{m}$ & & $\mathrm{m}$ & $\mathrm{m}$ & $\mathrm{m}$ & $\mathrm{m}$ & $\mathrm{m}$ & & $\mathrm{m}$ & $\mathrm{m}$ & $\mathrm{m}$ & $\mathrm{m}$ & $\mathrm{m}$ & & $\mathrm{m}$ & & $\mathrm{m}$ & $\mathrm{m}$ & $\mathrm{m}$ & \\
\hline & Lebanon & $\mathrm{m}$ & & $\mathrm{m}$ & $\mathrm{m}$ & $\mathrm{m}$ & $\mathrm{m}$ & $\mathrm{m}$ & & $\mathrm{m}$ & $\mathrm{m}$ & $\mathrm{m}$ & $\mathrm{m}$ & $\mathrm{m}$ & & $\mathrm{m}$ & $\mathrm{m}$ & $\mathrm{m}$ & $\mathrm{m}$ & & $\mathrm{m}$ \\
\hline & Lithe & 4.2 & (1.3) & 84.8 & (1.0) & 62.1 & (1.5) & 66.7 & (1.5) & 50.3 & (1.5) & 87.2 & (0.9) & 6.4 & $(2.0)$ & 10.2 & (1.7) & 4.9 & (2.2) & 7.5 & (2.3) \\
\hline & Macao (China & 9.7 & (1.6) & 93.8 & $(0.6)$ & 93.7 & $(0.8)$ & 82.4 & (1.2) & 65.3 & (1.4) & 93.3 & $(0.7)$ & 0.2 & (2.0) & 3.4 & $(1.2)$ & 0.0 & (1.1) & -2.2 & (1.8) \\
\hline & Malta & $\mathrm{m}$ & & $\mathrm{m}$ & $\mathrm{m}$ & $\mathrm{m}$ & & $\mathrm{m}$ & & $\mathrm{m}$ & & $\mathrm{m}$ & $\mathrm{m}$ & $\mathrm{m}$ & & $\mathrm{m}$ & $\mathrm{m}$ & $\mathrm{m}$ & $\mathrm{m}$ & $\mathrm{m}$ & $\mathrm{m}$ \\
\hline & Moldo & $\mathrm{m}$ & & $\mathrm{m}$ & & $\mathrm{m}$ & & $\mathrm{m}$ & & $\mathrm{m}$ & & $\mathrm{m}$ & & $\mathrm{m}$ & & $\mathrm{m}$ & & $\mathrm{m}$ & $\mathrm{m}$ & $\mathrm{m}$ & \\
\hline & Monte & $\mathrm{m}$ & & $\mathrm{m}$ & $\mathrm{m}$ & $\mathrm{m}$ & & $\mathrm{m}$ & & $\mathrm{m}$ & $\mathrm{m}$ & $\mathrm{m}$ & $\mathrm{m}$ & $\mathrm{m}$ & & $\mathrm{m}$ & $\mathrm{m}$ & $\mathrm{m}$ & $\mathrm{m}$ & $\mathrm{m}$ & $\mathrm{m}$ \\
\hline & Peru & 7.2 & $(1.2)$ & 93.2 & (0.6) & 91.3 & (0.9) & 83.7 & (1.0) & 49.8 & (1.3) & 91.8 & $(0.6)$ & $\mid$\begin{tabular}{|l|}
20.3 \\
\end{tabular} & $(2.2)$ & 15.7 & (1.7) & 17.4 & (1.7) & 11.1 & (1.8) \\
\hline & Qatar & $\mathrm{m}$ & & $\mathrm{m}$ & & $\mathrm{m}$ & & $\mathrm{m}$ & & $\mathrm{m}$ & & $\mathrm{m}$ & & $\mathrm{m}$ & & $\mathrm{m}$ & & $\mathrm{m}$ & & $\mathrm{m}$ & \\
\hline & Romani & $\mathrm{m}$ & & & & & & $\mathrm{m}$ & & $\mathrm{m}$ & & $\mathrm{m}$ & $\mathrm{m}$ & $\mathrm{m}$ & & $\mathrm{m}$ & & $\mathrm{m}$ & $\mathrm{m}$ & $\mathrm{m}$ & \\
\hline & Russia & 4.6 & (1.3) & 89.1 & (1.2) & 74.2 & (1.2) & 66.1 & (1.6) & 44.8 & (1.6) & 90.0 & (1.1) & 0.9 & (1.9) & 2.4 & (1.6) & -0.9 & (1.9) & -0.8 & (1.9) \\
\hline & & .2 & (1.5) & 96.3 & $(0.7)$ & 90.3 & $(0.8)$ & 78.9 & (1.3) & 69.4 & (1.5) & 95.5 & $(0.7)$ & -2.4 & (1.6) & 5.5 & (0.9) & -0.6 & (0.9) & -1.6 & (1.9) \\
\hline & Chine & 9.9 & (1.2) & 94.1 & $(0.6)$ & 89.8 & $(0.7)$ & 79.2 & (1.1) & 80.5 & (1.1) & 93.6 & (0.7) & -1.7 & $(2.0)$ & 9.8 & (1.1) & 1.0 & (1.1) & 9.9 & (1.6) \\
\hline & Thail & 8.9 & (1.4) & 92.0 & $(0.9)$ & 92.4 & $(0.8)$ & 80.0 & (1.1) & 78.2 & (1.4) & 91.5 & (0.9) & 16.7 & (2.0) & 13.6 & (1.4) & 12.7 & (1.3) & 12.2 & (1.9) \\
\hline & Trin & $\mathrm{m}$ & & $\mathrm{m}$ & & $\mathrm{m}$ & & $\mathrm{m}$ & & $\mathrm{m}$ & $\mathrm{m}$ & $\mathrm{m}$ & $\mathrm{m}$ & $\mathrm{m}$ & & $\mathrm{m}$ & $\mathrm{m}$ & $\mathrm{m}$ & $\mathrm{m}$ & $\mathrm{m}$ & $\mathrm{m}$ \\
\hline & Tun & $\mathrm{m}$ & & $\mathrm{m}$ & & $\mathrm{m}$ & $\mathrm{m}$ & $\mathrm{m}$ & & $\mathrm{m}$ & & $\mathrm{m}$ & $\mathrm{m}$ & $\mathrm{m}$ & & $\mathrm{m}$ & & $\mathrm{m}$ & $\mathrm{m}$ & $\mathrm{m}$ & $\mathrm{m}$ \\
\hline & Uni & $\mathrm{m}$ & & $\mathrm{m}$ & $\mathrm{m}$ & $\mathrm{m}$ & & $\mathrm{m}$ & & $\mathrm{m}$ & $\mathrm{m}$ & $\mathrm{m}$ & $\mathrm{m}$ & $\mathrm{m}$ & & $\mathrm{m}$ & $\mathrm{m}$ & $\mathrm{m}$ & $\mathrm{m}$ & $\mathrm{m}$ & $\mathrm{m}$ \\
\hline & Uruguay & 1.9 & (1.5) & 88.8 & (1.1) & 87.3 & (1.0) & 73.8 & (1.6) & 59.4 & (1.5) & 91.6 & $(0.9)$ & 7.7 & (2.1) & 12.4 & (2.0) & 9.5 & (1.7) & 10.8 & $(2.5)$ \\
\hline & Viet Nam & $\mathrm{m}$ & $\mathrm{m}$ & $\mathrm{m}$ & $\mathrm{m}$ & $\mathrm{m}$ & $\mathrm{m}$ & $\mathrm{m}$ & $\mathrm{m}$ & $\mathrm{m}$ & $\mathrm{m}$ & $\mathrm{m}$ & $\mathrm{m}$ & $\mathrm{m}$ & $\mathrm{m}$ & $\mathrm{m}$ & $\mathrm{m}$ & $\mathrm{m}$ & $\mathrm{m}$ & $\mathrm{m}$ & $\mathrm{m}$ \\
\hline & Arge & $\mathrm{m}$ & & $\mathrm{m}$ & $\mathrm{m}$ & $\mathrm{m}$ & $\mathrm{m}$ & $\mathrm{m}$ & $\mathrm{m}$ & $\mathrm{m}$ & $\mathrm{m}$ & $\mathrm{m}$ & $\mathrm{m}$ & $\mathrm{m}$ & & $\mathrm{m}$ & $\mathrm{m}$ & $\mathrm{m}$ & $\mathrm{m}$ & $\mathrm{m}$ & \\
\hline & & $\mathrm{m}$ & & $\mathrm{m}$ & $\mathrm{m}$ & $\mathrm{m}$ & $\mathrm{m}$ & $\mathrm{m}$ & & $\mathrm{m}$ & $\mathrm{m}$ & $\mathrm{m}$ & iil & $\mathrm{m}$ & & $\mathrm{m}$ & & $\mathrm{m}$ & $\mathrm{m}$ & $\mathrm{m}$ & \\
\hline & Malaysia*- & $\mathrm{m}$ & $\mathrm{m}$ & $\mathrm{m}$ & $\mathrm{m}$ & $\mathrm{m}$ & $\mathrm{m}$ & $\mathrm{m}$ & $\mathrm{m}$ & $\mathrm{m}$ & $\mathrm{m}$ & $\mathrm{m}$ & $\mathrm{m}$ & $\mathrm{m}$ & $\mathrm{m}$ & $\mathrm{m}$ & $\mathrm{m}$ & $\mathrm{m}$ & $\mathrm{m}$ & $\mathrm{m}$ & $\mathrm{m}$ \\
\hline
\end{tabular}

1. A socio-economically disadvantaged student is a student in the bottom quarter of the distribution of the PISA index of economic, social and cultural status (ESCS) within his or her country/economy.

2. A socio-economically advantaged student is a student in the top quarter of the distribution of the PISA index of economic, social and cultural status (ESCS) within his or her country/economy.

Note: Values that are statistically significant are indicated in bold (see Annex A3).

** See note at the beginning of this Annex.

Coverage is too small to ensure comparability (see Annex A4)

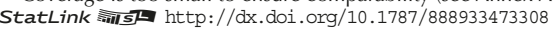


[Part 1/3]

Table III.13.19a Sense of belonging at school, by time spent on the Internet outside of school on weekdays

Percentage of students who reported "agree" or "strongly agree" (a) or who reported "disagree" or "strongly disagree" (d)

\begin{tabular}{|c|c|c|c|c|c|c|c|c|c|c|c|c|c|c|c|c|c|c|c|c|c|}
\hline & & & (Stu & w & who use & the & Int & for & $\begin{array}{l}\text { ss } \\
\text { s the }\end{array}$ & 1 & & & & & (Stude & ents $v$ & & the & & & 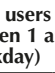 \\
\hline & & $\begin{array}{l}\text { I fee } \\
\text { an ou } \\
\text { (or le } \\
\text { of th } \\
\text { at scl }\end{array}$ & $\begin{array}{l}\text { llike } \\
\text { Itsider } \\
\text { fft out }^{\text {out }} \\
\text { ings) } \\
\text { hoool }^{d}\end{array}$ & $\begin{array}{l}1 \mathrm{~m} \\
\text { frie } \\
\text { eas } \\
\text { at sch }\end{array}$ & $\begin{array}{l}\text { nake } \\
\text { ends } \\
\text { sily } \\
\text { hool }^{\text {a }}\end{array}$ & $\begin{array}{l}\text { I feel } \\
\text { I bel } \\
\text { at sch }\end{array}$ & $\begin{array}{l}\text { like } \\
\text { likg } \\
\text { ong } \\
\text { noola }^{2}\end{array}$ & $\begin{array}{l}\text { If } \\
\text { awk } \\
\text { and } \\
\text { of } p \\
\text { in } \\
\text { sch }\end{array}$ & $\begin{array}{l}\text { eel } \\
\text { ward } \\
\text { out } \\
\text { lace } \\
\text { my } \\
\text { ool }\end{array}$ & $\begin{array}{l}\text { Oth } \\
\text { stude } \\
\text { seem } \\
\text { like n }\end{array}$ & $\begin{array}{l}\text { her } \\
\text { lents } \\
\text { n to } \\
\text { me }^{\text {a }}\end{array}$ & $\begin{array}{l}\text { If } \\
\text { lon } \\
\text { at sch }\end{array}$ & $\begin{array}{l}\text { ely } \\
\text { ely } \\
\text { nool }\end{array}$ & $\begin{array}{l}\text { If } \mathrm{fe} \\
\text { an o } \\
\text { (or } \\
\text { of } \mathrm{t} \\
\text { at } \mathrm{s}\end{array}$ & $\begin{array}{l}\text { ke } \\
\text { der } \\
\text { but } \\
\text { ss) } \\
\text { d d }^{d}\end{array}$ & $\begin{array}{l}\text { I ma } \\
\text { frien } \\
\text { easily } \\
\text { scho }\end{array}$ & $\begin{array}{l}\text { ake } \\
\text { nds } \\
\text { y at } \\
\text { ool }\end{array}$ & $\begin{array}{l}\text { I feel } \\
\text { I belo } \\
\text { at sch }\end{array}$ & $\begin{array}{l}\text { l like } \\
\text { long } \\
\text { hoo }\end{array}$ & $\begin{array}{l}\text { I fe } \\
\text { awky } \\
\text { and } \\
\text { of pl } \\
\text { in } \\
\text { scho }\end{array}$ & $\begin{array}{l}\text { ll } \\
\text { ard } \\
\text { out } \\
\text { ace } \\
\text { ay } \\
\text { ld }^{d}\end{array}$ \\
\hline & & $\%$ & S.E. & $\%$ & S.E. & $\%$ & S.E. & $\%$ & S.E. & $\%$ & S.E. & $\%$ & S.E. & $\%$ & S.E. & $\%$ & S.E. & $\%$ & S.E. & $\%$ & S.E. \\
\hline & Australia & 75.6 & (1.4) & 77.0 & (1.3) & 70.9 & (1.5) & 78.3 & (1.2) & 84.9 & (1.2) & 84.0 & (1.0) & 80.8 & $3 \quad(0.8$ & $\begin{array}{l}82.7 \\
\end{array}$ & (1.0) & 76.7 & (0.9) & 81.6 & $(0.9)$ \\
\hline & Austria & 37.6 & (1.1) & 79.0 & $(1.2)$ & 78.3 & (1.2) & 83.9 & (1.1) & 84.3 & (1.1) & 85.7 & (1.0) & 87.2 & $(0.9$ & 9.3 & (1.3) & 79.5 & (1.1) & 5.3 & (1.0) \\
\hline & Belgium & 87.6 & $(0.9)$ & 81.7 & (1.0) & 62.9 & (1.3) & 85.6 & $(0.9)$ & 89.3 & $(0.9)$ & 89.9 & $(0.8)$ & 88.7 & $(0.7$ & $\begin{array}{l}81.4 \\
\end{array}$ & $(0.9)$ & 64.0 & (1.0) & 87.8 & $(0.7)$ \\
\hline & Canada & $\mathrm{m}$ & & $\mathrm{m}$ & & $\mathrm{m}$ & $\mathrm{m}$ & $\mathrm{m}$ & $\mathrm{m}$ & $\mathrm{m}$ & $\mathrm{m}$ & $\mathrm{m}$ & $\mathrm{m}$ & $\mathrm{m}$ & $\mathrm{m}$ & $\mathrm{m}$ & $\mathrm{m}$ & $\mathrm{m}$ & $\mathrm{m}$ & $\mathrm{m}$ & $\mathrm{m}$ \\
\hline & Chile & 75.3 & (1.6) & 71.9 & (1.5) & 72.6 & (1.6) & 76.1 & (1.7) & 71.1 & (1.8) & 80.4 & (1.6) & 82.2 & 2) $(1.6$ & 75.1 & (1.9) & 79.5 & (1.7) & 83.0 & (1.5) \\
\hline & Czech Rep & 81.2 & (1.3) & 71.8 & $(1.8)$ & 72.6 & (1.8) & 82.1 & (1.3) & 78.5 & (1.6) & 80.0 & (1.4) & 83.2 & 2) $(1.1$ & ) 76.6 & (1.4) & 74.3 & (1.4) & 84.0 & (1.2) \\
\hline & Denmark & 86.6 & (1.5) & 78.6 & (1.9) & 72.6 & (2.0) & 83.8 & (1.7) & 85.5 & (1.5) & 87.2 & (1.3) & 89. & $+\quad(1.0$ & 1) 81.3 & $(1.2)$ & 75.1 & (1.4) & 87.2 & (1.0) \\
\hline & Estonia & 88.2 & (1.2) & 77.5 & $(1.7)$ & 78.9 & (1.6) & 86.4 & (1.2) & 81.1 & (1.6) & 86.5 & (1.5) & 90.5 & $5 \quad(1.0$ & $\begin{array}{l}\text { ) } 79.8 \\
\end{array}$ & (1.4) & 78.2 & (1.4) & 84.9 & (1.3) \\
\hline & Finland & 89.7 & $(1.0)$ & 79.3 & $(1.4)$ & 82.6 & (1.2) & 84.3 & (1.1) & 84.3 & $(1.2)$ & 90.0 & (1.1) & 91.4 & $4 \quad 0.7$ & 83.4 & $(0.9)$ & 85.5 & (1.0) & 87.3 & (0.9) \\
\hline & France & 79.0 & $(1.2)$ & 86.9 & $(1.1)$ & 44.3 & (1.5) & 85.0 & (1.0) & 90.2 & $(0.9)$ & 89.7 & $(0.9)$ & 81.6 & $5 \quad(1.1$ & 87.3 & $(0.9)$ & 43.0 & $(1.2)$ & 87.5 & $(0.9)$ \\
\hline & Germany & $\mathrm{m}$ & & $\mathrm{m}$ & & $\mathrm{m}$ & $\mathrm{m}$ & $\mathrm{m}$ & $\mathrm{m}$ & $\mathrm{m}$ & $\mathrm{m}$ & $\mathrm{m}$ & $\mathrm{m}$ & $\mathrm{m}$ & 7 & $\mathrm{~m}$ & $\mathrm{~m}$ & $\mathrm{~m}$ & $\mathrm{~m}$ & $\mathrm{~m}$ & $\mathrm{~m}$ \\
\hline & Greece & 84.9 & (1.3) & 79.6 & $(1.2)$ & 82.8 & (1.0) & 84.9 & (1.1) & 88.2 & (1.2) & 88.3 & (1.1) & 89.3 & 3) $\quad(0.9$ & 81.6 & (1.1) & 86.4 & (1.0) & 87.5 & $(0.9)$ \\
\hline & Hungary & 82.2 & (1.5) & 79.3 & (1.3) & 76.1 & (1.6) & 83.2 & (1.5) & 81.9 & (1.6) & 85.4 & (1.2) & 84.5 & ; $(1.1$ & 82.5 & (1.2) & 78.3 & (1.1) & 85.8 & (1.0) \\
\hline & Icela & .1 & (1.6) & 76.5 & (2.2) & 80.2 & (2.2) & 80.2 & (2.0) & 86.0 & (2.0) & 86.3 & (1.6) & 85.9 & )$(1.1$ & 78.2 & (1.4) & 83.8 & $(1.2)$ & 84.7 & (1.3) \\
\hline & Ireland & 84.6 & (1.3) & 80.4 & (1.4) & 77.8 & (1.4) & 86.7 & (1.2) & 91.3 & (1.0) & 88.3 & (1.1) & 85.1 & $(1.0$ & 82.0 & (1.0) & 78.1 & (1.4) & 84.1 & $(1.2)$ \\
\hline & Israel & $\mathrm{m}$ & $\mathrm{m}$ & $\mathrm{m}$ & $\mathrm{m}$ & $\mathrm{m}$ & $\mathrm{m}$ & $\mathrm{m}$ & $\mathrm{m}$ & $\mathrm{m}$ & $\mathrm{m}$ & $\mathrm{m}$ & $\mathrm{m}$ & $\mathrm{m}$ & $\mathrm{m}$ & $\mathrm{m}$ & $\mathrm{m}$ & $\mathrm{m}$ & $\mathrm{m}$ & $\mathrm{m}$ & $\mathrm{m}$ \\
\hline & Italy & 88.7 & $(0.9)$ & 82.6 & $(1.2)$ & 68.7 & (1.4) & 88.8 & (1.0) & 75.3 & (1.6) & 90.5 & (1.0) & 90.0 & $(1.0$ & ) 83.7 & (1.0) & 66.0 & (1.6) & 86.8 & (1.1) \\
\hline & Japan & 89.5 & $(0.7)$ & 70.1 & (1.0) & 83.7 & (0.7) & 83.7 & (0.8) & 76.9 & $(0.9)$ & 90.1 & $(0.6)$ & 89. & ( $\quad 0.8$ & 69.3 & (1.1) & 82.6 & (1.1) & 81.3 & $(0.9)$ \\
\hline & Korea & 91.4 & $(0.5)$ & 79.8 & $(0.8)$ & 81.1 & (0.9) & 90.5 & (0.5) & 82.9 & $(0.8)$ & 91.7 & $(0.5)$ & 93.1 & $(0.7$ & 80.2 & (1.1) & 79.0 & (1.4) & 91.8 & $(0.7)$ \\
\hline & Latvia & 4 & (1.3) & 75.5 & $(1.5)$ & 78.3 & (1.6) & 76.3 & (1.5) & 66.9 & (1.6) & 82.6 & (1.4) & 87.1 & $(1$. & 79.2 & (1.4) & 82.4 & (1.5) & 78.0 & $(1.5)$ \\
\hline & Luxembo & 9 & $(1.4)$ & 73.9 & $(1.5)$ & 64.2 & (1.5) & 77.9 & (1.4) & 78.5 & (1.3) & 83.8 & (1.4) & 8 & $3(1$. & ) 78.1 & (1.3) & 70.2 & (1.4) & 83.3 & (1.3) \\
\hline & $\mathrm{Me}$ & & $(1.0)$ & 70.8 & $(0.9)$ & 75.2 & (1.1) & 73.7 & $(0.9)$ & 68.3 & (1.2) & 76.6 & (0.9) & 75 & $3 \quad(1$. & ) 72.7 & (1.3) & 76.8 & (1.3) & 76.0 & (1.3) \\
\hline & Net & 91.5 & $(1.2)$ & 85.4 & - (1.5) & 83.5 & (1.6) & 87.6 & (1.2) & 92.6 & (1.0) & 93.5 & $(0.9)$ & 92.7 & $7 \quad(0.8$ & 85.2 & $(0.9)$ & 82.2 & $(1.2)$ & 88.9 & (1.1) \\
\hline & New & 78.4 & (1.9) & 79.5 & $(1.7)$ & 73.6 & (2.0) & 77.3 & (1.8) & 86.9 & (1.3) & 81.3 & (1.7) & 81.5 & $5 \quad(1.5$ & 82.1 & (1.7) & 80.0 & (1.6) & 82.4 & (1.7) \\
\hline & Norway & $\mathrm{m}$ & & $\mathrm{m}$ & & $\mathrm{m}$ & $\mathrm{m}$ & $\mathrm{m}$ & $\mathrm{m}$ & $\mathrm{m}$ & $\mathrm{m}$ & $\mathrm{m}$ & $\mathrm{m}$ & $\mathrm{m}$ & $\mathrm{m}$ & $\mathrm{m}$ & $\mathrm{m}$ & $\mathrm{m}$ & $\mathrm{m}$ & $\mathrm{m}$ & \\
\hline & Poland & 79.6 & (1.6) & 71.7 & $(2.0)$ & 65.0 & (1.7) & 77.7 & (1.9) & 71.2 & (1.9) & 81.8 & (1.7) & 79.5 & $5 \quad(1.2$ & 74.5 & (1.4) & 65.4 & (1.5) & 79.5 & (1.2) \\
\hline & Portugal & 86.9 & $(0.9)$ & 77.1 & (1.1) & 82.9 & (1.1) & 75.0 & (1.2) & 87.0 & (1.0) & 88.7 & (0.9) & 87.6 & $5 \quad(0.8$ & 78.3 & (1.1) & 84.6 & (1.0) & 77.6 & (1.2) \\
\hline & Slov & .5 & (1.5) & 74.4 & (1.3) & 70.1 & (1.6) & 76.3 & (1.4) & 75.2 & (1.5) & 77.7 & (1.5) & 79.4 & $4 \quad(1$. & 77.5 & (1.1) & 73.9 & (1.4) & 3 & (1.2) \\
\hline & Sloven & .8 & (1.1) & 76.0 & (1.4) & 78.1 & (1.3) & 84.7 & (0.9) & 78.5 & (1.2) & 86.4 & (1.0) & 4.6 & $(1.2$ & 77.6 & (1.6) & 76.6 & (1.5) & 8 & (1.2) \\
\hline & Spain & .9 & $(1.2)$ & 80.9 & (1.4) & 84.8 & (1.2) & 84.8 & (1.1) & 82.4 & (1.4) & 89.8 & (1.0) & 90.7 & 7 $\quad 0.8$ & 84.1 & (1.0) & 88.3 & (1.0) & 86.8 & (1.0) \\
\hline & Swede & .5 & (2.0) & 73.3 & (2.3) & 69.0 & (2.3) & 81.7 & (2.4) & 79.0 & $(2.2)$ & 82.3 & (1.9) & 81.5 & 5 $(1.4$ & 77.3 & (1.5) & 72.4 & (1.8) & 82.3 & (1.3) \\
\hline & Sw & 7.2 & (1.3) & 79.2 & (1.2) & 72.9 & (1.7) & 85.0 & (1.1) & 87.5 & $(1.2)$ & 90.9 & $(0.9)$ & 91.9 & ) $\quad(0.8$ & 83.7 & (1.1) & 75.5 & (1.3) & 88.3 & (1.1) \\
\hline & Turke & $\mathrm{m}$ & & $\mathrm{m}$ & $\mathrm{m}$ & $\mathrm{m}$ & & $\mathrm{m}$ & $\mathrm{m}$ & $\mathrm{m}$ & $\mathrm{m}$ & $\mathrm{m}$ & $\mathrm{m}$ & $\mathrm{m}$ & ר & $\mathrm{m}$ & $\mathrm{m}$ & $\mathrm{m}$ & $\mathrm{m}$ & $\mathrm{m}$ & min \\
\hline & United $\mathrm{K}$ & 30.8 & (2.3) & 75.2 & (2.5) & 67.8 & (2.5) & 82.6 & (2.0) & 85.5 & (1.7) & 85.3 & (2.1) & 84.8 & $\begin{array}{l}3 \\
\end{array}$ & $\begin{array}{l}\text { ) } 83.8 \\
\end{array}$ & (1.5) & 74.2 & (1.6) & 85.5 & (1.6) \\
\hline & United States & $\mathrm{m}$ & & $\mathrm{m}$ & $\mathrm{m}$ & $\mathrm{m}$ & & $\mathrm{m}$ & $\mathrm{m}$ & $\mathrm{m}$ & $\mathrm{m}$ & $\mathrm{m}$ & & $\mathrm{m}$ & m & $\mathrm{m}$ & $\mathrm{m}$ & $\mathrm{m}$ & $\mathrm{m}$ & $\mathrm{m}$ & $\mathrm{m}$ \\
\hline & OECD average & 83.4 & $(0.3)$ & 77.4 & $(0.3)$ & 74.2 & $(0.3)$ & 82.2 & (0.3) & 81.8 & $(0.3)$ & 86.0 & $(0.2)$ & 86.0 & $(0.2$ & ) 79.9 & $(0.2)$ & 76.3 & $(0.2)$ & 84.3 & $(0.2)$ \\
\hline & Alb & $\mathrm{m}$ & $\mathrm{m}$ & $\mathrm{m}$ & $\mathrm{m}$ & $\mathrm{m}$ & $\mathrm{m}$ & $\mathrm{m}$ & $\mathrm{m}$ & $\mathrm{m}$ & $\mathrm{m}$ & $\mathrm{m}$ & $\mathrm{m}$ & $\mathrm{m}$ & & $\mathrm{m}$ & $\mathrm{m}$ & $\mathrm{m}$ & $\mathrm{m}$ & $\mathrm{m}$ & \\
\hline & Alg & $\mathrm{m}$ & & $\mathrm{m}$ & $\mathrm{m}$ & $\mathrm{m}$ & $\mathrm{m}$ & $\mathrm{m}$ & $\mathrm{m}$ & $\mathrm{m}$ & $\mathrm{m}$ & $\mathrm{m}$ & $\mathrm{m}$ & $\mathrm{m}$ & 7 & $\mathrm{~m}$ & $\mathrm{~m}$ & $\mathrm{~m}$ & $\mathrm{~m}$ & $\mathrm{~m}$ & $\mathrm{~m}$ \\
\hline & Bra & 4.6 & $(0.9)$ & 72.4 & (1.1) & 72.0 & (1.1) & 77.9 & $(0.9)$ & 78.6 & (1.0) & 76.4 & (1.0) & 79.2 & 2) $(1.4$ & 73.3 & (1.4) & 77.6 & (1.4) & 81.3 & (1.3) \\
\hline & B-S & .1 & $(0.6)$ & 79.1 & $(0.6)$ & 65.8 & $(0.9)$ & 82.5 & (0.6) & 62.0 & $(0.8)$ & 79.2 & $(0.7)$ & 80.0 & ) $(1$. & $\begin{array}{l}76.8 \\
\end{array}$ & (1.9) & 63.8 & (2.5) & 9 & (1.8) \\
\hline & Bulg & 0.1 & (2.3) & 73.6 & $(2.2)$ & 68.2 & (1.8) & 63.9 & (2.1) & 70.7 & (2.0) & 69.2 & (1.9) & 76.1 & (1.7 & 77.2 & (1.7) & 69.2 & (1.8) & 76.8 & (1.5) \\
\hline & $\mathrm{CAB}$ & $\mathrm{m}$ & & $\mathrm{m}$ & $\mathrm{m}$ & $\mathrm{m}$ & & $\mathrm{m}$ & $\mathrm{m}$ & $\mathrm{m}$ & $\mathrm{m}$ & $\mathrm{m}$ & $\mathrm{m}$ & $\mathrm{m}$ & ר & $\mathrm{m}$ & $\mathrm{m}$ & $\mathrm{m}$ & $\mathrm{m}$ & $\mathrm{m}$ & $\mathrm{m}$ \\
\hline & Co & .1 & (1.1) & 69.8 & $(1.2)$ & 74.1 & (1.0) & 73.1 & (1.3) & 68.3 & (1.2) & 74.2 & (0.9) & 70.6 & $5(1.4$ & 69.5 & (1.6) & 72.8 & (1.6) & 72.2 & (1.7) \\
\hline & Cos & 3 & (1.2) & 70.0 & (1.4) & 74.1 & (1.3) & 72.6 & (1.5) & 71.9 & (1.5) & 76.2 & (1.1) & 74.2 & $2(1$. & 74.8 & (1.8) & 76.4 & (1.6) & 77.0 & (1.6) \\
\hline & & 5.3 & (1.1) & 82.7 & (1.1) & 82.2 & $(1.2)$ & 84.8 & (1.2) & 79.8 & (1.2) & 87.0 & (1.0) & 87.7 & $(1.1)$ & 83.4 & (1.1) & 83.5 & (1.4) & 87.7 & (1.1) \\
\hline & & $m$ & & $\mathrm{~m}$ & & $\mathrm{~m}$ & & $\mathrm{~m}$ & & $\mathrm{~m}$ & & $\mathrm{~m}$ & & $\mathrm{~m}$ & & $\mathrm{~m}$ & $\mathrm{~m}$ & $\mathrm{~m}$ & & $\mathrm{~m}$ & \\
\hline & Don & 7.1 & (1.4) & 62.6 & $(1.7)$ & 63.1 & (1.5) & 60.9 & (1.4) & 62.9 & (1.7) & 66.7 & (1.4) & 62.0 & ) $(2.1$ & 68.6 & (2.1) & 68.7 & (2.3) & 67.6 & (2.3) \\
\hline & FYRO & $\mathrm{m}$ & & $\mathrm{m}$ & $\mathrm{m}$ & $\mathrm{m}$ & & $\mathrm{m}$ & $\mathrm{m}$ & $\mathrm{m}$ & & $\mathrm{m}$ & & $\mathrm{m}$ & $\mathrm{m}$ & $\mathrm{m}$ & & $\mathrm{m}$ & & $\mathrm{m}$ & $\mathrm{m}$ \\
\hline & & $\mathrm{m}$ & & $\mathrm{m}$ & $\mathrm{m}$ & $\mathrm{m}$ & & $\mathrm{m}$ & $\mathrm{m}$ & $\mathrm{m}$ & $\mathrm{n}$ & $\mathrm{m}$ & $\mathrm{m}$ & $\mathrm{m}$ & ? & $\mathrm{m}$ & $\mathrm{m}$ & $\mathrm{m}$ & & $\mathrm{m}$ & \\
\hline & Ho & 6.6 & (1.1) & 80.3 & (1.1) & 73.2 & (1.6) & 78.3 & (1.1) & 77.9 & (1.1) & 80.8 & (1.1) & 80.3 & $\begin{array}{ll}3 & (1.3\end{array}$ & 85.1 & (1.3) & 75.9 & (1.6) & 83.0 & (1.2) \\
\hline & Indonesi & $\mathrm{m}$ & & $\mathrm{m}$ & & $\mathrm{m}$ & & $\mathrm{m}$ & $\mathrm{m}$ & $\mathrm{m}$ & & $\mathrm{m}$ & $\mathrm{m}$ & $\mathrm{m}$ & m & $\mathrm{m}$ & & $\mathrm{m}$ & & $\mathrm{m}$ & $\mathrm{m}$ \\
\hline & & $\mathrm{m}$ & & $\mathrm{m}$ & & $\mathrm{m}$ & & $\mathrm{m}$ & $\mathrm{m}$ & $\mathrm{m}$ & & $\mathrm{m}$ & & $\mathrm{m}$ & ר & $\mathrm{m}$ & & $\mathrm{m}$ & & $\mathrm{m}$ & $\mathrm{m}$ \\
\hline & Ko & $\mathrm{m}$ & & $\mathrm{m}$ & & $\mathrm{m}$ & & $\mathrm{m}$ & $\mathrm{m}$ & $\mathrm{m}$ & & $\mathrm{m}$ & & $\mathrm{m}$ & & 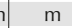 & & $\mathrm{m}$ & & $\mathrm{m}$ & \\
\hline & Leba & $\mathrm{m}$ & & $\mathrm{m}$ & $\mathrm{m}$ & $\mathrm{m}$ & & $\mathrm{m}$ & $\mathrm{m}$ & $\mathrm{m}$ & $\mathrm{m}$ & $\mathrm{m}$ & $\mathrm{m}$ & $\mathrm{m}$ & ר & $\mathrm{m}$ & $\mathrm{m}$ & $\mathrm{m}$ & $\mathrm{m}$ & $\mathrm{m}$ & $\mathrm{m}$ \\
\hline & Lith & & $(1.7)$ & 62.7 & $(1.7)$ & 55.0 & (1.3) & 63.7 & (1.7) & 60.1 & (1.5) & 68.0 & (1.7) & 9.5 & $5 \quad(1.5$ & 66.6 & (1.4) & 55.9 & (1.5) & 68.2 & (1.6) \\
\hline & $M$ & 8.4 & - $(1.2)$ & 75.7 & (1.4) & 61.4 & (1.6) & 77.3 & (1.3) & 63.6 & (1.6) & 79.2 & $(1.2)$ & 81.4 & $4 \quad(1.3$ & 75.7 & (1.5) & 63.5 & (1.6) & 77.9 & (1.4) \\
\hline & Malta & $\mathrm{m}$ & & $\mathrm{m}$ & & $\mathrm{m}$ & & $\mathrm{m}$ & & $\mathrm{m}$ & & $\mathrm{m}$ & & $\mathrm{m}$ & ר & $\mathrm{m}$ & & $\mathrm{m}$ & & $\mathrm{m}$ & \\
\hline & Mol & $\mathrm{m}$ & & $\mathrm{m}$ & $\mathrm{m}$ & $\mathrm{m}$ & $\mathrm{m}$ & $\mathrm{m}$ & $\mathrm{m}$ & $\mathrm{m}$ & & $\mathrm{m}$ & $\mathrm{m}$ & $\mathrm{m}$ & ר & $\mathrm{m}$ & $\mathrm{m}$ & $\mathrm{m}$ & & $\mathrm{m}$ & ? \\
\hline & Mo & $\mathrm{m}$ & & $\mathrm{m}$ & & $\mathrm{m}$ & & $\mathrm{m}$ & & $\mathrm{m}$ & & $\mathrm{m}$ & & $\mathrm{m}$ & n & $\mathrm{m}$ & $\mathrm{m}$ & $\mathrm{m}$ & & $\mathrm{m}$ & \\
\hline & Peru & 77.4 & (1.0) & 74.6 & $(1.0)$ & 74.6 & (0.9) & 73.8 & (1.0) & 75.9 & (1.0) & 81.5 & $(0.8)$ & 84.4 & $4 \quad(1.1$ & 78.2 & $(1.2)$ & 74.1 & (1.3) & 80.2 & (1.1) \\
\hline & Qatar & $\mathrm{m}$ & $\mathrm{m}$ & $\mathrm{m}$ & $\mathrm{m}$ & $\mathrm{m}$ & & $\mathrm{m}$ & $\mathrm{m}$ & $\mathrm{m}$ & $\mathrm{m}$ & $\mathrm{m}$ & $\mathrm{m}$ & $\mathrm{m}$ & $\mathrm{m}$ & $\mathrm{m}$ & $\mathrm{m}$ & m & & $\mathrm{m}$ & ? \\
\hline & & & & $\mathrm{m}$ & & $\mathrm{m}$ & & $\mathrm{m}$ & & $\mathrm{m}$ & & $\mathrm{m}$ & & $\mathrm{m}$ & & $\mathrm{m}$ & $\mathrm{m}$ & $\mathrm{m}$ & & $\mathrm{m}$ & \\
\hline & Russ & 7.7 & $(1.2)$ & 75.2 & (1.7) & 76.1 & (1.4) & 69.2 & (1.2) & 62.9 & (1.7) & 76.8 & (1.0) & 80.6 & $(1.3$ & $\begin{array}{l}75.8 \\
\end{array}$ & (1.4) & 75.5 & (1.7) & 75.2 & (1.5) \\
\hline & & & $(1.2)$ & 79.0 & (1.1) & 75.4 & (1.4) & 77.6 & $(1.2)$ & 78.7 & (1.2) & 82.6 & (1.0) & .5 & ) $(1.3$ & 81.3 & (1.3) & 81.5 & (1.1) & .0 & (1.2) \\
\hline & & & & 83.3 & $(0.9)$ & 89.8 & & 83.1 & $(0.8)$ & & (0.9) & & & 9 & $(0.8$ & 85.5 & (1.0) & 91.9 & (0.6) & 6 & $(1.0$ \\
\hline & Tha & 77.6 & (1.1) & 79.2 & $(0.9)$ & 74.6 & (1.0) & 67.8 & (1.3) & 59.8 & (1.3) & 79.0 & (1.1) & 82.3 & B $(1.0$ & ) 83.0 & (1.1) & 81.3 & (1.2) & 68.9 & (1.6) \\
\hline & Trin & $\mathrm{m}$ & & $\mathrm{m}$ & $\mathrm{m}$ & $\mathrm{m}$ & & $\mathrm{m}$ & $\mathrm{m}$ & $\mathrm{m}$ & & $\mathrm{m}$ & $\mathrm{m}$ & $\mathrm{m}$ & & $\mathrm{m}$ & $\mathrm{m}$ & $\mathrm{m}$ & & $\mathrm{m}$ & $\mathrm{m}$ \\
\hline & & $\mathrm{m}$ & & $\mathrm{m}$ & & $\mathrm{m}$ & & $\mathrm{m}$ & $\mathrm{m}$ & $\mathrm{m}$ & $\mathrm{m}$ & $\mathrm{m}$ & & $\mathrm{m}$ & n & $\mathrm{m}$ & $\mathrm{m}$ & $\mathrm{m}$ & & $\mathrm{m}$ & 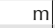 \\
\hline & & $\mathrm{m}$ & & $\mathrm{m}$ & & $\mathrm{m}$ & & $\mathrm{m}$ & $\mathrm{m}$ & $\mathrm{m}$ & $\mathrm{m}$ & $\mathrm{m}$ & $\mathrm{m}$ & $\mathrm{m}$ & ר & $\mathrm{m}$ & $\mathrm{m}$ & $\mathrm{m}$ & & $\mathrm{m}$ & ? \\
\hline & Uru & 69.5 & $(1.3)$ & 69.1 & (1.5) & 74.0 & (1.4) & 74.7 & (1.5) & 80.4 & (1.5) & 74.2 & (1.4) & 78.7 & $7 \quad(1.6$ & 73.0 & (2.0) & 78.7 & (1.5) & 81.4 & (1.3) \\
\hline & Viet Nam & $\mathrm{m}$ & $\mathrm{m}$ & $\mathrm{m}$ & $\mathrm{m}$ & $\mathrm{m}$ & $\mathrm{m}$ & $\mathrm{m}$ & $\mathrm{m}$ & $\mathrm{m}$ & $\mathrm{m}$ & $\mathrm{m}$ & $\mathrm{m}$ & $\mathrm{m}$ & ר & $\mathrm{m}$ & $\mathrm{m}$ & $\mathrm{m}$ & $\mathrm{m}$ & $\mathrm{m}$ & \\
\hline & & & & II) & & H & & m & & $\mathrm{m}$ & & & & & & $\mathrm{m}$ & & $\mathrm{m}$ & & & \\
\hline & Kazakhstan* & $\mathrm{m}$ & & $\mathrm{m}$ & & $\mathrm{m}$ & & $\mathrm{m}$ & & $\mathrm{m}$ & $\mathrm{m}$ & $\mathrm{m}$ & & & $\mathrm{m}$ & $\mathrm{m}$ & $\mathrm{m}$ & $\mathrm{m}$ & & $\mathrm{m}$ & \\
\hline & Malaysia** & $\mathrm{m}$ & $\mathrm{m}$ & $\mathrm{m}$ & $\mathrm{m}$ & $\mathrm{m}$ & $\mathrm{m}$ & $\mathrm{m}$ & $\mathrm{m}$ & $\mathrm{m}$ & $\mathrm{m}$ & $\mathrm{m}$ & $\mathrm{m}$ & $\mathrm{m}$ & & $\mathrm{m}$ & $\mathrm{m}$ & $\mathrm{m}$ & & $\mathrm{m}$ & $\mathrm{m}$ \\
\hline
\end{tabular}

Note: Values that are statistically significant are indicated in bold (see Annex A3).

* See note at the beginning of this Annex.

** Coverage is too small to ensure comparability (see Annex A4).

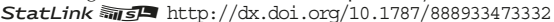




\begin{tabular}{|c|c|c|c|c|c|c|c|c|c|c|c|c|c|c|c|c|c|c|c|c|c|}
\hline & & & (Stude & ents wh & ho use & $\begin{array}{l}\text { Hig } \\
\text { the In } \\
\text { on a }\end{array}$ & $\begin{array}{l}\text { h Inter } \\
\text { ternet }\end{array}$ & $\begin{array}{l}\text { net use } \\
\text { betwe } \\
\text { l weekd }\end{array}$ & $\begin{array}{l}\text { ers } \\
\text { een } 2 \text { a } \\
\text { kday) }\end{array}$ & d & burs & day & & & (stude & & & $\begin{array}{l}\text { Ext } \\
\text { e the } \\
\text { on }\end{array}$ & er & fo & pre \\
\hline & & $\begin{array}{l}\text { I fee } \\
\text { an ou } \\
\text { (or le } \\
\text { of th } \\
\text { at sc }\end{array}$ & $\begin{array}{l}\text { Il like } \\
\text { Itsider } \\
\text { fft out }^{\text {out }} \text { ings) } \\
\text { hool }\end{array}$ & $\begin{array}{l}\text { I ma } \\
\text { frien } \\
\text { easi } \\
\text { at sch }\end{array}$ & $\begin{array}{l}\text { ake } \\
\text { nds } \\
\text { ily } \\
\text { nool }\end{array}$ & $\begin{array}{l}\text { I feel } \\
\text { I bel } \\
\text { at scl }\end{array}$ & $\begin{array}{l}\text { I like } \\
\text { long } \\
\text { hool }^{\text {a }}\end{array}$ & $\begin{array}{l}\text { I fee } \\
\text { awkw } \\
\text { and } \\
\text { of pla } \\
\text { in m } \\
\text { schoc }\end{array}$ & $\begin{array}{l}\text { el } \\
\text { Nard } \\
\text { out } \\
\text { lace } \\
\text { my } \\
\text { ool }^{\text {d }}\end{array}$ & $\begin{array}{l}\text { Oth } \\
\text { stude } \\
\text { seem } \\
\text { like } n\end{array}$ & $\begin{array}{l}\text { her } \\
\text { lents } \\
\text { n to } \\
\text { me }^{\text {a }}\end{array}$ & $\begin{array}{l}\text { If fe } \\
\text { lone } \\
\text { at sch }\end{array}$ & \begin{tabular}{l|} 
eel \\
ely \\
hool $^{\text {a }}$
\end{tabular} & $\begin{array}{l}\text { I feel } \\
\text { an out } \\
\text { (or left } \\
\text { of thir } \\
\text { at sch }\end{array}$ & $\begin{array}{l}\text { like } \\
\text { tsider } \\
\text { tt out } \\
\text { ings) } \\
\text { noold }\end{array}$ & $\begin{array}{l}\text { I ma } \\
\text { frien } \\
\text { easi } \\
\text { at sch }\end{array}$ & $\begin{array}{l}\text { ake } \\
\text { nds } \\
\text { ily } \\
\text { hool }\end{array}$ & $\begin{array}{l}\text { I feel } \\
\text { I belo } \\
\text { at sch }\end{array}$ & $\begin{array}{l}\text { I like } \\
\text { long } \\
\text { hoola }^{-}\end{array}$ & $\begin{array}{l}\text { I fe } \\
\text { awk } \\
\text { and } \\
\text { of } p \\
\text { in } \\
\text { scho }\end{array}$ & $\begin{array}{l}\text { eel } \\
\text { ward } \\
\text { out } \\
\text { ouce } \\
\text { my } \\
\text { oold }\end{array}$ \\
\hline & & $\%$ & S.E. & $\%$ & S.E. & $\%$ & S.E. & $\%$ & S.E. & $\%$ & S.E. & $\%$ & S.E. & $\%$ & S.E. & $\%$ & S.E. & $\%$ & S.E. & $\%$ & S.E. \\
\hline$\theta$ & Australia & \begin{tabular}{|l|}
77.7 \\
\end{tabular} & $(0.6)$ & 80.1 & (0.6) & 73.5 & $(0.7)$ & 79.7 & $(0.5)$ & 89.1 & $(0.4)$ & 84.1 & $(0.5)$ & 70.4 & $(1.0)$ & 76.3 & $(1.0)$ & 63.8 & $(1.2)$ & 70.7 & $(1.1)$ \\
\hline & Austria & 86.5 & $(0.7)$ & 78.6 & $(0.9)$ & 76.3 & (0.8) & 83.5 & $(0.8)$ & 83.8 & $(0.8)$ & 84.6 & $(0.8)$ & 82.8 & (1.1) & 75.4 & (1.4) & 70.6 & (1.4) & 77.5 & $(1.3)$ \\
\hline & Belgium & 88.8 & $(0.5)$ & 82.3 & $(0.6)$ & 63.6 & $(0.8)$ & 84.9 & $(0.6)$ & 89.2 & $(0.6)$ & 91.4 & $(0.5)$ & 81.2 & (1.2) & 81.3 & $(1.2)$ & 53.8 & $(1.5)$ & 77.0 & $(1.5)$ \\
\hline & Canada & $\mathrm{m}$ & & $\mathrm{m}$ & $\mathrm{m}$ & $\mathrm{m}$ & $\mathrm{m}$ & $\mathrm{m}$ & $\mathrm{m}$ & $\mathrm{m}$ & $\mathrm{m}$ & $\mathrm{m}$ & $\mathrm{m}$ & $\mathrm{m}$ & $\mathrm{m}$ & $\mathrm{m}$ & $\mathrm{m}$ & $\mathrm{m}$ & $\mathrm{m}$ & $\mathrm{m}$ & $\mathrm{m}$ \\
\hline & Chile & 82.0 & $(1.0)$ & 72.9 & (1.0) & 80.1 & (1.0) & 82.2 & $(0.8)$ & 79.2 & (1.0) & 85.2 & $(0.8)$ & 79.7 & (1.0) & 73.7 & $(1.2)$ & 76.3 & $(1.2)$ & 78.8 & $(1.0)$ \\
\hline & Czech Republic & 80.9 & (1.0) & 75.8 & (1.1) & 71.7 & (1.1) & 82.0 & $(0.8)$ & 82.4 & $(0.9)$ & 83.6 & $(0.8)$ & 72.6 & (1.4) & 74.7 & (1.6) & 63.2 & $(1.5)$ & 76.3 & (1.4) \\
\hline & Denmark & 87.7 & (0.6) & 79.5 & $(0.7)$ & 70.3 & (0.9) & 85.1 & $(0.7)$ & 85.8 & (0.9) & 87.6 & $(0.7)$ & 85.8 & (1.4) & 76.1 & (1.7) & 62.3 & $(1.7)$ & 80.8 & $(1.6)$ \\
\hline & Estonia & 88.8 & (0.7) & 75.7 & (0.8) & 81.2 & $(0.9)$ & 85.1 & $(0.7)$ & 77.5 & (1.0) & 86.5 & $(0.7)$ & 81.5 & (1.3) & 73.4 & $(1.6)$ & 70.6 & (1.8) & 76.3 & (1.9) \\
\hline & Finland & 88.2 & $(0.6)$ & 80.2 & $(0.8)$ & 80.4 & (1.0) & 83.1 & $(0.8)$ & 82.5 & $(0.8)$ & 88.4 & $(0.6)$ & 79.1 & (1.8) & 73.0 & (1.9) & 68.2 & (1.7) & 71.6 & (1.9) \\
\hline & France & 76.8 & $(0.9)$ & 87.1 & $(0.7)$ & 40.3 & (1.1) & 83.9 & $(0.7)$ & 90.8 & $(0.5)$ & 91.3 & (0.6) & 66.8 & (1.9) & 85.2 & (1.5) & 35.9 & (1.9) & 79.1 & (1.7) \\
\hline & Germany & $\mathrm{m}$ & & $\mathrm{m}$ & & $\mathrm{m}$ & $\mathrm{m}$ & $\mathrm{m}$ & $\mathrm{m}$ & $\mathrm{m}$ & $\mathrm{m}$ & $\mathrm{m}$ & $\mathrm{m}$ & $\mathrm{m}$ & $\mathrm{m}$ & $\mathrm{m}$ & $\mathrm{m}$ & $\mathrm{m}$ & $\mathrm{m}$ & $\mathrm{m}$ & $\mathrm{m}$ \\
\hline & Greece & 84.6 & $(0.8)$ & 80.6 & $(0.9)$ & 84.2 & (0.9) & 85.1 & $(0.9)$ & 88.0 & (0.8) & 88.4 & $(0.8)$ & 78.0 & (2.1) & 78.5 & (1.7) & 76.9 & (1.9) & 78.5 & (1.8) \\
\hline & Hungary & 83.2 & $(0.7)$ & 81.8 & $(0.7)$ & 75.8 & (0.9) & 83.0 & (0.9) & 83.4 & (0.8) & 85.6 & (0.8) & 79.6 & (1.4) & 80.7 & (1.3) & 68.7 & (1.6) & 79.2 & (1.4) \\
\hline & Iceland & 84.0 & $(0.8)$ & 77.3 & $(0.9)$ & 79.0 & (1.0) & 81.2 & (1.0) & 83.3 & $(0.9)$ & 84.7 & $(0.8)$ & 72.8 & (2.2) & 67.9 & (2.4) & 66.0 & (2.3) & 71.3 & (2.4) \\
\hline & Ireland & 83.7 & $(0.8)$ & 81.5 & $(0.8)$ & 73.2 & (1.1) & 82.4 & $(0.9)$ & 91.0 & (0.6) & 88.3 & $(0.7)$ & 77.1 & (1.6) & 80.3 & (1.3) & 62.5 & (2.0) & 76.9 & (1.3) \\
\hline & Israel & $\mathrm{m}$ & & $\mathrm{m}$ & & $\mathrm{m}$ & & $\mathrm{m}$ & $\mathrm{m}$ & $\mathrm{m}$ & $\mathrm{m}$ & $\mathrm{m}$ & $\mathrm{m}$ & $\mathrm{m}$ & $\mathrm{m}$ & $\mathrm{m}$ & $\mathrm{m}$ & $\mathrm{m}$ & $\mathrm{m}$ & $\mathrm{m}$ & $\mathrm{m}$ \\
\hline & Italy & 89.9 & $(0.6)$ & 83.0 & $(0.8)$ & 68.5 & (0.9) & 86.9 & (0.8) & 78.1 & $(0.8)$ & 89.8 & (0.6) & 87.9 & (0.9) & 84.4 & (1.1) & 66.8 & (1.3) & 84.4 & (1.0) \\
\hline & Japan & 87.9 & $(0.8)$ & 68.3 & (1.2) & 81.0 & (0.9) & 79.4 & (1.3) & 71.5 & (0.8) & 88.4 & $(0.8)$ & 80.1 & (1.9) & 62.7 & (2.3) & 76.7 & (2.0) & 67.6 & (2.0) \\
\hline & Korea & 89.8 & (1.0) & 78.0 & (1.3) & 76.8 & (1.3) & 86.8 & (1.0) & 80.8 & (1.2) & 89.8 & $(1.1)$ & 87.7 & (3.3) & 74.2 & $(4.1)$ & 78.8 & (4.6) & 83.0 & $(4.0)$ \\
\hline & Latvia & 85.3 & $(0.7)$ & 75.1 & (1.0) & 79.6 & (0.9) & 75.8 & $(0.9)$ & 68.7 & (1.0) & 83.9 & $(0.9)$ & 80.4 & (1.5) & 72.6 & (1.6) & 70.4 & (1.6) & 71.7 & (1.8) \\
\hline & Luxembourg & 86.0 & $(0.7)$ & 78.2 & $(0.8)$ & 69.4 & (1.0) & 82.8 & $(0.7)$ & 85.0 & $(0.8)$ & 87.4 & $(0.7)$ & 80.2 & (1.2) & 71.5 & (1.7) & 60.1 & (1.7) & 74.4 & (1.5) \\
\hline & Mexico & 80.5 & (1.1) & 74.8 & (1.0) & 78.3 & (1.1) & 80.4 & $(1.0)$ & 76.3 & (1.0) & 84.0 & $(0.9)$ & 75.2 & (1.4) & 75.2 & (1.3) & 76.4 & (1.5) & 75.7 & $(1.5)$ \\
\hline & Netherlands & 91.4 & $(0.6)$ & 85.7 & $(0.7)$ & 81.9 & (0.8) & 90.2 & $(0.7)$ & 92.6 & (0.6) & 92.7 & $(0.5)$ & 88.3 & (1.1) & 84.1 & (1.3) & 75.5 & (1.4) & 86.4 & $(1.2)$ \\
\hline & New Zealand & 78.3 & $(0.9)$ & 77.5 & $(0.8)$ & 73.8 & (1.0) & 78.3 & (1.0) & 88.5 & (0.7) & 83.5 & $(0.9)$ & 72.6 & (1.7) & 77.3 & (1.6) & 65.6 & $(1.8)$ & 72.2 & (1.6) \\
\hline & Norway & $\mathrm{m}$ & $\mathrm{m}$ & $\mathrm{m}$ & $\mathrm{m}$ & $\mathrm{m}$ & $\mathrm{m}$ & $\mathrm{m}$ & $\mathrm{m}$ & $\mathrm{m}$ & $\mathrm{m}$ & $\mathrm{m}$ & $\mathrm{m}$ & $\mathrm{m}$ & $\mathrm{m}$ & $\mathrm{m}$ & $\mathrm{m}$ & $\mathrm{m}$ & $\mathrm{m}$ & $\mathrm{m}$ & $\mathrm{m}$ \\
\hline & Poland & 78.9 & $(0.9)$ & 73.2 & $(0.9)$ & 61.1 & (1.2) & 77.0 & $(0.9)$ & 73.2 & (0.9) & 79.8 & $(0.9)$ & 74.9 & (1.8) & 75.1 & (1.8) & 58.8 & (1.9) & 73.1 & (1.8) \\
\hline & Portugal & 87.7 & $(0.6)$ & 78.5 & $(0.9)$ & 82.4 & $(0.7)$ & 77.5 & $(0.8)$ & 88.7 & $(0.7)$ & 89.6 & $(0.7)$ & 85.7 & (1.6) & 75.9 & (1.8) & 77.4 & (1.6) & 70.7 & (1.9) \\
\hline & Slovak Republic & 79.8 & $(0.8)$ & 77.5 & $(0.8)$ & 71.0 & $(0.9)$ & 79.5 & $(0.7)$ & 77.9 & $(0.8)$ & 82.5 & $(0.9)$ & 75.3 & (1.4) & 78.2 & (1.4) & 63.6 & (1.5) & 73.5 & $(1.5)$ \\
\hline & Slovenia & 82.6 & $(0.9)$ & 77.3 & $(1.2)$ & 74.6 & (1.1) & 82.1 & $(0.9)$ & 79.2 & (1.0) & 86.1 & $(0.8)$ & 75.7 & (2.1) & 76.1 & (2.1) & 64.4 & $(2.7)$ & 75.3 & $(2.0)$ \\
\hline & Spain & 90.8 & $(0.5)$ & 83.0 & $(0.7)$ & 88.3 & $(0.6)$ & 87.3 & $(0.7)$ & 86.9 & $(0.8)$ & 90.9 & $(0.7)$ & 89.9 & $(0.8)$ & 85.0 & (1.1) & 86.8 & (1.1) & 84.2 & $(1.2)$ \\
\hline & Sweden & 81.0 & $(0.7)$ & 75.8 & $(0.8)$ & 70.7 & $(1.0)$ & 81.0 & $(0.7)$ & 79.8 & $(0.8)$ & 81.8 & $(0.8)$ & 76.9 & (1.3) & 73.0 & (1.6) & 66.0 & $(1.7)$ & 75.7 & $(1.4)$ \\
\hline & Switzerland & 88.9 & $(0.9)$ & 81.0 & $(0.8)$ & 71.5 & (1.2) & 85.8 & $(0.9)$ & 88.4 & $(0.9)$ & 90.9 & $(0.6)$ & 86.4 & (1.9) & 80.0 & (1.7) & 59.9 & (2.4) & 80.2 & $(2.0)$ \\
\hline & Turkey & $\mathrm{m}$ & & $\mathrm{m}$ & $\mathrm{m}$ & $\mathrm{m}$ & $\mathrm{m}$ & $\mathrm{m}$ & $\mathrm{m}$ & $\mathrm{m}$ & $\mathrm{m}$ & $\mathrm{m}$ & $\mathrm{m}$ & $\mathrm{m}$ & $\mathrm{m}$ & $\mathrm{m}$ & $\mathrm{m}$ & $\mathrm{m}$ & $\mathrm{m}$ & $\mathrm{m}$ & $\mathrm{m}$ \\
\hline & United Kingdom & 81.4 & $(1.0)$ & 80.5 & $(0.9)$ & 70.9 & (1.0) & 81.9 & $(0.9)$ & 89.3 & $(0.8)$ & 88.6 & $(0.7)$ & 74.2 & (1.6) & 74.2 & (1.5) & 59.1 & (1.7) & 73.4 & (1.4) \\
\hline & United States & $\mathrm{m}$ & $\mathrm{m}$ & $\mathrm{m}$ & $\mathrm{m}$ & $\mathrm{m}$ & $\mathrm{m}$ & $\mathrm{m}$ & $\mathrm{m}$ & $\mathrm{m}$ & $\mathrm{m}$ & $\mathrm{m}$ & $\mathrm{m}$ & $\mathrm{m}$ & $\mathrm{m}$ & $\mathrm{m}$ & $\mathrm{m}$ & $\mathrm{m}$ & $\mathrm{m}$ & $\mathrm{m}$ & $\mathrm{m}$ \\
\hline & OECD average & 84.6 & (0.1) & 78.7 & $(0.2)$ & 74.1 & $(0.2)$ & 82.6 & $(0.2)$ & 83.1 & $(0.2)$ & 86.9 & $(0.1)$ & 79.3 & $(0.3)$ & 76.4 & $(0.3)$ & 67.1 & $(0.4)$ & 76.4 & $(0.3)$ \\
\hline & Albania & $\mathrm{m}$ & $\mathrm{m}$ & $\mathrm{m}$ & $\mathrm{m}$ & $\mathrm{m}$ & $\mathrm{m}$ & $\mathrm{m}$ & $\mathrm{m}$ & $\mathrm{m}$ & $\mathrm{m}$ & $\mathrm{m}$ & $\mathrm{m}$ & $\mathrm{m}$ & $\mathrm{m}$ & $\mathrm{m}$ & $\mathrm{m}$ & $\mathrm{m}$ & $\mathrm{m}$ & $\mathrm{m}$ & $m$ \\
\hline$\Xi$ & Algeria & $\mathrm{m}$ & & $\mathrm{m}$ & $\mathrm{m}$ & $\mathrm{m}$ & $\mathrm{m}$ & $\mathrm{m}$ & $\mathrm{m}$ & $\mathrm{m}$ & $\mathrm{m}$ & $\mathrm{m}$ & $\mathrm{m}$ & $\mathrm{m}$ & $\mathrm{m}$ & $\mathrm{m}$ & $\mathrm{m}$ & $\mathrm{m}$ & $\mathrm{m}$ & $\mathrm{m}$ & $\mathrm{m}$ \\
\hline & Brazil & 4.2 & $(0.8)$ & 75.3 & (1.0) & 79.8 & (1.0) & 85.8 & $(0.8)$ & 84.8 & $(0.8)$ & 83.7 & $(0.8)$ & 80.4 & $(0.7)$ & 74.6 & $(0.9)$ & 76.8 & $(0.9)$ & 83.1 & $(0.7)$ \\
\hline & B-S-J-G (China) & 75.2 & $(1.8)$ & 78.8 & (1.8) & 61.1 & (1.7) & 76.6 & (1.8) & 58.0 & $(2.1)$ & 77.4 & $(1.8)$ & 71.5 & (2.9) & 74.8 & $(2.5)$ & 60.1 & (2.4) & 71.6 & (3.2) \\
\hline & Bulgaria & 76.6 & $(1.0)$ & 76.8 & (1.0) & 70.7 & (1.1) & 77.9 & (1.0) & 74.7 & (1.0) & 79.5 & $(0.9)$ & 66.8 & (1.4) & 73.0 & (1.3) & 63.7 & (1.3) & 69.5 & (1.5) \\
\hline & CABA (Argentina) & $\mathrm{m}$ & $\mathrm{m}$ & $\mathrm{m}$ & $\mathrm{m}$ & $\mathrm{m}$ & & $\mathrm{m}$ & $\mathrm{m}$ & $\mathrm{m}$ & $\mathrm{m}$ & $\mathrm{m}$ & $\mathrm{m}$ & $\mathrm{m}$ & $\mathrm{m}$ & $\mathrm{m}$ & $\mathrm{m}$ & $\mathrm{m}$ & $\mathrm{m}$ & $\mathrm{m}$ & $\mathrm{m}$ \\
\hline & Colombia & 3.7 & (1.1) & 71.7 & $(1.2)$ & 76.1 & (1.2) & 76.2 & $(0.9)$ & 72.2 & $(0.9)$ & 77.9 & (1.0) & 72.9 & (1.3) & 69.9 & (1.3) & 74.9 & $(1.2)$ & 72.6 & (1.1) \\
\hline & Costa Rica & 76.3 & $(1.0)$ & 71.5 & $(1.2)$ & 75.5 & (1.1) & 77.5 & (1.1) & 72.6 & (1.3) & 78.2 & $(1.2)$ & 72.4 & (1.1) & 73.1 & $(1.1)$ & 74.6 & (1.1) & 73.5 & (1.0) \\
\hline & Croatia & 87.6 & $(0.7)$ & 85.3 & $(0.7)$ & 82.5 & $(0.8)$ & 85.8 & $(0.8)$ & 83.5 & $(0.8)$ & 88.7 & $(0.7)$ & 82.2 & (1.3) & 83.6 & $(1.2)$ & 75.4 & (1.6) & 81.0 & $(1.2)$ \\
\hline & Cyprus* & $\mathrm{m}$ & & $\mathrm{m}$ & & $\mathrm{m}$ & & $\mathrm{m}$ & & $\mathrm{m}$ & $\mathrm{m}$ & $\mathrm{m}$ & $\mathrm{m}$ & $\mathrm{m}$ & & $\mathrm{m}$ & $\mathrm{m}$ & $\mathrm{m}$ & $\mathrm{m}$ & $\mathrm{m}$ & $\mathrm{m}$ \\
\hline & Dominican Republic & 69.7 & (1.8) & 72.3 & (1.5) & 72.4 & (1.7) & 70.5 & (2.0) & 70.4 & (1.4) & 76.2 & (1.6) & 64.4 & (2.2) & 68.7 & (2.0) & 72.6 & (2.0) & 69.0 & (1.9) \\
\hline & FYROM & $\mathrm{m}$ & & $\mathrm{m}$ & $\mathrm{m}$ & $\mathrm{m}$ & & $\mathrm{m}$ & $\mathrm{m}$ & $\mathrm{m}$ & $\mathrm{m}$ & $\mathrm{m}$ & $\mathrm{m}$ & $\mathrm{m}$ & $\mathrm{m}$ & $\mathrm{m}$ & & $\mathrm{m}$ & $\mathrm{m}$ & $\mathrm{m}$ & $\mathrm{m}$ \\
\hline & Georgia & $\mathrm{m}$ & & $\mathrm{m}$ & $\mathrm{m}$ & $\mathrm{m}$ & & $\mathrm{m}$ & $\mathrm{m}$ & $\mathrm{m}$ & $\mathrm{m}$ & $\mathrm{m}$ & $\mathrm{m}$ & $\mathrm{m}$ & $\mathrm{m}$ & $\mathrm{m}$ & $\mathrm{m}$ & $\mathrm{m}$ & & $\mathrm{m}$ & $\mathrm{m}$ \\
\hline & Hong Kong & 75.0 & $(1.2)$ & 81.3 & (1.1) & 69.9 & (1.2) & 80.2 & $(0.9)$ & 77.7 & $(1.2)$ & 80.4 & (1.0) & 67.1 & (2.0) & 77.7 & (1.8) & 64.5 & $(2.0)$ & 73.2 & (1.9) \\
\hline & Indonesia & $\mathrm{m}$ & & $\mathrm{m}$ & $\mathrm{m}$ & $\mathrm{m}$ & & $\mathrm{m}$ & $\mathrm{m}$ & $\mathrm{m}$ & $\mathrm{m}$ & $\mathrm{m}$ & $\mathrm{m}$ & $\mathrm{m}$ & $\mathrm{m}$ & $\mathrm{m}$ & & $\mathrm{m}$ & $\mathrm{m}$ & $\mathrm{m}$ & $\mathrm{m}$ \\
\hline & Jordan & $\mathrm{m}$ & & $\mathrm{m}$ & & $\mathrm{m}$ & & $\mathrm{m}$ & $\mathrm{m}$ & $\mathrm{m}$ & & $\mathrm{m}$ & $\mathrm{m}$ & $\mathrm{m}$ & $\mathrm{m}$ & $\mathrm{m}$ & & $\mathrm{m}$ & & $\mathrm{m}$ & $\mathrm{m}$ \\
\hline & Kosovo & $\mathrm{m}$ & & $\mathrm{m}$ & & $\mathrm{m}$ & & $\mathrm{m}$ & $\mathrm{m}$ & $\mathrm{m}$ & & $\mathrm{m}$ & & $\mathrm{m}$ & & $\mathrm{m}$ & & $\mathrm{m}$ & & $\mathrm{m}$ & \\
\hline & Lebanon & $\mathrm{m}$ & & $\mathrm{m}$ & $\mathrm{m}$ & $\mathrm{m}$ & $\mathrm{m}$ & $\mathrm{m}$ & $\mathrm{m}$ & $\mathrm{m}$ & $\mathrm{m}$ & $\mathrm{m}$ & $\mathrm{m}$ & $\mathrm{m}$ & $\mathrm{m}$ & $\mathrm{m}$ & $\mathrm{m}$ & $\mathrm{m}$ & $\mathrm{m}$ & $\mathrm{m}$ & $\mathrm{m}$ \\
\hline & Lithuania & 71.9 & $(0.9)$ & 65.7 & (1.0) & 55.2 & (1.2) & 67.8 & (1.1) & 64.2 & (1.0) & 70.5 & (0.9) & 68.2 & (1.7) & 59.9 & (1.7) & 50.5 & (1.9) & 61.1 & (2.0) \\
\hline & Macao (China & 79.9 & $(0.9)$ & 76.0 & (1.0) & 58.8 & $(1.2)$ & 78.5 & $(0.9)$ & 66.3 & $(1.1)$ & 80.3 & $(0.9)$ & 75.3 & (1.8) & 77.6 & (1.7) & 55.3 & (1.9) & 76.2 & (1.9) \\
\hline & Malta & $\mathrm{m}$ & & $\mathrm{m}$ & $\mathrm{m}$ & $\mathrm{m}$ & & $\mathrm{m}$ & & $\mathrm{m}$ & & $\mathrm{m}$ & $\mathrm{m}$ & $\mathrm{m}$ & & $\mathrm{m}$ & & $\mathrm{m}$ & $\mathrm{m}$ & $\mathrm{m}$ & $\mathrm{m}$ \\
\hline & Moldova & $\mathrm{m}$ & & $\mathrm{m}$ & & $\mathrm{m}$ & $\mathrm{m}$ & $\mathrm{m}$ & $\mathrm{m}$ & $\mathrm{m}$ & $\mathrm{m}$ & $\mathrm{m}$ & $\mathrm{m}$ & $\mathrm{m}$ & $\mathrm{m}$ & $\mathrm{m}$ & $\mathrm{m}$ & $\mathrm{m}$ & $\mathrm{m}$ & $\mathrm{m}$ & $\mathrm{m}$ \\
\hline & Monteneg & $\mathrm{m}$ & & $\mathrm{m}$ & & $\mathrm{m}$ & & $\mathrm{m}$ & $\mathrm{m}$ & $\mathrm{m}$ & $\mathrm{m}$ & $\mathrm{m}$ & $\mathrm{m}$ & $\mathrm{m}$ & $\mathrm{m}$ & $\mathrm{m}$ & $\mathrm{m}$ & $\mathrm{m}$ & & $\mathrm{m}$ & $\mathrm{m}$ \\
\hline & Peru & 83.9 & $(0.9)$ & 77.8 & (1.0) & 67.4 & (1.1) & 82.2 & (1.0) & 80.8 & (1.0) & 84.4 & (1.0) & 82.3 & (2.0) & 79.2 & (1.9) & 62.6 & (2.1) & 80.1 & (1.8) \\
\hline & Qatar & $\mathrm{m}$ & & $\mathrm{m}$ & $\mathrm{m}$ & $\mathrm{m}$ & $\mathrm{m}$ & $\mathrm{m}$ & $\mathrm{m}$ & $\mathrm{m}$ & $\mathrm{m}$ & $\mathrm{m}$ & $\mathrm{m}$ & $\mathrm{m}$ & $\mathrm{m}$ & $\mathrm{m}$ & $\mathrm{m}$ & $\mathrm{m}$ & $\mathrm{m}$ & $\mathrm{m}$ & $\mathrm{m}$ \\
\hline & Roman & $\mathrm{m}$ & & $\mathrm{m}$ & & $\mathrm{m}$ & & $\mathrm{m}$ & $\mathrm{m}$ & $\mathrm{m}$ & $\mathrm{m}$ & $\mathrm{m}$ & $\mathrm{m}$ & $\mathrm{m}$ & $\mathrm{m}$ & $\mathrm{m}$ & $\mathrm{m}$ & $\mathrm{m}$ & $\mathrm{m}$ & $\mathrm{m}$ & $\cdots$ \\
\hline & Russia & 83.5 & $(0.9)$ & 71.9 & (1.0) & 75.7 & $(0.8)$ & 74.9 & (0.9) & 65.1 & (1.1) & 81.5 & $(0.8)$ & 78.0 & (1.9) & 71.2 & (1.4) & 71.0 & (1.3) & 71.0 & $(1.2)$ \\
\hline & Singapc & \begin{tabular}{|l|}
77.7 \\
\end{tabular} & $(0.8)$ & 81.0 & $(0.9)$ & 77.2 & (1.0) & 77.2 & $(0.8)$ & 83.2 & $(0.8)$ & 83.1 & $(0.8)$ & 70.2 & (1.7) & 78.6 & (1.5) & 65.9 & (1.5) & 69.6 & (1.4) \\
\hline & Chin & 9.4 & $(0.6)$ & 85.6 & (0.6) & 89.8 & (0.6) & 82.9 & $(0.8)$ & 72.0 & (1.0) & 88.3 & $(0.7)$ & 87.2 & $(0.8)$ & 87.6 & (1.1) & 87.5 & (1.0) & 80.3 & $(1.2)$ \\
\hline & Thailand & 83.4 & (1.0) & 85.4 & (0.9) & 82.3 & (0.9) & 70.0 & (1.2) & 64.8 & $(1.2)$ & 84.7 & (1.0) & 76.1 & (2.0) & 82.7 & (1.1) & 76.1 & (1.4) & 63.4 & (2.1) \\
\hline & Trinidad and Tobago & $\mathrm{m}$ & & $\mathrm{m}$ & $\mathrm{m}$ & $\mathrm{m}$ & & $\mathrm{m}$ & $\mathrm{m}$ & $\mathrm{m}$ & $\mathrm{m}$ & $\mathrm{m}$ & $\mathrm{m}$ & $\mathrm{m}$ & $\mathrm{m}$ & $\mathrm{m}$ & $\mathrm{m}$ & $\mathrm{m}$ & & $\mathrm{m}$ & $\mathrm{m}$ \\
\hline & Tunisia & $\mathrm{m}$ & & $\mathrm{m}$ & & $\mathrm{m}$ & & $\mathrm{m}$ & $\mathrm{m}$ & $\mathrm{m}$ & & $\mathrm{m}$ & & $\mathrm{m}$ & $\mathrm{m}$ & $\mathrm{m}$ & & $\mathrm{m}$ & $\mathrm{m}$ & $\mathrm{m}$ & $\mathrm{m}$ \\
\hline & United Arab Emirates & $\mathrm{m}$ & & $\mathrm{m}$ & & $\mathrm{m}$ & & $\mathrm{m}$ & $\mathrm{m}$ & $\mathrm{m}$ & $\mathrm{m}$ & $\mathrm{m}$ & $\mathrm{m}$ & $\mathrm{m}$ & $\mathrm{m}$ & $\mathrm{m}$ & $\mathrm{m}$ & $\mathrm{m}$ & $\mathrm{m}$ & $\mathrm{m}$ & $\mathrm{m}$ \\
\hline & Uruguay & 79.4 & $(1.1)$ & 74.8 & $(1.2)$ & 81.0 & (1.0) & 82.4 & (1.1) & 88.9 & $(0.8)$ & 82.5 & $(0.9)$ & 76.9 & (1.0) & 73.5 & (1.1) & 78.1 & (1.0) & 77.9 & (1.1) \\
\hline & Viet Nam & $\mathrm{m}$ & $\mathrm{m}$ & $\mathrm{m}$ & $\mathrm{m}$ & $\mathrm{m}$ & $\mathrm{m}$ & $\mathrm{m}$ & $\mathrm{m}$ & $\mathrm{m}$ & $\mathrm{m}$ & $\mathrm{m}$ & $\mathrm{m}$ & $\mathrm{m}$ & $\mathrm{m} \mid$ & $\mathrm{m}$ & $\mathrm{m}$ & $\mathrm{m}$ & $\mathrm{m}$ & $\mathrm{m}$ & $\mathrm{m}$ \\
\hline & & $\mathrm{m}$ & & $\mathrm{m}$ & & $\mathrm{m}$ & $\mathrm{m}$ & $\mathrm{m}$ & $\mathrm{m}$ & $\mathrm{m}$ & & $\mathrm{m}$ & $\mathrm{m}$ & $\mathrm{m}$ & $\mathrm{m}$ & $\mathrm{m}$ & $\mathrm{m}$ & $\mathrm{m}$ & 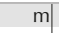 & $\mathrm{m}$ & \\
\hline & Kazakhstan** & $\mathrm{m}$ & & $\mathrm{m}$ & $\mathrm{m}$ & $\mathrm{m}$ & $\mathrm{m}$ & $\mathrm{m}$ & $\mathrm{m}$ & $\mathrm{m}$ & $\mathrm{m}$ & $\mathrm{m}$ & $\mathrm{m}$ & $\mathrm{m}$ & $\mathrm{m}$ & $\mathrm{m}$ & $\mathrm{m}$ & $\mathrm{m}$ & $\mathrm{m}$ & $\mathrm{m}$ & \\
\hline & Malaysia** & $\mathrm{m}$ & $\mathrm{m}$ & $\mathrm{m}$ & $\mathrm{m}$ & $\mathrm{m}$ & $\mathrm{m}$ & $\mathrm{m}$ & $\mathrm{m}$ & $\mathrm{m}$ & $\mathrm{m}$ & $\mathrm{m}$ & $\mathrm{m}$ & $\mathrm{m}$ & $\mathrm{m}$ & $\mathrm{m}$ & $\mathrm{m}$ & $\mathrm{m}$ & & $\mathrm{m}$ & $\mathrm{m}$ \\
\hline
\end{tabular}

Note: Values that are statistically significant are indicated in bold (see Annex A3)

* See note at the beginning of this Annex.

** Coverage is too small to ensure comparability (see Annex A4).

StatLink त्नाIs http://dx.doi.org/10.1787/888933473332 
[Part 3/3]

Table III.13.19a Sense of belonging at school, by time spent on the Internet outside of school on weekdays

Percentage of students who reported "agree" or "strongly agree" (a) or who reported "disagree" or "strongly disagree" (d)

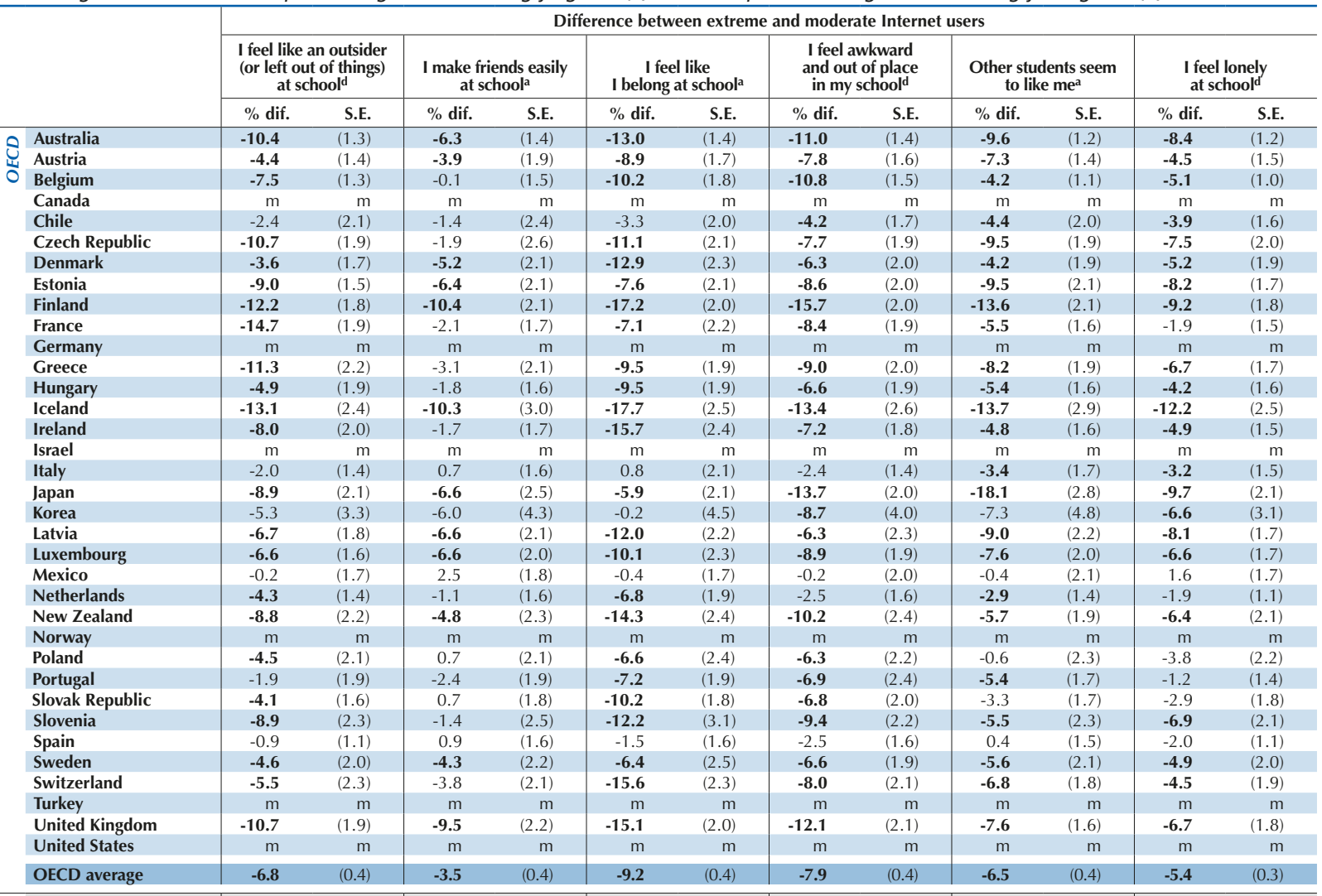

\begin{tabular}{|c|c|c|c|c|c|c|c|c|c|c|c|c|}
\hline Albania & $\mathrm{m}$ & $\mathrm{m}$ & $\mathrm{m}$ & $\mathrm{m}$ & $\mathrm{m}$ & $\mathrm{m}$ & $\mathrm{m}$ & $\mathrm{m}$ & $\mathrm{m}$ & $\mathrm{m}$ & $\mathrm{m}$ & $\mathrm{m}$ \\
\hline Algeria & $\mathrm{m}$ & $\mathrm{m}$ & $\mathrm{m}$ & $\mathrm{m}$ & $\mathrm{m}$ & $\mathrm{m}$ & $\mathrm{m}$ & $\mathrm{m}$ & $\mathrm{m}$ & $\mathrm{m}$ & $\mathrm{m}$ & $\mathrm{m}$ \\
\hline Brazil & 1.2 & (1.6) & 1.3 & (1.7) & -0.7 & (1.7) & 1.8 & (1.7) & -1.5 & (1.4) & -1.7 & (1.5) \\
\hline B-S-J-G (China) & -8.5 & (3.4) & -2.0 & (3.1) & -3.7 & (3.4) & -9.3 & $(4.1)$ & 2.0 & $(4.0)$ & -9.8 & (3.6) \\
\hline Bulgaria & -9.3 & $(2.3)$ & -4.3 & $(2.3)$ & -5.6 & $(2.3)$ & -7.3 & $(2.0)$ & -5.4 & $(2.0)$ & -6.7 & $(2.2)$ \\
\hline CABA (Argentina) & $\mathrm{m}$ & $\mathrm{m}$ & $\mathrm{m}$ & $\mathrm{m}$ & $\mathrm{m}$ & $\mathrm{m}$ & $\mathrm{m}$ & $\mathrm{m}$ & $\mathrm{m}$ & $\mathrm{m}$ & $\mathrm{m}$ & $\mathrm{m}$ \\
\hline Colombia & 2.3 & (1.9) & 0.3 & $(2.1)$ & 2.2 & (1.9) & 0.4 & $(2.0)$ & 1.1 & $(2.2)$ & -2.4 & (1.6) \\
\hline Costa Rica & -1.9 & (1.8) & -1.7 & $(2.1)$ & -1.8 & (1.6) & -3.5 & $(1.7)$ & -3.4 & $(2.0)$ & -2.4 & $(1.8)$ \\
\hline Croatia & -5.5 & (1.9) & 0.2 & $(1.7)$ & -8.1 & $(2.2)$ & -6.7 & $(1.8)$ & -5.5 & $(1.8)$ & -4.9 & (1.7) \\
\hline Cyprus* & $\mathrm{m}$ & $\mathrm{m}$ & $\mathrm{m}$ & $\mathrm{m}$ & $\mathrm{m}$ & $\mathrm{m}$ & $\mathrm{m}$ & $\mathrm{m}$ & $\mathrm{m}$ & $\mathrm{m}$ & $\mathrm{m}$ & $\mathrm{m}$ \\
\hline Dominican Republic & 2.4 & (3.3) & 0.1 & $(2.8)$ & 3.9 & (2.8) & 1.5 & (3.0) & 5.4 & $(2.5)$ & 3.8 & (2.9) \\
\hline FYROM & $\mathrm{m}$ & $\mathrm{m}$ & $\mathrm{m}$ & $\mathrm{m}$ & $\mathrm{m}$ & $\mathrm{m}$ & $\mathrm{m}$ & $\mathrm{m}$ & $\mathrm{m}$ & $\mathrm{m}$ & $\mathrm{m}$ & $\mathrm{m}$ \\
\hline Georgia & $\mathrm{m}$ & $\mathrm{m}$ & $\mathrm{m}$ & $\mathrm{m}$ & $\mathrm{m}$ & $\mathrm{m}$ & $\mathrm{m}$ & $\mathrm{m}$ & $\mathrm{m}$ & $\mathrm{m}$ & $\mathrm{m}$ & $\mathrm{m}$ \\
\hline Hong Kong (China) & -13.2 & (2.4) & -7.3 & $(2.2)$ & -11.4 & $(2.5)$ & -9.8 & $(2.0)$ & -8.3 & $(2.4)$ & -9.4 & (2.1) \\
\hline Indonesia & $\mathrm{m}$ & $\mathrm{m}$ & $\mathrm{m}$ & $\mathrm{m}$ & $\mathrm{m}$ & $\mathrm{m}$ & $\mathrm{m}$ & $\mathrm{m}$ & $\mathrm{m}$ & $\mathrm{m}$ & $\mathrm{m}$ & $\mathrm{m}$ \\
\hline Jordan & $\mathrm{m}$ & $\mathrm{m}$ & $\mathrm{m}$ & $\mathrm{m}$ & $\mathrm{m}$ & $\mathrm{m}$ & $\mathrm{m}$ & $\mathrm{m}$ & $\mathrm{m}$ & $\mathrm{m}$ & $\mathrm{m}$ & $\mathrm{m}$ \\
\hline Kosovo & $\mathrm{m}$ & $\mathrm{m}$ & $\mathrm{m}$ & $\mathrm{m}$ & $\mathrm{m}$ & $\mathrm{m}$ & $\mathrm{m}$ & $\mathrm{m}$ & $\mathrm{m}$ & $\mathrm{m}$ & $\mathrm{m}$ & $\mathrm{m}$ \\
\hline Lebanon & $\mathrm{m}$ & $\mathrm{m}$ & $\mathrm{m}$ & $\mathrm{m}$ & $\mathrm{m}$ & $\mathrm{m}$ & $\mathrm{m}$ & $\mathrm{m}$ & $\mathrm{m}$ & $\mathrm{m}$ & $\mathrm{m}$ & $\mathrm{m}$ \\
\hline Lithuania & -1.3 & $(2.3)$ & -6.7 & $(2.1)$ & -5.4 & $(2.1)$ & -7.1 & $(2.4)$ & -6.5 & $(2.4)$ & -6.5 & (2.5) \\
\hline Macao (China) & -6.1 & $(2.2)$ & 1.9 & $(2.4)$ & -8.1 & $(2.3)$ & -1.7 & $(2.6)$ & 2.7 & (2.6) & -2.7 & (2.4) \\
\hline Malta & $\mathrm{m}$ & $\mathrm{m}$ & $\mathrm{m}$ & $\mathrm{m}$ & $\mathrm{m}$ & $\mathrm{m}$ & $\mathrm{m}$ & $\mathrm{m}$ & $\mathrm{m}$ & $\mathrm{m}$ & $\mathrm{m}$ & $\mathrm{m}$ \\
\hline Moldova & $\mathrm{m}$ & $\mathrm{m}$ & $\mathrm{m}$ & $\mathrm{m}$ & $\mathrm{m}$ & $\mathrm{m}$ & $\mathrm{m}$ & $\mathrm{m}$ & $\mathrm{m}$ & $\mathrm{m}$ & $\mathrm{m}$ & $\mathrm{m}$ \\
\hline Montenegro & $\mathrm{m}$ & $\mathrm{m}$ & $\mathrm{m}$ & $\mathrm{m}$ & $\mathrm{m}$ & $\mathrm{m}$ & $\mathrm{m}$ & $\mathrm{m}$ & $\mathrm{m}$ & $\mathrm{m}$ & $\mathrm{m}$ & $\mathrm{m}$ \\
\hline Peru & -2.1 & $(2.3)$ & 1.0 & $(2.2)$ & -11.5 & $(2.4)$ & -0.1 & $(2.0)$ & -0.6 & (1.9) & -2.0 & (2.0) \\
\hline Qatar & $\mathrm{m}$ & $\mathrm{m}$ & $\mathrm{m}$ & $\mathrm{m}$ & $\mathrm{m}$ & $\mathrm{m}$ & $\mathrm{m}$ & $\mathrm{m}$ & $\mathrm{m}$ & $\mathrm{m}$ & $\mathrm{m}$ & $\mathrm{m}$ \\
\hline Romania & $\mathrm{m}$ & $\mathrm{m}$ & $\mathrm{m}$ & $\mathrm{m}$ & $\mathrm{m}$ & $\mathrm{m}$ & $\mathrm{m}$ & $\mathrm{m}$ & $\mathrm{m}$ & $\mathrm{m}$ & $\mathrm{m}$ & $\mathrm{m}$ \\
\hline Russia & -2.6 & (1.9) & -4.6 & (1.7) & -4.5 & $(2.0)$ & -4.2 & (1.9) & -3.3 & (2.9) & -4.1 & (1.9) \\
\hline Singapore & -9.3 & (2.1) & -2.7 & $(2.1)$ & -15.6 & (1.8) & -11.4 & $(1.8)$ & -10.9 & (1.9) & -10.7 & (1.9) \\
\hline Chinese Taipei & -3.3 & $(1.2)$ & 2.0 & $(1.4)$ & -4.4 & $(1.2)$ & -5.3 & $(1.4)$ & -5.1 & $(2.2)$ & -3.6 & $(1.3)$ \\
\hline Thailand & -6.3 & $(2.3)$ & -0.3 & (1.6) & -5.2 & (1.7) & -5.5 & $(2.8)$ & -1.7 & $(2.5)$ & -2.1 & $(2.0)$ \\
\hline Trinidad and Tobago & $\mathrm{m}$ & $\mathrm{m}$ & $\mathrm{m}$ & $\mathrm{m}$ & $\mathrm{m}$ & $\mathrm{m}$ & $\mathrm{m}$ & $\mathrm{m}$ & $\mathrm{m}$ & $\mathrm{m}$ & $\mathrm{m}$ & $\mathrm{m}$ \\
\hline Tunisia & $\mathrm{m}$ & $\mathrm{m}$ & $\mathrm{m}$ & $\mathrm{m}$ & $\mathrm{m}$ & $\mathrm{m}$ & $\mathrm{m}$ & $\mathrm{m}$ & $\mathrm{m}$ & $\mathrm{m}$ & $\mathrm{m}$ & $\mathrm{m}$ \\
\hline United Arab Emirates & $\mathrm{m}$ & $\mathrm{m}$ & $\mathrm{m}$ & $\mathrm{m}$ & $\mathrm{m}$ & $\mathrm{m}$ & $\mathrm{m}$ & $\mathrm{m}$ & $\mathrm{m}$ & $\mathrm{m}$ & $\mathrm{m}$ & $\mathrm{m}$ \\
\hline Uruguay & -1.8 & $(2.0)$ & 0.5 & $(2.4)$ & -0.7 & (1.7) & -3.5 & (1.9) & 1.8 & (1.7) & -1.0 & (1.9) \\
\hline Viet Nam & $\mathrm{m}$ & $\mathrm{m}$ & $\mathrm{m}$ & $\mathrm{m}$ & $\mathrm{m}$ & $\mathrm{m}$ & $\mathrm{m}$ & $\mathrm{m}$ & $\mathrm{m}$ & $\mathrm{m}$ & $\mathrm{m}$ & $\mathrm{m}$ \\
\hline Argentina** & $\mathrm{m}$ & $\mathrm{m}$ & $\mathrm{m}$ & $\mathrm{m}$ & $\mathrm{m}$ & $\mathrm{m}$ & $\mathrm{m}$ & $\mathrm{m}$ & $\mathrm{m}$ & $\mathrm{m}$ & $\mathrm{m}$ & $\mathrm{m}$ \\
\hline Kazakhstan** & $\mathrm{m}$ & $\mathrm{m}$ & $\mathrm{m}$ & $\mathrm{m}$ & $\mathrm{m}$ & $\mathrm{m}$ & $\mathrm{m}$ & $\mathrm{m}$ & $\mathrm{m}$ & $\mathrm{m}$ & $\mathrm{m}$ & $\mathrm{m}$ \\
\hline Malaysia** & $\mathrm{m}$ & $\mathrm{m}$ & $\mathrm{m}$ & $\mathrm{m}$ & $\mathrm{m}$ & $\mathrm{m}$ & $\mathrm{m}$ & $\mathrm{m}$ & $\mathrm{m}$ & $\mathrm{m}$ & $\mathrm{m}$ & $\mathrm{m}$ \\
\hline
\end{tabular}

Note: Values that are statistically significant are indicated in bold (see Annex A3).

* See note at the beginning of this Annex.

** Coverage is too small to ensure comparability (see Annex A4).

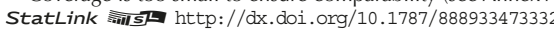




\begin{tabular}{|c|c|c|c|c|c|c|c|c|c|c|c|c|c|c|c|c|c|c|c|c|c|}
\hline & & & (Stud & ents & vho us & $\begin{array}{l}\text { Lo } \\
\text { e the } \\
\text { on a }\end{array}$ & $\begin{array}{l}\text { w Inte } \\
\text { Intern } \\
\text { typica }\end{array}$ & $\begin{array}{l}\text { rnet } \\
\text { et for } \\
\text { al we }\end{array}$ & $\begin{array}{l}\text { isers } \\
\text { less th } \\
\text { kday) }\end{array}$ & an 1 & hour $p$ & er day & & & (Studen & its & $10 \mathrm{u}$ & $\begin{array}{l}\text { Mode } \\
\text { the In } \\
\text { on a }\end{array}$ & $\begin{array}{l}\text { erate I } \\
\text { ternet } \\
\text { a typic }\end{array}$ & $\begin{array}{l}\text { nterne } \\
\text { betwe } \\
\text { al wee }\end{array}$ & $\begin{array}{l}\text { t users } \\
\text { een } 1 \text { a } \\
\text { kday) }\end{array}$ \\
\hline & & 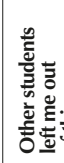 & 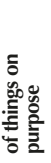 & & 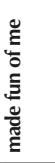 & & 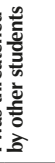 & 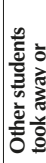 & 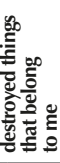 & & 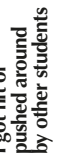 & 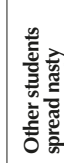 & 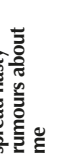 & 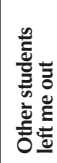 & 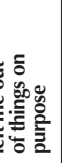 & & 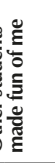 & & $\begin{array}{l}0 \\
0\end{array}$ & 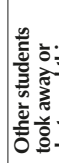 & 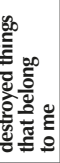 \\
\hline & & $\%$ & S.E. & $\%$ & S.E. & $\%$ & S.E. & $\%$ & S.E. & $\%$ & S.E. & $\%$ & S.E. & $\%$ & S.E. & $\%$ & S.E. & $\%$ & S.E. & $\%$ & S.E. \\
\hline & Australia & 13.4 & (1.1) & 16.0 & $(1.2)$ & 7.5 & $(0.8)$ & & $(0.7)$ & 5.7 & $7 \quad(0.7)$ & 10.6 & (1.0) & 9.9 & $(0.8)$ & 12.5 & $(0.8)$ & 4.7 & $(0.5)$ & 3.9 & $(0.4)$ \\
\hline & Austria & 5.9 & $(0.8)$ & 10.4 & $(0.9)$ & 3.0 & $(0.6)$ & 4.9 & $(0.6)$ & 4.5 & $5 \quad(0.7)$ & 6.4 & $(0.7)$ & 4.4 & $(0.6)$ & 10.2 & $(0.9)$ & c & c & 4.5 & $(0.6)$ \\
\hline & Belgium & 6.8 & $(0.7)$ & 10.1 & $(0.7)$ & 2.6 & $(0.4)$ & $2 . \varepsilon$ & $(0.5)$ & 3.1 & $1 \quad(0.5)$ & 8.9 & $(0.7)$ & 4.7 & (0.5) & 9.4 & $(0.7)$ & 1.8 & $(0.3)$ & 2.6 & $(0.4)$ \\
\hline & Canada & $\mathrm{m}$ & $\mathrm{m}$ & $\mathrm{m}$ & $\mathrm{m}$ & $\mathrm{m}$ & $\mathrm{m}$ & $\mathrm{n}$ & $\mathrm{m}$ & $\mathrm{n}$ & $\mathrm{m}$ & $\mathrm{m}$ & $\mathrm{m}$ & $\mathrm{m}$ & $\mathrm{m}$ & $\mathrm{m}$ & $\mathrm{m}$ & $\mathrm{m}$ & $\mathrm{m}$ & $\mathrm{m}$ & $\mathrm{m}$ \\
\hline & Chile & 9.6 & (1.0) & 11.6 & (1.4) & c & c & 6.8 & $(0.8)$ & 3.8 & $8 \quad(1.0)$ & 10.4 & $(1.3)$ & 7.3 & (1.1) & 7.9 & (1.1) & c & c & 3.4 & $(0.7)$ \\
\hline & Czech Republic & 10.6 & (1.1) & 11.9 & $(1.2)$ & 4.1 & $(0.7)$ & 7.1 & $(1.0)$ & 5.7 & $.7 \quad(0.7)$ & 11.4 & $(1.2)$ & 7.3 & $(0.8)$ & 8.4 & $(0.8)$ & 3.9 & $(0.6)$ & 5.2 & $(0.7)$ \\
\hline & Denmark & 4.9 & (1.0) & 6.1 & (1.2) & c & c & ( & c & & c & 6.4 & $(1.2)$ & 4.5 & $(0.7)$ & 7.8 & $(0.9)$ & c & c & 3.1 & $(0.5)$ \\
\hline & Estonia & 5.7 & (1.1) & 11.7 & (1.4) & c & c & ( & $\mathrm{c}$ & & c & 5.1 & $(0.9)$ & 4.9 & $(0.7)$ & 11.2 & (1.1) & c & c & 3.3 & $(0.6)$ \\
\hline & Finland & 6.1 & $(0.8)$ & 8.5 & $(0.8)$ & c & c & ( & c & 4. & $.4 \quad(0.6)$ & 5.1 & $(0.8)$ & 5.3 & $(0.7)$ & 7.4 & $(0.6)$ & c & c & c & c \\
\hline & France & 6.7 & $(0.9)$ & 12.0 & (1.0) & 3.6 & $(0.5)$ & 2.7 & $(0.5)$ & 2.9 & $.9 \quad(0.5)$ & 7.0 & $(0.7)$ & 5.1 & (0.6) & 10.6 & $(0.9)$ & c & c & 2.5 & $(0.5)$ \\
\hline & Germany & $\mathrm{m}$ & $\mathrm{m}$ & $\mathrm{m}$ & $\mathrm{m}$ & $\mathrm{m}$ & $\mathrm{m}$ & $\mathrm{n}$ & $\mathrm{m}$ & $\mathrm{n}$ & $\mathrm{m}$ & $\mathrm{m}$ & $\mathrm{m}$ & $\mathrm{m}$ & $\mathrm{m}$ & $\mathrm{m}$ & $\mathrm{m}$ & $\mathrm{m}$ & $\mathrm{m}$ & $\mathrm{m}$ & $\mathrm{m}$ \\
\hline & Greece & 4.5 & $(0.7)$ & 8.9 & $(0.9)$ & 3.3 & (0.5) & $5 .($ & $(0.7)$ & 4. & $\begin{array}{ll}.6 & (0.8)\end{array}$ & 7.1 & (1.0) & 3.3 & (0.6) & 7.8 & $(0.8)$ & c & c & 3.9 & $(0.7)$ \\
\hline & Hungary & 8.7 & (1.3) & 9.3 & (1.1) & 4.5 & (1.0) & 4.8 & $(0.9)$ & 4.2. & $.2(0.9)$ & 9.8 & (1.4) & 7.9 & $(0.9)$ & 7.5 & $(0.8)$ & c & c & 4.0 & $(0.7)$ \\
\hline & Iceland & $\mathrm{C}$ & C & c & C & c & C & $c$ & C & & C & c & c & C & c & 3.9 & $(0.6)$ & c & C & C & c \\
\hline & Ireland & 6.4 & (0.9) & 8.5 & (1.1) & c & C & c & C & & c & 4.7 & (0.8) & 4.5 & (0.6) & 6.3 & $(0.7)$ & c & c & 2.9 & $(0.5)$ \\
\hline & Israel & $\mathrm{m}$ & $\mathrm{m}$ & $\mathrm{m}$ & $\mathrm{m}$ & $\mathrm{m}$ & $\mathrm{m}$ & $\mathrm{n}$ & $\mathrm{m}$ & $\mathrm{n}$ & $\mathrm{m}$ & $\mathrm{m}$ & $\mathrm{m}$ & $\mathrm{m}$ & $\mathrm{m}$ & $\mathrm{m}$ & $\mathrm{m}$ & $\mathrm{m}$ & $\mathrm{m}$ & $\mathrm{m}$ & $\mathrm{m}$ \\
\hline & Italy & $\mathrm{m}$ & $\mathrm{m}$ & $\mathrm{m}$ & $\mathrm{m}$ & $\mathrm{m}$ & & n & & & $\mathrm{m}$ & $\mathrm{m}$ & $\mathrm{m}$ & $\mathrm{m}$ & $\mathrm{m}$ & $\mathrm{m}$ & $\mathrm{m}$ & $\mathrm{m}$ & $\mathrm{m}$ & $\mathrm{m}$ & $\mathrm{m}$ \\
\hline & Japan & 3.7 & (0.4) & 13.8 & $(0.8)$ & 2.0 & $(0.3)$ & & $(0.3)$ & 7.6 & $\begin{array}{ll}0 & (0.5)\end{array}$ & 5.1 & (0.5) & 3.7 & $(0.5)$ & 16.2 & $(0.9)$ & 1.9 & $(0.3)$ & 2.3 & $(0.3)$ \\
\hline & Korea & 1.1 & $(0.2)$ & 9.4 & $(0.6)$ & c & c & 1. & $(0.2)$ & & C $\quad$ c & 2.3 & $(0.3)$ & c & $\mathrm{c}$ & 12.3 & (1.1) & c & $=\quad \mathrm{c}$ & c & c \\
\hline & Latvia & 14.0 & (1.4) & 13.0 & (1.5) & 6.0 & (0.8) & 6.8 & $(0.9)$ & 6.8 & $\begin{array}{ll}8 & (0.9)\end{array}$ & 11.0 & (1.2) & 11.8 & (1.0) & 14.4 & (1.3) & 6.6 & $(0.7)$ & 7.1 & (1.0) \\
\hline & Luxembourg & 6.1 & (0.8) & 8.3 & (1.0) & c & & 4. & $(0.7)$ & & c & 8.8 & (1.0) & 3.7 & $(0.7)$ & 5.1 & $(0.8)$ & & c & C & c \\
\hline & Mexico & 9.9 & $(0.7)$ & 13.3 & $(0.8)$ & 4.5 & $(0.5)$ & 4. & $(0.6)$ & 5.7 & $.7 \quad(0.5)$ & 9.5 & $(0.7)$ & 7.8 & $(0.8)$ & 11.0 & (1.0) & 3.4 & $(0.5)$ & 4.2 & $(0.6)$ \\
\hline & Netherlands & c & c & c & c & c & c & & c & & c & c & $\mathrm{c}$ & c & c & 4.0 & $(0.5)$ & & c & c & $\mathrm{c}$ \\
\hline & New Zealand & 13.9 & (1.6) & 18.9 & (1.8) & 9.7 & (1.4) & 8. & $(1.1)$ & 6. & $9 \quad(1.1)$ & 10.8 & (1.4) & 9.0 & $(1.1)$ & 14.3 & (1.3) & 4.7 & $(0.9)$ & c & c \\
\hline & Norway & $\mathrm{m}$ & $\mathrm{m}$ & $\mathrm{m}$ & $\mathrm{m}$ & $\mathrm{m}$ & $\mathrm{m}$ & n & $\mathrm{m}$ & $\mathrm{n}$ & $\mathrm{m}$ & $\mathrm{m}$ & $\mathrm{m}$ & $\mathrm{m}$ & $\mathrm{m}$ & $\mathrm{m}$ & $\mathrm{m}$ & $\mathrm{m}$ & $\mathrm{m}$ & $\mathrm{m}$ & $\mathrm{m}$ \\
\hline & Poland & 8.8 & (1.1) & 11.8 & (1.3) & 4.2 & $(0.8)$ & & c & 4. & $.3 \quad(0.8)$ & 11.2 & (1.2) & 7.0 & $(1.0)$ & 9.3 & (1.1) & c & c & 3.1 & $(0.5)$ \\
\hline & Portugal & 4.1 & $(0.6)$ & 5.4 & $(0.6)$ & 2.9 & $(0.4)$ & $3 .($ & $(0.5)$ & 2. & $.1(0.4)$ & 6.1 & $(0.7)$ & 3.6 & $(0.5)$ & 5.3 & $(0.7)$ & 2.2 & $(0.4)$ & 2.3 & $(0.4)$ \\
\hline & Slovak Rep & 10.8 & (1.0) & 10.7 & (1.1) & 4.8 & $(0.7)$ & 5. & $(0.8)$ & 4. & $\begin{array}{ll}3 \quad(0.6) \\
\end{array}$ & 10.2 & (0.9) & 10.6 & $(1.1)$ & 9.0 & $(0.8)$ & 3.6 & $(0.5)$ & 4.4 & $(0.6)$ \\
\hline & Slovenia & 4.6 & $(0.7)$ & 7.9 & $(0.9)$ & 1.7 & $(0.3)$ & & $(0.4)$ & 2. & $.5 \quad(0.4)$ & 6.9 & $(0.8)$ & 5.0 & $(0.7)$ & 7.8 & $(0.9)$ & 2.4 & $+(0.5)$ & 2.9 & $(0.5)$ \\
\hline & Spain & 6.2 & (0.9) & 9.0 & $(1.0)$ & c & c & & $(0.7)$ & 4.1 & $1 \quad(0.7)$ & 6.7 & $(0.7)$ & 3.6 & $(0.6)$ & 6.5 & $(0.7)$ & c & $=\quad \mathrm{C}$ & 2.7 & $(0.6)$ \\
\hline & Sweden & C & c & 9.8 & (1.7) & c & c & & c & & c & c & c & c & c & 6.6 & $(1.0)$ & c & c & c & c \\
\hline & Switzerland & 6.3 & $(0.8)$ & 8.3 & $(0.8)$ & c & C & & $(0.6)$ & 2.6 & $6 \quad(0.5)$ & 5.5 & $(0.8)$ & 4.0 & $(0.6)$ & 9.0 & $(0.8)$ & c & c & 3.9 & $(0.6)$ \\
\hline & Turkey & $\mathrm{m}$ & $\mathrm{m}$ & $\mathrm{m}$ & $\mathrm{m}$ & $\mathrm{m}$ & $\mathrm{m}$ & $n$ & $\mathrm{~m}$ & n & $\mathrm{m}$ & $\mathrm{m}$ & $\mathrm{m}$ & $\mathrm{m}$ & $\mathrm{m}$ & $\mathrm{m}$ & $\mathrm{m}$ & $\mathrm{m}$ & $\mathrm{m}$ & $\mathrm{m}$ & $\mathrm{m}$ \\
\hline & United Kingdom & 13.4 & (1.8) & 14.6 & (1.7) & c & & & c & & c & 9.9 & (1.6) & 9.1 & $(1.2)$ & 13.3 & (1.5) & & $(0.8)$ & C & C \\
\hline & United States & $\mathrm{m}$ & $\mathrm{m}$ & $\mathrm{m}$ & $\mathrm{m}$ & $\mathrm{m}$ & $\mathrm{m}$ & & $\mathrm{m}$ & & $\mathrm{m}$ & $\mathrm{m}$ & $\mathrm{m}$ & $\mathrm{m}$ & $\mathrm{m}$ & $\mathrm{m}$ & $\mathrm{m}$ & & $\mathrm{m}$ & $\mathrm{m}$ & $\mathrm{m}$ \\
\hline & OECD average & 7.7 & $(0.2)$ & 10.7 & $(0.2)$ & 4.3 & $(0.2)$ & 4.5 & $(0.2)$ & 4. & $\begin{array}{ll}.5 & (0.2)\end{array}$ & 7.9 & $(0.2)$ & 6.2 & $(0.2)$ & 9.1 & $(0.2)$ & 3.6 & $(0.2)$ & 3.6 & $(0.1)$ \\
\hline & Albania & $\mathrm{m}$ & $\mathrm{m}$ & $\mathrm{m}$ & $\mathrm{m}$ & $\mathrm{m}$ & $\mathrm{m}$ & $\mathrm{m}$ & $\mathrm{m}$ & $\mathrm{m}$ & $\mathrm{n}$ & $\mathrm{m}$ & $\mathrm{m}$ & $\mathrm{m}$ & $\mathrm{m}$ & $\mathrm{m}$ & $\mathrm{m}$ & $\mathrm{m}$ & $\mathrm{m}$ & $\mathrm{m}$ & $\mathrm{m}$ \\
\hline 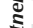 & Algeria & $\mathrm{m}$ & $\mathrm{m}$ & $\mathrm{m}$ & $\mathrm{m}$ & $\mathrm{m}$ & $\mathrm{m}$ & & $\mathrm{m}$ & & $\mathrm{m}$ & $\mathrm{m}$ & $\mathrm{m}$ & $\mathrm{m}$ & $\mathrm{m}$ & $\mathrm{m}$ & $\mathrm{m}$ & $\mathrm{m}$ & $\mathrm{m}$ & $\mathrm{m}$ & $\mathrm{m}$ \\
\hline & Brazil & 8.5 & $(0.6)$ & 9.3 & $(0.7)$ & 5.0 & $(0.5)$ & & $(0.6)$ & 4.2 & $2(0.4)$ & 8.6 & $(0.5)$ & 6.9 & $(0.9)$ & 8.3 & $(0.8)$ & 2.9 & $(0.5)$ & 4.7 & $(0.7)$ \\
\hline & B-S-J-G (China) & 6.8 & $(0.5)$ & 11.0 & $(0.6)$ & 2.4 & $(0.3)$ & 12.0 & $(0.8)$ & 3. & $4 \quad(0.3)$ & 4.9 & $(0.4)$ & 10.9 & $(1.4)$ & 13.9 & (1.6) & 5.1 & $(0.8)$ & 12.8 & (1.6) \\
\hline & Bulgaria & 11.3 & (1.5) & 13.9 & $(1.2)$ & 9.2 & (1.4) & 9.9 & $(1.5)$ & 10. & $9 \quad(1.7)$ & 14.7 & (1.5) & 7.4 & $(0.9)$ & 10.6 & (1.3) & 5.1 & $(0.8)$ & 4.6 & $(0.9)$ \\
\hline & CABA (Arge & $\mathrm{m}$ & & $\mathrm{m}$ & & $\mathrm{m}$ & & & & & $\mathrm{m}$ & $\mathrm{m}$ & $\mathrm{m}$ & $\mathrm{m}$ & $\mathrm{m}$ & $\mathrm{m}$ & $\mathrm{m}$ & $\mathrm{m}$ & $\mathrm{m}$ & $\mathrm{m}$ & $\mathrm{m}$ \\
\hline & Colombia & 10.1 & $(0.7)$ & 13.0 & $(0.9)$ & 4.4 & $(0.5)$ & & $(0.7)$ & 5.6 & $6(0.7)$ & 11.3 & $(0.8)$ & 7.8 & $(1.0)$ & 10.9 & $(1.4)$ & 3.2 & $(0.6)$ & 4.0 & $(0.7)$ \\
\hline & Costa Rica & 8.1 & (0.9) & 11.6 & (1.0) & 4.9 & (1.0) & & & 3.2 & $2(0.6)$ & 11.2 & (1.0) & 7.5 & $(1.0)$ & 11.0 & (1.0) & 3.9 & $(0.6)$ & c & c \\
\hline & Croatia & 4.3 & (0.6) & 7.6 & $(0.8)$ & 3.6 & $(0.7)$ & 3.2 & $(0.6)$ & 4.6 & $6(0.6)$ & 8.5 & $(0.9)$ & 3.0 & $(0.5)$ & 5.9 & $(0.6)$ & 2.6 & $(0.5)$ & c & \\
\hline & Cyprus* & $\mathrm{m}$ & $\mathrm{m}$ & $\mathrm{m}$ & $\mathrm{m}$ & $\mathrm{m}$ & $\mathrm{m}$ & $\mathrm{n}$ & $\mathrm{m}$ & $\mathrm{n}$ & $\mathrm{m}$ & $\mathrm{m}$ & $\mathrm{m}$ & $\mathrm{m}$ & $\mathrm{m}$ & $\mathrm{m}$ & $\mathrm{m}$ & $\mathrm{m}$ & $\mathrm{m}$ & $\mathrm{m}$ & $\mathrm{m}$ \\
\hline & Dominica & 16.7 & (1.2) & 17.3 & (1.4) & 10.5 & $(1.0)$ & 13.4 & (1.0) & 6.3 & $3(0.8)$ & 14.5 & (1.1) & 16.1 & (1.9) & 13.0 & (1.7) & c & c & 8.5 & $(1.2)$ \\
\hline & FYROM & $\mathrm{m}$ & $\mathrm{m}$ & $\mathrm{m}$ & $\mathrm{m}$ & $\mathrm{m}$ & $\mathrm{m}$ & $\mathrm{m}$ & $\mathrm{m}$ & $\mathrm{n}$ & $\mathrm{m}$ & $\mathrm{m}$ & $\mathrm{m}$ & $\mathrm{m}$ & $\mathrm{m}$ & $\mathrm{m}$ & $\mathrm{m}$ & $\mathrm{m}$ & & $\mathrm{m}$ & \\
\hline & Georgia & $\mathrm{m}$ & $\mathrm{m}$ & $\mathrm{m}$ & $\mathrm{m}$ & $\mathrm{m}$ & $\mathrm{m}$ & & & & $\mathrm{m}$ & $\mathrm{m}$ & $\mathrm{m}$ & $\mathrm{m}$ & $\mathrm{m}$ & $\mathrm{m}$ & $\mathrm{m}$ & $\mathrm{m}$ & $\mathrm{m}$ & $\mathrm{m}$ & $\mathrm{m}$ \\
\hline & Hong & 7.5 & $(0.7)$ & 21.2 & (1.3) & 6.0 & $(0.6)$ & 8.8 & $(0.6)$ & 7.7 & $7 \quad(0.8)$ & 10.0 & (0.9) & 6.8 & $(0.8)$ & 24.0 & (1.5) & 4.7 & $(0.8)$ & 9.6 & $(0.9)$ \\
\hline & Indonesi & $\mathrm{m}$ & & $\mathrm{m}$ & $\mathrm{m}$ & $\mathrm{m}$ & & $\mathrm{n}$ & & $\mathrm{n}$ & $\mathrm{m}$ & $\mathrm{m}$ & $\mathrm{m}$ & $\mathrm{m}$ & $\mathrm{m}$ & $\mathrm{m}$ & $\mathrm{m}$ & $\mathrm{m}$ & $\mathrm{m}$ & $\mathrm{m}$ & \\
\hline & Jordan & $\mathrm{m}$ & $\mathrm{m}$ & $\mathrm{m}$ & $\mathrm{m}$ & $\mathrm{m}$ & & $\mathrm{n}$ & $\mathrm{m}$ & & $\mathrm{m}$ & $\mathrm{m}$ & & $\mathrm{m}$ & $\mathrm{m}$ & $\mathrm{m}$ & $\mathrm{m}$ & $\mathrm{m}$ & & $\mathrm{m}$ & \\
\hline & Kosovo & $\mathrm{m}$ & $\mathrm{m}$ & $\mathrm{m}$ & $\mathrm{m}$ & $\mathrm{m}$ & $\mathrm{m}$ & n & $\mathrm{m}$ & & $\mathrm{m}$ & $\mathrm{m}$ & $\mathrm{m}$ & $\mathrm{m}$ & $\mathrm{m}$ & $\mathrm{m}$ & $\mathrm{m}$ & $\mathrm{m}$ & $\mathrm{m}$ & $\mathrm{m}$ & $\mathrm{m}$ \\
\hline & Lebanor & $\mathrm{m}$ & & $\mathrm{m}$ & $\mathrm{m}$ & $\mathrm{m}$ & & & & & $\mathrm{m}$ & $\mathrm{m}$ & $\mathrm{m}$ & $\mathrm{m}$ & $\mathrm{m}$ & $\mathrm{m}$ & $\mathrm{m}$ & $\mathrm{m}$ & $\mathrm{m}$ & $\mathrm{m}$ & $\mathrm{m}$ \\
\hline & Lithuania & 8.1 & (0.9) & 9.4 & $(0.9)$ & 5.9 & $(0.8)$ & $5 .($ & $(0.7)$ & 5. & $1 \quad(0.8)$ & 8.0 & (1.0) & 5.1 & $(0.7)$ & 7.7 & $(0.9)$ & 3.0 & $(0.5)$ & 3.4 & $(0.5)$ \\
\hline & Macao $(\mathrm{Cl}$ & 9.4 & (1.0) & 18.8 & (1.2) & 6.1 & $(0.8)$ & 9.5 & $(0.9)$ & 3.7 & $.7(0.6)$ & 9.0 & (1.0) & 8.8 & $(0.9)$ & 18.0 & (1.1) & 6.0 & $(0.7)$ & 7.9 & $(0.8)$ \\
\hline & Malta & $\mathrm{m}$ & & $\mathrm{m}$ & $\mathrm{m}$ & $\mathrm{m}$ & & $\mathrm{n}$ & & & $\mathrm{m}$ & $\mathrm{m}$ & & $\mathrm{m}$ & & $\mathrm{m}$ & $\mathrm{m}$ & $\mathrm{m}$ & & $\mathrm{m}$ & \\
\hline & Moldova & $\mathrm{m}$ & $\mathrm{m}$ & $\mathrm{m}$ & $\mathrm{m}$ & $\mathrm{m}$ & & $\mathrm{n}$ & $\mathrm{m}$ & & $\mathrm{m}$ & $\mathrm{m}$ & $\mathrm{m}$ & $\mathrm{m}$ & $\mathrm{m}$ & $\mathrm{m}$ & $\mathrm{m}$ & $\mathrm{m}$ & $\mathrm{m}$ & $\mathrm{m}$ & $\mathrm{m}$ \\
\hline & Montene & $\mathrm{m}$ & & $\mathrm{m}$ & & $\mathrm{m}$ & & & & & $\mathrm{m}$ & $\mathrm{m}$ & & $\mathrm{m}$ & & $\mathrm{m}$ & $\mathrm{m}$ & & & $\mathrm{m}$ & \\
\hline & Peru & 6.5 & (0.5) & 7.6 & (0.6) & 2.8 & $(0.4)$ & 5.2 & $(0.5)$ & 3.8 & $\begin{array}{ll}.8 & (0.4)\end{array}$ & 9.6 & $(0.7)$ & 5.6 & $(0.6)$ & 6.5 & $(0.7)$ & 2.5 & $(0.5)$ & 4.9 & $(0.8)$ \\
\hline & Qatar & $\mathrm{m}$ & $\mathrm{m}$ & $\mathrm{m}$ & $\mathrm{m}$ & $\mathrm{m}$ & & n & $\mathrm{m}$ & & $\mathrm{m}$ & $\mathrm{m}$ & $\mathrm{m}$ & $\mathrm{m}$ & $\mathrm{m}$ & $\mathrm{m}$ & $\mathrm{m}$ & $\mathrm{m}$ & $\mathrm{m}$ & $\mathrm{m}$ & $\mathrm{m}$ \\
\hline & Roman & $\mathrm{m}$ & & $\mathrm{m}$ & $\mathrm{m}$ & $\mathrm{m}$ & & & & & $\mathrm{n}$ & $\mathrm{m}$ & $\mathrm{m}$ & $\mathrm{m}$ & $\mathrm{m}$ & $\mathrm{m}$ & & $\mathrm{m}$ & $\mathrm{m}$ & $\mathrm{m}$ & 1 \\
\hline & Russia & 18.3 & (1.3) & 9.2 & (1.1) & 4.9 & $(0.7)$ & & $(0.8)$ & 3.5 & $5 \quad(0.7)$ & 7.7 & (0.9) & 15.7 & (1.5) & 8.9 & (1.1) & 4.5 & $(0.8)$ & 4.9 & $(0.8)$ \\
\hline & Sing & 14.4 & (1.3) & 20.6 & (1.4) & 5.9 & $(0.7)$ & 6. & $(0.8)$ & 6.6 & $6 \quad(0.7)$ & 10.3 & $(0.8)$ & 10.4 & $(1.0)$ & 15.2 & (1.0) & 3.8 & $(0.6)$ & 4.0 & (0.6) \\
\hline & Chi & 3.2 & $(0.3)$ & 7.3 & $(0.5)$ & c & & 3.2 & $(0.4)$ & & c & 3.1 & $(0.4)$ & 3.6 & $(0.5)$ & 6.9 & $(0.7)$ & c & c & 3.3 & $(0.4)$ \\
\hline & Thailand & 12.5 & $(0.8)$ & 19.5 & $(0.9)$ & 9.6 & $(0.7)$ & 10.3 & $(0.8)$ & 8. & $1 \quad(0.7)$ & 11.1 & $(0.7)$ & 12.8 & (1.1) & 21.3 & (1.4) & 8.4 & $(0.9)$ & 9.7 & $(0.9)$ \\
\hline & Trinidad a & $\mathrm{m}$ & $\mathrm{m}$ & $\mathrm{m}$ & $\mathrm{m}$ & $\mathrm{m}$ & $\mathrm{m}$ & $\mathrm{n}$ & $\mathrm{m}$ & $\mathrm{n}$ & $\mathrm{m}$ & $\mathrm{m}$ & $\mathrm{m}$ & $\mathrm{m}$ & $\mathrm{m}$ & $\mathrm{m}$ & $\mathrm{m}$ & $\mathrm{m}$ & $\mathrm{m}$ & $\mathrm{m}$ & $\mathrm{m}$ \\
\hline & Tunis & $\mathrm{m}$ & & $\mathrm{m}$ & $\mathrm{m}$ & $\mathrm{m}$ & & $\mathrm{n}$ & & $\mathrm{n}$ & $\mathrm{m}$ & $\mathrm{m}$ & & $\mathrm{m}$ & $\mathrm{m}$ & $\mathrm{m}$ & $\mathrm{m}$ & $\mathrm{m}$ & $\mathrm{m}$ & $\mathrm{m}$ & $\mathrm{m}$ \\
\hline & United Arab Er & $\mathrm{m}$ & & $\mathrm{m}$ & $\mathrm{m}$ & $\mathrm{m}$ & $\mathrm{m}$ & & $\mathrm{m}$ & & $\mathrm{m}$ & $\mathrm{m}$ & $\mathrm{m}$ & $\mathrm{m}$ & $\mathrm{m}$ & $\mathrm{m}$ & $\mathrm{m}$ & $\mathrm{m}$ & $\mathrm{m}$ & $\mathrm{m}$ & $\mathrm{m}$ \\
\hline & Uru & 10.5 & (1.0) & 11.5 & (1.0) & 5.3 & $(0.7)$ & 4.8 & $(0.6)$ & 5.2 & $2(0.6)$ & 9.4 & $(1.0)$ & 7.5 & $(0.9)$ & 9.2 & $(1.0)$ & c & c & c & C \\
\hline & Viet Nam & $\mathrm{m}$ & $\mathrm{m}$ & $\mathrm{m}$ & $\mathrm{m}$ & $\mathrm{m}$ & $\mathrm{m}$ & $\mathrm{n}$ & $\mathrm{m}$ & $\mathrm{n}$ & $\mathrm{m}$ & $\mathrm{m}$ & $\mathrm{m}$ & $\mathrm{m}$ & $\mathrm{m}$ & $\mathrm{m}$ & $\mathrm{m}$ & $\mathrm{m}$ & $\mathrm{m}$ & $\mathrm{m}$ & $\mathrm{m}$ \\
\hline & Arge & $\mathrm{m}$ & $\mathrm{m}$ & $\mathrm{m}$ & $\mathrm{m}$ & $\mathrm{m}$ & $\mathrm{m}$ & $\mathrm{n}$ & $\mathrm{m}$ & & $\mathrm{m}$ & $\mathrm{m}$ & $\mathrm{m}$ & $\mathrm{m}$ & $\mathrm{m}$ & $\mathrm{m}$ & $\mathrm{m}$ & $\mathrm{m}$ & $\mathrm{m}$ & $\mathrm{m}$ & $\mathrm{m}$ \\
\hline & Kaz & $\mathrm{m}$ & $\mathrm{m}$ & $\mathrm{m}$ & $\mathrm{m}$ & $\mathrm{m}$ & $\mathrm{m}$ & $\mathrm{n}$ & $\mathrm{m}$ & & $\mathrm{m}$ & $\mathrm{m}$ & $\mathrm{m}$ & $\mathrm{m}$ & $\mathrm{m}$ & $\mathrm{m}$ & $\mathrm{m}$ & $\mathrm{m}$ & $\mathrm{m}$ & $\mathrm{m}$ & \\
\hline & Malaysia** & $\mathrm{m}$ & $\mathrm{m}$ & $\mathrm{m}$ & $\mathrm{m}$ & $\mathrm{m}$ & $\mathrm{m}$ & $\mathrm{n}$ & $\mathrm{m}$ & $\mathrm{n}$ & $\mathrm{m}$ & $\mathrm{m}$ & $\mathrm{m}$ & $\mathrm{m}$ & $\mathrm{m}$ & $\mathrm{m}$ & $\mathrm{m}$ & $\mathrm{m}$ & $\mathrm{m}$ & $\mathrm{m}$ & $\mathrm{m}$ \\
\hline
\end{tabular}

Note: Values that are statistically significant are indicated in bold (see Annex A3).

* See note at the beginning of this Annex.

** Coverage is too small to ensure comparability (see Annex A4).

StatLink inst $\mathrm{http}: / / \mathrm{dx}$.doi.org/10.1787/888933473352 
[Part 2/3]

Table III.13.20a Being bullied at school, by time spent on the Internet outside of school on weekdays

Percentage of students who "agree" or "strongly agree"

\begin{tabular}{|c|c|c|c|c|c|c|c|c|c|c|c|c|c|c|c|c|c|c|c|c|c|}
\hline & & & (Stude & ents & ho use & $\begin{array}{l}\text { the } \\
\text { on a }\end{array}$ & Inte & $\begin{array}{l}\text { rnet } \\
\text { t bet } \\
\text { a wee }\end{array}$ & $\begin{array}{l}\text { users } \\
\text { ween } 2 \\
\text { ekday) }\end{array}$ & and 6 & hours & day & & & & Stude & ents $w$ & ho use & $\begin{array}{l}\text { Extrer } \\
\text { the Ir } \\
\text { on a }\end{array}$ & $\begin{array}{l}\text { me Int } \\
\text { nterne } \\
\text { typica }\end{array}$ & $\begin{array}{l}\text { terne } \\
\text { t for }\end{array}$ \\
\hline & & 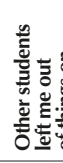 & 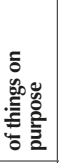 & & 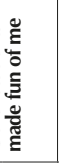 & & 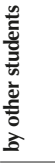 & 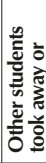 & 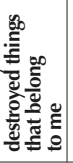 & 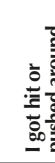 & 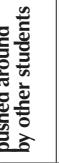 & 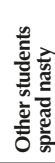 & 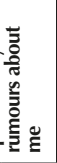 & & 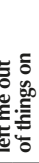 & $\begin{array}{l}1 \\
0 \\
0\end{array}$ & 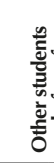 & 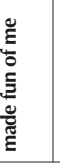 & 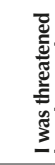 & 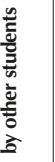 & 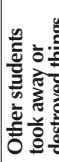 \\
\hline & & $\%$ & S.E. & $\%$ & S.E. & $\%$ & S.E. & $\%$ & S.E. & $\%$ & S.E. & $\%$ & S.E. & $\%$ & & S.E. & $\%$ & S.E. & $\%$ & S.E. & $\%$ \\
\hline 0 & Australia & 11.4 & $(0.5)$ & 13.1 & $(0.5)$ & 5.6 & $(0.4)$ & 4.5 & $5(0.3)$ & 4.6 & $(0.4)$ & 10.0 & (0.4) & 18.7 & & 1.1) & 22.1 & (1.0) & 12.8 & (0.9) & 9.8 \\
\hline & Austria & 5.6 & (0.4) & 12.3 & $(0.8)$ & 2.6 & $(0.4)$ & 4.5 & $5(0.4)$ & 3.8 & (0.4) & 7.5 & $(0.5)$ & 6.4 & & 0.8) & 13.4 & (1.2) & 4.3 & $(0.7)$ & 7.8 \\
\hline & Belgium & 5.0 & $(0.3)$ & 10.2 & $(0.5)$ & 1.9 & $(0.2)$ & 2.3 & $(0.3)$ & 2.2 & $(0.3)$ & 8.6 & $(0.5)$ & 9.2 & & 1.1) & 16.1 & (1.2) & 5.5 & $(0.8)$ & 4.7 \\
\hline & Canada & $\mathrm{m}$ & $\mathrm{m}$ & $\mathrm{m}$ & $\mathrm{m}$ & $\mathrm{m}$ & $\mathrm{m}$ & $\mathrm{m}$ & $\mathrm{m}$ & $\mathrm{m}$ & $\mathrm{m}$ & $\mathrm{m}$ & $\mathrm{m}$ & $\mathrm{m}$ & & $\mathrm{m}$ & $\mathrm{m}$ & $\mathrm{m}$ & $\mathrm{m}$ & $\mathrm{m}$ & $\mathrm{m}$ \\
\hline & Chile & 5.9 & (0.5) & 8.5 & (0.6) & 2.0 & $(0.3)$ & 3.2 & $2(0.4)$ & 2.5 & (0.4) & 7.6 & (0.6) & 7.3 & & 0.7) & 10.1 & $(0.8)$ & 3.3 & $(0.5)$ & 4.7 \\
\hline & Czech Republic & 8.7 & (0.6) & 10.3 & $(0.7)$ & 3.2 & $(0.4)$ & 7.3 & $3 \quad(0.6)$ & 6.9 & (0.6) & 12.9 & $(0.7)$ & 14.1 & & 1.4) & 14.9 & (1.3) & 7.4 & $(0.9)$ & 9.8 \\
\hline & Denmark & 5.8 & (0.5) & 12.0 & $(0.6)$ & 1.6 & $(0.3)$ & 3.7 & $7 \quad(0.3)$ & 3.1 & (0.3) & 7.7 & $(0.5)$ & 8.2 & & 1.2) & 14.3 & (1.1) & 2.8 & (0.6) & 6.4 \\
\hline & Estonia & 6.2 & (0.5) & 14.0 & $(0.8)$ & 2.2 & $(0.3)$ & $3 . c$ & $9 \quad(0.5)$ & 4.3 & (0.5) & 6.5 & $(0.5)$ & 9.4 & & 1.0) & 16.1 & (1.3) & 5.2 & $(0.7)$ & 5.2 \\
\hline & Finland & 6.4 & (0.5) & 10.5 & $(0.7)$ & 2.9 & $(0.4)$ & 2.4 & $\begin{array}{ll}4 & (0.3)\end{array}$ & 5.0 & (0.5) & 6.7 & (0.5) & 13.2 & & 1.6) & 17.3 & (1.8) & 5.9 & (1.2) & c \\
\hline & France & 5.9 & (0.4) & 9.9 & $(0.7)$ & 1.8 & $(0.3)$ & 2.0 & $\begin{array}{ll}0 & (0.3)\end{array}$ & 2.5 & $(0.3)$ & 7.1 & $(0.6)$ & 9.5 & & $1.2)$ & 15.7 & (1.2) & c & c & C \\
\hline & Germany & $\mathrm{m}$ & $\mathrm{m}$ & $\mathrm{m}$ & & $\mathrm{m}$ & $\mathrm{m}$ & $\mathrm{m}$ & $\mathrm{m}$ & $\mathrm{m}$ & $\mathrm{m}$ & $\mathrm{m}$ & $\mathrm{m}$ & $\mathrm{m}$ & $n$ & $\mathrm{~m}$ & $\mathrm{~m}$ & $\mathrm{~m}$ & $\mathrm{~m}$ & $\mathrm{~m}$ & $\mathrm{~m}$ \\
\hline & Greece & 4.7 & $(0.5)$ & 9.9 & $(0.6)$ & 2.1 & $(0.4)$ & 3.3. & $3 \quad(0.5)$ & 2.9 & (0.4) & 6.6 & $(0.7)$ & 5.7 & & $0.8)$ & 12.6 & (1.5) & C & c & 5.7 \\
\hline & Hungary & 8.4 & (0.6) & 8.5 & $(0.6)$ & 2.7 & $(0.3)$ & 4.4 & $4 \quad(0.5)$ & 2.9 & (0.3) & 11.3 & $(0.7)$ & 11.9 & & $0.9)$ & 13.0 & (1.0) & 5.7 & $(0.8)$ & 6.2 \\
\hline & Iceland & 4.1 & (0.5) & 6.4 & $(0.6)$ & 2.5 & $(0.3)$ & c & c & 2.2 & (0.4) & 4.4 & $(0.5)$ & 8.5 & & 1.6) & 12.0 & (1.9) & c & c & C \\
\hline & Ireland & 5.8 & $(0.4)$ & 8.2 & $(0.6)$ & 2.6 & $(0.3)$ & 3.1 & $(0.3)$ & 2.7 & $(0.3)$ & 5.4 & $(0.4)$ & 7.8 & & 1.2) & 12.7 & (1.3) & 6.3 & (1.0) & 5.5 \\
\hline & Israel & $\mathrm{m}$ & $\mathrm{m}$ & $\mathrm{m}$ & $\mathrm{m}$ & $\mathrm{m}$ & $\mathrm{m}$ & $\mathrm{m}$ & $\mathrm{m}$ & $\mathrm{m}$ & $\mathrm{m}$ & $\mathrm{m}$ & $\mathrm{m}$ & $\mathrm{m}$ & & $\mathrm{m}$ & $\mathrm{m}$ & $\mathrm{m}$ & $\mathrm{m}$ & $\mathrm{m}$ & $\mathrm{m}$ \\
\hline & Italy & $\mathrm{m}$ & $\mathrm{m}$ & $\mathrm{m}$ & $\mathrm{m}$ & $\mathrm{m}$ & $\mathrm{m}$ & $\mathrm{m}$ & $\mathrm{m}$ & $\mathrm{m}$ & $\mathrm{m}$ & $\mathrm{m}$ & $\mathrm{m}$ & m & n & $\mathrm{m}$ & $\mathrm{m}$ & $\mathrm{m}$ & $\mathrm{m}$ & $\mathrm{m}$ & $\mathrm{m}$ \\
\hline & Japan & 5.7 & (0.6) & 20.3 & $(0.9)$ & 2.4 & $(0.4)$ & 3.4 & $4 \quad(0.4)$ & 10.0 & $(0.6)$ & 7.3 & (0.6) & 9.1 & & 2.2) & 23.2 & (3.0) & C & c & c \\
\hline & Korea & c & c & 9.9 & (0.9) & c & c & & c & c & c & 3.0 & (0.5) & & c & c & c & c & c & c & c \\
\hline & Latvia & 12.3 & $(0.8)$ & 13.9 & $(0.9)$ & 5.4 & (0.6) & 6.0 & $\begin{array}{ll}0 & (0.6)\end{array}$ & 7.1 & (0.7) & 12.6 & $(0.8)$ & 13.8 & & 1.4) & 19.5 & (1.5) & 10.3 & (1.1) & 10.7 \\
\hline & Luxembourg & 4.3 & $(0.5)$ & 7.0 & $(0.6)$ & 2.4 & $(0.3)$ & 3.0 & $\begin{array}{ll}0 & (0.4)\end{array}$ & 2.2 & (0.3) & 6.8 & $(0.6)$ & 8.1 & & $0.9)$ & 12.3 & (1.1) & 4.7 & $(0.7)$ & 6.0 \\
\hline & Mexico & 7.1 & $(0.7)$ & 11.8 & $(0.9)$ & 3.2 & $(0.4)$ & 3.6 & $6 \quad(0.4)$ & 4.0 & (0.4) & 7.9 & $(0.7)$ & 10.6 & & $0.8)$ & 16.1 & (1.3) & 5.3 & (0.8) & 6.1 \\
\hline & Netherlands & 2.4 & $(0.3)$ & 3.9 & $(0.4)$ & c & c & $1 . \mathrm{c}$ & $9 \quad(0.3)$ & 1.8 & (0.3) & 4.7 & $(0.4)$ & & c & & 5.4 & $(0.7)$ & c & c & C \\
\hline & New Zealand & 11.9 & $(0.8)$ & 16.8 & $(0.8)$ & 7.4 & $(0.6)$ & 5.2 & $2 \quad(0.6)$ & 5.4 & $(0.5)$ & 11.5 & $(0.6)$ & 17.3 & & 1.4) & 20.4 & (1.7) & 10.8 & (1.4) & 8.2 \\
\hline & Norway & $\mathrm{m}$ & $\mathrm{m}$ & $\mathrm{m}$ & $\mathrm{m}$ & $\mathrm{m}$ & $\mathrm{m}$ & $\mathrm{n}$ & $\mathrm{m}$ & $\mathrm{m}$ & $\mathrm{m}$ & $\mathrm{m}$ & $\mathrm{m}$ & $\mathrm{m}$ & $n$ & $\mathrm{~m}$ & $\mathrm{~m}$ & $\mathrm{~m}$ & $\mathrm{~m}$ & $\mathrm{~m}$ & $\mathrm{~m}$ \\
\hline & Poland & 7.4 & $(0.5)$ & 11.3 & $(0.7)$ & 2.9 & $(0.4)$ & 3.8 & 8 & 3.7 & $(0.5)$ & 12.9 & $(0.8)$ & 11.9 & & (1.5) & 16.1 & (1.6) & 7.3 & (1.2) & 6.5 \\
\hline & Portugal & 4.6 & $(0.5)$ & 6.7 & $(0.5)$ & 3.1 & $(0.4)$ & 2.6 & $6 \quad(0.3)$ & 1.8 & $(0.3)$ & 5.1 & $(0.5)$ & 6.2 & & $0.8)$ & 9.0 & (1.2) & 3.7 & $(0.7)$ & 3.8 \\
\hline & Slovak Rep & 7.9 & $(0.6)$ & 9.0 & $(0.6)$ & 3.7 & $(0.5)$ & 5.8 & $8 \quad(0.6)$ & 3.8 & $(0.5)$ & 11.2 & $(0.8)$ & 12.4 & & (1.1) & 12.8 & $(1.2)$ & 6.0 & $(0.9)$ & 7.7 \\
\hline & Slovenia & 4.4 & (0.6) & 8.8 & $(0.8)$ & 1.9 & $(0.3)$ & 3. & $\begin{array}{ll}4 & (0.4)\end{array}$ & 4.0 & $(0.5)$ & 8.4 & $(0.7)$ & 10.0 & & (1.4) & 11.9 & (1.4) & 6.4 & (1.1) & 5.7 \\
\hline & Spain & 3.5 & $(0.4)$ & 6.8 & $(0.5)$ & 1.8 & $(0.3)$ & 3.4 & $4 \quad(0.5)$ & 2.1 & $(0.2)$ & 5.3 & $(0.4)$ & 6.0 & & $0.7)$ & 10.3 & $(0.8)$ & 3.7 & $(0.5)$ & 4.6 \\
\hline & Sweden & 5.6 & (0.4) & 8.6 & $(0.5)$ & 3.0 & $(0.3)$ & 3.4 & $4 \quad(0.4)$ & 4.3 & $(0.4)$ & 5.9 & $(0.5)$ & 9.2 & & 0.9) & 12.2 & (1.1) & 5.7 & (0.8) & 6.3 \\
\hline & Switzerland & 4.3 & $(0.5)$ & 11.1 & $(0.8)$ & 2.2 & $(0.4)$ & 4.2 & $2(0.6)$ & 2.1 & $(0.3)$ & 6.7 & $(0.6)$ & 10.4 & & (1.2) & 15.9 & (1.5) & 5.2 & (1.0) & 7.1 \\
\hline & Turkey & $\mathrm{m}$ & $\mathrm{m}$ & $\mathrm{m}$ & $\mathrm{m}$ & $\mathrm{m}$ & $\mathrm{m}$ & $\mathrm{m}$ & $\mathrm{m}$ & $\mathrm{m}$ & $\mathrm{m}$ & $\mathrm{m}$ & $\mathrm{m}$ & $\mathrm{m}$ & & $\mathrm{m}$ & $\mathrm{m}$ & $\mathrm{m}$ & $\mathrm{m}$ & $\mathrm{m}$ & $\mathrm{m}$ \\
\hline & United Kingdom & 9.1 & $(0.6)$ & 12.9 & $(0.8)$ & 4.8 & $(0.4)$ & 3.7 & $7 \quad(0.4)$ & 4.1 & $(0.5)$ & 9.4 & $(0.6)$ & 16.9 & & (1.4) & 21.1 & (1.3) & 11.2 & (1.0) & 7.9 \\
\hline & United States & $\mathrm{m}$ & $\mathrm{m}$ & $\mathrm{m}$ & $\mathrm{m}$ & $\mathrm{m}$ & & & $\mathrm{m}$ & $\mathrm{m}$ & $\mathrm{m}$ & $\mathrm{m}$ & $\mathrm{m}$ & $\mathrm{m}$ & n & $\mathrm{m}$ & $\mathrm{m}$ & $\mathrm{m}$ & $\mathrm{m}$ & $\mathrm{m}$ & $\mathrm{m}$ \\
\hline & OECD average & 6.4 & $(0.1)$ & 10.4 & $(0.1)$ & 3.0 & $(0.1)$ & 3.8 & \begin{tabular}{|ll}
3 & $(0.1)$
\end{tabular} & 3.8 & $(0.1)$ & 7.9 & $(0.1)$ & 10.5 & & $(0.2)$ & 14.7 & (0.3) & 6.3 & $(0.2)$ & 6.7 \\
\hline & Albania & $\mathrm{m}$ & $\mathrm{m}$ & $\mathrm{m}$ & $\mathrm{m}$ & $\mathrm{m}$ & $\mathrm{m}$ & $m$ & $\mathrm{~m}$ & $\mathrm{~m}$ & $\mathrm{~m}$ & $\mathrm{~m}$ & $\mathrm{~m}$ & $\mathrm{~m}$ & & $\mathrm{~m}$ & $\mathrm{~m}$ & $\mathrm{~m}$ & $\mathrm{~m}$ & $\mathrm{~m}$ & $\mathrm{~m}$ \\
\hline ఏ & Algeria & $\mathrm{m}$ & $\mathrm{m}$ & $\mathrm{m}$ & & $\mathrm{m}$ & & & $\mathrm{m}$ & $\mathrm{m}$ & $\mathrm{m}$ & $\mathrm{m}$ & $\mathrm{m}$ & $\mathrm{m}$ & & $\mathrm{m}$ & $\mathrm{m}$ & $\mathrm{m}$ & $\mathrm{m}$ & $\mathrm{m}$ & $\mathrm{m}$ \\
\hline & Brazil & 6.1 & $(0.4)$ & 8.0 & $(0.7)$ & 2.8 & $(0.4)$ & 3.9 & $9(0.5)$ & 1.8 & $(0.3)$ & 5.9 & $(0.5)$ & 7.1 & & $0.5)$ & 9.9 & $(0.5)$ & 4.0 & (0.4) & 5.6 \\
\hline & B-S-J-G (China) & 8.1 & (0.9) & 14.6 & (1.4) & 4.2 & $(0.7)$ & 13.5 & $5(1.3)$ & 4.9 & $(0.7)$ & 10.5 & (1.3) & 10.3 & & 2.1) & 17.3 & (2.2) & c & c & 17.6 \\
\hline & Bulgaria & 6.0 & (0.5) & 10.9 & (0.6) & 3.0 & $(0.4)$ & 5.6 & $5(0.5)$ & 6.4 & (0.5) & 10.2 & $(0.7)$ & 8.3 & & $0.9)$ & 13.3 & (1.0) & 7.3 & (0.8) & 8.5 \\
\hline & $\mathrm{CAB}$ & $\mathrm{m}$ & $\mathrm{m}$ & $\mathrm{m}$ & $\mathrm{m}$ & $\mathrm{m}$ & & & $\mathrm{m}$ & $\mathrm{m}$ & $\mathrm{m}$ & $\mathrm{m}$ & $\mathrm{m}$ & $\mathrm{m}$ & n & $\mathrm{m}$ & $\mathrm{m}$ & $\mathrm{m}$ & $\mathrm{m}$ & $\mathrm{m}$ & $\mathrm{m}$ \\
\hline & Colombia & 6.1 & (0.6) & 8.9 & $(0.7)$ & 1.9 & $(0.3)$ & 3.1 & $1 \quad(0.4)$ & 3.1 & (0.4) & 10.3 & $(0.7)$ & 8.3 & & $0.7)$ & 11.8 & (0.8) & 2.8 & (0.4) & 4.1 \\
\hline & Costa Rica & 6.9 & (0.8) & 10.6 & (1.0) & 3.8 & $(0.6)$ & & c & c & & 10.5 & (0.9) & 9.0 & & $0.7)$ & 13.1 & (1.0) & 5.6 & (0.6) & 2.4 \\
\hline & Croatia & 5.0 & (0.4) & 7.1 & $(0.7)$ & 3.2 & $(0.3)$ & 3.2 & $2 \quad(0.5)$ & 3.2 & (0.5) & 8.3 & (0.6) & 8.0 & & $0.9)$ & 12.7 & (1.0) & 6.7 & (0.8) & 5.6 \\
\hline & Cyprus* & $\mathrm{m}$ & $\mathrm{m}$ & $\mathrm{m}$ & $\mathrm{m}$ & $\mathrm{m}$ & $\mathrm{m}$ & $\mathrm{m}$ & $\mathrm{m}$ & $\mathrm{m}$ & $\mathrm{m}$ & $\mathrm{m}$ & $\mathrm{m}$ & $\mathrm{m}$ & 1 & $\mathrm{~m}$ & $\mathrm{~m}$ & $\mathrm{~m}$ & $\mathrm{~m}$ & $\mathrm{~m}$ & $\mathrm{~m}$ \\
\hline & Dominic & 5.2 & (1.5) & 14.4 & (1.3) & 5.9 & (0.9) & 8.7 & $7 \quad(1.1)$ & 3.7 & $(0.7)$ & 13.3 & (1.3) & 17.2 & & 1.2) & 13.8 & (1.3) & 8.3 & (1.0) & 11.4 \\
\hline & FYROM & $\mathrm{m}$ & $\mathrm{m}$ & $\mathrm{m}$ & $\mathrm{m}$ & $\mathrm{m}$ & & $\mathrm{m}$ & $\mathrm{m}$ & $\mathrm{m}$ & & $\mathrm{m}$ & $\mathrm{m}$ & $\mathrm{m}$ & n & $\mathrm{m}$ & $\mathrm{m}$ & & $\mathrm{m}$ & $\mathrm{m}$ & $\mathrm{m}$ \\
\hline & Georgia & $\mathrm{m}$ & $\mathrm{m}$ & $\mathrm{m}$ & $\mathrm{m}$ & $\mathrm{m}$ & & $\mathrm{m}$ & $\mathrm{m}$ & $\mathrm{m}$ & & $\mathrm{m}$ & $\mathrm{m}$ & $\mathrm{m}$ & n & $\mathrm{m}$ & $\mathrm{m}$ & $\mathrm{m}$ & $\mathrm{m}$ & $\mathrm{m}$ & $\mathrm{m}$ \\
\hline & Hong & 8.2 & $(0.7)$ & 27.9 & (1.2) & 7.0 & (0.6) & 10.7 & $7 \quad(0.7)$ & 10.0 & $(0.8)$ & 8.4 & $(0.7)$ & 12.1 & & 1.3) & 32.6 & (2.1) & 10.6 & (1.5) & 13.0 \\
\hline & Indonesi & $\mathrm{m}$ & $\mathrm{m}$ & $\mathrm{m}$ & $\mathrm{m}$ & $\mathrm{m}$ & $\mathrm{m}$ & m & $\mathrm{m}$ & $\mathrm{m}$ & & $\mathrm{m}$ & $\mathrm{m}$ & $\mathrm{m}$ & n & $\mathrm{m}$ & $\mathrm{m}$ & $\mathrm{m}$ & $\mathrm{m}$ & $\mathrm{m}$ & $\mathrm{m}$ \\
\hline & Jordan & $\mathrm{m}$ & $\mathrm{m}$ & $\mathrm{m}$ & & $\mathrm{m}$ & $\mathrm{m}$ & $\mathrm{m}$ & $\mathrm{m}$ & $\mathrm{m}$ & & $\mathrm{m}$ & $\mathrm{m}$ & $\mathrm{m}$ & n & $\mathrm{m}$ & $\mathrm{m}$ & $\mathrm{m}$ & $\mathrm{m}$ & $\mathrm{m}$ & $\mathrm{m}$ \\
\hline & Kosovo & $\mathrm{m}$ & $\mathrm{m}$ & $\mathrm{m}$ & & $\mathrm{m}$ & $\mathrm{m}$ & $\mathrm{n}$ & $\mathrm{m}$ & $\mathrm{m}$ & & $\mathrm{m}$ & $\mathrm{m}$ & $\mathrm{m}$ & n & $\mathrm{m}$ & $\mathrm{m}$ & & $\mathrm{m}$ & $\mathrm{m}$ & $\mathrm{m}$ \\
\hline & Lebanon & $\mathrm{m}$ & $\mathrm{m}$ & $\mathrm{m}$ & $\mathrm{m}$ & $\mathrm{m}$ & $\mathrm{m}$ & $\mathrm{n}$ & $\mathrm{m}$ & $\mathrm{m}$ & $\mathrm{m}$ & $\mathrm{m}$ & $\mathrm{m}$ & $\mathrm{m}$ & $n$ & $\mathrm{~m}$ & $\mathrm{~m}$ & $\mathrm{~m}$ & $\mathrm{~m}$ & $\mathrm{~m}$ & $\mathrm{~m}$ \\
\hline & Lithuania & 5.8 & $(0.7)$ & 7.6 & (0.6) & 3.6 & (0.6) & 3.0 & (0.4) & 3.3 & $(0.5)$ & 6.8 & (0.6) & 9.9 & & (1.2) & 14.0 & (1.3) & 6.9 & (1.0) & 5.2 \\
\hline & Macao (Chi & 8.9 & (0.6) & 20.0 & $(0.8)$ & 5.5 & $(0.5)$ & 7.4 & $4 \quad(0.5)$ & 3.8 & (0.4) & 8.4 & (0.6) & 12.7 & & (1.6) & 24.5 & (2.0) & 8.2 & (1.2) & 10.7 \\
\hline & Malta & $\mathrm{m}$ & $\mathrm{m}$ & $\mathrm{m}$ & & $\mathrm{m}$ & $\mathrm{m}$ & $\mathrm{m}$ & $\mathrm{m}$ & $\mathrm{m}$ & & $\mathrm{m}$ & $\mathrm{m}$ & & $n$ & $\mathrm{~m}$ & $\mathrm{~m}$ & & $\mathrm{~m}$ & $\mathrm{~m}$ & $\mathrm{~m}$ \\
\hline & Moldo & $\mathrm{m}$ & $\mathrm{m}$ & $\mathrm{m}$ & & $\mathrm{m}$ & $\mathrm{m}$ & $\mathrm{m}$ & $\mathrm{m}$ & $\mathrm{m}$ & & $\mathrm{m}$ & $\mathrm{m}$ & $\mathrm{m}$ & $n$ & $\mathrm{~m}$ & $\mathrm{~m}$ & $\mathrm{~m}$ & $\mathrm{~m}$ & $\mathrm{~m}$ & $\mathrm{~m}$ \\
\hline & Monte & $\mathrm{m}$ & & $\mathrm{m}$ & & $\mathrm{m}$ & $\mathrm{m}$ & & $\mathrm{m}$ & $\mathrm{m}$ & & $\mathrm{m}$ & $\mathrm{m}$ & $\mathrm{m}$ & $n$ & $\mathrm{~m}$ & $\mathrm{~m}$ & $\mathrm{~m}$ & $\mathrm{~m}$ & $\mathrm{~m}$ & $\mathrm{~m}$ \\
\hline & Peru & 4.8 & (0.6) & 7.2 & $(0.7)$ & c & c & 4.2 & $2 \quad(0.5)$ & 2.2 & $(0.4)$ & 8.8 & $(0.7)$ & 5.7 & & (1.0) & 10.2 & (1.6) & c & c & 6.8 \\
\hline & Qata & $\mathrm{m}$ & $\mathrm{m}$ & $\mathrm{m}$ & $\mathrm{m}$ & $\mathrm{m}$ & $\mathrm{m}$ & n & $\mathrm{m}$ & $\mathrm{m}$ & & $\mathrm{m}$ & $\mathrm{m}$ & m & $n$ & $\mathrm{~m}$ & $\mathrm{~m}$ & $\mathrm{~m}$ & $\mathrm{~m}$ & $\mathrm{~m}$ & $\mathrm{~m}$ \\
\hline & Romania & $\mathrm{m}$ & $\mathrm{m}$ & $\mathrm{m}$ & & $\mathrm{m}$ & & & $\mathrm{m}$ & $\mathrm{m}$ & & $\mathrm{m}$ & $\mathrm{m}$ & $\mathrm{m}$ & ר & $\mathrm{m}$ & $\mathrm{m}$ & $\mathrm{m}$ & $\mathrm{m}$ & $\mathrm{m}$ & $\mathrm{m}$ \\
\hline & Russia & 17.2 & (1.6) & 11.4 & (1.1) & 3.8 & (0.6) & 4.2 & $2(0.8)$ & 1.9 & (0.5) & 7.9 & $(0.7)$ & 21.0 & & 1.9) & 16.2 & (1.5) & 6.8 & (1.7) & 7.8 \\
\hline & Sins & 9.6 & $(0.5)$ & 16.2 & $(0.7)$ & 3.2 & $(0.3)$ & 4.2 & $2(0.4)$ & 4.3 & (0.4) & 7.2 & (0.5) & 17.4 & & 1.3) & 24.5 & (1.3) & 6.4 & (0.8) & 6.4 \\
\hline & Chinese Taipei & 3.2 & $(0.3)$ & 6.3 & $(0.5)$ & c & c & 3.7 & $7(0.5)$ & c & & 3.5 & $(0.4)$ & 3.5 & & $0.6)$ & 6.9 & $(0.7)$ & c & c & 3.8 \\
\hline & Thailand & 10.2 & $(0.8)$ & 17.4 & (1.1) & 6.3 & $(0.6)$ & 7.3 & $(0.8)$ & 4.9 & $(0.6)$ & 9.3 & $(0.7)$ & 13.6 & & 1.2) & 22.2 & (1.7) & 9.5 & $(1.2)$ & 10.6 \\
\hline & Trin & $\mathrm{m}$ & & $\mathrm{m}$ & & $\mathrm{m}$ & & $\mathrm{m}$ & & $\mathrm{m}$ & & $\mathrm{m}$ & $\mathrm{m}$ & $\mathrm{m}$ & & $\mathrm{m}$ & $\mathrm{m}$ & $\mathrm{m}$ & $\mathrm{m}$ & $\mathrm{m}$ & $\mathrm{m}$ \\
\hline & Tunisia & $\mathrm{m}$ & $\mathrm{m}$ & $\mathrm{m}$ & & $\mathrm{m}$ & & $\mathrm{m}$ & $\mathrm{m}$ & $\mathrm{m}$ & & $\mathrm{m}$ & $\mathrm{m}$ & $\mathrm{m}$ & n & $\mathrm{m}$ & $\mathrm{m}$ & & $\mathrm{m}$ & & $\mathrm{m}$ \\
\hline & United A & $\mathrm{m}$ & $\mathrm{m}$ & $\mathrm{m}$ & $\mathrm{m}$ & $\mathrm{m}$ & $\mathrm{m}$ & & $\mathrm{m}$ & $\mathrm{m}$ & $\mathrm{m}$ & $\mathrm{m}$ & $\mathrm{m}$ & $\mathrm{m}$ & n & $\mathrm{m}$ & $\mathrm{m}$ & $\mathrm{m}$ & $\mathrm{m}$ & $\mathrm{m}$ & $\mathrm{m}$ \\
\hline & Urug & 6.9 & $(0.5)$ & 9.3 & $(0.7)$ & 3.1 & $(0.4)$ & 3.2 & $2(0.4)$ & 2.9 & $(0.4)$ & 6.3 & $(0.7)$ & $9.8-1-x-10$ & & $0.8)$ & 10.8 & $(0.8)$ & 4.9 & $(0.5)$ & 4.4 \\
\hline & Viet Nam & $\mathrm{m}$ & $\mathrm{m}$ & $\mathrm{m}$ & $\mathrm{m}$ & $\mathrm{m}$ & $\mathrm{m}$ & $\mathrm{m}$ & $\mathrm{m}$ & $\mathrm{m}$ & $\mathrm{m}$ & $\mathrm{m}$ & $\mathrm{m}$ & $\mathrm{m}$ & n & $\mathrm{m}$ & $\mathrm{m}$ & $\mathrm{m}$ & $\mathrm{m}$ & $\mathrm{m}$ & $\mathrm{m}$ \\
\hline & Arg & $\mathrm{m}$ & $\mathrm{m}$ & $\mathrm{m}$ & $\mathrm{m}$ & $\mathrm{m}$ & $\mathrm{m}$ & $\mathrm{m}$ & $\mathrm{m}$ & $\mathrm{m}$ & $\mathrm{m}$ & $\mathrm{m}$ & $\mathrm{m}$ & $\mathrm{m}$ & n & $\mathrm{m}$ & $\mathrm{m}$ & $\mathrm{m}$ & $\mathrm{m}$ & $\mathrm{m}$ & $\mathrm{m}$ \\
\hline & Kaz & $\mathrm{m}$ & $\mathrm{m}$ & $\mathrm{m}$ & & $\mathrm{m}$ & $\mathrm{m}$ & $\mathrm{m}$ & $\mathrm{m}$ & $\mathrm{m}$ & & $\mathrm{m}$ & $\mathrm{m}$ & $\mathrm{m}$ & n & $\mathrm{m}$ & $\mathrm{m}$ & $\mathrm{m}$ & $\mathrm{m}$ & & $\mathrm{m}$ \\
\hline & Malaysia** & $\mathrm{m}$ & $\mathrm{m}$ & $\mathrm{m}$ & $\mathrm{m}$ & m & $\mathrm{m}$ & n & $\mathrm{m}$ & $\mathrm{m}$ & $\mathrm{m}$ & $\mathrm{m}$ & 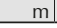 & m & & $\mathrm{m}$ & $\mathrm{m}$ & & $\mathrm{m}$ & $\mathrm{m}$ & $\mathrm{m}$ \\
\hline
\end{tabular}

Note: Values that are statistically significant are indicated in bold (see Annex A3)

* See note at the beginning of this Annex.

** Coverage is too small to ensure comparability (see Annex A4).

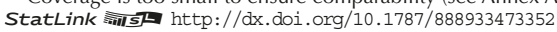




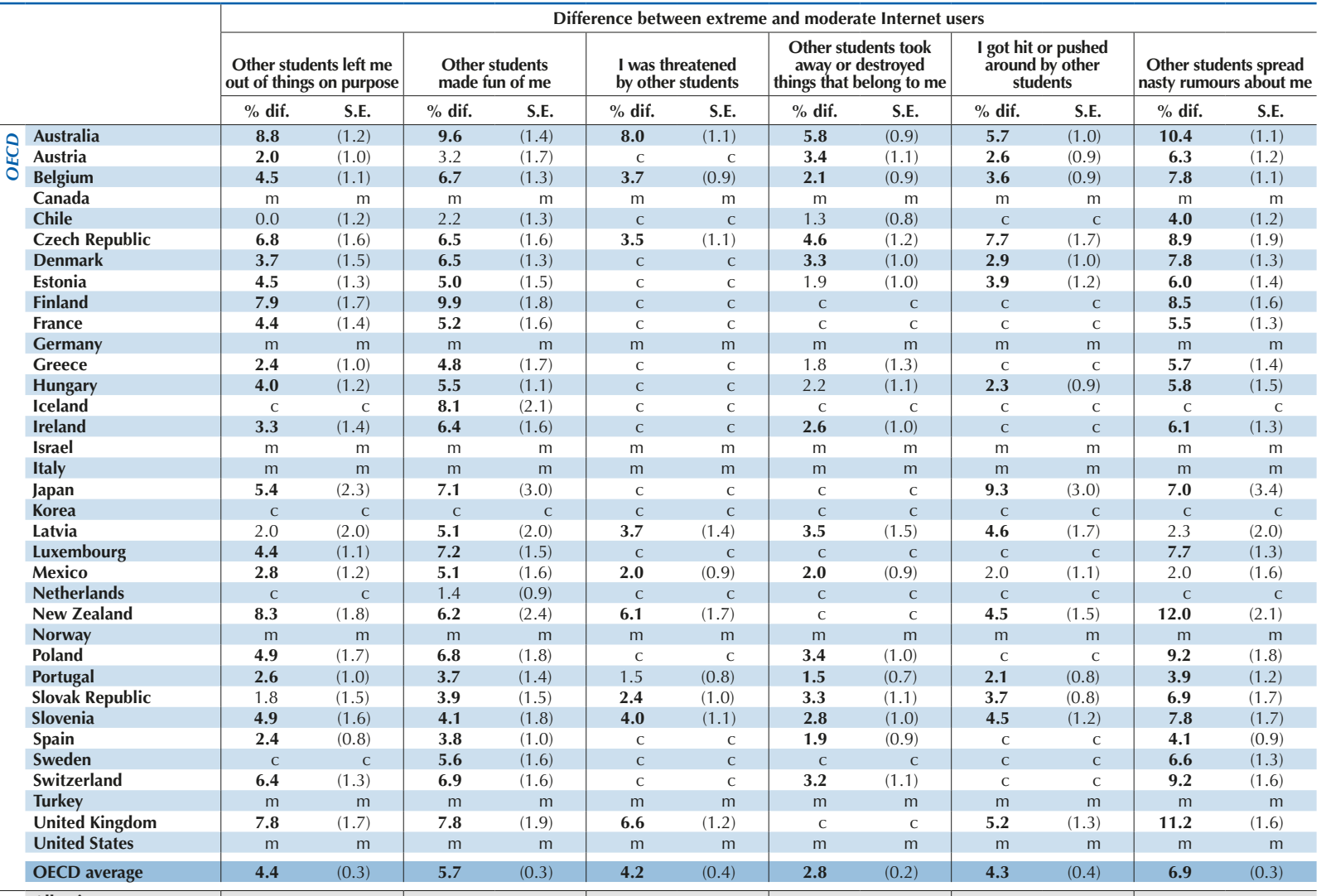

\begin{tabular}{|c|c|c|c|c|c|c|c|c|c|c|c|c|}
\hline Albania & $\mathrm{m}$ & $\mathrm{m}$ & $\mathrm{m}$ & $\mathrm{m}$ & $\mathrm{m}$ & $\mathrm{m}$ & $\mathrm{m}$ & $\mathrm{m}$ & $\mathrm{m}$ & $\mathrm{m}$ & $\mathrm{m}$ & $\mathrm{m}$ \\
\hline Algeria & $\mathrm{m}$ & $\mathrm{m}$ & $\mathrm{m}$ & $\mathrm{m}$ & $\mathrm{m}$ & $\mathrm{m}$ & $\mathrm{m}$ & $\mathrm{m}$ & $\mathrm{m}$ & $\mathrm{m}$ & $\mathrm{m}$ & $\mathrm{m}$ \\
\hline Brazil & 0.2 & $(1.0)$ & 1.7 & $(1.0)$ & 1.1 & $(0.7)$ & 0.9 & $(0.8)$ & -0.2 & $(0.7)$ & 1.7 & $(1.0)$ \\
\hline B-S-J-G (China) & -0.6 & (2.4) & 3.3 & (2.4) & c & C & 4.8 & (3.0) & 0.1 & (1.9) & 3.4 & (1.9) \\
\hline Bulgaria & 0.9 & $(1.3)$ & 2.7 & (1.7) & 2.2 & $(0.9)$ & 3.9 & (1.1) & 5.9 & $(1.2)$ & 7.3 & (1.5) \\
\hline CABA (Argentina) & $\mathrm{m}$ & $\mathrm{m}$ & $\mathrm{m}$ & $\mathrm{m}$ & $\mathrm{m}$ & $\mathrm{m}$ & $\mathrm{m}$ & $\mathrm{m}$ & $\mathrm{m}$ & $\mathrm{m}$ & $\mathrm{m}$ & $\mathrm{m}$ \\
\hline Colombia & 0.6 & (1.3) & 0.9 & (1.6) & -0.4 & $(0.7)$ & 0.1 & $(0.9)$ & -0.8 & (1.0) & 1.2 & (1.6) \\
\hline Costa Rica & 1.5 & $(1.1)$ & 2.1 & (1.5) & 1.6 & $(0.8)$ & C & c & C & c & 7.7 & (1.4) \\
\hline Croatia & 5.0 & $(1.1)$ & 6.8 & $(1.2)$ & 4.1 & $(0.9)$ & c & c & c & c & 10.3 & (1.5) \\
\hline Cyprus* & $\mathrm{m}$ & $\mathrm{m}$ & $\mathrm{m}$ & $\mathrm{m}$ & $\mathrm{m}$ & $\mathrm{m}$ & $\mathrm{m}$ & $\mathrm{m}$ & $\mathrm{m}$ & $\mathrm{m}$ & $\mathrm{m}$ & $\mathrm{m}$ \\
\hline Dominican Republic & 1.0 & $(2.1)$ & 0.8 & (2.0) & c & c & 2.9 & (1.5) & c & c & 4.3 & (2.0) \\
\hline FYROM & $\mathrm{m}$ & $\mathrm{m}$ & $\mathrm{m}$ & $\mathrm{m}$ & $\mathrm{m}$ & $\mathrm{m}$ & $\mathrm{m}$ & $\mathrm{m}$ & $\mathrm{m}$ & $\mathrm{m}$ & $\mathrm{m}$ & $\mathrm{m}$ \\
\hline Georgia & $\mathrm{m}$ & $\mathrm{m}$ & $\mathrm{m}$ & $\mathrm{m}$ & $\mathrm{m}$ & $\mathrm{m}$ & $\mathrm{m}$ & $\mathrm{m}$ & $\mathrm{m}$ & $\mathrm{m}$ & $\mathrm{m}$ & $\mathrm{m}$ \\
\hline Hong Kong (China) & 5.3 & (1.5) & 8.6 & (2.5) & 5.9 & (1.6) & 3.4 & (1.7) & 6.8 & (1.9) & 5.9 & (1.6) \\
\hline Indonesia & $\mathrm{m}$ & $\mathrm{m}$ & $\mathrm{m}$ & $\mathrm{m}$ & $\mathrm{m}$ & $\mathrm{m}$ & $\mathrm{m}$ & $\mathrm{m}$ & $\mathrm{m}$ & $\mathrm{m}$ & $\mathrm{m}$ & $\mathrm{m}$ \\
\hline Jordan & $\mathrm{m}$ & $\mathrm{m}$ & $\mathrm{m}$ & $\mathrm{m}$ & $\mathrm{m}$ & $\mathrm{m}$ & $\mathrm{m}$ & $\mathrm{m}$ & $\mathrm{m}$ & $\mathrm{m}$ & $\mathrm{m}$ & $\mathrm{m}$ \\
\hline Kosovo & $\mathrm{m}$ & $\mathrm{m}$ & $\mathrm{m}$ & $\mathrm{m}$ & $\mathrm{m}$ & $\mathrm{m}$ & $\mathrm{m}$ & $\mathrm{m}$ & $\mathrm{m}$ & $\mathrm{m}$ & $\mathrm{m}$ & $\mathrm{m}$ \\
\hline Lebanon & $\mathrm{m}$ & $\mathrm{m}$ & $\mathrm{m}$ & $\mathrm{m}$ & $\mathrm{m}$ & $\mathrm{m}$ & $\mathrm{m}$ & $\mathrm{m}$ & $\mathrm{m}$ & $\mathrm{m}$ & $\mathrm{m}$ & $\mathrm{m}$ \\
\hline Lithuania & 4.8 & (1.4) & 6.3 & (1.6) & 3.9 & $(1.2)$ & 1.8 & (1.1) & 1.7 & (1.1) & 6.1 & (1.3) \\
\hline Macao (China) & 3.9 & (1.9) & 6.6 & $(2.2)$ & 2.3 & (1.3) & 2.8 & (1.7) & 2.2 & (1.4) & 4.4 & (2.0) \\
\hline Malta & $\mathrm{m}$ & $\mathrm{m}$ & $\mathrm{m}$ & $\mathrm{m}$ & $\mathrm{m}$ & $\mathrm{m}$ & $\mathrm{m}$ & $\mathrm{m}$ & $\mathrm{m}$ & $\mathrm{m}$ & $\mathrm{m}$ & $\mathrm{m}$ \\
\hline Moldova & $\mathrm{m}$ & $\mathrm{m}$ & $\mathrm{m}$ & $\mathrm{m}$ & $\mathrm{m}$ & $\mathrm{m}$ & $\mathrm{m}$ & $\mathrm{m}$ & $\mathrm{m}$ & $\mathrm{m}$ & $\mathrm{m}$ & $\mathrm{m}$ \\
\hline Montenegro & $\mathrm{m}$ & $\mathrm{m}$ & $\mathrm{m}$ & $\mathrm{m}$ & $\mathrm{m}$ & $\mathrm{m}$ & $\mathrm{m}$ & $\mathrm{m}$ & $\mathrm{m}$ & $\mathrm{m}$ & $\mathrm{m}$ & $\mathrm{m}$ \\
\hline Peru & 0.1 & (1.3) & 3.7 & (1.7) & C & C & 1.9 & (1.3) & C & C & 3.0 & (1.6) \\
\hline Qatar & $\mathrm{m}$ & $\mathrm{m}$ & $\mathrm{m}$ & $\mathrm{m}$ & $\mathrm{m}$ & $\mathrm{m}$ & $\mathrm{m}$ & $\mathrm{m}$ & $\mathrm{m}$ & $\mathrm{m}$ & $\mathrm{m}$ & $\mathrm{m}$ \\
\hline Romania & $\mathrm{m}$ & $\mathrm{m}$ & $\mathrm{m}$ & $\mathrm{m}$ & $\mathrm{m}$ & $\mathrm{m}$ & $\mathrm{m}$ & $\mathrm{m}$ & $\mathrm{m}$ & $\mathrm{m}$ & $\mathrm{m}$ & $\mathrm{m}$ \\
\hline Russia & 5.3 & $(2.0)$ & 7.3 & $(2.0)$ & 2.3 & (1.9) & 2.9 & $(1.8)$ & c & c & 6.9 & (1.6) \\
\hline Singapore & 6.9 & (1.6) & 9.3 & (1.7) & 2.6 & $(1.0)$ & 2.4 & $(1.0)$ & 2.9 & $(1.0)$ & 5.4 & (1.4) \\
\hline Chinese Taipei & -0.1 & $(0.7)$ & 0.0 & (1.0) & c & c & 0.4 & $(0.8)$ & c & c & 1.6 & $(0.8)$ \\
\hline Thailand & 0.8 & $(1.7)$ & 0.9 & $(2.2)$ & 1.1 & (1.5) & 0.9 & (1.5) & -0.7 & (1.4) & 0.9 & (1.7) \\
\hline Trinidad and Tobago & $\mathrm{m}$ & $\mathrm{m}$ & $\mathrm{m}$ & $\mathrm{m}$ & $\mathrm{m}$ & $\mathrm{m}$ & $\mathrm{m}$ & $\mathrm{m}$ & $\mathrm{m}$ & $\mathrm{m}$ & $\mathrm{m}$ & $\mathrm{m}$ \\
\hline Tunisia & $\mathrm{m}$ & $\mathrm{m}$ & $\mathrm{m}$ & $\mathrm{m}$ & $\mathrm{m}$ & $\mathrm{m}$ & $\mathrm{m}$ & $\mathrm{m}$ & $\mathrm{m}$ & $\mathrm{m}$ & $\mathrm{m}$ & $\mathrm{m}$ \\
\hline United Arab Emirates & $\mathrm{m}$ & $\mathrm{m}$ & $\mathrm{m}$ & $\mathrm{m}$ & $\mathrm{m}$ & $\mathrm{m}$ & $\mathrm{m}$ & $\mathrm{m}$ & $\mathrm{m}$ & $\mathrm{m}$ & $\mathrm{m}$ & $\mathrm{m}$ \\
\hline Uruguay & 2.3 & $(1.1)$ & 1.7 & (1.5) & c & c & c & c & c & c & 2.2 & (1.1) \\
\hline Viet Nam & $\mathrm{m}$ & $\mathrm{m}$ & $\mathrm{m}$ & $\mathrm{m}$ & $\mathrm{m}$ & $\mathrm{m}$ & $\mathrm{m}$ & $\mathrm{m}$ & $\mathrm{m}$ & $\mathrm{m}$ & $\mathrm{m}$ & $\mathrm{m}$ \\
\hline Argentina** $^{* *}$ & $\mathrm{~m}$ & $\mathrm{~m}$ & $\mathrm{~m}$ & $\mathrm{~m}$ & $\mathrm{~m}$ & $\mathrm{~m}$ & $\mathrm{~m}$ & $\mathrm{~m}$ & $\mathrm{~m}$ & $\mathrm{~m}$ & $\mathrm{~m}$ & $\mathrm{~m}$ \\
\hline Kazakhstan** & $\mathrm{m}$ & $\mathrm{m}$ & $\mathrm{m}$ & $\mathrm{m}$ & $\mathrm{m}$ & $\mathrm{m}$ & $\mathrm{m}$ & $\mathrm{m}$ & $\mathrm{m}$ & $\mathrm{m}$ & $\mathrm{m}$ & $\mathrm{m}$ \\
\hline Malaysia** & $\mathrm{m}$ & $\mathrm{m}$ & $\mathrm{m}$ & $\mathrm{m}$ & $\mathrm{m}$ & $\mathrm{m}$ & $\mathrm{m}$ & $\mathrm{m}$ & $\mathrm{m}$ & $\mathrm{m}$ & $\mathrm{m}$ & $\mathrm{m}$ \\
\hline
\end{tabular}

Note: Values that are statistically significant are indicated in bold (see Annex A3)

* See note at the beginning of this Annex.

** Coverage is too small to ensure comparability (see Annex A4).

StatLink 해내 $\mathrm{http}: / / \mathrm{dx}$.doi.org/10.1787/888933473352 
[Part 1/3]

Table III.13.21 Engagement with school, by time spent on the Internet outside of school on weekdays

Results based on students' self-reports

\begin{tabular}{|c|c|c|c|c|c|c|c|c|c|c|c|c|c|}
\hline & \multicolumn{6}{|c|}{$\begin{array}{l}\text { Low Internet users } \\
\text { (Students who use the Internet for less than } 1 \text { hour per day } \\
\text { on a typical weekday) }\end{array}$} & \multicolumn{6}{|c|}{$\begin{array}{c}\text { Moderate Internet users } \\
\text { (Students who use the Internet between } 1 \text { and } 2 \text { hours per day } \\
\text { on a typical weekday) }\end{array}$} \\
\hline & & \multicolumn{2}{|c|}{$\begin{array}{c}\text { Students arrived late } \\
\text { for school in the } \\
2 \text { weeks prior } \\
\text { to the PISA test }\end{array}$} & $\begin{array}{r}\text { Stud } \\
\text { a whol } \\
\text { in the } \\
\text { to th }\end{array}$ & $\begin{array}{l}\text { kipped } \\
\text { of school } \\
\text { ess prior } \\
\text { A test }\end{array}$ & $\begin{array}{l}\text { Studen } \\
\text { classes } \\
\text { prior } t\end{array}$ & $\begin{array}{l}\text { ed some } \\
2 \text { weeks } \\
\text { ISA test }\end{array}$ & $\begin{array}{r}\text { Studen } \\
\text { for s } \\
2 \mathrm{y} \\
\text { to t }\end{array}$ & $\begin{array}{l}\text { ived late } \\
\text { in the } \\
\text { prior } \\
\text { A test }\end{array}$ & $\begin{array}{r}\text { Stud } \\
\text { a who } \\
\text { in the } \\
\text { to } t\end{array}$ & $\begin{array}{l}\text { cipped } \\
\text { of school } \\
\text { ks prior } \\
\text { A test }\end{array}$ & $\begin{array}{l}\text { Studen } \\
\text { classes } \\
\text { prior } t\end{array}$ & $\begin{array}{l}\text { ed some } \\
2 \text { weeks } \\
\text { ISA test }\end{array}$ \\
\hline & & $\%$ & S.E. & $\%$ & S.E. & $\%$ & S.E. & $\%$ & S.E. & $\%$ & S.E. & $\%$ & S.E. \\
\hline 0 & Australia & 25.0 & (1.3) & 15.2 & (1.3) & 37.7 & (1.8) & 25.1 & (1.1) & 13.1 & (0.9) & 37.9 & $(1.2)$ \\
\hline 过 & Austria & 7.3 & $(0.8)$ & 14.8 & $(1.4)$ & 29.6 & (1.8) & 8.2 & $(1.0)$ & 13.2 & (1.1) & 32.1 & $(1.7)$ \\
\hline 0 & Belgium & 4.8 & $(0.6)$ & 9.9 & $(0.8)$ & 48.6 & (1.6) & 4.6 & $(0.5)$ & 7.8 & $(0.8)$ & 46.3 & (1.3) \\
\hline & Canada & $\mathrm{m}$ & $\mathrm{m}$ & $\mathrm{m}$ & $\mathrm{m}$ & $\mathrm{m}$ & $\mathrm{m}$ & $\mathrm{m}$ & $\mathrm{m}$ & $\mathrm{m}$ & $\mathrm{m}$ & $\mathrm{m}$ & $\mathrm{m}$ \\
\hline & Chile & 8.7 & $(1.0)$ & 16.7 & (1.5) & 65.8 & (1.8) & 8.4 & $(1.1)$ & 14.4 & (1.4) & 62.3 & (2.0) \\
\hline & Czech Republic & 6.0 & $(0.9)$ & 8.1 & $(1.0)$ & 48.0 & (1.7) & 4.6 & $(0.6)$ & 6.9 & $(0.7)$ & 46.5 & (1.4) \\
\hline & Denmark & 11.1 & $(1.5)$ & 20.1 & $(1.7)$ & 39.7 & (2.4) & 12.8 & $(1.1)$ & 21.0 & $(1.5)$ & 44.7 & (1.8) \\
\hline & Estonia & 17.8 & $(1.8)$ & 28.3 & $(2.0)$ & 38.5 & (1.7) & 17.8 & $(1.3)$ & 30.1 & (1.6) & 36.6 & (1.7) \\
\hline & Finland & 34.4 & (1.5) & 44.1 & (1.6) & 28.3 & (1.7) & 33.6 & (1.6) & 45.3 & (1.5) & 29.1 & (1.3) \\
\hline & France & 8.7 & $(1.0)$ & 18.4 & (1.3) & 45.4 & (1.4) & 6.9 & $(0.8)$ & 20.5 & (1.3) & 49.2 & (1.4) \\
\hline & Germany & $\mathrm{m}$ & $\mathrm{m}$ & $\mathrm{m}$ & $\mathrm{m}$ & $\mathrm{m}$ & $\mathrm{m}$ & $\mathrm{m}$ & $\mathrm{m}$ & $\mathrm{m}$ & $\mathrm{m}$ & $\mathrm{m}$ & $\mathrm{m}$ \\
\hline & Greece & 14.9 & (1.4) & 37.8 & $(2.2)$ & 49.1 & (1.7) & 15.9 & $(1.4)$ & 38.2 & (1.8) & 51.2 & (1.4) \\
\hline & Hungary & 6.4 & $(1.1)$ & 14.3 & (1.4) & 33.5 & (1.8) & 6.3 & $(0.8)$ & 13.0 & (1.3) & 31.4 & (1.3) \\
\hline & Iceland & C & c & 16.0 & $(2.3)$ & 41.4 & (2.7) & c & C & 12.0 & (1.1) & 44.4 & (2.1) \\
\hline & Ireland & 17.3 & $(1.3)$ & 16.1 & $(1.2)$ & 28.5 & (1.5) & 20.6 & $(1.2)$ & 18.9 & (1.4) & 27.4 & (1.4) \\
\hline & Israel & 28.6 & $(1.8)$ & 40.0 & $(2.9)$ & 56.0 & (1.7) & 33.3 & $(1.8)$ & 39.1 & (1.9) & 56.6 & (2.1) \\
\hline & Italy & 49.5 & (1.9) & 36.9 & (2.0) & 33.4 & (1.8) & 49.2 & (1.8) & 38.0 & (1.9) & 32.3 & (1.8) \\
\hline & Japan & 1.2 & $(0.2)$ & 2.0 & $(0.3)$ & 9.0 & $(0.7)$ & c & c & 1.9 & $(0.3)$ & 9.4 & $(0.9)$ \\
\hline & Korea & 1.0 & $(0.2)$ & 1.7 & $(0.3)$ & 16.8 & (1.0) & c & $\mathrm{c}$ & 2.5 & $(0.4)$ & 20.6 & (1.3) \\
\hline & Latvia & 24.6 & (1.5) & 34.2 & (2.0) & 47.7 & (1.7) & 21.2 & $(1.6)$ & 32.3 & (1.6) & 49.6 & (1.7) \\
\hline & Luxembourg & 9.6 & (1.1) & 12.3 & (1.4) & 51.5 & (1.9) & 6.6 & $(0.9)$ & 11.6 & $(0.9)$ & 49.7 & (1.5) \\
\hline & Mexico & 25.4 & $(1.1)$ & 22.8 & (1.1) & 47.2 & (1.5) & 23.4 & $(1.4)$ & 22.7 & (1.4) & 47.8 & (1.8) \\
\hline & Netherlands & 5.9 & $(1.0)$ & 15.1 & $(1.5)$ & 50.1 & (1.9) & 3.7 & $(0.6)$ & 15.4 & (1.4) & 45.7 & (1.6) \\
\hline & New Zealand & 24.9 & $(2.0)$ & 21.1 & (1.9) & 41.5 & (2.3) & 19.5 & $(1.4)$ & 14.7 & (1.4) & 36.9 & (1.8) \\
\hline & Norway & $\mathrm{m}$ & $\mathrm{m}$ & $\mathrm{m}$ & $\mathrm{m}$ & $\mathrm{m}$ & m & $\mathrm{m}$ & $\mathrm{m}$ & $\mathrm{m}$ & $\mathrm{m}$ & $\mathrm{m}$ & m \\
\hline & Poland & 14.3 & (1.5) & 27.8 & (1.8) & 48.6 & (2.0) & 16.7 & $(1.4)$ & 33.1 & (1.9) & 55.0 & (1.8) \\
\hline & Portugal & 20.1 & $(1.2)$ & 31.3 & $(1.2)$ & 39.4 & (1.5) & 19.5 & $(1.2)$ & 29.6 & (1.4) & 41.0 & (1.7) \\
\hline & Slovak Republic & 49.1 & $(1.8)$ & 49.0 & $(1.4)$ & 35.3 & (1.7) & 47.5 & (1.8) & 45.8 & (1.8) & 30.9 & (1.6) \\
\hline & Slovenia & 9.3 & $(0.9)$ & 23.1 & $(1.3)$ & 44.6 & (1.6) & 9.2 & $(0.9)$ & 25.2 & (1.4) & 47.8 & (1.7) \\
\hline & Spain & 21.7 & $(1.3)$ & 26.7 & $(1.3)$ & 36.0 & (1.6) & 18.0 & $(1.2)$ & 32.3 & (1.8) & 40.8 & (1.8) \\
\hline & Sweden & c & c & 15.5 & $(2.2)$ & 52.2 & (3.1) & 4.4 & $(0.7)$ & 9.4 & $(1.2)$ & 48.4 & (1.9) \\
\hline & Switzerland & 5.8 & $(1.0)$ & 12.7 & $(1.2)$ & 41.8 & (1.7) & 7.1 & $(0.7)$ & 12.7 & $(1.0)$ & 41.4 & (1.6) \\
\hline & Turkey & $\mathrm{m}$ & m & $\mathrm{m}$ & $\mathrm{m}$ & $\mathrm{m}$ & $\mathrm{m}$ & $\mathrm{m}$ & $\mathrm{m}$ & $\mathrm{m}$ & $\mathrm{m}$ & $\mathrm{m}$ & $\mathrm{m}$ \\
\hline & United Kingdom & 21.8 & $(2.2)$ & 31.1 & $(2.7)$ & 26.4 & (2.5) & 21.2 & (1.9) & 30.5 & (2.0) & 28.0 & (2.1) \\
\hline & United States & $\mathrm{m}$ & $\mathrm{m}$ & $\mathrm{m}$ & $\mathrm{m}$ & $\mathrm{m}$ & $\mathrm{m}$ & $\mathrm{m}$ & $\mathrm{m}$ & $\mathrm{m}$ & $\mathrm{m}$ & $\mathrm{m}$ & $\mathrm{m}$ \\
\hline & OECD average & 17.0 & $(0.3)$ & 22.1 & $(0.3)$ & 40.4 & $(0.3)$ & 17.2 & $(0.2)$ & 21.7 & $(0.3)$ & 40.7 & $(0.3)$ \\
\hline$\stackrel{2}{2}$ & Albania & $\mathrm{m}$ & $\mathrm{m}$ & $\mathrm{m}$ & $\mathrm{m}$ & $\mathrm{m}$ & $\mathrm{m}$ & $\mathrm{m}$ & $\mathrm{m}$ & $\mathrm{m}$ & $\mathrm{m}$ & $\mathrm{m}$ & $\mathrm{m}$ \\
\hline$\cong$ & Algeria & $\mathrm{m}$ & $\mathrm{m}$ & $\mathrm{m}$ & $\mathrm{m}$ & $\mathrm{m}$ & $\mathrm{m}$ & $\mathrm{m}$ & $\mathrm{m}$ & $\mathrm{m}$ & $\mathrm{m}$ & $\mathrm{m}$ & $\mathrm{m}$ \\
\hline ฐั & Brazil & 42.4 & (1.4) & 46.2 & $(1.3)$ & 38.8 & (1.2) & 43.4 & (1.7) & 40.5 & (1.7) & 35.2 & (1.8) \\
\hline 2 & B-S-J-G (China) & 1.4 & $(0.2)$ & 7.4 & $(0.4)$ & 35.8 & $(1.2)$ & c & c & 10.6 & $(1.3)$ & 44.0 & $(2.1)$ \\
\hline & Bulgaria & 42.0 & $(2.2)$ & 44.7 & $(2.3)$ & 51.3 & (2.4) & 39.6 & (1.8) & 38.7 & (1.9) & 50.8 & (2.5) \\
\hline & CABA (Argentina) & $\mathrm{m}$ & $\mathrm{m}$ & $\mathrm{m}$ & $\mathrm{m}$ & $\mathrm{m}$ & $\mathrm{m}$ & $\mathrm{m}$ & $\mathrm{m}$ & $\mathrm{m}$ & $\mathrm{m}$ & $\mathrm{m}$ & $\mathrm{m}$ \\
\hline & Colombia & 43.0 & (1.4) & 43.4 & (1.5) & 39.5 & (1.6) & 44.0 & (1.8) & 44.4 & (1.4) & 41.1 & (2.1) \\
\hline & Costa Rica & 40.5 & (1.9) & 40.7 & $(1.5)$ & 48.7 & (1.8) & 36.7 & $(2.1)$ & 37.5 & (2.3) & 47.0 & $(2.2)$ \\
\hline & Croatia & 12.6 & $(1.1)$ & 21.4 & (1.3) & 35.7 & (1.6) & 7.4 & $(0.8)$ & 19.0 & (1.4) & 37.5 & (1.5) \\
\hline & Cyprus* & $\mathrm{m}$ & $\mathrm{m}$ & $\mathrm{m}$ & $\mathrm{m}$ & $\mathrm{m}$ & $\mathrm{m}$ & $\mathrm{m}$ & $\mathrm{m}$ & $\mathrm{m}$ & $\mathrm{m}$ & $\mathrm{m}$ & $\mathrm{m}$ \\
\hline & Dominican Republic & 51.7 & (1.5) & 55.8 & $(1.6)$ & 40.8 & (1.6) & 48.7 & $(2.2)$ & 50.9 & (2.0) & 35.5 & (2.0) \\
\hline & FYROM & $\mathrm{m}$ & $\mathrm{m}$ & $\mathrm{m}$ & $\mathrm{m}$ & $\mathrm{m}$ & $\mathrm{m}$ & $\mathrm{m}$ & $\mathrm{m}$ & $\mathrm{m}$ & $\mathrm{m}$ & $\mathrm{m}$ & $\mathrm{m}$ \\
\hline & Georgia & $\mathrm{m}$ & $\mathrm{m}$ & $\mathrm{m}$ & $\mathrm{m}$ & $\mathrm{m}$ & $\mathrm{m}$ & $\mathrm{m}$ & $\mathrm{m}$ & $\mathrm{m}$ & $\mathrm{m}$ & $\mathrm{m}$ & $\mathrm{m}$ \\
\hline & Hong Kong (China) & 3.4 & $(0.6)$ & 4.7 & $(0.6)$ & 23.7 & $(1.2)$ & c & c & 4.2 & $(0.6)$ & 19.8 & $(1.3)$ \\
\hline & Indonesia & $\mathrm{m}$ & $\mathrm{m}$ & $\mathrm{m}$ & $\mathrm{m}$ & $\mathrm{m}$ & $\mathrm{m}$ & $\mathrm{m}$ & $\mathrm{m}$ & $\mathrm{m}$ & $\mathrm{m}$ & $\mathrm{m}$ & $\mathrm{m}$ \\
\hline & Jordan & $\mathrm{m}$ & $\mathrm{m}$ & $\mathrm{m}$ & $\mathrm{m}$ & $\mathrm{m}$ & $\mathrm{m}$ & $\mathrm{m}$ & $\mathrm{m}$ & $\mathrm{m}$ & $\mathrm{m}$ & $\mathrm{m}$ & $\mathrm{m}$ \\
\hline & Kosovo & $\mathrm{m}$ & $\mathrm{m}$ & $\mathrm{m}$ & $\mathrm{m}$ & $\mathrm{m}$ & $\mathrm{m}$ & $\mathrm{m}$ & $\mathrm{m}$ & $\mathrm{m}$ & $\mathrm{m}$ & $\mathrm{m}$ & $\mathrm{m}$ \\
\hline & Lebanon & $\mathrm{m}$ & $\mathrm{m}$ & $\mathrm{m}$ & $\mathrm{m}$ & $\mathrm{m}$ & $\mathrm{m}$ & $\mathrm{m}$ & $\mathrm{m}$ & $\mathrm{m}$ & $\mathrm{m}$ & $\mathrm{m}$ & $\mathrm{m}$ \\
\hline & Lithuania & 22.2 & (1.4) & 36.8 & (1.5) & 43.0 & (1.7) & 19.4 & $(1.1)$ & 36.3 & (1.8) & 44.5 & (1.6) \\
\hline & Macao (China) & 5.4 & $(0.7)$ & 8.4 & $(0.9)$ & 30.7 & (1.6) & 4.2 & $(0.7)$ & 8.5 & $(0.9)$ & 24.7 & $(1.2)$ \\
\hline & Malta & $\mathrm{m}$ & $\mathrm{m}$ & $\mathrm{m}$ & $\mathrm{m}$ & $\mathrm{m}$ & $\mathrm{m}$ & $\mathrm{m}$ & $\mathrm{m}$ & $\mathrm{m}$ & $\mathrm{m}$ & $\mathrm{m}$ & $\mathrm{m}$ \\
\hline & Moldova & $\mathrm{m}$ & $\mathrm{m}$ & $\mathrm{m}$ & $\mathrm{m}$ & $\mathrm{m}$ & $\mathrm{m}$ & $\mathrm{m}$ & $\mathrm{m}$ & $\mathrm{m}$ & $\mathrm{m}$ & $\mathrm{m}$ & $\mathrm{m}$ \\
\hline & Montenegro & $\mathrm{m}$ & $\mathrm{m}$ & $\mathrm{m}$ & $\mathrm{m}$ & $\mathrm{m}$ & $\mathrm{m}$ & $\mathrm{m}$ & $\mathrm{m}$ & $\mathrm{m}$ & $\mathrm{m}$ & $\mathrm{m}$ & $\mathrm{m}$ \\
\hline & Peru & 36.5 & $(1.0)$ & 37.9 & $(1.0)$ & 57.9 & $(1.2)$ & 39.3 & (1.6) & 41.1 & (1.5) & 63.7 & (1.6) \\
\hline & Qatar & $\mathrm{m}$ & $\mathrm{m}$ & $\mathrm{m}$ & $\mathrm{m}$ & $\mathrm{m}$ & $\mathrm{m}$ & $\mathrm{m}$ & $\mathrm{m}$ & $\mathrm{m}$ & $\mathrm{m}$ & $\mathrm{m}$ & $\mathrm{m}$ \\
\hline & Romania & $\mathrm{m}$ & $\mathrm{m}$ & $\mathrm{m}$ & $\mathrm{m}$ & $\mathrm{m}$ & $\mathrm{m}$ & $\mathrm{m}$ & $\mathrm{m}$ & $\mathrm{m}$ & $\mathrm{m}$ & $\mathrm{m}$ & $\mathrm{m}$ \\
\hline & Russia & 19.5 & (1.3) & 33.7 & (1.9) & 52.9 & (2.0) & 20.6 & (1.7) & 33.0 & (1.8) & 51.8 & (1.8) \\
\hline & Singapore & 10.5 & $(1.1)$ & 9.6 & $(0.9)$ & 23.1 & (1.3) & 11.8 & $(1.0)$ & 13.2 & (1.1) & 19.5 & (1.5) \\
\hline & Chinese Taipei & 1.3 & $(0.2)$ & 6.1 & $(0.6)$ & 28.2 & $(0.9)$ & c & c & 6.5 & $(0.7)$ & 30.4 & (1.2) \\
\hline & Thailand & 31.3 & $(1.2)$ & 38.3 & $(1.1)$ & 33.1 & (1.1) & 31.9 & $(1.8)$ & 39.3 & (2.0) & 34.5 & (1.8) \\
\hline & Trinidad and Tobago & $\mathrm{m}$ & $\mathrm{m}$ & $\mathrm{m}$ & $\mathrm{m}$ & $\mathrm{m}$ & $\mathrm{m}$ & $\mathrm{m}$ & $\mathrm{m}$ & $\mathrm{m}$ & $\mathrm{m}$ & $\mathrm{m}$ & $\mathrm{m}$ \\
\hline & Tunisia & $\mathrm{m}$ & $\mathrm{m}$ & $\mathrm{m}$ & $\mathrm{m}$ & $\mathrm{m}$ & $\mathrm{m}$ & $\mathrm{m}$ & $\mathrm{m}$ & $\mathrm{m}$ & $\mathrm{m}$ & $\mathrm{m}$ & $\mathrm{m}$ \\
\hline & United Arab Emirates & $\mathrm{m}$ & $\mathrm{m}$ & $\mathrm{m}$ & $\mathrm{m}$ & $\mathrm{m}$ & $\mathrm{m}$ & $\mathrm{m}$ & $\mathrm{m}$ & $\mathrm{m}$ & $\mathrm{m}$ & $\mathrm{m}$ & $\mathrm{m}$ \\
\hline & Uruguay & 49.8 & (1.8) & 38.9 & (1.6) & 62.4 & (1.6) & 47.7 & $(1.8)$ & 32.4 & (1.9) & 63.7 & (1.8) \\
\hline & Viet Nam & $\mathrm{m}$ & $\mathrm{m}$ & m & m & $\mathrm{m}$ & $\mathrm{m}$ & $\mathrm{m}$ & $\mathrm{m}$ & $\mathrm{m}$ & m & m & m \\
\hline & Argentina** & $\mathrm{m}$ & $\mathrm{m}$ & $\mathrm{m}$ & $\mathrm{m}$ & $\mathrm{m}$ & $\mathrm{m}$ & $\mathrm{m}$ & $\mathrm{m}$ & $\mathrm{m}$ & $\mathrm{m}$ & $\mathrm{m}$ & $\mathrm{m}$ \\
\hline & Kazakhstan** & $\mathrm{m}$ & $\mathrm{m}$ & $\mathrm{m}$ & $\mathrm{m}$ & $\mathrm{m}$ & $\mathrm{m}$ & $\mathrm{m}$ & $\mathrm{m}$ & $\mathrm{m}$ & $\mathrm{m}$ & $\mathrm{m}$ & $\mathrm{m}$ \\
\hline & Malaysia** & $\mathrm{m}$ & $\mathrm{m}$ & $\mathrm{m}$ & $\mathrm{m}$ & $\mathrm{m}$ & $\mathrm{m}$ & $\mathrm{m}$ & $\mathrm{m}$ & $\mathrm{m}$ & $\mathrm{m}$ & $\mathrm{m}$ & $\mathrm{m}$ \\
\hline
\end{tabular}

Note: Values that are statistically significant are indicated in bold (see Annex A3).

* See note at the beginning of this Annex.

** Coverage is too small to ensure comparability (see Annex A4).

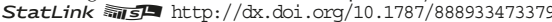




\begin{tabular}{|c|c|c|c|c|c|c|c|c|c|c|c|c|c|}
\hline & \multicolumn{6}{|c|}{$\begin{array}{c}\text { High Internet users } \\
\text { (Students who use the Internet between } 2 \text { and } 6 \text { hours per day } \\
\text { on a typical weekday) }\end{array}$} & \multicolumn{6}{|c|}{$\begin{array}{c}\text { Extreme Internet users } \\
\text { (Students who use the Internet for more than } 6 \text { hours per day } \\
\text { on a typical weekday) }\end{array}$} \\
\hline & & \multicolumn{2}{|c|}{$\begin{array}{c}\text { Students arrived late } \\
\text { for school } \\
\text { in the } 2 \text { weeks } \\
\text { prior to the PISA test }\end{array}$} & $\begin{array}{r}\text { Stud } \\
\text { a whol } \\
\text { in } t \\
\text { prior } t\end{array}$ & $\begin{array}{l}\text { kipped } \\
\text { of school } \\
\text { weeks } \\
\text { PISA test }\end{array}$ & $\begin{array}{l}\text { Student } \\
\text { classes } \\
\text { prior t }\end{array}$ & $\begin{array}{l}\text { ped some } \\
2 \text { weeks } \\
\text { PISA test }\end{array}$ & $\begin{array}{r}\text { Stude } \\
\text { in } t \\
\text { prior } t\end{array}$ & $\begin{array}{l}\text { ved late } \\
\text { ool } \\
\text { veeks } \\
\text { ISA test }\end{array}$ & $\begin{array}{r}\text { Stud } \\
\text { a whol } \\
\text { in } t \\
\text { prior } t\end{array}$ & $\begin{array}{l}\text { sipped } \\
\text { of school } \\
\text { veeks } \\
\text { IISA test }\end{array}$ & $\begin{array}{l}\text { Student } \\
\text { classes } \\
\text { prior t }\end{array}$ & $\begin{array}{l}\text { ped some } \\
2 \text { weeks } \\
\text { PISA test }\end{array}$ \\
\hline & & $\%$ & S.E. & $\%$ & S.E. & $\%$ & S.E. & $\%$ & S.E. & $\%$ & S.E. & $\%$ & S.E. \\
\hline 0 & Australia & 28.1 & $(0.7)$ & 14.3 & $(0.5)$ & 39.6 & $(0.8)$ & 37.1 & $(1.3)$ & 22.9 & $(1.2)$ & 49.2 & $(1.3)$ \\
\hline 岀 & Austria & 11.6 & $(0.8)$ & 18.0 & (1.1) & 35.8 & $(1.3)$ & 16.2 & (1.3) & 22.8 & $(1.2)$ & 41.9 & (1.6) \\
\hline ठే & Belgium & 6.5 & $(0.4)$ & 11.3 & $(0.7)$ & 50.8 & $(1.2)$ & 13.6 & (1.3) & 20.3 & (1.3) & 61.6 & (1.5) \\
\hline & Canada & $\mathrm{m}$ & $\mathrm{m}$ & $\mathrm{m}$ & $\mathrm{m}$ & $\mathrm{m}$ & $\mathrm{m}$ & $\mathrm{m}$ & $\mathrm{m}$ & $\mathrm{m}$ & $\mathrm{m}$ & $\mathrm{m}$ & $\mathrm{m}$ \\
\hline & Chile & 6.5 & $(0.7)$ & 16.8 & $(1.1)$ & 64.2 & (1.3) & 12.6 & $(1.0)$ & 24.2 & $(1.2)$ & 71.5 & (1.3) \\
\hline & Czech Republic & 7.9 & $(0.7)$ & 8.8 & $(0.6)$ & 52.5 & $(1.3)$ & 13.8 & $(1.2)$ & 14.5 & (1.1) & 61.2 & $(1.5)$ \\
\hline & Denmark & 16.7 & $(0.8)$ & 24.0 & (1.0) & 48.4 & (1.1) & 26.4 & (1.6) & 30.7 & $(2.2)$ & 51.2 & (1.9) \\
\hline & Estonia & 22.2 & $(0.9)$ & 33.6 & $(1.2)$ & 43.4 & $(1.2)$ & 33.4 & (1.8) & 46.4 & $(2.0)$ & 48.8 & (1.9) \\
\hline & Finland & 36.0 & $(1.1)$ & 48.8 & $(1.2)$ & 39.2 & $(1.2)$ & 44.3 & $(2.3)$ & 53.4 & (1.9) & 45.5 & $(2.0)$ \\
\hline & France & 10.3 & $(0.7)$ & 25.1 & (0.9) & 52.8 & $(1.2)$ & 17.6 & (1.8) & 37.5 & $(1.8)$ & 66.2 & $(1.8)$ \\
\hline & Germany & $\mathrm{m}$ & $\mathrm{m}$ & $\mathrm{m}$ & $\mathrm{m}$ & $\mathrm{m}$ & $\mathrm{m}$ & $\mathrm{m}$ & $\mathrm{m}$ & $\mathrm{m}$ & $\mathrm{m}$ & $\mathrm{m}$ & $\mathrm{m}$ \\
\hline & Greece & 19.7 & $(1.0)$ & 47.3 & (1.7) & 56.8 & $(1.2)$ & 29.9 & $(2.3)$ & 61.7 & (2.5) & 59.9 & (2.4) \\
\hline & Hungary & 6.0 & $(0.5)$ & 14.9 & $(0.8)$ & 31.9 & $(1.1)$ & 15.7 & $(1.4)$ & 28.7 & (1.5) & 47.7 & $(2.0)$ \\
\hline & Iceland & 4.6 & $(0.6)$ & 19.0 & $(1.2)$ & 52.6 & $(1.2)$ & 10.4 & $(1.3)$ & 29.3 & $(2.3)$ & 59.2 & $(2.5)$ \\
\hline & Ireland & 26.1 & $(1.0)$ & 24.7 & (1.1) & 30.8 & $(1.3)$ & 33.4 & $(1.8)$ & 31.7 & (1.6) & 40.6 & (1.9) \\
\hline & Israel & 33.9 & (1.3) & 38.3 & $(1.3)$ & 57.5 & $(1.7)$ & 42.1 & (1.6) & 45.7 & (1.6) & 62.5 & (1.5) \\
\hline & Italy & 54.8 & $(1.3)$ & 38.8 & (1.0) & 34.1 & (1.1) & 63.7 & $(1.3)$ & 46.9 & (1.5) & 41.5 & (1.7) \\
\hline & Japan & 1.8 & $(0.3)$ & 3.6 & $(0.5)$ & 14.0 & $(1.0)$ & C & C & 8.9 & (1.5) & 23.0 & $(2.3)$ \\
\hline & Korea & 3.1 & $(0.4)$ & 3.9 & $(0.5)$ & 23.6 & $(1.5)$ & c & c & C & $\mathrm{C}$ & 29.6 & (4.3) \\
\hline & Latvia & 23.5 & $(0.9)$ & 41.2 & $(1.4)$ & 54.3 & $(1.3)$ & 32.8 & $(1.7)$ & 45.0 & $(1.7)$ & 60.1 & $(2.0)$ \\
\hline & Luxembourg & 10.0 & $(0.7)$ & 13.9 & $(0.8)$ & 53.5 & $(1.1)$ & 17.2 & $(1.1)$ & 20.4 & $(1.2)$ & 59.4 & (1.6) \\
\hline & Mexico & 24.2 & $(1.0)$ & 25.9 & (1.3) & 49.2 & (1.3) & 31.5 & (2.0) & 32.2 & (1.7) & 54.9 & (1.6) \\
\hline & Netherlands & 4.8 & $(0.4)$ & 19.1 & $(0.9)$ & 50.5 & (1.1) & 8.1 & $(0.9)$ & 24.6 & (1.5) & 59.1 & $(1.8)$ \\
\hline & New Zealand & 23.4 & $(0.9)$ & 21.5 & $(0.9)$ & 44.6 & $(1.5)$ & 34.1 & (2.1) & 31.3 & $(1.8)$ & 54.4 & $(2.2)$ \\
\hline & Norway & $\mathrm{m}$ & $\mathrm{m}$ & $\mathrm{m}$ & $\mathrm{m}$ & $\mathrm{m}$ & $\mathrm{m}$ & $\mathrm{m}$ & $\mathrm{m}$ & $\mathrm{m}$ & $\mathrm{m}$ & $\mathrm{m}$ & $\mathrm{m}$ \\
\hline & Poland & 20.3 & $(1.0)$ & 38.7 & $(1.4)$ & 57.0 & $(1.3)$ & 30.9 & (1.9) & 49.8 & $(2.0)$ & 64.5 & $(2.1)$ \\
\hline & Portugal & 19.4 & $(0.9)$ & 31.4 & $(1.1)$ & 47.5 & $(1.3)$ & 25.5 & $(1.8)$ & 42.7 & (1.8) & 54.0 & $(2.1)$ \\
\hline & Slovak Republic & 49.6 & (1.3) & 48.1 & (1.0) & 35.1 & $(1.2)$ & 58.3 & $(2.0)$ & 54.4 & $(1.7)$ & 45.6 & (1.8) \\
\hline & Slovenia & 13.4 & $(0.9)$ & 31.2 & $(1.2)$ & 50.2 & $(1.2)$ & 20.0 & $(2.0)$ & 41.2 & $(2.1)$ & 57.2 & $(2.0)$ \\
\hline & Spain & 23.7 & $(0.8)$ & 32.1 & $(1.2)$ & 40.5 & $(1.0)$ & 34.1 & (1.5) & 41.9 & (1.6) & 48.9 & (1.6) \\
\hline & Sweden & 6.7 & $(0.5)$ & 14.0 & $(0.9)$ & 52.4 & $(1.0)$ & 14.6 & $(1.1)$ & 23.3 & (1.5) & 61.9 & $(1.6)$ \\
\hline & Switzerland & 10.5 & $(0.9)$ & 18.1 & (1.0) & 46.5 & $(1.6)$ & 16.8 & (2.0) & 28.7 & (2.6) & 57.2 & $(2.1)$ \\
\hline & Turkey & $\mathrm{m}$ & $\mathrm{m}$ & $\mathrm{m}$ & $\mathrm{m}$ & $\mathrm{m}$ & $\mathrm{m}$ & $\mathrm{m}$ & $\mathrm{m}$ & $\mathrm{m}$ & $\mathrm{m}$ & $\mathrm{m}$ & $\mathrm{m}$ \\
\hline & United Kingdom & 21.2 & $(1.0)$ & 32.8 & $(1.2)$ & 30.3 & (1.3) & 35.5 & (1.3) & 40.0 & (1.6) & 36.2 & $(1.8)$ \\
\hline & United States & $\mathrm{m}$ & $\mathrm{m}$ & $\mathrm{m}$ & $\mathrm{m}$ & $\mathrm{m}$ & $\mathrm{m}$ & $\mathrm{m}$ & $\mathrm{m}$ & $\mathrm{m}$ & $\mathrm{m}$ & $\mathrm{m}$ & $\mathrm{m}$ \\
\hline & OECD average & 18.2 & $(0.2)$ & 25.3 & $(0.2)$ & 44.7 & $(0.2)$ & 27.5 & $(0.3)$ & 34.5 & $(0.3)$ & 52.5 & $(0.4)$ \\
\hline 2 & Albania & $\mathrm{m}$ & $\mathrm{m}$ & $\mathrm{m}$ & $\mathrm{m}$ & $\mathrm{m}$ & $\mathrm{m}$ & $\mathrm{m}$ & $\mathrm{m}$ & $\mathrm{m}$ & $\mathrm{m}$ & $\mathrm{m}$ & $\mathrm{m}$ \\
\hline 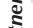 & Algeria & $\mathrm{m}$ & $\mathrm{m}$ & $\mathrm{m}$ & $\mathrm{m}$ & $\mathrm{m}$ & $\mathrm{m}$ & $\mathrm{m}$ & $\mathrm{m}$ & $\mathrm{m}$ & $\mathrm{m}$ & $\mathrm{m}$ & $\mathrm{m}$ \\
\hline กั & Brazil & 45.5 & $(1.2)$ & 41.0 & $(1.2)$ & 38.2 & $(1.2)$ & 51.9 & $(1.0)$ & 46.7 & (1.1) & 41.2 & $(1.0)$ \\
\hline 2 & B-S-J-G (China) & 3.4 & $(0.8)$ & 15.3 & $(1.3)$ & 47.4 & $(2.0)$ & 7.3 & (1.8) & 25.5 & (3.1) & 54.4 & (3.3) \\
\hline & Bulgaria & 42.4 & (1.4) & 44.1 & (1.5) & 52.9 & (1.3) & 50.2 & (1.6) & 54.1 & (1.6) & 62.0 & (1.4) \\
\hline & CABA (Argentina) & $\mathrm{m}$ & $\mathrm{m}$ & $\mathrm{m}$ & $\mathrm{m}$ & $\mathrm{m}$ & $\mathrm{m}$ & $\mathrm{m}$ & $\mathrm{m}$ & $\mathrm{m}$ & $\mathrm{m}$ & $\mathrm{m}$ & $\mathrm{m}$ \\
\hline & Colombia & 42.1 & (1.3) & 43.7 & $(1.3)$ & 44.7 & $(1.3)$ & 44.0 & $(1.2)$ & 46.6 & $(1.3)$ & 44.4 & (1.6) \\
\hline & Costa Rica & 35.1 & $(1.2)$ & 41.4 & (1.4) & 54.2 & $(1.7)$ & 40.5 & (1.3) & 48.6 & (1.5) & 59.6 & (1.3) \\
\hline & Croatia & 10.8 & $(0.7)$ & 24.0 & $(1.1)$ & 43.6 & (1.4) & 19.0 & (1.7) & 34.6 & (1.8) & 54.3 & (1.9) \\
\hline & Cyprus* & $\mathrm{m}$ & $\mathrm{m}$ & $\mathrm{m}$ & $\mathrm{m}$ & $\mathrm{m}$ & $\mathrm{m}$ & $\mathrm{m}$ & $\mathrm{m}$ & $\mathrm{m}$ & $\mathrm{m}$ & $\mathrm{m}$ & $\mathrm{m}$ \\
\hline & Dominican Republic & 52.4 & $(2.2)$ & 53.5 & $(2.0)$ & 41.4 & $(2.1)$ & 49.5 & (1.8) & 57.3 & $(2.0)$ & 46.4 & $(2.2)$ \\
\hline & FYROM & $\mathrm{m}$ & $\mathrm{m}$ & $\mathrm{m}$ & $\mathrm{m}$ & $\mathrm{m}$ & $\mathrm{m}$ & $\mathrm{m}$ & $\mathrm{m}$ & $\mathrm{m}$ & $\mathrm{m}$ & $\mathrm{m}$ & $\mathrm{m}$ \\
\hline & Georgia & $\mathrm{m}$ & $\mathrm{m}$ & $\mathrm{m}$ & $\mathrm{m}$ & $\mathrm{m}$ & $\mathrm{m}$ & $\mathrm{m}$ & $\mathrm{m}$ & $\mathrm{m}$ & $\mathrm{m}$ & $\mathrm{m}$ & $\mathrm{m}$ \\
\hline & Hong Kong (China) & 2.7 & $(0.4)$ & 4.6 & $(0.5)$ & 23.8 & $(0.9)$ & 5.8 & $(0.7)$ & 7.5 & (1.1) & 34.0 & $(2.0)$ \\
\hline & Indonesia & $\mathrm{m}$ & $\mathrm{m}$ & $\mathrm{m}$ & $\mathrm{m}$ & $\mathrm{m}$ & $\mathrm{m}$ & $\mathrm{m}$ & $\mathrm{m}$ & $\mathrm{m}$ & $\mathrm{m}$ & $\mathrm{m}$ & $\mathrm{m}$ \\
\hline & Jordan & $\mathrm{m}$ & $\mathrm{m}$ & $\mathrm{m}$ & $\mathrm{m}$ & $\mathrm{m}$ & $\mathrm{m}$ & $\mathrm{m}$ & $\mathrm{m}$ & $\mathrm{m}$ & $\mathrm{m}$ & $\mathrm{m}$ & $\mathrm{m}$ \\
\hline & Kosovo & $\mathrm{m}$ & $\mathrm{m}$ & $\mathrm{m}$ & $\mathrm{m}$ & $\mathrm{m}$ & $\mathrm{m}$ & $\mathrm{m}$ & $\mathrm{m}$ & $\mathrm{m}$ & $\mathrm{m}$ & $\mathrm{m}$ & $\mathrm{m}$ \\
\hline & Lebanon & $\mathrm{m}$ & $\mathrm{m}$ & $\mathrm{m}$ & $\mathrm{m}$ & $\mathrm{m}$ & $\mathrm{m}$ & $\mathrm{m}$ & $\mathrm{m}$ & $\mathrm{m}$ & $\mathrm{m}$ & $\mathrm{m}$ & $\mathrm{m}$ \\
\hline & Lithuania & 21.2 & $(1.0)$ & 41.0 & $(1.1)$ & 49.0 & $(1.0)$ & 27.2 & $(2.1)$ & 45.2 & $(2.1)$ & 53.8 & $(2.2)$ \\
\hline & Macao (China) & 6.4 & $(0.5)$ & 9.2 & $(0.6)$ & 27.7 & $(1.0)$ & 10.7 & $(1.3)$ & 13.0 & (1.4) & 38.4 & $(2.2)$ \\
\hline & Malta & $\mathrm{m}$ & $\mathrm{m}$ & $\mathrm{m}$ & $\mathrm{m}$ & $\mathrm{m}$ & $\mathrm{m}$ & $\mathrm{m}$ & $\mathrm{m}$ & $\mathrm{m}$ & $\mathrm{m}$ & $\mathrm{m}$ & $\mathrm{m}$ \\
\hline & Moldova & $\mathrm{m}$ & $\mathrm{m}$ & $\mathrm{m}$ & $\mathrm{m}$ & $\mathrm{m}$ & $\mathrm{m}$ & $\mathrm{m}$ & $\mathrm{m}$ & $\mathrm{m}$ & $\mathrm{m}$ & $\mathrm{m}$ & $\mathrm{m}$ \\
\hline & Montenegro & $\mathrm{m}$ & $\mathrm{m}$ & $\mathrm{m}$ & $\mathrm{m}$ & $\mathrm{m}$ & $\mathrm{m}$ & $\mathrm{m}$ & $\mathrm{m}$ & $\mathrm{m}$ & $\mathrm{m}$ & $\mathrm{m}$ & $\mathrm{m}$ \\
\hline & Peru & 44.4 & (1.6) & 44.6 & $(1.3)$ & 59.5 & $(1.7)$ & 52.4 & $(2.5)$ & 50.3 & $(2.2)$ & 63.9 & (2.6) \\
\hline & Qatar & $\mathrm{m}$ & $\mathrm{m}$ & $\mathrm{m}$ & $\mathrm{m}$ & $\mathrm{m}$ & $\mathrm{m}$ & $\mathrm{m}$ & $\mathrm{m}$ & $\mathrm{m}$ & $\mathrm{m}$ & $\mathrm{m}$ & $\mathrm{m}$ \\
\hline & Romania & $\mathrm{m}$ & $\mathrm{m}$ & $\mathrm{m}$ & $\mathrm{m}$ & $\mathrm{m}$ & $\mathrm{m}$ & $\mathrm{m}$ & $\mathrm{m}$ & $\mathrm{m}$ & $\mathrm{m}$ & $\mathrm{m}$ & $\mathrm{m}$ \\
\hline & Russia & 21.5 & $(1.0)$ & 38.1 & (1.3) & 55.0 & $(1.5)$ & 31.2 & $(2.0)$ & 46.6 & $(2.0)$ & 60.6 & $(2.1)$ \\
\hline & Singapore & 14.2 & $(0.9)$ & 14.1 & $(0.6)$ & 21.5 & $(0.8)$ & 21.9 & (1.1) & 17.3 & (1.1) & 35.9 & (1.6) \\
\hline & Chinese Taipei & 3.1 & $(0.3)$ & 11.8 & $(0.8)$ & 36.3 & (1.3) & 9.9 & $(0.9)$ & 23.9 & (1.5) & 45.3 & (1.8) \\
\hline & Thailand & 28.9 & $(1.2)$ & 45.5 & $(1.8)$ & 36.7 & $(1.4)$ & 36.0 & $(1.7)$ & 47.7 & $(2.3)$ & 44.5 & (2.3) \\
\hline & Trinidad and Tobago & $\mathrm{m}$ & $\mathrm{m}$ & $\mathrm{m}$ & $\mathrm{m}$ & $\mathrm{m}$ & $\mathrm{m}$ & $\mathrm{m}$ & $\mathrm{m}$ & $\mathrm{m}$ & $\mathrm{m}$ & $\mathrm{m}$ & $\mathrm{m}$ \\
\hline & Tunisia & $\mathrm{m}$ & $\mathrm{m}$ & $\mathrm{m}$ & $\mathrm{m}$ & $\mathrm{m}$ & $\mathrm{m}$ & $\mathrm{m}$ & $\mathrm{m}$ & $\mathrm{m}$ & $\mathrm{m}$ & $\mathrm{m}$ & $\mathrm{m}$ \\
\hline & United Arab Emirates & $\mathrm{m}$ & $\mathrm{m}$ & $\mathrm{m}$ & $\mathrm{m}$ & $\mathrm{m}$ & $\mathrm{m}$ & $\mathrm{m}$ & $\mathrm{m}$ & $\mathrm{m}$ & $\mathrm{m}$ & $\mathrm{m}$ & $\mathrm{m}$ \\
\hline & Uruguay & 48.1 & (1.3) & 38.8 & $(1.2)$ & 62.9 & $(1.3)$ & 56.0 & (1.3) & 43.5 & $(1.5)$ & 67.3 & $(1.3)$ \\
\hline & Viet Nam & $\mathrm{m}$ & $\mathrm{m}$ & $\mathrm{m}$ & $\mathrm{m}$ & $\mathrm{m}$ & $\mathrm{m}$ & $\mathrm{m}$ & $\mathrm{m}$ & $\mathrm{m}$ & $\mathrm{m}$ & $\mathrm{m}$ & $\mathrm{m}$ \\
\hline & Argentina** & $\mathrm{m}$ & $\mathrm{m}$ & $\mathrm{m}$ & $\mathrm{m}$ & $\mathrm{m}$ & $\mathrm{m}$ & $\mathrm{m}$ & $\mathrm{m}$ & $\mathrm{m}$ & $\mathrm{m}$ & $\mathrm{m}$ & $\mathrm{m}$ \\
\hline & Kazakhstan** & $\mathrm{m}$ & $\mathrm{m}$ & $\mathrm{m}$ & $\mathrm{m}$ & $\mathrm{m}$ & $\mathrm{m}$ & $\mathrm{m}$ & $\mathrm{m}$ & $\mathrm{m}$ & $\mathrm{m}$ & $\mathrm{m}$ & $\mathrm{m}$ \\
\hline & Malaysia** & $\mathrm{m}$ & $\mathrm{m}$ & $\mathrm{m}$ & $\mathrm{m}$ & $\mathrm{m}$ & $\mathrm{m}$ & $\mathrm{m}$ & $\mathrm{m}$ & $\mathrm{m}$ & $\mathrm{m}$ & $\mathrm{m}$ & $\mathrm{m}$ \\
\hline
\end{tabular}

Note: Values that are statistically significant are indicated in bold (see Annex A3).

* See note at the beginning of this Annex.

** Coverage is too small to ensure comparability (see Annex A4).

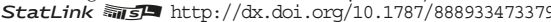


[Part 3/3]

Table III.13.21 Engagement with school, by time spent on the Internet outside of school on weekdays

Results based on students' self-reports

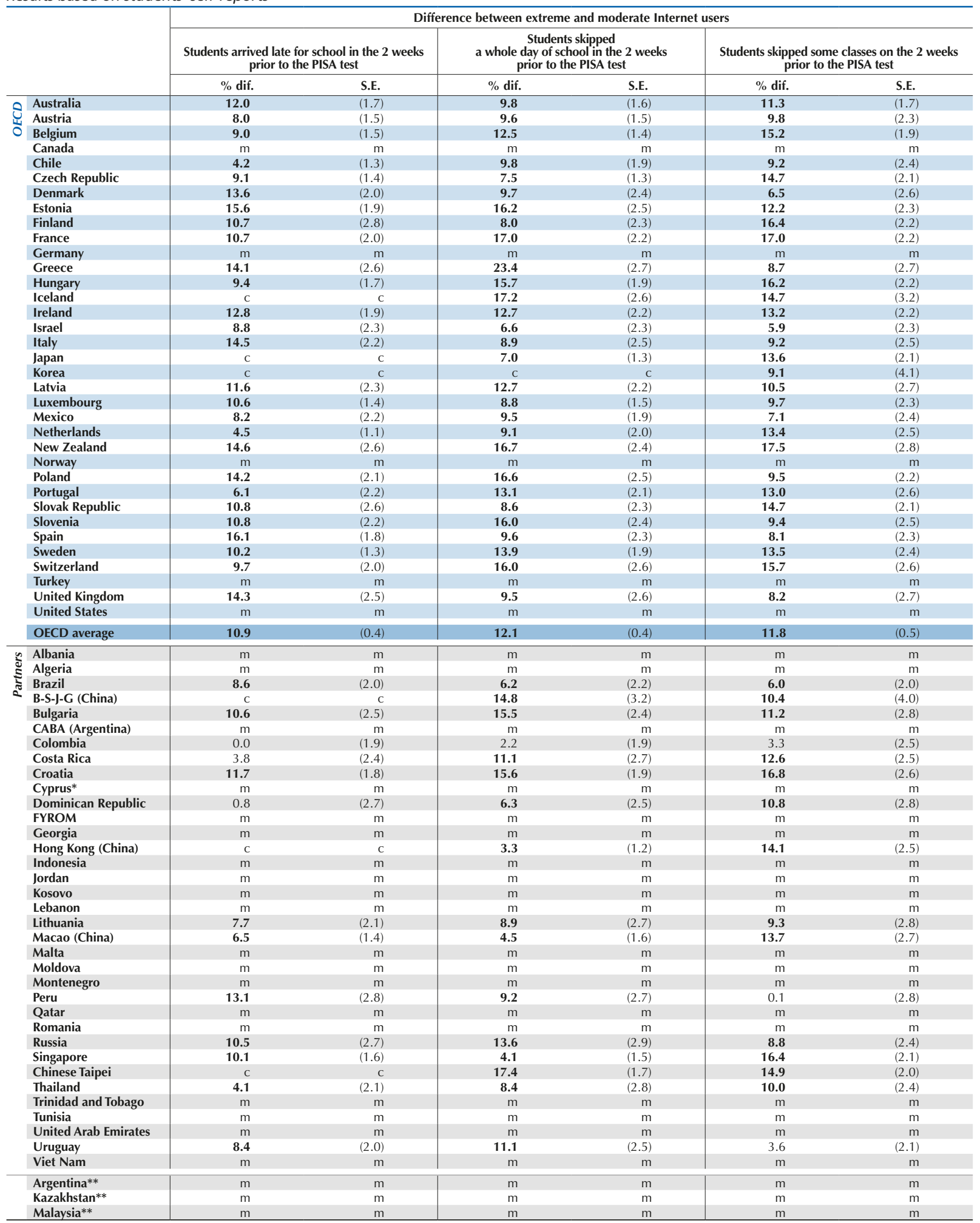

Note: Values that are statistically significant are indicated in bold (see Annex A3)

* See note at the beginning of this Annex.

** Coverage is too small to ensure comparability (see Annex A4)

Statlink क्ताst http://dx.doi.org/10.1787/888933473379 


\begin{tabular}{|c|c|c|c|c|c|c|c|c|c|c|c|c|c|}
\hline & \multicolumn{4}{|c|}{$\begin{array}{c}\text { Low Internet users } \\
\text { (Students who use the Internet for less than } \\
1 \text { hour per day on a typical weekday) }\end{array}$} & \multicolumn{4}{|c|}{$\begin{array}{c}\text { Moderate Internet users } \\
\text { (Students who use the Internet between } \\
1 \text { and } 2 \text { hours per day on a typical weekday) }\end{array}$} & \multicolumn{4}{|c|}{$\begin{array}{c}\text { High Internet users } \\
\text { (Students who use the Internet between } \\
2 \text { and } 6 \text { hours per day on a typical weekday) }\end{array}$} \\
\hline & & $\begin{array}{l}\text { Stud } \\
\text { to end } t \\
\text { at the } s\end{array}$ & $\begin{array}{l}\text { expect } \\
\text { ducation } \\
\text { lary level }\end{array}$ & $\begin{array}{r}\text { Stud } \\
\text { to comp }\end{array}$ & $\begin{array}{l}\text { expect } \\
\text { university }\end{array}$ & $\begin{array}{l}\text { Stud } \\
\text { to end } t \\
\text { at the } s\end{array}$ & $\begin{array}{l}\text { xpect } \\
\text { ducation } \\
\text { ary level }\end{array}$ & $\begin{array}{r}\text { Stud } \\
\text { to com }\end{array}$ & $\begin{array}{l}\text { expect } \\
\text { university }\end{array}$ & $\begin{array}{l}\text { Stud } \\
\text { to end } t \\
\text { at the } s\end{array}$ & $\begin{array}{l}\text { xpect } \\
\text { ducation } \\
\text { lary level }\end{array}$ & $\begin{array}{l}\text { Stuo } \\
\text { to com }\end{array}$ & $\begin{array}{l}\text { xpect } \\
\text { university }\end{array}$ \\
\hline & & $\%$ & S.E. & $\%$ & S.E. & $\%$ & S.E. & $\%$ & S.E. & $\%$ & S.E. & $\%$ & S.E. \\
\hline 0 & Australia & 43.4 & $(1.5)$ & 46.7 & $(1.6)$ & 36.4 & $(1.1)$ & 56.3 & $(1.1)$ & 34.0 & $(0.8)$ & 59.2 & $(0.9)$ \\
\hline 岙 & Austria & 61.7 & $(1.7)$ & 26.9 & (1.6) & 59.1 & $(1.2)$ & 32.2 & $(1.2)$ & 63.3 & $(1.3)$ & 29.1 & $(1.0)$ \\
\hline 0 & Belgium & 25.5 & $(1.2)$ & 35.7 & $(1.8)$ & 22.8 & $(1.2)$ & 39.1 & (1.3) & 26.0 & $(0.9)$ & 32.9 & $(1.2)$ \\
\hline & Canada & $\mathrm{m}$ & $\mathrm{m}$ & $\mathrm{m}$ & $\mathrm{m}$ & $\mathrm{m}$ & $\mathrm{m}$ & $\mathrm{m}$ & $\mathrm{m}$ & $\mathrm{m}$ & $\mathrm{m}$ & $\mathrm{m}$ & $\mathrm{m}$ \\
\hline & Chile & 27.7 & (1.9) & 52.5 & $(2.2)$ & 15.6 & (1.9) & 70.0 & (1.9) & 13.4 & $(0.8)$ & 73.2 & (1.1) \\
\hline & Czech Republic & 38.0 & $(1.6)$ & 54.6 & $(1.7)$ & 28.8 & $(1.8)$ & 62.9 & $(1.8)$ & 34.8 & $(1.1)$ & 57.4 & $(1.1)$ \\
\hline & Denmark & 61.7 & $(2.6)$ & 36.1 & (2.6) & 53.0 & $(1.8)$ & 44.2 & $(1.7)$ & 58.0 & $(1.3)$ & 38.2 & $(1.2)$ \\
\hline & Estonia & 25.7 & $(2.0)$ & 44.7 & $(2.0)$ & 21.5 & (1.6) & 49.3 & $(1.8)$ & 22.1 & $(0.9)$ & 44.7 & $(1.3)$ \\
\hline & Finland & 51.5 & $(1.7)$ & 30.2 & (1.5) & 51.9 & (1.6) & 30.1 & $(1.5)$ & 55.0 & (1.4) & 27.0 & $(1.3)$ \\
\hline & France & 52.7 & $(1.8)$ & 35.8 & (1.8) & 50.4 & $(1.7)$ & 38.8 & $(1.7)$ & 55.0 & (1.3) & 32.2 & (1.1) \\
\hline & Germany & $\mathrm{m}$ & $\mathrm{m}$ & $\mathrm{m}$ & $\mathrm{m}$ & $\mathrm{m}$ & $\mathrm{m}$ & $\mathrm{m}$ & $\mathrm{m}$ & $\mathrm{m}$ & $\mathrm{m}$ & $\mathrm{m}$ & $\mathrm{m}$ \\
\hline & Greece & 15.1 & (1.4) & 66.5 & (2.6) & 11.9 & (1.4) & 75.1 & $(2.0)$ & 13.6 & $(0.9)$ & 68.7 & $(1.8)$ \\
\hline & Hungary & 50.4 & $(2.4)$ & 37.5 & $(2.5)$ & 40.9 & (1.8) & 43.1 & $(2.0)$ & 41.5 & (1.5) & 37.8 & (1.3) \\
\hline & Iceland & 32.6 & (2.4) & 42.8 & $(2.2)$ & 30.5 & (1.6) & 45.3 & $(1.8)$ & 34.5 & $(1.0)$ & 37.4 & (1.1) \\
\hline & Ireland & 30.9 & (1.6) & 49.4 & (1.6) & 28.9 & (1.5) & 50.4 & (1.5) & 29.1 & (1.0) & 47.0 & (1.0) \\
\hline & Israel & 34.2 & $(2.1)$ & 54.3 & $(2.2)$ & 23.0 & (1.6) & 66.4 & (1.9) & 22.7 & $(1.2)$ & 67.2 & (1.6) \\
\hline & Italy & 33.6 & (1.9) & 39.3 & (1.8) & 27.3 & (1.5) & 41.4 & (1.4) & 27.6 & (1.4) & 42.0 & $(1.7)$ \\
\hline & Japan & 19.9 & $(0.9)$ & 63.5 & $(1.2)$ & 19.3 & $(1.2)$ & 64.4 & (1.5) & 24.2 & (1.6) & 53.9 & $(1.7)$ \\
\hline & Korea & 7.7 & $(0.6)$ & 79.9 & $(1.0)$ & 10.3 & $(0.9)$ & 73.3 & (1.3) & 15.9 & $(1.2)$ & 67.1 & (1.6) \\
\hline & Latvia & 34.1 & $(2.1)$ & 22.3 & $(1.7)$ & 26.6 & (1.6) & 27.3 & (1.6) & 24.1 & $(0.9)$ & 25.5 & $(1.0)$ \\
\hline & Luxembourg & 43.1 & $(1.7)$ & 39.0 & (1.6) & 34.5 & $(1.7)$ & 49.5 & (1.6) & 38.0 & $(0.9)$ & 46.1 & $(1.0)$ \\
\hline & Mexico & 29.4 & $(1.1)$ & 53.0 & (1.3) & 24.2 & (1.5) & 57.0 & (1.6) & 19.5 & (1.1) & 64.8 & (1.6) \\
\hline & Netherlands & 26.4 & $(2.0)$ & 15.7 & (1.4) & 26.6 & $(1.3)$ & 20.5 & (1.3) & 25.6 & $(0.9)$ & 18.9 & $(1.0)$ \\
\hline & New Zealand & 50.6 & $(2.3)$ & 38.0 & (2.4) & 31.4 & (1.8) & 51.5 & $(2.0)$ & 37.8 & (1.4) & 47.9 & $(1.2)$ \\
\hline & Norway & $\mathrm{m}$ & $\mathrm{m}$ & $\mathrm{m}$ & $\mathrm{m}$ & $\mathrm{m}$ & $\mathrm{m}$ & $\mathrm{m}$ & $\mathrm{m}$ & $\mathrm{m}$ & $\mathrm{m}$ & $\mathrm{m}$ & $\mathrm{m}$ \\
\hline & Poland & 38.4 & $(2.1)$ & 47.8 & $(2.1)$ & 35.4 & (1.8) & 49.8 & $(2.0)$ & 31.6 & (1.1) & 50.5 & $(1.2)$ \\
\hline & Portugal & 37.3 & $(1.8)$ & 39.6 & (1.8) & 30.3 & (1.7) & 44.3 & (1.9) & 33.1 & $(1.2)$ & 40.8 & (1.3) \\
\hline & Slovak Republic & $\mathrm{m}$ & $\mathrm{m}$ & $\mathrm{m}$ & $\mathrm{m}$ & $\mathrm{m}$ & $\mathrm{m}$ & $\mathrm{m}$ & $\mathrm{m}$ & $\mathrm{m}$ & $\mathrm{m}$ & $\mathrm{m}$ & $\mathrm{m}$ \\
\hline & Slovenia & 41.4 & $(1.4)$ & 29.2 & $(1.5)$ & 38.7 & $(1.6)$ & 27.4 & (1.4) & 45.0 & $(1.4)$ & 24.9 & $(1.1)$ \\
\hline & Spain & 38.1 & (1.9) & 49.6 & $(2.3)$ & 30.9 & (1.5) & 58.1 & $(1.8)$ & 31.8 & (1.1) & 55.4 & $(1.2)$ \\
\hline & Sweden & 39.8 & $(2.7)$ & 40.5 & $(2.8)$ & 34.8 & $(2.1)$ & 45.9 & $(2.2)$ & 37.5 & $(1.3)$ & 39.8 & (1.3) \\
\hline & Switzerland & 57.9 & $(1.8)$ & 28.3 & $(1.7)$ & 53.8 & (1.7) & 31.2 & (1.7) & 58.4 & $(1.3)$ & 26.2 & (1.4) \\
\hline & Turkey & $\mathrm{m}$ & $\mathrm{m}$ & $\mathrm{m}$ & $\mathrm{m}$ & $\mathrm{m}$ & $\mathrm{m}$ & $\mathrm{m}$ & $\mathrm{m}$ & $\mathrm{m}$ & $\mathrm{m}$ & $\mathrm{m}$ & $\mathrm{m}$ \\
\hline & United Kingdom & 44.8 & $(2.8)$ & 44.2 & $(2.9)$ & 39.4 & $(2.2)$ & 50.3 & $(2.5)$ & 46.3 & $(1.2)$ & 43.3 & $(1.3)$ \\
\hline & United States & $\mathrm{m}$ & $\mathrm{m}$ & $\mathrm{m}$ & $\mathrm{m}$ & $\mathrm{m}$ & $\mathrm{m}$ & $\mathrm{m}$ & $\mathrm{m}$ & $\mathrm{m}$ & $\mathrm{m}$ & $\mathrm{m}$ & $\mathrm{m}$ \\
\hline & OECD average & 37.7 & $(0.4)$ & 42.9 & $(0.4)$ & 32.3 & $(0.3)$ & 48.1 & $(0.3)$ & 34.5 & $(0.2)$ & 44.8 & $(0.2)$ \\
\hline 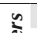 & Albania & $\mathrm{m}$ & $\mathrm{m}$ & $\mathrm{m}$ & $\mathrm{m}$ & $\mathrm{m}$ & $\mathrm{m}$ & $\mathrm{m}$ & $\mathrm{m}$ & $\mathrm{m}$ & $\mathrm{m}$ & $\mathrm{m}$ & $\mathrm{m}$ \\
\hline$\stackrel{\Xi}{\Xi}$ & Algeria & $\mathrm{m}$ & $\mathrm{m}$ & $\mathrm{m}$ & $\mathrm{m}$ & $\mathrm{m}$ & $\mathrm{m}$ & $\mathrm{m}$ & $\mathrm{m}$ & $\mathrm{m}$ & $\mathrm{m}$ & $\mathrm{m}$ & $\mathrm{m}$ \\
\hline ปั้ & Brazil & 42.9 & $(1.3)$ & 40.7 & $(1.2)$ & 34.6 & (1.9) & 47.3 & $(1.8)$ & 25.0 & (1.1) & 54.8 & (1.4) \\
\hline 2 & B-S-J-G (China) & 32.4 & $(1.7)$ & 44.9 & $(2.1)$ & 44.2 & $(2.8)$ & 31.2 & $(2.7)$ & 47.5 & $(2.1)$ & 25.5 & (1.8) \\
\hline & Bulgaria & 37.4 & $(2.6)$ & 32.7 & $(2.1)$ & 22.7 & (1.7) & 41.2 & (1.8) & 15.4 & (1.0) & 46.3 & (1.4) \\
\hline & CABA (Argentina) & $\mathrm{m}$ & $\mathrm{m}$ & $\mathrm{m}$ & $\mathrm{m}$ & $\mathrm{m}$ & $\mathrm{m}$ & $\mathrm{m}$ & $\mathrm{m}$ & $\mathrm{m}$ & $\mathrm{m}$ & $\mathrm{m}$ & $\mathrm{m}$ \\
\hline & Colombia & 19.2 & $(1.2)$ & 70.3 & $(1.3)$ & 15.8 & $(1.2)$ & 76.8 & $(1.7)$ & 10.8 & $(0.9)$ & 83.9 & (1.0) \\
\hline & Costa Rica & 25.5 & (1.4) & 50.2 & (1.4) & 17.7 & (1.6) & 56.4 & $(2.2)$ & 14.3 & $(0.9)$ & 55.6 & (1.4) \\
\hline & Croatia & 37.3 & (1.6) & 32.7 & (1.6) & 26.7 & (1.5) & 41.9 & (1.5) & 27.1 & (1.3) & 39.1 & (1.3) \\
\hline & Cyprus* & $\mathrm{m}$ & $\mathrm{m}$ & $\mathrm{m}$ & $\mathrm{m}$ & $\mathrm{m}$ & $\mathrm{m}$ & $\mathrm{m}$ & $\mathrm{m}$ & $\mathrm{m}$ & $\mathrm{m}$ & $\mathrm{m}$ & $\mathrm{m}$ \\
\hline & Dominican Republic & 35.1 & $(1.6)$ & 61.5 & $(1.7)$ & 31.7 & (1.9) & 65.5 & $(1.7)$ & 25.8 & (1.6) & 71.5 & (1.6) \\
\hline & FYROM & $\mathrm{m}$ & $\mathrm{m}$ & $\mathrm{m}$ & $\mathrm{m}$ & $\mathrm{m}$ & $\mathrm{m}$ & $\mathrm{m}$ & $\mathrm{m}$ & $\mathrm{m}$ & $\mathrm{m}$ & $\mathrm{m}$ & $\mathrm{m}$ \\
\hline & Georgia & $\mathrm{m}$ & $\mathrm{m}$ & $\mathrm{m}$ & $\mathrm{m}$ & $\mathrm{m}$ & $\mathrm{m}$ & $\mathrm{m}$ & $\mathrm{m}$ & $\mathrm{m}$ & $\mathrm{m}$ & $\mathrm{m}$ & $\mathrm{m}$ \\
\hline & Hong Kong (China) & 20.5 & $(1.3)$ & 51.8 & (1.5) & 13.1 & (1.3) & 63.5 & $(1.7)$ & 15.2 & (1.1) & 55.9 & (1.5) \\
\hline & Indonesia & $\mathrm{m}$ & $\mathrm{m}$ & $\mathrm{m}$ & $\mathrm{m}$ & $\mathrm{m}$ & $\mathrm{m}$ & $\mathrm{m}$ & $\mathrm{m}$ & $\mathrm{m}$ & $\mathrm{m}$ & $\mathrm{m}$ & $\mathrm{m}$ \\
\hline & Jordan & $\mathrm{m}$ & $\mathrm{m}$ & $\mathrm{m}$ & $\mathrm{m}$ & $\mathrm{m}$ & $\mathrm{m}$ & $\mathrm{m}$ & $\mathrm{m}$ & $\mathrm{m}$ & $\mathrm{m}$ & $\mathrm{m}$ & $\mathrm{m}$ \\
\hline & Kosovo & $\mathrm{m}$ & $\mathrm{m}$ & $\mathrm{m}$ & $\mathrm{m}$ & $\mathrm{m}$ & $\mathrm{m}$ & $\mathrm{m}$ & $\mathrm{m}$ & $\mathrm{m}$ & $\mathrm{m}$ & $\mathrm{m}$ & $\mathrm{m}$ \\
\hline & Lebanon & $\mathrm{m}$ & $\mathrm{m}$ & $\mathrm{m}$ & $\mathrm{m}$ & $\mathrm{m}$ & $\mathrm{m}$ & $\mathrm{m}$ & $\mathrm{m}$ & $\mathrm{m}$ & $\mathrm{m}$ & $\mathrm{m}$ & $\mathrm{m}$ \\
\hline & Lithuania & 30.9 & $(1.5)$ & 40.5 & $(2.0)$ & 15.2 & $(1.2)$ & 56.6 & (1.6) & 14.6 & (0.9) & 59.0 & (1.5) \\
\hline & Macao (China) & 20.2 & $(1.2)$ & 40.0 & (1.6) & 10.9 & $(1.1)$ & 52.0 & (1.7) & 11.9 & $(0.7)$ & 49.2 & $(1.0)$ \\
\hline & Malta & $\mathrm{m}$ & $\mathrm{m}$ & $\mathrm{m}$ & $\mathrm{m}$ & $\mathrm{m}$ & $\mathrm{m}$ & $\mathrm{m}$ & $\mathrm{m}$ & $\mathrm{m}$ & $\mathrm{m}$ & $\mathrm{m}$ & $\mathrm{m}$ \\
\hline & Moldova & $\mathrm{m}$ & $\mathrm{m}$ & $\mathrm{m}$ & $\mathrm{m}$ & $\mathrm{m}$ & $\mathrm{m}$ & $\mathrm{m}$ & $\mathrm{m}$ & $\mathrm{m}$ & $\mathrm{m}$ & $\mathrm{m}$ & $\mathrm{m}$ \\
\hline & Montenegro & $\mathrm{m}$ & $\mathrm{m}$ & $\mathrm{m}$ & $\mathrm{m}$ & $\mathrm{m}$ & $\mathrm{m}$ & $\mathrm{m}$ & $\mathrm{m}$ & $\mathrm{m}$ & $\mathrm{m}$ & $\mathrm{m}$ & $\mathrm{m}$ \\
\hline & Peru & 15.6 & $(0.8)$ & 62.4 & $(1.1)$ & 16.1 & (1.1) & 66.5 & (1.4) & 15.8 & $(0.8)$ & 70.9 & $(1.3)$ \\
\hline & Qatar & $\mathrm{m}$ & $\mathrm{m}$ & $\mathrm{m}$ & $\mathrm{m}$ & $\mathrm{m}$ & $\mathrm{m}$ & $\mathrm{m}$ & $\mathrm{m}$ & $\mathrm{m}$ & $\mathrm{m}$ & $\mathrm{m}$ & $\mathrm{m}$ \\
\hline & Romania & $\mathrm{m}$ & $\mathrm{m}$ & $\mathrm{m}$ & $\mathrm{m}$ & $\mathrm{m}$ & $\mathrm{m}$ & $\mathrm{m}$ & $\mathrm{m}$ & $\mathrm{m}$ & $\mathrm{m}$ & $\mathrm{m}$ & $\mathrm{m}$ \\
\hline & Russia & 59.1 & (1.8) & 13.1 & (1.0) & 45.5 & (1.9) & 16.3 & (1.4) & 40.7 & (1.8) & 18.8 & $(1.2)$ \\
\hline & Singapore & 4.0 & $(0.6)$ & 61.8 & (1.6) & 2.6 & $(0.5)$ & 69.6 & (1.3) & 2.5 & $(0.3)$ & 65.3 & $(0.9)$ \\
\hline & Chinese Taipei & 25.2 & $(1.0)$ & 55.8 & (1.3) & 24.0 & (1.3) & 52.9 & (1.4) & 27.7 & (1.1) & 43.9 & (1.3) \\
\hline & Thailand & 20.5 & $(1.1)$ & 62.5 & (1.4) & 15.7 & $(1.3)$ & 67.2 & $(2.2)$ & 10.0 & $(1.0)$ & 78.3 & (1.4) \\
\hline & Trinidad and Tobago & $\mathrm{m}$ & $\mathrm{m}$ & $\mathrm{m}$ & $\mathrm{m}$ & $\mathrm{m}$ & $\mathrm{m}$ & $\mathrm{m}$ & $\mathrm{m}$ & $\mathrm{m}$ & $\mathrm{m}$ & $\mathrm{m}$ & $\mathrm{m}$ \\
\hline & Tunisia & $\mathrm{m}$ & $\mathrm{m}$ & $\mathrm{m}$ & $\mathrm{m}$ & $\mathrm{m}$ & $\mathrm{m}$ & $\mathrm{m}$ & $\mathrm{m}$ & $\mathrm{m}$ & $\mathrm{m}$ & $\mathrm{m}$ & $\mathrm{m}$ \\
\hline & United Arab Emirates & $\mathrm{m}$ & $\mathrm{m}$ & $\mathrm{m}$ & $\mathrm{m}$ & $\mathrm{m}$ & $\mathrm{m}$ & $\mathrm{m}$ & $\mathrm{m}$ & $\mathrm{m}$ & $\mathrm{m}$ & $\mathrm{m}$ & $\mathrm{m}$ \\
\hline & Uruguay & 59.0 & $(1.5)$ & 30.6 & (1.6) & 47.2 & (1.9) & 42.8 & $(2.0)$ & 40.4 & (1.4) & 51.0 & $(1.3)$ \\
\hline & Viet Nam & $\mathrm{m}$ & $\mathrm{m}$ & $\mathrm{m}$ & $\mathrm{m}$ & $\mathrm{m}$ & $\mathrm{m}$ & $\mathrm{m}$ & $\mathrm{m}$ & $\mathrm{m}$ & $\mathrm{m}$ & $\mathrm{m}$ & $\mathrm{m}$ \\
\hline & Argentina** & $\mathrm{m}$ & $\mathrm{m}$ & $\mathrm{m}$ & $\mathrm{m}$ & $\mathrm{m}$ & $\mathrm{m}$ & $\mathrm{m}$ & $\mathrm{m}$ & $\mathrm{m}$ & $\mathrm{m}$ & $\mathrm{m}$ & $\mathrm{m}$ \\
\hline & Kazakhstan** & $\mathrm{m}$ & $\mathrm{m}$ & $\mathrm{m}$ & $\mathrm{m}$ & $\mathrm{m}$ & $\mathrm{m}$ & $\mathrm{m}$ & $\mathrm{m}$ & $\mathrm{m}$ & $\mathrm{m}$ & $\mathrm{m}$ & $\mathrm{m}$ \\
\hline & Malaysia** & $\mathrm{m}$ & $\mathrm{m}$ & $\mathrm{m}$ & $\mathrm{m}$ & $\mathrm{m}$ & $\mathrm{m}$ & $\mathrm{m}$ & $\mathrm{m}$ & $\mathrm{m}$ & $\mathrm{m}$ & $\mathrm{m}$ & $\mathrm{m}$ \\
\hline
\end{tabular}

Note: Values that are statistically significant are indicated in bold (see Annex A3).

* See note at the beginning of this Annex.

** Coverage is too small to ensure comparability (see Annex A4)

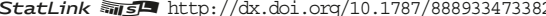


[Part 2/2]

Table III.13.22 Educational expectations, by time spent on the Internet outside of school on weekdays

Results based on students' self-reports

\begin{tabular}{|c|c|c|c|c|c|c|c|c|c|}
\hline & \multicolumn{4}{|c|}{$\begin{array}{c}\text { Extreme Internet users } \\
\text { (Students who use the Internet for more than } 6 \text { hours per day } \\
\text { on a typical weekday) }\end{array}$} & \multicolumn{4}{|c|}{ Difference between extreme and moderate Internet users } \\
\hline & & \multicolumn{2}{|c|}{$\begin{array}{l}\text { Students expect to end their } \\
\text { education at the secondary level }\end{array}$} & \multicolumn{2}{|c|}{$\begin{array}{l}\text { Students expect } \\
\text { to complete university }\end{array}$} & \multicolumn{2}{|c|}{$\begin{array}{l}\text { Students expect to end their } \\
\text { education at the secondary level }\end{array}$} & $\begin{array}{r}\text { Stu } \\
\text { to con }\end{array}$ & $\begin{array}{l}\text { ct } \\
\text { ersity }\end{array}$ \\
\hline & & $\%$ & S.E. & $\%$ & S.E. & $\%$ dif. & S.E. & $\%$ dif. & S.E. \\
\hline 0 & Australia & 43.8 & $(1.1)$ & 47.0 & $(1.2)$ & 7.4 & $(1.4)$ & -9.3 & $(1.5)$ \\
\hline 嵌 & Austria & 70.1 & (1.6) & 18.2 & (1.3) & 11.0 & $(2.0)$ & -14.0 & (1.7) \\
\hline $\bar{\sigma}$ & Belgium & 35.8 & $(1.7)$ & 22.8 & (1.5) & 13.0 & $(2.2)$ & -16.3 & (1.9) \\
\hline & Canada & $\mathrm{m}$ & $\mathrm{m}$ & $\mathrm{m}$ & $\mathrm{m}$ & $\mathrm{m}$ & $\mathrm{m}$ & $\mathrm{m}$ & $\mathrm{m}$ \\
\hline & Chile & 17.6 & (1.0) & 65.9 & $(1.2)$ & 2.0 & $(2.1)$ & -4.1 & $(2.3)$ \\
\hline & Czech Republic & 47.0 & $(2.1)$ & 46.7 & (1.9) & 18.2 & $(2.3)$ & -16.3 & $(2.4)$ \\
\hline & Denmark & 67.2 & (2.0) & 29.0 & $(1.9)$ & 14.2 & $(2.3)$ & -15.2 & $(2.3)$ \\
\hline & Estonia & 32.6 & (1.6) & 31.2 & (1.5) & 11.2 & $(2.3)$ & -18.0 & $(2.2)$ \\
\hline & Finland & 61.6 & (2.0) & 18.1 & (1.8) & 9.7 & (2.5) & -12.0 & (1.9) \\
\hline & France & 70.1 & (1.8) & 19.2 & (1.5) & 19.7 & $(2.2)$ & -19.6 & $(2.2)$ \\
\hline & Germany & $\mathrm{m}$ & $\mathrm{m}$ & $\mathrm{m}$ & $\mathrm{m}$ & $\mathrm{m}$ & $\mathrm{m}$ & $\mathrm{m}$ & $\mathrm{m}$ \\
\hline & Greece & 24.2 & (2.4) & 52.3 & $(2.8)$ & 12.3 & $(2.1)$ & -22.8 & $(2.6)$ \\
\hline & Hungary & 57.4 & (1.9) & 23.2 & $(1.3)$ & 16.6 & $(2.3)$ & -19.9 & $(2.2)$ \\
\hline & Iceland & 43.9 & (2.5) & 30.5 & (2.5) & 13.5 & (3.5) & -14.8 & (3.1) \\
\hline & Ireland & 39.6 & (1.9) & 35.3 & (1.9) & 10.7 & $(2.3)$ & -15.1 & $(2.4)$ \\
\hline & Israel & 29.5 & (1.7) & 60.5 & (1.8) & 6.4 & $(2.4)$ & -5.9 & $(2.5)$ \\
\hline & Italy & 38.2 & (1.5) & 32.3 & $(1.3)$ & 10.9 & $(1.7)$ & -9.1 & (1.7) \\
\hline & Japan & 42.3 & (3.4) & 34.4 & $(2.8)$ & 23.0 & (3.4) & -30.0 & $(2.8)$ \\
\hline & Korea & 26.5 & (4.5) & 55.1 & (5.5) & 16.2 & $(4.3)$ & -18.2 & $(5.2)$ \\
\hline & Latvia & 30.6 & (1.9) & 22.0 & $(1.6)$ & 4.0 & $(2.3)$ & -5.3 & $(2.2)$ \\
\hline & Luxembourg & 52.4 & (1.5) & 27.5 & (1.4) & 18.0 & $(2.4)$ & -21.9 & (2.1) \\
\hline & Mexico & 19.0 & (1.3) & 66.8 & $(2.0)$ & -5.1 & $(1.8)$ & 9.9 & $(2.4)$ \\
\hline & Netherlands & 28.2 & (1.6) & 10.6 & $(0.9)$ & 1.6 & $(2.1)$ & -9.9 & (1.6) \\
\hline & New Zealand & 50.2 & $(2.1)$ & 37.3 & $(2.1)$ & 18.8 & $(2.6)$ & -14.3 & (2.6) \\
\hline & Norway & $\mathrm{m}$ & $\mathrm{m}$ & $\mathrm{m}$ & $\mathrm{m}$ & $\mathrm{m}$ & $\mathrm{m}$ & $\mathrm{m}$ & $\mathrm{m}$ \\
\hline & Poland & 42.0 & $(2.2)$ & 39.8 & $(2.3)$ & 6.6 & $(2.3)$ & -10.0 & (2.5) \\
\hline & Portugal & 45.6 & $(2.2)$ & 33.2 & $(2.0)$ & 15.2 & (2.5) & -11.0 & (2.7) \\
\hline & Slovak Republic & $\mathrm{m}$ & $\mathrm{m}$ & $\mathrm{m}$ & $\mathrm{m}$ & $\mathrm{m}$ & $\mathrm{m}$ & m & $\mathrm{m}$ \\
\hline & Slovenia & 54.6 & (2.4) & 18.7 & $(2.1)$ & 15.9 & $(3.1)$ & -8.7 & (2.6) \\
\hline & Spain & 45.2 & (1.8) & 39.5 & (1.5) & 14.3 & $(2.3)$ & -18.6 & $(2.2)$ \\
\hline & Sweden & 50.2 & (1.6) & 31.8 & (1.3) & 15.4 & (2.6) & -14.1 & $(2.4)$ \\
\hline & Switzerland & 66.8 & (1.9) & 20.8 & (1.8) & 13.0 & $(2.5)$ & -10.4 & $(2.4)$ \\
\hline & Turkey & $\mathrm{m}$ & $\mathrm{m}$ & $\mathrm{m}$ & $\mathrm{m}$ & $\mathrm{m}$ & $\mathrm{m}$ & $\mathrm{m}$ & $\mathrm{m}$ \\
\hline & United Kingdom & 55.1 & (1.8) & 33.0 & (1.6) & 15.8 & $(2.8)$ & -17.3 & (3.1) \\
\hline & United States & $\mathrm{m}$ & $\mathrm{m}$ & $\mathrm{m}$ & $\mathrm{m}$ & $\mathrm{m}$ & $\mathrm{m}$ & $\mathrm{m}$ & m \\
\hline & OECD average & 44.4 & $(0.4)$ & 34.6 & $(0.4)$ & 12.1 & $(0.5)$ & -13.5 & $(0.5)$ \\
\hline 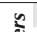 & Albania & $\mathrm{m}$ & $\mathrm{m}$ & $\mathrm{m}$ & $\mathrm{m}$ & $\mathrm{m}$ & $\mathrm{m}$ & $\mathrm{m}$ & $\mathrm{m}$ \\
\hline ฐँ & Algeria & $\mathrm{m}$ & $\mathrm{m}$ & $\mathrm{m}$ & $\mathrm{m}$ & $\mathrm{m}$ & $\mathrm{m}$ & $\mathrm{m}$ & $\mathrm{m}$ \\
\hline ปั & Brazil & 27.8 & (1.0) & 53.6 & $(0.9)$ & -6.8 & $(1.7)$ & 6.2 & (1.9) \\
\hline 2 & B-S-J-G (China) & 62.9 & (3.6) & 19.4 & (2.9) & 18.6 & (4.3) & -11.8 & (3.9) \\
\hline & Bulgaria & 25.1 & (1.4) & 36.2 & (1.5) & 2.4 & (2.0) & -4.9 & (2.1) \\
\hline & CABA (Argentina) & $\mathrm{m}$ & $\mathrm{m}$ & $\mathrm{m}$ & $\mathrm{m}$ & $\mathrm{m}$ & $\mathrm{m}$ & $\mathrm{m}$ & $\mathrm{m}$ \\
\hline & Colombia & 9.4 & $(0.8)$ & 83.5 & $(1.1)$ & -6.4 & (1.4) & 6.8 & (1.7) \\
\hline & Costa Rica & 13.5 & $(0.9)$ & 57.1 & (1.4) & -4.1 & $(2.0)$ & 0.7 & $(2.8)$ \\
\hline & Croatia & 42.6 & (2.3) & 28.2 & $(2.0)$ & 15.9 & (2.6) & -13.6 & $(2.1)$ \\
\hline & Cyprus* & $\mathrm{m}$ & $\mathrm{m}$ & $\mathrm{m}$ & $\mathrm{m}$ & $\mathrm{m}$ & $\mathrm{m}$ & $\mathrm{m}$ & $\mathrm{m}$ \\
\hline & Dominican Republic & 29.3 & (1.8) & 68.6 & (1.8) & -2.4 & (2.5) & 3.1 & $(2.4)$ \\
\hline & FYROM & $\mathrm{m}$ & $\mathrm{m}$ & $\mathrm{m}$ & $\mathrm{m}$ & $\mathrm{m}$ & $\mathrm{m}$ & $\mathrm{m}$ & $\mathrm{m}$ \\
\hline & Georgia & $\mathrm{m}$ & $\mathrm{m}$ & $\mathrm{m}$ & $\mathrm{m}$ & $\mathrm{m}$ & $\mathrm{m}$ & $\mathrm{m}$ & $\mathrm{m}$ \\
\hline & Hong Kong (China) & 25.3 & (1.9) & 44.7 & (1.8) & 12.2 & (1.9) & -18.8 & $(2.3)$ \\
\hline & Indonesia & $\mathrm{m}$ & $\mathrm{m}$ & $\mathrm{m}$ & $\mathrm{m}$ & $\mathrm{m}$ & $\mathrm{m}$ & $\mathrm{m}$ & $\mathrm{m}$ \\
\hline & Jordan & $\mathrm{m}$ & $\mathrm{m}$ & $\mathrm{m}$ & $\mathrm{m}$ & $\mathrm{m}$ & $\mathrm{m}$ & $\mathrm{m}$ & $\mathrm{m}$ \\
\hline & Kosovo & $\mathrm{m}$ & $\mathrm{m}$ & $\mathrm{m}$ & $\mathrm{m}$ & $\mathrm{m}$ & $\mathrm{m}$ & $\mathrm{m}$ & $\mathrm{m}$ \\
\hline & Lebanon & $\mathrm{m}$ & $\mathrm{m}$ & $\mathrm{m}$ & $\mathrm{m}$ & $\mathrm{m}$ & $\mathrm{m}$ & $\mathrm{m}$ & $\mathrm{m}$ \\
\hline & Lithuania & 20.3 & (2.0) & 53.7 & $(2.3)$ & 5.1 & $(2.3)$ & -2.9 & (2.6) \\
\hline & Macao (China) & 20.8 & (1.6) & 40.8 & $(2.0)$ & 10.0 & (1.9) & -11.2 & (2.6) \\
\hline & Malta & $\mathrm{m}$ & $\mathrm{m}$ & $\mathrm{m}$ & $\mathrm{m}$ & $\mathrm{m}$ & $\mathrm{m}$ & $\mathrm{m}$ & $\mathrm{m}$ \\
\hline & Moldova & $\mathrm{m}$ & $\mathrm{m}$ & $\mathrm{m}$ & $\mathrm{m}$ & $\mathrm{m}$ & $\mathrm{m}$ & $\mathrm{m}$ & $\mathrm{m}$ \\
\hline & Montenegro & $\mathrm{m}$ & $\mathrm{m}$ & $\mathrm{m}$ & $\mathrm{m}$ & $\mathrm{m}$ & $\mathrm{m}$ & $\mathrm{m}$ & $\mathrm{m}$ \\
\hline & Peru & 15.2 & (1.4) & 70.8 & (1.6) & -0.9 & $(1.7)$ & 4.3 & $(2.3)$ \\
\hline & Qatar & $\mathrm{m}$ & $\mathrm{m}$ & $\mathrm{m}$ & $\mathrm{m}$ & $\mathrm{m}$ & $\mathrm{m}$ & $\mathrm{m}$ & $\mathrm{m}$ \\
\hline & Romania & $\mathrm{m}$ & $\mathrm{m}$ & $\mathrm{m}$ & $\mathrm{m}$ & $\mathrm{m}$ & $\mathrm{m}$ & $\mathrm{m}$ & $\mathrm{m}$ \\
\hline & Russia & 44.2 & (2.2) & 16.9 & (1.1) & -1.2 & $(2.7)$ & 0.5 & (1.7) \\
\hline & Singapore & 3.5 & $(0.6)$ & 50.2 & (1.6) & 0.9 & $(0.8)$ & -19.4 & $(2.3)$ \\
\hline & Chinese Taipei & 45.5 & (1.8) & 27.8 & (1.6) & 21.5 & $(2.1)$ & -25.1 & $(2.1)$ \\
\hline & Thailand & 12.2 & (1.1) & 72.2 & $(1.7)$ & -3.5 & (1.6) & 5.0 & $(2.5)$ \\
\hline & Trinidad and Tobago & $\mathrm{m}$ & $\mathrm{m}$ & $\mathrm{m}$ & $\mathrm{m}$ & $\mathrm{m}$ & $\mathrm{m}$ & $\mathrm{m}$ & $\mathrm{m}$ \\
\hline & Tunisia & $\mathrm{m}$ & $\mathrm{m}$ & $\mathrm{m}$ & $\mathrm{m}$ & $\mathrm{m}$ & $\mathrm{m}$ & $\mathrm{m}$ & $\mathrm{m}$ \\
\hline & United Arab Emirates & $\mathrm{m}$ & $\mathrm{m}$ & $\mathrm{m}$ & $\mathrm{m}$ & $\mathrm{m}$ & $\mathrm{m}$ & $\mathrm{m}$ & $\mathrm{m}$ \\
\hline & Uruguay & 44.2 & (1.4) & 47.1 & (1.4) & -3.0 & $(2.3)$ & 4.3 & $(2.4)$ \\
\hline & Viet Nam & $\mathrm{m}$ & $\mathrm{m}$ & $\mathrm{m}$ & $\mathrm{m}$ & $\mathrm{m}$ & $\mathrm{m}$ & $\mathrm{m}$ & $\mathrm{m}$ \\
\hline & Argentina** & $\mathrm{m}$ & $\mathrm{m}$ & $\mathrm{m}$ & $\mathrm{m}$ & $\mathrm{m}$ & $\mathrm{m}$ & $\mathrm{m}$ & $\mathrm{m}$ \\
\hline & Kazakhstan** & $\mathrm{m}$ & $\mathrm{m}$ & $\mathrm{m}$ & $\mathrm{m}$ & $\mathrm{m}$ & $\mathrm{m}$ & $\mathrm{m}$ & $\mathrm{m}$ \\
\hline & Malaysia** & $\mathrm{m}$ & $\mathrm{m}$ & $\mathrm{m}$ & $\mathrm{m}$ & $\mathrm{m}$ & $\mathrm{m}$ & $\mathrm{m}$ & $\mathrm{m}$ \\
\hline
\end{tabular}

Note: Values that are statistically significant are indicated in bold (see Annex A3)

* See note at the beginning of this Annex.

** Coverage is too small to ensure comparability (see Annex A4).

StatLink ․ㅔㄷㅐ http://dx.doi.org/10.1787/888933473382 


\begin{tabular}{|c|c|c|c|c|c|c|c|c|c|c|c|c|c|c|c|c|c|}
\hline & \multicolumn{12}{|c|}{ Average life satisfaction, by time spent on the Internet outside of school on weekdays } & & & & \\
\hline & & Low In & $\begin{array}{l}\text { ternet } \\
\text { ers }\end{array}$ & $\begin{array}{l}\text { Moc } \\
\text { Intern } \\
\text { (Stude }\end{array}$ & $\begin{array}{l}\text { erate } \\
\text { et users } \\
\text { tts who }\end{array}$ & $\begin{array}{l}\text { High } \\
\text { us } \\
\text { (Stude }\end{array}$ & $\begin{array}{l}\text { nternet } \\
\text { ers } \\
\text { nts who }\end{array}$ & $\begin{array}{r}\text { Extrem } \\
\text { (Stude }\end{array}$ & $\begin{array}{l}\text { Internet } \\
\text { ers } \\
\text { tts who }\end{array}$ & & $\begin{array}{l}\text { ence bet } \\
\text { id other In } \\
\text { w, modera }\end{array}$ & $\begin{array}{l}\text { ween ex } \\
\text { ternet us } \\
\text { te and } h\end{array}$ & $\begin{array}{l}\text { reme } \\
\text { ers } \\
\text { gh) }\end{array}$ & $\begin{array}{l}\text { Change } \\
\text { with } \\
\text { on th }\end{array}$ & $\begin{array}{l}\text { n life satis } \\
\text { ne additio } \\
\text { ne Internet }\end{array}$ & $\begin{array}{l}\text { sfaction a } \\
\text { onal hour } \\
\text { t on week }\end{array}$ & $\begin{array}{l}\text { ssociated } \\
\text { spent } \\
\text { ddays }\end{array}$ \\
\hline & & $\begin{array}{l}\text { the Int } \\
\text { less tha } \\
\text { per da } \\
\text { typical }\end{array}$ & $\begin{array}{l}\text { rnet for } \\
11 \text { hour } \\
\text { y on a } \\
\text { veekday) }\end{array}$ & $\begin{array}{c}2 \text { hours } \\
\text { on a } \\
\text { wee }\end{array}$ & $\begin{array}{l}\text { n } 1 \text { and } \\
\text { per day } \\
\text { ypical } \\
\text { day) }\end{array}$ & $\begin{array}{c}6 \text { hour } \\
\text { on a } \\
\text { wee }\end{array}$ & $\begin{array}{l}\text { n } 2 \text { and } \\
\text { per day } \\
\text { ypical } \\
\text { kday) }\end{array}$ & $\begin{array}{r}\text { for m } \\
6 \text { hour } \\
\text { on a } \\
\text { wee }\end{array}$ & $\begin{array}{l}\text { re than } \\
\text { per day } \\
\text { ypical } \\
\text { kday) }\end{array}$ & $\begin{array}{r}\text { Before } \\
\text { for } 5 \\
\text { socio- } \\
\end{array}$ & $\begin{array}{l}\text { ccounting } \\
\text { Idents' } \\
\text { conomic } \\
\text { tus }\end{array}$ & $\begin{array}{r}\text { After ac } \\
\text { for st } \\
\text { socio- } \\
\text { st }\end{array}$ & $\begin{array}{l}\text { counting } \\
\text { idents' } \\
\text { conomic } \\
\text { tus }\end{array}$ & $\begin{array}{r}\text { Before ac ac } \\
\text { for stu } \\
\text { socio-ed } \\
\text { sta }\end{array}$ & $\begin{array}{l}\text { counting } \\
\text { dents' } \\
\text { onomic } \\
\text { tus }\end{array}$ & $\begin{array}{r}\text { After ac } \\
\text { for stu } \\
\text { socio-ec } \\
\text { sta }\end{array}$ & $\begin{array}{l}\text { counting } \\
\text { idents' } \\
\text { conomic } \\
\text { tus }\end{array}$ \\
\hline & & Mean & S.E. & Mean & S.E. & Mean & S.E. & Mean & S.E. & Dif. & S.E. & Dif. & S.E. & $\begin{array}{c}\text { Mean } \\
\text { change }\end{array}$ & S.E. & $\begin{array}{l}\text { Mean } \\
\text { change }\end{array}$ & S.E. \\
\hline & Australia & $\mathrm{m}$ & $\mathrm{m}$ & $\mathrm{m}$ & $\mathrm{m}$ & $\mathrm{m}$ & $\mathrm{m}$ & $\mathrm{m}$ & $\mathrm{m}$ & $\mathrm{m}$ & $\mathrm{m}$ & $\mathrm{m}$ & $\mathrm{m}$ & $\mathrm{m}$ & $\mathrm{m}$ & $\mathrm{m}$ & $\mathrm{m}$ \\
\hline & Austria & 7.85 & $(0.07)$ & 7.72 & $(0.06)$ & 7.43 & $(0.04)$ & 7.15 & $(0.10)$ & -0.45 & $(0.10)$ & -0.39 & $(0.10)$ & -0.12 & $(0.02)$ & -0.10 & $(0.02)$ \\
\hline & Belgium (excl. Flemish) & 7.59 & $(0.09)$ & 7.76 & $(0.07)$ & 7.40 & $(0.05)$ & 7.05 & $(0.15)$ & -0.49 & $(0.14)$ & -0.42 & $(0.14)$ & -0.12 & $(0.03)$ & -0.11 & $(0.03)$ \\
\hline & Canada & $\mathrm{m}$ & $\mathrm{m}$ & $\mathrm{m}$ & $\mathrm{m}$ & $\mathrm{m}$ & $\mathrm{m}$ & $\mathrm{m}$ & $\mathrm{m}$ & $\mathrm{m}$ & $\mathrm{m}$ & $\mathrm{m}$ & $\mathrm{m}$ & $\mathrm{m}$ & $\mathrm{m}$ & $\mathrm{m}$ & $\mathrm{m}$ \\
\hline & Chile & 7.20 & $(0.08)$ & 7.59 & $(0.10)$ & 7.40 & $(0.05)$ & 7.30 & $(0.07)$ & -0.08 & $(0.07)$ & -0.09 & $(0.07)$ & -0.01 & $(0.01)$ & -0.02 & $(0.01)$ \\
\hline & Czech Republic & 7.13 & $(0.07)$ & 7.27 & $(0.06)$ & 7.01 & $(0.05)$ & 6.77 & $(0.10)$ & -0.33 & $(0.10)$ & -0.26 & $(0.10)$ & -0.08 & $(0.02)$ & -0.06 & $(0.02)$ \\
\hline & Denmark & $\mathrm{m}$ & $\mathrm{m}$ & $\mathrm{m}$ & $\mathrm{m}$ & $\mathrm{m}$ & $\mathrm{m}$ & $\mathrm{m}$ & $\mathrm{m}$ & $\mathrm{m}$ & $\mathrm{m}$ & $\mathrm{m}$ & $\mathrm{m}$ & $\mathrm{m}$ & $\mathrm{m}$ & $\mathrm{m}$ & $\mathrm{m}$ \\
\hline & Estonia & 7.90 & $(0.08)$ & 7.72 & $(0.07)$ & 7.54 & $(0.04)$ & 6.98 & $(0.09)$ & -0.66 & $(0.09)$ & -0.61 & $(0.09)$ & -0.15 & $(0.02)$ & -0.14 & $(0.02)$ \\
\hline & Finland & 8.20 & $(0.06)$ & 8.16 & $(0.04)$ & 7.80 & $(0.04)$ & 7.33 & $(0.10)$ & -0.64 & $(0.10)$ & -0.59 & $(0.10)$ & -0.16 & $(0.02)$ & -0.15 & $(0.02)$ \\
\hline & France & 7.82 & $(0.06)$ & 7.79 & $(0.05)$ & 7.55 & $(0.04)$ & 7.43 & $(0.10)$ & -0.25 & $(0.11)$ & -0.19 & $(0.11)$ & -0.07 & $(0.02)$ & -0.06 & $(0.02)$ \\
\hline & Germany & $\mathrm{m}$ & $\mathrm{m}$ & $\mathrm{m}$ & $\mathrm{m}$ & $\mathrm{m}$ & $\mathrm{m}$ & $\mathrm{m}$ & $\mathrm{m}$ & $\mathrm{m}$ & $\mathrm{m}$ & $\mathrm{m}$ & $\mathrm{m}$ & $\mathrm{m}$ & $\mathrm{m}$ & $\mathrm{m}$ & $\mathrm{m}$ \\
\hline & Greece & 7.10 & $(0.06)$ & 7.08 & $(0.07)$ & 6.80 & $(0.05)$ & 6.60 & $(0.11)$ & -0.35 & $(0.12)$ & -0.34 & $(0.12)$ & -0.11 & $(0.02)$ & -0.10 & $(0.02)$ \\
\hline & Hungary & 7.33 & $(0.11)$ & 7.43 & $(0.07)$ & 7.13 & $(0.05)$ & 6.90 & $(0.09)$ & -0.35 & $(0.09)$ & -0.29 & $(0.09)$ & -0.09 & $(0.02)$ & -0.08 & $(0.02)$ \\
\hline & Iceland & 8.16 & $(0.12)$ & 8.08 & $(0.07)$ & 7.78 & $(0.06)$ & 6.97 & $(0.16)$ & -0.95 & $(0.16)$ & -0.88 & $(0.15)$ & -0.21 & $(0.02)$ & -0.20 & $(0.02)$ \\
\hline & Ireland & 7.63 & $(0.07)$ & 7.55 & $(0.06)$ & 7.20 & $(0.04)$ & 6.88 & $(0.10)$ & -0.49 & $(0.10)$ & -0.47 & $(0.10)$ & -0.13 & $(0.02)$ & -0.13 & $(0.02)$ \\
\hline & Israel & $\mathrm{m}$ & $\mathrm{m}$ & $\mathrm{m}$ & $\mathrm{m}$ & $\mathrm{m}$ & $\mathrm{m}$ & $\mathrm{m}$ & $\mathrm{m}$ & $\mathrm{m}$ & $\mathrm{m}$ & $\mathrm{m}$ & $\mathrm{m}$ & $\mathrm{m}$ & $\mathrm{m}$ & $\mathrm{m}$ & $\mathrm{m}$ \\
\hline & Italy & 7.08 & $(0.07)$ & 6.97 & $(0.07)$ & 6.79 & $(0.06)$ & 6.79 & $(0.07)$ & -0.11 & $(0.07)$ & -0.07 & $(0.07)$ & -0.04 & $(0.01)$ & -0.04 & $(0.01)$ \\
\hline & Japan & 6.93 & $(0.05)$ & 6.87 & $(0.05)$ & 6.73 & $(0.06)$ & 6.39 & $(0.12)$ & -0.46 & $(0.12)$ & -0.40 & $(0.12)$ & -0.10 & $(0.02)$ & -0.09 & $(0.02)$ \\
\hline & Korea & 6.41 & $(0.05)$ & 6.38 & $(0.06)$ & 6.26 & $(0.09)$ & 5.74 & $(0.25)$ & -0.64 & $(0.25)$ & -0.60 & $(0.25)$ & -0.10 & $(0.03)$ & -0.09 & $(0.03)$ \\
\hline & Latvia & 7.49 & $(0.08)$ & 7.65 & $(0.07)$ & 7.30 & $(0.05)$ & 7.05 & $(0.11)$ & -0.38 & $(0.11)$ & -0.39 & $(0.11)$ & -0.10 & $(0.02)$ & -0.10 & $(0.02)$ \\
\hline & Luxembourg & 7.49 & $(0.07)$ & 7.56 & $(0.07)$ & 7.34 & $(0.05)$ & 7.14 & $(0.08)$ & -0.29 & $(0.08)$ & -0.25 & $(0.08)$ & -0.06 & $(0.02)$ & -0.06 & $(0.02)$ \\
\hline & Mexico & 8.16 & $(0.05)$ & 8.45 & $(0.06)$ & 8.34 & $(0.04)$ & 8.27 & $(0.07)$ & -0.02 & $(0.07)$ & -0.05 & $(0.07)$ & 0.02 & $(0.01)$ & 0.01 & $(0.01)$ \\
\hline & Netherlands & 7.97 & $(0.06)$ & 7.92 & $(0.04)$ & 7.80 & $(0.03)$ & 7.65 & $(0.06)$ & -0.21 & $(0.06)$ & -0.21 & $(0.06)$ & -0.06 & $(0.01)$ & -0.06 & $(0.01)$ \\
\hline & New Zealand & $\mathrm{m}$ & $\mathrm{m}$ & $\mathrm{m}$ & $\mathrm{m}$ & $\mathrm{m}$ & $\mathrm{m}$ & $\mathrm{m}$ & $\mathrm{m}$ & $\mathrm{m}$ & $\mathrm{m}$ & $\mathrm{m}$ & $\mathrm{m}$ & $\mathrm{m}$ & $\mathrm{m}$ & $\mathrm{m}$ & $\mathrm{m}$ \\
\hline & Norway & $\mathrm{m}$ & $\mathrm{m}$ & $\mathrm{m}$ & $\mathrm{m}$ & $\mathrm{m}$ & $\mathrm{m}$ & $\mathrm{m}$ & $\mathrm{m}$ & $\mathrm{m}$ & $\mathrm{m}$ & $\mathrm{m}$ & $\mathrm{m}$ & $\mathrm{m}$ & $\mathrm{m}$ & $\mathrm{m}$ & $\mathrm{m}$ \\
\hline & Poland & 7.35 & $(0.08)$ & 7.43 & $(0.07)$ & 7.08 & $(0.05)$ & 6.89 & $(0.11)$ & -0.33 & $(0.11)$ & -0.32 & $(0.11)$ & -0.10 & $(0.02)$ & -0.10 & $(0.02)$ \\
\hline & Portugal & 7.49 & $(0.06)$ & 7.52 & $(0.07)$ & 7.26 & $(0.05)$ & 7.21 & $(0.09)$ & -0.17 & $(0.09)$ & -0.16 & $(0.09)$ & -0.05 & $(0.02)$ & -0.05 & $(0.02)$ \\
\hline & Slovak Republic & 7.55 & $(0.07)$ & 7.61 & $(0.06)$ & 7.52 & $(0.05)$ & 7.13 & $(0.09)$ & -0.42 & $(0.10)$ & -0.40 & $(0.10)$ & -0.07 & $(0.02)$ & -0.07 & $(0.02)$ \\
\hline & Slovenia & 7.48 & $(0.07)$ & 7.23 & $(0.08)$ & 7.00 & $(0.07)$ & 6.87 & $(0.11)$ & -0.34 & $(0.13)$ & -0.34 & $(0.13)$ & -0.11 & $(0.02)$ & -0.11 & $(0.02)$ \\
\hline & Spain & 7.47 & $(0.07)$ & 7.59 & $(0.06)$ & 7.43 & $(0.04)$ & 7.26 & $(0.07)$ & -0.22 & $(0.07)$ & -0.15 & $(0.07)$ & -0.05 & $(0.01)$ & -0.03 & $(0.01)$ \\
\hline & Sweden & $\mathrm{m}$ & $\mathrm{m}$ & $\mathrm{m}$ & $\mathrm{m}$ & $\mathrm{m}$ & $\mathrm{m}$ & $\mathrm{m}$ & $\mathrm{m}$ & $\mathrm{m}$ & $\mathrm{m}$ & $\mathrm{m}$ & $\mathrm{m}$ & $\mathrm{m}$ & $\mathrm{m}$ & $\mathrm{m}$ & $\mathrm{m}$ \\
\hline & Switzerland & 7.94 & $(0.07)$ & 7.83 & $(0.05)$ & 7.61 & $(0.04)$ & 7.37 & $(0.13)$ & -0.39 & $(0.13)$ & -0.36 & $(0.13)$ & -0.10 & $(0.02)$ & -0.09 & $(0.02)$ \\
\hline & Turkey & $\mathrm{m}$ & $\mathrm{m}$ & $\mathrm{m}$ & $\mathrm{m}$ & $\mathrm{m}$ & $\mathrm{m}$ & $\mathrm{m}$ & $\mathrm{m}$ & $\mathrm{m}$ & $\mathrm{m}$ & $\mathrm{m}$ & $\mathrm{m}$ & $\mathrm{m}$ & $\mathrm{m}$ & $\mathrm{m}$ & $\mathrm{m}$ \\
\hline & United Kingdom & 7.14 & $(0.11)$ & 7.40 & $(0.07)$ & 7.01 & $(0.05)$ & 6.59 & $(0.10)$ & -0.51 & $(0.10)$ & -0.46 & $(0.10)$ & -0.14 & $(0.02)$ & -0.13 & $(0.02)$ \\
\hline & United States & $\mathrm{m}$ & $\mathrm{m}$ & $\mathrm{m}$ & $\mathrm{m}$ & $\mathrm{m}$ & $\mathrm{m}$ & $\mathrm{m}$ & $\mathrm{m}$ & $\mathrm{m}$ & $\mathrm{m}$ & $\mathrm{m}$ & $\mathrm{m}$ & $\mathrm{m}$ & $\mathrm{m}$ & $\mathrm{m}$ & $\mathrm{m}$ \\
\hline & OECD average & 7.52 & $(0.02)$ & 7.54 & $(0.01)$ & 7.30 & $(0.01)$ & 7.03 & $(0.02)$ & -0.38 & $(0.02)$ & -0.35 & $(0.02)$ & -0.09 & $(0.00)$ & -0.09 & $(0.00)$ \\
\hline & Albania & $\mathrm{m}$ & $\mathrm{m}$ & $\mathrm{m}$ & $\mathrm{m}$ & $\mathrm{m}$ & $\mathrm{m}$ & $\mathrm{m}$ & $\mathrm{m}$ & $\mathrm{m}$ & $\mathrm{m}$ & $\mathrm{m}$ & $\mathrm{m}$ & $\mathrm{m}$ & $\mathrm{m}$ & $\mathrm{m}$ & $\mathrm{m}$ \\
\hline & Algeria & $\mathrm{m}$ & $\mathrm{m}$ & $\mathrm{m}$ & $\mathrm{m}$ & $\mathrm{m}$ & $\mathrm{m}$ & $\mathrm{m}$ & $\mathrm{m}$ & $\mathrm{m}$ & $\mathrm{m}$ & $\mathrm{m}$ & $\mathrm{m}$ & $\mathrm{m}$ & $\mathrm{m}$ & $\mathrm{m}$ & $\mathrm{m}$ \\
\hline & Brazil & 7.55 & $(0.06)$ & 7.68 & $(0.06)$ & 7.61 & $(0.05)$ & 7.43 & $(0.05)$ & -0.17 & $(0.06)$ & -0.17 & $(0.06)$ & -0.03 & $(0.01)$ & -0.03 & $(0.01)$ \\
\hline a & B-S-J-G (China) & 6.88 & $(0.05)$ & 6.75 & $(0.10)$ & 6.67 & $(0.10)$ & 6.89 & $(0.16)$ & 0.05 & $(0.17)$ & 0.07 & $(0.17)$ & -0.02 & $(0.03)$ & -0.01 & $(0.03)$ \\
\hline & Bulgaria & 7.28 & $(0.12)$ & 7.63 & $(0.07)$ & 7.39 & $(0.05)$ & 7.43 & $(0.07)$ & 0.01 & $(0.09)$ & 0.03 & $(0.09)$ & 0.00 & $(0.02)$ & 0.00 & $(0.02)$ \\
\hline & CABA (Argentina) & $\mathrm{m}$ & $\mathrm{m}$ & $\mathrm{m}$ & $\mathrm{m}$ & $\mathrm{m}$ & $\mathrm{m}$ & $\mathrm{m}$ & $\mathrm{m}$ & $\mathrm{m}$ & $\mathrm{m}$ & $\mathrm{m}$ & $\mathrm{m}$ & $\mathrm{m}$ & $\mathrm{m}$ & $\mathrm{m}$ & $\mathrm{m}$ \\
\hline & Colombia & 8.04 & $(0.06)$ & 7.96 & $(0.08)$ & 7.83 & $(0.05)$ & 7.59 & $(0.07)$ & -0.36 & $(0.07)$ & -0.32 & $(0.07)$ & -0.07 & $(0.01)$ & -0.06 & $(0.01)$ \\
\hline & Costa Rica & 8.32 & $(0.07)$ & 8.31 & $(0.08)$ & 8.18 & $(0.05)$ & 8.08 & $(0.06)$ & -0.18 & $(0.07)$ & -0.19 & $(0.06)$ & -0.04 & $(0.01)$ & -0.05 & $(0.01)$ \\
\hline & Croatia & 8.14 & $(0.06)$ & 7.95 & $(0.06)$ & 7.83 & $(0.05)$ & 7.72 & $(0.09)$ & -0.23 & $(0.09)$ & -0.22 & $(0.09)$ & -0.06 & $(0.02)$ & -0.06 & $(0.02)$ \\
\hline & Cyprus* & $\mathrm{m}$ & $\mathrm{m}$ & $\mathrm{m}$ & $\mathrm{m}$ & $\mathrm{m}$ & $\mathrm{m}$ & $\mathrm{m}$ & $\mathrm{m}$ & $\mathrm{m}$ & $\mathrm{m}$ & $\mathrm{m}$ & $\mathrm{m}$ & $\mathrm{m}$ & $\mathrm{m}$ & $\mathrm{m}$ & $\mathrm{m}$ \\
\hline & Dominican Republic & 8.38 & $(0.07)$ & 8.55 & $(0.09)$ & 8.44 & $(0.08)$ & 8.55 & $(0.08)$ & 0.11 & $(0.08)$ & 0.12 & $(0.08)$ & 0.02 & $(0.02)$ & 0.02 & $(0.02)$ \\
\hline & FYROM & $\mathrm{m}$ & $\mathrm{m}$ & $\mathrm{m}$ & $\mathrm{m}$ & $\mathrm{m}$ & $\mathrm{m}$ & $\mathrm{m}$ & $\mathrm{m}$ & $\mathrm{m}$ & $\mathrm{m}$ & $\mathrm{m}$ & $\mathrm{m}$ & $\mathrm{m}$ & $\mathrm{m}$ & $\mathrm{m}$ & $\mathrm{m}$ \\
\hline & Georgia & $\mathrm{m}$ & $\mathrm{m}$ & $\mathrm{m}$ & $\mathrm{m}$ & $\mathrm{m}$ & $\mathrm{m}$ & $\mathrm{m}$ & $\mathrm{m}$ & $\mathrm{m}$ & $\mathrm{m}$ & $\mathrm{m}$ & $\mathrm{m}$ & $\mathrm{m}$ & $\mathrm{m}$ & $\mathrm{m}$ & $\mathrm{m}$ \\
\hline & Hong Kong (China) & 6.58 & $(0.07)$ & 6.77 & $(0.06)$ & 6.40 & $(0.05)$ & 6.09 & $(0.10)$ & -0.46 & $(0.09)$ & -0.44 & $(0.09)$ & -0.09 & $(0.02)$ & -0.09 & $(0.02)$ \\
\hline & Indonesia & $\mathrm{m}$ & $\mathrm{m}$ & $\mathrm{m}$ & $\mathrm{m}$ & $\mathrm{m}$ & $\mathrm{m}$ & $\mathrm{m}$ & $\mathrm{m}$ & $\mathrm{m}$ & $\mathrm{m}$ & $\mathrm{m}$ & $\mathrm{m}$ & $\mathrm{m}$ & $\mathrm{m}$ & $\mathrm{m}$ & $\mathrm{m}$ \\
\hline & Jordan & $\mathrm{m}$ & $\mathrm{m}$ & $\mathrm{m}$ & $\mathrm{m}$ & $\mathrm{m}$ & $\mathrm{m}$ & $\mathrm{m}$ & $\mathrm{m}$ & $\mathrm{m}$ & $\mathrm{m}$ & $\mathrm{m}$ & $\mathrm{m}$ & $\mathrm{m}$ & $\mathrm{m}$ & $\mathrm{m}$ & $\mathrm{m}$ \\
\hline & Kosovo & $\mathrm{m}$ & $\mathrm{m}$ & $\mathrm{m}$ & $\mathrm{m}$ & $\mathrm{m}$ & $\mathrm{m}$ & $\mathrm{m}$ & $\mathrm{m}$ & $\mathrm{m}$ & $\mathrm{m}$ & $\mathrm{m}$ & $\mathrm{m}$ & $\mathrm{m}$ & $\mathrm{m}$ & $\mathrm{m}$ & $\mathrm{m}$ \\
\hline & Lebanon & $\mathrm{m}$ & $\mathrm{m}$ & $\mathrm{m}$ & $\mathrm{m}$ & $\mathrm{m}$ & $\mathrm{m}$ & $\mathrm{m}$ & $\mathrm{m}$ & $\mathrm{m}$ & $\mathrm{m}$ & $\mathrm{m}$ & $\mathrm{m}$ & $\mathrm{m}$ & $\mathrm{m}$ & $\mathrm{m}$ & $\mathrm{m}$ \\
\hline & Lithuania & 7.84 & $(0.07)$ & 8.00 & $(0.06)$ & 7.85 & $(0.05)$ & 7.70 & $(0.11)$ & -0.19 & $(0.11)$ & -0.21 & $(0.11)$ & -0.04 & $(0.02)$ & -0.05 & $(0.02)$ \\
\hline & Macao (China) & 6.51 & $(0.07)$ & 6.85 & $(0.07)$ & 6.57 & $(0.04)$ & 6.43 & $(0.10)$ & -0.20 & $(0.10)$ & -0.20 & $(0.10)$ & -0.04 & $(0.02)$ & -0.04 & $(0.02)$ \\
\hline & Malta & $\mathrm{m}$ & $\mathrm{m}$ & $\mathrm{m}$ & $\mathrm{m}$ & $\mathrm{m}$ & $\mathrm{m}$ & $\mathrm{m}$ & $\mathrm{m}$ & $\mathrm{m}$ & $\mathrm{m}$ & $\mathrm{m}$ & $\mathrm{m}$ & $\mathrm{m}$ & $\mathrm{m}$ & $\mathrm{m}$ & $\mathrm{m}$ \\
\hline & Moldova & $\mathrm{m}$ & $\mathrm{m}$ & $\mathrm{m}$ & $\mathrm{m}$ & $\mathrm{m}$ & $\mathrm{m}$ & $\mathrm{m}$ & $\mathrm{m}$ & $\mathrm{m}$ & $\mathrm{m}$ & $\mathrm{m}$ & $\mathrm{m}$ & $\mathrm{m}$ & $\mathrm{m}$ & $\mathrm{m}$ & $\mathrm{m}$ \\
\hline & Montenegro & $\mathrm{m}$ & $\mathrm{m}$ & $\mathrm{m}$ & $\mathrm{m}$ & $\mathrm{m}$ & $\mathrm{m}$ & $\mathrm{m}$ & $\mathrm{m}$ & $\mathrm{m}$ & $\mathrm{m}$ & $\mathrm{m}$ & $\mathrm{m}$ & $\mathrm{m}$ & $\mathrm{m}$ & $\mathrm{m}$ & $\mathrm{m}$ \\
\hline & Peru & 7.68 & $(0.05)$ & 7.64 & $(0.07)$ & 7.33 & $(0.06)$ & 7.26 & $(0.13)$ & -0.32 & $(0.13)$ & -0.27 & $(0.13)$ & -0.08 & $(0.02)$ & -0.07 & $(0.02)$ \\
\hline & Qatar & $\mathrm{m}$ & $\mathrm{m}$ & $\mathrm{m}$ & $\mathrm{m}$ & $\mathrm{m}$ & $\mathrm{m}$ & $\mathrm{m}$ & $\mathrm{m}$ & $\mathrm{m}$ & $\mathrm{m}$ & $\mathrm{m}$ & $\mathrm{m}$ & $\mathrm{m}$ & $\mathrm{m}$ & $\mathrm{m}$ & $\mathrm{m}$ \\
\hline & Romania & $\mathrm{m}$ & $\mathrm{m}$ & $\mathrm{m}$ & $\mathrm{m}$ & $\mathrm{m}$ & $\mathrm{m}$ & $\mathrm{m}$ & $\mathrm{m}$ & $\mathrm{m}$ & $\mathrm{m}$ & $\mathrm{m}$ & $\mathrm{m}$ & $\mathrm{m}$ & $\mathrm{m}$ & $\mathrm{m}$ & $\mathrm{m}$ \\
\hline & Russia & 7.93 & $(0.07)$ & 8.07 & $(0.08)$ & 7.67 & $(0.05)$ & 7.58 & $(0.09)$ & -0.25 & $(0.10)$ & -0.26 & $(0.10)$ & -0.08 & $(0.02)$ & -0.08 & $(0.02)$ \\
\hline & Singapore & $\mathrm{m}$ & $\mathrm{m}$ & $\mathrm{m}$ & $\mathrm{m}$ & $\mathrm{m}$ & $\mathrm{m}$ & $\mathrm{m}$ & $\mathrm{m}$ & $\mathrm{m}$ & $\mathrm{m}$ & $\mathrm{m}$ & $\mathrm{m}$ & $\mathrm{m}$ & $\mathrm{m}$ & $\mathrm{m}$ & $\mathrm{m}$ \\
\hline & Chinese Taipei & 6.65 & $(0.05)$ & 6.68 & $(0.05)$ & 6.49 & $(0.05)$ & 6.56 & $(0.07)$ & -0.04 & $(0.08)$ & 0.02 & $(0.08)$ & -0.03 & $(0.01)$ & -0.02 & $(0.01)$ \\
\hline & Thailand & 7.71 & $(0.05)$ & 7.95 & $(0.07)$ & 7.70 & $(0.04)$ & 7.46 & $(0.10)$ & -0.30 & $(0.10)$ & -0.28 & $(0.10)$ & -0.06 & $(0.02)$ & -0.05 & $(0.02)$ \\
\hline & Trinidad and Tobago & $\mathrm{m}$ & $\mathrm{m}$ & $\mathrm{m}$ & $\mathrm{m}$ & $\mathrm{m}$ & $\mathrm{m}$ & $\mathrm{m}$ & $\mathrm{m}$ & $\mathrm{m}$ & $\mathrm{m}$ & $\mathrm{m}$ & $\mathrm{m}$ & $\mathrm{m}$ & $\mathrm{m}$ & $\mathrm{m}$ & $\mathrm{m}$ \\
\hline & Tunisia & $\mathrm{m}$ & $\mathrm{m}$ & $\mathrm{m}$ & $\mathrm{m}$ & $\mathrm{m}$ & $\mathrm{m}$ & $\mathrm{m}$ & $\mathrm{m}$ & $\mathrm{m}$ & $\mathrm{m}$ & $\mathrm{m}$ & $\mathrm{m}$ & $\mathrm{m}$ & $\mathrm{m}$ & $\mathrm{m}$ & $\mathrm{m}$ \\
\hline & United Arab Emirates & $\mathrm{m}$ & $\mathrm{m}$ & $\mathrm{m}$ & $\mathrm{m}$ & $\mathrm{m}$ & $\mathrm{m}$ & $\mathrm{m}$ & $\mathrm{m}$ & $\mathrm{m}$ & $\mathrm{m}$ & $\mathrm{m}$ & $\mathrm{m}$ & $\mathrm{m}$ & $\mathrm{m}$ & $\mathrm{m}$ & $\mathrm{m}$ \\
\hline & Uruguay & 7.63 & $(0.06)$ & 7.86 & $(0.07)$ & 7.81 & $(0.05)$ & 7.54 & $(0.06)$ & -0.23 & $(0.07)$ & -0.27 & $(0.07)$ & -0.03 & $(0.01)$ & -0.05 & $(0.01)$ \\
\hline & Viet Nam & $\mathrm{m}$ & $\mathrm{m}$ & $\mathrm{m}$ & $\mathrm{m}$ & $\mathrm{m}$ & $\mathrm{m}$ & $\mathrm{m}$ & $\mathrm{m}$ & $\mathrm{m}$ & $\mathrm{m}$ & $\mathrm{m}$ & $\mathrm{m}$ & $\mathrm{m}$ & $\mathrm{m}$ & $\mathrm{m}$ & $\mathrm{m}$ \\
\hline & Argentina** & $\mathrm{m}$ & $\mathrm{m}$ & $\mathrm{m}$ & $\mathrm{m}$ & $\mathrm{m}$ & $\mathrm{m}$ & $\mathrm{m}$ & $\mathrm{m}$ & $\mathrm{m}$ & $\mathrm{m}$ & $\mathrm{m}$ & $\mathrm{m}$ & $\mathrm{m}$ & $\mathrm{m}$ & $\mathrm{m}$ & $\mathrm{m}$ \\
\hline & Kazakhstan** & $\mathrm{m}$ & $\mathrm{m}$ & $\mathrm{m}$ & $\mathrm{m}$ & $\mathrm{m}$ & $\mathrm{m}$ & $\mathrm{m}$ & $\mathrm{m}$ & $\mathrm{m}$ & $\mathrm{m}$ & $\mathrm{m}$ & $\mathrm{m}$ & $\mathrm{m}$ & $\mathrm{m}$ & $\mathrm{m}$ & $\mathrm{m}$ \\
\hline & Malaysia** & $\mathrm{m}$ & $\mathrm{m}$ & $\mathrm{m}$ & $\mathrm{m}$ & $\mathrm{m}$ & $\mathrm{m}$ & $\mathrm{m}$ & $\mathrm{m}$ & $\mathrm{m}$ & $\mathrm{m}$ & $\mathrm{m}$ & $\mathrm{m}$ & $\mathrm{m}$ & $\mathrm{m}$ & $\mathrm{m}$ & $\mathrm{m}$ \\
\hline
\end{tabular}

Note: Values that are statistically significant are indicated in bold (see Annex A3).

* See note at the beginning of this Annex.

mparability (see Annex A4)

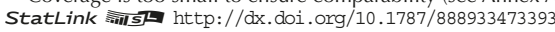


[Part 2/2]

Table III.13.23 Use of the Internet outside of school and life satisfaction

Results based on students' self-reports

\begin{tabular}{|c|c|c|c|c|c|c|c|c|c|c|c|c|c|c|c|c|c|}
\hline & \multicolumn{12}{|c|}{ Average life satisfaction, by time spent on the Internet outside of school on weekend days } & & & & \\
\hline & & $\begin{array}{r}\text { Low I } \\
\text { us } \\
\text { (Stude }\end{array}$ & $\begin{array}{l}\text { nternet } \\
\text { ers } \\
\text { nts who }\end{array}$ & $\begin{array}{c}\text { Mod } \\
\text { Intern } \\
\text { (Stude }\end{array}$ & $\begin{array}{l}\text { erate } \\
\text { t users } \\
\text { ts who }\end{array}$ & $\begin{array}{r}\text { High } \\
\text { u } \\
\text { (Stude }\end{array}$ & $\begin{array}{l}\text { ternet } \\
\text { ers } \\
\text { tts who }\end{array}$ & $\begin{array}{r}\text { Extrem } \\
\text { us } \\
\text { (Stude }\end{array}$ & $\begin{array}{l}\text { Internet } \\
\text { ers } \\
\text { nts who }\end{array}$ & & $\begin{array}{l}\text { erence bet } \\
\text { id other In } \\
\text { w, modera }\end{array}$ & $\begin{array}{l}\text { ween ex } \\
\text { ternet u } \\
\text { ate and } h\end{array}$ & $\begin{array}{l}\text { reme } \\
\text { ers } \\
\text { gh) }\end{array}$ & $\begin{array}{c}\text { Change } \\
\text { with } \\
\text { on the }\end{array}$ & $\begin{array}{l}\text { in life satis } \\
\text { one additio } \\
\text { Internet o }\end{array}$ & $\begin{array}{l}\text { sfaction a } \\
\text { onal hour } \\
\text { on weeker }\end{array}$ & $\begin{array}{l}\text { ociated } \\
\text { pent } \\
\text { days }\end{array}$ \\
\hline & & $\begin{array}{c}\text { for le } \\
1 \text { hour } \\
\text { on a } \\
\text { weeke }\end{array}$ & $\begin{array}{l}\text { ss than } \\
\text { per day } \\
\text { ypical } \\
\text { nd day) }\end{array}$ & $\begin{array}{c}\text { betwee } \\
\text { hours } \\
\text { on a } \\
\text { weeke }\end{array}$ & $\begin{array}{l}1 \text { and } 2 \\
\text { eer day } \\
\text { ypical } \\
\text { id day) }\end{array}$ & $\begin{array}{r}\text { betwee } \\
\text { hours } \\
\text { on a } \\
\text { week }\end{array}$ & $\begin{array}{l}2 \text { and } 6 \\
\text { oer day } \\
\text { ypical } \\
\text { id day) }\end{array}$ & $\begin{array}{r}\text { for mo } \\
\text { hours p } \\
\text { a typica } \\
d\end{array}$ & $\begin{array}{l}\text { e than } 6 \\
\text { er day on } \\
\text { weekend } \\
\text { ay) }\end{array}$ & $\begin{array}{r}\text { Before a } \\
\text { for st } \\
\text { socio- } \\
\text { st }\end{array}$ & $\begin{array}{l}\text { ccounting } \\
\text { Idents' } \\
\text { conomic } \\
\text { tus }\end{array}$ & $\begin{array}{r}\text { After a } \\
\text { for st } \\
\text { socio-e } \\
\text { st }\end{array}$ & $\begin{array}{l}\text { counting } \\
\text { idents' } \\
\text { conomic } \\
\text { tus }\end{array}$ & $\begin{array}{r}\text { Before ac } \\
\text { for stc } \\
\text { socio-ec } \\
\text { sta }\end{array}$ & $\begin{array}{l}\text { ccounting } \\
\text { Idents' } \\
\text { conomic } \\
\text { tus }\end{array}$ & $\begin{array}{r}\text { After ac } \\
\text { for stu } \\
\text { socio-ec } \\
\text { sta }\end{array}$ & $\begin{array}{l}\text { counting } \\
\text { dents's } \\
\text { onomic } \\
\text { tus } \\
\end{array}$ \\
\hline & & Mean & S.E. & Mean & S.E. & Mean & S.E. & Mean & S.E. & Dif. & S.E. & Dif. & S.E. & $\begin{array}{l}\text { Mean } \\
\text { change }\end{array}$ & S.E. & $\begin{array}{c}\text { Mean } \\
\text { change }\end{array}$ & S.E. \\
\hline & Australia & $\mathrm{m}$ & $\mathrm{m}$ & $\mathrm{m}$ & $\mathrm{m}$ & $\mathrm{m}$ & $\mathrm{m}$ & $\mathrm{m}$ & $\mathrm{m}$ & $\mathrm{m}$ & $\mathrm{m}$ & $\mathrm{m}$ & $\mathrm{m}$ & $\mathrm{m}$ & $\mathrm{m}$ & $\mathrm{m}$ & $\mathrm{m}$ \\
\hline & Austria & 7.85 & $(0.08)$ & 7.89 & $(0.07)$ & 7.54 & $(0.04)$ & 7.10 & $(0.07)$ & -0.58 & $(0.07)$ & -0.53 & $(0.07)$ & -0.14 & $(0.01)$ & -0.13 & $(0.01)$ \\
\hline & Belgium (excl. Flemish) & 7.68 & $(0.14)$ & 7.79 & $(0.08)$ & 7.57 & $(0.05)$ & 7.10 & $(0.09)$ & -0.53 & $(0.09)$ & -0.48 & $(0.09)$ & -0.12 & $(0.02)$ & -0.11 & $(0.02)$ \\
\hline & Canada & $\mathrm{m}$ & $\mathrm{m}$ & $\mathrm{m}$ & $\mathrm{m}$ & $\mathrm{m}$ & $\mathrm{m}$ & $\mathrm{m}$ & $\mathrm{m}$ & $\mathrm{m}$ & $\mathrm{m}$ & $\mathrm{m}$ & $\mathrm{m}$ & $\mathrm{m}$ & $\mathrm{m}$ & $\mathrm{m}$ & $\mathrm{m}$ \\
\hline & Chile & 7.12 & $(0.11)$ & 7.68 & $(0.11)$ & 7.48 & $(0.05)$ & 7.27 & $(0.05)$ & -0.16 & $(0.06)$ & -0.18 & $(0.06)$ & -0.02 & $(0.02)$ & -0.03 & $(0.01)$ \\
\hline & Czech Republic & 7.12 & $(0.08)$ & 7.34 & $(0.07)$ & 7.03 & $(0.05)$ & 6.86 & $(0.07)$ & -0.25 & $(0.08)$ & -0.20 & $(0.08)$ & -0.07 & $(0.02)$ & -0.06 & $(0.02)$ \\
\hline & Denmark & $\mathrm{m}$ & $\mathrm{m}$ & $\mathrm{m}$ & $\mathrm{m}$ & $\mathrm{m}$ & $\mathrm{m}$ & $\mathrm{m}$ & $\mathrm{m}$ & $\mathrm{m}$ & $\mathrm{m}$ & $\mathrm{m}$ & $\mathrm{m}$ & $\mathrm{m}$ & $\mathrm{m}$ & $\mathrm{m}$ & $\mathrm{m}$ \\
\hline & Estonia & 7.97 & $(0.09)$ & 7.70 & $(0.07)$ & 7.61 & $(0.04)$ & 7.09 & $(0.07)$ & -0.59 & $(0.08)$ & -0.54 & $(0.08)$ & -0.14 & $(0.02)$ & -0.13 & $(0.02)$ \\
\hline & Finland & 8.25 & $(0.08)$ & 8.17 & $(0.05)$ & 7.88 & $(0.04)$ & 7.47 & $(0.07)$ & -0.52 & $(0.07)$ & -0.49 & $(0.07)$ & -0.14 & $(0.01)$ & -0.14 & $(0.01)$ \\
\hline & France & 7.86 & $(0.09)$ & 7.90 & $(0.06)$ & 7.65 & $(0.03)$ & 7.45 & $(0.06)$ & -0.29 & $(0.07)$ & -0.25 & $(0.07)$ & -0.07 & $(0.01)$ & -0.07 & $(0.01)$ \\
\hline & Germany & $\mathrm{m}$ & $\mathrm{m}$ & $\mathrm{m}$ & $\mathrm{m}$ & $\mathrm{m}$ & $\mathrm{m}$ & $\mathrm{m}$ & $\mathrm{m}$ & $\mathrm{m}$ & $\mathrm{m}$ & $\mathrm{m}$ & $\mathrm{m}$ & $\mathrm{m}$ & $\mathrm{m}$ & $\mathrm{m}$ & $\mathrm{m}$ \\
\hline & Greece & 7.28 & $(0.09)$ & 7.13 & $(0.07)$ & 6.87 & $(0.05)$ & 6.65 & $(0.06)$ & -0.34 & $(0.07)$ & -0.33 & $(0.07)$ & -0.10 & $(0.02)$ & -0.10 & $(0.02)$ \\
\hline & Hungary & 7.35 & $(0.11)$ & 7.51 & (0.08) & 7.23 & $(0.05)$ & 6.90 & $(0.07)$ & -0.41 & $(0.08)$ & -0.37 & $(0.08)$ & -0.09 & $(0.02)$ & -0.09 & $(0.02)$ \\
\hline & Iceland & 8.20 & $(0.13)$ & 8.15 & $(0.09)$ & 7.94 & $(0.05)$ & 7.14 & $(0.10)$ & -0.87 & $(0.11)$ & -0.82 & $(0.10)$ & -0.20 & $(0.02)$ & -0.19 & $(0.02)$ \\
\hline & Ireland & 7.74 & $(0.10)$ & 7.59 & $(0.07)$ & 7.33 & $(0.04)$ & 6.86 & $(0.08)$ & -0.59 & $(0.08)$ & -0.58 & $(0.08)$ & -0.15 & $(0.01)$ & -0.14 & $(0.02)$ \\
\hline & Israel & $\mathrm{m}$ & $\mathrm{m}$ & $\mathrm{m}$ & $\mathrm{m}$ & $\mathrm{m}$ & $\mathrm{m}$ & $\mathrm{m}$ & $\mathrm{m}$ & $\mathrm{m}$ & $\mathrm{m}$ & $\mathrm{m}$ & $\mathrm{m}$ & $\mathrm{m}$ & $\mathrm{m}$ & $\mathrm{m}$ & $\mathrm{m}$ \\
\hline & Italy & 7.07 & $(0.08)$ & 7.03 & $(0.08)$ & 6.81 & $(0.06)$ & 6.73 & $(0.07)$ & -0.19 & $(0.07)$ & -0.16 & $(0.07)$ & -0.07 & $(0.01)$ & -0.06 & $(0.01)$ \\
\hline & Japan & 7.01 & $(0.06)$ & 6.87 & $(0.07)$ & 6.82 & $(0.05)$ & 6.53 & $(0.07)$ & -0.35 & $(0.07)$ & -0.31 & $(0.07)$ & -0.08 & $(0.01)$ & -0.07 & $(0.01)$ \\
\hline & Korea & 6.40 & $(0.06)$ & 6.55 & $(0.07)$ & 6.26 & $(0.05)$ & 6.18 & $(0.13)$ & -0.19 & $(0.13)$ & -0.14 & $(0.13)$ & -0.06 & $(0.02)$ & -0.05 & $(0.02)$ \\
\hline & Latvia & 7.44 & $(0.09)$ & 7.65 & $(0.08)$ & 7.41 & $(0.04)$ & 7.06 & $(0.07)$ & -0.41 & $(0.08)$ & -0.43 & $(0.08)$ & -0.08 & $(0.02)$ & -0.09 & $(0.02)$ \\
\hline & Luxembourg & 7.49 & $(0.09)$ & 7.68 & $(0.09)$ & 7.40 & $(0.05)$ & 7.13 & $(0.06)$ & -0.34 & $(0.06)$ & -0.31 & $(0.06)$ & -0.08 & $(0.01)$ & -0.07 & $(0.01)$ \\
\hline & Mexico & 8.20 & $(0.05)$ & 8.38 & $(0.06)$ & 8.37 & $(0.05)$ & 8.25 & $(0.06)$ & -0.05 & $(0.06)$ & -0.08 & $(0.06)$ & 0.01 & $(0.01)$ & 0.00 & $(0.01)$ \\
\hline & Netherlands & 8.05 & $(0.09)$ & 7.92 & $(0.06)$ & 7.87 & $(0.03)$ & 7.66 & $(0.05)$ & -0.25 & (0.05) & -0.25 & $(0.05)$ & -0.06 & $(0.01)$ & -0.06 & $(0.01)$ \\
\hline & New Zealand & $\mathrm{m}$ & $\mathrm{m}$ & $\mathrm{m}$ & $\mathrm{m}$ & $\mathrm{m}$ & $\mathrm{m}$ & $\mathrm{m}$ & $\mathrm{m}$ & $\mathrm{m}$ & $\mathrm{m}$ & $\mathrm{m}$ & $\mathrm{m}$ & $\mathrm{m}$ & $\mathrm{m}$ & $\mathrm{m}$ & $\mathrm{m}$ \\
\hline & Norway & $\mathrm{m}$ & $\mathrm{m}$ & $\mathrm{m}$ & $\mathrm{m}$ & $\mathrm{m}$ & $\mathrm{m}$ & $\mathrm{m}$ & $\mathrm{m}$ & $\mathrm{m}$ & $\mathrm{m}$ & $\mathrm{m}$ & $\mathrm{m}$ & $\mathrm{m}$ & $\mathrm{m}$ & $\mathrm{m}$ & $\mathrm{m}$ \\
\hline & Poland & 7.22 & $(0.10)$ & 7.41 & $(0.09)$ & 7.21 & $(0.05)$ & 6.92 & $(0.09)$ & -0.33 & $(0.10)$ & -0.33 & $(0.10)$ & -0.07 & $(0.02)$ & -0.07 & $(0.02)$ \\
\hline & Portugal & 7.37 & $(0.08)$ & 7.59 & $(0.06)$ & 7.36 & $(0.05)$ & 7.25 & $(0.06)$ & -0.15 & $(0.07)$ & -0.15 & $(0.07)$ & -0.04 & $(0.02)$ & -0.04 & $(0.02)$ \\
\hline & Slovak Republic & 7.61 & $(0.09)$ & 7.59 & $(0.07)$ & 7.54 & $(0.04)$ & 7.18 & $(0.07)$ & -0.39 & $(0.07)$ & -0.38 & $(0.07)$ & -0.07 & $(0.01)$ & -0.08 & $(0.01)$ \\
\hline & Slovenia & 7.60 & $(0.08)$ & 7.44 & $(0.07)$ & 7.06 & $(0.06)$ & 6.76 & $(0.09)$ & -0.51 & $(0.10)$ & -0.51 & $(0.10)$ & -0.15 & $(0.02)$ & -0.15 & $(0.02)$ \\
\hline & Spain & 7.58 & $(0.10)$ & 7.61 & $(0.08)$ & 7.46 & $(0.04)$ & 7.29 & $(0.06)$ & -0.22 & $(0.06)$ & -0.17 & $(0.06)$ & -0.06 & $(0.01)$ & -0.05 & $(0.01)$ \\
\hline & Sweden & $\mathrm{m}$ & $\mathrm{m}$ & $\mathrm{m}$ & $\mathrm{m}$ & $\mathrm{m}$ & $\mathrm{m}$ & $\mathrm{m}$ & $\mathrm{m}$ & $\mathrm{m}$ & $\mathrm{m}$ & $\mathrm{m}$ & $\mathrm{m}$ & $\mathrm{m}$ & $\mathrm{m}$ & $\mathrm{m}$ & $\mathrm{m}$ \\
\hline & Switzerland & 8.04 & $(0.07)$ & 7.78 & $(0.08)$ & 7.73 & $(0.04)$ & 7.40 & $(0.09)$ & -0.39 & $(0.09)$ & -0.37 & $(0.09)$ & -0.10 & $(0.02)$ & -0.09 & $(0.02)$ \\
\hline & Turkey & $\mathrm{m}$ & $\mathrm{m}$ & $\mathrm{m}$ & $\mathrm{m}$ & $\mathrm{m}$ & $\mathrm{m}$ & $\mathrm{m}$ & $\mathrm{m}$ & $\mathrm{m}$ & $\mathrm{m}$ & $\mathrm{m}$ & $\mathrm{m}$ & $\mathrm{m}$ & $\mathrm{m}$ & $\mathrm{m}$ & $\mathrm{m}$ \\
\hline & United Kingdom & 7.13 & $(0.14)$ & 7.44 & $(0.10)$ & 7.17 & $(0.05)$ & 6.60 & $(0.07)$ & -0.62 & $(0.08)$ & -0.58 & $(0.08)$ & -0.14 & $(0.02)$ & -0.14 & $(0.02)$ \\
\hline & United States & $\mathrm{m}$ & $\mathrm{m}$ & $\mathrm{m}$ & $\mathrm{m}$ & $\mathrm{m}$ & $\mathrm{m}$ & $\mathrm{m}$ & $\mathrm{m}$ & $\mathrm{m}$ & $\mathrm{m}$ & $\mathrm{m}$ & $\mathrm{m}$ & $\mathrm{m}$ & $\mathrm{m}$ & $\mathrm{m}$ & $\mathrm{m}$ \\
\hline & OECD average & 7.55 & $(0.02)$ & 7.59 & $(0.02)$ & 7.38 & $(0.01)$ & 7.07 & $(0.02)$ & -0.38 & $(0.02)$ & \begin{tabular}{|l|}
-0.36 \\
\end{tabular} & $(0.02)$ & -0.09 & $(0.00)$ & -0.09 & $(0.00)$ \\
\hline 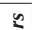 & Albania & $\mathrm{m}$ & $\mathrm{m}$ & $\mathrm{m}$ & $\mathrm{m}$ & $\mathrm{m}$ & $\mathrm{m}$ & $\mathrm{m}$ & $\mathrm{m}$ & $\mathrm{m}$ & $\mathrm{m}$ & $\mathrm{m}$ & $\mathrm{m}$ & $\mathrm{m}$ & $\mathrm{m}$ & $\mathrm{m}$ & $\mathrm{m}$ \\
\hline & Algeria & $\mathrm{m}$ & $\mathrm{m}$ & $\mathrm{m}$ & $\mathrm{m}$ & $\mathrm{m}$ & $\mathrm{m}$ & $\mathrm{m}$ & $\mathrm{m}$ & $\mathrm{m}$ & $\mathrm{m}$ & $\mathrm{m}$ & $\mathrm{m}$ & $\mathrm{m}$ & $\mathrm{m}$ & $\mathrm{m}$ & $\mathrm{m}$ \\
\hline & Brazil & 7.60 & $(0.06)$ & 7.83 & $(0.07)$ & 7.61 & $(0.05)$ & 7.39 & $(0.06)$ & -0.25 & $(0.06)$ & -0.26 & $(0.06)$ & -0.05 & $(0.01)$ & -0.06 & $(0.01)$ \\
\hline & B-S-J-G (China) & 6.93 & $(0.06)$ & 6.90 & $(0.08)$ & 6.70 & $(0.06)$ & 6.77 & $(0.10)$ & -0.08 & $(0.10)$ & -0.08 & $(0.10)$ & -0.04 & $(0.02)$ & -0.04 & $(0.02)$ \\
\hline & Bulgaria & 7.53 & $(0.11)$ & 7.51 & $(0.09)$ & 7.40 & $(0.06)$ & 7.38 & $(0.06)$ & -0.06 & $(0.08)$ & -0.05 & $(0.08)$ & -0.02 & $(0.02)$ & -0.03 & $(0.02)$ \\
\hline & CABA (Argentina) & $\mathrm{m}$ & $\mathrm{m}$ & $\mathrm{m}$ & $\mathrm{m}$ & $\mathrm{m}$ & $\mathrm{m}$ & $\mathrm{m}$ & $\mathrm{m}$ & $\mathrm{m}$ & $\mathrm{m}$ & $\mathrm{m}$ & $\mathrm{m}$ & $\mathrm{m}$ & $\mathrm{m}$ & $\mathrm{m}$ & $\mathrm{m}$ \\
\hline & Colombia & 8.00 & $(0.07)$ & 8.08 & $(0.07)$ & 7.88 & $(0.06)$ & 7.59 & $(0.06)$ & -0.38 & $(0.06)$ & -0.34 & $(0.07)$ & -0.07 & $(0.01)$ & -0.07 & $(0.01)$ \\
\hline & Costa Rica & 8.38 & $(0.07)$ & 8.45 & $(0.09)$ & 8.14 & $(0.06)$ & 8.07 & $(0.05)$ & -0.21 & $(0.06)$ & -0.23 & $(0.07)$ & -0.05 & $(0.01)$ & -0.06 & $(0.01)$ \\
\hline & Croatia & 8.22 & $(0.09)$ & 8.07 & $(0.07)$ & 7.89 & $(0.05)$ & 7.68 & $(0.07)$ & -0.30 & $(0.08)$ & -0.29 & $(0.08)$ & -0.08 & $(0.01)$ & -0.08 & $(0.01)$ \\
\hline & Cyprus* & $\mathrm{m}$ & $\mathrm{m}$ & $\mathrm{m}$ & $\mathrm{m}$ & $\mathrm{m}$ & $\mathrm{m}$ & $\mathrm{m}$ & $\mathrm{m}$ & $\mathrm{m}$ & $\mathrm{m}$ & $\mathrm{m}$ & $\mathrm{m}$ & $\mathrm{m}$ & $\mathrm{m}$ & $\mathrm{m}$ & $\mathrm{m}$ \\
\hline & Dominican Republic & 8.49 & $(0.08)$ & 8.57 & $(0.10)$ & 8.35 & $(0.08)$ & 8.49 & $(0.08)$ & 0.04 & $(0.09)$ & 0.04 & $(0.09)$ & 0.00 & $(0.02)$ & 0.00 & $(0.02)$ \\
\hline & FYROM & $\mathrm{m}$ & $\mathrm{m}$ & $\mathrm{m}$ & $\mathrm{m}$ & $\mathrm{m}$ & $\mathrm{m}$ & $\mathrm{m}$ & $\mathrm{m}$ & $\mathrm{m}$ & $\mathrm{m}$ & $\mathrm{m}$ & $\mathrm{m}$ & $\mathrm{m}$ & $\mathrm{m}$ & $\mathrm{m}$ & $\mathrm{m}$ \\
\hline & Georgia & $\mathrm{m}$ & $\mathrm{m}$ & $\mathrm{m}$ & $\mathrm{m}$ & $\mathrm{m}$ & $\mathrm{m}$ & $\mathrm{m}$ & $\mathrm{m}$ & $\mathrm{m}$ & $\mathrm{m}$ & $\mathrm{m}$ & $\mathrm{m}$ & $\mathrm{m}$ & $\mathrm{m}$ & $\mathrm{m}$ & $\mathrm{m}$ \\
\hline & Hong Kong (China) & 6.55 & $(0.07)$ & 6.71 & $(0.08)$ & 6.58 & $(0.05)$ & 6.15 & $(0.07)$ & -0.44 & $(0.07)$ & -0.41 & $(0.07)$ & -0.09 & $(0.01)$ & -0.08 & $(0.01)$ \\
\hline & Indonesia & $\mathrm{m}$ & $\mathrm{m}$ & $\mathrm{m}$ & $\mathrm{m}$ & $\mathrm{m}$ & $\mathrm{m}$ & $\mathrm{m}$ & $\mathrm{m}$ & $\mathrm{m}$ & $\mathrm{m}$ & $\mathrm{m}$ & $\mathrm{m}$ & $\mathrm{m}$ & $\mathrm{m}$ & $\mathrm{m}$ & $\mathrm{m}$ \\
\hline & Jordan & $\mathrm{m}$ & $\mathrm{m}$ & $\mathrm{m}$ & $\mathrm{m}$ & $\mathrm{m}$ & $\mathrm{m}$ & $\mathrm{m}$ & $\mathrm{m}$ & $\mathrm{m}$ & $\mathrm{m}$ & $\mathrm{m}$ & $\mathrm{m}$ & $\mathrm{m}$ & $\mathrm{m}$ & $\mathrm{m}$ & $\mathrm{m}$ \\
\hline & Kosovo & $\mathrm{m}$ & $\mathrm{m}$ & $\mathrm{m}$ & $\mathrm{m}$ & $\mathrm{m}$ & $\mathrm{m}$ & $\mathrm{m}$ & $\mathrm{m}$ & $\mathrm{m}$ & $\mathrm{m}$ & $\mathrm{m}$ & $\mathrm{m}$ & $\mathrm{m}$ & $\mathrm{m}$ & $\mathrm{m}$ & $\mathrm{m}$ \\
\hline & Lebanon & $\mathrm{m}$ & $\mathrm{m}$ & $\mathrm{m}$ & $\mathrm{m}$ & $\mathrm{m}$ & $\mathrm{m}$ & $\mathrm{m}$ & $\mathrm{m}$ & $\mathrm{m}$ & $\mathrm{m}$ & $\mathrm{m}$ & $\mathrm{m}$ & $\mathrm{m}$ & $\mathrm{m}$ & $\mathrm{m}$ & $\mathrm{m}$ \\
\hline & Lithuania & 7.90 & $(0.08)$ & 8.06 & $(0.07)$ & 7.92 & $(0.05)$ & 7.54 & $(0.08)$ & -0.41 & $(0.09)$ & -0.43 & $(0.09)$ & -0.07 & $(0.02)$ & -0.08 & $(0.02)$ \\
\hline & Macao (China) & 6.55 & $(0.09)$ & 6.73 & $(0.11)$ & 6.66 & $(0.05)$ & 6.48 & $(0.06)$ & -0.17 & $(0.07)$ & -0.15 & $(0.07)$ & -0.04 & $(0.02)$ & -0.04 & $(0.02)$ \\
\hline & Malta & $\mathrm{m}$ & $\mathrm{m}$ & $\mathrm{m}$ & $\mathrm{m}$ & $\mathrm{m}$ & $\mathrm{m}$ & $\mathrm{m}$ & $\mathrm{m}$ & $\mathrm{m}$ & $\mathrm{m}$ & $\mathrm{m}$ & $\mathrm{m}$ & $\mathrm{m}$ & $\mathrm{m}$ & $\mathrm{m}$ & $\mathrm{m}$ \\
\hline & Moldova & $\mathrm{m}$ & $\mathrm{m}$ & $\mathrm{m}$ & $\mathrm{m}$ & $\mathrm{m}$ & $\mathrm{m}$ & $\mathrm{m}$ & $\mathrm{m}$ & $\mathrm{m}$ & $\mathrm{m}$ & $\mathrm{m}$ & $\mathrm{m}$ & $\mathrm{m}$ & $\mathrm{m}$ & $\mathrm{m}$ & $\mathrm{m}$ \\
\hline & Montenegro & $\mathrm{m}$ & $\mathrm{m}$ & $\mathrm{m}$ & $\mathrm{m}$ & $\mathrm{m}$ & $\mathrm{m}$ & $\mathrm{m}$ & $\mathrm{m}$ & $\mathrm{m}$ & $\mathrm{m}$ & $\mathrm{m}$ & $\mathrm{m}$ & $\mathrm{m}$ & $\mathrm{m}$ & $\mathrm{m}$ & $\mathrm{m}$ \\
\hline & Peru & 7.65 & $(0.06)$ & 7.62 & $(0.07)$ & 7.46 & $(0.06)$ & 7.35 & $(0.09)$ & -0.23 & $(0.09)$ & -0.18 & $(0.09)$ & -0.05 & $(0.02)$ & -0.05 & $(0.02)$ \\
\hline & Qatar & $\mathrm{m}$ & $\mathrm{m}$ & $\mathrm{m}$ & $\mathrm{m}$ & $\mathrm{m}$ & $\mathrm{m}$ & $\mathrm{m}$ & $\mathrm{m}$ & $\mathrm{m}$ & $\mathrm{m}$ & $\mathrm{m}$ & $\mathrm{m}$ & $\mathrm{m}$ & $\mathrm{m}$ & $\mathrm{m}$ & $\mathrm{m}$ \\
\hline & Romania & $\mathrm{m}$ & $\mathrm{m}$ & $\mathrm{m}$ & $\mathrm{m}$ & $\mathrm{m}$ & $\mathrm{m}$ & $\mathrm{m}$ & $\mathrm{m}$ & $\mathrm{m}$ & $\mathrm{m}$ & $\mathrm{m}$ & $\mathrm{m}$ & $\mathrm{m}$ & $\mathrm{m}$ & $\mathrm{m}$ & $\mathrm{m}$ \\
\hline & Russia & 7.99 & $(0.08)$ & 8.06 & $(0.06)$ & 7.87 & $(0.05)$ & 7.40 & $(0.07)$ & -0.52 & $(0.06)$ & -0.53 & $(0.06)$ & -0.11 & $(0.01)$ & -0.11 & $(0.01)$ \\
\hline & Sing & $\mathrm{m}$ & $\mathrm{m}$ & $\mathrm{m}$ & $\mathrm{m}$ & $\mathrm{m}$ & $\mathrm{m}$ & $\mathrm{m}$ & $\mathrm{m}$ & $\mathrm{m}$ & $\mathrm{m}$ & $\mathrm{m}$ & $\mathrm{m}$ & $\mathrm{m}$ & $\mathrm{m}$ & $\mathrm{m}$ & $\mathrm{m}$ \\
\hline & Chinese Taipei & 6.73 & $(0.08)$ & 6.78 & $(0.06)$ & 6.60 & $(0.04)$ & 6.45 & $(0.05)$ & -0.22 & $(0.05)$ & -0.16 & $(0.05)$ & -0.05 & $(0.01)$ & -0.04 & $(0.01)$ \\
\hline & Thailand & 7.74 & $(0.08)$ & 7.93 & $(0.08)$ & 7.83 & $(0.04)$ & 7.50 & $(0.06)$ & -0.32 & $(0.07)$ & -0.30 & $(0.07)$ & -0.06 & $(0.01)$ & -0.06 & $(0.01)$ \\
\hline & Trinidad and Tobago & $\mathrm{m}$ & $\mathrm{m}$ & $\mathrm{m}$ & $\mathrm{m}$ & $\mathrm{m}$ & $\mathrm{m}$ & $\mathrm{m}$ & $\mathrm{m}$ & $\mathrm{m}$ & $\mathrm{m}$ & $\mathrm{m}$ & $\mathrm{m}$ & $\mathrm{m}$ & $\mathrm{m}$ & $\mathrm{m}$ & $\mathrm{m}$ \\
\hline & Tunisia & $\mathrm{m}$ & $\mathrm{m}$ & $\mathrm{m}$ & $\mathrm{m}$ & $\mathrm{m}$ & $\mathrm{m}$ & $\mathrm{m}$ & $\mathrm{m}$ & $\mathrm{m}$ & $\mathrm{m}$ & $\mathrm{m}$ & $\mathrm{m}$ & $\mathrm{m}$ & $\mathrm{m}$ & $\mathrm{m}$ & $\mathrm{m}$ \\
\hline & Arab Emirates & $\mathrm{m}$ & $\mathrm{m}$ & $\mathrm{m}$ & $\mathrm{m}$ & $\mathrm{m}$ & $\mathrm{m}$ & $\mathrm{m}$ & $\mathrm{m}$ & $\mathrm{m}$ & $\mathrm{m}$ & $\mathrm{m}$ & $\mathrm{m}$ & $\mathrm{m}$ & $\mathrm{m}$ & $\mathrm{m}$ & $\mathrm{m}$ \\
\hline & Uruguay & 7.64 & $(0.07)$ & 7.75 & $(0.10)$ & 7.84 & $(0.05)$ & 7.57 & $(0.06)$ & -0.19 & $(0.06)$ & -0.23 & $(0.07)$ & -0.02 & $(0.01)$ & -0.04 & $(0.01)$ \\
\hline & Viet Nam & $\mathrm{m}$ & $\mathrm{m}$ & $\mathrm{m}$ & $\mathrm{m}$ & $\mathrm{m}$ & $\mathrm{m}$ & $\mathrm{m}$ & $\mathrm{m}$ & $\mathrm{m}$ & $\mathrm{m}$ & $\mathrm{m}$ & $\mathrm{m}$ & $\mathrm{m}$ & $\mathrm{m}$ & $\mathrm{m}$ & $\mathrm{m}$ \\
\hline & $\mathrm{Ar}$ & $\mathrm{m}$ & $\mathrm{m}$ & $\mathrm{m}$ & $\mathrm{m}$ & $\mathrm{m}$ & $\mathrm{m}$ & $\mathrm{m}$ & $\mathrm{m}$ & $\mathrm{m}$ & $\mathrm{m}$ & $\mathrm{m}$ & $\mathrm{m}$ & $\mathrm{m}$ & $\mathrm{m}$ & $\mathrm{m}$ & $\mathrm{m}$ \\
\hline & Kazakhstan** & $\mathrm{m}$ & $\mathrm{m}$ & $\mathrm{m}$ & $\mathrm{m}$ & $\mathrm{m}$ & $\mathrm{m}$ & $\mathrm{m}$ & $\mathrm{m}$ & $\mathrm{m}$ & $\mathrm{m}$ & $\mathrm{m}$ & $\mathrm{m}$ & $\mathrm{m}$ & $\mathrm{m}$ & $\mathrm{m}$ & $\mathrm{m}$ \\
\hline & Malaysia** & $\mathrm{m}$ & $\mathrm{m}$ & $\mathrm{m}$ & $\mathrm{m}$ & $\mathrm{m}$ & $\mathrm{m}$ & $\mathrm{m}$ & $\mathrm{m}$ & $\mathrm{m}$ & $\mathrm{m}$ & $\mathrm{m}$ & $\mathrm{m}$ & $\mathrm{m}$ & $\mathrm{m}$ & $\mathrm{m}$ & $\mathrm{m}$ \\
\hline
\end{tabular}

Note: Values that are statistically significant are indicated in bold (see Annex A3).

* See note at the beginning of this Annex.

mparability (see Annex A4)

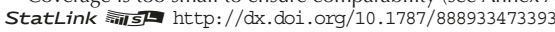


[Part 1/1]

Table III.13.24a Time spent on the Internet outside of school on weekdays and performance in science

Results based on students' self-reports

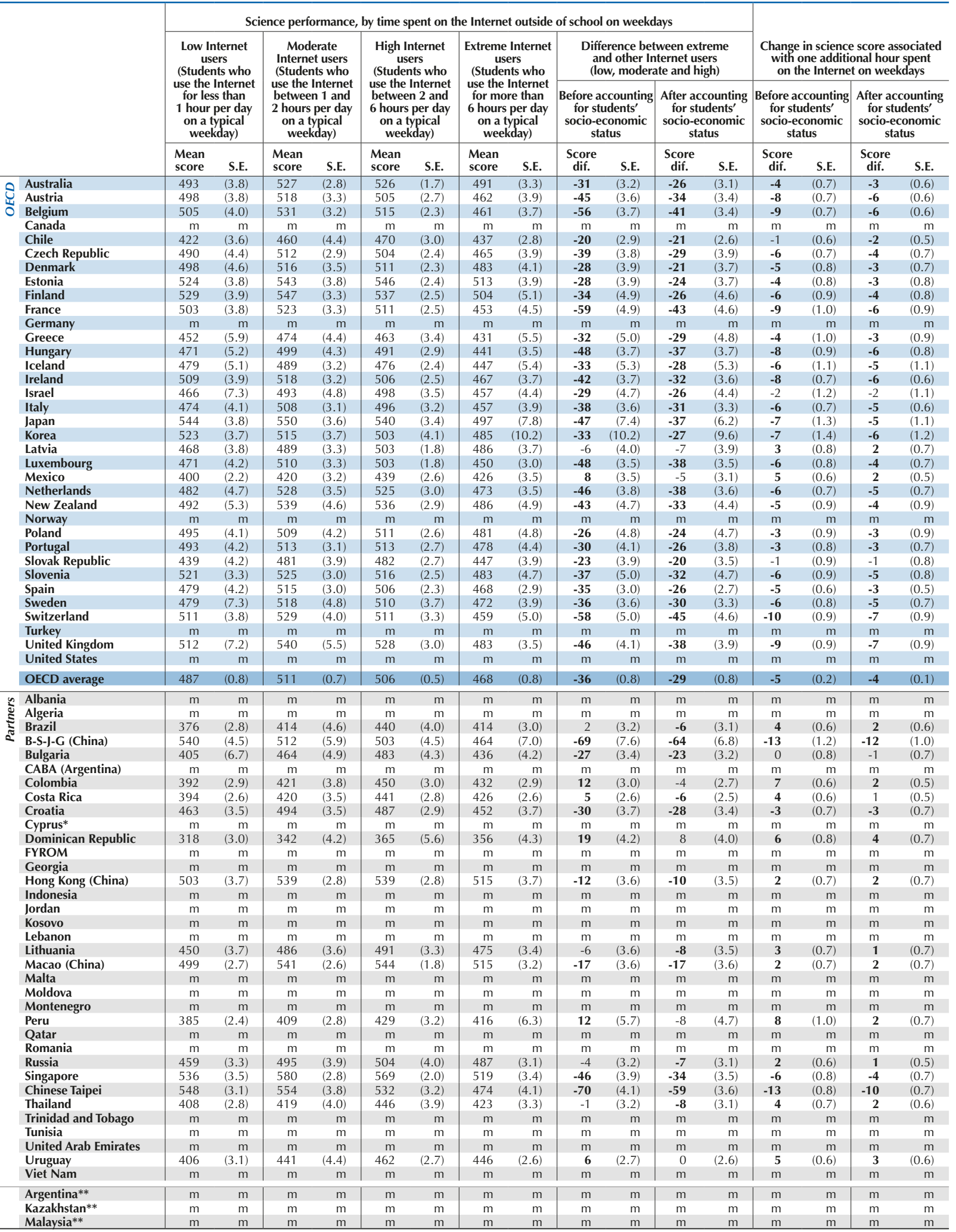

Note: Values that are statistically significant are indicated in bold (see Annex A3).

* See note at the beginning of this Annex.

** Coverage is too small to ensure comparability (see Annex A4).

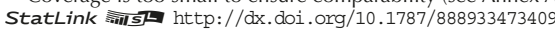


[Part 1/1]

Table III.13.25a Time spent on the Internet outside of school on weekend days and performance in science

Results based on students' self-reports

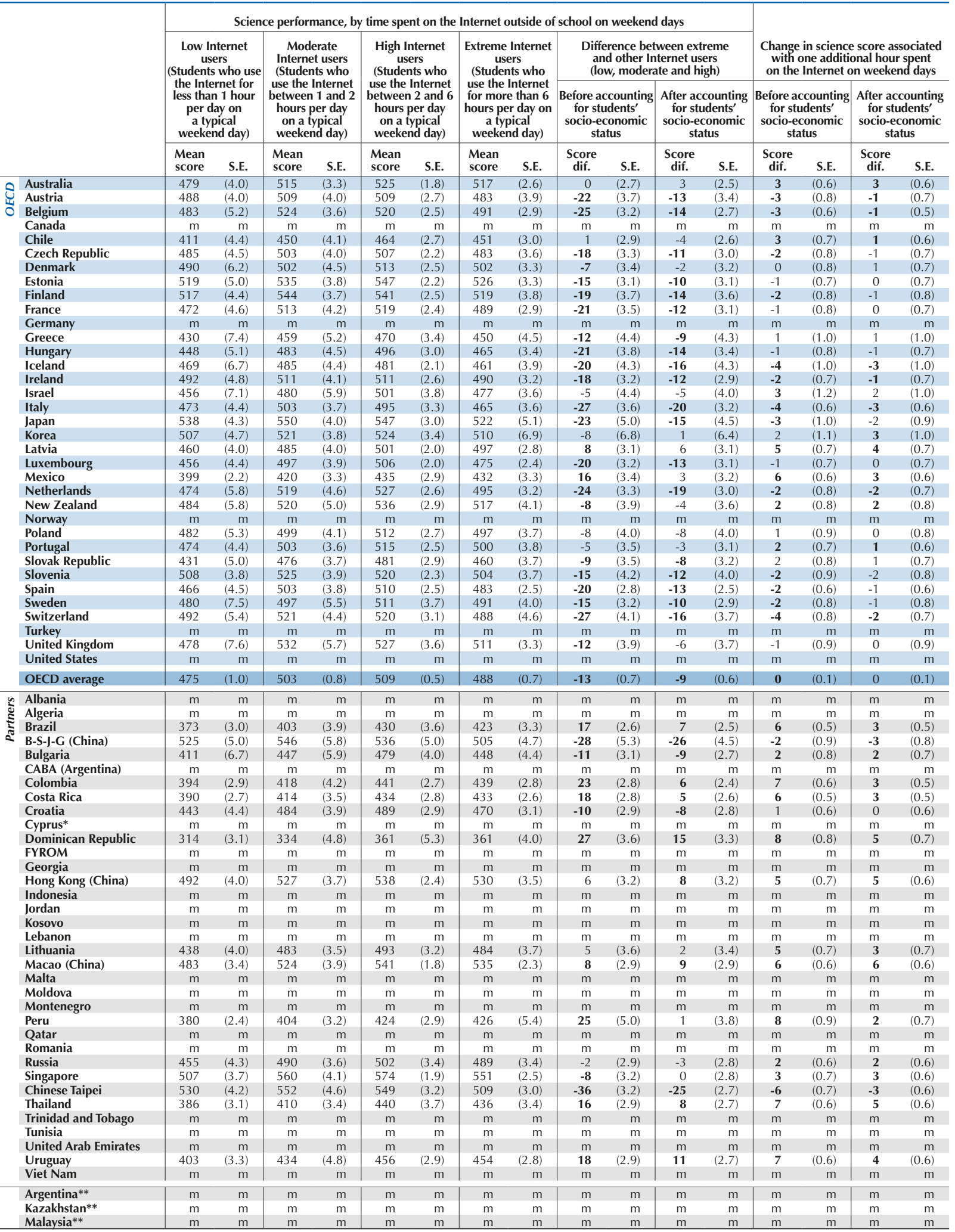

Note: Values that are statistically significant are indicated in bold (see Annex A3).

* See note at the beginning of this Annex.

** Coverage is too small to ensure comparability (see Annex A4).

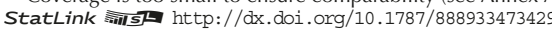


ANNEX B2

RESULTS FOR REGIONS WITHIN COUNTRIES

\section{Table B2.III.1 Regional differences in life satisfaction}

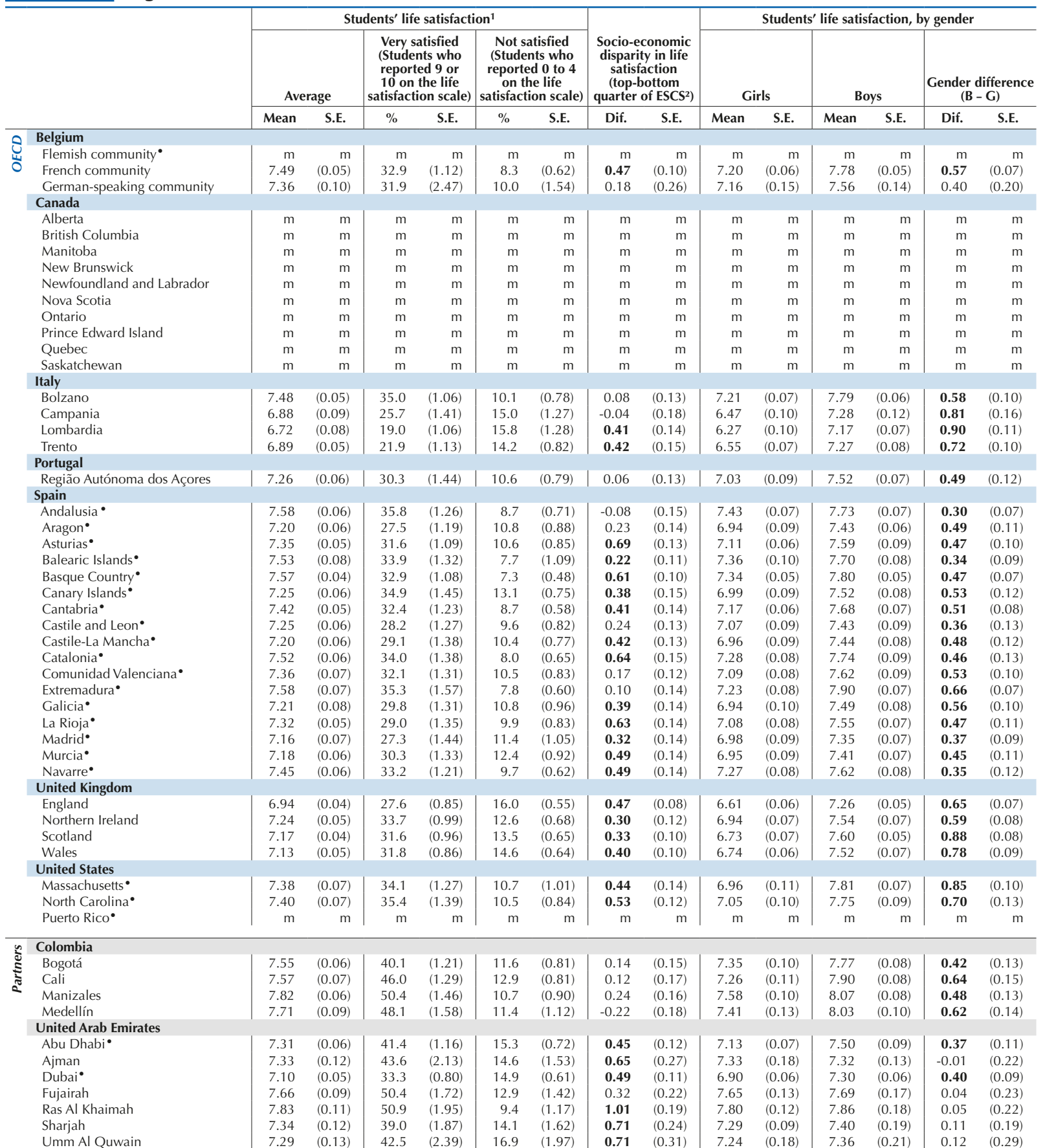

PISA adjudicated region.

1. PISA 2015 asked students to rate their overall satisfaction with life on a scale that ranges from 0 to 10

2. ESCS refers to the PISA index of economic, social and cultural status.

3. An extreme Internet user is a student who uses the Internet for more than 6 hours per day on a typical weekday.

Notes: Values that are statistically significant are indicated in bold (see Annex A3).

Results for the province of Quebec in this table should be treated with caution due to a possible non-response bias.

For Massachusetts and North Carolina, the desired target population covers 15-year-old students in grade 7 or above in public schools only (see Annex A2).

Puerto Rico is an unincorporated territory of the United States. As such, PISA results for the United States do not include Puerto Rico.

See Tables III.3.1, III.3.2, III.3.4, III.3.7, III.4.9, III.10.9 and III.13.23 for national data.

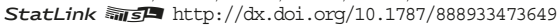


[Part 2/4]

Table B2.III.1 Regional differences in life satisfaction

\begin{tabular}{|c|c|c|c|c|c|c|c|c|c|c|c|c|c|c|c|}
\hline & & \multicolumn{8}{|c|}{$\begin{array}{l}\text { Students' life satisfaction, } \\
\text { by immigrant background }\end{array}$} & \multicolumn{6}{|c|}{$\begin{array}{c}\text { Average life satisfaction, } \\
\text { by quarters of science performance }\end{array}$} \\
\hline & & \multicolumn{2}{|c|}{$\begin{array}{c}\text { Non-immigrant } \\
\text { students }\end{array}$} & \multicolumn{2}{|c|}{$\begin{array}{c}\text { First-generation } \\
\text { immigrant } \\
\text { students }\end{array}$} & \multicolumn{2}{|c|}{$\begin{array}{c}\text { Second- } \\
\text { generation } \\
\text { immigrant } \\
\text { students }\end{array}$} & \multicolumn{2}{|c|}{$\begin{array}{c}\text { Difference } \\
\text { by migrant status } \\
\text { (non-immigrant - } \\
\text { first-generation) }\end{array}$} & \multicolumn{2}{|c|}{ Bottom quarter } & \multicolumn{2}{|c|}{ Top quarter } & \multicolumn{2}{|c|}{$\begin{array}{l}\text { Top - bottom } \\
\text { quarter }\end{array}$} \\
\hline & & Mean & S.E. & Mean & S.E. & Mean & S.E. & Dif. & S.E. & Mean & S.E. & Mean & S.E. & Dif. & S.E. \\
\hline$\theta$ & Belgium & & & & & & & & & & & & & & \\
\hline تي山ّ & Flemish community• & $\mathrm{m}$ & $\mathrm{m}$ & $\mathrm{m}$ & $\mathrm{m}$ & $\mathrm{m}$ & $\mathrm{m}$ & $\mathrm{m}$ & $\mathrm{m}$ & $\mathrm{m}$ & $\mathrm{m}$ & $\mathrm{m}$ & $\mathrm{m}$ & $\mathrm{m}$ & \\
\hline & French community & 7.51 & $(0.05)$ & 7.40 & $(0.13)$ & 7.60 & $(0.13)$ & 0.10 & $(0.14)$ & 7.35 & $(0.12)$ & 7.60 & $(0.07)$ & 0.25 & $(0.14)$ \\
\hline & German-speaking community & 7.46 & $(0.10)$ & 7.21 & $(0.32)$ & 6.84 & $(0.74)$ & 0.25 & $(0.33)$ & 7.21 & $(0.31)$ & 7.50 & $(0.20)$ & 0.29 & $(0.36)$ \\
\hline & Canada & & & & & & & & & & & & & & \\
\hline & Alberta & $\mathrm{m}$ & $\mathrm{m}$ & $\mathrm{m}$ & $\mathrm{m}$ & $\mathrm{m}$ & $\mathrm{m}$ & $\mathrm{m}$ & $\mathrm{m}$ & $\mathrm{m}$ & $\mathrm{m}$ & $\mathrm{m}$ & $\mathrm{m}$ & $\mathrm{m}$ & $\mathrm{m}$ \\
\hline & British Columbia & $\mathrm{m}$ & $\mathrm{m}$ & $\mathrm{m}$ & $\mathrm{m}$ & $\mathrm{m}$ & $\mathrm{m}$ & $\mathrm{m}$ & $\mathrm{m}$ & $\mathrm{m}$ & $\mathrm{m}$ & $\mathrm{m}$ & $\mathrm{m}$ & $\mathrm{m}$ & $\mathrm{m}$ \\
\hline & Manitoba & $\mathrm{m}$ & $\mathrm{m}$ & $\mathrm{m}$ & $\mathrm{m}$ & $\mathrm{m}$ & $\mathrm{m}$ & $\mathrm{m}$ & $\mathrm{m}$ & $\mathrm{m}$ & $\mathrm{m}$ & $\mathrm{m}$ & $\mathrm{m}$ & $\mathrm{m}$ & $\mathrm{m}$ \\
\hline & New Brunswick & $\mathrm{m}$ & $\mathrm{m}$ & $\mathrm{m}$ & $\mathrm{m}$ & $\mathrm{m}$ & $\mathrm{m}$ & $\mathrm{m}$ & $\mathrm{m}$ & $\mathrm{m}$ & $\mathrm{m}$ & $\mathrm{m}$ & $\mathrm{m}$ & $\mathrm{m}$ & $\mathrm{m}$ \\
\hline & Newfoundland and Labrador & $\mathrm{m}$ & $\mathrm{m}$ & $\mathrm{m}$ & $\mathrm{m}$ & $\mathrm{m}$ & $\mathrm{m}$ & $\mathrm{m}$ & $\mathrm{m}$ & $\mathrm{m}$ & $\mathrm{m}$ & $\mathrm{m}$ & $\mathrm{m}$ & $\mathrm{m}$ & $\mathrm{m}$ \\
\hline & Nova Scotia & $\mathrm{m}$ & $\mathrm{m}$ & $\mathrm{m}$ & $\mathrm{m}$ & $\mathrm{m}$ & $\mathrm{m}$ & $\mathrm{m}$ & $\mathrm{m}$ & $\mathrm{m}$ & $\mathrm{m}$ & $\mathrm{m}$ & $\mathrm{m}$ & $\mathrm{m}$ & $\mathrm{m}$ \\
\hline & Ontario & $\mathrm{m}$ & $\mathrm{m}$ & $\mathrm{m}$ & $\mathrm{m}$ & $\mathrm{m}$ & $\mathrm{m}$ & $\mathrm{m}$ & $\mathrm{m}$ & $\mathrm{m}$ & $\mathrm{m}$ & $\mathrm{m}$ & $\mathrm{m}$ & $\mathrm{m}$ & $\mathrm{m}$ \\
\hline & Prince Edward Island & $\mathrm{m}$ & $\mathrm{m}$ & $\mathrm{m}$ & $\mathrm{m}$ & $\mathrm{m}$ & $\mathrm{m}$ & $\mathrm{m}$ & $\mathrm{m}$ & $\mathrm{m}$ & $\mathrm{m}$ & $\mathrm{m}$ & $\mathrm{m}$ & $\mathrm{m}$ & $\mathrm{m}$ \\
\hline & Quebec & $\mathrm{m}$ & $\mathrm{m}$ & $\mathrm{m}$ & $\mathrm{m}$ & $\mathrm{m}$ & $\mathrm{m}$ & $\mathrm{m}$ & $\mathrm{m}$ & $\mathrm{m}$ & $\mathrm{m}$ & $\mathrm{m}$ & $\mathrm{m}$ & $\mathrm{m}$ & $\mathrm{m}$ \\
\hline & Saskatchewan & $\mathrm{m}$ & $\mathrm{m}$ & $\mathrm{m}$ & $\mathrm{m}$ & $\mathrm{m}$ & $\mathrm{m}$ & $\mathrm{m}$ & $\mathrm{m}$ & $\mathrm{m}$ & $\mathrm{m}$ & $\mathrm{m}$ & $\mathrm{m}$ & $\mathrm{m}$ & $\mathrm{m}$ \\
\hline & Italy & & & & & & & & & & & & & & \\
\hline & Bolzano & 7.53 & $(0.05)$ & 7.11 & $(0.27)$ & 6.59 & $(0.40)$ & 0.43 & $(0.27)$ & 7.37 & $(0.12)$ & 7.65 & $(0.09)$ & 0.28 & $(0.14)$ \\
\hline & Campania & 6.89 & $(0.09)$ & 6.51 & $(1.22)$ & 7.01 & $(0.58)$ & 0.37 & $(1.25)$ & 6.95 & $(0.20)$ & 6.96 & $(0.12)$ & 0.02 & $(0.23)$ \\
\hline & Lombardia & 6.81 & $(0.07)$ & 6.18 & $(0.22)$ & 6.23 & $(0.28)$ & 0.63 & $(0.23)$ & 6.44 & $(0.18)$ & 6.98 & $(0.13)$ & 0.54 & $(0.21)$ \\
\hline & Trento & 6.95 & $(0.06)$ & 6.27 & $(0.20)$ & 6.41 & $(0.24)$ & 0.68 & $(0.21)$ & 6.62 & $(0.14)$ & 7.14 & $(0.13)$ & 0.52 & $(0.19)$ \\
\hline & Portugal & & & & & & & & & & & & & & \\
\hline & Região Autónoma dos Açores & 7.26 & $(0.05)$ & 6.95 & $(0.69)$ & 7.40 & $(0.67)$ & 0.31 & $(0.69)$ & 7.38 & $(0.13)$ & 7.27 & $(0.15)$ & -0.11 & $(0.19)$ \\
\hline & Spain & & & & & & & & & & & & & & \\
\hline & Andalusia • & 7.60 & $(0.06)$ & 6.84 & $(0.29)$ & 7.56 & $(0.44)$ & 0.76 & $(0.30)$ & 7.82 & $(0.15)$ & 7.50 & $(0.12)$ & -0.32 & $(0.21)$ \\
\hline & Aragon` & 7.27 & $(0.06)$ & 6.76 & $(0.17)$ & 7.32 & $(0.40)$ & 0.51 & $(0.18)$ & 7.03 & $(0.12)$ & 7.36 & $(0.10)$ & 0.33 & $(0.16)$ \\
\hline & Asturias $\bullet$ & 7.40 & $(0.06)$ & 6.72 & $(0.24)$ & 6.66 & $(0.36)$ & 0.68 & $(0.26)$ & 7.09 & $(0.15)$ & 7.69 & $(0.11)$ & 0.60 & $(0.20)$ \\
\hline & Balearic Islands ${ }^{\bullet}$ & 7.60 & $(0.08)$ & 7.33 & $(0.16)$ & 7.10 & $(0.23)$ & 0.28 & $(0.16)$ & 7.55 & $(0.14)$ & 7.63 & $(0.10)$ & 0.08 & $(0.16)$ \\
\hline & Basque Country & 7.65 & $(0.04)$ & 6.64 & $(0.14)$ & 7.35 & $(0.71)$ & 1.01 & $(0.14)$ & 7.28 & $(0.10)$ & 7.83 & $(0.06)$ & 0.55 & $(0.11)$ \\
\hline & Canary Islands ${ }^{\bullet}$ & 7.28 & $(0.07)$ & 6.96 & $(0.18)$ & 7.23 & $(0.31)$ & 0.32 & $(0.21)$ & 7.30 & $(0.17)$ & 7.24 & $(0.11)$ & -0.06 & $(0.20)$ \\
\hline & Cantabria• & 7.45 & $(0.05)$ & 7.21 & $(0.18)$ & 7.29 & $(0.52)$ & 0.24 & $(0.18)$ & 7.43 & $(0.11)$ & 7.48 & $(0.10)$ & 0.05 & $(0.15)$ \\
\hline & Castile and Leon $\bullet$ & 7.32 & $(0.06)$ & 6.38 & $(0.20)$ & 6.84 & $(0.57)$ & 0.94 & $(0.20)$ & 7.08 & $(0.14)$ & 7.55 & $(0.09)$ & 0.46 & $(0.17)$ \\
\hline & Castile-La Mancha • & 7.24 & $(0.07)$ & 6.78 & $(0.25)$ & 6.63 & $(0.55)$ & 0.46 & $(0.25)$ & 7.10 & $(0.14)$ & 7.43 & $(0.09)$ & 0.33 & $(0.17)$ \\
\hline & Catalonia $\bullet$ & 7.64 & $(0.07)$ & 6.91 & $(0.10)$ & 7.60 & $(0.24)$ & 0.72 & $(0.11)$ & 7.16 & $(0.12)$ & 7.78 & $(0.10)$ & 0.62 & $(0.15)$ \\
\hline & Comunidad Valenciana ${ }^{\bullet}$ & 7.42 & $(0.07)$ & 7.08 & $(0.23)$ & 6.84 & $(0.53)$ & 0.34 & $(0.25)$ & 7.37 & $(0.18)$ & 7.40 & $(0.11)$ & 0.04 & $(0.22)$ \\
\hline & Extremadura ${ }^{\bullet}$ & 7.60 & $(0.07)$ & 6.54 & $(0.47)$ & 5.27 & $(1.50)$ & 1.07 & $(0.47)$ & 7.81 & $(0.14)$ & 7.52 & $(0.12)$ & -0.29 & $(0.20)$ \\
\hline & Galicia• & 7.23 & $(0.08)$ & 6.92 & $(0.24)$ & 6.79 & $(0.57)$ & 0.31 & $(0.25)$ & 7.21 & $(0.12)$ & 7.41 & $(0.11)$ & 0.20 & $(0.15)$ \\
\hline & La Rioja• & 7.45 & $(0.06)$ & 6.61 & $(0.18)$ & 6.49 & $(0.52)$ & 0.83 & $(0.20)$ & 7.19 & $(0.15)$ & 7.46 & $(0.11)$ & 0.27 & $(0.19)$ \\
\hline & Madrid• & 7.27 & $(0.08)$ & 6.70 & $(0.18)$ & 6.64 & $(0.21)$ & 0.57 & $(0.19)$ & 6.96 & $(0.15)$ & 7.42 & $(0.11)$ & 0.46 & $(0.17)$ \\
\hline & Murcia ${ }^{\bullet}$ & 7.28 & $(0.06)$ & 6.66 & $(0.19)$ & 7.11 & $(0.47)$ & 0.62 & $(0.20)$ & 7.15 & $(0.16)$ & 7.28 & $(0.11)$ & 0.12 & $(0.18)$ \\
\hline & Navarre ${ }^{\bullet}$ & 7.58 & $(0.06)$ & 6.75 & $(0.19)$ & 5.97 & $(0.44)$ & 0.83 & $(0.21)$ & 7.24 & $(0.14)$ & 7.69 & $(0.11)$ & 0.45 & $(0.20)$ \\
\hline & United Kingdom & & & & & & & & & & & & & & \\
\hline & England & 7.00 & $(0.05)$ & 6.68 & $(0.11)$ & 6.75 & $(0.17)$ & 0.32 & $(0.12)$ & 6.86 & $(0.10)$ & 6.99 & $(0.08)$ & 0.12 & $(0.13)$ \\
\hline & Northern Ireland & 7.24 & $(0.06)$ & 7.25 & $(0.12)$ & 6.96 & $(0.58)$ & -0.01 & $(0.14)$ & 7.09 & $(0.11)$ & 7.16 & $(0.11)$ & 0.07 & $(0.14)$ \\
\hline & Scotland & 7.17 & $(0.04)$ & 7.24 & $(0.23)$ & 6.36 & $(0.33)$ & -0.07 & $(0.23)$ & 7.28 & $(0.10)$ & 7.13 & $(0.09)$ & -0.15 & $(0.13)$ \\
\hline & Wales & 7.15 & $(0.05)$ & 7.07 & $(0.22)$ & 6.97 & $(0.22)$ & 0.08 & $(0.22)$ & 7.02 & $(0.11)$ & 7.29 & $(0.09)$ & 0.26 & $(0.14)$ \\
\hline & United States & & & & & & & & & & & & & & \\
\hline & Massachusetts ${ }^{\bullet}$ & $\mathrm{m}$ & $\mathrm{m}$ & $\mathrm{m}$ & $\mathrm{m}$ & $\mathrm{m}$ & $\mathrm{m}$ & $\mathrm{m}$ & $\mathrm{m}$ & $\mathrm{m}$ & $\mathrm{m}$ & $\mathrm{m}$ & $\mathrm{m}$ & $\mathrm{m}$ & $\mathrm{m}$ \\
\hline & North Carolina ${ }^{\bullet}$ & $\mathrm{m}$ & $\mathrm{m}$ & $\mathrm{m}$ & $\mathrm{m}$ & $\mathrm{m}$ & $\mathrm{m}$ & $\mathrm{m}$ & $\mathrm{m}$ & $\mathrm{m}$ & $\mathrm{m}$ & $\mathrm{m}$ & $\mathrm{m}$ & $\mathrm{m}$ & $\mathrm{m}$ \\
\hline & Puerto Rico ${ }^{\bullet}$ & $\mathrm{m}$ & $\mathrm{m}$ & $\mathrm{m}$ & $\mathrm{m}$ & $\mathrm{m}$ & $\mathrm{m}$ & $\mathrm{m}$ & $\mathrm{m}$ & $\mathrm{m}$ & $\mathrm{m}$ & $\mathrm{m}$ & $\mathrm{m}$ & $\mathrm{m}$ & $\mathrm{m}$ \\
\hline & Colombia & & & & & & & & & & & & & & \\
\hline$\Xi$ & Bogotá & 7.55 & $(0.06)$ & 7.83 & $(0.14)$ & 8.94 & $(0.38)$ & -0.28 & $(0.13)$ & 7.62 & $(0.15)$ & 7.58 & $(0.13)$ & -0.04 & $(0.17)$ \\
\hline & Cali & 7.57 & $(0.07)$ & 4.43 & $(1.38)$ & 6.92 & $(1.40)$ & 3.14 & $(1.41)$ & 7.61 & $(0.17)$ & 7.57 & $(0.10)$ & -0.04 & $(0.19)$ \\
\hline & Manizales & 7.83 & $(0.06)$ & $\mathrm{m}$ & $\mathrm{m}$ & 3.00 & $(0.00)$ & $\mathrm{m}$ & $\mathrm{m}$ & 7.90 & $(0.19)$ & 7.69 & $(0.14)$ & -0.21 & $(0.25)$ \\
\hline & Medellín & 7.71 & $(0.09)$ & 8.97 & $(0.47)$ & 8.08 & $(1.04)$ & -1.26 & $(0.47)$ & 7.92 & $(0.15)$ & 7.53 & $(0.18)$ & -0.39 & $(0.24)$ \\
\hline & United Arab Emirates & & & & & & & & & & & & & & \\
\hline & Abu Dhabi• & 7.49 & $(0.08)$ & 7.11 & $(0.08)$ & 7.29 & $(0.11)$ & 0.38 & $(0.11)$ & 7.32 & $(0.15)$ & 7.17 & $(0.11)$ & -0.15 & $(0.18)$ \\
\hline & Ajman & 7.69 & $(0.14)$ & 7.01 & $(0.23)$ & 6.94 & $(0.16)$ & 0.68 & $(0.23)$ & 7.03 & $(0.23)$ & 7.49 & $(0.26)$ & 0.46 & $(0.34)$ \\
\hline & Dubai & 7.48 & $(0.06)$ & 7.06 & $(0.06)$ & 6.86 & $(0.09)$ & 0.43 & $(0.08)$ & 7.17 & $(0.10)$ & 7.09 & $(0.08)$ & -0.08 & $(0.12)$ \\
\hline & Fujairah & 7.84 & $(0.10)$ & 7.40 & $(0.19)$ & 6.85 & $(0.34)$ & 0.44 & $(0.20)$ & 7.53 & $(0.26)$ & 7.62 & $(0.22)$ & 0.09 & $(0.37)$ \\
\hline & Ras Al Khaimah & 7.99 & $(0.11)$ & 7.57 & $(0.25)$ & 7.29 & $(0.22)$ & 0.42 & $(0.24)$ & 7.81 & $(0.24)$ & 7.67 & $(0.23)$ & -0.14 & $(0.36)$ \\
\hline & Sharjah & 7.62 & $(0.17)$ & 7.26 & $(0.14)$ & 7.10 & $(0.11)$ & 0.36 & $(0.19)$ & 7.24 & $(0.23)$ & 7.36 & $(0.20)$ & 0.12 & $(0.24)$ \\
\hline & Umm Al Quwain & 7.53 & $(0.15)$ & 6.74 & $(0.27)$ & 6.66 & $(0.40)$ & 0.79 & $(0.29)$ & 7.41 & $(0.41)$ & 7.23 & $(0.27)$ & -0.19 & $(0.45)$ \\
\hline
\end{tabular}

- PISA adjudicated region.

1. PISA 2015 asked students to rate their overall satisfaction with life on a scale that ranges from 0 to 10 .

2. ESCS refers to the PISA index of economic, social and cultural status.

3. An extreme Internet user is a student who uses the Internet for more than 6 hours per day on a typical weekday.

Notes: Values that are statistically significant are indicated in bold (see Annex A3).

Results for the province of Quebec in this table should be treated with caution due to a possible non-response bias.

For Massachusetts and North Carolina, the desired target population covers 15-year-old students in grade 7 or above in public schools only (see Annex A2).

Puerto Rico is an unincorporated territory of the United States. As such, PISA results for the United States do not include Puerto Rico.

See Tables III.3.1, III.3.2, III.3.4, III.3.7, III.4.9, III.10.9 and III.13.23 for national data.

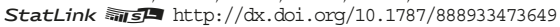




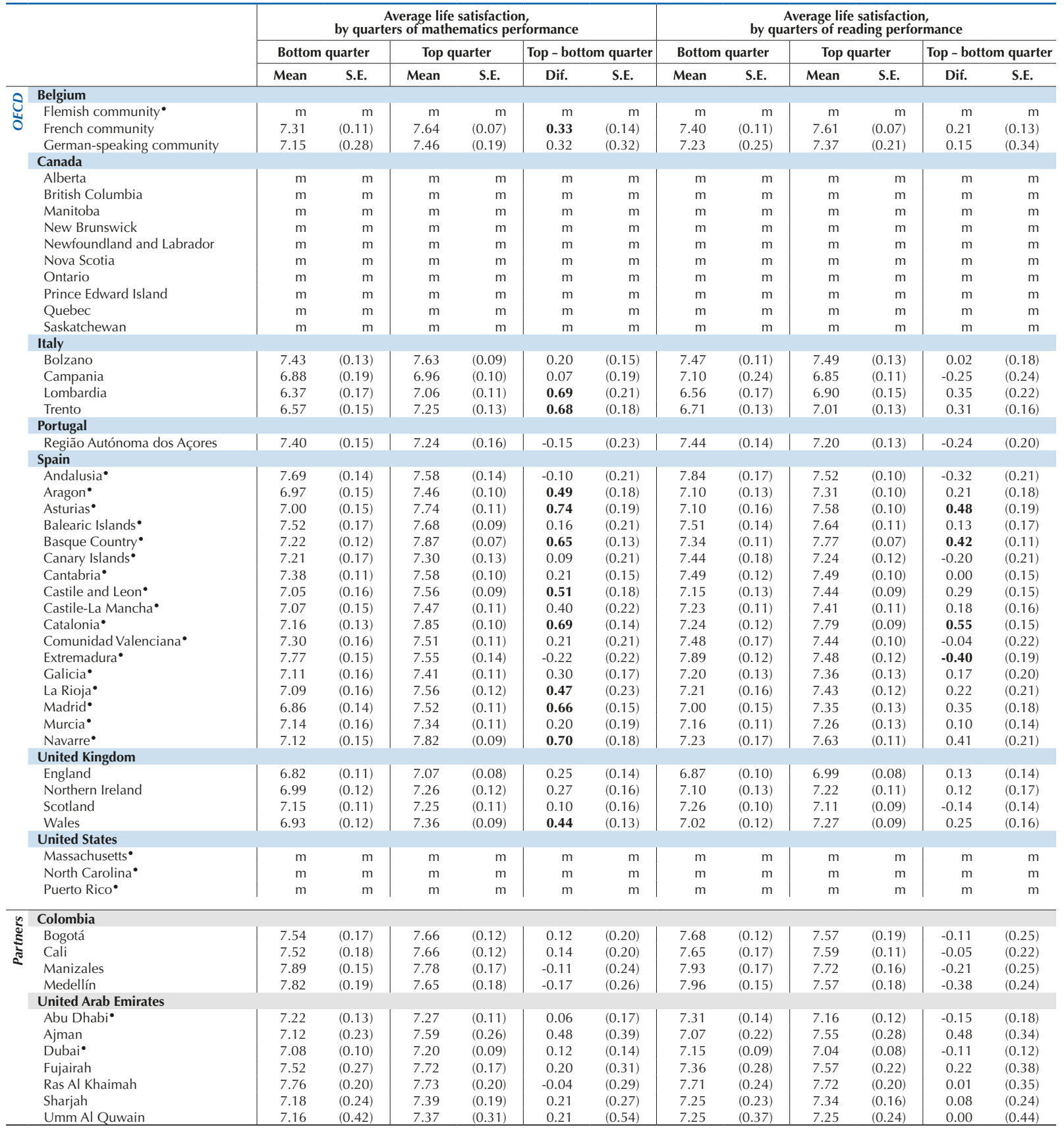

- PISA adjudicated region.

1. PISA 2015 asked students to rate their overall satisfaction with life on a scale that ranges from 0 to 10

2. ESCS refers to the PISA index of economic, social and cultural status.

3. An extreme Internet user is a student who uses the Internet for more than 6 hours per day on a typical weekday. Notes: Values that are statistically significant are indicated in bold (see Annex A3).

Results for the province of Quebec in this table should be treated with caution due to a possible non-response bias.

For Massachusetts and North Carolina, the desired target population covers 15-year-old students in grade 7 or above in public schools only (see Annex A2).

States. As such, PISA results for the United States do not include Puerto Rico.

See Tables III.3.1, III.3.2, III.3.4, III.3.7, III.4.9, III.10.9 and III.13.23 for national data.

StatLink तils $\mathrm{\text {nt }}$ htp://dx.doi.org/10.1787/888933473649 
A corrigendum has been issued for this page. See: http://www.oecd.org/about/publishing/Corrigenda_PISA2015IR_VolumellI.pdf ANNEX B2: RESULTS FOR REGIONS WITHIN COUNTRIES

[Part 4/4]

Table B2.III.1 Regional differences in life satisfaction

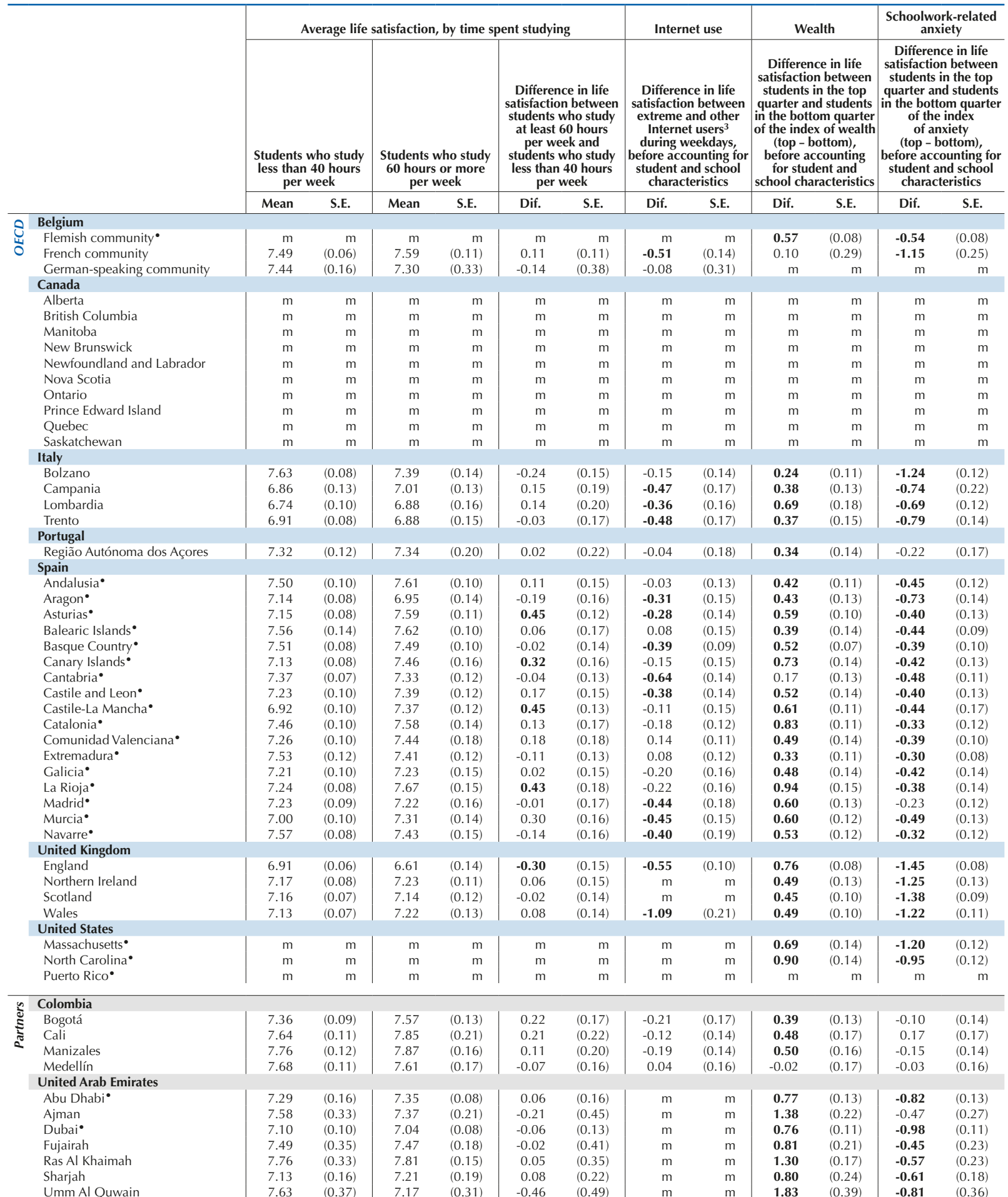

- PISA adjudicated region

1. PISA 2015 asked students to rate their overall satisfaction with life on a scale that ranges from 0 to 10 .

2. ESCS refers to the PISA index of economic, social and cultural status.

3. An extreme Internet user is a student who uses the Internet for more than 6 hours per day on a typical weekday.

Notes: Values that are statistically significant are indicated in bold (see Annex A3).

Results for the province of Quebec in this table should be treated with caution due to a possible non-response bias.

For Massachusetts and North Carolina, the desired target population covers 15-year-old students in grade 7 or above in public schools only (see Annex A2).

Puerto Rico is an unincorporated territory of the United States. As such, PISA results for the United States do not include Puerto Rico.

See Tables III.3.1, III.3.2, III.3.4, III.3.7, III.4.9, III.10.9 and III.13.23 for national data.

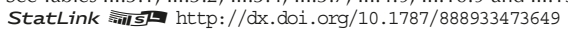




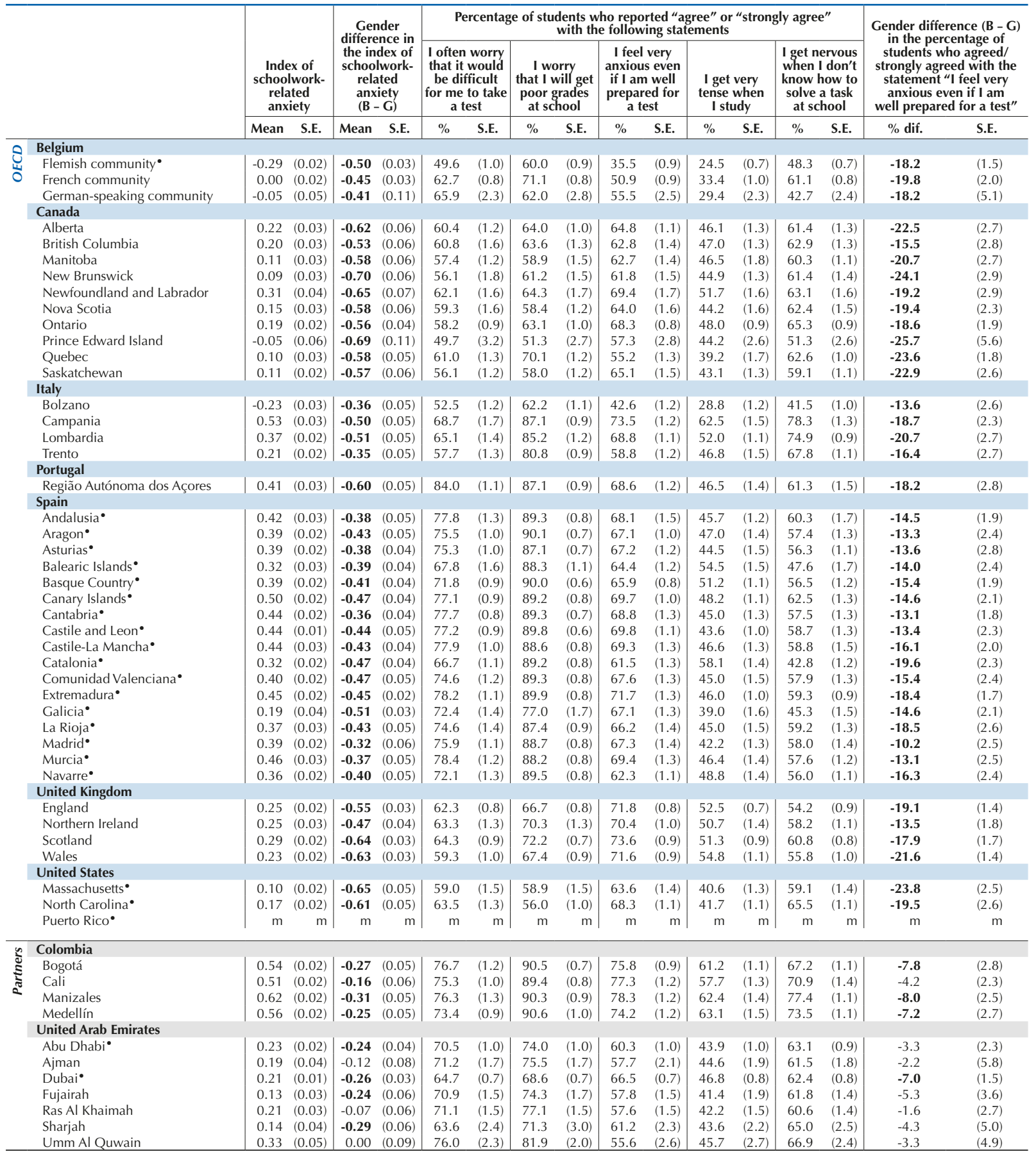

- PISA adjudicated region.

Notes: Values that are statistically significant are indicated in bold (see Annex A3).

Results for the province of Quebec in this table should be treated with caution due to a possible non-response bias.

For Massachusetts and North Carolina, the desired target population covers 15-year-old students in grade 7 or above in public schools only (see Annex A2).

Puerto Rico is an unincorporated territory of the United States. As such, PISA results for the United States do not include Puerto Rico.

See Tables III. 4.1, III. 4.2 and III. 4.5 for national data.

StatLink inilst http://dx.doi.org/10.1787/888933473656 
[Part 1/2]

Table B2.III.3 Regional differences in achievement motivation and education expectations

\begin{tabular}{|c|c|c|c|c|c|c|c|c|c|c|c|c|c|c|c|}
\hline & \multirow{2}{*}{\multicolumn{2}{|c|}{$\begin{array}{c}\text { Index } \\
\text { of achievement } \\
\text { motivation }\end{array}$}} & \multirow{2}{*}{\multicolumn{2}{|c|}{$\begin{array}{c}\text { Gender } \\
\text { difference } \\
\text { in the index } \\
\text { of achievement } \\
\text { motivation } \\
(B-G)\end{array}$}} & \multicolumn{10}{|c|}{$\begin{array}{c}\text { Percentage of students who reported "agree" or "strongly agree" } \\
\text { with the following statements }\end{array}$} \\
\hline & & & & & & \multicolumn{2}{|c|}{$\begin{array}{c}\text { I want top grades } \\
\text { in most or } \\
\text { all my courses }\end{array}$} & \multicolumn{2}{|c|}{$\begin{array}{l}\text { I want to be } \\
\text { able to select } \\
\text { from the best } \\
\text { opportunities }\end{array}$} & \multicolumn{2}{|c|}{$\begin{array}{l}\text { I want to be } \\
\text { the best, } \\
\text { whatever I do }\end{array}$} & \multicolumn{2}{|c|}{$\begin{array}{c}\text { I see myself } \\
\text { as an ambitious } \\
\text { person }\end{array}$} & \multicolumn{2}{|c|}{$\begin{array}{c}\text { I want to } \\
\text { be one of the best } \\
\text { students } \\
\text { in my class }\end{array}$} \\
\hline & & Mean & S.E. & Dif. & S.E. & $\%$ & S.E. & $\%$ & S.E. & $\%$ & S.E. & $\%$ & S.E. & $\%$ & S.E. \\
\hline 0 & Belgium & & & & & & & & & & & & & & \\
\hline & Flemish community ${ }^{\bullet}$ & -0.62 & $(0.01)$ & 0.14 & $(0.02)$ & 59.2 & $(0.7)$ & 90.2 & $(0.4)$ & 32.5 & $(0.8)$ & 54.8 & $(0.9)$ & 40.3 & $(0.9)$ \\
\hline 0 & French community & -0.24 & $(0.02)$ & 0.02 & $(0.03)$ & 88.0 & $(0.6)$ & 94.1 & $(0.3)$ & 47.9 & $(0.9)$ & 71.8 & $(0.9)$ & 43.2 & $(1.2)$ \\
\hline & German-speaking community & -0.56 & $(0.04)$ & 0.15 & $(0.08)$ & 73.2 & $(2.3)$ & 91.7 & (1.4) & 32.6 & $(2.2)$ & 57.7 & $(2.7)$ & 34.9 & (2.4) \\
\hline & Canada & & & & & & & & & & & & & & \\
\hline & Alberta & 0.41 & $(0.02)$ & -0.09 & $(0.05)$ & 87.8 & $(0.9)$ & 95.7 & $(0.5)$ & 89.7 & $(0.8)$ & 84.4 & $(0.9)$ & 77.5 & (1.0) \\
\hline & British Columbia & 0.31 & $(0.03)$ & -0.16 & $(0.05)$ & 85.7 & $(0.8)$ & 94.4 & (0.6) & 84.5 & $(0.9)$ & 80.4 & (1.4) & 74.0 & $(1.2)$ \\
\hline & Manitoba & 0.32 & $(0.03)$ & -0.18 & $(0.06)$ & 87.5 & $(0.7)$ & 95.4 & $(0.5)$ & 85.7 & $(0.9)$ & 82.4 & $(0.9)$ & 74.4 & $(1.0)$ \\
\hline & New Brunswick & 0.23 & $(0.03)$ & -0.17 & $(0.06)$ & 88.1 & $(1.2)$ & 94.6 & $(0.6)$ & 81.6 & $(1.1)$ & 82.2 & $(1.3)$ & 70.7 & (1.4) \\
\hline & Newfoundland and Labrador & 0.38 & $(0.03)$ & 0.00 & $(0.07)$ & 90.1 & $(1.0)$ & 95.7 & $(0.7)$ & 87.8 & $(1.2)$ & 84.5 & (1.3) & 76.2 & $(1.3)$ \\
\hline & Nova Scotia & 0.35 & $(0.03)$ & -0.18 & $(0.05)$ & 89.6 & $(0.7)$ & 96.4 & (0.6) & 87.8 & (1.0) & 80.6 & (1.4) & 73.4 & (1.3) \\
\hline & Ontario & 0.41 & $(0.03)$ & -0.20 & $(0.03)$ & 87.6 & $(0.7)$ & 95.9 & $(0.4)$ & 87.5 & $(0.7)$ & 82.3 & $(0.8)$ & 79.0 & (1.0) \\
\hline & Prince Edward Island & 0.29 & $(0.06)$ & -0.17 & $(0.12)$ & 84.8 & $(2.1)$ & 97.3 & $(0.9)$ & 84.2 & (1.9) & 83.5 & (1.9) & 78.4 & (2.4) \\
\hline & Quebec & 0.13 & $(0.04)$ & -0.05 & $(0.04)$ & 93.5 & $(0.6)$ & 95.1 & $(0.6)$ & 61.1 & (1.5) & 81.1 & (1.1) & 56.8 & (1.8) \\
\hline & Saskatchewan & 0.34 & $(0.02)$ & -0.20 & $(0.05)$ & 88.2 & $(0.8)$ & 95.2 & $(0.5)$ & 89.1 & $(0.8)$ & 84.6 & $(0.9)$ & 78.1 & $(1.0)$ \\
\hline & Italy & & & & & & & & & & & & & & \\
\hline & Bolzano & -0.65 & $(0.02)$ & 0.27 & $(0.04)$ & 62.1 & $(1.2)$ & 86.8 & $(0.8)$ & 33.6 & $(1.2)$ & 63.9 & (1.3) & 32.5 & $(1.2)$ \\
\hline & Campania & -0.06 & $(0.02)$ & 0.10 & $(0.04)$ & 92.4 & $(0.9)$ & 95.2 & $(0.8)$ & 62.1 & (1.4) & 75.5 & $(0.9)$ & 58.2 & (1.3) \\
\hline & Lombardia & -0.30 & $(0.02)$ & 0.11 & $(0.05)$ & 85.5 & (1.1) & 95.0 & $(0.7)$ & 48.0 & (1.8) & 68.7 & (1.4) & 45.4 & (1.3) \\
\hline & Trento & -0.36 & $(0.02)$ & 0.17 & $(0.04)$ & 85.1 & $(0.9)$ & 92.3 & $(0.7)$ & 41.7 & (1.3) & 68.7 & $(1.3)$ & 46.1 & (1.3) \\
\hline & Portugal & & & & & & & & & & & & & & \\
\hline & Região Autónoma dos Açores & -0.03 & $(0.03)$ & 0.04 & $(0.06)$ & 94.4 & $(0.6)$ & 90.7 & $(0.8)$ & 67.3 & (1.5) & 62.8 & $(1.3)$ & 57.1 & (1.4) \\
\hline & Spain & & & & & & & & & & & & & & \\
\hline & Andalusia ${ }^{\bullet}$ & -0.28 & $(0.03)$ & 0.06 & $(0.03)$ & 73.5 & $(1.2)$ & 92.4 & $(0.9)$ & 58.7 & (1.6) & 45.2 & $(1.7)$ & 56.3 & (1.4) \\
\hline & Aragon ${ }^{\bullet}$ & -0.27 & $(0.02)$ & 0.07 & $(0.04)$ & 70.9 & $(1.2)$ & 93.5 & $(0.5)$ & 58.6 & $(1.2)$ & 55.2 & $(1.6)$ & 55.4 & $(1.2)$ \\
\hline & Asturias• & -0.31 & $(0.02)$ & 0.08 & $(0.05)$ & 65.3 & $(1.2)$ & 92.2 & $(0.7)$ & 56.9 & $(0.7)$ & 52.4 & (1.5) & 52.3 & (1.3) \\
\hline & Balearic Islands ${ }^{\bullet}$ & -0.02 & $(0.03)$ & -0.04 & $(0.05)$ & 87.1 & (1.4) & 94.4 & $(0.6)$ & 63.8 & (1.3) & 57.8 & (1.3) & 59.1 & (1.4) \\
\hline & Basque Country ${ }^{\bullet}$ & -0.30 & $(0.02)$ & 0.10 & $(0.04)$ & 71.4 & $(1.0)$ & 91.9 & $(0.5)$ & 53.1 & $(0.9)$ & 54.8 & $(1.0)$ & 50.8 & (1.1) \\
\hline & Canary Islands ${ }^{\bullet}$ & -0.17 & $(0.03)$ & 0.14 & $(0.04)$ & 74.3 & (1.1) & 93.8 & $(0.6)$ & 60.3 & (1.6) & 51.6 & (1.5) & 55.8 & $(1.2)$ \\
\hline & Cantabria ${ }^{\bullet}$ & -0.19 & $(0.03)$ & 0.11 & $(0.05)$ & 71.6 & $(1.2)$ & 93.3 & $(0.7)$ & 61.6 & $(1.2)$ & 56.9 & $(1.4)$ & 57.3 & $(1.4)$ \\
\hline & Castile and Leon ${ }^{\bullet}$ & -0.23 & $(0.02)$ & 0.05 & $(0.05)$ & 72.9 & (1.1) & 93.6 & $(0.6)$ & 59.1 & (1.1) & 53.8 & (1.1) & 55.1 & (1.3) \\
\hline & Castile-La Mancha ${ }^{\bullet}$ & -0.21 & $(0.02)$ & 0.01 & $(0.04)$ & 72.0 & (1.3) & 94.0 & $(0.5)$ & 62.2 & $(1.2)$ & 53.6 & (1.1) & 57.5 & $(1.2)$ \\
\hline & Catalonia• & 0.11 & $(0.03)$ & 0.02 & $(0.05)$ & 91.4 & $(0.8)$ & 95.4 & $(0.4)$ & 68.4 & (1.5) & 62.4 & (1.3) & 63.4 & (1.8) \\
\hline & Comunidad Valenciana ${ }^{\bullet}$ & -0.16 & $(0.03)$ & -0.01 & $(0.06)$ & 73.9 & $(1.3)$ & 93.8 & $(0.5)$ & 61.7 & (1.7) & 56.0 & $(1.7)$ & 57.0 & (1.6) \\
\hline & Extremadura ${ }^{\bullet}$ & -0.18 & $(0.02)$ & 0.02 & $(0.05)$ & 74.8 & $(1.2)$ & 94.0 & $(0.7)$ & 64.8 & (1.1) & 50.2 & $(1.5)$ & 59.1 & $(1.2)$ \\
\hline & Galicia• & -0.29 & $(0.02)$ & 0.12 & $(0.04)$ & 79.2 & (1.4) & 94.4 & $(0.5)$ & 52.5 & (1.3) & 47.2 & $(1.3)$ & 46.2 & (1.3) \\
\hline & La Rioja• & -0.20 & $(0.03)$ & 0.07 & $(0.05)$ & 69.9 & $(1.3)$ & 93.7 & $(0.8)$ & 61.8 & (1.4) & 58.8 & (1.4) & 54.8 & (1.5) \\
\hline & Madrid• & -0.16 & $(0.03)$ & 0.15 & $(0.05)$ & 73.1 & (1.5) & 95.0 & $(0.6)$ & 64.3 & (1.5) & 57.0 & $(1.2)$ & 55.4 & (1.8) \\
\hline & Murcia• & -0.19 & $(0.03)$ & 0.07 & $(0.04)$ & 72.3 & $(1.2)$ & 93.7 & $(0.6)$ & 61.1 & $(1.7)$ & 49.8 & $(1.2)$ & 58.9 & (1.4) \\
\hline & Navarre ${ }^{\bullet}$ & -0.33 & $(0.02)$ & 0.05 & $(0.05)$ & 69.2 & (1.1) & 93.4 & (0.5) & 53.9 & (1.3) & 52.4 & $(1.0)$ & 49.3 & (1.2) \\
\hline & United Kingdom & & & & & & & & & & & & & & \\
\hline & England & 0.53 & $(0.02)$ & -0.01 & $(0.03)$ & 95.6 & $(0.4)$ & 97.8 & $(0.3)$ & 90.0 & $(0.5)$ & 83.8 & $(0.6)$ & 76.2 & $(0.7)$ \\
\hline & Northern Ireland & 0.43 & $(0.02)$ & 0.03 & $(0.03)$ & 94.9 & $(0.4)$ & 97.9 & $(0.3)$ & 88.5 & $(0.7)$ & 83.9 & $(0.9)$ & 73.5 & (1.0) \\
\hline & Scotland & 0.43 & $(0.02)$ & 0.11 & $(0.03)$ & 94.3 & $(0.5)$ & 98.0 & $(0.3)$ & 87.7 & $(0.6)$ & 81.1 & $(1.0)$ & 73.6 & (0.9) \\
\hline & Wales & 0.37 & $(0.02)$ & -0.02 & $(0.04)$ & 94.4 & $(0.4)$ & 97.1 & $(0.3)$ & 87.4 & $(0.7)$ & 80.6 & $(0.7)$ & 69.2 & $(1.0)$ \\
\hline & United States & & & & & & & & & & & & & & \\
\hline & Massachusetts ${ }^{\bullet}$ & 0.52 & $(0.03)$ & -0.03 & $(0.06)$ & 92.8 & $(0.6)$ & 97.4 & $(0.5)$ & 87.5 & $(0.8)$ & 88.1 & $(0.8)$ & 87.7 & $(0.7)$ \\
\hline & North Carolina ${ }^{\bullet}$ & 0.74 & $(0.02)$ & -0.12 & $(0.05)$ & 95.2 & $(0.5)$ & 97.9 & $(0.4)$ & 94.2 & $(0.7)$ & 85.3 & $(1.0)$ & 80.9 & (1.0) \\
\hline & Puerto Rico ${ }^{\circ}$ & $\mathrm{m}$ & $\mathrm{m}$ & $\mathrm{m}$ & $\mathrm{m}$ & $\mathrm{m}$ & $\mathrm{m}$ & $\mathrm{m}$ & $\mathrm{m}$ & $\mathrm{m}$ & $\mathrm{m}$ & $\mathrm{m}$ & $\mathrm{m}$ & $\mathrm{m}$ & $\mathrm{m}$ \\
\hline 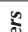 & Colombia & & & & & & & & & & & & & & \\
\hline$\approx$ & Bogotá & 0.50 & $(0.02)$ & -0.07 & $(0.03)$ & 95.9 & $(0.4)$ & 98.5 & $(0.3)$ & 92.7 & $(0.7)$ & 46.5 & (1.5) & 89.4 & $(0.6)$ \\
\hline ฐ & Cali & 0.53 & $(0.01)$ & -0.03 & $(0.06)$ & 96.3 & $(0.5)$ & 97.7 & $(0.4)$ & 93.4 & $(0.6)$ & 47.8 & $(2.1)$ & 89.3 & $(0.8)$ \\
\hline & Manizales & 0.59 & $(0.02)$ & -0.09 & $(0.05)$ & 96.0 & $(0.5)$ & 98.7 & $(0.3)$ & 93.2 & $(0.7)$ & 55.1 & $(1.2)$ & 88.8 & $(1.2)$ \\
\hline & Medellín & 0.50 & $(0.02)$ & -0.07 & $(0.04)$ & 95.2 & $(0.5)$ & 98.0 & $(0.3)$ & 89.9 & $(0.9)$ & 52.4 & $(1.3)$ & 86.2 & (1.0) \\
\hline & United Arab Emirates & & & & & & & & & & & & & & \\
\hline & Abu Dhabi • & 0.82 & $(0.02)$ & -0.18 & $(0.04)$ & 93.4 & $(0.5)$ & 94.9 & $(0.6)$ & 91.9 & $(0.5)$ & 90.6 & $(0.5)$ & 92.1 & $(0.6)$ \\
\hline & Ajman & 0.71 & $(0.03)$ & -0.25 & $(0.06)$ & 91.1 & $(0.8)$ & 93.6 & $(0.9)$ & 93.5 & $(0.9)$ & 90.4 & (1.0) & 91.3 & (1.0) \\
\hline & Dubai• & 0.75 & $(0.01)$ & -0.07 & $(0.03)$ & 94.5 & $(0.4)$ & 97.1 & $(0.2)$ & 91.8 & $(0.4)$ & 87.1 & $(0.5)$ & 90.7 & $(0.5)$ \\
\hline & Fujairah & 0.78 & $(0.04)$ & -0.35 & $(0.08)$ & 92.1 & (0.8) & 93.9 & (0.9) & 93.1 & (0.9) & 90.8 & $(1.3)$ & 91.8 & $(0.8)$ \\
\hline & Ras Al Khaimah & 0.87 & $(0.05)$ & -0.10 & $(0.10)$ & 94.5 & (1.1) & 95.2 & $(0.9)$ & 93.7 & $(1.0)$ & 93.0 & $(1.2)$ & 94.0 & (1.0) \\
\hline & Sharjah & 0.73 & $(0.04)$ & -0.07 & $(0.09)$ & 93.3 & $(1.0)$ & 95.8 & $(0.8)$ & 92.6 & (1.1) & 88.3 & $(1.3)$ & 90.8 & $(0.9)$ \\
\hline & Umm Al Quwain & 0.82 & $(0.05)$ & -0.01 & $(0.10)$ & 93.7 & $(1.2)$ & 93.4 & $(1.2)$ & 94.3 & $(1.1)$ & 89.1 & (1.6) & 92.8 & $(1.3)$ \\
\hline
\end{tabular}

- PISA adjudicated region.

1. ESCS refers to the PISA index of economic, social and cultural status.

2. Blue-collar occupations include skilled agricultural, forestry and fishery workers (ISCO-08 category 6), craft and related trades workers (ISCO-08 category 7), plant and machine operators and assemblers (ISCO-08 category 8) and elementary occupations (ISCO-08 category 9).

Notes: Values that are statistically significant are indicated in bold (see Annex A3).

Results for the province of Quebec in this table should be treated with caution due to a possible non-response bias.

Results for the province of Quebec in this table should be treated with caution due to a possible non-response bias.
For Massachusetts and North Carolina, the desired target population covers 15-year-old students in grade 7 or above in public schools only (see Annex A2).

Puerto Rico is an unincorporated territory of the United States. As such, PISA results for the United States do not include Puerto Rico.

Puerto Rico is an unincorporated territory of the United States. As such,
See Tables III.5.1, III.5.2, III.5.3, III.6.1 and III.10.15 for national data.

StatLink ints http://dx.doi.org/10.1787/888933473669 


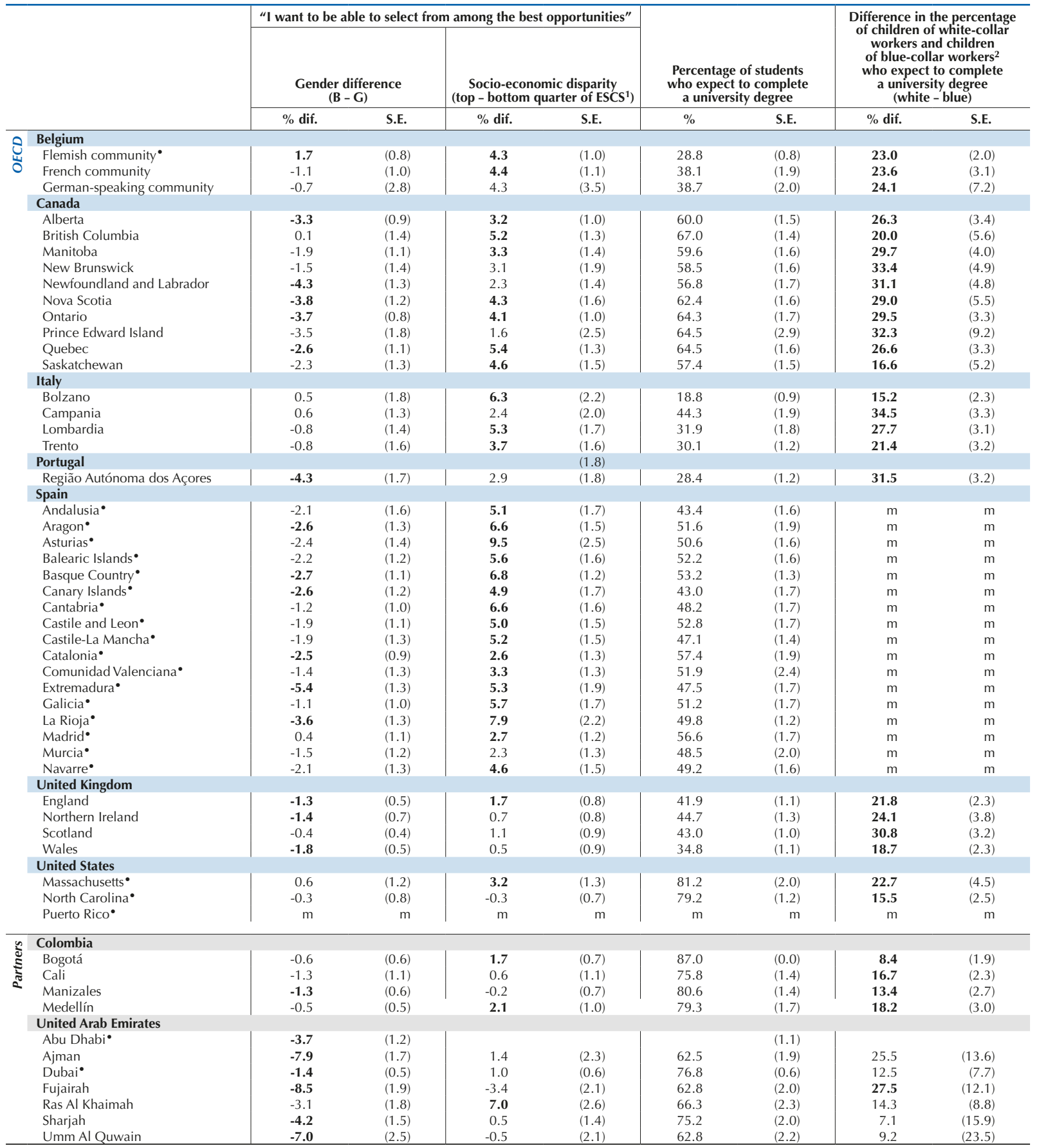

- PISA adjudicated region.

1. ESCS refers to the PISA index of economic social and cultural status.

2. Blue-collar occupations include skilled agricultural. forestry and fishery workers (ISCO-08 category 6). craft and related trades workers (ISCO-08 category 7). plant and machine operators and assemblers (ISCO-08 category 8 ) and elementary occupations (ISCO-08 category 9).

Notes: Values that are statistically significant are indicated in bold (see Annex A3).

to a possible non-response bias.

For Massachusetts and North Carolina. the desired target population covers 15-year-old students in grade 7 or above in public schools only (see Annex A2).

Puerto Rico is an unincorporated territory of the United States. As such. PISA results for the United States do not include Puerto Rico.

See Tables III.5.1. III.5.2. III.5.3. III.6.1 and III.10.15 for national data.

StatLink (i)ा St http://dx.doi.org/10.1787/888933473669 


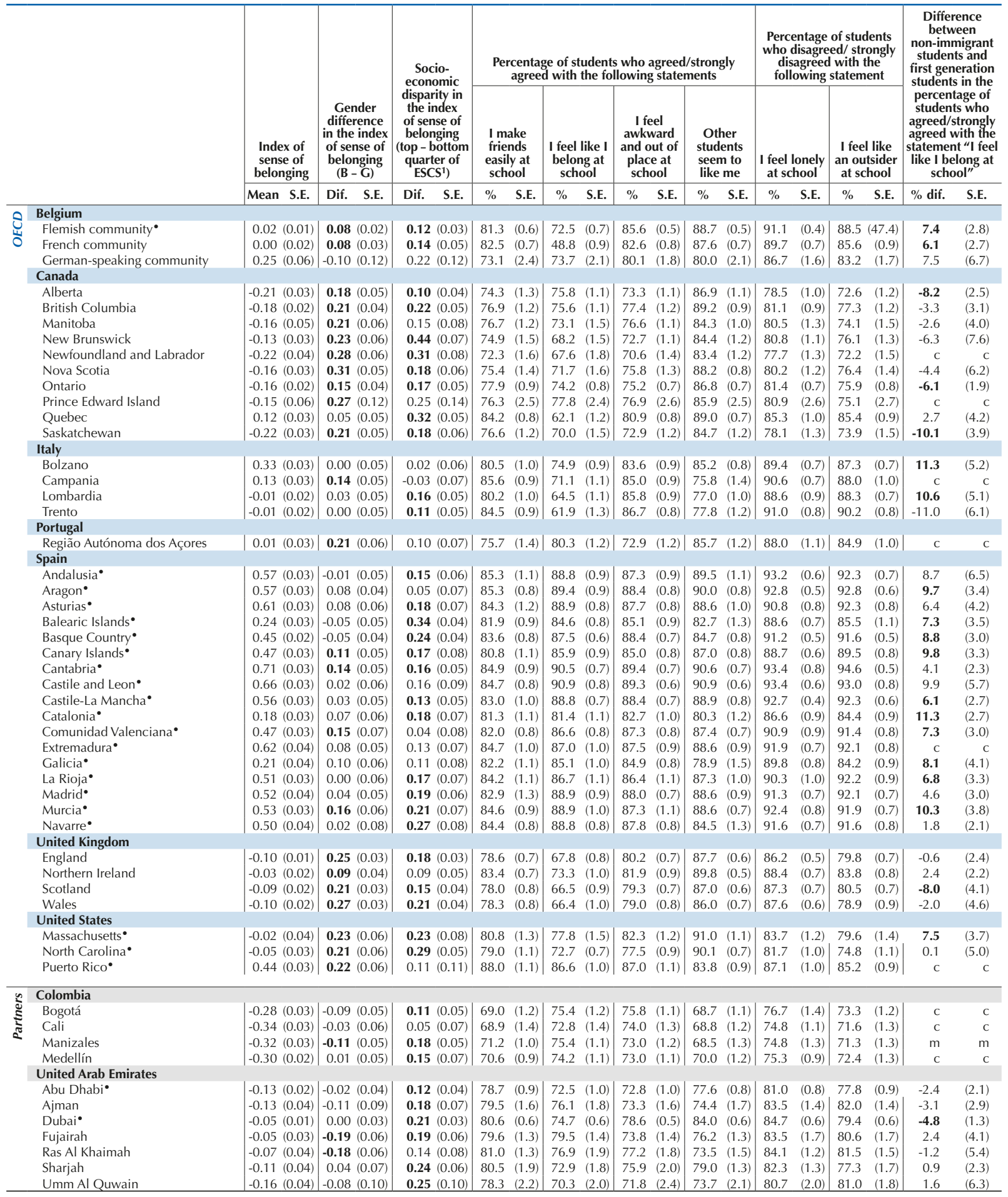

- PISA adjudicated region

1. ESCS refers to the PISA index of economic, social and cultural status.

Notes: Values that are statistically significant are indicated in bold (see Annex A3).

Results for the province of Quebec in this table should be treated with caution due to a possible non-response bias.

For Massachusetts and North Carolina, the desired target population covers 15-year-old students in grade 7 or above in public schools only (see Annex A2).

Puerto Rico is an unincorporated territory of the United States. As such, PISA results for the United States do not include Puerto Rico.

See Tables III.7.1 and III.7.6 for national data.

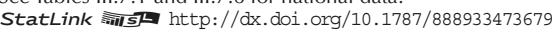




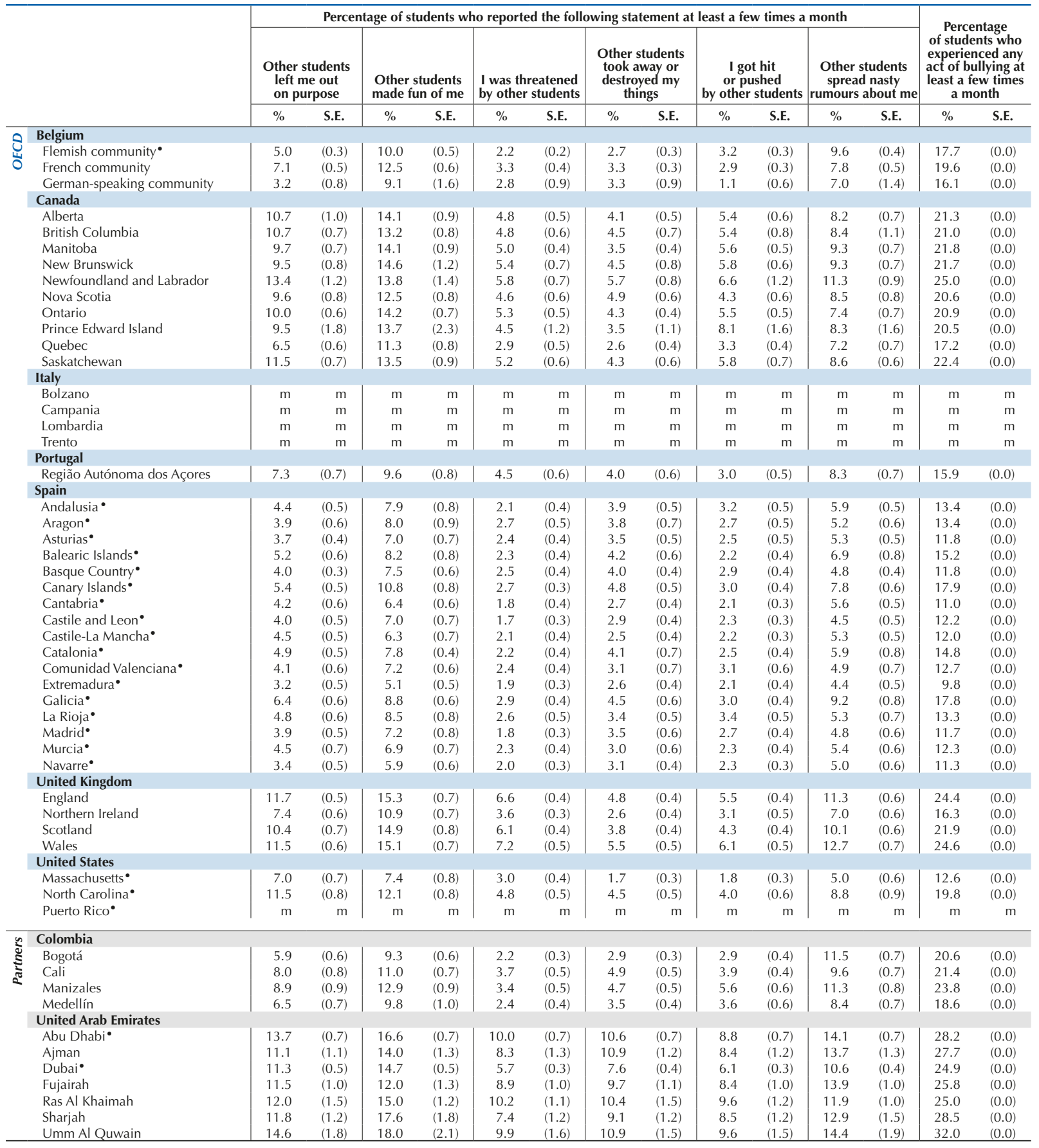

- PISA adjudicated region.

Notes: Results for the province of Quebec in this table should be treated with caution due to a possible non-response bias.

For Massachusetts and North Carolina, the desired target population covers 15-year-old students in grade 7 or above in public schools only (see Annex A2).

Puerto Rico is an unincorporated territory of the United States. As such, PISA results for the United States do not include Puerto Rico.

See Tables III.8.1, III.8.5, III.8.6 and III.8.10 for national data.

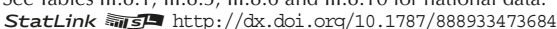


[Part 1/1]

Table B2.III.6 Regional differences in parental support and wealth

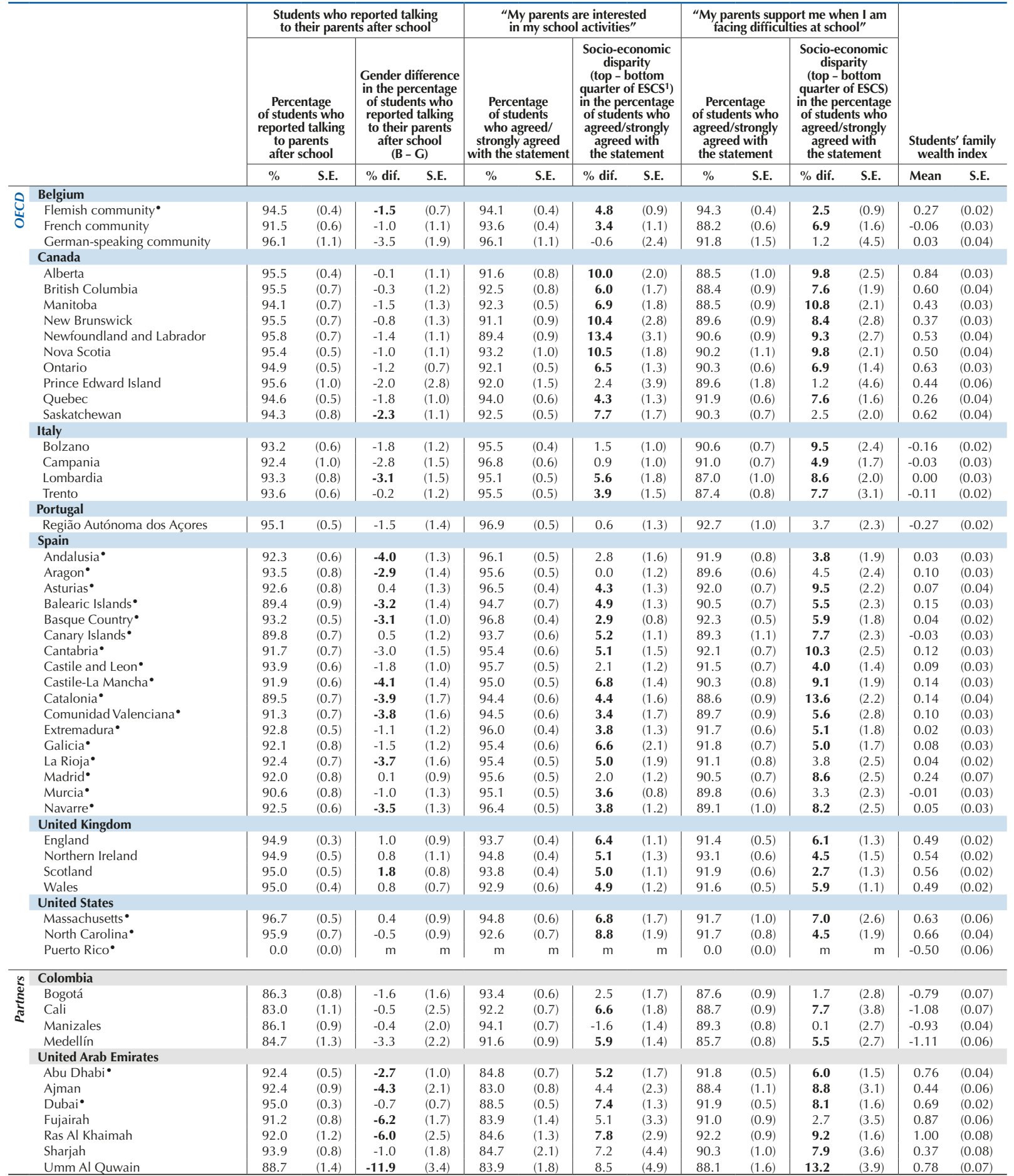

- PISA adjudicated region

1. ESCS refers to the PISA index of economic, social and cultural status.

Notes: Values that are statistically significant are indicated in bold (see Annex A3).

Results for the province of Quebec in this table should be treated with caution due to a possible non-response bias.

For Massachusetts and North Carolina, the desired target population covers 15-year-old students in grade 7 or above in public schools only (see Annex A2).

Puerto Rico is an unincorporated territory of the United States. As such, PISA results for the United States do not include Puerto Rico.

See Tables III.9.16, III.9.17, III.9.18, III.9.19 and III.10.6 for national data.

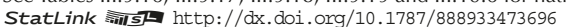




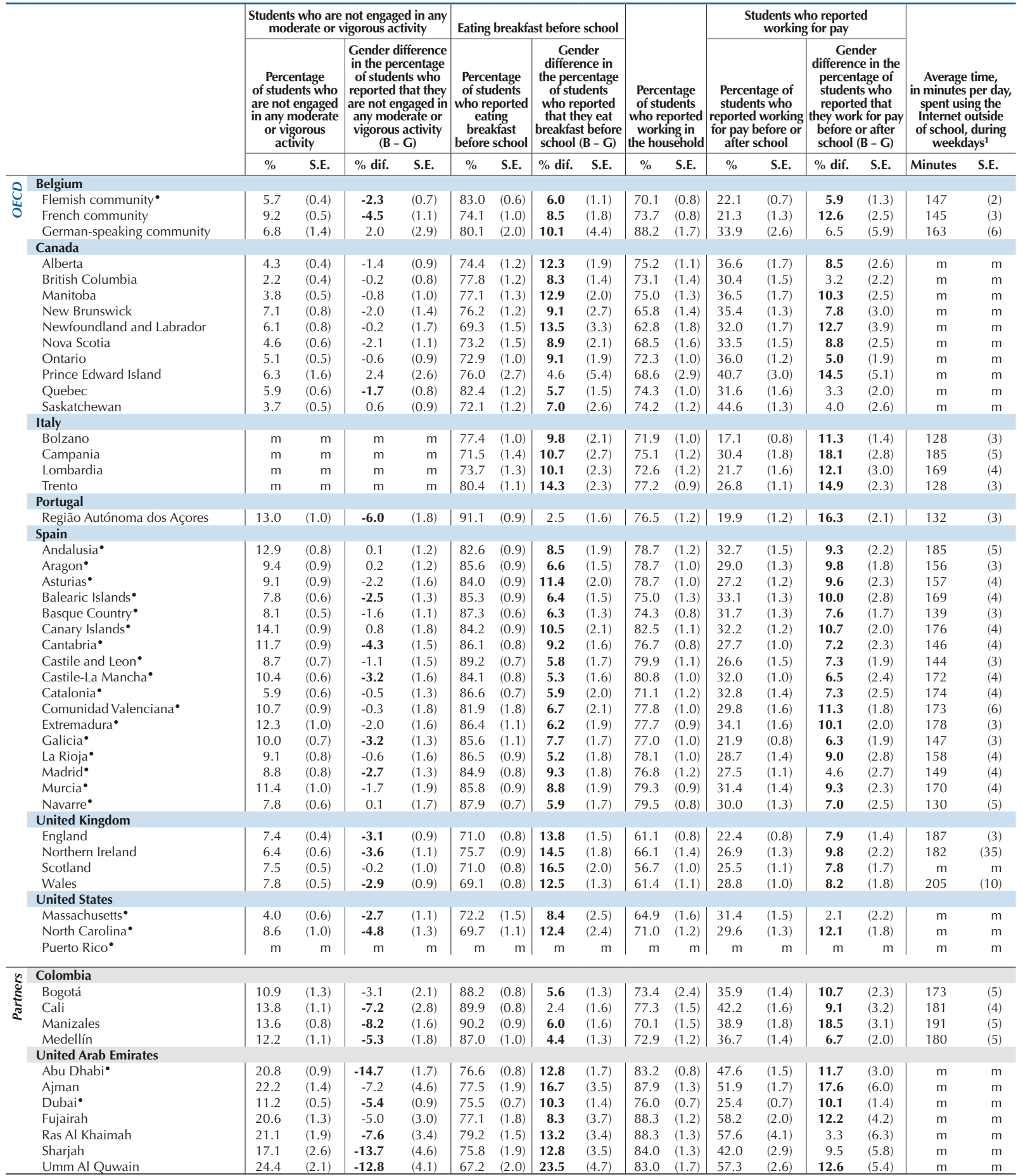

- PISA adjudicated region.

1. As the answers were given on a categorical scale, it is not possible to compute exactly the average time students spend on line. The numbers in this table thus report a lower bound for the number of minutes students spend on online activities, whereby the answer "between one and two hours", for instance, is converted into "61 minutes at least". Notes: Values that are statistically significant are indicated in bold (see Annex A3).

Results for the province of Quebec in this table should be treated with caution due to a possible non-response bias.

For Massachusetts and North Carolina, the desired target population covers 15-year-old students in grade 7 or above in public schools only (see Annex A2).

Puerto Rico is an unincorporated territory of the United States. As such, PISA results for the United States do not include Puerto Rico.

See Tables III.11.21, III.11.22, III.12.1, III.12.7 and III.13.7 for national data.

StatLink त्नाइ http://dx.doi.org/10.1787/888933473709 


\section{ANNEX B3}

\section{LIST OF TABLES AVAILABLE ON LINE}

The following tables are available in electronic form only, they may be found at: www.oecd.org/pisa.

Chapter 3 Students' satisfaction with their life

\begin{tabular}{|ll}
\hline WEB Table III.3.1 & $\begin{array}{l}\text { Students' life satisfaction } \\
\text { (http://dx.doi.org/10.1787/888933470461) }\end{array}$ \\
\hline WEB Table III.3.3b & $\begin{array}{l}\text { Life satisfaction, by deciles of performance in mathematics and reading } \\
\text { (http://dx.doi.org/10.1787/888933470491) }\end{array}$ \\
\hline WEB Table III.3.4 & $\begin{array}{l}\text { Life satisfaction, by quarters of performance in core PISA subjects } \\
\text { (http://dx.doi.org/10.1787/888933470502) }\end{array}$ \\
\hline WEB Table III.3.10 III.3.12 & $\begin{array}{l}\text { Students' satisfaction with life and time per week spent learning in and outside school } \\
\text { (http://dx.doi.org/10.1787/888933470561) }\end{array}$ \\
& $\begin{array}{l}\text { Life satisfaction among adolescents and adults } \\
\text { (http://dx.doi.org/10.1787/888933470589) }\end{array}$
\end{tabular}

Chapter 4 Schoolwork-related anxiety

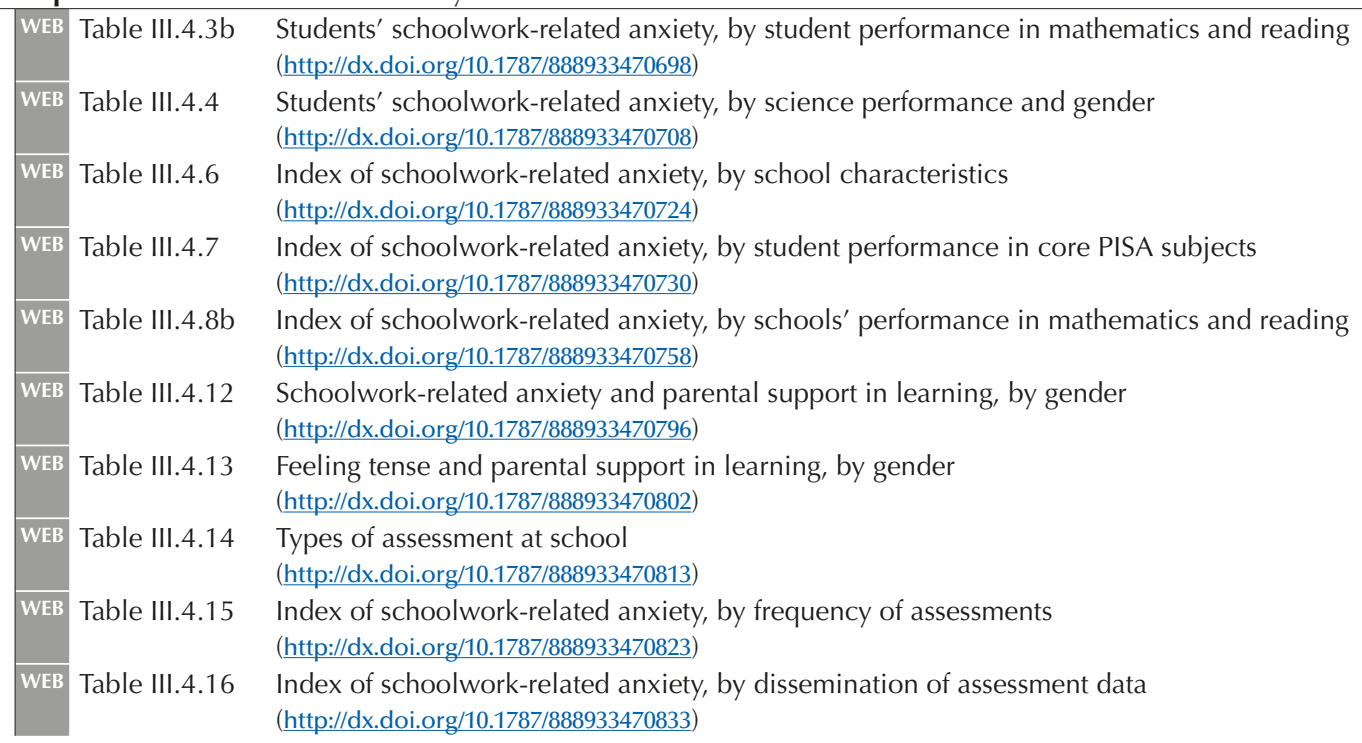

Chapter 5 Students' motivation to achieve

\begin{tabular}{|ll} 
WEB Table III.5.4 & $\begin{array}{l}\text { Index of achievement motivation, by school characteristics } \\
\text { (http://dx.doi.org/10.1787/888933470929) }\end{array}$ \\
\hline WEB Table III.5.5b & $\begin{array}{l}\text { Index of achievement motivation, by student performance in mathematics and reading } \\
\text { (http://dx.doi.org/10.1787/888933470944) }\end{array}$
\end{tabular}

Chapter 6 Students' expectations of further education

\begin{tabular}{|cl} 
WEB Table III.6.4 & $\begin{array}{l}\text { Students' expectations to complete their education at the secondary level, by student characteristics } \\
\text { (http://dx.doi.org/10.1787/888933471073) }\end{array}$ \\
WEB Table III.6.5 & $\begin{array}{l}\text { Students' expectations to complete their education at the secondary level, by school characteristics } \\
\text { (http://dx.doi.org/10.1787/888933471083) }\end{array}$ \\
WEB Table III.6.6a & $\begin{array}{l}\text { Expectations of further education, by level of student performance in science } \\
\text { (http://dx.doi.org/10.1787/888933471093) }\end{array}$ \\
\hline WEB Table III.6.6b & $\begin{array}{l}\text { Expectations of further education, by level of student performance in mathematics and reading } \\
\text { (http://dx.doi.org/10.1787/888933471100) }\end{array}$
\end{tabular}


Expectations of further education and mother's highest level of schooling (http://dx.doi.org/10.1787/888933471132)

EB Table III.6.9b

Expectations of further education and father's highest level of schooling (http://dx.doi.org/10.1787/888933471145)

WEB Table III.6.11 Students' expectations to complete a university degree and grade repetition (http://dx.doi.org/10.1787/888933471169)

EB Table III.6.12

Students' expectations to complete a university degree, by frequency of assessments (http://dx.doi.org/10.1787/888933471172)

WEB Table III.6.13 Parents' expectations of a science-related career for their child, by student and parent characteristics (http://dx.doi.org/10.1787/888933471180)

B Table III.6.14 Students' and parents' science-related career expectations, by gender (http://dx.doi.org/10.1787/888933471196)

Chapter 7 Students' sense of belonging at school and their relations with teachers

\begin{tabular}{|cl} 
WEB Table III.7.7 & $\begin{array}{l}\text { Index of sense of belonging, by school characteristics } \\
\text { (http://dx.doi.org/10.1787/888933471315) }\end{array}$ \\
\hline WEB Table III.7.8b & $\begin{array}{l}\text { Index of sense of belonging, by student performance in mathematics and reading } \\
\text { (http://dx.doi.org/10.1787/888933471331) }\end{array}$ \\
\hline WEB Table III.7.9 & $\begin{array}{l}\text { Immigrant students' sense of belonging at school, by countries of origin and destination } \\
\text { (http://dx.doi.org/10.1787/888933471342) }\end{array}$ \\
\hline WEB Table III.7.12 & $\begin{array}{l}\text { Index of sense of belonging and education expectations } \\
\text { (http://dx.doi.org/10.1787/888933471375) }\end{array}$ \\
\hline WEB Table III.7.19 & $\begin{array}{l}\text { Sense of belonging, by students' perceptions of their teachers' support } \\
\text { (http://dx.doi.org/10.1787/888933471440) }\end{array}$ \\
WEB Table III.7.20 & $\begin{array}{l}\text { Sense of belonging, by students' perception of teacher unfairness } \\
\text { (http://dx.doi.org/10.1787/888933471457) }\end{array}$ \\
WEB Table III.7.21 & $\begin{array}{l}\text { Schools that seek feedback } \\
\text { (http://dx.doi.org/10.1787/888933471468) }\end{array}$ \\
\hline
\end{tabular}

Chapter 8 Bullying

\begin{tabular}{|c|c|c|}
\hline WEB & Table III.8.3 & $\begin{array}{l}\text { Students' exposure to bullying, by immigrant background } \\
\text { (http://dx.doi.org/10.1787/888933471689) }\end{array}$ \\
\hline WEB & Table III.8.7b & $\begin{array}{l}\text { Index of exposure to bullying, by student performance in mathematics and science } \\
\text { (http://dx.doi.org/10.1787/888933471738) }\end{array}$ \\
\hline WEB & Table III.8.8 & $\begin{array}{l}\text { Index of exposure to bullying, by school performance in core PISA subjects } \\
\text { (http://dx.doi.org/10.1787/888933471749) }\end{array}$ \\
\hline WEB & Table III.8.11 & $\begin{array}{l}\text { Immigrant students and frequent bullying, by type of bullying and age at arrival } \\
\text { (http://dx.doi.org/10.1787/888933471772) }\end{array}$ \\
\hline WEB & Table III.8.12 & $\begin{array}{l}\text { Index of exposure to bullying and sense of belonging } \\
\text { (http://dx.doi.org/10.1787/888933471786) }\end{array}$ \\
\hline WEB & Table III.8.13 & $\begin{array}{l}\text { Being frequently bullied and changing schools } \\
\text { (http://dx.doi.org/10.1787/888933471794) }\end{array}$ \\
\hline WEB & Table III.8.14 & $\begin{array}{l}\text { Being frequently bullied and grade repetition } \\
\text { (http://dx.doi.org/10.1787/888933471803) }\end{array}$ \\
\hline WEB & Table III.8.17 & $\begin{array}{l}\text { Being frequently bullied, by students' perception of teachers' unfairness } \\
\text { (http://dx.doi.org/10.1787/888933471832) }\end{array}$ \\
\hline WEB & Table III.8.18 & $\begin{array}{l}\text { Students' exposure to bullying, by supportive parents } \\
\text { (http://dx.doi.org/10.1787/888933471840) }\end{array}$ \\
\hline WEB & Table III.8.19 & $\begin{array}{l}\text { Parents exchanging ideas on parenting with teachers, by child's exposure to bullying } \\
\text { (http://dx.doi.org/10.1787/888933471853) }\end{array}$ \\
\hline WEB & Table III.8.20 & $\begin{array}{l}\text { Teachers trained in classroom management, by schools' socio-economic profile } \\
\text { (http://dx.doi.org/10.1787/888933471862) }\end{array}$ \\
\hline WEB & Table III.8.21 & $\begin{array}{l}\text { Students who meet or talk with friends } \\
\text { (http://dx.doi.org/10.1787/888933471873) }\end{array}$ \\
\hline WEB & Table III.8.22 & $\begin{array}{l}\text { Students who meet or talk with friends, by student characteristics } \\
\text { (http://dx.doi.org/10.1787/888933471882) }\end{array}$ \\
\hline WEB & Table III.8.24 & $\begin{array}{l}\text { Relationship between talking with friends and life satisfaction, by gender } \\
\text { (http://dx.doi.org/10.1787/888933471903) }\end{array}$ \\
\hline
\end{tabular}


Chapter 9 Parental involvment, student performance and satisfaction with life

\begin{tabular}{|c|c|c|}
\hline WEB & Table III.9.2 & $\begin{array}{l}\text { Parents' activities with their child and at their child's school, by socio-economic status } \\
\text { (http://dx.doi.org/10.1787/888933471927) }\end{array}$ \\
\hline WEB & Table III.9.5 & $\begin{array}{l}\text { Parents' activities and students' high satisfaction with life } \\
\text { (http://dx.doi.org/10.1787/888933471959) }\end{array}$ \\
\hline WEB & Table III.9.7 & $\begin{array}{l}\text { Students' early science-related activities, by parents' educational level } \\
\text { (http://dx.doi.org/10.1787/888933471975) }\end{array}$ \\
\hline WEB & Table III.9.8 & $\begin{array}{l}\text { Students' early science-related activities, by parents' income category } \\
\text { (http://dx.doi.org/10.1787/888933471981) }\end{array}$ \\
\hline WEB & Table III.9.10 & $\begin{array}{l}\text { Students' early science-related activities and expectations of a science-related career, by gender } \\
\text { (http://dx.doi.org/10.1787/888933472005) }\end{array}$ \\
\hline WEB & Table III.9.12 & $\begin{array}{l}\text { Students' early science-related activities and self-efficacy in science, by gender } \\
\text { (http://dx.doi.org/10.1787/888933472027) }\end{array}$ \\
\hline WEB & Table III.9.14 & $\begin{array}{l}\text { Students' early science-related activities and enjoyment of science, by gender } \\
\text { (http://dx.doi.org/10.1787/888933472040) }\end{array}$ \\
\hline$\overline{E B}$ & Table III.9.17 & $\begin{array}{l}\text { Students who talk to their parents, by student characteristics } \\
\text { (http://dx.doi.org/10.1787/888933472072) }\end{array}$ \\
\hline WEB & Table III.9.19 & $\begin{array}{l}\text { Parents who give their child emotional support, by socio-economic status } \\
\text { (http://dx.doi.org/10.1787/888933472095) }\end{array}$ \\
\hline WEB & Table III.9.21 & $\begin{array}{l}\text { Parents' interest in their child's activities at school and science performance, by gender } \\
\text { (http://dx.doi.org/10.1787/888933472110) }\end{array}$ \\
\hline EB & Table III.9.27 & $\begin{array}{l}\text { Obstacles to parents' participation in their child's school activities, by socio-economic status } \\
\text { (http://dx.doi.org/10.1787/888933472175) }\end{array}$ \\
\hline
\end{tabular}

Chapter 10 Wealth, social status and inequalities in well-being

\begin{tabular}{|c|l|l|l|l}
\hline WEB Table III.10.3 & $\begin{array}{l}\text { Students' family wealth } \\
\text { (http://dx.doi.org/10.1787/888933472301) }\end{array}$ \\
\hline WEB Table III.10.4 & $\begin{array}{l}\text { Change in family wealth between 2006 and 2015 } \\
\text { (http://dx.doi.org/10.1787/888933472314) }\end{array}$ \\
\hline WEB Table III.10.5 & $\begin{array}{l}\text { Change in family wealth between 2012 and 2015 } \\
\text { (http://dx.doi.org/10.1787/888933472321) }\end{array}$ \\
\hline WEB Table III.10.11 & $\begin{array}{l}\text { Science performance, by family income } \\
\text { (http://dx.doi.org/10.1787/888933472386) }\end{array}$ \\
\hline WEB Table III.10.12 & $\begin{array}{l}\text { Life satisfaction and family income } \\
\text { (http://dx.doi.org/10.1787/888933472391) }\end{array}$ \\
\hline WEB Table III.10.17 & $\begin{array}{l}\text { Most popular occupations, by gender } \\
\text { (http://dx.doi.org/10.1787/888933473717) }\end{array}$
\end{tabular}

Chapter 11 Students' physical activities and eating habits

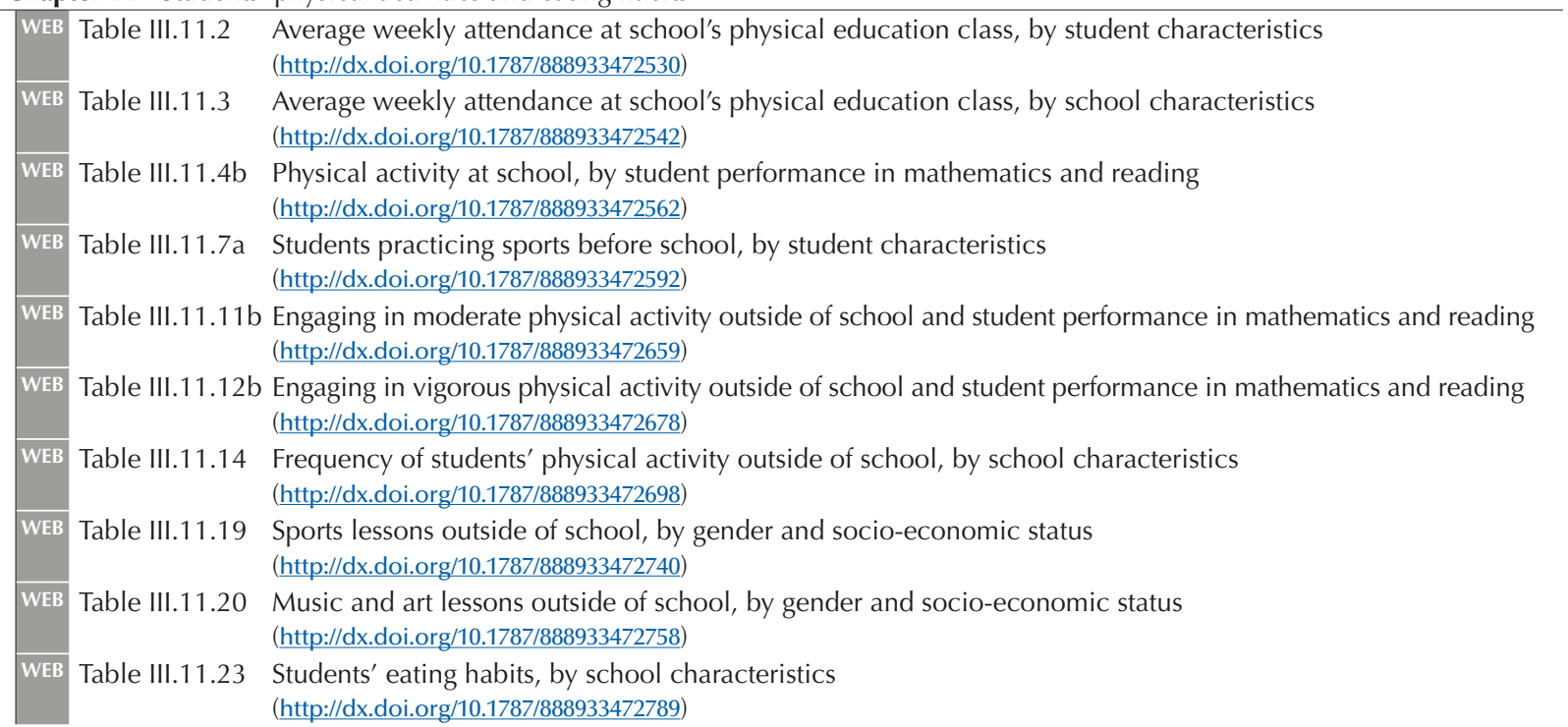


Table III.11.24b Eating breakfast and student performance in mathematics and reading (http://dx.doi.org/10.1787/888933472800)

WEB Table III.11.25 Eating breakfast and student performance in science, by gender (http://dx.doi.org/10.1787/888933472815)

WEB Table III.11.26b Eating dinner and student performance in mathematics and reading (http://dx.doi.org/10.1787/888933472836)

Table III.11.28 Eating habits and students' satisfaction with life, by gender (http://dx.doi.org/10.1787/888933472856)

Chapter 12 Students' paid and unpaid work

\begin{tabular}{|l|ll}
\hline WEB Table III.12.3 & $\begin{array}{l}\text { Students who work in the household and science performance, by student characteristics } \\
\text { (http://dx.doi.org/10.1787/888933473074) }\end{array}$ \\
\hline WEB Table III.12.4 & $\begin{array}{l}\text { Students who work in the household and life satisfaction } \\
\text { (http://dx.doi.org/10.1787/888933473083) }\end{array}$ \\
\hline WEB Table III.12.5 & $\begin{array}{l}\text { Disadvantaged and advantaged students who work in the household, by gender } \\
\text { (http://dx.doi.org/10.1787/888933473096) }\end{array}$ \\
\hline WEB Table III.12.6 & $\begin{array}{l}\text { Students who work in the household and well-being outcomes } \\
\text { (http://dx.doi.org/10.1787/888933473103) }\end{array}$
\end{tabular}

Chapter 13 Students' use of ICT outside of school

\begin{tabular}{|c|c|c|}
\hline WEB & Table III.13.1 & $\begin{array}{l}\text { Digital devices available at home } \\
\text { (http://dx.doi.org/10.1787/888933473152) }\end{array}$ \\
\hline WEB & Table III.13.2 & $\begin{array}{l}\text { Gender differences in using digital devices at home } \\
\text { (http://dx.doi.org/10.1787/888933473163) }\end{array}$ \\
\hline WEB & Table III.13.3 & $\begin{array}{l}\text { Change between } 2012 \text { and } 2015 \text { in digital devices available at home } \\
\text { (http://dx.doi.org/10.1787/888933473170) }\end{array}$ \\
\hline WEB & Table III.13.4 & $\begin{array}{l}\text { Change between } 2009 \text { and } 2015 \text { in digital devices available at home } \\
\text { (http://dx.doi.org/10.1787/888933473188) }\end{array}$ \\
\hline WEB & Table III.13.5 & $\begin{array}{l}\text { Change between } 2012 \text { and } 2015 \text { in age at which students started using a computer } \\
\text { (http://dx.doi.org/10.1787/888933473190) }\end{array}$ \\
\hline WEB & Table III.13.12 & $\begin{array}{l}\text { Use of online games/chat/social networks outside of school } \\
\text { (http://dx.doi.org/10.1787/888933473267) }\end{array}$ \\
\hline WEB & Table III.13.14 & $\begin{array}{l}\text { Change between } 2012 \text { and } 2015 \text { in the use of online games/chat/social networks outside of school } \\
\text { (http://dx.doi.org/10.1787/888933473285) }\end{array}$ \\
\hline WEB & Table III.13.15 & $\begin{array}{l}\text { Students' attitudes towards using the Internet } \\
\text { (http://dx.doi.org/10.1787/888933473294) }\end{array}$ \\
\hline WEB & Table III.13.17 & $\begin{array}{l}\text { Students' experiences with digital media and digital devices } \\
\text { (http://dx.doi.org/10.1787/888933473313) }\end{array}$ \\
\hline WEB & Table III.13.18 & $\begin{array}{l}\text { Students' experiences with digital media and digital devices, by student characteristics } \\
\text { (http://dx.doi.org/10.1787/888933473329) }\end{array}$ \\
\hline WEB & Table III.13.19b & $\begin{array}{l}\text { Sense of belonging at school, by time spent on the Internet outside of school during weekend days } \\
\text { (http://dx.doi.org/10.1787/888933473349) }\end{array}$ \\
\hline WEB & Table III.13.20b & $\begin{array}{l}\text { Being bullied at school, by time spent on the Internet outside of school on weekend days } \\
\text { (http://dx.doi.org/10.1787/888933473369) }\end{array}$ \\
\hline WEB & Table III.13.24b & $\begin{array}{l}\text { Time spent on the Internet outside of school on weekdays and performance in mathematics and reading } \\
\text { (http://dx.doi.org/10.1787/888933473413) }\end{array}$ \\
\hline WEB & Table III.13.25b & $\begin{array}{l}\text { Time spent on the Internet outside of school on weekend days and performance in mathematics and reading } \\
\text { (http://dx.doi.org/10.1787/888933473431) }\end{array}$ \\
\hline
\end{tabular}





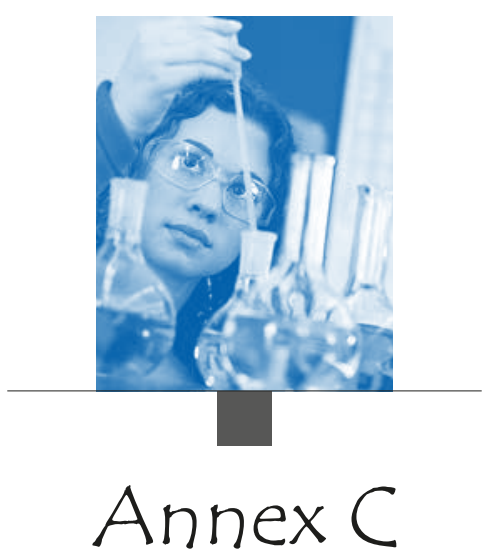

\section{THE DEVELOPMENT AND IMPLEMENTATION OF PISA:} A COLLABORATIVE EFFORT

\section{Notes regarding Cyprus}

Note by Turkey: The information in this document with reference to "Cyprus" relates to the southern part of the Island. There is no single authority representing both Turkish and Greek Cypriot people on the Island. Turkey recognises the Turkish Republic of Northern Cyprus (TRNC). Until a lasting and equitable solution is found within the context of the United Nations, Turkey shall preserve its position concerning the "Cyprus issue".

Note by all the European Union Member States of the OECD and the European Union: The Republic of Cyprus is recognised by all members of the United Nations with the exception of Turkey. The information in this document relates to the area under the effective control of the Government of the Republic of Cyprus. 
PISA is a collaborative effort, bringing together experts from the participating countries, steered jointly by their governments on the basis of shared, policy-driven interests.

A PISA Governing Board, representing each country, determines the policy priorities for PISA, in the context of OECD objectives, and oversees adherence to these priorities during the implementation of the programme. This includes setting priorities for the development of indicators, for establishing the assessment instruments and for reporting the results.

Experts from participating countries also serve on working groups that are charged with linking policy objectives with the best internationally available technical expertise. By participating in these expert groups, countries ensure that: the instruments are internationally valid and take into account the cultural and educational contexts in OECD countries and in partner countries and economies; the assessment materials have strong measurement properties; and the instruments emphasise authenticity and educational validity.

Participating countries and economies implement PISA at the national level through National Project Managers, subject to the agreed administration procedures. National Project Managers play a vital role in ensuring that the implementation of the survey is of high quality, and verify and evaluate the survey results, analyses, reports and publications.

External contractors are responsible for designing and implementing the surveys, within the framework established by the PISA Governing Board. Pearson developed the science and collaborative problem-solving frameworks, and adapted the frameworks for reading and mathematics, while the Deutsches Institut für Pädagogische Forschung (DIPF) designed and developed the questionnaires. Management and oversight of this survey, the development of the instruments, scaling and analyses are the responsibility of the Educational Testing Service (ETS) as is development of the electronic platform. Other partners or subcontractors involved with ETS include: cApStAn Linguistic Quality Control and the Department of Experimental and Theoretical Pedagogy at the University of Liège (SPe) in Belgium; the Center for Educational Technology (CET) in Israel; the Public Research Centre (CRP) Henri Tudor and the Educational Measurement and Research Center (EMACS) of the University of Luxembourg in Luxembourg; and GESIS - Leibniz-Institute for the Social Sciences in Germany. Westat assumed responsibility for survey operations and sampling with the subcontractor, the Australian Council for Educational Research (ACER).

The OECD Secretariat has overall managerial responsibility for the programme, monitors its implementation daily, acts as the secretariat for the PISA Governing Board, builds consensus among countries, and serves as the interlocutor between the PISA Governing Board and the international Consortium charged with implementing the activities. The OECD Secretariat also produces the indicators and analyses and prepares the international reports and publications in co-operation with the PISA Consortium and in close consultation with OECD countries and partner countries and economies at both the policy level (PISA Governing Board) and the level of implementation (National Project Managers).

\section{PISA Governing Board}

(* Former PGB member who was involved in PISA 2015) Chair of the PISA Governing Board: Michelle Bruniges and Lorna Bertrand*

\section{OECD countries and Associates}

Australia: Rhyan Bloor, Michelle Bruniges and Tony Zanderigo*

Austria: Mark Német

Belgium: Isabelle Erauw, Geneviève Hindryckx and Christiane Blondin*

Brazil: Maria Helena Guamaraes Castro, Maria Inês Fini, and Luiz Claudio Costa*

Canada: Tomasz Gluszynski, Kathryn O'Grady, Pierre Brochu* and Patrick Bussiere*

Chile: Carolina Flores, Claudia Matus and Leonor Cariola Huerta*

Czech Republic: Tomas Zatloukal and Jana Paleckova*

Denmark: Mette Hansen, Frida Poulsen, Elsebeth Aller* and Tine Bak*

Estonia: Maie Kitsing

Finland: Tommi Karjalainen

France: Thierry Rocher and Bruno Trosseille*
Germany: Martina Diedrich, Katharina Koufen, Elfriede Ohrnberger, Annemarie Klemm* and Susanne von Below*

Greece: Chryssa Sofianopoulou and Vassilia Hatzinikita*

Hungary: Sándor Brassói and Benõ Csapó*

Iceland: Stefán Baldursson and Júlíus Björnsson*

Ireland: Peter Archer, Jude Cosgrove* and Gerry Shiel*

Israel: Hagit Glickman and Michal Beller*

Italy: Roberto Ricci and Paolo Sestito*

Japan: Akiko Ono, Masaharu Shiozaki and Ryo Watanabe*

Korea: Bu Ho Nam, Jimin Cho, Jea Yun Park*, Sungsook Kim*, Keunwoo Lee* and Myungae Lee*

Latvia: Andris Kangro, Aḷona Babiča, Ennata Kivrina* and Dita Traidas*

Luxembourg: Amina Kafaï

Mexico: Eduardo Backhoff Escudero, Ana María Acevess Estrada and Francisco Ciscomani*

Netherlands: Marjan Zandbergen and Paul van Oijen*

New Zealand: Craig Jones, Lisa Rodgers*

and Lynne Whitney*

Norway: Marthe Akselsen, Anne-Berit Kavli* and Alette Schreiner* 
Poland: Jerzy Wisniewski, Hania Bouacid* and Stanislaw Drzazdzewski*

Portugal: Hélder Manuel Diniz de Sousa, Luisa Canto* and Castro Loura*

Slovak Republic: Romana Kanovska and Paulina Korsnakova* Slovenia: Andreja Barle Lakota, Mojca Straus and Ksenija Bregar-Golobic

Spain: Carmen Tovar Sanchez, Vicente Alcañiz Miñano* and Ismael Sanz Labrador*

Sweden: Eva Lundgren and Anita Wester*

Switzerland: Vera Husfeldt and Claudia Zahner Rossier Turkey: Kemal Bulbul, Mustafa Nadir Çalis* and Nurcan Devici*

United Kingdom: Lorna Bertrand and Jonathan Wright*

United States: Dana Kelly, Jack Buckley* and Daniel McGrath*

\section{Observers (Partner economies)}

Albania: Zamira Gjini and Ermal Elezi*

Algeria: Samia Mezaib and Mohamed Chaibeddra Tani*

Argentina: Elena Duro, Martín Guillermo Scasso* and Liliana Pascual*

Azerbaijan (Baku City only): Emin Amrullayev

Belarus (Republic of): Aliaksandr Yakabchuk and Mikalai Fiaskou

Bosnia and Herzegovina: Maja Stojkic

Brunei Darussalam: Dr. Azman Ahmad

Bulgaria: Neda Kristanova

Beijing-Shanghai-Jiangsu-Guangdong (China): Ping Luo

Colombia: Ximena Dueñas and Adriana Molina*

Costa Rica: Alicia Vargas and Leonardo Garnier Rimolo*

Croatia: Michelle Bras Roth

Dominican Republic: Ancell Scheker Mendoza

Former Yugoslav Republic of Macedonia: Natasha Janevska (PISA 2018) and Dejan Zlatkovski*

Georgia: Tamar Bregvadze and Natia Mzhavanadze*

Hong Kong (China): Ho-pun Choi, Fanny Yuen-fan Wan and Esther Sui-chu Ho*

Indonesia: Dr. Totok Suprayitno, Furqon Furqon* and Khairil Anwar Notodiputro*

Jordan: Khattab Mohammad Abulibdeh

Kazakhstan: Serik Irsaliyev and Almagul Kultumanova*

Kosovo: Anila Statovci Demaj

Kyrgyzstan: Jarkyn Ryskulova

Lebanon: Nada Ouweijan

Lithuania: Rita Dukynaite

Macao (China): Leong Lai

Malaysia: Khairil Awang and Amin Senin*

Malta: Charles Mifsud

Moldova (Republic of): Anatolie Topala and Valeriu Gutu* Montenegro: Dragana Dmitrovic and Zeljko Jacimovic*

Morocco: Mohammed Sassi
Panama: Marelissa Tribaldos

Peru: Humberto Hildebrando Pérez León Ibañez and Liliana Miranda Molina*

Philippines: Elvin Ivan Yaw

Qatar: Khalid Abdulla Al-Harqan and Hamda Al Sulaiti*

Romania: Roxana Mihail and Daniela Bogdan

Russian Federation: Galina Kovaleva, Sergey Kravtsov and Isak Froumin*

Saudi Arabia: Mohamed Al-harthi

Serbia (Republic of): Zorana Lužanin

Singapore: Chern Wei SNG and Khah Gek Low*

Chinese Taipei: Peng Li-Chun, Gwo-Dong Chen*

and Chih-Wei Hue*

Thailand: Precharn Dechsri

Trinidad and Tobago: Mervyn Sambucharan

Tunisia: Riadh Ben Boubaker

Ukraine: Pavlo Khobzey

United Arab Emirates: Moza al Ghufly, Ayesha G. Khalfan Almerri, Ali Jaber Al Yafei and Khawla Al Mualla

Uruguay: Andrés Peri and Maria Helvecia Sanchez Nunez*

Viet Nam: Le Thi My Ha

PISA 2015 National Project Managers (* Former PISA 2015 NPM)

Albania: Rezana Vrapi and Alfons Harizaj*

Algeria: Samia Mezaib

Argentina: Liliana Pascual

Australia: Sue Thomson

Austria: Birgit Suchan

Beijing-Shanghai-Jiangsu-Guangdong (China): Wang Lei

Belgium: Inge De Meyer and Anne Matoul

Brazil: Aline Mara Fernandes

Bulgaria: Svetla Petrova

Canada: Pierre Brochu and Tamara Knighton*

Chile: Ema Lagos Campos

Chinese Taipei: Hsiao-Ching She and Huann-Shyang Lin

Colombia: Javier Juyar, Francisco Reyes*, Adriana Molina* and Julián P. Mariño*

Costa Rica: Lilliam Mora

Croatia: Michelle Bras Roth

Czech Republic: Radek Blažek and Jana Paleckova*

Denmark: Hans Hummalgaard, Niels Egelund* and Chantal Nielsen*

Dominican Republic: Massiel Cohen

Estonia: Gunda Tire

Finland: Jouni Välijärvi

Former Yugoslav Republic of Macedonia: Natasha Janevska and Dejan Zlatkovski

France: Irène Verlet

Georgia: Natia Mzhavanadze

Germany: Christine Sälzer and Manfred Prenzel

Greece: Chryssa Sofianopoulou 
Hong Kong (China): Esther Sui-chu Ho

Hungary: László Ostorics

Iceland: Almar Midvik Halldorsson

Indonesia: Ir. Nizam

Ireland: Gerry Shiel

Israel: Joel Rapp and Inbal Ron-Kaplan

Italy: Carlo Di Chiacchio

Japan: Akiko Ono

Jordan: Emad Ababneh

Kazakhstan: Irina Imanbek and Gulmira Berdibayeva*

Korea: Jaok Ku, JIMIN CHO* and Mi-Young Song*

Latvia: Andris Kangro

Lebanon: Bassem Issa and Antoine Skaf*

Lithuania: Mindaugas Stundza

Luxembourg: Bettina Boehm

Macao (China): Kwok Cheung Cheung

Malaysia: Muhammad Zaini Mohd Zain

Malta: Louis Scerri

Mexico: María Antonieta Díaz Gutierrez

Montenegro: Divna Paljevic Sturm

Netherlands: Jesse Koops and Johanna Kordes*

New Zealand: Steve May, Saila Cowles and Maree Telford*

Norway: Marit Kjaernsli

Peru: Liliana Miranda Molina

Poland: Barbara Ostrowska

Portugal: João Maroco

Qatar: Shaikha Al-Ishaq and Saada Al-Obaidli*

Moldova (Republic of): Valeriu Gutu

Romania: Silviu Cristian Mirescu

Russian Federation: Galina Kovaleva

Serbia: Dragica Pavlovic-Babic

Singapore: Chew Leng Poon, Elaine Chua and Pik Yen Lim*

Slovak Republic: Jana Ferencova

Slovenia: Mojca Straus

Spain: Lis Cercadillo Pérez

Sweden: Magnus Oskarsson

Switzerland: Christian Nidegger

Thailand: Nantawan Nantawanit and Suchada Thaithae

Trinidad and Tobago: Mervyn Sambucharan

Tunisia: Mehrez Drissi and Med Kamel Essid*

Turkey: Umut Erkin Taş

United Arab Emirates: Mouza Rashed Khalfan Al Ghufli

United Kingdom: Dawn Pollard and Juliet Sizmur

United States: Dana Kelly, Patrick Gonzales and Holly Xie*

Uruguay: Maria Helvecia Sánchez Nunez

Viet Nam: Thi My Ha Le

\section{OECD Secretariat}

Andreas Schleicher (Strategic development)

Marilyn Achiron (Editorial support)

Peter Adams (Project management)
Francesco Avvisati (Analytic services)

Yuri Belfali (Strategic development)

Marika Boiron (Translation support)

Rose Bolognini (Production support)

Guillaume Bousquet, (Analytic services)

Esther Carvalhaes, (Analytic services)

Claire Chetcuti (Administrative support)

Anna Choi (Analytic services)

Cassandra Davis (Dissemination co-ordination)

Alfonso Echazarra, (Analytic services)

Juliet Evans (Administration and partner country/economy relations)

Hélène Guillou (Analytic services)

Carlos González-Sancho (Analytic services)

Tue Halgreen (Project management)

Miyako Ikeda (Analytic services)

Jeffrey Mo (Analytic services)

Chiara Monticone (Analytic services)

Bonaventura Francesco Pacileo (Analytic services)

Judit Pál (Analytic services)

Mario Piacentini, (Analytic services)

Giannina Rech (Analytic services)

Daniel Salinas (Analytic services)

Lisa Smadja (Administrative support)

Michael Stevenson (Dissemination co-ordination)

Sophie Vayssettes (Project management)

\section{PISA 2015 science expert group}

Jonathan Osborne (SEG Chair) (Stanford University, United States and United Kingdom)

Marcus Hammann (Munster University, Germany)

Sarah Howie (University of Pretoria, South Africa)

Jody Clarke-Midura (Harvard University, United States)

Robin Millar (University of York, United Kingdom)

Andrée Tiberghien (University of Lyon, France)

Russell Tytler (Deakin University, Australia)

Darren Wong (National Institute of Education, Singapore)

\section{Extended group}

Rodger Bybee (Biological Sciences Curriculum Study (BSCS), United States)

Jens Dolin (University of Copenhagen, Denmark)

Harrie Eijkelhof (Utrecht University, Netherlands)

Geneva Haertel (SRI, United States)

Michaela Mayer (University of Roma Tre., Italy)

Eric Snow (SRI, United States)

Manabu Sumida (Ehime University, Japan)

Benny Yung (University of Hong Kong, Hong Kong, China)

\section{PISA 2015 problem solving expert group}

Arthur Graesser (Chair) (The University of Memphis United States)

Eduardo Cascallar (Katholieke Universiteit Leuven, Belgium) 
Pierre Dillenbourg (Ecole Polytechnique Fédérale de Lausanne, Switzerland)

Patrick Griffin (University of Melbourne, Australia)

Chee Kit Looi (Nanyang Technological University, Singapore) Jean-François Rouet (University of Poitiers, France)

\section{Extended group}

Rafael Calvo (University of Sydney, Argentina)

Tak Wai Chan (National Central University of Taiwan, China) Stephen Fiore (University of Central Florida, USA) Joachim Funke (University of Heidelberg, Germany) Manu Kapur (National Institute of Education, Singapore) Naomi Miyake (University of Tokyo, Japan)

Yigal Rosen (University of Haifa, Israel) Jennifer Wiley (University of Illinois at Chicago, USA)

\section{PISA 2015 questionnaire expert group}

David Kaplan (Chair as of 2014) (University of WisconsinMadison, United States)

Eckhard Klieme (Chair until 2013) (German Institute for International Educational Research, Germany (DIPF), Frankfurt, Germany)

Gregory Elacqua (Universidad Diego Portales, Chile)

Marit Kjærnsli (University of Oslo, Norway)

Leonidas Kyriakides (University of Cyprus, Cyprus ${ }^{1}$ )

Henry M. Levin (Columbia University, United States) Naomi Miyake (University of Tokyo, Japan)

Jonathan Osborne (Stanford University, United States)

Kathleen Scalise (University of Oregon, United States)

Fons van de Vijver (Tilburg University, Netherlands)

Ludger Wößmann (University of Munich, Germany)

\section{Technical advisory group}

Keith Rust (chair) (Westat, USA)

Theo Eggen (Cito, Netherlands)

John de Jong (Pearson, UK/VU University Amsterdam, Netherlands)

Jean Dumais (Statistics Canada, Canada)

Cees Glas (University of Twente, Netherlands)

David Kaplan (University of Wisconsin-Madison, USA and DIPF, Germany)

Irwin Kirsch (ETS, USA)

Christian Monseur (Université de Liège, Belgium)

Sophia Rabe-Hesketh (University of Berkeley, USA)

Thierry Rocher (Ministère de l'Éducation Nationale, France)

Leslie A. Rutkowski (University of Oslo, Norway)

Margaret Wu (Victoria University, Australia)

Kentaro Yamamoto (ETS, USA)

1. See note at the beginning of this annex.
PISA 2015 Lead Contractors

Educational Testing Service (UNITED STATES) - Cores 2, 3 and 7 lead contractor

Irwin Kirsch (International project director)

Claudia Tamassia (International project manager)

David Garber (Project management, paper booklets and coding) Larry Hanover (Editorial support)

Lisa Hemat (Project support)

Isabelle Jars (Project management, questionnaires)

Judy Mendez (Project support and contracts)

Eugenio Gonzalez (Training and data products)

Kentaro Yamamoto (Director, psychometrics and analysis)

Matthias von Davier (Director, psychometrics and analysis)

Chentong Chen (Psychometrics and analysis)

Haiwen Chen (Psychometrics and analysis)

Qiwei He (Psychometrics and analysis)

Lale Khorramdel (Manager, psychometrics and analysis)

Hyo Jeong Shin (Psychometrics and analysis)

Jon Weeks (Psychometrics and analysis)

Marylou Lennon (Test development coordinator, science and collaborative problem solving)

Marylou Lennon (Test Development Coordinator, Science and Collaborative Problem Solving)

Eric Steinhauer (Test Development, Lead, Science and Collaborative Problem Solving)

Janet Koster van Groos (Test Development, Science)

Marshall L Freedman (Test Development Science)

Israel Solon (Test Development Science)

Jakub Novak (Test Development Science)

Nancy Olds (Test Development Science)

Paul Borysewicz (Test Development, Collaborative

Problem Solving)

William Sims (Test Development, Collaborative

Problem Solving)

Peter Cooper (Test Development, Collaborative

Problem Solving)

Michael Wagner (Director, platform development)

Jason Bonthron (Platform development and authoring)

Paul Brost (Platform development)

Ramin Hemat (Platform development and authoring)

Keith Keiser (Platform development and coding system)

Debbie Pisacreta (Interface design and graphics)

Janet Stumper (Graphics)

Ted Blew (Director, data analysis, research and technology)

John Barone (Director, data analysis and database preparation) Mathew Kandathil (Leader, data analysis and data management)

Kevin Bentley (Data products)

Hezekiah Bunde (Data management)

Karen Castellano (Data analysis)

Scott Davis (Data analysis)

Chantal Delaney (Data management)

Matthew Duchnowski (Data management)

Ying Feng (Data management) 
Zhumei Guo (Data analysis)

Laura Jerry (Data analysis)

Lokesh Kapur (Data analysis)

Debra Kline (Data analysis leader)

Phillip Leung (Data products leader)

Alfred Rogers (Data management leader)

Carla Tarsitano (Data management leader)

Sarah Venema (Data products)

Tao Wang (Data products)

Lingjun Wong (Data analysis)

Yan Zhang (Data management)

Wei Zhao (Data analysis)

Deutsches Institut für Internationale Pädagogische Forschung (DIPF, GERMANY)

(German Institute for International Educational Research) Core 6 lead contractor

Eckhard Klieme (Study director, questionnaire framework and development)

Nina Jude (Management and questionnaire development)

Sonja Bayer (Questionnaire development and analysis)

Janine Buchholz (Questionnaire scaling)

Frank Goldhammer (Questionnaire development)

Silke Hertel (Questionnaire development)

Franz Klingebiel (Questionnaire development)

Susanne Kuger (Questionnaire framework and development) Ingrid Mader (Team assistance)

Tamara Marksteiner (Questionnaire analysis)

Jean-Paul Reeff (International Consultant)

Nina Roczen (Questionnaire development)

Brigitte Steinert (Questionnaire development)

Svenja Vieluf (Questionnaire development)

\section{Pearson (UNITED KINGDOM) - Core 1 lead contractor}

John de Jong (Programme director)

Catherine Hayes (Programme manager)

Elise Bromley (Programme administrator)

Rose Clesham (Content lead, scientific literacy)

Peter Foltz (Content lead, collaborative problem solving)

Christine Rozunick (Content lead, scientific literacy)

Jon Twing (Psychometric consultant)

Michael Young (Psychometric consultant)

Westat (UNITED STATES) - Cores 4 and 5 lead contractor

Keith Rust (Director of the PISA consortium for sampling and weighting)

Sheila Krawchuk (Sampling, weighting and quality monitoring)

Andrew Caporaso (Weighting)

Jessica Chan (Sampling and weighting)

William Chan (Weighting)

Susan Fuss (Sampling and weighting)

Amita Gopinath (Sampling and weighting)

Evan Gutentag (Weighting)

Jing Kang (Sampling and weighting)

Veronique Lieber (Sampling and weighting)
John Lopdell (Sampling and weighting)

Shawn Lu (Weighting)

Martha Rozsi (Weighting)

Yumiko Siegfried (Sampling and weighting)

Joel Wakesberg (Sampling and weighting)

Sipeng Wang (Weighting)

Erin Wiley (Sampling and weighting)

Sergey Yagodin (Weighting)

Merl Robinson (Director of Core 4 Contractor for Survey Operations)

Michael Lemay (Manager of Core 4 Contractor for Survey Operations)

Jessica Chan (National Centre Support, Quality Control)

Lillian Diaz-Hoffman (National Centre Support, Quality

Control)

Sarah Hartge (National Centre Support, Quality Control)

Beverley McGaughan (National Centre Support,

Quality Control)

PISA 2015 Contributors, working with Lead Contractors

Australian Council for Educational Research (AUSTRALIA) Core 5 contributor

Eveline Gebhardt (Project director)

Alla Routitsky (Within-school sampling)

Charlotte Waters (Within-school sampling)

Jorge Fallas (Within-school sampling)

Renee Chow (Within-school sampling)

David Tran (Programmer)

Martin Murphy (School sampling)

Clare Ozolins (School sampling)

Greg Macaskill (School sampling)

Jennifer Hong (School sampling)

Jorge Fallas (School sampling)

Renee Chow (School sampling)

Thomas Stephen (School sampling)

Center for Educational Technology - Core 3 contributor on test development

Tali Freund (Test Development Coordinator, Science and Collaborative Problem Solving)

Rachel Mintz (Test Development, Lead, Science)

Nurit Keinan (Test Development, Science)

Hava Ben-Horin (Test Development, Science)

Sherman Rosenfeld (Test Development, Science)

Lilach Tencer-Herschkovitz (Test Development, Science)

Nadav Caspi (Test Development, Science)

Elinor Shaked-Blazer (Test Development, Science)

Sara Hershkovitz (Test Development, Lead, Collaborative Problem Solving)

Cecilia Waisman (Test Development, Collaborative Problem Solving)

Helit Heffer (Test Development, Collaborative Problem Solving)

Estela Melamed (Test Development, Science

and Collaborative Problem Solving) 
cApStAn Linguistic Quality Control (BELGIUM) - Core 3 contributor on linguistic quality control

Steve Dept (Project director, translatability assessment,) Lieve Deckx (Verification management, cognitive units) Andrea Ferrari (Linguistic quality assurance and quality control designs)

Musab Hayatli (Right-to-left scripts, cultural adaptations)

Elica Krajceva (Verification management, questionnaires) Shinoh Lee (Verification management, cognitive units) Irene Liberati (Verification management, cognitive units) Roberta Lizzi (Verification management, trend content) Laura Wayrynen (Translation and verification operations)

GESIS-Leibniz Institute for the Social Sciences (GERMANY) - Core 3 contributor on test development Anouk Zabal (Test Development Coordinator, Science and Collaborative Problem Solving, Software Testing)

Dorothee Behr (Test Development, Science and Collaborative Problem Solving, Software Testing)

Daniela Ackermann (Test Development, Science and Collaborative Problem Solving, Software Testing)

HallStat SPRL (BELGIUM) - Core 3 contributor as the translation referee

Beatrice Halleux (Consultant, translation/verification referee, French source development)

Luxembourg Institute for Science and Technology (LUXEMBOURG) - Core 2 Contributor on the development of the computer-based platform for the background questionnaire and cognitive assessment

Jehan Bihim (Questionnaire development)

Joël Billard (Multilingual framework and questionnaire development)

Cyril Hazotte (System administration)

Anne Hendrick (Platform Leader, project co-ordination)

Raynald Jadoul (Project management and software architecture) Isabelle Jars (Project management and testing)

Lionel Lecaque (Software quality and knowledge base administration)

Primaël Lorbat (Multilingual framework and questionnaire architecture)

Matteo Melis (Portal integration and questionnaire development)

Jean-François Merche (System integration and administration)

Vincent Porro (Lead designer and staff co-ordination)

Igor Ribassin (Workflow development and offline tools development)

Somsack Sipasseuth (Workflow development and knowledge base integration)

Nicolas Yodi (Portal integration and questionnaire development)

\section{Statistics Canada (CANADA) - Core 6 contributor} on questionnaires

Sylvie Grenier (Overall management)

Tamara Knighton (Overall management)

Isabelle Thorny (Implementation Delivery System)
Ginette Grégoire (Implementation Delivery System) Martine Lafrenière (Implementation Delivery System) Rosa Tatasciore (Implementation Delivery System)

Unité d'analyse des Systèmes et des Pratiques d'enseignement (aSPe, BELGIUM) - Core 3 contributor on coding training

Dominique LaFontaine (Project supervisor)

Ariane Baye (Coding training, reading)

Isabelle Demonty (Coding training, mathematics)

Annick Fagnant (Coding training, mathematics)

Geneviève Hindryckx (Coding training, science)

Anne Matoul (Coding training, reading)

Valérie Quittre (Coding training, science)

University of Heidelberg (GERMANY) - Core 3 contributor on test development

Daniel Holt (Test Development, Collaborative Problem Solving) Andreas Fischer (Test Development, Collaborative Problem Solving)

Ursula Pöll (Test Development, Collaborative Problem Solving) Julia Hilse (Test Development, Collaborative Problem Solving) Saskia Kraft (Test Development, Collaborative Problem Solving) Florian Hofmann (Test Development, Collaborative Problem Solving)

University of Luxembourg (LUXEMBOURG) - Core 3 contributor on test development

Romain Martin (Test Development Coordinator, Science)

Samuel Greiff (Test Development Coordinator, Collaborative Problem Solving)

Sara Wilmes (Test Development, Science)

Sophie Doublet (User Testing)

Vincent Koenig (User Testing)

Katja Weinerth (User Testing)

\section{Publication layout}

Fung Kwan Tam 



\section{ORGANISATION FOR ECONOMIC CO-OPERATION AND DEVELOPMENT}

The OECD is a unique forum where governments work together to address the economic, social and environmental challenges of globalisation. The OECD is also at the forefront of efforts to understand and to help governments respond to new developments and concerns, such as corporate governance, the information economy and the challenges of an ageing population. The Organisation provides a setting where governments can compare policy experiences, seek answers to common problems, identify good practice and work to co-ordinate domestic and international policies.

The OECD member countries are: Australia, Austria, Belgium, Canada, Chile, the Czech Republic, Denmark, Estonia, Finland, France, Germany, Greece, Hungary, Iceland, Ireland, Israel, Italy, Japan, Korea, Latvia, Luxembourg, Mexico, the Netherlands, New Zealand, Norway, Poland, Portugal, the Slovak Republic, Slovenia, Spain, Sweden, Switzerland, Turkey, the United Kingdom and the United States. The European Union takes part in the work of the OECD.

OECD Publishing disseminates widely the results of the Organisation's statistics gathering and research on economic, social and environmental issues, as well as the conventions, guidelines and standards agreed by its members. 


\section{PISA 2015 Results: STUDENTS' WELL-BEING VOLUME III}

The OECD Programme for International Student Assessment (PISA) examines not just what students know in science, reading and mathematics, but what they can do with what they know. Results from PISA show the quality and equity of learning outcomes achieved around the world, and allow educators and policy makers to learn from the policies and practices applied in other countries. This is one of five volumes that present the results of the PISA 2015 survey, the sixth round of the triennial assessment.

Volume I, Excellence and Equity in Education, summarises student performance in science, reading and mathematics, and defines and measures equity in education. It focuses on students' attitudes towards learning science, including their expectations of working in science-related careers. The volume also discusses how performance and equity have evolved across PISA-participating countries and economies over recent years.

Volume II, Policies and Practices for Successful Schools, examines how student performance is associated with various characteristics of individual schools and school systems, including the resources allocated to education, the learning environment and how school systems select students into different schools, programmes and classes.

Volume III, Students' Well-Being, describes the relationships among 15-year-old students' social life, learning attitudes and performance at school.

Volume IV, Students' Financial Literacy, explores students' experience with and knowledge about money.

Volume V, Collaborative Problem Solving, examines students' ability to work with two or more people to solve a problem. It also explores the role of education in building young people's skills in solving problems collaboratively.

\section{Contents of this volume}

Chapter 1: Overview: Students' well-being

Chapter 2: Students' well-being: What it is and how it can be measured

Chapter 3: Students' satisfaction with their life

Chapter 4: Schoolwork-related anxiety

Chapter 5: Students' motivation to achieve

Chapter 6: Students' expectations of further education

Chapter 7: Students' sense of belonging at school and their relations with teachers

Chapter 8: Bullying

Chapter 9: Parental involvement, student performance and satisfaction with life

Chapter 10: Wealth, social status and inequalities in well-being

Chapter 11: Students' physical activities and eating habits

Chapter 12: Students' paid and unpaid work

Chapter 13: Students' use of ICT outside of school

Chapter 14: What PISA 2015 results on students' well-being imply for policy

Consult this publication on line at: $\boldsymbol{h t t p : / / d x . d o i . o r g / 1 0 . 1 7 8 7 / 9 7 8 9 2 6 4 2 7 3 8 5 6 - e n ~}$

This work is published on the OECD iLibrary, which gathers all OECD books, periodicals and statistical databases.

Visit www.oecd-ilibrary.org and do not hesitate to contact us for more information.

OECDpublishing

www.oecd.org/publishing
ISBN 978-92-64-27381-8

$982017021 \mathrm{P}$
9

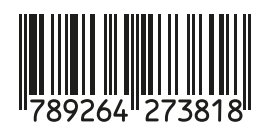

